y)

Non 5 s

- $1(2 y)$

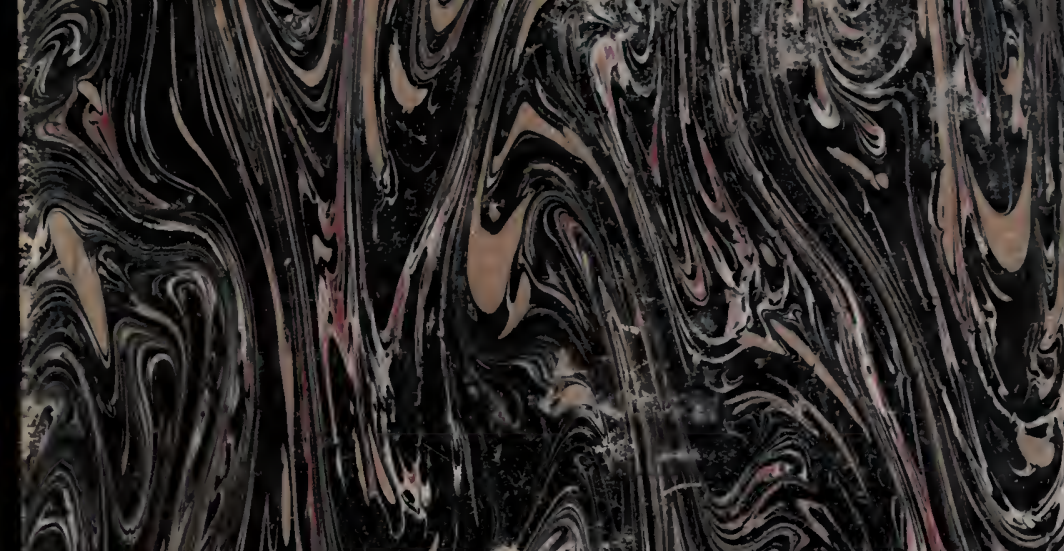

9.1.

min
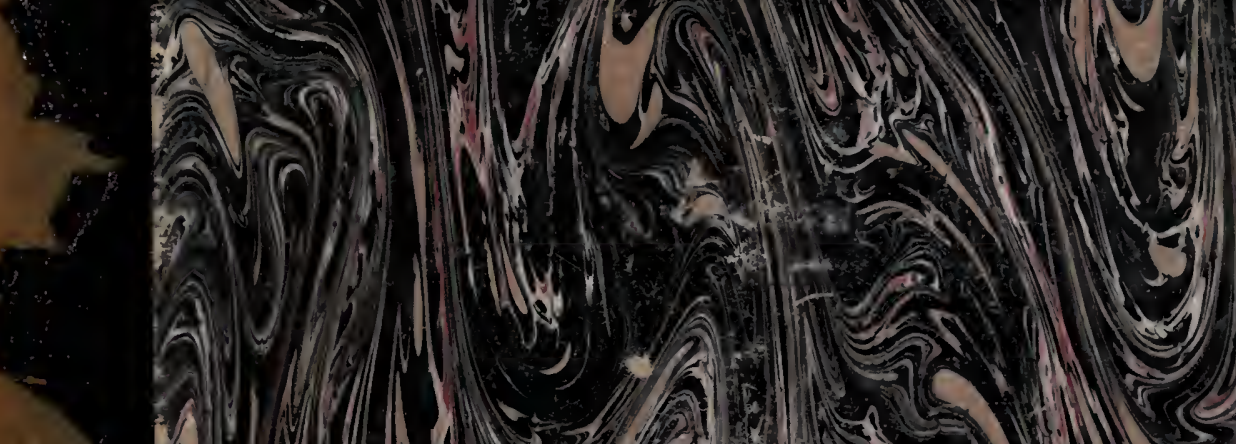

S ( N

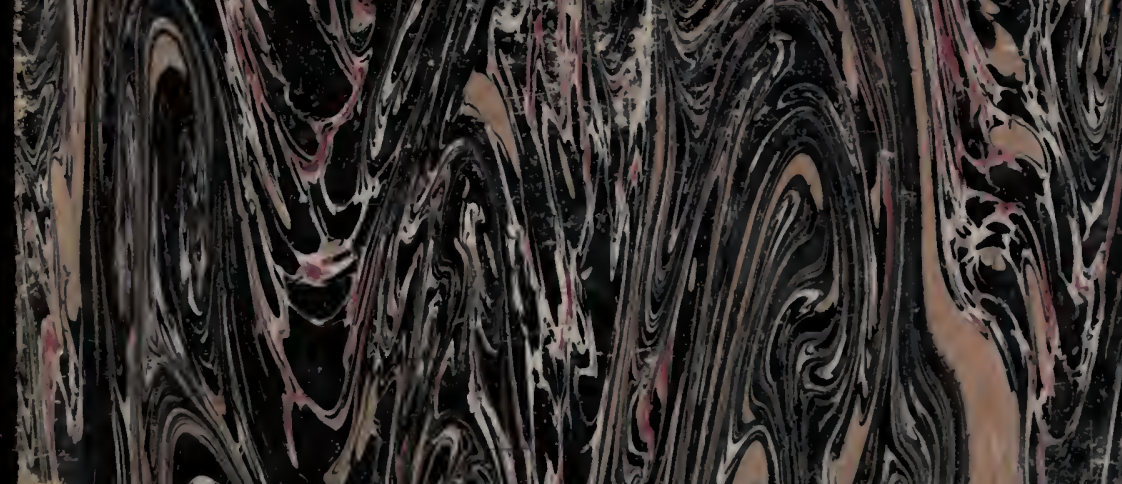

- a y a a d s

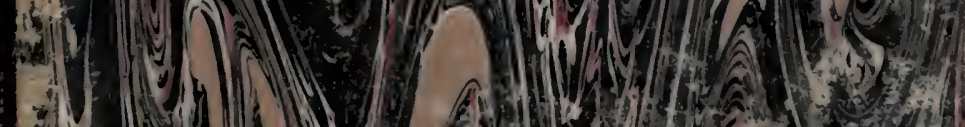

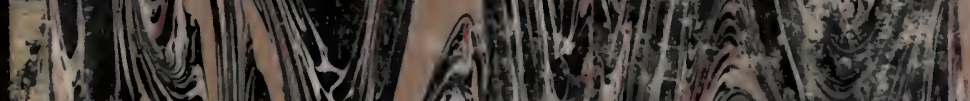

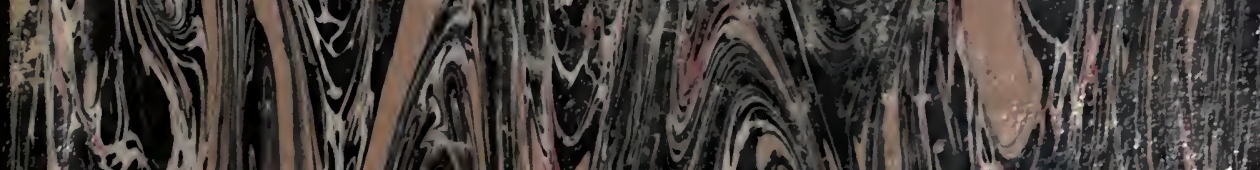

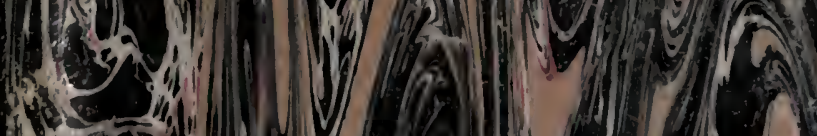


THE UNIVERSITY

OF ILLINOIS

LIBRARY

872

N63a

1856 
The person charging this material is responsible for its return on or before the Latest Date stamped below.

Theft, mutilation, and underlining of books are reasons for disciplinary action and may result in dismissal from the University.

UNIVERSITY OF ILLINOIS LIBRARY AT URBANA-CHAMPAIGN

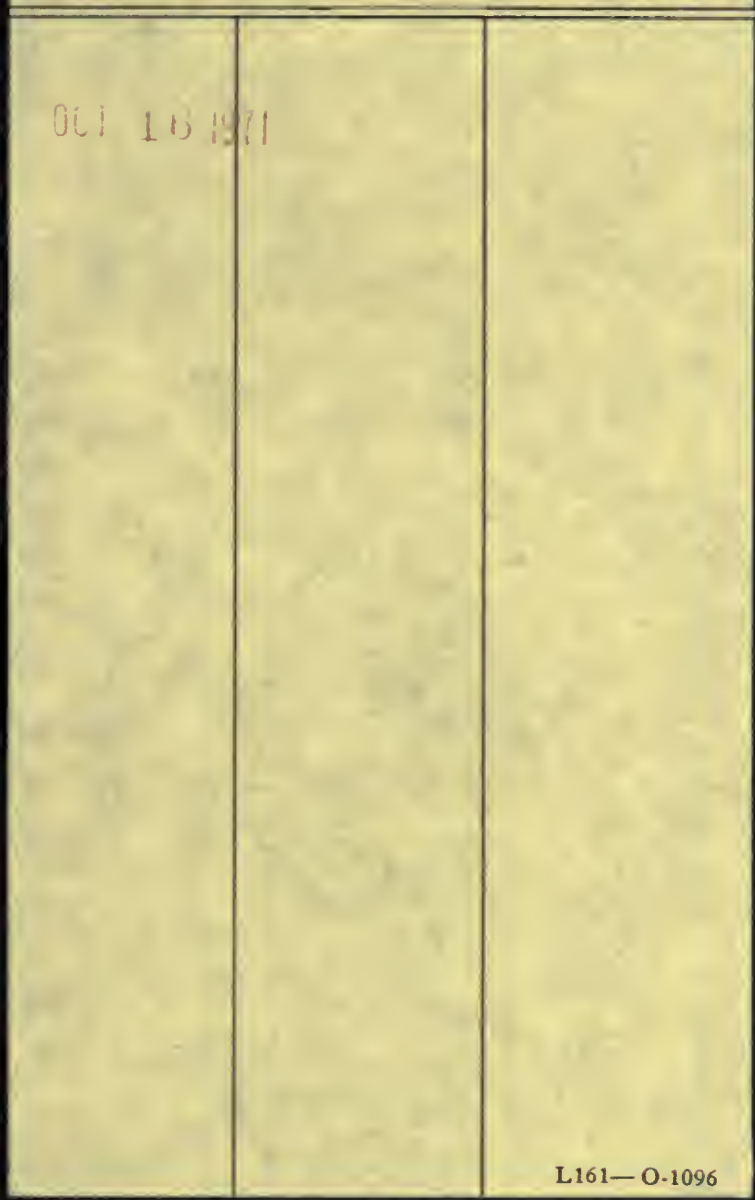





\section{COLLECTION}

DES

\section{AUTEURS LATINS}

AVEC LA TRADUCTION EN FRANCGAIS,

PUBLIEE SOCS LA DIRECTIOX

DE M. NISARD,

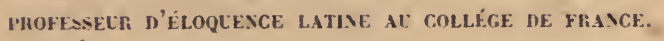





\section{COLLECTION}

\section{DES \\ AUTEURS LATINS}

AVEG LA TRADUCTION EN FRANGAIS,

PUBLIEE SOLS LA DIRECTIOX

DE M. NISARD,

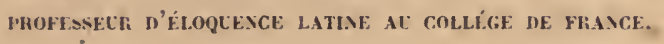


人

cis 20

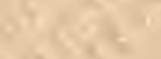

$3 y^{2}$

$33^{3} \times$

$-$

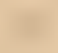

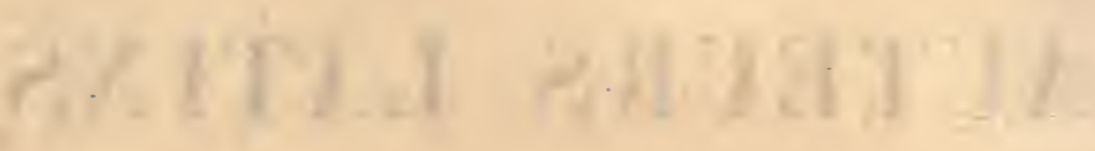
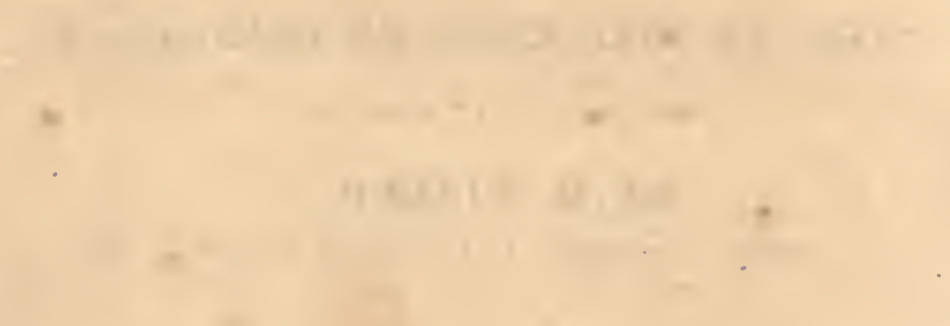

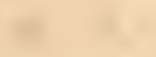

$\sqrt{2}+x^{2}$

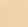




\section{LES}

\section{AGRONOMES LATINS.}





\section{LES}

\section{AGRONOMES LATINS,}

\section{CATON, VARRON, COLUMELLE,}

\section{PALLADIUS,}

AVEC LA TRADUCTION EN FRANÇAIS,

'PUBLIÉS SOUS LA DIRECTION

\section{DE M. NISARD,}

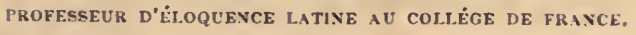

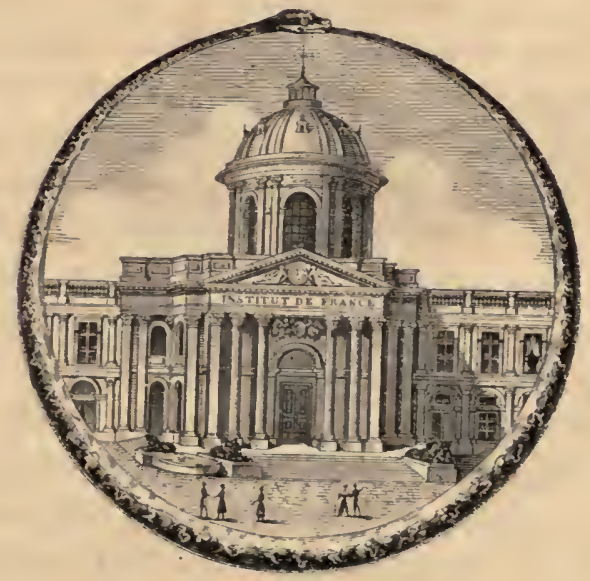

\section{PARIS,}

CIIEZ FIRMIN DIDOT FRERES; LIBRAIRES, MURIMLURS IDE L'INSTITUT UE FRANCE,

RUR JACOH, N 56 .

M DCCC LVI. 



\section{AVERTISSEMENT DES ÉDITEURS.}

Ce volume cst le recueil complet des quatre agronomes latins, Caton, Varron, Columclle, Palladius. Nous n'avons pas cru devoir y joindre le Traité de l'Art vétérinaire de Végèce, moins parce que la matière ne sen rattache pas exclusivement à l'agriculturc, qu'à cause du peu d'estime qu'en font les hommes compétents, ct du mauvais état du texte qui est corrompu en mille endroits, et rempli d'interpolations. L'art vétérinaire moderne trouverait fort peu de lumières dans un ouvrage où l'on devine à grand' peine, à travers les obscurités d'un texte si souvent douteux, quelques notions médicales encore plus imparfaites que les notions anatomiques qui y sont mèlées.

Il n'en est pas de mème des traités d'agronomie, sauf peut-être celui de Palladius qui ajoute trop peu d'observations personnelles à celles qu'il reproduit de Columelle. L'agriculture moderne $\mathbf{y}$ peut trouver d'utiles enseignements. En Italie, Caton, Varron, Columelle, Palladius, sont toujours les classiques de l'agriculture. La plupart des procédés qu'ils indiquent sont encore pratiqués utilement sur le mème sol qu'a sillonné la charrue de Caton. En France, un autre climat, une autre nature de terrain, ont demandé et suggéré d'autres procédés; mais bon nombre des procédés aneiens $\mathbf{y}$ sont et $\mathrm{y}$ seront toujours en usage. Ces procédés forment comme la tradition technique de l'agriculture. On en peut aussi reconnaitre la tradition morale dans les excellentes règles de conduite que contiennent ces traités en ce qui regarde les rapports du maître et des serviteurs, esclaves chez les anciens, chez nous compagnons libres du travail de l'agriculteur. Il y aura toujours profit à suivre cettc double tradition.

C'est à nos agriculteurs que nous adressons cc rccueil. Il en est un grand nombre, l'honncur de notrc société, qui joignent à des connaissances théoriques une pratique intelligente de leur-art, ct qui donnent tout autour d'cux des exemples hienfaisants, dont l'cffet est d'améliorer 
de proche en proche les héritages, et d'ajouter à l'aisance des petits eultivateurs. Ils ne verrout pas sans intérèt, en une infinité d'endroits de ce reeueil, la scienee agronomique latine conseiller ce qu'ils pratiquent, et euscigner ce qu'ils font.

Quant aux lecteurs qui reeherehent dans les ouvrages spéeiaux cette partic des généralités qui en est la philosophie, ou à ceux qu'intéresse plus particulièrement la langue, Caton dans sa brièvetẻ si originale, Varrou dans son exactitude métlodique, Columelle dans son abondanee ingénieuse et souveut poétique, mème quand il n'écrit pas en vers (1), Palladius enfin, quoique plus see, leur offriront un grand nombre de vérités générales exprimécs avee éloquenee, et dans une langue quelquciois égale à celle des grands modèles de la latinité.

I.e texte que nous avous suivi, en nous réservant la liberté d'y faire des clıangements toujours autorisés par les manuscrits, est celui de la collection si justement estimée de Gottlob Schneider.

(1) Le $x^{\text {me }}$ lirre de Cclumelle est en vers. Il y traite des jardins. 


\section{NOTICE SUR CATON.}

Le premier des écrivains latins qui redigea par écrit ses expériences agrononiques fut M. P. Caton, dit Major ou l'Ancien, surnommé aussi Censorius. De tous les ourrages qu'il a publiés, celui qui traite de l'économie rurale est le seul que le tenups ait épargné.

Caton naquit l'an 520 de Rome, 234 avant J. C., d'une famille peu illustre, à Tusculum, aujourd'lıui Frascati, petite ville située à quelques lieues de Rome. Après avoir passé sa première jeunesse à la compagne, il se rendit à Rome, et y fréquenta le barreau. Quoiqu'il ne tînt à aucune famille distinguée, il parvint aux plus grandes dignités de l'État. Il fit plusieurs campagnes dans la seconde guerre punique. Fn 549, il fut adjoint comme questeur au grand Scipion l'Africain, avec lequel il se brouilla, pendant l'exercice de ses fonctions, pour le reste de sa vie. En quittant l'Afrique, il trouva Ennius en Sardaigne; il l'amena à Rome, et reçut de lui les premières leçons de grec. Neuf ans après, il fut consul, fit une campagne glorieuse en Espagne, et obtint l'honneur du triomphe. En 570, il fut censeur; dans l'exereice de cette fonction, il ne montra pas moins de passion que de sévérité. Il mourut en 605 , au moment où éclata la troisième guerre punique. Comme magistrat, comme général d'armée, comme jurisconsulte, comme orateur, Caton acquit une grande considération, que sa justice rigoureuse et l'austérité de ses mœurs contribuaient à augmenter. Il était l'ennemi du luxe et de tous les arts qui amollissent le caractère; mais il ne haissait pas les lettres; il les cultiva au contraire pendant toute sa vie, et ne dédaigna pas d'apprendre le grec à l'âge de trente ans. Sa passion pour le bien public le rendit souvent injuste en politique et irréconciliable dans ses inimitiés. On connaît la haine qu'il portait à la ville de Carthage, dont il ne cessait de demander la destruction.

Caton possédait dans le pays des Sabins un bienfonds qu'il cultivait dans les intervalles de loisir que lui laissaient les affaires de la République. Les expériences qu'il avait recueillies dans ses travaux rustiques furent consignées dans son ouvrage intitulé De Re rustica; mais il ne se donna pas la peine de les rédiger avec métlıode ou en suivant un plan général. Les cent soixante-deux chapitres dont ce recueil est composé, sont autant de recettes, de remarques ou de préceptes, qui ont été mis par écrit à mesure que les travaux des cliamps en fournissaient l'occasion. Ce sont de courtes plirases succinctes, jetées sur le papier sans que l'auteur se soit donné la peine de les orner par des transitions, ou de varier son style, qui n'est ni pur ni élégant.

Les défauts de diction de cet ourrage et la conıparaison qu'on en a faite avec des passages d'autres écrits de Caton, cités par les écrivains postérieurs, ont fait penser à plusieurs critiques que ce recueil n'est pas authentique. Les raisons qu'on donne à l'appui de cette conjecture ne sont pas de nature à prévaloir contre l'opinion commune, qui attribue à ce grand homme un recueil d'observations écrit sans prétention littéraire, et qui est moins un ouvrage ex professo, qu'une espèce de journal qu'il tenait probablement pour l'usage de son fils, de ses fermiers et de ses esclares. 


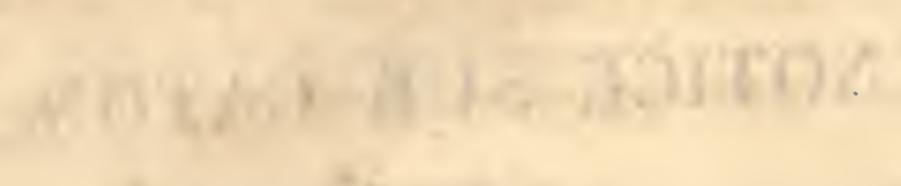




\section{PORCIUS CATON. ÉCONOMIE RURALE.}

Le négoce serait une carrière lucrative, si elle n'était pas si chanceusc; il en serait de même de l'usure, si ce métier était aussi honnête qu'il est avantagcux. Les lois de nos ancétres condamnaient le voleur à l'amende du double, tandis qu'elles imposaient celle du quadruple à l'usuricr. Cette disposition nous montre combien l'usurier étaità leurs yeux un citoyen plus pernicieux que le voleur. Lorsqu'ils voulaient loucr un bon citoyen, ils lui donnaient les titres de bon agriculteur, de bon fcrmier : ces expressions étaient pour eux la dernière limite de la louange. Pour moi, j'estime un négociant actif, désireux d'accroitre sa fortune; mais, comme je l'ai dit, cette carrière est semée d'écucils et de périls. C'est parmi les cultivateurs que naissent les meilleurs citoyens et les soldats les plus courageux; que les bénćfices sont honorables, assurés, et nullement odieux : ceux qui se vouent à la cullụre n'ourdissent point de dangereux projets. Maintenant j'arrive à mon but, et ces réflexions sont les préliminaires de l'ouvrage que j'ai promis.

\section{I. - Aclat et disposition du domaine.}

Lorsque vous vous décidez à faire l'acquisition d'un domaine, gardez-vous de l'acheter à tout prix; n'épargnez pas les visites, et ne vous contentez pas de l'explorer une fois. Plus vous

\section{PORCIUS CaTO.}

\section{DE RE RUSTICA.}

Est interdum prastare mercaturis rem quaerere ni tam periculosum siet; et item foenerari, si tam honestum siet. Majores enim nostri lıoc sic lıabueruut, et ita in legibus posuerunt, furem dupli condemnari, fæneratorem quadrupli. Quanto pejorem civem existimarint fueneratorem, quan furem, hinc licet existimari. Et virum bonum cum laudabant, ita laudabant, bonum agricolam bonumque colonum. Amplissime laudari existimabatur, qui ita laudabatur. Mercatorem autem strenuum studiosumque rei quarendæ existimo; verum ( ut supra dixi) periculosum et calamitosum. At ex agricolis et viri fortissimi et milites strenuissimi gignuntur, maximeque pius quæstus slabilissimusque consequitur, minimeque invidiosus : minimeque male cogitantes sunt, qui in eo studio occupati sunt. Nunc (ut ad rem redeam) quod promisi institutum principium lioc erit.

1. - Quomodo agrum emi pararique oporteat.

Prodium quum parare cogitabis, sic in animo la. cirón. le verrez, plus vous lui trouverez de cliarmes s'il est fertile. Examinez soigneusement les apparences extérieures des voisins; clles sont brillantes dans une bonne contréc. Lorsque vous y entrcz, ménagez-vous les moyens d'en sortir : choisisscz un ciel serein, peu troublé par les tempêtes; que le sol soit excellent, et renferme en luí-même toutes ses qualités. Autant que possible, il sera au pied d'une montagne, il regardera le midi; la situation en sera sainc; il sera entouré d'unc population laborieuse, auprès d'une eau salutaire, non loin d'une ville populeuse, au bord d'une mer ou d'une rivière navigable et renommée. Le domaine sera de ceux qui changent rarement de propriétaires, qu'on vend à regret, et qui possèdent des bâtiments commodes. On recherchera pour prédécesseur un homme qui mettebeaucoup de sagacité dans ses cultures et dans ses constructions. Quand vous ferez vos visites, portez votrc attention sur le nombre des pressoirs et des futailles : s'ils sont en petit nombre, vous pouvez en conclure que le rendement est modique. Regardez moins la quantité que l'arrangement convenable des attirails. Rejetez également la pénuric et le luxe dans le nombre des instruments. Souvenez-vous qu'un champ très-productif, comme un homme prodigue, est ruineux, s'il occasionne un excès de dépense.

beto, uti ne cupide emas, neve opera tua parcas visere, et ne satis lıabeas semel circumire. Quoties ibis, toties ung is placebit, quod bonun erit. Vicini quo pacto niteant, id aninum advertito : in bona regione bene nitere oportelit : et uti eo cum introeas, circumspicias, uti inde exiri possit : uti bonum cælum lıabeat, ne calamitosum siet. Solo bono, sua virtute valeat. Si poleris, sub radice montis siet, in meridem spectet, loco salubri, operariorum copia siet, bonumque aquarium, oppidum validum prope siet, aut mare, ant amıis, qua naves anbulant, aut ria bona, celebrisfue. Siet in is agris, qui non sæpe dominos mı• tant : qui in his agris praedia vendiderint, quos pigeat vendidisse : uti bene adificatum siet. Caveto alienam disciplinan temere contempas. De domino bono colono, bonoque adificatore melius emetur. Ad villam cum renies, videto vasa torcula et dolia multane sient. Ubi ıon erunt, scito pro ratione fructumm esse. Instrumenti ue magui siet, loco bono siet. Viteto quan minini instrumenti, sumptuosusque ager ne siet. Scito iden agrum quod lıominem, quanvis quæstuosus siet, si sumptuosus erit, rclinq̨uere non nultum. Præelium quod primum sict, si me rogabis, sic dicam. De omnibus agris, optimoque loco si emeris jugcra agri centum, vinea est prima, si viıo 
M. P. GATON.

Si vous me demandez quel est le meilleur domalne, je vous répondrai : Sur un domaine de ecut arpents et bien situé, la vigne est la meilleure récolte, si clle est productive : je place ensuite un potager arrosable; au troislème rang, une oseraie; au quatrieme, l'olivier; au cinquième, une prairle; au sixlème, les eéréales ; au seplieme, un taillis; puis un verger, ct enfin une forit de chènes.

\section{II. - Devoirs du chef de famille.}

Arrivé à sa maison de campagne, le premier devoir du propriétaire est de saluer ses pénates; puis le méme jour, s'il en a le loisir, il fait le tour de son domaine; sinon il remet cette besogne au lendemain. Dès qu'il a bien examiné l'etat des cultures, les travanx acherés, et ceux qui ne le sont pas, il fait venir le lendemain son intendant, lui demande ce qui a été fait, ee qui reste à faire; si chaque travail a été fait à temps, ets'il est possible de termincr ce qui est ineomplet : il l'iuterroge sur la quantité de vin, de blé ou d'autres denrées qu'on a récoltées. Une fols ces particularités connues, il fait la supputation des iraraux et des jours. Si le travail ne lui parait pas suffisant, l'intendant chcrche à se faire absoudre en alléguant les maladies des esclaves, leurs désertions, l'inclémence de la température, les corvées publiques. Quand il a fait l'énumération de tous ces contre-temps ct d'autres semblables, repassez le compte en présence de l'intendant. Lorsque le temps a été à la pluie, cherchez combien de jours ont étć pluvieux; rappelez les travaux qu'on peut exécuter alors, le lavage et le goudronnage des futailles, lc balayage des bátiments, la ventilation des grains, la récolte des fumiers et leur stratification, le nettoyage des

multo siet; secundo loco lortus irriguus, tertio salictum, quarto oietum, quinto pratum, sexto campus frumentarius, septimo silva credua, octavo arbustum, nono glandaria silva.

\section{1. - Patris familias officia.}

Pater familias ubi ad villam venil, ubi larem familiarem salutavil, fundum eolem die, si potest, circumeat : si non eo die, at postrilie. Ulí cognovit quomodo fundus cultus sich, operaque qua facta infectaque sient, postridie cjus diei vilicun rocet, roget quid operis siet factun, quid restet. Sal lsne tempori oprera sient confecta, possitne que reliqna slent conficere : el quid factum vini, frumenti, aliarumque rerum omnium. Ubi ea cognovit, rationem inirc oportet operarum, dlerum, si cl opus non apparet. Dicit vilicus sedulo se fecisse, serros non valuisse, tempestates malas furisse, serros aufugisse, opus publlcun effecisse. Ubi cas aliasque causas multas direrit, ad rationem operum rperarumque vilicum revoca. Cum tempestates pluria fuerint, videto quot dies, quave opera per imbrem fieri potuerint, dolia lavari, picari, villam purgari, frumentum traosferri, stercus foras efferri, sterquilinium fieri, semen purgari, funes veleres sarciri, novosque fleri : centones, cuculiones faniliam oportuisse sibi sarcire. Per ferias no- semences, le raccommodage des vieilles coldes et la fabrication des neuves : les gens devaient rajuster leurs capuehes et leurs hardes. Ne fallaitil pas aux jours fériés curer les anciens fossés, paver la voie publique, couper les buissons, bécher le jardin, nettoyer les prairies, tresser les haies, extirper les épines, broyer les grains, enfin nettoyer partout? Si les esclaves ont été malades, pourquoidonner tant denourriture? A près avoir mis beaucoup de calme dans ces informations, on donnera ses ordres pour achever cc qui reste à faire; on fera lc compte de la eaisse, du grain en magasin, de tous les fourrages en provision, des vins, des huiles; on prendra note de ce qui a été vendu, de ce qui a été payé, de ce qui reste à percevoir, de ce qu'il y a encore à vendre. Il recevra les cautions qui sont à présenter : il passera la revue des denrées en provision; s'il juge quelque objet nécessaire pour l'année courantc, il le fäit acheter; s'il y a du superflu, il le fait vendre : il met en location ce qui est à louer; qu'il prescrive (et son ordre doit être confié à ses tablettes) les ouvrages qui seront exécutés à la fcrme, et ccux qui le seront à forfait. Il fera la revue du bétail, afin de constater les ventes à effectuer. Si les prix sunt suffisants, il vendra ee qui lui reste en huilc, vin et froment. Il mettra en vente les bœufs en retour d'âge, les veaux et les agncaux sevrés, la laine, les peaux, les attirails hors de service, la ferraille, les esclaves vieux ou maladifs, enfin tout ce dont il n'a pas besoin. Le maitre de la maison sera marchand plutôt qu'acheteur.

\section{1. - Travaux que le débutant doit faire exécuter sur son domaine.}

\section{Dès son début, le propriétaire s'occupera de}

tuisse fossas veteres tergeri, viam publicam muniri, vepres recidi, liortum fodiri, pratum purgari, virgas vinciri spinas runcari, expinsi far, mundicias fieri. Cum servi ægrotarint, cibaria tanta dari non oportuisse. Ubi lıac cognita æquo animo sient, quæve reliqua opera sient, curare uti perficiantur : rationes putare argentarianı, frumentariam, pabuli causa qua parata sunt; rationem vinariam, oleariam, quid venierit, quid exactum siet, quid reliquum siet, quid siet quod veneat; qux satis accipiunda sient, satis accipiantur. Reliqua quæ sieut, ul compareant. Si quid desit in annum, ati paretur; qux supersint, uti veneant : quxe opus sient locato, locentur : qua opera fieri velit, et qua locare velit, uti imperet, et ea scripta relinquat : pecus consideret. $\Lambda$ uctionem uti faciat. Vendat oleum, si precium liabeat, vinum frumentumque quod supersit. Vendat boves vetulos, armenta delicula, oves deliculas, lanam, pelles, plostrum vetus, ferramenta retera, servum senem, servum morbosum, et si quid aliud supersit, rendat. Patrem familias vendacern, non emacem, esse oportet.

III. - Quomodo agrum in adulescentia conserere (patremfamilias) oporteat.

Prima adolescentia patrem faıniliæ agrum conserere 
planter; mais il réflechira longtemps avant de bâtir. Pour planter, ce n'est pas la réflexion qu'il faut, c'est l'action. Si son domainc est planté, l'agrieulteur pourra songer à bâtir lorsqu'il aura atteint sa trente-sixième année. Bátissez dans de telles proportions que votre domaine soit en rapport avec vos construetions, et vos constructions avec votre domaine. Il faut qu'un pèrc de famille possède de beaux bâtiments d'exploitation, qu'il y réunisse des celliers pour l'huile, pour le vin, des futailles nombreuses, afin qu'il puisse attendre la hausse ; ce qui augmentera sa fortune, et donnera du relief à sa prudence et à sa réputation. Il aura de bons pressoirs, afin que le travail soit bon. De peur qu'elle ne s'altère, l'olive sera pressée immédiatement après la récolte. Songez aux grandes tempêtes qui arrirent tous les ans, et qui ne manquent pas de faire tomber les olives. Si vous faites la réeolte de bonne heure, et que vos ustensiles soient en ordre, vous n'aurez rien à redouter des tempêtes, votre huile sera meilleure et plus verte. Si au contraire l'olive séjourne trop longtemps sur le sol ou sur un plancher, elle pourrit, et ne produit qu'une huile désagréable. Toute espèce d'olive donne une huilc verte ct de bon choix, si on la fabrique à propos. Sur une surfaee de cent ringt arpents plantés d'oliviers, il faut avoir deux assortiments d'ustensiles. Si les arbres sont vigoureux, les rangs serrés et la eulture judicieuse, il faudra trois machines solides et isolées, afin que si les meules venaient à se briser, on puisse en avoir de reehange; chaque machine aura ses lanières dc cuir; on réunira six leviers, douze aiguilles, des câbles particuliers, deux moufles grecques glissant sous des cordes de genêt. On marchera plus vite arec

studiose oportet, ædificare diu cogitare oportet ; conserere cogitare non oportet, sed facere oportet. Ubi setas acces. sit ad annos Xxxm, tum xdificare oporlet, si agrum con. situm habeas. Ita ædifices, ne villa fundum quærat, neve fundus villam. Patrem familiæ villam rusticam bene ædificatam lıabere expedit, cellam oleariam, vinariam, dolia multa, uti lubeat carilatem expectare; et rei et virtuti et glorix erit. Torcularia bona labere oportet ut opus bene effici possit. Olea ubi lecta siet, oleum fiat continuo, ne corrunıpatur. Cogitato quotannis tempestates magnas venire, et oleam dejicere solere. Si cilo sustuleris, et vasa parata crunt, danıni nilıil erit ex tempestate, et oleum viridius et melius fiet. Si in terra et tabulato olea niminm diu erit, putescel, olcum foctidum fiet. Ex quaris olea oleum viridius et bonum fieri polest, si tempori facias. In jugera oleti cxx. vasa biua esse oportet. Si olelum bonum beneque frequens, cultumque erit, trapetos bonos, privos, impares esse uportet : si orbes contriti sient, ut commutare possis; funes loreos privos, vecles senos, fibulas duodenas, nedipontos privos lorens, troclileas sraccanicas binas, quae funibus sparteis ducantur. Orbicnlis superioribus octonis, inferioribus senis citius duces. huit poulies en haut et six en bas; si on raut faire des roues, le travail est moins expéditif, ınais aussi moins pévible.

IV.-Il faut aroir des étahles bien construites, et un bon roisinage.

Ayez de bonnes étables, de bonnes écuries, et des råteliers : les barres de ceux-ci seront dis. tantes d'un pied; avec celte disposition, les bœufs ne gaspilleront point leur nourriture. Ayez des bâtiments de maitre en rapport avec votre fortune. Si votre campagne est assise sur un bon fond, bien construite et orientée; si elle est meublée convenablement, vous la visiterez plus souvent et plus volontiers; elle s'améliorera, on commettra moins de fautes, et on récoltera davantage, ear rien ne remplace l'œil du maître. Soyez affable à l'égard de vos roisins, et n'offensez pas vos gens sans raison. Si vous obtenez l'affection du voisinage, vous écoulerez plus facilement vos produits, et vous trouverez sans peire des bras pour exécuter vos travaux à la journée ou à forfait. Si vous bâtissez, ils vous aideront en payant de leur personne, ou en vous donnant leurs attelages et leurs matériaux. S'il vous arrive quelque chose de fâcheux (ce qu’à Dieu ne plaise !), ils vous prêteront une assistanee bienveillante.

\section{V. - Devoir de l'intendant.}

Voici les devoirs de l'intendant : toute sa conduite sera bien réglée; il observera les jours de fètes, respectera le bien d'autrui et fera respeeter lc sien. Il apaisera les disputes de ses domestiques; si quelqu'un a commis une faute, la punition sera équitablement proportionnée au délit. Il veillera à ce qu'ils soient bien entretenus, qu’ils ne souffrent ni la faim ni la soif, et surtout

Si rotas voles facere, tardius ducentur, sed minore labore.

IV. - Bubilia uti bene ædificata habeantur, et vicinia bona.

Bubilia bona, bonas præsepis, faliscas clatratas. Clatros interesse oportet pede. Si ita feceris, pabulum bores non ejicient. Villam urbanam pro copia adificato. In bono pradio si bene adificaveris, beneque posireris: ruri si recte habita reris, libentius et sæpius renies, fundus melior erit, minus peccabitur, fructi plus capies. Frons occipilio prior est. Vicinis bonus esto. Familiam ne siveris peccare. Si te libenter vicinitas videbit, facilius tua vendes, operas facilius locabis, operarios facilius conduces. Si ædificabis, operis, jumentis, materia adjurabunt. Si quid (bona salule) usus venerit, benigne defendent.

\section{V. - Villici officia. (qualia oportet tiant.)}

Hæc erunt vilici officia. Disciplina bona utalur. Fe. rix serventur. Alieno manum abstineat. Sua servet diligenter. Litibus fanilix, supersedeat. Si quis quid delique. rit, pro noxa bono modo vindicet. Familix male ne sit, ne algeat, ne esuriat; opere hene exerceat : fasiliusmalo et 
ओ̀ ce qu'ils s'abstiennent de mal faire ou de voJer. Le mal ne se fera du'autant qu'il lo voudra bien; ct s'jl l'a permis, le maitre ne laissera pas son indulgence impunie. Qu'il soit reconnaissaut du blen quion lui a fait, afin de stimuier les autres à bien faire. L'intendant sera sédentaire, toujours sobre, ct n'ira pas ailleurs quêter un festin. Qu'il tienne les domestiques en haleine, ct fasse exécuter les ordres du maitre. Qu'il ne se croie pas plus habiic que le proprićtaire; qu'il traite les amis de sa maison comme les siens propres. Quill éconte ceux qu'il lui aura donnés pour conseils. Que ses pratiques religicuses soient confinées dans les carrefours, ou près de son foyer. Qu'il ne prête à personne ni semence, ni aliments, ni grain, ni vin, ni huile. Qu'il soit seulement en relations avec deux ou trois fermes, pour prêter ou pour emprunter ec dont on a besoin; après cela ii n'aura d'affaires avec qui que ce soit. Qu'il compte souvent avec le maitre. Qu'il ne retienne pas contre les conventions ni les ouvriers, ni les journaliers, ni les vignerons. Qu'il n'achète ou ne récolte rien à l'insu du maitrc. Qu'il éloigne les parasites; qu'il ne consulte ni aruspice, ni augure, ni devin, ni astrologue. Qu'il n'épargne pas sur la semence, c'est une mauvaise économic. Qu'il surveille tous les travaux, afin qu'il sache comment ils s'exéeutent; ct que, sans se fatiguer, il paye souvent de sa personne. Ce faisant, il connaitra les dispositions de ses gens, qui n'en seront que plus ardents au travail : il n'aura pas autant de loisir pour se promener, mais sa santé sera plus robuste ct son sommeil plus paisible. Debout lc premier, il se couchera le dernier : auparavant il s'assurera si les portes de la ferme sont closes,

alieno prohibebit. Vilicus si nolet male facere, non faciet. Si passus erit, dominus impune ne sinat esse. Pro beneficio gratiam referat, ut aliis recte facere libeat. Vilicus ne sit ambulator, sobrius siet semper, ad cocnam ne quo eat. Faniliam exerceat : consideret, qux dominus inıperaverit, fiant. Ne plus censeat sapere sc, quam dominum. Amicos domini, cos habeat sibi amicos. Cui jussus siet, auscultet. Rem divinam nisi compitalibus in compito aut in foco ne faciat. Injussu domini credat nemini. Quod lominus crediderit, exigat. Satui semen, cibaria, far, vimun, oleum mutuum dederit nemini. Duas aut tres familias liabeat, unde utenda roget, et quibus det : proterea nemini. Rationem cum domino crebro putet. Operarium, ınercenarium politorem diutius eundem ne liabeat die. Ne quid emisse relit insciente domino, ne quid dominum celavisse velit. Parasitum ne quem habeat. Harıspicenı, angurem, hariolum, chaldeum ne quem consuluisse velit. Segetem ne defrudet : nam id infelix est. Opus rusticum omne curet uti sciat facere, et id faciat sæpe, dum ne lassus fiat. Si fecerit, scibit in mente familix quid siet, et illi animo aequiore facient. Si loc faciet, minus libeloit ambulare, et valebit rectius, et dormibit libentius. Prinus cubitu surgat : postremus cubitum eat. Prius vil. Ian videat clausa uti siet, et uti suo quisque loco cubet, si cliacun est couché à son poste, et si les animaux sont affourragés Il aura le.plus grand soin des boufs, et flattera les bouviers, afin que leurs animaux soient bien tenus: Il tiendra en bon état les eliarrues et les socs. Il ne eonduira ni troupeaux, ni chariots, ni eharrues, sur la terre détrempée; sans cette précaution, les endroits piétinés seront stériies pour trois ans. Les troupeaux et les bœufs reevront régulièrement de la litière; leurs pieds scront nettoyés. Qu'il éloigne la galle des moutons et du gros bétail; que tous les travaux se fassent à propos; car en agriculture tout s'enchaine de telle sorte, qu'un travail retardé retarde tous les autres. Si la litic̀re manque, on prendra des feuilles de chêne, et on les mettra sous les pieds des moutons et des bœufs. Qu'il ait soin d'amasser un bon tas de fumier; qu'il le conserve avec soin; et lorsqu'il le transportera, qu'il l'étende et l'éparpille. L'automne est le moment du transport. C'est à l'automne qu'on découvre les racines des oliviers et qu'on les fume. Qu'il coupe les ramilles de peupiier, d'orme et de chêne; qu'il les entasse pour les donner aux bre. bis avant qu'elles ne soient complétement séchées. Quant au regain et aux herbes de la seconde coupe, elles seront bien sèches, dans le même but. Après les pluies d'automne il sèmera les raves, les fourrages, et les lupins.

vi. - Destination des différentes pièces de terre.

Voici ce qu'il faut observer dans la destination des terres aux différents produits. On réservera au froment les terres riches, aérées, dépouillées d'arbres. Si le sol est souvent couvert de brouillards, il faudra surtout y semer des raves, des radis, du millet, et du sorghs. Le sol

et uti jumenta pabulum labeánt. Boves maxima diligentia curatos habeto. Bubulcis obsequitor, partim, quo libentius boves curent. Aratra vomeresque facito uti bonos labeas. Terram cariosam caveto ne ares, neve plostrum, neve pecus impellas. Si ita non caveris, quo impuleris, triennii fructum amittes. Pecori et bubus diligenter substernatur; nngulac curentur. Scabiem pecori et jumentis caveto. Id ex fame, et si impluit, fieri solet. Opera omnia mature conficias face. Nam res rustica sic est : si unam rem sero feceris, omnia opera sero facies. Stramenta si deerunt, frondem iligneam legito; eam substernito ovibus bubusque. Sterquilinium magnum stıde ut liabeas. Stercus sedulo conserva, cum exportabis, spargito et comminuito. Per autumnum evehito. Circum oleas antumnitate ablaqueato, et stercus addito. Frondem popul. neam, ulmeam, querneam credito, per tempus eam condito, non peraridam, pabulum ovibus. Item fœenun cordum, sicilimenta de prato ea arida condito. Post imbrem autumni rapinam, pabulum, lupinumque serito.

\section{VI. - Quibus locis agrum conseri oporteat.}

Agrum quibus locis conseras, sic observari oportet : Ubi ager crassus, et lietus est sine arboribus, euu agrum frumentarium esse oportet. Idem ager si ncbulosus est, 
qui sera en même temps gras et chaud recevra les olives de conserve, les longues, les salentines, les orchites, les posea, celles de Sergianum, de Colminium, et les blanches. Multipliez surtout celle qu'on s'accorde à regarder comme la plus productive dans cette circonstance. Les espèces sc plantent à une distance de vingt-cinq à trente pieds. On ne troure pas pour une plantation d'olivicrs de meilleure exposition que celle qui est exposée au vent de l'ouest et regarde le soleil.

Si le terrain est plus maigre et plus froid, on y plantera l'olivier Licinius; si vous plantez cette varićté dans une terre grasse et chaude, votre huile scra mauvaise, l'arbre s'épuisera en produisant, et se couvrira d'une mousse roussâtre et parasitc. Sur les lisières des champs et au bord des chemins, plantez des ormes et des peupliers, afin d'avoir des feuillards pour vos troupeaux et vos boufs, et afin d'avoir du bois sous la main lorsque le besoin se présente. Sur les portions humides et longeant les rivières, plantez des cimes de peuplier et des roseaux. Plantez ccux-ci de la manière suivante : avec le tranchant de la houe vous faites des trous dans lesquels vous insérez des stolons de roseaux, à une distance de trois pieds les uns des autres. Plantez-y l'asperge sauvage, d'où naîtront des asperges ordinaires; car le roseau s'associe bien à l'asperge sauvage, parce qu'on le bine, qu'on le brûle, et qu'il donnc de l'ombre à propos. Entourez votre plantation de roseaux d'un rideau de saules grees, qui vous donneront des ligatures pour la vigne.

Voici ce qu'il faut observer dans le choix du terrain des vignobles : dans celui qui est estimé le meilleur pour la vigne, et qui est exposé au soleil, plantez la petitc race d'Aminée, l'Albe

rapa, raplıanos, milium, panicum id maxime seri oportet. In agro crasso, ef calclo olean conbitivam, radium ına joren, Salentinam, orclitem, poseam, Sergianam colninianam, albicerem. Quam earum in his locis optinam dicent esse, eam maxime serito. Hoe genus olex in $\mathbf{x x v}$ aut in $\mathbf{x x x}$ pedes conserito. Ager oleto conserundo, qui in ventum Favonium spectabit, et soli ostentus erit, alius honus nullus erit. Qui agér frigidior et maerior erit, ibi oleam Licinianam seri oportet. Sin in loco crasso aut caldo reveris, hostus nequam erit, el ferundo arbor peribit, et muscus rnber nolestus erit. Circum coronas, et circun vias ulmos serito, et partin populos, uti frondeu ovihus et bubus labeas, et materia, si quae opus sit, parata erit. Sicubi in his locis ripa, aut locus humectus erit, ibi ca. cumina populorum serito et aruudinetım. Id lıoc modo serito : bipalio vortilo, ibi oculos arundinis pedes teruos aliun ab alio serito. Ibi corudam serito, unde asparagi fiant. Nam couvenit arundiuelun cun coruda, co quia foditur, et incenditur, et umbran per tenipus habet. Salicem gracam eireum arundiıetum serito, uli siet qui vineam alliges. Vineam quo in agro couseri oportet, sic observato. Qui locus viun optimus dicelur esse, el osleutus suli, ili double, et le petit gris. Le sol riche, eouvert de brouillards, convientspécialement à la grande race d'Aminée, au murgentin, à l'apicien ct aultiea. nien; les autres vignes, surtout les espèces bătardes, prospèrent partout.

VII. - Lieux où il faut planter les arbustes et les arbris. seaux.

La terre qui est peu éloignée des villes veut être plantće en vergers; le bois ou les ramilles peuvent ou être vendues, ou être réservées pour l'usage du maítre. Voici ce qu'il faut semer daus cc mêne terrain, et quellc espèce de vigne il faut marier aux arbres : c'est le grand et lc petit amineen, et l'apicien. On conserve ces raisins dans des pots noyès au milieu des mares, ou dans. du vin euit, ou dans du moût, ou bien dans de la piquette. Ceux que vous suspendrez seront les raisins à graines fermes, et les gros aminéens. On peut également les sécher au foyer d'un forgeron, aussi bien qu'au soleil. Les fruits seront les pommes de coing, la cognasse des Cantius, les Quirinienres, et d'autres fiuits de garde, telles que les pommes vineuses et les grenades. Pour que ces fruits ne tombent point prématurément, on enfouira au pied des arbres de l'urinc ou du fumier de porc. Les poires seront celles d'Anicius, iet des semailles excellentes confites dans du vin cuit), la tarentine, la vendange et la courge. Plantez aussi et greffez bon nombre d'autres espèces, des olives orchites, ct posiennes, qui sont les meilleures à confire, soit entières dans la saumure, suit meurtries dans l'huile de lentisque. Dès que les orchites seront noires et sèches, saupoudrez-les de sel que vous secouerez cinq jours après; exposez-les au soleil pendant deux jours, ou bien mettez-les dans du vin cuit

Amineum minnseulum, et geminum engeneum, lıelveolum uninusculum conserito. Qui loeus erassus erit, aut netulosior, ibi Amineum majus, aut Murgentinum, Apicium, Lucanum serito. Cxterae vites, miscella maxime, in qucmvis agrum conveniunt.

\section{VII. - Quo in loco arbusta el virga serantur.}

Fundo suburbano arbustum maxime convenit labere, et ligna et virga venire possunt, et domino erit, qui utatur. In coden füudo suum quidquid conseri oporlet, ar. bustoque vitem copulari. Aminnxum misusculum, et majusculum, et Apieium. Ilxe in ollis, olle in vinace is conduntur; eadem in sapa, in musto, in lora recte con. duntur; quas suspendas duracinas, animıteas ınajores, vel ad fabrum ferrarium pro passis ea recte servautur. I'ona, mala struthea, eotouea scantiana, Quirinian, iteun alia conditiva mala mustea, et P'unica, ( eo lotiun suillum ant stercus ad radicem addere oportet, uti stabilia mala fiant, ) Jira rolema, Aniciana, et sementiva, (lixe conditiva in sapa bona erunt,) Tarentina, musten, et eucur. bitina. Item alia genera quamplurima serito, aut inserito. Oleas orchites, posias, eac optime conduntur vel virides 
sans les saler. Lorsque vous voudiez eonserver des cormes, suit par la dessiceation, soit daus une infusion de vin euit, faltes-les bien séeher auparavant : agissez de même pour les polres.

VIII. - Dans quelles tcrres il faut mettre les différentes especes d'oliviers.

Miettez la figue marisque dans un sol crayeux et découvert : mettez au contraire dans une terre riche ou fermée les espèees d'Afrique, de Cadix, de Sagonte, les télanes noires à longs pédoncules. Si vous avez un pré arrosé, vous ne manquerez pas de foin; s'il ne l'est pas, fuınez-le afin d'avoir du foin. Près de la ville, vous aurez des jardins dans tous les styles, toutes sortes d'arbres d'ornement, des oignons de Mégare, le myrte palissadé, soit le noir, soit le blane, le laurier de Delphes, celui de Cypre, celui des forèts, des noix nues, des avelines de Préneste et de Grèce. Un jardin de ville, surtout pour celui qui n'en a polnt d'autre, doit être planté et orné avec tout le soin possible.

IX. - Il faut confier les saussaies aux terrains liunides.

Il eonvient de planter les saules daus les terres aquatiques, humides, ombragées, et près des rivières. Examinez si vous en avez besoin ehez vous, ou si vous les destinez à la vente. Si vous a vez de l'cau, attachez-vous surtout aux prairies arrosées. Si vous n'avez pas d'eau, faites encore des prairies sèehes autant que vous pourrez; c'est le meilleur usage que vous puissiez faire de votre domaine.

in muria, vcl in lentisco contuse. Orchitesubi nigræe erunt et sice $x$, salc confriato dies $v$. postea salem excutito, in solem ponito biduum, rel sine sale in defrutum condito. Sorba in sapa cum vis condere, vel siccare, arida facias item pira eodem modo facias.

\section{vil. - Ficos plurium generum quo loco serere oporteat.}

Ficos mariscas in loco cretoso et apertu serito : Africanas, et Herculanas, Saguntinas, Libernas, Telanas atras pediculo longo, eas in loco crasso, aut stercorato serito. Pratum si irriguum habebis, fuenum non deficiel. Si non es it, siccum, ne fornum desiet, summittitn. Sub urbe hortum onue genus, coronamenta omne genus, bulbos megaricos, nurtum conjugulum et album et nigrum, laurum Delphicam, et Cypricam, et silvaticam, nuces calvas, a vellanas Pranestinas, ct Gracas, lixe facito uti serantur. Fundum urbanum, ef qui cum fundım solım lıabehit, ita paret, itaque conserat, uti quam solertissimum labeat

\section{IX. - Uti salicta locis aquosis serantur.}

Salicta locis aquosis, lumectis, umbrosis, propter au1. nes ibi seri oportet. Et id videto, uti aut domum opus sient, aut ut venire possint. Prata irrigua, si aquan liabebis, potissinum facito : si aquam non habebis, sicca quan plurima facito. Hoc est prodium quod ubi vis expedit Gicere.
X. - Nombre d'aides, de boeufs, d'aincs, de domestiques el d'iustruments dont il faut se pourvoir.

Mobilier et personnel pour deux cent quarante arpents en oliviers : Un intendant, une surveillante, cinc manœuvres, trois bouviers, un porcher, un ânier, un berger; en tout treize personnes. Trois paires de bœufs, trois ânes avec bâts, pour le transport des engrais; un autre âne, cent brebis. Instruments pour l'huile : einq rouleaux montés, une ehaudière de trente quadrantals (28 pintes parisiennes), son couverele, trois erochets en fer, trois vases pour l'eau, deux entonuoirs, une chaudière de cinq quadrantals, son couverele; trois eroehets, une petite cuvette, deux amphores à huile, une urne de cinquante pots, trois écumoires, un seau à puiser de l'ear, un bassin, un pot, un vase à laver les mains, un bassin en écu, un pot à l'eau, un vase à trois becs, un chandelier, un boisseau, trois grands ehars, six araires avec leurs socs, trois jougs avec leurs lanières, six harnais de bœufs, un râ. teau en fer, quatre civières à fumier, six paniers à fumier, trois demi-bâts, trois couvertures pour les ânes. Ustensiles en fer: huit fourehes, huit sarcloirs, quatre pelles, cinq houes, deux râteaux à quatre dents, trois faux à foin, six faux à ehaume, cinq croissants, trois haches, trois coins, un pilon à blé, deux pelles à feu, un fourgon, deux réchauds; cent tonnes pour l'huile, douze bassins, dix tonneaux pour les mares, dix pour les fèves, dix tonnes à vin, vingt pour le froment, une pour les lupins, six cruches à vin, une aiguière, une baignoire,

\section{X. - Quot conservos, quot boves asinosque et ministros atque utensilia habere oporteal.}

Quomodo oletum agri jugerum ccxc. instruere oportet : vilicum, vilicam, operarios $\nabla$. bubulcos 111 . subulcum 1 . asinarium 1. opilionem 1. Sumna lıminum xuı. boves trinos, asinos ornatos clitellarios, qui stercus vectent, 11 . asinum unum, oves c. vasa olearia instructa juga $v$. ahcnum quod capiat quadrantalia $\times x \times$. operculum aheni, uncos fcrreos 11 . urceos aquarios $\mathrm{m}$, infidibula $\mathrm{u}$. ahenuin quod capiat quadrantalia $\nabla$. aheni opcrculum, uncos ul. labellım polulum, amplıoras olearias 11 . urnam quinyuagena. riam unam, trullas 111 . situlum aquarium unum, pelvim unam, matcllionem, trullium, scutriscum, matcllam, nasiternam, candelabrum, sextarium, plostra majora 11. aratra cum vomerilous vi. juga cum loris oriata 111 . ornamcuta bubus vi. irpicem unum, crates stercorarias iv. sirpcas stercorarias 111 . semuncias 111 . instrata asinis 111 . ferraineuta, ferreas viul. sarcula viu. palas Iv. rutra v. rastros quadridentes II. falces foenarias ilı. stramentarias vi. arborarias v. sccures III. cuneos III. fistulam farrariam 1. forpices 11. rutabulum I. foculos 11. dolia olearia c. labra xı. dolia quo vinaceus condat $x$. anurcaria $x$. vinaria $x$. frumentaria xx. lahrun lupinarium uuum, serias vı. Jabrum eluacium unum, solium unum, labra aquaria II. opercula doliis, seriis priva plura, molas asinarias unas, et trusatiles unas, hispanienses uuas, molilia 11. abacum 
deux bassins pour l'eau; des couvercles pour les tonneaux et les futailles; unc paire de meules tournées par les ânes, une paire tournée à bras d'hommes, une paire à l'espagnole; trois colliers, un buffet, deux plats en cuivre, deux tables; trois grands banes, un siége dans la chambre à coucher, trois escabelles, quatre tabourets, deux fauteuils; un lit dans la chambre à coucher, quatre lits de sangle et trois autres lits; un pilon en bois, un pour fouler la laine, un métier à tisserand; quatre pilons, liun pour les féves, l'autre pour le froment, un pour les semences, un pour coneasser les noyaux ; un boisseau, un demi-boisseau; huit matelas, huit couvertures, seize oreillers; dix draps, trois serviettes , six casaques pour les esclaves.

XI. - Dans un autre système, nombre d'ailes et d'ou. vriers qu'il faut mettre à la disposition de l'intendant.

Pour cent arpents de vigne on aura : un intendant, une surveillante, dix ouvriers, un bouvier, un ânier, un homme pour les saules, un berger : en tout, seize personnes; deux bœufs, deux ânes pour les chars, un pour la meule; trois attirails de pressoirs avec leurs agrès; des futailles suffisantes pour recevoir le produit de cinq vendanges, et donnant chacune huit cents mesures; vingt futailles pour les mares, vingt pour le froment; pour chacune delles les couvercles et chaperons nécessaires; six urnes couvertes de genêt, quatre amphores du même genre; deux entonnoirs, trois passoirs à osier, trois passoirs pour arrêter les fleurs; dix vaisseaux pour le moût; deux chars, deux charrues; un joug pour les chars, un joug pour la vigne, un pour les ânes; un disque d'airain ; un collier de meule; une chaudière de la contenance d'un

1. orbes aheneos 11. mensas 11. scamna magna m. scamnum in cubiculo unum, scabilla 11 . sellas IV. solia 1 . Lectum in cubiculo 1. lectcs loris subtentos iv. et lectos tres communes, pilàm ligneam unam, fullonicam unam, telam jogalem unam, rilas duas, pilum fabarium unum, farrearium uuum, seminarium unum, qui nucleos succeruat unum, modium unum, semodium unum, culcitas vıı. instragula vilı. pulvinos xv. operimenta $x$. mappas 11. centones pueris $\mathrm{v}$.

XI. - Alia institutio, quot et quibus conservis alque operis instrui villicum oporteat.

Quomodo vineam jugerum c. instruere oportet : vilicum, vilicam, operarios $\mathrm{x}$. bubul cum 1 . asinarium 1 . salictarium 1. suloulcum I. Summa lommiues xvı. boves 1t. asinos plostrarios 11. asinum molariun I. vasa torcula instructa ıII. dolia $\mathbf{v}$. ubi vindenixe esse possint, culleum Dccc. dolia ubi vinaceos condat, $\mathrm{xx}$. frumentaria $\mathrm{xx}$. opercula dolio. rum, el tectoria priva. Urnas sparteas vi. anıplıoras spar. teas Iv. infidibula 11 . cola vitilia 11 . col a, qui forem demant, tria, urceos mustarios decem. Plostra duo. aratra duo. juga plostraria duo, iugum vinarium 1 . jugum asiuarium 1. orbem aheneum 3 . molile 1. abeneum, quod capit culleum unum. operculum aheni unum, uncos ferreos III. culleus, a vec son couvercle, pour la cuisine; trois crochets en fer; deux vases pour l'eau; unc am. phore à trois anses, un bassin, un pot à l'eau, une aiguière, un seau à puiser l'eau, un rafraichissoir, une écumoire; un chandelier, un vase de nuit; quatre lits, un banc, deux tables, un buffet, un garde-manger, une garde-robe, six grands bancs, une roue à puiser l'eau, un boisseau ferré, un demi-boisseau; une auge à lessive; un détrempoir, une auge à lupins, dix cruches à vin; dix couvertures pour les boufs et les ânes; trois demi-bâts; trois corbeilles pour les lies, trois roues tournées par les ânes, une roue à bras. Ustensiles en fer : six ser. pettes pour la vigne; cinq serpettes pour les ligatures, trois croissants, trois serpes, cinq haches et quatre coins; dix socs en fer, six bèches, quatre houes, deux râteaux à quatre dents, quatre hottes à fumier, un panier pour le même usage ; quarante faueilles pour la vlgne, six croissants pour les frayons; deux réchauds, deux pinces à feu, un fourgon; vingt paniers d'Améria, sept paniers de semeur; quarante baquets, quarante pelles de bois, deux auges; quatre matelas, quatre couvertures, six oreillers, six couvre-pieds; trois serviettes, six casaques d'eselaves.

XIL - Quantité et dénominations des ustensiles porr le pressoir.

Il faudra pour le pressoir cinq séries d'ustensiles; cinq arbres montés, „trois de reehange, cinq treuils, un de rechange; cinq courroies, cinq cordes de retour, cinq cábles, cinq poulies, dix cordes d'attache, cinq leviers et cinq assiettes pour les arbres; trois cuves, quarante blocs, quarante boucles, quarante frettes en bois, pour

alıenum coculum, quod capiat culleum, urceos aquarios II. Amphoram, nasiternam I. pelvim 1. matellionem 1 . trullium 1. situlum aquarium 1. scutriscum, trullaw, candelabrum, matellam, lectos iv. scamnum 1. mensas 11. abacum 1. aream vestiariam 1. armarium promptuarium 1. scamna longa vi. rotam aquariam 1. modium præeferatum 1. semodium 1. labrum eluacrum 1. solium. labrum lupinarium 1. serias $\mathbf{x}$. Ornamenta bobus 11. ornamenta asinis instrata III. semuncias 11 . sportas facarias 111 . molas asinarias unas, trnsatiles unas. Ferramenta, falces vineaticas $\mathbf{v}$. sirpiculas $\mathbf{v}$. falces silvaticas $\mathbf{v}$. arborarias III. secures $v$. et cuneos iv. romeres ferreos $\mathrm{x}$. palas $\mathrm{vi}$. rutra quatuor, rastros quadifdentes 11. crates stercorarias IV. sirpeam stercorarian I. falculas vineaticas $\mathrm{XL}$. falculas 1 uscarias x. Foculos 11. forpices 11. rutabulum, corbulas Amerinas Xx. quala satoria Vur. alveos XL. palas ligneas XL. lintres 11 . culcitasıv. instragula iv. pulvinos vi. operimenta vi. mappas ill. centones pueris vi.

XII. - Quot et quæ in torculari parari vasa oporteat.

In torcularium quae opus sunt vasis quinis. Prela tem. perata v. supervacanea 111 . suculas v. supervacaneaıı $\mathbf{~}$. funes loreos $\mathbf{v}$. subductarios $\mathbf{v}$. medipontos $\mathbf{v}$. troclileas $\mathbf{x}$. capistra $\mathbf{v}$. assercula v. ubi prela sita sient $\mathbf{v}$. serias 
empicher les arbres de se fendre; cinq meules, dix seaux à puiser, dix baquets, dix pelles en bois, einq rables en fer.

XIII. - Disposition du pressoir et du cellier d olires.

A l'époque du pressurage voici ce qu'il faut avoir au pressoir : un vase en cuivre de la contenance de cinq quadrantals; trois croes en fer, un disque d'airain; une paire de meules, un crible, un tamis; une hache, unc cruche à vin, un levier, un lit monté pour les hommes libres faisant l'office de gardiens; un esclave du troisiène degré couchera avec les ouvriers; de vicilles et de neuves corbeilles; une corde de hamac; un oreiller, un cuir, deux lampes grillées, un charnier; unc échelle, des futailles à huile, leurs couvereles; quatorze bassins à huile, deux grandes gondoles, deux petites; trois écumoires d'airain; deux amphores à luilc, un vase pour l'cau, une urne de quarante mesures; un setier pour l'luile, une cuvette; deux entonnoirs, deux éponges; deux pots en terre, un autre de la contenance d'unc urne (quatre conges), trois barres avec leurs clavettes; deux tabourets, une balance, un poids unique de cent livres, une série de divers poids.

\section{XIV. - Clauses à proposer à l'arclitecte pour batir une maison de campagne.}

Si vous faites bâtir à forfait une campagne entièrement neuve, voici les obligations de l'entrepreneur. Conformément au désir, il construira toutes les murailles en moellons unis avec de la chaux, les piliers en pierres solides, les poutres qui sont nécessaires, les seuils, les jambages de porte, les linteaux, les lambourdes, les étais, les

III. rectes $\mathrm{xL}$. fibulas $\mathrm{xt}$. confibulas ligneas, qui arbores comprimat, si disliascent, et cuneos vı. trapetos $v$. cupas minusculas $x$. alreos $x$. palas ligneas $x$. rutra ferrea $v$. XIIl. - Quomodo torcularium et cellam oleariam parare oporteat.

In torcularium in usu quod opus est. Urceum, aheneum 1. quod capiat quadrantalia quimque, uncos ferreos tres, orbeu aheıeum unun, molas unas, cribrum unum, inceruiculum unın, securim unam, scannum unum, seriam vinariam unam, clavam torcularii unam, lectum stratum, ubi duo custodes liberi cuhent, et tertius servus una cum factoribus uti cubet. fiscinas novas veteres. epidromum, pulvinum, corium unum, lucernas craticulas duas, caruarium unum, scalas uñas. In cellaın oleariam hæc opus sunt. Dolia olearia, opercula, labra olearia xiv. conclias majores duas, et minores duas, trullas aheucas tres, amphoras olearias duas, urceun aquarium unım, urnam quinquagenariaın unam, sextarium oleariım unum, labellum unum, infidibula duo, spongias duas, urceos fictiles 11. urnales 11. trullas ligneas dıas, claves cum clostris in cellas duas, trutiuam unam, centumpoudium incertum unum, et poudera certa.

XIV. - Villam adificandam fabro quomodo locaveris.

Villam xdificandam si locabis novam ab solo, faber hece étables d'hiver pour les boufs, les rateliers pour l'été, l'écurie, les chambrettes pour les esclaves, trois garde-mangers, une table ronde, deux chaudières, dix toits à porc, un foyer, une porte cochère et une autre à la disposition du maitrc, les fenêtres, dix barreaux de dix pieds pour les grandes fenêtres et pour les petites, six lucarnes; trois bancs, cinq chaises; deux métiers de tisserand, six carreaux transparents, un petit mortier à piler lc grain, un métier de foulon; les chambranles; deux pressoirs. Le propriétaire fournira les matériaux, les objets nécessaires à la main d'œuvre; il fera tailler et polir, il sera tenu de fournir une scie et un cordeau; cependant il n'est tenu qu'à couper et à travailler les matériaux. C'est l'entrepreneur qui fournit la pierre, la chaux, lc sable, l'eau, la paille, et la terre employée au mortier. Si l'édifice vient à être frappé de la foudre, il faut y prononeer des paroles sacrées. Voici le prix du travail pour un honnête homme qui fournit largement tout ce qui est nécessaire, et qui paye consciencieusement : les pannes occupent deux pieds sur le toit, et on supputera ainsi : celle qui ne sera pas entière, et qui aura été échancrée d'un quart, sera comptée comme une demi. Les faítières seront comptées pour deux pannes; tontes celles qui auront de plus grandes dimensions seront comptées pour quatre. Faites conduire de la chaux et des pierres jusqu'à un pied au-dessus du sol, et ne mettez aux parties latérales, aux chambranles et aux croisées que ce qui est strictement nécessaire. Les autres conditions cousistent à composer toute la bâtisse de moellons unis à la chaux. Le prix des ouvrages énoncés ci-des-

faciat oportet. Parietes omnes (uti jussitur) calce et cementis, pilas ex lapide angulari, tigna omnia quæ opus sunt, limina, postes, jugamenta, asseres, fulmentas, prosepis bubus libernas, et æstivas faliscas, equile, cellas familix, carnaria 111. orbem, alıena 11 . haras x. focum, januam maximam, et alteram quam volet dominus, fene. stras, clatros in fenestras majores, et minores bipedales $x$. lumina vı. scamua 11 . sellas v. telas jogales duas, luminaria vı. paullulam pilam, ubi triticum pinsant, unam, fullonicam unam, antepagmenta, vasa torcula duo. Hæc res materiem, et quæ opus sunt dominus præbebit, etad opus dabit, (succidet, dolabit lineabit secabitque materian duntaxat conductor) lapidem, calcem, arenam, aquan, paleas, terram, unde lutum fiat. Si de cxlo villa tacta siet, de ea re verba divina uti fiant. Huic operi precium ab domino bono, qui bene prabeat quæ opus sunt, et numos fide bona solvat. In tegnlas singulas 11 . in tectum: sic numerabitur tegula : integra qua non erit, unde quarta pars aberit, duæ pro una, conliciares qua erunt, pro binis putabuntur : iu aliis quot erunt, in singulas quaternæ numerabuntur. Villa, lapide calce fundamenta supra terram pede, cateros parietes' ex latere, jugamenta et antepagmenta, quæ opus erunt, indito. Cætera lex uti villa ex calce cementis; pretium in tegulas singulas $\mathrm{N} . \mathbf{5}$. loco salubri bono domino lrxc, quae supra precia posita 
sus s'évalue à un nummus sestertius par panne. La main-d'œuvre se calcule sur ce pied, si l'on bâtit dans un canton salubre et pour un homme de bon accord ; mais tout propriétaire conseiencieux ajoutera un quart en sus s'il fait bâtir dans une contrée malsaine où l'on ne peut travailler pendant l'ćté.

\section{XV. - Manière de construire les murailles.}

Les murs auront cing pieds de hauteur, et seront faits avec des moellons liés avec du sable et de la chaux; la pièce de comble aura un pied d'épaisseur, sur un pied et demi de hauteur, quatorze de longueur, et on devra exiger sur le devis qu'elle soit crépie. S'il exige qu'on donne aux murailles de la campagne cent pieds carrés, c'est-à-dire dix pieds en tout sens, ou une figure ayant cinq pieds d'une face et une perche de vingt pieds de l'autre, il faudra payer dix nummus; et s'il veut une fondation ayant un pied et demi d'épaisseur, il devra fournir par chaque pied de longueur un boisseau de chaux et deux de sable.

XVI. - Conditions à imposer pour la cuisson de la chaux.

Quand on fait cuire la chaux à charge de partage, voici les conditions des deux parties. Le chaufournier monte le four, le chauffe, en retire la chaux et débite le bois; le maître fournit la pierre, lc bois, en un mot tout ce qui est nécessaire.

XVII. - Époque convenable pour l'abattage des bois.

Le temps le plus favorable à la coupe du chêne rouvre, et des essences à échalas, c'est depuis le solstice jusqu'aux frimas. Quant aux essences qui portent du fruit, c'est l'époque de la maturité

sunt. ex signo manupretium erit : pestilenti, ubi rest ate fieri non potest, bono domino pars quarta precii accedat.

XV. - Maceriæ quomodo ædificentur.

Macerias ex calce, cementis, silice, uti dominus omnia ad opus prabeat, altam $\mathbf{P}$. v. facito, et columen P. I. crassam P. I. s. longam P. siv. et uti sublinat locari oportet. Parietes vill $x$ si locet in pedes $\mathrm{G}$. id est, P. X. quoquororsum, libellis in pedes $\mathrm{v}$. et pertican unam $\mathbf{P}$. vic. $\mathbf{N}$. $X$. Sesiuipedalem parietem dominus fundamenta faciat, et ad opus prabeat calcis in 8 . singulos longitudinem opus est wodium unum, arenæ modios duos.

$$
\text { XVI. - Calx quo pacto locetur. }
$$

Calcem partiario coquendan qui dant, ita dant. Perficit, el coquit, et ex fornace calcem eximit calcarius, et ligna conficit ad fornacem. Dominus lapidem, ligna ad foruacen, quod opus siet, prabet.

Xvil. - Materies qul tempore anni tempestiva sit.

Robns, materies item pro ridica, ubi solstitium fuerit ad brumam semper tempestiva est. Quæ materies semen de ceux-ci qui est la meilleure. Les essences qui ne fructifient point sont bonnes à couper lorsque la séve monte. On peut abattre en toute saison les essences qui portent en même temps des fruits verts et des semences mûres : tels sont les cyprès et les pins. En effet, dans ces arbres il y a deux sortes de fruits ; l'un mûr, bon à cueillir et près de tomber, lorsqu'il touche à la fin de la première année : alors il faut couper l'arbre à l'époque des semailles; si l'on attendait plus tard, il faudrait reculer de huit mois. L'autre n'a pas encore un an, et a une couleur verte. Il est avantagcux de couper l'orme quand ses feuilles com. mencent à tomber.

XVIII. - Construction du pressoir.

Si vous voulez construire un pressoir á quatre cuves, que celles-ci soient opposées les unes aux autres, et montées ainsi qu'il suit : Les arbres auront deux pieds d'équarrissage sur neuf de longueur, y compris les mortaises, et les tenons qui les termineront supérieurement, et la portion dc leur pied qui sera engagée dans le patin; ouvrez le logement des aiguilles de trois pieds neuf pouces en hauteur, sur six doigts de largeur; ou vrez une mortaise à un pied et demi du sol; donnez deux pieds à l'entre-jumelles, écartez-les de deux pieds des murs; mettez dix-huit pieds entre ces jumelles et la paire de poteaux qui appartient à ce même pressoir; donnez à chaque poteau deux pieds de diamètre et dix pieds de hauteur, y compris les tenons qui doivent les terminer supérieurement, et la partie qui sera engagée dans le patin. Le treuil doit avoir neuf pieds de longueur, sans compter celle de ses tourillons. L'arbre doit avoir vingt-cinq pieds

habet, cum semen maturum habet, tum tempestiva est. Quæ materies semen non liabet, cum glubet, tum tempestiva est. Ea quæe semen viride et maturum habet, uti senıen de cupresso, de pino, quidvis anni legere possis Item quidris anni matura est, et tempestiva, ibi dum sunt nuces bimæ, inde semen excidet, et anniculæ eæ ubi primum incipiunt liascere, tum legi oportet, per sementim primum incipinnt matura esse. Postea usque adeo sunt plus menses vut. Hornotinæe nuces virides sunt. Ulmus, cum folia cadunt, tum utraque tempestiva est.

\section{XvilI. - Torcularium quomodo æditices.}

Torcularium si ædificare voles, quadrinis rasis uti contra ora sient, ad liunc modum vasa componito: arbores crassas P. Il. altas P. Ix. cum cardinibus, foramina longa P. III. s.二 exculpta digitos v. Ab solo foramen primuin, P. I. s. inter arbores et arbores, et parietes P. 11. in 11 . arbores P. 1. Z- arbores ad stipitem primum directos P. XVr. stipites crassi P. u. alti cum cardinilus $\mathbf{P}$. $\mathbf{X}$. sucula prater cardines $P$. $1 x$. prelum longum $P$. $x x v$. inibi lingulan P. Il. S. pavimentum binis vasis cum caualibus dizobus P. xxxiv, trapetibus locun dextra, sinistra, 
de longucur, y compris la partic engagée entre les jumelles, laguelle aura deux pieds et demi de longueur. Ia surfaec du hangar qu'oecujent deux pressolrs, y compris leurs deux bassins et deux trapètes, aura trente-trois pieds de largeur, prise sur la longueur du hangar; dans cette surface seront pris, entre un pressoir à droite et un à gauehe, vingt pieds pour placer les deux trapetes appartenant à ces dcux pressolrs; entre les poteaux d'un pressoir et ceux du pressoir de la seconde couple qui est sur le même alignement, il faut un espaee de dix.huit pieds pour les charrois. Entro ces derniers poteaux appartenant a la seconde couple des pressoirs et le mur qui est derrière leurs jumelles, il y aura vingt-deux pleds : ainsi lc total de l'emplacement qu'il faut pour loger ces quatre équipages est de soixante-slx pieds de longueur sur trente-six pieds de largeur entre murs. Aux places où vous dresserez vos jumelles, faites de bons fondemens, de einq pieds de profondeur; couvrezen, d'une pierre dure d'un pied et demi d'épaisscur, la superfieie, qui sera de slx pieds et demi de longueur sur deux pieds et demi de largeur. Vous creuserez dans cettc pierre un logement pour les pieds des deux jumelles; établissez done dans ce logement vos deux jumelles. Ce qu'il y restera de vide entre le pied de l'une et celui de l'autre doit être rempli par une pièce de chêne; et s'il s'y trou ve quelque faux joint, on coulera du plomb. Les tenons supérieurs des jumelles auront six doigts de hauteur, et elles seront coiffíes d'un chapeau de chêne. Vous ferez de même (le bons fondements de cinq pieds de profondeur, pour placer les poteaux; vous y poserez sur son lit de carrière, et bien de niveau, une pierre de taille longue de deux pieds et demi, large de deux pieds et demi, et épaisse d'un pied et demi. Sur celte pierre vous poserez un poteau; et sur

pavimentum $\mathbf{P} . \mathrm{xx}$. inter binos stipites vectibus locum $\mathrm{p}$. גrü. Alteris vasis ex adversum ab stipile extremo ad parietem, qui pone arbores est, P. xxı1. Summa torculario, vasis quadriuis longitudine $P_{0} L X Y 1$, latitudine $P_{0} \times x x v 1$ in. ter parietes. Arbores ubi statues, fundanıenta bona facito alta $\mathrm{P} . \mathbf{v}$. inibi lapides silices totum forum longum $\mathrm{P}$. $\mathbf{v}$. latum P. II. 8. crassum P. 1. S. Ibi foramen pedicinis duobus facito. Ibi arbores pedicino in lapide statuito. Inter duas arbores, quod loci supererit, robore ex. pleto, co pluinbum infundito, superiorem jartem arbo. rum digitos sex altam facito siet, eo capitulum robustum indito. Uti siet stipites ubi stendamenta P. v. facit, funto; ibi silicen longum P. I1. 8. latum P. 11. s. crassum r. 11. s. planum statuito, ibi stifútes statuito. Item alterum stipiten statnito. Insuper arbores stipitesque trabem planam imponito, latam P. 11. crassam p. 1. longam P. $\mathbf{x \times \times} \times 1$. rel duplices indito, si solidas non habebis. Sub eas trabes inter canales, et parietes extremos, ubi trapeti stent, trabeculam pedum xxi1]. s. imponito une pierre semblable, et assise de même, vous poserez l'autre poteau de cette paire. Sur les jumelles et les poteaux de chaeun des deux pressoirs, vous poserez une poutre horizontalement, large de deux pieds, grosse d'uu pied et longue de trente-sept pieds, ou deux poutres de cette même longueur et jumellées, si vous n'en avez pas d'assez grosses. Sur ces poutres vous poserez, entre les murs qui terminent la longueur du hangar et le passage des voitures (c'est l'emplacement des trapètes), vous poserez, dis-je, une poutre de vingt-quatro pieds de longueur, ct d'un pled et demi d'équarrissage en une plèce, s'il se peut, slnon en deux pièees jumellées. Sur ces poutres posez des bouts d'autres poutres, qui s'appuieront indireetement, par le moyen du poitrail, sur les jumelles et les poteaux ; ct sur cette charpente élevez une maçonnerie pour en joindre lc poids à celui des bois, et l'augmenter jusqu'à ce qu'il y en ait assez. L'aire de chaque pressoir sera fondée à cinq pleds de profondeur; elle sera ronde, et aura six pieds de diamètre; le bassin, qui sera rond aussi, n'aura que trois pieds de diamètre, et un pied trois quaris de profondeur. Le pavé de la totalité du hangar aura été creusé de deux pieds de profondeur, et le fond en aura été assuré à l'aide de Ia hie; après quoi l'on aura étendu nne couche de demi-pied d'épaisseur en menu ciment, avec chaux et sable, et d'autres couches semblables, jusqu'à ce qu'on ait regagné son premier niveau. Mais pour les aires et les bassins, voici la facon de les paver : lorsque vous aurez bien vivelé et aplani la surface des fondements, couchez une première assise de gravier, sable et chaux, et la battez. Faites une seconde assise pareille, recourrez celle-ci d'une couche épaisse de deux doigts, en ehaux et ciment, de tessons passés au crible; cette couche faite, battez-la, frottez-

sesquipedalem, aut binas pro singulis eo supponito. In iis trabeculis trabes, quie insuper arbores stipiles stant, collocato. In is tignis parietes extruito, jungitoque mate. rix, uti oneris satis liabeat. Aream ubi facies, P. v. fulldamenta alta facito, lata P. rı. aream, et canalem rotun. dam facito latam P. Iv. s. =- Cæterum pavimentum totum fundamenta pedum duorum facito. Fundamenta primum fistucato, postea cementis minutis, et calce are nato semipedem unumquodque corium struito. Pavimen. ta ad lunc modum facito, ubi libraveris, de glarea, et calce arenato primum corlum facito; id pilis subigito, item alterum corium facito. eo calcem cribro succretam indito alte digitos duo. Ibi de testa arida pavimentum struito. Ubi structum crit, pavito, fricatoque oleo, uti pa. vimentum bonum siet. Arbores, stipitesque robustas facito, ant pineas. Si trabes minores facere voles, canales extra columnam expolito. Si ita feceris, trabes pedum x xul. longa opus erunt. Orbem olearium latum pedibus iv. punicauis coagmentis facito, crassum digitos v1. facito, 
Ia et polissez-la à l'huile, ct rous aurez de bonnes aires de pressoirs et de bous bassius. Vous choisircz eutre le chêne ou le pin pour faire vosjumelles et vos poteaux. Si vous voulez vous dispenser d'employer des poutres aussi longues que Ic porte la fixation précédente, entez-les par entailles; et dès lors il suffira d'avoir des poutres de vingtcinq pieds. La table qui couvrira les tas à pressurer aura quatre pieds de diamètre; les pièees en seront jointes et assemblées par clefs à la carthaginoise; elles auront six doigts d'épaisseur, elles seront liées extérieurement par clefs à queue d'aronde de bois d'yeuse, maintenues en place par des chevilles de cornouiller. Elles serout eneore affermies dans leur assemblage par trois barres fixées par des clous de fer. Cette table sera d'orme, ou de cornouiller. Si vous a vez le l'un et de l'autre bois, entremêlez-les.

XIX. - Ustensiles pour la fabrication du vin : poteaux, et leur disposition.

Si ces équipages sont destinés au pressurage du raisin, les jumelles et les poteaux auront deux pieds de liauteur de plus; on terminera les entr'ouvertures des jumelles à un pied au-dessous du chapeau, par un logement ouvert d'un demipied en hauteur comme en largeur, pour recevoir une aiguille particulière. Chaqque tête du treuil sera percée de trois trous de part en part, ce qui produira six orifices pour recevoir les barres; le premier trou sera percé à un demipied du tourillon, les autres seront distribués a vec égalitẻ sur la longueur de la tête. Le croc sera sur le point milieu de la longueur totalc du treuil, et le milieu de l'intervalle qui se trouvera entre les poteaux doit être marqué par ce croc. Pour que l'arbre soit bien établi dans sa juste direction, vous aurez soin, en taillant le pied, de vous jauger fidẻlement sur le milieu de la largeur de l'arbre, à l'effet que ce milieu con-

subscudes iligneas adindito. Eas ubi confixeris, clavis corneis occludito. In eum orbem tris catenas indito. Eas catenas cum orbibus clavis ferreis corrigito. Orbem ex ulmo, aut ex corylo facito. Si utrumque habebis, alternas indito. XIX. - Quot vasa vinaria, quibus stipitibus et qualiter facias.

In vasa rinaria stipites arboresque binis pedibus altiores facito, supra foramina arborum pedem quacque uti absient. Una fibula locum facito semi pedem quoquover. sum. In suculam sena foramina indito. Foramen, quod primum facies, semipedem ab cardine facito, cxetera dividito quam rectissime. Porculum in media sucula facito. Inter arbores medium quod erit, id ad median collibrato, ubi porculım figere oportebit. Uti in medio prelum recte situm siet. Lingulam cum facies, de medio prelo collibrato, ut inter arbores bene conveniat. Digitum pollicem laxamenti facito. Vectes longissimos pedum xvul. secundos peilum xvi. tertios pedum xiv. remissarios pedum xu. alteros pedun $x$. tertios pedun vil. coure précisément arce le milieu de l'entre-jumelle. Vous laisserez un travers de pouce de jeu eutre cette pièce ct les jumelles. Les plus longs leviers dont on puisse faire usage ont dix-huit pieds, les seconds seize, les troisièmes quatorze; ceux dont on use le plus communément sont de douze, de dix, et de lruit pieds seulement.

XX. - Ajustage du pilier pour le pressoir.

Comment il faut ajuster le trapète. Il faut que la petite colonne de fer qui s'élève sur le mi. liaire soit fixée invariablement, et bien verticalement : pour cet effet, enfoncez des coins de bois de saule tout autour, dans la boîte où elle est engagée; gardez-vous d'y couler du plomb, pour l'affermir : si elle vacille, arrachez-la plutôt, et posez-la de nouveau avec des coins de bois de saule, jusqu'à ce que vous soyez parvenu à la rendre stable et bien d'aplomb. Faites les moyeux des meules d'olivier orchite, et assurezles dans la pierre, à laide du plomb que vous conlerez entre la pierre et le bois; ayez soin d'éviter qu'ils ne ballottent : s'ils viennent à vaciller à l'essieu, remboittez les boîtes d'une seule pièce épaisses d'un travers de pouce, et faites cn sorte que les deux orifices de chacune s'effleurent exacternent de chaque côté, et puissent tous deux être fixés par clous, crainte que la boite ne se derauge.

XXI. - Commissure de la cuve avec le pressoir.

Donnez dix pieds de lougueur à l'essieu : qu’il soit de la grosseur que demandent les moyeux des meules : donnez à la partic qui en formera le milieu, et séparera les meules l'une de l'autre, toute-la grosseur que demandera la coloune de fer pour y être reçue : faites daus cette même partie le logement du sommet de la colonne; garnissez-le intérieurement d'une boîte de fer ajus-

XX. - Trapeti columnella quo sil concinnanda modo.

Trapetum quomodo conciunare oporteat. Columellam. ferream, qux in miliario stat, eam rectam stare oportet in medio ad perpendiculum, cuneis salignis rircunfigi oportel bene. Lo plumbun effundere caveto, ne labet columella. Si movebitur, exinito, denuo codem modo facito, ne se moveat. Modiolus in orbis oleaginos ex orchite olea facito, et cos circumplumbalo, caveto ne laxi sient. Si antem labent in cunaun, eo indito tunicas solidas et latas digitım pollicem. Facito lalveam, bifariam habeant, quas figas clavis duplicibus, ne cadant.

\section{XXI. - Cupa trapeti quomodo fabrefiat.}

Cupam facito r. x. tam crassam quam modioli postulabunt, mediam inter orbis quæ conveniat, tan crassam quam colımella ferrea erit. Eam mediam perlundito, uti columellam indere possis. Eo fistulan ferream indito, quas il columellam conveniat, et in cupan. Inter cupau dextra sinistra perfundito kate digilos primoris $\mathbf{~ V .}$ alte digitos. 
tée au diamètre de la eolonne et à celui de l'essieu. Vers le milieu de eet essieu, tant à droite qu'à gauehe, faites des trous larges de quatre pointes de doigts, et profonds de trois; attaehez sous eette piece, qui est suffisamment large dans cette partie, une platine de fer pereée, pour livrer passage d la colonne; garnissez de lames de fer les quatre parois latérales de ehaeun des trous que vous aurez pratiqués de droite et de gauehe dans la face intérieure de l'essieu. Repliez sur cette surface ehaeune de ces quatre lames introluites dans ehaque trou. Sur les parties repliées de toutes les lames insérées dans les trous de droite et de gauche, appliquez-en d'autres plus minees, que vous clouerez ensemble, pour eontenir les premières, dont la destination est d'empécher que les trous ne s'élargissent; quant à la destination de ees trous, elle est de reeevoir les pieds-pendants. Armez les parties de eet essieu qui doîrent être engagées dans les moyeux, chacune de quatro picees de fer en forme de goutières, que vous entaillerez dans le bois de toute leur épaisseur, et percerez dans le milieu, pour les fixer laide de petits elous. Vous pereerez ehaque fuscé de l'essieu à sa sortie de la meule, et en même temps deux des pièces de l'armature pour placer l's, qui s'opposera à ce que la meule ne s'éloigne trop de l'épaulement. Pour assurel mieux ees armatures, embrassez-en les bouts extérieurs au moyen d'une frette du poids d'une livre, et large de six doigts, pereée dessus et dessous au droit du trou de l's; tout cela est néeessaire pour empêcher que l'essieu ne soit mâehé par la pierre. Mettez entre l'épaulement de ehaque fusée et la meule, ainsi qu'entre la meule et l's, des rondelles de fer bien lissées, erainte que cette partie de l'essieu et l's ne soient promptement usées. Le eorps de eet essieu peuit être d'orme ou de hêtre. II en coûtera, pour le fer façonné et posé par le même ouvrier, soixante nummi ; pour le plomb, quatre; pour le salaire de l'ouvrier qui aura ajusté l'essieu et les moyeux dans la pierre, luuit; pour le maitre ouvrier s'entend. Il faut que le même ouvrier ajuste aussi le trapète : la somme totale de la dépense sera de soixante-douze nummi, sans eompter le salaire des aides dont on aura eu besoin.

XXII. - Comment l'ouvrier doit disposer le pressoir.

Voiei à quoi il faut prendre garde, quand on ajuste ees sortes de machines : que le bassin soit bien de niveau; que les meules en roulant soient eonstamment éloignées du rebord d'un travers de petit doigt; qu'elles ne touehent point au champ du bassin, de peur qu'elles ne le meurtrissent : qu'il y ait entre la meule et le miliaire un doigt de jeu; s'il y en a trop, on le revêtira d'une eorde dont la grosseur sera égale à ce qu'il y a de trop au jeu; on roulera eette eorde autour du miliaire, en le serrant fortement, et en pressant le plus qu'on pourra les révolutions de la corde les unes auprès des autres. Si les meules portent sur le ehamp du bassin, rehaussez le miliaire à l'aide de tourtenux de bois percés pour être entilés par la eolonne, et dont l'épaisseur soit telle, que les meules se trouvent suspendues ì la hauteur convenable; de même, pour ajuster les meules relativement aux rayons du bassin, ayez recours aux rondelles de bois ou de fer de diverses épaisseurs, que vous mettrez entre l'épaulement et la meule, ou entre la meule et l's, suivant l'exigenee du eas, à l'effet que les meules suivent exactement leur ehemin, sans trop s'approcher ni s'éearter du rebord ou du miliaire. Une de ees machines a été vendue, aux environs de Suessa, quatre eents nummi et une livre d'huile; il en a coúté soixante nummi pour l'ajuster en place, soixante-deux tant pour le transport qui en a été fait par les bœufs, que pour primoris tres, sub cupa talsulam ferrcam lata cupa media crit, pertusam figito, qux in columellam conveniat. Dextra sinistra foramina ubi feceris, laminis eircnnplectito, replicato in interiorem partem cupx omnis quatuor lamings : dextra sinistra foramina utrinque secus laminas. Sublaminas polulas minutas supponito, eas inter sese configito, ne foranina majora fiant, quo copmla minuscula indentnr. Cupam, qua fini in modiolos erit, utrinque secus imbricibus ferreis quatuor desues, ibi ntrinque secus facito, qui figas. Imbrices medias elavulis figito. Supra imbrices extrinsecus cupam pertundito, qua clavus eat qui orbem eludat. Insuper foramen librarium ferreum digitos sex latum indito, pertusum utrunque secus qua clavus cat. IIae omıia cjus rei causa fiunt, uti ne cupa in lapide con. teratur. Armillas iv. facito, quas eircum orhem indas, ne cupa et chavus conterantur intrinsecus. Cupam materia ulmea aut faginea facito. Ferrum factum, quod opus erit, uti idem faber figat. I1s. Lx. opus sunt, enm plumbun cupau enito ns Iv. cupam gui couciunet, ef modiolos qui indat, et plumbet, operas fabri dunlaxat is. viu. Jdem trapetum onortet accommodet. Summa sumpti Us. Lxxi1. prater adjutores.

\section{XXII. - Quomodo faber trapetum accommodet.}

Trapetum hoc modo accommodare oportet : librator uti statuatur pariter. Ab labris digitum minimum orbem abesse oportet. $\Lambda$ b solo mortarii orbes cavere oportet, ne quil mortarium terant. Inter orbem, et niliarium unum digitum interesse oportet. Si plus intererit, atque orbes nimium aberunt, fumi eirennligato miliarium arete crebro, uti expleas quou nimium interest. Si orbes altiores crunt, atqque nimium mortarimm deorsum teret, orbienlos ligneos pertusos in miliarium, in columellam supponito, eo altitudinem temperato. Eodem modo latitudinem orbjcolis ligneis, aut armillis ferreis temperato, usfuc dum reete temperabitur. Trapetus emptus est in Suessano us. cccc. et olei p. l. conposturm us. Lx. vectura boum, operas sex homines vi. cum bubulcis us. Lxu cupan ol. 
les journées de six hommes, y compris les bouviers. L'essieu tout appareillé a coúté soixantedouze nummi en argent, et vingt-cinq pour l'luile : ainsi le tout se monte à six cent dixneuf nummi. Il en a été vendu une tout appareillée à Pompéi, qui a coûté trois cent quatrevingt-quatre nummi d'achat, et deux cent quatre-vingts pour le transport. Il est toujours indispensable de faire ajuster ces machines chez soi en les y mettant en place, et pour cela il en coûte soixante nummi pour les frais ; ainsi toutes montées elles reviennent à sept cent vingtquatre nummi. Si vous voulez remonter de vieux trapètes avec de moyennes meules, qui n'aient qu'un pied et trois doigts d'épaisseur sur un pied de diamètre, et dont l'ouverture ait un demipied de diamètre de part en part, il faudra, lorsque vous les aurez fâit apporter chez vous, les faire ajuster relativement aux rayons des bassins de vos trapètes. On trouve de ces moyennes meules près des murs de Rufrus, pour cent quatre-vingts nummi, et il en coûte trentc pour les faire ajuster : on les achète le même prix à Pompéi.

\section{XXIII. - Préparatifs pour la vendange.}

Au moment de la vendange, faites toutes les dispositions nécessaires; faites laver les vases, raccommoder les paniers, enduire de poix les fủts et autres ustensiles; pendant les jours pluvicux on préparera et on raccommodera les corbeilles : achetez des charrettes, salez les olives qui se détachent. Coupez les raisins demi-mûrs pour faire du vin précoce, qui servira de boisson aux ouvriers lorsque le moment en sera venu. Distribuez dans les futailles tout le raisin intact et sec que vous aurez coupé chaque jour. Si cela est nécessairc, mettez dans le moût du vin cuit pro-

natam ns. Lxxit. pro oleo ns. xxv. s. s. us. ncxxix. Poinpeiis emptus oruatus us. cccxxciv vectura ns. ccxxc. Dosti melius concinuatur, et accommodatur. Eo sumpti opus est HS. Lx. Sumina IIS. DCcxiv. Si orbes in veteres trapetos parabis medios crassos P. I. digitos 111 . altos P. 1 . foramen semipedem quoquoversum; eos cum advexeris, ex trapeto temperato. Ii emuntur ad Rufri macerias us. cxxc. temperantur Hs. xxx. tantidem Pompeiis emitur.

XXIII. - Quæ ad vindemimam in tempore parari opus sit

Face ad vindemiam, quæ opus sunt, uti parentur, vasa laventur : corbulæ sarciantur : picentur dolia : qux opus sunt, picentur, cum pluet; quala parentur, sarciantur. Far molatur. Menæe emantur. Oleæe caducæ saliantur. Uvas miscellas ad vinum præliganeuın, quod operarii bibant, ubi tempus erit, legito. Succum puriter omnium dierun pariter in dolia dividito. Si opus erit, defrutum indito in mustum, cineris lixivi cocti partem quadragesinam addito defruto, vel salis sesquilibram in culleum. Marmor si indes, in culleum libram indito. Id indito in urnam, misceto cum musto. Id indito in dolium. Resinan si indes', in venant de mère-goutte à la dose d'une partie sur quarante, ou une livre et demie de sel par culléus. Si vous le traitez avec du marbre pulvérisé, n'en mettez qu'unc livre, que vous délayerez préalablement dans une urne avec du moût, et que vous introduirez ensuite dans le fût. Si on y met de la résine, on la pulvérisera soigneusement, ct on l'emploiera à raison de trois livres par cul. léus; on la mettra dans unc clisse en jonc qu'on suspendra dans le tonneau : on l'agitera de temps à autre, pour en hater la dissolution. Du reste, quelle que soit la nature du mélange, vin cuit, craie ou résine, il faut le remuer fréquem. ment pendant vingt jours, et le maintenir continuellement en mouvement. Il faut aussi ajouter dans chaque futaille ct par portions égales Ic vin de second pressurage.

XXIV. - Fabrication du vin grec et du vin de paille.

Recette pour faire du vin grec: Prenez des raisins apicius à leur complète maturité ; mêlez au moût deux quadrantals de vieille eau de mer ou un boisseau de sel. Suspendez-le dans un sac, et le laissez fondre dans le moût. Si vous voulez avoir un vin paillet, prenez moilié de vin apicius et moitié de vin gris, et ajoutez-y un trentième de vin vieux cuit. Règle généralc : dans toute espèce de vin artificiel mettez-y un trentieme de vin cuit.

XXV. - Fabrication du vin cuit.

Lorsque le raisin sera mûr et la vendange arrivée, gardez lc premier pour votre maison et vos gens; ayez soin de ne faire la cueillette que par un temps sec et lorsque le fruit est bien mûr, de peur que le vin ne mente à sa réputation. Étendez tous les jours les mares nouveaux sur un lit de sangle, qui servira de crible; foulez-les

culleum musti P. IIt. bene comminuito, indito in fiscellanı et facito uti in dolio musti pendeat. Eam quassato crehro, uti resina condeliquescat. Si indideris defrutum, aut marmor, aut resinam, dies $\mathbf{x} \hat{\mathbf{x}}$. permisceto crebro, tribulatn quotidie. Tortivum mustum circumcidaneum suo cuique dolio dividito, additoque pariter.

XXIV. - Vinum gracum et helveolum quo fiat modo.

Vinum gracum hoc modo fieri oportet : Uvas Apicias percoctas bene legito. Ubi delegeris, in ejus musti culleun aquæ mariuæ veteris quadrautalia 11 . vel salis puri modium. Eum in fiscella suspendito, sinitoque cum musto distabescat. Si helveolum vinum facere voles, dimidium helveoli, dimidium apicii rini indito, defruti veteris parten trigesimam addito. Quicquid vini defrutabis partem trigesimam defruti addito.

XXV. - Vinum coctum quo tial modo.

Quum vinum coctum erit, el quum legetur, facilo uti servetur familix primum. Sicque facito studeat bene percoctum siccumque legere, ne vinum nomen perdat. Vinaceos quotidie recentes succernito, lecto castibus sub. 
dans des futailles ou dans des euves euduites de poix, couvertes ensuite ermétiquement avee un lut, et pendant l'hiver vous les ferez domuer aux bocufs : ou blen trempez-les dans de l'eau, et dans peu vous en aurez une piquette pour vos eselaves.

\section{XXY. - Mettre les vases en ordre après la vendange.}

Après la vendange mettez en place tous les vases du pressoir, les paniers, les cabas, les câbles, les barres et les aiguilles; faites nettoyer deux fois par jour les futailles remplies. Qu'à chaque tonneau soit affecté un balai pour en frotter l'extérieur. Trente jours après l'entonnage, lorsque les futailles ont rejeté toutes les pellieules, placez les bondes, si vous voulez tirer au clair; c'est iei le moment le plus conveuable.

\section{Xxvil. - Semailles.}

Semez pour la nourriture des bœufs l'ocimum, la vesee, le fenugree, la féverolle, l'ers. Semez ces fourrages d trois reprises différentes. Vous songerez ensuite à la semaille des autres récoltes. En même temps creusez dans une terre reposée des fosses pour les oliviers, les ormes, la vigne, et les figuiers. Si le terrain n'est pas humide, plantez des oliviers pendant la semaille, bourgeounez les jeunes pousses de ceux qui ont été plaités auparavant, et déchaussez les arbres.

XXVıII. - Comment il faut planter l'olivier, la vigne, le figuier et les autres arbres.

Quand vous transplanterez des oliviers, des ormes, des figuiers, des arbres fruitiers, des pins et des cyprés, enlevez-les avec leurs racines et le plus de terre possible, entourez-les de liga-

tento cribrum illito, vel rei parato, eos conculcato in dolia picata, vel in lacum vinarium picatum. Id bene operito, jubeto oblini, quod des bubus per hiemem. Indidem, si roles, lavito paulatim. Erit lorea familiæ, quod bibat.

XXVI. - Quod, vindemia facta, vasa reponantur.

Vindemia facta vasa torcula, corbulas fiscinas, funes, patibula, fibulas jubeto suo quidquid loco condi. Dolia cum rimo bis in die face extergeantur. Privasque scopulas in dolia facito liabeas illi rei, qui labra doliorum circumfrices, ubi erit lectum dies triginta; si bene deacinata eruut dolia, oblinito. Si voles de face demere vinum, tum erit ci rei optinum tempus.

i XXVII. - Sementim, uti facias.

Seinentim facito, ocinum, viciam, foenum Graecum, falam, ervum, pabulum bubus. Alteram, et tertiam pa. buli sationem facito. Deinde alias fruges serito. Scrobis in vervacto oleis, ulmis, vitibus, ficis, simul cum semine serito. Si erit locus siccus, tum oleas per sementim serito, et qua ante satx erunt, teneras tum suppilato, et arbores ablaqueato.

XXVIII. - Oleas, vites, ficos, ceterasque arbores cum seres, quomodo seras.

Oleas, ulmos, ficos, poma, vites, pinos, cupressos cum seres, hene cum radicibus eximito cum terra sua quam inents, afin de pouvoir les transporter. Craignez. surtout de les arracher ou de les transporter lorsqu'il venteou qu’il pleut. Une fois placés dans la fosse, eouvrez-les avee la terre de la surface : couvrez toutes les raeines avec de la terre, que vous foulerez soigneusement sous vos pieds, et qu'enfin vous passerez de votre mieux avee des dames et des battes; vous eouperez la flèehe des arbres qui auront plus de cinq pieds de hauteur, vous placerez à la cicatrice un lut que vous assurerez avee des feuilles.

XXIX. - Répartition du fumier entre les arbres cultivés.

Enfouissez-en la moitié dans la terre destinée aux plantes fourragères; si cette terre est déjà emplantée d'oliviers, déehaussez les pieds et mettez-y de l'engrais; semez vos graines, mettez un quart de fumier sur les oliviers déelraussés, là où ils en auront un pressant besoin, et enterrez-le. Réservez l'autre quart pour les prairies, surtout pour les parties qui sont exposées au vent Favonius; charriez vos engrais lorsqu'il n'y a pas de lune.

XXX. - Des feuillards comme nourriture des bœufs et des moutons.

Donnez à vos bœufs des feuilles d'orme, de peuplier, de chêne, de figuier, autant que vous en aurez. Distribuez au $x$ brebis toutes vos feuilles vertes. Jusqu'à ce que les autres fourrages soient mûrs, distribuez votre fevillage aux brebis dans des pares établis sur les terres que vous devez ensemencer. Si vous réfléchissez combien nos hivers sont longs, vous conserverez autant que possible les fourrages sees amassés pour la froide saison.

plurima, circumligatoque uti ferre possis. In alveo aut in corbula ferri jubetn. Caveto cum rentus siet aut imber, effodias, aut seras. Nam id maxime cavendum est. In scrobe cum pones, summam terran subdito. Postea operito terra radicibus fini, deinde calcato pedibus bene, deinde fistucis rectibusque calcato quamoptime poteris. Id erit ei rei primum. Arbores crassiores digitis $v$. quac erunt, eas praccisas serito, oblinitoque fimo summas, et foliis alligato.

XXIX. - Stercus ad arbores colendas uti dividas.

Stercus dividito sic. Partem dimidiam in segetem, ubi pabulum seras, inrelito. Et si ibi olea erit, simul ablaqueato, stercusque andito. Postea pabulum serito, partem quartam circunı oleas ablaqueatas, qua maxime opus erit, addito, terraque stercus operito. Alteram quartam partem in pratum reservato, idque tum maxime opus erit, ubi favonius flabit. Evehito luna silenti.

XXX. - Quomodo bubus des et ovibus frondem.

Bubus frondem ulmeam, populneam, querneam, ficul. neam, usquedum lıalebis, dato. Ovibus frondem viridem, usquedum liabebis, præbeto. Ubi sementim facturus eris, ihi ores delectato, et frondem usque ad pabula matura dato. Pabulum aridum quod condideris in hieme, quam maxime conservato, cogitatoque liiems quam longa siet. 
XXXI. - Choses nécessaires pour la récolte des olires.

Préparez tout ce qui est nécessaire pour la récolte des olives : les osiers bien aoûtés, des saules coupés en un temps opportun pour tresser les paniers, raccommoder les vieux, et pour faire des aiguilles. Faites enfouir dans les fumiers ou plonger dans les mares les fascines trop sèches d'yeuse, d'orme, de noyer et de figuier, afin de les en tirer au besoin pour faire les aiguilles. Taillez des leviers d'yeuse, d'olivier, de laurier et d'orme, afin qu'ils soient prêts à temps. Le charme noir est le neilleur bois pour les arbres du pressoir. Abattez les trones d'ormes, de pins, de noyers et d'autres espèces au dernier quartier de la lune, après midi, lorsque le vent du sud ne souffle pas. La meilleure époque est celle de la maturité des semences. Il ne faut ni les couper ni les façonner lorsque la pluie vient de tomber. Les essences qui ne fructifient point sont bonmes à couper quand l'écorce se détache. Quand le vent du sud souffle, ne tonchez pas sans nécessité ni aux bois, ni aux vins.

XXXII. - Époque conrenable à l'élagage des arbres.

Commencez de bonne heure la taille des vignes et des arbres. Multipliez la vigne au moyen de tranchées, et autant que possible élevez-la verticalement au-dessus de l'ouverture. Dans lataille des arbres, faites en sorte que les rameaux épargnés s'étalent, qu'ils soient coupés conrenablement et pas trop multipliés, que les sarments soient bien accolés à toutes les branches. Craignez surtout que la vigne ne pende en festons ou ne soit étranglée sur les nœuds; que les sarments soient également répartis sur les arbres et en nombre suffisant : et si vous le jugez nécessaire,

XXXI. - Ad oleam cogendam qux opus sint.

Ad oleam cogendam quæ opus erunt, parentur. Vimina matura, salix per tempus legatur, uti siet unde corbulæ fiant, et veteres sarciantur. Fibulæ unde fiant, arida ilignex, ulmex, nucese, ficulnex, face uli in stercus, aut in aquam conjiciantur. Inde ubi opus erit, fibulas facito. Vectes iligneos, aquifolias, laureos, ulmeos facito, uti sient parati. Prelum de carpino atra potissimum facito; ulmeam, pineam, nuceam, lanc atque aliam materiem omnem cum effodies, luna decrescente, eximito, post meridiem, sine vento austro. Tum erit tempestiva, cum semen suum maturum erit. Caretoque per rorem trahas, aut doles. Qux materies semen non habebit, cum glubet, tempestiva erit. Vento austro caveto, ne quam materiem, neve vinum tractes, nisi necessario.

XXXII. - Uti mature arbores putentur.

Vineas, arboresque mature face ut incipias putare. Vites propages sulcos, sursum vorsum, quo ad ejus facere poteris, vitis facito uti ducas. Arbores hoc modo putentur, rami uti divaricentur, quos relinques, et uti recte credantur, et ne nimium crebri relinquantur. Vites bene nodentur per onines ramos. Diligenter caveto ne vitem pracipites, et ne nimium prastringas. Arbores facito uti bene maritæ sint, détachez-en quelques-uns, mettez-les en terro, et deux ans après vous les sćparerez de la mèresouche.

XXXIII. - Soins à donner à la vigne et à son rajeunis. sement.

Déliez soigneusement la vigne qui aura été bien attachée; et afin que les sarments ne se jet tent point de côté, conduisez-la toujours en ligns: verticale, si rien ne l'empêche; et réservez d'espace en espace des branches à fruit et de réserve. Élancez-la le plus haut possible, liez-la fortement, mais pourtant sans l'étrangler. Voici les soins que vous lui donnerez ensuite. A l'époque des semailles découvrez les racines. Quand elle est taillée, travaillez à la bêche tout le circuit, labourez la terre des intervalles, et promenez-y le soc en long et en large. Plantez les jeunes vignes le plus tôt possible, rabattez les ancien. nes, et taillez.les le moins que vous pourrez : vous ferez mieux néanmoins, si vous en avez besoin, de les coucher en terre, et de séparer de la souche les rejetons qui en proviendront. C'est alors le moment favorable pour tailler les jeunes vigues bien portantes. Si les ceps sont rares dans votre vigne, creusez des fosses, mettez-y du vif, plant que vous aurez soin d'aérer en abattant tout ce qui l'ombragerait, et en le biuant fréquemment. Semez de la dragée dans les vignes au retour d'âge ; si la terre est épuisée, n’y laissez mûrir aucune plante; enfouissez près des souches du fumier, de la paille, des mares, ou tout autre engrais qui en ranime la végétation. Quand la vigne se couvrira de feuilles, épamprez-la. Aux jeunes vignes multipliez les ligatures, afin que les pousses ne se brisent point. Quant à celle

vitesque uti satis multæ asserantur, et sicubi opus erit, de arbore dejiciantur, et in terram deprimantur, et biennio post pracidito releres.

XXXIII. - Vinea quomodo curetur, et vetus renovetur.

Vineam sic facito, uti curetur : Vitem bene enodatam deligato recte, flexuosa uti ne siet, sursum vorsum semper ducito, quoad ejus poteris, vinarios, custodesque recte relinquito. Quam altissimam vineam facito, alligatoque recte, dum ne nimium constringas. Hoc modo eam curato. Capita vitium per senientim ablaqueato. Vineam putatam circumfodilo. Arare incipito, ultro citroque sulcos perpetuos ducito. Vites teneras quamprimum propagato, sic occato, veteres quam minimum castrato; polius, si opus erit, dejicito, biennioque post pracidito. Vitem novellam resecari tum erit tempus, ubi valebit. Si vinea a vite calva erit, sulcos interponito, ibique viviradicem serito, umbram ab sulcis renoveto crebroque fodito. In vinea vetere serito ocimum, si macra erit; quod granum capiat ne serito, et circum capita addito stercus, paleas, vinaceas, aliquid horum, quo rectius valeat. Ubi vinea frondere coperit, panıinato. Vineas novellas alligato crebro, ne canles præfringantur. Et quæ jam in perticam ibit, ejus pampinos teneros alligato leviter, corrigitorne, uti recte 
qui commencera déjà à courir sur la perche, vous lierez légerement ses jeunes bourgeons, vous les redresserez afin qu’ils s'élaneent droits. Quand enfin le raisin se colore, l'elevez les sarments, dépouillez-les de leurs feuilles, dégagez les grappes, et sarelez au pied des souches. Coupez et dénudez les saules à temps opportun, puis vous les mettrez en paquets ; conservez l'écorce, et quand vous en aurcz besoin pour la vigne, faites-la macérer dans l'eau, pour en faire des liens. Vous conserverez également l'osier à panier.

XXXIV. - Exécution des semailles : terrains où on les fait.

Je revieus à la semaille; semez d'abord les terrains froids et marécageux : vous sèmerez ensuite les terres plus sèches. Gardez-vous de remuer une terre boueuse. Le lupin prospère dans un sol ferrugineux, friable, consistant, caillouteux et sablonneux, pourvu qu'il ne soit pas luumido. Semez de préférence le froment épeautre dans un terrain crayeux, uligineux, ferrugineux et humide. Partout où la terre sera sèche, sans mauvaises herbes, découverte, il faudra préférer le froment ordinaire.

XXXV. - Terrains propres aux feves, au seigle et à l'orge.

Semez les féveroles dans les terres compactes, à l'abri des intempéries; le fénugrec et la vesce dans les terres les plus propres; le seigle, le froment, dans les lieux découverts, élevés, exposés à de longues insolations; la lentille dans un sol rocailleux et ferrugineux; l'orge dans les défrichements nouveaux, ou sur un champ indéfiniment productif; les plantes estivales dans

spectent. Ubi ura varia fieri coperit, vites subligato, pampinato, II vasque expellito, circum capita sarito. Salictum suo tempore coedito, glubito, arcteque alligato. Librum conservato, cum opus erit in vinea, ex eo in aquam conjicito, alligato. Vimina unde corbulæe fiant, conservato:

XXXIV. - De sementi faciunda, et quo loco.

Redeo ad scmentim. Ubi quisque locus frigidissimus, aquosissimusque erit, ibi primum serito. In calidissinis locis sementim postremum fieri oportet. Terram cave cariozam tractes. Ager rubricosus et terra pulla, materina, rudecta, arenosa : item qua aquosa non erit, ibi lupinum bonum fiet. In creta, et uligine, et rubrica, et agro qui aquosus erit, semen adoreum potissimum serito; quxe loca sicca et non herbosa erunt, aperta ab umbra, ibi triticum serito.

XXXY. - Quis locis faba, siligo et hordeum seri debeat.

Fabam in locis validis non calamitosis serito. Viciam et fonum Græecum guam minime lıeıbosis locis serito. Siliginem, triticum in loco aperto, celso, ubi sol quam diutissime siet, seri oportet. Lentim in rudecto et rubricoso loco, qui herbosus non siet, scrito. Hordeum qui locus novus erit, aut qui restibilis fieri poterit, serito. Trime- les pièces qui n'ont pu être emblavées assez tot, et qui sont assez fertiles pour ne pas demeurer' improductives. Les navets, les colraves, dans un terrain naturellement riche ou bien fumé.

XXXVI. - Quel est le meilleur fumier pour les céréales.

Répandez la colombine sur les prés, les jardins ou les moissons. Entassez judicieusement le fumier de chèvres, de moutons, de bœufs, et tous les engrais analogues. Répandez ou versez l'amourque au pied des arbres, à la dose d'une amphore 'sur les pieds les plus forts, et d'une urne sur les individus les moins développés, après y avoir ajouté la moitié de son poids d'eau, et après avoir déchaussé modérément les racines.

XXXVII. - Ennemis des céréales.

Ce qui nuit au sol, c'est de le labourer quand il est mouillé, d'y semer du pois chiche qu'on arrache, et qui est salé. L'orge, le fenugrec, l'ers, épuisentla terre, ainsi que toutes les réeoltes qu'on arrache. Ne plantez pas de fruits à noyau dans les terres destinées aux moissons. Le lupin, la fève, la vesce, servent d'engrais. II en est de même des chaumes, des tiges de lunin, des pailles dé céréales, des féverolles, des balles, des feuilles d'yeuses et de chéne. Détruisez dans vos récoltes l'ièble et la ciguë; dans les saussaies, les herbes élevées etles glaīeuls. Comme ces plantes ont une odeur désagréable, faites-en de la litière pour les brebis et les bœufs. Détachez le brou des fruits à noyaux, jetez-le dans un réservoir; ajoutez-y de l'eau, et mélangez exactement le tout ensemble avec un râble. Vous mettez cette pâte, ainsi que les noyaux torréfiés ; au pied desoliviers que vous aurez préalablement

strem quo in loco sementim maturam facere non potueris, et qui locus restibilis crassitudine fieri poterit, seri oportet. Rapinam (et) coles rapicii unde fiant, et raphanum in loco stercorato bene aut in loco crasso serito.

XXXVI. - Quod stercus præstantius ad segetem.

(Quæ segetem stercorant.) Stercus columbinum spargere oportet in pratum, vel in lortum, vel in segetem. Caprinum, ovillum, bubulum, item cxeterum stercus omne sedulo conservato. Amurcam spargas, vel irriges ad arbores, circum capita majora amplıoras, ad minora urnas cum aquæ dimidio addito, ablaqueato prius non alte.

\section{XXXVII. - Quæ mala in segete sint.}

Si cariosam terram tractes, cicer quod vellitur, et quod salsum est, eo malım est. Hordeım, fœnum Græcum, ervum, lıæc omnia segetem exsugunt, et amnia quæ velluntur. Nucleos in segetem me indideris. Qua segeten stercorant fruges, lupinum, faba, vicia. Stercus unde facias, stramenta, lupinum, paleas, fabalia, acus, frondem iligneam, querneam. Ex segete vellito ebulum, cicutam, et circum salicta herbam altam, ulvamque. Eam substernito ovibus, bubusque frondem putidam. Partem de nucleis succernito et in lacum conjicito : eo aquam ad. 
déchaussés. Si vous avez une vigne souffrante, eoupez-en des sarments en tronȩons, que vous enfouirez dans le sillon de la eharrue ou dans une tranchée. Travaux à faire pendant les veillées d'hiver. Façonnez en pieux et en échalas les bois que vous aurez mis à couvert pour les faire séeher; liez les fagots; sortez les fumiers. Ne touchez pas au bois tant que la lune n'est pas visible, ou qu'elle n'est pas arrivée à sa dernière phase. La meilleure époque pour couper et déraeiner les arbres, e'est pendant les sept jours qui suivent la pleine lune. Attachez-vous principalement à ne couper, à ne charpenter, et même, autant que possible, à ne pas toucher de bois qui soit humide, gelé ou couvert de rosée. Sarclez et binez deux fois le froment, hersez l'a. voine. Les branches provenant de la taille de la vigne et des arbres seront rassemblées et tressées en panier; le bois de figuier sera mis au feu; et on mettra les autres bois en monceaux pour l'usage du propriétaire.

\section{XXXVIII. - Four à chaux.}

Donnez au four à chaux dix pieds de largeur, vingt pieds de hauteur, et diminuez la largeur jusqu'au sommet, qui ne doit avoir que trois pieds. Si vous n'avez qu'un seul foyer, ménagez à l'intérieur un espace suffisant pour contenir la ecndre, afin de n'être pas contraint de la tirer au-dehors; mettez beaucoup de șoin à cette construetion; donnez au mur d'appui des dimensions assez grandes pour embrasser tout le contour de la partie inférieure. Si vous avez deux foyers, le cendrierdevient superflu. Si on a besoin d'enlever de la cendre, on fait le feudans un foyer, pendant qu'on décharge l'autre. Chauffez sans cesse,

dito, permisceto rutro bene. Inde lutum circum oleas ablaqueatas addito, nucleos combustos item addito. Vitis si macra erit, sarmenta sua concidito minute, et ibidem inarato, ant infodito. Per hiemem lucubratione hæc facito. Ridicas et palos quos pridie in tecto posueras, siccos dolato, faculas facito, stercus egerito, nisi intermestri, lunaque dimidiata. Tum ne tangas materiem, quam effodies aut præeciles abs terra : diebus septem proximis, quibus luna plena fuerit, optime eximetur. Omnino caveto, ne quam materiam doles, neu crdas, neu tangas si potes, nisi siccam, neu gelidam, neu rorulentam. Frumenta face bis sarias runcesque, arenamque distringas. De vinea et arloribus putatis sarmenta degere, et fascinam face, et vitis, et ligna in caminum ficulna, et codicillos domino in acervum comjoneto.

$$
\text { XXXVIII. - De fornace calcaria . }
$$

Fornacem calcariam pedes latam $\mathrm{x}$. facito, altam pedes $\mathrm{xx}$. usque ad pedes 111 . summam latam redigito. Si uno præfuruio coques, lacunam intus magnam facito, uti satis siet, ubi cinerem concipiat, ne foras sit educendus. Fornaccmque bene struito. Facito fortax totam fornacen infimam complectatur. Si duobus prafurniis coques, lacuna niliil opus erit. Cum cinerc eruto opus erit, altero pric. et entretenez le feu pendant la nuit et à toute heure. Ne chargez la fournaise que de bommes pierres, très-blanches, et sans marbrures. Lorsquevous ereuserez le four, faitesl'ouverture verticale. Une fois le déblai fini, disposez l'emplacement du four dans la région la plus basse et la moins exposée aux vents. Si votre four est peu élevé, ménagez une assise pour l'exhausser avec des briques, ou des moellons que vous relierez extérieurement avec du mortier. Quand le feu sera introduit, si la flamme s’échappe ailleur's qu'au eratère par quelque fissure, vous fermerez le passage avee du mortier. Prenez bien garde que le vent ne s'engouffre daus le foyer. Abritez-vous surtout contre le vent du midi. La ealcination des fragments voisins du cratère vous amnoncera que toute la masse est caleinée : alors aussi les pierres inférieures s'affâissent, et la flamme ne sort plus avec des tourbillons de fumée. Si vous ne trouvez pas de débouché pour vos bois et vos bourrées, et que vous n'ayez pas non plus de pierres à chaux, convertissez vos bois en charbons, et brûlez sur vos champs les broussailles et les sarments auxquels vous ne trouverez pas d'emploi. La combustion terminée, semez des pavots.

XXXIX. - Travaux à faire pendant le mauvais temps.

Lorsque les temps seront mauvais, et le travail des champs impossible, amoncelez les engrais sur le tas à fumier. Nettoyez les étables, les bergeries, la basse-cour et toute la ferme. Entourez les futailles de cereles en plomb, en bois de chêne, ou avec des tresses de sarments. Vous pourrez vous servir de toute espèce de vaisselle vinaire, si vous avez soin de la raceom-

furnio eruito, in altero ignis erit. Ignem caveto ne intermittas, quin semper siet, neve noctu, neve ullo temporé intermittatur, caveto. Lapidem bonum in fornacem quam candissimum, quam minime varium indito. Cum fornacem facies, fauces procipites deorsum facito. Ubi satis foderis, tum fornaci locum facito, uti quam altissima et quam minime ventesa siet. Si parum altam fornacem liabebis, ubi facies, lateribus summam struito, aut cementis cun luto summam extrinsecus oblinito. Cum ignem subdideris, si qua flamma exibit, nisi per orben summum, luto oblinito. Ventus ad profurnium caveto ne accedat. Inibi austrum caveto maxime. Hoc signi erit, ubi calx cocta erit, summos lapides coctos esse oportebit. Item infimi lapides cocti cadent, et flamma minus fumosa exibit. Si ligna et virgas uon poteris vendere, neque lapidem habebis unde calcem coquas, de lignis carbones coquito, virgas et sarmenta, quæ tilıi usioni supererunt, in segete comburito. Ubi eas combusseris, ibi papaver serito.

XXXIX. - Quid confici per tempestatem debeat.

Uhi tempestates male erunt, cum opus fieri non poterit, stercus in sterquilinium egerito. Bubile, ovile, cortem, villam bene purgato. Dolia plumbo vincito, vel materie quernea, viti sicca alligato. Si bene sarseris, aut beno 
moder, de la cercler, de fermer les fentes avec du lut, de les enduire exactement avec de la poix. Voicl la formule du lut pour les tonneaux : une livre de cire, une de résine, et deux fois molns de soufre. On dispose toutes ces substanees dans un vase nouveau, on y ajoute du gypse pulvérisé, et on amalgame le tout jusqu'à eonsistance d'un platre pour raecommoder les futailles. Dès que vous aurez appliqué le lut, prenez deux partics de eraic brute et une de chaux, faites un mélange que vous moulcrez en forme de petites briques, que vous cuircz au four, ct qui, après a voir été pulvérisées, seront appliquées sur le lut, pour en masquer la couleur. Pcndant la pluie cherchez quels travaux restent à fałre dans l'inté. rieur; curez les réservoirs, plutôt que de de. meurer inoccupé: songcz que l'oisircté n'arrête pas le eours des dépenses.

\section{XL. - Travaux dı printemps.}

Creusez les tranchées ct les sillons des pépinières. Changez de place les plants de vigne : provignez les vignes; plantez dans les lieux fertiles et humides des ormes, des figuiers, des arbres fruitiers, des oliviers. Après midi, quand le vent du sud ne souffle pas et qu'il n'y a point de lune, greffez les figuiers, les oliviers, les poiriers, les pommiers et les vignes. Greffez de la manière suivante les oliviers, les figuiers, les poiriers et les pommiers. Coupez le scion par une section un peu oblique, afin que l'eau trouve un ćcoulement. Quand vous le coupez, prenez bien gäde de léser le liber. Munissez-vous d'un bâton de bols dur et bien effilé, ainsi que d'osier grec fendu en deux, prenez encore de l'argile ou de la eraic, un peu de sable et de la

alligareris, et in rimas medicamentum indideris, beneque picaveris, quodvis dolium vinarium facere poteris. Mediramentum in dolium hoc modo facito : Ceræ 1. I. resinæ p. 1. sulfuris $p_{\text {? }} \because$. Hac omnia in calicem novum indito. Eo addito gypsum contritum, uti crassitudo fiat quasi $\mathrm{em}$. plastrum, eo dolia sarcito. Ubi sarseris, qui colorem cundeun facias, creta crudx partes duas, caleis tertia commisceto : inde laterculos facito, coguito in fornacem, tum conterito, idque inducito. Per imbrem in villam quæerito quid fieri possit. Ne cessetur, munditias facito. Cogifato, si niltil fiet, nihilo minus sumtum futurum.

XL. - Quid veris tempore fiat.

Per ver lixe fieri oportet. Sulcos et serobes fieri seminariis. Vitiariis locum verti. Vites propagari. In locis cras. sis et humectis ulmos, ficos, poma, oleas seri oportet. Ficos, oleas, mala, pira, vites inseri oportet luna silenti post meridiem, sine vento austro. Oleas, ficos, pira, mala hoc modo inserito: Quenı ramum insiturus cris, praridito, inclinato aliquantum, ut aqua defluat. Cum praceides, caveto ne librum convellas. Sunito tibi sureulum durum, eun pracacuito, salicem grxecam discindito. Argillam, vel cretam coaddito, arenac paululum, et fimum bubulum. Hac una hepe condepsito, quam maxime uti lentum fiat. fiente de bêtes à cornes. Pétrisser le tout jusqu'à consistance gluante. Prenez l'osier fendu, roulez-le sur la souche coupée, afin que l'éeoree ne se lacère point. Ccla fait, vous insérerez le bâtolı sec et effilé jusqu'à la profondeur de deux pouces entre l'écorce et le bois : saisissant le scion de l'arbre que vous voulez propager, vous lui faites obliquement une cntaille de deux pouces, vous retirez le baton sec que vous aviez enfoncé, ct vous insérez à sa place la branche que vous vouIcz greffer. Appliquez l'écorce eontre l'éeoree, et enfoncez jusqu'à la partie où commence l'entaille. Opérez de même pour une seconde, une troisième, une quatrième, ou pour tel nombre de greffes que vous voudrez multiplier. Serrez plus fortement la branche avec l'osier grec, enduisez la tige avec lo lut que vous avez pétri jusqu'à l'épaisseur de trois bons doigts : couvrez le tout d'une étoffe spongieuse que vous liez autour de l'ćcorce, afin qu'elle ne tombe point. Entourez le sujet de paille bien ficelée, afin que la gelée ne puisse lui nuire.

XLI. - Manière de greffer la vigne, le poirier et le pommier.

La vigne se greffe au printemps ou pendant la fleur; cette dernière époque est la plus favorable. On greffe les poiriers et les pommiers au printemps, pendant einquante jours, au solstice et à la vendange; la greffe de l'olivier et du figuier se pratique au printemps. Voici comment on greffe la vigne : coupez la tige que vous voulez greffer, et fendez-la par le milieu de la eavité médullaire; insérez dans la fente les scions que vous aurez taillés en biset, en appliquant moelle contre moelle. Il y a encore unc autre méthode.

Capito tibi scissam salicem, ea stirpem pracisum cireumligato, ne liber frangatur. Ubi id feceris, surculum ari. dum præacutum inter librum et stirpem artito primores digitos duos. Postea capito tibi sureulum, quod genus inserere voles, cum prinorem præacuito obliquum primores digitos duos. Surculum aridum quem artiveras eximito, eo artito surculum, quem inserere voles. Librum ad librum vorsum facito, artito usque adeo quo proacue. ris. Ideın alterum surculum, tertium, quartum facito. Quot gencra voles, tot indito. Salicem graceam amplius circumligato, luto depsto stirpem ohlinito, digitos cras. sum III. Insuper lingua bubula obtegito, si pluat, ne aqua in librum permanet. Eam linguam insuper librum alligato ne eadat. Postea stramentis circundato, alligatoque, ne gelus noceat.

XLI. - Vitis insitio, pirorumque et malorum, quali modo tiat.

Vitis insitio una est per ver, altera est cum uva florot, ea optima est. Pirorum ac malorum insitio per ver, et per solstitium dies quinquaginta, et per vindemiam. Olea et ficor.um insitio est per ver. Vitem sie inserito. Proceidito quam inseres. Eam mediam diffindito per medullam. Eo surculos præacutos artito, quos inseres, medullam $\mathrm{cmm}$ 
Si les deux eeps sont contigus, on prend de chacun une jeune branche qu'on taille obliquement, et qu'on ticut collées l'une contre l'autre avec une lanière d'écorce. Troisième méthode. Perforez avee une tarière la souche que vous voulez y greffer; insérez dans la cavité deux scions de l'espèce que vous voulez multiplier, après les a voir taillés obliquement jusqu'à la moelle. Faites en sorte qué les moelles soient en contact, et qu'en les enfonçant les faces obliques des scions coinncident l'une sur l'autre dans lc trou qui a ité perforé. Donwz à chaque scion une longueur de deux pieds, couchez-les daus la terre, relevezen l'extrémité vers la souche, en les maintenant dans cette position au moyen de crossettes fixées au milieu de leur longueur, et en les courrant de terre. Enduisez toutes les parties de lut bien pétri , liez-les et les recouvrez comme pour les oliviers.

XLII. - Autre manière de greffer l'olivier et le figuier.

Enlevez avec l'écussonnier l'écorce du figuier ou de l'olivier sur lequel vous vous proposez de grefier. Enlevez parcillement un morceau d'écorce avec un œil à l'arbre que vous voulez propager; mettez à la place du premier celui que vous a vez enlevé en dernier lieu, et faites qu'il recouvre parfaitement la portion dénudée, qui devra avoir trois doigts et demi de long sur trois de large; enduisez-le de lut, ct couvrez comme pour les autres greffes.

XLIII. - Plantation de la vigne el de l'olivier.

Dans les terrains aquatiques, il faudra crcuser des fossés trapézoïdes, larges de trois pieds de gueulc, profonds de quatre pieds; le fond n'aura de largeur qu'un pied et une palme. Vous les

medulla componito. Altera insitio est : Si vitis vitem con. tinget, vilem utrinque teneram pracacuito oblique, inter sese medullam cum medulla libro colligato. Tertia insitio est : Terebra vitem quam inseres, jertundito, co duos surculos vitigineos, quod genus esse voles, insectos obliquos artito ad medullam. Facito is medullam cum medulla conjungas, artitoque ea qua terebraveris, alterum ex allera parle. Eos surculos facito sint longi pedes bimos: cos in terram dimiltito, replicaloque ad vitis caput, medias vitis vinclis in terran defigito, terraque operito. Hac omnia luto depsto oblinito, alligato, integitoque ad eundem inodum, tanquam oleas.

XLII. - Ficorum el olearum insitio alio modo.

Ficos et oleas altero modo. Quod genus aut ficum, aut oleam esse voles, inde librum scalpro eximito, alterum librum cum gemma de eo fieo, quod genus esse roles, eximito; apponito in eum locum, unde execaveris in alterum genus; facitonue uti conveniat. Librum longun facito digitos III.s. latum digitos tres. Ad eundem modum oblinito, integito, uti cætera.

XLIII. - Viles et oltæ quomodo infodiantur.

Sulcos, si locus aquosus erit, alveatos esse oportet la. combleiez. avec des pierrailles, et si vous n'avez pas de pierres, avec des perches de saules placées lougitudinalement et transversalement par lits alternatifs; ou bien, à défaut de perches, avec des fagots de sarment. Vous ferez ensuite des tranchées de trois pieds de gueule, de quatre pieds de profondeur, et dirigées de telle sorte que l'eau s'en écoule dans les fossés : c'est là qu'on plante l'olivier. Aux tranchées et aux fosses pour les vignes on ne donnera pas moins de deux pieds et demi en tout sens. Si l'on veut que la vigne et l'olivier prennent un développement rapide, il faut bêcher unc fois par mois les tranchées où on les aura plantés, ainsi qu'autour des pieds d'oliviers, jusqu'à ce qu'ils soient arrivés à l'âge de trois ans. Adoptez aussi cette pratique pour les autres arbres.

XLIV. - Époque de l'élagage de l'olivier.

Commencez la taille des oliviers quinze jours avant l'équinoxe du printemps; on pourra encore tailler avantageusement quarante-cinq jours après cette époque. Voici la manière de procéder, si le sol est fertile : retranchez les rameaux secs et tous ceux que le vent aura brisés. Si la terre est ingrate, coupez des branches vives, labourez, élaguez, afin de décharger les souches.

\section{XLV. - Longueur des boutures d'olirier.}

Donnez trois pieds de long aux boutures d'olivier destinées à être plantées dans des fossés, et, en les coupant et les habillant, jrenez bien garde d'offenser l'écorce. Ne donnez qu'un pied de long à celles que vous mettrez en pépinière, et plantez-les de cette manière. Le terrain devra être meuble, rcmué avec le bident et bien

tos summos pedes 111. altos pedes iv. infimum latum pe dem unum, el palmum, eos lapide consternito. Si lapis non erit, perticis saligneis viridibus controversis collatis consternito : si pertica non erit, sarmentis colligatis. Postea scrobes facilo altos P. III. S. latos pedes IV. et facilo de scrobe aqua in sulcum defluat, ita oleas serito. Vitibus sulcos el propagines, ne minus pedibus 11. s. quoquoversus facilo. Si voles rinea cito creseat, et olea quam severis, semel in mense sulcos sarrito, et circum capita oleagina quot mensibus usque donec trima erunt, fodere oportet. Eodem modo cieteras arbores procurato.

XLIV. - Olivetum quo tempore putetur.

Olivetum diebus $\mathrm{xv}$, ante squinoctium vernum incipito putare. Ex eo die dies XLv. recte putabis. Id lioc modo putato. Qua locus recte ferax erit, quæ arida erunt, et siquid ventus interfregerit, ea omnia eximilo. Qua locus ferax non erit, id plus concidito, aratoque. Bene enoda. to, stirpesque leveis facilo.

XLV. - Quantam taleam oleaginam decidas.

Taleas oleaginas, quas in scrobe saturus eris, tripedaneas decidito, diligenterque tractato, ne libcr iaboret, cum dolabis aut secabis. Quas in seminario salurus eris, 
nivelé. Pour planter la bouture, on l'enfoneera a vec le pied. Si elle ne deseend pas assez profondément, il faut la faire entrer de foree avee un maillet ou la tête de la houe, en faisant attention de ne pas déehirer l'éeoree. Ne faites jamais de trou avee un pied pour y placer la bouture : en plantant ainsi, le seion reprendra mieux, si on le place dans la position qu'il avait sur l'arbre. Les boutures sont assez fortes à la troisième année, lorsque leur éeoree eommenee $\dot{a}$ changer. Soit que l'on transplante dans des fossés ou dans des sillons, il faut mettre trols boutures à la fois, en les distaneant quelque peu. Il ne eonvient pas que les seions aient plus de trois pouees ou de trois yeux hors de terre.

\section{XLVI. - Formation de la pépinière.}

Choisissez le terrain le mieux composé, le plus déeouvert et le plus abondamment fumé, dont la nature se rapproche de eelledu sol où lesplantsseront transportés, et qui ne soit pas éloigué de celui-ei. Cultivez-le au bident, épierrez-le, entourezle debonnes elótures; plantez en lignes de tellesorte que les boutures soient espaećes d'un pied et demi en tout sens; enfoneez les boutures avee le pied; si vous ne pouvez le faire pénétrer assez, aidezvous du maillet ou de la tête du bident. Disposez vos plants de manière qu'ils ne sortent de terre que de la hauteur du doigt. Couvrez de fiente de vache la section supérieure de la bouture; placez une marque à ehaque pied ; sarelez fréquemment, si vous voulez aetiver la végétation. Suivez le même procédé pour les autres semailles.

pedalis facito, cas sic iuserito. Locus bipalio subactus siet, beneque terra tenera siet beneque glutus siel. Cum taleam demiltes, pede taleam opprimito. Si parum descenlet, malleolo aut mateola adigilo, caretoque ne libtum scindas cum adiges. Palo prius locum ne feceris, quo ta. leam demittas : si ita severis uti stet talea melius vivet. Talex ubi trima sunt, tum denique matura sunt, ubi liber sese rertet. Si in scrobibus aut in sulcis seres, ternas taleas ponito, easque disaricato. Supra terram, ne plus 1v. digitos transversos enineant, vel oculos serito.

XLVI. - Seminarium quo fiat modo.

Seninarium ad hunc modum facito : Locum quam optimum et apertissimum et stercorosissimum poteris, et quam sinillimum genus terra ex, ubi semina positurus eris, et uti ne nimis longe semina ex seminario ferantur, cum locum bipalio vortito, delapidato, circumque sepito bene, et in ordine serito, in sesquipedem quoquororsum taleam demittito, opprimitoque pede. Si parum deprimere poteris, malleo aut mateola adigito. Digilum supra terram facito semina emincant, fimoque bubulo summam taleam oblinito, signumque apud taleam apponito, erebroque sarito, si voles eito semina crescant. Ad eundem moduin alia semina serito.
XLVII. - Pépinière de róscaux et de vigue.

Plantez les œilletons à trois pieds les uns des autres. Suivez la même méthode et la même disposition pour les plants de vigne. Rabattez la vigne a sa deuxième année, transplantez à la troisième année, si les troupeaux y ont aceès. Quand vous serez disposé à planter la vigne, ayez soin qu'elle ait été reeepée trois fois avant de l'aceoler aux arbres. Quand elle aura einq œils sur vieux bois , mariez-la : semez-y tous les ans des poireaux, afin d'en tirer quelque produit.

XLVIII. - Exéculion et entretien des semis de eyprès, de poirier, de noyer, de pin et d'autres arbres.

F́tablisssz les pépinières d'arbres fruitiers comme celles d'olivier. Plantez séparément ehaque espèee de bouture. Cultivez au bident le terrain réservé aux eyprès, et semez au commeneement du printemps. Élevez vos billons à la hauteur de einq pieds, ajoutez-y un engrais bien divisé, sarelez, et brisez les mottes. Aplanissez l'arête du billon, et ménagez-y une faible dépression. Semez alor's aussi dru que pour le lin, et eriblez au-dessus de la terre à l'épaisseur d'un travers de doigt. Vous aplanirez la surface a vee vos pieds ou avee des semelles en planches, vous entourerez le earré a vee des erosses, sur lesquelles vous placerez des perehes, qui elles-mêmes porteront une eouverture de sarments ou des elaies de figuier, pour abriter les semis eontre le froid et le soleil. Elles seront assez élevées pour permettre à un homme de eheminer dessous. Sarelez souvent, et arrachez les mauvaises herbes aussitôt qu'elles se hasardent à poindre : car en enlevant une herbe déjà bien enra-

XLVII. - Arundinelum et vitiarium uti seratur.

(Harundinem sic serito. Ternos pedes oculos disponilo.) Vitiarium eodem modo facilo, seritoque. Ubi vitis bima erit, resecato. Ubi trima erit, eximito. Si pecus pascetur, ubi vitem serere voles, ler prius resecato, quam ad arborem ponas. Ubi $v$ nodos veteres liabebit, tum ad arbo. rem ponito. Quotannis porrinam inserito, quotannis lıabebis quod eximas.

XLVIII. - Semina cupressi, piri, nucis, et pini, eeterarumque arborum qualiter serantur ac foveantur.

Pomarium seminarium ad eundem modum, atque olea. ginum facilo. Suum quidquid genus talearum serito. Semen cupressi ubi seres, bipalio vortilo. Vere prinı serito. Porcas pedes quinos latas facito. Eo stercus minutum addito, consarito, glebasque comminuito. Porcam planam facito, paulum concavam. Tum semen serito erebrum tanquam linum, eo terram cribro incernito, altam digitum transversum. Eam terram tabula aut pedibus complanato, furcas cireum offigilo. Eo perticas infendito. Eo sarmenta aut erates ficarias imponito, qux frigus defendant, et solem. Uti subtus homo ambulare possit, facito. Crebro runcato. Simul herbx inceperiut nasei, eximito. Nan si lierbam duram velles, cupressos simul evelles. Ad cun- 
clnée, vous arracherez en méme temps les cyprès. Suivez le même procédé pour la semaille et la couverture de la semence des poiriers et des pommiers. Semez de mêne le pin pignon, comme étant de la même famille.

XLIX. - Transplantation d'une vieille vigne.

Si vous voulez transporter ailleurs une vigne déjà vieille, il faut que les sarments en soient vigoureux. Taillez-la d'abord, et ne lui laissez pas plus de deux yeux. Déchaussez-la juscju'aux racines, et prenez garde de léser les ralicules. Cela étant, disposez le plant dans une fosse ou une tranchée; couvrez la terre que vous foulez aux pieds. Traitez comme à l'ordinaire cette nouvelle vigne, liez-la, donnez-lui une bonne direction, et béchez-la souvent.

L. - Manière de semer les prés.

Fumez vos prés au commencement du printemps, lorsque la lune n'est pas visible; ceux qui sont arrosables, aussitôt que le vent de l'ouest soufflera. Dès que vous aurez mis vos prairies cn défense, vous les ncttoierez des mauvaises herbes, que vous arracherez jusqu'à la racine. Dès que vous aurez taillé la vigne, mettez en monceaux les souches et les sarments. Élaguez les figuiers, tenez élevée la tête de ces arbres, afin que la vigne ne les domine point. Établissez des pépinières; sarclez les anciennes. Toutes les opérations seront terminées avant qu'on ne commence la culture de la vigne. Aussitôt que le festin sacré aura été béni et consommé, ouvrez les travaux de culture, mettez la charrue dans les terrains les plus secs, et labourez en dernier lieu les plus tenaces et les plus humides, pourru qu'ils ne se durcissent point auparavant.

dem modum semen pirorum, malorum, serito, tegitoque. Nuces pineas ad eundem modum, nisi tanquam alium serito.

XLIX. - Uti vinea vetus de loco transferatur.

Vineam veterem si in alium loeum transferre voles, duntaxat brachinm crassam licebit. Primum deputato, binas gemmas ne amplius relinquito. Ex radieibus bene effodito, usque radices persequitor, et careto ne radices saucies, Ita uti fuerit, ponito in serobe, aut in sulco, operitoque, et bene oceulcato. Eodem modo vineam statuito, alligato, flexatoque uti fuerat, erebroque fodito.

\section{L. - Prata quo modo serantur.}

Prata primo vere stercorato luna silenti, quxe irrigua non erunt, ubi favonius flare corperit. Cum prata defendes, depurgato, herbasque malas omneis radieitus effodito. Ubi vineam deputaveris, acervum lignorum virga. rutnque facilo. Ficos interputato, et in viuea fieos subra. dito alte, ne eas vilis scandat. Seminaria faeito, et vetera resareito. Hoc facito antequam vineam fodere incipias. Ubi daps profauata comestaque erit, verno arare incipito, et loca primunı arato qua siccissima erunt : et qua crassissima et aquosissima erunt, ea postremum arato, dum u. irius obdurescant.

LI. - Propagatio olce ponorumque.

Propagatio pomorum, aliarmu arborum. Ab aıbore abs

\section{LI. - Multiplieation de l'olivier et du pommier.}

Vous coucherez en terre les drageons qui sortent du sol ; vous mettrez la flc̀clıe à l'air, afin qu'ils puissent s'enraciner; arrachez et plantez. les deux ans après. Il faut multiplier de la même manière en plantant des bourgeons, le figuier, l'olivier, le grenadier, le cognassier, et les autres pommiers, le laurier, le myrte, le noyer de Préneste et le platane.

LII. - Procédé plus compliqué de multiplication.

Si vous voulez mettre plus de soin dans vos procédés de multiplication, il faudra déposer vos plants dans des pots ou des paniers troués, et les enterrer ainsi daus les fosses. Afin que les boutures s'enracinent sur l'arbre même, pcrcez le fond du panier ou le pot, et insérez-y le rameau que vous avez dessein de faire enraciner. Remplissez de terre le pot ou le panier, foulezle, et laissez-le sur l'arbre. Quand la bouture a pris racine, coupez la branche au-dessus du vase. Coupez le panier de haut en bas; si c'est un pot, cassez-le, et placez dans la terre la bouture avec le vase ou le panier. Faites la mème chose pour la vigne; coupez la bouture à la deuxième année, et plantez arec le vase. Ce procédé s'emploie pour la multiplication de toute espèce de végétal.

\section{LIII. - Fenaison.}

Coupez le foin à temps, et n'aitendez pas trop tard. Fauchez avant la maturité des semences, et mettez à part le meillcur, que vous donnerez aux bœufs à l'époque des labours de printemps, avant que la dragée ne soit mûre.

terra pulli qui nascentur, eos in terram deprimito, extollitoque primorem partem, uti radieem capiat : inde biennio post effodito, seritoque. Ficum, oleam, malım Punicum, cotoneum, aliaque mala omnia, laurum, myrtum, nuces Prannestinas, platanum. Hæe omnia a capite propa. gari eximique, serique eodem modo oportet.

\section{LII. - Quæ diligentius propagari voles.}

Quæ diligentius propagari voles, in aulas, aut in qualos pertusos propagari oportet, et cum is in serobem deferri oportet. In arboribus, ubi radices capiant, calıcem pertundito per fundum, aut qualum. Ramum, quem radicem capere voles, trajicito. Eum qualum, aut calicem terra impleto, calcatoque bene, in arhorem relinquito. Ubi ita fuerit ramum sub qualo pracidito. Qualum incidito ex una parte per imum. Si vero calix erit, conquassato. Cum co qualo, ant ealice iu serobem ponito. Eoden nodo vitem facito, eam anıo post precidilo, seritoque eum quaalo. Hoc modo quod genus vis propagabis.

\section{LIII. - De foenisicio.}

Fonun, ubi tempus erit, secato, caveloque ne seto seces. Priusıjuan semen maturum siet, secalo : et quod optimum faumu erit, seorsum condito. Per ver cum arabitur, antequam ucinmm nascatur, des quod edant bubus. 
L.IV. - Nourriture des buufs.

Voici comment il eonvient de préparer le fourrage des boufs. Une fois les semailles terminées, cueillez, serrez, et faites maeérer les glands. II fant douner à ehaque tête un demi-boisseau par jour; et, s'ilsue sont pas oceupés, il sera préférable de les envoyer eux-mèmes à la glandće, ou bien on leur donnera des mares de raisin qu'on atura entassés dans des futailles. Pendant le jour ils seront au paturage, et pendant la nuit ils reeevront ehaeun vingt-einq livres de foin : si l'on n'en a pas, oll y suppléera par des fevillards d'yeuse et de lierre terrestre. Conservez les pailles de froment et d'orge, les gousses de fèves, de lupin, les vesees, et les tiges des autres végétaux. On abritera suns le toit celles de ces pailles qui out le fanage le plus abondant; on les saupoudrera de sel, et on les administrera en guise de foin. Quand on commeneera au printemps à leut en faire la distribution, on y ajoutera un boisseau de glands, ou de mares ou de lupins maeérés, avec quinze livres de foin. La dragée est le premicr fourrage ì douner aussitòt qu'il est mùr. Réeoltez-le à la main, afin qu'il repousse; car clle ne monte plus après la faux. Vous donnerez de la dragée jusyu'à ce qu'elle se sèche, puis la vesee, le pa-uis, et après eelui-ei les feuilles d'orme; mêlez-y des feuillards de peuplier, si vous en avez, afin que la feuille d'orme dure plus longtemps. A défaut de feuilles d'orme, affourragez avee celles de chène et de figuier. II n'y a rien de plus lucratif que les soins que l'on prodigue aux boufs. On ne doit les laisser en pâture que pendant l'hiver lorsqu'ils ne labourent plus; ear, lorsqu'ils ont une fuis eonsominé du vert, ils en espèrent

\section{LIV. - Bubus palsulum.}

Pabulum hoc modo parari darique oportet. Ubi scmentin patraveris, glandeın parari legique oportet, et in ayuan conjici. Inde senodios singulis bubus in dies dari oportet; et si non laborabunt, pascaulur, satius erit. Aut modiun vinaciormm quos in doliun condideris. Interdin pascito, noctı foni pondo $x x v$, uni bovi dato. Si frenum non erit, froulem iligueam et ederaceam dato. Palcas triticeas, et ordeaceas, acus fabaginum, viciam, vel de lupino : iteın de carteris frugibus omnia condito. Cum stramenta condes, qua luerbosissima cruut, in tecto condito, et sale spargito: deinde ea pro focno dato. Ubi verno dase caperis, modium glandis aut vinaciorum dato, aut unchlım lıpini macerati, et fueni pondo xv. Ubi ocinum tenıestivunı erit, dato primmm. Manibus carpito, id renascetur. Quod falenla secueris, non renascetur. Usque ocinum dato, donec arescat, ita temperato, postea viciam dato, postea panicum dato, secundum panicum frondem ulmeam dato. Si populnean liabebis, admisceto, ut ulnca satis siet. Uloi ulneam non liabebis, querneam et fienlncam dato. Nilil est quod magis expediat, quam boves bene curare. Bores nisi per liemem, cuin non arabunt, pasci non oportet. Nam viride cum edunt, id semper expec- toujours; et lorsqu'ils sont au travail, il faut les museler avee des paniers, afin qu'ils ne puissent brouter l'herbe.

$$
\text { LV. - Bois pour le mallre. }
$$

Serrez dans la bûeherie le bois destiné au propriétaire; laissez all grand air les trones d'oliviers, et les raeines disposées en moneeaux.

LVI. - Quantilé de nourriture pour les gens.

Les travailleurs reeviont pour l'hiver quatre boisseaux de froment, et quatre et demi pour l'été ; l'intendant et son épouse, l'agent et le bou. vier, chaeun trois boisseaux ; les esclaves entravés, quatre livres de pain pendant l'hiver, cind livres depuis l'instant où ils eommeneent à bêcher jusqu'à la maturité des figues: pour le reste du temps la ration sera réduite à quatre livres.

\section{LVII. - Quantité de vin pour les gens.}

A près la vendange, ils ont de la piquette pour boisson pendant trois mois. Au quatrième mois, ils auront par jour une hémine de vin, c'est-àdire deux eonges et demi par mois ; au einquième, sixième, septième, huitième mois, ils cn auront un setier par jour, c'est-à-dire cinq conges par mois, enfin pour le neuvième, dixième et onzième mois, ils en recevront trois hémines par jour, e'est-à-dire une amphore par mois. En outre on donnera un congé à chaque individu pour les Saturnales et les Compitales. T elle est la quantité de vin que chaque homme consomme dans l'année. On y ajoutera pour les esclaves entravés une ration proportionnée à la somne des travaux : le chiffre de dix quadrantals par année n'est pas trop élevé.

tant. Et fiseellas habere oportet, ne herbain sectentur cam arabunt.

\section{LV. - De lignis domini.}

Ligna donino in tabulato condito, codicillos oleaginos, radices in acerro sub dio metas facito.

\section{LVI. - Familia cibaria quanta dentur.}

Fanilix cibaria qui opus facient per hiemem, tritici modios Iv." per astatem modios IV. s. vilico, vilica, ejistata, opilioni modios 111. compeditis per liemem panis P. 1v. Ubi vincam fodere cucperint, panis P. v. usque. aleo dum ficus esse caperint, deinde ad $1.1 \mathrm{r}$. redito.

\section{LVII. - Vinum familic quantum delur.}

Viun familia. Ubi vindemia facta erit, loran bilsant menses 11 . Mense quarto heninas in dies, id est, in mense congios II. s. Mense quiulo, sexto, septimo, octavo, iu dies sextarios, id est, in mense congios quiuque. Nono, decimo, nulecimo et duodecimo, in dies lieminas ternas : id est amplioran. Iloe amplius Saturnalibus, et Compitalibus in singulos homines congios. Summa vini in honiues singulos inter annum (Q. ViI) comperlitis uli quiçuii.] operis facient pro portione addito : eos non est uimiun in annos singulos vini quadrantalia $x$. ebilocre. 
LVI11. - Bume chère pour les gens.

Conservez la plus grande masse que vous pourrez d'olives tombées spontanément, pour la cuisine des domestiques. Serrez également les olives récoltées à propos, et dont on ne peut tirer qu'une faible quantité d'huile, et ménagezles, afin que la provision s'épuise le moins qu'il sera possible. Quand les olives seront consommées, donnez de la saumure et du vinaigre. Distribuez à chaque personne un setier dhuile par mois. Un boisseau de sel suffira aux besoins annuels de chaque consommateur.

LIX. - Vêtements des gens.

On leur donnera tous les deux ans une tunique de trois pieds et demi de long et des saies. Toutes les fois qu'on leur fournira une tunique ou une saie neuve, on reprendra la vieille pour en faire des casaques. On leur fournira aussi tous les deux ans une bonne paire de forts souliers.

LX. - Aliments des bouts.

La consommation annuelle de chaque paire de bœufs seélève à cent vingt muids de lupins, ou deux cent quarante de glands, einq cent (juatre-vingts livres de foin et autant de dragée, vingt muids de féverolles, trente muids de ves. ces. Semez done assez de vesces pour pouroir en laisser monter en graines. Pour le fourrage, semez-le à plusieurs reprises différentes.

LXI. - Manière de cultiver les champs.

Quel est le premier principe d'une bonne agriture? c'est de bien labourer. Quel est le second? c'est de labourer. Quel est le troisième? c'est de fumer. Celui qui remuera fréquemment et profondément la terre couverte d'oliviers, détruira

LVIII. - Pulmentarium familiæ quantum detur.

Pulmentarium familia, olexe caduca quam plurimun condito. Postea oleas tempestivas, unde minimum olei fieri poterit, eas condito, parcito, uti quam dintissime durent. Ubi olex comesx erunt, lialecem et acetum dalo. Oleum dato in nienses unicuique sextarium ı. Salis unicni. yule in auno modium satis est.

\section{LIX. - Vestimenta familix.}

Vestimenta familix tunicam P. 111. s. saga alternis annis. Quolies cuique tunicam aut sagnm dabis, prius reterem accipito, unde centones fiant. Sculponeas bonas alternis annis dare oportet.

$$
\text { LX. - Bubus cibaria. }
$$

Bubus cibaria annua in juga singula lupinı modios cxx. aut glaudis nodios ccxL. foeni poudo, 10xxo ocini, fabx modios xx. viciæ modios xxx. Praterea grauatui (genera. tim) videto uti satis vicia seras. Pabulum cum seres, mul. tas sationes facilo.

$$
\text { LXI. - Quomodo ager colatur. }
$$

Quid est agrum bene colere? bene arare. Quid secun. dum ' A rare; tertio, Stercorare. Qui oletum sapissime et allissime miscebit, is temuissimas radices exarabit. Si male juscru'aux moindres chevelus des racines; celui qui labourera superficiellement, forcera Ics racines à ramper à la surface, à prendre un développement exagéré, qui absorbera la force végétative de l'olivier. (Quand vous labourerez pour du froment, faites-le convenablement, à temps opportun, et non lorsque la terre est à moitié trem. pée). Les autres soins de culture cousistent à beaucoup planter, à enlever soigneusement les jeunes sujets, et à les replacer à propos, eni laissant beaucoup de terre autour de leurs nom. breuses racines. Une fois les racines bien couvertes, piétinez la terre, afin d'empêcher l'eau de leur nuire. Si l'on veut savoir à quelle époque il convient de planter les oliviers, je répondrai que c'est pendant la semaille si le terıain est sec, et au printemps s'il est gras.

\section{LXII: - Nombie de cliars.}

Vous aurez autant de chars que de paires de bœufs, de mulets, et d'ânes.

\section{LXIII. - Longueur des courroies.}

Le câble de pressoir aura cinquante-cinq pieds de long; la courroie des chars aura soixante pieds, les guides vingt-six pieds; les courroies de jougos pour les chars dix-huit pieds; la petite colde quinze pieds; les courroies de jougs pour les charrues auront seize pieds, et la courroie huit pieds.

LXIV. - Cueillette de l'olive.

Cueillez l'olive aussitot qu'elle est mûre, et ne la laissez que le moins possible sur la terre et sur le plancher, car elle y pourrit. Ceux qui font la récolte désirent qu'il y ait beaucoup d'olives tombées, afin d'aller plus vite en besogne. Les

arabil, radices sursum adibunt, crassiores fient, et in radices rires olea abibunt. (Agrum frumentarium cum ares, bene et tempestive ares, sulco vario ne ares.) Cætera cultura est multum serere, el diligenter eximere semina, et per tempus radices plurimas cum terra ferre. Ubi radices bene operueris, calcare bene, ne aqua noceal. Siquis quacrat, quod tempns olese serenda siet, agro sicco per sementiu, agro lato per ver.

\section{LXII. - Quot plostra habere oporteat.}

Quot juga borerum, mulorum, asinorum labebis, totidem plostra esse oportet.

\section{LXIII. - Funem quam longum esse oporteal.}

Funem torculum esse oportet extentum. P. Ev. Funem loreum in plostrum P. LX. lorea retinacula longa $\mathbf{P}$. $\mathbf{X X V}$. subjugia in plostrum $\mathbf{P}$. XVı11. funiculum $\mathbf{P} . \mathbf{X V}$. in aratrum subjugia lorum P. Xvi. funiculum P. VIII.

LXIV. - De olea legenda.

Olea ubi matura erit, quam primum cogi oportel, quam minimum in terra et in tabulato esse oportet. In terra et in tabulato putescit. Leguli volunt, nti olea caduca quan. plurima sit, quo plus legalur. Factores, ut in tabulato di! 
pressureurs soulnaitent qqu’elles séjournent longtemps sur le planclıer, afin qu'elles blétissent et s'expriment avee plus de facilité. Ne eroyez pas que l'olive prenne de l'aeeroissement sur le plancher. Plus vous mettrez de promptitude dans le travail, mieux vous vous en trouverez, soit - pour la quantité, soit pour la qualité de l'huile que vous obtiendrez du même nombre de boisseaux d'olives récoltées. L'olive qui a séjourné longtemps sur la terre ou sur le planeher donne une huile moins abondante et moins délieate. Transvasez l'huile deux fois par jour, si vous le pouvez; car l'huile qui demeure longtemps en contaet avec les marcs et les lies devient trèsmauvaise.

LXV. - Manière de faire l'huile verte.

On ne laisse l'olive que le moins de temps possible sur la terre. Si elle est sale, lavez-la, séparez-la des feuilles et des impuretés; travaillez-la le surlendemain ou lo troisième jour. Cueillez rolive des qu'elle est noire. L'huile sera d'autant plus estimée que l'olive sera plus acerbe : néanmoins le propriétaire trouvera un très-grand avantage à ne travailler que des fruits bien mûrs. Si lors de la réeolte les olives sont frappées par la gelée, il ne faut les pressurer que le troisième ou le quatrièmé jour. Si vous le jugez convenable, yous lés saupoudrerez de sèl. Ayez soin que les eelliers et les pressoirs soient portés à une ehaleur très-élevéc.

LXVI. - Devoirs du surreillant et dı livreur.

Il aura un œil vigilant sur le pressoir et sur le eellier. Autant que possible il n'y laissera pénétrer aueun étranger. Il fera apporter dans toute, les manipulations la plus sévère propreté et les

sit, ut fracida sit, quo facilius efficiant. Nolito credere oleum in tabulato posse crescere. Quam eitissime conficies, tam maxime expedict, et totidem modiis collectar plus olei efficient, et melius. Olea quac diu fuerit in terra, aut in tabulato, inde olei minus fiet et deterius. Oleum si moteris, bis in die depleto. Nam oleun quam diutissine in amurca et in fraeibus erit, tam deterrinum erit.

\section{LXV. - Oleum viride quomodo fiat.}

Oleum viride sic facito : Oleam quam primum ex terra tollito. Si inquinata erit, lavito, a foliis et stereore pur. gato. Postridie aut post diem tertium, quam lecta erit, facilo. Oleam ubi nigra erit, stringito. Quam acerbissima olea oleum facies, tam oleum oplimum erit. Dontino de unatura olea oleum fieri maxime expediet. Sigelicidia erunt, cum oleam coges, triduum, aut quatriduum post oleum facito. Eam oleam, si voles, sale inspergito. Quam calidissimum toreularium et cellam labeto.

LXVI. - Custodis et capulatoris officia.

Custodis et capulatoris officia. Servet diligenter cellam et torculiurium. Caveat quam uinimum in torculariun et in cellam iıtroeatur. Qıam mundissime purissinęque fiat, soins les plus minutieux; il aura soin qu'on ne se serve que de vases en euivre, et que les noyaux n'entrent pas dans la eomposition de l'huile; s`il en était autrement, l'huile aurait une saveur désagréable. Revêtez de plomb la fosse où doit couler l'huile. Aussitôt que les pressureurs ont donné une pression avee le levier, le sommellier saisit son bassin, et enlève l'huile rapidement et soigneusement, et sans interruption. Qu'il prenne garde de ne pas enlever l'amourque. On déposera d'abord l'huile dans une euve, puis dans une jatte. On sortira toujours de ces vases les lies et l'amourque. Sitôt que l'huile sera sortie de la fosse, on enlèvera tous les dépôts.

LXVII. - Devoirs du surveillant au pressoir.

Les ouvriers oceupés au pressoir tiendront toujours leurs vases propres, et s'efforeeront de bien pressurer les olives jusqu'à ee qu'elles soient épuisées. Ils ne devront pas eharpenter de bois dans le pressoir, mais enlever souvent l'huile fabriquée. Pour ehaque pain pressuré on donnera aux ouvriers un setier d'huile, et de plus ee qui est néeessaire pour alimenter la lampe. Tous les jours on emportera les lies, et on enlèvera l'amourque qui s'est déposée jusqu'à, ee que l'huile ait été transvasée dans la dernière tonne qui se trouve dans le eellier. On passera l'éponge dans les eabaes. Tous les jours on transvasera l'huile jusqu'à ee qu'elle soit entonnée. On surveillera sévèrement au pressoir et au cellier, afin qu'on ne dérobe aucune portion d'huile fabriquée.

LXVIII. - Suspendre les ustensiles employés à la fabri. cation de l'huile et du vin.

Après la réeolte du vin et de l'olive, relevez les arbres des pressoirs, serrez dans le garde-man-

vase aheneo, neque nueleis ad oleum ne utatur. Nam si utetur, oleum male sapiet. Cortiuam plumbeam in lacun ponito, quo oleum fluat. Ubi factores vectibus prement, continuo capulator conclıa oleum, quam diligentissime poterit, tollat nee eesset. Amurcam caveat ne tollat. Oleum in labrum primum indito. Inde in alterum dolium indito. De is labris fraees amurcamque semper subtrahito. Cum oleum sustuleris de cortina, amurcam delırito.

\section{LXVII. - Custodis in torculari officia.}

Qui in toreulario erunt, vasa pura labeant, eurentque uti olea bene perficialur, heneque siceetur. Ligna iu torculario ne cacdant. Oleum frequenter capiant. Factorilous det in singulos factus, olei sextarios, et in lucernam quod ojus sict. Fraces quotidie rejiciat. Amurcam commutet usque adeo, donec in lacum, qui in cella est, postremum pervenerit. Fiscinas spougia effingat. Quotidie oleo lacum commutet, donec in dolium pervenerit. In torculario et in cella careat diligenter, ne quid olei surripiatur.

LXVIII. - Vasa olearia et vinaria extollere.

Ubi vindeuria et oleitas facla erit, prela extollito, funes torculos, medipontos, subductarios in earnario, aut in 
ger ou sur les arbres cux-mêmes, les câbles et les cordages ; remettez à leur place les poulies, les aiguilles, les leviers, les rouleaux de bois, les cabaes, les paniers, les corbeilles, les pressoirs, les échelles, et toutes les barres qu'on aura employées.

LXIX. - Manière d'enduire les futailles.

Laissez-les pendant sept jours remplies d'amurque, mouillez tous les jours, soutirez ensuite l'amurque, et laissez sécher les futailles. Lorsqu'elles seront asséchées, enduisez-les avec une dissolution de gomme préparée deux jours auparavant. Chauffez les futailles un peu moins que pour les enduire de poix; de légers copeaux suffiront. Lorsqu'elles seront modérćment échauffées, on les àspergera d'eau de gomme et on frictionnera. Quatre livres de gomme suffiront pour un füt de cinquante setiers, si l'on a soin de bien frotter.

LXX. - Recette contre les maladies des bœufs.

Si vous redoutez l'invasion d'une maladie, administrez-leur une potion formée de trois grains de sel, de trois feuilles de laurier, de trois feuilles de poireaux, trois gouttes de rocamboles, trois d'ail, trois grains d'encens, trois tiges de sabine, trois feuilles de rue, trois tiges de bryonne, trois fèves blanches, trois charbons ardents et trois setiers de vin. On se tiendia debout pendant qu'on récoltera, qu'on broiera ct qu'on administrera cette potion; on devra aussi être à jeun. On la fera avaler à chaque bœuf pendant trois jours en trois fois, et on aura soin de fractionner la dose de manière qu'il ne reste plus rien après en avoir administré truis fois à chacun. Recommandez que le bœuf qu'on médi-

prelo suspendito. Orbes, fibulas, rectes, scutulas, fiscinas, corbulas, quala, scalas, patibula, omnia, queis usus erit, iı suo quidque loco reponito.

we.s. LXIX. - Dolia quomodo imbuantur.

Dolia olearia nova sic imbuito. Amurca impleto dies vır. Facito ut amurcam quotidie suppleas. Postea amurcam eximito et arfacito. Ubi arebit, cummim pridie in aquam infundito. Ka postridie diluito. Postea dolium calfacito. Minus quam si picare velis tepeat, satis est. Lenibus lignis facito calescat. Ubi temperate tepebit, tum cummim indito, postea linito. Si recte liveris, in dolium quinquagenarium cummim P. IV. satis erit.

\section{Bubus medicamentum.}

Bubus medicamentum. Si morbum metues, sanis dato salis micas 111 , folia laurea 111 , porri fibras 111 , IIpici spicas III, alii spicas 1II, tlıuris grana III, lierbæ sabinæe plantas 111, ruta folia 111 , vitis albae caules 11 , fabulos

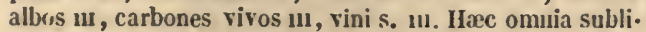
miter legi, teri, darique oportet. lejunus siet qui dabit. Ter triduum de ea potione unicuique bovi dato. Ita dividito, cum ter unicuique dederis, omnem alssumas. Bos. que ipsus, et qui dabit, facito ut uteruque sublimiter stent. Vase ligneo dato. camente et celui qui le sert soicnt debout, et qu'on emploie un vase en bois.

LXXI. - Traitement des boufs au début d'une maladie.

Si les animaux sont déjà souffrants, donnezleur immédiatement un œuf cru de poule, qu'ils avaleront sans le briser. Le lendemain faites-leur prendre une tête d'oignon broyée dans une hémine de vin. Le bœuf et l'opérateur seront debout et à jeun pendant l'opération.

LXXII. - Manière de prévenir les fissures des sabots.

Afin que les bœufs ne dégradent point leurs sabots, endulsez de poix fluide le dessous de la corne avant qu'ilsu'entreprennent quelque voyage . que ce soit.

LXXIII. - Manière d'administrer les médicaments aux boufs.

Tous les ans, aussitôt que les raisins commenceront à noircir, administrez aux bœufs un médicament qui les préserve de maladie. Quand vous verrez la dépouille d'un serpent, prenez-la et mettez-la cn réserve, pour ne pas la chercher au moment du besoin. Broyez cette peau avec de la farine, du sel, et du serpolet; délayez dans du vin, et vous donnerez à boire cette potion à tous vos bœufs. Veillez à ce que pendant l'été vos bœufs reçoivent une eau salubre et limpide; leur santé est à ce prix.

LXXIV. - Recelte pour faire le pain depsiticus.

Faites ainsi le pain depsiticus. Lavez proprement vos mains et lc mortier. Mettez la farine, ajoutez-y de l'eau peu à peu, et mélangez bien le tout. Une fois la pâte faite, moulez-la, et faites cuire sous la tuile.

\section{LXXV. - Du libum.}

Manière de faire le pain de sacrifice. Broyez

$$
\text { LXXI. - Bos si ægrotare cœperit. }
$$

Bcs si xgrotare coperit, dato continuo ei unum ovum gallinaceum crudum, integrum facito devoret. Postridie caput ulpici conterito, cum hemina vini, facitorjue ebibat. Subliuiter terat et vase ligneo det. Bosque ipsus, et qui dabit, sublimiter stet. Jejuıus jejuno bovi dato.

LXXII. - Boves ne pedes subterant.

Boves ne pedes subterant, priusquam in riam quoquam ages, pice liquida cornua infima uıguito.

LXXIII. - Quomodo bubus medicamentum detur.

Ubi uvæ variæe coperint fieri, bubus medicanıentum dato quotannis, uti valeant. Pellenı anguinam ubi videris, tollito et condito, ne quæeras cum opus siet. Eam pellem, et far, et salem, et serpullum, lıac omnia una conterito, cum vino dato bubus bibant omnibus. Per æestatem boves aquam bonan et liquidam bibant semper curato. Ut valeant refert.

LXXIY. - Panem depsiticum sic facito.

Panem depsiticum sic facito. Manus, mortariunıque bene lavato. Farinam in morlarium indito, aqua paulatim addito, subigitoque pulclıre. Ubi bene subegeris, defiugito, corfuitoque sub testu. 
bien deux livies de fromage dans le mortier; quand il y sera, mêlez-y une livie de farine de froment, ou sculement une demi-livre de fleur dc farine, si vous le désirez moins eompact, et ineorporez lc tout avec soin. Moulez vos pains, placez-les-sur des feuilles, et laissez les cuire lentement sous la tuile et sur une plaque chaude.

$$
\text { LXXVI. - De la placenta. }
$$

Prenez deux livres de farine de scigle pour faire l'assisc des boulettes, et quatrc livres de gruaux de première sorte que vous faites macérer dans l'eau. Aussitôt qu'ils sc seront amollis, placez-les dans un pétrin bien propre, et laissezles se ressuyer. Pétrissez ensuitc à la main. Quand vous les aurez bien travaillés, ajoutezy peu à peu quatre livres de farine, etfaites vos boulettes avec le mélange. On les arrange dans unc eorbeillc pour les faire sécher, et on polit les contours aussitôt qu'elles sont ressuyécs; ce travail se fait sur chaque bol en particulier. Cette besogne termince, eflleurez et frottez avec unc étoffe imbibée d'huile toutc la surface des boulettes et l'assisc où elles seront placées. Chauffez le foyer et le surtout qui serviront à la euisson. Ilumcetez ensuite et mélangez les deux livios de farine de sciglc, qui serviront à faire l'assise, après les avoir mêlées d̀ quatorze livres de fromage de brebis. Il faut que ce fromage ne soit ni acide, ui vieux. Laissez macérer le mélangc, et cliangez-le trois fois dans de nouvelle eau. Retirezle ensuite, et cxprimez-en l'eau avee vos mains ; et une fois bien égoutté, placez-le dans un pétrin bien propre, sans laisser de grumeaux. Prenez ensuite un tamis à farine, et tamisez lc fromago sur le pétrin. Ajoutez quatre livres de miel fin,

LXXY. - Libum hoc modo facito.

Libum hoc modo facito. Casei P. 11. bene disterat in mortario. Ubi bene distriverit, farinß siligineat libram, ant si voles tenerius esse, selibram similaginis solum codem inclito, permiscetoque cum caseo bene. 0 vimm ı. addito, et una permisceto bene. Inde panem facito. Folia subdito. In foco caldo sub testu coquito leniter.

LXXVI. - Placeutam sic facito.

Placentam sic facito. Farinæ siliginex L. 11. unde solum facias, in tractal farina L. IV. et alica prima L. I1. alicam in àuam infundito. Ubi bene mollis crit, in mortalium purum indito, siccatoque bene. Deinde manibus de. psito. Ubi bene subactum erit, farinæ L. IV. paulatim addito. Id utrunque tracta facito. In qualo, ubi arescant, componito. Ubi arebunt, componito puriter. Tum facies in singula tracta. Ubi depsieris, panno oleo uncto tangito, et circumtergeto, unguitoque, "bi tracta erunt, focum, ubi cornus; calfacito bene et testum. Postea farinæ L. 11. conspergito, condepsitoque. Indc facito solum tenue. Casei ovilli $r$. xıv. ne acidum siet et bene recens, in aquam indito. Ibi macerato, aquam ter mutato. Inde eximito, siccatoque bene paulatim [manibus,] siccm bene in mortarium imponito. Ubi omne casenm bene siccaveris, in mortarimm purum manibus condepsilo, comminnitoruc quam maxime. Deinde cribrum farinarium yur un sumito, et incorporez-le soigneusement avee le fromage. Plaeez sur unc table propre, d'un pied carré, le pavé de la placenta, que vous aromatiserez avec des feuilles de laurier trempées dans l'huile. Pla. eez un premier lit de boulettes sur tout le fond du pavé, et saupoudrez-les avec le mélange de micl et de fromage que vous prendrez dans le pétrin; ajoutez une seconde couche de boulettes que vous saupoudrerez avec ce qui vous restera de miel et de fromage mélangés. Mettez encorc une rangée de boulettes sur le rebord que vous replierez ensuite vers l'intérieur, et préparez le foyer. Aussitôt qu'il a aequis une chaleur modérée, placez-y votre placenta, couvrez d'un couverele chaud sur lequel vous mettrez de la braise, ainsi que tout autour. Prenez votre temps pour opérer la cuisson; soulevez deux ou trois fois le couvercle, pour voir comment elle marehe; aussitôt qu'elle sera à son terme, enlevez la placenta, enduisezla_de miel : telle est la placenta d'un sémodius.

$$
\text { LXXVII. - De la spira. }
$$

Disposez tout dans les mêmes proportions que pour la placenta, si ce n'est que vous rangez autrement les boulettes sur l'assise : enduisez-les bien de miel; tressez-les eusuitc comme une eorde que vous placez sur l'assise, en mettant soigneusement des boulettes simples dans les interstices. Dans tout le reste agissez et cuisez comme pour la placenta.

\section{LXXVIII. - De la scriblita.}

On met sur le moulc les boulettes qu'on saupoudre de fromage, eomme une plaeenta faite sans miel.

caseumque per cribrum facito transeat in mortarium. Postea indito mellis boni $P$. Iv. s. id una bene commisceto $\mathrm{cmm}$ casco. Postea in tabula pura, quxe pateat $\mathrm{r}$. I. ilhi balteum ponito, folia laurea uncta supponito, placentam fingito. Tracta singula in totum solum primun po. nito, deinde de mortario tracta linito, tracta addito singulatim, item linito usque adeo, donec omne caseum cum melle altusıs eris. In summım tracta singnla indito, postea solum contralito ornatorjne focum. * De ve primo, tem. peratoque, tunc placentam imponito testo caldo, operito pruna insuper, ef circum operito. Vide to ut bene, et otiose percoquas. A perito, dum inspicias, bis ant ter. Ubi cocta erit, eximito, et mclle unguito : læac erit placenta semo. dialis.

\section{LXXVII. - Splram sic facito.}

Spiram sic facito. Quantum voles pro ratione, ita uti placeuta fit, eadem omnia facito, nisi alio modo fingito in solo tracta. Cumn melle oblinito hene. Inde tamguam restim tractes facito, ita imponito in solo, dein plicis completo bene arcte. Catera omnia quasi placent:un facias, facito, coquitoque.

\section{LXXVIII. - Scriblitam sic facito.}

Scriblitam sic facito. In balteo tracta ex caseo, al eundem ınodum facito, uti placentam sine melle. 


\section{LXXIX. - Des boulettes.}

Mélangez pareillement du fromage avce du gr'uau ; faites-en autant de beignets que vous jugerez à propos. Versez de l'huile dans une ehauclière bien ehaude; ne euisez à la fois qu'un ou deux beignets : retournez-les fréquemment aree deux baguettes; lorsqu'ils sont euits, retirez-les et enduisez-les de miel, saupoudrez-les de pavots et servez ainsi.

\section{LXXX. - De l'encytus.}

Faites l'eneytus de la méme manière que les beignets, si ce n'est que vous vous servez d'un vase ereux et percé; vous mettez également dans de l'huile ehaude, et vous donnez une forme élégante. Retouruez-le à différentes reprises avee deux baguettes, frottez-le d'huile, dorez-le; et quand il ne sera plus trop ehaud, servez-le avec du miel ou du vin miellé.

$$
\text { LXXX1. - De l'ernéum. }
$$

L'ernéum se fait eomme la placenta, et avec les mêmes ingrédients. Après les avoir bien mélés dans une auge, on les introduit dans le moule de terre appelé hirnéa, qu'on plonge dans une marmite en cuivre remplie d'eau ehaude. On fait euire à la flamme. Après la euisson on brise l'hirnéa, et on sert.

\section{LXXXII. - De la poule.}

Faites la sparita eomme la spira, si ee n'est que vous n'employez ni fromage ni miel, et que les boulettes sont grosses comme le poing. Placezles sur l'assise, aussi épaisse que pour la spire, ct faites euire de même.

\section{LXXIX, - Globos sic facito.}

Glubos sic facito. Caseum cum alica ad eundem modum misceto. Inde quantos voles facere facito. In alsemm cal. dum unguen indito. Singulos aut binos coquito, versatoque crebro duabus rudibus ; coctos eximito. Eos melle unguito, papaver infriato, ita ponito.

\section{LXXX. - Encytum uti facias.}

Encytum ad eundem modım facito, uti globos, nisi calicem pertusum cavum liaheas. Ita in unguen caldum fundito. Hoc in restim quasi spiram facito. Idque duabus rudibus vorsato, prastatoque. Item unguito, coloratoque, caldun ne nimium. Id cum melle, aut cum inulso appo. nito.

\section{LXXXI. - Erneum sic facito.}

Erneun tanquıam placentam facito, eadem omnia indito qua in placentam. Id permiscelo in alveo. Indito in hirneam fictilcm, cam denittito in aulam alıeneam aynac calida plenam. Ita coquito ad ignem. Ubi coctum erit, liruean confringito, ita ponito.

\section{LXXXII. - Spierilam quomodo facies.}

Spaeritam sic facito, ila uti spiram, nisi sic fingito. De tractis, caseo, melle, sphaeras pugmum altas facito. Eas iu solo componito, deusas eudeu modo componito atqque spiram, itenxpue coryuitu.
LXXXIII. - Prière pour les Iweufs.

Manière de faire des vœux pour la santé des boufs. Au milieu du jour transportez-vous dans une forêt, off rez à Mars Silvanus pour ehacun de vos bœufs trois livres de farine de froment, quatre livres et demi de lard, quatre livres ot demi. de viandes suceulentes, et trois setiers de vin. Vous ferez déposer le vin dans un vase, et les autres offrandes dans un autre. Peu importe que cette besugne soit faite par un csclave ou par un homme libre. La eérémonie terminée, vous eonsommerez l'offrandé sur le lieu même. Écartez du lieu du saerifice la présenee et les regards des femmes. Vous pourrez faire eette offrande une fois tous les ans, si vous le jugez à propos.

\section{LXXXIV. - Du sarilluml}

Manière de le faire. Mélangez exaetement unc demi-livre de farine, deux livres et demi de fromages, trois onees de miel, comme pour le libum, et ajoutez un œuf. Frottez d'huile un plat de terre, dans lequel vons déposerez tous vos ingrédients préalablement mélangés. Fermez le vase avee son couvercle, et tâchez que la cuisson pénètre jusqu'au centre du gâteau; e'est là qu'il a le plus d'épaisseur. Aussitôt qu'il est euit reti. rez-le du plat, enduisez-le d'huile, saupoudrezle de pavots, remettez-lc quelque temps sous le couverele; retirez-le sur le plat avec des euillers.

LXXXY. - Potage à la carthaginoise.

Sa euisson. Faites bien digérer dans l'eau une livre de gruau, placez-lc ensuitc dans une auge

\section{LXXXIII. - Votum pro bubus.}

Fotum pro bubus, ut valeant, sic facito. Marti Silvaso. in silva interdius, in capila slngula boum votum facilo farris adorei libras 11 . et lardi P. IV. S. et pulpae P. IV. S. viti sextarios tres. Id in unnm vas liceto conjicere, et vinum item in unum vas liceto conjicere. Kan rem divinau rel servis, vel liber licebit faciat. Ubi res divina facta erit, statim ibidem consumito. Mulier ad eam rem divinam ur. adsit, neve videat quomodo fiat. Hoc volum in amos singulos, si voles, licebit vorere.

\section{LXXXIV. - Savillum sic facito.}

Sivillum lıoc modo facito. Farinæ selibram, carsei p. It. s. una comunisceto quasi libum, mellis. 1" - - el ovum umun Catinum fictile oleo unguito. Ubi omuia bene commiscue. ris in catinum, indito eatinum testo, operito. Videto ut bene percoquas mediun, ubi altissimun est. Ubi coctum crit, catinum exinito, melle unguilo, papaver iufrialo, sub testum subde paulisper, postea eximito. Ita pone curs catillo, et lingulis.

\section{LXXXY. - pultem Punicam sic facito.}

Pultem Punicam sic coquito. Libranı alice in ąpan indito, facito uti bene madeal. Il iufundito in alvenu pu rum, co casei recentis r. ut. mellis. P. S. ovuu unum, 
propre, incorporez-y trois livres de fromage nouveau, une demi-livre de miel, ct faites cuire dans une marmite neuve.

LXXXVI. - Bouillie de froment.

Manière de la préparer. On met une demi-livre de pur froment dans un mortier propre, on le lave bien, on cn détache l'écorce, et on le tamise; après l'avoir mis dans une marmite, on le fait euiro dans de l'eau pure. Après la cuisson on y ajoute du lait peu, à peu jusqu'à ce qu'il s'y forme une crème épaisse.

LXXXVII. - Amyllum.

Manière de le préparer. Nettoyez votre seigle, mettez-le dans un cuvier, et ajoutez-y de l'eau deux fois par jour. Décantez dix jours après; et quand le grain sera gonflé, broyez-le dans un cuvier propre, et laissez-le déposer comme des lies. Placez le dépôt dans un linge, exprimez-en la fécule daiss une casserole neuve, ou dans un pétrin. Opérez de même sur la totalité, et faites macérer dans l'eau ce nouveau produit. Exposez la casserole au soleil, afin de faire sécher la fécule. $\Lambda$ près la dessiceation on la serre dans un second cuvier, et on la fait cuire avec du lait.

LXXXVIII. - Blanchiment du sel.

Remplissez d'eau pure une amphore dont le goulot soit cassé, et exposez-le au soleil ; suspendez-y un sachet de sel commun, que vous aurez soin d'agiter et de remplacer à mesure qu'il sc fondra. Répétez cette opération plusieurs fois par jour, jusqu'à ce que pendant deux jours le sel refuse de se fondre. Vous reconnaitrez le point de saturation à ce signe. Si vous projetez dans l'eau un mana sec ou un œuf, et qu'il surnage, vous obtiendrez une saumure convenable pour

omnia una permisceto bene. Ifa insipito in aulam novam. LXXXVI. - Graneam triticeam sic facito.

Graneam triticeam sic facito. Selibram tritici puri in mortarinm purum indat, lavet bene, corticemque deterat bene, eluatque bene. Postea in aulam indat, et aquam puram, coquatque. Ubi coctum erit, lacte addat paulatim usque adeo, donec cremor crassus erit factus.

LXXXvil. - Amyllum slc facito.

Amyllum sic facito. Siliginem purgato bene, postea in alveum indat, eo addat aquan bis in die. Die decimo aquam exsiccato, exurgeto bene, in alveo puro misceto bene, facito tanquan fax fiat. Id in linteum novuu indito, expriniito cremorem in patinam novan, ant in mortariun. Id omne ita facito, et refricato denuo. Eam patinam in sole ponito, arescat. Ubi arebit, in aulam novam indito, inde facito cum lacte coquat.

LXXXVIII. - Salem candidun sic facito.

Salen candidun sic facito. Anıphoram defracto collo puram impleto aqua pura, in sole ponito : ibi fiscellam run sale populari suspendito, et quassato, suppletoque illeutidem. Id alipnoties in die [quntidie] facito, usque adeo donec sal desiverit tabescere bidum. Id signi erit, unanan aridan, vel orum demittito: si uatabit, ea unu- assaisonner la viande, le fromage et la maree. Cette saumure placée dans des plats demeurera exposée au soleil, jusqu'à ce qu'elle se solidifie et donne la fleur de sel. Quand le ciel se couvrira de nuages et pendant la nuit vous mettrez les vases à couvert; vous ne les abandonnerez à l'air que lorsque le soleil luira.

LXXXIX. - Engraissement des poules et des oies.

On enferme les jeunes poules qui commencent à pondre, et on leur prépare une pâtée de folle farine ou de farine d'orge. On en fera des boulettes, qu'on trempera dans l'eau avant de les leur glisser dans le gosier. Tous les jours on augmentera la dose, et leur ration n'aura d'autre limitc que leur appétit. On les servira deux fois par jour, ct à midi on leur donnera à boire en ne laissant l'eau à leur disposition que pendant une heurc. On engraissera les oies de la même manière, si ce n'est qu'avant tout on les fera boire, et que tous les jours on leur servira deux fois de la boisson et de la nourriture.

\section{XC. - Engraissement des pigeonneaux.}

Aussitôt que vous aurez pris un jeune rami er, donnez-lui des fèves torrifiées par la cuisson; insufflez-lui de l'eau dans le bec, et cela pendant sept jours. Triturez ensuite des fèves et du froment, et faites bouillir en mettant les fèves dans la proportion d'un tiers. Lorsque la farine est dans le vase, manipulez-la et faites-la cuire proprement. La cuisson achevée, travaillez la pâte après avoir trempé vos mains dans l'huile. Au commeneement vous pétrirez grossièrement, et vous ferez ensuite une pâte plus homogène en trempant toujours vos mains dans l'huile, jusqu'à ceque vous puissiez faire des boulettes. Vous

ries erit, qua vel carnem, vel caseos, vel salsamenta condias. Eam muriam in labella, vel in patinas in sole ponito. Usque adeo in sole habeto, donec concreverit. Inde flos salis fiet. Ubi nubilahitur, et noctu sub tecto ponito. Quotidie, cum sol erit, in sole ponito.

LXXXIX. - Gallinas et anseres sic farcito.

Gallinas et anseres sic farcito. Gallinas teneras, qua primum parient, concludat, polline, vel farina ordeacea conspersa turundas faciat. Eas in aquam intinguat, in os indat. Paulatim quotidie àddat. Ex gula consideret, quod satis siet. Bis in die farciat, et meridie bibere dato, nec plus aqua sita siet horam unam. Eodem modo anseren alito, nisi prius dato bibere, et bis in die, bis escam.

\section{XC. - Palumbum rccentem sic farcito.}

Palumbum recentem sic farcito. Uti prensus erit, ei fa. bam coctam tostam primum dato. Ex ore in ejus os inflato item aquam. Iloc dies vil. facito. Postea fabam fresan puram, et far purum facito, et faba tertia pars ut infervescat. Cum far insipiat, puriter facito, et coquito bene. Id ubi excoxeris depsito lene, oleo manum unguito. Prinum pusillum, postea magis depses, oleo tangito depsitoque, dunı poteris facere turundas, ex aqua dato, escam temperato. 
donnez de l'eau et de la nourriture sans la prodiguer.

$$
\text { XCI. - Construction de l'aire. }
$$

Bêchez la place destinée à l'aire, arrosez-la d'amurque jusqu'à saturation. Ensuite pulvérisez les mottes; nivelez et frappez avec la batte. Ar rosez encore d'amurque, et laissez séeher. Avec ees précautions vous n'avez à redouter ni les ravages des fourmis ni l'envahissement des herbes.

XCII. - Préservatif contre le clıarançon.

Pour prévenir les attaques du eharancon et les dégats des eampagnols, faites un lut avee de l'amurque et de la paille haehée, que vous laissez détremper et que vous gáehez convenablement : vous en étendez une couche ćpaisse sur tout le grenier, vous ajoutez par-dessus une eouehe d'amurque. Lorsque le lut sera sce, vous pourrez déposer dans votre grenier du froment non ćchauffé sans avoir à redouter le charançon.

XCrII. - Traitement des oliviers stériles.

Déehaussez les oliviers stériles et cntourez-les de paille. Arrosez ensuite le pied de l'arbre avee un mélange eomposé de parties égales d'eau ct d'amurque. Une urne suffit aux plus grands arbres; on proportionne la dose aux plus petits. Cettc opé ration augmente encore le produit des arbres qui ne sont pas stériles, mais il ne faut pas les envelopper de paille.

XCIV. - Traitement du fignier qui ne tient pas ses fruits.

Opérez de même sur les figuiers afin que leur fruits ne tombent pas prématurément; de plus à l'approehe du printemps battez leurs pieds. Avec

\section{XCI. - Aream sic facilo.}

Aream sic facito. Locum uli facies confodito, postea amurca conspergito bene, sinitoque combibat. Postea com. minuito glebas bene. Deinde coæquato, et pariculis verberato. Postea denuo amurca conspergito, sinitoque arescat. Si ita feceris, neque formicæ nocebunt, neque herbæ nascentur.

\section{XCII.-Frumento ne noceat curculio.}

Frumento ne noceat curculio, neu mures tangant, lutum de amurca facito, palearum paulum addito, sinito macerescant bene, et subigito bene, eo granarium totum oblinito crasso luto, postea conspergito amurca omne quod lutaveris. Ubi aruerit, eo frumentum refrigeratum condito, curculio non nocebit.

$$
\text { XCIII. - Olea si fructum non ferat. }
$$

Olea si fructum non feret, ablaqueato. Postea stramenta circumponito. Postea amurcam cum aqua coinmisceto æequas partes. Deinde ad oleam circumfundito, ad arborem maximam amphoram unam commixti sat est. Ad mi. nores arbores pro ratione indito. Et idem hoc si facies ad arbores feraces, eæ quoque meliores fient. Ad eas stramenta ne addideris.

XCIV. - Fici uli grossos teneant.

Fici uti grossos teneant, facito omnia, quo modo olex, et hoc amplius. Cum ver adpetet, terram adaggerato bene. eette précaution les figues tiendront, les arbres ne se eouvriront point de chaneres et seront beaucoup plus produetifs.

\section{XCV. - Moyen d'éloigner le ver coquin de la vigne:}

Pour soustraire la vigne aux ravages du ver eoquin, laissez déposer les fèces de l'amurque, mettez-en deux conges dans un vase d'airain, et faites euire à une douee ehaleur, en remuant avec une spatule jusqu'à la eonsistanee du miel. Pulvérisez ensuite séparément dans un mortier un tiers de bitume et un quart de soufre, et pendant que l'amurque est chaude eneore, versez-y eette poudre par petites portions; remuez avee la spatule, et faites cuire dereehef en plein air ; car dans un appartement le mélange s'enflammerait au moment où l'on ajouterait le soufre et le bitume. Laissez refroidir dès que la préparation a acquis la consistance de la glu. Etendez une couche du mélange sur le eep et sous les branches, et le ver. eoquin ne paraîtra pas.

\section{XCVI. - Préservatif contre la gale des moutons.}

Le meilleur préservatif contre la gale des moutons consiste à prendre et épurer de l'amurque, qu'on mélange avec des lies de bon vin et de l'eau dans laquelle on a fait macérer des graines de lupin. Après la tonte on ènduit de cette eomposition tout le corps des moutons, qu'on tient cnsuite en moiteur pendant deux ou trois jours. Lavez-les ensuite dans de l'eau de mer, ou si vous n'en avez pas à proximité, employez de l'eau tenant du sel en dissolution. Ce traitement prévient non-seulement la gale, mais il favorise en-

Si ita feceris, et grossi non cadent, et fici scabræ non fient, et multo feraciores erunt. ?

$$
\text { XCV. - Convolvulus in vinea ne tiat. }
$$

Convolvulus in vinea ne siet, amurcam condito, puram bene facito, in vas alıenum indito congios II. Postea igni leni coquito, rudicula agitato crebro usque adeo, dum fiat tam crassum, quam mel. Postea sumito bituminis tertiarium, et sulfuris quartarium. Conterito in mortario seorsum utrunque. Postea infriato quam minutissime in amurcam caldam, et simul rudicula misceto, et denuo coquito sub dio. Nam si in tecto coquas, cum bitumen et sulfur additum est, excandescet. Ubi erit tam crassum, quam viscum, sinito frigescat. Hoc vitem circum caput, et sub braclia unguito, convolvulus non nascetur.

\section{XCVI. - Oves ne scabræ fiant.}

Oves ne scabre fiant, amurcam condito, puram bene facito, aquam, ubi lupinus deferverit, et fæcem de vino bono inter se omnia commisceto pariter. Postea cum detonderis, unguito totas, sinito biduum aut triduum consudent. Deinde lavito in mari : si aquam marinam non habebis, facito aquam salsam, ea lavito. Si lıæc sic feceris, neque scabræ fient, et lanx plus, et meliorem baho. bunt, et ricini non erunt molesti. Eodem in omnes quadrupedes utito, si scabræe erunt. 
core la production d'une laine plus abondante et meilleure, et empéche les piqûres des tiques. Ėmployez également le remède contre la gale de tous les quadrupèdes.

XCVII. - Application de l'amurque.

Frottez d'amurque bouillie les essieux, les courroies, les souliers et les cuirs, vous en augmenterez la durée.

XCVIII. - Recette contre la teigne des liabits.

L.es artisons ne rongeront point les vêtements que vous serrerez dans un buffet dont l'intérieur, les pieds, le fond et les coins auront été frottés d'amurque réduite à moitié de son volume par la euisson. Lorsque cet enduit sera sec, mettez vos habits dans le buffet : les artisons ne s'en approeheront point. Si vous enduisez de cette manière tous vos meubles en bois, ils seront préservés de la pourriture, et ils deviendront brillants quand rous les nettoicrez. Donnez aussi une couche à votre vaisselle d'airain après l'a voir nettoyée. Une fois qu'elle sera endiite, frottez-la de nouveau avant de vous en servir; clle deviendra brillante, et la roullle n'en ternira point l'éelat.

XCIX. - Conservation des figues sèches.

On conserve saines les figues sèches qu'on met dans un vase en terre dont on a enduit les parois intérieurs d'amurque bouillie.

\section{C. - Précaution pour remplir une jatte d'lıuile.}

Quand vous voudrez emplir d'huile une jatte nouvelle, lavez-la soigneusement auparavant avee de l'amurque non épurée; remuez jusqu'à ee qu'elle soit bien imbibée. Par ce moyen l'huile n'est pas absorbée par le vase, eile devient plus délicate, et ce vase Iui-même est moins fragile.

\section{XCVII. - Amurcx unguentum.}

Amurca decocta axem unguito, et lora, et calciamenta, et coria : omnia meliora facies.

\section{XCVIII. - Vestimenta ne tineæ tangant.}

Vestimenta ne tinexe tangant, amurcam decoquito ad dinidium; ea unguito fundum arcx, et extrinsecus, et pedes, et angulos. Ubi ea adaruerit, vestimenta condito. Si ita feceris, tineæ non nocebunt. Et item ligneam suppellectilem omnem si ungues, non putescet : et cum ea terseris, splendlidior fiet. Item alıenea omnia unguito, sed prius extergeto bene. Postea cum unxeris, cum, uti voles, extergeto, spendidior erit, et ærugo non erit molesta.

XCIX. - Fici aridæe ut integræ sint.

Fici aridæ si voles ut integræe sint, in vas fictile condito. Id amurca decocta unguito.

\section{C. - Oleum sic in metretam indes.}

Oleum sic in metretam novam inditurus eris : amurca ita uti est cruda prius colluito, oppilato; agitatoque diu, ut bene combibat. Id si feceris, metreta oleum non bibet, et oleum melius faciet, et ipsa metreta firmior crit.

CI. - Virgas myrteas uti serves; item aliud genus.

Virgas murteas si voles cum bacis servare, (et) item aliud
CI. - Conservation des branches de nyite et autres.

Pour conserver des lonehes de myrte avec leurs baies, des rameaui de figuiers avec leurs fruits, ou telle autre espèee de fruit qu'il vous plaira, rassemblezet liez-les en petits paquets, que vous plongerez dans l'amuroque de manière que eelle-ei déborde. Vous prendrez un peu sur le vert les fruits que vous voudrez ainsi eonserver. Fermez hermétiquement le vase qui les eontient.

CtI. - Détruire les effets de la morsure des serpents sur les hoenfs et autres animaux.

Quand un bœuf ou un autre quadrupède a ćté mordu par un scrpent, prencz un verre de ectte semence de cumin que les médecins noniment smyrneum, et broyez-la dans une hémine de bon vin. Injectez-la par les narines, et appliquez sur la morsure de la fiente de pore. Employez le même remède pour l'homme, si le même cas arrive.

$$
\text { CIII. - Hygiène des boufs. }
$$

Aspergez d'amurque la nourriture des boufs que vous désirez voir frais et vigoureux, et de ceux qui refusent de manger, afin de réveiller leu. appétit. Pour qu'ils s'y aecoutument vous en domnercz peu d'abord, et vous augmenterez graduellement la dose. Plus rarement chaque cinquième ou sixième jour vous en mettrez dans leur boisson, eomposée de parties égales d'eau et d'amurque. Ce traitement maintiendra vos bœufs en meilleur état, et à l'abri des maladies.

CIV. - Vin des gens pour l'liver.

Mettez daus une futaille dix quadrantals de vin doux, et deux quadrantals de fort vinaigre. Versez-y également deux quadrantals de vin cuit,

genus quod vis, et si ramulos ficulneos voles cum foliis, inter se alligato, fasciculos facito, eos in amurcam denittito, supra stet amurca facito. Sed ea quæ demissurus eris, sumito paulo acerbiora. Vas, quo condideris, oblinito plane.

CII. - Si bovem aliamve quadrupedem serpens momorderit.

Si bovem, aut aliam quamvis quadrupedem serpens momorderit, Melanthii acetabulum, et, quod medici vo. cant smyrueum, conterito in vini veteris hemina. Id per nares iudito, et ad ipsum morsum stercus suillum apponito. Et idem hoc (si usus venerit) lomini facito.

\section{CIII. - Boves uti valeant.}

Boves uti valeaut, et curati bene sient, et qui fastidient cibum, uti magis cupide appetant, pabulum, quod dabis, amurca spargito; primo paululum, dum consuescant, postea magis; et dato rarenter bibere commixtam cum aqua, æequabiliter quarto quintoque die. Hoc si feceris ita, boves et corpore curatiores erunt, et morbus aberit.

\section{CIV. - Vinum familiæ per hiemem.}

Vinum familiæe per hiemen qui utatur. Musti quadrantalia x. in dolium indito, aceti acris quadrantalia 1 . Eodem infundito sapa quadrantalia duo, aqua dulcis quadranta- 
et cinquante d'eau douce. Avec un bâton brassez le mélange trois fois par jour et pendant eing jours consécutifs. Ajoutez-y soixante-quatre setiers d'eau de mer puisée depuis quelque temps. Placez le couvercle sur le tonneau, ct tenez-le fermé peudant dix jours. Ce vin se consommera jusqu'au solstice; s'il en reste après cettc époque, ce sera un vinaigre très-fort et très-limpide.

CV. - Procédé pour faire du vin grec sur un terroir éloigné de la mer.

Si votre domaine estéloigné dc la mer, préparez du vin gree de la manière suivante : versez vingt quadrantals de moût dans une chaudière d'airain ou de plomb, et mettez sur le feu, que vous éteindrez aussitôt que le vin bouillonnera. Après le refroidissement vous le transraserez dans un fût de la contenance de quarante setiers. Vous fercz dissoudre dans un vase à part un boisseau de sel dans un quadrantal d'eau douce; cette saumure faite, vous l'introduirez dans le tonneau. Broyez dans un morticr du souchet odorant et du calamus, et vous en introduirez un setier dans lc liquide pour l'aromatiser. Trente jours après vous placerez la bonde, et au printemps vous le mettrez dans des amphores. Après l'avoir laissć pendant deux ans exposé au soleil vous le mettrez à couvert. Ce vin rivalisera avec celui de l'île de Cos.

\section{CVI. - Confection de l'eau de mer.}

Prenez un quadrantal d'eau en pleine mer dans un cudroit où l'eau douce n'a pas d'accès, ajoutcz-y une demi livre de sel égrugé, agitez le mć-

lia 2. Hac rude miscelo ter in die dies $\mathbf{v}$. continuos. Eo addlito aqua marina reteris sextarios Lxiv. et operculum in dolium imponito, et oblinito dies $x$. Hoc sinum durabit tibi usque ad solstitium. Si quid superfuerit post solstitium, acetum acerrinum ct pulcherrimunn erit.

$\mathrm{CV}_{\wedge}-\mathrm{Si}$ ager a mari longe aberit, vinum grocum sic facito.

Qui ager longe a mari aberit, ibi vinum Græcum sic facito. Mnsti qnadrantalia $\mathrm{xx}$. in alıeneum, ant plumbeum infundito, ignem subdito. Ubi bullabit vinum, ignem subducito. Ubi id vinum refrixerit, in dolium quadragenarium infuudito; seorsum in vas aqque dulcis quadrantal r. infundito. Salis mod. 1. sinito muriam fieri. Ubi muria facta erit, eolem in dolium infundito. Schoruum, et calanum in pila contındito, quod siet sextarium unum eodem in doliam infundito, ut odoratum siet. Post dies xxx. dolium oblinito. Ad ver diffundito in amphoras. Biennium in sole sinito positum esse. Deinde in tectum conferto. Hoc vinum d elerius non erit quam Coum.

CVI. - Aquæ marinæ concinnatio.

Aquæ marinx quadrantal ı. ex alto sumito, quo aqua dulcis non accedit, sesquilibram salis frigito, codem indilo, et rade misceto usque adeo, donec ovum gallinaceum coctumnatabit, desinito miscere. Eodem vini reteris, vel lange avec un bâton, et ne cessez que lorsqu'un ouf de poule cuit surnage. Versez dans le liquide deux conges de vin vicux, soit d'Aminéc, soit de vin blane mêlé, et brassez soigneusement le mélange. Mettez le tout dans un vase enduit de poix que vous boucherez. Quand on veut préparer une plus grande quantité d'eau de mer, on augrmente les doses à proportion.

CVII. - Composition pour enduire les futailles afiu qu'el. les parfument et conservent le vin.

Mettez six conges de vin cuit dans une chaudière de cuivre ou de plomb. Prenez une héminc de racines d'iris en poudre et cinq livres de mélilot odorant, que vous broierez le plus exactement possible, arec l'iris; tamisez et faites cuirc avec le vin déjà rapproché à un feu clair de sarment. Remuez afin qu'il ne se forme pas d'empâtement. Lorsque le liquide est réduit à moitié, laissez-le refroidir, versez-le dans un vase enduit do poix et parfumé, que vous boucherez. Frottez de cette composition les bords de vos futailles.

CVIII. - Manière de déterminer si un vin sera de garde ou non.

Pour essayer si votre vin eșt de garde ou non, mettez dans une coupe neuve la moitié d'un acetabulum de fin gruau et un setier de vin nouveąu soumis à l'essai ; mettez le tout sur des charbons ardents jusqu'à ce qu'il doune deux ou trois bouillons; filtrez, et enlevez le gruau. Apres avoir exposé le liquide à l'air, goûtez-le le lendemain matin. S'il parait bon, le vin renfermé dans la futaille sera de durée; s'il est aigrelet, il ne scra pas de garde.

aminei, vel miscelli albi congios II. infundito, misceto probe. Postea in ras picatum confundito, èt oblinito. Siquis plus roles aqua marinæ concinnare, pro porlione ea omnia facito.

CVII. - Quomodo labra doliorum circumlinias, odorala ut sint, et ne quid vitii in rinum accedat.

Quo labra doliorum circunlinas, ut bene odorata sient, et nequid vitii in vinum accedat. Sapre congios vı. quan optima infundito in aheneum, aut in plumbeum ct iris aridx contusæ heminam, et sertam Campanicam P. v. bene odoratam, una cum iri contundas quam minutissime, per cribrum cernas, et una cum sapa coquas sarmentis, et levi flamma. Commoreto, videto, ne aduras. Usque coquito, dum dimidium excoquas. Ubi refrixerit, confundito in vas picatum bene odoratum, et oblinito, et utito in labra doliorum.

CFIII. - Vinum si voles experiri duraturum sil, nec ne.

Vinum si roles experiri duraturum sit, nec ne, polentam grandem dimidium acclabuli in caliculum novum illdito, et vini sextarium de eo vino quod roles experiri, codem infundito, et imponito in carbones, facito his, ant ter inferreat. Tum id percolato, polentam abjicito. Vinum ponifo sub dio. Postridie mane gnstato. Si id sapiet, quod in dolio est, scito duratırum. Si subacidum erit, non dı. ralkt. 
CIX. - Manière de rendre doux un viu dur.

Préparez quatro livres de farine de lentille, et faites-les digérer dans quatre cyathus de vin cuit : faites ensuite des massepains, et laissez-les maeérer un jour et une nuit. Jetez le tout dans votre vin en futaille, et tenez fermépendant deux mois. Ce vin sera distingué par sa douceur et par son bouquet, autant que par sa belle eoloration et son arome.

CX. - Procélé pour enlever au vin sa mauvaise odeur.

Si vous voulez enlever au vin une odeur désagréable, faites rougir au feu un fragment de tuile neuve, euduisez-le ensuite de poix, suspendez-le à une petite corde, et laissez-le seulement plonger jusqu'au fond du tonneau, que vous tiendrez bouché pendant deux jours. L'opération a très-blen réussi lorsqu'une seule fois la mauvaise odeur a disparu : si elle persiste, répétez l'opération jusqu'd ee qu'elle disparaisse totalement.

CXI. - Manière de découvrir si on a mélé ou non de l'eau au vin.

Voulez-vous savoir si on a mêlé ou non de l'eau à votre vin? préparez un vase en bois de lierre, et emplissez-le avee le vin que vous soupçonuez avoir été sophistiqué. Quand il contient de l'eau, le vin filtre au travers des parois du vase et l'eau reste, car le bois de lierre laisse passer le vin.

\section{CXII. - Fabrication du vin de Cos.}

Si vous voulez faire du vin de Cos, prenez de l'eau de mer loin des rivages, lorsque les flots ne sont point agités, lorsqu'aueun vent ne les soulève, et dans un endroit où elle ne soit point al-

\section{CIX. - Vinum asperum tene tieri.}

Vinum asperum quod erit, lene et suave si voles facere, sic facito. De ervo farinam facito lib. Iv. et vini eyathos Iv. conspergito sapa. Postea facito latereulos. Sinito conıbibant noctem et diem. Postea commisceto ellm eo vino in dolio, et oblinito dies Lx. Id vinum erit lene, et suave, et bono colore, et bene odoratum.

\section{CX. - Odorem deteriorem vino demere}

Odorem deteriorem demere vino si voles, testam de tegula erassam puram calfacito in igni bene. Ubi calcbit, eam picalo, resticula alligato, testam demittito in dolium infimum leniter, sinito biduum oblitum dolium : si demptus erit odor deterior, id optime; si non, sxepius facito, usque dım odorem malum dempseris.

CXI. - Si voles scirein vinum aqua addita sit, nec ne.

Si voles scire in vinum aqua addita sit, nec ne, vascu. lum facito de materia ederacea. Vinum id, quod putabis aquan labere, codem mittito. Si habebit aquam, vinum effluet, aqua manebit. Nam non conlinet vinum vas ederaceum.

$$
\text { CXII. - Vinum Coum si facere voles. }
$$

Vinum Coum si voles facere, aquam ex alto marinam sumito, mari tranquillo, cum ventus non erit, dies Lxx. térée par une eau douee. Après l'avolr puiséo trente jours avant la vendange, on la verse dans un tonneau sans le remplir, en laissant sur sa contenanee un espace vide de cinq quadrantals. Placez la bonde, en ménageant toutefois un aeè̀s à l'air. Après un espace de trente jours, tirez au elair et transvasez doucement dans une autre futaille, en laissant au fond les matières déposées. Vingt jours après, transvasez encore l'eau de mer dans un autre tonneau où elle séjournera jusqu'à la vendange. Laissez bien mûrir sur tiges le raisin que vous destinez à la fabrication du vin de Cos. Lorsqu'une fois il aura été alternativement exposé à la pluie et à la sécheresse, récoltez-le, et exposez-le au soleil pendant deux jours, ou à l'air pendant trois jours, si le temps n'est pas pluvieux : mais s'il vient à pleuvoir, étendez-le sur des claies à l'abri, et retranchez les grappes qui pourriraient. C'est alors que dans une futaille de einquante setiers on met dix quadrantals d'eau de mer. Égrappez à la main les graines de raisins noirs, et mettez-les dans le tonneau jusqu'à ce qu'il soit plein, afin qu'elles s'imprègnent d'eau de mer. Le tonneau rempli, vous placez la bonde sans intercepter tout ǹ fait l'aecès à l'air. Au bout de trois jours retirez les graines, foulez-les sur le pressoir, et serrez votre vin dans des futailles bien sèches, saines et propres.

CXIII. - Recette pour communiquer au vin une odeur agréable.

Pour donner au vin un arome délicat, employez le procédé suivant. Prenez une brique enduite de poix, couvrez-la de braise doucement

ante vindemiam, quo aqua duleis non perveniet. Ubi lıuseris de mari, in dolium fundito, nolito implere, quadrantalibus $v$ minus sit, quam plenum. Opereulum imponito, relinquito qua interspiret. Ubi dies $\mathrm{xxx}$ præterierint, transfundito in alterum dolium puriler, et leviter. Relinquito in imo quod desederit. Post dies $x x$ in alterun dolium item transfundito, ita relinquito usque ad vindemiam. Unde vinum Coum facere voles, 11 vas relinquito in vinea, sinito bene coquantur. Et ubi pluerit, et siecaverit, tum deligito. Et ponito in sole biduum, aut triduum sub dio, si pluviæ non erunt, si pluvia erit, in tecto in eratibus componito, et si qua acina corrupta erunt, depurgato. Tum sumito aquam marinam Q. s. s. E. in dolium quinquagenarium infundito aqux marin $\mathrm{Q}$. $\mathrm{x}$. Tum acina de uris miscellis decerpito de scopione, in idem dolium usque dum impleveris, manu comprinito, ut combibant aquam marinam. Ubi impleveris dolium, opereulo operito, relinquito qua interspiret. Ubi triduum praterierit, eximito de dolio, calcato in torenlario, et id vinum condito in dolia lauta, et pura, et sicca.

\section{CXIII. - Ut odoratum bene sit.}

Ut odoratum bene siet, sie facito : sumito testam picatam : eo prunam lenem indito, suffito serta, et schoeno, et palma, quam habent unguentarii, ponito in dolio, et 
elıauféce, parfumez-la de mélilut, de jone, et de eette espèce de baume que l'on trouve ehez les marelıands de eosmétiques. Plaeez-la dans un tonneau et fermez, afin que l'odeur ne disparaisse pas avant de l'emplir. Ces préliminaires termiiles un jour arant le pressurage, entonnez le vin aussitôt qu'il passera du pressoir dans le bassin, couvrez la futaille pendant quinze jours, en ménageant une entrée ì l'air, et placez la bonde. Quarante jours après vous transvaserez dans des amphores en ajoutant dans ehacune un setier de vin euit, et en prenant la précaution de ne l'emplir que jusqu'à l'origine des anses. Exposez vos amphores au soleil sur le sol nu, de peur que l'humidité ne s'y introduise, et abandonnez-les ainsi pendant quatre jours seulement. Après ce temps iransportez et entassez-les au cellier.

\section{CXIV. - Vin pour les maux d'estomac.}

Si vous voulez obtenir un vin qui fasse un lon estomae, aussitôt après la vendange, au moinent où l'oll déehausse les vignes, découvrez l's raeines des eeps en nombie suffisant pour fiire la quantité de vin que vous jugez nécessaire, et faites-leur une marque. Isolez et débarbez les racines. Répandez au pourtour du eep de la raeine d'cllébore, que vous aurez préalablement broyée dans un mortier. Répandez-y éga!ement du fumier fait, de laeendre vieille et deux partics de terre, et réchaussez. Récoltez à part les raisins de ees eeps. Ce vin eonservé pendant longtemps est laxatif, pourvu qu'on ne.le mélange pas à l'autre. Buvez avant vos repas un verre de ee vin trempé d'eau : il vous relachera sans suite fâcheuse.

operito, ne olor exeat, ante quam vinum indas. Hoc facito pridie quam vinum infundere voles; de lacu quam primum viuum in dolia indito, sinito dies $\mathrm{xv}$. operta ante quam oblinas, relinquito qua iuterspiret vimım. Postea oblinito. Post dies xz. diffundito in amploras, et addito in singulas auplıoras sapæe sextarium unum. Amphoras nolito inplere nimium, ansarum infimarum fini. Et amploras nolito im. plere nimium, ansarum infimarum fini. Et amploras iı sole ponito, ubi lierba non siet; et amphoras operito, ne aqua accedat, et ne plus quadriduum in sole siveris. Post quatriduum in culleum componito, et instipato.

CXIV. - Vinum si voles concinnare ad alvum.

Vinum si voles concinnare, ut alvum bonum faeiat, secunclum vindeniam, uli vites ablaqueantur, quantın putalis ei rei satis esse vini, tot vites ablaqueato, et signato. Viarum radices circunsecato, et purgato. Veratri radices contundito in pila, eas radices dato circum vitem. Et sterc.is vetus, et cinerem veterem, et duas partes terræ circundato radices vitis. Terram insıper injicito. Iloc viuum seorsum legito. Si voles servare in vetustatem, ad alvum moveudam servato, nec commisceas cum cetero vino. De m) vino cyatlıum sumito, et misceto afpua, et Jibilo ante arnam. Sine periculo alvum movelit.
CXY. - Vin contre les olstructions.

Introduisez eneore dans une amphore de vin loux une poìnée d'ellébore noire que vous retirez du vase après la fermentation; gardez ee vin pour rendre l'estomae plus libre. Si vous de. sirez préparer un vin purgatif, à l'époque des dé. chaussages marquez de eraie rouge les ecps que vous réservez à eet usage, pour ne pas les coufondre avee les autres. Disposez au tour des raeines trois petits paquets d'ellébore noire, et recouvrez-les de terie. Mettez à part la réeolte de ees eeps, mêlez-en un cyathus dans votre boisson ordinaire : ce sera un relâchant ct un purgatif innocent.

CXVI. - Conservation des lentilles.

Faites infuser du laser dans du vinaigre, mettez vos lentilles dans ce vinaigre ainsi préparé, et exposez au soleil. Faites-les ensuite tremper dans de l'huile, et quand elles auront été séchées, elles se eonserveront bien saines.

CXVII. - Manière de confire les olives blanclies.

Il faut les abattre avant qu'elles se colorent, et les faire maeérer dans une eau qu'on ehange souvent. Une fois bien macérées, il faut les faire égoutter, les mettre dans du vinaigre; ajoutez de l'huile et une demi-livre de sel par boisscau d'olives. On aura préparé séparément un vinaigre aromatisé avee du fenouil et des lentisques; si vous voulez y mettre vos olives, servez-vous-en de suite, foulez-les avee vos mains bien sèehes dans un vase de terre, et ne les enlevez qu'au moment de servir.

CXV. - vinum ad alvum movendam.

In vinum mustum veratri atri manipulum conjicito in amphoram. Ubi satis efferverit, de vino manipulım ejicito, id vinum servato ad alvum movendam. Vinum ad alvum movendam concinnare si roles : Vites cum ablaqueabuntur, signato rubrica, ne admisceas cum catero vino. Treis fasciculos veratri atri circumponito circum radices, et terram insuper injicito. Per vindemiam de is vitibus, quod delegeris, scorsum servato, cyallıum in cxeteram potionem indito, alvum movebit, et postridie perpurgabit sine periculo.

CXVI. - Lentim quomodo servari oporteat.

Lentim quomodo servari oporteat. Laserpitium aceto diluito, permisceto lent im aceto laserpitiato, et ponito in sole. Postea lentim oleo perfricato, sinito arescat, ita integra servabitur tecte.

CXVII. - Olex albx quomodo condiantur.

Olex albxe quemadmodum condiantur. Ante quam nigra fiant contundantur, et in aquam dejiciantur. Crebro arquam mutes, deinde ubi satis maceratac erunt, exprimas, et in acetım conjicias, et oleum arldas, salis selibram in modium olearum. Foniculum, et lentiscum seorsum condas in acetum. Si una admiscere voles, cito utitor, in orculam cal. cato, manibus siccis, cmm uti woles, sụmito. 
CxVIIT. - Manière de confire les olives hanches, pour les cousoumer aussilót apurès la venuauge.

l'renez parties égales de vin doux et de vinaigre. Traitez-les ensuite de la manière que nous venons de déerire.

CXIX. - Mauière de faire l'épityrum blanc, noir ct bigarré.

Recette pour faire l'épityrum, soit blane, soit noir, soit marbré. Assaisonnez de la manière suivante des olives blanches, noires et bigarrées, après en avoir òté les noyaux. Coupez-les, mettez-les dans un assaisonnement d'huile, de vinaigre, de coriandre, de cumin, de fenouil, de l'ue et de menthe. Faites-les confire dans un vase de terre, laissez les baigner daus l'huile, et servez ainsi.

Cxx. - Procédé pour a voir du vin doux toute l'année.

Si vous voulez conserver au vin sa douceur pendant foute une année, mettez-le dans une ampliore dont les parois auront été enduites de poix, et descendez-le dans un puits; après qu'il y aura séjourné pendant trente jours, retirez-le: il sera doux pendant toute l'année.

\section{CXXI. - Galeau alı vin doux.}

Arrosez de moût un boisseau de farine de seigle, ajoutez-y de l'anis, du cumin, deux livres de graisse, une livre de fromage et de la sciure le bois de laurier; moulez le gatenu, mettez-y des feuilles de laurier en le faisant cuire.

CXXII. - Vill contre les rétentions d'urine.

Broyez dans un mortier du chèvrefeuille ou du genévrier, mettez-en une livre dans deux con-

CXVIll. - Oleam albam secundum vindemiam qua utaris.

Oleam albain quam secundum vindemiam uti roles, sic condito. Musti fantundem addito, quantum accti. Cartera item condito ila, uli supra scriptum est.

CXIX. - Epityrum album, nigrum, et varium.

Epityrum album, nigrum, variumque sic facito. Ex oleis allis, nigris variisque nucleos ejicito. Sic conditu. Con. cilito ipsas : addito oleun, acetum, coriandrum, cuminum, forniculum, rutam, mentam. In orculam condito, oleuin supra siet, ita utilor.

CXX. - Mustum si voles totum annum habere.

Mustum si roles totum anuum lıbere, in amploram inustum indito, et corticem opyicalo, demittito in piscinam. Post xxx. dien eximito. Totum annum nustum erit.

CXXI. - Mustaceos sic facito.

Mustaceos sic facilo. Farinæ siligince modium unum musto conspergito. Anisum, cuminum, adipis P. IJ. casci libram, et de virga lauri deradito, codem addito. Et ubi definxeris, lauri folia subtus addito, cun coques.

CXXII. - Vinum concinnare ad lolium.

Vinum concinnare, si lotium difficilius transibit. Capreidam, rel juniperum contundito in pila, libram isdito ges de vin vicux, et faites-les louillir dans un vase d'airain ou de plomb. Apres le refroidissement, mettez-le dans une lagœena, et prenez-en un verre le matin à jeun : cela vous fera du bien.

$$
\text { CXXIII. - Viu pour les sciatiques. }
$$

Mettez en copeaux un morceau de bois de genévrier de la grosseur d'un demi-pied. Faites bouillir dans une conge de vin vieux; après le refroidissement, versez dans unc lagoena, et daus la suite vous en prendrez un verre tous les matins à jeun : cela vous fera du bien.

CXXIV. - Renfermer les cliens pendant le jour.

Renfermez vos chiens pendant le jour, afin que pendant la nuit ils soient plus ardents et plus vigilants.

CXXV. - Vin de myrlc.

Faites sécher à l'ombre des branches de myr. te noir, et couvrez-les ainsi jusqu'à la vendange. Broyez-en alors un demi-boisseau dans une urne de vin, et bouchez le vase. Aussitôt que la fer. mentation se calme, enlevez le bois de myrte. Cettc potion est excellente quand on est resserré, contre les maux dc côtés et contre les coliques.

CXXVI. - Préservatif contre la colique, la dyssente. rie, les teignes et les vers.

Si vous souffrez d'une indigestion, de la dyssenterie, si les teignes et les vers vous tourmentent, prenez trente grenades sures, broyez-les, mettez-les dans un vase avec trois conges d'un vin noir et dur, et bouchez. Trente jours après vous pouvez le débouclier et vous en servir, en le prenant à jeun à la dose d'une hémine.

iu duobus congiis vini veteris in vase alıcreo, vel in plum. beo defervefacito. Ubi refrixerit, in lagoenam indito. Id mane jejunus cyathum sumito : proderit.

CXXIII. - Vinum ad ischiacos.

Vinum ad iscliacos sic facito. De junipero materiam, semipedem crassam concidito minutim. Eam iufcrvefacito cum congio vini veteris. Ubi refrixerit, in lagœnam confundito, et postea id utito vini eyathum mane jejunus: proderit.

CXXIV. - Ut interdiu canes clausos babeas.

Canes interdiu clausos esse oportet, ut noctu acriores et vigilautiores sint.

CXXv. - viuum myrteum sic faclto.

Vinum murteum sic facito: Murtam nigram arfacito iu umbra. Ubi jam passa erit, servato ad vindemiam : in urnam musti contundito murtae semodium, id oblinito. Ubi desiverit fervere mustum, murtam eximilo. Id est ad alvum crudam, et ad lateris dolorem, et ad coliacum.

CXXVI. - Ad tormina, et si alvus non consistat, et sl tinex ac lumbricl molesti exsistant.

Ad tormina, et si alvus non consistet, et si tenia, et lumbrici molesti eruut, $\mathrm{xxx}$ mala Punica acerba sumito, contundito, indito in urceum, et vini nigri austeri congios tres, vas oblinito. Post dies xxx. aperito, et ulito : jejunus lieninam bilsito. 
CXXVII. - Reniede contre les indigestious et les réten. tions d'urine.

Cueillez des fleurs de grenadier lorsqu'elles s'épanouiront, mettez-en trois mines dans une amphore, ajoutez-y un quadrantal de vin vieux et une mine de raeine de fenouil. Bouchez l'amphore, ne l'ouvrez qu'après un mois, et servez-vous de la liqueur. Quand vous voudrez digérer ou uriner, vous pourrez en boire à volonté sans aucun danger. Le vin préparé de cette manière est également un préservatif contre la teigne et les vers. Quand un enfant en est tourmenté, ne le laissez pas souper. Le lendemain prenez une drachme d'encens, une draelıme de micl euit, et un sctier de vin d'origan, administrcz-lui le remède à jeun à la dose de trois oboles, suivant son ûge, et une hémine de vin. Faites-le monter dix fois sur la pierre à moudre et sauter en bas; ordonnez-lui là promenade.

CXXvilr. - Crépissage des habitations.

Si vous voulez erépir votre habitation, choisissez une terre où domine soit la craie, soit l'ocre; mêlez-y de l'amurque et de la paille haehée. Laissez fermenter le tout pendant quatre jours. Après quoi vous le travaillerez avec le ráble, et vous vous en servirez pour crénir. Cet enduit éloignera l'humidité nuisible, ne se laisscra pas entamer par les rats, empêehera l'herbe de crốtre et les murs de se lézarder.

\section{cxxix. - Aire à battie le blé.}

Bćehez la terre en la pulvérisant, arrosez-la damurque en telle abondance, qu'elle en soit saturce autant que possible, pulvérisez-la de

CXXVII. - Ad dyspepsiam et stranguriam.

Ad dyspepsiam et stranguriam [mederi]. Malum Punirum ubi lorebit, colligito. Tris minas in amphoram in. fundito. Vini Q. I. Veteris addito, et fonicnli radicem puram contusam minam. Oblinito amphoram, et post dies $\mathbf{x x x}$ aperito et utitor. Ubi voles cibum concoquere, et lotium facere, hinc bibito quantum voles sine periculo. Idem vinum tenias perpurgat, et lumbricos, si sic concinnes. Incuenatum jube esse, postridie thuris draclımam 1; conterito, et mel coctum drachmam unam, et vini sextarium origaniti, dato jejuno, et puero pro atale triobolum, et vini heminaın. Supra pilam inscendat, et saliat decies, et deaubulet.

CXXVIII: - Habitationem delutare.

Si habitationem delutare vis, terram quam ınaxime cretosam, vel rubricosan sumito, eo amurcam infundito, paleas indito. Sinito quatriduum fracescat. Ubi bene fra. cuerit, rutro concidito; ubi concideris, delutato. Ita neque aspergo nocebit, neque mures cava facient, neque herba nascetur, neque lutamenta scindent se.

CXXIX. - Area frumentaria quomodo tiat.

Arean uli frumentum teratur, sic facito : Cunfodiatur minute terra, amurca bene conspergatur, nt combibat nouveau, et nivelez-la à l'aide du cylindre ou de la batte. Ce nivellement empêchera les fourmis de la soulever, et les pluies de la détremper.

CXXX. - Répandre de l'amurque au pied des arbres:

Arrosez d'amurque crue les trones d'olivier et les autres bois; exposez-les au soleil pour favoriser l'imbibition. Cela les empêchcra de fumer, et en facilitera la combustion.

CXXXI. - Ofrande pour les bœufs.

Faites aux dieux une offrande pour la santé de vos bœufs. Commencez à labourer au printcmps : débutez par les sols pierreux et sablonneux, et terminez par eeux qui sont les plus compactes et les plus humides.

CXXXII. - Manière de la faire.

Voici eoinment il faut faire cette offrande : présentez à Jupiter Dapalis une coupe de quelque vin que ee soit. Ce jour sera chómé par les bœufs, par les bouviers, et par ceux qui feront le sacrifice. Au moment du sacrifice vous ferez cette pric̀re : " Jupiter Dapalis, je remplis mon devoir en t'offrant cette coupe de vin dans ma maison et au sein de ma famille; à cette eause daigne l'avoir pour agréable. "Lavez ensuite vos mains, prenez le vin, et dites: « Jupiter Dapalis, agrée ce festin que je dois t'ofirir. Reçois ce vin placé devant toi. " Si vous le trouvez bon, présentez une offrande à Vesta. Le festin présenté à Jupitcr consiste en un morceau de pore ròti, et en une eoupe de vin intacte. Faites eette offrande sans y toucher; le festin terminé, semez le millet, le panis, l'ail et la lentille.

quam plurimum. Comminuíto terram, et cylindro ant pa. vicnla coxquato. Ubi coxquata erit, neque formica mo. leslæ erunt, et cum pluerit, lntum non erit.

\section{CXXX. - Ligna amurca aspargantur.}

Codicillos oleaginos, et cætera ligna amurca cruda perspergito, et in sole ponito, perbibant bene. Ita neque fumosa erunt, et ardeburit bene.

CXXXI. - Dapem pro bubus.

Dapem pro bubus piro florente facito. Postea rermo arare incipito. Ea loca primum arato quae rudecta arenosaque erunt. Postea uti quaque gravissima atque aquosis. sima erunt, ita postremo arato.

CXXXII. - Dapem quomodo facias.

Dapen lıoc modo fieri oportet. Jovi dapali culignain vini quantum vis polluceto. Eo die feria bulvus et bubulcis, et qui dapem facient. Cum pollucere oportebit, sic facies. Jupiter dapalis, quod tibi fieri oportet, in domo familia mea culignam rini dapi, ejus rei ergo macte hac illace dape pollucenda esto. Manis interluito. Postea vinum sinnilo. Jupiter dapalis, (macte istace dape pollucenda esto.) Nacle vino inferio esto. Vesta si voles dato. Daps Jovi assaria pecuina, nrna vini Jovi caste. Profanato sine conlagione. I'ostea dape facta serito milinm, panicum, alium, lentin. 
CXXXIII. - Multiplicatiou des arbres fruiticrs $\mathrm{rt}$ autres.

Les drageons que poussent les raeines des arbres seront couchés en terre, et leur sommet re. levé, afin qu'ils puissent prendre racines. Levezles en temps propiee et plantez-les soigneuscment. I. figuier, l'olivier, le grenadier, le eognassier, le poirier-coin, tous les pommiers, le laurier de $\mathrm{Cy}$ pre, eclui de Delphes, le myrte épithalame, lo inyrte blane et le noir, le noyer d'Avelino, celui de Préneste, le platane, se propagent de boutures culevées à la souchc principale. Les arbres qu'on affectionne seront plantés soigneusement dans les pots. Pour leur faire prendre racines sur l'arbie mème, on se munit d'un pot trouć ou d'un petit panier. On y fait passer la branche, on les lemplit de terie qu'on a soin de tasser, et on les laisse sur l'arbre. Deux ans après on coupe la branehe au-dessous du point d'insertion, et on la plante avec le panier. On pourra ainsi faire prendre des racines vigoureuses à toute espèce d'arbres. Pour multiplier la vigne on emploic aussi ces paniers, qu'on remplit bien de terre; on sìvre l'année suivante, et on plante un pieu

CXXXIV. - Avant la moisson iumoler la tıuie précilanéc.

Arant la moisson, faites de la manière suivante ¿e sacrifiec de la truie précidanće: immolezà Cérès la truie précidance, femelle du pore, avant de couper l'épeautre, le blé, l'orge, la fève, et la semené de raves $L a$ vin et l'encers nous rendront propices Janus, Jupiter et Junon. Avant de sacrifier la truic, présentez un gâteau à Janus cn lui faisant cette prière: "Janus, notre pèrc, au wom de mon humble offrande, je te présente mes

CXXXill. - Propagatio pomorum, cxterarumque arlorum.

Propagatio promorum, cxterarumque arborum. Arboriłus al) terra pulli (qui uati erunt, $\cos$ in terram deprinito, cxtollito uti radicen capere possint. Inde tibi tempus erit, effudito, seríloque recte. Ficum, olean, malum Punicum, maa strutliea, cotonea, aliaque mala omnia, laurum Cypriam, Delphicam, prunum, nıyrtuin canjuguluin, et mytun album et uigrum, nuces $\Delta$ vellanas, Pranestinas, platauum ; lıec omnia genera a capitibus propagati eximique all lunc norlum oportebit. Qua diligentius seri voles, iu cylicibus seri oportet. In arboribus radices uti capiant, valicen jertusum sumito tibi, aut quasillum, per eun ramulum transerito, eum quasillum terra impleto calca. toque, in arborem ret'nçuito. Ubi biennium erit, ranmum tenerum infra pracidito, cun quasillo berito. Ko modo quod vis genus arborum ficere poteris, uti radices bene labeant. Ilem vitem in quasillum propagato terraque benc operito, anno post precidito, cum qualo serito.

CXXXIV. - Antequam messem incipias, uti porcum priccidaneum facias.

Priusquam unessin facies, porcam pracidurenm lnc modo fieri opurtet Cereri porca previdanea, parco fie. ıiı, priusquau, lıasce fruges cotulantur, far, triticuu, ordeum, fabam, semen rapiciuu, tlure, vino, Jaıo, Jovi, Junoni profalo. Priusquan porcum fominam in. supplieations afin que tu $\mathrm{m}$ 'accordes ta protection pour moi, pour mes enfants, pour ma maison et nies gens : "Offrez aussi à Jupiter un gâteau et cette prière : " Jupiter, au nom de ce gâteau, je te eonjure d'écouter mes prières, et de nous ae. corder ta protection, à moi, à mes cnfants, à ma maison, et à mes gens. "Présentez ensuite le vin à Janus en lui disant : Janus, notre père, a vec un gâteau je t'ai adressé ma prière suppliante : reçois de mêmeavec bonté ce vin que je t'offre." Adressez-vous cnsuite à Jupiter : "Jupiter, recois ce gâteau, roçois ce vin placé devant toi. " Alors immolez la truie précidanće. Aussitôt que les entrailles auront ćté divisées, on présentera à Janus son gâteau, et on l'adorera comme précédemment. On offrira de même à Jupiter des prières et le gâteau, comme on l'a déjà fait. On présentera du vin à Janus et à Jupiter, comme lorsqu'on leur offrait les gateaux. Ensuite on consacre à Cérès les entrailles de la vietime, et du vin.

CXXXV. - Lieux où il faut acleter les tuniques, les casaques, les ustensiles de fer et autres.

On se pourvoira à Rome de tuniques, de toges; de saies, de casaques ct de sabots; à Calvi et à Minturne, de capuchons, d'ustensiles en fer, de faux, de pelles, de houes, de haches, de harnais, de chausse-trapes, de chainettes; à Vénafre, de pelles; à Suesse et en Lueanie, de chars; à Albe, de traîneaux ; à Rome, de futailles et dé bassins; de tuiles à Venafre. Pour lesterres compactes les araires devront être tirés de Rome, et de la Campanie pour les terres porcuses : les meilleurs jougs se tirent de Rome; on y trouvera

molabis, Jano struem commoveto sic : Jane pater, te liac strue coumovenda bonas preces precor, uti sies volens jropitius mili, liberisque ueis, domo familiaque mex. Ferctum Jovi moveto et mactato sic: Jupiter te hoc fecto olunovendo bonas preces precor, uti sies volens propitius mili liberisque meis, domo familixuve mex. Factus hocfercto. l'ostea Jano vinun dato sic : Jaue pater, uli te strue comnovenda lonas preces bene jrecatus sun, cjusde:n rei ergo macte vino inferio esto. P'ostea Jovi sic : Jupiter unacte fecto esto. Macte vino inferio esto. Postea porcan pracidaneam inmolato. Ubi exta prosecta erunt, Jano struem counmoveto, nhactatoque ilem uti prius obmoveris. Jovi fertum olomoveto, maclatoque item uti prius feceris. Item Jano vinunr dato, et Jovi vinum dato, ita uti prius datum ob struem obmorendam, ef ferctum libanduin. Postea Cereri exta et vinum dato.

CXXXV. - Tunica et centones, ferramenta et reliqua utensilia ubi emantur.

Roma tunicas, togas, saga, censones, sculponeas : $\mathbf{C a}$ libus et Minturnis cuculliones, fertamenta, falces, palas, ligones, secures, oruamenta, murices, cutellas: Veuafro, palas. Sıcssic, et in Lucanis plostra, treblx $A$ lbx : Romar dolia, labra : tegulae ex Venafro. Aratra in teriam validam Romauica lwua erunt, iu teı'au pullam Campanica, juga liomavica optima crunt. Vouis indutilis optimus erit. 
aussi les socs les plus acérés. On tirera les trapètes de Pompeĩa; les clous, de Nole, prìs des murs de Rufrus; les serrures, de Rome. On trouvera à Capoue des seaux, des jattes à huilc, des vases pour l'cau, des urnes pour le vin, et tous les autres ustensiles en cuivre. On trouvera à Nole les corbeilles de Campanie, et ce sont les meilleures. Les cordes de poulies et toute la corderie se tirent de Capoue. Les corbeilles romaines viennent de Suesse et de Casinum : mais celles de Rome sont préférables. Celui qui fait faire à Casinum des câbles de pressoir les payera cinquante écus chez Tunnius; à Vénafre', C. Mennius les fait payer cent écus. Huit bons cuirs no sont pas de trop pour ces câbles. Les nótres ne devront être ni vieux, ni maniés, ni imprégnés d'unc trop grande quantité de sel. On les tannera et on les huilera, puis on les fera sécher. On devra couper le câble sur une longueur de soixante-douze pieds, et lui donner trois tourons, dont chaeun aura neuf courroies de deux doigts de large. Quand il sera cablé, il ne mesurera plus que quarante-neuf pieds en longueur. La jonction sur les coutures aura une course de trois pieds; il ne restera ainsi que quarante-six pieds. En le violentant par l'extension, il s'allongera de cinq pieds et aura une longueur totale de cinquante ct un pieds. Pour les plus grands pressoirs il fant que le cable ait cinquante-einq pieds ; cinquanteun suftisent pour les petits. La longueur la plus convenable de la courroie pour les charrettes est de soixante pieds; la petite corde aura quarantecinq pieds : les guides pour la eharrettc auront trente-six pieds; les guides pour l'arairc vingtsix, les traits vingt-sept et demi; les cuirs qui fixent lc timon aux jougs auront dix-neuf pieds; la petitc corde quinze pieds. Pour la charrue les premiers auront douze pieds, et la seeonde huit

Trapeti Pompeiis. Nolæe ad Rufri maceriam claves. Clostra Romx. Ilama, urnx olearix, urcei aquarii, urnx vinarix, alia vasa alıcnea Capue. Nolx fiscinx.Campaniç. Hæ hanic utiles sliut. Funis subductarius, spartum omne Capuac. Fisciuas Romanicas Suessa, Casino. Ea optimas eruut Romx. Finnem torculum si quis faciet Casini L. Tınnius. Venafri C. Mennius L. F. eo indere oportet coria lxous vu. Nostratia recentia qua depsta sient, quam minimum salis labeant, ea depsere et ungnere ungnine prius oportet, tum siccare. Funem exordiri oportet longum pedes Lxxil. toros III. liabeat, lora in toros simgulos $\mathrm{Ix}$. lita digitos u. Cum tortus erit longus peles xux. In commissura abilbunt pedes 11 , reliquum erit pedes xLVı. Ubi extentus erit, accedent p. v. longus erit P. L. Funem torculum extentum longum esse oportet pedes LV, maximis vasis : ninoribus peles L. Funem loreum in plostrum justum pedes Lx. Semifuniam pedes xiv. Lorea retinacnla in plostrum ped. xxxy, ad aratrum ped. xxvi lora proc. der toria ped. xivu. s. suljugia in plostrum bora p. xr. funi-

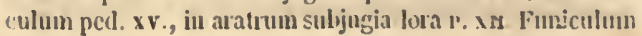

pieds. Les pressoirs les plus grands auront quatre pieds et denıi, les meules auront trois pieds et demi de diamètre, sur un pied et une palme d'épaisseur par le milieu, au sortir de la carrière; il y aura deux doigts de distanec entre le miliair'e et le rebord du bassin; ee reburd aura cinq doigts d'épaisseur. Ceux du seeond ordrec auront quatrc pieds et une palme de largeur; il y aura un pied un doigt entre le miliaire et le rebord du bassin; ce rebord aura cinq doigts d'épaisseur; leurs meuIes auront trois pieds et einq doigts d'épaisseur. Vous ferez dans les meules un trou rond qui les traversera de part en part, en conservant d'un côté à l'autre le même rayon de six pouees. Ceux. du troisième ordre auront quatre pieds de lar. geur. Il y aura un pied entre le miliaire et le rebord du bassin; ce rebord aura cing doigts d'épaisseur; la meule aura trois pieds deux doigts de diamètre et un pied ct deux doigts d'épaisseur. Lorsque le trapètc aura été amené à l'endroit où vous voudrez le placer, vous le monterez et l'ajusterez sur le lieu même.

CXXXVI. - Conditions à imposer au colon partiaire.

Dans le territoire de Cassinum et de Vénafre on donnera au métayer le huitième du produit daus un bon sol, le septième dans un sol ordinaire, le sixième dans un sol médioere si le partagc se fait au panier, et le cinquième s'il se fait au boisseau. Dans les meilleurs terrains de Vénafre on ne donne au eolon que la neuvième partic mesurée avant le dépicage. Si l'on fait moudre en commun, le métayer payera son droit de mouture proportionnellement à la part qui lui est attriluée. H aura la cinquième partic du produit de l'orge et des fèves après lc battage.

ped. vul. Trapetos latos maximos ped, Iv. s. ortis altos ped. III.s. orbis medios (ex lapicidinis cum eximet) crassos pedem, et palınum. Inter miliarium et labrum ped. 1. digitos II. labra crassa digitos v. Secundarium trapetum latum ped. Iv. et palmum. Inter miliarinm et labrum pedenı unum, digitnm unum, labra crassa digilos $v$. orbes altos ped. nII. et digitos v. crassos ped. 1, et digitos III. Foramen in orbes semiped. quoquoversum facito. 'Tertium trapetıun latnm ped: iv. inter miliarum et labrum ped. I. labrum dig. V. orbis altus pel. 111. digitos n1. crassos ped. I. digitos 11 . Trapetum ubi arvectum erit, ubi statues, ibi et commodato, concinnatoque.

CXXXv1. - Pollintionem quo pacto dari opportent.

Politionem quo pacto dari oporteal. In agro Casinata et Venafro in loco bono parte octava corbi dividat, satis bono septima, tertio loco sexta; si gramun molio divilde?, parti quiuta. In Venafro ager optinus ix parti corloi divilat. Si communiter pisunt, qua ex parte politoti pars c'st, cam parten in pistrinunı politor. Ordemm quiuta uno! is, fabau quiula modio dividat. 
CXXXV11. - Couditions à inıposer au vigneron partiaire.

Que le propriétaiı surveille d'une manière sévèrc les vigues, les terres, les arbres et les cultures qu'il laisse en métayage. II abandounera au colon le foin et les fourrages nécessaires a l'entretien des boufs que réclament les travaux. Tout le reste sera partagé sans distinction.

CxxxyiIJ. - Traraux permis aux boufs les jours de fete.

Il est permis d'atteler les boufs pendant les jours fériés, pourvu que ce soit pour le transport du bois, des pailles et du blé qu'on ne dunue point. Les mulets, les chevaux, les ânes ne chóment jamais que les fites de famille.

CXXXIX. - Manière d'çagner un bois.

Préliminaires usités à Rome avant d'élaguer un bois. Offrez un porc en expiation, et prononcez ces paroles : " Qui que tu sois, dieu ou déesse, divinité à qui ce bois a été consacré, accepte l'offrande queje te fais avant del'élaguer. En mémoi. re de ce sacrifice pardonne cet élagage que nous ferons, moi ou les miens sous mes ordres. C'est dans ce but qu'en t'offrant ce porc en expiation, je te conjure d'accorder ta protection à moi, à ma maison, à mes gens et à mes enfants. Agrée loffrandc expiatoirc de ce porc que je vais te sacrifier.

CXL. - Sacritice expiatoire a offrir en cas de défricliemen t.

Si vous voulez défricher, faites un autre sacrifice expiatoire de la mème manière, si ce n'est que vous y ajoutez ees paroles: " En cas qu'on vienne à y travailler. "Une fois la besogne eom-

CXXXVII. - Vineam redemtori partiario quomodo des.

Vineam curandam partiario bene curet; fundum, arbustum, agrum frumentarium. Partiario fonum et pabullum, quod bubus satis siet, qui illic sient. Cætera omnia pro indiviso.

\section{CXXXVIII. - Boves quomodo feris conjungere licet."}

Boves feriis conjungere licet. Hoc licet facere, arvelıut ligna, fabalia, frumentun, fuod non disturus erit. Mulis, equis, asinis ferix $u$ ul $x$, uisi si in falmilia sunt.

CXXXIX. - Quemadmodum lucum collucare debeas.

Lucum conlıcare Romano inore sic oportet. Porco pia. culo facito. Sic rerba concipito : Si deus, si dea es, quojum illud sacrum est, uti tili jus siet porco piaculo facere, illiusce sarri coercendi ergo. Harumce rerum ergo sive ego sive quis jussu meo fecerit, uti id recte factum siet. Ejus rei ergo te lioc porco piaculo immolando bonas preces pre. cor, uti sies valens propitius mili, domo familiseque meis, lilierisque meis. Harunce rerum ergo macte lioc porco piaculo immolando esto.

CXL. - Si fodere velis altero piaculo quid facere debeas.

Si fotere velis, altero piaculo, coden modo facito; lioc amplius dicito, operis faciundi causa : tum opus quotidie mencée, travaillez tous les jours sur quelyue. partie; car s'il y a interruption à cause des fítes publiques ou de famille, il faut recommencel le sacrifice.

\section{CXLI. - Purification des terres.}

Filites circuler autour de la terre la victime suovitaurilienne. Je t'ordonne, Manius, de promener cette triste victime autour de mon domaine et de ma terrc, soit en totalité, soit szulement sur la partie que tu jugeras à propos de purifier, afin qu'à l'aide des dicux le succès couronne mes entreprises. Auparavant offrez du vin á Janus et à Jupiter, et dites: Mars notre père, je te conjure d'êtrc propice à moi, à ma maison et à mes gens ; c'est dans cette intention que j'ai fait promener une triple victime autour de mes champs, de mes terres et de mes biens, afin que tu en ćcartes, éloigne et détourne les maladies visibles et invisibles, la stérilité, la dévastation, les calamités et les intempéries : afln que tu fasses grandir et prospérer mes fruits, mes grains, mes vignes et mes arbres : aftn que tu conserves la vigueur à mes bergers et à mes troupeaux, et que tu accordes santé et prosperité à moi, à ma maison et à mes gens. Aussi, pour purifier mes champs, mes terres et mes biens, et pour faire un sacrifice expiatoire, daigne agréer ces trois victimes à la mamelle que je vais immoler. Mars notre père, agréez dans ee but ces trois jeunes victimes. Saisissez le couteau pour empiler les galettes et le gâteau, et offrez-les. A mesure qu'on immolera le porc, l'agneau et le veau, on dira : Sois glorilié par cettc victime suovitaurilienne.

per partes facito ; si intermiseris, aut feriæ publicæ aut faniliares intercesserint, altero piaculo facito.

CXLI. - Si agrum lustraveri s, quid tunc facere debeas.

Agrum hustrare sic oportet. Impera snoritaurilia circun!agi. Cum divis rolentibus, quodque bene ereniat, mando tibi Nani, uti illace suovitaurilia fundum, agrum, terramque ineam quota ex parte sive circumagi, sive circumferenda censeas, uti cures lustrare. Janum, Jovemque vino præfamino, (sic dicito:) Mars pater te precor, quæsoque uti sies volens propitius mili, domo, familixque nostræ, quojus rei ergo agrum, terram, fundumque meum suovitauralia circumagi jussi. Ut tu morbos visos, invisosque, viduertatem, vastitudinemque, calamitates, intemperiasque prohibessis, defendas, averruncesque. Utique tu fruges, frumenta, vineta, virgultaque grandire, beneque evenire sinas. Pastores, pecuaque salva servassis, quisque bonam salutem valetudinem(yue milui, domo, fauiliaeque rostra. Harumce rerum ergo fundi, terræ agrique mei lustrandi, lustrique faciendi ergo sicuti dixi macte lisce suovituarilibus lactentibus immolandis esto. Mars pater ejusdem rej ergo, macte hisce suoritaurilibus lactentibus esto. Item cultro facito struem, et fertum uti adsiet. Inde obmoveto. Ubi porcum immolabis, agnum, vitulumque, sic oportet, Ejusque sei ergo macte lisce suovitaurilibus immolandis eslo. Nouyiuare retat matren, neque agnum, vitulumque. Si minus in onmes litabit, sic verba concipito : Mars pater, 
II n'est point permis de prononeer les mots pore, agneau, veau. Si ees victimes n'ont point apaisé la divinité, on fait cette prière : Mars notre père, si quelque ehose t'a déplu dans ee sacrifice des trois jeunes victimes, accepte en expiation ees trois autres. Si on présume que l'une ou deux des vietimes n'a pas étéagréée, on fait eette prière: Mars notre père, puisque le sacrifice de ee pore ne t’a pas été agréable, aceepte ce pore en explation.

\section{CxLII. - Devoirs de l'Intendant.}

11 fera ce que le maitre conımande, exécutera les travaux que réclame la terre. 11 fera les achats et les préparalifs convenables; il se procurera et soignera-les provisions de bouche et des vètements pour les gens de la ferme; il écoutera surtout attentivement les ordres du maitre. Il faut de plus qu'il so mette en rapport avee la ménagère, et qu'il sache lui donner ses ordres pour que le maitre, à son arrivée, trouve préparé et bien en ordre ee dont il a besoin.

CXLIII. - Devoirs de la première servante.

Il surveillera la ménagère, afin quelle remplisse ses devoirs. Si le maittre te l'a domée pour épouse, n'en eherche point d'autres. Inspire-lui de la erainte, et fais en sorte qu'elle ne soit point prodigue; qu'elle voie le moins possible ses voisines ou d'autres femmes; qu'elle ne reeoive personne ni à la ferme, nichezelle; qu'elle ne mange point ailleurs et ne soit pas eoureuse : qu'elle ne fasse polnt de sacrifice; qu'elle ne elarge personne d'en faire pour elle; sans l'ordre du maitre ou de la maitresse; qu'elle se souvienne que le propriétaire offre des sacrifices pour tous ses gens. Amie de la propreté, qu'elle tienne toujours la ferme propre et balayée; que tous les jours avant

si quid tibi in illisce suovitaurilibus lactentibus, neque satisfactını est, te hisce suovitaurilibus piaculo. Si uno, duobusve duhitaverit, sic verba concipito : Mars pater, quuod tibi illoce porco, neque satisfactum est, te loce poreo piaculo.

\section{CXLII. - Villici officia.}

Villci officia quas sunt, qua dominus prxcepit, ea om. nia quas in fundo fieri oportet, quaque emi pararique oportet, quomodoque cibaria, vestimenta familix dari oportet, eadenı uti curet, faciatque moneo, dominoque diclo antiens sit. Iloc amplius, quomodo vilicam uti oportet, et quoiriodo ex imperari oportet, uti alventı do. unini, qua opus sunt, parentur, curenturque diligenter.

\section{CXLIII. - Villicae oflicia.}

Vilicx qua sunt officia, curato faciat. Si eam tibi dederit dominus uxorem, ea esto contentus. Ea te metuat. Facito ne nimium luxuriosa siet.' Vicinas aliasque mulieres quan minimum utatur. Neve domum, neve ad sese reci. piat. Ad cornam nequo eat, neve ambulatrix siet. Rem divinam ni faciat, neve mandet, qui pro ea faciat, injussı domini, aut dominx. Scito dominum pro tota fumilia rem de prendreson repos l'âtre soit propre et balayé. A l'arrivée des kalendes, des ides, des nones et des jours de fète, elle suspendra au foyer une couronne de fleurs. Daus ces jours elle eonsacrera tous ses loisirs à prier les lares de la maison. Que toujours elle ait des aliments préparés pour toi et pour les gens; qu'elle ait un poulailler bien peuplé et des oufs en abondance; qu'elle fasse une ample provision de poires sceches, de sorbes, de figues, de raisins euits au soleil, de sorbes confites dans du vin euit, des poires et des raisius en eaisse, et des coings. Qu'elle enfouisse dans la terre des potscontenant des raisins stratifiés avec des mares. Qu'elle tienne également sous la terre des noix fraiehes de Préneste enfermées dans des potsde terre. Qu'elle ait en réservedes coingrs de Seantium, des coings sauvages, et tous les autres fruits de garde. Cette provision doit se renouveler avee soin toutes les années. Elle saura se proeurer de bonne farine et du gruau fin.

\section{CXLIII. - Conditions pour la récolte des olives.}

Voiei à quelles conditions il convient de donner à forfait la récolte des olives. Que toutes les olives soient dillgemmient récoltées à la guise du propriétaire, ou de son rcmplaçant, ou de celui à qui les fruits ont été vendus. On ne les pincera point, on ne les gaulera pas non plus sans l'ordre du maitre. Si quelqu'un enfreint la loi, son travail ne sera payé ni à lui, ni à l'entrepreneur de la eucillette. Ceux qui sont oeeupés à la récolte jureront devant le maítre, ou devant son préposé, qu'ils n'ont soustrait, ni eux ni leurs camarades, aucune portion de la récolte d'olives faite sur le domaine de L. Manlius. Si quelqu'un refuse le serment, ni le propriétaire ni l'entrepreneur ne lui payeront point sa part pro-

divinam facere. Munda siet. Villam conversam mundamque liabeat. Focum purum circumrersım quotidie, prius. quam cubitum eat, habeat. Kalendis, Idibus, Nonis, festus dies cum erit, coronam in focum indat. Per eosdemque dies Lari familiari pro copia supplieet. Cibum tibi et familiæe curet uti coctum habeat. Gallinas inultas, et ova uti labeat. Pira arida, sorba, ficos, uvas passas, sorba in sapa, et pira, et uvas in doliis, et mala struthea. Uvas in vinaceis, et in urceis, in terra obrutas. Et nuces Pronestinas recentes in urceo in terra obrutas liabeat. Mah Scau. tiana in doliis, et alia, que condi solent, et silvatica. Ha'c omnia quotannis diligenter uti condita labeat. Farinam bonam, et far subtile sciat facere.

\section{CXLIV. - Lex olex legendx.}

Oleam legendam hoc modo locare oportet. Oleam cogito recte omnem arbritratu domini, aut quem custodem fecerit, aut cui olea venierit. Oleam ue stringito, neve verberato injussu domini aut custodis. Si adversus ea quis fecerit, quod ipse co die delegerit, pro eo nemı solvet, neque debebitur. Oleam qui legerint, omnes juranto ad lominum, ant ad custolem, sese oleam non surripuisse, nçue quemuluam suo dolo inalo, ea oleitate ex fundo $\mathbf{L}$. 
portionnelle, et il ne lui scra rien dủ. 11 présentera une eaution pour la bomerécolte desolives, et cette eaution devra être agréée par L. Manlius. Les échelles seront rendues dans le mème itat qu'elles auront été prêtées, execpté celles qui auraient été brisées par suite de vétusté. Si clles sont détériorées, on en rendra de pareilles, ou bien le prix en sera déduit par experts. Si par la faute del'entreprencur le propriétaire éprouve quelque dommage, il faut entrer en composition. On prendra pour arbitre un homme bien famé. L'entrepreneur est tenu d'avoir assez de monde pour eueillir et pour amasser les olives; s'il ne le fait pas, on diminue sur le prix la valeur du travail qu'il a cédẻ ou sous-loué. II ne s'appropriera ni fruit, ni bois provenant de la plantation. Si quelqu'un de ses ouvriersen emporte, on déduira sur le prix convenu quarantesestertii pour chaque soustraction, et l'entrepreneur ne donnera pas ectte somme à l'ouvrier. Toutes les olives seront mesurées bien propres dans le boisseau à olives. Il oceupera constanment einquante personnes, dont les deux tiers pour faire la récolte à la main. Il ne faut pas permettre qu'un ouvrier employé à la récolte ou au pressurage des olives soit payé plus cher que de coutume, à moins que lentrepreneur $11^{\circ}$ affirme qu'il se l'est associc pour ce moment. Si eela a lieu, le maittre ou son préposé peut exiger le serment de tous les associés. S'ils refusent de jurer, personne ne paye ni ne doit payer le travail qu'exigent la réeolte et la manipulation des olives. La bonne main pour une récolte de douze eents muids sera de einq muids d'olives salćes, neuf livres d'huile épurée, eing sestertii et eing quadrantals de vinaigre pour toute la réeolte; si l'on ne donne point d'olives

Maulii. Qui corunı non ita juraverit, quod is legerit omne, pro eo argenfum nenı dahit, ne(jue debebitur. Olean coni recte, satisılato arbitratu L. Manlii. Scala ita uti clata eruut, ita reddito, nisi qua velustate fracta: eruul. Si non erunt, reddet xcyuas, aut arbitratu deducelur. Si quill redemtoris opera domino damni datum erit, resol. vito. Id viri boni arbitratu dedıcetur. Legulos ynot opus crunt, prabeto, et strictores. Si non prakuerit, quanti conductum erit, aut locatum crit, deducetur, tanto mi. uus debeljitur. De fundo ligna et oleam ne deportato. Qui oleaun legerit, qui deportarit, in singulas deportationes ss. ․ 11. deducentur, neque id debebitur. Onnen olean puram metietur morlio oleario. Assiduos lıonines quinquaginta prabeto, duas partes strictorum ןrobeto. Nic quis concedat, quo olea legunda et faciunda carius locetur. Extraquan si quem socium impracsentiarun dixerit. Si quis adrersum en fecerit, si domiuus aut custos volent, jurent onnes socii. Si non ita juraverint, pro ea olea legunda, et faciunda nemo dabit, necpue de. bebitur ei, qui nou ila juraverit. Accessiones in mod. accedit olea salsa mod. v. olei puri r. Ix. In tota olcitate ss. v. aceli quadrantilia v. Quod olea salsa non acceperint, dum oleam legent, in modios singrilos ss. s. S. dabunlur. salées, on payera cliaque muid à raisun de cinn sestertii.

CXLV. - Conditions pour la fabrication de l'luile.

Marehé à forfait pour le pressurage de l'olive. Travaillez conseieneieusement au gré du pro. priétaire ou de l'homme à qui il a confié la surveillanee de la fabrication. Employez, si eela est néeessaire, des séries d'ustensiles. Choisissez pour ouvriers des hommes agréables au surveillant ou à celui qui a acheté l'huile. Servez-vous du trapète. Si le proprićtaire a été foreé de louer des ouvriers supplémentaires, ou de faire marché avee un autre, entrez en composition, ou le prix convenu vous sera forećment diminué. Ne détournez aucune portion de l'huile, ni pour vous en servir ni pour la dérober, et n'employez que celle qui vous aura été donnée par le surveillant ou par le propriétaire. Si on a volé de l'huile, elaque soustraction sera punie d'une amende de quarante sestertii, ou d'une égale dininution sur le prix. Ceux qui fabriquent l'huile jureront de. vant le proprićtaire ou devant son intendant qu'ils n'ont soustrait, cux ni personne, ni huile ni olive de la provenanee du domaine de L. Manlius. Ceux qui ne prêteront point ee serment ne reeevront pas de l'entrepreneur le prix de leur travail, et le proprićtaire ne le devra pas à l'entrepreneur. $\mathrm{Ne}$ vous associez personue sans l'agrément du proprićtaire ou du surveillant. Si par la faute de l'eutrepreneur le propriétaire a éprouvé quelque dommage, on fera une déduction sur l'estimation d'un homme d'une probité reconnue. S'il demande de l'huile verte, le proprićtaire domucra de l'huile et du sel pour prix supplémentaire et deux victoires.

\section{CXLV. - Lex olex faciundx.}

Otean faciundun lac lege oportet locire. Facito recte arbitratu dounini, aut custolis, qui id negotiun curabit. Si sexjugis vasis opms erit, facito. Ilomines cos dato, qui placebunt aut custodi, aut qui eam olcam emerit. Trapeti facilo. Si operarii condncti erunt, aut facienda locita erit, pro co resolvito, aut deducetur. Oleum ne tangit, utendi causa, neque furandi causa, nisi quod custos dederit, aut donimus. Si sumpserit, in singulas sunıpsiones Ss. $N$. XL. dedncentur, neque debcbitur. Factores, qui oleum fecerint, omnes juranto aut ad dominum, aut ad custodem, sese de fundo L. Manlii, neque alimn quemquam sno dolo malo, oleun, neque olean surripuisse. Qui eorum non ita juraverit, qua cjus pars erit, omuc deducetur, neque del)ebitur. Socium nequem labeto, nisi quem douninus jusserit, ant custos. Si quid redenturis opera domino danni clatnm erit, viri boni arhitratu de. lucetur. Si viride oleum opus siet, facito. Accedet olemu, et sal sua usioui, quod satis siet, vasarium vict. 1 . 
CXLVI. - Vento des olives sur pied.

Ollves à vendre sur pied dans le territoire de Vénafre. L'acheteur ajoutera au prix d'adjudication le eentième pour frane-vingt. L'enchère ae. tuclle est à einquante sestertii, quinze eents livres d'huile poids de Rome, deux eents livres d'huile verte, einquante muids d'olives tombées, dix muids d'olives cueillies à la main, le tout mesuré avee le muid à olives, dix livres d'lıuile à graisser. Pour l'usage des poids et des muids on abandonnera au maitre deux eotyla dela première huile qui eoulera. L'adjudieataire, quand même il aurait sous-loué, payera les olives réeoltées et pressurées dans l'espace de dix mois à partir des ealendes de novembre, sans reculer le payement après les ides. Ces fournitures seront livrées de bonne foi et saus retenue soit au maitre, soit à son préposé, et on sera tenu de présenter une caution. Jusqu'à ee que l'acheteur se soit libéré en totalité ou du moins en grande partic, les ustensiles qu'il aura apportés sur le fonds serviront de nantissement, et on ne pourra en emporter quoi que ee soit. Si l'on en emporte, ils appartiendront au maitre. Les pressoirs, les eâbles, les échelages, les trapètes, et tous les objets qui auront été prètés par le maî. tre seront remis en bon état, à l'execption de ceux qui auront été brisés par vétusté. Si l'adjudicataire ne paye pas ee qu'il doit aux ouvriers employés à la récolte et au pressurage, le proprićtaire payera, s’il le juge à propos; mais l'adjudieataire devra et remboursera eette somme au proprićtaire, et ses ustensiles eautionneront cette somme, eomme il a été dit ei-dessus.

CXLVII. - Vente des raisins pendants.

L'acheteur laissera sur place les lies et les mares

CXLVI, - Lex olex pendentis.

oleam pendentem liac lege venire oportet. Olea pendens in fundo Venafro renibit. Qui oleam emerit, anplius, quam quanti emerit, omnis pecuniae centesima accedet. Praconium prasens ss. L. et olcum, Romanici pondo m. D. viridis 1'. cc. olex caduca mod. L. strictiva mod. x. modio oleario nensum dato. Unguinis pondo x. Ponderilous modiisque domini dato * iri prima eotulas duas. Dies argento ex $\mathrm{K}$. Nov. mensium $\mathrm{x}$. olex Icgendxe faciunda quxeque locata est, et si emtor locarit ldibus solvito. Recte lıxc dari, fierique, satisque dari domino, aut cui jusscrit, promittito, satisque dato arbitratu domini. Donicum solutum erit, aut ita satis datum erit, qua in fundo illata erunt, pigneri sunto. Ne quid corum de fundo deportato. Si quid deportaverit, domini esto. Vasa torcula, funes, scalas, trapetos, si (quid et aliud datum crit, salva recte redlito, nisi qua vetustate fracta erunt. Si unn redilet, aequum solvito. Si emtor lcgulis et factoribus qui illic opus fecerint, non solverit, cui dari oporıhit, si dominus volct, solvat. Emtor domino debeto, et id satis dato, proçue ea re ita, uli s. s. E. item pigneri sunto.

Cxl.VI1. - Lex vini pendentis.

Jac lege vimum pendens renic oportet. Viuaceos illu. de ralsin, sans les épuiser. Il emportera son vin aux premières ealendes d'vetobre; s'il n'est pas emporté, le maitre en disposera à son gré; les au. tres eonditions sont les mêmes que pour les olives sur pied.

CXLVIII. - Vente du vin en cercles.

Chaque eulleus livré à l'acheteur se mesurera sur le pied de quarante-une urnes de vin qui ne sera ni acide ni graisseux. On le fera déguster trois jours avant la vente par un gourmet expert. Si l'aeheteur ne le fait pas, le vin sera tenu pour dégusté. Si par le fait du propriétaire la dégustation n'a pu être effectuée sous trois jour's, il sera laissé à l'acheteur un délai proportionnel au retard. Le vin sera mesuré avant les calendes de janvier qui suivront la vente; sinon, il sera mesuré aux risques du proprićtaire, en lui eomptant néanmoins ee qui aura été mesuré aupara. vant. Si l'acheteur l'exige, le propriétaire jurera qu'il l'a fait en eonscience. L'acheteur enlèvera le vin aux calendes d'vetobre. S'il ne le fait pas, le propriétaire en disposera; les autres eliarges sont les mêmes que pour l'olive sur pied.

\section{CXLIX. - Location d'un pâturage.}

Conditions de louage pour un pâturage d'lıiver. Déterminez les limites du pâturage, et permettez-en la dépaissanec aux ealendes de septembre; si l'herbage est see, défendez-en l'entrée lorsque les poiriers eommeneeront à fleurir; ; si la prairie est arrosée, la dépaissanee eessera aussitôt que les voisins de ehaque eôté le permettront, ou bien prenez avee eux un jour fixé d'avanee. Dans tout autre eas, le pâturage eessera aux ealendes de mars. Le maître se réservera le droit,

tos, et frecm relinquito. Locus vinls ad $\mathrm{K}$. Octob. primas dabitur. Si non ante ea exportaveris, dominus vino, quod volet, faciet. Catera lex qua olex pendenti.

CXLVIII. - Lex vlno in doliis.

Vinum in doliis hoc modo venire oportct. Vini in culleos singulos quadragenx et singula urua dabuntur; quod neque aceat, neque muccat, id dabitur. In triduo proximo, viri boni arbitratu, degustato. Si non ita fecerit, vinmm pro degustato erit. Quot dies per dominum mora fucrit, quo minus vinum degustet, totidem dies emtori procedent. Vinum accipito ante $\mathrm{K}$. Jan. primas, Si non ante acceperit, dominus viıum adnetictur. Quod admensum erit, pro eo dominus resolvito. Si eintor postularit, doniuns jusjurandum dabit, verum fecisse. Locus viuis arl K. OC. tohres primas dabitur. Si ante non deportaverit, dominus vino yuod volet faciet. Catera lex qua olex pendenti.

$$
\text { CXLIX. - Lex pabulo. }
$$

Qua lege pabulum libernum venire oporteat. Qua ven. das fini, dicilo. Palunlum frui occipito $\mathrm{ex}$ Kalsul. Septem. brilus. Prato sicco decedat, ubi pirus florere coperit : prato irriguo, ubi super inferque vicinus permittel tum decedito, vel dicm certam utrique facilo. Catero pabulo Kalend. Martiis cedito. Bubus domitis binis, canterio uni, 
pendant toute la durée du paeage, de mettre sur son terrain une paire de bœufs domptés et un eheval de somme : il se réservera également l'usage des légumes, des asperges, des bois, de l'eau, et le droit de passage. Si l'herbager ou les gardiens font éprouver quelque dommage au propriétaire, on s'en référera à la déeision d'un lomme juste : il en sera de même si le loeataire a été lesé soit par lo propriétaire, soit par ses gens, soit par ses troupeaux. Jusqu'à ce que le prix de location ait été payé en numéraire ou par hypothèque, les troupeaux et ceux qui les soignent servent de nantíssement au propriétaire; s'il s'élève des contestations sur différents points, elles seront portées au tribunal de Rome.

$$
\text { CL. - Cession du revenu d'un troupeau. }
$$

Conditions pour la cession du rendement d'un troupeau de brebis. L'usufruitier donnera au proprićtaire pour elaque tête une livre et deni de fromage mi-sec, la nıoitié du lait qu'on traira les jours de fètes, et de plus une urne de lait. A ces conditions on comptera eomme faisant partie de l'usuriruit tout agneau qui aura vécu un jour et une nuit, et l'usufruit finira aux ealendes de juin; ce sera à celles de mai si l'année est interca. laire. Le preneur ne promettra pas plus de trente agncaux. Les brebis non féeondes serout comptées sur le pied de deux pour une, relativement à la rente. Les agneaux et la laine ne se vendront qu'en plein jour. La caution ne sera levéc qu'après dix mois. Le petit-lait de dix brebis servira à l'engraissement d'un pore. Le preneur fournira aussi pendant deux mois un berger qui servira de gage jusqu'à ee que le propriétaire soit pajé ou soldé en hypothèques.

cum emtor pascet, domino pascere recipitur. Olcris, asparagis, lignis, aqua, itinere, actu domini usioni recipifur. Si quid entor, aut pastores aut pecus emtoris domino damni dederit, boni viri arbitiratu resolvat. Si quid domiuus, aut fanilia, aut pecus emtori damni dederit, viri boni arhitıatu resolvelur. Donicum pecuniam satisfecerit, aut delegarit, pecus et familia, qua illic erit, pigneri sunto. Si quid de iis rebus controversia erit, Ronıe judicium tiat.

\section{CL. - Fructus ovium qua lege renierit.}

Fructum ovium lıac lrge venire oportet. In singulas casei P. I. S. diuidlum aridum, lacte feriis quod mulserit dimidium, et proterea lactis urnam I. Ilisce legibus agnus diem et noctem qui vixerit, in fructum, et kill. Jun. emtor fiuctu decedat. Si interkalatum erit, K. Maiis. Aguos $\mathbf{x x x}$, ne amplius promittat. Ores ųux non pepererint, hina pro singulis in fructu celent. Die lamam et agnos veuclat. Ineuses $\mathbf{x}$ ab coactore releyet. Porcos serarios in oves denas singulos pascat. Conductor 11 . menses pastorem prabeat. Doncc domino satisfecerit, aut solverit, pigneri asto.
CLI. - Manière de semer le cyprds:

Je dols à M. Percennius. Nolanus la manière de recueillir et de semer la semenec de cyprès, de multiplier cet arbre et de le disposer en bosquets. La semence du eyprès de Tarente se récolte au printemps, tandis que le bois ne s'abat qu'au moment où l'orge jaunit. On expose au soleil la semence ainsi ríeoltée; on la nettoie, et on la serre bien sèehe dans un endroit ehaud. On sème au printemps dans cette terre très-légère que nous nommons friable, et dans un endroit peu èloigné de l'eau. On commenee par distribuer sur le terrain une bonne couche de fumier de chèvre ou de moutons. Vous retournerez le terrain avec le bident, vous incorporerez l'engrais avec lesol, que vous débarrassez des planles adventices et des gramens. Après avoir exactement pulvérisé la terre, disposez-la par planehes de quatre pieds de large, et légèrement concaves afin qu'elles puissent retenir l'eau, et entre chacune desquelles vous ménagerez un sentier, afin de pouvoir arracher les mauvaises herbes; sur les planches ainsi arrangées vous répandrez la semence de eyprès, aussi drue que pour le lin. Vous la recouvrirez, à l'épaisseur d'un demi- travers de doigt, aree de la terre que vois ferez passer par le erible. Vous aplanirez la surface soit avec une planche, soit avec vos mains, soit avec vos pieds. Si les pluies se font attendre au point que la terre se dessèche, introduisez sur les planches une légère lame d'eau. Si vous n'avez pas un cours d'eau, transportez-en sur vos planches, et arrosez doucement. II faut arroser ehaque fois que le besoin s'en .fait sentir. Arrachez les mauvaises herbes aussitôt qu'elles paraissent, et si faibles qu'elles soient; arrach ez-les

\section{CL. - Quo pacto cupresseta seri oporteat.}

Semen cupressi quaudo legi, seri, propagarique oporteat, et quo pacto cupresseta seri oporteat, Manius Percennius Nolanus ad luunc modum monstravit. Semen cupressi Tarentinæe per ver legi oportet, maturum, ului hordeum flavescit. Id ubi legeris, in sole ponito, semen purgato. Id aridum condito : uti aridum expositum siet. Per ver serito in loco ubi terra tenerrima erit, quam pullam vocant, ubi aqุua propter siet. Eum locum stercorato primum bene stercore caprino, aut ovillo. Tum rortito bipalio, terram cum siercore bene permisceto, depurgato ab herba graminibusque. Bene terram comminuito. Areas facito pedes latas quaternos : subcavas facito, uti aquam continere possint. Infer eas sulcos facito, qua herbas de areis purgare possis. Ubi areæ factae erunt, semen serito crebrum, ita uti linum seri solet. Eo cribro terram incernito, dimidialum digitum terram altam succernito. Id bene tabula, aut manibus, aut pedibus complanato. Si quando non pluet, uti terra sitiat, aquam irrigato leniter in areas. Si non lıbebis unde irriges, gerito, inditoque leniter. Quotiescunque opus erit; facito uti aquan addas. Si herbe natic crumt, facito uti ab herbis purges. Quan tencri- 
surtout pendant l'été, et toutes les fois que vous en sentirez la nécessité. Ces précautions sont de rigucur; et dès que la semaille est faite il faut couvrir la terre d'un paillis, qu'on enlève dès que les cyprès commencent à germer.

CLII. - Balais suivant la méthode de Memius et de Man. lius.

Procédés des Manlius pour faire les balais de branchages. Pendant les trente jours qui suivent la vendange, il faut faire des balais avec des ramilles sèches prises sur un orme, et liées autour d'un bâton. On s'en sert pour frotter les flanes intérieurs des futailles, afin que les lies ne s'attachent pas à leurs parois.

\section{CLIII. - Vin de lies.}

Ayez pour cela deux cabacs à olives de Campanie, remplissez-les de lies, placez-les sous le pressoir, et exprimez-en le vin.

CLIV. - Manière de mesurer ie vin sux .tcheteurs.

Manière commode de délivrer le vin aux acheteurs. Ayez pour cela une cuve de la contenance d'un culleus, munie sur ses bords de quatre alıses qui en faciliteront le déplacement. Percezla au fond d'un trou exactement fermé par un robinet. Percez-la également d'un trou affleurant la contenance d'un culleus. Placez-la au milieu des futailles sur unc élévation, afin que le vin qui y est contenu puisse s'ćcoulcr daus le culleus de l'acheteur : quand celui-ci sera rempli, fermez yotre cure.

mis lerbis, el quoties opus erit purges per astatem. Ita uti dictum est, fieri oportet, et ubi semen satum siet, stranentis operiri oportet, ubi germen nascere coperit, tum demi.

Clll. - Quæ Memius et M. Manlius de, vino emtoribus admetiendo monstraverint.

De scopis virgeis Q. A. M. Manlii monstraverunt. In diebus $\mathbf{x x x}$, quibus viuum legeris, aliquoties facito scopas virgeas ulmeas aridas, in asserculo alligato, eabus latera duliis intrinsecus usque bene perfricato, ne fax in lateribus adlıarescat.

\section{CLIII. - De vino fæcato.}

Vinum focatum sic facito. Fiscinas olearias Campanicas duas illæ rei liabeto. Eas facis impleto, sub prelumque subdito, exprimitoque.

\section{CLIV. - Vinum emtoribus quomodo admetiaris.}

Vinum emtoribus, sine molestia quomodo admetiaris. Librum culleare illa rei facito. Id habeat ad summum ansas iv. uti transferri possitur. Id imum pertundito. Fa fistulam subdito uti obturarier recte possit. Et ad sunmum, qua fini culleum capiet, pertundito. Id in suggestu, inter dolia positum habeto, uti in cullexum, de dolio vinum salire possit. Id impleto. I'ostea obturate.
CLV. - Pendant l'hiver procurer un écoulement à l'eau des champs.

Il faut dessécher les terres.arables pendant I'hiver. Sur. les hauteurs on tiendra bien évidées les rigoles d'écoulement. C'est surtout à l'entrée de l'automne, quand la terre est pulvérulente, qu'il faut redouter la présence de l'eau. Lorsque la pluie s'annoncera, on cmmènera tous ses gens avec des fourches et des sarcloirs, pour ouvrir les caṇaux d'écoulement et conduire.l'eau sur les chemins, afin qu'elle ne séjourne pas sur les récoltes. Quand il pleuvra sur la ferme, on explorera tous les bâtiments; et si l'cau filtre quelque part, on indiquera avec du charbon les endroits où les tuiles demandent à être remplacées. Pcndant la moisson, si l'eau demeure stagnante, soit sur les javelles, soit sur les blés en tige, soit dans les rigoles, il faut écarter et détourner les obstacles qui s'opposent à son écoulement.

CLỴI. - Remèdes préparés avec les choux.

Le chou est le premier de tous nos légumes. On le mange cru ou cuit. Si on veut le mangel cru, on le fait macérer dansdu vinaigre. II se digère à merveille, relâche le ventre et les voies urinaires; c'est, dans tous les cas, unc nourriture saine. Si dans un repas vous désircz boire largement et manger avec appétit, mangez auparavant des choux confits dans du vinaigre, et autant que bon rous semblera; et de même après le repas mangez-en cinq feuilles. environ, vous screz comme si vous n'aviez ni bu ni mangé, et vous pourrez de nouveau boire à votre aise. Si vous

\section{CLV. - Per hiemen de agro aquam pellere.}

Per liemem aquam de agro depelli oportet. In monte fossas inciles puras habere oportet. Prima autumnitate cum pluvius est, tum maxime ab aqua periculum est. Cum pluere incipiet familiam cum ferreis sarculis exire oportel, incilia-aperire, aquam deducere in vias, et segetem curare oportet, uti fluat. In villa cum pluet, circum. ire oportet, sicubi perpluat, et signare carbone, cum desierit pluere, uti tegula mutetur. Per segetem in fru. mentis, aut in segete, aut in fossis sicubi aqua constat, aut aliquid aqua obstat, id emittere, patefieri, removeri. que oportet.

\section{CLVI. - Medicamenta brassicx.}

[De brassica quod concoquit.] Brassica est, quæ omni, bus oleribus antistat. Eam esto vel coctam, vel crudam. Crudam si edes, in acetum intinguito. Mirifice concoquit. Alrum bonam facit, lotiumque ad omnes res salubre est. Si voles in convivio multum bibere, coenareque libenter, ante coenam esto crudain quantum voles ex aceto. Et ilem, ubi conaveris, comesto aliqua v. folia, reddent te quasi nilil ederis, (biberisque,) bibesque quantum voles. Alrum si voles dejicere superioren, sumito brássicæ qua levissima erit, $\boldsymbol{P}$. Iv. Inde facito manipulos requales tres, colligatoque. Postea ollam statuito cum aqua. Ubi occipiet fervere paulisper, demittito unum ma. 
a vez l'épigastıe embiurrassé, prenez quatre livres d'une espèee de chou très-lécrère, faites en trois bouquets égaux; fieelez-les. Mettez ensuite sur le feu une marmite pleine d'eau, et jetez-y un des. houquets dès que le premier bouillon paraitra. I.orsqu’ensuite elle reeommencera à bouillir, ellfoneez-le un peu, et laissez-le pendant que vous compterez jusqu'd vingt-einq : retirez-le alors. Proeédez de même pour le sceond et pour le troisième bouquet; mettez-les ensuite ensemble et pilez-les. Après les avoir retirés, exprimez-en le sue à travers un linge dans une petite eoupe en terre, à la quantité d'une hémine. Jetez-y un grain de sel gros eomme une lentille, du eumin grillé seulement pour lui en donner l'odeur : exposez ensuite la coupe à l'air pendant une nuit sereine. Celui qui voudra boire de eette liqueur prendra auparavant un bain ehaud, boira de l'eau miellée, et se eouehera à jeun. Le lendemain il prendra la potien, se promènera pendant quatre heures, et vaquera à ses affaires s'il en a à soigner. Aussitôt que l'envie de vomir le saisira, il se couchera et se purgera. II ivaeuera une si grande quantité de bile et de pituite, que lui-même se demandera avee surprise d'où elle peut provenir. Lorsqu'ensuite il ira à la selle, il boira une hémine d'eau, ou un peu plus. S'il eontinue à être reláché, il prendra deux eonges de fine farine, qu'il jettera dans l'eau; il en boira un peu, et ne sera plus tourmente. Si on est travaillé par la eolique, on fera macérer des choux dans de l'eau ; après la macération on les jettera daus de l'eau chaude, et on les fera cuire jusqu'à ee qu'ils s'amollissent. Après avoir déeanté l'eau, on assaisonnera aveedu sel, un peu de eumin et de fin gruau. On y ajoutera aussi de l'huile, et on fera

nipulum, fervere desistet. Posten ubi ocejpiet fervere, paulisper demittito usque admodum dum quinquies quinrjue numeres. Tum eximito. Iten facito alterum inanipu. lıun, item tertium, postea conjicito et contundito. Item cximito, in linteum exugeto sucum, quasi liemiuan, in pocillum fictile. Eo indito salis micam quasi ervum, et cuniui fricti tantum quod oleat. Postea ponito poeillum iı sereno moetu. Qui poturus erit, lavet calida, bibat ałpuaı mulsan, cubet inecenatus. Postea mane bibat sucum, , luambuletque lıoras IV. Agal, negotii si quid lıabebit. Ubi libido veniet nausea, eumque appreliendel, decumbat, purgetque sese. Tantum bilis, pituitaeque ejieiet, uti ijse niretur, unde tautum siet. Postea ubi deorsum versus ibit, lieminam, ant pauto plus bibat. Si amplius ibit, sumito fariure minuta conchas duas, iuftict in aquan, paulum bibat, consistet. Verum quil)us tormina molesta erunt, brassicam in aquam macerare oportet. Ubi ntacerata elit, conjicito in aquan calidam, coquito usque do. nec ea commadebit bene. Aquam defundito. Postea salem arldito, et cumini paulılum, et pollinen polentre. Eodem sdditu el olemn, postea fervefacito. Infundito in cationum, uti frigescat. Lo interito, quod volet, cibi postea elit. Sed si poterit solam brassicau esse, edit. Lt si siue febre bouillir ; après quoi on versera sur un plat pour laisser refroidir. On les mêlera, pour les manger, avee tel autre aliment qu'on voudra : mais on fera mieux de manger les ehoux seuls, si on le peut. Si l'on n'a point de fièvre, on les prendra a veeun vin noir et dur, et on ne boiraque le moins d'eau possible, mais s'il y a fièvre, il faudra adopter l'eau. On en fera prendre tous les matins, mais peu à la fois, afin de ne pas provocuer le dégoût, et qu'on les trouve toujours agréables. On les administrera de la même manière aux hommes, aux femmes et aux enfants. Jarrive maintenant à ecux qui ont les voies urinaires trop resserrées et embarrassées. Prenez des ehoux et jetez-les dans l'eau bouillante, faites-les euire un peu, pour leur enlever leur erudité : ensuitc déeantez presque toute l'eau; ajoutez-y beaucoup d'huile, du sel, et un peu de cumin; faites bouillir. On en avalera le bouillon fioid et on mangera les choux, et eela tous les jours, alin que le remède soit plus prompt.

CLVH. - Variétés et qualités des chonx.

Avant tout il eonvient de eonnaître le caraetère et les propriétés des diver'ses espèces de ehoux. Il entretient la santé, et s'allic merveilleusement avec le ehaud, le sec, l'humide, le doux, l'amer et l'âere : il réunit à lui scul les pro. priétés de ce remède eomposé qu'on appelle des sept vertus. Abordons maintenant l'étude des espèces. La première est nommée lisse; elle est grande, à feuillage étalé, la tige haute. Eille est robuste et possède une grande vertu. La seconde espèec est erispéc et se nomme apiacon; le port de eette espèce en révèle les propriétés médieinales; elle est plus énergique que la préeédente. La troisième, que l'on appelle douee, $\Omega$ une tige

crit, dato vini atri duri. Aquatum bibat quam minimum. Si febris erit, aquam. Id facito quotidie mane. Nolito nuıl. tum dare, ne pertaedeseat, IIti possit porro libenter esse. Ad eundem moduın viro et mulieri, el puero dato. Nunc: de illis quiluns agre lotium it, quibusque substillum est. Sumito brassieam, conjieito in aquam ferventem, coquito paulisper, uti subcruda siet. Postea aquam defun. dito non oinnem. Eo addito oleum bene, et salem, et cumini paululum iufervefacito paulisper, postea inde juscu lun frigidum sorbere, et ipsam hrassican esse oportet. Uti quam primum exeoquat, quotidie id facito.

CLVII. - Quot brassicx genera, et qux natura.

Priucipinm te cognoscere oportet, qux genera brassic $x$ siut, et cujusmodi naturan liabeant. Omuia ad salutem temperat, commutatque sese semper cum ealore, ( et rigore) arido, simul humido, et dulci, et amaro, et acri. Sed qua vocatur * septem bona in conınixturam, natura omnia lase habet brassica. Nune uti cognoseas naturam carmm, prima est, levis qua nominatur. Ea est grandis, Iatis foliis, caule magno : validam lıabet natı. ram, ef vim magnam ltabet. Altera est erispa, apiacon vocatur. Haxe est aspera et uatura bona ad eurationem. 
courte; sa feuille est tendre, mais la plus amère de toutes, et son sue peu abondant a un effet violent. Sachez d'abord qu'elle possède plus de propriétés médicinales que les autres espèees de ehoux. On l'applique piléc sur toutes les plaies et sur toutes les tumeurs. Ce topique nettoiera tous les uleères, et les guérira sans douleurs. Elle travaille les abeès et les ouvre. Elle nettoic et guérit les plaies infectes, et les eancers qui résistent aux autres remèdes. Mais avant de l'appliquer, passez-la à l'eau chaude, et faites-en deux eataplasmes par jour : vous enlèverez ainsi toute l'infection. Le eancer noir sent mauvais, et jette une sanie dégoûtante. Le eaneer blane est atussi purulent; mais le eaneer fistulcux ne s'ćpure que sous la chair à l'intérieur. Pilez du chou sur toutes ces sortes de maux, et vous les gućrirez : c'est ec qu'il y a de micux pour ees affections. Yous guérirez pareillement les luxations en les lavant deux fois par jour avec de l'eau chaude, et en y appliquant du chou pilé. Si vous en mettez deux fois par jour, vous eouperez la doulcur, ct s'il y a contusion vous la résoudrez et la gućrirez. Le ehou broyé guérit aussi les ulec̀res et les chaneres qui naissent aux mamelles. Si l'ulcere ne peut supporter l'acrimonie du chou, mèlez à eelui-ci de la farine d'orge, ct appliquez-le ensuite : il guérira tous les ulcères de ectte nature, tandis qu'aucun autre remède n'eût pu ni les guérir ni les nettoyer. Pour guérir les uleères des enfants et des jeunes filles, mêlez au chou de ia farine d'orge. Si vous voulez couper, laver et faire sécher des feuilles de chou que vous faites digérer dans du sel et du vinaigre, vous obtiendrez un aliment des plus

Validior est, quam qua supra scriptà est. Item est tertia, quic lenis vocatur, minutis caulibus, tenera, et acerrima omnium est istarum, tenui succo velıementissima. lit prinum scito, de omnibus brassicis nulla est illiusmodi medicamentosior. Ad omnia vulnera, tumores eam contritan imponito. Hacc omnia ulcera purgabit, sanaque faciet sine dolore. Eadem tumida concoquit, eaden crumpit. Eadem vulnera putida, canceresque purgabit, sanosfue facict, quod medicamentum aliud facere non potest. Verum priusquam id imponas, aqua calida multa lavato. Postea bis in dic contritam imponito. La omnem putorem adimet. Cancer ater, is olet, et saniem spurcam mittit. Albus purulentus est. Sed fistulosus subtus suppurat sul) carne. In ea vulnera lujuscemodi teras hrassicain, sanını faciet. Optima est ad lıjuscemodi vulnus. Et luxa. tum si quod est, bis die aqua calida foveto, brassicam tritam opponito, cito sanum faciet. Si bis die apponitur, lolores auferet. Et si quid contusum est, erumpet. Si luassicam tritam apposueris, et sanun faciel : et si quid in mammis ulceris natum, et carcinoma, brassicam tritam opponito, sanum faciet. El si uleus acrimoniam cjus ferre non poterit, farinam lıordeaceam nisceto, ita opponito. Ifujuscemodi ulcera omnia lıxe sana faciet : quod aliud medicamentum facere uon potest, neque purgare. Et pue:o, et puella si ulcus erit lujuscemorli, fariuan sains. Pour lo rendre plus agréable, vous l'arroserez de vinaigre micllé, vous l'aromatiserez de menthe sèche, de rue, de eoriandre pilée, et vous y mettrez du sel. Cet aliment est oxeellent, détruitla souree de toutes les maladies; il a des proprićtés laxatives, et guérit les maux dont le eorps contiendrait déjà le germe. Maux de tête, maux d'ycux, il chasse tout, ii guérit tout. II faut le prendre à jeun le matin. Il guérit la mélaneolie, le spleen, les palpitations de cœur, les inaladies du foie, des poumons, les tiraillements des entrailles, et toutes les douleurs internes. Ratissez dessus du laser, et vous le rendrez meilleur. Lors. que tous les viseères gorgés de nourriture ne peuvent s'insinuer dans toute la masse du eorps, il en résulte toujours quelque maladic. Lorsque votre estomac surehargć par un excès d'aliments ne peut évacuer, mangez du chou préparé comme il a été dit, et en proportion de la eonsom. mation que vous avez faite; ct vous n'aurez a redouter aueune maladic. Rien n'est si efficace contre la goutte que le chou eru, si on le mange associć à la rue et à la eoriandre, ou bien assaisonné de laser ratissé, d'oxymel et de sel. Ce remède rendra le mouvenent à toutes les phalan. ges végétales ; il n'est pas dispendieux; ct d'aillcurs, le fût-il, il faudrait on essayer pour sa santé. C'est à jeun qu'il faut le prendice. On gućrira par le meme moyen les personnes sujettes aux insomnies, en leur administrant du ehon grillé, frotté d'huile iorsqu'il est chaud, et légèrement salé. Plus elles en mangeront, plus prompte sera leur guérison. Ordonnez le trailement suivant à eeux qui ont des tranchées : Faire bien maeérer des feuilles de chou, les mettre dans

lordeaceam addito. Et si voles eam consectam, lautam , ( siccam,) sale, aceto sparsan esse, salubrius niliil erit, Quo libentius edas, aceto mulso spargito, mentam siccam, et rutam, coriandium sectam, sale sparsam paulo, Libentius edes. Id bene faciet, et mali niliil sinet iı corpore consistere, et alvum bonan faciet. Si quid antea mali intus erit, omnia sana faciet. De capite, et de oculis omnia deducet, et sannm faciet. Hanc mane esse oportet jejunum. Et si bilis atra est, et si lienes turgent, et si cor dolet, et si jecur, ant pulmones, aut pracordia, uıo verbo omnia sana facict, iutro qux dolitabunt. Eodem silplium inradito, bonum est. Nam venæe omnes, ubi sufflate sunt ex cibo, non possunt perspirare in toto corpore, inde aliqui morbus nascitur. Ubi ex multo cibo. alvus non it, pro portione brassica si uteris, (id ut te mo. neo) nihil istorum usu veniet morbis. Verum morbum articularium nulla res tantım purgat, quantım brassica cruda, si eam edes cum ruta et coriandro concisam. Sic et laserpitium inrasum cum brassica ex (aceto) oxymelli, et sale sparsa. IIac si uteris, omnes articulos poteris experiri. Nulhıs sumptus est : et si sumptus esset, tamen valetudinis causa experirer. Ilanc oportet mane jejuuum esse. Omnis qui insomniosus est, liac eadem curatione saum facies. Verum assam brassicam, et unctam caldaun, salis paulum dato homini jejuno. Quam plurimum 
une marnite, et les laisscr bouillir; décanter l'eau apres la cuisson, ajouter beaucoup d'huile, un peu de sel, du cumin et du fin gruau; faire bouillir de nouveau, puis dresser sur un plat. On mangera le chou sans pain, s'il est possible; sinon on $y$ fera tremper un peu de pain : s'il n'y a pas de fièvre, on donnera du vin bien coloré. La guérison sera prompte. Si une personne débile fait usage du chou ainsi apprêté, elle reprendra bientôt ses forces. Voici qui est plus surprenant: Conservez l'urine d'une personne qui aura mangé des choux, faites-la chauffer, préparez-en un bain à une personne malade : elle sera guérie. Cela est sanctionné par l'expérience. Si vous lavez de cette urine les enfants d'une constitution débile, íls deviendront robustes pour toujours, et ceux dont la vue sera affaiblie verront plus clair en frottant leurs yeux de ce liquide. Les maux de tête et de cerveau disparaltront, si on lave ces parties avec cette urine. Jaınais la femne ne manifestera d'exhalaisons spéciales à certaines régions quand elles auront été lavées avec cette urine; et voici comment elle devra s'y prendre. Aussitót que l'urine aura bouilli dals un vase en cuivre, on placera celui-ci sous une chaise percée sur laquelle la femme s'asseoira, et on l'enveloppera de ses vêtements. Le chou sauvage possède les propriétés les plus énergiques. Il faut le faire sécher, et le broyer bien menu. Si l'on veut purger quelqu'un, on lui défend de souper la veille, et le lendemain matin on lui administre à jeun le chou broyé, à la dose de quatre cyathus d'eau. Ce purgatif, supérieur à l'ellébore et à la sammonée, n'a pas de suite fâcheuse, et fortifie le corps : il opérera mêmc

ederit, tam citissime sanus fiet ex eo morbo. 'Tormina quibus molesta erunt, sic facito : brassicam macerato bene, jostea in aulam conjicito, defervefacito trene. Ubi cocta erit bene, aquam defundito. Eo addito oleum bene, et salis paululum, et cuminum, ot pollinem polentio. Postea ferve bene facito. Ubi ferverit, in catinum indito. Dato edit, si poterit, sine pane; si non, dato panem purum. Ibidem madefaciat. Kt si febrim non labebit, dato vinum atrum bibat. Cito sanus fiet. Et loc, si quando usus venerit, qul debilis erit, hac res sanum facere potest. Brassicam edit ita, uti s. s. E. Et loc amplius. Lotium conservato ejus, qui hrassicam esitarit. Id calfacito. Eo hominem demittito, cito sanım facies hac cura. Expertım lioc est. Item pueros pusillos, si laves eo lolio, nunquam debiles fient. Ei quibus oculi pasum clari sunt, co lotio innngito, plus videbunt. Si caput aut cervices dolent, eo lotio caldo lavito, desinent dolere. Et si mulier eo lotio locos forebit, nunquam ii virosi fient. Et fovere sic oportet : ubi in scutra fervefeceris, foeta sub sellam supponito pertusam. Eo mulier assidat, (operito,) circum vestimenta cam dato. Brasslca erratica maximam vin liabet. Eam arfacere, et conterere oportet bene minıtan. Si quidem purgare voles, pridie ne cœenet, mane jejuno dato brassica trita decoctacque aqua cyathos iv. fiulla res tan bene purgabit, neque ellehorum, neque sur les malades désespérés. Voici comment il convient de traiter celui qui prend le remèdc. Administrez-le sous forme liquide pendant sept jours : si le malade veut manger, donnez-lui du rôti; si cette nourriture lui répugne, donnez-lui du chou cuit et du pain, du vin trempé : défendez le bain et prescrivez les frictions huileuses. Celui qui se sera ainsi purgé jouira longtemps d'une bonne santé, et ne sera jamais malade que par sa faute. Si quelqu'un est affligé d'un ulcère récent ou invétéré, appliquez-lui de ce chou sauvage, sur lequel vous aurez versé de l'eau, et il sera guéri. Si c'est une fistule, introduisez à l'intérieur une tente de ce chou; si la fistule ne peut recevoir la tente, délayez le chou, introduisez-le dans une vessie à laquelle vous adapterez un tuyau; pressez les flanes de la vessie, afin que la préparationentredans la fistule. Ce remède sera iufailliblc. Lechou broyé avec du miel guérit aussi les ulcérations récentes et invétérées sur les. quclles.il a été appliqué. S'il vous est venu un polype dans le ncz, mettez dans le creux de la main du chou sauvage broyé, et approchez-le des fosses nasales : aspirez fortement. $\mathrm{Au}$ bout de trois jours le polype disparaitra. Aussitôt qu'il sera ton bé, continuez encore le remède pendant quelques jours, àfin de détruire les racines mêmes du polype. Si vous êtes quelque peu sourd, broyez des feuilles de chou avec du vin, exprimez le suc, que vous instillerez tiède dans votre oreille ; et vous sentire $z$ aussitót que vous entendez plus clairement. A ppliqué à faible dośe sur les dartres, le chou les fait disparaitre sans déterminer d'ulcération.

scamoneium, ef sine periculo; et scito salubrem esse corpori. Quos diffidas sanos facere, facies. Qui lac purgatione purgandus erit, sic eum curato : sorbitione liquida hoc per diesviı. dato. Ubi esse volet, caruem assam dato. Si esse non volet, dato brassicam coctam, et panem, et bibat vinum leue dilutum, lavet raro, utatur unctione. Qui sic purgatus erit, diutina valetudine utetur, neque ullus morbus veniet nisi sıa culpa. (Et) si quis ulcus tetrum, vel recens habebit, hanc brassicam eriatican aqua spargito, opponito, sanum facies. Et si fistula erit, turundam intro trudito. Si turundam non recipiet, diluito, indito in resicam, eo calamum alligato. Ita prenito, in fistulam introeat. La res sanum faciet cito. Et ad omnia ulcera retera et nova oontritam cum melle opponito, sanum faciet. Et si polypus in naso introierit, brassicam erraticam aridam tritam in malım conjicito, et ad nasum admoveto. Ita subducito susum animam quam plurimum poteris. In triduo polypus excidet. Et ubi exciderit, tamen aliquot dies item facito, ut radices polypi persanas facias. Auribus si parum audies, terito cum vino brassicant, sucum exprimito, in aurem intro tepidum instillato. Cito te intelliges plus audire. Depetigini spurca brassicam opponito, sanain faciet, et ulcus non faciet. 
CLY゙III. - Préparatıons lavatives.

Si vous voulez que le canal digestif demeure libre, mettez dans une marmite six setiers d'eau, et l'extrémité osseuse d'un jambon. A défaut de cette dernière partie employez un morceau de jambon d'une demi-livre, et coupé dans la partie la moins grasse. Lor'sque la cuisson touche à son terme, ajoutez-y deux petites têtes de choux, deux bettes avec leurs racines, un peu de polypode, de mercuriale, deux livres de muscles, un têtard, un scorpion, six escargots, et une poignée de lentilles. Faites réduire toutes ces substances jusqu'à trois setiers, sans y mettre d'huile. Prenez un setier de ce breuvage lorsqu'il sera tiède; ajoutez-y un cyathus de vin de Cos; buvez et reposez-vous. Prenez de même la scconde et la troisième portion, et vous serez purgé. Si vous voulez hoire par-dessus du vin de Cos, vous en avez la liberté. De toutes les substances que je viens d'indiquer, une seule suffirait pour relâcher; mais leur réunion constitue un breuvage aussi efficace qu'agréable.

CLIX. - Remèdes contre les écorchures.

Quand on voyage, on préviendra les écorchures en portant sous l'anus un petit rameau de grande absynthe.

CLX. - Charme contre les luxations.

Le charme suivant guérit les luxations : Prenez un roseau vert de quatre ou cinq pieds de long; coupez-le par le milieu, et que deux hommes le tiennent sur vos cuisses; commencez à chanter : IN ALIO. S. F. MOTAS VarA, DARIES

\section{CLVIII. - Alvum dejicere hoc modo oportet.}

Alrum dejicere hoc modo oportet. Si vis bene tibi dejicere, sume tibi ollam, addito eo aquae sestarios vi. et eo addito ungulam de perna. Si ungulam non habebis, addito de perna frustum. r. s. quam minime pingue. Ubi jam coctum incipit esse, eo addito brassicæe coliculos 11 . beta coliculos 11. cum radice sua felicula paulum, herba mer. curialis non multum. Mutulorum L. 11. piscem capitonem, et scorpionem 1. cochleas vi. et lentis pugillum. Hac omvia decoquito usque ad sestarios tres juris. Oleum ne ad. didel is. Indidem sume tibi sestarium unum tepidum. Adde vini Coi cyathum unum. Bibe, interquiesce. Deinde iterum eodem modo, deinde tertium. Purgabis te bene. Et si voles insuper vinum Coum mixtum bibere, licebit bibas. Ex iis tot rebus, quot scriptum est, unum, quod corum vis, alvum dejicere potest. Verum ea re lot res sunt, uti bene dejicias, et suave est.

\section{Ad intertriginem remedia.}

Intertrigini remedium in viam cum ibis, absinthii Pon. tici surculum sub anulo habeto.

\section{CLX. - Luxum ut excantes}

Luxum si quod est, hac cantione sanum fiet. IIarındinein prende tibi viridem $\mathrm{P}$. Iv. aut $\mathrm{v}$, lohghm. Median
DARDARIES ASTARAMIES DISSUNAPITER, et CONtinuez le charme juscju'à ce que les deux morceaux soient réunis; agitez un fer au-dessus; Iorsque les deux parties seront réunies et se toucheront, saisissez-les, et coupez-les en tous sens : vous en ferez une ligature sur le membie cassé ou. fracturé, et il sera guéri. Cependant pour un membre démis ou cassé, répétez tous les jours le même charme : ou le suivant, pour une fracture: Huat hanat huat ista pista sista, doMIABO DAMNAUSTra; ou bien encore : HUAT HAUT HAUT ISTA SIS TARSISARDANNABON DUNNA USTRA.

CLXI. - Manière de cultiver les asperges.

Il faut défoncer un sol convenablement liumide, ou un terrain bien engraissé. Après le défoncement, on le disposera en planches, afin qu'on puisse sarcler et nettoyer à droite et à gauche sans piétiner la terre. Dans la formation des planches, on ménagera autour de chacune d'elles un sentier d'un demi-pied de largeur; on sème ensuite en ligne, en mettant deux ou trois semences dans un trou fait au plantoir, etqu'on recouvre ensuite de terre. L'ensemencement terminé, on éparpille du fumier sur la surface des planches vers l'équinoxe du printemps; lorsque le germe poussera, on sarclera fréquemment, en faisant attention de ne pas arracher les asperges avec les mauvaises herbes. La première année de la plantation, on couvrira le semis de paillis pendant l'hiver, pour le préserver des gelées. Au printemps on le découvrira, on le sarclera et on le nettoiera.

diflinde, et duo homines teneant ad coxendices. Incipe cantare, in AL10. S. F. MOTAS VETA, DARIES DARDARIES ASTATARIES Dissunapiter, usque dum coeant. Ferrum illsuper jactato. Ubi coierint, et allera alteram tetigerit; id manu prende, et dextra sinistra pracide. Ad luxum, aut ad fracturam alliga, sanın fiet. Et tanen quotidie cantato in alio, S. F. vel luxato. Vel hoc modo, nust na. Nat liUat ISTA PISTA SISTA, DoMlabo DAMNAUSTRA, et luxato. Vel hoc modo, nuat navt naUt ISTA SIS TAR SIS ARDANAABON DUNXALSTRA.

\section{CLXI. - Asparagus quomodo seratur.}

Asparagus quomodo seratur. Locum subigere oportet bene, qui habeat lumorem, aut loco crasso : uhi erit snbactus, areas facito, ut possis dextra sinistraque sarire, runcare, ne calcetur. Cum areas deformabis, intervallum facito inter eas semipedem latum in omnes partes. Deindo serito. Ad lineam jalo grana bina aut terna deniltito. Et eodem palo cavum terrae operito. Deinde supra areas ster. cus spargito, bene serito. Secundum aquinoctium ver. num, ubi erit natum, herbas crebro purgato, cavetoqu10 ne asparagus una cum herba vellatur. Quo anno severis, substramentis per liemem operito, ne peruratur. Deinde primo vere aperito, sarito, ruucatoque. Post annum tertium, quam severis, incendito vere primo. Deinde ne ante sarueris, quam asparagus natus crit, ne in sarimndo radices locdas. Tertio, aut quarto anno asparaginm vellito 
Après la troisième annéc qui suit l'ensemen. eements on brûle les tiges au printemps. Gardezvous bien de sauler avant la poussce des tiges, ear le sanlage peurrait offenser les racines. A la Iroisième ou à la quatrième annće, vous eouperez les asperges sur les racines; car'si vous les eassez, il se formera de nouvelles souches qui s'éloufferont. Vous pourrez les eouper jusqu'à ce qu’ils montent en graine. Les semenees murissent à l'automne; lorsqu'elles auront été récoltćes, on mettra le fou aux tiges ct on reeommenecra à sareler et à fumer dès que l'asperge joussera. L'asperge est déjà au déclin vers la lunitième ou la neuvième anncé; on l'arraclie alors, pour la transporter dans un autre terrain bien défoneé et bien fumé. On fait des tranchées deslinées à reeevoir les pattes d'asperge. On ne doit pas laisser entre eelles.ei un intervalle de moins d'un pied. En les arrachant ereusez tout autour, afin que l'extraction ne présente pas de diffieultés ; prenez garde surtout de les déchirer. Entourez-les d'une bonne dose de fumier de mouton, e'est le meilleur pour eet objet : tout autre engrais favorise la multiplicatiou des mauvaises herbes.

Cl.XII. - Salage des jambons, fricandeaux de Pouzzoles.

Procédé pour saler les jambons dans une fu-

al) ralice. Nam si defringres, stirpes fient, et intermorien. tur. Usque lieebit vellas, donicum in semen videris ire. Semen maturum fit ad autumnum. Ita cum sumpseris scmen, incendito, et cum coeperit asparagus nasei, sarito, et stereorato. Post annos vill. aut ix. eum jam est velus, ligerito, et iı quo loco positurus eris, terram bene subigito, et stercorato. Deinde fossulas facito, qua radices aspraragi denittas. Intervallum sil ne minus pedes singulos inter radices asparagi. Vellito, sic cireunfodito, ut facile evellere possis. Caveto ne frangatur. Stercus ovillum ‘ (uan plurinum fae ingeras : id est optimum ad ean rem. Aliud stereus herbas creat.

CI.Xll. Salsura pernarum et offella Puteulanx.

Promas sallire sic oportet, in dolio, aut in seria. Cum taille ou dans un saloir. Iorsene vos jambons seront aehelés, retranehez-en l'extrémité osseuse. Employez pour ehaeun un muid de sel romain trituré. Mettez-en un lit au fond de la tomue ou du saloir : stratifiez vos jambons en plaeant la penu en bas, et mettez une sceonde couche de sel. Faites un second lit de jambons, que vous eouvrez de la même manière. P’’enez bien garde que Ies cliairs ne soient en contact, et eouvrez-les tous de sel. Lorsque tous les jambons scront entonnés, mettez au-dessus une eouche de sel qui les couvrira et que vous égaliserez. $\Lambda$ près qu'ils auront séjourné dans le sel pendant einq jours, enlevez-les avee le sel. Replacez au fond dı saloir les jambons qui ćtaient à la surfaec, couvrez-les et stratifiez-les comme préeédemment. Après l'intervalie de donze jours retirez définitivement les jambons, seeouez-en le scl, et mettez-les à un eourant d air pendant deux jours. Essuyez-les avec une éponge le troisième jour', et frottez-les d'huile; suspendez-les à la fumée pendaut deux jours, après quoi vous les retiretez. Frollez-les d'huile et de vinaigre mêlés ensemble, suspendez-les au garde-inanger : ils ne scront attaqués ni par les teignes ni par les vers.

pernas emeris, ungulas earum pracidito. Salis Romanien. sis moliti in singulas semorlius. In fundo dolii, aut serise salem sternito. Deinde pernam ponito. Culis deorsum spe. etet. Sale obruito totan. Deinde alteran iısıper pouilo. Eodem modo obruito. Caveto, ne earo carnem tangat. Ita ommes obruito. Cubi jam omnes composueris, sale insuper obrue, ne earo appareat. Equalem facito. Uli jam dies $\mathbf{v}$. in sale fueriut, exinito omnes cum suo sale. Qua tum summie fuerint, imas facilo. Eodemque modo obruito, et eomponito. Post diem omnino duodleciumun pernas eximito, et saleu onnem detergeto, et suspeulito in vento bidum. Die tertio extergeto spongia hene, perunguito oleo. Suspendito in fumo biduum. Tertio die de. milo. Perunguito oleo et aceto conmixlo. Suspendito in camario. Nee linea, nec remes tangent. 


\section{SUR L'ÉCONOMIE RURALE DE CATON.}

Istroductios Mujores enim nostrilloc sic habuerunt, et ita in legibus posuerunt, furem dupli, faneratorem quadrupli. On a lieu de supposer que Caton fait allusion aux lois des Douze Tables. Tacite nous apprend que ces lois défendaient l'usure; mais ni lui ni d'autres ne font mention de la peine qu'elles prononcaient contre les usuriers. Pour ce qui concerne les voleurs, il nous reste un fragment de ces lois, où nous lisons: " Si adorat furto, quod nec manifestum escit, duplionem luito. „L'arersion que notre auteur arait d'ailleurs pour l'usure était telle, que lorsqu'on lni demandait un jour re que c'était que faire l'usure, il ne répondit qu'en de. mandant à son tour ce que c'était que tuer un homme.

Cnsp. I. De omnibucs agris, optimoque, etc... Nous royons par ce passage qu'une récolte d'osier était regar. déc comme une chose si intéressante, que Caton met une oseraie immédiatement après la vignne et le jardin, pour la valeur de son produit.

Crap. If. Centones, cuculiones familiam oportuisse sibi sarcire... Le cento était l'habillement des gens de la campagne qui leur courrait tout le corps, tandis que le cuculio leur enreloppait seulement la tête et les épaules.

Crap. III. Les Romains, comme nous l'apprend CoIumelle, 1,6 , divisaient leurs metairies en trois parties : l'une, qu'ils appelaient villa rustica, était destinée aux opérations rustiques, et comprenait l'habitalion du métayer et de tous ceux qui étaient employés sous ses orJres, les basses-cours, les étables, les liangars pour meltre à couvert les voitures et les instruments de culfure; l'autre, qu'ils désignaient sous le nom de villa rructuaria, serrait de réserve anx productions de la terre. Cetle partie de la métairie se composait des greniers, des celliers, des pressoirs, etc. La troisième partie, appelée rilla urbana, était réservée à l'habitation du propriétaire.

Crap. V. Rem divinam, nisi compilalibus in compito aut in foco ne faciat. Les compitalia étaient des lêtes qui se célébraient dans les carréfours en l'lıonneur des dieux lares. Varron nous explique très-bien l'étymo. logie de cc mot, qu'il fait dériver de compitus, carrefour, (ubi viæ competunt), oil deux chenins se rencontrent. Voici ses expressions : " Compitalia, deis attributus laribus - ubi viæ competunt, tnm in compitis sacrificatur: quotannis is dies concipitur. "

Chap. IX. Si aquam non habebis, sicca quam pluri. ma facito. Hoc est prcedium quod ubi vis expedit facere. L.e préceple renfermé dans ces paroles est la conséquence naturelle de la manière de voir de Caton. D'après lui, le produit le plus sùr est celui qu'on retire de l'éducation des bestiaux. Quelqu'un lui demandant un jour quel étail le meilleur moyen de s'enrichir promptement, il répondit que c'était de s'appliquer à nourrir des besflaux. La même personne insistant encore pour savoir quel était le moyen qui approchait le plus de celui-là, il répondit que c'était encore de nourrir des bestiaux, mais d'une maniere moins parfaite. Ciḉron, en rapportant cette anec. dote dans ses Offices, $\mathbf{I I}, \mathbf{2 5}$, lui fait nieme ajonter que Ie troisième moyen serait de nourrir des bestiaux, quoiqu'on le fit mal. Mais on suppose avec raison que ces dernières paroles sont de l'invention de l'orateur romain, puisque Pline, en citant le mẻme trait, XVIII, 5 , n'en fait aucune mention. Columelle même, liv. VI, dans la préface, assure qu'il est impossible qu'un lomme aussi expérimenté que Caton ait donné cette troisième réponse, puisqu'on perdrait plus à mal nourrir des bestiaux qu'on ne peut gagner à le bien faire.

Crap. XXXVI. Au sujet de ce chapitre, Dickson (Traité de l'agriculture des anciens) nous fait observer que l'u. sage établi en Angleterre de semer quelquefois du sarrasin, du froment, du trèfle, des pois et d'autres légumes, pour être retournés comme engrais, nous a été transmis par les anciens, qui araient sourent recours à cet expédient. Les Grecs employaient ordinairement les féres à cet effet; et Théophraste nous apprend que dans la Macédoine et en Thessalic les cultivateurs les retournaient en fleur. Au lieu de fêres, les Romains employaient généralement des lupins. Varron, liv. I, ch. 23 , nous dit: " II y a des " plantes qu'on cultive moins pour en tirer du profit dans " le moment présent, que pour augmenter celui de l'an* née suirante : ce sont celles qui, laissées sur la terre " après avoir èté coupées, contribuent à la rendre d'un " meilleur rapport. C'est par cette raison que, lorsqu'une " terrc est trop maigre, on emploie en guise de fumier le " lupin qui n'est pas encore monté en graine, ou bien même "la tige des feres dont les cosses ne sont pas encore " assez formées, pour qu'il y ait plus de profit à récolter " la fère elle-même."

Columelle, en parlant de ce genre d'entrais, nous dit aussi : a Je pense que lorsque le cultivateur manque de " fumier, il ne doit pas oublier d'aroir recours aux lu" pins; car si on les sème daus un champ stérile vers " le 18 de septembre, et qu'on les retourne à la cliarrue " ou à la bẻche, ils produiront l'effet des meilleurs " engrais. Il faut les retourner lorsqu'ils sont en fleur " pour la seconde fois, dans les terrains sablonneux; et " à leur troisième floraison dans les terres fortes. Dan le " premier cas, on les enterre lorsqu'ils sont tendre en" core, afin qu'ils poutrissent plus promptement, et se " melent avec le sol franc. Dans le second, on les laisse " derenir durs et roiles, afin qu'ils puissent soutenir plus " longtemps les mottes solides dans un état de division, " jusqu'à ce que les rapeurs que les chaleurs de l'été " font exhaler aux plantes qui se putréfient puissent les " pénétrer et les dissoudre. "

Nous royons par là que les Romains étaient très-attentifs à la manière de retourner des végétaux pour servir d'engrais : et peut-être est-ce le défaut du même soin qui a fait manquer tant de fois une expérience dont le succès ne saurait être douteux. Les terres légères d'Italie ont beaucoup à souffrir de l'action du soleil pendant la saison chande; pour cette raison, lorsqu'on y semait des lupins pour les fertiliser, on les retournait pendant qu'ils étaient tendres, afin qu'ils pussent se mèler promp. tement à la terre, et avant que le soleil en eut fait évaporer les sucs. Il u'eu est pas de mène des terres fortes : 
elles ont besuin d'etre divlsées. ce qui ne se fait pas sans lifliculté : aussi, lorsqu'on y semait des lupius pour en. grais, on ne l's retounait que lorsqu'ils avaient acquis une cousistance qui les reudait capables de supporter la terre et de la tenir onverte. Par là, les rayons du soleil s'y introduicaient, et faisaient exlıaler, des plantes en putréfaction, des rapeurs qui luunectaient et dissolvaient cette terre dure et conupacte.

pliıe couseille de faire labourer immédiatement un champ de lupius qui a clé mangé en vert. C'est ici une circonslance à laquelle les anciens paraissent avoir donné lieaucoup plus d'attention que les mudernes. En effet, l'olyjet paralt assez. important. Lorsqu'une plante est coupée verte, comme le fourrage, il y a certainement une grande quantité de sève dans la portion de la tige qui est laissće sur pied, ainsi que dans la racine. Or, si cette partie de la plante est abandonnée dans cetle situation à la chaleur dn soleil, il est probable que non-senlement toute cette sève sera évaporée, mais encore qu'aussi long. temps que la plante couservera cette puissance de succion par laquelle clle tire sa nourriture de la terre, elle contivueı de la romper en pure perte, puisqu'elle épuisera ainsi la terre d'une sève que le soleil fera èvaporer. Mais Inrsque ces racines encore pleines de suc sont labourées it enfuuies, elles se pourrissent et rendent tons ces sucs à la terre, en meme tenuns qu'elles y excitent une fermentation utile. Nous coupons aussi quelquefois l'iviaie et les lérumes verts pour fourrage; nous devions, dans ce cas, suive le conseil des anciens, d'autant plus que, quel que soit l'efret de la racine de l'ivraie sur la terre lorsqu'on Ji laisse se flétrir d'elle-inene, il est certain que plus tôt une terre, après aroir été récoltée, est labourèe, et plus tôt elle se répare.

Cuap. XXXVIII. La description que nolls fait Caton de la manière de construire les fours et de cuire la claux est très-importante. Nous voyons par là que la cliaux était bien connue des Romains, quoique avaut le temps de Pline ils ne paraissent pas l'avoir employée comme engrais. Le procédé dont nous nous servons aujourd'lui pour cuire notre cliaux est Irès-différent de celui que nous donne Caton. En Angleterre, nous dit Dickson, on mêle les matières combustibles avec la pierre destinée à faire I clıax, au lieu que les anciens les séparaient. Il est naturel de penser que les premiers essais pour cuire la cliaux furent de placer la pierre dans le feu, ou de meler les matières calcaires et combustibles. Dans cette supposition, leur séparation, suivant la métlode romaine, était un degré de perfection.

Du temps de Pline, on se serrait de cliaux lans quel. ques parties des Gaules poirr fumer les terres à blé, et on l'arait reconnue très-bonne en Italie pour la rigne et l'o. livier. Ce meme auteur cite également la clıaux comme très-firorable aux cerisiers : "Cerasos praccoces facit, co. gitque inaturescere cal $x$ admota radicibus. (En couvrant de cluaux la racine des cerisiers, on lıate la croissance de cet arlore, et on arance la maturité de ses fruits.)

Ce passage nous montre donc que l'usage de cette substance était connue des Romains conme engrais. Les cerises ne furent connues en ltalie qu'après les victoires de Lıcullus sur Mitliridate; or, ce Romain les apporka l'an 680 de la républi iue, ou environ deux cents ans avant Pline. Nous pourons supposer que: puisque de son temps l'on arait reconnu l'efficacité de la clıaux pour les cerisiers, on avait fait plusieurs tentatives de ce genre; et il est probable qu'à cette énoque son usage comme engrais aurail été aussi répandı en Italie qu'il l'est parmi nous, s'il ent autant convenu à son climat qu'il conrient aı nơtre.

Cuıp. LXXIV. Panis depsticius, que porte le texte de Gessner, signifie, fout simplement un pain peitri. II est plus probable que Caton entend parler du panis testitius (on testratius), pain cuit sous la cloche, qui se distinguait du pain orliunire, apıelé furnacens (cuit dans le four), par son excellente qualité. Nous lisons en effet dans Varron, liv. IV : " Testuatium, quod in testu caldo coquebatur, ut etiam nunc id faciunt matronæ. "

Cusp. LXXV. Sur le libum, la placenta, les tiacta et l'alica. Le libum était, ainsi que son origine l'indique (libare), une espèce de gâteau offert aux dienx dans les li. bations usitées dans les sacrifices. Ces gateanx étaient faits de fariue, de miel et d'huile. Les placenta (du not $\pi \lambda \alpha \xi, \pi) \alpha^{\prime} \times 0_{;}$, croate ) semblent aroir été des gateaux plus compactes. D'autres font dériver le mot placenta de ce. lii de placare, comme pour indiquer qu'ils servaient a apaiser les dieux auxquels on les offiait en sacrifice.

Les tracta sont une espece de gaufies, oll plutôt de masse-pains d'une pate croquante, puisque les Romaius s'en servaient pour épaissir les sauces, comme nous nous serrons de cliapelure de pain. Tiacta provient sans doute de tractare qui vent dire manier, parce qu'il fallait bean. coup pétrir cette pate pour la rendre légère : on prétend que notre mot tarte a la mème origine.

L'alica, selon Pline, XYIII, 11, était une composition faite de grains d'épeantre concassés, auxq̨uels on ajontait, pour les attendrir et pour les blanclir, une espèce de craie particulière qui se tronvait entre Puteoli (aujourd'luui Pouzzoles) et Naples, sur le mont Leucogée (aujourd'lui la Lumera). Cefte craie était si essentielle à la composi. tion de l'alica, et l'alica elle-même si précieuse, qu'duguste fit payer une somı considérable par an sur son trésor aux Napolitains, pour qu'ils en approvisionnassent une colonie qu'il avait ćtablie à Capoue. Pline assure en effet quecette composition ćtait très-saine, et il lui donne la palme sur toutes les espèces de ragnùts que l'on faisait arec les grains. Quand les graius d'épeautre concassés n'avaient été que dépouillés de leur enveloppe, comme ici, c'était de l'alica prima; ensuite on les concassait de noureau, on les faisait passer par un crible : ceux qui élaient trop gros pour passerdonnaientl'alica secunda, et les plus raffinés l'alica tertia.

Cuap. LXXVII. La spira ( $\sigma \pi s i ; \alpha$ ) était, ainsi que le mot l'inclique, uı gateau d'une forme spirale.

Cuap. LXXVIII. Les scriblite (du mot scribillare, scribo) étaient des pièces de pátisserie sur lesquelles il y avait tontes sortes de dessins ou d'inscriptions : Circum. lata diu mensis scriblita secundis. (Martial., lib. III.) Dum scrillite scriblitae cestuant occurrite. (Plant. Puen.)

CaAp. LXXX. Les encyta son! des espèces de beignets.

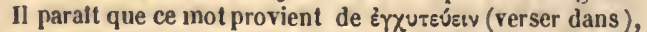
parce que ces pièces de pátisserie étaient trempées dans l'huile : apres quoi on les faisait passer à travers un moule.

Casp. LXXXI. L'erneum était encore une pièce de patisseriequi, d'après Turnebus, tirait son nom de hir, hir. nea (petit vase plat), et d'apres Scaliger, de bpveov.

Cuap. LXXX11. La sphcerila ou sparila doit son nom aux pièces de patisserie sphériques qui entraient dans sa composition.

Cusp. LXXXIV. Savillum, pièce de patisserie appelce ainsi à cause de sa douceur et de sa suavité (Savior et sa. viala se disaient autrefois pour suavior et suavilas). D’a. près la recefte que nous donne Caton pour préparer ce gátean, il n'est guère probable qu'il serait encore du gout de nos jours, au point de mériter le titre de savillum.

Cirap. LXXX II. Quant à l'amulum, Pline nous dit que. cette pâte ét.it apjùelée ainsi, parce que pour la fabriquer 
on employait le grain sans le moudre : Appellatum $a b$ eo quod sine mola ( $a$ privatif et mola) fiat.

Cuap. CXXXII. Jovi dapali culignam et... Jupiter était appelé Dapalis, parce qu'on lui donnait un repas splendide a l'occasion de ces fetes; el on le plaçait entre Minerve et Junon.

Cnap. CXXXIV. Prizlsquam messim facies, porcam procidaneam hoc modo fieri oportet. On appelait praecidansa ( $p r c e c c d o$ ) toute victime qu'on immolait avant les antres; mais la truie prcecidanea était en particulier celle qu'on ofrrait à Cérès avant de couper le blé. C'était un sacrifice imposé à celui qui n'avait pas rendu les derniers devoirs à quelqu'un de sa famille.

Chap. CXXXYl et CXXXVII. Relativement au partage de la récolte, dont nous parle Caton dans ces deux chapitres, Dickson nous faitobserver que les premiers fermiers qui aient existé cliez les Romaius se trouvaient placés sous d'autres conditions que chez nous. Il appartenait au propriétaire de pourvoir la ferme de tous les instruments uecessaires, et le fermier recevait en échange une certaine portion des produits pour les travaux de culture. Il s'appelait tantot politor, par rapport à l'occupation à laquelle il se livrait (polire terram); tantot partuarius par rap. ports à sa position vis-à-vis du propriétaice dont il était en quelque sorte l'associé en recevant une partie du produit de la ferme pour prix de son travail.

Qıant à la portion même de la récolte qui revenait au politor, elle était, ainsi que nous le voyons dans le chapitre cxxxyı, extrêmement faible; ce qui nous fait supposer que le fermier ne faisait aucune dépense pour la culture, et que cette portion lui était livrée exempte de toutc déduction. En Égypte, le roi, comıne propriétaire, ne recevait que la cinquième partie. Mais cette convention avait été établie par Joseplı pendant la grande famine, et elle n'avạit dú souffrir aucune difficulté : d'ailleurs le roi n'avait aucune dépense à faire, et recevait le cinquième du produit comme rente du fond. En Angleterre, quelquefois on afferme sur le nême pied que le politor romain, pour ce qui concerne le inode de payement. Mais au lieu du sixième, qui était le maximum du droit du politor, le fermier anglais reguit six dixièmes ou trois cinquièmes, la rente payée au propriétaire étant un tiers; ce qui avec la dìme fait quatre dixièmes ou deux cinquiènies. Lorsqu'une terre est affermée sur ce pied, non-seulement le fermier cultive, mais il fournit le bétail, les us. tensiles et la semence; et exceptè le transport à la grange, le baltage et le rannage, le propriétaire a ses deux cinquièmes exempts de toute cliarge. Il est impossible de supposer que le politor dut fournir tout ce que fournit le fermier anglais; la portion dans la récolte était trop faible pour cela. Caton ne dit pas par qui la semence était fournie. Était-elle prélevée sur la récolte avant le partage, ou était-ce le propriétaire qui la donnait? Il est évident que ce ne pourait être le politor, car cela lui eât enlevé la moitié de sa portion; il est probable uème qu'elle n'était pas fournie en commun, et que c'était le propriétaire seul qui la prenail sur sa part.

Les coloni dont parle Columelle paraissent avoir été sur un antre pied que les politores on partuarii. Ils payaient une rente pour leur ferme, comme tont nos fermier's actuels. Colunelle les appelle fermiers libres (subliberis colonis) pour les distinguer des politores ou partua. rii. Ceux-ci étaient sous la direction absolue des proprić. taires dans toute la conduite de la ferme, tandis que les fermiers libres n'étaient tenus qu'aux conditions de leur bail.

Il parait, d'apres Caton et Columelle, que les fermiers ro. mains étaient astreints à certaines cultures sur leurs fermes; de sorte qu'ils étaient soumis non-seulement à un plan établi pour la succession des récoltes, mais encore ils étaient dans l'obligation de cultiver d'une manière déterminée les différentes productions. Cette circonstanco s'explique par le haut degré de perfection auquel l'agriculture était parvenue en Italie. Les opérations étaient bien entendues, la culture était réglée suivant la nature du sol et des productions, et l'ordre des saisons permettait de fixer avec plus de précision les temps convenables pour les différents travaux. Ces restrictions d'ailleurs imposées aux fermiers pouvaient être très-avàntageuses à l'agriculture; et Columelle conseille méme aux propriétaires d'être plus exacts á exiger la culture que le payement, parce que le fermier, recueillant de bonnes récoltes, oserait moins solliciter l'indulgence du maitre pour le payement de la rente.

Chap. CXLI. Les suovilaurilia étaient le plus grand et le plus considérable sacrifice que l'on offrait au dieu Mars. Ce sacrifice se faisait pour la lustration ou l'expiation des clianps, des fonds de terre, des armées, des villes et pour attirer la protection des dieux par cet acte de religion. Les suovitaurilia étaient distingués en grands et petits: les petits étaient ceux où l'on imınolait de jeunes animaux, un jeune cochon, un agneau, un reau; les grands étaient ceux où l'on immolait des animaux par. faits, qui a vaient toute leur taille, comme le verrat, le bé. lier, le taureau. Avant les sacrifices on faisait faire à ces anima ux trois fois le tour de la chosedont on voulait faire l'expiation, comme le dit Virgile : "Que la victimequi doit " être offerte soit promenée trois fois autour des mois. " sons. " Le verrat était toujours immolé le premier, comme l'animal qui nuit le plus aux semences et aux moissons, et successivement le bélier et le taureau. Les suovitau. rilia étaient cliez les Romains, comme nous l'avons dit, un sacrifice offert à Mars; mais chez les Grecs le même sacrifice se faisait en l'honneur d'autres dieux encore; comme, par exemple, en l'lionneur de Neptune, dans Homère, et en celui d'Esculape dans Pausanias.

Chap. CXLIII. Kalendis, idibus, nonis, festus dies cum erit, coronam in focum indat. Cette couronne de fleurs était mise dans l'âtre en l'lonneur des dieux lares, dont le siége principal était dans le foyer. Elle était d'une grandeur extraordinaire; et Festıs nous dit: " Donatica corouæ dictæ, quod lis victores in ludis donabantur, qua postea nagnificentiæ causa iustitutæ sunt super moduın aptarum capilibus, quali amplitudine funt, cum lares ornantur: w Suttone nous apprend que cetle coutume élaut tombée dans l'oubli, Anguste la rétablit, en ordonnant qu'on déposât ces couronnes dans l'atre deux fois l'an, au printemps et a l'été : Compitalitiis lares ornari bis anno instituit, vernis floribus et æestivis. 


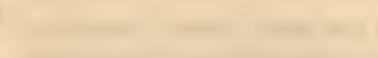

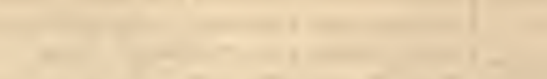

\section{$\cdot$}
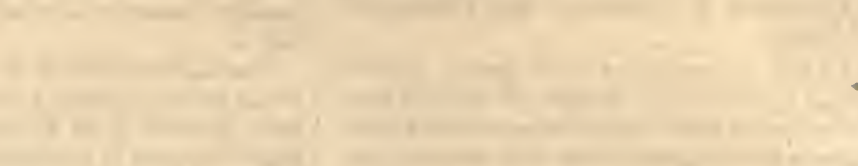

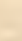

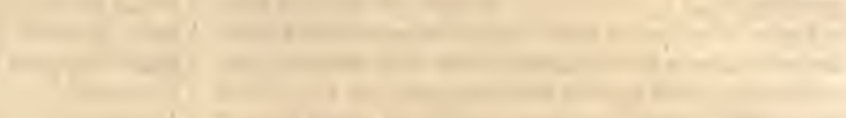

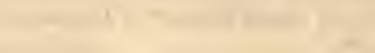

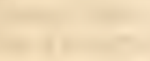

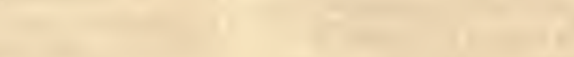

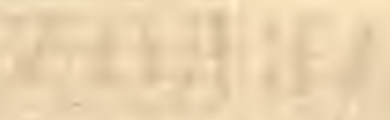

(n)

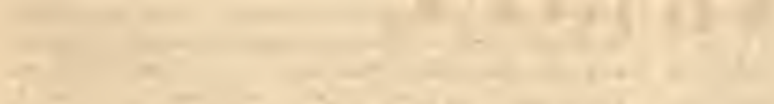

$\sqrt{2}$

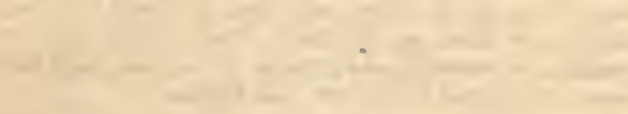

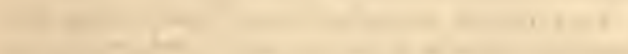

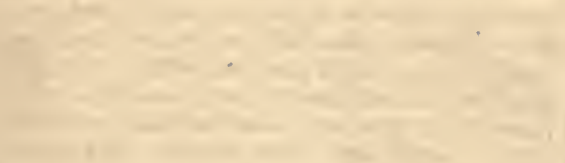

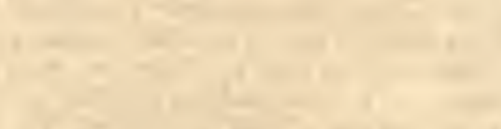

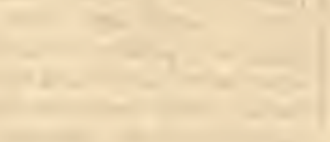


VARRON. 


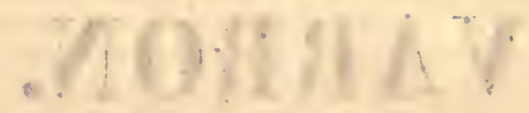




\section{SUR VARRON (1).}

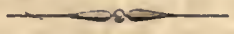

M. Térentius Varron, le plus savant des Ro- mains, au jugement de Cicéron, s'ètait rendu célèbre par un grand nombre d'ouvrages, dont la plupart ne sont pas parvenus jusqu'à nous. Parni ces deruiers, on doit citer l'histoire de sa vie : le gramınairien Clıarisius faisait un grand éloge de ce morceau, dont la perte est si regrettable. On sait donc fort peu de chose sur Varron, et le peu qu'on sait ne repose que sur des conjectures tirées soit des auteurs anciens, soit de ses propres écrits. Nous ne laisserons pas de rapporter ici tous les passages qui peurent jeter quelque lumière sur sa vie et ses travaux, en indiquant autant qu'il nous sera possible la date de ses principaux ouvrages et la nature de ceux qui ont èté perdus.

Nous trouvons d'abord dans Pline, 1. viI , $\$ 53$, un passage où il est question de ses parents. C'est Varron lui-mêne qui parle, citant comme un double exemple de mort subite celle du mari de sa taute maternelle Corfidius et celle du frère de ce Corlidius. Tous deux étaient chevaliers romains. lirnesti pense que c'est le Corfidius dont Cicéron a fait untion dans sa liarangue pour Ligarius : on voit mêne dans une de ses lettres (ad Att. xIII, 44) qu'il roulait supprimer son nom, parce que Corfidius était nıort quand la harangue fut prononcée. Varrou parle encore dans son traité $D e$ re rustica (liv. 11) de Caĩus Fundanius son beau-père, et de Fundania, femme de celui-ci. Nous supposons que cest ce Fundanius qui avait écrit un ouvrage sur les phénomènes de la nature, inité de celui d'Aristote, et qui a été fort loué par les grammairiens. Varron ajoute (liv. III De re rust.) que le fonds de terre appartenant à sa tante était situé dans la Sabine. Il était lui-ıneme de Réatine, et Sidoine Apollinaire lui donne toujours le surnom de Réatinus, pour le distinguer de Publius Térentius Varron Atacinus. Synımaque le désigne aussi par ce surnom.

On ignore quelles charges il brigua, et quelles sont celles dont il fut revêtu. Suivant Fabricius, il aurait été tribun, et cet honneur n'est pas le seul qu'il aurait obtenu. Cette conjecture nous paraît fondée, en ce qui concerne le tribunat, sur un passage des Antiquilés de Varron (apud Gellium) qui se trouve placé parmi les fragments, à la suite de ses ouvrages.

Nous voyons dans Pline (liv. Xxxv, $§ 49$ ) un autre

(1) Cette notice est un résumé du savant travail dont Scliteider a fait préréder son édition de barron, dans la collection qu'il a donnéc des Scriptores rei rustice. passage qui semblerait prouver que Varron cxerca l'édilité. a On trouva, dit-il, dans une nuaison de - Iacédémone un plafond remarquable par l'excel* lence du travail ct la beauté des peintures. Ce " plafond ayant ćté détaché de la muraille, et mis “ dans une caisse, fut transporté à Rome par les « soins des ćdiles Muréna et Varron, qui`en ornè" rent la salle des comices. Mais on peut douter que ce Varron soit le sarant ćcrirain qui nous occupe. Le même Pline (liv. II) nomme Vitruve à la place de Varron. Ernesti, s'appuyant sur une lettre de Cicéron (xIII, 10), fait de Varron le questeur de M. Brutus lorsque celui-ci partit pour la Gaule. Mais il est certain que le M. Térentius Varron qui accompagna Brutus dans la Gaule n'avait rien de comınun que le nom arec le Varron de Réatine. Ernesti aurait pu s'en assurer par la lèttre même de Cicéron dont nous reproduisons ici les ternies (Ep. 1.13-10) :

" Lorsque M. Térentius Varron, dit Cicéron, " vint au Forum, il rechercha mon amitié. Cette " amitié s'est accrue avec le temps. II se plaît aux " mêmes études que moi; il s’en occupe avec ar“ deur, ainsi que j'ai pu le voir souvent, et même * avec succès. Il était en relations très-assidues arcc * les fermiers de la république, ce qui ne laissait " pas de me fáire quelque peine. Il éproura de " grandes pertes, ct se jeta dans la carrière du bar* reau, avant les changenents survenus dans la " république. Il s'y distingua par sa probité autant " que par ses talents, regardant comme très-liono* rable et très-légitimennent acquis le gain qu'il * retirait de sa profession. "

Cicéron parle encore (ad Div. xIII, 2) d'un A. Térentius Varron Muréna qui faisait le commerce en Achaie, etlui recommande son affranchi Tiron, alors dans cette province, et malade; mais on ne sait quel est ce T. Varron Muréna. On ne sait pas non plus que conclure de ce passage de Cicéron (ad Div. Ix, 10), où Décinus Brutus lui dit : Je ıe pourrais sutfire a à la dépense, eussé-je à ma disposition les trésors a de Varron. Corradus pense que e'est une allusion au traité de Varron sur les richesses. Manutius n'est pas de cet avis : il prétend qu'il s’agit d'Antoine, et qu'à la place de Varronis il faut mettre Baronis, terme de mépris dont Brutus se serait servi pour flétrir son ennemi. Quant au poëte Térentius Varron Atacinus, ainsi appelé du nom d'un fleuve ou d'un village de la province de Narbonne, il vivait dans le même temps. Horace et Oride ont célébré ses louanges. Werusdorff a donné la liste 
de ses ouvrages dans son Epître critique sur les poëtes latins du second ordre, adressée à Rulınkenius. Sidoine A pollinaire (liv. vi, 32) cite les deux Varron, mais saus savoir com ment on doit les distinguer. a De quel Varron veut-on parler? dit-il; est-ce " de Varron Atacinus, ou bien de Térentius Varron?" $\mathbf{A}$ quoi Rulnkkenius répond très-justement, en s'appuyant sur un passage deSymmaque (Epist. IX-32) : " Tu sais bien que ce n'est pas de Térentius le Co* mique qu'il s'agit, mais de Varron de Réatine, lc " père de l'érudition latine. "

Varron s'était acquis les bonnes grâces de Pom pée, dont il embrassa le parti contre César. Il lui resta fidèle jusqu' au moment où sa cause fut perdıe sans ressources. Pompée l'avait employé dans la guerre contre les pirates et contre Mitliridate. Appien, De bell. Mithridat., dit que Cuéus Statius Varus confia à Varron la garde des mers d'Ionie et de Sicile, jusqu'à l'Acarnanie; d'où l'on peut conclure qu'il fut préteur. En eftet, Appien ajoute que les préteurs avaient été envoyés pour garder ces deux mers. Varron, dans son traité De re rust., (1. 11) a fixé d'une manière très-précise les limites de son commandenıent ınaritine. a Je n'ai rien avancé, " dit-il, qui ne m'ait été assuré par ceux qui possèa dent les plus beaux pâturages en Épire, lorsque a je commandais la flotte entre la Sicile et l'íle de " Délos, pendant la guerre contre les pirates. „ Ön peut rapporter à cette époque ce que dit Varron de certains poissons (De re rust., liv. III, ch. 17, \$4). Il suppose que c'est Accius qui parle : " Ces poissons, ^ dit-il, ne sont-ils pas encore plus sacrés que ceux " que tu as vus en Lydie, qui, accourant par trou" pes au son de la flute grecque, vinrent jusqu'à " l'extrémité du rivage, et inême près de l'autel " où tu sacrifiais : personne n'osait les toucher. " Pline parle aussi du commandement cxercé par Varron, comme chef de la flotte, dans la mer de Sicile (I. III, \$16) : * Pyrrhus, roi d'Épire, eut, dit^ il, le projet d'unir ces deux rivages au moyen " d'un pont jeté sur le détroit (le détroit qui sépare " l'Adriatique de la mer Ionienne, entre Apollo" nie et Hydronte, et qui a cinquante mille pas * de largeur). Varron avait eu le même dessein " lorsqu'il commandait la flotte de Pompée, pen" dant la guerre contre les pirates; mais d'autres " soins l'en empêchèrent. " On voit encore dans Pline (1. vi $\$ 19)$ un passage où il est question de Varron; c'est au sujet de la iner Caspienne. Il rapporte une observation faite par Varron sur la qualité des caux de cette mer : " L'eau de cette mer, dit-il, est " douce, au rapport de Varron, qui en fit porter à "Pompée, pendant la guerre contre les pirates. " C'est sans doute l'énorme masse d'eau apportée a par les fleuves qui s'y jettent, qui l'empêche " d'être salée. Varron ajoute qu'il fut reconnu " alors qu'on pouvait en sept jours transporter " les marchandises indieunes de l'Inde à la Bac" triane et au fleuve Icare, lequel vient se per" dre dans l'Oxus pour passer à la ner Caspienne, * dans les eaux du Cyrus, et, au bout d'un voyage a par terre de ciny jours au plus, déboucher daus "le Pont par le Plıasc. "C'est eucore d'après Varron qu'il parle des Opliogènes, habitants des bords de l'IIcllespout, dont la salive guérissait la morsure des serpents. Lnfin, s'il faut l'en croire, Varron aurait écrit que le roi Ptolémée, lors dc l'expédition de Judée, avait fourni à Pompée un corps de huit mille cavaliers entretenus à ses frais : et qu'il lui avait donné un festin où se trouvaient mille convives, ayant chacun devant eux un vase d'or qu'on changeait à mesure que les services se succédaient. Ce fait semble remonter à l'an 691 de la fondation de Roine.

Varron mérita dans cette guerre la couronne na-. vale qui lui fut décernée au retour (Plin., vII, $\$ 31$; $x V I, \$ 3$ ). On y ajouta de l'argent. Pline domne le cliffre de la somme (1. xxxvir, $\$ 6$ ) : "On accorda, a dit-il, à la république et aux questeurs qui avaient " défendu les côtes, une somune de mille taleuts : " chaque soldat eut six nille sesterces. "On trouve une leçon différente dans une ancienne édition de Pline. Suivant cette leçon, on n'aurait donné que deux mille sesterces a cliacun des soldats. Appien, de son côté, dit quinze cents draclımes. Quoi qu'il en soit, nous croyons qu'on a eu tort de joindre ici la république aux questeurs.

Nous avons dit que Varron embrassa le parti de Pompée dans la guerre civile. Il commandait les troupes que ce dernier avait en Espagne. Cicéron en parle dans une de ses lettres à Dolabella (Fam. Ix, 13) : "Caïus Subérinus Calénus, voulant rester " neutre, dit-il, s'était retiré en Espagne avec Var" ron, avaat le commencement des hostilités. Per" sonne ne pouvait supposer, après la défaite d'A" franius, que la guerre dút s'étendre jusque dans " cette province. Mais à peine arrivé, il tomba dans a le malheur qu'il voulait éviter : en effet, Pompée le " supplia si instamment de prendre les armes, que, " sous aucun prétexte, il ne put s'y refuser. "César fit la guerre à Afranius et à Pétréius cn Espagne, l'an 705 de Rome. Varron avec ses légions défendait l'Espagne inférieure (Bell. civ., l. I-XXXYIII); et César (id., XVII-XX) ne laisse pas de lui donner de grands éloges. Plus tard, lorsqu'il n'y eut plus d'espoir, Varron lui livra ses troupes, et vint au-devant de lui jusqu'à Cordoue, où il lui rendit un compte fidèle de l'état de la province, et lui remit l'argent qu'il en avait tiré. Il tenait encore pour Pompée à l'époque où fut livrée la bataille de Pharsale (Cic., De div., 1,32). Cicéron raconte qu'étant à Dyrrachium, où il commandait la flotte des Rhodiens, un des partisans de Poinpée vint le trouver, et dit qu'un des ranıeurs, qui avait le don de divination, lui avait annoncé qu'avant trente jours la Grèce nagerait dans le sang; que Dyrrachium serait livré au pillage, toute la flottc brûlée et mise en fuite. Cicéron ajoute que cette prédiction lui causa une grande terreur, ainsi qu'à Marcus Varron et à M. Caton, qui étaient avec lui. Peu de jours après on vit arriver Labiénus, éclıappé du désastre de Plıarsale. Ces événements se passèrent en l'an 706 de Rome, et Varron a paru y faire allusion daus un passage de ses. Igronomiques ( $\mathrm{L}, 4$, \$5). 
A près avoir déposé les armes, il s'était retiré à Cumes et à Tusculum, où il cultivait en paix les belles-lettres, quoiqu'il ne fut pas sans inquiétude sur les dispositions du dictateur à son égard. Mais César, lui ayant pardonné, le chargea, sur sa demande, d'organiser les bibliothèques grecques et latines qu'il avait l'intention de fonder, et qui furent ouvertes peu de temps après, vers l'an 707 de la fondation de Rome.

Les premières bibliothèques grecques et latines établies à Rome avaient été fondées par Pollion, qui fit placer dans l'atrium les bustes des écrivains les plus célc̀bres. Il l'avait en outre décoré des dépouilles prises sur les Dalmates. Tous les anciens auteurs sont d'accord pour célébrer la magnificence de cette partie du monumeut. Il est à croire que c'est cette galerie de bustes qui donna à Varron l'idée de son traité sur les Images, désigné par les grammairiens sous le titre d'Hebdomades. AuluGelle parle avec éloge des deux livres d'Homère et d'Hésiode qui faisaient partie de cet ouvrage.

Quant aux livres sur les Bibliotheques, cités par le grammairien Sosipater, nous ignorons s'ils furent composés en même temps que les Hebdoma des, ou si Varron les y réunit plus tard. Suivant Nonius, Varron disait, dans le premier livre des Ilebdomades, qu'il avait divisé son traité en sept parties, pour imiter lesalcyons, qui mettent sept jours à faire leur nid sur la mer. Aulu-Gelle (I. III, clı. 11) rapporte encore quelques lignes de Varron tirées du livre des Jours, et qui s'appliquent à la statue de Démétrius. C'est une inscription placée au-dessous de cette statue, et dont voici le sens :

"Celui-ci est Démétrius, qui en a eu autant que "l'année a de jours. "

C'est du moins ce que porte la première édition de Mercurius. Scaliger, dans ses Catalectes, complète l'idée :

a Celui-ci est Démétrius, à qui on éleva autant " de statues en airain qu'il y a de jours dans lan" née, » ce qui a été entendu de Démétrius de Phalìre. Ce passage de Pline ( 1 . xxxıv, $\$ 12$ ) paraît autoriser l'explication de Scaliger : « Je pense, dit-il, * qu'il n'y a point d'homme à qui on ait élevé au. a tant de statues qu'à Démétrius de Phalère. On " lui en avait érigé trois cent soixante, d'après le « nombre des jours qu'on donnait alors à l'année. - Ces statues furent bientôt renversées. * A propos du livre Ier, Aulu-Gelle (LIII, ch. II) dit que M. Varron avait mis sous le portrait d'Homère une inscription conçue en ces termes : "Cette chèvre blan" che indique la place où repose Homic̀re; car une " chc̀vre blanche est la victime que les habitants " d'Ios offrent en sacrifice à sa mémoire. v

On voit dans le poëme d'Ausone sur la Moselle (v. 306) que le dixième livre des Hebdomades était consacréaux architectes; et Symmaque (I. II, Epist. 2) dit que ce livre coutenait l'éloge de plusieurs personnages célèbres.

Le passage suivant nous fait connaître quel était l'àge de Varron lorsqu'il termina les Hebdomades. Cest Aulu Gelle qui parle (1. III, ch. 10) : Varron
" dit, à la fin des Hebdomacles, qu'il est sur le point " d'avoir parcouru sept fois douze années (il avait - alors 78 ans), et qu'il a écrit sept fois soixante-dix " livres, dont il a perdu un assez grand nombre " lorsqu'il était proscrit, et que sa bibliothèque fut " pillée. " On verra plus bas que sa maison de Casinate fut occupée et détruite par Antoine pendant la guerre civile.

Il avait quatre-vingts ans lorsqu'il écrivit ses Agronomiques, ainsi qu'il le dit lui-mêtne dans sa préface; d'où l'on peut conclure que cet ouvrage fut comiposé vers l'an 717 de Rome. Les $\| l e b$. domades, ou livres sur les Images, durent être composés deux ans auparavant. Aulu-Gelle a tiré de cette préface les observations qu'il a faites sur la vertu du noinbre sept, et dont quelques-unes témoignent d'une rare sagacité. Pour les autres, il est permis de douter de leur exactitude.

L.es Questions épistolaires, adressées par Varron à Appianus, furent composées après la mort de César. Aulu-Gelle (1. XIv, ch. 7) cite plusieurs passages du livre $1 \mathrm{v}$, où il est question de la curie Hostilia, de la curie Pompéia, et de la nouvelle coutume qui s'était introduite dans le sćnat, pour demander l'avis des sénateurs. On ue lira pas sans interêt le passage d'Aulu-Gelle : "Cn. Pompée, dit« il, fut nommé consul pour la première fois avec a M. Crassus. Occupéjusqu'ici des soins de la guerre, " il ignorait, au moment d'entrer en cliarge, de " quelle manière on doit convoquer le sénat, et en " général tout ce qui concerne l'administration " intérieure. Il pria son ami Varron de lui faire un " mémoire sur le cérémonial à observer, où il pût " apprendre ce qu'il derait faire et dire en consul" tant le sénat. Varron fit le mémoire; mais, dans * le quatrième livre des Questions épistolaires, il a nous apprend lui-même que cet ouvrage a pćri. a Pour réparer cette perte, il donne dans ses lettres " de nombreuses instructions sur le même sujet."

Outre ce mémoire, Varron avait composé pour Pompée un traité des règles de la navigation, au moment où celui-ci allait partir pour la guerre d'Espagne. Ce traité, auquel l'auteur avait donné le nom d'Éphémérides, a été perdu. Suivant toute apparence, il aurait été écrit en l'an 677 de Rome, époque de l'expédition de Pompée en Espagne.

Il n'y a point d'ouvrage où l'on trouve de meilleurs renseignements sur les écrits de Varron, sur les époques où ils ont été composés, et la manièrc dont on doit les classer, que le livre qui nous est resté des Académiques de Cicéron. Cicéron avait dédié ec livre ainsi que les trois autres, aujourd'hui perdus, à T. Varron, d'après le conseil de son ami Atticus, dont les instances avaient pu seules l'y décider. En effet, il y avait de la répugnance, à cause du caractère de Varron, qu'il n’a pas flattédans une deses lettres à Atticus (I. XIII, 25) où il le dépeint comme un esprit chagrin, difficile, et très-jaloux de sa supériorité dans les lettres. " Tu sais comme il est, dit-il à son ami :

a Son esprit soupçonneux accuse linnocent (1).

(1) Traduit d'un rers grec cité par Cicéron. 
"Il tue semble que je l'entends se plaindre de ce " que je défends mieux ma cause que lui la sienne." 'Toutefois nous le voyous, dans ses Académi(jues, prier Varron de vouloir bien prendre le parti d'Antioclıus contre Pliilon, dans la querelle qui s'était b́levée entre ces deux philosoplies sur diverses ques. lions de morale et de métapliysique. Il se elıarge à son tour de faire valoir les raisons.de Philon. En outre, il rappelle à Varron une promesse qu'Atticus, leur ami commun, lui a faite de sa part. Il s'agissait d'un livre que Varron devait soumettre à son jugement. Il lui annonce qu'il est impatient de le voir,

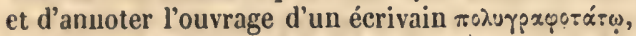
ainsi qu'il l'appelle dans ses lettres à Atticus. Voici ce qu'il lui fait dire à cette occasion (Académiq., clı. 1); c'est Varron qui parle: « J'ai, dit-il, entre les a llains un grand ourrage que je veux soumettre à " notre ani (désignant ainsi Cicéron), mais je m'oc" cupe en ce moment de le revoir et de le polir. "Cicéron répond que Libon, leur ami commun, lui a dit qu'il connaissait déjà cet ouvrage; et Varron, de son côté, ajoute qu'il y travaille sans relâche, et ne le quittera point qu'il ne l'ait terminé. Ce que dit Attieus , à la suite de cette conversation, prouve qu'il ćtait question du Traité sur la langue latine, que Varron adressa depuis à Cicéroı, et qui denıanda beaucoup de temps à son auteur. "Les muses de Varron, " dit-il, se taisent bien plus longtemps qu'à l'ordia naire. Je ne crois pourtant pas qu'il demeure " oisif : je crois plutôt qu'il ne veut pas nous mettre « dans la confidence. »

Varron possédait, à cette époque, une maison dans la terre de Cumes, près celle de Cicéron. Mais il s'en défit bientôt, à cause de la guerre qui désolait ces campagnes, et alla se fixer dans une des provinces les plus éloignées de l'Italie, à Casinate. Cicéroı l'en félicite dans une de ses lettres. « Je désire, lui " écrit-il, que vous soyez satisfait de votre nouvelle " acquisition; jo ne puis qu'approuver la résolu" tion que vous avez prise de vous retirer au loin. " Mais il n'y avait pas lieu de le félieiter. En effet, c'est cette inaison de Casinate qui fut pillée environ un an après par Antoine, lorsque César était occupé au siége d'Alexandric; ce qui ferrait remonter cet événement à l'an 708 de la fondation de Rome.

Nousavons dit que Varron travailla pendant longtemps à son traité sur la langue latine. On peut déterminer d'une manière assez précise le temps qu'il apporta à la composition de cet ourrage. Cicéron (ad Att., 1. XIII, 12) dit : "Voilà deux ans que Varron m'a " promis de me dédier son ourrage; mais clepuis " ee temps, il n'a pas avancé d'un pas. "Il nous apprend dans une autre lettre qu'il a tini les Acadćmiques. Or cette lettre, (1. xII, 23) ainsi que toutes les autres du même livre, appartient à l'annće 708 . Il est naturel de supposer qu'il envoya son ouvrage à Varron peu de temps après l'avoir terminé; et l'on sait que Varron répondit à ce présent par un autre, c'est-à-dire en envoyant à Cicéron le 'Traité sur la langue latine. Ce serait done en l'an 708 de Ronie, ou tout au plus l'annce suivante, que Varron aurait ınis la dernière main à ce traité, qui l'aurait ainsi occupé pendant près de trois ans.

Quant aux Agronomiques, on croit que cet ouvrage suivit de très-près le 'Traité sur la langue latine. Cé n'est pas l'opiniou de certains commentateurs, qui le supposent éerit huit ans après, en l'an 716 de Rome. Mais si l'on veut faire attention que Varrou avait quatre-vingts ans lorsqu'il publia le Traité sur la langue latine, oı admettra difficilement qu'il ait commencẻ un autre ouvrage à quatre-vingt-lıuit ans, presque à la veille de sa mort, pour ainsi dire; car il mourut à quatre-vingt-dix ans. Il paraît iılpossible de rien affirmer à ce sujet.

Après avoir indiqué, autant qu'il était en nous, à quelle époque ont été composés les ouvrages qui nous sont parvenus, nous allons essayer de retrouver la date de ceux qui ont été perdus, en nous guidant sur les Académiques de Cicéron, l'un des monuments de l'antiquité qui renferment le plus de détails sur la personne et les écrits de Varron.

Cicéron (Académ., liv. I, clı. I) lui fait tenir ces paroles : " Quant aux choses que personne n'avait " encore cnseignées, et que les amis de la science ne " pouvaient trouver nulle part, j'ai tâché autant que " je l'ai pu (car je n'ai pas une grande admiration " pour mes ouvrages) de les faire connaître à mes " concitoyens. Ce sont des reelierelıes qu'on ne pou" vait demander aux Grees, ni même aux Latins, " depuis la mort de notre ami Alius. "

Cicéron lui répond (cl. 3) : "Oui, Varron, vous " avez réussi. Étrangers dans notre ville, nous er" rions counme des voyageurs; vos ourrages nous " ont pour ainsi dire conduits par la main au sein " de nos foyers, et, grâce à vous, nous pouvous en" fin reconnaître qui nous sommes et où nous vi" vons. C'est vous qui nous avez rérélé l'åge de no" tre patrie, la succession des temps, les droits de " la religion et du sacerdoce; vous nous avez fait * connaîtrel'administration intérieure, la discipline “ militaire, l'emplacement des quartiers et des lieux " les plus remarquables : vous nous avez dévoilé " les ehoses divines et humaines, les noms, les espè"ces, les fonctions et les causes."

Il est évident que ce passage s'applique à l'ouvrage connu sous le nom d'Antiquités. Les anciens auteurs l'ont tous désigné ainsi, et rappellent mıême le titre de chacun des livres qui le eomposaient. Saint Augustin (C. Div., vi, 3) dit que Varron avait consacré vingt-cing livres aux antiquités lıt maines, et seize livres aux autiquités divines. II ajoute qu'il dédia l'ouvrage à César, lorsque eelui-ci était grand pontife. Laetance, qui s'accorde sur ce point avec saint Augustin, rapporte les premières lignes du traité sur les choses divines. "J'ai parlé, dit "Varron, des closes humaines : je vais parler des a choses divines, qui out ćté instituées par les lom" mes. "Il se déeida à écrire cet ouvrage sur les exlıortations d'Alius Stilo, son ami, qui l'aida de ses conseils. Cet $\mathrm{Elius,}$, dont le nour a été eité plus lıaut, était de la classe des ehevaliers. Cicéron a fait counaître son mérite dans le Brutus (p. 56). "C'ća tait, dit-il, un loume ćminent, aussi remarquable 
- par la pureté de ses mocurs que par son savoir. - Il était également versé dans les lettres grecques n et latines, et connaissait à fond tout ce qui se rap* porte à notre histoire, soit dans les temps ann ciens, soit dans les temps modernes. Nul ne dé" chiffrait plus habilement les anciens manuscrits. " C'est lui qui a formé notre Varron, v etc.

Ce passage, où il est question des Antiquités, fut écrit en 707 , ce qui prouve que l'ouvrage avait paru avant cette époque. II résulte d'un autre passage cité par Aulu-Gelle (1. XIII, ch. 13), que Varron avait exercé les fonctions de tribun. " I.orsque " j'étais triumvir, dit-il, je fus cité par le tribun . Porcius ; je pris l'avis des principaux magistrats, * me conformant au droit ancien. Quand j'ai été - tribun du peuple, je n'ai fait citer personne, et " j’ai laissé libres ceux que mes collègues citaient. " Il dédia toute la partie des Antiquités qui regarde les choses divines à J. César, auprès duquel il était rentré en grâce vers l'an 706, ainsi que nous l'avons dit plus haut. Le traité des Choses divines paraît l'avoir occupé pendant deux ans.

On voit encore dans Cicéron que Varron avait composé des satires dans sa jeunesse. Ces satires, imitées de Ménippe, et dont on a recueilli quelques fragments, étaient écrites en vers de six pieds. Il les a vait appelées les Ménippées, du nom du poëte grec qu'il avait pris pour modèle. D'autres lés ont désiguées sous le titre de Cyniques. C'est le nom que leur donne Aulu-Gelle dans les citations qu'il en fait. 11 y en avait une qui faisait allusion à ce qu'on appelait la conspiration de C. Pompée, de César et de Crassus (an 694 de Rome); et Appien (Bell. civ. II, 9) dit que l'auteur l'avait publicee sous le titre

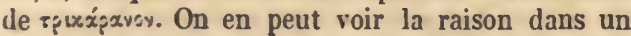
passage de Varron (De vil a populi romani, ad No. nium), où l'on rencontre cette phrase à propos du mot biceps : " Ft il fit deux villes d'une seule : c'est " là le principe de nos discordes civiles. "

Cicéron (Epist ad. Att., XIII, 48) cite encore un ourrage de Varron; c'est un éloge de Porcia, sceur de Caton, et femme de Domitius Enobarbus. On voit par la date de la lettre que cet éloge fut somposé par Varron vers l'an 709 de la fondation de Rome.

On ne trouve rien de plus dans Cicéron qui ait rapport à Varron, et nous n'avons plus pour nou: guider que de simples fragments. Nous allons essayer à l'aide de ces fragments, de retrouver la date des ouvrages dont nous avons encore à nous occuper.

Dans le traité De lingua latina, Varron parle de son livre de Estuariis; d'où il faut conclure que ce livre a été composé avant l'ar 708, le traité De lingua latina ayant été publié à cette époque.

Dans le même traité (page 16), il cite son livre sur lorganisation $\mathrm{du}$ peuple romain en tribus. Notre observation s'applique également à cet ouvrage.

Vitrure, dans la préface de son liv. vII, parle des dix-neuf livres de Varron connus sous lc titre de Libri disciplinarum, dédiés à M. C. Rufus. AuluGelle (1. X, 101) cite un fragment. duliv. v : * Et - Pompée se montra timide, lorsque, pour ne mettre a nitertium, ni tertio consul, il supprima les der- nières lettres. "Cette plirase se rapporte évidemment à l'érection du théâtre de Pompée. Cn. Pompée, qui avait été élu le troisicme, se trouva, par le fait, être le seul consul, les deux autres ayaut été condamnés pour cause de brigue. Cette élection eut lieu en l'àn de Rome 699. D'un autre côté, on voit dans les Commentaires de César (Bell. civ.) que M. Rufus, partisan de Pompée, et l'un des hommes les plus instruits de son temps dans tout ce qui concernait l'antiquité, fut tué en $\mathbf{7 0 6}$; d'où il résulte que les 19 livres Disciplinarum, adressés à ce M. Rufus, furent composés entre les années 699 et 706 de la fondation de Rome.

Arnobius, en parlant de l'ouvrage De gente populi romani, dit que. Varron avait embrassé un espace de deux mille aunées, depuis le déluge de Deucalion et Pyrrha, jusqu'au consulat d'Hirtius et de Pansa; ce qui fatit supposer que cet ouvrage avait déjà été publié en l'an 710 de Rome.

- Les livres Sur la vie et les usages du peuple romain, dédiés à Pomponius Atticus, paraissent avoir été écrits en l'an 704, époque de la mort de l'orateur Hortensius. Pline (1. XIV, 17) fait parler ainsi Varron : a Hortensius laisse à son héritier plus de " dix mille amphores de vin. "Nonius dit que ce passage est extrait du livre III. Il en cite un autre duliv. Iv, à l'occasion du verbe obstrigillare . « Lors* que Curion imita cet exemple, il disait à ses amis, " pour les empêclıer d'insister, qu'il s'opposerait à ^ ce qu'on lui décernât le triomplıe, et qu'il aimait " mieux n'être pas consul une seconde fois. " Ceci se rapporte à l'année 703 de Rome. Nonius cite encore un passage tiré du liv. Iv, où il est question du mot cœcum, à l'occasion des ordres secrets donnés par les consuls à T. Ampius, et auxquels Cicéron fait allusion dans sa lettre à Atticus (VIII, 2). Or cette lettre a été écrite en l'an 704 de Roine. Enfin nous trourons dans Nonius une dernière citation extraite du même livre, où il est dit que César, ne voulant pas laisser en Espagne le corps de troupes qui formait sa réserve, revint sur ses pas pour envelopper Pompée, et le presser des deux côtes. Il est évident que ce fait remonte à l'an 705 . Les livres Sur la vie et les usages du peuple romain ont donc été composés entre les années 703 et 705 , comme nous venons de le dire tout à l'heure.

Appien (Bell. civ., Iv, 47) parle d'un Varron qui fut mis au nombre des citoyens proscrits par les triumvirs, après la mort de César. Il aurait mêne été massacré en présence d'Antoine. Mais on ne peut rien affirmer à ce sujet. Il y avait plusieurs Varron à Rome du temps des proscriptions; et peut-être le passage d'Appien, et celui de Velléius Paterculus, qui rapporte le même fait, s'appliquent-ils à un de ceux-là plutôt qu'à notre Varron.

Pline (1. xxxv, 46) dit quelques mots de la mort de Varron. "Varron, dit-il, voulut être enseveli à a la manière pythagoricienne, c'est-à-dire dans des * feuilles de myrte et d'olivier noir. "Valère Maxime en parle aussi à propos de ses nombreux ourrages. « $\mathrm{T}$. Varron, dit-il, peut être cité comme excm" ple d'une vie aussi longue que bien remplie. II 
" vécut près d'un sièele, sans eesser un instant de " produire; et l'on peut dire que la maladie qui mit - fin à son existence arrèta en même temps le cours " de sa vie et celui de ses travaux. "C'est le seul renseignement qu'on ait sur la mort d'un homme dont la vie, nalgré les citations assez nombreuses à l'aide desquelles nous en avons cherché les traces, restera toujours à peu près incounue. Ce qui nous reste de ses ouvrages n'est pas d'ailleurs marqué de ces qualités qui pernettent de deviner le caractère de l'homme d'après lé style de l'éerivain, et qui suppléent au manque de renseignements authentiques. 


\section{T. VARRON.}

\section{DE L'AGRICULTURE.}

\section{LIVRE I.}

I. Si j'avais du loisir, Fundania, je donnerais unc meilleure forme à eet ouvrage. 'T'u l'auras tel que peut le faire un honıme qui se dépêehe : car si l'on peut dire que l'existenee n'est qu'une bulle d'air, e'est encorc plus vrai quand on est vieux. J'ai quatre-vingts ans; c'est l'annonce de plier bagage et de sc tenir prêt à partir. Tu viens d'aeheter un fonds de terre, dont tu voudrais, par unc eulture bien entendue, tirer le meilleur parti possible; et tu réclames à ce sujet mes soins et mes conseils. J'y ferai de mon mieux : je tâcherai même que mes instructions te profitent et pendant ma vie et après ma mort. Les paroles de la Sibylle ont bien pu être l'oraele non. seulement de ses contemporains tant qu'elle a véeu, mais, après sa mort, de générations auxquelles elle ne pensait guère. Ses livres, après tant de siècles, sont encore solennellement consultés chaque fois qu'il y a parti à prendre par suite d'évé1. ements surnaturels. Ne pourrais-je pas, mol, de mon vivant, donner quelques a vis utiles à ceux qui me touchent de si près? Je vais donc composer pour toi trois livres qui tc serviront de guide, et auxquels tu pourras recourir au besoin pour toutes les indications relatives à la culture. Et puisque les dieux, dit-on, viennent en aide à

\section{TERENTII VARRONIS}

\section{RERUM RUSTICARUM}

\section{DE AGRIGUL'TURA.}

\section{LIBER I.}

1. Otium si essem consecutus, Fundania, commodius tibi hacc scriberem, qua nunc, ut potero, exponam, cogitans, esse properandum, quod [ut dicitur] si est homo bulla, co magis senex. Annus enim octogesimus admonet me, ut sarcinas colligam ante quam proficiscar e vita. Quare, quoniam emisti fundum quem bene colendo, ffuctuosum cum facere velis, meque ut id mihi habeam cnrare roges, exjeriar. Et non solum, ut ipse quoad vivam, quid fieri oporteat ut te moneam, sed etiam post mortem. Neque patiar Sibyllam non solum cecinisse, qua, dum viveret, prodessent hominibus, sed etiam qux cun perisset ipsa, et id etiam ignotissimis quoquc lominibus; ad cujus libros tot annis post publice solemus redire, cum qui s'adresse à eux, je commencerai par invoquer, non pas les Muses, à l'exemple d'Homère ct d'Ennius, mais bien les douze grands dieux qui composent le conseil céleste. Je n'entends pas ces divinités citadines, six d'un sexe et six de l'autre, dont les statues dorées se dressent au Forum; mais bien les douze intelligences qui président aux travaux des laboureurs. Je commencerai done par invoquer Jupiter et Tellus, dont la puissanee embrasse le ciel, la terre, et tout ce que produit l'un et l'autre; parce que ce sont les générateurs de l'humanité, et que nous leur donnons les noms de pèrc et de mère. J'invoquerai en second lieu le Soleil et la Lune dont nous observons le cours quand il s'agit d'ensemencer ou de récolter; en troisième lieu, Gérès et Bacchus, puisque les fruits qu'ils nous donnent sont indispensables à la vie. C'est par.eux que la terre nous fournit aliments et boisson. En quatrième lieu, j'invoquerai le dieu Robigus et la déesse Flore, puisque l'un préserve de la rouille les blés et les arbres, et que l'autre les fait fleurir à temps : d'où les fêtes robigales en l'honneur de Robigus, et les jeux floraux en l'honneur de Flore. J'invoquerai encore Minerve et Vénus, dont l'une veille sur les plants d'oliviers, et l'autre préside au jardinage. C'est en leur honneur qu'on institua les fêtes appelées

desideramus quid faciendum sit nobis ex aliquo portento : me, ne dum vivo quidem, necessariis meis quod prosit facere. Quo circa scribam tibi tres libros indices, ad quos revertare, si qua in re quares, quenadmodum quidque te in colendo oporteat facere. Et quoniain [ut aiunt] dei facientes adjurant, prius invocabo eos; nec, ut Homerus et Ennius, Musas, sed xı deos consentis : neque tamen e.os urbanos, quorum imagines ad forum auratie stant, sex mares, et fominæ totidem, sed illos xiı. Deos, qui maxine agricolarum duces sunt. Primum, qui omnes fructus agriculturæ cæelo et terra continent, lovem, et Tellurem. Itaque quod ii parentes magni dicuntur, Iuppiter, pater appellatur, Tellus, terra mater. Secundo Solem et Lunam, quorum tempora observantur, cunı quadam seruntur et conduntur. Tertio Cererem et Liberum, quod horum fructus maxime necessarii ad rictum. Ab his enim cibus et potio venit e fundo. Quarto Robigunı ac Floram, quibus propitiis, neque robigo frumenta atgue arhores corrumpit, neque non tempestive Borent. Itaque publica Robigo feria robigaria; Flora ludi floralia instituti. Item adveneror Minervam et Venerem, quaruu unius procuratio oliveti alterius hortorum; quo nonine 
mestica vinalia. Eunfin j'adresserai mes prières à la déesse Lympha et au dieu Bonus Eventus: car de même que sans l'eau toute végétation est chétive et misérabie, de même sans le bon succès point de cuiture qui vienne à bien. Maintenant que j’ai invoqué toutes ees divinités, je vais te faire part d'entretiens que j'eus dernièrement sur l'agrieulture, et qui contiennent tout l'enseignement pratique dont tu peux avoir besoin. En cas d'insuffisance, $j$ 'indiquerai les ouvrages tant grees que latins auxquels tu pourrais a voir recours. Les auteurs grees qui ont traité ineidemment de diverses parties de l'agriculture sont au nombre de plus de cinquante. Voici ceux que tu pourras, dans l'occasion, consulter avec fruit: Hiéron de Sieile et Attalus Philométor; parmi les philosophes, Démoerite le physieien, Xénophon, disciple de Socrate, et les péripatétieiens Aristote et Théophraste; Architas le pythagoricien; ainsi qu'Amphiloehus d'Athènes, Anaxipolis de Thase, Apollodorus de Lemnos, Aristophane de Mallus, Antigonus de Cyme, Agathoele de Chio, Apollonius de Pergame, Aristandre d'Athènes, Baeehius de Milet, Bion de Solos, Cheresté et Chéréas d'Athènes, Diodore de Prienne, Dion de Coloplion, Déophane de Nicée, Épigène de Rhodes, Évagon de Thase; Ies deux Euphronius, eelui d'Athènes et celui d'Amphipolis, Hégésias de Maronéa, deux Ménandre, l'un de Brienne et l'autre d'Héraelée; Nieésius de Maronéa, Pythion de Rhodes. Parmi les autres dont la patrie m'est ineonnue, je eitcrai Androtion, Eschrion, Aristomène, Athénagoras, Cratès, Dadis, Denys, Euphiton, Euphorion, Eubolus, Lisimaque, Mnaséas, Mé-

rustica vinalia instituta. Nec non etiam precor Lymplsam, ac Bonum Eventum, quoniam sine aqua omnis arida ac misera agricultura, sine successu ac bono eventu, frustratio est, non cultura. Iis igitur deis ad venerationem adrocatis, ego referam sermones eos, quos de agricultıra habuimus nuper, ex quilsus quid te facere oporteat animadvertere poteris, in queis qua non inerunt et quares, indicabo a quibus scriptorilus reperias et gracis, et nostris. Qui grace scripserunt dispersim, alius de alia re, sunt plus quinquaginta. Hi sunt, quos tıl lıabere in consilio poteris, cum quid consulere voles, Hieron Siculus et Attalus Philometor : de philosophis, Democritus phy. sicus, Xenophon Socraticus, Aristoteles et Theophrastus peripatetici, Arclıytas pythagoreus, iten Ampliilocluns Atheniensis, Anaxipolis Thasius, Apollororus Lemnius, Aristoplıanes Mallotes, Antigonus Cymæus, Agatlocles Clius, Apollonius Pergamenus, Aristandrus Atheniensis, Bacchius Milesius, Bion Soleus, Clıæresteus et Clıæreas Atluenienses, Diodorus Prienaus, Dion Colophonius, Dioplanes Niciensis, Epigenes Rlodius, Evagon Tlıasiıs, Euplıronii dıo, unus Atheniensis, alter Ainplıpolites, Hegesias Maronites, Meuandri duo, umus Prienæus, alter Ileracleotes, Nicesius Maronites, Pythion Rlıodius. De reliquis, quorum qua fuerit patria uon accepi, sunt Audrotion, Aschuion, Aristomenes, Atluenagoras, Cra. nestrate, Pleutiphane, Persis, et Théophile. Tous les auteurs que je viens de nommer ont éerit en prose; d'autres ont éerit en vers sur le même sujet : tels sont Hésiode d'Ascra et M énéerate d'Éphèse. Le plus en réputation de tous est Magon de Carthage, qui a écrit en langue punique, et renfermé dans vingt-huit livres tout ce qui se trouvait avant lui épars ç̀ et là dans différents ouvrages. Plus tard Cassius Denys d'Utique en fit une traduetion greeque en vingt livres, qu'il dédia au préteur Sextilius, et dans laquelle, nonobstant ce retranehement de huit livres sur l'œuvre de Magon, il sut fondre de nombreux emprunts faits aux auteurs grees dénommés ci-dessus. Vint ensuite Diophane de Bithynie, qui fit de ees vingt livres un bon abrégé en six, offert par lui au roi Déjotarus. Je veux enehérir eneore sur sa brièveté, et resserrer en trois livres la substance de son ouvrage. Le premier traitera de l'agrieulture, le seeond du régime des troupeaux, et le troisième en général de l'engrais des animaux dans une métairie. J'élaguerai dès ie premier tout ce qui, selon moi, n'a pas un rapport direct avee l'agrieulture. Ainsi je eommencerai par circonserire la matière; puis je la traiterai suivant ses divisions naturelles. Mes observations seront puisées à trois sources : ma propre pratique, mes lectures, et ce que j'ai reeneilli de vive voix de l'espérienee d'autrui.

II. Je m'étais rendu au temple de Tellus le jour de la fête des semailles, sur l'invitation du gardien, que nous appelons avec nos aneêtres $a d i$ timus, et dont nos puristes ont changé le nom en celui d'cedituus. J'y trouvai C. Fundanius mon beau-père, C. Agrius, chevalier romain, de la

tes, Dadis, Dionysius, Eupliiton, Euphorion, Eubolus, Lysimachus, Mnaseas, Menestratıs, Pleutliphanes, Persis, Theophilus. li, quos dixi, omnes soluta oratione scripserınt. Eazdem res etiam quillam versibus, ut Hesiodus Aseræus, Menecrales Ephesius. Hos nobilitate Mago Carthaginiensis prateriit ponica lingua, quod res dispersas comprehendit libris Xxıx. Quos Cassius Dionysius Uticen. sis vertit libris xx. Ac græeca lingua Sextilio protori mi. sit : iu quæ volumina de gracis libris eorum, quos dixi, adjecit non pauca, et de Magonis dempsit instar librorum vir. Hosce ijssos utiliter ad vi. libros relegit Dioplianes in Bitlynia, et misit Dejotaro regi. Qno brevius de ea re conor tribus libris exponere, mo de agricultura, altero de re pecuaria, tertio de villalicis pastionibus; lıc libro circumcisis rebus, quae non arbitror pertinere ad agriculturam. Itaque prius ostendam, quae secerni oporteat ab ea, tum de lis rebus dicam, sequens naturales divisiones. Ea crunt ex radicibus trinis, et qua ipse in meis fundis colendo animadverti, et quæ legi, et qua a peritis andii.

II. Sementivis feriis in æedem Telluris veneram rogatus ab ædilimo, ut dicere didicimus a patribus nostris : it corrigimur a recentilus urbanis, ab æedituo. Offendi ini C. Fundanium soccrum neın, et C. Agrium equitem R. Socraticum, el P. Agrasium publicanum, spectautes in 
doctrine de Socrate, et le partisan P. Agrasius. Tous trois regardaient une earte d'Italie tracée sur la muraille. - Que faites-rous ici? leur disje. Est-ce la féte des semailles qui rous amène, pour employer vos vacances comme faisaient nos pères et nos ancêtres? Notre présence, dit Agrius, a, j'imagine, la même cause que la vótre, l'invitation du gardien. Et si j'ai rencontré juste, attendez avec nous son retour. II a dû comparaitre devant l'édile, à qui appartient la surintendance de ce temple, et nous a fait prier de l'attendre ici. Eh bien, leur dis-je, faisons, en l'attendant, application du vieux proverbe : Le Romain triomphe assis. Très volontiers, dit Agrius; ct eomme il est de eeux qui pensent que le plus long d'un voyage e'est de franchir le seuil, il prit sans facon place sur un banc, et nous l'imitâmes. Quand nous fủmes assis, Agrasius, prenant la parole, nous dit: Vous autres qui avez parcouru tant de pays, en avez-vous vu de mieux cultivés que l'I talie? Pour moi, dit Agrius, je ne pense pas qu'il y en ait un seul où le sol soit comme chez nous, universcllement en rapport. Par une division très-naturelle, Liratosthène a fait de notre globe deux parties, dont l'une s'étend vers le midi, et l'autre vers le nord. Incontestablement la partie septentrionale est la plus sainedes deux, et conséquemment la plus fertile. II faut done reconnaltre cette partie, et l'Italie notamment, comme plus propre à la culture que ' Asie. L'Italie d'abord est en Europe; en second lieu, on y trouve une température plus douce qu'en penétrant dans l'intérieur de cette partic du monde, où règne un hiver permanent. Ce qui est tout simple, puisqu'elle a des régions situées entre le cercle polaire et l'axe même du ciel,

pariete pictam Italiam. Quid vos hic, inquam, num ferixe sementivac otiosos luc adduxerunt, ut patres, et avos solebant nostros? Nos vero (inquit Agriıs) ut arbitror, eadem causa, quæ le, rogatio aditimi. Itaque si ita est, ut annuis, morere oportet nobiscum, dum ille revertatur. Nam accersitus ab xdile, cujus procuratio bujus templi est, nonduın rediit, et nos, ut expectaremus se, reliquit qui rogaret. Vultis igitur interea vetus proverbium, quod est, Romanus sedendo vincit, usurpemus, dum ille veเห่t? Sane, inquit Agrius, et simul cogitans, portam itineri dici longissimam esse, ad subsellia sequentibus nobis procedit. Cum consedissenus, Agrasius, Vos, qui multas perambulastis terras, ecquam cultiorem Italia vidis. tis, inquit? Fgo vero, Agrius, nullam arbitror esse, quae tam tola sit culta. Primum cum orbis terræ divisus sit in duas partes ab Eratosthene, maxime secundum natu. ram ad ineridiem versus, et ad septentriones, et sine dulio quoniam salıbrior pars septentrionalis est, quam meridiana ; et quæ salubrior, illa fructuosior : dicendum ıxagis eam fuisse opportunam ad colendum quam Asiam, ibique Italiam. Primun quod est in Europa : secundo, quod liac temperatior pars est, quam interior. Nain intus pene sempiternæ lyyemes. Neque mirum, quod sunt regiones inter circulum septentrionalem, et inter cardi. nù le soleil est invisible six mois de l'année. On dit mème que des glaces étcrnelles couvrent la mer dans ces parages, et $y$ rendeut la navigation impossible. Eh bien I dit Fundanius, croyez-vous un tel sol capable de produire, ou ses productions susceptibles de culture? Pacuvius l'a dit: Sous un soleil ou sous une nuit sans fin, toute régétation périrait par le chaud ou par le froid. Même dans ce pays, où le jour et la nuit nous sont mesurés convenablement par alternative, je ne puis vivre pendant l'été à moins de couper, par un somme, la journée en deux parties. Comment donc faire là où l'année n'a qu'un jour et une nuit de six mois ehacun, pour semer, eultiver et recueillir? En Italie au contraire, quelle est la production utile à la vie qui ne croisse et ne prospère? Quel froment comparable au froment de Campanie? quel blé, au blé d'Apulie? quel vin, au vin de Falerne? quelle huile, à l'huile de Venafre? A cette multitude d'arbres qui couvre le sol de notre pays, ne dirait-on pas d'une vaste fruiterie? Est-elle plus peuplée de vignes, ectte Phrygie áu $u \varepsilon \lambda s_{s \sigma \sigma \alpha}$ (vinicole), comme l'appelle Homère? ou cette Argos que le même poëte appelle $\pi$ roúrupos, (frugifère) est-elle plus abondante en blé? Dans quel pays du monde un arpent de terre produit-il dix et même quinze cullei de vin, comme certaines contrées de l'Italie? M. Caton n'a-til pas écritces mots dans son livre des Origines : - On appelle gallo-romaines les terres comprises * entre Riminum et le Picentin, et qui furent " distribuees à l'armée des Gaules. Là on récolte " quelquefois dix cullei par chaque arpent de " terre. " D'ailleurs, ne royons-nous pas à Faenza (Faventia) des vignobles rapporter, par arpent, trois cents amphores; ce qui leur a fait donner

nem cacli, ubi sol etiam sex mensibus continuis non videtur. Itaque in oceano in ea parte ne narigari quidein posse dicunt propter mare congelatum. Fundanius. Em ibi tu quicquam nasci putas posse, aut coli natun? Verum enim est illud Pacuvii, Sol si perpetuo sit, ant nox, flammeo vapore, aut frigore terræ frucius omnes interire. Ego lic, ubi nox et dies modice redit, et abit, tamen astivo diem si non diffinderem meo insititio somno meridie, vivere non possem. Illic in semestri die, ant nocte, quemadmodun quicquain seri, aut alescere, aut meli possit? Contra quid in Italia utensile non modo non nascitur, sed etiam non egregium fit? quod far conferau Campano? quod triticum Appulo? quod vinuin Falerno? quod oleum Venafro? Non arboribus consita Italia est, ut tota pomarium videatır? An Phırygia magis vitihus cooperta, quam Homerus appellat $\alpha \mu \pi \varepsilon \lambda \dot{s} \sigma \sigma \alpha \mathrm{v}$, quam liaec?

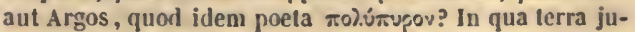
gerum unum denos et quinos denos culleos fert vini, quot quadam in Italia remiones? An non M. Cato scribit iu libro Oritinum sic? ager gallicus romanıs vocalur, qui viritim cis Ariminum datus est ultra agrum Picentium. In eo agro aliquotfariam in singula jugera dena cullea vini fiunt. Nonue item in agro Fareutiuo; a quo ibi treceurine appellantur vi tes, quod jugerum trecenas amplioras ted- 
le nom de trécennaires? Votrc ami L. Martius, ajouta-t.il cn me regardant, qui est préposé à la surveillance des arsenaux, m'a certainement dit que ses vignes de Faenza lui rendaient tout autant. Lc cultivateur en Italie considère avant tout leux clıoses: D'abord, la récolte donnera-t-clle l'équivalent des avances et de la peinc? Puis, l'air du pays est.il salubre? Quiconque néglige aur préalable un de ces deux points est un fou. Qu'on lui clierche des tuteurs dans ses parents de l'une ou de l'autre branclie. Nul homme s'nsé ne peut vouloir se mettre à découvert des frais de culture, si d’avance il voit qu'il n'a pas de rćcolte a attendre, ou qu'il risque de la perdre par l'insalubrité du pays. Mais voici, je pense, des homnes plus compétents que moi sur cette matière; car je vois venir C. Licinius Stolon et $\mathrm{Cn}$. Tremellius Scrofa. Le premier compte parmi ses ancêtres les auteurs de nos lois sur la mesure dcs terres. Cictte loi, qui défend à tout citoyen romain de posséder plus de cinq cents arpents, est d'un Licinius qui acquit le surnom de Stolon par les soins qu'il donnait à la culture; soins qu'il portait à ce degré de minutie qu'on n'aurait pla trouver le moindre rejeton (stolon) inutile dans toutes ses propriétés. Il fouillait autour des arbres pour arracher cettc végétation parasitc qu’on appelle stolon. C'est encore de cette même race que tire son origine, cet autrc C. Licinius qui, étant tribun du pcuple $\mathbf{3 6 5}$ ans après l'expul. sion des rois, conduisit le premicr le peuple romain du lieu des comices dans le Forum, et y fit accepler la loi qui assignait à chaque citoyen sept arpents de terrc. L'autre est Cn. Tremellius Scrofa, votre collègue dans la commission des vingt distributeurs des terres de la Campanie. C'est

dat? Simul aspicit me, Certe, inquit, L. Martius prafectus fabrum tuus in fundo suo laventiæ lianc nultitudi. nein dicebat suas reddere viles. Duo in primis spectasse videntur Italici lomines colendo, possentne fructus pro impensa ac labore redire, et utrum salulser locus esset an non? quorum si alterutrum decollat, et nililominus quis vult colere, mente est captus, atque ad agnatos et geutiles est deducendus. Nemo cuin sanus debet velle impensain ac sumptum facere in culturam, si videt non posse refici : nec, si polest reficere fructus, si videt eos fore, ut pestilentia dispereant. Sed opinor qui lıec com. modius ostendere possint, adsunt. Nam C. Licinium Stolonem, el Cn. Tremellium Scrofam video venire. Unum cujus majores de modo agri legen tulerunt. Nam Stolonis illa lex, qua votat plus $D$. jugera lıabere civem R., et quıi propter diligentiam culturæ Stolouun confirmavit cognomen, quod nullus in ejus fundo reperiri poterat stolo, quod effodiebat circum arbores, e radicibus, quæ nascerentur e solo, quos stolones appellaluant. Ejusdem gentis C. Licinius, tribunus pleb. cum esset, post reges exactos annis cccixv. prinns populım ad leges accipiundas in septem jugera forensia, e comitio cluxit. Alterum collegam tuun, $\mathbf{x x}$ vir qui fuit al agros dividundos Campanos, video luc venire, Cn. 'Tremelliun Scrofam, ri. un homme rempli de qualités, et qui passe pour le Romain le plus versé dans la science de l'agriculture. Et ce n'est pas sans cause, repartisje; car ses terres doivent à ses soins un aspect que bien des gens préferent à celui des royales constructions de tant d'autres. J'entends ceux qui visitent une maison de campagne non pour y chercher, comme dans celles de Lucullus, des galeries de tableaux, mais des greniers bien garnis. D'ailleurs, ajoutai.je, ses fruiteries ont l'avantage d'être situćes au bout de la voie Sacrée où les fruits se vendent au poids de l'or. Iàdessus les deux nouveaux venus nous rejoignent, et Stolon nous dit : Arrivons-nous trop tard? le diner cst-il déja mangé? Où est donc L. Fundilius, notre liote? Rassurez-vous, reprit Agrius; on n'a pas encore ôté l'ocuf qui, dans les jeux du Cirque, annonce la cloture des courses. Nous n'avons meme pas vu encorc celui qui est le signal des pompes du banquet. En attendant qu'il apparaisse, et que notre hôte soit de retour, parlez-nous de l'utilité de l'agriculture, ou de ses jouissances, ou des deux choses à la fois. Car c'est dans vos mains qu'est aujourd'hui le sceptre de cette science, comme autrefois dans celles de Stolon. Il y a, dit Scrofa, une distinction à faire. Bornous-nous l'agriculture à ce qui est relatif à l'ensemencement des terres? ou faut-il comprendre dans cette dénomination ce qui touche à la population animale des campagnes, les troupeaux, le gros bétail? Je vois que tous ceux qui ont ćcrit sur cette scicnce en langue punique, en grec ou en latiu, ont dépassé les limites de leur sujet. C'est en quoi je pense qu'il ne faut pas les imiter, reprit Stolon. Je suis de l'avis de ceux qui ont resser ré

rum omnibus virtutibus politum, qui de agricultura Romanus peritissimus existimatır. An non jure? inquam. Fundi enim ejus propter culturam jucundiore spectaculo sunt multis, quam regie polita æedifieia aliorum, cum hn. jus spectatum veniant villas, non ut apnd Lucnllnm, ut videant pinacothecas, sed oporotliecas. Hujusce, inquam, pomaria sımma sacra via, ubi poma veneunt, contra auream imaginem. Illi interea ad nos. Et Stolo, Nun cœna comesa ingnit venimus? nam non $\mathbf{L}$. videmus Fundilium, qui nos adrocavit. Buno animo este, inquit Agrius. Nan non modo ovum illud sublatum est, quod ludis circensibus novissimi curriculi finen facit quadrigis, sed ne illui quidem ovum vidimus, quod in ceriali pompa solet csse primunı. Itaque dun id nobiscum una videatis, ac venit æritimus, docete nos, agricultura quam summam habeat utilitatemne an voluptatem, an utrunque. Ad te euim rudem esse agricultura nunc, olim ad Stolonen fuisse dicuut. Scrofa, Prius, inquit, discemendum, utrım quie serantur in agro, ea sola sint in cultura, an etiam quie inducantur in rura, ut oves, et armenta. Video enim qui de agricultura scripserunt, et pornice, et grace, et latine, latius vagatos, quam oportuerit. Ego vero, inquit Stolo, eos non in omni re imitandos arbitror, et eo melius fecisse quosdam, qui minore ponerio finierunt, ex. 
le domainc de la science, cu écartant tout ce qui n'a pas a vec elle une relation immédiate. Ainsi le soin des troupeaux, que nombre d'auteurs ont rattaché à l'agriculture, me parait appartenir plu. tot au régime pastoral qu'au régimc agricole. Aussi avons-nous des noms différents pour les préposés en chef à l'un et l'autre office. Nous appelons les uns villici, les autres magistri pecorum (maitres des troupeaux). Le villicus est celui qui est spécialement chargé de la culture de la terre. (Le nom lui vient de villa (exploitation rurale), parce que c'est lui que regarde le soin de la rentrée des récoltes à la villa et dé leur sortie pour lá vente. Cest ainsi qu'aujourd'hui ericore les paysans, au lieu de dire via (route), disent vea, dérivé de vectura (transport); de même qu'ils disent vella au lieu de villa, dérivé de veho (je transporte), comprenant par vella le lieu où l'on porte, et d'où l'on transporte. C'est par là même analogie que le métier de voiturer (vectura) se dit vellaturam facere. Assurément, dit Fundanius, l'agriculture est une chose, et le nourrissage une autre; mais ces choses se touchent. La flùte de droite et la flutte de gauche sont distinctes, mais connexes. L'une est là pour le chant, l'autre pour l'accompagnement. Ajoutez, repris-je, qu'à la vie pastorale áppartient la première partie; à la vie agricole la seconde. C'était là du moins lesentiment du savant Dicéarque, qui, dans son tableau des mœurs primiti vés de la Grèce, nous apprend qu'en ces temps reculés les hommes menaient la vie des pasteurs; qu'ils ne savaient ni labourer la terre, ni planter, ni tailler les arbres; et qu'il faut rapporter à une période plus récente les premiers essais de la culture. Ainsi ce dernier art est subordonné au premier, comme la

clısis partibus, qux non pertinent ad hanc rem. Quare tota pastio, quæ conjungitur a plerisque cum agricultura, magis ad pastorem, quam ad agricolam pertinere videlur. Quocirca principes, qui utrique rei praponuntur, vocabulis quoque sunt diversi, quod unus vocatur vilicis, alter magister pecoris. Vilicus agri colendi causa constitutus, atque appellatus a villa quod ab eo in eam conveliuntur fructus, et evehuntur, cum veneunt. A quo rustici etiam nunc quoque viam, ream appellant, propter vecturas; et vellam non villam, quo velıunt, et unỏe vehunt. Item dicuntur, qui recturis vivunt, vellaturam facere. Certe, inquit Fundanius, aliud pastio, et aliud agricultura, sed affinis. Et ut dextera tibla alia quam sinistra, ita ut tamen sit quodam modo conjuncta, juod est altera ejus. dem carminis modorum incentiva, altera succentiva. Et quidem licet adjicias, inquam, pastorum vilaın esse iifcentivam, agricularum succentivam, auctore doctissimo homine Dicæarcho, qui Graciæ vita qualis fuerit ab initio, hobis ostendit, ut superioribus temporibus finisse doceat, cum homines pastoriciam ritam agerent, neque scirent etiam arare terram, aut serere arbores, aut putare; ab his inferiore gradu ætatis susceptan agriculturam. Quocirca et succinit pastorali, quod est inferior, ut tibia sinistra a dex- flûte de gauche l'est à la flùtede droitc. A vec votré musique, dit $\mathbf{\Lambda}$ grius, non-seulement vous enlevez au maitre les troupeaux qu'il possède, et à l'esclave le péculc que le maitrelui abandonne, mais encore vous annulcz la loi rurale qui défend de mener paitre, sur un terrain de nouvelle plantation cette race d'animaux que l'astrologie a placée dans le ciel près du Taureau, je veux dire les chèvres. Prenez gardede citer exactement, interrompit Fundanius. La loi dit encore : Et autres espéces de bétail. Car il y a certainement des animaux qui sont le fléau de la culture, notamment les chèvres, dont vous vieneź de parler. Elles ont la dent venimeuse, et détruisent, en broutant, tou. tes les jeunes plantes, et surtout les vignes et les oliviers. Aussi est-il reçu parmi nous qu'à telle divinité on sacrifie un bouc, tandis que telle autre en repousse l'offrande; symbole d'aversion pour l'animal chez toutes deux. L'une veut sa mort; l'autre ne vieut pas mêmele voir. C'est ainsi qu'on immole les boucs à Bacchus, père de la vigne, comme pour leur faire payer de leur tête les torts qu'ils lui font : tandis qu'au contraire nous ne voyons jamais immoler à Minerve aucun individu de cette race,' précisément parce qu'on prétend que l'olivier devient stérile du moment que la dent d'un bouc y a touiché, rien que la salive de l'animal étant un poison pour cette plante. C'est encore pour la même raison qu'il n'entre de chèvres pour victimes qu'une seule fois par an dans le temple d'Athènes. Ét encore n'est-ce là qu'un sacrifice qu'on a jugé nécessaỉre pour empêcher cette race de nuire à l'olivier, qu'on dit avoir pris naissance dans cette ville. II n'y a, repris-je, de bestiaux utiles à l'agriculture que ceux dont le travail contribue à rendre les

træ foraminibus. Agrius, Tu, inquit, tibicen non solum adinis domino pecus, sed etiam servis peculium, quibus domini dant, ut pascant, atque etiam leges colonicas tollis, in quibus scribimus, Colonus in agro surculario ne capra natum pascat : quas etiam astrologia in calum recepit, non longe ab Tauro. Cui Fundanius, Vide, inquit, Agri, ne istuc sit ab hoc, cum in legibus étiam scribatur, pecus quoddam. Quædam enim pecudes culturä sunt inimicæ, ac veneno, ut istæ, quas dixisti, capræ. Ex enim omuia novella sata carpendo corrumpunt, noi mininum viles, atque oleas. Itaque propterea institutum diversa de causa, ut ex caprino genere ad alii dei aram hostia adduceretur, ad alii non sacrificaretur, cum ab eodem odio alter videre nollet, alter etiam videre pereuntem vellet. Sic factum, ut Libero patri repertori vitis hirci immolarentur, proinde ut capite darent pœenas; contra, ut Minervæ caprini generis nihil immolareni, propter oleam, quod eam , quam læserit, fieri dicunt sterilem : ejus enim saliram essc fructuis venenum. Hoc nomine etiam Atheris in arcem non inigi, practerquam semel ad necessarium sacrificium, ne arbor olea, quæ primuın dicitur ibi nata, a capıa tangi possit. Nec ulla, inquam, pecudes agriculturne sunt propriæ, nisi qux agrum opere, q̧" rultior sit, ad. 
champs fertiles; et ce sont ceux qu'on attelle à la charrue. S'il en est ainsi, dit Agrasius, comment unc terre se passerait-elle de bestiaux, puisque l'engrais, cet ćlément si essentiel de toute culture, ce sont les bestiaux qui le produisent? Alors, dit Agrius, il faut admettre aussi qu'un troupeau d'esclaves fait partic de l'cxploitation agricole, si l'on juge à propos d'en entretenir un pour le même motif. Vous errez en cc que vous dites : Cus troupeaux peuvent être utiles; donc il faut avoir des troupeaux. Ce n'est pas une conséquence. Avec ce raisonnement on arriverait à encombrer une métairie des professions les plus étrangères au travail des champs, de tisserands, d'ouvriers en draps, et autres. Eh bien, dit Scrofa, séparons de l'agriculture proprement dite le nourrissage des bestiaux. Quelle distinction faut-il faire encore? Irons-nous, repris-je alors, imiter les deux Saserna, et discuter, commeils l'ont fait dans leurs livres, si l'art du potier n'a pasplus d'analogie que la science des mines avec l'agriculture? Sans contredit la matière vient du sol, mais n'est pas plus pour cela du ressort de l'agriculture que ne le sont les carrières et les sablonnières. Ce n'est pas que si tel fonds de culture peut admettre concurremment ce genre d'exploitation, je prétende qu'il faille l'exclure, ct négliger le profit qu'on peut en tirer. Sans doute si, dans un fonds qui avoisine une grande route, il se trouve un em:placement propice à la réccption des voyageurs, on fera bien d'y construire une auberge. Mais ce genre d'entrcprise, quels qu'en soient les bénéfices, ne saurait être considéré comme du domaine de l'agriculture. Car, dans les profits qu'on peut tirer directement ou indirectement de sa terre, il n'y a de vraiment agricole que ce

juvare, ut ex, qux junctx arare possunt. Agrasins, si istuc ita est, inquit, quomodu pecus remoreri potest ab agro, cım stercus, quod plurimum prodest, greges pecorum ministrent? Sic, inquit Agrius, venalium greges dicemus agriculturam esse, si propter istan rem hahen. dnm statnerimus. Sed error linc, quod pecus in agro esse potest, et fructus in agro ferre. Quod non sequendun. Nam sic eliam res aliæe diversa ab agro erunt assumendx : ut si habeas plures in fundo textores, atque institutos histonas, sic alios arfifices. Scrofa, Dijungamus igitur, inquit, pastionem a cultura, et si quis quid rult aliut. Anne ego, inquam, sequar Sasernarum patris et filii libros? ac magis putem pertinere, figlinas quemadmodnm exerceri oporteat, quam argenti fodinas, aut alia et alia metalla, quæ sirie dubio in aliqno agro finnt? Sed ut ueque lapicidinx, neque arenariæ ad agriculturam pertinent, sic figlinx. Neque ideo non in quo agro ido. rex possunt esse, [non] exercenda, atque ex eis capinndi fructus : ut etiam si ager secundum viam, et opportu. uus viatoribus locus, xdificandx tabernne diversoriæ, ¿qu taınen quantvis sint fructuosæ, nililo magis sunt agriculturæe partes. Non enim si quis propter agrum aut etiam in agro profectus domino, agriculturæ acceptum qui est produit d'ensemencement. Stolon m'interrompit. Vous etes jaloux de ec grand auteur, dit-il. Ce n'est que par esprit de critique que vous l'attaquez à l'endroit des poteries. Il a dit ailleurs d'excellentes choses qui rentrent certainement dans notre sujet, et dont vous ne parlez pas, afin de n'être pas obligé d'en faire l'éloge. Cette saillie fit sourire Scrofa, qui connaissait l'ou vrage ct ne l'estimait guère; mais Agrasius, qui en jugeait différemment, croyant aussi lc connaitre, demanda à Stolon ce qu'il en pensait. Voici, dit Stolon, la recette que donne cet auteur pour détruire les punaises: Faites infuser dans de l'eau - un concombre sauvage. Partout où vous répana drez de cette eau, les punaises n'approcheront " point. „Ou bien encore: «Frottez votre litavec du " fiel de bœuf délayé dans du vinaigre. „ Eh bien, dit alors Fundanius s'adressant à Scrofa, voilà pourtant qui toucheà l'agriculture. Oui, dit Scrofa, autant que son onguent épilatoire : Prenez " une grenouille jaune; faites-la bouillir dans l'eau " jusqu'à réduction des deux tiers, et frottez-vous "aver le résidu. "Moi, repris-je, je citerais plus volontiers le passage qui traite de l'incommodité dont est affligé Fundanius. Il souffre des pieds au point que la douleur lui fait rider le front. Vite la citation, s'écria Fundanius. J'aime mieux apprendre à guérir mes pieds qu'à planter des pieds de poirée. Quant à cela, dit Stolon en souriant, je me fais fort de vous communiquer la formule telle que l'auteur l'a déposée dans son livre, et que je l'ai entendue lire par Torquenna. Il faut d'abord que le malade, sitôt qu'il commence à sentir des douleurs aux pieds, pense à celui qui doit opérer sa guérison. Eh bien, reprit Fundanius, je pense à vous; guérissez mes

referre debel, sed id modo, qnod ex satione terra sit uatum ad fruendum. Suscipit Stolo, Tu, inquit, invides tanto scriptori, et obstrigillandi causa figlinas reprehendis, cum proclara quædam, ne laudes, prætermittas, quæ ad agriculturam vehementer pertineant. Cum subrisisset Scrofa, quod non ignorabat libros, et despiciebat, et Agrasius se scire modo putaret, ac Stolonem rogasset, ut diceret, coepit : Scribit cimices quemadmodum interfici oporteat lis verbis. Cucumerem anguinum condito in aquam, eamque infuudito quo roles, uulli accedent. Yel fel bubulum cum acelo mixtum, ungnito lectum. Funda. nius aspicit ad Scrofam, Et, tamen verum dicit, inquit, hic, ut loc scripserit in agricultura? Ille, Tam herclo quam froc si quem glabrum facere velis, quod jubet ranam luridan conjicere in aquam, usque quo ad tertiam partem decoxeris, eoque ungnere corpus. Ego quod magis, inquam, pertineat ad Fundanii valetudinem, et in eo libro est, satius dicam : nam hujusce pedes solent dolere, et in fronte contraliere rugas. Dic sodes, inquit Fundanius nam inato de meis pedibus audire, quam quemadmodum pedes betaceos seri oporteat. Stolo subridens, Dicam, inquit, cisdem, quibus ille verbis scripsil, vel Tarquennam audivi. Cnm homini pedes dolere coepissent, qui tui me. 
pieds. Écoutez done, continua Stolon : "Que Ia terre garde la maladie, et que la santé reste ici ! Il nous recommande de dire à jeun ces paroles trois fois neuf fois, de toucher la terre, et de cracher en mêtne temps. Vous trouverez encore, repris-je, daus le livre des Saserna beaucoup d'autres secrets miraculeux également étrangers à l'agriculture, et qu'il faut laisser où ils sont. D'ailleurs; ajoutai-je, de semblables digressions se rencontrent dans beaucoup d'auteurs. Le traité d'agriculture de Caton lui-même en fourmille. On y trouve entreautres des procédés pour faire la placenta, pour apprêter le libum, pour saler les jambons. Vous oubliez, dit Agrius, un article important : " Voulez-vous, dit Caton, boire beaua coup et manger encore davantage ? A valez avant " de vous mettre à table du chou cru, macéré dans a du vinaigre, et prenez-en cinq feuilles cncore " après le repas."

III. Nous venons, dit Agrius, d'écarter de l'agriculture tout ce qui lui est étranger : il nous reste à parler de ce qui forme le domaine de la science. Qu'est-ce que l'agriculture? Est-ce un art? et si c'est un art, quel est son principe et sa fin? Stolon se tournant vers Scrofa, C'est à vous, notre supérieur à tous en rang, en âge et en lumières, à nous résoudre ces diverses questions. Scrofa, sans se faire prier, s'exprima ainsi : L'agriculture est un art, et un art aussi grand qu'il est nécessaire. II nous apprend quel sol est propice à telle semence, quels travaux sa culture exige, et quelles qualités de terroir promettent des récoltes abondantes et continues.

IV. Les éléments de cet art sont les mêmes dont Ennius a dit qu'ils constituent le monde : l'eau,

minisset, ei mederi posse. Ego tui memini, medere meis pedibus. terra pestem teneto. salus mi maneto [in meis pedibus.] Hoc ter novies cantare jubet, terram taıgere, despuere, jejunum cantare. Multa, inquam, ilem alia miracula apud Sasernas invenies, quæ omnia sunt diversa ab agricultura, et ideo repudianda. Quasi vero, inquam, noll apud cateros quoque scriptores talia repe. riantur. An non in magni illius Calonis libro, qui de agricultura est editus, scripta sunt permulta similia? ut lixec, quemadmodum placentam facere oporteal, quo pactu libum, qua ratione pernas salire. Illud non dicis, inquit Agrius. Quod scribit, Si velis in convivio multum libere, cornareque libenter, ante csse oportet brassicam crudam ex aceto, et post aliqua folia.

III. Igitur, inquit Agrasius, quæ dijungenda essent a cultura cujusmodi sint, quonian discretum, de is rebus dicendum, quse in scientia sint. Ecquis in colendo nos docet ars sit an quid aliud, et a quibus carceribus decurrat ad metas. Stolo cum aspexisset Scrofam, Tu, inquit, ct atate, et honore, et scientia quod præstas, dicerc debes. Ille non gravatus, Primum, inquit, non modo est ars, sed etiatn necessaria ac magna. Eaque est scienlia, qua docet, quis sint in quoquo agro serunda ac faciunda, quæque lerra maximos perpetuo reddat fructus.

IV. Ejus principia sunt eadem, quæ numdi esse Enuius la terre, l'air, et le feu. Avant done de confier vos semences à la terre, il importe d'étudier ces différents éléments, source premic̀re de touls: production. C'est de cette connaissance que devront partir les agriculteurs pour conduire leurs travaux au double but d'être utile et de plaire : l'un solide, l'autre agréable. Mais au solide est due la préférence sur ce qui est de pur agrément. II peut résulter toutefois de la même disposition, qu'une terre gagneà la fois en aspect et en produit; qu'elle soit de meilleure défaite et augmente de valeur réelle. De belles lignes d'oliviers, par exem. ple, ou d'autres arbres à fruit, auront cet avantage. A égalité de valeur entre deux objets, qui n'aime mieux payer plus cher celui qui flatte la vue? Sous lerapport d'utilité, préférez le fonds de terre le plus salubre; car, sans salubrité, point de récolte assurée. Dans un sol malsain, si fertile qu'il soit, le fruit du travail, à chaque instant, peut êtrc détruit par des fléaux de tout genre. Là où l'on a sans cesse à compter avec le trépas, il s'agit, pour le cultivateur, non de recueillir, mais de vivre. Ainsi, dans toute contrée malsaine la culture n'est en quelque sorte qu'un jeu de hasard, auquel le propriétaire risque sa vie et sa fortune.

La science toutefois peut atténuer le mal; car, sans avoir d'action directe sur l'insalubrité, dont les conditions résident dans le sol et l'atmosphère, et procèdent de la nature, nous y pouvons beaucoup cependant. On parvient par une attention intelligente à en atténuer les effets. Les influences malignes ou du sol ou des eaux, les miasmes fétides qui s'exhalent en certaines localités, l'exposition à un soleil trop ardent ou à des vents

scribit, aqua, terra, anima, et sol. Hæc enim cognoscunda prius, quam jacias cemina, quod initium fructuum orilur. Hinc profecti agricolie ad duas metas dirigere debent, ad utilitatem et voluptatem. Utilitas quærit fructum, voluptas delectationem. Priores partes agit, quod utile est, quanı quod delectat. Nec non ea quæ faciunt [cultura] honestiorem agrum, pleraque non solum fructuosiorem eundem faciunt; ut cum in ordinem sunt consita arbusta atque oliveta, sed eliam vendibiliorem, alque adjiciunt ad fuud, pretium. Nemo eninı eadem utilitate non formosius quod est, emere mavult pluris, quam si est frucluosus turpis. Utilissimus autem is ager qui salubrior est, quam alii, quod ibi fructus certus. Contra quod in pestileati quansvis in feraci agrocalamitas colonun ad fructus pervenire nor patitur. Etenim ubi ratio cun orco habetur, ibi non modo fructus est incertus, sed etiam colentium vita. Quare ubi salubritas nou est, cultura non aliud est, alque alea domini vita, ac rei familiaris. Nec lıæe non deminuitur scientia. Ita enim salubritas, qux ducilur c cælo ac terra, non est in nostra potestatc, sed in naturæ, ut tamen multum sit in nobis ; quod graviora quæ suut, ea diligentia leviora facere possumus. Etenim si propler terran aut aquam, odoremve, quem aliquo loco eructat, pestilentior est fuudus, aut propter cali.regionenı ager calidior sit, aut ventus uon bonus flet : lıec vitia emcndari soleut domiri 
entraires, tous ces inconvénients sc corrigent par des dépenses bien entenducs. On voit de quelle importance est la position topographique des bátiments d'exploitation, leur étendue, et l'exposition de leurs ouvertures, portes, portiques et fenêtres. N'a-t-on pas vu la science d'llippocrate, dans un temps de peste, préserver' de la conlagion non-seulement une maison, des champs, mais des villes entières? Mais où vais-je chercher le témoignage d'Hippoerate? N'avonsnous pas ici notre ami Varron, qui, lorsque l'arméc et la flotte se trouvaient à Corcyre, et que toutes les maisons regorgeaient de malades et de morts, fit percer de nouvelles fenêtres pour donner passage au vent du nord, murer les anciennes qui laissaient pénétrer l'air infecté, pratiquer de nouvelles portes, et qui, par mille autres soins de ce genre, parvint à ramener ses compagnons sains et saufs dans leur patrie?

V. Nous avons déterminé les principes de l'agriculture ct son but : il nous restc à examiner les différentes parties dont sa science se compose. Quant à moi, dit Agrius, je suppose que le nombre doit en être infini, quandje vois cette multitude de Jivres que Théophraste a composés sous les titres d'histoire des plantes et des causes de la végétation en général. A monavis, reprit Stolon, ces livres conviennent bien moins aux hommes qui cultivent la terre qu'à ceux qui fréquentent les écoles des philosophes. Ce qui ne veut pas dire que les uns et les autres ne puissent y rencontrer des enseignements utiles. Quoi qu'il en soit, veuillez nous expliquer vous-même les différentes parties de l'agriculture. Elle en comprend, dit Scrofa, quatre principales. Elles consistent a bien connaitre : la première, le fonds à exploiter, la nature du sol et ses éléments constitutifs; la se-

scientia ac sumptu; quod permagni interest, ubi sint positæ villæ, quantæ sint, quo spectent porticibus, ostiis ac fenestris. An non ille Hippocrates nedicus in magna pestilentia non unum agrum sed multa oppida scientia servavit ? Sed quid ego illım roco ad testimonium? Non hic Varro noster, cum Corcyræe esset exercitus ac classis, et omnes domus repletæe essent rgrotis ac funeribus, immisso fenestris novis aquilone, et obstructis pestilentibus, januaque permutata, cxteraque ejus generis diligentia, suos comites ac familiam incolumes reduxit?

V. Sed quoniam agricultura, quod esset initiom et tinis dixi, relinquitur quot partes ea disciplina habeat, ut sit videndum. Equidem innumerabiles milii videntur, inquit Agrius, cum lego libros Theoplırasti complures, qui inscri-

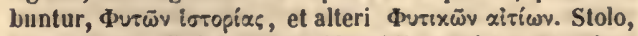
Isti, inquit, libri non tam idonei iis, qui agrum colere volunt, quam qui scholas plilosoplıorum. Neque eo dico, quod non habeant et utilia, et communia quxedam. Quapropter tu potius agricultura partes nobis expone. Scrofa, Agriculturæ, inquit, quatuor sunt partes summæ : e queis prima cognitio fundi; solum partesque ejus quales sint; secunda, quæe in eo fundo opus sint ac debeant esse conde, le personnel et le matériel nécessaires à son expluitation; la troisième, les façons que lc terrain exige; la quatrième enfin, quelles époques de l'année conviennent à chacune d'elles. Chacune de ces quatre parties se subdivise ellemême au moins en deux autres. Les deux subdivisions de la première ont pour objet, l'une la terrc clle-même, et l'autre les bátiments et les étables. La seconde partie prineipale, quiembrasse tout l'effectif d'un fonds de culture, a également deux subdivisions, dont la première comprend les travailleurs, et la seconde les instruments aratoires. La troisième partie principale, qui a pour objet la direetion des travaux, renferme d'une part lesopérations préparatoires, et, de l'autre, le choix des lieux où l'on doit les exécuter. La quatrième partie, qui traite des différentes époques de l'année, comprend, dans sa première subdivision, tout ce qui a rapport à la révolution annuelle da soleil et au cours mensuel de la lune. Je commeneerai par parler de ces quatre parties principales; puis je traiterai avec plus de détail les huit subdivisions.

VI. En considérant un fonds sous le rapport du sol, nous avons à examiner quatre points principaux, savoir la configuration du terrain, sa qualité, l'étendue de la propriété, et quelles chances de sécurité elle offre par ellę-même. Un terrain doit sa configuration à la nature, qui l'a bien ou mal disposé, ou à la main de l'homme, qui l'a transformé pour la culture en bien ou en mal. Parlons d'abord de la configuration naturelle. Nous reconnaissons trois genres de terrains simples : celui des plaines, celui des collines, et celui des montagnes; des mixtes, yui se combinent de deux de ces genres ou des trois ensemble. On en trouve de fréquents exemples. Il y a pour chacun des

culturæ causa; tertia, quæ in eo prædio colendi causa sint faciunda; quarta, quo quidquid tempore in eo fundo fieri conveniat. De his quatuor generibus singulex inini. mum in binas dividuntur species. Quod halet prima ea, quæ ad solum pertinent terræ, et quæ ad villas, et stabula. Secunda pars, quie moventur, atque in fundo debent esse cultura causa, est item bipartila : de hominibus, per quos colendum, et de reliquo instrumento. Tertia pars, quæ de rebus, dividitur; quæ ad quamque rem sint præparanda, et ubi quxeque faciunda. Quarta pars de temporibus, quæ ad solis circumitum annuum sint referenda, et quæ ad Lunæ menstruum cursum. De primis quatuor partibus prius dicam, deinde subtilius de orto secundis.

VI. Jgitur primum de solo fundi videndum lıæc quatuor. Quæ sit forma, quo in genere terræ, quantus, quam per se tutus. Fornæ cum duo genera sint, una quam natura dat, altera quam sationes imponunt : prior, quod alins ager bene natus, alius male; posterior, quod alius fundus bene consitus est, alius male : dicam prius de naturali. Igitur cum tria genera sint a specie simplicia agrorum, campestre, collinum, et montanum, est ex is tribus quartum, ut in eo fundo, in quo hac due vel tria subst, 
trois genres simples des systèmes de culture différents. Sans contredit celui qui convient aux plaines ne peut s'appliquer, soit aux montagnes où la température est bien moins élevée, soit aux collines, où elle est plus froide que dans les premières localités, et plus chaude que dans les secondes. Cette différence entre les fonds de terrain- simple est d'autant plus sensible qu'ils occupent respectivement plus de superficie. Plus le sol est découvert, plus la chalcur a d'intensité. C'est ce qui fait qu'en certains cantons l'atmos. phère est si ardente et si lourde, et que dans les régions élevées, sur le Vésuve, par exemple, l'air est plus léger, et par conséquent plus sain. Ceux qui cultivent des terrains bas souffrent pendant l'été, au lieu que ceux qui cultivent des terrains élevés souffrent davantage pendant l'hiver. L'hiverest la saison propice pour ceux qui cultivent des plaines, parce qualor's les prés sont en herbe, et les arbres en état d'êtrc taillés. L'été au con. traire est favorable à cenx qui cultivent les hauteurs, parce que durant cette saison les pâturages y abondent, tandis qu'ils sont brûlés dans les plaines. D'ailleurs l'air alors n'y est que frais ; ce qui convient aux opérations forestières. Pour le sol des plaines, le plan incliné vaut mieux que l'absolu niveau; car le défaut de pente tend à former des marécages, les eaux ne trouvant pas d'écoulement. Aussi le terrain est-il d'autant plus défectueux qu'il est plus inégal; ce qui multiplie les bas fonds où l'eau séjourne. L'époque des semailles arrive plus tôt dans les plaines que sur les hauteurs, où l'on est obligé de gagner de vitesse, et d'attendic plus tard les récoltes. Certains arbres, comme l'érable et le sapin, n'atteignent toute leur hauteur, tout leur dévelop-

ut multis locis licet videri. E quibus tribus fastigiis sinplicibus, sine dubio intimis alia cultura aptior, quam summis, quod lıxc calidiora quam sumına : sic collinis, quod ea tepidiora quam infima, aut summa. Hæc appa. rent magis ita esse in latioribus regionibus, simplicia cum sunt. Itaque ubi lati campi, ibi magis restus. Et eo in Apu. lia loca calidiora ac graviora. Et ubi montana, ut in Vesuvio, quod leviora, et ideo salubriora. Qui colunt deorsum, magis restate laborant : qui sursum, magis hieme : verno tempore in campestribus maturius eadem illa seruntur, quam in superioribus : et celerius hic, quam illic coguntur. Ner non sursum;, quam deorsum, tardius seruntur ac metuntur. Quaciam in montanis prolixiora nascuntur ac firmiora, propter frigus, ut abietes ac sappini. Hic, quod tepidiora, populi ac salices : sursum fertiliora, ut arbutus ac quercus : deorsum, ut nuces græcæ ac mariscæ fici. In collibus humilibus societas major cum campestri fructu, quam cum montano : in altis contra. Propter hac tria fastigia formæe, discrimina quæ. dam funt sationum, quod segetes meliores existimantur esse cainpestres, vinexe collinæ, silvæ montanx: plerunque lilierna iis esse.meliora, qui coluut campestria, quod tunc prata ibi herbosa, putatio arborum tolcrabilior. pement, que sur les montagnes, grâce à l'air víf qui y domine. D'autres, tels que les peupliers et les saules, ne prospèrent que dans les températures moyennes, comme la nôtre. 11 en est qui ne réussissent que dans les terrains ćlevés, comme l'arbousier et le chêne. D'autres entin n'aiment que les terrains bas, comme l'amandier et le figuier. Les productions des collines, suivant leur degré d'élévation, se rapprochent plus ou moins de cclles des plaines et des montagues. La culture varie suivant ces trois conditions du sol : on préfère les plaines pour le blé, les coteaux pour la vigne, et, pour les forĉts ; les montagnes. Toutes ces considérations doivent être respectivement pesées pour la culture de chaque ordre de terraiu.

VII. En ce qui concerne la configuration naturelle, dit Stolon, je suis assez de l'avis de Caton, que le meilleur fonds de terre est celui qui se trouve placé au pied d'une montagne, et exposé au midi. Mais je soutiens, répond Scrofa, qu'en fait de culture, le produit est en raison de ce que l'aspect plaît plus à l'œil. C'est l'effet de la plantation en quinconce, et de l'observation des distances pour les pépinières. Aussi nos pères, avec leurs méthodes vicieuses, ne tiraient-ils, d'une égale superficie de terrain, que des blés et des vins inférieurs aux nôtres en quantité comme en qualité. C'est qu'avec la symétrie on méuage mieux l'espace, et que, par suite, chaque plant est moins exposé à se voir intercepter par son volsin l'influence du soleil, de la lune ou de l'air. Un exemple va rendre ceci plus sensible. La même quantité de noix, qui se tasse parfaitement dans un boisseau avec les coques entières, va difficilement entrer dans une mesure d'un boisseau et demi, quand vous l'aurez concassée. Vos plants,

Contra æstiva montana his locis commodiora, quod ibi tum et pabulum multum, quod in campis aret : ac cultura arborum aptior, quod tum illic frigidior aer. Campester locus is melior, qui totus æquabiliter in unam partem vergit, quam is qui est ad libellam æquus, quod is, cum aquae non labeat delapsum, fieri solet uliginosus. Eo ma. gis si quis est inxquahilis, eo deterior, quod fit propter lacunas aquosus. Hac atque hujuscemodi tria fastigia agri ad colendum dlspariliter lıabent momentum.

VII. Stolo, Quod ad hauc formam naturalem pertinet, de eo nou incommode Cato ridetur dicere, cum scribit optimum agrum esse, qui sub radice montis situs sit, et spectet ad meridianam cæli partem. Subjicit Scrofa, De formæ cultura hoc dico, quæ specie fiant renustiora, sequi, ut majore quoque fructu sint : ut qui babent arbusta, si sata sunt in quincuncem propter ordines, atque intcrvalla modica. Itaque majores nostri ex arvo aque magno, sed male consito, et minus multum, et minus bonum faciebant vinum et frumentum, quod quæ suo quidque loco sunt posita, ea minus loci occupant, et minus oflicit aliud alii ab sole ac luna, et vento. Hoc licct conjectura vidcre cx aliquot rebus, it nuces integras, quas uno modio comprehendere possis, quod putamina suo loco ques. 
dûment alignés, en seront plus accessibles à l'action du soleil et de la lune, vous dunneront plus de raisins ou d'olives, qui viendront mieux à maturité; double résultat entraînant ces deux conséquenees, meilleure réeolte d'huile et de vin, augmentation de profit. Nous voici arrivés à la seconde partie, qui traite desindieations auxquelles on reeonnaît quine terre est bonne ou mauvaise. C'est en effet de la qualité de la terre que dépend le ehoix des fruits qu'on peut y semer et reeucillir, et le genre de culture qui lui est appliquable. Ie même sol ne convient point également à toutes sortes de productions. Celuici est spéeialement propre à la vigne; cclui-là au blé; et tel, à telle autre production. C'est ce qui fait sans doute qu'il y a dans l'ille de Crète, près de Cortynia, un platane qui, même en hiver, ne se dépouille point de ses feuilles. Théophraste en mentionne un pareil dans l'île de Cypre. Il y a aussi devant la ville de Sybaris, que l'on appelle aujourd'hui Thurium, un ehêne qui offre le même phénomène. Nous voyons enfin, dans les campagnes d'Éléphantine, des figuiers et des vignes qui ne s'effeuillent jamais. C'est encore par la même raison que beaucoup d'arbres portent des fruits deux fois par an, comme les vignes de Smyrne près la mer, et les pommiers dans les eliamps de Consentinum. Autre preuve de ectte observation. La culture donne en meilleure qualité les fruits que la nature sauvage produit en plus grande abondanee. On peut citer eueore les plantes qui ne peuvent vivre que dans un terrain aqueux, ou même au milieu de l'eau. Encorc ne vieunent-elles pas indistinetement dans toute espèce d'eau, puisque les unes réussissent mieux dans les laes, eomme les roseaux dans le pays de Réate; les autres en eau courante, comme

que habet untura composita, cum easdem si fregeris, vix sesquimodio concipere possis. Praterea qua arbores in ordinem sala sunt, eas equahiliter ex omnibus partibus sol ac luna coquunt. Quo fit, ut ivie et olea plures nascantur, et ut celerius coquantur; quas res dias sequuntur altera illa dno, ut plıs reddant mustiet olei, et pretii pluris. Sequitur secundun illud, quali terra solnm sit fundi, a qua parte vel maxime bonus aut non bonus appellatur. Refert enim, qux res in eo seri nascique, et cujusınodi possint. Non enim eadem onnia in eodem agro recte possunt. Nam ut alius est ad vitem appositus, alius ad frumentum, sic de cxteris alius ad aliam rem. Itaque Cretie ad Cortyniam dicitur platanus esse, qua folia hieme non anittat. Itemque in Cypro, ut Theoplurastus ait, una. Item Sybari, qui nunc Thurii dicuntur, quercus simili esse natura, quae est in oppidi conspectu. Item contra atque apnd nos lieri ad Elephantinen, ut neque ficus neque vites amittant folia. Propter eandem rausain multa sunt bifera, ut vites apud mare Smyrna : malus bifera, ut in agro Consentino. Idem ostendit, quod in locis feris plura ferunt : in iis quxe sunt culta, meliora. Kaden de causa sunt, quar non possunt vivere nisi in les aunes d'Épire; d'autres enfin dans la mer, comme les squilles et les palmiers, au dire de Théophraste. Quand j’étais à la tête de l'armée, j'ai vu dans lintérieur de la Gaule Transalpine, près du Rhin, des contrées où il ne croît ni vignes, ni oliviers, ni pommiers; où l'on emploie une sorte de craie blanche pour fumer la tcrie ; et où les habitants, au lieu de sel marin ou fossile, se servaient de charbons salés, qu'ils obtenaient de la eombustion de certains bois. Stolon prit alors la parole, et dit : Caton, en examinant l'uue après l'autre les différentcs espèces de terres, les échelonne suivant leur qualité, et les divise en neuf classes. Dans la première, il met les terres à vignes, qui rapportent avec abondance un vin de bonne qualité; dans la seeonde, les terres de jardin d'une irrigation faeile; dans la troisième, les terrains propres aux saules; dans la quatrième, les terres qui conviennent aux plants d'oliviers. Dans la cinquième classe sont les prairies; dans la sixième, les terres à blé; dans la septième, les bois en coupe réglée; dans la huitième, les vergers ; dans la neuvième enfin, les terres où l'on récoltc le gland. Je sais bien, dit Scrofa, que Caton a écrit cela; mais ee n'est pas l'avis de tout le monde. Il en est qui mettent les bonnes prairies en première ligne ; et je suis de ce nombre. Nos pères les appelaient parata, et non prata à causo de leur produetion spontanée. César Vopiscus, en plaidant un jour devant les censeurs, eita la campagne de Roséa comme la nourricière de l'Italic. L'éehalas qu'on y oubliait la veille, disait-il, ne se retrouvait plus le lendemain; parce que l'herbe l'a vait recouvert entièrement.

VIII. Les vignobles ont des adversaires qui prétendent que !es frais de culture absorbent ie

loco aquoso, ant etiam aqua. Et id discriminatim, ut alia in lacubus, ut arundines in Reatino; alia in fluminibus, ut in Epeiro arbores alni; alia in mari, ut scribit Theophrastus, palmas et squillas. In Gallia transalpina intus ad Rhenum, cum exercitum ducerem, sliquot regiones accessi, ubi nec vitis nec olea' nec poma nascerentur; ubi agros stercorarent candida fossicia creta : ubi salem nec fossicium, nec maritimum haberent, sed ex quibuisdam lignis combustis carbonibus salsis pro eo uterentur. Stolo, Calo quidem, inquit, gradatim præponens, alium alio agrum meliorem dicit esse in novem discriminibus, quor sit primus, uhi vinex possint esse bono vino et multo; secundus, ubi hortus irriguus; tertius, ubi salicta; quartus, ubi oliveta ; quintus, ubi pratum; sextus, uhi campus frumentarius; septimus, ubi cædua silva; octavus, ubi arbustum; nonus, ubi glandaria silra. Scrofa, Scio, inquit, scribere illum. Sed de hoc nou consentiunt omnes, quod alii dant primatum bonis pratis, ut ego quoque : a q xedilicius, causam cum ageret apud censores, cainpos losere Italix dixit esse sumen, in q̨uo relicta pertica mostridie non apparèret propter lierbau. 
produit. Les vignobles de quelle espèce dis-je? car il y en a plusieurs. L'espèce rampante, qui n’a pas besoin d'échalas, et qu'on rencontrcen Espagne; et l'espèce à haute tige, si commune en Italie, et dont les ceps sont isolés et maintenuus en direction verticale par des échalas, ou assujettis ensemble par le haut à l'aide de traverses. C'est ce qu'on appelle marier la vigne. 0 n emploie comme traverses, ou des perches, ou des roseaux, ou des cordes, ou la vigne elle-même. Le premier de ces moyens est en usage à Falerne; le second à Arpinum; le troisième à Brindes, et le quatrième dans la campagne de Milan. On procède à cette opération de deux manières, par lignes directes, ou par lignes croisées. C'est la plus ordinaire en Italie. Si le maitre de la vigne tire de son propre fonds la matière qu'il emploie comme soutien, il n'a plus à redouter la dépense. Elle n'est même qu'insensible, au cas où il peut s'approvisionner dans le voisinage. Pour qu'il ait cette matière à sa disposition, il suffit, dans l'un des trois premiers cas, que sa propriété produise, soit du saule, soit des roseaux, soit du jonc ou quelque plante analogue. Dans lc quatrième, il faut des arbustes propres à servir aux ceps de conducteurs. Dans la campagne de Milan on se sert à cet effet des éra. bles; à Canusium, on emploieles figuiers, dont on entrelace les branches aux vignes. Quant aux échalas, il y en a quatre espèces. D'abord ceux qu'on tire du cœur de chène ou de genévrier; ce sont les plus solides et ceux qui servent le mieux. Puis ceux qui proviennent de branches faconncees en pieux ou perches, qu'il faut choisir de bois compact, pour plus de durée, etqu'on retourne quand l'humidité de la terre les a pourris d'un bout, pour les enfouir par l'autre. II s'en fabrique subsidiairc-

VIII. Contra vineam sunt qui putent sumptu fructum devorare. Refert, inquam, quod genus vineæ sit, quod sunt multæ species ejus. Aliæe enim humiles ac sine ridicis, ut in Hispania : aliæe sublimes, ut quæ appellantur jugatæe, ut pleræque in Italia. Quarum nomina duo, pedaınenta el juga. Quibus stat recta vinea, dicuntur peda. uenta. Qux transversa junguntur, juga : ab eo quoque vinea jugatie. Jugorum genera fere quatuor, pertica, arundo, restes, viles. Pertica, ut in Falerno; arundo, it in Arpino; restes, ut in Brundisino; vites, ut in Mediola. nensi. Jugationis species dux, una directa, ut in agro Cauusino: altera compluviata, in longitudinem et latilu. dinem jugata, ut in Italia pleræque. Hæec ubi domo nas. cuutur, vinea non metuit sumplum; ubi multa ex propinqua villa, non valde. Frimum genus quod dixi, maxime quærit salicta. Secunduın, arundineta. Tertium juncela, aut ejus generis rem aliquam. Quarlum arbusta, ubi traduces possiut fieri vitium, ut Mediolanenses faciunt in arboribus, quas vocant opulos; Canusini in tıarundulatione in ficis. Pedamentum item fere quatuor generum. Unum robustum, quod optimum solet afferri in vineam e quercu ac junipero, el vocatur ridica. Alterum palus e pertica, melior-e dura, guod diuturuior : quem cum infi- ment d'une troisicme espèce avec des roseaux, quand on manque de matériaux pour les deux premières. On prend plusieurs tiges de roseaux, qu'on assujettit ensemble avec un lien d'écorce d'arbre et qu'on introduit dans des tubes de terre cuite, pour faire écouler l'humidité. La quatrième espèce pourrait être qualifiée d'échalas naturels. Ce sont les arbres qui en font l'office. Les rameaux de la vigne, qui s'élancent de l'un à l'autre, sont appelésparles uns traduces, et par les autre rum$p i$. Il faut que la vigne s'élève à hauteur d'homme, et que les échalas soient espacés de manière à ce qu'un attelage de bœufs puisse labourer dans les intervalles. C'est un vignoble peu coûteux que celuiqui, sans exigerde soutiens, rend la contenance d'un acratophore. On distingue deux sortes de vignes. Les grappes de l'une ra mpent sur lesol. Cette espèce est commune dans certains cantons d'Asie, et les renards y vendangent autant que les hommes. La présence des souris est encore une cause de déchet; à moins qu'on n'ait le soin de multiplier les souricières dans les vignobles, ainsi que cela se pratique dans l'ile de Pandataire. Quant à l'autre espèce de vignes, on éloigne de la terre, en les élevant, les pousses qui promettent du raisin. On place à cet cffet, au-dessous de ces pousses, à l'endroit où se forment les grappes, dc petites branches en fourche de deux pieds de longucur en viron. Par ce moyen, les sarments ainsi soutenus deviennent insensiblement, pour les vendanges à venir, des branches à fruit, que l'on attache en conséquence au cep avec une petite corde, ou cet autre lien que nos ancétres appelaient cestus. Dans les pays qui produisent cette espèce de vignes, quand le dernier vendangeur a montré ses talons, lc maítre prend soin de faire rentrer chez lui toutes ces

mum terra voluit, puter evertitur, et fit solum sununum. Tertium quod horum inopiæ subsidio misit arundinetun. Inde enim aliquot colligatas libris demittunt in tubulos fictiles cum fundo pertuso, quos cuspides appellant, qua humor adventicius transire possit. Quartum est pedanen. tum nativum ejus generis, ubi ex arboribus in arbores traductis vitibus vinea sit: quos traduces, quidam rum. pos appellant. Vinese altitudinis modus, longiludo hominis. Intervalla pedamentorum, qua boves juncti arare possint. Ea minus sumptuosa vinea, quæ sine jugo ministrat acratophoro vinum. Hujus genera duo, unum, iu quo terra cubilia præbet uvis, ut in Asia multis locis, qux sæepe vulpibus et lominibus fit communis. Nec non, si ja. rit humus mures, uninor fit vindenia : nisi totas vineas op. pleris muscipulis, quod in insula Paudataria faciunt. Alterum genns vineti, nbi ca morlo removetur a terra vitis, qux ostendit se afferre uvan. Snb eam, ubi nascitur uva, subjiciuntur circiter bipedales e surculis furcillæ, ne vindemia pereat, et vindeunia facta deni(pue discat pendere in pal. mam aut funiculo aut vinctu, quod antiqui rocaban: cestum. Ibi dominus sinul ac vidit occipitium rindemiatoris furcillas reducit libernatum in tecla, ut sine sumpluz earum opera altero anno uti jossit. Hac consuctudine ine 
fourches, afin de les remettre en œuvre, sans nouveaux frais, l'année suivante. A Réate on n'y manque jamais. Du reste, le mode de culture appliqué à la vigne dépend surtout de la nature du sol. En eflet, dans les terrains humides il importe d'élever davantage la vigne; car le jus de la treille, lorsque la grappe se forme et grossit, ce n'est pas dc I'enu qu'il demande, comme lorsqu'il est dans la coupe, mais du soleil; et c'est pour cela que les ceps tendent continuellement à grimper après les arbies.

IX. Il importe done, comme je viens de le dire, de bien connaître la qualité de la terre, ct à quel genie de production elle est propre ou impropre. Le mot terre a trois acceptions différentes. un sens général, un sens propre, ct un sens mixtc. Il est pris dans le sens général, lorsqu'on dit le globe de la terre, la tcrre d'Italie, ou de toute aulre contrée ; car alors on comprend dans cettc dénomination la pierre, le sablc, et les éléments divers dont la terre est composée. Le mot est pris dans le sens propre, lorsqu'on dit la terre d'une manière absolue, sans qualification ni épithc̀te. Enfin il est pris dans le sens mixte, lorsqu'on parle de la terre comme propie à reccvoir les semences et à les développer. C'est aiısi qu'on dit : une terre argilleuse, unc terre pierreuse, etc. Le mot terre, pris dans ce dernier sens, présente une idée non moins complexe que dans le sens général, et suppose un même composé de diverses substances. En effet, tout cet amalgame de corps étranger's que la terre, prise dans le sens général, renferme dans son scin, suivant les variétés de sa puissance génératrice, pierre, marbre, moellon, silex, sable, argile, rubrique, poussière, craie, gravier, charbon (résidu de la combustion des racines quand la terre est chauffée par le solcịl jụsqụ’à l'incandescence), toụt cet

Italia utuntur Reatini. Hxc ideo variefas maxime, quod terra cujısmodi sit, refert. Ubi enim natura humida, ibi altius vitis tollenda, quod in partu et alimonio vinum non, int in calice, quxerit aquam, sed solem. Itaque ideo, ut arbitror, primum e vinea in arbores ascendit vitis.

IX. 'Terra, inquam, cujısmodi sit refert, et ad quam rem bona, ant non bona sit. Ea tribus modis dicitur, communi, proprio, et mixto. Communi, ut cum dicinus orbem teriæ, et terram Italiam, aut quam aliam. In ea enim et lapis et arena et cretera ejus generis sunt in nominando comprehensa. Altero modo dicitur terra proprio nomine, quæ nullo alio vocabulo neque cognomine adjecto appelJatur. Tertio modo dicitur terra, quæ est mixta, in qua seri potest quid et nasci; ut argillosa, aut lapidosa, sic alia; cum in lıac species non minus sint multæ, quam in illa communi, propter admixtiones, in illa enim, cum sit dissimili vi ac potestate, partes permultx, in queis lapis, marmor, rudus, arena, sabulo, argilla, rubrica, pulvis, creta, glarea, carbunculus : [id est, quæ sole perferve ita fit, ut radices satorum comburat] ab is, quæ proprio nomine dicitur terra, cum est adınixta ex his generibus amalgame, dis-je, se retrouve dans ce qu'on appelle terre pris dans le sens propre, et la fait qualifier d'argileuse, de sablonneuse, etc., suivant l'élément qui domine. Ces différentes espèces de substances constituent donc autant d'espèces de terre, dont chacune comporte au moins trois degrés dans son essence. Un terrain pierreux, par exemple, ou l'est excessivement, ou l'est médio. crement, ou ne l'est presque point. Mêmes distinctions à faire dans chacune des autres espèces. De plus, chacun de ces degrés de relation est luimême subdivisible en trois, puisqu'on y rencontre ou l'extrême sécheresse, ou l'extrême humidité ou l'habitude intermédiaire, toutes modifications qui n'ont pas unc médiocre influence sur le revenu. Acussị le cultivateur expérimenté sèmera plutôt du fioment que du blé commun dans un terrain humide, donnera, si son terrain est sec, la préférence à l'orge sur le blé, et confiera indifféremment l'un ou l'autre à un terrain mixte.

Il est d'autres distinctions à faire, plus subtiles encore que les précédentes. Pour un teriain sablonneux, par exemple, il importe de savoir si le sable est blanc ou rouge; car le sable blanc ne convient pas aux pépinières, qui réussissent parfaitement dans le sable rouge. Il importe encore beaucoup de classer les terres selon qu'elles sont grasses ou maigres, ou entre les deux. Autant les grasses sont fertiles, autant les maigres le sont peu. Dans ces dernières point d'arbres touffus, point de vignes de rapport, point de paille fournie, point de grosses figues. Témoin les champs de Pupinia : on n'y voit qu'arbres chétifs, que prés arides, et envahis par la mousse. Dans les cantons, au contraire, où la terre est grasse, commc en Etrurie, partout de belles récoltes, et belles tous les ans; des arbres à feuillage épais, et de la moussc nulle part. Le partiqu'on tire d'une terre moyenne

aliqua re, tum dicitur aut cretosa, aut glareosa, et sic ab) aliis generum discriminibus mixta. Et uti lorım varictates, ita genera hæc, ut præterea subtiliora sint alia. Nam minimun in singula facies terua, quod alia terra est valde lapidosa, alia mediocriter, alia prope pura. Sic de aliis generibus reliquis admixtæ terræ tres gradus ascendunt eosden. Praterea ha ipsæe terux species ternas in se liabent alias, quod partim sunt humidiores, partim aridiores, partiı nıediocres. Neque non hæc discrimina pertinent ad fructus velıementer. Jtaque periti in loco lıuinidiore far adoreum potius serunt, quam triticum; contra in aridiore hordeum potius, quam far, in mediocri utrunque. Proterea etiam discrimina omnium horum generum subtiliora alia, ut iı saluulosa terra, quod ibi refert, sabulo albus sit, an rubicundıs : quod subalbıs ad serendos surculos alienus, colltra rubicundior appositus. Sic magna tria discrimina terrip, quod refert utrum sit macra, an pinguis, an mediocris. Quod (ad culturam) pirguis fuecundior ad multa, macra contra. Itaque in iis, ut in Pupinia, neque arbores prolixas, neque vitcs feraces, neque stramenta videre crassa possis, neque ficum nrariscau, et arbores plerasque, ac 
conme celle des environs de Tibur, est en raison de sa plus grande affinité avec les grasses qu'arec les maigres. Diophane de Bithynie, reprit alors Stolon, dit avec assez de raison qu'on peut juger de la qualité d'urie terre par induction tirée de son apparence extérieurc, ou de ce qu'elle produit naturellement. On examine, dans le premier cás, si sa couleur est claire ou foncée, si elle est légère, facile à remuer, friable ou compacte; dans le second cas, si sa végétation spontanée est abondante et promet maturité. Mais continuez, parlez-nous maintenant de la troisième partie, qui a pour objet les différentes mesures établies dans chaque pays.

$X$. Scrofa reprit en ces termes : Chaque pays a sa mesure particulière. Daus l'Espagne ultérieure, on mesure les terres par jugum; en Campanie, par versus; et, dans la campagne romaine, ainsi que dans tout le Latium, nous procédons par jugerum. On appelle jugum l'étendue que deux boufs attelés ensemble peuvent labourer en un jour ; versus, une superficie de cent pieds carrés. Le jugerum contient deux aclus quadratus; et un actus quadratus est de cent vingt pieds carrés. L'actus quadratus est appelé en latin acnua. La moindre des fractions d'un jugerum s'appelle scrupulum, et a dix pieds en longueur et autant en largeur. D’après ces bases, les arpenteurs comptent habituellement l'excédant du jugerum par onces, sextant, ou quelque autre partie aliquote de l'as, puisque le jugerum se compose de deux cent.quatre-vingt-huit scrupules, ce qui forme précisément le même nombre d'unités qu'en contenait notre ancien as avant la

prati retorrida, et muscosa. Contra in agro pingui, ut in Iletruria, licet videre segetes fructuosas, ac restibiles, et arbores prolixas, et omnia sine musco. In mediocri autem terra, ut in Tiburti, quo propius accedit, ut non sit macra, quam ut sit jejuna, eo ad omnes res commodior, quam si inclinarit ad illud quod deterius. Stolo, Non male, inquit, qux sit idonea terra ad colendum, aut non, Dioplanes Bithynius scribit, signa sumi posse aut ex ipsa, aut ex iis quæ nascuntur ex ea. Ex ipsa, si sit terra alba, si nigra, si levis, qua cum fodiatur, facile frietur, naturaque non sit ciueritia neve vehementer densa. Ex iis autem, qux enata sunt fera, si sunt prolixa, atque ea qua ex is nasci debent, earun rerum feracia. Sed quod sequitur, tertium illud de modis dice.

X. Ille, Modos, quibus metirentur rura, alius alios constituit. Nam in Hispania ulteriore metiuntur jugis, in Campania versibus, apud nos in agro romano ac latino jugeris. Jugum vocant, quod juncti boves uno die exarare possint. Versum dicunt centum pedes quoquoversum quadratum. Jugerum, quod quadratos duos actus liabeat. Actus quadratus, qui et latus est pedes cxx, et longus toliden. Is modus acnua latine appellatur. Jugeri pars minima dicitur scripulum, il est deceun pedes in longitu. dinem et latitudinem quadratum. Ab hoc principio mensores nonnunquam dicunt in subsicivum esse unciam agri, aut sextantem, aut quid aliud, cum ad jugerum pervene. guerre punique. Deux jugera réunis, du temps de Romulus, formaient un héritage. C'était, diton , la part que Romulus avait affectée à chaque citoyen, comme transmissible à ses héritiers. Dans la suite, cent héritages prirent le nom de centurie. La centurie est une surface carrée, dont chacun des côtés a deux mille quatre cents pieds de longueur. Quatre de ces centuries jointes ensemble, de manière à ce qu'il y en ait deux de chaque côté, s'appellent saltus dans les partages publies des terres.

XI. Il est arrivé souvent que, faute de mesure exacte de la propriété, on a donné aux båtiments plus ou moins d'étendue qu'il ne fallait : deux erreurs très-préjudiciables à la bonne gestion du bien et à son revenu. En effet, lorsque les bâtiments sont plus grands que la terre ne comporte, les frais'de construction et d'entretien sont relativement trop considérables aussi. Quand ils sont trop petits pour la grandeur du fonds, la récolte peut se perdre. Qui doute en effet qu'il ne faille donner plus de développement aux celliers quand on a des vignobles, aux greniers quand on a des terres à grain? Quand vous construirez une métairie, ayez soin de vous ménager une prise d'eau dans son enceinte, ou le plus possible à proximité. Le mieux est d'aroir chez soi la source; sinon, qu'elie ait du moins un cours constant. A défaut d'eau vive, établissez des citernes intérieures, et $d i s$ abreuvoirs à ciel ouvert; les unes pour vos gens, les autres pour votre bétail.

XII. Pour vos constructions, choisissez de préférence le pied d'un coteau boisé, riche en pâturages, et l'exposition la plus saine. La meilleure

runt : id habet scripula ccLxxxvir. quantum as antiquns noster ante bellum Punicum pendebat. Bina jugera quorl a Romulo primum divisa [dicebantur] viritim, qux [quod] hæredem sequerentur, hæredium appellarunt. Hæc postea centum Centuria dicta. Centuria est quadrata in omnes quatuor parles, ut liabeat latera longa pedum $\infty \infty \mathrm{C}$. B. Hae porro quatuor centurixe conjunclæ, ut sint in utram. que partem binæ, appellantur in agris divisis viritim publice saltus.

XI. In modo fundi non animadverso lapsi sunt multi, quort alii villam minus magnam fecerunt quam modus postulavit, alii majorem, cum utrumque sit contra rem faniliarem ac fructum. Majora enim tecta et ardificamus pluris, et tuemur, sumptu majore. Minora cum sunt quan postulat fundus, fructus solent disperire. Dubium enim non est, quin cella vinaria major sit faciunda in eo agro, ubi vineta sunt anıpliora : ut lıorrea, si frumentarius ager est. Villam adificandum potissimun, ut intra septa (villa:) habeat aquam : si non, quam proxime. Primum, qux ibi sit nata ; secundum, qua inlluat pereunis. Si omnino aqua non est viva, cisterne faciunda sub lectis, et lacus sulı dio, ex altero loco ut homines, ex altero ut pecus uti possit.

XII. Dandum operam, ut potissumum sub radicibus montis silvestris villam ponas, ubi pastiones sint lata, ita ut contra ventos, qui saluberrimi in agro fabunt. Quice 
de toutes est le levant d'équinoxc; car oll y a de l'ombre en cté et du soleil en hiver. Etes-vous forcé de bátir au bord d'un fleuve? ouvrez vos jours de l'autre côté, sans quoi les habitations seraient froides pendant l'liver et peu saines pendant l'èté. Il faut éviter avec un soin égal le voisinage des lieux maréeageux : d'abord, parce que les mêmes inconvélients s'y trouvent; et puis, parce que les marais venant à sc dessécher engendrent une multitude d'insectes imperceptibles qui s'introduisent par la bouche et les narines avec l'air que l'on respire, et occasionnent ainsi des maladies graves. Mais, dit Fundanius, si j'hèritais d'une terre dans cette condition, qu'aurais-je à faire pour me préserver de ses malignes influences? A cette question, dit Agrius, la réponse est faeile. Vendre le plus cher, et, si l'on nc trouve acheteur, déguerpir le plus tôt possible. Scrofa contisua en ces termes : II faut encore éviter que la facade ne se trouve dans la direction d'un vent pernicieux; ct ne point bâtir dans le creux d'un vallon. Unc assiette élevée èst préférable, le moindre souffle suffisant pour dissiper les émanations inférieures, s'il y en a. Un bâtiment où le soleil donne tout le jour est dans la condition la plus saine. Il ne craint pas l'invasion des insectes : le vent les emporte, ou la sécheresse les tue. Les iuondations, les débordements sont à craindie pour ceux qui habitent les lieux bas et les gorges profondes. Ajoutez que les voleurs peuvent plus facilement les y surprendre. Double danger, dont on se préserve en se plaçant sur les lieux élevés.

XIII. Dans la distribution des étables, réservez aux bœufs la partie qui est la plus chaude en hiver. Pour les liquides, tels que le vin et l'huile, ayez

josita est arl exortus aequinoctiales, aptissima, quod æes. tate habet umbram, hieme solem. Sin cogare secundum llumen adificare, curandum ne adversuun eum ponas. Hieme enim fiet velıementer frigida, et astate non salubris. Advertendum etiam si qua erunt loca palıstria, et propter easilen causas, et quod arescunt, crescunt animalia quarlam minuta, quæe non possurit oculi consequi, et per ara inlus in corpus per os ac nares perveniunt, atque efficiunt difficiles norbos. Fundanius, Quid potero, inquit, facere, si istiusmodi mi fundus lareditate obvenerit, quo minus pestilentia noceat? istuc vel ego possum respondere, inquit Agrius. Vendas quot assibus possis : aut si wequeas, relinquas. At Scrofa, Vitandum, inquit, ne in eas partes spectet villa, ex quibus ventus gravior afllare soleat; neve in convalli cava. Et ut potius in sublini loco aclifices. Qui quod perflatur, si quod est quod adiersarium inferatur, facilius discutitur. Pruterea, quod ab sole toto die illustratur, salubrior est, quod et bestiolx si qua prope nascuntur aut inferuntur, aut eflantur, aut aritudine cito pereunt. Nimbi repentini, ac torrentes fuvii periculosi illis, qui in lumilibus ac cavis locis aedificia liabent, et repentina pradonum manus, quod improrisos facilius opprimere possunt. Ab lioc utroque superiora luca tuliora. des celliers au niveau du sol. Les vases destinés à les contenir devront également être placés ì ras de terre. Pour les denrcées sèches, tels que les fèves, les lentilles, l’orge et le blé, on établira des espèces de planeher's. Ménagez à vos domestiques un lieu de réunion où, lorsqu’ils soupfrent de la fatigue, de la chaleur, ou du froid, ils puissent se reposer ct se remettre. Logez le villicus près de la porte d'entrée, afin qu'il ait l'œil sur ce qui entre et sort pendant la nuit, hommes et choses. Précaution indispensable, quand il n'y a pas de portier surtout. La cuisine encore devra être placée à proximité de sa surveillance. En temps d'hiver on y vaque à divers soins avant le jour : oll y prépare, on y fait un premier repas..On devra ménager dans la basse-cour des remises spacieuses pour les charrettes et les autr es ustensiles, afin qu'ils soient à couvert de la pluie. En les laissant en plein air, on s'expose à les voir enlever par les voleurs, ou endommager parles injures du temps. Dans les grandes exploitations il est bon d'avoir deux basses-cour's, l'une intérieure, l'autre cxtérieure. Dans la basse-cour intérieure on devira ménager un bassin destiné à reeevoir les eaux pluviales, qui en passant près des stylobates, et coulant sur un plan inclinć, formeront un abreuvoir, où les bœufs, revenant des champs, pourront boire et se baigner pendant l'été, ainsi queles oies, et les por'es lorsqu'ils reviendront des pâturages. Il en faut un également dans la cour extérieure, pour faire tremper les lupins, et autres graines dont l'emploi exige un séjour sous l'eau. Cette cour, étant continuellement jonchée de litière et de pail!e que les bestiaux foulent sous leurs pieds, devient comme une fabrique d'engrais pour les champs. Chaque

XIII. In villa facianda stahula, ita ut bubilia siut ibi, lieme quxe possunt esse caldiora. Fruclibus (lumidis,) ut est vinum et oleum, loco plano potius cellas faciundum, item ubi vasa vinaria et olearia (stent;) aridis ut est faba, lens hordeum far (et triticum) in tabulatis. Familia ubi versetur providendum, si fessi opere, aut frigore, aut calore, et ubi comnodissime possiut se quiete reciperare. Vilici proxime januam cellam esse oportet, eumque scire, qui introeat aut exeat noctu, quidve ferat : prosertim si ostiarius est nemo. In primis culina videnda, ut sit admota, quod ibi hieme antelucanis temiporibus aliquot res conficiuntur, cibus paratur, ac capitur. Faciundum etian plaustris ac exetero instımmento omni, quilsus cælun pluvium inimicum, in colıorte ut satis magna sint tecta. Hæc enim si intra clausum iu conseplo, et sub dio, furem non modo metuunt, sed adversus tempestatem nocentem non resistunt. Cohortes in fundo magno dure aptiores. Una, ut interius complurium habeat lacum, uli aqua saliat, qua intra stylobatas cum venit, sit semipiscina. Boves enim ex arvo aestate reducfi lic bibunt, lic perfunduntur. Nec minus e pahulo cun redierunt auseres, sues, porci. In cohorte exteriore lacum esse oportet, ubi maceretur lupinum, item alia, quae denissa ju aquam ad usum aptiora fiunt. Colors exterior crebro operta stramentis ac 
ferme doit avoir deux fosses à fumier, ou une fosse unique divisée en deux compartinents. I'un des côtés est destiné à recevoir le fumier nouveau que l'on apportera des étables; et c'est dans l'autre que l'on prendra l'ancien fumier, pour le porter dans les champs. Plus le fumier est récent, moins il est bon; et plus il est macéré, meilleur il est pour engraisserles terres. II faudra surtout le garantir du soleil, en l'entourant de tous côtés de branches et de feuillages, afin d'empêcher que le soleil n'en retire le suc, qui est le principe de l'engrais. Aussi les agriculteurs expérimentés ne négligent-ils jamais de mènager l'écoulement des eaux, de facon à entretenir l'humidité dans ces réserves. Il en est même qui y font déposer la vidange des lieux d'aisance. Il faut, en outre, construire un vaste bâtiment, où l'on puisse mettre à couvert toute la récolte. Ce local, qu'on appelle nubilarium, doit être voisin de l'aire où l'on bat le blé. Il doit être d'une dimension proportionnée à l'étendue de la propriété, et ne s'ouvrir que d'un seul côté, qui est celui de l'aire. Le déplacement des gerbes de l'un à l'autre en devient plus facile et plus prompt en tempsde pluie. Les fenêtres du nubilarium devront être percées de manière à laisser l'air $\mathbf{y}$ circuler aisément. Les constructions, dit Fundanius, influent sans contredit beaucoup sur le rapport, quand elles sont conçues suivant l'intelligente simplicité de nos ancêtres, plutôt que suivant les idées de luxe d'aujourd'hui. On travaillait alors en vue del'utile; on ne songe maintenant qu'à satisfaire aux fantaisies les plus extravagantes. Alors le propriétaire avait de grands bátiments de ferme, et se logeait en ville à l'étroit. C'est généralement le contraire aujourd'hui. A cette époque, une métairie était citéc quand elle avait de vastes étables, un bon office, des celliers à vin et à huile proportionnés à la grandeur du fond, avec un plancher incliné venant aboutir à un réservoir; précaution d'autant plus nécessaire, que la fermentation du vin nouveau brisant souvent les tonneaux d'Espagne et même les futailles d'Italie, le vin se trouvait recueilli dans cette espèce de récipient. C'est ainsi que nos ancêtres avaient soin de pourvoir une métairie de tout ce qui répondait aux besoins de la culture. Aujourd'hui, au contraire, on ne vise qu'à rendre l'habitation du maittre aussi vaste et aussi élégante que possible. On rivalise de luxe avec ces villa que les Métellus et les Lucullus ont élevées pour le malheur de la république. De nos jours, le point essentiel est d'exposer au vent frais de l'orient les salles où l'on prend les repas pendant l'été, et au couchant celles où se tiennent les festins pendant l'hiver. $\mathrm{Nul}$ ne songe à donner une exposition convenable aux fenêtres des celliers à vin et à huile, ainsi que le faisaient nos ancêtres ; ce qui est fort important, puisque le vin, renfermé dans les tonneaux, a besoin de fraicheur, tandis que l'huile demande un air plus chaud. Ajoutons qu'une colline est, sauf empêchement, l'emplacement le plus convenable à l'établissement d'une ferme.

XIV. Je vais parler maintenant des clôtures qu'il faut établir pour la sûreté générale ou partielle de l'établissement. Il y en aquatreespèces : la clôture naturelle, la clôture champêtre, la clôture militaire, et enfin la clôture artificielle. Chacune de ces espèces peut se subdiviser en plusieurs autres. La première espèce, faite de haies vives, s'appelle clôture naturelle, parce qu'elle est formée d'épines et de broussailles, ct qu'elle a ra- palea, occulcata pedibus pecudum, fit ministra fundo, ex ea quod cvelıatur. Secundum villam duo liahere oportet sterquilinia , aut unum bifaria $m$ divisum. Alteram enins in partem ferri oportet e villa novum fimum, ex altera veterem tolli il agrum. Quorl enim infertur recens, minus bonum. Id cum flacuit, melius. Necnon sterquilinium meliusillud, cujus latera etsummum virgis ac ftondc vindicatum ab sole. Non enim sucum quem quærit terra, solem antc cxugere oportel. Itaque periti qui possint ut eo aqua influat, eo nonine faciunt. Sic enius maxime retinetur sucus; in eoquc quidam sellas familiaricas pomunt. Ædificium facere oportet, sub quod tectum totam fundi subjicerc possis mcssem, quod rocant quidam nubilarium. Id secundum aream faciundum, ubi triturus sis frumentum, magnitudine pro modo fundi ex una parti apertunı, et id al) area, quo et in trituram proruere facilc possis, et si nubilare copperit, inde ut rursus celeriter rejicere. FenesIras liabere oportet ex ea parti, unde commodissime per. nari possit. Fundanius, Fructuosior, inqquit, est certe fundus propter adificia, si potius ad antiģuorum diligentiam, quam ad lıorum luxuriam dirigas æedificationem. Illi enim faciebant ad fructuum rationem, lii faeiunt ad libidines indomilas. Ilaque illorun villa rusticac eraut unajoris quam urbanæ, quæ nunc sunt pleræque contra. Illic lau. dabatur-villa, si habebat culinam rusticam bonam, præsepias láxas, cellan vinariam et oleariam ad modum agri aptam, et pavimento proclivi in lacum. Quod sæpe, ubi conditum novum vinum, orce ut in Hispania fervore musti ruptæ, nec non dolia ut ill Italia, ne vinum porlueret. Item cælera ut essent in villa hujuscemodi, quæ cultura quæreret, providebant. Nunc contra villam urbanam quam maximam ac politissimam habeant, dant operam : ac cum Metelli ac Luculli villis pessimo publico aedificatis certant. Quo hi laborant, ut spectent sua astiva triclinaria ad frigus orientis, liberna ad solem occidentcm, potius quam, ut antiqui, in quam partem cella vinaria aut olearia fenestras haberet, cum fructus in ea vinarius quærat ad dolia æra frigidiorem, ita olearia caldiorem. [Item videre oportet, si cst collis, nisi quid impedit, ut ibi potissimum ponatur villa.]

XIV. Nunc de septis, qua tutandi causa fundi, aut partis fiant, dicam. Earum tutelarum genera iv. unum naturale, alterum agreste, tertium militare, quartum fabrile. Horum unumquodque species liabet plures. Prinum natu. rale sepimentum viva sepis, quod obseri solet virgultis aut spinis, quod lıabet radices, ac viatoris practereuntis, 
cine en terre. C'cst celle qui redoutc le moins que les passants, par imprudence, n'y mettent le feu. La seconde espèce est faite de bois coupé. On emploie, à cet effet, des pieux que l'on entrelaee de broussailles, ou que l'on perce de deux ou trois trous dans leur épaisseur, pour y faire pas. ser transversalement autant de longues perches. On peut également construirc cette clóture avec des trones d'arbres horizontalement superposés, et assujettis l'un à l'autre. La troisième cspèce, appelée clôture milliaire, consiste en un fossé avec remblais en terrasse. Le fossé, pour avoir les conditions voulues, doit être assez profond pour contenir toutes les eaux des pluies, ou recevoir celles provenant de la propriété. Le remblai ne forme bonne clotture qu'autant qu'il est pratiqué en deça du fossé, ou qu'il s'élève assez haut pour ne pouvoir être aisément franchi. Cette clóture est prineipalement adaptée aux propriétés riveraines d'une grande route, ou de quelque cours d'eau. On peut voir dans les environs de Crustu. mium, non loin de la voie qui conduit aux salines, plus d'un exemple de l'emploi du fossé conjointement avec le remblai, comme préeaution contre les débordements. On appelle murs les remblais sans fossés, qui sont en usage dans la campagne de Réate. La quatrième et dernière espèce, la clóture artificielle, est en maçonnerie, ct de quatre sortes de matériaux : savoir, de pierres de taille, comme à Tusculum; de briques cuites, comme dans la Gaule; de briques crues, comme dans les champs sabins; enfin de bloes composés de terre et de cailloux jetés en moule, comme en Espagne et daus la plaine de Tarente.

XV.A défaut de clôtures, on marque encore les limites d'une propriété par des pieds d'arbres; ce

lascivi non metuit facem ardentem. Secunda sepes est ex agresti ligno, ser uon vivit. Fit ant palis statulis crebris, ac virgultis implicatis; aut latis perforatis, et per ea foramina trajectis longuriis fere binis aut ternis : aut ex arboribus truncis demissis in terram deinceps constitulis. Tertium militare sepimentum est fossa et terreus agger. Sed fossa ita idonea, si omnem aquam, qux e cxlo venit, recipere polest, aut fastigium habet, ut exeat e fundo. Agger is bonus, qui intrinsecus junctus fossa, aut ita arduus, ut eum transcendere non sit facile. Hoc genus sepes fieri secuudun vias publicas solent, et secundum amnes. Ad viam salariam, in agro Crustumino, videre licet locis aliquot conjunctos aggeres cum fossis, ne flumen agris noceat. Aggeres qui faciunt sine fossa, eos quidam vucant muros, it in agro Reatino. Quartum fabrile sepimentum est novissimum, maceria. Hujus fere species quatuor : quod fiunt e lapide, ut in agro Tusculano: quod e lateribus coctilibus, ut in agro gallico : quod e lateribus crudis, ut in agro Sabino : quod ex terra et lapillis compositis in formis, ut in Hispania et agro Tarentino.

XV. Præterea sine septis fines prodii, sationis, notis arborum tutiores fiunt, ne familix rixentur cum vicinis, ac limites ex litibus judicem quarant. Serunt alii circum quiéviteles querelles de volsiuage, et prévient les procès. Quelques-uns plantent des pins tout autour, comme l'a fait ma femme dans une terre qu'clle possède au pays des Sabins. D'autres se servent de cyprès, comme j'ai fait moi-mêmedans une propriété près du Vésuve; d'autres eneore emploient les ormes, comme plus d'un propriétaire de Crustumium. Eten effet, iln'y a pas d'arbre préférable à celui-là dans tout pays de plaines comme celuidont nous venons de parler. Nul n'est plus profitable comme soutien des haies et des vignes, comme abri le plus recherché par le gros bétail et les troupeaux, ct comme pourvoyeur de menu bois pour la haie, l'âtre et le four. Voilà bien, dit Scrofa, mes quatre points principaux d'observation pour les agriculteurs : configuration de la propriété, qualité du sol, dimension, et clóture.

XVI. Il nous restc à considérer ce qui est cn dehors de la propriété; car la propriété est singulièrement intéressée aux conditions d'entourage. Ces conditions sont encore au nombre' de quatre : Le pays est-il sùr? Offre-t-il débouchés et ressources? A-t-on à proximité les voies de communication, routes ou rivières navigables? Eufin y a-t-il avantage à espérer, ou préjudice à craindre du voisinage? D’abord, en ce qui concerne la sûreté, il est tel fonds d'une excellente nature que je ne conseillerais pas d'exploiter, à cause des déprédations auxquelles sa situation l'expose. Il en est plus d'un qui ont cet ineonvénient, près de Célie en Sardaigne, et, en Espagne, sur les confins de la Lusitanie. En ce qui touche au second point, les terres les plus avantageuses sont celles qui offrent le plus de facilités pour la vente de ce qu'elles produisent, et l'acqui-

pinos, ut habet uxor in Sabinis. Alii cupressos, ut ego lıabui in Vesuvio. Alii ulmos, ut multi laabent in Crustumino : quod ubi id pote, ut ibi, quod est campus, nulla potior arbor serunda, quod maxime fructuosa, quod et sustinet sepem, ac colit aliquot corbulas uvarum, et frondem jucundissimam ministrat ovibus ac bubus, ac virgas prabet sepibus et foco ac furno. Scrofa, igitur primum lıæc, quæe dixi, quatuor videnda agricolæ, de fundi forma, terræ natura, de modo agri, de finibus tuendis.

XVI. Relinquitur altera pars, quæe est extra fundum. Cujus appendices vehementer pertinent ad culturam pro. pter a flinitatem. Ejus species totidem : Si vicina regio est infesta. Si quo neque fructus nostros exportare expediat, neque inde quæ opus sunt, apportare. Tertium, si vix aut fluvii qua portentır, aut non sunt, aut idonei non sunt. Quartum, si quid ita est in confinibus fundis, ut nostris agris prosit aut noceat. $\mathrm{E}$ queis quatuor, quod est primum, refert, infesta regio sit necne. Multos enim agros egregios colere non expedit propter latrocinia vicinorum, ut in Sardinia quosdam qui sunt prope Celiem, et in Hispania prope Lusitanianı. Quæ vicinitatis evectos lıabent idoneos, quæ ibi nascuntur ubi vendant, et illinc evectos opportunos ad ea qua in fundo opus sunt, quod 
sition de tout ce qu'exigent les besoins de l'exploitation. Il est des fonds de terre, en effet, où le blé et le vin manquent, et doivent être tirés d'ailleurs. En d'autres, au contraire, on est obligéà trafiquer d'un excédant de ces mêmes denrées. Ainsi, dans le voisinage des villes, on cultive avantageusement dans les jardins les violettes, les roses, et autres fleurs qui sont recherchées sur leurs grands marchés; tandis que le mème genre de culture ne conviendrait point à une fermc éloignée de tout pareil centre de débit. J'ajoute qu'avec la proximité d'une ville, d'un bourg, ou seulement d'une maison de campagne ou terre opulente, où l'on trouve, d'une part, à achetcr à bas prix ce qui manque, et, de l'autre, à placer son superflu, comme échalas, perches, roseaux, un fonds est placé dans une condition plus avantageuse non-seulement que celui où l'on a de grandes distances à franchir, mais que souvent où l'on aurait tout sous la main. Aussi, beaucoup de propriétaires préfèrent-ils louer à l'année, de leurs voisins, les médecins, les foulons et les ouvriers dont ils pourraient avoir besoin, que d'entretenir ces professions en permanence dans leurs domaines. La mort d'un seul ouvrier, dans le premier cas, entraine les plus graves préjudices. Les riches seuls, ex ploitant sur une grande échelle, peuvent se permettre cette complication de leur personnel domestique.

Il se peut cependant que la nécessité en fasse une loi à d'autres que les riches. En cas d'éloignement de toute ville ou bourg, par exemple, il est bon d'avoir des forgerons, ou gens d'autres métiers, à demeure. On évite par là que les domestiques de la ferme ne suspendent leur travail, et ne perdent en allées et venues un temps qui serait mieux employé au profit de l'établissement.

propterea sunt fructuosa. Multi enim labent in prædiis, quibus frumentum aut vinum aliudre quid desit importandum. Contra non pauci, quibus aliquil sit exportandum. Itaque sub urbe colere hortos late expedit, sic violaria, ac rosaria, item multa, quæ urbs recipit, cum eadem in longinquo prædio, ubi non sit quo deferri possit venale, non experiat colere. Item, si ea oppida aut viciniæ aut etiam diritum copiosi agri ac villæ, unde non care emere possis, quæ opus sunt in fundum, quibusque quae supersint venire possint ; ut quibusdam pedamenta, aut pertica, aut arundo; fructuosior sit fundus, quam si longe sint importanda, nonnunquam etiam, quam si colendo in tuo ea parare possis. Itaque in hoc genus coloni notius anniversarios habent vicinos, quibus imperant medicos, fullones, fabros, quam in villa suos habeant : quo. rum nonnunquan unius artificis mors tollit fundi fruclum. Quam partem latifundii divites domesticx copix mandare solent. Si enim ab fundo longins absunt oppida aut vici, fabros parant, quos habeant in rilla : sic cateros necessa. rios artifices, ne de fundo familia ab opere discedat, ac profestis diebus ambulet feriata potius, quan opere faciundo agrum fructuosiorem reddat. Itaque ideo Sasernx
C'est en ce sens que Saserna défend dans son livre que personne ne sorte de la ferme, excepté le villicus ou intendant, ou celui qu'ilaura lui-même désigné. La défense serait encore mieux conçue en ces termes : Nul domestique sans l'ordre du métayer, ni le métayer lui-même sans l'ordre du maitre. Saserna veut de plus qu'aucune absence n'excède un jour de durcee, ou ne se répète plus fréquemment que le service ne l'exige. En troisième lieu, le voisinage de routes praticables pour les voitures, ou de fleuves navigables, augmente beaucoup la valeur d'une terre; car ce sont là, comme on sait, les deux grands moyens de communication. Enfin l'essence même des plantations limitrophes doit encore être prise en considératiou. Si c'est une chenaie, par exemple, qui vous avoisine, vous auriez tort de mettre des oliviers auprès ; car ce bois leur est antipathique au point que vous verriez vos arbres, nonseulement diminuer de produit, mais éviter le contact des chênes, en se rejetant en arrière. C'est ce que fait la vigne, lorsqu'elle se trouvc placée auprès des plantes potagères. Par une propriété semblable à celle des chênes, la présence d'un gros noyer ou d'un certain nombre de plants du même arbre suffit pour frappcr de stérilité tout l'cntourage.

XVII. J'ai traité spéculativement des quatrc conditionsintrinsèques de la culture, et de quatre ordres de considérations extéricures qui s'y rattachent. Je vais parler maintenant de la pratique, où quelques-uns veulent faire la distinction de deux parties, à sivoir les bras qui travaillent, et les instruments sans lesquels ils ne peuvent travailler; ce sont les instruments que d'autres veulent diviser en trois genres, savoir, le genre parlant, qui comprend les esclaves; le genre

liber præcipit, ne quis de fundo exeat præter rilicum promum, et unum, quem vilicus legat. Si quis contra exierit, ne impune abeat. Si abierit, ut in vilicum animadvertatur. Quod potius ita præcipiendum fuit, nequisinjussn vilici exierit, neque vilicus injussu donini longius, quam ut eodem die rediret, neque id crebrius, quam opus esset fundo. Tertio eundem fundum fructuosiorem facinnt veclurx, si vix sunt, qua plaustra agi facile possint : aut flumina propinqua, qua navigari possit. Quibus utrisque rebus evelii atque invehi ad multa pradia scimus. Quarto refert etiam ad fructus, quemadmodum vicinus in confinio consitum agrum haleat. Si enim ad limitem querquetum liabet, non possis recte secundum eam silvam serere oleam, quod usque eo est contrarium natıra, ut arbores non solım minus ferant, sed etiam fugiant, ut introrsum in fundum se reclinent, ut vilis adsita ad olus facere solet. Ut quercus, sic juglandes magnæ et crebræ finitimæ, fundi oran faciunt sterilem.

XVII. De Fundi iv partibus, qux cum solo harent, et alteris iv, qua extra fundum sunt, et ad culturam pertinent, dixi. Nune dicam agri quibus rehus colantur. Quas res alii dividunt in duas partes, in homines et admo- 
à voix inarticulée, qui comprend les bœufs; le genre muet, qui comprend les véhicules. $\mathrm{La}$ culture s'exerce, ou par des esclaves, ou par des lommes libres, ou par un mélange des uns et des autres. Les hommes libres, qui cultivent euxmêmes la terre, sont pour la plupart de pauvres gens, aidés de leur famille, ou des journaliers gui se chargent, moyennant salaire, de travaux, tels que les vendanges et la fenaison. II y a encore une troisième classe de gens employés aux travaux de la terre. Ce sont ceux que nos ancêtres désignaient sous le nom doborarii (travailleurs à forfait), qu'on rencontre en grand nombre en Asie, en Egypte et dans l'Illyrie. J'ai à dire des uns et des autres que, dans les terrains insalubres, il vaut mieux employer des gens à gages; et que, même dans les lieux sains, on fait bien de leur donner encore de préférence les gros ouvrages, tels que la rentrée des vendanges et des moissons. Voici ce que recommande Cassius, à propos de ces manœuvres. Choisissez des sujets propres à la fatigue, au-dessus de vingt-deux abs, et qui montrent des dispositions pour l'agriculture. On juge de leur aptitude par des travaux d'essai, ou en les questionnant sur ce qu'ils faisaient chez leur précédent maitre. Pienez pour les diriger des esclaves qui ne soient ni insolents, ni timides; qui aient une teinture d'instruction, de bonnes manières, de la probité, et qui soient plus âgés queceux qu'ils surveillent : ils en seront mieux écoutés. Cette position, par-dessus tout, exige l'intelligence des travaux rustiques : car l'esclave n'est pas là seulement pour donner des ordres : il doit mettre la main à l'œuvre; montrer par l'exemple ce qu'il faut faire, afin que

nicula lıominum, sine quibus rebus colere non possunt. Alii in tres partes instrumenti genus rocale, et semirocale, et mutum. Vocale, in quo sunt servi. Semivocale, in quo sunt boves. Mutum, in quo sunt plaustra. Onınes agri coluntur hominibus servis aut liberis aut utrisque. Liberis, aut cum ipsi colunt, ut plerique pauperculi cum sua progenie : aut mercenariis, cum conducticiis liberorum operis res majores, nt vindemias, ac fuenisicia administrant : iique quos obxrarios nostri vocitarunt, et etiam nunc sunt in Asia, atque Rgypto, et in Illyrico complures. De quibus universis hoc dico : Graria loca utilius esse mercenariis colere, quam servis, et in salıbribus quoque locis opera rustica majora, ut sunt in conden. dis fructibus vindemix ant messis. De tis cujusmodi esse oporteat, Cassius scribit lıxe : Operarios parandos esse, qiui laborem ferre possint, ne minores annorum $x \times u$, et ad agriculturam dociles. Eam conjecturam fieri posse ex aliarum rerum imperatis, et uno eorum e novitiis requisito, ad priorem dominum quid factitarent. Mancipia esse oportere neque formidolosa, neque animosa. Qui præsint esse oportere, qui literis et aliqua sint humanitate imbuti, frugi, ætate majore, quam operarios, quos dixi. Faciliıs enim his, quam minore natu sunt dicto audientes. Præeterea potissimum eos praesse oportet, qui periti sint rerum rusticarım. Non solum enim debere imperare, ses subordonnés comprennent que ce sont ses talents et son expérience qui le placent au-dessus d'eux. Il ne faut pas permettre au chef d'employer les coups pour se faire obéir, quand il peut arriver au même but par de simples remontrances. Évitez également d'avoir plusieurs esclaves de la même nation; car c'est une source continuelle de querelles domestiques. II est bon de stimuler, par des récompenses, le zèle des chefs; de leur former un pécule, de leur faire prendre des femmes parmi leurs campagnes de servitude. Les enfants qui naissent de ces unions attachent les pères au sol; et c'est par suite de ces mariages que les esclaves d'Épire sont si réputés et se vendent si cher. Quant aux chefs, on fera bien de flatter leur amour-propre, en leur donnant de temps à autre quelque marque de considération. Il est bon également quand un ouvrier se distingue, de le consulter sur la direction des ouvrages. Cette déférence le relève à ses propres yeux, en lui prouvant qu'on fait cas de lui, qu'on le compte pour quelque chose. Stimulez encore son zèle par de meilleurs traitements, une nourriture plus choisie, des vêtements moins grossiers, l'exemption de certains travaux; ou bien encore par la permission de faire paitre à son profit quelques bestiaux sur la propriété da maître. C'est ainsi qu'on tempère l'effet d'un ordre un peu dur, d'une punition un peu sévère, et qu'on leur inspire le bon vouloir, etl'affection que le domestique doit toujours avoir pour son maltre.

XVIII. Pour limiter le personnel d'une exploitation rurale, Caton prend pour base l'étendue et le genre de culture. C'est sur celle des oliviers

sed etiam facere, ut facientem imitentur, et ut animadvertant eun cum causa sibi præesse, quod scientia præstet et usu. Neque illi concedendum ita imperare, ut verberibus coercent potius quam verbis, si modo idem efficere possis. Neque ejusden nationis plures parandos esse. Ex eo enim potissimum solere offensiones domesticas fieri. Præefectos alacriores faciundum præmiis : dandaque opera, ut liabeant peculium, et conjunctas conserras, e quibus liabeaut filios. Eo enim fiunt firmiores, ac conjunctiores fundo. Itaque propter las cognationes Epiroticae familize sunt illustriores ac cariores. Ad injiciendum voluptatem his prafectura, honore aliquo liabendi sunt : et de operariis, qui præstabunt alios, communicandum quoque cum is, quæ faciunda sunt opera. Quod ita cum fit, minus se putant despici, atque aliquo nımero lıaberi a domino. Studiosiores ad opus fieri liberalius traclando, ant cibariis, ant vestitu largiore, aut remissione operis, concessioneve, ut peculiare aliquid in fundo pascere $i \hat{\text { }}$. ceat, aut hujuscemodi rerum aliis, ut quibus quid gravius sit imperatum, aut animadversum, qui consolando eorum restituat voluntatem, ac benevolentiam in dominum.

XVIII. De familia : Cato dirigit ad duas metas, ad certum modum agri, et genus sationis, scribens de olivetis, et vinetis, ut duas formulas. Unam in qua. pracipit fucmodo olivelım agri jugerum Cc.xL instruere oporteat. Li. 
et des ı ignes qu'il raisonne. Mais les deux formules qu'il nous a données sont d'une application génèrale. La première suppose un plant d'oliviers de deux cent quarante jugera, et il porte à treize le nombre des esclaves; à savoir, un villicus tt sa femme, cinq ouviiers, trois bouviers, un ânier, un porcher, un berger. L'autre formule est basée sur un lot de cent jugera de vignes, pour lequel il faut avoir quinze esclaves; savoir,. un villicus et sa femme, dix ouvriers, un bouvier, un ânier, un porcher. En traitant du même sujet, Saserna nous dit dans son livre qu'un seul homme suffit pour labourer liuit jugera de terre en quarante-cinq jours. Car, bien que quatre journées suffisent rigoureusement pour chaque jugerum, l'auteur alloue treize jours de plus pour maladies, mauvais temps, négligence du serviteur, ou excès d'indulgence chez le maître. Licinius prenant alors la parole: Ni l'un ni l'autre de ces auteurs, dit-il, ne s'est montré fort clair dans son systeme. Si Caton a voulu faire entendre (comme cétait sans doute son intention) que l'on doit augmenter ou diminuer le nombre des esclaves en raison de l'étendue de la propriété, il n'aurait dû comprendre, dans cette catégorie, ni le villicus ni sa femme. Et, en effet, dans le cas même où une plantation d'oliviers aurait moins de deux cent quarante jugera, on ne peut toujours avoir moins d'un villicus. Et dans le cas ou l'étendue serait double ou triple de cette mesure, il ne faudrait pas prendre deux ou trois villicus pour cela. C'est donc le nombre des ou vriers, ou simplement bouviers, qu'on augmente ou restreint, suivant l'étendue du fonds de terre. Encore faut-il que tout le terrain soit d'une même nature. S'il est assez inégal , âprc et montagneux pour ne pouvoir être labouré dans toutes ses parties, il s'ensuit naturellement qu'un moindre nom-

cit enim in eo modo hæc mancipia xu lıabenda, vilicum, vilicam, operarios $\nabla$, bubulcos 11 , asinarium 1 , snbulcun 1, opilionem 1. Alteram formulam scribit de vinearum jugeribus centum, ut dicat haberi oportere hæc $\mathrm{xv}$ mancipia, vilicnm, vilicam, operarios $x$, bubulcum, asina. rium, subulcum. Saserna scribit, satis esse ad jugera vu lominen unum : ea debere eum confodere diebus xLv, tametsi quaternis operis singula jugera possit. Sed relinquere se operas xu, valetudini, tempestati, inertıa, indulgentiæ. Licinius, Horum neuter satis dilucide modulos reliquit nobis. Quod Cato si voluit (ut debuit) uti pro portione ad majorem fundum rel minorem adderemus, vel demeremus, extra familiam debuit dicère vilicum et vilicam. Neque enim, si minus ccxu jugera olireti colas, non possis minus uno vilico habere : nec si bis tanto ampliorem fundum aut eo plus colas, ideo duo vilici aut tres habendi fuere. Operarii modo, et bubulci pro portione lemendi, rel addendi, ad minores, majoresve modos fundorum. Hi quoque si similis est ager. Sin est ita dissimilis, ut totus arari non possit, ut si sit confragosus, alque arduus clivis, minus multi opus sunt boves et bre de boufs, et par conséquent de bouviers, devient nécessaire. Je n'insiste pas sur un autre inconvénient du calcul de Caton. C'est qu'il a pris pour ex emple une superficie de deux cent quarante jugera, qui n'est pas unité de mesure. Il eût dû compter par centuric, ou contenance de deux cents jugera. $0 r$, comme pour arriver à ce chiffre il faut retrancher, des deux cent quarante jugera de Caton, quarante, c'est-à-dire le sixième de deux cent quarante, comment s'y prendra-t-on, voulant être conséquent, pour retrancher des treize escla ves la sixième partie? L'embarras ne serait pas moindre à prendre le sixième de onze, chiffre des esclaves, non compris le villicus et sa femme. Veut-on admettre avec Caton que, pour cultiver cent jugera de vignes, il faut un personnel de quinze esclaves? Alors, pour une centurie de terre plantée moitié en vignes, moitié en oliviers, il faudrait avoir deux villicus avec leurs femmes; ce qui serait absurde. Il nous faut donc chercher une autre base pour déterminer proportionnellement le nombre d'inđividus nécessaires. Et Saserna en indique une préférable à celle de Caton, quand il dit qu'il faut pour le labour de chaque jugerum quatre journées du travail d'un homme. Maintenant, nour convenir aux domaines de Saserna, qui étaient situés dans la Gaule, ce chiffre n'est pas nécessairement ap. plicable, comme conséquence, aux terrains montagneux de Ligurie. En résumé, l'on arrive plus facilement à déterminer l'importance, tant du personnel que du matériel, nécessaire à l'exploitation, en portant son attention sur trois choses principales; savoir, la nature des propriètés environnantes; leur étendue; le nombre d'individus employés à leur culture; et enfin les modifications en plus ou en moins que ce nombre peut subir avec avantage. La nature nous a montı́

bubulcl. Nitto illud, quor modum, neque unum nec modicum proposuit ccxL jugerum. Nodicus enim centu. ria, et ea cc jugerum, e quo quum sexta pars sit ea xi, quæ de ccxl demuntur, non video quemadmodum ex ejns præcepto demam sextanı partem (et) de xulı mancipiis : nililo magis, si vilıcum et vilicam removero, quemadmodum ex xı sextam partem demam. Quod autem ait in c jugeribus vinearum opus esse $x \mathbf{x}$ mancipia, si quis lıa. bebit centuriam, quæ sit dimidium vineti, dimidium oliveti, sequetur, ut duo vilicos, et duas vilicas habeat : quod est deridiculum. Quare alia ratione modus manci piorum generatin est animadrertendus, et magis in hoc Saserna probandus, qui ait singula jugera quaternis operis uno operario ad conficiendum satis esse. Sed si hoc in Sasernæ fundo in Gallia satis fuit, non continuo idem in agro Ligustico montano. Itaque de familia magnitudine et reliquo instrumento commodissime scies, quantuh pares, si tria animadverteris diligenter. In vicinitate pra. dia cujusmodi sint, et quanta, el quot quarque lommibus colantur; et quot additis operis aut demtis nelius, aut deterius babeas cultum. Bivium enim nobis ad culturam 
deux voies à suivre pour la culture de la terre; les expériences, et l'imitation. C'est en taltonnant que les premiers agriculteurs ont établi les principes : leurs enfants n'ont guère fait qu'imiter. Nous devons, nous, procéder par les deux voies : imiter d'une part nos prédécesseurs, ct, sur quelques points, essayer d'innover; tout en prenant toujours, non lc hasard, mais le raisonne. ment pour guide. $\mathrm{Si}$, par excmple, nous mus décidons à donner, au second labour de nos vignes, plus ou moins de profondeur que ne font les autres; que ce ne soit jamais par simple caprice. C'est en vue d'un résultat positif qu'ont agi ceux qui les premiers sarclèrent deux fois ou trois fois la terre, ceux qui tentèrent la greffe des figuiers en été, ce qu'on n'avait coutume de faire qu'au printemps.

XIX. En ce qui concerne les instruments dits à voix inarticulée, Saserna prétend que deux attelages de bœufs suffisent pour deux jugera de terre; tandis que Caton exige trois attelages pour un plant d'oliviers de deux cent quarantejugera. De sorte que, si nous en eroyons Saserna, il ne fảut qu'un attelage pour cent jugera; et si nous nous en rapportons à Caton, un attelage ne suffit que pour quatre-vingts. Quant à moi, je pense que ni le ealcul de Caton, ni celui de Saserna, ne s'appliquent universellement à toutes espèces de terre; mais que l'un ou l'autre peut se trouver juste pour quelques fonds de terre en partieulier. Les terrains sont plus ou moins difficiles à labourer. Il en est que les bœufs ne parviennent à ouvrir qu'avec des efforts inouïs, et tels que souvent la charrue se brise, laissant son soc dans le sillon. D'où il suit que tant que la nature du sol à cultiver ne nous est pas parfaitement connue, le plus sûr est de prendre pour règle la coutume du propriétaire qui nous a précédés,

dedit natura, experientiam et imitalionem. Antiquissimi agricolæ tentando pleraque constituerunt, liberi eorum magnam partem imitando. Nos utrumque facere debemus, et imitari alios, et aliter ut faciamus experientia teutare quædam; sequentes ıon alcam, sed rationem aliquam : ut si altius repastinaverimus, aut minus, quam alii, quod momentum ea res habeat. Ut feccrunt ii in saricndo iterum et tertio, et qui insitiones ficulıas ex verno $\mathrm{tcm}$ pore in sestivum contulerunt.

XIX. De reliqua parte instrumenti, quod semivocale appcllatur, Saserna ad jugera cc arvi boum juga duo salis esse scribit; Calo in olivetis ccxu jugerum boves trinos. Ita si Saserna dicit verum, ad centum jugera jugum opus est, si Cato, ad octogena. Sed ego neutrum modum lıorum ad omnem agrum convenire puto, et utrumque ad aliquem. Alia enim terra facilior aut difficilior est. Aliam terram boves proscindere nisi magnis viribus non possunt, et sæe fracta bura relinquunt vomcres in arvo. Quo sequendum uobis in singulis fundis, dum sumus novicii, triplicem regulam, superioris domini institutum, et vicinorum, et experientiam quandam. Quod addit asinos, ou celle des propriétaires voisins; et de ne se per. mettre d'abord que de rares expériences. Catơn dit plus loin que, dans un plan d'oliviers de deux cent quarante jugera, il faut trois ânes pour porter le fumier, et un quatricme pour tourner la mcule. Il ajoute que dans une vigne de cent jugera on a besoin d'un attelage de bœufs, d'un attelage d'ânes, et enfin d'un âne qui tourne la meule. En parlant de ces instruments à voix inarticulée, Caton n'aurait-il pas dû ajouter, tou chant le bétail, qu'il faut cn resteindre le nombre au strict nécessaire, afin de simplifier leservice des instruments qui se suignent eux-mêmes; e'est-à-dire les esclaves. En fait d'espèces, les brcbis sont toujours préférables aux cochons; non pas seulement pour ceux qui ont des prés, mais pour ceux même qui n'en ont pas; car, en élevant des moutons, on ne songe pas seulement à tirer parti de son fourrage, on veut encore se procurer un engrais.

$X X$. Touchant les quadrupèdes, il faut s'assürer en premier lieu des qualités requises pour les bœufs de labour. Ceux qu'on achète àvant qu'ils n'aient travaillé ne doivent pas avoir moins de trois ans, ni plus de quatre. Il les faut robustes et bien appareillés, sans quoi le plus fort, au travail, épuiserait le plus faible; qu'ils soient larges de front, avec les cornes écartées et noires autant que possible, le poitrail large et les cuisses char: nues. Si les animaux ont déjà servi, n'employez pas en pays rudes et montagneux ceux qui n'auraient labouré qu'en pays de plaines, et réeiproquement. Si ce sont de jeunes bœufs n'ayant point encore senti le joug, il faudra leur engager le cou dans des fourches, et ne les laisser manger qu'en cette posture. Quelques jours de cetté pratique les rendront maniables et faciles à dompter. Ensuite on les accoutumera insensiblement

qui stercus vectent, treis, asinum molarium, in villea jugerum c jugum boum, asinoıun jugum, asinum nolarium; in hoc genere semivocalium, adjiciendum de pecore, ea sola, quße agri colendi causa erunt, (ut solent esse pecuaria,) pauca habenda, quo facilius mancipia, qua solent se tueri, et assidua esse possint. In eo numero non modo qui prata habent, nt potius oves quam sues liabeant, curant, sed etiam qui prata non liabent, quia non solum pratorum causa habere debent, sed etiam propter slercus.

XX. Igitur de omnibus quadrupedibus prima est probatio, qui idonei sint hoves, qui arandi causa emunlur, quos rudis, neque minoris trimos, neque majoris qua. drimos paraudum, ut viribus magnis sint ac pares, ne in opere firmior imbecilliorem conficiat : amplis cornibus, et nigris potius quam aliler : ut sint lata fronte, uaribus sinis, lato pectore, crassis coxendicibus. Hos veleranos ex campestribus locis non emeudum in dura ac montana : nec non, ita si incidit ut sit; vitandum. Norellos cum quis emerit juvencos, si eorum colla in furcas destitutas iucluserit, ac dcclerit cibum, diebus paucis erunt man. 
an joug, en attelant toujours un jeune bœuf avec un bœuf déjà rompu au service, dont l'exemp!e l'liabitue d'abord à la soumission. On commencera par les faire marcher sur un sol uni ; sans leur faire encore tirer de charrue; puis on les attellera à une charrue légère, qu'ils ne tireront d'abcrd que dans du sable, ou dans une terre qui cède aisément. Quant aux bœufs destinés aux charrois, on commencera également par les faire tirer d'abord des voitures sans charge, en les conduisant de préférence au milieu des villes ou des bourgs. Ils se familiarisent ainsi avec les bruits et le mou. rement des lieux habités; ce qui est un grand pas de fait pour leur éducation. Lorsqu'on aura commencé par mettre un bouf à la droite, il ne faut point l'y remettre toujours : c'est lui ménager une espèce de repos dans le travail, que de le changer de côté de temps à autre. Dans les contrées où la terre est peu compacte, comme dans les champs de Campanie, on remplace les boufs par des vaches ou des ânes, qu'il sera d'autant plus facile d'accoutumer à tirer une charrue légère. Pour tourner la meule, et pour faire les transports nécessaires dans la propriété même, les uns se servent d'ånons, les autres de vaches; d'autrès encore emploient des mulets, selon que le fourrage est plus ou moins abondant. Il est, par exemple, plus aisé de nourrir un ânon qu'une vache; mais la vache est d'un plus grand rapport. Dans le choix de ses animaux de trait, le cultivateur aura toujours égard à la nature du sol. S'il est montueux et difficile à labourer, il faut des bêtes plus robustes, et dont on puisse tirer autant de travail et plus de profit.

XXI. Il est bon d'avoir des chiens, en petit nombre, et de bonne garde. On les dresse à veiller la nuit et à dormir le jour, renfermés et à la chaíne ; quand ils sont låchés, leur activité en redouble. Voilà tout ce que nous avons à dire des quadrupèdes que l'on ne soumet point au joug; ainsi que des troupeaux. Un propriétaire de prés, qui n'a pas de bestiaux à lui lorsqu'il a vendu ses fourrages; doit se procurer des troupeaux étrangers, pour les faire paitre et parquer dans ses prairies.

XXII. Quant aux instruments dits muets, comme paniers, futailles, etc., voici les principales recommandations que nous avons à faire. En premier lieu, ne rien acheter de ce qu'on peut recueillir ou confectionner sur les lieux ; ce qui comprend toute espèce d'ustensile qui se fabrique en osier, ou dont on a sous la main la matière première ; tels que paniers, corbeilles, traineaux, maillets, râteaux. Il en est de même de tout ce quon fait de chanvre, lin, jone, genêt, feuilles de palmier; comme les câbles, les cordes, et les nattes. Quant aux divers ustensiles qu'on ne peut point tirer de son fonds, il faut, en les achetant, regarder moins à l'apparence qu'ả l'utilité ; car on paye moins cher, et le revenu s'en trouve mieux. Proximité, qualité et bon marché; voilà les conditions essentielles pour les acquisitions de ce genre. Le choix et le nombre des différents instruments est subordonné à l'importance de l'exploitation, et se multiplie en raison de son étendue. C'est ce qui fait sans doute, dit Stolon, que Caton raisonne sur une superficie donnée, quand il dit que celui qui cultive un plant d'oliviers de deux cent quaraute jugera doit avoir, au nombre de cinq, chaque espèce de vases nécessaires à la confection de l'huile, dont il donne ainsi l'énumération: chaudières, pots, vases à trnis anses, etc., le tout en cuivre. En fait d'ustensiles en bois et fer, il veut sueti, et ad domandum proni. Tum ita subigendum, ut minutatim assuefaciant, et ut tironem cum reterano adjungant. Imitando enim facilius domatur. Et primum in æquo loco, et sine aratro, tum eo levi simul gradi faciant, ut principio per arenam aut molliorem terram leniter procedant. Quos ad recturas item instituendum, ut inania primum ducant plaustra, et si possis, per vicum aut oppidum. Creber crepitus, ac rarietas rerum consuetu. dine celerrima ad utilitatem adducit. Neque pertinaciter, quem feceris dexterum, in eo manendum. Quod si alternis fit sinister, fit laboranti in alterutra parte requies. Cbi terra levis, ut in Campania, ibi non bubus gravibus, sed raccis aut asinis quod arant, eo facilius ad aratrum leve adduci possunt. Ad molas, et ad ea, sí quæ sunt, quße in fundo convelıuntur, [in qua re] alii asellis, alii vaccis ac mulis utuntur, exinde ut pabuli facultas est. Nam facilius asellus, quam racca alitur; sed fructuosior lıze. In eo agricole loc spectaudum, quo fastigio sit fundus. In confragoso enim ac difficili hæc valentiora parauduu, et potius ea, quæ plus fructum reddere possint, cum idem operis faciant.

XXI. Canes potius cuin dignitate et acres paucos habendum, quam multos. Quos consuefacias potius noctu VARROX. vigilare, et interdiu clausos dormire catena vincros, ut soluti acriores fiant. De indomitis quadrupedibus, ac pecore [faciundum:] Si prata sunt in fundo, neque pecus dominus habet, danda opera ut pabulo rendito, alienum pecus in suo fundo pascat, ac stabulet.

XXII. De reliquo instrumento muto, in quo sunt corbulæ, et dolia et alia, hæc præcipienda. Quæ nasci in fundo ac fieri a domesticis poterunt, corum ne quid ematur, ut fere sunt, quæ ex riminibus et maleria rustica fiunt, ut corbes, fiscina, tribula, mallei, rastelli. Sic quæ fiunt de cannabi, lino, junco, palma, scirpo, ut funes, restes, tegetes. Quæ e fundo sumi non poterunt, ea si cmpta erunt potius ad utilitatem, yuam ob speciem, simptu fructum non extenuabunt. Eo magis, si inde einpta erunt potissimum, ubi ea et bona, et proxine, et vilissimo emi poterunt. Cujus instrumenti raria discriınina ac multitudo agri maguitudine finitur, quod plura opus sunt, si fines distant late. Ilaque, Stolo inquit, proposita magnitudine fundi, de eo genere Cato scribit. Oliveti jugera CCXı qui coleret, eum instruere ita oportere ut faceret rasa olearia juga $\mathbf{v}$, quæ nembratim enumerat. Ut ex xere alıenea, urceos, nasiternan, item alia. Sic e ligno et ferro, ut plostra majora tria, aratra cum vunie. 
qu'on ait trois grandes charrettes, six charrues avec leurs socs, quatre civières à fumier, etc. Passant ensuiteaux différents instruments de fer seulement, huit fourches, autant de sarcloirs, quatre bêches, etc. Quant au mobilier d'exploitation d'un vignoble, Caton l'a déterminécomme il suit, en calculant sur une superficie de cent jugera: trois pressoirs complets, des futailles garnies de leur couvercle, en nombre suffisant pour contenir huit cents $\mathrm{cul}$ $l e i$; vingt vaisseaux à transporter le raisin pendant les vendanges; vingt autres réservés pour le blè, etc. Si Caton, contrairement à d'autres auteurs, exige un sigrand nombre de cullei, c'est, je crois, pour qu'on ne soit pas forcéde faire argent, chaque année, du produit de ses vignes; car le vin se vend plus cher quand il est vieux, et la même qualité se place avec plus ou moins d'avantage, suivant le cours du moment. Catoll entre ensuite dans de grands détails touchant les quantités et espèces d'instruments de fer, tels que serpes, bêches, râteaux. Il descend même jusqu'aux subdivisions de quelques espèces. Ainsi, sous le nom générique de faux, il distingue différentes sousespèces, dont voici les quantités pour chacune : six serpes à tailler la vigne; cinq à couper les liens des ceps; pareil nombre de serpes à faire du bois; trois à émondage, et dix propres à couper les ronces. Scrofa prenant alors la parole, nous dit : Tout propriétaire devra faire un inventaire détaillé de tout ce mobilier rustique, et en emporter unc copie à la ville. Le villicus, de son côté, aura soin que tous ces ustensiles soient disposés avec ordre, chacun à la placequi lui a été assignée. Il devra surtout avoir autant que possible sous ses yeux tous les objets qu'il ne pourra garder sous clef, notamment ceux d'un usage moius lađbituel; comme les paniers et les vases, dont on n'a be-

ribus sex, crates stercorarias quatuor, item alia. Sic de ferramentis quæ sint et quot opus ad multitudinem, it furcas ferreas octo, sarcula totidem, dimidio minus pa. las, item alia. Item alteram formulam instrumenti fundi vinarii fecit, in qua scribit : Si sit centum jugerum, laabere oportere vasa torcularia instructa tina, dolia cum operculis culleorum octingentorum, acinaria xx, frumentaria Xx. Item ejusmodi alia. Quæ minus multa quidem alii, sed tantum munerum culleorum scripsisse puto, ne cogeretur quotanuis veudere vinum. Vetera enim quam nova, et eadem alio tempore quam alio pluris. Item sic de ferramentorum varietate scribit permulta, et genere, et multitudine qua sint, ut calces, palas, rastros. Sic alia, quorum nonnulla genera species liabent plures, ut falces. Nam dicuntur ab eodem scriptore vineatiche opus esse sex, sirpicula $\mathrm{v}$, silvatic $\mathrm{v}$, arboraria 111 , et ruscaria: $\mathrm{x}$. Hic hac. At Scrofa, instrumentum et supellectilem rusticam omnem oportet liabere scriptam in urbe et rure dominum. Vilicum contra ea ruri onnia certo suo quaeque loco ad villam [debent esse] posita. Qua non possunt esse sub clavi, quam maxime facere ut sint in conspectu oportet. Eo magis ea, qua in rariore sunt usu, ut quibus in vin- soin qu'au temps des vendanges, etc. Car plus les objets sont en vue, moins ils sont exposés aux déprédations des voleurs.

XXIII. Agrasius prit alors la parole, et dit : Vous nous avez parlé jusqu'à présent du fonds de terre en général, et des divers instruments nécessaires à sa culture : de sorte que, des quatre parties de l'agriculture, vous avez épuisé les deux premières. J'attends maintenant la troisième partic. Comme je n'entends par revenu, dit Scrofa, que ce que la terre produit quand elle a été ensemencée, nous n'avons récllement que deux points à examiner; savoir, la qualité de la semence et celle du sol. Telle terre conviendra particulièrement au foin, telle autre au blé; celle-ci à l'olive, celle-là au raisin. Il en est de même de tout ce qui appartient à la dénomination générique de fourrage, comme le basilic, les céréales coupées en vert, la vesce, le sainfoin, le cytise, le lupin. C'est une erreur de croire qu'une terre grasse puisse recevoir indifféremment toute semence, et qu'en une terre maigre on ne puisse rien semer. On fera bien au contraire de choisir une terre maigre pour tout ce qui ne demande pas beaucoup de suc, comme le cytise et les légumes; à l'exception toutefois des pois chiches, qu'il faut cependant considérer comme légume, si l'on comprend sous ce nom tout ce qui se récolte par extraction de la tige, par opposition à ce qui se cueille seulement; car légume vient de legere, cueillir. Dans les terres grasses on pourra semer tout ce qui demande plus de nourriture; comme les racines potagères, le froment, le seigle, le lin. Certaines plantes sont cultivées, non pas tant pour le produit immédiat qu'on en retire, que pour l'amélioration d'une récolte à venir; parce que leurs fanes coupées et laissées sur la terre y servent d'engrais. C'est par cette raison que

demia ntuntur, ut corbulæ, et sic alia. Quæ enim res quotidie videntur, minus netuunt furem.

XXIII. Suscipit Agrasius : Et quoniam labemus illa duo prima ex divisione quadripartita, de fundo, et de instrumento, quo coli solet; de tertia parte expecto. Scrofa : Quonian fructum, inquit, arbitror esse fundi eum, qui ex en satus nascitur utilis ad aliquam rem : duo consideranda restant, quæ, et quo quidque loco maxime expediat serere. Alia enim loca apposita sunt ad foenum, alia ad frumentum, alia ad vinum, alia ad oleum. Sic ad pabulum qua pertinent, in quo est ocimum, farrago, vicia, Medica, cytisum, lupinum. Neque in pingni terra omnia seruntur recte, neque in macra nihil. Rectius enim in tenuiore terra ea quæ non multo indigent suco, ut cytisım et legumina, prater cicer : hoc enim quoque legumen, ut cætera, quæ velluntur e terra, non subsecantur : qua quod ita leguntur, legumina dicla. In pingui rectius, qua cibi sunt majoris, ut holus, triticum, siligo, linum. Quædam etiam serunda non tam propter præsentem fructum, quam in annum prospicientem, quod ibi subsecta atque relicta terram faciunt meliorem. Itaque lupinum cum necdum siliculam cepit, et nonnunquam fabalia, si 
dans une terre trop maigre on emploie, en guise de fumier, des tiges de lupin non encore monté en graine, ou bicn mème celles des fèves, avant que la cosse n'ait atteint le degré de formation où elle est bonne à cueillir. Mettons à part les plantes dont le produit est de pur agrément, et qui peuplent nos jardins et nos parterres, aussi bien que cclles qui, sans contribuer à l'alimentation, sont cependant indispensables à l'économie rurale ; tels que les saules et les roseaux, et autres régétatious qui exigent un sol humide. Certaines plantes se plairont dans un terrain sec; d'autres préféreront des lieux ombragés, comme l'asperge sauvage et l'asperge domestique; d'autres enfin ne devront être semées que dans des lieux exposés au soleil, dont la chaleur est indispensable à leur croissance; telles sont, par exemple, les violettes et les autres plantes des jardins. Mais l'osier, dont on fait des paniers, des claies et. des vans, demande un autre sol et une autre culture. Les bois en coupe réglée, et ceux qu'on laisse croitre pour les chasses, veulent aussi des terroirs et des régimes différents. Il faudra également réserver des endroits convenables au chanvre, au din, au jonc, au sparte, d'où l'on tire les matériaux employés à botteler la paille des bøufs, à faire des ficelles, des cordes et des cábles. D'autres terrains reçoivent indifféremment diverses espèces de plantes. C'est ainsi que nous voyons souvent introduire des plantesde jardin et autres dans les vergers de formation nouvelle, dont les arbres, récemment aligriés, n'ont pas encore eu le temps d'étendre leurs racines; pratique dont on s'abstient soigneusement quand les arbres ont pris du développement, de crainte de leur nuire. Ceci, reprit Stolon, se concilie assez bien avec ce qu'a écrit Caton, à propos des semailles, qu'une teıre grasse, bien fumée, où l'on ne voit aucun arbre, est ce qu'il faut au froment ; 'et qu'un sol ombragé convient anx raves, au raifort, au millet et au panais.

XXIV. Les espèces dolives qui prospèrent en terre grasse et chaude sont, l'olive à confire, le $r a$ dius major de Salente, l'orchis, la posea, la ser. giane, la colminienne et l'albicère (blane de cire). Entre toutes ces variétés, cultivez de préférence celle qui flatte le plus le goût local. L'exposition au vent d'ouest, et en plein soleil, est la plus favorable à cet arbre. Le sol est-il quelque peu froid et maigre? plantez-y l'olive licinienne. Dans un terrain de qualités contraires, cette espèce ne rend jamais l'hostus complet, malgré un luxe de fruits qui l'épuise; et l'arbre est bientôt rongé d'une mousse rougeâtre. L'hostus est ce qui s'exprime d'huile à chaque factus; et l'on appelle factus un tour de pressoir. La contenance d'un fac. tus est, suivant les uns, de cent soixante modius d'huile; d'autres le font descendre à cent vingt seulement, et réduisent en proportion le nombre et la contenance des mesures fractionnaires. Caton conseille plus loin de former un rideau d'ormes et de peupliers autour de son domaine : on en tire des feuilles pour la nourriture des bœufs et brebis, et du bois pour soll usage. Mais nous pensons, quant à nous, que cette prescription n'est rien moins que générale; et que là où elle est uti. lement appliquée, ce n'est pas en vue seulement du feuillage, qu'on se procure par ce moyen. $\mathrm{On}_{3}$ peut d'ailleurs, sansincon vénient, border d'arbres sa propriété du còté du nord ; car, ainsi placés, ils n'interceptent pas les rayons du soleil.Si le terrain est humide, ajouta Stolon, toujours d'après la même autorité, choisissez de préférence les peupliers ad siliquas non ita pervenit ut fabam legere expediat, si ager macrior est, pro stercore inarare solent. Nec minus ea discriminanda in conserundo, quæ sunt fructuosa, propter volıptatem, ut quæ pomaria ac floralia appellantur. Item illa quae ad hominum victum ac sensum delec. tationemque non pertinent, neque ab agri utilitate sunt dijuncta. Idoneus locus eligendus ubi facias salictum et arundinetum, sic alia, quæe humidum locum quærunt. Contra ubi segetes frumentarias, ibi fabam rotissimum seras. Item alia, qua arida loca sequuntur : sic ut um. brosis locis alia seras, ut corrudam, quod ita petit asparagus : et apricis, ut ibi seras violam et loortos facias, quod ea sole nutricantur. Sic alia et alio loco serunda, ut liabeas vimina, unde riendo quid facias, ut sirpeas, vallos, crates. Alio loco ut seras ac colas silvam caduam, alio ubi aucupare. Sic ubi cannabim, linum, juncum, spartum, unde nectas bubus paleas, lineas, restes, funes. Quædam loca eadem alia ad serundun idonea. Nam et in recentibus pomariis desitis seminibus, in or dinemque arbusculis positis primis annis ante quam radices longius procedere possint, alii conserunt hortos, alii quid aliud. Neque cum convaluerunt arbores, idem faciunt, ne violent radices. Stolo ad hæc: Quod ad lıace pettinet, Cato non nale, quod scribit de sationibus, ager crassus et lae. tus, si sit sine arboribus, eum agrum frumentarium fieri oportere. Idem ager si nebulosus sit, rapa, raphanos, miliun, panicum.

XXIV. In agro crasso et calido oleam conditaneam, radium majorem, Sallentinam, orchitem, poseam, sergianam, colminiam, albicerem : quam earum in his locis optimam dicent esse, eam maxime serere. Agrum oliveto conserundo, nisi qui in ventum faronium spectet, et soli ostentus sit, alinm bonum nullum esse. Qui ager frigidior et macrior sit, ibi oleam Licinianam seri oportere. Si in loco crasso aut calido posueris, hostum nequam fieri, et ferendo arborem perire, et muscum rubrum molestuu csse. Hostum rocant, quod ex uno facto olei reficitur. Factum dicunt, quod uno tempore conticiunt. Queın alii CLX aiunt esse modiorum, alii ita minus magnum, ut ar cxx descendat et exinde, ut rasa olearia quot et quanta lıabeant, quibus conficiunt illud. Qnod Cato ait circum fundum ulmos et popnlos, unde frons ovibus et bubus sit, et materies, seri oportere. Sed hoc neque in omnibus fundis opus est, neque in quibus est opus, propter frouldeın maxime. Sine delrimento ponuntur ah septentrionali plagn, quod non officiunt soli. Ille adjicit ab eodem scrip. 
et les roseaux. A cet effet, on retournera la tcrre avee une houe, puis on mettra les boutures de roseaux à trois pieds l'un de l'autre, en les entremelant d'asperges sauvages, qui en produiront de bonnes à manger; car roseaux et asperges exigent à peu près mème culture. On critourcra ces plantations d'osier frane, dont on pourra se servir plus tard pour lier les vignes.

XXV. Ce que doit observer, quant au choix du terrain, celui qui plante de la vigne, le voici : L'exposition la plus clıaude et conséquemment la plus vincuse doit être réservée au petit aminéen, au raisin double dit fortuné, ct au petit raisin gris. Où le terrain est gras et le ciel nébuleux, il faut mettre le gros aminéen, Ic murgantin, l'apicius ct le lucanicn. Les autres espèces, et surtout les raisins noirs, se plaisent indifféremment partout.

XXVI. Les vignerons apportent un soin particulier à placer l'échalas de telle sorte que la vìgne en soit abritéc du cóté du septentrion. Lorsqu'on se sert de cyprès vif cn guise d'échalas, on plante alternativement une rangée de ceps et une rangée de cyprès, cn empéchant toutefois ces derniers de dépasser la hauteur d'un éelualas ordinaire. Il ne faut pas non plus que la vigne soit trop rapprochéo des choux et autres légumes; ce voisinage lui est antipathique. Je crains bien, dit Agrius, se tournant-vers Fundanius, que le gardien du temple ne revienne avant que nous soyons arıivés à la quatrième partie, c'est-à-dire aux vendanges, que j'attends avee impaticnce. Rassurez-vous, dit Scrofa, il va lui-même apprêter les paniers et les urnes.

XXVII. Nous avons deux divisions du temps: l'année, ou la révolution complète du soleil; et le

tore : Si locus humectus sit, ịbi cacumina populorum serunda et arundiuetum. Id prius bipalio verti, ili oculos arundiuis pedes ternos alium ab alio seri, ibi quoque corrudam, unde asparagi fiant; aptam esse utrique eandem fere culturam. Salicein gracam circum arundinetum seri oportere, uti sit, qui vitis alligari possit.

$\mathrm{XXV}$. Vinea, quo in agro serunda sit, sic ubservandum. Qui locus optimus vino sit, et ostentus soli, Aminemm minusculum, et geminum eugeneum, helveolum minus. culım seri oportere. Qui locus crassior sit, aut nebulosus, ibi Amineum majus, aut Murgenlinum, Apicium, Lucaum seri. Cateras rites, et de lis niscellas maxime, in omne genus agri convenire.

XXVI. In omni vinea diligenter observant, ut ridica vitis ab septentrione versus tegatur. Et si cupressos vivas pro ridicis inserunt, alteruos ordines imponunt : neque eas crescere altius, quam ridicas patiuntur; neque propter olus adserunt vites, quod inter se lıec inimica. Agrius Fundanio, vereor, inquit, ne ante aditinus reniat luc, quam hine ad quartum actum accedamus. Vindeniam enim expecto. Bono animo es, inquit Scrofa : fiscinas expediet ac urnam.

XXVIJ. Et quoniam tempora duorum generum sunt, unum annale, quod sol circnito suo finit : alterum nens- mois qui suit celle de la lune. Je parlerai d'abord du cours annuel du soleil. Cet cspace de temps, considéré par rapport aux fruits de la terre, est divisé en quatre parties, chacune à peu près de trois mois; ou, plus exactement encore, en huit, dont chacune est d'ın mois et demi environ. La première division est celle des saisons : le printemps, l'été, l'automne et l'hiver. Le printeinps cst l'époque de certaines semailles, et celle du premier labour donné à la terre, afin d'en extirper toutes les mauvaises herbes avant qu'elles aient jeté leur graine. Le sol, soulevé en glèbe par le labour, devient alors plus accessible à l'action du solcil et des pluies, et plus maniable pour les façons ultérieures. II faut à la terıe deux labours au moins; et trois valent encore mieux. On fera la moisson en été; et c'est en automne, et par un temps bien sec, qu'il faudra faire la vendange et procéder aux coupes des bois. On abat l'arbre à ras de terre; mais il ne faut déterrer la souche qu'après les premières pluies, afin d'empêcher la pousse de nouveaux rejetons. C'est en hiver qu'on fera la taille des arbres, en choisissant toutefois le moment où il n'y a sur lcur écoree ni frimas, ni pluie, ni glaçons.

XXVIII. Le printemps commence lorsque le soleil est dans le Verseau; l'été, lorsqu'il entre dans le Taureau ; l'automne, lorsqu'il passe dans le Lion; et l'hiver, lorsqu'il atteint le Seorpion. Mais comme le premier jour de chaque saison est le $23^{\mathrm{e}}$ de l'entrée successive du soleil dans chaque signe, il s'ensuit que le printemps est de 91 jours; l'été, de 94 ; l'automne, de 91 ; et l'hiver, de 89 . Ce caleul étant mis en rapport avec les divisions de notre année civile, le premier jour

truum, quod luna circumiens comprehendit : prins dicam de sole. Ejus cursus annalis primum fere circiter ternis mensibus ad fructus est divisus in Iv partes, et idem snbtilius sesquimensibus in vu. In quatuor, quod divi. ditur in ver, et æstatem, et autnmnum, et hiemem. Vere sationes qußdam fiunt, terram rudem proscindere oportet, quæ sunt ex ea enata, prius quam ex is quid seminis cadat, ut sint exradicata ; et simul glabas ab sole percalefactas aptiores facere ad accipiundum imbrem, et ad opus faciliores, relaxatas. Neque eam minus bis arandum, ter melius. \&state fieri messes oportere. Autumno siccis tempestatibus vindemias, ac silvas excoli commodissime : tunc præcidi arbores oportere secundum terram. Radices antem prioribus imbribus ut effodiantur, ne quid ex lis nasci possit. Hieme putari arbores duntaxat lis temporibus cum gelu cortices et imbribus careant, et glacie.

XXVIII. Dies primus est veris in Aquario, æestatis in Tauro, autumui in Leone, hiemis in Scorpione. Cum uniuscujusque horum quatuor signorum dies tertins et vicesimus quatuor temporum sit primus; efficitur, ut ver dies liabeat $\mathrm{xcl}$, xestas xcly, autumnus xcl, hiems xclx. Quæ redacla ad dies civiles nostros, qui nunc sunt, primi veni temporis ex a. d. vil Id. Feb. xstivi ex a. d. vin Id. 
du printemps correspondra au $\delta^{\bullet}$ des ides de févijer; le premier de l'été, avec le $8^{\circ}$ des ides de mai; le premier de l'automne, avec le $4^{\mathrm{e}}$ des ides d'août; et le premier de l'hiver, a vec le $5^{\circ}$ des ides de novembre. 11 est plus exact encore de partager l'année entière en huit périodes distinctes. La première, de $\mathbf{4 5}$ jours, commence lorsque le soleil se couche au point d'où s'élève le vent Favonius, et dure jusqu'à l'équinoxe du printemps. La seconde, de 46 jours, dure de l'équinoxe du printemps jusqu'à l'ascension des Pléiades. La troisième, de 48 jours, du lever des Pléiades au solstice; la quatrième, de $\mathbf{2 4}$ jours, du solstice à l'arrivée de la Canicule. La cinquième, de 68 jours, de l'arrivée de la Canicule à l'équinoxe d'automne. La sixic̀me, de 45 jour's, de l'équinoxe d'automne à la disparition des Plćiades. La septième, de 44 jours, de la disparition des Pléiades au solstice d'hiver; et la huitième enfin, de $\mathbf{4 5}$ jours, commençant au solstice d'hiver, et durant jusqu'au temps où le soleil se couche au point d'où s'élève le vent Favonius.

XXIX. La première période est le temps d'établir des pépinières de toute espèce, de tailler la vigne et de la déchausser, de couper les racines qui sortent de terre, d'échardonner les prés, de planter des saussaies, de sarcler lesterres qui sont déjà labourées et ensemencées, et qu'on appelle $s e$ getes, pour les distinguer des arva, qui sont des terres labourées, mais non encore ensemencées. Quant aux terres appelées novales, on comprend sous ce nom toutes celles qui ne sont ensemencées et renouvelées, pour ainsi dire, que tous les deux ans. Remarquons encore que, donner le premier labour, s'exprime par le mot proscindere (fendre), tandis qu'on désigne le second par le mot offringcre (briser), parce que cette dernière facon a pour but de briser la glèbe que la

Naii ; autumnales ex a. d. II Id. Sext.; hiberni ex a. d. Iv Id. Novemb. Subtilius discretis temporibus observanda quxdam sunt, eaque in partes vur dividuntur. Primum a faronio ad xquinoctium vernum dies xLv. Ilinc ad Vergiliarum exortum dies XLVI. Ab loc ad solstitium dies xLVuI. Inde ad Caniculie signum dies xxıv. Dein ad æequinoctium autumnale dies Lxvı. Exin ad Vergiliarum occasum dies xLv. Ab lıoc ad brumam dies xuv. Inde ad favonium dies $\mathbf{x} . \mathrm{V}$.

XXIX. In primo intervallo, inter favonium et rquino. ctium vernum, hæc fieri oportet. Seminaria omne genus ut serantur, putari in primis, circum vites ablaqueari, radices, qux in summa terra sunt, pracidi, prata purgari, salicta seri, segetes sariri. Seges dicitur, quod aratım satum est : arvum, quod aratum, nec dum satum est. Novalis, ubi satum fiit ante quam secunda aratione renovelur. Rursum terram cum primum arant, proscindere appellant; cum iterum, offringere dicunt ; quod prima ara. tione glabæ grandes solent excitari, [cum iteratur, offringere vocant.] Tertio cum arant jacto semine, [bores] lirare dicuntur : id est, cum tabellis additis ad romerem simul première n'aura fait que soulever. On emploie le mot lirare (sillonner) pour désigner l'acte pal lequel on donne le troisième labour, au terrain déjà ensemencé. Cette opération se fait au moyen do deux planches attachées au soc, et disposées de telle sorte que, tout en recouvrant les semences jetćes sur les arrêtes, on creuse en même terrips des sillons qui donnent un écoulement facile aux eaux pluviales. Ceux qui n'ont a cultiver qu'une propriété de médiocre étendue, comme on en trouve beaucoup en Apulie, font d'ordinaire passer la herse sur leurs terres, afin de micux atteindre les mottes qui pourraient être restées sur les arêtes. La trace profonde que laisse en terre le soc de la charrue s'appelle sulcus (sillon), et la saillie qui se forme entre deux sillons s'appelle porca (arète), de porricere (mettre à distance, élevé), parce que la semence se trouve pour ainsi dire exhaussée au-dessus du sol. C'est encore dans le même sens qu'on se sert du mot porricere pour signifier l'action d'offrir aux dieux les entrailles des victimes.

XXX. Dans la seconde période, comprise entre l'équinoxe de printemps et le lever des Pléiades, on vaquera aux travaux que voici : sarcler les terres labourées, ou leur donner le premicr labour; couper les saules et enclore les prés; mettre la dernière main à ce qui resterait imparfait des travaux de la période précédente; planter les arbres avant la germination et la floraison; car tout arbre qui ne garde ses feuilles qu'une partie de l'année n'est plus propre à être planté, lorsqu'il en a pris de nouvelles. Il y a encore le travail de plantation et de taille des oli. viers.

XXXI. Durant la troisième période, comprise entre le lever des Pléiades et le solstice, on devia bêcher ou labourer les jeunes vignes, et les

et satum frumentum operiunt in porcis, et sulcant fossas, quo pluvia aqua delabatur. Nonnulli postea, qui segetes non tam latas habent (ut in Appulia) id genus praedii per saritores occare solent, si quæe in porcis relictx grandiores sunt glæbæ. Qua aratrum vomere lacunam striam facit, sulcus vocatur. Quod est inter duos sulcos, elata terra, dicitur porca, quod ea seges frumentum porricit. Sic quoque exta deis cum dabant, porricere dicebant.

XXX. Secundo intervallo inter vernum aquinoctium, et Vergiliarum exortum lıac fieri debent. Segetes runcari, boves terram proscindere, salicem cacli, prata defendi. Quæ superiore tempore fieri oporfuerit, et non suut absoluta; ante quam gemmas agant ac llorescere incipiant, seri. Quod si, quse folia mittere soleut, ante frondem florere inceperint, statim ad sereudum idonex non sunt. Oleam seri interputarique oportet.

XXXI. Tertio intervallo, inter Vergiliarum exortum et solstitium, lıæe fieri debent. Vineas novellas fodere, aut arare, et postea occare, id est comminuere, ne sit glaba. Quod ita occidunt, occare dictum. Vites pampinari, sed a sciente. Nam id quam putare majus; neque in arbusto, 
Lerser; c'est-à-dire briser les mottes saus en laisser une seule. On désigne cette dernière opération par le mot occare, dérivé lui-même d'occidere (détruire); eomme pour faire entendre qu'on anéantit les mottes de terre. C'est encore le momeut d'épamprer les vignes, soin qu'il ne faut confier qu'à des mains intelligentes; ear cette općration, exclusivement propre à la vigne, est d'une plus grande importance encore que celle de la taille des arbres à fruits. Épamprer c'est ne laisser sur un sarment que les deux ou même les trois premiers brins que vous aurez reconnus comme les plus forts, et retrancher tous les autres, de crainte que le cep ne soit pas en état de fournir a tous une nourriture suffisante. C'est dans cette vue qu'on eommence par couper les pieds de vigne au moment où ils sortent de terre, afin qu'à la seconde pousse on ait un sarment plus vigoureux, et qui donne des bourgeons micux nourris. Quand le cep sort de terre mince et effilé comme un jonc, cette faiblesse le rend impuissant à pousser des rameaux productifs; on l'appelle ạlors flagellum. Mais le cep vigoureux, et qui promet des grappes, s'appelle palma. Flagellum vieut de flutus (souffle), en changeant une lettre; mot qui signifie objet de peu de consistance. Le palma (cep à porter fruit) tire son nom probablement du mot parilema, dérivé de parire (pro. duire), dont, par une suppression de lettre assez commune dans notre langue, on aura fait palma.

Il y a aussi les pousses appelées capreoli (vrilles de la vigne), espèce de filament en forme de spirale, ou de boucles de cheveux. Cette végé. tation de la vigne s'euroule comme autant de serpents antour de ce qui croît près d'elle; d'où le nom de capreoli, dont la racine est capere, prendre.

Toute espece de fourrage, basilic des champs (ocimum), dragée, vesce, etc., se coupeà la même ćpoque. Le foin proprement dit se fauche en der.

sed in vinea fieri. Pampinare est ex sarmento coles qui nati sunt, de iis, qui plurimun valent, primum ac se. cundum, nonnunquam eliam tertium relinquere, reliquos deeerpere, ne relictis colibus sarmentum nequeat miuisIrare sucum. Ideo in vitiario primitus, eum exil vitis, tota resecari solet, ut firmiore sarnento e terra exeat, atque in pariendis colibus vires lıabeat majores. Ejuneidum enim sarmentum propter infirmitaten sterile, neque $\mathrm{ex}$ se potest ejicere vitem. Quam vocaut minorem flagellum, majorem etiam unde uvæe nascuntur, palmam. Prior, litera uна uи. tata, derlinata a ventiflatu, siniliter flabellum ac flagellunt. posterior quo ea vitis immittitur ad u vas pariuudas, dicta mimo videtur a pariendo parilema : exin mutatis literis, ut in multis, dici copta palua. Ex altera parte parit ca. preolum. Is est coliculus viteus intortus, ut ciucinaus. Is enim vites ut teneat, serpit ad locuu capiundım. Ex quo a capiendo capreolus dictus. Omue pabulum, prinuun ocimuı, farragineu, viciam, novissime fenum secari. Ocinun tictun a gracto verbo $\dot{w} \times \mathrm{s} s$, quod venit cito. Si- nier. Ocimum vient du grec ùxuc (hatif). Son lomonyme des jardins a la même propriété. Ce nom vient peut-être aussi de ce que cette plante láche le ventre aux bœufs, à qui on en donne, comme purgation, par ce motif. C'est une espèce de fève que l'on récolte en vert, avant que la cosse ne soit formée. Le farrago (dragée) est un mélange d'orge, de vesce et autres plantes légumineuses, qui se sème à la fois, et se coupe également en vert pour nourrir les bestiaux. Le nom de ferrago lui vient, ou de l'instrument de fer avee lequel on le coupe, ou de ce que, primitivement, c'était les terres, ayant produit du blé (farracice segetes ); qu'on choisissait pour cette culture. Ce mélange se donne, au printemps, aux chevaux et bêtes de sommc. II commence par les purger, et ensuite il les engraisse. Vicia (la vesce) tire son nom de vincere (lier), parce que cette plante a, comme la vigne, des vrilles (capreoli) avec lesquelles elle s'accroche aux tiges des lupins ou autres plantes voisines, qu'elle enveloppe de ses étreintes. Si vos prairies sont arrosables, il faudra procéder à leur irrigation aussitôt que vous en aurez enlevé le foin. Ne manquez pas, surtout en temps de sécheresse, d'arroser chaque soir les arbxes fruitiers, dont le nom poma vient probablement de leur besoin continuel de boire (potare, potus.)

XXXII. La plupart des cultivateurs font la moisson pendant la quatrième période, du solstice d'été à la canicule; parce qu'ils prétendent que le blé, pour acquérir la consistance de la maturité, doit rester quinze jours dans sa balle, quinze jours en lleur, et quinze jours en graine. C'est aussi le moment d'acliever ec qui reste de labours à faire, et qui sont alors d'autant plus profitables que la terre est plus échaufféc. Un premier labour étant donné à la terre, faites $y$ repasser la charrue, afin d'écraser les mottes que le premier n'aura fait que soulever. C'est en-

militer quo ocimum in horto. Hoc amplius dictum oeinum, quod citat alvum bubus, et ideo is datur ut purgentur. Id ex fabuli segete viride sectum ante quam genat siliquas. Contra, ex segete, ubi sata admixta ordeım et vieia et legumina pabuli causa, viridia quod ferro cæsa, ferrago dicta, aut nisi quod primum in farracia segete seri cueptum. Ea equi et jumenta cætera verno tempore purgautur, ac saginantur. Vicia dieta a vineiendo, quod item capreolos habet ut vitis, quibuscum sursum vorsum serpit ad scapum lupini, aliumve quem, ut hareat, id solet vincire. Si prata irrigua liabebis, simulac foenum sustıleris, irrigare. In poma, quæ insita erunt, siccitatibus aquam addi quotidie vesperi. A quo, quod indigent potı, pona dieta esse possunt.

XXXII. Quarto intervallo inter solstitium et caniculam plerique messem faciunt, quod frumentum dicunt quiu. decim diebus esse in vaginis, quindeeim florere, quiude. cin exarescere, cum sit nuaturun. Arationes absolvi, quæe co fruetuosiores fiuut, quo calidiore terra aratur. Cuu 
core l'époque des semailles pour la vesce, les lentilles, les pois chiches, la cicerole, et autres plantes comprises sous le nom générique, soit de legumina, soit de legaria (qu'on leur donne dans quelques contrées de la Gaule). Ces deux mots ont une origine commune, legere (cueillir), parce qu'en récoltant on cueille au lieu de couper. Restet-il encore des mottes dans vos vignes, après le second labour? passez-y la herse deux fois, si le plant est vieux; trois fois, s'il est nouveau.

XXXIII. Pendant la cinquième période, e'està-dire depuis la canicule jusqu'à l'équinoxe d'automne, il faut couper la paille, la botteler, achever les labours, émonder les arbres, et faire la seconde coupe des prairies arrosables.

XXXIV. Dès le commencement de la sixième période, c'est-à-dire, à partir de l'équinoxe d'automne, il faut (suivant nos auteurs) procéder aux semailles, y consacrer les quatre-vingt-onze jours qui suivent, et ne semer, une fois venu le solstice d'hiver, que dans le cas de nécessité absolue. L'ob. servation est importante; car ce qu'on sème avant lève en sept jours, et tout ce qui se sème après se montre à peine au bout de quarante. Il ne faut cependant pas, d'après les mêmes auteurs, semer avant l'équinoxe, parce que la semence est exposée à pourrir, si le temps devient contraire. L'époque du coucher des Pléiades doit être choisie pour semer la fève; mais c'est entre l'équinoxe d'automne et le coucher des Pléiades qu'il faut cueillir le raisin et faire les vendanges. Immédiatement après, on commence à tailler la vigne, à provigner, et à plauter les arbres à fruit. Dans les contrées où le froid se fait sentir de bonne heure, il vaut mieux ajourner ces travaux au printemps de l'autre année.

XXXV. Pendant la septième période, c'est-à-

proscideris, offringi oportet, id est iterare, ut frangantur glsebre. Prima enim aratione grandes globe ex terra scin. duntur. Serendum viciam, lentem, cicerculam, erviliam, cæeteraque, quæ alii legumina, alii (ut Gallicani quidam) legaria appellant, utraque dicta a legendo, quod ea non secantur, sed vellendo leguntur. Viueas veteres iterun occare, novellas etian tertio, si sunt etiam tum glæbb.

XXXIII. Quinto intervallo inter caniculam et aquinoctium autumnale oportet stramenta desecari, et acervos construi, a ratro ofringi , frondem credi, prata irrigua iterum secari.

XXXIV. Sexto intervallo ab æquinoctio autınnali incipere (scribunt) oportere serere, usque ad diem xcı post brumam, nisi qua necessaria causa coegerit, non serere : quod tantum intersit, ut ante brumam sata septimo die; quæ a bruma sata, xL die xix existant. Neque ante æquinoctium incipi oportere putant, quod si minus idonere tempestates sint consecuta, putescere semina soleant. Fabam optime seri in Vergiliarum occasu. Uvas autem legere et Vindensian facere inter apuinoctium autumnale et vcrgiliarum occasum. Dein vites putare incipere, et propagare, et serere poma. Harc alirjut regionibus, ubi dire depuis le coucher des Pléiades jusqu'ausolsticed'hiver, il faut (toujours d'après les mêmes autorités) planter les lis et le safran. Pour faire un plant de rosiers, on choisit des pieds qui aient déja pris racine; on en fend la tige, dans sa longueur, en brins d'une palme environ, qu'on couvre de terre, et qu'on transplante après, lorsqu'ils ont pris racineà leur tour. $Q$ uant au $x$ violettes, leur culture a le grave inconvénient d'exiger des planches surélevées. A cet effet, on ramasse la terre à l'elltour. Or, cette terre est entralnée et balayée par les arrosements ou les pluies, et le sol de la propriété s'appauvrit d'autant. Quand le soleil s'est couché au point de l'horizon d'où s'élève Favonius, c'est lé temps, jusqu'au lever de l'Arcture, de transplan. ter le serpolet venu de graine. Cette herbe doit son nom à ses habitudes rampantes (quod serpit). On peut encore creuser de nouveaux fossés, nettoyer les anciens, tailler la vigne et les arbres auxquels elle est mariée; mais il faut suspendre tout travail durant les quinze jours qui précèdent et les quinze jours qui suivent le solstice d'hiver. Certains arbres cependant, les ormes, par exemple, peuvent encore être plantés dans cet intervalle.

XXXVI. Dans la huitième période, c'est-à-dire depuis le solstice d'hiver jusqu'au lever du Favonius, il faut faire écouler du sol les eaux qui y séjournent, et le sarcler, sl la saison a été sèche et que la terie soit friable. Il faut encore tailler les vignes et les arbres fruitiers; et quand on ne peut plus travailler aux champs, ex pédier, au logis, tout ce qui peut se faire sous un toit pendant les veillées d'hiver. Toutes ces règles doivent être consignées par écrit, et la copie doit en être placée en vue dans la ferme, afin que tous, et notamment le villicus, puissent bien s'en pénétrer.

XXXVII. Les jours lunaires doivent encore

maturius frigora fiunt asperiora, melius verno tempore.

XXXV. Septimo intervallu inter Vergiliarum occasım, et brumam, hæc fieri oportere [dicunt.] Serere lilium, et crocum; quod jam egit radicem, rosetum conciditur radicitus in virgulas palmares, et obruitur. Ilæec eadem postea transfertur facta viviradix. Violaria in fundo facere non est utile, ideo quod uecesse est terra adruenda pulvinos fieri, quos irrigationes, et plnvia tempestates abluunt, et agrum faciunt macriorem. Ab favonio usque ad Arcturi exortum recte serpullum e seminario transferri : quod dictum ab eo quod serpit. Fossas novas fodere, reteres tergere, vineas arbustumque putare, dum in $\mathrm{xv}$ die. bus ante et post brumam ut pleraque ne facias : nec non tum aliquid recte seritur, ut ulmi.

XXXVI. Octaro intervallo inter brumam et favonium hæc fieri oportet. De segetibus, si qua est aqua, deduci : sin siccitates sunt, et terra teneritudinem liabel, sarire. Vineas, arbustaque pulare. Cum in agris opus fieri non potest, qua sub tecto possunt, tunc conficienla antelıcano tempore hiberno. Qua dixi, scripta, et proposita ha. bere in villa oportet, maxime ut vilicus norit.

XXXVII. Dies luuat es quı pue ohservindi, quui quodaun: 
être l'objet d'une attention toute spéciale. Ils se partagent ell dcux sćries : l'une, où la lune nouvellc va toujours croissant jusqu'à ce qu'elle soit pleine; et l'autre, où elle décroît successivement jusqu'au jour intermédiairc de l'ancienne et nouvelle lune. Cejour, dernier d'une lunaison et premier d'uncau-

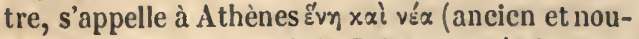

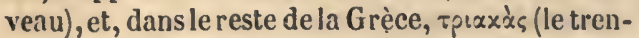
tième). Il y a des travaux qu'il vaut mieux faire pendant la croissance de la lune que sur son déclin, et réciproquement. La moisson des blés par exemple, et les coupes de bois, sont dans cette dernière catégorie. Pour moi, dit Agrasius, je tiens de mon père, et j'ai pour principe de ne jamais faire tondre mes brebis quand la lune décroît. Jene me fcrais pas même couper les cheveux, de peur de devenir chauve. Qu'est-ce, demanda Agrius, que les quartiers de la lune, et quelle est leur influence relative sur l'agriculture? Comment, dit Tremellius, n'avez-vous donc jamais entendu parler à la campagne dutroisième jour avant que la lune ne croisse, et du huitième avant qu'elle ne décline? Et ne savez-vous pas qu'en fait des travaux qui ne sc font qu'en croissance il en est qu'il vaut micux entreprendre avant qu'après ce luuitième jour ? et qu'en fait de travaux à faire en décroissance, le moment qu'il faut choisir est celui où l'astre jette le moins de lumière? C'est là tout ce que je puis vous dire touchant les quartiers de la lune, et leur influence sur les travaux rustiques. On pourrait, dit Stolon, diviser encore l'année en six partics, en faisant acception à la fois du cours de la lume ct de celui du soleil. En effet, tous les biens de la terre passent successivement par cinq pluases, dont la dernière est leur entrée dans le modius ou la futaille, en état de maturité. Ils en sortent ensuite pour les besoins de la vie. C'est la sixième et dernièrc de leurs phascs, dont

modo biparliti. Quod a nova luna crescit ad plenam, et inde rursus ad novam lunam decrescit, quoad reniat ad intermenstrumm, quo die dicitur luna esse extrema et prima; a quo euın diem Atlıenis appellant Ěvf, $x \alpha i$ vé $\alpha$,

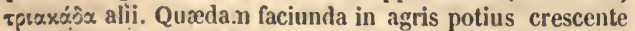
luma quan senescente. Quzedam contra, qux metas, ut frumenta, et codıam silvam. Ego ista etian, inquit Agra. silus, toon solum in ovilus tondendis, sed in meo capillo a patre acceptum servo, ut decrescente luna tondens calvus fiam. Agrius : Quemadmodum, inquit, luna quadripartita? et quid ea divisio ad agros pollet? Tremellius : Nunquam rure audisti, inquit, octavo Janam [lunam] et crescentem, et contra senescentem ; et qua crescente luna fieri oporteret, [et] tamen quædam melius fieri post octavo Janam [lunam,] quanı ante? et si qux senescente fieri conveniret, melius quanto minns baberet ignis id astrum? Dixi de quadripartita forma culturæ agri. Stolo: Est alte. ra, inquit, teniporum divisio conjuncta quodammodo cum sole et luna, qua in sex partita, quod oinnis fere fructus quinto denique gradu pervenit ad perfectum, ac videt in villa dolium ac modium; unde sexto prodit ad usum. voici l'énumération : savoir première pliase, préparation; deuxième phase, ensemencement ou plantation ; troisième, nutrition; quatrième, récolte; cinquième, emmagasinement; sixième, consommation.

Les soins de préparation varient suivant l'espèce de culture : creuser des fosses, biner, aliguer, vollà pour les vignobles ou le verger; labourer, bècher, voilà pour les céréales et plantes potagères. Certains arbres veulent que le terrain soit remué plus ou moins profondément avec le hoyau, suivant le plus ou le moins d'extension de leurs racines. Celles du cyprès, par exemple, en ont fort peu; tandis que les racines d'un platane sont susceptibles d'un développement extraordinaire. C'est au point qu'au dire de Théophraste, on voyait à Athènes, dans le Lycée, un platane encore jeunc, dont les racines n'avaient pas en longueur moins de trente-trois coudées. Telle culture exige un double labour à la charrue, avant que la semence ne soit confiée à la terre. Quant aux prairies, il ne leur faut aucun travail préparatoire, si ce n'est d'en fermer l'entrée aux bestiaux dès que le poirier est en fleur, et dc les arroser en temps opportun, quand on a des moyens d'irrigation.

XXXVIII. Examinons maintenant comment il faut engraisser les champs, et quelle espèce de fumier est préférable. Cette distinction n'est rien moins qu'indifférente. Suivant Cassius, il n'y a pas de meilleur engrais que la fiente des volatiles en général, les oiseaux aquatiques exceptés. Mais celle des pigeons a la supériorité, à cause de cette chaleur qui lui est propre, et qui excite puissamment la fermentation dans la terre. Il faut l'éparpiller dans les champs comme de la graine, et non l'y mettre en tas comme le fumier des bestiaux. Quant à moi, je pense que la fiente provenant des volières de grives et de merles mé-

Primo præparandum, secundo serendum, tertio nutricandum, quarto legendum, quinto condendum, sexto promendum. Ad alia in praparando faciendi scrobes, aut repastinandum, aut sulcandum, ut si arbustum aut pomarium facere velis. Ad alia arandum, aut fodiendum, ut si segetes instituas. Ad quædam bipalio vertenda terra, plus aut minus. Alix eniın radices angustius diffundunt, it cupressi, aline latius, ut platani, usque eo, ut Theophrastus scribat, Athenis in Lycreo, cum etiam tunc jlatanus novella esset, radices trium et triginta cubitorum cyisse. Quaedam si bubus et aratro proscideris, et iterandum ante, quam semen jactes. Item praparatio si qua fit in pratis, id est, ut defendantur a pastione, quod fere observant a piro florente : si irrigua sunt, ut tempestive irrigentur.

XXXVIII. Quæ loca in agro stercoranda videndum, et qui, et quo genere potissimum facias : nam discrimina ejus aliquot. Stercus optimum scribit esse Cassius volucrium, praterpalustrium ac nantium. Delisce prastarecolumbiuum, quod sit calidissimum, ac fermentare possit terram. Id ut semen aspergi oportere in agro, non ut de pe- 
rite la préférence, parce qu'elle forme non-seulement un bon cngrais pour les terres, mais eneore une nourriture pour les bœufs et les coehons, qu'elle rend plus gras. Aussi les prix de baux de ces volières sont-ils moins élevés quand le propriétaire s'en réserve les ordures. Cassius place comme fumier après la fiente des pigeons, les excréments humains; et, en troisième ligne, ceux des chèvres, brebis ct anes. Le fumier de cleval est moins bon pour la culture des céréales, tandis qu'il convient parfaitement aux prairies; comme en général tout fumier provenant de la litière des bêtes de somme; car l'orge dont on les nourrit active singulièrement la pousse de l'herbe. Pour ménager les bras, la fosse à fumier doit être à proximité de la ferme. Voulez-vous empêcher que les serpents n'y pullulent? enfoncez au milieu un morceau de bois de chêne.

XXXIX. Pour la seeonde phase (ensemencement ou plantation), tout dépend de saisir le moment propice. Autant que l'expusition des lieux, il importe d'observer la saison favorable à la semence ou plant qu'on va confier à la terre. Ne voyons-nous pas en effet telle plante fleurir au printemps, et telle autre en été ? ce ne sont pas les mêmes non plus qui fleurissent en automne et en hiver. On les sème, greffe et récolte plus tôt ou plus tard, suivant leur nature. En général, le printemps, pour greffer, est préférable à l'automne; ce qui n'empêche pas d'attendre le solstice pour le figuier, et même les jours d'hiver pour le cerisier.

Les végétaux se propagent de quatre manières diffërentes : savoir, par la voie de nature d'abord; en second lieu, par moyens artificiels, tels que trausplantation d'une raeine toute formée d'un ter-

core acervatim poni. Ego arbitror proeslare ex aviariis tırdorum ac merularum, quod non solum ad agrum utile, sed etian ad cibum ita bubus ac subus, ut fiant pingues. Itarque qui ariaria conducunt, si caveat dominus, stercus ut in fundo maneat, minoris conducunt quam ii, quibus id accedit. Cassius secundum columbinum scribit esse hominis. Tertio caprinum, et ovillum, et asininum. Minime bonum equinum, sed in segetes. In prata enim vel optimum ut cxterarum veterinarum, quæ ordeo pascuntur, quod multam facit herbam. Sterquilinium secun. dum villam facere oportet, ut quam paucissimis operis egeratur. In eo si in medio robusta aliqua materia sit depacta, negant serpentem nasci.

XXXIX. Sationis autem gradus secundus hanc labet naturam, ad quod tempus cujusque seminis apta sit ad serendum. Nam refert in agro ad quam partem cxli quisque locus spectet, sic ad quod quaque tempus res facilline crescat. Nome videnus alia florere verno tempore, alia astivo : neque eadem autumnali, qux hilierno? Itaque alia seruntur, atque inseruntur, et metuntur ante, ant post, quam alia, et cum pleraque vere melius, quam antumno inserantur, circiter solstitium inseri ficos, nec non brumalibus diebus cerasos. Quare cum semina fere gquatuor siut generun, qua per se fiunt a natura, alia ex industria, qua transferuntur e terra in terram, ut faciunt rain dans un autre; enfouissement par un bout d'un rameau détaché d'une plante, et qui devient plante lui-même; enfin, insertion sur un arbre d'une branche empruntée à un autre arbre. Examinons maintenant les conditions de lieux et de temps qu'exige chaeune de ces opérations.

XL. La semencc, principe de toute végétation, est ou visible ou invisible. Elle est invisible lors. qu'elle est répandue dans l'air, comme le prétend le physicien Anaxagore; et apportée sur les champs par la pluie qui tombe, suivant l'opinion de Théophraste. Les semences visibles méritent la plus grande attention du cultivateur. Il en est de tellement menues que l'œil ne peut les saisir; celles de cyprès, par exemple. Car les noix rondes comme des balles, à écorce minee, que produit cet arbre, ne sont pas sa semence; elles n'cn sont que l'enveloppe. La nature nous a donné les germes; c'est à l'expérience à faire le reste. Il est une végétation spontanée qui naît sans que personne s'en mêle; et une production artificielle procédant de la première, et -qu'il faut Ia main de l'homme pour féconder. Quand on emploie la semence naturelle, il faut prendre garde qu'elle soit passée ou mélangée, et surtout ne pas prendre par ressemblance une graine pour une autre. L'action du temps sur certaines semences va jusqu'à en changer la nature. Ainsila graine de chou produit des raves, et celle des raves des choux, si l'on a laissé vieillir l'une etl'autre. Quant au second mode de propager les plantes au moyen de racines toutes formées, ayez soin que la transplantation ne s'opère ni trop tôt ni trop tard. Les époques favorables, selonThéophraste, sont le printemps, l'automne, et le lever de la $\mathrm{Ca}$ -

riviradices; quæ ex arboribus dempta demittuntur in humum; quæ inseruntur ex arboribus in arbores; de singulis rebus videndum, qux quoque tempore locoque facias.

XL. Primum semen quod est principium genendi, id duplex; unum, quod latet nostrum sensum; alterum, quod apertum. Latet, si sunt semina in aere, ut ait plyysicus Anaxagoras; et si aqua quae influit in agrum inferre solet, ut scribit Theoplurastus. Illud quod apparet ad agricolas, id videndum diligenter. Quædam enim ad cernen. dum usque adeo parva, ut sint obscura, ut cupressi. Non enim galbuli, qui nascuntur, id est tanquam pila parvæ corticiæ id semen; sed in is intus. Primigenia semina dedit natura, reliqua invenit experientia coloni. Nam prima, quæ sine colono, priusquam sata, nata; secunda, qux ex is collecta, neque priusquam sata nata. Prima semina videre oportet, ne vetustate sint exsucta, ant ne sint admixta aut ne propter similitudiuem sint adulterina. Semen velus tantum valet in quibusdam rebus, ut naturan commutet. Nam ex semine brassica vetere sato nasci aiunt rapa, et contra ex raporum brassicam. Secunda seinina videre oportet, ne unde tollas, nimium cito, ant tarde tollas. Tempus enim idoneum, quod scribit Theoplirastus, vere et autumno et Canicula exortu : neque omnibus locis ac generibus idem. In sicco el 
nlcule. Mals il y a des distinctions à faire, suivant la qualité du sol et l'espèce de la plante. Ainsi lorsque le sol est aride, maigre, argileux, et dépourvu conséquemment d'humidité naturelle, il faut choisir le printemps. Ce sera l'automne, si la terre est bonne et grasse, au contraire; car elle serait trop humide au printemps. Quelques-ıns fixent à trente jours la période d'exécution de ces travaux. Le troisième mode, où l'on procède par bouture, c'est-à-dire en détachant d'un arbre des branches qu'on met provisoirement en terre, exige une attention toute particulière à bien choisir le moment de la transplantation; ce qui doit avoir lieu avant que les boutures aient poussé fleurs ou bourgeons. Avant tout, ll aura fallu les séparer dé. licatement de l'arbre, et uon les en arracher; car plus on leur a laissé de pied, plus elles ont de consistance, et plus vite elles prennent racine. II faut aussi se dépêcher de les mettre en terre avant que la sève ne se dessèche. Pour se pro: curer des boutures d'oliviers, il suffit de couper une jeune branche de grosseur égale aux deux extrémités, et d'un pied environ de longueur ; c'est ce que les uns appellent clavola, et les autres talea. Quant au quatrième mode de propagation, qui consiste à prendre une branche sur un arbre pour l'insérer dans un autre, l'arbre sur lequel on prend la greffe, celui sur lequel on ente, le moment où l'on fait cette opération, et le procédé qu'on emploie, sont autant d'objets de séricuse considération. On ne saurait greffer le poirier sur le chêne par exemple; ni sur le pommier non plus. C'est ce qu'observe religieusement quiconque a foi dans lesaugures : car autant de greffes différentes sur un arbre, nous disent-ils, autant de coups de foudre qui doivent le frapper. Si l'on greffe sur un

macro lnco, et argilloso, vernum tempus idoneum, quo ıninıs lıabet lıumoris. In terra bona ac pingui, autımno, quod vere multus lımmo ; quam sationem quidam me. liuntur fere dicbus xxx. Tertium genus seminis, quod ex arbore per surculos defertur in terram, [sic in luumum demiltitur, in quibusdam tamen] est videndum, ut eo tempore sit deplantatum quo oportet. Id enim fit ante quam gemnare aut llorere quid incipit : et qux de arbore transferas, ut ea deplantes potius quam defringas : quod plantæ solum stabilins, quo latius, ut radices facilius mittat. Ea celeriter antequam sucus exarescat, in terram demittendum. In oleagineis seminibus [arbores] videndum, ut sit de tenero ramo ex utraque parte sequabiliter pracisum, quas alii clavolas, alii taleas appellant, ac faciunt circiter pedales. Quartum genus seminis, quod transit ex arbore in aliam, videndum, qua ex arbore in quam trans. feratur, et qno tempore, et quemadmodum obligetur. Non enim pirum recipit quercus; ueque enim si malus pirum. Hoc sequuntur multi, qui aruspices andiunt multum, a quibus proditum, in singulis arboribus quot genera insila sint, uno ictu tot fulmina fieri illud, quod fulmen concepit. $\mathrm{Si}$ in pirum silvaticam inseveris pirmm quanvis bouan, won fore tain jucundum, quain si in eam, qux poirier sauvage un autre poirier, si bonne d'ailleurs qu'en soit l'espèce, on obtient un fruit moins savoureux qu'en opérant sur un poirier cultivé. Règle générale : quand on greffe un arbre sur un autre de même essence, pommier sur pommier, par exemple, il fautque l'arbre dont on emprunte la greffe soit d'une espèce meilleure que celui sur lequel on l'applique. On a dernièrement imaginé une nouvelle manière de greffer, qui exige deux arbres voisins. Au moyen d'une ouverture pratiquée dans l'arbre qu'on désire greffer, on introduit une petite branche attirée de l'arbre dont on veut avoir le fruit. Cette branche doitêtre entaillée des deux côtés, au point de contact, avec une serpette; de sorte qu'à l'endroit où elle ressort son écorce s'adapte parfaitement à l'écorce de la branchequ'elle traverse. 0 n aura soin encore que l'extrémité de la branche entée se dresse vers lo ciel. L'année suivante, lorsque la greffe a bien pris, on opère sa séparation de l'arbre auquel elle a d'abord appartenu.

XLI. A quelle époque faut-il greffer chaque espèce? c'est la première considération. Nous devons remarquer à ce sujet que nombre d'essences d'arbres qui étaient greffées jadis au printemps, le sont aujourd'hui pendant le solstice d'été : tels sont les figuiers, dont le bois a peu de densité, et conséquemment besoin de chaleur. Aussi cette culture ne peut-elle réussir dans les pays froids ; l'humidité est encore nuisible à leurs greffes récentes. Ce bois pourrit vite quand il est jeune; on pense doncavec raison que le meilleur moment pour le greffer est l'époque de la canicule. Quant aux plantes moins délicates de leur nature, on attache au-dessus de leurs greffes un vase rempli d'eau, dont on laisse tomber le

silvestris non sit. In quamcunque arborem inseras, si ejusdem generis est duntaxat, ut si utraque malus, ita inserere oportet referentem ad fructum, meliori genere ut sit surculus, quam est, quo veniat, arbor. Est altera species ex arbore in arborem inserendi nuper animiadversa in arboribus propinquis. Ex arbore, e qua quis vult ha. bere surculum, in eam, quam inserere vult, ramulum traducit, et in ejus ramo præciso, ac difisso implicat. Enm locum qui contingit, ex utraque parte, quod intro est, falce extenuatur, ita ut ex una parti, quod calum visurum est, corticem cum cortice exæquatum haleat. Ejus ramuli, quam inseret, cacumen ut directum sit ad calum, curat. Postero anno cum compreliendit, unde propagatum est ab altera arbore praccidit.

XLI. Qno tempore quæque transferas, hac in primis videnda, quod quae prius verno tempore inserebantur, uuncetiam solstitiali, ut ficus, quod densa materia non est, et ideo sequitur caldorem. A quo fit, ut in locis frigidis ficeta fieri non possint. Aqua recenti insito inimica. Tenellum enim cito facil putre. Itaque quod inseritur Caniculae signo, commodissime existimatur inseri. Que autem natura minus sunt mollia, vas aliquod supra alligant, unde stillet lente aqua, ne prius exarescat surculus, quaun 
contenu goutte à goutte, afin que le rameau inséré ne se dessèche point avaut son incorporation à l'arbre. Il faut conserver intacte l'écorce des greffes, et se garder, lorsqu'on les apprête, d'en mettre la moelleà nu. Il est bon même qu'elles soient enduites d'argile, et assujetties avec une lanière d'écorce, pour les garantir au dehors de la pluie ou de la chaleur. Par une précaution du mème genre, on fait l'incision de la vigne trois jours avant de la greffer, afin de débarrasser le cep de son humidité surabondante; ou bien si on a commencé par greffer, on place l'incision un peu au-dessus de la greffe, pour ménager un écoulement à l'humidité cn cas de besoin. Les figuiers, les grenadiers, et en général tous les arbres d'une uature moins aqueuse, se greffent sans exiger ces précautions. Quelques boutures, par exception celles de figuier, sont de ce nombre, et ne se transplantent que lorsqu'elles sont en bourgeons.

Des modes de propagation, la greffe est celui qu'on applique de préférence aux plantes qui sont, comme les figuiers, trop tardives pour venir de semence. La semence naturelle de cet arbre est cette graine qu'on trouve dans la figue quand on la mange, et qui est si menue qu'à peine elle pourrait =produire quelques chétifs rejetons. En général, toute semence sèche et compacte estlente à pousser. Plus sa substance est relâchée, plus son développement est hâtif. C'est le mème rapp?rt qui existe, dans le règne animal du mâle, à la femelle. Ainsi le figuier, le grenadier, et la vigne, dont la nature est analogue à la mollesse féminine, croissent-ils plus rapidement que le palmier, le cyprès, et l'olivier, qui sont d'une consistance plutôt sèche qu'humide. Aussi, pour avoir des figuiers, vaut-il mieux recourir aux boutures que d'attendre à voir lever la graine ;à moins tou-

coalescat. Cujus surculi corticem integrum servandum, et eum sic exacuendum, ut non denudes medullain. Ne extrinsecus imbres noceant, aut nimius calor, argilla oblinendum, ac libro obligandum. Ilaque vitem triduo ante quam inserunt, desecant, ut qui in ea nimius est liumor difluat ante, quam inseratur. Aut in qua inserunt, in ea paullo infra, quam insitum est, incidunt : unde humor alventicius efluere possit. Contra in fico et malo punica, et si qua etiam lorum natura aridiora , continuo. In aliis translationibus videndum, ut quod transfertur ca. cumen, luabeat gemmam, ut in ficis. De his [primis] qua. tuor generibus seminum, quadam quod tardiora, surcu. lis potius utendum, ut in ficetis faciunt. Fici enim semen naturale intus in ea fico, quan edimus. Quxe sunt minuta grana, e quibus parvis, quod enasci coliculi vix queunt. Omnia eninı minuta et arida ad crescendum tarda; ea quæ laxiora, et foecundiora; ut formina, quam mas. Et proportione in virgultis item. Itaque ficus malus punica et vitis propter foemineam mollitiam ad crescendum prona. Contra palma et cupressus et olea in crescendo tarda. In lıc enim humidiora guam aridiora. Quare ex terra potius in seminariis surculos de ficeto, quain grawa tefois qu'on ne puisse faire autrement, et qu'il y ait nécessité de recevoir son plant d'outre-mer, ou d'en expédier à cette destination. Dans ce cas, on attache cn colliers, au moyen de petites cordes, des figues bonues à manger; et quand elles sont bien sèches, on peut les empaqueter etles en voyer où l'on veut. On n'a plus qu'à les mettre en terre pour obtenir une pépiniere de figuiers. C'est ainsi que les figues de Chio, de Chalcis, deLydie, d'A frique, et d'autres contrées d'outre-mer, ont émigréen Italie. La même observation s'appliqueà l'olivier, dont la semence est un noyau. Le germe étant bien plus lent à se développer par le moyen de ce noyau mis en terre que par l'usage du talea dont nousavons parlé, c'est le lalea qu'on emploie pour former les pépinières.

XLII. Pour le sainfoin il faut une terre qui n'ait ni trop de sécheresse ni trop d'humidité, et soit d'une nature intermédiaire. Les auteurs prétendent qu'un sol dans cette condition n'exige comme semence qu'un modius et demi de sainfoin par jugerum. On sème cette plante comme le blé et le foin c'est-à-dire en jetant la graine sur la terre.

XLIII. On sème la graine de cytise, comme celle de chou, dans une terre bien labourée. Lorsqu'ensuite le cytise est venu, on le transplantc, en mettant entre chaque plant un pied et demi de distance; ou bien on prend d'un cytise vigoureux de petites boutures que l'on met en terre, en les espaçant de même que les tiges qui viennent de graine.

XLIV. La semence d'un jugerum est, en fèves, de quatre modii ; en blé, de cinq ; en orge, de dix ; en froment, de dix. Cette proportion cependant varie selon la qualité du sol; en plus, si ia terre est grasse; en moins, si elle est maigre. Pour

de fico expedit obruere : præter si aliter nequeas : ut si quando quis trans mare semina mittere, aut inde petere vult. Tum enim resliculas per ficos, quas edimus, maturas perserunt, et eas cum inaruerunt, complicant, ac quo volunt mittunt, ubi obruta in seminario pariant. Sic genera ficorum, Cliæe, ac Chalcidicæ, et Lydiæ, et Africanx : item cxtera transmarina in Italiam perlata. Simili de causa olese semen cum sit nucleus, quod ex eo tardius enascebatur colis, quam e taleis, ideo potius in seminariis taleas, quas dixi, serimus.

XLII. De Medica in primis observes, ne in terram nimium aridam aut variam, sed temperatam scmell demittas. In jugerum unum, si est natura temperata terra, scribunt opus esse Medica sesquinodium. Id seritır ita, ut semen jactatur queinadmodum scilicel cun pabulum et frumentum seritur.

XLIII. Cytisum seritur in terra bene subacta tanquau semen brassica : inde differtur, et in sesquipeden ponitur. Aut etiau de cy tiso duriore virgula deplantantur, et ita pangitur in serendo.

XLIV. Seruutur fabx modii Iv in jugero, trilici $v$, ordei $v 1$, farris $x$. Sed nonnullis locis paullo amplius aut 
cette appréciation on fera blen d'observer les habitudes locales, et, a vee d'autant plus de raison, que la même quantité de semence rend en eertains endroits dix pour un, et quinze en d'autres; comme en Étrurie par exemple, et en quelques cantons d'Italie. A Sybaris, dit-on, le rendement ordinaire est du centuple. Il en est de mème à Garada en Syrie, et à Bysaeium en Afrique. II importe encore beaucoup de distinguer pour l'ensemeneement, entre les terres neuves, celles qu'on appelle restibiles et qui rapportent tous les ans, et les jachères, où la produetion n'est qu'alternative. A Olynthe, dit alors Agrius, on moissonne tous les ans; mais on dit que de trois ans en trois ans la récolte est plus abondante. Après ehaque récolte, dit Lieinius, il faudrait toujours laisser un an de repos à la terre, ou au moins, de deux années l'une, ne lui confier que des semences assez légères pour ne point l'épuiser.

Parlez-nous maintenant, dit Agrius, de la troisième phase, des productions de la terre, e'està-dire de la nutrition. Toute plante, reprit Licinius, reeoit de la terre sa nourriture et son accroissement. Devenue adulte, elle concoit; et, après avoir porté le temps néeessaire, elle enfante des fruits ou des épis : en sorte qu'elle repıoduit un germe en tout semblable à celui dont elle est née. Si vous arrachez une fleur de poirier ou de tout autre arbre, si vous en cueillez le fruit eneore vert, il ne pousse plus rien de toute l'année à l'endroit de cette mutilation; ear les plantes ne peuvent avoir deux portées en un an. Elles produisent comme les femmes aceouchent, à leur époque.

XLV. L'orge lève habituellement le septième jour; le blé le suit de près. Les légumes sortentpresque tous de terre au bout de quatre ou einq jours; à l'exeeption eependant de la fève, qui pousse un peu plus tard. La germination pour le millet, le sésame, et les graines analogues, est à peu près de la méme durée, à moins de retard provenant de la température ou de la condition du sol. Les plantes élevćes en pépinières sont d'une délicatesse extrême. Si le pays est froid, il faut dans la saison d'hiver les couvrir de feuilles ou de paille. II faut encore, quand le froid est suivi de pluie, prendre garde que l'eau ne séjourne auprès; ear la gelée est un poison pour leurs tendres racines aussi bien que pour leurs jeunes pousses, qui même en sont arrêtées davantage dans leur développement. Les plan. tes en automne et en hiver profitent plus dans la partie qui est sous terre, et qui conserve toujours un certain degré de chaleur vivifiante, que dans la partie qui est au-dessus, et que le froid de l'air frappe de tous côtés. C'est ee qu'on voit dans toute végétation de natureque la main de l'homme n’a pas eneore touchée. La croissance dans les raeines est bieu plus rapide que dans la partie supérieure de la tige, sans toutefois dépasser le point où s'arrête l'influenee des rayons du soleil. L'extension que prennent les racines est subordonnée à deux causes différentes, à leur essence d'abord, ensuite à la nature du sol, où elles s'ou vrent plus aisément passage les unes que les autres.

XLVI. Nous voyons parfois des effets surprenants de ees mêmes eauses. Ainsi les feuilles de eertaines plantes indiquent, par leur seule position, l'époque de l'année où l'on se trouve. On est sûr par exemple que le solstice d'été est passé, si- minus. Si enim locus crassus, plus : si macer, minus. Quare observabis, quantuu iu ea regione consnetndo erit serendi : ut tantum facias, quantum valet regio ac genus terræ; ut ex eodem semine aliubi cum decimo redeat, aliubi cun quintodecimo, ut in Hetruria, et locis aliquot in Italia. Iu Sybaritano dicunt etian cum centesimo redire solituın. In Syria ad Garada, et in Africa ad Byzacium item ex modio uasci centum. Illud quoque multım interest in rudi terra, an in ea seras, qua quotanuis obsita sit, qua vocatur restibilis : an in vervacto, quxe interdum requierit. Cui Agrius : In Olyntlia quotannis restibilia esse dicunt, sed ita ut tertio quoque anno uberiores ferant fructus. Licinius : Agrum alternis annis re. linqui oportet, aut paullo levioribus sationibus serere, id est, qua minus sugunt terram. Dicetur, inquit Agrius, de tertio gradu, De nutricationibus, atque alimonis eorum. Licinius : Quxe nata sınt, inquit, in fundo alescunt, adulta concipiunt, prægnantia, cum sunt matura, pariunt poma, aut spicam : sic alia simile ei, a quo profectum, reddunt semen. Itaque si florem, acerbumve pirum, alindve quid decerpseris, in eodem loco eodem anno nilhil renascitur, quod prognationis diem idem bis hiabere non potest. Ut enim inulieres lıabent ad partım lies certos, sic arbores ac fruges.
XLV. Primum plerımque e terra exit ordeum diebus vi, nec multo post triticum. Legumina fere quatriduo aut quinque diebıs, proterquam faba. Ea euim serins aliquanto prodit seges. Ostendit idem milium, et sesama, et cætera similiter æquis fere diebus, præterquam si quid regio aut tempestas vitii attulit, quo minus ita fiat. Qure in seminario nata, si loca erunt frigidiora, qux molli natura sunt, per brumalia tempora tegere oportet fronde aut stramentis : si erunt imbres secuti, videndum necubi aqua consistat. Venenum enim gelum radicibus tenellis sub terra, et supra virgultis, quæ nec eodem tempore xque crescunt. Nam radices autumno aut lieme magis sub terra, quam quie supra adolescunt, quod tectæe terræe tepore propagantur, supra terram aere frigidiore cinguntur. Idque ita esse docent silvestria, ad quæe sator non accessit. Nam prius radices, quam ea qua ex is solent nasci, crescunt. Neque radices longius procedunt, nisi quo tepor venit solis. Duplex causa radicum, quod et radices materia alia, quam alia longius projicit natura : et quod alia terra alia facilius viam dat.

XLVI. Propter ejusmodi res admiranda discrimina sunt naturalia, quod ex quibusdam foliis propter eorum versuram, quod sit anni tempus, dici possit, ut olea et populus alba et salix. Horum enim folia cum converterunt 
tót que les feuilles de l'olivier, du peuplier blanc et du saule se sont retournées. Un phénomène non moins singulier est celui qu'offre la fleur appelée tournesol, que nous voyons se tourner le matin vers le soleil levant, et le suivre dans sa course jusqu'à son coucher, le calice toujours ouvert de son côté.

XLVII. Les plantes élevées et greffées dans des pépiuières, comme le figuier et l'olivier, étant, ainsi que nous l'avons dit, d'une délicatesse extrême, il faudra avoir soin de leur former un abri de deux planches, attachées de gauche et de droite. On devra également arracher toutes les herbes autour de leur pied, et s'y prendre pour cela de bonne heure, car si on laisse fortifier cette végétation parasite, elle résiste et se rompt, plutôt que de céder à la main. Quant à l'herbe des prairies, qui croit pour la fenaison seulement, il ne faut pas l'arracher quand elle se forme, mais il faut craindre de marcher dessus, eten éloigner les troupeaux et toute espèce de bétail. Les hommes eux-mêmes doivent s'interdire d'y passer. L'herbe disparaít sous les pas, et la trace devient sentier.

XLVIII. On appelle épi dans le blé le point culminant de la tige. Lorsque l'épi d'orge ou de froment est entier, il se compose de trois parties adhérentes l'une à l'autre, sa voir le grain, la balle et les barbes, sans compter la gaine qui enveloppe le grain au commencement de sa formation. On appelle grain le corps solide qui se trouve dans l'intérieur de l'épi; balle, la pellicule qui renferme le grain; et barbes, ces sortes d'aiguilles longues et fines dont la balle est comme défendue. La balle est donc l'étui du grain, et les barbes en forment la palissade. Les barbes et le grain sont choses assez connues;

se, solstitium dicitur fuisse. Nec minus admirandnm, quod fit in floribus quos rocant heliotropia, ab eo quod ad solis ortum mane spectant, el ejns iter ita sequuntur ad occasum, ut ad eum semper spectent.

XLVII. In seminario qua surculis consita, et eorum molliora erunt natura cacumina, ut olea ac ficus, ea summa integenda binis tabellis dextra et sinistra deligatis, lierbxq не eligendx : ex dum tener $x$ sunt vellendx. Prius enim arida facta rixantur, ac celerius rumpuntur, quam serguuntur. Contra herba in pratis ad spem foenisicia nata non modo non evellenda in nutricatu, sed etiam non calcanda. Quo pecus a prato ablegandum, et omue jumentum, (ac) etiam lomines. Solum enim hominis exitium lierbae, et semitx fundamentum.

XLVIII. In segetibus anten frumentum, in quo culmus extulit spicam : ea quxe mutilata non est, in ordeo ct tritico tria liabet continentia, granum, glumım, aristam : et etiani primitus spica cum oritur, vaginam. Granum dictum, quod est intimum solidum. Gluma, qui est folliculus ejus. Arista, qua ut acus tenuis longa eminct e gluma. Proinde ut grani theca sit gluma, et apex arist?. Arista et granum omnibus fere notum : gluma paucis. mais peu de gens savent ce que c'ese que la balle. Aucun auteur, à ma connaissance, n'en a parlé, excepté Ennius daus sa traduction des livres d'Évhémérus. L'étymologie du mot gluma (balle) parait être glubere (écorcer, peler), parce qu'en effet il faut dépouiller le grain de cette pellicule qui le couvre. On donne par la même raison le nom de gluma à la peau qui couvre la pulpe de nos figues. Arista (barbe) vient du mot arescere, sécher, parce que c'est la partie de l'épi qui se sèche la première. Granum (grain) vient de gerere, porter; car c'est pour le grain que l'épi doit porter, et non pour la balle ou les barbes, que l'on sème le blé; de même qu'on plante la vigne afin qu'elle porte non pas des pampres, mais des grappes. Spica, l'épi que les paysans par tradition appellent encore speca, parait être dérivé de spes (espérance), parce qu'on sème avec l'espoir de recueillir. On appelle muticus (écorné) l'épi qui n'a point de barbes, parce qu'elles font aux épis l'office de cornes. Lorsque l'épi commence à se former, il est renfermé dans une petite enveloppe verte qui le dérobe entièrement; c'est ce qu'on appelle vagina, gaine, nom qu'on donne également au fourreau qui contient l'épěe. L'extrémité supérieure de l'épi mûr', et qui est d'un volume moindre que le graill, est ce qu'on appclle frit; l'extrémité inférieure au point de sa jonction avec la tige, etqui est également moindre que le grain, s'appelle urruncum.

XLIX. Stolon avait fini de parler; et persone ne le questionnant, il pensa qu'on ne désirait pas en savoir davantage sur la nutrition des plantes. Alors il annonca l'intention de passer aux récoltes. Dans les prairies basses, dit-il, l'herbe doit être fauchéc au moment où elle commence à se sécher. On la retourne avec la fourche jusqu'à

Itaque id apud Ennium solnm scriptum scio esse in Erhemcri libris versis. Videtur vocabulum etymon liabero a glubendo, quod eo folliculo deglubitur granum. Itiqne codem vocabulo appellant fici ejus, quam edimus, folliculum. Arista dicta, quod arescit prima. Granum a gerendo. Id enim ut gerat spica, seritur frumentum, non ut glunam aut aristam gerat : ut vitis seritur, non ut pampinum ferat, sed uram. Spica antem, quam rustici, ut accepcrunt antiquitus, vocant specam, a spc videtur nominata. Eam enim quod sperant fore, serunt. Spica mutica dicitur, quæ non lıabet aristam : eæe enim quasi cornua sunt spicarum, quæ primitus cum oriuntur, neque plane apparent, qua sub latent lierlıa, ea vocatur ragina, ut in qua latet conditum gladium. Illud anfem summa in spica jan matura, quod est minus quam gra. num, vocatur frit. Quod in infima spica, ad culmum stramenti summum, item minus quam granum est, ap. vellatur urruncum.

XLIX. Cum conticuisset nce interrogaretur, de nutricatu credens nilil desiderari : Dicam, in'juit, de fructl. busmaturis capiendis. Et illic, primum de pratis summis. sis, herba cum crescere desiit, et astu arescit, sulsscari 
complète dessiccation. II faut alors la botteler avant de la transporter à la ferme; puis on passc le râteau sur le pré pour ramasser l'herbe qui sera restée à terie, que l'on ajoute aux meules de foin. I a feuaison terminée, viennent les regains; opération qui consiste à passer une scconde fois la faux avee plus de soin, afin d'atteindre les herbes qui ont éehappé à la première coupe, et qui forment de petites touffes à la superficie du pré; c'est, je crois, du mot sectio (coupc) qu'est venu eelui de sicilire, faire le regain.

L. Messis, moisson, dont meto est la racinc, se dit proprement de tout ce qu'on moissonne, et notamment du blć. On moissonne les grains de trois manières. La première, usitée dans l'Ombrie, consiste à couper le tuyau à ras de terre, et à lier sur place au fur et à mesure. Quand on a formé un eertain nombre de javelles, on les reprend une à une pour séparer l'épi de sa tige. On réunit tous les épis dans un panicr qu'on porte à l'aire. La paille qu'on a laissée se met ensuite en tas. Pour la seconde manière, en usage dans le Picénum, on se sert d'un instrument de bois recourbé, à l'extrémité duquel est adaptée une petite scie de fer. Cet instrument réunit en faiseeau les épis qu'il hache sur pied, laissant la paille debout, pour être sciée plus tard. La troisième manière, qui se pratique aux environs de Rome, et dans beaucoup d'autres contrées, est celle-ci. On coupe la paille par le-milieu, en tenant la tige par le bout de la main gauche; et c'est là, je pense, l'origine du mot messi.s (moisson), qui viendrait alors de medium (milieu). On eoupe ensuite le ehaume ou la partie qui se trouvait au-dessous de la main, et qui tient en-

falcibus debet, et quoad perarescat, furcillis versari. Cum peraruit, de his manipulos ficri ac veli ad villam. Tum de pratis stipnlam rastellis eradi, atque addere foenisicix cumulım. Quo facto sicilienda prata, id est, falcibus cousectanda, qua foniseces pratcrierunt, ac quasí lierba tuberosum rcliquerunt campum. A qua sectione arbitror dictum sicilire pratum.

L. Messis proprio nomine dicitur in iis, quae metuntur, maxime in frumento, ct ab eo est vocabulo declinata. Frumcuti tria genera sunt messionis, unım, ut in Umbria, ubi falce secundum terram succidunt stramentum; ct nuanipulum, ut quemque subsccuerunt, pounut in tcrra. Ubi eos fccerunt multos, itcrum cos percenscnt, ac de singulis secant inter spicas ct stramentum : spicas conjiciunt in corbem, atque in aream nittunt. Stramenta relinquunt in segcte, unde tollantur in acervum. Altero modo mctunt, ut in Piceno, ubi ligneum liabent incurvum batilium, in quo sit extremo serrula ferrea. Hæec cum comprcliendit fascem spicarum, desccat, et stra. menta stantia in segele relinquit, ut postca subsecentur. Tertio modo metitur, ut sub urbc Roma, et locis plerisque, ut stramentum medium subsecent, quod manu siristra summum prehendunt : a quo medio messem dictam puto. Infra manum stramentum, quod terra liact, core à la terre par sa racine. Quant a la paille adhérente à l'épi, on la met dans des paniers, et on la porte à l'aire. Là on la sépare pour laserrer dans un lieu découvert, palam; ee qui peut bieı être l'étymologie de palea (paille) : quelques-uns dérivent son autre nom stramentum du verlse stare (être debout), et de stamen son substantif. D'autres lc font venir de stratus (étendu), parce qu'on étend la paille quand elle sert de litière aux troupeaux. La moisson se fait dès que le blé est mûr. Dans les eonditions ordinaires, un homme peut, dit-on, expédier son arpent en un jour, ramasser les épis dans une eorbeille, et les porter à l'aire.

LI. L'aire doit être en plein clıamp et placée sur une éminence, afin que le vent y souffle de tous eótés. Donnez-lui une dimension proportionnée à l'importance de la récolte; que sa surface soit eirculaire de préférenee, et légèrement exhaussée au centre, pour ménager aux eaux un prompt éeoulement en cas de pluie; car du eentre à la eirconférence rien de plus eourt que le rayon. Formez-en le sol de terre bien battue, de glaise s'il est possible : autrement la ehaleur y opère des gerçures où l'eau séjourne, ou qui servent de retraite aux rats et aux fourmis. On prévient ces inconvénients en enduisant l'aire de marc d'huile. Rien n'empêche mieux l'herbe de pousser, et e'est la mort aux fourmis et aux taupes. Quelques-uns, pour plus de solidité, ont des aires pavées ou même earrelées. D'autres, comme les Bagiennis, poussent l'attention jusqu'à les couvrir, pour les mettre à l'abri des orages, très-fréquents dans cette contrée vers l'époque de la moisson. En pays ehaud, quand l'aire est sans toit, il faut ménager dans le voisinage des espèces

postea subsecatur. Contra quod cum spica stramentun lıret, corbibus in arean defertır. Ubi discedit in aperto loco palam : a quo potest nomiuata esse palea. Alii stramentum a stando, ut stamen dictum putant. Alii ab stratu, quod id substernatur pecori. Cum est matura se. ges, metendum, cum in ea jugerum fere una opera pro. pemorlum in facili agro satis esse dicatur : messas spicas corbibus in aream deferre delent.

LJ. Aream esse oportet in agro sublimiori loco, quam perflare possit ventus. Hanc esse modicam pro magnitudine segetis, potissimum rotundam, et mediam paullo extumidam, (ut si pluerit, non consistat aqua, et quam brevissimo itinere extra aream defluere possit. Onne porro brevissimum in rotundo e medio ad extremum) so. lidam terra pavita, maxime si cst argilla, ne restu pæ. minosa in rimis ejus grana oblitescant, et recipiant aquan, et ostia aperiant muribus ac formicis. Itaque amurca solent perfundere. Ea enim herbarum est inimica, et formicarum, et talparum venenum. Quidam aream ut ha. beant solidam, muniunt lapide, aut etiam faciunt pavimentum. Nonnulli etiam tegunt areas, ut in Bagiennis, quod ibi sæpe id temporis anni nriuntır nimbi. Ubi ca retecta, et loca calida, prope aream faciundum umbia. cula, quo succedant lıomines in æestı tempore męridiano. 
d'abris, où les ouvriers puissent se mettre à l'ombre pendant l'ardeur du jour.

LiI. La plus belle partie de la récolte et la plus forte en épis doit ètre mise à part pour semences. C'est dans l'aire qu'on sépare le grain de l'épi; ce qui s'opère au moyen d'un traineau qu'on fait tirer par des bêtes de somme. Le traineau est formé d'une planche garnie en dessous de for ou de pierres pointues, laquelle supporte le conducteur ou quelque poids équivalent. Cette machine, qui se promène sur les épis, en détache le grain qu'ils contiennent. Le traîneau consiste quelquefois en une réunion de soliveaux garnis de dents et de roulettes. C'est alors ce qu'on appelle le chariot à la carthaginoise. Cette forme comporte de même un conducteur assis, et un attelage de bêtes de somme. Elle est usitée dans l'Espagne citérieure, et autres lieux. Quelquesuns se contentent de faire fouler les épis par leurs bêtes, qu'ils poussent à coups de gaule, et dont le trépignement remplit le même office. Quand le blé est bien battu, on le vanne avec un instrument appelé vallum ou vallabrum, en ayant soin de choisir pour cette opération un moment où le vent n'ait qu'assez de force pour emporter les parties légères qu'on appelle acus, en sorte que le froment reste par l'effet de son poids, et arrive à la corbeille épurć.

LIII. La moisson faite, on vend le droit de glaner, ou bien l'on arrache le chaume pour le porter à la métairie. S’il reste trop peu d'épis, et que la main-d'œurre soit chère, il vaut mieux y faire paitre les troupeaux. Car la considération dominante est que le bénéfice ne soit pas alssorbé par les frais.

LIV. Lorsque le raisin est mûr, on procède aux vendanges. Il faut examiner d'abord par

LII. Quæ seges grandissima atque optima finerit, scorsum in aream secerni oportet spicas, ut semen optimum labeat. E spicis in area excuti grana. Quod fit apud alios jumentis junctis ac tribulo. Id fit e tahula lapidibus aut ferro asperata, quo imposito auriga aut pondere grandi trahitur jumentis junctis, ut discutiat e spica grana : aut ex assibus dentatis cum orbiculis, quod rocant plostellum ponicum. In eo quis sedeat atque agitet, quße tra. hant, jumenta, ut in Hispania citeriore, et aliis locis faciunt. Apud alios exteritur grege jumentorum inacto, et ibi agitato perticis, quod ungulis e spica exteruntur grana. lis tritis, oportet e terra subjactari vallis aut ventilabris, cum rentus spirat lenis : ita fit, ut quod levissimum est in $\mathrm{e}$, atque appellatur acus, evannatur foras extra aream, ac frumentum quod est ponderosum, purum ve. uiat ad corbem.

I.III. Messi facta spicilegium venire oportet, aut dumi legere stipulam : aut si sunt spica rarx, et operæ caræ, coinpasci. Summa enim spectanda, ne in ea re sumtus fructum snperet.

LIV. In vinetis uva cum erit matura, vindemiam ita fieri oportet, ut videas a quo genere uvarum, et a quo quelle espèce de raisin, et dans quelle partie du vignoble, la récolte doit commencer. Car lc raisin précoce, ainsi que le miscella (mélange), qu'on appelle vulgairement raisin noir, mûrissent longtemps avant les autres espèces. Il faut donc les cueillir les premiers. On doit aussi débuter par le côté du vignoble le plus exposé au soleil. On fait ensuite un triage du raisin à manger en grappe, et de celui dont on fait du vin. Le premier choix va droit au pressoir, et de là au tonncau. Le raisin de table est mis à part dans des paniers, puis renfermé dans des vases de terre, qu'on dépose au fond d'une futaille où le marc est resté. On le garde aussi dans des amphores enduites de poix, que l'on descend au fond d'un réservoir d'eau; ou bien on le fait-sécher dans l'aire, avant qu'il n'entre au gardemanger. Quand le raisin est foulé, remettez sous le pressoir les pédicules et les peaux; on en exprime ainsi ce qui peut $y$ rester de vin doux, et l'on augmente d'autant la cuve. Lorsque le marc ne rend plus, on coupe tout ce qui déborde le pressoir, pour le presser de nouveau. Le résultat de ce dernier tour du pressoir s'appelle circumci. situm (vin de rognure); mais on le met à part, parce qu'il sent le fer. Quand le mare a été bien pressuré, on le jette dans des tonneaux qu'on remplit d'eau. On obtient par là une boisson du nom de lota (piquette), contraction de lota acina (lavure de marc), et qui se donne aux ouvriers en guise de vin pendant l'hiver.

LV. Nous arrivons maintenant à la récolte des olives. Tant que le fruit se trouve à portée, ou qu'on peut y atteindre avec le secours d'une échelle, il vaut mieux le cueillir que le gauler; l'olive froissée se dessèche, et rend moins d'huile. Il vaut mieux encore la cueillir à la main

loco vineti incipias legere. Nam et pracox et miscella, quam rocant nigram, multo ante coquitur; qno prior legenda : et quæ pars arbusti ac vinexe magis aprica, prius debet descendere de vite. In vindemia diligentius uva non solum legitur ad bibendum, sed eligitur ad edendum. Itaque lectius defertur in forum vinarium, unde in dolium inane veniat : electa in secretam corbulam, unde in ollulas addatur, et in dolia plena vinaceoruin contruda. tur; alia, qux in piscinam in amphoram picatam descendat; alia, quæ in aream, ut in carnarium ascendat. Quæ calcatæ urac erunt, earum scopi cum folliculis subjiciendi sub prelum, ut si quid reliqui habeant mnsti exprimatur in eundem lacum. Cum desiit sub prelo fluere, quidam circuncidunt extrema, et rursus premunt : et rarsus cum expressum, circuncisitum appellant, ac seorsum, quod expressum est, servant, quod resipit ferrum. Expressi aciuorum folliculi in dolia conjiciuntur, eogne aqua additur : ea rocatur lora, qnod lota acina, ac pro vino operariis datur hieme.

LV. De oliveto. Oleam quam manu tangere possis e terra ac scalis, legere oportet potins quam quat re; quod ea, quae vapulavit, macescit, nec dat tantum olei. Qua 
nue qu'avec le doigtier, dont la dureté meurtrit la baie et même écorce les branches de l'arbre, qui en sont plus exposées à l'action du froid. Quand le fruit se trouve hors de portée, on doit se servir plutôt de roseaux que de perches pour l'abattre; car de deux inconvénients, il faut choisir le moindre. Il faut surtout avoir soin de ne point gauler à rebours, afin que le fruit en tombant n'entraine pas avec lui lc bourgeon; sans quoi l'arbre serait frappé de stérilité l'année suivante. On dit communément que les oliviers ne donnent de récolte, de pleine récolte au moins, que de deux années l'unc. L'habitude de gauler n'en est pas certainement la moindre cause. Comme le fruit de la vigne, l'olive quand elle est rentrée sert à deux fins : ou on la mange en naturc, ou l'on la convertit en un liquide onctueux que le corps humain s'applique concurremment en dedans et en dessus ; car il nous suit au bain et au gymnasc. L'olive à faire de l'huile est jour par jour mise en tas sur des planches, où on la laisse quelque temps macérer. Ensuite chaque tas, par ordre de formation, se transporte au trapèze. C'est ainsi qu'on appelle un appareil composé de deux meules, d'une pierre dure et rocailleuse. L'olive qu'on laisse en tas trop longtemps fermente, et donne de l'huile rance. Aussi, dans le cas où l'on ne pourrait l'employer dans le temps voulu, il est bon de remuer les tas pour faire prendre l'air au fruit. On tire de l'olive deux produits différents, savoir, l'huile que tout le monde connait, et le marc, dont l'utilité est trop ignorée; car on le voit généralement couler sans profit des pressoirs dans les champs, où il iaisse de larges places noires, et parfois stériles, quand la terre a été profondément imbibéc. Or cette substance a, pour qui sait en faire usage, une sorte d'application utile, principalement en matière d'agriculture. Répandue au pied d'un arbre, d'un olivier notamment, partout où on l'emploie, elle détruit toute végétation nuisiblc.

LVI. Agrius s'adressant alors à Stolon. Me voilà, dit-il, assis depuis longtemps dans la ferme, les clefs à la main, et attendant toujours que vous y fassiez entrer la récolte. Eh bien, dit Stolon, me voilà; je suis sur le seuil, ouvrez la porte. En ce qui concerne le foin, il vaut mieux le rentrer directement que le laisser en meules à décourert : les bestiaux du moins l'aiment mieux ainsi, comme on peut s'en assurer cn leur dommant le choix de l'un et de l'autre.

LVII. Pour le blé, il faut le serrer dans de hauts greniers, où les vents soufflent du nord et le l'est, et où l'humidité ne puisse pénétrer d'au* cun côté. Que les murailles ct le sol en soient revêtus d'un mastic composé de marbre pilé, ou du moins de glaise mêlée à de la paille de froment et du marc d'huile. Cet enduit préserve les greniers des rats ou des vers, et contribue en mème temps à dọnner au grain de la consistance et de la fermeté.Quelques personnes humectent leur grain de marc d'huile, dans la proportion d'un quadrantal par mille modii environ; d'autres répandent ou plutôt égrugent au-dessus de la craie de Chalcis ou de Carie, de l'absinthe, et autres substances analogues. Certains cultivateurs ont des greniers souterrains ou caveaux appelées $\sigma \varepsilon ı$ pot, comme on en voit en Cappadoce et en Thrace; ailleurs on se sert de puits, comme dans l'Espagne ci. térieure, ct aux environs d'Osca et de Carthage. manu stricta, melior ea, quæ digitis nudis legitur, quam illa quae cum digitalibus. Duricies enim corum non solum stringit bacam, sed etiam ramos glubit, ac relinquit ad gelicilium retectos. Quæ manu tangi non poterunt, ita quati debent, ut alundine potius quam pertica feriantur. Gra. vior enim plaga medicum quarit Qui quatiet, ne adversam cædat. Sxpe enim ita percussa olea secum defert de ramulo plantain. Quod facto, fructum amittunt pos. teri amii. Ut lıæc non minima causa, quod oliveta dicant alternis annis non ferre fructus, ant non xque magnos. Olea ut uva per idem bivinm redit in villan, alia ad cibum eligitur, alia ut eliquescat, ac non solum corpus intıs unguat, sed etiam extrinsecus : itaque dominum et in balneas, et gymnasium sequitır. Hace, de qua fit oleum, congeri solet acervatim per dies singnlos in tabulata, uti ibi mediocriter fracescat, ac primus quisque acervus demittatur per serias ac vasa olearia ad trapetas, qua res molæ olearix e duro el aspero lapide. Olea lecta si nimium diu fuit in acerris, caldore fracescit, et oleuin fotidum fit. Itaque si nequeas mature conficere, in acervis jactando ventilare oportet. ${ }^{\circ} \mathrm{Ex}$ olea fructus duplex; oleum, quod omnibus notum, et amurca, cujus utilitatem quod ignorant plerique, licet videre e torculis oleariis fluere in agros, ac non solum denigrare terranı, sed multitudine facere sterilem : cum is humor modicus, cum ad multas res, tum ad agriculturam pertineat velıementer, quod circum arborum radices infundi solet, maxime ad oleam, et ubicunque in agro lierba nocet.

LVI. Agrius : Jan dudum, inquit, in villa sedens ex. pecto cum clavi te Stolo, dum fructus in villam referas. Ille: Em quin adsum. Vénio, inquit, ad limen, fores aperi. Primim frenisicia conduntur melius sub tecto, quam in acervis, quod ita fit jucundius pabulum. Ex eo intelligitur, quod pecus ntroque posito libentins est.

LVII. At triticum condi oportet in granaria sublimia, qua perflentur vento ab exortu ac septentrionum regione, ad qua nulla aura lumida ex propinquis locis adspiret. parietes et solum opere tectorio marmorato loricandi : si minus, ex argilla mix to acere e frumento et anurca, quod murem et vermem non patitur esse, et graula facit solidiora ac firmiora. Quidam ipsum triticum conspergunt, cum addant in circiter mille modium quadrantal amurce. Item alius aliud adfriat, aut aspergit, ut Claalcidicam ant Caricam cretam, aut absinthinm. Item lıujns generis alia. Quidam granaria lıabent sub terris, speluncas, quas vocant oecpous, ut in Cappadocia, ac Tluracia. Alii, ut in Hispania citeriole, putcos, ut in agro Cartlaginiensi, et Oscensi. Horum solum palcis substernint : et curant 
Le sol au fond de ces puits est couvert de paille; aucune humidité n'y pénc̀tre, car on ne les ouvre jamais; ni même un souffle d'air, si ce n'est lorsqu'il y a nécessité de recourir à la réserve. L'air en étant exclu, il n'est pas à craindre que le charancon s'y mette. Le blé dans les puits sc conserve cinquante ans, et le millet pourrait même s'y garder plus d'un siècle. D'autres enfin construisent dans leurs champs mêmes des greniers qui sont comme suspendus. On en voit de ce modèle dans l'Espagne citéricure, et dans certaines contrées de l'Apulie. Ces greniers sont éventés non-seulement des côtés par les courants qui viennent des fenêtres, mais encore par l'air qui frappe dessous en leur plancher.

LVIII. Les fèves et autres légumes se conservent très-longtemps, sans se gâter, dans des vaisseaux à huile que l'on recouvre de cendre. Caton dit aussi que le petit et le gros aminéen, ainsi que le raisin dit apicius, se gardent très-bien dans des pots de terre ; mais qu'on les conserve également ou dans du vin cuit jusqu'à la diminution des deux tiers, ou tout simplement dans du vin doux. II ajoute que le lucarina (raisin ferme) et l'aminéen scantien sont de toutes les espèces de raisins ceux qui se conservent le mieux suspendus.

LIX. Quant aux autres fruits, comme les poires, coings, les seantiennes, les quirinieunes, les pommes rondes, les pommes appelées autrefois mustea (douces comme le moút), et qu'on appclle aujourd'hui melimela (douces comme le miel), tous se conservent très-bien sur la paille en lieu sec et frais. Aussi quand on fait construire un fruitier, il faut avoir soin d'en ourrir les fenêtres au nord, et de laisser un libre accès aux vents qui soufflent de ce côté. Il importe tou-

ne humor, aut aer tangere possit, nisi cum promitur ad usum. Qno enim spiritus non pervenit, ibi non oritur curculio. Sic conditum triticum manet rel annos quinquaginta: milium rero plus annos centum. Supra terram granaria in agro quidam sublimia faciunt, ut in Hispania citeriore, et in Appulia quidam, quxe non solum a lateribus per fenestras, sed etiam subtus a solo ventus refrige. rare possit.

LVIII. Faba et legumina in oleariis vasis oblita cinere perdiu incolumia servantur. Cato ait unam Amineam mi. nusculan et majorem et Apiciam in ollis commodissime condi. Eadem in sapa et musto in lora, recte. Quas suspendas opportunissimas esse duracinas et Amineas Scantianas.

LIX. De pomis, conditira mala struthea, cotonea, Scantiana, Quiriniana, orbiculata, et quæ antea mustea vocabant, nunc melimela appellant, lıæc omnia in loco arido et frigido supra paleas posita servari recte putant. Et ideo oporotliecas qui faciunt, ad aquilonem ut fenes. tras habeant, atque it ex perflentur, curant. Neque tanen sine foriculis : ne cum humorem amiserint, perti. naci vento vieta fiant. Ideoque in iis, camaras marmorato, tefuis de les garnir de volets; ear lc vent continu finit par oteraux fruits leur suc, et les rendre in. sipides. Pour plus de fraicheur encore, on recouvre en stuc les voûtes, les murailles et même les planchers de ces fruiteries. On voit même certaines personnes y faire dresser des lits potır pren. dre leurs repas. Eten effet quand on estassez riche pour forcer l'art à faire d'une salle à manger une galcrie de peintures, pourquoi se refuserait-ou la jouissance toute naturelle de contempler en dinant une variété de beaux fruits rangés dans une agréable symétrie? N'imitons pas toutefois ceux qui, donnant un diner à la campagne, étalent somptueusement dans leur fruiterie la dépouille de tous les marchés de Rome. Quant à la manière de conserver les pommes, les uns les posent sur des planches ou tablettes de marbre; d'autres préfèrent les mettre sur de la paille ou des cardes de laine. On conserve les grenades en les mettant avec la branche dans des futailles remplies de sable. Les poires aniciennes, ainsi que celles qui mûrissentau temps dessemailles, seconservent mieux confites dans du vin cuit jusqu'à la diminution des deux tiers. Quant aux cormes et aux poires, on les coupe ordinairement par morceaux qu'on fait dessécher au soleil. On pourra même conserver les cormes sans les couper, pourvu qu'on les place dans quelque lieu sec et frais. Les raves sont coupées par morceaux, et conservées dans la graine de moutarde. Les noix se gardent mieux dans du sable. Il en est de même des grenades qu'on cueille à leur point de maturité. Pour les grenades qui ne sont pas encore mûres et qui tiennent à la branche, il faudra les mettre dans un pot sans fond qu'on enfoncera dans la terre, après avoir enduit la branche de poix, pour la soustraire à l'influence de l'air' exté-

et parietes, pavimentaque faciunt, quo frigidius sit : in quo etiam quidam triclinium sternere solent cœnandi causa. Etenim in quibus luxuria concesserit, ut in pinacothece faciant, quod spectaculnm datur ab arte, cur non quod natura datum utantur in venustate disposita ponorum? præsertim quidem, cum id non sit faciendum, quod quidam fecerunt, ut Romæ coemta poma rus intu. lerint in oporothecen instruendam convivii causa. In oporothece mala manere putant satis conmode alii in tahulis, ut in opere marmorato, alii substrata palea, rel etiam floccis : mala punica demissis suis surculis in dolio are$n æ$ : mala cotonea, struthea in pensilibus junctis : contra in sapa condita manere pira Alliciana, et sementira. Sorba quidam dissecta, et in sole macerata, ut pira; et sorba per se ubicunque sint posita in arido facile durare. Servare rapa consecta in sinape, nuces juglandes in arena, punica mala et in arena jam decerpla, ac matura, (ut dixi,) et etiam immatura cum hærent in sua virga, si demiseris in ollam sine fundo, eamque si conjeceris in terram, et obteris circum ramum, ne extrinsecus spiritus afflet, ea non modo integra eximi, sed etiam majora, quam in arbore unquam pependerint. 
rieur : quand vous le retirez ensuite, le fruit se présente non-seulement intact, mais d'une grosseur qu'il n'eût jamais acquise sur l'arbre.

LX. A l'égard des olives de table, Caton nous dit que l'on conserve très-bien les orchites et les posea tant sèches que vertes dans de la saumure, ou dansde l'huile de lentisque, si elles sont meurtries. Il ajoute que si l'on veut que l'orchite conserve son beau noir, il faut la mettre dans du sel, dont on la laisse s'imprégner pendant cinq jours; puis on jette le sel, et on expose le fruit pendant deux jours au soleil. On peut aussi confire la même espèce sans sel, en la faisant infuser dans du vin doux cuit jusqu'à réduction de moitié.

LXI. Les agricultcurs expérimentés ont bien raison de conserver le marc d'huile en tonneaux avec autant de soin que l'huile et le vin : voici comme il faut s'y prendre. On le fait bouillir aussitôt qu'il sort du pressoir, et on le verse dans des vaisseaux, apıès l'avoir laissé refroidir. Il $\mathbf{y}$ a encore d'autres manières d'apprêter le mare d'huile; on le mélange avec du moût par exemple.

LXII. Comme on ne met les fruits en serre qu'en vue de les en tirer plus tard, il nous reste encore à faire quelques observations sur ce qui constitue la sixième et dernière phase des productions de la terre. On retire les fruits de l'endroit où l'on les a serrés, soit pour les consommer, soit pour les vendre, ou bien encore pour les mieux garder. Quant à l'époque à laquelle il faudra les retirer, elle dépend de la nature même des fruits qu'on veut livrer à la consommation, ou préserver de tout accident.

LXIII. Il faut tirer le blé đu grenier sitót que le charançon commence à le ronger. On l'exposera alors au soleil, en plaçant à proximité des

LX. De olivitate, oleas esui optime condi scribit Cato, orchites, et pauseas aridas, vel virides in muria, vel ill lentisco contusas. Orchites nigras, sale si sint coufriatæ dies quinque, et tum sale excusso, bidunm si in sole posita fuerint, manere idoneas sulere : casdem sine sale in defrutum condi.

LXI. Recte amurcam periti agricol $x$ tam in doliis con. dunt, quam oleum, ant vinum. Ejus conditio, cum expressa olea, quod statim efluxerit de ea, decoquuntur duxe partes, et refrigeratum conditur in vasa. Sunt item alixe conditiones, itt ea, in qua adjicitur mustum.

LXII. Quod nemo fructus condit, nisi ut promat, de eo quoque vel sexto gradu animadvertenda pauca. Promint condita aut propterea, quod sint tuenda, aut quod utenda, aut quod vendenda. Ea quase dissimilia sunt inter se, aliud alio tempore tiendum et itendum.

LXIII. Tuendi causa promendum id frumentum, quod curculiones exesse incipiunt. Id enim cum promptun est, in sole ponere oportet, atque aquar catinos, quod eo conveniunt, ut ipsi se necent, curculiones. Sub terra qui habent frumentum in iis, quos vocant oespous, quod cum periculo introitur recenti apertione, ila ut quibus. bassins pleins d'eau, où ces insectes ne tarderont pas à venir se noyer. Ceux qui ont leur blé sous terre, dans des ca veaux appelés oetpol, ne devront y entrerqu'après les avoir laissés ou verts pendant quelque temps. Car si l'on voulait s'y iutroduire immédiatement après leur ouverture, on courrait risque de suffoquer, comme il en est des exemples. Le blé que vous aurez conservé en épis pour le faire servir à votre consommation doit être retiré pendant l'hiver; on le fait moudre et ensuite on le torréfie.

LXIV. Le mare d'huile est un résidu de substance aqueuse, mêlé aux matières que l'huile dé. pose au fond des vaisseaux de terre où on la renferme. Voiei comme on s'y prend d'ordinaire pour le conserver : on dégage le mare en soufflant dessus du liquide qui surnage au bout de quinze jours de dépôt : on le transvase ensuite. Et la même opération se répète jusqu'à douze fois pendant six mois consécutifs, de quinze jours en quinze jours, de façon que la dernière ait lieu dans le déclin de la lune. On fait ensuite bouillir le mare dans des chaudières à un feu doux jusqu'à réduction de moitié, puis on le met en réserve pour s'en servir au besoin.

LXV. Quand le moût est mis en tonneau pour faire du vin, on doit s'abstenir de tirer tant que dure l'ébullition, même lor'squ'elle est assez a vancée pour que le vin puisse être regardé comme fáit. Si l'on veut boire du vin vieux, il ne faudra le tirer qu'au bout d'une année; car le vin n'est réputé vieux qu'après un an d'existence. Si le cru tourne à l'aigre, il faut consommer de suite, ou vendre le raisin en grappe. Il y a des vins dont la qualité augmente par la durée; tels sont ceux de Falerne par exemple.

LXVI. Les olives blanches, quand on les em-

dam sit interclusa anima, aliquanto post promere, quam aperuerint, oportet. Far, quod in spicis condideris per messem, et ad usus cibatus expedire velis, promendum hicme, ut in pistrino piusatur ac torreatur.

LXiv. Amurca cum ex olea expressa, qui cst himmor aquatilis ac retrimentum, conditum in ras fictile, id quidam sic solent tueri, diebus Xv ex eo, quod est levissimum ac summum, deflatum ut trajiciant in alia vasa, et hoc iisdem intervallis, duodecies sex nensibus proximis, item faciant. Cum id novissime, polissimum trajiciant, cum senescit luna. Tunc decoquunt in alıenis levi igni duas partes quoad regerunt, tum denique ad usum recte promitur.

LXV. Quod mustum conditur in dolium, ut habeamus vinum, non promendum dum fervet, neque etiaindum processit ita, ut sit vinum factum. Si vetus bibere velis, quod non fit ante, quam accesserit annus, tum, cum fuerit anniculum, promito. Si vero est ex eo genere uva, quod mature coacescat, ante vindemiam consumi, aut venire oportet. Genera sunt vini, in quo Falerna, quæ quanto plures annos condita liabuerunt, tanto cums prompta sunt fructuosiora. 
ploic avant qu'clles ne soient parfaitement confites, ont un goût amer qui rebute le palais. II en est de mêrne des noires, à moins qu'ou ne les trempe dans le sel avant de s'en servir. Cette précaution les rend très-mangeables.

LXVII. Moins on conserve les noix, les dattes et les figues, et plus elles sont savoureuses; si la garde se prolonge, les figues perdent leur goût, les dattes moisissent et les noix se dessèchent.

LXVIII. Quant aux fruits qu'on suspend pour les faire sécher, raisins, pommes et cormes, les yeux seuls indiquent le moment de les livrer à la cunsommation. En effet, on voit aisément, par le legré d'altération de leur couleur et le point de lcur dessication, quand il faut les manger, pour ne pas attendre qu'ils ne soient plus bons qu'à jeter. Les cormes rentrées tout à fait mûres doivent être mangées promptement; vertes, elles sont plus de garde ; car il leur faut le temps d'acquérir la maturité qu'on ne leur a pas laissé prendre sur l'arbre.

LXIX. C'est pendant l'hiver qu'on tire du grenier le blé destiné à la consommation domestique, qu'on doit torréfier pour le rendre propre d la panification. Le blé de semence y reste jusqu'au moment où la terre est préparée pour le recevoir : ilen est de même en général de toutc espèce de graine. Il ne faut leur faire voir le jour qu’au moment de les employer. Pour ce qu'on destine au marché, il faut attendre le moment de ven-

LXVI. Oleas albas, quas condideris, novas si celeriter promas, nisi condieris, propter amaritudinem illas respuit palatum. Item nigras, nisi prius eas sale maceraris, ut libenter in os recipiautur.

LXVII. Nucem juglandem, et palmulam, et ficum Sabinam quanto citius promas, jucundiore ulare, quod retustate ficus fit pallidior, palmula cariosior, nux aridior.

LXVIII. Pensilia, ut 11 ra, mala, et sorba, ipsa ostendunt, quando ad usum oporteat promi : quod colore mutato et contractu acinorum, si non demseris ad edendum, ad abjiciendum descensurum se minitantur. Sorbum maturuin mite conditum citius promi oportet : acerbum cuim suspensum lentius est. Quod prius domi maturitatem assequi vult, quam nequit in arbore, quam mitescat.

LXIX. Messum far promendum lieme in pistrino ad torrendum, quod ad cihatım expeditum esse velis. Quod al sationem, tum promendum, cum segetes maturæ sunt ad accipiendum. Item quæ pertinent ad sationem, suo quorque teminore promenda. Quæ vendenda, videndum, qua quoque tempore oporteat promi. Alia enim, quae dre avec avantage. Telle production ne peut se conserver sans s'altérer; il faut se presser de s'en défaire. Cette autre est plus de garde, attendez que son prix s'ćlève. Qui sait attendre, non-seulement retire l'intérêt de sa marchandise, mais en obtient quelquefois un prix double. Stolon parlait encore, lorsqu'un affranchi du gardien entre tout en pleurs, en nous suppliant d'excuser si l'on nous a fait si longtemps attendre; et en même temps il nous invite aux funérailles de son maitre pour le lendemain. Nous nous levons tous en nous écriant : Quoi! à ses funérailles? Qnelles funérailles? Alors l'esclave nous raconte, toujours pleurant, que son maître vient d'être frappé d'un coup de couteau, et que le meurtrier s'est perdu dans la foule. Seulement, par une exclamation qu'il avait faite, on jugeait que le crime était l'effet d'une méprise. L'esclave ajoutait que, tout occupé de reconduire son maitre au logis, d'envoyer chercher promptement. un médecin, il n'avait pas eu le temps de nous avertir plus tôt, ct que nous serions sans doute disposés à trouver sa conduite naturelle. Son empresscment, il est vrai, n'avait pas empèché son patron de rendre l'âme peu de temps après; mais il croyait néanmoins n'avoir fait en cela que son devoir. Nous ne le trouvámes que trop excusé, et nous descendimes tous du temple pour retourner chez nous, plus ėmus de l'accident, par rapport à l'humanité, que surpris de ce que Rome en était le théátre.

mauere non possunt, ante quam se comnutent, ut cele. riter promas, ac vendas : alia quie servari possunt, ilt tum vendas, cum caritas est. Sæe enim diutius servata non modo usuram adjiciunt; sed etiam fructım duplicant, si tempore promas. Cum hæc diceret Stolo, renit libertus adituni ad nos llens, et rogat ut ignoscamus quod simus retenti, et ut ei in funus postridie prodea. mus. Onnes consurgimus, ac simul exclamamus, quid? in fanus? quod funus? quid est factum? Ille flens narrat ab nescio quo percussum cultello concidisse, quem qui esset, animadvertere in turba non potuisse, sed tantum. modo exaudisse rocem, perperam fecisse. Ipse, cum patronum domum sustalisset, et pueros dimisisset ut medicum requirerent, ac mature adducerent; quod potius illud administrasset, quam ad nos renisset, ærquim esse sibi ignosci. Nec si eum servare non potuisset, quin non multo post animam efflaret, tamen putare se fecisse recte. Non moleste ferentes descendimis de æede, et de casu humano magis querentes, quam admirantes id Romæ factum, discedimus omnes. 


\section{LIVRE II}

\section{DE L'ÉDUCATION IES BESTIAUX.}

Nos grands aieux avaient bien raison de mettre l'homme des ehamps au-dessus de l'homme des villes. En effet autant les habitudes d'une maison de plaisanee semblent oiseuses à nos eampagnards, s'ils les comparent à la laborieuse agitation d'une ferme, autant cette première exis. tenee paraissait-elle active à nos ancêtres auprès de la paresse des eitadins. Aussi avaient-ils partagé lcur temps de facon à ne donner aux affaires de la ville que deux jours sur neuf, consacrant les sepl autres exelusivement aux oecupations rurales. Tant qu'ils sont restés fidèles à eette coutume, ils y ont gagné sous deux rapports : d'abord leurs ehamps rapportaient davantage, et eux-mémes se portaient mieux. En second lieu, ils pouvaient se passer de ces gymnases de toute espèce dont le raffinement des Grees a rempli leurs maisons de villes, et qu'il nous faut avoir, nous, maintenant dans nos demeures, depuis le premier jusqu'au dernier. On ne croirait pas avoir de maison de eampagne, si l'on ne pouvait se donner le plaisir d'en décorer de noms grees toutes les distributions. Mpoxoticiv (antiehambre) $\pi \alpha \lambda \alpha i \sigma \tau p \alpha$ (palestre), $\alpha \pi 0 \delta$ uríprov (ves-

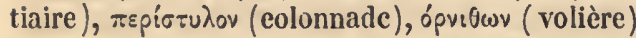

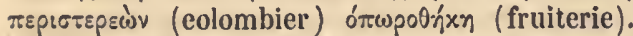
Comme de nos jours il n'est guère de ehefs de fa. mille qui, laissant là faux et charrue, n'ait émigré dans l'enccinte de Rome, et ne eonsacre à applaudir au eirque et au théatre les mains jadis oecupées aux champs et aux vignobles, il en ré. sulte qu'aujourd'hui nous payons pour qu'on nous apporte d'Afrique et de Sardaigne le blé qui

\section{LIBER 11.}

DE RE PECUARIA.

Viri magni nostri inajores non sine causa præponebant rusticos Romanos urbanis. Ut ruri enim, qui in villa vivunt ignaviores, quam qui in agro versantur in aliquo opere faciundo : sic qui in oppido sederent, quam qui rura colerent, desidiosiores putabant. Itaque annum ita liviserunt, ut nonis modo dicbus urbanas res usurpa. rent, reliquis vis ut rura colerent. Quod dum servaverunt ustitutum, utrumque sunt consecuti, ut et cultura agros fœcundissimos liaberent, et ipsi valetudine firmiores es. sent : ac ne Grxcorum urbana desiderarent gymnasia, quæ nunc vix satis singula sunt : nec putant se labere villam, si non inultis rocabulis retineant Graccis, quum

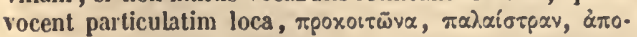

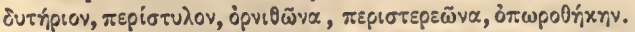
Igitur quod nunc intra murum fere patres familia correp. serunt relictis falce et aratro, ct manus movere maluerunt in theatro ac circo, quam in segetibus ac vinetis, frumentum locamus, qui nobis advelıat, qui saturi fiamus ex Africa, et Sardinia : et navibus vindemiam condimus nous nourrit, et que nous allons par mer faire vendange à Cos et à Chio. Les fondateurs de cctte ville, qui n'étaient eux que des pâtres, avaient voulu que leurs descendants fussent des cultivateurs; et, au mépris de leurs lois, l'ambition de leurs descendants a converti les champs en prairie, sans même faire de différence entre paítre des troupeaux et Iabourer la terre. Autre chose cependant est le laboureur et le pâtre. Pour se nourrir aussi des champs, le bouf de labour n'en diffère pas moins du bœuf de páturage. Le bouf en troupcau ne produit pas; il consomme. Le bœuf sous le joug, au contraire, contribue à la production du blé dans les guérets et du fourrage dans les jachères. Je le répètc, la science du cultivateur differe essentiellement de celle du patre. Le but du cultivateur est de tourner à son profit tout ee qu'il fait produire à la terre; celui du patre, de retirer tout le parti possible de son troupeau. Mais comme il y a un rapport intime entre ces deux choses, puisque d'un côté le profit peut être plus grand à faire consommer le fourrage sur place qu'à le vendre ; et que de l'autre l'engrais, l'élément de féeondation le plus indispensable à la terre, est essentiel. lement une provenance du bétail, il s'ensuit que tout possesseur de biens fonds doit embrasser les deux sciences, être à la fois agriculteur et éleveur de troupeaux, et porter ses soins même sur toute espèce animale qui peut se trouver dans une ferme et ses dépendances. Car les volières, les garennes, les viviers, sont toutes industries dont le profit n'est rien moins que méprisable. J'ai traité de l'agriculture dans un premier livre dédié à ma femme Fundania, qui fait elle-même valoir une terre. Celui-ci, mon eher Niger Tur-

ex insula Coa , et Chia. Itaque in qua terra culturam agri docuerunt pastores progeniem suam, qui condiderunt urbem, ibi contra progenies eorum, propter avaritiam contra leges ex segetibus fecit prata, ignorantes non idem esse agriculturam et pastionem. Alius enim opilio, et arator : nec si possit in agro pasci, armentarius non aliud ac bubulcus. Armentum enim id, quod in agro natum non creat, sed tollit dentibus. Contra, bos domitus causa fit, ut commodius nascatur frumentum in segete, et pa. bulum in novali. Alia, inquam, ratio ac scientia coloni, alia pastoris; coloni, ut ea quæ in agricultura nascantur e terra fructum faciant. Contra pastoris, ut ea quæ nata ex pecorc. Quarum quoniam societas inter se magna, propterea quod pabulum in fundo compascere, quam vendere plerumyue magis expedit domino fundi; et stercoratio ad fructus terrestres aptissima, et maxime ad id pecus apnositum : qui habet prædium, habere utramque debet disciplinam, et agriculturæ, et pecoris pascendi, et etiam villaticæ pastionis. Ex ea enim quoque fructus tolli possunt non mediocres, ex ornitlıonibus, ac leporariis, et piscinis. E queis quoniam de agricultura librum Fundanize uxori propter ejus fundum feci : tibi Niger Turrani noster, qui veliementer delectaris pecore, prop. 
ranius, je l'écris pour vous, amateur passionné de tout ce qui touche au régime pastoral; vous, que ce goût conduit si souvent aux foires de $\mathrm{Ma}$ cra, et qui trouvez dans ce genre de spéculation de quoi satisfaire à de très-coûteuses exigences. La táche ne sera pas difficile pour moi, possesseur autrefois de bétail sur une grande échelle; car j'ai eu de nombreux troupeaux de l'espèce ovine en Apulie, et à Réate, des haras considérables. Je ne traiterai toutefois que sommairement la matière, me bornant à recueillir ici des entretiens que j'ai eus avec quelques amis, grands propriétaires de bestiaux en Epire, à l'époque de la guerre des pirates, lorsque je commandais les flottes de la Grèce, entre la Cilicie et l'île de Délos.

I. Ménas venait de se retirer; et Cossinius se tournant vers moi. Nous ne vous laisserons pas partir, me dit-il, que vous n'ayez achevé de nous cxpliquer ces trois parties dont vous aviez déjà commencé à nous entretenir, lorsque vous avez été interrompu. Qu'est-ce que ces trois parties? dit Murrius; ne serait-ce point celles dont vous me parliez hier, et qui concernent l'éducation des bestiaux? - Précisément, reprit Cassinius. Nous étions allés voir Pétus qui était indisposé ; et là, Varron avait commencé une dissertation sur l'origine de cette science, sur la haute considération qu'elle mérite, et sur toutes les conditions de sa pratique. Il a été interrompu par l'arrivée du médecin. Je ne veux me charger, repris-je alors, que des deux premières parties composant l'histolique (ítopixòv) de la science. Je vous diraice que jesais; quelle est son origine, et combien d'estime lui est due. Quant à la troisième, qui est la partie

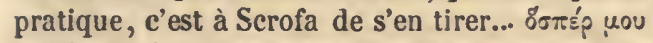

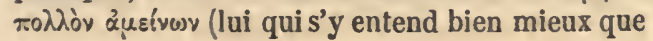

tcrea quod te emturientem in campos Macros ad mercatın adducunt crebro pedes, que facilius sumtibus multa poscentibus ministres, quod eo facilius faciam, quod et ijse pecuarias habui grandes, in Appulia oviarias, et in Reatino equarias: [qua] de re pecuaria breviter ac sum. matim percurram, ex sermonibus nostris collatis cum iis, qui pecuarias habuerunt in Epeiro magnas, tum cum piratico bello inter Delum et Ciliciam Gracia classibus proessem, iucipianı line.

Cap. I. Cum Menas discessissel, Cossinius mibi, Nos te non dimiltcmus, inquit, ante quam tria illa explicaris, quæ cœperas nuper dicere, cum sumus interpellati. Quæ tria? inquit Murrius. An ea, quæ mihi heri dixisti de pastoricia re? Ista, inquit ille, quæ cœperat hic dissercre, qux esset origo, qux dignilas, qux ars : cum Pctam fessunı visere venisscmus, ni nıedici adventus nos iuterrupisset. Ego vero, inquam, dicam duntaxat, quod est ítopixìv, de duabus rebus primis, quae accepi, de origine, et dignilate. De tertia parte, ubi est de arte, Scrofa suscipict : ut scinigracis pastoribus di-

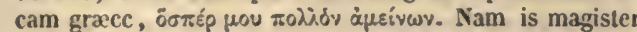
C. Lucilii Hirpi generi tui, cujus nobiles pecuaria in Bru. moi). On peut bien parler grec à des gens qui sont Grees à moitié. Scrofa, en effet, n'en a-t-il pas remontré à C. Lucilius Hirpus, votre gendre, si célèbre par les beaux troupeaux qu'il possède au pays des Brutiens? - Très-volontiers, dit Scrofa ; mais à la condition qu'en retour vous autres Épirotes ct pâtres par excellence, vous nous ferez part de tout ce que vous savez sur ce sujet, pour me récompenser de ma complaisance; car ols a tonjours quelque chose à apprendre. Je m'étais donc ainsi renfermé, de mon choix, dans la partie purement théorique de la science : ce u'est pas queje ne fusse aussi propriétaire de troupeaux en Italie ; mais n'est pas joueur de cithare quiconque a l'instrument en main, et je pris la parole ainsi : L'homine et les animaux doivent avoir été de tout temps dans l'ordre de la nature. Soit que l'on admette un principe générateur, avec Thalès de Milet et Zénon de Cittium; soit quavec Pythagore de Samos et Aristote de Stagire, on en veuille nier l'existence, il faut convenir avec Dicéarque que la vie humaine, en remontant jusqu'à sa condition le plus ancienne ment connue, a successivement passé par bien des transformations, avant d'arriver à sa forme actuelle; et que, dans cetle condition primitive, l'homme se nourrissait des productions spontanées de la terre, vierge de tout ensemencement. A l'état de nature a succédé la vie pastorale; seconde période, où l'homme, au lieu de se repaître exclusivement de glands, d'arbouses, de mûres et autres fruits sauvages, enlevés aux forêts et aux buissons, choisit parmi les animaux, hôtes des bois comme lui, les espèces dont il peut s'approprier la substance, les emprisonne, et les apprivoise. 0 n suppose avec assez de raison qu'il s'empara d'abord des brebis, commeétant la conquête

tiis habentur. Sed hæc ita a nohis accipietis, inquit Scrofa ut ros, qui estis Lpirotici, pecuarii atbletæ, remuneremiui nos, ac quæ scitis, proferatis in medium. Neıno enim omnia polest scire. Cum accepissem conditionem, ot meæ partes essent primæ, non quo uon ego pecuarias in Italia habeam, sed non omnes qui liabent citharam, sunt citharœdi : igitur, inquam, et lomines et pecua cum semper fuisse sit necesse natura. Sire enim aliqnod fuit principium generandi animalium, ut putavit Thales Mile. sius, et Zeno Cittieus : sive contra principium horum extitit nullum, ut credidit Pytlıagoras Samius, et Aristoteles Stagerites; necesse est liumana vitæ a summa memoria gradatim descendisse ad hanc ætatem, ut scribit Dicararclus : et summum gradum fuisse uaturalem, cum viverent homincs ex is rebus, qux inviolata ultro ferrct terra : ex lac vita in secundam descendisse pastoriciam, e feris atque agrestibus, ut ex arborihus ac virgultis de. cerpendo glandem, arbutum, mora, pomaquc colligerent ad usum; sic ex aninualibus, cum propter eandem utilj. tatem qua possent silvestria deprehenderent, ac concln. dcrent, et mansuescerent. In queis primum non sine causa putant oves assumtas, et propter utilitatem, cl propter 
la plus facile et la plus profitable. Ces animaux en effet, d'un naturel si doux, eonvenaient parfaitement à la condition primitive de l'homme, à qui ils fournissaient du lait et du fromage pour sa nourriture, des peaux et de la laine pour couvrir son corps. Après la vie pastorale vint la vie agrieole, troisième période de l'humanité, qui garda longtemps plus d'un trait des deux préeédentes. De nos jours encore on retrouve plusieurs espèces de bétail à l'état sauvage dans certaines contrées. Les brebis par exemple en Phrygie, où on les voit errer par troupeaux, et les ehèvres dans l'île de Samothrace. Ces dernières, dont l'espèee s'appelle en latin rota, abondent en Italie, sur les monts Fiscellum et Tetrica. Quant aux pores, tout le monde sait qu'il y en a de sauvages, à moins qu'on ne veuille regarder le sanglier comme un autre animal. Les boufs se trouvent également à l'état le plus sauvage en Dardanie, en Médie, et en Thrace. Les ânes sauvages (onagres) ne sont pas rares dans la Phrygie et la Lyeaonie; il y a des ehevaux sauvarges dans quelques eontrẻes de l'Espagne eitérieure. Voilà pour l'origine de la scienee, je passe à l'estime quì lui est due. Les plus illustres personuages de l'antiquité étaient tous des pấtres; les langues greeque et latine en portent toutes deux témoignage. Voyez les aneieus poètes qui appellent !eur héros tantôt roגúapvos (riche en agneaux), tantôt $\pi 0 \dot{\lambda}_{u} \mu r_{1} \lambda o_{0}$ (riche en brebis), tantôt enfin $\pi 0 \lambda u-$ coútry (riche en troupeaux de bœufs.) Ces mêmes poëtes nous parlent de brebis dont la toison était d'or, par allusion sans doute à leur extrême eherté. Telle était la brebis d'Atrée à Argos, dont ee prinee se plaint d'avoir été dépouillé par Thyeste; et le bélier qu'Éétès possédait en Colchide, but de l'expédition de ees fils

placiditatcm. Maxime eniın lıæ natura quietæe, et aptissimæ ad vitam lıominum. Ad cibum enim lacteet caseum adhibitım, ad (corpus) vestitum et pelles (et lanam) attulerunt. Tertio denique gradu a vita pastorali ad agriculturam dcs cenderunt. In qua ex duobus gradibus superioribus reti. nuerunt multa. Et quo desccnderant, ibi processerunt longe, dum ad uos pervenirct. Etiam nunc in locis multis genera pecudum ferarum sunt aliquot, ut in Plırygia cx ovibus, ubi greges videntur complurcs; ut in Samothrace caprarum, quas latine rotas appellant. Sunt enim in Italia circum Fiscellum et Tetricam montes multa. De suibus nemini ignotum, nisi qui apros non putat sucs vocari. Boves perferi etiam nunc sunt inulti in Dardania, et Me. dica, et Tlıracia. Asini feri in Plırygia, et Lycaonia.' Lqui feri in Hispaniæe citerioris regionibus aliquot. Origo, quam dixi : dignitas, quam dicam. De antiquis illustrissimus quisque pastor erat, ut ostendil graca et latina lingua,

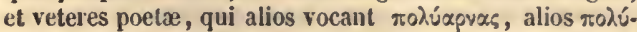

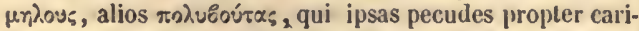
tem aureas labuisse pelles tradiderunt, ut Argis Atrens, quam sibi Tlıyestem subdıxc queritur : ut in Colchide Leta, ad cujus arietis pellen profecti regio gencrc di. de rois connus sous le nom d'Argonautes. Enfin telles étaient, en Libye, celles qu'enfermait le jardin des Hespérides, d’où Hercule ravit les pommes d'or (mala); c'est-à-dire, suivant la tradition, des troupeaux de ehèvres et debrebis, qu'il transporta d'Afrique en $\mathrm{G}$ rèce. Et en effet les Grees, pour rappeler par le son le cri de ees animaux, leur ont donné le nom de $\mu \tilde{r}_{i} \lambda \alpha$, onomatopée que les Latins ont rendue plus expressive en changeant une seule lettre, bela. Car on entend plutôt bee que me quand une brebis crie. De ee mot on a fait ensuite le verbe belare, en retranchant une lettre, comme dans beaucoup d'autres dérivés. Si le bétail n'eût pas été en honneur ehez les anciens, les astronomes ne lui auraient certes pas emprunte plusieurs noms de signes, dans la deseription qu'ils ont faite du ciel. Loin d'avoir la moindre hésitation à placer ces noms au zodiaque, plus d'un auteur, en énumérant les douze signes, commence par ceux qui portent des noms d'animaux, et donne ainsi le pas au Bélier et au Taureau sur Apollon et sur Hercule, qui, tout dieux qu'ils sont, ne viennent qu'cn troisième lieu, sous le nom de Gémeaux. Et, peu contents de, n'a voir en noms de bétail qu'un sixième du nombre des signnes, ils y ont introduit le Capricorne pour eompléter le quart.

Les noms de ehèvre, de bouc et de chien, que portent différentes eonstellations, sont également empruntés au bétail. Des terres, qui plus est, et des mers ne tirent-elles pas leurs noms de la même source, témoin la mer Égée, qui doit le

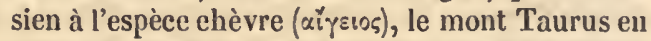
Syrie, le mont Canterius dans le pays des Sabins; le Bosphore de Thrace et le Bosphore cimmérien. Il y a des villes dont les noms n'ont pas d'autre origine : par exemple, la ville greeque qu'on nomme

cuntur Argonauta: : ut in Libya (ad) Hesperidas, unde aurea mala, id est, sccundum antiquam consucludinem, capras et oves, [quas] Hcrcules ex Africa in Graeciam cxportavit. Ea enim (a) sua voce Gracci appellaruıt $\mu$ nุ $\lambda . x$. Nec multo secus nostri ab eadem roce, sed alia litera bela vocarunt. Non enim me, sed bee sonare videntur oves vocen efferentes : a quo belarc dicunt, extrita litera, ut in multis. Quod si apud antiquos nou maguæe di. gnitatis pecus esset, in caclo dcscribendo astrolugi non appellassent eorum vocabulis signa, quie non modo nou dubitarunt ponere, scd ctiam ab lis principibus xu signa multi nuneraut : ut ab ariete el tauro!, cum ea præpone. rent Apollini, et Ilerculi. Ii enin dii ea sequuntur, sed appellantur Genuini. Nec satis putarunt de xul signis scxtam partem obtincre pecudum nomina, nisi adjecissent, ut quartam tenercnt, capricornum. Praterea a pecuariis addiderunt capram, lıœedos, canes. An non itcm in nıri teriaque ab his regionum notie? [a pceore] in mari, quod norninaverunt a capris $A$ gcum pelagus : ad Syriam montem Taurum : in Sabinis Canterium montcm : Bus. phorum unum Thracium, altcrum Cimmerium. Nonue in

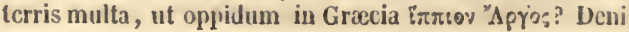




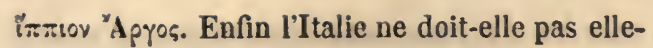
même son nom aux veaux (viluli), comme le prétend Pison? Qui oserait nier que le peuple romain n'ait eu des pâtres pour ancêtres? Qui ne sait que Faustulus, père nourricier de Romulus ct Remus, et l'instructeur de leur jeunesse, était un simple pâtre? N'étaient-ils pas des pâtres euxrnêmes ces fondateurs de notre ville, comme le prouve leur choix pour la fonder, du jour même des Parilia? Ne dit-on pas encore aujourd'hui, suivant l'ancienne coutume, tant de bœufs, tant de brebis, pour exprimer la valeur de certaines choses? Notre plus ancienne monnaie n'a-t-elle pas une figure de bétail pour effigie? Et n'était-ce pas avec une charrue attelée d'un bœuf et d'une vache qu'autrefois on tracait l'enceinte d'une ville, et qu'on marquait l'emplacement de ses portes? Enfin les suovitaurilia, c'est-à-dire les victimes solennelles que l'on promène autour du peuple romain pour le purifier, qu'est-ce autre chose qu'un verrat, un bélier, et un taureau? Combien n'avons-nous pas de noms propres empruntés soit au gros, soit au petit bétail? au petit bétail, comme ceux de Porcius, d'Ovinius, de Caprilius; au gros bétail, comme ceux de Taurius, d'Equitius. Enfin les Annius n'ont-ils pas reçu le surnom de Capra, les Statilius celui de Taurus, et les Pomponius celui de Vitulus? Et combien on en citerait d'autres! Reste à dire en quoi consiste la science même du nourrissage; c'est ce dont notre ami Scrofa, à qui la palme est décernée par le siècle en fait d'économie rurale, va s'acquitter beaucoup mieux que moi. Tout le monde alors tourna les yeux vers Scrofa, qui commenca en ces termes : Cette science consiste à se procurer du bétail et à le nourrir, afin do tirer le plus d'argent possible de la chose même d'où vient le mot argent. Car pecunia (argent. monnayé) est dérivé de pecus; le bétail étant regardé comme la base de toute richesse. Cette science se divise en neuf parties, ou, si l'on veut, en trois, qui se subdivisent chacune en trois autres. La première de ces trois parties comprend le petit bétail, dont on compte trois espèces, savoir: les brebis, les chèvres, et les pores; la seconde comprend le gros bétail, qui se forme également de trois espèces, savoir, les boeufs, les ânes et les ehevaux; la troisième et dernière partie, qui n'est qu'accessoire et non d'un produit immédiat, mais qui cependant est inhérente à la matière, comprend les mulets, les chiens et les bergers. Chacune de ces neuf parties en renferme neuf autres relatives, savoir, quatre à l'acquisition du bétail, quatre à son entretien, et une dernière qui se rapporte à ces deux objets à la fois; ce qui ne fait pas moins de quatre-vingt-une parties, toutes indispensables, et d'une importance majeure. D'abord, pour se procurer de bon bétail, il importe avant tout de savoir à quel âge on doit prendre chaque espèce. Les boufs, par exemple, se payent moins cher en deçà d'un an et passé dix, parce que le bœuf ne commence à servir qu'á sa seconde ou à sa troisième année, et ne sert plus après sa dixième. En général, la première et les dernières années des bestiaux sont toujours stériles. La seconde des quatre parties qui se rattacheut à l'acquisition a pour objet la formeex térieure du bétail, considération qui influe beaucoup sur la qualité. Poul l'acheteur, un bœuf aux cornes noirâtres vaut mieux qu'un bœuf aux cornes blanches; une chèvre de grande taille, qu'une petite chèvre. Quant au porc, il doit être long de corps et court de tête. La troisième partie consiste à s'as- que Italia a vitulis, ut scribit Piso. Romanorum vero po. pulum a pastoribus esse ortun quis non dicit? quis Faustulum nescit pastorem fuisse nutricium, qui Boinulum et Remum educarit? non ipsos quoque fuisse pastores obtinebit, quod Parilibus potissimum condidere ur. bem? non item, quod multa etiam nunc ex vetere instituto bubus et ovibus dicitur? et quod aes antiquissimum, quod est flatum, pecore est notatum? Et quod urvo urbis , cum condita est, tauro, et racca (junctis), qui essent uuri et porte definitum? Et quod populus Rom. cum lustratur, suovitaurilibus circumaguntur verres, aries, taurus? Et quod nomina multa habemus ab utroque pe. core, a majore et a minore? A minore, Porcius, Ovinius, Caprilius : sic a majore Equitius, Taurius.... cognomina adsiguificari, quod dicuntur ut Annii Capræ, Statilii Tauri, Pomponii Viluli : sic a pecudibus alii multi. Reliquum est de scientia pastorali, de qua quod est dicen. dum, Scrofa nosler, cui hrec aetas defert rerum rusticarum onısium palınam, quo melius potest, dicet. Cum convertissent in eum ora omnes, Scrofa : Igitur, inquit, est scientia pecoris parandi, ac pascendi, ut fructus ytam possunt maximi capiantur ex ea, a quibus ipsa pecunia nominata est. Nam omnis pecuniæe pecus fundamentum. La partes habet novem discretas, ter ternas; ut sit una de minoribus peculibus : cujus genera tria, ovis, capra, sus. Altera de pecore majore, in quo sunt item ad tres species natura discreti, boves, asini, equi. Tertia pars est in pecuaria, qua non paratur, ut ex is capiatur fructus, sed propter ea, ut ex ea sint, muli, canes, pastores. Harum unaquæque in se generales partes labet novenas, quarum in pecore parando necessaria quatuor; alteræ in pascendo totidem; præterea communis una. Ita fi unt omnes partes minimum octoginta et una, et quidem necessariæe, nec parvæ. Primum ut bonum pares pecus, unum scire oportet, qua xtate quamque pecudem parare, habereque expediat. Itaque in bubulo pecore minoris emitis anuiculam et supra decem annorum, quod a bima, aut trima fructum ferre incipit, neque longius post decimum annum procedil. Nam prima atas omnis pecoris et extrema sferilis. E quatuor altera pars est cognitio formæ uniuscujusque pecudis, qualis sit. Magni enim interest, cujusmodi quæque sit, ad fructum. Ita potins hovem emunt cornibus nigrantibus, quam albis : capram auplam, quam parvam : sues procero corpore, capitibus 
surer de la race. Celle des ânes d'Areadie est célèbre dans la Grèce comme en Italie celle des âncs de Réate. C'est au point que j'ai vu un âne se vendre soixante mille sesterces, et deux paires de chevaux, à Rome, aller jusqu'à quatre cent mille. La quatrième partie se rapporte aux formes de droit qui régissent l'acquisition du bétail, et aux précautions légales dont cette propriété s'entoure. Pour qu'elle passe sûrement d'une main à une autre, il faut bien faire iutervenir quelques formalités. Ce n'est pas tout, en fait de transaction, qu'on soit convenu d'un prix et qu'on le paye. L'état sanitaire, bon, mauvais ou douteux, amène autant destipulations différentes dans un marché de bétail. Viennent après l'achat quatre ordres de considérations d'une autre nature. Il s'agit de nourrir son bétail, de le faire multiplier, d'élever les petits, de le conserver sain. Touchant la nourriture, qui est le premier de ces quatre ordres, il y a troischoses à observer relativement aux espèces : les conditions de lieux de parcours, l'époque de l'année où le bétail y doit être conduit, et ce qu'il faut qu'il y trouve à paitre. Ainsi des localités montueuses et du feuillage à brouter, voilà ce qui convient aux chèvres, plutôt que de gras páturages.

C'cst le contraire pour les cavales. Il y a encore, suivant les localités, pacage d'été et pacage d'hiver. Ainsi les troupeaux de brcbis de l'Apulie vont passer la campagne d'été dans le Samnium, après que la déclaration en a été faite aux fermiers de la république, qui l'enregistrent; car il ne faut pas encourir les peines portées par la loi des censeurs. Ainsi, pendant la même saison, les mulets quittent les plaines de Roséa pour les hautes montagnes de Gurgur. Il faut en der-

ut sint parvis. Tertia pars est, quo sint seminio quaren. lum. Hoe nomine enim asini Arcadiei in Græeia nobilitati, in Italia Reatiıi, usque eo, ut mea memoria asinus venierit sextertiis millibus $\mathbf{L x}$, et unæ quadriga Romæ constiteriut quadringentis millibus. Quarta pars est de jure in parando, juemadmodum quamque peeudem emi oporteat civili jure. Quod enim alterius fuit, id ut fiat meum, neeesse est aliquid intercedere. Neque in omnihus satis est stipulatio, aut solutio numorum ad mutationem domini. In emtione alias stipulandum statim, esse e valetudinario, alias e sano pecore, alias e neutro. Altera partes quatuor sunt, cun jam emeris, olsservandxe, de pastione, de futura, de untricatu, de sautitate. Pascendi primus loeus qui est, ejus ratio triplex. In qua regione quanciue potissimum pascas, et quando, et queis? ut eapras in montuosis potius loeis et fruticibus, quan in lier. bidis campis; equas eontra. Neque eaden loca, astiva et liiberna idonea omnibus ad paseendum. Itaque greges ovium longe abiguntur ex Appulia in Samnium astiva. tum, atque ad publicanum protitentur, ne, si inscriptum pecus paverint, lege censoria eommittant. Muli e Rosea campestri restate exiguntur in Gurgures altos montes. Qui potissinum quæeque pecudum pascatır, lıabenda ra. nier lieu fairc acception des aliments particulièrcment propres à cliaque espèce de bétail, ce qui ne se borne pas à donner du foin aux chevaux et aux bœufs, et du gland aux pores, à qui le foin ne saurait convenir. Il faut encorc savoir à propos ajouter de l'orge et des fèves à la provende, et faire manger aux bœufs du lupin; du cytise et du sain-foin aux bêtes laitières. Un mois avant la saillie, on augmente la ration des bćliers et des taureaux, pour leur donner des forces, tandis qu'on diminue celle des vaches et des brebis; car on prétend, avec raison, que les femclles concoivent mieux quand elles sont maigres. La génération est l'objet de la seconde partie; ct j'appelle génération la période intermédiaire entre la conception et l'instant où Ia bête met bas; car c'est le commencement et le but de la génération. Il faut s'occuper avant tout de l'accouplèment, et de l'époque où la femelle admet le mále. Pour la race portant soie, c'est depuis le lever de Favonius jusqu'à l'équinoxe du printemps; pour la race ovine, du coucher de l'Arcture à celui de l'Aiglc. Il faut en outre observer préalablement un temps de séparation nécessaire entre les máles et les femelles, lequel est ordinairement de deux mois pour toute espèce de troupeaux. La gestation a aussi des soins particuliers, la délivrance arrivant plus tôt ou plus tard, suivant les espèces. La jument par excmple porte un an, la vache dix mois, la truie quatre, la brebis cinq, et la chèvre autant. Un phénomène de génération qui passe toute croyance, et qui est cependant de toute vérité, se voit sur les côtes de Lusitanie en Espayne, près de la ville d'Olysippe, sur lc mont Tagro. Là les cavales conçoivent du vent, comme il arrive assez souvent chez nous

$t$ io. Nec solum, quod fœno fit satura equa, aut bos, eum sues hoc vitent, et quxrant glandem : sed quod ordeum, et faba interdum sit quibusdam objiciendum, et dandum bubus lupinum, et lactariis Mediea, et eytisum. Præterea quod ante admissuram diebus $x x x$ arietibus, ac tanris datur plus cibi, ut vires lıabeant: forminis bubus denitur, quod macescentes melius coneipere dieuntur. Seeunda pars est de fotura. Nune appello foeturam a coneeplu ad partum : hi enin prognationis primi et extreni fines. Quare primum videndum de adnissione, quo quicque tempore ut ineant facere oporteat. Nam, ut suillo pecori a fa ronio ad aequinoctium vernum putant aptum, sic ovillo ab Areturi oecasu, usque ad Aquila oecasum. Pra. terea lıbenda ratio, quanto aute quam iucipiat admissura fieri, mares a forminis secrelos habeant : yuod fere in nnuibus binis mensibus ante fuciunt et armentarii, et opiliones. Altera pars est in foelura, quie sint observanda, quod alia alio tempore parere solet. Equa enim ventren fert xu menses, vaeca decem, ovis et capra quinque, sus quatuor. In foetura rés incredibilis est in Hispania, sed est vera, quod in Lusitania ad oceanum in ea regione, ubi est oppidum Olysippo, monte Tagro, quadam e vento certo tempre concipiunt equa, ut hie gallinæ quix 
aux poules dont les œufs sont appelés írįvéuos (concus du vent); mais les poulains concus de cette manière ne vivent pas plus de trois ans. Quant aux petits qui viennent à terme, ou après, il faut les nettoyer et les faire lever avec précaution, de crainte qu'ils ne soient (pendant la nuit) écrasés sous la mère. Les agneaux qui naissent après terme, et qui ont conséquemment séjourné plus que le temps normal dans les flanes de la mère, s'appellent chordi, mot dérivé de yóprov (arrière-faix). La troisième partie, la formation des élèves consiste à examiner combien durera, à quelles heures, et en quel lieu se fera l'allaitement des petits; et si la mère manque de lait, à leur donner une nourrice. Les élèves qu'on fait de cette façon sont appelés subrumi, ce qui veut dire, sous la mamelle. Rumis était, à ce que je crois, l'ancien mot usité pour exprimer mamelle. On sèvre ordinairement les agneaux au bout de quatre mois, les boucs au bout de trois, et les porcs au bout de deux mois. Comme à cet âge ces derniers sont assez purs pour pouvoir être offerts en sacrifice, on les appelait autrefois $s a$ cres (sacrés); c'est à eux que Plaute fait allusion, lorsqu'il dit : Combien coûtent les porcs sacrés? On appelle dans le mème sens opimi les bœufs d'engrais que l'on destine aux sacrifices publics. La quatric̀me partie concerne le régime sanitaire, matière aussi importante que complexe; car une bête malade peut vicier tout un troupeau, et d'un mal individuel faire un désastre général. Il faut distinguer deux sortes de maladies : celles qui, de même que les maladies des hommes, réclament la présence du médecin; et celles qui, pour leur guérison, ne demandent que les soins du pátre. Cette partie en renferme trois autres:

que solent, quarım ova iтr,vépı a appellant. Sed ex his equis, qui nati pulli, non plus triennium virunt. Qux nata sunt matura, et cliorda, ut pure et molliter stent, videndum, et ne obterantur. Dicuntur agni chordi, qui post teıpus nascuntur, ac remansennt in volvis intimis. Vocant yoriov, a quo chordi appellati. Tertia res est, de nutricatu quid observari oporteat, in quo, quot diebus matris sugant mannmam, et id quo tempure, et ubi : et si parum habet lactis mater, ut subjiciat sub alterius man. mam, qui aprellantur subrumi, id est sub manma. Antiquo enim rocabulo mamma rumis, ut opinor. Fere ad quatuor mensis a mamma non dijunguntur agui, hœdi tres, porci duo; e queis, quom puri sunt ad sacrificium, ut inmolentur, olim appellati sacres, quos appellat Plautus, cum ait : Quanti sunt porci sacres? sic bores altiles, ad sacrilicia publica saginati, dicuntur opimi. Quarta pars est de sanitate : res multiplex, ac necessaria; quod inorbosum pecus, et vitiosum, et quando non valet, sæepe məgna gregen afficit calamitate. Cujus scientix genera duo : unum ut in lominem, ad quem adhibendi medici; alterum, quo ipse etiam pastor diligens mederi possit. Ejus partes sunt tres; nam animadrertendum, qua cujusque morbi sint causx, quxque signa earum causarum savoir, les causes des maladies, les symptômes qui les annoncent, et le traitement qu'il faut appliquer à chacunc. En général, les maladies du bétail ont pour cause l'excès du chaud ou du froid; quelqquefois l'excès de travail ou son contraire, le manque d'exercice, ou bien encore l'inobservation d'un temps de repos, quand on les fait boire ou manger immédiatement après le travail. La présence d'une maladie se manifeste par des symptômes. Ceux de la fièrre occasionnce par l'excès de chaleur ou de froid sont : la bouche béante, la respiration entrecoupée : et le corps brûlant. Voici le traitement qu'il faut suivre dans ce cas : On baigne l'animal, on le frotte avec de l'huile et du vin tiède; on lo met à la diète, on le couvre bien pour que le froid ne puisse l'atteindre, et on ne lui donne à boire que de l'cau qu'on a fait tiédir. Si ce traitement ne fait point d'effet, pratiquez une saignée; des veines de la tête surtout. Les autres maladies ont également des causes et des signes particuliers. Le pasteur: en chef doit en avoir par écrit le détail circonstancié. Reste la question du nombre; neuvième subdivision, commune, ainsi que nous l'avons dit, aux deux premières. Lorsqu'on veut élever des bestiaux, il importe avant tout d'en fixer les quantités, d'examincr combien de troupeaux le fonds comporte, et de combien de têtes chacun doit se composer, afin de n'avoir en terrains ni déficit ni superflu; car il y a perte dans les deux cas. Il faudra de plus, pour chaque troupeau, avoir des notes exactes du nombre des brebis en état de porter, de celui des béliers, de leurs petits mâles et femelles, et enfin des bêtes de rebut, dont il faut se défaire. Quand une mère a trop de nourrissons, certains pattres lui en reti-

sint, et qua quemque morbum ratio curandi sequi debeat. Fere morborum causæ erunt, quod laborant pro. pter æstus, aut propter frigora, nec non etiam propter nimium laborem, aut contra, propter nullam exercitationem, aut si cum exercueris, statim sine intervallo cibum aut potionem dederis. Signa autem sunt, ut eorum, qui sive ex astu, sire e labore febrem hahent, adapertum os, humido spiritu crebro, et corpore calido. Curatio autem, cum hic est morbus, hac. Perfunditur aqua, et perunguitur olco et vino tepefacto, et item cibo sustinetur, et injicitur aliquid ne frigus cadat, sitienti aqua tepila datur. Si lıc genus rebus non proficitur, demitur sanguis, maxime e capite. Item ad alios morbos alia causi, etiam alia signa in omni pecore, qux scripta liabere oportet magistrum pecoris. Relinquitur nonum, quod dixi, de numero, utriusque partis connune. Nam et qui parat pecus, necesse est constituat mu. merum, quot greges, et quantos sit pasturus, ne aut saltus desint, aut supersint, et ideo fruclus dispereant. Proterea scire oportet in grege quot foeminas habeat, (juæ parere possunt, quot arietes, quot utriusque generis soboles, quot rejicula sint alienandx. In alimoniis, si sunt plures nati, ut quidam faciunt, seqguendum, ut 
rent. Imitez-les. Ce qui reste profite mieux.

Prenez-y garde, dit Attieus. II y a dans vos catégories quelque chose qui cloehe, qui cadre mal avec vos définitions de gros et petit bétail. Essayez, par cxemple, d'appliquer vos neuf divisions aux ehapitres des pasteurs et des mulets : vos principes sur l'accouplement ct la gestation y feraient une belle figure! Passe pour les chiens, ̀̀ qui ces notions sont du moins applieables. Je vous conec̀de même les pasteurs, parce qu'on leur permet dans les fermes, et même dans leurs stations d'été, d'avoir des femmes avec eux. L'on gagne à cela de les attacher davantage à leurs troupeaux, et d'obtenir des naissances un aeeroissement de son domestique ; ce qui fait fruetifier l'exploitation. Cette multiplication de neuf par neuf, repris-je, peut bien n'être pas tout à fait rigotureuse. C'est une facon de parler, comme on dit les mille vaisseaux de l'expédition de Troie, le tribunal des centumvirs (des cent juges) à Rome. Il n'y a qu'à retrancher, en ce qui coneerne les mulets, les deux parties relatives à la conecption et à la gestation. Du mulet? s'écria Vaccius. Est-ce qu'on n'a pas vu à Rome des inules porter et mettre bas? Je m'empressai de chanter sur le même ton, en citant un passage de Magon et un de Diouysius, où il est dit que la gestation est d'un an ehez les juments et les mules. Or, si e'est un prodige en Italie, ajoutai-je, comment ailleurs la ehose est-elle trouvée toute naturelle? N'est-il pas vrai que les hirondelles et les eigognes, qui produisent en Italie, ne pondent point en d'a utres contrées? I gnorez-vous eneore que le palmiel-datte, qui donne des fruits en Syrie et en Judée, ne rapporte pas en Italie? Allons, dit alors Serofa, si vous tenez abso-

quosdam subducas. Quar res facere solet, ut reliqui melius erescant. Vide, inquit Atticus, ue te fallat, et novenn istie partes non extant extra preeoris minoris ae majoris nomen. Quo pacto enim erunt in mulis et pastoribus novená partes, ubi nec armissura, nee fuetura observantur? In canibus enim video posse dici. Sed do etiam in lominilus posse novenarium retineri numerum, quod in libernis habent in villis mulieres, quidam etiam in astivis, et id pertinere putant, quo facilius ad greges pastores retineant, et puerperio familiam faciant majorem, et rem pecuariam fruetuosiorem. $\mathrm{Si}$, inquam, numerus non est, itt sit ad amussim, ut non est, eum dieimus mille naves iisse ad 'Troiam, centunvirale esse judieium Romæ : deme (si vis) duas res de mulis, admissuram et parturam. Vaccius : Parturam, inquit? proinde ut non aliquo. ties dicatur Roma peperisse mulan. Cui ego ut sucineı en, subjicio, Magonem et Dionysium seribere, mulan st equam, cum conceperint, duodecimo mense parere. Quare non, si lic in Italia cum peperit mula sit portentiım, adsentiri omnes terras. Neque enim hirnndines et ( ironia, qux in Italia pariunt, in om nibus terris pariunt. Nuı scitis palunulas caryotas in Syria parere in Judaea, in Ilitia non posse? Sed Scrofa: Si exigere mavis sine mu. lument à avoir nos quatre-vingt-une divisions complctes, abstraction faite de la faculté r'epro. duetive des mulets, nous avons de quoi rempli. la double lacune: II est en effet deux cspèces de produits qu'on tire par sureroît des troupeaux, et qui conslituent deux nouveaux sujets de considérations supplémentaires. L'un de ces produits provient de la tonte qu'on fait aux brebis et aux chèvres, en coupant ou arrachant leur toison. L'autre, plus généralement pratiqué, eonsiste dans le lait et le fromage. Les Grees ont houré eette matière d'un nom partieulier, тuportotíx (fabrieation des fromages) et leurs auteurs en ont beaueoup parlé.

II. Voilà ma tâche aceomplie; j'ai posé les questions et leurs limites : à votre tour, célc̀bres Épirotes. Développez devant nous chaque division de la matière, et voyons un peu quelle est la portée des pasteurs de Pergame et de Malède. Alors Attieus, dont le nom de famille était encore T. Pomponius, et qui s'appelle, Cécilius Attieus aujourd'hui, prit la parole et dit : Je vois bien que c'est à moi de parler le premier, puis. que vous semblez me désigner des yeux. Je traiterai douc des troupeaux que j'appelle, d'après vous, primitifs. Vous venez de nous dire en effet que, parmi ees animaux sauvages, les brcbis furent les premières dont l'homme se soit emparé, qu'il ait apprivoisces. Il faut avant tout n'acheter que de bonnes brebis : elles sont réputées telles quant à l'âge, lorsqu'elles ne sont ni trop vieilles, ni trop jeunes. Les unes ne sont pas aetuellement, les autres ne sont plus de rapport. Préférez eependant l'âge où le produit est en expectative, à eelui qui n'a d'avenir que la mort. Voici les conditions quant aux formes extérieures des

larum fcetura et nutricatu numerum octoginta et unum, est qui expleas duplicem istam lacuuam : quod extraordinariæ' fruetuum species duæ accedunt magnæ. Quarum Ina est tonsura, quod oves ae capras detondent, aut vellint : altera, qua latius patet, est de lacte et caseo, quan scriptores graci separatim tuportortav appellaverunt ae seripserunt de ea re permulta.

II. Sed quoniam nos nostrum pensum absolvimns, ae limitata est pecuaria quastio : nune rursus vos reddite nobis, o Epeirotx, de una quaque re, ut videamus, quid pastores a Pergamide, Maledove potis sint. Atticus, qui tune T.Pomponius, nune Q. Cocilins eog tomine eodem : Ego opinor, inquit, incipiam primus, quoniam in me videre conjecisse oculos : et dicam de primigenia pecuaria. $\boldsymbol{E}$ feris enim pecudibns primum dicis oves compreltensas ab hominibus, ac mensuefactas. Has primuın oportet bo. nas emere. Qux ita (cognuseuntur) ab ætate, si neque vetulæ sunt, neque meræ agnæ: quod alteræ jan nondum, alterx jam non possunt dare fruetum. Sed ea melior ælas, quam sequitur spes, quain ea quam mors. De forma, ovem esse oportet corpore amplo, qua lana unulta sit et molli, villis altis, et densis toto eorpore, maxime eircum cervicem et collum, ventrem quorjue ut habeat pilo. 
brebis: grande taille, laine abondante et soyeuse, et touffue par tout le corps, mais principalement vers la tète et autour du cou; le dessous du ventre bien fourni. Nos ancêtres nommaient apicce les brebis au ventre dégarni, et les mettaient au rebut. Ayez soin qu'clles soient basses sur jambes, et à queue longue, si elles sont de race italienne; à queue courte, si elles sont originaires de Syrie. Le premier point à constater, c'est la qualité de la race; il y a deux moyens d'en juger. En prenier licu, le bélier a-t-il le front bien garni, les cornes torses tendant à se réunir vers le museau, l'œil roux, les oreilles fournies, beaucoup d'ampleur de poitrine, d'épaules et de croupe, une longue ct large queue? Eu second licu, les agneaux issus de lui sont-ils de belle venue? Il faut voir encore si le bélier a la langue noire ou mouchetce, car les agneaux qu'il produira seront respectivement de laine noire ou mouchetée. Quant à l'achat, les formes en sont réglees par la loi , dont les dispositions sont plus ou moins modifiées par la coutume des lieux. Quelques-uns, en fixant un prix par tête, stipulent que deux agneaux choisis (venus après terme), ou deux brebis éventées, ne seront comptés que pour un. On se sert d'ailleurs pour cette espèce de transaction d'une forme traditionnelle, que voici : L'acheteur dit au vendeur : " Me les vendez-vous pour tant? „et, après réponse affirmative et engagement de l'acheteur d'en payer le prix, ce dernier ajoute, suivant la teneur de la formule : "Me garantissez-vous loya- lement que ces brebis sont saines, selon les * conditions requises pour cette espèce de bétail, a qu'il n'en est aucune dc borgne, sourde, ni a de pelće sous le ventre, ou qui provienne de

sum. Itaque qux id non laberent, majores nostri apicas ap. pellabant, ac rejiciebant. Esse.oportet cruribus lumilibus, candis observare ut sint in Italia prolixis, in Syria bre. vibus. In primis videndum, ut boni seminis pecus habeas. ld fere ex duabus rebus potest animadverti, ex forma, et progenie. Ex forma, si arietes sint fronte lana restiti bene, tortis cornibus pronis ad rostrum, ravis oculis, lana opertis auribus, amplo pectore, scapulis et clunibus latis, cauda lata et longa. Animadrertendum quoque linguane nigra, aut varia sit, quod fere qui eam liabent, nigros aut varios proci eant agnos. Ex progenie autem animadrertitur, si agnos procreant formosos. In emtionibus jure utimureo, quod lex praescripsit. In ea enim alii plura, alii jauciora excipuut. Quidam enim pretio facto in singulas oves, ut agni clıordi duo pro una ore aunumerentur, et si cui retustate dentes absunt, item binæ prosingulis ut procedant. De reliquo antiqua fere formula ntuntur. Cum emtor dixit : Tanti suut mi emtæ? et ille respondit: Sunt, et expromisit numos : entor slipulatur prisea formula sic : lllasce oves, qua de re agitur, sanas recte esse, uti pecus ovillum, quod recte sanum est, extra luscam, surdam, minam, (iil est, ventre glabro,) neque de pe. core molboso esse, habereque recte licere, haec sic recte
" troupeau malade; ct quc j'en serai bicn dû. " ment propriétaire? * Ces formalités accomplies, le troupeau n'est encore considéré comme ayant changé de maître, qu'après le recensement ; mais elles suffisent, d'après la législation, de contrats pour qu'achcteur ou vendcur puissent être judiciairement contraints, le premier à livrer même avant d'avoir reçu le prix ; le second, à payer ledit prix. Je vais traiter maintenant des quatre autres parties : dc l'alimentation, de la propagation, de l'éducation des jeunes, et de l'état sanitaire. Le premier soin est de bien pourvoir à la nourriture des brebis, autant au dedans qu'au dehors. Les étables devront être bicn situées, à l'abri du vent, et tournées au levant plutôt qu'au midi. Le sol en devra être uni, et de plan incliné, afin d'être facilement balayć et tenu propre; car, dans l'humidité, la laine des brebiss'altère, la corne de leurs pieds se pourrit, ct inévitablement les bêtes devicnnent galeuses. Le feuillage de leur litière doit être renouvelé au bout de quelques jours, pour leur procurer un coucher plus doux et plus propre : elles n'en mangent que mieux. Il faut cncore séparer du reste par des cloisons les brebis malades, ou prêtes de mettre bas : cette précaution n'est guère praticable qu'aux troupeaux qui séjournent dans les fermes. Mais dans les bois et loin des habitations on aura soin de se prémunir de claies, filcts, et autrés ustensiles propres à construire des pares d'isolement. Le pacage des troupcaux exige des excursions tellement lointaines, qu'il y a quelquefois plusicurs milles entre les stations d'été et celles d'hiver. Qui le sait mieux que moi? dis. je; car j'ai des troupeaux qui paissent l'hiver en Apulie, et l'été sur la montagne de Réate. Le

fieri spondesne? Cum id factum est, tamen grex dominum non mutavit, nisi si est adnumeratım. Nec non emptor pote ex emto rendito illum damnare, si non tradet, quam. ris uon solverit numos : ut ille emtorem simili judicio, si non reddit pretium. De alteris quatuor rebus deinceps dicam, de pastione, fœtura, nutricatı, sanitate. Primum providendum, ut totum annum recte pascantur intus, et foris. Stabula idoneo loco ut sint : ne ventosa : qux spectent magis ad orientem, quam ad meridianum (tempus.) ubi stent, solum oporiet esse eruderatum, et proclivum. ut everri facile possit, ac fieri purum. Non enim solum ca uligo lanam corrumpit orium, sed etiam unguias, ac scabras fieri conit. Cum aliquot dies steterunt, subjicere oportet virgulta alia, quo mollius requiescant, purioresque sint. Libeutius enim ita pascuntur. Faciendum quorjue septa secreta ab aliis, quo incientes secludere possis, item quo corpore æro. Hæec magis ad villaticos greges animadvertenda. Contra illi in sajtibus qui pascuntur, et a teclis absunt longe, portant secum crates, aut retia, quilus colıortes in solitudine faciant, cateraque utensilia. Longe enin et late in diversis locis pasci solent, ut nuulta nillia absint sape libernx pastiones ab astivis. Ego vero sciu, inguam, nam mibi greges in Appulia hiberuabant, ๆ'i 
sentier, calles publica, chemin réservé aux troupeaux, qui relie ces deux stations ensemble, pourrait être assimilé à un joug, aux extrémités duquel sont assujettis deux paniers qu'on veut porter ensemble.

Quand on fait paitre les brebis sans changer de eontrée, il y a, suivant les saisons, des distinc. tions à faire dans les heures de la journée. L'été, e'est au point du jour qu'on mène le troupeau au paturage. L'herbe, alors humide de rosée, est bien plus savoureuse qu'à l'heure de midi, où la ehaleur l'a desséchée. Quand le soleil a paru, c'est le moment de le conduire à l'abreuvoir : il retourne, après, plus gaillard à la pâture. Vers midi on le met à l'ombre sous des rochers ou des arbres touffus, en attendant que la grande ardeur soit passée. Puis aux approches de la soirće, quand l'air est rafraichi, on le fait paitre de nouveau jusqu'au coucher du soleil. On aura soin qu'il aie toujours les rayons à dos, car les moutons ont la tête d'unc sensibilité extrême. Le soleil couché, après un intervalle de repos, on fait eneore boire ses bêtes, et paitre de nouveau jusqu'à nuit fermée, parce qu'alors l'herbe aura repris la saveur di matin. Cette pratique doit s'observer serupuleusement depuis le lever des Pléiades jusqu'à l'équinoxe de l'automne. Dans un ehamp récemment moissonné, la présence d'un troupeau est doublement avantageuse. II s'engraisse des épis tombés; et, par le fumier qu'il y dépose, mêlé à la paille broyéc sous ses pieds, la terre se trouve tout amendée pour une récolte à venir. Le régime de pacage pour l'hiver et le printemps offre les différences que voici. On mène au pâturage les brebis à l'heure où les frimats de la nuit ont disparu, et on les y laisse

in Realinis montibus restivabant. Cum inter lıæc bina loca, ut jugum coutinet sirpiculos, sic calles publice distantes pastiones; easque ibi, ubi pascuutur in eadem regione, tamen temporibus distingunt, ut xestate, quod cum prima luce exeunt pastum, propterea quod tune herba roscilla meridianam, quae est aridior, jucunditate præstat : sole exorto potum propellunt, ut redintegrantes rursus ad pastum alacriores faciant. Circiter meridianos æstus, dum defervescant, sub umbriferas rupes, et arbores patulas subjiciunt, quoad refrigeratur aer, et vespertino rursus pascuit ad solis occasuin. Ita pascere pecus oportet, ut averso sole agat. Caput enim maxime ovis molle est. $\mathbf{A b}$ occasu parvo intervallo interposito ad bibendum appellunt, et rursus pascunt, quoad contenebravit. Iterum enim tum jucunditas in lıerba redintegrabit. Hac ab vergiliarum exortu ad aquinoctium autımnale maxime observant. Quibus in locis messes sunt facto, inigere est utile duplici de causa, quod et caduca spica saturantur, et obtritis strameutis, et stercoratione faciunt in annum segetes meliores. Pieliquae pastiones liberno ac verno tempore hoc mutant, quod pruina jam exhalata, propellunt in pabulum, et pascunt diem totum, ac meridiano tempore semel agere putum satis liabent. Quod ad pastiones attiuet, tout le jour, ne les faisant boire qu'une fois vers l'heure de midi. C'est à peu près là tout ce qu'on peut dirc touchant l'alimentation des brebis. Je passe à la propagation de l'espèce. Il faut, deux mois a l'avance, séparer le bélier étalon du reste du troupeau, et le nourrir plus largement que de coutume. Le soir, au retour du pâturage, mettez devant lui une ration d'orge : il en aura plus de force, et supportera mieux les fatigues de son rôlc. Le véritable moment de la monte est depuis le eoucher de l'Arcture jusqu'à celui de l'Aigle : tout agnean conçu plus tard est chétif et grête. La brebis porte cent cinquante jours, et eonséquemment mettra bas à la fin de l'automne, époque où la température est assez douce, et où l'herbe, renouvelée par les premières pluies, commence à sortir de la terre. Pendant tout le temps de la monte les brebis ne doivent boire qu'à la même source; un changement d'eau ne manquerait pas d'altérer leur laine et de nuire à leur fruit. Sitôt que toutes les brebis sont pleines, de nouveau on les sépare des béliers, dont l'importunité ne leur est plus que nuisible. Ne souffrez jamais qu'elles subissent le mâle avant l'âge de deux ans : plus tôt, elles ne donnent que des agneaux imparfaits, et elles-mêmes s'épuisent. L'âge de trois ans va encore mieux pour produire. Pour empécher les approches du bélier, on enferme aux brebis les parties sexuelles dans de petits paniers de joncs, ou de toute autre matière ; mais le meilleur préservatif, e'est de faire paître séparément mâles ct femelles. J'arrive maintenant à l'édueation. Quand les brebis sont prêtes à mettre bas, on les fait entrer dans des étables réser vées à cet effet. Là on tient les nouveaunés près du feu deux ou trois jours, au bout des-

hæc fere sunt : quod ad foturam, quæe dicam. Arietes, quibus sis usurus ad foturam, himestri tempore ante secernendum, et largius pabulo explendum. Cum redierunt ad stabnla e pastu, ordeum si est datum, firniores fiunt ad laborem sustinendum. Tenupus optimum ad admittendum ab Arcturi occasu ad Aquilæ occasum, quod qua postea concipiuntur, fiunt vegrandes, atque imbecillie. Ovis pragnans est diebus cL. Itaque fit partus exitu autımuali, cum aer est modice temperatus, et primitus oritur lierba inbribus primoribus evocata. Quamdiu admissura fit, eadem aqua uti oportet, quod commutatio et lanam facit variam, et corrumpit nterum. Cum omnes conceperunt, rursus arietes secernendi : ita factis prægnantibus quod (si) sunt molesti, obsunt. Neque pati oportet minores, quam bimas saliri, quod neque natım ex lis idoneum est, seque non ipsæ funt (etiam) deteriores : et non meliores, quam trimæ admissæ. Detarrent ab saliendo fiscellis e junco, aliave qua re, quod alligant ad naturam. Commodius servantur, si secretas pascunt. In nutricatı cum parere coperunt, inigunt in stabula ea, quæ lıabent ad eam rem seclusa, ibique nata recentia ad ignem prope ponunt, quoad convaluerunt, biduum aut tridunm retinent; lum agnoscant matrem agni , et pabulo 
quels ils sont en état de reconnaitre leur mère, et de manger seuls. Les mères brebis sont en état d'aller paitre avec le reste du troupeau : on retient les petits à l'étable, pour les faire téter le soir, au retour. Puis on les met de nouveau à part, de crainte qu'ils ne soient foulés aux pieds pendant la nuit. Le matin, avant de conduire les mères au páturage, on fait encore téter lcs agneaux, afin qu'ils soient allaités pour toute la journée. Au bout de dix jours environ, on les attache, a vec des écorces d'arbres ou quelques autres liens légers, à des pieux plantés à quelque distance les uns des autrés, de crainte qu'en courant çà et là tout le jour, ils ne fassent injure à leurs faibles membres. S'ils ne cherchent pas le pis d'euxmêmes, il faut les en approcher, en leur frottant les lèvres de beurre ou de saindoux, et en leur faisant ensuite flairer le lait quelque temps. Après on mettra devant eux de la vesce moulue, ou de l'herbe tendre, le matin avant le páturage, et le soir au retour. On continuera ce régime jusqu'au quatrième mois inclusivement : quelquesuns s'abstiennent de tirer leurs brebis pendant ce temps, mais il vaut mieux ne point discontinuer de les traire : les laines n'en sont que plus belles et les bêtes que plus fécondes. Lorsqu'on sèvie les agneaux, il y a des soins à prendre pour les empêcher de dépérir par envie de téter. Il faut les affriander par un choix de nourriture, et veiller à ce qu'ils ne souffrent jamais du froid ou du chaud. Quand ce besoin a cessé de se faire sentir, alors laissez-les se mêler avec le reste du troupeau. On ne châtre les agneaux qu'à l'âge de cinq mois, en choisissant, pour cette opération, une température moyenne. En fait de bélier, il faut choisir de préférence, pour élever, ceux dont

se saturent. Deinde dum matres cum grege pastum prodeunt, retinent agnos, ad quos cum reduotae ad vesperum, aluntur lacle, et rursus discernuntur, ne noctu a matribus conculcentur. Hoc item faciunt mane ante quam matres in pabulum exeant, ut agni satulli fiant lacte. Circiter decem dies cum præterierunt, palos offigunt, et ad eas alligant libro, aut qua alia re levi distantes, ne toto die cursantes inter se teneri delibent aliquid membrorum. Si ad matris mammam non accedet, admovere oportet, et labra agni unguere butyro aut adipe suilla, et olfacere labra lacte. Diebus post paucis objicere lis viciam molitam, aut lierbam teneram, ante quam exeunt pastum, et cum reverterunt. Et sic nutricantur quoad facti sunt quadrimestres. Interea matres corum his temporibus non mulgent quidam, melius qui omnino perpetuo, quod et lanæe plus ferunt, et agnos plures. Cum depulsi sunt agni a matribus, diligentia adlibenda est, ne desiderio senescant. Itaque deliniendım in nutricatu pabuli bonitate: et a frigore et astu ne quid laborent, curandum. Cum oblivione jam lactis non desiderant matrem, tum denique compellendum in gregem ovium. Castrare oportet agnum non minorem quinque mensium, neque ante quam calores aut frigora se fregerunt. Quos arietes submittere rolunt, les mères font habituellement deux agneaux d'une seule portée. Les recommandations sont pour la plupart applicables à l'espèce qu'on appelle pellita, à cause des peaux dont on l'enveloppe; précaution que l'on prend pour les brebis d'Attique et de Tarente, afin de mieux conserver la finesse de leur laine, et faire qu'elle se tonde, lave et teigne mieux. Les étables et mangeoires exigent également plus de soin, de propreté que celles des brebis à grosse laine. Le sol en doit être pavé, afin que l'urine n'y séjourne point. Les brebis ne refusent aucune nourriture; paille, feuilles de figuiers, feuilles de vigne. On peut aussi leur donner du son, mais par mesure réglée, pour qu'elles n'en aient ni trop ni trop peu; car l'un ou l'autre excès en fait un aliment contraire. Le cytise et la cyzeine sont ce qui leur convient le mieux. Cette nourriture les: engraisse, et leur donne du lait en abondance. Quant à l'état sanitaire, il y aurait beaucoup à dire; mais, je le répète, celui qui a charge de troupeau devra avoir par écrit, dans un livre, tout ce qui concerne ce sujet, et porter avec lui sa pharmacie. Reste à déterminer le nombre de têtes d'un troupeau : c'est tantôt plus, tantôt moins. II n'y a pas là-dessus de règle positive. En Épire, on confie d'ordinaire cent brebis à grosses laines à un seul berger; et l'on a deux bergers pour le même nombre de chèvres.

III. Cossinius prenant alors la parole : Allons, mon cher Faustulus, dit-il, assez bêlé comme cela. C'est à mon tour; permettez-moi de vous parler des chèvres avec le Mćlanthius d'Homère, et prenez en même temps une leçon de brièveté. Pour former un troupeau de chèvres, il faut les choisir avant tout d'âge à produire, et à pro-

potissimum eligunt ex matribus, quæ geminos parere solent. Pleraque similiter faciendum in ovibus pellitis, quæ propler lanæ bonitalem, ut sunt Tarentinæe et Atticæ, pellibus integuntur, ne lana inquinetur, quo minus vel infici recte possit vellus, vel lavari ac putari. Harum præsepia ac stabula ut sint pura, majorem adlibent diligentiam, quam lirtis.Itaque faciunt lapide strata, ut urina necubi in stabulo consistat. His quacunque jubentur, rescuntur, ut folia ficulnea, et palea, et vinaceæ. Furfures objiciuntur modice, ne parum, aut nimium saturentur. Utrumque enim ad eorpus alendum inimicum. At maxime amicum cytisum, et Medica. Nam et pingues facit facil. lime, et genit lac. De sanitate sunt multa, sed ea (ut dixi) in libro scripta magister pecoris habet : et qux opus ad medendum, portat secum. Relinquitur de numero, quem faciunt alii majorem, alii minorem. Nulli enim hujns moduli naturales. Illud fere omnes in Epeiro facimus, ne minus habeamus in centenas oves hirtas singulos loomines: in capras binos.

III. Cui Cossiniıs : Quoniam satis balasti, inq̧uit, 0 Faustule noster, accipe a me cum Homerico Melantlio cliordo de capellis, et quemadmodum oporteat breviter dicere, disce. Qui caprinum gregem constituere vult, in 
duirc le plus longtemps possible. II les faut done plutôt jeunes que vieilles. Quant anx conditions cxtéricures, prencz des bêtes grandes ct fortes, qui aient la tailleeffilée et la toison épaisse, à moins que ce ne soit de l'espèce à poil ras; car l'une et l'autre cxiste. Elles devront en outre aroir sous le museau deux excroissances de chair : e'est un signe de féconditć. Plus la chèvre a les mamelles grosses, plus elle a de lait, et plus son lait a de consistance. Les indices de qualité supérieure chez le bouc sont le poil blanc, la tête et le cou ramassés, et l'épiglotte allongée. On forme un meilleur troupeau par achat en bloc d'animaux ḷabitués à être ensemble, qu'cn allant les reeruter de eôté et d'autre. Je m'en réfère, quant à la race, à ce qu'Atticus vient de dirc touchant celle des brebis : avee cette différence toutefois que la première cspèce est dans ses habitudes aussi calme que l'autre cst remuante. Voiei ce que dit Caton, dans ses Origines, de sa singulière agilité : "Sur les monts de Soracte et Fiscella on voit des chèvres sauvages sauter de rochers en rochers, franehissant un intervalle de soixante pieds et plus. "Nos brebis et nos chèvres domestiques ont une originc sauvage. C'est de ces dernières que l'île de Caprée, sur les côtes d'Italie, tire son nom. Comme les chèvres qui donnent deux petits à la fois sont sans contredit d'une meilleure race que les autres, les mâles qui en proviennent doivent être destinés de préférence à la propagation de l'cspèce. Quelques personnes tiennent ì se procurer des ehèvres de l'île de Média, qui passe pour fournir les plus bcaux sujets de l'espèee. En ce qui concerne les achats, on devrait, sclon moi, s'écarter un peu de la formule ordinairc; car affirmer que des ehèvres sont saines, e'est ce que nulle personne d'esprit

eligendo animadvertat oportet, primum ætatem, ut eam paret, qua jam ferre possit fructum, et de is ean potius, quxe diutius : novella enim quam velus utilior. De forma videndum, ut sint firmx, magnx, corpus lene ut labeant, erebro pilo, nisi si glabræ sunt. Duo enim genera earum. Sub rostra duas ut mammulas pensiles habeaut : quod ex focenndiores sunt. Ubere sint gran. diore, ut et lac multum, et pingue liabeant pro portione. Hircus melior is et potissimum pilo albo, ac cervice et collo brevi, gurgulione longiore. Melior fit grex, si non est ex colleetis comparatus, sed ex consuetis una. De seininio dieo eadem, qux Attieus in ovibus. Iloe aliter, ovium semen tardius esse, quo hæ sunt plaeidiores; eontra caprile mobilius esse. De quarum velocitate in Originum libro Cato scribit hæc : In Sauracti, Fiscello eapræe feræe sunt, quac saliunt e saxo pedes plus sexagenos. Oves enim, quas pascimus, ortxe sunt ab ovibus feris, sic capre, quas alimus, a eapris feris sunt ortw, a queis propter Italiam Caprasia insula est noninata. De capris quod meliore semine ex, qua bis pariant, ex his potissimum mares solent submilti ad adınissuras. Quidam etiam dant operam, ut ex insula Media capras habeant, quod ibi sain ne peut faire entendre, puisque cet animal n'est jamais sans fièvire. Il y a done quelques mots à retrancher aux termes généraux du contrat, et c'cst le sens de la rédaction que Manilius nous cn donne dans ses livres : “ Me répondez-vous que ces chèvres sont aujourd'hui cn bon état, qu'elles boivent, et qu'elles sont bien et dûment ma propriétć? "De subtils physiologistes prétendent, et c'est un fait consigné dans les éerits d'Archélaïs, que les chèvres ne respirent pas, comme lo reste des animaux, par les narines, et que chez elles cette fonction sc fait par l'oreille. Quant à l'entretien, ce qui forme la première partie du sceond ordrc de considérations, voici ce que j'ai à en dire : L'exposition convenable pour les étables à chèvres est le levant d'hiver; ear ces animaux sont très-sensibles au froid. Comme pour le bétail en génćral, le sol de ces étables sera pavé de pierres ou de briques, afin qu'clles soient plus exemptes d'humidité et plus facilement tenues propres. On choisira la même exposition pour les pares où les chèvres stationnent la nuit dans les lointains pâturages, et le sol en devra être couvert d'une litière de feuillage. $\mathrm{Du}$ reste, ce qu'on vient de dire sur le régime alimentaire de la racc ovine est également applicable aux ehèvres, si ee n'est qu'elles aiment mieux gravir des hauteurs boisées que paitre de plain pied dans les prairies. Elles broutent avec une prédilection marquée les pousses d'arbrisseaux sauvages, et s'attaquent volontiers aux plans cultivés : d’où est venu le nom de capra (chèvre), dérivé de carpere (cueillir). Aussi, dans les baux de location, stipulc-t-on d'ordinaire l'interdietion de faire paître les chèvres', dont la dent est fatale aux plantations. Et les astronomes n'admettent cet animal dans le ciel qu'en dehor s

maximi ae pulclıerrimi existimantur fieri lıodi. De emtione aliter dico atque fit, quod capras sanas sanus nemo pro. mittit. Nunquam enim sine febri sunt. Itaque stipulantur paucis exceptis verbis : ae Mamilius scriptum reliquit sic : Illas capras hodie recte esse, et bibere posse, habereque recte licere, liax spondesne? De quibus admirandum illud, quod etiam Archelaus scribit, non ut reliqua animalia naribus, sed aurilous spiritum ducere solere pastores euriosiores aliquot dicunt. De alteris quatuor, quod est de pastu lıc dieo. Stabulatur pecus melius ad hibernos ex or. tus si spectat, quod est alsiosum. Id ut pleraque lapide, aut testa substerni oportet, eaprile quo minus sit uliginosum, ac lutulentum. Foris cum est pernoctandum, item in eandem partem cali qux spectent, septa oportet substerni virgultis, ne oblinantur. Nec multo aliter tuendun lıoc pecus in pastu, atque ovillum, quod tamen habet sua propria quædam, quod potius silvestribus saltibus deleetantur, quam pratis. Studiose enim de agrestibus fruticibus pascuntur, atque in locis cultis virgulta earpunt : itaque a carpendo capre nominatx. Ob hoc in lege locationis fundi exeipi solet, ne eolonus cajra uatum in fundo pascat. Harum enim dentes ininici satıonis, quas etiam astrologi ita rece. 
du cerele aux douze signes (les deux Chevreaux et la Chèvre ne sont pas loin du'Taureau). En ce qui concelne la propagation, les boucs destinés à la monte sont; comme les béliers, séparés quelque temps du troupeau, et on les présente aux ehèvres à la fin de l'automne; les femelles couvertes à cette époque mettent bas au bout de quatre mois, c'est-ǹ-dire dans la saison du printenıps. Touchant l'éducation des jeunes boucs, nous nous borneroas à faire remarquer qu'à l'âge de trois mois ils peuvent déjâ faire partie du troupeau. Que pourrais-je dire de la santć de ce bétail, qui, en quelque sorte, n'est jamais sain ? Toutefois celui ciui a la charge du troupeau devrait avoir par écrit, dans son livre, des recettes pour certaines de leurs maladies, ainsi que pour guérir les blessures qu'elles se font en sc battant, ou en paissant dans les buissons épineux. Reste à dèterminer la foree d'un troupeau. Elle doit être moindre pour les chèvres que pour les brebis. L'instinct des unes est de se disperser capricieusement et d'errer à l'aventure; celui des autres est de se réunir et de se masser en quelque sortc sur un même point. Aussi, dans la Gaule, préfère-t-on diviser les troupeaux de chevres. Les grands troupeaux sont trop sujets à la contagion, et exercent de trop grands ravages; eínquante têtes sont ceusées suffire pour en former un. Et l'accident arrivé dernièrement à Galérius vient à l'appui de cette opinion : ce chevalier romain possède environ mille jugera de terre dans les environs de Rome. Il entend dire un jour à un berger qui amenait dix chèvres à la ville, qu'elles lui rapportaient chacune un denier par jour. Galérius aussitôt de se former un troupeau de mille chèvres,

perunt in cxlum, ut extra limbum xn signorum excluserint. [Sunt duo Hoedi, et Capra non longe a Tauro.] Quod ad foturam pertinet, desistente autumno exigunt a grege in campos, hircos in caprilia, item ut in arietibus dictum. Quæ concepit, post quartum mensem reduit tempore verno. In nutricatu hodi, trimestres cum sunt facti, tum submittuntur, et in grege incipiunt esse. Quid dicam de earum sanitate, quae nunquam sunt sanæ? uisi tamen illud unum, quardan scripta habere magistros pecoris, quibus remediis utantur ad morbos quosdam earum, ac vulneratum corpus, quod usu venit is sepe, quod inter se cornibus pugnant, atque in spinosis locis páscuntur. Relinquitur de numero , qui in gregibus est minor caprino, quam in ovillo, quod capra lascivæ, et quæ dispergant se. Contra oves, qua se congregant et condensant in locum unum. Ita. que in agro gallico greges plures potius faciunt, quam magnos, quod in magnis cito existat pestilentia, quæ ad pernicien eos perducat. Satis magnum gregem putaut esse circiter quinquagenas. Quibus assentiri putant id, quod usu venit Gaberio equiti R. Is enim, cum in suburbano mille jugerum lıaberet, et a caprario quodam, qui adduxit capellas ad urbem $x$, sibi in dies singulos denarios (singulos) dare audisset, coegit mille caprarum, sperans se capturum de pradio in dies singılos denarium mille. espérant ainsi retirer chaque jour mille deniers de son fonds. Mais il lui fallut en rabattre; ear une maladie vint peu après enle ver tout son troupeau. Cependant du côté de Sallence et de Casinum on a des troupeaux de cent têtes. La mème divergence d'opinion se rencontre touchant le nombre des femelles que l'on peut faire couvrir par uI même mále. Quelques personnes, et je suis de ce nombre, comptent dix chèvres pour un bouc; d'autres, comme Ménus, en comptent quinze; d'autres, vingt, comme Murrius.

IV. Maintenant qu'un de nos porchers italiens entre en scène, et nous expose la théorie de son état : mais qui peut en parler plus pertinemment que l'hommequi a Scrofa(truie) pour surnom? Afin que vous le sachiez, dit alors Trémellius, vous et tous ceux qui m'écoutent, ce surnom n'est pas originaire dans ma famille, et je ne suis rien moins qu'un descendant d'Eumée. Le premier de nous qui l'ait porté est mon grand-père. Il était questeur de Licinius Nerva, préteur de Macédoine, et se trouvait commander l'armée en l'absence de ce dernier. Les ennemis, croyant l'occasion favorable pour un coup de main, entreprirent de forcer son camp. Mon grand-père, en exhortant les siens à courir aux armes et à faire une sortie contre les assaillants, se vanta de les repousser eomme la truie chasse ses petits d'auprès d'elle. Il tint parole : l'ennemi fut battu et dispersé; si bien que le préteur en recueillit le titre d'Imperator, et mon grand-père eut le surnom de Scrofa. Mais ni mon bisaieul, ni aucun des Trémellius, ne l'ont porté antérieurement; et je ne suis pas moins que le septième préteur de ma famille. Ce n'est pas que je refuse de vous dire ce que je sais du bétail portant soies. Je me suis toujours

Tantum enim fefellit, ut brevi omnes amiserit morbo. Contra in Sallentinis et in Casinati ad centenas pascunt. De maribus et fominis idem fere discrimen, ut alii ad denas capras singulos parent hircos, ut ego : alii etiam ad $x \mathbf{x}$, ut Menas : nonnulli etiam, ut Murrius, ad viginti.

IV. Sed quis e porculatoribus italicis prodit, ac le suillo pecore expedit? tametsi Scrofam potissimum de ea re dicere oportere, cognomen ejus sigmificat. Cui Tremellius : Ignorare, inquit, videre, cur appeller Scrofa. Ita. que ut etiam li propter te sciant, cognosce meam gentem suillum cognomen non liabere, nec me esse ab Eumico ortum. Avus meus primum appellatıs est Scrofa, qui quastor cum esset Licinio Nervæ prætori in Macedonia provincia relictus, qui præesset exercitui, dum prætor rediret, hostes arbitrati occasionem se liabere victoriac, impressionen facere coperunt in castra. Avus, cun colırtaretur milites, ut caperent arma, atque exirent contra, dixit, celeriter se illos ut Scrofa porcos disjecturum. Id quod fecit. Nam eo prælio hostes ita fudit, ac fugavit, ut eo Nerva protor Imperator sit appellatus, avus cognomen invenerit, ut diceretur Scrofa. Itaque proavus , ac superiores, de Tremelliis nemo appellatus Scrofa ; nec minus septimus sum deinceps pratorius in gente nostra. Nec tamen defugio, quin dican quae scio de suillo 
bcaucoup occupé d'agriculture, et conséquemment je ne puis être étranger à cc sujet, non plus que vous autres grands nourrisseurs de bestiaux. Quel cultivateur en effet n'a pas de pores chez lui ? et qui de nous n'a pas entendu dire à son père : " Bien insouciant ou bien pcu économe, est celui qui tirc de la boucheric et non de son fonds le lard de son garde-manger!" Pour avoir un troupeau de pores dans une bonne condition, il faut que chaque bête qui le compose soit d'âge ct de forme convenables. Par formes convenables on entend ampleur de membres, tête et pieds compris, et robe unicolore plutôt que bigarrée. Le verrat, avec ces mêmes qualités, doit avoir la tête particulièrement grosse. Les présomptions touchant la qualité de la race se forment sur l'aspect des animaux, leur progéniture ct lcur origine. Sur l'aspect, sont-ils verrat ou truie, la beauté relative de l'espèce; sur la progéniture, font-ils beaucoup de petits? sur l'origine; leur pays natal est-il réputé pour en produire de gros plutôt que de petits? Pour l'achat on se sert de la formulc suivante : "Me répondez-vous que ces truies sont saines, que la propriété m'en est bien et dûment acquise, franche de toute répétition; et qu'enfin elles ne proviennent point de troupeau malade? Quelques personnes y ajoutent : " Et qu'elles ne sont pas atteintes de la fièvre ni de la diarrhcé? "En fait de pâturages, ce sont les endroits marécageux qui conviennent à cette espèce de bétail, qui se plaít dans l'eau et même dans la fange. On dit que les loups, lorsqu'ils ont trouvé un porc, traincnt cette proie jusqu'à ce qu'ils trouvent de l'eau, leurs dents ne pouvant supporter l'extrême chaleur de sa chair. Les porcs se repaissent surtout de glands, mais aussi de fèves, d'orge, ct de toute autre espèce de grain. Cette nourriture non-seulement les engraisse, mais donnc à leur chair un goût très-agréable. En été, on les mène paitre le matin, et à midi on les fait stationner quelque part, où il y ait de l'ombrage et surtout de l'eau. Dans l'après-midi on les fait paitre de nouveau lorsque la chaleur est tombée. Jans l'hiver le pâturage ne leur convient que lorsque la gelée blanche a disparu, et que la glace est fondue entièrement. On enferme deux moisà l'a vance les verrats qu'on destine à la monte. L'époque la plus favorable pour l'accouplement est depuis Favonius jusqu'à l'équinoxe du printemps; car comme les truies portent quatre mois, elles mettront bas au moment où la terre abonde cn páturages. Il faut qu'clles aient un an avant d'être couvertes; et mieux serait d'attendre vingt mois, afin qu'elles aient deux ans à l'époque de mettre bas. La période de leur fécondité dure, dit-on, sept ans après la première portée. Pour les disposer à être saillies, on les mène dans des endroits humides et marécageux, où elles puissent se vautrer dans la fange, ce qui produit sur elles l'effet d'un bain pour l'homme. Quand toutes les truies sont pleines, on les sépare encore des verrats. Ces derniers commencent à saillir à huit mois, et cette faculté leur dure un an dans sa plénitude et va ensuite déclinañt jusqu'à ce qu'ils ne soient plus bons qu'à en voyer au boucher, par qui leur chair est distribuée au peuple. Les Grecs appellent le porc $\tilde{\delta} \varsigma$; ils l'appelaient autrefois $\theta \tilde{c} \varsigma$, dérivé du verbe $\theta$ ústv, immoler, comme pour faire entendre que ces animaux ont étéles premières victimes immolécs aux autels des dieux. La coutume en a subsisté dans les mystères de Cérès, dans les solennités qui accompagnent la pecore. Agri enim culturx ab initio fui studiosus : nec de pecore suillo milii et vobis, magnis pecuariis, ea res non est communis. Quis enim fundum colit nostrun, quin sues trabeat, et qui non audierit patres nostros dicere, ignavum, et sumpluosum esse, qui succidiam in carnario suspenderit potius ab laniario, quam cx domestico fundo? Ergo qui suum gregenı vult habere idoneum, eligere oportet primum bona atate, secuudo bona forma. Ea est, cum amplitudine membrórum, præterquan pedibus et capite, unicoloris polius quam varias. Cum hrec eaden ut habeant verres videndum, tum ntique sint cervicibus amplis. Boni seminis sues animadvertuntur a facie, et progenie, et regione (cxli.) A facie, si formosi sunt verres, et scrofa. A progenie, si porcos nultos pariunt. A regione, si potius ex lis locis, ubi nascuntur, amplas quam exilis pararis. Emi solent sic : lllasce sues sanas esse, habereque recte licere, noxisque præstari, neque de pecore morboso esse, spondesne? Quidam adjiciunt perfunctas esse a febri, et a foria. In pastu locus luuic pecori aptus uliginosus, quod delectatur non solum aqua, sed etiam luto. Itaque ob eam rein aiuut lupos cunı sint nacti sues, tralıere usque ad aquam, quod dentes fervorem carnis ferre nequeant. Hoc pecus alitur maxime glande, deinde faba, et ordeo, et cxtero frumento. Quae res non modo pinguitudinem efficiunt, sed etiam carnis jucundum saporem. Pastum exigunt restate mane, et antequam æstus incipiat, (meridie) subigunt in umbrosum locum, maxine ubi aqua sit. Post meridiem rursus lenito fervore pascunt. Hiberno tempore non prius exigunt pastum, quam pruina evanuit, ac colliquefacta est glacies. Ad fouturam verres duobus mensibus ante secernendi. Optimum ad admissuram tempus a favonio ad aequinoctium vernum : ita enim contingit, ut æstate pariat. Quatuor enim menses est prægnans. Et tunc parit, cum pabulo abundat terra. Neque minores admittendae quam anniculæ. Melius xx nienses expectare, ut bimæ pariant. Cum coperunt, id facere dicuntur usque ad septimum annum recte. Admissuras cum faciunt, prodigunt in lutosos limites ac lustra, ut volutentur in luto, quæ est illorum requies, ut lavatio hominis. Cum omnes conceperunt, rursus segregant verres. Verris octo mensiunı incipit salire : permanet, ut id recte facere possit, ad primum. Deinde it retro, quoad perreniat ad lanium. Ilic enim conciliator suilla carnis datıs populo.Sus græce dicitur ǔ olinı $0 u ̄ s$ dictus, ab illo verbo quod dicunt Qúeıv, quorl est immolare. Ab suillo enim genere pecoris im- 
eonclusion d'un traité de paix; et la tradition nous en fait retrouver des vestiges dans les cérémonies de mariage des anciens rois et des hauts personnages d'Étrurie, dont le sacrifice d'un pore pour les nouveaux mariés, chacun de leur côté, était la cérémoniepréalable. Le même usage existait chez les habitants du Latium, et dans les eolonies grecques d'Italie. Le nom de porcus chez nous et celui de yoipos chez les Grees est même encore employé par les femmes, les nourrices principalement, pour désigner les parties sexuelles d'une fille nubile. C'est une expression figurée de l'aptitude aux rites de l'hymen. On a dit que le pore était prédestiné par la nature à paraitre sur nos tables, et qu'clle avait animésa substance, comme l'homme la sale, dans ce scul but de conservation. La charcuterie des Gaules a toujours été renommée pour l'excellence et la quantite de ses produits. I'exportation considérable de jambons, de saueissons et autres confections de ce genre, qui se fait anuuellement de ce pays à Rome, témoigne de leur supériorité comme goût. Voici en quels termes parle Caton de leur quantité : On voit en Italie des fosses à conserver le lard, qui contiennent jusqu'à trois et quatre mille pièces de lard gaulois. Le porc arrive quelquefois à un tel degré d'embonpoint qu'il ne peut plus marcher ni mème se tenir sur ses pattes, et qu'il faut le transporter en charrette. Attilius, Espagnol aussi instruit que digne de foi, parle d'un pore tué en Lusitanie dans l'Espagne citérieure, dont le sénateur L. Volumnius reçut deux côtes avec une très-petite partie de filet, lc tout pesant vingt-trois livres. Le groin de l'animal, depuis le cou jusqu'au boutoir, avait, disait-il, un pied et trois doigts de longueur. Voiei, dis-je,

molandi initium primum sumptum videtur, cujus vestigia, quod initiis Cereris porci immolantur, et quod initiis pacis fuedus cum feritur, porcus occiditur, et quod nuptiarum initio antiqui reges ac sublimes viri in Hetruria in conjunctione nuptiali nova nupta et novus maritus primum porcum immolant. Prisci quoque latini, et etiam Græci in Italia idem factitasse videntur. Nam et nostræ mulieres, maxime nutrices, naturam, qua forminæ sunt, in virginibus appellant porcum, et graca yoïpov, significantes esse dignum insigni nuptiarum. Suillum pecus donatum ab natura dicunt ad epulandum. Itaque iis animam datam esse proinde ac salem, quæ serraret carnem. $\mathbf{E}$ queis succidias Galli optimas et maximas facere consueverunt. Optimarum signum, quod etiam nunc quotannis e Gallia apporlantur Romam pernæ tomacinæ, et taniacæ, et petasiones. De magnitudine Gallicarum succidiarum Cato scribit his verbis : In Italia in scrobes terna atque quaterna millia aulia succidia. Vere sus usqueadeo pinguitu. dine crescere solet, ut se ipsa stans sustinere non possit, neque progredi usquam. Itaque eas si quis quo trajicere vult, in plostrum imponit. In Hispania ulteriore, in Lusitania, sus cum esset occisus, Attilius Hispaniensis minime nendax, et multarum rerum peritus in doctrina, dicebat un fait qui n'est pas moins curicux, et dont j'ai été témoin oculaire. En Arcadie une truie avait tellement engraissć, qu'elle ne pouvait plus se lever; si bien qu'une souris avait fait un trou dans sa chair et s'y était mise en gésinc. La même chose, dit-on, est arrivée chez les Vénètes. La première portée d'unc truie donne la mesure de sa fécondité ultérieure, car les suivantes n'en diffèrent pas beaucoup. En ce qui concerne l'alimentation des pourceaux, autrement dite porculation, on laisse les petits pendant deux mois avec leur mère, et on ne les en sépare que lorsqu'ils sont en état de manger seuls. Les pourceaux nés en hiver sont toujours chćtifs : la cause en est d'abord dans la rigueur de la saison; puis dans le peu de lait que peut leur fournir à cette époque la mère, dont ils mordillent quelquefois les tettes au point de la blesser avec lcurs dents. II faut donner à chaque truie une cahute à part, où clle puisse élever ses petits séparément : autrement ceux-ei s'attacheraient à des truies étrangères, et il en résulterait un mélange qui finirait pa. détériorer la race.

L'annèe se trouve naturellement divisée en deux pour les truies. Elles mettent bas deux fois l'an, ont quatre mois de gestation à chaque portée, nourrissent pendant les deux autres. Les cahutes où elles sont enfermées doivent avoir trois pieds cn hauteur, et un peu plus en largeur; le degré d'élévation au-dessus du sol y doit êtrc calculé de mauière à empêcher de la part de la truie les mouvements qui la feraient avorter; mais il doit être suffisant pour que le porcher puisse aisément voir dans l'intérieur quand il y a risque pour les petits d'être écrasés par la mère.' Pour la facilitè du nettoiement, on y ménagera une

L. Volumnio senatori missam esse offulam cum duabus costis quæ penderet 11 et $\mathbf{x x}$ pondo : ejusque suis a cute ad os pedem et 11 digitos fuisse. Cui ego: non minus res admiranda, quum mi esset dicta, in Arcadia scio me esse spectatum suem, quæ præ pinguitudine carnis non modo surgere non posset, sed etiam ut in ejus corpore sorex exesa carne nidum fecisset, et peperisset mures. Hoc etiam in vineta factum accepi. Sus ad foeturam qua: sit foecunda, aninadvertunt fere ex primo partu, quod uon multum in reliquis mutat. In nutricatu quam porcu. lationem appellabant, binis mensibus porcos sinunt cum matribus. Secundum ea cum jan pasci possint, secernunt. Porci qui nati hieme, fiunt exiles propter frigora, et quod matres aspernantur, propter exiguitatem lactis, et quod dentibus sauciantur propterea mammæ. Scrofa in sua quæque hara suos alat oportet porcos, quia alienos non aspernantur : et ideo si conturbati sunt in fotura, fit deterius. Natura divisus earum annus bifariam, quod bis parit in anno, quaternis mensibus fert ventrem, binis nutricat. Ilaram facere oportet circiter trium pedum altam, et latam amplius paulo, ea altitudine abs terra ne dum exilire velit jragnans, abortet. Altitulinis modus sit ut subulcus facile circunıspicere possit, ne qui por- 
porte dans le senil, qui seraćle vée d'un pied et une palme de hauteur; ee qui empêche les pourceaux de sortir avec leur mère. Le porcher, chaque fois qu'il nettoiera les eahutes, devra y répandre du sable, ou toute autre matière propre ì dessécher l'humidité. Il faut donner aux truies qui ont mis bas une nourriture plus abondante, afin qu'elles puissent fournir du laitsuffisamment à leurs petits. On y mettra chaque jour cnviron deux livres d'orge détrempée, et la ration est doublée, c'est-à-dire répétće soir et matin, quand on n'a pas autre chose à leur donner. On appelle les petits laclentes (cochons de lait) tant qu'ils tettent; et quelquefois delici (de lacte) après le sevrage. Dix jours après leur naissance, ils sont regardés comme purs; et nos ancêtres les appelaient alors sacrés, c'est-à-dlre propres à servir de victimes. Et nous trouvons ici le commentaire d'un passage des Ménechmes de Plaute. l'un des personnages de la pièce, dont la seène est à Epidamne, eroyant qu'un autre est fou, et a besoin d'un saerifice expiatoire, demande : * Combien coûtent ici les pores sacrés $"$ ? Ceux qui ont des vignes donnent à leurs pores le mare et les épluehures de raisin. Dès que les pourceaux ne sont plus lactentes (coehons de lait), ils deviennent nefrendes, e'est-à-dire qui ne peuvent encore frendere (casser la feve).

Porcus est un vieux mot grec tombé en désuétude, qu'on a remplaeé dans ce pays par celui de Koipov. Il faut faire boire deux fois par jour les truies pendant leur nourriture : elles en ont plus de lait. La truie doit faire autant de petits qu'elle a de mamelles. Si elle en fait moins, on la regarde comme n'étant point de bon rapport; sl elle en fait davantage, on crie au prodige.
Nous avons cu ce genre la vieille tradition de la truie d'Énće, qui mit bas à Lavinium trente pourceaux blanes. Et le miraele se trouva confirıné, quand trente ans plus tard Albo fut fondée par les habitants de Lavinium. On voit eneore dans cette dernière ville des monuments publies de cette truic et de ses pourceaux. Leur effigie $y$ est coulée en bronze, et les prêtres nous montrent le eorps de la mère eonservé dans la saumure Dans les premiers jours les truies peuvent nourrir jusqu'à huit poureeaux. Passé ce moment, les éleveurs entendus ne manquent pas d'en soustraire la moitié, à mesure qu'ils grandissent ; car la mère ne peut avoir assez de lait pour que toute la portée réussisse. Pendant les dix premiers jours, les truies ne devront point quitter leurs cahutes, si ce n'est pour aller boire aux abreu voirs. Au bout de ce temps on peut les mener paître, mais seulement dans le voisinage, afin qu'elles puissent revenir souvent allaiter leurs petits. Ceux-ci, quand ils ont pris une certaine croissanee, suivent volontiers la mèrc au pâturage : alors on les enferme à part ou on les fait paître séparément, pour les aceoutumer à supporter facilement eette privation : ils y sont faits au bout de dix jours. Le poreher devia ainsi habituer les pores à obéir au son du cornet. Pour y parvenir il aura soin de faire retentir une fois cet instrument avant d'ouvrir la porte, et de leur faire trouver en sortant de l'orge répandue en trainées. On en perd moins de cette manière qu'en leur présentant le grain en tas, et tous peuvent en approeher plus aisément; on les habitue ainsi à se réunir au son du cornet, et l'on n'a plus à craindre qu'ils ne s'égarent lorsqu'ils sont dispersés dans les bois. Un an est le bon âge pour châtrer les verrats; au moins faut-il qu'ils ccllus a matre opprimatur; et ut facile purgarc possit cubilc, in haris ostinm csse oportet, et limen inferius altum palmipedale, ne porci ex hara, cum mater prodit, transilire possint. Quotiescunquc haras subnlcus purgat, toties in singulas arenam injicerc oportet, aut quid aliud qnod exugat humorcm ; et cum pepererit, largiore cibatu sustentare, quo facilins lac suppeditarc possit. In quibus hordei circiter binas libras aqua madefactas darc solent, et hoc quoquc conduplicant, ut sit mane et vesperi, si alia quae objiciant non habuerint. Cum porci dcpulsi sunt a mam. ına, a quibusdam delici appellantur, neque jam lactentes dicnntur. Qui a partn decimo die habentur puri, et ab eo appellantur ab antiquis sacres, quod tum ad sacrificium idonei dicuntur primum. Itaque apud Plautum in Menæchmis, cum insanum quem putat, ut pietur in op. pido Epidamno, interrogat : Quanti lic porci sunt sacrcs? Si fundus ministrat, dari solent vinacea, ac scopii ex uvis. Amisso nomine lactentis, dicuntur nefrcndes, ab co quod ıondum fabam frenderc possunt, id est, frangere. Porcus graecum est nomen antiquum, scd obscuratum, quod unc enm vocant yoĩpos. In eorum fretu scrofa bis die ut bibant, curant, lactis causa. Parcre tot oportet porcos, quot mamnıas lıabeat. Si minus pariat, frnctuariam ilo- neam non esse. Si plures pariat, esse portentum. In quo illud antiquissimum fuisse scribitur, quod sus Eneæ Lavinii $x \times x$ porcos pepererit albos. Itaque quod portenderit, factum $x \times x$ annis, ut Lavinienses condiderint oppidum Albam. Hujus suis, ac porcorum cliam nunc vestigia apparcnt Lavinii : quod et simulacra cornm ahenca etiam nunc in publico posita, et corpus matris ab sacerdotibus, quod in salsura fuerit, demonstratur. Nutricari octonos porcos parvulos primo possunt : incremento facto, a peritis dimidia pars removeri solet, quod ncc mater potest sufferre lac, neque congenerati alescenda roborari. A partu decen diebus proximis non producunt ex haris matrem proterquam potum. Proteritis decem diebus sinunt exire pastum in propinquum locnm villa, ut crebro reditn lacte alere possit porcos. Cum crevcrunt, cupinnt sequi matrem pastum : domique secernunt a matribus, ac seorsum pascunt, ut desiderium ferre possint parentis, quod decem diebus assequuntur. Nutrices subulcus debct consuefacere, ommia ut faciant ad bucinam. Primo cum inclusernnt, cum bucinatum cst, apcriunt, ut exire possint in eum locum, ubi ordeum fusum sit in longitudine. Sic enim mimus disperit, quam si in acervos positum, ct plures facilius accodunt. Ideo ad bucinam 
n'aient pas moins de six mois. Ils quittent le nom de verrat après eette opération, pour prendre celui de maïales. Touchant le régime sanitaire, je me borne à une observation. Si le lait de la mère vient à manquer aux petits, donnez-leur jusqu'à l'âge de trois mois du froment rôti (eru, il relàche trop le ventre). Reste eneore la question du ehiffre.Généralement on compte dix verrats par cent truies; d'autres en veulent moins de dix. On n’est pas fixé non plus sur la force du troupeau : je regarde, moi, cent têtes eomme un nombre convenable. Quelques.uns le font plus grand, et vont a cent einquante. Il en est qui doublent le premier nombre; d'autres vont même eneore plus loin. lin général, plus un troupeau est restreint, moins il est eoûteux, et moins le porcher a besoin d'aides. Or la question pour ehaeun est eelle des plus grands profits, et non du plus ou moins grand nombre de têtes : $c^{\prime}$ est done par les eireonstanees qu'il faut se déterminer. Ainsi parla Serofa.

V. En ce moment survient le sénateur Q. Luciénus, l'homme du monde le plus aimable et le plus enjouć, et notre ami commun à tous. Salut, ehers Co-Epirotes, dit-il en entrant; salut aussi à

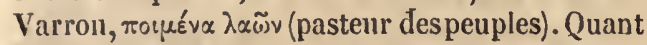
à Scrofa, je lui ai déjà donné le bonjour ee matin : on lui rend des saluts, non sans le gronder d'arriver si tard au rendez-vous. Patienee, dit-il, manvais sujet que vous êtes, voici mon dos et un fouct; vous, Murrius, venez çà, et voyez-moi payer rançon à la déesse Palès, afin d'en pouvoir témoigner, au cas où ees gens-là voudraient me faire payer deux fois. Attieus se tournant alors vers Murrius, Veuillez, lul dit-il, mettre Lucié- nus au fait, tant de ce qui a été dit que de ce qui reste à dire, afin qu'il puisse prendre role dans l'entretien. En attendant nous allons passer au sceorid acte, c'est-à-dire mettre en scène le gros bétail. Ceei est mon rôle, dit Vaccius, puisqu'il est question de bocufs et de vaches. Je vous ferai part de mes notions sur cette matière: ceux qui y sont étrangers pourront s'instruire; les autres me relèveront, si je me trompe. Vaccius, lui dis-je, prenez-y garde. C'est un sujet eapital que le bœuf en fait de bétail; en Italie surtout, pays qui lui doit le nom qu'il porte. Car en Grèce autrefois, si l'on ell croit Timée, un

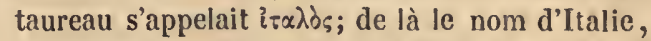
contrée où bœufs et veaux (vituli) abondent, et sont d'une beauté extraordinaire. Selon d'autres, l'Italie doit son nom au fameux taureau Italus, qu'Hercule poursuivit depuis la Sieile jusqu'en ce pays. Le bœuf est le ministre de Cérès, et l'associé de l'homme dans les travaux rustiques. Les aneiens le regardaient comme inviolable, et ils punissaient de mort quiconque tuait un de ees animaux : témoin les lois de l'Attique et du Péloponnèse. C'est encore au taureau que Buzugès d'Athènes et Onogure d'Argos doivent leur célébrité. Je sais, dit Vaceius, que le taureau a quelque chose de majestueux; que son nom ( $\beta$ ũ $\varsigma$ ), en composition, est signifientif de grandeur; exemples :

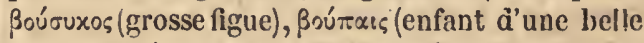

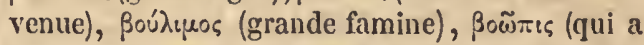
de grands yeux;) et que de plus on appelle $b u$ mamma (pis de vache) le raisin à gros grains. Je sais eneore que e'est sous la forme d'un taureau que Jupiter, amoureux d'Europe, enleva de son convenire dicuntur, ut silvestri loco dispersi ne dispe. reant. Castrantur verres commodissime anniculi, utique ne minores, quam semestres : quo facto nomen mutant, atque e verribus dicuntur maiales. De sanitate suun unum - unodo exempli causa dicam. Porcis lactentibus si scrofa - lac non potest suppeditare, triticum frictum dari oportet, (c'udum enim solvit alvum) vel ordeum objici ex aqua, quoad fiant trimestres. De numero, in centum sues decem verres satis esse putant. Quidam etiam hinc demunt. Greges majorum inaquabiles habent. Sed ego modicum puto ceutenarium. Aliquot majores faciunt, ita ut ter quinquageuos habeant. Porcorum gıegem alii duplicant, alii etiam majorem faciunt. Ninor grex, quam major, minus sumptuosus, quod comites subuleus panciores quærit. Itaque gregis numerum pastor ab sua utilitate constituit, non ut quot verres liabeat : itl enim a natura sumendum. Ilac lic.

V. At Q. Lucienus senator, lımo quansis lumanus, ac jocosus, introiens, fauniliaris omniun nostrum, бuvn-

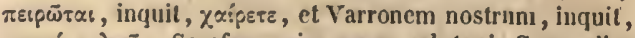
$\pi \circ \mu \varepsilon \varepsilon \alpha \lambda \alpha \omega \tilde{v}$. Scrofam enim mane salutavi. Cum alius eum salutasset, alius conviciatus esset, qui tam sero venisset ad constitutum : Videbo jam ros, iuquit, balatrolies, et hue afferam meunı corium, ef flagra. Tu vero, Murri, reni mi adrocatus, dum asses solvo Palilibus, si postea a me repelant, ut testimonium perhibere possis. Atticus Murrio: Narra isti, inquit, eadem, qui sermones sint labiti, et quid reliqui sit, ut ad partes paratus veniat : nos interea sccundum actım de majoribus adtexamus. In quo quidem, inquit Vaccius, meæ partes, quoniam boves ibi. Quare dicam, de bubulo pecore, quam acceperim scientiam : ut si quis quid ignorat, discat; si quis scit, nuncubi labar observet. Vide quid agas, inquam, Vacci. Nam bos in pecuaria maxima debet esse auctoritate : prosertim in Italia, quæ a bubus nomen !rabere sit existimata. Gracia enim antiqua (ut scribit Timæus) tall-

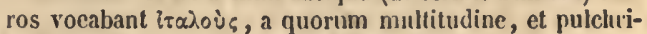
tudine, et foetu vitulorum, Italiam dixerunt. Alii scripselunt, quod e Sicilia IIercules persecutus sit co nobilem taurum, qui dicerelur Italus. Ific socius lıominum in rustico opere, et Cereris minister. Ab hoc antiqui manus ita abstineri volnerunt, ut eapite sanxerint, si quis oecidisset. Qua in re testis Attice, testis Peloponuesos. Nam ab hoc pecore Athenis Buzuges nobilitatus, Argis 'Ovó rupos. Novi, inquil ille, majestatem boum, ct ab his diei ple-

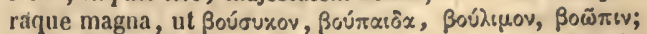
livam quoque bumammam. Præeterea scio hunc esse, in quem potissimum Juppiter se convertit, cuin exportavit per mare e Plocnice anans Europam; hunc esse, qui filios Neptuni e Menalippa servarit, ne in stabulo infau. 
pays cette belle Phénicienne, et traversa la mer avec elle. Je n'ignore pas non plus que c'est un taureau qui empêcha les enfants de Neptunc ct de Ménalippe d'être écrasés dans une étable par un troupeau de bœufs. Je sais enfin que les abeilles qui nous donnent le miel le plus doux naissent du cadavre d'un bœuf en putréfaction; ce qui fait que les Grecs les appellent Boúyovas (nées d'un bœuf), expression que Plautius a latinísée, Iorsqu'il disait au préteur Illyrius, accusé d'avoirécrit contre le sénat : Soyez tranquille, je vous renIrai aussi innocent que celui qui a écrit la Bugonia (naissance des abeilles).

Il y a quatre âges pour la race bovine. Au premier âge, l'animal s'appelle'veau ; au deuxième, juvencus (bouvillon); au troisième, taureau jeune; au quatrième, taureau fait. La femelle prend successivement, suivant l'âge, les dénominations de génisse, de jeune vache, et de vache. Taura est le nom qu'on donne à une vache stérile. Une vache pleine se nomme horda; d'où le mot hordicalia, fêtes où l'on immole des vaches pleines. Quand on veut achetcr un troupeau de gros bétail, il faut d'abord s'assurer que les bêtes ont atteint l'âge de génération, et sont encore en état de produire. On les choisira saines et bien prises dans leurs membres, de grande taille et de forme allongée, noires par les cornes, larges du front, avec les yeux grands et noirs, les oreilles velues, les joues raplaties, l'épine dorsale plutôt concave que convexe, les naseaux ouver's, les lèvres noirâtres, le cou long et musculeux, le fanon pendant, le coffre développé, les côtes bien attachées, les épaules larges, le fessier charnu, une queue qui balaye lcurs sabots et se termine en bouquet de poils lé.

tes grex boum obtereret. Denique ex hoc putrefacto nasci dulcissimas apes mellis matres, a quo eas Graci ßouróvas appellant, et hinc Plautium locutum esse latine, cum llirrium pratorem renunciatum Romam in Senatum scriptum liabere. Sed bono aninıo es, non minus satisfaciam tilbi, quam quił Bugoniam scripsit. Primum in bu. bulo genere ætatis gradus dicuntur quatuor. Prima vitulorum, secunda juvencorum, tertia boum novellorum, quaita vetulorum. Discernuntur in prima vitulus et vi tula; in secunda juvencus et juvenca; in tertia et quarta, taurus et vacca. Quæe sterilis est vacca, taura appellata; qua pragnans, loorda. Ab eo in fastis dies hordicalia no. minantır, quod tunc lıordæe boves immolantır. Qui gregen armentorum emere vult, observare debet primum, ut sint lıæ pecudes retate potius ad fructus ferendos integrae, quam jam expartæe; ut sint bene compositæ, ut integris membris, oblongæ, a mpla, nigrantibus cornibus, latis frontibus, oculis magnis et nigris, pilosis auribus, compressis malis, subsimi, ne gibberi, sed spina leviter remissa, apertis naribus, labris subnigris, cervicibus crassis ac longis, a collo palearibus demissis, corpore amplo, bene costatos, latis humeris, bonis clunibus, codam profusam assque ad calces ut liabeant, inferiorem partem frequen- grèrement frisés, les jambes courtes et droites, légèrement renflées au genou, et tournées en dehors, les pieds étroits, et qui ne s'entrechoquent point dans la marche; les ongles lisses, serrés et bien égaux; le poil uni et doux au toucher. En fait de couleur, le noir a le premier rang; le poil rouge foncé, le second; le rouge pâle, le troisième; le blanc ne vient que le quatrième : ce pelage leur indique donc le dernier, et le noir, le premier degré dans l'échelle de force des animaux. Des deux intermédiaires, le second vaut mieux que le troisième; et tous sont préférables en pelage pie (tacheté de noir et de blane). Il ne faut prendre les males que de bonne racc ; ce dont on juge par leurs formes extérieures, et par celles des veaux issus d'eux, qui doivent leur ressembler en tout. Leur provenance est aussi un point essentiel. La race gauloise est généralement la meilleure que nous ayous eń Italie, ct la plus propre au travail; le bœu ligurien est paresseux. Ceux d'Épire sont les meilleurs de toute la Grèce, et l'emportent même sur ceux d'Italie; quelques personnes cependant ac. cordent à ces derniers, comme victimes à offrir dans les sacrifices et les prières publiques, une préférence méritée, par leurs formes colossales et leur pelage éclatant. C'est ce qui fait que les bœufs de poil blane sont moins communs en Italie que dans la Thrace, notamment vers le golfe Mélas, où l'on n'en rencontre guère d'une autrc couleur. Voici les termes de marché usités pour ce genre de bétail, lorsqu'il a déjà subi le joug: "Me répondez-vous que ces bœufs sont sains, et qu'en les prenant je suis à l'abri de toute répétition ultérieure? S'ils ne sont pasdomptés, on stipule comme il suit : Me répondez-vous

tibus pilis subcrispam, cruribus potius minoribus, rectis, genibus eminulis, distantibus inter se, pedibus non latis, neque ingredientibus qui displodantur, nec cujus un. gnlae divaricent, et cujus ungues sint leves et pares, corium atlactu non asperum ac durum, colore potissimum nigro, dein robeo, tertio lielvo, quarto albc. Mollissimis enim lic, ut durissimus prinus. De mediis duobus prior quam posterior melior; utrique pluris quam nigri, et albi. Neque non præterea, ut mares seminis boni sint, quorum et forma est spectanda, et qui ex his orti sunt, ut respondeant ad parentum speciem : et præterea qui. bus regionibus nati sunt, refert. Boni enim generis in Italia plerique Gallici ad opus : contra nugatorii Ligustici. Transmarini Epirotici non solum meliores totius Grocia, sed etiam Italix. Tametsi quidam de Italicis, quos prop. ter amplitudinem præstare dicunt, ad victimas faciunt, atque ad deorum servant supplicia. Qui sine dubio ad res divinas propter diguitatem amplitudinis el coloris præponendi : quod eo magis fit, quod albi in Italia non

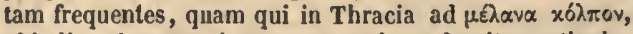
ubi alio colore pauci. Eos cum emimus domitos, stipulamur, sic : Illosce bores sanos esse, noxisque præstari? cum emimus indomitos, sic : Illosce jurencos sanos recte, 
que ces bouvillons sont sains, qu'ils proviennent d'un troupeau sain, et qu'en les prenant je suis à l'abri de toute répétition ultérieure? „ Les formules sont moins concises, si l'on suit les prescriptions de Manilius. L'on retranche la clause de santé, quand les animaux sont achetés pour la boucherie ou pour les autels. Les forêts où les bœufs trouvent abondamment de jeunes pousses ct du feuillage à leur portée sont les lieux de pâturage qui leur conviennentle mieux. Aussi on les tient l'hiver au bord de la mer, et l'été sur les hauteurs boisées. Quant à la propagation de l'espèce, voici les règles que j'observe. Un mois avant l'accouplement, j'empêche mes vaches de se gorger de nourriture, parce que, maigres, elles conçoivent plus facilement. Mes taureaux, au contraire, sont engraissés deux mois à l'avance, a vec force paille et foin, et fourrage vert; et pendant tout ce temps jem'attacheà les séparer des femelles, comme Atticus. Je prends pour soixante-dix vaches deux taureaux, l'un d'un an, l'autre de deux; jattends pour leur livrer la femelle, le lever de l'astre que les Grees appellent $\Lambda$ úp $\alpha$ et les Romains Fides, et je réunis ensuite mes taureaux au reste du troupeau. On tient comme indicatif de sexe, pour le fruit conçu, le cóté par où le taureau se retire après l'acte consommé, prenant la droite de la vache, si c'est un mâle; et la gauche, si c'est une femelle. A vous, lecteurs d'Aristote, ajouta-t-il en se tournant vers moi, d'expliquer cette circonstance. Ne faites pas saillir une vache avant deux ans, afin qu'elle en ait trois lorsqu'elle vêle pour la première fois. Mieux serait encore qu'elle en eût quatre. Les vaches sont fécondes dix ans, et quelquefois plus. L'éprque de conception la plus favorable pour elles est la période de quarante jours que suit le

deque pecore sano esse, noxisque prastari spondesne? Paulo verbosius lıne, qui Mamilii actiones sequuntur. Lanii, qui ad cultrum bovem emunt, et qui ad altaria, lostix sanitatem non solent stipulari. Pascuntur armenta commodissime in nemoribus, ubi virgulta, et frons multa : lieme [cum libernant] secundum unare, astn abiguntur in montes frondosos. Propter foeturam liac servare soleo. Ante admissuram inensem ınum, ne cibo et potione se impleant, quod existimantur facilius macra concipere. Contra, tauros duobus mensibus ante admissuram lierba et palea ac furno facio pleniores, et a fominis secerno. Habeo tauros tolislem, quot Atticus, ad matrices Lxx duo, unum anniculun, alterum bimum. Hoc secundum astri exortum facio, quod Graci vocant $\Lambda$ upxv, Fidem nostri. Tum denique tauros in gregem redigo. Mas an fomina sit concepta, significat descensu taurus cum init. Siquidem, si inas est, in dexteriorem partem abit : si foenina, in sinisteriorem. Cur loc fiat, vos videritis, inquit mili, qui Aristotelem legitis. Non minores oportet inire bimas, ut trimx pariant; co melius s̀i quadrinı. Pleræque pariunt in decem annos, quadan etiam in plures. Ipxime idoneum tempus ad concipiendum a Delplini lever du Dauphin, un peu après. Car unc vachs qui aura conçu à cette époque vêlera dans la saison la plus tempérée de l'annćc, le temps de sa gestation étant de dix mois. J'ai trouvé. dans un livre à ce sujet, une assertion bien sirgulièrc : c'est qu'un taureau châtré est encore prolifique quand on le mène saillir immédiatement après l'opération. On choisira pour faire paitre les vaches des lieux bas, abondants en herbe, et assez spacieux pour qu'elles ne se gênent, ne se heurtent, ni ne se battent. Quelques-uns, pour éviter la piqûre des taons, et de certains insectes qui les attaquent sous la queue et les rendent furieuses, les tiennent enfermées pendant l'ardeur du jour, et mollement couchées sur une litière de feuilles ou de verdure. En ćté on doit les mcner boire deux fois par jour, ct une seule fois elr hiver. Lorsqu'elles sont prêtes à vêler, il faudra mettre du fourrage frais près des étables, pour les affriander quand elles sortent; car en cet état elles sont sujettes à être dégoûtées. Les lieux où elles se retirent doivent être préservés du froid, qui les maigrit autant que la faim. Durant l'allaitement il faut séparer à l'étable les petits de leurs mères; de crainte qu'ils ne soient écrasés pendant la nuit. On ne les laissera approcher d'elles qu'une fois le matin, et une fois au retour des pâturages. A mesure que les veaux grandissent, il faut soulager les mères, en leur mettant du fourrage vert dans la crêche. Le sol, dans les étables à vaches comme dans toutes autres, doit être construit en pierre ou matériaux équivalents, afin de conserver saine la corne de leurs pieds. A partil de l'équinoxe d'automne, les veaux paissent a vec leurs mères. Il ne faut pas les châtrer avant l'âge de deux ans. Si l'opération a lieu plus tôt, ils ont peine à s'en remettre plus

exortu usque ad dies xu, aut paulo plus. Qux enin ita conceperunt, temperatissimo anni tempore pariunt. Vaccæe enim mensibus decem sunt prægnantes. De quibus admirandum scriptum inveni, exemptis testiculis, si statim admiseris taurum, concipere. Eas pasci oportet in locis viridibus, et aquosis. Cavere oportet, ne aut angustius stent, aut feriantur, aut concurrant. Itaque quod eas æs. tate tabani concitare solent, et bestiolæ quædam miunta sub cauda, ne concitentur, aliqui solent includere septis. lis substerni oportet frondem, aliudve quid in cubilia, quo mollins conquiescant. Estate ad aquam appellendum bis, lieme semel. Cum parere copperunt, secundum sta. bula pabulum servari oportet integrum, quod egredientes degustare possint : fastidiosæ enim fiunt. Et providendum, quo recipiunt se, ne frigidus locus sit. Algor enim eas et famis macrescere cogit. In alimoniis armenticium pecus sic contuendum, lactentes cum matribus ne cubent : ob. teruntur enim. Ad eas mane adigi oportet, et cunı redierunt e pastu. Cum creverunt vituli, levandie matres pabulo viridi objiciendo in prasepiis. Item his, ut fere in omnibus stabulis, lapides substernendi, aut quid item, ne ungnla putrescant. Ab requinoctio autununali ına jas. 
tard; ils deviennent indoeiles, et impropres au travail. Chaque année, suivant la pratique adoptéc pour toute espèce de bétail, on fait un triagre des bêtes de rebut, que l'on retranche du troupeau; car elles y tiennent inutilement la place qu'oceuperaient des sujets productifs. Lorsqu'une vache a perdu son veau, remplacez-lc par une autre dont la mère n'a pas assez de lait pour le nourril. Aux veaux de six mois on donne du son de froment, de la farinc d'orge, de l'herbe bien tendre, et on les fait boire matin et soir. Les précautions sanitaires sont multiplices. J'ai extrait des livres de Magon toutes les prescriptions qui s'y rapportent, et je les fais lire souvent à mon bouvier. J'ai déjà dit que le rapport du nombre des taureaux à celui des vaches est de deux pour solxante, et qu'il faut un male d'un an et un de deux. Certaines personnes ccpendant veulent que la proportion soit plus ou moins forte. Notre Attieus, par exemple, n'a cue deux taureaux pour soixante-dix vaches. La force du troupeau varie également. Mini, je suis de l'avis de ceux qui regardent cent têtes comme un nombre suffisant. Atticus et Luciénus, ont des troupeaux de cent vingt têtes chacun. Ainsi parla Vaccius.

VI. Murrius, qui était revenu a vee Luciénus, pendaut que Vaccius parlait, dit alors: Moi, je me propose de traiter les ânes; car je suis de Réate, c'est-à-dire d'un pays d'où viennent les meilleurs et les plus grands. J'y ai fait des sujets que j'ai vendus même à des Arcadiens. Celui qui veut former un beau troupeau d'anes doit avant tout prendre les mâles et les femelles à l'âge où l'on peut en tirer lignée le plus longtemps possible. II les choisirn robustes, de belle forme, de bonne taille et de bonne race, $c^{*}$ est-à-dire originaires l"un pays réputé pour cette production. C'est ce qui fait que l'Areadie est le marché aux ânes pour le P'éloponnèse, et Réate pour l'Italie; car de ce queles murènes ont si bon goùt sur les côtes de Sicile, ct les esturgeons sur celles de Rhodes, il ne s'ensuit pas qu'on trouve ces poissons de même qualité dans toutes les mers. Il y a deux espèces d'ânes : les ânes sauvages qu'on appelle onagres, et quiabondent en Phrygie et Lyeaonie, et les ânes privés, comme ils sont tous en ltalie. L'âne sau. vage est propre à la propagation de l'espèce, car sa progréniture s'apprivoise facilement; tandis que celle d'un âne privé n'est jamals sauvage. Les petits resseınhlent toujours à leurs père et mère. Il faut done bien choisir ceux-ci sois le rapport des formes extérieures. Les conditions de vente et de livraison sont à peu près les mêmes que pour tout autre bétail, et contiennent également des clauses de garantie sanitaire, et contre toute répétition ultérieure.

La farine et le son d'orge conviennent parfaitement aux ânes pour nourriture. Les ânesses doivent être couvertes avant le solstice, pour mettre bas au solstice de l'année suivante; car elles portent une année entière. On fera bien de ve point les faire travailler pendant la durée de la gestation, car la fatigue nuit à leur fruit. Quant au male, il faut continuer à l'employer, car pour lui ce sont les intermittences de travail qui sont nuisibles. Pour nourrir les petits, on suit les mêmes règles que pour les poulains. La première année, on les laisse avec leur mère. A partir de la seconde, on nc les en sépare pas sauf, la nuit, ayant toutefois soin de les attacher avec un licou un peu lâche, ou quelque lien analoguc. La cuntur cum matribus. Castrare non oportet aute bimatum ; quod diflicnlter, si aliter feceris, se recipiunt. Qui autem postea castrantur, duri et inutiles fiunt. Item ut in reliquis gregilus pecuaris, delectus quotannis labendus, el rejicula rejiciundx, quod locum occupant earun quxe ferre possmut fructus. Si quæ amisit vitulum, ei supj:0nere oportet eos, quibus non satis lactis prabent matres. Semestribus vitulis objiciunt furfures triticeos, et farinam ordecteam, et teneram lierbam : et ut bibant mane et vesperi, curant. De sanilate sunt complura, qua exscripta de Magnis libris, armentarimm menm crebro ut aliquil legat, curo. Numerus de tauris et vaceis sic lıabendus, ut in sexaginta unus sit anniculus, alter binus. Quidam labent aut minorem, aut majorem Itumerım [gregrmm. Nam apud eum duo tauri in septuaniuta matribus sunt. Numernm gregum alins facit aliun. Quidam centenarium modicum putant esse, ut ego. Atticus centumviginti haleet, ut Lucienus. Haec ille.

VI. At Mnrrius, qui, dum lorjuitur Vaccius, cum Lucieno rediisset, Ego, inquit, de asinis potissimum dican, q̧ood suแ heatinus, ubi optimi et maximi fiunt, e quo seminio ego lic procreavi pulles, et ipsis $\Lambda$ rcadibus ven. didi alinguoties. Jgitur asinorum gregem yui facere vult bonum, primum vilendum, ut mares fominasque bona atate sumat, utique ut quan diutissime fructum ferre possint : firmos, omnibus partibus lonestos, corpore amplo, seminio bono : ex his locis, unde optimi exeunt, quod faciunt Peloponnesii, cum potissimum eos ex Arca. dia emant; in Italia ex agro lientino. Non enim si mura:nxe optimx flutic sunt in Sicilia, et ellops ad Plıodon, continuo hi pisces in omni mari similes nascuntur. Hormm genera duo. Unum ferum, (1uos vocant onagros, in Plırygia et Lycaonia sunt greges multi. Alterum mansuetum, ut sunt in Italia omnes. Ad seminationem onagrus idlo. neus, juod e fero fit mansuctus facile, et e mansueto ferus Inuncuam. Quod similes parentmm genuntur, eligendi et mas et formina, cum dignitate ut sint. In mercando item ut caterx plecudes emtionibus, et traditionibus do. minum mutant, et de sauitate ac noxa solet caveri. Commode pascuntur farre, et furfuribus ordeaceis. Admittuı. tur ante solstitium, ut eoden tempore alterius anni pariant. Duodecimo enim mense conceptum semen reddunt. Pragnantes opere levant. Venter enim labore nationen reddit deteriorem. Marem non dijungunt ab opere, quoul remissione laboris lit deterior. In pastu eadem fere obsetvant, yłæ in erpuis. Secundum partum pullos anno nou 
troisième année, on commence à les dresser pour l'espèee de travail à laquelle on les destine. Touchant la quantité, on n'a pas ordinairement d’ânes en grande réunion, si ce n'est pour le transport des marchandises. Leur occupation la plus ordinaire est de trainer la meule, de porter aux ehamps, de labourer même, dans les terres légères, comme celles de Campanie. On ne les voit guère en nombre que dans les convois organisés pour amener à dos d'âne de Brindes ou d'Apulie à la côte, les huiles, lés vins, les blés, et autres denrées.

VII. A mon tour, dit alors Luciénus, d'ouvrir la barrière, et de lancer mes chevaux. Et je ne prends pas seulement pour texte les coursiers mâles dont, comme Atticus, je ne veux comme étalon qu'un pour dix juments; je vais aussi parler des cavales, que le vaillant Q. Mo. dius Équiculus n'estimait pas moins pour la gucre. Veut-on former des troupeaux de chevaux et de cavales, tels qu'on en roit dans le Pèlopounèse et dans l'A pulie? A vant tout il faut s'assurer de l'âge des individus, qui, dit-on, ne doit pas être au-dessous de trois ans ni au. dessus de dix. C'est aux dents qu'on reconnait l'â:ge du cheval, ainsi que de tout animal qui a le pied fendu. et même celui des bêtes à cornies. $\Lambda$ deux ans et demi le cheval commence à perdre les quatre dents du milieu, deux d'en haut, ct deux d'en bas. En entrant dans sa quatrième année, il lui tombe cncore, à chaque mâclıoire, les deux voisines de celles qu'il a déjà perdues; et les grosses dents appelées molaires commencent alors à pousser. Quand il atteint sa cinquième année, il en perd encore deux autres de

removent a matre. Proximo anno noctibus patiuntur esse cum lis, et leniter capistris, aliave qua re habent vinclos. Tertio anuo domare incipiunt ad eas res, ad quas quisque eos vult lıabere in usu. Relinquitur de numero, ruorum greges non sane tiunt, nisi ii, qui oncra portent : idleo quod plerique deducuntur ad molas, aut ad agriculturam, ubi quid velıendum est; aut etiam ad arandum, ubi levis est terra, ut in Campania. Greges fiunt fere mercatorum, ut eorum qui e Brundisino, aut Appulia aselis dossuariis comportant ad mare oleum aut vinum, itemque frumentum, ant quid aliud.

VII. Lucienus : Ego quoque adreniens aperiam carceres, inquit, et equos emiltere incipiam, nec solnm mares, quos admissarios habeo, ut Atticus singulos in fominas denas, e queis foeminas $\mathbf{Q}$. Modius Equiculus vir fortissimus etiam patre militari juxta ac mares lıbere solebat. Horum equorum, et equarum greges qui habere vol uerint, ut habent aliqui in Peloponneso, et in A ppulia, primum speclare oportet xtatem, quam procipiunt videndum ne sint minores trima, majores decem annorum. Etas cogrioscitur equorum, et fere onnium quie ungulas indivisas lıahent, et etiam cormutorum, quod equus triginta mensium primum dentes medios dicitur amittere, duo superiores, totillem iuferiores. Incipientes quartum agere annum i illem ejiciunt, et totidem proximos corum q̧uos anise- la même manière. Il en repousse en place, qui, creuses d'abord, commencent à se remplir dans la sixième aunée; de sorte qu'à sept ans le clie. val a son rátelier complet. A partir de cette époque, il n'y a plus de signe certain de son âge; seulement lorsque la bète a les dents saillantes hors de la bouche, les sourcils blanes, et que ses salières se creusent au-dessous des sourcils, on suppose qu'elle a seize ans. Il faut aux cavales une taille moyeune, c'est-à-dire ni grande ni petite; la croupe et les flanes larges. L'étalon, au contraire, doit être choisi de hautc taille, d'une belle structure, et toutes ses proportions doivent être en harmonie. Un poulain promet de devenir beau cheval, s'il a la tête petite, les membres bien attachés, les yeux noirs, les nascaux ouverts, les oreilles bien plantées, le cou large et souple, la crinière fournie, brune, frisée, d'un crin soyeux, et qui retombe du côté droit; le poitrail plein et développé, les épaules fortes, le ventre cffacé, les reins serrés par le bas, le dos large, l'épine double, et le moins possible en saillie; la queue ample et légèrement frisée, les jambes droites, égales et plutôt longues; les genoux arrondis, étroits etsurtout point cagneux; la corne dure, et le corps parsemé de petites veines qui s'apercoivent au travers de la peau; circonstance qui rend son traitement beaucoup plus facile en cas de maladie. L'origine du cheval est un point de la dernière importance, car il y a des races sans nombre. Les plus estimées prennent le nom des contrées dont elles sont originaires; ainsi on dit en Grèce la race thessaliennc ou de Thessalie, et chez nous les races apulienne, roséanienne, d'Apulie, de Roséa.

runt, et incipiunt nasci quos vocant columellares. Quinto anno incipienti item eodem modo amiltere binos. Quos caros habent tum renascentes eis, sexto anno implere, septimo omnes labere solent renatos, et completos. His majores qui sunt, intelligi negant posse. Præterquam cum dentes sint facti brocchi, et supercilia cana, et sub ea lacunx, ex observalu dicunt eum equum habere annos sede. cim. Forma esse oportet magnitudine media, quod nee vastas nec minutas decet esse equas : clunibus ac rentribus latis. Equos ad admissuram quos velis liabere, legere oportet amplo corpore, formosos, nulla parte corporis inter se non congruenti. Qualis finturus sit equus, e pullo conjectari potest, si caput liabet non magnum, nec mem. bris confusis : si est oculis nigris, naribus non angustis, auribus applicatis, (cervice molli, ) non angusta, juba crebra, fusca, subcrispa, subtenuibus setis, implicata in dexterioren partem cervicis, pectus latum et plenum, humeris latis, ventre modico, lumbis deorsum versum pressis, scapulis latis, spina maxime duplici; $\sin$ minus, non extanti, coda ampla subcrispa, cruribus rectis aqua. libus, potius figura altis, genibus rotundis, nec magnis, nec introversus spectantibus, ungulis duris : toto corpure ut labeat venas, qux animadverti possint, quod qui lı. juscemodl sit, el cum est reger, ad medendum est appositus: corpore multo. De stirpe magni iuterest qua sitt, 
Un bon augure dans un jeune cheval, c'cst lorsqu'en paissant avec les autres, il se montre empressé à disputer la supériorité à la course ou dans toutc autre circonstance; ou bien encore lorsqu'en traversant un fleuve il devance tous les autres à la tête du troupeau, sans regarder derric̀re lui. L'achat des chevaux se fait à peu près de la même manière que celui des bœufs et des ânes; et la propriété en change de mains, à peu près dans les formes qu'on trouve consignées dans le livre de Manilius. Il n'y a pas de meilleure nourriture pour les chevaux que l'herbe dans les prés, le foin sec à l'écurie. Lorsqu'une cavale a pouliné, il faut ajouter de l'orge à sa provende, et la faire boire deux fois par jour. Quant à la propagation; l'époque de la monte est de l'équinoxe du printemps au solstice, afin que les juments puissent mettre bas en temps propice pour le poulain, qui vient au monde le dixième jour du douzième mois après l'accouplement. Les chevaux qui proviennent d'une conception postérieure à l'époque marquée sont en général défectueux, et plus ou moins impropres à l'usage qu'on se propose d'en faire. Ainsi, dès que le printemps sera venu, le peroriga devra présenter l'étalon à la jument deux fois par jour. On appelle peroriga celui qui est chargé de faire accomplir aux chevaux l'acte générateur. Sa présence est nécessaire pour te. nir les cavales à l'attache, afin qu'elles soient saillies plus promptement, et que l'étalọn ne perde point sa semence par excès d'ardeur. Quand les juments se défendent de l'approche du mâle, c'est un avertissement qu'elles ont été suffisamment saillies. Si l'étalon montre quelque répugnance pour la jument, on frotte les partics naturelles de cette dernière, au moment de ses pertes annuelles, avec de la moelle d'oignon ma.

quod genera sunt multa. Itaque ad hoc nobiles a regionibus dicuntur, in Graecia Thessalici equi, a terra Appuli, ab Rosea Roseani. Equi boni futuri signa sunt, si cum grega. libus in pabulo contendit in currendo, aliave qua re, quo potior sit : si, cum flumen trajiciendum est, gregi in primis prægredifur, ac non respectat alios. Emtio equina similis fere ac boum, et asinorum, quod eisdem rebus in emtione dominum mutant, ut in Manilii actionibus sunt perscripla. Equinum pecus pascendum in pratis potissimum herba; in stabulis ac præesepibus, arido foeno. Cum pepererunt, ordeo adjecto bis die danda aqua. Horum foturse initium admissionis facere oportet ab æquinoctio verno ad solstitium, ut partus idoneo tempore fiat. Duodecimo enim mense, die decimo, aiunt nasci. Quæ post tempus nascuntur, fere viliosa, atqne inutilia existunt. Admittere oportet, cum tempus anni venerit, his in die, mane et vesperi per origam. Is ita appellatur, quiqui admittit. Eo enim adjutante equæ alligatæ celerius adınit. tuntur, neque equi frustra cupiditate impulsi semen ejiciunt. Quoad satis sit admitti, ipsæ significant, quod se defendunt. Si fastidium saliendi est, scillæ medium con- rin pilée dans l'eau jusqu'à ce qu'elle ait acquis la densité du miel; puis on les fera flaircer à l'étalon. Je citerai à ce propos un fait incroyable, mais qui n'en est pas moins réel. Un étalon se refusait obstinément à saillir sa mère. Le perorigu s'avisa de lui couvrir la tête, le ramena en cet état auprès d'elle, et l'accouplement eut lieu. Mais on n'cut pas plutôt cnlevé le bandeau qui cachait les yeux de l'animal, qu'il se jeta sur le peroriga, et le déchira à belles dents. Quand les cavales sont pleines, il faut les ménager au travail, et ne pas les exposer au froid, ce qui leur serait fatal pendant la gestation. Par ce motif, il faut préserver de toute humidité le sol de leurs écuries, et tenir closes portes et fenêtres. On adaptera aussi de longues barres aux mangeoires pour séparer les cavales, et lcs empêcher de se battre entre elles. Pendant tout le temps de leur portée, il ne faut pas qu'elles soient poussées de nourriture, ni qu'elles souffrent de la faim. Il y a des personnes qui ne font saillir les cavales que de deux années l'une: les mères, disent-ils, s'en conservent plus longtemps, et les poulains en sont plus forts. Suivant eux, il en est des cavales comme des terres qu'on ne laisse pas reposer : cette production continue les épuise. Les poulains de dix jours vont paltre avec leur mère. Évitez qu'ils stationnent dans l'étable, dont le fumier brûle leurs sabots délicats. A cinq mois, on leur donne, chaque fois qu'ils rentrent à l'écurie, de la farine d'orge avec du son, ou toute autre production végétale de leur goût. A l'âge d'un an, on leur donne de l'orge en nature et du son, jusqu'à ce qu'ils ne tettent plus; ce n'est qu'après deux ans révolus qu'on les sèvre. De temps à autre il faut les flatter de la main pendant qu'ils sont avec la mère, afin que plus tard ils ne s'effarouchent

terunt cum aqua ad mellis crassitudinem: tum ea re na. turam equx, cum menses ferunt, tangunt; contra, ab locis equæ nares equi tangunt. Tametsi incredibile, quod usu venit, memoriæ mandandum. Cum equus natrem ut saliret adduci non posset, et eum capite obvoluto peroriga adduxisset, et coegisset matrem inire, cum descendenti demsisset ab oculis, ille impetum fecit in eum, ac mordicus interfecit. Cum conceperunt equæ, videndum ne aut laborent plusculum, aut ne frigidis locis sint, quod algor maxime præynantibus obest. Itaque in stabulis ab liumore prolibere oportet lumum, clausa habere ostia, ac fenestras, et inter singulas a prasepibus in terjicere longurios, qui eas discernant, ne inter se pugnare possint. Prægnantem neque impleri cibo, neque esurire oportet. Alternis qui admittant, diuturniores equas, et meliores pullos fieri dicunt, itaque ut restibiles segetes essent exuctiores, sic quotannis quæ prægnantes fiant. In decem diebus secundum partum cum matribus in pabulum prodigendum. Ne ungulas comburat stercus cavendum tenellas. Quinquemestribus pullis factis, cum redacti sunt in stabulum, objiciendum farinam ordeaceam molitam cum furfuribus ; 
pas d'être touchés. Par le mèmemotif, on suspend des mords dans leurs écuries, pour qu'ils s'accoutument, dès le jeune âge à en supporter la vue et à en entendre le cliquetis. Lorsque les poulains auront pris l'habitude d'approcher quand on lcur tend la main, il faudra de temps à autre leur mettre sur le dos un enfant, qui d'abord s'y couche à plat ventre, et ensuite s'y tient assis. Pour ce manége, il faut que le cheval ait trois ans. C'est l'âge où sa croissance est faite et où il commence à avoir des muscles. Il en est qui prétendent qu'un cheval peut être dressé à un an et demi; mais le plus sûr est d'attendre qu'il ait trois ans : à partir de ce moment, on lui donne du fourrage composé de céréales de toute espèce coupées en vert; ce qui est pour l'animal une purgation très-salutaire. Il faut pendant dix jours le mettre à ce régime pour toute nourriture. Le onzième jour on lui donnera de l'orge, dont on augmentera graduellement la mesure jusqu'au quatorzième. La ration de ce jour servira de base pour les dix suivants. II faut lui faire prendre ensuite un exercice modéré, le frotter d'huile quand il sera en sueur, et, si le temps est froid, allumer du feu dans l'écurie. Parmi les jeunes chevaux, les uns sont plus propres pour la guerre et les autres pour les transports, ceuxci pour la monte et ceux-là pour la course, ou à la voiture. II s'ensuit qu'il faut varier entre eux les soins de l'éducation. L'homme de guerre choisit et dresse les chevaux suivant des conditions tout autres que l'écuyer ou le conducteur des chars du cirque. On comprendra également que le cheval qu'on destine au transport à dos doit être dressé d'autre façon que le cheval de selle ou de trait. On veut sur le champ de ba-

et si quid aliud terra natum libenter edent. Anniculis jam factis dandum ordeum et furfures, usque quoad erunt lactentes. Neque prius biennio confecto a lacte removendum. Eosque cum stent cum matribus, interdum tractandun, ne cum sint dijuncti, exterreantur. Eadenrqne causa ibi frenos suspendendum, ut equuli consuescant et videre eorum faciem, et e motu audire crepitus. Cum jam ad nıanus accedere consuerint, interdum imponere iis puerum, bis aut ter pronum in ventrem, postea jam sedentem. Hæc facere cum sit trimus; tum enim maxime crescere, ac lacertosum fieri. Sunt qui dicant post annum et sex menses equulum domari posse, sed melius post trimum, a quo tenpore farrago dari solet. Hæc enim purgatio maxime necessaria equino pecori. Quod diebus decem facere oportet, nec pati alium ullum cibum gustare. Ab undecimo die usque ad quartum decimum dandum ordeum, quotidie adjicieutem minutatim. Quod quarto die feceris, in eo decem diebus proximis manendum; ab eo tempore mediocriter exercendum : et cum sudarit, perunguendum oleo. Si frigus crit, in equili facicndus ignis. Equi quod alii sunt ad rem militarem idonei, alii ad vectıram, alii ad admissuram, alii ad cursuram, alii ad rhedam, non item sunt spectandi atque lıabendi. Itaque peritus belli alios eligit, atque alit, ac docet : aliter quadrigarius, ac taille un coursier plein de feu. Pour faire route, on préfère un cheval paisible. C'est afin de ripondre à cette diversité de vues que l'on a imaginé de châtrer les chevaux. Privé de ses testicules, et conséquemment de liqueur séminale, l'animal devient plus maniable. On appelle canterii les chevaux châtrés, de même que maïales les pores, et capi les coqs rendus, par cette opération, impropres à la propagation de l'espèce. Quant à la médecine des chevaux, la multitude des maladies et la diversité des symptómes en rendent la science très-compliquée; et il est indis. pensable que le chef d'un haras en ait les diffe. rentes prescriptions couchées par écrit. C'est ce qui nous explique pourquoi les Grees appellent i $\pi \pi i x \tau p o r$ (médecins des chevaux) ceux qui traitent les maladies du bétail en général.

VIII. Pendant ce discours, un affranchi de Ménate vint nous avertir, de la part de son mâtre, que les liba étaient achevés, et que tout ćtait prèt pour le sacrifice : ceux qui voudraient y prendre part n'avaient donc qu'à venir. Quant à moi, m'écriai-je, je ne vous laisse point partir que vous ne m'ayez donné le troisième acte dans lequel figurent les mulets, les chiens et les pâtres. En ce qui touche les mulets, dit Murrius, il y a peu à dire. Les mulets et les bardeaux sont des bâtards engendrćs de deux espèces différentes, et entés pour ainsi dire sur une souche hétérogène, puisque le mulet provient d'une cavale et d'un âne, et que le bardeau est le produit d'un cheval et d'une ânesse. Tous deux sont de bon usage, mais nuls pour la propagation. On fait nourrir un ânon nouveau-né par une jument; il en devient plus fort, car le lait de jument est meilleur que celui d'ânesse, et, dit-on, que tout autre lait.

desultor. Neque itcm, qui vectarios facere vult; neque codem modo parantur ad ephippium, aut ad rhedam : quod int [ad rem militarem, quod] ibi ad castra habere volunt acres, sic contra in viis habere malunt placidos. Propter quod discrimen maxime institutum, ut castrentur equi. Demptis enim testiculis fiunt quietiores, (et) idco quod semine carent; ii canterii appellantur, ut in su. bus maiales; in gallis gallinaceis capi. De medicina, vel plurima sunt in equis et signa morborum, et gcnera cu. rationum, qux pastorem scripta habere oportet. Itaque

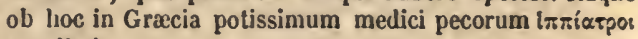
appellati.

VIII. Cum lıæc loqueremur, venit a Menale libertus, qui dicat liba absoluta esse, et rem divinam paratam; si vellent, venirent illuc, et ipsi pro sc sacrificarentur. Ego vero, inquam, vos ire non patiar ante, quam mili reddideritis tertium actum de mulis, de canibus, de pasto. ribus. Brevis oratio de istis, inquit Nurrius. Nam muli et himni bigeneri, atıue insiticii, non suopte genere ab radicibus. Ex equa enim et asino fit mulus. Contra ex equo et asina linnus. Uterque eorum ad usum utilis, partus fructu neuter. Pullum asininum a partu recentem subjiciunt equa, cujus lacte ampliores fiunt, quod id lacte quam asininum, ac alia omnia dicunt esse melius. Pra- 
Plus tard on lui donne pournourriture de la paille. La nourrice, non plus, ne doit pas être négligée; car il faut qu'elle allaite concurremment son propre poulain. L'âne, élevé de cette manièrejusqu'à l'âge de trois ans, peut être employé à saillir les cavales, et ne les dédaignera point, habitué qu'il est de vivre toujours au milieu d'elles. L'employer plus jeune serait le faire vieillir plus tôt; et il ne donnerait que do faibles produits. Au défaut d'ânes élevés par des cavales, on choisit, pour étalon, lo plus grand et le plus fort qu'on peut trouver. Il faut surtout qu'il soit de bonne race, de celle d'Arcadie, par exemple, si l'on s'en rapporte aux anciens, ou, suivant notrc propre expérience, de celle de Réate, où l'on vient les chercher de trois cents et même de quatre cents milles de distance. On achète les ânes absolument comme les chevaux. Ce sont les mêmes stipulations ct les mêmes garanties. On les nourrit principalement d'orge et de foin, dont on augmente In mesure quelque temps avant la monte, pour leur donner plus de vigueur. Quant à l'époque où le peroriga devra donner les ânes aux juments, elle est absolument la même pour les étalons des deux espèces. Le mulet ou la mule, produit de l'accouplement, devra être élevé avec soin. Les mulets nés en pays humides ct marécageux ont la corne du pied molle; mais quand on a soin de leur faire passer l'été sur les montagnes, comme c'est la coutume dans le Réate, elle acquiert un degré de dureté sans pareille. L'âge et la forme sont à considérer, pour qui veut former un troupeau de mulets. L'âge, afin qu'ils soient de force à porter unc charge; la forme, afin que l'œil trouve plaisir à les contempler. Un couple de mulets attelés peut tirer toute espèce de voi-

terea educant eum paleis fœno, ordeo. Matri suppositicix quoque inserviunt, quo equa ad ministerium lactis cibum pullo prabere possit. Hic ita eductus a trimo, potest ad. Initti. Neque enim aspernatur, propler consuetudinem equinam. Hunc minorem si alluiseris, et ipse citius senescit, et qux ex eo concipiuntur fiunt deteriora. Qui non labent eun asinum quem supposuerunt equae, et asinum arlmissarimm habere volunt, de asinis quam amplissimum formosissimumque possunt, eligunt. Quique seminio natus sit bono, Arcadico, ut antiqui dicebant, ut nos experti sunus, Reatino : ubi trecenis ac quadrigenis millibus admissarii aliquot venierunt. Quos cmimus item ut equos, stipulamurque in emendo, ac facinus in accipiendo idem, quod dictum est in equis. Hos pascimus pracipue forno atgue ordeo, et id ante admissuram largius facimus, ut cibo suffundamus vires ad fueturam. Eodem tempore, quo equos adducentes, iidemque ut ineant equas per origas curamus. Cun peperit equa mulum, aut mulam, nutricantes educamus. Hi, si in palustribus locis atque uliginosis nati, habent ungulas molles : iidem si exacti sunt a'stivo tempore in montes, quod fit in agro Reatino, durissimis ungulis fiunt. In grege mulorum parando spectanda u'tas et forma. Alterum, ut vecturís sufferre labores pos. ture. Homme de Réate, continua Murrius en sa. dressant à moi, je pourrais donner mon opinion comme autorité sur cette matière; mais vous avez cu vous-même des troupeaux de cavales dans vos domaines, et vous vous êtes fait un revenu des mulcts que vous en avez tiré. Le bardeau (hinnus) est le produit d'un cheval et d'une ânesse ; il est moins grand et plus roux que lc mulet, ressemble au cheval par les oreilles, et à l'âne par la crinière et la queue. Il est, comme le clicval, un an dans le ventre de sa mère; et c'est aussi aux dents qu'on reconnaît son âge.

IX. Maintenant, dit Atticus, il ne nous reste plus à parler que des chiens, race intéressantc, pour nous autres surtout qui élevons des animaux à laine. Lc chien est le gardien du bétail en général; mais il est le défenseur naturel des brebis et des chèvres. Le loup est là sans ecsse qui les guette, et nous lui opposons les chiens. Quant aux animaux portant soie, verrats, pores châtrés et truies, ils tiennent du sanglier, dont la dent est si meurtrière à nos chiens dans les chasses, et ont tous de quoi se défendre. Que dirai-je? Un loup ayant un jour paru au milieu d'un troupeau de mulets au pâturage, ceux-ci aussitôt, par un mouvement instinctif, formèrent un cercle autour de lui, et le tuèrent à coup de pieds. Quant aux taureaux, ils se serrent croupc contre croupe, présentant au loup les cornes de tous côtés. Pour en revenir à mon sujet, il y a deux espèces de chiens : d'abord les chiens de chasse qui sont dressés pour la bête fauve et le gibier, et les chiens de garde qui sont de la dépendance du berger. Je me borne à traiter de ces derniers, en suivant les neuf divisions méthodiques que vous avez indiquées pour le ré-

sint; alterum ut oculos aspeclu delectare queant. Hisce enim binis conjunctis omuia vehicula in viis ducuntur. Hæc me Reatino auctore prolrares, milii inguit, $\mathrm{n}$ isi tu ipse domi equarum greges haberes, ac mulorum greges vendidisses. Hinnus qui appellatur, est ex equo et asina, minor quam inulus corpore, plerumque rubicundior, auribus ut equinis, juban et caudan similem asini. Item in ventre est (ut equus) menses duodecim. Hosce item ut equulos et educunt, et alunt, et atatem eoruur ex dentibus cognoscunt.

IX. Relinquitur, inquit Atticus, de quadrupedibus, quod ad canes attinet, maxime ad nos, qui pecus pascimus lanare. Canis enim ita custos pecoris, ut ejus, quod en comite indiget ad se defendendum. In quo generc sunt maxime oves, deinde capra. Has enim lupus captare solet, cui opponimus canes defeusores. In suillo pecore tamen sunt, qux se vindicent, sues, verres, maiales, scrofx. Prope enim liac apris, qui in silvis sape dentibus canes occiderunt. Quid dicam de pecore majore? cum sciam mulorum gregem cum pasceretur, eogue venisset lupus, ultro mulos circumfluxisse, et ungulis cæulendo cum occidisse? et tauros solere diversos assistere clunibus continuatos, et cornibus facile propulsare $h_{\text {nqus? }}$ ? quarce 
gime général des bestiaux. Il faut d'abord choisir des chiens d'âge convenable. Trop jeunes ou trop vieux, loin de défendre les brebis, ils ne peuvent se défendre eux-mêmes, ct deviennent la proie des animaux féroces. Quant à l'extérieur, prenez-les de belle forme, de grande taille, avec les yeux noirs ou roux, les narines de même couleur, les lèvres rouges en tirant sur le noir, ni trop retroussées, ni trop pendantes. On examinera encore s'ils ont les mâchoires allongées et garnies de quatre dents, deux en bas, et deux cn haut; celles d'en bas saillantes en deliors de la gucule; celles d'en haut droites, perpendiculaires, moins apparentes, mais également aiguës, ct recouvertes en parties par les lèvres. II est cssentiel encore que les chiens aient la tête fortc, les oreilles longucs et souples, le cou gros ct bien attaché, les jointures des ergots écartées les unes des autres, les cuisses droites, et tournées plus en dedans qu'en dehors; les pattes larges et le pas bruyant, les doigts écartés, les ongles durs et recourbés, la plante du pied molle, et pour ainsi dire dilatable comme du levain, ct non pas dure comme de la corne; le corps effilé au point de jonction des cuisses, l'épine du dos ni saillante ni convexe, la queue épaisse, la voix sonore, la gueule bien fendue, et le poil blanc dc préférence, afin qu'on puisse facilement les distinguer des bêtes fauves dans l'obscurité de la nuit. On veut aux chiennes de grosses tettes de dimension égale. La race des chiens est eneore une chose à considérer. Il y a celle de Laconie, cellc d'Épire, celle de Salente, ainsi désignées des pays d'où elles tirent leur origrine. Voulez-vous acheter des chiens, ne vous adres-

de canibus, quoniam genera duo, unım veuaticum, ct pertinct ad feras bestias, ac silvestres : alterum, quod cnstodix causa paratur, et pertinet ad pastorem : dicam leco ad formam artis dispositam in novem partes. Primum statc idonea jaramdi, quorl catuli et retuli neque sibi, neque ovibus sunt prosiclio, et feris bestiis nonnunquam proedac. Facie debent essc formosi, magnitudine ampla, oculis nigrantibus ant ravis, naribus congruentibus, labris subnigris aut rubicundis, ncque resimis supcrioribus, nec peudulis subtus, mento suppresso, et ex eo enatis duobus dentibus dextra et sinistra, paulo cninulis, superioribus dircetis potius, quam brocclis : acıtos, quos labeant, labro tectos : capilibus et auriculis magnis, ac narcis : crassis cervicibus, ac collo: inlcrnodiis articulorum longis : cruribus rectis, $\mathrm{ct}$ potius varis, (juan vatiis : pedilous uagnis, et altis, qui ingredicuti ei displodantur : digitis discretis : unguibus duris, ac curvis : solo ncc ut corneo, ucc uimium duro, sed ut ferınentato, ac molli : a femi. uibus summis corpore sıppresso : spina neque eminula, neque curva : cauda crassa, latratu gravi, lialu maguo; colore potissimum albo, quod in tenebris specie Iconina. praterea firninas volunt cssc mammosas a:(jualibus pa. pillis. Item videudun, ut boni seninii siut. Itayne a regiouibus appellantur Lacunes, Epirotici, Sallentini. Viden-
Sez ni aux bouchers, ni aux chasseurs de profession. Les chiens de boucher ue sont point dressés à suivre le bétail ; et les chiens de chass9 laissent là les brebis pour courir après le prcmier lièvre ou cerf qui vient à passer. Les meilleurs chiens sont ceux qu'on achète à des ber. gers, ct qui sont déjà dressés à suivre les troupeaux, ou ceux dont l'éducation n'est point encore faite. Le chien prend facilement toute habitude qu'on veut lui donuer, et s'attache plus au berger qu'au troupeau. P. Aufidius Pontianus d'Amiternum avait acheté des troupeaux de brebis au fond de l'O mbrie. Les chiens étaient compris dans le marché, et les berger's devaient aceompagner les troupeaux jusqu'à la foile d'Héraclée et aux bois de Métaponte. En conséquence, arrivés au lieu convenu, mes gens retournèrent chez eux sans les chiens. Mais, peu de jours après, ceux-ci, regrettant sans doute leurs anciens maîtres, vinrent d'eux-mêmes les rejoindre en Ombrie, à plusieurs journées de distance ct, sans s'être nourris autrement que de ce qu'ils trouvèrent dans les champs. Notez bien qu'aucun de ces berger's sans doute n'avait fait usage de la recette reeommandée par le livre de Saserna. "Pour se faire suivre d'un chien, on n'a qu'à lui donner une grenouillc cuite dans l'eau. Il importe d'avoir ses chiens tous de même race; car cette espèce d'affinité fait qu'ils se soutienncnt. Quant à l'achat, qui est le quatrième dans l'ordre des considérations, même forme de transmission de la propriété; ct mèmes stipulations. de garantie, en cas de répétition ou de maladie de l'animal, pour les chiens que pour tout autre bétail, sauf les cxceptions qui peuvent être

dum ne a venatoribus, aut laniis canes emas. Alteri, quod ad pecus sequendum iuertes. Alteri, si viderint leporem, aut cervum, [quod] eum potius, quam oves sequentur. Quare aut a pastoribus emta melior, qux oves scqui consuevit : aut sine ulla consuctudine qua fuerit. Canis euim facilius quid assuescit, eaque consuctudo firmior, qux sit ad pastores, quam quae ad pecudes. P. Aulidius Pontianıs Amitcrninus, cum greges ovium cmisset in Unloria ultima, quibus grcgibus sinc pastoribus canes accessisseut; pastores nt deducerent in Metapontiuos saltus, ct Heraclea emporinm : iude cun domum redisscnt, qui ad locun deduxerant, e desiderio lıminum dicbus paucis postca cancs sua sponte, cum dierum multorum via intercsset, silsi ex agris cilvaria prohuerunt, atque in Unulbriam al pastores reslierunt. Neque cormn quisquan fccerat quod in ayricultura Saserna preccpit : Qui vellet se it canc sectari, uti ranam objiciat coctam. Magni interest ex semine csse cancs colcm, quod cognati maxime inter se sunt prasidio. Sequitur yuartum de emtione : fit alterius, cun a priore domino sccundo tradıtum est. De sauritate et noxa stipulationes fiunt exdcm, (|иæ in pecorc, nisi quod lıic utilitcr exceptım est. Alii pretiun faciunt in singula capjita caumn; alii ut catuli scquıautur matrem; alii ut bini caluli unius canis uunerum obtineant, ut solent 
utiles. Quelques-uns fixent le prix à tant par tête; d'autres introduisent la condition que les petits suivront leur mère; d'autres enfin stipulent que deux petits ne comptent que pour un adulte, de même que deux agneaux pour une brebis. En général on comprend dans le marché tous les chiens qui ont coutume d'être ensemble. La nourriture du chien a plus de rapport avec la nourriture de l'homme qu'avec celle de la brebis, puisqu'on lui donne des os et des restes de table, et non des herbes ou des feuilles. Il faut a voir grand soin de lui donner à manger; autrement la faim lui fait déserter le troupeau et chercher sa vic aillcurs. Parfois aussi, poussé par le besoin, il pourrait démentir l'ancien proverbe, et commenter la fable d'Actéon, en tournant ses dents contre son maitre. On fera bien de leur donner du paln d'orge détrempé dans du lait; une fois habitués à cette nourriture, ils ne s'éloignent pas facilement. Quand il meurt une brebis, gardezvous de leur en laisser manger la chair, de peur qu'ils n'y prennent goût, et ne veuillent plus s'en passer ensuite. On donne du bouillon fait avec des os, ou les os eux-mèmes, après les avoir cassés. Ils se fortifient les dents à ronger; et l'avidité avec laquelle ils cherchent la moelle leur ćlargit la gueule, en donnant du jeu à leurs máchoires. Habituez-les de bonne heure à prendre leur repas de jour dans les lieux mêmes ou pait le troupeau, et celui du soir dans l'étable. Quant à la propagation de l'espèce, on fait couvrir les chiennes aux premiers jours du printemps. C'est l'époque où elles sont en chaleur (catuliunt). Une chienne, fécondée alors, met bas vers le solstice; car cette espèce porte ordinairement trois mois. Il faut dans l'intervaiie ia nourrir de pain d'orge

bini agni ovis. Plerique ut accedant canes, qui consuermnt esse una. Cibatus canis propior hominis, quam ovis. Pascitur enim e culina et ossibus, non herbis aut frondibus. Diligenter ut labeant cibaria providendum. Fames enim lıos ad quxerendum cibum ducet, si non prabebitur, et a pecore abducet. Nisi si (ut quidam putant) etiam illuc perveneriut, proverbinın ut tollant antiquum : vel etiam ut $\mu \bar{v} \theta 0 v$ aperiant de Actæone, atque in dominum afferant rlentes. Nec non ita panem ordeaceum dandum, ut non potius eum in lacte des intritum, quod eo consueti cibo uti, a pecore non cito desciscunt. Morticina ovis non patiuntur vesci carne, ne ducti sapore minus se abstineant. Dant etiam jus ex ossibus, et ea ipsa ossa contusa. Dentes enim facit lirmiores, et os magis patulum : propterea quod velıementius diducuntur malæ, acrioresque fiunt proptur medullarum saporen. Cibum capere consuescunt interdiu, ubi pascuntur : vesperi, ubi stabulantır. De foe tura, principium admitteudi faciunt veris principio : tunc enim dicuntur catulire, id est, ostendere velle se maritari. Quæ cum admissæe, pariınt circiter solstitio. Prognantes enim solent esse ternos menses. In fotura dandum potius ordeaceos quam triticeos panes. Magis enim eo aluntur, et lactis præbent majorcun faculfatem. In nutricatu secuu. de préférence à celui de froment, parce qu'il est plus nourrissant et donne plus de lait. Quant aux petits, il faut tout d'abord choisir dans une portée ceux qu'on veut élever, et jeter les autres. Plus on en Ste à la mère, plus ceux qui restent deviennent forts, lc lait étant moins partagé. On leur fait un lit de paille, ou de quelque substance analogue; car, mollement couchés, ils profitent mieux. Les petits chiens commencent à voir clair au bout de vingt jours. On les laisse avec leur mère pendant les deux premiers mois, et peu à peu ils s'en déshabituent d'eux-mêmes. On dresse les chiens en en réunissant plusieurs qu'on excite à se battre ensemble : cet exercice les dégourdit. Mais il ne faut pas le pousser au point de les fatiguer et de les affaiblir. Pour les accoutumer à l'attache, on commence par un lien léger, en les battant chaque fois qu'ils font mine de le ronger, jusqu'à ce qu'ils en perdent l'habitude. Quand il pleut, on garnit leur loge d'herbes et de feuillage, afin de les tenir propres et de les préserver du froid. Quelques-uns croient, en les chátrant, leur ôter l'envie de s'éloigner du troupeau. D'autres s'abstiennent de cette opération, qui, selon eux, les énerve. Il en est encore qui leur frottent les oreilles et l'entre-deux des ergots avec des amandes pilées dans de l'eau, pour les garantir des mouches, des tiques et des puces, dont la piqûre engendre des ulcères dans ces parties. On empêche les chiens d'être blessés par les bêtes féroces, au moyen d'une espèce de collier qu'on appelle mellum; c'est une large zone de cuir bien épais, qui leur entoure le cou. On a soin de la hérisser de clous à tête, de la garnir, en dessous, d'un autre cuir plus douillet, qui recouvre la tête de ces clous, et empêche le fer d'en-

dum partum si plures sunt, statim eligere oportet quos Jabere velis, reliquos abjicere. Quam paucissimos relique. ris, tam optimi in alendo fiunt propter copian lactis. Substernitur eis acus, aut quid [item] aliud, quod molliore cubili facilius educantur. Catuli diebus $\mathbf{x x}$ videre incipiunt. Duobus mensibus primis a partı non dijungnntur a matre, sed minutatim desuefiunt. Educunt eos plures in unum locum et irritant ad pugnandum, quo fiant acriores, neque defatigari patiuntur, quo fiant segniores. Consıe quoque faciunt ut alligari possint, primum levibus vinclis : quæ si abrodere couantur, ne id consuescant facere, verberibus eos deterrere solent. Pluviis diebus cubilia substernenda fronde aut pabulo, duabus de causis, ut ne oblinantur, aut perfrigescant. Quidam eos castrant, quod eo minus putant relinquere gregem. Quidam non faciunt, guod cos credunt minus acres fieri. Quidam nucibus græcis in aqua tritis perungunt aures, ef inter digitos; quod muscæ, et riciui, et pulices soleant (si lioc unguine non sis usus) ea exulcerare. Ne vulnerentır a bestiis, imponuntur lis collaria, quæ vocantur mellum, id est cingulum circum collum ex corio firmo cum clavulis capitatis, quxe intra capita insuitur pellis mollis, ne noceat collo duritia ferri. Quod si lupus, aliusve quis luis vulne- 
tamer la peau du chien. Du moment qu'une bête féroce, loup ou autre, a senti les clous qui garnissent le collier, tous les chiens du troupeau, avec ou sans collier, sont à l'abri de ses attaques. Le nombre des chiens doit être en raison de la force du troupeau. D'ordinaire on en compte un par berger; mais cette proportion peut varier dans certains cas. Si, par exemple, les bêtes féroces abondent dans le pays, il faut multiplier les chiens. C'est une nécessité quand l'on conduit un troupeau à quelque lointaine station d'hiver ou d'été, et quoon a des forêts à traverser; à un troupeau sédentaire un couple de chiens suffit. Il est bon que ce soit mâle et femelle : ils en sont plus attachés, et, par émulation, plus hardis. D'ailleurs, sl l'un des deux est malade, le troupeau ne chठme pas. Ici Atticus regarda autour de lui, comme pour dire : Ai-je oublié quelque chose? Voilà un silence, m'écriai-je, qui appelle en scène un autre interlocuteur.

X. En effet, l'acte ne sera fini 'que lorsqu'on nous aura instruit de tout ce qui concerne le personnel des pâtres; proportions numériques et conditions individuelles. Cossinius dit alors : Pour le gros bétail il faut des hommes faits; pour le menu, des enfants suffisent. Mais il faut plus de force physique chez les pâtres nomades, qui passent leur vie par voie et par chemin, que chez ceux qui paissent leurs troupeaux dans les environs d'une ferme et rentrent chaque soir au logis. Aussi ne voit-on remplir cet office au milieu des bois que par des hommes dans la vigueur de l'âge, et bien armés; tandis que pour le pacage sédentaire, il ne faut qu'un petit garçon, de même qu'une petite fille, pour tout surveillant. Dans les pâturages éloignés les bergers doivent pendant

ratus est, reliquas quoque canes facit, quæ id non habent, ut sint in tuto. Numerus canum pro pecoris multitudine solet parari. Fere modicum esse putant, ut singuli sequantur singulos opiliones: de quo numero alius alium modum constituit. Quod si sunt regiones ubi hestiæ sint multa, debent esse plures. Qnod accidit is, qui per calles silvestres longinquos solent comitari in æstiva et hiberna. Villatico vero gregi in fundum satis esse duo, et id marem et fominam. Ita enim sunt assiduiores, quod cum altero idem fit acrior, et si alter indesinenter æger est, ne sine cane grex sit. Cum circumspiceret Atticus ne quid praterisset : Hoc silentium, inquam, vocat alium ad partes.

X. Reliquum enim in hoc actu, quot, et quod genus sint habendi pastores. Cossinius, ad majores pecudes xtate superiores, ad minores etiam pueros, et utroque horum firmiores, qui in callibus versentur, quam eos, qui in fundo quotidie ad rillam redeant. Itaque in saltibus licet videre juventutem, et eam fere armatam; cum in fundis non modo pueri, sed eliam puellæ pascant. Qui pascunt, eos cogere oportet, in pastione diem totum [esse,] pascere communiter; contra, pernoctare ad suum quem. que gregem. Esse omnes sub uno magistro pecoris : eum, esse majorem natu potius quam alios, el peritiorem quam le jour réunir et faire paitre en commun leurs troupeaux, et pendant la nuit rester séparément chacun auprès du sien. Ils seront tous placés sous les ordres d'un seul intendant, de plus d'àge et d'expérience que ses subalternes; car on obéit assez volontiers à plus vieux et plus instruit que soi. Il ne faut pas cependant qu'il soit vieux au point de moins supporter les fatigues de sa condition; car les vieillards non plus que les enfants ne sont propres à franchir des sentiers difficiles, et à gravir des montagnes à pied; fatigues aux- quelles sont journellement exposés ceux qui mènent paitre au loin le gros bétail, notamment les troupeaux de chèvres, qui se plaisent sur les rochers ou dans les forêts montagneuses. Il faut donc se procurer des pâtres robustes, alertes et agiles, pourvus de membres bien dispos, et capa. bles non-seulement de suivre les troupeaux, mais encore de les défendre contre les bêtes féroces et les brigands; des hommes en état de soulever les fardeaux pour charger les bêtes de somme, de courir si le cas l'exige, et de lancer des traits. Tout peuple n'est pas apte indifféremment aux fonctions de pâtres ; un Basculien, un Turdulien ne saurait s'en tirer. Les Gaulois y sont éminemment propres, surtout s'il s'agit du service des bêtes de somme. En ce qui concerne l'acquisition, il y a six manières d'obtenir la propriété d'un pâtre : $1^{\circ}$ par droit d'hérédité; $2^{\circ}$ par voie demancipation, c'est-à-dire en les recevant d'une personne qui est en condition légale d'en transmettre la possession; $3^{\circ}$ par cession, opérée, où, et à qui de droit; $4^{\circ}$ par investiture d'usucapion; $5^{\circ}$ par adjudication. Le pécule du pâtre passe ordinairement à l'acheteur par droit d'accession, à moins qu'on ne s'en réserve la proprlété par

reliquos : quod is, qui ætate et scientia præstant, animo æquiore reliqui parent. Ita tamen oportet ætate præstare, ut ne propter senectutem minus sustinere possit labores. Neque enim senes, neque pueri callium difficultatem, ac montium arduitatem, atque asperitatem facile ferunt : quod patiendum illis, qui greges sequuntur, præsertim armenticios ac caprinos, quibus rupes ac silva ad pabulandum cordi. Formæ hominum legendæe, ut sint firmæ, ac veloces, mobiles, expeditis membris : qui non solum pecus sequi possint, sed etiam a bestiis" ac prædonibus defendere : qui onera extollere in jumenta possint, qui excurrere, qui jaculari. Nun omnis apta natio ad pecuariam, quod neque Basculus, neque Turdulus idonei. Galli appositissimi, maxime ad jumenta. In em. tionibus dominum legitimum sex fere res perficiunt : si hæreditatem justam adiit : si, ut debuit, mancipio ah eo accepit, a quo jure cirili potuit : aut si in jure cessit, cui potuit cedere, et id ubi oportuit : aut si usu cepit : aut si e præda sub corona emit : tumve cum in bonis sec. tioneve cujus publice renit. In horum emtione solet acce. dere peculiurn, aut excipi, et stipulatio intercedere, sa. num eum esse, furtis noxisque solutum : ant si mancipio non datur, dupla promitti : aut si ita nacti, simpla. Cibus 
une clause partieulière. On stipule en outre que l'eselave qu'on aehète est sain, et que l'aequéreur est garant de toute répétition en raison de vols qu'il pourrait avoir eommis, ou des dommages qu'il pourrait avoir causés. Suivant les conventions faites entre les deux parties, le vendeur s'engage à payer, en cas d'évietion, le double du prix, ou à rendre simplement la somme qu’il a reçue. Les pâtres devront prendre leurs repas séparément, chaeun auprès-de son troupeau; mais le soir on fera souper en commun - tous ceux qui obéissent au même intendant. l'iutendant en chef devra pourvoir à tout ce qui est nécessaire aux hommes et au troupeau pendant les voyages. Ce soin doit surtout s'étendre à l'entretien des pátres, et au traitement des bestiaux en cas de maladies. Les maitres doivent avoir à eet effet des bêtes de charge, juments ou autres, propres à porter à dos tout ce qui est nécessaire. Quant à la propagation de l'espèce, les pâtres oeeupés sur le fond même peuvent facilement y trouver une campagne; Vénus pastorale n'en demande pas plus. Quant à ceux qui séjournent continuellement dans les bois et les montagnes, ct n'ont d'autre abri contre les injures du temps que des cabanes construites à la hâte, beaucoup sont d'avis qu'on fait bien de leur associer des femmes qui suivent les troupeaux, préparent les repas des pâtres, et sont pour cux un lien qui les attache au devoir. Ces femmes devront être robustes sans ctre difformes, et non moins capables de travail que les hommes. Le type s'en rencontre en beaueoup de contrées, notamment en Illyrie; on les voit mener paître elles-mêmes le bétail . apporter le bois pour faire du feu, et préparer les repas, en gardant avee soin les différents ustensiles dans les cabanes.
Quant i lallaitement, je mo borne à dire que les mères sont elles-mêmes nourriees. Ici, Tré mellius, se tournant vers moi : C'est préeisément, dit-il, ee que vous m'avez dit vous-même avoir vu en Liburnie, des mères de famille avec une charge de bois sur les épaules, et en même temps un ou deux nourrissons sur les bras. Que vous en semble auprès de nos languissantes aceouehées, étendues sur des lits de repos pendant plusieurs jours? n'est-ce pas une pitié? Le fait est vrai, lui dis-je, mais voiei qui est plus fort : on voit en Illyrie des femmes grosses qui, sentant qu'elles vout aecoucher, quittent un moment leur ouvrage, vont à quelques pas se délivrer, et reviennent, portant un enfant qu'elles semblent plutôt avoir trouvé que mis au monde. Autre particularité : les filles de vingt ans, qu'on appelle vierges en ce pays, peuvent, sans blesser la coutume, s'abandonner au premier venu avant le mariage; aller seules où bon leur semble, et avoir des enfants. Touchant la question médicale, l'intendant doit avoir par ćerit tout ce qui coneerne les maladies auxquelles hommes et bestiaux sont sujets, afin d'être en état de les guérir sans avoir reeours au médecin. On voit que l'intendant doit avoir une teinture des lettres, pour remplir convenablement ses devoirs ; sans quoi il ne pourrait même rendrc compte à son maitre de sa gestion. Quant au chiffe relatif du nombre des bergers, on le hausse, on le baisse suivant les cas : j'ai, moi, un berger pour quatre-ringts brebis à grosse laine, et Attieus pour cent. On peut en simplifier le nombre en faisant les troupenux plus considérables; de mille têtes par exemple, ce qui ne serait pas sans inconvénient avec des troupeaux moindres, comme ceux d'Atticus et les miens ne sont ell effet que de sept cents bêtes; corum debet esse interlius separatim uuiuscujusque gregis. Vespertinus in coena, qui sunt sub uno magistro, communis. Nagistrum providere oportet, ut omnia sequantur instrumenta, quæ pecori et pastorihus opus snnt, maxime ad victum hominum, et ad medicinam pecudum : ad quam ren habent jumenta dossuaria domiui, alii equas, alii pro lis quid aliud, quod onus dorso ferre possit. Quod ad foeturam lumanam pertinet pastorum, yui in fundo perpetuo maneint, facile est, quod habeant conservam in villa. Nec lıac Venus pastoralis longius quid quxerit. Qui autem sunt in saltibus, et silvestribus locis pascunt, et non villa, sed casis repentinis imbres ritant : his mulieres adjungere, quae seguantur greges, ac cibaria pastoribus expediant, eosque assiduiores faciant, utile irbitrati inulti. Sed cas mulieres esse oportet frmas, non turpes, qua in opere, ut in multis regionibus, non cedant viris, at in Jllyrico passim videre licet, quod vel pascere yecus, vel ad focum afferre ligna, ac cibum coquere, vel ad casas instrumentum servare possunt. De nuIricatı hoe dico, easlem fere el nutrices, et matres. Tremellius simul aspicit ad me, et, Ut te audii dicere, inquit, cam in Liburniam venisses, te vidisse matres familias co. rum afferre ligna, ct simul pueros, quos alerent, alias singulos, alias binos, quac ostenderent foetas nostras, qua in conopeis jacent dies aliquot, esse cjuncidas, ac con. temnendas. Cui ego: Certe, inquam; nam in Illyrico loc amplius, prægnantem sæpe, cum venit pariendi tempus, non longe ab operc discedere, ibique enixam puerum referre, quem non peperisse, sed invenisse putes. Nec non etiam loc, quas virgines ibi appellant, nonnunquan annorum xx, quibus mos eorum non denegavit, ante nuptias ut suecumberent quibus vellent, et incomitatis ut vagari liceret, et filios habere. Quæ ad valetudinem pertinent bominum ac pecoris, ut sine medico curari possint, magistrum scripta labere oportet. Is enim sine literis idoneus non est, quod rationes dominicas pecuarias con. ficere nequidquam recte polest. De numero pastorum alii angustius, alii laxius constituere solent. Ego in octogenas hirfas oves singulos pastores constitui, Alticus in centenas. In gregibus ovium, sed magnis, quos milliarios fa. ciunt quidam, facilins de summa hominum detrahere possuut, quam de minoribus, ut sunt et Attici et mei. Septin. genarii enim mei : tu opinor, octingenarios habuisti. Nec tamen non ut nos arietum decimam partem. Ad cquarum 
vous en avez eu, je crois, de huit eents, où eependant les mâles ne se trouvaient qu'en même proportion, c'est-à-dire un bélier sur dix brebis. Pour un troupeau de cinquante cavales il faudra deux hommes, chacund'eux ayant à sa disposition une jument dressée, pour lui servir de monture lorsqu'il eonduira ses eavales dans les pâturages d'liver ou d'été, soit en A pulie, soit dans le pays des Lucaniens.

XI. Maintenant que nous avons rempli notre tâehe, dit Cossinius, allons-nous-en. Pas encore, m'éeriai-je; il faut au préalable qu'on ait traité, comme nous en sommes convenus, des deux produits supplémentaires qu'on tirc des troupeaux, savoir, le lait ou fromage, et la laine des brebis. Cossinius alors reprit en ces termes : Le lait de brebis, en effet, et après lui le lait de ehèvre, sont de tous les aliments liquides celui qui contient le plus de substance nutritive. Comme purgatif, le lait de eavale se place le premier; puis viennent successivement le lait d'ânesse, le lait de vaehe, ct enfin le lait de chèvre. En outre, les proprićtés du lait varient, suivant la qualité de la nourriture, la condition du bétail, et l'époque où l'on trait.

De la qualité de la nourriture: l'orge, la paille, et en général tout fourrage sec, mais de nature substantielle, donne un lait nourrissant. Le lait est purgatif s'il provient d'un bétail mis au vert, surtout quand le vert contient de ees herbes qui ont un effet laxatif sur le corps humain. De la condition du bétail : le lait d'une bête saine et de bon âge vaut sans doute mieux que celui d'une bête malade ou vieille. De l'époque où l'on trait: lc meilleur lait est eelui qu'on prend sortant du pis, et qui n'a pas été tiré trop tôt après que la

gregen quinquagenarium bini homines. Utique uterque horum ut secimm habeat equas domitas singulas in is regionibus, in quibus stabulari solent equas abigere, ut in Appulia, et in Lucanis aceidit sape.

XI. Quoniam promissa alssolvimus, inquit, eamus. siquidem, inquam, adjeceritis de extraordinario pecudum fructu, ut proedictum est, (de) lacte, caseo, et tonsura lana. Est enin lac omnium rerum, quas cibi causa capimus, liquentium maxime alibile, et id ovillım, inde caprisum. Quod autem maxime perpurget, est equinum, tum asininum, dein bubulum, tum capriuum. Sed lorum sunt discrimina quaedam, et a pastionibus, et a pecudum natura, et a mulctu. A pastionibus, quod fit ab ordeo, et stipula, et omnino arido et firmo cibo pecude pasta, id alibile. Ad perpurgandum id, quod ab viridi pascno, et eo magis si usa est ea lierba, qua ipsa sumta perpurgare corpora nostra solet. A pecudum natura, quod lac melius est a ralentibus, et ab is qua nondum veteres sunt, quam si est contra. A mulgendo, atque ortu optimum est id quod neque emunctum longe abest a mulso, neque a partu continuo est sumtum. Ex loc lacte casei qui funt, maximi cibi sunt bubuli, et qui difficillime transeaut sumti; secundo ovilli; minimi cibi, et qui facillime bête a mis las. Les fromages de vache sont les plus agréables au goût, mais les plus difficiles à digérer. Ceux do brebis viennent après. Lés moins appétissants, mais les plus digestifs, sont ceux de lait de ehèvre. II faut encore distinguer entre fromage mou ct de façon récente, et fromage vieux et see. Le fromage mou est plus délicat comme aliment, et tient moins à l'estomae. C'est le contraire quand il est see et vieux. La confeetion des fromages dure du lever des Pléiades de printemps au lever des Pléiades d'été. On trait les animaux le matin pendant la durée du printemps, et à midi dans les autres saisons : ce n'est point toujours une règle fixe ; elle est subordonnée aux circonstances de pâturage et de loealité. Pour faire cailler deux congii de lait, on prend gros comme une olive de présure. Celle du lièvre ct du chevreau est meilleure que celle de l'agneau : quelques personnes se servent pour cela du lait qui sort du figuier, mêlé de vinaigre. On emploie encore d'autres substanees. Les Grees appellent le lait de figuier ỏròs, (suc), tantôt đáxpuos (larme). Je serais porté à croire, dis-je, que le figuier que l'on voit auprès de la chapelle Ruminale $\mathbf{y}$ fut planté par des bergers; car e'est là qu'on fait, pour les enfants à la mamelle, des saerifiees où l'on offre du lait au lieu de vin. On disait autrefòis rumis ou ruma pour mamelle; et encore aujourd'hui on appelle subrumi les agneaux qui tettent, comme on dit lactentes, de lac. Cossinius continua, et dit: Il faut aussi saupoudrer de sel les fromages, de sel fossile préférablement au sel marin. Quant à la tonte des brebis, je commence toujours par m'assurer si elles ne sont point galeuses ou affectées d'ulcères, afin de commencer, dans ce cas, par les guérir. L'époque de la tontc

dejiciantur, caprini. Est etianı discrimen, utrum casei molles ac recentes sint, an aridi et veteres. Cum molles sunt, magis alibiles, in corpore non resides : veleres et aridi contra. Caseum facere incipiunt a vergiliis vernis exortis ad astivas vergilias. Mulgent vere ad caseum facinndum mane, aliis temporibus meridianis horis : tametsi propter loca, et pabulum disparile non usquequaque idem fit. In lactis duos congios addunt coagulum ma. gnitudine olex, ut coeat. Quod melins leporinum, et hordinum quam agninum. Alii pro coagulo addunt de fici ramo lac, et acetum. Aspergunt item aliis aliquot rebus,

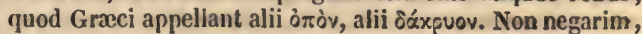
inquam, ideo apud divæ Rumina sacellum a pastorihus satam ficum. Ibi enim solent sacrificari lacte pro vino, et pro lactentibus. Mammace enim rumis, sive lunaz, nt ante dicebant, a rumi; et inde dicuntur subrumi agni : lactenles, a lacte. Quin aspergi solent sales : melior fos. silis quam marinus. De tonsura ovium, primum animarlverto ante quam incipiam facere, num scabiem aut ulcera lrabeant, ut, si opus est, ante curentur, quam tondean. tur. Tousura tempus inter acquinoctium vernum, el solstitium, cum sudare inceperunt oves. A quo sudore recens lana tousa sucida appellata est. Tonsas recentes co- 
est l'espace de temps compris entre l'équinoxe du printemps et le solstice, c'est-à-dire lorsque les brebis commencent à transpirer. C'est ce qui fait qu'on nomme la laine nouvellement coupée sucida (laine avec le suint). Immédiatement après la tonte on frotte les brebis d'un mélange de vin et d'huile. Quelques-uns ajoutent de la cire blanche et du saindoux. Si on les couvre de peaux, il faut, avant de les envelopper, enduire l'intérieur de la même substance. Quand on blesse une brebis en la tondant, on applique à la plaie un emplâtre de poix fondue. Ici on tond les brebis à grosse laine au temps où se fait la moisson de l'orge, ailleurs, c'est avant la fenaison. A l'exem. ple des habitants de l'Espagne citérieure, quelques personnes tondent leurs brebis deux fois par an, de six mois en six mois. Elles se donnent double táche dans l'espoir d'obtenir plus de laine; de même qu'on fauche deux fois les prairies, pour en tirer plus de foin. Les gens soigneux étendent sous les brebis de petites nattes, pour qu'aucun floconnese perde. Il faut pour la tonte un temps serein, et le moment le plus favorable est de la quatrième heure à la dixième ; car la grande chaleur, qui met en sueur les brebis, donne à la laine plus de poids, de moelleux, et d'éclat. La laine fraichement coupée s'appelle vellus ou velumen (ce qui s'arrache); d'où l'on voit clairement que la coutume d'arracher la laine a précédé celle de la tondre. Ceux qui procèdent cncore suivant l'ancienne méthode font jeuner les brcbis trois jours à l'avance, parce que l'animal étant affaibli, la laine cède plus facilement à la main. On dit que les premiers barbiers sont venus de Cilicie vers la $454^{\circ}$ année de la fondation de Rome (c'est ce qui résulte du nom de l'inscription d'Ardée); et qu'ils ont été introduits en Italie par

dem die perungunt vino, et oleo : non nemo admixta cera alba, et adipe suilla. Et si ea tecta solet esse, quam habuit pellem injectam, eam intrinsecus eadem re perinungunt, et tegunt rursus. Si qua in tonsura plagam accepit, eum locum oblinunt pice liquida. Oves hirlas tondent circiter ordeaceam messem : ill aliis locis ante fonisicia. Quidam has in anno bis tondent, ut in Hispania citeriore, ac semestres faciunt tonsuras. Duplicem impendunt operam, quod sic plus putant fieri lanæ. Quo nomine quidam bis secant prata. Diligentiores tegeticulis subjectis oves tondere solent, nequi flocci intereant. Dies ad eam rem sumuntur sereni, et iis id faciunt fere a quarta ad decimam horam : quoniam sole calidiore tonsa ex sudore ejus lana fit mollior, et ponderosior, et colore meliore. Quam demplam ac conglobatam, alii vellera, alii velu. mina appellant. Ex quorum vocabulo animadverti licet, prius lanæ vulsuram quam Lonsuram inventam. Qui etiam nunc vellunt, ante triduo lıabent jejunas, quod languidæ minus radices lanæ retinent. Omnino tonsores in Italia primum venisse ex Cilicia dicunt post R. C. A. ccccur; ut scriptum in publico Arder in literis extat, eosque adduxisse P. Ticinium Menam. Olim tonsores nun
P. Lieinius Ména. La prolixité de la chevelure et de la barbe, dans les statues antiques, témoigne encore d'un temps où l'on ne coupait ni l'une ni l'autre. Si la brebis, reprit Cossinius, nous fournit la laine dont nous nous habillons, le poil de la chèvre s'emploie diversement pour la marine, la construction des machines de guerre, et les procédés de l'industrie. Certains peuples se couvrent le corps de la peau même des brebis, comme les Gćtules et les Sardes. Cet usage paraít même avoir existé chez les Grecs d'autrefois, comme on le voit par la dénomination de $\delta$ ip$\theta \varepsilon p i x \varsigma$, donnée dans leurs tragédies à certains vieillards, et sur notre théâtre, aux personnages d'habitudes rustiques; pour témoins, le jeune homme dans l'Hypobolimée de Cécilius, et lc père dans. l'Heautontimorumenos de Térence. La tonte des chèvres est en usage en Phrygie, où l'espèce à longs poils est commune. C'est de cette contrée que nous viennent les tissus de poil que nous appelons cilices, ainsi nommés parce que c'est en Cilicie qu'a commencé l'habitude de tondre les chèvres. Ainsi parla Cossinius, sans trouver de contradicteurs. En ce moment vint à nous un affranchi de Vitulus, sortant des jardins de ville de son patron. Mon maitre, nous dit-il, m'envoie vous prier de moins entamer son jour de fête, et de venir le trouver le plus tôt possible. Nous acceptâmes l'invitation, mon cher Niger, Turranius, Scrofa et moi, nous allámes rejoindre Vitulus dans ses jardins. Le reste de la société s'en retourna les uns chez eux, les autres chez Ménas.

fuisse adsignificant antiguorum statuæ, quod pleræque labent capillum, et barbam magnam. Suscipit Cossinius : Ut fructum ovis e lana ad vestimentum, sic capra pilos ministrat ad usum nauticum, et ad bellica tormenta, et fabrilia vasa. Neque non quadam nationes harum pellibus sunt vestitæ, ut in Getulia et in Sardinia. Cujus usum apud antiquos quoque Græcos fuisse apparet, quod in tragodiis senes $a b$ liac pelle vocantur oipoepial, et in comodiis; qui in rustico opere morantur, ut apud Caci. lium in Hypobolimzo habet adolescens, apud Terentium in Heautontimorumeno senex. Tondentur, quod magnis villis sunt, in magna parte Phrygia ; unde cilicia et cætera ejus generis fieri solent. Sed quod primum ea tonsura in Cilicia sit instituta, nomen id Cilicas adjecisse dicunt. Illi lıoc. Neque ab hoc, quod mutaret Cossinius. Et simul vituli libertus in urbem veniens ex hortis divertitur ad nos: Et ego ad te missus, inquit, ibam domum rogatum, ne diem festum faceres breviorem, et mature veni. res. Itaque discedimus ego et Scrofa in hortos ad Vitulum, Niger Turrani noster. Alii partim domum, partim ad Menatem. 
LIVRE III.

I. L'existence humaine a deux modes, $\mathbf{Q}$. Pinnus, manifestement aussi distincts de théâtre que d'origine, la vie des champs et celle des cités. La vie champêtre est de beaucoup la plus ancienne. Longtemps avant qu'il y eût des villes, les campagnes avaient des habitants. Pour la Grèce, suivant la tradition, la plus anciennedes eités est Thèbes, fondée en Béotie par le roi 0 gygès. Pour la campagne romaine, c'est Rome, création du roi Romulus, ( car c'est maintenant qu'on peut dire, avec plus vérité qu'on ne pouvait faire à l'époque où éerivait Ennius : " qüil y a environ sept cents ans, plus ou moins, que la célèbre ville de Rome a été bâtie sous les auspices les plus augustes") Or, en admettant que l'existence de Thèbes soit antérieure au cataclysme d'Ogygès, on ne saurait cependant faire remonter à plus de deux mille ans la fondation de cette ville. Maintenant rapprochez cette date de celle où l'on a commencé à cultiver les champs, où les hommes n'avajent d'autres demeures que des cabanes et des chaumières, ne sachant ce que e'était que portes ni que murailles : il s'établit une antériorité presque immémoriale de l'habitation agricole sur l'habitation urbaine. Et il n'y a pas là de quoi surprendre : la nature nous a donné les campagnes, c'est l'art qui a construit les villes. Or l'invention des arts en Grèce ne remonte, dit.on, qu'à mille ans, tandis que de tous temps la terre a été susceptible de culture. Mais la vie agricole n'est pas seulement la plus ancienne, elle est encore la plus recommandable. Ce n'était pas sans raison que nos ancêtres constamment reportaient la population de la ville dans la campagne. Rome, en

\section{LIBER TERTIUS.}

1. Cum dua vitæe traditæ sint lominum, rustica, et $1 \mathrm{r}$ naba, Q. Pinni, dubium non est, quin lıæ non solum loco discretae sint, sed etiam tempore diversam originem labeant. Antiquior enim multo rustica, quod fuitt empus, cuın rura colerent homines, neque urbem haberent. Etenin vetus. tissimum oppidum cum sit traditum Graecum, Boctix Thebæ, quod rex Ogyges ædificarit; in agro Romano Roma, quam Romulus rex : (nam in hoc nunc denique est, it dici possit, non cum Ennius scripsit, Septingenti sunt paulo plus aut minus anni, augusto augurio postquam inclita condita Roma est.) Thebr, qua ante cataclysmon Ogygi condita dicuntur, ex tamen circiter duo millia annorun et centum sunt. Quod tempus si referas ad illud principinm, quo agri coli sunt cupti, atque in casis et tuguriis liabitabant, nec murus nec porla quidl esset sciebant: immani numero annorum urbanos agricolæ prostant. Nec miruin, quod divina natura dedit agros, ars humana sedificavit urbes. Cum artes omnes dicantur in Græcia intra mille annorum repertæ, agri nunquam non fuerint in terris, qui coli possint. Neque solum autiquior cultura agri sed etiam melior. Itaque non sine faisant de ses eitoyens des paysans, assurait si subsistance pendant la paix, et son intégrité en cas de guerre. Il y avait une signification dans tous ces noms de mère et de Cérès donnés indistinctement à la Terre; dans cette croyance de la sainteté, de l'utilité de la profession de cultivateur, qui faisait honorer ceux qui l'exerçaient comme les seuls restes de l'antique race de Saturne. C'est dans le même esprit qu'oll a nommé Initia (initiation) les cérémonies particulières du culte de Cérès. Une autre preuve de l'antériorité de la vie champêtre sur la vie des cités, e'est le nom même de la ville de Thèbes, nom qu'elle a reçu de la nature de son sol, et non de son fondateur. Car, dans l'ancienne lan. gue de la Grèce, comme encore aujourd'hui chez les Éoliens, peuple originaire de la Béotie, un monticules'appelait Teba sans aspiration; et le mot est encore usitć parmi les Pélasges, venus de la Grèce dans la campagne sabine. Il en existe même un monument dans le pays; car on voit sur la voie Salaria, non loin de Réate, une butte milliaire qui s'appelle Tebæ. L'cxiguïté des possessions dans l'origine ne comportait pas de distinction entre l'agriculture et l'éducation des bestiaux. Issus de bergers, les hommes de ce temps semaient et faisaient paître leurs troupeaux dans le même champ; mais plus tard, quand quelques-uns se furent agrandis, les troupeaux furent mis à part, et l'on vit surgir les dénominations spéciales de pâtre et de cultivateur. L'occupation du premier est elle-mème divisible en deux parties, que l'on n'a point jusqu'ici distinguées suffisamment. Autre en effet est lc régime des animaux nourris dans l'intérieur d'une ferme, et de ceux quon mène paitre au dehors : celui-ci constitue une profession bien

causa majores nostri ex urbe in agris redigebant suos cires, quod et in pace a rusticis Romanis alebantur, et in bello ab his tuelantur. Nec sine causa Terram eandem appellabant matrem, et Cererem, et qui eam colerent, piam et utilem agere vitam credebant, atque eos solos reliquos esse ex stirpe Saturni regis. Cui consentaneum est, quod Initia vocantur potissimum ea, qua Cereri finnt sacra. Nec minus oppidi quoque nomen Theba indicant antiquiorem esse agrum, quod ab agri genere, non a conditore nomen ei est impositum. Nam lingıa prisca et in Gracia Æoleis Bootii sine afllatu rocant collis Tebas : et in Sabinis, quo e Gracia venerunt Pelasgi, etiam nunc ila dicunt. Cujus vestigium in agro Sabino via Salaria non longe a Reate milliarius clivus appellatur Tebx. Cum agriculturam primo propter paupertatem maxime indiscretam haberent, quod a pastoribus qui erant orti in eodem agro et serebant et pascebant: qui postea creveruut, peculia diviserunt, ac factum, ut dicerentur alii agricolæ, alii pastores. Quie ipsa pars duplex est, tametsi ab nullo satis discreta, quod altera est villatica pastio, altera agrestis. Hæc nota et nobilis, quod et pecuaria appellatur, et inultum homines locupletat, et ob eam rem aut conduc- 
aux bouehers de la ville? Mais qui m'empéehe, dit Axius, d'avoir des abeilles dans ma villa? Est-ce que le miel de Sicile ne se fait que chez Séjus, et ne peut-on obtenir à Réate que du miel corse? serait-ce que le gland que Séjus achète a la vertu d'engraisser les sangliers, tandis que mon gland, qui ne me coûte rien, les ferait maigrir? Mais, reprit Appius, Mérula n'a point dit (que vous ne puissiez faire chez vous les mêmes ćlèves que Séjus; seulement j'ai vu de mes propres yeux que vous ne le faites pas. Car il y a deux espèces de nourriture : l'une que j'appellerai champêtre, et qui comprend le bétail; l'autre, sédentaire, et qui embrasse pigeons, poules, mouehes à miel, et en général tout ce qu'on veut élever dans l'enceinte d'une villa. Magon de Carthage, Cassius Dionysius, et quelques autres, ont traité cette matière spécialement en différents endroits de leurs ouvrages, dont Séjus paraît être imbu. Aussi tire-t-il plus de profit de sa seule vilia par les nourritures qu'il y fait, que d'autres n'en savent recueillir de la culture d'un fonds tout entier. En effet, dit Mérula, j’ai vu chez lui des bandes immenses d'oies, de poules, de pigeons, de grues, de paons, ainsi qu'une multitude de loirs, poissons, sangliers, et autres gibiers de chasse. L'affranehi qui tient ses livies, et que Varron a vu, m'a assuré, quand il me faisait les honneurs en l'absence de Séjus, que son maître tirait de sa villa pius de cinquante mille sesterces par an. Comme Axius paraissait tout étonné, je lui demandai s'il connaissait le fonds de ma tante maternelle, sur la voie Salaria, daus le pays sabin, à vingt-quatre milles de Rome. Assurément, dit-il, puisque c'est là que je m'arrête à midi, lorsque, pendant l'été, je me rends de Rome à Réate; et que je passe la nuit, lors-

hic apros macellario Scjus ? Qui minus ego, inquit Axius, istas habere possum in Reatina villa? nisi si apud Sejum Siculum fit niel, Corsicum in Reatino : et hic aprum glans cum pascit emticia, facit pinguem; illic gratuita exilem. Appius, posse ad te fieri , inquit, Sejanas pastiones non negarit Merula : ego, non esse, ipse vidi. Duo enim genera cum sint pastionum : unum agreste, inquo pecuariae sunl, alterum villaticum, in quo sunt gallinæe ac columbre et apes et cxtera, qux in villa solent pasci : de quibus et Poenus Mago et Cassins Dionysius el alii quid separatim ac dispersim in libris reliquerunt, quos Sejus legisse videtur, et ideo ex lis pastionibus ex una villa majores fructus capere, quam alii faciunt ex toto fundo. Cerle, inquit Merula. Nam ibi vidi greges magnus anserum, gallinarum, colımbarum, grumm, pavonum, nec non glilium, piscinm, aprorım, el catera venationis. Lx quibus rebus scriba librarius libertus cjus, qui apparuit Varronl, et me absente patrono lospitio accipiebat, in annos singulos plus quinquagena millia [e villa] capere dicebat. Axio admiranti : Certe nosti, inquam, materteræe mex fundum in Sabinis , qui est ad quartum et vicesimum lapidem via salaria a Roma. Quidni, inquit? ubi astate diem meridie dividere soleam, cum eo Reate ex urbr, que j'en reviens pendant l'hiver. Eh bien, reprisje, il y a dans eette villa une volière, dont il est sorti à ma connaissance, dans une seule année, jusqu'à einq mille grives, qui ont été vendues trois deniers pièce; de sorte que ce seul produit a donné cette année-là soixante mille sesterces, le double du revenu de votre métairie de Réate, bien qu'elle n'ait pas moins de deux cents $j u$ gera. Quoi! soixante milles sesterces, s'écria Axius; soixante mille! vous plaisantez, sans doute. Non, je dis soixante mille. Soit. Mais vous conviendrez que pour arriver à ce chiffre il faut la coïncidence d'un festin publie, ou d'un triomphe extraordinaire, tel que celui de Métellus Scipion; ou bien encore de ces repas de corps, dont le grand nombre a fait, à certaines époques, renchérir les vivres de nos marchés. Mais, année commune, vous serez longtemps à réaliser un bénéfiee aussi considérable. Soyez persuadé au contraire qu'une volière ne vous fait jamais faux bond, et que, par le temps qui court, on n'a pas à rabattre des espérances qu'on y a fondées. Car où est l'année où vous ne voyiez un festin de triomphe, ou de ces repas de corps qui affluent au point de faire renchérir les vivres? Vous pourriez dire, ajouta Mérula, que, dans ee temps de profusion, ces publiques bombances sont quotidienıes à Rome. L. Albutius, homme fort savant, eomme vous le savez tous, et dont nous avons des satires dans le goût de celles de Lucilius, ne disait-il pas que son fonds du pays albain rapportait bien moins que sa villa? que le revenu de l'un était au-dessous de dix mille sesterces, etcelui de l'autre au-dessus de vingt? Le même auteur prétcndait qu'avec une villa près de la mer, dans une localité de son choix, il se serait fait par an plus de cent mille sesterces. Dernièrement

aut cum inde venio hieme, noctu ponere castra. Atque in lac villa qui esl ornithon, ex eo uno quinque millia scio venisse turdorum denariis ternis, ut sexaginta millia ea pars reddiderit eo anno villæ, bis tantum quam tuus fundus ducentum jugerum Reate reddit. Quid? sexaginta, inquit Axius? LX? LX? derides. Sexaginta, inquam. Sed ut ad lunc bolum pervenias, opus erit tibi aut epulum aut triumpluus alicujus, ut tunc fuit Scipionis Metelli, aut collegiorum' canæ, qua tunc innumerabiles excandefaciebant annonam macelli. Reliquis annis omnibus et lıanc expectabis summam. Spero non tibi decoquet [ nou] ornitlon. Neque hoc accidit his moribus, nisi raro, ut decipiaris. Quotus quisque enim est annus, quo non videas epulum, aut triumplıum, aut collegia [non ] epu. lari, quæ nunc innumerabiles incendunt annonam? Sed propter luxuriam, inquit, quodammodo epulun quotidianum est intra januas Romæ. Nonne item L. Albutius lıomo (ut scitis) apprime doctus, cujus Luciliano clıaractere sunt libelli, dicebat in Albano fundum suum pastionibus semper vinci a villa? agrun enim minus dena millia reddere, villam plus vicena. Idem secundum mare quo loco vellet, si parasset villam, se supra centum millia e villa recepturum. Age non M. Calo nuper cum Lucall. 
encore, M. Caton n'a-t-il pas vendu pour quarante mille sesterces de poissons provenant des viviers de Lucullus, dont il venait d'accepter la tutelle? Mon cher Mérula, dit Axius, veuillez m’accepter pour élève dans l'art de faire des élèves dans une villa. Je ne dis pas non, reprit Mérula; mais il faut me payer d'avance par un dîner. Vous l'aurcz dès aujourd'hui; et à l'avenir, je vous ferai tâter souvent des élc̀ves que vous m'aurez appris à faire. J'ai peur, dit Appius, que vous ne me fassiez manger quelque oie ou paon mort dans votre basse-cour. Qu'importe, reprit Axius, que les oiseaux ou poissons que l'on vous sert soient morts de leur belle mort ou d'autre manière? vous ne pouvez les manger vivants. Mais je vous en prie, Mérula, initiez-moi à cette science de la basse-cour; veuillez nous en exposer les principes et les ressources. Mérula accepta la tâche de bon cœur.

III. Un propriétaire doit avant tout connaître les espèces animales qu'on nourrit dans une villa ou dans ses dépendances, en vue de profit ou d'agrément. Il y a pour cela trois régimes différents à étudier : celui de volière, celui de la garenne, celui du vivier. J'entends par volière le lieu où l'on renferme toutes espèces d'oiseaux; par garenne, non pas ce que le mot signifiait pour nos ancêtresà la troisième génération, c'est-à-dire un parc exclusivement peuplé de lièvres, mais un enclos attenant à la villa, où l'on peut nourrir du gibier de toutes sortes. J'entends enfin par vivier toute réserve de poisson d'eau douce ou salée, dépendant d'une villa. Chacun de ces trois régimes est au moins double. Ainsi la théorie de la volière comprend en deux parties les espèces volatiles auxquelles la terre suffit, telles que les paons, les tourterelles, les grives; et celles à qui il faut la terre et l'eau, comme les oies, les

accepit tutelam, e piscinis ejus quadraginta millibus sextertiis vendidit pisces? Axius : Merula mi, inquit, recipe me quæso discipulum villaticæ pastionis. Ille : Quin simulac promiseris minerval, id est conam, incipiam, inquit. Axius : Ego vero non recuso vel hodie, et ex ista pastione crebro. Appius : Credo simulac primum ex isto villatico pecore mortui erunt anseres aut pavones. Cui ille: Quid enim interest utrum morticinas editis volucres an pisces, quos nisi unortuos estis nunquam? Sed oro te, inquit, induce me in viam disciplinæe villaticæe pastionis, ac vim fornamque ejus expone. Merula non gravate:

1II. Primum, inquit, dominum scientem esse oportet earum rerum qua in villa circumve eam ali ac pasci possint, ita ut domino sint fructui ac delectationi. Ejus disciplinæ genera sunt tria, ornithones, leporaria, piscinæ. Nunc ornithonas dicu omnium alitum, quae intra parietes villa solent pasci. Leporaria te accipere volo, non ea quxe tritavi nostri dicebant, ubi soliti lepores sint, sed omnia septa, aflicta villa qua sunt, et labent inclusa animalia, quæ pascantur. Similiter piscinas dico eas, qua in aqua dulci aut salsa inclusos liabent pisces ad villam. Ilarum sarcelles, les canards. La théorie de la garenne distingue également entre les sangliers, chevreuils et lièvres, d'un côté, et les abeilles, escargots et loirs, de l'autre. Entin la théorie du vivier se divise aussi en deux classes, celle des poissons de mer, ct celle des poissons d'eau douce. L'at tention doit donc se porter sur six parties différentes. On commencera par s'entuurcr de gens de trois professions, des oiseleurs, chasseurs et pêcheurs; ou du moins on aura respectivemcint recours à leur entremise pour se procurcr des mères pleines, dont les esclaves, sous la surveillance du maître, soignent la progéniture, l'élc. vent, l'engraissent jusqu'à ce qu'elle soit bonne à envoyer au marché. Certaines espèces, comme les loirs, les escargots et les poules, s'obtiennent sans qu'il soit besoin pour cela de faire interve. nir oiseleurs, chasseurs ou pĉcheurs; et ce genre de spéculation a commencé sans doute par s'exelcer sur celles qui sont les hôtes ordinaires de toute villa. Les poulets, dans l'origine, ne se sont pas multipliés seulement par les soins des augures, et pour le besoin des auspices; plus d'un chef de famille aussi, dans nos campagnes, donna des soins à leur propagation. On s'avisa, dans la suite, de former dans le voisinage de la villa des enclos entourés de murailles, tant pour s'y livrer à la chasse que pour y établir des ruches pour les abeilles, qui d'abord n'avaient d'autre abri que l'entablement d'un toit. Plus tard on creusa des viviers remplis d'eau douce, et dans lesquels on emprisonna les poissons pêchés seulement dans lcs rivières. On voit que chacune des trois parties de l'industrie de la basse-cour a passé par deux degrés, marqués, le premier, du caractère de la frugalité antique, le second, de la tendance aux raffinements des siècles postérieurs. Dans la première période, en effet, nos ancêtres

singula genera minimum in binas species dividi possunt; in prima parte ut sint, quæ terra modo sunt contenta, ut sunt pavones, turtures, turdi. Altera species sunt, qua non sunt contenta terra solum, sed etiam aquam requi. runt, ut sunt anseres, querquedulæ, anates. Sic alterunı genus illud venaticum duas habet diversas species : unam, in qua est aper, caprea, lepus. Altera item extra villam quæ sunt, ut apes, cocleæ, glires. Tertii generis aquatilis item species duæ, partim quod labent pisces in aqua dulci, partim quod in marina. De his sex partibus : ad ista tria genera artificum paranda, aucupes, venatores, piscatores, aut ab lis emenda, quae tuorum servorum diligentia tuearis in fotura ad partus, et nata nutricere saginesque, in macellum ut perveniant. Neque non etiam quadam assumenda in villan sine retibus aucupis, venatoris, piscatoris, ut glires, coclea et gallinæ. Earum rerum cultura instituta prima, ea quæ in villa lualsentur. Non enim solum aıgures Romani ad auspicia primum pararunt pullos, sed etiam patres familiae rure. Secunda, qua macerie ad villam venationis causa cluduntur, et propter alvearia. Apes enim subter subgrundas ab initio 
aux bouehers de la ville? Mais qui m'empéehe, dit Axius, d'avoil' des abeilles dans ma villa? Est-ee que le miel de Sieile ne se fait que ehez Séjus, et ne peut-on obtenir à Réate que du miel corse? serail-ee que le gland que Séjus aehète a la vertu d'engraisser les sangliers, tandis que mon gland, qui ne me eoûte rien, les ferait maigrir? Mais, reprit Appius, Mérula n'a point dit que vous ne puissiez faire ehez vous les mêmes ćlèves que Séjus; seulement j’ai vu de mes propres yeux que vous ne le faites pas. Car il y a deux espèees de nourriture : l'une que j'appellerai ehampêtre, et qui comprend le bétail ; l'autre, sédentaire, et qui embrasse pigeons, poules, mouches à miel, et en général tout ee qu'on veut élever dans l'enceinte d'une villa. Magon de Carthage, Cassius Dionysius, et quelques autres, ont traité eette matière spécialement en différents endroits de leur's ouvrages, dont Séjus parait être imbu. Aussi tire-t-il plus de profit de sa seule vilia par les nourritures qu'il y fait, que d'autres n'en savent reeueillir de la eulture d'un fonds tout entier. En effet, dit Mérula, j’ai vu ehez lui des bandes immenses d'oies, de poules, de pigeons, de grues, de paons, ainsi qu'une multitude de loirs, poissons, sangliers, et autres gibiers de ehasse. L'affranehi qui tient ses livres, et que Varron a vu, m'a assuré, quand il me faisait les honneurs en l'absenee de Séjus, que son maître tirait de sa villa pius de einquante mille sesterees par all. Comme Axius paraissait tout étonné, je lui demandai s'il eonnaissait le fonds de ma tante maternelle, sur la voie Salaria, daus le pays sabin, à vingt-quatre milles de Rome. Assurément, dit-il, puisque c'est là que je m'arrête à midi, lorsque, pendant l'été, je me rends de Rome à Réate; et que je passe la nuit, lors-

hic apros ınacellario Sejus? Qui minus ego, inquit Axius, istas liabere possum in Reatina villa? nisi si apud Sejum Siculum fit mel, Corsicum in Reatino: et hic aprum glans cum pascit emticia, facit pinguem; illic gratuita exilen. Appins, posse ad te fieri, inquit, Sejanas pastiones non uegavit Merula : ego, non esse, ipse vidi. Duo enim genera cuı sint pastiouum : unum agreste, in quo pecuariae sunt, alterum villaticum, in quo sunt gallina ac columbae et apes et cactera, quax in villa solent pasci,: de quibus et Poeuus Mago et Cassius Dionysius et alii quid separatim ac dispersim in libris reliquerunt, quos Sejus legisse vicletur, et ideo ex lis pastionibus ex una villa majores fructus capere, quam alii faciunt ex toto fundo. Certe, inquit Merula. Nam ibi vidli greges magnos anserum, gallinarum, coluubarum, grumm, pavonum, nec non glirium, piscium, aprorum, et catera veuationis. Lx quibus rebus scriba librarius libertus ejus, qui apparuit Varronl, at ine absente pationo lospitio accipiebat, in annos siu. gulos plus quinquagena millia [e villa] capere dicehat. Axio aduiranti : Certe nosti, inquam, matertera ure fundum in Sabinis, qui est ad quartum et vicesimum la. pidem via salaria a Roma. Quidui, inguit? ubi astale diem neridie dividere solean, cum eo Reate ex urlsr, que j'en reviens pendant l'hiver. Eh bien, reprisje, il y a dans eette villa une volière, dont il est sorti à ma eonnaissanee, dans une seule année, jusqu'à einq mille grives, qui ont été vendues trois deniers pièce; de sorte que ee seul produit a donné eette année-là soixante mille sesterees, le double du revenu de votre métairie de Réate, bien qu'elle n'ait pas moins de deux eents jugera.Quoi! soix ante milles sesterees, s'éeria Axius; soixante mille! vous plaisantez, sans doute. Non, je dis soixante mille. Soit. Mais vous eonviendrez que pour arriver à ce ehiffre il faut la eoineidenee d'un festin publie, ou d'un triomphe extraordinaire, tel que eelui de Métellus Seipion; ou bien eneore de ees repas de eorps, dont le grand nombre a fait, à certaines époques, renehérir les vivres de nos marehés. Mais, année eommune, vous serez longtemps à réaliser un bénéfiee aussi eonsidérable. Soyez persuadé au eontraire qu'une volière ne vous fait jamais faux bond, et que, par le temps qui court, on n'a pas à rabattre des espéranees qu'on y a fondées. Car où est l'année où vous ne voyiez un festin de triomphe, ou de ees repas de eorps qui affluent au point de faire renehérir les vivres? Vous pourriez dire, ajouta Mérula, que, dans ee temps de profusion, ees publiques bombances sont quotidienues à Rome. L. Albutius, homme fort savant, eomme vous le savez tous, et dont nous avons des satires dans le goût de eelles de Lueilius, ne disait-il pas que son fonds du pays albain rapportait bien moins que sa villa? que le revenu de l'un était au-dessous de dix mille sesterees, et eelui de l'autre au-dessus de vingt ? Le même auteur prétendait qu'avee une villa près de la mer, dans une loealité de son ehoix, il se serait fait par an plus de cent mille sesterees. Dernièrement

aut cum inde venio lieme, noctu ponere castra. Atque in lac villa qui est ornitlon, ex eo uno quinque millia scio venisse turdorum denariis ternis, ut sexaginta millia ea pars reddiderit eo anno villæ, bis tantum quam tuus fundus ducentum jugerum Reale reddit. Quid? sexaginta, inquit Axius? LX? LX? derides. Sexaginta, inquam. Sed ut ad lunc bolum pervenias, opus erit tibi aut epulum aut triumplus alicujus, nt tunc fuit Scipionis Metelli, aut collegiorum' conæ, qua tunc innumerabiles excandefaciebant annonam macelli. Reliquis annis omnibus et lianc expectabis sımmam. Spero non tibi decoquet [nou] ornithon. Neque lıoc accidit lis moribus, nisi raro, ut decipiaris. Quotus quisque enim est annus, quo non videas epulıu, aut triumplıum, aut collegia [non ] epılari, quæ nunc innumerabiles incendunt annonam? Sed propter luxuriam, inquit, quodammodo epuluın quotidianum est intra januas Romæ. Nonne iten L. Albutius lıomo (ut scitis) apprime doctus, cujus Luciliano charactere sunt libelli, dicebat in Albano fundum suum pastio. nibus semper vinci a villa? agrum enim minns dena millia reddere, villam plus vicena. Idem secundun mare quo loco vellet, si parasset villam, se supra centum millia e villa recepturum. Age non $\mathbf{M}$. Calo nuper cum Lucell. 
encore, M. Caton na-t-il pas vendu pour quarante mille sesterees de poissons provenant des viviers de Lucullus, dont il venait d'aceepter la tutelle? Mon cher Mérula, dit Axius, veuillez m'accepter pour élève dans l'art de faire des élèves dans une villa. Je ne dis pas non, reprit Mérula; mais il faut me payer d'avance par un dîner. Vous l'aurcz dès aujourd'hui ; et à l'avenir, je vous ferai tâter souvent des élèves que vous m'aurez appris à faire. J'ai peur, dit Appius, que vous ne me fassiez manger quelque oie ou paon mort dans votre basse-cour. Qu'importe, reprit Axius, que les oiseaux ou poissons que l'on vous sert soient morts de leur belle mort ou d'autre manière? rous ne pouvez les manger vivants. Mais je vous en prie, Mérula, initiez-moi à cette science de la basse-cour; veuillez nous en exposer les principes et les ressources. Mérula accepta la tâche de bon cœur.

1II. Un propriétaire doit avant tout connaittre les espèces animales qu'on nourrit dans une villa ou dans ses dépendances, en vue de profit ou d'agrément. Il y a pour cela trois régimes différents à étudier : celui de volière, celui de la garenne, celui du vivier. J'entends par volière le lieu où l'on renferme toutes espèces d'oiseaux; par garenne, non pas ceque le mot signifiait pour nos ancètresà la troisième génération, c'est-à-dire un parc exclusivement peuplé de lièvres, mais un euclos attenant à la villa, où l'on peut nourrir du gibier de toutes sortes. J'entends enfin par vivier toute réserve de poisson d'eau douce ou salée, dépendant d'une villa. Chacun de ces trois régimes est au moins double. Ainsi la théorie de la volic̀re comprend en deux parties les espèces volatiles auxquelles la terre suffit, telles que les paons, les tourterelles, les grives; et celles à qui il faut la terre et l'eau, comme les oies, les

accepit tutelam, e piscinis ejus quadraginta millibus sextertiis vendidit pisces? Axius : Merula mi, inquit, recipe me quæso discipulum villaticæ pastionis. Ille : Quin simulac promiseris minerval, id est cœnam, incipiam, inquit. Axius : Ego vero non recuso vel hodie, et ex ista pastione crebro. Appius : Credo simulac primum ex isto villatico pecore mortui erunt anseres aut pavones. Cui ille: Quid enim interest utrum morticinas editis volucres an pisces, quos nisi mortuos estis nunquam? Sed oro te, inquit, induce me in riam disciplina villatica pastionis, ac vim formamque ejus expone. Merula non gravate:

III. Primum, inquil, dominum scientem esse oportet earum rerum qua in villa circumve eam ali ac pasci possint, ita ut domino sint fructui ac delectationi. Ejus disciplina genera sunt tria, ornithones, leporaria, piscinx. Nunc ornithonas dico omnium alitum, qux intra parietes villa solent pasci. Leporaria te accipere volo, non ea quae tritavi nostri dicebant, ubi soliti lepores sint, sed omnia septa, aflicta villae qua sunt, et lıabent inclusa aninialia, quæ pascantur. Similiter piscinas dico eas, quac in aqua dulci aut salsa inclusos labent pisces ad villam. Harum sarcelles, les canards. La théorie de la garenne distingue également entre les sangliers, chevreuils et lièvres, d'un côté, et les abeilles, eseargots et loirs, de l'autre. Entin la théorie du vivier se divise aussi en deux classes, cellc des poissons de mer, et celle des poissons d'eau douce. L'at tention doit done se porter sur six parties différcntes. On commeneera par s'entuurer de gens de trois professions, des oiseleurs, chasseurs et pêcheurs; ou du moins on aura respeetivement recours à leur entremise pour se procurer des mères pleines, dont les esclaves, sous la surveillance du maître, soignent la progéniture, l'éle. vent, l'engraissent jusqu'à ce qu'elle soit bonne à envoyer au marché. Certaines espèces, comme les loirs, les eseargots et les poules, s'obtiennent sans qu'il soit besoin pour cela de faire interve. nir oiseleurs, chasseurs ou pêcheurs; et ce genre de spéculation a commencé sans doute par s’exereer sur celles qui sont les hôtes ordinaires de toute villa. Les poulets, dans l'origine, ne se sont pas multipliés seulement par les soins des augures, et pour le besoin des auspices; plus d'un chef de famille aussi, dans nos campagnes, donna des soins à leur propagation. On s'a visa, dans la suite, de former dans le voisinage de la villa des enclos entourés de murailles, tant pour s'y livrer à la chasse que pour y établir des ruches pour les abeilles, qui d'abord n'avaient d'autre abri que l'entablement d'un toit. Plus tard on creusa des viviers remplis d'eau douce, et dans lesquels on emprisonna les poissons pêchés seulement dans les rivières. On voit que chacune des trois parties de l'industrie de la basse-cour a passé par deux degrés, marqués, le premier, du caractère de la frugalité antique, le second, de la tendance aux raffinements des sièeles postérieurs. Dans la première période, en effet, nos ancêtres

singula genera minimum in binas species dividi possunt; in prima parte ut sint, quæ terra modo sunt contenta, ut sunt pavones, turtures, turdi. Altera species sunt, qua non sunt contenta terra solum, sed etiam aquam requi. runt, ut sunt anseres, querquedulæ, anates. Sic alterunı genus illud venaticum duas labet diversas species : unanı, in qua est aper, caprea, lepus. Altera iten extra villam qux sunt, ut apes, coclex, glires. Tertii generis aquatilis item species duæ, partim quod labent pisces in aqua dulci, partim quod in marina. De his sex partibus : ail ista tria genera artificum paranda, aucupes, venatores, piscatores, aut ab his emenda, quæ tuorum servornm diligentia tuearis in fœetura ad partus, et nata nutricere saginesque, in macellum ut perveniant. Neque non etian quadam assumenda in villam sine retibus aucupis, venatoris, piscatoris, ut glires, coclex et gallinæ. Earum rerum cultura instituta prima, ea qua in villa lialsentur. Non enim solum augures Romaui ad auspicia primum pa. rarunt pullos, sed etiam patres fanilixe rure. Secunda, qua macerie ad villann veuationis causa cluduntur, et propter alvearia. Apes enim subter subgrundas ab Initio 
n’avaient dańs leurs villas que deux places réservées à la volaille (aviaria), et consistant, l'une, en une cour basse, où ils nourrissaient les poules, dont les œufs et les poulets étaient tout le produit. L'autre est une tourelle servant de colombier, et située dans la partie supérieure du bâtiment. On a changé ce nom d'aviaria, et nous avons aujourd'hui des ornithones (volières), création de la sensualité moderne, dont la construction occupe plus de place que toute une villa d'autrefois. On en peut dire autant des garennes. Celle de votre père, $\Lambda$ xius, n'a jamais pour hôtes que des lièvres. On ne voyait point alors de ees immenses emplacements où l'on enferme de murs plusieurs jugera de terre, pour entretenir une multitude de sangliers et de chevreuils. Alors se tournant vers moi : Lorsque M. Pison, ditil, vous vendit son fonds de Tusculanum, combien y avait-il de sangliers dans le pare? Alors, je vous le demande, eonnaissait-on d'autres viviers que des vịviers d'eau douce, et d'autres poissons que des chiens de mer et des mulets? Aujourd'hui il n'y a pas un Rlinton gui ne dise que, pour ne nourrir que cette sorte de poissons, autant vaudrait un étang rempli de grenouilles. Philippe se trouvant un jour à Casinum, Ummidius, son hôte, lui servit un heau loup marin pèché dans votre rivière, Varron. A peine Philippe en cut-il goûté, qu'il le cracha en s'écriant: Je veux mourir, si je n’ai pas cru que e'ćtait du poisson. Vous voyez, dis-je, comıne le luxe de notre siècle a étendu les garennes ct prolongé les viviers jusqu'à la mer, en y faisant entrer en masse les poissons marins. N'est-ce point de ees derniers que Sergius et Licinius ont tiré l'un son nom d'Orata, et l'autre celui de Muréıa? Qui ne connait les fameux viviers des Philippes, des Hortensius et des Lucullus? Eh bien, reprit Mérula, dites-moi maintenant, Axius, de quelle époque je dois prendre mon sujet.

IV. Pour moi, répondit Axius, j’ai toujours aimé, comme dit le proverbe, à me tenir au camp derrière les principia (quartier général). Commencez donc par le siècle présent; j'aime mieux cela que de vous voir remonter au temps passé; car, après tout, les paons rapportent plus que les poules. Je ne vous eacherai même pas mon désir de vous entendre parler en premier lieu des volières (ornithones) : les grives ont domné bien du prix à ce nom, et les soixante mille sesterces que ces oiseaux rapportent à Fircellina m'ont communiqué une étrange démangeaison d'en posséder aussi. Eh bien donc, reprit Mérula, il y a deux espèces de volières : l'une d'agrément, comme celle de notre ami Varron à Casinum, et qui a trouvé beaucoup d'admirateurs; l'autre de rapport, et dont on fait commeree. On consacre à Rome des enclos fermés de murs à ce genre de spéculation; on les loue même à la campagne, notamment dans le pays sabin, naturellement très-fréquenté pour les grives. Lucullus a imaginé de se donner une volière à deux fins. II a fait construire à eet effet, dans l'intérieur de la sienne à Tusculum, une espèce de salle à manger, où il pouvait prendre le plaisir de la bonne ehère, et jouir doublement du spectacle de' ses grives, ici rôties et étalées sur un plat, là voltigcant prisonuières autour des fenêtres : eombinaison assez villatico usx terto. Tertix piscinx dulces fieri copta, et e fluminibus captos recepere ad se pisces. Onmibus tribus lis generibus snut hini gradus : superiorcs, quos frugalitas antiqua; inferiores, quos luxuria postcrior adjecit. Primus enim ille gradıs antiquus majorum nostrum erat, ill "uo essent a viaria, duo duntaxat : in plano cohors, in qua pasecbantur gallinse, et earum fructus erant ova et pulli. Alter sublinis, in quo erant columbe in turribus, aut summa villa. Contra, uunc aviaria sunt nomiıe mutato, quod rocantur ornitloncs, qua palatum suave dounini paravit, ut tecta majora lıabeant, quan tum liabebant tolas villas, in quibus stabulcutur turdi ac parones. Sic in sccunda parti ac leporario pater tuus, $\boldsymbol{A} x \boldsymbol{x}$, praterquam lepusculum e renatione vidit nunquam. Neque enim erat magnum ịl scptum, quod nunc, ut habeant multos apros ac capreas, complura jugera maceriis concludunt. Non tun, inquit mili, cum emisti fundum Tusculanum a M. Pisone, in leporario apri fuerunt multi? In terlia parti quis laabebat piscinam, nisi dulcem, et in ca dunlaxat squalos ac mugiles pisces? Quis contra nunc Rluinton non dicit sua uihil interesse, utrum iis piscibus stagnum habeat plenum an ranis? Non Philippus cum ad Umınidiun hospitem Casini divertisset, et ei e tuo finmine lu. pum piscem formosum apposuissct, atque ille gustasset et expuisset, dixit : Percam, ni piscem putavi esse? Sic nostra ixtas, inquam, luxuria propagavit leporaria, ac piscinas protulit ad mare, et in eas pelagios greges piscium revocavit. Non propter hos appcllati Sergius Orata, et Licinius Murena? Quis enin propter nobilitatem ignorat piscinas Plilippi, IIortensii, Lucullorum? Quare unde velis me incipere, $\boldsymbol{A} x \boldsymbol{i}$, dic.

IV. Ille: Ego vero, inquit, (ut aiunt) post principia in castris, id est, ab lis potius temporibus, quam superioribus: quod ex pavonibus fructus capiuntur majores, quam e gallinis. Atque adeo non dissimulabo, quod volo, de ornithone primum, quod lucri fecerunt loc nomen turdi; sexaginta enim millia Fircellina excande me fccerunt cupidilate. Merula : Duo sunt, inquit, ornithonis gencra : unun delectationis causa, ut Varro lic fecit noster sub Casino, quod amatores invenit multos : alterum fructus causa, quo genere macellarii et in urbe quidam la. bent loca clausa, et rure maxime conducta in Sabinis, quod ibi propter agri naturam frequentes appareut turdi. Ex lis tertii generis voluit esse Lucullus conjunctun aviarium, quod fecit in Tusculano, it in eodem tecto ornitlınis inclusum triclinium laberet, ubi delicate conitaret, ct alios videret in mazonomo positos coctos, alios volitarc circum fenestras captos. Quod inutite invenerunt. 
mal entcndue, car les ébats de ces oiseaux ne réjouissent pas tant la vue que leur odeur désagreable n'offense l'odorat.

V. Or, comme je pense, Axius, que vous tenez principalement aux volières, dont on tire profit, je parlerai, non pas de celles où l'on mange des grives, mais de celles où on les engraisse, pour les manger. On élc̀ve á cet effet un péristyle, ou un bâtiment en forme de dôme, fermé par le haut d'un toit ou de filets, et qui puisse contenir quelques milliers de grives et de merles. Quelques-uns y ajoutent d'autres espèces qui sc vendent également cher, lorsque les oiseaux sont engraissés; des cailles par exemple, et des miliaria (oiseaux qui se nourrissent de millet). On y fait arriver l'eau par le mojen d'un conduit; ou, ce qui vaut encore mieux, on l'y fait serpenter dans de petits canaux assez étroits pour être d'un nettoiement facile. Trop de largeur fait qu'ils se salissent trop vite, et occasionne une déperdition d'eau. 11 faut que l'écoulement en soit ménagé de façon qu'elle neséjourne ni ne dépose, ce qui est pernicieux pour les oiseaux. La porte de la rolière doit être basse, étroite, et avoir la forme de ce qu'on appelle cochlea dans les amphithéâtres destinés aux combats de taureaux. Les fenêtres y seront rares, et disposées de manière à ne laisser aperceroir au dehors ni arbres ni oiseaux; car cette vue et les regrets qu'elle réveille font maigrir les oiseaux prisonniers. N'y laissez pénétrer de jour que ce qu'il en faut aux grives pour reconnaître où est le perchoir, le manger et l'eau. On enduira portes et fenêtres d'une couche bien lisse de mastic, pour empêcher les rats et autres ennemis de s'introduire dans la volièrc. L'intérieur des murs

Nam non tantum in eo oculos delectant intra fenestras aves volitantes, quantuin olfendit, quod alienus odor opplet nares.

V. Sed quod te malle arbitror, Axi, dicam de loc ornithone, quod fructus causa faciunt, unde, non ubi, sumuntur pingues turdi. Igitur testudo, aut peristylum tectum tegulis aut rete, fit magna, in qua millia aliquot turdorum ac merularum includere possint. Quidam cum eo adjiciunt præterea ares alias quoque, quæ pingues veneunt care, ut miliariæ ac coturnices. In hoc tectum aquain venire oportet per fistulam, et eam potius per canales angustas serpere, quæ facile extergeri possint; si enin late ibi diffusa aqua, et inquinatur facilius, et bi. bitur inutilius; et ex eis caduca, quie abundat, per fistu. lam exire, ne luto aves laborent. Ostium lıahere fummile et angnstum, et potissimum ejus generis, quod coclilean apjuellant, ut solet esse in cavea, in qua tauri pugnare solent. Fenestras raras, per quas von videantur estrinse. cus arbores aut aves; quod earum aspectus ac desiderium nacrescere facit volucres inclusas. Tantum luminis locunn habere oportet, ut aves videre possint ubi assidant, ubi cibus, ubi aqua sit. Tectorio tacta esse levi circum ostia ac fenestras, ne qua intrare nus aliave qua bestia pos. sera garni tout autour de bâtons à percher, et l'on y appuiera d'un bout des perches enfoncées de l'autre en terre, et croisées de distance en distance par d'autres perches transversales, à l'instar des cancelli du théâtre. On aura soin de mettre à portée de l'eau à boire, et des boulettes faites de pâte pétrie avec des figues. Quand on voudra faire une levée de grives, il faudra, vingt jours à l'avance, augmenter la nourriture, et n'y plus employer que de la farine supérieure. (Dans cette cspèce de cage devront également se trouver des planches sur lesquelles les oiseaux puissent se poser par voie de supplément ou de diversion aux perches.) Attenante à la volière doit s'en trouver une autre plus petite, dans laquelle on dépose les oiseaux trouvés morts dans la grande; car il faut que l'intendant puisse toujours rendre compte à son maittre du nombre exact confié à ses soins. Les oiseaux qu'on juge en état d'être retirés devront être chassés de la grande volière dans la petite, pourvue à cet effet d'une plus large porte, et qui a plus de jour que la première, avec laquelle elle communique. Quand on a le nombre de grives que l'on veut dais cet endroit appelć seclusorium, on les y tue hors de la vue des autres, que ce spectacle pourrait attrister et faire périr elles-mêmes, plus tôt qu'il ne faut pour celui qui spécule sur leur mort. Les grives ne ressemblent pas aux autres oiseaux de passagre qui ne déposent leurs cufs que dans les champs, comme les cicognes, ou que sous les toits, comme les hirondelles; elles pondent partout. Malgré le nom masculin (turclus) de cet oiseau, il y a des grives femelles, de mème qu'il y a des merles mâles, bien que le nom qu'on leur donne (merula) soit du genre féminin. II $\mathbf{y}$

sit. Circum hujus ædificii parietes intrinsecus multos esse palos, ubi aves assidere possint; præterea et perticas inclinatas ex luumo ad parietem, et in eis transversas gradatim inodicis intervallis perticas annexas ad speciem cancellorum scenicorum (deorsum in terram esse aquam, quam bibere possint; ) cibatui offas positas. Eat maxime glomerantur ex ticis et farre mixto. Diebus vigiuti antequam quis tollere rult turdos, largins dat, cibumque plus ponit, et farre subtiliore incipit alere. In lioc tecto caveaque tabulata liabeant aliquot ad perticas supplementum. Contra loc aviarium est aliud minus, in quo qua mortuæ ibi sunt aves, ut domino numerum red. dat, curator servare solet. Cuul opus sunt, ex lıoc ariario ut sumantur, idonexe excluduntur in minusculum aviarium, quod est conjunctun cum majore, ostio et lu. mine illustriore, quod seclusorium appellant. Ibi cum eum numerum habet exclusum, quem sunere vult, onıes occidit. Hoc ideo in secluso clam, ne reliqui, si videant, despondeant aumum, atque alieno tempore venditoris moriantur. Non ut advena volucres pullos faciunt, in agro ciconia, in tecto hirnndines, sic aut hic aut illic turdi, qui cum sunt noniue nares, re vera frumina quoque sunt: neizue id non secutun ut esset in merulis, n!n? 
a des oiseaux de passage, commc les hirondelles ct les grues, et des oiseaux domestiques, tels que les pigeons et les poules. Les grives appartiennent a la première classe. Filles traversent chaque annce la mer, pour venir en Italic vers l'équinoxe d'automne et s'en retourner vers l'équinoxe de printemps. A une autre époque arriveut dans nos contrées une quantité prodigieuse de tourterelles et de cailles, dont on peut observer le passage dans les íles voisines de Ponti, de Palmaria et de Pandataria; car ces oiseaux y font une pause de quelques jours à leur arrivée en Italie, et une autre quand ils repassent la mer au retour. - Eh bien, dit Appius à Axius, vous n'avez qu'à jeter là cinq mille sesterces; et vienue un triomphe ou un festin public, vous voilà en possession des soixante mille où vous voulez arriver. Puis se tournant vers moi : A vous appartient, me dit-il, de nous parler de l'autre espèce de volière, vous qui en avez une auprès de Casinum pour votre plaisir seulement, et qui, non content d'avoir dans cette construction surpassé la volière de M. Lænius Strabo, notre hôte à Brundusium, le premier qui se soit avisé de renfermer des oiseaux daus un cabinet en péristyle et couvert d'un filet, avez encore laissé loin derrière vous la splendide volière de Lucullus à Tusculum. - Vuus savez, lui répondis-je, que j'ai dans ma villa de Casinum un ruisseau profond et limpide, qui la tra verse entre deux quais en pierre. Sa largeur est de cinquante-sept pieds; et il faut passer sur des ponts pour communiquer d'une partie de ma propriété à l'autre. Mon cabinet de travail est situé à l'endroit où le ruisseau prend sa source; et de ce point, jusqu'à une île

nomine fominino mares quoque siut. Praterea volucres eum partim advena? sint, ut lirundines et grues; paıtinı vernacula, ut gallin ac columbx : de illo genere sunt turdi adventicio, ae quotannis in Italiam trans mare advolant circiter æequinoetium autumuale, et codem revolant ad aquinoctium verum. Et alio tempore turtures ae eoturnices immani numero. Iloc ita fieri apparet in insulis propinquis Pontiis, Palmariæ, I'andatariæ. Ibi enim it unima volatura eum veniunt, morantur dies paucos requiescendi causa. Idenique faciunt eum ex Italia trans mare remeant. Apnius Axio : Si quinque inillia luc conjeceris, inquit, et erit epulum ac tıiumphus, sexaginta millia quæ vis statiu in foenus des licebit. Tum miht : 'Tu die illud alterum genus ornithonis, qui animi causa constitutus a te sub Casino fertur, in quo diceris longe vieisse non modo arelictypon inventoris nostri äpviOotpo๑єíw M. Lænii Strabonis, qui Brundusii lospes noster primus in peristylo liabuit exedra conclusas aves, quas pasceret objecto rete, sed etiam in Tusculano magno sedifieio Lueulli. Cui ego : Cum habeam sub oppido Casino flumen, quod per villam fluat liquidum et altum, marginibus lapideis, latum pedes 1 vı, et e villa in villam pontibus transeatur, longum P. 850, direetum ab insula ad Mıscum, qua est ab imo lluvio, ubi confluit altera amnis formée par sa jonction à un autre cours d'enu, il y a une distance de huit cent cinquante pieds. Le long de scs bords règne, sur unelargeur de dix pieds, unc promenade à ciel découvert; entre cette promenade ct la campagne se trouve l'emplacement de ma volière, fermée de gauchc et de droite par des murs pleins et élevés. Les lignes extérieures de l'édifice lui donnent quelque ressemblance avec des tablettes à écrirc, surmontées d'un chapiteau. Dans la partie reetangulaire, sa largeur est de quarante-huit pieds, et sa longueur de soixante-douze, non compris le chapiteau demicirculaire, qui est d'un rayon de vingt-sept pieds. Entre la volière et la promenade qui figure la marge inférieure des tablettes, s'ouvre un passage voûté aboutissant à une esplanade. De chaque cóté un portique régulier soutenu par des colonnes en pierre, dont les intervalles sunt occupés par des arbustes nains. Un filet de chanvre s'étend du haut du mur extérieur jusqu'à l'architrave; et un semblable filet joint l'architrave au stylobatc. L'intérieur est rempli d'oiseaux de toutes espèces, qui reçoivent la nourriture au travers des filets. Un petit ruisseau leur porte ses eaux. En deçà du stylobate, règnent à gauche et à droite, le long des portiques, deux viviers assez étroits, et qui, séparés par un petit sentier, s'étendent jusqu'à l'extrémité de l'esplanade. Ce sentier conduit à un tholus, espece de salon en rotonde, entouré de deux rangs de colonnes isolées. Il cn existe un. semblable dans la maison de Catulus, si ce n'est que des murs pleins remplacent la colonnade. Au delà est un bocage de haute futaic enfermé de murailles, et dont l'épais couvert ne laisse pénétrer le jour que

ad summum flumen, ubi est Museum. Circum hijus ripas ambulatio sub dio, pedes lata dehos. Ab hac ambulatione in agrum versus ornithonis locus ex duabus partibus dextra et sinistra maceriis altis conelusus. Inter quas bcus, qui est ornithonis, deformatus ad tabnlx literaria speciem cum capitulo, forma qua est quadrata, patet in latitudinem 1. XLVII, iu longitudinem P. LXXı; qua ad capitulum rotundus est, $P$. xxvır. Ad lıac, ita ut in mar. gine quasi infimo tabula descripta sit ambulatio, ab ornithone plumula, in qua media sunt eavea, qua introrsus iter in aream est. In limiue, iu lateribus dextra et sinistra porticus sunt primoribus colunnis lapideis, intermediis arbuseulis lumilibus ordinatæe, cum a summa macerie ad epistylium tecta porticus sit rete cannabina, et ab epistylio ad stylobaten. Hæ sunt avibus omue ge. nus oppletæ, quibus eibus administratur per retem, et aqua rivulo tenui affluit. Secundum stylobatis interiorem parten, dextra et sinistra, ad summam aream quadra. tam, e medio diversæ duæ non latæe, sed oblongae sunt piscinæ ad porticus versus. Inter eas piscinas tantunmodo accessus semita in tholım, qui est ultra rotundıs columnatus, ut est in xede Catuli, si pro parietibus feceris columnas. Extra eas columnas est silva manu sata, grandilsus arboribus tecta, ut infinı perluceat tuta, septa 
par en bas; l'espace est decinq pieds entre les colonnes extérieures, qui sont de pierre, ct les eolonnes intérieures, qui sont de sapin, ct trèsminces de fût. I,'entre-colonnement intérieur est rempli, au lieu de murs, par un filet de cordes à boyaux; espèce de clòture à jour, qui laisse la vue du bocage, sans qué les oiseaux puissent s'échapper. Un autres filet remplit également l'entre-deux des colonnes intérieures. L'espace intermédiaire des deux colonnades est garni de perchcirs formés par des bâtons enfoncés dans chaque colonne, et régulièrement étagés comme les gradins d'un théâtre. Cette partic de la volière est principalement réservée aux oiseaux à voix harmonieuse, comme morles et rossignols. Un petit tuyau leur fournit de l'ear, et on leur donne à manger par les mailles du filet. Au pied du stylobate règne une assise en pierres d'un pied neuf pouces d'élévation à partir de la base du socle. Le socle lui-même a deux pieds de hauteur au-dessus du niveau d'un bassin, et cinq pieds de largeur; ce qui donne aux convives la facilité de cireuler entre les colonnes et les lits. Le bassin est entouré d'une espèce de trottoir large d'un pied; une petite île en occupe le centrc. On a creusé le socle dans tout son pourtour, pour y faire des niches à canards. Au milieu de l'île s'élève une petite colonne, dans laquelle est scellée un axe, qui au lieu de table porte une roue avec ses raies; mais ces raies soutiennent, en guise de jantes, une table creusée en tambour, large de deux pieds et demi, et profonde d'une palme. Cette table n'est servie que par un jeune esclave, qui, par un simple mouvement de rotation, fait passer successivement, à portée de chaque convive, les coupes et

maceriis altis. Intra tholi columnas exteriores lapideas et totidem interiores ex abicte lenues, locus est P. V. lalus. Inter columnas exteriores pro pariete reticuli e nervis sunt, ut prospici in silva possit, et qua ibi sunt, neque avis ea transire. Inter interiores columnas pro paricte rete aviarium est objectum. Inter has et exteriores gradatim substructum ut $\theta \varepsilon c \tau p i c t o v$ aviun. Mutuli crebri onuibus columnis impositi, sedilia avium. Intra retem aves sunt omne geuns, nuxime cantrices, ut lusciniola ac merulae, quilous aqua ministratur per canaliculam, eibus objicitur sub retem. Subter columnarum stylohatem est lapis a falere peden et dodrantem alta, ipsum falere ad ino pedes altum a stagno, latum ad quinque, ut in culcitas et columellas convivie pedibns eircumire possint. Infimo iıtra falere est stagnum cum margine pedali, et insula in unedio parva. Circuin falere et navalia sunt excavata anatium stabula. In insula est colunella, in quna intus axis, qui pro mensa sustinet rotam radiatam, ita ut ad extremum, ubi orbile solet esse aculum, tabula cavata sit, ut tympanum in latitudinem duo pedes et semipeden, in altitudinem palmunı. Hac ab uno puero, qui ministrat, ita vertitur, ut omuia una ponautur et ad bibendnm, et ad edendum, et admoveantur ad omnes convivas. Ex les plats. Les lits sont dressés sur le socle, du sein duquel sortent les canards pour nager dans le bassin, lequel communique par un petit ruisseau avec les deux viviers; de sorte qu'on voit les petits poissons passant librement de l'un à l'autrc. J'oubliais de vous dire que, de la table qui se trouve à l'extrémité des raies de la roue, coule, à la volontć de chaque convive, de l'eau chaude ou de l'eau froide, selon le robinct qu'il veut ouvrir. On voit, dans la coupole qui couvre ce salon, l'étoile Lucifer pendant le jour, et l'étoile Hespérus pendant la nuit; elles en suivent le bord, et marquent les heures. Dans le haut de cette coupole est peinte autour d'un tourillon la rose des huit vents, comme dans l'horloge que fit l'artiste de Cyrrhus pour la ville d'Athènes; et une aiguille, supportéc par le tourillon, se meut de façon à indiquer quel vent souffle au dehors. Pendant que je parlais, une grande rumeur s'élève du champ de Mars. Il n'y avait pas de quoi surprendre de vieux athlètes des comices, dans ce paroxysme de fièvre électorate; notre curiosité s'en émut cependant. Sur ce point arrive Pantuléjus Parra, qui nous dit que, pendant qu'on faisait le relevé des suffrages, un individu avait étć surpris jetant furtivement de nouveaux bulletins dans l'une des bourses, et que les adversaires du candidat ainsi favorisé avaient traîné lc délinquant devant le consul. Pavo se lève aussitôt : le bruit courait que l'auteur de la fraude était le gardien du eandidat pour lequel il avait roté.

VI. Axius prit alors la parole, et dit : Voilà Fircellius parti ; on peut maintenant parler des paons tout à son aise. Lui présent, un mot de traver's eût pu, à raison de la parenté, vous atti.

suzgesto faleris, ubi solent esse $\pi \varepsilon p t \pi \varepsilon \tau \alpha \dot{\sigma} \mu \alpha \tau \alpha$, prodeunt anates in stagnum, ac nant, e quo rivus pervenit in duas, quas dixi, piscinas, ae piseiculi ultro ac eitro conmeant : cum et aqua calida et frigila ex orbi ligneo nensaque, quam dixi in primis radiis esse, epitoniis versis ad unumqueinque faetum sit int fluat convivan. Intrinsecus sub tholo stella Lueifer interdiu, noctu Hesperus ita circumeunt ad infimum hemisphacrium, ac moventur, ut indicent quot sint horæ. Iu eodem hemisplaxio medio circun cardinem est orbis ventorum oeto, ut Athenis in horologio, quod fecit Cyrrhestes. Ibique eninens radius a cardine ad orbem ita movetur, ut enm tangat ventum, qui flet, ut in. tus scire possis. Cum lıxe loqueremur clamor fit in eampo. Nos atlileta comitionum una, eum id fieri non miraremur propter studia suffragatorum, et tamen scire vellemus, quid esset, venit ad nos Pantulæjus Parra. Narrat ail tabulam, cum dirimerent, quendam depreliensum tesserulas conjicientem in loculnm, eum ad consu. lem tractum a fautoribus competitorum. Pavo surgit, quod ejus candidati custos dicebatur depreliensus.

VI. Axius. De parone, inquit, libere licet dicas, quoniam discessit Fircellins, qui secus si quid diceres de iis, gentilitatis causa fortasse an tecum duceret serram. Cui Me. 
rer une prise de bec avec lui, Mérula reprit done en ces termes : J'ai vu introduire l'habitude de former des troupeaux de paons qui se vendent si cher. On dit que M. Aufidius Lurco tire des siens plus de soixante mille sesterces par an. Si l'on en veut faire un revenu, il faut avoir un peu moins de máles que de femelles; c'est le contraire si l'on n'a en vue que l'agrément, car le mâle l'emporte au coup d'œil. On prétend qu'on rencontre des troupes de paons sauvages à Samos dans le bois sacré de Junon, et dans ceux que Pison possède dans l'île de Planasia. Pour former un troupeau, prenez des sujets de bon âge et de belles formes; car en fait d'oiseaux, c'est à celui-là que a nature a donné la palme de la beauté. Les femelles ne sont pas propres à la multiplication avant deux ans, ni après cet âge. On nourrit les paons de grain, d'orge surtout. Lurco donne à six paons un modius d orge par mois. Il augmente a mesure au temps de la ponte, et même un peu avant qu'ils ne commeneent à accoupler. Son intendant doit lui rendre par chaque paonne trois petits, qui, devenus grands, se vendent cinq deniers la pièce; prix que l'on ne tire guère du plus beau mouton. Il achète en outre des œufs de paons, qu'il fait couver à des poules. Quand les petits sont éclos, il les fait passer dans une (spèce de voûte servant de loge aux autres. Il faut que ces loges soient assez spacieuses pour que chaque oiseau $\mathrm{y}$ trouve son gite à part, et que l'intérieur en soit crépi avec soin, de sorte que ni serpent ni bête malfaisante ne puisse s'y introduire par aueune ouverture ni crevasse. On mćnagera devant l'entrée un espace où les paons puissent aller prendre leur nourriture, les jours où le soleil donne. L'un et l'autre emplacement a

rula : De paronibus nostra memoria, inquit, greges lıaberi copti, et venire magno. Ex iis M. Aufidius Lurco sestertiùm sexagena millia numùm in anno dicitur capere. yi aliquanto pauciores esse debent mares quan fueminæ, si ad fructum spectes; si ad delectationem, contra : formosior enim mas. Pavonum greges agrestes transmarini esse dicuntur in insulis, Sami in luco Junonis, item in Planasia insula M. Pisonis. Hi ad greges constituendos parantur bona atate et hona forma. Huic enim natura formæe volucribus dedit palmam. Ad admissuram ha minores bima non idonea, nee jam majores natı. Paseuntur omue genus objecto frumento, maxime ordeo. Itaque senis his dat in menses siıgulos ordei singnlos modios, ila ut in fotura det uberius, et ante quam salire incipiant. Is a procuratore ternos pullos exigit, eosque cum creverunt, quinquagenis denariis vendit, ut nulla oris hunc assequatur fructuin. ''racterea ova emit ac supponit galliuis, ex quibus ex iis excusos pullos refert in testudinem eam, in qua pavones habet. Quod tectum pro multitudine pavonum fieri debet, et liabere cubilia discreta, tectorio levata, quo neque serpens, neque bestia accedere ulla possit. P'raterea habere locum ante se, quo pastum exeant diebus apricis. Utrunque locum purum esse iulunt lax besoin d'être toujours proprement tenu. Le gardien les visitera sourcnt la pelle à la main, pour enlever la fiente, qu'il doit conserver avec soin; car clle est d'une grande utilité pour la culture des champs, et peut en outre servir de litière aux jeunes paons. Q. Hortensius fit le premier, dit-on, servir cette espèce de volatiles dans le festin d'installation de son augurat; prodigalité qui eut l'approbation des voluptueux, plutôt que des gens honuêtes et d'habitudes rigides L'exemple néanmoins fut contagieux, et le prix de ces oiseaux a depuis monté à tel point, qu'un œuf de paon se vend maintenant cinq deniers, ct l'oiseau lui-même facilement cinquante. Un troupeau de cent paons rapporte sans peine quarante mille sesterees, et même soixante mille, si, comme fait Albutius, on exige trois petits par chaque mère.

VII. A ce moment un appariteur vint, de la part du consul, avertir Appius que les augures étaient mandés : celui-ci quitta aussitôt la villa publique. A peine fut-il parti, qu'une volée de pigeons vint s'y abattre. Si par hasard, dit alors Mérula à Axius, vous aviez monté un co-

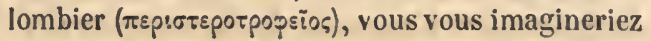
que ces pigeons sont à vous, tout sauvages qu'ils sont; car un colombier a d'ordinaire des hôtes de deux espèces. Les pigeons sauvages d'abord, que d'autres appellent saxatiles, et qui habitent les tours et le faite (columen) des métairies. Aussi est-ce du mot columen, que leur est venu le nom de columba. En effet, leur timidité natu. relle leur fait toujours rechercher les points les plus élevés des bátiments. Cette espc̀ce hante done prineipalement les tour's; c'est là qu'ils dirigent leur vol au retour des champs, et c'est de

volucres. Itaque pastorem earum eum batillo circumire oportet, ac stereus tollere ac conserrare; quod et ad agriculturam idoneum est, et ad substramen pullorum. Primus hoc Q. Hortensius angurali aditiali cona posuisse dicitur. Quod potins factum tum luxuriosi, quam severi boni viri laudabant. Quem cito seeuti multi extulerunt eorum pretia, ita ut ova corum denariis veneant quinis, ipsi facile quinquagenis, grex centenarius facile quadragena millia sextertia ut reddat, ut quidem Albutius aiehat, si in singulos ternos exigeret pullos, perfici sexagena posse.

VII. Interea venit apparilor Appii a consule, et augures ait cilari. Ille foras exit e villa. At in villam intro iurolant

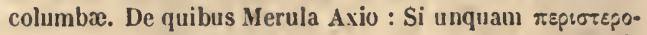

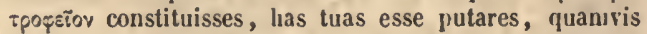

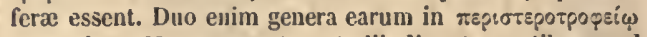
esse solent. Unun agreste, ut alii dicunt saxatile, quod labelur in turribus ac columinibus villa, a quo appellat $x$ columbe, qux propter timorem naturalem summa loca in tectis captant. Quo fit, ut agrestes unaxime sequantur turres, in quas ex agro evolant suapte spoute ac remcant. Alterum geus illud columbarum est clementius, quod cibo domestico eontentun intra linina januæ solet pasei. 
là qu'ils revolent aux champs. La seconde espèce est plus sociable, et vient volontiers chereher sa nourriture sur le seuil des maisons. Son plumage est presque toujours blanc, tandis que celui de la première est bigarıé, mais sans aucun niélange de blane. De l'union de ces deux espèces on en forme unc troisième, de couleur mélangée. C'est principalement sur eelle-là qu'on spéeule. Elle vit en eommun dans un local appelé par les

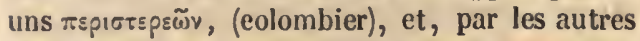

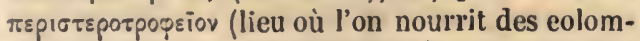
bes), et qui en contient quelquefois jusqu'à cinq mille. Un eolombier doit être construit en voûte et se terminer en forme de dôme, avec une porto étroite et des fenêtres à la carthaginoise, ou plus larges même, garnies dc treillis au dedans et au dehors, de manière à laisser entrer le jour, tout en fermant le passage aux scrpents et autres animaux dangereux. Les parois intérieures sont enduites de stuc, et la même applieation est faite autour des fenêtres en dehors, afin que ni rat ni lézard ne puisse s'y introduire; car rien n'est timide comme la eolombe. On disposera pour ehacque couple de pigeons des boulins de forme cireulaire, distribués avec ordre et serrés les uns eontre les autres, pour qu'il en tienne davantage, et de façon à remplir tout l'espace compris entre le sol et la voûte. Chaque boulin aura une ouverture qui permette au pigeon d'entrer et de sortir librement, et l'intérieur en sera de trois palmes en tous sens. A ehaque rang de boulins seront adaptées des tablettes de deux palmes de largeur, qui serviront de vestibule aux pigeons, et surlesquclles ils pourront se reposer avant d'entrer. L'on ne conduira au colombier que de l'eau limpideet pure, afin que les pigeons puissent à la

Hoc geuus maxime est colore albo. Illnd alterum agreste sine albo, vario. Ex lis duabus stirpibus fit miscellum tertium genus fructus cansa, atque incedunt in locum

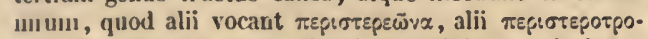
çєโ̃ov. Iu quo uno sxpe vel quinque millia sunt iuclusx.

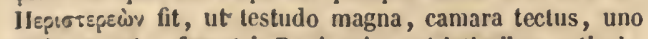
ostio angusto, fenestris Punicanis, aut latioribus reticulatis, utrinque ut locus omnis sit illustris, neve qua serpens, alindve quid animal maleficum introire queat. Intrinsecus quam levissimo marmorato toti parieles ac cainarie oblinuntur, et extrinsecus circum fenestras, ne inns aut lacerta qua adrepere ad columbaria possit. Niluil enim timislius columba. Singulis paribus columbaria fiunt rolunda in ordiuem crebra. Ordines quam plurimi esse pos. sunt a terra usque ad camaram. Columbaria singula esse oportet, ut os liabeant, quo introire et exire possint; in. tus ternorum palmorum ex omnibus partibus. Sulı ordines singulos tabula ficta ut siıt bipalınes, quo utantur vestibulo, ac prodeant. Aquam purain esse oportet, qux influat, unde et bibere, et ubi lavari possint. Permundac enim sunt lax volıcres. Itaque pastoren colımbarinın quolquot mensilus crebro oprortet everrere. Iist enim quod cum inquinat locum appositum ad agriculturan, ita ut fois y boirc et se baiguer; car leur propreté est proverbiale : aussi le gardien doit-il balayer lo colombier plusieurs fois par mois ; la fiente, qui le salirait en s'y amassant, est d'ailleurs d'une grande utilité pour la eulture de la terre, au point que quelques auteurs la regardent comme Ic meilleur de tous les engrais. Le gardien doit aussi donner ses soins aux pigeons malades, retircr les morts du colombier, ainsi que les petits qui sont bons à être vendus. Les femelles eouveuses seront placées dans un lieu particulier, où elles se trouveront séparées des autres par un filet, en conservant cependant la faeulté de sortir. Il y a deux raisons pour en agir ainsi. Au cas où les mères viendraient à languir, et à se rebuter d'unc réclusion trop prolongée, elles peuvent se refaire par une excursion en plein air. D'un autre côté, l'attachement à leur couvée garantit leur retour, à moins que le corbeau ou l'épervier ne soient lí pour l'intercepter. Pour détruire ees ennemis, les gardiens enfoncent en terre deux baguettes couvertes de glu, et reeourbées l'une sur l'autre. L'épervier fond sur le pigeon attaché comme appât entre ces baguettes, et se trouve pris au piége, en s'empêtrant dans la glu. Une conséquence bien connue de l'instinet qui ramène toujours le pigeon au colombier, c'est l'habitude qu'ont prise certaines personnes d'en apporter dans leur sein au théâtre, pour leur y donner la volée; ee qu'elles ne feraient pas, si elles n'avaient la eertitude de voir les pigeons revenir au logis. On place la nourriture dans des mangeoires adossées aux murs du colombier, et qui se remplissent à l'extérieur au moyen de tuyaux. Les pigeons aiment le millet, le blé, l'orge, les pois, les haricots, et l'ers. On fera bien d'attirer autant que

hoc optimum esse scripserint aliqui. Sive quxe colımba quid offenderit, ut medeatur. Si qua perierit, ut efferatır. Si qui pulli idonei sunt ad vendendum, promat. Item quas foeta sunt, ut certum locum disclusum ab aliis rete lia. beant, quo transferantur, et quo foras erocare possint matres. Quod faciunt duabus de causis. Una, si fastidiunt aut inclusac consenescunt, quo libero aere cum exierint in agros, redinlegrentur. Altera de cansa propter pulliciem. Ipsa enim propter pullos, quos liabent, utiquc redeunt, nisi a corvo occisæ aut ab accipitre intercepta. Quos columbarii interficere solent, duabus virgis viscatis defixis in tcrram inter sc curvatis, cum inter eas posuerint obligatum animal, quod impetere soleant accipitres, qui ita de. cipiuntur, cum se obleverunt visco. Columbas redire solere ad locum licet animadrertere, quod multi in thea. tro e sinu missas faciunt, [atque ad locum redeunt] qua: nisi reverterentur, non enitterentur. Cibus apponitur circum parietes in canalibus, quas extrinsecus per fistulas supplent. Delectantur milio, tritico, ordeo, piso, faseolis, ervo. Item feras las in turribus ac summis villis qui lıabent, agrestes colımbas, quoad possunt, inmitten-

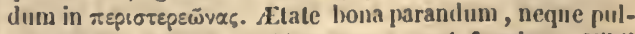
los, neque vclulas, totidem mares quot fueminas. Nili\} 
possible dans le colombier les pigeons sauvages, qui séjournent sur les tours et les combles des métairies voisines. Quand on achète des pigcons, il faut les prendre de bon age, ni trop jeunes ni trop vieux, et qu'il y ait autant de mâles que de femelles. Rien qui pallule comme les pigeons; en quarante jours la mère conçoit, pond, couve et élève ses petits; et c'est à recommencer tout le long de l'année, sans autre intermittence que lapériode de solstice d'hiver à l'équinoxe du printemps. Elles ne font que deux petits à la fois, qui, à peine arrivés à leur croissance ct à leur force, fécondent la mère dont ils sont sortis. Les personnes qui engraissent les petits pour les vendre plus cher les renferment à part, ils ont déjà leurs plumes; puis les gorgent avec du pain blane mâché, qu'elles leur donnent dcux fois par jour en hiver, et trois fois en été; le matin, à midi, et le soir; la ration de midi est retranchée l'hiver. On laisse dans le nid ceux qui commencent seulement à s'emplumer, après leur avoir cassé les pattes, et on donne à mauger aux mères cu conséquence. Les élèves qu'on fait par ce procédé engraissent plus promptement et sont toujours plus blanes que les autres. Une paire de pigcons d'une belle couleur, d'une bonne race, et qui n'a point de défaut, se vend ordinairement à Rome deux cents nummi, et quelquefois millc, si elle est d'une beauté remarquable. Le chevalier romain L. Axius avait même refusé cette somme pour une seule paire de pigeons, qu'il nc voulait pas donner à moins de quatre cents deniers. Si je pouvais me procurer, s'écria.alors notre Axius, un colombier comme je le désire, j'irais vite acheter des boulins de terre cuite, et je les enverrais à ma villa. Comment, dit Pica, est-ce que nombre de personnes n'ont pas des boulins

columbis foceundius. Itaque diehus quadragenis concipit, et parit, et incubat, et educat. Et loe fere totum anuum faciunt : tantummodo intervallum faciunt a bruma ad ayuinoctium vernum. Pulli nascuntur bini, qui simulae creverunt et labent robur, cum matribus pariunt. Qui solent saginare pullos eolumbinos, quo pluris vendant, secludunt cos, cum jam pluma sunt tecti. Deinde mandu. (ato candido fareiunt pane: lieme loe bis, astate ter, ılane, meridie, vesperi. Hieme demunt cibum medium. Qui jam pinnas incipiunt labere, relinquunt in nido illisis cruribus, et matribus uberius ut eibo uti possint ohjiriunt; eo enim totum diem se, et pullos paseunt. Qui ita edncantur, celerius pinguiores fiunt quanı alii, et candidiores. Parentes corun Romæ, si sunt formosi, bono colore, integri, boni seminis, paria singula vulgo venennt ducenis numis, nec non eximia singulis millibus numuın, yuas nuper eum mercator tanti emere vellet a L. Axio equite Rom. minoris quadringentis denariis daturum ne-

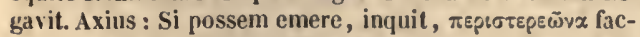
tum, quemadmodum in xdibus eum labere veliem, fictilia columl aria jam iissem emtum, et misissen ad villam. Quasi vero, inquit Pica, non in urbe quorjue sint multi, columbaria qui in tegulis labent. An tibi non videntur sur le toit même de leur maison? A vec cet appareil, dont la valeur va jusqu'à cent mille sesterces, peut-on dire qu'ils n'ont pas de colombiers? Je vous conseille moi, de vous en donner un à Rome en employant le même moyen et d'attendre que vous ayez appris à en tirer un as ct demi par jour, avant de vous lancer dans des constructions plus dispendieuses à la campagnc.

VIII. Continuez, dit alors Axius à Mćrula; et Mérula reprit en ecs termes : De même que pour les pigeons, on doit pour les tourterelles disposer un local proportionné à la quantité qu'on en veut avoir. Il y faut, comme dans les colombiers, cau pure, portc, fenêtres, et des murs bien crépis; mais au lieu de boulins on attachera aux murailles des bâtons ou juchoirs régulic̀rement étagés, et couverts de petites nattes de chanvre. Il faut que le rang d'en bas soit élevé de trois pieds au moins au-dessus du sol; qu'il $y$ ait un intervalle de neuf pouces entre tous les autres, et que le plus élevé soit à un demi-pied de distance de la voûte. Les bâtons à jucher doivent avoir même longueur à partir de la muraille. Les tourterelles n'en doivent sortir ni jour ni nuit. On leur donne pour nourriture du froment sec, dans la proportion d'un demi-modius pour cent vingt tourterelles. La place doit être balayéc tous les jours, pour que la fiente qui s'y amasse n'incommode point les oiseaux. Ellc a d'ailleurs son emploi cn agriculture. L'époque de la moisson convient plus que toute autre pour engraisser les tourterelles. En aucun temps de l'année les mères ne sont en si bon état, ne font autant de petits, propres à engraisser à leur tour. C'est done ce moment que la spéculation doit surtout saisir.

IX. Je voudrais bien, dit alors Axius, savoir

Labere $\pi є \rho เ \tau \tau \rho є \tilde{v \propto \varsigma, ~ e u m ~ a l i q u o t ~ s u p r a ~ c e n t u m ~ m i l l i u m ~}$ sextertium habeant instrumentum? e queis alicujus totum emas censeo, et ante quam arditicas rure magnum, condiscas his in urbe quotidie luerum assem semissem condere in loeulos.

VIII. Tum Merula : Perge deineeps. Ille : Turturibus item, inquit, locum constituendum proinde magnum, ae multitudinem alere velis; eumque item, ut de columbis dictum est, ut labeat ostium ac fenestras et aquam puram, ac parietes, ac camaras munitas tectorio. Sed pro columbariis in pariete mutulos, aut palos in ordinem, supra tquos tegeticula cannabina sint imposita. Infimun orlinem oportet abesse a terra non minus tres pedes, inter reliquos dodrantes, a summo ad camaranı ad semipedem, aeque latmm ac nuutulus a pariete extare potest, in quibus dies noetesque paseuntur. Cibatui quod sil, objiciunt triticun siccum in centenos vieenos turtures fere semodium, quotilie everrentes eorum stabula, a stercore ne offendantur, quod item servafur ad agrom eolendurr. Ad saginandum appositissimum tempus circiter messem. Ftenim matres eorum tunc optima sunt; tune pulli plurimi gignuntur, qui arl farturam meliores. Itaque eorum fructus id temporis naxime eonsistit. 
comment on engraisse les poules et les pigeons ramiers. Si Mćrula voulait bien encore nous l'apprendre, nous compléterions alors ce qui reste à dire des autres animaux. Mérula reprit en ces termes: Il y a trois espèces de poules; les poules de basses-cours, les poules sauvages, et les poules d'Afrique. Les poules de basse-cour se voient par toute la campagne et dans les fermes. Les personnes qui se proposent d'établir un poulailler (opvitoc_ocxsıos), et qui vculent, comme les habitants de Délos, en tịrer tout le parti possible, ont cinq choses principales à considérer : $1^{\circ} \mathrm{L}$ 'achat. De quel nombre de poules faut-il former son poulailler, et dans quelles conditions individuelles? $2^{\circ}$ La multiplication de l'espèce; quels soins exigent l'accouplement et la ponte? $3^{\circ}$ Les œufs; comment on fait couver et éclore? $4^{\circ}$ Les pous. sins; de quelle façon; et par qui doit-on les fairc élever? $5^{\circ}$ Et cette question n'est qu'un appendice des quatre autres : comment s'engraisse cettc volaille? Poule est le nom générique de la femelle; coq, celui du mâle ; on appelle chapons ceux que la castration a privés d'une partie de leur masculinité. On châtre les coqs, pour en fairc des chapons, en leur brûlant avec un fur rouge les ergots à l'extrémité des pattes, jusqu'à ce que la peau s'en détache; puis on enduit la plaie avec de la terre à potier. Celui qui se propose de former un poulailler-modèle doit le peupler des trois espèces, mais surtout de la poule ordinaire. Dans l'achat de cette dernière espèce il faut rechercher les plus fécondes. On les reconnait au plumage roux, aux ailes noires, aux ergots de grandeurs inégales, à la grosse tête, à la crêtc large et élevée. Choisissez des coqs lascifs. Les indices de cette qualité sont des formes mem-

IX. Axjus: Ego quæ requiro farsura (assuræ) membra de palumbis, et gallinis dic sodes Merula : tum de reliquis, si quid idoneum fuerit, racemari licebit. Igitur sunt gallina qua vocantur, genierum trium, villaticæ, et rusti. cae, et africanæ. Gallina villatica sunt, quas deincejs rure habent in villis. De lis qui opv:006roxseioy instituere volunt, iidem adlibita scientia ac cura, ut capiant magnos fructus (ut maxime factitaverunt Deliaci) lıac quinque maxime animadvertant oportet : de emtione, cujusnodi, et yuan multas parent, de fuetura, quenadmorlum arlmittant et pariant; de ovis, quemadmodum incubent et excudant; de pullis, quemadmodum et a quibus educentur. Hisce appendix adjicitur pars quinta, quemadmodum saginentur. E queis tribus generibus proprio nomine vocantur fuemina qux sunt villatica, gallinx; mares galli; capi semimares, quod sunt castrati. Gallos castrant, ut siut capi, candenti ferro inurentes calcaria ad infima crura, usque dum rumpantur. At quod extat ulcus, oblinunt figlina creta. Qui spectat ut opvibolooxsiov perfectum luabeat, sint licet genera tria paranda, maxime villaticas galliuas. E queis in parando eligat oprorlet foecundas; plerunque rubicunda pluma, nigris piunis, inparibus digitis, magnis capitibus, crista erecta, amplas. Hae enim ad partiones sunt aptiores. Gallos salaces; qui animadver- brues, la crête d'un rouge ćclatant, le bec court, fort et aigu, l'œil fauve ou noir, le jabot d'un rouge tirant sur le blanc, le cou bigarré, ou nuancé d'or, les cuisses velues, les pattes courtes, les ergots allongés, la queue développée, et bien fournie. Remarquez encore si vos coqs se redressent avec fierté; s'ils chantent fréquemment; s'ils se montrent acharnés au combat; si, loin de craindre pour eux-mêmes, ils sont disposés à protéger leurs poules. II y a cependant une exception à faire pour les coqs de Médie, de Tanagra et de Chalcis, qui, tout beaux et tout belliqueux qu'ils sont, n'ont qu'une médiocre aptitude à la propagation. Pour deux cents poules, il faut un lieu clos, dans lequel on dispose deux cabanes l'une à côté de l'autre, toutes deux au soleil levant. Chacune aura dix pieds de longueur, cinq pieds de largeur, et à peu près autant en hauteur. Les fenêtres auront trois pieds' de large sur quatre de haut, et seront tissues à claires voies, de façon à laisser entrer beaucoup de jour, sans livrer passage à aucune bête nuisible. On ménagera de plus entre ces cabanes un passage pour le gardien du poulailler. Dans chaque cabane se trouveront des perches en nombre suflisant pour servir de juchoir à toutes les poules. Vis-à-vis de chaque perche on creusera dans le mur des trous qui serviront de uids; on ménagera en outre une espèce de cour fermée, où les poules puissent rester pendant le jour et s'ébattre dans la poussière, et où se trouvera aussi une grande cellule serrant d'habitation au gardien. Tout le tour du poulailler sera garni de nids, creusés ou attachés fortement aux murs; car le moindre dérangement pendant l'incubation peut nuire aux œufs. Quand les poules commencent à pon-

tuntur, si sunt lacertosi, rubenti crista, rostro brevi, pleno, acuto, oculis ravis, aut nigris, palea rubra subalbicanti, collo vario, aut aureolo, feminibus pilosis, cruribus brevibus, unguibus longis, caudis magnis, frequentibus pinnis. Item qui elati sunt, ac vociferant sxpe, in certa. mine pertinaces, et qui animalia, quæ nocent gallinis, non modo non pertimescant, sed etiam pro gallinis propugnent. Nec tamen sequendum in seminio legendo Tanagricos, ac Medicos, et Chalcidicos, qui sine dubio sunt pulclıri, et ad præliandum inter se maxime idonei, sed ad partus sunt steriliores. Si ducentas alere relis, locus septus attribuendus, in quo duæ cavex conjuncta maguæ constituenda, quæ spectent ad exorientem versus, itræque in longitudinem circiter decem pedum, latitudine dimidio minores, in altitudine paullo humiliores. Utrisque fenestræ latifudine tripedali, uno pede altiores e viminibus factæ raris, ita ut lumen prabeant multum, neque per eas quidquam ire intro possit, qua nocere solent gallinis. Inter duas ostium sit, qua gallinarius curator earun ire possit. In caveis crebra pertica trajecta sint, ut ounnes sustinere possint gallinas. Contra singulas perticas іи pariete (exsculpta) sint culilia earum. Ante sit (ut divi) vestibuium septum, in quo diurno tempore esse possint, atque in pulvere volutari. Praclerea sit cella grandis, in 
dre, il faut étendre daus leurs nids de la paille, qu'on eniève lorsqu'elles eommencent à eouver, pour en remettre de nouvelle; car la vieille paille engendre des puces, et d'autres vermines qui tourmentent et inquiètent les poules; ce qui fait que les œufs sont couvés inégalement, ou même se gâtent. On prétend qu'il ne faut pas douner à une poule plus de vingt-cinq œufs à couver, lors même qu'elle est assez féconde pour en pondre davantage. L'époque la plus favora. ble à l'incubation est depuis l'équinoxe du printemps jusqu'à celui d'automne. On ne fera done point couver les œufs pondus avant ou après cette époque, non plus que ceux qui proviennent de poules pondant pour la première fois. En général on choisira pour couver de vieilles poules plutôt que des jeunes, et, de préférence, celles qui n'ont ni le bec ni les ongles pointus; les autres sont plus propres à pondre qu'à couver. L'âge le plus convenable est celui d'un an ou deux. Si l'on fait couver à une poule, des œufs de paon, il faut laisser passer dix jours avant d'ajouter des œufs de poule afin que tous puissent éclore en mème temps; car on a des poulets au bout de vingt jours, tandis qu'il en faut trente pour obtenir des paonneaux. On tient les poules qui couvent renfermées nuit et jour; ce n'est que le soir et le matin qu'on les laisse sortir un instant, pour leur donner leur nourriture. Le gardien doit de temps à autre visiter les nids et retourner les œufs, pour que la ehaleur puisse les pénétrer de toutes parts. Pour s'assurer si un œuf est plein ou vide, on le plonge dans l'eau. S'il est vide, il surnage; s'il est plein, il va à fond. Ceux qui secouent les œufs dans ce but ont tort; car ils risquent de brouiller le germe, qui est le

qua curator habitet, ita ut in parietibus circum omni posita sint cubilia gallinarum, aut exsculpta, aut afficta firmiter. Motus enim cum incubant nocet. In cubilibus, cum parturient, acus substernendım. Cum pepererunt, tollere substramen, et recens aliud subjicere, quod pulices et cxtera nasci solent, qua gallinam conquiescere non patiuntur; ob quam rem ova aut inæquabiliter maturescunt, aut consenescunt. Quæ velis incubet, negant plus Xxv oportere ova incubare, quamvis propter foecundita. tem pepererit plura. Optinum esse partum acquinoctio verno, ad autumnale. Itaque qua ante aut post nata sunt, et etiam prima eo tempore, non supponenda : et ea quæ subjicias potius vetulis, quam pullastris, et qua rostra aut ungues non liabeaut acutos, qua dehent potius in con cipiendo occupata esse, quam incubando. Appositissima ad partum sunt annicula, aut bimæ. Si ova gallinis pavonina subjicies, cum jam decem dies pavonina fovere copit, tum denique gallinacea subjicere, ut una excudant. Gallinaceis enim pullis bis deni dies opus sunt, pavoninis ter deni. Eas includere oportet, ut diem et noctem incubent, prater quam mane et vespere, dum cibus ac potio eis datur. Curator oportet circumeat diebus interpositis aliquot, ac vertat ova, uti aquabiliter concalefiant. Ova plena sint, atque utilia, necne? animadverti aiunt possc, principe de vie. On dit encore qu'un signe cer. tain qu'un ouf est vide est sa transparenee lorsqu'on l'interpose à la lunière. Pour conserver les œufs, on les frotte avec du sel égrugé, ou bien on les trempe dans la saumure pendant trois ou quatre heures; puis on les met, après les avoil bien essuyés, dans du son ou de la paille. Les œufs ne doivent être couvés qu'en nombre impair. Le gardien du poulailler peut, dès le quatrieme jour de l'ineubation, connaitre les oufs qui ont été féeondés ou non : il suffit de les tenir devant le jour. Il jette alors ceux qui ne montrent aucun ehangement, pour en mettre d'autres à leur place.

Il faut tirer de chaque nid les poulets à mesure qu'ils naissent, et les donner à élever à unc mère qui n'en aura pas beaucoup. S'il reste moins d'œufs que de poussins éclos, il faudra retirer les premiers pour les donner à d'autres poules qui n'en ont pas encore d'ćclos, en observant toutefois de ne jamais laisser à une poule plus de trente poussins à eonduire. Dans les 15 premiers jours on domne aux poulets tous les jours de la farine d'orge bien détrempée dans l'eau et mêlée avee de la graine de eresson. De eette manière on n'aura pas à craindre que l'orge ne se gonfle daus l'estomae des poulets. On placera cette nourriture sur de lạ poussière, et non sur la terre sèche et dure, qui blesserait leur bec délieat. Ne leur donnez point d'eau dans les premiers jours. Quand la queue commenee à leur pousser, il faut enlever souvent de la tête et du cou la vermine qui les ferait dépérir. On brûlera autour du poulailler de la corne de eerf, pour en écarter les serpents, dont l'odeur seule suffit pour faire périr les poulets. Il faut les

si demiseris in aquam. Quod inañe, valat; plenum, desidit. Qui, ut hoc intelligant, concutiant, crrare, quod in eis vitales renas confundant. In isilem aiunt, cum ad lumen sustuleris, quod perluceat, id esse ob inane. Qui laec volunt diutius servare, perfricant sale minuto, aut muria, tres ant quatuor horas; eaque abluta condunt in furfures, aut acus. In supponendo ova olservant, ut sint numero imparia. Ova, quæ incubantur, lıabeantne semen pulli, curator quatriduo, postquam incubari cœepit, intelligere potest, si contra lumen tenuit, et purum uniusmodi esse animadvertit, putant ejiciendum, et aliud subjiciendum. Excusos pullos subducendum ex singulis nidis, et subjiciendum ei, quæ lıabeat paucos. Ab eaque, si reliqua sint ova pauciora, tollenda, et subjicienda aliis, quæ nondum excuderunt, et minus liabent $x x x$ pullos. Hoc enim gregem majorem non faciendum. Objiciendum pullis diebus $\mathrm{Xv}$ primis mane suljecto pulrere (ne rostris noceat terra dura) polentanı mix tam cum nasturtii semine, et aqua aliquanto ante facta intrita, ne tum denique in eorum corpore turgescal. Aqua prolibendum. Quando de clunibus coeperint labere pinnas, e capite et e collo eorum crebro eligendi pedes. Sæe enim propter cos consenescunt. Circum caveas eorum incendendum cornum cer. vinum, ne quæ serpens accedat : quarum bestiarum ex 
conduire souvent au soleil et sur des tas de fumier, où ils puissent s'ébattre à leur aise, ils en sont meilleurs. On fera bien même d'y mener tout le poulailler en été, et tant que la température est douce et que le soleil donne. On aura la précaution d'étendre au-dessus du clos un filet, qui les empèche de s'envoler, et les préserve en mème temps desoiseaux de proie. Épargnez-lcur l'excès du chaud aussi bien que l'excès du froid : l'un est aussi nuisible que l'autre. Quand les poulets commenceront à avoir des plumes, il faut les habituer à ne suivre qu'une poule ou deux, afin que les autres ne soient occupées quà pondre. L'incubation ne doit commencer quaprès le renouvellement de la lune. Les œufs qu'on fait couver plus tôt ne réussissent presque jamais. Il ne leur faut que vingt jours environ pour éclore. J'ai parlé trop longuement peut-être des poules ordinaires : pour compensation je ne dirai qu'un mot des autres espèces. Les poules sauvages sont fort rares à Rome, et l'on n'en rojt guère d'apprivoisées, si ce n'est en cage; elles ressemblent d'aspect, non de plumage, aux poules d'Afrique, plutôt qu'à celles de ferme, quand on n'a rien fait pour les déguiser. On les dépose souvent en parade dans les pompes publiques, avec des perroquets, des merles blanes, et comme objets rares et curieux. Elles ne pondent et couvent volontiers que dans les bois, et ne produisent guère à l'état domestique. Ce sont elles qui ont fait appeler Gallinaria l'île que l'on voit dans la mer de Toscane, près d'Italie, vis-à-vis d'Intemelium, d'Albium Ingaunum, et des montagnes de Ligurie. Suivant d'autres, ce nom vient des poules ordinaires, transportées là originairement par des matelots, et dont la race s'y est perpétuéc à l'état sauvage. Les poules d'Afrique sont grandes, bigarrées, et ont le dos en saillie. Les Grees les appellent $m \dot{e}$ léagrides. Ce sont les dernières que l'art culinaire a imaginé d'offrir auะ palais blasés de notre époque : leur rareté les fait payer très-cher. Les poules ordinaires sont celles qu'on engraisse le plus souvent. On les enferme à cet effet dans un lieu chauffé doucement, où elles aient peu d'espace et de jour. Le mouvement et la lumière nuisent à leur embonpoint. On les choisit à la taille, en exceptant toutefois celles qu'on appelle à tort mélices, puisque leur véritable nom est Melicæ; de même que nos ancêtres disaient Thélis au lieu de Thetis, le nom domestique donné origiuairement aux poules qu'on faisait venir de Médie à cause de leur grandeur, est resté désormais à cette race, qui s'est perpétuée dans notre pays, et a conservé avec son type une grande ressemblance. Pour les engraisser, on leur arrache les plumes des ailes et de la queue, et on leur donne en abondance des boulettes faites avec de la farine d'orge, à laquelle on peut ajouter aussi de la farine d'ivraie, ou de la graine de lin pétrie dans de l'eau tiède. On leur donne à manger deux fois par jour; mais il faut s'assurer avant le second repas si le premier est digéré. Après, quand elles ont mangé, on leur purge la tête de vermine, et on les renferme de nouveau; ce régime se continue pendant vingt-cinq jours, et au bout de ce temps les poules sont engraissées. Quelques-uns, dans le même but, leur donnent du pain de froment émietté dans de l'eau, et y mêlent du vin généreux et qui ait du bouquet. On prétend par ce moyen rendre les poules grasses et tendres en vingt jours. olore solent interire. Prodigendi in solem et in sterquilinium, ut se rolutare possint, quod ita alibiliores fiunt. Ne(jue pullos tantun, sed omne òsve $\theta_{0}$ ocoxziov, cumæstate, tum utique cum tempestas est mollis...... atque in apricum, intento supra rete, quod prohiheat eas extra septa evolare, $\mathrm{ct}$ in eas involare extrinsecus accipitrem, aut quid aliud; evitare item caldorem et frigus, quod utrumque lis ariversum. Cum jam pinnas liabebunt, consuefacien. Jum, ut unam aut duas sectentur gallinas, ceterse ut potius ad pariendum sint expeditx, quam in nutricatu oc(1)pata. Incubare oportet incipere secundum noram lusain, food fere qua ante, pleraque non succedunt. Dirlus fere $x x$ excudunt. De quibus villaticis, quoniam rel uimium dictum, brevitate reliquı compensabo. Gallins rusticae sunt in urlse rarx, cavea videntur Romæe, similes facie non lis villaticis gallinis nostris, sed Africanis, aspectı ac facie incontaminata. In ornatilus publicis solent poni cum psittacis ac merulis albis, item aliis iı genıs rebus inusitatis. Teque fere in villis ova ac pullos faciunt, sed in silvis. Ab his gallinis dicitur insula Gallinaria appellata, quac est in mari Thusco secundum Italiam contra montes Ligusticos, Intemelium, Albiun Ingaunum. Alii ab his villaticis in- rectis a nautis ibi feris factis procreatis. Gallinæ Africanæ sunt grandes, variæ, gibberæ, quas $\mu \varepsilon \lambda \varepsilon x \gamma p i \varepsilon x$ appellant Graci. Hæ novissimæ in triclinium ganearium introierunt e culina, propter fastidium lıminum. Veneunt propter pelıuriam magno. De tribus generibus gallinæ saginantur maxime villatica. Eas includunt in locum tepidum et angustum et tenebricosum, quod molus earum el lnx pinguitudini inimica, ad hanc rem electis maximis gallinis, nec continuo his, quas Melicas appellant falso, quod anti. qui ut Thetin Thelim dicebant, sic Medicam Melicam vocabant. Hæ primo dicebantur, quia ex Media propter magnitudinem erant allatx, quaque ex iis generatæe postea propter similitudinem ampla omnes. Ex iis erulsis ex alis pinnis et e cauda farciunt turundis ordeaceis; partim ad. mixtis ex farina loliacea, aut semine lini ex aqua dulci. Bis die cibum dant, observantes ex quibusdam signis, ut prior sit concoctus, quam secundum dent. Dato cibo, quum perpurgarunt caput, ne quos habeant pedes, rursits eas coucluduut. Hoc faciunt usque ad dies $x \times 7$. Tunc denique pingues fiunt. Quidam et triticeo pane intrito in aquam mixto vino bono et odorato farciunt, ita ut diebus $\mathrm{xx}$ pingues reddant ac teneras. Si in farciendo nimio cilso fastidinut, remittendum in datione pro portione, sicut 
Si l'on s'apercoit que l'excès de nourriture les rebute, il faut en diminuer la quantité de jour en jour jusqu'au dixième, suivant la progresssion que l'on a observée en l'augmentant, de sorte que la ration soit égale le vingtième jour et le premier. Les 'pigeons ramiers s'engraissent de la même manière que les poules.

X. Passez à présent, dit Axius, à ces hôtes de villa, que vous autres Philhellènes appelez amphibies (àup̣ibı), espèees auxquelles la terre ne suffit pas, et dont l'entretien exige encore de ces

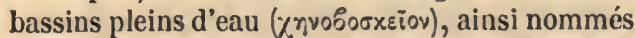
quand vous y élevez spécialement des oies. Seipion Métellus et M. Séius ont quantité d'élèves de cette dernière espèce. Mérula reprit : Quand Séius a formé ses troupeaux d'oies, il a porté ses soins sur les einq points prineipaux dont j'ai parlé en traitant des poules : attention à bien choisir, multiplication de l'espèce, ponte, naissance des petits, et engraissement. L'esclave qui les aehetait avait ordre de n'en prendre que de grande taille et de plumage blanc; car leur progéniture est presque toujours à leur ressemblance. C'est qu'il y a une autre espèce qu'on appelle oies sauvages, au plumage bigarré , qui n'aime point à se joindre aux oies domestiques et sapprivoise diffieilement. L'époque la plus favorable à l'accouplement est celle du solstice d'hiver. Les oies pourront alors pondre et couver depuis les calendes de mars jusqu'au solstice. Ces oiseaux s'accouplent ordinairement dans l'eau; ; et, l'aete eonsommé, ils plongent dans la rivière ou le bassin. Ils ne font pas plus de trois pontes par an. On disposera pour ehaque oie une eabane de deux pieds et demi de tour, où la femelle puisse déposer ses œufs; et on y étendra de la paille pour litière. On marque les

decem primis processit, in posterioribus ut diminuant eadem ratione, ut vigesimus dies et primus sit par. Eodem modo palumbes farciunt, ac reddunt pingues.

$X$. Transi, inquit Axius, nunc in illud genus, quod ros philograci vocatis $\alpha \mu \rho i \beta ı v$, quod non est ulla villa ac terra contentum, sed requirit piscinas, in quibus ubi

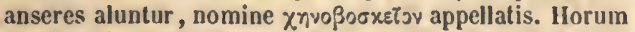
greges Scipio Metellus, et M. Sejus habent magnos aliquot. Merula : Sejus, inquit, ita greges comparavit anserum, ut hos quinque gradus observaret, quos in gallinis dixi. Hi sunt de genere, de fuetura, de ovis, de pullis, de sagina. Primum jubebat servum in legemio observare, ut essent ampli et albi : quod plerumque pullos similes sui faciunt. Est enim alterum genus varium, quod ferum vocatur, nec cum is libenter congregatur nec xque fit mansuetun. Anseribus ad admittendum tempus est aptissimum a bruma : ad pariendum et incubandum a kal. Martii usque ad solstitium. Saliunt fere in aqua, dein merguntur in flumine aut piscina. Singulæ non plus quam ter in anno pariunt. Singulis ubi pariant, faciundum haras quadratas circum binos pedes, et semipedem eas sub. sternendum palea. Notandun earum ova aliquo signo, œufs de manière à les reconnaitre, car une oie ne fait éclore que les siens. On lui en donno ordinairement neuf ou onze à eouver; jamals plus de quinze, ni moins de sept. Elle eouve trente jours si la température est froide, et vingteinq quand le temps est doux. Lorsque les oisons sont éclos, on les laisse les cinq premiers jour's avec leur mère. Il faut ensuite, si le temps est beau, les eonduire tous les jours à la prairie, au marais ou aux bassins. On leur dispose des cellules au-dessous ou au-dessus du sol, lesquelles n'en doivent pas contenir plus de vingt. Il faut en exclure soigneusement toute humidité, et tapisser le sol de paille ou de quelque ehose d'analogue. On doit également veiller avec soin a ce qu'aucun animal nuisible, tel que la belette, ne puisse y pénétrer. On fera paître les oies dans des lieux humides où l'on sème exprès des herbes à graines, celle notamment qu'on appelle seris, qui reverdit par le seul contaet de l'eau, quelque desséehée qu'elle puisse être. Il ne faut pas leur laisser paitre cette herbe à la tige; on l'arrache pour la leur offrir. Sans cette préeaution, il est à craindre qu'ils ne détruisent le plant sous leurs pieds, ou qu'ils ne erèvent à foree d'en manger. En effet, ces oiseaux sont tellement gloutons, que si l'on ne modère pas leur avidité, ils font des efforts à se tordre le cou pour déraeiner quelque plante. Cette partie, ainsi que la tête, est ehez eux le eôté faible. A défaut de cette herbe, on leur donnera de l'orge ou toute autre espèce de grains. On peut aussi, suivant la saison, les nourrir de toute espèce de fourrage, avec les mêmes préeautions que j'ai indiquées pour la seris. Lorsqu'ils couvent, on met devant eux de lorge broyée dans de l'eau. Quant à leurs petits, on les nourrira les deux premiers jours avee de

quod aliena non excudunt. Ad incubandum supponunt plerumque $1 \mathbf{x}$ aut $\mathbf{x ı}$ : qui hoc minus, vı : qui hoc plus, $\mathbf{x} \mathbf{v}$. Incubat tempestatibus dies $\mathbf{x x x}$, tepidioribus $\mathbf{x x v}$. Cum excndit, quinque diebus primis patiuntur esse cum matre. Deinde quotidie serenum cum est, producunt in prata, item piscinas, aut paludes : iisque faciunt lıaras sn. pra terram aut subtus, in quas non inducant plus vicenos pullos. Easque cellas provident, ne habeaut in solo humorem, et ut molle lıabeant substramen e palea, aliave qua re, neve qua eo accedere possint mustelx, alineve hestix, quæ noceant. Anseres pascunt in humidis locis, ubi pabulum serunt, quod aliquem fructum ferat seruutque lis herbam, qua vocatur seris, quod ea aqua tacta etian cum est arida, fit viridis. Folia ejus decerpentes dant, ne si eo inegerint ubi nascitur, aut obterendo perdant, aut ipsi cruditate pereant. Voraces enim sunt natura. Quo temperandum iis, qui propter cupiditatem sxpe in pascendo, si radicem prenderunt, quam educere velint e terra, abrumpunt collum. Perimbecillum 'enim id, ut caput molle. Si hac herba non est, dandum ordeum, aut frumentum aliud. Cum est tempus farraginis, dan. dum ut in seri dixi. Cum incubant, ordeun is intrituแ 
la páte ou de l'orge en nature; puis, les trois jours suivants, on leur donnera dans un vase du cresson sortant de l'eau, et haché très-fin. Lorsqu'ils sont en âge d'être renfermés dans les cabanes dont j’ai parlé plus haut, leur nourriture sera de la pâte de farine d'orge, du fourrage, ou toute espèce d'herbe tendre hachée menu. Les oisons qu'on véut engraisser doivent avoir de quatre à six noois. Il faut alors les enfermer à part, et les nourrir avec de la pâte de fleur de farine détrempce, dont on leur donnera tant qu'ils voudront trois fois par jour. Après chaque repas on les fera boire copieusement; en suivant cc régime pendant deux mois, ils seront engraissés suffisamment. A chaque repas il faut nettoyer les lieux où ils prennent leur nourriture; car ils se plaisent dans la propreté, mais ils ne quittent jamais unc place sans l'avoir salie.

XI. Veut-on élever des troupeaux de canards, et former ce qu'on appelle un vri, footpopsiov (lieu où l'on nourrit des canards), il faut avant tout choisir, si l'on peut, un terrain de marécage ; c'est celui qui leur convient le mieux. A defaut de cela, ayez un emplacement où se trourc un İac naturel, un étang ou un bassin fait de main d'homme, avec des degrés par lesquels les canards puissent descendre. Le clos qui leur sert d'habitation doit être entouré d'un mur de quinze pieds de hauteur, comme celui que vous avez vu dans la ferme de Séius, et n'avoir 'qu'une scule porte. Le long du mur régucra une suite de petites loges couvertes de toits, construites uniformément ct d'une largeur convenable. Chacune aura un vestibule pavé de briques dans toute son étendue. Le clos lui-même scra traversé dans toute sa longueur d'un canal

in aqua apponendum. Pullis primum biluo polenta, aut ordeun appouitur, tribus proximis nasturtium viride consectum mitulatim ex aqua in ras aliquod. Cum autem sunt iuclusi in liaras, aut speluncas, ut dixi, victui objiciunt his polentan ordeaceam, aut farraginem, lierbamve teneram aliquam concisam. Ad saginandum eligunt pullos quatuor sexre menses qui sunt nati. Eos iucludunt in saglnarlo ibique polentam, et pollinem aqua madefacta lant cibum, ita ut ter die saturent. Secundum cibum large ut bibanı faciunt potestatem. Sic curati circiter duobus mensibus funt pingues. Quotiescunque sumserunt, locus solet purgari : quod ipsi amant locum purum, neque ipsi ullun, ubi fuerint, relinquunt purum.

XI. Qui auten volunt greges anatium liabere, ac cons-

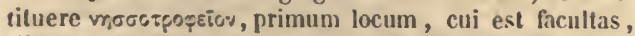
eligere oportet palustren, quod eo maxime delectantur. Si id nou, potissimum ibi, ubi sit naturalis aut lacus, ant stagnum, aut manufacta piscina, quo gradalim descendere possint. Septum altnm esse oportet ubi verseutur, ad pedes $\mathrm{xr}$, ut vidistis ad villam Sei, quod uno ostio claudatur. Circum totum parietem intrinsecus crepido lata, in qua secundum parietem sint tecta cubilia : ante eas ves. tilulum earun ex xquatum tectorio opere testaceo. In eo VARRON. toujours plein. C'est là qu'on dépose ce quils mangent, c'est là qu'ils trouvent de quoi boire. Les canards se nourrissent ainsi. Les murs seront rccouverts d'un enduit bien poli, pour empêcher les chats et autres animaux nuisibles de s'y introduire. On étendra en outre sur le clos un filet à larges mailles, dans le double but d'empêcher l'aigle de fondre sur les canards, et les canards de s'envoler au dehors. Lcur nourriture se compose de blć, orge, marc du raisin, ct quelquefois áussi d'écrevisses et autres petits animaux aquatiques de cette espèce. II faut une large prise d'eau pour que les bassins soient alimentés constamment et renouvelés sans cesse. Quelques espèces sont encore élevées comme les canards : ce sont les sarcelles et les phalerides. II en est de même des perdrix, qui, au rapport d'Archélaüs, conçoivent, rien que d'entendre le mâle. On n'élève pas ces dernières espèces comme les autres, en raison de leur fécondité et de la délicatesse de leur chair; mais on les engraisse, si l'on vcut, par les mêmes moyens. Voilà, je crois, le premier acte de la basse-cour terminé. Je n'ai plus rien à dire.

XII. Cependant Appius était de retour; et après les questions réciproques sur ce qui s'était dit et fait de part et d'autre, Nous en sommes donc, dit-il, au second acte, c'est-à-dire à ces parcs annexés de nos villas, qu'on appelle er:core leporaria, d’après leur ancienne destination spéciale. Aujourd'hui il ne s'agit plus d'un arpent ou deux, où l'on réunit quelques lièvres; mais de vastes espaces, de forêts entières, où l'on ren. ferme par bandes les cerfs et les chevreuils. $\mathrm{On}$ dit que Q. Fulvius Lupinus a dans les environs de Tarquinia un enclos de quarante arpents, où,

perpetua canalis, in quam el cibus jonitur iis, et immit. titur aqua. Sic enim cibun capiunt. Onmes parieles tectorio lerigantur, ne fales, aliave qua bestia introire ad nocendun possit, idque septum totum rete grandibus maculis integitur, ne eo inrolare aquila possit, neve ex ea evolare anas. Pabulum iis datur triticum, ordenın, vinacei uvæ. Nonnunquam etiam ex aqua cammari, el quadaı ejusmodi aqualilia. Qux in eo septo erunt piscinx, in eas aquam large influere oporlet, ut semper recens sit. Siut item non dissimilia alia genera, ut querquedula, plaalerides. Sic perdices, qux, ut Arclielans scribit, voce maris audita, concipiunt. Quæ, ut superiores, neque propter focunditatem, neqne propter suavilatem sqginantur, sed sic pascendo funt pingues. Quod ad rilla. ticarum pastionum primum actum pertinere sum ratus, dixi.

XII. Interea redit Appius, et percunctati nos ab illo, et ille a nobis, quidesset dictum ac faclum, Appius: Sequitur, inquit, actus secundi generis, afficticius ad villam qui solet esse, ac nomine antiquo a parte quadam, leppora. rium appellatum. Nam neque solum lepores eo includun. tur silva, ut olim in jugero agelli, aut duobus, sed etiam cervi aut caprea in jugeribus multis. Q. Fulvius Iupintis 
indépendamment des animaux dont nous venons de parler, on trouve des moutons sauvages. Des pares plus spaeieux eneore se rencontrent sur le territoire de Statonia, et en beaucoup d'autres endroits. T. Pompéius a dans la Gaule transalpine un pare consacré à la ehasse, qui n'a pas moins de quarante mille pas carrés. Dans ces enclos sont en outre des enceintes particulières réservées aux eseargots et aux abeilles, et des tonneaux où on élève des loirs. Rien de plus facileque la garde, l'entretien et la multiplieation de ces animaux, les abeilles exeeptees. Tout le monde sait en effet qu'un parc doit être envilonné de murailles bien crépies, pour empêcher les chats, les fouines, etc., d'y pénétrer, et assez élevées pour que les loups ne puissent les franchir. On sait qu'il faut également qu'un parc abonde en gîtes où les lièvres puissent se rendre invisibles pendant le jour, et se tapir dans les broussailles et sous les herbes; et que les arbres y doivent former une voûte assez épaisse pour empêcher l'aigle de s'y abattre. Personne enfin n'ignore qu'il suffit de quelques lievres et hases pour que ee gibier pullule aussitôt. Deux eouples vont peupler tout un parc. IA race est prolifique au point quesi vous ouvrez une mère qui vient à peine de mettre bas, vous allez la trouver déjà pleine. Arcliélaüs nous apprend que pour connaître l'âge d'une hase on n'a qu'à examiner eombien d'orifiees elle a au ventre ; car le nombre en diffère dans ces animaux selon leurâge. On a un proeédé nouveau pour engraisserles lièvres: c'est de les prendre dans le pare, et de les plaeer dans des eages étroites et fermées. On compte trois espèees de lièvres. La première est notre lièvie d'Italie, qui a les pattes courtes par

dicitur lıabere in Tarquiniensi septa jugera $\mathrm{xL}$, in quo sunt inclusa non solum ea, qux dixi, sed etiam oves ferre, etiam loc majus lic in Statoniensi, et quidam in locis aliis. In Gallia vero transalpina T. Pompeius tantum septum venationis, ut cirriter $\infty \infty \infty \infty$ passuum to. cum inclusmm liabeat. Praterea in eodem consepto fere lubere solent [ de animalibus] coclearia, atque alvearia, aturue etiam dolia, uli habeant conclusos glires. Sed horum omuium cusfodia, incremenlum, et pastio aperta, jraxierquam de apibus. Quis enim ignorat sepla e maceriis ita esse oportere in leporario, ut leclorio tacla sint, et siut alta? alterum ne faclis, aut malis, aliuve qux bestia introire possit, alterum ne lupus transilire : ibiqure esse lalebras, nhi lepores interiliu delitescant in virgnllis, atque herbis : et arbores patulis ramis, qua aquilie im. peliant conatus. Quis item nescit paucos si lepores, mares ut fominas intromiserit, brevi tempore fore ut impleatur? tanta foccunditas lujus quadrupedis. (Quatuor enim modo intromissis in leporarium, brevi solet repleri.) Fit enim sape cum habent catulos recentes, alios nt in ventre habere reperiantur. Itaque de his Archelaus scribit, annorum quot sint si quis velit scire, inspicere oportere, foramina nalura, quæe sine dubio alius alio habet plura. I!oc q1:orue nuper iustitutum nt saginarentur lepores, dévant et très-longues par derrière, le poil fauve sur le dos, blane sous le ventre, de longues oreilles. On dit que, pleines, les hases sont en état de eoncevoir de nouveau. Les lièvires deviennent très-grands dans la Gaule transalpine et dans la Macédoine ; ils restent de taille moyenne dans l'Espagne et en Italie. La seconde espèce, que l'on reneontre dans la partie de la Gaule voisine dis's Alpes, ne differe de la première que par le pelage, qui est tout blanc. On en apporte rarement à Rome. La troisième espc̀ce, qu'on appelle aussi cuniculi (lapins), est originaire d'Espagne, et ressemble beaucoup aux nôtres; sauf pour leur taille, qui est plus petite. L. Alius a cru que lepus (lièvre) venait de levipes (au pied léger), à cause de la vitesse de cet animal. J'imagine, moi, que lepus vient d'un aneien mot grec; ear les Eoliens de Béotie appelaient un

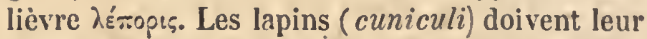
nom aux terriers (cuniculi) qu'ils font sous terre pour se cacher. Les trois espèces doivent, autant que l'on peut, être réunies dans les pares. Quant aux deux premières, continua Appius en s'adres. sant à moi, je ne doute pas que vous ne les ayez. dans le vôtre; mais vous, qui êtes resté si longtemps en Espagne, peut-être vous êtes-vous aussi procuré des lapins.

XIII.S'adressant ensuite à Axius : Vous n'êtes pas sans savoir, lui dit-il, que le sangliel est aussi gibier de parc, et qu'on engraisse sans trop de peine l'animal qui y entre sauvage aussi bien que celui qui y est né dans la domestieité. Vous avez vu vous-même, dans cette propriété que Varron a aehetée de M. Pupius Pison, aux environs de Tusculum, les sangliers et les chevreuils

cum exceptos e leporario condunt in caveis, et loco clauso faciunt pingues. Eorum ergo tria genera fere sunt. Unum Italicum hoc nostrum pedibus primis humilibus, posterioribus altis, superiore parte pulla, ventre alloo, auribus longis. Qui lepus dicitur, cum pragnans sit, tamen conci. pere. In Gallia transalpina et Macedonia funt permagni : in Ulispania et in Italia mediocres. Alterius generis est, quod in Gallia nascitur ad Alpes, qui lioc fere mutant, quod toti candidi sunt. IIi raro perferuntur Rornam. Tertii generis est, quod in IIispania nascitur, sinilis nostro lepori ex quadām parte, sed lıumile, quem cuniculum ap)pellant. L. Aflius putabat ab eo dictum leporem, [a celeri tudine,] quod levipes esset. Ego arbitror a graco rocabulo

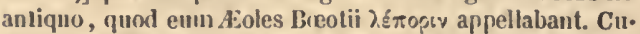
niculi clicti ab eo, quod sub terra cuniculos ipsi facere soleant, ubi lateant in agris. IJorum omniun tria genera, si possis, in leporario habere oportet. Duo quidem ulique te habere puto, et quod in Ilispania anuis ita fuisti multis, ut inde te cuniculos persecutos credam.

XIII. Apros quidem posse habere in leporario, nec magno negotio ibi et captivos, et cicures, qui ibi nati siut, pingnes solere fieri, scis, inquil, Axi. Nam quem fundun in Tusculano emit hic Varro a M. Pupio Pisone, vidisti ac buccinan inflatam cello tempore apros et capreas conve. 
se rassenbler au son du eor, à heure fixe, pour prendre leur nourriture; tandis que d'un terire réservé aux exercices gymuastiques, on jetait aux uns du gland et aux autres de la vesec, ou quelqu'autre semblable pâture. Quant à cette scène, répondit $\Lambda x i u s, j$ jen ai vu la représentation ehez Q. Hortensius, et sur une bien plus grande ćchelle. Il a sur le territoire de Laurente un bois de plus de cinquante arpents, entouré le murailles qu'il appelle uon pas son leporarium, mais son onprorpopeiov. Au milieu du bois est une espèce d'élévation, oì l'on avait disposé trois lits, et où l'on nous servit à souper. Quintus fit venir Orphéc, qui arrive en robe longue la cithare à la main, et qui, sur l'ordre qu'il en reçoit, se met à sonner d'une trompette. Au premier son de l'instrument nous nous voyons entourés d'une multitude de cerfs, de sangliers et autres bêtes fauves; si bien que le spectacle ne nous parut pas au-dessous des ehasses sans bêtes féroces, dout les édiles nous donnent quelquefois le plaisil au grand circue.

XIV. A postrophant alors Mérula : Appius, ditil, vous a bien faeilité votre rôle. Ce qui eoneerne la clıasse, et e'était le sceond acte, vient d'être expédié en un tour de main. Quant aux eseargots et aux loirs, je vous en tiens quitte; et ce n'était pas une affairc. La chose est pourtant moins simple que vous ne semblez le croire, mon cher Axius, reprit Appius. Encore faut-1] aux eseargots un liéu qui leur convienne ; et pour eela il le faut en plein air, et entouré d'eau de toutes parts; sinon vous risquez de courir après les petits, et même après les gros que vous aurcz mis là pour y multiplier. L'eau vous tient lieu de fugitivarius si le soleil n'y donne pas trop, et si la rosée y abonde : c'est ee qu'on peut trou-

nire ad paluulum, cum e superiore loco e palastra apris effunderetur glans, capreis vicia aut quid alind. Ego vern, inquil ille, apud Q. Hortensium cum in agro Laurenti

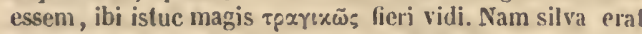
(nt dicehat) supra quinquaginta jugerum maceria sepla, juod non leporarium sed onptotpopeiov appellabat. Ibi erat locus excelsus, ubi triclinio posito cuenabamus. Qnintus Orplıea vocari jussit, Qui cum eo venisset cum stola et cithara, et cantare esset jussus, Inccinam inflavit, ubi tauta circumfluxit nos cervorum, aprorum et creterarum quadrupedum multitudo, ut non minıs formosum mili visım sit spectaculum, quam in circo maximo aedilium sine Africauis bestiis cum fiunt veuationes.

XIV. Axius : Tuas partes (inquit) sublevavit Appius, - Merula noster. Quod ad venationem pertinet, breviter secundus transacturs est actus. Nec de cocleis, ac glirilus quaro, quod reliqum est. Neque enim maguum emolı. mentum esse potest. Non istuc tam simplex est, inquit Ap. pius, quam tu putas, o Axi noster. Nam et idoneus sul dio sumendus locus cocleariis, quem circun totum aqua claudas, nequas ibi posneris ad partum, non liberos earum, sed ipsas quæras. Aqqua, inquam, finiendx, ue fugitivaritıs sit parandus. Locus is melior, quem et non corpuit sol, et ver de micux à défaut de rosće maturelle, inconvénient propre aux lieux trop exposés; ou si le lieu, même couvert, est dépourvu de ces rochers ou tertres dontl'eau baigne le pied, alors il faut produire artifieiellement la rosée; et voici par quel procédé. Au moyen d'un tuyau qui se termine par un eertain nombre de petits mamelons, on lance avee force de l'eau, qui, retombant sur une plerre, regaillit en gouttes de tous eôtés. L'eseargot vit de peu, et l'on est dispensé de pourvoir à sa nouıriture; il la trouve lui-même en rampant sur la terre, ou sur les parois des rochers, à moins que quelque ruisseau interposi ne lui fasse obstacle. Oı en voit étalés dans les marchés, vivre assez longtemps de leur propre substance. Il suffit de leur jeter de temps à autre quelques feuilles de laurier avee un peu de son. Les cuisiniers, en les préparant, ne savent pas toujours s'ils sont morts ou en vie. Il y a plusieurs espèces d'eseargots : l'espèee petite et blanchâtre qui vient de Réate, la grosse que nous tirons de l'lllyrie, et la moyenne qui nous est apportée d'Afrique. Ce n'est pas que eette différenee de grosseur tienne précisément aux pays : l'Afrique, par exemple, nous en voie des escargots que nous nommons solilana, et qui sont si gros que leu: eoquille peut eontenir jusqu'à quatrevingts quadranles de liquide. Et les provenanees de deux autres pays offrent aussi respectivement des dim'usious exceptionnelles. Ces auimaux pondent une prodigieuse quantité d'œufs très-petits, et dont la coque, très-tendre dans l'origine, s'endureit avec le temps. Ils les déposent dans des monceaux de terre en forme d'îlots, daus lescuels ils ouvrent un large passage à l'air. Pour les engraisser, on les enferme dans un pot de terre percé de plusieurs trous, que l'on frotte ì l'intérieur de

tangit ros. Qui si naturalis non est (ut fere non sunt in aprico loco) neque luabeas in opaco, nt facias, ul suul sub rupilons ac montibus, funrum alluant raclices lacus ac fluvii, manu facere oportet roscidum. Qui fit, si eduxeris fistulam, et in ean Inammillas imposueris lemues, quac ernclent aquam, ita ut in aliquem lapidem incidat ac late dissipetur. Parvus is cibus opus est, et is siue uninistratore. Et lunne, dum serpit, non solum iu area reperit, sed etiam si rivus uon prolubet, itl parieles stantes inve. nit. Denique ipsec ex se runimantes ad propolam vitam diu profucunt, cum ad eam rem pauca laurea folia interjiciant, el aspergant fírfures non multos. Itafue cocas has vivas an mortuas coquat, plerumqune uescit. Genera coclearum sunt plua, ut miuntie albula', qua affermulu' c. Peation, et univiure, gure de Illyrico apportanfur, et me. diocres, quxe ex Africa afferuntur. Non quo uou iu lis regionibus quilusdam locis eir ungुnituliuilıts quacdau sint dispariles : nam et value amplie sunt ex Africa, quas vocautur solitane, ila ut earum calices quadrantes octo. ginta capere possint, et sic: in aliis tegiombus eadem in ter se collate et miuores sumt, ac. majores. Hac in foturi parimut innumerabilia. Larum senten mimutum ac testa ıolli, diuturuitate oblurescit. Magnis insulis in areis 
farine délayée dans du vin cuit, jusqu’à réduction des deux tiers. Les trous sont là pour laisser pénétrer l'air. On voit que cette espèce a la vie dure.

XV. L'enceinte où l'on élève des loirs ne ressemble en rien à celle qui est réservée aux cscargots, puisqu'au lieu d'eau ce sont des murailles qui l'environnent. Ces murailles doivent être de pierre lisse ou bien crépies en dedans, pour que les loirs ne puissent trouver jour à s'échapper. On plantera dans cette enceinte de jeunes chênes qui portent du gland; et quand il ne s'en trouve point sur les arbres, il faudra en jeter aux loirs, ainsi que des châtaignes, pour leur servir de nourriture. Il y sera pratiqué des trous assez larges pour qu'ils puissent $\mathbf{y}$ faire leurs petits. Ne leur prodiguez pas l'eau. Les loirs boivent peu, et ils aimeut être à sec. On les engraisse dans des vaisseaux tels qu'on en voit dans beaucoup de fermes, et qui ne ressemblent point aux vaisseaux ordinaires. Les potiers qui les fabriquent ont soin d'y pratiquer sur les côtés des rainures et un enfoncement servant à passer à ces animaux la nourriture qui leur convient, ct qui consiste en glands, noix ou chataignes; on posc par-dessus un couvercle, et privés de jour, ces loirs engraissent promptement.

XVI. Il ne nous resie plus à traiter que le troisième acte de la basse-cour, c'est-à-dire les viviers. Commient, le troisième? s'écria Axius; parce que, dans votre jeunesse, vous vous êtes habitué, par motif d'économie, à vous passer de vin au miel, est-ce une raison pour que nous soyons privés de miel aussl, nous autres? I.e fait est vrai, dit Appius. Mes parents m'avaient laissé sans fortune, avec la charge de deux frères et de

factis, magnum bolum deferunt aeris. Ilas quoque sagiuare solent ita, ut ollam cum foraminibus incrustent sapa et farre, ubi pascantur; quie foranina liabcat, ut intrave aer possit. Vivax enim lıec natura.

XV. Glirarium autem dissimili ratione habetır, quod non aqua, sed maceria locus sepitur. 'Tota levi lapide, ant tcctorio intrinsecus incrustatur, ne ex ea erepere possit. In co arbusculas esse oportet, quae ferunt glandem. Qua, cum fructum non ferunt, intra maccriam jacere oportct glandem ef castaneam, unde saturi fiant. Faccre his ca ros oportct laxiores, ubi pullos parere possint. Aquan csse tenuem, quod ca non utuntur multuin, et aridum locum quaxrunt. Hi saginantur in doliis, quae ctiam iu villis lıalient multi, quae figuli faciunt multo aliter atque alia; guod in lateribus enrum semilas faciunt, et carum, ulij ribum constituant. In lioc dolium addunt glandem, ant uuces juglandes, aut castaneam. Quibus in tenebris, cum rumulation positum est in doliis, fiunt pingues.

XVI. Appius : Igitur relinquitur, inquit, de pastionc villatica tcrtius actus de piscinis. Quid tcrtius? inquit Axius. An quia tu solitus es in adolescentia tua domi mulsun non bibere propter parsimoniam, nos mel neglige. deux socurs. J'ai marié sans dot l'une de mes sœurs à Lucullus, qui m'a depuis institué son héritier. Ce n'est qu'alors que j’ai moi-même commencé à boire du vin au miel; mais, à ma table, il y en a toujours eu pour mes convives. A cela près, il appartient à moi, bien plus qu'à vous, de connaitre à fond les habitudes de cetto race ailée, à qui la nature a si singulièrement départi le don d'industrie. J'ai plus que vous étudié son merveilleux instinct; et je vais le prouver. Écoutez-moi. Je laisse à Mćrula le soin d'exposer, arec cette méthode dont il vient de nous donner des preuves, les pratiques observées par tous les méliturges (gens qui font du miel). Les abeilles sont engendrées par d'autres abeilles, ou naissent spontanément du corps d'un bœuf en putréfaction. C'est ce qui a fait dire à Archélaüs, dans une de ses épigrammes, "que les mouches à miel sont la génération ailèe d'un bœuf mort. „ Le même auteur dit encore que les guêpes sont engendrées par des chevaux, et les abeilles par des veaux. Les abeilles ne vivent point solitaires comme les aigles. A l'exemple de l'homme, elles aiment à sc réunir. Les geais en font autant, mais non dans le même but. Les abeilles s'associent pour travailler, pour édifier; chez les geais, rien de semblable. On ne voit point chez eux ces combinaisons d'intelligence, cette adresse d'exécution qui se remarquent dans les constructions des abeilles, et daus leur prẻvoyance à remplir leurs magasins. Il y a pour les abeilles trois ordres d'occupation: Ia sub. sistance, l'édification, et le grand œuvre. Autres soins demandent la préparation du repas et celle de la cire, celle de la cire et celle du miel, la confection du miel et celle de l'al véole. Chaque cellule d'un rayon a six angles, ce qui fait autant de

mus? Appius : Nobis verum dicit, inquit. Nam cum pauper cum duobus fratribns et dualıus sororibus essem relietus ; [quarum] alteram sine dote dedi Lucullo, a quo lıareditate me cessa primum, ct primus mulsum domi mea bibcre copi ipse, cum interea uiluilo minus pene quotidie in convivio onnibus darcm mulsum. Prxterea mcum erat non tuun, eas novisse volucres, quibus plurimunı natura ingenii atque artis tıibuit : itaque eas melius me nosse quam te, ut scias, de incredibili earum avium na-

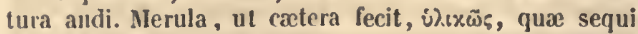
melitturgi solcant, demonstrabit. Primum apes nascuntır partim ex apibus, partim ex bubulo corpore putrefacto. itaque Arclielaus in epigrammate ait eas esse ... Boòs pot-

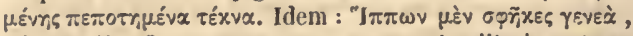
$\mu \dot{\sigma} \sigma / \omega \nu$ ¿̇े $\mu \varepsilon \hat{\varepsilon} . \iota \sigma \sigma \alpha$. Hax apes non sunt solitaria natura, ut aquilx, sed ut honines. Quod si hoc faciunt etiam graculi, at non ilem: quod lic societas operis et adificiorum, quod illic non est. Hic ratio atque ars; ab his opus facere discunt, ab his ærlificare, ab his cibaria condere. Tria enim lıarum, cibus, domus, opus : neque idem quod cibus cera, 1 ec quod ea mel, nec quod mel domus; (non) in faro sex angulis cella, totidem, quot lia- 
côtés que l'abeille a de pattes. Remarquons qu'il est démontré par les géomètres qu'un hexagone inscrit dans un cercle y occupe plus de surface qu'un polygone de moins de côtés. Les abeilles vont pâturer au dehors; mais c'est dans l'intérieur de la ruche que s'élabore ce doux produit si agréable aux dieux et aux hommes. Le miel trouve place sur les autels aussi bien que sur nos tables, tant au début d'un repas qu'au second serviec. Les abeilles ont des institutions comme les nôtres, une royauté, un gouvernement, une société organisée. La propreté est de lcur essence. Jamais on ne les voit se poser dans le voisinage d'immondices ou d'exhalaisons fétides. Ce n'est pas qu'elles reeherchent les parfums : on les voit punil, au contraire, de leur aiguillon quiconque s'approche parfumé de leurs cellules. Elles n'ont point l'indifférente avidité des mouches; aussi ne vont-elles jamals s'abattre, comme celles-ci, sur la viande, le sang, ou la graisse. Les aliments d'une saveur douce peuvent seuls les attirer. Incapables de nuire, elles ne gâtent rien de ce qu'elles effleurent en butinant. Timides par nature, elles n'en résistent pas moins à outrance, si l'on essaie de les troubler dans leur travail. Elles ont pourtant le sentiment de leur extrême faiblesse. On les appelle favorites des Muses, parce que s'il arrive qu'un essaim se disperse, on n'a qu'à frapper sur des cymbales, ou les mains l'une contre l'autre, pour les réunir. Et de même que les hommes ont assigné à ces déesses l'Olympe et l'Hélicon pour leur séjour, de même la nature a abandonné da ces insectes les montagres incultes et fleuries. Elles suivent leur roi partout, le soutiennent quand il est fatigué, et le portent sur leur dos quand il ne peut plus voler, tantelles attachent de prix à sa conservation.

het ipsa pedes. Quod geometræ $\mathfrak{\xi} \xi \dot{\alpha} \gamma \omega$ vov fieri in orbi rotundo ostendurt, ut plurimum loci includatur. Foris pascentur, intus opus faciunt : quod, dulcissimum quod est, et diis et lominibus est acceptum. Quod favus venit in altaria, et mel ad principia convivii, et in secundam meusam administratur. Ha ut hominum civitates, quod lic est et rex et imperium et societas, quod sequuntur omnia pura. Itaque nulla harum assidit in loco inquinato, aut $e o$, qui male oleat, neque etiam in eo, qui bona olet ungueuta. Itaque his unctus qui accessit, nungunt. Non ut muscre liguriunt. Quod nemo las videt, ut illas, in carue aut sanguine aut adipe. Ideo modo considunt in quo est sapor dulcis. Minime malefica, quod nullius opus vellicans facit deterius : neque ignava, ut non, qui ejus opus conetur disturbare, resistat. Neque tamen nescia sua imbecillitatis; quæ cum causa musarum esse dicantur volucres, quod et siquando displicatæ sunt, cymbalis et plausibus numero reducunt in locum unum. Et ut his diis Helicona atque Olympon altribuerunt lomines, sic his floridos et incultos natura attribuit montes. Re. geul suum sequuntur quocunque it, et fessum sublevant; et, si neçuit volare, succollant, quod eum servare vo.
Elles aiment le travail et dêtestent les paresseux ; aussi les voit-on constamment faire la guerre aux bourdons, et les expulser de leur société; car ils dévorent le miel sans aider à le faire. Souvent même on voit un gros de bourdons fuir devant quelques abeilles qui les poursuivent en murmurant de courroux. Elles bouchent, avec une matière que les Grees appellent Ẻpı $\alpha^{\prime} \times \eta$, tous les trous au travers desquels l'air pourrait pénétrer dans lcurs rayons. Les abeilles observent la discipline d'une armée, dorment à tour de rôle, répartissent entre elles la besogne, et envoient au loin des espèces de colonies. Elles obéissent à la voix de leur chef, comme les soldats au son de la trompette, et, comme eux, elles ont leurs signes de guerre et de paix. Mais j'ai peur que toute cette physiologie des abeilles ne fatigue notre cher Axius, qui aimerait mieux entendre parler de ce qu'elles rapportent. Je passe donc la lampe à Mérula : à son tour d'entrer en lice. Je ne sais, dit Mérula, si mes notions sur ce point pourront vous satisfaire; mais j'aurai pour autorité un homme que vous connaissez tous, et qui tire tous les ans cinq mille livres de miel de ruches qu'il a louées. J'ai encore notre arni Varron qui m'a dit avoir eu sous ses ordres en Espagne deux frères véiens, tous deux du eanton de Falisque, lesquels sont devenus fort riehes, bien que leur père ne lcur eût laissé qu'une petite ferme d'un arpent au plus; et voiei comment. Tout alentour du bâtiment ils ont place des ruches, transformé une partie de leur champ en jardin, et planté le reste en thym, cytise et mélisse, cette plante que les uns ap-

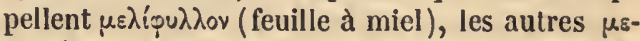

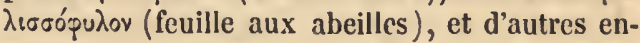
core $\mu$ ś $\lambda$ เvov. Grâce à ces dispositions, ils ne

lunt. Neque ipse sunt inficientes, nec non oderunt inertes. Itaque impetentes a se ejiciunt fucos, quod hi neque adjuvant, et mel consnmunt : quos vocificantes plures persequuntur etiam pauca. Extra ostium alvei obturant omnia, qua venit inter favos spiritus, quam épเ $\theta \alpha x_{x}$, appellant Gracci. Omnes ut in exercitu vivunt, atque alternis dormiunt, et opus faciunt pariter, et ut colonias mit. tunt. Hique duces conficiunt quaxdam ad rocem ut initatione tubse. Tum id faciunt, cum inter se signa pacis ac belli habeant. Sed o Merula, Axius noster ne, dum lıæc andit plysica, fatiscat, quod de fructu nilil dixi, nunc cursu lampada tibi trado. Merula : De fructu, inquit, lloc dico, quod fortasse an tibi satis sit $A x i$, in quo auctorem labeo nou solum, qui alvearia sua locata liąbet quotannis quinis millibus pondo mellis, sed etiam hune Varronem nostrum, quem audivi dicentem, duo nilites se luabuisse in Ilispania fratres Vejanios ex agro Falisco locupletes, quibus cum a patre relicta esset parva villa, et agellus non sane major jugero uno, los circum villam totam alvearium fecisse, et liortum lıabuisse, ac reliquum tliymo et cytiso obsevisse, et apiastro, qutod alii $\mu . \varepsilon \lambda i q u \lambda$.

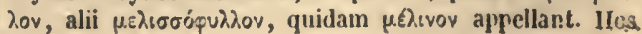


retiraient jamais noins de dix mille sesterees par an cle leur miel. Remarquez eependant qu'ils attendaient pour le vendre un moment favorable, et n'ètaient jamais pressés de s'en défaire eoûte que eoûte. Eh bien! s'ècria Axius, enseignezmoi où je dois placer des ruches, ct quels soins il faut leur douner pour en tirer d'aussi beaux produits. Mérula répondit : Quant aux ruehes

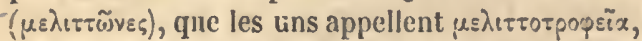
les autres mellaria, elles doivent être plaeées près de la métairie, dans uı lieu sans éeho; car lopinion générale est què cet effet du son effarouche les abeilles. Il leur faut un lieu assez élevé, quii ne soit ni brûlè pendant l'été, ni privè de soleil pendant l'hiver; pâture abondante dans le voisinage, et de l'eau pure. Si la nature n'y a pourvu, le propriétaire aura soin de faire venir à proximité des ruehes les plantes que les abeilles recherehent le plus, eomme la rose, le serpolet, la mélisse, lc pavot, les fèves, les lentilles, les pois, la dragée, le sauehet, le sainfoill, et surtout le eytise, qui convient tant aux abeilles malades. Cette plante a eneore l'avantage de fleurir depuis l'èquinoxe du printemps jusqu'à celui d'automne. Autant le eytise leur est précieux sous lc rapport sanitaire, autant le thym l'est pour la préparation du miel. Si le iniel de Sieile a la palme, il la doit à l'abondanee et a l'excellente qualité du thym que produit cette île. Aussi quelques personnes vont-elles jusqu'à arroser les pépinières plantées à l'usage des abeilles, de thym broyé et détrempé dans de l'eau tiède. Quant à l'emplaeement des r'uches, il faut le choisir le plus rapprochẻ possible de la villa. Quelques-uns, pour plus de sûreté, lesinettent sous le portique même. Les ruches sont

nunquam minus, ut peracque ducerent, dena millia sex. tertia ex melle recipere esse solitos. Tum cos et velle expectare, ut suo potius tempore mercatorem admitterent, quam celerins alieno. Dic initur, inquit, ubi el cujusmodi me facere oporteat alvearium, ut magnos capiam fruc-

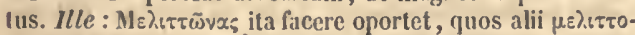
тpop̧eix appellant, eandem rem quidam mellaria. Primum secundun villam, polissimum ubi non resonent imagines. llic enim sonus liarum fuga [causa] existimatur esse. P'rocerum esse oportet aere temperato, neque astate fervido, neque hieme non aprico, ut spectel potissimum id hibernos ortus, quac prope se loca habeat ea, nbi pa. linlum sit frequens ct aqua pura. Si pabulım maturate non est , ea oportet dominum serere, quac maxime sequuuntur apes. lia sunt, rosa, serpyllum, apiastrum, papaver, faba, lens, pisum, ocinum, cylerun, Medica, et nıxime 'ytisum, quod minus valentibus ntilissimnm est. Etenim al) sequinoctio verno florere incipit, et permanet ad alte$1 \mathrm{um}$ xequinoctium antumni. Sed $n t$ loc aptissimum ad sanitaten apium, sic ad mellilicium thymum. Propter hoc Siculnm mel fert palmam, guod ibi tliymum bonum ct trequens est. Itaque quidan thymum contundunt in pila, et diluunt in aqua tepida : co conspergunt oninia seminaria consita apiun cáusa. Quod arl locum pertinet, lıoc de forme circulaire. On en fait dosier quand on en a, de bois, d'écorce, de trones d'arbres creusés, ou de poterie; d'autres les font carrées avee de la férule, et leur donnent environ trois pieds de long sur un pied de large. Il faut toutefois en restreindie les dimensions, sì l'on n'a pas assez d'abeilles pour les remplir; ear trop d'espaee vide les décourage. On a donné aux ruches le nom d'alvus (ventre), du mot alimonium (nourriture); c'est pourquoi on les fait étroites par le milieu, et renflées par le bas pour figurer un ventre. Les ruches d'osier doivent être enduites en dedans et en dehor's avee de la bouse de vache, pour faire disparaître leurs aspérités, qui rebuteraient les abeilles. On les assujettit par rangs le long des murs, de facon qu'il n'y ait pas d'adhérenee entre elles, et qu'elles soient à l'abri de toute seeousse. La même distance qui sépare le premier rang du second doit régner entre le second et le troisième. Au lieu d'en ajouter un quatrième, on fera mieux, dit.on, de s'en tenir aux deux premiers. On pratique au milieu de chaque ruche de petits trous de droite et de gauche, pour que les abeilles puissent entrer et sortil ; et on y pose un couverele qu'on peut lever à volonté, lor'squ'on veut en retirer lo miel. Les ruehes en écorces sont les meilleures. Celles en terre cuite sont les moins bonnes, parce qu'elles sont plus accessibles au froid en hiver et à la chaleur en èté. Le mellarius, e'està-dire celui qui est ehargé du soin des ruches, doit les visiter trois fois par mois, au printemps et en été, y pratiquer de légères fumigations, les purger d'immondiees, et en ehasser les vermisseaux. Il veillera soigneusement à ee qu'il n'y ait pas plusieurs rois dans une même ruche;

genus potissimum eligendum juxta viliam; non quo non in villa porticu quoque quidam (quo tutius essent) alvearia collocarint. Alvos, ubi sht, alii faciunt ex viminibus rotundas, alii c ligno ac corticibus, alii ex arbore cava, alii fictiles, alii etiam ex ferulis quadratas longas circiter pedes ternos, latas pedem, sed ita uti cum parum sit qua compleant, eas coangustent, ne in rasto loco et inani despondeant aninum. Hæc ommia vocant a mellis alimonio alros : quas ideo videntur medias facere angus. tissimas, ut figıram imitentur earım. Vitiles fimo bubulo oblinunt intus et extra, ne asperitate absterreantur. Easque alvos ita collocant in mutulis parietis, ut ne agitentur, neve inter se contingant, cum in ordinem sint positx. Sic intervallo interposito, alterum et tertium ordinem infri faciunt, et aiunt potius linc derni oportere, quam addi quartnm. Nedia alro, (in) qua introeant apes, faciunt foramina parva dextra ac sinistra. Ad extrema, qua mellarii favum eximere possint, opercula imponunt alvis. Optimx fiunt corticex, deterrima fictiles, quod et frigore hieme et restate calore veluementissime commoventur. Verno tempore ct astivo fere ter in mense mellarius inspicere debet fumigans leviter eas, et a spurcitiis purgare alvum, et verniculos ejicere. Practerea ut auimadverial, ne reguli plures existant : inutiles cuim fiunt propter 
car cette pluralité cause des séditions, et le trarail languit. Selon quelques auteurs, les chefs sont de trois couleurs, noire, rouge et mélangée; Ménécrate n'en admet quc deux, le noir et le mélangé. Comme le mélangé est sous tous les rapports préférable au noir, il faut que le mellarius tue cclui-ci touteș les fois qu'il se reneontre avec l'autre dans une même ruche. Cette royauté double, source de factions, est la perte d'une ruche; car il en résulte l'expulsion ou l'émigration d'une partie des abeilles, lorsqu'un prétendant triomple ou se voit ehassé. Pạrmi les abeilles, on regarde comme les meilleures celles qui sont petites, rondes et bigarrécs. Lc bourdon ( $f u r$ ) qu'on appelle aussi fucus est noir, et large de ventre. Il y a une autre espèce d'abeille qui ressemble à la guêpe ; elle ne s'associe point aux travaux des abeilles ordinaires, et leur nuit au contraire par ses morsures; aussi celles-ci l'expulsent-elles toujours de leur communauté. Il faut distinguer les abeilles sauvages des abeilles privées. Les premières séjournent dans les bois et les lieux incultes, les autres dans les champs cultivés. Les abeilles sauvages sont velues et petites, mais plus laborieuses que les abeilles privées. En achetant de ces insectes, on doit s'assurer s'ils ne sont point malades. C'est un signe de bonne santé lorsque les essaims sont denses, les mouches luisantes, et qu'il y a dans leur travail précision et netteté. C'est un signe de maladie lorsque les abeilles sont velues, hérissées, poudrcuses, à moins toutefois qu'elles ne soient alors pressées de travail, ce qui peut leur donner cette apparencc négligée et malingre. Quand on juge à propos de transférer les ruehes, il faut mettre uue grande circonspeetion dans le choix du lieu ct du moment. Pour le moment, le printemps est préférable à l'hiver: car dans la saison froide les abeilles ont peine a s'habituer aux changements de demeurc, et sont disposées à déserter. C'est ce qui arrive certainement, si d'un lieu qui leur convient vous les transportez dans un autre moins propiee à leur páture.

Le changement de ruche sans changement de place exige encore certaines précautions. On frotte par cxempleles nouvelles ruches de mélisse, ee qui est pour les abeilles un grand appât, et dans chacune on place près de l'ouverture quelques rayons de miel; cette provision toute faite leur donne le change sur leur translation. La nourriture qu'elles trouvent all commencement du printemps, dans les fieurs d'amaudier et de cornouiller, les rend presque toujours malades: on les guérit avec de l'urine. On appelle pro. polis la matière dont se servent les abeilles, surtout en été, pour boucher l'ouverture de leur ruche. C'est la même substance que les médecins emploient pour les emplâtres. Aussi se vendelle dans la rue Sacrée plus cher que le miel même. On appelle érithace cellc qui colle les rayons ensemble, et qui est essentiellement distincte du miel et de la propolis; on lui suppose une vertu attractive. Quand on veut, par exemple, qu'un essaim se fixe sur une branche d'arbre ou ailleurs, on n'a qu'à frotter la place avec de l'érithace mêlée de mélisse. Les rayons sont un composé de cire, à plusieurs compartiments, dont chaeun a autant dc côtés que la nature a donné de pattes à l'abeille, c'est-à-dire six. seditiones. Et, ut quidam dicunt, tria genera cum sint ducum in apibus, niger, ruber, varius, ut Menecrates scribit duo, niger, et varius : qui ita, melior; ut exjediat mel. lario, cunı duo sint eaden alvo, interficere nigjum, quem scit cum altero rege esse seditiosum, et corrumpere alrum, quod fuget, aut cum multitudine figetur. De reliquis apibus optima est parva, raria, rotunda. Fur, qui vocatur ab aliis fucus, ater est, lato ventıe. Vespae qua sinilitudinem habet apis, neque socia est operis, et nocere solet morsu, quam apes a se secernunt. Ex differunt inter se, quae ferae el cicures sunt. Nunc feras dico, (рих in silvestriluus locis pascitant; cicures, qure in cultis. Silvestres minores sunt magnitudine et pilosie, sed opifices magis. In emendo entorem videre oportet, va. lesut an sint atgrae. Sanitatis signa, si sunt frequentes in cxamiue, et sin iticke ; et si opus, quod faciunt, est axquabile ac leve. Minus valeutium signa, si sunt pilosne et lorridle, aut pulvernlenta, nisi opilicii eas urget teınpus. Tum eniın propter laboren asperautur, ac macescunt. Si transferen. diat sunt alvi in alium loem , il facere diligenter oportet, 't tempora, quibus il potissimum fiacias, animadvertendunn; et loca, quo trausferas, illonea providenduns. Tem. pera, ut verno potius quan liberno, yuorl hieme diflievilter consuescunt, guo sunt translatie, manere : itarque fu. giunt plerumque. Si e bono loco transluleris eo, ubi idonea pabulatio non est, fugitiva fiunt. Nec si ex alvo in alvum in eodem loco trajicias, negligenter faciendum. Sed et alvus, in quam transiturae sunt apes, apiastro perfricanda, quod illicium hoc illis : èt favi melliti intus ponendi, a faucibus non longe, ne cum animadverterint, ant inopiam escie liabuisse dicantur, aut cum sunt apes morbide propter primores vernos pastus, qui ex floribus nucis grace et cornu fiunt. Coliacas fieri, atque urina pota refici. De his propolim vocant, e quo faciunt ad foramen introitus protectum in alvum maxime rstate. Quam remı etiam ıomine eodem nediçi utuntur in emplastris. Propter quam rem etiam carius in Sacra via, yuan mel venit. Erithacen vocant, quo favos extremos inter se couglutinant, quod est alind melle, propoli : itaque in hoc vin esso illiciendi. Quo circa examen ubi volunt considere, eum ranum alianıve quam rem oblinunt hoc, admixto apiastro. lavus est, quem fingunt inulticavatum e cera, cum siıgula cava sena latera lıabeant, quot singulis pedes dedit uatura. Neque quae affermutur ad quatuor res faciendas, propolim, erituacen, favum, mel, ex iisdem omnibus rebus carpere dicuntur. Simplex ministerium, quod t malo punico of asparago (ilunn carpaut solum, ex olea arloro ceram, e fico mel, sed non lonum. Duplex ministerium 
Ce n'est pas indistinctement de toutes plantes que les abeilles recueillent de quoi eomposer ces quatre diffërentes substances, propọlis, érithace, rayon et miel. Telle ne fournit, comme la grenade et l'asperge, que la nourriture ; ou, comme l'olivier, qque la cire; ou, comme le figuier, que du miel, le. quel est assez médiocre. Telle autre, comme les fèves, la mélisse, la courge et le ehou, contiennent deux éléments, nourriture et cire; ou, comme le pommier et le poirier sauvages, miel et nourriture ; ou, comme le pavot, eire et miel. D'autres enfin réunissent les trois principes élémentaires, de la eire, du miel et de la nourriture, comme l'amandier et le chou sauvage. Il y a aussi un grand nombre de fleurs sur lesquelles elles recueillent tantôt une seule, tantôt plusieurs de ees substances. On doit établir une distinction entrc les plantes dont elles font un miel liquide, comme la bruyère, et celles dont elles font un miel épais, comme le romarin. Le miel du figuier est insipide; le miel du cytisc vaut mieux ; mais le meilleur de tous provient du thym. Comme elles ne se désaltèrent que dans l'eau la plus pure, il faut qu'elles trouvent dans le voisinage de leurs ruches un petit eourant ou un réservoir, où l'eau n'ait pas plus de deux ou trois doigts de profondeur. On y jettera de petits cailloux oudes briques, formant au-dessus del'eau des points où les abeilles puissent se poser pour boire. On doit veiller avec soin à ce que l'eau soit toujours très-claire, ce qui influe singulièrement sur la qualité du miel. Comme l'essaim ne peut sortir partous lestemps pour butiner, il faut qu'il trouve dans ce cas la nourriture tout à portée, de peur que, réduites à ne vivre que de leur miel, lcs abeilles ne mettent à sec la ruche. A cet effet on fait bouillir dans six congii d'eau dix livres de figues; et de la pâte qui cn résulte on pétrit des es-

praberi, ut e falı, apiastro, cucurbita, bıassica, ceram et cibuın. Nec uon aliter duplex, quod fit e malo et piris silvestribus, (ibum et mel. Item aliter duplex, quod e papavere, ceram et mel. Triplex ministerium quoque fierl, uti ex nuce grzeca, et e lapsana, cibum; mel, ceram. Iten ex aliis floribus ita carpere, ut alia ad singulas res sunant, alia ad plures. Nec non etiam alind discrimen se. quuntur in carptura, (aut eas scquatur,) ut in melle quod ex alia re faciunt liquidum mel, ut ex siseræ flore : ex alia coutra, spissum, ut e rore marino. Sic ex alia re, ut c lico mel insuave, e cytiso bonum, e thymo optinum. Cibi pars, quod potio, et ea is aqua liquida; unde bibant, esse oportet, eamque propinquam, quæ præterfluat, aut in aliquem locum inlluat, ita ut ne altitudine ascendat duo aut tres digitos : in qua aqua jaceant testæe aut lapilli, ita ut extent paulum, ubi assidere et bibere possint. In qua diligenter lıabenda cura, ut aqua sit pura, quod ad mellificium bonum vehementer prodest. Quod non omnis tempestas ad pastum prodire longius patitur, praparandus lis cibus, ne tum melle cogantur solo vivere, ant relinquere exinanitas alvos. Igitur ficorum pin- pèces de gâteaux qu'on place auprès des ruches. Certaines personnes y mettent aussi de petits vases remplis d'eau emmiellée, sur ehacun desquels surnage un moreeau de laine de la plus grande propreté : par ce moyen les abcilles peu vent en quelque sorte sucer l'eau, et ne risquent ni d'en trop boire, ni de se noyer. Il doit $y$ avoir un vase pour ehaque ruehe, et on les remplit à mesure qu'ils se vident. D'autres broient dans un mortier des raisins sees et des figues, et versent du vin réduit aux deux tiers par la cuisson. Du résidu ils font ensuite de petits pâtés qu'ils jettent non loin des ruehes, dc façon à ce que les abeilles les trouvent sur leur passagc dans leurs exeursions au dehors. Quand unc émigration se prépare (cc qui arrive quand un grand nombre de naissances étant venues à bien, les anciennes de la ruche vculent cnvoyer la génération nouvelle en colonic, ainsi quo les Sabins par l'aeeroissement de leur population furent souvent obligés de lc faire), eette résolution s'annonce par deux signes précurseurs. D'abord, quelques jours avant, on voit surtout le soir, près de l'ouverturc de la ruehe, des groupes d'abeilles acerochées les unes aux autres par pelotons, et formant comme autant de grappes; ol: biell eneore, sur le point de s'envoler, ct quand a déjà eommeneé le mouvement de retraite, eiles fontentendre une rumeur extraordinaire, eomme d'unearmée qui lève le eamp. Les plus promptes voltigent autour de la ruche, attendant que les autres, qui ne se sont pas encore rassemblees, les rejoignent. Quand le mellarius aperçoit cesymptôme, il n'a qu'à jeter sur les abeilles de la poussière, et à frapper en même temps sur quelque instrument de euivre, pour répandre l'effroi parmi elles. Il pourra ensuite les conduire où bon lui semblera, en ayant soin de placer aux licux de leur destination nouvelle une branche

gnium circiter decem pondo decoquunt in aqna congiis sex, quas coactas in offas prope apponunt. Alii aquam mulsam in vasculis prope ut sit curant; in qua addunt lanam perpuram, per quam sugant : uno tempore ne potı nimium impleantur, aut ne incidant in aquam. Singula vasa ponunt ad alvos singulas, et liac supplentur. Alii uvam passam, et ficum, cum pinserunt, affundunt sapam, atguic ex co factas offas apponunt ibi, quo foras (lieme) in pabulum procedere tamen possint. Cum exa. men exiturum est, quod fieri solet cum adnatæ prospere sunt multæ, ac progeniem veteres emittcrc volunt fn coloniam, ut olim crebro Sabini factitaverunt propter multitudinem liberorum; lujus quod duo solent proire signa scitur. Unum, quod superioribus diebus, maxime vespertinis, multa ante foramen ut uva alia ex aliis pen. dent conglobatx. Alterum, quod cun jam evolaturæ sumt, ant etiam inceperunt, consonant vehementer, proinde ut milites faciunt, cun castra movent. Quæ primo tım exierunt, in conspectu volitant, reliquas qua nondum con. gregatie sunt respectantes, dum conveniant. Cum a mellatio id fecisse sunt animadversa, jaciundo in cas put 
d'arbre ou tout autre objet frotté d'érithace, de mélisse, et cnfin de tout ce qui attire les abeilles. Quand il a réussi à les arrêter, il y place une ruche frottéc intérieurement des mêmes subs. tances, et, entourant les abeilles d'une légrère fumigation, il les oblige à y entrer. Une fois qu'elle y a pris pied, la nouvelle colonic y fixe si bien sondomicile, qu'en vain l'on rapprocherait d'ellc la ruche qu'elle vient de quitter, c'est la nouvelle qu'elle préfère. Voilà tout ce que je crois avoir à dirc de l'éducation des abeilles. Passons au but principal de leur entretien, qui est le profit qu'on en retire. On enlève les rayons lorsque les ruches sont pleines. Les abeilles font elles-mêmes connaitre ce moment. On a lieu de présumer qu'il est venu lorsqu'on entend un bourdonnement dans les ruches, et qu'on voit les abeilles se trémousser cn entrant et cn sortant; ou bien encore lorsqu'en ôtant le couvercle, on voit les cellules couvertes comme d'une pellieule de micl, signe qu'elles sont eniièrement remplies. II y en a qui prétendent qu'en cnlevant le miel on doit cn laisser dans la ruche la dixième partie, et que si l'on enlève tout, les abeilles désertent. Quelques-uns même en laissent davantage. Il en est des abeilles comme des terres : on augmente le rapport d'un champ en le laissant sc reposer de tems à autre; on augmente celui des abeilles, et cn même temps on les attache davantage à leur ru. che, en y laissant la totalité ou du moins la plus grande partie du miel. On enlève les ray ons pour la première fois au lever des Pléiades; pour la seconde fois, à la fin de l'été, avant que l'A reture soit entièrement levée; et pour la troisième, après le coucher des Pléiades. A cette dernière épo. que on ne doit jamais ôtcr plus du tier's du miel,

verenı et circumtinnicndo æere perterritas quo voluerit perducet. Non longe inde ramum vel quid aliud oblinunt erithace atque apiastro, cxeterisque rebus, quibus delectantur. Ubi consederunt, afferunt alvum prope eistem illiciis illitam intus : et prope apposita, fumo leni ciremm. cundo cogunt eas intrare : ut quxe in novam coloniam cum introierunt, permancut adeo libenter, ut etiam si proximan posueris illam alvum, unde exicrunt, tamen novo domicilio potius sint contentx. Quod ad pastiones pertinere sum ratus, quoniam dixi, uunc jam, cujus causa adlibetur ea cura, de fructu dicam. Eximendorum favorum signum sumunt $\mathrm{cx}$ ipsis, cum plenas alvos habent, et cum illos geminaverint. Ex apibus conjecturam capiunt, si intus faciunt bombum, et cum intro eunt ac foras, trcpidant, et si opercula alvi cum favorum foramina rcmoveris, obducta videntur (mellis) membrauis, quouiam tunc sunt repleti melle. In eximendo quidam dicunt oportere novem partes tollere, decimam relinquere. Quod si omne eximas, fore ut discedant. Alii lıc plus relinquunt, quam dixi. Ut in aratis, qui faciunt non restibiles segetes, plus tollunt frumenti ex intervallis : sic in alvis, si non quotannis cximas, aut non quoque multum, et magis (liis) assiduas habeas apes, et mragis fructuoses. Eximendorum favoruın prinsum putant esse tcmpus vergiliarum exortu, quand même la ruche serait pleine; les deux autres tiers y resteront comme provision d hiver. Quand la ruche n'est que médiocrement fournie, la levćc du miel ne doit se faire ni d'un seul coup, ni cn présence des abeilles, afin de ne pas les décourager. Si dans les rayons qu'on enlève il se trouve une portion qui soit vide de miel, ou tant soit peu endommagée, il faudra la retrancher avec le couteau. II faut veiller avec soin à ce que parmi les abeilles les plus fortes n'oppriment les plus faibles, ce qui amènerait une diminution notable dans le rapport des ruches. On choisit en consćquence les moins vigoureuses, pour les soumettre à un autre roi. Lorsqu'on s'apercoit qu'elles se battent souvent entre elles, il faut les asperger avec de l'eau mêlée de miel : Aussitót tout cesse, et les combattants se pressent les uns contre les autres pour sucer le li. quide. L'effet de ce moyen est encore plus sensible quand, au lieu d'eau, c'est du vin mêlé de miel que vous répandez sur les abeilles. Attirées alors par l'odeur du vin, elles se recherchent avec plus d'empressement, et s'enivrent en le sucant. Quand les abeilles se montrent paressellses à sortir, et restent dans les ruches en trop grand nombre, il faut avoir recours aux fumigations, et placer dans leur voisinage quelques herbes odoriférantes, surtout de la mélisse et du thym. Les plus grands soins sont indispensables pour les cmpêcher de périr de l'excès du fioid ou de la chaleur. Lorsqu'en butinant elles vicnnent à être surprises par une averse ou par un froid subit, ce qui est rare toutefois, et qu'abattues par les grosses gouttes d'cau, elles sont jetées à terre privées de force et de mouvement, il faut les ramasser, et les mettre, dans un vase qu'on

sccundum astate acta, ante quam tolus exoriatur arctu. rus. Tertium post vergiliarum occasum, et ita si foccunda sit alvus, ut ne plus tertia pars eximatur mellis, reliquum liemationi relinquatur. Si vero alvus non sit fertilis, ubi quid eximatur, exentio cum est major', neque universam, neque palam facere oportet, ne deficiant animum. Favi qui eximuntur, siqua pars nilhil habet, aut habet inquinatum, cultello prusecatur. Providendum ne iufirmiores a valentioribus opprimantur. Eo enin minuitur fructus. Itaque imbecilliores secretas subjiciunt sul) alte. rum regem. Quxe crebrius inter se pugnabunt, aspergi eas oportet aqua mulsa ; quo facto non nodo desistunt pugua, sed etian conferciunt se lingentes, eo magis, si mulso sunt asporsie, quo propter odorem avidius applicant se, atque obstupcscunt potantes. Si ex alvo minus frequentes cvadunt, ac subsidit aliqua pars, suffumigandum, et prope apponendum aliquid bene olentium lıelsarun, maxime apiastrum et tliymum. Providendum veliementer ne propter sestum, aut propter frigus dispereant. Si quando subito imbri in pastu sunt oppressa, aut frigore subito, ante quam ips $x$ providerint id fore, (quod accidit raro, ut decipiantur) et imbris guttis uberibus oflensm jacent prostratx et aflict $x$, colligendum eas in vas aliquod, ct reponcndum in tecto loco, ac tepido. P'romenduil 
plaeera dans un lieu couvert où règne une chaleur douee, et les y tenir jusqu'a ce que le temps soit bien assuré. On répand alors sur elles de la cendre de bois de figuier, ehaude plutôt yue tiède; puis on seeoue légèrement le vase, sans toucher les abeilles, et on l'expose au soleil. J.orsqu'elles sentent la chaleur, elles se remettent et reprennent vie, comme des mouehes qui ont été submergées. Il faut leur appliquer ce traitement non loin des ruehes, pour qu'elles puissent y retourner dès qu'elles seront revenues ì elles, et repreudre leur ouviage avec une foree nouvelle.

XVII. Nous voyons alors revenir Pavo. Si vous voulez lever l'anere, dit-il, on procède en ee moment au serutin; et le prceco (erieur) a déjà commencé à proclamer l'édile nommé par chaque tribu. Aussitót Appius se lève pour aller féliciter son eandidat sur le lieu même, ct s'en retourner ensuite dans ses jardins. Mérula s'adressant alors à Axius : A un autre jour, dit-il, le troisième aete de la basse-eour. Tous se levèrent, et je restai seul avec Axius. Nous nous regardâmes un instant en silenee, comme pour nous dire : Notre candidat à nous viendra bien lui-ınême nous trouver. Enfin Axius me dit: Le départ de Mérula ne me fait pas autrement faute; ear le reste du sujet ne m'est rien moins qu'étranger. On distingue deux espèees de viviers, les viviers d'eau douce, et ceux d'eau salcee. Les premiers, formant chez les gens du peuple et dans les fermes ordinaires une industrie assez luerative, ne sont alimentés que par l'eau qu'y fournissent les nymphes. Les viviers d'eau salée, au contraire, sont créés par les nobles pour le faste plus que pour l'utilité. C'est Neptune qui y apporte de l'eau et des poissons.

deinde quam maxime tempestate hona, et cinere facto e ficnlneis lignis infriandum paulo plus caldo quan tepidiore; deinde concutiendum leviler ipsas vase, ut manu nou tangas, et ponendum in sole. Quæ enim sic concalue. ruut, restituunt se, ac reviviscunt, ut solet similiter fieri iu muscis aqua necatis. Ifoc facinndum secundum alvos, ut reconciliatre ad suum quxque opus et domicilium redeant.

XVIf. Interea redit ad nos Pavo: Et, si vultis, inquit, ancoras tollere, latis tabulis sortitio fit tribuum, ac copti sint a præcone renuntiari, quem quaque tribus fecerint adilem. Appius confestim surgit, ut ibidem candidato suo gratularetur, ac discederet in liortos. Merula : Tertium aclum de pastionibus villaticis postea, inquit, tibi reddam, Axi. Consurgentilus illis, Axius mili, respectantibus nobis, quod et candidatum nostrum venturum sciebamus, Non laboro, iıquit, lıc loco discessisse Merulam. Reliqua enim fere mili sunt nota. Quod cum piscinarum genera sint duo, dulcium et salsarum : alterum apud plebem, et et [non] sine fructu, ubi lymphæ aqquam piscinis nostris villaticis ministrant, illa aulem maritima piscina nobilium, quilous Neptunus ut aquam sic et pisces ministrat, magris ad oculos pertinent quan ad vesicam, el potius narsupinu donnini eximaniuut quam implent. P'rimum
Ils contribuent à vider la bourse du maltre plutôt qu'à la remplir. On les construit à grands frais . ct c'est à grands frais qu'on les peuple et qu'on les entretient. Hirtius retirait douze mille sesterces des bátiments dépendant de ses viviers; mais lo seul entretien de ses poissons engloutissait tout le profit. Et rien n'est moins surpreuant. Je me rappelle qu'un jour il prêta à César six mille murènes, à condition qu'elles lui seraient rendues au poids : e'est la quantité prodigieuse de ces poissons qui fit monter sa villa au prix de quatre millions de sesterees. On a bien raison d'appeler nos vivier's d'intérieur et de petites gens des viviers doux, et ceux des nobles, des viviers amers. Parmi nous autres, en effet, on se contente d'un seul vivier d'eau douce : et quel amateur de viviers maritimes n'en veut avoir plusieurs communiquant de l'un à l'autre, à l'imitation de Pausias et des peintres de son éeole, qui ont de grandes boîtes divisées en autant de cases qu'ils emploient de nuanees deeire? Nos nobles ont des viviers àcom. partiments, servant à parquer en quelque sorte les poissons par espèce; et jamais euisinier ne fera sommation à ceux-ei de comparaitre sur table : ils sont saerés, Varroll, plus saerés que ceux que vous vîtes en Lydie, pendant un saerifiee que vous faisiez près dela mer, s'attrouper sur le rivage au son de la flûte d'un Gree, et venir presque sur l'autel'sans que personne osât y toueher. C'est dans ce même pays que vous avez vu des íles danser en rond. Notre ami Hortensius, au temps où il possédait eneore à Bauli ces viviers qui lui avaient coûté si cher, envoyait (je le sais pour l'avoir vu de mes ycux dans les visites fréquentes que je lui ai faites à sa villa), envoyait acheter à Puteoli (Pouzzoles) le poisson qu'on ser-

enim a dilicantur magno, secundo implentur magno, tertio aluntur magno. Hirrius circum piscinus suas ex sedificiis duodena millia sextertia capiebat. Eam- omnem mercedem escis, quas dabat piscibus, consumebat. Non mirum. Uno tempore enim memini luuic Casari sex millia muranarum mutua dedisse in pondus, et propler piscium multitudinem quadragies sextertio villam venisse. Quare nostra piscina ac mediterranea plebeia recte dicitur dulcis, et illa amara. Quis enim nostrum non una contentus est lac piscina? quis contra maritimas non ex piscinis singulis plures conjunctas habet? [Pluris. ] Nam ut Pausias et creteri pictores ejusdem generis loculatas magnas liabent arculas, ubi discolores sint cerxe, sic li loculatas lıabent piscinas, ubi dispares disclusos liabeant pisces, quos, proinde ut sacri sint, ac sanctiores quam illi in Lydia, quos sacrificauti tibi, Varro, ad tibicinem græecum gregalim venisse dicebas ad extremum litus atque aram, quod eos capere auderet nemo, cum eodem tempore insulas Ludinorum ibi chorevusas vidisses, sic hos pisces nenı cocus in jus vocare audet. $Q$. Hor tensins familiaris noster cun piscinas haberet magna pecunia aclificalas ad Baulos, ita sxpe cum eo ad villam fui, ut illum sciam senuper in canam pisces P'uteulos millere emtum solitum. Neque 
vait sur sa table. Ét c'était peu qu'il s'interdît de manger du sien; il fall lait qu'il lui donnât à manger lui-même, montrant autant et plus de sollieitude pour l'appétit de ses surmulets que je n'en puis aroir pour eelui de mes ânes de Roséa. Et ce n'était pas certes à aussi peu de frais qu'il leur fournissait eau et pâture. Car à quoi se réduit l'entretion de mes ânes, qui sont d'un si beau produit? Un petit palefrenier, quelque peu d'orge et l'eau de mes sourees, voilà tout ee qu'il faut; tandisqu'Hortensius avait à son serviee une armée de pêeheu:s continuellement oeeupée à lui. fournir des masses de petits poissons, pour les repas des gros. lit quand la mer était grosse, et que tous les filets du monde u'auraient pas anıené un seul poisson, il fallait, pour remplaeer cette nourriture vivante, épuiser le marehé à la marée des salaisons qui sont la nourriture du peuple. Hortensius vous aurait laissé prendre tous les mulets de voiture de son éeurie, plutôt qu'un seul -mulet barbu de ses viviers. Et quels soins il donnait à ses poissons quand ils étaient malades! il n'en avait pas plus pour ses eselaves. 11 eût plutôt laissé un de ces derniers boire de l'eau froide en maladie, cu'un de ses chers poissons. Il faisait peu de cas des viviers de M. Lucullus, l'homme, disait-il, le plus indifférent au bien-être de ses poissons : clıez ce dernier, les pauvres bètes n’avaient point de bass-

satis erat eum non pasci piscinis, nisi cos ipse pasceret ultro; ac majorem curam sibi lıaberet, ne cjus esurirent mulli, quam ego halseo, ne mei in Rosea esuriaut asini. Et quiden utraque re, et cibo et potione, cum uon paulo sumptuosius, quam ego his, uninistıaret victum. Ego cullu uno servulo, ordeo non multo, aqua domestica, mens multinumos alo asinos : llortensius primum qui ministrarent piscatores labebat complures, et ii pisciculos unimutos aggerelant frequenter, ut a majorihus absumerentur. Proterea salsamenta in eas piscinas emtitia conjiciehat, cum mare turbaret, uti per tempestatem suis piscibus e macello celariorum, nti e mari, obsonium proheret, cum neque everriculo illi in litus educere possent vivam saginam, plebeix con $x$ pisces. Celerins volnutate Iortensii ex equili educeres rhedarios, ut tili laberes, untos, quan e piscina barbatum mulkum. Atque illi non minor cura (ejus) erat de agrutis piscilus, quam de ıniuns valentibus servis. Itaque minus laboralat, ne servus arger, quan apuan lrigidam libserent sni pisces. Etenim laa; incuria laborare aiebat M. Lucullum, et piscinas ejus sins d'été; leur eau u’était pas renouvelée; on les y laissait eroupir. Parlez-moi de L. Lucullus, qui avait fait ouvrir une montagne près de Naples, dans le seul but d'introduire dans ses viviers l'eau de la mer, que ehaque marée y apportait et remportait. Pour les poissons c'était un autre Neptune. Il avait ménagé à ses ehers nourrissons un plus frais séjour pour l'été, imitant en cela la soblicitude des pasteurs apuliens, qui, au temps des grandes chaleurs, conduisent leurs troupeaux sur les montagnes du pays sabin. Sa passion pour ses viviers de Baies était portée à ee point, qu’il avaitdonné earte blanehe à son arehitecte pour la construction d'un eanal souterrain, communiquant de ses viviers avec la mer, afin que la marée, au moyen d'une écluse, pût deux fois par jour, depuis le premier quartier jusqu'à la nouvelle lune, y entrer et en ressortir après les avoir rafraîchis. Pendant que nous parlions ainsi, un bruit de pas se fait entendre à notre droite, et nous voyons entrer notre candidat avee les insignes de sa nouvelle dignité. Nous allons au-devant de lui; et après l'avoir félicité, nous l'escortons au Capitole. Puls nous nous séparons, pour rentrer clıacuı. cliez nous. Voilà, mon cher Pinnius, le résumé suecinct des conversations que nous avons eles sur l'entretien de la basse-cour.

despiciebat, quod astivaria idonea non haberet, ac residem aquuam, et locis pestilentibus lıabitarent pisces ejus. Contra ad Neapolin L. Lucullus posteaquam perfodisset montem, ac maritima flumina immisisset in piscinas, qua reciproce fluerent, ipsi Nepfuno non cedere de piscatu. Factum esse enim, ut amatos pisces suos videatur propter aestus eduxisse in loca fiigidiora, ut Appuli solent pecuarii facere, quod propter calores in montes Salinos pecus ducunt. In Baiano autem tanta ardebat cura, ut arclitecto permiserit, vel ut suam pecuniam consumeret, dunımodo perduceret specus e piscinis in mare, objectaculo quo aestus bis quolidie ab exorta luua ad proximam novam introire, ac redire rursus in mare posset, ac refrigerare piscinas. Nos lıec. At strepitns a dextra, et cum lata candidatus noster designatus aedilis se in villam. Cui nos occidimns et gratulati in Capitolium prosequimur. Ille iude eundo suain domuu, nos nostram. O Pinni nos. ter, sermonem de pastione villatica sunumatim lunc, quem exposin, luabeto. 


\section{SUR L'AGRICULTURE DE VARRON.}

\section{LIVRE I.}

11. Pruterquam ad necessarium sacrificium. Allu. sion au sacrifice de trois cents chères qu'oul offrait à Jiane une fois par an, à Atlıènes, d'après le vau de Miltiade. Alien, V. H., 11, 25.

Jubet terram tangere, despuere. Les anciens ne prononçaient jamais le nom de Tellus sans toucher la terre; ou celui de Jupiter, sans lever les yeux vers le cicl. Pour détruire les charmes, ils cracliaient trois fois, et se frottaient le front de la salive (Ter cane, tu dictis despue carminibus. Tibulle.) Cetle coutume de cracher parait avoir été également en usage dans la médecine nagique.

Quemadmodum placentam facere oporteat, etc... Pour la préparation de la placenta, dı libum et des jambons, voir l'Économie rurale de Caton, clı. LXXıv, LXXF. et cLxII.

Vil. De forma cullura. Qu'est-ce que la culture de la forme? On aura beau lire, avec Ursinus: De culturce for'ma; il sera toujours difficile de rattaclier cette pensée à celle qui précède. Nous regardons ces mots comme l'addition d'un copiste qui aura voulu éclaircir une plırase dẻjà sıffisamment claire par elle-même, et n'a fait que l'obs. curcir.

Itaque Creta ad Cortyniam dicitur platanus esse. Pline, XI1, rapporte le même fait, et se moque à ce sujet de la crédulité des Grecs, qui s'imaginaient que c'était sous cet arbre que Jupiter s'était uni d̀ Europe.

Item Sybari, quce nunc Thuris. Pline dit à ce sujet que leclıçne dont il est ici fait mention, n'entrant en pousse ỵu'au milieu de l'été, gardait par conséquent ses feuilles plus longtemps que les autres, et que c'était là tout le iniracle.

Candida fossicia creta..... Scheider remarque avec raison quil ne s'agit 'pas ici de la craie qui s'emploie comme couleur ainsi que le dit à tort Sab. de la Bonneterie, mais bien de celte matière fossile que les Gaulois applaient marga, et qui, sous le nom de marne s'emploie encore fréquemmeut en France en place de fumier.

Carbonibus salsis, etc.... Ce sont, suivant Pline, des clıarbons de clıêne qu'on éteignait en jetant dessus de l'eau salée.

Ex quo antiqui prata parata appellarunt. Les anciens Ronıains accordaient aux prairies la préférence sur toıite autre culture; et le nom qu'ils leur avaient donné signifiait qu'clles étaient toujours prètes à rapporter, sans exiger des travaux préparaloires.

VIII. In har passage en disant que les branches des figuiers avaient besoiñ d'être liées ensemble par des roseaux, pour leur donner plus de consistance. Celte explication, quadopte également Saboureux de la Bonneterie, est désappronvée par Sclıneider, qui propose de lire : arundinatio. Le passage qu'il cite a l appui de cette leçon : Torta per obliquos it vitis in orbe corymbos, Verberat et palma calamos fuitante flagello: Vinea pamipineos subarun. dinat ebria campos, nous fait penser qu'harundulatio a ici la signification d'arundinatio, et que l'un est mis a Ia place de l'autre.

Acratophoros, espèce de vase dont parle égalemcit Cicéron, de Finibus, III, 4.

$\mathrm{X} . \mathrm{Id}$ habet scripula ccLxxxvi quantum as antiquus noster ante bellum punicum. L'as romain contenait, avant la première guerre punique, deux cent quatre-vingtluuit scripula, altendu qu'il pesait une livre ou douze onces, et quue chaque once était de 24 scripula.

XIII. Fundauius fructuosior, etc. Valère Maxime, vIı, 1,7 , raconte à ce sujet que M. Émilius Porcina s'altira l'indignation da peuple romain, et fut mème mis en accusa. tion pour avoir fait construire dans ses domaines une villa trop somptueuse. Ce fait remonte à l'an 616 de la fondation de Rome.

XIV. Primum naturale sepimentum vivae sepis, quod obseri solet virgultis aut spinis, quod habet radices, ac viatoris... Allusion àla coutume qu'avaient les Romaius de porter des llambeaux allumés dans leurs voyages, ou leurs promenades nocturnes.

Ad viam Salariam in agro Crustumino. C'est cette même voie dont parle Cicéron, De natura deor., 111, 5, et qui conduisait de la porte Colline au pays sabin.

Quod ex terra et lapillis compositis in formis, al in Hispania... Ces espèces de clotures sont aujourd'hui en. core en usage dans plusieurs parties de la France, où elles sont connues sous le nom de pisé. Goiffon, dans son traité de l'Art du maçon piseur, entre dans de grands détails sur ce mode de cloture.

XVII. Alii in tres partes instrumentigenus: vocale, in quo sunt servi, semivocale in quo sunt boves, mutumin quo sunt plaustra. Celto assimilation de l'esclave a l'instrunient passif et inerte, cette gradation de la close à la bête et de la bête à l'être lummain, qui ne consiste que dans la voix, ou dans la voix plus ou moins articulée, est l'expression la plus naïve de l'excès d'insensibilité où l'an. tiquité était tombée à l'égard de toute une classe d'hommes qui ne devait originairement cette condition qu'au mal. lseur d'être vaincus.

Iique quos oborarios nostri vocitarunt. Nous avons traduit obcerarios par l'expression engagés d forfait. Cette interprétation ne s'éloigne pas de la racine, et s'accorde mieux qu'endetté ou obéré avec le sens général du pas. sage, où il est fait distinction des diverses conditions de salaire. Nous n'ignorons pas cependant que Varron, dans ses Origines, en général fort douteuses, mais qui pourraient avoir raison sur ce point, dit que le mot obcerarii exprime le contrat par lequel le débiteur s'acquitte, en louant son travail pour un temps donné.

XVIII. Cato dirigit ad duas metas.... (Voir le traité d'agriculture de Caton, cl. $\mathbf{x} \mathrm{ct} \mathbf{x l}$ ).

opilo. Scaliger fait venir le mot opilo du grec aimó.

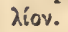

XXI. Clousas dormire... Ce passage paraît appartenir au livre II ; sans doute l'ordre des chapitres aura été interverti par quclque copiste peu intelligent. 
XXVY. Propter eas adserumt.... Nous avons cru levoir, avec Pontedera, clanger dans la traduction eas en olus, leçon qui se troure d'ailleurs justifiée par le passage du clıp. 16, où nons lisons : Ut vitis adsit ad olus favere solet. Scaliger, qui défend ens, a tort de croire qu'il y avait antipatlie entre la vigne et le cyprès.

XXIX. Dicitur porca quod ea, seges frumentum por. ricit. Varron se nıontre prodigue, et n'est pas toujours lieureux en étymologies. Il suffit des nombreuses contradictions où il tombe à cet égard pour prourer combien ses cunjectures sont lıasardées. Ainsi, par exemple, le mot messis, dit-il dans un endroit, ne s'entend proprement que des clioses qui se moissonnent (quae metuntur); et plus bas, en parlant des différentes manières de moisson. ner, il fait dériver le même mot de medius, parce que, en coupant le blé, on le tenait par le nilieu.

XXXI. Quod ita occidunt, occare dicunt. Antre preu ve de la manie de Varron pour les étynıologies. En effêt, comme l'acte qu'exprime le mot occare implique l'idée de destrnction, notre auteur n'a point hésité à faire dériver ce mot de occidere, détruire; bien qu'il soit prouvé que occatio a pour racine le verbe oeccecare. Ici Pon pent ojpposer à Yarron l'autorité de Cicéron lui-mème (de Senectute, cap. 15).

XL. Ut sint obscura. Yoici ce que dit Pline, $x$ ru, 14 , de la semence du cyprès: Minimis id granis constat, ut vix perspici qucedam possint; non omiltendo naturce miraculo etian parvo gigni arbores. Un na. turaliste morlerne a fait renarquer qu'il y avait quelque exagération dans ce que disent les ancieus de l'exiguité des semences du cyprès.

Quas alii clavolas, alii taleas appetlant. Thicopliraste appelle en effet la cime d'un arbre $\tau x)$ si $x$. De ce mot les Latins ont fait talca.

Hoc sequuntur mutti... Voici ce que Pline dit, 15, 17 , à ce même sujet : " Au reste, la religion ne permet pas qu'on greffe les arbres iuliffirenment les uns sur les autres; elle défend d'enter sur l'épine . larce qu'il serait difficile d'en détourner la fondre.

Ex arbore, e qua quis vult habere surculum, in eam, quam inserere vutt, ramutum traducit, et in ejus ramo praciso ac difisso impticat. Ce passage est presque impossible à construire grammaticalement, à moins d'adinettre arec Pontedera que l'ordre primitif des mots a été entièrement interverti par les copistes; de sorle qu'il faudrait construire la plirase de la manière suivante: Traducit tum ramutum ex utraque parte, qua fissuram intrat, falce extenuatum in ejus ramo praciso ac difisso implicat, qui contingit ita, ut ex una parte, qua coltum visurus est, etc. Columelle parle du même procédé, $\mathbf{v}, 11$; Pline en fait aussi mentiou au lirre $x \mathbf{s} u, 30$.

XLI. In crescendo tarda, in hoc enim humidiora quam aridiora. A quoi faire rapporter in hoc? Les commentateurs s'épuisent en vaines conjectures. Gessner aroue franchementque ces paroles sont des plus obscnres; mais il ajoute que cette raison ne lui arait pas paru suffisante pour les effacer.

XLIV. Seruntur faba modii $I V$ in jugero, tritici $\boldsymbol{v}$, ordei $V I$, etc.... On troure dans les auteurs des notions très-curieuses sur la fertilitẻ de certains sols dans les temps anciens. Ce que dit Varron sur celle des-en. virons de Sybaris et de Bysacium est confirmé sur tous les points par Pline, qui s'étend plus longuement sur ce sujet. D'après cet auteur, on y recueillait dans cette dernière localite jusqu'd cent cinquante fois la semence; le même auteur ajonte, xriI, 10, que le gourerncur de ce pays envoya à Auguste près de quatre cents tiges produites par uu senl grain. On envoya également une toufto de trois cent quarante tiges à Néron.

XLV. Ere frigore cinguntur, etc. Entre les différentes leçons, qui portent les unes tinguntur, les autıes tanguntur, et d'autres encore stringuntur, ou restrin. guntur, nous a vons cru devoir nous décider pour cingun. tur, à cause du passage de Tlı́oplıraste dont cette plirase

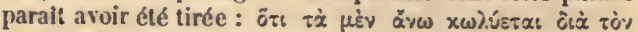

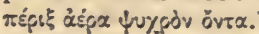

Nisi quo tepor venit solis. Cette leçon, que nous avons rétablie dans le texte arec Schneider, est parfaite. ment justifiee par ce passage de Pline, xv $t, 56$ : Quida non altius descendere radices, quam solis calor tepe. faciat.

XLVIII. Ea que nutilata non est, in ordeo et tritico. Ce passage rappelle celui de Cickron, De seneclute, 15: Quce nixa fibris stirpium sensim adote. scit, culmoque erecta genicutato vaginis jam quasi pubescens includitur; e quibus quum emerserit, fundit, etc.

L. Batillum. L'usage du batillum résulte clairement d'un passage de Pline, xvil, 72 : Galliarum latifundiis valli pragrandes dentibus in margine infestis ducibus rotis per segetem impelluntur, etc.... Sclineider pense? que le batillum n'est autre close que le vallum dont nous parle Pline, xvur, 72.

LV. Qui quatiet, ne adversum, etc... Pline dit, $\mathrm{xv}$, 3: Qui cautissime agunt, arundine levi ictu, nec adversos percutiunt ramos; sic quoque, etc....

Per serias ac vasa olearia et.... Qua res.... Cette phrase porte l'empreinte des différentes corrections telltées par les nombreux commentateurs. Nous nous bornerons à faire renarquer qu'en lisant per sena vasa aı lieu de perserias, et en faisant rapporter sena aux six pressoirs dont parle Varron, I, 22, on ferait disparaltre toufe difficulté.

LIX. Et que antea mustea vocabant, nunc melimela appetlant. Pline parle également de ces pommes dites mustea et melimela, xv, 15: Mustea a celeritate mitescendi, quia nunc melimela dicuntur a sapore melteo.

Mala cotonea, struthea in pensilibus junctis. Cette plırase a été certainement falsifiée. Il a été impossible de la lier avec ce qui précède, et de l'expliquer suffisamment.

LX. Pauseas aridas. Le mot aridas ne se trouve point dans le texte de Caton cité par Varron. Pline, qui rapporte le même texte, l'a retranclié également; Ponterlera le remplace par albas. Ce qu'il y a de certain, e'est que le mot albas est aussi déplacé que celui d'aridas, et qu'il serait peut-être plus raisonnable de lire virides.

LXI. Quod statim.... Tout ce chapitre est entaché d'incorrection, et nous sommes portés à croire qu'il ne formait qu'un avec celui qui précède; de sorte qu'il fatdrait peut-être rétablir le texte de cette manière : $\mathrm{Cum}$ est olea expressa, quod statim effluxerit de ea, qui est humor aquatilis ac retrimentum, conditum in vas fictileid quidem sic solent tueri, etc; ... tunc decoquunt in ahenis leni igni duas partes, et refrigerutum condunl in vasa; tum denique ad usum recte promitur. Sunt item alice conditiones.... mustum. Ce qui nous confirue encore dans cette conjecture, $c^{\prime} e s t$ le passage de Pline, $\mathbf{x v}, 4$ : Oliva condiuntur amurrca sapave....

LXIII. In sole ponere oportet aque catinos. Il est indispensable d'intercaler entre oportet et aquœe la particule atque, qui se troure d'ailleurs dans les ancienses sditions. 


\section{LIVRE II.}

Ivтnoductios. Itaque annum ita diviscrunl, ul no. nis modo diebus urbanas res usurparent, reliquis vi ut rura colerent. Tous les neuf jours, il y avait à Rome uII ınarclıé public appelé nundince. Comme les liabitants de la campagne s'y rendaient en foule, on profitait de ces jours pour faire passer des lois qui toutefois ne pouvaient etre publiées qu'après avoir été proposées ainsi pendant trois jours de marclı́s consécutifs, afin que les citoyens fussent à inême d'eu prendre connaissance.

Si non multis vocabulis retinneanl gracis. IIpoxoเ $\tau$ wैv b́ait la pièce qui précédait la clıımbre à concher, et dans

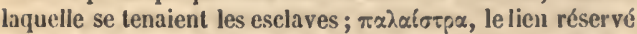

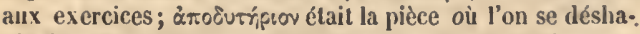
billait avant d'entrer aux bains; òpvoẅv était le nom

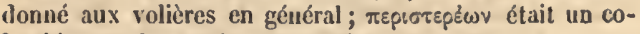

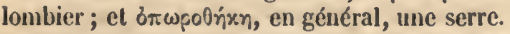

1. Cıım Menas discessisset.... Déjà Scaliger et Ursinus s'étaieut aperçus que ce commencement de clapitre ćtait tronqué, et qu'il devait nécessairement y avoir existé quelque autre préambule. C'est ce qui paralt surtout résulter du chapitre 8, où nous lisons : Vcnit a Mcnate libertus, qui dicat, liba absoluta esse; et puis du clıpitre 5, qui porte : Cum Q. Licienum alius salutasset, alius convicialus esset, qui lam sero venissel ad constitutum.

Cossinius. C'est sans doute L. Cossinius dont parle Cicéron in Orat. pro Balbo, c. 23 , ainsi que le fait obsorver Eruesti dans son index Ciceronianus.

Thales Milesius, l'un des sept sages de la Grece. Il fut le premier des philosophes qui s'occupa d'astrononie, el qui prédit une éclipse de solcil. Il mourut dans un age très-avancé, en assistant à un combat de lutteurs.

Zeno Cittius, chef de la secte des stoïciens, et tellement respecté à Athènes, que c'était chez lui qu'on déposait les clefs de la ville.

Diccarchus, chef d'une secte de philosophes qui portent son uon. Fils d'un simple commerçant, il voyagea pour s’instruire. Il mourut à Métaponte en Italic. La rénération qu'on avait pour lui était si grande, qu'on fit de sa maisou un temple, où on l'adora conme un dieu.

Latine rotas... Ce passage a donné lieu à de nombreuses conjectures. On se demandait avec raison comment les chèvres de la Samothrace pouvaient être appelées en latin rota. Ursinus et Scaliger ont proposé de lire platyccro. tas. Schneider aime mieux lire strepsiccrotas; c'est cette espèce de chevreuil qui a le bois droit et cannelé, et dont parle Pline, $\mathrm{xl}, 45$. Cette dernière variante nous parait mériter la préférence.

Qui ipsas pecudes propter carilatem aurcas ha. buisse pclles tradiderunt. La tradition d'un bélier d'or, conservé dans la famille des Pélopides comme une espece de palladiun de la royauté, se trouve rappelée dans le Thyeste de Sénèque. Le vol de ce bélier est l'un des prin. cipaux griefs articulés par Atrée contre son frère...

Quod nominaverunt a capris Egeum pelagus. Les chèvres s'appellent en grec aiүદৎ.

In Sabinis Canterium montem. Canterius est le nom que les Romains donnaient à un cheval hongre.

Quod Parilibus potissimum condidere urbem. Les Parilia étaient les fetes que les patres célébraient en l'lonncur de la déesse et du dieu Palès, le 11 des kalendes de mai.

Urvo urbis... Voici ce que nous dit Servius dans ses commentaires de Virgile : "Lorsque les anciens voulaient batir une ville, ils attelaient un taureau ct une raclıe à une charrue, en prenant le soin de mettre la rache du cóté de l'emplacenent de la ville. Puis, retroussant leur robe el s'en courrant la tête (ce qu'on appelait se ceindre à la manière des Sabins), ils conduisaient cette cliarrue, le inanche conrbé, dn cơté de l'emplacement de la ville, pour faire tomber les mottes de terre de ce cóté, et tră. çaient Im silion de toute la longucur des murs qu'ils devaient donner à la ville, en relevant le soc aux endroits testiués à l'euplacement des portes. Quant au mot zivum lui-meme, voici ce que nous dit Varron dans son trailé des Origines, iv, 32: Imburum ficlum ab urbo, quod ita flexum, ut redeat sursum vcrsus, ut in aratro quod cst urbum; puis plus loin: Bura a bubus; alii hoc a curvo urvum appellant.

Cum luslratur, suovitaurilibus... Les suovitauri. lia étaient le plus considérable sacrifice que l'on offrait au dieu Mars. Ce sacrifice se faisait pour la purification ou l'expiation des clamps, des fonds de terre, des armées, des villes. Les sucovitaurilia étaient distingués en grands et petits; les petits étaient ccux où l'on immolait de jeunes animaux, un jeune cochon, un agneau, un veau; les grauds étaient ceux qui se faisaient aver. les ménes auimaux adultes, verrat, bélier, et taureau. Avant les sacrifices on- promenait trois fois ces animaux autour de la chose impure. On immolait toujours le verrat le prenier, comme l'animal qui nuit le plus aux semences et aux moissons, et successivement le bélier et le taureau. Clıez. les Grees le meme sacrifice avait lieu en l'lonneur d'autres dieux; par exemple, de Neptune (voir Homère), ou d'Esculape (voir Pausanias).

Monte Tagro, quadam c vento certo temporc aoncipiunt cquae. Pline, $\mathrm{x}, 60$, nous dit : Quidam $e$ vento putant ea generari, qua de causa etiam zephyrica appcllantur. Servius, dans ses commentaires de Virgile, Géor., II, 278, fait également allusion à ce passage: Hoc ctiam Varro dicit: In Hispania ulteriore verno tempore cquas, nimio ardore commotas, contra rigidiores ventos ora palefacerc ad sedandum calo. rcm, et cas exinde concipere ct cdere pullos, licet ve. loces, dici tamen minimc duraturos; nam brevis ad. modum vitoe sunt.

Chordi. Pline, vu, 47 : Chordos vocabant antiqui post id tcmpus nalos.

II. Ventrcm quoque ut habeat pilosum. Itaque quce id non haberent, majores nostri apicas appellabaut, ac rejiciebant. Pline parle également de ces brebis apicá, et nous dit: quibus venter nudus esset, apicas appel. labant damnabantquc.

Item bince pro singulis ul procedant. Nous faisons remarquer avec Sclineider que le mot procedant a dans ce passage la signifieation de valeant, ducantur, numercntur; cette locution a été d'ailleurs parfaitement expliquée`dans Gronovius ad Livium, v, 48, p. 213, toin. 11.

Cum inter hac bina loca, ut jugum continet sir. piculos, sic calles publica dislantes pastioncs. Les calles étaient des cliemins réservés aux troupeaux dans les forêts qu'il fallait traverser, lorsqu'on les conduisait des pâturages d'été à ceux d'hiver. Sclıneider pense an contraire qu'il y avait dans les forêts, de distance en di:tance, des places entières qui étaient abandonnées aux troupeaux lorsqu'ils étaient conduits aux pâtarages d'luiver ou d'été, et que c'était la ce que l'on appelait calles pu. blica.

Ita pascere pecus oportet, ut averso sole agat. Voici ce que nous dit Columelle à ce mone sujet : Si quidem plurimum refert ut ne pascentium capita siut adice. su soli, qui plerumque nocet animalibus oriente pre. 
dicto sidere. Pline fait la même recommandation, run, 73 .

Quamdiu admissura fit, cadem uqua uti oportet, quot commutatio el tanam facit variam, el cortum. pil uterum. Les Géoponiques nous recominaudent éga-

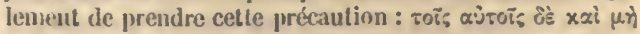

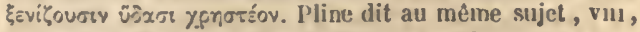
47 : Mutalio aquarm polusque variat lanicinium.

Deterreut ab saliendo fiscetlis e junco, atiare qua re yrod altigant ad naturam. La signification de fiscelta résulte suffisamment du passage de Caton, 5 , oủ il est dit : Il inuorte que les brenfs aient la bouclie garnie de petits paniers, pour qu'ils ne brouttent pas l'lierbe en lalourant. Boves fiscellas habere oportet, ne herbain sectentu, cum arabunt.

Dum agnoscant matres agni, et pabulo se satu. rent. Ici nous arons pris pour guide Crescentius, qui génératement nous a été d'une grande utilité pour l'in. telligence du texte de Varron. Cel auteur a écrit en latin un traité d'agriculture extrait en partie des agronomes romains, et cela à une époque où Varron était certes moins dénaturé par les commentateurs qu'il ne l'est atjourd'lui. Voici ce qu'il dit sur ce point : Cum parere incipiunt oves, pastores eas injiciunt in ea stabula, quce ad eam rem habent seclusa, ibique agnos, recenter natos, ad ignem apponunt, et per biduum retinent cum matribus, dum cognoscant matrem et pabulo se satu. rent.

Sed ea (ut dixi) in libro scripta magister pecoris habet. Varrou s'oublie en ce moment, ou plutót ne pense plus à ses interloculeurs; car cest Alticus qui jarle, et c'est Scrofa seul qui pouvait dire ut dixi.

III. O Faustule noster. Allusion au nom du patre qui avait nourri Romulus et Rémus pendant leur enfance. Mélanthius était le gardien des clıèvres d'Ulysse à Itliajue.

Nunquam enim sine febri sunt. Gessner raconte à ce propos le fait suivant : Un enfant né à Nimes pendant la peste de 1629 avait perdu sa nourrice à la suite de la contagion. Ellevé par une clière, il fut dìs son enfance ell proie à une espéce de fiève, qqui ne le quitta point le reste de ses jours.

Quod capras sanas sanus nemo promittit. Jeu de mots résultant de l'opposition du sens propre au sens figuré dans le mot sanus.

De quibus admirandum illud; quod eliam Ar. chelaüs scribit, non, ut reliqua animalia, navibus, sed auribus spirilum ducere. Cette absurde notion se trouve égalentent clıez Pline, liv. VIII : Auribus eas spiraie, non naribus. Aristote, en rapportant cette observation, la traite de fable.

IV. Sed quis e porculaloribus. L'origine que donne Tremellius de son surnon de Scrofa est bien différeute de celle rapportée par Macrobe : "Les esclaves d'u certain Tremellius avaient volé une truic à un de ses voisins, et l'avaient tuée. Celıi-ci, averti de ce rol, fit cerner la maison de Tremellius de façon que rien n'en pht sortir, et le somma de lui rendre la truie. Tremellius cache l'animal sons les couvertures du lit où reposait sa fenme, et permet ensuite au réclamant de faire toutes les per(juisitions qu'il roudra. On arrive au lit, et Tremellius afirme par serment qu'il n'a cliez lui d'autre truie que celle qui est couchéc là. Celte plaisanterie lui valut le surnom de Scrofa.

Nec me esse ab Eumceo orlum. Fuméc était le gardien des porcs d'Ulysse; Homère en fait l'éloge dans le te livre de l'Odyssce.
Qui qurestor cum esset Licinio Nerva... Tite-Live nous apprend que Licinius Nerva avait d'abord été envoys en Naućtvine pour faire l'inspection des troupes, et qu'il fut fail préteur l'an 587 de la fondation de Rome.

Itaque is animam datam esse proinde ac salem, qure servaret cai'nem. Les ancieus affectionnaient singulièrement cette idée, car ils l'ont souvent reproduite. Leur esprit philosophique se plaisait à matérialiser l'åme, en l'assimilant an sel qui rivilie. Cicéron, de Nat. Deot., 11, 61, en fait honneur à Clırysippe.

Pliue, vul, 77, nous dit aussi: Animalium hoc maxime brutum, animamque ei pro sale datam non illepide existimabatur.

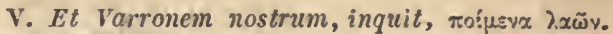
Allusion plaisamment familière à la qualification hoinérique des rois et des princes.

In quo quidem, inquit Vaccius, mea partes, quo. niam boves ibi et vacce. Jeu de mots sur l'analogie de vaccius et de vacca.

Ab hoc ( $a$ bove) antiqui manus ita abstineri voluerunt, ut capite sanxerint, si quis occidisset. Ovide fait dire à Pytlıagore, dans son livre contre l'usage de se nourrir de la chair de ces animaux :

Quid meruere boves, animal sine fraude dolisque, Innocuum, simplex, natum tolerare labores? Or., Mét., xr, 120.

Pline nous apprend également que le bouf qui cultivait la terre était telleınent respecté des anciens Romains, qu'il y cut un citoyen accusé el condanné pour aroir tıé un de ces animaux; ce crime égalant à leurs yeux celui dil meurtre d'un ln!jourcur. Le mème fait est rapporté par Valère Maxime, vul, 8.

Nam $a b$ hoc pecore Athenis Buzuges nobilitatus, Argis Onogyros.

Pline, v11, 57, prétend qu'il y eut un Atıénien du nom de Buzugès qui fut l'inventeur de la manière d'atteler des boufs à la charrue; d'antres auteurs pensent que $c$ ? noun n'est pas un nom propre, mais une épithète douncé à l'inventeur, et formée des deux mots ßoūs, bour, et

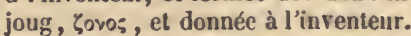

Quant à Onogyros, nous n'en trouvons trace dans aucun auteur ancien.

Non minus satisfaciam tibi quam qui Bugoniam scripsil. Ce qui résúlte des différents commeutaires de ce passage est que bugonia était une locution usitée pour exprimer ce qu'il y a de plus agréable. Scaliger, après avoir comparé an texte les explications de Turnèbe, ajoute assez plaisamment : Si quid voluerit Varro nescio; quid notuerit scio.

Ne gibberi, sed spina leviler remissa. Le mot gibberi ne se rapporte nullement à nares, comme le pense à tort Gessner, inais bien à spina, comme le fait observer Dicksoll.

Lanii qui ad cultrum bovem emunt, et qui ad altaria, hostice sanitatem non sotent stiputati. Cetle phrase parait être en contradiction avec tout ce que nous savous des sacrifices de l'autiquité, puisque les victimes qu'on immolait devaieut avaut tout être sans défauts. Gessner dit à ce sujet qu'un animal peut être exenpt do défau ts, sans être sain; de sorte qu'olı aurail pu immoler un bneuf affecté de la fière, pourvu qu'il ne fint ni borgue ni boiteux. Sclnneider, an contraire, fait observer que cette clause de la santé était retrancliée, par la senle raison que les prêtres eux-momes avaient coutume de s'assurer de l'état sanitaire des victimes, sans avoir besoin d'en demander des garanties au vendeur. 
Ifoc secundum astri exortum facio, quod Greci rocaut $\Lambda$ úpav, Fidem nostri. Cctte constellation se lève, d'après Pline, le jour des nones de janvier, l'lin., vıı, 26.

VI. Non enim si murcence optimce flutce sunt in Si. cilia, et ellops ad Rhodon, continuo hi pisces in omni mari similes nascuntur. Les nurance fluto sont ce qu'on appelle en grec $\pi \lambda \tilde{\omega} \tau \alpha_{1}$. Macrobe nous apprend que ces poissons étaient appelés flutoe, parce que, à force de flotter à la superficie des eaux, ils élaient en quelque sorte grillés par l'ardeur du soleil, au point que perdaut toute leur souplesse, ils ne pouvaient plus se plouger dans la mer, et qu'il était facile de les prendre à la main.

VII. Etas cognoscitur equorum, et fere omnium qui ungulas indivisas habent. Ce passage, relatif à l'age du clieval et aux moyeits de le recounaitre à ses dents, est très-obscur, et parait avoir subi de nombreuses altérations. Schneider a recours, pour l'expliquer, aux Géopoulques; et voici comment il rétablit le texte: Quinto anno incipiente, item eoden modo amittere binos (scilicet utrinque) tum quos caros habent renascenles, eis sexto anno impleri (incipiunt). Ce qui pa. rait du reste confirmer cette interprétation, c'est le $11^{\circ}$ livre de Pline, cl.. 64, où nous lisons : Amittit tricesinıo mense primores utrinque binos. Sequenti anno totidem proximos, cum subeunt dicticolumellares. Quinto anno incipiente, binos amittit, qui sexto anno renas. cuntur. Septimo anno omnes habet et renatos et im. mutabiles.

Corpore nulto. Ces deux mots paraissent avoir appartenı à une plirase entière, dont ils ont été délachés mal à propos. Dans l'isolement où nous les trouvons ici, uous avons pensé qu'il fallait les séparer du reste du texte en les mettaut entre parentlièses.

Cum menses ferunt, signifie littéralement : lors des pertes mensuelles. Déjà les Géoponiques avaient relevé cette erreur en substituant annuelles à mensuelles, ce qui est aussi plus conforme à l'histoire naturelle; car on jrétend que ce phénomène chez les juments ne se reproduit que tous les ans. Il paraît au surplus que cette locution, cum menses ferunt, ne doit poiut être prise dans le sens absolu que lui donnent les commentateurs, et que menses s'entend de toule perte périodique; comine le mot menstruation ne comporte pas précisément pour limite l'intervalle d'un mois.

Eademque causa ibi fronos suspendendum. Virgile dit aussi : Primus equi labor est stabuto frous audire sonantes. Oride s'est servi de la même expression : frana sonantia.

Quod quarto die feceris. II parait que le mot die, que nous trouvons dans le texte de Sclineider, est l'altération de decimo; de sorte que dans le principe on li. sait quarto decimo feceris, ce qui est d'ailleurs plus conforme au sens de la plirase.

VIII. Nam nuli et hinni bigeneri, alque insiticii, non suopte genere ab radicibus. Pline et Columelle nous parlent également de ces hinni. Le prenuier nous dit au livre vıu, chap. 44: Equo el asina genitos mares hinnos antiqui vocabant, contraque mulos quos asini et equce generarent. L'autre, vı, 37, s'exprime ainsi : Qui ex equo et asina concepti generantur, quamvis a patre nomen traxerint, quod hinni vocantur, matri per omnia magis similes sunt.

IX. Proverbium ut tollant antiquum : vel etiam $u t \mu \tilde{v}$ ov aperiant de Actoone, atque in dominum afferant dentes. Tous les commentateurs se sont mépris sur le seus de cette phrase, en supposant que Varron avait voulu faire allusion à l'ancien proverbe : tot servi; tot hostes, et par extension tol canes, tot hostes. Cette erreur les entraine à dénaturcr la signification véritable de tollant, et à la traduire par rappeler. Nous croyons, an contıaire, que Varron par le mot proverbium n'entend autre clıose que la fidélité proverbiale des cliens; et en laissant au mot tollant sa signitication de detruire, oter, nous sommes naturellement amenés à traduire pro. verbium tollere par dementir le proverbe. Quant à la fable d'Actéon, tout le monde sait qu'il a été dévoré de ses propres chiens.

Catuli diebus $\boldsymbol{X} \boldsymbol{X}$ videre incipiunt. Ce chiffre parait être contredit par l'expérience. Déjà Aristote a fait observer que le nombre de jours pendant lesquels ils sont privés de la vue déprend de l'époque de l'année où ils sont venus au monde. D'ailleurs Pline nous dit, vı11, 40, que plus la mère a de lait, plus la vue tarde à leur venir; de sorte cependant que ce n'est jamais après le $21^{\mathrm{e}}$ ui avant le $7^{e}$ jour de leur naissance.

X. In emtionibus dominum legitimum sex fere res perficiunt: si horeditatem justam adiit: si, ut debuit, nuancipio ab co accepit, a quo jure civili po. tuit: aut si in jure cessit, cui potuit cedere, et id ubi oportuit : aut si usu cepit..... La nuncipation de certains fonds privilégiés se faisait avec beaucoup) de solennité, et en présence de cinq témoins. Ce que les Romains appelaient cessio in jure était un mode d'ac. quisition bielı plus simple que la mancipation; il suffisait pour cet acte judiciaire de trois persomines; l'acquéreur, le propriétaire et le prêtenr. L'usucapion était l'acquisition du droit de propriété à titre de possession paisible; après un temps prescrit par les lois.

Ant si e proeda sub corona emit. Les esclaves se ven. daient cliez les Romains comme se vendent chez nous les animaux. Varron met les pâtres dans la classe des mulets et des chiens : on leur meltait une couroune sur la tète, comme nous attaclions de la paille à la croupo des clievaux qui sont à vendre.

XI. Non negarim, inquam, ideo apud divce Ru. mince sucellum a pastoribus satam ficum. Relativement à ce figuier dont parle Varron, on lit dans Pline, $\mathrm{xx}$, 20 : Cotitur ficus arbor in foro ipso ac comitio Rome nata, sacro fulguribus ibi conditis, magisque ob memoriam ejus, quce nutrix fuit Romuli et Reni conditoris appellala; quoniam sub ea inventa est lupa, infuntibus prabens rumen.

\section{LIVRE III.}

I. Etenim vietustissimum oppidum cum sit tradi. tum grocum, Baotia, Thebce, quod rex Ogyges cedificarit. Ogygès est le plus ancien roi dont parle l'histoire; c'est pour cela que les Grecs se servaient d u mot çrúrıov pour désigner une clıse forte ancienne.

Nam in hoc aunc denique est, ut dici possit, non cum Ennius scripsit, septingenti sumt paulo ptus aut minus anni, anguslo augurio postquam inclila condita Roma est. Le poëte Fnnius mourut l'an 585 de la fondation de Rome, sous le consulat de Marcius Pliilippus et de Servilius Cépion; ainsi le comput cité, et qui se trouve dans ses. Annales, écrites en 555, était de son vivant un anaclyonisme. II n'en était pas ainsi du temps de Var. ron; car c'était èn 717 de la fondation de Rome qu'il composait son livre, ct c'est en 727 , suivant Eusčbe, qu'il mourut, à l'àge de 90 ans. 
Nam lingua prisca el in Gracia colcis Brotii sine afflatu vocant collis:Tebas. Scaliger s'attache à prouver que l'origine que Varron donue à la ville de Thèbes est un mot plıénicien qui signifiait navicula, petit vaisseau : ce qui vient à l'appui de cette explication, c'est qu'on appelle en hébreu une arche arca (theibe).

II. Mihi dum dirimentur, inquit, suffragia, vis potius villa publice utamur umbia. Lorsque le peuple romain était assemblé dans le champ de Mars pour donuer son suffrage, une partie se retirait dans la villa publique pendant qu'on dépouillait le scrutin, et le reste se unettait à l'ombre sous des tentes que les candidats fiisaient dresser dans le champ de Mars pour eux et leurs partisans. Comme ces tentes étaient mal construites, mal rouvertes, et souvent frop petites pour le nombre de persounes qu'elles avaient a recevoir, Varron les appelle di. midiatce. On voit dans ovide qu'elles étaient couvertes de fenillages et de toges : Sunt quibus e ramis frondea facta casa est. Pars sibi pro rigidis calamos statucre columnis, Desuper extentas imposuere togas.

sedcbat ad sinistram ei Cornelius Merula consuluri familia ortus, et Fircellius Pavo Reatinus, ad dextram Minutius Pica, et $\boldsymbol{M}$. Petronius Passer. Tons ces noms sont des noms d'oiseaux, ce qui motive la plaisanterie d'Axius.

Nunc ubi hic vides citurm aut aurum? On juge, par plusieurs épigrammes de Marlial, que ce bois était plus précieux à Rome que l'or même. Mensa citrea. Ac. cipe, felices, atlantica munera, silvas : Aurea quidederit dona, minota dabit. Pline dit également que si lus lommes reprochaient à leurs femmes leur luxe en pierres précieuses, celles-ci reproclıaient à leurs maris leurs folles dépenses pour des tables en citronnicr.

Vestigium ubi sit nullum Lysippi aut Antiphili, sed crebra satoris et postoris. Lysippe, fanıenx sculp. teur, qu'Alexandre, regardait comme le seul digne de faire sa statıe, élait de Sicyone. Pline, xxxvı , 7 , nous dit qu'il avait fait 1500 statnes, et que chacune d'elles aurait suffi pour faire sa réputation comme sculpteur. Ce nombre est calculé d'après la quantité de pièces d'or que l'on tronra après sa mort dans une cassette ou il avait coutume d'en mettre une en réserve chaquie fois qu'il touclıait le prix d'une statue. Qnant à Antipliile, Pline nous dit qu'il était Égyptien, et peintre médiocre : Varron le met à cơlé d'un fameux sculpteur, pour faire ressortir le manvais gont de son temps, qui consistait à avoir des tableaux représentant des personnages dans le genre bouffon connu le nom de gryllus.

Nisi si apud Seium Siculum fit mel, Corsicum in Reatino. Le miel de Sicile était un miel doux, provenant d'llybla, où le tlyym abondait; tandis que le miel de Corse avait un gout amer, papce qu'il était extrait de l'ausinthe.

L. Albutius, homo apprime doctus, cujus Luciliano charactere sunt libelli. Ce n'est point ce mème Albu. tins, comme le dit à tort S. de la Bonneterie, qui pendant son exil à Athènes s'occupait de sciences, et dont parle Cicéron dans son traité De finibus, liv. r, cl. 3 ; l'Albutius dont parle Varron a écrit des satires dans le style de Incilius, premier poëte satirique des Latins.

Mincrval. On appelait Minerval le présent que les écoliers faisaient à leur maitre le jour de la fête de Minerve.

JII. Quis habebat piscinam, nisi dulcem, et in ea dumtaxat squalos ac mugiles pisces. Squalus signifie vil poisson dont les écailles sont très-ralıteuses. Pline,
Ix, 24 , met ces sortes de poissons dans la classe de ceux qui au lien d'aretes nont que des cartilages; avec cette difference qu'ils ne sont point plats, comme les autres poissons cartilagineux. Quant aux mugiles, le même au. teur nous dit, Ix, 16, que ces poissons sont si souples et si légers qu'ils sautent par-dessus un vaisseau; il ajoute plus loin que lorsqu'ils sont efrayés, ils se caclıent la tête dans l'eau, et s'imaginent dès lors que le reste de leur corps est également caclıé. Suivant l'interprétation des traducteurs de Pline, nous arons rendu mugiles par mulets. Cependant le passage de Varron que nous avons cité au commencement de cette note a fait demander à plu. sieurs conmentateirs comment les mulets, poissons de mer, pouvaient se conserver dans l'eau douce; objection qui, tombe d'elle-même, puisque tout le monde sait que les mulets vivent également daus les rivières et dans l'eaı salée.

Quis contra nunc Rhinton. Gessner prétend que sous ce nom emprunté Varron veut désigner les comé. diens Ésope père et fils, lous deux connus par leur gour. mandise et leur prodigalité; comme on peut le voir dans Pline, $x, 51$ et 72 . Ce passage de Varron peint d'ailleurs on ne peut mieux le luxe des Romains de cette époque ; et Columelle, vin, 16, 4, le reproduit de la manière suivante: Itaque Tetentius Varro, Nullus est, inquit, hoc seculo nebulo ac Rhinton, qui jam non dicat nihil sua interesse, utrum ejusmodi piscibus, an ranis frequens habeat vivarium.

IV. Ille ego vero, inquit, (ut aiunt) post prin. cipia in castris. On appelait principia castrorum l'endroit où était la tente du général, celle des tribuns mili. taires et des premiers officiers. C'est là aussi que se gardaient les aigles des légions et les drapeaux des colıortes. On lui donnait le nom de principia, parce que c'ètait la tête dı camp (principium). De là ces locıtions : esse apud principia, in principiis, post principia.

V. Ut miliarice et coturnices. Relativement à miliarice, Varron dit dans son Traité de la langue latine, livre $4^{\mathrm{e}}$ : Ficedulce et miliaria dictce a cibo: quod alte. rae fico, alterce milio fiant pingues. Nous avons en français le mot becfigue qui correspond à ficedulce; mais celui de miliaria (oisean qui se nourrit de millet) n'a pas d'équivalent dans la languc.

Ostium habere humile, et angustum, et potissi. mum ejus generis, quod cochleam appellant. Ces espèces d'entrées étaient, d'après Gessner, cintrées, et ourertes dans une seile partie; de sorte que, tournant sur elles-mêmes au noyen d'une vis, elles ne livraient à l'animal d'autre passage que celui qu'on voulait bien lui donner.

Ad speciem cancellorum scenicorum. Les cancelli étaient des places réservées aux speclateurs dans les théâtres. Elles consistaient dans des planches parallèles aux gradins, et garnies de barres perpendiculaires pour soutenir le dos de ceux qui étaient assis sur le gradin in. férieur, afin qu'ils ne pussent pas se jeter en arrière sur ceux dı gradin supérieur.

In quo diceres longe vicisse non modo Archctypon inventoris nostri bprootpopsíw. $M$. Laelii Strabonis. Pline, $x, 50$, nous parle aussi de cette invention : Avia. ria primus instituit inclusis omnium generis avibus, M. Lalius Strabo, equestris ordinis Brundisii. La description que Varron nous donne ici de sa volière est un des morceaux les plus intéressants et en meme temps l'un des plus obscurs de tout l'ourrage. Il a de tout temps fait le sujet des reclierches les plus actives de la part des savants, qui se sont atfachés surtout à rétal:tir 
un texto mutile, corrompu et défiguré de mille manières frar les anciens copistes et par les grammairiens. Il est vrainent d regretter que de nos jours aucun architecte antiquaire n'ait ajporté dans l'étude de ce monument ses notions spéciales et pratiques au seconrs de la pliilologie. Jl eu serait résulté sans donte de nouvelles lumières sur l'ćconomie de ce singulier specimen de l'antiquité, qui, dans la relation confuse et presipuc énigmatique que nous en ont transmise les mauuscrits, présente encore uu curieux aperçu de l'état de l'art, du luxe et des mours an temps où écrivail l'auteur. Parmi les plilosoplıes nous devous placer an premier rang Turncbe, qui dans ses Animadver. siones, liv. $\mathrm{xx}$, clı. 18 , a discuté ce passage avec une profonde érudition, et essayé, sur les seuls éléments que lui fournissait le texte, de reconstruire la voliere en entier. S. A. de Segner a également décrit une jartic de cette ro. liere (de Ornithone Yarronis minore el rotundo.; Lipsice, 1773). Goiffon, de l'École royale vétérinaire, nous a domns une traduction de ce cliapitre, avec des notes exégétiques. C'est ce travail que Sab. de la Bonneterie a entièrenent reproduit daus sa traduction, sans indiquer la source où il arait puisé; et lıatons-nous d'ajouter que c'est la un des meilleurs chapitres de son onvrage. Ce. pendaut le travail de Goiffon est loiu d'être complet : la situation des parties qui composent la volière n'est pas toujours indiquée avec exactitude; il a glissé sur les difficultés grammaticales, et u’a pris conseil que de son inagination pour interpréter des passages obscurs que la critịue était seule en droit d'éclaircir.

$A b$ insula ad Musaren quce est ab imo fluvio. Celle topographie du cabinet de travail de Varron rapjelle celui de Cicéron. Ventım in insulam est, dit.il, Leg., 11, 1 ; hae veranihil est antenius; cten im hoe quasirostro fin. ditur Fibrenus et, divisus aequaliter in duas partes, latera hoce alluit, rapideque dilapsus, cito in $1 \mathrm{inum}$ confluit, et tantum eomplectitur, quod satis sit medice patcestre loci. Qno effecto, tanquam id habuerit ope. ris ae muneris, ut hanc nobis effleeret sedem ad disputandum, statim proeipitat in lirem.

Deformatus ad tabula lilterarice speciem cum capitulo. Sealiger fait remarquer que la formo des tablettes al moyen desquelles les enfants apprenaient à lire et à écrire était celle d'un carré long, et surmonté d'une espèce de cliapiteau troué, qui servait à les suspendre.

Ad hac, ita ut in margine quasi infimo tabulce descripta sit ambulatio, ab ornithone plumula, in qua mediu sunt crvece, qua introrsus iter in aream est. Tous les commentateurs regardent unaumement le mot plumula comıne ayant été vicié dans son origine. Gessner suppose qu'il y avait eu primitirement $\mathbf{P}$. Iscccc via, c'est-à-dire, via pedum nongentorum. Goiffon traduit ainsi : " De sorte cependant qu'il y a entre cette prome. " nade et ma volière une esplanade de 58 pieds de long, " au milien de laquelle répond la principale porte par "Iaquelle on y entre. "Cette manière de traduire ferait croire qu'il avait ainsi corrigé le texte : $A b$ hac inter ornithonem area est $P$. longa, in qua media sunt caveze. Il remarque dans une note que cavea a ici la signification, de porte, passage. Scliueider réfute cette interprétation en ajoutant que cavece doit plutôt appartenir a la plurase suivante : Hae sunt (cavea) avibus omue gentus. Quant au mot plumula, il n'est guc̀re possible d'y trouver l'indication primitive d'un cliffre, les différeutes proportions de la rolière ayant été assez déterıninées pour que l'auteur n'ast pas besoin d'y reve. nir. Avec Sclmeider il fant lire : a Ambulatio $a b$ ornithone disjuncta, in qua media introilus in arcam est, et restituer ensuite à la plirase hac sunt le mot carect.
Secunlum stylobatis inleriorem parlem, dextra et sinislra, ad summam aream quadratam, e medio diversa dua non late, sed oblonga sunt piscince ad porticus versus. Goiffon traduit ces mots de la manière suivante : " A quelque distance de la face intérieure dn " stylobate, tant de celle qui règne depuis l'entrée princi"pale jusqu'su mur à droite, que de celle qui règne de" puis cette même entrée jusqu'au mur à gauche, com" mencent deux viviers peu larges etc. "Il ajoute dans une note que le premier tilet formait le ciel de la plus grande partic de la volière, et qu'il n'y avait que les por. tiques qui fussent couverts, de façon à garantir de la pluie. Les oiseaux n'avaient aucun accès sous ce couvert, puisque le second filet descendait de l'architrave au stylobate, et que l'un comme l'autre étaient le terme inté. rienr de la partie quadrangulaire de la volière, oir les oiseaux ćtaicut reufermés.

Or, d'ap̧rès Goiifon, tont l'espace carré aurait été tendu de filets, et les portiques occuperaient la même place que Varrou avait assignée à la promenade. S’il en était aiusi, le petit ruisseau qui porte ses eaux aux grives devenait iuntile, juisqu'elles auraient pu se désaltérer aux viviers. D'ailleur's les mots secundum stylobat is interiorem par. tem, ne permettent point de supposer que les portiques se trouvaient pris de la promenade, puisque, comme Gessuer le remarque très-luien, c'est la partie quae aream interiorem, non maceriem, exteriorem respicit. Entraiué par cette première erreur, Goiffon devait naturellement se míprendre sur le sens des mots ad porticus versus, qu'il traduit en disant : " en sens opposé à celui du por" tique. "

Inter eas piscinas tantum modo accessus semita in thol um, qui est ultra rotundus columnalus, ut est in cede Catuli, si pro parictibus feceris columnas. Catulus est le colleggue de Marius au consulat, qui délit les Cinulıres, et que ce meme Marius condamna ensuite à mourir, malgré les instances de plusieurs citoyens qui demandaient sa gráce. Catulus s'enferma dans sa cliambre á coucher, et s'aspliyxia par la vapeur du claarbon allumé. Quant au tholus, Vitruve, 1, 71, 11011s dit: Tholos inlelliginu erectiores tesludines, lemplis addi solitas quas Itali tribunas vocant. Ce mème autenr dit encore, iv, 7 : Tholum Gatti laternam appeltant. De là l'origine du mot lanterne d'un clóne, dont nous nous ser'vons encore aujourd'hui.

Inter has et exleriores gradatim substructum ut Dextpióıv avium; mutuli crebri omnibus columnis impositi, sedilia avium. L'explication de ce passage résulte tout simplement de celle que nous avons dornée plus haut, relativement au mot caneclli. Nous noui bornerous à remarquer que dans notre traduction nous avous mis à profit la correction proposée par Sclıneider (sunt strueta, ut 0satpiòเov, mutulis erebris impositis sedilia avium), sans pourtant oser la receroir dans le texle.

De Segner proposait de lire : inter culeitas et columel. las; conjecture lieureuse, que nous avons suivie avec Goiffon en traduisant.

Ex swggeslo faleris, ubi solent esse. Sclinelder a raison de dire que tont ce passage serait mieux placé plus liaut apress la phrase : circum falere uti navalia sum exeavata anatimm.... de sorte que la plirase suivante conmencerail par : Tum el aqua, etc.... Nous comprenons eu effet que Varron devait d'abord finir la description du socle arant de conmencer celle de la table, pour l'interrompre ensuite et revenir au socle.

Intrinsecus sub tholo stella Lueifer interdiu, no. ctu hesperus ita eireumeunt ad infimum hemisphce. rium, ac moventur, ut indicent quot sint horce. Goir. 
fon fait observer que les anciens, maurais astronomes, faisaient deux étoiles de cette planète que nous connaissons sons le nom de Vénus, et qui, comme dit Pline, mieux instruit que Varron, prévient le jour le matin, comme un antre solcil, et en prolonge sa lumière le soir, comme une autre lune. Nous croyons plutơt que l'arclijlecle a eniprunté les innages Lucifer et Hespérus pour distinguer les leures du jour et celles de la nuit.

In eodem hemisphario medio circum cardinem est orbis ventorum octo, ut Athenis in horologio, quod fecit Cyrrhestes. Vitruve, 1 , parle aussi de cette liorloge: Sed qui diligentius perquisierunt, tradiderunt cos esse octo: maxime quiden Andronicus Cyrrhestes, qui etiam exemplum collocavit Athenis, turrim marmo. ream, octogonon, et in singulis lateribus octogoni singulorum ventorum imagines exsculptas contra suos cujusque flatus designavit... On voit que le mot de Cyirhestes signifie citoyen de Cyrrhus, ville de Syrie, et que le nom de l'artiste était Andronicus. Il faut supposer qu'il arail eu une grande célébrité, pour que Varron se contentat de l'appeler ici tout court le citoyen de Cyrrbus.

Les anciens n'avaient d'abord distingué que 4 vents, puis 8 , et enfin 12; mais ils aimerent mieux s'en tenir à l'ancienne division en huit, ainsl que nous l'apprend Pline, 2, 47.

Narrat ad tabulam, cum dirimerent, quendam deprehensum tesserulas conjicientem in loculum. Voici la manière dont se faisait l'élection des magisIrats. Clacun apportait un bulletin, tabula, sur lequel était écrit le nom de son candidat; ou plutôt on donnait dans le champ de Mars meme un bulletin blanc à chaque ciloyen, afin qu'il le rempltt du nom qu'il jugerait à pro. pos. Clıacun déposait son bulletin dans une urne; et quand il s'agissait eusuite de dépouiller le scrulin, diri. mere (diribere), on ćcrivait sur des tablettes le nombre de votes obtenu par chaque caudidat; ou bien encore on prenait dans l'urne les bulletins portant le même nom, pour les réunir dans une urne on bourse particulière, loculus. Il y a vait autant de ces bonrses que de candidats. Comme celle operation rendait la fraude très-facile, il avait été nécessaire d'instituer des gardiens, custodes, chargés de la prévenir, el qui se surveillaient réciproque. ment. La fraude la plus commune consistait dans linsertion par une seule personue de plusieurs bulletins portant le mème uom dans l'urne générale ou dans la bourse particulière. Plutarque, dans la vie de Caton d'Utique, rapporte un fait de ce genre. Caton s'étant aperçu, dans des comices tenus pour l'élection des édiles, qu'il y avait un grand nombre de bulletins qui étaient tous écrits de la même main, décourrit la fraude, et fit annuller tout le scrutiu.

v1. Axius, de pavone, inguit, libere licet dicere, quoniame discessit Firccllius. Axius plaisante sur le mot pavo, paon, qui était le surnom de Fircellius.

Ex is $M$. Aufidius Lurco. Pline, $\mathbf{x}, 23$, constate ce fait en disant : Pavonem cibi gratia Roma primus occidit orator IIortensius aditiali cœna sacerdotii. Saginare primus instituit circa novissinum piraticum belluin Mr. Aufidius Lurco, exque eo quostu reditus se. stertium sexagena millia habuit.

VII. Fenestris punicanis. Ce sont sans doute des fenctres grilléts. Les Cartlıginois paraissent avoir été en général d'isabiles clarpentiers; Caton vaute beaucoup les punica coagmenta (joints, jointurts); Cicéron, les punicrinos lectos; et Pline cite plus d'une fois les punicos lec. tos et le lorculare punicun.

IX. Ut maxime factilaverunt Deliaci.
Pline, $x, 50$, nous dit que ce peuple est le premier qui ail engraissé les poules; art qu'il porta si loin, qu'il y avait, du temps de Cicéron, des personnes à Délos qui, à la seule inspection d'un nuf, pouvaient indiquer la poule qui l'avait pondu, et donnaient ainsi un démenti au proverbe se ressembler comme deux aufs, Columelle, VIII, 2, parlo également de cette industrie des lıabitants de Délos: $\mathrm{Hu}$. jus igitur villatici generis non spernendus est reditus, si adhibcatur educandi scientia; quam plerique Græe. corum, el pracipue coluerunt Deliaci.

Similes facie non his villaticis gallinis nostris, sed africanis. Scaliger remarque que les gallina afri. cance sont les memes que les Français appellent poules de Guinéc.

Gallince africance sunt grandes, varia, gibberce, $q$ uas $\mu \varepsilon \lambda \varepsilon \alpha \gamma p i \delta x_{5}$ appellant Grceci. Pline, 10,20 , nous apprend que ces poules portent le nom de $\mu \varepsilon \lambda s x_{\text {ppió }} x_{5}$, parce qu'elles venaient, à certaines époques de l'année, se battre sur le tombeau de Méléagre en Béotie. C'est par une raison analogne que celles qui venaient tous les ans à Troie se battre sur le tombeau de Memnon étaieut appelées Mcmnonida.

X. Cum excudit, quinque dicbus primis patiuntur esse cum matre. Columelle fait la meme recommandation; mais il veut que la mère soit enfermée, et qu'on ne laisse sortir mère et petits, après le cinquième jour, que si lo temps est beau.

XII. Lapinus dicitur habere in Tarquinicnsi scpto jugera $\mathrm{xL}$, in quo sunt inclusa non solum ea quce dixi, sed etiam ovcs ferce. Pline parle également de ce Fulvius, vull, 78 : Vivaria aprorum caterorumque sil. vestrium primus togati generis invenit Fulvius $L \imath$. pinus, qui in Tarquinensi feras pascerc instituit. Lo même auteur l'appelle, 1x, 82, Hirpinus. Festus nous apprend à ce propos que Lupinus a la mème étymologie que Hirpinus, puisque les Samnites appelaient un loup irpus, au lieu de lupus.

Alterum ne felis aut melis aliave bestia. La plu. part des commentateurs expliquent malis par taxus, blaireau, et Sab. de la Bonneterie partage cette opinion. Saumaise pense que ces animaux sont les mêmes qu'on appelle vulgairement martes. Mais la marle, reclierchée pour sa fourrure, habite ordinairement les contrées septentrionales. Nous arons cru devoir traduire micelis par fouine, antre espèce de rongeur, bien connue par les ravages qu'elle exerce dans les basses-cours.

Fit enim sape cum habent catulos recentes, alios $u t$ in ventre habere rcperiantur. Pline exprime par stperfatare la fécondité extraordinaire de ces animaux : Solus prater dasypodem superfoetat, aliud educans, aliud in utero pilis vestitum, alind implume, aliud inchoatum gerens pariter.

Itaque de his Archelaüs scribit, annorum quot sint si quis velit scire, inspicere oportet foramina natura, qua sine dubio alius alio habet plura. Voici comment Crescentius s'exprime à cel égard : Itaque qui scire volet masculum a fomina discernere, ut Arcadius scribit, natura foramina debet inspicere; nam sine dubio masculus unum, famina duo inve. niuntur habcre, si caute et subtiliter inspiciatur. II paratt que cet auteur a cru deroir expliquer ainsi les pa. roles de Varron, dont le sens lui paraissait absurde. II l'est en effet; mais l'observation de Crescentius n'est pas applicable à l'lıase plus particulièrement qu'à toute autro femelle; et il n'est pas besoin d'y regarder de très-près.

Alterius generis est, quod in Gallia nascitur ad 
Alpes, qui hoc fere mutanl, quod toti candidi sunt. Pline, en parlant de cette espèce de lièvres, dit avec naiveté: In Alpibus candidi, quibus hibernis mensibus pro ci. batu nivem credunt esse.

Cuniculi dicti ab co, quod sub lerra eunieulos ipsi facere soleant, ubi lateant in agr is. I'line dit au mène sujet : Leporum generis sunt et ques Irispania cuniculos appellat, etc. En effet, le mot cuniculi parait, d'après ce que nons dit Polyle, tirer son origine d'une peuplade es. pagnole appeléc Koúveov.

Duo quidem utique te habere pulo, el quod in Hispania annis ita fuisti multis, ut inde le euniculos persecutos eredam. Varron avait fait la guerre en Espa. gne sous les drapeaux du parti de Pompée, et ne revint en Italie qu'apres la bataille de Munda.

XIII. Quod non leporarium, sed Onplotpopeiov appellabat. Leporariam (de lepus) est un parc à lièvres, tandis que Onplotpopeiov (de orjplos, bete et тререเv nourrir) est un endroit ou l'on enferme toutes sortes de betes fauves.

Ut non minus formosum mihi visum sit spectacu. lum, quam in Cireo maximo aedilium, sine afriea. nis. Il se pourrait que Varron, en ajoutant sine africanis, ait voulu faire allusion à un sénatus-consulte qui défendait d'importer pour les jeux d'édiles des bètes fau. ves d'Afrique.

XIV. Aqua, inquam, finiendae, ne fugitivarius sit parandus. On appelait fugitivarius celui qui, moyennant récompense, courait à la reclierclıe des esclaves fugitifs, et qui les ramenait clrez leur maitrc.

Et hunc, clum serpil, non solum in area reperil, sed etiam si rivus non prohibet, in parietes stantes -invenit. Parietes, littéralement mur vertical. Celte condition, qui est celle de tous les murs aussi bien, que l'interposition du ruisseau dont il est question dans le texte, nous a fait penser que Varron avait ici employé le mol parietes pour exprimer les flanes d'un rocher.

XV. Gliarium aulen dissimili ratione habelur, quod non aqua, sed maecria locus sepitur. Les Romains mangeaient les loirs, ainsi que nous l'apprend Apicius, Art. eoqu., 8, 9; il y eut même des lois portées par les cen. seurs pour mettre un frein à ce raffinement de luxe, qui rechicrclıait dans les mets la rareté plutôt que la délica. tesse.

Quibus in lencbris, cum cumulalim posilum est in roliis, flunt pingues. Le texte est ici visiblement altéré. La traduction a suivi le sens de la leçon donnée par Scaliger: cum aular positum est in tenebris.

XVI. Preteren meum erat non tuum, eas novisse volucres. Appius fait sans doute allusion à son nom, qui vient de apis, abeille. Nous avons vu plus haut que Vaccius a prétendu, par une raison analogue, que c'était à lui le parler des vaches et des bocufs.

Quod si hoc faciunt etiam graculi, at non idem. Varron, dans soı traité de la langue latine, fait dériver le mol graculus de gregatim volare, voler en troupe. It est plus probable que l'on doit en chercher l'origine dans xpopw, qul exprlme le cri de ces oiseaux; graculas, ph ce cas, ne serait qu'un diminutif de gracus.

Quod favus venit in altarla, et mel ad principia convivii, et in secundam mensam administrutur. Les Romains commençaient leur repas par boire un lipuide micllế qu'ils appelaient mulsum; c'est de ce mot qu'on a formé celui de promulsis, pour désigner le commencement d'un repas.

Et ut quidam dicunt, lria gener a cum sint du. cum in apibus, niger, ruber, varius. Nous ne connaissons dans l'antiquité ancun auteur qui ait établi tecte triplo distinction; mais tous admettent deux cliefs de couleur différente

Eœ differunt inler se, qua feræe et cicures sunt Pline, qui traite du meme sujet, appelle ces abeilles silveslres ou rusticx; pour le reste, il est tout à fait d'accord. avec Varron.

XVII. Inlerea redit ad nos $P a v o, E l$, sivultis, inquit, ancoras lollere, latis tabulis sorlilio fit lribuum. Cicéron fait mention de deux espèces de tirages au sort : dans le premier cas il s'agissait d'établir l'ordre dans lequel les tribus devajent donner leurs suffrages; dans le second, lorsque les suffrages étaient dejjà donnés, 'et qu'ils se trouvaient partagés en nombre égal sur plusieurs candidats, on tirait encore au sort pour savoir celui qui sc. rait nommé édile. Ce dernier tirage ne se faisait que la. tis tabulis, comme dit Varron; et il est constant qu'il ne s'agit dans notre passage que de cette seconde espèce.

Nam ul Pausias, et ecteri piclores ejusdem generis loculata magnas habenl arculas, ubi discolores sint cerce, sie hi locula las, etc... Ce peintre, natif de Sicyone, était, de même qu'Apelle, disciple de Pamplite; son genre était la peinture appelée incaustum (encaustique), parce qu'on y employait le feu. Quant à celle dont parle ici Varron, elle est moins connuc : il parait qu'on gravait d'abord des tablettes de bois, et qu'on remplissait ensuite les traces laissées par le burin de cire fondue et de différentes couleurs, suivant l'objet qu'on voulait reproduire. Lorsqu'on éclıauffait ensuite ces tablettes, la circ s'imprimait davantage dans ces sillons, et donnait au talleau la con. sistance nécessaire.

Sic hos pisees nemo cocus in jus vocare audet. II y a jci un jeu de mots résultant de la double signification de jus, et qui n'a pas d'équivalent dans notre langue. Var. ron parle d'une espèce de poissons très-estimée, qu'au. cun cuisinier n'ose voeare in jus c'est-à-dire, appeler, en justice dans un sens, ou mettre à aucune sauce, dans l'autre.

Cum codem lempore insulas Ludinorum ibi cho. reuusas vidisses; sic hos pisees. Cette plirase trouve son explication dans le passage de Pline, où on lit : In l.y. dia, qua vocantur Calamino, non ventis solum, sed ctiam contis quo libeat impulsa, multorum eivium Mithridatico bello salus. Sunt et in Nymphao parva saltuares dictee, quoniam symphonice eanlu ad iclus modulanlium pedum moventur. 
GOLUMELLE. 

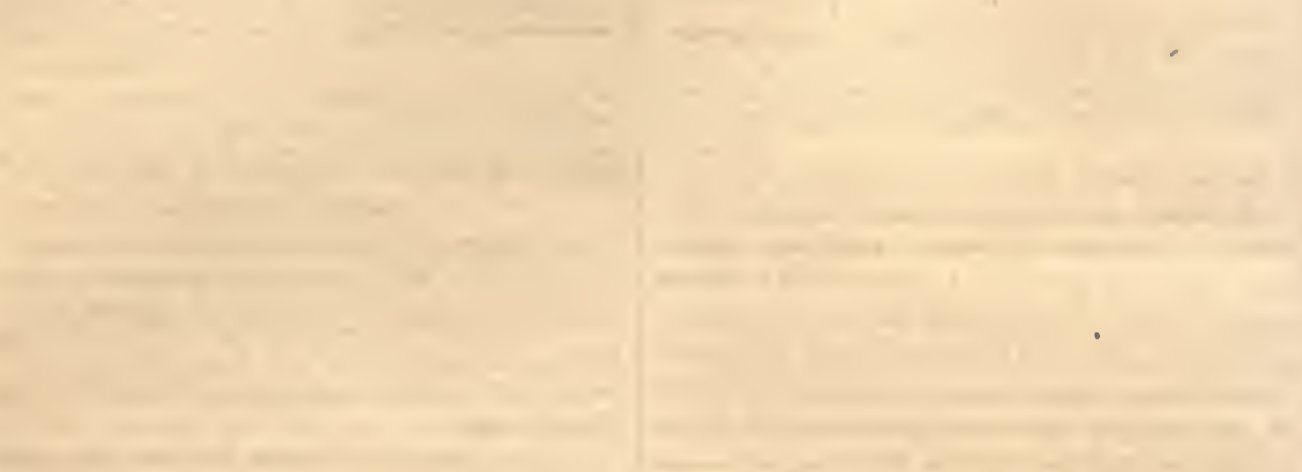

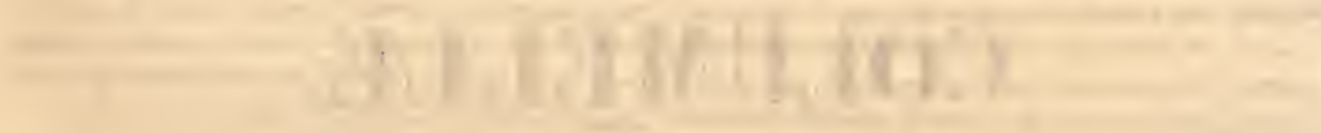
, n

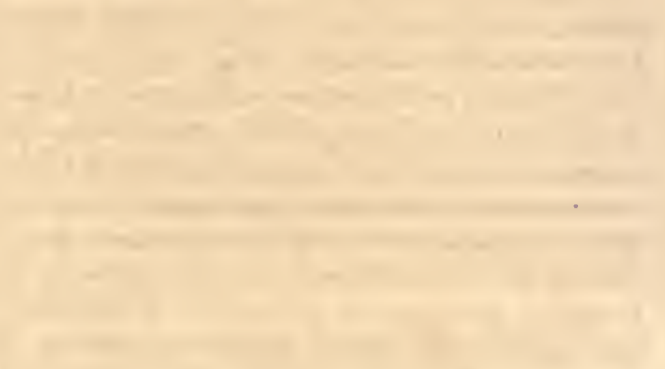

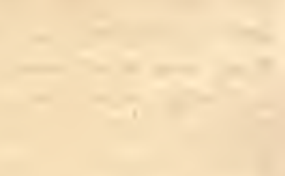




\section{NOTICE SUR COLUMELLE.}

Lucius-Junius-Moderatus Columelle naquit à Gadès (Cadix), sous le règne d'Auguste ou de Tilbère. Son père, Marcus Columelle, avait des possessions dans la province de Bétique. Le fils se rendit à Rome, où il passa sa vie, à l'exception de quelques voyages qu'il fit en Syrie et en Cilicie. On ignore s'il alla dans ces' pays en simple voyageur ou avec quelque mission du gouvernement, car on ne sait rien des circonstances de sa vie. Il parle de Cornelius Celsus et de Sénèque comme de ses contemporains. Il nous reste de Columelle deux ouvrages, l'un intitulé De re rusticâ, en douze livres; l'autre $D e$ arboribus. Ce dernier faisait peut-être partie d'un ourrage sur l'agriculture, en quatre lirres, que Columelle avait publié comme première édition de celui que nous avons en douze livres. De cctte manière Cassiodore avait raison de dire que Columelle a vait composé seize livres sur l'économie rurale. Des douze livres du De re rusticá, le premier traite de l'utilité et de l'agrément de l'économie rurale, et de ce qu'il faut pour établir une bonne économie; le second, des clıamps, de la manière de les ensemencer, et de la moisson; le troisième, des vignes et des vergers; le quatrième termine la matière de la culture des vignobles; dans lc cinquième, Columelle enseigne la manière de diviser et de mesurer le temps; il y parle aussi des arbres; le sixic̀me traite des bestiaux et de leurs maladies: le septième, du petit bétail, tel que les brebis, les chèvres et les pores; le huitième, de la basse-cour; le neuvième, des abeilles; le dixième, ćcrit en hexamètres, traite des jardins; le onzième fait connaître les devoirs d'un fermier, et traite ensuite du jardinage; le douzième, qui est le plus long, donne toutes sortes d'instructions et de recettes nécessaires à ceux qui s'occupent d'éco. nomie rurale.

Dans les premières éditions, le traité Des Arbres était donné comme le troisième livre du grand ouvrage, qui ainsi était composé de treize livres. $\mathrm{Ce}$ petit traité a été très-utile aux critiques pour rétablir le texte du cinquième lirre, qui est fort incorrect dans le petit nombre de manuscrits qui nous restent de Columelle. Cet auteur paraît avoir été peu lu. Parmi les anciens, Servius, Cassiodore et Isidore sont les seuls qui le citent. Il tomba presque dans l'oubli après que Palladius en eut fait un abrégé; aussi Vincent de Beauvais, et Pierre de Crescentiis, que Sclineider appelle diligentissimum veterum rei rusticæ scriptorum lectorem, ne le connaissaient pas.

Le style de Columelle est pur et élégant; si on peut lui faire un reproche, c'est d'être trop recherché pour la matière qu'il traite. La lecture de son ouvrage est peut-être plus agréable pour l'homme de lettres qu'elle n'est utile au cultivateur.

(Extrait de Schocll.) 



\section{J. MODERATUS COLUMELLE.}

\section{DE L'AGRICULTURE.}

\section{LIVRE PREMIER.}

PRÉFACE.

\section{A publius silvinus.}

J'ai souvent entendu les hommes les plus itlustres de I'État se plaindle de la stérilité du sol et de l'inelémence de la température, qui depuis longtemps auraient diminué les productions de la terre. D’autres, pour atténuer par quelque raison la gravité de leurs plaintes, assignent à ees effets une cause déterminée, en disant que la terre, fatiguée et épuisée par sa trop grande fertilité, ne peut plus fournir aux besoins des hommes avee la même libéralité qu'autrefois. l'our moi, mon cher Publius Silvinus, je pense qu'ils ont tort de parler ainsi. En effet, comment s'imaginer que la nature, douće par le eréateur du monde d'une fécondité toujours nouvelle, ait été frappée tout à coup de stérilitè? On ne saurait persuader à un bomme de bon sens que la terre vieillisse comme l'homme, elle qui, à l'exemple de la Divinité, a reęu eı partage une jeunesse éternelle; ectte terre que nous appelons la mère commune de toutes choses, puisqu'elle a enfanté tout ee qui est, et qu'elle enfantera tout ce qui doit être dans les temps à venir. Loin d'attribuer à l'instabilité de l'utmos. phère les maux dont nous nous plaignous, je pense qu'il en faudrait ehereher la eause dans notre insouciance. Nous avons ạbandonné la eulture de nos terres au dernier de nos eselaves, qui les traite en véritable bourreau; tandis que les hommes les plus éminents parmi nos ancétres n'ont point dédaigné d'en faire leur prineipale oecupation. Chose étrange! tous ceux qui veulent apprendre l'art de bien dire choisissent parmi les oratcurs celui dont l'ćloquence pourra leur servir de modèle; ceux qui veulent apprendre les règles du calcul et de l'arpentage ont soin de choisir le maitre le plus capable de les en instruirc. Il en est de même de ceux qui apprennent la musique ou la danse. S'agit-il de bátir? on a recours aux maeons et aux architectes; de confier un vaisseau à la mer? on le met sous la conduite du pilote le plus habile; de faire la guerre? on invoque le secours des hommes de guerre les plus expérimentés. Eufin, pour ne point entrer dans plus de détails, quel que soit le genre d'étude auquel on s'applique, on s'adresse toujours au guide le plus sûr. A plus forte raison, si l'on veut prendre des lecons de sagesse et de vertu, faudra-t-il choisir son précepteur dans la elasse des sages. Eh bien! la sciencequi se rappro= che le plus de la sagesse, et qui est même inti-

\section{JUNII MODERATI COLUMELLE}

\section{DE RE RUSTICA.}

\section{LIBÉR PRIMUS.}

\section{AD peb. SILVIXU IREFATIO.}

\footnotetext{
- Sapenumero civitatis nostra principes audio culpantes modo agrorum info'cunditaten, modo carli per multa jam tempora noxiam frugibus intemperiem : quosdam etiam pradictas querimonias velut ratione certa mitigantes, quod existiment, ubertate nimia prioris avi defatigatum et effoctum solum nequire pristiua benignilate prabere murtalibus alimenta. Quas ego causas, Publi Silvine, procul a veritate abesse certum habeo, quod neque fas existimare, rerum naturain, quam primus ille nundi genitor perpetua forcunditate denavit, quasi quodam morbo sterilitatc affectanı : neque pruden. tis credere, fellurem, quæ divinan et aternam juventam
}

sortita, communis omnium parens dicta sit, quia ct cuncta peperit semper, et deinceps paritura sil, velut ho. minem consenuisse. Nec post laxe reor intemperantia caeli nobis ista, sed nostro potius accidere vitio, qui rem rusticam pessimo cuique servorum, velut carnifici, noxae dedimus, qnam majorum nostrorum optimus quisque et optime tractaverit. Atque ego satis mirari non possum, quid ita dicendi cupidi seligant oratorem, cujus imitentur eloquentiam; nensurarum et numerorum moduu rinıan. tes, placitae disciplinac consectentur magistrum; vocis et cantus modulatorem, nec minus corporis gestieulatorem, scrupulosissime requirant saltationis ac musicx rationis studiosi ; jan qui adificare velint, fabros et architectos ad. vocent; qui navigia mari concredere, gubernandi peritos, qui bella moliri, armorum et militix guaros; et ne singula persequar, ei studio, quod quis agere velit, consultissinum rectorem adlibeat; denique animi sibi yuisque formatoren preceptoremque virtutis e coetu sapieutum arcessat : sola res rustica, qua sine dubitatione proxima et quasi consulguinea sapientia est, tam disccutibus egeat quan magis. tris. Adliuc enim scholas rhetorum, et, ut dixi, gcome- 
mement liée avec clle, l'économie rurale cufin. cette science est la seule qui n'ait ni disciples qui l'apprennent, ni maitres qui l'enseignent. Nous avons des écoles de rhéteurs, de géomètres, de musieiens; j'en ai même vu où l'on enseignait les professions les plus viles, comme l'art d'apprêter les mets, de les rendre plus friands, d'ordonner un repas somptueux, de parer les cheveux, la têtc : ce n'est qu'en fait d'agriculture que je n'ai jamais connu ni professeur ni élève. Et cependant qui pcut dirc que cesoicnt là des arts nécessaires? Quand nous n’aurions personne pour nous enseigner ces futilités, la république y perdrait-elle beaucoup? en seraitelle moins florissante que du temps de nos ancêtres? Nos cités ont été heureuses, sans avoir connu ni avocats, ni jeux publics; et les cités à venir n'en seraient pas plus malheureuses, pour no les connaitre jamais. Mais les hommes ne sauraient vivre ni subsister sans l'agriculture. Cc qui n'est pas moins étrange, e'est que l'art qui est le plus utilc à la conservation de notre corps et à l'cntreticn de notre vie, est celui qu'on a le moins perfectionné de nos jours. On rejette avec dédain lc moyen le plus innocent d'augmenter son patrimoine, et on a recours à tous ccux qui sont contraires aux lois de la justice. Oscrait-on regarder comme légitimes les richesses que nous procure la guerre? richesses toujours teintes de sang, fortune souvent fondée sur le malheur d'autrui. Ou bien les hasards de la mer et les chances du commerce sont-ils préférables aux dangers de la guerre? et l'homme, attachć essentiellement à la terre, doit-il braver toutes les lois de la nature pour se confier aux flots, s'exposer à la fureur des vents et des vagues, et parcourir comme un oiscau de passage

trarun musicorumque, vel quod magis mirandum est, contemptissimorum vitiorum officinas, gulosius condiendi cilıs, et luxuriosius fercula struendi, capitumque el capillorum concinnatores non solunı esse audivi, sed et ipse vidi. Agricolationis neque doctores qui se profiterentur, neque discipulos cognovi. Cum etiam si prodictarum artium professoribus egeret civitas, tamen, sicut apud pris$\cos$, florere posset respublica. Nam sine Indicris artihus atque etiam sine causidicis olim satis felices fuere, futuraque sunt urbes : at sine agri cultoribus nec consistere mortales, nec ali posse manifestum est. Quo magis prodigii simile est, quod accidit, ut res corporibus nostris vitacque utilitati maxime conveniens minime usque in lıoc tempus consummationem lıaberet; idque sperneretur geuus amplificandi relinquendique patrimonii, quod omni crimine caret. Nam cxtera diversa et quasi repugnantia dissident a justitia, $\mathrm{n}$ isi requius existimamus cepisse pro. dam ex militia, quæ nohis niliil sine sanguine et cladibus alienis affert. An bellum perosis, maris et negotiationis alea sit optabilior, ut rupto natura foedere terrestre animal lıono ventorum et maris objectus iræ se fluctibus audeat credere, sempetque, rilu volucrum, longinqni des coutrées éloignées et inconnues? Quelle profession est enfin plus honorable que celle du eultivateur? Est-ce le méticr de l'usurier, odieux même à ccux qu'il semble secourir pour un mo. ment? Ou bicn est-ce cettcautre profession que nos ancêtres qualifiaient de canina (dechienne), paree qu'elle eonsiste à aboyer contre les personnes les plus riehes, et à sacrifier l'innocent au coupable? brigandage infâme, justement méprisé de nos ancêtres, mais toléré de nos jours dans l'cnceinte de wos murs, et installé en plcin forum. Regarderez-vous comme une ressourec honnête cette importunité intéressée d'un client qui, rôdant aux portes des hommes puissants de l'époque, sc tient aux ćcoutes dans l'antichambre, pour s'assurer si son maitre est encorc endormi, n'osant point s'adresser aux valets, qui ne daigneraient peut-être pas lui répondre? Estee donc un sort si heureux que de s'exposer aux rebuts d'un esclave attaché par des chaines à la garde d'une porte, de se morfondre la nuit devant cette même porte qui reste sourde aux instances les plus vives; et tout eela pour acheter par toutes les misères de la servitude l'honneur des faisceaux et le pouvoir, payé quelquefois de la perte du patrimoinc? car les honneurs ne s'obtiennent qu'en ćchange de services onéreux et à foree de présents. Or, si les bons citoyens doivent repousser tous ees moyens d'aceroître leur fortune, il n'en reste-plus qu'un seul qui puisse être regardé comme noble et honnête, c'est la culture de la terre. Si les errements de nos ancêtres sur ce point étaient suivis même par des personnes peu instruites de la théorie, pourvu qu'elles fussent propriétaires des terres à eultiver, les biens de campagne auraient à souffrir moins de pertes, car le travail desmaittres compenserait

littoris peregrinus ignotum pererret orbem? An foeneratio probabilior sit, etiam his invisa, quibus succurrere vide. tur? Sed ne caninum quidem, sicnt dixere veteres, stıdium prostantius locupletissimum quemque adlatrandi et contra innocentes ac pro nocentibus, neglectum a unajoribus, a nobis etiam concessum intra mœnia et in ipso foro latrocinium? An lionestius duxerim mercenarii salutatoris mendacissimun aucupium circumvolitantis limina potentiorum, somnumque regis sui rumoribus augurantis? neque enim roganti, quid agatur intus, respondere servi dignantur. All putem fortunatius a catenato repulsum janitore sape nocte sera foribus ingratis adjacere, miserrimoque famulatu per dedecus, fascium decus et imperimm, profuso tamen patrimonio, mercari? liam nec gratuita servitute, sed donis rependitur lıonor. Quae si et ipsa et eorum similia bonis fugienda sunt : superest (ut dixi) unum genus liberale et ingenumm rei familiaris augendx, quod ex agricolatione contingit. Cujus pracepta si vel temere ab indoctis, dum tamen agrorum possessoribus, antiquo more adıinistrarentur, minus jacturac paterentur res rusticx. Nam industria dominorum cum ignorantia detrimentis multa pensaret : ncc quorum commodun 
les ineonvénients de l'ignoranec; outre que ceux dont l'intérèt y serait engagé ne voudraient point être taxés toute leur vie de négligence pour leurs propres affaires, et que le désir de s'instruire les conduirait bientôtà la connaissance de l'agriculture. Mais dans le siècle où nous vivons, on dédaigne de cultiver ses champs soi-même; on ne prend même pas la peine de choisir un neé. tayer habile, ou du moins un homme qui ait l'intelligence de l'esprit, et la vigueur néecssaire pour apprendre en peu de temps ce qu'il ignore. Un homme riche achète-t-il un fonds de terre? il y relègue, pour en avoir soin, le plus énervé de ses valets ou de ses porteurs, et le plus cassć par les années; sans songer que les travaux auxquels il le destine demandent dans la personne qui en est chargée, non-seulement de la science, mais encore la force du corps et la vigueur de l'âge. Si au contraire c'estun homme d'nne fortune médiocre qui fasse cet achat, il met à la tête des travaux quelque mercenaire qui n'est plus en état de gagner sa vie par ses journees, qui ne pourra lui apporter aucun profit, et qui n'a pas même les premières notions d'agriculture. Lorsque je réfléchis à cela, et que je cherche à découvrir les causes de cet abandon et de cette insouciance, je me prends à craindre qu'on n'en soit venu au point de regarder'l'agriculture comme une profession criminelle, ignominieuse, et indigne d'un homme libre. Cependant nous voyons, par le témoignage de tous nos auteurs, que nos ancétres se faisaient une gloire de cultiver leur champ. Quintius Cincinnatus, qui avait sauvé un consul assiégẻ avec son armée, fut arraché à la charrue pour prendre la dictature. Vainqueur, il déposa les insignes de cette magistraturc avec plus d'empresse-

ageretur, tota rita rellent imprudentes nerotii sui conspici ; eoque discendi cupidiores agricolationem pernosce. rent. Nunc et ipsi pradia nostra colere dedignamur, et nullius momenti ducimus peritissimum quemque villicum facere : vel si nescium, certe vigoris experrecti, quo celerius, quod ignorat, addiscat. Sed sive fundum locuples mercatus est, e turba pedisequorum lecticariorumque defectissimum annis et viribus in agrum relegat; cum istud opus non solum scientiam, sed et viridem xtatem cum robore corporis ad labores sufferendos desideret : sive mediarum facultatum dominus, ex mercenariis aliquem, jam recusantem quotidianum illud tributum, [qui rectigalis esse non possit] ignarum rei, cui profuturus est, magistrum fieri jubet. Quæ cum animadvertam, sxpe mecum retractans ac recogitans, quain turpi consensu deserta exoleverit disciplina ruris, vereor ne flagitiosa et quodammodo pudenda, aut inhonesta videatur ingenuis. Yerum cum pluribus monumentis scriptorum admonear, apud antiquos nostros fuisse glorix curam rusticationis; $\mathrm{ex}$ qua Quintius Cincinnatus obsessi consulis et exercitus liberator, ab aratro vocatus ad dictaturam venerit, ac rursus fascibus deposilis, quos festiuantius viclor reldiderat, quıau ment qu'il n'en avait montré pour les accepter ; et s'en lectourna à sa charrue pour reprendire la culture de son petit patrimoine de quatre arpents de terre. C. Fabricius et Curius Dentatus, l'un après avoir chassé Pyrrhus des frontières de I'Italie, l'autre après avoir subjugué les Sabins, labourèrent eux-mêmes les sept arpents qui leur étaient échus dans le partage des terres prises sur l'ennemi, et les cultirèrent avec autant de soin et d'industrie qu'ils avaient mis de valeur à les conquérir. Enfin, pour ne pas pousser plus loin mes citations, lorsque je considère que tant de citoyens romains, célèbres par leurs victoires, se sont distingués, soil en défendant, soit en cultivant les terres qu'ils avaient ou conquises ou reçues en héritage, je ne puis attribuer qu'à la mollesse et au luxe de notre siècle le dégoût qu'on affecte aujourd'hui pour les anciennes coutumes et les seuls travaux qui soient dignes de l'homme. Nous avons abandonné la faux et la charrue; pour aller nous établir dans l'enceinte des villes, et (ce que Varron reprochait déjà à nos aỉeux) les mains qui applaudissent dans les théatres et les cirques laissent reposer les guérets et les vignobles. Nous admirons les gestes de ces êtres efficminés qui, sur la scène, empruntent à la fenıme tous ses mouvements, et qui, pour tromper les yeux des spectateurs, imitent un sexe qui n'est pas le leur. Ne songeant qu'à la débauche, et aux moyens d'en supporter les fatigues, nous prenons des bains laconiens, pour nous délivier de nos indigestions journalières; nous provoquons des sueurs abondantes, pour exciter notre soif: Ics nuits se passent dans la débauche et dans l'ivresse; les jours sont consacrés aux jeux et au sommeil, et nous nous estimons heureux de ne

sumpserat imperator, ad eosdem juvencos et quatnor jugerum avitum herediolım redierit : itemque $\mathbf{C}$. Fabricius, et Curius Dentatus, alter Pyrrho fiuibus Italia pulso, domitis alter Sabinis, accepta, quxe viritim dividebantur, captivi agri septem jugera non minus industrie coluerit, quam fortiter armis quaesierat: et ne singulos intempestive nunc persequar, cum tot alios Romani generis intuear me. morabiles duces hoc semper duplici studio floruisse, vel defendendi, rel colendi patrios quasitosve fines : intelligo luxuria et deliciis nostris pristimm morem virilem! lue vitam displicuisse. Onıes enim (sicut M. Varro jam tenporilus avorum conquestus est) patresfamilia falce et aratro relictis intra murum correpsimus, et in circis po. tius ac theatris, quam in segetibus et rinctis manus mo. venus : attonitique miramur geslus efforminatorun, quod a natura sexum viris denegatum mulicbri motn mentiantur, decipiantque oculos spectantium. Mox deindo ut apti reukamus ad ganeas, quotidianam cruditatem La. conicis excoquimus, et exsucto sudore sitim quxrimus, noctesque libidinibus et ebrietatibus, dies lndo vel somu consunimus; ac nosmetipsos ducimus fortunatos, quod nec orieutem solem vidiuus nec occidentem. Ilaqgue istaun 
voli le suleil ni au moment de son lever, ni lorsqu'il se eouche.

Aussl cette vie láche, efféminée, ve produitelle que la faiblesse et la maladie; et nos jeunes geus sont si débiles, si exténués, que la mort ne trouve presque plus rlen d détruire. Ce ne sont plus les vrais deseendants de Romulus, dont la vie se passait presque tout entière dans les exereiees de la ehasse ou les travaux de l'agrieulture. Endureis d'avanee à toutes les fatigues, la guerre n'était qu'un jeu pour eux. Aussl préférait-on les habitants de la eainpagne d̀ ceux de la ville. Et, par la même raison qu'on regardait les eultivateurs renfermés dans l'enelos des métairies eomme plus paresseux que eeux qui travaillaient au dehors, on considérait les habitants des villes eomme plus lâches et plus indolents que eeux qui eultivalent leurs champs ou dirigeaient les travaux des laboureurs. Tout le monde sait que les assemblées ne se tenaient que les jours de marehé (nundince), c'est-d̀-dire tous les neuf jours. On avait établi eet usage, afin de ne s'oceuper des affaires de la ville qu'une seule fois tous les neuf jours, et de pouvoir se livrer le reste du temps aux soins du labourage. C'est que les hommes les plus éminents de la république habitaient alors la eampagne; et toutes les fois qu'on jugeait à propos de tenir un eonseil pour les affaires publiques, on les faisait venir de leurs métairies pour les appeler au sénat; de là le nom de viatores donné à ceux qui étaient chargés de les eonvoquer. Tant que subsista eet usage de eultiver les terres, les aneiens Sabins Quirites, ainsi que les Romains nos aneêtres, récoltèrent à travers le feu et le fer, et malgré les dévastations continuelles des ennemis, de plus riches moissons que nous n'en récoltous de nos

vitam socordem persequitur valetudo. Nam sic juvenum corpora fluxa et resoluta sunt, ut uihil mors mutatura videatur. At ineliercules vera illa Romuli proles assiduis venatibus nec minus agrestibus operibus exercitata, firmissinis pravaluit corporibus, ac militiam belli, $\mathrm{cmm}$ res postulavit, tacile sustinuit durata pacis laborilus, semperque rusticam plebem praposuit urbana. Ut enim (yii in villis intra consepta morarentur, quam qui foris terram molirentur, ignaviores lıabitos; sic eos, qui sub umbra civitatis intra monia desides cunctarentur, quan qui rura colerent [administrarentve opera colonorum,] segniores visos. Nundinarum etiam conventus manifestum est propterea usurpatos, nt nonis tamtummodo diebus urbana res agerentur, reliquis administrarentur rustica. illis enim temporibus, ut ante jam diximus, proceres ci. vitatis in agris morabantur : et cum consilium publicum desiderabatur, e villis arcessebantur in senatum. Ex quo, qui eos evocabant, viatores nominati sunt. Isque mos dum servatus est perseverantissimo colendorum agrormm studio, veteres illi Sabini Quirites atavique Romani ıuamquam intêr ferrum et ignes hosticisque incursionibus vastatas fruges largius tamen condidere, quam nos, quibus diuturna permittente pace prolatare licuit rem rusti- jours, bien gu'une longue paix nous ait permis d'apporter de grands perfeetionnements dans l'a. grleulture. C'est ee qui fait que dans le Latium, cette terre de Saturne, où les dleux cux-mê. mes avaient pris la peine d'enseiguer l'agrieulture à leurs enfants, nous en sommes réduits, pour éviter la famine, à tirer le blé de pays situés au delà des mers; et le vin, des iles Cyelades, de la Bétique et de la Gaule. Cela ne doit d'ailleurs point nous étomner, puisque de nos jour's e'est une opinion généralement aecréditée, qu'un métier aussi vil que l'agrieulture n'a besoin d'aueun apprentissage. P'our moi, lorsque j'envisage eette seienee dans toute son étendue, et que je repasse dans mon esprit les diverses parties qui composent, comme autant de membres, ce vaste eorps, je eralns bien de voir arriver la fin de mes jours avant d'avoir pénétré dans toutes les branehes de cette doetrine universelie. Quiconque en effet veut se donner pour avoir atteint la perfection de eet art, doit avoir approfondi la nature des ehoses, observé la différenee des elimats, connaitre les produetions qui eonviennent aux différentes contrées, avoir présent à l'esprit l'é. poque du lever des astres et celle de leur eoucher, pour ne pas eommeneer ses travaux dans un temps où il sera menacé de pluies ou de vents, et s'exposer à en perdre tout le fruit. Il doit aussi observer l'état de l'atmosphère et la mar. ele des saisons, qui ne suivent point toujours unc règle fixe et invariable, puisque l'été et l'hiver ue se présentent pas toutes les années sous les mêmes formes. Le printemps n'est pas toujours pluvieux, ni l'automne humide. Or, persoune ne saurait, à mon avis, prévoir toutes ces eireonstances, sans être doué d'une grande sagacité et pourvu des connaissanees les plus variées. II n'est point

cam. Itaque in hoc Latio et Saturnia terra, ubi dii cul. tus agrorum progeniem suam docuerani, ibi nuıc ad lastam locanus, ut nobis ex transmarinis provinciis aul. vehatur frumentum, ne fame laboremus : et vindenias condimus ex insulis Cycladibus ac regionibus Baticis Gallicisque. Nec mirum; cum sit publice concepta, et confirnata jam vulgaris existimatio, rem rusticam sordidum opus, et id esse negotium, quod uullius egeat ma. gisterio praceptoris. $\Lambda t$ ego, cum aut magnitudinem totius rei, quasi quandam vastitatem corporis, aut par. tium ejus velut singulorum membrorum numerum recenseo, vereor ne supremus ante the dies occupet, quan universan disciplinam ruris possin cognoscere. Nan qui se in hac scientia perfectum volet profiteri, sit oportet rerum natura sagacissimus, declinationum mundi non ignarus : ut exploratum habeat, quid cuique plagæ coll. veniat, quid repugnet : siderum ortus et occasus memoria repetat, ne imbribus veutisque imminentibus opera in. choet, laboremque frustretur. Cxli et ani prasentis mo. res intueatur. Neque enim semper eundem velut ex pre. scripto liabitum gerunt : nec omnibus annis codem vultu venit astas ant hiems : nec pluvium semper est ver, aut fnmidus autumuus. Qua præenoscere sine lumine anini 
dommé à tout le monde de bien juger la qualité d'une terre, de diseerner la nature des terrains et de déterminer les genres de produetions, et de savoir ee qu'on peutattendre ou non des propriétés du sol. Qui est eelui qui a jamais embrassé toutes les parties de l'économic rurale au point de savoir toujours bien distribuer ses terres, praliquer les labours, et distinguer les différen. tes espèees du sol qui peuvent, les unes par leur couleur, les autres par leur qualité, tromper le regard le plus exereć? Il y a des contrées où la terre noire est la meilleure, comme par exemple dans la Campanic; il y en a d'autres où la terre rouge et grasse mérite la préférence sur toutes les autres. Dans la Numidie, en Afrique, une terre friable l'emporte par sa féeondité sur le sol le plus fort, tandis qu'en Asic et en Mysie une terre compacte et visqueuse est la plus fertile. Il faut savoir, à la simple inspection d'un terrain, déterminer le genre deculture applicable aux collines, aux plaines, aux jachères, à la terre humide et fertile en herbes, et au sol see et aride. On ne doit point non plus ignorer tout ce qui concerne la plantation et l'entretien des pépinières et des vignes, dont on compte un nombre infini d'espèees différentes. Enfin il faut qu'il ait aussi les eonnaissanees néeessaires eoneernant l'aequisition et l'entretien des troupeaux; ear nous pensons que l'édueation des bestiaux doit faire partie de l'éeonomie rurale, bien que, par sa nature, elle en soit essentiellement dislinete. L'édueation des bestiaux, considérée en elle-mème, n'est point non plus une seience simple; elle renferme autant de parties qu'elle eompte de sujets différents : les eheraux, les bœuís et les brebis demandent tous des soins partieuliers. A ne considérer que les brebis, on fait une dis-

et sine exquisilissimis disciplinis non quemquam posse rrediclerim. Jam ipsa terrie varietas, et cujusque soli fıa. luitıs, quid nobis neget, quid promittat, paucorum est discerucre. Contemplatio vero cunctarum in ea disciplina jartiun quanto cuique contigit, ut et segetum arationumque perciperet usum, et varias dissimillimasque Ierrarum species pernosceret? quarum nonnulla colore nomullic qualitate fallunt : atque in aliis regionibus nigra terra, quan pullam vocant, ut in Campania, est laudathilis, in ahiis pinguis rubrica melius respondet; quibusrlam sicut in Africa Numirlix putres arenx focunditate vel robustissimum solum viucunt ; in Asia Mysiaque densa et glutinosa terra maxime exuberat; atque in lis ipsis traheret cognitum, quid (ferret aut) recusaret collis, quild campestris positio, quid cultus, quid silvester ager, quid lumidus et gramiuosus, quiil siccus et spurcus; rationem quoque dispiceret in arboribus vineisque, quarum infiuita sunt genera, conserendis ac tuendis; et in necoribus pas andis conservandisque : quoniam et hanc alscivimus quasi agriculturie partem, cum separata sit ab) agricolatione pastoralis scientia, nec ea tamen simplex. Quippe aliıd exiggt expinum, atyue aliud bubulum ar. tinction entre celles de Tarente et celles dont la laiue est moins fine. Il en est de même des chevres : eelles qui sont privées de eornes, ou qui n'ont presque pas de poil, demandent à être élevées autrement que celles qui ont beaucoup de poil et des eornes, comme les ehèvres de Cilicie. L'entretien des truies et eelui des verrats sont aussi deux choses très-différentes. En outre, les truies pelées demandent un autre elimat et d'autres soins que eelles qui ont beaucoup de soies; enfin, pour ne point nous borner à l'édueation des animaux au nombre desquels sont eomprises les différentes espèees de volailles et les abeilles, qui est eelui qui connait tous les genres de greffe et de taille, et les diverses cultures applieables aux fruits et aux légumes? Qui sait seulement distinguer les mille espèces de figuiers et de rosiers qui exigent, chacune, des soins particuliers? Ne voyons-nous pas mêmele plus souvent négllger des objets beaueoup plus importants ? Ccpendant beaucoup de personnes ont déjà commencé à retirer des bénéfices considérables des plantations de cette dernière espèce. Je ne parlerai ni des genêts ni des saussaies; je ne dirai rien non plus ni des prés, ni des roseaux, plantations qui, suns demander de grands soius, ont besoin eependant d'une eertaine culture. Je sais bien qu'en exigeant de celui qui se livre aux travaux rustiques tant de connaissanees diverses pour devenir un agrieulteur parfait, je ralentirais peut-être le zèle des commençants, qui, justement effrayés de la variété et du grand nombre des seiences qui se rattachent à l'agriculture, ne voudront pas tenter une entreprise dans laquelle ils désespèrent de réussir. Cependant il est bon, ainsi que M. Tullius le dit très-bien dans son traité de l'orateur, il est bon de tout essayer

mentum, aliud pecus ovillum; et in co ipso dissimilem rationem postulat Tarentinum atque liirtun : aliud caprinum ; et id ipsum aliter curatur mutilım et raripilum, aliter cornutum et setosum, quale est in Cilicia. Porcula. toris vero et subulci diversa professio, diversæ pastiones : nec eundem glabræ sues densieque cæli statum, nec eandem educationen cultumve quorunt. Et ut a pecoribus recedam, quorum in parte avium cohortaliun et apium cura posita est; quis tanti studii fuit, ut super ista, quac enumeravimus, tot nosset species insitionun, tot putationum? tot pomorum olerumque cultus exerceret? tot generibus ficorum, sicut rosariis impenderet $\mathrm{cu}$. ram? cum a plerisque etiam majora negligantur; quam. quam et ista jam non minima vectigalia multis esse coperunt. Nam prata et salicta, genistæque et arundines quamris tenuem nililoninus aliquaum desiderant industriam. Post laanc tam multarım tamrque nultiplicium rerum pradicationem non me praeterit, si, quem desiderauns agricolam, quemque describimus, exegero a jarticipibus agrestium operum, tardatum iri studia discen tium, qui lam varix, tamque vastae scientiac des peratione conterriti, nolent experiri, quod se consequui possp dift:- 
quaud il s'agit, ou de rechercher ce qui peut ctre atile au genre humain, ou de conscrver et de transmcttre à la postéritć ce qui a été trou vé et reconnu comme tel par nos prédécesseurs. Quand mème nous ne l'emporterions pas sur eux par le génie, et fussions-nous privés des ressources que nous présentent les arts et les sciences, nous ne devons pas pour cela nous abandonner à l'oisiveté : il faudrait, au contraire, poursuivre avec persévérance des travaux que nous avons reconnus être le plus utiles à l'homme et le plus conformes à la sagesse. Aspirons toujours au premier rang; nous recueillerons encore assez d'honneur si nous n'arrivons qu'à la seconde place. Les muses du Latium n'ont pas seulement admis daus leur sanctuaire Accius et Virgile; elles ont aussi honorablement accueilli dans leur temple les poëtes du sccond et du troisième ordre. La merveilleuse éloquence de Cicéron décou. ragea-t-cllc les Brutus, les Célius, les Pollion, les Messala, et les Calvus? Cicéron lui-même ne s'est pas laissé effrayer par les foudres que lancaicnt Démosthène ct Platon. Enfin le vicil Homère, ce père de toute éloquence, a-t-il arrèté, par les flots inépuisables de sa divive poćsie, le zèle et l'ardeur de ceux qui voulaient marcher sur ses traces? Est-ce que depuis tant de siècles des artistes moins célèbres qu'un Protogène, qu'un Apclle, qu'un Parrhasius ont, dans leur admiration pour ces grands maîtres, renoncé à leurs propres travaux? La beauté du Jupiter Olympien et de la Minerve de Phidias, tout en ravissant les artistes tels que Bryaxis, Lysip. pe, Praxitèle et Polyclète, no les a pourtant pas empêchés de faire tous leurs efforts pour arriver à la perfection. Si cn toute chose les grands

dent. Yerumtamen quod in oratore jam M. Tullius rectissime dixit, par est eos qui generi liumano res utilissimas conquirere, et perpensas exploratasque memorix tradere concupiverint, cuncta teutare. Nec si vel illa prastantis ingenii vis, vel inclytarum artium defecerit instrumentum, confestim debemus ad otium et inertian devalvi : sed quod sapienter speravimus, perseveranter consectari. Summum enim culmen affectantes satis loneste rel in secundo fastigio conspiciemur. Nam Latix musæ non solos adytis suis Accium et Virgilium recepere, sed eorum et proximis et procul a secundis sacras concessere serles. Nec Brutum aut Cælium Pollionemre cum Messala et Calvo deterruere ab eloquentiae studio fulınina illa Cice. ronis. Nam neque (ille) ipse Cicero territus cesserat tonantibus Demostheni Platonique : nec parens eloquentix, deus ille Mreonius, vastissimis fluminibus facundie sua posteritatis studia restiuxerat. Ac ne ninoris quidem fame opifices per tot jam secula videmus laborem sumu destituisse, qui Protogenem Apellenque cum Parrloasio mirati sunt. Nec pulchritudine Jovis Olympii Minervaque Phidiace sequentis atatis attonitos piguit experiri Bryaxiu, Lysipjun, Praxitclem, Polycletum, quid efficere, ant quousque progredi possent? Sed in anni ge. mailıres sont admirés ct honorés, ceux qui brillent au second rang n'en sont pas moins appréciés comme ils doivent l'être. L̇n admettant done que le cultivateur n'atteigne point au modèle que nous venons de tracer; qu'il ne soit véritablemeut supéricur dans aucune des sciences qu'exige l'agriculture; qu'il n'ait pas pénétré dans la nature intime des choses avec la sagacité d'un Démocrite ou d'un Pythagore; qu’il ne sache pas calculer le mouvement des astres ou les effets des vents avec la perspicacité d'un Médon et d'un Eudoxe; qu'il ne possède ni la science de Chiron ou de Mélampode dans l'éducation des bestiaux, ni l'expérience de Triptolème ou d'Aristée dans le labourage des terres, il aura déjà fait beaucoup s'il égale dans la pratique nos Trémellius, nos Sasernas et nos Stolons. Mais si l'agriculture n'exige point un génie supérieur, on ne saurait $y$ réussir sans être doué d'un certain jugemcut. On a eu tort de s'imaginer que c'est la science la plus facile, et qui demande le moins de discernement. Il est inutile de m'étendre davantage sur l'agriculture en général. Toutefois, a vant de traiter en détail et avec ordre les différentes parties qui la composent, je dois faire précéder ces livres de quelques considérations, que je crois ap. partenir essentiellement à l'ensemble de cetto science.

I. Quiconque veut s'appliquer à l'agriculturo doit réunir les trois conditions fondamentales, la connaissance de l'art, les ressources nécessaires pour faire face aux dépenses, et la volonté del'exćcution. Car, comme dit Trémellius, celui-là aura seul des terres bien cultivées, qui saura, pourra et voudia leur donner les soins qu'clles demandent.

nere scientia et sumnis admiratio venerationue et info. rioribus merita laus contigit. Accedit lıuc, quod ilte, quem nos perfectum esse volumus agricolam, si quiden artis consummatæe non sit, nec in universa rerum naturd sa. gacitatem Democriti vel Pythagora fuerit consecutus, et in motibus astrorum ventorumque Metonis providentiam vel Eudoxi, et in pecoris cultu doctrinam Clirouis ac Melampodis, et in agrorum solipue molitione Triptolemi aut Aristei prudentiam : multum tamen profecerit, si usu Tremellios Sasernasque et Stolones nostros aequaverit. Potest enim nec subtilissima, nec rursus, quod aiunt, pingui Minerva res agrestis adıninistrari. Nam illud procul vero est, quod plerique crediderunt, facillimam esse ncc ullins acuminis rusticationem. De cujus universitate nilil attinet plura nunc disserere: quandoquidem cuncta partes ejus destinatis aliquot voluminibus explicandac sunt, quas ordine suo tunc deınum persequar, cum prafatus fnero, quae reor ad universam disciplinam maxime per. tinere.

I. Qui studium agricolationi dederit, antiquissima sciat haec sibi adrocanda, prudentiam rei, facultatem inpendendi, voluutatem agendi. Nam is demum cultissimum rus habebit, ut ait Tremellius, qui et colere sciet et potcrit et ro- 
Lascience et la volonté ne suffiront jamais sans les dépenses que nécessitent naturellement les différents travaux agricoles; de même que la volonté, jointe aux ressources nécessaires, serait impuissante si elle n’était point dirigée par la seience. En toutc chose, ct principalement quand il s'agit d'agriculture, le point essentiel est de savoir ce qu'il faut faire; car la volonté et les moyens d'exécutiun ne sont rien sans les connaissances nécessaires, et il n'en peut résulter que des dommages pour le cultivateur. En effet, des travaux légèrement entrepris entrainent dans des dépenses qui ne produisent rien. Ainsi tout chef de famille qui, véritablement attaché à ses intérêts, tient à augmenter son patrimoine, et à le faire valoir d'après les principes d'une bonne agriculture, doit a vant tout consulter sur chaque chose l'avis des cultivateurs les plus expérimentés de son époque, étudier arec soin les ouvrages des anciens, peser mûrement leurs opinions et leurs prineipes, pour être à même de juger si les règles qu'ils nous ont laissées peurent cneore trouver leur application dans l'état actuel de l'agriculture. Jc sais bien que quelques auteurs, très-distingués d'ailleurs, ont pensé que le temps avait apporté des changements notables dans la disposition du climat et des saisons. Hipparehus, célèbre professcur d'astronomie, annonce dans ses ouvrages, qu'un jour les póles du monde changeront de position; ct Sasernas, auteur eștimé d'un traité d'économic rurale, parait avoir adopté cette opinion. Dans lc livre qu'il nous a laissé sur l'agriculture, il prètend que certaines contrées, où la rigueur excessive de l'hiver ne permettait pas autrefois de conserver des plantations d'oliviers et

let. Neque enim scire aut relle cuiquam satis finerit sine sumptibus, quos exigunt opera : nec rursus faciendi aut impendendi voluntas (facultasque) profuerit sine arte, quia caput est in omni negotio, nosse quid agendum sit, maximeque in agricultura, in qua voluntas facultasque citra scientiam sape magnam dominis afferunt jacturam, cum imprudeuter facta opera frustrantur impensas. Itaque diligens paterfamilias, cui cordi est ex agri cultu certam sequi rationem rei familiaris augendæ, maxime curabit, ut atatis suæ prudentissimos agricolas de quaque re consulat, et cominentarios antiquorum sedulo scrutetur, atque astimet, quid eorum quisque senserit, quid pracceperit : an universa, quæe majores prodiderunt, lıujus temporis culturae respondeant, an aliqua dissonent? Nultos enim jam memorabiles auctores comperi persuasumı habere, longo sevi situ qualitatem creli statumque mutari, corum. que consultissimuin astrologix professorem Ilipparchum prodidisse, tempus fore, quo cardiues mundi loco noverentur: idque etiam non spernendus auctor rei rustica Saserna videtur adcredidisse. Nanı co libro, quem de agricultura scriptum reliquit, mutatum cali situm sic collıgit, quod qua regiones antea propter lienis assiduam violeutian aullan stirpen vitis aut olea depositam, cuslodire poluerint, nunc mitigato [jam] et intepescente de vignes, sont aujourd'luui tres-fertiles en olives et en raisin, ee qui lui fait supposer que le froid qui régnait auparavant dans ces contrées s'est considérablement radouei. Que cette raison suit fausse ou vraie, c'est à l'astrologue seul à l'examiner. Quant aux autres traités d'agriculture, éerits presque tous en langue punlque par des aiteurs africains, le cultivateur ne doit pas les ignorer, bien qu'il s'en trouve plusieurs dont les prineipes ont été reconnus faux dans la pratique par nos fermiers. 'l'rémellius aussi a signalé un grand nombre d'erreurs dans ces traités; il les explique par la différence qui existe entre le sol, la température et les productions de l'Italie et de l'Afrique. Toutefois, si les principes d'agriculture de nos jours s'écartent des règles suivies dans les temps passés, on ne doit pas pour cela négliger la lecture des anciens ouvrages. On y trouve beaucoup plus de chosesà approuver qu'à rejeter. Nous a vons eneore une foule d'auteurs grees qui ont éerit sur l'agriculture; nous citerons en première ligne l'illustre poète Hésiode de Béotie, qui a beaucoup contribué au progrès de notre seience. Viennent ensuite Démocrite d'Abdère, Xénophon le disciple de Socrate, Archytas de Tarente, Aristote et Théophraste, l'un le maitre, l'autre le principal disciple des péripatéticiens, quí ont tous prêté à l'agriculture l'appui de lcurs lumières. Parmi les Siciliens, Hiéron, son disciple Épicharmus, ainsi que Philométor et Attalus, ont également contribué au progrès de cette science. Athènes aussi a produit une foulc d'autcurs qui ont traité de l'agriculture. Les principaux d'entre eux sont : Chéréas, Aristandros, Amphilochus, Euphronius, fils d'Euphron, na-

pristino frigore largissimis olivitatibus Liberique rindemiis exuberent. Sed lıæc sire falsa seu vera ratio est, literis astrologix concedatur. Catera non dissinulanda eruut agror um cultori præcepta rusticationis, quæ cun plurina tradiderint Pœui ex Africa scriptores, multa tamen ab his falso prodita coarguunt uostri coloni; sicut Tremellius, qui querens id ipsum tamen excusat, quod Italixe et Africa solum calumque diversa natura, nequeat eosdem proventus habere. Quircunque autem propter disciplinam ruris nostrorum temporum cum priscis discrepant, non deterrere debent a lectione discentem. Nam multo plura reperiuntur apud veteres, quæ nobis probanda sint, quam quæ repudianda. Magna porro et Grocorum turba est, de rusticis rebus praecipiens; cujus princeps celeberrimus vates non minimum professioni nostra contulit IIesiotus Bneotius. Magis deinde eam juvere fontibus orti sapientia Democritus Abderites, Sociaticus Xenophon, Tarentinus Archytas, peripatetici magister ac discipulus Aristoteles cum Theophrasto. Siculi quoque non mediocri cura negotium istud prosecuti sunt Ilieron et Epicharmus discipulus, Piilometor et Attalus. Athenx vero scriptorum frequentiam pejererunt, e queis probatissimi auctores Chacreas, Aristandros, Ampliilochus, Euplıronius ; Chrestus Euplıronis, non, ut multi putant, Anplipolites, qui 
tif d'Athènes et non pas d'Amphipolis, bien qu'Euphronius d'A mphipolis, avec lequel il a été souvent eonfondu, passe lui-même pour un bon agrieulteur. Dans les íles, l'agrieulture n'a point été négligée : témoin Épigène de Rhodes, Agathroele de Chio, kivagon et Anaxipolis de Thasus. Ménandre et Diodore, compatriotes de Bias, l'un des sept sages de la Grèee, se sont fait remarquer surtout par leurs eonnaissances agrieoles. Bacehius et Mnaséas de Milet, Antigonus de Cymće, Apollonius de Pergame, Dion de Colophon, IIégésias de Maronia, ne le eédèrent en rien aux auteurs que nous venons de eiter. Diophane de Bithynie a résumé et réuni en six livres les volumes nombreux de Dionysius d'Utique, interprète ct eommentateur de Magon le Carthaginois. Il y a eneore une foule d'auteurs dont nous ignorons la patrie, mais qui ont pourtant apporté leur tribut au progrès de cette seienee : ee sont Androtion, Assehrion, Aristomène, Athenagoras, Cratès, Dadis, Dionysius, Euphyton, Euphorion. Nous avons eneore, pour notre traité, mis à eontribution a vec autant de confianee Lysimaque et Cléobule, Ménestrate, Pleutiphane, Persis et Théophile. Enfin, pour aceorder le droit de bourgeoisie romaine à l'agrieulture, qui avait été jusqu'alors une seienee greeque, puisque les auteurs qui la traitèrent ćtaient Grees eux-mêmes, eitons d'abord M. Caton le Censenr, qui le premier a écrit en latin sur l'éeonomie rurale; puis les deux Saserna, père et fils, qui ont cherehé à approfondir davantage; Serofa 'Trémellius, qui lui a prêté le seeours de son éloquenee; M. Térentius, qui lui a donné une forme plus élégante; ct cnfin Virgile, qui l'a embellie par le charme de ses vers. N'oublions pas non plus les

et ipse laudahilis labetur agricola, sed indigena soli At. tici. Iusula quoquc curam istam celebraveruut. ut testis est Rhodius Ejpigenes, Clius Agatlocles, Evagon, et Anaxipolis Tlıasii. Unius quoque de septem Biantis illius populares Menander et Diorlorus in primis sibi viodicavejunt agricolationis prudentiam. Nec lis cesserc Nilesii Bacclius et Mnaseas, Antigouus Cymacus, Pergamenus Apollonius, Dion Coloplıonius, IJegesias Maronites. Nam quidem Dioplanes Bitlıynius Uticensem totum Dionysiun, Poni Magonis interpretem, per Inulta diffusum voluniua, sex epitomis circumscripsit. Et alii tamen obscuriores, quorum patrias non accepimus, aliqpor stipendium nostro studio contulerunt. Hi sunt Androtion, Aschrion, Aristomenes, Athenagoras, Crates, Dadis, Lionysius, Eupliyton, Euplıorion. Nec minori fide pro virili parte tributum nobis intulerunt Lysimachus, et Cleobulıs, Nenestratus, Pleutiplıanes, Persis et Thieoplilus. Et ut agricolationem Ronuna tandem civitate donemus, (nam adluc istis auctoribus Graecac gentis fuit) jam nunc. M. Catonem Censorium illum memoremus, qui eam latine loqui primus instituit. Post hunc duos Sascrnas, patrem et filium, qui pam diligentius erudierunt; ac deiude Scrofam Trentellium, qui etiam eloquenteın reddidiı; et M. Terentium, qui expolivit; mox éléments d’agriculture que nous devons à Julius Hyginus. Mais le plus grand lionneur revient it Magon, le père de l'éeonomic rurale, et dont l'ouvrage remarquable, divisé en vingt-huit livres, a été traduit par l'ordre du sénat. Rendons eneore hommage aux hommes de no. tre époque, Cornélius Celsus ct Julius Attieus, dont l'un nous a donné un traité eomplet d'agrieulture en einq livres, et l'autre une monographie sur le genre de culture applicable aux vignes, en un seul livre. Julius Grécinus, que l'on peut regarder comme le diseiple d'Attieus, a également légué à la postérité deux livres relatifs à la culture des vignes. Son ouvrage, bien qu'il traite du même sujet, est plus agréable et en mème temps plus profond que celui de son maítre. Ainsi, mon cher Silvinus, eonsultez avec soin tous ees auteurs, avant d'aborder l'étude de l'agrieulture. Mais ne eroyez pas que les préeeptes qu'ils-vous donnent vous rendent de suite un eultivateur parfait : ces sortes de livres sont bien moins propres à former un maitre qu'à instruire celui qui l'est déjà. La pratique et l'cxpérience, voilà ce qui est le point prineipal dans les arts. En toute chose on peut puiser un enseiguement utile dans ses propres fautes; ear lorsque une expérience, pour avoir été mal faite, ne réussit point, nous évitons de retomber dans les erreurs que nous avons eommises; et l'instruetion du maítreéelaire le disciple sur le chemin qu'il doit suivre dorénavant. On ne doit donc point s'attendre à ee que les préeeptes que nous allons donner conduisent seuls à la perfection de eet art; tout ce qu'on peut en espérer, c'est qu'ils aideront à y parvenir. Celui qui les aura lus sera loin d'être un cultivateur parfait; il lui faudra eneore la vo-

Virgiliuı, qui carminum quoque potentem fecit. Nec postremo quasi paedagogi ejus meninisse dedignemur, Julii Hygini : veruntamen ut Cartlagineusem Magonenı rusticationis parentem unaxiuc veneremur : nam luijus octo et viginti memorabilia illa volumina ex senatusconsulto in Latinum sermonem conversa sunt. Non minorem tamen laudem meruerunt nostrorum temporum viri, Cor. nelius Celsus et Julius Atticus; quippe Cornelius totum corpus disciplinæe quinque libris complexus est; lic de una specie culturae pertinentis ad vites singularem librum edidit. Cujus velut discipulus Juo volumina similium praceptorum de vineis Julius Grxcinus composita face. tius el cruditius posteritati tradenda curavit. Hos igitur, Publi Silvine, prius quam cum agricolatione contralıs, arlvocato in consilium : nec tamen sic mente dispositus, velut summam totius rei sententiis eorum consecu turus : quippe ejusmodi scriptorum inonumenta magis instrunnt, quan faciunt, artificem. Usus et experientia dominantur in artibus : neque est ulla discipliua, in qua non peccando discatur. Nam ubi quid perperam aduinistratum cessit improspere, vitatur quod fefellerat : illuminatque rectau viam docentis magisterium. Quare nostra pracepta non consummare scientian, sedadjuvare promittunt. Nec sta. tim quisquain compos agricolationis erit lis perlectis ra- 
DE I'AGRICUITURE, LIV. I.

ionté et les r'ssources nécessaires pour les mettre: à exécution. Ce sont des appuis que nous offrons à ceux qui voudront s'en servir, mais qui ne peuvent rien par eux-mêmes. Il faut encore se trouver dans les conditions que nous venons d'indiquer. Il y a plus : toutes ees conditions réunies, e'est-ì-dire un travail assidu, l'expèrience du mćtayer, la volonté de dépenser, et la fuculté de le faire, ne valent pas, à beaucoup près, la seule présence du maitre. Si le maitre ne surveille pas activement les travaux, il arrivera ce qui arrive dans une armée lorsque le général ('st absent : tout sera négligé, personne ne fera son devoir. Je pense que e'est là le véritable sc'ns des paroles que Magon a placées en têtc de son ouvrage. "Quiconque veut acheter une terre, dit-il, doit vendre sa maison, de peur qu'il ne se plaise plus à la viıle qu'à la campagne; celui qui fait beaucoup de cas d'une maison n'a pas besoin de fermc. Je m'en tiendrais même à ee price'epte, s'il pouvait être observé dans ce tempsci. Mais puisqu'aujourd'hui l'ambition nous appelle souvent à la ville, et qu'elle nous y retient encore plus souvent, je pense qu'il est plus conmode d'avoir un bien de campagne qui en soit proehe, afin qu'on puisse s'échapper tous les snirs, si occupé qu'on soit, pour y aller après les affaires du barreau terminées. Car pour ceux qui achètent despropriétés éloignées, presque au delà des mers pour ainsi dire, ceux-là abandonnent de leur vivant leur patrimoine à leurs héritiers, et, qui pis est, d leurs eselaves, avant la mort de leur maitre. En effet, rassurés par l'éloignement du proprietaire, ils se livrent à tous les viees; et, en attendant que de nou veaux maitres viennent prendre possession du domaine, ils songent plus a le piller qu’à le cultiver.

tionibus, nisi et otire eas voluerit, ef per facultates polierit. Idenque liec relut adminicula studiosis promitliums, nou profntura per se sola, sed cum aliis. Ac ne ista quidem prasidia, ut diximus, non assidnus labor et ex. perieutia villici, non facultates ac roluntas inpendendi tanlum pullent, quantum rel una prasentia domini : qua nisi frequens operibus intervenerit, ut in exercitu cum alxest imperator, cuncta cessaut officia. Maximerjue reor hoc significautem P(enum Magonem, suorum scrip). torum prinordiun talibus auspicatıun sententiis : "Qui agrum paravit donum venolat, ne malit urbanum, quam ruslicun larem colere; cui unagis cordi fuerit urbanum donicilium, rustico priedio non crit opus." Quod rgo prareptum, si possel lis temporibus observari, non iununtarem. Nunc quonian plerusque nostrum civilis anlitio sape evorat, ac sappius detinet evocatos, seyuitur ut suburbanm pradimu commolissiumu esse puten, quo rel occupato quoticianus excursus facile post negolia fori contingat. Nam qui longiuc|ua ne dicam transmarina rura incrcautur, velut lacededibus patriunonio suo, vel quod gravius est, vivi cedunt servis suis : quoniau quirlem et illi tam louga douniuoruı dislaulia cormmpuntur, et corrupti post flagitia, 'pute coumsiscrunt, sub LULS MI.H.
II. II imporle done que le fonds de terre quion voudra acheter ne soit pas éloirné de la ville, afin que le maitre puisse souvent le visiter. II suffira d'annoneer son arrivéc prochaine, pour que cette crainte contienne le métayer et ses gens dans les limites du devoil. Le maitre séjournera donc à la eampagne le plus de temps qu'il lui sera possible; et ce temps ne doit être consacré ni à l'agréınent ni à l'oisiveté. Un chef de famille, vẻritablement attaehé à ses intérêts, doit visiter toutes les parties de ses possessions, et à toutes les époques de l'année. Il examinera avec soin la nature du sol, aussi bien daus le temps où les fruits sont eneore en herbe et en feuilles, que dans celui oú ils sont arrivés à leur point de maturité. Il se rendra bien eompte des différents travaux qui doivent être exécutès dans les différentes parties de son domaine. Un ancien proverbe, déjà cité par Caton, nous dit que le plus grand fléau d'une terre, c'est d'avoir un maitre qui, au lieu d'ordonner lui-même les travaux qu'elle exige, est forcé de prendre eonseil de son métayer.

Qu’on ait acquis unc propriété par héritage ou par transaction, il importe avant tout de conuaitre la nature du sol où elle se trouve. Dans le eas où elle serait placée dans des conditions defavorables, il faudrait s'en defaire, pour en acheter une autre. Si la fortunc cxaueait mes vœux, je lui demanderais une terre situéc dans un climat sain et fertile, partic en plaine, partie ell eollines légèrement inclinées du côtć du midi ou de l'orient: elle se composerait de terrains labourables, de bois et de terrains ineultes; elle se trouverait près de la mer, ou d'un fleuve navigable qui faciliterait l'exportation de ses différents produits, et l'importation des denrées né-

expectatione successorum, rapinis magis quam culturis student.

1I. Censco igitur in propinquo agrum mercari, (quo et frequenter dominus reniat, et frequentius se renfurum, quam sit venturns, denunciet. Sub lıoc enim metı cuu familia villicus erit in ofticio. Quicquid vero dabitur occasionis, ruri moretur. Quæ non sit mora segnis, nec umbratilis. Nan diligentem palremfanilias decet agri sui particulas onnes et omni tempore anni frequentius circum. ire, quo prudentius naturam soli sive in frondibus ct lıerbis, sive jan maturis frugihus contemplelur : nec ignoret quilłnuid in co recte fieri poterit. Nan illud vetus est [et] Catonis, agrum pessime nul lari, cujus dominus quid in eo faciundum sit, non docet, sed audit rillicıu. Quapropter vel a majoribus traditum possidenti vel emppturo fundum praecipua cura sil scire, quod maxime regionis genus probetur : "It vel careat inulili, vel mercetur laudabilem. Quod si roto fort una subscripserit, agrum labebimus salubri crelo, uberi globa, parte campestri, parte alia collitus vel al orientem vel ad meridiem nolliter derexis; terrenisque alıs ac cultis, atque aliis sılvestribus et aspetis, nec procul a mai aut navigabili tlumine, фино deportiri finctus, et per quol merces iuvehi 
cessaires à son exploitation. Ies plaines qui entoureraient les bátimenls de la métairie seraient distribuées en prairies, en terres labourées, en saussaies, et en plantations de roseaux. Quant aux collines, la partic qui ne sera point plantée d'arbres sera réservéc exelusivement au blé, bien qu’il vienne mieux dans des plaines médiocrement sèches et grasses, que dans des terrains en pente. Par eette raison, les terres à blé, même les plus élevées, devront être aplanies autant que possible, et présenter une pente très-douce, e'est-à-dire ressembler autant que possible aux plaines. Pour les autres collines, elles seront plantées d'oliviers, de vignes et d'arbres, dont oı tirera les éehalas nécessaires pour soutenir les premiers. Il y aura d'autres collines qui fourniront le bois et les picrres pour les différentes eonstructions, et d'autres eneore qui serviront de paturages aux troupeaux. L'eau qui déeoulera des montagnes (dans eette ferme modèle) se répandra en ruisseau dans les prairies, les jardins et les saussaies, et arrivera, au moyen de canaux, jusque dans l'eneeinte de la métairie. Des troupeaux de gros bétail et d'autres quadrupèdes paitront en foule dans les ehamps et les bois. Mais une situation telle que nous la désirons est rare et difficile à trouver : la meilleure sera toujours celle qui réunira le plus grand nombre de ces avantages; une propriété qui n’en aurait que quelques-uns liest point encore à dédaigner.

III. Poreius Caton dit qu'en achetant une propriété, il faut envisager avant tout deux clioses: la salubrité du climat, et la féeondité du sol. Celui qui voudrait eultiver une terre qui ne satis. ferait point à ees deux eonditions ne peut être qu'un fou, qu'il faudra plaeer sous la tutelle de

possint. Campus, in prata et arva salictaque et arundineta digestıs, acdificio sulyaceat. Colles alii vacui arboribus, ut solis segctibus serviant; qua tamen ntodice sircis ac pinguibus campis melius quam pracipitibus locis proveniunt. Jleoque ctiam celsiores agri frumentarii plauicies lıbere, ct quuanı mollissime devexi, ac simillimi debent csse campestri positioni. Alii deinde colles olivetis vinetisque et carum futuris pedamentis vestiantur, materiam lapidemquc, si necessitas æediticandi coegerit, nec minus pecudibus pascua præberc possint. Tum rivos lecurrentes in prata ct liortos ct salicta, villaque aquas salicntes denittant. Nec absint greges armentorum, cxterorumque quadrupedum culta ct dumeta pascentium. Sed lıæc positio, quan desideranus, difficilis et rara paucis contingit. Proxima est luuic, quac plurima ex lis habet : tolerabilis, quæ non paucissima.

III. Porcius quidem Cato censebat in cniendo inspiciendoque agro præcipuc dıo esse consideranda, sa. lubritatem cali et ubertatcm loci : quorum si alterum deessel, ac uilıilo minus quis vellet incolere, mente csse captıu, atque cum ad agnatos et gentiles deducendum. Deminem euiu sanum debcre facere sumptus in cultura ste- ses parents paternels. Quel lomme de bon sens voudrait en effet se mettre en frais pour cultive. un terrain inglat? De même, si le terrain est bon et fertile, mais le climat malsain, il est rare que le maitre puisse jouir des fruits de son tra. vail. En effet, dans une eontrée où il faut lutter eoustamment avec la mort, non-seulement la récolte, mais la vie même du propriétaire ne sont point en sûreté; ou, pour mieux dire, la mort y est plus certaine que les bénéfices qu'il se promettait. Caton ajoute à ees deux points principaux trois autres qu'il n'importe pas moins de prendre en eonsidération: ce sont les routes, l'eau et les environs. Les bonnes routes sont d'une grande utilité pour une terre; d'abord et prineipalement par rapport aux voyages du maître, qui se rendra toujours avee d'autant plus de plaisir à sa terre, qu'il n'aura point à craindre les incommodités d'une route diffieile; seeondement par rapport à l'exportation et l'importation, puisque les bonnes routes augmentent le prix des fruits qu'on emporte, et diminuent celui des denrées qu'on veut faire rentrer à la métairie. Car plus la eommunieation est faeile, moins il y a de frais de transport. De plus : les frais de voyage seront moins eonsidérables, surtout, si l'on fait la route sur des bètes de louage, ce qui est toujours moins eoûteux que d'avoir à entretenir des attelages à soi. Enfin les eselaves qui doivent aceompagner le maitte auront plus de facilite pour le suivre à pied. Quant à la qualité de l'eau, c'est là un point dont l'importanee saute tellement aux yeux qu'il est inutile de la démontrer davantage. Qui oserait en effet douter de la néeessité d'une eau de bonne qualite, sans laquelle personne, quelle que soit d'ailleurs sa constitution, ne saurait prolonger

rilis soli : nec rursus pestilenti quanıvis feracissimo pinguique agro dominum ad fructus pervenire. Nam ubi sit cum orco ratio ponenda, ibi non modo perceptionem fructuum, sed et vitam colonorum esse dubiam, vel potius mortem quæstı certiorem. Post lıac duo principalia subjungebat illa non minus intuenda, viam ct aquau et vicinum. Multum conferre agris iter conmodum : primum, quod est maximum, ipsam prosentiam domini, qui libentius conmeaturus sit, si vexationem via non reformidet. Deinde ad invelienda ct exportanda utensilia; quae res frugibus conditis augct pretium, et ninuit in. pensas rerum invectarum : qui minoris apportentur eo, quo facili nisu perveniatur. Nec nilil esse etiam parvo vehi, si conductis jumentis iler facias, quod magis expedit, quam tueri propria. Servos quoque qui secuturi pa. tremfamilias sint, non agre iter pedibus ingredi. De bonitate aqua ita omnibus clarım est, ut pluribus non sit disserendun. Quis enim dubitet, eam maxime probatam haberi, sine qua nemo uostrum vel prosperæ vel adversæ valetudinis vitam prorogat? De vicini conmodo non est quidem certum, quem nonnunquam mors alia:que nobiscum (diversx) causæ mutant. Et ídco quidau re. 
la vie? Quant à l'avantage qu'on peut retirer de ses voisins, e'est un point sur leçuel on ne pent rien déeider d'avanee, puisque la mort peut nous les ravir, ct d'autres circonstances peuvent en amener de nouveaux. Les personnes qui n'admettent point à ce sujet les opinions de Caton nous paraissent être dans une grande erreur. En effet, s'il est d'un homme sage de savoir supporter l'adversité, il n'y a que l'insensé qui puissc vouloir conjurer le malheur. Or, c'est précisément ce que ferait cclui qui donnerait son argent pour acquérir un mauvais voisin. D'ailleurs, tout homme né de parents libres a dû entendre dire dès sa premic̀re jeuncsse qu'on ne perdrait jamais de bœuf, s'il n'y avait pas de mauvais voisins. Ce proverbe peut s'appliquer non-seulement aux bestiaux, mais à toutes sortes de valeur, quelle qu'cn soit la naturc. Beaucoup de personnes ont mieux aimé abandonner leurs pénates et fuir leur domicile, que de rester exposées aux vexations de leurs voisins. Des peuples tout enticrs, ne pouvant supporter la méchanceté de leurs voisins, ont quitté le sol de lcur patrie, et sont venus chercher un refuge dans des pays étrangers : témoin les Achéens, les Hibériens, les Albariens, ainsi que les peuples auxquels nous devons notre origine, les Pélasgiens, les Aborigènes ct les Arcadiens. Euffin, pour ne pas nous bortuer à ces calamités publiques qui fiappèrent des nations entières, l'histoire ne nomme-t-elle pas une foule d'hommes privés qui se sont sigualés, soit dans la Grèce, soit dans notre Hespérie, comme des voisins intolérables? Le fameux Autolycus n'était certes pas un voisin bien accommodant, et l'on ne dit pas que Cacus, établi sur le mont Aventin, ait fait le bonheur de ceux qui habitaient le mont Palatin. Si je

spuunt Cafonis sententiam : qui tamen multum videntur errare. Nam quemadınodum sapientis est, fortuitos casus magno animo sustinere, ita dementis est ipsum sibi malan facere fortunam: quod facit, qui nequam vicinum suis uumis parat, cum a primis cunabnlis, si mouto li-

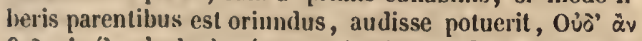

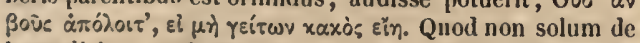
bove dicitur, sed etiam de omnibus partibus rei nostra familiaris : alleo quidem ut multi prætnlerint carere penatibus, et propter injurias vicinorum sedes suas profu. geriut. Nisi aliter existimamus diversum orbem gentes universas petiisse relicto patrio solo, Achicos dico et llilheros, Albanos quoque, nec miuus Siculos, et, ut primordia nostra contingam, Pelasgos, Ahorigines, Arcadas, quan quia malos vicinos ferre non potuerant. Ac ne tantum de publicis calamitatibus loquar, privatos quoque mentoria tradiclit et in regionibus Graciae et in lac ipsa Ilesperia detestabiles fuisse vicinos; nisi si Antolycus ille cuiquau poluit tolerabilis esse conlerminus; aut A ventini montis incola Palatinis ullum gaudiun finitimis suis Cacus altılit. Nalo euin proteritorum, quan prosentium meminisse, ne vicinum meun nomincm, qui nec arborem prends mes exemples dans le passé, et non dans le présent, c’est parce que je ne veux point uonmer un de mes propres voisins qui n'épargne ni arbre tout venu, ni arbrisseaux plantés en pépinière, qui arrache l'échalas, appui de la vigne, ct qui ne laisse point paître tranquillement les troupeaux dans les prairies. C'est donc avec raison, á mon avis, que Porcius nous conseille de fuir un pareil fléau, et qu'il avertit le futur agronome de se mettre en garde contre un tel malheur. Nous ajouterons aux préceptes de Caton celui qu'un des sept sages a laissé à la postérité : c'est de garder un milieu et une juste mesure en toute chose ; et cela doit s'appliquer à l'acquisition des biens fonds aussi bien qu'à toutc autre affaire. D'après ce principe, gardons-nous avant tout d'acheter plus de terres que nos moyens ne nous permettent d'en cultiver; c'est du moins le véritable sens de la bclle sentence de notre poëte, lorsqu'il nous dit : Admircz, si vous voulez, une grande ferme, mais n'en cultivez qu'une petite. Le savant poëte a, ce me semble, voulu consigner dans ces vers un ancien proverbe que nous devons à la nation la plus industrielle du monde, aux Carthaginois. La terre, disent-ils, ne doit pas être plus forte que le laboureur. C'est qu'en effet lorsque la terre et le laboureur sont aux prises, si la ferme l'emporte, le fermier. sera ruiné. D'un autre côté, un petit champ bien cultivé rapporte plus qu'un grand qui le serait mal. Aussi nos ancêtres tirèrent-ils plus de profit des sept arpents de terre que le tribun Licinius, après l'expulsion des rois, avait assignés à chaque citoyen, que nous n'en tirons aujourd'hui des guérets les plus étendus. Curius, dont nous avons parlé plus haut, pensait que c'était là une fortune plus que suffisante même pour un con-

prolixioreun stare nostræ regionis, nec inviolatum seminarium, nec pedamentum adnexun vinea, nec etiam pecudes negligentius pasci sinit. Jure igitur, quantum inea fert opinio, M. Porcius talem pestem vitare censuit, et in prinis futurum agricolam pramonuit, ne sua sponte ad eam perveniret. Nos ad cretera præcepta illud adjicimus, quod sapiens unus de seplem in perpetuum posteritali pronnuciavit, adlibendun modum mensuramque rebus; idque, ut non solını aliud acturis, sed et agrum paraturis dictum intelligatur, ne majorem, quam ratio calculorum patiatur, emere velint. Nam luc pertinet praclara nostri poeta sententia : Laudato ingentia rura, exiguum colito. Quod vir erudissimus, ut unea fert opinio, traditum retus proceptum numeris signavit. Quippe acutissinnan gentem renos dixisse convenit, imbecilliorem agrum quam agricolam esse debere: quoniam, cnm sit colluctandum cum eo, si fundus prevaleat, allidi dominum. Nec dubium quin minus rerdat laxus ager non recte $\mathrm{cul}$ tus, quan angustus eximie. Ideoque post reges exactos Liciniana illa septena jugera, qua plebi tribunus viritinı diviserat, majores quaxestus antiquis retulere, quam nunc nobis probent amplissima vetereta. Tanta quidem Curius 
sul et un triomplialeur. En effet, lorequio le peu. ple: Iui offrait einquante arpents à litre décécompense après la victoire qu'il venait de remporter, et qui était due à son habileté et à son courage, il refusa ee présent, et se eontenta de la portion du dernier des citoyens. Plus tard, forsque nos victoires ct l'extermination de nos funemis curent laissé beaueoup de terres vacantes, on regarda comme un crime chez un sénateur de posséder plus de cinc cents arpents. C. Licinius fut condamné, pour avoir outre-passé par cupidité la mesure fixée pour elaque eitoyen par la loi qu'il avait portée lui-même pendant son tribunat. Et ce n'était pas seulement pour le punir de son orgueil qu'on le condamnait, mais paree qu'on regardait comme un crime de laisser incultes des champs déjà ravagés par les ennemis, ce qui ne pouvait manquer d'arriver lorsqu'un eitoyen romain en possédait plus que sa fortune ne lui permettait d'en cultiver. Comme en toutes ehoses, on gardera dans l'acquisition des terres une juste mesure ; et on n'en aura qu'autant qu'il en faut pour paraître les avoir achetées a l'effet d'en jouir, et non pas pour en ctre surchargé soi-même, ni pour enlever à d'autres le đroit d'en user : à l'exemple de ces gens immensément riches qui possc̀dent des pays tout entiers, riont ils ne pourraient même pas faire le tour à clieval. Ils sont foreés de les abandonner aux bestiaux ct aux bêtes féroces qui les ravagent; ou bien ils les peaplent de citoyens emprisonnes pour dettes, ou d'esclaves attachés à la chaine. L'étendue même des fermes doit donc dépendre hon-seulement de la volonté, mais encore des ressources de chaeun; car il ne suffit pas, comme je l'ai dit plus haut, de vouloir posséder, il faut sucore pouvoir eultiver.

Dentatus, quem paulo ante retulimus, prospero duetı parta victoria, ob eximian virtıtem defereute populo praenii nomine quinquaginta soli jugera, supra consularem triumplaalemque fortunam putavit satis esse : repustiatoque publico munere populari ae plebeia mensura coutentus finit. Mox etiam cum agrorum vastitatem vietoria: uostrat et interniciones loostium fecissent, eriminosum tamen senatori fuit supra quingenta jugera possedisse, suarne lege $\mathbf{C}$. Licinius damnatus est, qnod agri nodmm, quem iu nagistratu rogatione tribunicia promulgaverat, immorlica possidendi libidine transeendisset : nec magis quia superbum videbatur tantum loci detinere, ‘nam quia llagitiosum, quos lostis profugiendo desolas. set agros, novo more civem Romanum supra vires patrimonii possidendo deserere. Modns ergo, qui in omnibus rebus, etiam parandis agris adlibebitur. Tantum enim obtinendum est, qnanto est opus, ut emisse videamur, quo potiremur, won quo onerarenur ipsi, atque aliis fruendım erijerenus; more propotentium, qui possident fines gentium, gnos ne eircumire equis quidem valent; sed proculcandos perudiluus, et vastandos (ae popntandos) feris derelinquunt, aut oceupatos nexu civium, et
IV. Nous arrivons maintenant au précepte que Céson nous a donné le premier, et que Caton a irgalement adopté : e'est de visiter souvent la ter'e qu'on se propose d'acheter. Une première inspection ne suffit point pour nous faire découvrir ses avantages ou ses défauts caelés; ce n'est qu'en la visitant sonvent que nous pouvons la juger. Nos aneêtres nous ont indiqué le moyen d'examiner une terre, et de discerner: si elle est grasse et fertile. Nous en parlerons en son lien, lorsqu'il sera question des différentes espèess dle terre. Mais sans entrer ici dans ce détail, je reviendrai encore sur cet axiome qu'on ne saurait eiter trop souvent, et qui est attribué à M. Attilius Régulus, fameux général du temps de la première guerre punique; c'est que, de même qu'il ne faut pas aeruérir un fonds de terre, si fertile qu'il soit, lorsque le climat en est irsalubre, de même il ne faut pas non plus aehefer une propriété dont le sol est stérile, si salubre que soit le climat. $\mathrm{Or}^{\circ}$, ce conseil qu'Attilius donnait aux eultivateurs de son époque avait d'autant plus de poids dans sa bouche, qu'il parlait d'après sa propre expérience. En effet, l'histoire nous apprend qu'il cultivait une terre ingrate et pestilentielle dans le territoire de Pupinia. De même yu'un homme intelligent ne doit point aeheter une propriété dans toutes sortes d'endroits, ni se laisser tromper par les avantages d'un sol fertile ou d'une situation agréable, de même un bon chef de famille doit ehereher à faire fructifier et tirer un bon produit des biens qu'il a aequis soit par transaction soit par lıéritage, quelle qu'en soit la nature. Dans cette vue nos devanciers nous ont laissé beaucoup de préceptes qui ont pour but d'améliorer un climat nualsain, d'atténuer des exhalaisons pestilentielles, et de

ergastulis tenent. Modus antem erit sua euique I morerata ] voluntas facultasque. Ne(jue euim satis est, ut jam prins dixi, possidere velle, si colere non possis.

IV. Se(puitur deiuceps Cacsoniaum pracep,tum, quo fertur usus etiam Calo Marcus, agrum esse revisendum sxpins eım, (juem velis mercari. Nam prima inspectione neq̧ue vitia neque virtutes abditas ustendit, quae mox retractantibus facilius applarent. Inspectionis quoque vilut formula nobis a majoribus trarlita est agri pingnis ae lacli : de enjus qualitate dicemns suo loco, cum de generibns terra disscremus. In universum tamen quasi testificandum atque sapius.pradicandum habeo, quod primo jam Punico bello dux inclutissimus M. Attilius Regnlus dixisse memoratır, fundnm sicuti ne foccundissimi quidem soli, cum sit insalubris; ita nec effeti, si vel saluberrimns sil, parandnm : quod Attilius actartis sux agricolis majore cum auctoritate suadebat peritus usu. Nam Pupinia pestilentis simul et exilis agri cultorem fuisse eum loquuntur historiæ. Quapropter cum sit sapientis non ulsique emere, nec aut ubertatis illecebris ant delieiarum concinnitate decipi: sie vere industrii patrisfamilias est quicquid aut emerit ant acceperit, ficere fructuosum atque ufile : quonian et 
vaincre a foree de travail et de soin l'ingratitude du sul dans une contrée stérile. Or, vous atteindrez ee but, si rous suivez, comme ceux d'un oracle, les conseils du plus véridique des pro. phètes : " Cherchez à bien connaitre d'avanceles vents et les elimats, le mode de culture pratiqué par vos prédéeesseurs, et la nature du sol, afin que vous sachiez ce que chaque contrée peut rapporler, et ee qu'elle refuse au cultivateur. „ Cependant, quelle que soit l'autorité des aneiens cultivaleurs, elle ne doit point nous faire renoncer à nos propres expériences nouvelles. Si ces sortes d'essais ne sont pas sans ineonvénient, il en résulte toujours du moins un avantage réel pour la ferme; parce qu'en général on ne cultive jamais de terre sans en retire un profit queleonque, ct que le maitre, en essayant, parvient à connaitte le geure de culture qui convient le mieux à sa ferme. Les essais augnientent le produit des champs les plus fertiles; c'est pourquoi il ne faut jamais craindre de les tenter, surtout dans les terres grasses, où l'on peut être sûr que le produit dédommagera toujours de la peine qu'on aura prise et des dépenses qu'il aura fallu fairc. Mais de même qu'il est important de eonnaître la qualité d'un fonds, et la manière de le eultiver, il ne l'est pas moins de savoir comment la métairie doit être bâtie, et quelle doit être sa disposition pour en tirer un bon parti. Sous ce rapport, les hommes les plus illustres ne sont pas toujours exemptsd'erreur : témoin L. Lucullus et Q. Scévola. La villa de Lueullus était plus grande que ne le comportait la ferme, tandis que celle de Scévola avait le défaut contraire. L'un et l'autre défaut sont également nuisibles aux intérêts du proprietaire. Si les bâtiments sont trop vastes, ils

gravioris cali multa remedia priores tradidernnt, quibus mitigetur pestifera lnes; et in exili terra cultoris pru. dentia ac diligentia maciem soli vincere polest. Hac antem consequemur, si verissimo vali velut oraculo crediderimus dicenti : Venlos et proprium cali prediscere morem cura sit ae palrios cullusque habitusque loco. rum, el quid qureque ferat regio et quid quague re. cusel : nec contenti tamen auctoritate vel priormm vel prasentium colonorum nostra prætermiseriınus exempla, novarue teutaverimus experimenta. Quod etsi per parles nomunuquam damnosum est; in summa tamen fit compendiosım, quia nullıs ager sine profectu colitur, simul ac tentaudo possessor eflicit, ut in id formetur, quod ma. sime praslari possit. Ea res etiam feracissimos agros uti. liores reddit. Itaque uusquam experimentormm varietas onitteuda est ; longeque etian in pingui solo magis audendum, quoniam neclaborem nec sumptum frustratur effectus. Sell cum refert, qualis fundus et quo nodo colatur; Imun villa qualiter acdificetur, et quam utiliter clisponatır. Multos enim deerrasse, memoria prodidit, sicut prastantıssinos viros I. Lucullum et Q. Scatulam, fuornm alter majores after mimus amplas, quun postulavit modus agti, villas evtrusit, cum utınupue sit contıa rem faui- néeessitent de grands frais de eonstruction et d'entretien; s'ils sont petits par rapport au fonds de terre, on est exposé à perdre une grande partie de la récoltc. En effet, toutes les productions de la terre, eelles qui sont sèelies aussi bien que celles qui sont liquides, se gattent faeilement, si l'on n'a pas d'endroits couverts, spaeielıx et conlmodes, où l'on puissc les resserrer. L'habilation du maitre doit être aussi élégante que sa fortune le lui permet, afin qu'il vienne avec plaisir a sa campagne, et que le séjour qu'il y fera lui paraisse agréable. S'il se fait aeeompagner de sa femme, dont le sexe et le goût sont plus délieats, ces sortes d'embellissements seront d'autant plus néeessaires qu'elle consentira plus ficilement à rester avec son époux. Qu'un agrieulteur bâtisse donc élégamment, sans se laisser entraíner d'ailleurs à des dépenses excessives. Vos bâtiments, nous dit Caton, devront être proportionnés à l'étendue de vos terres, de crainte que votre villa ne eoure après votre ferme, ou votre ferme après votre villa. Nous allons expliquer maintenant quelle est la meilleure situation d'une villa. Il ne suffit point de la placer dans une contrée salubre, il faut encore choisir pour son emplaeement la partie la plus saine de la ferme tout entière. Lorsque l'air qui environıe le bâtiment est corrompu, la santé est exposée à mille influenees nuisibles. Il y a des endroits qui aux solstices souffrent moins de la chaleur que les autres, mais où le froid est insupportable dans l'hiver, comme, par exemple, Thèbes en Béotie. Il y en a d'autres où l'hiver est doux, mais où la ehaleur est pesante en été, comme Chaleis dans l'Eubée. Il faut donc ehercher un air tempéré, qui ne soit ni trop chaud ni trop froid,

liarem. Diffusiora enim consepta non solum pluris aedificamus, sed etiam impensis majoribus tuemur : at minora cun suıt, quam postulat fundus, dilabitur fructus. Nam et liumidae res et siccae, quas terra progeneral, facile vitiantır, si aut non sunt, aut propter angustias incom. moda sunt tecta, quibus inferantur. Pro portione etiam facultatum, quam optime paterfamilias debet labitare, ut et libentius rus veniat, et degat in eo jueundius; IItiqus vero, si etiam matrona comitabitur, cujus ut sexus ita animus est delicatior : qua mobrem amo'nilate aliqua demerenda erit, quo patientins morefur $\mathrm{cum}$ viro. Elegauter igitur adificel agricola : nec sit tamen acdificator; atque arex peden tantum complectatur, quod ait Cato, quantum ne villa fundum quaerat, nevo fundus villam : cujus universum situm qualem oporteat esse, nunc explicalir mus. Quod inclıatur aediticium, sient salıhri regione ita saluberrima parte regionis debet coustitui. Nam circunifu. sus aer corruptus plurimas affert corporibus nostris causas offensarum. Sunt quadam loca, qux solstitiis ninus concalescunt, sed frigorihus hiemis intolerabiliter lıorrent, sicut Thebas fernnt Borotias. Sunt qua tepent lieme, sed astate sievissime candent, ut affimant Euboicam Chalci. deur. Petalu igitur aer calore et frigore temperatus, qui 
tel qu'il est communément vers le milieu des collines; par la raison que eette partic n'est ni assez enfoncée pour être engourdie par les gelées de l'hiver ou brûlée par les ehaleurs de l'été, ni assez élevée pour avoir rien à redouter soit des vents, qui sont toujours furieux sur le haut des montagnes, soit des pluies, qui tombent a vee plus de violenee dans les endroits élevés que partout ailleurs. La situation la plus favorable pour une villa sera done au milieu d'une colline; on aura soin toutefois d'y choisir un endroit plus élevé que le reste du terrain, de erainte que les torrents formés par les pluies ne viennent à entrainer les fondements de l'édifiee, lorsqu'ils se précipitent dans la plaine.

V. Il faut qu'il $y$ nit des eaux vives qui eoulent à travers la métairie, soit qu'elles $\mathrm{y}$ prennent lcur souree, soit 'qu'elles la prennent au dehors; qu’il y ait dans le voisinage un lieu d'où l'on puisse tirer sa provision de bois, et qui présente des pâturages. S'il ne s'y trouve point d'eau courante, on cherehe dans les environs un puits qui ne soit pas profond, et dont l'eau ne soit ni amère ni salée. Si l'on manque absolument d'eau courante, et qu'on ne trouve même pas d'eau de puits, on eonstruira de vastes eiternes à l'usage des hommes, et des abreuvoirs pour les bestiaux. On y reeueillera dans les uns comme dans les autres l'eau des pluies, qui est très-boune, surtout lorsqu'on la fait passer à travers des tuyaux de terre cuite quil la eonduisent dans une citerne couverte. Après l'eau des pluies la meilleure est celle qui, prenant sa source dans lesmontagnes, s'y préeipite à travers des rochers, eomme par exemple l'eau du mont Guareenus en Cam. panie. On place au troisième rang l'eau qu'on tire des puits creusés sur des collines, ou du moins dans des vallées d'une certaine élévation.

fere medios obtiuet colles, quod neque depressus lieme pruinis torpet, aut torretır astate vaporibus, neque elatus in summa montinm perexiguis ventorum motibus aut pluviis omni tempore anni savit. Hæc igitur est medii collis optima positio, loco tamen ipso paululun intumescente; ne cum a vertice torrens imbribus conceptus adfluxerit, fundamenta convellat.

V. Sit autem vel intra villam vel extrinsecus inductus fons peremis; lignatio, pabulunque vicinum. Si decrit fluens unda, putealis quaratur in vicino, quae non sit lıaustus profundi, non amari saporis aut salsi. Hace quo. que si deficiet, et spes arctior aquo manantis coegerit, vastre cisternx lıminibus piscinaque pecoribus instruantur, colligendae aquæ tandem plıviali, qua salubritati corporis est accommodatissima. Sed ea sic lıabetur eximia, si fictilibus tubis in contectam cisternam deducatur. Iuic proxima fluens agua e montibus oriunda; si per saxa pra. ceps devolvitur, ut est in Guarceno Campanize. Tertia pu. tealis collina, rel qua non infima valle reperitur. Deterrima palustris, qux pigro lapsu repit. Pestilens, quı in palucle semper consislit. Hic iłem tanen lı!mor, quamvis
La pire de toutes e'est l'eau maréeageuse, dont le mouvement est lent et presque impereeptible. Quant à celle qui eroupit dans les marais, sans jamais s'écouler, elle est véritablement pestilentielle; et cependant, si nuisible qu'elle soit, elle se corrige par l'eau des pluies qui tombent dans l'hiver. On voit par là eombien l'eau des pluies doit être salutaire, puisqu'elle a la vertu de pu. rifier l'eau des marais. Aussi, comme nous l'avons dit, c'est la meilleure qu'on puisse employer pour servir de boisson. En outre, les ruisseaux contribuent beaucoup à modérer les chaleurs de l'été, et à rendre le pays plus agréable. Si leur eau est douce, et que la position le permette, il faudra les faire passer à travers la villa; mais s'il y a une rivière très-écartée des collines, et que l'élévation de ses rives ainsi que la salubrité du pays ne s'opposent point à placer la villa sur ses bords, il faut toujours faire en sorte que la villa ait l'eau derrière, etnon par devant. De cette manière la façade de l'édifice sera garantie des vents nuisibles, et se trouvera exposée à ceux qui sont regardés comme favorables. En effet, la plupart des rivières sont couvertes en été de vapeurs malfaisantes, et en hiver de brouillards, qui peuvent, s’ils ne sont dissipés par la violenee des vents, devenir funestes aux hommes et aux bestiaux. Dans les endroits salubres, la villa doit, comme je l'ai dit, regarder l'est ou le sud, tandis que dans les elimats nébuleux elle doit avoir l'exposition du nord. Une villa est toujours convenablement placée au pied de la mer, lorsqu'elle en est assez proche pour que les vagues battent le pied du bâtiment, et viennent s'y briser; au lieu qu'elle serait mal sur la plage ou à quelque distanee des flots. En effet, lorsqu'on fait tant que de s'écarterdela mer, il faut s'eu écarter beaucoup, toute la plage étant, jusqu'à une cer-

nocentis natura, temporibus [tamen] liemis edomitus imbribus mitescit; ex quo ealestis aqua maxime salubris intelligitur, quod etian venenati liquoris eluit perniciem. Sed liane potui probatissimam diximus. Cæterum ad æesta. tum temperandos calores et amoenitatem locorum pluri. mun conferunt salientes rivi, quos, si conditio loci patic. tur, qualescunque dummodo dulces utique perducendos in villam censeo. Sin summotus longius a collibus erit amnis, et loci salubritas editiorque situs ripæ permittet superponere villam profluenti, cavendum tamen erit, ut a tergo polius, quam prae se flumen liabeat, et ut redificii frons aversa sit ab infestis ejus regionis ventis, et amicissimis adversa ; cum plerique a mnes astate vaporatis lieme frigidis nebulis caligent. Qua nisi vi majore inspirantium ventorum submorentur, pecudibus lominibusque conferunt pestem. Optime autem salubribus, ut dixi, locis ad orientem vel [ad] meridiem, gravibus ad septentrionem villa convertitur. Eademque semper mare recte conspicit, cum pulsatur, ac fluctu respergitnr; nunquam ex ripa, sed lıaud paulın submota a littnre. Nam prestat a mari longo potius interrallo, quam brevi rcfugisse; quia tucdia sunt 
taine distance, remplie de vapeurset d'exhalaisons dangereuses. Une ferme ne doit pas être non pluss située près d'un marais ou d'une route militaire. l.es marais développent pendant les chaleurs de l'été des vapeurs nuisibles, et engendrent des inscetes armés d'aiguillons, et dont les essaims nombreux assaillent l'homme. Les marais fourmillent encore deserpents et d'autres reptiles qui, privés de l'humidité de l'hiver, sortent de cette fange, mise en fermentation par les ardeurs du soleil. Tout cela occasionne souvent des maladies, dont les causes sont tellement eachées que les médecins eux-mêmes ne peuvent pas toujours les découvrir. Il règne, en outre, dans ces contrées une sorte de remugle et une humidité qui ronge les instruments de eulture, pourrit les meubles, et gâte les fruits serrés dans les greniers aussi bien que ceux qui sont laissés à découvert.

Le voisinage d'une grande route n'est pas non plus favorable à l'emplacement d'une ferme, tant à eausc des dégâts que les voyageurs peuvent faire aux récoltes, qu'à cause des visites fréquentes dont on est incommodé. Pour éviter tous ces inconvéuients, il ne faudra bâtir la métairie ni sur un grand ehemin, ni dans un endroit pestilentiel, mais dans une situation élevée de sorte que la facade des bâtiments soit tournée vers le point du eiel où le soleil se lève à l'équinoxe. Cette position, tout en exposant l'habitation aux vents d'été, la défend de ceux d'hiver. Plus le terrain s'abaisse à l'est, plus il reçoit facilement les vents d'été, et moins il donne accès aux tempètes d'hiver; la chaleur du soleil levant y résout plus promptement les rosées glacées. Ces avantages sont d'une grande importance, parce qu'en général tous les lieux quí ne sont point

splatia gravioris lıalitus. Nec paludem quidem vicinam esse oportet adificiis; nec junctam militarem viam, quod illa caloribus noxium virus eructat, et infestis aculeis armata gignit animalia, qua in nos densissimis examinibus involant; tum etiam nantium serpentiumque pestes, liberna destituta uligine, coeno et fermentata colluvie vere luatas cunitti, ex quibus sxpe contralıuntur cxci morbi, quorum cansas ne medici quidem perspicere queunt; s'l et auni tolo tempore situs atque lumor instrumentum ı usticum supellectilemque et inconditos conditosque liructus corrumpit : lıæc antem pratcreuntium viatorum populationibus, et assiduis devertentium lospitiis infestat rem familiarem. Propter qua censeo ejusmodi vitare incommorla, villamque uec in via nec pestilenti loco, sed procul et editiore situ condere, sic ut frons ejus ad orientem aequinoctialem directa sit. Nam ejusnıdi positio medium temperatumque libramentum veutorum hiemalium et astivorum tenet : quantoque fuerit adilicii solum pronius orienti, tanto et restate liberius capere perflatus, et lienis procellis niuus infestari, et matıtino regclari ortu poterit, ut concreti rores liquescant : yuoniau fere pestileus habetur, quod est leuotun ar, sinistım soli et apricis flalibus; 'puibus si caret, uulli exposés au soleil et aux vents secs sont regardés conme malsains. En effet, dans toute la nature il n'y a point d'autre force qui puissc aussi facilement séeher ou balayer les vapeurs de la nuit, la rouille, et cette humidité sale qui s'attache it tout, et qui est aussi dangereuse pour les hommes que pour les troupeaux, les plantes et les fruits. Quand on veut construire sur un terrain en pente, il faut commeneer à bátir sur la partic la plus basse du coteau. Non-seulement les folldations qui auront été jetées dans ce renfoneement soutiendront le poids de l'édifice, mais elles serviront de contrefort et d'appui aux constructions qu'on voudra ajouter dans la suite, lorsqu'il faudra agrandir la métairie. Les anciennes constructions formeront alors un contrepoids assez puissant pour soutenir les nouvelles. Si l'on commenęait au contraire par jeter sur la partie supérieure du coteau les fondations destinées à porter toute la masse des bátiments, les constructions qu'on ajouterait dans la suite formeraient des faux-points et des erevasses. Fn effet, toutes les fois qu'une nouvelle construetion est ajoutée à un ancien bâtiment qui menace ruine, le vieil édifice, à force de soutenir la masse qui s'éléve auprès de lui, finit par céder; et le nouvel édifice venant à pencher du côté de l'ancien à mesure que celui-ci s'affaisse, succombe pcu à peu sous sa propre masse, jusqu’à ce qu'il ait été entrainć dans la ruine du premier. C'est ce vice de construction qu'il faudra éviter, en jetant les premières fondations.

VI. La distribution d'une mótairie doit répondre à l'ensemble de la ferme. Elle se composera de trois parties : l'habitation du maître, les bâtiments rustiques, et les greniers. L'habitation

alia vis potest nocturnas pruinas, et quodcunque rubiginis aut spurcitiæ resedit, siccare atque detergere. Hæc antem cum hominibus afferant perniciem, tum et armentis et virentibus eorumq̨ue fructibus. Sed quisquis adificia volet in declivibus areis extruere, semper ab inferiore parte auspicetur : quia cum ex depressiore loco fuerint orsa fundamenta, non solum superficiem suam facile sustinebunt, sed et pro fultura et substructione fungentur, adversus ea, qua mox, si forte villam prolatare libuerit, ab superiore parte applicahuntur : quippe ab imo prostructa villenter resistent contra ea, qua postmodum superpositi incumbent. At si summa pars clivi fundata propriam nolem susceperit, quidquid ab inferiore mox apposueris, fissum erit rimosıunque. Nam cum veterialstruitur recens xdificium, quasi surgenti reluctans oneri cedit; et quod prius extructum imminebit cedenti, panlatim degravatum pondere suo proceps attrahetur. Igitur id structura: vitiun cum prinum statin fundamenta jaciuntur, evifau. dum est.

VI. Modus auten menbrorumque numerus aptelur universo consepto, et dividatur in tres partes, urbanan, rusticam et frucluarian. Urbana rursus in liben na $\mathrm{ft}$ astiva sic digeratur, ut spectent licinalis teniponis cubl- 
du maitre sera divisèe en appartements d'été et en appartements d'hiver. Les clıambres à coucher des appartements d'hi ver aurontl'exposition In soleil levant d'hiver, et les salles à mangrer, celle du suleil couehant équinoxial. Les ehambres à eoueher des appartements d'été seront ('xposées au midi équinoxial, et les salles à manrel; au soleil levant dhiver. Les bains seront tournés vers lo soleil couchant d'été, afin d'être bien éelairés depuis midi jusqu'au soir. Les promenoirs seront sous le midi équinoxial, afin qu ils aient beaucoup de soleil en hiver et peu en été. Les bâtiments dits rustiques se composeront d'abord d'un offiee vaste et bien exhaussé, afin que la elıa'pente soit à l'abri du feu, et que les gens de la maison puissent s'y tenir commolément dans toutes les saisons de l'année. I.es chambres des eselaves libres auront l'exposition du midi équinoxial. Quant aux esclaves enchaînés, on leur fera sous terre une prison aussi saine que possible, et éclairée par des fenêtres nombreuses, étroites, et assez exhaussces pour qu'ils ne puissent y atteindre avee la main. Les étables destinées aux bestiaux ne devront être ni trop chaudes ni trop froides. Les animaux soumis au joug auront des étables d'été et des étables d'hiv'er. Pour lesautresespèces d'animaux qu'on entretient également dans l'intérieur d'une ferme, on leur ménagera pour l'hiver des retraites eouvertes, et pour l'été des enceintes a découvert, mais entourees dehautes murailles, pour qu'ils y soient en sûreté et n'aient point á eraindre les attaques des bètes féroees. Toutes ces sortes d'étables seront eonstruites de manière à ce que l'eau ne puisse y pénétrer du dehors, et que eelle provenant dés animaux s'en éeoule le plus promptement possible, afin que la pourriture ne gagne

cula brumalem orientem : conuationes, aequinoctialem occidentem. liursus astiva cubicula spectent meriliem arjuinuctialem, sed conationes ejusitem temporis prospectent hibernum oriculem. Balnearia occidenti astivo advertantur, ut sint post meridiem et uspue in vesperum illustria. Amludationes meridiano aequinoctiali subjecte sint, "It lieme plurimum solis $\mathrm{ct}$ astate minimmm recipiant. At in rustica parte magna et alta culiua ponetur, ut et contignatio careat incendii periculo, et in ca commode familiares omni tempre anni morari queant. Optime solutis servis cella meridieun aquinoctialem spectantes fient : viuctis quam saluberriunm suliterraneum ergastulum, plurimis idque angustis illustratum fenestris, atque a terra sic editis, ne unanu contingi possint. Pecudibus fient stabula, qux neque frigore neque calore infeslentur. Domitis armentis duplicia bubilia sint, liberna alque astiva. Cateris antem pecoribus, qua intra villam esse convenit, ex parte tecta loca, cx parte sul dio parietibus altis circumsepta, ut illic per biemeu, lic per restatem sine violentia ferarum conymiescant. Sed oninia slabula sic ordinentur, ne quis lumo iitfuere possit : et n! quisque ibi conceptus fuerit, 'juan cclerrime dilaba- ni les fondations desmurs, ni la corne des pieds des bestiaux. Les étables destincees aux bœufs auront neuf ou même dix pieds de largeur, pour donner à l'animal la facilité de se coucher, et laisser au houvier la liberté de tourner autoul delui. Les mangeoires devront ĉtre ả une hauteur convenable, afin que les boufs et les autres bestiaux, étant debout, puissent y manger commodément. Le métayer aura sa chambre près de la porte principale, pour qu'il soit à même de surveiller ceux qui sortent ou qui cntrent. Par la même raison l'intendant aura la sienne au-dessus de la porte même, de sorte qu'il pourra cn même temps surveiller de près le métayer. Non loin de là on établira le magasiı destiné à recevoir les instruments aratoires. Dans ce nagrasin, on ménagera un cabinet où l'on puisse fermer à elef les ustensiles de fer. Les buu. - viers et les bergers auront leurs cabanes près des étables, afin qu'ils soient à même de donner aux bestiaux les soins qu'ils demandent. Tous ces gens seront logés le plus près possible le's uns des autles, afin que le métayer ne perde point de temps cn visitant les différentes parties de la fer'ne, et qu'eux-mènes puissent se surveil ler mutuellement, et rendre compte du plus on du moins de zèle qu'ils mettent dans leurs fonctions respectives. Les bátiments à provision se composerout du cellier a huile, du pressoir, du cellier à vin, du cellier à vin euit, du grenier à foin, du grenier à paille, des resserres, et du grenier à blé. Les picees à fleur de terre seront réservées à la garde des liçuides destinés à la vente, comme le vin et l'luuile. On placera sur des espèes de planchers ou d'élages les fruits sees, tels que le blé, le foilu, les feuillages, la paille, et toutes les autres especes de fourrages.

tur, ut nec fundamenta parietum corrumpantur, nec ungular pecudum. Lata buhilia esse oportebit pedes decem vel nimime novem : qua mensura et ad procumbendum pecori et jugario ad circumieunlum laxa ministeria prabeat. Non allius exlita csse prasepin convenit, quam ut bos ant jumentum sine incommodo stans vesci possit. Villico juxta jannam fiat labitatio, ut intrantium exenntiumque conspectum labeat. Procuratori supra januam ob easdem causas : et is tamen villicum observet ex vicino : sitque ntrique provimum horrenm, quo conferatur omne rusticum iustrumentum ; et infra ill ipsum clansus locns, quo ferramenta condauitur. Bubulcis pastoribusque cella ponantur juxta sua pecora, ut ad eorum curam sil opportumus excursus. Omnes tamen quam proxime alter ab alterodebent habitare, ne villici diversas partes circun?cuntis sedulitas distendatur, ef ut inter se dilizentixe et negligentix cujusque lestes siut. Pars anten fructuaria dividitnr in cellam oleariam, torcularian, cellam vinariam, defrutariam, fomilia paleariaque et apothecas ef loorrea, ut ex is quie sunt in plano, custodiam recjpian! lıumidarum ı er um tanq̧uam vini ant olei venalium; siccac autem res congeranur tabulatis, ut fiumenta, formm, 
Les grenicrs, auxquels conduira un escalier, auroult de petites fenètres croisées, liviant passage aux aquilons. Cette position, étant la plus fraiche et la moins humide, est très-favorable à la conservation des grains. Le cellier à vin, situé en pleine terre, aura la mène exposition; mais il devra se trouver très-éloigné des bains, du four, du trou à fumier, de toutes les immondices d'où s'íclıappent des émanations fétides, ainsi que des citernes ou des eaux saillantes, dont les évaporations gâtent le vin. Beaucoup de eultivateurs pensent que le lieu le plus favorable pour serrer le grain est une grange avec un comble arqué, et dont le sol en terre, d'abord remué ct huniecté avec de l'amurque nouvelle et non salée, a été ensuite battu et eonsolidé avec des battes, comme les pavés connus sous le nom de Signinum opus. Puis, lorsque l'ouvrage est see, on le recouvre avec un enduit dur, détrempé avec l'amurque au lieu d'eau, et mêlé avec de la ehaux et du sable. On enfonce ensuite ce morticr dur; à force de le battre avee les battes les plus pesantes, on le polit, et on en remplit soigneusement tous les joints etangles formés par le pavé ct les nurs; ear les fentes qui se forment ordinairement dans ces parties offrent des retraites ass'ırées aux animaux qui viennent de dessous terre. Les greniers se composeront de plusieurs eompartiments, dont ehaeun renfermera les differentes sortes de légumes et de fruits. Les murs seront revètus d'une eouche de mortier délayee dans l'amurque; mais au lieu de paille on mettra dans cette composition des feuilles desséchées d'olivier sauvage, ou, à lcur défaut, de toute autre espèee d'olivier. Lorsque ectte eou-

fronles, palex, ceteraque pabula. Sed granaria, ut. dixi, scalis arleantur, et modicis fenestellis aquiloniluns inspir entur. Nam ea corli positio maxime frigida et minine lumida est; qua utraque perennitatem conditis frumentis afferunt. Eadem ratio est (qua) in plano sitae vinaria cellæ, qua submota procul esse debet a balineis, furno, sterquilinio, reliquisque immunditiis tetrum odorem spirantibus : nec minus a cisternis aquisve salientibus, quilous extralitur lınmor, qui vinum corrumpit. Neque me prateril, sedeu frumentis optiman quibusdan videri horreum canara contectum, cujus solum terreuun prius quam consternatur, perfossum et amurca recenti non salsa madefactum, velut Signizum opus pilis condensatur. Tum deinde cum exaruit, simili molo pavimeuta testacea, quie pro aqua receperint amurcam mixta ealci et areux, supersternuntur, et magna vi paviculis inculcautur atque expolinutur, omuespue parietum et soli juncturae testaceis pulviuis fibulautur : quoniam fere cum in lis partibus adificia rimas egerunt, cava prabent et latehras subterraneis aninalibus. Sed et laculus dis. fiugunntur granaria, ut separatin quappue leguniua po. nantur. Parietes oblinuntur amurcal subacto lıto, cui jo paleis aduista sum arida oleastri, vel si pa nou sunt, clea folis. Deinde cunn pactictum tectorium naruit, rus sus anurca ı cspergil uı, qqua siccata founcutun infer- che sera bicn sèche, on l'arrosera de nouveau aree de l'amurque, qu'on laissera entièrement sécher' avant de rentrer le blé dans le grenier. Cette préeaution est excellente, surtout pour préserver le blé des charanconset d'autres animaux, qui ne tarderaient point à le ronger si on la négligeait. Néanmoins si le grenier v'est pas exposé d'une manière assez favorable, le grain le plus choisi ne tarde pas à s'y moisir. Lorsqu'on n'a rien à eraindre de l'humidité, le blé peut se conservel' dans des fosses ereusées en terre, ainsi que cela se pratique dans quelques provinees d'outre-mer. En déposant les grains dans ees espéees de puits ap. pelés siros, on rend en quelque sorte une seconde fois à la terre les productions qui sont sorties de son sein. Pour nos eontrées, qui ne sont que trop sujettes à l'humidité, nous préférons des greniers élevés au-dessus du sol, et eonsl ruits de la manière que nous venons d"indiquer. Ciest du moins le moyen le plus sûr pour garantir le blé des eharançons. Lorsque ee malheur est arrivé, beaueoup de personnes pensent qu'il suffirait, pour en arrêter les progrès, de renouveler l'air daus les tas de grains par la ventilation : c'est une crreur manifeste; car loin de chasser les charançous, on !es disperse ainsi sur la totalité des moneeaux. Si au contraire on ne touehe point au grain, les couehes supérieuresseront seules rongées par ces inseetes, qui ne pénètrent pas dans le blé à plus d'une palme de profondeur. $\mathrm{Or}$, il vaut mieux perdre ce qui est déjà gâté, que d'exposer toute la récolte. Lorsque plus tard on voudra livrer le blé à la consommation, on n'aura qu'à mettre à part lescouches supérieures, pour ne prendre que eelles qui sont restées intaetes. Quoique ces ob-

(ur. Ea res als noxa curculionum et similium aninıaliunı commodissime videtur conditas fruges defendere; qun nisi diligenter repositx sint, celeriter ab els consumun. tur. Sed il genus horrei, quod scripsimus, nisi [sit in] sicca positione villa quamvis granum robustissimum corrumpit situ : qui si nullus adsit, possunt etiam defossa frumenta servari, sicut transmarinis quibusdam provinciis, ubi puteorum in modum, quos appellant siros, exlıansta lumus, editos a se fructus recipit. Sed nos in no. stris regionibus, qua redundant uligine, magis illam po. sitionem pensilis horrei, et lanc curam pavinentorum et parietuu probanus : quoniam, ut retuli, sic enunila sola el latera liorreorum prohibent curculionem. Quod genus exitii cum ineidit, unlti opinantur arceri posse, si esesa? fruges in liorreo ventilentur, et quasi refrigerentur. II] autem falsissimum est : neque enim loc facto expelluntur animalia, sed imuiscentur lotis acervis : qui si manuant immoli, sumınis tantum partibus infestantur, quoniau iufra mensuram palui non naseilur curculio : lougeque prastat id solum, quoul jam vitiatım est, quam totum periculo subjicere. Xam cum exiget usus, facile est, pu sublato, quod vitiatum erit, infegro inferiore uti. [Sed] have, etsi extrinserus, mou tanu intempestive videor hor loco refulisse. Tor cularia pracipue cellayne olearice calite esse debent, quia commodius onmis liquor rapurs. 
servations soient étrangères au sujet que je traite, je ne les crois pourtant pas déplacées iei. Les celliers à huile doivent être chauds, et les pressoirs encore plus, parce qu'en général les liquides se dissolvent par l'effet de la chaleur et se contractent par le froid; et que si l'huile, lorsqu'elle sort en petite quantité, vient à se condenser, elle ne tarde pas à devenir rance. Mais il faut que la chaleur soit naturelle, et résulte du climat, et de l'exposition même du cellier. On évitera a vec soin l'emploi du feu, car la fumée et la suie enlèveraientà l'huile sa saveur. C'est pour cette raison que les pressoirs doivent recevoir le jour du midi, pour qu'on puisse se passer de feu et de lumière lorsqu'on pressera l'olive. Le lieu où l'on fera bouillir le vin ne sera ni étroit ni obscur, afin que eelui qui est chargé de ce soin y soit à son aise. Le lieu où l'on sìche le bois nouvellement coupé sera placé également dans la partie réservée aux traveaux rustiques de la métairie, auprès des bains destinés aux gens de la maison. Quant à ces bains, qui ne doivent point manquer dans une ferme, on n'en permettra l'usage aux esclaves que les jours de fête; car ils affaiblissent le corps quand ils sont trop fréquents. Les celliers à vin seront placés au-dessus des endroits d'où il sort habituellement de la fumée, parce que les vins y vieilliront plus vite, et que la continuité de la fumée les fera parvenir de bonne heure à leur maturité. 'Toutefois, on ménagera un autre cellier pour y déposer les vins vieux; ear ils se gâteraient par suite d'une fumigation trop prolongée. Nous en avons assez dit sur la situation de la métairie, et la distribution de ses différentes parties. Les dépendanees d'une ferme se composent d'un four, d'un moulin d'une grandeur proportionnée au nombre de colons qui doivent l'ha-

solvitur, ac frigoribus magis eonstringitur. Olenm, quod ıninus provenit, si congelatur, fracescet. Sed ut calore naturali est opus, qui contingit positione coli et deelinatione, ita non est opus ignibus aut fammis : quouian fumo et fuligine sapor olei corrumpitur. Propter quod torcular debet a meridiana parte illustrari, ne necesse habeamus igies lucernamque adlibere, cum premitur olea. Cortinale ubi defrutum fiat, nee angustum nee obscurum sit, ut sine ineonımodo minister, qui sapan decoquet, versari possit. Fumarium quoque, quo materia; si non sit janıridem caesa, festinato siccetur, in parte rusticx villa fieri potest junctum 1 usticis balneis. Nam eas quoque refert rsse, in quibus familia, sed tantum feriis, lavetur. Neque cnim corporis rolori convenit frequens usus ea. rum. Apothecae recte superpotientur lis loeis, unde plerunque fumus exoritur : quoniam vina celerius velusteseunt, quæ luni quodam tenore procoquem maturitatem trahuıt. Propter quod et aliud tabulatum esse debebit, quo amoveantur ne rursus nimia suffitione medicata sint. Qund ad villæ pertiuet situm partiumque ejus dispo. sitioneu, satis dictum est. Circa villaun deinceps laac esse oportebit : furmum et pistrinum yquantum futurus biter, et enfin de deux réservoirs d'eau, dont l'un sera destiné aux oies et aux bestiaux, et dont l'autre servira pour tremper les lupins, l'osier, les verges, et d'autres objets de cette nature d'un usage journalier. On ménagera en outre deux trous à fumier, l'un pour recevoir le fumier nouveau qui doit y séjourner toute l'annéc, l'autre pour le fumier ancien, qui de là est conduit aux ehamps. Ces deux fossés doivent, ainsi que les réservoirs, être légèrement inelinés, murés et pavés, pour que l'humidité du fumier ne puisse s'échapper. Ce n'est qu'en conservant ses sues que le fumier conservera toutes ses forces. II faudra même l'humeeter continuellement, afin que les semences de ronees et de mauvaises herbes qui se trouvent mêlées à la paille et à la litière y pourrissent, et n'aillent pas germer dans les champs où l'on doit transporter le fumier. Les cultivateurs expérimentés couvrent avee des claies ou des branchages tout l'engrais qu'ils retirent des bergeries et des étables, de crainte que le vent ne le dessèche, ou que l'action du soleil ne le consume. L'aire se trouvera placée, autant que possible, sous les yeux du maitre ou de son intendant ; le mieux est de la paver en pierres dures. Lorsque le sol oppose une forte résistance aux pieds des bestiaux et au poids des traineaux, le grain se détache plus vite de l'épi; et quand le blé est vanné, il est plus propre et moins rempli de petits cailloux et de terre que s'il a été battu sur le sol nu. Près de l'aire on ménagera un lieu couvert, où l'on puisse transporter les gerbes à demi battues, pour les mettre à l'abri, dans le cas où une pluie imprévue viendrait interrompre les travaux. Cette précaution, que l'inconstance du temps rend indispensable en Italie, devient inutile dans beaueoup de contrées d'outre-

numerus colonorum postulaverit : piscinas uninimum duas : alteram, quae anseribus ac pecoribus serviat; al. teram, in qua lupinum, vimina et virgas atque alia, qux sunt usibus nostris apta, maceremus. Sterquilinia quoque duo sint: unum, quod nova purgamenta reeipiat, et in annum conservet; alterum, ex quo vetera veliantur : sed utrumque more piscinarum devexum leni clivo, et extruetum pavitumque solum habeat; ne lumorem trans. mitlant : plurimum enim refert, non adsiceato succo fi. mum vires continere, et assiduo maeerari liquore, ut si qua interjeeta sint stramentis aut paleis spinarum vel graminum semina, intereant, nec in agrum exportala segetes herbidas reddant. Ideoque periti rustiei, quidquid ovilibus stabulisque conversum progesserunt, superpositis virgeis eratibus tegunt, nec arescere ventis simunt, aut solis ineursu patiuntur exıri. Area, si eompetit, ita col. stituenda est, ut vel a domino vel certe a procuratore despici possit. Eaque optina est silice constrata, quod et celeriter fiunenta deteruntur, non cedente solo pulsibus ungularum tribularumque, et eadem erentilata mundiora sunt, lapillisyue carent et glabulis, quas per trituram fere terrena remiltit area. Huie autem nubilariun ap- 
mer, où il ne pleut jamais en été. Les vergers et les potagers devront être entourés de haies, et se trouver à peu de distance de la métairie, et placés de telle sorte qu'ils puissent receroir l'écoulement des égouts de la cour, des bains, ainsi que la lie d'huile qui s'écliappe du pressoir; car ces substances sont également profitables aux arbres et aux légumes.

VII. La métairie se trouvant ainsi disposée, l'attention du maitre devra se porter sur tous les autres objets, et prineipalement sur les gens de la maison : ceux -cise divisent en deux classes, les fermiers et les eselaves. Les eselaves sont libres ou enehainés. Il se montrera facile, accommodant pour ses fermiers; il sera plus sévère pour l'ouvrage que pour le payement de la rente. Cette eonduite leur est plus agréable, et tourne à notre profit. En effet, lorsqu'une terre est bien cultivée, il en résulte presque toujours du bénéfice, et rarement de la perte, à moins que la réeolte ne soit ravagée par les pillages, ou détruite par l'intempérie de la saison; de sorte que le fermier n'osera pas demander de remise. De son côté, le propriétaire ne doit pas non plus tenir rigoureusement à l'exactitude dans l'accomplissement des engagements que le fermier a contractés; par exemple, l'époque du payement, la livraison du bois, et mille autres choses qui causent plus d'embarras que de dépense. En génćral, il ne faut pas être trop exigeant pour certaines ehoses qu'on aurait droit de réclamer. Nos ancêtres disaient avec raison que l'extrêne rigueur est souvent la plus grande des oppressions. Toutefois gardons-nous de puusser trop loin l'indulgence; car, ainsi que l'usurier

plicari debet, maximeque in Italia, propter inconstan. tiam cali, quo collata senitrita frumenta protegantur, si subitaneus imber incesserit. Nam in transmarinis quibus. daun regionibus, ubi astas pluvia caret, supervacuum est. Ponaria quoque et hortos oportet septo circumdari, 't esse in propinquo, atque in ea parte, quo possit omnis stercorata colluvies cortis balineorumque et oleis expressa amurca sanies influere : nam ejusmodi quoque latatur alimentis et olus et arbor.

VII. Ilis omnibus ita vel acceptis vel compositis, pracipua cura domini requiritur, cum in cæeteris rebus, tum mavime iu hominibus. Atque hi vel coloni vel servi sunt, soluti aut vincti. Cumiter agat cum colonis, facilenque se prabeat. Avarius opus exigat, quam pensiv. nes : quoniam et minus joffendit, et tamen in universum magis prodest. Nam ubi sedulo colitur ager, plerumque compendiun, uunquam (nisi si cali major vis aut prado. nis ircessit) detrimentum affert, eoque remissionem colonus petere won audet. Sed nec domiuus in unaquaque re, cum culunum obligaverit, tenax esse juris sni debet, sicut in diebus pecuniarum, ut lignis et cateris parvis ac cessionibus exigendis, quarum cura majoren molestiam yı inı impensam rusticis affert. Nec sane est vindicandum nobis quidquidl licet. Nan summum jus antịui sumnam putabant crucem. Nec sursus in totum icmiltendum : quo.
Alphius avait coutume de le dire, les meilleures créances deviennent mauvaises, si l'on n'en sollicite point le payement. J'ai entendu dire à L. Volusius, ancien consulaire, homme puissamment riche, que le fonds le plus avantageux pour un chef de famille était celui qui serait cultivé par des fermiers nés sur la propriété mẻme. Attachés à la ferme depuis le bereeau, ils la regardent comme leur patrimoine. Je suis également convaincu que l'on ne gagne pas à changer souvent de fermier. Mais il serait encore moins avantageux d'affermer sa terre à un habitant de la ville, qui eultive par ses gens plutòt que par lui-même. Un fermier de cette sorte, dit Saserna, vous donne un proeès en place de la rente. Il vaut donc mieux prendre nos fermiers dans les paysans nés sur nos terres, et choisir celui d'entre eux qui sera le plus assidu au travail, toutes les fois que nous ne pourons cultiver nous-mêmes, ou qu'il n'est pas avantageux de faire cultiver par nos esclaves. C'est ce qui arrive dans les contrées malsaines et stériles. Mais pour peu que le climat soit sain et la eontrée féconde, un bien exploité par un fermier rapporte toujours moins que celui qui aurait été cultivé par le maítre lui-même ou par son métayer, à moins toutefois que celui-ci ne soit uı eselave indolent ou rapace : ce qui n'arrive ordinairement que par la faute du maitre et par sa négligence. II dépendait de lui de ne point contier à un tel homme la gestion de ses affaires, cu de la lui retirer. Lorsqu'un fonds est assez éloígaé pour que le chef de famille ne puisse s'y rendre souvent, il vaut mieux le confier à des fermiers libres qu'à des mélayers esclaves, sur-

nıam vel optima nomina non appellando fieri mala furue. rator Alphius lixisse verissime fertur. Sed et ipse nostra memoria veterem consularen virumque opulestissimum L. Volusium assererantem audivi, [patrisfamilias ] felicissimum fundum esse, qui colonos indigenas laberet, et tanquam in paterna possessione natos jain inde a cunabulis longa familiaritate retineret. Ita certe inea fert opinio, rem malam esse frequentem locationem fundi : pejorein tamen urbanum colonum, qui per familiam mavult agrum quam per se colere. Saserna dicebat ab ejusınodi homine fere pro mercede litem reddi. Propter quod operam dandam esse, ut et rusticos et eosdem assiduos colonos reti. neamus, cum aut nobismetipsis non licuerit, aut per domesticos colere non expedierit : quod tamen non evenit, uisi in his regionibus, quæ gravitate caeli solique sterilitate vastantur. Caterum cum mediocris adest et salubritas et terra bouitas, nunquam non ex agro plus sua cuique cura reddidit quam coloui : non nunquam etiam villici, nisi si maxima vel negligentia servi vel rapacitas intervenit. Quæ utraque peccata plerumque vitio domini vel counmitti vel foveri nilil dubium est : cum liceat aut cavere, ne talis praficialur negotio; aut jam prapusitus ut submoveatur curare. In longinquis tamen fundis, in quos non est facilis excursus patrisfamilias, cun omue genus agri tolerabilius sit sub liberis colonis, qquam sub villicis 
tout quand ee sont des terres à blé, que le fermier ne peut aussi faeilement dégrader que des vignes ou d'autres plantations. Les cselaves en général font beaucoup de tort à leur maîtrc. Ils louent les boufs à des itrangers, les nourrissent mal, ainsi que les autres bestiaux, ct labourent la terre sans exaetitude. Outre cela, ils comptent plus de semences qu'ils n'en cmploient, ne prennent pas assez de soin des terres ensemencées pour les faire venil à bien, et diminuent chaque jour par lcur fraude ou leur négligence le grain que l'on a transporté dans l'aire pour le battre, ou ils le volent eux-mèmes, ou ils lc laissent voler, faute de surveillance. Le blé, une fois scrré dans les greniers, n'est point porté avé fidélité sur leurs comptes; de sorte que, par le fait du régisseur autant que par celui des grens de la maison, la proprićté sera dégradce et dépréciće en peu de temps. Je pense done que si le maitre ne peut lui-même surveiller sa terre, il fera mieux de l'affermer.

VIII. Après les fermiers, ee sont les esclaves qui doivent occuper l'attention du maître. II examinera avec soin les fonctions auxquelles il les destine, et les travaux qu'il juge à propos de leur confier. A vant tout, je conseillerai de ne point prendre un métayer parmi les eselaves qui se scront rendus agréables par la beauté de leur corps, ou par l'excreice de ces arts frivoles qui tiennent du luxe des villes. Ces eselaves sont láches, paresseux, accoutumés à passer leur temps aux promenades, au cirque et aux théatres, à hanter les tavernes et les mauvais lieux. Si ce goût vient à les suivre au milicu des travaux de la campagne, le maitre en ressentira les suites funcstes, moins dans la perte de son

servis labere, tum praecipue frumentarium, quem et minime (sicut vineas aut arbustum) colouus evertere potest, et maxime vexant servi, qui boves elocant, costeuque et catera pecora male pascunt, nec industric terram vertunt, lougeque plus impulant seminis jactl, quam quol severint : sed nec quod terra mandaverint sic adjuvant, ut recte proveniat : idque cum in aream contuleruut, per trifuran quotidie miuuunt vel fraude vel negligentia. Nam et ipsi diripiunt, et al) aliis furibus non custodiunt. Sed nec couditum cum tisle rationibus inferunt. Ita tit, ut el actor et familia peccent, et ager sapius iufametur. Quare talis generis pradium, si, ut dixi, domini prasentia cariturum est, censeo locandum.

VIII. Proxiuna est cura de servis, cui quemque oflicio prapoucre couveniat, quosqne et qualibus opteribus destinare. Igilur pramoneo ne villicunı ex co genere servo. ruu, qui corprore placuerunt, iustıtuamus : ne ex eo quidem ordiue, qui urbanas ac delicalas arteis exercuerit. Socors et somuiculosum genus id nancipiorum, otiis, campo, circo, theatris, alex, popiux, lupanaribus consuctum, numquam 10 easuem ineptias sumniat, ynas cunl iu agriculturaun transtulit, non tantum in ipso servo, fuantum in universa te detrimeuti dominus capit. Ifigendun est ruslu is operibus al intante dualtus, it inspectus esclave que dans celle de tout son patrimoine. On choisira done pour métayer un homme expérimenté, et endurci aux travaux des champs dès son enfance : ct si l'on rien trouve pas, on le prendra parmi les esclaves dont la vie a étć entièrement consacrée au travail. Un jeune homme n'est pas plus apte à ces fonetions qu'un vicillard; le premier n'aura point l'autorite nćcessaire pour se faire obeir de ceux qui sont plus âgés que lui, et l'autre succombera sous le poids des travaux. On choisira done un homme dans la force de l'age, robuste et vigoureux, connaissant bien l'agrieulture, ou du moins assez attentif pour pouvoir se mettre promptement an fait de cette science; car il ne faut pas que ceux dont le devoir est d'obéir instruisent celui qui leur commande. II est impossible d'ailleurs qu'un homme puisse bien faire exéeuter les travaux, s'il a besoin de demander d'abord des instruclions à ccux qui lui sunt subordonnés. Un régisseur pourra très-bien administrer une ferme sans savoir écrire, pourvu qu’il ait la memoire sûre. Un tel régisseur, nous dit Cornélius Celsus, apportera plus souvent à son maittre de l'argent que des livres de compte, parce que son ignorance ne lui permettrait pas de les falsitier, et qu'il n'oserait non plus les faire falsifier par d'autres, de crainte qu'on ne découvrit la fraude. On donnera au métayer pour compagne une femme prise dans les csclaves, qui l'attachera davantage à la ferme, et l'aidera dans sa besogne. On défendra cxpressément au métayer ou au régisseur de prendre ses repas avec les autres gens de la maison, et bien moins eneore a vec les étrangers. Cependant il lui sera permis d'admettre à sa table de tempsà autre, et surtout les

experimentis. Si tamen is non erit, de iis proficiatur, qui servitutem laboriosam tolera verunt. Jamque is transcenderil retatem priuxe juventie, nec dum scuectutis attigerit : illa, ne (ct) auctoritatem detralıat ad imperinm, cuin majores dedignentur prirere adolescentulo : liac, ne lahoriosissimo snccumbat operi. Nediae igilur sit atlat is et firmi roboris, peritus rerum rusticarum, aut certe mavimac cura, quo celerins adıliscat. Nam non est nostri negotii alterum imperare et alterun ducere. Neque enim recte opus exigere valet, qui, quid aut 'pualiter ficieudum sit, ab subjecto discit. Polest etian illiteratus, dummoto tenacissina sit memorix, rem sitis commole alministrare. Ejusmodi villicum Cornelius Celsus ait sitpius uumos domino quam librum afferre, quia nescius literarun vel juse minus possil raliones contiugere, rel per ạliuın propter conscientian fiaudis timeat. Sed qualieunque villico contubernalis mulier assignanda est, quae contineat eum, et in quibustam rebus tamen ailjuret. EiJemque actori proxcipiendum est, ne couviclum cum do. mestico, multogue uninus cunı extero labeat. Nonumn. quam tameu eum, queu assidue sedulun et fortem in operibus administraudis comoverit, fomoris causa unence

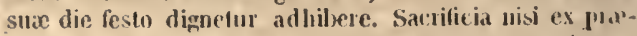

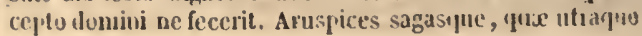


Jours de fète, celui qui aura montré le plus d'assiduité au travail, et de lui donner ainsi une marque de distinction. II ne fera point de sacrifices sans en recevoir l'ordre de son maitre. II ne recevra chez lui ni devins ni magiciens, qui, profitant de la superstition des hommes, les entrai. neut aux dépenses et les plongent ensuite dans le ('rime. Il ne fréquentera pas non plus la ville, ni les marehés et les foires, si ce n'est pour aeheter ou vendre tout ce qui sera de son ressort. Un métayer, nous dit Caton, n'est point un coureur do pavé; il ne doit point dépasser les limites de sa ferme, si ce n'est pour apprendre quelque nouveau procédé relatif à la culture : eneore ne faut-il pas dans ee cas qu'il s'éloigne trop, pour qu'il puisse être de retour en peu de temps. Il ne souffrira point qu'on fasse dans ses domaines de sentiers nouveaux, ou qu'on y pose d'autres bornes que celles qui s'y trouvent déjà. Il ne recevra point d'hôte chez lui, à moins que ce ne soit un ami ou parent de son maitre. De même qu'on doit lui faire toutes ces défenses, on doit aussi l'exlıorter à prendre soin des instruments de culture et des ustensiles de fer. Il est nécessaire qu'il y en ait deux fois autant qu'il en faut pour le nombre des eselaves qu'il oceupera. II mettra en réserve les instruments de reehange, après s'étre assuré qu'ils sont en bol ćtat, pour n'être jamais contraint de reeourir à ses voisins, parce que le temps que perdent les esclaves pour en aller chercher d'emprunt a plus de valeur que l'argent qu'on dépenserait pour en acheter. II tiendra ses gens vêtus avec plus de commodité que de délieatesse, et il aura soin qu'ils soient garantis du froid, du vent et de la pluie. Des fuurrures garnies de manches rempliront parfititement ce but, ainsi que d'anciens citones, ou manteaux à capuchon. Les ouvriers ainsi

genera vana snperstitione rudeis animos ad impensas, ac deinceps ad flagitia compellunt, ne admiserit : neque urLem neque ullas mundinas noverit, uisi encudac venden. direve pertineutis ad se tei causa. Villicus enim, quod ait Cato, ambulator esse non debet, nec egredi terminos, nisi ut addiscat aliquam culturam : el loc si ita in viciuo est, ul cito remeare possit. Semitas uovosque limites in agro fieri ne patiatur : neve lıspitem nisi amicum faniliareuque domini necessarium receperit. Ut ab his arcendus, ita exlortandus est ad instrumenti ferranentorumque $\mathrm{cu-}$ ram : ut duplicia quam uumerus servorum exigit refecta et reposita custodiat, ne quid a vicino petendum sit: quia plus in operis servorum ( avocandis, ) quam iu pretio rerun ejusınodi consumitur. Cultam vestilaumue familiam magis utiliter quam delicate labeat, munitampue diligenter a vento, frigore pluviaque; quac cuncta prolibisentur Inllibus manicatis, centonilus cunfectis, vel sagis cucullis. It si fiat, uullus dies tam intolerabilis est, yuo non ;ib divo moliri aliquil possit. Nec tantum operis agrestis sit artifex, sed et animi, ruantum servile patitur ingenimu, virtutibus iustructus, ut neque remisse neque cru. vêtus pourront travaillır en plein air, me̊nt par le temps le plus orageux. II ne suffit pas que le métayer soit propre aux travaux rusliques; il faut cncore qu'il ait des qualités morales, autant que le comporte l'état de servitude dans lequel il est né, afin qu'il n'exerce pas son pouvoir sans rigueur comme sans mollesse. Il eneouragera les esclaves qui sc distingueront parmi les autres, et usera d'indulgence envers les moins laborieux, afin que tout en eraignant sa sévérité ils n'aient point à se plaindre de sa rigueur. En conséquence, il mettra plus d'activité à les surveiller et à les préserver d'unc faute, que d'empressement à les punir, lorsqu'ils en auront commis par sa propre nigligenee. Or, la surveillanee la plus efficace quion puisse exercer sur l'homme le plus pervers, c'est d'exiger de lui avec rigueur la tâehe qu'on lui aura preserite, en ayant eonstamment l'oeil sur lui. Par ce moyen, ceux qui ont la conduitc des différents travaux rempliront exactement leurs devoirs; et les autres esclaves, après la fatiguc de la jour. née, goûteront volontiers le repos et le sommeil, au lieu de s'abandonner aux plaisirs et à la débauche. Plût aux dieux que les bonnes et anciennes eoutumes, qui de nos jours sont tout à fait tombées en oubli, fussent remises en vigueur! Si lc métayer les suivait, il n'exigerait de serviec de la part des esclaves que dans l'intérêt du maître; il ne prendrait ses repas qu'en présenee des grens de la maison, et sa nourriture serait semblable à la leur. Par ee moyen, il veillerait avec soin à ce que le pain dont il mangerait Iui-même fût bien fait, et que les autres aliments fussent apprêtés sainement. II ne laisserait sortir personne de la ferme, à moins qu'il ne jugeât à propos de l'envoyer lui méme quelque part; ee qu'il ne doit faire d'ailleurs que

deliter imperet; semperque aliquos ex melioribus foveat, parcat tamen etiam minus bonis : ita ut potius timeant ejus severitatem, quam crudelitatem delestentur. Id contingere poterit, si maluerit custodire subjectos, ne peccent, quam negligentia sua committere, ut pnniat delinquentes. Nulla est autem major vel nequissimi lıominis custodia, quam operis exactio, ut jusla reddantur, ut villicus sem. per se reprasentet. Sic enim et magistri singulorum officiorum sedulo munia sua exequentur, el ceteri post defa. tigationem operis quieti ac somno potius, quam deliciis operam dabunt. Jam illa vetera, sed optimi noris, qua nunc exoleverunt, utinam possiut obtineri : ne conservo ministro quoquam nisi in re domini utatur; ne cibum uisi in conspectı fauilia capiat, neve alium, quam qui cateris prabetır. Sic enim curalbit, ut et panis diligenter confiat, et reliqua salubriter apparentur. Ne extru fues nisi a se missum progredi sinat : sed nec ipse miltat, nisi ma. gna necessitate cogente. Neve negotietur sili, pecuniamve domini aut animalibus aut rebus aliis promercalıbus occupet. Ilac enim negotiatio curam villici avocat, ner, unquam patitur eun cum rationibus domini paria facere; 
fort rarement, ct lorsqu'il aura été eontraint par une nécessité impérieusc. Le métaycr ne doit point trafiquer pour son compte, ni employer l'argent de son maitre pour acheter du bétail ou d'autres denrées. Ce commerce, en détournant son attention des affaires de son maitre, l'empécherait de mettre dans les comptes l'exac. titude nécessaire; et quand on lui demandera it de l'argent, il ne pourrait donner que des marcliandises. Il est encore un point fort essentiel : c'cst que Ic métayer, loin de s'imaginer savoir les choses qu'il ignorc réellement, soit toujours disposé à apprendre celles qu'il ne sait pas encore. On ne tire jamais d'une opération agricole, quelque bien faite qu'elle soit, un profit égal à la perte qui en rćsultera si elle a été mal exécutée. II n'y a qu'un seul principe fondamental en agriculture, c'est de ne jamais revenir plusieurs fois aux différents travaux des champs: lorsqu'il faut retoucher à cequi a été mal fait par imprudenec ou par négligence, le dommage qui en résulte est irréparable; et quel que soit le profit que l'on en tire dans la suite, il ne saurait jamais compenser les avantages qu'eût présentés l'entreprise menée à bien dès l'abord. Pour les autres esclaves, voici les règles de conduite quc j’ai toujours fidèlement observées, sans avoir jamais eu sujet de m'en repentir. Je prends un ton plus familier avec les esclaves de la campagne surtout quand leur conduite est irréprochable, qu'avec ceux de la ville. Commela doueeur d'un maître apporte quelques soulagements à leurs travaux longs et pénibles, jc pousse quelquefois la familiarité jusqu'à badiner avec eux, et leur permettre de rire et de plaisanter avec moi. Souvent aussi, surtoutquand il s'agit d'une nouvelle entreprise, je les consulte comme s'ils en savaient plus que moi ; et c'est ce qui me met en état dejuger de l'esprit et des dispositions de chaeun d'eux. D'ailleurs, j'ai toujours eru remarquer qu'ils abordent avec un courage tout particulicr les travaux sur lesquels ils ont été consultés, s'imaginant sans doute que je ne les a vais entrepris que par leur conseil. Outre cela, c'est un devoir pour tout propriétairc prudent de visiter souvent les esclaves qui sont en prison, afin de s'assurer s'ils sont bien enchainés, si la prison elle-même est assez sûre et solide, si le métayer n'en a enchainé ni déehaîné quelques-uns à l'insu de son maître; car il y a deux points principaux auxquels lc métayer doit sc conformer: d'abord, de ne jamais óter les chaines, sans la permission du chef de famille, à ceux qu'il aura condamnés a cette peine; ensuite, de ne point mettrc en liberté ceux qui auront étć enchainćs de son autorité privée, avant d'en avoir instruit son mâ̂tre. En général, les esclaves enchaînés doivent être, de la part du maittre, l'objet d'une surveillance particulière. Il s'assurera par lui-même s'ils ne sont privés ni de vêtements, ni des autres choses qui leur sont nécessaires. Il duit y veiller d'autant plus serupuleusement que ees malheureux étant soumis à plusieurs supérieurs, au mé. tayer, aux chefs d'atelier et aux geôliers, sont plus que les autres exposés à souffrir toutes soltes d'injustices, et n'en sont que plus redoutables dans les cas où la cruauté et la cupidité de ceuxci les réduisent au désespoir. Aussi, un propriétaire véritablement attaché à ses intérêts doit s“in. former, soit auprès d'eux, soit auprès des ouvricrs libres qui méritent le plus de confiance, si l'on donne aux eselaves enchainés ce qui leur revient de droit, conformément à sesordres; il goûtera luimêmeleur pain et leur boisson. Il examinera l'état de leurs vêtements, de leurs manches et de leurs chaussurcs. Souvent aussi il leur accordera la permission de lui porter les plaintes qu’ils peuvent sed ubi numeratio exigetur, rem pro nunis ostendit. In universum tamen hoc inaxime obtinendum ab eo est, nequid se putet scire quod nesciat, quneratque semper addiscere, quod ignorat. Nam cunı nultum prodest perite quid facere, tum plus obest perperam fecisse. Unum enim ac solum dominatur in rusticatione, quicquid exigit ratio cultura semel facere : quippe cum emenlatur vel intprudentia vel negligentia, jam res ipsa decoxit, nec in tantım postınodum exuberat, ut et se amissam restituat, et quastum temporum prateritorum resarciat. In cateris servis hac fere pracepta servanda sunt, qux me custodisse non ponitet, ut rusticos, qui modo non incommode se gessissent, sxepius quam urbanos familiariusque ulloquerer; et cum hac conitate domini levari perpetuum laborem corum intelligerem, nonnunquam etiam jocarer, et plus ipsis jocari permittereun. Jam illud sxpe facio, ut quasi cum peritioribus de aliquibus operibus novis deliberen, et per hoc cognoscan cujusque ingenium, quale quamque sit prulens. Tun etian libentius eos il opus aggredi video, de quo secum deliberatum, et consilium ipsorum susceptum putant. Nam illa solenria sunt omnilus circumspectis, ut ergastuli mancipia recognoscant; ut explorent, an diligenter vincta sint; an ips sedes custodiæ satis tutæ munitæeque sint : num villicus aut alligaverit quempiam domino nesciente, ant revinxerit. Nam utrumque maxime servare debet, ut et quem paterfamilias tali pena multaverit, villicus nisi ejustem permissu compedibus non exinat: et quem ipse sua sponte vinxerit, ante quam sciat dominus, non resolvat: tantoque curiosior inquisitio patrisfamilias debet esse pro tali genere servorum, ne aut in vestiariis aut in cxeteris probitis injuriose tractentur, quanto et pluribus subjecti, ut villicis, ut operum magistris, ut ergastulariis , magis olnoxii perpetiendis injuriis, et rursus sxvitia atque avaritia lasi magis timendi sunt. Itaque diligens dominus, cum et ab ipsis, tum et ab solutis, quibus major est fides, quarat, an ex sua constitutione justa percipiant. Atque ipse panis potionisque bonitatem gustu suo exploret; ves- 
avoir à faire contre ceux qui les traitent avee trop de cruauté cl les frustrent des clioses nécessaires. Pour moi, autant je m'empresse de faire droit à ceux dont les plaintes sont justes, autant je sévis contre ceux qui cherchent à exciter des séditions dans la maison, ou à calomnier leurs supérieurs. D'un autre còté, je me plais toujours à récompenser ceux dont la conduite aura été irréprochable. Quant aux femmes esclaves, nous avons toujours dispensé de tout travail et même rendu à la liberté celles qui avaient élevé plusieurs enfants; une esclave qui a vait mis au monde trois garçons n'était plus assujettie à faire aucun ouvrage; celle qui en a vait davantage était entièrement libre. Une conduite équitable et sage de la part d'un chef de famille contribue beaucoup à l'accroissement de son patrimoine. De retour à la campagne, le propriétairc noubliera jamais d'invoquer les dieux pénates; ce devoir rempli, il ira à l'instant même, ou, s'il est trop tard, le lendemain, visiter ses terres, et inspecter toutes les parties de la ferme; il s'assurera si son absence n'a pas apporté du relâchement dans la surveillance ou dans l'ordre établi, si l'on n'a point dépouillé ses vignes, ou ses arbres fruitiers. Ensuite il comptera ses bestiaux, ses esclaves; il passera en revue les instruments de culture et les meubles du ménage. En suivant tous ces conseils pendant plusieurs années, il parviendra à ćtablir une habitude d'ordre dont il jouira dans sa vieillesse; et alors, quelque affaibli qu'il soit par l'âge, il n'aura point à craindre de devenir le jouct ou la dupe de ses gens.

IX. II nous reste encore à parler des qualités physiques et morales que nous devons rechercher

tem, manicas, pedumque tegmina recognoscat. Sxpe efiam querendi potestatem faciat de is, qui aut crudeliter eos aut fraudulenter infestent. Nos quidem aliquando juste dolentes tam vindicamus, quam animadrertimus in eos, qui seditionibus familiam concitant, qui calumniantur ma gistros suos : ac rursus præmio prosequimur $\mathrm{Cos}$, qui strenue atgue industrie se gerunt. Fæminis quojue foecundioribus, quarum in sobole certus numerus lionorari debet, otium nonnunquam et libertatem dedimus, cum plures natos elucassent. Nam cui tres erant filii, vacatio; cui plures, liberlas quoque contingebat. Hace et justitia et cura patrisfamilias multum confert augendo patrimonio. Sed et illa meminerit, cum e civitate rencaverit, deos penates adorare: deinde si tempestivum erit, confestim, si minus, postero die fines oculis perlustrare, et omnes parles agri revisere atque æstimare, num quid absentia sua de disciplina et custodia remiserit; num aliqua vitis, num arbor, num fruges absint : tun etiam pecus et familiam recenseat, fundique instrumentum, ct supellectilen : quae cuucta si per plures annos facere instituerit, bene moratam disciplinam, cum senectus ad venerit, obtinebit. Nec erit ulla ejus retas annis ita confecta, ut spernatur a servis. dans les esclaves, d'après la nature du travail auquel ils sont destinés. Ceux qu'on voudra mettre à la tête des travaux devront se distinguer par leur intelligence et leur zèle : deux qualités plus essentielles dans leurs fonetions que la stature et la vigueur du corps, parce que ce service demande une surveillance active, et une connaissance parfaite de l'agriculture. Quant à celui qui conduit les bœufs, ces qualités seraient insuffisantes, s’il n'était en état de se faire craindre de ses bestiaux par une voix forte et une taille imposante. Mais il doit tempérer la force par la douceur, et chercher plutôt à inspirer de la frayeur qu'à se montrer brutal. De cette manière les bœufs lui obéiront plus volontiers, et supporteront mieux et plus longtemps les fatigues, que s'il les aceablait de travail ct de coups. Je parlerai en son lieu a vec plus de détail des devoirs des chefs des travaux et de ceux des laboureurs. Il suffit de faire remarquer, pour le présent, que la hauto stature et la force physique indispensables pour le laboureur ne sont d'aucune utilité aux chefs des travaux. Il faudra par conséquent choisir toujours les premiers parmi les esclaves d'une taille élevée, ct pour les raisons que je viens d'indiquer, et parce que, des différents travaux rustiques, il n'en est aucun qui fatigue moins un homme grand que le labourage; ce qui se comprend parfaitement quand on considère qu'en labourant il marche presque droit, et qu'il peut s'appuyer sul' le manche de la charrue. Quant aux ouvriers ordinaires, appelés médiastini, il n'est pas nécessaire qu'ils soient d'une grande taille, pourvu qu'ils aient la force nécessaire pour supporter les travaux. Il importe peu que les gens qui travaillent la vigne soient petits, pourvu qu'ils aient

IX. Dicendum etiam est, quibus operibus quemque luabitum corporis aut animi contribuendum putemus. Magistros operibus oportet praponere sedulos, ac frugalissimos. Ea res utraque plus quan corporis statura ro. burque confert luuic negotio : quoniam id ninisterium custodia diligentis et artis officium est. Bubulco quam ris necessaria, non tamen satis est indoles mentis, nisi eum vastitas vocis et habitus metuendum pecudibus efficit. Sed temperet vires clementia : quoniam terribilior debet esse quam sicrior, ut et obsequantır ejus imperiis, et diutius perennent boves non confecti vexatione simul ope. rum verberumque. Sed qux sint magistrorum munia quxque bubulcorum, silo loco repetam. Nunc admo. nuisse satis est, nilhil in his, in illis plurimum referre vires et proceritatem. Nam longissimum quemque arato. rem, sicut dixi, faciemus, et propter id, quod paullo ante retuli, et quod in re rustica nullo minus opere fatigatur prolixior, quia in arando stive pene rectus innititur. Mediastinus qualiscunque status potest esse, dummodo perpetiendo labori sit idoneus. Vinex non sic altos quemadmodum latos et lacertosos viros exigunt. Nam is lıabitus fossuris et putationibus caterisque earum culturia magis aptus. Minus in hoc officio quam in crteris agrico 
les ćpaules larges et les muscles développès. Ils seront plus propres à bêcher et tailler la vigne, et à lui donner toutes les facons qu'elle demande. La bonne conduite est moins importante pour les vignerons, qui travaillent toujours en compaunie et sous les yeux d'un elief, que pour les autres ouvriers. Commegénéralement les hommes vieieux ont l'esprit plus vif, et que la culture de la vigne exige non-seulement des gens robustes mais encore intelligents, on donne ordinairement ces travaux à ceux qui sont à la chaîne. Hâtonsnous d'ajouter que, quel que soit le genre d'ouvrage, un homme honnête, et doué de la même aplitude, s'en acquittera toujours mieux qu'un mauvais sujet : eeei soit dit en passant, et pour ne point donner à penser que j'aine mieux faire cultiver mes terres par des misérables que par des gens honnêtes et probes. Toutefois, on conviendra qu'il est nécessaire d'établir une certaine distinction dans les différents travaux d'agrieulture, c'est-à-dire qu'on ne doit point les faire exéeuter indifféremment par toutes sortes de gens. Du moins ce ne serait pas là une pratique bien avantageuse pour lc propriétaire; car lorsque ehaque ouvrier n'a pas sa besogne fixe et déterminée, il craiut toujours en avanȩant son propre ouvrage d'avancer celui de ses compagnons, ct il cherche à se soustraire au travail par tous les moyens possibles. En outre, quand plusieurs sont occupés au même ouvrage, on ne peut reconnaitre quel est celui qui s'est mal acquitté de sa tâche. Il importe donc d'établir d'abord une distinction entre les laboureurs, les vignerons, 't les ouvriers ordinaires, et de les diviser, les uns eomme les autres, en plusicurs classes, dont chaeune ne se composera pas de plus de dix hommes. Les aneiens, qui appelaient ces classes déeu- ries, approuvaient fort cette institulion. En effet, dix hommes sont faciles à surveiller, tandis que l'attention du elief serait distraite si ee nombre était dépassé. Lorsque la ferme est d'une grande étendue, on répartira les déeuries sur les différentes parties qui la composent. En distribuant la besogne, on fera toujours en sorte de ne jamais laisser un ouvrier seul, et même deux ensemble, parce que quand ils sont dispersés en petit nombre, ils nc peuvent être suffisamment surveillés; d'un autre côté il ne faut pas qu'ils soient occupés plus de dix au même ouvrage; ear étant en trop grand nombre, ils se reposent l'un sur l'autre pour la tâche qui leur est imposée en commun. Cette division de travail aura l'avantage d'exeiter une lonable émulation parmi les ouvriers, et de nous fairc connaitre les paresseux. Une fois cette espèce de lutte établie, la punition qui frappera les retardataires sera trouvée juste par les autres et supportéc sans murmure. Nous venons d'exposer les différents détails qui doivent en premier lieu occuper l'attention de celui qui se destine a l'agriculture : Ia salubritć, les routes, les voisins, l'eau, la situation et la distribution d'une ferme, les métayer's et les esclaves : nous voici arrivés à la eulture elle-même; nous en traiterons dans le livre suivant, avec l'étendue que demande l'importance du sujet.

\section{LIVRE II.}

1. Vous me demandez, mon cher Publius Silvinus (et je ne ferai point attendre ma réponse) pourquoi j'ai eommeneé, dès le premier livre de mon ouvrage, par réfuter presque tous les anciens auteurs qui ont ćerit sur l'agriculture, et lasio frugalitatem requirit, quia et in turba et sub monifore vinitor opus facere debet. Ac plerunnue velocior animus est improborum [hominum,] quem desiderat luıjus operis conditio. Non solum enim fortem, sed el acuuninis strenui nuiustrum postulat. Ilecque vineta pluriıuum per alligatos excoluntur. Nihil tamen ejusdem agilitatis homo frugi non melius, quam nequam faciet. Hoc interposui, ne quis existimet, in ea me opinione versari, qua malim per noxios quam per innocentes rura colere. Sed et illud censeo, ne confundautur opera familix, sic It omnes omnia exequantur. Nam id minime conducit agricola, seu quia nemo suum proprium aliq̨uod esse opus credit : seu quia cum euisus est, non suo sed conıununi officio proficit, ideoque labori multum se subtrahit; nec tamen viritim malefactum deprehenditur, quod fit a multis. Propter quod separandi sunt aratores a vinitorilus, (et vinitores al) araloribus, ) iqque a mediastinis. Classes eliam non majores quam denum hominum faciunde, quas decurias appellaverunt antiqui et maxime pro. baverunt, quod is numeri molus in opere commodissime custodiretur, nec prateuntis moniton is diligentiam mul. titudo coufunderet. Itaque si latior est ager, in regio- nes diducendix: sunt cx classes, divilundumque ita opus, ut neque singuli binive sint, quoniam disprersi non facile custodiuntur : nec tamen supra decem, ne rursus uhi nimia turba sit, id cpus arl se pertinere singuli non existiment. Hac ordiuatio uon solum concitat armulationem, sed et deprehendit ignavos. Nam cum certamine opus excitetur, tum in cessantes animadversio justa et sine querela videtur adliheri. Sed nimirum dum qux maxime providenda sunt agricolae fuluro praecipimus, de salubritale, de via, de vicino, de aqua, situ villx, fundi modo, colonorun et servorum generibus, officiorun operumque distributione, tempestive per haxc ad ipsum jam terrae cultum pervenimus, de quo pluribus libro iusequente mox disserimus.

\section{LIBER SECUNDUS}

I. Qumris ex me, Pulli Silvine, quod ego sine cunctatione non recuso docere, cur priore libro veterem opiuionem fere omnium, qui de cultu agrorum locuti sunt, a principio confestim repulerim, falsamque senten- 
paı rejeter comme fausse l'opinion qu'ils ont que la terre, faliguée, épuisée par l'action du temps et le travail des hommes, est accablée maintenant sous le poids de la vieillesse. Jc n'iguore point que vous respectez beaucoup l'autorité des auteurs illustres, et surtout cellc de Trémellius, qui a laissé à la postérité un ouvrage écrit arec autant d'érudition que d'élégance, et renfermant la plupart des règles relatives à l'économie rurale. Entrainć sans doute par l'estime qu'il avait rouée aux anciens qui ont éerit sur la même matièrc, Trémellius s'était imaginé que la terre, mère commune de toutes choses, actuellement dans la décrépitude, ressemblait à ces vieilles femmes qui ont cessé d'enfanter. Je serais assez disposé à partager cette opinion, si l'on ne voyait plus de fruits sur la terre. Mais, pour me servir de la même comparaison, une femme cst regardée comme stérile, non pas quand elle n'a plus deux ou trois enfants à la fois, mais lorsqu'elle a tout à fait cessé d'en mettre au monde. Une fois qu'une femme n'est plus jeune, elle a beau vivre longtemps par delà, la fécondité que les années lui refusent ne lui cst jamais rendue. Au lieu que la terre, qu'elle ait été laissée en friche par un accident ou volontairement, répond au soin du laboureur, et compte avee usure le repos qu'on lui a laissé, dès qu'on la cultive de nouveau. Ce n'est donc pas la vieillesse qui peut aroir diminué la fécondité de la terre : car une fois la vieillesse venue, il n'y a plus de retour, et nous -ne pouvons ni rajeunir, ni repren. dre notre première vigueur. D'un autre cóté, ce ne peut être la fatigue du terrain qui diminue la récolte du cultivateur; car il $y$ aurait de la folie à penser que la fatigue soit une suite de la

tiam repudiarerim censentium longo sevi situ longique jan teınoris exercitatione fatigatam et effortam lıumum consenuisse. Nec te iguoro cum et aliorum illustrium scriptorum tum procipue Tremellii auctoritatem revereri, qui cum jlurima rusticarum rerum procepta simul eleganter et scite memoria prodiderit, videlicet illectus nimio favore priscorum de simili materia disserentium falso credidit, parentem omnium terram, sicut muliebrem sexum xtate anili jam confectam, progeuerandis esse furtibus inlıabilem. Quod ipse quoque confiterer, si in totum nulla fruges provenirent. Nan el hominis tum demun declaratur sterile senium, nun cum desinit mulier trigeminos ant geminos parere, sed cum oinnino nullum conceptum edere valet. Ilaque transactis juventa tempo. rilus, etian si longa vita superest, partus tanen aunis denegatus non restituitur. At e contrario seu sponte seu quolibet casu destituta lunnus, cum est repetita cultu, magnu fienore cessationis colono respondel. Non ergo est exiguarum frugum causa terra vetustas, si modo cum semel invasit senectus, regressum non labet, nec revi. rescere aut repubescere potest; sed ne lassitudo quidem soli ininuit agricula Iructum. Neque enim prudentis est adduci tanquam in lominibus nimix corporis exercitationi, culture et de l'agitation des terres, comme elle est dans les hommes un résultat d'un exercice violent, ou d'un fardeau trop considérable. Vous m'objecterez peut-être l'assertion de Trémellius, qui affirme que toute terre sauvage et vicrge produit avec abondance après une première culture, tandis que les années suivantes el!e ne répund plus arce la même abondance au soin du cultivateur. Le fait que Trémellius avance est exact; mais il n'a pas cherché à en approfondir la cause. Si une bruyère transformée en champs est plus féconde que tout autre sol, ce n'est point parce que la terre est plus jeune, plus neuve, mais parce qu'ayant été suffisamment engraissée par Ic feuillage des arbres et les herbes qui y croissaient sans culture, elle se prête avec plus de facilité à la nutrition des plantes. Mais dès qu'une fois les racines de ces herbes ont été arrachées par les herses et les charrues, et que les arbres ayant été coupés ont cessé de nourrir de leur feuillage la terie qui les produisait ; que les feuilles qui tombaient des arbres et arbrisseaux, au lieu de rester couchées sur le sol comme auparavant; sont retournées par le soc de la charrue, enterrées et incorporées aux couches inférieures et moins fertiles de la terre; il arrivera nécessairement que le terrain lui-même, privé de son ancienne nourriture, maigrira promptement. Si donc les champs répondent aujourd'hui moins largement à nos espérances, il ne faut en accuser ni l'épuisement du sol, ainsi que l'ont fait ia plupart de nos auteurs, ni la vieillesse de la terre, mais notre propre négligence. Car les récoltes seraient toujours abondantes, si nous voulions en quelque sorte renouveler la terre par des engrais fréquents, opportuns, et sagement distri- aut oneris alicujus ponderi, sic cultibus et agitationibus agrorum fatigationem snccedere. Quid ergo est, inquis, quod asseverat Tremellius intacta et silvestria loca, cum primum copperint cultum exuberare, mox deinde non ita respondere labori colonorum? videt sine dubio quid eve niat, sed cur id accidat, non pervidet. Neque enim idcirco rudis et modo ex silvestri liabitu in arvum transducta focundior lsaberi terra debet, quod sit requietior et junior ; sed quod nultorum annorum frondibus et herbis, quas suapte natura progeneralsat, velut saginata largioribus pabulis, facilius edendis educandisque frugibus sufficit. At (uin perrupta rastris et aratris radices lierbarum, ferroquc succisa nemora frondibus suis desierunt alere natrem, quaque temporibus autumni frutetis et arboribus delapsa folia superjaciebantur, mox cońversa vomeribus, et inferiori solo, quod plerumque est exiliıs, permista, atque absumta sunt : sequitur, ut destituta pristinis alineutis macrescat humus. Non igritır fatigatione, qquemadmodıu plurimi credillerunt, nec senio, sed nostra scilicet inertia ininus beuigne nobis arva respondent. Licet enim majoren fructum percipere si frequenti et tempestiva et nodica stercoratione terra refoveatur. De cujus cultu diclnros nos priori volumine polliciti jam nunc disseremus. 
luués. J'arrive maintenant à la culture de la terre; ainsi que je l'ai pronis dans le premier livre.

II. Les cultivateurs les plus estimés eomptent trois espèees de terrain : la plaine, les eollines, et les montagnes. Dans les plaines, le meilleur terrain est celui qui n'est point exactement de niveau, mais un peu en pente; dans les collines, celui qui s'élève en pente douce; dans les montagnes, celui qui, sans être trop élevé ni trop âpre, est cependant couvert d'herbes et de bois. Ces trois espèces de terrains se divisent en six autres espèces, d'après les differentes qualités du sol, suivant qu'il est gras ou maigre, meuble ou fort, humide ou see; et toutes ces qualitès étant mélangées entre elles forment des variétés infinics. Nous ne croyons pas qu'il soit utile de les énumérer. En effet, la seience ne doit point'se perdre dans le détail des espèces, qui sont innombrables; elle doit procéder avec méthode, et se borner a ces classifications principales, que l'intelligenee saisit aisément et que la langue peut définir avec exactitude. Il suffit pour cela de réunir les qualités les plus dispara-

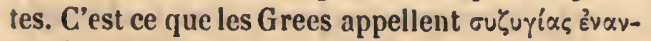

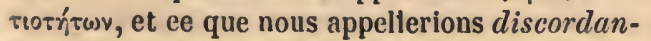
tium comparationes. Remarquons, en général, qu'entre les différents végétaux il y en a beaucoup plus qui se plaisent dans la plaine que sur des eollines, et bien plus encore qui viennent sur un sol gras que sur un sol maigre. Je ne puis décider si les terrains humides l'emportent sur les terrains sees pour le nombre et la variété de leurs produetions, puisqu'il y a une infinité de plantes qui réussissent également sur ces deux terrains; mais ee qu'il y a de certain, c'est que la terre forto ne eonvient pas aussi bien aux productions agricoles qu'un sol franc et meuble;

II. Callidissimi rusticaruın rerum, Silvine, genera ter. reni tria esse dixerunt, campestre, collinum, montanun. Campum non aquissima situm planicie nec perlihrata, sed exigue prona; collem clementer et molliter assurgentem; montem non sublimem et asperum, sed nemorosım ct herbidum maxime probaverunt. His autem generibus singulis senæ species contribuuntur, soli pinguis vel macri, soluti vel spissi, lıumidi vel sicci : qua qualitates inter se mista vicibus et alternata plurimas efliciunt agrurum varietates : eas enumerare non est artificis agricolx. Neque enim artis officium est, per species, qua sınt imumerabiles, evagari; sed ingredi per genera, qua possunt cogitatione mentis et anbita verborum facile copulari. Recurrendum ost igitur ad qualitatım inter se dissidentium quasi quasdam conjunctiones, quas Graeci

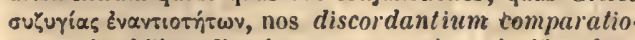
nes, tolerabiliter dixerimus. Atque eliam signiticandın est, ex omnibus, quae terra progeneret, plura campo ma. gis quam colle, plura pingui solo quam macro lactari. be slccaueis et riguis non comperimus, utra numero vincant, quonian utuinque pene intinita sunt, qua siccis queque humidis tocis gaudent; sed ex lis nilıil non melius resoluta lıumo quam deusa provenit. Quod noster aussi Virgile, en faisant l'ćloge d'un clıamp ferlile, a-t-il ajouté: Et dont la terre est friable el di. visée; car c'est pour la rendre telle qu'on la laboure. En effet, cultiver n'est autre ehoso que diviser la terre, et y exciter une sorte de fermentation; c'est ee qui fait qu'un terrain naturellement gras et meuble rapportera toujours plus qu'un autre, parce qu'en donnant de meilleures réeoltes il exigera le moins le culture, et que la eulture en sera moins dispendieuse. Ainsi donc un sol qui réunirait ces deux qualités devrait être regardé comme le plus fertile. Celui qui vient après est le sol gras et ferme; il récompense avec usure le cultivateur de sa dépense et de ses peines. Le troisième est le sol naturellement arrosé; le fruit y vient pour ainsi dire delui-même, et sans que le propriétaire soit obligé de rien débourser. Caton voulait même que ce terrain fût le premier, préférant de beaucoup le revenu des prés à tout autre revenu. Mais cette question est étrangère à notre sujet, puisque nous avons ì traiter ici des façons qu'il faut donner à ia terre, et non pas de sa quantité. Il n'y a point de plus mauvaise espèce de terre que eelle qui est sèehe et dure, tant paree qu'elle est diffieile à labourer que parce qu'elle ne dédommage point le eultivateur de ses peines. D'un autre còté, si on l'abandonne, elle ne prorluit suffisamment ni prés ni pâturages. Ainsi, soit qu'il y travaille, soit qu'il la laisse en friehe, le propriétaire regrettera toujours de l'avoir acquise, et l'on doit la fuir comme on fuirait un lieu pestilentiel. En 'effet, si une contrée pestilentielle porte la mort avec elle, une terre stérile amène la faim, qui est la compagne affreuse de la mort. C'est du moins le sentiment du poëte gree, lorsqu'il nous dit qu'il n'y a point de sort

(uoque Virgilius cum et alias fócundi arvi laudes retılisset, aljecit : Et cui putre solum : namque hoc imitrmucr arando. Feque enim aljud est colere, quam resolvere et fermentare terram. Ideoque maximos qurestus ager probet ilem pinguis ac putris, quia cum plurimmm reddat, minimum poscit : et quod postulat, exiguo labore atque impensa conficitur. Prestantissimum igitur tale solum jure dicatur. Proximum deinde luvic pinguiter densın, quod inıensam coloni laboremque magno fietı remuneratur. Tertia est ratio loci rigui, quia sine impensa fructum reddere polest. IIanc primam Cato esse dicebat, qui maxime reditum pratorum cateris anteponebat : sed nos de agitatione terra nunc loquimur, non de situ. Nullum deterius habetur genus, quam quod est siccum pariter et densum et macrum; quia cum difficulter tractetır, tım ne tractatım quidem gratiam refert: nec relictum pratis vel pascuis abunde sufficit. Itaque hic ager sive exercetur seu cessat, colono est pa!nitendus, ac tanquam pestilens refingiendus. Nam ille mortem farit, hic teterriman comitem mortis famem : si tamen Graecis camnenis habenus fidem clamitantilus : $\Lambda$ «น

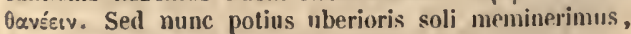
cujus demonstranda est dıplex tractalio, culli ot silrestris: 
plus miserable que de mourir de falm. Occupons nous d'abord du termin fertile : on peut le considérer sous deux faces, comme cultivé ou comme inculte. Nous parlerons en premier lieu des procédés à employer pour faire d'un terrain inculte une terre labourable. En effet, avant de cultiver un champ, il faut commencer par lui donner l'existence; on devra done examiner si ce terrain est scc ou humide, s'il est couvert d'arbres ou de pierres, de joncs ou d'herbes, de fougères ou de broussailles. S'il est humide, il fau. dia faire des fossés pour le dessécher, et donner de l'écoulement aux eaux. Nous counaissons deux espèces de fossés, eeux qui sont cachés, et ceux qui sont larges et ouverts. Ces derniers convienuent mieux aux terrains épais et remplis d’argile; mais dans les terrains plus friables on en fait quelques-uns de cachés et quelquesuns d'ouverts, en sorte que l'eau qui se trouve dans les premiers ait son écoulement dans les autres. II fuut aussi que les fossés ouverts soient plus larges par le haut que par le bas, et qu'ils présentent deux talus, en se resserrant jusqu'au fond, comme une tuile creuse posée sur le dos en forme de gouttière. En effet, si les parois de ees fossés sont droites, ils sont bientôt niinés par les eaux, et comblés par les terres qui s'éboulent d'en lıaut. D'un autre côté, on fera pour les fossés caehés des tranchées de trois pieds de profondeur, que l'on remplira jusqu'à moitić de petites picres ou de gravier pur, et l'on recouvrira le tout avec la terre tirée du fissé. Si l'on n'a ni pierre ui gravier, on formera, au moyen de branches liées ensemble, des câbles auxquels on donnera la grosseur de la capacité du fond du eanal, et qu'oll disposera de inanière à remplir exactcınent ce vide. Lorsque les câbles seront bien enfoncés dans le fond du eanal, ou les re-

De silvestri regione in arvorum forman redigenda prius dicemus, quronian est astliquius facere agrum quam colere. Incultum igilur locum consideremus, siccus an lü. midus; neınorosus arloribus, an lapidiluss confragosus; juncone sit, an gramine restitus, ac filictis aliisve frutetis impeditus. Si lummidus erıt, abundantia uliginis ante siccetur fossis. Farum duo genera cognorinus, cacaru:n et patentiuın. Spissis atque cretosis regionibus aperta: relin. quuntur : at ubi solutior lumus est, aliqua fiunt patentes, upaedam etian ohcrecantur, ita $n \mathrm{l}$ in patentes ora lian. tia cacarum conpetant : sed patentes latius apertas summa parte declivesque; et ad solum coarctatas, in. bricibus supiais similes facere conveniet. Nam quaruın recta sunt latera, celeriter arjuis viliantur, el superioris soli lapsibus replentur. Opertm rursus olscacari debelıut, sulcis in altitudinem tripudanean depressis : qui cum parte dimidia lapides miutos vel untlan glarean rece. fyerint, aequentur superjectn terra, quie fuerat effossa. Vel si nec lapis erit nec glarea, sarmentis cunuexus velut funis informabitur in eam crassitudinem, quau solum fossie pussit anguste quasi accommodatam coarctatanq̨ue couvirira de feuilles de cyprès, de pin ou de tout autre arbre, qu'on comprimera fortement, après a voir couvert le tout avec la terre tirée du fossé : aux dcux extremités on posera en forme de contreforts, eomine cela se pratique pour les petits ponts, deux grosses pierres qui en porteront une troisième, le tout pour consolider les bords du fossé, et favoriser l'entrée et l'écoulement des eaux. Quant aux terrains couverts d'arbres et de buissons, il y a deux manières de les défricher : on arrache, pour netloyer le terrain, les arbres avee les racines; ou si les arbres sont rares, on les coupe sur pied, on brûle ce qui en reste, on en mélange la cendre avec la terre, en la labou. rant. Quant aux terrains pierreux, on les rend propres à la culture en ayant soin d'en retirer les pierres. S'il y en a une gl'ande quantité, on les rassemblera en tas dins une partie du champ, afin de pouvoir en débarrasser le reste du terrain; ou bien encore on les enterrera dans une tranchée profonde; ce qu'il ne faudra faire que dans le cas où la main-d œuvre ne sera pas tiop chèrc. Les joncs et les herbes sont enlevés par le défoncement du sol. La fougère doit être arrachée à plusieurs reprises : ce qui peut se faire également avec la charrue; car cette plante, lorsqu'elle est souvent arrachée, disparait dans l'espace de deux ans, suitout quand on a soin de fumer la terre, et $d^{\prime} y$ planter des lupins ou des fèves. De cette manière on tire même quelque profit du remède qu'on a employé. On comprendra aisément que la fougère doit disparaître dès qu'on a fumé et couvert de nouvelles plantes le terrain qui la portait. Souvent mème on n'a qu'a l'enlever successivement avec la faux, ce qu'un enfant peut faire sans peine : cela suffit pour la détruire au bout du temps que nous arons indiqué. Après avoir fait connaitre le modé de dé-

capere. Tum per inum contendetur, ut super calcatis $\mathrm{cu}$. pressinis vel pineis, aut, si eac non erumt, aliis frondilus terra contegatur; in principio atque exitu fusse more ponticulormm binis saxis tantumnodo pilarum vice, constitutis, et singulis superpositis, ut ejusmodi constructio ripam sustineat, ne prorcludatur lumoris illapsis atque exitus. Nemorosi frutetosiune tractus duplex cura est, vel extirpandis radicitıs arboribus ef removendis; vel, si rare sint, tautum surcidendis incendendisque et ina. randis. At saxosum facile est expedire leclione lapidum, quorum si magna est abundantia, velut quibusdam substructionibus partes agri sunt occupandx, ut reliqux cuundentur : vel in altitudinem sulco depresso lapides obruendi. Qund tamen ila facieudun crit, si suadebit operarum vilitas. Junci et gramin is pernicies repastiuatius est; filicis, frequens extirpatio : quae vel aratro fieri potest, quoniam intra bieunium sxpius convulsa unoritur : cclerius etiam, si eolem teınpore stercores, et lıpino rel faba couseras, It cuu aliq̨uo redilu medearis agri vitio. Naınquue constat, filicem satiouibus et stercoratione facilius interini. Verum et si subinde nascenten falce deci. 
frichement des terres incultes, nous voici arrivés aux solns à donner aux jachères. Mais avant d'aborder ce sujet il est bon de donner quelques préceptes généraux à ceux qui se livrent à l'étude de l'économie ruralc. Je me rappelle que beaucoup de nos anciens auteurs qui ont écrit sur l'agriculture ont regardé comme les signes infaillibles d'un sol gras et fertile en grain, une certaine douceur de la terre, l'abondance des arbres et des herbes, et une couleur noire ct cendrée. De ces trois signes, y y a deux sur la certitude desquels je ne voudrais pas prononcer. Mais pour la couleur, je ne puis assez m'étonner que tous les auteurs, et surtout Cornélius Celsus, dont les connaissances ne s'étendent pas seulement à l'agriculture, mais à la nature entière, se soit trompé au point de n'avoir pas apercu tant de marals et de terres à salines qui sont également noires et cendrées. En général, c'est la couleur de tous les terrains où l'eau n'a pas d'écoulement. C'est une remarque que j'ai toujours faite, à moins que je ne me sois trompé en pensant que des marais fangeux, une terre aigre et humide, ne pouvaient pas plus produire de grains que les terres à salines situées sur le bord de la mer. Mais l'erreur des anciens est trop manifestc, pour que nous insistions davantage. Nous disons done que la couleur de la terre n'est point une marque certaine de sa bonté; on doit en chercher d'autres qui soient plus propres à faire connaître une terre à grains, e’est-à-dire une terre dont le sol est gras. Car de même que la nature a donné aux bestiaux les plus robustes des couleurs différentes et variées à l'infini, elle a donné aux terres les plus fortes une plus grande diversité de cou-

das, quod vel puerile opus est, intra prodictum tempus vivacitas ejus absumitur. Sed jam expediendi rudis agri rationem sequitur cultorum novalium cura, de qua mox quid censeam profitebor, si quae ante discenda sunt,arvorum studiosis proccepero. Plurimos antiquorum, qui de rusticis rebus scripserunt, memoria repelo quasi confessa nec ubbia signa pinguis ac frumentorum fertilis agri prodidisse, dulcedinem soli propriam, lierbarum et arborum proventum, nigrum colorem vel cinereun. Nihil de cæeteris ambigo; de colore satis admirari non possum, cum alios tum etiam Cornelium Celsum, non solum agricolationis sed universæ naturæ prudentem virum, sic ef sententia et visu deerrasse, ut oculis ejus tot paludes, tot etiam campi salinarum non occurrerent, quibus fere contribuuntur pradicti colores. Nullum enim temere videmus locum; qui molo pigrum contineat luumorem, nou eundem vel nigri vel cinerei coloris, risi forte in eo fallor ipse; quod non putem aut in solo limosæ paludis et uliginis amaræ, aut in maritimis areis saliuarum gigui posse lata frumenta. Sed est manifestior hic antiquorum error, quam it pluribus argumentis convincendus sit. Non ergo color tanquauı certus auctor, testis est bonitatis arvorum. Et ideo frumentarlus ager, id est pinguis, magis aliis qualitatibus æstinrandus est. Nam ut fortissinæ pecudes lcurs. Il ne nous reste done qu'd nous assurer que la terre que nous voulons cultiver est grasse; et cela même importerait peu, si le sol manquait d'une certaine douceur. Nous pouvons nous as. surer de la présence de ces deux qualités au moyen d'une expérience assez facile. Il suffit de verser un peu d'eau sur une motte de terre, et de la broyer ensulte entre ses mains: si la terre est gluante, s'il en reste aux doigts pour peu qu'on la touche, c'est-à-dire si, d'après l'expression de Virgile, elle colle aux doigts comme de la poix; enfin, si elle ne s'éparpille point lorsqu'on la jette par terre, nous pouvons eonclure qu'elle cst naturellement remplie de suc et de graisse. De même, si vous remettez dans une tranchée la terre que vous venez d'en extraire, et qu'en la refoulant il s'en trouve trop pour la remplir, de facen que cette terre semble avoir fermenté ct s'être gonflée, vous pouvez encore ĉtre sûr que c'est une terre grasse; si au contraire il en manque pour combler le fossé, la terre est maigre; si elle le remplit juste, elle est médiocre. Toutefois ces expériences ne sont pas toujours certaines, à moins qu'elles n'aient été pratiquées sur l'espèce de terre appelée pullula (terre foncée), et qui est ordinairement très-favorable aux grains. On connaît aussi la bonté d'une terre à son goût; on prend à cet effet quelques mottes de terre dans la partie du champ qui parait la plus mauvaise, et on les délaye dans un vase de terre rempli d'eau douce; on filtre ensuite l'eau comme on filtre le vln qui est sur la lie, et on la goûte. Nous connaítrons ainsi le goût de la terre du champ tout entier, puisqu'il sera le même que celui que les mottes auront communiqué à l'eau. Indépendamment de ces

diversos ac pene innumerabiles, sic etiam robustissim terræe plurimos et varios colores sortitæ sunt. Itaque considerandum erit, ut solum, quod excolere destinamus, pingue sit. Per se tamen id parum est, si dulcedine caret; quod utrumque satis expedita nobis ratione contingit discere. Nam perexigua conspergitur aqua glaba, manu. que subigitur, ac si glu tinosa est, quamvis levissinı tactu pressa inliarescit, Et picis in morem addigitos lentes. cit habendo, ut ait Virgilius, eademque illisa humo non dissipatur : quæ res admonet nos, inesse tali materiæ naturalem succum et pinguitudinem. Sed si velis scrohibus egestam lıumum recondere et recalcare, cuin aliquo quasi fermento abundaverit, certum erit, esse eam pinguem; cum defuerit, exilem; cum aquaverit, mediocrem. Quan. quam ista quße nunc retuli, non tam vera possunt videri, quam si sit pullula terra, quxe melius proventu frugum approbatur. Sapore quoque dignoscemus, si ex ea parte agri, quæ maxime displicebit, effossæ glebx, et in fictili vase madefactæ dulci aqua permisceantur, ac more foculenti vini diligenter colatæe gustu explorentur. Nam yualem traditum ab eis retulerit lumor sapurem, talem esse dicemus ejus soli. Sed citra hoc experimentum multa sunt, quæ et dulcem terram et frumentis lıabilen siguificent, ut juncus, ut calamus, ut gramen, ut trifulium, 
expérlences, il y a d'autres moyens propres à nous faire connaitre si une terre est douce et favorable aux grains. Par exemple, la grande quantité de jones, de roseaux, d'herbes, de trèfle, d'hièble, de ronces, de prunelles, et de beaucoup d'autres plantes bien connues de ceux qui cherchent des sources, nous indiquent que les veines de terre qui les produisent sont douces. Nous ne devons point nous en tenir à la surface du sol; il faut explorer les couches inférieures, pour nous assurer qu'elles sont également terreuses. Pour le blé, il suffit qu'il y ait de la bonne terre jusqu'd deux pieds de profondeur; pour les arbres, il en faudra quatre : cet examen fait, on prépare le champ pour l'ensemencement. Plus un champ aura été préparé avec soin et intelligence, plus il sera fertile. Les plus anciens auteurs ont exposé dans leurs livres certaines maximes que les cultivateurs auront à suivre comme une loi pour le labourage de la terre. D'abord les boufs seront accouplés au joug, étroitement serrés, afin qu'ils marchent d'un pas grave et imposant, le corps droit, la tête levée, que leur cou soit moins fatigué, et que le loug se trouve bien posé sur leurs épaules. Ce mode d'attelage est celui qui est le plus généralement adopté. Quant à celui qui est usité dans quelques provinces, et qui consiste à attacher les boufs au joug par les cornes, il est avec raison condamné par tous ceux qui ont écrit sur l'agriculture. Car la force de ces animaux réside dans la poitrine et le cou, et non dans les cornes: dans la première position, ils poussent de tout le poids de leur corps; au lieu que dans l'autre ils sont tourmentés et souffrent beaucoup, ayant leur tête constamment ramenée en arrière. On se sert aussi pour cette dernière

ebulum, rubi, pruni silrestres, et alia complura, quæ etiam indagatoribus aquarum nota, non nisi dulcibus terrae venis educantur. Nec contentos esse nos oportet prima specie summi soli, sed diligenter exploranda est inferioris materix qualitas, terrena necne sit. Frumentis autem sat erit, si æque bona suberit bipedanea humus : arboribus altitudo quatuor pedum abunde est. Hæc cum ita explorarerimus, agrum sationibus faciundis expediemus. Is autem non minimum exuberat, si curiose et scite subigitur. Quare antiquissimum est formam hujus operis conscribere, quam velut sectam legemque in proscindendis agris sequantur agricolæ. Igitur in opere boves arcte junctos habere conrenit, quo speciosius ingrediantur sublimes et elatis capitibus, ac minus colla eorum labefactentur, jugumque melius aptum cervicibus insidat. Hoc enim genus juncturæ maxime probatum est. Xam illud, quod in quibusdam provinciis usurpatur, ut cornibus illigetur jugum, fere repudiatum est ab omnibus, qui procepla rusticis conscripserunt; neque immerilo. Plus enim queunt pecudes collo et pectore conari, guam cornibus. Atque hoc modo tota mole corporis totoque pondere uituntur : at illo, retractis et resupinis capitibus excru- position de charrues bien plus petites, qui ne peuvent pas faire de sillons profonds; ce qui est cependant nécessaire pour activer la végétation, car plus la terre est labourée d̀ fond, plus les grains et les arbres y prennent d'accroissement. En ceci je ne suis point de l'avis de Colsus, qui, pour diminuer les frais de culture, voulait qu'on labourât la terre avec de petits socs enclavés dans de petits bois, qui pourraient être trainés par des bœufs également faibles ct petits. Sans doute les dépenses s'augınentent à proportion que les bêtes de somme employées au labour sont fortes et robustes; mais notre auteur n'a point pensé qu'il y eût plus à gagner par la récolte des fruits qu'à perdre par l'achat des bestiaux, surtout en Italie, où les champs plantés d'oliviers et de vignes veulent être sillonnés plus profondément qu'ailleurs. Ce n'est qu'ainsi que les racines exubérantes, toujours nuisibles aux vignes et aux olives, peuvent être coupées par le soc de la charrue, tandis que celles qui sont dans la terre même en tirent plus facilement le suc dont elles se nourrissent. Ajoutons toutefois que la méthode de Celsus peut être d'une application utile en Numidie ct en Égypte, où les terres plantées de grains ne portent presque pas d'arbres. D'ailleurs, dans ce pays le soc le plus léger peut sans difficulté retourner le sol, qui n'est qu'un sable gras et fin comme de la cendre. L'homme qui laboure doit marcher sur la terre déjà ouverte; il dirigera la charrue de manière à faire alternativement un sillon oblique et un sillon plein et droit, sans laisser nulle part ce que les agriculteurs appellent des scamna (veaux), c'est-à-dire des portions de terre solides et dures. Il aura soin de retenir les bœufs dans leur marche, lorsqu'ils

ciantur, agreque terræ summam partem levi admodum romere sauciant. Et ideo minoribus aratris moliuntur, qui non valent alte perfossa noralium terga rescindere: quod cum fit, omnibus virentibus plurimum confert. Nam penitus arris sulcatis majore incremento segetum arbo. rumque fuetus grandescunt. Et in loc igitur a Celso dissentio, qui reformidans impensam, quæ scilicet largior est in amplioribus armentis, censet exiguis vomeribus et dentalibus terram subigere, quo minoris forma bubus administrari id possit; ignorans, plus esse reditus in ubertate frugum, quam impendii, si majora mercemur armenta, prasertim in Italia, ubi arbustis atque oleis consitus ager altius resolvi ac subigi desiderat, ut et summa radices vitium olearumque vomeribus rescindantur; quæ si maneant, frugibus obsint; et inferiores penitus subacto solo. facilius capiant humoris alimentum. Potest tamen illa Celsi ratio Numidiae et Egypto convenire, ubi plerumque arboribus viduum solum frumentis seminatur. Atque ejusınodi terram pinguibus arenis putrem veluti cinerem solutam. quamvis levissimo dente moveri satis est. Bubulcum autem per proscissım ingredi oportet, alternisque versibus obli- . quum tenere aratrum, et:alteruis recto plenoque sulcare : 
approchent d'un arbre, de erainte que si le soc de la charrue vient à heurter eontre cet obstacle, les bœufs n'en éprouvent une forte commotion au cou, ou qu'ils ne donnent de leurs eornes trop violemment contre le trone, ou qu'ils ne l'entament avee l'extrémité du joug, et n'en détachent quelques branches. Le laboureur les gouvernera plutôt par la voix que par des coups, qui ne doivent être que sa dernière ressouree, et lorsque les boufs refusent opiniâtrément d'obéir. Il ne se servira jamais d'un aiguillon, ce qui rendrait l'animal rétif et le ferait ruer; il pourra eependant avoil reeours de temps à autre au fouet. Il n'arrêtera jamais ses boufs au milieu d'une ligne; ce n'est qu'au bout du sillon qu'il les laissera se reposer, pour qu'ils aient plus d'ardeur au travail, et qu'ils parcourent plus vite la longueur du sillon. Il est dangereux pour les bestiaux douvrir un sillon de plus de cent vingts pieds de longueur; car ils se fatiguent trop lorsqu'on dépasse eette longueur. Uuand ils seront arrivés au détour, le laboureur les arrêtera et portera le joug en avant, afin de leur rafraiehir le cou; ear s'il ne prenait point régulièrement eette précaution, cette partie de leur corps s'enflammerait, enflerait, et finirait par' se couvrir d'ulcères. Le bouvier ne se servira pas moins de sa ha ehe que du soc, afin de eouper les souehes déjà brisées par la charrue, et d'enlever les racines exubérantes qui poussent toujour's en abondanee dans un terrain planté d'arbres.

III. Lorsque le laboureur aura dételé et détaché ses bœufs, il les frottera, leur pressera le dos avee la main, en soulevant la peau, pour l'empècher de s'attacher au corps, ce qui leur causerait

sed ita necubi crudum solum et immotum relinquat, quod agricolæ scamnum vocant. Boves cum ad arborem vene. rint, fortiter retinere ac retardare, ne in radicem majore nisu vomis impactıs colla commoveat, neve aut cornu hos ad stipitem vehementius offendat, aut extremo jugo truıcım delibet ramuınue deplantet. Voce potius quam verberibns terreat, ultimaque sint opus recusantibus re. media plagx. Nunquam stinulo lacessat juvencum, quod retrectanten calcitrosumque eum reddit. Nonnunquam tamen admoneat flagello. Sed nec in niedia parte versura consistat, detque requiem in summa, ut spe cessandi totum spatium bos agilius enitatur. Sulcum autèn ducere longiolem, quam pedum centumviginti, contrarium pecori est; quoniam plıs aeqno fatigatur, ubi hunc unodum excessit. Cim ventum erit ad versuram, in priorem partem jugum propellat, et boves inlibeat, ut colla eorum refrigescant, quae celeriter conflagiant, nisi assidue refrigerentur et ex eo tumor ac deinde ulcera in. vadunt. Nec minus dolabra, quam vomere bubulcus utatur; et prafractas stirpes summasque radices, quibus ager ar. busto consitus implicatur, omues refodiat ac persequatur.

III. Boves cum ab opere disjunxeril, substrictos con. fricet, manibusque comprimat dorsum, et pellem revel. lat, nec patiatur corpori adlırere, quia et genıs morbi une maladie très-dangereuse. Il leur frollera éga. lement le eou, et leur fera avaler du vill, s’ils sont trop échauffés : deux sectarii suffiront pour ehaque animal. Mais il ne faut pas les attacher à la mangevire avant qu'ils aient eessé d'ètre en sueur, et repris haleine; et lorsqu'il sera temps de les faire manger, il ne faudra pas leur donner d'abord une grande quantité de nourriture, ni la leur donner tout à la fuis; mais peu à peu par parties. On les mènera ensuite à l'abreuvoir, et on les excitera à boire en sifflant; quand ils auront bu suffisamment, on les reconduira à l'étable ; et e'est alors seulement qu'on achèvera de leur donner la quantité de fourrage qu'on jugera nécessaire pour les rassasier. Nous eroyons en avoir assez dit sur les devoir's du laboureur; nous allons traiter maintenant des temps des labours.

IV. L'eau séjournant longtemps dans les terres grasses avant qu'elles aient été labourées, on doit leur donner le premier labour à l'époque où commencent les chaleuri, et lorsque toutes les mauvaises herbes, sorties de la terre, ne sont point eneore montées en graine. On fera alors un grand nombre de sillons, si serrés les uns contre les autres, qu'on puisse à peine distinguer les traees du soe. De cette manière toutes les mauvaises herbes seront arraehées ct détruites. Il fautqu'une jachère soit si bien réduite par des labour's réitérés, qu'elle n'ait presque plus besoin d'etre hersée après avoir été ensemeneée. Les ancieus Romains prétendaient qu'une terre qui a besoin d'ètre hersée après les semailles a été mal labourée. Le maitre s'assurera par lui-même que les labours ont été bien faits. Il ne doit pas s'en rapporter à sa vue, qui pourrait le tromper en lui

maxime est armentis noxium. Colla subigat, merumque fancibus, si xstuaverint, infundat. Satis gutem est singulis binos sextarios pribere : sed aute ad praesepia boves religari non expedit, quam sudare atque anlıelare desierint. Cum deinde tempestive potuerint vesci, non multum nec universum cibum, sed partibus et paulation prabere convenit. Qnem cum absumpserint, ad aquan duci oportet, sibiloque allectari, quo libentius bibant: tum demum reductos largiori pabulo satiari. Ilactenus de officio bubulci dixisse abunde est. Sequitur ut tempora quoque subigendi arvi pracipianus.

IV. Pingues campi, qui diutius continent aquam, prosciudendi sunt anni tempore jam incalescente, cum ouneis herbas ediderint, neque adluuc earum semina maturue. rint : sed tam fiequentibus densisque sulcis arandi sunt, ut vix dignoscatur, in utram partem vomer actus sit : quoniam sic omnes radices herbarum perrupta necautur. Sed et compluribus iterationibus sic resolvatur vervactum in pulverem, ut vel nullam vel exiguam desideret occationem, cum seminaverimus. Nam veteres Romani dixerunt male subactum agrum, qui satis frugibus nccandus sit. Euu porro an recte aretur, frequenter explorare debet agricola. Nec tantum visı, qui fallitur nomnunguam superIssa terra latentibus scamnis, verum etian tactu, qui mi- 
cachant les grosses mottes eouvertes d'une terre pulvérisée; il s’en assurera également par le toucher, qui le trompera moins. A cet effet, il enfoncera unc forte perche au travers des sillons : si elle pénètre partout sans rencontrer de résistance, il est évident que tout le sol a été bien remué; mais si elle reneontre quelque corps dur qui s'oppose à son passage, c'est une preuveque la terre n'a point été suffisamment retournée. I.es laboureurs saehant que le maitre ne s'en rapportera pas à eux sur ce point, $\mathrm{y}$ apporteront une plus grande attention. Les terres humides doivent donc reeevoir le premier labour après les ides du mois d'avril; lc second, vingt jours après le solstice, c'est-à-dire vers le 8 ou lc 9 des calendes de juillet; enfin, le troisième vers les ealendes de septembre. Les cultivateurs expérimentés prétendent qu'on ne doit pas labourer depuis le solstice d'été jusqu'à l'époque que nous venons d'indiquer, à moinsque la terre, comme il arrive souvent, n'ait été trempée par des pluiesimprévues semblables à celles d'hiver, auquel eas rien n'empêche de labourer au mois de juillet; mais en aucunc époque de l'année il ne faut toueher à une terre bourbeuse, ou à un champ qui n'aurait été qu'à moitié mouillé par des pluies légères; c'est ce que les gens de la eampagne appellent une terre varia et cariosa. La terre est dans ce cas lorsqu'après une longue sécheresse il survient de petites pluies qui ne font que mouiller la surface, sans pénétrer dans le sol. Pour peu qu'on ait touché à une terre mouillée et bourbeuse, elle devient pour toute l'année impropre à la culture; elle ne pourra plus être ensamencée, ni hersée, ni sarelée. D'un autre eôté, une terre qui a été labourée dans le temps où elle n'était qu'à demi humectée devient stérile pour trois années de suite. Prenons done un juste mi-

nus decipitur : cum solidi rigoris admota pertica transversis sulcis inseritur. Ea si æqualiter ac sine offensione peuetravit, manifestum est, totum solum deinceps esse ınotum : sil autem subeunti durior aliqua pars obstitit, crudum vervactum esse demonstrat. Hoc cum sæpius bu. bulci fieri vident, non committunt scamna faccre. Igitur uliginosi campi proscindi debent pust idus mensis Aprilis. Quo tempore cum arati fuerint viginti diebus interpositis circa solstitiun, quod est nonum rel octavum calend. Julias, iteratos esse oportebit, ac deinde circa Septembris calendas tertiatos : quoniam in id tempus ah astivo sol. stitio convenit inter peritos rei rustic non esse arandum, nisi si magnis, ut fit nonnunquam, ac sulbitaneis imbribus quasi libernis pluviis terra permaduerit. Quod cum accidit, niliil prohibet, quo minus mense julio vervacta subi. gantur. Sed quandoque arabitur, obscrvabimus, ne lutosus ager tractetur, neve exiguis nimbis semimadidus, quam terram rustici variam cariosamque appellant. Ea est cum post longas siccitates levis pluvia superiorcm partem glacbarum madefccit, infcriorem non attigit. Nau gure limoso versantur arva, toto anno desinunt posse trac- licu pour le labourage, et elıoisissons l'époque où les terres ne sont ni trop humides, ni absolument dépourvues de suc; car le trop d'humidité les rend, eomme j'ai dit, bourbeuses et fangeuses. Pour celles que la chaleur a desséehées, elles ne peuvent jamais être labourées comme il faut. En effet, leur dureté empêche le soc de la eharrue d'y mordre ; ou si elle ne va pas jusqu'à l'empêcher d'y pénétrer parquelque endroit, il ne les pulvérise pas assez, mais il enlève de grosses mottes qui ne font qu'embarrasser le sol sur lequel elles restent étendues, et qui s'opposent à ee qu'il soit bien biné, la résistance qu'elles apportent au seeond labour faisant sauter le soc hors du sillon, comme s'il venait à reneontrer des fondations qui s'opposent à son passage; d'où il arrive qu'il se forme de nouveaux amas de terre qui fatiguent extrêmement les bœufs quand on vient labourer le champ. Ajoutez à cela que toutes les terres, même les plus fertiles, étant plus maigres dans le fond qu'à la surface, ces grosses mottes qui viennent à se lever entraíneut avec elles les parties inférieures de la terre, lesquelles se trouvent alor's à la superficie. Il en résulte que la partie la moins féconde de la terre se trouvant ainsi mêlée à la partie la plus grasse, le champ donne toujours une réeolte moins abondante. Le laboureur lui-même n'a vance que lentement dans sa besogne, et il ne peut l'achever daus le temps voulu, à eause de la dureté du sol. C'est pourquoi je pense qu'il ne faut pas biner pendant la sécheresse les terres qui ont déjà reçu un premier labour : il faut attendre la pluie, afin que la terre étant suffisamment amollie soit plus faeile à cultiver. Un arpent de terre bien humeeté peut être expédié en quatre journées de travail; car il faut deux jours pour lui donner le premier labour, un autre jour pour le second, trois quarts

tari, nec sunt habilia sementi aut occationi aut sarritioni. At rursus, quae varia subacta sunt, continuo trienuio stcrilitate afficiuntur. Medium igitur temperamentum maxime sequamur in arandis agris, ut neque succo careant, nec abundent uliginc. Quippe nimius liumor, ut dixi , limosos lutososque reddit. At qui siccitatibus aruerunt, expediri probe non possunt. Nam vel respuitur duritia soli dens aratri, vel si qua parte penetravit, non minute diffundit lumum, sed vastos cxespites convellit; quibus objacentibus impeditum arvum minus recte potest iterari; quia ponderibus glæbarum sicut aliquibus obstantibus funda. mentis vomis a sulco repellitur : quo evenit, ut in iteratione quoquc scamna fiant, ct boves iniquitate operis pessime multentur. Accedit lıc, quod omnis lıumus quamvis lotissima, tamen inferiorem partem jejuniorem habet, eamquc attralıunt excitatæ majores glæbæ. Quo evenit, ut infocundior materia mista pinguiori segeten minus uberem reddat, tum etiam ratio rustici aggravatur exiguo profectu operis. Justa enim fieri nequeunt, cum induruit ager. Itaque siccitatibus censeo quod jam proscissum est itcrare, pluviamque opperiri quæ madefacta terra, facilem 
pour le troislème, et un quart pour disperser la semence sur les raies (lira). Les cultivateurs donnent le nom de porea à ces raies, qui, formées par le labour, et se trouvant entre deux rayons assez éloignés l'un de l'autre, présentent une couche sèche et élevée pour la semence. Les collines dont le sol est gras doivent recevoir le premier labour après ies scmailles trimestrielles, c'est-d̀-dire au mois de mars, on bien dès le mois de février, si la douceur de la température et la sécheresse de la contrée ie nermettent. On les binera depuis le milieu d'avril jusqu'au solstice, et on les tiercera ell septembre, vers l'équinoxe. Pour cultiver un jugerum de terre de cette dernière espéce, il faut autant de journées que pour les terres humides. Les terrains en pente doivent toujours ètre labourés en travers (du talus), pour éviter la difficulté que présente la montée roide (le talus), et pour diminuer les fatigues des hommes et des bêtes. Mais quand on donnera à ces terrains le second labour, il faudra faire le sillon un peu obliquement, c'est-à-dire le diriger tantôt du côté le plus élevé, tantôt du côté le plus bas du versant, afin que la terre soit égalcment amcublie des deux eótés, et que le fort de l'opération ne suive pas toujours la même trace. Un terrain pauvre dans une plaine humide ne doit être labouré pour la première fois que vers la fin du mois d'avril; la terre sera binée en septembre, et prête à recevoir la semence vers l'équinoxe. Un terrain de cette nature exige moins de travail, et est expédié en moins de temps que tout autre ; trois jours suffisent pour un jugerum. II ne faut pas non plus labourer en été les terres situées dans une descente; ce n'est que vers les calendes de septembre qu'on pourra leur donner

nobis culturam prabeat. Sed jugerum talis agri quatuor operis expeditur : nam commode proscinditur duabus, una ileratur, tertiatur dodrante, in liram satum redigitur, quadrante opera. Liras autem rustici vocant easdem porcas, cum sic aratum est, ut inter duos latius distantes sulcos medius cumulus siccam sedem frumentis probeat. Colles ptrguis soli peracta satione trimestri inense Martio, si vero tepor cali siccitasque regionis suadebit, Fe. bruario statim proscindendi sunt. Deinde ab Aprili medio usque in solstitium iterandi, tertiandique Septembri circa aequinoctium. Ac totidenı operis, quot uliginosi canıi, excolitur jugerun. Sed tali agro in arando maxime est observandum, senıper ut transversus mons sulcetur. Nam hac ratione difficultas acclivitatis infringitur, laborque pecudum et lominum commodissime sic minuitur. Paulum tamen quotiescunque iterabitur, modo in elatiora modo in depressiora clivi obliquum agi sulcum oportebit, ut in utramque partem rescindamus, nec eodem vestigio terraın moliamur. Exilis ager planus, qui aquis abundat, primum aretur, ultima parte mensis Augusti, sulvinde Septenıbri sit iteratus, paratusque sementi circa æquinoctium. Expeditior autem labor ejusmori solo est, eo quod pau. ciores impenduntur operæ: nam tres uni jugero sufficiunt. le premler labour. Si on les ouvrait plus tôt, le scleil d'été consumerait leur suc, et leur ôterair toute leur force de végétalion. C'est pourquoi on fera bien de les labourer entre les calendes et les ides de septembre, et de les biner immédiatement après, afin qu'elles puissent être ensemenećes aux premières pluies d'équinoxe. Remarquons encore que dans les terres de cette nature il faut semer non sur les arêtes, mais dans les sillons.

V. Avant de biner une terre pauvre, on ferabien de la fumer; car le fumier est pour le sol une espèce de nourriture qui l'engraisse. On disposera à cet effet des tas de fumier, chacun de cinq modii, environ dans les plaines; on les placera à une distance plus grande les uns des autres que dans les terrains en pente; c'est-à-dire on laissera dansles unes huit et dans les autres six pieds d'intervalle entre chaque tas. On doit engraisser les terres au déclin de la lune, ce qui est très-important pour les préserver des mauvaises herbes. Pour un jugerum il faut vingt-quatre charretées d'engrais quand on approche davantage les tas les uns auprès des autres, et dix-huit, quand on les éloigne davantage. Dès que le fumier sera éparpillé sur la terre, on labourera pour l'enfouir, afin que le hâle du soleil ne lui fasse pas perdre sa force, et que la terre ineorporée avec cet aliment puisse s'en engraisser. C'est pourquoi, lorsque les tas seront disposés dans un champ, il ne faudra point en éparpiller plus que le laboureur n'en pourra couvrir de terre dans une journée de travail.

VI. Après a voir montré la manière de préparer la terre pour recevoir les semences, parlons maintenant des semences elles-mêmes, et de leurs dif-

Item graciles clivi non suut astate arandi, sed circa Septembres calendas : quoniam si ante hoc tempus proscillditur, effoeta et sine succo lumus westivo sole peruritur, vullasque virium reliquias liabet. Itaque optime inter calendas et idus Septembris aratur, ac subiule iteratur, ut primis pluviis aquinoctialibus conseri possit : neque in lira, sed sub sulco talis ager seminandus est.

V. Prius tamen quam exilem terram iteremus, stercorare conveniet : nam eo quasi pabulo gliscit. In campo rarius, in colle spissius acervi stercoris instar quiucpue modiorum dispouentur, atque in plano pedes intervalli quoquo versus octo, in clivo duobus minus relinqui sat erit. Sed id nobis decrescente luna fieri placet : nam ea res herbis liberat segetes. Jugerum autem desiderat, quod spissins stercoratur, velıes quatuor et viginti; quod rarius, duodeviginti. Disjectum deinde protinus fimum inarari et obrui convenit, ne solis halitu vires amittat, et ut permista lumus predicto alimento pinguescat. Itaque cum in agro disponentur acervi stercoris, non debet major modus eorum dissipari, quam quem bubulei eodem die possint obruere.

VI. Quoniam semeuti terram docuimus præparare, nunc seminum genera persequemur. Prima et utilissima 
férentes espèces. Les premières et les plus utiles à l'homme sont le froment et le grain adoreum (l'épeautre). Nous connaissons plusieurs espèces de froment; mais celui qu'il faut semcr de préférence, c'est le froment appelé robus, parce qu'il l'emporte sur les autres espèces par son poids et sa blancheur : il faut mettre dans la seconde classe le siliga, qui nous donne un pain léger. On mettra dans la troisième classe les trémols, qui sont une espèce desiliga : cc grain est d'une excellente ressource pour les cultivateurs, lorsqu'ils n'ont pu faire leurs semailles en temps opportun à cause des pluies, ou pour toute autre raison. Les autres especes de froment ne sont d'aucune utilité, et ne peuvent iutéresser que les personnes qui cherchent la vaine gloire d'en posséder la plus grande variétć. Quant au grain appelé adoreum (épeautre), on en compte pour l'usage ordinaire quatre espèces différentes. Celui qu'on appelle clusinum est d'une couleur blanche ct brillante; le vennuculum, divisé en deux espèces, l'une rouge, l'autre blanche, est plus pesant que le clusinum; l'épeautre trimérien, appelé aussi halicastrum, l'emporte sur les autres espèces par sa qualité et son poids. Le cultivateur doit soigneusement conserver les semences de toutes ces espèces de froment et d'épeautre, parce qu'il arrive rarement que la situation d'un champ soit assez heureuse pour qu'on puisse se contenter d'une seule espèce, et qu'une terre se trouve toujours mélangée de parties humides et de partics sèches. Or le froment vient mieux dans une terre sèche, tandis que l'épeautre supporte sans inconvénient l'humiditć.

VII. Quoiçu'il y ait bien des espèces de légumes, les plus agréables ct les plus utiles à l'homme sont la fève, la lentille, le pois, le haricot, le pois

sunt lıominibus frumenta, triticum et semen adoreum. Tritici genera complura cognovimus. Verum ex his maxime serendum est, quod rolus dicitur : quoniam et pondere et nitore præestat. Secunda conditio est habenda siliginis, cujus species in pane procipua pondere deficitur. Tertium erit trimestre, cujus usus agricolis gratissimus. Nam ubi propter aquas aliamve causam matura satio est omissa, prasidium ab loc petitur. Id genus est siliginis. Reliqux tritici species, nisi si quos multiplex varielas frugum et inanis delectat gloria, supervacua sunt. Adorei autem plerumque videnus in usu genera quatnor. Far, quod appellatur Clusinum candoris nitidi; far, quod vocatur vennuculum, rutilum, atque alterum caudidum, sed utrum. que majorisponderis quam Clusinum. Semen trimestre, quod dicitur lıalicastrum, idque pondere et bonitate est priccipuum. Serl liac genera tritici et adorei, propterea custodienda sunt agricolis, quod raro quisquam ager ita situs est, ut uno semine contenti esse possimus, interveniente parte aliqua vel uliginosa vel arida. Triticum autem sicco loco melius coalescit. Adoreum minus iufestatur lulmore.

VII. Leguminum genera cum sint complura, maxime grata et in usu hominum videutur faba, lenticula, pisum, chlche, le chanvre, le millet, le panis, le sésame, le lupin, le lin et l'orge, dont on fait des tisanes. Les meilleurs fourrages sont d'abord la luzerne, le fenugrec et la vescc; puis la cicerole, l'ers, et les blés coupés en herbe. Nous parlerons d'abord des plantes servant à notre usage, et nous commencerons par rappeler un vieux précepte de nos ancêtres : c'est d'ensemencer d'abord les tcrrains froids, ensuite ceux qui sont tempérés, et enfin les terrains chauds. Les règles que nous allons établir s'appliquent principalement aux contrées tempérées.

VIII. Notre poëte nous recommande de ne point semer $d u$ froment ni de l'épeautre avant le coucher des Pléiades : car voici ce qu'il dit dans ses vers : Si vous labourez une terre pour y récolter du froment et de l'épeautre, et que vous vouliez avoir des épis bien remplis, attendez que les filles d'Atlas se couchent le matin. Or les filles d'Atlas se couchent le trente-unième jour après l'équinoxe d'automne, c'est-à-dire vers le 9 des calendes d'octobre. On peut voir par là que les semailles du froment durent quarante-six jours, depuis le coucher des Pléiades, qui tombc au neuvième jour des calendes de novembre, jus. qu'au solstice d'hiver. Les cultivateurs les plus expérimentés observent cette règle pendant les quinze jours qui précèdent et les quinze qui suivent le solstice d'hiver; ils s'abstiennent de labourer la terre, de tailler la vigne, et d'émonder les arbres. Sans doute cette pratique est bonne à suivre quand le climat est tempéré et que le sol n'est point humide. Mais dans les terres naturellement moites et maigres, froides ou même ombragées, il faudra faire les semailles avant les calendes d'octobre, pen. dant que la sécheresse de la terre le permet et

plıaselus, cicer, cannabis, milium, panicum, sesama, lupinum, linum eliam, et ordeum, quia ex eo ptisana est. Item pabulorum oplima sunt Medica et fœenum Græcum, nec minus vicia. Proxima deinde cicera et ervum et farrago, quæ est ex ordeo. Sed de his prius disseremus, qux: nostra causa seminantur, memores antiquissimi praecepti, quo monemur, ut locis frigidis occissime, tepidis celerius, calidis novissime seramus. Nunc antem proinde ac si temperata regioni pracepta dabimus.

VIII. Placet nostro poëtx adoreum atque etiam triticum non ante seminare, quam occiderint Vergilia. Quod ipsum numeris sic edisserit : $\boldsymbol{A} t$ triticeam in messem, robustaque farra Exercebis humum, solisque inslabis aristis, Ante tibi Eoa Atlantides abscondantur. Absconduntur autem altero et trigesimo die post antumnale xquinoclium, quod fere conficitur nono calend. Octobris : propter quod intelligi debet tritici satio dierum sex et yıa. draginta ab occasu Vergiliarum, qui fit ante diem $1 x$ calend. Novemb. ad bruma tempora. Sic enim servaut prudentes agricolæ, ut quindecim diebus prius, quan couficiatur bruma, tolidemque post eam confectam neque arent, neque vitem aut arborem pulent. Nos quoque non abuuimus in agro temperalo et minime lumido sementeu 
que les nuages sont encorc suspendus en l'air, afin que les raeines des blés puissent prendre assez de force pour résister aux frimas, aux gelées et aux pluies d'hiver. Dans tous les cas, et alors même que les semailles auraient été faites à temps, nous ne devons point nous dispenser de faire de larges branehées et un grand nombre de sillons d'éeoulement, appelés elices, afin de réunir toutes les eaux dans des saignées et de les conduire hors des ehamps. Je sais bien que quelques auteurs défendent expressément d'ensemencer les terres avant qu'elles aieut été suffisam. ment humectées par la pluie ; et je ne doute pas en effet qu'il n'en résulte un grand avantage pour la culture même, si la pluie tombe en temps op. portun; mais si elle se fait attendre, comme cela arrive souvent, les semailles n'er doivent pas moins être exécutées, quelle que soit d'ailleurs la sécheresse du sol. C'est là du moins lá pratique qu'on suit dans certaines provinees où, par la nature même du elimat, les̀ pluics sont fort tardives. En effet, le grain semé et hersé dans un sol sec ne s'y eorrompt pas plus que dans un grenier; et lorsqu'il survient une ondée de pluie, les semailles de plusieurs journées lèvent en une seule. Trémellius aussi affirme (et moi-même j'ai pu m'en assurer par mes propres expériences) que le blé semé dans une terre des. séehée par le soleil, et que les' pluies n'ont point encore humectée, n'aura rien à souffrir des fourmis ou des oiseaux. Dans tous les cas, on fera bien de mettre dans un terrain de eette nature de l'épeautre en place du froment, parce que lc grain de l'épeautre est renfermé dans une cap. sule forte et solide, qui pcut résister longtemps à l'humidite.

sic fieri debere. Caterum locis uliginosis atque exilibus aut frigidis ant etian opacis plerunque citra calendas Octoloris semiuare convenire, dum sicca tellure licet, dum nubila pendent, ut prius cunvalescant radices frumenforım, quam liibernis imbribus aut gelicidiis pruinisve infestentur. Sed quamris tempestive sementis confecta erit, cavebitır tamen, ut patentes liras crebrosque sulcos aquarios, quos nonnulli elices vocant, faciansus, ct oinnem liumorem in colliquias, atque inde extra segetes derivemus. Nec ignoro quosdam veleres anctores pracepisse, ne seminarentur agri, nisi cum terra pluviis permaduisset. Quod ego, si tempestive competat, magis conducere agricola non dubito. Sed si, quod evenit nonnunquam, seri sunt imbres, quamvis sitienti solo recte semen committitur : idque etiam in quibusdam provinciis, ubi status talis cæli est, usurpatur. Nam quod sicco solo ingestuun et inoccatum est, perinde ac si repositnm in lorreo uon corrumpitur, atque ubi venit imber, multorum dierum senentis uıo die surgit. Tremellius quidem asseverat, prius quam impluerit, ab avilus aut formicis sata Ion iufestari, dum æestivis serenitalibus ager aret. Idque eliam siepius nos experti verum adlutc esse non comperimus. Magis aple tanıen in ejusmodi agris adorenm quam triticum seritur : quoniam folliculum, quo continetır,
IX. II faut ordinairement pour un arpent de terre quatre mesures de froment si la terre est bonne, et cinq, si elle est médivcre. Neuf mesures d'épeautre suffisent pour un bon terrain, mais il en faut dix pour un terrain de qualité moyenne. Bien que les auteurs ne soient point d'accord sur cette quantité, c'est pourtant cellc que nous jugeons la plus eonvenable, d'après notie proprc expérienee. Si pourtant quelqu'un ne veut point s'y conformer, il pourra suivre les préeeptes de ceux qui prétendent qu'un terrain fertile est bien ensemencé avec cinq mesures de froment et lıuit d'épeautre, et qu'on doit observer les mèmes proportions pour les terres médioeres. Nous sommes bien loin nous-mème de nous conformei toujours aux ehiffres que nous venons d'indiquer, puisqu'ils doivent nécessairement varier suivant les lieux, les saisons et le climat.

Quant à la différence des lieux, il y a des plaines et des terrains en pente, des terres grasses, des terres moyënnes et des terres pauvres. Pour ce qui est de la différence des saisons, il y a les semailles d'automne et celles qui se font à l'approehe de l'hiver. Fn automne on sème plus clair qu'en hiver. Quant au elimat, il est tautôt pluvieux, tantôt sec; s'il est pluvieux, on sème clair, comme pour les semailles d'automne; s'il est see, on sème plus épais, eomme pour les semailles d'hiver: Toutes les espèces de grains réussissent bien dans une plaine ouverte, ehaude, exposée au soleil, et dont le sol est meuble. Quoique les collines donnent ordinairement un grain plus gras, les récoltes du froment y sont pourtant moins abondantes. Les terres fortes, crayeuses et fraîehes sont bonnes pour le siligo et lc far. L'orge ne réussit bien que dans une

firmum et durabilem adversus longioris temporis lıumorem liabet.

IX. Jugerum agri pinguis plerumque modios tritici quatuor, mediocris quinque postulat : adorei modios no. ven, si est læetum solum; si mediocie, decem desiderat. Nam quamvis de mensura minus auctoribus convenit, luanc tamen videri commodissimam docuit noster usus; quem si quis sequi recusat, utatur praceptis eorum, qui hene uberem campum in singula jugera tritici quinque, et adorei octo modiis obserere proccipiunt, atque hac portione mediocribus agris semfna prabenda censent. Nobis ne istain quidem, quam pradiximus, mensuram semper placet servari, quod eam variat aut loci ant temporis aut cali conditio. Loci, cnm vel in campis vel collibus frumentum seritur, atque his vel pinguibus vel mediocribus vel macris. Temporis, cum autumno aut etiam ingruente lieme frumenta jacimus. Nam prima sementis rarius serere permittit, novissima spissius postulat. Cæeli, cutn ant pluvium aut siccum est. Nam illıd iden quod prima sementis, loc quod ultima desiderat. Omne autem frumentum maxime campo patente et ad solem prono apri. coque et soluto laetatur. Collis enim quamvis granum robustius aliquanto, minus tamen tritici reddit. Densa cretosaque et uliginosa lımmus siligineın et far adoreuı 
terre sèche et meuble. Tous les autres grains dont nous venons de parler veulent une terre fertile, qu'on laissera reposer une annéc sur deux.

L'orge au contraire n'admet point de milicu, et exige un sol ou très-gras ou très-pauvre. Les autres grains se soutiennent, même quand on a été obligé de les semer dans un sol limoneux ct mouillé par des pluies continuelles : l’orge au contraire, jetće dans une terre boueuse, ne tarde poiut à périr. Lorsqu'une terre est passablement crayeuse ou fraiche, il faut y semer un peu plus que cinq mesures de siligo : quantité que j'ai indiquée plus haut pour les terrains de cette nature. Si au contraire unc terre est sèche et meublc, grasse ou maigre, quatre mesures suffiront. En effet, par la loi des contraires, une terre maigre demande autant de semence qu'une terre grasse. Le grain, à moins d'être semé très clair sur les terres pauvres, produit des épis petits et vides, tandis que dans les terres riches le grand nombrc de tiges qui partent d'une même racine fait que la récolte est aussi épaisse, alors même que le blé y est semé clair. Remarquons encore qu'un champ planté d'arbres demande un cinquième de semences de plus qu'un terrain vide ct découvert. Nous n'avons parlé jusqu'à présent que des semailles d'automne, qui sont en effet les principales. Il y en a d'autres que la nécessité nous force de faire : ce sont celles que lcs cultivateurs appellent semailles trimestrielles. Elles se pratiquent avec succès dans les contrées froides et exposées aux neiges, où l'été est humide et sans grandes chaleurs; elles réussissent rarcment ailleurs. Ces semailles doivent êtrc faites promptement, et toujours avant l'équi-

non incommode alit. Ordeum nisi solutum et siccum locun non patitur. Atque illa vicibus annorum requietum agitatumque alternis et quam læetissimum volunt arvum. Hoc nullam mediocritatem postulat : nam vel pinguissina vel macerrima lumo jacitur. llla post continuos imbres, si nccessitas cxigat, quanris adhuc limoso et madente solo sparseris, injuriam sustinent. Hoc si lutoso conmiseris, emoritur. Siliginis autem vel tritici, si mediocriter cretosus uliginosusve agcr est, etiaın panlo plus, quam, ut prius jam dixi, quinque modiis ad sationem opus est. At si siccus ct resolutus locus, idemque rel plngnis, vel exilis est, quatuor; quoniam e contrario macer tantundeu seminis poscit. Nam nisi rare conscritur, vanam et utinutam spicam facit. At ubi ex uno seninc pluribus culunis frulicavit, ctianı ex rara segetc densain faeit. Inter catcra quoque non ignorare debcmus, quinta partc scmi. nis anplius occupari agrum consitun arbusto, quam racunm ct apertum. Atque adluc de sationc autumnali loquimur : lıanc enim potissinıa ducimus. Sed est et altera, cum cogit necessitas : trimestrem vocant agricolie. Ha locis pragelidis ac nirosis, ubi xestas cst hil. ınida et sine vaporibus, recte committitur. Cateris adıno. dum raro respondet : quam tanen ipsam ccleriter et utique noxe du printemps. Si le climat et l'état de la température permettent de les faire plus tôt, elles n'en réussiront que mieux. On a tort de penser qu'il y a une espèce particulièrc de blé qui puisse pousser en trois mois, puisque le même grain semé en automne vient beaucoup mieux. Cependant il y a quelques espèces qui réussissent mieux que d'autres aux secondes semailles, parce qu'elles supportent sans inconvénient la chaleur modérée du printemps; tels sont le siligo, l'orge de Galatie, l'alicastrum, et la fève de Marsie : quant aux autres grains qui sont plus forts, il faudra toujours les semer a vant l'hiver dans les contrées tempérées. Quelquefois la terre jette une matière liquide, salée et amère, véritable poison qui détruit les semences déjà mûres, et rase en quelque sorte. toute une portion du champ. Sitôt qu'on aura aperçu dans une terre de ces places nues et dépouillées, il faudra les marquer, afin de bien les reconnaitre et de remédier à ce mal en temps convenable. On se sert à cet effet de fiente de pigeon (de la colombine), ou à son défaut de feuilles de cyprès, qu'on répand partout où l'humidité ou toute autre émanation pestilentielle ont fait périr la semence, et qu'on mêle avec la terre, en la labourant avec la charrue. Mais le souverain remède, et sans lequel les autres ne sauraient être d'aucune utilité, c'est de faire écouler l'humidité au moyen d'une saignée. Il y a des personnes qui prennent un panier à semer, le garnissent d'une peau d'lıyène, et y laissent séjourner quelque temps le grain avant de le semer, convaincus que cette précaution leur fera obtenir une récolte abondantc. II arrive souvent que des animaux qui habitent sous terre font périr le grain qui a déjà mis une

ante aquinoctium vernum eonveniet peragere. Si vero locorum et cali conditio patietur, quanto maturius severimus, tanto commodius proveniet. Neque enim est ullum, sicut multi crediderunt, natura trimestre semen : quippe idem jactum autumno melius respondet. Sunt nihilominns quadam aliis potiora, qux sustinent veris tepores, ut siligo ct ordeum Galaticum, ct halieastrum, granumque fabæ Marsiç. Nam cæetera robusta frumenta semper ante liicmem scri debent in regionibus tcmpcratis. Solet autcm salsam nonnunquam et amaram uliginem vomere terra, quae quamvis matura jam sata manante noxio humore corrumpit, et locis calentibus sine ulla stirpc seminum areas reddit. Lia glahreta signis adhibitis notari convenit, ut suo tempore vitiis ejusmodi medeamur. Nam ubi vel uligo, vel aliqua pestis scgetem enecat, ibi colımbinum stercus, vel si id non est, folia cupressi convenit spargi et inarari. Sed antiquissimum est, omnem inde lumorem facto sulco deducere : aliter vana erınt pradicta remedia. Nonnulli pelle lıyænæ satoriam trimodiam vestiunt, atque ita ex ea , cum paulum immorata sunt semina, jaciunt, non dubitantes proventura, quæ sic sata sint. Quadam etiam sulterrancie pestes adultas segetes radicibus subsectis enecant. Id ne fiat, remedio est aqua-mistus succus 
certaine croissance en ravageant les racines. On remédle à ce mal en laissant tremper les semences, avant de les confier à la terre, dans de l'eau, à laquelle on a mêlé de l'extrait de l'herbe que les paysans appellent joubarbe. Quclques personnes prennent de l'extrait de concombre sauvage, et la racine pilée de cette plante, qu'ils mêlent cnsemble; ils délayent ensuite ce mélange dans l'eau, et y laissent tremper le grain avant de le semer. D'autres encore, lorsqu'ils s'aperçoivent que les semailles sont en danger, arrosent les sillons a vec cette même préparation, on avec de l'amurque non salée, et parviennent alnsi à chasser les animaux nuisibles. J'ai encore un conseil à donner : c'est de choisir pour semence, après la moisson, le meilleur grain qui se trouve dans l'aire. C'est ce que nous recommande également Celse, lorsqu'il dit de recueillir les meilleurs épis quand la récolte a été médiocre, et de les mettre à part pour en tirer le graln qui doit servir de semence. Quand la récolte a été plus abondante, le grain battu doit être nettoyé au crible; et celui qui tombe au fond, à cause de sa grosseur et de son poids, doit toujours être conservé pour semence. C'est là une précaution utile, quelle que soit d'ailleurs la nature du terrain. En effet, si à la vérité les grains dégénèrent plus promptement dans les terres humides, les terrains secs ne sont pas toujours exempts de cet inconvénient, à moins qu'on ne choisisse bien les semences. Sans doute le grain pesant n'est pas toujours produit par une semence pesante, mais il est évident qu'une semence pauvre et légère ne saurait produire un grain fort et lourd. Aussi Virgile, entre autres bonnes choses sur les semences, dit: Jen ai vu des mieux choisies et des mieux préparées qui dégénéraient, si lon n'avait soin

herhx, quam rustici sedum appellant; nam hoc medicamine una nocte semina macerala jariuntur. Quidam $\mathrm{cu}$ cumeris anguini humorem expressum, et ejusdem tritam radicem diluunt aqua, similique ratione madefacta se. mina terro mandant. Alii lac eadem aqua vel amurca insulsa, cum carpit infestari seges, perfunclunt sulcos, et ita noxia animalia submovent. Illıd deinceps priecipiendum labeo, ut demessis segetibus jan in area futuro seınini consulamus. Nam quod ait Celsus, ubi mediocris est fructus, optiman quamque spicam legere oportet, separa. timque ex ca semen reponere; cum rursus anıplior messis provenerit, quidquid exteretur, capisterio expurgandum erit, et semper quod propter magnitudinem ac pondus in imo subsederit, ad senen reservaudum. Nam id plurimum prodest, quia quamvis celerius locis lumidis, tamen etian siccis frumenta degenerant, nisi cura talis adhihea. tur. Neque enin dubinm est, ex robusto semine posse fieri non robustum. Quod rero protinus ex levi natum sit, nunquam robur accipere manifestum est. Ideoque Virgilius cum et alia tum et hoc de seminibus præclare sic disseruit: Vidi ego lecta diu et multo spectata labore Degenerare tamen, ni vis humana quotannis maxima quaque manu legeret; sic omnia fatis In pejus ruere, chaque année de les trier, et de réserver les plus grosses: tant les choses vont en déclinant, tant le destin précipite la fin des étres!

Si le grain rouge, coupé en deux, cst également rouge en dedans, il n'y a pas de doute qu'il ne soit sain; mais lorsque cette espèce est blanchâtre en dehors et blanche en dedans, elle doit être regardée comme légère et fausse. Ne nous laissons point tromper par le siligo, que les cul. tivateurs recherchent tant; ce n'est qu'un fromeut dégénéré; et quoiqu'il l'emporte par la blancheur, il lui est inférieur en poids. Il réussit dans un climat humide, et convient par conséquent aux contrées où il y a des eaux courantes. Nous n'avons pas besoin d'aller chercher ce grain bien loin, ni de nous donner beaucoup de peine pour nous en procurer, puisque toutc espèce de froment, semée dans une terre humide, se trans forme en siligo à la quatrième récolte. Le meilleur grain après le froment, c'est l'orge, que les paysans appellent tantôt hercasticum, tantôt cantherinum ; elle est meilleure pour le bétail, et. plus saine pour la nourriture des hommes que le mauvais froment. II n'y a pas de grain qui sauve plus de la misère dans les cas de disette. On la sème dans une terre franche et sèche, et dans un sol très-bon ou très-pauvre. En effet, l'orge étant le grain le plus fatigant pour la terre, on la met dans un terrain riche, dont la fertilité ne saurait être épuisée, ou dans un sol si pauvre qu'il ne peut produire autre chose. On la sèmera sur le second labour, après l'équinoxe si la terre est en vigueur, et avant l'équinoxe si elle est pauvre, ayant toutefois soin d'observer dans l'un et l'autre cas la proportion de cinq mesures par jugerum. On la moissonne plus tôt que tout autre grain, et avant même qu'elle soit

ac retro sublapsa referri. Granum autem rutilum si, cum diffissum est, eundem colorem interioren habet, integrum esse non dubitamus. Quod extrinsecus albidun, intus etiam conspicitur candisum, leve ac vanum intelligi debet. Nec nos tanqnam optabilis agricolis fallat siligo. Nam hoc trilici vilium est, et quamris candore prastet, pondere tamen vincitur. Verum in humido slatu cali recte provenit; et ideo locis manantibus magis apta est. Nec tamen ea longe nobis aut magna difficultate requirenda est. Nam omne triticum solo uliginoso post tertiam sationem convertitur in siliginem. Proximus est lis frumentis usus ordei, quod rustici li exastichum, quidam etiam cantherinum appellant : quoniam et omuia animalia, quae ruri sunt, melius quam triticum, et lominem salubrius quam malum triticum pascit. Nec aliud in egenis rebus magis inopiam defendit. Seritur soluta siccaque terra, et vel provalida-vel exili, quia constat arva segetibus cjus macescere : propter quod pinguissimo agro, cujus nimis viribus noceri non possit, aut macro, cui nihil aliud, committitur. Altero sulco .seminari debet post æquinoctium, media fere sementi, si læeto solo : si gracili, maturius. Jugerum quinque modii occupabunt. Idque ubi panlum maturuerit, festipantius quam ullum aliud frumentum. 
arrivéc à sa parfaite maturité; car ayant une tige très-faible, et n'étant point recouverte de balle qui enveloppe son grain, elle est aisément détachéc de l'épl, et par la même raison se bat plus aisément que les autres espèces. Après la récolte, la terre qui l'a portée doit être mise en jachère, à moins qu'on ne la fume avec soin, pour dissiper les mauvaises influences (qualités) qu'il lui a communiquées. L'autre espèce d'orge, que les uns appellent distichum, les autres galaticum, est fort pesante et blanche; mêlée avec le froment, elle fait un excellent pain de ménage. On la sème vers le mois de mars, dans un sol gras mais frais. Si la douceur de l'hiver permet de la semer aux ides de janvier, elle n'en viendra que mieux. Six mesures d'orge suffisent pour un arpent. Le panis et le millet, que j'ai rangés plus haut dans la classe des légumineux, doivent également être comptés au nombre des grains, parce qu'en plusieurs contrées on en fait du pain. Comme ils demandent un sol léger et meuble, ils réussissent non-seulement dans un terrain sablonneux, mais même dans le sable, pour peu que le climat soit moite et humlde; car ils redoutent un sol sec et argilcux. Il ne faudra pas les semer avant le printemps, parce qu'une ehaleur modérée est la température quil leur convient le plus. Aussi la fin de mars est l'époque la plus propre pour les confier à la terre. Leur culture est peu dispendieuse pour le laboureur, puisqu'il n'en faut que quatre setiers pour ensemencer un arpent. Il faut les sarcler souvent, pour le débarrasser des mauvaises herbes qui gêneraient leur croissance. Lorsqu'ils sont en épis, on les cueille à la main, avant que la chaleur ne les entrouvre; puis on les suspend pour les faire sécher au soleil. Quand

demetendum erit. Nam et fragili culmo, et nulla vestitum palea granum ejus celeriter decidit, iisdemque de causis facilius teritur, quam cretera. Sed cum ejus messem sus. tuleris, optinum est novalia pati anno cessare : si minus, stercore saturare, et omne virus, quod adliuc inest terræ, propulsare. Alterum quoque genus ordei est, quod alii distichum, Galaticunı nonnulli vocant, ponderis et canJoris eximii, adeo ut tritico mistum egregia cibaria fanilixe prabeat. Seritur quam pinguissimis sed frigidis locis circa Martium mensem. Melius tamen respondet, si clementia liemis permittit, cum seminatur circa idus Janvarias. Jugerum sex nodios postulat. Inter frumenta etian pasicum et milium poneuda suut, quamvis jam leguminilus ea contribuerim. Nam multis regionibus cibariis eorum coloni stistinentur. Levem solutanque lumnum desiderant. Nec in sabuloso solo, sed in arena quoque proveniunt, modo lumido cxlo vel riguo solo. Nam siccum cretosunque refurınidaut. Ante ver seri uon possunt, quoniam teporihus maxime lsetantur. Ultima tanien parte Martii mensis comnodissime terræ committuntur. Nec inpensa gravi rationem cul toris vnerant; quippe sextariis fere quatıor jugerum implent ; frequenten tamen exignnt sas ritionem ef runcationem, ut herbis liberentur. Ea cum on a pris ces précautions avant de les serrer, ils se conservent mieux et plus longtemps que les autres grains. Le millet nous donne un pain d'assez bon goût, surtout quand il est mangé chaud. Le panis et même le millet, pilés dans un mortier, et débarrassés du son, fournissent un potảge au lait qui n'est point à dédaigner.

$X$. Nous avons traité avec assez d'étendue des différentes espèces de blé; passons maintcnant aux légumes. Le lupin est celui qui doit d'a. bord fixer notre atteution, parce qu'il demande le moins de culture, qu'il coûte très-peu, et que de toutes les semences c'est la plus utile pour le fonds. En cffet, le lupin fournit un excellent engrais pour les vignes maigres et épuisées, ainsi que pour les terres en général. Il réussit dans le sol le plus ingrat, et, mis en réserve, il peut se conserver des siècles entiers. Cuit, ou seulement trempé dans l'eau, il sert de nourriture aux bœufs pendant l'hiver, et peut même, dans un temps de détresse, apaiser la faim des hommes. Il se sème au sortir de l'aire, et c'est par consé. quent de tous les légumes le seul qui n'a pas besoin de séjourner préalablement dans un grenier. On peut le semer au mois de septembre, avant l'équinoxe, ou bien immédiatement après les ealendes d'octobre, dans des jachères non labourées. La négligence du laboureur, en le cultivant, ne saurait point lui porter préjudice. Tout ce qu'il demande, c'est la chaleur modérée de l'automne, pour prendre promptement sa croissance; car s'il n'a point assez de consistance avant l'hiver, les froids peuvent lui devenir dangereux. On fera bien de placer ce qui restera de semence de lupin sur un planeher, à la portée de la fumée; car si on le laissait exposé à l'humidité, les vers ne manqueraient pas

spicas ediderunt, prius quam semina hient astibus, manu carpuntur, et suspensa in sole cum assiccata fuerint, reconduntur, atque ita reposita pereunant diutius quam cætera. Panis ex milio conficitur, qui antequam refrigescat, sine fastidio potest assumi. Panicum pinsitumet evolutum furfure, sed et milium quoque pultem quavis in copia maxime cum lacte nou fastidiendam prabet.

X. Quoniam de frumentis abunde pracepimus, de legu. minibus deinceps disserauus. Lupini prima ratio est, quod et minimum operarum absumit, et vilissime enitur, et maxime ex is quax seruntur, juvat agrum. Nam vineis [jam ] emaciatis, et arvis optimum stercus prabet, ac vel effoto solo provenit, vel repositum in granario patitur arum. Boves per hiemem coctum maceratumque probe alit. Famem quoque, si sterilitas annorum incessit honu. nibus, conmode propulsat. Spargitur statim ex area. Alque id solum omnium leguminum nou desiderat requiem in loorreo, sire Septembri mense ante aquinoctium, seu protinus a calendis Octobribus crudis novalibus ingeras. Et qualitercunque obruas, sustinet coloni negligentian. Teporem tamen autunni desiderat, ut celeriter confirunetur. Nam si non ante hiemem convaluerit, frigoribus anligitur. Reliqgum quod senini superest, in tabulafuu, 
de s'y mettre et d'en ronger le germe; de sorte qu'il ne pourrait plus pousser. Ainsi que je viens de le dire, le lupin se plaît dans une terre maigre, et surtout dans une terre rouge; ee qu'il redoute le plus, e'est l'argile et le limon. Dix mesures suffisent pour ensemeneer un arpent. A près le lupin vient le faséole, qu'on sème ou dans une terre qu'on aura laissée reposer, ou mieux eneore dans une terre grasse et labourée chaque année. II n'en faut que quatre mesures pour un arpent. Il en est de même du pois; seulement il demande une terre légère et meuble, une exposition ehaude et un eiel pluvieux. On le sème au commeneement des semailles, dès l'équinoxe d'automne, dans la mème proportion que le faséole; ou bien en prenant une mesure de moins pour chaque arpent. Pour les fèves, il faut leur réserver une terre naturellement riche, ou bien fumée. Si le terrain, après s'être reposé une année, est situé dans une vallée où il puisse recevoir l'humidité des terrains supérieurs, la semenee doit être répandue d'abord sur la terre solide, puis enterrée par un premier labour, ensuite mise en sillon, et enfin hersée, pour qu'elle soit enterrée plus profondément eneore; ear il est néeessaire que la raeine de eette plante soit entièrement reeouverte. Mais si vous voulez semer la fève dans un ehamp qui ne s'est pas reposé auparavant, et qui vient de produire une réeolte, il faudra couper la paille, et répandre vingt-quatre eharretées de fumier par arpent. De même, lorsque vous aurez semé dans un terrain non eultivé, vous commeneerez par retourner la semenee par un premier labour; puis vous sillonnerez, et vous herserez ensuite. Il y a des personnes qui s'imaginent que dans les pays froids les fèves n'ont pas besoin d'étre hersées, parce que les mottes défendent les jeunes plantes des gelées blanelies et les abritent du froid, en les entretenant dans une douee chaleur. D'autres eroient qu'une récolte de fèves peut tenir lieu d'engrais : ee qui revient à dire, ee me semble, non que eette réeolte enriehit la terre eomme ferait le fumier, mais qu'elle l'épuise moins que toute autre plantation. Quant à moi, je suis convaineu qu'un champ est bien mieux disposé pour le blé lorsqu'il n'a rien rapporté du tout, que lorsqu'on lui aura fait porter une récolte de fèves. Suivant Trémellius, quatre mesures de semence suffisent par arpent; moi je pense qu'il en faut six si le sol est riehe, et un peu plus s'il est paurre. Les fèves ne souffrent point de terrains maigres ou eouverts de brouillards; elles réussissent souvent assez bien dans un sol dur et eompaet. Une partie des se. menees doit être jetée vers le milieu du temps des semailles, et une autre partie à la fin : ee second ensemeneement est appelé semailles scptimontiales. En général, les fèves se sèment de bonne heure : quelquefois pourtant les semailles tardives réussissent mieux. Le solstice d'hiver passé, il n'est plus temps de semer la fève. Le printemps est l'époque la moins fa vorable à son en. semeneement. Il y a eependant une fève de printemps qu'on doit semer en février, enaugmentant d'un einquième la quantité de semenee qu'on $\mathrm{em}$ ploie, en la semant à temps. Elle a de petites tiges et peu de gousses : aussi les vieux eultivateurs préfèrent-ils la paille des premières semées à la réeol te entière des dernières. Mais, en quelque temps de l'année qu'on sème la fève, il faudra faire en sorte que la totalité de la sernenee soit jetée en terre au quinzième jour de la lune, si toutefois quo fumus pervenit, optime reponis: Quoniam si humor iıvasit, vermes giguit; qui simulatque oscilla lupinorum adederunt, reliqua pars enasci non potest. Id, ut dixi, exilem ainat terram, et rubricain præcipue. Nain cretam reforınidat, liınosoque non exit agro. Jugerum decem modii occupant. Ab hoc recte plıaselus terra mandabitur, vel in vetereto, vel melius pingui et restibili agro. Nec amplius quatuor modiis jugerum obseretur. Similis quoque ratio est pisi, quod tamen facilem et solutan terra $m$ de. siderat tepidunique locum et calum frequentis liumoris. Earlem mensura jugernm vel molio minus quam phaselum licet obserere primo tempore sementis ab aquinoctio autunnali. Faba pinguissimus locus vel stercoratıs des. tinatur, et si veteretum erit in valle situm, quod a superiore parte succum accipit; prins autem jaciemus semina, deinde proscindemus teriam, proscissanıque in liran revocabinus occabimusque, quo altius largiore humo contegatur. Nam id plurimum refert, int radices enatorum seminum penitus demersa sint. Sin autem proximæ inessis occupandum erit restibile, desectis stramentis quatuor et viginti velıes stercoris in jugerum disponemus dissipa. bimusque. Et similiter cum semen crudo solo ingesserimus, inarahimus, imporcatumque occabimus : quamvis sint, qui negent locis frigidis oportere occari fabam, quia extantes glæebæe a gelicidiis adhuc eam teneram vindiceut, et aliquem teporem frigore laboranti probeant. Sunt etiam qui putent in arvis lanc eandem vice stercoris fungi. Quod sic ego interpretor, ut existimem, non sationibus ejus pinguescere lumum, sed minus lianc quam cætera semina vim terra consumere. Nam certum habeo, frumentis utiliorem agrum esse, qui nilıil, quam qui istam siliquam proximo anuo tulerit. Jugerum agri, ut Tremel. lio, quatuor; ut nobis videtur, fabæ sex occupant modii, si solum pingue sit : si mediocre, paulo a mplius. Laque nec macrum nec nebuloșum locum patitur. Densa tamen lumo sxpe commode responchet. Media sementi pars seri, et pars ultima debet, qua septimontialis satio dicitur. Tempestiva frequentius, uonnunquam tamen sera inelior est. Post hrumam parum recte seritur, pessime vere : quanvis sit etiam trimestris faba, quæ mense Februario seralur, quinta parte amplius quam matura. Sed exignas paleas, nec multam siliquam facit. Veteres itaque rusticos plerumque dicentes audio, malle se matura fabalia quam fructum trimestris. Sed quocunque tempore auni seretur, opera danda erit, ut quantum destinaverimus in sationem, tantum quintadecima luna, si tamen en non 
celte planète n'est pas encore ce jour-là derrière les rayons du soleil, ee que les Grees appellent áró́троибเร; sinon, on la jettera en terre dès le quatorzième jour, pendant que la lune eroit encore, alors qu'on ne pourrait pas reeouvrir dans la même journée tout ce qu'on aura semé. Car alors ni les rosées de la nuit, ni d'autresaecidents, ne pourront nuire à la semence, pourvu qu'elle soit défendue eontre les bestiaux et les oiseaux.

Les ancieñs agrieulteurs, et Virgile lui-même, voulaient qu'on trempát la fève dans la lie d'huile ou dans du nitre, afin que « Les grains devins. sent plus gros dans leurs cosses souvent trompeuses, et que l'action d'un feu léger les ramollit et en hátât la germination.

Nous avons fait l'ohservation nous-même que eette préparation rend la fève moins sujette à être endommagée par le eharaneon. Voiei encore un autre procédé, dont nous avons également reconnu l'utilité par notre propre expérience. On cueille les fèves avant le jour, et pendant que la lune déeroît ; puis on les fait sécher dans l'aire, on les bat, on les vanne, et on les porte dans.le grenier avant que la lune commenee à eroître. Avec ees préeautions, les fèves seront à l'abri des eharançons. La fève légume peut être battue en peu de temps sans le secours des bestiaux, et nettoyée de même, sans eelui du vent. Il suffira de mettre quelques bottes déliées à l'extrémité de l'aire; trois ou quatre hommes les pousseront devant eux avee le pied, en traversant le milieu de l'aire, et les battront en même temps avec des fourehes ou des bátons. Lorsqu'ils serout arrivés à l'autrc extrémité de l'aire, ils entasseront la paille en laissant le grain sur l'aire, pour recommencer à battre d'autres bot- tes de la mème manière. La partie la plus grossière de la paille est effectivement détaehée du reste par ce battage ; mais, pour séparer du grain la partie légère qui tombe des gousses, on a recours à un autre procédé. Quand on rassemble un tas de grain entremêlé de ces petites pailles, on le jette à quelque distance avec des vestilabres (pelles a vanner); la pnille, comme étant la partie légère, tombe presque aussitôt, tandis que la graine plus pesante vole plus loin, et va retomber, sans mélange de corps étrangers, à l'endroit où le vanneur avait l'intention de la jeter. Les lentilles se sèment pendant le temps des semailles, depuis la croissance de la lune jusqu'au douzième jour apıès la nouvelle lune. On leur choisit ordinairement un sol maigre et meuble, ou bien un terrain riehe, mais sec; car les lentilles, à l'époque de leur floraison, périssent aussi bien par l'exeès d'humidité que par une surabondance de sue nutritif. Pour qu'elles se lèvent plus promptement, et qu'elles grossissent davantage, on fera bien de les meler a vee du fumier sec avant de les semer, et de les laisser dans eet état pendant qua* tre ou einq jours. On les sème à deux époques différentes. Le premier ensemencement se fait de bonne heure, au milieu du temps des semailles; et le seeond plus tard, au mois de février. Un modius suffit pour un jugerum. Si l'on veut préserver la lentille des eharançons, qui la mangent même pendant qu'elle est en eosse, il faut la jeter dans l'eau au sortir de l'aire, afin de séparer le bon grain de celui qui est vide et qui surnage. On la fait ensuite sécher au soleil, on la frotte a vee du vinaigre et de la raeine de laser pilée; puis on l'essuie bien, et on l'expose de nouveau au soleil pour la faire sécher. Lor'squ'elle sera bien rafraîehie, on
Iranscurret eo die solis ralios, quoul Græci ảjóxpovorv rocant, si miuss, quartadecima utique adluc lunx crescente lumine spargatur, etiam si confestim tolum seınen operiri non poterit. Nilil enim nocebitur ei nocturuis roribus aliisve ex causis, dun a pecore et avibus vindice. tur. P'riscis auten rusticis nec minus Virgilio prius amurca vel nitro macerari eam et ita seri placuit, Grandior ul fotus siliquis fallacibus esset, et quamvis igni exiguo moperala maderent. Nos quoque sic medicatam comperi. mus, cum ad uaturitatem perducta sit, minus a eureu. lione infestari. Sed et illud, quod deiuceps dicturi sumus, experti pracipiuns. Silente luua faban vellito aute lucem. veinle cum in area exaruerit, confestim, prins quan luua incrententum capiat, excussam refrigeratamque in granariuu conferto. Sic conilita a curculionflous erit iunoxia. Maximeque ex leguminilus en ef sine jumentis teri el sine vento purgari expeditissime sic poterit. Morlicus fasciculorum tumerits resolutus in extrema parte area collocetur, ipuen per longissimum ejus melimmque śratimu tres vel quafuor houniues promoveant pellibus, et laculis furcitlisve runtuulant : deinde cum ad alteram partem arese perveneriut, in acervun culmos regerant. Nam semiua exrussa in area jacebunt, superque ea paula- tim codem modo reliqui fasciculi exentientur. Ac durissinix quidem acus tejectas separatierne erunt a cudentibus : minute vero, qux: de siliquis cnm faba reselerint, aliter secernentur. Nam cum acervus paleis granisyuse mistus in unum fuerit congestus, paulatim ex eo veutila bris per longius spatium jactetur. Quo facto palea, qux? levior est, citra decilet : faba, quax longins enittitur, pura eo perveniet, yuo ventilator eam jaculabitur. Lenfin modo a dimidiata luna usque in duodecimam solo tenui et 1esolnto vel pingui et sieco maxime loco seri convenit : nain in flore facile Inxuria et lumnore corrumpitur. Qua: ut celeriter prodeat et ingrandescat, autequanı seratur fimo arilo permisceri debet, et cum ita quatriduo ant quincpue dichus recpieverit, spargi. Sationes ejus duas servamus, alteran maturam per mediam sementim, se. riorem alteran mense Felmruario. Jngerum agri paulo plus quaın modius occupat. Fa ne surculiouibus absumatur (nam etiam dum est in silipua, exestur) curandum erit, ut cum extrita sit, in aquan demittatur, et ab iuani, quxe profiums inuatat, separelur solida: tum in sole sic:celur, et ridice silphii trita cum aceto aspergatur, defij. ceturque (oleo), atque ita rursus in sole siccatis et mox refrigerata reconlatur, si inajor est modus, in horreo; si 
la scrrera dans un grenler, si on en a une grande quantité; sinon, dans des vaisseaux qui servent à garder l'huile ou des viandes salées. Les vaisseaux remplis, on les bouchera sur-le-champ avec du plâtre. En retirant ensuite la lentille pour la consommation, on la trouvera saine et intacte. "Elle se conserve également, lorsque pour tout apprêt on la mêle avec de la cendre. Il ne faut semer la graine de lin que dans les pays où le prix du lin est assez élevé; car rien n'est plus nuisible à la terre que cette graine : elle demande un sol très-riche et passablement humide. Le temps de son ensemencement est depuis les calendes d'octobre jusqu'au lever de l'Aigle, qui arrive le 7 des ides de décembre. Huit modii suffisent pour un jugerum. D'après l'avis de beaucoup de personnes, il faut la senier le plus clair possible, quand lc terrain est maigre, afin que le lin qu'on en tirera n'en soit que plus fin. On dit encore que lorsqu'elle est semée dans un terrain gras au mois de février, il en faut six modii pour un jugerum. Le sésame demande à être semé de bonne heure, si le terrain est humide; s'il est sec, on pourra le semer depuis l'équinoxe d'automne jusqu'aux ides d'octobre. Il demande en outre un sol meuble, friable, et de la nature de celui que les paysans appellent pullum. Il réussit aussi dans un terrain sablonneux et gras, ou même dans une terre de ramas. On le sème dans la même propartion que le millet et, Ic panis, en prenant quelquefois deux sextarii de plus par jugerum. J'ai vu moi-mẻme dans lês plaines de la Cilicie et de la Syrie semer ce légume au mois de juin et de juillet, et le récolter en automne en état de parfaite maturité. La cicercula, qui ressemble beaucoup au pois, doit être semée au mois de janvier ou de fé-

minor, in vasis oleariis, salsamentariisque. Quæ repleta cum confestim gypsata sunt, quandoque in usus prompserimus, integram lentem re periemus. Potest tamen etiam citra istan medicationem cineri mista commode servari. Lini semen, nisi si magnus est ejus in ea regione, quam colis, proventus, et pretium proritat, serendum non est. Agris enim procipue noxium est. Itaque pinguissimum locum et modice humidum poscit. Seritur a calendis Octo. bribus in ortum Aquilæe, qui est vn idus Decemb. Jugerum agri octo modiis obseritur. Nonnullis placet macro solo et quam spississimum semen ejus conımitti, quo te. nuius linum proveniat. Idem etiam si lato solo seratur inense Februario, $\mathbf{x}$ modios in jugeruın jaci oportere dicunt. Sesama, quæ rigantur, maturius ; quæ carent lıumore, ab aequinoctio autumnali serenda sunt in idus Oc. tob. Putre solum, quod Campani pullum vocant, ple. rumque desiderant. Non deterius tamen etiam pinguibus harenis vel congesticia lumo proveniunt : tautunque seminis, quantum milium panicumque, interdum etiam duobus sextariis amplins in jugerum spargitur. Sed loc idem semen Cilicia Syrixque regionibus ipse vidi mense Junio Julioque conseri, et per autumnum cum permatu. ruerit, tolli. Cicercula qua piso est similis, mense Ja- vrier, dans un sol gras et sous un climat humide; on la sème cependant, dans quelques contrées de l'Italie, avant les calendes de novembre. Trois modli de ce légume suffisent pour un jugerum. C'est de toutes les plantes légumineuses celle qui épuise le moins la terre. Cependant il est assez rarc de la voir bien réussir, car à l'époque de sa floraison elle est très-sensible aux vents du midi et à la sécheresse : deux inconvénients qui sont presque toujours à craindre à l'époque de l'annéc où elle perd sa fleur. Le pois ariétinus (de bélier) et le pois carthaginois doivent être semés en temps de pluie, pendant tout le mois de mars, dans un sol très-riche et fertile. Ce légume fatigue beaucoup la terre, ct quelques cultivateurs expérimentés défendent même de le semer. Pour le faire lever plus tôt, il est à propos de laisser tremper la graine dans l'eau la veille de l'ensemencement. On prend trois modii par jugerum. Le chanvre exige un terrain gras, fumé et arrosé, ou bien une terre basse, humide, et profondément labourée. On ell sème six grains dans l'espace d'un pied carré, au lever de l'Areture, qui tombe à la fin du mois de février, vers le cinq ou le six des calendes de mars. Si le temps est à la pluie, on peut le semer sans danger à l'équinoxe du printemps. On doit comprendre au nombre de ces légumes les navets et les raves, puisqu'ils servent de nourriture aux paysans. La rave présente plus d'avantages que les navets, d'abord parce qu'elle devient plus grosse, et parce qu'elle nourrit non-seulement les hommes, mais les bestiaux, surtout dans la Gaule, où on la donne aux animaux pendant tout l'hiver. Les deux espèces exigent une terre franche et meuble, et ne réussissent point dans un sol dur et épais. Il y a toutefois cette différence, que les

nuario aut Februario seri debet lacto loco, calo humido. Quibusdam tamen Italia locis ante calend. Noremb. se. ritur. Tres modii jugerum impleut. Nec ullım legumen minus agro nocet. Sed raro respondet : quoniam nec siccitates nec austros in flore sustinet; quæ utraque incommoda fere eo tempore anni sunt, quo deflorescit. Cicer quod a rietinum vocatur, itemque alterius generis, quod Punicum, seri mense Martio toto potest cælo hunido, loco quam latissimo. Nam etiam id terram laedit : atque ideo improbatur a callidioribus agricolis. Quod tamen si seri debeat, pridie macerandum erit, ut celerius enascatur. Jugero nodii tres abunde sunt. Cannabis solum pingue stercoratumque et riguum vel planum atque lummidın et alte subactum deposcit. In quadratun peden seruntur grana sex ejus semiuis Arcturo exoriente, quod est ultimo mense Februario circa sextum aut quintum calend. Mart. Nec tamen usque in aquinoctium verumm, si sit plusius cacli status, improbe seretur. Ab his leguminibus ratio est lıabeuda naporum raporumque : nam utraque rusticos implent. Magis tamen utilia rapa sunt, quia et majore incremento proveniunt, et non lominern solum, verum etiam bores pascunt, pracipue in Gallia, ubi lijberna cibaria prodictis pecudibus id olus prabet. Solum 
raves se plaisent dans les terres basses et humides, au lieu que les navets préfèrent les terrains élevés, sees et légers; aussi ccux-ci réussissentils mème dans le gravier et le sable. Au reste, la qualité du sol pcut complétement changer leur nature, puisque dans tel ou tel sol les raves se changent en navets au bout de deux ans, ou les navets en raves. On les sème très-bien l'un et l'autre dans les terrains arrosés depuis le solstice; et dans les terrains secs, à la fin du mois d'août, ou au commencement de septembre. La terre qui les reçoit doit être rompue par des labours et des hersages multipliés, fumée abondamment, ce qui est d'autant plus important, que non-seulement elles y viennent mieux, mais qu'une terre ainsi travaillée donne encore de belles moissons après qu'on les $\mathrm{y}$ a recueillis. Il ne faut pas plus de quatre sextarii de graines dc raves pour ensemencer un jugerum. Il en faut un quart de plus pour les navets, parce que le navet ne grossit pas tant, et que ses racines sont menues et perpendiculaires. Voilà donc les plantes qu'on doit semer pour l'usage des hommes. Voici maintenant celles qui sont destinées aux bestiaux. D'abord les différentes espèces de fourrages, la luzerne, la vesce, l'herbage d'orge, le fenugrec, l'erse, et la cicerole. Ce sont là les principales plantes fourragères, car nous ne croyons pas devoir les nommer toutes. Celles-ci sont les seulcs (qu'il soit nécessaire de semer, à l'exception toutefois du cytise, dont nous parlerons plus bas, dans les livres qui traitent des différentes espèces d'arbrisseaux. De toutes les espèces de fourrages, la luzerne est sans contredit la meilleure, parce qu'une fois seméc, ellc dure dix ans, ct

putre et solutum res utraque desiderat, nec densa nas. citur lıumo. Sed rapa campis et locis humidis lactantur; napus derexam amat et siccam tenuique propiorem terram. Ilaque glareosis sabulosisque arvis melior exit, locique proprietas utriusque semen commutat. Namque in alio solo rapa biennio sata convertuntur in napum, in alio napus raporum accipit speciem. Riguis locis utrumque recte ab solstitio seritur : siccis, ultima parte mensis $\Delta u$ gusti vel prima Septembris. Subactum solum pluribus iteralionibus aratri vel rastri largoque stercore satiatum postulaut. Nam id plurimum refert, non solun quod melius ea proveniunt, sed quod etiam post fructum eo. ruu sic tractatum solum segetes opinas facit. Jugerum agri non amplius quatuor sextariis raporun seminis obse rendum est : quarta parte amplius napi spargendum, quia non in ventrem latescit, sed tenuem radicem deorsum agit. Atque lıæc hominum causa serenda censenus, illa pecudum. Paluulorum genera complura, sicut Medj. cam, et riciam, farraginem quoque ordcaceam, et avenain, fornum Gracum, nec ninus ervum, et ciceram. Nain catera neque enumerare ac minus setere digna. mur : excepta tamen cyliso, de qua dicenns in iis libris, quos de generibus surculorum conscripsiuns. Sed ex iis, qua placent, eximia est lierba Medica; quorl cum fournit quatre et mème six coupes dans l'annéc. En outre elle bonifie la terre, engraissc toute espèce de bétail maigre, et scrt de remèdc aux animaux malades. Un jugerum est plus que suffisant pour nourrir trois chevaux pendant toute une année. Voici la manière de la cultiver. Les terres qu'on veut semer en luzerne, au printemps, doivent être labourées au commencement d'octobre, afin qu'elles puissent se résoudre et s'adoucir pendant tout l'hiver. Vers les premiers jours de février, on les laboure une seconde fois, on en enlève toutes les pierres, et on brise les mottes. En mars on leur donne un troisième labour, et on les herse. La terre étant ainsi bien réduite, on la forme en planches semblables à celles d'un jardin, de dix pieds de large sur cinquante de long, afin de pouvoir les arroser par les senticrs, et qu'il y ait des passages des deux côtés pour la commodité des sarcleurs. On les couvre ensuite de vieux fumier, et on les ensemence vers la fin d'avril : la proportion est d'un cyathus pour un espace de dix pieds de long sur cinq de large. Sitôt que la graine est semée, elle doit être recouverte avec des râteaux de bois, précaution très-essentielle, et sans laquelle la semence serait bientôt brûlée par le -soleil. Une fois dans la terre, la luzerne ne doit plus ètre touchée par des instruments de fer; on la nettoiera, comme je l'ai dit, avec des râteaux de bois, ct on la sarclera fréquemment, pour que l'herbe parasite ne l'étouffe pas quand elle est encore faible. On la laisse sur pied, jusqu'à ce que la graine ait commencé à tomber. Mais lorsqu'elle est bien venue, on peut la couper aussi tendre qu'on le veut, pour la donner aux

semel seritur, decem annis durat; quod per annum deinde recte quater, interdum etiam sexies demelltur; quod agrum stercorat; quod omne emaciatum armentum ex ea pinguescit, quod argrotanti pecori remedium est; quod jugerum ejus toto anno tribus equis abunde sufficit. Seritur, ut deinceps præcipiemus. Locum, in quo Medicam proximo vere saturus es, proscindito circa calendas octobris, et eum tota lieme putrescere sinito. Deinde calendis Februariis diligenter iterato, et lapides omnes eligito, glacbasque offingito. Postea circa Nartium mensem tertiato et occato. Cum sic terram subegeris, in morem horli areas latas pedum denum, longas pedum quinquagenum facito, ut per semitas aqua ministrari possit, aditusque utraque parte runcautibus patcat. Deinde velus stercus injicito. Atque ita mense ultimo Aprili serito tantum, quantum ut singuli cyatlii seminis locum occupent decem pedum longum et quinque latum. Quod ubi feceris, ligneis rastris, id enin nultum confert, statim jacta semina obruantur : na:m celerrime sole aduruntur. Post salionem ferro tangi locus non debet. Atque, ut dixi, ligneis rastris sarriendus et identidem runcandus est, ne alterius generis lıerba invalidan Medicam perimat. Tardıus mes. sem primam ejus facere oportebit, cum jam seminum aliquam partens ejecerit. I'ostea quan voles teneram, cuın 
bêtes de somme; mais arec ménagement les premières fois, et jusqu'à ce qu'elles $y$ soient faites, de peur que eette espèee de fourrage ne leur soit préjudiciable dans sa nouveauté, soit en les gonflant, soit en leur faisant faire trop de sang. Après avoir été coupée, la luzerne doit ćtre arrosée fréquemment; et au bout de quelques jours, lorsque les rejetons commencent à pousser, il faut la débarrasser de toutes les herbes étrangères. Cultivée ainsi, elle fournira six eoupes par année, et durera six ans. La resce a deux semailles: l'une pour fourrage vers l'équinoxe d'automne (il en faut sept modii par jugerum); l'autre pour monter en graine au mois de janvier ou même plus tard : on n'en emploie que six modii. Ces deux ensemencements peuvent être faits dans une terre erue; mais si le terrain a reçu un premier labour, cela n'en vaudra que mieux. Cette semence n'aime point la rosée; c'est pourquoi il ne faut la jeter en terre qu'après la seeonde ou la troisième heure du jour (huit ou neuf heures du matin), lorsque toute humidité a été dissipéc par le soleil cu par le vent. Il ne faut semer que ee qui peut être reeouvert dans la journée; ear si la nuit survenait avant que cette opération fût terminée, la moindre humidité suffirait pour gâter la semence. Il faut également avoir soin de ne point semer la vesce avant le vingt-cinquième jour de la lune, pour que les limaçons ne puissent pas lui nuire. Quant aux fourrages de grains, on les sème dans des terres 'qui ne se reposent jamais, et qui ont été bien fumées, et labourées deux fois. Ces fourrages sont très-bons lorsqu'on ensemence un jugerum avee dix modii d'orge eantherinum, vers l'équinoxe d'automne, immédiatement avant les

prosiluerit, deseces licet, et jumentis prabeas; serl inter iritia parcius, dum consuescant, ne noritas pabuli noceat. Inflat enim, et nultum creat sanguinem. Cum secueris antem, sxpius eam rigato. Paucos deinde post dies, ut copperil fruticare, omues alterius generis herbas eruncato. Sic culta sexies in anno demeti poterit, et permanebit annis decem. Viciæ autem dux sationes sunt. Prima, qua paluuli causa circa aequinoctium autumuale serimus septem modios ejus in uuum jugerum. Secunda, qua sex modios mense Januario vel etiam serius jacimus semini progenerando. Utraque salio potest cruda terra fieri, sed melius proscissa : idque genus pracipue non amat rores, cum seritur. Itarye post secundam diei horam vel tertiam spargendum est, cun jam onuis lımmor sole ventove delersus est : neque amplins projici debet, quam quod eodem dic possit operiri. Nam si nox incessit, quantulocunque lumore prius, quam obruatur, corrumpitur. Olsservandum erit, ne ante quintam et vigesimam lumam terra mandetur. Aliter satæe fere limacem nocere comperimus. Farraginem in restibilistercoratissimo loco et altero sulco serere convenit. Ea fit optima, cum cautlierini ordei decenı modiis jıgerum obseritur eirca aequninoctium antumnale, sed impendentibus pluviis, it consita rigataque imbribus pluies; de sorte qu'arrosée aussitot que fumée, l'orge puisse lever de suite, et devenir assez forte pour résister aux rigneurs de. l'hiver. Kn effet, lorsque les autres fourrages viennent à manquer à cause du froid, eelul-ci fournit, étant coupé, une très-bonne nourriture pour les bœufs et les autres bestiaux. Fréquemment pâturé, il dure jusqu'au mois de mai. Si l'on veut tirer de la graine de ces herbages, il faudra dès les calendes de mars empécher les bestiaux d'en approeher, ct en général les préserver de tout ce qui pourrait les empeccher de monter en graine. Il en est de même de l'avoine, que l'on doit semer en automne, et dont on fauehe une partie, soit pour en faire du foin, soit pour en faire manger tandis qu'elle est en vert. Le fenugrec, que les paysans appellent siliqua, a deux semailles : l'unc pour fourrage au commencement du mois de septembre, vers l'équinoxe, comme la vesee; l'autre, pour moissonner, a la fin de janvier ct au commencement de févrler. On prend sept modii de semence par jugerum dans le premicr cas, et six dans le second. De quelque faẹon qu'on le sème, il réussit très-bien dans un sol eru, pourvu qu'on enterre la semence par un labour peu profond, dont les sillons soleut étroits. En effet, si la semence est couverte de plus de trois pouces de terre, elle ne lève que très-diffieilement. Aussi beaucoup de personnes, pour obvier à cet inconvénient, labourent d'abord avec de petites charrues, sèment ensuite, et couvrent la semence avec des sarcloirs. L'ers se plait dans un terrain maigre et see : l'abondance du suc qu'il trouverait dans un sol riche et fertile le ferait périr. On le sême en automne ou bien après le solstice de l'hiver, à la fin de jan-

celeriter prodeat, ct confirmetur ante hiemis violentiam Nam frigoribus cum alia pabula defecerunt, ea bubus caterisque pecudiluus optime desecta probetur, et si depascere sæpins voles, usque in mensem Maium sufticit. Quod si ctiam semen voles ex ea percipere, a calend. Martiis pecora depellenda, et ab omni noxa defendenda est, ut sit idonea frugibus. Similis ratio avenæe est. Caditur in foenum vel pabulum, dum adlıuc viret, quas autumno sata ; partim semini custoditur. Fœenum Gracum, quod siliquaun vocant rustici, duo tempora sationun lıabel : quorum alterum est Septembris mensis, cum pabuli causa seritur, jisdem dicbus quibus vicia circa requinoctium : alterum antem mensis Januarii ultimi, vel primi Februarii, cum in messem seminatur. Sed hac salione jugerum sex modiis, illa septem occupamus : utraque cruda terra non incommode fit : daturque opera, ut spisse aretır, nec tamen alte. Nam si plus quatuor digitis adobrutum est semen ejus, non facile prodit. Propter quod nonnulli prius quaun serant, mininis aratris proscindunt, atque ita jaciunt semina, el sarculis adobrumnt. Ervum autem letatur loco macro nec lıumido, quia luxuria plerumque corrumpitur. Potest (et) autumuo seri, nec minus post brumam, Januarii parte novissima, rel toto 
vier, ou bien encore pendant tout le mois de fevrier, pourvu que ce soit avant les calendes de mars. Les ngriculteurs prétendent que ce mois est peu favorable à eette plante; et une récolte d'ers provenant des semailles de mars, nuit aux bestiaux et surtout aux bœufs, qui deviennent rétifs lorsqu'ils en mangent. II en faut cinq modii par jugerum. Les eiceroles éerasécs se donnent aux boufs en place d'ers, dans la Béotie et en Espagne. On les broie avec une meule suspendue, on les fait détremper dans l'eau jusqu'à ce qu'elles soient amollies; puis on les mêle avec de la paille, pour les donner aux bestiaux. I! faut douze livres d'ers pour un jugerum, et quinze de eicerole. La cicerole eon vient igalement à l'homme, pulsqu'elle n'est point désagréable à manger; elle a le même goût que le pois, dont elle ne diffère d'ailleurs que par sa couleur moins fraiche, et tirant davantage sur le noir. On la sème au mois de mars, après un labour ou deux, selon le plus ou moins de fertilité du sol qu'on lui réserve. C'est de cette dernière eonsidèration que dépend également la quantité de semence, puisque pour un jugerum il en faut tantốt quatre modii, tantốt trols, et quelquefois mème deux et demi.

XI. Nous avons parlé jusqu'à présent des semences en général, et de l'époque des semailles; nous allons indiquer quel est le genre de culture qui convient à ehaque plante, et eombien elles exigrent de journées de travail. L.es semailles finies, on procède au sarclage. Les auteurs ne sont pas d'accord sur l'opportunité de cette opération. Selon les uns, elle n'est d'aucune utilité, puisque les racines du grain seraient découvertes ou coupées par le sarcloir, et que si les froids venaient après, la gelée fernit périr les

Februario, dum ante calendas Martias : quem meusem universum negant agricola huic legumini convenire, quod co tempore satum pecori sit noxium et pracipue bubus, quos pabulo suo cerebrosos reddat. Quinque mo. diis jngerum obseritur. Cicera bubus ervi loco fresa datur in Ilispania Batica : qua cum suspensa mola divisa est, pauluun aqua maceratur, dum lentescat, atque ita mista paleis subtritis pecori prabetur. Sed ervi dnodecim libra satisfaciunt uni jugo, cicere sexdecim. Eaden hominibus won inutilis neque injncunda est. Sapore certe niliilo differt a cicercula, colore tantum discernitur : nam est obso. letior, et nigro propior. Seritur primo vel altero sulco, mense Martio ita ut postulat soli latitia : quoul eadem qua. tuor moxliis, noununquam et tribus, interdum etiam duobns ac semolio jugerum occupat.

XI. Quoniam quando quidque serendum sit persecuti sunus, nuıc quemadmodum quotque operis sill. gula eorum quie retulimus colenila sint, demonstrabimus. Peracta sementi, sequens cura est sarritionis; de qua non convenit iuter auctores. Quidan negaut eam quidquan proficere, yuol frumenti sadices sarculo detegantur, aliqua etiam succillantur, $\rightarrow$, si frigora incesseriut post sar- cérínles. Les mêmes auteurs ajoutent qu'il vant mieux attendre quo les inauvaises herbes soient toutes venues, pour les ex tirper et herser le elıamp. Selon les autres, le sarclage est une opération très-utile, pourvu qu'elle ne soit pas faite partout de la même manière et à la même époque. Pour les sols chauds et secs, lorsque les grains sont en état d'être sarclés, il faut remuer la terre de manière à les couvrir et à les faire épaissir : ee premier sarclage fait avant l'hiver doit être suivi d'un sceond. Dans les pays froids et maréeageux, il ne faudra sareler qu'après l'hiver ; mais au lieu de courrir les grains, on se borne à remuer la terre par un sarelage à plat. Notre propre expćrience nous a prouvé cependant que le sarelage pendant l'hiver est bon dans beaucoup de contrées, pourvu que le temps soit sec et doux. Je ne prétends pas néanmoins que cela doive se faire dans tous les pays; on fera bien en général de suivre la pratique établie dans les différentes contrées. Dans l'Égypte et l'Afrique, par exemple, qui jouissent d'avantages particulicr, le eultivateur ne touche plus à la terre depuis les semailles jusqu'à la moisson, parce que l'état de l'atmosphère et la bonté du sol sont tels, que rarement on y voit lever d'autres herbes que eelles produites par les semences. Ce phénomène s'explique soit par la rareté des pluies, soit par la nature toute particulière du sol. Mais dans les pays où le sarclage est nécessaire, on ne doit point toucher les ehamps avant que les plantes no couvrent les sillons, quelque favorable que soit d'ailleurs la température. Le froment et l'épeautre peuvent être sarclés dès qu'ils eommencent à pousser leur quatrième feuille, l'orge lorsqu'elle pousse sa einquième, les fèves et les autres légumes lorsqu'ils sont élevés de quatre doigts

ritionem, gelu frumenta enecentur : satius aulem ea esse tempestive runcari et purgari. Pluribus tamen sarriri placet : sed neque eodem modo neque iisdem temporibus usque quaque fieri. Nam in agris siccis et apricis, simulac primum sarritionem nati queant segetes, debere eas permota terra arlobrui, ut finticare possint : quod ipsum ante hiemem fieri oportere, deinde post lienem iterari. Jı locis autem frigidis et palustribus plerumjque trausacta hieme sarriri nec adobrui, sed plana sarritione terram permoveri. Multis tamen nos regionibus aptam esse liema. lem sarritionem comperinus; duntaxat ubi et siecitas cali et tepores pernittunt. Sed nec istud ubique fieri cen. senus : verum incolarum consuetudine uti. Sunt enim regionum propria munera, sicut Egypti et Africa, quibus agricola post sementem ante messem segetem uon attingit ; quoniam corli conditio et terra bonitas ea est, ut vix ulla herba exeat, nisi ex semine jacto, sive quia rari sunt inbres, sen quia qualitas lumi sic se cultoribus praluet. In iis antem loris, ubi desideratur sarritio, non ante sunt attingendac segetes, etiam si cali status permittit, quam cum sata sulcos contexerint. Triticumque et adorem, cum quatuor fibras habere coperint, ordeum cum yuin. 
au-dessus du sol. Il faut cependant en excepter le lupin, qu'il est dangereux de sarcler, parce qu'il n'a qu'unc seulc racine; si elle est coupée ou seulement blesséc par le fer, toute la tige meurt. Mais alors même qu'il n'y aurait pas cet inconvénient à craindre, il serait tout à fait inutile de sarcler le lupin, parce que de toutes les plantes c'est la seule qui, loin d'être étouffée par les mauvaises herbes, les fait périr ellesmêmes. Quant aux autres semences, elles pourraient, à la rigueur, être sarclées, bien qu'elles soient mouillées par la pluie; mais si on veut les préserver de la rouille, il ne faudra faire cette opération que lorsque la terre sera bien sèche. L'orge surtout ne doit être touchée que dans l'é. tat de sécheresse complète. Beaucoup de personnes défendent de sarcler les fèves, parce qu'elles pensent qu'on peut les arracher à la main lorsqu'elles sont mûres, et les séparer des autres herbes qui ont été laissées pour en faire la récolte en foin. Cornćlius Celsus est lui-même de cet avis, puisqu'il compte parmi lés qualités de ce légume celle de produire du foin dans le champ où il a été récolté lui-même. Celui qui voudrait favoriser ainsi la végétation des mauvaises herbes me paraît un cultivateur bien ignorant; car c'cst diminuer de beaucoup le produit de la fève elle-même, que de laisscr auprès d'elle des herbes qu'on aurait dû arracher. D'ailleurs il serait peu prudent de donner plus de soin à la nourriture des bestiaux qu'à celle des hom. mes, surtout lorsqu'on peut se procurer du fourrage par la culture des prairies. Je suis tellement convaincu que le louage (sarclage) est favorable aux feves, que je pense qu'on doit faire cette opération à trois reprises différentes. En effet, j'ai remarqué que ce légume, ainsi cultivé, non-

que, faba et catera legumina cum quatuor digitis a terra extiterint, recte sarrientur, excepto tameu lupino, cujus semini contraria est sarritio, quoniam unam radicen habet, quas sive ferro snccisa est seu vulnerata, totus frutex emoritur. Quod etiam si non fieret, supervacuus tamen esset cultus, cuin sola hæc res adeo non infestetur herbis, ut ipsa herbas perimat. Atque alixe segetes rel humida moveri possunt, melius tamen siccæ sarriuntur, quoniam sic tractatæe non infestantur rubigine. Hordeum vero nisi siccissimum tangi non debet. Fabam multi ne sarriendam quidem putant, quod et manibus, cum maturuerit, ducta secernatur a cæetera runcatione, et internatx herbæe fono reserventur. Cujus opinionis etiam Cornelius Celsus est, qui inter cateras dotes ejus leguminis hanc quoque enumerat, quod sublata faba fonum ex codem loco secari posse dicat. Sed mili videlur pessimi agricolæ, committere, ut satis herba proveniat. Frugibus enim plurimum detrahitur, si relinquitur runcatio. Neque [enim] est rustici prudentis magis pabulis studere pecudum, quam cibis hominum; cum præesertim liceat illa quoque cultu pratorum consequi : adeoque fabam sarriendam censeo, ut existimem debere ellam ter sarriri. Nam sic cultam comperimus seulcment rapporte plus de fruit, mais que les gousses sont tellement minces, que si après avoir rempli un modius de fèves vous les dépouillez de leurs gousses, et que vous les mesuriez de nouveau, le boisseau sera presque aussi plein; de sorte que la cosse qui en est retranchce diminue pcu de leur volume. J'ai déjà dit que le sarclage d'hiver se fait très-avantagcusement après le solstice, au mois de janvier, lorsque lc temps cst serein et sec, et qu'il n'y a point de gelées. Dans l'exécution de ce travail, la seule précaution qu'on aura à prendre, c'est de ne pas attaquer les racines, mais de les recouvrir et d'y amonceler la terre, de manière que les plantes puissent s'étendre par-dessus. Il cst avantageux de viser à ce but dès le premier sarclage ; mais il serait nuisible de se conduire de même, en sarclant pour la scconde fois; car le blé, ayant cessé d'étendre ses racines, pourrit promptement s'il est couvert de terre. Aussi ne faudra$t$-il au second sarclage que remuer bien également le sol, ce qui doit être fait à peu près vingt jours après le solstice d'hiver, avant que le blé commence à sc nouer; plus tard, les chaleurs de l'été et la sécheresse, succédant au sarclage, fe. raient périr les plantes. Après avoir sarclé, il faut arracher les mauvaises herbes, en prenant garde toutefois de toucher aux blés lorsqu'ils sont en fleur. Ainsi on fera cette opération, soit avant la floraison, soit immédiatement après que la fleur sera tombée. Toutes les espèces de blé et d'orge, et en général toutes les graines qui ne sont point partagées en deux lobes, jettent leur épi entre le troisième et le quatrième nœud: lorsque l'épi est sorti, elles perdent leur fleur en huit jours, et grandissent encore pendant quarante autres jours, avant. d'arriver à leur

non solum multiplicare fructum, sed et exiguam portionem in valvulis liabere, fresæeque [ejus et expurgatæ] modiun pene tain plenum esse, quam integra, cum vix minuatur mensura detractis putaminibus. Alque in totum, sicut ante jam diximus, hiherna sarritio plurimum juvat diebus serenis ac siccis post brumam confectam mense Januario, si gelicidia non sint. Ea porro sic debel fieri, ne radices satorum ladautur, et ut potius adobruantur, cumulisque exaggerentur, ut latius se frutex humi diffundat. Id prina sarritione fecisse proderit, secunda oberit; quia cum pullulare desiit frumentum, putrescit si adobru. tum est. Nihil itaque amplius in iteratione, quam remolliri terra debet æqualiter : eamque transacto æquinoctio verno statim peragi oportet intra dies viginti, ante quam seges in articulum eat, quoniam serius sarrita corrumpitur insequentibus restivis siccitatibus et caloribus. Subjungenda deinde est sarritioni runcatio, curandumque ne florentem segetem taugamus : sed aut antea, aut mox cum defloruerit. Omne autem frumentum et hordeım, quicquid denique non duplici semine est, spicam a tertio ad quartum nodum emittit, et cum totam edidit, octo diebus deflorescit, ac deinde grandescit diebus quadra- 
maturité complète. Celles au contraire qui sont partagées en deux lobes, comme la fève, le pois, la lentille, fleurissent en quarante jours, et grandissent en même temps.

XII. Calculons maintenant le nombre de journées qu'il faut employer pour conduire les grains jusqu'à l'aire, à partir du jour où nous les avons semés. Il faut pour quatre ou cinq modii de froment quatre journées de laboureur, une de herseur, deux journées de sarcleur pour la première fois, et une pour la seconde; une journée de celui qui arrachera les mauvaises herbes, et une et demie du moissonneur; ce qui forme un total de dix journées et demie. Il en faut autant pour cinq modii de siligo. Neufou dix modii d'épeautre demandent autant de journées de travail que cinq modii de froment. Pour cinq modii d'orge il faut trois journées de laboureur, une de herseur, une demie de sarcleur, une de moissonneur; total, six et demie. Quatre ou six modii de fèves demandent quatre journées de laboureur dans des jachères, et une dans un terrain qui rapporte sans se reposer. Il faut une journée et demie pour les herser, une et demie pour les sarcler la première fois, une journée pour les sarcler la seconde fois, une autre journée pour les sarcler la troisième fois, et enfin une dernière journće pour les moissonner; ce qui fait un total de sept ou huit journées de travail. Six ou sept modii de vesce demandent dans des jachères deux journées de laboureur, et une journée dans une terre où l'on récolte toutes les années. Ajoutez à cela une journée pour le hersage et une autre pour la moisson, etswous aurez en total trois ou quatre journées de travail. Cinq modii d'orge exigent autant de journées de laboureur que

ginta, quibus post florem ad maturitatem devenit. Rursus qua duplici semine sunt, ut faba, pisum, lenticula, die. bus xu florent, simulque grandescunt.

XII. Et ut jam percenseamus, quot operis in aream perducantur ea, quæ terræ credidimus : tritici modii quatuor vel quinque bubulcorum operas occupant quatuor, occatoris unam, sarritoris duas primum, et unam cum iterum sarriuntur, runcatoris unam : messoris unam et dimidiam, in totum sumınam operarum decem et dimidiam. Siliginis modii quinque totidem operas desiderant. Seminis modii novem rel decem totidem operas quot tritici modii quinque postulant. Ilordei modii quinque bu. bulci operas tres exigunt, occatoriam unam, sarritoriam unam el dimidiam, messoriam unam, summam operarum sex et dimidiam. Fabæ modii quatuor vel sex in vetereto deras operas bubulcorum detinent, at in restibili unam. Occantur sesquniopera, sarriuutur sesquiopera, iterum sarriuntur una opera, et tertio una, metuntur una. Summa fit operarum octo vel septem. Vicixe modii sex rel septem in vetereto bubulcorum duas operas volunt, in restibili unam : item, occantur una opera, metuntur una. Summa fit operarum quatuor vel trium. Ervi modii quinque totidem operis conseruntur, occantur una : item singulis sar. cinq modii de vesce. Il faut également une journée pour les herser, une autre pour les sarcler, une autre encore pour arracher les mauvaises herbes, et une dernière pour les moissonner; ce qui fait en tout six journées. Il faut le même nombre de journées pour mettre cn terre six ou sept modii de fenugrec; la récolte se fait en une journée. Il faut également six journées pour quatre mudii de faséole; le hersage et la moisson ne demandent l'un et l'autre qu'une journée. Six journées suffisent pour quatre modii de cicerole ou de pois, trois journées pour le labour, et trois autres journées pour les herser, les sarcler et les recucillir. Un sesquimodius de lentille demande trois journées de laboureur, une de herseur, deux de sarcleur, une pour arracher les mauvaises herbes, une enfin pour recueillir la graine; en tout huit journées. Il faut un jour pour mettre en terre dix modii de lupin, un autre pour les herser, et un autre encore pour les moissonner. Quatre sextarii de millet et la même quantité de panis demandent quatre journées de laboureur, trois de herseur, et trois de sarcleur (le nombre de journées nécessaires pour les cueillir n'est point déterminé). Trois modii de pois chiches sont semés dans trois journées, hersés dans deux, sarclés en une seule; il en faut une autre pour la débarrasser des mauvaises herbes, et trois pour les cueillir; au total, dix journées. Huit ou dix modii de lin se sèment en quatre journées et se hersent en trois; se sarclent en une seule et se cueillent en trois : ce qui fait en tout onze journées. Six sextarii de sesame ont besoin de trois journées pour étre labourés, de quatre pour être hersés, de quatre antres pour être sarclés la première fois, de deux pour la seconde, et de

riuntur, runcantur, metuntur : quæ cuncta sex operas occupant. Siliquæ modii sex vel septem totidem operis obruuntur, metuntur una. Phaseoli modii quatuor obruuntur totidem operis, occantur una, metuntur una. Cicera vel cicerculx modii quatuor operas bubulcorum tres pos. tulant, occantur opera ura, runcantur una, velluntur una. Summa fit sex operarum. Lentis sesquimodius totidem operas desiderat, occatur una, sarritur duabus, runcatur una, vellitur nna. Summa fit operarum octo. Lupini modii decem obruuntur una, occantur una, metuntur una. Milii sextarii quatuor, totidemque panici bubulcorum operas occupant quatıor, occantur operis tribus, sarriuntur tribus : quot operis carpantur, incertum est. Ciceris modii tres operis totidem seminantur, occantur duabus, sarriuntur una, runcantur una, velluntur tribus. Summa fit undecim operarum. Lini decem modii rel octo quatuor. jugis conseruntur, occantur operis tribus, runcantur una, velluntur tribus. Summa fit undecim operarum. Sesami sextarii sex tribus jugis a proscissione coluntur, occautur operis tribus, sarriuntur quatıor, et sarriuntur iterum duabus, runcantur una, vellunturduabus. Snmma fit ope.. rarum quindecim. Cannabis seritur, ut supra docuimus : sed incertum est, quantam impensam curamque deside. 
deux autres eneore pour être eueillis, ee qui fait en tout quinze journées. Pour le ehanvre, nous avons indiqué plus haut eomment on le sème; mais il nous est impossible de déterminer d'une manière préeise le temps et les dépenses (qu'exige sa eulture. La semence de luzerne est recouverte, non pas avee la eharrue, mais, eomme nous l'avous dit plus haut, avee des rá. teaux de bois. Un jugrerum de terre, ensemeneé de luzerne, est hersé en deux journées, sarelé en une, et moissonné en une autre. II résulte de cet aperȩu qu'un domaine de deux eents jugera peut ètre eultivé a vee deux attelages de bœufs, deux laboureurs et six ouvriers ordinaires, pourvu qu'il n'y ait pas d'arbres sur le fonds. Si éest au contraire un terrain planté d'arbres, Saserna nous apprend que le mème nombre de jugera peut très-bien être eultivé avec trois ouvriers de plus. Nous voyons en outre, par ec détail que nous venons de donner, qu'un joug de bœuis suffit pour semer cent vingt-eing modii de firoment, et pour la même quantité de légumes; de sorte que les semailles d'automne se moutent à deux eent einquante modii, auxquels il faut ajouter encore soixante-quinze modii provellant des semailles des trémois. En voiei la preuve: les semenees qui veulent quatre labours exigent eent quinze journées de travail pour vingteinf jugera. En effet, vingt-einq jugera de terre, füt-elle de l'espèee la plus forte, se labourent pour la première fois en einquante journées, pour la seeonde en vingt-eing, pour la troisième en quarante, y eompris le reeouvrement de la semenee. Les autres plantes légumineuses prennent soixante jours, ee qui fait deux mois. On peut porter à quarante-cinq le nombre de jours pluvieux ou fériés pendant lesquels on ne travaille point. Les semailles finies, il y a eucore trente

ret. At Medica obruitur non aratro, sed, $\mathrm{nt}$ dixi, ligneis rastellis. Jugerum agri ejus occant dıo, sarrit uıus, metit unus. Hac consummatione operarum colligitur posse agrum ducentorum jugerum subigi duobus jugis boum totidem(jue bubulcis et sex mediastinis, si tamen vacet arboribus : at si sit arhustum, eundem molum Saserna tribus hominibus adjectis asseverat probe sat is excoli. Qua nos ratio docet, sufficere posse jugum boum tritici centum viginti quinque modiis, totidemque leguniunm, ut sit in asse autunnalis satio modiorun ducentorun quinquaginta : et post hanc nihilo minus conserat trimestriun uodios quinque et septuaginta. Hoc deinde sic probatur. Semiua, quæ quarto sulco seruntur in jugeribus viginti quinque, desiderant bubulcorum operas $\mathbf{C x v}$. Nam proscinditur is agri modus quanvis durissini quinjuaginta operis, iteratur quinque el viginti, tertiatur et colseritır xi. Legumina occupant operas Lx, id est menses dıos. I'luviales quorue et feria. Ium computanlur, quibus uon aralur, dies quinque et $\mathrm{xu}$. Item peracla sementi, quibus reipuiescunt, dies xxx. Sic in asse fiunt octo menses et dies $x$. Snpersunt tamen de anno tres reliqui meuses et dies $\mathrm{v}$ et $\mathrm{xx}$, ๆuos absumamus jours de repos : ce qui fait en tout huit mois et dix jours. It restera done sur l'annce trois mois et vingt-cinq jours, qui sont employés à semer du grain de trimestre, ou à charrier du foin, du fourrage, du fumier, et d'autres objets néces. saires.

XIII. De ees différentes productions dont je viens de parler, les unes, nous dit eneore Saserna, fument et bonifient la terre, et les autres l'amaigrissent et l'épuisent. Il ajoute que les lupius, les fèves, la vesee, la lentille, l'ers, la eieerole, le pois, servent d'engrais. Quant au lupin, je n'en fais aucun doute, non plus que pour la vesee que l'on emploie en fourrage, pourvu qu'on ait fait passer la eharrue par-dessus, après l'avoir fauehée lorsqu'elle était eneore verte, et que le soc ait brisé et eouvert de terre, avant qu'elles fus. sent séehées, les raeines oublicées par la faux. La vesce peut alors servir de fumier. Mais si, après avoir enlevé le fourrage, on laisse les raeines se flétrir, elles épuisent la terre en lui enlevant toute sa séve, et en la privant de sa force. C'est ee qui arrive à l'égard de la fève et des autres légumes, qui paraissent engraisser la terre. Mais il faut avoir soin de labourer après avoir réeolté, sinon ees légumes ne seraient d'aueune utilité pour les réeoltes suivantes. Trémellius nous ap. prend que do toutes les plantes dites légumineuses, le pois ehiehe et le lin sont eelles qui nuisent le plus à la terie par le poison qu'elles y déposent; l'un paree qu'il est d'une nature salée, et l'autre paree qu'il est d'une nature trop éehauffante. C'est ee que Virgile a voulu faire entendre, lorsqu'ila dit: Une récoltede lin brîle le champ, de même que l'avoine et les pavols, qui nous plongent dans le sommeil de la morl. En effet, on ne saurait douter que les plantes dont parle le poëte n'épuisent beaueoup la terre; il en est đe

aut in satione trimestrium, aut in vecturis fueni et pabu. lormn el stercoris aliorumque utensilium.

XIII. Sed ex is, quæ retuli, seminibus, idem Saserna putat aliis stercorari et juvari agros, aliis rursus permi et emaciari. Stercorari lupino, faba, vicia, ervilia, lente, cicercula, piso. De lupino nilil dubito, atque etiam de pabulari vicia, si tamen ean viridem desectan confes. tim aratrun subsequatur, et quod falx reliquerit, prins. quam inarescat, vomis rescindat atqque obruat : id enim cerlit pro stercore. Nam si radices ejus desecto pabulo re. lictie inaruerint, succum ommen solo auferent, vimque terra alsument, yood etiam in faba cieterisque leguminibus, quibus terra gliscere videtur, verisimile est accidere: ut nisi protinus sublata messe corum proseindatur, nihil iis segetibus, qux deinceps in eo loco seminari debent, profuturum sit. Ac de is quoque legumiribus, quar vel. Iuntur, Tremellius obesse maxime ait solo virus ciceris et lini : alterum quia sit salsa, alterun quia (sit) fervila natura : quod etiam Virgilins significat dicendo : Urit enim lini campum seges, uril avence, Urunt lethero perfasa papavera somno. Neque enim dubium, jun et 
nême du millet et du panis. Mais tout terrain épuisé par ces sortes de plantations trouvera un remede prompt et efficace dans le fumier, qui en l'engraissant lui rendra ses forces perdues. II faut donc fumer la terre non-sculement pour les semences déposées dans les sillons, mais à cause des arbres et des arbrisseaux, qui profitent de cette nourriture. C'est pourquoi si le fumier est, comme il me semble, d'une si grande utilité pour les cultivateurs, je pense qu'il faut en traiter a vec beaucoup de soin, d'autant que les anciens auteurs, sans avoir passé cet objet sous silence, n'en ont cepeudant parlé que très-légèrement.

XIV. Il y a trois espèces principales de fumier : celui que nous fournissent les oiseaux, celui qui provient des hommes, et celui que nous donne le bétail. Le fumier qui provient des oiseaux passe pour le meilleur de tous; encore met-on au premier rang la fiente que l'on tire des colombiers; ensuite celle des poules et des autres oiseaux, excepté les oiseaux qul séjournent dans l'eau ou dans les marais, tels que les canards et les oies dont le fumier même est très-nuisible à la terre. La fiente de pigeon est aussi celle qui nous parait devoir être préférée, parce que nous avons remarqué que, répandue avec modération sur la terre, clle la fait fermenter. Je mets au second rangles excréments humains, pourvu qu'ils soient mélangés a vec les immondices de la cour ; car cette espècc de fumier est par elle-mêmed'une nature si chaude, qu'employée seulc, elle brûlerait le sol. L'urine, si on la garde six mois, est très-bonne pour les arbres et les vignes; il n'y a pas d'engrais qui leur soit aussi favorable : elle ajoute de plus au goût et au parfum des fruits, surtout de la pomme

iis seminibus infestetur ager, sicut etiam milio et panico. Sed omui solo, quod pradictorum leguminum segetibus fitiscit, una præesens medicina est, ut stercore adjures, et alısumptas vires hoc relut pabulo reforeas. Nec tantum jropter semina, qquæe sulcis aratri committuntur, verum etiam propter arbores ac virgulta, qux majoren in modum laelantur ejusmodi alimento. Quare si est, ut videtur, ayricolis utilissimum, diligentius de eo dicendum existimo, cum priscis aucloribus quamris non omissa res, levi tauren admodum cura sit prodita.

XIV. Tria igitur stercoris genera sunt pracipue, quod ex avibus, quod ex hominibus, quod ex pecudibus confit. Avium primum habetur, quod ex columbariis egeritur. Deinde quod gallinæ cxlcracque volucres edunt : exceptis tamen palustribus ac nantibus, ut anatis et anseris : nam id noxium quoque est. Maxime tamen colum. binum probamus, quod modice sparsum terrain fermentare comperimus : secundum deinde, quod homines faciunt, si et aliis villa purgamentis immisceatur, quoniam ferrentioris natura est, et idcirco terram perurit. Aptior cst tamen surculis hominis urina, quam sex mensibus passus veterascere si vitibus aut pomorun arlorilıus adlibeas, unllo alin magis fructus exuberat : nec solum ca res nas. jorem facit proventum, sed etiam saporem el odorcu vini et du raisin. On peut aussi se servir de vieille lie d'huile sans sel, pour arroser les arbres à fruits et surtout les oliviers, en la coupant avec cette urine, quoiqu'cmployée seule, ello leur soit aussi très-bonue. On se sert de ces deux substances pendant l'hiver, ou même au printemps avant les chaleurs, pourvu qu'on ait préalablement déchaussé les vignes et les arbres. On met au troisième rang le fumier qul provient du bétail, et encore admet-on des différences : celui des ânes est regardé comme le meilleur ; en effet, ces animaux måchent très-lentement, leur nourriture est mieux digérée, de sorte que leur fiente est assez putréfiée pour qu'elle puissc immèdiatement être répandue sur les terres : vient ensuite le crotin de mouton, puis celui de chèvre, et en dernier lieu le fumier de bestiaux et des autres bêtes de somme. Le pire de tous les engrais est celui des pourceaux.Indépendamment deces différentes es. pèces de fumier, les cendres et les charbons sont encore d'un emploi très-utile. La tige de lupin coupée tient aussi lieu d'un excellent fumier. Je sais bien qu'il y a des fermes où l'on ne peut avoir ni bétail ni oiseaux; mais dans ces fermes mêmes celui qui manquerait d'engrais ne scrait qu'un cultivateur paresseux. Ne peut-il pas recueillir toutes sortes de feuilles, couper les buissons, et ratisser les grands chemins? Ne peut-il pas aussi enlever les fougères qui croissent sur les terres de ses voisins, saus leur faire le moindre tort, puisqu'au contraire c'est leur rendre servicc? Il mêlera le tout avec les immondices de la cour de la ferme. Il fera également une fosse, et, ainsi que nous l'avons conseillé pour le trou à fumier, il jettera dans cette fosse les cendres, le curage des fossés et des égouts, le chaume, et en général

pomorumque reddit meliorem. Potest et vetus amurca, qux salem non habet, permista huic commode, frugiferas arbores et priccipue oleas rigare. Nam per se quoque adhibita multum jurat. Sed usus utriusque maxime per hie. mem est, et adhic vere ante astivos yapores, dum etiam vites et arhores oblaquealx sunt. Tertium locum obtinet pecudum stercus, atque in eo quoque discrimen est : nam optimum existimatur, quod asinus facit; quoniam id animal lentissime mandit, ideoque facilius concoquit, et bene confectum atque idoneum protinus arvo fimum reddit. Post lıæe quæ diximus, ovillum, et ab hoc caprinum est, mox creterorum jumentoram armentorumque. Deter. rimum ex omnibus suillum lıabetur. Quin etiam salis pro. fuit cineris usus et favillæe. Frutex vero lupini succisus optimi stercoris rim prabel. Nec ignoro, quoddam esse ruris genus, in quo neque pecora, neque aves laberi pos. sint : attamen inertis est rustici eo quoque loco defici ster. core. Iicet enim quamlibet frondem, licet e vepribus et 0 viis conpitisque congesta colligere; licet filicem sine $\cdot$ in. juria vicini etiam cum ofticio decidere, et permiscere cum purgamentis cortis ; licet depressa fossa, qualem ster(r). ri rcponendo primo voluunine fieri pracepiums, ciucren conımique cloacarunı el culmos cateraque qua everrull. lur, in unum congerere. Sed coden medio loco robustam 
tout ce qu'on balayye des bâtiments. La seule précaution qu'il aura à prendrc , c'est d'enfoncer au milieu de cette fosse un morceau de bois de robre, ce qui empêchera les serpents venimeux d'y venir chercher une retraite. Voilà ce qu'il faut faire dans les campagnes où il n'y a pas de bestiaux; quant à celles où il y en a, on tire le fumier des endroits qu'on balaye tous les jours, tels que la cuisinc et la faiterie, ou de ceux qui ne sont nettoyés que les jours de pluie, tels que les étables et les bergeries. Si le terrain ne doit rapporter que du blé, il n'est point nécessaire de séparer les différentes espèces de fumier les unes des autres; mais s'il cst également couvert d'arbres et de prairies, les engrais doivent être séparés suivant leurs espèces : ainsi le crotin de chèvres, et la flentc des oiseaux, auront chacun leur place particulière. Toutes les autres immondices qui tiennent lieu de fumier doivent être ramassées dans la fosse dont nous venons de parler, ct entretenues dans un état d'humidité continuelle, afin que les graines d'herbes qui s'y trouveront mêlées avec la paille et les autres ordures puissent y pourrir. Pendant les mois d'été, le fumier doit être remué souvent, et cn quelque sorte repétri arec une fourche en fer, afin de favoriser la putréfaction et de le rendre meilleur. Je regarde comme de mauvais cultivateurs tous ceux qui ne tirent pas par mois une charretée de fumier de chaque espèce de petit bétail, dix charretées du gros, et autant des hommes qui peuvent rassembler leurs propres excréments journaliers, ainsi que les immondices de la cour et des batiments. Je remarquerai encore que le fumier qui a séjournć un an en tas est le meillcur pour les céréales, car il a acquis toute sa force, et ne pro-

materiam defigere convenit. Namque ea res serpentem noxiam latere in stercore prohibet. Hac ubi viduus pecudibus ager. Nam ubi greges quadrupedum versantur, quædam quotidie, ut culina et caprile, quædam pluviis diebus, ut bubilia et ovilia debent emundari. Ac si tantum frumentarius ager est : niliil refert genera stercoris sepa. rari : sin autem surculo et segetibus atque etiam pratis fundus est dispositus, generatim quodque reponendum est, sicut caprarum et avium. Reliqua deinde in pradictum locum concavum congerenda, et assiduo lumore satianda sunt, ut herbarum semina culmis cæterisque rebus immista putrescant. Estivis deinde mensibus non aliter, ac si repastines, totum sterquilinium rastris permis. ceri oportet, quo facilius putrescat, et sit arvis idoneum. Parum auten diligentes existimo esse agricolas, apud quos minores singulæ pecudes tricenis diebus minus quam singulas itemque majores denas vehes stercoris efficiunt, totidemque singuli homines, qui non solum ea purgamenta, quæ ipsi corporibus edunt, sed et quæ colluvies cortis et selificii quotidie gignit, contrahere et congerere possunt. Illud quoque præcipiendum habeo, stercus omne quod tempestive repositum anno requieverit, segelibus esse naxime utile; nam et vires adhuc solidas lıabet, et duit point de mauvaises herbes; tandis qu'il perd de sa qualité à mesure qu'il vieillit. Mais, pour les prairies, le fumier doit être aussi nouveau que possiblc; car plus il est frais, plus il produit d'herbes. On le répandra particulièrement au mois de février, à la lune croissante, circonstanee qui contribuc à augrmenter le revenu du foin. Nous reviendrons d'ailleurs à ce sujet, quand il sera question des différentes espèces de graine cn particulicr.

$X V$. Quiconque veut préparer ses terres a recevoir du grain doit y distribuer de petits tas de fumier au mois de septembre, pendant que la lune est dans son déclin; il doit faire les semailles en automne, ou en tel temps de l'hiver qu'il voudra, s'il doit les faire au printemps. Il faut dix-huit charges de fumier par jugerum dans la plaine, et vingt-quatre en pays montueux. Mais, comme je l'ai dit plus haut, il ne fera la stratification du fumier, que lorsqu'il sera près de semer. Si, par une cause queleonque, on n'a pas pu fuiner en temps convenable, il faudra, avant de sarcler, répandre ou plutôt semer sur les champs à grains de la fiente tirée des volic̀. res, ct réduite en poudre. A défaut de cette fiente, on y jettera à la main le crotin de chèvres, en le mêlant à la terre avec le sarcloir. Ce procédé contribue beaucoup à bonifier et à enrichir les terres. Que les cultivateurs n'oublient point qu'une terre qui n'cst pas fumée se refroidit, que celle qui l'est trop se consume, et qu'on gagne plus à fumer suuvent et avec modération, que de le faire avec excès. Une terre aqueuse demande plus de fumier qu'un terrain sec. La première, toujours froide et mouillée, se réchauffe par l'effet de l'engrais, tandis que l'autre, déjà écliauffée

herbas non creat : quanto auten vetustius sit, minus prodesse; quoniam minus valeat. Itaque pratis quam recentissimum debere injici, quod plus herbarum progeneret : idque mense Februario luna crescente fieri oportere. Nam ea quoque res aliquantum foeni fructum adjuvat. De cietero usus stercoris qualis in quaque re debeat esse, tum dicemus, cum singula persequemur.

XV. Interim qui frumentis arva præparare volet, si autumno sementem facturus est, mense Septembri : si vere, qualibet hienis parte modicos acervos luna decres. cente disponat, ita ut plani loci jugerum duodeviginti, clivosi quatuor et viginti veles stercoris teneant : et, it paulo prius dixi, non antea dissipet cumulos, quam erit araturus. Si tamen aliqua causa tempestivam stercorationem facere prohibuerit, secunda ratio est, ante quam seras more seminantis ex aviariis pulverem stercoris per segeteın spargere. Si et is non erit, caprinum nanu jacere, atque ita terram sarculis permiscere. Ea res latas segetes reddit. Nec ignorare colonos oportet, sicuti refrigescere agrum, qui non stercoretur, ita peruri, si nimium stercoretur : magisque conducere agricolæe, frequenter id potíus, quam immodice facere. Nec dubium, quin aquosus ager majorem ejus copiain, siccus minorem desideret. Aller, 
par ellc-mẻme à cause de sa sécheresse, tinirait par se consumer, si l'on y mettait trop d'engrais. Or, si un terrain sec ne peut se passer de fumier, il ne faut pourtant pas qu'il y en ait trop. Si par hasard un cultivateur se trouvait absolument dépourvu de fumier, il lui sera très-avantageux de faire ce que je me rappelle avoir vu pratiquer avec succès par mon oncle paternel, M. Columelle, homme fort savant, ct agriculteur trèshabile. Il mélait de l'argile aux terres sablonneuses, ou du sable aux terres argileuses et dures : par ce moyen il fertilisait non-seulement les champs à grains, mais il se procurait les plus belles vignes. Il ne voulait point qu'on mit du fumier dans les vignes, de crainte d'enlever au vin son goût et sá saveur. Il pensait au contraire que la vendange serait bien plus abondante si l'on apportait dans les vignes de la terre de ramas, recueillie dans les buissons, ou toute autre terre prise ailleurs. Quant à moi, je suis convaincu que lorsqu'un cultivateur manque de fumier, il a toujours une excellente ressource dans les Iupins, qui, semés dans un champ stérile vers les ides de septembre, coupés et retournés en temps convenable à la charrue ou à la houe, produiront l'effet des meilleurs engrais. Or il n'y a pas de temps plus favorable pour couper le lupin dans les lieux sablonneux que le moment de sa seconde fleur, et de la troisième dans les terres rouges. Dans le premier cas, on l'enterre lorsqu'il est encore tendre, afin qu'il pourrisse plus aisément et se mele avec le sol franc. Dans le second, on le laisse durcir, pourqu’il puisse supporter plus longtemps le poids des mottes, et les tenir en quelque sorte suspendues, jusqu'à ce que, pénétrées et

quod assiduis humoribus rigens loc adhibito regelatur : alter, quod per se tepens siccitatibus, hoc assumpto largiore torretur; propter yuod nec deesse ei talem materiam, nec superesse oportet. Si tamen nullum genus stercoris suppetet, ei multum proderit fecisse, quod M. Columeltam patruum meum doctissimum et diligentissimum agri. colam sxpenumero usurpasse memoria repeto, ut sabulosis locis cretam ingereret: cretosis ac nimium densis sabutum : atque ita non solum segetes latas excitaret, verum ctiam pulcherrimas vineas efficeret. Nam idem ne. gabat stercus vitibus ingerenduen, quod saporem vini corrumperet : melioremque censebat esse matcriam vindemiis exuberandis, congesticiam vel de repribus vel denique liam quamlibet arcessitam et adrectam humum. Jam vero et ego reor, si deficiatur omnibus rebus agricola, lu. pini certe expeditissimum præsidium non deesse : quod cun exili solo circa idus Septembris sparserit el inaraverit, idque tempestive vomere vel ligone succiderit, vim optima stercorationis exlibebit. Succidi autem lupinum sabulosis locis oportet, cum secundum florem; rubricosis, cum tertium egerit. Illic dum tenerum est convertitur, ut celeriter ipsum putrescat, permisceaturque gracili solo: hic jam robustius, fuod solidiores glxbas diutius susti. dissoutes par les chaleurs de l'été, clles solent réduites en poussière.

XVI. Le laboureur pourra exécuter tous les préceptes que nous avons donnés sur la culture, s'il a soin de se pourvoir non-seulement des espèces de fourrages dont nous avons parlé, mais encore d'une grande quantité de foin, afin de pouvoir entretenir aisément des bêtes de somme, sans lesquelles il lui serait difficile de bien cultiver la terre. C'esst pourquoi il faut qu'il s'adonne aussi à la culture des prés, auxquels les anciens Romains donnaient la palme sur tous les autres objets de culture : aussi leur avaient-ils donné le nom de prata, pour faire entendre qu'ils étaient toujours prêts (parata) à rapporter sans exiger de grands soins. M. Porcius les a aussi vantés, par la raison que les mauvais temps ne leur font point de tort comme aux autres parties de la campagne, et que, sans exiger de frais, ils produisent toutes les années un revenu assuré, qui même est divisé en deux branches, puisqu'ils ne rendent pas moins en pâturages qu'en foin. Nous observerons donc qu'il y en a de deux espèces : les prés secs et les prés arrosés. Lorsque le terrain est fertile et gras, il n'est pas besoin qu'il soit arrosé d'un ruisseau; et on regarde comme meilleur le foin qui vient de lui-même dans un terrain plein de sucs; que celui que l'on n'obtient qu'à force d'eau, quoique cependant l'eau soit nécessaire lorsque la maigreur de la terre l'exige. Car on peut faire des prairies dans une terre quelconque, soit qu'elle soit compacte, soit qu'elle soit réduite en poussière ; et cela quoiqu'elle soit maigre, pourvu cependant qu'on ait la faculté de l'arroser. Mais il faut que ce ne soit ni une campagne trop en-

neat et suspendat, ut ex solibus æstivis vaporatæ resol. vantur.

XVI. Alque lıxc arator exequi poterit, si non solum, quas retuli genera pabulorum providerit, verum ctiam copiam foeni, quo melius armenta tueatur, sine quibns terram commode moliri difficile est : ct ideo necessarius ci cultus est etiam prati, cui veteres Romaui primas in agricolatione tribuerunt. Nomen quoque indiderunt ab eo, quod protinus esset paratum, nec magnum laborem desideraret. M. quidem Porcius et illa commemoravit, quod nec tempestatihus afligeretur, ut alix partes ruris, minimique sumptus egens, per omnes annos praberet reditum, neque eum simplicem, cum etiam in pabulo non minus redderet, quam in foelo. Ejus igitur animadvertimus duo genera, quorum alterum est siccaneum, alterum riguum. Lxto pinguique campo non desideratur influens rivus, ineliusque lıabetur fœenum, guod suapte natura succoso gignitur solo, quam quod irrigatum aquis elicitur, qua tamen sunt necessariæ, si macies terra postulat. Nanı et in densa et resoluta humo quamvis exili pratum fieri potest, cum facultas irrigandi datur. Ac nec campus concara positionis esse neque collis prorupta debet : ille, no collectam diutius contineat aquam; hic, ne statim proccipi- 
foncée dans une vallée, ni une colline trop roide : l'un, pour éviter que l'eau qui s'y amasse n'y séjourne trop longtemps, l'autre, pour éviter qu'elle ne s'en écoule trop préeipitamment. On pourra néanmoins mettre en prairies une colline dont la pente sera douce, si elle est grasse ou arrosée. Mais ce sont les plaines surtout qui sont bonnes pour eet objet, lorsqu'étant légèrement deelives, elles ne permettent pas aux pluies ou aux ruisseaux qui les arrosent, d'y séjourner trop longtemps, et qu'au contraire l'eau dont elles sont couvertes y trouve un écoulement lent. C'est pourquoi , s'il s'y trouve en quelques parties des mares qui soient stagnantes, il faut les détourner par des tranehées; car l'abondanee ainsi que le défaut d'eau sont également funestes aux herbes.

XVII. La culture des prairies demande plus d'attention que de travail. Cette attention eonsiste d'abord à n'y laisser ni souehes, ni épines, ni herbes qui prennent trop d'aeeroissement, mais à les arracher toutes, les unes avant l'hiver et pendant l'automne, comme les ronees, les broussailles, les jones; les autres pendant le printemps, comme la chicorée et les épines, qui paraissent au solstice; à n'y laisser paitre ni pores, parce qu'ils fouillent dessous la terre avec leur groin et qu'ils enlèvent le gazon, ni grands bestianx, si ce n'est lorsque le sol est très-see, parce qu'ils y plongent la corne de leurs pieds, qu'ils foulent l'herbe et qu'ils en coupent les racines. Ensuite il faut aider de fumier au mois de février, peudant que la lune croft, les terrains maigres et qui vout en pente. Il faut y ramasser, pour les porter plus loin, toutes les pierres et tout ce qui pourrait nuire à la faux, et en interdire l'entrée aux bestiaux plus tôt ou

tem fundat. Potest tamen mediocriter acclivis, si aut pingnis est aut riguus ager, pratum fieri. At planities maxime talis probatur, qua exigue prona non patitur diutius inbres aut influentes rivos immorari, sed ut quis eam supervenit huuюr, lente prorepit. Itaque si palus in aliqua parte subsidens restagnat, sulcis derivanda est. Quippe aquarum abundantia atque penuria graninibus aqque est exitio.

XVII. Cultus antem pratorum magis cura yuam haloris est. Primum, ne stirpes aut spinas valiliorisque incrementi lserbas inesse patiamur : alque alias ante hienıem, et per autumnum extirpemus, nt rubos, virgulta, juncos : alias per ver evellamus, ut intuba ac solstitiales spinas : ac neque suem velimus impasci, quoniam rostro suffodiat el cespites excitet; neque pecora majora, nisi cum siccissimum solum est, quia udo demergnnt ungulas et atterunt, scinduntıue radices herbarum. 'Tun deinde macriora et pendula loca mense Februario luna crescente, fimo juvanda sunt. Ounespue lapides et siqua objacent falcilus uoxii, colligi tebent, ac longins exprortari, submittique pro natura locorum, aut temporius aut plus tard, suivantla nature des lieux. Il se trouve aussi des prairies qui, par trop de vétusté, sont couvertes d'une mousse aneienne ou épaisse. Les agrieulteurs sont dans l'usage d'y remédier en y semant de nouvelles graines, qu'ils prennent dans des meules de foin, ou en y répandant du fumier; mais ni l'un ni l'autre de ees remèdes ne fait autant d'effet que si l'on y jetait souvent de la cendre, paree que c'est le vrai moyen de détruire cette mousse. Il faut eependant convenir que tous ces remèdes et même le dernier sont trop lents, et que le plus efficaee est de recommeneer à labourer en entier la place. Mais les soins que nous venons de détailler ne solit que pour les prairies qui étaient toutes formées, avant de venir en notre possession. Si all contraire il nous en fallait former de nouvelles, ou en renouveler d'aneiennes (ear il y en a beaucoup, comme je l'ai dit, qui vieillissent et qui deviennent stériles faute de soins ), il faudrait labourer le terrain, quelquefois même dans l'intention d'y semer du blé, parce que ces sortes de terrains, négligés depuis longtemps, donnent de belles moissons. Ainsi, après avoir donné un premier labour, pendant l'été, au terrain que nous destinons à mettre en prairies, et l'avoir biné plusieurs fois pendant l'automne, nous y sèmerons des raves ou des navets, ou même des fèves, ensuite du blé l'année d'après; la troisiènıe année, nous le labourerons encore avec soin, et nous arracherons jusqu'aux racines toutes les herbes trop fortes, les ronces et les arbres qui s'y trouveront, à moinsque nous n'ayons intérêt d'en conserver les fruits; après quoi nous y sèmerons de la vesee mêlée avee de la graine de foin; ensuite nous briserons les mottes de terre avec des sareloirs, nous unirons le sol en y fai- serius. Sunt etiam qunadam prata situ vetustatis obducta, quibus meleri solent agricolae veteri eraso musco seminibisque de tabulato superjectis, vel ingesto stercore. Quorum neutrum tantum prodest, quantum si cinerem sajius ingeras. Ea res muscum enecal. Attamen pigriora sunt ista remedia, cum sit efficacissimum de integro locum exarare. Sed hoc, si prata accepimus, facere debemus. Sin autem. nova fuerint instituenda, vel antigua renovanda, (nam multa sunt, ut dixi, qua negligentia exolescant, et fiant sterilia) ea expedit interdun eliam frumenti causa exarare, quia talis ager post longam desidiam latas segetes affert. Igitur eum locum, quem prato destinaverimus, astate proscissum subactumque saęinins per autumnum rapis vel napo vel etiam faba conseremus; insequente deinde anno, frumento : tertio diligenter arabimus, om-. nesyue valicliores lierbas et rubos et arbores, qux interveniunt radicibus, extirpabimus, nisi si fructus arbnsti id facere nos prolnilueril. Deinde viciam permistam seminibus funi seremus. 'Tun glabas sarculis resolvenus, et inducha crate coaryuabimus, grumosıue, quos ad versurau ple- 
saut passer la herse, et uous ćparpillerons les gruneaux de terre que le tirage des herses accumulc communément aux détours, de facon qu'il ne reste nulle part d'obstacle qui puisse offenser la fanx. II ne faudra pas couper cette vesec qu'elle ne soit très-mûre, et qu'elle n'ait commencé à laisser tomber sa graine sur terre. C'est alors qu'il faut y envoyer le faucheur, et mettre en bottes l'herbe qu'il aura fauclice, pour l'enlever : ensuite il faudra arroser ce terrain, si l'on a de l'enu à sa disposition, pourvu cependant que la terre en soit compacte. Car si elle est réduite en poudre, il ne sera pas bon d'y faire couler de grands ruisseaux d'eau avant que le terrain soit bien affermi et consolidé par l'herbc, parce que l'impétuosité de l'ean délayerait la terre, et ne laisserait pas aux licrbes dont elle aurait découvert les racines le temps de bien prendre. Par la mème raison, il ne faut pas non plus envoyer les bestiaux dans les prairies lorsqu'elles sont encore jeunes et que le pied y enfonce, mais il faut $\mathrm{y}$ faucher l'herbe à mesure qu'elle lèvera; car les bestiaux, comme je l'ai déjà dit, enfoncent la corne de leurs pieds dans le sol lorsqu'il est trop mou ; et venant à eouper les raeines des herbes, ils ne leur donnent pas le temps de s'étendre et de s'épaissir. Cependant nous permettrons, la seeonde année, au petit bétail d'y entrer après la fenaison, pourvu que la sécheresse et la nature du lieu ne s'y opposent point. La troisième année, lorsque les prés seront solides et fermes, ils pourront aussi admettre les grands bestiaux : mais il faudra surtout avoir soin de fumer les terrains maigres, et encore plus lorsqu'ils seront élevés, vers le temps où le soleil se couche au point d'où souftle le vent Favonius, c'est-à-dire vers les ides du mois de février, en

rumque tractx faciunt crates, dissipabimus ita, [ut] necubi ferramentum fuenisecis possit offendere. Sed eam viciam non convenit ante desecare, quam permaluruerit, et aliqua senina subjacenti solo jecerit. Tum fonisecas oportet iu. ducere et desectam herbam religare et exportare : deinde locum rigare, si fuerit facultas aqua : si tamen terra deu. sior est; man iu resoluta luumo non expedit inducere majorem vim rivoruu, prius quam couspissatum et herbis colligatum sit soluı : quoniam impelus aquarum proluit terram, mulatisque radicilous gramina non patitur coalescere. Propter quod ne pecora quilem oportet teneris adluc et subsileutibus pratis imnittere, sed quoties herba pro. silıerit falcibas desecare. Nam pecudes, ut ante jam dixi, molli solo infigunt uugulas, atque interruptas non simunt lierbarum radices seipere et condeusari. Altero tamen anuo ninora pecora post fienisicia permittentus admitti, si modo siccitas et conditio loci patietur. Tertio deinde cum pratum solidius ac dırius erit, polerit etiam uajures recipere, pecudes. Sed in fotum curaudum est, ut secumdum Fav(1) tii exortum, meuse Februario, circa idus, iumistis semini- mélant avec le fumier de la graine de fớn. Car lorsque les terrains supérieurs recoivent cette nourriture, ils la communiquent en même temps aux terrains inférieurs, parce que la pluie qui survient, ou les ruisseaux quon y fait couler de main d'homme, entrainent avec eux le sue du fumier dans les parties basses : aussi les agrieulteurs prudents fument-ils ordinairement davantage les collines que les vallées, mẻme dans les terres iabourées, parce que, comme je l'ai dit, les pluies entrainent toujours dans les bas-fonds tout le sue le plus gras.

XVIII. Le meilleur temps pour couper le fuilt est avant qu'il soit desséché, parce qu'il foisoune davantage, et fournit une nourriture plus agréable aux bestiaux. Or il y a un milieu a garder en le faisant sécher, pour éviter de le ramasser ou trop sec, ou trop vert: l'un, parce que, lorsqu'il a perdu tout son suc, il ne tipnt plus lieu que de litière; l'autre, parce que, s'il en a trop conservé, il pourrit sur les planchers, et que souvent, en s'y échauffant, il prend feu et oceasionne des incendies. II arrive aussi quelquefois que, lorsque le foin est coupé, la pluie vient à l'aecabler; auquel cas, s'il est abso. lument trempé, il sera inutile de l'emporter tant qu'il sera humide', et l'on fera nieux pour lors d'en laisser sécher la superficie au suleil; après quoi on le retournera, et lorsqu'il sera sec des deux côtés, on l'amassera par rangées, pour le lier ensuite en bottes. On ne tardera pas surtout à entasser le foin dans la métairic et à l'y mettre à l'abri; ou si l'on n'est pas à mème de l'y porter ou de le mettre cn bottes, au moins faudra-t-il arranger en meules tout ce qui en aura été séché convenablement, et faire en sorte que les combles de ces meules soient

bus fueni macriora loca et utique cel siora stercorentur. Nan editior clivus prabet etiam subjectis alimentun, cum su. perveniens inber aut manu rivus perductus succum stercoris in inferiorem parten secum trahit. Alque ideo fere prudentes agricola etian iu aratis collem magis, quan vallem stercorant : quonian, ut dixi, pluvia semper omnem pinguiorem materiam in ima deducunt.

XVII. Foeuum auten denetitur optime ante quam inarescat; nan et largius percipitur, et jucundiorem cibun peculibus probet. Est autem modus iu siccando, ut neque peraridum neque rursus viricle colligatur; allerum, guюd omnen succum si amisit, stramenti vicem ob. tinct, alterum, (quod,) si ninium retinuerit, in tabulato putrescit; ac srepe cum concaluit, irnem creat el inceu. dium. Noununguam etiam cum fornum cadimus, iuber oppressit: quod si permaduit, inutile est mdutu movere; melinsque patiemur superiorem partem sole siccari. Tunc demum contvertenus, et utrinque siccatun cuartabinus in strigiul, atıue ita manipulos vinciemus. Nec onuino cunctabinur, "juo minus sub tectum congeratır, vel si 
très-finement aiguisés en pointe : c'est le moyen de bien préserver le foin des accidents de la pluie; et quand il n'en surviendrait point, il ne serait pas moins à propos de faire ces meules, afin que s'il reste quelque humidité dans l'herbe, elle se ressuie et se purifie au tas. C'est pour cela que lorsque le foin a été mis en tas au hasard et sans précaution, les cultivateurs prudents ne l'arrangent pas, après qu'il a été porté à la majson, sans l'avoir laissé quelques jours se digérer lui-même et se ralentir. Mais déjà le foin de la moisson touche à la fenaison. Pour la bien faire, il faut préalablement préparer les instruments nécessaires à la récolte des grains.

XIX. Quant à l'aire, si la terre doit en servir, il faut, pour qu'on y puisse battre le grain commodément, qu'elle ait été ratissée d'abord, ensuite labourée et arrosée de lie d'huile sans sel, dans laquelle on aura mêlé de la paille, parce que cettc préparation garantira le blé contre les ravages des rats et des fourmis; cnsuite on l'aplanira à la hie, ou bien on l'affermira avec une meule; puis on y remettra de la paille et on la battra de nouveau, pour la laisser ensuite sécher au soleil. Il y en a cependant qui aiment mieux, pour former une aire, choisir une portion de terrain plantée en fèves, sur laquelle ils battent ces fèves; et, après les avoil ramassées, ils polissent la place en continuant d'y battre les favarts, parce que les animaux, en les foulant aux pieds, brisent en même temps toutes les herbes avec la cornede leurs pieds; moyennant quoi l'aire, étant dégarnie d'herbes, devient assez unie pour qu'on y puisse battre le grain.

XX. Pour ce qui concerne la moisson, dès qu'elle sera mûre, il faudra la faire prompte- ment, et avant qu'elle solt brûlée par les chaleurs du soleil d'été, qui sont extrêmes au lever de la Canicule: car lc moindre retard est préjudiciable, d'abord parce qu'il donne lieu au pillage des oiseaux et des autres animaux; en seeond lieu, parce que les tiges et les tuyaux venant à se dessćcher, les grains et les épis même ne tardent pas à tom. ber, ou que s'il survient des mauvais temps ou des tourbillons de vent, les blés sont versés pour la plus grande partie. C'est pourquoi il ne faut pas remettre au lendemain à moissonner, mais il faut le faire dès que les blés sont uniformément jaunis, et avant que les grains en soient absolument durs, mais dès qu'ils commencent à tirer sur le rouge, afin qu'ils grossissent dans l'aire et au tas, plutót que sur terre; car il est constant que lorsqu'ils sont récoltés à temps, ils prennent de l'accroissement par la suite. Oril y a plusieurs façons de moissonner : bien des personnes coupent la tige par le milieu avee des faux armées d'un très-long manche, dont les unes sont à bec, les autres à dents : d'autres enlèvent l'épi même, soit avec des fourches, soit avec des râteaux; ce qui est très-aisć à pratiquer dans une moisson peu abondante, mais très-diffieile dans une moisson bien fournie. Si l'on a moissonné avec des faux, et que l'on ait par conséquent coupé une partie des tiges, il faut sur-le-champ mettre la moisson en tas, ou la porter dans lc lieu où les batteurs transportent le blé lorsqu'ils sont surpris de la pluie, ensuite la battre après qu'elle aura été convenablement essorée par la chaleur : au lieu que si l'on n'a coupé que les épis, on peut les mettre en réserve dans un grenier eu attendant l'hiver, pour les battre ensuite à coups de bâton, ou les fairc fouler aux pieds des bestiaux. Mais si le cas non competit $\mathrm{ut}$ in villam foenum portetur, at in manipulos colligatum certe quicquid ad eum modum, quo debet, sic. catum erit in metas exstrui conveniet, easque ipsas in angustissimos vertices exacui. Sic enim comnodissime fœnum defenditur a pluviis, qua etian si non sint, non alienum tamen est prodictas metas facere; ut si quis liumor herbis inest, exudet, atque excoquatur in acervis. Propter quod prudentes agricolæ quamvis jam illatum tecto non ante componunt, quam per paucos dies aliquos temere congestum in se concoqui et defervescere patiantur. Sed jam fœnisicia sequitur cura messis, quam ut recte possimus percipere, prius instrumenta praparanda sunt, quibus fruges coguntur.

XIX. Area quoque si terrena erit, ut sit ad trituram satis liabilis, primum radatur, deinde confodiatur, permistisque paleis cum amurca, qux salem non accepit, extergatur, nain ca res a populatione murium formicarum. que frumenta defendit. Tum æequata paviculis vel molari lapide condensetur, et rursus superjectis paleis inculcetur, atque ita solibus siccanda relinquatur. Sunt tamen, qui prati ohjacentem favonio tritura destinant, areamque de. messa faba et injecta expoliunt : nam dum a pecudibus legumina proculcantur, herbæ etiam ungulis atteruntur, atque ita glabrescit et fit idonea trituris area.

$\mathbf{X X}$. Sed cum matura fuerit seges, ante quam torreatur vaporibus orstivi sideris, qui sunt vastissimi per ortum Canicula, celeriter demetatur. Nam dispendiosa est cunctatio. Primum, quod avibus prædam cæeterisque animalibus prabet : deinde quod grana et ipsa spica culmis arentibus et aristis celeriter decidunt. Si vero procel. la ventorum aut turbines incesserint, major pars ad terram defluit : propter quæ recrastinari non dehet, sed aqualiter flaventibus jam satis, ante quam ex toto grana indurescant, cum rubicundum colorem traxerunt, messis facienda est, ut potius in area et in acervo, quain in agro grandescant frumenta. Constat enim, si tempestive decisa sint, postea capere incrementum. Sunt autem nuelendi genera complura. Multi falcibus veruculatis, atque is vel rostratis vel denticulatis merlium culmum secant : multi mergis, alii pectiuibus spicam ipsam legunt, idque in rara segete facillimum, in densa difficillimum est. Quod si fal. cibus seges cum parte culmi demessa sit, protinus in acervum vel in nubilarium congeritur, et subinde opportunis solibus torrefacta proteritur. Sin autem spicx tantummodo 
cebéait que l'on batte dans l'aire le blé muni de sa tige, il n'y a point de doute que les ehevaux ne soient préférables pour eette opération aux bœu fs, et si l'on n'a pas un nombre suffisant d'attelages, on pourra y joindre des rouleaux ou des traineaux : ear, avec ces deux espèees de maehines, on vient très-aisément à bout de briser les tiges. Si au eontraire les épis sont seuls, on iait mieux de les battre à coups de bâton et de les vanner. Mais lorsque le grain est pêle-mêle avee la paille, on vient à bout de les séparer l'un de l'autre par le seeours du vent. Le vent F'avonius passe pour le meilleur en cette occasion, paree qu'il souffle doucement et uniformément dans les mois d'été. II n'y a eependant qu'un agrieulteur négligent qui puisse se résoudre à l'attendre, pareeque, tandis que nous l'attendons, la rigueur de l'hiver peut nous surprendre. C'est pourquoi, lorsque les blés ont été battus dans l'aire, il faut les y mettre en tas, de faecon qu'ils puissent être nettoyés par toutes sortes de vents; et s'il arrive même que le vent ne souflle d'aueun eôté pendant plusieurs jours, il faudra les vanner, de peur qu'à la suite d'un trop long ealme il ne survienne de fortes tempêtes, qui fassent perdre le travail de toute l'année. Quand le grain aura été bien nettoyé, il faudra eneore le nettoyer une seeonde fois avant de le serrer, si l'on est dans l'intention de le garder plusieurs années; ear plus il est nettoyé, moins il est sujet à être rongé par le eharanȩon: mais si on le destine à être consommé sur-le-champ, il ue sera pas nécessaire de le purger de nouveau, et il suffira de le faire raîraichir à l'ombre, et de le porter ensuite au grenier. On ne s'y prend pas autrement pour les légumes que pour les autres grains, paree que, de même qu'eux, ou on les consomme sur-le.

recisæe sunt, possunt in lorreum conferri, et deinde per liemem vel baculis excuti rel exteri pecudibus. At si competit, ut in area teratur frumentum, niliil dubium est, quin equis melius quam bubus ea res conficialur : et si pauca juga sunt, adjicere tribulam et tralıam possis; quæe res utraque culmos facillime comminuit. ipse autem spicæ: inelius fustibus cuduntur, vanuisque expurgantur. At ubi paleis imınista sunt frumenta, rento separentur. Ad eam rem Faronius liabetur eximius, qui lenis atqualisque astivis mensibus perflat : quem tamen opperiri lenti est agricola : quia sape dum expectatur, sæeva nos hiems deprehendit. Itaque in area detrita frumenta sic sunt agge. randa, ut onni flatı possint excerni. At si compluribus diebus undique silebit aura, vannis expurgentur, ne post nimiam veutorum segnilien vasta tenuestas irritum faciat tolius anni laborem. Pura deinde frumenta, si in annos recouduntur, repurgari debent. Nam quauto sunt expoli. tiora, minus a curculionibus exeduntur. Sin protinus usui destinanlur, uiliil attinet repoliri, satisque est in umbra refrigerari, et ita granario inferri. Leguminnn quoque non ehamp, ou on les serre pour les garder. Voilà le profit auquel aboutit enfin le travail du laboureur, et qui eonsiste à reeueillir les semenees qu'il avait eonfiées à la terre.

XXI. Mais eomme nos aneêtres ont pensé qu'on devait autant rendre eompte de son loisir que de ses oceupations, nous croyons aussi devoir prévenir les eultivateurs de ee qu'ils ont droit de faire les jours de fète, et de ee quil leur est interdit ees jours-là. Car il y a des choses, eomme dit le poëte, qu'il est permis de faire les jours de féte: il n'y a point de religion qui ait défendu de donner un libre écoulement aux ruisseaux, de planter une haie devant une terre ensemencéc, de tendre des piéges aux oiseaux, de mettre le feu aux buissons, ou de plonger dans un fleuve un troupeau de brebis pour lui procurer la santé, quoique les pontifes prétendent qu'on ne doit point fermer de haies une terre ensemeneće les jours de fêtes; comme ils défendent aussi de baigner les brebis pour embellir leur laine, et ne permettent de le faire que pour leur procurer la santé. Aussi Virgile, pour montrer eomment il était permis de baigner un trouprau dans une rivière les jours de fêtes, a-til ajouté, De le plonger dans un fleuve pour lui procurer la santé, paree qu'en effet il y a des maladies pour lesquelles il est bon de baigner les bestiaux. Voiei eneore des travaux que les rites de nos aneêtres permettent de faire les jours de fètes : breyer le blé, eouper du bois à brûler, faire de la ehandelle de suif, eultiver une vigne affermée, nettoyer et curer les réservoirs, les mares, les aneiens fossés ; repasser les près, éparpiller le fumier sur les terres, arranger le foin sur les planehers, réeolter les fruits des plaus d'oliviers qu'on a pris à ferme, étendre les pom-

alia cura est, quam reliquorum frumentorum : nam ea quoque vel statim absumuntur, vel reconduntur. Atque loc suprenum est aratoris emolumentum percipiendorum seminum, quae terra crediderat.

XXI. Sed cum tam otii quam negotii rationem reddere majores nostri censuerint; nos quoque monendos esse agricolas existimamus, quæ feriis facere, quæque non facere debeant. Sunt enim, ut ait poeta, quxe festis exer. cere diebus Fas, el jura sinunt. Rivos deducere nulla relligio veluit, segeti prolendere sepem, Insidias avibus moliri, incendere vepres, Balanlumque gregem fuvio mersure salubri. Quamquam pontilices negant segetem feriis sepiri debere. Velant quoque lanarum causa lavari ores, nisi propter medicinam. Virgilins quod liceat feriis flunine abluere gregem procepit, et idcirco adjecit, fluvio mersare salubri. Sunt enim vilia, quorum causa pecus utile sit lavare. Feriis autem ritus majorum etiam illa per. mitlit, far pinsere, faces incidere, candelas sebare, vineam conductam colere; piscinas, lacus, fossas vetcres tergere et purgare, prata sicilire, stercora aquare, fuenum 
mes, les poires, les figues ; faire du fromage, porter sur son dos on charger sur un mulet de bat des arbres pour les planter: mais il n'est pas permis de se servir pour les porter d'un mulet attelé à une voiture, ni de planter ceux qui auraient été nortés ainsi, ni de labourer la terre, ni d'élaguer les arbres, pas même de s'oceuper des semailles, à moins que l'on n'ait préalablement immolé un petit chien, ni de couper le foin, le lier ou le porter. Il n'est pas même permis, suivant les observanees prescrites par les pontifes, de faire la vendangre les jours de fêtes, ni de tondre les brebis, à moins que l'on n'ait eneore immolé un petit chicn. Il est aussi permis de faire du vin euit, et d'en mêler dans le vin : il est permis de eueillir le raisin, ainsi que les olives que l'on. destine à confire. Il n'est pas permis de eouvrir de peaux les brebis. Tout travail relatif aux légumes qui sont dans un jardin est permis. Il n'est pas permis d'ensevelir un mort les jours de fêtes publiques. M. Porcius Caton a dit qu'il n'y avait point de fètes pour les mulets, pour les chevaux, ni pour les ânes. Il permet aussi d'atteler les bœufs pour apporter du bois et du blé ehez soi. Nous avons lu dans les ouvrages des pontifes que ce n'est qu'aux fêtes denicales qu'il n'est pas permis d'atteler les mulets, mais qu'on peut le faire les autres fêtes. Je suis sûr que quelques personnes, voyant que je viens d'entrer dans le détail de ce qui eoncerne la solennité des fètes, désireront que je leur enseigne aussi les rites usités par les anciens dans les saerifices d'expiation, et dans tous les autres sacrifices que l'on fait pour les biens de la terre; aussi je ne refuse pas de prendre cette peine, mais je remets à le faire dans un livre à part que j'ai dessein de composer, lorsque j'aurai donné tous les précep-

in tabulata componere, fructus oliveti conductos cogere, mala, pira, ficos pandere, caseu causa collo vel nulo clitellario afferre : sed juncto adre. here non permittitur, nec apportata serere, neque terram aperirc, neque arborem collucare : sed ne sementem quidem administrarc, nisi prius catulo fecris : nec focuum secarc aut vincire aut vehere : ac ne vindemiam quidem rogi per religiones pontificum feriis licet : nec oves tondere, nisi si catulo feceris. Defrutum quorjue facerc, et defrutare vinum licet. Uvas itcmque olivas conditui legere licet. Pellibus oves vestiri non licet. In horto qunicquid olerum calıs facias, omne licet. Feriis publicis hominem mortunm sepelire non licet. M. Porcius Cato mulis, equnis, asinis mullas esze ferias dixit. Idemque boves permittit conjungere lignorum et frumentorum advehendorum causa. Nos apud jontifices legimus, feriis tantum denicalibus mulos jungerc non licere, cxteris licere. Ioc loco certum habeo finosilam cum solennia festorum percensuerim, desideraturos lustrationum caterorumque sacrificiorum, quæ pro frugibus finnt, morem priscis usurpatum. Nec ego alonuo docendi curam : sed differo in eum librun, tes de l'agriculture. En attendant, je terminerai íci ce trailé, me réservant à domner dans le suivant ce que je tiens des anciens auteurs sur les vignolles, et sur les plants d'arbres mariés à des vignes, comme ce que j’ai découvert moi-même depuis eux.

\section{LIVRE TROISIEME.}

\section{J'ai donné jusqu'ici la culture des guérets,} comme dit le premier des poëtes. Car, puisque j'ai à traiter les mêmes objets que lui, rien ne m'empèche, $\mathbf{P}$. Silvinus, d'entrer cn matière par les premières paroles de son poëme célèbre. Nous voici done à présent venus au soin des arbres, et c'est même la partie la plus étendue de l'agrieulture. Il y a des arbres de différentes espèees, qui tous se montrent sous des formes variées : il y en a de bien des espèces qui, comme dit le même poëte, viennent d'eux-mémes et sans $y$ être forcés par aucun homme, comme il y en a beaueoup qui ne viennent qu'après avoir été plantés de main d'homme. Mais ceux qui ne viennent pas par le secours des hommes, tels que ecux des forêts et les sauvageons, portent chacun des fruits ou des semences d'un earaetère qui leur est propre; au lieu que eeux qui ont été cultivés sont les plus propres à rapporter des fruits pour notre usage. Il faut done parler d'abord de l'espèce d'arbres qui nous fournit des aliments. On la divise en trois partics : car un rejeton queleonque produit ou un arbre tel que l'olivier, ou un arbrisseau tel que le palmier des champs, ou un troisième genre de production que je ne voudrais appeler proprement ni arbre

quem componere in animo est, cum agricolationis totam disciplinam perscripsero. Finem interim prosentis dispu. tationis faciam, dicturus exordio sequente, quæ de vineis arhustisque prodidere veteres auctores, quaeque ipse mox comperi.

\section{LIBER TERTIUS.}

I. Hactenus arvorum cultus, ut ait pracstantissimus pocta. Nihil enim prohibet nos, P. Silvine, de iisdem rebus dicturos celeberrimi carminis auspicari principio. Sequitur arborum cura, quax pars rei rustica vel maxima est. Ea. rum species diversæe el multiformes sunt. Quippe varii generis (sicnt auctor idem refert) nullis hominum cogen. tibus ipsce sponte sua veniunt: nultic etiam nostra manu satæ proceduut. Sed quae non ope lumana gignuntur, silvestres ac ferne sui cujusque ingenii poma vel semina gerunt : at quibus labor adhibetur, magis apta sunt frugibus. De $c o$ igitur prius genere dicendum est, quod nohis alimenta prabet; idque tripartito dividitur. Nam ex surcu. 
ui arbrisseau, tel qu'est la vigne. Nous la préférons justement aux autres plantes, non-seulement à eause de la douccur de son fruit, mais encore à eause de la facllité avec laquello clle répond aux soins de l'homme, dans presquo toutes les contrées et sous tous les climats du monde, si l'on en excepte les climats glacés ou brûlants, et parcc qu'elle vient aussi heureusement dans les plaines que sur les collines, dans les terres épaisses que dans celles qui sont en poussière, souvent mème daus les terres malgres que dans les grasses, et dans les sèches que dans celles qui sont humides. Elle est surtout la seule plante qui réussisse sous diverses températures, soit qu'elle soit sous un póle froid, soit qu'elle soit sous un pôle chaud ou sujet aux tempêtes. II est cependant intéressant de distinguer quelles espèces de vignes on culti. vera, et quel genre de culture on leur donnera, suivant les différentes positions des pays : car la eulture de la vigne n'est pas la mème pour tous les elimats nl pour tous les terroirs; et non-seulement cette plante n'est pas d'une seule espèee, mais il n'est pas aisé de prononcer quelle est la meilleurc espèce de toutes, parce qu'il n'y a que l'expérlence qui puisse apprendre quelle est celle en partieulier qui sera plus ou moins propre à tel ou tel pays. Cependant un cultivateur eclairé regardera comme certain que le genre de vignes qul supportera, sans en être ineommodé, les neiges et les frimas, sera propre aux plaines; que celui qul supportera la sécheresse et les vents, sera propre aux collines : il départira à un champ gras et fertile une vigne maigre, et qui ne soit pas naturellement trop féconde; à un terrain maigre une vigne féconde; à un terrain épais une vigne forte et qui ait beaucoup de bois ; à un terrain réduit en poussière et fertilc, une vigne qui ait peu de bois. II saura qu'il ne faut pas planter des lieux lumides en vignes dont le raisin ait un grain tendre et gros, mais en vignes dont le raisin aura le grain dur, petit, et fourni de beaucoup de pepins; et qu'il faut, d'un autre coté, mettre dans un terrain sec des vignes d'une nature différente. Mals, outre cela, le propriétaire da terrain saura encore que les différentes températures de l'air influent plus que le terraln même sur les vignes, comme le frold ou lo chaud, la séeheresse ou l'humidité, la grêle et le vent ou le calme, le temps serein ou le temps nébuleux : ainsi il mettra sous un climat froid ou nébuleux deux espèces de vignes, ou les hátives dont les fruits préviendront l'hiver par leur maturité, ou celles dont le grain sera ferme et dur, parce qu'elles défleuriront au milieu des brouillards, et que leur fruit mûrira ensuite aux gelées et aux frimas, comme les autres mûrissent aux chaleurs. Il mettra également avec hardiesse les vignes fermes, et dont le grain sera dur, sous un climat sujet aux vents et aux orages; d'un autre côté, il mettra dans un climat chaud les vignes les plus tendres, et celles dont le raisin sera le plus serré : il destinera à un terrain sec celles que des pluies et des rosées continuelles pourriraient; à un terrain humide, celles qui souffriraient de la sécheresse; à un terrain sujet à la grêle, celles dont les feuilles seront dures et larges, afin que leur fruit soit plus à couvert : car pour les contrées où le temps est calme et serein, il n'y a pas de vignes qui ne leur conviennent, quoique les meilleures seront celles dont les grains et les grappes tomberont le plus aisément. Mais s'il faut choisir à souhait un terrain et un climat pour les vignes, le meilleur terrain (d'après l'opinion de Celsus, qui est très- to rel arbor procedit, ut olea : vel frutex, ut palma campestris: vel tertium quiddam, quod nec arborem nec fructicenı proprie dixerimus, ut est vitis. Hanc nos cate. ris stirpibus jure praponinus, non tantum fructus dulcedine, sed etiam facilitate, per quam omni pene regione et omui declinatione mundi, nisi tamen glaciali rel pracervida, curae mortalium respondet, tamque felix campis, (quam collibus proreuit, et in densa non minus quam in resoluta, sape etiam gracili; atque pingui et nuacra, siccaque ef uliginosa. Tum sola maxime utcunque patitus intemperien cacli vel sub ase frigillo, vel acstuoso procel. losopue. Refert tamen, cujus generis aul quo habitu viten pro regionis statu colere censeas. Neque enim omui cxelo solove cultus ilem; neque est unum stirpis ejus genus; guodque pracipuum est ex omnibus, non facile dictu est, cun suum cuique regioni magis ant minus aptum esse doceat usus, Exploratum tamen luabebit prudens agricola genus vilis lıabile campo, quod nebulas pruinamque sine noxa perfert; colli, funod siccitatem ventosque patitur. Pingui et uberi dabit agro gracilen viten, nec uatura uimis frocundam, nacro feracem, terrid deusa vehementem, multaque materia frondentem; resoluto et lato solo, rari sarmenti, lummido loco sciet non recte mandari fructus te. neri et anplioris acini, sed callosi et angusti frequentisque vinacei; sicco recte contribui diversx [quoque] natura semina. Sed et post hæc non ignorabit dominus loci, plıs posse qualitatem cacli frigidam vel calidam, siccam rel roscidam, grandinosam ventosamque vel placidanı, serenam vel nebulosam : frigidæeque aut nebulosæ dıßrum generun viles aptahit, seu pracoques, quarun naturitas frugum pracurrit liemem; seu firmi durį̣ue acini, quarum inter caligines uv $x$ deflorescunt, et nox gelicidiis ac pruinis, ut aliarum calorilus, nitescmut. Ventoso quoque et tumultuoso statu cali fidenter easiem tenaces ac Juri acini comnittct. Rursus calido teneriores uberioresque concredet. Sicco destimabit eas, qua pluriis aut continuis rorilus putrescuut; roscido, qux slccitatilıus laborant ; grandinoso quae foliis duris latisque sunt, quo melius prolegant fructum. Nam placida et serena regio nultam non recipit : commodissime tamen ean, cujus vel uvie rel acini celeriter decidunt. At si roto est eligen. dus vineis locus et status cieli, sicut censet verissiue 
conforme à la vérité) sera celul qui, sans être trop épais ni réduit en poussière, approehera le plus de cettc dernière qualité; eelui qui, sans être maigre ni fertile, approchera cependant le plus de la fertilité; celui qui, sans être en plaine ni esearpé, tiendra cependant d'une plainc élevée; celui qui, sans être sec ni humide, sera cependant modérément arrosé; celui qui, sans avoir beaueoup de sources d'eau sur sa surface ni dans ses entrailles, fournira néanmoins aux racines de la vigne une humidité suffisante, qu’il tirera des lieux circonvoisins; humidité qui ne devra être ni amère ni salée, pour qu'clle ne corrompe point le goût du vin, et qu'cllc n'arrête point l'accroissement des plantes par l'espèce de rouille dont elle les couvrirait, s'il en faut croire Virgile, qui s'cxprime ainsi : Mais les terres salées, el celles qui passent pour amères, sont nuisibles aux fruits; les labours ne les adoucissent pas, et elles ne conservent ni la qualité du vin ni la réputation des fruits. La vigne, comme je l'ai dit ci-dessus, ne veut ni unc température glaciale, ni unc température brûlante : elle se plait cependant plus dans les climats chauds que dans les climats froids; la pluie lui fait plus de tort que le beau temps, et elle aime mieux une contrée sèehe qu'unc eontréc trop pluvieuse; comme ellc aime un vent modéré et doux, tandis que les tempêtes lui sont pernicieuses. Telles sont les qualités du climat et du sol qui sont le plus à rechercher.

II. On plante des vignes soit pour en manger le raisin, soit pour en faire du vin. Il n'y a pas de profit à faire un vignoble pour en destiner le raisin à être mangé, à moins que le terrain où oul le formera ne soit si voisin des villes, que l'on puisse trouver son compte à vendre le raisin aux mar-

Celsus, optimum est solum nec densum nimis nec resolutum, soluto tamen propius : nec exile nec latissimum, proximum tamen uberi : nec campestre nec proceps, simile tamen edito campo : nec siccum nec uliginosum, modice tamen roscidum : quod fontibus non in summo, non in profundo terro scaturiat; sed ut vicinum radicibus lummorem subministret : eumque nec amaruın nec salsum, ne saporem vini corrumpat, et incrementa virentium veluti quadam scabra rubigine coerceat : si modo credimus Virgilio dicenti : Salsa autem tellus, et quae perhibetur amara, Frugibus infelix; ea nec mansuescit arando, Nec Baccho genus aut promis sua nomina servat. Colum porro neque glaciale vinea, sicut prodixi, nec rursus restuosum desiderat. Calido tamen potius quam frigido latatur; imbribus magis quam serenitatibus offenditur; et solo sicco quam nimis pluvio est amicior; perflafu modico lenique gaudet, procellis obnoxia est. Atque hæc maxime probabilis est cæli et soli qualitas.

II. Vitis autem vel ad escam vel ad defusionem deponitur. Ad escam non expedit instituere vineta, nisi cum tam suburbanus est ager, ut ratio postulet inconditum chands, sans avoir la peine de le garder, conutne on vend tous les autres fruits. Lorsque l'on sera dans ce cas, il faudra surtout avoir des vignes hatives et du maroquin, en un mot du raisiu pourpré, de celui à gros grains, de celui à longs grains, de celui de Rhodes, de celui de Libye et de celuides monts Cérauniens : il faut planter alors non-sejulement les vignes qui sont recommandables par le goût agréable de leur fruit, mais aussi celles qui lc sont par leur belle apparenee, comme celles dont les grappes ont la forme d'une couronne, celles dont les grappes ont trois pieds, celles dont le grain pèse une uncia, celles qui ressemblent aux coings, de même que celles dont on serre le raisin dans des vases, pour le garder pendant l'hiver, comme les venucula et celles de Numldie qu'on a reconnues depuis peu être bonnes pour cet objet. Mais lorsqu'on veut faire du vin, on clioisit la vigne qui est forte en fruit et en bois, parce que l'un contribue beaucoup aux revenus du cultivateur, et l'autre à la longue durce de la plante; mais il faut préférer célle qui, ne se couvrant pas trop tôt de feuilles et quittant sa fleur de bonne heure, sans mûrir trop tard, se défend en même temps aisément contre les gelées, le brouillard et la brûlure, sans que la pluie la pourrisse, ou que les sécheresses la réduisent à rien. Voilà eomme il faut la choisir, ne fût-elle que médiocrement fẻeonde, pourvu que l'on ait un terroir où elle puisse ren. dre un vin d'un goût fin et recherché. Car si le terroir donne au vin un goût déeidément mauvais ou commun, il vaudra mieux planter la vigne qui sera la plus abondante, afin d'augmenter son revenu par la multiplieité du produit. Il arrive presque toujours, en quelque terroir que ce soit, que les vignobles des plaines donnent du

fructum mercantibus velut pomum vendere. Quæ cum talis est conditio, maxime pracoques et duracinæ, tum denique purpuren el bumasti, dactylique et Rhodix, Libyex quoque et cerauniæ. Nec solum quæ jucunditate saporis, verum etiam quæ specie commendari possint, conseri debent : ut steplanitæ, ut tripedaneæ, ut unciariæ, ut cy. donilæ. Item quarum uvæ temporibus hiemis durabiles vasis conduntur, ut venuculæ, ut nuper in hos usus explorata Numisiana. At ubi vino consulimus, vitis eligitur, qua et in fructı valet et in materia : quod alterum ad reditus coloni, alterum ad diuturnitatem stirpis plurimum confert. Sed ea tum procipua est, si nec nimis celeriter frondet, et primo quoque tempore deflorescit, nec nimis tarde mitescit : quin etiam pruinas et caliginen et carbunculum facile propulsat, eademque nec imbribus putrescit, nec siccitatibus abolescit. Talis nohis eligatur vel mediocriler focunda, si modo is locus labetur, in quo gustus nobilis pretiosusque fluit. Nam si sordislus aut vilis est, feracissiman quamque serere conducit, ut multiplicatione frugum reditus augeatur. Fere autem omni statu locorım campestria largius vinum sed jucundius afferunt collina : 
vlıi en plus grande quantité que eeux des collines, et que eeux-ei le donuent plus agréable, ¡juoique entre ees derniers même, quand le elimat en est modéré, ceux qui sont exposés aux aquilons en donnent plus abondamment, et que ceux qui le sont au vent du midi le donnent plus excellent. Car il n'y a point de doute que eertaines vignes ne soient de nature à être tantôt supérieures, tantót inférieures à elles-mênıes par la qualité de leur vin, suivant la position des lieux. II n'y a que les vignes Aminées qui passent pour préférables à toutes les autres par le goût du leur, sous quelque climat qu'elles soient placées, pourvu qu'il ne soit pas trop froid; et eela quand même elles seraient dégémérées, quoique, si on les eompare entre elles, elles donnent un vin tautút meilleur, tantôt moins bon. Ces vignes, quoique portant toutes le mêmenom, ne sont pas eependant resserrées dans les bornes d'une seule espèee. Nous avons connu les deux espèces de vraies Aminées, dont la plus petite défleurit plus lôt et mieux que la plus grande : aussi est-elle propre à être mariée aux arbres, ainsi qu'à être attachée au joug; si ee n'est que dans le premier cas il lui faut une terre grasse, au lieu que dans le second cas une terre médioere lui suffit. Elle est aussi bien meilleure que la plus grande espèee, parce qu'elle a plus de foree pour supporter les pluies et les vents; au lieu que cette dernière se corrompt promptement lorsqu'elle est en fleur, ineonvénient quiarrive eneore plutôt quand elle est attachée au joug que quand elle est marice aux arbres. Aussi n'est-elle pas propre à formel des vignobles, puisqu'elle l'est à peine à garnir des plants d'arbres, si ee n'est dans une terre très-grasse et humide; car pour une terre médioere, elle n'y vaut rien; elle vaut moins encore dans une terre maigre. On la reconnaît à la multitude de ses longs sarments, à la grandeur

(циæ tamen ipsa modico statı cxeli magis exuberant Aquiloni prona; sed sunt generosiora sub Austro. Nec dubium, quin sit ea uonnullarum vitium natura, ut pro locorum sitı bonitate vini modo viucant, morlo superentur. Sola traduutur Aıniseae excepto caeli statu nimis frigido, ubicuncule siut, eliam si degenerent, sibi comparata, magis aut minus probi gustus viua priebere, et catteras omneis sapure prascedere. Fix cun sint unius nominis, uon แuau speciem geruut. Duas germanas cognovimus, qua. rum minor ocius et melius deflorescit, habilis arbori nec non jugn: illic pinguen terram, hic nuediocrem desiderat, longeque pracedit majorem, quia et insbres et veutos fortius patitur. Jan nıjor celeriter in flore corrumpitur, et nayis in jugis, quam in arboribus. Ideogue non est rineis apta, vix etian arbusto, nisi prapingui et uvida terra : nan nec mediocri valet, multoque minus in evili. Prolixarum frexuentia materiarum foliorumque et uvarun) et acinorum magnitudiue dignoscitur, interuodiis quuque rarior. Largis fructibus a minore superatur, gustu non vincitur. Et has quidem utracque Amiuex. Verum et de ses feuilles et à la grosseur de ses grains : elle a aussi moins de nœuds que la petite espéee, et produit des fruits en moindre quantité; mais elle ne lui eède pas pour le goût. Ces deux espèces de vignes sont toutes deux Ani. nées; mais il y en a eneore deux autres espèees, qui sont les Aminées doubles : on les appelle jumelles, paree qu'elles produisent des grappes doubles; le vin en est plus dur, mais it se garde aussi longtemps que eelui des deux premières. Tout le monde connait très-bien la plus petite de ces deux espèces, paree que les collines renommées du Vésuvium dans la Campanie, et celles du Surrentum, en sont eouvertes. Elle aime le souffle du vent Favonius en été ; celui du Midi la tourmente : aussi dans les autres contrées de l'Italie est-elle moins propre à faire des vignobles qu'à garnir des plants d'arbres, au lieu que, dans les pays que nous venons de nommer , les jougs soutiennent commodément son bois et son fruit. Sa grappe ne diffère pas beaucoup de celledela petite Aminée vraie, si ce n'est qu'elle est double; de même que la grappe de la grande double ressemble assezá celle de la grande Aminée vraie, avec eette différenee qu'elle vaut mieux que la petite double, en ee qu'ellc est plus féconde même dans un terrain médioere; au lieu que nous avons déjà dit que la grande A minée vraie ne réussissait bien que dans un teprain très-gras. Il y a quelques personnes qui font aussi un grand eas de l'Aminée lanata, que l'on appelle ainsi, non pas qu'elle soit la seule de toutes les vignes Aminées dont les feuilles soient blanchies de duvet, mais paree que c'est celle dont les feuilles sont le plus dans ce cas. Cette Aminée donne à la vérité de bon vin, mais il est plus léger que celui des préeedentes. Elle jette aussi beaucoup de bois : c'est ee qui fait souvent qu'elle ne défleurit pas comme il

aliæ duæ geminæ ab eo quod duplices uvas exigunt, cognomen tralunt austerioris vini, sed aque perennis. Earum uninor vulgo notissima : quippe Canpanix celeberrimos Vesuvii colles Surrentinosque vestit. Hilaris inter astivos Favonii flatıs, Austris afligitur. Cæeteris itaque partibus Italix non tam vineis quan arbusto est idonea, cum pradictis regionibus conımodissime jugum sustineat. Materiam fructumque, nisi quol dupliceu, , uon absimilem minori germanæe gerit, sicut major gemina majori germana: quxe tamen (minor) liac melior est, quod foecundior etiam mediocri solo: nam illam nisi propingui nolı respondere jam alctum est. Lanatanı quoujue Anineam quidam maxime probant, qua lioc vocabulum non ideo usurpat, quod sola ex omnibus Anineis, veıum quod praceipue canescit lanugine. Sane boni vini, sed leuioris, quam superiores, crebram y̧uoque materian fundit; atque ideo propter pampiui densitatem siepe parum recle deflurescit, eademyue na. turo fructu celeriter putrescit. Super liunc numerun, quem retulinus, singularis lıbetur Aninea majori ge. mina ıon dissimilis, prima specie pampini et trunci, sed 
faut, à cause de la multitude de ses pampres, rt que lorsque son fruit est mûr, il pourrit promptr'ment. Outre toutes les Aminées que nous venons de détailler, il y a eneore une Aminćc particulière, qui, au premier coup d'œil, l'essemble assez à la grande double par l'extérieur de ses pampres et de son cep, mais qui lui est un peu inférieure par le goût de son vin, quoiqu'il soit de très-bonne qualité : elle est cependant préférable à cette dernière par les propriétés suivantes : d'être plus fertile, de quitter mieux sa fleur, d'avoir les grappes bien fournies et blanchâtres, et le grain très-yros, et de ne point dégénérer dans un terrain médiocre; aussi la met-on dans la classe des vignes les plis fécondes. Les vignes de Nomentum ne tiennent que le second rang après les Aminées par la qualité de leur vin, mais elles lear sont supérieures par leur fécondité, parce que souventelles ont autant de fruit qu'elles en peuvent porter, et qu'elles le défendent très-bien. Mais la plus petite de ces vignes est la plus fertile; sa feuille est moins déeoupée et son bois moins rouge que dans les Aminées : c'est cette couleur qui leur a fait donner le nom de rubellian $\infty$; on les appelle encore $f a$ einia, parce que leur vìn rend plus de lie que d'autres. Mais elles dédommagent de eet ineonvénient par la multitude de leurs grappes, qu'elles produisent également sur le joug eomme sur l'arbre, quoique mieux encore sur l'arbre. Elles supportent bravement les vents et les pluies; elles quittent promptement leur fleur, et en conséquence mûrissent plus tôt et résistent à toutes les ineommodités, si ee u'est à la chaleur : car, comme elles ont des grappes dont le grain est déjà menu et la peau dure, la ehaleur le rend eneore plus coriace : elles se plaisent surtout dans un terrain gras, qui soit en état de proeurer quelque fécondité à leurs grappes, naturellement grêles et pe-

vini sapore aliquanto inferior, qquamvis generosissimis sit proxima, prafereuda efiam propuiis virtutibus : nam et feracior est, et flore melius cxuitur, spissasfue et allodlas uvas ac tumidioris aciui gerit, gracili arvo uon desciscit, atque ileo inter uberiunas vites uumeralur. Nomentanx vini nobilitate subsequntur Amineas, fiecuulitate vero etiam praveniunt : quippe cum se frequenter impleant, et il, quocl ediderunt, oplime lueaufur. Sed earum quoque feracior est minor, cujus et folinm parcius scinditur, et materia non ita rubet ut majoris, a quo colore rubellianx nunenpantur : cxdemque facinix, quo plus quam cxetera faccis afferunt. Id tamen incounmodum repensaut uvarum multitudine, quas et in jugo sed [et] in arbore melius exlibent. Ventos et imbres valenter sufferunt, et celeriter defiorescunt, et ideo citius milescunt, omnis incommodi patientes proter caloris. Nanı quia minuti acini et lura eutis uvas habent, aestibus contralıuulur. Pingui arvo maxime gaudent, quod ubertatem aliquam natura [tracilibus et] exilibus uvis probere valet. Frigidum ac tites. Les eugenice s'accommodent tres-bien d'un sol ainsi que d'un elimat froid ct eouvert de rosée, tant qu'elles sont sur la colline d'Albe; car dès qu'el les changent de elimat, elles répondent à peine à leur réputation; de mème que le raisin des Allobroges, qui donne un vin bien inférieur lorsqu'on l'a ehangé de pays. Il y a trois espèces de raisin muscat, qui sont aussi re commandables par leurs grandes qualités : toutes les trois sont fertiles, et s'accommodent assez bien du joug et des arbres : il y en a eependant une meilleure que les deux autres, et dont les feuilles ne sont point eouvertes de duvet; pour les deux espèces dont les feuilies en sont eouvertes, quoiqu'elles soient semblables entre elles par les feuilles et par les branehes à fruit, elles montrent cependant une différence sensible dans la qualité de leur vin, puisque le vin de l'une des deux acquiert plus tard que l'autre ce goût fait que la vétusté donne en général au vin. Elles sont très-fertiles dans un terrain gras, et ne laissent pas de l'être dans un terrain médioere: leur fruit est hatif, ee qui fait qu'elles conviennent très-fort aux lieux froids: leur vin est doux, mais il est pernieieux à la tête, aux nerfs, et aux autres vaisseaux du corps. Si on ne vendange pas promptement, les pluies et les vents les dévastent, ainsi que les abeilles; ce qui leur a fait donner le nom de ces animaux (apiance). Elles sont très-élèbres par l'exeellence de leur goût. Il y a cependant des vignes, même de la seconde elasse, qui peu ventêtre recommandables par leur produit et leur féeondité, telles que la Biturica et la basilica, qui se divise en deux espèees, à la plus petite desquelles les Espagnols donnent le nom de cocolubis. Ces deux vignes sont celles qui approehent le plus des premières dont nous avons parlé; elles laissent toutes les autres à une grande distance après elles, ear leur

roseilum solum et cxlnm commodissime sustinent eugenixe, dum sunt in Albano colle. Nam mutato loco vix nomiui sno respondent. Nec uinus Allobrogica, quarum viui jucuuditas cum regione mutatur. Maguis etiam dotibus ties apianx commendant ur, ommes feraces jugoque et arboribus satis ilonex: generosior tamen una, qux nudis foliis est. Nam dua lanatie quamvis frondibus et palmitum pari facie fluxura qualitate sunt dispariles, cum tarlius altera recipiat cariem vetıstatis. Pingıi solo feracissinne, mediocri quoque focundx, praccoquis fixtus : ideoque frigidis locis aptissimæ, vini duleis, sed capili nervisque, [venisqne] non apta. Nisi mature leeta pluviis ventisque et apibns afferunt proedam, quarum vocabulo propter lanc populationem cognomiuantur. Atque lıe pretiosi gustıs eeleberrima. Possunt tamen elian secundxe notae vites proventu et ubertate commendari, qualis est Bituica, qualis basilica, quarum minorem cocolubem rocaut IIispani, longe omnium primis utroejue proxima. Nau et velustatem vinum carum patitur, et ad bonitalem alipuam 
vin segarle longtemps sans se gâter, et aequiert unime un certain degré de bonté après quelques années. Elles surpassent même par leurfíeondité toutes eelles que j'ai nommées d'abord, ainsi que par leur force, ear elles supportent très-bravement les tempêtes et les pluies : elles rendent beaucoup de vin, et ne dégénèrent point dans un terrain maigre; elles souffrent plutôt le froid que l'eau, et l'eau que la sécheresse, sans eependarit que les ehaleurs les ineommodent. Après celles-ci viennent la visula et la petite vigne d'Algos, qui se plaisent toutes deux dans une terre médioere : ear, lorsqu'elles sont dans une terre grasse, elles prennent trop de foree, et dans une maigre au contraire elles sont de petite venue, etn'ont pas de fruit : elles aiment mieux le joug que les arbres; mais eependant celle d'Argos est également fertile lorsqu'elle est grimpée haut, et elle y produit de grands bois et de grosses grappes. Pour la visula, à qui les planehers les plus bas conviennent davantage, elle donne des sarments eourts et des feuilles larges, qui servent dès lors à garantir ses fruits de la grêle : si cependant on ne les eueille pas au premier moment qu'ils sont mûrs, ils tombent à terre, et l'humidité les pourrit mème avant qu'ils soient tombés. On cite eneore les vignes helvolw, que quelques personnes appellent variæ : le raisin n'en est ni pourpré, ni noir; et c'est sa couleur entre rouge et blanc qui leur a fait donner, si je ne me trompe, le nom d'helvolce (paillet). Le plus noir est meilleur, eu égard à la quantité de vin ru'il rend; mais le plus blane est le plus recherehé pour le goût du sien, et nil'un ni l'autre ne conserve également sa couleur : ees deux vignes produisent l'une comme l'autre du vin blane, dont la quantité est alternativement plus ou moins grande de deux années l'une. Elles cou-

per annos venit. Jam vero ipsæ focunditate præstant omnibus, quas ante retuli, tuın etianı patientia : quippe turbines imbresque [fortissime] sustinent, et commode fluunt, nec deficiunt macro solo. Frigora melius quam humores sustinent, humores commoditus quam siccitates, nec caloribus tamen contfistantur. Visula deinde $a b$ his et minor argitis terro mediocritate lotantur; nam in pingui nimiis viribus luxuriant; in macra tenues et vacuse fructu veniunt : aniciores jugo quam arboribus, sed argitis etiam in sublimibus fertilis vastis materiis et uvis exuberat. Humillimis tabulatis aptior visula brevem ma. teriam, durum et latım folium exigit, cujus amplitudine fructus suos optime adversus grandinem tuetur : qui tamen nisi primo quoque tempore maturi legantur, ad ter. ram decidunt : lıumoribus etiam prius, quam deflıant, putrescunt. Sunt et lielvolae, quas nonnulli varias appellant, neqie purpurex neque nigrse, ab helvo (nisi fallor) colore vocitatie. Melior est nigrior abundantia vini, sed lıac sapore pretiosior. Color acinorum in ueutra conspicitur aquualis : utraque candidi musti alterna vice annoruu phus vrent mleux les arbres, mais elles ne laissent pas que de bien eouvrir le jour : elles sont fertiles même dans un terrain médinere, de mêmo que la grande et la petite pretia; mais ees dernières sont plus reeommandables par la qualité de leur vin : elles ont beaucoup de bois et de feuilles, et mûrissent promptement. L'albuelis valit micux, eomme dit Celsus, sur les eollines que dans les plaines, sur les arbres que sur le joug, au haut des arbres qu'au bas; et elle est abondante tant en bois qu'en fruits. Quant aux petites vignes qui viennent de la Grèee, telles que eelles de Maréotide, eelles de Tharse, eelles de Psitlia et les Sophortia, elles sont à la vérité d'un goùt agréable, mais elles rendent peu de vin dans nos pays, vu la petite quantité de grappes qu'elles portent et la petitesse de leurs grains. Cependant l'inerticula noire, que quelques Grees appellent amethyston, peut être rangée presque dans la seconde elasse, paree qu'elle produit de bon vin, et qu'il n'ineommode point; e'est même ee qui a fait donner ees noms à eette vigne, paree que ee vin n'a pas la foree d'attaquer les nerfs, quoiqu'il ne laisse pas de piquer le goût. Celsus fát une troisième elasse des vignes qui ne sont réeommandables que par leur fertilité, telles que les trois Helvenaciæ, dont les deux plus grandes sont regardées comme pareilles entre elles, paree que leur vin n'est ni de moindre qualité ni moins abondant dans l'une que dans l'autie. L'une des deux, queles habitants des Gaules appe!lent emarcum, ne rend qu'un vin médioere; et l'autre, qu'ils appellent longue ou avare, donne du gros vin, et non pas aussi abondamment que semble le pro. mettre le nombre de ses grappes, lorsqu'elles commeneent à paraitre. La plus petite, qui est en même temps la meilleuro de ees trois vignes, se distingue très-bien à sa feuille, qui est plus ronde

aut minus afferunt. Melius arborem, sed et jugum commode vestiunt: mediocri quoque solo fuecundse, sicut pretia minor et major. Sed ex generositate vini magis commendantur, et frequentibus materiis froudent, et eito maturescunt. Albuelis utilior, 11 ait Celsus, in colle quam iu campo; in arbore quan in jugo ; in sumna arbore quan iI ina : ferax et materixe frequentis et uva. Nam yux Gracula vites sunt, ut Marcoticn, Thasix, Psithix, Sophortis, sicut habent probabilem gustum, ita nostris regionibus el raritate uvarum et acinorum exiguitate ninus flunt. Inerticula tamen nigra, quam quidan Graeci anıethyston appellant, potest in secunda quasi tribu esse, quod et boni vini est et innoxia, unde etiam nomen traxit, quod iners luabetur in tentanlis nervis, quamvis gustu uon sil hebes. Tertium gradum facil earum Celsus, qux foccunditate sola commendantur : ut tres Ilelvenacixe, quarum duae majores nequaquanı minori bonitate et abundantia musti pares lıahentur : earum altera, quan Galliarum incolxe enırcum vocant, metiocris vini : et altera, quam longam apprellant, eandemque avatan, sordisli viui, nec tam largi 
que celle des deux autres: elle a son méritc, tant parce qu'elle supporte très-bien la sćcheresse ainsi que le froid, pourvu qu'il ne soit pas accompagnéde pluie, que parce que son vin se conserve en quelques pays même jusqu'à la vétusté, et principalement parce qu'clle est la seulcqui fasse honicur au terroir même lc plus maigre par sa fertilitć. Mais la spionia est plutôt magnifique par l'abondarrec du vin qu'elle rend et par la grosseur de ses grappes, qu'elle n'est fertile par lcur quantité; il cn est de même de l'oleayinia, die la Murgentinc qui est la même que la Pompécnne, de la Numidienno, de la venucula qui est la même que la scripula et la sticula, de la noire de Fregelle, de la merica, de celle de Rhétic, et de la grande arcelaca, qui est la plus abolldante de toutes celles que nous ayons connues, et que beaucoup de personnes ont confondue à tort avec celle d'Argos. Car je ne dirais pas aisément avec assurance dans quelle classe on doit mettre les suivantes, qui ne sont venues à ma connaissanec que depuis peu de tcmps; je veux dire la pergulana, l'irtiola et la fercola; parce que, quoique je les connaisse pour être assez fécondes, je n'ai pas cependant encorc été à même de juger de la qualitć de leur vin. Nous avons encore fait la découverte d'une vigne hâtive, que nous n'avions pas connue auparavant: cette vigne, appeléc par les Grees dracontion, peut être comparée par sa fécondité et par la douceur de son goût à l'arcelaca, à la basilica et à la Biturica, et par la qualité de son vin à l'Aminée. Il y a cncore bien d'autres espèces de vignes, dont nous ne pouvons ni fixer le nomlıre, ni dire les noms avee quelque certitude : car, commc dit lc poëte: Il u'est pas important den détailler le nombre; et vouloir les connaí-

quam ex numero uvarunı prima specie promittit. Minima et optima e tribus facillime folio dignoscitur, nam rolundissimum omnium id gerit: alque est laudabilis, guod siccitales maxime perfert, qnod frigora sustinet, dum tamen sine imloribus sit; quod nonuullis locis etiam viuum ejus in vetustatem diffunditur; quod prercipue sola macerrinum quoque solum fertilitale sua commendat. Ut spionia dapsilis musto et amplitudine magis u varum, quan numero fertilis, ut oleaginia, ut Murgentina, eademque Pompeiana, ut Numisiana, ut venucula eademque scirpula atque sticula, ut nigra Fregellana, ut merica, ut Rhatica, ut omnium quas cognovimus copiosissima arce. laca major, a multis argitis falso existimata. Nam lias nu. per mili cognitas, pergulanam dico et irtiolam fereolamque, non ftcile asseverem, quo gradu habendx' sint : quosl ctsi satis fuecundas scio, nondum tamen de bonitate vini, guod afferunt, judicare polui. Unam etiam pracoquem vitem nobis ante hoc tempus incoguitam (in) Graca consuetudine dracontion rocitari comperimus, quæ foccunditate jucunditateve arcelacx basiliceque et Biluricie comparari possit, generositate vini Amineæ. Multa præterea sunt genera vitium, quarum nec numerum nec appeltationes tre toutes, e'est vouloir savoir combien le Zéphyre agite de grains de sable dans la mer de Libye. En cffet, chaque contréc et presque chaque partic des différentes contrées ont des espèces de vignes qui leur sont particulic̀res, et auxquelles elles donnent chacune un nom à sa guise : il sc trouve même tclles vignes qui ont changé de nom cn changeant de terroir; d'autres qui, en changeant de terroir, ont aussi changé de qualité, comme nous l'avons dit ci-dessus, de façon à ne pouvoir plus êtrc reconnues. Aussi, dans notre Italie même, sans parler de toutc l'ćtendue du globe, des peuples, quoique voisins les uns des autres, ne s'accordent-ils pas sur les noms qu'ils donnent aux vignes; et souvent il arrive qu'ils leur endonnent chacun de différents. C'est pourquoi un maitre prudent ne doit pas retarder ses disciples par la recherche dc cette nomenclature, à laquelle il ne pourra jamais les faire parvenir; mais il leur doit donner en général ce préceptc qu'ont donné Celsus et Caton avant lui : savoir, qu'il ne faut pas planter d'autres espèces de vignes que celles qui ont une réputation établic, ni en garder longtemps d'autres que celles dont l'expérience aura confirmé la bonté : et, comme dit Julius Græcinus, lorsque nous trouverons dans un pays beaucoup de facilités qui nous engageront à $\mathrm{y}$ planter des vignes de renom, il faudra choisir les meilleures; au lieu que s'il n'y a ricn ou peu de chose qui nous y excite, nous donnerons plutôt dans les vignes les plus feltiles, parce que le mérite de celles-ci ne sera jamais inférieur à celui des premières dans la même proportion que leur abondance sera supćrieure à la lcur. Mais je dirai par la suite en son lieu ce que je pense au fond de cet avis, quoique je l'aic déja approuvé mol-même plus haut;

cum certa fide referre possumus. Neque enim, ut ait poeta, numero comprendere refert; Quem qui scire velit, Libyci velit aquoris idem Discere quam multe zephyro versentur harenc. Quippe universæ reginnes regionumque pene singulæ parles liabent propria vitiuu genera, qua consuetudine sua nominant; quædam etiam stirpes cum locis vocabula mutaverunt; quxdam propler mutalionem locorum, sicut supra diximus, etiam qualitate sua decesseruut, ita ut dignosci non possint. Ideoque? in lac ipsa Italia, ne dicam in tam diffuso terrarum orbe, vicinæe eliam nationes nominibus earum discrepant, variantque vocabula. Quare prudentis magistri est ejusmodi nomenclationis aucupio, quo potiri nequeant, studiosns non demorari; sed illud in totum procipere, quod et Celsus ait et ante cum M. Cato, nullum genus vitium conserendum esse nisi fama, nullum diulius conservandum nisi experimento probatum : alque ubi multa invitabunt regionis conmoda, ut nobilem vilem conseramus, generosam requiremus, inquit Julius Græcinus : ubi nilil erit aut non multum, quod proritet, feracitatem potius sequemur, quax non eadem porlione vincitur pretio, qua vincit ahundantia. Sed de lac sententia, quamquam et ipse paulo 
ear mon but est de montrer comment on peut former des vignes qui soient abondantes, et dont le vin soit préeieux en même temps.

III. Maintenant, a vant de disserter sur la plantation des vignes, je erois qu'il ne sera pas hors de propos d'examiner et de nous assurer si la eulture des vignes est dans le cas d'enrichir un chef de famille. En effet, cet examen doit servir eomme de fondement à notre dissertation, puisqu'il serait presque inutile de donner des préeeptes sur la faecon de planter les vignes, tant que l'on ne serait point d'aceord avec nous sur la question préalable, s'il en faut aroil ; d'autant que le doute sur cette question est si général, qu'il y a même plusieurs partieuliers qui évitent et qui redoutent une terre disposée en vignobles, estimant qu'il faut plutôt désirer d'avoir en sa possession des prés, des pâturages ou des bois taillis. Car pour les vignes mariées à des plans d'arbres, il y a de grands déhats à leur sujet même parmi les auteurs, Saserna désapprouvant cette espèee de eulture, et Trémellius l'approuvant au contraire très-fort. Mais nous pèserons aussi ees différentes opinions en leur lieu. En attendant, il faut commeneer par montrer à ceux qui veulent s'adonner à l'agrieulture, que le revenu des vignes est très-considérable. Je pourrais citer à cette oceasion cette ancienne fertilité des terres, qui, comme l'avait auparavant dit $\mathbf{M}$. Catoll, et eomme l'a répété ensuite Térentius Varron, rapportaient par jugerum planté en vignobles six eents urnœ de vin; car Varron assure positivement ce fait dans le premier livre de son Économie rurale, où il dit mêmeque ce revenu. était commun, non pas dans une contrée seulement, mais encore dans le eanton de Faventia et dans les terres gauloises, qui sont aujourd:hui in-

ante idem censuerim, quid tamen arcanius judicem, suo locu mox dicam. Propositun est enim docere, qua ratione vinex pariter feraces et pretiosæe fluxuræe possint constitui.

III. Nunc prius quam de satione vitium disseram, non alienum puto, velut quoddam fundamentum jacere disputationi futuræ, ut ante perpensum et exploratum ha. beamus, an locupletet patremfamilias vinearum cultus. list enim pene adluc supervacuum de his conserendis praccipere, dum quod prins est, nondum concedatur, an omnino sint labendx? Idque adeo plurimi dubitent, ut multi refugiant et reformident talen positionem ruris, atque optabiliorem pratorum possessionem pascuorumque vel silva ceduæ judicent. Nam de arbusto etiam inter anctores noll exigua pugna fuit, abnnente Saserna genus id ruris, Tremellio maxime probante. Sed et lanc senten. tiam suo loco astimabimus. Interim studiosi agricolatio. nis loc pripum docendi sunt, uberrimun esse reditum vinearmu. Alque ut omittam veterem illam felicitatem arrorum, quilsus et ante jam M. Cato, et mox Terentius Varro prodidit, singula jugera vinearum sexcenas urnas vini prabmisse; id chim maxime asseverat in primo libro herum rusticarun Vario; nec una regione provenire soli. eorporées au Pleenum : ainsi on ne peut pas douter de la vérité de ce fait pour ces temps-là. Mais, sans parler de cetteaneienne fertilité, la eontrée de Nomentum n'est-elle pas eneore aujourd'hui célèbre par la plus haute réputation en ce genre, surtout dans la partie qui en appartient à Sénèque, puisqu'il est de fait que les terrains en vignobles qu'y possède eet homme d'un génie et d'une érudition rare, lui rapportent ordinairement huit cullei de vin par jugerum? Car on a regardé eomme un prodige ee qui est arrivé à nos terres dans la Ceretania, savoir, qu'un cep ait porté ehez vous plus de deux mille grappes, que quatre-vingts eeps aient rapporté ehez moi, la seeonde année depuis leur greffe, sept cullci de vin, et que de nouvelles vignes en aient rapporté pour la première fois cent amphorce par jugerum. Quand on compare à ce produit eelui des prés, des pâturages et des bois, qui passent pour ètre d'un grand profit à leur maître lorsqu'ils lui rapportent eent sestertii par jugerum (ear je ne parle pas du blé, puisqu'à peine pouvons-nous nous rappeler un temps où il ait produit quatorze pour un dans la plus grande partie de l'Italie), on se demanderait volontiers pourquoi les vignes sont si déeriées. Ce n'est pas non plus, dit Græeinus, par rapport à quelque viee qui leur soit inhérent, mais bien par celui des eultivateurs. Ce vice consiste premièrement en ce que personne n'apporte d'attention dans le choix du plant, d'où il arrive que presque tout le monde forme des vignobles où il ne se trouve que des ceps de la pire espèee ; en second lieu, en ce qu'on ne donne pas au plant une édueation convenable pour lus faire prendre des forces, et lui faire jeter des tiges avant qu'il soit desséehé; et enfin en ee que, si par hasard le plant parvient à sa grandeur, on

tum, verum et in Faventino agro et in Gallico, qui nunc Piceno contribuitur : lis certe temporibus Nomentana regio celeberrima fama est illustris, et pracipue quam, possidet Seneca, vir excellentis ingenii atque doctriua, cujus in proodiis vinearum jugera singula culleos octonns reddidisse plerumque, compertum est. Nam illa viflentur prodigialiter in nostris Ceretanis accidisse, ut aliqua vitis apud te excederet uvarum numerum duorum millinm, et apud me octogenxe stirpes insita intra biennium septenos culleos peræequarent, ut prima vinex centeuas amploras. jugeratim praberent, cum prata et pascua et silva, si centenos sestertios in singula jugera efliciant, optime domino consulere videantur. Nam frumenta majore quideu parte Italiæ quando cum quarto responderint, vix meninisse possumus. Cur ergo res infanis est? non quiden suo, sed hominum inquit vitio Graciuns. Primum, quod in explorandis seminibus nemo adlibet diligentiam, et ideo pessini generis plerique vineta conserunt : deinde? sata non ita nutriunt, nt ante convalescant ac prosiliant. quam retorrescant : sed et si forte adoleverint, negligenter, colnnt. Jam illud a principio nilil referre censent, que locum conserant; inmo etian selignut deterimam parte:ı 
le cultive nighigemment. D'alsord on ne eroit pas yu'il soit important, dès le principe, de ehoisir le lieu où l'ou veut planter des vignes : on choisit au contraire pour cet objet la plus mauvaise partic de ses terres, comme si les terrains qui ne peuvent servir à autre chose étaient ceux dont la vigne dût le mieux s'aceommoder : on ne remarque pas même quelle est la vraie facon de la planter, ou quand on l'a remarquée, on ne s'y conforme point : ensuitc il cst rare qu'on assigrue une dot à ses vignes, e'est-à-dire qu'on tienıce prêt tout ce qui est nécessaire pour les cultiver, quoique l'omission de ceseul point oceasionue toujours un nombre de journées employées à faux, et épuise d'autant le coffie-fort du propriétaire. La plupart visent aussi à avoir dans le moment préseut le plus de fruit qu'ils peuvent, sans s'embarrasser de l'a venir, ct, comme s'ils ne vivaient qu'au jour la journée, ils font la loi à leurs vigues, et les chargent de beaueoup de branches à fruit, sans avoir égard à leur postérité. Lorsqu'ils ont commis toutes ces fautes, ou tout au moins lc plus grand nombre, il n'y a rien qu'ils n'aimassent mieux au monde que d'arouer leurs torts; et ils se plaignent que leurs viguobles ne l'épondent pas aux soins qu'ils y dounent, quand c'est eux-mêmes qui les ont perdus par leur avarice, par leur ignorance ou par leur négligenee. Mais s'il est certain au contraire que ceux qui joigrient l'attention aux connaissanees l'etirent de chaque jugerum de vignes, je ne dis pas quaranteou au moins trente amphorce de vin, yuoique je le pense, mais vingt, suivant le calcul de $G$ raceinus qui va néanmoins au rabais, n'est-il pas vrai qu'ils viendront aisément à bout d'aceroit re leur patrimoine, plus que tous ceux qui sont si attachés à leur foiu et à leurs légrumes? Cct au- teur au reste est bien loin de se tromper, juisqu'il voit au contrnirc clairement et en bou calculateur que, de compte fait, eette espèce de eulture est celle qui est la plus avantageuse pour augmenter sa fortune. Car quoique les virgnes exigent de très-grandes dépenses, il ne faut cependant pas avoir pour sept jugera plus d'un vigneron : eneore le vulgaire eroit-il bien taire en l'aequérant à bas prix, ou en le'ehoisissant parmi les escla ves criminels que l'on vend à l'enean ; au lieu que je pense, contre l'avis du plus grand nombre, qu'un vigueron de prix est un article très-essentiel. Quoi qu'il cn soit, quand on l'aurait acheté huit mille sestertii, quand le fouds lui-même de sept jugera en aurait coúté sept mille, et qu'il en coûterait encore deux mille pour les ceps de chaque jugerum avec leur dot, c'està-dire, avec leurs appuis et leurs ligatures, il se trouverait donc qu'on n'aurait dépensé au total que vingt-neuf mille sestertii : ajoutez à cela trois mille quatre cent quatre-vingts nummi pour l'intérêt à six pour cent par an des deux premières années, où ces vignes ne rapportent pas encore de fruits, parce qu'elles sont, pour ainsi dire, dans leur enfance; cela fera au total, le principal et les intćrêts compris, la somme de trente-deux mille quatre cent quatre-vingts nummi. Or si un proprićtaire voulait placer cette somme sur des vignes, de même que ceux qui prêtent à usure placent leur argent sur leurs débiteur's, à condition que le vigneron serait tenu de lui en payer en rente perpétuelle l'intérêt à six pour cent dont nous venons de parler, il ne recevrait par an que mille neuf eent cinquante sestertii. Mais, d'après ce ealeul même, le revenu des sept jugera de vignes l'emportera encore, suivant l'opiuion de Gl’xcinus, sur l'intérêt de ces trente-deux mille agroruın, fanquam sola sit huic stirpi maxime terra idonea, quix uilsil aliud ferre possit. Sed ne ponendi guidenı tationenı aut perspiciunt, aut perspectam exequuntur: lun etian dotem, id est inslrumentum, raro vineis protparant; cun ea res, si omissa sit, plurimas operas nec ıimus arcam patris fanilias semper-exhanriat. Fructum vero plerique quam uberrimum prassenten consectautur, nec provident finturo tempori, sed quasi plane in diem vivant, sic imperaut vitibus, et eas ita multis palmitibus (unerant, ut posteritati non consulant. Hoec omnia vel rerte plurina ex lis cun commiserint, quidvis malunt "fuam"suam culpam confiteri; querunturque non responlere sibi vineta, qua vel per avaritiam vel inscitiam vel per negligentiam perdiderunt. At si, qui cum scientia soriaverint diligentiam, non, ut ego existimo, quadragenas vel certe tricenas, sed ut Graecinus minimum computans licet, inquit, amploras vicenas percipient ex singulis jugeribus : omneis istos, qui futmun suum et olera amplexautur, increntento patrimonii farile superabunt. Nec in hoc errat : quipre ut diligens ratiociuator calculo posito $\checkmark$ idet, id genus agricolationis maxime rei familiari conducere. Nan ut anplissmas impensas vincat poscant, non tamen excedunt septem jugera unius operam vinitoris, quenı vulgus quidem parvi acris, vel de lapide noxium posse comparari putat; sed ego plurimorum opinioni dissentiens pretiosum vinitorent in prinis esse censeo : isque licet sit emptus [sex, vel potius] sestertiis octo nillibus, cum ipsum solum septem jugerum totiden millibus nu• morum partum, vineasyue cum sua dote, ill est cum pedamentis et viminibus, binis millibus in singula jugera positas duco : fit tum in assem consummatum pretium sestertiorun xxıx millium. Huc accelunt semisses usurarum sestertia tria millia, et quadringenti octoginta nuui biemuii temporis, quo velut infantia vinearum cessat a fructu. Fit in assem summa sortis et usurarum $\times x \times ı$ millium quadringentorum Lxxx numorum. Quod quasi nomen, si ut fanerator cum debitore, ita rusticus cum vineis suis fecerit, ejus summæ ut in perpetuun prædictam usuram semissiun dominus constituat, percipere debet in annos singulos mille nongentos quinquaginta sesterties uumos; qua computatione vincit tamen reditus viı jugerum, secundum opiuionem Gixcini, usuram triginta duorum millium quadringentorum ocloginta unmorum. Quyly! ut deterrini generis sint vinex, tanen si culta, singuius 
quatre cent quatre-vingts nummi. Car, si mauvaises que soient ces vignes, pour peu cependant qu'clles soient cultivées, elles rapporteront, sans contredit, un culleus de vin parjugerum; etquand on ne vendrait les quarante urno que trois cent nummi, qui est le moindre prix du marché, les sept cullei ne laisseraient pas de faire une somme de deux mille sestertii et cent nummi, somme qui serait au-dessus de l'intérêt à six pour cent. Mais le calcul que nous faisons n'est que d'après la supposition de Græcinus : car, pour nous, nous croyons qu'il faut arracher les vignes quand elles rapportent moins de trois cullei de vin par jugerum. Encore supposons-nous dans notre calcul qu'il n'y aura point de profit à faire sur les marcottes du champque l'on cultivera au pastinum, quoique cet objet soit seul capable d'acquitter tout le prix qu'aura coûté le terrain, pourvu que ce soit un terrain d'Italie et non de province. C'est un point sur lequel il ne peut rester aucun doute à quiconque examinera avec attention ma méthode et celle d'Atticus : en effet, jc plante vingt mille marcottes par jugerum de vignes, dans les rangées des ceps. Atticus en plante, à la vérité, quatre mille de moins que moi; mais quand sa méthode serait préférable à la mienne, il n'y aurait pas de terrain, si méchant qu'il fût, qui ne rendit plus qu'il n'aurait coûté. Car, mettons qu'il périsse six mille de ces marcottes par la négligence du cultivateur, un acheteur payera néanmoins volontiers trois mille nummi les dix mille qui resteront, et trouvera encore son profit à ce marché; or cette somme n'est-elle pas d'un tiers plus forte que les deux mille sestertii, que nous avons dit ci-dessus être le prix de ces vignes par jugerum? Mais il y a plus, puisque, par mes soins, $j$ 'en suis venu au point que les paysans me payent, sans difficulté, six cents nummi le

utique culleos vini singula earım jugera peræequabunt : utque trecentis numis quadragenæ urnæe reneant, quod mini. mun pretium est annonæ; consummant tamen septenı cullei sestertia duo millia et centum numos : ea porro summa excedit usuram semissium. Atque hic calculus quem posuimus, Gracini rationem continet. Sed nos extirpanda vineta censemus, quorum singula jugera minus quam ternos culleos prabent. Et adhuc tamen sic computarimus, quasi nulla sint viviradices, quæ de pastinato eximantur : cum sola ea res omnem impensam terreni pretio suo liberet; si modo nou provincialis, sed Italicus ager est. Neque id cuiquan dubium esse debet, cum et nostram et Julii Attici rationem dispunxerit. Nos [jam] enim vicena millia malleolomm per vineæ jugerum inter ordines pangimus. Ille mi. nus quatuor millibus deponit : cujus ut rincat ratio, nullus tamen vel iniquissimus locus non majorem quæstum reddet, quam acceperit impensam : siquidem, ut cultoris ne. gligentia sex millia seminum intereant, reliqua tamen decem millia tribus millibus numorum libenter et cum lucro redemptorum erunt. Quæ summa tertia parte superat duo millia sestertiorum, quanti constare jugerum vinearım pre. millier de marcottes. Il est vrai que tout autre aurait de la peine à faire un commerce aussi lucratif : car il est très-difficilc de s'imaginer combien mes champs, tout petits qu'ils sont, rapportent de vin, ainsi que vous l'avez vu, Silvinus, par vos propres ycux; et l'on m'en croirait à peine sur ma parole. Jc n'ai donc supposé à la marcotte qu'un prix médiocre et commun, afin de pouvoir amener plus promptement à mon sentiment, ct sans m'exposer à aucune contradiction, ceux qui, par ignorance, redoutent cettc espèce de culture. Concluons done que, soit le produit des marcottes venues dans le terrain labouré au pastinum, soit l'espérance des vendanges futures, tout nous doit engager à planter des vignes. Après avoir montré qu'il est raisonnable de le faire, nous allons donner les préceptes relatifs à leur éducation.

IV. Celui dont le projet est de former des vignobles doit surtout prendre garde de s'en rapporter aux soins des autres plutôt qu'aux siens propres, relativement aux marcottes, en les achetant : il doit au contraire planter chez lui l'espècc de vignes qu'il aura le plus éprouvée, et fairc une pépinière dont il puisse tirer ce qui lui en sera nécessaire pour garnir sa terre de ceps. Car du plant étranger, qui se trouve transplanté chez nous d'une contrée différente, s'habitue moins bien à notre sol que celui qui en est natif; ct il appréhende, comme tout homme étranger dans un pays, le changement de climat et de terrain. On ne peut mème jamais être assuré de sa bonté, parce qu'il est toujours incertain si celui qui l'a plarté en a examiné avec soin l'espèce, et s'il l'a bien éprouvé auparavant. C'est pourquoi il ne faut pas croire que ce soit trop d'attendre deux ans pour juger si du plant est dans le cas d'êtrc transplanté, parce qu'il sera toujours très-inté-

diximus : quanquam nostra cura in tantum jam processit, ut non inviti sestertiis sexcentis numis singula millia viviradicis a me rustici mercentur. Sed vix istud alius prostiterit. Nam nec quisquam nobis facile crediderit, tantam in agellis esse nostris abundantian vini, quautam tu. Silvine noristi. Mediocre itaque vulgatumque pretiun viviradicis posui, quo celerius nullo dissentiente perduci possent in nostran sententiam, qui propter ignorantian genus hoc agricolationis reformidant. Sive ergo pastinationis reditus seu futurarum spes vindemiarum colortari nos debet ad positionem vinearum. Quas quonianı docuimus rationis esse conserere, numc institutionis earum pror cepta dabimus.

IV. Cui vineta facere cordi est, præcipue caveat, 11 . alienæe potius cura quam suac credere velit, neve mercetur viviradicem. Sed genus surculi probatissimum doini conserat, faciatque vitiarium, ex quo possil agrum vineis vestire. Nam quae peregrina ex diversa regione semina transferuntur, ninus sunt familiaria nostro solo, quaı. vernacula : coque velut alienigena refornidant mutatan. carli lociplue positionem. Sed nec certam generositatis. 
rassant, ainsi que je l'ai dit, d'avoir planté des espèees recherchées. Ensuite on se souviendra de choisir avec attention le terrain que l'on se proposera de planter en vignes. Quand on aura jugé qu'il est tel qu'il doit être, il faudra le travailler au pastinum avee le plus grand soin; lorsque cette opération sern faite, il ne faudra pas moins d'attention pour planter la vigne, et quand elle sera plantée on s'attachera à la eultiver avec le plus grand soin : car ce n'est que d'après tous ces procédés qu'on pourra estimer si un ehef de famille a bien ou mal fait de confier son argent à sa terre, plutôt que de le faire valoir dans l'oisiveté. Je vais done traiter à présent de ehaeun des devoirs que je viens de prescrire.

V. Il ne faut point faire de pépinière de vignes dans une terre maigre, ni dans une terre humide : comme il faut eependant que eette terre ne soit pas totalement dépourvue de sues, on la ehoisira plutôt médiocre que grasse. Quoique presque tous les auteurs aient désigné pour eet objet le terrain le plus gras, je ne erois pas que leur systeme soit avantageux au eultivateur; car quoique les plantes déposces dans un terrein ro. buste $\mathrm{y}$ premnent avec facilité et $\mathbf{y}$ poussent promptement, si cependant, lorsqu'elles seront devenues des marcottes formées, on vient à les transplanter dans un terrain plus manvais, elles se desscécheront, et ne pourront plus y eroître. Or un eultivateur prudent doit plutôt transplan. ter de la mauvaise terre dans une meilleure, que de la bonne dans une plus mauvaise. C'est pourquoi la médiocrité est la qualité que j'approuve le plus dans le ehoix du terrain, parce que e'est

fidem pollicentur, cum sit incertum, an is, qui conseruerit ea, diligenter exploratum probatumque genus surculi deposuerit. Quamobrem biennii spatium longun esse minime existimandum est, intra quod utique tempestivitas seminum respondet; cum semper, ut dixi, plurimum retulerit exquisiti generis stirpen deposuisse. Post lıec deinde meminerit, accurate locum vineis eligere : de quo cum judicaverit, maximam diligentiam sciat adhihendam pastinationi : quạm cum peregerit, non minore cura vitem conserat : et cum posuerit, summa sedulitate cultura serviat : id enim quasi caput et columen est impensarum; quoniam in eo consistit, melius an sequius terræ mandaverit paterfamilias pecuniam, quam in ofio tractare. Igitur unum quodque eorum qua proposui, suo jam persequar ordine.

V. Vitiarium neque jejuna terra, neque uliginosa faciendum est : succosa tamen ac mediocri potius, guam pingui; tametsi fere omnes auctores huic rei latissimum locum destinarerunt. Quod ego minime reor esse pro agricola. Nam depositae stirpes valido solo, quamris celeriter comprehendant atque prosiliant, tamen cum sunt viviradices factoe, si in pejus transferantur, retorrescunt, nec adolescere queunt. Prudentis autem coloni est, ex dete (iori terra polius in meliorem, quan ex nicliore in dete. celle qui participe le plus du bon et du mauvals à la fois : car, soit que par la suite on soit obligé, lorsque le plant sera venu, de le transférer dans un terrain maigre, il s'apereevra à peine de la différence de sa position, en ne quittant qu'une terre qui était médiocre pour une qui sera maigre; soit que le terrain où on le plantera soit plus gras, il y viendra bien plus tôt et y sera plus fertile. D'un autre côté, il n'est pas raisonnable de former une pépinière dans un terrain trèsmaigre, parce que la plus grande partie des marcottes y dépérit, et que celles que l'on peut sauver n'arrivent que très-tard au point néeessaire pour être transplantées. Ainsi un terrain médioere et légèrement sec est le plus propre à former une pépinière. Il faudra eommeneer par le retourner à la houe, après quoi on laissera, entre les rangées sur lesquelles sera aligné le plant, des espaces de trois pieds que l'on cultivera ; et l'on mettra quatre-vingts mailletons (crocettes) dans ehaeune des rangées, qui auront deux eent quarante pieds de longueur. Ce nombre demandera pour un jugerum entier trois mille deux eents mailletons. Mais, avant d'en venir là, il faut examiner et choisir les mailletons; ear, eomme je l'ai souvent dit, le point que l'on doit regarder eomme la base de cette opération, c'est de ne planter que les espèees dont on sera le plus sûr.

VI. II y a deux choses à observer dans le choix du plant; ear il ne suffit pas d'examiner en général si la mère dont on le tire est féconde, mais il faut eneore examiner plus particulièrement s'il a été tiré des parties du trone qui ont la vertu produetriee et qui sont les plus fertiles. Or on ne doit pas juger de la fécondité d'une vigne

riorem transferre. Propter quod mediocritas in electione loci maxime probatur, quoniam in confinio boni malique posita est. Sive enim postmodum necessitas postulaverit tempestira semina jejuno solo committere, non magnan sentient differentiam, cum ex mediocri terra in exilem translata sunt : sive latior ager conserendus est, longe celerius in ubertate coalescunt. Rursus tenuissimo solo vitiarinm facere minime rationis est, quoniani malleolorum pars major deperit, et quæ superest, tarde fit idonea translationi. Ergo meliocris et modice siccus ager vitiario est aptissimus, isque bipalio prius subigi debet, quæ est altitudo pastinationis, cum in duos pedes et semissem convertitur humus, ac deinde tripedaneis relictis spatiis, quæe per semina excolantur, in singulis ordinibus, qui ducenos quadragenos pedes obtinent, octogeni malleoli pangendi sunt. Is numerus cousummat per totum jugerum seminum millia tria et ducenta. Verum hane curam prevenit inquisitio et electio malleolorım. Nam ut sæpe jam retuli, quasi fundamentum est prodictae rei, probatissimuin genus stirpis deponere.

VI. Sed electio dupliciter facienda est : non enim solum focundam esse matrem satis est, ex qua semina petuntur, sed adhibenda ratio est subtilior, ut ex his partilus trunci sumantur, qua el genitales sunt ef maxime fertiles. Vitis 
dont on eherehc à a voir de la race, d'après le seul motif qu'elle porte beaucoup de grappes, d'autant que eette multiplieité de grappes peut provenir de la grandeur du cep et de la multitude de ses branches à fruit, et que quoiqu'une vigne soit chargée de beaucoupde grappes, on ne pourra pas dire néanmoins qu'elle soit fertile, si elle n'en a qu'une seule sur ehaque branche : mais s'il y a un grand nombre de grappes sur chaque pampre de eette vigne, si elle jette beaucoup de branehes à fruits de chacun de ses boutons, si enfin les branches qui sortent de son bois dur, ou les rejetons des pampres eux-mêmes, produisent quelques raisins, une telle vigne étant sans difficulté féconde, e'est sur elle que l'on doit choisir des mailletons. Or un mailleton est une (crocette) jeune branche à fruit, née sur un fouet de l'année précédente : ce nom lui vient desa ressemblanee avee un petit maillet, puisqu'il déborde de droite et de gauehe dans la partie par laquelle on l'a séparé de l'ancien sarment. Nous pensons qu'il faut choisir les mailletons sur les ceps les plus féconds, dans tous les temps indifféremment où l'on taille la vigne, et les mettre en terre avee attention dans un lieu médiocrement humide, mais non marécageux, en leur laissant trois ou quatre boutons hol's de terre, pourvu cependant que l'on regarde eomme un point très-essentiel d'examiner si la vigne dont on les a tirés n'est point sujette à perdre sa fleur, si son raisin n'a point de difficulté à grossir, et s'il ne mûrit pas trop tôt ni trop tard, paree que, dans le premier eas, il est molesté par les oiseaux, comme il l'est dans le sceond par les mauvais temps de l'hiver. Mais une seule vendange ne suffit pas pour nous mettre à même

ạtem foccunda, cujus progeniem studemus submittere, non tantum debet eo xestimari, quod uvas complures exi. git. Potest enim trunci vastitate id accidere et frequentia palmitum : nec tamen eain feracem dixerim, cujus singulac uva in singulis sarmentis conspiciuntur; sed si per unumquenque pampinum major nunerus uvarum dependet; si ex singulis gemmis compluribus materiis cum fructu gerninat; si denique etiam e duro virgam cum aliquibus racemis citat; si etiam nepotum fructu gravida est : ea sine dubitatione ferax destinari dehet legendo mallcolo. Malleolus autem novellus est palmes inuatus prioris anıi flagello, cognomiuatısque ad similitıdinem, quod in ea parte, quą decirlitur ex vetere sarmento, prominens utrinque mallei specienn proclıt: Hut ex foecundissima stirpe legendum censemus omni tempore, quo viuce putautur, ac super terram gemn is tribus vel quatuor extantibus diligenter obrueuduu loco modice lunido, non uliginuso : dum tanen antiquissimun șit consillerare, ne vitis, ex qua is sumitur, ancipitem floris lıa. beat eventum, ue difficulter acinus ingrandescat, ne aut pracoquem aut serae maturitatis fructum afferat. Nam illa voluclibus, hace etiam tempestatilus liemis infestatur. fale porro genus non una comprobatur vindemia. l’otest de reeonnaitre si une vigne jouit de ees avantages, puisqu'il peut arriver, soit par la fertilité de l'année, soit par d'autres raisons, qu'une vigne, quoique naturellement stérile, produise une fois par hasard avec ahondance. Mais lorsqu'on sera assuré de la bonté d'un eep après plusieurs années de serviee, pour m'exprimer ainsi, on ne doit point douter de sa fécondité. Cependant il n'est pas nćcessaire de pousser ses recherches sur ce point au delà de quatre ans : e'est ordinairement là le temps requis pour mettre en évidence la bonté des plantes, parce que c'est eelui qu'il faut au soleil, en suivant l'ordre des signes depuis le commencement de sa course, pour revenir au point du zodiaque dont il était parti. Ceux qui s'occupent de l'astronomie donnent à cette pèriode, qui comprend mille quatre eent soixante et un jours entiers, le nom d' $\dot{x} \pi 0 x \alpha=\alpha$ -

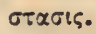

VII. Mais je suis eertain, P. Silvinus, qu'il y a longtemps que vous demandez tout bas de quelle espèce doit être cette vigne féconde que nous déerivons avee tant de soin, et si nous entendons parler de quelqu'une de celles qui passent communément pour être les plus fécondes; ear le plus grand nombre vante la Biturica, beaueoup la spionia, quelques-uns la basilica, et d'autres l'arcelaca. Nous ne refusons pas effectivement nos éloges à ces espèces de vignes, puisqu'elles rendent beaueoup de vin. Mais la règle que nous nous proposons de donner est de planter des vignes d'une telle espèec, qu'en ne rapportant pas de fruits moins abondants que les précédentes, elles soient en outre d'un goût distingué, tel que celui des Aminées, ou tout au moins d'un goût approchant.

enim vel anni proventu vel aliis de causis etiam natura. liter infoecunda vitis semel exuberare. Sed ubi plurium velut emeritis annorum stipendiis fides surculo constitit, nilıil dubitandum est de fuecunditate. Nec tamen ultra qua. driennium talis extenditur inquisitio: id enim tempus fere virentium generositatem declarat, quo sol in eandeu partem signiferi per eosdem numeros redit, per quos cursus sui principium ceperat. Q uem circuitum meatus die. rum integrorım mille quadrigentorum sexaginta unius

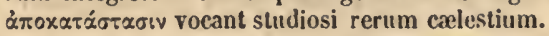

VII. Sed certum labeo, P. Silvine, jaududum te tacitum requirere, cujus generis sit ista foecunda vitis, quam nos tam accurate describimus, anne de iis aliqua significetur, qua vulgo nunc labentur feracissinae. Pluriui namque Bituricam, multi spionian, quidam basilicaı, nonnulli arcelacam laudibus efferunt. Nos quoque lifec genera non fraudamus testimonio nostro : sunt enim largissiut vini : sed proposuimus docere viıeas ejusmodi conserere, qua nec nuinus uheres fructus pradictis geueribus afferant, et sint pretiosi saporis, velut Amiuei, vel certe uon procul ab eo gustu. Cui nostrac senteutius scio pene ounniuu agricolarum diversam esse opiniouem, qua de smineis inveterata longo jan tenupore convaluil, 
Je sais que presque tous les agriculteurs sont en cela d'un avis différent du mien, et qu'ils tiemnent à l'opinion ancienne qui a prévalu sur lc comptc des vignes Aminées, par laquelle on croit depuis longtemps qu'elles sont affectées d'une stérilité naturelle dans ces pays-ci. Ceei nous force done à reprendre les ehoses de plus haut, et à confirmer par unc multitude d'exemples notre méthode, qui se trouve condamnéc par la négligenee autant que par l'imprudence des cultivateurs, afin de la tirer des ténèbres de l'ignoranee qui l'ont obscureie, ct de répandre sur clle le jour pur de la vérité. C'est pourquoi il ne sera pas hors de propos de nous occuper avant tout de ce qui parait pouvoir faire revenir de cette erreur, devenus publiqque.

VIII. Si nous voulons donc, P. Silvinus, pénétrer par les yeux peręants de l'esprit jusqu'à la nature des ehoses, nous trouverons qu'clle n'a établi, relativement à la fécondité, qu'une loi unique et égale pour les plantes, eomme pour les hommes et les autres animaux, et qu'elle n'a point partagé ses faveurs particulières à eertaines nations ni à certaines eontrées, comme si elle eût voulu en priver totalement les antres. Il y a des nations à qui elle a donné à la vérité la faculté d'engendrer une postérité nombreuse, comme, par exemple, les Égyptiens et les Afrieains, ehez qui l'on voit très-fréquemment et presque habituellement les femmes aecoucher de deux enfants à la fois; mais elle a voulu en même temps qu'il se trouvât aussi en Italie des cxemples d'une fécondité singulière : témoin ces deux femmes d'Albe, de la famille des Curiaees, mères ehaeune de trois enfants ì la fois. Elle a donné de l'éelat à la Germanie par ses armćes eomposées d'hommes très-grands; mais elle n'a pas absolument privé les autres

tauquan natali et ingenita sterilitate laborantibus : quo magis nobis ex alto repetita compluribus exemplis firmanda ratio est, quae desidia nec minus imprudentia co. lonorum damnata, et relut ignorantia teneliris olicxcata luce veritatis caruil. Quare non intempestivum est nos ad ca praverti, quæ videntur lunc publicum errorem corrigere posse.

VIII. Igitur si rerum naturam, P. Silvine, velut acrioribus mentis oculis intueri velimus, reperiemus parem legem focunditatis eam dixisse virentibus, atque hominibus caterisque animalibus : nec sic aliis nationibus re. gionilusve proprias tribuisse dotes, ut aliis in totum siinilia ınunera denegaret. Quibusdam gentibus numerosam progenerandi sobolem dedit, ut Egyptiis et Afris, quibus gemini partus familiares, ac pene solemnes sunt : sed et Ilalici generis esse voluit eximix foecunditatis Albanas Curiatix familix trigeminorum matres. Germaniam decoravit altissinorum hominum exercitibus; sed et alias gentes non in totum fraudavit praccipux staturic viris. Nam et M. Tullins Cicero testis est riomanum fuisse civem Navium Pollionem pede longiorem quam quentquam natlons d'hommes de la plus haute taille, puisque M. Tullius Cieéron assure qu'il s'est trouvé un eitoyen romain, nommé Nævius Pollion, qui avait un pied au-dessus des plus grands hommes, et que nous avons ćté nous-mèmes tout réeemment à portée de voir, dans la pompe des jeux du cirque, un Juif de nation, qui était d'une taille plus haute que celle du Germain le plus grand. Je passe aux bestiaux. La ville de Mévania est célèbre par la taille et la force de ses bêtes de somme, commu la Ligurie l'est par la petitesse des siennes : cependant on voit à Mévania de petits bœufs, comme on voit quelquefois dans la Ligurie des taureaux d'une force remarquable. L'Inde passo pour surprenante par la grosseur de ses bêtes féroees : qui est-ce qui contestera cependant qu'il y en ait iei d'aussi grosses, puisque nous voyons des éléphants nés dans l'enceinte mème de notre ville? Je reviens aux productions de la terre. On prétend que la Mysie et la Libye sont fertiles en blé, sans cependant que les eampagnes de l'Apulie et de la Campanie manquent de riches récoltes; que le Tmole et lc Coryee sont fameux par leurs fleurs de safran, comme la Judée et l'Arabie le sont par l'exeellence de leurs plantes odiférantes, quoique notre ville elle-même ne manque pas de ces sortes de plantes, puisque nous voyons déjà venir en feuilles, dans plusieurs de ses quartiers, la cannelle et l'arbrisseau qui produit l'eneens, aiusi que nous y voyons des jardins fleuris de myrrhe et de safran. Ces exemples nous prouvent donc que l'Italie répond très-bien aux soins de ses habitants, puisqu'elle s'est habituée, moyennant l'applieation des cultivateurs, à porter les produetions de presque tout l'univers; de façon qu'il doit nous rester eneore moins de doute à cet égard par rapport à un fruit «qui

longissimum : et nuper ipsi videre potuimus in apparatu pompx Circensium ludorum Judax gentis hominem proceriorem celsissimo Germano. Transeo ad pecudes. Armentis sublimibus insignis Mevania est, Liguria parvis : sed et Mevaniæ bos humilis et Liguriæ nonnunquam tau. rus eminentis statura conspicitur. India perhibetur moli. bus ferarum mirabilis : pares tamen in hac terra vastitate beluas progenerari quis neget? cum intra monia nostra natos animad vertamus elepliantos. Sed ad genera frugum redeo. Mysiam Libyamque largis aiunt abundare frumentis; nec tamen Apulos Campanosque agros opimis defici segetibus. Tmolon et Corycon florere croco; Judxam et A rabiam pretiosis odoribus illustrem haberi; sed nec no. stram civitatem praedictis egere stirpibus : quippe compluribus locis urbis jam casiam frondentem conspici. mus, jam tuream plantam, florentesque lıorlos myrrho et croco. His tamen exemplis nimirum admonemur, curæ mortalium obsequentissimam esse Italiam, qua pene totius orbis fruges adlibito studio colonorum ferre didicerit. Quo minus dubitemus de eo fructu, qui velut indigena peculiarisque et vernaculus est lujus soli. Neque enim 
est comme natif de ce pays, et que l'on peut regarder eomme étant propre à notre sol, et comme y ayant pris naissance. Car il est conslant que les vignes des eantons de Céeube, de Massique, de Surrentum et d'Albe sont, par l'execllenee de leur vill, les premières de toutes celles qui sont sur la terre.

IX. Peut-ètre nos vignes n'ont-elles pas toute la fécondité qu'on pourrait désirer; mais l'industrie d'un eultivateur peut les aider à l'acquérir. Car si la nature, ectte mère si bienfaisante de toutes les productions en tout genre, a cnrichi, comme je viens de le dire, chaque nation et ehaque contrés des dons particuliers qu'elle leur a faits, sans cependant en avoir privé absolument les autres, pourquoi douterions-nous qu'elle eût suivi aussi la même règle par rapport aux vignes? Pourquoi (en voulant que certaines espèces d'entre elles, comme la Biturica ou la basilica, fussent plus particulièrement fécondes que d'autres) aurait-elle rendu les Aminées stériles, au point que sur plusieurs milliers de ceps il ne s'en pût pas trouver, même en très-petit nombre, qui fussent fécondes, comme il s'est trouvé parmi les habitants de l'Italie des femmes fécondes, telles que ees sœurs d'Albe dont nous avons parlé? Non-seulement lc contraire est vraiscmblable, mais même l'expérience nous en a démontré la vérité, puisque nous avons eu en notre possession des vignes Aminées qui avaient ce earactère de fécondité, tant dans le canton d'Ardée, qui nous a appartenu jadis pendant un long espace de temps, que dans celui de Carseole et dans eelui d'Albe. Nous n'en comptions à la vérité qu'un très-petit nombre dans ce cas; mais aussi leur fertilité était telle, que ehaquc cep rapportait trois urno de vin quand il était attaché au joug, et dix amphorce quand il était en treilles. Au sur-

dubium est Massici Surrentinique et Albani atque $\mathbf{C x}$. cubi agri vites omniuns, quas terra sustinet, in nobilitate viui principes esse.

1X. Focunditas ab his forsitan desideretur : sed et laxc adjuvari potest cultoris industria. Nam si, ut panllo ante retuli, benignissina rerum omnium parens natura yuasigue genteis atque terras ita muneribus propriis di. fdvit, ut tamen cateras non in universum similibus do. ilbus fraularef : cur eam dubitemus etiam in vitibus pradictam legem servasse? ut quamvis earun genns aliquod praecipue foecundum esse voluerit, tanquam bituricum aut basilicum; non tanen sic Amineum sterile reddiderit, $n t$ ex mulfis millibus ejus ue paucissimæ quidem vites frecundx tanquam in Italicis liominibus Albanæ illæ sorores reperiri possint. Id auten cum sit verisimile, tum etian verum esse nos docuit experimentum, cum et in Ardeatino agro, quem multis tenıporibus ipsi ante possediuus, et in Carseolano ilemque in Albano generis Amiuei vite's lıujusmodi nota labuerinus, numero quidem perpasucis, verum ita fertiles, ut in jugo singula ternas plus, eette féeondité que nous attribuons aux vignes Aminées ne doit pas paraître incroyable : ear comment Terentius Varron, et avant lui M. Caton, auraient-ils pu assurer que les anciens cultivateurs retiraient de chaque jugerum de vignes six cent urnoe de vin, si les Aminées, qui étaient presque les seules que l'on connût alors, n'eussent pas été fécondes? à moins que nous ne pensions qu'ils aient eultivé des Biturica ou des basilica, quoique nous ne connaissions que depuis très-peu de temps ees dernières, que nous avons même tirées ineontestablement des provinces éloignées, et quoiqu'il soit reconnu comme un fait certain, mème aujourd'hui, que les vignes Aminées sont les plus anciennes de toutes. Si quelqu'un donc, après avoir éprouvé par plusieurs vendanges des vignes Aminées, en trouvait de telles que les miennes, dont je parlais tout à l'heure, ct qu'il les distinguat des autres pour en tirer des mailletons qui seraient très-féconds, il pourrait parvenir par ce moyen à faire des vignobles aussi bons que fertiles : ear il n'est point douteux que la nature elle-même n'ait voulu que les enfants ressemblassent à leur mère; ce qui a fait dire à ce berger dans les Bucoliques: De méme que je savais que les petils chiens et les chevreaux ressemblaient à leurs mères. C'est pour cela que ceux qui s'adonnent aux combats sacrés conservent avee le plus grand soin la race des ehevaux d'attelaggc les plus légers, parce qu'ils se flattent de l'espérance de remporter des victoires, en multipliant la progéniture des plus exeellents animaux. Ainsi, fondons l'espérance d'une vendange abondante sur le choix du plant tiré des vignes Aminées les plus fertiles, de même que l'on fonde l'espérance de la victoire sur le choix des races issues de juments qui ont été victorieuses dans les jeux olympiques; et ne nous désis-

urnas praberent, in pergulis autem singulæ denas aınplıoras peræquarent. Nec incredibilis debet in Annineis lıæc foecunditas videri. Nam quemadnıodum Terentius Varro et ante eum M. Calo possent affirmare, sexceıtenas urnas priscis cultoribus singula vinearum jugera fudisse, si fuecunditas Anineis defuisset, quas plerumque solas antiqui noverant? nisi si putamus ea qua nuper ac modo plane longinquis regionibus arcessita notitia nostra sunt tradita, Iiturici generis aut basilici vineta eos coluisse, cum vetustissimas quasque vineas adluc existimenus Amineas. Si quis ergo tales, quales paulo ante possedisse me retuli, Amineas pluribus vindemiis exploratas notet, ut ex his malleolos feracissimos eligat, possit is pariter generosas vineas et uberes efficere. Nihll enim du. bium est, quin ipsa natura sobolem matri similem esse voluerit. Undeetiam pastor ille in Bucolicis ait : Sic canibus calulos similes, sic matribus hedos noram. Unile sacrorum certaninum studiosi pernicissimarum quadrigaruu semina diligenti observatione custodiunt, et spen futurarum victoriarum concipiunt propagala sobole geue 
tons pas de ec projet sous le prélexte que son exécution demandera un temps considérable, puisqu'elle ne souffrira pas d'autre retard que celui qu'entraînera nécessairementl'épreuve d'un cep, et que, dès qu'on se sera assurć de sa fécondité, on l'aura bientôt multiplié par la voie de la greffe. C'est un fait certain, et dont vous pouvez rendre témoignage, vous surtout, P. Silvinus, qui devez vous rappeler très-bien quc j'ai peuple deux jugera entiers de vignes en deux ans, avec les greffes que m'avait fournies unc seule vigne hátive que vous possédiez dans la Ceretania. Combien en cffet vous imaginezvous que l'on aurait pu enter de vignes dans le même espace de temps, avec les mailletons qu'auraieut $\mathrm{pu}$ fournir ces deux jugera, puisqu'ils n'étaient eux-mêmes que le résultat d'un seul cep? Si done, ainsi que je l'ai dit, nous voulons y apporter du soin, et ne point ménager notre peine, nous formerons aisément, par la voie que je viens de prescrire, des vignes Aminées aussi fertiles que lc peuvent être les Biturica ou les basilica : il suffira pour ecla d'avoir l'attention, en transférant le plant, de ne le point mettre sous un climat diffeirent de celui où il était auparavant, ni dans un terrain d'une autre nature, et de le maintenir dans l'habitude à laquelle il était fait, parce qu'ordinaircment un cep dégénère, lorsque la situation du terrain ou la température de l'air lui sont contraires, de même que si on le tire d'auprès d'un arbre pour l'attacher au joug. C'est pourquoi nous le transférerons d'un lieu froid dans un lieu froid, d'un lieu chaud dans un qui le soit pareillement, et d'un plant de vigne dans un autre de la mème naturc. Cependant les ceps de raisin Aminée

rosi armenti. Nos quoque pari ratione velut olympionica. rum equarum, ita feracissimarum Aminearum seminibıs electis, larga vindemix spem capiamus. Neque est quorl temporis tarditas quemquam deterreat: nam quidlpuid mora est, in exploratione surculi absumitur. Cæeterum cun foccunditas vitis comprobata est, celerrime insitıonibus ad maximum numerum perducitur. Ejus rei testimonium tu procipue, Publisilvine, perhibere nobis potes, cum pulchre memineris, a me duo jugera vinearum intra tempus biennii ex una praccoque vite, quam in Ceretano tıo possides, insitione facta consummata. Quemnam igitur existimas vitium numerum intra tantundem temporis interseri posse duorum jugerum malleolis, cum sint ipsa duo jugera unius vitis progenies? Quare si, ut dixi, laborem et curam velimus adlibere, facile prodicta ratione tam feraces $\Lambda$ minei generis vineas constituemus, quam Biturici aut basilici : tantum retulerit, ut in transferendis scminibus similem statum cxli locique etipsius vitis lıabitum observemus : quoniam plerumquedegenerat surculus, si aut situs agri aut aeris qualitas repugnat, aut etiam si ex arbore in jugum defertur. Itaque de fi igidis in frigida, de calidis in similia, de vineis in vineas transfereụu6: Magis tamen ex frizido statu stirps Aminea potest sont plus en état de supporter un climat chaud au sortir d'un froid, que d'en soutenir un froid au sortir d'un chaud, parce que toutes les espèces de vignes, et surtout celle-là, aiment naturellement micux la chaleur que le froid. Mais la qualité du sol cst aussi très-intéressante, et il faut toujours transférer le plant d'un sol maigre ou médiocre dans un meilleur. Car une plante accoutumée à un terrain gras ne peut absolument se faire à la maigreur d'un autre, à moins qu'on ne le fume fréquemment. Voilà les préceptes génćraux que nous avions à donner, relativement à l'attention avec laquelle on doit choisir les mailletons. Maintenant voici un précepte particulier pour les choisir non-seulement sur une vigne très-féconde, mais encore sur la partic la plus féconde de cette vigne.

X. Le plant le plus fertile n'est pas, comme les anciens auteurs l'ont dit, l'extrémité de ce qu'on appelle la tête de la vigne, e'est-à-dire, ses derniers fouets, et les plus allongés : car c'est eneore un point sur lequel les agriculteurs se trompent. La premièrc cause de lcur erreur est la beauté et la multitude des grappes que l'on voit ordinaircment sur les sarments les plus allongés d'une vigne, quoiqu'on ne doive pas s'y laisser tromper, puisque ccla nc provient point d'unc fertilité qui soit naturellement inhérente à cette branche, mais de l'avantage de sa position, parce que tout le suc et toute la nourriture ne font que glisser légèrement sur les autres partics du tronc, jusqu'à ce qu'ils soient parvenus à son extrémité. En cffet, tous les aliments des plantes sont attirés comme une espèce d'âme végétante vers leurs parties supérieures, par l'effet d'une aspiration naturelle qui se fait à travers la

calidum sustinere, quam ex calido frigidum : quonian cum omue vitis genus tum maxime pradictum naturaliter lactatur tepore potius quam frigore. Sed et qualitas soli plurimum juvat, ut ex macro aut mediocri transdu. catur in melius. Nam quod assuetum est pingui, nullo modo maciem terre patitur, nisi sæpius stercores. Atque hac de cura eligendi malleoli generatim procepimus; nunc illnd proprie specialiter, it non solum ex fuecundissima vite, sed etiam e vitis parte feracissima semina eligantur.

X. Feracissima autem semina sunt, non ut veteres au. ctores tradiderunt, extrema pars ejus, quod caput vitis appellant, id est, ultimum et productissimum Dagellım : nam in eo quoqne falluntur agricola. Sed erroris est cansa prima species, et numerus uvarum, qui plerumque cous. picitur in productissimo sarmento. Quie res nos decipere non debet. Id enim accidit non palmitis ingenita fertilitate, sed loci opjortunitate, quia reliquas trunci partes lumonor omnis et alimentum, quod a solo ministratur, transcurrit, dım ad ultimum perveniat. Naturali enim spiritu oınıe alimentum virentis quasi quxdam aninıa per medullam trunci reluti per siphonem, quem diabeten vocant nechanici, tralutur in summum : quo cum frervenerit, ibj 
moelle du trone, comme a travers un de ces siphons rue les machinistes appellent diabetes; et lorsqu'ils y sont parvenus, ils s'y arrètent et s'y consument. C'est pour cela que les sarments les plus forts d'un cep sont ceux qui sortent ou de sa tête, ou de la partie de son pied la plus voisine de ses raeines. Les sarments qui sortent du bois dur sont également stériles, quoiqu'ils soient très-robustes; ct cela par deux raisons : parce qu'ils n'ont point de fruit, et parce qu'ils sont nourris du suc le plus voisin de la terre, et par conséquent le plus entier et le plus pur. On approuve au contrairc ceux de l'extrémitć supérieure, comme étant fertiles ct robustes, par la raison qu'ils sortent d'une partie tendre de la vigne, et qu'ainsi que je le disais à l'instant, toute la nourriture qui est parvenue jusqu'à eux ne se distribue plus ailleurs; au lieu qu'on regardc comme les plus maigres ceux qui se trouvent entre les uns et les autres, parce que le suc ne fait que les effleurer, étant intereepté en partie par les sarments de dessous, et attiré en partie par ceux de dessus. II ne faut done pas regarder comme intrinsèquement féconds les fouets des extrémités soit supérieures, soit inférieures, quand même ils rapporteraient beaueoup de fruits, puisqu'ils ne lc feraient que parce qu'ils y seraient forcés par leur position; et les sarments qui doivent passer pour tels sont bien plutôt ceux qui, étant au milieu de la vigne, ne sont point néanmoins stériles, quoique dans une mauvaise position, et qui font preuve de leur bonté par l'abondance de leurs fruits. Le plant pris de cette partie dégénère rarement après qu'il est transféré, parce 'qu'il trouve infailliblement alors une meilleure position au sortir d'une mauvaise. En effet, ou on le dépose dans une terre labourée au pastinum, ou on le greffe sur un tronc de vignes; et dans les deux cas il trouve toujours une nourriture

consistit atque consumitur. Unde etiam materixe velıe. mentissime reperiuntur aut in capite vitis aut in crure viciıo radicilıns. Sed et hae steriles, quae e duro citantur, ac duplici, ex causa rohusta sunt : quod a fretu vacant, quodque ex proximo terra integro alque illibato succo aluntur : et illa fertiles ac firma, quia e tenero prorepunt, et quidquid, ut supra dixi, ad eas alimenti perve. nit, individumn est. Media: sunt macerrima, quia transcurrit linc parte aliqua interceptus, illinc ad se tractus lımmor. Non debet igitur ıltimun flagellnm quasi focunlum observari, etiam si plurimum afferat; sicpnidem loci ubertate in fructum cogitur : sed id sarnentum quod me. dia vite sitmm, nec importuna quidem parte deficit, ac numeroso foetu benignitatem suam ostendit. Hic surculus translatus rarins degenerat, quonian ex deteriore statı meliorem sortitur. Sive cuim nastinato deponitur, sive trunco inseritur, largioribıs satiatur alimentis, quam prius, cum esset in egeno. Itaque custodiemus, it ex plus abondante que celle qu'il avait par le passé, puisqu'il en manquait absolument. Ainsi nous olserverons de prendre le plant dans les parties que nous venons de désigner, auxquelles les paysans donnent le nom d'humerosi, pourvu cependant (que nous ayons vu précédemment ces parties porter du fruit. Car s'il arrivait qu'clles n'en cussent point porté, quoiqu'clles soient à la vé. rité celles que l'on doive rechereher dans la vigne, nous ne croyons pas néanmoins que ce fût une raison suffisante pour assurer la fertilité du mailleton qu'on y prendrait. C'est pourquoi rien n'est plus faux que l'opinion de ces agrieulteurs, qui pensent qu'il n'est pas important d'examiner combien de grappes a porté un sarment, pourvu qu'il soit pris sur une vigne fertile, et qu'il ne soit point de ceux qui sortent du bois dur, et que l'on appelle des sarments pampinaria. Cette opinion, qui provient de l'ignorance dans le choix du plant, est cause que les vignes commeneent par être peu fécondes, et qu'elles finissent par devenir absolument stériles. Qui est-ce en cffet qui, depuis la longue suite d'années qui se sont écoulées jusqu'à nous, s'est avisé de donner à un agriculteur un ordre conforme à ce que nous venons de dire, err l'envoyant choisir des mailletons? Il y a plus: qui est-ce qui ne commet pas cc soin précisément aux gens les plus ignorants, et à ceux qui sont ineapables de faire toute autre besogne? Aussi cet usage est-il cause que cette opération, qui est cependant une des plus importantes, est tonjours faite par les plus im. prudents et les plus nonchalants de tous les hommes, parce qu'ainsi que je le disais tout à l'heurc, on députe à cette fonction l'homme le plus inutile que l'on puisse trouver, et celui qui est incapable de supporter tout autre travail ; d'où il arrive que quand un tel homme aurait quelques connaissanees sur le choix des mailletons, il les déguise ou ne les met point en usage par noncha-

pradictis locis, quos liumeros rustici vocant, semina legamus, ea tamen, qua attulisse fructum antea animadverterimus. Nam si fatu vacua sint, quanvis laulabilem partem vitis nihil censemus ad feracitatem conferre malleolo. Quare vitiosissima est eorum ayricolarum opinio, qui minimum referre crelıut, quot uvas sarmentım labuerit, dum ex vite fertili legatur et non ex duro trunco euatım, quod pampinariın vocant. Irec antem opinio, quı orta est ex inscitia seminum eligendorun, primun jarum frennilas vineas, deinde etiam nimis steriles reduit. Quis enim omniuo jam per tam longam seriem annorum agricola malleolum legentibus pracepit ea, qua paulo ante retulimus? Immo quis non imprudentissimum quemque, et eum qui nilil alind operis facere valeat, huic negotio delegat? Itaque ex luac consuetudine veuiunt imprudentissini ad rem naxime necessariam; deinde etiam infirmissimns et inutilissimus quisque, ut dixi, qui nullım alimn laborem ferre queat, luuic officio applicatur. Is porro 
lance; qu'il ne se pique d'aucune attention ni d'aucun serupule, pourvu qu'il vienne à bout de compléter la quantité des mailletons que lc métayer lui aura ordonné de clioisir ; et qu'enfin il n'a en vue que de remplir la tâclıc qui lui est imposée : ce à quoi il parvient d'autant plus aisément, que, quand il s'est agi de l'instruirc, ses maîtres, pour lui donner la facilité de suivre leurs préceptes, se sont bornés à luì prescrirc de ne point arraeher les sarments sortis du bois dur, mais de prendre le plant dans tout le reste du cep. Pour nous, nous suivons un usage que la raison nous avait dicté, et que l'cxpérience a confirmé depuis, c'est-à-dire que nous ne choisissons pas d'autre plant, et que nous ne pensons pas même qu'il y en ait d'autre fructifiant que celui qui, placé dans la partie de la vigne destinée à sa reproduetion, y a porté du fruit. Car eelui qui, placé dans unc partie stérile, s'est montré ou fertile ou robuste quoique sans fruits, n'a qu'une apparenee trompeuse de féeonditć, sans avoir réellement la faculté de se reproduire. La raison nous démontre la vérité incontestable de cettc proposition, si nous admettons une fois que toutes les parties des plantes qui produisent des fruits ont chacune des fonctions qui leur sont spécialement affeetées, de la mêmc manière que chaque membre de notre corps a ses fonctions particulières. Nous voyons en effet que l'âme a été suufflée dans l'homme, comme pour conduire et diriger ses membres; que ses sens lui ont été départis pour discerner les objets par le toueher, l'odorat, l'ouĩc et la vue; que les pieds ont été mis à la place qu'ils occupent pour mareher, comme les bras à la leur pour cmbrasser; que, sans m'étendre ici plus que de raison dans les détails des fonctions de tous nos membres, les oreilles ne peuvent

ctiam si quam scientiam eligendi malleoli habet, eam propter infirmitatem dissimulat, ac superponit : et ut nnmerum, quen villicus imperavit, explere possit, nilhil curiose, nilil religiose, administrat: unumque est ei propositum, peragere laboris sui pensum : cum tamen, ut et sciat, et quod scit exequatur, loc solum praceptum a magistris acceperit, ne pampinariam virgam deplantet, rietera omnia ut seminibus contribuat. Nos autem primum rationem secuti, nunc etian longi temporis experimentum, non aliud semen eligimus, nec frugiferum esse ducimus, nisi quod in parte genitali fructum attulerit. Nam illud quidem, quod loco sterili laetum robustumque sine foetu processit, fallacem forcunditatis imaginem præfert, nec ullam generandi rim possidet. Id procul dubio verum esse ratio nos admonet, si inodo ut in corporibus nostris propria sunt officia cujusque nembri, sic et frugiferarum stirpium partibus propria munia. Videmus lıominibus inspiratam velut aurigain rectricemque meubrorum animam, sensusque injectos ad ea discernenda, quæ tactu, quarque uaribus auribusque et oculis indagantur; pedes rien faire de ce qui est du distriet des yeux, comme ceux-ei ne peuvent rien faire de ce qui est du district des oreilles; que de même la faculté d'engendrer n'a pas été donnéc aux mains ni aux pieds, mais que le père de l'univers, voulant que eette faeulté fût hors de la portée des hommes, l'a cachéc dans l'intéricur du ventre, afin que ce fût comme en seeret et à couvert que cet éternel Créateur des êtres, douć d'une raison divine, pût s'oecuper, pour ainsi dire, à mélanger, dans eertains lieux cachés du corps, les éléments saerés de l'esprit qui nous anime, avee les prineipes terrestres de notre constitution, pour former par là cette machine animéc. Il a suivi la même loi pour la formation des bestiaux et des plantes, comme pour celle des différentes espèces de vignes. En effet, la nature, qui est la mère de toutes ces différentes espèees de vignes, a commeneé par jeter en terre leurs raeines, pour servir, pour ainsi dire, de fondements sur lesquels elles se tiendraient comme sur des pieds; ensuite elle a posé leur trone par-dessus, comme pour leur former une certaine stature de corps et une eertainc eontenance : après quoi elle a étendu leurs branches de côté et d'autre, comme autant de bras, dont clle a fait sortir en guise de mains des tiges et des pampres, en donnant aux uns la vertu de porter des fruits, et en se contentant de eouvrir les autres de feuilles, qui servissent à protéger et d̀ défendre ces fruits. Si done parmi tous ces membres nous ne choisissons pas, ainsi que nous l'avons dit ci-dessus, ccux qui, étant destinés à la génération, sont chargés de fruits et de semenee, mais que nous nous en tenions à ceux qui ne servent, pour ainsi dire, qu'à les couvrir è à les ombrager, et qui sont sans fruit, nous ne travaillerons qu'à nous procurer de l'ombrage, et non pas à parve-

ad gressum compositos, brachia ad conıplexum : ac ne per omnes vices ministeriorum vagetur insolenter oratio, niliil aures agere valent, quod est oculorum, niliil oculi, quod aurium; nec generandi quidem data est facultas manibus aut plantis : sed quod hominibus ignotum voluit esse geni. tor universi, ventre protexit; ut divina praedita ratione rerum rternus opifex, quasi quibusdam secretis corporis in arcano atque operto sacra illa spiritus elementa cun terrenis primordiis misceret, atque hanc animantis machinx speciem effingeret. Hac lege pecudes ac virgulta pro. genuit, hac vitiun genera figuravit, quibus eadem ipsa mater ac parens primum radices velut fundamenta quadam jecit, ut is quasi pedibus insisterent : truncum deinde superposuit velut quandam staturam cornoris et habitus : mox ramis diffudit quasi brachiis : tum caules et pampinos elicuit velut palmas. Eorumque alios fructu donavit, alios fronde sola vestivit ad profegeudos tutandosque partus. Ex lis igitur, ut supra diximus, si non ipsa membra genitalia conceptu atque foctu gravida, sed tanquam tegmina et umbracula corum, qua fruclibus-vidua sunt, leg̣erimus 
nir à la vendange. En ce cas-là, on me demandera pourquoi, si ma comparaison cst justc, jc condamne un panpre, quoiqu'il ne sorte pas du bois dur, mais d'une branche tendre, par la raison qu'il n'a pas de fruit, comme s'il n'en de. vait jamais avoir méme par la suite? puisqu'on peut conclure, $d u$ raisonnement quc je faisais tout à l'heure, que de même que chaque partie du corps a une fonction particulière qui ne convient point aux autres, un mailleton né dans une partie favorable de la vigne doit demêmeavoir la faculté d'engendrer, quoique quelquefois il ne montre point de fruits. Je ne désavoue pas que tout mon raisonnement n'ait été fondé sur cette comparaison ; mais, malgré cet aveu, je déclare hautement que lorsqu'une branche ne rapporte point de fruits, quoiqu'elle soit née dans une partie de la vigne destinée à en rapporter, elle n'a pas mêmc la puissance de se reproduire : et cela ne contredit pas ma comparaison. Car il est évident qu'il se trouve ėgalement des hommes qui n'ont pas la puissance d'engendrer, quoiqu'il ne lcur manque aucun membre; de sorte qu'il est trèscroyable qu'une branche qui n'a pas de fruits n'en produira jamais, quoiqu'clle soit sortie d'une partic de la vigne destinée à sa reproduction. C'est pour cela que les agriculteurs, pour en revenir à leur usage, donnent, à ces branches qui n'ont rien produit, le nom de spadones; ce qu'ils ne feraient pas, s'ils ne les soupconnaient pas d'être incapables d'en produire. C'est même cette dénomination qui m'a suggéré la méthode de ne pas choisir des maillctons qui n'auraient pas produit de fruits, quoiqu'ils fussent sortis d'une partie louable de la vigne Ce n'est pas que j'ignore que de pareils mailletons ne sont pas absolument stériles, puisque j'avoue que les pampres même, qui sont sortis du bois dur, acquièrent la fécondité la sceonde année, et que c'est pour cela qu'on les taille en coursons, afin qu'ils puissent reproduire. Mais aussi j’ai remarqué que les fruits qu'ils donnent ne sont pas tant leur ouvrage que celui de leur mère : car, comme ils ticnnent à unc branche qui cst naturellement fertile, ils ne s'habituent peu à peu à porter du fruit qu'en partageant les aliments et la semence féconde de leur mère, et en tenant, pour ainsi dire, au scin qui les nourrit : au lieu qu'une branche qui aura été arrachée avant d'être à son point ct avant d'avoir atteint, pour m'exprimer ainsi, l'âge de pubcrté fixé par la nature, n'est pas propre, vu qu'clle est comme en enfance, je ne dis pas à la conception, mais même au coït, soit qu'on l'insère sur un tronc ou dans une autre branche fendse à cet cffet, soit qu'on la mettc en terre; ct dès là elle perd totalement la faculté d'engendrer, ou du moins cette faculté s'altère chez elle. C'est pourquoi je suis fort d'avis que l'on s'attache, en choisissant le plant, à prendre, sur une partie féconde de la vigne, des branches, qui répondent d'avance de leur fécondité future par les pleins fruits qu'elles auront eus. Ne nous contentons pas cependant de cclles qui auront rapporté chacune lcur grappe, mais préférons surtout celles qui sc seront fait distinguer par la plus grande abondance de fruits. Ne louerions-nous pas un bcrger qui s'attacherait à avoir de la race des bêtes qui auraient mis bas deux petits à la fois, comme un pasteur qui donnerait à ses chèvres des boucs nćs de mères qui se seraient rendues recommandables, pour avoir mis bas trois petits à la fois? Or nos éloges ne pourraient être fondés que sur ce que les petits sont prćsumés devoir toujours répondre à la fécondité de leurs parents. Suivons donc aussi cette méthode
IImbra scilicet, non vindemix laboraverimus. Quid ergo est? cur quamris non sit e duro pampinus, sed e tenero natus, si tamen orbus est, etiam in futurum quasi sterilis lamnatur a nobis? Modo enim disputatio nostra colligehat unicnique corporis parti proprium esse attributum offcium, quod scilicet ei conrenit; ut malleolo quoque, qui opportuno loco natus est, focunditatis vis adsit, etiam si interin cesset a partu. Nec ego abnuerim loc me insti. tuisse argumentari. Sed et illud maxime proliteor, palmitem quaunvis frugifera parte enatum, si fructum non attulerit, ne vim quidem forcunditatis habere. Nec hoc illi sententice repugnat. Nam et homines quosdam non posse generare, quamvis omnium membrorum numero constante, ınanifestum est; ne sit incredibile, si genitali loco virga uata fruclu careat, carituram quoque esse foetu. Itaque ut ad consuetudinem agricolarum revertar, ejusmodi surculos, qui niliil attulerint, spadones appellant: quod non facerent, uisi eos suspicarentur inlıabiles frugibus. Qua et ipsa appellatio rationem mili subjecit non eligendi malleolos quamvis probabili parte vitis enatos, si fructum non tulissent : guanquam et hos ipsos seiam non in totun ste. rilitate affectos. Nam confiteor pampinarios quoque, cum e duro prorepserint, tempore anni sequentis acquirere forcunditatem, et ideo in resecen submilti, ut progenerare possit. Verum ejusmodi partum comperimus non tam ipsius rusecis, quam naterni esse muneris. Nam quia inhxel stirpe sux, qun est natura ferax, mistus adtuc parentis alimentis, et foccundi partus seminibus ac velut altricis uberibus eductus, paullatim fructum ferre condiscit. At quxe citra naturæ quandam pubertatem, immatura atque intempestiva planta direpta trunco vel terrac vel etiam stirpi recisæ inseritur, quasi puerilis ætas, ne ad coitum quidem, nedum ad conceptum habilis rim generandi vel in totum perdit, rel certe minuit. Quare magnopere censeo in eligendis seminibus adhibere curam, ut e fructuosa parte vitis palmites legamus eos, qui futuram $f(x-$ cunditatem jam dato fructu promittunt. Nec tamen contenti simus singulis uvis, maximeque probeinus eos, qui numerosissimis foetibus conspiciuntur. An non opilionem laudihimus ex ea inatre sobolem propagantem, qua gemi. nos enixa sit; et caprarium subinittentem fuxtus earun pecudum, qua trigemino partu commendautır? vilelicet 
dans les vignes, d'autant plus que nous sommes assurés, par l'expérience, que les semences éprouvées avec le plus grand soin ont néanmoins quelquefois de la disposition à dégénérer, par une malignité qui leur est comme naturelle : c'est cc que le poëte chcrche à nous ineulquer, cumme si nous étions sourds à la vérité, lorsqu'il dit: J'ai vu que des semences choisies depuis longlemps, et éprouvées avec le plus grand soin, finissaient par dégénérer, à moins que la prudence humaine ne fit un ehoix toutes les annecs des plus fortes d'entre elles, tant it est érit dans le destin que tout empire déeline en rétrogradant : car on doit supposer qu'il n'a pas entendu parler seulement des graines ct des lígumes, mais des semences de toutes les autres parties de l'agriculture. Si des observations, suivies pendant un long espace de temps, nous ont fait découvrir, comme cela est certain, que des mailletons qui avaient été chargés de quatrc grappes de raisin lorsqu'ils tenaient à leur mère, avaicnt dégénéré de cette fécondité après en avoir ćté séparés pour être déposés en terre, au point d'en rapporter quelquefois une et souvent deux de moins; combien, à plus forte raison, devons-nous croire que ceux qui n'auront porté (juc deux grappes ou peut-être une seule, lorsqu'ils étaicnt attachés à leur mère, seront dans le cas de dégénérer, puisque les plus fertiles redoutent souvent eux-mêmes cette séparation? Aussi avoucrai-je franchement que je suis plutôt le démonstratcur de la méthode que je propose ici que je n'en suis, l'inventeur, afin que personne ne s’imagine que je veuille dérober à nos ancê:tres les ćloges qui leur sont dus. Car il est constant qu'ils ont été dans les mêmes sentiments que moi sur cet objet, quoiqu'on n'en trouve au- cun vestigc dans d'autres écrits, si ce n'est danz les vers de Virgile que nous venons de citer; et qu'eneorc ce poëte ne semble les appliquer qu'aux graines des légumes. En effet, comment auraientils rejeté la branche sortie du bois dur, ou même la flèche d'un mailleton fécond, quoiqu'ils eussent approuvé le mailleton lui-même, s'ils eussent cru que la partic de la vigne dans laquelle on devait choisir le plant était unc chose indifférente. Mais le vrai dc la chose est qu'ils n'ont condamné très-piudemment les branelıes sortics du bois dur, ainsi que les fleches des mailletons, comme inutiles à la plantation, que parce qu'ils ćtaient convaincus que la faculté de sc reproduire était inhércntc à certains membres, pour ainsi dire, de la vigne. Si cela est ainsi, il n'y a point de doute qu'ils n'aient encore beaucoup plus désapprouvé les branches qui, quoique nées dans une partie fructifiantc de la vigne, n'avaient point de fruit. En effet, s'ils croyaient ne devoir faire aucun cas de la flèchc, c'est-à-dire, de l'extrémitć supérieure du mailleton, quoiqu'elle fit ellc-même partie d'une branche fructifiante, à plus forte raison devons-nous conclure, par unc suite de raisonnements, qu'ils désapprouvaient un fouet, fût-il sur la meilleure partie de la vigne, lorsqu'il était stérile : à moins cependant qu'ils ne se fussent imaginé (ce qui serait absurde) qu'un fouet, qui n'aurait rien valu dans le temps qu'il tenait à sa mère, devenait fertile quand il en était séparé pour êtrc transporté ailleurs, et qu'il se trouvait privé de la nourriture de sa mère. Nous avons traité cet article peut-être cn plus de paroles que n'en exigeait la nécessité de défendre la cause de la véritć; mais cependant nous en avons encorc moins dit qu'il n'en fallait pour détruire l'opinion quia sperat parentum foecunditati prolem responsuram. Et nos sequemur in vitibus lranc ipsam rationem, tanto quidem magis, quod compertum lıabemus, naturali quadam malignilate desciscere interdum quamvis diligenter probata semina : idque nobis poeta velut surdis veritatis inculcet dicendo, Vidi lecta diu, et multo spectata labore Degenerare tamen, ni vis humana quotannis Maxima quaque manu legeret. Sic omnia fatis In pejusruere, ac retro sublapsa referri. Quod Ion tantum de semi. nibus leguminum, sed [in] tota agricolationis ratione dictum esse intelligendum est : si modo longi temporis nhservatione comperimus, quod certể conıerimus, euın malleolum, qui quatuor uvis tulerit, deputatum et in terram depositurm, a foecunditate materna sic degenerare, ut interdum singulis, non nunquam etiam hinis uvis minus afferat. In quantum autem censemus defecturos eos, qui binos aut fere singulos fotus in matre tulerint, cum etiam feracissimi translationem sæe reformident? Itaque hujus rationis demonstratorem magis esse me quam invento. rem, libenter profiteor : ne quis existimet, fraudari majores nostros laude merita. Nam id ipsum sensisse cos non dubium est, quanvis nullo alio sit scripto proditum, ex. ceptis quos retulimus numeros Virgilii, sic tamen ut de seminibus leguminum præcipiatur. Cur enim aut e duro natam virgam, aut etiam ex foecundo malleolo, quem ipsi probassent, decisam sagittaın repudiabant, si niliil inter. esse ducebant, ex quo loco semina legerentur? Num quin vim focunditatis certis quasi membris inesse non dubita. bant, idcirco pampinarium et sagittam velut inutiles ad deponendum prudentissime daninaverunt? Quod si ita est, nihil dubium est, multo magis ab his improbatum esse etiam illum palmitem, qui frugifero loco natus fructum non attılisset. Nan si sagittan, id est superiorem parten inalleoli, vituperandam censebant, cum esset ea. dem pars surculi frugiferi, quanto magis vel ex optima vitis parte natum flagellum, si est sterile, improbatum ab his ratio ipsa declarat? Nisi tamen, quod est absurduın, crediderunt id translatum et abscissum a sua stirpe, de. stitutumque materno alimento, frugiferum, quod in ipsa matre nequam fuisset. Atque lıac [et] forsitan pluribus dicta sunt, quam exinebat ratio veritatis : minus tamen multis, quam postulabat prave detorta et inveterata opinio rusticorum.

XI. Nunc ad reliquum ordinem propositæ disputationis 
fausse et invétérée des paysans sur cette matière.

XI. Maintenant, pour suivie l'ordre que j’ai annoneé, je passe aux autres articles de ce traité. Après l'attention que je vieñs de prescrire dans le choix des mailletons, vient l'opération qui consiste à retourner la terre au pastinum, pourvu cependant qu'on ait eu soin de s'assurer de sa qualité : car il est certain que la qualité de la terre contribue beaucoup elle-même à la bonté ainsi qu'à l'abondance des fruits. Ainsi, avant d'cxaminer ce genre de culture, nous croyons qu'il est très-important de choisir, si on est à même de le faire, une terre en friche, préférablement à celle qui aurait déjà porté des moissons, ou nourri des arbres mariés à des vignnes. Car quant aux vignobles qui sont détruits par le laps de temps, tous les auteurs conviennent que si on recommencait à les planter en vignes, ils ne réussiraient jamais, parce que l'intérieur de leur sol se trouve comme empêtré dans des filets formés par la multitude de racines qui l'embarrassent, outre qu'il est imprégné de ce venin et de cette moisissure qu'imprime la vieillesse, dont l'espèce de poison émousse la terre et l'engourdit. C'est pour cela qu'il faut plutôt choisir un terrain sauvage; et quand même il serait embarrassé par des broussailles ou par des arbres, il scrait toujours aisé de l'en débarrasser, parce que toute production qui vient de soi-même ne jette pas de racines bien profondes, mais qu'elle les éparpille sur la superficie de la terre : de sorte que, pour peu qu'on les coupe avec le fer ou qu'on les arrache à la main, il sera aisé de retourner avec le hoyau le peu qui en sera resté dans l'intérieur. du sol, et de l'amasser en tas pour servir à faire fermenter la terre. Si cependant l'on n'a point de terrain en friche, le meilleur dont on pourra se servir ensuite sera un terrain dégarni d'arbres : au défaut de ce dernier, on destinera aux vignes un verger où les arbies soieıt rares, ct un plant d'oliviers auxquels il n'y ait point eu de vignes mariées. Le plus mauvais, comme je l'ai dit, cst cclui qui était habitué précédemment à porter des vignes. Si néanmoins l'on est contraint par la nécessité d'en employer un de cette nature, il faut auparavant en extirper tous les ceps sans en laisser un seul, puis le fumer en entier avec du fumier sec, ou, si l'on n'en a point, avec toute autre espèce de fumier, pourvu qu'il soit le plus nouveau que faire se pourra, et cnsuite le retourner, et amasser sur la superficie de ec terrain toutes les racines que l'on aura arrachées avec soin, pour les y brûler : enfin le recouvrir avec profusion, après l'avoir labouré au pastinum, soit de vieux fumier, parce qu'il n'engendre point d'herbes, soit de terie rapportée, prise dans des buissons. Mais lorsqu'on a des terres en friche dégarnies d'arbres, il faut examiner, avant de les labourer au pastinum, si ellessont propres à produire des arbrisseaux ou non : c'est ce qu'on reconnaitra très-aisément a la seule inspection des plantes qui y seront venues d'elles-mêmes, puisqu'il n'y a point de sol, si dégarni de plantes qu'on le suppose depuis longtemps, qui ne produise quelques arbrisseaux, tels que des poiriers sauvages, des pruniers ou au moins des ronces : car, quoique ces plantes soient des espèces d'épines, elies sont cependant ordinairement fortes, d'une belle venue, et couvertes de fruits. C'est pourquoi, si l'on s'aperçoit que ces plantes ne soient point desséchces ni galcuses, mais qu'elles soient au contraire lisses, propres et hautes, on jugera que la terre qui les porte scra propreà nourrir.des arbrisseaux. Au surplus, ces observations

rineis destinatur. Ultima est, ut dixi, conditio restibilis vinen. Nam si necessitas facere cogit, prius quicquid est residua vitis extirpari debet : deinde totum solum sicco fino, aut si id non sit, alterius generis quam recentissimo stercorari, atque ita converti, et diligentissime rifossa omnes radices in summum regeri atque comburi : lunc rursus vel stercore vetusto, quia non gignit herbas, vel de repribus egesta lumo pastinatum large contegi. At ubi pura novalia et ab arboribus sunt libera, considerandum est ante, quam pastinemus, surcularis necne sit terra : idquie facilline exploratur per stirpes, qux. sua spoute proveniunt. Neque enim est ullum tam viduum solun virgultis, ut non aliquos surculos progeneret, tanquam piros silvestres et prunos, vel rubos certe. Nam hacc quamvis genera spiuarum sint, solent tamen forlia ct larta et gravida fructu consurgere. Igitur si non retorrita nec scabra, sed levia et nitida, et prolixa foccundaq̨ue viderimus, ean intelligemus esse terram surcularem. Sed lıo in totun : at illud, quod rineis praccipue est idn. neum, propric consideranclum, ut prius reluli, si facilis est lıumus et modice resolıta, quam diximus pullan vocitari : nec quia sola $e a$, sed quia sit habilis maxime 
sont générales ct s'appliquent a toute espèce d'arbrisseau, au lieu que voici ce qu'il faut examiner, comme je l'ai dit ci-dessus, pour juger si un terrain est bon spécialement pour les vignes : c'est si la terre en est mollc et médiocrement friable, lelle que celle que nous avons dit que l'on appelait pulla; non pas que cette terre soit absolument la seule qui soit propre aux vignobles, mais parec que c'est celle qui l'est le plus. Qucl est en effet l'agricultear, fût-il des plus minces, qui Ignore que le tuf lc plus dur et le charbon, pour pcu qu'ils aient ćté broyés et entassés sur la superficie du sol, s'amollissent et se réduisent en poussièrc par les mauvais temps et les gelées, ainsi que par les chaleurs de l'été, et qu'ils rafraichissent très-bien les racines de la vigne pendant l'été, el même temps qu'ils ne laissent point évaporer le suc de la terre? deux points très-essentiels pour nourrir les arbrisseaux. Par la même raison on approuve aussi le gravier bien menu et les champs pleins de gros sable et de pierres mouvantes, pourvu cependant qu'il s'y trouve de la terre girasse mêlée parmi, autrement on les rcjette absolument. Le eaillou même (suivant mon opinion) n'est pas moins ami de la vigne, pourvu qu'il soit un peu recouvert de terre, parce qu'étant frais et conservant bien l'humidité, il n'en laisse pas dessécher les racines au lever de la Canicule. Hyginus assure aussi d'après Trémellius, et je n'en disconviens point moi-même, que le pied des montagnes couvert de la terre qui s'est écroulée du haut, de même que les vallées exhaussées par les terres que les fleuves et les inondations y ont apportées, sont des terrains particulièrement bons pour les vignes. La terre remplie d'argile passe pour être bonne à la vigne: car pour l'argilc purc dont se servent les potiers, et que quelques personnes appellent argilla,

vinetis. Quis enim rel mediocris agricula nesciat, etiam durissimum toplıum vel carbuneulum, simulatque sunt confracti, et in summo regesti, tempestatibus et gelu nee minus estivis putrescere caloribus ac resolvi; eosque pulcherrime radices vitium per astatem refrigerare, suecumque retiuere? quae res alendo surculo sunt accommo. datissimx. Siınili quoque de eausa probari solutam glaream calculosumique agrum et mobilem lapidem : si tamen laxe pingui gleba permista sunt; nam eadem jejuna maxime culpantur. Est autem, ut nea quoque fert opinio, vineis amicus ctiam silex, eui superpositum est modieun terrenum, quia frigidus et tenax lumoris per ortum $\mathrm{Ca}$ uicula non patifur sitire radices. Hyginus quidem seeutus Tremellium pracipue montium ima, qua a verticibus delluentem liumum receperint, vel etiam valles, qua Huminum alluvie et inundationibus conereverint, aptas esse vineis asseverat, me non dissentiente. Crelosa lummus utilis habetur viti : nam per se ipsa creta, qua utuntur figuli, quamque nonnulli argll!am vocant, iuimicissima est : nee minus jejunus sabulo, et quicquid, ut ait Julius Atticus, retorrichim surculuin facit, id autem solum vel elle leur est très-contraire, ainsi que le sable qui n'est mêlé d'aucune bonne terre, et cn général, comme dit Julius Atticus, tout ce qui est capa. blc de dessécher les arbrisseaux, c'est-à-dire les terrains très-humides, salés, amers, secs et brû. lés. Cependant les anciens ont approuvé le sable noir et rouge, qui sont mêlés d'une terre humide; mais pour les terres où il se trouve du charbon, ils ont déclaré qu'clles maigrlssaient la vigne, à moins qu'on nc les aidât avec du fumier. La terre rouge, comme dit le même Atticus, est épaisse, et peu propre d laisser un passage libre aux racines; mais unc fois qu'elle leur a livré passage, elle nourrit très-bien la vigne: il est vrai qu'ellc est plus difficile à cultiver qu'une autre, puisqu'on ne peut la labourer, ni quand elle est humide, parce qu'elle est trop gluante, ni quand elle est trop sèche, parce qu'elle est alors excessivement dure.

XII. Mais, pour ne pas nous jeter ici dans le détail de toutes les sortes de terrains dont le nombre est infini, il ne sera pas hors de propos de rapporter une espèce de formulc qu'a donnée Julius Græcinus, et d'après laquelle se trouvent fixées les limites entre lesquelles sont comprises les terres qui sont bonnes pour les vignes. Car voici ce que dit cet auteur : qu'il y a des terres chaudes ou froides, humides ou sèches, dilatées ou épaisses, légères ou pesantes, grasses ou maigres; mais qu'un terrain trop chaud ne peut pas souffrir de vignes, parce qu'il les brûle; non plus qu'un terrain très-froid, parce qu'il ne laisse point aux racines, qui sont gelées et comme engourdies par le trop grand froid, la faculté de s'étendre; ni un terrain humide, parce que, dès que les vignes viennent à pousser, la moindre chaleur leur fait tirer de terre plus d'humidité qu'il ne leur en faut, et que cette humidité les

uliginosum est, vel salsum; amarum etiam, vel sitieulo. sum et peraridum. Nigrum tamen et rutilum sabulonem, qui sit vividæe terræ permistus, probaverunt antiqui. Nam earbuneulosum agrum, nisi stercore adjuves, macras vineas efficere dixerunt. Gravis est rubrica, ut idem Atticus ait, et ad compreltendendum radieibus iniqua. Serl alit eadem vitem, cum tenuit; verum est in opere difficilior : quod neque lumentem fodere possis, quod sit glutinosissima, nee ninium siecam, quia ultra modum pricdurá.

XII. Sed ne nune per infinitas terreni species evagemur, non intempestive eommemorabimus Julii Graecini cons. eriptam velut formulam, ad quam posita est limitatio ter. ra vinealis. Idem enim Gracinus sie ait : Esse aliquam terram calidam rel frigidam, lıumidam vel siccam, raraın vel densam, levem aut gravem, pinguem aut macram : sed neque nimium calidum solum posse tolerare vitem, quia iuurat; neque pragelidum, quoniam velut stupentes et eongelatas radiees nimio frigore moveri ıon sinat; qux tum demum se promunt, eum modico tepore evocantur. Humorem terra justo majorem putrefacere deposita se- 
pourrit. Il dit encore que d'un autre côté la trop grande séelieresse laisse mancuer les plantes de leur nourriture naturelle, ou qu'elle les fait ab. solument pétir, ou enfin qu'clle les rend galeuses et desséchées; que la terre trop ćpaisse, ne boit pas la pluie et ne reçoit pas facilement les influences de l'air ; qu'elle se fend très-a isément et donne lieu par là à des crevasses, à travers lesquelles le soleil pénètre jusqu'aux racines des plantes; qu'enfin elle comprime et étrangle, par la même raison, les plantes qui y sont eomme en prison et resserrées; que celle qui est dilatèe outre mesure laisse passer les pluies comme à travers un entonnoir, outre que le soleil et le vent la tarissent et la dessèchent entièrement; que la terrc épaisse ne cède presque à aucune culture, et que la lėgèrene peut êtrcaffermie presque par aucunc; que celle qui est très-grasse et très-abondante pèche par son trop de fertilité, comme la maigre ct la mince par son peu de suc. Il faut, ajoute-til, qu'il se trouve un grand tempérament entre toutes ees espèces de terres, variées comme clles le sont, ct que ce tempérament soit tel que celui qui n'est pas moins à désirer pour nos corps, dont la bonne santé ne se soutient que par une. mesure compassée, pour ainsi dire, de chaud et de froid, d'humide et de sec, d'épais et de dilatć. Il convient cependant que ce tempérament ne doit pas être au même point d'équilibre dans la terre destinée aux vignes, qu'elle doit l'être dans nos corps; mais il veut que la balance penche plus d'un côtć que de l'autre, comme, par exemple, que cette terre soit plus chaude que froide, plus sèche qu'humide, plus dilatée qu'épaisse, et ainsi des autres qualités semblables, vers lesquelles celui qui forme des vignobles doit diriger son attention : toutes qualités qui,sc- lon mon avls, seront plus profitables encore, si elles sont aidées de la température du climat. II s'est élevé à cette oceasion unc dispute parmi les anciens, sur le côté du eiel vers lequel doivent être tournées les vignes : Saserna approuve en premier lieu le côté du lever du soleil, ensuite le midi, puis le couchant. Tremellius Serofa prétend que la position du midi est la meilleurc. Virgile rejette positivement celledu eouehant, en ces termes: Que vos vignobles ne soient point exposés au soleil couchant. Démocrite et Magon approu vent le septentrion, paree qu'ils pen sent que les vignes qui sont tournées de ce côté du cicl sont les plus fertiles, quoique à la vérité leur vin ne soit pas le meilleur. Pour nous, il nous a semblé qu'il serait mieux de preserire en général que les vignobles fussent exposés all midi dans les lieux froids, ct à l'orient dans les licux chauds, pourva cependant que ees licux ne fussent pas infestés par les vents du midi ou par ceux di sud-est, comme le sont les eôtes maritimes de la Bétique : car, dans le cas où lc pays serait sujet à ces vents, il vaudrait micux les tourner au point du ciel d'où souffle le vent Aquilon ou le vent Favonius. Quant aux provinces brûlantes, telles que l'Égypte et la Numidie, on ne peut y exposer les vignes qu'au septentrion. Lorsque ces points auront été tous bien examinés, nous en viendrons enfin à labourer la terre au pastinum.

XIII. Il faut donner la méthode de cette culture, tant aux agriculteurs qui se proposent de cultiver la vigne à la mode d'Italie, qu'à ceux qui se proposent de la cultiver à la mode des provinces; car pour ce qui est des contrées éloi. gnées, on n'y connaît pas cette façon de retourner le terrain en le labourant, mais on y plante mina : rursus nimiam siccitatem destituere plantas natırali alimento, aut in totum necare, aut scabras et retorridas facere : perdensam liumum cælesteis aquas non sorbere, nec facile perflari, facillime perrumpi, et probere rimas, quibus sol ad radices stirpium penetret; eandeul. que velut conclausa et coarclata semina comprimere atque strangulare : raram supra modum velut per infundi. bulum transmittere imbres, et sole ac vento penitus sic. cari atquue exolescere : gravem terram vix ulla cultura virci; levem vix ulla sustineri : pinguissimam et lietissimam luxuria, macram ac tenuem jejunio laborare. Opus est, inquit, inter lıas tam diversas inæqualitates magno temperamento, quod in corporibus quoque nostris desideratur, quorum bona valetudo calidi et frigidi, lumidi et aridi, densi et rari certo el quasi examinato inodo continetur. Nec tamen loc temperamentum in lerra, quæ vineis destinetur, pari momento libratum esse debere ait, sed in alteram partem propensius; ut calidior terra sit quam frigidior, siccior quam lıumidior, rarior quam deıl. sior, et si qua sunt his similia, ad qux contemplationeın suam dirigat, qui vineas instituct. Qwa cuncta, sicut ego reor, magis prosunt, cum suffragatur eliam status call : cujus quam regionem spectare debeant vinex, retus est dissensio, Saserna maxime probante solis ortum, mox deinde nıeridiem, tum occasum: Tremellio Scrofa præ. cipuam positionem meridianam censente : Virgilio de in. dustria occasum sic repudiante : Neve tibi ad solem ver. gant vineta cadentem: Democrito et Magone landantibus cali plagam septentrionaleu, quia existiment ei subjectas feracissimas fieri vineas, qua tamen bonitale vini superentur. Nobis in universmun praccipere optimunı visum est, ut in Iocis frigidis meridiano vineta subjiciantur ; tepidis orienti advertantur : si tamen non infestaburtur Austris Eurisque, velut or maritina in Batica. Siu autem regiones pradictis ventis fuerint obnoxia, melius Aquiloni vel Favonio committeutur. Nam ferventihus provinciis, ut Egynto et Nunidia, uni septentrioni rectius opponentur. Quibus omnibus diligenter exploratis, tum demum pastinationem suscipienıus.

XIII. Ejus autem ratio cum Italici generis futuris agricolis, tum etiam proyincialibus tradenda est : quonian in longinquis et remotis fert regionibus istud genus vertenili et subigendi agri minime usus patur, sed aut scrobibus ant sulcis plerumque vinexe couseruntur. [Scrobibus vineta sic 
communément les vignes dans des fosses ou dans des tranchées. Voiei coinme on les plante dans les fosses. Ceux qui sont dans l'usage de plauter lcurs vignes dans des fosses commeneent par fouiller le terrain à deux pieds de profondeur, sur une longueur d'environ trois pieds, et sur la largeur déterminće par celie de l'instrument dont ils se servent; après quoi ils étendent de côté et d'autre des mailletons, de façon que les racines en soient vers le milieu de la fosse et que les extrémités, après avoir fait un coude, se relèvent à ses deux bouts : ensuite ils reconvent le tout de terre, à l'exception de deux yeux qu'ils laissent hors de terre; et cnfin ils aplanissent le terrain. Ils reeommencent la même opération, enl laissant entre la seconde fosse et la première un intervalle de la même longueur que la fosse mème, sans le labourer, ct continuent toujours sur la même ligne, jusqu'à ce qu'ils aient fini une rangée. Ensuite ils laissent, entre cette rangée et eelle d'à eòté, un intervalle tel que le requiert l'usage où chacun est de eultiver les vignes, soit ì la charrue, soit an hoyau, et recommencent une seconde rangée, qu'ils achèvent de la même façon. Si l'usage est de bêcher simplement la terie, le moindre intervalle qu'il faut laisser entre chaque rangée doit être de einq pieds, et le plus grand, de sept; mais si l'on se sertde bœufs et de charrues, le moindre sera de sept pieds, et il sera suffisamment grand à dix. Il y en a cependant qui disposent le plan en quineonee de dix pieds d'intervalle en tout sens, afin de pouvoir labourer la terre comme on laboure les novales, tant en ligne droite qu'en travers. Cette dernière faecon de disposer un vignoble ne fait pas le profit du cultivateur, si ce n'est dans les pays où, le sol etant très-fertile, la vigne prend beaueoup d'accroissement en tout sens. Mais ecux qui redoutent les frais de la eulture au pastinum, et qui veulent cependant s'en rapproeher en quel-

ponuntur.] Quibus vitem mos est scrobibus deponcre, fere per tres longitudinis, perque duos pedes in al titudinem cavato solo, ruantum latitudo ferramenti patitur, malleolos utrinque juxta latera fossarum consternunt et adversis scrobium frontibus curvatos erigunt : duabusque gemmis supra terrain eminere passi reposita lumo cæetera coseguant : qua faciunt in eadem linea intermissis totidem pedum scamnis, dum peragant ordinem. Tum deincle relicto spalin, prout cuique mos est vineas colendi vel aratro vel bidente, sequentem ordinem instituunt. Et si fossore tantum terra versetur, minimum est quingue pedum in. terordinium, septem maximum : sin bubus el aratro, minimum esi septem pedum, satis amplum decem. Non. nulli tamen om nem vitem per denos pedes in quiucuncem disponunt, ut more novalium terra transversis adversisque sulcis proscindatur. Id genus vineti non conducit agricolæ, nisi ubi lietissimo solo vitis amplo incremento con. surgit. At qui pastinationis impensam reformidaut, sed sliqua tameu parte pastinationem imitari student, paribus que partle, forment des tranchées de slx pieds de largeur, en laissant entre chacune des espaces de même largeur sans les labourer; et après les a voir fouillées à trois pieds de profondeur, ils en relèvent la ter'e sur les bords à la même hauteur, et arrangent leurs ceps ou leurs mailletons à dos de ces tranehées. Il y en a qui vont au ménage par rapport aux dimensions de ces trancliées, en ne leur domnant que deux pieds neuf pouees de profondeur et cinq pieds de Iargeur. Quand la première rangée cst finie, ils laissent un espace trois fois plus grand que la largeur de la tranchée sans le cultiver, et fouillent ensuite la tranchée de la rangée suivante; et quand ils ont achevé cette opération dans tout le terrain qu'ils destinent à leur vignoble, ils relèvent à dos des tran:hées les mareottes ou les jeunes branches qu'ils ont coupées tout nouvellement, et plantent une multitude de mailletous entre le plant qui est rangé par ordre. Lorsque ees mailletons se sont fortifiés par la suite, ils les propagent dans des fosses qu'ils font en sens contraire des premières, sur le terrain qu'ils avaient laissé sans le labourer, et arrangent ainsi leurs vignobles par intervalles égaux. Au reste, ces faẹons de planter la viggne, que nous venons de rapporter, sont dans le eas d'être tantôt adoptées, tantôt rejetées, selon la nature ou la bonté de chaque eontrée. $\mathbf{A}$ prèsent je me propose de donner la méthode de labourel. un terrain au pastinum. D'abord, soit que le terrain que nous aurons destiné $a$ des vignes soit garni d'arbres mariésà des vignes, soit que ce soit un terrain sauvage, il faut en arracher toutes les broussailles et tous les a rbres qui s'y trouveront, et les mettre de eôté, de peur que celui qui le labourera au pastinum ne soit retardé dans son travail, ou qu'après que le terrain aura été labouré, il ne soit affaissé par le poids des arbres qui y seront étendus, et exposé à être foulé aux pieds par ceux qui iront enlever les branches et

alternis spatiis omissis senum pedum latitudinis sulcos dirigunt, fodiunt $q u e$ et exaltant in tres pedes, ac per latera fossarum vitem vel malleolum disponunt. Avarius quislam dupondio et dodrante altum sulcum, latum pedum quininue faciunt : deinde ter tanto amplius spatium crudum relinquunt : atque ita sequentem sulcum infodiunt. Quod cum per definitum vinetis locum fecerunt, in latcribus sulcorum viviradices vel decisos quam recentis. simos palmites novellos erigunt, consitis compluribus inter ordinaria semina mallcolis, quos, postea quam convaInerint, crudo solo, quod emissum est, transversis scrobibus propagent, atque ordinent vineam paribus interval. lis. Serl ear, quas retulimus, vinearum sationes, pro natura et benignitate cujusque regionis aut usurpanda ant repudiandx sunt nobis. Nunc pastinandi agri propositum est rationenı traderc. Ac primum omnium ut sive arbus. tum sive silvestrem locum vincis destinaverimus, omnis frutex atque arbor erui et submoveri debet, ne postea fossorem moretur, nere jam pastinatum solum jacentibus 
les trones d'arbres qu'on y aura lalssés. Car il n'est pas peu important que la terre que l'on aura labource au pastinum soit très-gonflée, et qu'on n'y voie, si faire se peut, aucune trace de pieds sur la superficie, afin qu’étant remuce également dans toutes ses parties, elle cède avec flexibilité aux racines du jeune plant, de quelque côté que ces racines veuillent y pénétrer, et qu'elle ne repousse point leur tendance à croitre par sa dureté; mais que leur servant, pour ainsi dire; de nourrice, elle les reçoive clans son tendre sein, qu'elle se laisse imbiber des eaux du ciel pour les distribuer au plant qu'elle aura d nourrir, et concoure, dans toutes ses parties, à élever sa nouvelle progéniture. Il faut fouiller les plaines à la profondeur de deux pieds et demi, les terrains en pente à celle de trois pieds, et les collines plus escarpées jusqu'à celle de quatre, parce que, si l'on n'y faisait point un lit de terre labourée au pastinum beaucoup plus profond que celai que l'on fait dans une plaine, la terre renant à s'ébouler de haut en bas, il resterait à peine la quantité suffisante de terre gonflée par le labour au pastinum. D'un autre côté, il ne fạut pas mettre la vigne à moins de deux pieds de profondeur, même dans lo bas des vallćes; car il vaut mieux n'en pas planter, que de la laisser comme suspendue sur la superficie de la terre, à moins cependant que la rencontre d'une source d'eau marécageuse, telle qu'il s'en trouve dans le canton de Ravenue, n'empêche de creuser au delà d'un pied et demi de profondeur. Il ne faut pas commencer cette opération, comme font la plupart des cultivateurs de nos jours, par fouiller peu à peu une tranchée, pour ne parvenir ainsi que par deux ou trois degrés successifs à la profondeur que l'on veut donner à son labour au pastinum;

molibus imprimatur, et exportantium ramos atque truncos ingressu proculcetur. Neque enim parum refert suspensissimun esse pastinatum, et, si fieri possit, vestigio quoque inviolatum : ut mota aequaliter lumus novelli seniuis radicibus, quamcunque in partem prorepserint, molliter cedat, nec incrementa duritia sua reverberet, sed tenero velut in nutritio siuu recipial, et cælestes admittat imbres, eosque alendis seminibus dispenset, ac suis omnibus partibus ad educandam prolem novam conspiret. Campestris locus alte duos pedes et semissem info. diendus est; acclivis regio treis, praruptior vero collis vel in quatuor pedes rertendus, quia cum a superiore parte in inferiorem detralitur humus, vix justum pastinationi prabet regestum : nisi multo editiorem ripam, quam in plano feceris. Rursus depressis vallibus minus alte duolus pedibus deponi vineam non placet. Nam prastat non conserere, quam in summa terra suspendere, nisi si sta. tim uligo palustris obvia, sicut in agro Ravennate, plus quam sesquipedem prolibeat infodere. Primun auteu pradicti operis exordium est, non ut hujus temporis ple tiyue faciunt agricolos, sulcum paulatim exaltare, et ita mais il faut la foulller sans interruption jusqu'à la profondeur entière qu'elle doit avoir, en se réglant sur un cordeau, pour que les côtés en soient droits, et en arrangeant par derrière soi la terre au fur et à mesure qu'on la fouillera, jusqu'à ce qu'on soit parvenu à la profondeur ordonnée : on promènera ensuite le cordeau, en le tenant bien droit, dans toute la profondeur de la fouille, et on fera en sorte que la largeur du fond soit la répétition de celle d'en haut, par laquelle on aura commencé. Il faut qu'il y ait un inspec. teur adroit et vigilant, qui fasse dresser les bords de la tranchée à angles droits, qui en fasse bien remuer la terre en dedans, et qui veille à ce que la terre qui tient à la tranchée, et qui n'est point encore labourée, soit confondue avec celle de la tranchée lorsqu'on viendra à la labourer par la suite, conformément à ce que j’ai prescrit dans le livre précédent, en donnant la manière de labourer les guérets, lorsque j'ai averti de prendre garde qu'on n'y laissât en aucun cndroit des bosses de terre qui ne seraient pas remuées, et qu'on ne cachât des parties de terrains dures sous des moltes de terre. Nos ancêtres avaicnt imaginé une espèce de machine, dont ils se servaient pour se faire rendre compte de cet ouvrage : c'était une règle faite exprès, au milieu de laquelle était une petite verge, dont la longueur était modelée sur la profondeur que devait avoir le fossé, et dont le point de contingence sur la règle se trouvait vis-à-vis le haut de ses bords. Les paysans donnent à celte espèce de mesure le nom de ciconia, mais elle est stjette elle-même à erreur, parce qu'elle donne des résultats différents, selon qu'elle est perpendicu. laire ou inclinée. Nous avons donc ajouté quelques parties à cette machine pour terminer les contestations et les disputes que l'on peut avoir.

secundo rel tertio gradu perrenire all destinatam pastina. tionis altitudinem : sed protinus æqualiter linea posita rec. tis lateribus perpetuam fossam educere, et post tergun motam lumum componere; atque in tautun deprimere, donec altitudiuis mensuram datam ceperit. Tum per. omno spatium gradus aqualiter|movenda linea est : obtinendum. que, ut eadem latitudo in imo reddatur, quas coepta est in summo. Opus est autem perito ac vigilante exactore, qui ripan erigi jubeat, sulcumque vacuari, ac tolum spa. tiun crudi soli cum emota jaun terra committi, sicut prä. cepi superiore libro, cum arandi rationem traderen, nonendo, necubi scamna omittantur, et quod est durunı, summis glabis obtegatur. Sed huic operi exigemdo quasi quaudanı machiuam conımenti majores uostri regulau fa. bricaverunt, in cujus latere virgula pronniueus ad ean altitudinen, qua depı imi sulcun oportet, contiugit sumunam ripa partem. Id genus niensura cicouiau vocant rustici. Sed ea quoque fraudem recipil, quouian pluri. mum interest, utrum eam pronan an reclam pous. Nos itayue huic machiux quasdam partes adjeciuus, quis contendentium liten disputationemugue dirinerent. Nam 
avee les ouvriers. Car nous avons croisć deux règles l'une sur l'autre dans la forme de la lettre arrecque $X$, de façon que les deux extrémités de ces règles sont éeartées l'une de l'autre à la distance de la largeur que le laboureur au prstinum doit donner à sa tranchée; après quoi nous avons attaché eette aneienne ciconia au milieu de I'X, qui est lc point de contingence de ees deux règles, de façon qu'elle se trouve fixéc comme sur une base sur laquelle elle est dressée perpendieulairement; ensuite nous avons mis au-dessus de la petite verge qui est au milicu de la règle transversale un niveau d'artisan. Lorsqu'on enfonce dans la tranchée eet instrument ainsi disposé, il termine de part et d'autre toutes les eontestations qui pourraient survenir entre le propriétaire et l'entreprencur, sans porter préjudiee ni à l'un ni à l'autre. Car les rayons de l'étoile, que nous avons dit ressembler à la lettre greeque, mesurent et nivellent avec exactitude le fond du fossé, puisque l'on s'aperçoit par la position même de la machine si elle est inclinée en devant ou en arrière, attendu que le niveau qui est au-dessus de la petite verge dont nous avons parlé donue la preuve de l'une ou de l'autre position, et met l'inspecteur de l'ouvrage à l'abri d'être trompé. L'ouvrage mesuré et nivelé de cette manière va toujours en avant, eomme un gućret que l'on laboure; et à mesure que l'on fait mareher le eordeau, on lui fait eomprendre autant d'espaec de terrain que la fouille de la tranchće doit avoir de longueur et de largeur. Voilà la manière la plus approuvée de préparer le terrain.

$X I V$. Vient après eela la plantation de la vigue, qu'il est temps de faire ou au printemps oudans l'automne: au printemps préférablement, si le climat est pluvieux ou froid, si le terrain

duas regulas ejus latitudiuis, qua pastinator sulcum facturus est, in specien Gracae literae $\mathbf{X}$ decussavinus, atque ita medie parti, qua regulx committuntur, antiquam illan ciconiam infiximus, ut tanquam supposita basi al perpendiculum nornata insisteret : deinde trans. versx, qua est iı latere, virgula fabrilem lilelkam superposuinus. Sic compositum organum cum in sulcum deunissum est, litem donini et conductoris sine injuria ciilucit. Nam stella, quam diximus Gracæe litera faciem obtinere, pariter ina fossæe solum metitur, atque perlibrat; quia sive prouum seu resupinum est, positione maclina eleprelıenditır. Quippe pradictæ virgnla superposita libella alterutrum ostendit, nec patitur exactorem operis decipi. Sic permensum et perlibratum opus in similitudinew vervacti senper procedit : tantumene spatii linea promota occupatır, quautum effossus sulcus longitudinis ac latitudinis obtinet. Atque id genus praparandi soli proba. tissimum est.

XIV. Sequitur opus vinea conserendac, quae vel vere vel antmuno temprestive deponitur. Vere melius, si aut pluvius aut fi igidus status cxli cst, aut ager pinguis, [ aut est gras ou que ce soit une eampagne plate et humide; dans l'automne au contraire, si le climat est sec ou chaud, si c'est une eampagne de petite qualité et aride, ou que ee soit une colline maigre ou esearpée. La plantation du printemps se fait pendant quarante jours à peu près, depuis les ides de février jusqu'à l'équinoxe; et eelle d'automne depuis les ides d'oetobre jusqu'aux ealendes de déecmbre. Il y a deux façons de planter la vigne, toutes deux également usitées par les eultivateurs; savoir, par mailletons ou par marcottes. Les mailletons sont plus d'usage dans les provinces, parce qu'on ne s'y attache pas à avoir des pépinières, et qu'on n'y est pas dans l'usage de faire venir des mareottes; au lieu que la plupart des eultivateurs d'Italic ont désap. prouvé a vee raison eette méthode de planter par mailletons, parce que la marcotte a bien des avantages sur le mailleton : en effet, elle cst moins sujette à périr que le mailleton, vu qu'clle a plus de force pour soutenir le ehaud, le froid et les autres mauvais temps; de plus, elle eroit plus promptement, d'où il résulte qu'elle est plus tót en état de donner des fruits; et d'ailleurs il n'y a aucun danger à eourir en la transplantant souvent. On peut néanmoins planter très-bien des mailletons en guise de mareottes dans des terres pondreuses et faciles, au lieu que des terres épaisses et dures exigent absolument de la vigne toute faite.

$\mathrm{XV}$. On plante done la vigne dans une terre labourée au pastinum, préalablement nettoyée, hersée et aplanic, en laissant einq pieds d'intervalle entre chaque rangée si le terrain est maigre, et six s'il est médioere : mais il en faut laisser sept dans une terre grasse, afin que le bois de la vigne, qui scra infailliblement diffus et haut daus une pareille terre, trouve un espaeo suffi-

campestris, ] et uliginosa planilies : rursus autumno, si sirca, si calida est aeris qualitas : si exilis atque aridıs campus, si macer praeruptusve collis; vernaque positionis dies fere quadraginta sunt ab idibus Februariis usque in aquinoctium : rursus autumnalis ab idibus Octol. in cal. Decenbres. Sationis autem duo genera, malleoli vel vivi radicis, quod utrumque ab agricolis usnrpatur, et in provinciis magis malleoli. Neque enin seminariis stılent, nec usum habent faciendae viviradicis. Hanc sationen cultores Italia plerique jure improbaverunt, quoniam plurimis du. tibus prastat viviradix. Nam ninus interit, cum et calorem et frigus ceterasque tempestates propter firmitatem facilius sıstineat : deinde adolescit maturius. Ex quo evenit, ut celerius quoque sit temprestiva edendis fructibus : tın etiam niliil dubium est, sæpius translatım. Potest tamen malleolus protinus in vicem viviradicis conseri s0. luta el facili terra. Caterum densa et gravis utique vileu desiderat.

XV. Seritur ergo prius [in] ennndala inoccataque rt arpuata pastinatione, macro solo, quinis pedibus inter adiues omissis; mediocri, senis. In pingui vero septenus 
sant où il puisse s'étendre. Il sera aisé de fairc de la sorte un plan de vignes en quinconce. Il faudra.pour cet effet coudre sur un cordeau des moreeaux de pourpre ou de tout autre drap d'une couleur éclatante, d'espaces en espaces mesurés chaeun par un nombre de pieds égal à la mesure de l'intervalle d'entre les rangées; et lorsque ce cordeau sera ainsi marqué, on le tendra à travers le terrain labouré au pastinum, et l'on fichera en terre des roseaux vis-à-vis chacun des endroits où se rencontreront ces morceaux de pourpre, moyennant quoi on fera ses rangées également espacées. Quand cela sera fait, celui qui doit faire les fosses se mettra à l'ouvrage, et, sautant alternativement un des espaces marqués sur la rangée , il fouillera, depuis un roseau jusqu'à celui qui le suit, une fosse qui n'ait pas moins de deux pieds et demi de profondeur dans les terrains plats, de deux pieds neuf pouces dans ceux qui vont en pente, et même de trois pieds dans ceux qui sont escarpés : ces fosses étant fouillées à cette profondeur, on $\mathrm{y}$ déposera les marcottes, de façon qu'elles soient couchées à l'opposite l'une del'autre depuis le milieu de la fosse, etrrelevées à ses deux côtés opposés près des roseaux. La fonetion de celui qui plantera consistera d'abord à enlever de terre les marcottes avec soin et sans les gâter, à les transporter des pépinières dans le moins de temps possible après les avoirenlevées de terre, et même, si faire se peut, à l'instant précis où il voudra les planter; ensuite à les rogner en entier comme de vieilles vignes, en les réduisant à un seul bois très-fort, et en unis. sant les nœuds et les cicatrices qui s'y trouveront, à en couper même les racines, s'il s'en trouve d'endommagées (accident auquel il faut lien prendre garde lorsqu'on les enlève de terre);

pedum spatia danda sunt, quo largiora vacent intervalla, per quæ frequentes prolixæque materiæ diffundantur. Hæc in quincuncern vinearum metatio expeditissima ratione conficitur. Quippe linea per totidem pedes, quot destinaveris interordiniorum spatiis, purpura vel quolibet alio conspicuo colore insuilur. Eaque sic denotata per repastinatum intenditur, et juxta purpuram calamus defigitur. Alque ita paribus spatiis ordines diriguntur. Quod deinde cum est factum, fossor insequitur, scrobemque alternis omissis in ordinem spatiis a calamo ad proximum calamum non minus altum quam duos pedes et semissem planis locis refodit : acclivibus in dupondium et dodrantem : præcipitibus efiam in tres pedes. In lanc mensuram scrobibus depressis viviradices ita deponuntur, ut a media scrobe singula in diversum sternantur, et contrariis frontibus fossarum ad calamos erigantur. Satoris autem officium est, primum quam recentissimam, et si fieri possit, eodeuı inourento, quo serere velit, de seminario transferre plantan, diligenter exemptan et integram : deiude cam velıt veteranam vitem tolan exputare, et arl unam unateriam firmissimam redigere, nolosqune et cicaltices allevare : si ynix eliam radices, quod maxime carendum est, ne fiat enfin a les arranger, en les courbant de facon que les racines des deux mareottes qui sont dans la mêmc fosse ne s'entrelacent pas mutuellement, ce qu'il sera facile d'empêeher, en disposant au fond des fosses, transversalement et par le milieu, quelques pierres, dont ehacune n'excède pas le poids de einq livres. Ces pierres paraissent servir (ainsi que Magon l'a écrit) à écarter l'eau des racines pendant l'hiver, et à les préserver du chaud pendant l'été. Virgile, d'après cet auteur, preserit de protéger et de fortifier le plant, en ces termes : Metlez au fond de la fosse des pierres qui puissent boire l'eau, ou des coquillages inutiles; et peu après il ajoute : Il s'est trouvé des gens qui chargeaient les racines du poids d'une grosse pierre ou de celui d'une grande brique, pour leur servir de rempart contre les pluies et contre l'ardeur de la Canicule, lorsque cette constellation vient $\dot{a}$ faire gerser les campagnes altérées. L'auteur carthaginois que nous venons de citer prouve que le marc de raisin mêlé avec du fumier donne de la vigueur au plant qui est déposé dans des fosses, parce que le marc le provoque et l'exeite à jeter de nouvelles racines, et que le fumier est bon tant pour entretenir la chaleur dans les fosses pendant les hivers froids et humides, que pour donner de la nourriture et de l'humidité aux plantes pendant l'été. Mais si le terrain dans lequel on plante la vigne parait de petite qualité, il croit qu'il faut aller chercher au loin de la terre grasse pour la mettre dans les fosses: au reste, c'est la cherté des vivres dans un pays, et le prix des journées, qui nous apprendront si cette opération sera avantageuse ou non.

XVI. Une terre, labouréc au pastinum et médiocrement humide, sera bonne pour recevoir

in eximendo, laboraverint, eas amputare : sic deinde cur. vatam deponere, ne duarum vitium radices implicentur. Id enim vitare facile est per imum solum juxta diversa latera fossarum dispositis paucis lapidibus, qui singuli non excedant quinquelibrale pondus. Ili videntur, ut Mago prodit, et aquas hiemis et vapores astatis propulsare radicibus : quem secutus Virgilius tutari semina et muniri sic pracipit : Aut lapidem bibulum autsqualentes infode conchas. Et paulo post : Jamque reperti Qui saxo super atque ingentis pondere testa Urgerent: hoc effusos mu. nimen ad imbres, Hoc ubi hiulca sitifindit Canis astifer arva. Idemque Ponus auctor probat vinacea permista stercori depositis seminilus in scrobe admovere, quod illa: provocent et eliciant novas radiculas : hoc per hiemem frigsentem el liumidam scrobibus inferre calorem tempeslivum, ae per astatem vireutibus alimentun et liumorem prabere. Si vero solım, eni vitis comniltitur, videtus. evile, longius arcessitam pinguem lunum scrobibus inferro censet : quod an expediat, regionis annona operarumqueratio nos docebif.

XVI. Exigue humidum pastinatum sationi convenit; melius tamen vel aridn quan lutoso semen conmittitur : 
le plant; Il vaudra cependant mieux le mettre dans un terrain see que dans un terrain bourbeux ; ct lorsque la partie du plantqui excède la fosse ell dehors se trouvera avoir un trop grand nombre de nouds, on eoupera ee qu'il y en aura de trop par en haut, en ne laissant que deux boutons hors terre, et on eomblera la fosse de terre; ensuite, Iorsqu'on aura aplani tout le terrain labouré au pastinum, on plantera des mailletons entre les mareottes qui sont dans les raugées : il suffira d'en mettre daus l'espaec vacant entre les vignes et sur la même ligne. En suivant eette méthode, les mailletons eroîtront mieux eux-mêmes, et il restera suffisamment de terrain libre pour pouvoir eultiver le plant qui est dans les rangées : c'est eneore pour servir de ressouree qu'on plaeera ees mailletons sur la même ligne que les mareottes, paree qu'on pourra en prendre dans le nombre jour remplacer les mareottes qui viendront à périr. Il faudra inettre einq mailletons dans l'espace d'un pied : mais on laissera un pied de vide sur l'intervalle qui est entre les mareottes, de faẹon que les mailletous les plus voisius des mareottes en soient à une distanee égalé de part et d'autre. Julius Atticus eroit queseize mille mailletons sont suftisants pour une plantation de ectte nature; cependant nous en plantons quatre mille de plus que lui, paree qu'il en périt toujours une grande partic par la uegligenee des cultivateurs, et que plus on met de plant daus, un terrain, plus les aulres herhes inutiles deviennent elair-semées.

XVII. Il s'est élevé d'assez grandes disenssions entre les auteurs sur la faecon de planter le mailleton. Quelques-uus ont eru que le fouet était bon à être planté en entier et tel qu'on l'avait détaelé de sa mère, de faęon qu'ils le partageaient en plusieurs moreeaux de einq bou-

Idque cum supra summam scrobem eompluribus internodiis productun est, quod de cacumine superest, duabus geunis tantum supra terram relictis amputatur, et ingesta humo scrohis completus coxquatur; deinceps pastiuato malleolus ordinariis vitibus interserendus est : cumque sat erit medio spatio, quod vacat inter vites, per unam line, m depangere. Sic enim melius et ipse convalescet, et ordinariis seniubus modice vacuum sulum ad eulturam prabebitur. In eadem deinde linea, in qua vịviradix obtinebit ordinem sum, prasidii causa, quorum ex numero propagari possit in locum demortua vitis, quilıque malleuli pangendi sunt per spatinm pedale: isque pes itumedio in. terordinio sumitur, ut ab utraque vite paribus intervallis distent. Tali consitioni Julius Atticus abunde putat esse malleolorum sexdecim millia. Nos tamen plus quatuor nillibus conserimus, quia negligentia cultorum magna pars deperit, et interitu seminum cxtera, qux virent, rarescunt.

XVII. De positione surculi non minima disputatio fuit inter anctores. Quidant totum flagellum, sicut erat matri detracturn, crediderunt sationi convenire : idque per tons ou mime de six, et qu'un fouet donnalt à lui seul une multitude de boutures qu'ils nettaient toutes en terre. Mais je n'approuve pas eette méthode, et je suis plutôt de l'avis des auteurs qui ont nié que l'extrémité supérieure du bois fût propre à porter du fruit, et qui n'en ont admis que le eôté par lequel il tenaitau vieux sarment, en rejetant d'ailleurs toutes les flèehes. Les paysans donnent le nom de fleehe à l'extrémité supérleure du mailleton, soit paree que ectte partie est la plus éloignée de la nière, et qu'elle semble élancée loin d'elle, soit paree qu'étant effilée par le haut, elle a guelque ressem. blanee avec l'espèee de dard qui porte ee nom. Les agriculteurs les plus avisés ont done déelaré qu'il ne fallait point planter eette flèehe, sans nous donner à la vérité la raison de leur sentiment, sans doute paree qu'étant très-versés dans l'agrieulture, eette raison leur paraissait évidente, etqu'clle sautait aux yeux de tout le monde. En effet, eomme tout pampre, pour peu qu'il soit fécond, produit beaueoup de fruit jusfju'au eillquième ou jusqu'au sixième bouton, et que passé eette distance, tel long qu'il soit, il s'en produit plus, ou ne produit tout au plus que de très-petit raisin, les alleiens ont eu raison d'imputer la stérilitéà l'extrémité supérieure du mailleton. IIs - laissaient aussi au nouveau sarment une partie du vieux, lorsqu'ils plantaient le mailleton : mais l'expérienee a eondamné eette méthode, paree que tout ee qui restait de l'aneicn bois pourris. sait bientôt par l'humidité dès qu'il était enl terre, et que sa eorruption entrainait la perte des raeines tendres qui l'avoisinaient, au m(m) nnt qu'elles eommeneaient à sortir; après quoi la partie supérieure du mailleton se desséchait aussi. Mais, dans la suite, Julius Attieus et Cornćlius Celsus, les plus célèbres auteurs de notre sièele,

gemmas quinas vel etiam senas partiti, complures taleolas terra mandaveruut. Quod ego nimime probo; Imagisque assentior lis anctoribus, qui negaverunt essc idonean frugibus superiorem partem materix, solanque ean, qua est juncta cum vetere sarmento probaveruut, cicte? rum omnem sagittam repudiaveruut. Sagitlan rustici vo. cant novissimam partem surculi, sive quia longius recessit a matre, et quasi emicuit atque prosiluit : sive quia cacı. mine attenuata pradicti teli speciem gerit. Hanc ergo jrudentissimi agricola negaverunt conseri debere : nec tanen semtentia sua rationem nobis prodiclerunt; videlicet quia ipsis in re rustica multum callentibus prompta eral et aute oculos pene exposita. Omnis enim foccundus pampinus intra quintam aut sextam gemmam fructu exulserat, reliqua parte quamvis lungissima vel cessat, vel-perexiguus ostendit racemos. Quấm ob causam sterilitas cacıminis jure ab antiquis incusata est. Malleolus autem sic ab iisdem pangebatur, ut novello sarmento pars aliqua veleris lıacreret. Sed hanc positionem damnavil usus. Nan quicquid ex vetere materia relichun erat; depressu!̣n atgue obrutum celeriter lunnore putrescebat, proximasque 
sc conformant en cela aux Saserna père et fils, coupèrent tout ce qui élait resté de l'ancienne branehe à travers le nœud même dout était sorti le nouveau bois, et ne mirent ainsi en terre que le mailleton uniquement, avec sa partie qui déborde par en bas.

XVIII. Mais Julius Attieus n'enfoncait en terre ces mailletons qu'après en avoir plié et recourbé la tète, afin qu'ils n'échappassent pas au pastinum. C'est le nom que les agriculteurs donıent à l'iustrument de fer à deux cornes avec lequel ils enfoncent en terre le plant, et c'est de ce mot qu'est venu celui de repastinato, appliqué aux anciennes vignes qu'on a vait arrachées pour les replanter : car c'était le terme propre dont on se servait pour désigner un vignoble ancien qu'on avait remis de nouveau en vignoble, au lieu qu'aujourd'hui, par un usage qui prouve l'ignoranee où l'on est de l'antiquité, on' appelle repastinalus tout terrain que l'on prépare par le labour à recevoir des vignes. Mais revenons a notre but. La facon de planter de Julius Atticus est vicieuse à mon avis, en ce qu'elle admet un mailleton dont la tète est tortillée; et il y a plusieurs raisons qui dọivent déterminer à l'éviter. Premièrement, toute plante qui a été tourmentée et brisée, a vant d’ètre déposée en terre, ne vient pas si bien que si clle y eût été déposée entière, et sans avoir souffert aucune altération; ell second lieu, une plante que l'on a recourbée et rclevée vers le haut de la terre en l'y déposant, s'oppose, comme pourrait faire un croc, aux efforts du fossoyeur, lorsque le temps est venu de l'enlever; et il semble que ce soit un croehet ficlsé cn terre, qui se cassc plutôt que de se laisser arraeher. En effet, le bois est facile à se rompre du côté par lequel on l'a tordu et recourbé en le met-

radices teneras et vixdum prorepentes vitio suo enecabat : quod cum acciderat, superior pars seminis retorrescebat. Mox Julius Atticus et Cornelius Celsus, ælatis nostræ celeberrini auctores, palrem atque filium Sasernam secuti, quicquid residui fuit ex vetere palına per ipsaın comınissuram, qua nascitur materia nova, resecuerunt, atque ita cum suo capitulo sarmentum depresserunt.

XVIII. Sed Julius Atticus præetorto capite et recurvato, ne pastinum effugiat, pradictum semen demersit. Pastinunı autem vocant agricola ferramentum bifurcum, quo senniıa panguntur. Unde etiam repastinari dictæe sunt vivese veleres, quæ refodiebantur. Hæec enim propiria appellatio restibilis vineti erat; uune anliquitatis imprudens consuetndo quicuuid emoti soli vineis praeparatur, repastinatum vocat. Sed [ redeamus] ad propositum. Vitiosa est, ut mea fert opinino, Julii Attici satio, quxe coutortis cajpitilus malleolum recipit; ejusque rei vitanda non una ralio rst. Primum quod nulla stirps ante quaun deponatur vexata ct infracta melins provenit, quam qux integra et inviolata sine injuria deposita esl : deiude quicquid recurvmın et sursmu versus sjectans demersum est, cmn tempestivum : xunitur, in usulum laani repuguat obluctanti fossori, et tant en terre, alteudu que c’est le cóté par lequel il a souffert : c'est aussi ce qui fait qu'il perd la plus grande partie de ses racines, qui se brisent. Mais quand je passerais sous silence ces inconvénients, en voiei au moins un que je ne puis dissimuler, et qui s'oppose le plus à cettc méthode : en parlant tout à l'beure de l'extrémitć supéricure dusarment, que je disais qu'on appelait la flèehe, j'avais tiré cette conséquence-ci, savoir, que le fruit ne paraissait guère qu'entre les cinq ou six boutons les plus voisins du vieux sarment. Or, en reployant le mailleton, on en perd précisément cette partie, qui est cependant la partic féeonde, parce que le côté qui est reployé emporte à lui seul trois ou quatre boutons, et que les deux ou trois autres yeux qui peuvent encore rapporter du fruit sont entièrement enfoneés sous terre, où, restant ensevelis, ils ne donnent point de bois, mais seulement des racines : par où il arrive qu'en plantant des mailletons, nous tombons dans le même inconvénient que nous cherehions à éviter, en défendant de planter la partie du mailleton appelée la flèche. Nous nous trouvons dès lors forcés de les fairc plus longs, si nous voulons les ployer $\mathrm{cn}$ les plantant : or il est certain qu'en les faisant plus longs, on y laisse les boutons les plus voisins de l'cxtrémité supérieure, tout stériles qu'ils sont ; moyennant quoi il n'en provient que de ces pampres stériles, ou au moins peu fertiles, quo les paysans appellent racemarii. Que vous diraije encore? qu'il est très-intéressant que le mailleton que l'on met en terre prenne racine à l'endroit même par lequel il teuait à sa mère, et qu'il se cicatrise promptement? En effet, s'il ne se cicatrise pas promptement, il attire trop d'eau à travers la moelle qui se trouve à jour, comme à

velut uncus infixus solo, ante quam extralıatur, prarumpitur. Nan fiagilis est ea parte materia, qua torta et re. curvata, cuın deponeretur, ceperat vitium. Propler quuorl prafraclam majorem partem radicum amittit. Sed ut in. commoda ista prateream, certe illnd, quod est inimicissimum, dissimulare nequeo; nam paulo ante, cum de summa parte sarmenti disputarem, quam sagittam dixeram rocitari, colligebam fere intra quintam vel sextan gemman, qua sint proxima reteri sarmento, fructum edi. Ilanc ergo foecundan partem consumit, qui conturquet malleolum ; quoniaun et ea pars, quæ duplicatur, tres gemmas vel quatuor obtimet, et reliqui duo vel tres fructuarii oculi penitus in terram deprimuntur, mersique non materias sed radices creant. Ita evenit, ut yuorl in sagilta non serenda vitaverimus, id sequamur in ejusmodi ntal. leolo, quem necesse est facere longiorem, si volumus de. lortum depangere. Nec dubhum, quin genme cacumiui proximx, qux sunt infecundx, in eo relinfquantur, ex quibus pampini pullulant vel sleriles vel certe minus feraces, quos rustici vocant racemarios. Quid? quod jluri numu interest, ut malleolus, qui deponitur, cal part: " pua est a matre decisus, coalescat, et celeriter cicalricem du- 
travers un tuyau ; ensuite de quoi cette eau ereuse le trone, et forme par ees creux des retraites aux fourmis et aux autres animaux qui font poulrir le pied des vignes : or e'est préeisément ee qui arrive au plant qu'on a ployé en le mettant en terre; car, eomme on l'a entièrement brisé dans sa jartie inféricure lorsqu'on l'a arraché de la mère, il a la moelle à jour au moment qu'on le met en terre; et les eaux venant à s'y insinuer, ainsi que les animaux dont je viens de parler, il vieillit promptement. Ainsi la meilleure facon de planter un mailleton est de le planter droit : aussi bien, dès que sa tête est insérée entre les cornes du pastinum, il est aisé de la retenir dans la gorge étroite de cet instrument et de l'enfoncer en terre; et ce sarment ainsi planté prend bien plus tôt raeine, attendu que eette manœuvre ne l'empêehe pas d'en jeter par sa tête, qui est le eôté par lequel il a été coupé, et que, lorsque ces racines sont erues, elles aident à cicatriser la plaie; d'ailleurs cette plaie même, qui se tronve tournée vers le bas de la terre, ne reçoit pas tant d'eau que si elle était reeourbée et relevée en haut, et qu'elle laissât filtrer à travers la moelle du mailleton, comme à travers un entonnoir, toute l'eau de la pluie qui viendrait à tomber sur elle.

XIX. La longueur qu'il faut donner à un mailleton n'est point fixe, paree qu'il doit être plus court quand il a beaucoup de boutons, et plus long quand il en a moins. Cependant il ne doit pas avoir plus d'un pied de longueur, ni moins de neuf pouees; plus petit, il ne serait qu'à fleur de terre, et par conséquent souffrirait de la soif pendant l'été; plus long, il serait trop profondément en terre, et dès lor's on aurait trop de difficulté à l'enlever par la suite, lorsqu'il aurait pris sa croissanee : encore eette méthode est-elle

cat ? Nam si id factum non est, velut per fistulam, ita per apertam vitis uedullam nimius lummor trahitur, idemıłne truncum cavat : unde formicis aliisque animalibus, quxe putrefaciunt crura vitium, latebra prabeutur. Hoc autem cvenit retortis seminibus. Cum enim per exemptionem inæ partes eorum prafracta sunt, aperta medulla deponuntur atque irrepentibus aquis pradiclisque animalibus ce. leriter senessunt. Quare pangendi optima est ratio recti malleoli, cujus imum caput, cum consertum est bifurco pastini, angustis faucibus ferramenti facile continetur ac leprimitur : idque sarmentum sic depressum citius coales(it. Nam et radices e capite, qua recisum est, emittit, exejue cum accreverunt, cicatricem obducunt, et alioquin plaga ipsa deorsum spectans nou tantum recipit lumorem, quantum illa, qux reflexa et resupina more infundibuli per medullam transmittit quicquid aquarum cxelestium superflıxit.

XIX. Longitudo, quæ debeat esse malleoli, parum certa est, quoniam sive crebras gemnas labet, brevior facien. dus est : seu raras, longior. Attamen nec major pele nec dodrante nirior tsse dehet : lic ne per summa terra sitiat astatibus ; ille ne depressus altius cum adoleverit, exemp. pour les plats pays, car l'on peut en planter d'un pied et une palme de longueur dans les terrains montueux, où la terre est sujette à s'ébouler. Nous en plantons au eontraire dans les vallées et dans les plaines humides qui n'ont que trois bourgeons, e'est-à-dire un peu moins de neuf pouces, mais cependant plus d'un demi-pied. On les appelle trigemmes; non pas qu'ils n'aient strietement que trois bourgeons, puisqu'ils en fourmillent ordinairement aux environs de l'ineision qu'on leur a faite pour les séparer de leur mère, mais parce qu'il ne leur reste que trois jointures et autant de bourgeons, en ne eomptant point eeux qui foisonnent sur leur tête. J'ajouterai à tous ces préceptes qu'il faut que tout homme qui plante des mailletons ou des mareottes évite le trop grand vent, comme le soleil, s'il ne veut pas que ees plantes se dessèehent. On pourra les préserver avec quelque sueeès de ec double danger, en mettant au devant un moreeau d'étoffe ou tout autre genre de eouverture assez épaisse pour les en garantir ; mais il vaut encore mieux ehoisir, pour faire ees plantations, un jour qui soit sans aueun hâle de vent, ou du moins où le vent soit léger : ear, pour le soleil, il estaisé de les en garantir en leur procurant de l'ombre. Voiei encore quelques objets dont nous n'avons point parlé, et sur lesquels il est à propos de dire un mot avant de terminer ee traité : ees objets eonsistent à savoir s'il y a de l'utilité à avoir de plusieurs espèees de vignes; s'il faut, dans le eas où l'on en aura plusieurs, les séparer et les distinguer l'une de l'autre, ou les confondre et les mêler ensemble. Nous allons eommencer par résoudre la première de ees questions.

$\mathbf{X X}$. Pour répondre à cette question, un agrieulteur avisé doit planter la vigne qu'il croira

tionem difficilem prabeat. Sed hæc in plano. Nam in clivosis, ubi terra decurrit, potest pelmipedalis deponi. Vallis et uliginosi campi situs patitur etiam trigemmem, qui est paullo minor dodrante, longior utique semipede. Isque non ab eo trigemmis dictus est, quod omnino trium ocı. lorum est, cum fere cirea plagam, qua matri abscisus est, plenus sit gemmarum; sed quod his exceptis, quibus est frequens in ipso capite, tres deinceps articulos totidemijue gemmas labet. Super cxtera illud quoque sire malleolum sive viviradicem serentem pramoneo, ne semiua exarescant, immodicum ventum solemque vitare, qui uterque non incommode arcetur objectu vestis aut cujuslibet densi tegminis. Veruntamen præstat eligere sationi silentis vel certe placidi spiritus dien. Nam sol umbraculis facile depellitur. Sed illud etiam, quod nondum traclidimus, ante quam disputationi clausulami imponanus, dicendun est ; uniusne an plurinm generum vites labendac sint, exque separata ac distinct $x$ specialiter, an confus $x$ et nist $x$ ca. tervatim. Prius disseremus de eo, quod primum proposuimus.

XX. Prudentis igitur agricola est vitem, quan præcipue probaverit, nulla interveniente alterius notie stirpe 
la meilleure, sans la mélanger d'aucune autre espèce, et en augmenter toujours la quantité le plus qu'il pourra; mais un agricultcur prévoyant doit en planter de différentes espèces, parce qu'il n'y a jamais d'année assez douce ni assez tempérée, pour qu'il ne se trouve aucune cspèce de vignes qui soit dans le cas de souffrir : car si l'année est sèche, la vigne qui a besoin d'humidité souffre; si elle est pluvieuse, c'est celle à qui il faut de la sécheresse qui souffre; si ellc est froide et sujettc aux brouillards, c'est celle qui ne peut supporter les vents brûlants; et si elle est chaude, c'est celle à qui la chaleur ne vaut rien. Mais, sans entrer jei dans le détail des dommages que peuvent causer aux vignes tous les temps différents qui sont à l'intini, on peut dire en général qu'il y a toujours quelque chose qui leur nuit: d'où il arrive que, si nous n'en avons planté que d'une seule espèce, et que le temps qui est funeste à cette espèce se fasse sentir, nous serons absolument privés de vendange, puisque, faute d'avoir différentes espèces de ceps, nous n'en aurons point qui nous servent de ressource; au lieu que, si nous avons formé des vignobles de différentes espèces de vignes, il s'en trouvera infailliblement quelques-unes, dans le nombre, qui, n'ayant point souffert, porteront du fruit. Cependant ce motif ne doit point nous faire multiplier à l'infini les différentes espèces de vignes; et il suffira que nous en ayons le plus que nous pourrons de celles que nous aurons jugées les meilleures, ensuite de celles qui en approcheront le plus, et enfin d'une troisième ou même d'une quatrième espèce : de façon que nous nous en tenions à une bande, pour m'exprimer ainsi, de quatre vignes de ehoix, parce qu'il suffit de tenter la fortune par la voie de quatre sortes de vendanges, ou de eing tout au plus. Quant à la seconde question que j’ai proposée, je ne

conserere, numerumque quam maximum ejus semper algere. Sed et providentis est diversa quoque genera deponere. Neque enin unquam sic mitis ac temperatns est anıus, ut nullo iuconumodo vexet aliquod vitis genus. Sive enim siccus est; id quod lummore proficil, contrista. tur : seu pluvius; quod siccilatibus gandet : seu frigidus et pruinosus; quod non est patiens uredinis : seu fervens; 'juod vaporem non sustinet. Ac ne nunc mille tempesta. tum injurias persequar, senıper est aliquid, quod vineas offendat. Igitur si unum genus severimus, cum id acciderit quod ei noxium est, tota vindemia privabimur. Neque enim ullum erit subsidium, cui diversarum notarum stirpes non fuerint. Quod si varii generis vineta fecerimus, aliquill ex is inviolatum erit, quorl fructum perferat. Nec tamen ea causa nos debet compellere ad multas vitium varietates : sed quod judicarerimus eximium genus, id quantx possumus multitudinis efficiamus; deinde qutor proximan a prinю: tum cuod est tertie notx vel quartae quoque : eatenus velut athletarım quodam contenti siınıs tetradio. Satis est cuim per quatuor vel sum!num quin'pue doute point qu'il ne faille distribuer les vignes par classes, et en arranger chaque espèce dans des carrés particuliers, séparés les uns des autres, ainsi que les différentes classes, par des sentiers et des chemins plus ou moins larges. Si je suis convaincu de la nécessité de cette méthode, ce n'est pas que j'aic pu gagner sur mes gens de s'y conformer, ni qu'avant moi elle ait jamais été suivie par aueun de ccux qui l'out le plus approuvée. Car il faut convenir que cest la plus difficile de toutes les opérations rustiques, parce qu'elle demande une très-grande attention dans le choix du plant, et quelque counaissance dans le discernement des espèes ; dcux choses qui supposent ordinairement un trèsgrand bonheur et une prudence consomméc. Néanmoins, quoiqu'il arrive quelquefois (comme dit le divin Platon) que nous nous laissions séduire par la beauté d'une chose qui nous a frap. pès, et que nous nous décidions à courir après elle, sans que l'infirmité de la nature humaine nous permette de l'atteindre, nous pourrons parvenir à ce que nous proposons ici, sans de grandes difficultés, pour peu que nous vivions assez longtemps, et que nous réunissions la seience et les facultés avec la boune volonté. Il faut, à la vérité, persévérer dans le même projet pendant une portion assez considérable de notre vie, si nous voulons parvenir à discerner au bout de quelques années un grand nombre de vignes, d'autant que tous les temps ne sont point favorables pour s'occuper de ce disceluement : car il y a des vignes que l'on ne peut distinguer ni à leur couleur, ni à leur tronc, ni à leurs fouets, parce qu'il ne s'y trouve aucunc différence; au lieu qu'on les distingue trèsbien à leur fruit quand il est mûr, et à leurs feuilles. Je n'oserais eependant pas assurcr que tout autre que le chef de famille lui-même puisse

genera vindemix fortunam opperiri. De altero, quod mox proposueram, nilhil dubito, quin per species digerendas vites disponendoque sint in proprios lortos, senitis ac decumanis distinguendæ: non quod aut ipse potuerim a meis familiaribus hoc obtinere, aut ante me quisquam eormun, qui quam maxime id probaverit, effecerit. Est enim omuinur rusticorunı operum difficilimum, quia et summam diligen. tiam legendis desiderat seminibus, et in lis discernendis maxima plerumque felicitate et prudentia opus est ; sed ill. terdum (quod ait divinus auctor plato) rei nos pulcluritudo tralit vel ea consectandi, qua propter infirmitatem commortalis natura consequi nequeamus. Istud tamen, si atas suppetat ef scientia facultasque cum voluntate congruant, non agerrime perficiemus : quamvis non minimo xtatis spatio perseverandım sit, ut magnus numerus per aliquot annos discernatur. Neque enim onne tempus permittit ejus rei jndıcium; naın vites, qua propter similitıdinem coloris aut trunci hagellormuve dignosei nequenut, maturo fructu foliis(yue declarantır. Quaın tanen diligenr tian nisi per ipsum patrem familias exhiberi posse now 
apporter toute l'attention nécessaire pour cela : en effet, il n'y a qu'un homme négligent qui puisse s'en rapporter à son métayer, ou mème à son vigneron; d'autant qu'il y a encore aujourd'hui très-peu d'agriculteurs qui sachent faire le discernement des ceps de raisin noir, quoique ce discernement dépende sans contredit do la plus simple des opérations, puisque l'homme le moins attentif peut aisément distinguer la coulcur des grappes.

XXI. J'ai cependant un moyen à donner pour parvenir en très-peu de temps à ce que je viens de proposer, au cas que l'on ait déjà d'anciens vignobles : il consiste à planter dans des carrés séparés des mailletons de toutes les différentes espèces de vignes dont ils auront été tirés; moyenuant quoi je ne doute point qu'on ne retire en peu d'années plusieurs milliers de mailIctous de ces pépinières, et que l'on ne soit à même par là de faire des plants de vignes différentes, et distribuées par cantons. II y a plusieurs motifs d'utilité qui peuvent nous déterminer à prendre ce parti : le premier, pour commencer par les plus légers, consiste $^{\circ}$ ell ce que dans toutes les opérations de la vie, je ne dis pas seulcment par rapport à l'agriculture, mais encore par rapport à tout autre art, les choses qui sont distinguées par leurs espèces pirticulières charment bien plus un connaisseur que celles qui sont comme jetées au hasard çà et là, et confondues, pour ainsi dire, en tas : le second consiste en ce qu'un homme, venant à jeter les yeux sur une terre plantée comme il faut, nc pourra s'empêcher, si pcu versé qu'il soit daus In vie rustique, d'admirer avec un plaisir extrême la bonté de la nature, lorsqu'il verı́a d'un côté des vignes Biturica chargées de fruits, de l'autre des helvolce qui ne leur céderont en rien, ici des arcelacce, là des spionice ou des basi-

affirmarerim. Nam credidisse villico vel etiam viuitori, socordis est, cum, quod longe sit facilius, adhuc perpau• cissimis agricolis contigerit, ut nigri vini stirpe carcant, quamvis color ura possit vel ab imprudentissimo depreliendi.

XXI. Illa tamen una mili ratio suppetit, celerrime quod proposuimus efticiendi, si sint veteranæ vincx, ut separatim surculis cujusque generis singulos hortos inseramus : sic paucis annis multa nos millia malieolorum ex insitıs percepturos, atque ita discreta scmina per regiones consi. turos uiluil dubito. Ejus porro facienda rei nos utilitas multis de causis compellere potest : et ut a levioribus incipiam, primum, quod in omni ratione vita non solum agricolationis sed cujusque disciplinæ prudentem delectaust impensius ea, quæ propriis geueribus distinguuntur, quam quax passim velut abjecta et quodam acervo confusa sunt. Deinde quod vel alicnissimus rusticx vita, si in agrum teurpestive [cousitum] veniat, summa $\mathrm{cum}$ voluptate nafurae bcuignitatem uiretur, cuu istinc Biturice fructibus opinix, linc pares iis leelvolx respondeant : illinc arceli- licce, qui feront leur pendant; et qule la terre qui portera toutes les années ces fertiles productions, semblable à une mère perpétuellement grosse, présentera aux mortels son sein rempli de moût pour les nourrir. Au milieu de ec speetacle, il verra briller l'automne chargé de tous còtés dc fruits de toutes les couleurs, et secondé par Bacchus portant ses pampres courbés sous le raisin blanc, jaune, rougc, et brillant par son éclat pourpré. Mais, quelque plaisir que ces objets soient capables de causer, l'utilité l'emportera encore sur l'agrément. En cffet, lc chef de famille trouvera d'autant plus de plaisir à venir à sa terre, pour assister au spectacle que lui présen tera son propre bicll, que ce spectacle sera plus riche; et ee que le poëtc dit de Bacchus, que tout devient beau partout oil il porte ses regards, pourra s'appliquer à lui-même, puisque les fruits foisonnent toujours en plus grande quantité quand le maître est présent, et dans tous les lieux où ses regards se portent souvent. Mais je ne m'en ticns pas à cet avantage, qui peut avoir égalcment licu à l'oceasion des vignes même qui ne sont pas séparées par espèces; et je passe à d'autres avantages plus essentiels, qui résulteront de leur distribution par classes. Toutes les différentes espèces de vignes ne délleurissent pas également, et ne parviennent pas dans le même temps à leur maturité. C'est pourquoi il devient absolument nécessaire que ceux dont les vignobles ne sont pas distribués par différentes espèces essuient de deux inconvénients l'un, ou qu'ils recueillent le fruit tardif avec le fruit hâtif, ce qui fera tourner leur vin à l'aigre, ou que s'ils attendent que le raisin tardif soit mûr, ils perdent la vendange du raisin hâtif, qui, étant exposé aux ravages occasionnés par les oiseaux, par les pluies et par les vents, finira communément par être dévasté. S'ils veulent au contrairc

cre, rursus illine spionix basilicave conveniant, quibus alma teliıs annıa vice velut aterno quodam puerperio lieta mortalibus distenta musto demittit ubera. Intcr qua patre favente Libero foetis palnitilıus vel gencris alli vel flaventis ac rutili vel purpureo nitore micantis, undique versicoloribus pomis gravidus collucet autumnus. Sed haxc quamvis plurimum delectent, utilitas tamen vincit volu. ptatem. Nam et pater familias libentius ad spectaculun rci sux, quanto est ca luculentior, desccndit; ct, quod de sacro numinc poeta dicit, $E t$ quocunque deus circum caput egit honestum, verum quocunquc domini prasentis oculi frequenter accesscre, in ea parte majorem in modum fructus exulscrat. Sed omitto illud, quod indescriptis etiam vitibus contingcre potest : illa qux sınt mavine spectanda, persequar. Diversa nota stirpes nec paritir deflorescunt, nec ad matuı itatcm simul perveniunt. Quau oh causam, qui separata generibus vineta non irabel, patiatur alterum incommodum nccesse est, ut aul serum fructum cum pracoque elevet, qua res nox acorcm firil; ant si maturitatem serotini expectet, anitlat vindemiun 
rectacillir le fruit de chaque espèce de vignes à part, et chacun dans leur temps, il faut d'abord qu ils s'cxposent au hasard d'ètre trompés par les vendangeurs, pareequ'ils ne pourront pas leur donner ả eliacun un chef pour les observer, et pour leur ordouner de ne pas cucillir le raisin vert avec le mûr. II arrivera en outre que le raisin, quoiqu'à son point de maturité, se trouvant mélangé de diffẻrentes espèces, ne pourra jamais se conserver longtemps, parce que le goût du meilleur sera corrompu par celui du plus mauvais, et que lc goût de plusieurs se trougera réuni en un seul. Dès lors, l’agriculteur sera contıaint par la nécessité de presser la vente de son vin; au lieu qu'il gagnerait beaucoup plus s'il pouvait la diffèrer jusqu'à l'annéc expirée, ou du moius jusqu'à l'été. Cette séparation des vignes par classes a encore d'autres commodités considérables, qui consistent en ce que le vigneron fera plus aisément la taille de chacune, quand il saura de quelle espècc de vignes sera couvert le carré qu'il aura. à tailler; au lieu que cette opération est d'une exécution très-diffleile dans les vignobles de différents plants, parce que la taille se fait le plus souvent dans un temps où les vignes n'ont pas même de feuilles sensibles, auxquelles on puisse les reconnaitre. Il importe encorc beaucoup que le vigneron laisse plus ou moins de bois aux vignes, suivant la nature de chaque espèce différente, et qu'il les excile en leur laissant de longs fouets, ou qu'il les réprimc en les taillant de court. Bien plus, le côté du ciel vel's lequel sera tournéc chaque espèce de vignes n'est pas un point moins important : car toutes les vignes ne se plaisent point dans une position chaude, non plus que daus une position froide; ct chaque cep a, au contraire, sa vertu parti-

præcoquem, quæ plerumque populationibus volucrum pluviisque aut ventis lacessita dilabitur. Si vero interjectionibus capere cujusque generis fructum a veat, primum necesse est, ut negligentix vindeniatorum aleam subcat: ueque eniu singulis totidem antistites lare potest, qui observent, quique pracipiant, ne acerba ura [cum maturis] denetantur: deinde etiam quarum vitium maturitas competit, cunı diversa uotx sint, melioris gustus ab deieriore corrumpitur, confususque in unum multarum sa. por vetustatis impatiens fit. Atque ideo necessitas cogit agricolam musti annonan experiri : cum plurimum pretio accedat, si venditio vel in aunum vel in astatem certe differri possit. Jam illa generum separatio summam commoditatem habet, quod vinitor suam caique facilius puta. tionein reddet, cum scit cujus tota sit hortus, quem de. putat : idque in vineis consenineis observari difficile est; quia major pars putationis per id tempus aduinistratur, quo vitis neque folium notabile gerit. At multum interest, pituresne an pauciores materias pro natura cujusque stir. jis vinitor summittat, prolixisne flagellis incitet, an angusta putatione vitem coerceat. Quin etian quam corli fartem spectel genus quodque vineti plurinum refert. culière, qui fait que les uns se fortiflent au midi parce que le froid les fatiguc, que les autres cherchent le côté du septentrion parec qu’ils souffrent du chaud, ct que quelques-uns sc plaisent dans la température modéréc soit de l'oricıt, soit du couchant. Or, quiconquc met à part les diffèrentes espéces de vignes dans des carrés différents, observe toutes ces varićtés d'après la situation et l'assiettc des lienx. Il en retire cncore un autrc avantage qui n'est pas peu considérable, et qui consiste en ce qu'il a moins de peine à vendanger, et qu'il lui en coûte moins dc frais. En effet, on cueille à temps, dans ce cas-là, le raisin qui mûrit le prenier, ct on diffèrc, sans aucun ïnconvénient, de cueillir celui qui n'est pas encore mûr; de sorte que le raisin qui est mûr depuis longtemps ne se joint pas avec celui qui n'est qu'à son point, pour fail'c précipiter la vendange, et pour forcer de louer un grand nombre de journaliers à quelque prix quc cesoit. Voici encore un avantage considérablc qui en résulte : c'est que l'on peut serrer et mettre à part le vin de chaque goût différent, sans lc mélanger ct dans toute sa pureté, soit qưil soit fait avec du raisin Bituricus, soit qu'il soit fait avec du basilicus ou du spionicus; et que ces différents vins étant ainsi serrés, comme il ne s'y trouve point de qualités disparates qui les empêchent de se conserver, ils acquièrent du renom en vicillissant, leur goût cessant d'avoir rien d'ignoble après quinze ans ou un peu plus, puisque c'est le temps après lequel presque tous les vins sont au point de ne plus acquérir que dc la bonté, à mesure qu'ils vieillissent. Il est donc très-utile, comme nous nous sommes proposé de le prouver, dc séparer les unes des autres les différentes espèces de vignes. Si on ne peut pas

Neque enim omne calido statu, nec rursus frigido letafur; sed est proprietas in surculis, ut alii meridiano axe convalescant, quia rigore vitiantur; alii Sententrionem desiderent, quia contristantur astu; quidam temperamento lactentur Orientis rel Occidentis. Ilas differentias servat pro situ et positione locorum, qui genera per lıortos separat. Illam quoque non exiguam sequitur utilitatem, quod et laborem vindemine minorem patitur et sumptum. Fam ut quxque maturescere incipiunt, tempestive leguntur, et quæ nondum maturitatem ceperunt uvæ, sine dispendio differuntur. Nec pariter vietus atque tempestivus fructus pracipitat vindemiam, cogitque plureis operas quantocunque pretio conducere. Jam et illud magna dotis est, posse gustum cujusque generis non mistum, sed vere merum condere ac separatim reponere, sive est ille Bituri. cus seu basilicus, seu spionicus. Quar genera cum sic diffusa sunt, quia uihil intervenit diversa naturæ, quod re. pugnet perpetuitati, nolilitautur. Neque euim post annos quindecim vel paulo plures depretıendi potest ignobilitas in gustu : quoniam fere omne visum eam qualitatem sor. titum est, ut retustate acquirat bonitatem. Quare, ut di. cere instituimus, utilissima est generum dispositio; quam 
cependant y parvenir, il y a un second procédé à suivre, (quí eonsiste à ne planter ensemble de différentes espèees de vignes que celles qui produiront du raisin d'un même goût, et qui mûrira dans le même temps. On peut aussi, si l'on a du goût pour les fruits, planter des têtes de figuiers, de pommiers et de poiriers à l'extrémité des rangées, pourvu qu'on n'en mette que sur les lisières du vignoble qui sont exposées au septentrion, de peur que quand ees arbres seront venus, ils nombragent trop les vignes : on les greffera lorsqu'ils auront deux ans, ou bien on les transportera quand ils seront déjà forts, pourvu qu'ils soient de bonne qualité. Voilà pour ee qui coneerne la plantation des vignes. Reste la partie la plus importante, je veux dire celle qui coneerne leur eulture : partie que nous traiterons au long dans le volume suivant.

\section{LIVRE QUATRIEME.}

Vous dites, P. Silvinus, que lorsque vous eûtes fait à plusieurs amateurs d'agrieulture la leeture du livre que j'ai eomposé sur la plantation des vignes, il s'en trouva quelques-uns qui, en approuvant tous les autres préeeptes que j'ai donnés, en relevèrent un ou deux : premièrement, celui par lequel j'ai voulu que l'on donnat trop de profondeur aux fosses destinées à reeevoir des plans de vignes, puisque j'ajoute neuf pouees à la profondeur de deux pieds fixée par Celsus et par Attieus; secondement, celui par lequel je veux que chaque mareotte n'ait qu'un seul appui; ee qui leur parait peu prudent, paree que ees deux auteurs ont diminué les frais, en permettant d'éearter une mareotte en deux bran-

si tamen obtinere non possis, secunda est ratio, ut diversa notxe non alias conseras vites, quam quæ saporem consimilem, fructumque maturitatis ejnsdem præbeant. Potes jam, si te cura pomorum tangit, ultimis ordinibus in ea vineti fine, qua subjacet septentrionibus, ne cum increverint obumbrent, cacumina ficorum pirorumve et malorum depangere, qua vel inseras interposito biennii spatio, vel si generosa sint, adulta transferas. Hactenus de positione vinearum. Superest pars antiquissima, ut præcipianus ctiam cultus earum, de quibus sequenti volumine pluribus disseremus.

\section{LIBER QUARTUS.}

I. Cum de vineis conserendis librum a me scriptum, $\mathrm{Pu}$. bli Silvine, compluribus agricolationis studiosis relegisses, quosilam repertos esse ais, qui catera quidem nostra præcepta laudassent, unum tamen atque alterum reprehendissent : quippe seminibus vineaticis nimium me profundos censuisse fieri scrobes adjecto dodrante super altitudinem bipedaneam, quam Celsus et Atticus prodiderant; singulasque viviradices singulis adminiculis parum prudenter ches, pour lui taire couvrlr deux appuis sur la même ligned'une rangée. Au reste, ees deux objeetions sont plutôt fondées sur une équivoque que sur un caleul eertain. En effet pour eommencer par répondre à la première, Pourquoi, dans la supposition que nous devions nous eontenter d'une fosse de deux pieds, pensons-nous néanmoins qu'il faille labourer la terre au pastinum plus profondément que nous ne devons planter la vigne? Quelqu'un dira que e'est afin qu'il se trouve sous le pied de la vigne de la terre tendre, et dont la dureté n'écarte pas et ne repousse pas les raeines qui ehereheront à s'y introduire : mais lorsqu'on aura fouillé le terrain à la bêehe, à l'effet d'y faire des fosses à la profondeur de deux pieds et demi, et que l'on aura enfoncé les plantes dans eette terre ainsi remuée, je demande s'il ne se trouvera pas eneore de la terre tendre s ous leurs raeines, puisque la terre de ees fosses sera réellement gonflée à plus do deux pieds et demi de hauteur, attendu que la terre d'un terrain plat est infailliblement plus gonflée lorsqu'elle est fouillée que lorsqu'elle ne l'est pas. D'ailleurs la plantation de quelque plante que ee soit n'exige sûrement pas, généralement parlant, qu'il se trouve sous elle un lit de terre ameublie bien profond; et il suffit, si ce sont des vignes, d'en étendre sous leurs raeines un demi-pied, afin qu'elles y trouvent pour ainsi dire l'hospitalité, et qu'elles y prennent leur accroissement, comme des enfants dans le sein de leur mère. Confirmons eeel par l'exemple des vignes mariées à des arbres : n'est-il pas vrai que, lorsque nous eouchons les mareottes dans les fosses ereusées pour ees sortes de vignes, nous ne mettons que très-peu de terre pulvérisée sous elles? La meilleure méthode est done de la.

contribuisse, cum permiserint iidem illi anctores minore sumptu geminis materiis unius seminis diductis duo continua per ordinem vestire pedamenta : quæ utraque reprehensio a varam magis liabet æstimationem, quam veram. Etenim (ut quod prius proposni, prius refellam) si contenti bipedanea scrobe futuri sumus, quid ita censemus altius pastinare tam lıumili mensura vitem posituri? Dicet aliquis, ut sit inferior tenera subjacens terra, quæ non arceat, nec duricie sua repellat novas irrepentes radiculas. Istud quidem contingere potest etiam, si ager bipalio moveatur, et deprimatur scrobis in regesto, quod est fermentatum, plus dupoudio semisse. Nam semper in plano refusius egesta humus tumidior est, quam gradus soli crudi. Nec sane positio seminum præaltum sibi cubile substerni desiderat : verum abunde est semipedaneam consitis resolutam vitibus terram subjicere, quæ velut hospitali atque etiam materno sinu recipiat incrementa virentium. Exemplun ejus rei capiamus in arbusto, ubi cum scrobes defodimus, admodum exiguum pùlveris viviradici subjicimus. Verior igitur causa est depressius pastinandi, quoniam jugata vineta melius consurgunt altioribus demissa scrobibus. Nam bipedanei vix etiam provincialibus agricolis ap. 
bourer la terre au pastinum bien profondément, parce que les vignes destinées aux jougs s'élèveut davantage à proportion de ce qu'elles sont plantées dans des fosses plus profondes. En effet, les fosses de deux pieds de profondeur sont à peine dans le cas d'ètre adoptées, même par les cultivateurs de province, quoique ceux-ci arrêtent communément leurs vignes très-bas, et près de terre : car, pour les vignes qui sont destinćes au joug, elles doivent être assurées sur des fondements plus profonds, parce qu'elles ont besoin de plus de secours et de plus de terre, dès là même qu'elles doivent monter plus haut; et c'est pour cela que lorsqu'il s'agit de marier la vigne à des arbres, personne ne s'avise de lui faire des fosses qui aient moins de deux pieds de profondeur. Au reste, les agriculteurs tirent peu de profit des principaux avantages résultants d'une plantation peu profonde : en effet, ces avan. tages consistent en ce que le plant se fortifie en moins de temps, parce qu'il n'est pas fatigué par une trop grande charge de terre qu'il ait à porter, et en ce qu'il est plus fertile, par la raison qu'il est plus à la superficie de la terre. Or ces deux raisons, sur lesquelles s'oppnie Julius Atticus, sont réfatées par l'exemple des vignes mariées aux arbres, puisque celles-ci donnent sans contredit des ceps beaucoup plus forts et plus fertiles que les autres, ce qu'elles ne feraient pas, si le plant enterré profondément était dans le cas de souffrir. Que ne pourrais-je pas ajouter à ces obscrvations? Que si d'un côté une terre làourée au pastinum semble se gonfler, comme si elle était en fermentation, au moment qu'elle est ameublie et dilatée, d'un autre côté, peu de temps après le labour, elle s'affaisse en se condensant, et se détache des racines de la vigne, qui dès lors semblent nager sur la superficie du sol : or cetıacident arrive moins souvent dans notre facon de planter la vigne, puisque uous l'enfoncons davantage en terre. Car quant à ce qu'on dit que le plant souffre du froid au fond de la terre, à la véritć nous n'cn disconvenons pas; mais ce ne sera pas une profondcur de deux pieds neuf pouces qui scra capable de produire cet effet, lors surtout qu'ainsi que nous venons de le dirc, nous voyons les vignes marices aux arbres se garantir de cette incommodité, quoiqu'elles soient plantées plus profondément.

II. L'autre opinion dans laquelle ils sont, que l'on épargne des frais en attachaut les foucts d'un seul pied de plant à deux échalas différents, est fausse. En effet, ou le cep de la vigne vient à périr, auquel cas il se trouve deux échalas sans vignes, et dès lors il faut le remplacer par deux marcottes, et ce nombre excédent sera à la charge du caltivateur; ou ce cep vit, auquel cas s'il ne porte que du raisin noir, ou qu'il ne soit pas fertile, comme il arrive souvent, le fruit manquera non pas sur un seul échalas, mais sur plusieurs. Les personnes même les plus avisées en agriculture croient qu'une vigne serait peu fertile, fût-elle de la meilleure espèce, si elle était ainsi divisée sur deux échalas, par la raison que le suc nourricier formerait alors unc espèce de claic. Cest pour cela qu'Atticus lui-mème ordonne de propager les anciennes vignes par sautelle, plutôt que de les coucher tout à fait en terrc, parce que les sautelles prennent aisément racinc en peu de temps, de façon que chacune se trouve avoir ses racines particulières, sur lesqnelles elle cst stable comme sur ses fondements; au licu que lorsque la vigne a été couchée tout de son long en terre, son suc nourricier a plus de chemin à parcourir, une fois qu'elle a embarrassé ct comme fermé de claies le terrain qui se trouve sous elle; outre qu'elle est tourmentée par une trop grande probari possunt, apud quos humili statu vitis plerumque juxla terram coercetur, cum quæ jugo destinalur, altiore fundamento stabilienda sit : et, si modo scandit excelsius, plus alimenti terraeque desideret. $\mathbf{E t}$ ideo in maritandis arhoribus nemo miuorem tripedanea scrobem vitibus com. parat. Cæterum illa parum prosunt agricolarum studio pracipua commoda humilis positionis, quod et celeriter adolescant semina, qua non fatigentur multo soli pressa pondere, fiantque uberiora, qua leviter suspensa sint. Nam utraque ista Julii Altici ratio convincilur exemplo arhustiræ positionis, quæ scilicet multo validiorem fertilioremque stirpem reddit; quod non facerent, si laborareut altius demersa semina. Quid, quod repastinata lumus, dum est recens soluta laxataque, velut fermento quodam intumescit? cum deinde non longissimam cepit retustatem, condensata subsidit, ac velut innatantes radices vitium, summo solo dlestituit? Iloc autem minus accidit nostra sationi, in qua majore mensura vilis demittitur. Nam quod in profundo senina frigore laborare dicuntur, nos quoyue non diffitemur. Sed non est dupondii et dodranlis altitudo, quxe istud efficere possil; cum præsertim, quod pauls ante retulimus, depressior arbustivæ vitis satio tamen effugiat proedictum incommodum.

11. Alterum illud, quod minori impensa duos palos unius seminis flagellis censent maritari, falsissimum est. Sive enim caput ipsum demortuum est, duo viduantur statumiua, et mox viviradices tolidem substituendae sunt, quae numero suo rationem cultoris onerant : sive vivit, el ut sape evenit, vel nigri est generis vel parum fertilis, non in uno sed in pluribus pedamentis fructus claudical: quanquam etiam generosso stirpis vilem sic in duos palos divisam rerum rusticarum prudentiores existimant minus fertilem fore, quia cratem factura sit. Et idcirco veteres vineas mergis propagare potius, quam totas sternere, jdem ipse Atticus procipil : quoniam mergi mox facile radican. tur, ita ut quxque vilis suis radicibus tanyuam propriis fundamentis innitatur. IJaec autem, quae loto est prostrata corpore, cum inferius solım quasi cancellavit atque irreti. 
multitude de raeines, qui sont enchevêtrées l'une a vec l'autre, et sous lesquelles elle sueeombe, de même que si elle était chargéc de beaucoup de branclıes à fruit. Ainsi je préfércrais en tou tpoint, risque pour risque, la méthode de planter deux marcottes à celle de n'en planter qu'une seule, ct j'aimerais mieux ne pas regarder comme un a vantage qu'on doive préférer à tout, ce qui peut oecasionner de bien plus grands dommages dans tous les cas. Mais l'objet que nous avons traité dans le livre précédent exige que nous entamions celui que nous avons promis de traiter dans celui-ci.

III. En quelque genre de dépenses que ce soit, la plupart des hommes, comme dit Græcinus, montrent plus de courage à commeneer une nouvelle entreprise, qu'à la suivre quand elle est aclicvée. Quelques-uns, ajoute-t-il, bâtissent des maisons entières à commencer par les fonde. ments; et lorsque la batisse en est achevée, ils ne les embellissent pas. D'autres fabriquent avec soin des vaisseaux ; et lorsqu'ils sont faits, ils négligent de mème de les équiper et de les fournir l'hommes. Ceux-ci ont la passion d'acheter des bestiaux, ceux-là celle d'acheter des esclaves, et ni les uns ni les autres ne sont sensibles au soin de les entretenir; de mème qu'il s'en trouve beaueoup qui détruisent par leur inconstance les bienfaits qu'ils ont versés sur lcurs amis. Au reste, ne soyons pas surpris de ees exemples, Silvinus, puisqu'il y a bien des gens qui nourrissent avec lésine des enfants nés d'un légitime mariage, qui avaient fait tout l'objet de leurs vœux avant qu'ils les eussent, et qui négligent de leur donner aucune éducation soit du côté de l'esprit, soit du eôté du corps. Que doit-on conclure de là? que communément les cultivateurs tombent aussi dans la même faute, Iorsqu'ayant fait de très-belles plantations de vignes, ils les abandon-

vit, cratem facit, et pluribus radicibus inter se connexis angitur, nec aliter quam si multis palmitibus gravata deficit. Quare per omnia pratulerin dnobus potius seminihus depositis, quam unico periclitari, nec id velut compendinm consectari, quod in utramque partem longe majus afferre possit dispendium. Sed jam prioris libri dispulatio repetit a nobis promissum sequentis exordium.

III. In omni genere impensarum, sicut ait Grxcinus, plerique uova opera forlius auspicantur, quam tuentur perfecta. Quidan, inquit, ab inclıoato domos extruuut, nec praedificatis cultum adlibent. Nonnulli strenue fabricant navigia, uec cousummata perinde instrunnt armamentis ministrisque. Quosdam emacitas in arınentis, quosilam exercet in comparandis mancipiis : de tuendis nula cura tangit. Multi etiam beneficia quae in amicos contulerınt, levitate destrumnt. Ac ne isla, Silvine, miremur, liberos suos monnulli nuptiis votisque quısitos avare nutriunt. mec disciplinis aut cateris corporis excolunt instrumentis. Qufd is colligitur? scilicet plerumque simili genere peccari etiam ab agricolis, qui pulcherrime positas vineas, nent par différents motifs avant qu'elles aient pris leur aecroissement. Les uns ne veulent pas entrer dans des dépenses qui reviennent toutes les années, et se persuadent que le premier revenu, et celul qui est le plus assuré, est de ne rien dépenser, comme s'ils eussent été contraints de planter des vignes, pour les abandonner ensuite par avarice. Il y en a quelques-uns qui simaginent qu'il est plus beau d'avoir de grands vignobles que d'en avoir de bien cultivés. J'en ai même connu un très-grand nombre qui étaient persuadés qu'il fallait cultiver une terre, mais qu'il importait peu qu'on la cultivát bien ou mal. Pour moi, je suis convaineu qu'il n'y a pas de blen de campagne, dequelque nature qu'il soit, qui puisse jamais être profitable, à moins qu'on ne le cultivea vee beaucoup de soin et de capacité; et que cela est encore plus vrai des vignes que des autres natures de biens. Car la vigne est une plante délicate, faible, qui ne peut souffrir rien de ce qui pcut lui nuire, qui communément se consume par trop de travail et de fertilité, et que sa fécondité fait périr, si elle n'est pas modćrée. Cc n'est pas que lorsqu'elle est une fois devenue forte à un certain point, et qu'clle a comme acquis la vigueur de la jeunesse, elle ne supporto alors la négligence du cultivateur. Mais si, lorsqu'ello est jeune, on ne lui fournit pas tout ce qui lui est nécessaire jusqu'à ce qu'elle ait pris sa croissance, elle maigrit cxcessivement, et tombe dans une langueur dont aucunes dépense's ne peuvent plus ensuite la relever. C'est pourquoi il faut l'abord poser, pour ainsi dire, ses fondements avec le plus grand soin, et arranger ses membres dès le premier jour qu'elle est plantée, comme on arrange ceux des enfants qui viennent de naitre; faute de quoi toutc la dépense qu'on. a faite pour elle tombe en pure perte, et quand on aura laissé passer le temps propre à chaque

antequam pubescant, variis ex causis destitunnt : ali sumptum annuum refugientes, et hunc primum reditım certissimum existimantes, inpendere niliil; quasi plane fuerit necesse vineas facere, quas mox avaritia -desererent. Nonnulli magna potius quaın culta vineta possidere pulchrum esse ducunt. Coguovi jam plurimos, qui persuasum lıabe. rent, agtum bonis ac malis rationibus colendum. At ego, cum omne genus ruris, nisi diligenti cura, sciteque exerceatır, frnctıosum esse non posse julicem, tum vel maxime vineas. Res enim est tenera, infirma, injuria ma. xime impatiens, qux plerumque nimia laboret uberlate; consumitur enim, si modım non adhibeas, fœcunditalc sua. Cum tamen aliquatenus sc confirmavit, et veluti juvenile robur accepit, negligentiam sustinet. Novella vere, dum adolescit, nisi omnia justa perceperit, ad ultiman redigitur maciem, et sic intabescit, ut nullis deincers im peusis recreari possit. Igitur sumina cura ponenda sunt quasi fundamenta, et ut membra infantium a primo sla. tim dic consitionis formanda : quod uisi fecerimus, omnis impensa in cassum recidat, nec practermissa cujızque rei 
opération sans la faire, on ne pourra plus le retrouver. Croyez-m'en, Silvinus, d'après mon expérience : une vigne bieu plantée, qui est de bonne espèce et cultivée par un bon agriculteur, récompense toujours avec le plus grand intérêt de l'argent qu'on a dépensé pour elle. C'est ce que ce même Græcinus̄ nous démontre nonseulement par la raison, mais encore par les exemples, dans le livre qu'il a composé sur les vignes, lorsqu'il raconte qu'il a souvent entendu dire à son père qu'un certain Parridius de Vetera, son voisin, avait pour tout bien deux filles et un terrain planté en vignes; qu'après avoir donnè le tiers de ce terrain en dot à sa fille ainée en la mariant, les deux tiers qu'il s'était réservés ne lui produisaient pas une moindre quantité de fruit que le tout aupara vant; qu'ensuite il avait marié sa fille cadette avec la moitié de ce qui lui était resté de ce fonds, et que ce second partage n'avait pas encore diminué le revenu qu'il tirait du fonds entier dans le principe. Quelle conjecture cet auteur prétend-il tirer de ce fait, si ce n'est que la dernière portion du fonds qui resta en sa possession fut mieux cultivée par la suite, que le fonds entier ne l'avait été d'abord ?

IV. P. Silvinus, plantons des vignes avec beaucoup d'ardeur, et appliquons-nous encore davantage à les cultiver. La seule façon de les planter qui soit très-avantageuse, est celle que nous avons donnée dans le premier livre, et qui consiste à les coucher en terre dans des fosses creusées sur un terrain labouré au pastinum, à peu près depuis le milieu de la fosse jusqu'à ses extrémités, où elles seront ensuite relevées perpendiculaírement, et attachées à des roseaux. II faut surtout prendre garde que ces fosses n'aient la forme d'une auge, et avoir soin au contraire que leurs bords soient bien perpendiculaires, et que

tempestivitas revocari qu cat. Experto mihi credc, Silvine, bene positam vineam bonique generis et bono cultore nunquam non cum magno foenore gratiam reddidisse. Idque non solum ratione sed etian exemplo nobis idem Gracinus declarat eo libro, quem de vineis scripsit, cum refert ex patre suo sæpe se audire solitum, Paridium quendam Veterensem vicinum suum duas filias et vineis consitum labuisse fundun; cujus partem tertiam nubeuti majori filiæ dedisse in dotem, ac niliilo minus rque magnos fru. ctus ex duabus partibus ejusdem fundi percipere solitum. Minorem deinde filiam nuptum collocasse in dimidia parte reliqui agri, nec sic ex pristino reditu detraxisse. Quod quid convincit? meli us scilicet postea cultam esse tertiam illam fundi partem, quam antea universam.

IV. Et nos igitur, Publi Silvine, magno animo vineas ponamus, ac majore studio colamus. Quarum consitionis sola illa commodissima ratio est, quam priore tradidimus exordio, ut facta in pastinato scrobe, vitis a media fere parte sulci prosternatur, et ad frontem ejus ab imo usque recla nateries exigatur, calamoque applicetur. Id enim praccipue observandum est, ne similis sit alveo scrobis, les angles en soicut bien prononcés. Car si la vigne n'est que penchée, et comme appuyée sur les bords d'une auge, elle est en butte aux blessures qu'on peut lui faire lorsqu'on la dechaussera: en effet, pour peu que le fossoyeur, en la déchaussant, veuille fouiller profondément autour de son pied, il l'endommage infailliblement, si elle présente sous son instrument une surface inclinée, et souvent même il la coupe tout à fait. Souvenous-nous done de donner au sarment une direction droite depuis le fond de la fosse jusqu'en haut, pour ensuite l'attacher à son appui : suivons après cela le reste de la méthode que nous avons prescrite dans le premier livre, e'est-à-dire, aplanissons la terre autour de ce sarment, en laissant sortir deux de ses bourgeons en dehor's; ensuite, après avoir planté des mailletons dans les rangées des ceps, ameublissons et pulvérisons bien, par de fréquents labours, le terrain qui aura déjà été retourné au pastinum. En effet, pour que les mailletons, les marcottes et les autres espèces de plants que nous aurons mis en terre se fortifient, il faut que la terre soit bien attendrie et bien douce, qu'elle fournisse ses sues nourriciers aux ceps sans les communiquer à des herbes inutiles, et que sa dureté ne comprime pas, comme il arrive dans des terres plombées, les plantes encore trop nouvelles.

V. Pour dire le vrai, on ne doit point fixer le nombre de fois qu'il faudra retourner le sol au hoyau, parce qu'il est constant que plus on répétera cette opération, plus les plantes profiteront. Mais comme, eu égard à la dépense dans laquelle elle jettera, il faut se borner à un certain nombre de fois, la plupart ont cru qu'il suffisait de bêcher les nouveaux plants de vignics une fois par mois, depuis les calendes de mars jusqu'à celles d'octobre, et d'en extirrer

sed ut expressis angulis relut ad perpendiculnm frontes ejus dirigantur. Nam vitis supina, et velnt recumbens in alvco deposita, postea quum ablaqueatur, vulneribus ob. noxia est. Nam dum exaltare fortius orben ablaqueatio. nis fossor studet, obliquam vitem plerumque sauciat, et non nunquam præcidit. Meminerimus ergo usque ab imo scrobis solo rectum adminiculo sarmentum applicare; et ita in summum perducere. Tum cætera, ut priore libro præcepimus. Ac deinde duabus genmis super extantibus terram coæquare. Deinde malleolo inter ordines posito crebris fossionibus pastinatum resolrere atque in pulverem redigere. Sic enim optime et viviralices et reliq̨ua semina, quæ deposuerimus, convalescent, simul ac tenera lıumus nulis lierbis irrepentibus humorem slirpibus præ. buerit : nec duritia soli novellas adhuc plantas velut arcto vinculo compresserit.

V. Numerus autem rertendi soli bidentibus, ut verum fatear, definiendus non est, cum quanto crebrior sit, plıs prodesse fossionem couveniat. Sed quoniam inıpensarum ratio morlun postulat, satis plerisque vlsum est, ex calendis Martiis usque in Octobres trigesimo quoque die 
toutes les herbes et surtout le gramen, parce que si on n'arrache pas entièrement ces herbes à la main, et qu'on nc les jette pas sur la superficie du sol, si peu qu'il en reste qui soient couvertes de terre, elles revivront, et finiront par brûler le plant de vignes, au point de le rendre en peu de temps galleux et desséché.

VI. Soit que la vigne ait été plantée par mailletons, soit qu'elle l'ait étć par marcottcs, il est bon de la façonner dès le principc et d'en supprimer toutes les parties superflues, en l'épamprant souvent, pour empêcher que ses forces et toute sa nourriture ne s'éparpillent en plus d'une tige. Cependant on lui laisse dans le commencement deux pampres, atin qu'il y en ait un qui serve de ressource, au cas que l'autre ne vienne à périr; mais lorsqu'ils auront par la suite pris un peu de force, on en retranchera le plus mauvais; et pour empêcher que celui que l'on aura laissé ne puisse être abattu par les vents orageux, il sera bon de l'attacher, à mesure qu'il s'élèvera, avec des liens tendres et lâches, jusqu'à ce qu'il soit en état de saisir l'appui qui lui est destiné, avec les vrilles qui lui tiennent lieú de mains. Quoique nous pensions qu'il ne faut pas moins épamprer les mailletons que les ceps qui sont dans les rangées, on peut néanmoins se dispenser de leur faire cette opération, quand îa rarcié des journaliers empêchera de la faire; au lieu qu'on ne s'en dispensera jamais à l'égard des ceps cqui sont dans les rangées, à moins qu'on ne pense à se pourvoir de provins pour la suite, parce que cette opération leur est nécessaire pour empêcher que la trop grande multitude de fouets ne les maigrisse, et afin qu'ils n'aient chacun qu'unc tige à nourrir. On aura soin de provoquer l'accroissement de cette tige en y appliquant un appui suffisam-

novella vineta confodere, onnesque herbas et pracipue gramina extirpare, quæ nisi manu eliguntur, et in summum rejiciuntur, quantulacinque parte adobruta sunt, reviviscunt, et vitium semina ita perurunt, ut scabra atque retorrida efficiant.

VI. Ea porro sive malleolos seu viviradices deposuimus, optimum est ab initio sic formare, ut frequenti pampinatione supervacua detrahamus; nec patiamur plus quam in unain materiam vires et omnealimentum conferre. Primo tamen bini pampini submittuntur, ut sit alter subsidio, si alter forte deciderit. Cum deinde paulum indu. ruere virgæ, tum deteriores singulæ detrahuntur. Ac ne quæ relictæ sunt procellis ventorum decutiantur, molli et laxo vinculo adsurgentes subsequi conveniet, dum clavi. culis suis quasi quibusdam manibus adminicula compre. hendant. Hoc si operarum penuria facere prohibet in mal. leolo, quem et ipsum pampinare censemus : at certe in ordinariis vitibus utique obtinendum est, ne pluribus flagellis emacientur, nisi si propaginibus futuris prospiciemus : sed ut singulis materiis serviant, quarum incrementa elicere debemus, applicato longiore adminiculo, per quod prorepant in tantum, ut sequentis anni jugum exsupe- ment élevé, pour qu'en sc glissant le long de cet appui, elle puisse passer par-dessus le joug auquel on l'attachera la seconde année de sa plantation, et en descendre en se courbant do l'autre côté pour porter du fruit. Lorsque les vignes auront atteint cette hauteur, il faudra rompre leur cime afin qu'elles prennent du corps, et qu'elles ne s'affaiblissent pas en se jetant dans une longueur superflue. Nous épamprerons cependant le sarment même que nous laisserons mon. ter en tige, depuis son pied jusqu'à la hauteur de trois pieds ct demi, et nous arracherons souvent tous les rejetons qu'il pourra avoir jetés sur ses cótés dans ce premier temps. Mais il ne faudra toucher à rien de ce qui sera poussé sur sa partie supérieure; et il sera plus à propos d'attendre l'automne pour le tailler avec la serpette, que de l'épamprer en été, parce que sitôt qu'on l'a épampré, il parait toujours un rejeton à l'endroit même d'où on en a ôté un, et que ce nouveau rejeton venant à pousser, il ne reste plus d'œil sur la tige qui puisse donner du fruit l'année suivante.

VII. Le temps propre à épamprer, en tel cas qu'on lc fasse, c'est lorsque les pampres sont assez tendres pour se laisser abattre au moindre toucher; car, pour peu qu'ils soicnt devenus trop durs, il faut alors ou faire de plus grands efforts pour les arracher, ou les tailler à la serpette. Or ce sont deux choses qu'il faut également éviter : l'une, parce que les efforts nécessaires pour les arracher déchirent la mère; l'autre, parce que la taillo lui fait une blessure qui est toujours pernicieuse dans une plante encore verte, et qui n'est pas encore parvenue à son degré de maturité. En effet, la plaie qui en résulte n'est pas circonscrite par les tra-

rent, $e t$ in fructum curvari possint. Ad quam mensuram cum increverint, cacumina infringenda sunt, ut potius crassitudine convalescant, quam supervacua longitudine attenuentur. Idem tamen sarmentum quod in materiam submittimus, ab imo usque in tres pedes et semissem pampinabimus, et omnes ejus intra id spatium nepotes enatos sæpius decerpemus. Quidquid deinde supra germinaverit, intactum relinqui oportebit. Magis enim convenit proximo autumno falce deputari superiorem partem, quam astivo tempore pampinari, quoniam ex eo loco, unde nepotem ademeris, confestim alterum fundit: quo enato, nullus relinquitur oculus in ipsa materia, qui sequenti anno cum fructu germinet.

VII. Omnis autem pampinationis [ea] est tempestivitas, dum adeo teneri palmites sunt, ut levi tactu digiti decutiantur. Nam si vehementius induruerint, aut majore nisu convellendi sunt, aut falce deputandi; quod utrumque vitandum est. Alterum, quia lacerat matrem, si revellere coneris : alterum, quia sauciat, quod in viridi et adhuc stirpe immatura fieri noxium est. Neque enim eatenus plaga consistit, qua restigium fecit acies : sed æstivis caloribus falce vulnus penitus impressum latius inarescit ita, 
ces de l'instrument; mais la blessure, qui se trouve imprimée trop profondément, dessèche beaucoup plus loin la plante pendant les chaleurs de l'été, au point même qu'une très-grande partie du corps de la mère en meurt. C'est pourquoi, si l'on est foreé d'avoir recours à la serpette, parce que les pampres seront déjà trop durs, il ne faudra pas les séparer de la mère en entier, mais il faudra en laisser une partie, comme on le pratique à l'égard des coursons, afin que le dommage que la ehaleur oceasionnera ne tombe que sur ectte partie. On en laissera jusqu'au premier noud d'où il doit sortir des rejetons sur le cóté du pampre, paree que la violenee de la chaleur ne pénètre pas au delà de cette distance. Quant aux mailletons, on suit la même méthode pour les épamprer, comme pour exeiter leur tige à s'allonger au cas que l'on veuille les employer dès la première année, comme j'ai souvent fait. Mais si l'on se propose de les couper absolument, pour ne les employer que la seconde année, il faudra étêter la tige unique à laquelle on les aura réduits, dès que cette tige aura plus d'un pied de long, afin qu'ils s'affermissent plus du côté de la tête, et qu'ils deviennent plus robustes. Voilà la première façon que demandent les vignes depuis leur plantation.

VIII. Les temps suivants demandent des soins plus étendus, ainsi que l'ont écrit Celsus et Atticus, qui sont les auteurs que notre siècle a le plus approuvés en matière d'agrieulture : ear il faut déchausser la vigne après les ides d'octobre, ct a vant que les froids ne surviennent. Cette opération sert à mettre à jour les petites racines qui ont poussé pendant l'été : et l'agriculteur sensé les tranche avee le fer, parce que s'il les laissait se fortifier, celles d'au-dessous s'affaibliraient, et il en résulterait que la vigne jetterait

ut non minimam partem de ipso matris corpore enecet. Atque ideo si jam caulibus duris falcem adhiberi necesse est, [ii] paulum ab ipsa matre recidendum est, et vielut reseces relinquendi sunt, qui caloris excipiant injuriam, eatenus qua nascuntur a latere palınites. Ultra enim non serpit raporis violentia. In malleolo similis ratio est pampinandi, et in longitudinem eliciendi materiam, si eo velimus anniculo uti, quod ego sæe feci. Sed si propositum est utique recidire, ut bimo potius utamur, cum ad unum pampinum jam redegeris, et is ipse excesserit pedalem longitudinem, decacuminare conveniet, ut in cervicem potius confirmetur, et sit robustior. Atque hæc positorum seminum prima cultura est.

VIII. Sequens deinde tempus, ut prodidit Celsus et Atticus, quos jure maxime nostra atas probavit, post idus Octobris ampliorem curam deposcit. Nam prius quam frigora invadunt, vitis ablaqueanda est. Qırod'opus adapertas ostendit astivas radiculas, easque prudens agricola ferro decidit. Nam si passus est convalescere, inferiores deficiunt, atque evenit ut vinea summa parte terreni radices agat, quæ et frigore infestentur et caloribus majorem sur la superficie du terrain des racines exposées à être dévastées par le froid ou échauffées par les chaleurs, au point que la mère serait infailliblement trop altérée au lever de la Canicule. C'est pourquoi, lorsqu'on aura déchaussé les vignes, il faudra en couper toutes les racines qui auront poussé en deẹa d'un pied et demi de profondeur; mais on ne s'y prendra pas pour cette amputation de la même façon que pour celles que l'on faitaux parties supérieures de la vigne. Car il ne faudra ni unir la plaie, ni appliquer le fer à la mère ellemème, parce que si l'on coupait une racine trop près du trone, ou il en renaitrait plusieurs autres de la cicatrice qui aurait été faite, ou l'eau des pluies d'hiver, qui séjourne dans les laes formés autour de la plante par la fouille faite à son pied, venant à se geler au solstice d'hiver, brûlerait ces blessures encore nouvelles, et pénétrerait à la moelle. Pour éviter ces inconvénients, il faudra s'écarter à peu près d'un doigt du trone, pour ne couper les petites racines qu'à eette distance. Lorsqu'on a ôté ces racines a vec ces précautions, elles ne se multiplient plus, et leur séparation du trone le préserve de tout accident. Quand cela est fait, si l'on est dans un pays où l'hiver soit doux, il faut laisser la vigne, ainsi déchaussée, à l'air ; au lieu que s'il est trop rude, il faut recouvrir, avant les ides de décembre, les petites fosses que l'on a faites au pied de la vigne en la déehaussant. Si même l'on est dans un pays où l'on ait les plus grands froids à eraindre, il faudra répandre sur les -racines de la vigne, avant de la recouvrir, un peu de fumier ou de fiente de pigeon, si on le troure plus commode, ou verser dessus six sextarii de vieille urine, que l'on aura gardée à cette intention. 11 faudra déchausser les vignes à chaque automne pendant les cinq premières annėes, jusqu'à ce qu'elles

in modum æstuent, ac veliementer sitire matrem in ortu Canicula cogant. Quare quicquid intra sesquipedem natum est, cum ablaqueaveris, recidendum est. Sed hujıs non eadem ratio est amputandi, quæ traditur in superiori parte vitis. Nam minime adlevanda plaga est, minimeque applicandum ferramentum ipsi matri : quoniam si juxta truncum radicem praccideris, aut ex cicatrice plures enascentur, aut hiemalis, quæ ex pluviis consistit in lacusculis ablaqueationis aqua, brumæ congelationibus nova vul. nera peruret, et ad medullam penetrabit, quod ne fiat, recedere ab ipso codice instar unius digiti spatio conveniet, atque ita radiculas præcidere; quxe sic ademptæ non amplius pullulant, et a catera noxa truncum defendunt. Hoc opere consummato, si est liems in ea regione placida, patens vitis relinquenda est : $\sin$ riolentior, id facere nos prolibet, ante idus Decembris pradicti lacusculi coæquandi sunt. Si vero etian prægelida frigora regionis ejus suspecta erunt, aliquid fini, vel, quod est commodius, columbini stercoris, aut in liunc usum proparatæ veteris urinæ senos sestarios, antequam vitem adobruas, radicibus superfundes. Sed ablaqueare omnibus autumnis opor- 
soient dans toute leur foree; mais une fois que leur trone aura pris sa eroissanee, on pourra ne faire ectte opération qu'environ tous les trois ans, tant parce qu'en suivant eette méthode le pied des vignes se trouvera moins souvent endommagé par le fer, que parce qu'il faut plus de temps aux vignes pour jeter de ees petites raeines, lorsque leur trone a pris de la eonsistance.

IX. Après le déchaussement des vignes vient la taille, qui, suivant les préeeptes des aneiens auteurs, doit être faite de façon que la vigne soit réduite à une seule petite tige, qui ne porte que deux bourgeons près de terre. On ne doit pas tailler la vigne auprès de la jointure d'un nœud, pour ne pas en intimider l'œil; mais on la taille à peu près vers le milieu de l'espace qui est entre deux nœuds, en tenant la serpette obliquement, de peur que, si la cicatriee était horizontale, la pluie qui viendrait á tomber ne s'arrêtât dessus. Il ne faut pas non plus que la plaie soit inelinée du côté où se trouve le bouton, mais du côté opposé, afin qu'elle verse ses pleurs à terre plutôt que sur le bourgeon. Car autrement l'eau qui en découlerait aveuglerait l'œil, et l'empêeherait de se développer en feuilles.

$\mathrm{X}$. Il y a deux temps pour tailler la vigne; mais le meilleur (comme dit Fragon) est de la tailler au printemps avant qu'elle bourgeonne, paree qu'étant alors pleine de sucs, il est plus facile de lui faire une plaie et d'unir cette plaie dans toute sa surface, outre qu'elle résiste moins à la scrpette. Celsus et Atticus ont suivi cet auteur. Pour nous, nous eroyons qu'il ne faut ni trop arrêter l'aceroissement des plantes en les taillant de trop court, à moins qu'elles ne soient de la dernière faiblessc, ni les tailler toujours au printemps. Mais la première année qu'elles sont plantées, il faut les aider à venir en les bêchant fré-

tebit primo quinquennio, dum vitis convalescat : uhi vero truncus adoleverit, fere triennio intermitlenilus est [ejus operis] labor. Nam et minus ferro crura vitium larluntur, nec tain celeriter radicula inveterato jam codice enascuntur.

IX. Ablaqueationem deinde sequitur talis putatio, nt ex praccepto veterum anctorum vitis ad unam virgulam revocetur, duabus gemmis juxta terram relictis. Quæe putatio non debet secundum articulum fieri, ne reformidet oculus, sed medio ferc internodio ea plaga obliqua falce fit; ne si transversa fuerit cicatrix, cxlestem superincilentem aquam contineat Sed nec ad eam partem, qua est genıma, verum ad posteriorem declinatur, ut in terram potius devexa, quam in gerinen delacrumet. Namque de. pluens lumor cacat oculım, nec patilur frondescere.

-X. Putandi autem duo sunt tempora : melius autem, ut ait Mago, vernum, antequam surculus progerminet, quoniam lumoris plenus facilem plagam et levem et aequalem accipit, nec falci repugnat. Hunc autem secuti sunt Celsus et Atticus. Nobis neque angusta putatione coercenda semina videntur, nisi si admodum invalida sunt; neque utique quemment, e'est-à-dire, tous lis mois pendant lesquels clles sont en feuilles, et en les épamprant souvent, afin qu'elles acquièrent des forces, et qu'elles n'aicnt pas plus d'un sarment à entrete. nir. Lorsqu’elles auront élevé ce sarment, nous eroyons qu il sera nécessaire de l'éplucher en automne, ou au printemps si on le trouve plus convenable, et de le délivrer des rejetons que celui qui aura épampré pourra lui avoir laissés dans sa "partie supérieure, pour le mettre ensuite sur le joug, parce que la vigne qui peut s'élever audessus du joug avec le fouet de la première année, est lisse, droite et sans eieatrice. Il est vrai que c'est ce que l'on voit arriver rarement, et chez peu d'agriculteurs; aussi est-ce pour eela que les auteurs que je viens de citer ont été d'avis que l'on coupât absolument les prémices de la vigne. D'un autre eóté, la taille du printemps n'est pas certainement la meilleure pour tous les pays : effectivement il n'y a pas de doute qu'il ne faille la préférer dans les pays froids; mais pour ceux qui sont exposés au grand soleil, et où l'hiver est doux, la meilleure et la plus naturelle est celle de l'automne, puisque e'est le temps auquel les plantes se depouillent de leurs fruits et de lcurs feuilles, en vertu d'une loi éternelle prescrite, pour ainsi dire, par la Divinité.

XI. Je pense que voilà ce qu'on doit faire à la vigne, soit qu'on l'ait plantée en marcottes, soit qu'on l'ait plantée en mailletons : car l'expérience a condamné l'opinion dans laquelle étaient les anciens, qu'il ne fallait point approcher lo fer des mailletons d'un an, comme s'ils eussent redouté son tranchant; crainte vaine qu'ont eue Virgile, Sascrna, les Stolons et les Catons. Au reste, ces auteurs n'étaient pas seulement dans l'erreur, en ce qu'ils ne touehaient point à la chevelure que jetaient les plantes la première an-

verno recidenda. Sed primo quidem anno, quo snnt posita, frequentibus fossionibus omnibus meisibus dum frondent ac pampinationibus adjuvanda sunt, ut robur accipiant, nec plus quam uni inaterise serviant. Quam ut educaverint, autumno vel vere, si nagis competit, adradenda, et nepotibus, quos pampinator in superiore parte omiserat, liberanda censemus, atque ita in jugum imponenda. Ea enim levis et recta sine cicatrice vinea est, qua se prini anni flagello supra jugum extulit, quod tamen apud paucos agricolas et raro contingit. Ideoque pradicti auctores primitias ritis resecare censuerunt. Sed nec utiqne rema omnibus regionibus uelior putatio est. Nam ubi cxium frigidun est, ea sine clubio eligeuda est. Ubi vero aprica loca sunt, mollesque hiemes, optima et maxime naturalis est autumualis : quo tempore divina quadam lege ot aterna fructum cum fronde stirpes deponunt.

XI. Hoc facire, sive viviradicem sive malleolum conseveris, censeo. Nam illan reterem opinionem damnavit usus, non esse ferro tangendos anniculos malleolos, quo. niam reformident. Quod frustra Virgilius et SasernaStolo. nesquce Catones timuerunt : qui mon solum in eo errabant, 
née, mais encore en ce que, lorsqu'ils en venaient á couper la marcotte au bout de deux ans, ils la coupaient tout entière, à ras terre et près de la jointure du trone, afin qu'elle repoussát sur le bois dur. En effet, l'expérience, cette maittresse des arts, nous a appris, au contraire, à façonner les accroissements des mailletons dès la première année, et à empêcher que la vigne, fertile en feuillages superflus, ne devienne trop touffue; de même qu'elle nous a appris à ne pas la contenir autant que les anciens l'ordonnaient, en la coupant tout entière. En effet, cette méthode lui est contraire, tant parce que, lorsqu'on a coupé le plant à ras de terre, la plupart des ceps meurent comme s'ils étaient frappés d'un coup au-dessus de leurs forces, que parce que ceux qui résistent à cette blessure, et qui n'en meurent point, portent pour la plus grande partie des sarments moins féconds, puisque, de l'aveu de tout le monde, les pampres qui sortent du bois dur sont le plus souvent sans fruit. Il faut donc prendre un milieu, et ne pas cuuper le mailleton à ras de terre, ni l'exciternon plus à donner un bois trop long, mais remarquer le courson de l'année précédente, pour laisser, au-dessus de la commissure même de l'ancien sarment, un ou deux bourgeons, dont il sortira du bois.

XII. Après la taille vient le soin d'échalasser la vigne: mais cette première année ne demande pas encore de pieux ni de forts échalas; car j’ai remarqué qu'une jeune vigne s'accommodait communément mieux d'un petit appui que d'un fort pieu. C'est pourquoi, ou nous mettrons auprès de chaque vigne deux vieux roseaux (de peur qu'étant nouveaux ils ne prennent racine), ou, si la situation de la contrée nous le permet, nous

quod primi anni capillamenta seminum intacta patieban. tur, sed et post biennium, cum viviradix recidenda erat, omisen superficiem amputabant solo tenus juxta ipsum articulım, ut e duro pullularet. Nos autem magister artium docuit usus, primi anni malleolorum formare incrementa, nec pati vitem supervacuis frondibus luxuriantem silvescere; nec rursus in tantum coercere, quantum antiq̨ui pracipiebant, ut tolam superficiem amputemus. Nam id quidem rationi nuxime contrarium est. Primun quod cum ad terram decideris, semina, velut intolerabili affecta vulinere, pleraque inlereunt, nonnulla etiam, qux pertinaciur vixerunt, minus fuccundas materias afferuut : siquidem e duro quæe pullulant, onnium confessione pampinaria sæpissime fructu carent. Media igitur ratio sequenda est, ut neque solo tenus malleolum recidamus, nec rursus in longiorem materiam prorocenus : sed adnodato superioris auni pollice, supra ipsam comnissuram veteris sarmenti unam vel duas gemmas relinquemus, ex quibus germinet.

XII. Putationem sequitur jam pedandxe vinexe cura : verum hic anıus nondun vehementern palum aut ridicam lesiderat: notatum est enim a me plerumque teneram ricean melius adminiculo modico quam rehementi palo enfoncerons en teric de vieux échalas abandon. nés, auxquels nous attacherons des perches, qui traverseront la file des ceps par en bas. Les paysans appellent cette espèce de joug un canterius. 11 est en effet très-important que le pampre de la vigne trouve quelque chose qu'il puisse saisir dès qu'il commence à s'allonger et avant de se courber, afin qu'il ait la facilité de s'étendre plutôt horizontalement que perpendiculairement, et qu'il soutienne plus aisément l'impétuo. sité des vents, à l'aide de ce canterius qui le soutiendra. Il sera à propos que ce joug n'aille pas jusqu'à quatre pieds de hauteur, jusqu'à ce que la vigne se soit fortifiée.

XIII. Quand la vigne aura été échalassée, il faudra la lier. La fonction de celui qui la liera consistera à la bien attirer en ligne droite sur le joug : si le pieu est placé tout auprès d'elle, comme il a plu à quelques auteurs de le placer, celui qui la liera observera en l'attachant de ne pas se régler sur les sinuosités du pieu, si par hasard il est tortu, parce que cette méthode la rendrait erochue; mais si on a laissé un intervalle entre le cep et le pieu (comme Atticus et quelques autres agriculteurs ont prétendu qu'on devait faire, et comme je suis assez d'avis qu'on fasse), il faut joindre le cep à un roseau droit, et l'y attacher à l'aide de plusieurs ligatures, pour le conduire ainsi au joug. La nature des liens dont on se servira pour attacher le plant, n'est point une chose indifférente : en effet, tant que la vigne est jeune, il faut l'attacher avcc des liens trèsdoux, parce que, si l'on se servait de branches de saule ou d'orme, ellc se couperait à mesure qu'ellc grossirait. Les meilleurs liens seront done de genêt, de jonc coupé dans les marais, ou de

adquiescere. Itaque aut reteres, ne novæ radicem agant, arundines singulis viticulis applicabimus binas, aut si regionis conditio permittit, de vepripus liastilia, quibus adnectantur singulæ transversæ perticæ in unam partem ordinis : quod genus jugi canterium vocant rustici : plurimum id refert esse, quod paulum infra curvationem vitis prorepens painpinus statim apprehendat, et in Irausversa potius se fundat, quan in edita, ventosque facilius susti. neat subnixus canterio. Idque jugun intra quartum pedem convenit allevari, dum se vinea corroboret.

XIII. Impedationem deinde sequitur alligator, cujus officium est, ut rectam vitem producat in jugum. Quxe sive juxta jalum est posita, ut quibusdau placuit anctoribus, observare debebit, qui adnectit, ॥e in alliganda inateria flexum pali, si forte curvos est, sequeuduu putet; nam ea res uncam vitem facit : sire, ut Attico et nonnullis aliis agricolis visum est, inter vitem et palum spatium relinquitır, quod nec milıi displicet, recta arundo adjungenda stirpi est, et ita per crebra retiuacula iu ju. gum perducenda. Vinculi genus quale sit, qno religantur semiua, plurimum refert. Nam dum novella virea est, quam mollissímo nectenda est : quia si viminibus salicis aut ulmi ligaveris, increscens vitis se ipsa pracidit. Optima 
glaieuls. Cependant les feuilles mème de roseaux, séchées à l'ombre, ne sont point d'un mauvais usage en cette occasion.

XIV. Il faut avoir les mêmes attentions pour les mailletons, c'est-à-dire, qu'après les avoir réduits par la taille à un ou deux boutons pendant l'automne, ou au printemps avant qu'ils bourgeonuent, il faudra les attacher au joug. La perche que j'ai appelée canterius sera plus près de terre pour les mailletons que pour les ceps qui sont dans les rangées : : car clle ne doit pas être ćlevée à plus d'un pied, afin que les pampres encore tendres trouvent quelque chose à quoi ils puissent s'acerocher avec leurs vrilles, et que les vents ne les déracinent point. Ensuite le fossoyeur retournera, par de fréquentes fouilles faites au hoyau, la superficie du terrain, et le pulvérisera bien également. Nous approuvons très-fort cette espèce de fouille faite à plat; car pour celle que l'on appelle en Espagne fouille d'hiver, et que l'on emploie pour enlever la terre du pied des vignes, et la rassembler dans les allées qui sont entre les rangées, elle nous parait inutile, paree que les vignes ont déjà été déchaussées en automne, etque cette opération, qui en a découvert les racines supérieures, s'est £sit sentir jusqu'aux racines les plus profondes, en leur transmettant les pluies d'hiver. On doit faire ees sortes de fouilles autant de fois que la premiere année, ou une fois de moins. Car il faut surtout avoir soin de remuer souvent le terrain, jusqu'à cc que les vignes aient pris assez d'aceroissement pour le couvrir de leur ombre, ct pour empêcher les herbes d'y croître à leur picd. On doit aussi épamprer les vignes cette année comme la précédente, parce qu'il faut encore contenir, pour ainsi dire, l'enfance du plant, et ne lui pas laisser plus d'un fouet; d'autant plus qu'à un âge aussi tendre

est ergo genista, vel paludibus desectus juncus, aut ulva. Non pessime tamen in umbra siccata faciuut in lunc usum arundinum quoque folia.

XIV. Sed et malleolorum similis cura agenda est, ut ad Innam aut duas gemmas deputati autumno vel vere, prius quam germinent, jugentur. lis, ut dixi, canterius propius a terra, quam vitibus ordinariis submittendus est : neque enim editior esse debet pedali altitudine, ut sit quem teneri adhuc pampini capreolis illigent suis, ne ventis explantentur. Insequitur deinde fossor, qui crebris bidentibus æqualiter et minutim soli terga comminuat. Hauc planam fossuram maxime nos probamus. Nam illa, quam in Ilispania hibernam appellant, cum terra vitibus detralitur, et in media spatia interordiniorum confertur, supervacua nobis videtur : quia jam pracessit autumnalis ablaqueatio, qux nudavit summas, et ad inferiores ra. diculas hibernos transmisit imbres. Numerus autem fossio. nis aut idem esse debet qui primi anni, aut una minus. Nam utique frequenter solum exercendum est, dum id incre. mento suo vites inumbrent, nec patiantur herbam subcrestere. Pampinationis eadem debet esse ratio hujus anni, il ne résisterait pas à la eharge du fruit et à celle du bois tout à la fois.

XV. Mais lorsque la vigne est parvenue, au bout d'un an et six mois, à être vendangée, it faut la peupler sitôt après en avoir cueilli le fruit, et propager les mailletons qu'on a mis en terre ceteffet; ou si l'on n'en a pas, il faut attirer des sautelles des ceps qui sont dans les rangées, et les conduire à un pieu différent de celui qui soutient ces ceps ; car il est très-intéressant de bien garuir encore tous les appuis de la vlgne par de nouvel. les plantations. On ne la garnira pas néanmoins par-dessous, dans le moment qu'on sera prêt à la vendanger. On appelle sautelle une branche d'un eep courbée en terre près de son appui, et dont on conduit l'extrémité à un pieu qui n'est point garni, après l'avoir recouverte de terre dans une fosse suffisamment profonde. Cette branche donne par la suite beaucoup de bois, qui sort de toute la partie qui est arquée, et que l'on applique à son appui dès qu'il est venu, pour le faire parvenir au joug. L'année suivante, on coupe jusqu'a la moelle du cep la partie supérieure de la sautelle, à l'endroit méme où on l'a courbée, de peur que le fouet qui en sera sorti n'attire à lui toutes les forces de sa mère, et afin qu'il s'habitue peu à peu à tirer sa nourriture de ses propres racines. A l'åge de deux ans, on coupe la sautelle très-près de la branche qu'on a laissé venir sur la partie arquée; ensuite on bèche profondément au pied de cette nouvelle plante ainsi séparée de sa mère, et on laisse une petite fosse autour d'elle; après quoi on la coupe jusqu'à ras terre du fond de cette fosse, et on la recouvre de terre, afin qu'elle pousse des racines par en bas, paree que si on la coupait sans tant de précautions sur la superficie du sol, elle pourrait germer par le bout qui avoisinerait la terre, ce qu'il faut prévenir.

atque prioris. Adluuc enim compescenda quasi pueritia seminum est, nec plus quam in unum flagellum est submittenda : tanto quidem magis, quod tenera ejus atas non sustinet et fotu et materiis onerari.

$X V$. Sed cum annicula mensiumque sex ad vindemiam perducta est, sublato fructu protinus frequentanda est, et prosidiarii malleoli propagandi sunt, qui in hunc usum fuerant depositi, vel, si ne hi quidem sunt, ex ordinaria vite iu alterum palum mergus est attrahendus. Nam plu. rimum interest adluc nova consitione pedamen omne ve. stiri; nec mox vineam tum subseri, cum fructus capien. dus est. Mergi genus est, ubi supra terram juxta suum adminiculum vitis curvatur, atque ex alto scrobe submersa perducitur ad vacantem palum : tum ex arcu vehenenter citat materiam, qua protinus applicata suo pedamento ad jugum evocatur. Sequente deinde anno insecatur superior pars curvaturæ usque ad medullam, ne totas vires matris propagatun flagellum in se tralıat, et ut pau. latim condiscat suis radicibus ali. Bima deinde praciditur proxime palmam, quæ ex arcu submissa est. Et id quorl a matre abscissum recessit, confestim alte circumfoditur, 
Il n'y a pas de temps plus favorable pour couper les sautelles que depuis les idés d'octobre jusqu'à celles de novembre, afin que leur's racines puissent se fortifier pendant l'hiver. En effet, si on faisait cette opération au printemps, qui est le temps auquel les branches commencent à se charger de boutons, elles tomberaient en langueur, en se trouvant privées tout à coup de leur mère.

XVI. On suit la mème méthode pour transférer les mailletons. Car on est à temps, après les ides d'octobre du second automne, de les enlever pour les planter, si le climat et la nature du terrain le permettent : mais si la rigueur du climat et la mauvaise disposition du terrain s'y opposent, il ne sera temps de le faire qu'au printemps d'ensuite. Il ne faut pas laisser trop longtemps les mailletons dans les vignes, de peur qu'ils n'épuisent la force du terrain, et qu'ils ne nuisent aux plantes qui sont dans les rangées, et qui se fortifieront d'autant plus aisément, qu'elles seront plus promptement délivrées de la compagnie des marcottes : on peut au contraire garder dans des pépinières des vignes de trois ou même de quatre ans, pourvu qu'on les coupe entièrement ou qu'on les taille de court, parce qu'on ne destine pas ces pépinières à la vendange. Dès que la vigne que l'on a plantée a passé deux ans et demi, c'est-à-dire, son troisième automne, il faut l'attacher à des appuis plus forts que ceux qu'elle a, et ne pas faire cette opération de caprice, ni au hasard. Car ou on fiche le pieu auprès du cep; auquel cas on l'en éloignera cependant d'un pied, tant afin d'éviter qu'il ne presse ou n'endommage ses racines, qu'afin que le fossoyeur puisse fouiller de tout côté autour du plant, et on le posera de façon qu'il protége la vi-

et scrobiculo facto ad imum solum præciditur, adobruiturque, ut et radices deorsum agat, nec ex propinquo negligenter in summa terra resectum progerminet. Tempus autem non aliud magis idoneun est liunc mergum amputandi, quam ab idib. Octob. in idus Novemb. ut hibernis mensibus suas radices confirmet. Nam si vere id fecerimus, quo gemmare palmites incipiunt, matris alimentis subito destitutus languescit.

XVI. Eadem ratio est in transferendo malleolo. Nam [in] secundo autumno, si cæli et loci qualitas patitur, commodissime post idus Octobris exemptus conseritur : sin autem aliqua terræ vel aeris repugnat injuria, tempestivitas ejus in proximum ver differtur. Neque diutius in vineis relinquendus est, ne soli vires absumat, et ordinaria semina infestet : quæ quanto celerius liberata sunt consortio viviradicum, tanto facilius convalescunt. At in seminario licet trimam atque etiam quadrimam vitem re. sectam vel anguste putatam custodire : quoniam non consulitur vindemix. Cum mensem trigesimum excessit posita vinea, id est tertio autumno, veliementioribus statuminibus statim impedanda est, idque non ut libet aut fortuito faciendum. Nam sive prope truncum defigitur palus, pe. dali tamen spatio recedendum est, ne aut premat radicem gne, en recevant sur lui toute la violence du froid et l'impétuosité des aquilons : ou on le fiche dans l'entre-deux des rangées; auquel cas, atin qu'il ait plus de stabilité pour porter le joug et les fruits, il faut le bien enfoncer, ou même faire préalablement un trou dans la terıe avec un piquet, pour qu'il soit enfoncé plus profondément. Car plus l'échalas est posć pl'ès du cep, plus il est stable, sans même être bien enfoncé, parce que le cep et lui, se touchant mutuellement l'un l'autre, se soutiennent réciproquement. Il fautensuite attacher aux appuis de forts jougs, qui seront faits ou de perches de saules, ou de plusieurs roseaux joints pour ainsi dire en bottes, pour qu'ils aient une certaine résistance, et qu'ils nes'affaissent pas sous le poids des fruits. Car ou pourra déjà laisser deux sarments à chaque cep du plant, à moins cependant qu'il ne se trouve quelques ceps dont la petitessc exige qu'on les taille de plus court ; auquel cas on ne leur laissera qu'une branchc à fruit, et même garnie de très-peu d'yeux.

XVII. Les perches donnent un joug plus solide, et qui coûte moins de peine à fabriquer qu'un joug de roseaux, qui demande plus de journées de travail avant que les vignes y soient attachées, parce qu'il faut lier ensemble ces roseaux en différents endroits, après avoir renversé la tête des uns vis-à-vis le pied des autres, afin que ce joug soit également gros dans toute sa longueur. En effet, si toutes les têtes des roseaux étaient réunies d'un seul côté, la faiblesse de ce côté cédant à son poids, les fruits seraient renversés par terre dans le temps de leur maturité, et exposés aux chiens et aux bêtes fauves; au lieu que lorsqu'un joug sera formé de plusieurs

aut vulneret, et ut fossor tamen ab omni parte semina circunfodiat ; isque palus sic ponendus est, ut frigorum et Aquilonum excipiat violentiam vitemque protegat : sive medio interordinio pangetur, vel defodiendus est, vel prius paxillo perforato solo, altius adigendus, quo facilius et jugum et fructum sustineat. Nam quanto propius truncum ridica statuitur, etiam leviter defixa stalilior est : quoniam contingerus vitem mutua vice sustinelur et sustinet. Statu. minibus deinde firmiora juga sunt alliganda, eaque vel saligneis perticis vel compluribus quasi fasciculis arundinum connectuntur, ut rigorem habeant, nec pandentur onere fructuum. Nam binæ jam materix singulis seminibus submittendx erunt : nisi sl tamen gracilitas vitis alicujus angustiorem putationem desiderabit, cujus unus palmes atque idem paucorum oculorum erit relinquendus.

XVII. Perticxe jugum firmius faciunt, minusque operosum. Arundines pluribus operis jugantur, quoniam et plu. ribus locis nectuntur. Exque inter se conversis cacuminibus vincienda sunt, ut requalis crassitudo totius jugi sit. Nam si cacumina in unum competunt, imbecillitas ejus par tis gravata pondere jam maturum fructum prosternit, et ca. nibus ferisque reddit obnoxium. At cum jugum In fascem pluribus arundinibus alterna cácuminum vice ordinatum 
roseaux liés en bottes, de façon que les têtes en scrout alternativement tournées de différents côtés, il pourra communément être de bon usage pendant einq ans. Pour ce qui est de la taille et des autres façons, il n'y a pas d'autre méthode à suivre que celle qu'ou aura suivie pour les deux premic̀res années ; c'cst-à-dire, qu"il faut déchausser avec soin les ceps pendant l'automne, et appliquer de même des provins aux pieux qui ne seront jas garnis. Car il ne faut jamais laisser passer une seule année sans renouveler cette dernière opération, d'autant que si les choses que nous plantons ne peuvent pas être immortelles, nous avons cependant un moyen de pourvoir à leur perpétuité, en substituant d'autre plant au lieu et place de celui qui meurt, et en ne laissant pas périr toute l'espèce par une négligence continuée pendant plusieurs années. Il faut aussi donner alors aux vignes plusieurs fouilles, quoiqu'on puisse s'en tenir à une de moins que la première année; commell faut aussi les épamprer souvent, et ne pas se contenter d'en ôter les feuilles superflues une ou deux fois pendant le courant de l'été. On doit surtout mettre à bas tout ce qui sera poussé au-dessous de la tête du tronc : de même, lorsque chaque œil aura jeté sous le joug deux pampres à la fois, quoique ces pampres montrent une belle apparence de fruits abondants, il faudra en retrancher un, afin que l'autre profitedavantage, et qu'il soit plus en état de nourrir le fruit qu'on lui aura laissé. A trois ans et cinc mois, lorsque la vendange sera finie, il faudra tailler la vigne de façon à lui laisser plusieurs fouets, qui la partageront en forme d'étoile. Mais le devoir principal du vigneron consiste à la ravaler par la taille environ à un pied de distance au-dessous du joug, afin que toutes les

est, fere quunquennii prabet usum. Neque enim est alia ratio putationis aul cxterx culturæ, quam qux primi biennii. Nam et autumnalis ablaqueatio sedulo facienda, nec minus vacantibus palis propagines applicandæ. Hoc enim opus nunquam intermittendum est, quin omuibus instauretur annis. Neque enim ea, quæ seruntur a nobis, immortalia esse possunt. Attamen æternitati corum sic consulimus, it demortuis seminibus alia substituamus : nec ad occidionem universum genus perduci patimur complurium annorum negligentia. Quin etiam crebræ fos. siones dandxe, quamvis una possit detralıi cultura prioris anni. Pampinationes quoque sæpe adbibendx. Neque enim satis est semel aut iterum tota astate viti detrahere fron. dem supervacuam. Pracipue autem decutienda sunt omnia, qua infra trunci caput egerminaverint. Item si oculi singuli sub jugo binos pampinos emiserint, quam ris largos fructus ostendant, detrahendi sunt singuli palmites, quo lactior, qux superest materia, consurgat, et reliquum melius educet fructum. Post quadragesimum et alterum mensem percepta vindemia sic instituenda est putatio, ut submissis pluribus fagellis vitis in stellam dividatur. Sed putatoris officium est pedali fere spatio citra jugum parties tendres qui viendront à pousser au-dessus de sa tête à travers ses bras soient animées, et qu'en se recourbant par-dessus le joug, elles se précipitent vers la terre, sans cependant y atteindre. Il faut néanmoins proportionuer le nombre de ces branches tendres à la force du trone, et ne pas en laisser plus que la vigne n'en peut nourrir. Communément à cet âge, lorsqucle terrain et le tronc sont bons, la vigne n'en peutsupporter que trois, et rarement quatre. Celui qui les liera aura soin de les distribuer chacune d'un côtés différent, parce qu'il ne servirait de rien que le joug füt croisé et divisé en étoile, si on n'y attachait pas les branches à fruit dans la même forme. Il est vrai que tous les agriculteurs n'ont pas adopté cette forme, et que plusieurs se sont contentés, au contraire, d'arranger ces branches d'une façon plus simple. Cependant la vigne a plus de consistance pour soutenir le poids de ses sarments et celui de son fruit, lorsqu'étant attachée de deux côtés au joug, elle est retenue par un contrepoids égal comme par des espèces d'ancres : de plus, lorsqu'elle est soutenue par tous les cótés, elle étend son bois en plus de bras, et le développe plus aisément qu'elle ne le fait lorsqu'elle a une multitude de branches entassées sans ordre sous un simple canterius. Néanmoins quand la vigne ne s'étendra pas beaucoup en lar. geur, ou qu'elle sera peu fertile, et que d'ailleurs le climat ne sera point sujet aux orages ni aux tempêtes, elle pourra se contenter d'un seul joug. Car pour les pays où les pluies scront abondantes et les tempêtes impétueuses, et où la vigne, étant ébranlée par l'abondance dès eaux ou comme suspendue sur des collines escarpées, aura besoin de beaucoup de soutiens, il faudra la fortifier de toutes parts, et la soutenir, pour

vitem compescere, ut e capite, quicquid teneri est, per brachia emissum provocetur, et per jugum inflexum præcipitetur ad eam mensuram, qua terram non possit contingere. Sed modus pro viribus trunci servandus est, ne plures palmites submittantur, quam quibus vitis sufficere queat. Fere autem pradicta xtas lacto solo truncoque tres materias, raro quatuor desiderat, quß per totiden partes ab alligatore dividi debent. Nihil enim refert jugum in stellam decussari atque diduci, nisi et palmites adjugentur. Quam tamen formam non omnes agricola probarerunt : nam multi simplici ordine fuere contenti. Yerum stabilior est vinea et oneri sarmentorum et fructui ferendo, quæ ex utrargue parte jugo devincta pari libramento velut ancoris quibusdam distinetur. Tum etian per plura brachia ma. terias diffundit, et facilius eas explicat undique subnixa, quam quae in simplici canterio frequentibus palmitibus stipatur. Potest tamen, si vel parum late disposita vinea rel parum fructuosa caelumque non turbidum nec procel. losum habeat, uno jugo contenta esse. Nam ubi magna vis et incursus est pluviarum procellarumque, ubi frequentibus aquis vitis labefactatur, ubi præcipitibus clivis velut pendens plurima prasidia desiderat; ibi quasi qualrato 
ainsi dire, avec un bataillon carré. Quant aux terrains chauds et secs, il faudra y ćtendre le joug de tous cótés, afin que les pampres, qui viendront en tout sens, se réunissent ensemble, et qu'en s'épaississant en forme de voûte, ils couvrent de leur ombre la terre qui sera altércé; au lieu que dans les pays froids et sujets aux gelées, on se contentera de ranger les pampres sur une seule ligne, parce que de cette façon la terre se séchera plus facilement, et que le fruit mûrira mieux et jouira davantage d'un air salutaire: D'ailleurs les fossoyeurs auront alors plus de liberté et de commodité pour lancer le hoyau, le fruit sera plus sous les yeux des gardiens, et les vendangeurs le cueillerònt plus cornmodément.

XVIII. Quand on voudra disposer ses vignobles en ordre, il faudra faire des carrés séparés entre eux par des sentiers, qu'on remplira chacun de cent ceps, ou, comme d'autres aiment mieux faire, distribuer tout son terrain par semi-jugera. En distribuant ainsi ses vignobles, outre l'avantage qu'on leur procure d'être plus exposés au soleil et au vent, il devient aussi plus facile au propriétaire d'y fixer ses regards et d'y porter ses pas, deux choses très-salutaires au fond. D'ailleurs cette distribution le met à portée d'estimer avec certitude le nombre de journées qu'il aura à exiger, parce qu'on ne peut pas se tromper, lorsque les jugera sont partagés en portions égales. Bien plus, la distribution faite par carrés diminue, pour ainsi dire, la fatigue du travail, à proportion de ce que ces parties sont plus petites, et excite en conséquence les travailleurs à dépêcher leur ouvrage : car l'immensité d'un travail urgent décourage communćment les ouvriers. Il est encore très-utile de connaitre les forces de ses vignes et le produit de chacune en

circumfirmanda est agmine. Calidis vero et siccioribus locis in omnem partem jugum porrigendum est, ut prorepentes undique pampini jungantur, et condensati camerae more, terram sitientem obumbrent. Contra pluviis et frigidis et pruinosis regionibus simplices ordines instituendi : nam et sic facilius insolatur lumus, et fructus percoquitur, perflatumque salubriorem habet: fossores quoque liberius et aptius jactant bidentes, meliusque perspicitur a custodibus fructus, et commodius legitur a vindemiatore.

XVIII. Sed quoquo vineta placuerit ordinare, centenæ stirpes per singulos hortos semitis disting!!antur : vel, ut quibusdam placet, in semijugera omnis modus dirimatur. Qua distinctio præter illud commodum, quod plus solis et renti vitibus probet, tum etiam oculos et vestigia domini, res agro saluberrimas, facilius admittit, certamque æstimationem in exigendis operibus probet. Neque enim falli possumus per paria intervalla jugeribus divisis. Quiı. etiam ipsa hortulorum descriptio quanto est minoribus modulis concisa, fatigationem veluti minuit, exstimulatque eos qui onera inoliuntur, et ad festinanduin invitat. Nam fere vastitas instantis laboris animos debilitat. Non niliil etiam prodest vires et proventum cujusque partis vi. particulier, pour pouvoir juger quelles sont cclles qui ont besoin de plus ou moins de culture. En outre, ces sentiers livrent noll-seulement aux vendangeursmais eucore à ceux qui vont raccommoder les jougs et les appuis de la vigne, un passage libre et facile, à travers lequel les uns et les autrespeuvent porter les fruits ou les ćchalas.

XIX. Quant à la hauteur dont le joug doit être élevé de terre, il suffira de dire que sa plus petite élćvation est de quatre pieds, et sa plus grande de sept. Il faut cependant éviter cette dernière dans les jeunes plants; car on ne doit pas commencer par élever d'abord les vignes à une si grande hauteur, et il ne faut les y conduire qu'après une longue suite d'années. Au r'este, plus le sol et le climat sont humides et les vents doux, plus il faut élever le joug : car pour lors la fertilité des vignes permet de les laisser monter plus haut, et le fruit étant écarté de terre est moins sujet à se pourrir; outre que c'est la seule façon dont il puisse jouir des effets salutaires du vent, qui sèche en peu de temps les brouillards et les rosées pestilentielles, et qui contribue beaucoup tant à faire défleurir la vigne qu'à en améliorer le vin. Les terrains maigres au contraire ou ceux qui vont en pente, ainsi que ceux qui sont brûlés par la chaleur, ou trop exposés à la violence des tempêtes, demandent des jougs plus bas. Mais si tout se trouve conforme à nos désirs, nous ferons monter nos vignes à cinq pieds de hautcur, ni plus ni moins; quoiqu'il n'y a point de doute que plus elles seront montées sur des jougs élevés, plus le vin qu'elles donneront sera d'un goût délicat.

XX. Quand la vigne a été échalassée et mise au joug, elle a besoin dessoins de celui qui doit la lier. Ce qu'il aura le plus à cœur, ainsi que je

nearum nosse, ut æstimemus, quæ magis aut minus co. lenda sint. Vindemiatoribus quoque hæ semitæ et jugum pedamentaque sarcientibus opportunam laxitatem prabent, per quam vel fructus vel statumina portentur.

XIX. De positione jugi, quatenus a terra levandum sit, hoc dixisse abunde est : humillimam esse quatuor pedum, celsissimam septem. Quæ tamen in norellis seminibus vitanda est. Neque enim lıæc prima constitutio vinearum esse debet, sed per annorum longam seriem ad hanc altitudinem vitis perducenda est. Caterum quanto humidius est solum et calum, placidioresque veuti, tanto est altius attollendum jugum. Nam lætitia vitium patitur celsius evocari, fructusque submotus a terra minus putrescit : et hoc uno modo perflatur ventis, qui nebulam et rorem pestiferum celeriter adsiccant, multunque ad dellorescen. dum et ad bonitatem yiui couferunt. Rursus exilis terra et acclivis torrensque restı, vel quæ vehementibus procellis obnoxia est, lumilius jugum poscit. At si cuncta coupetunt voto, justa est altitudo vinea pedum quinque : nec tamen dubium, quin vites tanto inclioris saporis prac leant mustum, quauto in editiora juga consurgunt.

$\mathrm{XX}$. Pedatam vineam jugatamque sequilur alligaturis 
l'ai dit ci-dessus, est de conserver la tige dans une direction droite, et de ne pas se régler sur les tortuosités de l'échalas, de peur que sa mauvaisc tournure ne fasse contracter a la vigne les mêmes défauts. Ce point est non-seulement intéressant pour donner un bel aspect à la vigne, mais encore pour lui procurer de la fécondité, de la force et de la durée. Car quand le trone est droit, il porte sa moelle dans la même direction; moyennant quoi le suc de la terre, qui lui doit servir de nourriture, passe plus facilement à travers cette moelle, et parvient au haut de la plante, en suivant, pour ainsi dire, un chenin qui ne se trouve barré par aucun détour ni par aucun obstacle; au lieu que les vignes, qui sont courbées et torses, ne sont pas égalcment abreuvées de ce suc dans toutes leurs parties, tant à cause des obstacles que les nœuds apportent à son passage, qu'à cause de leur tortuosité, qui retarde la filtration des eaux de la terre, en leur opposant, pour ainsi dire, des mauvais pas. C'est pourquoi, lorsque la vigne est montée en ligne droite jusqu'au haut du pieu, on l'y attache avec un lien, de peur que le poids de ses fruits ne l'affaisse et ne la courbe. Ensuite, à partir de l'endroit qui a été lié le plus près du joug, on arrange ses bras de côté et d'autre, ct on recourbe en terre à l'aide d'un autre lien les branches à fruit, après les avoir fait passer sur le joug. Moyennant cela, il arrive que d'un côté ce qui pend du joug se charge de fruit, et que d'un autre côté la courbure occasionne de nouvelles pousses aux environs du lien qui la retient au joug. Il y en a qui ćtendent au-dessus du joug les parties que nous précipitons par en bas, et qui les y retiennent en les liant à diverses reprises; mais je ne crois pas leur méthode bonne. En effet, lorsque les branches à

cura, eui antiquissimum esse debet, ut supra dixi, rectam conservare stirpem, nec flexum ridicæ persequi, ne pravitas statuminum ad similitudinem sui vitem configuret. Id non solum ad speciem plurimum refert, sed ad ubertatem et firmitatem, perpetuitatemque. Nam rectus truncus similem sui medullam gerit, per quam velut quodam itinere sine flexu atque impediniento facilius terrx matris alimenta meant, et ad summum perveniunt. At qux curva sunt et distorta, ron acqualiter alliduntur inhibentibus nodis, et ipso flexu cursum terreni luumoris veluti salebris retardante. Quare cum ad summum palum recta vitis extenta est, capistro constringitur, ne foetu gravata subsidat curveturque. Tum ex eo loco quod proximum jugo ligatum est, brachia disponuntur in diversas parles, palmaque superpositze deorsum versus curvantur vinculo. Itaque id quod jugo dependet, fructu impletur : rursusque curvatura juxta vinculum materiam exprimit. Quidan eam partem, quam nos pracipitamus, supra jugum porrigunt, et erebris viminibus innexis contiuent; quos ego minime probandos puto. Nam dependentibus jalmitibus neque pluvix neque pruinx grandinesve fruit sont pendantes, les pluies, les brouillards et les grêles ne leur nuisent pas autant qu'elles leur nuisent, lorsqu'étant liées ensemble elles semblent se présenter en face aux mauvais temps. Cependant ces mêmes branches à fruits, que l'on aura laissé perdre, doiveut être liées avant que le fruit mûrisse, é quand les grappes commenceront à tourner et qu'elles seront encore en verjus, afin que les pluies puissent moins les pourrir, et que les vents et les bêtes ne les dévastent pas. Il faut, le long des chemins et des sentiers, tourner les branches à fruit en dedans du plan, pour que les passants n'y causent au. cun dommage. Voilà la manière de conduire au joug la vigne, quand il est temps de l'y mettre. Car si elle est faible ou courte, il faut la couper à la hauteur de deux bourgeons, afin qu'elle jette un bois plus fort, et qui puisse monter tout d'un trait au joug.

XXI. Quand la vigne a cinq ans, on ne la taille pas autrement que pour lui continuer la forme que nous avons désignée ci-dessus, et pour l'empêcher de s'étendre par en haut, en faisant en sorte que sa tête reste toujours à environ un pied au-dessous du joug, et qu'elle se distribue en quatre parties, c'est-à-dire, en autant de parties qu'ellea de brasou deduramenta, suivant l'expression de quelques personnes. II suffira de laisser à chacun de ces bras une branche à fruit, jusqu'à ce que les vignes aient toutc leur force. Mais lorsque, quelques années après, elles seront parvenues, pour ainsi dire, à la vigueur de la jeunesse, le nombre des branches à fruit qu'on leur laissera ne sera plus fixe. En effet, la fertilité du terrain en exigera davantage, et sa maigreur en comportera moins; d'autant quesi on ne réprime pas une vigne trop abondante en fruit, elle quitte mal sa fleur, et nc

tanfum nocent, quantum religatis, et quasi tempestatibus oppositis. Iidem tamen palmites prius quam fructus mitescant, variantibus adhuc et acerbis uvis, religari debent, quo minus roribus queant putrescere, aut ventis ferisve vastentur. Juxta decumanum atque semitas palmites in. trinsecus flectendi sunt, ne praeterenntium incursu lazdantur. Et hac quidem ratione tempestiva vitis perducilur ad jugum. Nam quæe vel infirma vel brevis est, ad duas gemmas recidenda est, quo relsementiorem fundat materiam, quæ protinus emicet in jugum.

XXI. Quinquennis vinex non alia est putatio, quam ut figuretur, quemadmodum institui dicere supra neve supervagetur; sed ut caput trunci pedali fere spatio sit inferius jugo, quaternisque brachiis, quxe duramenta quidam vocant, dividatur in totidem partes. Hæc brachia sat erit interim singulis palmitibus in fructum submitti, donec vineæ justi sint roboris. Cum aliquot deinde annis, quasi juvenilem æatatem ceperint, quot palmites relinqui de. beant, incertum est. Nam loci latitia plures, exilitas pau. ciores desiderat. Siquidem luxuriosa vitis nisi fructu com. pescitur, male deflorescit, et in materiam fiondemque 
donne que du bois et des feuilles; comme, d'un autre côté, quand elle est faible, elle souffre, pour peu qu'elle en soit trop chargée. C'est pourquoi, dans un terrain gras; on pourra laisser deux fouets à chaque bras, sans cependant changer le cep au point d'avoir plus de huit branches à fruit à nourrir, à moins que la fertilité du terrain n'en exige absolument davantage. Effectivement, un cep qui a plus de branches que nous ne venons de dire a plutôt l'air d'une vigne en treille qu'en vignoble. On ne doit pas non plus souffrir que les bras d'une vigne deviennent plus gros que son trone : mais toutes les fois que l'on pourra laisser croittre des fouets sur leurs côtés, il faudra les couper eux-mêmes par en haut, afin qu'ils ne montent pas au delà du joug; de façon que la vigne soit toujours renou. velée par de jeunes branches, que l'on mettra au joug lorsqu'elles seront devenues assez longues pour y atteindre. Mais s'il s'en trouve quelquesunes de rompues, ou qui ne soient pas assez longues, pour peu qu'elles soient dans une partie qui puisse servir à renouveler la vigue l'année suivante, il faudra les tailler en courson d'un pouce, que les uns appellent custos, les autres resex, et d'autres prcesidiarius. Ce courson n'est autre chose qu'un sarment de deux ou trois boutons, que l'on conserve à dessein de renouveler la vigne par son moyen, parce que, dès qu'il a produit des branches à fruit, on coupe tout l'excédent de l'ancien bras, qui est au-dessus de l'œil dont ces branches sont sorties. Cette méthode, par laquelle les vignes auront été mises en bon état, sera celle qu'il faudra toujours suivre par la suite.

XXII. Mais si nous avons acquis des vignes qui aient été conduites d'une autre façon, et que,

effunditur : infirma rursus, cum onerata est, afmigitur. Itaquue pingui terra singulis bracliiis licebit bina injungere flagella, nec tamen numerosius onerare, quam ut una vitis octo serviat palnitibus; nisi si admodnm nimia ubertas plureis postulabit. Illa enim pergulæe magis, quam vineæ figuram obtinet; quæ supra hunc modum materiis distenditur. Nec debemus committere, ut brachia pleniora trunco sint : verum assidue, cum modo e lateribus corum flagella licuerit submittere, amputanda erunt superiora duramenta, ne jugum excedant : sed novellis palmis semper vilis renovetur. Quæ si satis excreverint, jugo superponantur : sin aliqua earum vel profracta, vel parum procera fuerit, locumque idoneum obtinebit, unde vitis anho sequenti renovari debeat, in pollicem tondeatur, quem quidam custodem, alii resecem, nonnulli prasidiarium appellant, id est, sarınentum genmarum duarum vel trium, ex quo cum processere frugiferæ materiæ, quicquid est supra retusti brachii amputatur, et ita ex novello palmite vitis pullulascit. Atque liac ratio bene institutarum vinea. rum in perpetuum custodienda erit.

XXII. Si vero aliter formatas acceperimus vineas, et multorum annoruın negligentia supervenerint jugum, con- pouravoir été négligées pendant plusieurs années, elles soient montées au delà dú joug, il faudra examiner de quelle longueur sont les bras qui excèdent la mesure que nous venons de fixer; car s'ils n'ont que deux pieds ou un peu plus, on pourra encore remettre toutc la vigne au joug, pourvu que son pieu soit appliqué au tronc mêmc. En effet, il suffira pour lors d'écarter le pieu du trone, et del'enfoncer en terre sur la ligne où est la vigne, vis-à-vis le vide que forment deux de ses bras entre eux; après quoi on penchera la vigne pour la conduire à cet appui, et moyennant cela elle se trouvera à la portée du joug. Mais si ses bras sont beaucoup plus allongés, ou qu'ils soient dans le cas d'atteindre jusqu'à un quatrième ou même jusqu'à un cinquième échalas, on pourra à la vérité les rétablir, mais à plus grands frais, en courbant en terre des sautelles; et à l'aide de ces sautelles, dont nous approuvons fort l'usage, la vigne se propagera très-promptement. Cependant si elle est vieille, et que la superficie de son tronc soit rongée, cette opération demandera une grande attention; au lieu qu'il en faudra moins, si elle est dans toute sa vigueur et son intégrité. En effet, il suffira pour lors, après l'avoir déchaussée, de la fumer largement en hiver, et de la tailler de court; après quoi on l'ouvrira avec la pointe d'un instrument de fer, dans la partie la plus verte de son écorce, entre trois ct quatre pieds de terre; ensuite on donnera de fréquentes fouilles au terrain, afin qu'elle puisse s'animer et jeter des pampres, surtout de l'endroit où on l'aura ouverte : communément il sort un germe de cette cicatrice, et si le produit en devient très-long, on le laisse croítre coınme un fouet; au lieu que s'il est moins long, on le taille

siderandum erit, cujus longitudinis sint duramina, quæ excedunt prædictam mensuram. Nam si duorum pedum aut paulo amplius fuerint, poterit adhuc universa vinea sub jugum mitti, si tamen palus trunco est applicitus. Is enim a vite submovetur, et in medio spatio duorum ordinum ad lineam pangitur : transversa deinde vitis ad statumen perdıcitur, atque ita jugo subjicitur. At si duramenta ejus longius excesserint, ut in quartum aut etiam in quintum statumen prorepserint, majore sumptu restituetur. Mergis namque, qui nobis maxime placent, propagata celerrime provenit. Hoc tamen si vetus et exesa est superficies trunci; at si robusta et integra, minorem operam desiderat. Quippe hiberno tempore ablaqueata fimo satiatur, angusteque deputatur, et inter quartum ac tertium pedem a terra viridissima parte corticis acuto mu. crone ferramenti vulneratur. Frequentibus deinde fossuris terra permiscetur, ut incitari vitis possit, et ab ea maxime parte, quæ vulnerata est, pampinum fundere. Plerımque autem germen de cicatrice procedit, quod sive longius prosilıerit, in flagellum submittitur: sive brevius, in pollicem : sive admodum exiguum, in furunculum : is ex quolibet vel minimo capillamento fieri potest. Nanı ubi 
en courson, et s'il est absolument court, on le taille en forme de verrue; car le moindre petit filament peut être taillé de cette dernière façon. Or, dès qu'un pampre est sorti du bois dur avec unc ou deux feuilles, pourvu que ce pampre vienne à maturité, sans avoir été ni coupé ni épluché, il donnera, le printemps suivant, un bois considćrable; et lorsque ce bois sera consolidé, et qu'il aura formé une espèce de'bras, on pourra dès lors couper la partie du bras qui montait au-dessus du joug, et par conséquent laisser le reste au joug. Plusieurs personnes, pour avoir plus tôt fait, coupent les vignes qui sont dans ce cas à plus de quatre pieds de terre, sans rien redouter de cette amputation, parce qu'ordinairement la plupart des ccps se prêtent naturellement à jeter de nouvelles pousses auprès de la cicatricc. Mais nous n'approuvons pas cettc méthode, larce que communément une trop grande plaie, quand elle n'est pas surmontée d'une partie de bois bien portante, avec laquelle elle puisse se consolider, est bientôt desséchce par l'ardeur du soleil, ou pourrie par les pluies et les rosées qui succèdent à ce premier accident. Cependant, Iorsqu'on sera forcé de couper absolument un cep, il faudra d'abord le déchausser, puis le couper un peu au-dessous de la superficie du sol, afin que la terre dont on le recouvrira puisse le mettre à l'abri de l'ardeur du soleil, sans cependant cmpêcher le passage des nouvelles branches qui sortiront de ses racines, afin qu'clles puissent se marier à leurs échalas, ou couvrir de leurs provins les échalas du voisinage qui ne seront point garnis. Cette espèce d'opération ne pourra néanmoins se faire que lorsque les vignes seront plantées assez profondément pour que leurs racines ne vacillent pas sur la superficie du sol, et qu'elles seront d'une bonne espèce.
Autrement ce serait peinc perdue : parce que si ce sont des vignes dégénćrées, on aura beau les renouveler, elles conscrveront toujours ce premier vice, et que si elles tiennent à peine sur la superficie de la terre, elles périront avaut que d'avoir pris une certaine force. Ainsi, dans le premier cas, on fera mieux de les greffer arec des entes fruclueuses; et dans le second, il faudra les extirper entièrement et en replanter de nouvelles, pourvu cependant qu'on y soit déterminé par la bonté du sol. Car si 'e'est par le vice du sol qu'elles sont devenues stériles avant même que d'ĉtre vieillies, nous ne croyons pas qu'on doive les rétablir en aucune façon. Or les vices de terrain qui finissent presque toujours par détruire les vignobles sont la maigrcur et la stérilité, un goût salé ou amer inhérent à la terre, l'humidité, une position trop inclinée et escarpée, une terre trop ombragée et privée des rayons du soleil, des vallées sablonneuses, dc même qu'un tuf sablonneux, un sable plus maigre qu'il ne faut, et dans lequel il n'y a pas plus de terre que dans du gravier pur, et toutc autre circonstance pareille, qui met la terre hors d'état de fournir à la vigne sa nourriture. Au reste, lorsqu'un terrain n'a aucun de ces désavantages ni d'autres semblables, on peut en faire un vignoble qui rapportera toutes les années sans se reposer, en se conformant à la méthode que nous avons donnée dans lc premier livre. Mais pour les vignobles d'une espèce mauvaise, et qui, tout robustes qu'ils sont, ne rapportent pas de fruit à cause de leur stérilité, on les corrigera, comme nous avons dit, par le moyen de la greffe, dont nous traiterons en son lieu, lorsque nous eu serons venus à cettc matière.

XXIII. Comme il scmble que nous avons peu unius aut alterius foli pampinus prorepsit e duro, dum. morlo ad maturitatem perveniat, sequente vere, si non adnodatus neque adrasus est, vehementem fundit materiam : qua cum convaluit et quasi braclium fecit, licet tunc superragatam partem duramenti recidere, et ita reliquam jugo subjicere. Multi sequentes compendium tem. poris, tales vineas supra quartım pedem detruncant, nilril reforinidantes ejusmodi resectionem : quoniam fere plu. rimarum stirpium natura sic se commodat, ut juxta ci. catricem novellis frondibus repullescant. Sed hrec quidem ratio minime nobis placet. Siquidem vastior plaga nisi habeat superpositam valentem materiam, qua possit ino. lescere, solis halitu torretur : mox deinde roribus et imbribus putrescit. Attamen cum est utique vinea recidenda, prius ablaqueare, deinde paulum infra terram convenit amputare, ut superjecta lumus vin solis arceat, et e radicibus novellos prorumpentes caules transmiltat, qui possint vel sua maritare statumina, rel si qua sunt vidua in propinquo, propaginibus vestire. Hacc autem ita fieri debebunt, si vinere altius positx nec in sumno labantes radices labebunt, et si boni generis erunt. Namque aliter incassum dependitur opera. Quoniam degeneres etiam renovatæ pristinum sérvabunt ingenium; at quæ summa parte terræ vix adhærebunt, et deficient ante quam convalescant. Altera ergo vinea fructuosis potius surculis illserenda erit, altera funditus extirpanda et reserenda, si -modo soli bonitas suadebit. Cujus cum vitio consenuit, nullo modo restituendam censemus. Loci porro vitia sunt, quac fere ad internicionem vineta perducunt, macies el sterilitas terra, salsa vel amara uligo, praceps et prarupta positio, nimiun opaca et soli aversa vallis, arenosus etiam tofus, vel plus justo jejunus sabulo, nec minus terreno carens ac nuda glarea, et siqua est proprietas similis, quæ vitem non alit. Cæeterum si vacal his et lrorum similibus incommodis, potest ea ratione fieri restibilis vinea, quam priore libro pracepimus. Illa rursus mali generis vineta, quæ quamris robusta sint, propter sterilitatem fructu carent, ut dixinıs, emendantur insitione facta, de qua sıo loco disseremus, cun ad eam disputationem pervenerimus.

XXIII. Nunc quoniam parum videmur de putatione vinearum locuti, maxime necessariam partem propositi ope 
parlé de la taille, nous allons à présent traiter avec plus de soin ectle facon, qui est la plus essentielle de toutes celles que nous proposons de donner aux vignes. Il faut done, lorsque la température douce et modérée de la contrée où nous cultiverons le permettra, commencer la taille après la vendange, vers les ides d'octobre, pourvu cependant que les pluies d'automne soient préalablement tombées, et que les sarments aient acquis la force qu'ils doivent avoir : car la sécheresse oblige de la remettre à un temps plus éloigné. Mais si une température froide et sujette aux gelées blanches menaçait d'un hiver rude, nous remettrions cette opération aux ides de février. On pourrait aussi user du même délai, dans le cas où l'on n'aurait que des possessions de vignes peu étendues : car lorsque l'étendue de nos possessions nous empêchera de choisir notre temps, il faudra talller les parties de nos vignobles les plus vigoureuses pendant les froids, les plus maigres au printemps ou pendant l'automne, celles qui scront sous le midi, en hiver et même pendant le solstice; et celles qui seront exposées à l'aquilon, au printemps et pendant l'automne. Il est incontestable que telle est la nature de cet arbrisseau, que plus on le taille de bonne heure, plus il donne de bois, de même que plus on le taille tard, plus il donne de fruit.

XXIV. Au surplus, en tel temps que le vigneron taille la vigne, il a trois choses principales à observer : la première est d'avoir le plus qu'il pourra les fruits en vue; la seconde, de prendre ses précautions dès le moment de la taille, pour rẻser. ver pour l'année suivante le bois qui promettra le plus; enfin d'assurer à la vigne la plus longue durée; car la négligence sur un seul de ces points, quel qu'il soit, est capable de porter un grand pré-

ris diligentius persequemur. Placet ergo, si mitis actem. perata permittit in ea regione, quam colimus, cxli clementia, facta vindemia secundum idus Octobris auspicari putationem : cum tamen æquinoctiales pluviæ præcesserint, et sarmenta justam maturitatem ceperint. Nam siccitas seriorem putationem facit. Sin autem cæeli status frigidus et pruinosus hiemis violentiam denuntiat, in idus Felor. lianc curam differemus. Atque id licebit facere, si erit exiguus possessionis modus. Nam ubi ruris vastitas electionem nobis temporis negat, valentissimam quamque partem vineti frigoribus, macerrimaın vere, vel autumno, quill etian per brumam meridiano axi oppositas vites, aquiloni per ver et autumnum deputari coureuict. Nec dubium, quin sit loorum virgultorum natura talis, ut quanto maturius detonsa sint, plus materix, quanto serius, plus fructus afferant.

XXIV. Quandoque igitur vinitor loc opus obibit, tria pracipue custodiat. Primum ut quam maxime fiuctui consulat. Deinde ut in annum sequentem quam loxtissimas jam hinc eligat materias; tum etiam, ut quam longissimam perennitatem stirni acquirat. Nam quicquid ex his omittitur, magnum aftert domino dispendium. Vitis au- judice au propriétaire. Comme une vigne est divisée cn quatre parties, elle est aussi tournée vers quatre aspects du ciel différents; et comme cha. cun de ces aspects a ses propriétés différentes, ils demandent aussi des variétés dans l'arrangement des vignes, à raison de la différence de leur exposition. C'est pourquoi les bras exposés au septentrion sont ceux qui doivent souffrir le moins de taille, surtout si on les taille lorsqu’ils sont déjà menacés du froid, qui ne manquerait pas debrûler les cicatrices de l'opération. On ne leur laissera donc qu'un sarment le plus près du joug que faire se pourra, avec un courson au-dessous, qui servira à renouveler la vigne l'année suivante. Au midi, au contraire, on laissera un plus grand nombre de branches à fruit, qui serviront d'ombrage à la mère, lorsqu'elle sera tourmentée par les chaleurs de l'été, et qui empêcheront que le fruit ne se dessèche avant sa maturité. Pour le levant et le couchant, ils admettent tous deux très-peu de différence dans la taille, parce que la vigne ne voit pas le solell pendant moins d'heures sous l'une de ces positions que sous l'autre. Il faudra donc laisser du bois à proportion de la bonté du terrain et de celle du cep. Voilà les principes généraux de la taille; en voici de particuliers auxquels il faudra se conformer dans le détail. Car, pour commencer par le bas de la vigne comme par ses fondements, pour m'exprimer ainsi, il faut 'toujours écarter avec la doloire la terre dont son pied est environué; et s'il se trouve de ces rejetons qui tiennent à ses racines, nommés par les paysans suffrago, il faut les arracher avec soin, et unir la plaie avec le fer, pour empêcher que les eaux de l'hiver n'y séjournent. En général il vaut toujours mieux arracher les rejetons qui poussent d'un

tem cum sit per quatuor divisa parteis, totidem cæli regiones aspicit. Qux declinationes cum contrarias inter se qualitates habeant, variam quoque postulant ordinationeın pro conditione sua positionis in partibus vitium. Igitur ea braclia, quæe septentrionibus objecta sunt, paucissimas plagas accipere debent, et magis si putabuntur in gruentibus [jam] frigoribus, quibus cicatrices inuruntur. Itaque una tantummodo materia jugo proxima, et uuus infra eam custos erit submittendus, qui vitem mox in annum renovet. At e contrario per meridiem plures palmites submittantur, qui laboranten matrem ferroribus xestivis opacent, nec patiantur ante maturitatem fructum inarescere. Orientis atque occidentis lıaud sane magna est in putatione differentia, quoniam solem pari horarum numero sub utroque axe vitis accipit. Modıs itaque ma. teriarum is erit, quem dictabit lıumi atque ipsius stirpis letitia. Ilse in universum; illa per parteis custodienda sunt. Nam ut ab ima vite quasi a quibusdam fundamentis incipiaın, semper circa crus dolabella dimovenda terra est. Et si soboles, quam rustici suffraginem rocant, radicibus adhæret, diligenter explantanda ferroque allevanda est, ut libernas aquas respuat. Nam priestat ex vulnere 
endroit qui a été taillé, que de laisscr une cicatrice pleine de nœudset rude; parce que, dans le premier cas, la plaie ne tarde pas à se cicatriser, au lieu que, dans le second cas, elle se cave et se pourrit. A près avoir ainsi soigné le pied de la vigne, il faut examiner ses cuisses et son tronc, pour n'y laisser ni pampres sortis du bois dur, ni tumeur semblable à une verrue, à moins que la vigne ne soit montéc plus haut que le joug, et qu'elle ne demande à être ravalée. Mais s'il arrive qu'une partie du tronc qui aura été coupé soit desséchée par l'ardeur du soleil, ou que la vigne ait été creusée soit par les eaux, soit par les animaux nuisibles qui se seront insinués dans sa moelle, il faudra se servir de la doloire pour la délivrer de tout le bois mort, et ensuite la ratisser avec la serpe jusqu'au vif, afin qu'elle se cicatrise-dans une partie verte. Il ne sera pas difficile d'enduire ces plaies, aussitôt qu'clles seront unies, avec de la terre détrempée préalablement dans de la lic d'huile, parce que cettc espèce d'enduit écarte de la vigne les vers et les fourmis, et la préserve du soleil et de la pluie; ce qui fait qu'elle reprend plus tôt, et qu'elle conserve son tronc toujours vert. II faut encore éplucher le corps de la vigne en arrachant l'écorce sèche et gersée qui pendra du haut du tronc, parce que la vigne délivrće de ces espèces d'immondices ne s'en porte que mieux, et que le vin qu'elle donne est moins sujet à la lie. Il faut aussi écarter et ratisser avec lo fer la mousse qui tient le pied de la vigne resserré comme entre des entraves, et qui la maigrit par sa saleté, et par la léthargie dans laquelle elle la plonge. Voilà ce qu'il y a à faire dans le bas de la vigne. Je vais prescrire également ce qu'il faut lui faire au corps.

sobolem repullescentem vellere, quam nodosam et scabram plagam relinquere. Hoc enim modo celeriter cicatricem ducit, illo cavatur atque putrescit. Percuratis deinde quasi pedibus crura ipsa truncique circumspiciendi sunt, ne aut pampinarius palmes internatus aut verucæ similis furunculus relinquatur : nisi si jugo superjecta vitis desiderabit ab inferiore parte revocari. Si vero trunci pars secta solis afflatu peraruit, aut aqnis noxiisve animalibus, quæ per medullas irrepunt, cavata vitis est, dolabella conveniet expurgare quicquid emortuum est : deinde falce eradi vivo tenus, ut a viridi cortice ducat cicatricem. Neque est difficile mox allevatas plagas terra, quam prius amurca madefeceris, linere. Nam et teredinem formicamque pro. hibet, solem etiam et pluviam arcet ejusmodi litura, propter quæ celerius coalescit, et fructum viridem conservat. Cortex quoque aridus fissusque per summa trunci dependens, corpore tenus delibrandus est. Quod et melius vitis quasi sordibus liberata convalescit, et minus vino facis affert. Jam vero muscus, qui more compedis crura vitium devincta comprimit, situque et veterno macerat, ferı o destringendus et eradendus est. Atque hæc in ima parte vitis. Nec minus ea, quæ in capite servanda sint, deinceps præcipiantur. Plagæ, quas in duro vitis accipit,
Les plaies que l'on fait à la vigne dans le dur de son bois doivent être obliques et bien unies, parce qu'étant faites de cette manière, elles se guérissent plus promptement, et laissent plus facilement écouler l'ear jusqu'à ce qu'elles soient cicatrisées; au lieu que les plaies qui sont faites horizontalement recoivent plus d'eau sur leur surface, ct la gardent plus longtemps. C'est donc une faute que le vigneron doit surtout éviter. Il faut couper les sarments gourmands, ainsi que les vieux; ceux qui sont nés dans une mauvaise place, les tortus et ceux qui sont tournés vers la terre; et laisser les jeunes et ceux qui promettent du fruit, pourvu qu'ils soient droits. Il faut couper avec la serpe ceux qui sont secs et vieux, ainsi que les ergots des coursons de l'année, et conserver les bras tendres et verts. Quand la vigne sera montée à environ quatre pieds de hauteur, il faudra lui former quatre bras, dont chacun sera tourné vis-à-vis les quatre pointes de l'étoile formée par le joug. Mais il faudra prendre garde de laisser deux sarments ou davantage sur la même ligne et du même côté d'un bras, parce que la vigne souffre beaucoup quand toutes les parties de ses bras ne travaillent pas également, et qu'au lieu de distribuer de la nourriture à ses enfants par portion égale, ellcn'est têtée que d'un seul côté; parce qu'il arrive de là que celui de ses vaisseaux dont tout le suc est épuisé sèche comme s'il était frappé de la foudre. On appelle focaneus la branche à fruit qui sort communément entre deux fourchons : les paysans lui ont donné ce nom, parce que, naissant entre deux des bras dans lesquels la vigne se partage, elle tient ce passage assiégé, et intercepte la nourriture de ces deux bras. On a donc bien soin de la

obliquæ rotundæque fieri debent. Nam citius coalescunt, et quamdiu cicatricem non obduxerunt, commodius aquan fundunt : transversa plus humoris et recipiunt et continent. Eam culpam maxime, vinitor, fugito. Sarmenta lata, vetera, male nata, contorta, deorsum spectantia recidito; novella et fructuaria [recta] submittito. Braclia tenera et viridia servato; arida et vetera falce amputato. Un. gues custodum aunotinos resecato. In quatuor ferme pedes supra terram vitem elalam totidem brachiis componito, quorum singula spectent decussati jugi partes. Tun singulis vel unum flagellum, si macrior vitis erit; vel duo, si pinguior, brachio cuique submittito, eaque jugo superposita præcipitato. Sed meminisse oportebit, ne in eadem linea unoque latere lrachii esse duas materias plu. resve patiamur. Namque id maxime vitem infestat, ubi non omnis pars brachii pari vice laborat, neque æqua portione succum proli suæ dispensat : sed ab uno latere exsugitur. Quo fit ut ea vena, cujus omnis humor absumitur, velut icta fulgure arescat. Vocatur etiam focaneus palmes, qui solet in bifurco medius prorepere, et idcirco eum prædicto vocabulo rustici appellant, quod inter duo brachia, qua se dividit vitis, enatus velut fances obsidet, atque utriusque duramenti trahens alimenta præripit. 
retrancher aussi, et de l'arracher comme une espèce de rivale, avant qu'elle se soit fortifiée. Si cependant elle a déjà assez pris de force pour que l'un des deux brasen ait souffert, on retranche le plus faible des deux, et on la lui substitue; car l'un des bras étant ainsi coupé, la mère n'aura pas plus de peine à entretenir les deux autres parties qui resteront. Ainsi il faut mettre à un pied de distance au-dessous du joug la tête de la vigne, donts'écarteront, ainsi que je l'ai dit, ses quatre bras, sur lesquels on renouvellera la vigne chaque année, tant en coupant d'anciennes branches à fruit qu'en en laissant croitre de nouvelles, qu'il faudra choisir à cet effet avec intelligence. Car lorsque la vigne abonde en bois, le vigneron doit prendre garde en la taillant de ne pas lui laisser les branches qui seront les plus voisines du bois dur, c'est-à-dire, du tronc et de la tête de la vigne, non plus que celles qui en seront les plus éloignées. En effet, si les premières ne sont d'aucune utilité pour la vendange, parce qu'elles rapportent peu de fruit, attendu qu'elles sont semblables à celles qui sortent du trone à son pied, les secondes épuisent la vigne, parce qu'elles sont chargées de trop de fruit, et qu'elles s'étendent jusqu'à un second et un troisième pieu, ce que nous avons dit être vicieux. Il sera donc bon de laisser les branches qui se trouveront dans le milieu des bras, parce qu'on peut en espérer du fruit, et qu'il n'y a pas à craindre qu'elles maigrissent le cep. Il y a des personnes qui montrent plus d'avidité à se procurer une grande quantité de fruit, en laissant les fouets des extrémités avec ceux du milieu, et en taillant en outre en courson le sarment le plus proche du bois dur. Mais je ne crois pas qu'on doive suivre cette méthode, à moins que la vigueur, tant du sol que du

Hunc ergo tanquam æmulum diligenter iidem amputant, et adnodant, priusquam corroboretur. Si tamen ita prævaluit ut alterutrum brachium afflixerit, id quod imbecillius est, tollitur, et ipse focaneus submittitur. Reciso enim brachio, æqualiter utrique parti vires mater subministrat. Igilur caput vitis pede infra jugum constituito, unde se pandant quatuor (ut dixi) brachia, in quibus quotannis vitis renovetur, amputatis veteribus, et submissis novis palmis, quarum delectus scite facieudus est. Nam ubi magna inateriarum facultas est, putator custodire debet, ne aut proximas duro, id est a trunco et capite vitis relinquat, aut rursus extremas. Nam illæ minimum vinde. mix conferunt, quoniam exiguum fructum prabent, similes scilicet pampinariis : ha vitem exhauriunt, quia nimio foetu onerant, et usque in alterum ac tertium palum, quod ritiosum esse diximus, se extendunt. Quare medio in braclio commodissime palmæ submittentur, qua nec spem vindemia destituant, nec emacient stirpem suam. Nonulli fructus avidius eliciunt, extrema et media lagella submittendo, nec minus proximum duro sarmentum in custodem resecando : quod faciendum, nisi permittentibus soli et trunci virihus, minime censeo. Nam ita se trone, ne le permette : car ces fouets se couvrent d'une si grande quantité de grappes, qu'elles ne peuvent plus parvenir à lcur maturité, à moins que la bonté de la terre ou la fertilifé durtrone ne s'y prêtent. On ne doit pas tailler de branches en courson, lorsque celles dont on attend les fruits les plus prochains sont situées dans un lieu convenable, parce qu'il suffit de lier ces branches et de les courber vers la terre, pour exciter le bois à en sortir au-dessous de la ligature. Mais si la vigne s'étend plus loin que la méthode des agriculteurs ne lui permet de le faire, et qu'en s'élançant du côté de sa tête elle jette ses bras sur les toits des jougs voisins qui ne lui sont point destinés, on laissera auprès du tronc un courson vigoureux et très-long, garni de deux ou trois nœuds : ce courson jettera l'année suivante du bois, dont on formera un nouveau bras qui paraftra comme sortir du pouce; après quoi on coupera les autres bras, et la vigne se trouvera renouvelée et pourra être contenue dans les bornes de son joug. Mais en laissant ce courson, voici ce qu'il faudra surtout observer : premièrement, que la plaie n'en soit pas horizontale ni tournée en face du ciel, mais oblique et penchée vers la terre, moyennant quoi elle se défendra d'elle-même contre la gelée, et se garantira du soleil; secondement, que la taille n'en soit point allongée en forme de flèche, mais courte et arrondie comme les ongles, parce que dans le premier cas la partie blessée se dessèche plus tôt, et que la plaie se fait sentir dans une plus grande étendue; au lieu que dans le second cas elle se remet plus tôt de sa blessure, laquelle d'ailleurs s'étend moins au loin. Il faut aussi se garder trèsparticulièrement d'une méthode fort.vicieuse, que je vois néanmoins être usitée par plusieurs

induunt uvis, ut nequeànt maturitatem capere, si benignitas terræ atque ipsius trunci lætitia non adsit. Subsidiarius idemque custos in pollicem resecari non debet, cum palmæ, ex quibus proximi fructus sperantur, idoneo loco sitæ sunt. Nam ubi ligaveris eas, et in terram spectantes deflexeris, infra vinculum materias exprimes. At si longius, quam ritus agricolarum permittit , a capite vitis emicuerit, et bracliiis in aliena jugorum compluvia perrepserit, custodem validum et quam maximum juxta truncum duorum articulorum vel trium relinquenıus, ex quo quasi pollice proximo anno citata materia formetur in braclium : ut sic recisa vitis ac renovata intra jugum contineatur. Sed in sulsmittendo custode hæc maxime sunt observanda. Primum ne resupina cxlum sed prona potius plaga terram spectet : sic enim et gelicidiis ipsa se protegit et ab sole obumbratur. Deinde ne sagittæ sed nec ungulæ quidem similis fiat resectio : nam illa celerius et latius emoritur, hæc tardius et angustius reformidat. Quodque etiam usurpari vitiosissime animadverto, maxime vitandum est. Nam dum serviunt decori, quo sit brevior custos, et similis pollici, juxta articulum sarmentum recidunt. Id autem plurimum officit, quoniam se- 
personnes, qui, lorsqu'elles taillent un sarment en courson, n'ont égard qu'à la beauté du coup d'œil, et le coupent à cet effet près de la jointure, afin qu'il soit plus court, et qu'il ressemble plus parfaitement au pouce; mais cette méthodo est très-pernicieuse, parce qu'il arrive de là que l'œil voisin de la plaie souffre dans les commencements du froid et de la gelée, et, par la suite, de la chaleur. Le meilleur est done de couper le courson vers le milieu de l'entre-nœuds, ct d'incliner la plaie du côté opposé à l'œil, afin qu'elle ne répande pas ses plcurs sur lui, ainsi que nous l'avons déjà dit ci-dessus, et qu'elle ne l'aveugle pas lorsqu'il scra prêt à bourgeonner. Mais si l'on n'a pas de quoi faire un courson, il faudra chercher dequoi faire une tumeur, laquelle, pour être coupée de très-court à pcu près dans la forme d'une verruc, n'en donnera pas moins le printemps suivant du bois, qui servira à remplacer des bras ou des branches à fruit. Si l'on ne trouve pas même de ces sortes de tumeurs, il faudra faire une ouverture à la vigne, en y appliquant le fer à l'endroit d'où l'on voudra faire sortir des pampres. Je suis encore très-fort d'avis que l'on délivre de leurs vrilles et de leurs rejetons les branches à fruit que l'on destine à la vendange. Mais il faut s'y prendre autrement pour les couper, que pour couper les pampres qui sortent du tronc : car on applique rudement la serpe pour couper ras ce qui sort du bois dur, afin que la plaie se cicatrise plus promptement; au lieu qu'on s'y prend plus doucement quand il s'agit de couper ce qui sort du bois tendre, comme, par exemple, les rejetons, parce qu'ordinairement ils sont garnis sur le côté d'un œil qu'il faut ménager, sans l'offenser avec la serpe. Or si l'on y appliquait le fer trop rudement, on cnlèverait absolument l'œil, ou tout au moins on l'en-

cundum plagam posita gemma pruinis et frigore tum deinde $x$ stu laboral. Optimum est igitur nedio fere internodio subsidiarium toudere palmitem, devexamque resectionem facere post gemmam, ne, ut [jam] antea diximus, superlacrymet et gemmantem cæcet oculum. Si resecis facultas non erit, circumspiciendns est furunculus, qui, quamvis angustissime præcisus in modum verrucæ, proximo rere materiam exigat, quanı vel in bracliuun vel in fructuariun remiltamus. Si neque is reperiatur, saucianda ferro est alque exulceranda vitis in ea parte, qua pampinum studemus elicere. Jam vero ipsos palmites, quos vindemix præparamus, clavicnlis ac nepotibus liberandos magnopere censeo. Sed in is recidendis alia conditio est, atque alia in is, qua procedunt e trunco. Nam quicquid est, quod e duro prominet, vehementius applicata falce adnodatur et eraditır, quo celerius obdu. cal cicatricen. Rursus quicquid e tenero processit, sicut nepos, parcius detondelur : quoniam fere conjunctam ge. rit ab latere gemmam, cui consulendum est, ne falce destringatur. Pressius enim si adnodes applicato ferro, aut lota tollitur, aut convulneratur. Propter quod palmes, dommagerait du même coup; d'où il arriverait que le pampre qui est prêt à germer scrait faible et peu fertile, outre qu'il serait plus sensible aux injures des vents, parce qu'il serait sorti de la cicatrice sans aucune vigueur. Il est difficile de déterminer la longueur que l'on doit donner au bois qu'on laissera à la vigne. La plupart cependant ne lui donnent que la longueur suffisante pour pouvoir passer sur le joug et se recourber de l'autre côté, sans néanmoins aller jusqu'à terre. Pour nous, nous croyons qu'il faut entrer dans un plus grand détail sur cet objet, et examiner en premier lieu quelle est la nature de la vigne, parce que si elle est robuste, elle pourra porter de plus long bois; en sccond lieu, si le sol est gras, parce que s'il ne l'est pas, quelque robuste que soit la vigne, nous la ferions bientôt périr en l'amaigrissant par de trop longs fouets. Au reste, on n'estime pas la longueur d'une branche à fruit d'après sa mesure intrinsèque, mais d'après lc nombre de ses bourgeons : car lorsque ses nœuds sont très-éloignés l'un de l'aútre, on peut lui laisser assez de longueur pour aller presque jusqu'à terre, attendu que malgré cette longueur clle jettera peu de pampres. Mais lorsque les nœuds d'une branche à fruit sont drus, et qu'elle montre beaucoup d'yeux, quoique courte, elle donne. néanmoins un grand nombre d'autres branches à fruit, et produit des grappes en abondance, raison pour laquelle il faut de toute nécessité ménager dans ce cas-là sa longueur, pour que la vigne ne soit point chargée de branches à fruit trop hautes. II faut encore que le vigneron examine si la vendange de l'année précédente a été abondante ou non, parce qu'il doit épargner les vignes après une forte récolte, et par conséquent les tailler alors plus court; au lieu qu'après une moindre récolte, il doit leur faire la loi. Par-des-

quem mox in germinatione citaverit, imbecillis ac minus fructuosus erit, tum etiam magis obnoxius ventis; scilicet qui infirmus de cicatrice prorepseril. Ipsius autem materiæ, quam subıniltemus, longitudini modum difficile est imponere. Plerique tamen in tantun provocant, ut curvala et praecipitata per jugum nequeat terram contingere. Nos subtilius dispicienda illa censemus. Primun vitis habilum; nam si robusta est, ampliores materias sustinet : deinde soli quoque pinguitudinem; qux nisi adest, quamvis validissimam vitem celeriter necabimus procerioribus emaciatam flagellis. Sed longi palmites non mensnra, verum gemmarum numero astimantur. Nam ubi majora sunt spatia inter articulos, licet eonsque materiam producere, dum pene terram contingal : nililo minus enin paucis frondescet pampinis. At ubi spissa internodia frequentesque oculi sunt, quamvis breve sarmentum multis palmilibus virescit, et numeroso foctu exuberal. Quare modus talis generis necessario maxime est adli. bendus, ne procerioribus frucluariis oneretur. Et ut considerel vinitor, proximi anni magna necne fuerit vindemia. Nain pust largos fructus parcendum est vitibus, et 
sus tout cela, nous pensons eneore que toute la besogne dont nous parlons doit être faite avec des instruments de fer qui soient forts, minces et bien tranchants : car une serpe émoussée, épaisse et de peu de résistance retarde celui qui taille la vigne, et dès lors il fait moins d'ouvrage, quoiqu'il ait plus de peine. En effet, soit que l'instrument plie, comme il arrive quand il n'est pas ferme, soit qu'il pénètre difficilement, comme il arrive quand il est émoussé et épais, celui qui taille trouve alors de plus grands obstacles à vaincre, outre que les plaies, qui sont raboteuses et inégales quand l'opération n'a pas été faite en un seul coup mais en plusieurs, déchirent la vigne: d'où il arrive souvent qu'on est obligé de rompre ce qu'on aurait dû couper, et que I'humidité pourrit la vigne qui est ainsi déchirée et raboteuse, sans que les plaies qu'on lui a faites puissent se guérir. C'est pourquoi il faut bien a vertir celui qui doit tailier la vigne qu'il ait à aiguiser la lame de son instrument, pour le rendre, autant qu'il pourra, aussi tranchant qu'un rasoir. Il faut aussi qu'il sache de quelle partie de la serpe il doit se servir pour chaque opération différeute ; car j'ai souvent reneontré plusieurs personnes qui dévastaient les vignobles, faute d'a voir ectie connaissance.

XXV. Or telle est l'ordonnance et la figure de la serpe du vigneron. La partie la plus voisine du manche; qui présente la lame dans une direction droite, s'appelle culterá eause de sa ressemblance avec un couteau ; celle qui est recourbée s'appelle sinus; celle qui deseend de la courbure s'appelle scalprum, celle qui la suit et qui est crochue s'appelle rostrum; eelle qui surmonte cette dernière dans la forme d'une moitié de lunes'appelle securis; enfin celle qui part de l'extrémité de la serpe, et qui est penchée sur le devant en forme

ileo anguste putandum : post exiguos, imperandum. Su. per cetera illud etiam censemus, ut duris tenuissimisque et acutissimis ferramentis totum istud opus exequamur. Obtusa enim et hebes et mollis falx putatorem moratur, corfue ninus operis efficit, et plus laboris affert vinitori. Nam sive curvatur acies, quod accidit molli; sire tardius penetrat, quod evenit in retuso et crasso ferrameuto; majore nisu est opus. Tum eliam plagx aspera atque ince. quales vites lacerant. Neque enim uno sed sxpius repetito ictu res transigitur. Quo plerumque fit, ut guod pracidi debeat præefringatur, et sic vitis laniata scabrataque putrescat lumoribus, nec plagæ consanentur. Quare ma. gnopere monendus putator est, ut prolixet aciem ferramenti, et quantum possit noracula sinilem reddat. Nec ignoret in quaque re qua parte falcis utendum sit. Nam plurimos per hanc inscitiam vastare vinela comperi.

$\mathrm{XXY}$. Est autem sic disposita vinitorize falcis figura, ut capulo pars proxima, quxe rectam gerit aciem, culter ob similindineın nonninetur; quæ flectitur, sinus; quæ a Rexu procurrit, scalprum; qua deinde adunca est, rostrum appeltatur; cui superposita semiformis luna species COLEYELLE. de pointe, s’appelle mucro. Chacune de ees parties a sa fonetion particulière, pourvu que le vigneron soit habile à manier/cet instrument. Car, lorsqu'il veut couper quelque chose en appuyant la main devant lui, il se sert du culter; Iorsqu'il veut tirer la main à lui, il sé sert du sinus; lorsqu'il veut unir la plaie, il se scrt dá scalprum; lorsqu'il veut creuser, il se sert du rostrum; lorsqu'il veut donner un coup, il se sert de la securis; et lorsqu'il veut nettoyer un endroit dont l'ouverture est étroite, il se sert du mucro. La plus grande partie de l'ouvrage que l'on fait sur les vignes doit être faite en tirant à soi plutôt qu'en frappant, paree qu'une plaie faite de eette manière s'unit du même trait, attendu que le vigneron commenee par mesurer son coup avant d'appliquer le fer pour couper ee qu'il a envie de couper; au lieu qu'en frappant ia vigne, il blesse le cep de plusieurs coups, pour peu qu'il vienne à manquer le premier (comme il arrive souvent). Ainsi la meilleure taille et la plus sûre est eelle que l'on fait en conduisant la serpe (ainsi que je l'ai dit), et non pas en donnant un coup.

XXVI. Toutes les opérations précédentes finies, le soin de soutenir la vigne et de la mettre au joug pour lui donner de la stabilité, leur succède, comme nous l'avons déjà dit ci-dessus. L'échalas est préférable au pieu en cette oceasion, encore y a-t-il du choix à faire : car le meilleur échalas est celui qui est fait de bois d'olivier, de chêne, et de liége, ainsi que de toute autre espèce de chêne fendu avec des coins; viennent ensuite les appuis ronds et longs, dont les plus approuvés sont ceux de bois de genévrier, de laurier et de cyprès. Les pins sau vages sontégalement bons à cet usage, et le sureau même n'est pas mauvais. $\mathrm{Au}$ reste, quelque bons que soient ces appuis et

securis dicitur. Ejusque velut apex pronus imminens mucro vocatur. Harum partium qußeque suis muneribus fungitur, si modo viuitor gnarus est iis utendi. Nam cum in adversum pressa manu desecare quid debet, cultro utitur : cum retraliere, sinu : cum allevare, scalpro : cum incavare, rostro : cum ictu cxedere, securi : cum in angust) aliquid expurgare, mucrone. Major autem pars operis in vinea ductin potius quam cresim facienda est. Nam ea playa quæ sic ellicitur, uno vestigio allevatur. Prius enim putator applicat ferrun, atque ita quæ destinavit pracidit. Qui casim vitem petit, si frustratus est, quod sape evenit, pluribus ictibus stirpem vulnerat. Tutior igitur, et utilior putatio est, quæ, ut retuli, ductu falcis non ictu conficitur.

XXVI. Hac peracta, sequitur, ut ante jam diximus, adminiculandæ jugandæque vineæ cura, cui stabiliendæ melior est ridica palo, neque ea quallibet : nam est pracipua cuneis fissa olea, quercus et suber, ac si qua sunt similia robora: tertium obtinet locum pedamen teres, idque maxime probatur ex junipero, tum ex lanru el cupressu. Recte etıam faciunt ad eam rem silvestres piuus, 
tous les autres semblables, il faut néanmoins les retuucher après la taille, les unir avec la doloire dans les parties qui en seront pourries, changer de cóté ceux qui seront sains, retirer ceux qui seront ou cariés ou plus courts qu'il ne faudra, et en remettre de meilleurs à leur place; relever ceux qui seront couchés par terre, et redresser ceux qui pencheront. On mettra de nouveaux liens aux jougs, au cas qu'ils n'aient pas besoin d'être rcfaits à neuf ; mais s'ils paraissaient être dans le cas d'ètre refaits, il faudrait attacher des perches ou des roseaux à la vigne avant d'y appliquer les pieux; et ce ne sera qu'après que le joug sera fait ainsi, que l'on rassemblera, par le moyen de l'échalas, tout le cep vis-à-vis de son pied et sous ses bras, ainsi que nous l'avons prescrit pour les jeunes vignes, en évitant d'attacher les vignes toutes les années à un seul et même endroit, de peur que les ligatures répétées ne finissent par couper le tronc et par l'étrangler. Ensuite on distribuera les bras en quatre parties sous l'étoile formée par le joug, et l'on attachera les jeunes branches à fruit sur le joug, sans forcer nature, mais en les courbant légèrement pour les laisser aller comme elles voudront, de peur de les rompre si on les pliait, et d'en faire tomber des bourgeons déjà gros. Lorsqu'il arrivera que deux sarments prendront leur direction d'un même côté du joug, on mettra une perche entre deux, afin que les branches à fruit, se coulant sur cette perche, forment le toit du joug, pour en descendre ensuite et prendre leur direction vers la terre, comme s'ils se plongeaient du faîte de ce toit. Pour que cela soit habilement exécuté, celui qui liera les branches se souviendra de ne pas en tordre le sarment en l'attachant, mais de courber simplement tout.le bois qu'il mettra sur le joug ct qui pourra en être précipité,

atque etiam sambuci probabiles usu statuminis. Hæc corumque similia pedamenta post putationem retractanda sunt, partesque eorum putres dedolandae acuendæque; atque alia convertenda, quæ proceritatem liabent : alia submovenda, qua rel cariosa vel justo breviora sunt, eorumque in vicem idonea reponenda, jacentia statueıda, declinata corrigenda. Jugo, si non erit opus novo, sarturse recentia vincula inserantur : si restituendum videbitur, ante quam vitis palo applicetur, perticis vel arundinibus connectalur, ac tum demum, sicut in novella præcipimus, vilem juxta caput, infraque brachia colligemus cum ridica : idque facere non oportebit omnibus aunis eodem loco, ne vinculum incidat, et truncum strangulet. Brachia deinde sub stella quadi ipartito locabimns, tenerosque palmites super jugum lif̧abimus niluil repugnantes naturæ, sed ut quisquis obsequetur, leviter curvabitur, ne deflexus frangatur, neve jam tumentes gemmse detergeantur. Atque ubi duæ materiæ per unam partem jugi mittentur, media pertica interveniat, diremptaeque palmæ per jugorum compluvia decurrant, et velut mersa cacuminibus in terram despiciant. Id ut scite fiat, meminerit de facon que ce bois paraisse plutôt appuyé sur la perche, que suspendu à la ligature qui le reticnt. Car j'ai souvent remarqué que les paysans, en attachant sans précaution les branches a fruit au joug, les y mettaient de façon qu'il semblait qu'elles ne faisaient que pendre de la ligature qui les retenait, quoique les branches ainsi attachées se rompent lorsqu'elles viennent à être chargées du poids des pampres et des grappes.

XXVII. Lorsque les vignobles auront été ordonnés de la manière que nous avons prescrite, nous nous hâterons de les nettoyer, et d'en retirer les sarments et les bouts d'échalas. II ne faudra cependant les enlever que dans un temps où le terrain sera sec, de peur que celui qui doit fouiller la terre ne trouve trop de difficulté à le faire, dans le cas où clle aurait été trop piétinéc pendant qu'elle était bourbeuse. On doit envoyer tout aussitót cet ouvrier dans les vignes, sans attendre qu'elles disent mot; parce que, si on ne l'y envoyait qu'après qu'elles auraient commencé à bourgeonner, il ferait tomber une grande par. tie de la vendange. C'est pourquoi il faut les be'cher très-profondément avant qu'elles bourgeonnent, entre l'hiver et le printemps, afin qu'elles pullulent plus gaiement et plus abondamment; ensuite lorsqu'elles seront couvertes de feuilles et de grappes, il faudra diminuer le nombre de leurs sarments pendant qu'ils seront encore tendres et jeunes. Mais le vigneron, qui s'était auparavant servi du fer pour les décharger, ne sc servira plus alors que de la main, pour réprimer l'ombrage et faire tomber les pampres superflus. Car il importe très-fort que cette opération soit faite habilcment, puisque les vignes gagnent encore plus à être épamprées qu'à être taillées. En effet, quoique la taille leur soit utile, cette opć

alligator, ne torqueat sarmentum, sed tantum inflexum devinciat, et ut omnis materia, quæe nondum potest pracipitari, jugo superponatur, ut potius innixa perlica, quam e vinculo dependeat. Sxe enim notavi per imprudentian rusticos subjicere jugo palmam, et ita colligare, ut soli) vimine suspendant. Qua vinea cum accipit pampini ot uvarum pondus, infringitur.

XXVII. Sic deinde ordinata vineta festinabimus emun. dare, sarmentisque et calamentis liberare. Quæ sicco tamen solo legenda sunt, ne lutosa hunıus inculcata majorem fossori laborem præbeat, qui protinus adhuc silentibus vineis inducendus est. Nam si palmis incientibus progemmantibusque fossorem immiseris, magnam partem vindemiæe decusseril. Igitur ante quan germinent, per dirortium veris atque hieınis quam altissime fodiendæ vineæ sunt, quo lætius atque hilarius pullulent, eneque ubi se frondibus [et uvis ] vestierint, teneris caulibus nec dum adultis mo. dus adhibendus est. Idemque vinitor, qui ante ferro, nunc manu decutiet, umbrasque compescet, ac supervacuos pampinos deturbabit. Nam id plurimum refert non inscite facere, siquidem vel magis pampinatio, quam putatio ri- 
ration les blessc par là mème qu'clle les eoupe; au lieu que l'opération par laquelle on les épampre les guérit plus doucement et sans les blesser, outre qu'elle prépare la taille de l'année suivante, en la rendant plus faeile. Elle laisse aussi moins de eicatrices à la vigne, parce que la partie du cep, dont on n'a retranché que du vert et du tendre, se guérit toujours promptement. Outre cela, les branches qui sont ehargées de fruit prennent plus de force, et le raisin, trouvant plus de faeilité à se cuire au soleil, mûrit mieux. C'est pourquoi un vigneron prudent et habile doit exa. miner et juger quels sont les endroits de la vigne nù il laissera croître le bois de l'annće suivante, et ne pas seulcment ôter les branches qui nont point de grappes, mais encore celles qui ont du fruit, si leur nombre est excessif; car il arrive quelquefois à certains yeux de jeter trois pampres à la fois, auquel cas il en faut retrancher deux, afin que ces yeux aient plus de faeilité à nourrir le seul qui restera. Un paysan sage doit donc supputer si la vigne ne s'est pas chargée de plus de fruit qu'elle n'en peut porter. C'est pourquoi non-seulement il doit arracher les feuilles superflues, ce qu'il nc faut jamais manquer de faire, mais il doit encore faire tomber quelquefois une partie du fruit, pour soulager la vigne trop ehargée du poids de ses mamelles. Il y a même des cas particuliers où celui qui épampre doit, s'il est habile, faire tomber le fruit, quoiqu'il n'y en ait pas plus qu'il n'en pourrait mûrir. En effet, si la vigne se trouve fatiguée par les récoltes abondantes d'une suite d'années préeédentes, il est juste de la laisser se reposer et se refaire, et de pourvoir par-là au bois des années suivantes. Pour ce qui est de rompre l'extrémitć des sarments, pour réprimer la trop grande fertilité de

tibus consulit. Nam illa quamvis multum juvat, sauciat tamen et resecat : hæc clementius sine vulnere medetur, et anni sequentis expeditiorem putationem facit. Tum etiam ritem minus cicatricosam reddit : quoniam id ex quo viride et tenerum deccrptum est, celeriter consanescit. Super lıæc materix, qua fructum habent, melius convalescunt, et uvæ commodius insolatæ percoquuntur. Quare prudentis est, ac maxime callentis rinitoris astimare ac dispicere, quibus locis in annum debeat materias submittere; nec orbos tantum detralıere palmites, verum etiam frugiferos, si supra modum se numerus eorum profuderit. Siquiden evenit, nt quidam oculi trigeminis palmis egerminent, quibus hinos detralıere oportet, quo commodius singulos alumnos cducent. Est enim sapientis rustici reputare, num majore fructu vitis se induerit, quan ut perferre eum possit. Itaque non solum fronden supervacuam debet dccerpere, quod semper faciendum est, verum interdum partem aliquam foctus decutcre, ut uhere suo gravatam vitem levet. Idque faciet variis de causis pampinator in. dustrius, etiam si non erit major fructus, quam ut maturescere queat. Si autem continuis superioribus annis dapsili proventu fatigata vitis fuerit, requiescere ac refici par la vigne, de retraneher tous les pampres qui sortent des parties dures ou du tronc, à l'exception d'un ou de deux que l'on sera obligé de garder pour renouveler la vigne, comme encore d'arracher tout ce qui pousse sur la tête de la vigne entre ses bras, d'ôter les branches qui, étant sur. les bras mêmes, oecupent inutilement la mèrc, toutes stériles qu'elles sont, ce sont des ouvragés à la portée du premier venu, et même d'un enfant.

XXVIII. Le temps qu'il faut choisir de préférence pour épamprer la vigne, e'est arant qu'elle montre sa fleur; mais on pourra encore répéter cette opération quand elle l'aura quittée. Pour ce qui est du temps intermédiaire, c'est-à-dire, des jours pendant lesquels le raisin se formera, il ne faut pas entrer pour lors dans les vignes, parce qu'il est dangereux d'agiter le fruit pendant qu'il est en fleur' mais dès qu'il est sorti de l'enfance, pour m'exprimer ainsi, et qu'il est dans l'adolescenee, il faut l'attacher, le dépouiller de toutes ses feuilles, et le faire grossir à l'aide de fouilles fréquentes : car plus on pulvérisera la terre, plus il deviendra gros. Je ne disconviendrai pas que la plupart de ceux qui ont donné des préceptes d'agriculture avant moi s'étaient contentés de trois fouilles : de ce nombre est Græcinus, qui dit qu'on peut regarder comme suffisant de bêeher trois fois la vigne, quand elle est en état. Celsus et Atticus convicnnent aussi qu'il y a trois mouvements naturcls dans la vigne, ou plutót dans toute espèce d'arbres : l'un qui les fait germer, le second qui les fait fleurir, et le troisicme qui les fait mûrir. Ils pensent donc que les fouilles servent à animer ces mouvements, parce que la nature ne parvient à l'objet de ses désirs qu’autant qu’elle est aidéc par le travail joint à

erit, et sic futuræ materiæ consulendum. Nam cacumina flagellorum confringere luxuriæ coluprimendæ causa, vel dura parte trunci sitos pampinos submovere, nisi ad renovandam riten unus atque alter servandus est, tum e capite quicquid inter brachia virel explantarc, atque eos, qui per ipsa duramenta sterilcs, nequicquam matrem opacant, palmites detergere cujuslibet vel pueri est officium.

XXVIII. Tempus autem pampinationis ante, quam florem vitis ostendat, maxime est eligendum : sed et postea licet eandem repetere. Medium igitur eorum dierum spatium, quo acini formantur, vinearum nobis aditum negat. Quippe florentcm fructum inovere non expcdit : pubescentem vero, et quasi adolescentem convenit religare, foliisque oinnibus nudare, tum et crebris fossionibus implere : nam fit uberior pulverationibus. Nec infitior plcrosque ante me rusticarum rerum magistros tribus fossuris contentos fiisse. Ex quibus Gracinus, qui sic refert : potest videri satis esse constitutam vineam ter foderc. Celsus quoque et Atticus conscntiunt, tres esse motus in vite seu potius in omni surculo naturales : unum, quo gcrminet; alterum, quo floreat; tertium, quo maturescat. Ilos ergo motus censent fossionibus concitari. Non enim natura quod rult 
l'étude. 'lelle est la culture des vignes, laquelle aboutit à la vendange.

XXIX. Je reviens à présent à la partie de ee traité, dans laquelle je me suis engagé à donner les préceptes qui eoneernent les greffes de la vigne et le soin de les entretenir. Julius Atticus a dit que le temps propre à greffer était depuis les ealendes de novembre jusqu'à eelles de juin, qui est tout le temps pendant lequel il assure qu'on peut conserver les greffes sans qu'elles bourgeonnent; d'où nous devons conelure qu'il n'y a point de temps de l'année d'excepté, selon lui, pourvu que l'on puisse avoir du sarment, dont la séve ne dise mot. J'aceorderais volontiers ectte proposition fans les autres espèces de plantes, dont l'écorce est plus ferme et plus pleine de sue que celle de la vigne. Mais je ne serais pas sineère, si je déguisais qu'il y a de l'imprudenee, en fait de vignes, à permettre aux paysans de les greffer dans le eours d'un aussi grand nombre de mois. Ce n'est pas que j'ignore que la greffe faite à la vigne au solstice d'hiver prend quelquefois; mais il est de notre devoir de prescrire, non pas ce qui résulte par hasard d'une ou de deux expériences, mais ce qui arrive eommunément et par des raisons certaines. Je pourrais tout au plus consentir, jusqu'à un eertain point, à cette méthode, s'il ne s'agissait d'en eourir les risques que sur un petit nombre de ceps, paree qu'on pourrait alors remédier à cette témérité par de plus grands soins qu'on y apporterait. Mais il est nécessaire d'ćcarter tous les doutes relativement aux cas où l'immensité de l'ouvrage qu'il y aurait à faire partagerait les soins de l'agriculteur, même le plus exact. Ce que prescrit Atticus est done absolument contraire aux vignes. Effectivement le

satis efficit, nisi eam labore cum studio juveris. Alque lıxe eolendarum vivearum eura finitur vindemia.

XXIX. Redco nune ad eam partem disputationis, qua suin professus vitium inserendarum tnendarumque insi. tionum pracepta. Tempus inserendi Julius Attieus tradidit ex calend. Novemb. in ealendas Junias, quoad posse custodiri surculum sine gernine affirmat. Eoque debemus intelligere nullam partem auni excipi, si sit sarmenti silentis facultas. Id porro in aliis stirpium generibus, quæ firnioris et succosioris libri sunt, posse fieri sane concesserim. In vitibus uimis temere tot mensium rusticis insitionem perınissan dissimulare non est fidei mexe : non quod ignorem, bruma temporibus aliquando insitam vitem comprelieudere; sed non quid in uno vel altero experimento casu fiat, verum quid certa ratione plerumque proveniat, discentibus praceipere debemus. Etenim si exiguo numero periclitanduin sit, in quo major eura temeritati medetur, possum aliquatenus counivere. $\mathrm{Cum}$ vero vastitas operis efiam diligentissimi agrieolx curam distendit, omnem scrupulum submovere debemus. Est enim eontrarium, quod Attieus praeipit. Nam idem per brumam negat reete putari vineain. Qux res quamvis minus lædat vitem, merito tameu fieri prohibetur, quod frigoribus omnis sureulus même auteur eonvient qu'il n'est pas à propos de tailler les vignes pendant lo solstice d'hiver (en quoi il a raison, paree que, quoique cette opération leur fasse moins de tort que la greffe, cependant tous les arbres sont eugourdis dans les temps froids, et la gelée empèche qu'il ne se fasse dans leur éeorce aueun mouvement qui puisse guérir la plaie) : et cependant il permet de les greffer dans le même temps, quoique la manière dont il veut qu'on le fasse eonsiște à tronquer le eep en entier, et à le fendre à l'endroit où il aura été tronqué. La meilleure méthode est done de greffer lorsque le temps commeneera à se radoucir après l'hiver, et lorsque la nature donnera du mouvement aux bourgeons et à l'écorce, et qu'on ne sera plus menacé du froid, qui pourrait brûler la greffe ou la plaie oc. casionnée par la seission du cep. Je permettrais cependant volontiers de greffer la vigne en automne, dans le cas où on serait pressé, paree que la température de l'air est assez semblable dans cette saison à celle du printemps. Mais en quelque temps que l'on veuille greffer, on saura qu'il n'y a pas d'autres soins à se donner pour le choix des greffes, que ceux que nous avons preserits dans le premier livre, en donnant des préceptes sur le choix des mailletons. Lors done qu'on aura ehoisi sur une vigne de bonne qualité les mailletons les plus féeonds et les plus mûrs, et qu'on les en aura séparés, on prendra, pour faire l'opération die la greffe, un jour où le temps soit doux, et où il ne fasse pas de vent. Ensuite on examinera si la greffe, est bien ronde dans toute sa longueur, et bien ferme; si la moelle n'en est pas spongieuse, et si elle a beaucoup de bourgeons et des entre-nœuds trè-courts. Car il est très- rigore torpet : nee propter gelicidia cortieem movet, ut cicatrieem consanet. Atque idem Altieus non prolibet eoden ipso tempore inserere, quod tum et totius obtrun. catione vitis et eum ejusden resectionis fissura præeeipit fieri. Verior itaque ratio est inserendi tepentibus jam dicbus post hiemem, cuin et gemma se et cortex naturaliter movet, nec frigus ingruit, quod possit aut sureulum insitum aut fissuræ plagam inurere. Permiserim tamen festinantibus autumno vitem inserere : quia non dissimilis est ejus aeris qualitas vernæ. Sed quocunque quis tempore destinaverit inserere, non aliam seiat esse euram surculis explorandis quam qua tradita est priore libro, cum de malleolis eligendis procepimus. Quos ubigenerosos et foeundos et quam maturissimos viti detraxerit, diem quoque tepidun silentemque a ventis eligat. Tum consideret surculum teretem solidique eorporis, nec fungosæ medullæ, crebris etianı gemmis et brevibus internodiis. Nam plurinum interest non esse longum sarmentum, quod inseratur; el rursus plures oeulos, quibus egerminet, inesse. Itaque si sunt longa internodia, neeesse est ad unam vel summum duas gemmas recidere surculuin, [ ne proeeriorem faciamus, quam] ut tempestates [et] vertos, et imbres inmobilis pati possit. Inseritur autem vitis vel recisa vel integra per. 
intéressant que le sarnient que l'on veut insérer ait, sans être long, beaueoup d'yeux par où il puisse germer. Il est visible que s'il a des entrenœuds bien longs, on se trouvera dans la néeessité de ne lui laisser qu'un bourgeon ou deux tout au plus, afin de le réduire à une longueur telle, qu'il puisse soutenir les orages, les vents et les pluies sans branler. On greffe la vigne, ou en la coupant, ou en la perẹant de part en part avee une tarière. Mais la première faęon est la plus usitée, et eelle que presque tous les agrieulteurs connaissent; au lieu que la seconde est plus rare, et que peu d'agrieulteurs l'emploient. Je parlerai d'abord de eelle qui est le plus en usage. On eoupe eommunément la vigne hors de la terre; quelquefois eependant on la coupe dans la terre même, à l'endroit où elle montre le plus de solidité et le moins de nœuds. Lorsqu'on la greffe près de terre, on enterre la greffe jusqu'à la cime; au lieu que lorsque la greffe est insérée au-dessus de la terre, on enduit exaetement la plaie avec un lut pétri exprès, que l'on reeouvre de mousse, le tout bien attaehé, afin qu'elle puisse être garantie des ehaleur's et des pluies. On taille la greffe à peu près dans la forme d'une flûte, de facon quelle puisse joindre les lèvres de la fente. Il faut qu'il se trouve un nœud dans la vigne au. dessous de eette fente, qui paraisse la bander, pour ainsi dire, afin de l'empêeher de faire des progrès plus étendus. Quand ce nœud serait à la distanee de quatre doigts de l'endroit où l'on aura eoupé le eep, il ne faudrait pas moins lier la vigne avant de la fendre, de peur que le tranchet de la serpe, en ouvrant un chemin à la greffe, ne fasse une plaie qui bâille plus que de raison. La greffe que l'on insérera ne doit pas ètre aiguisée sur une hauteur de plus de trois doigts; mais on l'aiguisera de façon qu'elle soit bien unie dans les parties qui auront été ratis-

forata terebra. Sed illa frequentior et pene omnibus agrico lis cognita insitio; liaec rarior et paucis usurpala. De ea igitur priıs disseram, quæ magis in consuetudine est. Reciditur vitis plerumųue supra terram, nonnunquam tamen et infra, quo loco magis solida est atque enodis. Cum supra terram insita est, surculus adobruitur caeumine tenus : at cum editior a terra est, fissura diligenter subaeto luto linitır, atque superposito musco ligatur, quod et ealores et pluvias areeat. Temperatur ita surculus, ut calamo non absimilis coagmentet fissuram, sub qua nodus in vite desideratır, qui quasi alliget eam fissuram, nec rimam patiatur ultra procedere. Is nodus etiam si quatuor digitis a reseetione abfuerit, illigari tamen cum prius, quam vitis findatur, conveniet, ne, cum scalpro faetum fuerit iter surculn, plus justo plaga liiet. Calamus adradi non amplius tribus digitis clebet: [allevari] atque is ab ea parte, qua raditur, ut sit levis. Eaque rasura ita dedneitur, ut medul. lan contingat uno latere, atque altero paulo iltra corticen destringatur, fizuretur(ume in speciem cumei, sic ut ab iina paite aeutus surculus, latere altero sit tenuior, atqque sées, c'est-à-dire, jusqu'à la moelle d'un eôté, et du eóté opposé jusque passé l'éeoree seulement; de sorte qu'elle ait la figure d'un coin, dont l'un des eotés aiguisés sera plus minee, et l'autre plus épais, afin qu'on puisse l'insérer par le eóté le plus minee, et la serrer par le eóté le plus épais, jusqu'à ce qu'elle joigne des deux eótés les lères de la fente; ear à moins que l'ćcoree de la greffe ne soit appliquée à eelle de la vigne de faẹon qu'il n'y ait aucun jour entre elles deux, la greffe ne pourra jamais eroître avee le eep. On peut se servir de plusieurs sortes de liens pour la greffe dont nous parlons. Les uns se servent d'osier, d'autres entourent la fente avee de l'écoree, la plus grande partie l'attaehent avee du jone; tet e'est une très-bonne méthode, paree qu'autrement, dès que l'osier vient à se séeher, il pénètre dans l'éeoree et la eoupe. C'est pour éviter eela que nous adoptons plutôt une ligature peu serrée, pourvu que lorsqu'elle aura entouré le trone, on la resserre, en insérant dans les vides de petits eoins de roseaux. Mais le soin le plus important qu'il y ait à prendre eonsiste à déehausser la vigne avant l'opération, à en couper les racines qui sont à la superfieie de la terre ou les rejetons, et à recouvrir de terre le trone après l'opération. Dès que la greffe aura pris, la vigne demandera eneore de nouveaux soins : ear il faudra l'épamprer souvent lorsqu'elle eommeneera à germer, et arracher eneore plus souvent les rejetons qui sortiront de ses flanes et de ses racines; ensuite il faudra lier le pampre qui sera sorti de la greffe, de peur que la greffe elle-même ne soit ébranlée par les seeousses du vent, ou que ce pampre eneore tendre ne soit abattu. Lorsqu'il aura pris de l'aeeroissement, il faudra le délivrer de ses rejetons, à moins qu'on ne les laisse eroítre pour propager la vigne, dans le eas où la place serait

altero plenior : perque tenuiorem partem insertus eo latere arctetur quo est plenior, et utrinque contingat fissuram. Nam nisi cortex cortiei sic applicetur, ut nullo loeo trans. lueeat, nequit coalescere. Vinculi genus ad insitionem non unum est. Alii viminibus obstringunt; nonnulli circumdant libro fissuram; plurimi ligant junco, quod est aptissiuum. Nam vimen, cum inaruit, penetrat et insecat corticem. P'rop)ter quod molliora vinenla magis probamus, quxe cum eircumvenere truncum, adaetis armndineis cuneolis archuntur. Sed antiquissinum est, et ante liaec ablaqueari vitem, radicesque summas vel soboles amputari; et post hxe adobrui truncum; isque cum comprehendit, aliam rursıs exigit curam. Nam sepius pampinandus est, cum germinat, frequeutiusque detrahendae sunt soboles, qua a lateribus radicibusque prorepunt. Tum quod ex insito profundit subligandum, ne rento surenlus [ motus ] labefictetur, aut explantetur tener pampinus. Qui cum excrevit, nepotibus orbandus est, nisi si propter penurian et calvitium loei submittitur in propagines. Antumnus deinde falcem maturis palnuitibus adiuovet. Sed putationis custoditur 
dégarnie de ceps. Ensuite, lorsque les branches à fruit seront en état d'être taillées, on y appliquera la serpe en automne. Mais voici la méthode que l'on observera en taillant la greffe: dans les endroits où l'on n'aura pas besoin de marcottes, on n'attirera qu'une tige au joug, et l'on coupera toutes les autres, en observant de faire la plaie à ras du tronc, sans cependant écorcher lc dur du bois. Il n'y a pas d'autre facon d'épamprer la vigne grefféc, que cclle que l'on suit à l'ćgard des nouvelles marcottes; mais il faut la tailler de facon à lui laisser peu de bois jusqu à la quatrième année, temps auquel la plaie du tronc sera cicatrisée. Voilà comme on s'y prend pour la greffe en fente. Quant à celle qui se fait en perçant la vigne avec une tarière, il faut, après a voir examiné quel est le cep le plus fertile dans le voisinage de celui que l'on vcut greffer, en attirer unc branche à fruit semblable à ces branches que l'on fait passer d'arbres en arbres, sans les séparer de la mère qui les nourrit, et l'introduire par le trou qu'on aura fait au cep. Cette façon de greffer est la plus sûre et la plus certaine, parce que, quand mème cette branche ne prendrait pas dès le premier printcmps, elle se trou veraitindubitablement forcée de prendre au second, sitôt qu'elle serait suffisamment grossie. Lorsque cette greffe a pris, on la sépare de sa mère; après quoi on coupe la partie supérieure de la vigne que l'on a greffée, jusqu'à l'endroit où la greffe y a été insérée. Si l'on n'cst pas à mềme de faire venir ainsi du voisinage une longue branche, on prend le sarment le plus nouveau que l'on peut trouver; et après l'avoir arraché du cep, on le ratisse légèrement, et seulement au point de l'écorcer; puis on l'ajuste au trou; ensuite on enduit d'un lut la vigne après l'avoir coupée, afin que le tronc entier soit employć à nourrir cette vignc étrangère : ce qui n'est pas nćcessaire à l'ćgard de ces Iongs sar-

ea ratio, ut ubi nulla desideratur propago, unus surculus erocetur in jugum; alter ita recidatur, ut adxcquetur. plaga trunco, sic tamen, ne quid radatur e duro. Pampinandum ıon aliter est, quam in novella viviradice; putandum vero sic, ut usque li quartum annum parcius imperetur, dum plaga trunci ducat cicatricem. Atque Lac per fissuram insitarum est ordinatio. In illa autem, quæ fit per terebrationem, primum ex vicino fructuosissimam oportet considerare vi. tem, ex qua velut traducem iulæerentem matri palmitem attrahas, et perforamen transmittas. IIxcenim tutior et certior est insitio, quoniam, etsi proximo vere non comprelıendit, sequente certe, cum increvit, conjungi cogitur, et mox a matre reciditur, atque ipsa superficies insitæ vitis usque ad receptum surculum obtrincatur. Ilujus traducis si non est facultas, tum detractum viti quam recentissimum eligitur sarmentum, et leviter circumrasım, ut cortex tantum detrahatur, aptatur foramini, atque ita luto circumlinitur resecta vitis, ut totus truncus alienigenis surculis serviat. Quod guidem non fit in traduce, qui a ments dont nous venons de parler, puisqu'ils solıt nourris dans le sein de leur mère, jusqu'à ce qu'ils commencent à croître avec la nouvelle vigne. Mais l'instrument de fer dont se servaient les anciens pour percer les vignes est différent de celui que l'expérience m'a fait découvrir, et qui est plus convenable à cette opération, parce que l'ancienne tarière, qui était l'unique que les ancieus agriculteurs connussent, formait dc la sciure, et brûlait la partie qu'on perforait; d'où il arrivait que quand cette partic avait une fois été brûlée, elle reverdissait rarement, ou qu'elle ne reprenait pas avec les autres parties, et que la greffe que l'on y avait inséréc ne mordait pas. D'ailleurs on ne pouvait jamais assez retirer la sciure du trou, pour qu'il n'en restât pas une certaine quantité, qui empèchait que le corps de la greffe ne s'appliquât immédiatement à celui de la vigne. Nous avons done imaginé pour cette espece de greffe une tarière que nous appelons gauloise, et que nous avons reconnue pour être plus convenable et plus utilc que l'autre, parce qu'elle perce le tronc sans le brûler à l'endroit du trou. En effet, cette tarière ne forme point de sciure, mais simplement des copeaux qu'il est facile d'ôter; dc sorte que la plaic est unie, et qu'elle embrasse plus aisément dans toute sa superficie la branche qui y est insérée, vu qu'il ne s'y rencontre point de duvet, tel que celui qui était occasionné par l'ancienne tarière. Que vos vignes soient donc entièrement greffées après l'équinoxe du printemps : greffezles en raisin noir dans les lieux secs et arides, et en raisin blane dans Ies lieux humides. Il n'y a pas de nécessité de multiplier les greffes sur un même tronc, pourvu qu'il soit assez menu pour qu'une seulc greffe puisse recouvrir toute la plaie lorsqu'elle viendra à croître, et que la place soit d'ailleurs assez garnie de ceps pour nc pas exiger qu'on en substitue de nouveaux à

materno sustinetur ubere, dum inolescat. Sed alind est ferramentum, quo priores vitem perforabant, aliud quod ipse usu nunc magis aptum comperi. Nam antiqua terebra, quam solam veteres agricolæ noverant, scobem faciebat, perurebatque eam partem, quam perforaverat. Deusti porro raro revirescebat, vel cum priore coalescebat, [ in eaque ] nec insitus surculus comprehendebat. Tum etiau scobis nunquam sic eximebatur, nt non inhareret foramini. Ea porro interventu suo prohibebat corpus surculi corpori vitis applicari. Nos terebram, quam Gallicam dicimus, ad hanc insitionem commenti longe habiliorem utilioremque comperimus; nam sic excavat truncum, ne foramen inmat. Quippe non scobem sed ramenta facit, quibus exemptis plaga levis relinquitur, quax facilins ommi parte sedentem surculum contingat, nulla interveniente lanugine, quam excitabat antiqua terebra. [ Igitır seculldum vernum $x$ quinoctium perfectam vitimm insitionen habeto, locisque aridis et siccis nigram vitem inserito, hn. midis albam.] Neque est ulla ejus propagandi necessitas, 
la place de ceux qui pourraient être morts. Si cependant le cas arrivait, on insérerait, dans le trou pratiqué à la vigne, deux sarments, l'un qu'on enterrerait en forme de sautelle, et l'autre qu'on laisserait monter au joug, pour rapporter des fruits. Il ne sera pas inutile non plus d'élever les pampres qui viendront sur l'are d'une sautelle ainsi enterrée, et l'on pourra en peu de temps, si le cas se présente, ou les propager, ou leur laisser rapporter du fruit.

XXX. Comme nous avons donné les préceptes qui nous ont paru les plus utiles, tant pour for. mer des vignobles que pour les cultiver, il faut à présent donner la façon de se pourvoir d'appuis, de jougs et de liens, attendu que ce sont des espèces de dots que l'on doit toujours tenir prêtes pour les vignes; et que, dans le cas où un agriculteur n'en serait pas pourvu, il n'aurait aucun motif de former des vignobles, parce qu'il faudrait qu'il allât chercher hors de son fonds toutes les choses qui lui seraient nécessaires, et que non-seulement le prix qu'il mettrait à les acheter augmenterait les dépenses de ses vignes, comme dit Atticus, mais que cette acquisition même lui serait tress-onéreuse quand il l'aurait faite, en ce qu'il ne pourrait les importer dans son fonds que dans un temps très-peu commode, qui est celui de l'hiver. C'est pourquoi il faut commencer par avoir une oseraie, un plant de roseaux, des forêts communes, ou des bois plantés exprès en châtaigniers. Atticus pense qu'il suffit d'un jugerum d'oseraie pour dttacher les ceps de vingt-cinq jugera de vignes; d'un jugerum de roseaux pour fournir de jougs vingt jugera de vignes; et qu'un jugerum de chátaigneraies fournira de pieux un aussi grand nombre de $j u$ gera de vignes, qu'un jugerum de roseaux en fournira de jougs. Le saule vient très-bien dans

si modo tam mediocris est crassitudo trunci, ut incremeutuın insiti plagam possit contingere; [ et] nisi tamen va. cuus locus demortui capitis vitem reposcit. Quod cum ita est, alter ex duobus surculis mergitur, alter eductus ad jugum in fructum submittitur. Neque inutile est ex ea vile, quam merseris, euascentes in arcu proplaginis pampinos educare, quos possis mox, si ita competet, vel propagare vel arl fructum relinquere.

XXX. Quoniam constituendis colendisque vineis, qua videhantur utiliter pracipi posse, disseruinus; pedami. ıım jugorunique et viminum prospiciendorum tradenda ralin est. Haec enim quasi quædam dotes viueis ante pra. parantur. Quibus si deficitur agricola, causam faciendi vineta non labet, cum umnia, quae suut necessaria, extra fundum quierenda sint : nec emptionis tantum (sicut ait Atticus) pretium onerat ritis rationem', sed est etiam com. paratio inolestissima. Convehenda sunt enim tempore iniüuissimo hiberno. Quare salices viminales atque arundiheta vulgaresque silva, vel consulto consita [e] castaneis, prius facienda sunt. Salicum viminaliun (ut Atticıs putat) singula jugera sufficere possunt quinis et vigenis jngeribus un terrain arrosé ou marécageux, quoiqu'il ne vienne pas absolument mal dans un terrain plat et gras. Il faut retourner ces terrains au hoyau (suivant le précepte des anciens) à la profondeur de deux pieds et demi : n'importe quelle espèce d'osier on plantera, pourvu qu'il soit trèsfiexible. On estime cependant qu'il y a trois espèces principales de saule: le saule grec, le saule gaulois, et celui du pays des Sabins, que plusieurs appellent saule d'Améria. Le saule grec est jaune, le gaulois est d'une couleur de pourpre passé, et ses baguettes sont très-minces ; celui d'Amérie les a grêles et rouges. On les plante ou par cimes, ou par boutures. Les perches des cimes sont bonnes à planter, quolqu'elles soient d'une certaine grosseur, pourvu cependant qu'elles n'excèdent pas la grosseur du poids de deux livres : ou peut très-bien les enterrer abso. lument, de façon que leur extrémité soit à la superficie du sol. On couvre légèrement de terie les boutures après les $\mathrm{y}$ avoir enfoncées, et elles doivent avoir un pied et demi de long. Quand le terrain est arrosé, il faut écarter ces plantes davantage; aussi laisse-t-on alors entre chacune un intervalle de six pieds en quinconce, au lieu que les terrains secs exigent qu'elles soient plus resserrées : mais il faut cependant qu'il y ait assez d'espace entre elles pour que ceux qui les cultiveront puissent en approcher facilement. II suffira pour cela de donner cinq pieds d'espace aux rangées, quoique dans ces mêmes rangées les plantes ne soient espacées que de deux pieds. Il faut les planter avant qu'elles germent : tout le temps que leur séve u'est point en mouvement convient à cette opération. Il faut aussi ne les tirer des arbres, que lorsqu'elles seront ressuyées, parce que si oll les coupe quand elles sont couvertes de rosée, elles réussissent mal : c'est pourquoi on évite en général

ligandæ vinese, arundineti singula jugera vigenis jugandis : castaneti jugerum totidem palandis, quot arundineti jugaudis. Salicem vel riguus ager vel uliginosus oplime, nec incommode tamen alit planus et pinguis. Atque is de. bet converti bipalio; ita enim procipiunt veteres, in duos pedes et semissen pastinare salicto destinatum solum. Nec refert cujus generis vimen seras, dum sit lentissimum. Putant tamen tria esse genera praecipue salicis, Gracie, Gallica, Sabinæe, quam plurimi vocant Amerinain. Graeca flavi coloris est; Gallica obsoleti purpurei et tenuissimi; Amerina salix gracilem virgam et rutilam gerit. Atque hæ vel cacuminibus vel taleis deponuntur. Pertica cacuminum modicæ plenitudinis, quæ tamen dipondiarii orbiculi crassitudinem non excedat, optime panguntur eousque dum ad solidum demittantur. Talex sesquipedales terreno immersa paululum obruuntur. Riguus locus spatia laxiora desiderat, eaque senum pedum per quincuncem recte faciunt; siccaneus spissiora, sic ut sit facilis accessus co. lentibus ea. Quinum pedum interordinia esse abunde est, ut tamen in ipsa linea consitionis alterna vacuis intermis. sis bipedaneis spatiis consistant semiua. Satio est eorum 
les jours de pluie, lorsqu'on veut tailler les saules. II faut bêcher les saussaies peudant les trois pre. mières années, aussi souvent que les jeunes plants de vignes : mais lorsque les saules sont devenus forts, ils se contentent de trois fouilles. Faute de les eultiver ainsi, ils manquent promptement, puisqu'il arrive, même en les cultivant ainsi, qu'il en périt beaueoup, malgré les soins que l'on prend. Pour remplacer ceux qui périront, il faudra avoir recours aux sautelles que l'on prendra sur les saules voisins, dont on courbera les têtes pour les enterrer, afin qu'elles servent à suppléer par la suite tout ce qui sera mort. Lorsque la sautelle aura un an, on la sévrera de sa mère, afin qu'elle puisșe, comme la vigne, tirer sa nourriture de ses propres racines.

XXXI. Il faut planter du genêt dans les lieux trop secs, qui ne s'accommoderont pas d'autres espèees d'arbrisscaux. Les liens qu'on en fait sont très-souples, outre qu'ils sont assez fermes. On le sème en graine; et lorsqu'il est venu on le transporte ailleurs en barbue de deux ans, ou bien on le laisse à l'endroit même où il a été semé; auquel cas on peut le couper ensuite toutes les années près de terre, eomme les moissons. Les autres espèces de liens, tels que les ronees, demandent un plus grand travail; mais on ne peut pas eependant s'en dispenser au défaut des premiers. Le saule dont on tire les perehes demande à peu près la même terre que eelui dont on tire des branches pliables. II vient eependant mietıx dans un terrain arrosé que dans tout aytre endroit. On le plante par boutures, auxquelles on ne laisse qu'unc seule perche, lorsqu'elles sont germées. On le bêche souvent, on arraehe les herbes qui eroissent à ses pieds, et on l'ébourgeonne comme la vigne, afin de

priusquam germinent, dum silent virga, quas arboribus detralıi siccas convenit. Nam roscidas si recideris, parum prospere proveniunt. Ideo pluvii dies in exputauda salice vitantur. Fodienda sunt primo triennio salicta crebrins, ut novella vineta. Cum deinde convalueriut, tribus fossuris cortenta sunt; aliter culta celeriter deficiunt. Nam çuanıis adlibeatur cura, plnrima salices intereunt. Quarum in locum ex propinquo mergi propagari debent, curvatis et defossis cacuminibus, quibus restituatur quicunid intereidit. Anniculıs deinde mergus decidatur a stirpe, ut suis radicibus tanquam vitis ali possit.

XXXI. Perarida loca, qua gems id virgultorum non recipiunt, genistam postulant. Ejus cum sit satis firmum, tum etiam lentissimum est vinculum. Seritur autem semine, quod cum est natum, vel defertur bima viviradix, vel relicta cum id tempus excessit, ounibus anuis more segetis juxta terram demeti. potest : coctera vincula, quualia sunt ex rubo, majorem operam, sed in egeno tamen recessariam exigunt. Perticalis fere salix eundem agrum, quem viminalis, desiderat; unelior tamen riguo provenit; atque ea taleis conseritur, et cum gerninavit, ad unam perticam submittitur, crebroque foditur atque exherbalur, l'exeiter à donner des branehes qui soient plutót longues que grosses : cultivé ainsi, on ne le coupe que la quatrième année; au lieu que celui dont on veut faire des liens peut être coupé dès la première année à deux pieds et demi de terre, afin que le trone produise des rejetons, et puisse être arrangé en bras, comme les vignes basses. Si cependant le terrain est trop see, on fera mieux de ne couper ce dernier qu'à deux ans.

XXXII. On laboure la terre au pastinum pour le roseau, mais, à la vérité, peu profondé. ment; néanmoins il est mieux de le planter au hoyau. Quoique eette plante soit très-vivace, et qu'elle s'aceommode de toute sorte de terrains, elle réussit eependant mieux dans un terrain ameubli que dans un terrain eompacte; dans une terre humide que dans une terre seche; dans les vallées que sur les hauteurs; et il y a plus d'avantage à la mettre sur les bords des fleuves, sur les lisières des sentiers, et dans les lieux couverts d'épines, qu'en plein ehamp. On plante soit un caïeu de la racine du roseau, soit une bouture de sa canne, ou bien on le couche tout entier en terre. Les caïeux mis en terre, à trois pieds dedistance les uns des autres, donnent en moins d'un an des perches en état d'être employées. La bouture, ainsi que le roseau entier, demandent un temps plus long. Mais, soit qu'on plante une bouture de la longueur de deux pieds et demi, soit qu'on mette en terre un roseau entier, il faut que la tête de l'un comme de l'autre plant soit toujours hors de terre, parce que si on les couvrait entièrement, ils pourriraient tout à fait. Les trois premières anućes, on ne les eultive pas autrement que les autres arbrisseaux dont nous venons de parler : lorsque par la suite ils sont vieillis, il faut leur donuer une secondo

nec minus quam vinea pampinatur, ut in longitudinem [ramorum] potius quam in latitudinem evocetır. Sic culta quarto demum anno caditur. Nam qua vinculis praparatur, potest annicula procidi ad senissem supra dnos pedes, ute trunco fructicet, et in braclia velut llumilis vinea disponatur; si tamen siccior fuerit ager, bima potius reseca. bitur.

XXXII. Arundo minus alte pastinato, melius tamen bipalio seritur. Ea cum sit vivacissima, nec recuset ullum locum, prosperius resoluto, quam denso; humido, quam sicco; vallibus, quam clivis; flunninum ripis, et limiti bus ac vepretis commodius quam medis agris deponilur. Seritur bulbus radicis, [setitur] et talea calami, nec minus toto prosternitur corpore. Bulbus tripedaneis intervacantibus spatiis obrutus anno celerius unaturan perticam præbet. Talea, et tota arundo serius priedicto tempore evenit. Sed sive recisa in dnpondium el semissem talea, sive tota arundines prostrata deponantur, exstent earum cacumina oportet : quod si obruta sunt, totxe putrescunt. Sed cultus arundiuetis prino lriennio non aliıs est, quanı cxteris. Cum deinde consenuit, repastinandum esı. Ea est autem seneclus, cum vel exaruit situ et inertia plu- 
façon au pastinum. Ils sont ceusès vieux, lor'sque Ic duvet dont ils sont couverts les a dessćehés, et qu'ils u'ont rien produit pendant plusieurs années, ou lorsqu'ils sont si épaissis, qu'ils ne donnent plus que des roseaux grêles, ct semblables à des flageolets. Mais, dans le premier cas, il faut les extirper entièrement; au lieu que, dans le second cas, on peut se contenter d'en couper quelques-uns de distance en distance pour les éclaireir : les paysans appellent cette opération castratio. Néanmoins on ne peut jamais les couper qu'à l'aveugle, puisqu'il n'y a rien sur terre à quoi l'on puisse distinguer ccux qu'il faut ôter de ceux qu'il faut laisser. Il vaut toujour's mieux chátrer le roseau avant le temps de sa coupe, parce que les eannes indiquent alors clairement ce qu'il en faut arraclier. Le temps favorable pour donner aux roseaux une seconde facon au pastinum, de même que pour les planter, c'est avant que leurs yeux soient germés : on les coupe cusuite après le solstice d'hiver, attendu qu'ils profitent jusque là; après quoi ils s'arrêtent, parce que les froids de l'hiver les roidissent. Il faut les. bêcher aussi fréquemment que les vignobles. Il faut aussi, quand ils sont maigres, les aider avec dela cendıe, ou avec toute autre espèce de fumier ; c'est dans cette vue que la plupart mettent le feu dans les plants de roseaux après la coupe.

XXXIII. Le châtaignier approche de la nature des robres : c'est pour cela qu'il est très-bon pour fournir les vignes d'appuis. La clâtaigne semée dans un terrain labouré pour la seconde fois au pastinum lève promptement; ct si l'on en coupe la production au bout de cinq ans, clle se ranime comme le saule, et les pieux que l'on en a faits durent presque jusqu'à la coupe suivante. Je ehâtaignier veut une terre douce et ameublie, sans néanmoins se déplaire dans un

rium aunorum, vel ita densatum est, ut gracilis et cannæe similis arunto prodleat. Sed illud de integro refodi debet; hoc potest intercidi et disrarari, quod opns rustici stipationem vocant : qux tamen resectio arundineti cxeca est, quia non apparet in terra, quid aut tollendum sit aut relinqquendum : tolerabilius famen arundo castratur ante quam cseditur : quatenus calami velut indices demonstrant, quid eruendum sit. 'Tempus repastinandi et conserendi est prius quam uculi arundinum egerminent. Cæclitur deinde post brumam : nam usque in id tempus incrementum capit. Ac tum compescitur, cum obrignit hiberno figore. Fodiendum quoties et vineta. Sed [et] macies ejus cinere vel alio stercore juvanda est, propter quod cxsum plerique incendunt arındinctum.

XXXIII. Castanea roboribus proxima est, et ideo stabiliendis vineis habilis. Tum in repastinato uux posita cele. titer emicat, et post quinq̧uenuium exsa more salicti recreatur, neque in palum formata fere usque in alteram cesionem perennat. Ea pullam terram et resolutam desi. derat; sabuloneu lumidum vel refractum tcfum non sable humide, ni dans un tuf pulvérisć : il recherele les hauteurs ombragécs et septentrionales, et craint les terrains compactes, ainsi que ceux qui sont pleins de terre rouge. On sème les châtaignes depuis le mois de novembre jusqu'à la fin de l'hiver, dans une terre sèche et façonnée au pastinum pour la seconde fois, à la profondeur de deux pieds et demi; on les sépare l'une de l'autre d'un demi-pied dans les rangées, et on laisse un intervalle de cinq pieds entre chaque rangée. 0 n les enfonce dans des sillons ereusés à neuf pouees de profondeur; et lorsque ces sillons sont ensemencés, on y fiehe, avant de les aplanir, un petit roseau à côté de chaque châtaigne, afin que ces roseaux servant de signaux pour faire connaître les endroits où les châtaignes sont semées, on puisse bêcher la terre et en arracher les mauvaises herbes avec plus de précaution. Dès qu'elles ont des tiges qu'on peut transférer, ce qui arrive au bout de deux ans, on en arrache quelques-unes d'espace en espace, en laissant deux pieds de vide entre chaque arbrisseau, de peur qu'elles ne viennent à maigrir, pour ctre trop drues. Si on les avait semees plus drues dans le principe, ce n'était que pour obvier aux différents accidents qui pouvaient survenir. En effet, il arrive quelquefois que le défaut de pluie les dessèche, ou que la trop grande abondance d'eau les pourrit avant qu'elles soient germées; d'autres fois, qu'elles sont dévastćes par les animaux qui vivent sous terre, tels que les rats et les taupes : et c'est la raison pour laquelle on voit souvent les nouvelles châtaigneraies se dégarnir. Lorsqu'il est besoin de les repeupler, il vaut mieux, si l'on est à même de le faire, abaisser des perches des arbres voisins cn façon de sautelle pour les propager, que d'en arraeher pour les planter. En effet, ces perehes, restant comme immobiles à lour place, produisent

respuit; opaco et septentrionali clivo loctatur; spissum solum et rubricosum reformidat. Seritur ab Novembri mense per totam hiemein sicca terra el repastinata in alti. tudinem dupondii et semissis. Nuces in ordinem semipedalibus; ordines autem quinum pedum spatiis dirimuntur. In altitudinem dodrantis castanea depressis sulcis commiltitur. Qui ubi nucibus sunt consiti, prinsquam complanentur, breves arundiues ab latere castanearum pangultur, ut per loos sationis indices tutius fodi et runcari pos. sint. Simulatque semina stilaverint, etiam bima transferri queunt, intervelluntur, ac bini pedes arbusculis vacui relinquuntur, ne densitas plantas emaciet. Spissius autem semen propter varios casus deponitur. Nam interdum prius quam euascatur, aut siccitatibus nux iuarescit, aut aquarum abundantia putreseit : interdmin subterrancis animalibus sicuti muribus et talpis infestatur. Propter qua sxpe novella castaneta calvescunt : alque ubi frequentanda sunt, melius ex vicino, si competit, mergi more pertica declinala propagafur, qиau exempta reseritur. llace enim velnt inmmola sua sedo vehementer germinab. 
beaucoup de boutons; au lieu que celles qui ont ćtć mises en terre après avoir été arrachées avec leurs racines sont deux ans à se remettre. C'est pour cela qu'on a remarqué qu'il ćtait plusavantageux de faire des forêts de châtaigniers en semant la chataigne elle-même, qu'en la plantant en barbues. Si l'on se règle, en semant des châtaignes, sur les distances que nous venons de fixer ci-dessus, un terrain d'un jugerum contiendra deux mille huit cent quatre-vingts châtaigniers, qui donneront aisément (comme dit Atticus) douze mille échalas. En effet, on fend ordinairement les branches voisines de la souche en quatre, et les autres qui sont plus petites que celleslả, en deux. Ces espèces d'appuis, ainsi fendus, se conservent plus longtemps que les pieux ronds dans toute leur longueur. Quant aux fouilles que ces plantes exigent, et d la façon de les arranger, e'est la même culture que pour la vigne. On doit les éclaircir un peu d̀ deux ans, et même à trois ans, indépendamment de ce qu'il faut y ippliquer deux fois le fer au commencement du printemps, si on veut les exciter à monter haut. On peut aussi semer le gland du chêne de la même facon, mais on coupe cet arbre deux ans plus tard que le chataignier; c'est pourquoi le bon sens veut que l'on cherche à gagner du temps en semant préférablement des châtaignes, à moins que l'on n'ait en sa possession des montagnes pleines de buissons et de graviers, ou des terres de la iature de celles que nous avons désignées ci-dessus, qui demandent plutôt du gland que de la châtaigne. J'ai traité jusqu'ici assez au long, et non sans quelque utilité, autant que je puis m'en flatter, des vignobles d'Italie et de tous leurs accessoires; je vais donner à présent la culturc des vignes telle qu'elle est en usage chez les agriculteurs de province, ainsi

At qua radicibus exempta et deposita est, biennio reformidat. Propter yuod compertum est commodius nueibus yuam viviradicibus ejusmodi silvas institui. Spatia hujusee sationis, qua supra scripta sunt, capita castanearum recipiunt Mudccctxxx, cujus summx, sicut ait Atticus, ex facili jugera singula prabebunt shatuminum duodena millia. Etenim talex propius stirpem reeisæ quadrifidas plerumque, ac deinde secundxe lalese ejusdem arboris bifidas ridicas subministrant : quod genus fissilis adminieuli manet diutius quam teres palus. Cultus idem est [fossionis positionisque] qui vineæ. Supputari debet lima, quin etian trima : nam bis ferro repetenda est veris prin. cipio, ut incitelur ejus proceritas. Polest etiam quercus simili ratione seri; verum biennio tardius quan castanea deciditur. Propter quod ratio postulat tempus polius [u. crari, nisi si dumosi glareosique montes, atque ea genera terre, quæs supra diximus, glandem magis, quan castaneam postulabunt. Hac de vineis Italicis vinearumque instrumentis, quantum reor, nor inutiliter et abunde disserui : mox agricolarum provincialium vineaticos nec minus Lostratis et Gallici arbusti cultus traditurus. que celle des plants d'arbres mariés aux vignes, tant ceux de notre pays que ceux de la Gaule.

\section{LIVRE V.}

\section{Vous m'avez dit, Silvinus, qu'il manquait,} dans les premiers livres que je vous ai adressés sur la formation et la culture des vignobles, bien des choses que les amateurs des travaux rustiques voudraient y trouver; et je ne disconviendrai pas que je n'en aie omis quelques-unes, quoique j'aie néanmoins fait une recherche exacte de tout ce que les agrieulteurs de notre siècle et ceux des siècles précédents ont laissé par écrit : mais en promettant de donner des préceptes d'économie rurale, je ne m'étais pas engagé, si je ne me trompe, à donner tout ce qui pouvait appartenir à cet art immense; et il me semble au contraire que je ne m'étais engagé qu'à en donner la plus grande partie. En effet, un ouvrage de cette étendue aurait dépassé la portée d'un seul homme, puisqu'il n'y a aucune science ni aucun art que le génie d'un seul homme ait conduit à sa perfeetion. Aussi, de même qu'il suffit à ur bon chasseur qui court après des bêtes fauves dans une forêt immense, d'en prendre le plus qu'il peut, et qu'on n'a jamais fait un crime à persomne de n'avoir point pris toutes celles qui s'y trouvent; il doit également nous suffire d'avoir donné la plus grande portion d'une matière aussi etendue que celle que nous avons entrepris de traiter, d'autant que les choses qu'on nous accuse d'a voir omises dans notre ouvrage, et que l'on aurait voulu y trouver, sont des choses étrangères à notre profession. Dernièrement, par exemple, notre ami M. Trébellius prétendait que j'aurais dû donner des règles pour mesurer les terres, dans la persuasion où il était que la mé-

\section{LIBER QUINTUS.}

I. Superiorilous libris, quos ad te de constituendis colendisque vineis, Silvine, scripseram, nonnulla defuisse dixisti, qua agrestium operum stucliosi desiderarent; neque ego infitior aliqua me præteriisse, quanvis inquirentem sedulo, quxe nostri seculi cultores quxeque veteres literarum molumentis prodiderunt : sed cum sim professus rustica rei pracepta, nisi fallor asseveraveram, quæe vastitas ejus scientia contineret, non cuneta me diclurum, sed plurima. Nam illud in unius lıominis prulentiam cadere nol! poterat. Neque enim est ulla disciplina aut ars, qua singulari consummata sit ingenio. Quapropter ut in magna silva boni renatoris est indagantem feras quanplurimas capere; nee cuiquam culpæe fuit non omnes cepisse : ita uobis abunde est, tam diffuse materix, quam suscepimus, maximan partem tradidisse. Quippe cum ea velut onissa desiderentur, qua nou sunt propria nostra professionis, ut pro. xime, cum de commetiendis agris rationem M. Trebellius noster requireret a me, vicinum adeo atque conjunctum esse consebat demonstranti, quernadıodun agrum pasti. 
thode de labourer un terrain au pastinum, et celle de le mesurer lorsqu'il était ainsi labouré, étaicnt deux choses qui se tenaient ensemble, et qui n'en faisaient qu'une seule ; mais je lui répondis que ce n'était point là la fonction d'un agriculteur, mais cellc d'un arpentcur; d'autant que les architectes, qui sout cependant ceux qui doivent counaitre mieux que personne la méthode des mesures, ne daignent point examiner par eux-mèmes eclle des bâtiments dont ils ont donné les plans, après qu'ils sont achevés, et qu'ils croient qu'il y a bien de la différence entre les objets qui sont de leur profession et de lcur ressort, et les objets dépendant de la profession des personnes dout la fonction est de mesurer les édifices lorsqu'ils sont achevés, et de supputer la dépense à laquelle ils doiveut monter. Cet cxemple est une raison de plus pour me faire croire qu'on doit pardonner à notre science si elle se contente d'enseigner comment chaque chose doit être faite, sans aller jusqu'à calculer la mesure des ouvrages faits. Néanmoins, comme vous me demandez aussi vous-même, Silvinus, à titre d'ami, les préceptes relatifs aux mesures, je veux bien me rendre à vos désirs, pourvu que vous demeuriez convaincu que e'est plutôt l'affaire des géomètres que des gens de la campagne, et que vous m'excusiez, au cas que je tombe dans quelque erreur sur une matière dont je ne m'attribue pas la connaissance. Ainsi, pour entrer en matière, toutes les mesures d'une surface quelconque se réduisent à celle du pied, qui est composé de seize doigts. La multiplication du pied donne graduellement le pas, l'actus, le clima, le jugerum, le stadium, la centuria, et d'autres espèces de mesure encore plus considérables. Le pas est de cinq pieds. L'actus minimus (comme dit M. Varron) est de quatre

nemus, precipere etiam pastinatum quemadmodum metiri debeamus. Quod ego non agricola sed mensoris officium esse diceham; cum prosertim ne architecti quidem, quibus necesse est mensurarum nosse rationem, diguentur consummatorum adificiorum, quæ ipsi disposueriut, mo. lum comprehendere, sed aliud existiment professioni sux convenire, aliud eorum, qui jam extructa metiuntur, et imposito calculo perfecti operis rationem computant. Quo ınagis veniam tribuendam esse nostræ disciplinæ censeo, si ealenus progreditur, ut dicat, qua quidque ratione faciendum, non quantum id sit quod effecerit. Verum quouiam familiariter a nobis tu quoque, Silvine, pracepta inensurarum desideras, obsequar voluntati tux, cum eo, ne dubites id opus geometrarum magis esse quam rusticorum, desque veniam, si quid in eo fuerit erratum, cujus scientiam mili non vindico. Sed ut ad rem redean, nodus omnis areæ pedali mensura comprehenditur, qui digitorum est $x \mathrm{r}$. P'es multiplicatus in passus et actus et climata et jugera et stadia centuriasque mox etiam in ma. jora spatia procedit. Passus perles habet v. Actus mini. mus (ut ait M. Yarro) latitudinis pedes quatuor, longitu- pleds de largeur sur cent vingt de longueur. Le clima est de soixante picds cn tous sens. Liactus quadratus est un carrć dont ehaque côté a cent vingt pieds. Le double de cet actus donne le jugerum, qui a tiré son nom de jungere, join. dre, réunir, parce que le jugerum se compose de deux actus réunis (junctum). Mais les paysans de la province de Bétlque donnent le nom d'acnua à cet actus, commo ils donnent celui de porca à une largeur de trentc pieds sur une longueur de cent quatre-vingts. Les Gaulois donnent aussi le nom de candetum à une surface de cent pieds mesure de ville, ou à une surface de cent cinquante pieds mesure de campagne : ils appellent encore arepennis un semi-jugerum. Ainsi deux actus forment, comme je l'ai déjà dit, un jugerım, qui comprend deux eent quarante pieds de long sur cent vingt pieds de large, lesquels, multipliés l'un par l'autre, donnent un produit de vingt-huit mille huit cents pieds carrés. Vient ensuite le stadium, qui est de cent vingt-cinq pas, c'est-à-dire, de six cent vingt-cinq pieds, lesquels cent vingt-cinq pas, multipliés par huit, font mille pas, et par conséquent cinq mille pieds. Nous appelons aujourd'hui centuria une mesure de deux cents jugerc (comme dit le même Varron), au lieu qu'autrcfois cette mesure n'était que de cent jugera; aussi était.ce de ce nombre qu'elle tirait son nom. Mais quoiqu'on l'ait portée au double par la suite, elle a conservé son ancien nom; de même que les tribus ainsl nommées, dans l'origine, du nombre des trois classes dans lesquelles le peuple ro. main fut divisé, conservent encore aujourd'luui leur ancienne dénomination, quoiqu'elles soient en plus grand nombre. Il nous a fallu commencerpar expliquer brièvement tous ces mots, comme étant inséparables des calculs que nous donne-

dinis habet pedes cxx. Clima quoquo versus pedum est: Lx. Actus quadratus undique finitur pedibus cxx. Hoc duplicatum facit jugerum, et ab eo, quod erat junctum, nomen jugeri usurpavit : sed hunc actum provincix $B$ :ticæ rustici acmuam rocant : idenque triginta pedum. latitudinem et cLxxx longitudinem porcam dicunt. At Galli candetum appellant in areis urbanis spatium centun pedum, in agrestihus antem pedum CL. [quod aratores. candetum nominant] Semijugerum quoque arepennem vocant. Ergo ( ut dixi) duo actus jugerum efficiunt longitudine pedun ccxL, latitudine pedun cxx. Qua utraeque. summa in se multiplicatæ quadratorum faciunt pedum viginti octo millia et octingentos. Stadium deinde habet passus $\mathbf{C X X v}$, id est pedes $\mathbf{D C x \times v}$, qua mensura orties multiplicata efficit mille passus, sic veniunt quinque millia pedum. Centuriam nunc dicinus (ut idem Varro ait) ducentorum jugerum modum. Olim autem ab centum jugeribus vocabatur centuria, sed mox duplicata nomen re. tinuit : sicuti tribus dicta primum a partibus populi tripartito divisi, qux tamen muc multiplicata pristinum. nonen possident. Haec uon aliena, nec procul a ratiocinio, 
rous par la suite. Venons maintenant à notre bui. On ue trouvera pas iei toutes les parties dans lesquélles le jugerum peut se diviser, et nous nè donnerons que le nom de eelles qui entrent dans l'estimation des ouvrages à régler, paree qu'il eût èté inutile de nous perdre dans le détail des plus petites pareelles qui n'entrent point en eompte. I.e jugerum est done (eomme nous l'avons dit) do vingt-huit mille huit cents pieds earrés, lesquels font deux cent quatre-vingt-huit scripula. Or, pour commeneer par la plus petite partie, e’est-à-dire, par la moitié du scripulum, la einq cent soixante et seizième partie du jugerum est de einquante pieds; e'est la moitié de son scriqulum : la deux eent quatre-vingt-lınitième partie est de eent pieds ; c'est le scripulum entier : la cent quarante-quatrième partie est de deux eents pieds; ee sont deux scripula : la soixante et douzième partie est de quatre cents pieds ; c'est la sextula, qui équivaut à quatre scripula : la quarante-huitième partie est de six eents pieds; c'est le sicilicus, qui équivaut à six scripula: : la vingt-quatrième partie est de mille deux eents pieds; e'est la semuncia, qui équivaut à douze scripula : la douzième partie est de deux mille quatre eents pieds; e'est l'uncia, qui équivaut à vingt-quatre scripula: la sixième partie est de quatre mille huit eants pieds; c'est le sextans, qui équivaut à quarante-huit scripula : la quatrième partie est de sept mille deux cents pieds ; c'est le quadrans, qui équivaut à soixante et douze scripula: la troisième partie est de neuf mille six eents pieds; c'est le triens, qui équivaut à quatre-vingt-seize scripula : la troisième partie, plus la douzième, sont de douze mille pieds; e'est le quincun $x$, qui équi vaut à eent vingt

quod tradituri sumus, breviter prxfari oportuit. Nune veuiaunus ad propositum. Jugeri partes non omncs posuimus, sed eas, qux cadunt in sestimationem facti operis. Nam minores persequi supervacuum fuit, pro quibus nulla merces depeuditur. Igitur (ut diximus) jugcrum labet quadra. torum pcdum viginti octo millia et octingentos : qui pedes efliciunt scripula ccLxxxvı1. Ut autem a minima partc, id cst ab dimidio scripulo incipiam, pars quingentesima septuagesima sexta pedes efficit quinquaginta ; id est jugeri diunidium scripulum. Pars ducentesima octogesima octava podes centum ; loc est scripulum. Pars cxuv pedes cc, lioc est scripula duo. Pars scptuagesima et secunda pedes cccc, huc est sextula, in qua sunt scripula quatuor. I'ars quadiagcsima octava pedes DC, loc est sicilicus, in quo sunt scripula sex. Pars vigesina quarla pedes mille ducentos, hoc est semuncia, in qua seripula xı. Pars duodecina duo millia ct quadringentos, hoc est uncia, in qua sunt scripula xxiv. l'ars sexta pedes quatuor millia ct octingentos, loc est sextans, in quo sunt scripula xuvu. Pars quarta pedes septem millia el ducentos, lioc est quadrans, in quo sunt scripula Lxxı. Pars tertia pedes novem millia, et sexcentos, hoc est triens, in quo sunt scripula xcvı. Pars tertia et una duodecima pedes duodecim millia, hoc est quincunx, in rjto sunt scripula cxx. Pars dimidia pedes qua- scripula: la moitié est de quatorze mille quatre eents pieds; e'est le semis, qui équivaut à eent quarante-quatre scripula : Ia moitié, plus la douzième partie, sont de seize mille huit eents pieds; e'est le $\operatorname{septun} x$, qui équivaut à eent soixante et huit scripula: les deux tiers sont de dix-neuf mille deux eents pieds; c'est le bes, qui équivaut à eent quatre-vingt-douze scripu$l a$ : les trois quarts sont de vingt et un mille six eents pieds ; c'est le dodrans, qui équivaut à denx eent seize scripula : la moitié, plus le tiers, sont de vingt-quatre mille pieds; e'est le dextans, qui équi vaut à deux eent quarante scripula : les deux tiers, plus le quart, sont de vingt-six mille quatre eents pieds; e'est le deunx, qui équivaut à deux eent soixante et quatre scripula : le jugerum entier est de vingt-huit mille eent pieds; e'est l'as, qui équivaut à deux eent quatre-vingthuit scripula. Si la surfaee d'un jugerum formait toujours un reetangle, et qu'en la mesurant on lui trouvât toujours deux eent quarante pieds en longueur et eent vingt pieds en largeur, il serait très-faeile d'en faire le ealeul : mais eomme la différence dans la forme des terres est matière à difficulté, nous allons indiquer ei-dessous toutes les figures génériques qui nous serviront eomme de formules applieables à toutes les autres espèces de figures.

II. Tout terrain a la forme d'un earré parfait; ou d'un rectangle, ou d'un eoin, ou d'un triangle, ou d'un eerele; quelquefois même il a la forme d'un demi-cerele, ou d'un are de eercle, et souvent il présente la figure d'un polygone. La mesure d'un earré parfait est très-faeile à trouver. En effet, eomme eette figure présente le même nombre de pieds de tous les eôtés, on

tuordecim millia et quadringentos, hoc est semis, in quo sunt scripula cxuv. I'ars̉ dimidia et una duodeciuna, pedes sexdecim millia ct octingentos, hoc est sejtunx, in quo surt scripula cLXviı. Partes duxe tertix pedes decem noven millia et ducentos, loc cst bes, in quo sunt scripula cxcn. Partes tres qnarta pedes unnm et viginti millia et scxcentos, lioc cst dodrans, in quo sunt scripula ccxvi. Pars dimidia et tertia ped. viginti quatuor millia, hoc est dextans, in quo sunt scripula ccxL. Partes dua tertiae et una quarta pedes viginti sex millia et quadringentos, lıc est deunx, in quo sunt scripnla cclxiv. Jugerum poles viginti octo millia et octingentos, lioc est as, in quo sint scripula ccLxxxvur. Jugeri autem modus si semper quadraret, et in agendis mensuris in longitudineın luaberct pcdes ccxL, in latitudinen pedes cxx, expeditissimum esset ejus ratiocinium. Scd quonian divers agrorum format veniunt in disputationem, cujusque generis species subji. ciemus, quibus quasi formnlis utemur.

II. Omnis ager aut quadratus, aut longns, aut cuncatus, aut triquelrus, aut rotundus, aut etiam semicirculi, vel arcus, nonnunquam etiam plurium angulorum forman exlibet. Quadrati mensura facillima est. Nam cum sit undi(puc pedum totidem, multiplicantur in se duo latera, et qua summa ex multiplicatione cffecta est, cam dicemus 
DE L'AGRICULTURE, LIV. V.

en multiplio les deux côtés l'un par l'autre, et l'on dit que lc produit de cettc multiplication donne la somme totalc des pieds carrés qu'elle contient. Par exemple, si c'est un terrain de cent picds en tous sens, nous disons : Cent fois cent font dix mille. Nous en conclurons done que ce terrain contient dix mille pieds carrés, qui font un tricns, plus une sextula du jugerum; et ce sera sur ce pied-là qu'il faudra calculer l'ouvrage qui aura été fait. Mais si le terrain est un rectangle qui ait, par exemple, la figure du jugerum, c'est-à-dire deux cent quarante pieds de long sur cent vingt de large, comme je viens de le dire ci-dessus, on multipliera les pieds de la largeur par ceux de la longueur, de cette façon : Cent vingt fois deux cent quarante font vingthuit mille huit cents. Nous dirons donc que ce sera le nombre de pieds carrés que contiendra un $j u$ gerum dc terre, et il en sera de même de tous les terrains rectangles. Mais si le terrain a la forme d'un coin, par exemple, qu'il ait cent pieds de long, et vingt pieds de large par un côté sur dix par l'autre, pour lors nous additionnerons ensemble les deux largeurs : la somme totale sera trente, dont la moitié est quinze, que nous multiplierons par la longueur, ce qui produira mille cinq cents pieds. Nous dirons donc que c'est le nombre de pieds carrés que contient ce coin; nombre qui équivaudra à une semuncia du jugerum, plus trois scripula. Mais si vous avez à mesurer un triangle équilatéral, voici comme vous vous y prendrez : Soit un terrain triangulaire dont chaque côté ait trois cents pieds; multipliez ce nombrc par lui-même : le produit est de quatrc-vingt-dix millc pieds : prenez le tiers dc ce produit, c'est-à-dire trente mille;

esse quadratorum pedum. Tanquam est locus quoquo versus c pelum : ducimus centies centenos, fiunt decen millia. Dicemus igitur eum locum habere decem millia pedum quadratorum, qua efficiunt jugeri trientem, et sextulam, pro qua portione operis effecti numerationem facere oportebit. At si longiur fuerit, quam latior, ut exempli causa jugeri forma pedes habeat longitudinis CcxL, latitudinis pedes cxx, ita ut paulo ante dixi : latitudinis pedes cum longitudinis pedibus sic multiplicabis. Centies ricies duceni quadrageni fiunt riginti octo millia et octingenti. Dicemus jugerum agri tot pedes quadratos labere. Similiterque fiet de omnibus agris, quorum longitudo major sit latitudine. Sin autem cuneatus ager fuerit, ut puta longus pedes centum, latus ex una parte pedes $x x$, et ex altera pedes $x$ : tunc duas latiludines componemus, fiet utraque summa pedes xxx. Hujus pars dimidia est quindecim, quam cum longitudine multiplicando efficiemus pedes mille et quingentos. Hos igitur in eo cuneo quadratos pedes esse dicemus, quæ pars erit jugeri semuncia et scripula tria. At si tribus paribus lateribus triquetrum metiri debueris, hanc formam sequeris. Esto ager triangulus pedum quoquo versus tricentorum. Ilunc numerum in se multiplicato. Fiunt pedum nonaginta millia. Hujus summa partem tertiam sumito, id est triginta millia. Item sumito decumam, id est novem prenez encore Ic dixic̀me, c'est-à-dire neuf mille, et additionnez ces deux sommes: le total sera de trente-neuf mille pieds. Nous dirons que c'est le nombre de pieds carrés que contient ce triangle équilatéral, mesure qui donne un $j u$ yerum, plus un triens, plus un sicilicus. Mais si le terrain est un triangle rectangle, commc dans la figure ci-dessous, qui présente un angle droit, il faudra calculer autrement : Soit Ia ligne d'un des cótés qui forme l'angle droit, de cinquante pieds, et celle de l'autre côté qui forme le même angle, de cent pieds ; multipliez ainsi ces deux sommes l'une par l'autre: cinquante fois cent font cinq mille; dont la moitié est deux mille cinq cents, cc qui fait une uncia, plus un scripulum de jugerum. Si le terrain est rond, de façon qu'il présente un cercle parfait, prenez alnsi les pieds : Soit une surface ronde dont le diamètre ait soixante-dix pieds ; multipliez ainsi ce nombre par lui-même : Soixante-dix fois soixante-dix font quatre mille neuf cent; multipliez cette somme par onze, vous aurez cinquante-trois mille neuf cents pieds. Je prends la quatorzième partie de cette somme, savoir, trois mille huit cent cinquante pieds, et je dis que c'est le nombre de pieds carrés qui sc trouvent dans ce cercle, laquelle somme donne une sexcuncia, plus deux scripula et demi de jugerum. Si le terrain est un demi-cercle, dont la base ait cent quarante pieds et le rayon soixante et dix, il faudra multiplier ainsi le rayon par la base : Soixante et dix fois cent quarante font neuf mille huit cents, qui, multipliés par onze, donnent cent sept mille huit cents, dont le quatorzième est sept mille sept cents. C'est le nombre de pieds que nous dirons être dans ce demi-cercle,

millia. Utranıue summam componito. Fiunt pedes triginta norem millia. Dicemus hanc summam pedum quadratorum esse in eo triquetro, quæ mensura efficit jugerum, et trientem, et sicilicum. Sed si triangulus disparibus fuerit late. ribus ager, tanquam in subjecta forma, qua habet rectum angulum, aliter ratiocinium ordinabitur. Esto unius late. ris linea, quæ facit angulum rectum, pedum quinquaginta, et alterius pedum centum. Has duas summas in se multiplicato, quinquagies centeni funt quinque millia. Horum pars dimidia duo millia quingeni, qua pars jugeri unciam, et scripulum efficit. Si rotundus ager erit, ut circuli specien? luabeat, sic pedes sumito. Esto area rotunda, cujus diametros luabeat pedes Lxx. Hoc in se multiplicato, septuagies septuageni fiunt quatuor millia et noningenti. Hanc summain undecies multiplicato, fiunt pedes quinquaginta tria unillia nongenti. Hujus summæ quartam decimam subduco, sci licet pedes tria millia octingenti, et quinquaginta. Hos esse quadratos in eo circulo dico, qux summa eficit jugeri sexcunciam, scripula duo et dimidium. Si semicirculus fuerit ager, cujus basis llabeat pedes cLx, curvatura autem latitudo pedes Lxx : oportebit multiplicare latitudiuem cum basi. Septuagies centeni quadrageni fiunt novem millia et octingenti. Hæc undecies multiplicata fiunt centum septem millia et octingenti. IIıjus summæ quarta decima 
et qui font un quadrans, plus cing scripula de jugerum. Mais s'il se trouve moins d'un demi-cercle, voici comme nous mesurerons l'arc: Soit un arc dont la base ait seize pieds et la largeur quatre pieds, j'ajoute la largeur à la base; la somme totale est de vingt pieds, que je multiplie par quatre; le produit est quatre-vingts, dont la moitié est quarante : de même la moitié des seize pieds de la base, c'est huit pieds, qui, multipliés par eux-mêmes, font soixante-quatre; j'en prends la quatorzième partie, c'est quatre pieds et un peu plus; ajoutez cela à quarante, la somme totale sera quarante-quatre pieds. Je dis donc que c'est le nombre de pieds carrés que contient l'are, et qui font la moitié d'un scripulum de jugerum, moins un vingt-cinquième de scripulum. Si le terrain est un hexagone, voici comme on le réduira en pieds carrés : Soit, par exemple, un hexagone dont chacun des côtés ait trente pieds; je multiplie ainsi un côté par lui-même: :Trente fois trente font neuf cents; je prends le tiers de cette somme, qui est trois cents; j'y ajoute le dixième, qui est quatrevingt-dix ; somme totale, trois cent quatre-vingtdix, qu'il faut multiplier par six, parce quil $y$ a six còtés : le produit sera de deux mille trois cent quarante. Nous dirons douc que c'est le nombre de pieds carrés que contient cet hexagone. Ainsi il aura une uncia de jugerum, moins un demi-scripulum et un dixième de scripulum.

III. Si l'on a bien conçu les principes de ce raisonnement, il ne sera pas difficile de mesurer les terres ; mais il serait trop long et trop épineux d'entrer ici dans le détail de toutes les différentes formes qu'elles peuvent avoir. Je vais à

est septem millia et septingenti. Hos pedes esse dicemus in semicircuio, qui efficiunt jugeri quadrantem scripula quinque. Si autem minus quam semicirculus erit, arcum sic metiemur. Esto arcus, cujus basis habeat pedes xv?, latitudo autem pedes Iv. Latitudinem cum basi pono. Fit utrumque pedes xx. IIoc duco quater. Fiunt Lxxx. Horum pars dimidia est xL. Item sexdecim pedum, qui sunt basis, pars dimidia viı. Hi viu in se multiplicati, fiunt Lxıv. Quartam decimam partem duco, ea efficit pedes Iv paulo amplius. Hoc adjicies ad quadraginta. Fit utraque summa pedes xuIv. Hos in arcu quadratos esse dico, qui faciunt jugeri dimidium scripulum, quinta et vigesima parte $\mathrm{mi}$ nus. Si fuerit sex angulorum, in quadratos pedes sic redigitur. Esto hexagonum quoquo versus lineis pedum $\mathrm{xxx}$. Latus umum in se multiplico. Tricies triceni fiunt DCCCC. Hujus summæ tertiam partem statuo ccc, ejusdem partem decumam Xc. Fiunt cccxc. Hoc sexies ducendum est, quoniam sex latera sunt, qua consummata efficinnt duo inillia trecenteni et quadraginta. Tot izitur pedes quadra. tos esse dicemus. Itaque erit jugeri uncia dimidio scripulo et decima parte scripuli minus.

III. His igitur veiut primordiis talis ratiocinii perceptis non difficiliter mensuras inibimus agrorum, yuorum nunc omneis persequi species et longum et arduuin est. Duas présent ajouter à ce que j'ai dit deux formules dont se servent souvent les agriculteurs lorsqu'ils sont dans le cas d'arranger des plantes. Soit un terrain de douze cents pieds de long sur cent vingt de large, dans lequel on veuille arranger des vignes de façon qu'il y ait cinq pieds d'intervalle entre chaque rangée : je demande combien il faudra de plantes, en laissant une distance de cinq pieds entre chacune. Je prends le cinquième de la longueur, c'est deux cent quarante, et le cinquic̀me de la largeur, c'est vingt-quatre ; j'ajoute toujours à chacune de ces sommes une unité pour la plante de l'extrémité des rangées que l'on appelle angularis : j'ai donc une premièrc somme de deux cent quarante et un, et une seconde de vingt-cinq. Je multiplie ainsi ces sommes : Vingt-cinq fois deux cent quarante et un font six mille vingt-cinq. Vous direz que c'est le nombre de plantes qui seront nécessaires. De même, si on veut les mettre à six pieds de distance les unes des autres, on prend la sixième partie de la longueur de douze cents, qui est deux cents, et la sixième partie de la largeur de cent vingt, qui est vingt; on ajoute à chacune de ces sommes l'unité que j'ai mentionnće aux plantes angulares, ce qui fera deux cent un, et vingt et un; on multiplie ainsi ces sommes l'une par l'autre : Vingt et une fois deux cent un c'est quatre mille deux cent vingt et un, qui est le nombre des plantes que l'on dira être nécessaires. De même, si on veut les mettre à sept pieds l'une de l'autre, on prend la septième partie de la longueur et de la largeur, et l'on ajoute les unités pour les plantes angulares, et par ce moyen, et en procédant de mème, on trou ve le nombre des plantes nécessaires. Enfin quelque nombre

etiam nunc formulas præpositis adjiciam, quibus frequenter utuntur agricolæ in disponendis seminibus. Esto ager longus pedes mille ducentos, latus pedes cxx. In eo vites disponendx sunt ita, ut quini pedes inter ordines relin. quantur. Quæro quot seminibus opus sit, cum quinum pedum spatia inter semina desiderantur. Duco quintam partem longitudinis, fiunt $c c x L$; et quintam partem latitu. dinis, loc est $x \times 1 v$. His utrisque summis semper singulos asses adjicio, qui efficiunt extremos ordines, quos vocant anguịares. Fit ergo altera summa ducentorum quadraginta unius, altera viginti quinque. Has summas sic multiplicato. Quinquies et vicies duceni quadrageni singuii, fiunt sex miliia et viginti quinque. Totidem dices opus esse seminibus. Similiter inter senos pedes si voles ponere, duces sextam partem longitudinis mille ducentorum, fiunt cc. et sexfam latitudinis $\mathrm{cxx}$, id est $\mathbf{x x}$. His summis singulos asses adjicies quos dixi angulares esse. Fiunt $\mathrm{ccl}$, el $\mathrm{xx1}$. Has summas inter se multiplicabis, vicies et semel ducentos et unum, atque ita efficies quatuor millia ducentos et viginti unum. Totidem seminibus opus esse dices. Similiter si inter septenos pedes ponere voles, septimam partem longitudinis et latitudinis duces, el adjicies asses angula. res, eodem inodo eodemque ordine consummabis numerum seminum. Denique quotcunque pedum spatia facienda 
de pieds d'intervalle qu'on yeuille mettre entre chaque plante, on divise la longueur et la largeur en autant de parties qu'il y a de picds d'intervalle, et on y ajoute les deux unités dont nous avons parlé. Cela étant ainsi, il s'ensuit qu'un jugerum de terrain qui a deux cent quarante pieds de long sur cent vingt de large aura besoin, si on dispose les plantes à trois pieds d'intervalle entre les rangées (qui est lc moindre intervalle que l'on doive laisser en plantant des vignes), de quatre-vingt-une plantes pour la longueur, et de vingt-cinq pour la largeur, sur laquelle elles seront alignées à cinq pieds de dis. tance l'uue de l'autre; lesquels nombres, multipliés l'un par l'autre, donneront deux mille vingt-cinq plantes. Mais si l'on arrange les vignes à quatre pieds de distance l'une de l'autre en tous sens, la rangée en long contiendra soixante et une plantes, et celle en large en contiendra trente et une, lesquels nombres domneront pour le jugerum mille huit cent quatre-vingt-onze ceps de vignes. Si on les arrange à quatre pieds de distance dans la longueur et à cinq pieds dans la largeur, la rangée contiendra en long soixante et une plantes, et vingt-cinq en large; au lieu que si on les plante à cinq pieds de distance l'une de l'autre sur la longueur, la rangée comprendra sur cette longueur quarante-neuf plantes, et la largeur en cuntiendra toujours vingt-cinq : ces deux nombres multipliés l'un par l'autre font mille deux cent vingt-cinq. Mais si l'on veut arranger les vignes dans un terrain de même surface à six pieds de distance l'une de l'autre, il n'y a point de diffculté qu'il ne faille donner quarante et un ceps de vignes à la rangée en longueur, et vingt et un à celle en largeur, qui, multipliés l'un par l'autre, donneront le nombre de huit cent

censueris, totam partem longitudinis et latitudinis duces, et pradiclos asses adjicies. Haec cum ita sint, sequitur uti jugerum agri, qui habet pedes ccxu longitudinis, et la. titudinis pedes cxx, recipiat inter pedes terıos (hoc enim spatium minimum esse placet vitibus ponendis) per longitudinem semina $L \times x_{1}$, per latitudinem inter quinos pedes semina $x x v$. Qui numeri iuter se multiplicati fiunt semi. num duo millia et viginti quinque. Vel si quoquo versus inter quaternos pedes vinea erit disposita, longitudinis ordo lıabebit semina $2 \times 1$, latitudinis $\times x \times 1$, qui numeri efficiunt in jugero vites mille octingentas et nonaginta unam. Vel si in longitudinem per quaternos pedes, in latitudinem per quinos pedes fuerit disposita, ordo longitudinis labebit semina Lx1, latitudinis Xxv. Quod si inter quinos pedes consitio fuerit, per longitudinem of din is habebit semina $x u x$, et rursus per latitudinem semina $\mathbf{x x v}$. Qui numeri duo inter se multiplicati efficiunt mille ducentum et viginti quinque. At si per senos pedes eundem vitibus locum placuerit ordinare, nilil dubium est quin longitudini dandæ sint $\times$ ul vifes, latitudini autem viginti una. Quæe inter se multiplicatæ efficiunt numerun, DCcClXI. Sin autem inter septenos pedes vinea fuerit constituenda, ordo per longitudinem re. soixantc ct un. Si l'on veut arranger les ceps de vignes à sept pieds de distance l'un de l'autre, la rangée contiendra sur la longueur trentecinq ceps, ct dix-huit sur la largeur, lesquels nombres, multipliés l'un par l'autre, font six cent trente : nous dirons done que c'est le nombre de plantes qu'il faudra préparcr. Si on plante les ceps de vignes à huit pieds dc distance les uns des autres, la rangée en long prendra trente et une plantes, et celle en large en prendra seize, lesquels nombres, multipliés l'un par l'autre, font quatre cent quatre-vingt-seize. Si on les plante à neuf pieds deddistance, la rangée en long prendra vingt-sept plantes, et celle en large en prendra quatorze, lesquels nombres, multipliés l'un par l'autre, font trois cent soixante et dix-huit. Si on les plante à dix pieds de distance, la rangée en long prendra vingt-cinq plantes, et celle en large en prendra treize, lesquels nombres, multipliés l'un par l'autre, donnent trois cent vingtcinq; et pour ne pas pousser notre calcul à l'infini, on mettra les plantes dans la même proportion, selon qu'il plaira à chacun de faire les intervalles plus ou moins larges. Ce que nous avons dit des mesures des terres, et du nombre des plantes qu'il y faut employer pour les garnir, doit suffire. Je reviens à l'ordre que je m'étais prescrit.

IV. J'ai observé qu'il y avait plusieurs sortes de vignes en province : mais de toutes celles que j'ai connues par moi-même, il n'y en a pas que j'approuve plus que celles qui, semblables à de petits arbrisseaux, ont la jambe courte, et se tiennent toutes seules et sans appuis; et après elles, celles que les paysans appellent canteriatce, ct qui sont soutenues sur des appuis, et attachées chacune à des jougs séparés. Viennent ensuite celles qui sont environnées de roseaux

cipiet capita triginta quinque, per latitudinem xvı1. Qni numeri inter se multiplicati efficiunt Dcxxx. Totidem dicemus semina præparanda. At si inter octonos pedes vinea conseretur, ordo per longitudinem recipiet semina $\times x_{1}$, per latitudinem autem xvi. Qui numeri inter se multiplicati efficiunt ccccxcri. At si inter norenos pedes, ordo in longitudinem recipiet semiua viginti septen, el in latitudinem quatuordecim. Hi numeri inter se multiplicati faciunt ccclxxvur. At si Inter denos pedes, ordo longitudinis recipiet semina $x \times \mathbf{v}$, latitudinis $x \ldots$. Hi numeri inter se multiplicati faciunt cccxxv. Et ne in infinitun procedat disputatio nostra, eadem portione, ut cuique placuerint laxiora spatia, semina faciemus. Ac de mensuris agrorum numerisque seminum dixisse abunde sit. Nunc ad ordinem redeo.

IV. Vinearum provincialium plura genera esse comperi. Sed ex iis, quas ipse cognovi, maxime probantur velut arbusculx brevi crure sine adminiculo per se stantes : deinde qux pedaminibus adnix $æ$ singulis jugis imponuntur: eas rustici canterialas appellant. Mox qua defixis arundinibus circummunitx per statumina calamorum materiis ligalis in orbiculos gyrosque flectuntur : eas nou 
fichés en terre, et dont le bojs, attaché à ces roseaux qui leur servent de soutiens, est arrondi en forme de cercle. 11 y en a qui appellent ces vignes characata. Les vignes de la pirc condition sont celles qui sont renversées, et qui à la sortic du cep tombent à terre et y restent étendues. $0 \mathrm{n}$ les plante toutes à peu près de la même faẹon, c'est-à-dire qu'on met le plant ou dans des fosses ou dans des sillons : car les agriculteu's des pays étrangers ne sont point au fait de notre labour au pastinum; et d'ailleurs il est presque inutile dans les pays où le sol est naturellement ameubli et réduit en poussière, puisque c'est ce que l'on cherche à imiter par le labour à la charrue (commc le dit Virgile), de même que par celui au pastinum. Aussi la Campanie, quoique dans notre voisinage et par conséquent à portée de prendrc exemple sur nous, n'est pas dans l'usage de donner cette façon à la terre, parce quela facilité avec laquelle son sol se prêtc n'exige pas qu'on prenne tant de peine. Quant aux provinces dont le terrain trop compact exige de grandes dépenses, le paysan parvient, par le moyerı des sillons, à ce que nous ne pouvons obtenir qu'en labourant la terre au pastinum; je veux dire à placer son plant dans un sol bien amolli, et dès lors en état de lui prêter un pas. sage facile.

V. Mais je vais reprendre l'une après l'autre toutes les vignes que je viens de nommer, pour traiter de chacune à part, suivant l'ord re dans lequel je les ai annoncées. Celle qui sc ticnt toute seule et sans appui doit être mise dans une fosse si le terrain est léger, et dans une tranchée s'il est épais : mais ces fosses et ces tranchées seront bien plus avantageuses lorsque, dans les pays tempérés et où l'été n'est pas brûlant, elles auront été

nulli characatas rocant. Ultima est conditio stratarum vilium, qux ab enata stirpe confestim velut projecta per lumum porriguntur. Oınnium autem sationis fere eadem est conditio. Nam vel scrobe vel sulco semina deponuntur. Quoniam pastinationis expertes sunt exterarum gentium agricolæ : quæ tamen ipsa pene supervacua est iis locis, quibus solum putre, et per se resolıtum est : namque hoc imilamur arando, ut ait Yirgilius, id est etiam pastinando. Itaque Campania, cum vicinum ex nobis caperc possit exemplum, non utitur hac molitione terræ. quia facilitas cjus soli minorem operam desiderat. Sicubi autem densior ager provincialis rustici majorem poscit impensam, quod nos pastinando effrcimus, ille sulco facto consequitur, ut laxius subacto solo deponat semina.

V. Sed ut singula earum qux proposui vinearum genera jersequar, proedictum ordinem repetam. Vitis qua sine adminiculo suis viribus consistit, solutiore terra, scrobe; densiore, sulco ponenda est. [Sed et] scrobes et sulci plurimum prosunt, si in locis temperatis, in quibus aestas non est præfervida, ante annum fiant, (juam vineta con. scrantur. Soli tamen ante bonitas exploranda est. Nam si jejuno atque exili agro semina deponentur, sub ipsum faites dans l'année qui précédera la plantation des vignes. II faut cependant s'assurer auparavant de la bonté du terrain, parce que si le tcrrain auquel on destine le plant est maigre et léger, il faut faire ces fosses et ces tranchees vers le temps même de la plantation des vignes. $\mathrm{Si}$ on fait les fosses dans l'année qui préeédera la plantation des vignes, il suffira de leur donner trois pieds de longueur sur autant de profondeur, et deux pieds seulcment de largeur; ou bien, si l'on doit écarter les rangées de quatic pieds les unes des autres, il sera plus commode de faire ces fosses en carrés parfaits de quatre pieds, sans cependant leur donner plus de trois pieds de profondeur. Au reste, on déposera lc plant aux quatre coins de ces fosses, en mettant dessous de la terre bien ameublie; après quoi on les comblera. Quant aux intervalles qui seront entre les rangées, nous n'avons rien autre chose à prescrire, si ce n'est que les agriculteurs fassent attention à leur donner plus de largeur, s'ils doivent labourer leurs vignes à la eharrue, et à Icur en donner moins, s'ils doi vent les labourer au hoyau', pourvu cependant qu'ils ne leur donnent jamais plus de dix pieds, ni moins de quatre. II y a néanmoins bien des personnes qui, en faisant leurs rangées, n'y laissent que deux ou tout au plus trois pieds de distance entre chaque plante, tandis qu'ils laissent au contraire un plus grand intervalle entre les rangées, afin de faciliter davantage le passage à ceux qui bêchcront ou qui laboureront la vigne. Pour les soins qu'exige la plantation, ce sont absolument les mêmes que ceux que j'ai prescrits dans le troisième volume. Cependant Magon le Carthaginois ajoutc à cette méthode un précepte, qu'il fait consister à ne pas remplir entièrement la fosse de terre au moment

tempus sationis scrobis aut sulcus faciendus est. Si ante annum fiant, quam vinea conseratur, scrobis in longitudinem altitudinemque defossus tripedaneus abunde est; la. titadine tamen bipedanea : vel si quaterna pedum spatia inter ordines relicturi sumus, coinmodius, habetur caudem quoquo versus dare mensuram scrobibus, non amplius tamen quam in tres pedes altitudinis depressis. Cæterum quatuor angulis semina applicabuntur subjecta minuta terra, et ita scrobes adobruentur. Sed de spatiis ordinum eatenus præcipiendum labemus, ut intelligant agricolæ, sive aratro vineas culturi sint, laxiora interordinia relinquenda, sive bidentibus, angustiora : sed neque spatiosiora quam decem pedum, neque contractiora quam quatuor. Multi tamen ordines ita disponunt, ut per rectam lineam binos pedes, aut [ut] plurimum ternos inter semina relinquant : transversa rursus laxiora spatia faciant, per quæ velfossor vel arator incedat. Sationis autem cura non alia debet esse, quam qua tradita est a me tertio volumine. Unum tamen luuic consitioni Mago Carthaginiensis adjiciı, ut semina ita deponantur, ne protinus tofus scrobis terra compleatur, sed dimidia fere pars ejus sequente biennio paulatim adacgnetur. Sic enim putat vitem cogi deorsum 
qu'on y met le plant, mais à en laisser à peu près la moitié de vide, de façon qu'elle ne soit combléc que par degrés deux ans après : il imagine que c'est un moyen sûl pour contraindre la vigne a jeter ses racines par en bas. Je ne disconviendrai point qu'on ne puisse tirer quelque utilité de cette méthode dans les terrains sees, mais je ne crois pas qu'on doive la suivre dans les pays marécageux, non plus que daus eeux où le cicl est pluvieux, parce que l'eau qui séjourne en trop grande abondance dans ces fosses à demi vides tue le plant avant qu'il se soit fortifié. C'est pourquoi je crois qu'il vaut mieux eombler les fosses aussitôt qu'on y a déposé le plant; mais quand une fois il aura pris, il faudra, apı’ès l'équinoxe d'automne, le déchausser exactement et profondément, et, après avoir coupé les petites racines qu'il pourra arolr jetées sur la superficie du sol, le recouvrir de terre au bout de quelques jours. C'est le moyen de parer à deux inconvénients eu même temps, en empêchant que le plant ne jette ses racines par en haut, et que les pluies immodérées ne l'endommagent tant que ces racines seront encore faibles. Mais il n'y a point de doute que dès qu'elles auront pris des forees, les eaux du ciel ne leur fassent beaucoup de bien. C'est aussi pourquoi il sera bon de laisser les vignes découvertes et déchaussées pendant tout l'hiver, dans les pays où la douceur de cette saison s'y prêtera. Pour ce qui regarde lit nature du plant qu'il faut employer, c'est un point sur lequel les auteurs ne sont point d'aceord. Les เหเs pensent qu'il vaut mieux planter tout de suite des vignes par crossettes; les autres, qu'il les faut planter par marcottes: j’ai déjà déclaré dans les volumes précédents ma facon de penser sur eet oljet. J'ajouterai néanmoins ici qu'il y a des terres dans lesquelles le plant qui a été transféré

agere radices. Hoc ego siccis locis fieri utiliter non negaverim; sed ubi aut uliginosa regio est, aut cacli status im. brifer, minime facjundun censeo. Nam consisteus in semipleısis scrobibus nimius lıumor, antequam convalescant, senina necat. Quare utiliıs existimo, repleri quiclem strobes stirpe deposita, sed cum semina comprelienderiut, station post æequinoctium autumuale debere diligenter atque alte ablaqueari, et recisis radiculis, si quas in sumıno solo cilaveriut, post paucos dies adobrui. Sic enim utrunıque incomınodum vitabitur, ut nec radices in superiorem partem evocentır, neque immodicis plıviis paruu valida vexenter semina. Ubi vero jan corroborata fuerint, nilil dubium est, quin cæelestibus.aquis plurimnm juven. tur. Itaque locis, quibus clementia hiemis perınittit, adapertas vites relinquere et tota lieme ablaqueatas liabere eas conveniet. De qualitate autem seminum inter auctores non convenit. Alii malleolo protinus conseri vineam melius existimant, alii viviradice : de qua re quid sentiam, jam superioribus voluminibus professus sutr. Et nunc taınen lioc adjicio, esse quosdam agros, in quibus non ac. que bene translata semina quam immota respondeant : sed colvyelif d'un lieu à un autre ne roéussit pas anssi bien que cclui qu'on n'a point remué de sa place, quoi. que ce eas arrive très-rarement. Il faut done remarquer avec soin et examiner ce que chaque pays comporte, comme ce qu'il refuse. Quand la plante sera en terre, je veux dire la erossette ou la mareotte, on la faennnera de manièrequ'elle donne un eep qui puisse se soutenir sans appui. Or e'est à quoi on ne pourra pas parvenir sur-lechamp : pn cffet, si l'on ne commence pas par donner des appuis à la vigne lorsqu'elle est tendre et faible, les pampres se renverseront à terre à mesure qu'ils pousseront. C'est pourquoi oll attache la plante, en la mettant en terre, a un roseau qui sert à protéger et à former pour ainsi dire son enfance, jusqu'à ce qu'elle soit parvenue à la hauteur que veut lui donner l'agrieulteur; hauteur qui ne doit pas être considérable, puisqu'il ne faut pas la laisser monter à plus d'un' pied et demi. Lor'squ'ensuite elle aura pris des forces, et qu'elle pourra se soutenir sans appui, on lui laissera prendre sa croissance ou du côté du pied, ou du côté des bras. Car il y a deux façons de cultiver ees vignes : les uns aiment micux qu'elles soient réduites à leur pied, les autres aiment mieux qu'elles soient distribuées en bras. Ceux qui ont à cour de distribuer leur vigne en bras doivent conscrver tout lc bois qui sera poussé autour de la eicatrice qu'ils lui auront faite en la coupant toute jeune par le haut, et le distribuer en quatre bras chacun de la longueur d'un pied, de facon qu'il y en ait un qui soit tourné vers chaque partie du monde. Cependant on ne laisse pas dès la première année à ces bras toute la longueur que nous venons de fixer, de peur que la vigne ne soit trop chargée pendant qu'elle est encore frêle, mais on neles y fait parvenir qu'à la suite de plu-

istud rarissime accidere. Notandım item diligenter explo. randum esse, quid quaque ferat regio, quid quceque. recuset. Depositam ergo stirpen, id est, malleolum vel viviradicen, formare sic conveuit, ut vitis sine pedamine consistat. IIoc autem protinus effici non potest. Nam nisi adminiculum tenerx [viti] atque infirma contribueris, prorepens pampinus terix se applicabit. Itaque posito semini arundo adnectitur, quæ velut infantiam ejns tucatur atque edncet, producatque in tantam staturam, quantanı permittit agricola. Ea porro non debet esse sublimis : nam usque in sesquiperienı coercenda est. Cum deinde robur accipit, et jam sine adjnmento consistere ralet, aut capitis aut bracliorum incrementis adolescit. Nam dux species lunjus quoque culturx sınt. Alii capitatas vineas, alii brachiatas magis probant. Quibus cordi est in brachia $\mathrm{v}$ tem componere, convenit a summa parte, qua decisa no. rella vitis est, quicquid juxta cicatricem citaverit, conservari, et in quatuor bracliia pedalis mensura dividere, ita ut omnein partem cxli singula aspiciant. Sed lıxc braclia non statim primo auno tam procera submittuntur, ne ousretur exilitas ritis; sed compluribus putationibus in prop- 
sicurs tailles. Il fatut de plus laisser des especes de cornes cn saillie sur les bras, et étendre ainsi la vigne entic̀re en tous sens, en l'arrondissant. La méthode usitée pour tailler ces vignes est la mème que celle que l'on suit en taillant les visynes qui sont attachées au joug; avcc cettc différence néanmoins qu'or laisse aux coursons qui doivent donner le plus long bois quatrc ou ciuq bourgeons, au lien qu'on n'en laisse que deux à ccux qui sont destinés à renouveler la vigne. Pour ce qui est de la vigne que nous avons dit être réduite à son pied, on ôte tout lc sarment qui environne le eep jusqu'au corps même du tronc, et oll ne laissc qu'un ou deux bourgeons adhérents au tronc. On peut suivre hardiment eette méthode dans les terrains arrusés ou très-gras, qui ont assez de foree pour suffire tout à la fois au fruit ct au bois. Ceux qui donnent cette forme à leurs vignes les cultivent principalement à la charruc : aussi est-ce pour cela quiils leur otent tous leurs bras, afin que les troncs, n'ayant point de parties saillantes, ne soient pas en risque d'être endommagés par la charrue ou par les bœufs. Car il arrive communément que lorsque les vignes sont distribuées en bras, les bœufs en arrachent de petites branches, soit avec le pied, soit avec la corne : sourent même cet accident est occasionné par le manehe de la charrue, pour peu que le laboureur s'attache à raser les rangées avec le soc, et à labourer le plus près qu'il peut de la vigne. Telles sont les façons que l'on donne soit aux vignes réduites à leur picd, soit à celles qui sont distribuées en bras, avant qu'elles bourgeonnent. Mais lorsqu'elles sont germées, le fossoycur vient à son tour, et remue avec le hoyau les parties du terrain auxquelles le bou-

dictam mensuram educuntur. Deinde ex bracliis quasi quaedam cornua prominentia relinqui oportet, atque ita totam vitem onni parte in orbem diffundi. Putationis antem ratio eadem est, quxe in jugatis vitilus : uno tamen differt, yuod pro materiis longioribus pollices quateruum aut quinum genmarum relinquuntur : pro custodibus autem bigemmes reseces fiunt. In ea deinde vinea quam capitatam diximus, juxta ipsan matrem usque ad corpus sarmentum detralitur, una aut altera tautummodo gemma relicta, qua ipsi trunco allixet. Hoe autem riguis ant pinguissinis locis fieri tuto potest, cun vires terræ et fructum et materias valeut probere. Naxime auten aratris excolunt, qui sic fornatas vineas liabent, et eam rationein sequuntur detralıendi vitibus braclia, quod ipsa capita siue ulla extantia ueque aratro neque hubus ob. noxia sunt. Nam in brachialis plerumque fit, ut aut erure aut cornibus boum ramuli vitium defringantur: sæpe etiam stiva, dum sedulus arator vomere perstringere ordinem, et quam proximam partem vitium excolere studet. Atque lixc quiden cultura vel bracliat is vel capitatis [vitibus,] antequam gemnıent, adlibetur. Cum deinde ge:miuareriut, fossor insequitur, ac bidentibus eas partes vier n'a pas pu atteindre. Ensuite, dis que la vigne dome du bois, arrive celui qui doit l'épamprer : ec dernicr en retranche les pampres superflus, et laisse les branehes à fruit, qu'on a soin de lier en forme de eouronne lorsqu'clles ont pris une ecrtaine consistance; cc qu'on fait pour dcux raisons : la première, de peur que si on laissait les pampres en liberté, ils ne s'étendissent trop, et n'attirassent à eux toute la nourriture; la seconde, afin que la vigne étant ainsi liée, laisse encore un passagc libre au bouvicr et au fossoyeur pour la cultiver. Voici la manic̀re dont on épamprera : Dans les lieux couverts, humides et froids, on dépouillera entièrement la vigne en été, c'est-à-dire qu'on ôtera toutes les feuilles des branches à fruit, afin que lo fruit puisse mûrir, ct que l'humidité nc le fasse pas pourrir; au lieu que dans les licux sees, chauds, et exposés au soleil, on aura soin au contraire de laisser quelques pampres qui serviront à couvrir les grappes; et s'il s'en trouve trop peu, on garantira le fruit de la chalcur avec des feuilles, et quelquefois avec de la paille, qu'on y apportera d'ailleurs à cet effet. M. Columelle, mon oncle paternel, qui était un homme trèsinstruit dans les beaux arts, et l'agricultcur le plus attentif de la province de Pétique, eouvrait les vignes de nattes de palmier vers le lever de la Canicule, parce qu'ordinairement, au temps où cette constellation parait, certaines contrées de eette provinee sont si vexées par le vent du sudest, appelé Vulturnus par les habitants, que si on n'y prenait pas le soin de eouvrir les vignes, le fiuit se eonsumerait comme si la flamme eût passé dessus. Telle est la culture de la vigne qui est distribuéc en bras, ct de eelle qui est réduitc à son picd. Car pour celle que l'on attache à un

subigit, quas bubulcus non potuit pertingere. Mox uhi unaterias vitis exigit, insequitur pampinator, et supervacuis deterget, fructuososque palmites submittit, qui cum induruerunt, velut in coronam religantur. Hoc duabus ex causis fit : una, ne libero excursu in luxuriau properent, omuiaque alimenta pampini absumant ; altera, ut religata vitis rursus aditum bubulco fossorique in excolenda se prabeat. Pampinandi aulem modus is erit, $\mathrm{ul}$ opacis locis lumidisque et frigidis xstate vitis nuletur, foliaque palmitibus detralıantur, ut maturitatem fructus capere possit, et ne situ putrescat : locis autem siecis calidisque et apricis e contrario palmitibus uvæ contegautur; et si parum pampinosa vitis est, advectis frondibus et interdum stramentis fructus muniatur. M. quidem Columella patruus meus, vir illustribus disciplinis eruditus, ac diligentissimus agricola Baticæ provineix, sub ortu Caniculae palmeis tegretibus vineas adumbrabat, quoniaun plerumque dicti sideris tempore quadam partes ejus regionis sic infestantur Euro, quem incolx Vulturnum appellant, ut nisi tegminibus vites opacentur, velut laalitu flammeo fructus uratur. Aturue lıec capitatoe bracliatarue vitis cultura est. Nam illa, (juße uni jugo superponitur, aut quæ 
senl jonır, ainsi que eclle dont on laisse croitle le bois pour l'attacher' à des roseaux ruil lui servent d'appui en l'arrondissant en forme de cerele, elles demandent à peu près l'une et l'autre la même culture que les virgnes attachces au joug. J'ai cependant vu des gens qui enterraient sur la superficie du sol, en forme de provins, de longs sarments de vignes characalce, surtout quand c̈ćtait du raisin helvenacus, et qui ensuite redressnient auprès d'un roseau ces sarments que nos agrieulteurs appellent mergi et les Gaulois canlosocci, et les laissaient croitre, dans la vue d'en tirer du fruit. S'ils les couvrent de terre, c'est qu'ils s'imaginent que par ce moyen la terre fournirr? plus de nourriture à ces branches à fruit. Aussi les coupent-ils apiès la vendange comme des sarments inutiles, pour leur ôter toute communication avec le eep. Pour nous, nous conseillons de s'en servir lorsqu'on les aura séparés de leur mère, en guise de marcottes, pour remplir les vides des rangées, au cas qu'il s'y trouve des ceps morts, ou pour former de nouveaux plants; d'autant que la partic de ces sarments qui a été enterrée est toujours fournie d'une assez grande quantité de racines qui, dès quelles sont léposćes dans les fosses, y prennent très-bien. Enfin, reste à parlèr de la culture des vignes couchées à terre. On ne doit entreprendre cette culture que dans les climats les plus sujets aux vents, parce qu'elle est d'un travail diffieile pour les agriculteurs, et que les vignes de eette espèce ne donnent jamais de vin de bon goût. Il faudin, dans les pays qui n'admettront par leur constitution que ec genre de culture, déposer les crosettes dans des fosses de deux pieds; et lorsqu’elles seront germées, on les réduira à un seul bois, que l'on contiendıa la première année dans les bornes de deux bourgeons; ensuite quand

materiis submissis arundinum statuminibus per orbem connectitur, fcre eandem curam exigit, quan jugata. Non nullos tamen in vineis clıaracatis aniuadverti, ct maxime elvenaci generis, prolixos palmites quasi propagincs sum. mo solo adob'uerc, deinde rursus ad arundines crigere, et in fructum submitterc, quos nostri agricola mergos, Galli candosoccos vocant, eosque adobruunt siniplici ex causa, quot cxistiment, plus alimenti terram probere fructuariis flagellis. Itaque post viudemiam velıt inutilia sirmenta decidunt, et a stirpe submoveut. Nos autem pracipimus easlem virgas, cum a matre fuerint praecisa, siculí demortıis vitibus ordines vacent, aut si uovellam quis viucam instituere velit, pro viviradice poncrc. Qu1niam quidem partes sarmentoruin, quae fucrant olırutie, satis multas labent radices, qux dejosita: scrobibus confestim compreliendant. Supercst reliqua illa cultura prostrata vinea, qua nisi violentissimo cali statu suscipi non debet. Nam et difficilem laliorem colonis cxhibet, nce unquam generosi saporis vium prabet. Atque ulvi regiouis conditio solan ean culturam recipit, bipedaneis scrolibus malleolus deponitur. Qui cum egcrminavit, ad umau ma- celles auront produit l'année suivantedes branelies à fruits, on en laissera croître une seule, et on supprimera toutes les autres: enfill, après que eelle que l'on aura laissé croître aura donné du fi'uit, on la taillera d'assez court, pour qu'étant couchée à terre elle ne s'étende pas au delà de l'intervalle qui est entre les rangées. Il n'y a pas non plus beaucoup de différence, quant à la taille, entre la vigne couchée à terre et celle qui se tient debout, si ee n'est que le bois qu'on laisse à celle qui est couchée à terre doit être moins long que celui qu'on laisse à l'autre. II en est de même de ses coursons, que l'on taille aussi courts que ceux qui ont la forme d'une verrue; mais après la taille, qu'il faut indispensablement faire en automne à ces sortes de vignes, on les renverse tout enlières sur un intervalle d'entre les rangées différent de celui où elles étaient couchées auparavant, afin que la partie du terrain qu'clles avalent précédemment. occupée puisse être fouillée ou labourée, et qu'après qu'on lui aura donné ces façons, on puisse les y remettre, et cultiver de méme l'autre partic. Les auteurs sont peu d'accord sur la facon d'épamprer ees vignes : les uns prétendent gu'il ne faut pas du tout les épampier, afin qu'elles soient en état de protéger leurs fiuits contre la violence des vents et contre l'ineursion des bètes; d'autres reulent qu'on les épampre avee modération, afin que, sans être surchargées de feuilles totalement inutiles, elles puissent néanmoins couvrir et protéger leur fruit : eette méthode me parait aussi la plus convenable.

VI. Mais e'est assez nous être oceupés des vignes : passons aux préeeptes qui coneernent les arbres. Quiconque voudra avoir un plant d'arbres mariés à des vignes, qui soit non-seulement bien garni et arrangé avec symétrie, mais encore de

teriam revocatur : caque primo anno compescitur in duas genmas : scquente deindc, cum palmiles profudit, unıs subnittilur, caeteri deculiuntur. At ille qui submissus est, cum fructum clidit, in eam longitudiuen deputatur, uti jacens nou excedat interordinii spatium. Nec magna cst pulationis differentia cubantis, et stantis recta viuex : nisi quorl jacenti viti breviores materia submitti debent, reseces quoque angustius iu nodum furuhculorun relinqui. Scd post putationem, quam utique autumno in ejusmodi vinea ficri oportct, vitis tota deflcctitur in alterun intcrordiuium : atque ita pars ca quae fuerat occupata, $\mathrm{vcl}$ foditur vel aratur, ct cum cxculta est, eandem vilen recipit, ut altcra quoque pars cxcoli possit. De pampioalioue talis vinex parun inter auctores conveuit. Alii negaut csse nudandam vitem, quo melius contra iujuriam veutorun feraruunuc suc:tum abscondat : aliis placet parcius pampinari, $\mathrm{ut} \mathrm{ct}$ vitis non in tolum supervacuis froudihus oneretur, et taueu fructun vestire aut protegere prossit : qua: ratio mili yuoque commodior videtur.

VI. Sed jam de vineis satis diximus. Nunc de arboribus procipicudum est. Qui volet fiequens ct dispositun arlu- 
hon rapport, veillera à ce que la mort qui détruira ces arbres ne le dégrarnisse pas, en prenant te soin d'en retirer au fur et à mesure ecux qui seront ou épuisés par la vieillesse, ou fatigués par les mauvais temps, et de leur substituer de jeuneq rejetons; ce à quoi il pourra aisément par. venil, s'il a une pépinière d'ormes toute prête. Je vais en conséquence m'attacher à preserire eomment il faudra faire cette pépinière, et de quelle espèce d'ormes il faudra la peupler. On convient qu'il y a deux espèces d'ormes, ceux des Gaules, qu'on appelle ormes d'Atinia, et ecux de notre pays, qu'on appelle ormes d'Italie. Trémellius Serofa s'était imaginé; sans aucun fondement, que l'orme d'Atinia ne produisait point de $s a$. mera (e'est le nom qu'on donne à la graine de cet arbre) : il est vrai qu'il n'en produit qu'une trèspetite quantité, ce qui fait même que quelques personnes le regardent comme stérile, et que le peu qu'il en a est caché entre les feuilles de la première pousse; aussi personne aujourd'hui ne s'avise-t-il de le semer en graine, mais tout le monde le plante par rejetons. Cet orme est plus beau et plus haut que celui de notre pays, et ses feuilles sont plus du goût des bœufs, puisque lorsqu'ils en ont mangé habituellement, et qu'on veut ensuite leur en donner de celles de l'autre espèce, ils en paraissent dégoûtés. C'est pourquoi, tant qu'on le pourra, on ne plantera dans tout son terrain que de l'orme d'Atinia, ou au moins l'on fera en sorte de mettre dans les rangées, alternativement et en nombre égal, des ormes d'Atinia et de ceux d'Italie. Moyennant cela on aura toujours un mélange de feuilles de l'un et de l'autre arbre, ct les bestiaux, ragoûtés par cette espèce d'assaisonnement, consommeront plus vigoureusement la quantité de nourriture qui leur

stım paribus spatiis frucluosurnque habere, operam da. lit, ne ennortuis arboribus rarescat, ac primam quamque senio aut tempestate afllictam submoveat, et in vicem no. vellam solvolem substituat. Id auteın facile consequi polerit, si ulmorum seminarium paratum labuerit : quod fuomodo et qualis generis faciendum sit, non pigebit deinceps praccipere. Limorum duo esse genera convenit, Gallicum et vernaculum : illud Atinia, lıoc nostras diciIır. Atiniam ulmum Tremellius Scrofa non ferre sameram, quod est semen ejus arboris, falso est opinatus. Nam rariorem sine dubio creat, et idcirco plerisque et sterilis videtur, seminibus inter frondem, quam prima germina. tione edit, latentibus. Itaque nemo jam serit ex samera, sed ex sobolibus. Est auten ulmus longe lactior et procerior, quam nostras, frondemque jucundiorem bubus prebet: qua cum assidue pecus paveris, et postea generis alterius frondem dare institueris, fastidium bubus affert. Itaque si tieri poterit, totum agrum genere uno Atiniœ ulmi conseremus : si minus, dabimus operam, ut in ordinibus disponendis pari numero vernaeulas et Atinias alternemus. Ita semper mista fronde utemur, et quasi lıoc condimento illectac pecudes fortius justa cibariortim conficient. Sed vitem maxine populus videtur alere, deinde sera nécessaire. Ies arbres auprès desquels la vigne vient le mieux sont d'abord le peuplier, préférablementad tout autre; ensuite l'orme, et même en troisième lieu le frêne. Beaucoup de personnes ont rejeté le peuplier, paree qu'il produit peu de fenillages, et qu'il n'est pas utile aux bestiaux. ()n plante a vec raison, dans les lieux escarpés et mon. tagneux où l'orme ne se plait pas, le frène, qui est un arbre très-agréable aux chèvres et aux brebis, et qui n'est pas sans utilité pour les bœufs. L'orme est préféré par le plus grand nombre, parce qu'il s'accommode très bien de la vigne, qu'il fournit un pâturage très-agréable aux bœufs, et qu'il réussit dans plusicurs espèces de terrains différents. Ainsi, si l'on se propose de créer un plant d'arbres mariés à des vignes, on préparcra d'avance des pépinières d'ormes ou de frènes, d'après le procédé que nous donnerons ci-dessous; car pour les peupliers, on fera mieux de mettre tout de suite dans le plan des branches prises sur la cime de ces arbres. On labourera donc la terre au pastinum, dans un terrain gras et médiocrement humide ; et après l'avoir hersée et ameublie avec soin, on la distribuera au printemps par planches. On jettera ensuite sur ces planches de la graine d'orme, qui commencera à rougir, et que l'on aura fait sécher au soleil pendant plusieurs jours, sans eependant lui avoir laissé le temps de perdre son suc, ou de trop s'endurcir : on la répandra très-druc pour en couvrir entière. ment ces planches, après quoi on la recouvrira de la hauteur de deux doigts avec de la terre bien ameublie, que l'on passera à cet effet au crible, et on l'arrosera légèrement : on finira par couvrir ces planches de paille, afin que les oiseaux ne becquètent pas la pointe des tiges quand la graine sera germée. Lorsqu'ensuite ces plantes

ulmus, post etiam fraxinus. Populus, quia raram, neque jloneam frondem pecori prabet, a plerisque repuliata est. Fraxinus, quia capris et ovibus gratissima est, nec inutilis bubus, locis asperis et montosis, quibus minus lætatur ulmus, recte seritur. Ulmus, quod et vitem commodissime patitır, fet jucundissimum pabulum bubus affert, variisque generibus soli provenit, a plerisque pra' fertır. Ifaque cui arbustum novum instituere cordi est, seninaria ulmorum vel fraxinorum parentur ea ratione, quan deinceps subscripsimus. Nam populi melius cacuminibus in arbusto protinus deponuntur. Igitur pingui solo et modice lıumido bipalio terran pastinalimus, ac diligenter occatam et resolutam verno tempore in ateas componemus. Sameram deinde, qua jam rubicundi coloris erit, et compluribus diebus insolata jacuerit, ut aliquem tamen succum et lentoren lıabeat, injicicmus areis, et eas totas seminibus spisse contegemus, atque ita cribro putrem terram duos alte digitos incernemus, et modice rigabimus, stramentisque areas cooperiemus, ne prodeuntia cacumina seminum ab avibus prærodantur. Ubi deinde prorepserint plantæ, stramenta colligemus, et manibus herbas carpemus : idqune leviter et curiose faciendum est, ue adluuc tenerae brevesque radicula ulınorum convellan- 
auront pris racine, on ramassera la paille de dessus les planehes, et on en arrachera les herbes à la main; il faut faire cette opération légèrement et avec attention, pour ne pas arracher en même temps les racines des ormes, qui seront encore tendres et courtes. On aura soin que les planches ne soient pas plus larges qu'il ne faut, pour que reux qui en arracheront les herbes puissent facilement en atteindre le milieu avec la main; car si on leur donnait plus de largeur, les plantes seraient exposées à être foulées aux pieds. II faut ensuite jeter de l'eau plutôt qu'en faire couler sur ces pépinières pendant l'été, avant le lever clu soleil ou sur le soir ; et lorsque les plantes aulont trois pieds de hauteur, il faudra les transférel dans une autre pépinière; mais, de peur qu'elles u'y jettent des racines trop profondes (ee qui par la suite causerait beaucoup d'embarras, lorsqu'il s'agira de les enlever pour les transporter dans une autre pépinière), il faudra ne leur faire que de petites fosses, qui ne seront éloignées les unes des autres que d'un pied et demi. On nouera ensemble les racines, si elles sont courtes; ou si elles sont plus longues, on les tortillera dans la forme d'une couronne, et, après les avoir enduites de bouse de vache, on les déposera dans ses fosses; enfin on foulera la terre à leurs pieds dans tout leur circuit avee grand soin. On peut aussi user de la même méthode à l'égard des plan. tes que l'on aura enlevées en tiges, comme il est nécessaire de faire pour les ormes d'Atinia, que l'on ne sème pas en graine. Mais les ormes de cette dernière espèce se plantent mieux pendant l'automne qu'au printemps : on en rompt très-doucement les petites branches avee la main, paree que les deux premières années ils craignent de sentir le fer. Ce n'est que la troisième année qu'on se sert de la serpette pour les tailler. Dès qu'ils sont en état d'ètre transplantés, on peut très-bien

tur. Atque ipsas quidem areas ita anguste compositas la. hebimus, ut qui runcaluri sunt, medias partes earum facile manu contingant : uam si latiores fuerint, ipsa seınina proculcata uoxam capieut. Estate deinde priıs quam sol oriatur, aut ad vesperum, seminaria conspergi sæpius quam rigari debent : et çum ternưm pedum plantæe fuerint, in aliud scminarium transfcrii, ac nc radices altius agant (qux res postmodum in eximendo magnum laborem affert, cum plantas in aliud seminarium transferre volumus) oportebit non maximos scrobiculos sesquipede inter sc distantes fodcre : deinde radices in nodum, si breves, vel in orbem coronx similem, si longiorcs erunt, inflecti, ct oblitas fimo hubulo scrobiculis deponi, ac diligenter circumcalcari. Possunt etiam collectxe cum stirpibus plantxe eafen rationc disponi : quod in Atinia ulmo fieri ncecssc cst, qia non seritur e samera. Sed lsec ulmus autumni temporc melius quam vere disponitur; paulatimquc ramuli ejus maun detorquentur, quouiam primo bieunio ferri reformidat ictum. Tertio deumm anno acuta falce alıraditur, atque inbi translationi jam idunca est, cx co temprore au. les planter depuis le moment de l'automue où lat terre aura été Irempée par les pluies, jusqu'au printemps, avant que leurs racines commencent à se peler lorsqu'on les déterre. Il faudra préparer des fosses de tıois pieds en tous sens pour receroir ces arbres, si la terre est lérère; et si elle est épaisse, y fairc des tranchées de la même profondeur. On aura soin en outre, ell les plantant dans les terrains couverts de rosée et sujets aux brouillards, d'exposer leurs branches au eôté du levant et à celui du couchant, afin que Ic milieu de l'arbre, qui est l'endroit où la vigne est liée et contre lequel elle s'appuie, recoive plus de soleil. Si l'on veut en même temps faire venir du grain dans ce terrain, on mettra ces arbres à quarante pieds de distance les uns des autres, pourvu que le terrain soit fertile; au lieu qu'on ne les séparera que de vingt pieds daus un terrain maigre, et dans lequel on ne sènera rien. Lorsqu'ensuite ils commeneeront à grandir, il faudra les façonner a vee la serpette, et y former des tabulata (étages d'arbres.) C'est le nom que les agriculteurs sont dans l'usage de donner aux branches et aux trones qui sont en saillie, et qu'ils raceoureissent ou allongent plus ou moins par la taille, selon qu'ils veulent donner plus ou moins de liberté aux vignes. Au reste, il vaut mieux leur donner plus de liberté dans un terrain gras, et les gêner davantage dans un terrain maigre. Ces sortes d'étages ne doivent pas être à moins de trois pieds de distance les uns des autres, et ils doivent être faits de facon que leurs branches supérieures ne soient pas sur une seule et même ligne avee les inférieures, parce qu'autrement l'inférieure occasionnerait un frottement continuel à la branche à fruit qui descendrait dc la supérieure, à mesure qu'elle germerait, et qu'elle finirait par en faire tomber le fruit. Mais quelque espèce d'arbres que l'on ait plantée, il ne

tumni, quo terra imbribus permaduerit, usque in vernum tempus, antequam radix ulmi in eximendo delibretur, recte seritur. Igitur in resoluta terra teruum pedum quoquo versus faciendi scrobes. At in densa, sulci ejusdem altitudinis ef latitudinis, qui arbores rccipiaut, preparandi. Sed dcinde in solo roscido et nebuloso conserenda sumt uluni, ut carum rami ad orientem et [in] occidentem dirigantur, quo plus solis medix arbores, quibus vitis applicata et religata inuititur, accipiant. Quod si ctian frumen. tis consulemus, uberi solo inter quadraginta pedes, exili: ubi niliil scrilur, inter viginti, arbores disponantur. Cun deinde adolescerc incipient, falce formanda, ct tabulata instituenda sunt. Hoc enim nomine usurpant agricolat ramos truncosque prominentes, eosque vel propius ferro compescunt, vel longius promittunt, ut vites laxills dif. fundantur: loc in solo pingui melius, illud in gracili. Tabulata inter se ne minus ternis pedibus absint, atque ita formentur, ne supcrior ramus in eadem linea sit, qua inferior. Nam demissum ex eo palmitem germinantem in. ferior atteret, ct fructum decutiel. Sed quameunque arbo 
faudra pas les tailler les deux premières années. Si par la suite l'orme ne prend qu'un faible aecroissement, il faudra au printemps, et avant qu'il quitte facilement son ćcorce, l'étêter auprès le la branche qui en paraîtra la plus brillante, en laissant eependant sur le trone, au-dessus de cette hranche, une tige de la hauteur de neuf pouces, a laquelle on attachera cette branehe, en l'appuyant auprès et en lui faisant prendre sa direction, afin qu'étant bien redressée, elle puisse dommer une cime à l'arbre. Ensuite il faudra eouper au bout d'un an eette tige qu'on avait laissée au trone, et ragréer la plaie. Si l'arbre n'a point de branche dont on puisse tirer ee parti, il suffira de le réduire à la hauteur de neuf pieds, en lui coupant toute la partie supérieure, afin que les nouvelles branches qu'il poussera, soient à. l'abri des bestiaux. Il faudra le eouper d'un seul coup, si l'on pent en venir à bout; sinon il faudra le seier, et ensuite ragréer la plaie avee la serpette, et la recouvrir d"un lut dans lequel on aura mêlé de la paille, pour que le soleil ou la pluie ne l'endommagent point. Un an ou deux après, lorsque les nouvelles branehes auront pris des forees, il faudra retrancher eelles qui seront inutiles, et laisser celles qui se prêteront à être arrangés. Quand un orme aura toujours été d'une belle venue depuis le moment de sa plantation, il faudra lui eouper avee la serpe les branches supérieures jusqu au noud qui les joint au trone. Mais si ses branehes sont déjà fortes, on leur laissera en les eoupant un petit bout de bois cn saillie sur le trone. Lorsqu'ensuite l'arbre aura pris toute sa foree, il faudra en rogner tout ee que l'on pourra atteindre a vee la serpe, et ragréer les plaies, sans cependant toueher au eorps mème de la mère. Voiei eomment il faudra façonner un

rem severis, eam biemio proximo putare non oportet. Post deinde si ulmus exiguum incrementım recipit, verno tempore, antequam librum demittat, flecacuminanda est jux a ramulum, qui videbitur esse nitidissimus, ita tamen, uti supra eum trunco stirpem dodrantalem relinquas, ad quam ductus et applicatus ramus alligetur, et correctus cacumen arbori probeat. Deinde stirpem post annum pro. cidi et allevari oportet. Quod si nullum ramulum arbor idoneum habuerit, sat erit novem pedes a terra relinqui, et superiorem parten detrnncari, nt nova virga, quas emiserit, ab injuria pecoris tuta sint. Sed si fieri poterit, uno ictu arborem procidi; si minus, serra desecari, et plagam falce allevari oportebit, eamque plagam luto pa. leato contegi, ne sole aut pluviis infestetur. Post annum aut biennium, cum enati ramuli recte convaluerint, supervacuos deputari, idoneos in ordinem submitti conveniet. Quse ulmusa positione bene provenerit, ejus summa virga falce debent enodari. At si robusti ramuli erunt, ita ferro amputentur, ut exiguam stirpem prominentem trunco relisquas. Cum deinde arbor convaluerit, quicquid falce cuntingi poterit, exputandum est, allevandumque eatenus, ne plaga corpori matris applicetur. Ulınum autem novellam forinare aic conveniet. Loco pingui octo pedes a terra sine ramo re- jeune orme dans un terrain gras. On lui laissera huit pieds sur terre sans branches, ou sept, quand le terrain sera moins gras; au-dessus de cet espaee on le distribuera en trois parties prises sur sa eirconférenee, à ehaeune desquelles on laissera une branche pour former le premier tabulatum. Ensuite, après a voir laissé trois pieds vacants pardessus, on arrangera d'autres branehes de facon qu'elles ue se trouvent pas sur la même ligne que eelles du tabulatum dont je viens de parler; et il faudra eontinuer d'arranger de la même façon l'arbre dans son entier jusquu’à sa eime. Au reste, on prendra garde en l'émondant de ne pas donner trop de longueur aux ergots qu'on lui laissera en eoupant ses branehes, eomme, au eontraire, on prendra garde de ne pas les eouper assez pres pour que le trone soit lui-même blessé ou écorehé, parce que le trone de l'orme une fois écorehé réussit mal. 11 faut aussi éviter que deux plaies différentes ne se réunissent en uno seule, paree que l'éeoree aurait de la peine à se eieatriser à la suite d'un tel maltraitement. On eulitivera aussi cet arbre sans diseontinuation, et on we se eontentera pas de l'avoir arrangé avec soin dans le principe, mais on bèehera encore antour de son trone, et on eoupera avee le fer, de deux années l'une, soit en entier, soit en grande partie, le feuillage qu'il aura donné, de peur que l'épaisseur de sol ombre ne nuise à la vigne. Lorsqu'ensuite eet arbre sera devenu vieux, on le pereera près de terre jusqu'à la moelle, pour domer une issue à l'humidité qui se sera amassíe dans sa partic supérieure. Il faut aussi planter la vigne auprès de lui, avant qu'il ait pris toute sa foree. Au' surplus, si l'on marie à un jeune orme une jeune vigne, il ne lui fera pas de tort; au lieu que si on lui en marie une vieille, il feril

linquendi, vel in arvo gracili septem pedes : supra quoil spatium deinde per cireuitum in tres partes arbor dividenda est, ac tribus lateribus singuli ramuli.submittendi primo tabulato assignentur. Mox de ternis pedibus superpositis alii rami subınittendi sunt, ita ne isdem lineis, quibus in inferiore positi sint. Eademque ratione usque in cacumen ordinanda erit arbor. Atque in frondatione cavendum, ne aut prolixiores pollices fiant, qui ex amputatis virgis relinquuntur, aut rursus ita alleventur, ut ipse truncus ladatur, aut delibretur : nam parum gaudet ulmus, qua in corpus nudatur. Vitandumque ne de duabus plagis una fiat, eum talem cicatricem non facile cortex compieliendat. Arboris autem perpetua cultura est, non solum diligenter eandem disponere, sed etiam truncum circumfudere, et quicquid frondis enatum fuerit, alternis annis ant ferro amputare aut astringere, ne nimia umbra viti noceat. Cum deinde arbor vetustatem fuerit adepta, propter terran vulnerabitur ita, ut excavetur usque in medullam, detur. que exitus humori, quem ex superiore parte conceperit. Vitem quoque, antequam ex toto arbor prævalescat, conserere convenit. At si teneram ulmum naritaveris, onus jam non sufferet : si vetustac vilem applicueris, conjugen necabit. Ita suppares esse alate ef viribus a. 
Inouril sa compagne. Ainsi, il faut qu'il y ait convenance d'âge et de vigueur entre ces arbres et les vignes qu'on marie avec cux. Mais lorsqu'on veut marier une vigne à un arbre, il faut préparer, pour les marcottes qu'on doit mettre auprès de lui, un fossé de deux pieds de largeur sur deux pieds de profondeur si la terre est légèrc, ou deux pieds neuf pouces si elle est épaisse, et de six pieds de longueur ou tout au moins de cinq. II faut que ce fossé soit au moins à un pied et demi de distance de l'arbre, parce que s'il jnignait les racines de l'orme, la vigne prendrait mal, et que quand même elle prendrait, l'arbre ne pourrait manquer de l'étouffer dès qu'il viendrait à croítre. On fera ce fossé en automne, si on en a la liberté, afin que la terre s'en ramollisse aux pluies et aux gelées. Ensuite, vers l'ćquinoxe du printemps, on y déposera deux ceps à la fois à un pied de distance l'un de l'autre, afin qu'ils couvrent plus tôt l'orme, et on prendra garde de ne pas les planter pendant que les vents du septentrion souffleront, ni pendant qu'ils seront couverts de rosće, mais on attendra qu'ils soient ressuyés : c'est une attention que j'ordonne d'avoir, non-seulement en plantant des vignes, mais cncore cn plantant des ormes et toute autre espèce d'arbres; comme j'ordonne encore, lorsqu'on les tire de la pépinière, de les marquer d'un côté arec de la sanguiue, pour se rappeler la position où ils étaient dans la pépinière, afin de les mettre dans la même position, parce qu'il est très-intéressant qu'ils regardent le côtć du ciel auquel ils sont accoutumés dès leur enfancc. Le temps le plus favorable pour planter les arbres et les vignes dans les cantons qui sout exposés au soleil, et où la température n'est ni trop froide ni trop pluvieuse, e'est en automne après l'équinoxe. Mais il faut, en les plantant, étendre dans
Ic fossé jusquu'à la profondeur d'un demi-pied la superficie de la terre, que l'on aura labourie a Ia charruc; développer toutes leurs racines, ensuite les fumer, selon mon opinion, après les avoir plantés; sinon les recouvrir au moins de cette terre labouréc, que l'on foulera aux pieds dans le circuit du tronc. Il faut mettre les vignes à l'extrémité du fossé la plus ćloignée de l'arbi’e, et en étendre le bois dans la largeur du fossé, pour les relever ensuite auprès de l'arbre; et enfin les entourer de haies, pour les mettre à l'abri des bestiaux. Au surplus, il faut accoter le plan de vigues aux arbres du côté du septentrion dans les pays chauds, du côté du midi dans les pays froids, ct du côté de l'orient ou de celui de l'occident sous un climat tempéré, afin qu'il ne soit pas incommodé peńdant toute la journée, soit par le soleil, soit par l'ombrc. Celsus pense qu'il ne faut pas approcher le fer de la vigne à la première taille qui suivra sa plantation, mais qu'il scra mieux d'entourer l'arbre arec les tiges de celte plante, qu'on tortillera a cet effet en façon de couronne, afin qu'elles jettent du bois en abondance de toute leur partie qui sera courbée, et qu'on puisse employer le plus fort de ce bois à former, l'année d'après, la tête de la vigne. Mais une longue expérience $m$ 'a convaincu qu'il est bien plus utilc de faire sentir la serpette aux vigues dès les premiers temps, et de ne pas les laisser se couvrir de sarments inutiles. Je pensc même qu'il faut couper jusqu'au second ou au troisième bourgeon le premier bois qu'on leur laissera, afin qu'il donne des branches à fruit plus robustes : dès que ces branches auront atteint le premier étagc, on les taillera; chaque anuée ou les fait monter d'un étage, laissant toujours sur l'étagre préeédent une vieille branche que l'on appliquera au trone de l'arbre, afin qu'elle so di- bores vitesque convenit. Sed arboris maritandac causa scrobis viviradici lieri debet latus pedum duorum, altus levi terra totidem pedum; gravi, dupondio el dodrante : longus pedum sex ant minimum quinque. Absit autem hic ab arbore ne minus sesquipedali spatio. Nam si radicibus ulni junxeris, male vitis comprehentet, et cunn temuerit, incremento arboris opprimelur. Inunc scrobem, si res permittit, autumuo facito, ut pluviis et gelicidiis naceretnr. Circa vernum deinde acquinoctium bince vites, quo celerius ulınum vestiant, pedem intér se distantes scrobibus deponenda : cavendumq̨ue ne aut septentrionalibus ventis aut rorulente sed sicce serantur. Hauc olservationem non solum in vilium posilione, sed in 11 ! morum caterarumqque arborum pracipio : et uli cum de seminario eximuntur, rnbrica notetur una pars, qua nos admoneat, ne aliter arbores constituamus, quan quemaduolum in semninario steterint. Plırimum enim refert, ut eam partem cxli spectent, cui ab tenero cunsueverumt. Melius autem lucis apricis, ubi cali stalıs neque prargelislus nejue nimitum pluvins est, antumn tenıpore et aıbores et bires pust x annisoctiun deponuntur. Sed ex ita cunscrenda sunt, nt summam lerrain, quae aratio subacta sit, semipedem alte substernamus, radicesque omnes explicemus, et depositas stercorata, ut ego existimo, si minus, certe subacta operiamus, et circumcalcemus ipsum seminis codiccm. Vites in ultimo scrolse deponi oporlet, materiasque earum per scrobem porrigi, deinde ad arborem erigi; alyue ab injuria pecoris caveis em mniri. Locis aulem pra:fervidis semina septentrionali parte abbori applicanda sunt : locis frividis a meridie, tenmerato slatı cacli, ant ah, oriente ant ab occidente, ne toto die solem vel umbranı patiantur. Proxina deinde pulatione melius existiuat Col. sus ferro alstineri, ipsosque coles in modum corona con. tortos arbori circundari, ut flexura materias profundal. quarum validissimam sequeute anno caput ritis facianus. Me autem longns docuit nsıs, multo ntilins esse prin.4 quoque tempore falcem vilibus admovere, nec supers.t. cuis sarmentis pati silvescere. Sed eam (purgue, qua: primo subnittefur, materiam ferro coercendam censco usque i: alteram vel lertian gemnam, quo robustiores palmiles agat : qui cunı primum tabnlatum apprehenderint, froxima putatione disponentur onnibusque annis aliquss in 
rige vers sa cime. Une fois que la vigne est mariée à l'arbre, les agrieultcurs lui imposent des lois constantes : la plupart garnissent les étages inféríeurs de beaueoup de sarments, pour avoir une plus grande quantité de fr'uits et trouver plus d'aisance dans la culture. Mais ceux qui reeherehent 'a qualité du vin exeitent la vigne à monter au plus haut des arbres, et, à mesure qu'elle jette de nou'reau bois, ils attirent ce bois vers la branche de l'arbre la plus élevie, de façon que le plus haut de la vigne gagne toujours le plus haut de l'arbre; e'est-à-dirc que les deux branches à fruit les plus élevées de la vigne s'unissent au trone de l'arbre vers sa cime, à laquelle tend leur direetion ; de sor'te qu'à mesure qu'une branche de l'arbre se fortifie, elle recoit la vigne entre scs bras. On mettra sur les plus fortes branches de l'arble un plus grand nombre de branehes à fruit de la vigne, qui seront toutes séparées les ures des autres; au lieu qu'on en mettra moins sur les plus petites. On attaehera la jeunc vigne à l'arbre avee trois tourons : l'un qui sera lié à la cuisse de l'arbre à quatre pieds de distanee de la terre, l'autre qui arrêtera la vigine par le haut, et le troisième qui l'embrassera par le milieu. II n'en faut pas mettre par le bas, paree que cela diminuerait les forees de la vigne : on le regarde cependant quelquefois comme nécessaire, lorsque l'arbre ayant été tronqué n'a point de branehes, ou rue la vigne a trop de vigueur et qu'elle s'étend trop. Les autres points à observer dans la taille sont de couper toutes les anciennes branches qui auront rapporté du fruit l'aunée précédente, et de laisser les nouvelles en les débarrassant partout de leurs vrilles, et en coupant les rejetons qu'elles peuvent avoir produits; comme aussi de

śuperius tabulatum excitabitur, rclicta semper una materia, (ұuße applicata trunco cacumen arboris spectet. Jamque viti constitutæe certa lex ab agricolis imponitur : plerique ima tabulata materiis frequentaut, uberiorem fructum ct magis facilem cultum sequentes. At qui bonitati vini student, in summas arbores vitem promovent : ut quæeque materia sedebit, ita in celsissimum quemquc ramum extendunt, sic, ut summa vitis sumuram arborem sequa. tur, id est, ut duo palmites extremi trunen arboris applicentur, qui cacumen ejus spectent, ct prout quisque ramus couvaluit, vitem accipiat. ['lenioribus ramis plures palmites alius ab alio scparati imponantur, gracilioribus pauciores; vitisque novclla tribus toris ad arborem relige. tur, uno, qui est in crurc arboris a terra quatıor pedibus listans; altero, qui summa parte vitem capit; tertio, qui meliam vitem complectitur. Torum imum imponi non oportet, quoniam vires vitis adimit. Interdum tameu necessurius habetur, cum aut arbor siue ramis truncata est, ant vitis pracvalens in luxuriam evagatur. Catcra pulationis ratio talis est, ut vetercs palmitcs, quibus proximi anni fructus pependit, omnes recidantur : novi, circumcisis undique caprcolis et nepotibus, qui ex lis nati suut, anıutatis, submittantur : et si lata ritis cst, ultimi po. laisser tomber par la pointe des rameaux de l'ar. bre les branehes les plus éloignées de la vigne préférablement aux autres si elle est abondante, les plus voisines du cep si elle est maigre, et celles du milieu si elle est d'une qualité moyenne, parce que les branches les plus éloignées sont celles qui rapportent le plus de fruit, et que les plus voisines du trone sont celles qui l'épuisent et qui l'exténuent le moins. Il est aussi fort utile aux vignes d'être délices toutes les années, parce qu'on les éclaireit alors plus commodément, et qu’elles se rafraichissent lorsqu'elles solit liées à une autre place, outre qu'elles sont moins blessées et qu'elles s'en portent mieux. II faut encore mettre les branches à fruit sur les étages, de facon qu'elles y soient liées au-dessus du troisième ou du quatrième bourgeon avant d'en descendre, et ne point scrrer la ligature, de crainte qu'elle ne coupe le sarment. Mais si l'étage est si éloignè qu'on ne puisse pas y conduire eommodément la branche de la vigne, on l'attachera sur la vigne même, en la liant au-dessus du troisième bourgeon. Nous preserivons ecei, paree que la partie de la branche qui descend de l'étage est celle qui se charge de fruits ; au lieu que celle qui est attachée a vee un lien tend à monter plus haut, et fournit du bois pour l'année suivante. Au reste, les branehes elles-mêmes sont de deux sortes: les unes sortent du bois dur, et, comme elles ne rapportent eommunément la première année que des feuilles sans fruit, on les appelle pampinarii; les autres sortent d'unc branche qui a un an, et on les appelle fructuarii, paree qu'elles produisent des fruits. Pour avoir toujours dans une vigne une grande quantité de ces dernières, on lie les branches au troisième bourgeon, afin que tout ec

tius palmites per cacumina ramorum pracipitentur; si graculis, tıunco proximi, si mediocris, medii; quoni:uı ultimus palmes plurimum fructum affert, proximus miıi. mum vitem exhaurit atque attenuat. Maxime autcm pio dest vitibns, omribus aunis resolvi. Nam et conumodius enodantur, et refrigcrantur, cum alio loco alligat $x$ suut, minusque læduntur, ac nelius convalescunt. Atque ipsos palmites ita tabulatis superponi convenit, ut a tertia gemma vel quarta religati dependeant, eosque non constringi, ne sarmentum vimine præcidatur. Quod si ita longe tabulatum est, uti materia parum commode in il perduci possit, palnitem ipsum viti alligatum supra ter. tiam gemman religabimus. Hoc ideo fieri pracipimus, quia quae pars palmitis pracipilata est, ca fructu induitur : at quac vinculo adnexa sursum tendit, ea materias sequenli anno prebet. Sed ipsorum palmitum duo genera suut : alterum, quod ex duro provenit, quod quia primo anno plerunque frondcm sine fructu affert, pampinarium vo. cant; alterum, quod ex anniculo palmite frocreatur : quod quia protinus creat, fructuarium appellaut. Cujus ut semper liabeamus copiam [in vinca,] palmitum partes ad tres gemmas religanda sunt, ut quicquid intra vinculum cet matcrias cxigat. Cun deinde amis ct roborc vitis con- 
(jui cst au-dessous de la ligature donne du bois. Lorsqu'cnsuite la vigne aura augmenté en force ell prenant des années, il faudio faire aller, sur les arbres qui se trouveront dans son voisinage, de longs sarments que l'on coupera néanmoins ai bout de deux ans pour cn faire passer de plus trndres à leur place, parce que les vieux sarments fitiguent la vigne. On est aussi quelquefois dans l'usare, quand la vigne ne peut pas embrasser larbre dans son entier, d'en coucher une partic en l('rre pour en faire venir deux ou trois provins, Iu'on fera monter à l'arbre, afin qu'il soit plus tôt couvert, en se trouvant environné d'une grande quantité de ceps. On ne doit pas laisser à une jeune vigne de sarments pampinarii, à moins qu'ils ne sortent d'un endroit où il scra nćcessaire de les laisser, pour les marier par la suite à une branche de l'arbre qui aura perdu ceux qui la garnissaient. Pour ce qui est des vieil!es vignes, les sarinents à feuilles dits pampinarii, qui y sont nés dans une place convenable, leur sont utiles; et on fait bien de les y laisser pour la plus grande partie, en les taillant au troisième bourgeon, parce qu'ils donnent du bois l'année suivante. Tout pampre né daus une place convenable, qui aura ćté rompu, soit lorsqu'on taillait la vigne, soit lorsqu'on la liait, ne doit pas être retranché pour peu qu'il lui reste un bourgeon, parce que l'année d'ensuite il donnera infailliblement des pampres, qui scront d'autant plus forts que ce bourgeon sera unique. On appelle procipites (branches précipitées) les branches à fruit qui sont sorties de celles de l'année, et que l'on attache au bois dur. Ces sortes de pampres rapportent à lì vérité beaucoup de fruit, mais aussi ils font bien du tort à la mère. C'est pourquoi il ne faut pas en précipiter, si ce n'est de l'extrémité des branches de l'arbre, ou dans le cas où la vigne serait montée plus haut que la cime de l'arbre.

valuit, traduces in proximam quamque arborem mittenda, casque post bienuium amputare [simul] atque alias teneriores transmittere conveuit. Nam vetustate vitem fatigant. Nonuunquam etiam cum arborem totam vitis compre. liendere nequit, ex usu fuit partem aliquam ejus deflexam terra immergere, et rursus ad eandeu arborem duas vel tres propagines excitare, ¡juo plurilus vitibus circumventa celerius vestiatur. Viti novella pampinarium immitti non oportet, nisi necessario loco natıs est, ut viluum ramum usaritet. Veteribus vitibus loco nati palmites pampinarii utiles sunt, et plerique ad tertian genmam resecti optime subunittuntur. Nam insequeuti anno materias fundunt. Quisquis auten pampinus loco natıs in exputando vel alligando fractus est, modo ut aliquam gemmam lıbuerit, ex toto tolli non oportet : quoniam proximo anno vel valitliorem materiam ex una creabit. l'racipites palmites di. cuntur, qui de lornotinis virgis enati in duro alligantur. Ili plurimum fructus afferunt, sed plurimum matri noceut. Ilayue nisi extremis ramis, aut si vitis arboris cacumen enjeraserit, pracipitari praluiteu non oprortet. Quod si
Sl cependant quelqu'un voulait laisser les branches de cette espèce, dans la vie d'a voir beaucoup de fruit, il faudrait qu'il commenẹat par les tortiller, ensuite qu'il les liât, et enfin qu'il les précipitát. En effet, elles jetteront pour lors une quantité de sarments derrière l'endroit où on les aura torlues, et, toutes précipitées qu'elles scront, elles attireront moins à elles les forces de la vigne, quoiqu'en donnant du fruit avec abondance. Il ne faut pas laisser plus dune année les branches précipitées. Il y a une autre espèce de branche à fruit qui sort d'une jeune branche, et que l'on attache dans le tendre de cette branche pour la laisser pendre : nous l'appelons bois tout court (materia), et elle donne du fruit et de nouveaux sarments en abondance. On donne encore à deux pampres venus d'une même tige, qu'on a laissés à la vigne, le nom de materia : j’ai montré plus baut quelle était la nature des sarments à feuilles dits pampinarii. Le pampre nomme pampre fourcheron (focaneus) est celui qui vient dans l'entre-deux des bras, comme au milieu d'une fourche (furca). J'ai observé que c'est la pire de toutes les tiges, parce qu'elle ne rapporte point de fruits, et qu'elle exténue les deux bras entre lesquels elle est nće; e'est pourquoi il faut la retrancher. Bien des gens se sont trompés en s'imaginant que lorsqu'une vigne était forte et bien fertile, elle devenait encore plus fertile si on la surchargeait et qu'on lui laissât beaucoup de branches à fruit , puis'łu'il arrive au contraire que plus une vigne a de branches, plus elle donne de pampres, et que par conséquent, étant couverte de beaucoup de fcuilles, elle quitte plus mal sa fleur, retient plus longtemps le brouillard et la rosée, et perd toutes ses grappes. Je pense done que lorsqu'une vigne est forte, on fera bien de la distribucr sur les branches de l'arbre, de disperser ses longs

tamen id genus colis propter fructum submittere quis velit, palınitem intorqueat. Deinde ita alliget et præcipitet. Nam et post eum locum quem intorseris, lactam materiam citabit, et præcipitata minus virium in se trahet, quamvis fructu exuberet. Praccipitem vero plus anno pati non oportet. Alterum est genus palınitis, quod de novello nascitur, et in tenero alligatum dependet : materiam vocamus; ea et fructum et nova llagella bene procreat : et jam si ex uno capite dux virga submiltantur, tamen utraque materia dicitur; nam pampinarius quam vim labeat, supra docui. Focaneus est, qui inter duo braclia velut in furca de medio nascitur. Eum colem deterrimum esse comperi, quod neque fructum ferat, et utraque brachia, inter quie natus est, attenuet. Itaque tollendus est. Plerique vilem validam et luxuriosam falso crediderunt feraciorem fieri, si unultis palnuitibus submissis oneretur. Nam ex pluribus virgis plures pampinos creat, et cuin se multa fionde cuoperit, pejus defloret, nebulasque et rores diutius contiuet, omnemque uvam perdit. Validam ergo vitem in $1 \mathrm{n}$ mos diducere censto, et traducibus dispergere atjue disra. 
sarments sur les arbres volsins, et de l'éelaireir, en précipitant une partie des branches à fruit; si elle est moins fertile, il faudrait abandonner ses materice en liberté. Au surplus, autant un plant d'arbres marićs à des vignes est recommandable par ses fruits et par la beauté de son aspeet lorsqu'il est bien garni, autant il est infruetueux et sans grâce lorsque la vieillesse l'a dégarni. Pour empêcher que cet accident n'arrive, un chef de famille attentif doit óter le premier arbre qui se trouvera aceablé de vieillesse, pour lui en substituer un autre plus jeune : auquel cas il évitera de se servir de marcottes, quoiqu'il en ait la faculté; mais il préférera des provins pris dans lo voisinage. Au reste, tel de ces deux partis qu'il preıne, il suivra la méthode que nous avons déjì donnée. C'est assez de préceptes pour les plants d'arbres mariés aux vignes à la façn d'Italie.

VII. II y a une autre espèce de plants d'arbres mariés aux vignes, qui est d'usage dans la Gaule: on l'appelle rumpolinum. Il faut pour cette espèce de plant des arbres bas et peu chargés de feuilles. L'aubier paraît y être très-convenable : c'est un arbre semblable au cornouiller. Il y a bien des personnes qui disposent encore pour ee plant des charmes, des cornouillers et des frênes sauvages, et quelquefois même des saules. Mais il ne faut employer le saule que dans les terrains liumides, où les autres arbres viendraient difficilement, parce que cet arbre corrompt le goût du vin. On pourra aussi y mettre des ormes en les itêtant dans leur jeunesse, et en les soignant de façon qu'ils ne montent pas à plus de quinze pieds de hauteur. Car j'ai remarqué qu'ordinairement ces rumpotina sont faits de façon que leurs étages ne vont qu'à huit pieds dans les lieux sees et

rare, certosque vinearios cules pracipitare, et si minus Iıxuriabitur, solıtas materias relinquere; ea ratio vitem feraciorem faciet. Sed ut densum arbustum commendabile fructu et decore est, sic ubi vetustate rarescit, pariter inutile et invenustum est. Quod ne fat, diligentis patrisfamilias est, primain quamque arborem senio defectam tollere, et in ejus locum novellam restituere, [vitem queat, ] nec eam viviradice frequentare, ea etsi sit facultas, sed, quod est longe melius, ex proximo propagare. Cujus utriusque ratio consinilis est ei quam tradidimus. Alune laxe de Italico arlousto satis praccepimus.

vil. Est et alterum genus arbusti Gallici, quıod vo. catur rumpotinum. Id desiderat arborem lumilem nec frondosam. Cui rei maxime videtır esse idonea opulıs : ea est arbor coruo similis. Quin etiam cornus et carpinus ct ornus non nunquam, et salix a plerisque in loc ipsum disponitur. Sed salix nisi in aquosis locis, ubi aliae arbores difliciliter comprehendunt, ponenda non est, quia viuj saporem infestat. Potest etian ulmus sic disponi, ut adlıc tenera decacuninetır, ne altitudinem quindecim pedum excedat. Nam fere ita constitulum rumpotiueluu animadverti, ut ad octo pedes locis siecis el clivosis, ad duo. montagneux, et à douze dans les lieux plats et humides. Communément on divise ces arbres en trois branehes, à ehacune desquelles on laisse de deux côtés plusieurs bras; après quoi on re. tranche presque toutes les autres branches dans le temps qu'on taille la vigne, de peur qu'ellis ne lui donnent trop d'ombre. Si l'on ne sème pas de blé sous les arbres des rumpotina, on les espace à vingt pieds de distanee des deux côtés; mals si l'on s'adonne a y mettre du grain, on lalsse entre eux quarante pieds de distance d'un côté, et vingt de l'autre. Le reste de la culture est la même que pour les plants d'arbres mariés à des vignes à la façon d'Italie, c'est-à-dire qu'on dépose les vignes dans de longs fossés, qu'on les cultive avee autant de soin, qu'on les distribue sur les branches des arbres; enfin qu'on fait passer d'arbre en arbre de nouveaux sarments longs que l'on attache ensemble, et que l'on renouvelle toutes les années en coupant les anciens. Si un de ces longs sarments, qui passent d'arbre en arbre, ne peut pas atteindre son voisin, on les réunit par le moyen d'une baguetto que l'on attache en travers. Lorsqu'ensuite le poids du fruit les fait courber, on les soutient avec des appuis qu'on met par-dessous. Au reste, plus on laboure profondément et plus on bêche au pied des plants d'arbres de cette espèce mariés à des vignes, ainsi qu'au pied de toute autre espèce d'arbres, plus ils rapportent de fruits : on voit par ce que nous avons dit plus haut s'il est de l'utilité du chef de famille de viser à cette abondance de fruits.

VIII. La culture de tous les autres arbres est à la vérité beaucoup plus simple que eelle de la vigne; mais l'olivier est eelui de tous qui entraine le moins de dépenses, quoiqu'il tienne le

decin locis planis et uliginosis tabulata disponantur. Plerunıue autem ca arbor in tres ramos dividitur, quilıus singulis ab utraque parte complura brachia submittuntur, tum onnes pene virgx, ne unbrent, eo tempore quo vitis putatur, abraduntur. Arboribus rumpotinis, si frumeı. tum non inseritur, in utramque partem viginti pedum spa. tia interveniunt : at si segetilus indulgetur, in alteram partem quadraginta peles, in alteram viginti relinquu॥tur. Cetera simili ratione aţ̧ue in arbusto Italico administrantur, ut vites longis scrobibus deponantur, ut earlem diligentia cureutur, atque in ramos diducantur, $11 \mathrm{t}$ wi trarluces omuibus annis inter se ex arboribus prosiunis connectantur, et veteres decidautur. Si tradux traduccu nou contingit, media virga inter eas deligetur. Cum deinde fructus pondere urgebit, subjectis adminiculis snsliueatur. lloc aulem gemus arbusti cxeteraeque omıes arbores quanto altius arantur et circumfodiuntur, majore fruclu exuberant; quod an expediat patrifamilias facere, reditus docet.

VHI. Onunis taneu arboris cultus simplicior quam vinearum est, longeyue ex ounibus stirpibus minorem inl. peusam desiderat olca, qux prima unnium an borum est. 
premier rang entre cux. En effet, quoiqu'il ne rapporte pas de fruits toutes les années de suite, mais seulement de deux années l'une à peu près, eependant il mérite le plus grand égard, tant pare qu'il se soutient sans une grande culture, et que, lorsqu'il n'a ni fleurs ni fruits, il ne demande presque aucune dépense, ou que, pour jeu quion en fasse, ses fruits se multiplient à pro. portion de cette dépense, que parce que, lorsyu’il est négligé pendant une suite d'années, il ue manque point eomme la vigne, mais qu'il rapporte dans ce temps-là même quelque profit au chef de famille, et qu'il ne lui faut qu'un an your se eorriger, pour peu qu'on le cultive de nouveau. C'est aussi pour eela que nous avons cru devoir donner avec soin des préceptes particuliers sur cette espèee d'arbre. Je crois yüil y a bien des sorles d'olives ainsi que de raisins, mais il n'en est venu que dix à ma eonnaissanee; savoir, l'olive Pausiu, l'Algiana, eelle de Licinius, eelle de Sergia, la Nevia, la Culminia, l'Orchis, la Regia (royale), la Cerciles (allongée) et la Murtea (de myrte). De toutes ces olives, la plus agréable est la Pausia, comme la Regia (royale) est la plus belle : ces deux espèces sont jlutôt bonnes à manger que propies à faire de l'huile. Si l'huile que l'on tire de la Pausia est d'un goût excellent tant qu'elle est verte, il fau eonvenir qu'elle se gâte en vieillissant. De même l'Orchis et la Cerciles sont meilleures à manger qu'à faire de l'luuile. Celle de Licinius domne la meilleure liuile, eelle de Sergia en donne le plus abondamment; et eommunément les plus grandes olives sout les meilleures à manger, comme les plus petites sont les meilleures dorit on puisse tirer de l'luaile. Aucune de ees espeees ne peut souffrir une température brûlante, non plus (ju'une température glaciale : c'est pourquoi el-

Tam quamvis non eontinuis annis, sed fere altero quoque Iructum afferat, eximia tamen ejus ratio est, quod levi cultu sustinetur, et eum se non induit, vix ullam impens.mm poscit. Sed et si quam recipit, subinde fruetus multiplicat : negleeta compluribus annis non ut vinea deficit, eoque iłso tempore atiquid etiam interim patrifamilias prestat, et eun adhibita cultura est, uno anno emendatur. Quare etian nos in hoc genere arboris diligenter pracipere censuimus. Olcarum, sicut vitium, plura geliera esse arbitror, sed in meam notitiam decen omnino pervenerunt : Pausia, Algiana, Liciniana, Sergia, Nevia, Culminia, Orchis, Regia, Cercitis, Murtea. Fx quibns bacca jueundissina est Pausix, speeiosissima Regix, sed utraque potius escre, quam oleo est idonea. Pausix tamen oleum saporis egregii, dum viride est; velustate corrumpifur. Orclis quoque et Radius metius ad escam quain in lịgunrem stringitır. Oleum optimuın Lieinia dat, plurimum Sergia : omnisque olca major fere ad escam, minor oleo est aptior. Nulla ex his generibus, aut pracervidum, aut gelidum statum cali patitur. Itaque arstuosis locis eeplentrionali colle, frigidis uncridiano gaudet. Sed nęue les se plaisent sur les colliues septentrionales dans les pays tres-chauds, et sur les méridionales dans les pays froids. Elles n'aiment pas encore les terrains bas, ainsi que les terralns trop élevés; mais clles préfèrent les pentes douees, telles que celles que nous voyons chez les Sabins daus l'Italie, ou par toute la province de Bétique. Bien des gens sont dans l'opinion que cet arbre ne peut pas vivre, ou qu'au moins il n'est pas fertile, t̀ une distanee de plus de soixante milles de la mer, quoiqu'il réussisse dans des climats qui en sont plus éloignés. La Pausia souffre trè-bien le chaud, et l'olive de Sergia le froid. Le meilleur terrain pour les olives est celui dont le fond est de gravier, pourvu qu'il s'y trouve au-dessus de l'argile mêlée au sable. Celui dont le sable est gras ne leur est pas moins favorable; les terres compaetes même s'accommodent très-bien de cet arbre, pour peu qu'elles soient moites et grasses. Mais il ne veut point d'un terrain où il n'y ait que de l'argile, surtout si les eaux y sourdent, et qu'elles y séjournent toujours en grande quantité. Les terres qui ne renferment qu'un sable maigre et du gravier pur lui sont aussi eontraires; en effet, quoique l'olivier n'y périsse pas, il n'y profite néanmoius jamais. On peut cependant le planter dans une terre à blé, ou dans des lieux qui auront porté aupararant des arbousiers ou des yeuses. Pour ee qui est du chêne, il laisse dans la terre, même après qu'il est abattu, des racines qui sont nuisibles aux plants d'oliviers, et dont lc poison tue ees arbres. Voilà ee que j'avais à vous dire de cet arbre en général. Je vais aetuellement passer au détail de sa culture.

IX. On préparera la pépinière destinée à meubler les plants d'oliviers dans un lieu bien aéré, dont le terrain soit médiocrement fort, mais

depressa loca neque ardua, magisque modicos eliros amat, quales in Italia Sabinorum vel tola provincia Batica vidouus. Hane arborem plerique existlınant ultra milliarium sexagesimum a mari aut non vivere aut non esse feracem. Sed in quibusdam locis reete valet. Optime vapores sustiuet Pansia, frigus Sergia. Aptissimum genus terrae est oleis, eui glarea subest, si superposita ereta sabulo adınista est. Non minus probabile est solum, ubi pinguis sabulo est. Sed et densior terra, si uvida et laeta est, commode recipit lıane arborem. Creta ex toto repudianda est, magis etian scaturiginosa, et in qua semper uligo consistit. Inimieus est etiam ager sabulo macer, et nuta glarea. Nam etsi nou emoritur in ejusinodi solo, nunquam tamen convalescit. Potest tamen in agro frumentario seri, vel ubi arbutus, aut ilex steterant. Nan quercus etiam excisa radices uoxias olireto reliuquit, quarum virus enecat oleam. Hac in universum de tolo genere hujusarboris habui dicere. Nuno per parles culturam ejus exsequar.

IX. Seminarium oliveto praeparetur en lo libero, terreuus modice valido, sed succoso, neque denso ne'pue sulut(1) solo, potius tamen resolulo; id geus fere tena uigra: 
pleln de suc, et d'un grain qui ue soit ni compacte ni trop meuble, mais cependant plutỏt de cette dernière qualité que de la première. Ces sortes de terres sont presque noires. Lorsqu'on aura labouré ce terrain au pastinum à trois pieds de profondeur, et qu'on l'aura environné d'un fossé profond pour en interdirc l'entrće aux bestiaux, on le laissera fermenter. Cela fait, on prendrasur les arbres les plus fertiles de jeunes branches longues, bien brillantes et faeiles à $\mathrm{cm}$ poigner, c'est-à-dire, de la grosseur d'un manelic d'instrument; on les eoupera sur-lc-ehamp pour avoir des boutures très-fraiches, en prenant garde d'endommager l'écoree, ou une partie de la bouture autie que celle à laquelle on aura appliqué la scie. On évitera facilement cet accident, en mettant un étai en forme de fourehe sous la branche que l'on sera prêt à couper, et en matelassant ue foin ou de paille la partie de cet étai sur laquelle posera cette branche, afin que les boutures y soient couchées mollement, et que leur écorce ne coure aucun risque quand on les coupera. On les sciera ensuite de la longueur d'un pied et demi, et on ragréera des deux eôtés avec la serpette l'endroit de la plaie. On y fera aussi une marque arec de la sanguine, afin de les mettre en terre dans la même position où elles étaient sur l'arbre, et de façon qu'elles soient dirigées de même par leur extrémité inférieure vers la terre, et par leur cime vers le ciel. Car si on renversait la bouturc en la mettant en terre, elle prendrait diffieilement et serait éternellement stérile, même après avoir acquis la plus grande vigueur. Il faudra enduire la tête et le pied des boutures de fumier mêlé avee de la cendre, et les enterrer entièrement, et de façon qu'clles soient recouvertes de terre ameublie à la hauteur de quatre doigts. On met à cause de

est. Qnam cum in tres pedes pastinaveris, et alta fossa circumdederis, ne aditus pecori detur, fermentari sinito. Tum ramos novellos proceros et nitidos, quos compreliensos manus possit circumvenire, hoc est manubrii crassitudine, feracissimis arboribus adinito, et [ex his] quam recentissimas taleas recidito, ita ut ne corticem aut ullam aliam partem, quam qua serra præciderit, locdas. Hoc autem facile contingit, si prius varam feceris, ct eam partem, supra quam ramum secaturus es, foeno aut stramentis texeris, ut molliter et sine noxa corticis talexe superposita secentur. Talex deinde sesquipedales serra praccidantur, atque earum plaga utraque parte falce le. ventur, et rubrica noteutur, ut sic quemadmodum in arbote steterat ramus, ita parte ima terram et cacumine cnelum spectans deponatur. Nam si inversa mergatur, difficulter comprehendet, et cum validius convaluerit, sterilis in perpetuum erit. Sed oportebit talearum capita et imas partes misto fimo cum cinere oblinire, et ita totas eas immergeri, ut putris terra digitis quatuor alte superveuiat. Sed binis indicibus ex utracpue parte muniautur : hi sunt de qualibet arbore brevi spatio juxta eas posili, cela, à une petite distance auprès d'elles, deux signaux d'un bois queleonque, un de chayue côté, mais attachés ensemble à l'aide d'un lien qui les unit par en haut, de peur qu'étant isolés, ils ne soient facilement renversés. L'objet de ces signaux est de prévenir l'ignorance des laboureurs, et d'empêcher que les boutures qui au. ront été plantées ne soient lésées lorsqu'on voudra cultiver la pépinière au hoyau ou au sarcloir. Il y a des personnes qui croient que le mieux est de transplanter dans des pépinières les bouquets des oliviers sauvages, en les arrangeant de même : mais qu'on les plante de l'une ou de l'autre facon, on doit toujours le faire après l'équinoxe du printemps, comme on doit aussi les sarcler le plus souvent que l'on pourra la première année, et les cultiver au râteau la seconde année et les suivantes, aussitôt que les petites raeines de ces plantes auront commeneé à prendre des forces. Mais il faudra s'abstenir pendant deux ans de les tailler; et la troisième année on leur laissera à chacune deux branehes, en sarclant fréquemment la pépinière. La quatrième année, on coupera la plus faible de ces deux branehes. Au bout de cinq ans de cette culture, ce seront de petits arbres bons à être transférés. On les transfère à propos dans le plant des oliviers pendant l'automne, si lc terrain est sec et qu'il ne soit point maréeageux, ou au printemps un peu avant qu'ils germent, s'il est gras et humide. On leur prépare un an d'avanee des fosses de quatre pieds de profondeur, et mème, si le temps n'a pas été favorable; on brûle de la paille dans ces fosses avant de les y mettre, afin que le feu ramollisse la terre, comme le soleil ou la gelée auraient dû le faire. L-'intervalle entre les rangées doit êtreau moins de soixante pieds d'un eôté et de quarante de l'autrc, si le terrain est gras

et [in summa parte] inter se vineulo connexi, ne facile singuli dejiciantur. Hoc facere utile est propter fossorum ignorantian, ut cum bidentibus aut sarculis seminariun, colere institueris, depositæe talex non lodantur. Quidan melius existimant radicum oculis silvestrium olearum hortulos excolere, et simili ratione disponere : sed utıum. que debet post vernum aquinoctium seri, et quam frequentissime seminarium primo anno sarriri : postero et sequentibus, cum jam radicula seminum convaluerint, rastris excoli. Sed biennio a putatione abstineri, tertio anno singnlis seminibus binos ramulos relinqui, et frequenter sarriri seminarium convenit. Quarto anuo ex duobus ramis infirmior amputandns est. Sic exculta quin. quennio arbusculæ labiles translationi sunt. Plantæ antem in oliveto disponuntur optine siccis minimeque uliginosis agris per autumnum, loctis et humidis verno tempore, paulo ante, quam germinent. Atque ipsis scrobes quater. num pedum proparantur anno ante : vel si tempus non largitur, prius quam deponantur arbores, stramentis alyıe virgis injectis incendantur scrobes, ut eos ignis purres faciat, quos sol et pruina facere debuerat. Spatium iuter 
et destiné à porter du blé, ou de vingt-cinq s’il est maigre et qüil ne soit point convenable aux grains. Mais il faut que la face des rangées soit tournée vers le point d'où souffle le vent Favonius, afin que ce vent les rafraichisse en été. Voici comment on s'y prend pour transférer ees petits arbres : avant de les déplanter, on marque a vec de la sanguine la partie qui était tournéc au midi, afin de les planter de la méme manière qu'ils l'étaient dans la pépinière. Ensuite on fait en sorte de laisser de la terre autour de l'arbre environ l'espace d'un pied, afin de l'arracher avec ectte motte. Pour empêcher que cettc motte ne se brise lorsqu'on déplantera l'arbre, il faut préparer de petites bagucttes de branches d'arbres liées ensemble, quc l'on appliquera à la mottc de terre avant de l'enlever, et que l'on liera sur ses côtés avec de l'osier, de façon que la terre étant resserrée par ces baguettes soit retenue comme dans unc prison. L'arbre étant ensuite déraciné, on travaillera légèrement la motte de terre avec unc bêche, et on attachera par-dessous des branches d'arbres sur lesquelles on le transportera. Avant de le déposer dans la fosse qui lui est destinée, il faudra en fouiller le fond a vee le hoyau, ensuite jeter dedans la terre qui aura été labourée à la charrue (si cependant la superficie de cette terre est grasse), et mettre dessous un lit d'orge. S'il y a de l'eau dans les fosses, il faudra la tarir entièrement avant d'y déposer les arbres, ensuite y jeter de petites pierres, ou du gravier mêlé avec de la terre grasse; enfin quand les arbres seront déposés, il faudra échancrer alentour les côtés de la fosse, et y mêler un peu de fumier avec la terre. Si l'on ne trouve pas à propos de planter l'arbre avec sa motte, il sera très.bon alors d'en dépouiller le tronc

ordines minimum esse debet pingui et frumentario solo sexagenum pedum in alteram partem, atque in alteram quadragenum : maero nec idoneo segetibus, quinum et vicenum pedum. Sed in Faronium dirigi ordines conveuit, ut arstivo perllatu refigerentur. Ipsæ autem arbusculp hoc modo possunt transferri : antequam explantes arbuseulam, rubrica notato partem ejus, qua meridiem spectat, ut eodem modo, quo in seminario erat, depona. tur. Deinde ut arbusculæ spatium pedale in circuitu relin. quatur, atque ita cum suo caspite planta eruatur. Qui raspes in eximendo ne resolvatur, nodicos surculos virgarum inter se connexos facce oportet, eosque pala, qua eximitur, applicare, et viminibus ita innectere, ut constricta terra velut indusa teneatur. Tum subruta parte ina leviter pala commovere, et suppositis virgis alligare, atque plantam transferre. Qux antequam deponatur, oportebit solum scrobis imum fodere bidentibus : deinde terram aratro subactam, si tamen pinguior erit summa lumus, imnittere, et ita ordei semiua substeruere, et si consistet in scrobibus aqua, ea omnis laturienda est, antequam demittautur arbores. Deinde ingerendi miuuti la. Juúe's vel glarea unista pingui solo, depositisque semini- de toutes ses branches, et de le déposer dans une fosse ou dans une tranchéc après avoir ragréé ces plaies, ct les avoir enduites de fumier et de cendre. Le trone le plus propre à ètre transféré est celui qui est de la grosseur du bras : on pourra néanmoins en transférer de beaucoup plus gros et de plus robustes; auquel eas il faudra les déposer de façon qu'ils n'excèdent que de très-peu le niveau de la fosse, pourvu qu'il n'y ait point de risque à courir de la part des bestiaux, parce que c'est le moyen qu'ils donnent plus de feuillages. $\mathrm{Si}$ cependant on n'a pas d'autre moyen de les garantir des bestiaux, il faudra les élever davantage de terre, afin qu'ils soient à l'abri de ce danger. Il faut encore les arroser dans les temps de sécheresse, et ne leur faire sentir le fer qu'au bout de deux ans; la première année on en retranchera les rejetons, en ne leur laissant qu'une seule tige qui sera plus haute que le plus grand bœuf, de peur que par la suite cet animal en labourant ne se blesse la cuisse ou quelque autre partie du corps contre ces arbres. Il est aussi très-bon de les munir de haies alentour après qu'ils sont plantés, et de distribuer le plant (quand il est formé et en état de produire des fruits) en deux portions qui porteront du fruit chacune leur année, parce que l'olivicr n'est pas fertile deux années de suite; mais comme il donne des tiges dans l'annéc pendant laquelle le terrain n'est pas ensemencé sous lui, et qu'il produit des fruits dans celle où il est ensemencé, il arrive de là que le plant étant ainsi distribué, est d'un rapport égal toutes les années. Du reste, il faut labourer lc plant a la charrie au moins deux fois par an, et fouiller profondément au pied des arbres avec le hoyau Lorsque la terre vient à sc fendre après

bus latera scrobis circumcidenda, et aliquid stercoris interponendum. Quod si cum sua terra planta non couvenit, lum optimum est omni fronde privare truncum, atque levatis plagis, fimoque et cinere oblitis, in scrobem vel sulcum deponere. Truncus autem aptior translationi est, qui brachii crassitudinem halset. Poterit etiam longe majoris incrementi et robustioris transferri. Quem ita convenit poni, ut si non periculum a pecore habeat, exiguum admodum supra scrobem emineat : lætius enim frondet. Si tamen incursus pecoris aliter vitari non poterit, celsior truncus constituefur, ut sit innoxius ab injuria pecorum. Atque etianı rigandx sunt planta, cum siccitates ineesserunt, nec nisi post biennium ferro tangendx. Ac primo surculari debent, ita ut simplex stilus altitudinem maxini bovis excedat; deinde arando ne coxam hos, alianre partem corporis offendat, optimum est etiam constitutas plantas circummunire caveis. Deinde constitutum jam et inaturum olivetum in duas partes dividere, qua alternis aunis fructu induantur. Neque enim olea continuo bieunio uberat. Cum subjectus ager consitus non est, arbor colienlum agit : cum seminibus repletur, fructum affert; ita sie divisum olirelum ounnibus annis acqualem teditum 
le solstice, par la force de la chaleur, il faut veiller à ce que le soleil ne pénètre pas par ees crevasses jusqu'aux raelnes des arbres. On les dćehaussera après l'équinoxe d'automne, et s'ils sont sur une hautcur, on disposera dans la partic supérieure de cette éminence des tranchées qui serviront à conduire l'eau bourbeuse jusqu'à leur souche. Ensuite il faudra arracher chaque année tous.les seions qui vieunent au pied de ces arbres, et les fumer de trois en trois ans, ou les arroser de lie d'huile. En fumant un plant d'oliviers de la façon que j'ai proposce dans le seeond livre, on fera du bien par la même occasion aux grains qui y serout scmés; mais si on ne veut chereher que l'avantage des arbres qui y seront plantés, il faudra leur donner à chacun en automne six livres de crottes de ehovres, ou un modius de cendre, ou un congius de lie d'huile, afin que ces fumiers, s'ineorporant à la terre pendant l'hiver, maintiennent leurs racines dans un eertain degré de clialeur. II faut, quand ils se portent moins bien, les arroser de lie d'huile, paree que, s'il survient des vers ou d'autres animaux pendant l'hiver, cette liqueur les fera mourir. Il arrive encore souvent, tant dans les terrains sees que dans les terrains humides, que les arbies sont molestés par la mousse; auquel cas, si on ne les en délivre point a vec le fer, ils ne se ehargent ni de fruit, ni même de beaucoup de feuilles. Il faut aussi tailler un plant d'oliviers au bout d'un certain nombre d'années, car on ue doit pas oublier un aneien proverbe qui dit qu'en labourant un plant d'oliviers, on le prie de rapporter du fruit; qu'en le fumant on l'en supplie, mais qu'en le taillant on l'y eontraint. Il suffira néanmoins de le faire tous les huit ans, de peur de couper trop souvent

adfert. Sed id minime bis anno arari debet : et bidentihus alte cireunfodiri. Nam post solstitium eum terra xestibus liat, eurandum est, ne per rimas sol ad radices arborum penetret. Post requinoctium autumnale ita sunt arbores ablaqueandx, ut a superiore parte, si olea in clivo sit, incilia exeitentır, qua limosam aquam ad codicem deducant. Omnis deinde soboles, qua ex ino stirpe nata est, quotannis extirpanda est, ac tertio quoque fimo pabulandx sunt olex. Atque eadem ratione stercorabitur oliretum, quam in seeundo libro proposui, si tamen segetibus prospicietur. At si ipsis tantummodo arboribus, satis facient singnlis stercoris caprini sex libra, (vel) stercoris sicci modii singuli, rel anurca insulsæe congius (sufficient). Stercus autumno debet injici, ut permistum liene rarlices olea calefaciat. Amurca minus valentibus infunilenda est. Nam per liemem, si vermes atque alia sulerint animalia, hoc medicamento necantur. Plernuque etiann locis siecis et lumidis arbores museo infestantur. Quem nisi lerramento raseris, nec fruetum nec latam frondem olen induet. Quin etian eompluribus interpositis anuis olivetum putandum est : nam veteris proverbii meuninisse convenit, eum qui aret olivetum, rosare fructum; les branches à fruit II arrive encore sonvent que ces arbres, quoique très-touffus, ne rapportent. aucun fruit. Il faut alors les percer avec une tarière gauloise, et faire passer par le trou qu'on y aura fait une bouture verte d'olivier sauvage : moyennant quoi l'arbre étant comme initié à une semence fécondc deviendra plus fertile. Mais il faut aussi quelquefois le pousser, en lui donnant, sans le déehausser, de la lie d'huile dans laqquelle il n'entre point de sel, avee de vieille urine de porc ou d'homme, l'une et l'autre dans une eertaine quantité proportionnce à sa grandeur; ear il n'en faudra qu'une urne pour les plus grands arbres, à moins qu'on n'y ajoute de l'cau à dose égale. Quelquefois aussi c'est le viee du terrain qui empéche les oliviers de donner du fruit. Voiei comment on y remédiera : on les déeliaus. sera cn creusant à lcur pied des lacs bien proforids; ensuite on y versera de la chaux en plus ou moins grande quantité, suivant la grandeur de l'arbre, de façon néanmoins qu'il cn faudia toujours un modius pour les plus petits. Si ce remède n'y fait rien, on aura recours en dernière ressource à la greffe. Or nous dirons par la suite eomment on doit s'y prendre pour greffer l'olivier. Il arrive aussi quelquefois qu'il se trouve dans l'olivier une branche un peu plus belle que les autres, auquel cas l'arbre tout entier tourne a mal, si on ne la coupe point. Ce que nous avons dit jusqu'iei sur les plants d'oliviers est suffisant. Restent les arbres fruitiers, sur lesquels nons allons donner des préceptes.

$X$. A vant de déposer en terre les semences de vos arbres fruitiers, il faut entourer soit de murailles ou de haies, soit d'un fossé esearpé, l'emplaeement que vous destinez à votre verger, pour en interdire l'entrée non-seulcment aux bestiaux,

qui stercoret, exorare; qui cxdat, cogere. Quod tamen satis erit oetavo anno feeisse, ne frnetnarii rami suhinls: amputentur. Solent etian quamvis lata arbores fructum non afferre. Eas terebrari gallica terebra convenit, at/juu? ita in foramen viridem taleam oleastri arcte immitti. sic velnt inita arbor foccundo semine fertilior extat. Sed sic lıæe ablaqneatione adjuvanda est infusa amurca insulsa enm suilla vel nostra urina vetere, cujus utriusque modus servatur. Nam maximx arbori, ut taulundein aq̣ıxe misceatur, urna abunde erit. Solent etiam vitio soli fiuc. tum olea uegare. Cui rei sie medebimur. Altis gyris abla. queabimus eas, deinde calcis pro magnitudine arboris plus minusve cireumdabimus : sed minima arbor modium po. stulat. Hoe remedio si nihil fuerit effectum, ad prosidliu!n insitionis confugiendum erit. Qnemadmodum antem ole:a inserenda sit, postmodo dicemus. Non nunquam eliam in olea; unus ramus cæeteris aliquanto est letior. Quem nisi recideris, tota arbor contristabitur. Ac de olivetis lax:tenus dixisse satis est. Superest ratio pomiferarmu arlonrum, eui rei deinceps procepta labimus.

X. Modum pomarii, priusquam senina seras circum. munire maccriis oportel vel sepe vel fossa praceipiti, $\mathrm{Lt}$ 
mais même aux hommes, parce que si les cimes des plantes se trouvaient souvent touehées par les hommes ou rongées par les bestiaux, elles ne pourraient plus jamais prendre d'aceroissement. Il est bon d'arranger les arbres par elasses, et cela pour plusieurs raisons, mais surtout afin que les plus faibles ne soient pas opprimés par les plus forts; d'autant que tous les arbres ne sont pas égaux entre eux, ni du eôté de la force, ni du côté de la stature; et qu'ils grandissent dans des intervalles de temps différents les uns des autres. La terre qui est eonvenable aux vignes l'est ègalement aux arbres. Faites des fosses un an avant de les planter : moyennant cela le terrain se ramollira au soleil et à la pluie, et ce que vous y mettrez viendra plus tôt. Mais si vous voulez faire vos fosses la mème annéc que vous planterez vos arbres, faites-les au moins deux mois d'avance; ensuite échauffezles en y brûlant de la paille : plus vous les ferez larges et ouvertes, plus les fruits que vous recueillerez seront beaux et abondants. On fera ees fosses semblables à des fours, dont le fond est plus ouvert que la gueule, tant afin que les raeines trouvent plus d'espace pour s'étendre, et que l'ouverture étant ètroite, le froid et le ehaud y pénètrent moins en hiver ou en été, quałin que la terre dont on les aura comblées ne soit point cntrainée par les pluies, si le terrain va en pente. Éloignez les arbres les uns des autres en les plantant, afin que lorsqu'ils seront grandis, ils trouvent un espace suffisant pour étendre leurs branches. En effet, si vous les plantez trop près les uns des autres, vous ne pourrez rien semer par-dessous, et ils ne produiront pas beaucoup de fruits, à moins que vous n'en arrachiez quel-

1. on solum pecori, sed et homini transitum negare valeat; quoniam si sxpius cacumina manu profracta aut a pecoribus prorosa sunt, in perpetuum semina incremen. tum capere nequeunt. Generatim autem disponere arbores utile est, maxime ne etiam imbecilla a ralentiore prema. tur, quia nec viribns nec magnitudine par est, imparique spatio temporis adolescit. Terra, qua vitibus apta est, etiam arboribus est utilis. Ante annum, quem seminare voles, scrobem fudito. Ita sole pluviisve macerabitur, et quod positum est, cito compreliendet. At si eodem anno et scrobem facere, et arbores serere voles, mininium ante duos menses scrobes fodito, postea stramentis incensis calefacito : quos si latiores patentioresque feceris, latio. res uberioresque fructus percipies. Sed scrobis clibano similis sit, imus summo patentior, ut laxius radices vagentur, ac minus frigoris hieme, minusque astate vaporis per angustum os penetret, etiain ul clivosis locis terra, quae in eum congesta est, a pluviis non alsluatur. Arbores raris intervallis serito, nt cum creveriut, spatium habeant, quo ramos extendant. Nam si spisse posueris, nec infra serere quid poteris, nec ipsæ fructuos $x$ erunt, nisi iutervulseris : itaque inter ordines quadragenos pedes miniunumque tricenos relinquere convenit. Semina lege crassa non uninus quam manubrium bidentis, recta, levia, ques-uns par-ci par-lá : ćest pourquoi il faut laisser quarante pieds d'intervalle, ou au moins trente, entre les rangées. Choisissez du plant dont la grosseur ne soit pas moindre que celle d'un manehe de hoyau qui soit droit, haut, sans uleères, et dont l'écorce soit entière : avec ces qualités il prendra bien et sous peu de temps. En prenant ces branches sur les arbres, ayez soin de choisir celles qui sont le plus exposées au soleil. Avant de transplanter de petits arbres, remarquez à quels vents ils étaient exposés auparavant, et ne les déplantez que pour les transférer d'un lieu élevé et see dans un teriain liu. mide : ayez surtout soin qu'ils aient trois eornes et au moins trois pieds de hauteur. Si vous voulez mettre deux ou trois petits arbres dans la même fosse, prencz garde qu'ils ne se touchent entre eux, parce que s'ils se touchaient, il est eonstant qu'ils pourriraient, ou que les vers les feraient mourir. Lorsque vous mettrez vos plantes en terre, enfoncez de droite et de gauche jusqu'au fond de la fosse des poignées de sarment de la grosseur du bras, de faẹon qu'elles en débordent un peu le niveau : eette préeaution vous donnera la faeilité de faire parvenir l'eau en été jusqu'à leurs raeines. Vous mettrez en terre la graine des arbres ainsi que le plant garni de racines en automne, c'est-à-dire vers les ealendes et les ides d'oetobre : pour les autres natures de plant, vous les y mettrez au commencement du printemps, avant que la pousse commence. Pour empêcher que les tei. gnes n'ineommodent les plants de figuiers, vous mettrez, au fond des fosses où seront ees arbres, une bouture de lentisque, la cime renversée. Ne plantez pas le figuier quand il fait froid : il

procera, sine ulceribus, integro libro. Ea bene, et ccleriter compreliendent. Si ex arboribus ramos sumes, de is quxe quotannis bonos et uberes fructus afferunt, cligito ab hnmeris qui sunt contra solem [orientem. Si cum radicu plantam posueris incrementum citius fnerit quam cateris quas severis. Arbor insita fructuosior est quam quæ insita non est, id est, quam] quæ ramis aut plantis ponetur. Sed ante quam arbusculas transferas, nota, quibus ventis antea fuerant constituta, postea manus adnoveto, ut de clivo et sicco in humidum agrum transferas. Trifurcam maxine ponito. Ea extet minime tribus pedibus. Si eodem scrobe duas aut tres arbusculas voles constituere, curato, ne iuter seso contingant : quoniam mutuo contactu aut computrescent, aut vermibus interibunt. Cum semina depones, dextera si. nistraque usque in imuın scrobem fasciculos sarmentorıın brachii crassitudinis demittito, ita ut supra terram paulum extent, per quos æestate parvo labore aquan radicibus sul. ministrare possis. Arbores ac semina cum radicibus autumno serito, hoc est circa calendas et idus Octob. Primo vere antequam germinent arbores, deponito : ac ne tinea molesta sit seminibus ficulneis, in imum scrobem leutisci talean in verso cacumine demittito. Ficum frigoribus ne serito. I.oca aprica, calculosa, glareosa, interdum et saxeta aunat. ljusmodi aı bor cito convalescit, si scrobes amplos pateu. 
aime les licux exposés au soleil, pleins do cailloux ou de gravier, et même quelquefois de roehers; et il grandit promptement, si on lui fait des fosses grandes et larges. Les figuiers de toutes les espèces, quoique différents entre eux par le goût de leurs fruits et par l'aspeet qu'ils présentent à l'ocil, se plantent d'une seule et même faẹon; mais on a égard à la variété des terrains, en ee que, lorsque lc terrain est froid en automnc et aqueux, on y met des figues hâtives, afin d'en reeueillir le fruit avant les pluies, et que, lorsqu'il est chaud, on y met des figues d'hiver. Mais si vous voulez rendre un figuier tardif, quoiqu'il ne le soit pas de sa nature, arrachez-en les petites figues qu'il donnera les premières, a vant qu'elles soient mûres; après quoi il en reviendra d'autres qui se conserveront sur l'arbre jusqu'à l'hiver. Il est encore souvent utile de couper le bout des cimes du figuier lorsqu'il commence àdonner des feuilles; c'est le moyen de rendre l'arbre plus fort et plus fertile. II scra aussi toujours à propos, dès que les figuiers auront eommencé à se couvrir de feuilles, de détremper de la terre rouge dans de la lie d'huile, et de répandre cette eomposition sur leurs racines avee des excréments humains. Cette opération augmente l'abondance du fruit, et fait qu'il est plus plein et que sa chair est meilleure. Il faut surtout a voir des figuiers de Livie, d'Afrique, de Chalcidie, des figuiers sulca, des figuiers de Lydie, des figuiers callistruthice, des figuiers topia, des figuiers de Rhodes et de libye, et des figuiers d'hiver, ainsi que de tous eeux qui promettent de donner du fruit deux. ou trois fois par an. Plantez vers les calendes de février l'amandier, qui bourgeonne avant tout autre arbre : il veut une terre dure, chaude et sèche, puisque, si vous lc mettez dans des terrains d'une autre qua-

tesque feceris. Ficorum genera, etsi sapore atque habitu distant, uno modo, sed pro differentia agri seruntur. Locis frigidis, et autumni ten poribus aquosis præcoques ponito, ut ante plıviam fructum deligas : locis caliclis hibernas serito. At si voles ficım quamvis non natıra seramı facere, tum grossulos, prioremve fructum decutito, ita alterum edet, quem in hiemem differet. Non nunquam cliam, cum frondere coperunt arbores, cacumina fici ferro summa prodest amputare : sic firmiores arbores et feraciores fiunt; ac semper conveniet, simulatque folia agère copperit ficus, rubricam amurca diluere, et cum stercore lumano ad radicem infundere. Ea res efficit uberiorem fructum, et farctum fici pleniorem ac meliorem. Serenda sunt autem pracipue Livianx, Africanæ, Chalcidicx, sulca, Lydix, callistrutlia, topix, Rlıodix, Libycx, liberuß, omnes etiam bifera et trifera flosculi. Nucem Graccam serito circa cal. Febr. quia prima genmascit : agrum durun, calidum, siccum desiderat. Nam in locis diversis nucem si deposueris, plerumque putrescit. Antequam nucem deponas, in aqua mulsa nec nimis dulci macerato. Ita jucundioris saporis fructum, cum adoleve- lité, il pourrit très-communément. A vant de semer l'amaudo, il faut la faire tremper dans de l'eau mélée de miel, qui ne soit pas trop douce : moyennant eela, lorsque l'arbre sera grand, il donnera du fruit de meilleur goût, et en attendantil se couvrira micux de feuilles et plus promptement. Yous mettrez trois amandes en triangle, de façon qu'elles soient éloignées l'une de l'autre d'un palmus tout au moins, et que celle qui forme le sommet du triangle soit tournéc au point du ciel d'où souffle le vent Favonius. Chacune des trois ne donnera qu'une seule racine et une seule tige; mais lorsque ehacune de ees racines aura gagné le fond de la fosse, la dureté de la terre veuant à s'opposer à son passage la fera recourber, et pour lors elle jettera d'autres racines nombrcuses, qui sembleront former autant de branches. Voiei la faeson dont vous pourrez faire des amandes et des avelines de Tarente. Vous mettrez dans la fosse que vous leur destinerez de la terre bien pulvériséc à la hauteur d'un demi-pied, et vous y sèmerez de la graine de férule. Lorsque cette graine sera venue, vous eacherez une amande ou une aveline dépouillée de son éeoree dans la moelle de la férule, que vous aurez fendue en deux à eet effet, et vous les mettrez ainsi en terre. Vous ferez cette opération avant les ealendes de mars, ou même entre les nones et les ides de ee mois. Il faut semer dans le même temps les noix, les pignons et les châtaignes. Il est à propos de planter le grenadier depuis le temps que nous vemons d'indiquer jusqu'aux calendes d'avril. Si son fruit est aigre ou peu doux, voiei eomme on le eorrigera : on répandra sur ses racines de la fiente de pore, des exeréments humains et de vieille urinc. Cette préeaution, en rendant l'arbre fertile, fera que son fruit sera vineux les premières années, et doux

rit, præbebit, et interim mclius atçue celerius frondebil. Ternas nuces in trigonun statuito, ut nux a nuce minine palmo absit, et anceps ad Favonium spectet. Omnis auten nux unam radicem mittit, et simplici stilo prorepit. Cum ad scrobis solum radix pervenit, duritia lumi coercita recurvatur, et ex se in modum ramorum alias radices emittit. Nucem Grecam ct Avellanam Tarentinam facere hoc modo poteris. In quo scrobe destinaveris nuces serere, in en terram minutan pro morlo semipedis ponito, ilsique semen ferula repangito. Cum ferula fuerit enata, eam findito, et in medulla ejus sine putamine nucem Gracan aut $\mathbf{A}$ vellanam abscondito, et ita adobruito. Hoc ante calend. Martias facito, vel etiam inter nonas et idus Mart. Eodem tempore juglandem et pineam et castaneam screre oportet. Malum Punicum ab eodem tempore usque in cal. Aprilis recte seritur. Quod si acidum aut minus dulcem fructum feret, loc modo emendabitur. Stercore suillo et liumano urinaque retere radices rigato. Ea res ef fertilem arborem reddet, et primis annis fructum vinosum, [et] post quinquennium dulcem, et apyrenum facit. Nos exiguum admodum laseris vino dilnimus, et ita cacumin? 
au bout de cinc] ans, ct que les gritins n'en seront point durs. Pour nous, nons nous sommes avisé de délayer tant soit peu de laser dans du vin, et d'en frotter le bout des eimes de ees arbres, et nous avons corrigé par là l'aigreur de leur fruit. On empiche les grenades de se fendre sur l'arlre, en enterrant trois pierres auprès de sa racine lorsqu'on le plante. Mais si l'arbre est déjà tont planté quand on s'apercoit de ce défaut, oll sème de la scille auprès de sa racinc. Lorsque les grenades d'un arbre sujet à ce vice sont déjà mûres, on emploie une autre méthode, qui consiste à tordre, avant qu'elles se crèrent, la queue par laquelle elles pendent à l'arbre On se sert aussi du même moyen pour les garder toute l'année sans qu'elles se gâtent. On plante les poiriers en automne avant le solstice d'hiver, de faęon qu'il y ait au moins vingt-einq jours d'interstice entre leur plantation et le solstice. Pour les rendre fertiles, il faut, lorsqu'ils sont grandis, les déehausser profondément, en fendre le trone près de la racine même, et insérer dans cette fente un eoin fait de bois gommeux de pin, qu'on y laissera : ensuite, lorsqu'on aura reehaussé l'arbre, on répandra de la eendre sur la terre. II faudra avoir soin de planter dans les vergers les poires de la mcilleure espèce, $e^{\prime}$ 'est- $\mathbf{a}-$ dire, celles de Crustumium, les poires royales, eelles de Signia, eelles de Tarente, eelles que l'on appelle poires de Syrie, les pourprées, les orgueilleuses, les ordeacea, les Aniciennes, les Nicviance, eelles de Favonius, celles de Lateran, eelles de Dolabella, celles de Turannius, la grosse poire, la poire micllée, la poire hâtive, eelle de Vénus, et d'autres encore, dont il scrait trop long de faire ici l'énumération. En outre, il faut, entre les différentes espèees de pommes, s'attacher prineipalement à la pomme

arboris summa oblevimus. Ea res emendavit acorem ma. horun. Mala Punica ne in arbore lient, remedio sunt lapilles tres, si, cum seres arboren, ad radicem ipsan collocuveris. At si jam arborem satam labueris, scillam secundum radicem arboris serito. Alio modo, cum jan nıatura mala fuerint, antequam rumpantur, ramulos, quibus dependent, intorqueto. Eoden modo servabuntur iicorrupta etian toto anno. Pyrum autumno ante brumam serito, ita ut minime dies xxv all brumam supersint. Qua ut sit ferax, cum adoleverit, alte eam ablaqueato, et juxta ipsam radicem truncun findilo, et in fissuram cnneun tedie pincex adigito, et ibi relinquito : deinde adobruta abliqueatione cinerem supra terram injicito. Curanduın est autem, ut quam generosissimis pyris pomaria conseramus. Ea sınt Crustumina', regia, Signina, Tarentiıa, quas Sỵria dicuntur, purpurea, superha, ordeaces, Aniriana, Nisviana, Favoniana, lateritana, Dolabelliana, Turra. niana, volema, mulsa, prococia, venerea, et quæedanı alia , ouorum enumeratio nunc longa est. Prseterea malorum geuera exçuirenda maxime Scandiana, Matiana, orbiculata, Sextiana, Pelusiana, Anerina, Syrica, melimela, cydenia : COLIEItI.I.L. de Seandius, à celle de Matius, à la pomme ronde, à celle de Sextius, à celle de Pelusium, à celle d'Améria, à la pomme rouge, à la pomme de micl, aux coiligs, qui sunt de trois espèces, savoir, les poires-coings, les coings d'or, et ceux qui mûrissent promptement : tous fruits nonseulement bons au gout, mais encore très-salutaires. Les cormes d'Arménie et de Perse sont aussi en grande faveur. On plante les pommicrs, les cormiers et les prunicrs depuis le temps où la moisson est à moitié faite, jusquaux ides de février. On plante les mûriers depuis les ides de février, jusqu'à l'équinoxe du printemps. Plantez le carrougier, que quelques personnes appellent xspátıov, ainsi que le pêeher, pendant l'automne, avant le solstice d'hiver. Si l'amandier est peu fertile, persez-en le trone, et enfoneez-y une pierre que vous laisserez se recouvrir de son écorce. Il faut, après avoir labouré et fumé la terre daus les jardins vers les calendes de mars, arranger des boutures de toutes les espèces d'arbres sur des eouches faites en planches. Il faut aussi prendre le soin, quand les plantes eommencent à avoir de jeunes branches, de les épamprer, pour ainsi dire, et de les réduire ì une seule tige la première année. Il faut encore, lorsque l'automne approche, et avant que le froid brûle leurs cimes, en arracher toutes les feuilles, et, après qu'elles seront ainsi dépouillées, les eouvrir avec des roseaux épais auxquels on aura laissé d'un cóté leur nœud, afin qu'il serve comme de chapeau à ees jeunes tiges, et qu'il les défende par conséquent du froid et de la gelée. Deux ans après, vous pourrez en toute sûreté les transférer et les établir dans des rangées, ou les greffer, sclon ce que vous voudrez en fairc.

XI. On peut greffer tel rejeton que l'on veut sur quelque arbre que ee soit, pourvu que l'écoree do

quorum genera tria sunt, struthia, clırysomelina, mustea. Qux omnia non solum voluptatem, sed etiam salubritatem afferunt. Sorbi quoque et Armeniaci atque Persici nou nuinima est gratia. Et mala, sorba, pruna, post median lieinem usque in idus Feb. serito. Mororum ab idib. Feb. usque ad aquinoctiun vernmm satio est. Siliquan Gracam, quam quidan xefárıov vocant, et P'ersicun ante brumam per autumnum serito. Anygdala, si parum ferax erit, forata arbore lapidem adigito, et ita lilırum arboris inolescere sinito. Omnium autem generum ranıs circa cal. Martias in hortis subacta et stercorata terra supra pulvinos arearum disponere convenit. Danda est opera, ut dum teneros ramulos liabent, veluti panipinentur, et ad unum stilum primo anno semina redigantur. Et cum autumnus incesserit, ante quam frigus cacumina adurat, omnia folia decerpere expedit, et ita crassis arundinibus, qua ab una parte nolos integros habeant, velut pileis induere, atque sic a frigore et gelicidiis teneras adlutc vir. gas tueri. Post viginti quatuor dejnde menses sire trans. ferre et disponere in ordineın voles, sive inserere, satis tuto utrumque facere poteris. 
la greffe ne soit pas différente de eeile de l'arbre sur lequel on la greffe : on peut greffer admirablement et sans serupule une greffe prise sur un arbre qui produit des fruits pareils à celui que l'on greffe, et qui les produit dans le même temps. Les anciens ont fait mention de trois espèces de greffe : l'une par laquelle l'arbre, étant coupé et fenclu, admet dans l'intérieur de son corps des scions eoupés sur un autre arbre; la seconde, par laquelle l'arbre que l'on greffe reçoit une crite coupée sur un autre arbre entre son écorec et son bois : ees deux sortes de greffes se font dans le printemps. La troisième est celle par laquelle l'arbre à greffer reçoit des boutons mêmes avce un peu d'ćcorce, sur une partie de son corps qu'on a écorcéc : c'est ee que quelques agrieulteurs appellent cinplastratio (grelfe cu éeusson), ct d'autres inoculatio (greffe par gemmes); cette dernière facon peut ĉtre employée à propos en été. Après a voil donné la manière de mettre ees greffes en usage, nous donnerons aussi une autre méthode que nous avons trouvée nous-même. 11 faut greffer tous les arbres dès qu'ils auront commencé à montrer des boutons, et dans le temps que la lune sera dans son croissant; mais il faut greffer l'olivier vers l'équinoxe du printemps jusqu'aux ides d'avril. Prenez garde que l'arbre sur lequel vous roudrez prendre des grefies, pour en enter d'autres, soit jeune et fertile, et qu'il ait beaucoup de nœuds. Lorsque ses boutons eommencerout à grossir, prenez vos greffes, épaisses d'un petit doigt et garnies de deux ou trois colnes, sur de petites branches d'un an, qui soient sur le côté de l'arbre tourné au lever du soleil ct 'bien intactes. Coupez, non sans précaution, avee une scie, l'arbre que vous voudrez greffer, à l'endroit où il est le plus brillant et sans cieatrice, ct faites en sorte de ne point endommager son écoree. Lorsqu'il sera eoupé, ragréez la plaie avec un instrument de fer bien tranehant; enfoneez ensuitc un eoin de fer ou d'os bien aiguisé entre l'écorce et le bois, au moins jusqu'à trois doigts, mais avee beaueoup de précaution, pour ne pas endommager ou rompre l'écorce. Ensuite ratissez d'un seul côté, avec une serpette bien tranchante, les greffes que vous voulez enter, sur une longueur égale à celle de l'ouverture formće par le coill fiché dans l'arbre, et de façon que vous n'endommagiez pas la mocllede ces greffesni leur écoree, du eôté que vous ne les aurez point ratissées. Quand vos greffes seront préparćes, vous arracherez le coin, et vous les enfoncerez sur-lechamp dans l'ouverture que vous aurez faite sur l'arbre par l'introduction du coin entre son écorce et son bois. Insérez-les par le eôté que vous aurez ratissó, de faeon qu'elles débordent l'arbre au moins d'un demi-pied en dehors. Vous ferez bien d'insérer dans le même arbre deux greffes a la fois ou un plus grand nombre, si son trone est plus gros, en laissant un intervalle de quatre doigts entre chacune. Il faudra vous régler pour cela sur la grandeur de l'arbre et sur la bonté de son écorce. Lorsque vous aurez introduit dans un arbre toutes les greffes qu'il pourra recevoil, vous les lierez soit avee de l'écoree d'ormes, soit avee du jone ou de l'osier : après quoi vous cnduirez avec un lut mêlé de paille', que vous aurez bien pétri, toute la plaie ainsi que l'intervalle qui est entre les greffes, de façon pourtant qu'il leur reste au moins quatre doigts entiers de déeouverts : vous mettrez ensuite pardessus de la mousse, que vous attacherez de façon que la pluie ne puisse pas les pénétrer. Il y a cependant des personnes qui aiment mieux faire une
XI. Omnis surculus omni arbori inseri potest, si non ost ei, cui inseritur, cortice dissimilis. Si vero etian similem fructum et eodem tempore affert, sine scrupulo sgregie inseritur. Tria genera porro insitionun antiqui tra. diderunt. Unum, quo resecta et fissa arbor resectos surculos accipit. Alterum, quo resecta inter librum et mate. riam semina admittit. Quse intraque genera verni temporis sunt. Terlium, quo ipsas gemınas cum exiguo cortice in partem sui delibratam recipit, qtiam rocant agricola: emplastrationem; vel, ut quidam, inoculationem. Hoc genus insitionis æs tivo tempore optime usurpatur. Quarum insitionum rationem cum tradiderimus, a nobis repertam quoque docebimus. Omnes arbores simalatque genmas agere coperint, luna crescente inserito; olivam autem circa acquinoctium rernum usque in idus Aprilis. Ex qua arbore inserere voles, et surculos ad insitionem sumpturus ('s, videto ut sit tenera et ferax nodisque crebris : et cum prinum gernina tumebunt, de ramulis anniculis, qui solis ortum spectabunt, et integri erunt, eos legito crassitudine digiti minimi. Surculi sint bifurci vel trifurci. Arborem, quam inserere voles, serra diligenter exsecato ca parte, qua maxime nitida el sine cicatrice est; dabis- que operam; ne librum lædas. Cum deinde truncum recideris, aculo ferramento plagam levato. Deinde quasi cuncum tenuem ferreum vel osseum inter corticem et materiem ne minus digitos tres, sed considerate, demittito, ne laedas aut rumpas corticem. Postea surculos, quos inserere voles, falce acuta ex ima parte deradito tantum, quantum cuneus demissus spatii dalit, atque ita, ne medullas neve alteriıs partis corticem ladas. Ubi sur. culos paratos habueris, cuneum vellito, statimque surculos in ea foramina, qua cuneo adacto inter corticem et materlam feceris, demittito. Ea autem fine, qua adraseris, surculos sic inserito, ut semipede vel amplius de arbore extent. In una arbore duos, vel si truncus vastior est, plures calamos recte inseres, dum ne minus quatuor digitorum inter eos sit spatium. Pro arboris magnitudine et corticis bonitate hace facito. Cum omnes surculos, quos arbor ea patietur, demiseris, libro ulmi vel junco ant vimine arborem constringito : postea paleato luto bene subacto oblinito totam plagam, et spatiım, quod est in. ter surculos, usque eo dum minime quatuor digitis insita extent. Supra deinde muscum imponito, et ita ligato, ne pluvia dilabatur. Quosdan tamen nagis delectat in trunco 
ouverture avee.la scie sur le trone de l'arbre, pour y introluire les greffes, et qui ragréent avee un bistouri bien aiguisé la partie qu'ils ont ainsi sciéc, pour y ajuster ensuite les greffes. Si vous voulez greffer un petit arbre, coupez-le par en bas, de façon qu'il n'en reste qu'un pied et demi sur terre; après l'avoir coupé, ragréez la plaie avec soin, et fendez très-légèrement le tronc par son milieu avec un bistouri bien tranchant, de facon que la fente n'ait que trois doigts de longueur : ensuite insérez un coin dans cette fente pour en écarter les lèvres, et enfoncez-y des greffes ratissées des deux côtés, de façon que leur écorce soit au niveau de celle de l'arbre. Lorsque vous aurez ajusté ces greffes avec soin, vous retirerez le coin, et vous lierez l'arbre, comme j'ai dit ci-dessus; ensuite vous entasserez de la terre autour de lui jusqu'à la greffe : cela contribuera à la défendre parfaitement contre les vents et la chaleur. La troisième espèce de greffe dont je vais parler, étant très-délicate, ne va pas à toute sorte d'arbres; et il n'y a guère que ceux dont l'écorce est humide, pleine de séve et forte, tels que les figuiers, qui s'cn accommodent. En effet, ces arbres rendant beaucoup de lait, et ayant l'écorce forte, on peut très-bien les grefler de la manière suivante. On choisit sur l'arbre dont on veut tirer la greffe de jeunes branches qui soient bien unies, et on y remarque le bouton le plus apparent, et qui promet le plus sûrement de germer. On trace autour de ce bouton une marque de deux doigts en carré, de facon que le bouton ćtant au centre de ce carré, on coupe l'écorce tout autour de lui avec un bistouri bien tranchant, et on l'enlève avcc attention de dessus l'arbre, en prenant garde de l'endommager. On choisit ensuite pareillement une branche très-

arboris locum seminibus serra facere, insectasque partes lenui scalpello levare, atque ita surculos aptare. Si pusil. lam arborem inserere voles, imam ahscindito, ita ut sesquipede e terra extet. Cum deinde pracideris, plagain diligenter levato : et r.edium truncum acuto scalpello permodice findito, ita ut fissura digitorum trium sit in ea. Deinde cuneum, quo diducatur, inserito, et surculos ex utraque parte derasos denittito, sic ut librum seminis libro arboris æequaleın facias. Cum surculos diligenter aptiveris, cuneum exinito, et arborem, ut supra dixi, alligato: deinde terram circa arborem adaggerato usque ad ipsum insitum. Ea res a vento et calore maxime tuebitur. Nos tertium genus insitionis invenimus, quod cum sit subtilissimum, non omni generi arlorum idoneum est, sed fere recipiunt talem insitionem, quæ humidum succosunıque et validın librum lıahent, sicut ficus. Nam et lactis plurimum mittit, et corticem robustum habet. 0 p. time itaque inseritur caprifici ramus. Ex arbore, de qua inserere roles, novellos et nitidos ranos eligito, in iisdem. que observato genmam, qux bene apparelsit, certamque spem germinis habebit : can duobus digitis quadratis cir. cumsignato, u1 gemma media sit : et ita acuto scalpello lisse de l'autre arbre cue l'on doit enter en écusson, et on la dépouille en lui coupant un moreeau d'écoree de même grandeur que le premier; après quoi on applique l'ćcusson qu'on arait préparé sur cette partie dépouillée, de façon qu'il y réponde exactement. Quand cela est fait, on lic bicn le tout autour du bouton, cn prenant garde de l'offenser Iui-même. Ensuite on enduit d'un lut les joints et les ligatures, en laissant un intervalle jusqu'au bouton, afin qu'il soit en liberté, et qu'il ne soit pas pressé par la ligature. On rogne les rejetons du pied de l'arbre greffé, ainsi queses branches supérieures, pour qu'il n'y reste rien qui puisse en attirer à soì la séve, et qu'il n'ait pas d'autres parties à nourrir préférablement à la greffe, et au bout de vingt et un jours on délie l'écusson : on greffe aussi parfaitement l'olivier de cette façon. Nous avous déjà montré la quatrième façon de greffer, lorsque nous avons traité des vignes : e'est pourquoi il est inutile de répéter ici la méthode que nous avons donnéc alors, et qui consiste à percer l'arbre avee une tarière. Mais comme les anciens ont prétendu qu'on ne pouvait pas enter toute sorte de scions sur toute sorte d'arbres, et qu'ils ont donnc, comme une loi iivariable, le terme que nous avons fixé nous-nême tout à l'heurc, en disant qu'il n'y avait pas d'autres entes qui pussent réussir sur un arbre, que celles qui étaient prises sur un arbre semblable au premier, tant par son écorce extérieure et intérieure que par son fruit; nous avons cru qu'il fallait dissiper l'erreur qui suit de cette opinion, et donner a la postérité un moyen d'enter telle espèce de greffe que l'on voudra, sur quelque arbre que ce soit. Mais pour épalgner au lecteur tout préambule, nous allons donner un exemple d'après lequel on pourra enter

circumcidito delibraloque diligenter, ne genımam ladas. Postea item alterius arboris, quam emplastraturus es, nitidissimum ranım eligito, el ejusdem spatii corticem circumcidito, et materiam delibrato. Deinde in ean partem, quam nudaveris, praparatum emplastrum aplato, ita ut alteræ delibratæ parti conveniat. Ubi ita lıec feceris, circa gemmam bene alligato, caretocque ne lædas ipsum germen. Deinde commissuras et vincula luto ollinito, spatio relicto, ut gemma libera vinculo non urgeatur. Arboris autem insitx sobolem et ramos superiores pracidito, ue quid sit, quo possit succus evocari, aut ne cui magis quam insito serviat. Post xxı diem solvito emplastrum. $\mathbf{F}$. loc genere optime etiam olea inserilur. Quartum illuil genus insitionis jam docnimus, cum de vitibus disputavimus. Itaque supervacuum est lioc loco repetere traditam rationem terebrationis. Sed cum antiqui negarerint josse omne genus surculorum in omnem arborem inseri, et illam quasi finitionem, qua nos paulo ante usi sunus, veluti quandam legem sanxerint, cos tantum surculos posse coalescere, qui sint cortice ac libro et fruclü consi. miles is arboribus, quibus inseruntur; existinavimus errorem bujus opinionis discutiendum, tradendanuy 
telle espèce de greffe que l'on voudra sur toute sorte d'arbres. On creusera d'abord une fosse de quatre pieds en tous sens auprès d'un olivier, à telle distanee que les branches les plus allongées de cet arbre y puissent atteindre. Ensuite on déposera dans cette fosse un petit figuier, er faisant attention à ce qu'il scit fort et brillant. Trois ans après, lorsque ce figuier aura déjà pris assez d'ac. croissement, on abaissera la branche d'olivier qui paraitra la plus brillante, et on l'attachera au pied du figuier; après quoi on coupera les autres petites branches qui dépendent de celle-là, en ne lui laissant que les eimes que l'on voudra em. ployer comme greffes. Ensuite on coupera le figuicr, on ragréera la plaie, et on le fendra par le milieu avec un coin, puis on ratissera des deux côtés les cimes de l'olivier, sans les déranger de la position dans laquelle elles tiennent à leur mère, après quoi on les insérera dans la fente du figuier; puis on retirera le coin, et on liera avec soin ces cimes, de façon qu'aucune force ne soit capable de les arracher. Moyennant cela le figuier se fortifiera avec l'olivier en trois ans, et ce ne sera que la quatrième année, et lorsqu'ils seront bien mariés ensemble, que l'on sèvrera les branehes de l'olivier, comme on sèvre les provins : on peut enter de cette façon telle greffe que l'on voudra sur quelque arbre que ce soit. Mais comme nous avons parlé à peu près de toutes les espèces d'arbrisseaux dans les livres préeédents, il est temps, avant de finir celui-ci, de parler du cytise.

XII. Il sera très-important d'avoir dans sa terre la plus grande quantité de cytises que l'on pourra, paree que cet arbrisseau est très-utile aux poules, aux abeilles, aux brebis et aux chè-

posteris rationem, qua possit omne genus surculi omni generi arboris inseri. Quod ne longiore exordio legentem fatigemus, unum quasi exemplum subjiciemus, quo possit onme genus surculi omnibus arboribus inseri. Scroben (juofiuoversus pedum quatuor ab arbore oliva tam longe fodito, ut extreni rami-olex possint eam contingere. In scrobem deinde fici arlusculam deponito, diligentiamque adlibeto, ut robusta et nitida fiat. Post triennium, cum jam satis amplum incrementum ceperit, ramuın olivæ, qui videtur nitidissimus, deflecte, et ad crus arboris ficulneie religa : atque ita amputatis cateris ramulis, ea tantum cacumina, quis inserere voles, relinque; tum arborem tici setrunca, plagamque leva, et inediam cuneo finde. Ca. cumina dejnde o!iv $x$, sicuti malri colıærent, ex utraque parte adrade, et ita fissuræ fici insere, cuneumque exime, diligenterque raınulos colliga, ne qua vi revellantur. Sic iuterposito triennio coalescet ficus cum olea, et tum demum quarto anno, cum bene coierint, velut propagines, ramulos olivæ a matre resecabis. Hoc modo omne genus in omnem arborem inseres. At prius quam finem libri faciamus, quoniam fere species surculorum omnium perse. cuti sumus prioribus libris, de cytiso dicere nunc tempestivun est.

X11. Cytisum in agro esse quam plurinum maxime vres, ainsi qu'aux boufs ct d̀ toutes sortes de bestiaux, tant parce qu'il les engraisse en peu de temps, et qu'il donne beaucoup de lait aux brebis, que parce qu'on peut l'employer huit mois en fourrage vert, et, passé ce temps, en fourrage sec : d'ailleurs il prend très-promptement dans toutes sortes de terres, même dans les plus maigres, et rien de ce qui nuit aux autres plantes ne lui fait tort. Si les femmes même manquent de lait, il faut détremper dans l'eau du cytise sec; et lorsqu'il y aura passé toute la nuit, on en exprimera le suc le lendemain, et on leur en donnera trois hemince à boire, en le coupant avec un peu de vin : c'est le moyen qu'elles so portent bien, et que leurs enfants se fortifient par l'abondance du lait qu'elles seront en état de leur fournir. On peut planter le cytise ou en automne ver's les ides d'oetobre, ou au printemps. Lorsque l'on aura bien labouré la terre, on fora de petites planches, sur lesquelles on sèmera en automne la graine du cytise, comme on sème la dragée; ensuite on arrangera ces plantes au printemps, de facon qu'il $y$ ait entre chacune quatre pieds d'intervalle en tous sens. Si vous n'avez pas de graine, vous mettrez en terre an printemps des cimes de eytise, auprès desquelles vous entasserez de la terre que vous aurez fumée auparavant. S'il ne vient point de pluie, vous les arroserez les quinze premiersjours, vous les sarelerez dès qu'elles eommenceront à montrer les premières feuilles, et trois ans après vous les couperez pour les donner aux bestiaux. II suffit de quinze livres de cytise vert pour le cheval, et de vingt livres pour le bœuf : on en donne aux autres bestiaux à proportion de leurs forces. On peut aussi planter assez commodément le cytise en bouture sur les

refert, quod gallinis, apibus, ovibus, capris, bubus quoque et omni generi pecudum utilissimus est : quod ex eo cito pinguescit, et lactis plurimum probet ovibus, tum etiam quod octo mensibus viridi eo pabulo uti et postea arido possis. Præterea in quolibet agro quamvis macerrimo celeriter comprelıendit: omnem injuriam sine noxa patitur. Mulieres quidem si lactis inopia premuntur, cytisum aridum in aqua macerare oportet, et cum tota nocte per. maduerit, postero die expressi succi ternas heminas permiscere modico vino, atque ita potandum dare : sic et ipsa valebunt, et pueri abundantia lactis confirmabuntur. Satio autem cytisi vel autuınno circa idus Octobris, vel vere fieri potest. Cum terram bene subegeris, areolas facito, ibique velut ocimi semen cylisi autumno serito. Plantas deinde vere disponito: ita ut inter se quoquoversus quatuor pedum spatio distent. Si senıen non liabueris, cacumina cytisorum vere deponito, et stercoratam terram circumaggerato. Si pluvia non incesserit, rigato quindecim proximis diebus : simulatque novam frondem agere cope. rit, sarrito, et post triennium deinde cadito, et pecori pracbeto. Equo abunde est viridis pondo $\mathrm{xv}$, buhus pondo vicena, cæterisque pecoribus pro portione virium. Potest etian circa sepem agri satis commode ramis cytisus seri, quoniam facile compreliendit, et injuriam sustinet. Aridum 
lislères des ehamps, parce qu'il prend faeilement et que rien ne lui fait tort. Si vous le donnez see aux animaux, il faut le leur épargner plus que s'il était vert, parce qu'il a alors plus de vertu; il faut mème le faire tremper auparavant dans l'eau, et le mêler avec de la paille, après l'avoir retiré de l'eau. Quand vous voudrez faire séeher du eytise, coupez-le vers le mois de septembre, lorsque sa graine eommencera à grossir, et mettez-le au soleil pendant quelques heures jusqu'à ee qu'il se fane; faites-le ensuite séeher à l'ombre, ct serrez-le après. C'est avoir assez donné jusqu'iei de préceptes relatifs aux arbres; j'exposerai dans le volume suivant ec qui eoncerne l'entretien et les remèdes des bestiaux.

\section{LIVRE VI.}

\section{PRÉFACE.}

Je n'ignore pas, Publius Silvinus, que quelques savants agrieulteurs ont désapprouvé l'entretien des bestiaux, et qu'ils ont rejeté constamment la profession des pâtres et des bergers, comme contraire à la leur. Je ne nierai pas même qu'ils n'aient eu quelque raison de regarder le but que se propose un pátre comme contraire à celui de l'agrieultcur, puisque celui-ci ne recherche que les terrains les mieux labourés et les plus dégarnis d'herbes, au lieu que l'autre court après les terres en friche qui en sont couvertes, et que l'un fonde toutes ses espérances sur les fruits de la terre, et l'autre sur ceux du bétail; d'où il arrive que la crue des herbes, qui est le point que le laboureur déteste le plus, est le prineipal objet des vœux du pâtre. Mais, quoique les vœux des uns et des autres soient dissemblables, il y a cependant une certaine

si dabis, parcius præbeto, quoniam vires majores habet, priusque aqua macerato, et exemptum paleis permisceto. Cytisum cum aridum facere roles, circa mensem Septembrem, ubi semen ejus grandescere incipiel, credito, paucisque horis, dum flaccescat, in sole lrabeto : deinde in umbra exsiccato, et ita condito. Hactenus de arboribus pracepisse abunde est, reddituro pecoris curam et remedia sequenli rolumine.

\section{LIBER SEXTUS.}

PR.FATIO.

Srio quosdam, Publi Silvine, prudentes agricolas pecoris abmuisse curan, gregariorumque pastorum velut ininicam sua professionis disciplinam constantissime repudiasse. Yeque infitior id cos aliģua ratione fecisse, quasi sit agricola contrarinm pastoris propositum : cum ille quam maxine subacto et puro solo gaudeat, lic novali graminosoque; ille fructum e lerra speret, hic e pecore; ideoque arator abouninetur, at contra pastor optet herba- unlon et une espèce de soeićté entre cux, tant parec qu'il est communément d'usage que nous fassions brouter les pâturages de notre fonds par des bestiaux qui nous appartiennent, plutôt que par des bestiaux étrangers, que parce que le fumier abondant que produisent les troupeaux contribue à multiplier les fruits de la terre. Aussi n'y a-t-il point de pays, pour peu qu'il rapporte du blé, qui n'ait autant besoin du secours des bestiaux que de celui des hommes. Nous appelons les bestiaux tantot jumenta, du mot juvare, aider, paree qu'ils nous aident dans notre travail, en portant des fardeaux; tantót armenta, du mot arare, labourer, parce qu'ils nous sont utiles à labourer la terre. C'est pourquoi je pense qu'il ne faut pas moins parfaitement connaitre l'entretien des bestiaux que la culture des champs, ainsi que l'ont preserit les anciens Romains. Je dirai même que l'usage d'avoir des bestiaux est le plus anciennement reçu dans l'agriculture, en même temps qu'il est le plus lucratif. Aussi est-ee pour cela que les mots de pecunia et de peculium paraissent tirer leur origine du mot pecus (bétail), parce que le bétail était la seule espèce de rieliesses que possédassent les anciens, et qu'eneore aujourd'hui non-seulement il y a des nations qui n'en possèdent pas d'autres, mais que nos cultivateurs même n'ont point d'objet qui leur rapporte davantage. C'était aussi l'opinion de M. Caton, lorsqu'il ne se contenta pas de rẻpondre à quelqu'un qui le consultait pour savoir à quelle partie de l'économie rurale il devait s'appliquer pour s'enrichir promptement, que c'était à bien nourrir des bestiaux; mais que, la même personne lui demandant de nouveau quel était le second moyen par lequel elle pourrait reeueillir

rum proventum. Sed in his tam discordantibus votis est tamen quocdam societas atque conjunctio : qnoniam et pabulum e fundo plerumque domesticis pecudibus magis quam alienis depascere ex usu est, et copiosa stercura. tione, qua contingit e gregibus, terrestres fructus exuberant. Nec tamen ulla regio est, in qua modo frumenta gignantur, quæ nolt ut hominum ita armentorum adjulorio colatur. Unde etiam jumenta et armenta nomen a re traxere, quod nostrum laborem, vel onera subvectando vel arando jurarent. Itaque sicul veleres Romani praceperunt, ipse quoque censeo tamı pecorum quam agrorum cultum pernoscere. Nam in rusticatione vel antiquissima est ratio pascendi eadenıque quastuosissima. Propler quod nomina quoque pecunia et peculii tracta videntur a pecore : quro. niam id solum veteres possederunt, et adhuc apud quasdam gentes unum hoc usurpatur divitiarum genus : sed ne apud nostros quidem colonos alia res uberior. Ut etiam M. Cato prodidit, qui consulenli, quam partem rei rusticas exercendo celeriter locupletari possel? respondit : Si bene pasceret; rursusque interroganti, quid deinde faciendo salis uberes fructus percepturus esset? affirma vit : Si mediocriter pasceret. Cacterum de tam sapienfe viro 
des fruits au moins médiocres, il l'assura que c'ćtait en nourrissant des bestiaux médioerement bien. Quelques auteurs raeontent même que cette persoune lui demandant eneore quel ćtait le troisième objet qui fût lueratif en agrifeulture, il assura que e'était le nourrissage des bestiaux, quand même il serait mal fait : mais je rongirais d'attribuer eette troisième répouse à un homme aussi sage, d'autant qu'il est constant qu'un pâtre négligent et ignorant eause plus de dommage qu'un pâtre entendu ct diligent ne fait de profit. Quant à la seconde répouse, il n'est point douteux que les fruits que produit le bétail ne soient toujours supérieurs à la négligence du propriétaire, quand elle n'est que légère. Ces raisons nous ont déterminé, Silvinus, à donner à la postérité cette partie de l'économie rurale avec tout le soin dont nous avons été capable, en suivant les préceptes de nos aneêtres. Ainsi, comme il y a de deux espèces de quadrupèdes, les uns que nous nous proeurons pour partager avec nous nos travaux, comme le bouf, la mule, le cheval ct l'âne, et les autres que nous nourris sons soit pour notre agrément, soit pour en tirer du revenu, ou pour l'employer à la garde des autres bestiaux, comme la brebis, la clı̀vre, le pore et le chien; nous traiterous d'abord de l'espèce de eeux que nous assoeions à nos travaux. Or, il n'y a point de doute, ainsi que Varron l'a dit, que le bouf ne doive tenir le premier rang cutre tous les autres bestiaux de eette espèce, par la considération que mérite cet animal, surtout en Italie, puisque l'on croit qu'il a donné son nom à ee pays, ct qu'it $\alpha \lambda$ ò est le nom que les Grees donnaient autrefois au taureau; mais encore plus dans cette ville où l'on s'est servi, en la batissant, do cet animal tant mâle que femelle pour en traeer, avee la charrue, les murs et les

piget dicere, quod eum quidam auctores memorant eidem quærenti, quodnam tertinm in agricolatione quastuosum esset? asseverasse, si quis vel male pasceret; cum prac. sertim majus dispendium sequatur inertem et inscium pastorem, quam prudentem diligentemque compendium. De secundo tamen responso dubium non est, quiu mediocrem negligentiam domini fructus pecoris exsuperet. Quam ob cansam nos hanc quoque partem rei rustica, Silvine, quanta valuinus industria, majorum secnti pracepta posteritati mandavimus. Igitur cum sint duo genera quadrupedum, quorum alterum paramus in consortium operom, sicut bovem, mulam, equum, asiuum; alterum voluptatis ac reditus et custodia causa, ut ovem, capellanı, suem, canem : de eo genere primum dicenus, cujus ısus nostri laboris est particeps. Nec dubium, quin, ut ait Varro, cateras pecudes bos honore superare debeat, prasertim [autem] in Italia, quæ ab loc nuncupationem

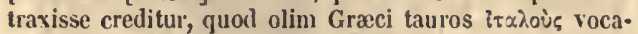
rent; et in ea urbe, cujus monibus condendis mas et formina boves aratro terminum signaverunt, velut pecus : guod item Alticis Allenis Cercris et Triptoleni fentur portes. Le premier rang lui est encore dû, paree qu'il passe à $\Lambda$ thènes pour avoir été lo ministre de Cérès et de Triptolème, parce qu'il tient une place dans le ciel parmi les eonstellations les plus brillantes, et qu'il est encore aujourd'hui.le plus laboricux compagnon de l'homme dans l'agrieulture. Aussi les anciens ont-ils toujours eu un si grand respeet pour cet animal, que e'était un crime aussi capital elıez eux d'avoir tué un bouf que d'avoir tué un citoyen. C'est done par le bouf que nous eommeneerons notre traité sur l'entretien des bestiaux.

I. Ce u'est point une chose aisée que de fixer les règles auxquelles on doit se eonformer, et les écarts que l'on doit éviter dans le choix des bœufs que l'on veut aeheter, d'autant que es animaux varient de taille, de caractère et de couleur, suivant la différence des pays et des elimats. Ceux de l'Asie, des Gaules ou de l'Épire diffèrent tous entre eux par la forme; et ce n'est pas seulement dans les pays différents que l'on trouve ces variétés, mais on les rencontre même dans les diverses parties de l'Italie. La Campanie donne communément des bœufs qui sont blanes et de petite taille, mais néanmoins propres au travail et au genre de culture qu'exige le sol dans lequel ils sont nés. Ceux de l'Umbrie sont grands et blancs : cette province en donne aussi de rouges, et qui ne sont pas moins estimés pour leur courage que pour leur taille. L'Étrurie et le La. tium en donnent de trapus, mais qui sont trèsforts à l'ouvrage. L'Apennin en donne de trèsrobustes, et qui supportent tout ee qu'il y a de plus diffieile, mais qui ne sont point de belle apparence. Au reste, malgré toutes ces variétés, il y a cependant des préeeptes que l'on peut regarder eomme généralement constants, et auxquels le laboureur doit se eonformer dans le ehoix

minister : quod inter fulgentissima sidera particeps cali : quod deinde laboriosissimus adluuc lominis socius in agricultura : cujus tanta fuil apud antiquos veneratio, ut tam capital esset bovem necuisse, quam civcm. Ab hoc igitur promissi operis capiamus exordium.

I. Qux in emendis bubus sequenda quæque vitanda sint, non ex facili dixerim; cum pecudes pro regionis celique statı et habitum corporis et ingenium animi et pili colorem gerant. Alia: formæ sunt Asiaticis, aliae Gallicis, Epiroticis alia. Nec tantum diversitas provinciarum, sed ipsa quoque Italia partibus suis discrepat. Campania plerumque boves progenerat albos et cxiles, labori tamen et culturæ patrii soli non inhabiles. Umbria vastos et albos; eademque robios, nec minus probabiles animis quam corporibus. Iletruria et Latium compactos, sed ad opera fortes. Apenniuus durissimos omnemque diflicultatem tolerantes, nec ab aspectu decoros. Quac cum tam varia el diversa sint, tamen quædam quasi communia el certa precepta in emendis juvencis arator sequi debet; eaque Mago Carthaginiensis ita prodidit, nt nos deinceps meno. rabiumus. Parandi sunt boves novelli, quadrati, grandibus 
des jeunes boufs qu'il veut acheter : nous allons les détailler tels que Magon lc Carthaginois les a déjà domnés. Il faut acquérir des boeufs qui soient jeunes et carrés, qui aient les membres grands, les cornes longues, noirâtres et fortes, lc front large et crépu, les yeux et le museau noirs, les oreilles hérissées, les narines camuses et ouvertes, le chignon long et charnu, le fanon ample et descendant presque jusqu'aux genoux, la poitrine large, les épaules vastes, le ventre gros et semblable à celui d'une bête pleine, les côtes allongées, les reins larges, le dos droit et plat ou même un peu affaissé, les fesses rondes, les jambes épaisses et droites, mais plutôt courtes que longues, les genoux bons et bien tournés', la corne des pieds grande, la queue traînante et bien garnie, un poil dru et court par tout le corps, dont la couleur soit rousse ou brune, et qui soit doux au toucher.

II. En supposant des veaux ainsi conformés, il faut, pendant qu'ils sont encore jeunes, les accoutumer à se laisșer manier, et à souffrir qu'on les attache à leurs mangeoires, afin qu'on ait moins de peinc à les dompter par la suite, et qu'il y ait moins de danger à le faire. Au surplus, je suls d'avis que l'on ne dompte pas les bouvillons avant l'âge de trois ans, ni passé celui de cinq, parce que dans le premier de ces âges ils sont encore trop délicats, et que dans le dernier ils résistent trop : or voici comme il faut s'y prendre pour dompter ceux que l'on aura pris dans un troupeau de bœufs sauvages. On commencera par leur préparer une étable spacicuse, où celui cqui sera employé à les dompter puisse tourner avec aisance, et d'où il puissie sortir sans courir aucun danger. La place qúi sera devant l'étable ne doit pas être resserrée, mais il faut que ce șoit une campagne ou un grand chemin bien large, afin

membris, cornibus proceris ac nigrantibus et robustis, fronte lata et crispa, hirtis auribus, oculis et labris nigris, nari. bus resimis patulisque, cervice longa et torosa, palearibus amplis et pene ad genua promissis, pectore magno, armis Vastis, capaci et tanquam implente utero, lateribus porreclis, lumbis latis, dorso recto planoque vel etiam sul). sidente, clunibus rotundis, cruribus compactis ac rectis, sed lrevioribus potius quam longis, nec genibus improlis, ungulis magnis, caudis longissimis et setosis, piloque (corporis denso brevique, coloris robii vel fusci, tactu corporis mollissimo.

11. Talis nota, vitulos oportet, cum adluc teneri sunt, consuescere manu tractari, ad prasepia religari, ut exiguus in domitura labor eorum et minus sit periculi. Verun nec ante tertium neque post quintun annum juvencos domari placet, quonian illa xtas adhuc tenera est, lıæc jam pracdura. Eos autem, qui de grege feri comprelıenduutur, sic subigi convenit. Primum oınnium spatiosum stabulım praparetur, ubi domitor facile versari, et unde degreali sine periculo possit. Ante stabulum unllne angustic sint, sed aut canıpus aut via late patens : ut cum produceulur que lorsque les bouvillons viendront à en sortir, ils aient toute liberté de courir, et que la peur ne les cxpose pas à s'embarrasser, au risque de se blesser, dans des arbres ou dans d'autres obstacles qui se rencontreraient sur leur passage. Il y aura dans cette étable d'amples mangeoires, au-dessus desquelles seront posées horizontalement en forme de jougs, à la hauteur de sept pieds de terre, des solives auxquelles on puisse attacher les bouvillons. On choisira cnsuite, pour essayer de les dompter, la matinée d'un jour serein, qui ne soit pas fète, et on leur attacliera aux cornes des cordes de chanvre. Quant aux courroies qu'on jette sur ces animaux quand oll veut les prendre, clles doivent être emmaillottées de peaux avec leur laine, afin qu'elles ne les blessent point au-dessous des cornes, partie- de leur front la plus délicate. Lorsqu'on aura pris des bouvillons, on les conduira aussitôt à l'étable, où on les attachera à des poteaux, de façon qu'ils aient une certaine liberté autour d'cux, et qu'ils soient séparés les uns des autres à quelque distance, de peur çu'ils ne se blessent mutuellcment par les effor'ts qu'ils feront pour' se détacher. Sils sont trop revêches, on les laissera jeter toute leur furie pendant vingt-quatre heures; $\mathrm{et}$ dès qu'elle sera un peu ralentie, on les fera sortir le matin, en ayant soin toutefois qu'il y ait une personne qui aille devant cux, plusieurs alltres qui les retiennent par derrière avec des cordes, et une qui les suive pas à pas, et qui réprime de temps en temps leurs efforts, en les frappant légèrement avec une massue de bois de saule. Mais si ce sont des boufs doux et tranquilles, on pourra les faire sortir de l'étable le jour même qu'on les y aura mis à l'attaclic, avant le soir, et les accoutumer à franchir à pas comptés, et sans s'effrayer, l'espace de mille pas.

juvenci, liberum labeant excursum ; ne pavidi aut arboribus aut objacenti cuilibet rei se implicent noxamque ca. piaut. Iu stabulo sint ampla prosepia, supraque trans. versi asseres in modum jugorum a lerra septem pedibus elati conligantur, ad quos religari possint juvenci. Dieu deinde, quo domituram auspiceris, liberum a tempestatibus et a religiouibus matutinun eligito : cannabinisque funibus cornua juvencorum ligato. Sed laquei, quibus copulantur, lanatis pellibus involuti sint, ne tenera frontes sub cornua ladantur. Cum deinde buculos comprelienderis, perducito ad stabulum, et ad stipites religato ila, ut exiguum laxamenti labeant, distentque inter se a liquanto spatio, ne in colluctatione alter alteri noceat. Si ninis as. peri eruut, palere unum diem noctemque desaviant. Simulalque iras contuderint, mane producantur, ita ut et ali. quis ante et a tergo consplures, qui sequuntur, retiuaculis cos contineant, et unus cun clava salignea procedens modicis ictibus subinde impetus eorum coerceat. Sin auten! placidi et quieti loves erunt, vel eodem die, quo alliga veris, ante vesperum licclit producere, et docere per mille passus composite ac sime pavore ambulare : cum domun 
Lorsqu'on les aura ramenés à la maison, on les attachera à des poteaux de très-près, et de façon qu'ils ne puissent pas remuer la tête. Quand ils seront attachés, il faudra les flatter, pour ainsi dire, par le ton de la voix, en s'approchant doucement d'eux, non pas par derrière ni par les eôtés, mais en face, afin qu'ils s'accoutument à envisager celui qui les abordera. Ensuite on leur frottera les narines, afin qu'ils s'habituent à connaitre l'homme à l'odorat. Il faudra aussi leur manier tout le dos quelque temps après, et verser dessus du vin pur, pour qu'ils se familiarisent avec le bouvier; comme il faudra aussi leur passer la main sous le ventre et entre les euisses, afin que par la suite ee genre d'attouchement ne les effraye pas lorsqu'on sera obligé d'y avoir recours pour leur ôter les tiques, qui s'attachent ordinairement à leur's cuisses. Celui qui les dompte doit, en faisant ces différentes opérations, se tenir sur leurs cótés, de peur d'attraper des coups de pied. Ensuite on leur ćcartera les mâchoires pour leur tirer la langue de la gueule, et on leur frottera de sel tout le palais; après quoi on leur fourrera dans la gueule des boules de pâte d'une livre pesant trempées dans de la graisse fondue bien salée, et on leur versera dans la gorge avee unc corne un sextarius de vin par tête. Avec ces espèces de caresses, il ne faudra guère que trois jours pour les apprivoiser, et ils recevront le joug le quatrième. On attachera à ce joug une branche d'arbre que l'on tirera à soi cn guise de timon, ct même on y joindra de temps cn temps quelques poids, pour éprouver leur patience dans le travail, en leur faisant faire de plus grands efforts. Après ces premiers essais, il faut les attacher à une charrette vide, et la lcur faire trainer d'abord peu de temps, ensuite dans un plus long espace de ehemin, en la char-

perduxeris, arcte ad stipites religato, ita ne capite moperi possint. Tum demum ad alligatos boves neque a posteriore jarte neque a latere, sed adversus, placide et eum quadan vocis adulatione venito, it accedentem cousuescant aspicere. Deiude nares perfricato, ut lıminem discant odorari. Mox etiam convenit tota tergora et tractare et respergere mero, quo familiariores bubulco fiant : velltri quoque el sub femina manum subjicere, ne ad ejusmodi tartum postmodum pavescant, et ut ricini qui plesumque feminibus inlærent, eximantur. Idque cum fit, a latere domitor stare dehet, ne calce contiugi possit. Post laæc diductis malis educito linguam, totumque eorum palatum sale defricato, libralesque offas in prasulsæ adipis liquamine tinctas in gulanı demittito, ac vini singulos sextarius per cornu faucibus infundito : nam per lıec blandimenta triduo fere mansuescunt, jugumque quarto die accipiunt, cui ramus illigatus tenonis vice trajicitur : interdum et pondus aliquod injungitur, ut majore nisu laboris exploretur patientia. Post ejusmodi experimenta vacuo plostru snbjungeudi, et paulatim longins cun oueribus producendi sunt. Sic perdousiti mox ad aiatrmm ins. geant peu à peu de cyuclque's poids. Quand ils steront ainsi domptés, il faudra les mettre aussitôt à la eharrue, mais dans un champ déjà labouré, de peur qu'ils ne se rebutent dans ees commencements par la difficulté de l'ouvrage, ou qu'ils ne meurtrissent leurs cous encore tendres, ell éprouvant trop de résistanee de la part de la terre. Au surplus j'ai enseigné dans le premier volume comment le bouvier doit gouverner ses bœufs dans le labourage. Il faut prendre garde que le bouf ne s'habitue à donner du pied ou de la corne dans le temps qu'on le dompte, parce que si on n'y met pas ordre dès le commencement, jamais on ne pourra le corriger par la suite de ce défaut, même lorsqu'il sera dompté. Au surplus, la méthode que nous venons de preserire pour dompter les bœufs n'aura lieu que dans le eas où l'on n'en aura point chez soi qui aient déjà servi : ear si on en a de domptés, la méthode la plus courte et la plus sûre sera celle-ci, que nous suivons dans nos campagnes. Lorsque nous voulons accoutumer un bouvillon à la charrette, nous y attelons avec lui le plus robuste et en même temps le plus tranquille des boufs domptés que nous ayons, pour le retenir quand il ira trop vite, et le faire avancer quand il s'arrêtera; et même, si nous ne plaignons point nos peines, nous fabriquons un joug où l'on puisse en atteler trois à la fois. Par ee moyen nous forçons les bœufs, si rétifs qu'ils soient, à se plier aux travaux les plus forts, parce que, des qu'un bouvillon paresseux est attelé cntre deux bœufs accoutumés à servir, ct qu'il est contraint, Iorsqu'il est attaché ainsi à la charrue, de travailler à la terre, il lui est impossible de refuser le service. En effet, s'il s'emporte et qu'il vienne à sauter, il est aussitôt contenu par les deux autres à leur gré; s'il s'arrête, il est obligé de les suirre

tituantur, sed in subacto agro, ne statim difficultaleu operis refurmident, neve adluc tenera colla dura proseissione terra contundant. Quemadmodum antem bubulcus in arando bovem instituat, primo proxcepi volumine. Curandum ne in domitura bos calce aut cornu quenquam contingat. Nam uisi lıæc caveantur, nunquan ejusmodi vitia quan vis subacto eximi poterunt. Verum ista sic agen. da pracipimus, si veteranum pecus non aderit. Nam si aderit, expeditior tutiorque ratio domandi est, quanı nos in nostris agris sequimur. Nam ubi plostro ant aratro juvencum consuescimus, ex domitis bubus valentissinum eundemque placillissimunı cum indomito jungimus: Is et procurrentem retrahit, et eunctantem producit. Si vero uon pigeat jugum fabricare, quo tres jungaulur, lıac machinatione consequemur, ut etiam contımaces boves gravissima opera nou recusent. Nam ubi piger juvencus nedius inter duos veteranos jungitur, aratroque injuncto terram moliri cogitur, nulla est imperium respuendi facultas. Sive enim efferatıs prosilit, duorum arbitrio iulıi. betur : seu consistit, duolus gradientibus etian insilıs obsequitur : seu conatur decumbere, a valentioribns sub- 
quand ils avancent; enfin s'il fait des efforts pour se couclier à terre, il est relevé et entrainé par ses camarades qui sont plus forts que lui, et dès là il se trouve nécessairement contraint dans toutes les circonstances à sc défaire de son opiniátreté; de sorte qu'il ne lui faut donner que très-peu de coups pour le faire parvenir à supporter le travail. 11 y a aussi des bœufs d'une certaine espèce qui sont toujour's lâches, même après avoir été domptés, et qui se couchent à terre dans les sillons. Je crois qu'il faut s'y prendre d'une manière particulière pour les corriger, sans recourir aux voies de la dureté. Car ceux qui s'imaginent que ce vice cédera plutôt à l'aiguillon, au feu ou à d'autres genres de tortures, qu'à tout autre moyen, ne connaissent pas quel est le véritable auquel il faut avoir recours, puisqu'il est certain qu'une opiniâtreté inébran. lable de la part du bouvicr fatiguc l'animal et le rend furieux. C'est pourquoi lo meilleur est de corriger un bœuf qui est dans l'habitude de se coucher à terre, en lui faisant souffrir la faim et la soif, sans lui tourmenter le corps, parce qu'il est plus sensible aux besoins naturels qu'aux coups. Ainsi, lorsqu'un bœuf se couchera à terle, il sera très-utile de lui garrotter les jambes, de facon qu'il ne puisse ni se tenir debout, ni marcher, ni paitre; moyennant quoi la diète et la soif le contraindront à se défaire de sa nonchalance. Cependant il faut avouer quc ce défaut est trèsrare dans les boufs natifs du pays où l'on se trouve, d'autant qu'en général tout bouf né dails le pays où il travaille est bien meilleur qu'un bœuf étranger, parce qu'il n'est point exposé à changer d'cau, ni de fouriage ou de climat, et qüil n'est point molesté par la nature de la contrée, commele serait celui qui aurait été emmené d'un pays plat et champêtı'e dans des lieux montagneux et sauvages, ou d'un pays montagneux

levatus tralitu1" : propter qua undique necessitate con. tumacian deponit, et ad patientiam laboris paucissimis verheribus perducitur. Est etiam post domituram molliorisgeneris bos, qui decumbit in sulco : eum non sæevitia, sed ratione censeoemendandum. Nam qui stimulis aut ignibus aliisque tormentis id vitium eximi melius judicant, verae rationis ignari sunt : quoniam pervicax contumacia plerumque savientem fatigat. Propter quod utilius est citra corporis vexationem fame potius et siti cubitorem hovem emendare. Nam eum velıementius afficiunt naturalia desideria, quam plagie. Itaque si bos decubuit, utilissinum est pedes ejus sic vinculis obligari, ne ant insistere aut progredi aut pasci possit. Quo facto inedia et siti compul. sus deponit ignaviam; quæ tamen rarissima est in pecore vernaculo : longeque omnis bos imdigena nielior est quain peregrinus. Nam neque aqua nec pabuli nec cali mutalione tentatur, neque infestatur conditione regionis, sicut ille, qui ex planis et campestribus locis in mnutaua et asprra perductus est, vel ex montanis in caınestria. Itaquue ctianı, cunı cogimur ex longinquo boves arcessere, curaı. dans un pays plat. C'est aussi pour cela que lorsque nous sommes forcés de faire venir des bœufs d'une contrée éloignée, nous devons avoir soin de ne les faire venir que d'une coutrée qui soit semblable à la nôtrc. Il faut aussi prendre garde d'en atteler deux ensemble, dont l'un soit moins gros que l'autre, parce que la disproportion dans la stature et dans la force clltraîne bientôt la perte du plus faible des deux. On estime cet animal lorsque son tempérament est plus paeifique que vif, pourvu qu'il ne soit point paresseux; lorsqu'il craint les coups et la voix de son maître, mais que, se confiant dans ses forces, il ne se laisse point intimider d'ailleurs par les sons qui peuvent frapper son oreille, ni par les objets qui se présentent à sa vue, et qu'il passe sans frayeur à travers des fleuves ou sur des ponts; enfin lorsqu'il consomme beaucoup de nourriture, et qu'il est lent à la mâcher. En effet, ceux qui mâchent à leur aise digèrent mieux que ceux qui le font précipitamment, ct dès lors ils se maintiennent plus que ces derniers dans la force du corps, sans devenir maigres. Au surplus, le bouvier peche autant en rendant søs bœufs gras qu'en les rendant maigres, parce que la taille des animaux destinés à travaill' l' doit être commode et médiocre, et qu'il doit plutôt être robuste en nerfs et en muscles que chargé de graisse, afin qu'il ne soit point opprimé tout à la fois tant par le poids de son dos que par la fatigue de l'ouvrage. Mais comme nous avons donnć les préceptes qu'il y a à suivre lorsque l'on veut acheter ou dompter des bœufs, passons à ce qui concerne leur entretien.

1II. Il faut laisser les boufs à l'air pendant li chaleur, et les mettre à couvert pendant le froid : c'est pourquoi on leur préparera, pour le s'jour qu'ils feront à l'étable pendant l'hiver, de la paille que l'on aura soin de couper et de mettre

dum est, ut in similia patriis locis traducantur. Item custodiendum est, ne in comparatione vel statura vel viribus impar cum valentiore jungatur. Nam utraque res inferiosi celeriler affert exitium. Mores lujus pecudis probabiles labentur, qui sunt propiores placidis quam concitatis, sed non inertes : qui sunt verentes plagarum et acclama. tionum; sed fiducia virium ner; anditı nec visu pavidi, nec ad ingredienda flumina aut pontes formidolosi : multi cibi [ edaces; ] verum in co conficiendo lenti. Nam hi melius concoquunt, ideoque robora corporım citra maciem conservant, qui ex commodo, quan qui festinanter mandunt. Sed tan vitium est bubulci pinguem quau exilem bovem rerldere : habilis enim et modica corporatura pecoris operarii debet esse, nervisque et nuusculis robusta, non adipibus obesa, ut uec sui tergoris mole nec labor? operis degravetur. Sed quoniaur quae sequenda sunt in emendis domandisque bubus tradidimus, tutelan eorun pracipiemus.

III. Boves calore sıb divo frigoribus intra tectum manere oportet. Itaque liberua stabulationi eorum prapar. 
par tas en aoủt, un mois après la moisson. La coupe de cette paille ne sera pas moins utile aux champs qu'aux bestiaux, paree que les eampagnes se trouveront débarrassćes par là des ronees, qui ne manquent pas ordinairement de mourir jusqu'aux racines lorsqu'elles ont été coupées eu été au lever de la Canicule, et que ces ronces étant mises sous la litière du bétail, augmenteront la quantité du fumier. Après eette opération prèalable, nous nous pourvoirons de fourrage de toute espèce, et nous ferons en sorte que ee bétail ne soit pas exposé à maigrir faute de nourriture. $0 r$, il y a plusieurs méthodes pour bien nourrir les bœufs; ear si le pays où l'on est donne du fourrage vert en abondance, personne ne doute que ee genre de nourriture ne doive être préféré à tout autre; mais c'est ee qui n'arrive que dans les lieux qui sont arrosés par des ruisseaux ou couverts de rosée. Aussi trouve-t-on dans les lieux de cette nature un trèsgrand avantage, qui consiste en ce que la journée d'un seul homme suffit à deux paires de bœufs à la fois, attendu qu'ils labourent ou qu'ils paissent alternalivement dans le même jour. Dans les pays plus secs, on donne de la nourriture aux bœufs dans leurs mangeoires, et eette nourriture varie suivant la nature différente de ces pays. Personne ne doute que la meilleure ne soit de la vesee liée en bottes et de la gesse, ainsi que du foin de pré. On entretient ce bétail moins avantageusement avee de la paille, quoique ce genre de nourriture fasse ressource partout, et que l'on n'en trouve pas même d'autre dans certaines euntrées. La paille que l'on estime le plus est eelle de millet, ensuite celle d'orge, et même en troisième lieu eelle de froment. Mais, indépendamment de la paille, on donne encore de l'orge aux bœufs qui ont fait leur journée. Au sur- plus, on règle différemment la mesure du fourrage qu'on leur donne suivant les différents temps de l'année. Au mois de janvier il faut leur don. ner à chacun quatre sextarii d'ers moulu et détrempé dans de l'eau a vec de la paille, ou bien un modius de lupins détrempés, ou enfin un scmo. dius de gesse détrempée, indépendamment de la paille qu'on leur donnera en abondance. On peut aussi, si l'on manque de légumes, mêler avee dela paille du mare de raisin, que l'on aura lavé pour en exprimer de la piquette, et le leur donner après qu'il sera séché ; quoiqu'il n'est point douteux qu'il n'y ait plus d'avantage à lc leur donner avec la peau des raisins et avant de l'avoir lavé, parce que ce marc, leur tenant licu de nourriture et de vin en même temps, a la vertu de les rendre gais et brillants, et d'augmenter lcur embonpoint. Si nous ne leur donnons pas de grains, il suffira de remplir de feuilles sèches un panier dont on se sert pour mesurer leur nourriture, dont la contenance soit de vingt modii; ou de lcur donner trente livres de foin, ou bien encore des feuilles vertes soit de laurier soit d'yeuse, en grande quantité; mais on y ajoutera du gland, pourvu que le pays en produise assez pour permettre de le faire, quoique eette dernière nourriture leur oceasionnerait la gale, si on leur en donnait jusqu'à les en rassasier. On peut encore leur donner un semodius de fèves moulues, pourvu que la récolte en ait élé abondante. Communément la même pitance leur suffit au mois de février. On doit ajouter quelque elıose à la quantité de foin qu'on leur donnera en mars et en avril, parce que e'est le temps où ils travaillent aux premiers labours de la terre. II suffira eependant de leur en donner à ehaeun quarante li vres. On fera bien néanmoins de couper pour eux du fourrage vert, depuis les ides d'avril jus. randa sunt stramenta, quæ mense Augısto intra dies triginta sublatæe messis præcisa in acervum extrui debent. Horum desectio cum pecori tum ayro est utilis : liberantur arva sentibus, qui acstivo tempore per Canicula ortum recisi plerumque radicitus intereunt, et strameuta pecori subjecta plurimum stercoris efliciunt. IFæe cum ita curaverimus, tum et omne genus pabuli preparabimus, dabimusque operam, ne penuria cibi macrescat pecus. Boves autem reete pascendi non una ratio est. Nam si ubertas regionis viride pabulum subministrat, nemo dubitat quin id genus cibi cæeteris præponendum sit : quod tamen nisi riguis aut roseidis locis non contingit. Itaque in iis ipsis rel maximum commodum est, quod sufficit una opera duobus jugis, quar eodem die alterna temporum vice vel arant vel pascuntur. Siccioribus agris ad prasepia boves alendi sunt, quibus pro conditione restionum cibi prabentur : cosque nemo dubitat, quin optimi sint vicia in fascem ligata, et cicereula itemque pratense focnum. Miuus commode tuenur armentum paleis, quю ubique et quibuslam regionibus sola prasidio subt. lia probantur maxime ex nilio, tum ex ordeo, mox etian ex tritico. Sed junentis justa operum reddentibus ordeun prater has prabetur. Bubus autem pro temporibus ami pabula dispensantur. Januario mense [ singulis ] fresi et aqua macerati ervi quaternos sextarios mistos paleis dare convenit, vel lupini macerati modios, vel eicereulx us.ceratæe semodios, et super liæc affatim paleas. Licet etiam, si sit leguminum inopia, et eluta et siecata vinaeia , qua de lora eximuntur, cum paleis miscere. Nee dubium [est,] quin ea longe melius cum suis folliculis, ante quam eluantur, proberi possint. Nam et cibi et vini vires habent, nitidumqne et lilare et corpulentum pecus faciunt. Si grano abstinemus, frondis aridx corbis pabulatorius modiorum viginti sufficit, vel foeni ponde trigiuta, vel sine modo viridis laurea et ilignea froudes. Et lis, si regionis copia permittat, glans adjieitur : qua nisi ad sa. tictatem detur, scahiem parit. Potest etian si proventus vilitatem facit, semodius fabse fres $æ$ præberi. Nense Februario plerumque eadem sunt eibaria. Martio et Aprili debet ad foni pondus adjiei, quia terra proscinditur : sat auten erit pondo quadragena singulis dari. Ab idilus tamen mensis sprilis usque in idus Juuias viride pabu- 
qu'à celles de juin : on pourra même eontinner de leur en donner dans les lieux plus froids, jusqu'aux calendes de juil!et. A partir de cette époque on les rassasiera de feuillages pendant tout l'été, ainsi qu'en automne jusqu'aux calendes de novembre, quoique ces feuillages ne leur seront bons que lorsqu'ils auront été mûris par les pluies ou par les rosées continuelles : les plus estimés sont d'abord ceux d'orme, ensuite ceux de frêne, puis enfin eeux de peuplier. Les pires sont ceux d'yeuse, de ehẻne et de laurier, quoiqu'à la fin de l'été on soit forcé d'y recourir, à dléfaut d'autres. On peut aussi fort bien leur donner des feuilles de figuier, si l'on en a abondamment, ou qu'il y ait de l'utilité á élaguer ees arbres. Celles d'yeuse sont encore meilleures que eelles de ehênc, pourvu que ce soitde l'espèce d'yeuse qui n'a point de piquants, paree que le bouf ne veut point de ees deruières, non plus que de celles de genévrier, à cause de ees piquants. Il faut, dans les mois de novembre et de déeembre, donner aux boufs à manger tant quils voudront pendant les semailles; cependant il suffit ordinairement de leur donner à ehacun un modius de gland, aree autant de paille qu'ils en voudront, ou bien un modius de lupins détrempés, ou sept sextarii d'ers arrosé d'eau et mêlé de paille, ou douze sextarii de gesse arrosée de même et mêlée de paille, ou un modius de mare de raisin, pourvu qu'on $y$ ajoute de la paille en abondance, comme je l'ai dit ei-dessus; ou enfin, si l'on n'a aueun de ces fourrages, quarante livres de foin sans aucun autre niélange.

IV. Mais il ne servira de rien de rassasier ce bétail de nourriture, si l'on n'apporte point toute l'attention nécessaire pour l'aider à se bien porter, et à conserver ses forces : or on parviendra à ces deux points en donnant aux bœufs

lum recte secatur : potest etiam in calend. Julias frigidioribus locis idem prestari : a quo tempore in calend. No vemb. tota astate et deinde autumuo satientur fronde; qux tamen nou ante est ntilis, quam cum maturuerit vel inbribus vel assiduis roribus : probaturque maxime ulmea, post fraxinea, et ab liac populnea. Ultima sunt ilignea el quernea et laurea : sed ea post astatem necessariæ deficientilus cateris. Possunt etiam folia ficulnea probe dari, si sit eorum copia, aut stringere arbores expediat. llignea tamen [vel] melior est quernea, sed ejus gene. ris, quol spinas uon labet; nam id quoque, uti junipeıus, resyuitur a pecore propter aeuleos. Novembri mense ac Decembri per sementem quantum appetit bos, tantum prabendum est : plerunıque tamen sufticiunt siugutis modii glandis et palex ad satietatem datie, vel lupini macerali modii, vel ervi aqua conspersi sextarii vu permisti paleis, vel cicercula similiter conspersa sextarii $x \|$ misti paleis, vel singuli modii vinaceorum, si iis, ut supra dixi, large palex adjiciantur; vel si nilil horum est, per se fo'ni juulo quadragiula.

W. Sed nun pruderit cibis satiari pecora, nisi omnis trois jours de sulte uno médecine eopieuse, composée de lupins et de eyprès broyés ensemble par portions égales, et infusés dans l'eau; on laissera cette médecine se reposer à l'air pendant une nuit entière, et on la leur fera prendre quatre fois par an, à savoir, à la fin du printemps, de l'été, de l'automne et de l'hiver. Souvent même on vient à bout de eliasser leur langueur et leur dégroût en leur mettant dans la gorge, quand ils sont à jeun, un œuf de poule cru tout entier, et en leur versant le lendemain dans les narines du vin, dans lequel on aura pilé des gousses d'ail ou d'oignon de Cypre. Au surplus, ces remèdes ne sont pas les seuls qui les maintiennent en bonne santé : il y a bien des gens qui mettent dans la même vue une grande quantité de sel dans leurs fourrages; quelques-uns leur ont donné avec suceès du marrube blane avec de l'huile et du vin; d'autres font infuser dans du vin pur des feuilles de poireaux; d'autres, des graius d'encens; d'autres enfin, de la savinière et de la rue, et leur donnent ees médicaments à boirc. Plusieurs les traitent avee des tiges dè eoulevrée blanche et des cosses d'er's; quelques-uns font infuser dans du vin une peau de serpent broyée. Le serpolet pilé dans du vin léger, et la seille hachée et macérée dans l'eau, leur' servent aussi de remèdes. Toutes ces potions données à la dose de trois hemince par jour, pendant. trois jours consécutifs, leur purgent le ventre, .et rétablissent leurs forees en chassant leurs maladies : cependant la lie d'huilc passe pour le remède qui leur est le plus salutaire, pourvu qu'on la mêle avec pareille quantité d'eau, et qu'on y accoutume ces bestiaux peu à peu. En effet, on ne peut pas leur en donner tout d'abord, mais on commence par en arroser leur nourriture; ensuite on en met dans leur eau en petite dose, et

adhibeatur diligentia, ut salnbri sint corpore, viresque conservent : qua utraque custodiuntur large dato per triduum ınedicamento, quod conıponitur pari poudere triti lupini, cupressique, et eum aqua nocte una sub divo habetur; idque quater anno fieri debet ultimis temporilus veris; aestatis, autumui, hienis. Sape etian languor et uausea discutitur, si integrum gallinaceum crulum ovun jejuni fancibus inseras, ac postero die spicas ulpiei vel allii cum vino conteras, et in naribus infundas : ueque hæc tan. tum remedia silubritatem faciunt. Multi et lary:) sale nis. cent pabula; quidam marrubium deterunt cum oleo et vino; quidam poriti fibras, alii grana thuris, alii sabiuam herban rutamque cum ınero diluunt ; eaque medicamenta potauda prabent. Multi canlibus vitis alba et valrulis ervi bulus medentur : nomnulli pellem serpentis olstritam cum vinu miscent. Est etiam remedio cum dulci vino tritum serpyllım, et concisa et in aqua macerata scilla. Qua oumes proedicte potiones triun heminarum singnlis diebus pur triduun datx alvum purgant, depulsisque vitiis recrean! vires. Maxime tamen habetur salutaris amurea, si tantun. deu acpua misceas, el ea pecus iusuescas; 'fua' protinus 
simplement pour la corriger ; enfln peu de temps après on la mêle avec leur eau par égale portion, et on leur en donne tant qu'ils en veulent.

V. Il ne faut pas exciter les boufs à courir en aucun temps de l'année, mais encore moins eu été, parce que cela leur lâche le ventre ou leur donne la fièvre. Il faut aussi prendregarde qu'une truie ou une poule ne vienne à se glisser du côté de leurs mangeoires, parce que les excréments de ces animaux, venant à se mêler avec le fourrage des bœufs, leur cause la mort : ceux d'une truie malade sont particulièrement capables d'occasionner une contagion dans le troupeau. Si ce malheur arrive, il faut sur-le-champ le faire changer de climat, et après l'avoir distribué en plusieurs pelotons, l'envoyer dans des pays éloignés, et séparer si bieu les animaux malades de ceux qui seront sains, qu'il ne s'en trouve aucun parmi ces derniers que la contagion puisse exposer à quelque danger. C'est pourquoi, lorsqu'on sera obligé de les élolgner, il faudra les conduire dans les lieux où aucun bétail n'aille paitre, de peur qu'en arrivant íls'n'apportent aussi la peste aux autres bestiaux qu'ils y trouveraient. Au surplus, si pestilentielles que soient leurs maladies, il faut travailler à les vaincre et à les chasser par des remèdes spécifiques. On mêlera donc à cet effet des raeines d'herbe d'or et de panicaut avec de la semence de fenouil, de la farine de froment moulu et du vin cuit jusqu'à diminution des deux tiers ; et après âvoir versé de l'eau bouillante sur ce mélange, on le fera prendre aux animaux qui seront malades. On peut encore faire une potion avec de la cannelle, de la myrrhe, de l'encens et du sang de tortue marine, infusés chacun par poids égal dans trois sextarii de vin vieux, et la leur verser dans les narines.

dari non potest, sed primo cibi asperguntur; deinde exigua portione medicatur aqua, mox pari mensura mista datur ad saturitatem.

V. Nullo autem tempore et minime restate utile est boves in cursum concitari : nam ea res aut cit alrum, aut movet febrem. Cavendum quoque est, ne ad præesepia sus aut gallina perrepat. Nam hoc quod decidit, immistum pabulo, bubus affert necem : et id proecipue, quod egerit sus agra, pestilentiam facere valet. Quæ cum in gregem incidit, confestinı mutandus est cxli status, et in plures partes distributo pecore longinquæ regiones petendx sunt, atque ita segregandi a sanis morbidi, ne quis interveniat, qui contagione carteros labefaciat. Itaque cum ablegabuntur, in ea loca perducendi sunt, quibus nullum impascitur pecus, ne adventu suo ctiam illi tabem afferant. Evincendi sunt autem quamvis pestiferi morbi, et exquisitis remediis propulsandi. Tunc panacis et eryngii radices foeniculi seminibus miscendx, et cum fricti ac moliti tritici farina candenti aqua conspergendx, eoque medicamine salivandum agrotum pecus. Tunc paribus casia ınyrrlınque et thuris ponderibus, ac tantunden sanguinis marina testudinis miscetur potio cum vini reteris sextariis tribus, et
Mais on partagera ce remède par portlons égales chacune du poids d'une sexcuncia, et il suflira de leur en donner avec du vin pendant trois jours. Nous avons encore reconnu que cette espèce de racine que les pâtres appelleut consiligo (de la pommelcee), est un remède très-efficace en pareil cas. Cette plante vient dans les montagnes des Marses en très-grande quantité, et est trèssalutaire à tous les bestiaux. On l'arrache do terre de la main gauche avant le lever du soleil, parce qu'on croit que, lorsqu'elle a été cueillie de cette facon, elle a plus de vertu. Voici la manière dont on prétend qüil faut l'employer. On grave en roud la partie la plus large de l'orcille. de l'animal avec une alêne de cuivre, de facon que le sang qui vient à couler de cette plaie semble tracer un petit cercle qui a la forme de la lettre 0 . Lorsque cette opération est faite, tunt daus la partie intérieure de l'oreille que dans sa partie extérieure, on perce d'outre en outre, avec la même alêne, le centre du petit cerele que l'on a décrit, et l'on insère cette racine dans ce trou. Dès que les lèvres de la plaie encore récente out saisi cette racine, elles la serrent si bien qu'elle ne peut plus s'échapper, et dès lors tout le travail de la maladie et le virus pestilentiel se portent vers cette oreille, jusqu'à ce que sa partie circonserite avec l'alêne tombe morte, et que la tête se trouve sauvée par là aux dépens de cette petite partie d'elle-même. Cornélius Celsus ordonne encore de leur verser dans les narines du vin, dans leguel on aura broyé des feuilles de gui. Voilà ce qu'il faut faire si tout un troupeau est malade : voici ce que l'on fera s'il n'y a que quelques bêtes qui le soient en particulier.

VI. Les rots fréquents, les murmures dans le ventre, le dégoût pour la nourriture, la contrac-

ita per nares infunditur. Sed insum medicamentum ponderis sescunciæ divisum, portione æequa per tridumm cum vino dedisse sat erit. Proesens etiam remedium cognovimus radicula, quaın pastores consiliginem vocaut. Ea in Marsis montibus plurima nascitur, onnique pecori maxine est salutaris. Lxeva manu effoditur ante soks ortum. Sic enim lecta majorem vim creditur habere. Usus ejus tra. ditur talis. Enea fibula pars auricula latissima circum. scribitur, ita ut manante sanguine tanquam $\mathrm{O}$ litcras ductus appareat orbiculus. Hoc et intrinsecus et ex superiore parte auricula cum factum est, media pars descripti or biculi eadem fibula transuitur, et facto foramini praclicta radicula inseritur; quam cum recens plaga comprelieurlit, ita continet, ut elabi non possit : in eam deinde auriculam omnis vis morbi pestilensque virus elicitur, donec pars, quæ filula circumscripta est, demortua excidit, et minimæe partis jactura caput conservatur. Cornelins Celsus etiam visci folia cum vino trita per nares infundere jubet. Hæc facienda, si gregatim pecora laborant : illa deinceps, si singula.

V1. Cruditatis signa sunt crebri ructus ac rentris soni tus, fastidia cibi, nervorum intentio, liebetes oculi. l'rop'- 
tion des nerfs, la faiblesse des yeux, sont des signes d'indigestion qui empechent le bœuf de ruminer et de se lécher. On y remédiera en lui donnant deux congii d'eau chaude, et trente feuilles de chou légèrement cuites dans du vinaigre; mais il faut qu'il s'abstienne un jour entier de toute autre espèce de nourriture. Quelques-uns le retiennent à la maison pour l'empêcher de paitre; après quọi ils font infuser dans un congius d'eau quatre livres de cimes de lentisque et d'olivier sauvage avec une livre de miel, le tout pilé ensemble; et après avoir laissẻ reposer cette infusion pendant une nuit en plein air, ils la lui versent dans la gorge. Quand ils lui ont fait prendre cette potion, ils lui donnent au bout d'une heure quatre livres d'ers détrempé, et lui retranchent toute autre boisson. On doit répéter cette opération trois jours de suite, jusqu'à ce que toutes les causes de la maladie soient dissipées. Mais si on néglige l'indigestion, elle est bientôt suivie de l'enflure du ventre et d'une douleur considérable dans les intestins, qui empêche l'animal de prendre sa nourriture, excite ses mugissements, ne lui permet pas de se tenir en place, et le force de se coucher souvent à terre, d'agiter sa tête, et de remuer continuellement sa queue. C'est un reméde infaillible en pareil cas, de serrer fortement la partie de la queue la plus voisine des fesses par le moyen d'une ligature, de verser dans la gorge de l'animal un sextarius de vin avec une hemina d'huile, et de lui faire faire promp. tement quinze cents pas. Si la douleur continue, il faut lui couper la corne alentour du pied, lui retirer les excréments par l'anus, en y insérant la main après l'avoir graissée, et le faire courir de nouveau. Si cela ne réussit pas encore, on broie une certaine quantité de figuier sauvage sec,

ter quæ bos neque ruminat neque lingua se deterget. Remedio erunt aquæ calidæ duo congii, et mox triginta brassicæ caules modice cocti et ex aceto dati. Sed uno die abstinendum est alio cibo. Quidam clausum intra tecta continent, ne pasci possit. Tum lentisci oleastrique cacuminum pondo iv, et libram mellis una trita permiscent aquar congio, quam nocte una sub dio habent, atque ita faucibus iufundunt. Deinde interposita hora macerati ervi quatuor libras objiciunt, aliaque potione prolibent. Hoc per tri. luum fieri debet, dum omnis causa languoris discutiatır. Nam si neglecta crudilas est, et inflatio ventris et intestinorum major dolor insequitur, qui nec capere cibos sinit, gemitus exprimit, locoque stare non patitur, sæpe decum. bere, et agitare caput, caudamque crebrius agere cogit. Manifestum remedium est proximam clunibus partem cauda vinculo reliementer obstringere, vinique sextariun cum olei hemina faucibus infundere atque ita citatum per mille et quingentos passus agere. Si dolor permanet, ungulas circumsecare, et uncta manı per anum inserta fimum extralıere, rursusque agere currentem. Si nec hoc profuit, tres caprifici aridi conterunlur, et cum dodrante aqua ca. lida dantur. Ubi nec laxe medicina processit, myrti syl- qu'on lui donne dans trols fois plus d'eau chaude. Si ce dernier reméde ne fait pas d'effet non plus, on pulvérise deux livres de feuillages de myrte sauvage, et après les avoir jetées dans deux sextarii d'eau chaude, on verse cette cau dans sa gorge avec un vase de bois, après quoi on lui tire du sang sous la queue; ct lorsqu'il en a coulé une quantité suffisante, on l'arrête par le moyen d'une ligature de papier; ensuite on le fait marcher vite, jusqu'à ce qu'il soit hors d'haleine. Voici encore des remèdes auxquels il faut avoir recours avant de lui tirer du sang : On jettera dans trois hemina de vin trois uncice d'ail moulu, et après lui avoir fait boire ce vin, on le forcera de courir; ou bien on pilera un sextans de sel avec dix oignons, en y ajoutant du miel bouilli, et on en fera un onguent qu'on lui fourrera dans le ventre; aprés quoi on l'excitera á marcher vite.

VII. La vue des oiseaux de rivière, et surtout des canards, peut aussi apaiser la douleur du ventre et des intestins. En effet, dés que les boufs qui sentent du mal aux intestins voient un canard, ils sont promptement délivrés de leurs tourments. La vue de cet animal guérit encore avec plus de succès les mulets et les chevaux. II arrive quelquefois que tous ces remedes sont inutiles, et que ces maux sont suivis d'une dyssenterie que l'on reconnait à un flux de ventre sanguinolent et glaireux. Pour y remédier, il faudra broyer quinze pommes de cyprés, avec le même nombre de noix de galle et pareil poids de fromage très-vieux, et jeter le tout dans quatre sextarii de vin dur, qu'on leur donnera en dose égale pendant quatre jours, sans les laisser manquer de cimes de lentisque, de myrte, et d'olivier sauvage vert. Le flux de ventre, en leur affai.

vestris foliorum duæ libræ lævigantur, totidemque sextarii calidæ aqua misti per vas ligneum faucibus infunduntur. Atque ita sub cauda sanguis emittitur. Qui cum satis profluxit, inhibetur papyri ligamine. Tum concitate agitur pecus eousque, dum anhelet. Sunt et ante detractionem sanguinis illa remedia : Tribus heninis vini tres uncix pinsiti allii permiscentur, et post eam potionem currere cogitur. Yel salis sextans cum cepis decem conteritur, et admisto melle decocto collyria immittuntur alvo, atque ita citatus hos agitur.

VII. Ventris quoque et intestinorum dolor sedatur visu nantium et maxime anatis. Quam si conspexerit, cui intestinum dolet, celeriter tormento liberalur. Eadem anas najore profectu mulos et equinum genus conspectu suo sanat. Sed interdum nulla prodest medicina. Sequitur torıninum vitium, quorum signum est cruenta et mucosa rentris proluvies. Remedio sunt cupressini quindecim coni, totidemque gallæ, et utrorumque ponderis retustissimus caseus. Quibus in unum tunsis admiscentur austeri vini quatuor sextarii, qui pari mensura per quatriduum dispensati dantur : nec desint lentisci myrtique et oleastri cacumina virilis. Alvus corpus ac vires carpit, operique 
simplement pour la eorriger; cnfin peu de temps uprès on la mêle avee leur eau par ćgale portion, et on leur en donne tant qu'ils en veulent.

V. Il ne faut pas exeitcr les bœufs à courir en aucun temps de l'annéc, mais encore moins elı été, parec que eela leur lâche le ventre ou leur donne la fièvre. Il faut aussi prendregarde qu'une truie ou une poule ne vienne à se glisser du côté de leurs mangeoires, paree que les excréments de ces animaux, venant à sc mêler avec le fourrage des bøufs, leur cause la mort : ceux d'unc truie malade sont particulièrement capables d'occasionner unc contagion dans le troupeau. Si ee malheur arrive, il faut sur-le-champ le faire changer de climat, et après l'avoir distribué en plusieurs pelotons, l'envoyer dans des pays éloignés, etséparer si bicu les animaux malades de ceux qui seront sains, qu'il ne s'en trouve aueun parmi ces derniers que la contagion puissc exposer à quelque danger. C'est pourquoi, lorsqu'on sera obligé de les éloigner, il faudra les conduire dans les lieux où aueun bćtail n'aille paitrc, de peur qu'en arrivant ils'n'apportent aussi la peste aux autres bestiaux qu'ils y trouveraient. Au surplus, si pestilentielles que soient leurs maladies, il faut travailler à les vainere et à les chasser par des remèdes spéeifiques. On mêlera douc à cet effet des raeines d'herbe d'or et de panicaut avee de la semenee de fenouil, de la farinc de froment moulu et du vin cuit jusqu'à diminution des deux tiers ; et après avoir versé de l'eau bouillante sur ce mélange, on le fera prendre aux animaux qui seront malades. On peut cneore fäire une potion avec de la cannelle, de la myrrhe, de l'eneens et du sang de tortue marine, infusés chaeun par poids égal dans trois sextarii de vin vieux, et la leur verser dans les narines.

dari non potest, sed primo cibi asperguntur; deinde exigua portione medicatur aqua, mox pari mensura mista datur ad saturitatem.

V. Nullo autem tempore et minime astate utile est boves in cursum concitari : nam ea res aut cit alvum, aut movet febrem. Cavendum quoque est, ne ad prosepia sus aut gallina perrepat. Nam hoc quod decidit, immistum pabulo, bubus affert necem : et id proecipue, qnod egerit sus ægra, pestilentiam facere valet. Quæ cum in gregem incidit, confestinı mutandus est cxeli statıs, et in plures partes distributo pecore longinquæe regioncs petendx sunt, atque ita segregandi a sanis morbidi, ne quis interveniat, qui contagione cateros labefaciat. Itaque cum ablegabuıttur, in ea loca perducendi sunt, quibus nullum impascitur pecus, ne adventu suo etiam illi tabem afferant. Evincendi sunt autem quamvis pestiferi morbi, et exquisitis remediis propulsandi. Tunc panacis et eryngii radices foeniculi seninibus miscendx, et cum fricti ac moliti tritici farina candcuti aqua conspergendx, eoque medicamine salivandum agrotun pecus. Tunc paribus casia myrrhaque et tluris ponderibus, ac tantundem sanguinis narina testıdinis miscetur potio cum vini veteris sextariis tribus, ct
Mais on partagera ec remède par portlons égales ehaeune du poids d'unc sexcuncia, et il suffira de leur en donner avec du vin pendant trois jours. Nous avons eneore reconnu que ectte espèce de raeinc que les pâtres appellent consiligo (de la pommelée), est un remède très-effieace en pareil cas. Cette plante vient dans les montagnes des Marses en très-grande quantité, et est trèssalutairc à tous les bestiaux. On l'arrache de terre de la main gauche avant le lever du soleil, parce qu'on croit que, lorsqu'elle a été cueillic de cetto faẹon, elle a plus de vertu. Voiei la manièrc dont on prétend qu'il faut l'employer. On grave en rond la partic la plus large de l'orcille de l'animal avec unc alêne de cuivre, de faẹon que le sang qui vient à eouler de eettc plaie semble traeer un petit cercle qul a la forme de la lettre 0 . Lorsque cettc opération est faite, tant dans la partie intérieure de l'oreille que dans sa partie extérieure, on perce d'outre en outre, avec la même alêne, le eentre du pẹtit eerele que l'on a déerit, et l'on insère eette racine dans ee trou. Dès que les lèvres de la plaie eneore réeente out saisi eette raeine, elles la serrent si bien qu'elle ne peut plus s'éehapper, et dès lors tout le travail de la maladie et lc virus pestilentiel se portent vers cette oreille, jusqu'á ee que sa partic circonserite avec l'alêne tombe morte, et que la tête se trouve sauvée par là aux dépens de eette petite partie d'elle-mème. Cornélius Celsus ordonne eneore de leur verser dans les narines du vin, dans lequel on aura broyé des feuilles de gui. Voilà ce qu'il faut faire si tout un troupeau est malade : voiei ce que l'on fera s'il n'y a que quelques bêtes qui le soient en partículier.

VI. Les rots fréquents, les murmures dans le ventre, le dégoût pour la nourriture, la contrae-

ita per nares infunditur. Sed ipsum medicamentum ponderis sescuncia divisum, portione aqua per tridumm cum vino dedisse sat erit. Praesens etiam remedium cognovimus radicula, quam pastores consiliginem vocaut. Ea in Marsis moutibus plurima nascitur, onınique pecori naxine est salutaris. Læeva manu effoditur ante soks ortım. Sic enim lecta najorem vim creditur labere. Usus ejus traditur talis. Enea fibula pars auricula latissima circumı. scribitur, ita ut manante sanguine tanquam 0 litcra ductus appareat orbiculus. Hoc et intrinsecus et ex supcriore narte auricula cum factum est, media pars descripti or. biculi eadem fibula transuitur, et facto foramini proedicta radicula inseritur; quam cum recens plaga conırehendit, ita continet, ut elabi non possit : in eam deinde auriculam omnis vis morbi pestilensque virus elicitur, donec pars, quæ fibula circumscripta est, demortua excidit, et miuimæ partis jactura caput conservatur. Cornelius Celsus etiam visci folia cum vino trita per nares infunderc julset. Hac facienda, si gregatim pecora laborant : illa deinceps, si singula.

VI. Cruditatis signa sunt crebri ructus ac ventris sonitus, fastidia cibi, nervorum intentio, bebetes oculi. Prop- 
tion des nerfs, la faiblesse des yeux, sont des signes d'indigestion qui empèehent le bœuf de ruminer et de se lécher. On y remédiera en lui donnant deux congii d'eau chaude, et trente feuilles de ehou légèrement euites dans du vinaigre; mais il faut qu'il s'abstienne un jour entier de toute autre espèce de nourriture. Quelques-uns le retiennent à la maison pour l'empêeher de paitre; après quọi ils font infuser dans un congius d'eau quatre livres de eimes de lentisque et d'olivier sauvage avee une livre de miel, le tout pilé ensemble; et après avoir laissé reposer eette infusion pendant une nuit en plein air, ils la lui versent dans la gorge. Quand ils lui ont fait prendre eette potion, ils lui donnent au bout d'une heure quatre livres d'ers détrempé, et lui retranelent toute autre boisson. On doit répéter cette opération trois jours de suite, jusqu'à ce que toutes les eauses de la maladie soient dissipées. Mais si on néglige l'indigestion, elle est bientôt suivie de l'enflure du ventre et d'une douleur eonsidérable dans les intestins, qui empêche l'animal de prendre sa nourriture, exeite ses mugissements, ne lui permet pas de se tenir en plaee, et le foree de se eoucher souvent à terre, d'agiter sa tête, et de remuer eontinuellement sa queue. C'est un remède infaillible en pareil cas, de serrer fortement la partie de la queue la plus voisine des fesses par le moyen d'une ligature, de verser dans la gorge de l'animal un sextarius de vin avec une hemina d'huile, et de lui faire faire promptement quinze eents pas. Si la douleur continue, il faut lui couper la eorne alentour du pied, lui retirer les exeréments par l'anus, en y insérant la main après l'avoir graissce, et le faire courir de nouveau. Si eela ne réussit pas eneore, on broie une ecrtaine quantité de figuier sauvage see, qu'on lui donne dans trols fois plus d'eau chande. Si ee dernier remède ne fait pas d'effet non plus, on pulvérise deux livres de feuillages de myrte sauvage, et après les avoir jetées dans deux sextarii d'eau ehaude, on verse eettc eau dans sa gorge avee un vase de bois, après quoi on lui tire du sang sous la queue; et lorsqu'il en a coulé une quantité suffisante, on l'arrête par le moyen d'une ligature de papier; ensuite on le fait mareher vite, jusqu'à ee qu'il soit hors d'haleine. Voiei eneore des remèdes auxquels il faut avoir recours avant de lui tirer du sang : On jettera dans trois hemince de vin trois uncice d'ail moulu, et a près lui a voir fait boire ee vin, on le foreera de courir; ou bien on pilera un sextans de sel avec dix oignons, en y ajoutant du miel bouilli, et on en fera un onguent qu'on lui fourrera dans le ventre; après quoi on l'exeitera à mareher vite.

VII. La vue des oiseaux de rivière, et surtout des canards, peut aussi apaiser la douleur du ventre et des intestins. En effet, dès que les bœufs qui sentent du mal aux intestins voient un eanard, ils sont promptement délivrés de leurs tourments. La vue de eet animal guérit eneore a vee plus de sueeès les mulets et les ehevaux. II arrive quelquefois que tous ees remèdes sont inutiles, et que ees maux sont suivis d'une dyssenterie que l'on reconnait à un flux de ventre sanguinolent et glaireux. Pour y remédier, il faudra broyer quinze pommes de eyprès, avee le même nombre de noix de galle et pareil poids de fromage très-vieux, et jeter le tout dans quatre sextarii de vin dur, qu'on leur donnera en dose égale pendant quatre jours, sans les laisser manquer de eimes de lentisque, de myrte, et d'olivier sauvage vert. Le flux de ventre, en leur affai- ter qux bos neque ruminat neque lingua se deferget. Remedio erunt aqua calida duo congii, et mox triginta brassicxe caules modice cocti et ex aceto dati. Sed uno die alstinendum est alio cibo. Quidam ciausum intra tecta continent, ne pasci possit. Tum lentisci oleastrique cacuminum pondo iv, et libram mellis una trita permiscent aq̣use congio, quam nocte una sub dio habent, atque ita faucibus iufundunt. Deinde interposita hora macerati ervi quatuor libras objiciunt, aliaque potione prohibent. Hoc per triduum fieri debet, dum omnis causa languoris discutiatur. Nan si neglecta cruditas est, et inflatio ventris et intestinorum major dolor insequitur, qui nec capere cibos sinit, gemilus exprimit, locoque stare non patitur, sæpe decumbere, et agitare caput, caudamque crebrius agere cogit. Manifestum renedium est proximam clunibus parten caudx vinculo reliementer obstringere, vinique sextariun cum olei liemina faucibus infundere atque ita citatum per mille et quingentos passus agere. Si dolor permanet, ungulas circumsecare, et uncta manu per anum inserta fimum extrahere, rursusque agere currentem. Si nec hoc profuit, tres caprifici aridi conteruntur, el cum dodrante aqua calida clantur. Ubi nec lıac medicina processit, myrti syl- restris foliorum duæ libræ lævigantur, totidemque sextarii calidæe aquæ misti per vas ligneum faucibis infunduntur. Atque ita sub cauda sanguis emittitur. Qui cum satis profluxit, iuhibetur papyri ligamine. Tum concitate agitur pecus eousque, dum anlielet. Sunt et ante detractionem sangninis illa remedia : Tribus lieminis vini tres uncix pinsiti allii permiscentur, et post eam potionem currere cogitur. Vel salis sextans cum cepis decem conteritur, et admisto melle decocto collyria immittuntur alvo, atque ita citatus los agitur.

VII. Ventris quoque et intestinorum dolor sedatur visu nantium et maxine anatis. Quam si conspexerit, cui intestinum dolet, celeriter tormento liberatur. Eadem anas najore profectu mulos et equinum genus conspectu suo sanat. Sed interdum nulla prodest medicina. Sequitur torıninum vitium, quorum signum est cruenta ef mucosa rentris proluvies. Remedio sunt cupressini quindecim coni, totidemque gallie, et utrorumque ponderis vetustissimıs caseus. Quibus in unum tunsis admiscentur austeri vini quatuor sextarii, qui pari mensura per quatriduum dispensati dantur : nec desint lentisci myrtique el oleastri cacumina viridis. Alsus corpus ac vires carpit, eperique 
son. S’il a les genoux enflés, on les bassinera avec du vinaigre ehaud, et on mettra dessus de la graine de lin ou du millet broyé, qu'on arrosera d'hydromel : il sera encore bon do lui appliquer sur les genoux des éponges trempées lans de l'eau bouillante et frottées de miel, en les pressant, et de les lui envelopper avee des bandages. S'il y a quelque humeur eachée sous l'enflure, on appliquera dessus du levain ou de Ia farine d'orge euite, soit dans du vin fait avee des raisins séehés au soleil, soit dans de l'hydromel; ensuite l'on attendra que l'apostume soit mûr, pour y appliquer le fer; et lorsqu'on en aura fait sortir le pus, on le pansera avec de la eharpic, ainsi que nous l'avons dit plus haut. Toute ouverture faite avee le fer peut également êtie guérie (suivant l'ordonnanee de Cornélius Celsus) avec de la raeine de lis, ou de la seille et du sel, ou de la renouée que les Grees appellent тoגúgovov, ou du marrube blane. Mais presque toutes les doulcurs du eorps qui ne șont ni oecasionnées par une blessure, ni invétérées, se dissipent mieux par les fomentations : quand elles sont aneiennes, on y applique le feu, et l'on fait distiller sur la partie brûlée du beurre ou de la graisse de chèvre.

XIII. La gale perd de sà malignité, lorsqu'elle est frottée d'ail bioyé : le même remède guérit les morsures des chiens enragés ou eelles des loups. Cependant eet aecident se guérit aussi bien avee de vieilles salaisons appliquées sur la plaie. Il y a eneorc un autre remède plus efficace pour la gale : on broie ensemble de l'origan et du soufre, et on les cuit avee de l'huile, de l'eau et du vinaigre, en y ajoutant de la lie d'huile; après quoi, lorsque cette composition est encore chaude, on la saupoudre d'alun de plume broyć. Ce médicament réussit très-bien

et. lini semen aut milium detritum conspersumque aqua mulsa imponendım - spongia quoque ferrenti aqua in. buta et expressa litaque melle recte genibus applicatur, ac fasciis circumdatur. Qnod si tumori subest aliquis humor, fermeritum rel farina ordeacea ex passo aut aqua mulsa decocta imponitur : et cum maturuerit s.uppuratio, rescinditur ferro, eaque emissa, ut supra docuimus, linamentis curatur. Possunt cliam, ut Cornelius Celsus pracipit, lihi radix aut scilla cum sale, vel sanguinalis lıerba, quam rohúyovov Graci appellant, vel marrubium ferro reclusa sanare. Fere antem omnis dolor corporis, si sine vulnere est, recens melius fomentis discutitur; retıs uritır, et supra ustum butyrum vel capritua instillatur adeps.

XIII. Scabies extenuatur trito allio defricta; eodemque remedio curatur rabiosæ canis vel lupi morsus, qui tamen et ipse imposito vulneri retere salsamento aeque bene sanatur. Et ad scabiem praesentior alia medicina est. Cunila lubula, et sulplıur conteruntur, admistaque amırca cum oleo atque aceto incoquuntur; deinde tepefactis scissum alımen tritun spargitur. Id medicamentum candente sole illitum maxime prodest. Ulceribus gallae tritar remedio
Iorsque l'on en frotte les bœufs à l'ardeur du soleil. Des noix de galle broyées remédient aux uleères, de même que du jus de marrube blane avee de la suic. II y a eneore une maladie dangereuse pour les bœuis, que les paysans ap. pellent coriago : eette maladic consiste en ee (que leur peau tient si fort à leur dos, (qu'en la prenant avee la main, on ne peut pas la séparer des eôtes. Cet aecident ne leur arrive jamais que lorsqu'ils sont tombés dans la maigreur à la suite de quelque maladie, ou que le froid a sueeédé chez eux à la sueur exeitée par le travail, ou en. fin lorsqu'ils ont été mouillés par la pluie dans le temps qu'ils étaient ehargés. Comme il n'y a rien de plus dangereux que eette maladie, il faut avoir soin, ponr la prévenir, de verser du vin sur les bœufs lorsqu'ils sont revenus de l'ouvrage, et qu'ils sont eneore échauffés et haletants, et de leur jeter dans la gorge des boulettes de graisse. Mais si eette maladic les tient déjà, il sera bon de faire bouillir dulaurier dans de l'eau, de leur bassiner le dos avee cette déeoction quand elle sera chaude, de le presser aussitôt en versant dessus une grande quantité d'huile et de vin, et de le manier partout, en tirant ia peau à soi. Cette opération sc fait très-bien à l'air et à l'ardeur du soleil. Il y a des personnes qui mélent ensemble du mare d'olives, du vin et de la graisse, et qui se servent de ec medicament après les fomentations que nous venons de preserirc.

XIV. C'est eneore une maladie très-grave que l'uleération des poumons : elle produit la toux, la maigreur, et finit par dégénérer en phthisie. Pour éviter que la mort ne s'ensuive, on leur introduit dans l'oreille, après l'a voir percée de la manière que nous avons enseignée plus haut, de la raeine de pommelée; après quoi on mêle la va-

suut; nec minus succus marrubii cum fuligine. Est et infesta pestis bubulo pecori, coriaginem rustici appellaut, cun pellis ita tergori adhacret, ut apprehensa manibus deduci a costis non possit. Ea res non aliter accilit, quam si bos aut ex languore aliquo ad maciem perductus est; aut sudans in opere faciendo refrixit, aut si sub onere pluvia madefactus est. Quxe quoniam peruiciosa sunt, custcdiendum est, ut cum ab opere boves redierint adluc aestuantes aulıelantesque, vino aspergantur, et offa arlipis faucibus corum inserantur. Quod si proedictım vitium inlıaserit, proderit decoquere laurum, et ea calda forere terga, multoque oleo et vino confestim subigere, ac per omues partes apprehendere et attralıere pellem. Idq̨ue optime fit sub dio, sole ferrente. Quidam fraces vino et adipi commiscent, coque medicanıento post fomenta pra. dicta utuntur.

XIV. Est etiam illa graris pernicies, cum pulmones exulcerantur. Inde tussis et macies, et ad ultimum plıthisis invadit. Quae ne mortem afferant, radix consiliginis ita, ut supra docuimus, perforatx auriculae inserifur, tum porri succus instar heminar pariolei mensurae mis. 
leur d'une hemina de jus de poireau avec pareille mesure d'huile, et on leur donne cette potion pendant plusieurs jours avec un sextarius de vin. Quelquefois le bouf, à cause d'unc enflure qui se trouve dans son palais, refuse la nourriture, jette de fréquents soupirs, et semble indécis sur le côté par lequel il tombera. Il faut alors lui déchirer le palais avec le fer pour en faire ruisseler le sang, et ne lui douner jusqu'à sa guérison que de l'ers écossé et détrempé, du fcuillage vert, ou de tout autre fourrage mollet. Sil a cu le cou meurtri dans le travail, le remède le plus efficace sera de lui tirer du sang de l'oreille; ou si on ne l'a pas fait à temps, d'y appliquer de l'herbe qu'on appelle avia, broyée avec du sel. S'il a eu la nuque ébranlée, et que cette partie se soit déjetée, on examinera de quel cóté le cou penchera, et on lui tirera du sang de l'oreille opposée; mais il faut auparavant battre d̀ coups de sarments la veine de cette oreille qui paraitra la plus saillante; ensuite, lorsque les coups l'auront fait gonfler, on l'ouvrira avec un petit couteau : le lendemain, on lui tirera encore du sang du même endroit, et on le dispensera de travailler pendant deux jours. Le troisième jour, on lui donnera unc tâche légère, et peu à peu on l'amènera à sa tâche ordinaire. Mais si la nuque, sans étre déjetée d'aucun côté, est enflée dans le milieu, on lui tirera du sang des deux oreilles. Si on négligeait de lui en tirer sous les deux jours qui suivront cet accident, le cou s'enflerait, les nerfs se tendraient, et il se formerait une dureté qui l'empêcherait de souffrir le joug. Nous avons découvert un remède excellent pour cette maladie, qui est composé de poix fondue, de moelle de bœuf, de suif de bouc et de vieille huile, le tout cuit ensemble à doses égrales. Voici comment on

cetur, et cum vini sextario potandus datur diebus complu. ribus. Interdum et tumor palati cibos respuit, crebrumque suspirium facil, et hanc speciem prabet, ut bos in latus pendere videatur. Ferro palatum opus est sauciare, ut sanguis prufluat, et exemptum valvulis ervum macera. tum, viridemque frondem, vel aliud molle pabulum, dum sanetur prabere. Si in opere collum contuderit, pra. sentissimum est remedium sanguis de aure emissus : aut si id factum non erit, herba, quæ vocatur avia, cum sale trita et imposita. Si cervix mota et dejecta est, conside. rabimus quam in partem declinet, et ex diversa auricula sanguinem detrahemus. Ea porro veua, quæ in aure videtur esse amplissima, saruento prius verberatur. Dein. de cunı ad ictum intumuit, cultello solvitur; et postero die iterum ex eodem loco sanguis enittitur, ac biduo ab opere datur vacatio. Tertio deinde die levis iujungitur labor, el paulatim ad justa perducitur. Quod si cervix in neutram partem dejecta est, mediaque intumuit, ex utraque auricula sanguis emittitur. Qui cum intra triduum, cum bos vitiun cepit, eınissus non est, intumescit collum, nerrique tenduntur, et inde nata durities jugum uon patitur. Tali vitio comperinus aureum esse nıedi. se servira de cette composition : Lorsquon aura dételé le bouf après son travail, on baignera la tumeur de sa nuque dans l'abreuvoir où il ira boire; et avant qu'elle soit entièrement séchée, on la frottera et on l'oindra avec ce médicament. Si l'animal refuse absolument le joug à cause de cette tumeur, il faut le laisser reposer pendant quelques jours sans le mettre au travail; après quoi on lui frottera le cou avec de l'eau froide, et on l'oindra avec de l'écume d'argent. Celsus se contente d'ordonner de mettre sur le cou, quand il est enflé, de l'herbe que l'on appelle avia broyée, comme je l'ai dit ci-dessus. Les clous qui infectent souvent le cou du bouf sont moins difficiles à guérir : car il est aisé de faire couler dessus goutte à goutte de l'huile d'une lampe allumée; il sera cependant mieux d'empêcher que ces clous ne se forment, ou que le cou des bœufs ne devienne chauve, ce qui n'arrive jamais que lorsqu'ils l'ont eu mouillé pendant le travail, soit par la sueur, soit par la pluie. Mais lorsque cet accident sera arrivé, on leur saupoudrela le cou de limaille de tuile avant de les dételer; ensuite, lorsque leur cou sera sec, on le mouillera de temps en temps avec de l'huile.

$X V$. Si le soc de la charrue a blessé un bœuf au talon ou à la corne du pied, faites fondre sur la blessure, par le moyen d'un fer chaud, de la poix dure et de la graisse de pore, enveloppées dans de la laine encore grasse avec du soufre. Le même rèmède est encore excellent à employer lorsqu'uu bœuf aura marché par hasard sur un chicot d'arbre, pourvu que l'on commence par retirer l'éclat qui lui sera entré dans le p.ed, ou lorsqu'il aura donne de la corne

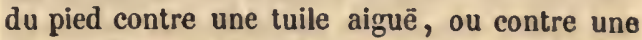
pierre. Si cependant la blessure est profonde,

camentum ex pice liquida et bubula medulla et hircino sevo et retere oleo aequis ponderibus compositum atque incoctum. Hac compositione sic utendum est. Cum disjun. gitur ab opere, in ea piscina, ex qua bibit, tumor cervi. cis aqua madefactus subigitur, prædictogue medicamento defricatur et illinitur. Si ex toto propter cervicis tumorem jugum recuset, paucis diebus requies ab opere danda est. Tum cervix aqua frigida defricanda, et spuma argenti illinenda est. Celsus quidem tumenti cervici herbam, quæ vocatur Avia, ut supra dixi, contundi et imponi jubet. Clavorum, qui fere cervicem infestant, minor molestia est : nam facile oleo per ardentem lucernam instillato curantur. Potior tamen ratio est custodieudi, ne nascantur, neve colla calvescant, qua non aliter glabra fiunt, nisi cum sudore aut pluvia cervix in opere nadefacta est. Itaque cum id accidit, lateritio trito prius, quam disjungantur, colla conspergi oportet : deinde cum id siccum erit, subinde oleo imbui.

XV. Si talum aut ungulam vomer laserit, picem duran et axungian cum sulfure el lana succida involutam candente ferro supra vulıus inurito. Quod idem remediuu optime facit exempta stirpe, si forte surculun calcaverıt, 
on la cerne à quelque distance avec le fer; après quoi on $y$ applique le fell, comme je l'ai preserit ci-dessus. Ensuite on la panse pendant trois jours en y versant du vinaigre, et en chaussant le pied de l'animal d'une bottine de genêt d'Espagne. Si le soc de la cliarrue lui a de même blessé la jambe, on met sur la plaie de la laitue de mer, que les Grees appellent ri0úrxiov, avee du sel. Lorsque les bœufs ont les pieds usés par-dessous, on les lave dans de l'urine de bouf que l'on a soin de faire chauffer, ensuite on allume une poignée de sarments; et lorsque le feu en est éteint, et quiil ne reste plus que de la cendre chaude, on les force de mareher dessus, et on leur frotte la corne du pied avee de la poix fondue et de l'huile, ou de la graisse de porc. Cependant les bocufs seront moins exposés à boiter, si , après les avoir dételés au sortir du travail, on leur làve les pieds daus unc grande quantité d'cau froide, et qu'on leur frotte avec du vieux oing les paturons, la couronne, et la séparation mème qui est entre les deux colnes du pied.

XVI. Il arrive eneore souvent au bœuf de se déboîter l'épaule, soit par la fatigue que lui aura oceasionnée un trop long travail, soit pour avoir fait de violents efforts en fendant un terrain trop dur, ou en reneontrant une raeine sur son passage. Il faut alors lui tirer du sang des jambes de devant, savoir, de la gauehe s'il s'est blessé l'épaule droite, et de la droite s'il s'est blessé l'épaule gauehe, ou même s'il s'est grièvement blessé les deux épaules; il faut de plus lui ouvrir les veines des jambes de derrière. Lorsqu'il a les cornes brisées, on les enveloppe de linges trempés dans de l'huile, du vinaigre et du scl, dont on les imbibe pendant trois jours consécutifs sans les développer; le quatrième jour,

aut acuta testa vel lapide ungulam pertuderit; quæ tamen si altius vulnerata est, latius ferro circumciditur, et ita inuritur, ut supra praccepi : lleinde spartea calceata per Iridnum suffuso aceto curatur. Iten si vomer crus salı.

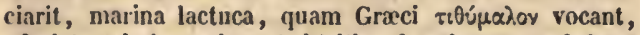
armisto sale imponitur. Subtriti pedes eluuntur calefacta bubula urina : deinde fasce sarmentorum incenso, cum jan ignis in favillam recidit, ferventibus cineribus cogitur insistere, ac pice liquida cum oleo vel axungia cornua ejus linuntur. Minus tanien claudicabunt armenta, si opere disjunctis multa frigida laventur pedes; et deinde suffragines, coronæe, ac discrimen ipsum, quo divisa est bovis ungula, vetere axungia defricentur.

XYI. Sxpe etian vel gravitate longi laboris, vel [cum] in proscindendo, aut duriori solo, aut obviae radici ob. luctatus, convellit armos. Quod cum accidit, e prioribus cruribus sanguis nittendus est : si dextrum armum læsit, in sinistro; si lavum, in dextro; si velıementius utrumque vitiavit, item in posterioribus crusibus venx solven. tur. Præfractis cornibus linteola sale atque aceto et oleo imbuta superponuntur, ligatisque per triduium eadem in. funduntur. Quarto demım axungia pari pondere cum on y met de la graisse de pore avee de la poix fondue en parties égales, et de l'ćcorce de pin pulvérisée; et enfin lorsqu'elles commencent à se cicatriser, on les saupoudre de suie. Les uleères négligés engendrent aussi souvent des vers : il suffit de verser le matin de l'eau froide sur ces vers, afin que la fraleheur de cette eau les resserre et les fasse mourir. Si on ne peut pas les fairc périr par ce moyen, on y applique du marrube blane, ou du poireau broyé avec du sel; c'est un poison qui les tue très-promptement. Mais dès que les uleères sont nettoyés, il faut tout de suite y mettre de la charpie avee de la poix, de l'huile et du vieux oing, et frotter même de ce médieament les parties circonvoisines, de peur qu'elles ne soient tourmentées par les mouelies, qui engendrent des vers pour peu qu'elles se posent sur les uleères.

XVII. La morsure d'un serpent est aussi mortelle aux bœufs, de mème que le venin empoisonné d'animaux plus petits, puisqu'il arrive souvent, lorsqu'un bouf est couclıé imprudemment au milieu des pâturages sur des vipères et sur des orvets, que ces animaux, fatigués de sa masse, le mordent. La musaraigne elle-mème que les Grees appellent $\mu u \gamma \alpha \lambda \tilde{n}$, quoiqu'elle ne soit armée que de petites dents, ne laisse pas que de leur donner une maladie dangereuse. On dissipe le venin de la vipère en scarifiant avec le fer la partie qui en est imprégnée, et en mettant sur la partie searifiée de l'herbe que l'on appelle personata (de la bardane) pilée avec du sel. Sa racine broyée est eneore plus utile, ainsi que le sésẻli de montagne. Le trèfle que l'on trouve dans les lieux pierreux passe pour très-efficace. Il a l'odeur forte, et assez semblable à celle du bitume,

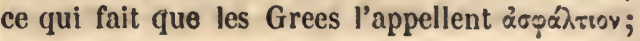

pice liquida, et cortice pineo, levigata imponitur. Et ad ultimum cum jam cicatricem ducunt, fuligo infricatur. Solent etiam neglecta ulcera scatere verminibus : qui si mane perfunduntur aqua frigida, rigore contracti decidunt. Vel si laac ratione non possunt eximi, unarrubium aut porrum conteritur, et admisto sale imponitur. Id ce. Jerrime necat prædicta animalia. Sed expurgat is ulceribus confestim adluibenda sunt linamenta cum pice et oleo vetereque axungia, el extra vulnera codem medicamento circumlinienda ; ne infestentur a muscis , quæe ubi ulceribus insederunt, vermes creant.

XVII. Est etiam mortiferus serpentis ictus, est et minorum animalium noxium virus. Nam et vipera et cxecilia sape cum in pascuo bos improvide supercubuit, lacessita onere morsum imprimit. Musque araneus, quem Graci

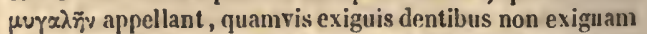
pestem molitur. Venena viperæe depellit super scarifica. tionem ferro factam lierba, quam vocant personatanı, trita et cum sale imposita. Plus etiam ejusdem radix contusa prodest, vel si montanum trifolium invenifur, qunil confragosis locis efficacissimum nascitur, odoris gravis,

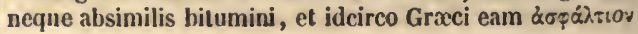


mais les habitants de notre pays lui donnent le nom de trèfle aigu à eause de sa figurc, paree qu'il a les feuilles longues et hérissées; mais sa tige est plus robuste que eelle du trèfle des prés. On mêle du jus de cette heıbe avee du vin, et on en verse dans la gorge des bœufs : on file aussi ses feuilles avee du sel, et on les étend sur la partie scarifiée en forme d'emplâtre émollient. Si l'on est dans un temps de l'année où l'on ne puisse pas trouver de cette herbe qui soit verte, on leur donne à boire du vin dans lequel on aura fait infuser de la graine de cette même herbc pulvérisée, et on en met sur la partie scarifiće les racines broyées avee la tiq̣e, et mêlées de farine et de sel délayés dans de I hydromel. Il y a eneore un remède efficaee, qui eonsiste à broyer cinq livres de cimes tendres de frêne avec cinq sextarii do vin et deux d'huile, et à leur verser dans la gorge le jus que l'on en aura exprimé, en mettant en même temps sur la partie blessée des cimes de eet arbre broyées avec du sel. La morsure de l'orvet oceasionne une tumeur et une suppuration, de même que eelle de la musaraigne; mais on guérit la première avee le secours d'une alêne de cuivre dont on pique la partie blessée, après quoi on l'enduit d'argile de cimolos délayée dans du vinaigre; au licu que la musaraigne paye de son corps même le mal qu'elle a fait. En effet on la fait mourir en la noyant dans de l'huile, et lorsqu'elle est macérée, on la pile, et l'on s'en sert eomme d'un médicament pour oindre la partie qu'elle a mordue; si l'on n'en a point sous sa main au moment que la tumeur annonce que le bœuf a été mordu, on broie du eumin, auquel on ajoute un peu de poix fondue et de graisse de porc, afin de lui donner la consistance

appellant; nostri autem propter figuram vocant acutum trifolium : nam longis et lirsutis foliis viret, caulemque tobustiorem facit, quam pratense. Hujus herbxe succus vino mistus infunditur faucibus, atque ipsa folia cum sale trita malagmatis more, scarificationi intenditur : rel si hauc herbam viridem tempus anni negat, semina cjus collecta et levigata cum vino dantur potanda, radicesque cum suo caule trita, atque hordeacea farinx et sali commista ex aqua mulsa scarificationi superpounntur. Est etiam prasens remedium, si conteras fraxini tenera ca. cumina quinque librarum, cum totidem vini et duobus sextariis olei, expressumque succum faucibus infundas; itemque cacumina ejusdem arboris cum sale trita lacsa parti superponas. Cæciliæ morsus tumorem, suppurationemque molitur. Idem facit etiam nuris aranei. Sed illius sanatur nova subula anea, si locum lasum compungas, cretaque cimolia ex aceto linas. Mus perniciem, quan, intulit, sno corpore luit : nam animal ijsum oleo mersum necatur, et cum impulruit, conteritur, coque medicamine morsus muris aranei linitur. Vel si id non adest, tumor. que ostendit injuriam dentium, cuminum conteritur, eique adjicitur exigum picis liquidae el axungise, ut néeessaire pour en faire un emplâtre, que l'on élend sur la plaie et qui en chasse tout le venin. Si la tumeur, avant de se dissoudre, se tourne en suppuration, il est très-bnn de l'ouvrir avee une lame de fer rouge, dans le temps que la sup. puration s'établit, et do brûler tout ce qu'il $\mathbf{y}$ aura de corrompu, en le frottant ensuite avec de la poix fondue et de l'huile. On est aussi dans l'usage d'ensevelir l'animal tout vivant dans de la terre à potier ; et lor'sque cette terre est séchée, on la sus. pend au eou des boufs. Cc traitement empeche que la morsure de la musaraigne ne leur cause aucun dommage. On guérit communément les maladies des yeux avee du miel, puisque s'ils sont enflés, on met dessus de l'hydiromel, dans lequel on aura jeté de la farine de froment : si l'on y aperçoit une taie, on la fera presque entièrement disparaitre avee du sel de montagne, du sel d'Espagne ou du sel ammoniac, ou même avee du sel de Cappadoce broyé bien menu, et melé avec du miel. Un os de sèehe broyé, dont on soufflera trois fois par jour dans l'œil avee un tuyáu, fera le mème effet, ainsi que la racine que les Grees appellent $\sigma$ ínọiov, et que le vulgaire nomme dans notrc langue laserpitium (laser). On en broie également tant et si peu que l'on veut, en y ajoutant dix fois autant de sel ammoniac, et on en souffle de même daus l'œil ; ou bien on écrase cette racine, et on l'applique sur l'œil après l'avoir trempée dans de l'huile de lentisque, et ellc chasse eette maladie. On guérira les fluxions en mettant sur les sourcils et sur les joues du gruau, sur lequel on aura versé de l'hydromel. La graine de panais sauvage, ainsi que lc jus de cram, appliquć sur les yeux avee du miel, en apaisera aussi la douleur. Mais tou. tes les fois qu'il entrera du miel ou d'autres sues

lentorem malagmatis habeat. Id impositum perniciem commovet. Vel si antequam tunor discutiatur, in suppurationem convertitur, oplimum est ignea lanina conversionem resccare, et quicquid vitiosi est, inurere, atque ita liquirla pice cum oleo linire. Solet etian ipsum animal rivum creta figulari circumdari; quae cum siccata est, collo boum suspenditur. Fa res innoxinm pecus a morsu muris aranei prabet. Oculorum vitia plerumque melle sanantur. Nam sive intumuerunt, aqua mulsa tritices farina conspergitur et imponitur : sive albun in oculo est, montanus sal Ilispanus vel Ammoniacus vel etiam Cappadocus, minute tritus et immistus melli vitium extc. nuat. Facit idem trita sepix testa, et per fistulan ter die oculo inspirata. Facit et radix, quam Graee oil.p̨ov vocant, vulgus autem nostra consueludine laserpitiun appellant. Hujus quantocunque ponderi decima pars salis anunoniaci adjicitur, eacpue pariter trita oculo similiter infunduntur, vel eadein radix contusa et cum oleo Ienlisci inuncta vi. tium expurgat. epiphoram supprimit polenta conspersa mulsa aqua, et in supercilia genastye imposita, pastinace. quorque agrestis senina, et suecus armoracex, cuin melle lavigata oculorum sedant dolorem. Sed puotiescunçue 
dans les remèdes qu'on emploiera, il faudra oindre les partles circonvoisines de l'œil avec de la poix fondue et de l'huile, pour empêcher qu'il ne soit molesté par les mouches, qui ne sont pas les seules que la douceur du miel et des autres médicaments y attirerait, puisque les abeilles y viendraient également.

XV́III. II arrive encore souvent qu'un bœuf avale une sangsue cachée dans l'cau qu'il boit, ce qui lui occasionne une maladie grave, parce que cet insecte s'attachant à sa gorge lui suce le sang, et que, venant à grossir, il finit par boucher tout passage à la nourriturc. Si cette sangsue est dans un endroit assez difficile pour qu'on ne puisse pas la retircr avec la main, on y insérera un thyau ou un roseau, à travers lequel on fera couler de l'huile chaude, qui fera mourir cet insecte dès qu'il cn sera atteint. On peut aussi faire parvenir jusque là à travers un tuyau l'odeur de la fumée de punaises brûlées. En effet, dès que cette vermine est sur le feu, elle jette une fumce qui, venant à remplir le tuyau de son odeur, fait parvenir cette odeur jusqu'à la sangsue, et la chasse de l'endroit auquel elle est adhérente. Mais si elle se trouvait collée aux parois de l'estomac ou aux intestins, on la ferait mourir en faisant avaler au bouf du vinaigre chaud par le moyen d'une corne. Quoique ce soit à l'usage des boufs que nous ayons prescrit tous les remèdes dont nous venons de donner le détail, il n'est point douteux néanmoins que la plus grande partie deces remèdes ne puisse également convenir à tous les autres bestiaux.

XIX. Mais il faut aussi fabriquer une machine, dans laquelle on enfermera les bêtes de somme et les boufs pour les panser, afin que les médecins vétérinaires puissent approcher d'eux en sécurité, et que ces quadrupèdes ne puissent pas, pendant

mel aliusve succus remedis adlibetur, circumliniendus erit oculus pice liquida cum oleo, ne a muscis infestetur. Nam et ad dulcedinem mellis aliorumque medicameutorum non hae solac, sed et apes advolant.

XVIII. Magnam etiam perniciem sæe affert lirudo hausta cım aqua. Ea adlıcrens faucibus sanguinem ducit, et incremento suo transitum cibis pracludit. Si tam diffi. cili loco est, ut manu trali non possit, fistulam vel aruudinem inserito, et ita calidum oleum infundito : nam co contactum animal confestim decidit. Potest etiam per fistulam deusti cimicis nidor immitti : qui нbi superponitur igni, fumum emittit, et conceptum nidorem fistula usque ad hirudincm perfert ; isque nidor depellit haerentem. Si tamen vel stomachum vel intestinum tcnet, calido aceto per cornu infuso necatur. Has medicinas quamvis bubus adlibendas præceperim, posse tamen ex lis plurima etiam omni majori pecori convenire nilıil dubium est.

XIX. Sed et machina fabricanda est, qua clausa, jumenta bovesque curentur, ut et tutus accessus arl pecudem medenti sit, nec in ipsa curatione quadrupes reluctando remedia respuat. Est autem talis machinæ forma. Roboreis le pansement résister aux remèdes en se débattant. Or, voici la forme de cette machine. On planchéie en bois de robre un espace de terrain long de neuf pieds, et large de deux et demi sur le devant ct de quatre sur le derrière. On plante sur la longueur de ce terrain quatre poteaux de droite et de gauche, chacun de sept pieds de haut, de façon qu'il y en ait un de fixé à chaque angle du terrain. Tous ces poteaux sont joints entre eux en forme de vacerrce (espèce de treillis) par six traverses, de façon que le quadrupède puisse être introduit par le côté de derrière, qui est le plus large, dans cette enceinte, coinme dans une cage dont il ne pourra pas sortir par l'autre côté, à cause des barres qui seront vis-àvis pour l'en empêcher. On attache en outre un joug aux deux poteaux de devant, et c'est à ce joug qu'on assujectit les bètes de somme, on qu'on lie les bœufs par les cornes. On peut aussi y fabriquer des carcans dans lesquels on insérera leur tête, de sorte qu'en faisant descendre des chevilles dans des trous que l'on y aura mėnagés, leur chignon soit tenu en respect. Le reste du corps sera bien étendu, et lié avec des cordes qui le retiendront aux traverses, de manière que l'animal restant immobile ne pourra pas résister ì la volonté de celui qui le pansera. Cette machine servira pour tous les grands quadrupèdes.

$\mathrm{XX}$. Comme nous avons donné assez de préceptes sur les bœufs, il est temps que nous parlions des faureaux et des vaches. J'estime qu'il faut préférer aux autres les taureaux dont les membres sont très-amples ct les mœurs pacifiques, et qui ne sont ni trop jeunes ni trop vieur. Quant au surplus, on observera à peu près, en les choisissant, toutes les règles que l'on observe dans le choix des boufs. Car un bon taureau ne differe pas autrement de celui qui est châtré, si

axibus compingitur solum, quod habet in longitudinem pedes novem, et in latitudinem pars prior dupondium semissem, pars posterior quatuor pedes. Huic solo septenum pedım stipites recti ab utroque latere quaterni applicantur. Ii autem in ipsis quatıor angulis affixi sunt, omnesque transversis sex temonibus quasi vacerro inler se ligantur, ita ut a posteriore parte, qua latior est, velıt in cavcam quadrupes possit induci, nec exire alia parte prolibentibus adversis axiculis. Primis autem duobus statuminibus imponitur firmum jugum, ad quod jumenta capistrantur, vel boum cornua religantur. Ubi potest ctian numella fabricari, ut inserto capile descendentibus per foramina regulis cervix catenctur. Caterum corpus laqueatum et distentum temonibus obligatur, immotumque medentis arbitrio est expositum. Ixec ipsa machina communis crit omnium majorum quadrupedum.

XX. Quoniam de bubus satis procepimus, opportune de tauris vaccisque dicemus. Tauros maxime inembris amplissimis, moribus placidis, media setate probandos censeo. Cæetera fere omnia eadem in his observabiums, quise in bubus eligendis. Neque euim alio distat honus 
ce n'est qu'il a le regard de travers, l'air plus vigoureux, les cornes plus courtes, le chignon plus charnu, et assez gros pour que cette partie fasse à elle seule la plus considérable partie de son corps; enfiu le ventre un peu serré, de façon qu'étant dressé sur ses pieds, il soit plus propre à couvrir les vaches.

XXI. On approuve aussi les vaches qui sont d'une taille très-haute et allongée, et qui ont le ventre très-grand, le front très-large, les yeux noirs et ouverts, les cornes belles, lisses et noiratres, les oreilles velues, les máchoires serrées, lc fanon très-long ainsi que la queue, la corne du pied et les jambes de moyenne grandeur. On désire aussi pour le surplus à peu près les mêmes qualités dans les femelles que dans les mâles, et surtout qu'elles soient jeunes, parce que, lorsqu'elles ont passé dix ans, clles ne sont plus propres à la génération; d'un autre côté, il ne faut pas les faire couvrir avant l'âge de deux ans. Si cependant il arrive qu'elles soient pleines avant cet âge, il faut leur enlever leur veau, et leur presser le pis pendant trois jours, de peur qu'elles ne tombent malades, et ensuite cesser de les traire.

XXII. On doit aussi avoir soin de faire un choix toutes les années dans ce bétail, ainsi qu'on le pratique à l'égard de toutes les autres espèces de troupeaux. Car il faut retirer du troupeau celles qui, étant épuisées ou vieilles, ne peuvent plus concevoir, et encore plus celles qui, étant naturellement stériles, y tiennent la place d'autres qui seraient fécondes, à moins qu'on ne dompte ces dernières pour les mettre à la charrue, parce qu'attendu leur stérilité, elles ne souffrent pas moins le travail et l'ouvrage que les jeunes bœufs. Ces sortes de bestiaux aiment pendant l'hiver

taurus a castrato, nisi quod huic torva facies est, vegetior aspectus, breviora cornua, torosior cervix, et ita vasta, ut sit maxima portio corporis, venter paulo substrictior, qui magis rectus et ad ineundas fominas habilis sit.

XXI. Vaccæ quoque probantur altissimn formæ longæque, maximis uteris, frontibus latissimis, oculis nigris et patentibus, cornibus renustis et levibus et nigrantibus, pilosis auribus, compressis malis, palearibus et caudis amplissimis, ungulis modicis, et modicis cruribus. Cætera unoque fere eadem in faminis, quæe et in maribus, de. siderantur, et pracipue ut sint novella : quoniam, eum excessernnt annos decem, fortibus inutiles sunt. Rursus minores bimis iniri nun oportet. Si ante tamen conceperint, partum carum removeri placet, ac per triduum, ne laborent, ubera exprimi, postea mulctra prohiberi.

XXII. Sed et curandum est omnibus annis [in lioc] $\mathfrak{x}-$ que atque in reliquis gregibus pecoris, ut delectus labeatur. Nam et enixæ et vetustate quæe gignere desierunt, suminovendae sint, et utique tauræ, qua locum foccundarum nccupant, ablegandxe vel aratro domandx; quoniam laboris et operis non minus quam juvenci, propter les paturages maritimes et qui sont exposés ausoleil; mais en été ils préferent ceux des forèts les plus couvertes et des montagnes les plus élevées à ceux des plaines. En effet, les jeunes vaches vivent plus longtemps dans des forets pleines d'herbages, dans des taillis et dans des lieux plantés de glaĩeuls, que partout ailleurs. La corne de leurs pieds se conserve mieux dans des lieux secs et pleins de pierres. Elles n'aiment pas autant les fleuves et les ruisseaux que les réservoirs. d'eau artificiels, parce que l'eau des fleuves, qui communément est très-fraiche, les fait avorter, au lieu que celle du ciel leur est plus agréable. Cependant les vaches souffrent plus aisément que les chevaux le froid du dehors; aussi passent-elles aisément l'hiver en plein air.

XXIII. Mais il faut leur faire des enclos d'une vaste étendue, de peur qu'étant renfermées dans un espace trop resserré, elles ne détruisent leur fruit mutuellement, et afin que les plus faibles. puissent se dérober aux coups des plus fortes. Les meilleures étables sont celles qui sont pavées . ou couvertes de gravier, quoique celles qui sont sablées ne soient pas mauvaises, les unes parce qu'elles n'admettent point l'eau de la pluje, les autres parce qu'elles s'en imbibent trop promptement; mais il faut que les unes et les autres soient en pente pour donner de l'écoulement d̀ l'humidité, et tournées au midi, afin de se sécher faci. lement, et de n'être point incommodées par les vents froids. Les pacages de ce bétail ne demandent pas de grands soins, puisque, pour que. l'herbe $y$ lève avec plus d'abondance, on se contente ordinairement d'y mettre le feu à la fin de l'été; parce que cette méthode fait repousser des pâturages plus tendres, et que d'ailleurs, en brûlant les ronces, elle empêche les broussailles de-

uteri sterilitatem patientes sunt. Ejusmodi armentum ma. ritima et aprica hiberna desiderat; æestate opacissima nemorum, ac montium alta magis quam plana pasciar. Nam melius nemoribus herbidis et frutetis et careetis... quoniam siccis ac lapidosis locis durantur ungula. Nec tam fluvios rivosque desiderat, quam lacus manu factos; quoniam et fluvialis aqua, qua fere figidior est, par. tum abigit, et calestis jucundior est. Omnis tamen externi frigoris tolerantior equino armento vacca est, ideoque facile sub dio libernat.

XXIII. Sed laxo spatio consepta facienda sunt, ne in. angustiis conceptun altera alterius elidat; et ut invalida. fortioris ictus effugiat. Stabula sunt optima saxo aut gla. rea strata, non incommoda tamen etiam sabulosa. IHa, quod imbres respuant; lıæc, quod celeriter exsorbeant, transmittantque. Sed utraque derexa sint, ut lumorem effundant; spectentque ad meridiem, ut facile siccentur, et frigidis rentis non sint obnoxia. Levis autem cura pascui est. Nam ut latior lierba consurgat, fere ultimo tempore restatis incenditur. Ea res et teneriora pabula recreat, et sentibus ustis fruticem surrecturum in altitudinem compes. cit. Ipsis vero corporibus affert salubritaten juxta consep. 
monter trop haut, comme clles le feraient sans cette précaution. Mais une chose qui contribuc beaucoup à la santé de leur corps, èest de mettre du sel auprès de leur enclos sur des pierres et dans des auges, dont elles s'approchent volontiers lorsqu'elles sont rassasiées de pâture, et que l'on sonne, pour ainsi dire, la retraite avec le signal usitć parmi les pâtres. Car il faut toujours avoir soin d'accoutumer celles (jui pourraient êtrc restées dans les forêts, à regagner leur enclos vers l'entréc de la nuit, au son du cor. De cette manière on pourra faire la revue du troupeau et le compter, pour s'assurer, ainsi qu'on le pratique dans la discipline militaire, si toutes les bêtes sont dans l'étable. On n'exerce pas néanmoins le même empire sur les taureaux, qui, se fiant sur leurs propres forces, crrent à leur gré dans les forêts, et auxquels on laissc la liberté d'aller et de revenir comme bon leur semble, sans les rappeler jamais, si ce n'est quand il s'agit de leur faire couvrir les vaches.

XXIV. On ne fait point saillir les taureaux qui ont moins de quatre ans, non plus que ceux qui cn ont plus de douze : ceux-là parce qu'étant, pour ainsi dire, dans l'eufance, ils sont regardés comme peu propres à peupler le troupeau ; ceuxci parce qu'ils sont épuisés par la vieillesse. On permet ordinairement aux mâles d'approcher des femelles au mois de juillet, afin que celles-ci étant remplies en ce temps-là, vêlent au printemps suivant, lorsque les pâturages seront déjà dans leur force, puisque leur portce est de dix mois. Elles ne souffrent pas l'approche du mâle qui leur aura été imposé par un maître, mais elles le rccherchent d'elles-mèmes : or c'est à peu près au temps que je viens de fixer que se rapportent chez elles les désirs naturels, parce qu'étant égayées par l'abondance des pâturages que leur a fournis le printemps, elles commenecnt alors

tum saxis et canalibus sal superjectus, ad quem saturx [xaluulo libenter recurrunt, cum pastorali signo quasi re. ceptui canitur. Nam id quoque semper crepusculo fieri lelet, ut ad sonum buccinx pecus, si quod in silvis sub. stiterit, septa repetere consuescat Sic enim recognosci grex poterit, numerusque constare si velut ex nilitari disciplina intra stabulorum castra manseriut. Sed non eadem in tauros exercentur imperia, qui freti viribus per nemora vagautur, liberos(pue egressus et reditus habent, nec revocantur nisi ad coitus fominarum.

XXIV. Ex his, qui quadrimis minores sunt, majoresque quam duodecim annorum, prohilentur adnissura : illi, quoniam quasi puerili atate seminandis armentis parum idonei hahentur; hi, quia senio sunt effuti. Mense Inlio foeminxe uraribus plerumqne permittende, .ut eo tempore conceptos jroximo vere adultis jam pabulis edant. Nam decem mensibus ventrem perferunt, neque ex imperio inagistri, sed sua sponte marem patiuntur. Atque in id fere ynod dixi tempus, natıralia congrumat desideria, quoniam satietate verni pabuli pecudes exlilarata lasci- à devenir laseives. Si la femelle refuse le mảle, ou que le taureau n'éprouve pas de désirs pour clle, on excite leur ardeur de la même manière qu'on excite celle des chevaux qui témoignent du dégoût pour les cavales, e'cst à-dirc, en portant à leurs narines l'odcur des parties génitales. Mais on a soin aussi de diminuer la nourriture des femelles vers le temps où elles doivent être couvertes, de peur que le trop grand embonpoint no les rende stériles, comme on a soin au contraire d'augmenter la ration des taureaux, afin qu'ils montrent plus de vigucur dans l'acte. Un mâle suffit à quinze vaches; et lorsqu'il a sailli une génisse, on peut reconnaitic d̀ certalns signes de quel sexe sera le produit qul en résultera. Nous disons qu'il a engendré un mâle, s'il s'est retirú par le côtć droit au sortir de l'accouplement, et une femelle, s'il s'est retirć par le côté gauehc; quoiqu'on ne puisse compter sur l'infaillibilite de ces signes que dans le cas où la vache, étant remplie au premier acte de copulation, ne se laissera plus approcher ensuite par le taureau; ce qui arrive rarement, parce que quelque plcine qu'elle soit, elle n'est pas encore rassasice de plaisir : tant il est vrai que les attraits flatteurs de la volupté étendent communément leur cmpire sur les bestiaux eux-mèmes, au delà des termes preserits par la nature. II n est point douteux que, dans les pays où les pâturages sontabondants, on ue puisse élever chaque année un veau de la. même vache, au licu que, dans ceux où il cn. manque, on ne doit faire couvrir les vaches que. de deux années l'une; ce qu'il faut surtout ob-. server à l'égard de celles qui sont employées à travailler, tant afin que les veaux puissent se rassasier de lait pendant une année entière, qu'afin que la vache, étant pleine, ne se trouve pas surchargée daus le même temps par le poids de l'ouvrage et celui de son ventre. Lorsqu'une vache

viunt in venerem, quam si aut fomina recusat, aut non appetit taurus, eadem ratione, qua fastidientibus equis mox praecipiemus, elicitur cupiditas odore genitalium admoto naribus. Sed et pabulum circa tenupus admissura subtralitur fuminis, ne eas steriles reddat nimia corporis obesitas; et tauris adjicitur, quo fortius ineant. Ununique marem quindecim vaccis sıflicere abunde est. Qui ubi juvencan supervenit, certis signis comprehendere licct, quem sexum generaverit : quoniam si parte dextra desi . luit, marem seminasse manifestum est ; si læva, fouminan. Id tamen verum esse non aliter apparet, quam si post ınum coitum forda non admittit taurum : quod et ipsum raro accidit. Nam quamvis plena foetu non expletur libidine: adeo ultra naturse terminos etiam in pecudibus plurinum pollent blandx voluptatis illecebro. Sed non dubium est, ubi pabuli sit latitia, posse omnibus amis partum edncari; at ubi penuria eff, alternis subınitti : quool maxime in operariis vaccis fieri placet, ut et vituli aunui temporis spatio lacte satientur, nec forda simul operis et uteri gravetur onere. Qua cum partum cdidit, nisi cilbis 
a mis bas, quelque bonne nourriee qu'elle soit, elle laissera manquer son vcau dialiments, si on ne la soutient pas par une nourriture abondante, vu la fatigue que lui occasionnera son état de souffrance. C'est pourquoi on lui donnera, après qu'elle aura vêlé, du cytise vert, de l'orge grillée et de l'ers détrempé, ou bien une paitc faite avec des herbes potagères tendres, auxquelles on ajoutera de la farine de millet grillée, et infusée pendant une nuit dans du lait. On préfère aux autres vaches, pour ce qui concerne la nourriture de leurs veaux, celles des Alpes, que les habitants de ces contrées appellent Cevœ : elles sont de petite taille et abondantes en lait, raison pour laquelle on leur retire leurs veaux, pour leur faire nourrir de tres-bon bétail qu'elles n'ont point porté. Si l'on n'a pas cette ressource pour la nourriture des veaux, on les nourrira de fèves broyées : on peut aussi très-bien leur donner du vin, et on doit même le faire particulièrement dans les troupeaux nombreux.

XXV. Les veaux sont souvent incommodés des vers, qui se forment communément à la suite d'une indigestion. C'est pourquoi il faut les régler dans leurs repas, afin qu'ils digèrent bien; ou s'ils sont déjà attaqués de cette maladie, on broie des lupins à demi-crus, comme pour un saliva. tum, et on en fait des boulettes qu'on leur fourre dans la gorge. On peut aussi broyer de la santoline avec une figue sèche et de l'ers, comme pour un salivatum; et après en avoir fait des boulettes, on les leur fait avaler. Un quart de graisse de porc, mêlé avec trois quarts d'hysope, fait le même effet. Le jus du marrube blane et le poireau peuvent causer également la mort à ces insectes.

XXVI. Magon est d'avis que l'on doit chátrer les veaux quand ils sont encore jeunes, et

fulta est, quamris bona nutrix, labore fatigata nato sub. Iralit alimentum. Itaque et fota cytisus viridis et torre. factum ordeum, maceratunique ervum prabetur, et tener vitulıs torrido molitoque milio, et permixto cum lacte salivatur. Melius etiam in lios usus Altinæ vaccxe paran. tur, quas ejus regionis incolæ Cevas appellant. Lææ sunt lumilis statura, laclis abundantes, propter quod renıtis earum futibus, generosum pecus alienis educatur uberibus : vel si hoc prasidium nou adest, faba fresa et vi. uun recte tolerat, idque præcipue in magnis gregibus fieri oportet.

XXV. Solent autem vitulis nocere lumbrici, qui fere uascuntur cruditatibus. Itaque moderandum est, ut bene concoquant : aut si jam tali vitio lahorant, lupini semicridi conteruntur, et offa salivati more faucibus ingeruntur. Potest etiam cuun arida fico et ervo conteri lierba Samlonica, et formata in offam, sicut salivatum demitti. liacit idem axungix pars una tribus partibus liyssopi per. mista. Marrubii quoque succus et porri valet ejusmodi necare animalia.

AXV1. Castrare vitulos Mago censet, dum adlunc teneri qu'il ne faut pas faire alors cettc opération avec le fer, mais qu'il faut comprimer leurs testieules avec un morceau de férule fendu, et les écraser ainsi peu à peu; parce qu'il pense que la eastration ainsi faite à l'animal dans un ácre tendre et sans plaie cst la meilleurc de toutes. Mais si l'on. veut attendre qu'il ait pris des forces pour la faire, il vaudra mieux le chátrer à l'âge de deux ans que dans sa première année. Il ordonue ellcore de faire cette opération au printemps ou pendant l'automne, quand la lune est dans son déclin. Lorsqu'on doit employer le fer, il veut que l'on commence par attacher le veau à la machine que nous avons décrite plus haut; ensuite qu'avant d'approcher le fer, on saisisse avec deux lattes de bois étroites, qui servent comme de tenailles, les nerfs des testicules, que les Grees appel-

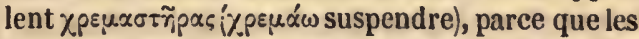
parties génitales y sont suspendues; qu'après les avoir saisis, on ouvre sur-le-champ l'enveloppe des testicules avec le fer, et qu'après les avoir comprimés pour les faire sortir de cette enveloppe, on les coupe de façon qu'on en laisse l'extrémité par laquelle ils tiennent à ces nerfs. En suivant cette méthode, le bouvillon n'a point. de danger à courir par l'éruption du sang : outre qu'il n'est point si efféminé qưil le serait si on le privait de toute masculinité, quoiqu'en conservant l'apparence du sexe masculin, il perde réellement la puissance d'engendrer. Ce n'est. pas néanmoins qu'il la pcrde dès le premier iustant, puisque si on lui laisse couvrir une femelle. aussitôt après ce traitement, il est certain qu'il en pourra résulter un produit; mais c'est un essai. qu'il ne faut pas lui laisser faire, de peur qu'il ne périsse d'un flux de sang. Au surplus, il. faut oindre la plaic avec de la cendre de sarment et de l'écume d'argent, empêcher l'animal de boire

sunt; neque id ferro facere, sed fissa ferula comprimere testiculos, et paulatim confringere. Idque optimum genus castrationum putat, quod adlibetur æetati teneræ sine vul. nere. Namubi jam induruit, melius binus quam anniculus castratur. Idque facere vere vel autumno luna decrescentepracipit, vilulumque ad maclinam deligare : deinde prius quam ferrum admoveas, duabus angustis ligneis regulis veluti forcipibus appreliendere testium nervos, quos

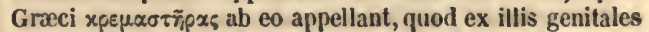
partes dependent. Comprehensos deinde testes ferro resc. rare, et expressos ita recidere, ut extrema pars eorum adlınens prodictis nervis relinquatur. Nam loc modo nec eruptione sanguinis periclitatur juvericus, nec in totum effominatur adempta onni virilitate; formanque servat maris cum generandi rim deposuit, quam tamenipsam non protinus amittit. Nam si patiaris eun a receuti curatione fominam inire, constat ex eo pusse generari. Sed. minime id permittendum, ne profluvio sanguinis intereat. Verum vulnera ejus sarmentitio cinere cum argeuti spuuta linenda sunt, abstinendusque eo die ab humore, et exiguo cibo alendus. Sequenti triduo velut ager cacuminibus ar- 
ce jour-là, et lui donner très-peu de nourriture. Les trois jours suivants on le ragoûtera à titre de malade, en lúi donnant des cimes d'arbres et du fourrage vert coupé par morceaux, et on l'empéchera de beaucoup boire. Il faut encore oindre la plaie pendant ces trois jours avec de la poix fondue, de la cendre et un peu d'huile, afin qu'elie se cicatrise plus promptement, et qu'elle ne soit point molestée par les mouches. C'est assez avolr parlé jusqu'ici des bœufs.

XXVII. Ceux qui ont à cour d'élever des chevaux doivent surtout se pourvoir d'un esclave entendu, et d'une grande quantité de fourrage; car si ces deux points peuvent être négligés jusqu'à un certain point à l'égard des autres bestiaux, le cheval demande qu'on y apporte la plus grande attention à son égard, de même qu'il veut la nourriture la plus abondante. Ce bétail se divise en trois espèces deraces : la race la plus noble, qui fournit des chevaux au cirque et aux combats sacrés; celle des mules, que l'on peut comparer à la première par le prix de ce qu'elle produit; et enfin la race commune, qui ne donne que des máles et des femelles médiocres. Plus chacune de ces races est distinguce, plus il lui faut d'abondants pâturages. On choisit pour les troupeaux de ce bétail des páturages étendus, marécageux et non montagneux, qui soient toujours arrosés, et plutôt libres qu'embarrassés par des arbres, et qui produisent souvent des herbes plus remarquables par leur mollesse que par leur hauteur. En fait de chevaux commuus, on laisse paître indifféremment ensemble les mâles et les femelles, et on n'observe pas de temps marqués pour les faire saillir. A l'égard des races nobles, on fera saillir les mâles vers l'équinoxe du printemps, afin que les cavales puissent élever leur poulain sans beaucoup de peine, attendu

borum el desecto viridi pabulo oblectandus, prolibendus. que multa petione. Placet etiam pice liquida et cinere cum exiguo oleo ulcera ipsa post triduum linere, quo et celerius cicatricem ducant, nec a muscis infestentur. Haclenus de bubus dixisse abunde est.

XXVII. Quibus cordi est educalio generis equini, maxime convenlt providere auctorem iudustrium, et pabuli copiam : qua utraque vel mediocria possunt aliis pecoribus adhiberi, summam sedulitatem el largam satietatem desiderat equitium. Quod ipsu m tripartito dividitur. Est enim generosa materies, quæ circo sacrisque certa. minibus equos præbet. Est mularis, quæ pretio fuetus sui comparatur generoso. Est et vulgaris, quæ mediocres foeminas naresque progenerat. Ut quæque est prastantior, ita ubere campo pascitur. Gregibus autem spatiosa et palustria, nec [non] montana pascua eligenda suut, rigua, nec unquam siccanea, vacuaque magis quam stirpibus impedita, frequenter mollibus potius quam proceris her. bis abundantia. Vulgaribus equis passim maribus ac fieminis jasci permittitur, nec admissuræe certa tempora servantur. Generosis circa vernum aquinoctium mares qu'il viendra an monde dans un temps pareil à celui dans lequel elles l'auront conçu, c'est-à-dire, quand les campagnes se trouveront gaies et bien fournies d'herbes au bout de onze mois passés; car elles mettent bas dans le courant du douzième. Il faut done surtout avoir soin que les femelles et les ćtalons qui voudront s'accoupler soient à portée de le faire dans le temps de l'année que je viens de marquer parce que si on les en em. pêchait, leur passion les ferait entrer en fureur plus que tout autrc animal: c'est même de là

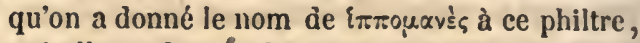
qui allume dans les hummes un amour aussi forcené que l'est la passion des chevaux. Effectivcment il n'est point douteux qu'il n'y ait des pays où les femelles brûlent d'une si grande ardeur de s'accoupler, que, quoiqu'elles solent privées de mâles, elles se remplissent sans cesse l'imagination de désirs effrénés, et se créent à elles-mèmes des plaisirs sous le vent, comme font les oiseaux de basse-cour. C'est aussi ce qu'exprime le poëte assez licencieusement en ces termes : Mais les cavales se font remarquer entre tous les autrcs animaux par leur fureur; et c'est Vinus cllemóme qui les a animées de cette ardeur, au temps que les chcvaux d'attelage de Glaucus de Polnia déchirèrent lc corps de leur maitre à bcllcs dents. En cffet, l'amourles conduil par. delà le haut du mont Ida, et leur fait traver. ser le bruyant Ascanius : elles grimpent lcs montagnes et passent les fleuves à la nage; et dès que le feu de l'amour s'empare de leur cceur passionné (ce qui arrive plutôt au printemps que dans toute autre saison, parce que c'cst le temps où la chaleur recommence à pćnćtrer la moelle de leurs os), clles se ticnnent toutcs surdes rochers élevés, la téte tournée vis-ì-vis le zéphire, pour recevoir avidement son souffle

jungentur, ut eodem tempore, quo conceperint, jam letis et herbidis campis post anni nessem parvo cunı lalıre foetum educent. Nam meuse duodecimo partum eduut. Maxime itaque curandum est pradicto tempore anni, ut tam focminis quam admissariis desiderantibus coeundi fiat potestas, quoniam id pracipue armentum si prohibeas, libidinis extimulatur furiis, unde ctiam veneno inditum est nomen i $\pi$ ropavè, quod equina cupidini similem mortalibus amorem accendit. Nec dubium, quin aliquot regionibus tanto flagrent ardore coeundi fuemina, ut etiam si marem non labeant, assidua et nimia cupiditate figurantes sıbi ipsa venerem colıortalium more avium veuto concipiant. Neque enim poeta licentius dicit : Scilicet ante omines furor est insignis equarum, Et mentem Venus ipsa dedit, quo tempore Glauci Potniades malis membra absumsere quadriga. Illas ducit amor trans Gargara, transque sonantem Ascanium; superant mon. tes et flumina tranant, Continuoque avidis ubi subdita flamma medullis, Vere magis, quia vere calor redit os. sibus, illa Ore omnes versa in Zephyrum, stantrupibus allis, Exceptantque leveis auras, et sape ullis Conju. 
léger; souvent même, lorsqu'elles ont été fécondées par le vont et sans aucun accouplement (effet merveilleux à raconter), elles courent à travers les rochers, les écueils et les vallees les plus profondes; non pas pour gagner, Eurus, les contrées où vous vous levez, non plus que celles ou se lève le soleil, mais bien celles oiu se lèvent Boréc et Caurus, ou le vent du midi, qui porte avec lui les nuages les plus noirs, et qui attriste le temps par le froid pluvieux qu'il amène. C'est mêrne un fait trèsconnu qu'en Espagne, sur le mont Sacer, qui s'étend vers l'occident auprès de l'Océan, il est souvent arrivé que des cavales ont été fécondées sans avoir été couvertes, et qu'elles ont élevé des poulains qu'elles avaientainsi mis au monde, quoiqu'on ne retirât aucune utilité de ces poulains, parce qu'ils mouraient dans l'espace de trois ans, avant de s'être fortifiés. Nous ferons donc en sorte, ailnsi que je l'ai dit, que les cavales ne soient pas tourmentées vers l'équinoxe du printemps par les appétits naturels de la volupté. Mais il faudra séparer pendant tout le reste de l'année les chevaux de prix d'avec les femelles, de peur qu'ils ne les saillent quand bon leur semblera, ou que, si on veut les empêcher de le faire, la vivaeité de leur passion n'occasionne quelque accident. C'est pourquoi il faut ou reléguer le mâle dans des pâturages éloignés de ceux des femelles, ou le retenir à l'étable : mais dans le temps où les femelles le demanderont, on le fortifiera par une nourriture abondante, et on l'engraissera à l'approche du printemps avec de l'orge et de l'ers, afin qu'il soit en état de suffire à leur passion, et de donner dès le prineipe, à la race qui doit sortir de lui, une vigueur d'autant plus grande, qu'il aura été lui-même plus vigoureux dans le moment de l'accouplement. II y a quelques auteurs qui ordonnent de l'engrais-

giis, ven lo gravida (mirabile dictu) Saxa per et scopulos et depressas convaltes Diffugiunt, non Eure tuos neque solis ad ortus; In Borcam Caurumque, aut unde nigerrimus Auster Nascitur, et pluvio contristal frigore ca. lum. Cum sit notissimum etiam in Sacro monte Hispanix, qui procurrit in occidentem juxta Oceanum, frequenter equas sine coitu ventrem pertulisse, futumque educasse, qui tamen inutilis est, quod triennio, prius quam adolescat, morte absumitur. Quare, ut dixi, dabinus operam, ne circa axuinoctium vernum equa desideris naturalibus angantur. Equos autem pretiosos reliquo tempore anni remorere oportet a fominis, ne aut eum volent, ineaut, aut si id facere prolibeantur, cupidine solicitati noxam contrahant. Itaque vel in longinqua pascua marem placet ablegari, vel ad prasepia contineri : eoque tenınore, quo vocatur a fueminis, roborandus est largo cibo, et appro. pinguante vere ordeo ervoque saginandıs, ut veneri su. persit, quantoque fortior inierit, firmiora semina probeart futura stirpi. Quiclan etiann pracipiunt eodem ritu, quo unulus, admissarium saginare, ut lac sagina hilaris plutibus ser de la manière dont on engraisse les mulets, afin que son embonpoint lui donne la gaieté nćcessaire pour satisfaire un plus grand nombre de femelles. Néanmoins, si ou ne doit pas donner moins de quinze cavales à un étalon, on ne doit pas non plus lui en donner plus de vingt. On peut l'employer à la génération depuis l'âge de trois ans jusqu'à celui de vingt. Si l'étalon est mou dans le plaisir, on le réveille par l'odorat, en lui mettant sous le nez une éponge avec laquelle on frotte auparavant les parties de la femelle. D'un autre côté, s'il se trouve quelque ca. vale qui ne veuille pas souffrir le mále, on vient à bout d'enflammer ses désirs en lui frottant les parties avec de la scille broyée. Quelquefois même on se sert d'un étalon ignoble et commun, pour exciter en elle le désir du coït. En effet, dès que cet étalon s'est approché d'elle, et qu'il a, pour ainsi dire, sollicité sa complaisance, on le retire pour la faire saillir par un étalon plus noble, au moment où elle est devenue plus patiente. Quand les cavales sont pleines, elles exigent plus de soins que dans d'autres temps, et il faut les fortifier par une ample pâture. Si pendant les froids de l'hiver les herbes viennent à manquer, on les retiendra à l'étable, et on ne leur fera pas prendre trop d'exercice, soit par le travail, soit par la course ; comme on ne les ex posera pas au froid, ni dans un lieu étroit et renfermé, de peur qu'elles ne détruisent respectivement leur fruit : toutes choses qui les font avorter. Si malgré ces précautions une cavale vient à tomber malade, soit en poulinant, soit en avortant, on la guérira avec de la filicula broyée et infusée dans de l'eau tiède, qu'on Iui fera prendre avec unc corne. Mais si ellea au contraire pouliné hcureusement, on se donnera de gardc de toucher à son poulain avec la main, parce que le moindre contact avcc un corps étran-

fominis sufficiat. Verum tamen nec minus quam quinde. cim, nec rursus plures quam viginti, unus debet implere. isque admissuræ post trimatum usque in amos viginti plerumque idoneus est. Quod si admissarius iners in veneremest, odore proritatur, detersis spongia fueminx locis, et admota naribus equi. Rursus si equa marem non pati. tur, detrita scilla naturalia ejus linuntur, quie res accendit libjdinem. Nonnunquam ignobilis quoque ac vulgaris elicit eupidinem coundi. Nam ubi admolus fere tentavit obsequium fominæe, abducitur, et jam patientiori generosior equus imponitur. Inde major prægnantibus adlibenda eura est, largoque pascuo firmandx. Quod si frigore licemis herbx defecerint, tecto contineantur, ac neque opere ueque cursu exerceantur, neque frigori committantur, nec in angusto clauso, ne aliæ aliarum conceptus elidant : nain linec omnia incommoda fortum abigunt. Quod si tamen aut partu aut abortu equa laboravit, remedio erit felicula trita, et aqqua tepida pernista, dataque per cornus Siı autem prospere cessit, minime manu contiugenduE pullus erit. Nam locditur etiam levissimo contactu. Tantum cura 
ger suffit pour le blesser. On aura seulement soin de le mettre avec sa mère dans un lieu qui soit à la fois et vaste et chaud, de peur que le froid ne lui nuise dans l'état de faiblesse où il sera, ou que sa mère ne l'écrase si le licu est trop resserré. Ensuite il faudra le faire sortir de temps en temps, pour empêcher que le fumier ne lui brûle la corne des pieds. Quelque temps après, lorsqu'il sera devenu plus fort, on le laissera aller avec sa mère dans les mêmes pâturages, de peur que lc chagrin de s'en voir privée ne la fasse tomber malade. Car l'attachement que ce bétail a pour ses petits lui cause plus de dommage qu'à tout autre, au cas qu'il n'ait pas la liberté de les voir. Les cavales vulgaires sont dans l'habitude de pouliner toutes les années; mais une cavale de race noble ne doit être saillie que de deux années l'une, afin que le lait de la mère, donnant plus de force au poulain, le prépare à bien supporter la fatigue des combats.

XXVIII. On estime qu'un étalon n'est pas propre à saillir les cavales avant l'âge de trois ans, mais qu'il peut engendrer jusqu'à vingt ans; au lieu qu'une cavale conçoit très-bielı, pourvu qu'elle ait deux ans passés, afin de pouvoir élever le poulain qu'elle aura mis bas après sa troisième année, et que, passé la dixième année de son âge, elle n'est plus bonne à ce service, parce que le poulain d'une mère aggée est paresseux et làche. Démocrite assure qu'il est en notıc pouvoir de faire concevoir à une cavale un mâle ou une femelle, à notre volonté : il ordonne à cet effet de lier, avec une ficelle de lin ou de telle autre matière que ce soit, le testicule gauche de l'étalon si l'on veut avoir un mâle, ct le droit si l'on veut avoir unc femelle : il pense même que l'on peut suivre le même procédé à l'égard de presque tous les bestiaux.

XXIX. On peut juger de la bonté naturelle d'un poulain dès sa naissance. En effet, s'il est gai, s'il est intrépide, s'il n'est cffrayé ni par les objets qui se présentent à sa vue, lli par les sons qui frappent son oreille pour la première fois, s'il court toujours à la tête d'un troupeau, s'il surpasse ses camarades par sa gaieté et par sa vivacité, et qu'ill'emporte même quelquefois sur eux à la course, s'il saute un fossé sans balancer", et qu'il passe un pont et traverse un fleuve de même, ce seront toutes marques d'un naturel distingué. Pour la forme du corps, elle consister à avoir la tête petite, les yeux noirs, les narines ouvertes, les orellles courtes et redressées, lc chignon flexible et épais sans ètre allongé, la crinière bien fournieet pendante sur le côté droit, la poitrine large et parsemée d'une multitude de muscles bien moulés, les épaules grandes et droites, les côtes arquées, l'épine du dos double, le ventre étroit, les testicules petits et bien appareillés, les reins larges et ravalés, la queue trainante ct garnie de poils longs, rudes et ondoyants, les jambes égales, hautes et droites, lc. genou cylindrique et petit, sans être tourné en dedans, les fesses rondes, les cuisses pleines de muscles et bien fournies, la corne des pieds dure, haute, concave, ronde, et surmontée d'une couronne légèrement saillante; l'ordonnance générale du corps grande, élevée, droite, qui paraisse agile au coup d'œil, et ronde sur la longueur autant que sa figure le comporte. Quant au caractère de ces animaux, on les estime lorsque, sans être emportés, ils ont de l'ardeur, et qu'avec de l'ardeur ils sont très-doux, parce que ce sont là ccux qui sont les plus portés à l'obéissance,

XXIX. Cum vero natus est pullus, confestim licet in. dolem æstimare, si liilaris, si intrepidus, si neque conspectu nova rei neque anditu terretur, si ante gregem procurrit, si lascivia et alacritate interilum et eursu certans rquales exuperat, si fossam sine cunctatione transilit, pontem flumenque transcendit. Haec erunt honesti auini documenta. Corporis vero forma constabit exiguo capite, nigris oculis, naribus apertis, brevibus auriculis et arrectis, cervice nolli lalaque nec longa, densa juba et per dextram partem profısa, lato et musculorum toris numeroso pectore, grandibus armis et rectis, lateribus inflexis, spina duplici, ventre substricto, testibus paribus et exiguis, latis lumbis et subsi lentibus, cauda longa et setosa erispaque, sequalibus attgue altis rectisque cruribus, tereti genu parroque neque introrsus spectanti, rotundis clunibus, feminibus torosis ac numerosis, duris ungulis et altis et concavis rotundisque, quibus coronæ mediocres superpositæ sunt. Sic universin corpus compositum, ut sit grande, sublime, erectum, ab aspectu quoque agile, et ex longo, quantum figura pernuittit, rotundum. Mores autem laudantur, qui sunt ex placido coneitati, et ex coneitato mitissimi. Nam hi et ad obsequia reperiuntur hali. 
et les plus patients dans les travaux des combats. Un clieval de deux ans est bon à être dompté pour les usages domestiques, mais quand on le destine aux combats il faut qu'il ait trois ans passés; de facon qu'on ne l'y expose pas avant la quatrième année expirée. Les marques auxquelles on distingue le nombre des années d'un cheval changent avec son corps. En effet, jusqu'à ce qu'il ait deux ans et demi, les dents du milieu lui tombent, tant les supérieures que les inférieures : il lui en repousse d'autres dans la quatrième année, après que celles que l'on appelle canini (dents canines ou ceillères) sont tombées; cnsuite les grosses dents supérieures tombent avant la sixième : dans le courant de la sixième anuée celles qui ont remplacé les premières rasent, et la septième année elles rasent toutes également : ensuite elles se creusent, et on ne peut plus connaitre son âge avec certitude. Cependant da la dixième année ses tempes commencent à caver, souvent ses sourcils se blanchissent, et les dents lui sortent de la bouche. C'est en avoir dit assez sur ce qui concerne le naturel, le caractère et le corps, ainsi que l'åge du cheval. Passons à présent aux soins qu'il faut prendre de cet animal, soit quand il se porte bien, soit quand il est malade.

XXX. Si, sans être malade, un cheval devient maigre, on vicnt plus promptement à bout de le rétablir avec du froment grillé qu'avec de l'orge; mais il faut aussi lui faire boire du vin dans le mème temps, et ensuite lui changer peu à peu ce genre de nourriture, en mêlant d'abord du son dans son orge, jusqu'à ce qu'on l'ait accoutumé aux fèves et à l'orge pure. Il faut que le corps des chevaus soit nettoyé tous les jours avec autant d'exactitude que celui de l'homme; et il est sou-

les, et ad certaminnm labores patientissimi. Equus bimns ad usum domesticum recte domatur; certaminibus autem expletu triennio : sic tamen ut post quartum demum an. num labori commiltatur. Aunorum nota cum corpore mutantur. Nan dum bimus et sex mensium est, medii deutes supcriores et inferiores cadunt. Cum quartum agit annum, is, qui cauini appellantır, dejectis, alios affert. Intra sextum deinde annum, molares superiores cadunt. Sexto anı, quos primus ınutavit, exæquat. Septimo omnes cxpleutur æequaliter, et cx eo cavatos gerit. Nec postea quot aunorum sit, mauifesto coinprehendi poles t. Decimo tameu anno tempora carari incipiunt, et supercilia nonnuaquam canescere, et dentes prominere. Hæc, qua ad animun $\mathrm{ct}$ mores corpusque et atatem pertinent, dixisse satis habeo. Nunc sequitur curam recte et miuus valentium demonstrare.

XXX. Si sanis est macies, celcrius torrefacto tritico, quam ordeo reficitur. Sed et vini potio danda est, ac deinde jaulatim cjusmodi cibi subtralıendi immistis ordeo furfuribus, duu consueseal falıa et puro ordeo ali. Nec uniums quolidie corpora jecudum quam lıminum defricanta sunt: ac sapre plus prodest juressa utanu subegisse terga, quam si largissiune cibos prabeas. I'alea vero enuis rent plus utile de leur manter le dos et de le presser avec la main, que de leur donuer la nourriture la plus abondante. Il est elreore très-intéressant de les maintenir dans la vigucur du corps et dans celle des pieds : on y parviendra en les menant à propos à l'étable, à l'euu et à leurs exercices, et en veillant à ce qu'ils soicnt tenus sèchement à l'étable, ct à ce que la corne de leurs pieds ne pourrisse point dans l'humidité. C'est ce que l'on évitera aisément, si leurs éta. bles sont planchéiées d'ais de robre, ou que l'on ait soin de les nettoyer de temps en temps et d'y étendre de la paille, si elles ne le sont point. Communément ce qui occasionne les maladies de ces animaux, c'est la lassitude, le chaud, et souvent le froid; c'est encore de n'avolr pas uriné au moment qu'ils en avaient besoin, d'avoir bu à la suite de l'exercice qu'ils auront pris, et pendant qu'ils étaient encore en sueur, ou d'avoir cté excités à courir après un long repos et sans interstice. Le repos est le seul remède de la lassitude, en y ajoutant cependant la précaution de leur verser dans la gorge de l'huile ou de la graisse avec du vin. On remédie au froid par les fomentations, ainsi qu'en leur frottant la tête et l'épine du dos a vec de la graisse chaude ou du vin. S'ils ne pissent pas, on a recours à peu près aux mêmes remèdes, puisqu'on leur verse sur les flanes et sur les reins de l'huile et du vin; mais si ce remède n'opère rien, on introduit par lorifice de leur membre une bougie mince faite avec du miel bouilli et du sel, ou bien on leur insère dans les parties soit une mouche vivante, soit un grain d'encens, ou un onguent de bitume. On emploie les mêmes remèdes lorsque l'urine leur brûle les parties. La douleur de la tête se manifeste par les larmes qui leur coúlent des yeux, par les

stantibus substernendac. Multum autem refert robur corporis ac pedum servare. Quod utrumque custodiemus, si idoneis temporibus ad prasepia, ad aquam, ad exercitationem pecus duxerimus; curæeque fuerit ut stabulentur sicco loco, ne lumore madescant ungulx. Quod facile evitabinus, si aut stabula roboreis axibus constrata, aut diligenter subindc enundata fuerit lumms, et palex snperjectæ. Plerumque jumenta morbos concipiunt lassitudiuc et astu, uonnuuquam el frigore, ct cum suo temporo uriuam non fecerint; vel si sudaut, et a concitatione confestim biberint; rel si cum diu steterint, subito ad cursum cxtinulata sunt. Lassitudini quies remedio cst, ita ut in fauces oleuin vel adcps vino mista infundatur. Frigori fomenta adlibentur, ct calefacto olco lumbi rigantur, caput. que et spina tepenti adipe vel rino liniuntur. Si urinam non facit, eadem ferc remedia sunt. Nam oleum immistun vino supra ilia et renes infunditur : et si hoc jarum profuit, ineHe decocto ct sale collyrium tenue inditur foramini, quo manat uriua, vel nusca vira, rel thuris nica, vel de bitumine collyrium inseritur naturalibus. Hac cadeu rentedia adbibentur, si urina genitalia decusscrit. Capitis: lvivem indicant lacryma, qua profluunt, auresquc flaccida; el cervix cum capite aggravata, et in terram sum 
oreilles qui devieunent pendantes, et par le ehignon qui s'appesantit aiusi que la tête, au point que sa pesanteur l'entraine à terre. Dans ee easlà, on leur ouvre la veine sous l'ceil, on leur fomente la bouche avec de l'eau chaude, et on les met ì la diète pendant une journée : le lendemain on leur donne à jeun une potion d'eau ehaude et de l'herbe verte; ensuite on étend sous eux du vieux foin ou de la paille molle, et on leur donne une seconde fois de l'eau à l'entrée de la nuit, avee un peu d'orge et deux livres et demie de vesee; après quoi on ne leur donne que très-peu de nourriture, jusqu'à ee qu'ils soient en état de rensplir leur táche ordinaire. Si les mâchoires leur font mal, il faut les fomenter avee du vinaigre ehaud, et les frotter avee du vieux oing : on em. ploiera aussi le même remède lorsqu'elles seront gonflées. Si un cheval s'est blessé les épaules, ou que son sang se soit extravasé dans eette partie, on lui ouvrira les veines aux deux jambes à peu près vers le milieu de la jambe, et on mêlera de la manne d'eneens avec le sang qu'on lui aura tiré, pour lui en frotter les épaules; mais afin de ne pas l'épuiser outre mesure en lui tirant trop de sang, on appliquera sur les veines qui auront été piquées de son crottin, que l'on y assujettira en l'enveloppant avee des bandes. Le lendemain on lui tirera du sang des mêmes veines, et on le pansera de même; mais on lui retranehera l'orge pour ne lui donner qu'un peu de foin. Depuis le troisième jour jusqu'au sixième, on lui versera dans la gorge avee la eorne la valeur de trois cyathi de jus de poireau, mêlés avee une hemina d'huile. Passé le sixième jour, on le fera mareher lentement, et au retour de la promenade on le fera nager dans l'abreuvoir; après quoi on le fortifiera peu à peu par une nourriture plus sueculente, jusqu'à ce qu'il soit en état de remplir

missa. Tum rescinditur vena, qux sub oenlo est, et os calda fovetur, ciboque abstinetur primo die. In postero autem potio jejuuo tepidæe aquæe probetur ae viride gramen, tun vetus fouım vel molle stramentum substernitur, crepusculoque aqua iterum datur, parumque ordei eum vieialibus, ut per exiguas potiones eibi ad justa perducatır. Si equo maxilla dolent, calido aceto fovendæe, et axungia vetere confricanda sunt, eademque medieina tumentibus adhibenda est. Si armos lacserit, aut sanguinem deniserit, medio fere in utroyue erure venne solvantur, et thuris polline eum eo qui profluil, sanguine im. misto, arni linantur, et ne plus justo exinaniatur, stereus ipsius jumenti fluentibus venis admotum faseiis obligetur. Postero quoque die ex isdem loeis sanguis detrahatur, codemque modo curetur, ordeoque abstineatur exigno fono dato. Post triduum deinde usque in diem sextum porri suceus instar trium cyathorum mistus eum olei lıemina faucibus per cornu iufundatur. Post sextum diem lente ingredi eogatur, et cum ambulaverit, in piseinam demitti cum conveniet, ita ut natet : sie paulatin firmioribus eibis adjutus ad justa perdueetur. At si bilis molesta sa tâehe ordinaire. Lorsque la bile vient ineommoder eet animal, son ventre se gonfle, et il ne peut plus rendre ses vents. On lui fourre alors la main dans le ventre après l'avoir graissce, pour ouvrir les eonduits naturels qui sont ohstrués, et en retirer le erottin; ensuite de quol on broie de l'origan et de l'herbe aux poux avee du sel, et, après avoir fait bouillir eette eomposition avee du miel, on en fait des suppositoires, qu'on lui introduit dans le ventre pour l'exciter à se vider et pour faire eouler sa bile. Il y a quelques personnes qui lui versent dans la gorge un quadrans de myrrhe broyée dans une lieminu de vin, et qui lui frottent l'anus avee de la poix fondue. Il y en a d'autres qui lui lavent le ventre avec de l'eau de mer, et d'autres avee de la saumu:e fraiclie. Il arrive eweore souvent que des vers semblables à eeux de terre s'attaehent aux intestins de ees animaux : on s'aperȩoit de cette maladie lorsque la douleur les fait eoueher souvent à terre, qu'ils portent la tête à leur ventre, et qu'ils remuent souvent la queue. Le remède le plus efficace est de leur fourrer la main dans le ventre pour en retirer le erottin, eomme il a été dit ci-dessus; ensuite de le leur laver avee de l'eau de mer ou de la saumure forte; enfin de leur verser dans la gorge un sextarius de vin, dans lequel on aura broyé de la raeine de eâprier. C'est le moyen de faire périr ees vers.

XXXI. Il faut mettre beaueoup de litière sous les ehevaux toutes les fois qu'ils sont malades, afin qu'ils soient plus mollement eouchés. On guérit promptement la toux de ees animaux dans son prineipe, en pilant dans un mortier des lentilles écossées, dont on fait infuser un sextarius, lorsqu'elles sont réduites à une farine très-fine, dans pareille mesure d'eau ehaude, et en leur versant cette potion dans la gorge. On continue ee est jumento, venter intumeseit, nec emiltit ventos. Manus uncta inseritur alvo, et obsessi naturales exitus adis. periuntur, exenıptoque stercore postea cunila bubula et lierba pedieularis eum sale trita et decoeta melli miscen. tur, alque ita facta collyria subjiciuntur, qua ventrem movent, bilemque omnem deducunt. Quidam myrria? trita quadrantem eum lemina vini faueibus infunduut, et anum liquida pice oblinunt. Alii marina aqua lavaut alvum, alii recenti muria. Solent etiam vermes quasi lumbriei nocere intestinis ; quorum signa sunt, si jumenta cum dolore erebro volutantur, si admovent caput utero, si caudam sappius jactant. Præesens medieina est, ita ut supra scriptum est, iuserere manum, et fimum eximere; deinde alvum mariua aqua vel muria dura lavare, postea radieem capparis tritam eu $m$ sestario aceti faucibus infundere; nam hoc modo prædicta intereunt animalia.

XXXI. Omni autem imbeeillo pecori alte substernendum est, quo mollius cubet. Recens tussis eeleriter sanatur, pinsita lente et a valvulis separata minuteque molita. Quac eum ita facta sunt, sextarius aquæe calida in eaulenı mensuram lentis nisect $s r_{6}$, et faucibus infunditur; similis- 
traitement pendant trois jours, en les ragoûtant à titre de malades, avec des lierbes vertes et des cimes d'arbres. On ne peut au contraire dissiper une toux invétérée qu'en leur versant dans la gorge trois cyathi de jus de poireau avec une hemina d'huile, et en leur donnant la nourriture que nous venons de prescrire. On frotte les dartres et toutes les parties affectées de gale avec du vinaigre et de l'alun. Quelquefois, lorsque ces maladies sont opiniâtres, on les frotte avec du nitre et de l'alun de plume mêlés ensemble à dose égale dans du vinaigre. On gratte les boutons jusqu'au sang avec une étrille au soleil le plus ardent ; après quoi on méle par portions égales des racines de chiendent, du soufre et de la poix fondue avec de l'alun, et on les panse avec ce médicament.

XXXII. On lave les entretaillures deux fois par jour avec de l'eau chaude; ensuite on les frotte de sel égrugé et bouilli a vec de la graisse, jusqu'à ce que le sang corrompu en sorte avec abondance. La gale est une maladie mortelle à ce quadrupède, si on n'a pas le soin d'y remédier promptement: lorsqu'elle n'est pas encore forte, on la frotte à l'ardeur du soleil, soit a vec de la gomme de cèdre ou de l'huile de lentisque, soit avec de la graine d'orties et de l'huile battues ensemble, soit avec de l'huile de baleine, ou avec cette liqueur que dépose le thon salé dans les plats; quoique la graisse de veau marin soit le remède le plus souverain contre cette maladie. Mais lorsqu'elle est déià invétérée, il faut a voir recours à des remèdes plus éuergiques ; c'est pourquoi on fait alors cuire dans de l'eau du bitume, du soufre et de l'ellébore blane, le tout en dose égale, a vec de la poix fondue et dı vieux

que medicina triduo adhibetur, ac viridibus herbis cacuminibusque arborum recreatur ægrotum pecus. Vetus autem tussis discutitur porri succo trium cyathorum cum olei hemina faucibus infuso, iisdemque, ut supra monuimus, cibis prabitis. Impetigines, et quicquid scabies occupat, aceto et alumine defricantur. Nonnunq̧uam, si (lıec) permanent, paribus ponderibus permistis nitro et scisso alumine, cum aceto linuntur. Papula ferventissimo sole usque eo strigile raduntur, quoad eliciatır sanguis. Tum ex aquo miscentur radices agrestis leederx, sulfurque et pix liquida cum alumine, [et] eo medicamine pradicta ritia curantur.

XXXII. Intertrigo bis in die subluitur aqua calida. Mox decocto ac trito sale cum adipe defricatur, dum sanguis emanet. Scabies mortifera lıuic qquadrupedi est, nisi celeriter succurritur : qux si levis est, inter initia canclenti sub sole rel cedria vel oleo lentisci linitur, vel urticae semine et oleo detritis, vel unguine ceti, quod in lancibus salitus llyyunus remiltit. Pracipue tamen huic noxie silutaris est adeps marini vituli. Sed si jam inveteraverit, vehementioribus opus est remediis. Propter quod bitumen, et sulfur, et veratrum pici liquidax, axungiaque veteri commista pari pondere iucoquuntur, atque ea comprosi. oing, et on se sert de cette composition pour la panser, après l'avoir grattéc préalablement avec un fer et l'avoir lavée avec de l'urine. On est encore parvenu souvent à la guérir, en la coupant jusqu'au vif avec un bistouri, et en pansant les plaies qui succédaient à cette opération avec dc la poix fondue et de l'huile. En effet, ce remède nettoie ces plaies et fait reprendre les chairs; lorsqu'elles sont reprises, il est très-bon de saupoudrer l'ulcère avec de la suie prise au cul d'une chaudière, afin qu'il se cicatrise plus tôt et que Ic poil y renaisse.

XXXIII. L'on écartera aussi les mouches qui s'attachent aux plaies, en versant dessus de la poix mêlée avec de l'huile ou de la graisse. On fait disparaitre les taies des yeux, soit en les frottant avec de la salive d'un homme à jeun et du sel, ou bien avec un os de sèche broyé a vec du sel gemme, soit en exprimant sur l'œil, à travers un linge, de la graine de carotte sauvage moulue. En général on soulage promptement toutes les douleurs des yeux en y appliquant une composition de jus de plantain et de miel dont la fumée n'ait point approché, - ou tout au moins de miel de thym, à défaut d'autres. Il est encore arrivé souvent que le saignement de nez a mis ces animaux en danger; mais on l'arrête en leur versant dans les narines du jus de coriandre verte.

XXXIV. Quelquefois cet animal languit, fautc d'appétit. On y remédie avec l'espèce de graine connue sous le nom de git (nielle), que l'on broie pour en faire infuser deux cyathi dans trois d'huile et un sexturius de vin, et les lui verser dans la gorge. On dissipe aussi l'envie de vomir, en lui faisant boire souvent une hemina de vin, dans laquelle on aura broyé une tête d'ail. II

tione curantur, ita ut prius scabies ferro erasa perluatur urina. Sæpe etiam scalpello usque ad vivum resecare et amputare scabiem profuit, atque ita factis ulceribus mederi liquida pice atque oleo, qux expurgant et replent vulnera seque. Qux cum expleta sunt, ut celerius cicatricem et pilum ducaut, maxime proderit fuligo ex alseno ulceri infricata.

XXXIII. Muscas quoque rulnera infestantes summovebimus pice et oleo vel unguine mistis et infusis. Cæretera ervi farina recte curantur. Cicatrices oculorum jejuna saliva et sale defricato extenuantur : vel cum fossili sale trita sepiac testa, vel semine agrestis pastinacie pinsito, et per linteum super oculos expresso. Omnisque dolor oculorum inunctione succi plantaginis cum melle acapno, vel si id non est, ntique thynino celeriter levatur. Nonnunquam etian per nares proflnvium sanguinis periculum attulit, idque repressum est infuso naribus viridis coriandri succo.

XXXIV. Interdum et fastidio ciborum languescit pecus. Ejus remedium esl genus seninis quod gil appellatur, cujus duo cyathi triti diluuntur olei cyathis tribus et vini sextario, atque ita faucibus infunduntur. Et nausea discutitur etian, si capnt allii tritum cum vini hemina sapius 
vaut mieux pereer les apostumes avec une lame de fer rougc qu'avee un instrument de fer froid : au reste, lorsqu'on en a fait sortir le pus, on les panse avee de la charpie. II y a encore une maladie pestilenticlle, dont l'effet est de maigrir tout à coup les cavales en peu de jours, et de les eonduire sous tcre : lorsque cela arrive, il est bon de leur verser dans les narines quatre sextarii de garum par tête, si elles sont de petite taille : car si elles sont de la grande taille, on leur en versera jusqu'à un congius. Ce remède attire toute la pituite par les narines, et purge entièrement ees animaux.

XXXV. Tout le monde connait encorc la rage des eavales, quoique ce soit une maladie rare: tel en est l'effet, que lorsqu'elles se sont mirées dans l'eau, elles sont saisies d'une passion vaine qui leur fait oublier le boire et le manger, et qui les fait pèrir dans la phthisie qui succède à cette passion. On s'apercoit de eette folie lorsqu'elles eourent çà et là au milieu des pâturages, comme si quclqu'un les excitait, ct qu'clles jettent les yeux de temps en temps de tous eôtés, comme si elles cherchaient et désiraient quelque chosc. On dissipe eette erreur de leur imagination en les menant à l'eau : en effet, dès qu'elles y ont remarqué leur difformité, elles perdent le souvenir de l'ancicnne image qui les avait frappées. Ce que nous avons dit suffit à l'égard des cavales en général. Voici des préceptes particuliers pour eeux qui veulent s'adonner à avoir des troupeaux de mules.

XXXVI. Quiconque veut élever des mules doit par-dessus tout avoir à cœur d'examiner et de choisir avec soin la femelle et le mâle dont il veut avoir de la race, parce que si l'un ou l'autre est défectueux, l'êtrc auquel ils donneront l'existence le sera aussi. Il faut prendre la eavale dans les dix prenières années de son âge,

potandum probeas. Suppuratio melius ignca lamina, quam frigido ferramento reseratur, et expressa postea linamentis curatur. Est etiam illa pestifera labes, nt intra pancos dies equæ subita macie et deinde morte corripianlur : quod cum accidit, quaternos sextarios gari singulis per nares infundere utile est, si minoris forınæe sunt : nam si majoris, etiam congios. Ea res omnem pituitam per nares elicit, et pecudem expurgat.

XXXV. Rara quidem, sed et hacc est equarum nota rabies, ut cum in aqua imaginem suam viderint, amore inani capiantur, et per lıunc oblita pabuli, tabe cupidinis intereant. Ejus vesania signa sunt, cum per pascua veluti extimulata concursant, subinde ut circumspicientes requirere ac desiderare aliquid videantur. Mentis error discutitur, si deducas ad aquam. Tum demum speculatae deformitatem suam, pristinæ imaginis abolent memoriam. Haec de nniverso equarum genere satis dicta sunt. Illa proprle procipienda sunt is, quibus mularum greges curs est submittere.

XXXVI. In elucando genere nularum antiquissimum attendu que c'est le temps pendant lequel elle se maintient dans une forme très-ample et trèsbcllc; il faut encore qu'elle ait les membres forts, et qu'elle soit en état de supporter le travail, afin qu'elle puisse s'accommoder aisément du genre étranger qu'on doit, pour ainsi dire, enter en elle, et s'habituer à porter un petit dont l'espèce ne s'accorde pas avec la nature de son ventre, pour lui transmettre non-sculement les dons de son curps, mais encore les qualités de son esprit. Car non-seulement la semence qu'elle recoit alors dans sa matrice a dc la peine à s'animer, mais il lui faut même du temps pour la faire parvenir au degré de perfection nécessaire après la collception pour être mise au jour, puisqu'à peinc les produits qui en résultent viennent-ils au monde au bout d'un an, ct dans le treizième mois à dater de l'accouplement ; encore tiennent-ils toujours plus de la lâchcté de leur pèrc que de la vigueur de leur mère. Néanmoins, si l'on a de la peine à trouver des cavales qui soient propres à ect usage, on en a encore plus à choisir le mâle, parce qu'il arri ve sou vent que l'expérience trompe sur le jugement qu'on en avait porté. En effet, bien des malles superbes en apparence donnent des races très-méprisables, soit du eôtć de la figure, soit du cóté du sexe, et ne font aucun profit au ehef de famille, ou parce qu'ils donnent des femelles de petite eorpulence, ou parce qu'en les donnant de belle corpulence, ils en donnent moins que de mâles; au lieu que d'autres, méprisables en apparence, sont souvent une source abondante de semences très-précieuses. Il s'en trouve quelquefois qui transmettent à la vérité leur noblesse à leurs enfants, mais qui, se trouvant émoussés par le plaisir, sont très-difficilement excités à l'amour. Les maitres de haras doivent faire approcher de pareils mâles auprès de femelles qui soient d'un caractère semblable, parce que la

est diligenter exquirere atque explorare parentem futura prolis focminam et marem : quorum si alter alteri non est idoneus, labat etiam quod ex duobus fingitur. Equam convenit quadrimam usque in annos decem amplissiına atque pulcherrima forma, memlris fortibus, patientissimam laboris eligere, ut discordantem utero suo generis alieni stirpem insitam facile recipiat ac perferat, et ad fotum non solım corporis bona, sed et ingenium conferat. Nam cum difticulter injecta genitalibus locis animentur semina, tum etiam concepta diutius in partum adolescunt, atque (peracto anno) mense tertiollecimo vix edun. tur, natisque inhæret plus socordix paterna, quam vigoris materni. Veruntamen (ut) equax dictos in usus minore cura reperiuntur, (ita) major est labor eligendi maris : quoniam sape judicium probantis frustratur experimentum. Multi admissarii specie tenus mirabiles pessiman solsolem forma rel sexu progenerant. Nam sive parvi corporis focminas fingunt, sive etiam speciosi plures mares, quam foeminx reditum patrisfamilix minuunt. At quidaun contemti ab aspectu pretiosissimorum seminum feraces 
nature a mis plus d'intimité entre les choses qui se ressemblent qu'entre celles qui sont dissemblables. Ainsi on obtient par ce manége qu'un mâle, après avoir été gagné par les caresses de la femelle qu'on lui a d'abord présentée, et qu'on lui a même fait saillir, est comme enflammé et aveuglé par la passion qu'elle a fait naître $\mathrm{cn}$ lul, et qu'il se jette à corps perdu sur celle dont il était auparavant dégoûté, lorsqu'on vient à lui ôter cette première avec laquelle il se plaisait.

XXXVII. Il y a encore une espèce de mâle tout différent de celui-là, puisqu'il est furieux dans sa passion et qu'il cause du ravage dans le troupeau, si on n'use pas d'adresse pour le contenir. En effet, il brise souvent ses liens et tourmente les cavales qui sont pleines, ou mord au chignon et au dos celles qu'on lui fait couvrir. Pour l'en empêcher, on l'attache à la meule, parce que, pour peu qu'il l'ait tournée, le travail modère la brutalité de sa passion, et on ne lui permet de la satisfaire que lorsqu'il est plus modéré. Il est même bon de ne pas faire saillir sans cette précaution ceux dont les passions sont plus douces, parce qu'il est très-important que le tempérament de ce bétail, Iorsqu'il est naturellement assoupi, soit secouć et réveillć par un exercice modéré, et que le mále ne couvre les femelles que lor'squ'il sera devenu plus vif, afin que par une certaine vertu occulte qui se communique à la semence même, elle se trouve formée de principes plus actifs. Au surplus, unc mule peut être engendrée nonseulement par une cavale et par un âne, mais encore par une ánesse et un cheval, de même que par un âne sauvage et une cavale. Quelques auteurs même qu'on ne doit pas passer sous silence, tels que Marcus Varron, et avant lui Dionysius et Magon, ont assuré que la portée des

sunt. Nonnunyuam aliquis generositatem suam natis exli. bet, sed lıebes in roluptate, rarissime solicitatur ad venerem. Hujusce seusum magistri lacessunt admota generis ejusilen fuemina, quoniam similia similibus familiariora fecit natura. Itaque objectæ asina cum superjectu chlan. diti sunt, velut incensum et obcaccatum cupidine, subtracta quam petierat, fastidita imponunt equa.

XXXVII. Est et alterum genus admissarii furentis in libidinem, quod nisi astu inhibeatur, affert gregi pernicien. Nan et sape vinculis abruptis gravidas inquietat, et cum admittitur, cervicibus dorsisque fueminarım imprimit ınorsus. Quod ne faciat, paulisper ad molam vinctus amoris savitiam labore temperat, et sic veneri modestior admittitur. Nec tamen aliter admittendus est etiam clementioris libidinis, quoniam multum refert naturaliter sopilum pecudis ingeuium modica exercilatione conculi atque excitari, vegetiorenuque factum marem forminx injungi, ut tarita quadam vi semina ipsa principiis agilioribus figurentur. Nula autem non solum ex equa et asino, sed ex asina et equo, itesncpue onagro et equa generatur. Quidam vero non dissimulandi auctores, Ht Marcus Varro, mules passait si peu pour une chose prodigicuse dans les contrées de l'A frique, que les habitants étaient habitués à les voir mettre bas autant que nous pouvons l'être à voir pouliner les cavales. Il faut cependant convenir qu'il n'y a rien, tant du côté du caractère que du côté de la figure, de supéricur à ce que produiț un âne, quoiqu'on puisse lui comparer à certains égards la créature qu'engendre un âne sauvage, si ce n'est que cette créature est indomptable et rebelle à l'esclavage, suivant l'habitude des animaux sauvages, et qu'elle a la corpulence décharnée de son père. Aussi un âne de cettc espèce est-il plus utile pour donner des petits-fils que pour donner des enfants. En effet, si l'on donne à une cavale le fils d'une ânesse et d'un âne sauvage, comme lc naturel sauvage se trouvera alors rompu pour avoir passé par différents degrés, le produit de cet accouplement sera pourvu de la figure et de la modération de son père, en même temps qu'il le sera de la force et de l'agilité de son grand-père. Les mulets engendrés par un cheval et une ânesse ressemblent plus universellement à leur mère, bien que le nom de hinnus (de hinnitus, hennissement) qu'on leur a donné semble faire croire le contraire. C'est pourquoi il est très-avantageux de ne destiner à donner des mules que des ânes dont l'expérience aura fait connaltre l'espèce pour être très-belle, ainsi que je l'ai déjà dit. Cependant - on ne doit pas en choisir qui n'aient déjà à la première vuc, le corpstrèsample, le cou fort, les cotes robustes et larges, la poitrine bien fournie de muscles et étendue, les euisses nerveuses, les jambes épaisses, et le poil noir ou moucheté : car de même que la couleur de souris n'est pas une couleur distinguée dans un ane, elle ne réussit pas non plus parfaitement dans unc mule. Au reste, il ne faut

et ante enm Dionysius ac Mago prodiderunt, mularum fortus regionibus Africie adeo non prodigiosos haberi, ut tam familiares sint incolis partus earum, quam sunt uobis equarum. Neque tanen ullum est in lioc pecore ant animo ant forma prostantius, quam quod seminavit asinus. Posset liuic aliquatenus comparari, quod progenerat onager, nisi et indomitum, et servitio contumax silvestris more, strigosum patris praferret labitum. Itaque ejus. modi admissarius nepotibus [magis] quam filiis utilior est. Nam ubi asina et onagro natus adnitlitur equa, per gradus infracla feritate quicquid ex eo proveuit, paternam formam et modestian, fortitudinem celeritatem(yue avitam refert. Qui ex equo) el asina concepti generantur, quamris a patre nomen traserint, quod hinni vocantur, matri per omnia magis similes sunt. Ilaque commodissimum est asinum destinare mularum generi seminando, cujus, ut dixi, species experimento est pretiosior. Veruntamen ab aspectu non aliter probari debet, quan ut sit anplissimi corporis, cervice valida, robustis ac latis costis, pectore musculoso et rasto, feminibus lacertosis, cruribus counpactis, coloris nigri rel maculosi. Nam muriuns cuu st 
pas nous laisser tromper par l'ensemble de la figure de ce quadrupède, quoique nous la trouvions telle que nous venons de la demander. Car comme les taches qui sont sur la langue ou dans le palais des béliers se font communémeut remarquer sur la toison des agneaux qu'ils produisent, il arrive de même que lorsqu'un âne a dés poils aux paupières ou aux oreilles qui sont d'une eouleur différentc de celle des autres poils de son corps, souvent il donne une race d'une couleur qui diffère de la sienne, et qu'il trompe son maítre, quelque attention que celui-ci ait apportée dans l'examen de sa couleur; puisque quelquefois même, sans avoir les signes particuliers que je viens d'assigner, il lui arrive de donner des mules qui ne lui ressemblent pas. Pour expliquer ce phénomène, il faut admettre que la couleur du grand-père revient à ses petits-fils par le mélange de la semence du père. Ainsi dès qu'un ânon, tel que je l'ai dépeint, vient de naitre, il faut l'enlever à sa mère, et le mettre sous une cavale sans qu'elle s'en aperçoive. Or il sera très-aisé de la tromper daus les ténèbres, parce que, pour peu qu'on lui ait retiré son poulain dans l'obscurité, elle nourrira cet ânon de même que si elle lui a vait donné le jour, et que, dès qu'elle se sera habituće à lui pendant l'espace de dix jours, elle lui présentera toujours par la suite ses mamelles, toutes les fois qu'il les cherchera. Un âne ainsi nourri s'accoutumera à aimer les cavales. Quelquefois même, quoiqu'il ait été élevé par sa propre mère, il pourra désirer leur commerce, s'il a vécu familièrement avec olles dès son enfanee. Mais on ne le laissera pas saillir avant l'âge de trois ans; et lorsqu'on iui permettra de le faire, il conviendra que ee soit au printemps, d'autant qu'il faudra le fortifier avec du fourrage vert

in asino vulgaris, tum etiam non optime respondet in mula. Neque nos universa quadrupedis species decipiat, si qualem probamus, conspicimus. Nam quemadmodum arietum quæe sunt in linguis et palatis maculæ, plerumque in velleribus agnorum deprelienduntur : ita si discolores pilos asinus in palpebris aut auribus gcrit, sobolem quoque frequenter facit divcrsi coloris, qui et ipse, etiam si diligcntissime in admissario exploratus est, sæpe tamen domini spem decipit. Nam intcrdum ctiam citra prædicta signa dissimiles sui mulas fingit. Quod accidere non aliter reor, quaın ut avitus color primordiis seminum mixtus reddatur nepotibus. Igitur qualem descripsi ascllum, cum est a partu statim genitus, oportet matri statim subtrali, et ignoranti equæe subjici. Ea optime tenebris fallitur. Nam obscuro loco partu ejus amoto, pradictus quasi ex ea na. tus alitur. Cui deinde cum decem diebus insuevit equa, semper postea desideranti præbet ubera. Sic nutritus admissarius equas diligere condiscit. Interdum etiam, quamvis materno lacte sit educatus, potest a tenero conversatus equis familiariter earum consucturlincm appetere. Sed non oportet minorem trimo nec majoren decenni coupépar morceaux ct de l'orge en abondance, et même rquelquefois lui donner des pâtes médicinales. On ne le donnera pas cependant à une jeune femelle qui n'ait point encore eu affaire au mâle, paree qu'elle le repousserait à coups de pieds lorsqu'il s'approcherait pour la saillir, et que l'offense qu'il en aurait reecue lui ferait conccvoir de l'aversion même pour quelque autre cavale que ce fût. Pour que cela n'arrive pas, on appruche de la cavale un ânon dégénéré et commun qui sollicite sa eomplaisance, mais auquel on ne permet pas de consommer l'acte, et lorsqu'une fois elle est disposée à recevoir patiemment les preuves de sa passion, on chasse sur-lechamp le mále trop vil pour elle, et on la fait saillir par un autre plus précieux. On a un em. placement disposé à cet effet, que les paysans appellent machina : cet emplacement est fermé par deux murs latéraux bâtis le long d'une petite éminence, et peu distants l'un de l'autre, afin que la femelle ne puisse pas se débattrc ou se détourner du mâle, qui se met en devoir de la saillir. Il y a deux issues à eet emplacement, une de chaque côté ; mais celle d'eu bas est munie de barreaux auxquels on attaehe la eavale, en la bridant au bas du talus, afin qu'étant baissée en devant, elle reçoive micux la semence de l'âne qui la couvrira, et qu'elle donne plus d'aisance à ce quadrupède, qui est plus petit qu'elle, pour lui grimper sur le dos par le côté le plus élevé. Lorsque la cavale a mis bas le produit de l'âne, on le lui laisse nourrir durant toute l'année suivante, qu'elle n'est pas pleine: et cette méthode vaut mieux que celle de quelques personnes, qui la font remplir par un cheval dans l'année même qu'elle a mis bas. Lorsqu'une mule aura atteint sa seconde année, on fera bien de la retirer d'auprès de sa mère; et

admitti. Alque idipsum si concedatur, vere fieri conveniet, cum et desecto viridi pabulo, et largo ordeo firmandus, nonnunquam etian salivandus erit. Nec tamen tenera fomina committetur. Nam nisi prius ea marem cognovit, adsilicntem admissarium calcibus proturbat, et injuria depulsum etiam creteris equis reddit inimicum. Id ne fiat, dcgener et vulgaris asellus admovetur, qui solicitct obsequia focmina : neque is tamen inire sinitur. Scd, si jam est equa veneris patiens, confestim abacto viliore, pretioso mari jungitur. Locus est ad hos usus extructus (machinam vocant rustici), qui duos parietes adverso clivulo inæedilicatos habet, et angusto intervallo sic inter se distantes, ne fomina conluctari, aut admissario ascendenti avertere se possit. Aditus est ex utraque parte, sed ab inferiore clatris munitus : ad qua capistrata in imo clivo constituitur equa, ut et prona melius ineuntis semina recipiat, et facilem sui tergoris ascensum ab editiore parte minori quadrupedi præbeat. Quæ cum ex asino conceptum edidit, partum sequenti anno vacua nutrit. Id enim utilius est, quam quod quidam faciunt, ut et fotam nihilominus admisso cquo impleant. Annicula mula recte a matre re- 
quand on l'en aura retirée, on la mènera paitre sur des montagnes ou dans des licux sauvages, atin que la corne de ses pieds se durcisse, et qu'elle soit propre à fournir par la suite de gralldes routes : car le mulet est plus propre à porter le bât que la mule; au lieu que celle-ci est plus agile que lui. Ce n'est pas que l'un et l'autre ne puissent très-bien être employés à fairc des conduites sur les chemins et à labourer commodément la terre, à moins que la cherté de ces quadrupèdes ne surcharge la dépense du paysan, ou que la terre ne soit d'un grain épais, qui contraigne d'avoir recours à la force des bœufs.

XXXVIII. Quoique j’aie déjà montré presque tous les remèdes qui conviennent à ce bétail en traitant des autres bestiaux, je n'omettrai cependant point quelques maladies qui lui sont particulières, et dont je vais donner les remèdes. Lorsqu'une mule a la fièvre, on lui donne du chou cru; lorsqu'elle est asthmatique, on lui tire du sang, et on lui verse la valeur d'une hemina de jus de marrube blanc, mêlée avec un scxtarius de vin et une semuncia d'huile d'encens; si elle a des éparvins, on y applique de la farine d'orge, après quoi on ouvre l'apostume avec le fer et on la panse avec de la charpic, ou bien on lui fait couler dans la narine gauche un sextarius d'excellent garum avec une livre d'huile, en ajoutant à ec médicament le blanc de trois ou quatre oufs, dont on a mis les jaunes à part. On est aussi dans l'usaǵe de lui ouvrir les cuisses, et quelquefois d'y appliquer lc feu. Lorsque le sang est descendu dans les jambes de ces animaux, on leur en tire ainsi qu'aux chevaux; ou si l'on a de l'herbe que les paysans appellent veratrum (l'ellébore blanc), on leur en donne en guise de fourrage. La graine de

peslitur, et amota montibus aut feris locis pascitur, ut ungulas duret, sitque postmodum longis itineribus habilis. Nam clitellis aptior mulus. Illa quidem agilior : sed uterque sexus et viam recte graditur, el terram commode proscindit; nisi si pretiun quadrupedis rationem rustici onerat, aut campus gravi gleba roliora boum deposcit.

XXXVıI. Medicinas hmjus pecoris plernmque jam in aliis generibus edocui : propria tamen quadan vitia non omittam, quorum remedia subscripsi. Febrienti muløo cruda brassica datur. Suspiriosa sanguis detrahitur, et cum sextario vini atque utei thuris semuncia, marrubii succus instar hemina mistus iutunditur. Suffraginosa or. leacea fariua imponitur, mox suppuratio ferro reclusa linamentis curatur : vel gari optimi sextarius cun libra olei per narem sinistram denittitur, admisceturyue buic medicanini trium rel quatuor ovorum allus liquor separatis vitellis. Femina secari, et iuterdum inuri soleut. Sanguis demissus in pedes, ita ut in equis emittitur : vel si est herba, quam veratrum rocant rustici, pro pabulo cedit. Est et voรxúxน๊os, cujus semen detritum et eum viuo datum predicto vitio medefur. Macies et languor submovetur sapjus data potione, qux recipit semunciam coltrelle. juscquianc broyéc, et prise dans du vin, remédie aussi à cette maladie. On chasse leur maigreur et leur langueur en leur donnant à différentes reprises une potion composéc d'une semuncia de soufre, d'un œuf cru, et d'un denarius pesant de myrrhe. On mêle ces trois drogues dans du vin, qu'on leur verse dans la gorge. Ces remèdes guérissent également la toux et les douleurs de ventre. Rien n'est plus souverain contre la maigreur que la luzerne : cette lierbe donnée aux juments au licu de foin, lorsqu'elle est encore verte, mais prête à se sécher, les engraisse; quoiqu'il faut leur en donner modérément, de peur que la trop grande quantité de sang qu'elle occasionnc ne les suffoque. Lorsqu'une mule est lasse et en sueur, on lui jette de la graisse dans la gorge, et on lui verse du vin pur dans la bouche. On suivra, pour le surplus de ce qui concerne ces animaux, les méthodes que nous avons données dans les premièrcs parties de ce volume, qui. étaient relatives aux soins que l'on doit prendre des bœufs et des chevaux.

\section{LIVRE VII.}

I. Ayant à parler du petit bétail, Silvinus, nous commencerons par l'ânon d'Arcadie, cet animal vil et commun, auquel la plupart des auteurs d'économie rurale veulent qu'on ait principalcment égard dans l'achat et l'entretien des bêtes de somme, et avec raison : en effet, on peut se le procurer même dans les campagnes qui manquent de påturagc, parce qu'il se contente de peu de fourrage, et qu'il n'est pas difficile sur le choix , puisqu'on le nourrit ou de feuilles ct d'épines, ou de buissons, ou de bottes de sarment. On peut même l'engraisser avec de la paille; que

sulphuris ovumque crudnm, et myrrha pondus denarii. Hac trita vino admiscentur, atque ita faucibus infunduntur. Sed et tussi dolorique ventris eadem ista æque medentur. Ad maciem nulla res tantum quantum Medica potest. Ea lierba viridis celerius, nec tarde tamen arida foeni vice saginat jumenta : rerum modice danda, ne nimio sanguine stranguletır pecus. Lassa et astuanti mula adeps in fauces demittitur, merumque in os suffunditur. Cxtera exequemur in mulis sic, ut priuribus hujus voluminis partibus tradidimus, qux curam loun equarumque contincut.

\section{LIBER VII.}

1. De minore pecore dicturis, I'. Silvne, principium tene. bit miıor Arcidico vilis lie vulgarisque asellus, cujus plerique rusticarum rerum auctores in emendis tueudisque: jnmentis pracipuam rationem volunt esse; nec injuria. Nam etiam eo rure, quod pascuo caret, contineri potest, exiguo el qualicunque jabulo contentus. Quippe vel fuliis spinisque vepraticis alitur, rel ubjecto fasce sarmeutorum. l'aleis vero, quæ pene onnibus regionibus abutudant. 
I'on trouve abondamment dans presque tout pays. D'ailleurs il souffre très-bravement la négligenee d'un surveillant ignorant, ainsi que les coups et la disette; aussi peut-on en tirer du service plus longtemps que de toute autre bête de somme, parce que, comme il supporte très-bien le travail et la faim, il est rare qu'il soit attaqué de quelque maladie. Cet animal, si facile à entretenir, rend néanmoins plus de services, et mìme de services nécessaires, qu'il n'est giand, puisqu'il laboure les terres avee des charrues légères, pour peu qu'elles soient aisées au labour, telles que eelles de la Bétique et de toute la Libye, et qu'il tire des voitures, pourvu qu'elles ne soient pas trop pesantes. Souvent mêrne, ainsi que le raconte le plus célèbre des poëtes, le conducteur d'un anon lent dans sa marche lui charge le dos de fruits vils, et lui fail rapporter, au retour de la ville, une meule ou une charge de poix noire. Mais le travail de cet aniinal le plus usité presque partout eonsiste à tourner la meüle et à moudre le blé. C'est pourquoi il n'y a point de eampagne qul puisse se passer i]'un ânon, eet animal étant très-nécessaire, ainsi que je viens de le dire, tant pour porter à la ville que pour en rapporter conmodément, sur son cou ou sur son dos, la plupart des ehoses qui servent à notre usage. Or nous avons suffisamment expliqué quelle était l'espèee de eet animal la plus recherehée, et quels soins il fallait en a voir, lorsque nous avons donné des préceptes sur les ânes de prix dans le livre préeédent.

II. Le seeond objet de nos soins après les grands quadrupèdes, ce sont les brebis, qui devraient même tenir le premier rang, si on avait égard ì la grande utilité qu'on en retire, puisque ee sont elles qui nous défendent le plus particulièrement contre la violenee du froid, et qui nous fournissent des vêtements avice le plus de libéralité. D'ailleurs non-seulement elles rassasient la faim du paysan par le fromage et le lait cju'elles lui fournissent avee profusion, mais elles garnissent eneore les tables des gens du beau monde d'une grande quantité de mets agréables. Elles servent même à nourrir des nations entières qui manquent de blé, et c'est de là que presque tous

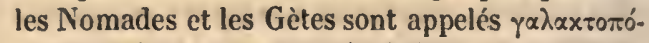
$\tau \alpha$. Ce bétail, quoique très-faible, comme l'observe prudemment Celsus, est d'une santé trèssûre, et n'est point sujet aux maladies pestilentielles. Cependant il faut le ehoisir d'une nature qui s'aceommode avee celle du pays où l'on est. C'est une attention que Virgile ordonne d'avoir en toute oceasion, non-seulement par rapport ì. ce bétail, mais encore par rapport à toutes les parties de l'éeonomie rurale, lorsqu'il dit que toutes les terres ne peuvent pas s'accommoder également de toutes sortes de choses. Les terroirs gras et les pays plats s'aceommodent de brebis hautes; les maigres et ceux où il y a des eollines s'aceommodent de eelles qui sont trapues; les forêts et les lieux montagneux n'en veulent que de petites, et les brebis que l'on eou. vre de peaux paissent à leur aise dans les prés et dans les plaines en jachères. Non-seulement l'espèee de ce bétail est un point essentiel à observer, mais sa couleur nel'est pas moins. Les habitants de notre pays regardaient autrefois les brebis de Milet, ainsi que eelles de la Calabria et de l'Apulia, comme les brebis de l'espèce la plus distinguée, et celles de Tarentum comme les meilleures de toutes. Aujourd'hui celles des Gatiles passent pour avoir le plus de renom, et notamment celles d'Altinum, ainsi que celles qui sont établées dans les eampagnes de la Maera, aux en. virons de Parme et de Mutina. Outre que la eou. etiam gliscit. Tum imprndentis cnstodis negligentian fortissime sustinet : plagarum et penurix tolerantissimus : propter qux tardius deficit, quan ullum aliud armentum. Nam laboris et famis maxime patiens, raro morbis afficitur. Hnjus animalis tam exignx tutela phnrima et necessaria opera supra portionem respondent, cum et facilen terram qualis iu Batica totaque Libye, (sit) levibus aratris proscindat, et non uninima pondera vehiculo trahat. Sxpe etiam, it celelverrimus poeta memorat :..... tardi costas agilator aselli Vilibus aut onerat pomis, lapidemque revertens Incusum aut atre massam picis urbe reportal. Jam vero molarum el conficiendi frumenti pene solenuis est lunjus pecoris labor. Quare omne rus tanquam maxime necessarim instrumentum desilerat asellum, qui, ut dixi, pleraque utensilia et veliere in urbem, et reportare collo vel ilorso commode polest. Qualis antem species ejus vel cura probatisslma sit, snperiore libro, cum de pretioso preciperetur, satis dictumn est.

II. Post majores quadrupedes ovilli pecoris secunda ratio est, quxe prina fit, si ad utilitatis magnitndinem referas. Nam id pracipne nos coutra frigoris violentiam protegit, corporibusque nostris liberaliora probet relamina. Tum etiam casei lactisque abundantia non solum agrestes saturat, sed etiam elegantium mensas jucundis et numerosis dapilns exornat. Quilonsdam vero nationibus frumenti expertibus victum commodat, ex quo Nonıdhum

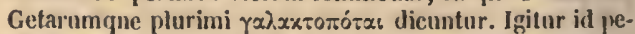
cus, quamvis mollissimum sit, ut ait prudentissime Celsus, valetudinis tutissim est, minimeque pestilentia laborat. Verum tamen eligendum est ad naturam loci : quod semper observari non so!um in lıoc, sed eliam in tota ruris disciplina Virgilius precerpit, cum ait : Nec vero terree ferre omnes omnia possunt. Pingnis el campestris situs proceras oves tolerat; gracilis et collinus quadratas; silvestris et montosus exiguas . pratis planisque novalibus tectum pecus commodissime pascitur. Idque non solum generi. bus, sed etian coloribus plurimum refert. Generis exiuni Calabras Apulasque et Milesias nostri existimabant, earumqne optinas Tarentinas. Nune Gallica pretiosiores lıbentur, earnmque priecipue Altinates. Item (pıx circa Parmam et Mutinan Macris stabulautur campis. Color allus cnm sit optimns, tum etian est utilissinus, quod 
leur blanche est la meilleure dars ee bétail, elle est cneore de la plus grande ressource, parce qu'arec eette couleur on peut se proeurer beaucoup d'autres couleurs, au lieu qu'on ne peut en avoir de blanehe avec aueune autre. Les couleurs brunes et noires, telles qu'on en trouve à Pollentia en Italie et à Corduba dans la Bétique, sont aussi par leur nature d'un prix recommandable. L'Asie donne même des brebis rouges, que l'on appelle erythrace (rouges). Mais lexpérience a fait trouver des moyens de multip:ier les varićtés de couleur dans ce bétail. Fn effet, eomme on avait amené d'Afrique, à des gens qui donnaient en speetacle des bêtes rares dans la ville munieipale de Gadès, entre plusieurs autres bêtes ferroces, des béliers sauvages et farouches d'une couleur admirable, M. Columelle, mon onele paternel, homme d'un génie pénétrant et célèbre agrieulteur, en aeheta quelques-uns, qu'il transporta dans ses terres, et qu'il fit accoupler avec ses brebis eouvertes de peaux, après les avoir apprivoisés. Les premiers résultats furent des agneaux dont la toison était à la vérité grossière, quoique de la même couleur que celle du père; mais ces agneaux ayant par la suite couvert des brebis de Tarentum, donnèrent des béliers dont la toison fut plus fine. Les agneaux engendrés de ccux-ci eurent la toison déliee et moelleuse de la mère, et la eouleur du père et du grand-père. Columelle prétendait que de cette façon l'espèce d'une bête sauvage, quelle qu'elle fut, se retrouvait toujours dans ses petits-fils, après que le naturel sauvage s'était trouvé adouci en passant par différents degrés. Je reviens à mon sujet. Il y a donc de deux sortes de brebis; eelles qui ont la laine douce, et celles qui l'ont grossière : mais quoiqu'il $\mathbf{y}$ ait, par rapport à l'une et l'autre espèce, des observations com-

ex eo plurimi fiunt, neque hic ex alio. Sunt etiam suapte natura pretio commendabiles pullus atque fuscus, quos prabent in Italia Pollentia, in Bretica Corduba. Nec miuus Asia rutilos, quos rocant erjtlurzeos. Sed et alias va. rielates iu hoc pecoris genere docuit usus exprimere. Nam cum in municipium Gaditamum ex vicino Africa miri coloris silvestres ac feri arietes, sicut aliæ bestix, munerariis deportarentur, M. Columella patruus mens acris vir ingenii, atque illustris agricola, quosdam mercatus in agros transtulit, et mansuefactos tectis ovibus admisit. Fa primum hirtos, sed paterni coloris agnos ediderunt, qui deinde et ipsi Tarentinis oribus impositi, tenniori3 velleris arietes progeneraverunt. Ex lis rursus quicquid conceptum est, materuam mollitiem, paternum et avitun retulit colorem. Hoc modo Columella dicebat, qualemcunque speciem, qux fuerit in bestiis, per nepotum gra. dus mitigata feritate rediisse. Sed ad proposiluin revertar. Ërgo duo genera sunt ovilli pecoris, nolle et lirsutum. Sed in utroyue vel enendo plura communia, quarlam tanien sunt propria geverosi, qux observari conveniat. Communia in cuendis gre gibus fere illa : si candor lanxe munes, auxquelles it faut avoir égard soit dans l'achat soit dans l'entretien de ecs animaux, il y en a eependant quelqques-unes de partieulières à l'espèee la plus distinguće. Voiei à peu près les observations communes auxquelles il faut avoir égard dans l'aehat des troupeaux. Puisque la blaneheur de la laine est ce que l'on recherche le plus, il faudra toujours choisir les plus blanes, parce que souvent il vient un agneau noiratre d'un bélier blane, et que jamais des béliers rouges ou gris n'en produisent de blanes.

III. Ainsi, quoiqu'un bélier ait la toison blanehe, ee n'est pas un motif suffisant pour l'approuver, à moins qu'il n'ait le palais et la langue de la mêmecouleur que la laine, puisqu'il donne des agneaux gris ou même bigarrés, lorsqu'il a ces parties du corps noires ou tachées. C'est ce que le poēte que j'ai déjà citẻ ei-dessus a trèsbien exprimé entre autres elıoses par ces vers : - Mais rojetez un bélier qui, tout blanc qu'il est, cache sous son palais humide une langue noire, de peur qu'il ne teigne de taches noirátres la toison de ses enfanls. Il en est de même des béliers roux ou noirs, dont le palais et la langue ne doivent pas non plus être d'une couleur différente de celle de leur laine (ainsi que je l'ai déjả dit); ils doirent encore moins être tachés surle eorps, et partieulièrement sur le dos. II ne faut pas par conséquent acheter de brebis qu'e!les n'aient leur laine au moment de l'achat, afin que l'on puisse mieux voir si elles sont d'une seule eouleur, paree que si l'unité de eoulcur ne se retrouve pas dans les béliers, les taches du père se transmettent ordinairement aux enfants. On estime surtout le bélier lorsqu'il est haut et long, qu'il a le ventre ravalé ct couvert de laine, la queue très-longue, la toison épaisse, le front large, les testicules gros et les cornes torse's : non

maxime placet, nunquam nisi candidissimos nares legieris : quoniam ex albo sxpe fuscus edilur partus; ex erythrao vel pullo nunquam geueratur albus.

111. Itaque non solum ea ratio est probandi arielis, si vellere candido vestitur, sed etiam si palatum atque lingua concolor lanæ est. Nam cum hæ corporis partes nigræe aut maculosx sunt, pulla vel etiam varia nascitur proles; idque inter catera eximie talibus numeris significavit idem qui supra: Illum autem, quamvis aries fil cundidis ipse, Nigra subest udo tanlum cui lingua palato, Rejice, ne maculis infuscet vellera pullis Nascentum. Una eademque ratio est in erythræis et uigris arietibus, quorum similiter, ut jam dixi, neutra pars csse debet discolor lana, multoque miuus ipsa universitas tergoris maculis variet. IJeo nisi lanatas oves emi non oportet, quo melius unitas coloris appareat: qua nisi praccipua est in arietibus, pateruac notx plerumque natis inha. rent. Halvitus autem maxime probatur, cum est altus atque procerus, ventre promisso atyue lanato, cauda lon. gissima, densiyue velleris, fronte lata, testibus amplis, intortis cornibus : non quia magis hic sit utilis, (nen 
pas qu'il soit alors d'une plus grancle utilité, puisqu'un bélier sans cornes vaut encore mieux, mais parec que les cornes ne lui nuisent pas autant lorsqu'elles sont torses que lorsqu'elles sont droites et biei ouvertes. Nous préférerions cependant dans certaines contrées, où la température de l'air est humide et venteuse, les boucs et les béliers qui auraient même de très-grandes cornes, parce qu'étant droites et hautes, elles mettraient la plus grande partie de leur tête à l'abri des tempêtes. Ainsi, si nous sommes dans un pays où l'hiver est le plus communément rude, nous choisirons cette espèce de béliers à grandes cornes: au lieu que si l'hiver est doux, nous préférerons un mâle sans cornes, parce qu'il y a cet incon vénient à craindre dans celui qui a des cornes, que, se sentant la tête armée avec une espèce de dard naturel, il cherche plus souvent les occasions dese battre, et qu'il importune trop les femelles. En effet, il poursuit avec beaucoup de violence ses rivaux (quoiqu'il ne suffise pas seul à couvrir lc troupeau), et il ne permet pas à d'autres de s'accoupler avec les brebis qui sont en chaleur, à moins qu'il ne soit harassé par le plaisir : au lieu que cclui qui n'a point de cornes, se sentant pour ainsi dire désarmé, n'est pas enclin à chercher dispute, en même temps qu'il est plus modéré dans ses plaisirs. Aussi les pâtres em. ploient-ils la ruse que voici pour réprimer la brutalité d'un bouc ou d'un bélier qui donne des coups de corncs : ils fiehent des pointes dans une planche de robre d'un pied de long, qu'ils attachent à ses cornes en tournant ces pointes du côté de son front. Cette précaution empêche l'animal, tout féroce qu'il est, de chercher dispute aux autres, parce qu'il ne peut pas donner un coup sans se blesser lui-même en se piquant du méme coup. Mais Épicharmus de Syracuse, qui a traité avec beaucoup de soin des re- mèdes des bestiaux, assure qu'on vicnt à bout d'adoucir un bélier qui est enclin à se battre, en lui percant les cornes avec unc tarière à l'endroit de leur courbure le plus voisin des oreilles. Le meilleur âge de ce quadrupède pour la génération est l'âge de trois ans : il ne cesse pas cependant d'y être propre jusqu'à huit. Il faut faire couvrir la femelle après sa seconde année: elle passe pour être dans le bon âge à cinq ans, et cesse de porter passé la septième annéc. Vous achèterez donc, comme je l'ai déjà dit, des brebis qui ne soient pas nouvellement tondues : vous ne prendrez point celles dont la laine sera tacliée et grise, parce que ce sont des couleurs peu sûres. Vous rejetterez aussi comme stériles celles qui, passé trois ans, auront les dents saillantes hors de la bouche; mais vous choisirez celles de deux ans qui auront le corps ample, le cou garni de longue laine, la toison douee, et le ventre également couvert de laine et ample, parce qu'il faut éviter les ventres petits et pelés. Ce sont à peu près là les observations auxquelles on aura égard dans l'achat de quelque espèce de brebis que ce soit. Voici celles qui sont relatives à leur entretien. II faut faire des étables basses et spacieuses, mais plus longues que larges, afin qu'elles soient et chaudes en hiver, et suffisamment larges pour qu'il n'y ait point de risque que les brebis pleines se blessent le ventre. On les exposera au midi, parce que ce bétail, quoique le plus vêtu de tous les animaux, est cependant celui qui s'habitue le moins au froid, ainsi qu'aux grandes chaleurs de l'été. C'est pourquoi on doit avoir devant l'entrée de ces étables une cour close par de hautes murailles, dans laquelle ces animaux pourront aller avec sûreté pendant les chaleurs de l'été. On fait aussi en sorte qu'il ne séjourne aucune humidité dans leurs étables, et qu'elles soient toujours couvertes de fougere très-sèche ou de est melior mutilus aries) sed quia minime nocent intorta potius, quam surrecta et patula cornua. Quibusdan tamen regionibus, ubi creli stątus uvidus ventosusque est, capros et arietes optaverinus vel amplissimis cornibus, quod ea porrecta altaque maximam partem capitis a tem. pestate defendant. Itaque si plerumque est atrocior liems, loc genus eligemus : si clementior, mutilum probabimus marem : quoniain est illud incommodum in cornuto, quod cum sentiat se velıt quodam naturali telo capitis armatum, frequenter in pugnam procurrit, et fit in fominas quoque procacior. Nam rivalen (quamvis solus admissura non suficit) violentissime persequitur, nec ab alio tempestive patitur iniri gregem, nisi cum est fatigatus libidine. Mutilus autem, cum se tanquam exar. matum intelligat, nec ad rixam promptus est, et in venere mitior. Itaque capri vel arietis petulci sæevitiam pastores lac astıtia repellnnt. Mensuræ pedalis robustam tabulam configunt aculeis, et adversam fronti cornibus religant. Ea res ferum prohibet a rixa, quonian stimulatum suo ictn ipsum se sauciat. Epicharmus autem Syracusanus, qui pecudum medicinas diligentissime conscripsit, alfirmat pugnacem arietem mitigari terebra secnndum auriculas foratis cornibıs, qua curvantur in flexum. Ejus quadrupedis atas ad progenerandım optima est trima : nec tamen inhabilis usque in annos octo. Fomina post bimatum ınaritari debet, juvenisque liabetur quinquenı is : fatiscit post annum septimum. Igitur, ut dixi, mercaberis oveis intonsas : variam canamque improbabis, quod sit incerti coloris. Najorem trima dente minacem sterilem repudiabis. Eliges bimam vasti corporis, cervice prolixi vili, nec asperi, lanosi et ampli uteri. Nam vitandus est glaber et exiguus. Atque hæc fere communia sunt in comparandis ovibus. Illa etiam tuendis : humilia facere sta. bula, sed in longitudinem potius, quam in latitudinem porrecta, ut simul et lieme calida sint, nec angustiæ foetus oblidant. Ea poni debent contra mediım diem : namque id pecus, qnamvis ex omnibus animalibus sit vestitissimum, frigoris tamen impatientissimum est, nec minus astivi vaporis. Itaque cohors clansa sublimi macerie praponi restibulo debet, ut sit in eam tutus exitus æstivandi; 
-haume, afin que les brebis soient couchées plus proprement et plus mollement lorsqu'elles au ront agnelé. II faut encore que les bergeries soient très-propres, de sorte que la santé des brebis, à la conservation de laquelle il faut principalement veiller, n'ait point à souffrir de l'humidité. Engénéral il faut donner à quelque espèce de bétail que ce soit une nourriture abondante : en effet, un troupeau, même peu nombreux, qui sera bien rassasié de fourrage, sera d'un plus grand profit à son maître que ne le serait un plus nombreux qui aurait souffert de la disette. Il faut rechercher les jachères, non-seulement parce qu'elles sont bien fournies d'herbes, mais encore parce qu'elles ne sont point ordinairement embarrassées par des épines : car, pour nous appuyer souvent de l'autorité du poëte divin, Si la laine est votre objet, commence $=$ par fuir les foréts piquantes, ainsi que labardane et le chardon, parce que ces plantes rendent les brebis galeuses, comme dit le même poëte, au cas qu'après la lonte, et avant qu'on ait lavéla sueur qui tient à leur peau, leur corps ait été déchiré par des épines piquantes; et que d'ailleurs cet accident diminue tous les jours la quantité de leur laine. En effet, plus la laine de ce bétail est épaisse et longue, plus elle est sujette d'un autre côté à être arrachée de son dos pendant qu'il pait, par les ronces qui l'accrochent comme autant de hamecons. Quant à celles qui sont couvertes de peaux, elles perdent aussi par là leur couverture, dont la réparation jette dans de grandes dépenses. Presque tous les auteurs conviennent que le temps où l'on peut faire couvrir le plus tôt les brebis est le printemps, vers la fête des Parilia, quand elles n'ont point agnelé pourlors, et vers le mois de juillet, quand elles ont agnelé daus cettc saison. Cependant le premicr de ces deux temps doit, sans contredit, être préféré à

delurupue opxera, ne quis lummor consistat, ut semper qnam aridissinis filicibus vel culnis stabula constrata sint, quo puius et mollius inculsent fueta: (sint quala mundissina) neque earum valetudo, quae praceipue custodienda est, infestetur uligine. Onınia antem pecudi larga prabenda sunt alinuenta. Nam vel exiguns numerus, cum pabulo saliatur, plus domino redlit, quam maximus grex, si senserit peuurian. Sequeris auten novalia non solum herbida, sel quae plerunupue villua sunt spinis; utamur euim siepins anctoritate divini carninis : Si libi lanilium curae est, primum aspera silva Lappaeque tribulique absint; q̨uюniam ea res, ut ait idem, scabras oves reddit, cum tonsis illolus adhcesit Sudor, el liirsuli secuerunt corpora vejres: tum etianı quotidie miunitur lana fructus, qua quanto prolixior in pecore concrescit, tanto magis obnoxia est rubis, quibus velut hanis inuucata pascentium tergoribus avellitur. Molle vero pecus etian velamen, quo protegitur, anittit, atque id nou parvo sumtı reparatur. Iuter auctores fere coustat, primum esse adınissurac tempus veruum I'arilibus, si sit ovis matura; sin vero l'autre, atin que, par une continuité d'opérations successives, la naissance des agneaux suc. cèdeà la vendange, comme la vendange aura succédé à la molsson, et que ces animaux puissent mieux supporter les froids et le jeûne dont ils sont menacés pendant l'hiver, par les forces qu'ils auront acquises en se rassasiant de fourrage pendant toute l'automne. En effet, l'agneau d'automne vaut mieux que celui du printemps, comme dit Celsus a vec beaucoup de raison, parce qu'il est plus essentiel que cet animal soit fortifié avant le solstice d'été, qu'il n'est essenticl qu'il le soit avant celui d'hiver, d'autant que c'est le seul de tous les animaux qui puisse naître sans risque au solstice d'hiver. Si le cas exige qu'on se procure plus de mâles que de femelles, Aristote, le plus grand connaisseur des phénomènes de la nature, ordonne d'observer, en faisant couvrir les brebis, le vent de septentrion pendant les jours secs, afin de faire paitre lo troupeau vis-à-vis ce vent, pour que les brebis l'aient en face pendant l'acte de la génération : si l'on veut se procurer des femelles, il faut au contraire chercher les vents du midi, et fairc couvrir les brebis dans la même position respectivement à ces vents. Car la méthode que nous avons enseignée dans le premier livre, qui consiste à serrer avec une ligature le testicule droit du mâle ou le gauche, au moment de la génẻra. tion, est d'une exécution difícile dans des troupeaux nombreux. Quand les brebis auront mis bas, lc berger qui conduit ses troupeaux dans des contrées éloignées élèvera presque tous les agneaux dans les pâturages où-il se trouvera, tandis que le métayer qui habite dans les environs d'une ville livrera au boucher les jeunes agneaux avant qu'ils' aient tâté de l'herbe, parce qu'il en coûtera peu pour les mener à la ville, et que lorsqu'on les aura scrrés, le lait

foeta, circa Julium mensem. Prius tamen hand dubie probabilius, ut messem vindemia, fructum deinde vinea. ticum foetura pecoris excipiat, et tolius antumni pabulo satiatus agnus ante mostitiam frigorum atque liemis jeju. ninu confirmetur. Nam melior est autumnalis rerno, sicut ait verissime Celsns; quia magis ad rem pertinet, nt ante xstivum quam hibernum solstitinm convalescat: solusquo ex omnibus bruma commode nascitur. Ac si res exigit, ut plurimi mares progenerandi sint, Aristoteles vir callidissinus rerum naturæ præcipit admissura tenıpore olservare siccis dicbus lalitus septeıntrionales, ut contra veutum gregem pascamus, et eum spectans admittatur pecus : at si fuemine generandie sunt, austrinos flatıs captare, itt eadem ratione matrices ineantur. Nam illul, quod priore libro docuimus, ut admissarii dexter vel etiam sinister vinculo testieulus obligetur, in magnis gregibus operosum est. Post foturam deinde longinqua regionis opilio fere omnem sobolem pastioni reservat : suburbanae [villicus enim] teneros agnos, dum adluc lierbia suut expertes, lanio tradit, quoniam et parvo sumptu 
de lcurs mères rendra un profit aussi considérable que celui qu'il rendait lorsqu'elles nourrissaient. 11 faudra cependant en laisser croître quelques-uus même dans le voisinage de la ville, parce que quand ce bétail est né dans le pays mème où l'on est, on en retirc bicn plus de profit que lorsqu'il est tiré d'un pays ćtranger. D'ailleurs il ne faut pas risçuer que le troupeau vienne à manquer tout entier à la fois à son maltre, lorsque toutes les têtes dont il est composé seront épuisées par la vieillesse, d'autant que le premier soln d'un pâtre, surtout quand il est attentif à son devoir, est de substituer toutes les années dans le troupeau autant ou même plus de têtes qu'il n'y en a de mortes ou de malades, parce qu'il arrive souvent que la rigueur des fioids le surprend, et que l'hiver fait mourir les brebis qu'il avait laissées dans le troupeau pendant l'automne, dans la persuasion où il était qu'elles pourraient aussi supporter l'hiver. Ces aecidents sont encore un motif qui doit le porter à ne compléter le troupeau qu'avee de jeunes agneaux, et qui soient déjà assez forts pour n'être pas surpris par l'hiver. Il joindra à cette attention celle de ne pas le compléter avee les agneaux qui seront nés de brebis âgées de moins de quatre ans ou de plus de huit, parce que dans aucun de ces deux âges une brebis n'est propre à élever un agneau: outre que le produit d'une vieille bête tient communément de la vieillesse de son origine, et qu'il est toujours ou stérile ou chétif, On doit garder la ventrée d'une brebis, pendant qu'elle est pleine, à peu près avee autant de eirconspeetion que les sages-femmes gardent lc fruit d'une femme grosse. On ne délivre pas non plus autrement eet animal que les femmes, et souvent même son travail est plus pénible à

devehuntur, et iis submotis, fructus lactis ex matribus non minor percipitur. Submitti tamen etiam in vicinia urbisquiutum quenque oportebit. Nam vernaculum pecus peregrino longe est ntilius : nec committi debet, ut totus grex effuctus senectute dominum destituat : cum prasertion boni pastoris vel prina cara sit annis omnibus in rlemor. tuarum vitiosaŕunque ovium locum totilem rel etiam plura capita substitucre : quoniam sape frigorum atqque hiemis savitia pastorem decipit, et eas oves interimit, ıuas ille tempore antumni ratus adlutuc esse tolerabiles, nou submoverat. Quo magis etiam propter hos casus, nisi yుı validissima non comprehendatur hieme, novaque progenie repleatur ummerus. Quod qui faciet, servare debebit, ne minori quadrina, neve ei, qua excessit annos octo, prolem submiltat. Niutra enim atas ad edıcandun est idonea : tum etianı juod ex vetere materia nascitur, plerumque congeneratun parentis senium refert. Nam vel sterile vel imbecillum est. Partus vero incientis pecoris non secus quan obsletricum more cuslodiri debet. Neque enim aliter hoc animal quam muliebris sexus enilitur, sæpiusque etiam, quaulo est omnis rationis iguarum, la. borat in partı. Quare veterinaria Ipedicina pudens esse proportion de ce qu'il est privé de toute raison. C'est pourquoi le maitre du troupeau doit être un homme instruit dans la médecine vétérinaire, afin que, selon le besoin, il soit en état, lorsque le foetus sera attaché en travers dans la matriee de la mère, de l'en tirer soit en entier soit par parties, saus mettre la mère en danger en le dis. séquant avee le fer, ee que les Grees appellent

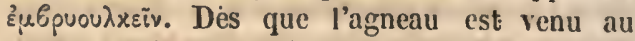
monde, il faut le mettle sur ses jambes, et l'approcher du pis de sa mère; ensuite même lui ouvrir Ja gueule, pour l'humecter du lait qu'on y fera dégoutter en pressant le bout du pis, afin qu'il apprenne à tirer l'aliment que lui doit fournir sa mère. Mais avant d'en renir là, on traira auparavant les premières gouttes de co lait, que les pâtres appellent colostra, parce que si on n'avait pas soin de les tircr, elles feralent mal à l'agneau. Deux jours après sa naissance, on l'enferme avec sa mère, afin qu'elle l'échauffe et qu'il apprenne à la reconnaître : après quoi, tant qu'il n'est pas en état de bondir, on le garde dans un enclos obscur et chaud; mais lorsqu'il commencera à bondir, il faudra l'enfermer dans un parc d'osier avee ceux de son âge, de peur qu'il ne maigrisse comme les enfants par trop de pétulance. Il faut aussi avoir soin que les plus jeunes agneaux soient séparés des plus forts, parce que ceux qui sont dejà robustes tourmentent eeux qui sont encore faibles : mais il suffit de faire eette séparation le matin avant que le troupeau sorte pour aller paître; ear on pourra d̀ l'entrée de la nuit, et lorsque les brebis seront de retour après s'être bien rassasiées, mettre les agneaux pêle-mêle avec elles. Lor'şu'ils commeneeront à être forts, on les nourrira dans l'étable avec du eytise ou de la luzerne, et même

debet pecoris magister, ut, si res exigat, vel integrum conceptum, cum transversus hixet locis genitalibus, extralıat, vel ferro divisum citra matris perniciem parti-

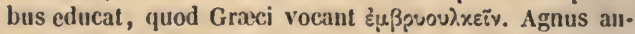
tem, cum est editus, erigi debet, atque uberibus admoveri, tum etiam ejus diductum os pressis lummectare papillis, it coudiscat maternum trahere alinentum. Sed prius quan loc fiat, exiguum lactis emulgendum est, quod pastores colostram vocant : ea nisi aliquatenus emittitur, nocet agno qui biduo quo natus est, cum matre claudatur, ut et ea partum suum fo veat, et ille matrem agnoscere condiscat. Alox deinde quamdiu non lascivit, obscuro et calido septo custodiatur; postea luxurianten virgea cum camparibus area claudi oportebit, ne velut juerili nimia exultatione inacescat : cavendunque est, ut tenerior separelıı a validioribus, quia rolıustus angit imbecillum. Satisque est mane prius quan grex procedat in pascua; deiude etiam crepusculo redeuntihus saturis ovibus aduiscere agnos. Qui dum firmi esse cueperint, pascendi sunt iutra stabulun cytiso, vel medica, tim etiam furfuribus, aut, si permittat annona, farina ordei vel ervi : deinde, ubi convaluerint, circa mei idiem pratis aut novalibus villse. 
avee du son par la suite, ou de la farine d'orge et d'ers, si la cherté de ces grains n'y met point d'obstacle: après quoi, lorsqu'ils auront pris toute leur force, il faudra mener les mères vers le midi dans des prés ou sur des jachères contiguës a la métairie, et faire sortir les agneaux de leur enclos, afin qu'ils apprennent à paitre au dehors. Quant au genre de fourrage quileur convient, nous observerons, soit en rappelant ce que nous avons dit précédemment, soit eu y ajoutant les choses que nous pouvons avoir omises alors, que les herbes qui leur sont le plus agréables sont celles qui viennent dans les campagnes qui ont reçu le premier labour à la charrue; qu'après elles, ce sont celles des prés qui ne sont pas trop humides; et qu'enfin celles des marais et des forêts passent pour être les moins bonnes. Il n'y a pas cependant de fourrages ui même depacages, si agréables qu'ils puissent être, qui ne cessent à la longrue de plaire aux brebis, à moins que le pâtre ne prévienne le dégoût qu'elles en prennent en leur donnant du sel : on met ce sel dans des auges de bois peudant l'été, afin qu'elles aillent le lécher au retour de la pâture, et qu'il serve comme d'assaisonnement à leur fourrage, pour exciter en eiles une ardeur égale tant pour boire qque pour paître. On subvient d'un autre côtẻ à la disette de l'hiver en remplissant les crèches des bergeries de nourriture : car on peut y mettre très á propos soit des feuilles d'orme ou de frêne, soit du foin d'automne que l'on appelle cordum, parce que ce foin est plus mollet et dès là même plus agréable que celui qui est cueilli dans son temps. On les nourrit aussi très-bien de cytise ct de vesce cultivée. Il faut cependant être aussi pourvu de paille de légumes, pour lescas où toutes les autres nourritures viendront à manquer. Car si l'on voulait s'en tenir à ne leur donner que

continuis matres admorendæe sunt, et a septo emittendi agui, ut condiscant foris pasci. De genere pabuli jam et ante diximus, ut nunc corum, 1qux ornissa sunt, memiuerimus, jucundissinıas herbas esse, quæ aratro proscissis arvis nascantar; deinde qux pratis uligine carentibus; palistres silvestresque minime idoneas liaberi. Nec tamen Illa sunt tam blanda pabula, aut etiain pascua, quorum gratia non exolescat usu continuo, nisi pecudium fastidio pastor occurrerit prabito sale, quod velut ad pabuli con. dimentum per astatem canalibus ligneis impositem, cum e pastu redierint ores, lambunt, atque eo sapore cupidinem bibendi pascendique concipinnt. At contra penuriæ hiemis succurritur oljectis intra tectum per præsepia cibis. Aluntur autem commodissine repositis ulmeis vel ex fraxino frondibus, vel autumnali fueno, quod cordum yocatur. Nam id mollius et ob loc jucundius est, quam malurum. Cytiso quoque et sativa vicia pulcherrime pascuntur. Secessaria tamen, ubi catera defecerunt, etian ex leguninibus palex. Nam per se ordeum, vel fresa cum [suis valvulis] faba [ vel] cicercula sumptuosior est, quam ut suburbanis regionibus salubri pretio possit prae. de l'orge, ou des fèves broyées avec leur cosse, ou $\mathrm{du}$ pois chiche, ce serait une trop grande dépense pour pouvoir y subvenir dans le voi. sinage des villes sans qu'il en couttât énormément, quoique ces graines seront sans contredit ce qu'il y aura de mieux à leur donner, dans le cas où leur bon marché le permettra. Quant aux temps auxquels il faut lesmener paitre ou boire, je suis du sentiment de Maron, lorsqu'il dit : Au lever de la conslellation de Lucifer, menöns le matin les troupeaux brouter les campagnes en. core fraiches, dans le temps que les herbes sont blanchies par la gelée, et que la rosée, qui est très-agréable au bétail, couvre l'herỏe tenilre. Ensuite, lorsque la quatrième heure du jour leur fera sentir la soif, conduisons-les a des puits ou vers des étangs profonds; menons-les au milieu du jour soit dans des vallées, comme dit lc même poëte, ờ cles chénes élevés, dont le bois sera consacré depuis longtemps à Jupiter, étendront au loin leurs branches; soit dans des foréts qu'une quantité d'yeuses, dont lombre sacrée invite à se reposer, rend impénétrables à la lumiere. Lorsqu'ensuite la chaleur sera tombée, menons-les boire une seconde fois, pour les faire paitre de nouveau vers le coucher du soleil, lorsque la fraîcheur du vesper aura tempéré l'air, et que la nuit en amenant la rosce commencera à refaire les foréts. Mais il faut observer en été, pendant le lever de la Canicule, de conduire le troupeau arant midi la tête tournée à l'occident, en le faisant avancer vers ce point du monde, et l'après-midi vers l'orient : car il est très-important que la tête des brebis ne soit point alors en face du soleil pendant qu'elles broutent, parce que cette constellation est ordinairement pernicieuse aux animaux à son lever. On les reliendra pendant les matinées d'biver et

beri : sed sicubi vilitas permitti, laaud dubie sunt optima. De temporibus autem pascendi, et ad aquam ducendi per æstatem non aliter sentio, quam ut prodidit Maro : $\mathbf{L u}$ ciferi primo cum sidere frigida vura Carpamus, dum mane novum, dum gramina canent, Et ros in tenera pecori gratissimus herba. Inde ubi quartasitim cali collegerit hor a, Ad puteos, aut alta greges ad stagna perducamus, medioque die, ut idem, ad vallem, Sicubi magna Jovis antiquo robore quercus Ingenteis tendit ramos, aut sicubi nigrum Ilicibus crebris sacra nemus accubat umbra. Rursus deinde jam mitigato vapore competlamus ad aquam, et iterum ad pascua producamus. Solis ad occasum, cuin frigidus aera vesper Temperat, et sallus reficit jam roscida luna. Sed observandum est sidus restatis per enersum Canicula, ut ante meridiem grex in occidentem speclans agatur, et in eam partem. progrediatur, post meridiem in orienten. Siquidem plurimum refert, ut ne pascentium capita sint adrersa soli, qui plerumque nocet animalibus oriente prædicto sidere. lieme et vere matutinis temporibus intra septa conti. neantur, dum dies arvis gelicidia detrahat. Nam pruinosa 
de printemps dans leur enclos, jusqu'à ce que ic solcil ait ressuyé la gelće blanche des campagnes, parce que l'herbe couverte de rosée occasionue dans ces saisons des fluxions aux bestiaux, et lcur láche le ventre. C'est pour cela aussi qu'il ne faut les laisser boire qu'une seule fois dans les tcinps de l'année froids et humides. Outre cela, celui qui suit le troupeau doit a roir l'œil de tous côtés, être vigilant (précepte applicable en général à tous ceux qui gardent des bestiaux, de quelque espèce qu'ils soient), et le gouverner avec beaucoup de douceur, car ces animaux sont très pacifiques, et souffrent tout en silence. Le conducteur se contentera de menacer les brebis avec la volx et la houlette, quand il s'agit de les rassembler et de les faire rentrer, sans jamals lancer de traits contre elles, sans s'écarter à une trop grande distance d'elles, et sans se coucher ni s'asseoir à terre. Il doit au contraire, lorsqu'il ne marche pas, se tenir debout, parce que le devoir d'un gardien est d'avoir les yeux postés, pour ainsi dire, sur une guérite très-élevée, pour empêcher de s'écarter des autres ou celles qui sont paresseuses et pleines, lorsqu'elles s'arrêtent, ou celles qui sont agiles et qui ont mis bas, lorsqu'elles vont trop vite, de peur qu'un voleur ou une bête féroce ne vienne à le tromper et à lui faire prendre le change. Mais tous ces préceptes sont généraux, et conviennent presque à toutes les espèces de brebis; au lieu que nous en allons donner de particuliers pour les espèces le plus estimées.

IV. Il est rarement avantageux d'avoir des brebis grecques, que l'on appelle communément brebis de Tarente, à moins que le propriétaire ne soit dans le cas d'avoir continuellement l'œil sur elles, parce que ce bétail demande de plus grands soins et plus de nourriture que les autres. Car si les bestiaux qui portent laine sont en général

[iis diebus] herba pecudi gravelinem creat, rentremque prolıit. Quare etianı frigidis humidisque temporibus anni semel [ tantum] ei potestas aquæ facienda est. Tum qui sequitur gregem circumspectus ac vigilans (id quod omnibus et omninm quadrupedum custodibus procipitur) magna clementia moderetır; ilemque propior quia silent, et in agendis recipiendisque ovibus adclamatione ac baculo minetur : nec unquam telum emittat in eas : neque ab his longius recedat : nec aut recubet, aut considat. Nam nisi procedit, stare debet, quandoguidem custodis officium sublimem celsissinamque oculorum veluti speculam de. siderat, ut neque tardiores et gravidas, dum cunclantur, neque agiles et foetas, dum procurrunt, separari a caeteris sinat; ne fur, aut bestia hallucinantem pastorem decipiat. Sed harc communia fere sunt in omni pecore ovillo. Nunc quæ sunt generosi propria dicenus.

IV. Græcum pecus, quod plerique Tarentinum rocant, nisi cum donini prasentia est, rix expedit haberi : siquidem et curam et cibun majorem desiderat. Nam cum sit úniveısun geuı lanigerum cæl is pecudibus mollius, plus délieats que les autres, eclui de Tarente l'est encore plus particulièrement, parce qu'il ne peut supporter aucune sorte de négligence et cucore moins de lésine, soit de la part du proprićtaire, soit de la part de l'intendant du troupeau, comme il ne peut pas non plus se faire au chaud ni au froid. Il prend le plus souvent sa nourriture à l'ćtable et rarement au dehors, et il lui en faut une très-grande quantité; de sorte que si le métayer lui en soustrait une portion par fraude, le désastre se met bientôt dans le troupeau. Il suffit de mettre dans les crèches de ces animaux, pendant l'hiver, trois sextarii d'orge pour chaque tête, ou quatre sextarii soit de fèves broyćes avec leur cosse, soit de pois chiches, en leur donnant par-dessus du feuillage sec, ou de la luzerne tant sèche que verte, ou du cytisc, ou même sept livres de regain, ou de la paille de légumes en abondance. Il ne peut y avoir qu'un très-petit profit à retirer de ce bétail sur la vente des agneaux, et il n'y en a aucun à faire sur le lait, parce qu'on tue communément les agneaux que l'on ne doit pas garder, très-peu de jours après leur naissance, sans attendre qu'ils soient faits, et que l'on en donne d'autres à allaiter aux mères qu'on a privées des leurs propres. Mais on ne donne qu'un agneau à deux nourrices, sans le frustrer de la moindre portion de leur lait, afin que s'en rassasiant davantage, il se fortifie promptement, et que la brebis qui aura agncle, ayant une nourrice associée avec elle, ait moins de peine à élever son agneau. Aussi faut-il observer avec très-grande attention de présenter tous les jours à ces agneaux le pis de leurs mères, ainsi que celui de ces mères étrangères qui, n'ayant point pour eux l'affection maternelle, ne chercheraient point à le leur présenter. Il faut élever plus de mâles dans ces sortes de troupcaux que dans ceux de brebis à laine grossière, parce

tum ex omnibus Tarentinum est mollissimum, quod nullam domini aut magistrorum ineptiam sustinet, multoque minus avaritiam; nec astus, nec frigoris patiens. Raro foris, plerumque domi alitur, et est avidissimum cibi; cui si quid detralitur fraude villici, clades sequitur gregem. Singula capita per hienem recte pascuntur ad præsepia tribus ordei vel fresæ cum suis valvulis fabæ, aut cicerculæ quatuor sextariis, ita ut et aridam frondem pra?. beat, aut siccan vel viridem medicam cytisumre, tın etiam cordi foeni septena pondo, aut leguminım paleas adfatim. Minimus in agnis rendundis in hac pecude, nec ullus lactis reditus baberi potest. Nam et qui submoveri debeut, paucissimos post dies quam editi sunt, immaturi fere mactantur; orhaque natis suis matres alienxe solsoli prabent ubera : quippe singuli agni binis nutricibus sub. mittuntur, nec quicquam subtrabi submissis expedit, quo saturior lactis agnus celeriter confirmetur, et parta nutrici consociata minus laboret in educatione fortıs sui. Quam ob causam diligenti cura servandum est, ut et suls quotidie matribus et alienis non amantibus agni subrumentur. 
qu' on les chatre avant qu'ils puissent couvrir les femelles, dès qu'ils ont deux ans passés ; et qu'on les tue pour vendre leurs peaux à des marehands qui les payent beaueoup plus eher que toutes les autres toisons, à eause de la beauté de la laine dont elles sont couvertes. Souvenons-nous de faire paitre les brebis greeques dans des eampagnes libres, et qui ne soient embarrassées ni par des arbrisseaux ni par des buissons, de peur que (comme je l'ai dit ci-dessus) leur laine ou leur couverture ne soit acerochée. Elles demandent les plus grands soins à la maison, mais elles n'en demandent pas moins au dehors, quoiqu'on ne les mène pas paitre tous les jours. Car il faut les déeouvrir souvent pour les rafraîchir, leur éplueher fréquemment la laine, et l'arroser de vin et d'huile; quelquefois même il faut la laver entièrement, lorsque le temps est assez beau pour permettre eette općration, qu'il suffira néanmoins de faire trois fois l'an. II faut eneore nettoyer souvent leurs bergeries, de faeon qu'elles soient toujours propres, et en balayer toute l'humidité oceasionnée par leur urine : il sera aisé de les tenir sèches au moyen de planehes pereées dont elles seront parquetées, et sur lesquelles le troupeau se eouchera. Il faut non-seulement purger leur habitation de la boue ou du fumier, mais eneore des serpents venimeux. A eet effet, sache qu'il faut brüler du cèdre odoriférant dans les étables, et chasser les serpents venimeux par l'odeur du galbanum brîlé. Souvent des vipères dangereuses à toucher se sont trouvées cachées sous des crèches que l'on n'avait jamais déplacées, et se sont enfuies d'effroi en voyant la lumière; souvent des coulewvres ont fixé leur séjour dans une étable. Dans l'un et l'autre eas, patre, ramassez des pierres, eomme le preserit le même auteur, ou prenez un báton de robre, et écrasez ces animaux au moment qu'ils vous menacent le plus, en gonflant leurs cous et en faisant entendre leurs sifflements. $\mathrm{Ou}$, pour prévenir les dangers que l'on eourt soi-même lorsqu'on est eontraint d'en renir à ectte extrémité, brûlez souvent des ehe. veux de femme ou de la eorne de eerf, dont l'odeur est exeellente pour chasser ces sortes d'animaux pestilentiels des étables. On ne peut fixer pour la tonte un temps eertain, et qui soit le même pour toutes les eontrées, paree que l'ćté n'est pas également tardif ni également hâtif dans tous les pays : ainsi la meilleure méthode est d'examiner les temps dans lesquels les brebis ne seront exposées à souffrir ni du froid lorsqu'on les aura tondues, ni du ehaud lorsqu'elles auront encore leur laine. Au surplus, en tel temps qu'une brebis ait été tondue, il faudra la frotter avec la eomposition suivante : On mêlera ensemble à doses égales du bouillon de lupins, de la lie de vieux vin et de la lie d'huile; et lorsque la brebis sera tondue, on l'arrosera de ee mélange de liqueurs; quand son dos, que l'on frottera bien pendant trois jeurs, en aura été bien imbibć, on la mènera le quatrième jour au bord de la mer, si elle est dans le voisinage, pour l'y plonger; mais si la mer est éloignée, on mettra du sel dans de l'eau de pluie qu'on laissera à l'air jusqu'à ce qu'elle en soit bien imprégnée; après quoi on s'en servira pour laver le troupcau. Celsus assure qu'en prenant toutes ees préeautions, ee bétail ne peut pas devenir galeux de l'année; mais un fait qui u'est point douteux, c'est que sa laine reviendra plus douee et plus longue qu'elle ne l'ćtait auparavant.

\section{Comme nous avons passé en revue les soins}

Plures autem in cjusmodi gregibns quam in hirtis masculos cnutrire oportet. Nam prius quam foeminas inire possint mares castrati, cum bimatum expleverint, cne. cantur, et pelles corum propter pulcluritudinem lanæ majore pretio quam alia vellera mercantibns traduntur. Liberis antem campis et omni surculo rubogue vacantibus ovem Grocam pascere meminevimus, ne, ut supra dixi, et lana carpatur el tegumen. Nec tamen ea minus sedulam curam foris, quia non quotidie proccdit in pascua, sed majoren domesticam postulat. Nam sxpins detegenda ct refrigeranda cst : sapius cjus lana diduccnda, vinoque ct oleo insuccanda, nonıunquam etiam tota cst eluenda, si diei permittit apricitas : idque ter anno fieri sat cst. Stabula vero frequenter everrenda $\mathrm{ct}$ purganda, lıumorque omuis urina devcrrendus cst, qui commodissime siccatur jerforatis tabulis, quibus ovilia consternuntur, ut grex su. percubet. Nec tantum cœno aut stercore, sed exitiosls quoque scrpentibus tecta libercntur : quod ut fiat, Disce et odoratam stabulis inccnderc ccdrum, Galbancoque agitarc graves nidore chelydros. Sapc sub immotis prcesepibus aut mala tactu Vipcra delituit, calımque Pxterrila fugit: Aut tcclo assuclus colubcr. Quare, ut idem jubet, capc saxa manu, cape robora pastor, Tollcntemque minas, cl sibila colla tumcnlem Dejice. Vel ne istud cum periculo facere necesse sit, muliebres capillos, aut cervina sæepius ure cornua : quorum odor maxime non patitur stabulis pracdictam pestem consistere. Tonsuræ ccrtum tempns anni pcr omnes regiones servari non potest : quoniau nec ubique tarde, nec celeriter astas ingruit : et est morus optimus considerare tempes. tates, quibus ovis neque frigns, si lanam detraxeris, neque astum, si nondum detonderis, sentiat. Verum ea quandoque detonsa fucrit, ungi debet tali medicamine : succus excocti lupini, veterisque vini fex, $\mathrm{ct}$ amurca pari mensura miscentur, eoque liquamine tonsa ovis imbuitur; at que ubi per triduum delibuto tcrgore medicanina perbibcrit, (quarto die, si est vicinia maris, ad littus dcducta mersatır : si minus, cxelestis aqua sub dio salibus iı lıunc usum dırata paulum decoquituŕ, eacjue grex perlıi. tur. Hoc modo curatum pecus toto aumo scabrum ${ }^{\circ}$ ficri non posse Celsus affirmat : nec dubium cst, quiı ctian ob eain rem laua mollior atque prolixior renascatur.

V. Lt quoniam recensuimus cultum curamique recte valentium, nunc quenadnodum vitiis aut morbo labo- 
et les attentions que demandent les brebis qui se portent bien, nous allons prescrirc à présent la façon dont on doit soulager celles qui sont défectueuses ou malades, quoique presque toute cette dernière partie ait déjà ćté épuisée lorsque nous avons donné dans le premier livre la façon de traiter les grands bestiaux. En effet, comme la constitution du corps est presque la même dans les petits quadrupèdes que dans les grands, il y a très-peu de différences à remarquer dans leurs maladies, comme dans les remèdes qu'on y applique; encore ces différences sont-elles légères : néanmoins, si légères qu'elles soient, nous ne les passerons point sous silence. Si un troupeau entier est malade, il faut, conformément à ce que nous avons ordonné ci-dessus, et que nous croyons devoir répéter de nouveau (parce que nous pensons que cette méthode est très-salutaire), changer dans ce cas-là les páturages et l'aiguade de toute la contrée, et chercher un autre elimat ( car c'est le remède le plus efficace). Mais il faudra avoir soin, en faisant cette mutation, de ehoisir des campagnes convertes d'arbies, si la maladie a été occasionnée par la chaleur et par l'ardeur du soleil, et des lieux exposés au soleil, si c'est le froid qui l'a occasionnée. On aura soin de conduire le troupeau doucement et sans le trop harceler, pour ne pas augmenter sa faiblesse par la fatigue d'un long clicmin, quoiqu'il ne faudra pas non plus le conduire absolument avec lenteur, ni sans le presser cn aucune manière; parce que s'il n'est pas expédient de trop érnouvoir les bêtes déjà fatiguées par la maladie, et de leur distendre les membres, il est utile d'un autre cóté do les cxercer modérément, ct de les réveiller, pour ainsi dire, de leur assoupissement, sans permettre qu'elles tombent dans l'engourdissement et meurent en léthargic. Lorsqu'cusuitc le troupeau sera arrivé à sa desti-

rautibus subveniendum sit, procipiemus : quanquam pars liac exordii pene tota jan exhausta est, cum de me. diciua majoris pecoris priore libro disputaremus. Quia cum sit fere eadem corporis natura minorum majorumque quadrupedum, pauca parvieque morborum et resnediorutn dilferentia possunt inveniri : quac tamen quantulaecuuque sint, non omittentur a nobis. Si ægrotat universum pecus, ut et ante praccepimus, et nunc, quia remur esse maxime salutare, iterum adseveramus, in hoc casu, quod est re. mediun 'prasentissimum, pabula mutemus et aquationes, totiusque regionis alium quaramus statum racli, curenusque, si ex calore et restu concepta pestis iuvasit, ut opaca rura : si invasit frigore, ut eligantur aprica. Sed modice ac sine festinatione persequi pecus oportebit, ne imbecillitas ejus longis itineribus aggravetur : nec tamen in totum pigre ac segniter agere. Nam quemadnodum fessas morbo pecudes veliementer agitare et extendere non convenit, ita conducit nediocriter exercere, et quasi torpentes excitare, nec pali veterno conseuescere atque exingui. Cum deinde grex ad locum fuerit perductus, in la. nation, on l'y distribuera anx colons du pays par petits pelotons : en effet, il se portera mieux étant ainsi divisé que s'il était entier, soit paree que l'air de la maladie elle-même sera moins contagieux dans un plus petit nombre de bêtes, soit parce qu'on trouvera plus de facilítés à donner ses soins à un troupeau dès qu'il sera moins nombreux. Voilà done ce que l'on aura à observer, si toutes les brebis généralement sont malades, en y joignant les autres préceptes que nous avons détaillés dans le livre précédent (pour ne pas répéter ici les mêmes choses). Voici à présent ce qu'il faudra observer. Iorsqu'il n'y aura que quelques bêtes malades. Les brebis sont infectées de la gale plus souvent que tout autre animal : cette maladie lcur vient communément, comme dit notre poètc, lorsqu'une pluie froide les a pénétréesjusqu'aux os, et qu'elles ont élé exposées en hiver aux gelées blanches; lors. qu'après la tonte on in'a pas eu recours au remède que nous avons donné; lorsqu'on n'a pas lavé dans la mer ou dans une rivière la crasse de leurs corps, occasionnée par les sueurs de l'été; lorsqu'après la tonte du troupeau, on l'a exposé à se blesser dans des buissons sauvages et dans des épines; enfin lorsqu'on l'a mis dans des étables qui avaient servi précédemment à des mules, à des chevaux ou à des ânes: mais c'est surtout le défaut de nourriture qui occasionne cette maladie, en oceasionnant la maigreur dont elle est une suite. On s'apercoit que cette maladie commence à gagner ecs animaux lorsqu'ils se grattent et se mordent la partie malade, qu'ils y portent la coine ou le pied, et qu'ils la frottent contre un arbre ou contre les murailles. Aussitôt donc que l'on voit une brebis occupée de ces petits manéges, il faut la prendre et écarter sa laine, pour examiner la peau de dessous, qui doit être rude et couverte d'une cspèee de crasse. 11

cinias colonis distribuatur. Nam particulatim facilius quam universus convalescit, sive quia ipsius norbi halitus minor est iı exiguo numero, seu quia expeditius cura major adlibetur paucioribus. Hace ergo et reliquua, ne nunc eadem repetamus, qux superiore exordio perecnsuimus, observare debemus, si universae laborabunt : illa, si singula. Oves frequentius, quam ullum aliud animal infestantur scabie; quae fere nascitur, sicut noster memorat poeta, Cum frigidus imber Altius ad vivum persedil, el horrida cano Bruma gelu, vel post tonsuram, si remedium pradicti medicaninis non arlhibeas, si arstivum suloreun mari vel llumine non abluas, si tonsum gregem patiaris silvestribus rubis ac spinis sauciari, si stabujo utaris, in quo mulæ aut equi aut asini steterunt : precipue tameı exiguitas cibi maciem, macies autem scabiem facit. Hace ubi coepit itrepere, sic intelligitur : vitiosum tocum pecudes aut morsu scalpunt, aut cornu vel ungula tundunt, aut arbori adfricant, parietibusve detergent : quod ubi aliquam facientem videris, comprelıendere oportebit, et lanan diducere : nam subest aspera cutis, et velut qua. 
faut aller au-devant de cette maladie des qu'elle commenee à paraitre, de peur qu'elle n'infeete fout le troupeau, et même promptement, d'autant que les brebis sont sujettes à la eontagion plus particulièrement encore que les autres bestiaux. Or il y a plusieurs remèdes, que nous allons tous donner ; non pas qu'il soit nécessaire de les employer tous à la fois, mais paree qu'il y en a dans le nombre que l'on ne peut pas trouver sous sa main dans eertaines contrées, et afin que sur la quantité on puisse au moins en trouver un seul dont l'application suffise pour les guérir. D'abord on peut employer avee sueeès la eomposition que nous avons donnée plus haut, e'est-à. dire, un mélange par portions égales de lie de vin, de lie d'huile et de bouillon de lupins, auquel on ajoutera de l'ellébore blane pilé. Le jus de la eiguè verte peut aussi enlever eette maladie : on eoupe à cet effet cette plante au printemps, lorsqu'elle eommenee à êtr'e en tige, saus altendre qu'elle soit en graine; on la pile, et on serre dans un vase de terre le jus que l'on en a exprimé, en y ajoutant un sernodius de sel rôti sur deux urnce de jus. Lorsque cela est fait, on enduit le vase pour le bien boucher, et on l'enfouit dans du fumier; après quoi ee médieament ayant été euit pendant toute l'année par la vapeur du fumier, on l'en tire pour l'appliquer elaud sur la partie malade, après l'avoir grattée préalablement jusqu'au vif avee une brique rude ou avec la pierre ponee. On traite aussi la mème maladie avec de l'huile euite jusqu'à diminution des deux tiers, comme avee de vieille urine d'homme, dans laquelle on plonge des tuiles ardentes. Mais il y a des personnes qui aiment mieux mettre eette urine sur le feu, pour la faire euire jusqu'à diminution d'un einqquième, avec pareille quantité de jus de eiguë verte, et qui y répandent ensuite de la poterie réduite en poudre, de la poix fondue, et du sel rôti à la dose d'un sexturius chaeun. Du soufre égrugé et de la poix fondue, épaissis ensemble par portions ígales à l'aide d'un feu leut, remédientégalement à cette maladic. Mais le poëme des Géorgiques assure qu'il n'y a point de meilleur remède que de couper avec le fer l'extrémitè des lèvres de chaque ulcère, parce que le virus subsiste ct fait des progrès tant qu'il n'est pas à découvert. C'est pourquoi il faut ouvrir les ulcères, et les traiter avee des médicaments, comme toute autre plaie. Il ajoute ensuite, avce non moins de prudence, que lorsque les brebis ont la fièvre, il faut leur tirer du sang du talon ou d'entre les cornes du pied, d'autant qu'il a très-souvent éte utile de prèvenir le ravage que peuvent causer les feux qui s'allument dans leur corps, et de piquer, entre les.extrémités de leurs pieds, la veine dont le battement annonce une trop grande abondance de sang. On leur tire eneore du sang sous les yeux, ainsi que des oreilies. Les elous infectent aussi les brebis de deux mi. nières : soit lorsque l'on voit du pus et une entretaillure dans la séparation même de la eorne du pied, soit lorsqu'il vient à s'y former une petite tumeur, vers le milieu de laquelle s'élève un poil semblable à un poil de chien, et sous laifuelle est renfermé un petit ver. Le pus et l'entretaillure disparaitront, soit en les frottant simplement avec de la poix fondue, ou avec de l'alun et du soufre mêlés ensemble dans du vinaigre, ou avec de l'alun broyé avec une jeune grenade dont les grains ne sont pas eneore formés, et arrosé de vinaigre; soit en les saupoudrant de vert-de-gris, soit en appliquant dessus une noix de galle brû- dam porrigo. Cui primo quoque tempore occurrendum est, ne totam progeniem coinquinet, si quidem celeriter cum et alia pecora, tum procipue oves contagione vexentur. Sunt autem complura medicamina, quac idcirco enumerabimus, non quia cunctis uti necesse sit, sed quonian nounullis regionibus quacdam reperiri nequeunt, ex plurilus aliquod inventum remedio sit. Facit antem commode jrimum ua compositio, quam paulo ante demonstravimus, si ad fecem et amurcam, succumque decocti lupini misceas portione xqua detritum album elleborum. Potest eliam scabriciem tollere succus viridis cicula : qua verno tempore, cum jan caulem nec adhuc semina facit, decisa contunditur, atque expressus liumor ejus fictili vase reconditur, duabus uruls liquoris admisto salis torridi semodio. Quod ubi factmon est, oblitum vas in sterquilinio defodilur, ac tolo anuo limi vapore concoctum mox promitur, tepefaclumque medicanentum illinitur scabre parti, quae tamen prius aspera testa defricta vel pumice redulceratur. Eidem remedio est amurca duabus partibus decocta : item velus hominis urina testis candentilus inusla. Quilam tamen tanc ipsam suljeclis ignibus quinta pale miuuu, admiscentq̨ue pari mensura succum viridis cicuta : deinde fignlaris triti et picis liquida, et fricti salis singulos sextarios infundunt. Facit etiam sulfuris triti et picis liquida modus aqualis igne lento coctus. Sed Georgicum carmen affirmat nullam esse prastantiorem medicinam, Quam si quis ferro potuit rescindere sum. mum Vlceris os : alitur vilium, vivitque tegendo. Itaque reserandum est, et ut cxtera vulıera medicanentis curandum. Subjicit deinde æeque prudenter, febricitantilus ovibus de talo vel inter duas ungulas sanguinem emilti oportere : nam plurimum id quidem Profuit incensos cestus averlere, et inter Ima ferire pedis salientem sanguine venam. Nos etian sub oculis et de auribus sanguinem detrahinus. Clavi quoque dupliciter infestant ovem, sive cum subluvies atque intertrigo in ipso discrimine ungula nascitur : selı cum iden locus tuberculum lıabet, cujus media fere parte canino similis extat pilus, eique subest vermiculus. Sublıvies, el intertrigo pice [per se] liquida, vel alumine et sulfure atque acelo mistis litac cureutur, vel austero punico malo, prius quam grana facial, cuns alumine pinsito, superfusoque acelo vel aris rubiginc infriata, vel combusta galla cum austero vino levigala, et superposita. Tuberculuni, cui subest vermiculus, férto 
lée, et pulvérisée dans du vin dur. Il faut eerner avee le fer la petite tumeur qui renferme un petit ver, mais en y apportant la plus grande précaution, de peur d'aller dans l'opération jusqu'au corps même de eet animal, paree que si on le blessait, il jetterait un jus venimeux sur la plaie, qui deviendrait en eonséquenee si ineurable, qu'il faudrait en venir par la suite à couper le pied de la brebis. Lorsqu'on aura eerné avec attention ectte petite tumeur, on arrosera la plaic de suif foudu, qu'on fera dégoutter d'une torehe enflammée. Il faut traiter une brebis pulmonique de la même manière qu'on traite une truie en pareil eas, c'est-à-dire qu'il faut lui insérer dans l'oreille la racine que les médeeins vétérinaires appellent consiligo (de la pommelée) : nous en avons déjà parlé, en donnant la méthode de traiter les grands bestiaux. Cette maladie vient eommunément à tous les quadrupèdes en été, lorsque l'eau vient à leur manquer ; e'est pourquoi fl faut les mettre à portée de boire eopieusesnent pendant les chaleurs. Celsus est d'avis que lorsqu'une brebis a les poumons attaqués, on lui domne antant de vinaigre fort qu'elle en pourra supporter, ou qu'on lui verse avee une petite corne, dans la narine gauehe, la valeur de trois hemina de vieille urine d'homme chaude, et qu'on lui insère dans la gorge un sextans de graisse de pore. Le feu saeré (la vérole), que les pâtres appellent pusuli (feu Saint-Antoine), est encore une maladie incurable : effectivement, si on ne l'arrête pas dès qu'une des bêtes du troupeau en sera atteinte, la eontagion qu'elle mettra dans le troupeau le fera périr en entier, d'autant que ni les remèdes ni le fer ne peuvent en approcher, paree qu'elle s'irrite eommunément au moindre contact avec un corps étranger. Les seuls remèdes qu'elle admette sont les fomentations de lait de elı̀vire, dont tout l'effet ne consiste encore qu'à tempérer la fureur de la maladie, en différant plutôt qu'en empêchant la défaite totale du troupeau. Mais Bolus de Men. desum, ce eélèbre auteur égyptien, dont les mensonges, auxquels les Grees out donné le nom

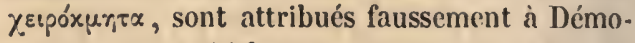
erite, pense qu'il faut examiner souvent et avee attention le dos des brebis, pour. voir si elles ne sont pas attaquées de eette maladie; et que dès que l'on en trouve une par liasard qui en est attaquée, le moyen d'en arrêter les progrès est de faire sur-le-champ une fosse à la porte de l'étable, d'y enterrer toute vivante et couchée sur le dos eelle qui sera couverte de pustules, et de laisser aller tout le troupeau sur elle. On elasse la bile, qui n'est pas une maladie moins pernieieuse aux brebis en été, en leur faisant boire de vieille urine d'homme; e'est eneore le remède qu'on donne à ce bétail quand il a la jaunisse. Mais si une brebis est ineommodée par la pituite, on lui insère dans les narines des brins de sarictte ou de pouliot sauvage enveloppés dans de la laine, et on les y remue jusqu'à ce qu'elle ait éternué. Lorsque les brebis ont la jambe rompue, on les guérit en l'enveloppant de laine imbibće d'huile et de vin, et en attachant ensuite autour de la fracture des éelisses, comme on fait anx hommes en pareil eas. La renouce eause encore une maladie grave aux brebis : lorsqu'elles ont mangé de eette herbe, elles ont tout le ventre tendu, sont resserrées, et rendent par la gueule une espèce d'éeume légère qui est d'une trèsmauvaise odeur. 11 faut alors leur tirer promptement du sang sous la queue dans la partie voisine des fesses, ainsi que de la lèvie supérieure. II quam cautissime circumsecari oportet, ne, dum amputalur, etiam, quod iufta est, auimal vulnereınus : id enim cum sauciatur, renenatan sanicm miltit, qua respersum vuluus ita insanabile facit, ut totns pes amputandus sit : sed $\mathrm{cum}$ tuberculum diligenter circumcideris, candens sevum vilneri per ardentem tedan iustillato. Orem pulmonariam similiter ut suem curari convenit, inserta per auriculam, quam veterinarii consiliginem vocaut : de ea jan diximus, cun majoris pecoris medicinam tıadidimus. Sed is morbus astate plerumque concipitur, si defuit aqua, propter quod vaporibıs ouni quadrupedi largius bibendi potestas danda est. Celso placet, si est in pulmonibus vitium, acris aceti tautum dare, quantum ovis sustinere possit : vel liumana veleris urina tepefactae trium hemiuarun instar per sinistiam narem corniculo infundere, atyue axungix sextantem faucibus inserere. Est cliam iusauabilis sacer iguis, quam pusulam vocant pastores : ea nisi compescitur intra primam pecuden, quæ tali malo correpta est, universum gregen contagione prosteıit: siquidem nec medicamentormun nec ferri remedia patitur. Nam pene ad onmem tactum excandescit : sola tamen fomenta non asperuatur lactis capriui, quod infusum tantum valet, ut cblandiatur igueam sxvitiam, differens magis occidionem gregis, quaım prohibens. Srl Egyptia gentis auclor memoralilis Bolus Meudesius,

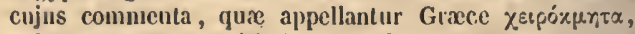
sub nomine Democriti falso produntur, censet propter lıac pestem sapjus ac diligenter ovium terga perspicere, ut si forte sit in aliqua tale vitium deprehensum, confestion scrobem deforliamus in limine stabuli, el vivam pecuden, qux fuerit pusulosa, resupinam olıtuamus, patianurque super obrutam meare tolum gregen, quod co facto unorbus propulsetur. IBilis astivo tempore non minima perticies potione.depellitur lıumana veteris urinæ, qua: ipsa remedio est etiam pecori atcuato. $\Lambda$ t si molesta pituita est, cunela bubulae, vel nepela sylvestris surculi lana iuvoluti naribus inseruutur, versanturque donec sternuat ovis. Fracta pecudum non aliter quam lıminum crura sastantur, iuvoluta lanis oleo atque vino insuccatis, et mox circumdatis ferulis couligata. Est eliam gravis pernicies lierbx sangninatia, quam si pasta est ovis, toto ventre distenditur, contraliturque, et spumam quandam tenuen tetri odoris expuit. Celeriter sanguiuem nitti oportet'sul cauda in ea parte qua proxima est clunibus, nec minus 
fiut inciser avec lc fer les oreilles des brebis qui ont de la peinc à respirer, et les fairc changer de pays ; pratique que nous eroyons néeessaire dans toutes les nualadies contagieuses. Il faut aussi secourir les agneaux lorsqu'ils ont la fièvre : on traira à cet cffet des brebis à part, et on mêlera le lait qu'on leur aura tiré avec pareille quantité d'eau de pluie, pour le faire boire aux agneaux ; bien des gens les guérissent en ce cas avec du lait de chèvres, qu'ils leur versent dans le gosier avee une corne. Il y a aussi une maladie dartreuse que les patres appellent ostigo, qui est mortelle aux agneaux qui tettent. Elle leur vient communément, de même qu'aux boucs, lorsque le pâtre les a laissés sortir imprudemment, et qu'ils ont mangé de l'herbe qui était couverte de rosée; ce à quoi il ne faut point les exposer. Mais lorsqu'il sera arrivé qu'ils en auront mangé, et qu'ils auront en conséquence la gueule et les lèrres couvertes d'ulcères sales, comme s'ils étaient attaqués de la pusula ! la vérole ), on y remédiera avec de l'hyssope et du sel broyés ensemble par portions égales, en frottant de cette composition le palais, la langue et toute la gueule de l'animal; ensuite après a voir lavé les ulcères avec du vinaigre, on les enduira de poix fondue et de graisse de cochon. Quelques personnes aiment mieux mêler ensemble un tiers de vert-de-gris et. deux tiers de vieux oing, pour cmployer ce médicament chaud; d'autres nettoient les uleères et le palais a vec des feuilles de cyprès broyées dans de l'eau. Nous avons déjà donné la méthode de la castration; car cette opération ne sc fait pas autrement aux agneaux qu'aux grands quadrupèdes.

VI. Comme nous arons suffisamment parlé des

in labro superiore vena solvenda est. Suspirio lahorantibus auricula ferro rescindendx, mutandaque regiones; quod in omnibus morbis ac pestibus fieri debere censeinus. Agnis quoque succurrendum est vel feloricitantibus, vel agritudine alia affectis. Qui ubi morbo laborant, admitti ad nuatres non debent, ne in eas peruiciem transfe. rant. Ilaque separatim inulgenda sunt oves, et cælestis aqua pari mensura lacti miscenda est, alque ea potio fe. bi icitantibus danda. Multi lacte caprino iisdem medeutur, quod per corniculum iufunditur faucibus. Est etiam mentigo, quam pastores ostiginem vocaut, mortifera lactentilus. Ea plerumque tit, si per imprulentiam pastoris enissi agni rel etiam hedi roscidas herbas deparerint, quod minime committi oportet. Sed cum id factum est, velut ignis sacer os atque labra fadis ulceribus obsidet. Remedio sunt liyssopus et sal aequis ponderibus contrita. Nain ea mistura palatum, atque lingua, totumque os perfricatur. Mox ulcera lavantur aceto, et tunc pice liquida cum adipe suilla perlinuntur. Quibusdam placet rubiginis anea tertiam partem duabus veleris axungix portionibus commiscere, tejefactoque uti medicamine. Non nulli folia cupressi trita iniscent aqux, et ita perluunt ulcera atque palatum. Castrationis autem ratio jam tradita est. Neque enim alia iı agnis, quam in majore quadrupede servatur. brebis, nous allons à présent passer aux chèvres. Ce genre de bétail recherche plus les lieux couverts de broussailles que les campagnes, et il s'accommode très-bien des lieux sauvages et des forêtsı pour sa pature. En effet, il n'a pas d'éloignement pour les buissons; les épines ne lui déplaisent point, et il préfère même à tout les arbrisseaux et les taillis. Les arbrisseaux qui lui plaisent sont l'arbousier, l'alaterne, le cytise sauvage, ainsi que les taillis d'yeuses et de chênes qui ne sont point hauts. Un bouc passe pour excellent quand il a sous la mâchoire deux petites verrues qui lui pendent du cou, le corps très-grand, les jambes grosses, le cou plein et court, les orcilles tombantes et lourdes, la tête petite, le poil noir, dru, brillant et très-long : car on ne tond pas moins cet animal que la brebis, et on se sert de son poil dans les camps, comme pour tresser des voiles à l'usage des malheureux matelots. Le bouc est assez propre à la génération à l'âge de sept mois, puisqu'il est si peu modéré dans ses désirs, qu'il viole sa mère dans le temps même qu'il la tette : aussi vieillit-il promptement et avant d'être parvenu à l'âge de six ans, parce qu'il se trouve épuisé par les plaisirs prématurés dont il a joui dès les premiers instants de son enfance. C'est pourquoi, pour peu qu'il ait cinq ans, on le regarde comme peu propre à couvrir les femelles. On approuve surtout les chèvres qui sont le plus ressemblantes au bouc tel que nous l'avons dépeint, pourvu qu'elles aient en outre le pis très-grand et beaucoup de lait. Nous acquerrons ce bétail sans cornes sous un climat tempéré, car il en a toujours dans les climats orageux et pluvieux. Pour ceux de ces auimaux qui servent à propager le troupeau, il faut qu'ils

VI. Et quoniam de oviario satis dictum est, ad caprinum pecus nunc revertar. Id autem geuus dumeta potius, quam campestrem situm desiderat : asperisque etian locis ac silvestribus optime pascitur. Nam nec rubos aversatur, nec vepribus offenditur, et arbusculis frutetisque maxime gaudet. Ea suut arbutus, atque alaternus cytisusque agrestis, nec minus iliguei querneique frutices, qui in altitudinem non prosilierunt. Caper, cui sub maxillis bioan verruculac collo rlependent, oplimus labetur, amplissini corporis, cruribus crassis, plena el brevi cervice, flaccidis et pragravantibus auribus, exiguo capite, [nigro ] densoque, et uitido atque longissimo pilo. Nam et ipse tondetur Usum in castrorum ac miseris velamina nautis. Est autem mensium septem satis liabilis ad progenera.ldum : quoniam immodicus libidinis, dum adluc uberibus alitur, inatrem stupro supervenit, et ideo ante sex aunos celeriter consenescit, quod immatura veneris cupidine primis pueritiae tempo ibus exlıaustus est. Itaque quinquennis parum idoneus laabetur forminis implendis. Capella procipue prohatur simillima lirco, quem descripsimus, si etiam est uberis maximi et lactis abundautissimi. llanc pecudem mutilam parabimus quieto cxli stafu : nam procelloso atque imbrifero cornuta semper. Nam et onıni regione maritos gregum mutilos esse oportebit : 
soient sans eornes en tout pays, paree que ceux qui en ont sont communément dangereux par leur pétulance. Mais il ne faut pas établer ce bétail au nombre de plus de cent têtes; au lieu quion peut mettre jusqu’à mille brebis dans une même étable, et qu'elles y seront aussi commodément que si elles étaient en plus petit nombre. Lorsque l'on commence à former un troupeau de chèvres, il vaut mieux l'acheter en entier que d'en prendre quelques-unes par-ci par-là dans différents troupeaux, afin qu'elles ne se séparent point par petits pelotons lorsqu'elles iront paitre, qu'elles se tiennent tranquillement à l'étable ensemble , et qu'il règne une plus grande union entre elles. I.e chaud nuit à la vérité à ce bétail, mais le froid lui est encorc plus pernicieux, et surtout quand les chèvres sont pleines, parce que les gelées de l'hiver détruisent leur fruit. Au reste, le chaud et le froid ne sont pas les seules causes de leur avortement, et il est également à craindre lorsqu'elles viennent à manger du gland sans s'en rassasier; aussi ne doit-on pas leur en laisser manger, à moins qu'on ne soit à portée de leur en donner abondamment. Le temps que nous preserivons pour les faire couvrir, e'est pendant l'automne, quelque temps avant le mois de décembre, afin qu'elles mettent bas à l'approche du printemps, lorsque les arbrisseaux commenceront à bourgeonner, et que les forêts se pareront de nouvelles feuilles. Il faut que le sol de leur étable soit naturellement couvert de pierres ou pavé à la main, parce qu'on n'ćtend point de litière sous ces animaux : et un pâtre attentif aura soin de la balayer tous les jours, pour n'y point laisser séjourner de crottes ni d'eau, et afin d'éviter qu'il s'y forme de la fange, toutes choses qui sont pernicieuses aux boues.

quonianı cornuti fere perniciosi sunt propter petulantiam. Sed numerum hujus generis majorem, quam centum capilum sub uno clauso non expedit lıabere, cum lanigera mille pariter commode stabulentur. Atquue uli capræ prinuur comparantur, melius est unum gregem totum, yuam ex pluribus particulatim mercari, ut nec in pastione separatim lacinixe diducantur, et in caprili majore concordia ufuietxe consistant. Huic pecudi nocet restus, sed magis frigus, et priecipue fnetx, quia gelicidio liemis conceptum vitiat. Nec tamen ea sola creant abortus, sed etiam glans cum citra satietatem data est. Itaque nisi potest affatim praberi, non est gregi permittenda. Tempus adınissur per anlunnum fere ante mensem Decembrem procipi. uns, ut propinquante vere, gemmantibus frutetis, [cuu primum silva nova germinant fronde,] partıs edatur. Ipsum vero caprile vel naturali saxo, vel manu constratum eligi debet, quoniam lıuic pecori nihil substernitur. Diligensque pastor quotidie stabulum converrit, nec patitur stercus aut lumorem consistere lutumve fieri, qux cuncta sunt capris inimica. Parit autem, si est generosa proles, frequenter duos, nonnunquam trigeminos. Pessima ast foctura cum matres bina ternos hados efficiunt. Qui
Quand les ehèvres sont de bonne race, elles font souvent deux petits a la fois, et quelquefois trois : le pire qui puisse arriver, c'est lorsque deux mères n'en font que trois à elles deux. Lorsque les chevreaux sont nés, on les élève de la même manière que les agneaux, avee cette différence qu'il faut réprimer davantage leur pétulance, et la contenir dans des bornes plus étroites. En outre, pour leur procurer du lait en abondanee, il faudra leur donner de la graine d'orme, ou dı cytise, ou du lierre, ou même des eimes de lentisque, et d'autres feuillages légers. Mais, de deux jumeaux, on gardera, pour entretenir le troupeau, celui qui paraitra le plus robuste, et on vendra l'autre aux marchands. II ne faut pas donner le boue à des chèvres qui n'aient qu'un an ou deux (quoiqu'elles soient en état de faire des petits à l'un ou l'autre de ces Ages), parce qu'on ne doit pas en élever dont la mère ait moins de trois ans : s'il arrive qu'elles en fassent à un an, on les leur ótera au moment de leur naissance; au lieu quion leur laissera ceux qu'elles auront mis bas à deux ans, jusqu'à ce qu'ils soient bons à être vendus. II ne faut pas non plus garder les mèrès passé l'âgre de huit ans, paree que la fatigue qu'elles éprouvent en mettant bas souvent les rend stériles. Le maître du troupeau doit être vif, dur, leste, très-laborieux, alerte, hardi, et en état d'aller sans peine à travers les rochers, les déserts et les buissons. II ne doit pas suivre le troupeau; comme font les pâtres des autres bestiaux, mais il doit communément le préceder ; car les chèvies elles-mêmes sont très-alertes et toujours prêtes à s'élancer en avant: c'est pour cela; qu'il faut de temps en temps les arrêter, de peur qu'elles ne courent trop vite, afin qu'en paissant lentement et avec tranquilité, leurs pis

ubi editi sunt, eodem molo, quo agni educantur, nisi quod magis hadorum lascivia compescenda, et arclius colibenda est. Tum super lactis abundantiam samera, vel cytisus, aut edera prabenda, vel etiam cacumina lentisci, aliaque tenues frondes objicienda sunt. Sed ex geminis singula capita, quae videntur esse robustiora, in supplementum gregis reservantur, cæetera mercantibus traduntur. Anticula vel bima capellæ (nam utraque alas partum edit) submitti hæedum non oportet. Neque enim educare nisi trima debet. Sed annicula confestim depellenda suboles. Bimx tamdiu adıniltenda, dum possit esse vendibilis. Nec ultra octo annos matres servandx sunt, quod assiduo partu fatigatæ, steriles existant. Magister autem pecoris acer, durus, strenuus, laboris patientissimus, alacer atque audax esse debet, et qui per rupes, per solitudines, per vepres facile vadat, et non, ut alterius generis pastores, seyuatur, sed plerumque itt antecedat gregem. Maxime strenuum pecus est capra, præcedens subinde, qux compesei debet, ne procurrat, sed placide ac lente pabuletur, ut et largi sit uberis, et non strigosissimi corporis.

VII. Alque alia geuera pecorum, cum pestilentia rexan- 
se grossissent, et qu'clles ne soient pas trop décharnées.

VII. Lorsqu'une maladie contagieuse doit affliger les autres espèces de bestiaux, on les voit auparavant maigrir de langueur et de malaise; les ehèvres scules tombent tout à coup, dans le moment méme qu'elles sont très-grasses et très-gaies, et meurent toutes par troupeaux : c'est le plus ordinairement l'abondance des páturagı̊s qui occasionne cet aceident. C'est pourquoi, dès que la maladie pestilentielle en aura attaqué une ou deux, on leur tirera du sang à toutes, et on ne les laissera pas paître pendant toute la journée, mais on les renfermera dans leur étable pendant l'espace de quatre heures vers le milieu du jour. Si c'est, au contraire, un autre genre de maladie qui les tourmente, on les médicamentera avec un breuvage composé de roseaux et de racines d'épine blanehe sauvage, qu'on broiera avec des pilons de fer, et sur lesquelles on versera de l'eau de pluie, la seule qu'on leur donnera à boire. Si ces précautions ne chassent point la maladie, il faut les vendre, ou si on ne peut pas même parvenir à s'en défaire, il faut les égorger et les saler. Ensuite on remontera au bout de quelque temps un autre troupeau, après avoir attendu uéanmoins que le maurais temps de l'année soit passé; e'est-à-dire qu'il ne faudra le former qu'en été, si on est en hiver, ou au printemps, si l'on est en automne. Mais lorsqu'il n'y en aura que quelques-unes de malades en particulier, on leur donnera à l'étable les mêmes remèdes qu'aux brebis. Ainsi, quand l'eau aura boursouflé leur peau, maladie que les Grees appellent ůşos! (hydrops, hydropisie), on leur fera une ouverture légère à la peau sous l'épaule, pour donner un écoulement à I'humeur morbifique ; après quoi on pausera la plaie occasionnée par l'opération avec

tur, prius morbo et languoribns macescunt, solæ capellæ quแamvis opinze atque lilares subito concidunt, velut aliๆ̧ua ruina gregatim prosternantur. Id acciderc inaxime solet nlertate pahuli. Quamobrem enm adhuc paucas pestis perculit, omuibus sanguis detrahendus : nec tota die pascenda, sed mediis quatuor loris intra septa claudendx. Sin alius languor infestat, poculo medicantur arundinis, et allke spinat radicibus, quas cum ferreis pilis diligenter contulerinus, admisceınus aquain pluvialem, solamque potaudam pecori probemus. Quod si ea res angritudinem uon depellit, rcudenda sunt pecora ; rcl, si neque id contiugere potest, ferro necanda saliendaque. Mox interposito spatio, convenict alium gregem reparare. Níc tamen antequam pestilens tenupus anui, sive id fuit hicmis, rertatur sestate, sive autumni, vere muletur. Cum vero singula donn lalorabunt, eadem remedia, qux etian ovibus, aullibelsinus; nan cum distendetur aqua culis, quorl vitiua Granci vocaut ụ̈̌̂, perniciosum transmittat lıunoren, t:un factum rulnus pice lliguida curetur. Cum efroptre loca genitalia tumclunt, aut secunda non responderint, defruti se rtarius, vel cum de la poix fondue. Lorsqu'après a voil mis bas elles auront les parties gonflées, ou que l'arrière-faix ne sera pas sorti heurcusement, on leur versera dans la gorge un sextarius de vin cuit jusqu'à diminution de moitié, ou, si l'on n'en a point, une pareille mesure de bon vin, et on leur remplira les parties de cérat liquide. Mais pour ne pas entrer ici dans le détail de toutes les maladies auxquelles elles sont sujettes, nous dirons en général qu'il faut les traiter de la manière que nous avons preserite plus haut pour les brebis.

VIII. Il ve faudra point non plus négliger de faire du fromage, surtout dans les cantons éloignés de tout, où l'on ne trouverait point son a vantage à porter le lait en nature. Si le fromacre est fait avec une liqueur peu épaisse, il faudra le vendre le plus tôt qu'il sera possible, et avant qu'il ait perdu le sue de la nouveauté; au lieu que s'il est fait avec une liqueur grasse et épaisse, on pourra le garder plus longtemps. Au reste, on doit le faire avec du lait pur et très-nouveau : ear loısqu'on laisse reposer le lait ou qu'on le mélange, il s'aigrit en peu de temps. On le fait communément eailler avec de la présure d'agneau ou! de chevreau, quoiqu'on puisse également le faire avec de la fleur de chardon sauvage, ou de la graine d'une espèce de chardon appelé cnecus, de même qu'aree le lait que rend le figuier, lorsqu'on fait une incision à son écorce dans les parties où elle est verte. En général, le meilleur fromage est celui dans la composition duquel il entre le moins de drogtres. Il faut pour un sinus de lait au moins la valeur d'un denarius d'argent pesant de présure, et il n'est poirst douteux que le fromage que l'on fait cailler avec de petites branehes de figuier n'ait un goût très-agréable. Lorsque le vase dans lequel on a tiré le lait est plein, il faut le tenir dans un certain degré de

id defucrit, honi vini tantundem faucibus infundatur, et naturalia cerato liquido repleantur. Sed ne nunc singula persequar, sicut in ovillo pecore prodictum est, caprino nedebinur.

VIII. Casei quoque faciendi non erit omittenda cura, utique longinquis regionibus, ubi mulctram devehere non expedit. Is porro si tenui liquore conficitur, quam celerrime vendendus est, dum adliuc viridis succum retinet : si pingui et opimo, longiorem patitur custodiam. Sed lacte fieri debet sincero et quam recentissimo. Nam requietunı vel aqua mistum celeriler acorem concipit. Id plerumque cogi agni aut haedi coagulo; quamris possit et agrestis cardui flore conduci, el seminibus cneci, nec minus ficulneo lacte, quod emittit arbor, si ejus virentem saucies corticem. Verum optinus caseus est, qui exiguum medicaminis labet. Minimum autem coagulum recipit sinum laclis argentei pondus denarii. Nec dubium quin fici ramulis glaciatus caseus jucundissime saplat. Sed mulctra, cum est repleta lactc, mon sine tepore aliquo dethet esse. Nec tamen admovenda est flannis, ut quibusdau placet, sed haud procul igué constitueuda, et confestion cun cols. 
chalcur, sans cependant le laisser trop près du feu, comme font certaines personnes, mais en l'en approchant à une certaine distance; et dès que le lait sera caillé, on le tirera de ce vase pour le mettre soit sur de petits paniers de jones, soit dans des corbeilles ou dans des moules, parce qu'il est très-important de passer le petit-lait dès lc premier moment, pour le séparer de la matière coagulće. C'est pourquoi les paysans n'attendent point qu'il se soit égoutté de lui-même, cc qu'il ne ferait que lentement; mais dès que le fromage est devenu un peu ferme, ils le ehargent de poids pour en exprimer le petit-lait. Quand cela est fait, on retire le fromage des moules ou des corbeilles, pour l'arranger aussitôt dans un licu frais et ombragé sur des tablettes très-propres, afin quil ne puisse pas se gater; après quoi on le saupoudre de sel égrugé, afin que toute la liqueur aeide qu'il contient se sèche; et lorsqu'il est bien raffermi, on le comprime violemment pour le rendre eneore plus compacte; puis on répand dessus du sel rôti, et on le charge de poids pour le condenser de plus en plus. Lorsqu'on a fait cette opération neuf jour's de suite, on lave les fromages dans de l'eau douee, et on les arrange ehaeun à l'ombre sur des elaies, de façon qu'ils ne se touchent pas mutuellement, et qu'ils soient à portée de se sécher tant soit peu; après quoi, pour qu'ils se conservent plus tendres, on les entasse sur différents planchers dans un lieu clos, et qui ne soit point exposé aux vents. Avec ees préeautions, le fromage ne se remplit pas d'yeux, et ne devient ni trop salé ni trop dur. Le premier de ces trois défauts arrive communément lorsquu'il n'a pas été assez comprimé; le second lorsqu'il a été trop salé; et le troisième lorsqu'il a été brûlé par le soleil. On peut transporter le fromage fait de cette façon même au delà des mers : car pour

crevit liquor, in fiscellas aut in calathos vel formas transferendus est. Nam maxime refert primo quoque tempore serum percolari, et a conereta inateria separari. Quam ob causam rustiei nec patiuntur quidem sua sponte pigro lıumore defluere, sed cum paulo solidior caseus faetus est, pondera superponunt, quibıs exprimatır serum : deinde ut formis ant calathis exemptus est, opaco ae frigido loco, ne possit vitiari: quamvis mundissimis tabulis componitur, aspergitur tritis salibus, ut exudet acidum liquorem : atque ubi duratus est, velıementius premitur, ut conspissetur. Et rursus torrido sale contingitur, rursus que ponderihus condensatur. Hoc cum per dies novem factum est, aqua dulci elıitur, et sub umbra cratibus in boc factis ita ordinatur, ne alter alterum caseus conlingat, et ut modice siccetur : deinde, quo tenerior permaneat, clauso neque rentis obnoxio loeo stipatur per complura tabulata. Sic neque fistulosus neque salsus neque aridus provenit. Quorum vitiorum primum solet ac. cidere, si parum pressıs; seeundum, si nimio sale im. butus; tertium, si sole exustus est. Hoc genus casei potest ctiam trans maria permitti. Nam is, qui recens intra pau. celui qu'on veut manger frais, on le fait avec de moindres apprêts, puisqu'après l'avoir retiré des paniers de jones, on se eontente de le tremper dans du sel ou dans de la saumure, et de le faire ensuite un peu séeher au soleil. Quelques-uns, a vant d'assujettir les bestiaux dans des eareans pour les traire, mettent, au fond du vase dans le. quel ils doivent tirer le lait, des pignons verts sur lesquels ils le tirent, et qu'ils n'otent que lorsqu'ils transfèrent sur des moules la matière coagulée. D'autres broient les coques même de ees pignons verts, et les mettent dans le lait pendant qu'il caille. Il y en a qui font coaguler avec le lait du thym broyé, et passé par un erible. On peut par la même méthode lui donner tel goût que l'on veut, en y ajoutant des ingrédients pris à son choix. Tout le monde connait la manièrc de faire le fromage que nous appelons manu pressum (pressé par la main). Car dès que le lait est un peu eaillé dans le vase où on l'a tiré, on le coupe pendant qu'il est encore tiède; et après avoir versé de l'eau bouillante par-dessus, on le faęonne à la main, ou bien on le met dans des moules de buis, afin qu'il en prenne la forme. Le fromage bien imprégné de saumure n'est pas d'un mauvais goût, quand on l'a eoloré par la suite avee de la fumée de bois de prunier-pomme ou de ehaume. Mais revenons à présent aux animaux dont eette digression nous a éeartés.

IX. En quelque genre de quadrupède que ce soit, on choisit avec attention l'espèce du mâle, parce que la progéniture est plus souvent ressemblante au père qu'à la mère. C'est pour eela que lorsqu'il est question de pores, on approuve les mâles quand ils sont remarquables par la grosseur générale de leur corps, pourvu cependant qu'ils l'aient plutôt earré ou rond que long; quand ils ont le ventre bas, les fesses très-dévcloppées, les

cos dies absumi debet, leviore cura confieitur. Quippe fiscellis exemptus in salem muriamque demittitur, ct nox in sole paulum siecatur. Nonumlli antequam pecus numel. lis inducant, virides pineas nuees in mulctram demiltunt, et mox super eas emulgent, nec separant, nisi cum transmiserint in formas coactam materiam. Ipsos quidam virides conterunt nueleos, et lacti perniscent, atque ita congelant. Sunt qui thymun contritum cribroque colatum cum lacte cogant. Similiter qualiscunque velis saporis efficere possis, adjeeto quod elcgeris condimento. Illa vero notissima est ratio faciendi casei, quem rlicimus manı pressum. Namque is pauluın gelatus in muletra dum est tepefaeta, reseinditur et fervente aqua perfusus vel man u figuratur, vel buxeis formis exprimitur. Est etiam non ingrali saporis muria perduratus, atque ita malini lini vcl culmi fumo coloratus. Sed jam redeamus ad originem.

IX. In omni genere quadrupedum species maris diligenter eligitur, quoniam frequentiıs patri similior est progenies, quam matri. Quare etiam iı suillo pecore verres probandi sunt totius quidem corporis amplitudine eximii, sed qui quadrati potius aut rotundi quam longi sint, ven- 
jambes et la corne du pied moins longues à proportion que le reste du corps, le cou ample et plein de glandes, le grouin court et camus. Mais ce qui est plus essentiel pour l'objet qu'on se propose, c'est que les máles soient très-lascifs : ils engendrent très-bien, pour peu qu'ils aient ul an et jusqu'à ce qu'ils en aient quatre, quoiqu'ils puissent couvrir les femelles même à six mois. Les truies sont dans le cas d'être approuvées lorsqu'elles ont la taille très-longue, et qu'elles ressemblent pour le surplus des membres aux verrats que nous venons de décrire. Si le pays où l'on est est froid et sujet aux brouillards, on choisira le troupeau dont la soie sera la plus dure, la plus fournie et la plus noire. S'il est tempéré et exposé au soleil, on pourra nourrir des pores pelés, ou mème des pores blancs, tels qu'en ont ordinairement les boulangers. La truie passe pour être en état de cochonner jusqu'à sept ans; mais plus elle est féconde, plus tôt elle vieillit. Quand elle a un al, elle conçoit assez bien; mais il faut qu'elle soit couverte au mois de février, afin qu'ayant porté quatre mois elle cochonne au cinquième, et dans un temps où les herbes seront déjà fortes, parce queles pores trouveront, moyennant cela, un lait qui sera bien à son point de maturité, et que, dès qu'ils cesseront de tetter, ils pourront se nourrir de la paille ainsi que de la graine qui viendra à tomber des légumes. C'est ainsi qu'on le pratique dans les cantons éloignés de tout, où l'on n'a point d'autre utilité en vue que celle de peupler le troupeau; car pour les pays voisins des villes, il faut $y$ vendre les cochons de lait, moyennant quoi les mères n'ayaut point la peine de les élever, donneront plutôt de secondes ventrées, et cochonneront par conséquent deux fois par an. Lorsque les máles ont commencé à couvrir les femelles dès l'âge de six ınois, ou

tre promisso, clunibus vastis, nec proinde cruribus aut ungulis proceris, amplæ et glandulosæ cerricis, rostris brevibus et resupinis. Maximeque ad rem pertinet, quam salacissimos esse. Ab annicula xtate commode progene. rant, dum quadrimatum agant : possunt tamen eliam semestres implere fœminam. Scrofe probantur longissimi status, et ut sint reliquis membris similes descriptis verribus. Si regio frigida et pruinosa est, quam durissima densæeque et nigræe selæ grex eligendus est; si temperata atque aprica, glabrum pecus rel etiam pistrinale album potest pasci. Fœemina sus habetur ad partus ellendos ido. nea fere usque in annos septem, qux quanto focundior est, celerius senescit. Annicula non improbe concipit, sed iniri debet mense Februario. Quatuor quoque nuensibus fota, quinto parere, cum jam lierbxe solidiores sunt, ut et firma lactis maturitas porcis contingat, et cum desierint uheribus ali, stipula pascantur, cxterisque leguminum caducis frugihus. Hoc autem fit longinquis regionibus, ubi niliil nisi submittere expedit. Nam suburbanis lacteus porcus ære mutandus est : sic enim mater non educaudo, labori subtralitur, celcriusque iterum conceptınn partım CULC'NELLLE: qu'ils ont souvent été employés à la génération, il faut les chátrer à trois ou quatre ans, afin de pouvoir les engraisser. On applique aussi le fer à la matrice des femelles, et on en bouche le passage en laissant cicatriser la plaie, afin qu'elles ne puissent pas engendrer; mais je ne vois pas la raison qui peut porter à faire cette opération, si ce n'est la disette de nourriture où l'on peut étre, puisque quand on a de la páture en abondance, il est toujours plus avantageux de se procurer des ventrées. Ce bétail s'accommode de toute sorte de campagnes, quelle qu'en soit la situation. En effet, il profite aussi bien sur les montagnes que dans les champs, et mieux néanmoins dans les terres marécageuses que dans cel les qui sont sèches. Les forèts lui sont aussi trèsconvenables lorsqu'elles sont couvertes de chénes, de liéges, de hètres, de cerri, d'yeuses, d'oliviers sauvages, de térébinthes, de coudriers et d'arbres à fruits sauvages, quelle que l'épine blanche sauvage, le carougier, le genévrier, le micacoulier, le pin, le cornouiller, l'arbousier, le prunier, le paliure et les poiriers sauvages, parce que ses fruits, mûrissant en divers temps, sont suffisants pour rassasier le troupeau toite l'année. Mais si l'on manque d'arbres, on s'attachera aux páturages des champs, en donnant la préférence à ceux qui seront limoneux sur ceux qui seront secs, tant afin que ces animaux puissent fouiller dans les marais pour y déterrer des vers, et se vautrer dans la boue, qui est une chose délicieuse pour eux, qu'afin qu'ils puissent avoir de l'eau à discrétion, parce qu'il est très utile qu'ellene leur manque pas, surtout pendant l'été, et qu'ils soient à portée d'arracher de terre les petites racines des forêts marécageuses qui sont de leur goût, telles que celles du jone d'eau, celles du jonc ordinaire, et celles du roseau dégéné-

edet. Idque bis anno faciet. Mrares, vel cum primum ineunt semestres, aut cum sapius progeneraverunt, trimi aut quadrimi castrantur, ut possint pinguescere. Fœminis quoque vulvæ ferro exulcerantur, et cicatricibus claudun. tur, ne sint genitales. Quod facere non intelligo quæ ratio compellat, nisi penuria cibi. Nam ubi est ubertas pabuli, submittere prolem semper expedit. Omnem purro situm ruris pecus hoc usurpat. Nam et montibus et cam. pis commode pascitur, melius tamen nalustribus agris, quam sitientibıs. Nemora sunt conrenientissima, quar vestimntur quercu, subere, fago, cerris, ilicibus, oleastris, termitibus, corylis, pomiferisque silvestribus, "ut sunt albx spinx, Gracæ siliquæ, juniperus, lotus, pinus, cornus, arbutıs, prunus, et paliurus, atque achra. des pyri. Hacc enim diversis temporibus mitescunt, ac pene toto anno gregem saturant. At ubi penuria est arborum, terrenum pabulum consectabimur, et sicco limosum pra. ferenus, ut paluden rimentur, effoliautque lumbricos, atque in luto volntentur, quod est huic pecori gratissi. ınm, quin etiam aquis abuti possint : namque [et] id fecisse inaxime per estalem profuit, et dulceis eruisse 
Ié, que le vulgaire appelle canna. Les truies engraissent aussi dans les ehamps cultivés, pourvu qu'ils soient couverts d'herbes ct plantés d'arbres à fruits de différentes espèces, afin qu'elles puissent y trouver dans les divers temps de l'année des pommes, des prunes, des poires, des noix de toutes formes, et des figues. Mais en quelque abondance que soient ces fruits, il ne faudra pas épargner pour eela les greniers, et on aura soin de leur donner de la pâture à la main lorsqu'il en manquera au dehors. C'est pourquoi on serrera a cet effet beaucoup de gland, qu'on plongera dans des réservoirs d'eau, ou qu'on fera séeher sul' des planchers à la fumée. Il faut aussi leur donner la facilité de'se nourrir de fèves et d'autres légumes semblables, lorsque le bon marché de ces denrées le permettra, et principalement au printemps, pendant que les pâturages verts seront encore en lait, attendu qu'ils sont communé. ment malsains pour les truies dans ce temps-là. C'est pourquoi, a vant de les mener le matin à la páture, on les sustentera avec des nourritures dont on aura fait provision, de peur que si elles mangeaient des herbes non mûres, ces herbes ne ieur lâehassent le ventre et ne les fissent maigrir par leur poison. Il ne faut pas non plus Ics renfermer toutes cnsemble comme les autres troupeaux; mais on fera des toits le long d'une galeric, dans lesquels on les renfermera quand elles auront mis bas, ou même quand elles seront pleines. En effet, si elles étaient renfermées comme tous les autres bestiaux par bandes et pêle-mêle, elles se vautreraient plus encore que les autres animaux les unes sur les autres, et se feraient avorter. C'est pourquoi il faut, comme je l'ai dit, construire des toits attenant les murailles, lesquelles auront quatre pieds de hauteur, de peur que la truie ne puisse en franchir la clóture. On ne doit

radiculas aqquatilis silvæx, tanquam scirpi juncique et degeneris arundinis, quam vulgus cannam vocat. Nam cul. tus quidcm ager opimas reddit sues, cum est graminosus, el pluribus gencribus pomorum consitus, ut per anni diversa tempora mala, pruna, pyrum, mulliformes nuces ac ficum probeat. Nec tamen propter hæe parcelur horreis. Nam sxepe de manu dandım est, cum foris deficit pabulum. Propter quod plurima glans vcl cisternis in aquam vel fumo tabulatis recondenda est. Fabæ quoque et similium leguminum, cum vilitas perınittit, facieuda est potcstas, et utiçue vere, dum adhuc lactent viridia pabula, qux suibus plerumque nocent. Itaque mane priusquam procedant in pascua, conditivis cibis sustinenda sunt, ne immaturis lerbis citetur alvus, eoque vitio pecus emacictur. Nec ut cetcri greges universi claudi debent, sed per porticus hara laciendæe sunt, guibus aut a partu aut etian pragnantes includantur. Nam pracipue sıes cater. vatim atque incondite cum sunt pariter inclusæ, sıper alias alia cubant, et foctus elidunt. Quare, ut dixi, juncta parietibus hara construendae sunt in altitudinem perlun quatuor, ne sus transilire septa queat. Nam conlegi unn pas non plus faire de couverture ì ces toits, afin que le gardien puisse faire la revue des pourceaux par en haut, et retirer de dessous les mères ceux qu'elles pourront avoir étoufrés en se vautrant sur eux. Ce gardicn doit être vigilant, diligent, industricux, soigneux. Il faut qu'il ait présentes à la mémoire toutes les truies qu'il a à nourrir, tant eelles qui ont déjà porté que les jeunes, afin de discerner la ventrée de chaeune. Il aura toujours les yeux sur celles qui seront pleines, et les renfermera dans leur toit, afin qu'elles y cochonnent. Dès qu'elles auront cochonné, il fera attention au nombre et à la qualité des pourccaux qui seront nés, et veillera surtout à ce qu'aucun ne soit élevé par une autre nourrice que sá mère : car dès que les pourceaux viennent à sortil de leur toit, ils se eonfondent aisément les uns avec les autres; et lorsque la truie est couchée, elle présente indifféremment son pis au pourceau d'une autre mère comme au sien propre. C'est pourquoi la principale fonction de celui qui prend soin de ces bêtes est de les renfermer chacune avec leurs petits. S'il n'a pas la mémoire assez sûre pour reconnaitre les petits de chaque truie, il leur fera sur le corps avec de la poix fondue une marque distinctive, qui sera la meme tant pour la mère que pour les petits, afin de reconnaître chaque ventrée, ainsi que la mère, soit à une lettre, soit à une autre marque semblable. Car lorsquion a un grand nombre de truies, il faut que le gardien emploie différentes marques, de peur qu'il ne vienne à les confondre, faute de mémoire. Cependant comme cette méthode pourrait être d'une exécution diffieile dans des troupeaux nombreux, il sera plus commode de construirc les toits de telle facon que la porte en soit placée à unc certaine hauteur, pour que la mère puisse passer par cette porte sans que les cochons de lait puissent

debet, ut a superiore parte custos numerum porcorum re. censeat, et si quem decumbens mater oppresscrit, cubanti subtrahat. Sit autem vigilans, impiger, industrius, navıs. Omuium, quas pascit, et matricum et juniorum meminissc debet, ut uniuscujusque partum consideret. Semper observet enitentem, claudatque ut in hara fortum edat. Tum denotet protinus quot el quales sint nati, et curct maxime ne quis sub nutrice aliena educetur : nam facillime porci, si evaserint haram, misccnt se, et scrofa cum decubuit, xque alieno ac suo probct ubera. Ifaque por. culatoris maximum officium est, ut unamquamųue cum sua prole claudat. Qui si memoria deficitur, quo minus agnoscat cujusque progeniem, pice liquida eandem notam scrofac et porcis imponat, et sive per literas sive per alias formas unumqquemque fotum cum matre distinguat. Nam in majorc numero diversis notis opus est, ne confundatur memoria custodis. Attanen quia id facere gregibus amplis videtur operosum; commodissimum est haras ita fabricarc, ut limen earum in tantam altitudinem consurgat, quantam possit nutrix evadere; lactens autem su. pergredi non possit. S ic nec alienus irrepit, et in cubili 
la franchir. Moyennant cette précaution, il ne se glissera pas de pourceaux étrangers dans aucun toit, ct chaque ventrée attendra sa mère dans Ic sien. Une ventrée ne doit pas néanmoins excéder le nombre dehuit têtes : non pas que j'ignore que la féconditć des truies peut en donner davantage, mais parce que celles à qui on en laisse élever un plus grand nombre cessent plus tôt de porter. II faut aussi sustenter arec de l'orge cuite celles auxquelles on laisse leurs petits, de peur qu'elles ne tombent dans une maigreur extrème, qui pourrait être suivie de quelque maladie. Celui qui prendra soin des pores balayera souvent leur cour, encore plus souvent leurs toits : car quoique cet animal soit malpropre quand il est à paitre, il veut cependant que sa retraite soit trèspropre. Voilà à peu près la façon de tenir les pores quand ils se portent bien.

X. L'ordre nous conduit à parler des soins qu'il en faut prendre lorsqu'ils sont malades. On reconnait que les truies ont la fic̀rre, lorsqu'elles portent la tête de travers et inclinée vers la terre; lorsqu'après avoir couru un certain temps, elles s'arrêtent tout à coụp au milieu des pâturages, et qu'étourdies par une espèce de vertige qui leur prend, elles tombent à terre. II faut remarquer de quel côté penche leur tête, pour leur tirer du sang de l'oreille opposée. On ouvrira aussi, à la distance de deux doigts des fessès, une veine assez grosse qu'elles ont sous la queue, après l'aroir nèanmoins fouettée avec des sarments, pour n'y introduire le fer que lorsque les coups de verges lauront suffisamment gonflée : la saignée faitc, on bandera la plaie avec de l'écorce de saule, ou même d'orme. A la suite de cette opération, on retiendra l'animal dans son toit pendant l'cspace d'un ou deux jours, et on lui donnera de l'eau tiède autant qu'il cu voudra, avec un sextarius de farine d'orge. Lorsque les pores ont les ćcrouelles, on leur tire du sang sous la langue; et après cette saignée, on leur frotte tout le grouin avec du sel égrugé et de la farine de froment. Quelques personnes s'imaginent que c'est un remède plus efficace de leur faire prendre avec une corne trois cyathi de garum, et de leur attacher au cou des tiges de férule fendues en deux, et suspendues avec un cordon de lin, de façon qu'elles portent sur leurs écrouelles. On regarde aussi comme un remède salutaire, lorsqu'ils ont envie de vomir, la sciure d'ivoire mêlée avec du sel rôti et des fèves broyées en farine bien menue, qu'on leur donne à jeun, et avant de les mener paître. Quelquefois aussi tout un troupeau de pores est malade à la fois, de facon qu'ils maigrissent, qu'ils ne prennent plus de nourriture, et que, lorsqu'on les mène paitre, ils se vautrent au milieu de la campagne, et paraissent oppressés par une espèce de léthargric qui les force à s'endormir au soleil d'été. Lorsque cet accident arrive, on renferme tout le troupeau dans une étable couverte, et on l'empêche pendant toute une journée de boire et de manger ; le lendemain on broie de la racine de concombre sauvage que l'on fait infuser dans de l'eau, dont on fait boire aux pores à leur soif. Dès qu'ils l'ont bue, l'envie de vomir leur prend, et ils se purgent par le vomissement. Quand ils ont rendu toute la bile qu'ils avaient dans le corps, on leur donne des pois chiches ou des fères sur lesquelles on verse une sanmure forte; après quoi on leur permet de boire de l'eau chaude (comme on fait aux hommes). Si la soif est pernicieuse en été à toute sorte de quadrupèdes, elle l'est encore plus aux pores qu'à tout autre : c'est pourquoi nous suam quisque matrem nidus expectat, qui tamen non lebet octo capitum numerum excedere : non quia igno. rem focundilatem scrofarum majoris esse numeri; sed quia celerrime fatiscit, quæ plures educat. Atque ere quibis partus submittitur, cocto sunt ordeo sustinenda, ne ad macien summam perducantur, et ex ea ad aliquam perniciem. Diligens autem porculator frequenter suile converrit, et sacpius lıaras. Nain quamvis predictum animal in pabulatione spurce versetur, mundissimun tamen cubile desiderat. Hic fere cultus est pecoris suilli recte valentis.

X. Sequitur ut dicamus, qua sit cura vitiosi. Febricitantium signa sunt, cum obstipae sues transversa capita ferunt, ac per pascua subito, cum paululum procurrerunt, consistunt, et vertigine correptæ concidıut. Earu n notanda sunt capita, quam in partem proclinentur, ut ex dirersa parte de auricula sanguinem nitlamus. Item sub cauda duobus digitis a clunibus intermissis renam feria. mus, quae est in eo loco satis ampla, eamque sarmento prius oportet verberari, deinde ab iclu virga fumentem ferro rescindi, detractoque sanguine colligari saligneo libro rel etiam uhneo. Quml cum fecerimus, unn aut altero die sub tecto pecudem continebimns, et aquam modice calidam quantam volent, farinaque ordeacea singulos sextarios prabebimus. Strumosis sub lingua sanguis mittendus est, qui cum profuxerit, sale trito cum farina triticea confricari totum os conveniet. Quidam presentius putant esse remedium cum per corno singulis ternos cyathos gari demittunt. Deinde fissas taleas ferularnm lineo funiculo religant : et ita collo suspendunt, ut struma ferulis contiugantur. Nauseantibns quoque salutaris hahelur eburnea scobis sali fricto, et fabx minute fresæ commista, jejunis. que prius quam in pascua prodeant objecta. Solet etiam universum pecus agrotare ita, ut emacletur, nec cibos capiat, productumque in pascua medio campo procumiat, et (zuodam reterno pressum somnos xstivo sub sole cap)tet. Quod cum facit, totıs grex (terto) clauditur stabulo, atque uno die abstiuetur potione et pabulo : postridie radix anguinei cucumeris trita et comnista cum aqua datur sitientibus : quam cum pecudes biberunt, nausea correptas romitant, atque expurgantur, omniģie hile depulsa, cicercula vel faba dura muria conspersa, deinde, sicut hominibus, aqua calida polanila permittitur. Sed cum onni quadrupedi per sestaten sıtis sit infesta, fum suillı 
ne prescrivons point de les mener deux fois pal jour à l'cau, comme on y mène les chèvres ou les brcbis; mais nous conseillons de les tenir continuellement, autant que faire se pourra, sur les bords d'un fleuve ou d'un étang, au lever de la Caniculc, parce qu'il ne suffit pas à ces animaux, qui sont très-chauds de leur nature, de boire l'eau, mais qu'il faut encore qu'ils y plongent leur corps, pour rafraichir leur graisse ainsi que leur ventre, distendu par la pâture dont il est plein, d'autant que rien ne leur plait autant que de se vautrer dans des ruisseaux ou dans des lacs bourbeux. Si la situation des lieux ne permet point de Icur procurer ces facilités, il faut au moins leur donner à boire de l'enu de puits, qu'on mettra abondamment dans leurs auges, parce que s'il arrivait qu'ils n'en cussent pas à discrétion, ils deviendraient bientôt pulmoniques. On guérit parfaitement cette maladie en leur insérant dans les orcilles de la racine de pommelée, plante dont nous avons déjà parlé a vec assez de détail en différentes occasions. Ils sont aussi tourmentés souvent par des douleurs de rate, parce que ce viscère est sujet à se vicier chez eux lorsqu'il survient unc grande sécheresse, et que, poul emprunter une citation aux Bucoliques, les fruits sont épars à terre sous l'arbre qui les a produits. En effet, ce bétail étant insatiable, pour peu quc les truies se soient livrées avec excès à la douceur de la pâture, elles sont tourmentées en été par un gonflement de rate. On y remédie en labriquant des auges de tamaris et de houx frelon, qu'on remplit d'eau, pour la leur présenter lorsqu'elles ont soif : en effet, le suc de ces bois est médicinal au point qu'étant ainsi filtré daus leur boisson, il arrête ce gonflement interne.

XI. On a l'attention de ne châtrer ce bétail

maxime est inimica. Quare non ut capellam rel orem, sic et lioc animal bis ad aquam duci procipimus : sed si fieri potest, juxta flunen aut staguum per ortum Canicula detineri : quia cum sit restuosissimum, non est contentum potione aqux, nisi obesam ingluviem atque distentam pabulis alvum demerserit ac refrigeraverit : nec ulla re magis gaudet, quam rivis atque conoso lacu volutari. Quod si locorum situs repugnat, ne ita fieri possit, puteis extracta et large canalibus immissa probenda sunt pocula, quibus visi affatim satientur, pulmonaria fiunt. Isque morbus optime sanatur auriculis inserta consiligine : de qua radicula diligenter ac sapius jam locuti sumus. Solet etiam vitiosi splenis dolor eas infestare, quod accidit, cum siccitas magna provenit, et, ut Bucolicon loquitur poëma, Strata jacent passim sua quaque sub arbore poma. Nam pecus insatiabile sues, dum dulcedinem pabuli consectantur supra modum, rstate splenis incremento laborant. Cui succurritur, si fabricentur canales ex tama. ricis trunco, repleanturque aqua, et deinde sitientibus admoveantur; quippe ligni succus medicabilis epotus inlestiunin tumorem compescit.

11 Castratiouis antem in hoc pecore duo tempora ser. qu'en deux temps de l'annéc, savoir, au printemps ct cn automnc; ct il y a deux manières de fairc cette opération. La première est celle que nous avons déjà donnée, et qui consiste à faire deux ouvertures, à l'effet de tirer un testicule par chacune : l'autre est plus belle, quoique plus périlleuse; mais quelque danger qu'il y ait à la faire, je ne la passerai pas sous silence. Après a voir ar. raché un des testicules et l'avoir coupé avec le fer, on insère le bistouri par cette première ouverturc, et l'on incise vers le milieu la peau qui sert de cloison aux deux testicules, à l'effet d'arracher de même le sccond testicule avec les doigts, qu'on a soin de recourber. De cette manière il n'y aura qu'une plaie, qu'on cicatrisera en y appliquant les remèdes que nous avons enseignés pour la première opération. Je ne crois pas non plus devoir passer sous silence un article qui intéresse la religion du chef de famille. Il y a des truies qui dévorent leurs petits : lorsque ce cas arrive, on ne doit pas le regarder comme un prodige, parce que ce sont entre tous les bestiaux ceux qui souffrent le moins patiemment la faim; de façon qu'il arrive quelquefois que lorsque des truies manquent de pâture, non-seulement clles dévorent les pourceaux de leurs pareilles (si on les laisse faire), mais encore les leurs propres. J'ai traité avec assez d'exactitude ( si je ne me trompe) des bêtes de somme et des autres bestiaux, ainsi que des maftres do troupeaux, qui sont chargés du soin de panser et d'entretenir les quadrupèdes, tant dans l'intérieur de la maison qu'au dehors.

XH. Je vais parler à présent, ainsi que je m'y suis engagé dans la première partie de ce traité, des gardiens muets du bétail, quoique cc soit à tort que l'on donne aux chiens le titre de gardiens

vantur, veris et autumni : et ejus administrandac duplex ratio. Prima illa, quam jam tradidimus, cum duobus vulneribus impressis per unamquamque plagam singuli exprimuntur testiculi. Altera est speciosior, sed magis periculosa, quam tamen non omittam. Cum virilem partem unam ferro resectam detraxeris, per impressum vulnus scalpellum inserito, et mediam quasi cutem, quæ interve. uit duobus membris genitalibus, rescindito, atque uncis digitis alterum quoque testiculum educito : sic fiet una cicatrix adlibitis coeteris remediis, quæ prius docuimus. Illud autem, quod pertinet ad religionem patrisfamilias, non reticendum putavi. Sunt quædam scrofæe, qua man. dunt fetus suos: quod cum fit, non lıabetur prodigium. Nam sues ex omnibus pecndibus impatientissinæ famis aliquando sic indigent pabuli, ut non tantum alienam, si liceat, sobolem, sed etiam suam consumant. De armentis cxterisque pecudibus et magistris, per quos quadrupedun greges liumana solertia domi forisque curantur afque ohservantur, nisi fallor, satis accurate disserui.

XII. Nunc ut exordio priore sum pollicitus, de mutis custodibus loquar; quamquam canis falso dicitur nutus custos. Nam quuls liominum clarius aut tanta vociferatione 
muets. En effet, trouve-t-on des hommes qui avertissent de la présence d'unc bète féroce, ou decelled 'un voleur, d'une manière plus intelligible ou avec des cris plus percants que ne lc font ces animaux par leurs aboiements? $Y$ a.t-il des serviteurs plus attachés à leur maître, des compagnons plus fidèles, des gardiens plus incorruptibles que les chiens? Peut-on enfin trouver des sentinelles plus vigilantes, et des vengeur's ou iles défenseurs plus courageux? Un agriculteur doit done se pourvoir d'un chien, et l'entretenir de préférence à tout autre animal, parce que ce sera lui qui gardera la métairie, les fruits, les gens de la maison, et les bestiaux. Il y a trois différentes méthodes à suivre dans l'acquisition comme dans l'entretien de cet animal, suivant les différents objets auxquels on le destine. En effet, il y a une espèce de chien que l'on ne choisit que pour éventer les embuscades dressées par les lommes, et qui sert à garder la métairie avec ses dépendances; au lieu que les chiens de la seconde espèce sont choisis pour repousser les attaques des hommes ainsi que celles des bêtes féroces; de sorte que ceux de cette seconde espèce ne doivent pas moins a voir l'œil sur les bestiaux qui paissent au dehors, que dans l'intérieur de la maison sur les étables. Il en est une troisième espèce que l'on n'acquiert que pour la chasse, et qui non-seulement n'est d'aucune utilité à un agriculteur, mais qui le détourne même de son travail ct lui fait négliger ses occupations. Il nous suffira donc de parler du chien des métairies et de celui des pâtres, puisque le chien de chasse est un objet absolument ćtranger à l'art que nous professons. Il faut choisir pour la garde de la metairie un chien d'une corporence très-ample, et dont l'aboiement soit étendu et sonore, tant afin qu'il puisse épouvanter les malfaiteurs, d'abord par le bruit de ses hurlements et ensuite même par son aspect, qu'afin

bestiam vel furem praedicat, quam iste latratu? quis fa. mulus amantior domini? quis fidelior comes? quis custos incorruptior? quis excubitor inveniri potest vigilantior? yuis denique ultor aut vindex constantior? Quare vel in primis loc animal mercari tuerique debet agricola, quod et villam et fructus familiamque et pecora custodit. Ejus antem parandi tuendique triplex ratio est. Namque unum genus adversus hominum insidias eligitur, et id villam quxque juncta sunt vill $x$ custodit. At alterum propellen. dis injuriis hominum ac ferarum; et id observat domi stabulum, foris pecora pascentia. Tertium venandi gratia comparatur; idupue uon solum niliil agricolam juvat, sed et avocat desidemque ab opere suo reddit. De villatico igitur et pastorali dicendum est : nam venaticus niliil per. tinet ad nostram professionem. Villæ custos eligendus est amplissimi corporis, vasti latratus canorique, ut prius auditu maleficum, deinde etiam conspectu terreat, et tamen nonnunquam ne visıs quidem lorribili fremitı suo fuget insidiantem. Sit auten coloris unius; isque magis ell. qu'il puisse mettre en fuitc ceux qui s'aviseraieut de tendre des embuhches, quelquefois mème avant d'en ètre aperçu, ct par la seule frayeur qu'iuspireront ses hurlements. Il faut qu'il soit d'une seule coulcur : on préférera la couleur blanche dans le chien du pátrc, et la noirc dans celui de la métairie ; quant aux couleurs bigarrées, on nc les approuve ni dans l'un ni dans l'autre de ces animaux. Lc pâtre donne la préférence à la couleur blanche, parce qu'elle ne peut pas êtrc confondue avec celle des bêtes féroces. En efiet, il est quelquefois très-essentiel, lorsqu'il s'agit de repousser des loups pendant l'obscurité du matin ou du soir, qu'il y ait une différence bien marquée entre la coulcur du chien et celle de ces bêtes, de peur que si la blancheur du chien ne le faisait pas reconnaitre, le pátre ne vint à le frapper, croyant frapper un loup. Pour le chien de la métairie, que l'on oppose aux attaques des hommes, il doit être noir, parce que si le voleur vient en plein jour, l'aspect de cet animal lui paraitra d'autant plus terrible; et que s'il vient de nuit, l'affinité de cette couleur avec les ténèbres l'empêchera même de l'apercevoir ; de sortc que l'animal, favorisé par l'obscurité, pourra s'approcher avec plus de sûreté de ceux qui se tiendraient en embuscade. On approuve plutôt un chien carré qu'un chien long ou court, pourvu qu'il ait la tête assez grosse pour qu'elle paraisso faire la plus considérable partie de son corps, les oreilles renversées et pendantes, les yeux noirs ou verdâtres et éclatants d'une lumière vive, la poitrine ample et bien garnie de poils, les épaules larges, les jambes épaisses ct hérissées, la queue courte, et enfin les pattes et les ongles très-larges, auquel cas on les appelle $\delta p \times x \times i$. Voilà la figure extérieurc du chien de métairie la plus à désirer. Son naturel ne doit être ni trèsdoux, niau contraire farouche et cruel, parce que dans le premier cas il caresse tout le monde,

gatur albus in pastorali, niger in villatico : nam varius in neutro est laudabilis. Pastor album prohat, quoniam est feræ dissimilis, magnoque opus interdun discrimine est in propulsandis lupis sub obscuro mane vel etiam crepu. sculo, ne pro bestia canem feriat. Villaticus, qui lıomimum maleficiis opponitur, sive luce clara fur advenerit, terribilior niger conspicitur : sire noctu, ne conspicitur quidem propter umbræ similitudinem, quanobrem tectus tenebris canis tutiorem accessum lıabet ad insidiantem. Probatur quadratus potins quam longus aut brevis, capils tam magno, ut corporis videatur pars maxima, dejectis et propendentibus auribus, nigris vel glaucis oculis acri lumine radiantibus, amplo villosoque pectore, latis armis, cruribus crassis et hirtis, cauda brevi, vestigionum articulis et unguibus amplissinis, qui Grace $\delta$ paxal appellantur. Hic erit villatici canis status proxcipue landanilus. Nores autem neque mitissimi, neque rursus truces atque crudeles; quod ilti furem quoque adulantır, hi ctiam do. mesticos invadunt. Satis est severos esse nec blaidos, ut 
sans en excepter les voleurs, et que dans le second cas il saute jusque sur les gens de la maison mêmc. II suffit qu'il soit sévère sans être caressant, ct que son œil s'enflamme toujours contre les étrangers, et quelquefois même contre ses camarades de servitude. Les chiens doivent surtout se montrer vigilants en tout ce qui concerne la garde à laquelle ils sont commis. Il ne faut pas qu'ils soient vagabonds; ils doivent au contraire être assidus, et plutôt circonspects que téméraires, parce que lorsqu'ils sont circonspects ils n'annoncent rien qu'ils ne soient certains d'a. voir vu; au lieu que lorsqu'ils sont téméraires, il arrive souvent qu'ils prennent l'alerte sur de vains bruits et sur des soupçons mal fondés. J'ai cru devoir entrer dans ec détail par rapport à leurs qualités, parce que, comme la nature ne forme point scule les mœurs, à moins que l'éducation n'y soit jointe, il faut, lorsque nous serons dans le cas d'en acheter, que nous les choisissions tels que nous venons de les dépeindre, et que lorsque nous ćlèverons ceux qui seront nés chez nous, nous les formions d'après ces principes. l'eu importe que les chiens de métairie soient lourds de corps et peu légers à la course, parce que leur ministère s'exerce plutôt de près et dans le lieu mème qu'ils occupent, que de loin et dans un champ spacieux. En effet, ils doivent toujours rester autour de l'encl os ct dans le bâtiment même, sans s'en écarter jamais à trop de distance. It leur suffit, pour bien remplir leurs fonctions, de flairer avec sagacité ceux qui viennent dans de mauvais desseins, de les épouvanter par leurs aboiements, et de ne s'en pas laisser trop approcher, ou de se jeter sur eux avec fureur, au cas qu'ils s'obstinent à avancer; d'autant que le premier devoir d'un chien est de ue point se laisser attaquer, ct le second de se venger avec courage ct persévérance lorsqu'on l'agace. Voilà pour ce

nonnunquam etiam conservos iratius intueantur, semper excandescant in exteros. Maxime autem debent in custo. dia vigilantes conspici, nec erronei, sed assidui, et circumspecti magis quam temerarii. Namilli nisi quod certum compererunt, non indicant : lii vano strepitu et falsa suspicione concitantur. Haec idcirco memoranda credidi, quia non natura tantum, sed etiam disciplina mores facit, ut et cum emendi potestas fuerit, ejusmodi probemus, et cum educabimus domi natos, talibus institutis forme. mus. Nec uultum refert an villatici corporibis graves et parum veloces sint : plus enim cominus et in gradu, quam eminus et in spatioso cursu facere debent. Nam semper circa septa et intra aedificiunı consistere, imo ne longius quidem recedere debent, satisque pulchre funguntur officio, si et advenientem sagaciter odorantur, et latratu conterrent, nec patiuntur propins accedere, vel constantius appropinquanten violeuter invadunt. Primum est enim non adtentari, secundum est lacessitum fortiter et perseveranter vinulicari. Atque hae de domesticis custodibus; Illa de pastoralibus. Pecuarius canis neque tam strigosus qui est des ehiens qui gardent la maison : voiei ce qui concerne ceux des pâtres. Le chien destiné à garder le bétail ne doit être ni aussi efllanqué ni aussi léger que celul qui est destiné à courir après les daims, les cerfs et les animaux les plus légers, comme il ne doit pas non plus être aussi gras ni aussi lourd que celui qui est destiné à garder la métairie et les greniers. Il faut néanmoins qu'il soit robuste, et meme prompt et dispos jusqu'à un certain point, parce qu'on le prend autant pour attaquer et pour se battre que pour courir, puisque sa destination est de repousser les embutches dressées par les loups, de suivre ces animaux lorsqu'ils s'enfuient avec leur proic, et de la leur faire lácher pour la rapporter. Aussi une taille longue et élancée est-elle plus convenable au chien des patres qu'une taille courte ou mème carrée, parce que (comme je l'ai dit) il est souvent contraint par nécessité de poursuivre avec rapidité les bêtes féroces : au surplus, on approuve ses membres lorsqu'ils sont semblables à ceux du chien de la métairle. II faut donner à peu près la même nourriture à ces deux espèces de chiens, c'est-à-dire que si l'on a des possessions assez étendues pour comporter plusieurs troupeaux de bestiaux, on pourra très-bien nourrir tous les chiens indistinctement avec de la farine d'orge trempée dans du petit-lait; au lieu que si la terre que l'on possède est plantée en arbrisseaux et sans paturages, on les nourrira de pain de blé et de froment, en y ajoutant cependant du bouillon de fèves qu'on leur donnera tiède, parce que s'il était bouillant, il leur donnerait la rage. It ne faut permettre à ce quadrupède, tant mále que femelle, de s'accoupler qu'au bout d'un an, parce que si on laissait accomplir l'acte de la génération avant ce temps, le plaisir, en lui affaiblissant le corps et en abattant ses forces, lui énerverait le courage. On ôtera aux

aut pernix debet esse, quam qui damas cervosque et ve. locissima sectatur animalia, nec tan obesus ant gravis, quam villæ horreique custos : sed et robustus nililominus, et aliquatenus promplus ac strenuus, quoniam et ad rixam et ad pugnam, nec minus ad cursum comparatur, cum et lupi repellere insidias, et raptorem ferum consequi fugientem, prædam excutere atque auferre debeat. Quare status ejus longior productiorque ad hos casus ma. gis habilis est, quam brevis aut etiam quadratus : quoniam, ut dixi, nonnunquam necessitas exigit celeritate bestiam consectandam. Cxteri artıs similes nembrts villatici canis rque probantur. Cibaria fere eadem sunt utrique generi præbenda. Nam si tam laxa rura sunt, ut sustineant pecorum greges, omnes sine discrimine canes ordeacea farina cum sero commode pascit. Sin autem surculo consitus ager sine pascuo est, farreo vel triticeo pane satiandi sunt, admisto tamen liquore coctae fabx, sed tepido : nam fervens rabiem creat. Huic quadrupedi neque formina neque mari nisi post aumum permittenda veuss est : quae si teneris conceditur, carpit el corpus el vires, 
chiennes leur première portéc, parce qu'une jeune chienne que l'on fait nourrir s'en acquitte toujours mal la première fois, et que ce travail l'empêche de prendre de l'accroissement dans sa stature. Les mâles engendrent vigoureusement jusqu'à dix ans; passé ce temps, ils ne paraissent plus propres à cette fonction, parce qu'une race issue de vieux chiens est toujours lâche. Les femelles concoivent jusqu'à neuf ans, et ne sont plus bonnes à rien passé dix ans. Il ne faut pas laisser sortir les petits chiens pendant les six premiers mois qui suivent leur naissance, jusqu'à ce qu'ils se soient fortifiés, si ce n'est pour les laisser aller jouer et folâtrer auprès de leur mere : au bout de ce temps, il faut les enchainer pendant le jour, et les détacher pendant la nuit. On ne doit jamais souffrir que ceux dont on veut conserver le naturel généreux soient élevés par une autre nourrice que par celle qui leur a donné le jour, parce que le lait qu'ils puiseront dans le sein maternel, joint au courage personnel de leur mère, leur donnera toujours plus d'ardeur et fortifiera bien autrement leur corps que ne pourrait faire celui d'une autrechienne. Si une chienne qui a fait des petits vient à manquer de lait, il conviendra de leur donner du lait de ehèvres préférablement à tout autre, jusqu'à ce qu'ils aient quatre mois. Il faut leur donner des noms qui ne soient pas trop longs à prononcer, afin qu'ils s'entendent plus tot appeler, quoiqu'it ne faille pas non plus leur en donner de trop courts, ni qui aient moins de deux syllabes. Tels scront les mots grees $\sigma x u ́ \lambda \alpha^{\xi}$ (petit chien). et $\lambda \alpha \dot{x}(1) v$ (chien de Laconie), et les mots latins ferox (fier) et celer (léger à la course) : tels seront encire pour les femelles les mots grees стоиว่े (prompte), ¿a $\lambda x\rangle_{\text {(forte), }}$ (ó)un (forte), et les mots latins lupa

animosque degenerat. Ptimus effæetæ partus amorendus est, quoniam tiruncula nec recte nutvit, et educalio totius babitus aufert incrementum. Mares juveniliter usque in anıos decem progenerant : post id tempus ineundis fueniuis non videutur labiles, quoniam seniorum pigra soboles existit. Vionnina concipiunt usque in annos noven, nec sunt utites post decinum. Catulos sex mensibus primis, dum corroborentur, emitti nou oportet, nisi ad matrem lusus ac lascivix cansa. Postea catenis per diem coutiuendi, et noctibus solrendi. Nec unquam eus, quorum generosam volumus indolem conservare, patiemur aliende untricis uberibus educari : quoniam semper et lac et spiritus uateruus longe magis ingenii atque iucrementa corporis anget. Quod si efliofa lacte deficitur, caprinum maxime conveniet proberi catulis, dum fiant mensium quatuor. Nuniniluns antem non longissinis appellandi sunt, quo celerius quisqque vocatus exaudiat : nec tanu’n brevioribns, quam quae duabns syllabis enun tientur, sicuti

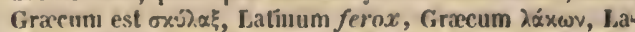

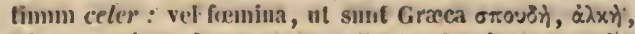

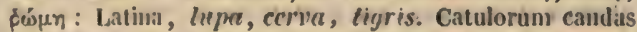
post diem quatragesimum, quam sint editi, sie eastrare (louve), cerva (blche), tigris. (tigresse). On coupera la queue des petits chiens quarante jours après leur naissance, de la manière suivante. $0_{11}$ prend avec les dents le nerf qui traverse les jointures de l'épine du dos et qui s'étend jusqu'à l'extrémité de la qucue; et après l'avoir un peu tiré à soi, on le rompt : moyennant cette opération, la queue ne prend jamais unc extension désagréable, et méme (si l'on en croit un grand nombre de pâtres) on préserve par là les chiens de la rage, qui est une maladie mortelle d cette espèce de bête.

XIII. Il arrive communément que les mouches ulcèrent pendant l'été les oreilles des chiens, au point que ces animaux finissent souvent par les perdre absolument. Four prévenir cet accident, il faut leur frotter les oreilles avec des amandes amères pilées; mais sỉ elles sont déjà infectées par les ulcères, on distillera sur la plaie de la poix fondue, cuite avec de la graisse de cochon. Les tiques tomberont aussi par l'applieation de ce médicament : car it ne faut pas les arracher avce la main, de peur d'oceasionner des ulcères, comme je l'ai dit ci-dessus. On guérit un chien sujet aux puces, en le frottant soit de cumin broyé avec de l'ellébore blanc à doses égales et trempé dans l'eau, soit de jus de concombre sauvage, ou, à défaut de ces drogues, en lui versant de vieillc lie d'huile sur tout le corps. S'il a la galc, on broie du gypse et du sésame en pareillc quantité, pour en faire avec de la poix fondue un onguent dont on frotte la partie malade. On croit ce remède également bon pour les hommes. Lorsque cette maladie est très-violentc, on la dissipc avec de la résine de cèdre. Il faut traiter lesautres maladies des chienssuivant les prèceptes que nous avons donnés pour les autres animaux.

conveniet. Nervus est, qui per articulos spinæ prorepit usque ad ultimam partem caudæe : is mordicus comprebensus et aliqnatenus eductus abrumpitur : quo facto neque in longitudinem eauda foedum eapit incrementum, et, ut plurimi pastores affirmant, rabies arcetur letifer morbus huic generi.

XIII. Fere auten per astatem sic muscis aures canum exulcerantur, sape ut totas amittant : quod ne fiat, amaris nncibus contritis linienda sunt. Quod si ulccrilus jam preoccupatxe fuerint, coctam picem liquidam suillae adipif nistam vulneribus stillari conveniet. Hoc eodem medica:mine contacti ricini decidunt. Nam manu non sunt vellendi, ne, ut ct ante: priedixeram, faciant ulcera. Pulicosa cani rencelia sunt sive eyminum tritum pari poudere cum. veratro, aquaq̧ue nistım et inlitum;-sen encumeris anguinei succus : vel si lıac non sunt, vefus amurca per totun corpus infusa. Si seabies infestabit, gypsi et sesani. tantundern conterito, et cum pice liquida permisceto, vitiosamqque partem linito : quod medicamentuın putatur. etiam lıoninibus esse conveniens. Eaden pestis si fuerit veliementior, cedrino liquore abolefur. Iseliqua vitia sicnt in cateris animalibus pracepimus, curanda sunt. Hacte- 
Nous terminerons ici ce qui regarde le petit bétail, et nous donnerons dans le volume suivant des préceptes sur les engrais que l'on fait dans l'intérieur des métairies; ce qui comprendra tout ce qui est relatif aux soins qu'exigent les oiseaux, les poissons et les quadrupèdes des forets.

\section{LIVRE VIII.}

I. Nous avons donné dans les sept premiers livres, Publius Silvinus, à peu près tout ce qu'il fallait pour compléter l'art de faire valoir et de cultiver les terres, ainsi que ce qui concernait la méthode de gouverner les bestiaux. Si nous ajoutons à ce traité le huitième livre que voici, c'est moins parce que les objets dont il y sera question sont essentiellement et immédiatement du ressort des gens de la campagne, que parce qu'ils concernent une administration qui ne peut avoir lieu que dans les campagnes ou dans les métairies, et que les profits qu'elle rapporte tournent plus à l'utilité des gens de la campagne qu'à celle des habitants des villes. En effet, l'engrais des volailles, ainsi que celui des gibiers et des poissons qu'on nourr it dans les métairies, ne laisse pas que de rapporter au cultivateur des profits considérables, de même que celui des bestiaux, tant parce que la fiente d'une partie de ces animaux sert de remède aux vignes qui sont trop maigres, ainsi qu'à tous les arbres et aux telres labourables, que parce que les élèves qu'il fait de la sorte fournissent non-seulement la cuisine de ses gens, mais encore sa table même d'excellents mets, et qu'enfin ils rehaussent le revenu de la métairie par l'argent qu'ils produisent à la vente. C'est pour cela que j'ai cru devoir aussi traiter de ces autres nourritures. Or elles se font communément ou dans la métairie même, ou dans

nus de minore pecore. Mox de villaticis pastionibus, quæ continent volucrum pisciumque et silvestrium quadrupe. dum curam, sequenti volumine pracipiemus.

\section{LIBER VIII.}

I. Quæ fere consummabant, Publi Silvine, ruris exercendi colendique scientiam, quxque pecuariæ negotiationis exigebat ratio, septem menoravimus libris. Hic nunc scquentis nutneri titulum possidebit : nec quia proximan propriamque rustici curam desiderent ea, quæe dicturi sumus, sed quia non alio loco; quam in agris aut villis de. leant administrari, ct tamen agrestibus magis, quam urbanis prosint. Quippe villatica pastiones, sicut pecuariæ, non minimam colono stipem conferunt, cum et avium stercore macerrimis vineis et omni survulo atque arvo medeantır; ct eisdem familiarem focum mensanique prc. tiosis dapibus opulentent; postremo venditorum animalium pretio villie reditum augeant. Quarc de hoc quoque genere pastionis dicendum censui. Est antem id fere vel ses environs. Celles qui se font dans la métairie sont comprises sous ce que les Grecs appellent

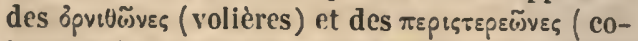
lombiers). On peut encore, lorsque l'on a de l'eau à sa disposition, y entretenir des 'i/0uotpop̧zix (des viviers); ce sont, pour m'exprimer plutôt en latin, comme les stabula (les étables) des oiseaux de basse-cour, et de ceux que l'on enferme dans des cabinets pour les engraisser, ou les receptacula (les retraites) des animaux aquatiques. On ménage aussi autour des métairies des

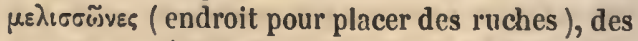
$\chi$ भy

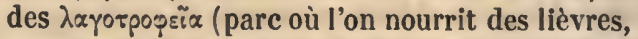
garennes.) Nous appelons encore tous ces différents lieux des apiaria, quand ils servent de retraites aux abeilles; des aviaria, quand ils en servent aux oiseaux aquatiques, qui se plaisent dans lés étangs et dans les réservoirs d'eau; ou enfin des vivaria, quand ils en servent aux bêtes fauves que l'on garde dans des bois clos.

1I. Je commencerai donc par donner des préceptes de nourriture et d'éducation relatifs à toutes les volailles et à toutes les espèces de gibier qu'on élève dans l'intérieur des métairies. On peut à la vérité mettre en question si les gens de la campagne doivent avoir chez eux de toutes ces espèces d'animaux; mais la question est résolue par rapport aux poules, et elles sont communément l'objet le plus habituel des soins que doivent prendre les agriculteurs. 0 n en compte de trois espèces : les poules de basse-cour, les poules sauvages et celles d'Afrique. Les poules de basse-cour sont celles que l'on voit ordinairement dans presque toutes les métairies. Les sauvages, qui leur ressemblent, sont celles que les oiseleurs prennent à la chasse; il s'en trouve beaucoup dans l'île de la mer de Ligurie, à laquelle

in villa, vel circa villam. In villa est, quod appellant Græci bै

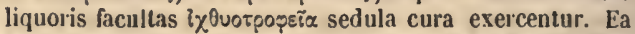
sunt, ommia ut Latine potins loquanıur, sicut arinm cohortalium stabula, nec minus earum, quæ conclavibus septæ saginantur, vel aquatilium animalium receptacula.

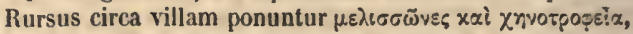

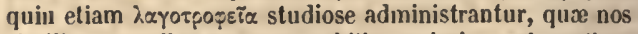
similiter appellamus apun cubilia, apiaria, vcl nantiım volucrum, quæ stagnis piscinisque lætantur, aviaria, vel etiam pecudum silvestrium, qua nemoribus clausis custodiuntur, vivaria.

II. Prius igitur de his pracipiam, qua intra septa vill pascuntur. Ac de aliis quidem forsitan ambigitur, an sint agrestibus possidenda : gallinarum vero plerumque agricolæ cura solennis est. Earum genera sunt vel cohortalium, vel rusticarum vel Africanarum. Cohortalis est avis, quæ vulgo per omnes fcre villas conspicitur : rustica, quæ non dissimilis villaticæ per aucupem decipitur, eaque plurima est in insula, quam nautæ iu Ligusticn mari sitam producto nomine alitis Gallinariam vocitaverunt: 
les matelots donnent le nom de gallinaria, forme allongée de gallina (poulc). Celles d'Afrique, que bien des gens appellent poules de $\mathrm{Nu}$ midie, ressemblent aux pintades; avec cette différence qu'elles ont la crête et la barbe rouges, au lieu que les pintades les ont bleues. Mais entre ces trois espèces d'oiseaux, c'est proprement à ceux de basse-cour que l'on donne le nom de poules lorsqu'ils sont femelles, celui de cogs lorsqu'ils sont mâles, et celui de chapons Iorsqu'ils ne sont males qu'à demi ; car c'est le nom qu'on leur donne lorsqu'on les a chátrés, pour éteindre absolument en eux tout penchant à la volupté. $\mathrm{Au}$ reste, on ne les réduit pas seulement à cet état en les privant des parties génitales, mais encore en leur brûlant les ergots avec un fer chaud; après quoi, lorsque l'action du feu les a consumés, on frotte avec de la terre à potier la plaie qui résulte de cette opération, jusqu'à ce qu'elle soit parfaitement guérie. II ne faut donc pas négliger le revenu que peuvent produire ces poules des métairies, pour peu qu'on les élève avec cette intelligence qui a rendu célèbres la plupart des Grees et principalement les habitants de Délos en cette partie. Il est vrai que comme ces peuples recherchaient ceux de ces animaux qui avaient la plus grande taille et qui montraient le plus de courage dans les combats, ils préféraient à tous les autres ceux de Tanagra et de Rhodes, ainsi que ceux de Chalcidie et de Médie, que le vulgaire appelle, par changement d'une lettre, poules de Mélie; au lieu que nous approuvons ceux de notre pays préférablement aux autres, parce que nous ne faisons point cas de cette passion des Grees, qui les portait à élever pour les combats les plus fiers de ces oiseaux. En effet, notre but est d'assurer un fond de revenu aux chefs de famille industrieux, et non pas aux gens qui s'a-

Africana est, quam plerique Numidicam dicunt, Meleagridi similis, nisi quod rutilam galeam et cristam capite gerit, qux utraque sunt in Meleagride cærulea. Sed ex lis tribus generibus cohortales founinæ proprie appellantur gallinæ, mares autem galli, semimares capi, qui hoc nomine vocantur, cum sunt castrati libidinis abolendx causa. Nec tamen id patiuntur amissis genitalibus, sed ferro candente calcaribus inustis, qux cum ignea vi consumpta sunt, facta ulcera dum consanescant, figulari creta linuntur. Hujus igitur villatici generis non spernendus est reditus, si adhibeatur educandi scientia, quam plerique Graecorum et procipue celebravere Deliaci. Sed et ii, quoniam procera corpora et animos ad prelia pertinaces requirebant, promipue Tanagricum genus et Rho. dium prohabant, nec minus Chalcidicum et Medicum, quod ab imperito vulgo litera mutata Melicum appellatur. Nobis nostrum vernaculum nuxime placet : omisso tamen illo studio Griecorum, qui ferocissimum quemque alitem certaminibus et pugnx prxparabant. Nos enim censemus instituere vectigal industrii patrisfamilias, non rixosarum avium lanistæ, cujus plerumque totum patri. donuent à dresser des oiseaux pour les combats, et qui compromettent tout leur patrimoine, au risque de s'en voir assez souvent dépouillés à l'occasion d'un coq qui aura remporté la victoire sur son adversaire. Ainsi, quiconque voudra suivre nos préceptes examinera d'abord le nombre de femelles qu'il lui faudra acquérir, et les qualités qu'elles devront avoir; ensuite la manière de les entretenir et de les engraisser ; troisièmement, les temps de l'anvée où il devra réserver leur ponte pour la faire couver et éclore par la suite, et enfin les soins qu'il aura à prendre pour que les poulets soient élevés comme il convient. C'est en effet par ces soins, et par les occupations qu'ils entrainent après eux, que l'on peut tirer parti de l'éconumie de la basse-cour, que les Grees appellent opviforpopía. Or le nombre qu'il s'en faudra procurer est de deux cents têtes; et ce nombre partagera les soins d'un seul et unique gardien, pourvu cependant qu'on lui associe une vieille femme ou un enfant, qui garderont ces oiseaux quand ils s'éloigneront, de peur qu'ils ne soient volés par les hommes qui leur tendront des piéges, ou enlevés par les animaux qui les guetteront. Il n'y a point de profit à acheter des poules, à moins qu'elles ne soient trèsfécondes. Il faut qu'elles aient le plumage rouge ou brun, et les ailes noires: on les choisira méme toutes, si faire se peut, de l'une de ces couleurs, ou d'une couleur qui en approche; ou du moins on évitera d'en avoir de blanches, parce qu'elles sont pour la plupart délicates, peu vivaces, et rarcment fécondes. D'ailleurs, comme la blan. cheur est une couleur saillante qu'on distingue de loin, plus elles sont blanches, plus elles sont exposées à être enlevées par les oiseaux de proie et par les aigles. Il faut done que celles qui sont destinées à pondre soient de couleur roussâtre,

monium, pignus alex, rictor gallinaceus pyctes abstulit. Igitur cui placebit sequi nostra præcepta, consideret oportet primum quam multas, et cujusmodi parare de. beat matrices, deinde qualiter eas tueri et pascere; mox quibus anni temporibus earum partus excipere; tum demuns ut incubent et excludant efficere; postremo ut commode pulli educentur operam dare. His enim curis et ministeriis exercetur ratio colıortalis, quam Graeci vocant opvitorpopiav. Parandi auten modus est ducentorum capitum, qux pastoris unius curam distendant : dum tamen anus sedula vel puer adlibeatur custos vagantium, ne obsidiis hominum, aut insidiatorum animalium diripian. tur. Mercari porro nisi foecundissimas aves non expedit. Ex sint rubicundæ vel fuscæ plumæ, nigrisque pennis : ac si fieri poterit, omnes hujus, et ab lioc proximi coloris eligantur. Sin aliter, vitentur albæ; quæ fere cum sint molles ac minus vivaces, tum ne focundx quidem facile reperiuntur : atque etiam conspicua propter insigne candoris ab accipitribus et aquilis sxpius abripiuntur. Sint ergo matrices robii coloris robusti corporis, quadrata, pectorosx, magnis capilibus, rectis rutilisque 
qu'elles aient le corps robuste et carré, la poitrine large, la tête grande, de petites lruppes droites et rouges, les oreilles blanches; qu'elles paraisscut très-amples sous cette forme, et qu'elles aient les ongles inégaux. Celles qui ont einq ongles, et dont les pattes ne sont point traversées par des éperons, passent pour les meilleures, parce que celles qui sc font distinguer par cet apanage réservé aux mâles ne se prêtent point aisément à la génération et dédaignent de souffrir le cog; outre qu'elles sont rarement fécondes, et qu'elles cassent même leurs œufs avec la pointe de leurs ongles, lorsqu'elles viennent à les eouver. Rejetez tout coq qui ne sera pas très-lascif, et recherchez dans ces animaux la même eouleur ct le même nombre d'ongles que dans les poules; on leur veut cependant une taille plus haute. Il faut qu'ils aient la crête haute, dc couleur de sang et biendroite; les yeux roux ou tirant sur le noir, le bee eourt et croehu, les oreilles trìs-grandes et très-blanches, la eravate d'un rouge tirantsur le blane et pendante comme la barbe d'un vieillard; les plumes du eou bigarrées ou d'un jaune d'or, et qu'en tombant sur les épaules elles couvrent le cou et le chignon; la poitrine large et pleine de museles, les ailes fortes et semblables à des bras, la queue très-longue et partagée en deux rangs; sur le côté de ehacun déborderont des plumes. Il faut encore qu'ils aient de grandes euisses, et qu'elles soient cowvertes de plumes qui se hérissent souvent; qu'ils aient les pattes fortes sans être longues, mais qu'elles soient armées offensivement eomme d'une espèce d'épieu toujours prêt à attaquer. Quoiço'on ne les destine point aux combats, et qun'on ne réserve point les coçs pour la gloire des victoires, on les approuve cependant très-fort quand ils sont d'une belle apparence, qu'ils sont

cristılis, albls auribus, et sub hac specie quam amplissinax, nec paribus ungulis : generesissimaeque creduntur, qux quinos labeut digitos, sed ita ne cruribus emineant transversa calcaria. Nam qua: hoc virile gerit insigne, contuuax ad coneubitum dedignatur almittere marem, raroque forcunda, ctiam cum inculat, caleis aculeis ova perfringit. Gallinaceos mares uisi salacissimos liabere non expelit. Atque in his quoque sicut in freminis, idem eolor, idemque numerus unguium, status altior quæritur : sublimes, sanguinereyne, nec olliqur erista : ravidi, vel nigrantes oculi : brevia et adunca rostra : maxima candidissimacyue aures : palea ex rutilo albicantes, quae velut incanx barbx dependent : juba deinde variæe, vel ex auro flava, per colla cervicesque in lumeros diffuse : tum lata el museulosa pectora, lacertosacque similes brachiis ala, tun procerissima caudx, duplici ordine, singulis utrinque prominentibus pinnis inflexa : quinetiam vasta femina et frequenter horrentibus plumis hirta: : robusta crura, nec longa, sed infestis velut sudibus nocenter ar. mata. Mares autem, quamvis nou ad pugnam neque ad victoria laudem propparentur, maxime tamen generosi fiers, vifs, éveillés, toujours prèts à ehanter, et qu'ils ne se laissent point aisément effrayer. En effet, ils doivent quclquefois faire tête aux autres animaux, et protèger la troupe de femelles auxquelles ils sont mariés, en tuant même les serpents qui les menacent, et tous les autres animaux pernicieux. On se pourvoit de einq femelles pour ehaque mâle de eette espèce; car pour l'espèce qui nous vient de Rhodes ou de Médie, comme ellc est lourde et pesante, et que les pères n'en sont pas bien laseifs ni les mères bien-fécondes, on n'en donne que trois à chaque coq; eneore sont-elles paresseuses non-seulement à eouver, mais encore plus à faire éelore le peu d'œufs qu'elles ont pondus, et rarement élèvent elles leurs poulets. Aussi ceux qui ont à eœur d'avoir dc ces espèces d'oiseaux à cause de leur beauté, font couver par des poules eommunes les œufs pondus par ees poules distinguées, et font nourrir ensuite par ecs mêmes poules les poulets qu'elles ont fait éclore de ees ceufs. Communément la volaille de Tanagra es. de la même. taille que celle de Rhodes et de Médie, et elle res. semble assez du côté des mœurs à. celle de notre pays, ainsi que celle de Chalcidic. Cependant les bâtards de toutes ces espèces, procréés de poules. de notre pays avee des mâles étrangers, sont d'cxeellents poulcts, parce qu'ils ont la forme cxtérieure de leur père, et qu'ils conservent la lubrieité des poules de notre pays. Je n'approuve pas. la volaille nainé, ni du côté de la féeondité, ni du eôté des autres genres de profit qu'on en peut espérer, à moins que quelqu'un ne soit eurieux de sa petitesse; et je n'en fais pas en: vérité plus de cas que des males qui aiment ì se battre ou qui ont l'humeur querelleuse, parce que eommunément eeux-ci molestent les autres et les empêchent de coquer les poules, sans cependant pou.

probantur, it sint elati, alacres, vigilaces, el ad sxepius eanendum prompti, nee qui facile terreantur : nam interdim resisteré debent, et prolegere conjugalenr gregem : quin et attollentem minas serpentem, vel aliul noxiun. animal interficere: Talibus autem maribus quinac singulis feminæe comparantar. Nam Rhodii generis aut Nediei propter gravitatem neque patres nimis salaees, nee forcundæ matres: quae tamen ternae singulis maritantur. EC cum pauca ova posuerınt, inertes ad ineubandum, nuultoque magis ad exeludendum, raro foetus suos edicaut. Ilaque quibus cordi est ea genera propter corporum speeiem possidere, cum exceperunt ova generosarun, vulgaribus gallsuis subjiciunt, ut ab his exelusi pulli uutriantur. Tanagriei plerunuque Rhodiis el Medicis amplitudine pares, non multum moribus a vernaenlis distaut, sicut et. Clıalcidici. Omnium tamen lorum generum nothi sunt. optini pulli, quos conceptos ex peregrinis maribus nostrates ediderunt. Nam et paternam speeiem gerunt; et sto lacitatem foccunditalemque vernaenlan retinent. Puniles: aves, nisi: quem lımilitas earum delectat, nee propler foseunditatem, nee propter alium teditum nimiun probe), 
voir eux-mèmes en satisfaire un grand nombre. II faut par conséquent réprimer leur pétulanee avee un morceau de quelque vieux cuir taillé en rond, que l'on perce par le milieu, et dans lequel on insère la patte de ces animaux, pour eorriger, à l'aide de cette espèce d'entrave, la férocité de leurs mours. Mais je vais donner des préceptes, suivant l'ordre que je me suis prescrit, sur l'entretien de toutes ees espèces de volaille.

III. Il faut placer les poulaillers du côté de la métairie qui est en face de l'orient d'hiver, attenant le four ou la euisine, afin que la fumée en parvienne â la volaille, parce que c'est une chose qui lui est très-salutaire. Toute la basse-eour, c'est-à-dire le poulailler, sera composée de trois cabanes construites l'une auprès de l'autre sur une seule ligne, et dont la face sera tournée du cóté de l'orient, comme je l'ai dit. Ensuite on pratiquera sur eette face une seule petite entrée pour la cabane du milieu : eette cabane, qui sera la moins haute des trois, n'aura que sept pieds en tous sens. Il faudra percer sur les murs de eette cabane, de droite et de gauehe, attenant le mur faisant face à l'entrée, deux portes, dont ehaeune communiquera à une des deux antres cabanes. On adossera à eemême mur un foyer dont la largeur sera telle, qu'elle ne: puisse point gêner les portes dont nous venons de parter, et que la fumée qu'il donnera puisse pénétrer dans les deux autres cabanes : celles-ci auront douze pieds tant de longueur que d'élévation, et leur largeur sera la mẻme que celle de la cabane du milien. L'élévation en sera eoupée en deux étages, qui laisseront quatre pieds de libres par en liaut et sept par en bas, puisqu'ils emporteront ehacun un pied. Ces deux étages sont faits pour la commodité des poules, et ils doivent être éclairés du cóté de l'orient chacun par une petite fenetre, qui servira aussi de passage aux poules, afin qu'elles puissent sortir le matin pour aller dans la cour, et rentrer le soir au poulailler. $\mathrm{Ob}$ servez néanmoins qu'il faudra avoir soin de les tenir tonjours renfermées pendant la nuit, afin qu'elles juchent plus en sûreté. On percera audessous des étages des fenêtres plus grandes que les précédentes, que l'on garnira de barreanx pour empécher les animaux nuisibles de se glisser dans le poulailler, sans cependant trop intercepter le jour, afin que l'habitation de ces oiseaux soit plus agréable. Celui qui prend soin des poules doit visiter de temps en temps les œufs de celles qui couvent ou de celles qui pondent. On đonnera à cet effet une telle épaisseur aux murs du poulailler, qu'on puisse y creuser des rangées de nids dans lesquels elles pondront ou feront éclore les poulets, paree qu'outre que cette méthode est plus belle à l'œil, elle leur est aussi plus salutaire que la pratique de quelques personnes, qui enfoncent profondément dans les murs des pieux, sur lesquels ils posent des paniers d’osier. Au reste, soit que les nids soient creusés dans les murs eomme nous l'avons dit, soit qu'ils soient formés par des panlers d'osier, it faudra qu'ils soient préeédés de vestibules par lesquels passeront les poules pour y parvenlr, soit qu'elles veuillent pondre, soit qu'elles veuillent eouver, parce qu'il ne faut pas qu'elles entrent de plein vol dans leurs nids, de peur qu'en se jetant sur leurs ceufs elles ne les cassent avec les pattes. On donnera ensuite à ces oiseaux la faeilité de monter aux étages des deux cabanes, en appliquant à la muraille de petits soliveaux un pea raboteux, tam lıercule, quam uec pugnacem, nec rixosa libidinis Inarem. Nam plerumque cateros infestat, et non patitur inire fuminas, cum ipse pluribus sufficere non queat. Impedienda est itaque procacitas ejus ampullaceo corio; quod cum in orbiculum formatum est, nedia pars ejus rescinditur, ef per excisam partem galli pes inseritur : eaque quasi compede colibentur feri mores. Sed, ut proposui, jam de tutela generis universi procipiam.

III. Gallinaria constitui debent parte villx, quxe hibernum spectat orientem : juncta sint ea furno vel culinæ, ut ad avem perveniat fumus, qui est huic generi pracipue salutaris. Totius autem officinæ, id est ornithonis, tres continux extruuntur cella, quarum, sicuti dixi, perpetua frons orienti sit obversa. In ea deinde fronte exiguus detur unus omnino aditus mediæ cella; quæ ipsa, e tribus minima, esse debet in altitudinem et quoquoversus pedes septem. In ea singuli dextro lavoque pariete aditus ad utramque cellam faciendi sunt; junctir parieti, qui est intrantibus adversus. Huic autem focus applicetur tam longe, ut nec impediat prodictos alitus, et ab eo fumus perveniat in utramqque cellam : exque longiludinis, ef altitudinis duodenos pedes lıabeant, nec plus latitudinis, quam nıedia. Sublimitas dividatur tabulatis, qqux sıpra se quaternos, et infra septenos liberos pedes labeant, quaniam ipsa singulos occupant. Utraque tabulata gallinis servire debent, et ea parvis ab oriente singulis illuminari fenestellis, qux et ips matutinum exitum prabeant avibus ad cohortem, wee minus vespertinum introitum. Sed' eurandum erit, ut semper noetibus claudantur, quo tu. tius aves maneant. Infra tabulata majores fenestrxe ape. riantur, et eae clatris muniantur, ne possiut noxia irrepere animalia : sic tamen, ut illustria sint loca, quo commodius habitent. Aviariusque subinde debet specnlari ant incubantis aut parturientis foetus. Nam etiam in is ipsis locis ita crassos parietes adificare convenit, ut excisa per ordinem gallinarum cnbilia recipiant : in quibus aut ova edantur, aut excludantur pulli : loc enim et salı. brius el elegantius est, quam illud, quod quidam faciunt, ut palis in parietes veliementer actis, vimineos qualos superimponant. Sive autem parietibus ita, ut diximus, cavatis, sive qualis vimineis praponenda erunt restibula, per quae matrices ad cubilia vel pariendi vel incubandi causa perveniant. Neque enim debent ipsis nidis involare, ne dum adsiliunt, pedibus ova confringant. Ascensus deinde avibus ad tabulata per utramque cellam datur junctis parieti modicis asseiculis, qui paulum fornıtis 
sur lesquels on pratlquera des espèces de marehes, afin que les poules ne glissent point en $\mathbf{y}$ montant. On appliquera aussi endehors, du côté de la cour, aux fenêtres dont nous avons parlé, de petltes échelles pareilles, sur lesquelles ees oiseaux se traineront lorsqu'ils iront prendre le repos de la nuit. Mais on veillera surtout à ee que ces poulaillers, ainsi que les autres lieux propres a nourrir des oiseaux, dont nous parlerons par la suite, soient revêtus tant en dedans qu'en dehors d'un enduit bien poli, pour empêcher les chats ou les eouleuvres d'en approcher, et en écarter les autres animaux nuisibles. 11 n'est pas à propos que ees oiseaux restent sur un planeher plein pour dormir, de peur qu'ils ne soient Ineommodés de leur propre fiente, qui leur oecasionnerait la goutte, si elle venait à séjourner autour de leurs pattes et de leurs ongles. Pour éviter cet accident, on équarrit des perehes, attendu que si elles étaient unies et arrondies dans toute leur longueur, elles ne pourraient pas retenir les oiseaux qui viendraient à se poser dessus; après quoi on les enfonce par les extrémités dans les deux murs opposés, de facon qu'elles solent élevées à la hauteur d'un pied au-dessus du plancher plein, et distantes de deux pieds l'une de l'autre. Telle sera la disposition du poulailler. Quant à la cour dans laquelle les poules auront la liberté de se promener, elle doit être plutôt sèche que propre; ear il est très-important qu'il ne s'y trouve point d'autre eau que eelle que l'on mettra dans un endroit marqué pour leur servir de boisson, et qu'il faudra avoir soin de tenir très-propre, parce que, lorsqu'elle est pleine de fumier, elle leur donne la pépie. On ne pourra eependant pas la eonserver pure, si on ne la tient pas renfermée dans des vases fabriqués exprès pour eet usage. On aura donc,

gradibus asperantur, ne sint advolantibus lubrici. Sed ab colorte foriusecus prædictis fenestellis scandula similiter injungantur, quibus irrepant aves ad requiem nocturnam. Maxime autem curabimus ut et loec aviaria et cretera, de quibus mox dicturi sumus, intrinsecus et extrinsecus poliantur opere tectorio, ne ad aves feles liabeant aut coluber accessum, et aque noxire prohibeantur pestes. Tabulatis insistere dormientem avem non expedit, ne suo laedatur stercore; quod cum pedibus uncis adhæ. sit, podagram creat. Ea pernicies ut evitetur, pertica dolantur in quadrum, ne teres levitas earum supersilientem volucrem non recipiat. Conquadratæ deinde foratis duohus adversis parietibus induuntur, ita ut a tabulato perlalis altitudinis, et inter se bipedalis latitudinis spatio distent. Hac erit cohortalis officinæ dispositio. Cxeterum colıors ipsa, per quam vagantur, non tam stercore, quam uligine careat. Nam plurimum refert aquam non esse iu ea nisi uno loco, q̨uam bibant, eamque mundissimam : nam stercorosa pituitam concitat. Puram tamen servare uon possis, nisi clausan vasis in lunc usum fabricatis. Sunt autem, qui aut aqua replenlur ant cibo plumbei pour contenir leur eau ct leur mangeaille, des augets de plomb, paree que l’on a observé qu'ils étaient meilleurs que des augets de bois ou de terre cuite. Ils seront fermés à l'aide de couvercles posés par-dessus, et percés de petits trous sur les eôtés un peu au-dessus du milieu de leur hauteur, de façon que ees trous, par lesquels les oiseaux pourront passer la tête, soient éloignés les uns des autres d'un palmus. Si ees augets n'étaient point couverts, les poules éparpilleraient avec leurs pattes le peu d'eau ou de mangeaille qui y serait renfermé. Il y a des personnes qui font ces trous par en haut sur les cou. vercles mêmes; mais il faut éviter eette pratique, paree que les poules, venant à se poser sur ces augets, salissent alors leur mangeaille et leur eau de leurs ordures.

IV. La meilleure mangeaille que l'on puisse donner aux poules, e'est de l'orge pilé dans un mortier et de la vesee : on peut leur donner également des pois chiehes et même du millet et du panis, pourvu eependant que le bon marché de ees denrées le permette. Mais lorsqu'elles sont trop chères, on peut très-bien leur donner de menues criblures de froment; car on ferait mal de leur donner cette espèce de blè en nature, même dans les endroits où il serait à très-bon marehé, paree qu'il leur est nuisible. On peut aussi leur donner de l'iviaie bouillie, ainsi que du son dont on n'aura guère séparé la farine, paree que si on n'en laissait point, il ne leur vaudrait rien, outre qu'il leur plairait peu. On approuve très-fort l'usage de leur donner, quand elles sont maigres, des feuilles et de la graine de cytise, qu'elles aiment beaucoup, d'autant qu'il n'y a point de pays où l'on ne puisse se pro. curer ees arbrisseaux en très-grande quantité. Quoique le mare de raisin les nourrisse passable.

canales, quos magis utiles esse ligneos, aut fictiles com. pertum est. Hi superpositis operculis clauduntur, et a lateribus super mediam partem altitudinis per spatia pal. maria modicis forantur cavis, ita ut avium capita possint admittere. Nam nisi operculis muniantur, quantulumeunque aquæ vel ciborum inest, pedibus everritur. Sunt qui a superiore parte foramina ipsis operculis imponant; quod fieri non oportet. Nam supersiliens avis proluvie veutris cibos et aquam conspurcal.

IV. Cibaria gallinis probentur optima, pinsitum or. deum et vicia, nec minus cicercula, tum etiam milium, aut panicum : sed lıæc ubi vilitas annonæ permittit. Ubi vero ea est carior, excrela tritici minuta conmode dautur. Nam per se id frumentum, etiam quibus locis vilissimum est, non utiliter prabetur, quia obest avibus. Potest etiam lolium decoctum objici, nec minus furfures modice a farina excreti : qui si nihil habent farris, uon sunt idonei, nec tantum appetuntur jejunis. Cytisi folia seminaque maxime probantur, et sunt huic generi gratissima : neque est ulla regio, in qua non possit hujus abbuscula copia csse vel maxima. Vinacea quamvis tolerabiliter pas 
ment bien, on ne doit cependant leur en donner que dans les temps de l'année où elles ne pondent point, parce qu'autrement elles pondraient rarement. et ne feraient que de petits œufs; mais rien n'empêche de les sustenter avec cette espece de nourriture après l'automné, lorsqu'elles ont absolument cessé de pondre. Au reste, quelqueespece de nourriture qu'on leur donne pendant qu'elles seront à errer dans la cour, il faudra la partager en deux portions, dont on leur jettera l'une au commencement du jour et l'autre avant la nuit, tant afin qu'elles ne s'éloignent pas trop au sortir de leurs retraites, et qu'elles y reviennent de meilleure heure et avant la chute du jour par l'espérance d'y trouver a manger, qu'afin qu'on soit plus souvent à portée d'en faire la revue, parce que les troupeaux de volaille échappent aisément à la garde de celui qui les veille. Il faut aussi mettre de la poussière et de la cendre le long des murs de la cour, dans tous les endroits qui s'y trouveront couverts d'une galerie ou d'un toit, afin que les poules puissent s'en jeter sur le corps, parce que c'est ainsi qu'elles nettoient leurs plumes et leurs ailes, si toutefois nous ajoutons foi à ce que dit Héraclite d'Éphèse, que la boue sert de bain aux truies, comme la poussière ou la cendre en servent aux oiseaux de basse-cour. On doit faire sortir les poules du poulailler après la première heure du jour, et les y renfermer avant la onzième. Tels seront les soins qu'il en faudra prendre dans le temps où on leur laissera la liberté de courir, quoiqu'il n'y aura pas d'autre différence dans ceux qu'on en prendra quand elles seront renfermées dans la mue, si ce n'est qu'on ne les en laissera point sortir, mais qu'on leur donnera à manger dans l'intérieur du poulailler trois fois par jour, et que la dose en sera plus forte que celle qu'on leur donne en dehors, puisqu'on leur

cant, dari non debent, nisi quibus anni temporibus avis furtum non edit : nam et partus raros, et ova faciunt exigua. Sed cun plane post autumnum cessant a foetu, possunt lıoc sibo sustineri. Attamen quxecunque dabitur esca per cohortem vagantibus, die incipiente, et jam in vesperum declinante, bis dividenda est, ut et mane non protinus a cubili latius evagentur, et ante crepusculum propter cibi spem temporius ad officinam redeant, possitque numerus capitum sxpius recognosci. Nam volatile pecus lacile custodiam pastoris decipit. Siccus etiam pulvis et cinis ubicunque coliortem porticus vel tectum protegit, juxta parietes reponendus est, ut sit quo aves se perfundant. Nam lis rebus plumam pinnasque emundant : si modo credimus Eplıesio Iferacleto, qui ait sues cono, colıntales aves pulvere vel cinere lavari. Gallira post primam emitti, et ante loram diei undecimam claudi debet : cujus vagx cultus lic, quen diximus, erit : nec tamen alius clausa, nisi quod ea non emittitur, sed intra ornithorem ter die pascitur majore mensıra. Nam singu. lis capitibus quaterni cyathl diurna cibaria sunt, cum donnera par jour la valeur de quatre cyathi de mangeaille par tête, au lieu qu'on n'en donne que deux à celles qui sont en liberté. Il faut aussi que celles qui sont renfermées trouvent un ample vestibule en dehors, où elles puissent aller se mettre au soleil, et quel'approche de ce vestibule soit défendue par des filets, de peur que les aigles ou les oiseaux de proie ne fondent sur elles. Au surplus, il n'y a de profit à faire ces dépenses et à prendre ces soins que dans les lieux où l'on peut tirer un bon prix de ces oiseaux. L'article le plus essentiel par rapport à cette espèce de troupeau, comme par rapport à tout autre, consiste dans la fidélité de celui qui est préposé à sa garde. En effet, pour peu qu'il manque á cette vertu vis-à-vis de son maítre, le lucre que celuici retirera du poulailler ne compensera jamais, quel qu'il soit, la dépense dans laquelle il le jettera. Nous avons assez parlé de l'entretien de ces animaux ; ainsi nous allons passer à d'autres objets, en suivant l'ordre que nous nous sommes prescrit.

V. Cette sorte de volaille pond d'habitude après le solstice d'hiver; les plus féconds commencent à pondre dans les lieux tempérés vers les calendes de janvier, et dans les pays froids après les ides du même mois. Mais il faut exciter leur fécondité par des nourritures convenables, pour les faire pondre de meilleure heure. On peut très-bien leur donner de l'orge à demi cuite tant qu'ils en voudront, parce qu'elle leur fera avoir de plus gros œufs, et qu'elle les fera pondre plus souvent. Il faut néanmoins assaisonner, pour ainsi dire, cette nourriture, en l'entremêlant avec des feuilles et de la graine de cytise, parce que l'une et l'autre passent pour avoir la vertu de beaucoup augmenter leur fécondité. La dose de la nourriture qu'on leur donnera sera, comme jo l'ai dit, de deux cyathi d'orge pour les poules

vagis [ ternl, vel] bini prabeantur. Habeat tamen etiam clausa oportet amplun vestibulum, quo prodeat, et ubi apricetur : idque sit retibus munitum, ne aquila vel accipiter involet. Quas impensas et curas, nisi locis, quibus harum rerum vigent pretia, non expedit adhiberi. Antiquissima est autem cum in omnibus pecoribus tum in loc fides pastoris; qui nisi eam domino servat, nullus ornithonis quastus vincet impensas. De tutela satis dictum est : nunc reliquum ordinem prosequemur.

V. Confecta bruma parere fere id genus avium consuevit. Atque earunı quæ sınt fnecundissimæ, locls tepidioribus circa calendas Januarias ova edere inciplunt; frigidis auteın regionibus eodem mense post idus. Sed cibis idoneis fuecunditas earum elicienda est, quo maturius partum edant. Optime prabetur ad satietatem ordeum senicoctum : nam et majus facit ovorum incrementum, et frequentiores partıs. Sed is cibus quasi condiendus est interjectis cytisi foliis ac semine ejuslem, qua utraque maxime putantur augere foccunditatem avium. Modus autem cibariorum sit, ut dixi, ragis binorum cyathorum 
qui seront en liberté, pourvu qu'on y mêle quelque peu soit de cytise, soit de resee ou de millet, à défaut de cytíse. Le gardien veillera à ce que ces olseaux alent, pour y déposer leur ponte, des retraites garnies de paille très-propre, qu'il aura soin de nettoyer de temps en temps, en y remettant de nouvelle litière et de la plus fraiche que faire se pourra, à la place de l'aneienne; sans quoi ils se trouveralent couverts de puees et d'autre vermine semblable, qu'ils apportent sur eux en rentrant dans leur retraite. Ce gardien doit être assidu et guetter les poules qui voudront pondre, et qui ne manqueront polnt d'a vertir du moment oủ elles le ferout, par des hoquets fréquents entrecoupés de eris perẹants. Il dolt done avoir l'œil sur elles jusqu'à ee qu'elles aient pondu, et visiter aussitôt leurs retraites, pour ramasser les œufs qu'elles auront faits. Il marquera aussi jour par jour ceux qul auront été pondus dans la journée, afin de donner les plus frais à eelles qui veulent couver, et que les paysans désignent par le nom de glocientes (poules qui gloussent ). On serrera ou l'on vendra les autres œufs ; mais les plus propres à être couvés sont les plus frais, quoiqu'on puisse aussl en faire couver de vieux, pourva qu'ils n'aient pas plus de dix jours. Communément lorsque les poules ont achevé leur première ponte, elles commeneent à vouloir couver vers les ides de janvier; mais il ne faut pas permettre à toutes de le faire, d'autant que les jeunes sont plus propres à pondre qu'à faire éclore des poulets : c'est pourquoi on leur fait perdre l'envie de couver, en leur passant une petite plume dans les narines. On permettra au contraire de couver à de vieilles poules qui l'auront déjà fait souvent; et il faudra s'être bien assuré préalablement de leur habitude, parce

ordei. Aliquid tamen admiscendum erit cytisi, rel si id mon fuerit, vicia aut milii. Cura autem debebit esse, cus. todi, cum parturient aves, ut habeant quam mundissimis paleis constrata cubilia, eaque subinde converrat, et alia stramenta quam recentissima reponat. Nam pulicibus, aliisque similibus animalibus replentur, quae secum affert avis, cum ad idem cubile revertitur. Assiduus autem lebet esse custos, et speculari parieutes, quod se facere gallinæ testantur crebris singultibus interjecta roce acuta. Observare itaque dum edant ova, et confestim circumire oportebit cubilia, ut qua nata sunt recolligantur, notenturqque quas quoque die sint edita, ut quam recentissima supponantur glocieutibus : sic enim appellant rustici ares eas que volunt incubare; cxetera vel reponantur, vel aere mutentur. Aptissima porro sunt ad excludendum recen. tissima quxeque. Possunt tamen etiam requieta supponi, dum ne vetustiora sint, quam dierum decem. Fere autem cum prinum partım consummaverunt gallinx, incubare cupiunt $a b$ idibus Januariis, quod facere non omnibıs. permittendun est; quoniam qnidem novella magis mendis, quam excludendis oris utiliores sunt : inhibeturque cupiditas incubandi pinnnla per nares trajecla. qu'il s'en trouve qui font très-bien éclore des poulets, comme il s'en trouve d'autres qui valent mieux pour les élever quand ils sont éelos, et qu'il y en a, au contraire, qui cassent et qui mangent non-seulement les œufs des autres poules, mais les leurs propres; auquel cas il faut sur-le-champ les leur ôter. Quand les poulets qui seront éclos sous deux ou trois poules seront encore tout jeunes, il faudra les transférer sous la garde d'une seule poule, qui sera celle que l'on jugera la meilleure nourrice; mais il faut faire cette opẹ́ration dès les premiers jours, et avant que la mère qu'on leur destinera, trompée par la ressemblance qui se trouvera entre ses petits et ceux des autres ponles, puisse les discerner les uns d'arec les autres. Cependant il y a une mesure à garder en cela, puisqu'il ne faut pas donner à la même poule plus de trente poulets, et que l'on prétend qu'elle n'en pourrait pas nourrir un plus grand nombre. On a soin de mettre sous les poules les œu fs que l'on veut leur faire couver en nombre impair, comme aussi d'en varier le nombre suivant les temps. Fn effet, il faut en mettre quinze et jamais plus au premier temps de l'incubation, c'est-à-dire, au mois de janvier; dix-neuf et jamais moins au mois de mars, et vingt et un depuis le mois d'avril et durant tout l'été jusqu'aux calendes d'octobre; après quoi il devient inutile de s'occuper de ce soin, parce que la plupart des poulets qui viennent à éclore pendant les froids ne peuvent pas vivre. Bien des gens pensent néanmoins que la couvée ne vaut rien même depuis le solstice d'été, parce que, quolqu'il soit aisé d'élever les poulets venus depuis ce temps-là, ils ne prennent cependant jamais un accroissement suffisant. Quoi qu'il en soit, il faut admettre la pratique d'en élever pen-

Veteranas igitur ares ad hanc rem eligi oportebit, quæ jam sæpius id fecerint; moresque earum maxime pernosci, quoniam aliæ melius excludunt, aliæe editos pullos commodius educant. At e contrario quxdam et sua et aliena ora comminuunt atque consumunt, quod facientem protinus submovere conveniet. Pulli antem duarım aut trium avium exclusi, dum adluuc teneri sunt, ad unam, qux sit melior nutrix, transferri debent, sed primo quoque die, dum mater suos et alienos propter similitudinem dignoscere non potest. Verumtamen servare oportet modun. Neque cnim debet major esse quam triginta capitum. Negant enim hoc ampliorem gregetn posse ab una nutriri. Numerus ovorum, quas subjiciuntır, impar observatur, nec semper idem. Nam primo tempore, id est mense Januario, quindecim, nec unquam plura subjici debent : Martio XIX, nec his panciora : unum et viginti Aprili : tola deinde æstate usque in calendas Octobris totidem. Postea supervacua est lujus rei cura, quod frigoribus exclusi pulli plerumque intereunt. Plerique tamen etiam ab restivo solstitio non putant bonam pullationem, quod ab eo tempore etiam si facilem educationem luabent, justnm tamen non capiunt incrementum. 
dant l'été dans le voisinage des villes, où les poulets pris sous l'aile de leur mère se vendent très-cher. Il faut aussi, lorsque l'on donne des cufs à couver, avoir toujours l'attention de ne le faire que quand la lune croit, et depuis son dixième jour jusqu'à son quinzième, parce que c'est ordinairement le meilleur temps pour les donner à couver, et qu'il est en outre essentiel de ménager cette opération de façon que la lune soit encore croissante dans le temps que les poulets viendront à éclore. Il faut vingt-un jours pour que les œufs de poules s'animent et qu'ils soient configurés en oiseaux, mais il en faut un peu plus de vingt-sept pour ceux de paonnes et d'oies. Si l'ou est dans le cas de donner de ces dernier's à couver à des poules, on commencera par les leur laisser couver pendant dix jours avant d'y joindre ceux de poules, qu'on leur donnera au nombre de quatre ou de cinq au plus, ayant soin de choisir les plus gros, parce que de petits œufs ne donnent jamais que de petite volaille. En outre, quand on voudra faire éclore un plus grand nombie de mâles que de femelles, on fera couver les plus longs œufs et les plus pointus; au lieu qu'on fera couver les plus ronds lorsqu'on voudra a voir plus de femelles. Voici la méthode de faire couver des oufs, telle qu'elle a été donnée par ceux qui apportent le plus grand scrupule dans ce genre d'administration. Ils commencent par choisir à cet effet les retraites les plus secrètes, afin que les mères qui scront occupées à couver n'y soient point inquiétées par les autres poules; cusuitc ils les nettoient avec soin avant de rien étendre dessus; puis ils parfument la paille qu'ils ont dessein d'y étendre avec du soufre et du bitume, et font dégoutter dessus une torche allumée. Lorsque cette paille est ainsi corrigée, ils

Verum suburbanis locis, uhi a matre pulli non exignis pretiis vencunt, probanda est rstiva educatio. Semper autem, cum supponuntur ova , considerari dehet, ut luna crescente a decima usquic ad quintamdecinam id fiat. Nam et ipsa suppositio per los fere dies est commodissina; et sic administrandum est, ut rursus cum exclu. duntur pulli, luna crescat. Diebus quibus animantur ova, et in speciem volucrum conformantur, ter septenis opus est gallinacco generi. At pa vonino et anserino, paulo amplius ter novenis. Quxe si quando fucrint supponenda gallinis, prius eas incubare decem diebus foetibus alienigenis patiemur. Tum demum sui generis quatuor ova, nec plura quam quinque fovenda recipient. Sed et haec quam maxiına : nam ex pusillis aves ıninuta nascuntur. Cum deinde quis volet quam plurimos mares excludi, longissima quixque et acutissima ova subjiciet : et rursus cum foniuas, quam rotundissima. Supponendi autem consuetudo tradita est ab iis, qui religiosius hrec administrant, ejusmodi. Primum quam secretissima cubilia eligunt, ne incubantes matrices $a b$ aliis avibus inquietentır : deinde aıtequam consternant ea, diligenter emundant, paleas. ipıe, quas substraturi sunt, sulfure et bitunine atque l'arrangent dans ces retraites, en y creusant des nids de facon que les poules, soit en s'y rendant, soit en les quittant, ne puissent pas faire rouler ni tomber leurs œufs. II y a mérne un très-grand nombre de personnes qui mettent sous cette paille un peu d'herbe et de scions de laurier, ainsi que des gousses d'ail et des clous de fer : toutes choses qu'ils regardent comme des préservatifs contre le tonnerre, qui gate les œufs et tue les poulets à demi formés, avant qu'ils aient toutes leurs parties développées. Celui qui met les œufs sous la poule se garde bien de les arranger dans le nid l'un après l'autre avec la main; mais il les porte tous dans une petite auge de bois, et les coule, ensuite tout doucement dans le nid qu'il a préparé pour les recevoir. Il faut mettre de la mangeaille auprès des poules qui couvent, afin que, ne souffrant point de la faim, elles restent dans leurs nids avec plus d'attache, et de peur que, si elles s'en éloignaient trop, leurs œufs ne vinssent à se refroidir. Quoiqu'elles les retournent elles-mèmes avec leurs pattes, il faut cependant que celui qui est elıargé de ce soin en fasse la revue lorsque les mères seront sorties du nid, et qu'il les retourne, tant afin qu'ils s'animent facilement, en prenant de la chaleur par tous les côtés également, que pour retirer ceux qu'elles pourraient avoir endommagés ou cassés avec leurs ongles. Quand cela sera fait, il examinera au bout de dix -neuf jours si les poulets ont percé la coque des oeufs avec leurs petits bees, et il écoutera s'ils piaulent ou gloussent, parce qu'il arrive souvent que l'épaisseur de la coque les em. péche d'en sortir. C'est pourquoi il faudra tirer avec la main les petits poulets qui tiendront en dedans des œufs, et les mettre sous la mère, afin qu'elle les échauffe, sans cependant continuer

ardente teda perlustrant, et expiatas cubilibus injiciunt, ita faclis concaratis nidis, ne [ab] advolantibus, aut [etiam] desilientibus evoluta decidant ova. Plurimi etiam. infra cubilium stramenta graminis aliquid, et ramulos. lauri, nec minus allii capita cum clavis ferreis subjiciunt : quae cuncta remedio creduntur esse adrersus tonitrua, quibus vitiantur ova, pullique semiformes interimuntur. ante quam toti partibus suis consummentur. Servat autem qui subjicit, ne singula ova in cubili manu componat, sed totum ovorum numerum in alveolum ligneum conferat, deinde universum leniter in praparatum nidum transfus. dat. Incubantibus autem galliuis juxta ponendus est cibus, ut satura studiosius nidis immorentur, nere longius evagatae refrigerent ova, quxe quamvis pedibus ipsæ convertant, aviarius tamen cum desilierint matres, circumire deliet, ac manu versare, ut aequaliter calore concepto facile animentur. Quin etiam si qua unguibus laesa vel fracta sunt, ut removeat. Idque cum fecerit, die undevigesimo animadvertat, an pulli rostellis ova pertuderint, et auscultetur, si pipiant. Yam sxepe propter crassitudinem putaninum ermmpere non queunt. Itaque liarentes pullos manı eximere oportebit, et matri fovendos subji- 
cette manœuvre plus de trois jours de suite. Car tout œuf dans lequel on n'entend point de gloussement au bout de vingt un jours ne renferme point d'être qui ait vie, et il faut alors le tirer de dessous la poule, afin qu'elle ne soit pas retenue trop longtemps à le couver par une vaine espérance de le voir éclore. Il ne faut pas enlever les poulets à leur mère à mesure qu'ils seront éclos un à un, mais il faut les laisser un jour avec elle dans le nid, et les empêcher de boire et de manger jusqu'à ce qu'ils soient éclos tous. Le lendemain du jour où toute la couvée sera éclose, voici comme on les retirera du nid. On les mettra sur un crible qui aura déjà servi à passer de la vesce ou même de l'ivraie; après quoi on les parfumera avec de la fumée de branches do pouliot, qu'on brûlera à cet effet, parce que cette plante passe pour avoir la vertu de préserver les jeunes poulets de la pépie, qui lcs tue de très-bonne heure; ensuite on les renfermera sous une cage avec.leur mère, et on les y nourrira modérément de farine d'orge cuite dans de l'eau, ou de farine de blé adoreus qu'on détrempera avec du vin, parce qu'il faut surtout éviter qu'ils ne prenneut quelque indigestion. C'est pour cela qu'on les renferme au bout de trois jours dans une cage a vec leur mère, et qu'on les tate tous avant de les en faire sortir pour prendre de nouvelle nourriture, afin de voir s'ils n'en ont pas qui soit restée de la veille dans leur gosier. En effet, s'ils n'ont pas le jabot vide, c'est une preuve d'indigestion; auquel cas on doit les empêcher de manger, jusqu'à ce que leur digestion soit achevée. Il ne faut pas non plus permettre aux jeunes poulets de s'écarter trop loin; mais il faut les retenir auprès de leur cage, en les nourrissant de farine d'orge jusqu'à ce qu'ils soient fortifiés, et prendre garde qu'ils ne soient atteints du souffle des serpents, dont l'odeur est

cere, idque non amplius triduo facere. Nain post unum et vigesimum diem silentia ova carent animalibus : eaque removenda sunt, ne incubans inani spe diutius detincatur efruta. Pullos autem non oportet singulos, ut quisque natus sit, tollere, sed une die in cubili sinere cum matre, et aqua ciboque abstinere, dum omnes excludantur. Postero die, cum grex fuerit effectus, hoc modo deponitur. Cribro viciario, vel etiam loliario, qui jam fuerit in usu, pulli superponantur, deinde pulegii surculis fumigen. tur. Ea res videtur prohibere pituitam, quæ celerrime teneros interficit. Post liac carea cum matre claudendi sunt, et farre ordeaceo cum aqua incocto, vel adoreo farre, vino resperso modice alendi. Nam maxime cruditas ritanda est: et ab hoc jam tertia die cavea cum matre continendi sunt, priusque, quam emittantur ad recentem cibum, singuli tentandi, ne quid, liesterni habeant in gutture. Nam nisi vacua est ingluvies, cruditatem significat, abstinerique debent, dum concoquant. Longius autem non est pernittendum tcueris evagari, sed circa caveam continendi sunt, et farina ordeacea pascendi dum si pestilenticlle pour ees animaux qu'elle les fait infailliblement mourir. On prévient cet aecident en brûlant souvent auprès d'eux de la corne de cerf, ou du galbanum, ou des cheveux de femme, parce qu'ordinairement la fumée de toutes ces matières chasse au loin ces animaux pestilentiels. Mais il faut aussi avoir soin qu'ils soient toujours maintenus dans une chaleur modéréc, parce qu'ils ne peuvent supporter ni le chaud ni le froid; aussi la meilleure méthode est-elle de les tenir enfermés avec leur mère dans l'intérieur du poulailler, et de ne leur laisser la liberté de courir qu'au bout de quarante jours. Il faut encore les prendre souvent entre les mains, dans les premiers jours du temps que l'on peut considérer comme leur enfance, et leur plumer le dessous de la queue, de peur que la fiente venant à salir les plumes de cette partie, elles rie s'endurcissent, et ne finissent par boucher les conduits naturels. Il arrive même souvent que, quelque préeaution que l'on prenne à cet égard, leur ventre n'a point d'issue pour se vider, auquel cas on le perce avec une plume pour faciliter l'expulsion de leurs excréments. Il faudra aussi empécher que la pepie ne devienne funeste tant aux poulets lorsqu'ils seront devenus forts, qu'aux mères elles-mêmes. A cet effet on leur donnera de l'eau très-pure dans des vases trèspropres, et on parfumera toujours les poulaillers, en les nettoyant de façon qu'il n'y reste point de fiente. Si malgré ces précautions ils sont attaqués de cette maladie, il $\mathbf{y}$ a des personnes qui leur fourrent dans le gosier des gousses d'ail détrempées dans de l'huile tiède. D'autres leur versent de l'urine d'homme tiède dans le bec, qu'ils tiennent bien serré, jusqu'à ce que l'amertume de cette liqueur les force de rejeter par les narines le résultat des nausées occasionnées par cette maladie. Il est encore bon de leur

corroborentur : cavendumque ne a serpentibus adflentur, quarum odor tam pestilens est, ut interimat universos. Id vitatur sæpius incenso cornu cervino, vel galbano, vel muliebri cipillo; quorum omnium fere nidoribus pradicta pestis submovetur. Sed et curandum erit, ut tepide habeantur. Nam nec calorem nec frigus sustinent. Optimum. que est intra officinam clausos liaheri cum matre, et post quadragesimum diem potestatem ragandi fieri. Sed primis quasi infantiæ diebus pertractandi sunt, plumulæque sub cauda clunibus detralienda, ne stercore coinquinata durescant, et naturalia procludant. Quod quamvis caveatur, sxpe tamen evenit, ut alvus exilum non labeat. Itaque pinna pertunditur, et iter digestis cibis prabetur. Sed et jam validioribus faclis, atque ipsis matribus etianı vitanda pituita pernicies erit. Quæ ne fiat, mundissimis vasis el quam purissimam prabebimus aquam : nec minus gallinaria senper fumigabinus, et enundata stercore liberabimus. Quod si tamen pestis permanserit, sunt qui spicas alii tepido madefactas oleo faucibus inserant. Quidam hominis uriua tepida rigant ora, et tamdiu conıpri- 
donner de cette vigne que les Grees appellent

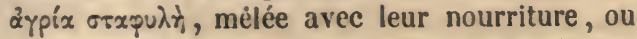
broyce et jetée dans l'eau qu'ils doivent boire. Ces remèdes ne s'emploient nénnmoins que dans le temps où la maladie n'est pas encore forte : car si lapepie enveloppe l'œil, et que les poulets refusent toute nourriture, on leur ouvre les joues avec un fer, et on en exprime tout le pus qui est rassemblé sous les yeux, après quoi on saupoudre la plaie avec un peu de sel égrugé. Cette maladie leur vient communément lorsqu'ils ont souffert du froid ou de la faim, de même que lorsqu'ils ont bu en été del'eau qui a croupi dans les cours, ou qu'on leura laissé manger des figues ou des raisins verts, quoiqu'ils n'en aient pas ćté rassasiés. Ce sont en effet toutes nourritures qu'il faut leur refuser : or, pour les en dégoûter, il suffira de leur présenter, quandils auront faim, une grappe de raisin sauvage vert cueillie dans des buissons, après l'avoir fait cuire avec de la fine farine de froment. Effectivement ces oiseaux, offensés par le goût de ce fruit, feront ensuite peu de cas de quelque espèce de raisin que ce puisse être. Il en sera de même de la figue sauvage, qui, mise dans- leur mangeaille après avoir été cuite, leur donnera également du dégoût pour les figues. Il faut aussi suivre par rapport à ce bétail l'usage qu'on pratique par rapport aux autres bestiaux, et qui consiste à choisir les meilleurs d'entre ces animaux et à vendre les moins bons, de facon que le nombre s'en trouve diminué toutes les années en automne, temps auquel ils cessent de rapporter du profit. On se défera donc des vieilles poules, c'est-à-dire, de celles qui auront trois ans passés, ainsi que de celles qui seront peu fécondes ou qui ne seront pas bonnes nourrices, et particulièrement de celles qui seront habituées à manger leurs propres œufs

munt, dum eas amaritado cogat per nares emoliri pituita nauseam. Uva quoque, quam Graci ảypixv vocant, cum cibo mista prodest; vel eadem pertrita, et cuns aqua potui data. Atque hæec remedia mediocriter laborantibus adhibentur. Nam si pituita circumvenit ocu. los, et jam cibos avis respuit, ferro rescinduntur genæe, et coacta sub oculis sanies omnis exprimitur : atque ita paulum triti salis vulneribus infricatur. Id porro vitium maxime nascitur cum frigore et penuria cibi laborant ares : item cum per æestatem consistens in colıortibus aqua potatur : item cum ficus aut uva immatura nec ad satietatem permissa est, quibus scilicet cibis abstinendre sunt aves : eosque ut fastidiant efficit uva labrusca de repribus immatura lecta, quæ cum farre triticeo minuto cocta objicitur esurientibus, ejusque sapore offensa aves oninem aspernantur uvam. Similis ratin est etiau raprifici, qua decocta cum cibo prabetur avibns, et ita fici fastidium creat. Mos quoque, sicut in cateris pecudibus, eligendi quamque optimam et deteriorenı vendendi, ser. vetur etiam in hoc genere, ut per autumui tempus omni. bus annis, cum fructus earum cessat, unmerus inogue ou ceux des autres. On se défera encore de celles qui auront commencé à chanter et même à gratter la terre à la mode des mâles, et enfin des poulets tardifs, qui, n’étant éclos qu'après le solstice, n'auront pas pu prendre tout leur accroissement. Quant aux mâles, on ne suivra pas la même méthode, et l'on conservera au contraire ceux d'entre eux qui seront buns, tant qu'ils seront en état de coquer les poules, d'autant que l'on trouve bien peu de bons coqs. Il faut aussi retrancher aux poules les nourritures coùteuses dans le temps où nous avons dit qu'elles cessaient de pondre, c'est-à-dire, depuis les ides de novembre. On se contentera de leur donner alors du mare de raisin, qui suffira pour les nourrir comme il faut, pour peu qu'on y joigne de temps en temps des criblures de froment.

VI. La conservation des œufs pendant un long espace de temps est encore un soin qui n'est pas étranger à la matière que nous traitons. On les garde fort bien pendant l'hiver en les enveloppant de paille, et en été en les tenant dans du son. Quelques personnes commencent par les couvrir pendant six heures de sel égrugé, de sorte qu'elles ne les enfoncent dans la p:ille ou dans le son qu'après les avoir essuyés. D’autres entassent par-dessus des fèves a vec leur peau, et beau. coup même y entassent des fèves moulues : d'autres les couvrent de sel non égrugé; d'autres enfin les fout durcir dans de la saumure chaude. Mais si le sel, égrugé ou non, préserve d'un côté les œufs de la corruption, d'un autre côté il diminue leur grosseur, en empêchant qu'ils ne restent pleins, ce qui éloigne l'acheteur. Aussi ceux même qui ne font que les tremper dans de la saumure ne les conservent-ils jamais dans leur entier.

VII. Quoique l'engrais des poules soit plutôt du

minuatur. Submorebimus autem veteres, id est, quæ trimatum excesserunt : item quæ aut parum facundæ, aut parum bonæ nutrices sunt, et præcipue quæ ova vel sua rel aliena consumunt : nec minus, quæ relut mares cantare, atque etiam calcare coeperunt : item serolini pulli, qui ab solstitio nati capere justum incrementum non potuerunt. In masculis autem non eadem ratio servabitur; sed tamdiu custodiemus generosos, quamdiu fominas implere potuerint. Nam rarior est in his avibus mariti bonitas. Lodem quorue tempore cun parere desinent aves, id est, ab idibus Yovembribus pretiosiores cibi subtrahendi sunt, et visacea prabenda, quae satis com. mode pascunt, adjectis interdum tritici excrementis.

VI. Ovorum quorue longioris temıporis custodia non aliena est huic curae : qux commode servautur per hicmem, si paleis obruas, astate, si furfuribus. Quidam prius trito sale sex horis adoperiunt : deiude eluuut, atque ita paleis aut furfuribus obruunt. Nonnulli solida, multi etiam fresa faba coaggerant : alii salibus integris adoperiunt : alii muria tepefacta durant. Sel omnis sal, quemadmodum non patitur putrescere, ita uinuit ova, nec 
ressort d'un volailler que de celui d'un homme de la campagne, j'ai cependant cru devoir en donner la méthode, par la raison que la pratique n'en est pas difficile. Il faut avoir pour cela un licu très-chaud, et dans lequel il pénc̀tre trèspeu de jour. On y mettra les poules renfermées chacunc dans des cages très-étroites, ou dans des panier's suspendus en l'air, de façon qu'elles y soient resserrécs au point de ne pouvoir pas se remuer. Mais il y aul'a une ouverture à chacun des deux côtés opposés de cetle cage ou de ce panier, de façon qu'elles puissent passer la tête par l'une de ces ouvertures, et le derrière ainsi que la queue par l'autre, afin de pouvoir prendie leur nourriturc et en rendre le superflu lorsqu'elle sera digérée, sans se salir avec leur fiente. On étendra sous elles de la paille très-propre ou du foin mollet, c'est-à-dire, du regain, parce que, si elles étaient couchécs durement, elles n'engraisseraient pas facilement. On leur arrachera toutes les plumes de la tête, ainsi que celles de dessous les ailes et celles des cuisses, tant afin qu'il ne s'y engendre point de vermine, qu'afin que la fiente ne leur occasionne pas d'ulcères aux parties. On leur donne pour nourriture de la farine d'orge, que l'on paitrit après l'avoir arrosée d'eau, et dont on fait des boulettes qui servent à les engraisser. On ne doit cependant lcur en donner qu'avec ménagement les premiers jours, et jusqu'à ce qu'elles soient habituées à cn digêrer une plus grande quantité, parce qu'il faut surtout éviter les indigestions, et ne leur donner par conséquent qu'autant de nourriture (qu'elles en pourront digérer. Il faut même éviter dc leur en donner de nouvelle avant d'avoir táté lcur jabot, et de s'être assuré qu'il n'y en reste point d'ancienne. Lorsqu'ensuite elles seront ras.

sinit plena permanere : quæ res ementem deterret. Itaque we in muriam quidem qui demiltunt, integritatem ovorum conservant.

VII. Pinguem quoque facere gallinam, quamvis fartoris, non rustici sit officium, tamen quia non ægre contingit, prascipiendum putavi. Locus ad hanc rem desideratur mavime calidus, et minimi luminis, in qno singulae caveis angustioribus vel sportis inclusa pendeant ares, sed ita coarctatx, ne versari possint. Verum habeant ex utraque parte foramina : unum, quo caput exeratur ; alterum, quo cauda clunesque; ut et cibos capere possint, et eos digestos sic edere, ne stercore coinquinentur. Substernatur autem inundissima palea, vel molle foenum, id est, cor. dum. Nam si dure cubant, non facile pinguescunt. Pluma omnis e capite et sub alis atque clunibus detergetır : illic, ne pediculum creet; lic , ne stercore loca naturalia exulceret. Cibus autem præbetur ordeacea farina, quæ cum est aqua conspersa et subacta, formantur offa, quibus aves saginantur. Ex tamen primis diebus dari parclus lchent, dum plus concoquere consuescant. Nam cruditas vitanda est maxime, tantumque probendum, quantum digerere possint : neque ante recens admovenda est, quam sasiécs, on desecndra la cage, ct on les en laissera tant soit peu sortir : non pas néanmoins pour leur permettre de courir, mais plutôt pour leur donner la liberté de chercher avec le bec la vermine qui peut les piquer ou les mordre. Voilà à peu près la méthode que suivent communément ceux qui engraissent la volaille. Car pour ceux qui ne tiennent pas à engraisser des poules, mais qui veulent encore les attendrir, ils versent de l'hydromel nouveau sur la farine que nous avons indiquće, pour les en farcir ensuite. Quelques-uns les engraissent avec du pain de froment trempé dans un quart de bon vin sur trois quarts d'eau. Une poule que l'on a commencé à mettre à l'engrais le premier jour de la lune (attention qu'il faut aussi avoir) se trouvera parfaitement engraissée le vingtième. Mais s'il arrive qu'elle se dégoûte de cette nourriture, il faudra lui en diminuer la dose pendant autant de jours qu'il y en aura d'écoulés depuis qu'on aura commencé à l'engraisser, de façon néanmoins que toute la durée de l'engraissement n'aille point jusqu'au vingt-cinquième jour de la lune. Au surplus, une des premières attentions qu'il faudra avoir consistera à réserver les plus grandes poules pour les tables les plus délicates : c'est le moyen d'etre bien dédommagé de sa peine et de sa dépense.

VIII. On emploie avec succès la même méthode pour rendre très-gras les pigeons ramiers ainsi que ceux de volière, quoiqu'il n'y ait pas autant de profit à engraisser ces sortes d'oiseaux qu'à les élever. En effet, c'est encore un genre de soin qui n'est pas étranger à la bonne économie d'un homme de la campagne, que celui de se pourvoir de ces animaux. Au reste, il y a moins d'embarras à les élever dans des contrées éloi-

tentato gutture apparuerit nihil veteris esca remansisse. Cum deincle satiata est avis, paululum deposita cavea dimittitur, sed ita ne vagetur, sed potius, si quid est quod eam stinulet aut mordeat, rostro persequatur. Hæc [enim] fere communis est cura farcientium. Nam illi qui volunt non solum opimas, sed etiam teneras ares efficere, mulsea recente aqua prædicti generis farinam conspergunt, et ita farciunt : nonnulli trilus aqua partibus unam boni vini miscent, madefactoque triticeo pane obesant avem; qua prima luna (quoniam id quoque custodiendum est) saginari copta , vigesima pergliscit. Sed si fastidiet cibum, totidem diebus minuere oportebit, quot jam farturæe processerint : ita tamen, ne tempus omne opimandi quintam et vigesimam Innam sıperveniat. Antiquissimum est autem maximam quanque a vem lautioribus epulis destinare. Sic enim digna merces sequitur operam et impensam.

vili. Hac eadem ratione palumbos columbosque cel. lares pinguissimos facere contingit : neque est tamen in columbis farciendis tantus reditns, quantus in educandis. Nam etiam horum possessiu non abhorret a cura boni rustici. Sed id genus niuore tutéla pascitur longinquis 
guées, parce qu'on les y laisse sortir librement, et qu'ils reviennent habituellement aux lieux qu'on leur y assigne sur le haut des tours ou dans des bâtiments très-élevés, moyennant des fenêtres qu'on y laisse ouvertes, et à travers lesquelles ils passent pour aller chercher leur nourriture. On leur y donne à la vérité pendant deux ou trois mois de la nourriture qu'on a soin d'avoir en réserve; mais pendant les autres mois ils se nourrissent eux-mêmes des grains qu'ils trouvent dans les clamps; au lieu qu'ils ne pourraient pas le faire également dans le voisinage des villes, où ils sont exposés à tomber dans les piéges de toute espèce que leur tendent les oiseleurs. C'est pourquoi on doit, dans ce dernier cas, les nourrir à la maison, en les renfermant dans un endroit de la métairie qui ne soit ni à fleur de terre ni froid, c'est-à-dire, sur un plancher construit en un lieu élevé, et exposé au midi d'hiver. On en creusera les murs, pour y disposer des rangées de nids de la manière que nous avons déjà prescrite en parlant du poulailler, et qu'il est inutile de répéter ici. Si l'on ne juge pas à propos de suivre cette méthode, on enfoncera dans les murs des corbeaux sur lesquels on mettra des planches, qui porteront ou des cases dans lesquelles ces oiseaux feront leurs nids, ou des sébiles de terre cuite, prẻcédées de vestibules qu'ils auront à traverser avant de parvenir à leurs nids. On doit revêtir tout le colombier ainsi que les nids mêmes des pigeons d'un enduit blanc, parce que cette couleur est celle qui plait le plus à cette espèce d'oiseaux. II faut ćgalement en lisser les murailles en dehors, et principalement aux environs de la fenêtre, qui sera placée de façon que le soleil l'éclaire pendant la plus grande partie des jours d'hiver, et qui donnera dans une cage assez ample et garnie de filets, pour empécher les oiseaux de proie d'y cntrer. Cette eage servira d'asile aux pigeons, qui sortiront du colombier pour se mettre au soleil, en même temps qu'elle donnera, aux mères qui couvent leurs œu fs ou leurs petits, la faculté de prendre l'air au dehors, ce qui leur est nécessaire pour empêcher que l'espèce de servitude à laquelle les réduirait une gêne continuelle ne les chagrine au point de tomber malades. En effet, il leur suffit de voltiger tant soit peu autour des bátiments pour s'égayer et se refaire, et pour retourner ensuite avec plus d'ardeur à leur couvée, qui ne leur permet pas de s'enfuir, ni même de s'écarter trop loin. Les vases dans lesquels on mettra leur eau doivent être semblables à ceux des poules, c'est-à-dire qu'ils doivent être percés de trous assez grands pour que les pigeons puissent passer leurs cous à travers pour y boire, sans cependant pouvoir y passer le corps au cas qu'ils veulent s'y baigner, parce qu'il ne leur est pas avantageux de se baigner, par rapport aux œufs, et aux petits qu'ils sont le plus suuvent occupés à couver. Au reste, il faudra répandre leur mangeaille le long du mur, parce que c'est ordinairement la seule partie du colombier où il n'y a point de fiente. La vesce ou l'ers, ainsi que la petite lentille, le millet et l'ivraie, et même les criblures de froment ou toute autre espèce de légumes dont on nourrit également les poules, passent pour être la meilleure nourriture de ces animaux. II faut balayer de temps en temps le colombier et le nettoyer, parce que plus il sera propre, plus le pigeon paraîtra gai, d'autant que c'est un oiseau si difficile à contenter, que souvent il prend sa demeure en aversion, et finit même par la quitter quand il a la faculté de s'envoler, ce qui arrive fréquemment dans les pays où on lui laisse une liberté entière. Voici un pré- regionihus, ubi liber egressus avibus permittitur: quo. niam vel summis turribus, rel editissimis ædificiis assi. gnatas sedes frequentant patentibus fenestris, per quas ad re. quirendos cibos evolitant. Duobus tamen aut tribus mensibus acceptant conditiva cibaria, cæetcris seipsas pascunt seminihus agrestibus. Sed hoc suburbanis locis facere non possunt, quouiam intercipiuntur variis aucupum insidiis. ltaque clausæe intra tectum pasci debent, nec in plano villae loco, nec in frigido: sed in edito fieri tabulatum oportet, quod aspiciat libernum meridiem. Ejusque parietes, ue jam dicta iteremus, ut in ornithone pracepimus, continuis cubilibus excaventur : vel si non ita competit, paxillis adactis tabulie superponantur, quxe vel loculamenta, quibus nidificent aves, vel fictilia columbaria recipiant, pra. positis vestibulis, per qua ad cubilia perveniant. Totus autem locus et ipsæ columbarum cellæ poliri dobent albo tectorio, quoniam eo colore præcipue delectatur lioc genus aviuın. Nec minus extrinsecus levigari parieles, inaxime circa fenestram : et ea sit ila posita, ut majore parte liiberni diei solem admittat, liabeatrgue appositam satis auplan caream retibus enunitam, quer exrludat accipi- tres, et recipiat egredientes ad apricationem columbas, nec minus in agros emiltat matrices, qua ovis vel pullis incubant, ne quasi gravi perpetua custodiæ servitio contristatx senescant. Nam cum paulım circa rediticia volita. verint, exlilaratx recreantur, et ad foetus suos vegetiores redeunt, propter quos ne longius quidem evagari aut fugere conantur. Vasa, quibus aqua prabetır, similia esse debeut gallinariis, qux colla bibentium admittant, et cupientes lavari propter angustias non recipiant. Nam id facere eas nec ovis nec pullis, qnibus plerumque incubant, expedit. Cæeterum cihos juxta parietem conveniet spargi, quoniam fere partes ex columbarii carent stercore. Commodissima cibaria putantur vicia, vel ervum, tum etiam lenticula, milinmque et lolium, nec ninus excreta trltici, et si qua sunt alia legumina, quibus etiam gallinæ aluntur. Locus autem subinde converri et emundari debet. Nam quanto est cultior, tanto letior avis conspicitur, eaque tam fastidiosa est, ut srepe sedes suas perosa, si detur avolandi polestas, relinquat. Id quod frequenter in his regionibus, ubi liberos habent egressus, accidere solet. Id ne fiat, vetus est Democriti praceptum. Genus arcipitris tinnunculum vorant 
cepte ancicu domné par Démocrite, pour obvier à cet accident. Il y a une espèce d'oiseau de proie, appclé finnunculus (crécerclle) par les gens de la campagne, qui fait communément son nid dans les batiments. On enferme done les petits de cet oiscau tout vivant dans les pots de terre, que l'on enduit de plâtre après les avoir couverts, ct on suspend ces pots dans les coins du colombier; au moyen de quoi les pigeons s'attachent si fort an même lieu, qu'ils ne l'abandonnent plus jamais. Il faut choisir, pour en élever d'autr's, les pigcons qui, sans être ni vicux ni trop jeunes, sont forts de corps, et avoir l'attention, autant que fairc se peut, de ne jamais séparer, les uns des autres, les petits d'une même couvée, parce qu'ordinairement, quand ils sont ainsi mariés ensemble, ils dounent un plus grand nombre de couvées; ou si on les sépare, il faut au moins éviter de marier ensemble des pigeons d'espèces différentes, tels que ceux d'Alexandrie et ceux de la Campanie, paree que ces animaux s'attachent moins à ceux qui ne leur ressemblent point qu'à ceux de leur espèce, ct que dès lors ils s'accouplent rarement, et souvent ue pondent point. Par rapport à leur plumage, on n'a pas approuvé dans tous les temps la même couleur, et les avis sont encore aujourd'hui partagés là-dessus : c'est pourquoi il n'est pas aisć de dire quelle est la meilleure. La couleur blanche, que l'on rencontre communément partout, n'est pas trop du goût de certaines personnes; il est vrai qu'elle n'est pas dans le cas d'être rejetée dans les plgeons que l'on tient renfermés; mais on ne saurait trop la désapprouver dans ceux qu'on laisse en liberté, parce qu'elle se fait remarquer très-aisẻment des oiseaux de proie. Pour leur fécondité, quoiqu'ellc soit très-inférieure à celle des poules, elle est néanmoins d'un produit encore plus grand que la leur, puisque, quand ils sont bons, ils élèvent des petits jusqu'à huit fois par an, et

rustici, qui fere in redificiis nidos facit. Ejus pulli singuli lictilibus ollis conduntur, spirantibusque opercula superponuntur, et gypso lita vasa in angulis columbariis suspen. duntur : quæ res avibus amorem loci sic conciliat, ne unquam deserant. Eligendx vero sunt ad educationem ueque vetula, nec nimium novellæ; sed corporis maximi : curandunque, si fieri possit, ut pulli, quemadmodum exclusi sunt, nuuquam separentur. Nam fere si sic maritato sunt, plures educant foetus. Sin aliter, certe ne alicni generis coujuugantur, ut Alexandringe et Campranæ. Minus euim impares suas diligunt, et ideo nec multum ineunt, nec seppius fotant. Plumæ color non semper, nec omuibus idem probatus est : atque ideo qui sit oplimus, non facile dictu est. Albns, qui ubiqque vulgo conspicitur, a quibusdam non nimium laudatur; nec tamen vitari debet in is, quxe clauso continentur. Nam in vagis maxime est impro. bandıs, quod eum facillime speculatur accipiter. Forcunditas autem, quamvis loıge minor sit quan est gallinarun, majorem tanen refert quastum. Nam et octies que l'argent qui revicut de ces élèves peut rem. plir le coffre-fort du propriétaire, ainsi que M. Varron, cet excellent auteur, nous le certifie cn disant que chaque paire de pigeons se vendait communément mille sestertii de son temps, quoique les mœurs fussent alors plus austères qu'elles nc lọ, sont à présent. En effet, notre siècle nous forcerait à rougir pour lui si nous ajoutions foi à ce qu'on raconte, qu'il se trouve des gens qui payent unc paire de pigeons jusqu'à quatre millc nummi. Ce n'est pas au reste que ceux qui dépensent ainsi un argent énorme pour avoir en leur possession des choses de pur agrément, ne soient encore plus cxcusables à mes yeux, que ceux qul épuisent le Phase du Pont et les étangs Scythiques des Palus-Méotides pour satisfaire leur gloutonnerie. Aujourd'hui même on pousse les choses jusqu'à se donner, au milieu de son ivresse, des rapports causés par les oiseaux du Gange et de l'Egypte. On peut aussi faire des engrais dans un colombier, ainsi que nous l'avons dit, puisque si l'on a des pigeons stériles ou qui soient d'une vilaine couleur, on les engraisse comme les poules. Il est plus aisé de le faire quand ils sont sous leurs mères et tandis qu'ils sont jeunes; on attend pour cela qu'ils soient devenus un peu forts, sans néanmoins qu'ils aient com. mencé à voler; et il suffit alors de leur ôter quelques plumes et de leur briser les pattes, afin qu'ils se tiennent tranquilles dans le même lieu, et de donner à manger copieusement à leurs mères, de facon qu'elles ne manquent pas de nourriture tant pour elles que pour leurs petits. Quelques personnes se contentent de leur attar cher légèrement les pattes, parce qu'elles s'imaginent qu'en les cassant elles leur causeraient unc douleur dont la maigreur pourrait devenir la suite. Mais cette méthode n'est point du tout favorable à leur engraissement, parce que, tant qu'ils font des efforts pour détacher leurs liens, ils ne

auno pullos elucat, si est bona matix; et pretiis eorum domini compleut arcam, sicut eximius auctor M. Varro nobis affirmat, qui prodidit etiam illis severioribus (suis) temporibus paria singula millibus singulis sestertiorum solita venire. Nam nostri pudet seculi, si credere volumus, inveniri qui quaternis millibus nummum binas aves mercentur. Quamquam vel los magis tolerabiles putem, qui oblectamenta deliciarum possidendi habendique causa gravi are et argento pensent, quam illos qui Ponticun Phasim et Scythica stagna Mrotidis eluaut. Jam nunc Gangeticas et Egyptias aves temulenter eructant. Potest tamen etiam in loc aviario, sicut dictum est, sagina exerceri. Nam si qua steriles aut sordidi coloris interveuiuıt, similiter ut gallinæ farciuntur. Pulli vero facilius sub nuatribus pinguescunt, si jam firmis, prius quam subvolent, paucas detrahas jinnas, et obteras crura, ut uno loco quiescant, præbeasque copiosum cibum parentibus, quo et se et eos abundantius alant. Quidam leviter obligant crura, quoniam si frangantur, dolorem, et ex eo 
resteut jamais en repos, et que l'espèee d'exercicc daus lequel ils sont dès lors continuellement est bien loin d'augmenter leur corpulenee; au lieu que la fracture des pattes ne leur cause de la douleur que pendant deux jours ou tout au plus pendant trois, et qu'elle leur ôte toute cspéranec de courir.

IX. Il est inutile d'élever des tourterelles, parce que cette espèce d'oiseaux ne pond point et ne fait point éclore de petits dans une volière. On les destinc à l'engrais telles qu'on les prend au vol; et dès lors il en coûte moins de peine pour les engraisser que pour engraisser les autres oiseaux, quoiqu'on ne puisse pas le faire dans tous les temps, puisque, telle peinc que l'on prenne, elles engraissent difficilement en hiver. Au surplus, e'est le temps où ces oiseaux sont à bon marché, parce que les grives donnent alors en très-grande quantitè. D'un autre côté, les tourterelles engraissent d'elles-mêmes en été, pourvu qu'elles ne manquent point de nourriture. En effet, on n'a rien autre chose à faire qu'à leur jeter de la mangeaille, et surtout du millet; non pas que le froment, ou quelque autre blé que ce soit, ne les engraisse pas aussi bien que le millet, mais parce que cettc graine est celle qui leur fait le plus de plaisir. On les engraisse cependant aussí en liver, ainsi que les pigeons ramiers, avec des boulettes de pain trempées dans du vin, plutót qu'avee toute autre nourriture. On ne leur fait pas, comme aux pigeons, des retraites qui soient distribuées par cases, ou creusées daus le mur, mais on enfonce dans la muraille des rangées de corbeaux, sur lesquels on étend de petites nattes de chanvre, garnies de filets en devant, pour les empêeher de voler, parec que l'exercice du vol les fait maigrir. On les y

maciem fieri putant. Sed nilil ista res pinguitudinis effieit. Nam dum vineula exerere conantur, non eonquiescunt; et hac quasi exercilatione corpori nilil adjiciunt. Fracta erura non plus quam bidui, aut summum tridui dolorem afferunt, et spem tollunt evagaudi.

1X. Turturum educatio supervacua est : quoniam id geuts in ornithone nee parit, nec exeludit. Volatura ita ut capitur, farlura destinatur : eoque leviore cura, quam cetera aves saginatur: verum non omnibus temporibus. Nam per hiemem, quamvis adhibeatur opera, difficulter gliscit, et lamen, quia major est turdi copia, pretium turturuı minuitur. Rursus æstate rel sua sponte, dummodo sit facultas eibi, pinguescit. Nilil enim aliud, quam oljicitur esca, sed pracipue unilium : nec quia tritico rel aliis frumentis minus erassescant; verum quod semine l:ujus maxime delectantur. Ilieme támen offe panis vino madefactre, sicut etiam palumbos, eelerius opinant, quam cateri cibi. Receptacula non tanquan columbis locu. lamenta, vel cellulæ cavatx efliciuntur, sed ad lineam mutuli per parietem detixi tegetionlas caunabiuas aecipiunt, prætentis retibus, quibus prolibeantur volare: quouianı si idl faciant, corpori detralıuıt. In his [auleu]] assidue nourrit journellement avec du millet ou du fro. ment : mais il ne faut point leur donner ees grains qu'ils ne soient sees. La valeur d'un semo. dius de mangeaille suffit par jour pour cent vingt tourterelles. On leur donne toujours de l'cau fraiche et très-propre, dans de petits vases scmblables à ceux dont on se sert pour les pigeons ct pour les poules, et on nettoie leurs nattes pour empêcher que la fiente ne leur brûle les pattes; il faut néanmoins conserver avec soin cette fiente, qui s'emploie à la culture des champs et des arbres, de même que celle de tous les oiseaux, à l'exception de ceux qui nagent. L'âge avancé de ces oiseaux n'est pas si favorable à leur engrais que la jeunesse : c'est pourquoi on choisit à peu près le temps de la moisson, temps auquel la couvée commence à se fortifier.

$X$. Il faut plus de soins et de dépenses pour les grives. On peut en nourrir dans tontes sortes de campagnes, quoiqu'il sera avantageux de le faire dans celles où on les aura prises. En effet, on les transporte difficilement dans d'autres contrécs, parec quie lorsqu'elles sont renfermées dans des cages, la plupart se désespèrent; la même chose leur arrive lorsqu'on les jette dans une volière au moment qu'elles ont été prises, et à la sortie du filet. Il faut donc, ponr éviter cet aecident, en mêler, parmi les nouvelles captives, d'aneiennement enrôlées, qui aient été élevées par les oiseleurs à l'effet de servir comme d'appeaux pour attirer les autres : ces aneiennes adouciront le chagrin des autres en voltigeant autour d'elles, et celles-ci s'aecoutumeront peu à peu à chercher à boirc et à manger, dès qu'elles verront celles qui sont privées le faire. Elles veulent un endroit qui soit exposé au soleil, et dis posé de la même façon que celui des pigeons,

paseuntur milin, aut tritieo. Sed ea semina dari uisi siccs non oportet. Satiatque semodius cibi in diebus singulis vicenos et centenos turtures. Aqua semper recens et quam mundissinna vaseulis, qualibus columbis atque gallinis, præbetur; tegetieulaeque emundantur, ne stereus urat pedes, quod tamen et [id] ipsum diligenter reponi debes ad eultus agrorum arborumque, sicut et omnium avium, præterquam nantium. Hujus avis atas ad saginam non tan vetus est idonea, quain novella. Ilaque eirea messem, cum jam confirmata est pullities, eligitur.

$\mathbf{X}$. Turdis major opera et impensa probetur, qui omui quidem rure, sed salubrins in eo paseuntur, in quo capti sunt. Nam diflieulter in alian regionem transferuntur, quia caveis clausi plurimi despondent : quol faciunt etiam cum codem momento temporis a rete in aviaria conjecti sunt. Itaqque ne id aceidat, veterani debent interunisceri, qui ab ancupibus in bunc usum nutriti quasi allectores sint eaptivorum, mostitiamque eorun mitigent intervolando. Sic enim consueseent el aquam et cibos appetere feri, si mansnetos id facere viderint. Locum aqque unuitum. et apricum, quam columbi desiderant : sed in eo trans. rersa perticxe perforatis parietibus adversis aptantur 
avec celte différence qu'il sera traversé par des perclies plantíes dans des trous faits aux deux murs opposés, sur lesquelles elles se jucheront lorsqu'elles voudront prendre du repos après avolr mangé. Ces perches ne doivent pas être plus élevées de terre qu'il n'est nécessaire pour qu'un homme puisse y atteiudre en se tenant debout. On met communément leur mangeaille dans les parties de la volière au-dessus desquelles il n'y a polnt de perches, afin qu'elle se maintienne plus propre. Au surplus, cette mangeaille consistera cn figues sèches broyées avec soin et mélées de fleur de farine, et on leur en donnera assez copieusement pour qu'il y en ait toujours de reste. II y a des personnes qui machent ces figues avant de les leur donner; mais il n'est pas à propos de suivre cette méthode quand on a une grande quantitẻ de grives, parce que les gens qu'on emplole à les mâeher sont d'un loyer cher, et qu'ils en avalent eux-mêmes une certaine quantité, vu la douceur de ce fruit. Bien des personnes pensent qu'il faut diversifier leur mangeaille, de peur qu'elles ne viennent à se dégoûter, si on ne leur donne toujours que la même chose. Cectte variétẻ consiste à leur donner en même temps de la gralne de myrte et de lentisque, ainsi que des baies d'olivler sauvage et de lierre, et même des arboux, paree que ces fruits, qui sont ceux après lesquels ces oiseaux courent ordinairement dans les champs, préviendront aussi leur dégoût lorsqu'ils seront tranquilles dans des volières, et qu'ils exeiteront leur appétit, ce qui est très-avantageux, d'autant que plus ils mangent, plus tôt ils engraissent. Quoi qu'il en soit, on mettra toujours auprès d'eux de petits augets pleins de millet, parce que c'est leur nourriture la plus solide, et qu'on ne leur donne.les autres choses que nous venons de détailler qu'en guise

quibus insideant, cum satiati cibo requiescere volunt. Eæe perlica non altius a terra debent sublevari, quam hominis statura patitur, ut a stante contingi possint. Cibi ponuntur fere partibus his ornitlionis, qua super se perticas non labent, quo mundiores permaneant. Semper autem arida ficus diligenter pinsita et permista polline præberi debet, tam large quidem ut supersit. Hanc quidam mandunt, et ita objiciunt. Sed istud in najore numero facere vix expedit, quia nec parvo conducuntur qui mandant, et ab is ipsis aliquantum propter jucunditatem consumitur. Multi varietatem ciborum, ne unum fastidiant, præbendam pu. tant ; ea est, cum objiciuntur myrti et lentisci semina; item oleastri, et ederacea bacce, nec minus arbuti. Fere cuim etiam in agris ab ejusmodi volucribus hac appetuntur, quæe in aviariis quoque desidentium detergent fastidia, faciuntque avidiorein volaturam, quod maxime expedit. Nam largiore cibo celerius pinguescit. Senıper tamen etiam canaliculi milio repleti apponuntur, quæ est firmissina esca. Nam illa qua supra diximus, pulmentariorum vice dantur. Vasa, quibus recens et munda præbeatur aqua, non dissimilia sint gallinariis. Hac impensa curaque $\mathbf{M}$. de bonnc chère. Les vases dans lesquels on leur mettra de l'eau fraiche et propre ne diffèrent en rien de ceux des poules. M. Terentius assure qu'avec de pareils soins et de pareilles dépenses, on vendait souvent les grives trois denarii pièce du temps de nos ancêtres, lorsque des triomphateurs voulaient régaler le peuple. Mais comme aujourd'hui le luxe de notre siècle a rendu ce prix très-commun, les paysans eux-mèmes ne doivent point dédalgner ce revenu. Nous avons parcouru à peu près toutes les espèces d'animaux que l'on nourrit dans l'enclos des métairies; il nous faut à présent traiter de ceux qu'on laisse aller paitre dans les champs.

XI. L'éducation des paons demande plutôt les solns d'un chef de famille d'un goût délicat que ceux d'un paysan grossier, quoiqu'elle ne soit point cependant étrangère même à un agriculteur, pour peu qu'il cherche à se procurer des plaisirs en tout genre, pour charmer la solitude de la campagne. La beauté de ces oiseaux fait plaisir aux étrangers eux-mêmes, à plus forte raison à ceux qui en sont propriétaires. On en garde aisément dans de petites f̂les couvertes de bois, telles qu'il s'en trouve près de l'Italie. En effet, comme cet oiseau ne peut pas voler haut ni au loin, et que d'ailleurs il n'y a point de voleurs ni d'animaux nuisibles à craindre dans ces iles, il peut y errer avec sûreté sans gardien, et trouver par lui-même la meilleure partie de sa nourriture. Les femelles s'y voyant aussi commc à l'abri de l'esclavage, y nourrissent volontiers leurs petits avec plus d'attache; de sorte que celui qui prend soin du troupeau n'a rien antre chose à faire, dans ce cas-là, qu'à le rappeler à certaines heures du jour auprès de la métairie par un signal quelconque. A mesure que les paons accourrout, il leur donnera un peu d'orge, pourleur ôter

Terentius ternis sæpe denariis singulos entitatos esse signíficat avorum temporibus, quibus qui triumphabant, populo dabant epulum. At nunc atatis nostræe luxuries quotidiana fecit hæe pretia : propter quæ ne rusticis quidem contemnendus sit hic reditus. Atque ea genera, qux intra septa villa cibantur, fere persecuti sumus. Nunc de his dicendum est, quibus etiam exitus ad agrestia pabula dantur.

XI. Pavonum educatio magis urbani patrisfamilice, quam tetrici rustici curam poscit. Sed nec hæc tamen aliena est agricolæ captantis undique voluptates acquirere, quibus solitudinem ruris eblandiatur. Harum autem decor avium etiam exteros nedum dominos oblectat. Itaque genus alifum nemorosis et parvulis insulis, quales objacent Italia, facillime continetur. Nan quoniam nec sublimiter potest, nec per longa spatia rolitare, tum etiam quia furis ac noxiorum animalinm rapina metus non est, sine custode tuto vagatur, majoremque pabuli partem sibi acquirit. Fœminæ quidem sua sponte tanquam servitio liberatie, studiosius pullos enutriunt : nec curator aliud facere debet, quam ut diei ccrto tempore, signo 
la faim, et il les comptera tous. Mais comme il est rarc qu'on soit dans le cas d'avoir une fle pareille en sa possession, il faudra se donner plus de soins dans les lieux situés au milieu de la terre ferme; et voici en quoi consisteront ces soins. On entourera d'une haute muraille une plaine couverte d'herbes et de bois : on appliquera des galeries à trois des côtés de cette muraille, et sur le quatrième on construira deux cabanes, dont l'une servira d'habitation au gardien des paons, et l'autre de retraite à ces oiseaux. On fera ensuite le long de ces galeries des enceintes de roseaux, en forme de cages pareilles à celles qui sont au-dessus des colombiers. Ces enceintes seront distribuées en plusieurs parties, et traversées par des espèces de treillis formés de roseaux, de façon que chacune de ces différentes parties ait deux entrées par chacun de ses côtés. La retraite de ces oiseaux doit être exempte de toute humidité. On y plantera sur le sol des rangées de petits pieux, dont l'extrémité supérieure sera aiguisée en pointe, pour pouvoir être introduite dans des perches transversales qui seront percées à cet effet. Les perches destinées à ètre posées sur ces pieux doivent être carrées, afin que l'oiseau puisse se jucher dessus. D'un autre côté, elles doivent s'enlever facilement de dessus les pieux, afin que, lorsque le cas l'exigera, on puisse les en retirer, pour donner la liberté du passage à ceux qui auront à balayer. Lorsque cet oiseau a atteint sa quatrième année, il engendre très-bien; au lieu qu'il est ou stérile ou peu fécond dans un âge plus tendre. Le paon a la lubricité des coqs, aussi lui faut-il cinq femelles : car s'il arrivait que, n'en ayant qu'une ou deux, il les coquât ou trop souvent ou lorsqu'elles seraient pleines,

dato, juxta villam gregem convocet, et exiguum ordei concurientibus objiciat, ut nec avis esuriat, et numerus advenientium recognoscatur. Sel hujus possessionis rara conditio est. Quare mediterraneis locis inajor adlibcnda cura est : eaque sic administretur. Hcrbidus silvestrisquc ager planus sublimi clauditur maceria, cujus tribus lateribus porticus applicantur, et in quarto dux cellx, ut sit altera custodis habitatio, atque altcra stabulum pavonum. Sub porticibus deinde per ordinem fiunt arundinea scyta in unodum cavearum, qualia columbarii tectis supcrponuntur. Ea septa distinguuntur velut clatris intcrcurrentibus calanis, ita ut ab utroque latere singulos alitus lıabeant. Stabulum autem carere dcbet uligiue, cujus.in solo per ordinem figuntur brcves paxilli, eorunque partes sumuna liugulas edolatas lıalent, quß transversis foratis perticis iuducantur. Iæ porro quadrata pertic $x$ [esse debent, quae] paxillis superponuntur, ut aven recipiant adsilienten. Sed idcirco sunt excmptilcs, ut cum res exigit, a paxillis deducta Jiberum aditum converrentilus stalsulun præbeant. Hoc genus arium, cum trimatum explevit, optime progencrat. Siquidem teuerior atas, aut sterilis, aut parum frecunda est. Masculus pavo gallinaceam salilcitatem labet, atque illco quinųue foeninas desiderat. il endommagerait les œufs à peine formés dans leur ventre, et les empêcherait de venir à bicn, en les faisant tomber de la matrice avant qu'ils soient à leur terme. Il faut, vers la fin de l'hiver, exciter l'ardeur de ces oiseaux, dans les deux sexes, par des nourritures qui les provoquent au plaisir. Ce qui y contribuera le plus, ce seront des fèves grillées à une flamme légère, qu'on leur donnera toutes chaudes et à jeûn tous les cinq jours, sans néaumoins excéder la mesure de six cyathi par tête. Il ne faut pas leur jeter de la mangeaille pour tous en commun, mais il faut en mettre séparément dans clincune des enceintes que j'ai dit qu'il fallait former de roseaux, en réglant la quantité de cette mangeaille sur le nombrc de cinq femelles et un mâle : il en sera de même de l'eau qui leur servira de boisson. Quand cette distribution sera faitc, on conduira les mâles avec leurs femelles, chacun dans leurs enceintes particulières; de sorte que tout le troupeau se repaitra également, sans qu'il survienne de différend entre les têtes qui le composent; car il se trouve aussi parmi les oiseaux de cette espèce des mâles qui cherchent à se battre, et qui empêchent les plus faibles de manger et de coquer, si on n'a pas soin de les séparer de cette façon. Communément, dans les lieux exposés au soleil, les mâles sont tourmentés du désir de coquer les femelles dès que les vents Favonii ont commencé à souffler, c'est-à-dire, entre les ides de février et le mois de mars. On reconnait l'ardeur de leur passion en les voyant se couvrir, comme s'ils s'admiraient eux-mêmes, avec les plumes brillantes de leur queue, ce qu'on appelle rolare (fairc la roue). Dès que le temps où les femelles ont dû

Nam si unam, vel alteraın foetam sæpius compressit, vix dum concepta in alvo vitiat ova, nec ad partum sinit perduci : quoniam immatura genitalibus locis excidunt. Ultima parte liemis concitantibus libidinem cibis utriusque sexus accendenda venus est. Maxime facit ad lıanc rem, si favilla levi torreas fabam, tepidamque des jejunis quiuto quoque die. Nec tamen excedas modum sex cyathorum in singulas aveis. Hacc cibaria non omnibus promiscue spargenda sunt, sed in singulis septis, quxe arundinibus contexi oportere proposueram, portione servata quinque forminarum et unius maris, poncnda sunt cibaria, nec minus aqua, qux sit idonea potui. Quod ubi factum est , mares [sinc rixa] diducuntur in sua quisque septa cum forninis, et aqqualiter universus grcx pascilur. Nam etian in hoc genere juguaces inveniuntur masculi, qui et a cibo et a coitu prolibent minus validos, nisi siut bac ratione separati. Fere autenı locis apricis ineundi cupiditas exercet mares, cun Favonii spirarc cueperunt, id est tenpus ab idibus Februariis ante Martimn mensem. Signa sunt extimulatx libidinis, cum semetipsum reluti mirantem cauda genmantibus pinnis protegit : idque cum facit, rotare dicitur. Post admissurie tenpus confestim matrices custodienda sunt, ne alibi quan in stabulo foctus edant: 
ére eoquées est passé, il faut les garder à vue, atin qu'elles ne pondent point ailleurs que dans leurs retraites : on leur tâtera souvent aussi les pirties arec les doigts, parce que leurs oufs s'y trouvent tout a l'entrée, quand elles sont prétes à pondre. Il faut donc renfermer celles qui seront dans ce cas-là, afin qu'elles ne pondent pas hors de leur enceinte. Il faut y étendre beaucoup de paille, surtout dans le temps oi elles pondront, afin que leurs œufs soient reçus plus sûrement : car elles pondent communément lorsqu'elles vienneut prendre le repos de Ia nuit, et qu'elles se sont juchées sur les perches dont nous avons parlé; et par conséquent plus l'endroit où leurs œufs tombent est voisin d'elles et mollet, plus ces œufs se conservent intacts. Il faut done visiter leurs retraites bien exactement tous les matins, dans le temps de la ponte, et ramasser les œufs qui seront à terre. Plus ils seront frais quand on les donnera à couver à des poules, plus ils écloront facilement; et il est très-intéressant pour le profit du chef de famille que ce soit à des poules à qui on les donne à couver, parce que les paonnes que l'on ne fait point couver pondent communément trois fois par an, au lieu que eelles que l'on fait couver perdent tout le temps de leur fécondité à faire éelore leurs œufs, eomme à élever leurs petits. La première ponte est communément de einq œufs, la seconde de quatre, et la troisième de deux ou trois. Il ne faut pas se hasarder à faire couver des ceufs de paonnes par des poules de Rhodes, qui ue nourrissent pas bien leurs poussins méme; mais on préndra pour cela de vieilles poules parmi celles de notre pays, en choisissant les plus grandes de cette espèce; et on leur fera couver pendant neuf jours, à commencer

sappinsque digitis loca foeminarum tenlanda sunt. Nam in promtı gerunt ova, quibus jam partus appropinquat. Itaque includendx sunt incientes, ne extra clausum foetum edant : maximeque temporibus is, quibus parturiunt, pluribus stramentis exaggerandum est aviariuın, quo tutius integri fortus excipiantur. Nam fere pavones, cum ad nocturuam requiem venerunt, prædictis perticis insistentes enituntur ova, quæ quo propius ac mollius deciderint, illibatam servant integritatcm. Quotidie ergo diligenter manc temporibus foetura stabula circumeunda erunt, et jacentia ova colligenda. Qua quanto recentiora gallinis subjecta sunt, tanto commodius excluduntur : idque fieri maxinc patrisfamilias rationi conducit. Nam fominæe pavolies, qux non incubant, ter anno fere partus edunt : at qux fovent ova, totum tempus focunditatis aut excludendis aut etiam educandis pullis consumunt. Primus est partus quinque fcre ovorum; secundus quatuor; tertius aut trium, ant duorum. Neque est quod committatur, ut Rlodiæ aves pavoninis incubent, quæ ne suos quidem foe tus commodc nutriunt. Sed veteres maximæ quaquc gallinæ vernaculi generis cligantur : exque norem diebus a primo lunx incremento, novenis ovis incubent, sintque ex his du croissant de la lune, neuf œufs, dont il y aura cinq de paonnes et quatre de poules : le dixième jour on retirera tous les œufs de poule, et on en remettra autant de nouveaux de la même espéce, afin qu'ils puissent éclore avec ceux de paonne lo trentième jour de la lune, qui est communémint celui de la nouvelle lune. Mais il faut que le gardien ne manque pas d'épier les moments où la mère sortira de la retraite, afin d'y entrer souvent pour retourner lui-même à la main les œufs de paonne, que les poules remuent plus difficilement que les leurs propres, attendu leur grosseur; et pour s'acquitter plus exactement de cette fonction, il aura soin de les marquer tous d'un seul côté avec une liqueur noire, afin de reconnaitre à cette marque quand la poule les aura retournés elle-même, ou non. Du reste, souvenons-nous qu’il faut employer à eette opération, ainsi que je l'ai déjà dit, les plus grandes poules de basse-cour; car si elles étaient d'une moyenne taille, il ne faudrait pas leur faire couver plus de trois œufs de paonnes avec six de. poules. Lorsque la poule aura fait éclore les petits, il faudra donner les poussins à nourrir à une poule, et rassembler les paonneaux à mesure qu'ils seront nés auprès d'une seeonde. jusqu'à ee qu'elle en ait un troupeau composé de vingt-einq têtes. Il ne faudra pas cependant retirer de dessous la poule les paonneaux, non plus que les poussins, dès le premier jour de leur naissance; et ce ne sera que le lendemain qu'il faudra les transférer avec celle qui doit les élever dans une eage, où on les nourrira les premiers jours avec de la farine d'orge humectée de vin, ou bien a vec une petite bouillie faite avee quelque espèce de blé que ee soit, et refroidie. Peu de jour's après on y ajoutera des porreaux de Taren- quinque pavonina, (et) cætera gallinacei generis. Decimo deinceps die omnia gallinacea subtrahantur, et totidem recentia ejusdem generis supponantur, ut trigesima luna, quie est fere nova, cum paroninis excludantur. Sed custodis curam non effugiat observare desilientem matricem, sxpiusque ad cubile pervenire, et pavonina ora, quæ propter magnitudinem difficilius a gallina moventur, versare manı : idquc quo diligentius faciat, una pars ovorum notanda est atramento, quod signum habebit aviarius, on a gallina conversa sint. Sed, ut dixi, meminerimus coliortales quam maximas ad hanc rem praparari. Qure si mediocris labitus sunt, non debent amplius quam terna pavonina, et scna generis sui fovere. Cum deinde fecerit pullos, ad aliam nutricem gallinacei dcbebunt transferri, et subinde qui nati fuerint pavonini ad unam congregari, donec quinque et viginti capitum grex efficiatur. Sed cum erunt editi pulli, siıniliter ut gallinacei primo die non moveantur : postero die cum educatrice transferantur in caveam : primisque diebus alantur ordeaceo farre vino resperso, nec minus ex quolibet frumento cocta pulticula, et refrigerata. Post paucos deinde dies huic cibo adjicien. dum erit concisum porrum Tarentinutn, et caseus mollis 
tum hachés et du fromage mou bien égoutté, parce qu'il est constant que le petit-lait nuit aux paonneaux. Des sauterelles, auxquelles on a arraché les pattes, passent aussi pour une nourriture qui leur est bonne, et il faut leur en donner jusqu'au sixième mois, après quoi il suffira de leur jeter de l'orge à la main. On peut aussi les mener trente-cinq jours après leur naissance aux champs, même sans avoir rien à craindre, parce que le troupeau suit la poule toutes les fois qu'il l'entend glousser, comme si c'était sa propre mère. Le gardien porte alors aux champs la mère renfermée dans une cage, et, après l'avoir fait sortir, il la garde à vue en lui liant la patte avec une longue ficelle, de sorte que les paonneaux puissent voltiger autour d'elle; après quoi, lorsqu'ils se sont bien repus, on les ramène facilement à la métairie, parce qu'ils ne s'écartent point, comme je l'ai dit, de leur nourrice, qu'ils entendent glousser. Tous les auteurs conviennent assez unanimement qu'il faut éviter de mener paítre, dans l'endroit où sera cette poule, d'autres poules qui élèveront des poussins, parce que, dès quecelles-ci, aperçoivent les paonneaux, elles cessent d'être affectionnées à leurs petits et les abandonnent avant de les a voir élevés, comme si elles les eussent pris en aversion, par la raison qu'ils ne ressemblent aux paons ni par la taille ni par la beauté. Ces oiseaux sont sujets aux mêmes maladies que celles auxquelles les poules sont ordinairement sujettes; aussi ne leur donne-t-on pas non plus d'autres remèdes que ceux que l'on emploie pour les poules, puisqu'on les guérit de la pepie, de l'indigestion et dequelque sutrc maladie que ce soit, avec les remèdes que nous avons indiqués. Passé le septième mois à compter depuis lcur naissance, il faut les enfer-

veliementer expressus; nam serum nocere pullis manifes. tum est. Locusta quoque pedibus ademtis utiles cibandis pullis habentur, atque iis pasci debent usque ad sextum mensem : postmodum satis est ordeum de manu præbere. Possunt autem post quintum et trigesimum diem quam nati sunt, etiam in agrum satis tuto educi, sequiturque grex velut matrem gallinam singultientem. Ea cavea clausa fertur in agrum a pastore, et emissa ligato pede longa linea [gallina] custoditur, ad quam circumrolant pulli. Qui cum ad satietatem pasti sunt, reducuntur in villam persequentes, ut dixi, nutricis singultus. Satis autem convenit inter auctores, non debere alias gallinas, quae pullos sui generis educant, in eodem loco pasci. Naul cun conspexerunt paroniuam prolem, suos pullos diligere desinunt, et imnaturos relinquunt, perosie videlicet, quod nec magnitudine, nec specie pavoniuis pares sint. Vitia quæ gallinaceo generi nocere solent, eadein has aveis iufestant : sed nec remedia traduntur alia, quan quæ gallinaceis adlibentur. Nam et pituita et cruditas, et si qua aliæ sunt pestes, iisdem remediis, qua proposuimus, prołhibentur. Septimum deinde mensem cum excesserunt, in stabulo cuin corteris ad nocturnam requiem de. mer avec les autres paons dans leurs retraites, pour $y$ prendre le repos de la nuit ; mais on prendra garde qu'ils ne se tiennent sur la terre; et on relèvera ceux qui pourraient se coucher ainsi, pour les poser sur les perches, afin que le froid ne les incommode pas.

XII. L'éducation des poules de Numidic est à peu près la même que celle des paons. Pour les poules sauvages, que l'on appelle rustica (poules de campagne), elles nc pondent point dans la captivité; ainsi nous n'avons rien à prescrire à leur sujet, si ce n'est qu'il faut leur donner à manger tant qu'elles en veulent, pour les rendre plus propres à couvrir les tables dans un festin.

XIII. Je passe aux oiseaux que les Grees appellent áup̧bio (amphibies), parce qu'ils ne se contentent pas de la pâture qu'ils trouvent sur terre, et qu'ils en cherchent aussi dans l'eau, n'étant pas plus habitués à la terre qu'aux étangs. Entre ces oiseaux, l'oie est l'espèce la plus recherchée par les gens de la campagne, parce qu'elle ne demande pas de grands soins, et qu'elle est de meilleur guet que le chien même, puisqu'elle trahit par son chant les gens qui sont en embuscade, ainsi qu'il arriva au siége du Capitolc, suivant ce que dit l'histoire, lorsque ces oiseaux firent entendre leur chant à l'arrivée des Gaulois, pendant que les chiens étaient restés muets. On ne peut pas néanmoins avoir d'oies partout, d'après l'opinion très-sensée de Celsus, qui dit que l'oie ne se soutient pas aisément sans eau, non plus que sans une grande quantité d'herbes, et qu'il y a du danger à en avoir dans de jeunes plants, parce qu'elle arrache toutes les pro. ductions tendres qu'elle peut y rencontrer. Mais il en faudra nourrir dans tout endroit où il se trouvera un fleuve ou un lac, et dans le voisi-

bent includi. Sed erit curandum, ne lumi maneant. Nam qui sic cubitant, tollendi sunt, et supra perticas imponendi, ne frigore lalorent.

XII. Nunidicarum eadem est fere, qua pavonum educatio. Cæeterum silvestres gallinæ, quæ rusticæ appellan. tur, in servitute non fuetant : et ideo nihil de his precipimus, nisi ut cibus ad satietatem præbeatur, quo sint conviviorum epulis aptiores.

XIII. Venio nunc ad eas aves, quas Græci vocant

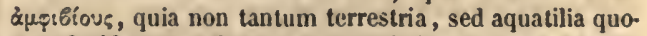
que desiderant pabula, nec magis liumo quam stagno consueverunt. Ejusque generis anser precipue rusticis gratus est, quod nec maximam curam poscit, et solertiorem custodiam quam cauis præbet. Nam clangore prodit insidiantem, sicut etiam memoria tradidit in obsidione Capitolii, cum adrentu Gallorum vociferatus est, canibus silentibus. Is autem nou ubique liaberi potest, ut existimat verissime Celsus, qui sic ait. Anser neque sine aqua, nec sine multa herba facile sustinetur, neque utilis est locis consitis, quia quicquid tenerum contingere potest, carpit. Sicubi vero flumen aut lacus est, herbæeque copia, nec nimis juxta satæ fruges, id quoque geuus nutriendum 
nage duquel il y aura beaucoup d'herbes et peu de terres ensemencées. Co n'est pas que nous pensions qu'on doive le faire, par la raison que cet oiseau rapporte beaucoup de profit; mais seulement parce qu'il n'est point à charge, quoiqu'on retire même un certain produit de ses petits et de ses plumes, que l'on peut arracher non pas seulement une fois l'an, comme la laine des brebis, mais deux fois, savoir au printemps et en automne. Il faut donc en élever au moins une petite quantité quand la situation des lieux le permet, et ne donner que trois femelles à chaque mále, parce que la pesanteur des mâles les empêche d'en couvrir un plus grand nombre. Il faut en outre, pour les mettre à l'abri, leur faire, dans l'intérieur de la cour et dans des coins retirés, des logettes dans lesquelles elles se coucheront et feront leur ponte.

XIV. Quant à ceux qui s'attachent à avoir par troupeaux des oiseaux qui nagent, ils doivent former des chenoboscia (des endroits où paissent les oies), qui ne feront honneur qu'au cas qu'ils soient disposés de la facen qui suit. On aura une cour séparée dont tous les autres bestiaux ne pourront pas approcher, et qui sera environnée d'une muraille de ncuf pieds d'élévation, avec des galerics rangées de façon qu'il $\mathbf{y}$ ait dans quelque coin une cabane pour le gardien. On construira ensuite sous ces galeries, avec du nıoellon, ou même avec de la petite brique, des logettes carrées: il suffit que chacune de ces logettes ait trois pieds en tout sens, et il faut que l'entrée en soit munie de petites portes solides, parce qu'on doit les fermer exactement dans le temps de la ponte de ces oiseaux. Ensuite s'il se trouve hors de la métairie un étang ou un fleuve à quelque distance des bâtiments, on ne cher-

est. Quod etiam nos facere censemus, non quia magni sit fruclus, sed quia minimi oneris. Attamen prastat ex se pullos atque plumam, quam non, ut in ovibus lanam, semel deinetere, sed bis anno, vere et autumno vellere licet. Atque ob lıas quidem causas, si permittit locorum conditio, vel paucos utique oportet educare, singulisque maribus lernas fominas destinare. Nam propter gravita. tem plureis inire uon possunt. Quinctiam intra colıortem, ut protecti sint, secretas singulis liaras facere oportet, in quibus cubitent et foctus ubi edaut.

XIV. Qui vero greges uantium possidere student, clie. nohoscia constituant, qua tum denum vigebunt, si fuerint ordinata ratione tali. Colıors ab omni catero pecore se. creta clauditur alta novem pedum maceria, porticibusque circumdata, ita ut in aliqua parte sit cella custodis. Sub porticibus deinde quadrata hara camentis vel etiam la. terculis extruuntur: quas singulas satis est liabere quoquo. versus pedes ternos, et aditus singulos firmis ostiolis munitos : quia per foeturam diligenter claudi debeut. Extra villam deinde non longe ab aedificio si est stagnum vel flumen, alia non quxratur aqua : sin aliter, lacus juscinarue ınạuu fiant, ut siut quibus inuriuare possint aves. chera pas a se procurer d'autre eau ; mais s'il n'y en a poivt, on fera des mares et des réservoirs d'eau artificiels, afin que ces oiseaux ne manquent point d'endroits ou ils puissent se plonger, parce que cette ressource leur est aussi nécessaire pour vivre que celle de la terre. On leur réservera aussi un terrain marécageux bien fourni d'herbes, ct entre autres páturages qu'on y sèmera, tels que la vesce, le trèfle et le fenu-grec. On n'oubliera pas surtout d'y semer de cette espèce de chicorée que les Grecs appellent $\tau \tau$ répıs (chicorée frisée). Il faut encore semer particulièrement de la graine de laitue, parce que c'eșt un herbage très-tendre et fort recherché par ces oiseaux, outre que c'est une nourriture excellente pour leurs petits. Toutes ces choses ainsi préparées, il faut avoir soin de choisir des mâles ainsi que des femelles de la plus grande taille, et dont la couleur soit blanche; car il y a une espèce d'oie bigarrée, qui était sauvage dans le principe, et qui n'est devenuc domestique que depuis qu'on l'a apprivoisée; mais il ne faut pas en élever, parce qu'elle n'est pas aussi féconde ni d'un aussi grand prix que les autres. Le temps le plus propre pour faire accoupler les oies, c'est depuis le solstice d'hiver, comme le plus propre pour les faire pondre et couver, c'est depuis les calendes de féviier ou de mars jusqu'au solstice, qui arrive vers la fin du mois de juin. Elles ne s'accouplent pas, comme les premiers oiseaux dont nous avons parlé, ell se tenant sur terre, mais elles le font communément dans des rivières ou dans des réservoirs d'eau. Elles pondent chacune trois fois par all, pourvu qu'on les empêche de faire éclore leurs œufs, ce qui est plus avantageux de faire que de les leur donner à couver à elles-mêmes, parce que les poules auxquelles on les donne à couver nour-

Nam sine isto primordio non magis quam sine terreno recle vivere queunt. Palustris quoque, sed herbidus ager destinetur, alque alia pabula conserantur, ut vicia, trifo lium, fonum Grocum, sed precipue genus intubi, quod бépเv Graeci appellant. Lacluca quoque in liunc usum semina vel maxime serenda sunt, quoniam et mollissimum est olus, et libentissime ab his avibus appetitur. Tum etiam pullis utilissima est esca. Hxc cum preparata sunt, curandum est, ut mares fominæque quam auplissimi corporis, et albi coloris eligantur. Nam est aliud genus varium, quod a fero mitigatum domesticum factum est. Id neque seque frecundum est, nec tam pretio. sum : propter quod minime uutriendum est. Anseribus admittendis tempus aptissinum est a bruma; mox ad pa. riendum, el ad iucubandum a Calen. Februariis vel Martiis usque ad solstitium, quod fit ultima parte mensis Junii. Iueunt autem non, ut priores aves, de quibus diximus, insistentes humi : nam fere in flumine aut piscinis id faciunt : singulseque ter anno pariunt, si prolubeantur foetus suos excludere, quod magis expedit, quam quum ipsæe suos fovent. Nam el a gallinis melins enutriuntır, et longe nuajor grex efficitur. Pariunt autem singulis fuetibus 
rissent mieux les petits qui en sont venus, et que lc troupeau devient par lá bien plus nombreux. Elles donnent einq œufs à la première ponte, quatre à la suivante, et trois à la dernic̀re : quelques personnes leur laissent élever les petits de cette dernière ponte, parce qu'elles ne doivent plus pondre de tout le reste de l'année. Il ne faut pas laisser pondre les femelles hors du clos qui leur est destiné; ainsi lorsqu'elles paraítront chercher un endroit pour y déposer leurs œufs, on leur tâtera le ventre en le pressant pour s'assurer de leur état, parce que, dès qu'elles approchent du moment de la ponte, on sent avec le doigt les œufs qui sont alors sur le bord de leurs parties, et on les conduira à leurs logettes, où on les enfermera afin qu'elles y pondent. Il suffira d'avoir observé cettc pratique une seule fois vis-àvis do chacune, parce qu'elles retournent toujours toutes à l'endroit dans lequel elles ont pondu une première fois. Mais lorsqu'on veut qu'elles couvent elles-mêmes les œufs de la dernière ponte, il faut a voir soin de marquer ces oufs afin de les reconnaitre, et de les mettre chacun sous celles qui les auront pondus, parce qu'on prétend que les oies ne font point éclore des œufs qu'elles n'ont point pondus, à moins qu'elles n'en couvent en même temps des leurs propres. Pour les poules, on leur donne à couver autant d'œufs d'oies que d'œufs de paonnes, c'est-à-dire cinq au plus et trois au moins; au lieu qu'on donne aux oies sept au moins et quinze au plus. Mais on doit a voir la précaution de mettre sous les œufs des racines d'orties, ce qui est unc espèce de rcmède contre les orties mêmes, dont la piqûre est mortelle aux oisons qui viennent d'éclore. Il faut trente jours pour que les oisons se forment et qu'ils sortent de l'œuf, lorsqu'il fait froid; car lorsqu'il fait chaud, il suffit de vingt-cinq jours, quoi- que le plus souvent on ne les voie éclore que le trentième jour. Tant qu'ils sont petits, on les nourrit les dix premiers jours dans la logettc où ils sont renfermés avec leur mère ; après quoi, lorsque le beau temps le permet, on les mène dans les prés et aux réservoirs d'eau. Il faut prendre garde qu'il ne leur arrive d'être piqués par des orties, et éviter de les envoyer aux paturages sans les avoir rassasiés auparavant de chicorée ou de feullles de laitue hacliées. En effet, s'ils y allaient quand ils sont encore faibles, sans avoir pris de nourriture auparavant, ils s'opiniatreraient si fort à arracher de terre les arbrisseaux ou les herbes, qu'ils se rompraient le cou. On fait bien de leur donner aussi du millet ou même du froment dans de l'eau. Lorsqu'ils sont devenus un peu plus foits, on les incorpore dans la troupe de leurs camarades, et on les nourrit d'orge : il est également utile d'en donner aux mères. II n'est pas à propos de mettre plus de vingt oisons dans la mème logette, comme il ne faut pas non plus en mettre de trop petits avec de plus grands, parce que les plus forts tueraient les plus faibles. Il faut tenir très-sèches les retraites dans lesquelles ils se couchent habituellement, et y étendre de la paille, ou, à défaut de paille, du foin, qui leur est également agréable. Pour le surplus, on observera les préceptes que nous avons donnés par rapport aux autres espèces de poussins, et qui consistent à empêcher qu'ils ne scutent l'odeur d'une couleuvre ou d'un furet, de même que celle d'un chat ou même d'une belette, parco que ces animaux pestilentiels font communément un carnage affreux de ces oiseaux, lorsqu'ils sont jeunes. Il y a des personnes qui donnent aux oies de l'orge détrempée, pendant qu'elles couvent, sans perinettre que les mères abandonnent souvent leurs nids : les mêmes personnes don- ova, primo quiıa, sequenti quaterna, novissimo terna : quem partum nonnulli permittunt ipsis matribus educare, quia reliquo tempore anni vacaturæ sunt a fotu. Minime autem concedendum est fominis extra septum parere, sed cum videbuntur. sedem quarere, comprimendæ stnt atque tentandæ. Nam si appropinquant partus, digito tauguntur ova, quæ sunt in prima parte locorum genita. lium. Quamobrem perduci ad lıaram debent, inclıdique ut foctum edant : idque singılis semel fecisse satis est, quoniam unaquxque recurrit eodem, ubi primo peperit. Sed novissimo foetu cum volumus ipsas incubare, notandi erunt uniuscujusque partus, ut suis matribus subjiciantur : qu(uliam negatur anser aliena excludere ova, nisi subjecta sua quoque labuerit. Supponuntur autem gallinis lıujus generis ova, sicut pavouina, plurima quinque, paucissima tria : ipsis autem anseribus paucissima vII, plurima $x \vee$. Sed custodiri debet, ut ovis subjiciantur herbæ urticarum, quo quasi remedio medicantur, ne noceri possit excusis anserculis, quos enecant urticæ, si te. neros pupugerint. Pullis anten formandis excudendisque triginta diebus opns est, cum sunt frigora : nam tepidis $\mathbf{x x v}$ satis est. Sæpius tamen anser trigesimo die nascitur, Atque is dum exiguns est, decem primis diebus pascitur in liara clansus cum matre : postea cum serenitas permit tit, producilur in prata, et ad piscinas. Cavendumque est, ne aut aculeis urticx compungatur, ant esıriens mittatur in pascuum : sed ante concisis intubis vel lac. tuca foliis saturetur. Nam si est adluc paruin firmus, et iudigens ciborum pervenit in pascuum, fruticibus aut solidioribus lıerbis obluctatır ita pertiıaciter, nt collıı abrumpat. Milium quoque aut etiam triticum mistum cum aqua recte probetur. Atque ubi se paulum confirmavit, in gregem coxqualium compellitur, et ordeo alitur : quod et matricibus prabere non iuutile est. Pullos autem nou expedit plures in singulas haras quam vicenos adjici; nec rursus omnino cum majoribus includi, quoniam validior enecat infirmum. Cellas, in quibus incubltant, siccissimas esse oportet, substratasque liabere paleas : vel si ene non sunt, crassissimım quodque fonum. Catera eadem, qua in aliis generibus pullorum servanda sunt, ne coluber, ne vipera, felesque, aut etiam mustela possit aspirare : qune fere peruicies ad iuternecionem prosteruunt teneros. Sunt 
nent aussi aux oisons, pendant les einq premiers jours depuis qu'ils sont éclos, du gruau ou de la farine détrempée, .comme aux paons. D'autres leur donnent eneore dans de l'eau du eresson vert haché en petits moreeaux, et cette nourriture leur est très-agréable. Par la suite, Jorsqu'ils ont quatre mois, on destine les plus grands d'entre eux à l'engrais, parce que la jeunesse est l'âge que l'on regarde eomme le plus propre pour les engraisser. L'engrais de ces oiseaux est facile à faire, puisqu'il n'y a absolument rien autre ehose a leur donner que du gruau et de la fleur de farine trois fois par jour, pourvu qu'on les mette à portée de boire copieusement, qu'on ne leur laisse point la liberté de courir, et quon les tienne renfermés dans un lieu chaud et obscur, toutes ehoses qui contribuent beaucoup à former la graisse. En suivant cette méthode, on vient à bout de les engraisser en deux mois, et il arrive même souvent que la couvée la plus jeune est engraissée au bout de quarante jours.

XV. Il faut prendre les mêmes soins pour former un endroit où l'on élèvera des canards; mais la dépense en sera plus eonsidérable, parce qu'on y renfermera, pour les y nourrir, non-seulement des canards, mais eneore des sareelles, des boscides, des phalerides, et d'autres oiseaux semblables, qui fouillent dans les étangs et dans les marais. On choisit à cet effet un terrain plat que l'on entoure d'une muraille de quinze pieds d'élévation; ensuite on le couvre avec un treillage ou avec des filets à grandes mailles, afin que ces oiseaux domestiques n'aient point la faculté de s'envoler, et que les aigles et les oiseaux de proie ne puissent pas fondre sur eux. On revêtira aussi toute cette muraille, tant en dedans qu'en dehurs, d'un enduit bien poli, de peur que les ehats ou les furets ne grimpent par-dessus. En-

qui ordeum maceratum incubantibus apponant, nec patiantur matrices sxpius nidum relinquere. Deinde pullis exclusis primis quinque diebus polentam vel maceratum far, sicut paronibus objiciunt. Nonnulli etiam viride nasturtium consectum minutatim cum aqua probent, eaque eis est esca jucundissima. Mox ubi quatuor mensium facti sunt, fartura maximus quisque destinatur, quoniam tenera xtas precipue liabetur ad hanc rem aptissima : et est facilis harum avium sagina : nam prater polentam et pollinem ter die nihil sane aliud dari necesse est, dummodo large bibendi potestas fiat, nec vagandi facultas detur; sintque calido et tenebricoso loco : qua res ad creandas adipes multum conferunt. Hoc modo duobus mensibus pinguescunt etiam majores. Nam tenerrima pullities sape $\mathrm{XL}$ diebus opina redditur.

XV. Nessotropliii cura similis, sed major impensa est. Nam clausa pascuntur anates, querquedula, boscides, phalerides, similesque volıcres, quxe stagna et paludes rimantur. Locus planus eligitur, isque munitur subliniter perlum quindecin maceria : deinde clatris superpositis, vel grandi macula retibns contegitur, ne aut cvolandi sit suite on creusera dans le milieu de cet enclos un bassin de deux pieds de profondeur, et dont la longueur, ainsi que la largeur, seront déterminées par la situation du lieu. On pavera en ouvrage de Signia les deseentes qui conduiront à l'eau, de peurqu'elles ne viennent à être dégradées par l'im. pétuosité de l'eau, qui coulera toujours à travers le bassin, au cas qu'elle vienne à se déborder. II ne faut pas que ces deseentes soient coupées en forme de degrés; mais elles doivent gagner l'eau insensiblement, de facon que l'on $\mathbf{y}$ descende eomme on deseend du rivage à la mer. Il faut paver en pierres et revêtir d'un enduit le sol du bassin dans tout son eontour, jusqu'aux deux tiers à peu près de sa longueur et de sa lar. geur ell tirant vers le centre, afin qu'il n'y puisse pas croítre d'herbes, et que cette partie du sol présente aux oiseaux, lorsqu'ils nageront, un espace libre et bien uni : d'un autre côté, le centre doit rester en terre-plein, pour qu'on puisse y semer des fèves d'Égypte et d'autre: herbes qui viennent ordinairement dans l'eau, et qui serviront à ombrager les retraites des oiseaux. Il s'en trouve, à la vérité, dans le nombre qui se plaisent à se tenir sous de petites forêts de tamaris, ou au milieu des plantations de jones d'eau; mais ce n'est pas un motif suffisant pour que ces petites forêts oceupent tout le bassill, et le contour, au contraire, n'en doit point être couvert, ainsi que je l'ai dit, afin que, lorsque les oiseaux seront ragaillardis par le beau temps, ils puissent s'ébattre entre eux , en nageant rapidement, et sans rencontrer d'obstacle qui arrête leur course. En effet, si d'un eôté ils sont bien aises de trouver des endroits où ils puissent se glisser, pour tendre des piéges aux bêtes aquatiques qui s'y tiennent eachées, ils seraient fâchés d'un autre côté de ne point trouver d'espaces

potestas domesticis avibus, aut aquilis rel accipitribus involandi. Sed ea tota maceries opere tectorio levigatur extra intraque, ne feles, aut viverra perrepat. Media deinde parte nessotropliii lacus defoditur in duos pedes altitudinis, spatiumque longitudini datur et latitudiui quantum loci conditio permittit. Ora lacus ne corrunpantur violentia restagnautis undæ, quæ semper iuflnese debet, opere Siguino consternuntur, eaque un in gradus oportet erigi, sed paulatim clivo subsidere, ut tamquam e litore descendatur in aquam. Solum autem stagni per circuitum, quod sit iustar modi totius duarum partiun, lapidibus inculcatis [ac] tectorio muniendum est, ne possit herbas evomere, præbealque nantibus aquæ puram superficiem. Media rursus terrena pars esse debet, ut colocasiis conseratur, aliisque familiaribus aquæ viridibus, quæ inopacant avium receptacula. Sunt enim quibus cordi cst vel iu silvulis tamaricum, aut scirporum frutetis immorari. Nec ob hanc tamen causam totus locus silvulis occupetur, sed ut dixi, per circuitum vacet, ut siue impedimento, cum apricilate diei gestiunt aves, uandi velo. citate concertent. Nam quemadmodum desiderant esse 
vides, qu’ils puissent traverser en liberté. Les bords du bassin seront en outre tapissés d'herbes en dehors de tous cótés sur une largcur de vingt pieds, et l'extrémité de tout le terrain sera garnie de logettes d'un pied en carré, dans lesquelles les oiseaux feront leurs nids, et qui seront construites en pierre le long des murailles, et rcvêtues d'un enduit. Ces logettes seront séparées l'une de l'autre par des arbrisseaux de buis ou de myrte, qui les courriront de leur ombrage sans monter plus haut que les murs. Ensuite on creusera en terre un petit canal qui régnera tout le long des logettes, et dans lequel on jettera tous les jours la nourriture des oiseaux, afin qu'elle soit entrainée par l'eau qui y coulera, parce que c'est la facon de nourrir ces sortes d'oiseaux. Parmi les productions que fournit la terre, ils aiment le plus le panis et le millet, ainsi que l'orge : on leur' donne aussi du gland et du mare de raisin, Iorsqu'on est à portée de le faire. Quant aux noul'risures aquatiques, on leur donnera, si l'on est à portée d'en avoir, des écrevisses, des alecula de ruisseaux, et toutes sortes d'autres foissons de rivières du nombre de ceux qui ne croissent pas beancoup. Les temps de l'accouplement de ces oiseaux sont les mêmes que pour les autres oiseaux sauvages, c'est-à-dire, que c'est le mois de mars et le suivant. II faut, pendant ces deux mois, jeter de tous côtés dans leurs retraites des brins de paille avec de petites branches d'arbres, afin qu'ils puissent les ramasser, pour les employer à la construction de leurs nids. Mais la chose la plus importante à faire, lorsque l'on veut former un endroit où I'on veut élever des canards, c'est de ramasser les œufs des oiseaux que nous venons de nommer dans les environs des marais, lieux où ils

quo irrepant, et ubi délitescentibus fluviaticis animalibus insilientur ; ita offenduntur, si non sunt libera spatia, qua permeent. Extra lacum deinde per vicenos undique pedes gramine ripæ vestiantur : sintque post hunc agri modum circa maceriam lapide fabricata et expolita tectoriis pedalia in quadratum cubilia, quibus innidificent ares : eaque contegantur intersitis buxeis aut myrteis fruticibus, qui non excedant altitudinem parietum. Statim deinde perpetuus canaliculus liuni depressus construatur, per quem quotidie misti cuu aqua cibi decurrant : sic enim pabulatur id geuus avium. Gratissima est esca terrestris leguminis panicum et milium, necnon et ordeum : sed ubi copia est, etiam glaus ac vinacea prabeutur. Aquatilis autem cibi si sitfacultas, datur cammarus, et rivalis alecula, rel si qua sunt incrementi parvi fluviorum animalia. Tenipora concubitus ealem qua cacterae silvestres alites observant Martii, sequentisque mensis : per quos festuca surculique in aviariis passim spargendi sunt, ut colligere possint aves, quibus nidos construant. Sed antıquissimum est, cum quis nessotrophion constituere volet, ut præedictarum avium circa paludes, in quibus plerumque fortant, ova colligat, et colıortalibus gallinis suljiciat. Sic enim exclusi pondent communément, et de les donner à couver à des poules de basse-cour, parce que, dics que les petits en sont éclos sous des poules et qu'ils ont été élevés par elles, ils perdent leur caractère sauvage, et ne manquent point de multiplier quand on vient à les renfermer dans des viviers; au lieu que si on voulait renfermer, aussitôt qu'on les aurait pris, des oiseaux habitués à une vie libre, ils tarderaient à pondre dans la captivité. C'cst en avoir assez dit sur l'entretien des oiseaux qui nagent.

$X$ VI. Mais en traitant des animaux aquatiques, je suis arivi véà parler des soins que l'on doit prendre des poissons; ainsi, quoique je regarde le profit qu'on en peut tirer comme très-étranger aux agriculteurs, (que peut-on en effet imaginer de plus opposé entre soi que la terre et l'eau? ) je ne négligerai pas d'en parler, parce que nos ancêtres ont célébré ce goût particulier, jusqu'au point de renfermer des poissons de mer dans de l'eau douce, et de prendre, pour nourrir des mulets et des chiens de mer, les mêmes soins que l'on prend aujourd'hui pour nourrir des murènes et des loups marins. En effet, ces anciens descendants de Romulus et de Numa, tout rustiques qu'ils étaient, avaient fort à cœur de se procurer. dans la vie qu'ils menaient à leurs métairies, une sorte d'abondance en tout genre, semblable à celle qui règne parmi ceux qui vivent à la ville. Aussi ne se contentaient-ils pas de peupler de poissons les viviers qu'ils avaient construits à cet effet, mais ils portaient la prévoyance jusqu'à remplir les lacs formés par la nature même de semences de poissons de mier qu'ils y jetaient. C'est ainsi que le lac Velinus et le Sabatinus, aussi bien que le Volsinensis et le Ciminius, sont parvenus à nous donner en abondance non-seulement

educatique pulli deponunt ingenia silrestria, clausique vivariis haud dubitanter progenerant. Nam si modo captas ares, quæ consuevere libero victu, custodiæ tradere velis, parere cunctantur in servitute. Sed de tutela naptium volucrum satis dictum est.

XVI. Verum opportune, dum meminimus aquatilium auimalium, ad curam pervenimus piscium, quorum reditum quamvis alienissimum agricultoribus putem (quid enim tam contrarium est, quam terrenum fujdo?), tamen non ounittam : nam et liarum studia rerum majores nostri celebraverunt, adeo quidem, nt etiam dulcibus aquis marinos clauderent pisces, atquie eadem cura mugilem scarumque nutrirent, qua nunc murana et lupus educantur. Magni enim astimabat velus illa Romuli et Numa rustica progenies, si urbanæe vitæ comparetur villatica, nulla parte copiarum defici. Quamobrem non solum piscinas, quas ipsi construxerant, frequentabant; sed etiam quos rerum natura lacus fecerat, convectis marinis seminilous replebant. Inde Vellnus, inde etiam Sabatinus, item Volsiniensis, et Ciminius lupos auratasque procreaverunt, ac si qua sunt alia piscium genera dulcis undæ tolerantia. Mox istam curam sequens retas abolevit, et la.utitia lo- 
des loups marins et des aurata, mais encore de toutes les autres espèces de poissons qui ont pu s'habituer à l'eau douce. Par la sulte, les siècles postérieurs ont abandonné ces soins, ct la magnificence des gens opulents a commencé à renfermer la mer et Neptune lui-même; cet usage subsistait déjà du temps de nos prédécesseurs; et le propos de Marcius Philippus, tout spiritue qu'il est, dénote cependant un raffinement de luxe poussé à l'excès. Cet homme mangeant un jour à la table de l'hôtequi le logeait à Cassino, et ayant goûté d'un loup marin péché dans un fleuve voisin qu'on lui avait servi, le cracha, et joignit à cette action impertinente ce propos : Je veux mourir, si je u'ai as cru d'abord que c'était un poisson. Ce serment contribua donc à rendre la gourmandise de bien des gens encore plus raffinée qu'elle ne l'avait encore été, et apprit aux palais les plus connaisseurs et les plus délicats à dédaigner les loups pris dans les rivières, pour ne vouloir que ceux qui auraient été fatigués en remontant le courant du Tibre. Aussi Terentius Varron assure-t-il qu'il n'y avait pas dans son siècle un seul fanfaron, ni un seul rhinthon, qui ne crût qu'autant valait avoir un vivier peuplé de grenouilles, comme d'en avoir un peuplé de ces sortes de poissons. Et cependant, dans le temps même auquel Varron fait remonter ce trait de luxe, on vantait beaucoup l'austérité de Caton, quoique celui-ci eût vendu lui-même, en sa qualité de tuteur de Lucullus, les viviers de son pupille, pour la somme énorme de quatre millions de sestertii. Les délices de la cuisine étaient dejà fort goûtées à cette époque, puisqu'on faisait des viviers qui communiquaient avec la mer, et que Sergius Orata et Lleinius Muræna ne se plaisaient pas moins à porter le surnom des poissons qu'ils avaient pris, que le Numantin et l'Isaurien s'étaient plu, avant eux, à porter celui des na-

cupletum maria ipsa Neptunumque clauserunt, ut jam tum avorum memoria circumferretur Marcii Philippi velut urbanissimum, quod erat luxuriosissimi factum atque dictuin. Nam is forte Casini cum apud lospitem copnaret, appositumque e vicino flumine lupum degustasset atque expuisset, improbum factum dicto prosecutus : Peream, inqult, nlsi piscem putavi. Hoc igitur perjurium multorum subtillorem fecit gulam, doctaque et erudita palata fastidire docult fuvialem lupum, nisi quem Tiberis adverso torrente defatigasset. Ilaque Terentins Varro : Nullus est, inquit, loc seculo nebulo, ac rlinthon, qui non jam dicat, nihil sua interesse, utrum ejusmodi piscibus, an ranis frequens habeat vivarium. Ac tamen iisdem temporibus, quibus laanc memorabat Varro luxuriem, maxime landabatur severitas Catonis, qui nihilo minus et ipse tutor Luculli grandi are sestertium millium quadringento. rum piscinas pupilli sui venditabat. Jam enim celelres erant delicix popinales, cum ad mare deferrentur viva. ria, quorum studiosissimi, velut ante devictarum gentiun Sumantinus et Isauricus, ita Sergius Orafa, of Licinins tions qu'ils avaient conquises. Mais comme les mœurs ont aujourd'hui pris leur pli, de façon que ces usages sont non-seulement très-communs, mais qu'ils passent même, au jugement de tout le monde pour très-louables et très-honnêtes, j’enseignerai aussi moi-même la manière dont un chef de famille doit s'y prendre pour tirer du profit de sa métairie dans ce genre, afin d'éviter de me donner, l'air d'être le censeur trop tardif de tant de siècles qui ont précédé celui-ci. Quiconque aura donc acheté ou des îles ou des possessions voisines de la mer, dans lesquelles il ne pourrait retirer aucun fruit de la terre, vu la maigreur du sol, qui se fait communément remarquer sur le bord de la mer, travaillera à s'établir un fonds de revenu sur la mer elle-même. Mais il faut communément com. mencer par examiner à cet effet la nature du terrain dans lequel on se sera déterminé à faire des viviers, parce que tous les rivages ne peuvent pas se faire à toutes sortes de poissons. On peut élever dams les contrées limoneuses des poissons plats, tels que la sole, le turbot, le passer : elles sont encore très-convenables pour les conchylia, les murex, les ostrece et les purpurce, ainsi que pour les coquillages des pectunculi, pour les balani et pour les sphondyli. Quant aux bassins aréneux, on peut très-bien, à la vèrité, y nourrir des poissons plats ; mais on y nourrira encore mieux les poissons de haute mer, tels que les auratce, les dentices et les umbrce, tant celles de Carthage que celles de notre pays; au lieu que ces bassins sont moins propres aux conchylia. D'un autre côté, une mer pleine de rochers nour. rira très-bien les poissons qui tirent leur nom de sa nature, c'est-à-dire, ceux que l'on appelle saxatiles, parce qu'ils se tiennent dans les rochers, tels que les memulce (les merles) les turdi et les melanuri. De même qu'il faut connaitre les différences qui sont entre les riva-

Murana captorum piscium læetabantur rocabulis. Séd quoniam sic mores obcalluere, non ut baec usitata, verum ut maxime laudabilia et honesta judicarentur : nos quoquo ne videamur tot (jam) seculorum seri castigatores, lunns etiam quxstum villaticum patrisfamilias demonstrabimus. Qui sive insulas, sive maritimos agros mercatus, propter exilitatem soli, quæe plerumque litori vicina est, fructus terrac percipere non poterit, ex mari reditum constituat. Hujus autem rei quasi primordium est, naturam loci contemplari, quo piscinas facere coustitueris. Non enim om. nibus litoribus omne genus piscium laberi potest. Limosa regio planum educat piscem, velut soleam, rlıombum, passerem. Eadem quoque maxime idonea est conchyliis, muricibus, et ostreis, purpurarumque, tum concharum pectunculis, balanis, vel sphondylis. At arenosi gurgites planos quidem non pessime, sed pelagios melius pascunt, ut auratas, ac dentices, Punicasque et indigenas, umbras : verum concliyliis minus apti. Rursus optime saxosum mare nominis sui pisces nutrit, qui scilicet, quod in petris sta. bulentur, saxatiles dicti supt, ut merula turdique , nec mị. 
ges, il faut aussi connattre celles qui sont entre les bras de mer, pour ne pas se laisser tromper par des poissons étrangers. En effet, tous les poissons ne s'accommodent pas de toutes sortes de mer: l'helops, par exemple, ne vit point dans d'autres mers que la mer de Pamphylie; et le faber, ce poisson que les habitants de Gadès, mon pays natal, mettent au nombre des meilleurs poissons, et que nous appelons, conformément à l'ancien usage, Zeus, ne vit que dans la mer Atlantique; enfin le scarus, que les cótes de l'Asie et de la Grèce donnent partout en abondance jusqu'à la Sicile, n'a jamais passé dans la mer de Ligurie ni dans celle d'Ibérie par les Gaules. Ainsi quand on prendrait quelques-uns de ces poissons pour les jeter dans ses viviers, on ne pourrait jamais les y conserver longtemps. Entre tous les poissons de prix de notre pays, on ne compte que la murène, qui, quojque originaire de la mer de Tarse et de la mer Carpathienne, qui est à l'extrémité de celleci, puisse soutenil quelques mers étrangères que ce soit, dans lesquelles elle se trouve transportée. Mais il est temps de parler de la position des viviers.

XVII. Nous pensons qu'un étang est parfait, lorsqu'il est disposéde facon que le flot de la mer, en y entrant, repousse celui qui y était entré avant lui, et l'empêche d'y séjourner longtemps. C'est en effet l'état qui ressemble le plus à celui de la mer même, qui, perpétucllement agitee par les vents, se renouvelle sans cesse, et ne peut jamais s'échauffer, par la raison que ses eaux inferieures, qui sont toujours les plus fraiches, remontent à sa partie supérieure. Au surplus, ou on taille cet ćtang en plein roc, ce qu'on est trèsrarement dans la possibilité de faire, ou on le construit sur le rivage en ouvrage de Signia.

nus melanuri. Atque ut litorum sic et fretorum differentias nosse oportet, ne nos alienigenæ pisces jlecipiant. Non enim ounni mari potest omnis esse, ut helops, qui Pauphilio profundo nec alio pascitur : ut Atlantico faber, qui et in nostro Gadium municipio generosissimis piscibus adnumera. tur, eumque prisca consuetudine Zeum appellamus: ut scarus, qui totius Asiæ Graciaque litoribus Sicilia tenus freruentissinus exit, nunquam in Lignsticum, nec per Gallias enavit ad Hibericum mare. Itaque ne si capti quidem perferantur in ıostra vivaria, diıtırni queaut possideri. Sola ex pretiosis piscibus muraeı, quanvis 'Tartesii, Carpathiique pelagi, quod est ultimum, vernacula, quovis lospes freto peregrinum mare sustinet. Sed jam de situ piscinarum dicendum est.

XVII. Staguum censemus exinie optimum, quod sic positum est, ut insequens maris unda priorem submovent, nec intra conseptum sinat remanere veterem. Namque id simillimum est pelago, quod agitatum ventis assidue renovatur, nec concalescere potest : quoniam gelidum ab imo fluctum revolvit in partem superiorem. Il autem stagnum vel exciditur in petra, cujus rarissima est occa-
N'importe de quelque façon il soit formé, pourvu qu'il soit dans le cas d'être continuellement rafralchi par des eaux nouvelles : mais, quel qu'il soit, il y faudra pratiquer auprès de la terre ferme des cavernes, dont les unes seront simples et droites, pour servir de retraites aux poissons couverts d'écailles, et les autres, sans être trop spacieuses, présenteront divers contours dans lesquels les murènes pourront se cacher, quoique quelques personnes évitent de mêler ces derniers poissons avec d'autres, parce que s'ils viennent à être attaqués de la rage, à laquelle ils sont communément sujets comme les chiens, il arrive très-souvent qu'ils poursuivent les poissons couverts d'écailles, et qu'ils les exterminent, en les mangeant en grande partie. Si la nature du lieu le comporte, il faut que l'eau trouve des passages qui lui soient ouverts sur tous les côtés du vivier, parce qu'elle sera plus aisément repoussée de l'étang où elle aura séjourné longtemps, quand elle trouvera une issue du côté opposé à celui par lequel le flot y sera entré. Nous estimons qu'il faut, si la situation du lieu le permet, pratiquer ces passages sur la partie inférieure de la digue qui retient la mer, de façon qu'à l'aide d'un niveau placé sur le sol de la terre, on soit assuré que l'eau de la mer est à sept pieds d'élévation au-dessus de ce sol. En effet, il suffira aux poissons qui seront dans l'étang d'y trouver de l'eay à cette hauteur, et, d'un autre côté, il n'y a point de doute que plus l'eau viendra du fond de la mer, plus elle sera fraiche, et par conséquent convenable aux poissons qui nageront dedans, Mais si l'endroit où nous aurons jugé à propos de placer notre vivier est de niveau avec l'eau de la mer, il faudra creuser un bassin à la profondeur de neuf pieds, et percer le canal, quí, servira de passage au flot, à deux pieds au-des--

sio, vel in litore construitur opere Signino. Sed utcunque. fabricatum est, si semper influente gurgite riget, habere. debet specus juxta solum, corumque alios simplices, et rectos, quo secedant squamosi greges, alios in cochleam retortos, nec nimis spatiosos, in quibus muræna delites. cant; quamquam nonnullis commisceri eas cum alterius notæe piscibus non placet : quia si rabie vexantur, quod huic generi velut canino solet accidere, savissime perse. quuntur squamosos, plurimosque mandendo consumunt; itineraque, si loci naturn permittit, omni lateri piscinæe dari convenit. Facilius enim vetus submovetur unda, cum quacunque parte fluctıs urget, per adversam patet exitus. Hos autem meatus fieri censemus per imam consepti partem, si loci situs ita competit, ut in solo piscina posita libella septem pedibus sublimius esse maris aquor ostendat : nam piscibıs stagni lıæc in altitudinem gurgitis mensura abunde est. Nec dubium, quin quanto magis, imo mari venit unda, tanto sit frigidior, quod est aptissimum nartibus. Sin autem locus, ubi vivarium constituere censemus, pari libra cum sequore maris est, in pedes novem defodiatur piscina, et iufra duos a summa 
sous de la partie supérieure de ce bassin. Il faudra aussi avoir soin que la bouche de ce canal soit très-large, parce qu'il n'est pas possible que l'eau qui sera stagnante dans le bassin au-dessous du niveau de la mer soit assez refoulée pour monter plus haut, sans que la nouvelle eau qui s'y rendra de la mer y vienne à grands flots. Bien des gens pensent qu'il faut pratiquer sur les cótés de ces sortes d'étangs de longues retraites pour les poissons, ainsi que des cavernes qui. aillent en serpentant, et dans lesquelles ils puissent se mettre à couvert lorsqu'ils auront trop chaud. Mais à moins que ces étangs ne soient dans le cas d'être traversés en tout temps par une eau nouvelle, qui vienne continuellement de la mer, cette méthode ne peut qu'être contraire aux poissons, parce que la nouvelle eau ne pénétrant pas facilement dans ces sortes de retraites, et l'ancienne n'en sortant qu'avec peine, elle est plus nuisible aux poissons en croupissant, que l'abri ne leur est avantageux. II faut cependant creuser sur les digues des espèces de cases, où les poissons puissent sc mettre à l'abri lorsqu'ils voudront éviter l'ardeur du soleil, et d'où l'eau puisse néanmoins s'écouler facilement, lorsqu'elle y sera entrée. Au surplus, on aura l'attention de mettre au-devant des canaux par lesquels le réservoir se dégorgera, des barreaux de cuivre dont les ouvertures soient assez petites pour empécher les poissons de passer à travers. Eit si la largeur de l'étang le permet, il sera à propos qu'il s'y trouve renfermés par-ci par-là des rochers du rivage, et surtout de ceux qui seront couverts d'algue, afin que cet étang représente, autant que le génie humain peut y arriver, l'image d'une mer véritable, et que les poissons qui seront renfermés s'aperçoivent le moins que faire se pourra de leur prison. Lorsque ces étangs seront ainsi disposés, on y

parte cuniculis rivi perducantur; curandumque est, ut quam largissime veniant, quoniam modus ille aquæ jacentis infra libraın maris non aliter exprimitur, quam si major recentls freti vis incesserit. Multi putant in ejus. modi stagnis longos piscibus recessus, et flexuosos in lateribus specus esse fabricardos, quo sint opaciores restuantibus latebra. Sed si recens mare non semper stagnum permeat, id facere contrarium est. Nam ejusmodi receptacula nec facile novas admittunt aquas, et difficulter veteres emittunt : plusque nocet putris unda, quam pro. dest opacitas. Debent tamen similes velut cellæ parietibus excavari, ut sint, quæ protegant refugientes ardorem solis, et uihilominus facile, quam conceperint aquam, remittant. Verum meminisse oportebit, ut rivis, per quos exundat piscina, pratigantur anei foraminibus exignis cancelli, quibus impediatur fuga piscium. Si vero laxitas permittit, e litore scopulos, qui præcipue herbis algæe vestiuntur, non erit alienum per stagni spatia disponere, et quantum comininisci valet hominis ingenium, repræsentare faciem [veri] maris, ut clausi quam minime custodiam sentiant. Hac ratione stabulis ordinatis aquatile mettra le troupeau aquatique; et de même que pour les productions de la terre il faut également, pour tout ce qui vit dans l'eau, avoir constamment devant les yeux le précepte qui ordonne d'observer ce que comporle chaque contrée. En effet, oll ne pourrait pas, quand on le voudrait, nourrir dans un vivier une aussi grande quantité de surmulets qu'on en voit quelquefois dans la mer, parce que ce poisson est très délicat, et que la captivité lui est insupportable : aussi est-il rare d'en trouver un ou deux sur plusieurs milliers qui s'habituent à leur prison; au lieu que nous avons souvent vu des troupcaux marins de láches mugiles et de loups voraces vivre dans des viviers. Par la même raison nous ferons attention à la nature de notre rivage, et nous n'y établirons des étangs que lorsqu'il est semé de ro. chers. Nous jetterons done dans ces étangs des turdi de toute espèce, des merulce et des mus. teloe avides, ainsi que des loups sans tache (car il y en a aussi de bigarrés). Nous y joindrons des murènes flottantes, que l'on compte entre les poissons les plus recherchés, et d'autres poissons de prix choisis dans l'cspèce des saxatiles : car il n'y a aucun profit, je ne dis pas à nourrir, mais même à prendre des poissons communs. Les espèces de poissons que nous venons de détailler peuvent également être renfermés dans des étangs formés sur un rivage sablonneux, comme dans des étangs pleins de vase et de limon; mais ceuxci sont plus convenables, ainsi que je l'ai dit précédemment, aux conchylia, et aux poissons qui se tiennent toujours au fond de l'eau. Nonseulement l'emplacement d'un étang destinć à contenir des poissons couchés à plat doit être différent de celui qui en contiendra de ceux qui se tiennent debout, mais on ne donne pas non plus la même nourriture aux uns et aux autres.

pecus inducemus; sitque nobis antiquissimum meminisse etiam in fluviatili negotio, quod in terreno pracipitur : $E t$ guid quaque feral regio. Neque enim si velimus, ut in mari non nunquam conspeximus, in vivario multitudinem mullorum pascere queamus, cum sit mollissimum genus, et servitutis indignantissimum. Raro itaque unus aut alter de multis millibus claustra patitur : at contra frequenter aninadvertimus intra septa pelagios greges inertis mugilis et rapacis lupi. Quare, ut proposueram, qualitatem litoris nostri contemplemur; et si videmus scopulosum, probemus. Turdi conplura genera, merulasque et avidas mustelas, tum etiam sine macula (nam sunt et varii) lupos includemus. Item flutas, quæ maxime probantur, murænas, et si quæ sunt alia saxatilis notæ, quorum pretia vigent. Nam vile ne captare quidem, nedım alere conducit. Possunt ista eadem genera etiam litoris arenosi stagnis contineri. Nam qux limo cœnoque lutescunt, ut ante jam dixi, concliyliis magis et jacentibus ajta sunt animalibus. Neque est eadem lacus positio, quæ recipit cubantes : neque eadem prabentur cibaria prostratis piscibus, quæ erectis. Namque soleis ac rhombis et simi- 
En efiet, on a soin de creuser un bassin à deux pieds sous terre pour les soles, les turbots et les poissons semblables, dans une partie du rivage qui ne manque jamais d'eau, même pendant le reflux de la mer. Ensuite on enfonec sur les bords de ce bassin des barreaux serrés les uns auprès des autres, et qui soient toujours plus élevés que l'eau, dans Ic temps même que le flux de la mer se fait sentir. Après quoi on l'entoure de digues jetées en avant, qui en referment toute l'étendue dans leur sein, et qui sont eonstruites de faeon qu'elles soient plus élevíes que le bassin même. Moyennant cela l'impétuosité des vagues de la mer se trouve brisće par la résistance du môle qui leur est opposé, et les poissons qui se trouvent dans une eau calme r'y sont point exposés à être chassés de la place qu'ils oecupent; outre que le vivier lui-même ne se eharge point de cet amas d'algue que la fureur de la mer vomit dans les temps orageux. Il faudra que ces môles soient coupés par-ci par-là par de petits passages très-étroits et semblables aux détours du Méandre, qui puissent laisser entrer dans le bassin les eaux de la mer pendant la plus violente tempête, sans que l'agitation du flot s'y fasse sentir. La nourriture des poissons qui sont eouichés à plat doit ếtre plus tendre que celle des saxaliles, paree que, n'ayant point de dents, ils la lèchent ou l'avalent entière, sans pouvoir la mâcher. C'est pourquoi, il faut leur donner des haleculce sèches, des chalcides salées et des sarlina pourries, ainsi que des ouies de scarus ct des intestins de pelamis ou de lacertus, ou des entrailles de maquereau, de charcharus et d'elacata; en un mot, de toutes les immondices des poissons salés que l'on jette hors des boutiques des vendeurs de marée. Si nous avons détaillé toutes ces espèces de nourri- tures, ce n'est pas qu'on les trouve sur toutes les cótes, mais c'est afin qu'on donnc à ces poissons eelles d'entre clles qu'on aura sous sa main. Dans le nombre des fruits verts, on peut leur donner des figues vertes et ouvertes en deux, ainsi que le fruit múr de l'arboisier qu'on aura broyé entre les doigts, descormes molles et concassées, et toutes les autres espèees de nourritures approehantes de celles que l'on avale, comme du fromage fait depuis peu de temps arec du lait nouvellement tiré, si la situation du lieu ou le bon marché du lait le permettent. Il n'y a cependant pas de páture qui leur soit plus eonvenable que les salaisons dont nous venons de parler, paree qu'elles ont de l'odeur, et que tous les poissons qui sont couehés à plat eherehent plutót leur nourriture a vec les narines qu'a vec ies yeux. En effet, comme ils sont toujours couehés sur le ventre, ils voient plutôt en l'air qu'ils ne distinguent ce qui peut être à terre de droite ou de gauche. Aussi lorsqu'on leur jette des salaisons, en suivent-ils l'odeur à la piste, jusqu'à ce qu'ils soient arrivés à l'endroit où est eette nourriture. Ces salaisons suffisent aussi pour nourrir les au. tres poissons saxatiles ou de pleine mer, quoiqu'on les nourrisse encore mieux avec les mêmes poissons quand ils sont frais. Car l'halecula nouvcllement pẻehée, le cammarus, le petit gobio, et en un mot tous les poissons qui ne grossissent point, serrent de nourriture aux plus gros. S'it arrive eependant que la violence des orages ne permette point de leur donner ce genre de nourriture, on leur donnera des boulettes de pain bis, ou des fruits de la saison coupés par morceaux. On leur jettera tous les jours des figues sèches, au cas qu'elles soient très-abondantes (comme dans les contrées de la Bétique et de la Numidie). Au reste, il ne faut pas se hasarder, comme font lihus animalihus humilis in duos pedes piscina deprimitur in ea parte litoris, qua profluo recessu nunquam destituitur. Spissi deiride clatri marginibus infiguntur, qui super aqquam semper emineant, etıam cum maris astus intumuerit. Mos prajaciuntur in gyrum moles, ita ut complectantur sinu suo, et tamen excedant stagni modum. Sic enim et maris atrocilas olyjectu crepidinis frangitur, et in tranquillo consistens piscis sedibus suis non exturbatur, neque ipsum vivarium repletur algarum congerie, quam tempestatibus eructat pelagi violentia. Oportebit autem nonnullis locis moles intercidi more Mxsndri, parvis sed angustis itineribus, qux quantalibet hiemis sa. vitia mare sine fuctu transmittant. Esca jacentium unollior esse debet, quam saxatilium. Xain quia dentibus ca. rent, aut lambunt cibos, aut integros hauriunt, mandere quidem non possunt. Itaque praberi conrenit tabenlèis lialeculas, et salibus exesam chalcidem, putremque sar. dinam, nec minus scarorum branclias, vel quicquid in. testini pelamis aut lacertus gerit : tum scombri, carchari. que et elacata ventriculos, et ne per singula enumerem, salsamentorum onnium purgamenta, quæ cetariorum COLUMFLLE. officinis everruntur. Nos autem plura nominavimus ge nera, non quia cuncta cunctis litoribus exeunt, sed ut ex his aliqua, quorum erit facultas, præbeamus. Facit etian ex pomis viridis adaperta ficus; et mitis digitis infracta unedo; nec minis elisum molle sorbum, quique sunt cibi sorbilibus proxini, ut e mulctra recens casens, si loci conditio vel lactis amona permittit. Nulla tamen aque, quam pradictæ salsuræ pabula commode dantur, (quoniain odorata sunt. Omnis enim jacens piscis magis naribus escan, quam oculis vestigat. Nam dum supinus semper cubat, sublimius aspectat, et ea qua in plano sunt dextra lavaque non facile pervidet. Itaque cum salsamenta objecta sunt, eorum sequens odorem, pervenit ad cibos. Cateri autem saxatiles aut pelagici satis ex his, sed recentibus melius pascuntur. Nam et halecula modo capta, et cantarus exiguusque gobio, quisquis denique est incrementi minuti piscis, majorem alit. Siquando tamen hiemis sævitia non patitur ejus generis escam dari, vel sordidi panis off $x$, vel siqua sunt temporis poma concisa prabentur. Ficus quıdem arida semper objicitur, exinie si sit, ut Batica Numjdiæeque regionibus, larga. Ca. 
bien des gens, à ne letur rien donner, sous le prétexte qu'ils peuvent se soutenir pendant un eertain temps, loisqu'ils sont renfermés. Car, pour. peu que le poisson n'ait pas été engraissé par les nourritures que lui aura données son maítre, se. maigreur annoncera, lorsqu'on viendra à le porter §u marché, qu’il n'a pas été pris en pleine mer, mais qu'il a été tiré d'un étang où on le gardait, ce qui diminuera beaucoup de son prix. Je finirai ee traitć-ci par ee genre de nourriture dépendante des métairies, afin que le leeteur ne soit point fatigué par la longueur d'un volume trop considérable; et je reviendrai dans le livre suivant aux soins que demandent les bêtes fauves, et à l'entretien des abeilles.

\section{LIVRE IX.}

\section{PRÉFACE.}

Je passc à l'entretien des bêtes fauves et à l'éducation des abeilles, que je pourrais aussi, P. Silvinus, appeler avee raison des nourritures de métairies, puisque c'était anciennement l'usage d'avoir auprès des métairies, et eommunément sous l'habitation du propriétaire, des pares remplis de levrauts, de chevreuils et de sangliers, afin que la vuc d'une chasse cireonserite dais un enclos pût flatter l'œil du propriétairc, et qu'il fût à portée de tirer des bêtes de ces pares, comme d'un garde-manger, dans le cas où il en avait besoin pour sa table. On logeait aussi, de notre temps même, des abeilles dans les masures de la métairic, ou sous des galeries couvertes et dans des vergers. Ainsi puisque nous a vons rendu raison du titre que nous assignons à ce traité-ci, suivons à présent par détail ehacun des objets que nous venons d'annoncer.

terum illud commilti non debet, quod multi faciunt, ut nihil prabeant, quia semetipsos etiam clausi diu tolerare possint. Nam nisi piscis domini cibariis saginatur, cum ad piscatorium forum perlalus est, macies inlicat eum non esse libero mari captum, sed de custodia elatum, propter quod plurimun pretio detralitur. Atque lıəc villatica pastio finem prosenti disputationi faciat, ne im. molico volumine lector fatigetur. Redibimus autem se. quentiexordio ad curam silvestrlum pecorum, cultumque apum.

\section{LIBER JX.} PR.F.FITIO.

Venio nunc ad tutelam pecudum silvestrium et anium educationem : quas et ipsas, Publi Silvine, villaticas pastiones jure dixerim; siquidem mos antiquus lepusculis ca. preisque, ac subus feris juxta villam plerumque subjecta dominicis lıabitationibus ponebat vivaria, ul et conspectu suo clausa venatio possidentis oblectaret oculos, et cum pxegisset usus epularum, velut e cella promerefur. Apibus quoque dahalur sedes adhuc nostra memoria vel iu
I. Les bêtes fauves, telles que les ehevreuils et les daims, ainsi que toutes les espèces d'oryx, do eerfs et de sangliers, sont tantôt un objet de magnificence et de plaisir pour un proprićtaire, tantót un objet de profit et de revenu. Mais ceux qui ne font elore un terrain que dans la vuc d'y jouir du plaisir de la chasse, se eontentent d'investir en forme de pare lo lieu le plus voisin de leurs bâtiments qui est susceptible de cette disposition, et de donner continuellement à la main de la nourriture et de l'eau aux bêtes qu'ils y renferment; au lieu que ceux qui tendent au profit ct au revenu ne balancent point à destiner aux animaux que nous venons de nommer, les forêts qu'ils peuvent avoir dans le voisinage de lcur métairie (car il est important qu'elles ne soient point éloignées de l'œil du maître); et si la nature leur refuse de l'eau, ils y font venir par le secours de l'art de l'eau courante, ou ereusent des mares qu'ils pavent en ouvrage de Signia, pour contenir l'eau de pluic à mesure qu'elle tombera du ciel. Chacun réserve à cette destination une étendue de forêts proportionnée à ses fa. cultés, et l'on ne manque pas de l'environner d'un mur construit en pierre, à chaux et à ciment-, pour peu que le bon marché tant de la pierre que des journées des ouvriers engage à le eonstruire ainsi; sinon on se contente d'un mur de brique erue, et de mortier de terre. Mais quand le chef de famille ne trouve son compte ni à l'une ni à l'autre de ces bâtisses, la raison veut qu'il ne ferme cet enclos que de vacerrce : c'est le nom que l'on donne à une espèce de treillis formé de bois de robre, de chêne ou de liége; car on cst rarement dans le cas d'y employer le bois d'olivier. En un mot, on choisit pour faire cette clóture tout ce qui résiste le plus longtemps aux

ipsis villa parietilus excisis, vel in protectis porticibus ac pomariis. Quare quoniam tituli, quem prascripsimus huic disputationi, ratio reddita est, ea nunc quæ proposuimus singıla persequamur.

1. Feræ pecudes, ut capreoli, damaeque, nec minus orygum cervorumque genera et aprorum, modo lautiliis ac voluptatibus dominorum serviunt, morlo quastui ac reditibus. Sed qui venationem voluptati suxe claudunt, contenti sunt, utcunque competit proximus aedificio loci situs, munire vivarium, semperque de manu cilsos et aquam prabere : qui vero quxstum redilumque desideraut, cum est vicinum villæ nemus (id enim refert non procul esse al, oculis domini) sine cunctatione prodictis animalibus destiuant. Et si naturalis defuit aqua, vel inducitur fluens, vel infossi lacus Signino consternuntur, qui receptam pluviatilem contineant. Modus silva pro cujusque facultalibus occupatur; ac si lapillis el operæ vilitas suadeat, liand dubic camenlis ef calce formatus circumdatur unurus : sin aliter, crudo latere ac lu to construc. tus. Ubi vero neutrum patrifamilia conducit, ratio postulat vacerris includi : sic euim appellatır genus clatrorum : idque fabricalur ex robore querceo, vel subereo. Nam 
ravages causés par la pluic, en se réglant sur la nature du pays où l'on est. Au reste, soit que l'on emploie des troules d'arbres dans leur entier, soit qu'on les fende en autant de parties que leur grosseur peut l'exiger, on les peree toujours de plusieurs troušsur les cótés ; et après les avoir fiehés en terre perpendiculairement autour du pare d'espaces en espaces, on insère des branehes d'arbres en traverse dans les trous pratiqués sur les cotés, afin de fermer entièrement tout passage aux bêtes fauves. 01 , il suffit, pour y parvenir, de fieher en terre les vacerro de huit pieds en huit pieds de distance, et de les treillisser transversalemcnt avec des barreaux, de telle sorte que les espaces vides qui formeront les mailles du treillis ne soient point assez larges pour laisser aux bêtes la liberté de s'enfuir. On peut elore de cette faeon des contrées même trèsrtendues, ainsi que des ehaines de montagnes entières, telles qu'on en voit dans les Gaules et dans quelques autres provinees; avec d'autant plus de facilitéqu'il y eroît une quantité immense de bois propre à fabriquer ces vacerra, et que toutes les autres choses nécessaires à ee genre d'économie s'y rencontrent heureusement. En effet, non-seulcment les fontaines y sont trèsmultipliées, ehose très-salutaire aux espèces de bêtes dont nous avons parlé, mais le sol leur fournit encore de la pâture de lui-même et avee la plus grande profusion. On clıoisit surtout des parties de forêts qui soient fertiles en productions données soit par la terre, soit par les arbres, parce que ces animaux n'ont pas moins besoin du fruit des robres que des herbes: on recherehe particulierement les forêts qui produisent en abondance les glands du chêne, de l'yeuse et du cerrus, l'arboux, et les autres fruits sauvages

olexe rara est occasio. Quidquid denique sub injuria pluviarum magis diuturnum est, pro conditione regionis ad hunc usum eligitır. Et sive teres arhoris truncus, sive ut crassitudo postulavit, fissilis slipes compluribus locis per latus efforatur, et in circuitu vivarii certis intervenien. tilous spatiis defixus erigitur : deinde per transversa lateruur cava transmittuntur amites, qui exitus ferarum ob. serent. Satis est autem vacerras inter pedes octonos deli. gere, serisque transversis ita clatrare, ue spatiorum laxitas, qua furaminibus intervenit, pecudi probeat fugam. Jloc autem modo licet etiam latissimas regiones tractusque Inontium claudere, sicuti Galliarum necnon et in aliis quibusdam provinciis locorum vastitas patitur. Nam et fabricandis iugens est vacerris materix copia, et catera in hanc $\mathrm{rcm}$ feliciter suppetunt; quippe crebris fontibus abundat solum, quod est maxine prodictis generibus salutare : tuu cliam sua sponte pabula feris benignissime subministrat : procipueque saltus eliguntur, qui et terrenls foctibus et arboribus abundant. Nam ut graminibus ita frugibus roburneis opus labent: maximeyue laudau. tur, qui sunt feracissimi quernec glaudis et ilignex, nec uinus cerrer, tun et arluuli, carterorumque pounotum dont nous avons donné un détail plus circonstancié en traitant des animaux de basse-eour. En effet, la pâture des bêtes fau ves est presque la même que eelle des animaux domestiques. Ce n'est pas qu'un ehef de famille attentif puisse s'en tenir aux nourritures que la terre produit d'elle-même, puisqu'il doit encore, dans les temps de l'année où les forêts ne fournissent point de pátures, subvenir aux besoins des animaux qu'il tient renfermés, avee les fruits des réeoltes qu'il aura serrés, en nourrissant ees animaux d'orge ou de blé adoreum, ainsi que de fèves et de mare de raisin en quantité, et en leur donnant de tout ee qui sera à très-bon marché. Mais, afin que les bêtes fauves remar(fuent que l'on prend soin de leur donner ees sortes de nourritures, il fau. dra en lâcher dans le pare une ou deux qui auront été préalablement apprivoisées à la maison, et qqui, pareourant tout le pare, amèneront avee elles, à l'endroit où la nourriture sera répandue; celles qui hésiteraient à s'y rendre. Ce n'est pas sculement pendant la disette de l'hiver qu'il est utile de suivre eette méthode, mais encore après que les bêtes fauves auront mis bas, afin qu'elles élèvent mieux leurs petits. Le gardien du pare doit done examiner souvent si elles ont mis bas, afin de les sustenter avee du blé, qu'il leur donnera à la main. Il ne faut pas laisser vieillir les oryx , les sangliers ni les antres bêter. fauves au delà de quatre ans, paree que, si elles grossissent jusqu’à eette époque, la vieillesse les fait ensuite maigrir. C'est pourquoi on aura soin de les veudre dans un temps ou la vigueur de l'áge soutienne la beauté de lenr eorps. On peut néanmoins garder les cerfs pendaut un plus grand nombre d'années, parec que leur jeunesse dure longtemps, attendu que la nature leur a donné

silvestrium, qux diligentius persecuti sùmus, cum do colıortalibus subus disputaremus. Nam eadem fere sunt pecudum silvestrium pabula, quæ dousesticarum. Contentus tamen non debet esse diligeus paterfamilias cibis, quos suapte natura terra gignit, sed temporibus anni, quibus silvae pabulis carent, condita messe clansis snccurrere, ordeoque alece, vel adorco farre aut faba, plurimumque etian vinaceis, quicquid denique vilissime constiterit, dare. Idque ut intelligant feræ pracberi, unau vel alteram domi mansucfactam conveniet inmittere, qua? pervagata totum vivarium cunctantes all objecta cibaria pecudes perducat. Nec solum istud per liemis penuriam fieri expedit, sed cum etiam fortx partus ediderint, quo melius educeut uatos. Itaque custos vivarii frequenter speculari debebit, si jau effectic sint, It manu datis sustileantur fumentis. Nec vero patiendus est oryx, aut aper, aliusve quis ferus ultra quadrimatum senescere. Nau usque in loc teinpus capiunt incremeuta, postea unaces. cuut senectute. Quare dım viridis atas pulcliritudinem corporis conselvat, ere mutandi sunt. Cervus tancu coupluribus annis sustineri polest. Nam diu juvenis possidetur, quod aevi longioris vitum soltilus est. I)e nuj. 
en partage une vle très-longuc. Ce que nous avous à preserlre relativement aux animaux de petite taille, tels que les levrauts, c'est de semer i leur Intention, sur de petites planehes dispersées de cóté et d'autre dans des pares qui seront eutourés de murailles, des mélanges de blé et d'herbes potagères, comme chicorée sauvage et laitue. On tirera aussi de ses greniers des pois ehiches, soit de ceux de Carthage, soit de ccux de notre pays, ainsi que de l'orge ct de la gesse, quion lcur donnera après les avoir fait tremper dans de l'eau de pluic, attendu que les Ievrauts ne font pas grand cas de ces sortes de grains yuand ils sont sees. On comprend aisément (quand je ne le dirais pas) qu'il y aurait peu de profit à renférmer ces animaux ou d'autres semblables dans des pares cntourés de vacerr $x$, puisque la petilesse de leur corps leur faciliterait ic moyen de se glisser à travers les mailles des treillis, et que, trouvant des passages ouverts, ils ne tarde. raient pas à s'enfuir.

1I. Je passe à I'entreticn des ruches a miel. II n'est guère possible de traiter ce sujet avec plus de détail que n'a fait Hyginus, avec plus de gráce et d'ornement queVirgile et avec plus d'éléganceque Celsus. En cffet, Hyginus a recueilli avec le plus grand soin tous les préceptes des anciens auteurs, qui étaicnt épars dans les monuments les moins connus : Virgile les a ornés des fleurs de sa poésie, ct Celsus a pris le milieu cntre ees deux auteurs. Aussi n'aurions-nous pas même entamé cette matière, si le complétement de l'art que nous avons entrepris d'enseigner ne l'eût pas revendiquée comme une de ses parties, ct si nous n'eussions pas craint que l'ensemble de l'ouvrage que nous avons commencé ne parût imparfait ct mutilé, comme si nous cn eussions coupé, pour ainsi dire, un membre. Au surplus, je serais plus porté à rejeter sur la licence ordinaire des poëtes les choses fabuleuses que l'on raconte sur l'origine des abcilles, et qui n'ont point été omises par Hyginus, qu'd̀ y ajouter fol. Effectivement ce n'est pas le fait d'un homme de la campagne de faire des recherches pour savoir s'il y a jamais eu une femme de trèsbelle figure, nomméc Mélissa, que Jupiter a changée en abcille, ou si (comme le dit le poëte Évhémerus) ce sont des frelons qui ont engendrí les abeilles avee le soleil; si ces abeilles, après avoir été élevées par les Nymphes Phryxonides, ont été les nourrices de Jupiter dans la caverne de Dieté, et si ce dicu, pour les en récompenser, a voulu qu'elles n'cussent pas d'autre nourriture que celle qu'elles lui avaient donnéc dans son cnfance : car quoique de parcils faits ne soient point déplacés dans la bouche d'un poëtc, Virgile s'est néanmoins contenté de les toucher sommairement, puisqu'il n'en dit que ce mot unique dans un de ses vers : Elles ont nourri le roi du ciel sous l'antre de Dicté. Il n'est pas plus du ressort des agriculteurs de savoir dans quel temps et dans quel pays ces insectes ont commencé à voir le jour, si c’est dans la Thessalie sous Aristćc, ou dans l'île Céa, comme l'écrit Évhémerus, ou sur le mont Hymette au temps d'Ércehthéus, comme Ie dit Euthronius, ou enfin dans la Crète au temps de Saturne, comme lc prétend Nicander; non plus que de savoir si les essaims se multiplient par accoupicment, comme nous le voyons pratiqué par les autres animaux, ou si ce sont les fleurs qui donnent aux abcilles des héritières de leur nom, comme l'assure notre ami Maron; enfin si c'est par le bec ou par une autre partic du corps qu'elIes rendent la liqueur du miel. C'est plutôt aux. personnes qui travaillent à pénétrer les seercts noris autem incrementi animalibus, qualis est lepus, haxc praccipimus, ut in is vivariis, qua maceria ununita sunt, farruginis et olerun feræ intubi lactucxque semina parvu. lis areolis per dirersa spatia factis injiciantur. Itemque P'unicum cicer, vel hoc veruaculım, nec minus ordeum, at cicercula condita ex horreo promantur, el aqua caelesti macerata objiciantur. Nam sicca non nimis ab lepusculis appetuntur. Haxc porro animalia vel similia his, eliam si. leute me, facile intelligitur, quam non expedial conferre in [il] vivarium, quod vacerris circumdatum est : siquiIeiu propter exiguitatem corporis facile clatris subrepunt, el liberos nacla egressus fugam moliuntur.

11. Venio munc ad alvorum curam, de quibus neque diligentius quidquam procipi putest, quam ab Hygino jam dictun est, uec ornatius quam Virgilio, nec elegan. tius quam Celso. Hyginus veterum auctorum placita secrelis dispersa monimentis industrie collegit : Virgilius poelicis floribus illuminavit : Celsus utriusque menorati adhibuit modun. Quare ne attentanda quidem nobis fuit hrec dispulationis materia, nisi quod consummatio sus. cepla professionis lanc quoque sui partem desiderabat, ne universitas inchoati operis nostri, velut membro aliquo reciso, mutila atque imperfecta conspiceretur. Atque ea, quæ Hyginus fabulose tradita de originibus apum non in. termisit, poetic $x$ magis licentine quam nostrx fidei concesserim. Nec sane rustico dignum est sciscitari, fuerit ne mulier pulcherrima specie Nelissa, quam Jupiter in apem convertit, an (ut Evhemerus poeta dicit) crabronibus et sole genitas apes, quas nymph Phryxonides elucaverunt, mox Dictaco snecu Jovis extitisse nutrices, casque pabula munere dei sortitas quibus ipsa parvum educaverant alumnum. Ista enim, quamvis non dedeceant poetam, summatim tamen et uno tantummodo versiculo leviter attigit Virgilius, cum sic ait : Dictaeo celi reyem pavere sub antro. Sed ne illud quidem pertinet ad agricolas, quando et in qua regione primum natæ sint : utrum in Thessalia sub Aristaco, an in insula Cea, ut scribit Evlıe. merus, an Erechthei temporibus in monte Hymello, ut Euthronius; an Creta Saturni temporibus, ut Nicander : non magis quam utrum examina, tanquam cæetera vide. mus animalia, concubitu sobolem procreent, an liæredem generis sui floribus eligant, quod affirmat noster Maro : 
de la nature, qu'aux gens de la campagne, d falre des reeherelies sur ees objets comme sur d'autres semblables; et ees sortes de recherches sont plus flatteuses pour des gens lettrés qui ont le loisir nécessaire pour lire, que pour des agrieulteurs occupés, attendu qu'elles ne sont d'aueune utilité ni pour le progrès de leur ouvrage, ni pour l'économic domestique.

III. Nous allons par conséquent nous renfermer dans les objets qui sont plus convenables à eeux qui font valoir des ruches. Le fondateur de la seete des péripatétieiens, Aristote fait voir, dans les livres qu'il a composés sur les animaux, qu'il y a de plusieurs sortes d'abeilles ou d'essaims; qu'entre les différents essaims, les uns sout composés de grandes abeilles, mais ramassées, qui sont noires et velues, et que d'autres sont composés d'abeilles plus petites à la vérité que les premières, mais également rondes, et dont la couleur est brune et le poil hérissé; qu'il y a des abeilles plus petites et moins rondes que les précedentes, quoique grasses et larges, et qui sont de couleur de miel; qu'enfin il y en a de très-petites et très-déliées dont le ventre est pointu, et qui sont lisses et marquetées d'une couleur tirant sur l'or. Virgile, quil s'appuie de l'autorité de ee philosophe, approuve aussi, entre autres, les abeilles qui sont très-petites, oblongues, lisses, luisantes et éclatantes comme l'or, et dont le corps est marqueté de taches uniformes, et dont les mours sont paisibles. En effet, les abeilles sont méchantes à proportion de leur grandeur, ainsi que de leur rondeur : néanmoins quand elles sont de bonue espèce, ceux qui prennent soin des ruches viennent aisément à bout d'apaiser leur colère, en les visitant souvent. En effet, plus on les soigne souvent, plus tòt elles s'apprivoisent; et lorsqu'on y met une certaine

et utrum evomant liquorem mellis, an alia parte reddant. llæc enim et his similia magis scrutantium rerun naturae latebras, quam rusticorum est inquirere. Studiosis quoque literarum gratiora sunt ista in otio legentibus, quanı negotiosis agricolis : quoniam neque in opere neque in re faıniliari quidquam juvant.

III. Quare revertamur ad ea, quæ alveorum cultoribus magis apta sunt. Peripatetica sect $x$ conditor Aristoteles In iis libris, quos de animalibus conscripsit, apun sive cxaminum genera complura demonstral, earumque alias vastas sed glomerosas, easdemque nigras et hirsutas apes labent : alias minores quidem, sed aque rotundas et infusci coloris horridique pili : alias magis exiguas, nec tam rotundas, sed obesas tamen et latas, coloris inelinsculi : nonnullas mininas gracilesque, et acuti alvi, ex aureolo varias atque leves : ejusque auctoritatem sequens Virgilins, maxime probat parvulas, oblongas, leves, nitidas, Ardenles auro, el paribus lita corpora gutlis, moribus etiam placidis. Naın quanto grandior apis, atque rotuudior, tanto pejor. Si vero sevior, masime pessima est. Sed tamen iracundia nota melioris attentlon, on peut les conserver jusqu'à dix ans : II n'y a cependant pas d'essaim qui puisse aller au delà de ee terme, quoiqu'on ait soin de remplacer toutes les années, par de jeunes abeilles, eelles que la mort aura enlevées, paree qu'ordinairement la peuplade entière d'une ruehe se trouve absolument éteinte à la dixième année. C'est pourquoi, pour éviter que cet aceident ne se fasse sentir au même temps dans toutes les ruches que l'on possède, il faudra continuelle. ment propager la race de ees inseetes, en prenant le soin au printemps de recueillir les nouveaux essaims dans le temps qu'ils paraftront, et d'augmenter le nombre de ses ruehes, d'autant qu'il arrive souvent 'à ees insectes d'être surpris par des maladies. Nous donnerons en leur lieu les remèdes qu'il faut appliquer à ees maladies.

IV. Dès qu'on aura fait un ehoix d'abeilles conformément aux préeeptes que nous venons de donner, on leur destinera des páturages. Ces pa. turages doivent être dans un canton très-solitaire et fermé aux troupeaux, sous un climat exposé au soleil et qui ne soit point orageux, ainsi que le preserit notre ami Maron en ces termes: Où les vents n'aient point d'accès, parce qu'ils empéchent ces insectes de porter leurs provisions jusqu'à leurs ruches, oì les brebis et les boucs n'insultent point les fleurs par leur pétulance el ne les détruisent point avec leurs cornes; où enfin les génisses errantes dans la plaine ne dissipent pas la rosée qui couvre les herbes, et ne les foulent point elles.mémes aux pieds à mesure qu'elles lèvent de terre. Il faut aussi que la contréeproduise beaucoup de petites plantes, et prineipalement du thym et de l'origan, ainsi que de la thymbre, ou de cette sarriette de notre pays, que les gens de la campagne appellent satureia. Il faut encore qu'il s'y trouve

apium facile delinitur assiduo interventu eorum qui cllrant [alvearia.] Nam cun sæepius tractantur, celerius mansuescunt, durantque si diligenter excultae sunt, in annos decem; nec ullum examen hanc setatem potest excedere, quamvis in demortuarum locum quotannis pullos substituant. Nam fere decimo ad internecionem anno gens universa totius alvei consumitur. Ihaque ne loc in toto fiat apiario, semper propaganda erit soboles, observandumque vere cum se nova profundent exanina, ut excipiantur, et domiciliorum numerus angeatur. Nam sæe morbis intercipiuntur, quibus quemadmodum mederi oportet, suo loco dicetur.

IV. Interin per has notas, quas jam diximus, probatis apibus destinari debent pabulationes, ereque sint secretissiıne, et ut noster pracipit Maro, vidux pecudibus, aprico et minime procelloso cali statu : Quo neque sit ventis aditus; nam pabula venti Ferre domum prohibent : neque oves hedique petulci Floribus insultent, aut crrans bucula campo Deculiat rorem, et sur. gentes allerat herbas. Eadentque regio fuecunda sit fruticis exigui, et maximo thymi aut origani, tum etian 
une grande quantité d'arbrisseaux de plus haut jet, tels que le romariı et les deux espèces de cytises, je veux dire eelui que l'on plante et celui qui vient de lui-même; le pin toujours vert et la petite yeuse, attendu que la grande est désapprouvée par tout le monde. On approuve encore le lierre, non pas préeisément à cause de sal bonté, mais paree qu'il donne beaucoup de miel. Quaut aux arbres, ceux qu'on approuve le plus sont les jujubiers rouge et blane, ainsi que le tamaris, et même les amandiers, les pêchers, les poiriers, en un mot la plupart des arbres à fruit, pour ne pas les nommer ici tous en détail. Entre les arbres sauvages, les robres qui portent du glaud sont execllents, ainsi que le térébinthe, lelentisque (qui lui ressemble, le eèdre odoriférant, et les tilleuls; les ifs sont les seuls de tous les arbres qui nuisent à ces lusectes. Il y a en outre unc infinité de graines, soit de eelles qui verdissent au milieu d'un gazon non cultivé, soit de celles que renferment dans leur sein les terres labourées, qui toutes produisent des fleurs très-recherchées par les abeilles : telles sont dans les terrains arrosés l'herbe de la eamomille, les tiges de l'aeanthe, eelles de l'asplıodèle, et les feuilles aiguës du nareisse: telles sont eneore dans les planelıes des jardins les lis resplendissants par leur blanelıeur, et les girofliers, qui ne leur cèdent point en beauté, ainsi que les roses de Carthage, les violettes jaunes et pourprées, et la jaeinthe de couleur bleu-céleste. On mettra aussi en terre des bulbes de safran, soit de celui de Corycos, soit de celui de Sieile, pour eolorer le miel et lui donner de l'odeur. Il naít encore, tant dans les guérets quedans les pâturages, une foule d'herbes molns estimées que les préeédentes, qui font foisonner le miel dans les rayons de eire, telles que le cliou sauvage, qui

liymbra, vel nostratis cunilac, quam satıreiam rustici vocant. Post haec frequens sit incrementi majoris surcnlus, ut rosuarinus, et utraque cytisus. Est enim sativa et altera sua spontis. Itemque senuper virens pinus, et minor ilcx : nam prolixior ab omnibıs improbatur. Ederæ quoque non propter bonitatem recipiuntur, sed quia praleut plurionum mellis. Arhores vero sunt probatissima, rutila atque allsa ziziphus, nec minus tamarices, tum ctiain anygdala, [et] persici, atque pyri, denique pomiferarum pleracque, ne singulis inmorer. Ac silvestrium comuod:ssime faciunt graudifcra robora, quin etiam teI chintlıs, nec dissiuilis huic lentiscus, et odorata ce. Irus, ac tilia. Solx ex omnibus nocentes taxi repudiantur. Mille praterea semina vol crudo cespite virentia, vel subacta sulco, flores anicissimos apibus creant, int sunt in irriguo solo frutices amelli, caules acanthini, scapus asploodeli, gladiolus narcissi. At in loortensi lira consita nitcnt candida lilia, nec his sordidiora Icucoia, tum punicca rosx, Intcolaeque, ct Sarrana viola, nec miuus ratestis Inminis hyacintlus, Corycius itcm Siculusque Imlbus croci deponitur, (pui coloret odloretquc mella. Jam vero notie vilioris immumerabiles uaseuntur herba cultis alque pascuis regiontibus, juic farorum ceras exuberant est très-eommun; le grand raifort, qui n'est pas plıs préeleux; certaines lierbes potagères, comme le rapistrum et la ehieorée sauvage, les fleurs du pavot noir, et enfin le panais sauvage et le panais

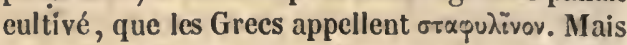
entre toutes les plantes, tant celles que j'ai détaillées que celles que j’ai omises pour abréger ( paree qu'elles sont innombrables), le thym est celle qui donne le miel du meilleur goût; après le thym vient la thymbre, le serpolet et l'origan. Le romarin et la sarriette de notre pays, que j'ai appelée salureia, quoique toutes deux excellentes, ne sont comptées qu'au troisième rang. Pour les fleurs du tamaris et du jujubier, ainsi que toutes les autres espèces de pâturages que nous avons détaillées, elles nedonnent plus qu'un miel d'un goût médioere. Cependant les miels qui passent pour les pires de tous sont celui des bois, qui est extrait du genet d'Espagne et de l'arbousier, et celui des métairies, que rendent les plantes potageres et les herbes que l'on fait venir dans du fumier. J'ai fait voir quelle est la situation des pâturages convenables aux abeilles, ainsi que les différentes espèees de nourritures qui leur sont propres; je vais traiter à présent des ruches ou maisonnettes où elles se retirent.

V. On placera les ruches des abeilles en faee du midi d'hiver, loin du tumulte et de la eompagnie tant des hommes que des bestiaux, et dans un lieu qui ne soit ni chaud ni froid, pareo que l'une et l'autre de ces températures leur est également nuisible. Il faut aussi que ee soit au fond d'une vallée, paree que lẹs abeilles qui iront ehercher leur pâture trouveront plus d'aisance, lorsqu'elles ne seront point chargées, à s'élever vers le sommet de la montagne, et qu'après avoir ramassé tout ce dont elles auront besoin, elles en

ut vulgares lapsanx, nec lis pretiosior armoracia, rapistrique olus, ct intubi silvestris ac nigri papaveris flores, tun agrestis pastinaca, et ejusicm nomiuis edonita,

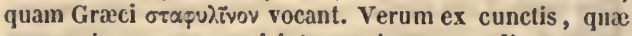
proposui, quaque omisi temporis compendia sequens (uam inexputabilis erat numerus) saporis pracipui mocla reddit thymus. Exinio dcinde prosimum thymbra, ser. pyllumque et origanum. Tertia notæ, sed adbuc generosic, niarinus ros et nostras cunila, quam dixi saturciam. Me. diocris deinde gustus tamaricis, ac zizipli florcs, reliqui. que, qua proposuimus, cibaria. Sed ex sordidis deterrimac uota mcl liabetur nemorense, quod ex sparto atque arbuto provenit : villaticum, quod nascitur in olcribus $\mathrm{ct}$ stcren. rosis herbis. Et quoniam situm pastionum atque etiau genera pabulorum exposui, nunc de ipsis receptaculis et domiciliis examinum loquar.

V. Sedes apibus collocauda est contra brumalem une. ridiem procul a tumultu, et catu hominum ac pecnduı, nec calido loco, ncc frigido : nam utraque re infcstantur' Hacc autem sit ima parte vallis, it ct vacua cun pro. dcuut pabulatum apes, facilius cditioribus advolent. 't collectis ntensilibus cum oncre per proctivia non agre de. voleut. Si villa situs ita competit, non est dubitandum, 
descendront sans pelne avec leur charge, en suivant la pente de la côte. Lorsque la situation de la métairie lc comporte, il n'est point douteux qu'il ne faille mettre les ruches dans la proximlté de ses bátiments, et dans un endroit qui soit clos de murailles, et a l'abri des odeurs qu'exhalent les latrines puantes, lc fumier et lc bain. Si cependant la situation de la métairic ne permet pas d'éviter ces odeurs, il sera encore plus avantageux d'en courir le danger, pourvu toutcfois qu'il n'en résulte pas de trop grandsinconvénients, que de mettre l'endroit où seront les ruches hor's de la vue du propriétaire. Mais si l'on rencontre des inconvénients de tout cóté, il faudra au moins placer les ruches dans une vallée voisine, et où il puisse souvent descendre sans se fatiguer ; car l'entretien des abeilles demande une grande fidélitéde la part de celui qui en est chargé. Or, comme la fidélité est une vertu très-rare, les visites du maitre en assureront la garde, d'autant que cette manutention n'est pas seulement ennemie d'un gardien fripon, mais qu'elle l'est encore d'un gardien négligent jusqu’à la malpropreté, et qu'elle n'est pas moins rebutée par le défaut de propreté que par la fraude. Au surplus, quel que soit l'endroit où seront placées les ruches, il ne faut pas que le mur qui l'environne soit très-élevé : sl cependant la crainte des voleurs détermine à le faire plus haut qu'il ne doit etre naturellement, il faut qu'il soit percé à trois pieds de terre de petites fenêtres rangées par ordre, pour la commodité des abeilles. On y joindra une chaumière tant pour servir d'habitation aux gardiens, que pour y serrer tous les ustensiles relatifs à cette branche de l'économie ruralc. Il faut surtout la garnir d'une provision de ruches toutes prètes pour les nouveaux essaims, ainsi que d'herbes médicinales, et de toutes les autres choses dont on peut avoir besoin lorsque les abeilles sont

quin æedificio junctum apiarium maceria circumdemus, sed iu ea parte, qux tetris latrinæe sterquiliniique et a balinei libera est odoribus. Verum si positio repugnabit, nec unaxina tamen incommoda congruent, sic quoque magis expediet sub oculis domini esse apiarium. Sin autem cuncta fuerint inimica, certe vicina vallis occupetur, quo sapius descendere non sit grave possidenti. Nam res ista maxiInam fidem desiderat; qua quonian rarissima est, interventu domini tutius custoditur. Neque ea curatorem fraıdulentum tantum, sed etiam immunda seguitia perosa est. Eque enim dedignatur, si minus pure habita est, ac si tractetur fraudulenter. Sed ubicumque fuerint al rearia, uon editissimo claudantur muro. Qui si metu pradonum sublimior placuerit, tribus elat is ab lumo pedibus, exiguis iu ordinen feuestellis apilus sit pervius : jungaturque tugurium, quod et custodes habilent, et [quo] condatur insfruuentum : sitque maxime repletum praparatis alveis ad usum novorum examinum, nec niuts herlsis salutaribus, et siqua sunt alia, quxe langueutibus adhilentur. Pal'naque vestibulum aut ingens olcaster obumbict, i't malades. Leur vestibule sera ombragé par des palmiers ou par de grands oliviers sautages, afin que lorsque les nouveanx rois commenceront à conduire les essaims dans la saisun du printemps, qui leur est la plus favorable, et que la jeunesse sortira des rayons pour aller folátrer, le coisinage l'invite à se garantir de la chaleur, en se cachant sous les arbres qui se présenteront pour la recevoir sous leurs feuillages. Il faudra aussi conduire dans le même endroit une eau de source qui y coulera continucllement, si l'on est à portée de le faire; sinon, en mettre à l'usage de ces insectes dans un canal artificiel, parce que l'eau est indispensable pour façonner non-seulement les rayons et le miel, mais encore les petits. Soit done que l'on y ail conduit des eaux courantes, comme je viens de le dire, soit qu'on y ait amassé de l'eau de pluie dans des canaux, il faudra avoir soin d'entasser sur ces eaux des branchages, afin que les abeil. les puissent se poser sur ces espèces de ponts multipliés, et déployer leurs ailes au soleil d'été, au cas que le vent d'est soit venu fondre sur elles pendant qu'elles se reposaient; et qu'il les ait éparpillées ou plongées dans l'eau. II faut encore planter, dans tous les environs de l'endroit où sont les ruches, de petits arbustes, et surtout de ceux qui contribuent a entretenir la santé des abeilles. En effet, le cytise et après lui l'arbre qui porte la casse, le pin, le romarin et même la sarriette et le thym, ainsi que les violettes ou telles autres plantes convenables que la qualité du sol permettra d'y avoir, ne sont pas moins propres à les guérir de leurs maladies qu'à les nourrir. On en éloignera nonseulement les plantes, mais encore toutes les autres choses d'une odeur forte et désagrćable, tellc que celle de l'écrevisse grillée au feu, ou celle d'un bourbier marécageux. Il faut également

cum prima novi ducent exam ina reges, Fere suo, ludelque favis emissajuventus: Vicina invitet decedere ripa calori, obviaque hospilis teneat frondentibus arbos. Tum perennis aqua, si est facultas, inducatur, vel extracla canali manu detur, sine qua neque favineque mella nec pulli denique figurari queunt. Sive igitur, ut dixi, proterfluens unda, vel putcalis canalibus immissa fuerit, virgis ac la. pidibus aggeretur apiun causa, Pontibus ut crebris possint consistere, et alas Pandere ad cestivum solem, si forte moranteis Sparserit, aul praceps Niepluno immer. serit Eurus. Conseri deinde circa totum apiarium debent arbuscula incrementi parri, maximeque propter sa. lubritatem (nam sunt etiam remedio langueutibus) cytisi, tum deinde casix atque pini ef rosmarinus : quiu etian cunila et tliymi frutices, item violanm, vel quxecunque utiliter depoui patitur qualitas terrar. Gravis et tetri odo. ris non solum virentia sed et qualibet res prohibeaulur, sicuti cancri uidor, cum est ignibus adustus, aut odor palustris coni. Nec minus vitentur cava tupis aut vallis.

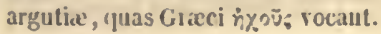


éviter les cavités des roches, ou les vallées retentIssantes, que les Grees appellent h̀yö (ćehos).

VI. Lorsqu'ou aura eonvenablement disposé l'endrolt pour l'entretien des abcilles, on fabriquera des ruehes de manière ou d'autre, suivant la nature du pays. Si le pays est fertile en liége, on emploiera aveo le plus grand succès l'écorce de ee bois à faire de très-bonnes ruclies, qui ne seront ni trop froides en hiver ni trop ehaudes en été; s'il est abondant en férules, on s'en servira également bien pour les faire, paree que la nature de la férule tient de l'écorce. Si l'on n'a ni liége ni férule, on les fera avee des tissus de saules, ou, si l'on n'a pas même de saules, on en fabriquera avec des trones d'arbres évidés ou sciés en planches. Les ruches de terre euite sont les pires de toutes, parce qu'elles sont brûlantes pendant les ehaleurs do l'été, et glaciales pendant les froids de l'hiver. On compte encore deux espèces do ruehes : les unes sont faites avee de la bouse, les autres sont eonstruites en brique. Celsus condamne l'une de ees espèces avec ralson, parce qu'clle est fort sujette au feu; et quoiqu'il approuve l'autre, il ne dissimule pas néanmoins le prineipal ineonvénient auquel elle est sujette, et qui consiste à ne pouvoir pas être transportée, si le cas l'exige : aussi suis-je bien ćloigné de penser eomme lui, que malgré cet inconvénient on puisse a voir des ruches do cette dernière espèce. En effet, non-seulement leur immobilité répugne aux arrangements que pourrait avoir à prendre le propriétaire, s'il voulait vendre sa terre ou en garnir une autre de ruehes ( raisons de convenanee qui ne regarderaient tout au plus que le ehef de famille lui-mème); mais elle rend eneore impossibles les seeours que demandent les abeilles en certaines oecasions. Cornmenten effet pourrait:on les transporter dans des

VI. Igitur orlinatis sedibus, alvearia fabricanda sunt pro courlitione regionis. Sire illa ferax est suberis, lıaud dubitanter utilissimas alvos facienus ex corticibus, quia nec hiene rigent, nec candent sestate; sive ferulis cxuberat, iis quoque, cum sint natura corticis similes, aequc comriode vasa fexuntur. Si neutrum aderit, opere textorio sali. cibus connecteptur : vel si nec haec suppetent, liguo cavato arboris aut in Iabulas desectae fabricaluntur. Delerrima est conditio fictilium, quax et acceuduutur astatis vaporibus, et gelantur lienis frigoribus. Reliqua suut alvorum genera duo, ut vel cx fimo lingantur, vel lateribus extruan. tur : quorum alterun jure dannavit Celsus, quoniam maxime est ignibus obnoxium; alterum probavit, quanvis inconmodum ejus pracipuum non dissimulaverit, quod, si res postulet, transferri non possit. Itarue non assentior ei, qui putat nililo minus ejus generis lıabendas csse alvos: neque enim solum id repugnat rationilus do. mini, quod inmobiles sint, cum vendere ant alios agros instruere velit; (hoc enim commolun pertinet ad utilitatem solius patris familias) sed, quod ipsarmun apium causa fieri debet, cuin aut murbo aut sterilitate et penuria lo. contrées différentes de celles où elles sont, dans le cas où ces inseetes seraient affligés par la maladie, la stérilité, ou cnfin par la disette des lieux? II faut par conséquent éviter absolument eette méthode. C'est ce qui fait que, quelque égard que j'aie pour l'autorité d'un personnage aussi savant, je n'ai pas cru devoir caeher mon scntiment, sans néanmoins prétendre m’élever au-dessus de lui. En effet, le motif qui touehe prineipalement Celsus, je veux dire la crainte que les ruches des abeilles ne soient exposées au feu ou aux voleurs, est de peu de conséquence, puisqu'on peut parer à ce double accident en les revêtant d'un ouvrage en briques qui les préservera des coups de main des voleurs, et qui les protégera contre la violenec des flammes, saus néanmoins empêcher que, Iorsqu'on sera dans le cas de les déplacer, on ne puisse les transférer facilement, en brisant l'assemblage de cette construction.

VII. Mais comme presque tout le monde s'accorde à regarder eette construction comme une opération embarrassante, il suffira, quelles que soient les ruehes qu'on jugera à propos d'employer, d'élever, tout le long du lieu où on les placera, une assise de pierres de trois pieds de laauteur sur une épaisseur égale ; et lorsque cette maéonnerie sera achevée, on la revêtira avec soin d'un enduit bien poli, pour empêcher les lézards, les serpents, ou tout autre animal nuisible, d'y monter. $\Lambda$ près quoi on posera sur cette muraille, soit des ruches de briques ( suivant le sentiment de Celsus), soit des ruches maçonnées (suivant notre opinion) par tous les cótés, à l'exeeption de eelui de derrière; ou plutôt on les arrangera en file, et on les mastiquera l'unc avec l'autre, suivant l'usage de presque tous ceux qui se livrent avee un certain soin a cette branche d'économie rurale, a vec de petites briques ou avec

corum vexatas conveniat in aliam rcgionem milti, nec propter pradiclam causam moveri poterunt, hoc maxime vitandum cst. Itaque quanvis doctissimi viri anctorita. tem reverebar, tamen ambitione submota, quid ipse censerem, non omisi. Nam quod maxime movet Cclsum, ne sint stabula vel igui, vel furibus obnoxia, potest vitari opere lateritio circumstructis alvis, ut impediatur rapiua praedonis, et contra flammarum violentiam protegantur : easdemque, cum fuerint movenda, rcsolutis structura compagibus, licebit transferre.

VII. Sed quoniam plerisque videtur istud operosum, qualiacnuque vasa placuerint, collocari debebunt. Sug. gestus lapirleus extenditur per totum apiarium in tres pedes altitudinis, (totidemque crassitudinis) extructus, isque diligenter opere tectorio levigatur, ita ne ascensus lacertis, aut anguibus, aliisve noxiis animalibus probeatur. Superpoumutur deinde, sive, nt Celso placet, lateribus facta donicilia, sive, ul nobis, alvearia, praxterquam a tergo circumstructa : seu, quod peue omnium in nsu est, qui modo diligenter ista curant, per ordinem vasa disposita ligantur, vel laterculis, vel cacmentis, ita ut 
du ciment, de faęon que chacune se trouve renfermée entre deux eloisons étroites, et que les faces en soient libres tant par devant que par derrière; parce qu'il faut les ouvrir quelquefois par la face de devant qui sert de passage aux abeilles, et plus souvent encore par eelle de derrière, qui est eelle par laquelle on soigne les essaims. Si l'on ne sépare point les ruehes par des cloisons, il faut au moins les placer de facon qu'elles soient à quelque distanee les unes des autres, afin que, lorsqu'il sera question de les visiter, celles auxquelles on sera obligé de toueher pour les soigner ne eausent point d'ébranlement à celles du voisinage qui seront collées contre les premières, et n'écrasent point les abeilles qui pourront se trouver dans les environs, d'autant que ces insectes redoutent la moindre secousse, comme devant entrainer la ruine totale de leurs ouvrages délicats. Il suffit qu'il y ait trois rangs de ruches distribués les uns au-dessus des autres, puisque, dans cette supposition même, celui qui prendra soin des ruches ne laissera pas eneore que d'avoir de la peine à regarder dans celles du rang supérieur. Les ouvertures du panier, qui servent d'entrée aux abeilles, seront plus inelinées que eelles de derrière, afin que la pluie ne puisse pas y pénétrer, ou qu'au moins, dans le cas où il y en serait entré, elle n'y puisse pas séjourner, mals qu'elle puisse au contraire s'en écouler par cette issue. Il convient, pour la même raison, que l'endroit où sont les ruches soit couvert comme des portiques, ou au moins qu'il soit ombragé avec des branchages enduits d'un mortier à la earthaginoise, qui ne les mettront pas moins à l'abri de la chaleur que du froid et de la pluie. Comme néanmoins la plus violente chaleur n'est pas aussi funeste à ce genre d'inseetes que l'hiver, il faut qu'il se trouve tou.

singula binis parietibus angustis contineantur, liberæ. que frontes utrinque sint. Nam et qua procedunt, nonnunquam patefacienda sunt, ef multo magis a tergo, quia subinde curantur examina. Sin autem uulli parietes alvis intervenient, sic tamen collocanda erunt, ut paulum altera ah altera distet, ne, cum inspiciuntur, ea, qux in curatione tractatur, lıærentem sibi alteram concutiat, vicinasque apes conterreat, quac omnem motum imbecillis ut cereis scilicet operibus suis tanquam ruinam timent. Ordines quidem vasorum superinstructos in altitudinem treis esse abunde est, quoniam summum sic quoque parum commode curator inspicit. Ora cavearum, qua praebent apibus vestibula, proniora sint quam terga, ut ne influant imbres, et si forte tamen ingressi fueriut, non inmorentur, sed per aditum enlıant. Propter quos convenit alvearia porticibus supermuniri; $\sin$ aliter, luto $\mathbf{P n}$ nico frondibus inlimatis admubrari, quod tegmen cum frigora et pluvias, tum et iestus arcet. Xec tamen ita nocet luic generi caloris astus, ut hiems. Itaque semper axdificium sit post apoiarimm, 'phorl Aquilonis excipiat iı. jmiam, stabulisque prabeat teporem. Nec niuus jusa jours, derrière l'endroit où sont les ruehes, un bâtiment queleonque qui les garantisse de l'injure de l'Aquilon, et qui leur procure une chaleur tempérée. Il ne suffit pas même que leur domieile soit garanti par un bátiment, mais il faut eneore qu'il soit exposé à l'orient d'hiver, pour que les abeilles jouissent du soleil à leur sortie du matin, afin d'être plus éveillées, attendu que le froid les rend paresseuses. Aussi faut-il, par cette raison même, que les ouvertures par les(juelles les abeil. les doivent entrer dans les ruches ou en sortir soient très-étroites, afin qu'il n'y pénètre que le moins de froid que faire se pourra. Il suffit qu'elles aient la largeur nécessaire pour que l'abeille puisse y introduire son corps : moyennant quoi ni le lézard venimeux, ni la race impure des hamnetons ou des papillons, ni les eloportes qui fuient la lumière, comme dit Maron, ne pourront aller dévaster les rayons en se glissant à travers les ouvertures qui servent d'entrce, , trop étroites pour leur livrer passage. Il est aussi trèsutile de pratiquer deux ou trois passages sur Ic même couvercle d'une ruche, à proportion de ce qu'elle sera plus ou moins peuplée; ces passages seront à quclque distanee les uns des autres, à l'effet de tromper le lézard qui guette, pour ainsi dire, à la porte, et qui attend que les abeilles viennent à sortir pour les tuer. Il ell périra effectivement beaucoup moins quand elles pourront éviter les attaques de ce cruel ennemi, en se sauvant par une issue différente de celle par laquelle elles seront sorties.

VIII. Nous avons suffisamment parlé tant sur les páturages des abeilles que sur les ruches et l'endroit où l'on doit les placer. Lorsqu'on aura pourvu à ces différents objets, il faudra penser à se procurer des essaims : ear on peut ou les acheter, ou les acquérir à titre gratuit. Maisil faut

domicilia, quamvis ædificio protegantur, obrersa tamen ad hibernum orientem componi debebunt, ut apricnm labeant apes matutinum egressum, et sint experrectio. res. Nam frigus ignaviam creat; propter quod etiam fora. mina, (quibus exitus aut introitus datur, angustissinı esse debent, ut quam ninimum frigoris admittant : ea. que satis est ita forari, ne possint capereplus unius apis increnentrum. Sic nec renenatus stellio, nec obscanum scarabei vel papilionis genus, lucifugacque blathe, ut ait Maro, per laxiora spatia januae favos populabuntur. Atque utilissimum est pro freruentia domicilii duos vel tres aditus in eodem operculo distantes inter se fieri coutra fallaciam lacerti, qui velut custos vestibulo prodenulibus inhians apibus affert exitium, exque pauciores iutereunt, cum licet vitare pestis obsidia per aliud vadentibus effr. ginn.

V111. Atque lıxe de pabulationibus, domiciliis, et sedilus eligendis almute diviınus : quibus provisis, seq̨uitur ut examina desideremus. Ea porro vel aere parta, vel gratnita contingnut. Sel quas pretio comparabiuns, sen IIpulusius pradictis comprobemus notis, et carum frequen- 
s'assurer de leur bonté a vee plus de circonspection dans le premier cas que dans le second, et vérifier avec plus d'attention les signes que noưs avons donnés pour les eonnaitre. Il faut aussi ouvrir les ruches avant de conclure le marehé, pour examiner si elles sont bien peuplées, ou, si l'ou n'a pas la faculté de les regarder à l'intéricur, il faut au moins fuire ses observations sur tout ee qu'on aura la liberté d'examiner, et voir, par exemple, si les abeilles retluent en grand nombre à l'ouverture qui leur sert d'entrée, et si le bourdonnement est assez bruyant. S'il arrive par hasard qu'elles soient toutes tranquilles dans la ruelic, et que l'on n'y entende aucun bruit, on pourra approcher ses lèvres de l'ouverture qui leur sert d'entrée, et souffler dans la ruche, pour juger, au frémissement qu'elles feront aussitôt entendre, si elles y sont en grand nombre, ou noll. On aura surtout l'attention d'en faire l'emplette dans le voisinage du pays où l'on sera, plutôt que dans des contrées éloignées, pareeque coinmunément le changement de elimat les effarouche. Si l'on n'est pas à portée de cela, et que l'on soit au contraire dans la néeessité de leur faire faire un long voyage, on aura soin d'éviter qu'elles ne soient molestées par les mauvais elıemins : c'est pourquoi on fera très-bien de les apporter alors sur sa tête et pendant la nuit, paree qu'il faut les laisser tranquilles pendant le jour. On aura eneore soin de leur verser des liqueurs qui leur soient agréables, pour leur servir de nourriture pendant tout le temps qu'elles seront renfermées. Lorsque ensuite elles seront arrivées à la maison, si le jour ne fait que eomineneer à luire, on attendra le soir pour ouvrir et plaeer la ruche, afin qu'elles ne sortent pour la première fois que le matin, et aprìs s'être 1'eposées pendant toute une nuit. Il faudra aussi observer, environ trois jours de suite, si elles

\footnotetext{
liam prius quam mercemur, apertis alvearibus considere. IIuıs : vel si non fuerit inspiciendi facultas, certe id quod contemplari licet, notabimus : an in vestibulo janux complures consistant, et veliemens sonus intus murmu. rantium exaudiatur. Atyque etiam sl ommes intra domici. lium silentes forte conquiescent, labris foramini aditus admotis, et inflato spiritu ex respondente earum subito fremitu potcrinus astimare vel inultitudinem, vel paucitatem. Procipue autem custoliendum est, ut ex vicinia potius, quam ex peregrinis regionibus petantur, quoniam solent cali novitate lacessiri. Qnod si non contingit, ae necesse lıabuerimus longinquis itineribus advelıere, $\mathrm{cn}$ rabimus ne salebris solieitentur, optimeque noetilus collo portabuntur. Nam diebus requies danda est, et infundendi suut grati apibus liqnores, quibus intra clausum alantur. Mox cun perlatie domum fuerint, si dies supervenerit, llec aperiri nec collocari oportelit alvum, nisi vesperi, ut apes plaridae nuane post wotius noctis requien egredian. fur : specularique debenus lere triduo, uum guid univer.
}

ne sortent pas toutes à la fois, parce que, si eela ćtait, ee serait un signe auquel on reconnaitrait qu'elles projetteraient de s'enfuir. Nous prescrirons bientót les remèdes auxquels il faut avoir recours pour les empêcher de le faire. Quant aux abeilles que l'on a reçues en présent, ou que l'on a prises dans les ehamps, on s'en contente quelles qu'elles soient, sans les examiner avee tant do serupule; quoique je ne voudrais en aequérir, fût-ce de l'une ou de l'autre de ces deux manières, que d'excellentes, parec que les mauvaises n'oceasionnent pas moins de frais que les bonnes, et qu'elles exigent aussi bien que cellesci les soins d'un gardien. Mais une attention trèsimportante qu'il faut avoir, c'est de ne point en mêler de mauvaises avec de bonnes, de peur que celles-ei dégénèrent également par le contact avec les premières. En effet, on retire moins de profit du miel, lorsque les essaims sont mélangés d'abeilles trop paresseuses. Cependant, eomme il arrive quelquefois que, vu la nature des lieux, ou se trouve obligé de s'en procurer de médiocres (ear on n'en doit jamais aequérir de mauvaises), nous allons donner la manière dont on s'y prendra pour chercher des essaims avee attention. Les abeilles n'ont rien de plus à cœur, dans tous les lieux garnis de bois qui leur sont conveuables ct propres à l'extraction du miel, que de s'approprier pour leur usage les sourees d'eau les plus voisines d'elles. Il est done à propos de se tellir auprès de ces souces d'eau, communément depuis la seconde heure du jour, afin d'examiner s'il y vient un grand nombre d'abeilles pour boire. Car sf l'on n'en voit que quelquesunes voltiger autour de l'eau, on jugera dis lors qu'il n'y en-a pas un grand nombre dans cet cndroit (à moins cependant que la multiplicité des filets d'eau courante ne les fasse paraitre plus ekair-semées à cause de leur dispersion ); et par

sx se profundant. Quod cum faclunt, fugam meditantur. Ea remediis quibus debeat inliberi, ınox praeipienus. At qua dono vel aueupio contingnnt, minus scrupulose probantur : quamquam ne sic quidem velim nisi optimas possidere, cum et Impensam et eandem operain custodis jostulent bonx, atque improbse : et qnod maxime refert, non sunt degeneres intermiscendx, qux infament generosas. Nam minor fruetus mellis respondet, cum segniora interveniunt examina. Verumtamen quoniam interdum propter eonditionem locorum vel mediocre pecus (nan malum nullo quidem modo) parandum est, curam vesti. gandis examinibus lac ratione adtribelimus. Ubiemnque saltus sunt idonei, mellifici, nihil antiquins apes, quam, (puibns utantur, vicinos eligunt fontes. Eos itaque conve. uit plerumque ab hora seeunda obsidere, specularique quæ turba sit aquantium. Nam si panca admodum circunvolaut (uisi tamen complura capita rivorum didactas faciunt rariores) intelligenda est carmm penuria, propter quam loeum quoque non esse incllifieum suspicabinur. 
eonséquent on conelura que l'endroit lul-même n'est pas propre au miel; au lieu que si elles s'y rendent en foule, on eoneevra dès lors l'espérance la mieux fondée de prendre des essaims à la chasse. Or, voiei eomıne on viendra à bout de les tronver. On s'assurera d'abord si ees essaims sont éloignés, ou non. $\Lambda$ eet effet, on préparera de la sanguine liquide, dans laquelle on trempera des brins de paille; et pour peu qu'on touehe avec ees brins de paille le dos des abeilles qui viendiont boire, il sera aisé de recommaitree, en restant au même endroit, eelles qui y reparaitront pour la seeonde fois; de sorte que si elles ne tardent pas à revenir, on jugera qu'elles sont dans le voisinage; au lieu que si elles sout un eertain temps sans reparaittre, on estimera la distanee du lieu de leur séjour par la longueur du temps qu'elles auront mis à revenir. Si l'on a remarqué qu'elles sont revenues promptement, ou pourra, au eas que l'un n’ait point de peine à les suivre au vol, aller jusqu'au lieu même de leur séjour; au lieu qu'il faudra reeourir à un expédient plus ingénieux à l'égard de eellesqui sembleront plus éloignées. Voiei en quoi ees soins eonsisteront. On eoupera une branche de roseau garnie d'un nœud à ehaeune de ses extrémités, et on la percera sur le eóté avee une tarière; ensuite après $\mathrm{y}$ avoir distillé par eette ouverture un peu de miel ou de vin cuit jusqu'à diminution de moitić, on la mettra auprès de la fontaine ; puis aussitôt que les abeil. les, attirées par l'odeur de cette liqueur qui leur est agréable, se seront introduites en foule dans cette branehe par son ouverture, on la prendra, et l'on en bouehera l'ouverture avee le pouee, pour ne laisser sortir qu'une seule abeille à la fois. Dès qu'il en sera sortie une, l'observateur remarquera le eoté par lequel elle prendra la fuite, et la poursuivra dans sa course aussi loin qu'il lui sera possible. Lorsqu'ensuite il eessera de l'a.

At si commeant frequentes, spem quoque aucupandi exaıina ınajorem faciunt; eaque sic inveuiuntur. Primum quam longe sint explorandum est, proparandaque in hanc icm liquida rubrica : qua cum festucis illitis contigeris apium terga fonten libantium, conınoratıs eodem loco fa. cilius redeuntes agnoscere poleris; ac si uon tarde id facient, scias eas in vicino consistere : $\sin$ antem serius, pro morxe teinpore zstimahis distantiam loci. Sed cun animadverteris celeriter redeuntes, non agre persequens iter volantinm al sedem perduceris examinis. In is anten qua longius meare videbuntur, solertior adhibelitur cura, qua talis est. Arundinis internodium cum suis articulis evciditur, et terebratur ah latere talea, per quod foranen exiguo melle vel defruto instillato, pouitur juxta fontem. Deinde cum ad odorem dulcis lipuaninis complures apes irrepserumt, toltitur talea, et apposito foramini pollice non eniltitur, nisi una, quae cun evasit, fugam suan demonstrat observanti : alque is, dum sufficit, persequifur evolantem. Cun deinde conspicere desiit aprem, tum pereevoir, Il en laissera sortir une seconde; et si eelle-ci tourne du même eòté que la première, il eontinuera sa route; au lieu que si elle tourne d'un autre eôté, il déeouvrira le trou pour en lais. ser sortir une troisième et une quatrième, en remarquant le côté vers lequel s'envolera le plus grand nombre, afin de eontinuer ses poursuites, jusqu'à ee qu'il soit parvenu à l'endroit où sera eaehé l'essaim. S'il est eaehé dans une eaverne, il en fera sortir les abeilles à l'aide de la fumée; et dès qu'elles seront sorties, il fera résonner de l'airain pı)ur les arrèter dans leur course. En effet, effrayées par le son de ce métal, elles s'arrêteront aussitôt sur un arbrisseau on sur le plus haut de la eime des arbres; de sorte (que eelui qui eherche à les prendre pourra les enfermer dans une ruehe, qu'il aura eu soin de préparer à eet effet. Mais si l'essaim est fixé dans un ereux d'arbre, soit qu'il en oecupe une branehe, soit qu'il en oeeupe le trone, il faudra, au eas que la petitesse de eette branche ou de l'arbre le permette, en eouper d'abord toute la partie supérieure, que les abeilles n'oeeuperont point, avee une seie très-affilée, afin d'avoir plus tôt fait; après quoi on en eoupera la partie inférieure qui paraîtra habitée par les abeilles. Ensuite, lorsque la branehe ou le trone de l'arbre seront eoupés tant par en haut que par en bas, on les enveloppera dans un moreeau d'étofle propre, ear e'est eneore un point très-important; et, après avoir enduit les trous qui pourront se trouver sur l'enveloppe, on les portera au lieu où on veut les placer; 'enfin on les mettra au rany des autres ruehes, après $y$ avoir pratiçué de petites ouvertures, eomme j’ai déjà dit. Au surplus, quand on eherehe des essaims, il faut s'y prendre dans la matinće pour aller à cette déeouverte, afin d'avoir toute la journée devant soi pour examiner la route que prennent les abeilles. En effet, s'il est déjả tard lorsqu'on

alteram emittit : et si eandem petit cxli partem, vestigiis prioribus inhæret. Si minus, aliam atque alian foraniıo adaperto patitur egredi ; regionemque notat, in quan plu. res revolent, et eas persequitur, donec ad latebrain per. ducatur examinis. Quod sive est abditum specu, funo elicitur, et cum erupit, aeris strepitu coercetur. Nam statim sono territum vel in frutice vel in editiore silva fronde considet, et a restigatore praparato vase recon. ditur. Sin autem sedem liabet arboris cava, et aut extat ramus, quem obtinent, aut sunt in ipsius arloris trunco, tunc, si mediocritas patitur, acutissima serra, quo cele. rius id fiat, pracciditur primun superior pars, quas ah apibus vacat; deinde inferior, quatenus viletur inlabitari. Tum recisus utraque parte nundo vestimento contegilur, quonian hoc quoque plurimum refert, ac si quibus rimis liat, illilis all lucmu perferlur: relictisque parvis, ut jan dixi, foraninibus, more cxterarum alvorum collo. catur. Sed indagatoren convenit matutiua tempora ves. tigandi elizere, ut spatium diei halveat, quo exploret 
eommenee à les observer, il arrive souvent qu'elles se retirent après avoir fini leur tâehe, sans revenir davantage à l'eau, quoiqu'elles soient dans le voisinage, et que par eonséquent celui qui eherehait l'essaim est dans le eas d'ignorer à quelle distanee il est de la fontaine. II y a des personnes qui, vers le eommeneement du printemps, lient en bottes de la citronnelle, et, eomme dit le poëte, de la mélisse commune et du mélinet, herbe peu estimée, avee d'autres plantes semblables qui sont agréables à cette espèce d'inseetes, pour en frotter des ruehes jusqu'à ce qu'elles se soient imprégnées de l'odeur et du sue de ees plantes; après quoi elles essuient ces ruehes et les humeetent avec un peu de miel; puls elles les arrangent dans des forêts auprès des sourees d'eau qui s'y trouvent, pour les reporter par la suite chez elles quand elles seront remplies d'abeilles. Mais il n'y a pas de profit à suivre eette pratique, si ee n'est dans les lieux où les abeilles seront en très-grande quantité, paree qu'il arrive souvent que les passants venant à trouver ees ruehes vides, les emportent; auquel cas l'avantage d'en avolr une ou deux pleinesn'est pas eomparable au désagrément d'en perdre plusieurs vides. Lorsqu'au eontraire les abeilles sonten très-grand nombre dans un endroit, quand même on viendrait à perdre plusieurs ruehes, le profit que rendraient les abeilles que l'on aurait trouvées dédommagerait amplement de eette perte. Telle est la façou de prendre des essaims sauvages.

IX. Voiei maintenant la façon de retenir les essaims nés elez soi. Le gardien ne doit jamais manquer de visiter avee attention l'endroit où sont les ruehes. En effet, quoiqu'il n'y ait point de temps où il ne faille donner des soins aux abeilles, elles cn exigent eneore de plus assidus

commeatus apium. Sxpe enim, si serius copit cas deno. farc, etiam cum in propinquo sunt, justis operum perac. tis se recipiunt, nec remeaut ąd aquam : quo evenit ut vestigator ignorct, quam longe a fonte distet examen. Sunt qui per initia veris apiastrum, atquc, ut illc vates ait, trita melissphylla et cerintha ignobile gramen, aliasquc colligant similes herbas, quibus id genus anima. lium delectatur, et ita alvos perfricent, ut odor ct succus vasis inlıareat: qua deinde mundata exiguo mellc respergant, et per nemora non longe a fontibus disponant, caque cum repleta sıut examinibus, domum rcferant. Sed lioc nisi locis, quibus abundant apes, facere non expedit. Nam sape vel inania vasa nacti, qui forte pratereunt, sccum auferunt : nç̧ue est tanti vacua perdere complura, ut uno vel altero potiare pleno. At in majore copia, etiam si multa intcrcipiuntur, plus cst quod in repertis apibus acquiritur. Atque hace est ratio capicndi silvestria exanina.

IX. Dcinceps talis altera est vernacula retincndi. Semper quidem custos sedule circumire debet alvearia. Nequc cnim ullum tempus est, quo non curam desiderent ; sct lorsqu'elles sentent le printemps approeher, et que leurs petits eommeneent à se multiplier, d'autant que eeux-ci ne eherehent qu'à s'enfuir, à moins que eelui qui est ehargé d'en prendre soin ne les guette pour les prendre sur-le-ehamp. Car telle est la nature des abeilles, que ehaque peuplade est engendrée eommunément avee ses rois, et que, dès que ees rois ont la foree nécessaire pour voler, ils dédaignent la eompagnie et encore plus le gouvernement de leurs aneiens, par la raison qu'il est impossible que l'autorité souffre aueun partage, je ne dis pas seulement parmi les hommes, qui sont des êtres raisonnables, mais eneore moins parmi les animaux, qui, n'ayant pas la faeulté de parler, manquent abso. lument de diseernement. C'est pour eela que les nouveaux ehefs marehent à la tête de leur jeunesse, qui se tient en pelotons pendant l'espace d'un ou deux jours à l'entrée même de la ruelıe, et qui annonce par sa sortie qu'elle se eherehe un domieile partieulier. Au surplus, lorsque eelui qui prend soin des abeilles lui en assigne un à l'iustant, elle s'en eontente eomme si e'était sa patrie; au lieu que si le gardien no lui en présentait pas un, elle irait ehereher des eontrées éloignées, eomme si elle était ehassée de son pays par les mauvais traitements qu'elle y aurait soufferts. Pour empêeher que eela n'arrive, un bon gardien doit observer les ruohes au printemps jusqu'à la huitième heure du jour, passé laquelle les nouvaux bataillons ne hasardent pas la fuite, et les examiner avec un œil attentif, soit lorsqu'ils sortent, soit lorsqu'ils rentrent, paree qu'il y en a qui s'éloignent sans tarder, dès qu'ils sont sortis de la ruehe. Il pourra s'assurer d'avance avee eertitude si les abeilles méditent leur fuite, en approehant l'oreille de ehaque ruehe vers le soir, d'autant qu'il s'y élève, environ trois jours avant

eam postulant diligentiorcm, cum vernant ct exundant novis fotibus, qui nisi curatoris obsidio protinus excepti sunt, diffıgiunt. Quippe talis est apium natura, ut pariter quxque plebs generctur cum regibus; qui ubi evolandi vircs adepti sunt, consortia dedignantur vetustiorum, multoque magis imperia : quippc cum rationabili gcneri mortalium, tum magis egentibus consilii mutis animalibus, nulla sit regni societas. Itaquc novi duces procedunt cum sua jurcntute, qua uno aut altcro die in ipso domicilii vestibulo glomerata consistens, egressu sno propriae desiderium sedis ostendit; caque velut patria contenta est , si a procnratore protinus assignctur. Sin autem defuit custos, velut injuria repulsa pcregrinam regionem petit. Quod ne fiat, boni curatoris cst vernis temporibus obscrvare alvos in octavam ferc diei lıoram, post quam noll tcmere se nova proripiunt agmina ; corumque egressus re. gressusquc diligenter custodiat. Nam quædam solcut, cum subito evaserunt, sine cunctatione sc proriperc. Poterit exploratam fugam prascisccre vesperlinis tentporibus auren singulis alveis admovendo. Siquiden fere ante triduun, quam er uplionem factura sint, velut militaria 
cette fuite, un tumulte et un bourdonnement semblables à eeux que font entendre des soldats qui vont dẻeamper; et que ee tumulte, ainsi que Virgile a très-grande raison de le dire, donne i connaitre d'avance le projet du peuple, puisque le son martial et sourd de lairain reproche aux paresseuses leur lenteur, et que l'on entend alors un bruit semblable au son brisé des trompettes. Il ne faut done pas perdre de vue celles qui font entendre ce bourdonnement, afin que le gardien soit prêt à tout événement, soit qu'elles sortent pour le combat (car elles se battent ou eutre elles, eomme il arrive dans les guerres civiles, ou avec d'autres peuplades, comme on se bat contre des nations étrangères ), soit qu'elles sortent dans l'intention de prendre la fuite. Au surplus, il est aisẻ d'arrêter le com. bat d'un essaim parmi lequel règne la diseorde, ou de deux essaims qui se battent l'un contre l'autre, puisque, comme dit le même poëte, il suffit, pour les apaiser, de jeter sur eux un peu de poussière, ou de les asperger avec du vin mêlé de miel, ou avec du vin fait de raisins séchés au soleil, ou enfin avec toute autre liqueur semblable, dont la douecur leur étant familière, ne manque jamais d'apaiser leur colère, quelque cruelle qu'elle soit. Il ne faut done pas autre chose pour coneilier à merveille entre eux les rois que la diseorde a désunis. Car il se trouve souvent plusleurs chefs dans une seule peuplade, auquel cas le peuple prend différents partis, comme il arrive dans les séditions exeitées par les grands : il faut cependant empêcher que cela n'arrive souvent, paree que la nation entière se consumerait par ces guerres intestines. C'est pourquoi, quand les ehefs sont de bon accord entre eux, la paix règne sans qu'il y ait de sang répandu : mais si l'on remarque que les ar- mées soient souvent en guerre, on aura soin de tuer les chefs qui excitent les séditions : quant aux batailles livrées, on les terminera en $y$ apportant les remèdes que nous venous de donner. Lorsqu'en conséquenee de ces remèdes l'armée se sera posée en pelotolı sur la branche voisine d'un arbrisseau vert, on examinera si l'essaim est accroché de façon que toutes les abeilles soient pendues les unes aux autres en forme de grappes; ee qui sera la preuve ou qu'il n'y a qu'un seul roi, ou qu'au moins, s'il y en a plusieurs, ils sont réconciliés de bonne foi entre eux; et on le laissera par conséquent dans cette situation jusqu'á ee qu'il revole à son domicile. Mais si l'essaim est partagé en deux ou même en plusieurs mamelons, pour m'exprimer ainsi, on ne doit pas douter alors qu'il ne s'y trouve plusieurs grands, et que ces grands ne soient encore animés les uns contre les autres. Dès lors il faut ehercher les chefs dans les pelotons où l'on verra que les abeilles seront le plus rassemblées. Après avoir done frotté sa main avec le jus des herbes dont nous avons parlé, e'est-àdire, a vee du jus de mélisse ou de citronelle, afin que les abeilles ne s'enfuient pas lorsqu'elles se sentiront toucher, on insérera légèrement les doigts dans les pelotons pour les sonder, en écartant les abeilles jusqu'à ce que l'on ait trouvé l'auteur de la diseorle, qu'il faudra éeraser.

X. Les rois sont un peu plus gros et plus allongés que les autres abeilles : ils ont aussi les pattes plus droites, mais les ailes moins grandes : ils sont d'une couleur agréable, propres et lisses, et n'ont ni poil ni aiguillon, à moins qu'on ne prenne pour un aiguillon cette espèce de gros poil qui leur sort du ventre, quoiqu'ils ne s'en servent jamais pour nuire. II s'en trouve aussi quelquesuns de bruns, qui sont hérissés de poils, et tels signa moventium tumultus ac murmur exoritur : ex quo, ut verissime dicit Virgilius, corda licet vulgi prosciscere. Namque morantes Martius ille aris ranci canor increpat, et vox Auditur fractos sonitus imilala $t u$. barum. Ilayue maxime observari debent, qua istud faciunt, ut sive ad pugnam eruperint, nam inter se tan. quam civilibus bellis, et cum alteris quasi cum exteris geutibus præliantur, sive fugæ causa se proripuerint, presto sit ad utrumque casum paratus custos. Pugna quidem vel unius inter se dissidentis vel duorum exami. num discordantium facile compescitur : nam ut idem ait, Pulveris exigui jactu compressa quiescit : aut mulso, passove, aut aliquo liquore simili resperso, vide. licet familiari dulcedine sxevientium iras mitigante. Nam eadem ınire etiam dissilentes reges conciliant. Sunt enim sape plures unius populi duces, et quasi procerum seditious plebs in partes diducitur : quoul fremuenter fieri prolibendum est, quoniam intestino bello tota gentes consumuntur. Itaque si couslat priucipibus gratia, manet pax incruenta. Sin autem sapius acie dimicanteis notaveris, duces seditionum interficere curabis : dimicantium rero pralia prædictis remediis sedantur. Ac deinde cum agmen glomeratum in proximo frondentis arbusculæ ramo consederit, animadrertito, an tolum examen in speciem unius uvæ dependeat : idque signum erit aut unum regem inesse, aut certe plures bona fide reconciliatos; quos sic patieris, dum in suum revolent domicilium. Sin autem duobus aut etiam compluribus velut uberibus diductum fuerit examen, ne dubitaveris et plures proceres et adlunc iratos esse. Atque in is partibus, quibus maxime videris apes glomerari, requirere duces debebis. Itaque succo prodicta. rum lierbarum, id est, melissopltylli rel apiastri manı illita, ne ad tactum diffugiant, leviter inseres digitos, et diductas apes scrulaberis, donec auctorem pugna, quen elidere debes, ] reperias.

$X$. Sunt autem lii reges majores paulo et oblongi magis quam catera apes, rectioribus cruribus, sed minus aulplis pinnis, pulcluri coloris et nitidi, levesque ac sine pilo, sine spiculo, nisi quis forte pleniorem quasi capillum, quem in ventre gerunt, aculeum putet, quo et ipso tamen ad nocendum non utuntur. Quidam etiam infusci atque luisuti reperiuntur, quorum pro lıabitu damnabis inge. 
qu'il suffit de les volr pour juger de la méchiancelé de leurs mours. Én effet, on reconzuit deux figures distinctes parmi les rois, comme parmi le reste des abeilles: les uns'se font remarquer par leur pecu terne el mouchetice on or; on les dislingue eneorc tant à leurs écailles rouges qu'a leur $b c c$, et ce sont eeux qu'on approuve le plus, parce qu'ils sont effectivement les mellleurs; car les moins bons, dont la couleur ressemble à celle de la salive crasseuse, sont aussl sales qu'un voyageur qui viont de traverser un chemin couvert de poussiere, dont la bouche dessichece crache contre terre; et, comme dit le même pocte, ils aiment la paresse, at ils trainent sans gloirc leur large ventre. Il faut done condaminer à la mort tous les chefs de la mauvaise espèce, et laisser régner sculs dans leur cour ceux de la bonne. On arrachera néaumoins les alles à ceux-ci même, quand ils feront trop souvent des tentatives pour prendre la fuite avec leur essalm; paree qu'un chef vagabond qui aura perdu ses ailes, se trouvant dès lors comme retenu dans des entraves, et se voyant privé de la ressource qu'il avait auparavant dans la fuite, n'osera plus sortir hors des limites de son royaume, et ne voudia pas mème en conséquence permettre au peuple soumis à son empire de s'écarter trop au loin.

XI. Il faut même quelquefois tuer le chef lorsqu'une vieille ruche ne contient plus un nombre suffisant d'abeilles, et qu'on est obligé de la repeupler avec un nouvel essaim. Ainsi, lorsqu'au commencement du printemps il sera né une nouvelle couvée dans une ruehe qui se trouvera dans ce ens-là, on en éerasera le nouveau roi, afin que son peuple reste avec eeux qui lui ont donné le jour, sans que la discorde règne parmi eux. S'il n'est sorti au contraire aucune progéniture des rayons de cette ruche, on pourra y

nium. Namque duce regum facies, duo corpora plebis. Aller crit maculis auro squalentibus ardens, Et rutilis clarts squamis insignis el ore. Atque linc maxime probatur, qui est melior : nam deterior, sordido sputo similis, tam fodus, Quam pulvere ab allo Cum venit, el sicco terram spuit ore viator. Et, ut idem ait, Desidia latam. que trahens inglorius alvum. Omnes igitur duces nota leterioris Dede neci, melior vacua sine regnet in aula. Qui tamen et ipse spoliandus est alis, ubi saepius cum examine suo conatur eruptione facta profugere. Nam velut qquadam compede retinebimus erronem ducem detractis nlis, qui fuga destitutus prasidio, finem regni uon audet excedere, propter quod ne ditionis quidem suæ populo permittit longius evagari.

XI. Sed nonnunquam idem necandus est, cum vetus alveare numero apium destituitur, atque infrequentia ejus alíquo examine replenda est. Itaque cum primo vere in eo vase nata est pullities, novus rex eliditur, ut nultitudo sine discordia cum parentibus suis conversetur. Quod si nullam progeniem tulerint favi, duas vel tres alvorum ineorporer les pruples de deux ou trois autres ruches, en premant eependant préalablement le soin de les asperger de quelque liqueur qui leur soit agréable. On les tiendra aussi renfermés pendant l'espace d'environ trois jours dans ee nouveau domicile, en y laissant néanmoins de petites ouvertures pour leur donner de l'air, et on les y nourrira jusqu'd ce qu'ils s'y soient accoutumés. Il y a des personnes qui préfèrent dans ee cas se défaire du plus vieux roi; mais cette méthode est tout à fait mauvaise. En effet, comme la troupe des vieilles abeilles, que l'on peut eonsidérer comme un sénat, ne voudra pas obéir aux plus jeunes, celles-ei ayant l'avantage de la foree, puniront et mettront à mort toutes celles qui s'obstineront à mépriser leur commandement. Il faut convenir qu'en laissant dans la ruche le roi des anciennes abeilles, il en résulte eommunément un inconvénient par rapport au plus jeune essaim, qui consiste en ce que ce roi venant à mourir de vieillesse, on voit naítre la licence et la division, comme on la voit naître dans une maison après la mort du chef de famille : mals il est aisé d'y remédier. On choisit à eet effet un autre ehef dans des ruches où il s'en trouve plusieurs, et on le transfère dans eelles qui n'en ont point, pour l'y mettre à la tête du gouvernement. On n'a pas non plus beaueoup de peine à remédier au défaut de mul. tiplication des abeilles, dans les ruches qui sont affligées de quelque maladie pestilentielle. En effet, aussitôt qu'on s'apereooit du désastre qui dépeuple une ruche, il faut en visiter les rayons, qui eontiennent la somenee dont les petits doivent éelore, et couper la partie des cires dans laquelle doit s'animer la postérité du sang royal. Or cette partic est aisée à reconnaître, parce qu'on la distingue communément à l'extrémité des cires, où elle surmonte les autres parties

plebes in unum contribuere licebit, sed prius respersas dulci liquore : tum demum includere, et posito cibo, dum conversari consuescant, exiguis spiramentis relictis triduo fere clausas labere. Sunt qui seniorem potius regem submoveant, quod est contrarium : quippe turba vetustior, velut quidam senatıs, junioribus parere non censent, atque imperia validiorum contumaciter spernentes ponis ac mortibus afficiuntur. Illi quidem incommodo, quod juniori examini solet accidere, cum antiquarun apium relictus a nobis rex senectute defecit, et tanquan domino mortuo familia nimia licentia discordat, facile occurritur. Nam ex iis alvis, quae plureis babent principes, dux unus eligitur : isque translatus ad eas, qua sine imperio sunt, rector constituitur. Potest autem ninore molestia in is domiciliis, qua aliqua peste vexata sunt, paucitas apium emendari. Nam ubi cognita est clades, frequentis alvi, si quos liabet favos, oportet considerare : tum deinde ceræ ejus qux semina pullorum continet, partem recidere, in qua regri generis proles aninatır. Est autem facilis conspectu, quouian fere in ipso fine cera. 
comme un bout de mamelle, et que l'ouverture en est plus large que celle des autres alvéoles, dans lesquels sont renfermés les petits du vulgaire. Celsus assure que l'extrémité des rayons est traversée par des tuyaux qui contiennent les petits du sang royal. Hyginus dit aussi, d'après l'autorité des auteurs grees, que le chef ne vient point d'un petit ver (comme les autres abeilles), mais que l'on trouve, sur les bords des rayons, des alréoles couverts, qui sont un peu plus grands que ccux qui contiennent la semence dont le peuple doit éclore; et que ces alvéoles sont remplis d'une espèce de crasse rouge, qui sert à former le roi avec des ailes, dont il est pourvu au moment de sa naissance.

XII. Voici encore des soins qu'exigent les essaims nés chez nous, quand par hasard ils font une sortie dans le temps que nous venons de dire, et que, dégoûtés de leur patrie, ils annoncent qu'ils cherchent à fuir plus au loin. On s'apercoit que les abeilles méditent ce projet quand elles s'éloignent du vestibule de leur ruche, au point qu'on n'y en voit plus rentrer aucune, et qu'elles s'élèvent au contraire sur-le-champ en l'air. Il faut alors effrayer le jeune essaim dans sa fuite, soit avee des sonnettes de cuivre, soit en faisant résonner des morceaux de pots de terre cassés, tels qu'on en trouve communément partout à terre; et dès que l'effroi l'aura ramené vers la ruche qui l'a vu naitre, et qu'il demeurera suspendu en peloton aux environs de cette ruche, ou qu'il aura gagné des feuillages voisins, le gardien frottera, avec les herbes dont nous avons parlé, le dedans d'une seconde ruche qu'il aura préparéu à cet effet, et l'aspergera à l'extérieur de gouttes de miel; après quoi il l'approchera du groupe formé par les abeilles, pour les

rum relut papilla uberis apparet eminentior, et laxioris fistulæ, quam sunt reliqua foramina, quibus popularis notæ pulli detinentur. Celsus quidem affirmat in extremis favis transrersas fistulas esse, quæ contineant regios pullos. Hyginus quoque auctoritatem Graccorum sequens negat ex vermiculo, ut cateras apes, fieri ducem, sed in circuitu favorum paulo majora, quam sunt plebeii seminis, inveniri recta foramina repleta quasi sorde rubri coloris, ex qua protinus alatus rex figuretur.

XII. Est et illa vernaculi examinis cura, si forte praedicto tempore facta eruptione patıiam fastidiens selem Iongiorem fugam denuntiavit. Id autem significat, cum sic apis evadit restibulum, ut nulla intro revolet, sed se confestim levet sublimius. Crepitaculis areis aut testa. rum plerumque vulgo jacentium [sonitu] terreatur fugiens juventus : eaque vel pavida cum repetierit alvun maternam, et in ejus aditu glomerata pependerit, vel statim se ad proximam frondem contulerit; protius custos novum loculamentum in lioc præparatum perlinat iutrinsecus præedictis herbis : deinde guttis mellis respersum admoveat : tum manibus, aut eliam trulla congregatas эpes recondat : atque, uti debel, adlitita catera cura, y renfermer soit avec la main soit encore avec une cuiller. Ensuite, quand il aura pris tous les autres soins convenables, il laissera cette ruche bien arrangée ct bien enduite dans le lieu méme où cette opération aura été faite, jusqu'à ce que le jour tombe; puis il la transportera au commencement du crépuscule, pour la mettre au rang des autres ruches. II faut aussi garnir de ruches vides l'endroit ou l'on élève des abeilles, parce qu'il y a tels essaiins qui se cherchent un domicile dans le voisinage même de leur ruche, aussitôt qu'ils en sont sortis, et qui s'cmparent de celui qu'ils trouvent non occupé. Voilà à peu prèsles soins qu'il faut prendre tant pour acquérir que pour conserver des abeilles.

XIII. Viennent à présent les remèdes qui leur sont nécessaires quand elles sont malades ou tourmentées par la peste. Il est rare, à la vérité, que des maladies contagicuses causent du désastre parmi les abeilles ; mais néanmoins, si le cas arrivait, il n'y a pas d'autre traitement à suivre que celui que j'ai prescrit pour les.autres bestiaux, c'est-à-dire qu'il faut transférer plus loin les ruches. Quant à leurs maladies particulières, il est plus aisé d'en découvrir les causes et d'en trouver les remedes, que dans les autres animaux. Leur plus grande maladie est celle qui leur vient tous les ans au commencement du printemps, quand la plante du tithymale est en fleur, et que les ormes font voir leur graine. En effet, comme elles ont souffert de la faim pendant l'hiver, ces premières fleurs excitent leur appétit, comme pourraient faire.des fruits de la primeur; et elles se remplissent avidement de ce genre de nourriture, qui d'ailleurs ne leur ferait aucun mal si elles n'en prenaient qu'avec sobriété. Lorsqu'elles s'en sont gorgées sans ména-

diligenter compositum et illitum ras interim-patiatur in codem loco esse, dum advesperaseat. . Primo deinde crepusculo transferat, et reponat in ordinem reliquarum alvorum. Oportet autem etiam vacua domicilia collocata in apiariis habere. Nam sunt nonnuHaexamina, qux cum processerint, statim sedem sibi quarant in proximo, eandemque occupent quam vacantem reperiunt. Hace fere acquirendarum, atque etiam retinendarum apium traditur cura.

Xil. Sequitur ut morbo vel pestilentia laborantibus remedia desiderentur. Pestilentixe rara in apibus per. nicles, nec tamen aliud, quam quod in cxtero pecore pracepimus, quid fieri possit reperio, nisi ut longius alvi transferantur. Morborum autem facilius [in lis] et causa dispiciuutur, et inveniuntur medicinæ. Maxinus autem annuus earum labor est initio veris, quo titliymali floret frutex, et quo sameram ulmi promunt. Nam quasi noris pomis, ita his primitivis floribus illect $a$ avide vescuntur post libernam fanem, alioquin citra satietatem tali no. cente cibo : quo cum se affatim replererunt, profluvio alvi, nisi celeriter succurritur, intereunt. Nam et tithymalus majorum quoque animalium ventrem solvit, et 
gement, elles périssent par un flux de ventre, à moins qu'on n'y remédic promptement, paree que le tithymale lache le ventre de tous les animaux, mème des plus grands, et que l'orme produit particulièrement cet effet sur les abeilles : c'est aussi la raison pour laquelle il est rare que des essaims restent longtemps bien peuplés dans les contrées de l'Italle, où il se trouve un grand nombre de plants d'arbres de cette espèce. On peut done donner aux abeilles au commenecment du printemps des nourritures médicamentées, tant pour empêcher qu'elles ne soient surprises par cette maladic, que pour les en guérir, au cas qu'elles en soient déjà attaquées. Car je n'oserais pas assurer, faute de l'avoir éprouvé par moi-même, la vérité d'un fait qu'avanee Hyginus d'après les plus grands auteurs, quoi que si quelqu'un veut s'en assurer, il pourra en fairc l'essai par lui-meme. Quoi qu'il en soit, il ordonne de prendre les cadavies des abeilles, que l'on trouve en tas sous les rayons quand cette maladie contagieuse s'est emparée d'elles, ct de les serrer dans un lleu see pendant l'hiver; il veut qu'ensuite, vers l'équinoxe du printemps, on les mette au soleil après la troisième heure du jour, lorsque la douccur du temps le permet, et qu'on les couvre de cendre de figuier. Cela fait, il assure qu'une chaleur vivifiante venant à les ranimer au bout de deux heures, clles reprennent vie et setrainent dans une ruche préparée à cet effet, qu'on a soin de mettre auprès d'elles. Pour nous, nous pensons qu'il faut plutôt les empêeher de mourir, en donnantaux essaims, lorsqu'ils sont malades, les remèdes que nous allons prescrire. Ces remèdes seront ou des grains de grenade pilés et arrosés de vin Aminé, ou des grains de raisin séchés au soleil et pilés dans un mortier avec pareille quantité de sumac de Syrie, et détrempés ensuite

proprie ulmus apium. Eaque causa est, cur in regionibus Italix, quæ sunt ejus generis arboribus consitæ, raro frequentes durent apes. Itaque veris principio si medicatos cibos prabeas, iisdem renediis et provideri potest, ne tali peste vexentur, et cum jam laborant, sanari. Nam illnd quod Hygjnus antiquos secutus autores prodidit, ijse non expertus asseverare non audet : volentibus tamen licebit experiri. Siquidem pracipit apium corpora, quæ cun ejusmodi pestis incessit, sub favis acervatim enecta reperiuntur, sicco loco per liemem reposita circa xyuninoctium vernum, cum clementia diei suaserit, post lıoram tertiam in solem proferre, ficulıeoque cinere olsrucre. Quo facto, affirmat intra duas horas cum vivido halitı caloris animata sunt, resumpto spiritı, si praparatum vas objiciatur, irrepere. Nos inagis ne intereaut, quæ deinceps dicturi sumus, xgris examinibus exlibenda censemus. Nam vel grana mali l'unici tunsa, et vino Amineo conspersa, vel uvæ passæ cum rore Syriaco pari mensura pinsita et austero vino insuccate dari debent : vel si per se ista frustrata sunt, omnia eadem aquis pon- dans du vin dur. SI l'un ou l'autre de ces mé dieaments ne fait point d'effet à lui seul, il faut les broyer tous ensemble par poids égal; et après les avoir fait bouillir dans un vase de terre avec du vin Aminé, les servir aux abeilles dans des augets de bois, lorsqu'ils seront refroidis. 11 y a des personnes qui leur donnent à boire, dans des tuiles ereuses, de l'eau miellée dans laquelle clles ont fait euire du romarin, après l'avoir laissé refroidir. D'autres mettent auprès des ruches de l'urine de bœuf, ou même de l'urine d'homme (comme Hyginus l'assure). Elles snnt encore sujettes à une maladic qui les affaiblit sensiblement, et qui fait que leur corps se rétrécit et devient hideux: on s'apereoit qu'elles en sont attaquées, quand les unes portent souvent hors de leurs domieiles les cadavres de celles qui sont mortes, et que les autres restent dans l'intérieur de leurs ruches plongées dans un morne silenee, comme il arrive dans un deuil public. Lorsque cela arrive, on met leur nourriture dans des augets de saule, et cette nourriture consiste principalement en miel bouilli, et broyé avee de la noix de galle ou avec des roses desséchées. Il faut aussi brûler du galbanum, dont l'odeur leur sert de médicament, et les soutenir, lorsqu'elles sont épuisées, a vee du vin fait de raisin see ou avec de vieux vin cuit, jusqu'à diminution de moitié. Mais le meilleur de tous les l'emèdes, c'est de la racine d'amelle; plante dont la tige est d'un jaune clail ct la fleur pourprée; on l'exprime après l'avoir fait bouillir avec de vieux vin Aminé, et on leur donne le jus qu'on en a tirć. Hyginus dit, dans le livre cu'il a composé sur les abeilles, qu'Aristomachus était d'avis qu'il fallait, pour secourir celles qui étaient malades, commencer par retrancher tous les rayons gâtés, ensuite substituer de nouvelle nourriture à l'ancienne, et enfiu les

deribus in unum levigata, el fictili vase cum Amineo vino infervefacta, mox etiam refrigerata, ligneis canalibus apponi. Nonnulli rorem mariuum aqua mulsa decoctum, cum gelaverit, imbricibus infusum pracbent libandum. Quidam bubulan vel hominis urinam, sicut Hyginus affirmat, alvis apponunt. Nec non etiam ille morbus nıxime est conspicuus, qui lıorridas contractasque carpit, cum frequenter aliæ mortuarum corpora domiciliis [suis] efferunt, alia intra tecta, "I in publico luctu, moesto silentio torpent. Id cum accidit, arundinis infusi canalibus offeruntur cibi, maxime decocti mellis, et cum galla vel arida rosa detriti. Galbanum etiam, ut cjus odore medicentur, incendi convenit, passoque el defruto velere fessas sustinere. Optime tamen facit amelli radix, cujus est frutex luteus, purpureus flos : ea cum vetere Aminco vino decocta exprimitur, et ita liquatus ejus succus datur. Hyginus quidem in eo libro, quem de apibus scripslt, Aristomachus, inquit, hoc morlo succurrendum taborantibus existinat : primum, ut omnes vitiosi favi tollan. tur, et cibus ex integro recens ponatur; deinde, ut 
parfumer. Il croit aussi qu'il cst utile, lorsque les abeilles sont dégénérécs par vieillesse, d'incorporer avec elles de nouveaux cssaims; ct il pense que, quelque danger qu'il y ait que les dissensions qui résulteront de ectte union ne fassent périr ces nouveaux essaims, cette recruc d'un nouveau peuple ne pourra que rejouir les anciennes abeilles, pourvu que, pour maintenir l'union parmi clles toutes, on ait soin d'écarter les rois de celles que l'on aura transférées d'un autre domicile, comme appartenant à un peuple étranger. Effectivement, il n'y a pas de doute que l'on ne doive transférer les rayons des essaims bien peuplés dans le temps où les petits sont formés, pour les mettre dans les ruches moins peuplées, afin que celles-ci se trouvent fortifiées quand cette nouvelle progéniture s'y trouvera comme adoptće. Mais il faudra avoir l'attention de n'y mettre dans ce cas-là que des rayons où les petits ouvrent déjà leurs cellules, et commencent à montrer la tête, en rongeant la cire qui les tient renfermés, et qui sert de couvercle à leurs alvéoles. Car si l'on transfere des rayons avant que les petits en soient éclos, ces petits, cessant d'être couvés, ne peurent manquer de perdıe la vie. Les abeilles meurent encore d'une maladie que les

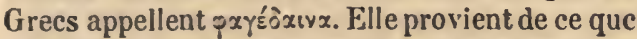
les abcilles étant dans l'usage de commencer par faire autant de cires qu'elles comptent en pouvoir remplir, il arrive quelquefois que ces premiers ouvrages étant finis, l'essaim s'écarte au loin pour aller chercher du miel, et se trouve opprimé dans les forêts par des pluies imprévues ou par des tourbillons de vent; ce qui est cause que la plus grande partie du peuple dont il est composé sc perd, et qu'ensuitc le peu qui en reste ne suffit plus pour remplir les rayons. Dès lors les parties de cire qui restent vides finissent par se pourrir;

fumigentur. Prodesse etiam putat apibus vetustate corruptis examen norum contribuere, quamris periculum sit, ne seditione consumantur, verumtamen adjecta multitudine lataturas. Sed ut concordes maneant, earum apum, quæ ex alio domicilio transferuntur, quasi peregrinæ plebis snbnoveri reges debere. Nec tamen dulium, quin frequentissimorum examinum favi, qui jam maturos liabent pullos, transferri, et subjici paucioribus debeant, ut tanquam nova prolis adoptione domicilia confirmentur. Sed et id cum fiet, animadvertenduın est, ut eos faros subjiciamus, quorum pulli jam sedes suas adaperiunt, et velut opercula foraminum obiluctas ceras erodunt exereutes capita. Naun si favos inumaturo fetu transtuleij. mus, emorientur pulli, cum foveri desierint. Sxpe etiam

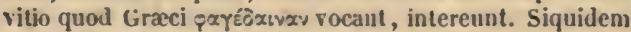
cun sit hæe apium consuetudo, ut prius tantum ceraruın confingant, quantum putent explere se posse : non nunquam evenit, ut consummatis operibus cereis, dum examen conquirendi mellis causa longius evagatur, subitis imbribus, aut turbinibus in silvis opprimatur, et majo. ren partem plebis amittat quod uhi factum est, reliqua COI.CYELLF. après quoi lc mal faisant des progrès insensibles, Ic miel se corrompt, et les abeilles clles-mêmes périsscnt toutcs. Pour prévenir cette maladie, il faut joindre deux peuplades cnsemble, afin qu'elles puissent venir à bout de rmplir les cires vides; ou, si l'on n'est pas ì portée d'avoir un second essaim, il faut couper les portions vides des rayons mêmes, avant qu'ils pourrissent. Mais il cst important de se servir pour cette opération d'un fer bien tranchant, dc peur qu'en y em. ployant un instrument trop émoussé, la difficultć de pénétrer ne force de donner un coup trop violent qui dérangerait les rayons de leur place, auquel cas les abeilles quitteraient leur domicile. C'est encore une cause de mortalité pour les abeilles, quand les fleurs viennent à être trop abondantes pendant une suite d'années, et qu'en conséquence ces insectes s'occupent plus à faire du miel qu'à multiplier. Il se trouve des gens qui, peu versès dans cette branche d'économie rurale, se félicitent alors, parce qu'ils voient abonder le fruit, et qu'ils ne font pas attention que les abeilles sont menacées par cela même de leur destruction, attendu qu'étant ćpuisées par un travail excessif, elles périssent pour la plus grande partie, et, que celles qui survivent à cet accident finissent par mourir également, faute d'être recrutées par des jeunes. S ill survient done un printemps où les fleurs pullulent excessivement dans les prairies et dans les champs, il sera très-bon de boucher les sorties des ruches de trois jours l'un, en y laissant nćanmoins de petites ouvertures par lesquelles les abeilles ne puissent pas sortir, afin qu'elles ne s'occupent pas tant à faire du miel, quand elles se verront privées de l'espérance de pouvoir remplir toutes leurs cires de cette liqueur, et qu'elles les remplissent au contraire de leur progéniture. Voilà à peu près les remèdes aux-

paucitas faris complendis non sufficit; tuncque racux ce. rarum partes computrescunt, et vitiis paulatim serpentilus, corrupto melle, ipse quoque apes intereunt. Id ne fiat, rel duo populi conjungi debent, qui possint adhuc integras ceras explere : vel si non est facultas alterius examinis, ipsos faros ante quam putrescant, vacuis par tibus acutissimo ferro liberare. Nam hoc quoque refert, ne adnodum liebes ferramentum (quia nou facile pene. tret) vehementius impressun favos sedibus suis commo. veat : quod si factum est, apes domicilinm relinquunt. Est et illa cansa interitus, quod interdun continuis an. nis plurini lores proveniunt, et apes magis mellificiis quam fortibus student. Itaq̨ue nonnulli, quibus minor est haruın rerunı scientia, magnis fructibus delectantur, iguo. rantes exitium apibus imminere, quoniam et nimio fatigatee opere plurina pereunt, nec ullis juventutis supplementis confrequentata novissime reliqua intereunt. Hakue si tale ver incessit, ut et prata et arva floribus abundent, utilissimum est tertio quoque die alrorum exitus pra:cludi, exiguis foraminibus relictis per qux non possint apes exire, itt ab opere mellifico avocata, quonian non 
quels on a recours quand les essaims sont altaqués de quelque maladie.

XIV. Voiei à présent les soins qu'il faut prendre des abeilles pendant le cours de toute l'annce, suivant la méthode excellente preserite par le même Hyginus. Depuis le premier équinoxe, yul tombe au unois de mars vers le huit des calendes d'avril, quand le soleil est au huitième degré du Bélier, jusq̊u'au lever des Pléiades, on a quarante-huit jours de printemps. Il dit donc (ju'il faut commeneer à donner ses soins aux abeilles pendant eet intervalle, en ouvrant les ruehes pour en oter toutes les immondices qui s'y seront amassées pendant l'hiver, et en les enfumant en dedans avee de la fiente de bœuf brûlée, nprès avoir détruit les araignées qui corrompent les rayons, parce que cette fiente est très-convenable aux abeilles, vu l'espèce d'affinité qui se trouve entre elles et cet animal. II faut aussi ther les petits vermisseaux que l'on appelle $t i$ nea (teignes), ainsi que les papillons: il suffit communément, pour tuer ces animaux pestilentiels qui s'attachent aux rayons, de mêler de la moelle de bouf avee de la fiente du même aniınal, et de les brûler de faẹon à leur eı faire sentil l'odeur. C'est avee de pareils soins que l'on forlifiera les essaims pendant le temps que nous venons de dire, et qu'on parviendra à leur donner plus de courage pour s'appliquer à leur ouviage. Mais il faut surtout que eelui qui prend soin d'élever des abeilles ait la préeaution, lor'squ'il aura à toucher aux rayons, de s'abstenir la veille des plaisirs de l'amour, comme de n'en pas approcher lorsqu'il sera ivre, ou sans s'être lavé préalablement. Il s'abstiendra aussi de presque toutes les nourritures dont l'odeur sera forte, telles que les salaisons et tous les jus qu'elies ren-

sperent se posse ceras omnes liquoribus stipare, fotibus expleant. Atque lıxc fere sunt examinum vitio laborantium remedia.

XIV. Deinceps illa totius anni cura, ut idem Hyginus commotissime prodidit. Ab æequinoctio primo quod nense Nartio circa ru calendas Aprilis in octava parte Arietis conficitur; ad exortum Vergiliarum dies verni temporis liabentur duodequinquaginta. Per lins primum ait apes $\mathrm{cl}$. randas esse adapertis alveis, it omnia purgamenta, quax sutt hiberno tempore congesta, eximantur, et araneis, qui favos corrumpunt, detractis fumus immittatur factus incenso bnbulo fimo. Hic enin quasi quadan cognatione generis maxime est apibus aptus. Vermicnli quoque, qui tinea vocantur, iteun papiliones enecandi suut : quae pestes plerunque favis adharentes decidunt, si fimo medullam bubulan misceas, et his incensis nidorem admoveas. llac cura per id tempus, quod diximus, examina firmahnntur, eaqne fortius operibus inservient. Verum ınaxime custodiendum est curatori, [qui apes uutrit], cum alros tractare debehit, uti pridie castus ab rebus venereis, neve temulentus, nec nisi lotus ad eas accedat, abstineatque omnilus redolentıbus esculenlis, ut sunt salsamenta; ot dent, telles eneore que l'acrimonie puante de l'ail ou de l'oignon, et de toutes les autres ehoses semblables. Au quarante-huitième jour de. puis l'équinoxe du printemps, e'est-à-dire, au lever des Pléiades, qui tombe vers le einq des ides de mai, les essaims commeneent à prendre de la foree et à fourmiller beaueoup : mais aussi eeux où il ne se trouve que peu d'abeilles périssent dans le même temps. C'est eneore dans ee temps-là que l'on voit naitre dans les extrémités des rayons des petits dont la taille est plus grande que celle des autres abeilles, et que quelques personnes prennent pour les rois. Mais il y a des auteurs grees qui les appellent olozpot (taons), parce qu'ils tourmentent les essaims et qu'ils ne les laissent point tranquilles : aussi ees mèmes auteurs ordonnent-ils de les tuer. Les ruches essaiment communément depuis le lever des Pléiades jusqu'au solstice qui tombe à la fin du mois de juin, vers le temps où le soleil est au huitième degré de l'Éerevisse; et il faut les gar. der alors avee plus de soin, de peur que leurs nouvelles progénitures ne prennent la fuite. Ensuite, depuis le solstice jusqu'au lever de la $\mathrm{Ca}$ nicule, ee qui fait un intervalle d'environ trente jours, on moissonne les rayons aussi bien que les biés. Mais nous nous réservons de preserire par la suite la manière de les enlever, lorsque nous traiterons de la eomposition du miel. Au reste, Démocrite et Magon, ainsi que Virgile, ont pensé que c'était dans ce temps-ei que l'on pouvait se proeurer des abeilles en tuant un bouvillon. Magon va même jusqu'à assurer qu'on peut obtenir le même résultat avee les entrailles d'un bouf : mais je pense qu'il est superflu de détailler eette méthode avee exactitude, et je me range à l'avis de Celsus, qui dit très-prudemment

eornm onnia liquamina; itemque foctentibus acrimoniis allii vel ceparum colterarumque rerum similium. Duodequinquagesimo die ab aquninoctio verno, cum tit Vergiliarum exortus circa vidus Maias, incipiunt examina viribus et numero augeri. Sed et iisdem diebus intereunt quxe paucas et ægras apes habent; codemque tempore progenerantur in extrenis partibus favorum amplioris magnitu. dinis quam sunt cæetere apes, eosque nonnulli putant esse reges. Verum quidam Gracorum auctores oiotpous appellant $\mathrm{ab}$ eo, quod exagitent, neque patiantur examina conquiescere. Itaque pracipiunt eos enecari. Ab exortu Vergiliarum ad solstitium, quod fit ultimo mense Julio circa octavam partem Cancri, fere examinant alvi : quo tempore rehementius custodiri debent, ne novæ soboles diflugiant. Tumque peracto solstitio usquue ad ortum Canicula, qui fere dies triginta sunt, pariter frumenta et favi demetuntur. Sed ii quemadmodum tolli deheant, mox dicetur, cum de confectura mellis præcipienuus. Cieterum hoc eodem tempore progenerari posse apes juvenco perempto, Democritus et Mago nec ininus Virgilins prodiderunt. Mago quidem ventribus etiam bubnlis islem fieri alfirmat, quam rationem diligentius prosequi supervacuum puto, 
que la perte de ce genre de bétail n'occasionne pas un assez grand dommage, pour chercher à se le procurer par une parcille voie. Au reste, une chose qu'il faut faire dans cet intervalle et jusqu'à l'équuinoxe d'automne, c'est d'ouvrir les ruches tous les dix jours, et de les enfumer. Car on convient généralement que, quoique cette opération ne plaise pas aux essaims, elle leur est néanmoins très-salutaire. Ensuite, lorsque les abeilles auront été ainsi parfumées et échauffćes, il faudra les rafraichir, en arrosant les parties des ruches qui seront vides, avec de l'eau très-fraichement tirée, et en nettoyant celles que l'on n'aura pas pu arroser, avec des plumes d'aigle ou de tout autre oiseau de grande taille, qui aient une certaine roideur. II faut encore balayer les teignes que l'on apercevra, et tuer les papillons qui se tiennent communément entre les ruches et qui détruisent les abeilles, tant parce qu'ils rongent les cires, que parce qu'il s'engendre de leurs excréments certains vers que nous appelons les tinece (teignes) des ruches. Aussi, lorsqu'il s'en trouve une grande quantité, cuinme il arrive dans le temps où la mauve est en fleur, on met le soir entre les ruches un vase d'airain semblable à ceux dont on se sert dans les bains pour faire chauffer l'eau; et aussitôt qu'on y a enfoncé une lumière, les papillons y accourent de tous côtés, et se grillent en voltigeant autour de la flamme, attendu que n'ayant ni la facilité de s'envoler par en haut, parce que le-vase est étroit, ni celle de s'éloigner du feu, parce qu'ils sont comme resserrés entre les parois du vase, ils sont en conséquence brủlés par le feu, dont ils sont trop voisins. L'Arcture se lève environ cinquante jours après la Canicule : cest alors que les abeilles font leur miel

consentiens Celso, qui prudentissime ait, non tanto interitu pecus istud amitti, ut sic requirendum sit. Verum hoc tem. pore, et usque in autumui aquinoctium decimo quoque die alvi aperiendæ et fumiganda sunt. Quod cum sit molestum examinibus, saluberrimum tamen esse convenit. Suffitas deinde, el astuantes apes refrigerare oportel, conspersis racuis partibus alvorum, et quam recentissini rigoris aqua infusa : deinde si quid ablui non poterit, pinnis aquila rel etiam cujus libet vastæ alitis, quæ rigoren lıabent, emundari. Prxterea ut tinear, si apparuerint, everrantur, papilionesque enecentur, qui plerumque intra alros morantes apibus exitio sunt. Nain et ceras erodunt, et slercore suo vermes progenerant, quos alrorum tineas appellamus. Itaque quo tempjore malva floreut, cum est earum maxima unultitudo, si vas aneum simile miliario vespere ponatur inter alros, el in fundum ejus lumen aliquod demittatur, undique papiliones concurrunt: dumque circa fanımulam volitant; aduruntur, quod nec facile ex angusto sursum evolare, nec rursus longius ab igne pos. sunt recedere, cum lateribus aneis circumveniantur: ideoque propinquo ardore cousumuntur. A Canicula fere post diem quinquagesimum Arcturus oritur, cum irrora. avec les fleurs couvertes de rosée, tant celles du thym que celles de l'origan et de la thymbre. Le meilleur miel parait être celui qu'elles font à l'équinoxe d'automne, qui tombe avant les calendes d'octobre, quand le soleil est au huitième degré de la Balance. Mais il faudra veiller, entre le lever de la Canicule et celui de l'Areture, à ce que les abeilles ne soient pas surprises par les assauts des frelons, qui se tiemnent communément devant leurs ruches pour les guetter à leur sortic. A près le lever de l'Areture, on moissonue pour la seconde fois les rayons vers l'équinoxe de la Balance (comme je viens de le dire). Ensuite, depuis l'équinoxe, qui tombe vers le huit des calendes d'octobre, jusqu'au coucher des Pléiades, les abeilles emploient quarante jours à mettre en réserve le mirl qu'elles ont extrait des fleurs du tamaris et des arbustes sauvages, et qui leur doit servir de nourriture pendant l'hiver : mais il ne faut rien retrancher de ce miel, de peur que si ces insectes étaient trop souvent molestés par les pertes qu'on leur ferait éprouver, le désespoir ne les portât à prendre la fuite. Depuis le coucher des Pléiades jusqu'au solstice d'hiver, qui tombe vers le huit des calendes de janvier, quand le soleil est au huitième degré du Capricorne, les essaims commencent à consommer le miel qu'ils ont mis en réserve, et qui sert à les soutenir jusqu'au lever de l'A reture. Je n'ignore pas la facon de calculer d'Hipparchus, qui prétend que les solstices comme les équinoxes arrivent lorsque le soleil est au premier degré des signes, et non pas lorsqu'il est au huitième : mais je m'en tiens, dans cette économie rurale, aux calendriers, d'Eudoxe, de Méton et des anciens astronomes, qui sont réglés sur les fêtes publiques, parce que cet ancien système est plus généralement connu des

tis floribus thymi et cunilæ tlıymbræque apes mella conficiunt : idque optimæ notæ emitescit antumni æquinoc: tio, quod est ante calend. Octobris, cum octavam partem Libræ sol attigit. Sed inter Caniculæe et Arcturi exortum cavendum erit, ne apes intercipiantur violentia crabronum, qui ante alvearia plerumque obsilianfur prodeuntibus. Post Arcturi exortum circa aequinoctiun Libre (sicut dixi) favorum secunda est exemptio. Ab æquinoctio deinde quod conficitur circa vu calend. Octobris ad Vergiliarum occasum diebus XL, ex floribus tamaricis et silvestribus frutetis apes collecta mella cibariis lienis reponunt. Quibus nihil est omnino detrahendum, ne sacpius injuria coutristatx velut desperatione rerum pro. fugiant. Ab necasu Vergiliarum ad brunam, qux fere conficilur circa vu calend. Januarii in octava parte Capricorni, jam recondito melle utuntur exanina, eoque usque ad Arcturi exortum sustinentur. Nec me fallit llippar. chi ratio, qux docet solstitia et æquinoctia non octavis sel primis partibus signorum confici. Verum in hac ruris disciplina sequor nunc Eudoxi et Metonis antiquorumque fastus astrologorum, qui sunt aptati publicis sacrificiis: yuia et notior est ista retus agricolis concepta opinio ; nec 
agrieulteurs, (qui sont habitués à s'y conformer; et qu'au eontraire la subtilité d'Hipparehus est au-dessus de l'intelligenee grossière des gens de la eampagne. Ainsi il faudia ouvrir les luehes, les parger de toute immondiee et les soigner avec beaucoup d'attention, dès que les Pléiades eommeneeront à se eoucher, paree qu'il n'est pas à propos de les remuer ni de les ouvrir pendant l'hiver. C'est pourcquoi, si l'on a eneore devant soi un reste d'automne, il faudra, après avoir nettoyé les ruches dans une journée où il aura fait très-beau temps, y enfoneer des couvereles yui parvienncht juscqu'aux rayons mêmes, sans laisser aueun vide, afin que les alvéoles, qui seront rétréeis par lâ, se maintiennent plus aisément ehauds pendant l'hiver : et c'est une opémition qu'il faut toujours faire, dans les ruches même qui ne sont habitées que par un petit nombre d'abeilles. Ensuite on bouchera par dehors, avee de la boue et de la fiente de bœuf mêlées enscmble, toutes les erevasses et tous les trous qui pourront s'y trouver, sans laisser d'autres ouvertures que eelles qui serviront de passages aux abeilles. Quoique les ruches solent sous un appentis, on ne licissera pas de les eouvrir encore avec du chaume et des feuilles entassées pardessus, pour les défendre, autant que faire se pourra, contre le froid et les mauvais temps. Quelques personnes y renferment dans l'intérieur des oiseaux morts, dont les entrailles sont vidées, et qui servent à procurer de la chaleur pendant l'hiver aux abeilles qui se eachent sous leurs plumes, d'autant que, lorsqu'clles ont consommé leur's provisions, elles mangent fort bien ces oiseaux pour assouvir leur faim, sans en rien laisser que les os, quoique, lor'squ'elles ont suffisamment de rayons, elles n'y touchent point. Car

tanen Hipparchi subtilitas pinguioribus, ut aiunt, rusticorunu literis necessaria est. Ergo Vergiliarum occasu primo statiun conveniet aperire alvos, et depurgare quidquid imuundi est, diligentiusque curare; quoniam per tempora hiemis non expedit movere aut patefacere vasa. Quam ob causaun dum adluc autunıni reliquiæ sunt, apricissimo die purgatis domiciliis opercula intus usque ad faros admovenda sunt, omni vacua parte sedis exclusa, quo facilius augustix carearum per liemem concalescant. Idque semper faciendum est etiam in is alvis, qua paucitate plebis infrequentes sunt. Quidquid deinde rimarum est aut foraminuu, luto et fimo bubulo mistis illinemus extrin. secus, nec nisi aditus, quibus commeent, relinquemus. Lit quamvis porticu protecta vasa uililo minus congestu culunorum et frondium supertegenus, quantumque res patietur, a frigore et tempestatibus inuniemus. Quidan exemptis interaneis occisas aves intus includunt, qux tempore liberno plumis suis delitescentibus apibus præ. bent teporem : tum etiain si sunt absunıpta cibaria, comn. unode pascuntur esurieutes, nec nisi ossa earum relinquunt. Siu autem favi sufficient, peruanent illibat $x$. Nec q̨uamvis amantissimas munditiarın offendunt odore l'odeur de ees oiseaux ne déplait point à ces inseetes, quelque délicats qu'ils soient sur l'article de la propreté. Nous eroyons néanmoins qu'il vaut mieux, lorsque les abeilles sont tourmentées par la faim pendant l'hiver, leur servir dans de petits eanaux placés vers l'entrée des ruches, des figues sèches pilées, et détrempées soit daus de l'eau, soit dans du vin euit, jusqu'à diminution de moitié, ou fait avec des raisins sees; auquel cas il faudra y tremper de la laine bien propre, afin qu'elles se posent sur cette laine pour tirer le sue de ees liqueurs, eomme à travers un siphon. On fera aussi très-bien de leur donner du raisin see broyé, et un peu humeeté d'eau. Au surplus, il faudra les soutenir avee ces sortes de nourritures non-seulement pendant l'hiver, mais eneore (ainsi que je l'ai dit) dans le temps où le tithymale et l'orme seront en fleur. Elles con. somment, dans l'espace de quarante jours à dater du solstice d'hiver, tout le micl qui est dans leur ruche (à moins que celui qui en prend soin n'y en ait laissé une trop grande quantité); et souvent mème, après avoir vidé les cires, elles se tiennent couchées auprès des rayons, sans prendre aueune nourriture, jusqu'au lever de l'Areture qui commence aux ides de février, et y restent engourdies à la manière des serpents, de façon que le repos seul leureonserve la vie. Pour empècher néanmoins qu'unetrop longue diète ne la leur fasse perdre, il est très-bon d'insinuer avee des siphons dans leurs ruches, au travers de l'entrée, des jus doux, qui serviront à leur faire supporter la disette de la saison, jusqu'à ce que le lever de l'Areture et l'arrivée des hirondelles leur annoucent des temps plus favorables. Aussi passé, ce mauvais temps, se hasardent-elles à aller aux pâturages dès que la gaieté de la saison le leur per-

suo. Melius tamen esse nos existimamus, tempore liberno fame laborantibus arl ipsos aditus in canaliculis vel contı. sam et aqua madefactam ficum aridan, vel defrutun aut passum præbere. Quibus liquoribus nundam Janam imbuere oportebit, ut insistentes apes quasi per siplıonem succum evocent. Uvas enim passas cum infregerimus, paulum aqua respersas probe dabimus. Atque lis cibariis non solum lieme, sed etiam quibus temporibus, ut jam supra dixi, tillyymalus, atque etiam ulmi florebunt, sustinendac sunt. Post confectam brumam diebus fere qua. draginta quidquid est repositi mellis, nisi liberalius a curatore relictum sit, consumunt, [et ] sæe etiam vacuatis ceris usque in ortum fere Arcturi, qui est ab idlib. Februariis, jejuna etian favis accubantes torpent more serpentun, et quiete sua spiritum conservant, quem tamen ne amittant, si longior fames incesserit, optimum est per aditum vestibuli siphonibus dulcia liquamina immittere, et ita penuriam temporum sustinere, dum Arcturi ortus et hirundinis adventus commodiores polliceantur futuras tempestates. Itaque, post hoc tempus, cum diei permittit hilaritas, procedere audent in pascula. Nam ab seruuinoctio verno sine cunctatione jam passim vagan.- 
met. En effet, aussitôt que l'équlnoxe du printemps est arrivé, elles ne tardent point à se répandre de côté et d'autre, pour ramasser les fleurs qui sont propres à les fairc multiplier, à l'effet de les porter dans leurs domiciles. Telle est la méthode qu'Hyginus preserit d'observer très-exactement pendant les différentes saisons de l'annéc. Au surplus, voici cc que Celsus ajoute à ces préceptes : il prètend que, comme il y a peu de contrées assez heureuses pour offrir aux abeilles des paturages d'hiver différents de ceux d'été, il ne faut pas laisser les essaims dans des lieux qui ne donnent pas après le printemps de fleurs qui conviennent aux abeilles; mais que, lorsque les páturages de cette saison sont con. sommés, il faut les transférer dans des lieux plus avantageux, où elles puissent se nourrir des fleurstardives du thym, de l'origan et de la thymbre. Il assure que c'est ainsi qu'on le pratique soit dans les contrées de l'Achaïe, d'où on les transfère dans les páturages de l'Attique et dans l'Eubée, soit dans toutes les íles Cyclades, d'où on les transfère dans la seule fle de Scyros, soit enfin dans la Sicile, où on les transporte des differentes contrées de cette ille à Hybla. Le même auteur prétend encore que les abeilles font la cire avec les fleurs, et le miel avec la rosée du matin; et que plus la cire est faite avec une matière agréable, plus.le miel est de bonne qualité. Au surplus, il ordonne de visiter avec attention l'intérieur des ruches avant de les transporter, et d'en oter les vieux rayons, ainsi que ceux où les teignes se seront mises ou ceux qui seront cliancelants, afin de n'en réserver qu'un petit nombre des meilleurs, etqu'en conséquence la plus grandc partie des rayons se trouve faite avec les meilleures fleurs. Il ordonne encore de ne porter que de nuit les ruches que l'on voudra changer

tur, et idoneos ad fuetum decerpunt flores, atque intra tecta comportant. Hacc observanda per anni tempora diligentissime Hyginus procepit. Cxterum illa Celsus adjicit , paucis locis eam felicitatem suppetere, ut apibus alia pabula hiberna atque alia probeantur xestiva. Itangue quibus locis post veris tempora flores idonei deficiunt, negat oportere immota cxanina reliıqui, sed vernis pastionibus absumptis in ea loca transferri, quæ serolinis foribus tliymi et origani tliymbroeque benignius apes alere possint. Quod fieri ait et Achaiæe regionihus, ubi transferuntur in Atticas pastiones, et Eubcea, et rursus in insulis Cycladibus, cum ex aliis transferuntur Scyrum, nec minus in Sicilia, cum ex reliquis ejus partibus in Iyblam conferuntur. lilemque ait ex floriluus ceras fieri, ex matutino rore mella, qux tanto meliorem qualitatem capiunt, quanto jucundiore sit materia cera coufecta. Sed ante translationem diligenter alros inspicere procipit, reteresque et tineosos, et labantes favos eximere : nec nisi paucos et optimos reservare, ut sinul etiam ex meliore flore quamplurini flaut : eaque vasa, qua quis transferre velit, non nisi uctibus et sine concussione portare. de lieu, et de ne les point agiter dans le transport.

$X V$. Dès la fin du printemps, ainsi que je l'ai déjà dit, vient la récolte du miel, à laquelle abou. tissent les travaux de toute l'année. On juge qu'it est temps de la fairc, lorsqu'on voit les abeilles chasser ct mettre en fuite les bourdons. Le bourdon cst un insecte très-ressemblant à l'abeille, mais plus gros qu'elle; ou, conme dit Virgile, c'est un bétail paresseux qui se tient auprès des rayons sans y travailler, et qui, loin d'amassei de la nourriture, consomme celle que les abeilles ont apportée. Cependant ces insectes paraissent coopérer en quelque façon à la multiplication des abeilles, en se tenant auprès de la semence dont elles doivent éclore. Aussi les abeilles vivent-elles d'intelligence avec eux tant qu'ils leur sont utiles pour couver et pour élever leur nouvelle progéniture, au lieu qu'elles les chassent hors de leurs domiciles, et que, comme dit le même poëte, elles les éloignent de leurs mangeoires dès que leurs petits sont éclos. Quelques auteurs ordonnent de les exterminer absolument; mais je suis sur cet article de l'avis de Magon, et je ne crois pas qu'on doive pousser les choses à cette extrémité; je pense all contraire qu'il faut modérer cette barbarie, parce qu'en faisant un carmage universel de cette engeance, il serait à craindre que les abeilles ne devinssent paresseuses; au lieu qu'en l'épargnant, elles n'en deviennent que plus actives pour réparer les dommages que ces insectes leur causent en consommant une portion de leurs vivres. Il ne faut pas, d'un autre cóté, laisser pulluler cette multitude de voleurs, de peur qu'ils ne finissent par piller tout le trésor des richesses qui ne leur appartiennent point. Lors donc que l'on verra de fréquentes disputes s'élever entre les bourdons

XV. Mox vere transacto sequitur, ut dixi, mellis vinJemia, propter quam totius anni labor exercetur. Ejus maturitas intelligitur cum animadvertimus fucos ab apibus expelli ac fugari. Quod est genus amplioris incrementi, simillimum api, sel, ut ait Virgilius, ignavum pecus, et immune, sine industria favis assidens. Nam nequo alimenta congerit, et ab aliis invecta consumit. Verumtamen atl procreationem sobolis conferre aliquid hi fuci videntur insidentes seminibus, quibus apes figurantur. Itaque ad fovendam (et educandam) novam prolem familiarius admiltuntur. Exclusis deinde pullis, extra tecta proturbantur, et ut ideun ait, a prosepibus arcentur. Hos quidam pracipiunt in totum exterminari oportere. Quod ego Magoni consentiens faciendum non censeo, verun sxvitia modum adlibendum. Nam nec ad occidionem gens iuterimenda est, ne apes inertia laborent, qua, cum fuci aliquam partem cibariorum absumunt, sarciendo damna fiunt agiliores : nec rursus multitudinem proedonum coales. cere patienduin est, ne universas opes alienas diripiaut. Ergo cum rixam fucorum et apiun sapius committi vidoris, adapertas alros inspicies, ot sive semipleni favi sint, 
et les abellles, on ouvrira les ruches pour les visitel à l'iutéricur, soit afin de différer la récolte du miel, sı les rayons ne sont qu'à demi pleins de eette liquetr, soit afin de la faire aussitôt, s'ils en sont remplis, et qu'ils soient reeouverts de eire par-dessus. Il faut communément cholsir la matinéc pour faire cettc opération, paree qu'il r'est pas à propos de vexer lesabeilles au miiieu de la chaleur, temps auquel elles sont déjà naturellement liritées. On se pourvoira à cet effet de deux instruments de fer d'un picd et deni de longueur ou un peu plus : l'un est un long couleau tranchant par les deux côtés, dont l'extrémité sera terminéc par un bistouri crochu; l'autre est un instrument plat ct très-tranehant d'un seul côté, à l'effet de mieux couper les rayons; ¿u lieu qu'on pourra les ratisser avec l'autre, ct è ôter les ordures qui pourront y être tombées. Mais lorsque la ruehe ne sera point munie d'unc cuverture par derrière, on y fera parvenir de la fumée de galbanum ou de fumier sec. On renferme à cet effet l'une ou l'autre de ces matieres, avee de la braise, dans un vase de terre garni d'anses comme une petite marmite : ee vase doit être pointu par un de ses eôtés, qui sera pereé d'un petit trou destiné à livrer passage à la fuméc ; au lieu qu'il sera plus gros par le côté opposé, et garni d'une large embouchure à travers laquelle on pourra souffler dedans. Quand on aura approehé cette marmite de la ruehe, on soufflera dans l'intérieur du vase pour pousser la fumée sur les abeilles; ct alor's ces insectes, qui ne peuvent pas supportercette odeur, se retireront aussitôt sur le devant de la ruche, et en sortiront meme quelquefois, de sorte qu'on aura la liberté de regarder à son aise en dedans. On remarque eommunément deux formes particulières de rayons dans les ruches, quand il s'y trouve deux essaims. En effet, quoi-

differantur : sive jam liquore completi, et superpositis ceris tamq̨uam opereulis obliti, demetautur. Dies vero castraudi fere matutinus oecupandus est. Neque enim convenit aestu mediu exasperatas apes lacessiri. Duobus autem ferramentis ad liune usum opus est, sesquipedali, vel paulo ampliore mensura factis, quorum alterum sit eulter oblongus ex utraque parte acie lata, uno capite aduncum lıabens scalprum; alterum prima fronte planum et acutissimum : quo melius hoc favi succidantur, illo eradantur, et quidquiid sordinm deeiderit, attrahatur. Sed ubi a posteriore parte, qua nullum est vestiluulum, patefactum fuerit alveare, fumum admovebimus factum galbano vel arido fimo. Fa porro vase fietili prunis immista conduntur : idquıe ras ansatum simile angustæe ollæ figu. ratur, ita ut altera pars sit acutior, per quam modico foramine fumus emanet : altera latior, et ore patulo, per quam possit aflari. Talis olla, eum est alveari objecta, spiritu admoto fumus ad apes promovetur. Quic confestim 1iiloris impatientes in priorem partem domieilii, et inter. dum cxtra vestibulum se confermut. Atque uloi potestas est liberius inspicicudi, fere, si dno sunt examina; duo que ces deux peuplades réunies vivent ensembic en bonne intelligenee, elles out néanmoins chacune leur méthode partieulière de façonner la eire, en lui donnant telle ou telle forme, dont elles ne s'éeartent jamais. Au reste, tous les rayons, de quelque facon quilssoient faits, sont toujours suspendus au haut de la ruche et légèrement adhérents à ses parois, sans jamais s'étendre jusqu'au plancher d'en bas, parce que c'est l'endroit qui sert de passage aux essaims. D'ailleurs la forme des cires est modelée sur celle de la ruche, de sorte que sa capacité sert de moule aux rayons, qui retraecnt la forme carrée, ronde ou même longue de la ruche. C'est pour cela qu'on rencontre souvent dans la même ruehe des rayons qui ont chacun leur forme différente. Mais, quels qu'ils soient, il ne faut jamais les enlever tous : on aura soin au contraire d'en laisser la cinquième partie à la première récolte, qui se fait dans un temps où les paturages sont encore abondants. dans les champs, et la troisième partie à la seconde réeolte, qui se fait dans un temps où l'hiver commence déjà à sc faire sentir. Cependant la proportion que nous fixons iei n'est pas. la même pour tous les pays, parce qu'il faut dans chaeun pourvoir à l'intérêt des abeilles proportionnellement à la multitude des fleurs et à l'abondanee des pâturages. Si les cires suspendues à la ruche sont perpendiculairement allongées, il faut couper les rayons avec l'instrument qui a la forme d'un couteau, et les recevoir par-dessous entre les deux bras, pour les tirer de la ruche; mais si les rayons sont attachés horizontalement au haut des ruches, il faut alors se servir de l'instrument qui a la forme d'une serpe, afin de les eouperd'un coup qu'on leur portera en face. On enlèvera ceux qui seront vieux ou défectueux, en laissant dans la ruche ceux qui ne seront point

genera guoque favorum inveniuntur. Nam etiam in concordia suum quaque plebs morem figurandi ceras fingendique servant. Sed onnes favi semper cavearum tectis et paululum ab lateribus adhærentes dependent, ita ne solum contingant : quoniam id prabet examinibus iter. Cæterum figura ecrarum talis est, qualis et lıabitus domicilii. Nam et quadrata et rotunda spatia nee miuus longa suam spe. ciem velut formæ quxdam favis prabent. Idcoque non semper ejusdem figuræ reperiuntur favi. Sed li qualescunque sint, non omnes eximantur. Nam priore messe, dum adluc rura pastionibus abundant, quinta pars favorum; posteriore, cum jam metuitur hiems, tertia relinqquenda est. Atque lic tamen modus non est in oinnibus regionibus certus : quoniam pro multitudine florum el ubertate pabuli apibus consulendum est. Ac si ceræ dependentes in longitudinem decurrunt, eo ferramento, quod est simile cultro, insecandi sunt favi, deinde subjectis. duobus brachiis excipiendi, atque ita promendi : $\sin$ autem transversi tectis cavearum inharent, tunc scalprato ferramento est opus, ut adversa fronte impressi desecentur. Eximi auten debent veteres vel ritiosi, et relimui 
gatés et qui seront pleins de miel, de même que ceux qui renfermeront des petits, parce qu'ilsser. viront à reproduire des essaims. Il faudra ensuite porter tout ce qu'on aura récolté de rayons dans le lieu où l'on voudra faire le miel, et boucher exactement toutes les fentes qui pourront se trouver aux murs ou aux fenêtres de cet endroit, afin queles abeilles n'y puissent pénétrer d'aucun côtė, parcequ'elles s'opiniâtrent à chercher, pour ainsi dire, les richesses qu'elles ont perdues, et que lorsqu'elles parviennent à les trouver, elles les consomment. C'est pourquoi il faut aussi faire des fumigations à l'entrée de cet endroit avec les matières dont nous avons déjà parlé, afin d'en écarter les abeilles au cas qu'elles fassent des tentatives pour y entrer. Quand les ruches auront été récoltées, s'il s'en trouve quelquesunes dont l'entrée soit barrée par des rayons, il faut les retourner d'un autre sens, afin que le côté de derrière y serve à son tour d'entrée. Lorsqu'il sera alors question de les récolter, on enlèvera les anciens rayons avant les nouveaux, et les cires se trouveront renouvelées par là; ce qui est d'autant plus intéressant que plus elles sont vieilles, pires elles sont. Si par hasard les ruches sont revêtues d'une maçonnerie, et qu'elles soient par conséquent immobiles, on aura soin de les châtrer tantôt d'un côté, tantôt de l'autre. Il faudra aussi que cette opé:ation soit faite avant la cinquieme heure du jour; sinon on ne la reprendra qu'après la neuvième, ou le lendemain matin. Au surplus, quelque quantité de rayons qu'on ait récoltée, il est à propros d'en extraire le miel le jour même de la récolte, et tandis qu'ils sont encore chauds. On suspend à cet effet dans un lieu obscur un panier de saule, ou un sac d'osier mince tissu à grandes mailles, dont la forme soit semblable à celle d'une borne renver.

maxime integri ac melle pleni, et siqui tantum pullos continent, ut exaunini progenerando reserventur. Omnis deinde copia farorum conferenda est in eum locum, in quo mel conficere roles, linendaque sunt diligenter fora. Inina parietum et fenestrarum, nequid sit apibus pervium, quae velut amissas opes suas pertinaciter vestigant, et persecutæ consumunt. Itaque ex iisdem rebus fumus etiam in aditu loci faciendus est, qui propulset intrare tentan. tes. Castrata deinde alvi si qua transversos favos in aditu labebunt, convertendxe erunt, ut alterna vice posteriores partes restibula fiant. Sic enim proxime cum castrabun. tur, veteres potius favi quam novi eximentur, cerayue novabuntur, qux tanto deteriores sunt, quanto vetustio. res. Quod si forte alrearia circumstructa et immobilia fuerint, curat erit nobis, ut semper modo a posteriore modo a priore parte castrentur. Idque fieri ante diej quintam horam debebit, deinde repeti vel post nonam, vel postero mane. Sed quotcunquıe favi sunt demessi, eodem dic, dum tepent, conficere inel conrenit. Saligneus qualus, vel tenui rimine rarius contextus saccus, inversa metx similis, qualis eśt quo vinum liquatur, obscuro loco suspen. sée, tels que ceux à travers lesquels on passe le vin; après quoi on $\mathrm{y}$ entasse les rayons les uns sur les autres, en observant néanmoins de rejeter de côté les portions de cire qui contiennent des petits ou de la crasse rouge, parce qu'elles ont un mauvais goût, et que le suc qu'elles rendraient corromprait le miel. Lorsqu'ensuite le niel que l'on aura passé sera tombé dans un bas. sin posé en bas pour le recevoir, on le transportera dans des vases de terre qu'on laissera ouverts pendant quelques jours, jusqu'à ce que cette espèce de moût ait cessé de bouillir. II faudra l'écumer souvent avec une cuiller. Quand ce miel sera fait, on pressera entre ses mains les morceaux de rayons qui seront restés dans le sac, et il en découlera du miel de la seconde qualité, que les gens les plus attentifs mettent à part, de peur qu'il ne détériore par son mélange le premier, dont le gout est excellent.

XVI. Quoique la cire soit une matière de modique valeur, comme on l'emploie cependant à bien des choses, ce genre de profit ne doit pas être négligé. On jette dans un vase de cuivie ce qui l'este des rayons, après qu'on en a exprimé le miel et qu'on les a bien lavés dans de l'eau douce; puis on vel'se de l'eau dessus, et on les fait fondre au feu. Quand cela est fait, on verse la cire, en la passant, sur de la paille ou sur du jonc, et on la fait cuire de nouveau autant que la première fois; ensuite on la verse dans tel moule que lion juge à propos, après l'avoir rempli d'eau, afin que, quand la cire sera figée, il soit aisé de la retirer du moule, parce que l'eau qui sera dessous l'empêclera de s'attacher à ses parois. Mais, puisque nous avons achevé notre dissertation sur les bestiaux et sur les nourritures que l'on fait dans les métairies, nous allons á présent donner en vers, pour satisfaire à l'empressement de

ditur : in eum deinde carptin congeruntur favi. Sed adhıbemla cura est, ut separentur ex partes cerarum, quæe vel pullos habent, vel rubias sordes. Nam sunt mali saporis, et succe suo mella corrumpunt. Deinde ubi liquatum mel in subjectum alveum defluxit, transfertur in vasa fictilia, quæ paucis diebus aperta siut, dum musteus fructus defervescat, isque sixpius ligula purgandus est. Moxdeinde fragmina favorum, qux in sacco remanserunt, retractata exprimuntur: alque id secundse notie mel delluit, et ab diligentioribus seorsum reyonitur, ne quod est primi saporis lıoc adlibito fiat deterius.

XVI. Ceræ fructus quamris xris exigui non tamen omittendus est, cum sit ejus usus ad multa necessarius. Expressæe favorum reliquixe, posteaquan diligenter aq̨ua dulci perlute sunt, in vas aneum conjiciuntur : adjecta deinde aqua liquantur ignibus. Quod uhi factunn est, cera per stramenta vel juncos defusa colatur, afque iteruirs similiter de integro coquitur, et in quas quis voluit formas aqua prins adjecta defunditur : eamque concretam facile est eximere, quoniam qui subest lumor non patitur formis inlaarere. Sed jam consumnata disputatione de villae 
notre aml Gallion, qui l'a désiré ainsl quo vous, Publius Sllvinus, ee qui nous reste à traitcr dc l'économie ruralc, je veux dire la culture des jardins.

\section{LIVRE DIXIÈME.}

\section{DE LA CULTURE DES JARDINS.}

\section{PRÉFACE.}

Recevez, Silvinus, le reliquat des intérêts que vous avez stipulés à ma charge, et au payement desquels je mesuis cngagé vis-à-vis de vous; reliquat au surplus très-mudique, puisqu'à la partie près que je vais acquitter en ce moment, j’ai soldé de compte avec vous par les neuf livres précédents. II ne me restedone plus qu'à traiter de la culture des jardins, cettc partie de l'ćconomie rurale qui, loin d'être négligée comme elle l'était autrefois par les anciens agriculteurs, est au contraire celle dont on parait s'oceuper le plus aujourd'hui. En effet, quoique la frugalité de nos ancêtres allát jusqu'à la parcimonie, les pauvres faisaient meilleure ehère de leur temps qu'ils ne la font à présent, parce que le lait le plus abondant, et la chair des bêtes fauves ou des bestiaux domestiques, ćtaient, ainsi que l'eau et le blé, la nourriture eommune des gens du plus bas aloi, comme de ceux du plus haut rang. Mais dès que les siècles suivants, et particulièrement le nôtre, ont vu augmenter le prix des mets recherchés par les débauchés, et que l'on n'a plus mesuré la bonté d'un repas sur l'appétit naturel, mais sur les dépenses qu'il a occasiounées, la pauvreté du peuple a néeessairement mis hors de sa portèe les mcts d'un prix trop élevé, et l'a réduiţ par là aux aliments les plus communs. C'est pour cela mêmc que nous devons douner des préceptes sur la eul-

licis pecudibus atque pastionibus, quæ reliqua nobis rusticarum rerum pars subest, de cultu hortorum, Publi Silvine, dleinceps ita, ut et thi et Gallioni nostro complacuerat, in carmen conferenus.

\section{LIBER DECIMUS. \\ DE CULtu hortonum. PRAFA'TIO.}

Fonoris tui, Silvine, quod stipulanti spoponderam tibi, reliquam peusiunculam percipe. Nam superioribus noven libris hac miuus parte debitum, quod numc persol. vo, reddideram. Superest ergo cultus hortorum seguis ac neglectus quondan veteribus agricolis, nunc vel celeberrimus. Siquidem cum parcior apud priscos esset frugalitas, largior tamen pamperibus fuit usus epularum lactis copia ferinaque ac domesticarum pecudum carne; velut aqua frumentoque summis atque humillinis vichum tolerantilins. Mox cum sequens et procipue nostra atas dapibus fibilinosa pretia constituerit, cornacque non naturalibus desideriis, sed censibus astimentur, plebeia pauperfas ture des jardins avec plus de soin que ne l'ont fait nos ancêtres, parce que les fruits qui cn proviennent sont aujourd'hui d'un usage plus général qu'ils ne l'étaient de leur temps. J'aurais eomposé ce traité en prose, ainsi quc je me l'étais d'abord proposé, afin de le joindre par suite aux livres précédents, si vous n'eussiez pas combattu mon projet par vos sollicitations continuelles, qui ont enfin vaincu ma résistance, et qui m'ont déterminéà mettre en vers des parties qui manquent au poëme des Géorgiques, et que Virgile a déclaré lui-même n'avoir omises que pour laisser à la postérité lc soin de les traiter après lui. Aussi n'aurais-je jamais eu la témérité de tenter une pareille entreprise, si le plus respectable des poëtes n'avait déelaré par là son intention. C'est donc comme par son inspiration que je me suis chargé, quoiqu'en hésitant, je l'avoue, vu la difficulté de l'entreprisc, mais non sans espoir de réussite, de traiter une matière délicate et presque sans corps, tel que celle-ci, qui est effectivement si mince, que, soit que l'on considère l'ensemble de mon ourrage, on peut la regarder commen'en faisant qu'une parcelle, soit qu'on l'examine à part, et qu'on la restreigne, pour ainsi dire, à ses linites, on ne peut en aucune manière lui donner une eertaine consistance. En effet, quoiqu'elle soit composée, pour m'exprimer ainsi, de plusieurs membres, sur chacun desquels il peut à la vérité se trouver quelque ehose à dire, ces mombres sont néanmoins aussi imperceptibles que des grains de sable, avec lesquels il est impossible (comme disent les Grees) de former un cordage, vu leur petitesse incompréhensible. Loin donc que ee fruit de nos veilles, quel qu'il soit, prétendeà des applaudissements particuliers, l'auteur se eroira au contraircassez favorablement traité, pour peu qu'on ne juge point que son travail dés.

submota a pretiosioribus cibis ad vulgares compellitur. Quare cullus lıortorum, quoniam [et] fiuctus magis in usı est, diligentius nobis, quain tradiderunt majores, pracipiendus est : isque, sicut institueram, prosa oratione prioribus subnecterelur exordiis, nisi propositum [meum ] expugnasset frequens postulatio tua, qux pervicit, ut poeticis nuneris explereın Georgici carminis omissas par. tes, quas tamen et ipse Virgilius significaverat, posteris se meinoraudas relinquere. Neque enim aliter istud nobis fuerat audendun, quam ex voluntate vatis maxime vene. randi ; cujus quasi numine instigante pigre sine dubio propter difficultatem operis, veruntamen non sine spe prosperi successus aggressi sumus tenuem admodum et pene viduatam corpore materiam, quæ tam exilis est, ut in consunmatione quidem totins operis annumerari veluti particula possit laboris nostri, per se vero et quasi suis finibus terminata nullo modo conspici. Nam etsi multa sunt ejus quasi membra, de quibus aliquid possunns effari, taınen eadem tam exigua sunt, ut, quod aiunt Grieci, ex incomprelıensibili parvitate arenæ funis effici nou possit Quare quidgruid est istud, quod elucubravinuus, adce 
honore les traités qui l'ont précédé. Mais cessons cette préfacc.

Je vous montrerai aussi, Silvinus, la culture des jardins, ainsi que les objets que Virgile nous a laissé le soin de traiter après lui, lorsqu'en se renfermant dans des bornes étroites, il chantait les moissons abondantes et les présents de Bacchus, et vous, grande Palès, et le miel émané du ciel. D'abord il faut, pour l'emplacement d'un jardin de bon rapport, choisir un champ gras qui renferne dans son sein des mottes de terre bien pulvérisées et des gazons faciles à s'ameublir, et qui ressemble, après les fouilles qu'on y aura faites, au sable le plus fin. Un terrain sera encore propre à cette destination par sa nature, lorsqu'il sera coutinuellement tapisséd'une grande quantité d'herbes, et qu'amolli par l'humidité, il produira les baies rouges de l'yèble : car on rejette les terrains secs, de même que ceux qui, couverts d'eaux marécageuses, sont sans cesse étourdis par les plaintes éternelles de la grenouille. La terre y sera également propre, quand elle produira spontanément sans aucune culture des ormes chargés de feuillages, (quand elle sera fertile en palmiers sauvages, quand elle aimera à se voir hérissée d'une forêt de poiriers sauvages, ou couverte des fruits à noyau du prunier, et qu'elle sera chargée de pommes qui y croîtront naturellement; pourvu toutefois qu'elle se refuse à produire les hellébores, ainsi que le carpasum dont le suc est pernicieux; qu'elle ne souffre pas les ifs, et qu'elle n'exhale point de poisons actifs. Peu importe qu'elle renferme dans son sein la mandragore, cette herbe funeste à la raison, qui resscmble à la moitić du corps humain, et qu'clle produise les fleurs de cette plante, ou la eigue affligeante, ou les férules cruelles aux mains, ou les broussailles épaisses des buissons cnnemis des jambes, ou le paliure avec ses épines piquantes. Il faut aussi qu'il se trouve, dans le voisinage, des rivières que le cultivateur saignera sans regretter sa peine, pour en faire venir les eaux au secours de ses jardins toujours altérés, ou qu'on ait la faculté de les arroser avec de l'eau de source amassée dans un puits, dont la profondeur incommode n'arrache point les entrailles de ceux qui seraient forcés de se comprimer le ventre pour la puiser. Il faudra clore ce terrain de murailles ou de haies hérissées, pour en interdire l'entrée tant aux bestiaux qu'aux voleurs. Ne courez point après les ouvrages sortis de la main de Dedalus, et n'ayez point recours à l'art de -Polyclète, de Phradmon ou d'Agelada, pour vous fabriquer un Ithyphallus; mais révérez dans le trone d'un vieil arbre façonné au hasard. cette divinité au membre terrible, qui, placée au milieu de votre jardin, effrayera sans cesse les enfants avec cet épouvantail, et menacera les voleurs de sa faux. Allons, courage, Muses Piérides : racontez-11ous en vers simples quelle culture il faut donner aux semences, quels sont les temps propres à les mettre en terre, quels soins elles exigent quand elles y sont, quelle est la saison où les fleurs commencent à venir, et où l'on voit paraitre des boutons dans les pépinières de rosiers de Pestum; enfin quelle est celle dans laquelle l'arbuste de Bacchus, ou tout autre arbre mitigé par une greffe étrangère, se courbent sous le poids deleurs fruits adoptifs. Lorsque le chien aura com. propriam sibi landem non rindicat, ut boni consulat, si non sit dedecori prius editis a me scriptorum monimentis. Sed jam præefari desinamus.

Hortorum quoque te cultus, Silvine, docebo, Atyue ea, quæ quoıdam spatiis exclusus iniquis, Cum caneret lotas segetes et munera Bacchi, Et te magna Pales, necnon cælestia mella, Virgilius nobis post se memoranda reliquit. P'riucipio selenı numeroso prabeat horto Pinguis ager, putres glebas resolutaque terga Qui gerit, et fossus gracileis imilatur arenas, Atque habilis natura soli, qua gramine læto Parturit, et rutilas ebuli creat uvila baccas.

Nanı neque sicca placet, nec quæ stagnata palude Perpetitur querulse semper convicia rana. Tum quæe sponte sua frondosas educat ulmos, Palmitibusque feris lælatur, et aspera silvis Aclırados, aut pruni lapidosis obruta pomis Gaudet, et iujussi consternitur ubere nıali : Sed negat helleboros, et noxia carpasa succo, Nec patitur taxos, nee strenua toxica sudat, Quantris semilominis vesano gramine futa
Mandragoræ pariat flores; mcestamque cicutam, Nec manibus mitis ferulas, nec cruribus aqua Terga rubi, spinisque ferat paliuron acutis. Vicini quoque sint amnes, quos incola durus Attralıat auxilio semper sitientibus hortis : Aut fons illacrimet putei non sede profuuda, Ne gravis hausturis tendentibus ilia vellat. 5 Talis luunus vel parietibus, vel sepibus hirtis Claudatur, ne sit pecori, neu pervia furi.

Neu tibi Dnedaliæ quarantur munera dextræ, Nec Polycletea nec Pliradmonis, aut Ageladx Arte laboretur : sed truncum forte dolatum

Arboris antiqua numen venerare 1tlıyphalli Terribilis membri, medio qui semper in horto Inguinibus puero, praedoni falce minetur.

Ergo age nunc cultus et tempora quatue serendis Seminibus, qux cura satis, quo sidere primum Nascantur llores, Prestique rosaria gemmeut, Quo Bacchi genus, aut aliena stirpe gravata Mitis adoptatis curvetur frugilus arbos, pierides tenui deducite carmine Musie. Oceani siticus cum jam canis laauserit undas, 
meneé à se désaltérer dans les caux de l'Oecean, et que 'Titan aura rendu les jours égaux aux nuits dansl'un et l'autre hémisphère; lorsque l'Automne rassaslé de fruits et secouant ses tempes se sera cmpourpré, en exprimant le raisin écumant de moût, il nous faudra retourner, avec le fer d'une bèche emmanchée de robre, la terre fatiguée, qui s'y prêtera avec douceur, pour peu qu'elle ait déjá été humectée par les pluies. Si elle est au contraire endurcie par la continuité d'un temps screin, et que, rebelle à tous nos efforts, elle reste en mottes, il faut faire couler par le secours de l'art, le long d'un chemin en pente, des ruisseaux propres à la désaltérer, afin qu'elle en remplisse sa bouche béante. Mais s'il arrive que ni le ciel ni la terre ne lui prêtent aucune humidité, et que la nature de la contrẻe ou Jupiter lui refusent de la pluie, on attendra que l'hiver soit venu, et que la eonstellation brillante donuéc par Baechus à la fille de Gnosos se cache sous la mer azurée au póle du monde, et que les Atlantides craignent de voir le soleil se lever vis-à-vis d'elles. $\mathrm{Or}$, lorsque Phébus commencera à ne plus se fier à l'Olympe, inais qu'il fuira en tremblant la partie antérieurc du Seorpion et ses armes cruelles, pour presser la croupe de Crotus; peuples, qui ignorez votre origine, n'épargnez pas la terre, que vous prenez $\mathrm{mal}$ à propos pour votre mère. Elle fut à la vérité la mère de ces enfants formés a vec l'argile de Prométhée; mais e'est une autre mère qui nous a donné le jour, dans le temps que l'impitoyable Neptune abima la terre sous les ondes, et qu'ébranlant le fond des abimes, il épouvanta les eaux du Léthé. Ce fut alors que le Tartare vit trembler pour la première fois le roi du Styx, tandis que les mânes

Lt paribus Titan orbem libraverit horis, Cum satur autumnus quassans sua tempora pomis, Sordidus et musto spumantes exprimet uvas; Tım mili ferrato versetur robore palæe Dulcis humus, si jam pluviis defessa madebit. At si cruda manet calo durata sereno, Tum jussi veniant declivi tramite rivi, Terra bibat fontes, et liantia compleat ora. Quod si nec cali nec campi competit humor, Jugeniumque loci vel Jupiter abuegat imbrem, Expectetur hiems, dum Baccli Gnosius ardor Equore cxeruleo celetur vertice mundi, Solis et adversos metuant Allantides ortus. Atque ubi jam tuto necdum confisus Olympo Sed trepidus profugit chelas et spicula Phœbus Jira Nepa, tergoque Croti festinat equino, Nescia plebs generis matri ue parcite falsæ. Ista l'romethex genitrix fuit altera cretæ : Altera nos enixa parens, quo tempore savus Tellurem ponto mersit Neptunus, et inum Concutiens baratlırum letlıxas terruit undas. Tumque semel Stygium regein videre trementem Tartara, cum pelagi streperent sub pondere manes. faisnient retentir leurs cris sous le poids des caux de la mer.

C'est donc une main féconde qui nous a eréés, lorsqu'il ne restait plus aucun mortel sur ee globe; et ee sont des rochers arrachés alors par Deucalion sur des montagnes élevées, auxquels nous devons notre origine. C'est pour ccla que vous êtes appelés au travail le plus dur et le pius assidu : ainsi prenez courage, chassez aujourd'hui de vos yeux un sommeil léthargique; commencez à arracher la verte ehevelure de la terre, et à déchirer ses vêtements avec la pointe recourbéc du soc. Que l'un sillónne avec de lourds ráteaux sa superficie, lente à rapporter des fruits ; que l'autre ne tarde pas à lui arracher les entrailles avec de larges marres, et à les entasser avee le gazon dont elle est couverte, tant pour les mettre à portće de recevoir les gelées blanches par lesquelles elles ont besoin d'être brûlées, et les exposer aux coups des vents froids et à la colère de Caurus, qu'afin que l'impétueux Borée les resserre et que l'Eurus les dilate. Lorsqu'ensuite le Zéphire seeourable aura dissipé par la chaleur de son souffle l'engourdissement eausé par les froidsde l'hiver, venus des monts Riphéens; lors. que la Lyrequittera le pôle céleste pour se plonger dans la mer, et que l'hirondelle aura chanté dans son nid le retour du printemps : rassasiez alors la terre, qui sort d'un long jeûne, de terres grasses rapportées, ou de crottes d'ânon dures, ou de fumier de bêtes de somme : que le jardinier ne rougisse point de porter lui-même, pour l'engrais des guérets épuisés, des paniers qui fléchiront sous la charge des immondices que les latrines auront vomies de leurs cloaques immondes.

Nos fœcunda manus viduo mortalibus orbe

Progenerat, nos abruptæe tum montibus altis Deucalionea cautes peperere. Sed ecce

Durior acternusque vocat labor : eia age segnes

Pellite nunc somnos, et curvi vomere dentis

Jam virides lacerate comas, jam scindite amictus.

Tu gravibus rastris cunctantia perfode terga,

Tu penitus latis eradere viscera marris

Ne dubita, et summo frondenti cespite mista

Ponere, quæ canis jaceant urenda pruinis,

Verberibus gelidis iræque obnoxia Cauri,

Alliget ut sævıs Boreas, Eurusque resolvat.

Post ubi Riplıæx torpentia frigore bruma

Candidus aprica Zeplıyrus regelarerit aura, Sidereoque polo cedet Lyra mersa profundo,

Veris et adventum nidis cantarit hirundo,

Rudere tum pingui, solido vel stercore aselli,

Armentive fimo saturet jejunia terræ,

Ipse ferens olitor diductos pondere qualos :

Pabula nec pigeat fesso prabere novali,

Immundis quaecunque vomit latrina cloacis.

65

Densaque jau pluviis, durataque summa pruiuis

Equora dulcis huıni repetat mucrone bidentis. 
Qu'il recommence encore à retourner avec la pointe du hoyau la terre qu'il avait déjà précédcmment ameublie, mais dont la superficie s'est condensée depuis par les pluies et endurcie par les gelées : qu'il broie bien ensuite l'herbe vivace du gazon avec les moltes de terrc, en mordant fortement avec la marre ou la houe les mamelles du terrain déjà dissoutes par la fermentation, afin de les réduire absolument en poudre : qu'il prenne aussi entre ses mains les sarcloirs devenus luisants à force d'être polis par le frottement de la terre, et qu'après a voir dirigé des sillons étroits perpendiculaires à de larges allées, il coupe encore ces sillous par de petits sentiers. Mais dès que la terre, ainsi embellie et distribuée en planches, aura déposé toutes ses impuretés, pour briller d'un nouvel éclat, et qu'elle demandera à receroir les semences qui lui conviennent, garnissez-la alors des différentes espèces de fleurs qui sont toutes autant d'astres terrestres, telles que la giroflée blanche, le souci d'un jaune éclatant, les têtes du nareisse, la gueule béante et terrible du lion saurage; les lis sous l'éclat desquels blanchissent les corbeilles, les jacinthes tant blanches que bleues : qu'on y voie aussi des violettes, soit de celles qui rampent à terre et dont la couleur est peu fonccee, soit de celles qui s'élevant sur leur tige sont teintes d'un or pourpré; enfin, qu'on y roie des roses dont la couleur imite celle qu'imprime la pudeur sur les joues. Semez alors l'herbe d'or, dout lc jus est médicinal, le glaucium au suc salutaire, et les pavots propres à enchaîner le sommeil lorsqu'il fuit de nos yeux : ajoutez-y les semences qui exaltent la faculté générative, tant en aiguillonnant les hom- mes qu'en anlmant les filles, c'est-à-dlrc; l'olgnon de Mégare, la seille que la contrée de Gétulie nourrit sur son sol, et la roquette que l'on sème auprès de Priape couronné d'épis, afin qu'elle excite les maris tardifs à rendre hommage à Vénus. Semez le cerfeuil qui rampe à terre, la chicorée agréable aux palais engourdis, la petite laitue aux feuilles tendres, l'ail enveloppé de ses gousses, l'oignon de Cypre dont l'odeur se fait sentir au loin, et tous les ingrédients qu'un habile cuisinier fait entrer dans l'assaisonnement des fèves qui servent de nourriture aux artisans. Semez le chervi, et cette racine produite par une graine d'Assyrie que l'on sert coupée par morceaux, avec des lupins détrempés, pour ex citer à boire la bière de Pelusium. On met aussi en terre dans le même temps les plantes que l'on peut confire à peu de frais, telles quc le câprier, la triste aunée et les férules menaçantes : on y met l'herbe rampantede la menthe, et les fleurs odoriférantes de l'aneth : on y met la rue, dont on se sert pour exalter le goût du fruit de Pallas, la moutarde qui fait venir les larmes à ceux qui se jouent d'elle, la racine du maceron, l'oignon qui fait pleurer, et l'herbe qu'on emploie à assaisonner le goût du lait, et qui annonce par son nom gree la vertu qu'elle a de faire disparaître les marques imprimées sur le front des esclaves fugitifs. On sème aussi alors ce légume multiplié sur tout le globe de la terre, qui croit autant pour le peuple que pour les rois superbes, et qui donne des tiges en hiver et des cimes au printemps, je veux dire le chou de toute espèce; et celui qui croît sur le rivage fertile en oignons de l'ancienne ville de Cumes, et celui du pays des Marrucini,
Mox bene cum glebis vivacem cespitis herbam Contundat marra vel fracti dente ligonis, putria maturi solvantur ut ubera campi.

Tunc tritura solum splendentia sarcula sumat, Angustosque foros arlverso limite ducens, Rursus in obliquum distinguat tramite parro. Verum ubi jam puro discrimine pectita tellus, Depositn squalore nitens sua semina poscit, Pangite tunc varios terrestria sidera flores, Candida leucoia, el flarentia lumiua caltıæ, Narcissique comas, et hiantis særa leonis Ora feri, calathisque virentia lilia canis, Nec nou vel niveos, vel caruleos liyacintlıos.

Tum quse pallet humi, quxe frondens purpurat auro, Ponatur viola, el nimimm rosa plena pudoris. Nunc medica panacem lacryma, succoque salubri Glancea, et profugos rinctura paparera somnos Spargite : quaeque viros acuunt, armantque puellis, 105 Jam Megaris veniant geuitalia semina bulbi, Et qux Sicca legit Gelulis obruta glebis : Et quie frugifero seritur vicina l'riapo, Excitel ut V'eneri tarulos eruca marilos.
Jam breve chærophylum, et torpenti grata palato Intyba, jam teneris frondens lactucula fibris, Alliaque infractis spicis, et olentia late Ulpica, quaque fabis lıabilis fabrilia miscet. Jam Siser, Assyrioque renit qua semine radix, Sectaque prabetur madido sociata lupino, Ut Pelusiaci proritel pocula Zylli.

Con alo vili quorjue salgama merce Capparis, et tristes inula, fernlaeque minaces, Plantantur : necnon serpentia graınina mentx, El bene odorati flores sparguntur anethi, Rutaque Palladixe bacca jutura saporem, Seque lacessenti fletum factura sinapis, Atque oleris pulli radix, lacrymosaque cepa Ponitur, el lactis gustum quæ conliat lıerba, Deletura quidem fronti data signa fugarum, Vimque suam idcirco profitetur nomiue Graio. Tum quoque conserilur, toto qua plurima terra Orbe virens pariter plebi regique superho Frigoribus caules, et veri cymata miltil : Quße pariunt veteres cesposo littore Cuma, Qua Jarrucini, quæ Signia monte Lẹino,
110 
et celul de Signia qui vlent sur le mont Lepinus, et celui de la fertile Capoue, et eelui des jardins situés au défilé de Caudium, et eelui de la ville de Stabie eélèbre par ses eaux de souree, et celui des campagnes du Vésuve, et celui de la docte Parthénope qu'arrose l'eau du Sebethus, et eelui qui vient dans les marais d'eau douee de Pompéi qui sont voisins des salines d'Hereule, et eelui du Siler qui roule des eaux transparentes, et ceIui que eultivent les durs Sabelli, dont la tige réunit plusicurs cimes, et celui du lac de Turnus, et celui qui croít auprès de Tibur dans des campagnes abondantes en fruits, et eelui de la eontrée des Brutii, et eelui de la ville d'Aricia, d'où nous vient le poireau. Dès que l'on aura confié ees semenees à une terre ameublie, on la ménagera pendant sa grossesse, à l'aide d'une culture et de soins assidus, dont elle rendra les intérêts multipliés en récoltes. Je préviens d'abord qu'il faut la mouiller abondamment, de peur que l'embryon qu'elle aura eoneu ne soit brûlé par la sécheresse. Mais lorsqu'elle approchera de ses couclıes, et qu'elle se dilatera en relâchant les liens qui la resserrent, parec qu'une progéniture fleurıe aura pullulé dans son ventre maternel, il faudra que le jardinier donne de l'eau avee modération aux prémices des plantes qu'elle portera dans son sein, qu'il les arrose assidùment, qu'il les peigne avee un instrument de fer à deux dents, et qu'il détruise les herbes qui suffoqueront les sillons. Si eependant les jardins sont situés sur des collines couvertes de buissons, et qu'il ne tombe point de ruisseaux du haut des forêts plantées sur la eime de ees eollines, il faut faire gonfler les terres par le labour, et former avee ees terres, en les amoncelant, des planches

Pinguls item Capua, et Caudinis faucibus lıorti, Vontibus et Stabix celebres, et Vesuia rura, Doctaque Partlıenope Sebeticle roscida lymplıa, Quæ dulcis Pompeia palus vicina Salinis Herculeis, vitreoque Siler qui deflnit amni, Qux duri prabent cymosa stirpe Sabelli, r.t Turis lacus, et pomosi Tyluris arva, Brutia qua tellus, et mater Aricia porri. Ine ubi credidimus resoluta semina terra, Assiduo gravidam cultu curaque fovemus, Ut redeant nobis cnmulato foenore messes. Et primum moneo largos inducere fontes, Ne sitis exurat concepto semine partum. At cum fota suos nexus adaperta resolvit, Florida cum soboles materno pullulat arvo, Primitiis planta modicos tum prabeat imbres Sedulus irrorans olitor, ferroque bicorni Pectat, et angentem sulcis exterminet lierbam. At si dumosis positi snut collibus lıorti, Nec summo nemoris labuntur vertice rivi, $\Lambda$ ggere praposito cumulatis area glebis Emineat, sicco ut consuescat pulvere plantit, très-élevées, afin que les plantes s'habituent à un sol poudreux et sec, et que si l'on vient à les transférer d'un lieu à un autre, elles n'aient point d'horreur pour les ehaleurs les plus arides. En. suite, aussitôt que l'animal qui tient le premier rang entre les signes du zodiaque eomme entre les bestiaux, et qui a fait passer la mer à Phrixus, fils de Néphélé, sans réussir à la faire passer à Hellé, aura élevé sa tête au-dessus des eaux, la terre ou vrira son sein à ses nourrissons, et, pressée par le désir de se marier avee les plantes qu'on lui aura confiées, elle demandera qu'oı lui donne des semenees adultes. Il vous faut done être vigilants, jardiniers, paree que le temps fuit à pas sourds, et que l'année s'écoule sans bruit. Voyez la plus douce des mères qui demande ses enfants, et qui soupire non-seulement après ceux d'entre eux qui sont sortis de ses cutrailles, mais eneore après erux qu'on peut regarder eomme ses beaux-fils. Donnez done sans tarder ees gages à leur mère ; le temps en est venu : environnezla de sa verte progéniture, eouronnez sa tête et arrangez sa ehevelure. Que l'ache verte serve de frisure à la terre fleurie; qu'elle se réjouisse en voyant flotter sa longue ehevelure de têtes de poireaux, et que la earotte ombrage son tendre sein. Que les plantes odoriférantes, qui nous sont venues des pays étrangers, deseendent à présent des montagnes siciliennes de la ville d'Hybla, renommée par son safran : que la marjolaine, nćc dans la luxurieuse Canope, arrive : qu'on mette aussi en terre la myrrhe d'Achaie, qui imite vos larmes, fille de Cyniras, et qui est préférable à la myrrhe liquide elle-même : enfin, que le jardinier transfère en pied les plantes qu'il aura semées en graine, telles que les fleurs éacides sorties

Nec mutata loco sitiens exhorreat xestus.

Mox ubi nubigenæ Plırixi, nec portitor IIelles, Signorum et pecorum princeps caput efferret undis, Alma sinum tellus jam pandet, adultaque poscens Semina depositis cupiet se nubere plantis : . Invigilate viri : tacito nam tempora gressu Diffuginnt, nulloque sono convertitur annus. Flagitat esse suos genitrix mitissima foetus,

140 Et quos enixa est partus jam quærit alendos, P'riviguasque rogat proles. Date nunc sua matri Pignora, tempus adest : viridi redimite parentem Progenie, tu cinge comam, tu digere crines. Nunc apio viridi crispetur tlorida tellus, Nunc capitis porri longo resoluta capillo Latetur, mollemque sinum staplıylinus inumbret. Nunc et odorata peregrino muiere plantas Sicaniis crocea descendant montibus Hyblae, Nataque jam veniant lilari sampsuca Canopo, Et litcrymas imitata tuas, Cinyreia virgo, Sed melior staclis ponatur Achaica myrrlıa : Et male damnati mossto qui sanguiue surgunt Licii flores, immortalesque amaranti, 
du sang de ec héros attristé par uue eondamnation injuste, les amarantes immortelles, et la variété infinie de couleurs que la nature produit si libéralement. Que le coramble vienne, tout ennemi qu'il est de la vue; et que les laitues, qui provoquent unsommeil salutaire, se hàtent d'arriver, pour exciter l'appétit affaibli par une longue maladie. Il y en a deux qui portent le nom de Cécilius Métellus, dont l'une est verte et épaisse, et l'autre est parée d'une chevelure brune. Il en est une troisième, qui a retenu le nom de la Cappadoce, sa patrie; elle est pâle, et a la tête aussi bien fournie qu'élégamment peignée. Pour la mienne, qui croít à Gadès sur la côte de Tartésus, elle a le pied blane, et la tête également blanehe et frisée. Enfin celle que l'ile de Cypre voit croltre dans les campagnes grasses de Paphos a la chevelure frisée et rouge, mais le pied blanc. Autant il y en a d'espèces particulières, autant on compte de temps différents pour les planter. Le Verseau met en terre la Cæeilia au commencement de l'année, et le Lupercus y met celle de Cappadoee dans le mois où l'on sacrifie aux morts. Mars, plantez celle de Tartésus d̀ vos calendes; et vous, déesse de Paphos, plantez également aux vôtres celle de cette ville : c'est le temps auquel elle aspire à s'unir avec sa mère, qui est pressée d'un désir égal; c'est le temps auquel ectte mère bien amollie se tient couchée sous un guéret aisé à pénétrer. Que la génération s'opère : voiei le temps preserit à l'univers pour engendrer; voiei le temps où l'amour va régénérer la nature : c'est à présent que l'âme du monde s'abandonne à Vénus, et qu'agitée par l'aiguillon de la volupté, elle cherche avec ardeur à se réu- nir à ses parties pour les remplir de sa progéniture. C'est à présent que le père de la mer et le maitre des eaux prodiguent leurs caresses, l'un à sa Thétys, l'autre à son Amphitrite; et déjà ces deux déesses ourrent leur sein pour donner à leur mari une postérité azurée, et peupler la mer de poissons. Le plus grand des dieux luimême, l'artifieieux Jupiter, rappelle le souvenir de ses aneiennes amours avec la fille d'Acrisius, en tombant dans le sein de sa mère sous la forne d'une pluie violente; et cette mère, de son coté, ne rejette pas les car'sses de son fils, puisquau contraire la terre enflammée de passion se livre à ses embrassements. C'est ce qui fait que les mers, que les montagnes, que tout l'univers enfin célèbre le printemps : c'est ce qui fait que les désirs les plus ardents s'allument avec l'amour dans l'imagination des hommes, ainsi que dans eelle des bestiaux et des oiseaux, et que cet amour pénètre la moelle de leurs os pour y exercer sa fureur, jusqu'à ce que Vénus, rassasiée de plaisirs, remplisse leurs membres fécondés, et enfante mille productions différentes, pour peupler continuellement l'univers d'êtres nouveaux, afin qu'il ne languisse pas dans le vide des siècles. Mais comment ai-je l'audace de permettre à mes chevaux des'emporter dans une voie trop élevée, et de traverser les airs d'une course rapide? II n'appartient qu'à un poëte particulièrement inspiré par le dieu de la poésie, et qui court après les lauriers de Delphes, de ehanter ces objets, ainsi que les causes des choses, ou l'être qui donne le mouvement aux orgies saerées de la nature, ou les lois seerètes du eiel. Que la chaste Cybèle anime un poěte par les Dindymes; que
Ft quos mille parit dives natura colores, Disponat plantis olitor, quos semine sevit. Nunc veniat quamvis oculis inimica coranıble, Jamque salutari properet lactuca sapore, Tristia quæ relevat longi fastidia morbi. Altera crebra virel, fusco nilet altera crine, Utraque Cacilii de nomine dicta Metelli. . Tertia, qux spisso sed puro vertice pallet, Hace sua Cappadoca servat cognomiua gentis. F.t mea, quam generant Tartesi littore Gades, Caudida vibrato discrimine, candida thyrso est. Cypros item Paphio quam pingui nutrit in arvo, Punicea depexa coma, sed lactea crure est. Quot facies, tolidem sunt tempora quanque serendi. Caciliam primo deponit Aquarius anno, Cappadocamque premit ferali mense Lupercus. Tuque tuis Mavors Tartesida pange calendis , Tuque suis Paplien iterum jam pange caleudis. Dum cupit, et cupidæe quarit se jungere matri, Et mater facíli mollissima subjacet arvo, Ingenera; nune sunt genitalia tempora mundi : Nunc amor ad coilus properat, uunc spiritus orbis
Baccliatur Veneri, stimulisque cupidinis actus Ipse suas adamat partes, et fotibus implet.

Nunc pater xquoreus, nunc et regnator aquarum, Ille suam Tethyn hic pellicil Amphitriten, Et jam cæruleo partus enixa marito Utrayure nunc reserat pontumque natantibus implet. Maximus inse deum posito jam fulmine fallax Acrisioneos reteres imitatur amores, Inque sinus matris violento defluit imbre. Nec genitrix nati uunc aspernalur amorem, Sed patitur nexus flammata cupidine tellus. Iline maria, line montes, line tolus denique mundıs Ver agit : hinc hominum pecudum volucrumqque cupido, Atque amor ignescit menti, sævitque medullis, Dum satiata Venus foccundos compleat artus, Et generet varias soboles, semperque frequentet Prole nova mundum, vacuo ne torpeat æevo. Sed quid ego infreno rolitare per athera cursu Passus equos audax sublimi tramite raplor? Ista canat, majore deo quem Delphica laurus Impulit, et rerum causas, et sacra moventem Orgia naturæ, sccretaque focdera cali, 
ce poëte, insplré par le Cithéron, par les montagnes de Nysa dédiées á Baechus, par celle du Parnasse qui lui est aussi consacrée, et par le silence favori des Muses qui règne dans la forêt Piéria, chante à grand bruit avee sa voix bacchique : Gloire à vous, dieu de Délos I gloire à vous, Évius, Évius! Pour moi qui m'égare en traitant d'objets moins importants que ceux-là, j'entends ma Calliope qui me rappelle, et qui mordonne de me renfermer dans un plus petit cerele, et de tramer avec elle un tissu de vers dont les fils soient plus grcles, e't qui puissent etre chantés sur quelque air pendant le travail du vigneron, suspendu aux arbres pour tailler les vignes auxquelles ils sont mariés, ou du jardinler oecupedans ses jardlns verdoyants. Passons donc aux opérations qui doivent suivre celles que nous avons déjà détaillées. Que l'on distribue dans l'intervalle étroit d'un sillon et le eresson alénois, mortel aux vers qui se forment secrètement dans un ventre ehargé de nourritures mal digérées, et la sariette dont le goût tient de ceux du thym et de la thymbre, et le coneombre et la courge, dont l'un a la tête tendre et l'autre l'a fragile. Que l'on plante l'artiehaut hérissé qu'lacchus trouve agréable lorsqu'il boit, et qui déplaît à Phébus lor'squ'il chante : tantôt il s'éleve garui de grappes pourprées, tantôt il verdit avec une chevelure de couleur de myrte, tantôt sa tête se penelie et ses feuilles s'entr'ouvrent, tantót il imite la pomme de pin par le piquant de sa pointe, tantôt il est évasé par en haut en façon de corbeille et hérissé d'épines menaẹntes; quelquefois il est pâle, et ressemble à la feuille torse de l'acanthe. Dès que le grenadier, dont le fruit s'a- doucit quand la peau de ses grains commenee do rougir, se couvrira de fleurs teintes de sang, il sera temps de semer le pied de veau : c'est aussi alors que l'on verra naitre les coriandres fameuses, ainsi que la nielle semblable au cumin par sa délicatesse; c'est alors que la baie de l'asperge s'élancera à travers son fanagc épineux, et que l'on verra la mauve, aecoutumée à suivre le soleil dans son cours, pencher la tête du côté de cet astre.

On voit aussi naitre alors la couleuvrée, qui a l'audace d'imiter tes vignes; dieu de Nysa, et qui, ne redoutant point les buisscons, se lève effrontément à travers les épines du poirier sauvage, et entortille les aunes inflexibles. Déjà la poirée, à la feuille verte et au pied blanc, s'enfonce dans un sol gras à l'aide d'un pieu ferré par la pointe, comme la seeonde lettre de l'alphabet, qui porte en grec le même nom que cette plante, s'imprime sur des tablettes à l'aide du stylet d'un maittre savant. La moisson des fleurs odoriférantes se prépare aussi à présent; déjà le printemps s'empourpre; déjà la terre, enceinte des productions bigarrées de l'année, se plait à en couronrer ses tempes; déjà les lotiers de Phrygie étalent leur blancheur éclatante, et les violettes ouvrent leurs yeux clignotants; déjà le lion báille, et la rose, dont les joues virginales commeneent à s'entr'ouvirir, interdite par la rougeur ingénue qui les couvrc, contribue dans les temples au culte des habitants des cieux, en associant son odeur à celle de Saba. Maintenant c'est vous que j̈implore, Achéloïdes, compagnes des Pégasides, chœurs de Dryades du mont Ménale, nymphes Napées, vous qui habitez les
Extimulat vatem per Dindyma casta Cybebes, l'erque Citlıeronem, Nysăaque per juga Bacehi, Per sua Parnassi, per amica silentia Musis Pierii nemoris, Bacclsea voce frementem Delie te Piran, et te evie evie Paean.

Ale mea Calliope cura leviore raganten Jam revocat, parroque jubet decurrere gyro, Et secunı gracili connectere carmina filo, Qua canat inter opus musa modulante putator l'endulus arbustis, olitor viridantibus liortis. Quare age, quod sequitur, parvo discrimine sulci Spargantur cacis nasturcia dira colubris, Indomito male sana cibo quas edueat alvus, Et satureia tlıyni teferens tlıymbræequc saporem, Et tenero cucumis, fragilique cucurbita collo. llispida ponatur cinara, qua duleis Iacclio Potanti venial, nec Plıcbo grata canenti. Hac modo purpureo surgit glomerata corymbo, Myrteolo modo crine viret, deflexaque collo, Nunc adaperta manet, nunc pinea vertice puugit, Nunc similis calatho, spinisque minantibus horret, Paliida nonnunquam tortos imitatur acantlios.
Mox ubi sanguineis se floribus induit arbos Punica, qux rutilo mitescil tegmine grani, Tempus aris satio, famosaque tunc coriandra Naseuntur gracilique melanthia grata cumino, Et baeca asparagi spinosa prosilit lıerba, Et moloelse, prono sequitur qua vertice solen : Quseque tuas audax imitatur Nysie viteis, Nec metuit senteis : nam vepribus improba surgens Achradas, indomitasque bryonias alligat alnos.

Nomine tum Graio, ceu littera proxina primæ Pangitur in cera docti muerone magistri : Sic ef luumo pingui ferratæ cuspidis ietu Deprimitur folio viridis, pede candida beta. Quin et odoratis messis jam floribus instat, Jam ver purpureum, jam versicoloribus anni tibus alma parens cingi sua tempora gaudet. Jam Plırygia loti gemmantia lumina promuut, Et conniventes oculos violaria solvunt, Oscitat et leo, et ingenuo confusa rubore

Virgineas adaperta genas rosa probet honores Cælitibus, templisque Sabæum miscet odorem.

Nunc vos Pegasidum conites Acheloidas oro, 
forêts de l'Amphrysus, les plaines de Tempé en Thessalie, la montagne Cyllene, les sombres campagnes du Lycæus, les cavernes dans lesquelles tombent continuellement des gouttes d'cau de la fontaine Castalie; je vous implore aussi, vous quil ramassiez les fleurs qui bordaient le fleuve Halésus en Sieile, dans le temps que la fille de Cérès, Proserpine, occupée de vos danses et du plaisir de cueillir des lis éclatants de la plaine d'Enna, fut enlevée pour devenir ensuite l'épouse du tyran du fleuve Léthé, préférant ainsi les tristes ombres aux astres, le Tartare au ciel, Pluton à Jupiter et la mort à la vie, pour posséder le royaume infernal : 0 vous que j'invoque en particulier, quittez le deuil, faites trêve à votre tristesse et à vos craintes, et tournez ici vos pieds délicats, à la démarche légère, pour entasser la chevelure de la terre dans vos corbeilles sacrées. On ne dresse point ici de piéges aux Nymphes, et elles n'y onit aucun enlèvement à craindre, puisque la chaste Fides et lez saints Pénates sont l'unique objet de notre culte. Tout respire ici les jeux et les ris sans nul danger, tout y est plein de vin, et l'on y fait des festins délicieux dans d'agréables prairies. Nous touchons au printemps qui chasse la gelée; nous arrivons au temps de l'année le plus doux : c'est à présent que le jeune Phébus invite à se coucher sur l'herbe tendre, et que l'on peut goúter le plaisir de se désaltérer avec l'eau des fontaines qui coulent en murmurant sur le gazon, sans craindre de la trouver glacée, ni trop échauffee par le soleil. Déjà les fleurs de la fille de Dioné couronnent les jardins : dejà l’on y voit éclore la rose plus éclatante que

Mienalidumque clioros Dryadum, nympliasque Napaeas, Quæ colitis nemus Amphrysi, quxe Thessala Tenıpe, 265 Qux juga Cyllenes, et opaci rura Lycxi, Antraque Castaliis semper rorantia guttis, Et quæ Sicanii flores legistis IIalesi,

Cum Cereris proles vestris intenta clıoreis Equoris Ennæi vernantia lilia carpsit, Raptaque, Lethæi conjux mox facta tyranni, Sideribus tristes umbras, et tartara ccelo Preposuit, ditemque Jovi, lellıumque saluti, Et nunc inferno potitur Proserpina regno :

Vos quoque jam posito lictu mastoque timore lluc facili gressu teneras adrertite plantas, Tellurisque comas sacris aptate canistris. Hic nullse insïdix nynıplis, non ulla rapina, Casta Fides nobis colitur sanctique Penates. Omnia plena jocis, sccuro pleua cachinuo, Plena mero, laetisque vigent convivia pratis. Nunc ver egelidum, nuuc est mollissimus annus, Dum Phobus tener, ac tenera decumbere in lierba Suadet, et arguto fugientes gramine fontes Nec rigidos potare juvat, nec sole tepentes. Jamque Dionzeis redimitur floribus hortus, Jan rosa mitescit Sarrano clarior ostro. la pourpre de Sarra. Oui, les jardins charmaints paraissent plus rayonnants par les fleurs dont ils sont émaillés, que le visage pourpré de Phébé, fille de Latone, lorsque Borée chasse les nuées devant elle ; ils brillent plusque le brûlant Sirius, que l'éclatant Pyroīs et que la face lumineuse de l'Hespérus, dans le temps que Lucifer reparaft au lever de l'aurore : ils sont plus resplendissarts que l'are céleste de la fille de Thaumas. Courage donc! allez sur la fin de la nuit, quand l'étoile du matin se lèvera, ou lorsque Phébus baignera ses chevaux dans la mer Hibérienne, cueillir la marjolaine qui couvie la terre de son ombre odoriférante, ainsi que la chevelure du narcisse et celle du balauste saurage. Et vous, Naĩade plus belle qu'un bel enfant, si vous voulez qu'Alexis ne dédaigne pas les richesses de Corydon, portez des violettes daus vos corbeilles, liez en bottes le baume et la cannelle avec le troëne blanc et les houppes du safran, et arrosez ces fleurs avec la liqueur pure de Baechus; car Bacchus peut seul assaisonner les odeurs.

Pour vous, gens de la campagne, qui cueillez les tendres fleurs a vec vos doigts endurcis, commencez à remplir de jacinthes bleues vos petits paniers d'osier blane : que les roses élargissent le tissu du jone tortillé, et que les soucis de couleur de feu fassent rompre les corbeilles sous leur poids, afin que Vertumnus se voie enrichi de ces marchandises printanières jusqu'à en regorger, et que le paysan qui les aura portées à la ville en revienne ses poches chargées d'argent, en marchant d'un pas chancelant, après avoir été bien abreuvé par Iacchus. Mais lorsque les

Nec tam nubifugo Borea Latonia Phœbe

Purpureo radiat vultu, nec Sirius ardor

Sic micat, aut rutilus Pyrois, aut ore corusco

IIesperus, Eoo remeat cum Lucifer ortu;

Nec tam sidereo fillget Thaumantias arcu :

Quam nitidis liilares colluceut fœtibus horti.

Quare age vel jubare exorto jam nocte suprema,

Vel cum Plıœbus equos in gurgite mersat Hibero,

Sicuhi odoratas praetexit amaracus umbras,

Carpite, narcissique comas, sterilisque balausti.

Et tu, ne Corydouis opes despernat Alexis,

Formoso Nais puero formosior ipsa

Fer calathis violam et nigro permista ligustro

Balsama cum casia nectens croceosque corymbos, Sparge mero Bacchi : nam Bacchus condit odores.

Lit ros agrestes, duro qui pollice molles

Demetitis flores, cano jam vimine textum

Sirpiculum ferrugineis cumulate lyyacinthis.

Jam rosa distendat contorti stamina junci,

Pressaque flammcola rumpatur fiscina caltha, Mercibus ut vernis dires Vortumnus abundet, Et titubante gradu multo madefactus Iacclio

Fre sinus gerulus plenos gravis urbe reportet.

Sed cum maturis flavebit messis aristis, 
épis mûrs auront jauni la moisson; lorsque Titan aura prolongé le jour en entrant dans les Gémeaux, et (qu'il aura englouti au milieu de ses flammes les pattes de l'écrevisse de Lerne, unisser. l'ail à l'oignon et le pavot de Cérès à l'anet; liez-les en bottes pour les aller vendre pendant qu'ils sont verts, afin de chanter les louanges solennelles de Fors-Fortuna quand vous aurez vendu ees marchandises, et que vous retournerez dans vos jardins eharmants. Comprimez aussi alors avec de lourds cylindres le basilic que vous aurez semé dans un guéret bien labouré et arrosé; comprimez-le, dis-je, afin de le faire épaissir, et pour empêcher que l'ardeur d'un sol trop ameubli ne brûle ses jeunes tiges, ou que la dent du petit puceron ne s'y attache, ou enfin que la fourmi ravissantc ne vienne à en dévaster la graine. Au reste, non-seulement le limacon enveloppé dans sa coquille et la chenille hérissće ont la hardiesse de ronger les feuilles des plantes lorsqu'elles sont tendres; mais il arrive même souvent, lorsque la tige déjà forte du chou jaunatre est grossie, ou que les cardes blanches de la poirée sont gonflées, et au moment même que Ic jardinier, croyant être en sûreté, se rẻjouit à la vue de ses plantes parvenues à l'adoleseence, et se prépare à mettre la faux dessous, parce qu'elles sont mûres, que l'impitoyable Jupiter lance une pluie durcie par la geléc, et détruit ainsi par la grêle les travaux des hommes et des bœufs. Souvent même il les dévaste en faisant tomber une pluie pestilentielle, qui donne naissance tant aux lisettes ennemies de Bacehus et des saussaies verdâtres, qu'à la chenille, qui, venant à se glisser dans les jardins, serpente sur

Atque diem gemino Titan extenderit astro, Ifauserit et flammis Lemnei braclia Cancri, Allia cum cepis, cereale papaver anetho Jungite, dumģue virent nexos deferte maniplos, Et celebres fortis fortunæ dicite laudes,

Mercibus exactis, liilaresque recurrite in lortos Tum quoque proscisso riguoque inspersa novali Ocima comprimile, el gravibus densate cyliniris, Kxurat sata ne resoluti pulveris astus, Parvulus aut pulex irrepens dente lacessat, Nen formica rapax populari semina possit. Nec solum teneras audent erodere frondes Implicitus conchæ limax, hirsutaque campe : Sed cum jam valido turgescit lurida caule Brassica, cumque tument pallentia robora beto, Nercibus atque olitor gaudet sccurus adultis, Et jam maturis quærit supponere falcem, Sxpe ferus duros jáculatur Jupiter imbres, Grandine dilapidans hominumque boumque labores: 330 Sxpe etiam gravidis irrorat pestifer undis, Ex quibus infest $x$ Baccho glancisque salictls Nascuntur volucres, serpitque eruca per hortos; Quos iuper ingrediens exurit semina morsu, leur surface, et brûle les semences par sa morsure; de sorte que leur tête se dépouille de ses cheveux, et que leur cimese dégarnit de feuilles, au point qu'elles languissent toutes, mutilées et eonsumées par un poison funeste. Des expériences nombreuses, jointes au travail, ont fait trouver aux malheureux habitants de la campagne des remèdes propres à les préserver des dommages qu'ils avaient á redouter de la part de ces monstres; et l'usage, ce grand maître, a montré aux agriculteurs les moyens d'apaiser la furcur des vents, et de détourner les mauvais temps par des sacrifices toseans. C'est de là que pour empêcher la méchante rubigo de brûler les herbes quand elles sont vertes, on l'apaise avec le sang et les entrailles d'un chien à la mamelle : c'est de là que le Tyrrhénien Tagès enterra, à ce qu'on raconte, sur les limites d'un chainp la tête d'un ânon d'Arcadie dépouillée de sa peau, et que Tarchon, pour détourner la foudre du grand Jupiter, entoura son habitation d'une haie de couleuvrée. De là le fils d'Amythaon, à qui Chiron avait enseigné bien des scerets, suspendit à des croix des oiseaux de nuit, pour empêcher les autres oiseaux de faire entendre leur chant lugubre sur le haut des toits. Pour empêclier de même que des animaux malfaisants ne rongeassent les jeunes pousses, il a été utile quelquefois de tremper les graines dans la lie grasse de la liqueur de Pallas extraite sans sel, ou de les rassasier de la suie qui s'attache aux foyers. Il a encore été utile de verser sur les plantes du jus amer de marrube, ou de les frotter sans ménagement avee du sue de joubarbe. Mais si aucun de ces remèdes ue parvient à écarter ces pestes, on aura
Quxe capitis viduata coma, spoliataque nudo Vertice, trunca jacent tristi consumpta veneno. llæc ne ruricolæe paterentur monstra, salıtis Jpsa novas artes varia experientia rerum Et labor ostendit miseris, ususque nıagister Tradidit agricolis, ventos sedare furentes, El tempestatem Tliuscis avertere sacris.

Ilinc mala rubigo virideis ne torreat lierbas, Sanguine lactentis catuli placatm el extis. lunc caput Arcadici nudum cute fertur aselli Tyrrlienus fixisse Tages in limite ruris.

Utque Jovis magni prohiberet fulmina Tarclıon, Sxpe suas sedes pracinxit vitibus albis.

Hinc Amytlıanius, docuit quem plurima Chiron, Nocturnas crucibus volucres suspendit, et altis Culminibus vetuit feralia carmina tlere.

Sed ne dira novas segetes animalia carpant, Profuit interdum medicantem semina pingui Palladia sine fruge salis conspergere amurca, Innatave laris nigra satiare favilla.

Profuit et plantis latices infundere amaros

Marrulii, multoque sédi contingere succo.

At si uulla valet medicina repellere pestem, 
recours à l'art de Dardanus, et l'on conduira trois fois autour des planches de son jardin, et de la haie qui l'environne, une femme qui sera pieds nus et qui aura la gorge découverte, et les cheveux épars à la manière des personnes affligées, dans le temps que, soumise aux.lois ordinaires de la jeunesse, ellc perdra, non sans en rougir, un sang impur. En effet, dès que cette femme en aura fait le tour au pas, on verra aussitôt (chose surprenante !) les chenilles, au corps entortillć, rouler à terre, de la même manière que l'on voit tomber d'un arbre qu'on secoue une nuée de fruits revêtus d'une pcau molle, ou couverts d'une écorce. C'est ainsi qu'autrefois Iolcos vit ce serpent qui, après avoir été assoupi par des enchantements magiques, était tombé de la toison du bélier de Phryxus. Mais il est déjà temps de couper les tiges qui doivent disparaitre les premières; il est temps d'arracher parle pied les laitues de Tartésus et de Paplios, et de lier en bottes l'ail ainsi que le poireau, qui se coupe de temps à autre. Dćjà la roquette, qui exciłe à la volupté, nait dans les jardins fertiles : dcija la patience, propre à faire couler l'urine, verdit sans culture, ainsi que les nerpruns et la scille: déjà l'on voit croitre la haie piquante, hérissée de houx-frclons, ainsi que l'asperge sauvage, dont la tige ne diffère en rien de celle de l'asperge cultivée : déjà le pourpier humide défend de la soif les bordures des planches, et la longue cosse du haricot, dont le voisinagc incommode l'arroche, commenceà s'élever : déjà l'on voit le concombre tortu suspendu sous des treilles, ou, tcl qu'un serpent d'eau qui se glisse sous les ombres fraiches du gazon, pour se garantir du soleil d'été, on le voit ramper à terre, ainsi que la courge

Dardanixe veniant artes, nudataque plantas Fomina, qux justis tunı demum operata juventse Legibus, obscano manat pudibunda cruore, Sed resoluta sinus, resoluto moesta capillo, Ter circum areolas et sepem ducitur horti. Quem cum, lustravit gradiens, mirabile visu 1 Non aliter quam decussa pluit arbore nimbus Vel leretis mali, vel tectie cortice glandis, Volvitur ad terram distorto corpore canipe. Sic quondam magicis sopitum cantibus anguem Vellere Phryxeo delapsum vilit Iolcos.

Sed jam prototomos tempus decilere caules, Et. Tartesiacos, Paphiosque revelleı thyrsos, Atque apio fasces et secto ciugere porro.

Jamque eruca salax fuecundo provenit horlo.

Lubrica jam lapathos, jam thamni sponte virescunt,

Et scilla, hirsuto sepes nunc horrida rusco

Prodit, et asparagi corruda simillima filo,

Humidaque andraclıne sitientes protegit antes,

Et gravis atriplici consurgit longa faselus,

Tum modo dependens trichilis, modo more chelydri

Sole sub astiro gelidas per graminis umliras

COLYYELL. pleine de pépins. Mais la forme de ces plantes varic : en effet, si vous avez à cour d'avoir des courges longues, et qui soient suspendues par le sommet grêle de lcur tête, choisissez-cn la graine dans la partic la plus mince de leur col; si vous en voulez avoir au contraire de grosses, dont le corps soit rond et le ventre très-gonflé, vous en tirerez la graine du milieu du ventre, et il cn résultera des productions énormes, dans lesquelles vous pourrez renfermer la poix de Narycium et le miel du mont Hymette en Attique, ou dont vous pourrez faire de petits seaux propres à contenir l'eau, ou des flacons à l'usage de Bacchus : vous pourrez encore vous en servir pour apprendre aux enfauts à nager dans les fleuves. Quant au concombre, dont la couleur est livide, qui naît avec un ventre gros et velu, et qui sc tient caché comme un serpent sous un fanage plcin de nœuds, et couché sur son ventre tortueux, qu'il ramasse toujours en rond; il est pernicieux, et donue lieu à des maladies aiguës pendant les étés violents, parce que son jus est fétide, et que la graine dont il est farci est visqueuse. Pour celui qui, se trainant vers l'eau qui coule sous une treille, semble exténué par la passion violente que lui inspire cette eau, dont il suit le cours, et qui est blanc et plus tremblant que le pis d'une truie qui a mis bas, et souvent même plus mollet que du lait caillé versé sur des paniers, il deviendra doux par la suite, prendra une couleur de safran et s'amollira en mûrissant, pour pcu qu'il tire sa nourriture d'un terrain arrosé. II pourra même servir un jour de ressource à l'homme dans ses maladies. Lorsque le chien d'Érigone, enflammé par le feu d'Hypérion, commencera à faire voir les productions des arbres,

Intortus cucunis pragnansque cucurbita serpit.

Una neque est illis facies. Nam si tibi cordi

Longior est, gracili capitis qux vertice pendet,

E tenui collo semen lege : sive globosi

Corporis, atque utero nimium quæ vasta tumescit,

Ventre leges medio, sobolem dabit illa capacem

Naryciæ picis, aut Actoci mellis Hymetti,

Aut habilem lymphis lamulam, Bacchove lagonam.

Tum pueros eadem fluviis innare docebit.

Lividus at cucumis grarida qui nascitur alro,

Hirtus, et ut coluber nodoso gramine tectus

Ventre cubat flexo, semper collectus in orben,

Noxius exacuit morbos astatis iniquæ.

Fotidus hic succo, pingui guoque semine fartus. At qui sub trichila manantem repit ad undam,

Labentemque sequens nimio tenuatur ansore,

Candidus, effota tremebundior ubere porca,

Mollior infuso calathis modo lacte gelato,

Dulcis erit, riguoque madescit luteus arvo,

Et feret auxilium quondam morlatibus agris.

Cum canis Erigones flagrans Hyperionis aestu

Arboreos aperit fuetus, cunulataque moris 
qu'il a appris l'art de l'agrienlture, mais eneore qu'il est fidèle et attaché a son maitre, article sans lequel la scienee d'un métayer, si éminente qu'on la suppose, ne sert de rien. Or le prineipal talent d'un maitre, en ce eas, consiste à savoir apprécier quels sont les offices et les travaux qu'il faudra départir à chacun. En effet, l'homme le plus robuste, s'il n'a pas l'intelligence de ce qu'il fait, ou le plus habile, s'il est invalide, ne pourront jamais venir à bout d'exécuter ce qu'on leur aura commandé. Il faut aussi examiner la nature de chaque opération. Il se trouve effectivement tels ouvrages qui ne demandent que de la foree, comme lorsqu'il s'agit de pousser des fardeaux ou de les porter; tels qui demandent nutant d'adresse que de foree, comme lorsqu'il s'agit de bêcher, de labourer, de eouper les moissons et de faucher les prés; quelques-uns pour lesquels il faut plus d'adresse que de foree, comme la taille et la greffe des vignes; d'autres enfin qui exigent la seience comme le point le plus eapital, tels que la nourriture des bestiaux et leur traitement en cas de maladie. Or le métayer, dont je parlais tout à l'heure, ne peut pas être bon juge de ees différentes opérations, s'il n'a pas l'habileté nécessaire pour pouvoir corriger ce qui se trouvera mal fait dans les unes ou dans les autres, parce qu'il ne suffit pas de reprendre ceux qui font mal, si l'on ne leur montre pas les moyens de bien faire. J'aime à me répèter sur cette matière. Il ne faut pas moins instruire un homme que l'on destine à être métayer, qu'il ne faut instruire un homme que l'on destine à être potier ou artisan : j'oserais même presque assures qu'à proportion de ce que ces métiers sont moins étendus que l'agriculture, ils sont plus aisés à apprendre que cet art, dont l'objet est si compliqué et si étendu, que si l'on voulait passer

beat, sine quibus nihil prodest villici summa scientia. Po. tissimum antem est in eo magisterio scire el rstimare, quale officium el qualis labor sit cuique injungendus. Nam uec valentissimus possit exequi quud imperatur, si nesciat quid agat; nec peritissimus, si sit invalidus. Qualitas itaque cujusque rei consideranda est. Quippe aliqua sunt opera tantummodo virium, tanquam promovendi onera portandique : aliqua sociata viribus et arti, ut fodiendi arandique, ut segetes et prata desecandi : nonnullis minus virium, plus artis adlibetur, sicul putationibus insitionibusque vineti : plurinum etiam scientia pullet in aliquibus, ut ín pastione pecoris alque ejusdem mediciıa. Quorum oınnium officiorum villicus, quod jam prius dixi, æstimator bonus esse non potest, nisi fuerit eliam peritus, ut in unoquoque corrigere queat perperam factum. Neque cnim satis est reprehendisse peccantem, si non doceat recti viam. Libenter igitur eadem loquor : tam docendus est futurus villicus, quam futurus figulus aut faber. Et liaud facile dixerim, num illa tanto expeditiora sint discentibus artificia, quanto minus ampla sunt. Rusticationis autem magna et diffusa materia est, partesque si velimus en revue ses différentes parties, il serait à peine possible de les compter toutes. Aussi ne puis-je me lasser de témoigner ma surprise sur un fait dont je me suis déjà plaint avee raison dans le premier livie de mon ouvrage, je veux dire sur ce qu'il s'est trouvé des gens quì excellaient dans tous les autres arts, quoique moins nécessaires à la vie que celui-ci, sans qu'il se soit trouvé de disciples ni de maitres d'agriculture; à moins que l'on ne veuille attribuer à l'étendue immense de cette science la crainte qu'il parait que chacun a eue de l'apprendre ou de l'enseigner, quoique ec ne fût pas une raison suffisante pour la négliger par une défiance honteuse de soi-même: En effet, on n'abandonne point comme elle l'art de l'éloquenee, paree qu'il ne s'est jamais trouvé d'orateur parfait ; la philosophie, paree qu'il n'y a ja. mais eu personne dont la sagesse ait été consommée ; puisqu'au contraire la plus grande partie des hommes s'encourage à acquérir la connaissance au moins de quelques portions de ces seiences, quoiqu'ils n'ignorent pas qu'ils ne pourront jamais parvenir à les posséder en entier. Est-ce done un motif suffisant de se taire, parce qu'on sait qu'on ne pourra pas devenir un orateur parfait, ou de se laisser aller à la négligenee, parce (qu'on désespérera d'acquérir la sagesse ? et n'estce pas un assez grand honneur que celui d'acquéril une parcelle, si petitequ'on la suppose, d'une grande chose? Mais, dira-t-on, qui est-ce qui pourra instruire un homme qui se destine à être métayer, s'il ne se trouve point de professeurs en ee genre? Je conviens mol-même qu'il est trèsdifficile d'apprendre à la fois tous les préceptes d'agriculture d'une seule et même personne : néanmoins, s'il est difficile de trouver quelqu'un qui soit instruit sur toutes les parties de cet art, on rencontre au moins, pour chaque partie isolée,

ejus percensere, vix numero comprehendamus. Quare satis admirari nequeo, quod primo scriptorum meorum exordio jure conquestus sum : cxlerarum artium minus vita necessariarum repertos autistites; agriculturæe neque discipulos neque preceptores inventos : nisi magnitudo rei fecerit reverentiam rel discendi vel profitendi pene iınmensam scientiam; cum tamen non ideo turpi desperatione oportuerit eam negligi. Nam nec oratoria disciplina deseritur, quia perfectus orator nusquain repertus esl; nec pliilosophia, quia nullus consummatx sapientix : sed c contrario plurimi semetijsos exliortantur vel aliquas partes earum addiscere, quamvis universas percipere non possint. Etenim qua probabilis ratio est obmutescendi, quia nequeas orator esse perfectus; aut in socordiam compelli, quia desponderis sapientiam? Magnæ rei quantulumcunque possederis, fuisse participem, non minina gloria est. Quis ergo, inquis, docebit futurum villicum, si nullus professor est? Et ego intelligo difficillimum esse ab uno velut auctore cuncta rusticalionis consequi præcepta. Verumtamen ut universæ disciplinæ vix aliquem consultum, sic plurimos partium ejıs invenias magistıos, per 
un grand nombre de mattres, at l'aide desquels un métayer peut devenir parfait. Il y a cn effet de bons laboureurs, d'excellents ouvriers pour fouiller la terre ou pour faucher le foin, comme pour avoir soin des arbres et de la vigne, ainsi que de bons médecins vétérinaires et de bons pâtres, dont chacun ne cachera pas les procédés de son art à quiconque voudra s'cn instruire. Celui donc qui se trouvera à la tête d'unc métairie après avoir été préalablement formé lui-même aux métiers particuliers des différents ouvriers de la campagne, évitera entre autres choses d'entretenir aucun commerce avec les esclaves de la maison, et encore moins avec les étrangers. Il sera très-tempérant tant sur le sommeil que sur le vin : ce sont en effet deux choses incompatibles avec l'exactitude, parce qu'un homme sujet à s'enivrer manque à ses devoirs autant qu'il les oublie, et qu'un dormeur en néglige une grande partie. Que peut en effet exécuter par lui-méme un homme qui dort contínuellement, ou que peut-il commander aux autres ? Il faut encore qu'il n'ait pas de penchant à l'amour, parce que s'il se livre une fois à cette passion, il ne pourra plus penser à autre chose qu'à l'objet de ses désirs; car lorsqu'on a l'esprit occupé d'une passion, on ne croit pas qu'il y ait de récompense plus flatteuse que le fruit de la volupté, ni de supplice plus dur que la privation. Il faut done qu'il soit le premier éveillé de tous, et qu'après avoir fait sortir, le plus tôt que la saison le permettra, les gens qui sont toujours lents à se mettre à l'ouvrage, il aille lestement à leur tête, parce qu'il est très-intéressant que les colous commencent leur besogne dès le matin, et qu'ils la fassent diligemment et sans intcrruption; d'autant que, comme le disait ce même

quos efficere queas perfoctum villicum. Nam et orator reperiatur aliquis bonus, et optimus fossor, aut fueni sector, nec minus arborator ef vinitor, tum etiam veterinarits et probus pastor, qui singuli rationem scientix sux desideranti non subtrahant. Igitur complurium agrestium formatıs artibus, qui susceperit officium villicationis, in primis conviclum domestici, multoque etiam magis exteri vitet. Somni et vini sit abstinentissinus, qua utraque sunt ininicissima diligentix. Nam et ebrioso cura offici pariter cum memoria subtrahitur; et somuiculosum plurima effugiunt. Quid enim possit aut ipse agere, aut cuiquam dormiens imperare? Tum etian sit a venereis amoribus aversus : quibus si se dediderit, non aliud quidquam possit cogitare, quam illud quod diligit. Nam viliis ejusmodi pellectus animus nec pramium jucundius quam fructum libidinis, nec supplicium grarius quam frustralionem cupiditatis existimat. Igitur primus omuium rigilet, faniliamujue semper ad opera cunclantem pro trmporilus anni festinanter producat, et strenue ipse proc. cedat. Plurimum enim refert colonos a primo mane opus argredi, nec lentos per otium pigre procedere. Siģujılem Ischomachus iden ille : Malı, iuquit, unius agileu indus-
Ischomachus que j’ai déjà cité, la journće blen. employee d'un seul ouvrier vaut mieux que celle. de dix ouvriers négligents et peu appliqués; $c t$. que si on laisse à un ouvrier la liberté de perdie son temps cn bagatelles, il en résulte toujours un. très-grand mal. En effet, de même que de deux voyageurs qui sont partis en ınême temps, celui qui va son chemin droit et sans s'arrêter devance souvent de moitié celui qui se sera amusé à chercher l'ombre des arbres, l'agrément des ruisseaux ou la fraicheur de l'air; de mème, en fait d'opérations rtistiques, il serait difficile de dire combien un ouvrier diligent l'emporte sur un ouvrier paresscux et nonchalant. 11 faut donc que le mé. tayer ait soin que les gens, en allant à l'ouvrage dès le point du jour, ne marchent point languissamment et à pas comptés, mais qu'ils le suivent au contraire avec ardeur, et, pour ainsi dire, comme un général qui mène bravement et gaiement son armée au combat. Il faut aussi qu'il les réveille au milieu du travail par des exhortations multipliées, et que de temps en temps, lorsqu'il en remarquera qui se décourageront, il prenne un moment leurs outils comme pour les aider, et qu'il mette lui-mếme la main à leur besogne, en les avertissant de la faire avec au. tant de courage qu'il l'aura faitc lui-même. II faut de même que, dès que le crépuscule sera venu, il n'en laisse aucun derrière lui, mais qu'il les suive tous comme un excellent pâtre, qui ne souffre jamais qu'aucune bête de son troupeau erre dans la campagne. Lorsque ensuite il sera rentréà la maison, il se comportera de mème qu'un berger vigilant, c'est-à-dire qu'il nc se retirera pas aussitôt dans sa chambre, mais c [u'il prendra le plus grand soin possible de chacun d'eux, soit en appliquant des remèdes sur les

trias, quam decem hominum negligentem et tardam operam. Quippe plurimum affert mali, si operario tricaudi potestas fiat. Nam ut in ilinere conliciendo sappe dinidio malurius pervenit is, qui naviter et sine ullis concessationibus permeabit, quam is, qui cum sit una profectus, umbras arborum fouticulorumque amonitatem rel aurie refrigerationem caltavit : sic iu agresti negotio dici vix potest, quid uarus operarius ignavo et cessatore praestet. Hoc igitur custodire oportet villicum, ne statim a prina luce fanilia cunctauter et languide procedat, sed velut in aliquod proelium cum vigore et alacritate animi praceden. tem eum tanquam ducem strenue sequatur, variisque exlıortationibus in opere ipso exluilaret laborantes : et interdum, tanquain deficienti succursurus, ferramentum auferat paruuper, el ipse fungatur ejus officio, moueatque sic fieri debere, ut ab ijso fortiter sit effectum. Atque ubi crepusculum iucesserit, neminem post se relınquat, sed omnes subsequatur more optimi pastoris, qui e grege uvllam necnden palitur in agro relinqui. Tum 7ero, cum tectum subierit, idem faciat, quod ille diligens opilio : nec in domicilio [suo] statim delilescat, sed agat cujusque maximan curam; sive quis, quod accidit plerumque, 
qu'il a appris l'art de l'agriculture, mais encore qu'il est fidèle et attaehé à son maitrc, artiele sans lequel la science d'un métayer, si éminente qu'on la suppose, ne sert de rien. Or le prineipal talent d'un maitre, en ce cas, consiste à savoir apprécier quels sont les offiees et les travaux qu'il faudra départir' à chaeun. En effet, l'homme le plus robuste, s'il n'a pas l'intelligenee de ce qu'il fait, ou le plus habile, s'il est invalide, ne pourront jamais venir à bout d'exéeuter ee qu'on leur aura commandé. Il faut aussi examiner la nature de eliaque opération. Il se trouve effectivement tels ouvrages qui ne demandent que de la foree, comme lorsqu'il s'agit de pousser des fardeaux ou de les porter; tels qui demandent autant d'adresse que de force, comme lorsqu'il s'agit de bêeher, de labourer, de eouper les moissons et de faucher les prés; quelques-uns pour lesquels il faut plus d'adresse que de foree, eomme la taille et la greffe des vignes; d'autres enfin qui exigent la science comme le point le plus capital, tels que la nourriture des bestiaux et leur traitement en eas de maladic. Or le métayer, dont je parlais tout à l'heure, ne peut pas être bon juge de ces différentes opérations, s'il n'a pas l'habileté nécessaire pour pouvoir eorriger ee qui se trouvera mal fait dans les unes ou dans les autres, parce qu'il ne suffit pas de reprendre ceux qui font mal, si l'on ne lcur montre pas les moyens de bien faire. J'aime à me répéter sur eette matière. Il ne faut pas moins instruire un homme que l'on destine à être métayer, qu'il ne faut instruire un homme que l'on destine à être potier ou artisan : j'oserais même presque assurer qu'à proportion de ee que ces métiers sont moins étendus que l'agrieulture, ils sont plus aisés à apprendre que cet art, dont l'objet est si compliqué ct si étendu, que si l'on voulait passer

beat, sine quibus nibil prodest villici summa scientia. Po. tissimum autem est in eo magisterio scire et restimare, quale officium et qualis labor sit cuique injungendus. Nam nec valentissimus possit exequi quol imperatur, si nesciat quid agal; nec peritissimus, si sit invalidns. Qualitas itaque cujusque rei consideranda est. Quippe aliqua sunt opera tantummodo virium, tanquam promovendi onera portandique : aliqua sociata viribus et arti, ut fodiendi arandique, ut segetes el prata desecandi : nounullis minus virium, plus artis adlibetur, sicut putationibus insitionibusque vineti : plurinum etiam scientia pollet in aliquibus, ut fin pastione pecoris alque ejusdem medicina. Quorunı omnium officior um villicus, quod jam prius dixi, astimator bonus esse non potest, nisi fuerit etiam peritus, ut in unoquoque corrigere queal perperam factum. Neque enim satis est reprehendisse peccantem, si non doceat recti viam. Libenter igitur eadem loquor : tam docendus est futurus villicus, quam futurus figulus aut faber. Et liand facile dixerim, num illa tanto expeditiora sint discentibus artificia, quanto minus ampla sunt. Rusticationis auten magna et diffusa materia est, partesque si velinus en revue ses différentes parties, il serait à peine possible de les eompter toutes. Aussi ne puis-je me lasser de témoigner ma surprise sur un fait dont je me suis déjà plaint avec raison dans le prenier livre de mon ouvrage, je veux dire sur ce qu'il s'est trouvé des gens qui excellaient dans tous les autres arts, quoique moins néeessaires à la vie que celui-ci, sans qu'il se soit trouvé de diseiples ni de maitres d'agriculture; à moins que l'on ne veuille attribuer à l'étendue immense de cette seience la crainte qu'il paraít que chacun a euc de l'apprendre ou de l'enseigner, quoique ec ne fût pas une raison suffisante pour la négliger par une défiance honteuse de soi-même. En effet, on n'abandonne point comme elle l'art de l'éloquence, parce qu'il ne s'est jamais trouvé d'orateur parfait; la philosophie, parce qu'il n'y a jamais eu personne dont la sagesse ait été consommée; puiscru'au contraire la plus grande partic des hommes s'encourage à aequérir la connaissance au moins de quelques portions de ces seiences, quoiqu'ils n'ignorent pas qu'ils ne pourront jamais parvenir à les posséder en entier. Est-ce done un motif suffisant de se taire, parce qu'on sait qu'on ne pourra pas devenir un olateur parfait, ou de se laisser aller à la négligence, parce qu'on désespérera d'aequérir la sagesse ? et n'estce pas un assez grand honneur que celui d'acqué. ril une parcelle, sí petitequ'on la suppose, d'une grande chose? Mais, dira-t-on, qui est-ce qui pourra instruire un homme qui se destine à être métayer, s'il ne se trouve point de professeurs en ce genre? Je conviens moí-même qu'il est trèsdifficile d'apprendre à la fois tous les préceptes d'agricultuled'une seule et même personne : néanmoins, s'il est diffieile de trouver quelqu'un qui soit instruit sur toutes les parties de eet art, on rencontre au moins, pour chaque partie isolée,

ejus percensere, vix numero comprehendanus. Quaro satis admirari nequeo, quod primo scriplorum meorun exordio jure conquestus sum : cneterarum artiun minus vita necessariarum repertos autistites; agriculturae neque discipulos neque præceptores inventos : nisi magnitudo rei fecerit reverentiam vel discendi vel profitendi pene in. mensam scientiam; cum tamen non ideu turpi desperatione oportuerit eam negligi. Nam nec oraloria disciplina deserilur, quia perfectus orator nusquam repertus est; nec philosophia, quia nullus consummatæ sapientix : sed c contrario plurini semetipsos exliortantur vel aliquas partes earum addiscere, quamvis universas percipere non possint. Etenim quæ probabilis ratio est obmutescendi, quia ne. queas orator esse perfectus; aut in socordiam compelli, quia desponderis sapientiam? Magnæ rei quantulumcun. que possederis, fuisse participem, non minima gloria est. Quis ergo, inquis, docebit futurum villicum, si nullıs professor est? Et ego intelligo difficillimum esse ab uno velut auctore cuncta rusticationis consequi precepta. Verumtamen ut universæ disciplinæ vix aliquem consultum, sic plurimos partiun ejus invenias magistros, per 
un grand nombre de maftres, a l'aide desquels un metayer peut devenir parfait. Il y a en effet de bons laboureurs, d'excellents ouvriers pour fouiller la terre ou pour faucher le foin, comme pour a voir soin des arbres et de la vigne, ainsi que de bons médecins vétérinaires et de bons pátres, dont chacun ne cachera pas les procédés de son art à quiconque voudra s'en instruire. Celui donc qui se trouvera à la tête d'une métairie après avoir été préalablement formé lui-même aux métiers particuliers des différents ouvriers de la campagne, évitera entre autres choses d'entretenir aucun commerce avec les esclaves de la maison, et encore moins avec les étrangers. II sera très-tempérant tant sur le sommeil que sur le vin : ce sont en effet deux choses incompatibles avec l'exactitude, parce qu'un homme sujet à s'enivrer manque à ses devoirs autant qu'il les oublie, et qu'un dormeur en néglige une grande partie. Que peut en effet exécuter par lui-même un homme qui dort continuellement, ou que peut-il commander aux autres? Il faut encore qu'il n'ait pas de penchant à l'amour, parce que s'ilse livre une fois à cette passion, il ne pourra plus penser à autre chose qu'à l'objet de ses dé sirs; car lorsqu'on a l'esprit occupé d'une passion, on ne croit pas qu'il y ait de récom. pense plus flatteuse que le fruit de la volupté, ni de supplice plus dur que la privation. Il faut done qu'il soit le premier éveillé de tous, et qu'après avoir fait sortir, le plus tôt que la saison le permettra, les geus qui sont toujours lents à se mettre à l'ouvrage, il aille lestement à leur tête, parce qu'il est très-intéressant que les colons commeneent leur besogne dès le matin, et qu'ils la fassent diligemment et sans interruption; d'autant que, comme le disait ce même

quos efficere queas perfoctum villicum. Nam et orator reperiatur aliquis bonus, et optimus fossor, aut firni sector, nec minus arborator et vinitor, tum etiam veterinarius et probus pastor, qui singuli rationem scientix suxe desideranti non subtralıant. Igitur complurium agrestium formalus artibus, qui susceperit officium villicationis, in primis convictum domestici, multoque etianı magis exteri vitet. Somni et vini sit abstinentissimus, qua utrarque sunt inimieissima diligentia. Nam et ebrioso cura officii pariter cum memoria subtrahitur; et somuiculosum plurima effugiunt. Quid enim possit aut ipse agere, aut cuiquuam dormiens imperare? Tum etian sit a venereis amoribus arersus : quibus si se dediderit, non alind quidqquam possit cogitare, quam illud quod diligit. Nam vitiis ejusmodi pelleefus animus nec piramium jueundius quam fructum libidinis, nec supplieium grasius quam frustrationem enpiditatis existimat. Igitur primus omniun vigilet, faniliamuge semper ad opera cunctantem pro tomporilus anni festinanter producat, et strenue ijse pro. cedat. l'lurimum enim refert colonus a prino mane opus aygredi, nec lentos per otium pigre procedere. Siquidem Isclomaclus idem ille : Malo, inquit, unius agilem indus.
Ischomachus que j’ai déjà cité, la journée bien. employée d'un seul ouvrier vaut mieux que celle. de dix ouvriers négligents et peu appliqués; et que si on laisse à un ouvrier la liberté de perdre son temps en bagatelles, il ell résulte toujours un. très-grand mal. En effet, de même que de deux voyageurs qui sont partis en inême temps, celui qui va son chemin droit et sans s'arrêter devance souvent de moitié celui qui se sera amusé à cherclier l'ombre des arbres, l'agrément des ruisseaux ou la fraicheur de l'air; de mème, en fait d'opérations rtistiques, il serait difficile de dire combien un ouvrier diligent l'emporte sur un ouvrier paresseux et nonchalant. 11 faut done que le mé. tayer ait soin que les gens, en allant à l'ouvrage dès le point du jour, ne marchent point languissamment et à pas comptés, mais qu'ils le suivent au contraire avec ardeur, et, pour ainsi dire, comme un général qui mène bravement et gaiement son armée au combat. Il faut aussi qu'il les réveille au milieu du travail par des exhortations multipliées, et que de temps en temps, lorsqu'il en remarquera qui se décourageront, il prenne un moment leurs outils comme pour les aider, et qu'il mette lui-mếme la main à leur besogne, en les avertissant de la faire avec autant de courage qu'il l'aura faite lui-même. II faut de même que, dès que le crépuscule sera veuu, il n'en laisse aueun derrière lui, mais qu'il les suive tous comme un excellent pâtre, qui ne souffre jamais qu'aueune bête de son troupeau erre dans la campagne. Lorsque ensuite il sera rentréà la maison, il se comportera de mémo qu'uı berger vigilant, c'est-à-dire qu’il ne se retirera pas aussitôt dans sa chambre, mais qu'il prendra le plus grand soin possible de chacun d'eux, soit en appliquant des remèdes sur les

triam, quam decem hominum negligentem el taidam operam. Quippe plurimum affert mali, si operario tricandi potestas fiat. Nam ut in itiuere conficiendo sape dimidio maturius pervenit is, qui naviter et sine ullis concessationibus jermeabit, quan is, qui cum sit uma profectus, umbras arborum fontienlorumque amcenitaten vel auræe refrigerationem captavit : sic in agresti negotio dici vir potest, quid uavus operarius ignavo et cessalore priestet. Hoc igitur custodire oportet villicum, ne statim a prinı luce fumilia cunetauter et languille jrocedat, sed velut in aliquod proelium cum vigore et alacritate animi proceden. tem eum tanquam ducem strenue sequatur, variisque exliortationibus in opere ipso exlinlaret laborantes : et interdum, tanquam defieienti suecursurus, ferramentun auferat paruuper, et ipse fungatur ejus omeio, moneatque sic fieri dehere, ut ab ijsso fortiter sit effectum. Atque ubi crepuseulum ineesserit, neminem post se relınquat, sed omnes subsequatur more optimi pastoris, qui e grege nullam peeudem patitur in agro relinqui. Tum zero, cum tectum subierit, idem faciat, guod ille diligens opilio : nec in domicilio [suo] statim delitescat, sed agat cujusque unaximau curam; sive upuis, quod accidit plerurnque, 
blessures que quelqu'un d'eux aura pu se faire en travaillant (ce qui arrive communément), soit en falsant transporter sur-le-champ à l'infirmerie ceux qui seront malades, et en ordonnant (qu'on leur fasse tous les traitements convenables. Il ne faudra pas qu'il néglige da vantage ceux qui se porteront bien; mais il veillera à ce que les gens chargés dusoin des provisions de bouche leur donnent à boire et à manger sans fraude. II accoutumera les ouvriers des champs à prendre toujours leurs repas autour du foyer de leur maitre et dc l'âtre de la maison, et il mangera lul-même en leur présence, pour leur montrer l'exemple de la frugalité, sans jamais s'étendre sur un lit, si ce n'est les jours de fêtes, pendant lesquels il s'occupera à faire quelques largesses a ceux qui se seront montrés les plus courageux et les plus tempérants. II les admettra même quelquefois à sa table, et se prêtera à leur accorder quelques autres marques de distinetion. Il visitera aussi pendant ces jours-là les instruments qui servent à tous les nuvrages de la cam. pagne, et ceux de fer plus souvent que les autres: il aura soin de les avoir tous par doubles, et de les faire raccommoder de temps en temps avant de les serrer, afin de n'être pas dans la nécessité d'en emprunter de ses voisins, pour remplacer ceux qui pourraient avoir été endommagés dans le travail, parce qu'il en contera toujours plus en journées de détourner des eselaves pour ces sortes d'emprunts, qu'il n'en coûterait pour aeheter de nouveaux instruments. Il tiendra les gens soignés et vêtus plutôt à profit que délieatement, c'est-à-dire de facon qu'ils sojent bien défendus tant eoutre le froid que contre la pluie; ee à quoi il parviendra parfaitement bien, en leur domnant des fourrures garnies de manehes et des saies avec leurs capuchons : car il n'en faut pas davan-

sauciatus in opere noxam ceperit, adhibeat fomeuta : sive aliter languidior est, in valetudinarium confestim deducat, et convenientem ci cateram curationem adliberi jubeat. Eorum vero, qui rerte valebunt, non minor labenda erit ratio, ut cibus et polio sine fraude a cellariis probeatur. Consuescatrue rustieos eirca larem domini foenmque fauiliarem semper cpulari ; atque ipse in conspeetu corum similiter epuletur, sitque frugalitatis exemplum : nec nisi saeris diebus accubans coenet, festosque sic agat, ut forlis. siınum quemque et frugalissimum largitionibus prosequatur, nonnumquam etian nensa sux adhibeat, et velit aliis quoque honoribus dignari. Tum eliam per ferias instrumentum rusticum, sine quo uullum opus effiei potest, recognoscat, et sapius inspieiat lerramenta : eaque semper duplieia comparet, ac subinde refeeta eustodiat, ne si quod in opere viliatum fuerit, a vieino petendum sit; quia plus in operis servorum a voeaudis, quam in pretio rerum lıu. jusmodi dependitur. Cultam vestitamque familiam utiliter magis habeat, quam delicate, id est ununitam diligenter a frigoribus et imbribus; qux utraque prohihentur optime nellibus manicatis, et sagatis cucullis : idque si fiat, om- tage pour les mettic en état de supporter en tra. vaillant la rigueur de presque tous les jours $d$ 'hi. ver. II faudra en conséquence qu'il fasse deux fois par mois la revue des habits des eselaves, ainsi que celle des instruments de fer, comme je l'ai dit, parce que cette revue répétée fréquem ment ne leur laissera ni prítexte pour manquer à leur devoir, ni espéranee d'impunité, au cas qu'ils viennent à y manquer. II appellera aussi tous les jours par leur's noms les eselaves qui seront à la chaine dans la prison, et il examinera s'ils sont scrupuleusement enchainés par les pieds, et si la prison est elle-même sûre et bien gardée; comme il ne délivrera pas, sans l'aveu du chef de famille, ceux qui auront été mis à la chaine par son ordre ou par celui de son maitre. II ne fera point de sacrifiees, si ce n'est avec la permission de son maître : il ne liera pas, sans ućcessité, connaissance avec des aruspices ou des sorcières, deux sortes de gens qui infeetent les âmes ignorantes du poison d'une vaine superstitíon. Il ne fréquentera ni la ville ni les marchés, si ce n'est pour vendre ou pour acheter les choses qui lui seront nécessaires; il ne doit pas même sortir des limites de sa colonie, ni fournir aux gens, en s'absentant, l'occasion de cesser leur travail ou de tomber dans quelque faute. $11 \mathrm{em}$. pêehera que l'on fasse des sentiers au travers des fonds, et qu'on n'y pose de nouvelles bornes. II donnera très-rarement l'hospitalité, si ce n'est aux amis de son maitrc. Il ne fera pas faire par ses camarades d'esclavage les choses qui selont de son ministère, et il ne permettra à personue de sortir hor's des limites (sauf le cas de la plus grande nécessité). Il n'emploiera pas l'argent de son maitre en achats de bestiaux ou d'autres marchandises, parce que cette habitude détourne un métayer de ses occupations, et qu'elle en fait

nis pene hiemalis dies in opere tolerari possit. Quare tam vestem servitiorum, quam, ut dixi, ferramenta bis debebit singulis mensibus recensere. Nam frequens recognitio nee impunitatis spem nec peccandi locum prabet. Ita. que maneipia [ vineta quæe sunt] ergastuli per nomina quotidie citare debebit atque explorare, ut sint diligenter eompedibus innexa : tum etiam eustodix sedes an tita et reete munita sit : nee, si quem dominus aut ipse viuxerit, sine jussu patrisfamilix resolvat. Sacrifieia nisi ex pracepto domini facere nesciat : aruspicenı sagannuc sua sponte non noverit, qua utraque genera vana superstitione rudes animos infestant. Non urbem, non ullas nundinas nisi vendendx aut emendar rei necessarix eausa frequen. taverit. Neque enim colonia sux terminos egredi debet, nec absentia sua familia cessandi aut delinguendi spatiun dare. Semitas novosipue limites in agro fieri prolibeal. Ilospitem uisi ex amicitia domini quan rarissime recipiat. Ad ministeria sua conservos non allibeat. Nec ulli terminos egredi, nisi magna coegerit necessitas, permittat. Pe. cuniam domini neque in yecore uec in aliis rebus proner. calibus oecupet. Hac enim res avocat villici curam, ct eum 
plutot un commerẹant qu'un agriculteur; outre qu'elle ne lui permet jamais d'apurer ses comptes vis-a-vls de son maitre, et que quand celuiei vient a lui demander de l'argent comptant, il n'a que des effets à lui représenter, au lieu d'argent. C'est done une chose qu'il doit absolument éviter : maisil doit encore plus éviter la passion de la chasse, soit au poil soit à la plume, attendu qu'elle lui ferait perdre un nombre de journées considérable. Il faudra aussi qu'il s'applique à observer ces points-ci, qui sont d'unc exécution très-difficile même dans les plus grands gouvernements, je veux dirc, à ne traiter ceux qui fui seront soumis ni trop durement ni trop doucement, à accorder toujours quelques faveurs d ceux qui se comporteront bien et qui seront appliqués à leurs devoirs, à pardonner mème aux plus méchants, et à user cnvers eux d'une modération telle qu'il les mette dans le cas de craindre plutôt sa sévérité que de détester sa cruauté; ehose a laquelle il pourra parvenir, s'il a plutôt l'attention d'empêcher qu'un ouvrler ne commette quelque faute, que de le punir tardivement après la faute faite. Or il n'y a pas de meilleur moyen pour empêcher l'homme, même le plus méchant, de commettre des fautes, que celui d'exiger de lui de l'ouvrage tous les jours : rien n'étant plus vrai que l'oracle de M. Caton, qui dit qu'en ne faisant rien les hommes apprennent à mal faire. Ainsi le métayer veillera à ce que tous les ouvrages soient faits a temps, chose qu'il obtiendra sans peine, s'il se fait toujours voir aux ouvriers; parce qu'alors ceux qui sont préposés aux différentes fonctions s'acquitteront exactement de leurs devoirs, et que les gens fatigués par l'exercice qu'ils auront pris en travaillaut se livreront plutôt au manger, au repos et au sommeil, qu'ils ne s'occuperont à mal faire. Or le point le plus à désirer dans toutes les par-

negotiatorem potius facit quam agricolam : nec unquam sinit [ cum ] cum rationibus domini paria facere; sed ubi [ zeris ] numeratio exigitur, res pro nummis ostenditur. Itique tam istud vitandum labebit, quam liercule fugien. fum venandi vel aucupandi studium, quibus rebus plurinix operse avocantur. Illa jam, qux etiam in majoribus innperiis difficulter custodiuntur, considerare dehelsit, ue aut crudelius aut renissius agat cum subjectis : semperque foveat bonos et selulos, parcat etiam ninus probis, et ita temperet, ut magis ejus vereantur severitatem, quam ut saviliam detestentur. Poteritque id custodire, si maluerit cavere ne peccet operarius, quam cum peccaverit, sero punire. Nulla est autcm vel nequissimi hominis anplior custorlia, quam quotidiana operis exactio. Nau illıd vcrum cst $\mathrm{M}$. Catonis oraculum, niluil agendo lıomines male agere discunt. Itaque curabit villicus, ut justa rcdJaulur. Istaque uon agre consequetur, si senıper se reprasentaverit. Sic enim et nagistri singulorum officiorum diligenter exequentur sua munia, et familia post operis excrcitationcm fatigata cibo juietiquı potius ac somno gुuam ties de l'administration d'une métairie, ainsi que dans le reste de la vie, c'est que celul qui ignore quelque chose soit convaincu de son ignorance, et que tous ses vœux tendent à s'en instruire. En effet, quoique la science soit de la plus grande utilité, l'imprudence ou la négligence sont encore plus nuisibles qu'elle n'est utilc, surtout en matière d'agriculture, parce que le point le plus important de cet art est de bien exécuter du premier coup toutes les opérations qu'exiǵc la méthode de la eulture. En effet, c'est en vain que l'on corrige quelquefois ce qui aura été mal fait par imprudence ou par négligence, puisque la chose est déjà perdue pour le maftre à qui elle ap. partient, et qu'clle ne réussit jamais assez par la suite pour réparer les pertes qu’elle a éprou vées dans le principe, et pour fairc retrouver le lucre qu'elle aurait dù produire. Qui est-ce en effet qul ignore combien le temps passé est irréparable? Le métayer, qui doit avoir continuellement cette maxime devant les yeux, prendra done garde de se trouver jamais pris au dépourvu et surchargé d'ouvrage, parce que l'économie rustique trompe souvent ceux qui se sont unc fois mis en retard : $c^{\circ}$ est ce qu'un des auteurs les plus anciens, Hésiode, a exprimé si énergiquement par ce vers: L'homme qui returle son ouvrage a toujours à lutter contre des pertes. C'est pourquoi un métayer doit supposer que ce proverbe vulgairc, Ne balancez point $\dot{a}$ planter, que les paysans n'appliquent qu'à la plantation des arbres, s'entend eigalement de la culture d'une terre; et il doit tenir pour certain qu'à moins de faire dans le cours de chaque jour l'ouvrage qu'il amène, on perd non pas seulement les douze heures dont est composé le jour que l'on aura perdu à ne rien faire, mais encorc l'année entière. En effet, comme chaque opération veut être faite jusqu'à un eertain point aux moments qui lui sont fixés; s'il

maleficiis operam dabit. In universa porro villicatione, sicut in catera vita, pretiosissimum est intelligere quenqque, nescire se quod nesciat, semperque cupere, quod ignoret, addiscere. Nam ct si inultum prodest scientia, plus tamen obest imprudentia vel negligentia, maxime in Insticatione; cujus est disciplinx caput semel fecjsse quicquid exegerit ratio culturæ. Nam quamvis iuterdum emenda ta sit perpo. ram facti imprudentia vel uegligentia; res tamen ipsa jan domino decoxit, nee mox in tantum exuberat, ut et jacturam capitis amissi restituat, et quæstum resarciat. Pralabentis vero temporis fuga quam sit irreparabilis, quis dubitct? Ljus igitur memor praccipue semper cavcat, ne" improvidus ab opere vincatur. Res est agrestis insidiosis. sima cunctanti, quod ipsum expressius vetustissimus auctor

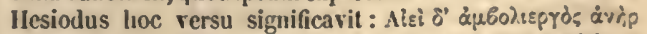

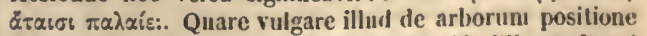
rusticis usurpatum, Serere ne dubites, id villicus ad agri totum cultum referri judicet, credatque, pratermissas non duodecim loras sed annum periisse, nisi sua quaque. lie quod instat effecerit Nam cum proprïs peuc momell. 
arrlve qu'il y en ait une qui ait été finie plus tard qu'elle n'aurait dû l'être, les aứres travaux qui la suivront se trouveront aussi faits trop tard, parce que le temps dans lequel ils auraient dú l'étre sera écoulé; et tout l'ordre des travaux se trouvant dérangé par là, les espérances de l'anncé entière s'évanouiront. C'est pourquoi il est nécessaire que nous donnions des préceptes qui renferment ce qu'il y a à faire dans le cours de chaque mois, et qui soient réglés sur l'influence des astres, parce que, comme dit Virgile, nous ne devons pas moins observer la saison de l'A'cture, les jours des Chevreaux et la constella. tion brillante du Serpent, que ne les observent ceux qui, voguant sur des mers orageuses pour relourner dans leur patrie, ont à passer par le Pont et le détroit d'Abydos, dans lequel abondent les poissons à écailles. Je conviens que j’ai -opposé bien des doutes contre ces sortes d'obser. vations dans les livres que j'ai composés contre les astrologues; mais mon unique objet dans ces traités était de démasquer l'effronterie avec laquelle les Chaldéens affirment que les changements de temps répondent constamment à des jours fixes, comme à des termes invariables; $2 \mathrm{u}$ lieu que dans notre art rustique nous ne donnons point dans des calculs aussi rigoureux, puisqu'il suffit à un métayer, pour son utilité, de prévoir les temps futurs autant que son esprit naturel le permet, pourvu qu'il tienne d'ailleurs comme un principe certain que l'influence d'une constellation se fáit sentir tantót avant son lever ou son coucher, tantot après, et quelquefois même à certains jours marqtiés de l'un ou de l'autre: en effet, sa prévoyance sera suffisante, pour peu qu'il puisse se garantir quelques jours d'avance des temps suspects.

II. Nous allons done preserire ce qu'il y aura

tis fieri quidque dcbeat : si unum opus tardius quam oporteat peraclum sit, cæteræ quoque, quæ sequuntur cultura, post justa tempora serius adhibentur, omnisque turbatus operis ordo spem totius anni frustratur. Quare necessaria est menstrui cujusque officii monitio ea, quße pendet ex ratione siderum et sæli. Nam ut ait Virgilius, tam sunt Archuri sidera nobis IIadorumgue dies servandi et lucidus anguis, Quam quibus in patriam ventosa per aquora vectis Pontus et ostriferi faucbs tentantur Abydi. Contra quam observationem multis argumentationibus disseruisse me non infitior in iis libris, quos adversus astrologos composueram. Scd illis disputationibus exigebatur id, quod improbissime Clualdæei pollicentur, ut certis quasi terminis, ita diebus statis aëris mutationes respondeant : in hac autem ruris disciplina non desideratır ejusmodi scrupulositas; sed, qnod dicitur, pingui Minerva quantum vis utile continget villico tempestatis futuræ præsagium, si persuasum habuerit, modo ante, modo post, interdum etiam stato die orientis vel occidentis competere vim sideris. Nam satis providus erıt, cui licebit ante multos dies cavere suspecta tempora. à faire dans le cours de cliaque mots, cn réglant les travaux de la campagne sur les différentes saisons, autant que la température de l'air le permettra; de sorte que le métayer étant prévenu, par la lecture de ce commentaire, de l'inconstance et des variétés du temps, il ne lui arrivera jamais d'être trompé, ou que du moins ce malheur ne lui arrivera que très-rarement. Et, pour ne pas nous écarter de ce qu'a prescrit le meilleur des poëtes, il commencera par donner le premier labour à la terre au commencement du printemps. Il est vrai qu'un homme de la campagne ne doit point observer le commencement du printemps à la manière d'un astronome, et de facon à attendre le jour marqué auquel on dit que commence cette saison; mais qu'il peut prendre quelques jours sur l'hiver, parce que, passé le solstice d'hiver, l'année commence à être tempérée, et que les jours devenant plus doux permettent d'entreprendre les travaux. II pourra donc (pour nous régler sur le premier mois de l'année romaine) commencer les travaux de la culture aux ides de janvier. Entre ceux auxquels il pourra mettre alors la main, il s'en trouvera qui appartenaient aux temps qui auront précédé celui-ci, et d'autres qui appartiendront aux temps qui le suivront; il achèvera donc les premiers qui n'auront pas été faits, et commencera les șeconds. $\Lambda u$ reste, il nous suffit de distribuer les travaux par demi-mois, parce qu'un ouvrage n'est pas censé fait trop tôt quand il l'est quinze jours avant lc temps que nous allons lui assigner, comme il n'est pas censé fait trop tard quand il l'est quinze jours après. Le jour des ides de janvier, temps venteux et incertain. Le dix-huit des calendes de février, temps incertain. Le dix-sept, le soleil entre dans le Verseau, le Lion commence à se coucher le matin;

II. Itaqne procipiemus, quid quoque mense faciendum sit, sic temporibus accommodantes opera ruris, ut permiserit status cali : cujus varietatem mutationemqie si ex hoc commentario fuerit præmonitus villicus, aut nuıquam decipietur, aut certe non frequenter. Et ue discedanuus ab optimo vate, [qui ait, ille] Vere novo terram proscindere incipiat. Novi antem veris principium nou sic observare rusticus debet, quemad nodum astrologus, ut expectet certum illum diem, qui veris initium facere dicitur : sed aliquid etian sumat de parte hiemis. Quoriann consumta bruma, jam intepescit aunus, permittilque clementior dies opera moliri. Possit igitur ab idibus Jannariis (ut principem mensem Romani anui observet) auspicari culturarum officia; quorum alia ex pristinis residua colisunmabit, atque alia futuri temporis incloobit. Satis autem eril per dimidios menses cxequui quodque tuegotium, quia ncque priefestinatum opus nimium immature videri possit ante quiudecim dies factum, nec rursus post totiden nimium tarde. Idibus Januariis ventosa tempestas el incertus statıs. xrıı cal. Feb. tempestas incerta. Xvi cal. Feb. sol in Aquarium transit; Leo mane incipit occidere; Afri- 
vent d'Afilque, quelquefois vent de midi avee de la pluie. Le seize, l'Écrevisse achève de se coucher; froid. Le quinze, le Verseau commence à se lever; le vent d'Afrique annonce le mauvais temps. Le onze, la Lyre se couche le soir; jour pluvieux. Le neuf, le coucher de la constellation de la Baleine annonec le mauvais temps, quelquefois mème il l'amène. Le six, la elaire étoile que l'on voit sur la poitrine du Lion se couche; c'est souvent un signe que l'on touche à la moitié de l'hiver. Le cinq, vent de midi ou d'Afrique; froid, jour pluvieux. Ic trois, le Dauphin commence à sc coucher, la Lyre se couche aussi. La veille des calendes, le coucher des astres dont nous venons de parler amène ls mauvais temps; quelquefois il ne fait que l'annoncer. Nous donnerons done la note des différents temps éventuels, en pareourant les autres demimois comme nous avons fait à l'égard de celuici, afin que le métayer puisse (ainsi que je l'ai déjà dit) se conduire avec prévoyance, soit en s'abstenant de certains ouvrages, soit en les dépêchant, suivant l'exigcnce des cas. Par' conséquent, si l'on a de grandes possessious en vignobles ou en arbres mariés à des vignes, on emploiera le temps qui s'écoulcra depuis le solstice d'hiver, en commencant aux ides de janvier jusqu'à l'arrivée du vent Favonius, à r'cprendre tout ce qui sera restéà faire de la taille d'automne; en évitant néanmoins de toucher à la vigne pendant les matinces, parce que son bois, encorc engourdi par la bruinc et par les gelées nocturnes, redoute alors le fer. C'est pourcquoi, en attendant le dégel, on pourra, jusqu'à la seconde ou à la troisième heure du jour, élaguer les buissons pour les empêcher de croître au point de couvrir tout lc champ, nettoyer les guérets,

cus, interdım Auster cum pluvia. xvi cal. Feb. Cancer desinit occidere; liemat. xv cal. Feb. Aquarius incipit oriri; ventus Africus tempestatem significat. $x 1$ cal. Feb. Fidieula vespere occidit. Dies pluvius. Ix caleı. liebr. ex occasu pristini sideris significat tempestatem : interdum etiam tempestas. vi calend. Feb. Leonis quae est in pectore clara stella occidit, nounumqquan significatur. Iliems bipertitur. v calend. Felor. Auster, aut. Africus, liemat, pluvius dies. in calend. Febr. Delphinus ineipit occidere. Item Fidicula occidit. Pridie calen. Februar. corum, qua supra sunt, sidelum oecasus, tempestatem facit : interdum tantuınmodo significat. Hoc igitur semestrium, et deinceps sequentia tempestatibus anuotitis percensuimus, quo cautior villieus (ut jan dixi) vel abstinere possit operibus, vel festinationem adlibere. Itaque al) idibus Januariis, quod labetur tempus inter biumam et adventum Favouii, si major est vinex vel arbusti modus, quicquid ex autumno putationis superfuit, repetendıum est, sed ita ne matutinis temporibus vitis saucietur : quonian pruinis et gelicidiis nocturnis adlıuc rigentes materia ferrum reformidant. Itaque dun lix regelatx siccantur, usque in horam secundain vel tertiam poteruut vepres alte. faire des fagots et enfin fendre du bois, afiu de ne se mettre à la taille que lorsque la journée commenecra à être plus supportable. Il faut aussi, daus les climats exposés au soleil et maigres ou sees, commencer à nettoyer les prés et à en interdire l'entréc aux bestiaux, afin que le foin $\mathbf{y}$ vienne en abondance. II est encore temps alors de donner les premiers labours aux terres sèches et grasses; car, pour les terres liumides et médiocres, il ne faudra les leur donner que vers l'été; quant à celles qui seront très-maigres ct sèches, elles ne deviont être labourées qu'd la fin de l'été et au commencement de l'automnc, afin d'être aussitôt ensemencées. Au surplùs, il est aisé de donner en deux journées le premier labour à un jugerum d'uue terre grasse pendant ce temps-ci, parec que le sol encore lumecté des pluies d'hiver se laisse cultiver alors facilement. Il faut aussi pendant le même mois sarcler, avant les calendes de février, les blés d'automne, soit grains adorea que quelques-uns appellent vernacula, soit froinents. Le temps de les sareler est celui où ils commencent à jeter quatre fanes. Ceux qui auront des journées de reste devant eux pourront aussi sarcler dès lors l'orge qui sera en état de l'être. Les fìves exigent encore le même genre de culture, pourvu que leur tige ait déjà quatre doigts de hauteur; car il ne serait pas à propos de les sarclcr auparavant, attendu qu'elles seraicnt encore trop tendres. Le mieux serait de semer l'ers dans le mois précédent, quoiqu'il n’y ait pas d'inconvénicnt à le semer dans ce mois-ci ou dans le sulvant; car pour ce qui est du mois de márs, c'est un temps pendant lequel les gens de la campagne défendent absolument de le mettre en terre. C'est à présent le temps de bêcher les vignes qui

nuari, ne incremento suo agrum occupent, segetes emundari, acervi virgarum fieri, ligna denique confici, ut tum demum tepenti jam die putatio administretur. Apricis etiam et macris aut aridis locis prata jam purganda, et a pecore sunt defendenda, ut foeni sit copia. Siccos quoque et pingues agros tempestivum est proscindere. Nam uliginosi, et medioeris liabitus, sub astatem vervagendi sunt; macetrini vero et aridi post astatem primo autumuo arandi, et sulinde conserendi. Sed jugerum agri pinguis loc tempore anni commole duabus operis proscinditur, quia liibernis pluviis adlıuc madens terra facilenı cultııı sui prabet. Eodenque mense ante cal. Felo. sarriendis: segetes autumnales, sive illa seminis adorei suut, quod quidam far vernaculum voeant, seu tritici : earunque tempestiva sarritio est, cum cnata frumenta quatuor fibiarum esse eoperunt. Ordeum quoque nıaturum, quilus superest opera, uuue demum sarrire debebunt. Sed et filla eandem culturam exigit, si jam coliculus cjus in quatuor digitos altitudinis creverit. Nam prius sarrivisse uimiun teneram uon expedit. Ervum melins quidem priore mens", nec tamen improbe hoc ipso vel proximo sereuns. Nau Martio nullo modu terix commiltendum esse rustici pux. 
sont échalassées et liées. Il faut se laàter de greffer vers les ides les arbres qui viennent les premiers en fleurs, tels que le cerisier, le jujubier, l'amandier et lo pêcher. C'est le temps prople à faire des échalas ainsi que des pieux ; e'est également eelui de couper le bols de eonstruetion : mais, soit qu'il s'agisse de l'une ou de l'autro de ees destinations, le meilleur est de le couper quand la lune est dans son déclin, depuis son vingtième jour jusqu'à son trentième, parce que l'on estime qu'étant coupé ainsi, il nc se pourrit jamais. On peut en une journée couper cent pieux et les aiguiser, comme on peut fendre dans le même espace de temps soixante échalas, soit de chène, soit d'olivier, les polir des deux cótés et les aiguiser. On peut encore faire dix pieux et cinq éehalas pendant la veillée du soir, et autant pendant celle du matin. Si c'est du bois de robre que l'on ait a travailler, un seul onvrier doit en tailler vingt pieds de long, de facon qu'ils soient bien équarris; ce qui formera la charge d'un vehis. Si c'est du pin, il ne faut ćgalement qu'un seul ouvrier pour en expédier vingt-einq pieds, et c'est ce qu'on appellera encore un vehis. Trente pieds d'orme ainsi que de frêne, quarante pieds de cyprès, et jusqu'à soixante pleds de sapiu et de peuplier, peuvent de même être très-bien équarris en une journée, et on donnera également le nom de vehis à toutes ces mesures. On doit aussi pendant ees jours. ci marquer d'une empreinte les agneaux qui sont sevrés, ainsi que les petits des autres bestiaux ct des grands quadrupèdes qui ne l'auront pas encore été. Le jour des calendes de février, la Lyre commence à se eoucher; lc vent d'orient et quelquefois eelul du midi s'élève avec de la grêle. Le trois des nones, la lyre se couche en entier,

cipiunt. Vinex, qune sunt palatx et ligatx, recte jam fodiuntur. Surculi, qui primum florem afferunt, statim circa idus insereudi sunt, ut cerasorum, tuberum, anygadalarum, persicorumque. Ridicis vel etian palis conficiendis, iloneum tempus est. Nec minus in adificia succidere arboren convenit. Sed utraque melius fiunt luna decrescente ab vigesima usque in trigesimam : quonian omıis materia sic caesa judicalur carie non infestari. Palos una opera cadere et exputatos acuere centun ummero potest : rillicas anten querneas, sive oleagineas findere, el dedolatas utraque parte exacuere numero sexagiuta. Item ad lucubrationem respertinau palos decem vel ridicas quinque conficere, totidenque per antelucanam lucubrationem. Materies si roborea est, alı uno fabro dolari ad unguen per quuadrata dehet pedum $\mathrm{xx}$ : hace erit vehis una. Pinus autem $\mathrm{v}$ el $\mathrm{xx}$ pedum aque ab uno expeditur, qua et ipsa velıis dicitur : nec minus ulmus et fraxinus pedum $x x x$; cupressus autem pedum $x_{1}$ : tum etiam sevagenum pedum abies atyue propulus, singulis operis ad unguen quadrantur, atı̣uc omnes lae mensurac similiter velies ajpellantur. Ilis eliam diehus maturi agni, el reliqui futus peculum, nec minus majora quadrupedia cha lactere signari debeut. Cal. P (cb). Fidis incipit occidere, ainsi que la moitié du Lion; vent d'aval ou de septentrion, quelquefis vent Favonius. Le jour des nones, la moitié du Verseau se lève; temps venteux. Le sept des ides, la eonstellation de Callisto se couehe, les vents Favonii commencent à souffler. Le six, temps venteux. Le trois, vent d'est. Pendant ces jours-ci, on nettoie les prés ou les champs dans les climats maritimes, chauds et sees, et on en laisse croître l'herbe pour en tirer du foin. Il faut alors éehalasser et lier le reste des vignes auxquelles les frcids de l'hiver auront empêché de donner ces façons, de peur que, si l'on tardait davantage à le faire, on n'endommageât leurs boutons qui seraient déjà gros, et qu'on n'arrachât leurs yeux. Il faut aussi aehover tant de bêeher les vignes dans les mêmes climats, que de tailler ou de lier les ceps mariés aux arbres, qui demandent tantot plus tantôt moins de facons. Il faut ensuite faire, entre les nones et les ides, des pépinières d'arbres à fruits, et transférer des pépinières dans leurs fosses les jeunes arbres qui seront bons à être plantés. II faut aussi terminer alors les façons au pastinum, que l'on aura commeneées dans le mois de décembre ou de janvier, et planter les vignes. Or, pour façonner au pastinum un jugerum de terraiı, il faut quatre-vingts journées, si on en fouille le sol à la profondeur de trois pieds; cinquante, si on ne le fouille qu'à eelle de deux pieds et demi; ou quarante, si on le fouille au hoyau à deux pieds de profondeur. Au reste, cette dernière mesure est la molndre de celles que l'on pourra donner au labour au pastinum, quand il s'agira d'un terraln sec dans lequel on voudra planter des arbrisseaux : car si l'on se propose de n'y mettre que des plantes potagères, une profondeur d'un pied et demi pourra être

ventus Ëuriıus, et interdım Auster cum grandine e6t. II nonas Feb. Fidis tota, et Leo medius occidit. Corus, aut Septenfrio, nommunquam Favonius. Nonis Febr. medix partes Aquarii oriuntur, ventosa tempestas. vu idus Febr. Callisto sidus occidit; Faronii spirare incipiunt. vı idus Febr. ventosa lempestas. 11 il. Feb. Eurus; per hosce dies locis maritimis el calidis ac siccis prata vel arva purgan. tur, et in fuenum submittumtur. Reliquæ partes vinearum propter brumam vel frigora omissa, nunc palandæe et al. liganda sunt, ne postea tumentes gemma ladantur, et oculi atlerantur. Item rinearum fossio iisdem locis peragenda, arbuslorumqque sive putatio sive alligatio finienda est, quorum justa certa esse non possunt. Inter nonas deinde et idus pomorum seminaria facienda sunt, et maturx plantix de semunariis in scrobes transferendae. Pastinatio quoque, qua mense Decemliri rel Ianuario copta est, jam numc includenda, et vitibus conserenda est. Pastinatur autenı lerreni jugerum ita, ut solum iı altitudinem trium pedum defodiatur operis $\mathbf{x x x}$ : vel in altitudinem dipondii se. missis, operis I, : vel ad bipalium, cui est altitudo duo. rum pedum, operis xL. Hac tamen iu agro sicco surculis conserendis minima pastinationis mensura est. Nam oleri bus dequoneudis possit vel sesquijpedalis altil udo satisfacere, 
suffisante; auquel eas un jugerum ne demandera communément que trente journées de travail. On doit aussi distribuer dans le même temps une portion de son fumier sur les prés, et en répandre une autre portion au pied des oliviers ct des autres arbres. Il faut eneore falre avee soin des pépinlères de vignes, et les remplir serupuleusement de erossettes très-réeemment tirées du eep. Il est bon de mettre alors en terre les peupliers, les saules et les frênes avant qu'ils soient en feuilles, de même que les ormes qui seront bons à être plantés, comme aussi de tailler ceux de ces arbres qui auront été plantés précédemment, de les bêcher autour de leur pled, et de couper les petites racines qu'ils auront jetées sur la superficie du sol pendant l'été. Il faut eneore jeter alors, avant la fouille des vignes, lıors des terres labourées, et ranger auprès des liaies, les sarments et les branches des arbres ınariés aux vignes, ainsi que les ronces, et en un not tuutes les immondices qui pourraient, si on les laissait à terre, retarder les ouvriers qui ont à fouiller la terre ou à lui donner toute autre facon. Il faut faire de nouvelles pépinières de rosiers ou soigner les anciennes, planter des roseaux ou même cultiver ceux qui l'auront été antéricurement, faire des saussaies ou en tailler les arbres, $\mathrm{y}$ arracher les mauvaises licrbes et les bêcher, semer le genêt en graine dans une terre façonnée au pastinum, ou même le déposer en pied dans des fosses. Les semailles des tremois ne sont pas non plus faites à contretemps dans ce moment-ci, quoiqu'il soit mieux de les faire dans les pays tempérés pendant le mois de janvier. Le jour des ides de février, le Sagittaire se eouche le soir; grand froid. Le seize des calendes de mars, la Coupe se lève le

qux plerumque in siıgula jugera triginta operis confieitur. lioc eotem tempore stercoris pars in prata digerenda, pars oleis et caxteris arboribus iuspergemla. Quineliam vitiaria diligenter facienda, malleolusque [quan recen. tissimus] curiosissime pangendus. Populos et salices et fraxinos, prius fuam froudeant, plautas(que ulmorum nunc ponere utile est, aut ante salas nunc exputare, et circumfodere, ac summas earum astivas radicalas amputac. Sirmenta yıoque vineis nondum fossis atque arbustis et segetilus ranos et rubos, quicquid denique jacens fodientem vel alio genere teran molienten potest inupedire, unuc egerese et ad sepem applicare oportet : rosiria uova conserere, vel autiqua curare : arundineta bunc ponere, vet etiam pristina colere : solicta facere, vel deputata ruucare ac forlere: genistam semine vel plantis iu pastinato vel etian sulco deponere. Trimestrium quoque satio uon est aliena luic tcmpori, quanvis tepidis regionilus melius administretur per mensem Januarium. Jibus Felsua. riis Sagitlarius vespere occidit; velıementer hicmat. $\mathrm{xr}$ callend. Martii vespere Crater oritur; venti unutatio. xv cal. Martii sol in P'sees tratusitum fateit, nonumpuan ventosa temuestas. xu et xu cal. Mantii favouius, ved Auster soir; cliangement de vent. Le quinze, le soleil entre dans les Poissons; le temps est quelquefois venteux. Le treize et le douze, vent I'avonius ou vent de midi, avee grêle et orages. Le dix, le Lion achève de se eoucher; les vents septentrionaux, que l'on appelle Ornithice, ont contume de souffler pendant l'espace de trente jours; après quoi les hirotıdelles arrivent. Le neuf, l'Areture se lève au commencement de la nuit; temps froid, vent d'aquilon ou d'aval; quelquefois il pleut. Le huit, le Sagittaire commence is se lever au erépuscule; temps variable, (quoiqu’on remarque le plus grand calme dans la mer Atlautique. Le sept, temps venteux; on aperçoit les liirondelles. Il est temps de faire pendant ee's jours-ci, dans les climats froids; les opérattions que nous avons détaillées ci-dessus; et quoiqu'il soit tard pour les faire dans les climats chauds, il ne faut pas néanmoins se dispenser de les y faire alors, si on ne les a pas faites précédemment. Au surplus, il parait que c'est le meilleur temps pour planter les crossettes et les marcottes, quoiqu'il n'y ait pas plus d'inconvénient à lés planter entre les calendes et les ides du mois suivant, pour'vu néanmoins que le pays ne soit pis très-chaud : il sera même mieux de différer à le faire jusque-là, si le pays est plus froid que chaud. On greffera aussi très-bien dans ce tempsci les arbres et les vignes dans les climats tenıpérés. Le jour des calendes de mars, vent d'Afrique, et quelquefois de midi arce de la grêle. Le six dis uones, le Vendaugeur, que les Grees appellent 'T purntri,p, parait; vent septentrional. Le quatre, vent Fuvonius et quelquefois vent de midi; froid. Le jour des uones, le Cheval se lève: le matin; vent d'aquilon. Le trois des ides, le Poisson du côté de l'aqquilon achève de se lever;

cum grandine et nimbis. x cal. Martii Len desiuit occiderc; venti Septentrionales, qui voeantur Ornitlia, per dies triginta esse solent; tum et hirundo advenit. Ix cal. Martii Areturus prima nocte oritur, frigidus dies Aquilone, vel Coro, interdum pluvia. vun cal. Martii Sagilla crepusculo incipit oriri, varix tempestates : llalcyonei dies vocantur, in Atlantico quidem mari summa tranquil. lilas nota est. vu cal. Martii ventosa tempestas, lirunda couspicitur. Per hos dies frigidis locis earmm rermm, quas supu:a scripsimus, tempestiva est administratio. Locis autem caliliorilus, quamvis sera, tamen necessaria. Cictel'um malleoli et viviradicis positio lujus esse tr'mporis viletır optima. Nec tamen deterior etian inter cal. et ilıs sequentis mensis, utique si uon sit ferventissiun regio: si vero etiam magis frigida, vel melior [ est ]. Insitio quo. que arhorum atyue vitium tepidis loeis loc tempore contunole administrabitur. Cal. Martii Africus; interduns Aus. ter cum grandiue. vi uonas Martii Viudeniator apparet, quem Grasci тpuүntйpa dicunt : Septeulıionales viuli. iv Nouas Martii Favouius, interduun Auster; hicurat. Nous Martii Equus mane oritur; flatus Aquilonis. su ilus Mtır. tii piscis ayuilonius desint oniri, Septentrionales vellt. 
veut septentrional. La veille des ides, le valsseau Argo se lève; vent f'uvonius ou vent de midi, quelquefois d'aquilon. On dispose à propos pendant ces jours-ci les jardins : mais j'en parlerai plus particulièrement dans leur lieu, afin qu'on ne m'impute pas d'a voir passé trop négligemment sur les fonctions du jardinier, en les confondant pour ainsi dire parmi cette bande de travaux que je suis occupé à décrirc, ou d'avoir interrompu en ce moment l'ordre des autres genres de culture que j’ai commencé à détailler. Ainsi, le temps qui s'écoule depuis le jour des calendes de mars jusqu'au dix de celles d'avril est un temps excellent pour tailler la vigne, pourvu néanmoins que 'l'on u'aperçoive pas encore de mouvement dans ses boutons. C'est aussi principalement dans ce temps que l'on prend sur les arbres avec succès des branches qui n'ont poilt encore commencé à bourgeonner, pour être employées cn greffes; comme c'est aussi alor's que l'opération de la greffe elle-mêmeest sans contredit la mieux faite, tant sur les vignes que sur les arbres. On préférc encore ce temps-ci pour planter la vigne dans les climats froids et humides; et il est aussi très à propos de déposer alors en terre les cimes des figuiers qui sont déjà garnies de leurs boutons. On sarcle aussi les blés à merveille pour la seconde fois : une journée suffit pour en sarcler trois modii. C'est le temps de nettoyer les prés, et d'en interdire l'entrée aux bestiaux dans les pays chauds et sees; il faut même commencer à le faire, comme nous l'avons dit ci-dessus, au mois de janvier: mais dans les pays froids on se contente de laisser croitre l'herbe des prés depuis les Quinquatria. Il faudra préparer dans ce temps-ci toutes les espèces de fosses dans lesquelles on se propose de mettre du plant en

Pridie idus Martii Argo navis exoritur, Favonius, aut Auster, interdum Aquilo. His diebus commode instrumntur horti, de quibus suo loco dicam secretius, ne inter lıanc quasi turbam operun negligentius olitoris officia descripsisse videar, aut unc ordinem reliquarum culturarum coptum interrupisse. Igitur a cal. Martiis eximia est vitium pulatlo usque in decimum calend. Apriles, si tamen se gemma nondum movent. Surculi quoque silentes ad insitionen numc praccipue utiliter leguntur, et ipsa insitio vitium atque arborum nunc est optima. Frigidis quoque locis et humidis vitium satio nunc pracipua est, sed et ficulnea cacumina jam tumentia utilissime deponun tur. Sarrilura quoque frumentorum iteratur egregie. Modios tres una opera recte sarrit. Prata purgare, et a pecore defendere jam tempestivum est : locis quidem calidis et siccis etiam [a] mense Januario, ut supra diximus, id fieri debet : nan frigidis vel a Quinquatribus jurata recte sub. miltuntur. Scrobes omnis generis, quos eris autumno consiturus, hoc tempore praparare oportebit : eorum quaternarii, hoc est quoquoversus pedum iv, si est conlmodum terrenum, xiv ab uno fiunt; ternarii autenı xviı. Caterum ad deponendas vites, vel non magni in. automne. Si le terrain est commode, un seut homme en fera cn une journée quatorze de celles que l'on nomme quaternarii, c'est-à-dire, de celles qui ont quatre pieds tant en largeur qu'en longueur, et dix-huit de celles qui en ont trois. Au reste, pour planter des vignes ou des arbres de basse tige, on fera une tranchée de ceut vingt pieds de longueur sur deux pieds de largeur et deux et demi de profondeur, et il ne faudra non plus qu'une journée pour la faire. C'est le temps de bêcher ct de façonner les pépinières de rosiers tardifs. Il est à propos de répandre en ce temps-ei de la lie d'huile extraite sans sel, autour des oliviers qui ne se porteront pas bien : il suffira de six congii de cette liqueur pour les plus grands arbres, d'une urne pour les arbres moyens, et à proportion pour les autres; ceux même qui se portcront bien n'en deviendront que plus fertiles si on les en arrose. Quelques auteur's ont prétendu quec'était le meilleur temps pour iormer des pépinières, de même qu'ilsont prescrit de semer alors sur des planehes les baies de laurier ou de myrte, et la graille des autres arbustes qui sont toujours verts. Les mêmes auteurs ont aussi été d'avis qu'il fallait planter depuis les ides de fívrier, ou même depuis les calendes de mars, l'or. thocissus et le lierre. Le jour des ides de mars, le Scorpion commenee à se coucher; il annonce le mauvais temps. Le dix-sept des calendes d'avril, il secouche; froid. Le seize, le soleil entre dans le Bélier; vent Favonius ou vent d'aval. Le douze, le Cheval se couche le matin; vent septentrional. Le dix, le Bélier commence à se lever; jour plu. vieux; quelquefois il neige. Le neuf et le huit, l'équinoxe du printemps annonce le mauvais temps. II ne faut pas manquer d'achever, depuis les ides, les opérations dont nous venons de par-

crementi arbores, sulcus qui sit pedum centum et viginti, latitudine bipedanea, in altitudinem deprimi debet dipondio semisse, eumque similiter una opera efficit. liosariun serotinum perfossum et cultum liabere jam tempus esł. Oleis laborantibus circum radices amurcam, qua salern nou labeat, nunc conveniel infundere : maximis sex congii, mediocribus arboribus urnte satisfaciunt, cxeteris aestimanda erit portio. Sed tamen quße niliil vitii habuerint, aliquanto lætiores fient, si amurca rigentur insulsa. Nonnulli loc optimum tempus esse seninariis instituendis dixerunt. Tum etiam baccas lauri el myrli cxterorumuque viridium semina in areolas disserere praceperunt. Orlliocissos, et eleras ab jdibus Fubruariis, vel eliam cal. Mar. tiis poni oportere iiden censuerunt. Jdibus Mart. Nepa incipit occidere; signiticat tempestatem. xvı calen. April. Nepa occidit; liemat. xv cal. A pril. Sol in Arietem transitum facit; Favonius, vel Corus. xul calen. April. Equus occidit mane; Septentrionales renti. $x$ cal. April. Aries Incipit exoriri; pluvius dies; interdun niugit. Ix et vut calendarum Aprilium, Equinoctium vernum tempesta. tem significat. Ab idibus eadem, qua supra, utique peragenda sunt : optime autem uliginosa ef pingnia toca nunc 
ler. On donne aussi pour lors à merveille les premierrs labours à la terre dans les licux humides et gras, et les seeonds sur la fin de mars aux guérets qui auront reẹu les premiers au mois de janvier. Si en taillant la vigne on a laissé de côté quelques treilles de raisin distingué, ou quelques ceps partieuliers mariés à des arbres dans les champs on dans les buissons, il faut sans contredit les tailler avant les calendes d'avril, passé lequel jour eette façon leur serait infructueuse pour ètre tardive. C'est aussi alor's qu'on commenee à semer pour la première fois le millet et le panis; eet ensemeneement doit être fini vars les ides d'avril. Il faut einq sextarii de chacune de ces graines, pour ensemencer un jugerum de terre. En outre, c'est encore le temps de châtrer les bêtes à laine, ainsi que les autres quadrupèdes. On peut effectivement châtrer très-bien tous les bestiaux, dans les pays tempérès, depuis les ides de février jusqu'à celles d'avril; et dans les pays froids, depuis celles de mars jusqu’à celles de mai. Le jour des calendes d'avril, le Scorpion se eouehe le matin; il annonee le mauvais temps. Le jour des nones, vent Favonius ou vent de midi avec de la grêle, et quelquefois dès la veille. Le huit des ides, les Pléiades se cachent le soir ; quelquefois il fait froid. Le sept, le six et le cinq, les vents de midi et d'Afrique annoncent le mauvais temps.

Le quatre, la Balance cemmence à se coucher au lever du soleil; elle annonce quelquefois le mauvais temps. La veille des ides, les Hyades se eachent; froid. II ne faut pas manquer pendant ees jours-ci de bêcher les vignes pour la première fois dans les pays froids, et cette opération doit être terminée avant les ides. Il faut aussi se hâtcr alors d'achever les opérations qui

demum proscinduntur : et quæ mense Januario vervacta fecimus, nunc ultima parte Martii sunt iteranda : et siqux pergula vitium generosarnm, vel siquæ in agris aut vepribus singulares arbores maritæ a putatoribus relicta sunt, ante calend. April. utique deputari debent; post quem diem sera et infructuosa fit lıujusmodi rerum cura. Miiii quoque et panici lıac prima satio est, qua peragi debet circa idıs April. utriusque seminis sextarii quini singula jugera occupant. Quinetiam pecus lanatum cxteraque quadrupedia tempus idonenm est castrandi. Locis autem tepidis ab idibus Februariis usque in idus Apriles, in locis frigidis ab idibus Martiis usque in idus Maias omnia recte pecora castrantur. Cal. Aprilibus Nepa occidit mane, tempestaten significat. Nonis April. Favonius aut Auster cum grandine, nonnunquam lıoc ilem pridie. Octavo idus Aprilis Vergiliæe vespere celantur, interdum hiemat. Septiıno idus Aprilis, et sexto, et quinto Austri et Africi tempestatem significant.

Quarto idus Aprilis, sole oriente, Libra occidere incipit, interdum tempestatem significat. Pridie iđl. Aprilis Suculae eelantur, liemat. His diebus locis frigidis prima vinearum fussio utique ante hus peragenda est : quacque mense auraient dû être faites au mois de mars après l'équinose. On ente encore très-bien alors les figuiers et les vignes. On peut arracher les mauvaises herbes des pépinières faites préeédemment, eomme on peut aussi les bêcher commodément. Il faut laver les brebis de Tarente avec dela saponaire, pour les disposer à la tonte. Le jour des ides d'avril, la Balance se couclie, ainsi que je l'ai dit ei-dessus; froid. Le dix-huit des calendes de mai, temps venteux et pluie, quoique ee ne soit pas une règle infaillible. Le quinze, le soleil entre dans le Taurean; il annonee la pluie. Le quatorze, les Hyades se eachent le soir; elles annoncent la pluie. Le onze, on est à la moitié du printemps; pluic et quelquefois grêle. Le dix, les Pléiades se lèvent avec le soleil; vent d'Afrique ou de midi, temps humide. Le neuf, la Lyre paraít au commencement de la nuit; elle annonce le mauvais temıs. Le quatre, communément vent de midi avec de la pluie. Le trois, la Chèvre se lève le matin; vent de midi, quelquefois de la pluie. $\mathrm{La}$ veille des calendes, la Canicule se cache le soir; elle annonce le mauvais temps. Nous continuerons pendant ces jours-ci les mêmes opérations que ci-dessus. On peut greffer en écusson ou autrement les olivier's, pourvu qu'ils commeneent à quitter leur écorce : on peut également enter en écusson les autres arbres à fruit. Rien n'empéche qu'on n'épampre aussi la vigne pour la première fois, paree que ses yeux, qui ne font que commencer à paraître, peuvent être abattus d'un coup de doigt. Outre cela, si en bêchant les vignes on y a dérangé quelque chose, ou qu'on en ait omis quelque partie par négligence, un vigneron attentif doit y remettre la main, et examiner les jougs qui pourront se trouver rompus

Martio post confectum æequinoctium fieri debnerunt, nunc denique quam primum exequenda sunt. Fici vitesque adliuc recte inseruntur : seminaria, quæ sunt ante facta, runcari, et adlunc commode fodiri possunt. Oves Tarentimæ radice lanaria lavari debent, ut tonsuræe preparentur. Idibus Aprilibus, ut snpra, Libra occidit, lieinat. Decimooctavo calen. Maias ventosa tempestas, et imbres, nec lıoc constanter. xv cal. Maias sol in Taurum transitum facit, pluviam significat. xıv cal. Maias Suculae se vesperi celant; pluviam significat. xı cal. Maias ver bipartitur, pluvia, et nonnunquam grando. Decino cal. Maias Vergilix cum sole oriuntur, Africus, vel Auster, dies hunnidus. Nono cal. Naias prima nocte Fidicula apparet, ternpestatem significat. Quarto calen. Maias Auster fere cum pluvia. Tertio cal. Maias mane Capra exoritur, Austrinus dies, interdum pluvia. Pridie cal. Maias Canis se vespero celat : tempestaten significat. Per los dies eadem quar sıpra persequemur, possuntque, si jam librum remittunt, inseriolex, vel emplastrari, cxteraeque pomifera arbores codem emplastrationis genere inseri. Sed et priona pampinatio recte inclıatur, dum prorepentes oculi digito decuti possint. Siqua præterea in vineis aut fossor disturbavit, 
pour les raceommoder, ou remetlee à leur place les pieux renversés, sans cependant faire tomber les jeunes pampres. II faut marquer d'une $\mathrm{cm}$ preinte dans le même temps les bestiaux de la scconde portée. $\Lambda$ ux calendes de mai, on prétend que le soleil reste pendant deux jours dans le mème degré de la Dodécatémorie. Le six des nones, l'Hyade se lève avee le soleil; vents septentrionaux. Le cinq, le Centaure parait entier ; il annonce le mauvais temps. Le trois, il annonce la pluie. La veille des nones, le Scorpion se couche à moitié; il annonce le mauvais temps. l.e jour des nones, les Pléiades se lèvent le matin; vent Favonius. Le sept des ides, c'est le commencement de l'été; vent Favonius ou vent d'aval, quelquefois même pluie. Le six, les Pléiades paraissent entières; v'ent Favonius ou vent d'aval, quelquefois aussi pluic. Le trois, la I.y're se lève le matin; elle annonce le mauvais temps. Il faut pendant ces jours ci arracher les mauvaises herbes des terres ensemencées, et commencer la coupe du foin. Un bon ouvrier fiuche un jugerum de pré à lui seul, et ne lie pas moins de douze cents bottes de quatre livres chacune. C'est aussi le temps de bècher le pied des arbres, et de recouvrir ceux qui sont déchaussés : on peut bêcher en une journée le pied de quatre-vingts jeunes arbres, celui de soixante et eing d'une moyenne grosseur, et celui de cinquante giands arbres. Il faudra pendant ce moisci bêeher souvent toutes les pépinières. En général, depuis les calendes de mars jusqu'aux ides de septembre, il fant les bêcher tous les mois, ainsi que les jeunes vignes. On taille les oliviers et on les débarrasse de leur mousse dans le cours des meimes jours, quand le climat est très-froid et

aut negligentia omisit, diligens vinitor restituere debet, et fracla juga considerate resarcire, aut disjectos palos reponere, ita ne teneros panıpinos explantet. Eodem tempore secundi foetus pecudes signari oportet. Cal. Maiis, lıoc biduo sol unam dicitur tenere particulam. vi nonas Majas Sucula cum sole cxorilur, Septentrionales renti. $\mathbf{v}$ nonas Maias Centaurus totus apparet, tempestatem significat. u nonas Maias idem sidns pluviam significat. Pridie nonas Maias Nepa medius occidit; tempestatem significat. Nonis Maiis Vergilia exoriuntur mane, Favonius. vu idus Maias astatis inilium, Favonius, aut Coras, interdum etian pluvia. v idıs Vergiliae tote apparent, Faronins, aut Corus, interdum et pluvia. Tertio idus Maias Fidis mane oritur, significat tempestatem. Per hos dies runcan. lae segetes sunt, foenisicia instituenda. Bonus operarius prati jugerum desecat, nec minus mille ducentos manipulos unns alligat, qui sint singuli quaternarum librarum. Arbores quoque tempus est ablaqueatas circumfodere, et operire : una opera novellas circumfodiet arbores octuaginta, unediocres LXV, magnas quinquaginta. Hoc mense seminaria onunia crebro fodere oportebit. Sed a calendis Martiis usque in jdus Septembres, omnibus mensibus non solun seminariis, sed etian novellis vineis danda fossio est. Jisden diebus, ubi prirgelidum el pluvium calum est, pluvieux. Au reste, si le pays est tempéré, il faudra répéter cetle opération dans deux saisons de l'année, savoir, depuis les ides d'octobre jusqu’à celles de décembre, et ensuite depuis celles de févricr jusqu’à celles de mars, pourvu cependant que ces arbres ne quittent point alors leur ćcorce. C'est dans le même mois qu'on peut planter pour le plus tard des boutures d'oliviers dans une pépinière façonnéc au pastinum : il faudra, lorsqu'elles seront plantées, les enduirc de fumier et de cendre mêlés ensemble, et les recouvril de mousse pour empêcher que le soleil ne les fende; mais il vaut mieux faire cette opération à la fin du mois de mars ou au commencement d'avril, ainsi qu'aux autres temps pendant lesquels nous avons ordonné de fournir les pépinières de pieds d'arbres ou de boutures. Le jour des ides de mai, la Lyre se lève le matin; vent de midi ou de sud-sud-est, quelquefois temps humide. Le dix-sept des calendes de juin, de mème. Le seize et le quinze, vent de sud-sudest ou de midi, avec de la pluic. Le treize, le soleil entredans les Gémeaux. Ledouzc, les Hya. des se lèvent; vent septentrional, et quelquefois vent de midi avec de la pluie. Le onze et le dix, l'Arcture se lève le matin; il annonce le mauvais temps. Le sept et le six, la Chèvre se lève le matin; vents septentrionaux. Depuis les ides jusqu'aux calendes de juin, il faut bêcher pour la seconde fois les anciennes vignes avant quu'elles commencent à fleurir. II faut aussi les épamprer, ainsi que toutes les autres vignes. Si l'on a soin de le faire souvent, la journée d'un enfant suffira pour en épamprer unjugerum. Il y a des pays où l'on tond alors les brebis, et où l'on se fait rendre compte du nombre des bestiaux tant nés que

olex putantır, et emuscantır. Cæterum tepidis regionilıs duobus temporibus anni facere istıd oportebit. Primo ab idibus Octobribus usque in idus Decembres, ilerum ab illibus Febnuariis usque in idus Martias, si tamen arbor librum non remittit. Hoc eodem mense in pastinato seminario norissima positio est olearis talece, eamque oportet, cum panxeris, fimo et cinere mistis oblinere, et superponere muscum, ne sole findatur, sed hoc opus melius fiet ullima parte mensis Martii, vel prima mensis April. et cateris temporibus, quibus præcipimus seminaria plantis vel rainis conserere. Idibus Maiis Fidis mane exoritur. Auster, aut Euronotıs, interdum dies humidıs. xvı calen. Junias idem quod supra. Xv et XV cal. Junias Euronotns vel Auster cum pluvia. xıv cal. Jun. sol in Geminos in. troitım facit. xu calen. Jun. Suculæ exoriuntur; Seplentrionales venti, nonnunquam Auster cum pluvia. xi et x calen. Junias A rcturus mane occidit, tempestatem significat. vu et vu et vi cal. Jun. Capra mane exorilur; Septentrionales venti. Ab jdib. usque in calend. Junias vete. ranam vineam priusquam florere incipiat, iterum fodere oportet, eandemque et cxteras omnes vineas identidem pampinare. Quod si sapius feceris, puerilis una opera ju. gerum vineti pampinabit. Quibusdam regionibus oves nunc tondentur, et pecoris uati aut amissi ratio accipitur. Itenı 
morts. Ceux qui ont semé des lupins dans la vue de fumer les eliamps, les reversent aussi alors en terie avee la charrue. I.e jour des calcndes et le quatre des nones de juin, l'Aigle sc lève; temps venteux et quelquefois pluie. Le sept des ides, l'Areture se couche; vent Favonius ou vent d'aval. Le quatre, le Dauphin se lève Ic soir; vent Favonius, quelquefois de la roséc. Si l'on s'est trouvé avoir plus d'ouvrage qu'on n'aura pu en faire, il faut achever pendant ees jours-ci les opérations qui appartenaient à la fin de mai. Il faut aussi reeharger la terre au pied de tous les arbres fruitiers que l'on aura bêchés, de sorte que cette opération soit finic avant le solsticc. Outre cela, on donnera le premier ou le seeond labour à la terre, suivant la qualité du sol ou la température du climat. Si la terre est difficile à labourer, il faut trois journées pour le premier labour d'un jugerum, dcux pour le second, et une pour le troisième : une journée suffit aussi pour recouvrir de terre la semence jetée dans deux jugera. Mais si la terrc est aisée à labourer, il suffit de deux journées pour le premier labour d'un jugerum, et d'une pour le seeond : une journée suffit pour recouvrir de terre la semenee jetée dans quatre jugera (ee qui se fait en formant de larges sillons dans unc terre déjà labouréc). Il suit de ce calcul qu'on peut aisément semer pendant l'automne, à l'aide d'unc seule paire de bœufs, cent cinquante modii de froinent et eent de légumes, quels qu'ils soient. Il faut pendant les mêmes jours préparer l'aire où l'on doit battre le blé, et y porter la récolte à mesure qu'elle aura étć faite. Il faut aussi reprendic la eulture des vignobles, quand on en a une grande quantité. Si l'on est à portée d'avoir du fourrage, on en donnera aux bestiaux avant le

‘ui lupinum stercorandi agri causa serit, nunc demum iratro subvertit. Cal. Jun. et iv non. Aquila exoritur; tempestas ventosa, et interdum pluvia. vu idns Jun. Arcturus occidit; Favonius, aut Corus. iv id. Jun. Delphi. nus vespere exoritur; Favonius; interdun rorat. His diehis, si opere victi sumus, eadem, quæ extremo mense Main, facienda sunt : item omnes arbores fructifere circumfossa aggerari debent, ut ante solstitium id opus peractum sit. Quinetiam pro conditione regionis et cali terra vel proscinditur vel iteratur : eaque, si est difficilis, proscinditur operis tribus, iteratur duabus, tertiatur nna, li. rantur autem jugera duo opera una. At si facilis est terra, proscinditur jugerum dluabus operis, iteratur una, lirantur una jugera quatuor, cum in subacla jam terra latiores porce sulcantur. Qua ratio colligit, ut per Aufumnum fa. cile possint uno jugo tritici obseri modii centum quinqua. ginta, cxterorumque leguminum modii centum. lisiem his diebus area triturx praparanda est : ut quaque res lesecta erit, in eam conferatur. Vinearum quoque cultus, quibus major est molus, iteratus esse debet ante solstifium. Pabulum, si facultas est, vel nunc vel etiam superioribus $\mathrm{xv}$ diebus, qui fuerunt ante calen. Junii, pecori solstice, ou dans ce temps-ci, ou même pendant les quinze jours qui précéderont le's calendes de juin. Mais si l'on conunence à manquer d'herbages verts, on leur donnera depuis ees calendes jusqu'à la fin de l'automne des feuilles d'arbres eueillies exprès. Le jour des ides de juin, la chaleur eommenee. Le treize des calendes de juillet, le soleil entre dans l'Écrevisse; il annonee le mauvais temps. Lc onze, le Serpentaire, que les Grees appellent $\delta$ วุเõ̃ $\chi 05$, se couehe le matin; il annonee le mauvais temps. Lc huit, le sept et le six, e'est le solstice ; vent Favonius, chaleur. Le trois, temps venteux. On continue ces jours-ci les mêmes opérations que ci-dessus. Mais il faut aussi couper la vesce qui doit servir de fourrage avant que les cosses en soient durcies, moissonner l'orge, cueillir les fèves tardives, battre celles qui auront été semées les premières et en serrer avee soin la paille, battre l'orge ct serrer toutes les pailles, cueillir les ruches qu'on a dû examiner ct soigner de temps en temps, c'est-à-dire tous les ncuf et dix jours, depuis les calendes de mai. On ne doit néanmoins récolter les rayons dans ce moment-ei qu'au eas qu'ils soient pleins et re. couverts de leurs pellieules; car si la plus grande partie s'en trouve vide, ou qu'elle ne soit point recouverte de cette pellieule, ce sera unc preuve qu'ils ne sont pas eneore d leur point de maturité, et par conséquent on retardera la réeolte du miel. Il y a des personnes dans les provinses d'outre-mer qui sèment le sésame ce mois-ei ou le suivant. Le jour des calendes de juillet, vent Favonius ou vent de midi, ct chaleur. Le quatre des nones, la Couronne se eouehe le matin. La veille des nones, la moitié de l'Écrevisse sc couche; chaleur. Le huit des ides, la moitié du Capricorne se couche. Le sept, Céphéus se lève

praberi oportet. A cal. antem Juniis, si jam deficit viridis herba, usque in ultimum Autumnum frondem caesaun prabebimus. Illibus Juniis ealor incipit. xul calen. Jul. sol introitum in Cancro facit; tempestatem significat. xr calen.

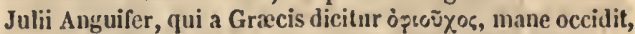
tempestatem significat. Octavo et vu et vi cal. Julii Solstitium, Favonins, ct calor. Tertio cal. Jul. ventosa tempestas. His cliebus eadem, qux supra. Sed et viciam in pabulum secare oportet, priusquam siliqux ejus durentur ; ordeum metere; fabam serotiuan ducere; fabam maturain conterere, et paleam ejus diligenter recondere, ordenm terere, paleasque omneis recondere; alvos castrare, quas subinde nono quoque aut decimo die ad cal. Maias considerare et curare oportet. Nunc autem si sunt pleni atque operculati favi, demeteudi sunt: sin autem majorc parte vacaut, aut sine operculis adaperti sunt, nondum esse maturos significatur : itaque mellatio est differenda. Quidam in provin. ciis transmarinis vel loc vel sefuente ntense sesima serunt. Calen. Juliis Favonius, rel A uster, cl calor. Quarto non. Jul. Corona occidit mane. Pridie nonas Jul. Cancer medius occidit; calor. Oclavo ilus Jul, Capricornus me. dius occidit. Septimo Jdus Jul. Cephens vespere exoritur, 
le soir; il annonce le mauvais temps. Le six, les prodromi commencent à souffler. On continue ces jours-ci les mêmes opérations que ci-dessus. On bine aussi à merveille dans le mème temps les guérets qui ont reçu le premier labour, comme on fait très-bien de défricher les bruyères, lorsque la lune est daus son déclin. Le jour des ides de juillet, l'Avant-Chien 'se lère le matin; il annonce le mauvais temps. Le treize des calendes d'août, le soleil entre daus le Lion; vent Favonius. Le neuf, la claire étoile que l'on aperçoit dans la poitrine du Lion se lève; quelquefois elle annonce le mauvais temps. Le huit, le Verseau commence a se coucher sensiblement; vent $\mathrm{Fa}$ vonius ou vent du midi. Le sept, la Canicule parait; vapeurs brûlantes. Le six, l'Aigle se lève. Le quatre, les claires étoiles que l'on aperçoit dans la poitrine du Lion se lèvent; quelquefois elles annoncent lc mauvais temps. Le trois, l'Aigle se couche; elle annonce le mauvais temps. On fait la moisson pendant ces jours dans les pays tempérés et maritimes; et dans l'espace des trente jours qui suivent la récolte, on ramassc, pour le mettre en tas, le chaume que l'on aurait laissé sur terre en coupant les épis. Il faut une journée pour scier un jugcrum de chaume. Dès qu'on l'aura enlevé hors du champ, on bêchera, sans attendre que la trop grande ardeur du soleil brúle les terres qui auront étè moissonnées, le pied de tous les arbres qui s'y trouveront, et on les re. chaussera. Ceux qui se disposent à faire des semailles considérables doivent aussi biner alors les terres. Quant à ce qui concerne la fouille et la culture des jeunes vignes, j’ai déjà répété souvent qu'il ne fallait laisser passer aucun mois jusqu'à l'équinoxe d'automne, sans s'en occuper. On se

tempestatem significat. Sexto id. Jul. Prodromi flare incipiunt. His diebus eadem quæ supra. Sed et proscissum vervactum optime nunc iteratur, et silvestris ager lecrescente Luna utilissime extirpatur. Idibus Juliis Procyon exoritur mane, tempestatem significat. Tertiodecimo cal. Augustas Sol in Leonem transitum facit; Favonius. [Nono calendas Augustas Leonis in pectore clara stella exoritur. Interdum tempestatem significat.] Octavo calen. Augustas Aquarius incipit occidere (clare); Favonius, rel Auster. Septimo cal. Augustas Canicula apparet; caligo restuosa. Sexto cal. Augustas Aquila exoritur. Quarto calendas Augustas Leonis in pectore clara stella exoritur; interdum tempestatem significat. Tertio calen. Augustas Aquila occidit; significat lempestatem. His diebus locis temperatis et naritimis messis conficitur, et intra dies triginta quam desecta est, stramenta praccisa in acervim conge. runtur. Jugerum stramentorım opera una desecat, quibus renotis priusquam sol acrior exurat terram, omnes arbo. res, qua fuerant in segete, circumfodere et adobruere oportet. Item quibus magna senentis pracparatır, nunc debent iterare. Nam de fodiendis colendisve novellis vi. neis, sæpius (jam) dixi nullum esse mensem onittendum, donec autumnale æequinoctium conficiatur. Meminisse alltem oportebit, ut per hos et Augusti mensis dies antelu. rappellera de cueillir des feuilles pour les bestiaux avant le lever du jour et après sa chute, tant à présent que pendant le mois d'août. Il faut éviter de bêcher les vignes, quelles qu'elles soient, pendant la chaleur, et avoir l'attention de ne le faire que le matin jusqu'à la troisième heure du jour, et depuis la dixième jusqu'au crépuscule. Il y a des pays, tels que la Cilicie et la Pamphylie, où l'on sème le sésame dans ce mois-ci. Pour ec qui est des contrées humides de l'Italie, on peut l'y semer à la fin du mois de juin. En outre, c'est le temps de suspendre des figues sauvages aux figuiers,'précaution que quelques personnes croient nécessaire pour empêcher que leur fiuit ne tombe, et pour le faire parvenir plus tôt à sa maturité. Le jour des calerides d'août, vents étésiens. $\mathrm{La}$ veille des nones, le Lion se lève à moitié; il annonce le mauvais temps. Le sept des ides, la moitié du Verseau se couche; temps brûlant et nébuleux. La veille des ides, la Lyre se couche le matin, etl'automne commence. On continue ces jours-ci les mèmes opérations que cidessus. Il y a cependant quelques rendroits où l'on récolte les rayons; mais s'ils ne sont pas pleins de miel, ni recouverts de leur pellicule, il faut en différer la récolte jusqu'au mois d'octobre. Le jour des ides d'août, le coucher du Dauphin annonce le manvais temps. Le dix - neuf des calendes de septembre, son couchęr, qui se fait le matin, annonce le mauvais temps. Le treize, le soleil entre dans la Vierge; il annonce le mauvais temps, tant pour ce jour-là que pour le suivant; quelquefois aussi il tonne. Ce même jour, la Lyre se couche. Le dix, elle amène communément le mauvais temps et de la pluie. Le sept, le Vendangeur sc lève le matin, et l'Arcture commence à se

canis et respertinis temporibus frondem pecudibus creda. mus. Item quascunque vineas culturi sumıs, ne per rstum, sed mane usque in tertiam, et a decima usque in crepusculum fodiamus. Quibusdam regionibus, sicut in Cilicia et Pamphylia, lıo inense sesama seruntur : Italin auten) regionibus humidis possunt ultimo mense Junio seri. Quinetiam tempus est ficulneis arboribus caprificum suspendere; quod quidam existimant idcirco fieri debere, ne fructus decidat, et ut celerius ad maturitatem perveniat. Calen. Augustis Elesix. Pridie non. Augusti Leo medius exoritur, tempestatem significat. vı id. Augusti Aquarius occidit medius, nehulosus æstıs. Pridie idus Ang. Fidis occidit mane, et Autumnus incipit. His diebus eadem qua supra. Nonnullis tamen locis favi demetuntur : qui si non sunt melle repleti, nec operculati, differenda est in mensem Octob. mellatio. Idib. Augustis Delplini occasus tempestatem significat. xix calen. Septemb. ejıs. dem sideris matutinus occasus tempestatem significat. xul cal. Septemb, sol in Virginem transitum facit. Iloc et sequenti die tempestatem significat, interdum et tonat. Hoc eodem die Fidis occidit. Decimo cal. Septenib. ex eodem sidere tempestas plerumque oritur, et pluvia.vi cal. Septemb. Vindemiator exoritur mane, et Arcturus incipit occidere; iuterdum pluvia. un cal. Septemb. humeri Virginis 
coucher; quelquefols il pleut. Le trois, les épaules de la Vierge se lèvent; les vents étésiens cessent de souffler, et quelquefois il fait froid. La veille des calendes, Andromède se lève le soir; quelquefois il fait froid. On ente ces jours-ci les figuiers en écusson : c'est ce que l'on appelle $\mathrm{em}$ plastratio. On aurait pu le faire également et mème plus commodément dans le mois précédent, après les ides de juillet, temps auquel certaines personnes entent aussi en écusson d'autres arbres. On fait la vendange en quelques endroits, comme, par exemple, daus les contrées maritimes de la Bétique et dans l'Afrique. Quant aux contrées qui sont plus froides que celles-là, on y pulvérise la terre par l'opération que les paysans appellent occatio, c'est-à-dire, en cassant dans les vignobles toutes les mottes de terre, pour les réduire en poudre. Avant de pulvériser la terre daus les vignobles, si les ceps en sont très-fluets, ou qu'ily en ait peu, on y jette dans le même temps trois ou quatre modii de lupins par jugerum, après quoi on les herse, et lorsqu'ils sont venus on les reverse en terre à la première fouille que l'on donne aux vignes, ce qui leur procure un as. sez bon fumier. Lorsque la température du climat est pluvieuse, comme il arrive dans les terroirs de l'Italie voisins des villes, bien des personnes dépouillent aussi alors les ceps de leurs pampres, afin que le fruit n'éprouve point de difficulté à mûrir, et que les pluies ne le pourrissent point. Dans les contrées plus chaudes au contraire, telles que les provinces que j'ai nommées ci-dessus, on ombrage les grappes à l'approche de la vendange, soit avec de la paille, soit avec d'autres matières propres à les couvrir, pour empêcher que les vents ou la chaleur ne les dessèchent. C'est encore le temps de faire du raisin sec, ainsi

exoriuntur : Etesix desinunt flare, et interdum hiemat. Pridie cal. Septemb. Andromeda vesperi exoritur; interdum hiemat. llis quidem diehus arbores ficorum inoculantur; quod genus insitionis emplastratio vocatur. Idque licet vel commodius facere superiore mense post idus Jul. quo tempore etiam aliarum arborum nonnulli emplastra. tionem faciunt. Quibusdam locis, ut in Bretica maritimis regionibus, et in Africa vindemia conficitur. Sed frigidioribus regionibus pulverationem faciunt, quau vocant rustici occationem, cum omnis gleba in vineis refringitur, et resolvitur in pulverem. Iloc eodem tempore prius quam vinex pulverentur, si perexilis est terra, vel rara ipsa vitis, lupini modii tres vel quatıor in singula jugera spar. guntur, et ita inoccantur; qui, cum fruticaverint, prima tım fossione conversi satis bunum stercus vineis prabent. Multi etiam, si pluyius est status cxli, sicut suburbana regione Italix, pampinis vitem spoliant, ut perconui fruc. tus possint, nec putrescere imbribus. At e contrario locis calidioribus, ut modo nominatis provinciis, circa vinde. miam adumbrantur vel stramentis vel aliis tegumentis urae, ne ventis aut caloribus exarescant. Hoc idem tempus est aridis uvis ficisque conficiendis, de quibus quemadmo. COL C.UELL. que des figues sèches. Nous donnerons en son lieu, lorsque nous parlerons des fonctions de la métayère, la manière de faire sécher les fruits au soleil. On fera bien aussi d'arracher au mois d'août la fougère et la lèche partout où il s'en trouvera, quoiqu'il vaille encore micux le faire vers les ides de juillet, avant le lever de la Cani cule. Le jour des calendes de septembre, chaleur. Le quatre des nones, le Poisson méridional achève de sc coucher; chaleur. Le jour des nones, l'Arcture se lève; vent Favonius ou vent d'aval. Le sept des ides, le Poisson septentrional achève de se coucher et la Chèvre se lève; elle annonce le mauvais temps. Le trois, vent Favonius ou vent d'Afrique; la moitié de la Vierge se lève. On fait commodément pendant ces jours-ci la vendange dans les contrées maritimes et chaudes, ainsi que les autres opérations que nous avous détaillées ci-dessus. Les seconds labours doivent aussi être achevés, au cas que les premiers aient été faits tard : car s'ils ont été faits de bonne heure, il faudra faire à présent les troisièmes. C'est aussi dans ce temps-ci que ceux qui sont dans l'usage de frelater le vin préparent à cet effet de l'eau de mer, en la faisant cuire chez eux : je donnerai la méthode de cette préparation, lorsque j'entrerai dans le détail des fonctions de la métayère. Le jour des ides de septembre, le mauvais temps est quelquefois anıoncé par la constellation de la Baleine. Le quinze des calendes d'octobre, l'Areture se lève; vent Favonius ou vent d'Afrique; quelquefois vent d'est, que quelques personnes appellent Vulturnus. Le quatorze, l'épi de la Vierge se lève; vent Favonius ou vent d'aval. Le treize, le soleil entre dans la Balance; la Coupe parait le matin. Le onze, les Poissons se couchent le matiu; le Bélier

dum passæ fiant, suo loco dicemus, cum villicæ persequemur officia. Filix quoque aut carex, ubicunque nascitur, Augusto mense recte extirpatur, melius tamen circa idus Julias ante Caniculæ exortum. Calend. Septembribus ca. lor. Quarto nonas Septemb. Piscis austrinus desinit occidere, calor. Non. Septemb. Arcturus exoritur, Favonius, vel Corus. vu idus Septemb. Piscis aquilonius desinit occidere, et Capra exoritur, tempestatem significat. Tertio idus Septembris Favonius ant Africus, Virgo media exoritur. His diebus locis naritimis et calidis vindemia et cælera, qux supra scripta suut, commode administrantur. Iteratio quoque arationis peracta esse debet, si serius terra proscissa est. Sil autem celerius, etiam tertiatum solım esse convenit. Hoc etiam tempore qui consueverunt rina condire, aquam marinam praparant, et advectan decoquunt : de qua conficienda, cum villicæ officia exequar, pracipiam. Id. Sept. ex pristino sidere uonnunquam tem. pestatem significat. xv cal. Oct. Arcturus exoritır ; Favo. nius, aut Africus, interdum Eurus, quen quidau Vulturuum appellaut. xıv cal. Oct. spica Virginis exoritur; Favonius, aut Corus. xulı cal. Octoh. sol in Librau trans. itum facit, Crater matutino tempore apparet. x/ cal. 
commence aussi à se coucher; vent Favonius ou vent d'aval, et quelquefois de midi, aree des pluies. Le dix, lo vaisseau Argo se couche; il annonce le mauvais temps; quelquefois même la pluie. Lo neuf, le Centaure commence à se lever le matin; il annonce le mauvais temps, quelquefols la pluie. Le huit, le sept ct le six; l'équinoxe d'automne annonce la pluie. Le cinq, les Chevrcaux se lèvent; vent Favonius, et quelque. fois vent de midi avec de la plule. Le quatre, la Vierge achève de se lever; elle annonce le mauvais temps. On fait pendant ces jours-ci la vendange dans plusieurs pays. Il y a différents avis sur le temps à choisir pour cette opération. Les uns ont cru qu'il en ćtait temps quand ils voyaient une partie des grappes s'amollir; d'autres, lorsqu'ils les voyaient colorées et transparentes; quelques-uns même attendaient qu'ils vissent tomber les pampres et les feuilles. Mais tous ces signes sont trompeurs, parce que l'excessive chaleur du soleil ou de l'aunée peut donner lieu à ces différents accidents, sans que le raisin soit mûr. C'est pourquoi quelques personnes se sont avisées de goûter le raisin, pour juger à sa saveur, selon qu'clle était aigre ou douce, s'il ctait temps de faire la vendange. Mais cette épreuve est encore ellc-même sujette à tromper quelquefois, parce qu'il y a tel raisin qui ne dcvient jamais doux, vu sa trop grande âpreté. II est donc à propos, ct c'est ce que nous pratiquons nous-mêmes, d'examiner la maturité naturelle du raisin même : or on la reconnaît aux pepins qui sont cachés dans les grains de raisin, lorsqu'en les faisant sortir au dehors on s'apercoit qu’ils sont tachés, etqu'il s'en trouve même déjà quelques-uns qui sont presque noirs. En effet, il n'y a rien autre chose qul puisse colorer le pepin que la maturité de la nature, puisqu'étant caché au centre des grains, il est à l'abri tant de l'ardeur du soleil que des vents, et que son humidité l'empêche de se cuire ou de se tacher, à moins que ce ne soit naturellement. Que le métayer sache done que dès qu'il se sera assuré de ce fait, il doit faire la vendange. Mais avant de commencer à cueillir le raisin, il faudra qu'il ait préparé dès le mois précédent (si faire se peut) toutes les choses dont il aura besoin ; sinon, qu'il ait au moins quinze jours d'avance enduit de poix cn partie, en partie nettoyé, rincé soigneusement avec de l'eau de mer ou avec de l'eau salée, et bien séché les futailles ainsi que leurs couvercles, les couloirs et les autres instruments sans lesquels on ne peut pas bien faire le moût; qu'il ait rincé et lavé avec soin, et, si le cas l'exige, enduit de poix les pressoirs et les cuves; qu'il ait préparé, afin de l'avoir sous sa main, le bois à brûler nécessaire pour faire cuirc le vin jusqu'à diminution de moitié ou des deux tiers; et qu'il ait mis en réserve longtemps d'avance le sel et les parfums qu'on a coutume d'employer pour frelater le vin. Il ne faut pas néanmoins que ces soins le détournent tout à fait des autres parties de la culture ; car on fait encore pendant ces jours-ci dans les lieux secs des planches de raves et de navets, comme on sème aussi à présent les herbages que l'on coupe avant qu'ils soient mûrs, pour servir de ressource aux bestiaux pendant l'hiver, ainsi que la siliqua, à laquelle les gens de campagne donnent le nom de fenugrec, et la vesce destinée à servir de fourrage. C'est encore alors qu'il faut semer lo plus de lupins, d'autant que quelques personnes
Oct. Pisces occilunt mane, item Aries occidere incipit; Favonius aut Corus, interdum Auster cum imbribus. $\mathbf{x}$ cal. Octob. Argo navis occidit; tempestatem significat, interdum etiam pluviam. Nono cal. Octob. Centaurus incipit mane oriri; tempestatem significat, interdum et pluviam. Octavo cal. Octob. et septimo et sexto Equinoc. tium autumnale pluviam significat. Quinto cal. Oct. Hæedi exoriuntur; Favonius, nonnunquam Auster cum pluvia. Quarto cal. Octob. Virgo desinit oriri; tempestatem significat. His diebus vindemix pluribus regionibus fiunt, quarum maturitatem alii aliter interpretati sunt. Quidam cun vidissent partem aliquam uvarum virescere, credideruut tempestiram esse vindemiam : quidam cum colo. ratas et perlucidas uras animadvertissent : nuunulli etiam cum pampinos ac folia decidere considerassent. Quæ omnia fallacia sunt : quoniam immaturis uvis earlem omnia possunt accidere, propter intemperiem solis aut anni. Itaque nonnulli gustu explorare maturitatem tentaverunt, ut sive dulcis esset sapor uvæ, sive acidus, proinde æestimarent. Sed et lıac ipsa res habet aliquam fallaciam. Nam quædam genera u varum nunquam dulcedinem capiunt propter aus. teritatem nimiam. Itaque optimum est (quod nos facimus) ipsam naturalem contenıplari maturitatem. Naturalis an. tem maturitas est, si cum expresseris vinacea, quæ acinıs celantur, jam infuscata, et nonnulla propemodum nigra fuerint. Nam colorem nulla res vinaceis potest afferre, nisi naturæ maturitas, prasertim cum in media parte acinorum sint, et a sole æestuante, et a ventis protegantur, lumorque ipse non patitur ea percoqui, aut infuscari, nisi suapte natura. Hoc igitur cum exploratum labuerit villicus, sciet rindemiam sibi esse faciendam. Sed antequam fructum cogere incipiat, cuncta praparanda erunt superiore (si fieri possit) mense : si minus, certe ut ante quindecim dies dolia partim picata, partim defricata et diligell. ter lota marina, vel aqua salsa et recte siccata; tum et opercula colaque et catera, sine quibus probe confici mustum non potest; torcularia vero, et fora diligenter emundata lotaque, et si res ita exegerit, picata; proparataque habeat ligna, quibus defrutum et sapam decoquat. Tum etiam salem atque odoramenta, quibus condire vina con. sueverint, multo ante reposita esse oportet. Nec tamen lıæc cura totum arocet eum a cxtera ruris cultura. Nam et napiuæ itemque rapinæ siccaneis locis per hos dies fiunt. Farrago ordeacea quoque, pecori futura per liemem prasidio, itemque siliqua, qnod rustici foenum gracını vocant, nec minus in pabulum vicia nunc demum conseritur. 
sont d'avis qu'il faut les porter dans les champs, pour y être scmés au sortir même de l'aire. C'est dans le même temps que l'on moissonne le millet et le panis, et que l'on sème les haricots destinés à être mangés; car il vaut mieux mettre cn terre à la fill d'octobre, vers les calendes de novembre, ceux qu'on réserve pour ètrc employés aux semailles. C'est pourquoi, eomme ces dernières opérations doivent être faites dans les champs par le métayer lui-mème, il pourra eonfier à la métayère le soin de celles qui peuvent être faites dans l'intérieur de la métairie, de facon néanmoins qu'il se réserve le soin d'examiner par ses propres yeux si elles auront été bien faites. Le jour des calendes d'octobre et le six des noncs annoncent quelquefois le mauvais temps. Le quatre des nones, le Charretier se couche le matin, et la Vierge achève de se coucher, ce qui annonce quelquefois le mauvais temps. Le trois, la Conroune commence à se lever; elle annonce le mauvais temps. $\mathrm{La}$ veille des nones, les Chevreaux se lèvent le soir, la moitié du Bélier se couche: vent d'aquilon. Le huit des ides, la claire étoile de la Couronne se lève. Le six, les Pléiades se lèvent le soir : vent Favonius, et quelquefois vent d'Afrique avee de la pluie. Le trois et la veille des ides, la Couronne se lève entière le matin; vent de midi, froid et quelquefois pluie. On a coutume de faire pendant ces jours-ci, dans les pays froids, la vendange et les autres opérations détaillées ci-dessus. On sème aussi dans les mêmes pays les blés des premières scmailles, et surtout l'adoreum. Il est aussi très-bon de semer alors lc froment dans les lieux ombragés. Mais puisque nous faisons mention des scmailles, il ne sera pas hors de propos de déterminer la quantité de semences cn tout genre qu'il faudra pour un jugerum de terre. On prendra donc quatre ou cinq modii de froment, neuf ou dix d'adoreum, cinq ou six d'orge, quatre ou einq sextarii de millet ou de panis, huit ou dix modii de lupins, quatre de haricots, trois ou quatre de pois, six de fèves, un de lentilles ou tant soit peu plus, neuf ou dix de graines de lin, trois ou quatre de gesse, deux ou trois de pois chiches, quatre ou cinq sextarii de sesame, sept ou huit modii de vesee si on la destine à servir de fourrage, et cinq ou six si on la destine aux semailles; quatre ou einq d'ers, sept ou huit d'orge si on doit le couper en herbe, et six de fenugrec. II faut semer un cyathus de graine d'herbe de Médie parjugerum, sur de petites planches longues de dix pieds et larges de cinq. On met six grains de chanvre dans un pied carré de terre. Le jour des ides d'vctobre et les deux jours suivants, quelquefois mauvais temps et souvent de la rosée. Le treize des calendes de novembre, le soleil entre dans le Seorpion; ce jour et le suivant, les Pléiades commencent à se coueher au lever du soleil; clles annoneent le mauvais temps. Le onze, la queue du Taureau se couche; vent de midi, quelquefois pluie. Le huit, le Centaure achève de se lever le matin; il annonce le mauvais temps. Le sept, lc front du Scorpion se lève; il annonce le mauvais temps. Le cinq, les Pléiades se couchent; l'hiver se fait sentir par le froid et par la gelée: le quatre, l'Arcture se eouche le soir; jour venteux. Le trois et la veille des calendes
Tum etiam lupini lıæc erit præcipua satio, quem quidam rel $\mathrm{ab}$ area protinus in agrum deferri putant oportere. Nilium et panicum loc tempore demetitur, quo faseolus ad escam seritur. Nam ad percipiendum semen ultima parte Octobris circa calendas Novembres melius obruitur. Quare cım hæc cuncta in agris exequi debeat, possit eorum curaın, quæ intra villam facienda sunt, villicæ delegare : ita tamen, ut ipse consideret an recte facta sint. cal. Octobribus, et sexto non. interdum tempestatem significat. Quarto non. Octobris Auriga occidit mane, Virgo desinit occidere; significat nonnunquam tempestatem. Tertio non. Octobris Corona incipit exoriri, significat tempestatem. Pridie non. Octobris IIædi oriuntur ves. pere; Aries medius occidit; Aquilo. Octavo id. Octobris Corona clara stella exoritur. Sexto id. Octobris Vergilia exoriuntur vespere; Favonius, et interdum Africus cum pluvia.

Tertio et pridie idus Octobris Corona tota mane exoritur, Auster libernus, et nonnunquam pluvia. Per hos dies frigidis regionibus vindemia, et cxtera, quæ supra scripta sunt, fieri solent, iisdemque regionibus frumenta matura seruntur, et pracipue far adoreum. Locis etiam opacis triticum nunc recte seritur. Et quonians sementis mentionem fecimus, non intempestive quantum cujusque seminis jugerum agri recipiat referemus. Jugerum agri recipit tritici modios, quatuor vel quinque, farris adorei modios novem vel decem, ordei modios quinque vel sex, inilli vel panici sextarios quatuor vel quinque, lupini modios octo vel decem, faseoli modios quatuor, pisi modios tres vel quatuor, fabæ modios sex, lentis modium unum vel paulo amplius, lini seminis modios novem vel decem, cicercula modios tres vel quatuor, ciceris modios duos vel tres, sesami sextarios quatuor vel quinque, viciæ pabularis modios septem vel octo, vicin seminalis modios quinque vel sex, ervi modios quatuor vel quinque, farra. ginis ordeacere modios septem vel octo, siliquae modios sex, medica singulos cyathos serere oportet in areolis longis pedum denum, latis pedum quinum. Cannabis grana sex in pede quadrato ponuntur. Idibus Octobribus et sequenti biduo interdum tempestas, nonnunquam rorat. Quarto et decimo calendas Novembres sol in Scorpionem transitum facit. Tertiodecimo et duodecimo calendas Novembris solis exortu Vergiliæ incipiunt occidere; tempestatem significat. Undecimo calendas Novembris Tauri cauda occidit; Auster, interdum pluvia. Octaro ca. lendas Novembris Centaurus exoriri mane desinit; tempestatem significat. Septimo calendas Novembris Nepre Irons exoritur; tempestatem significat. Quinto calendas Novembris Vergiliæ occidunt; liemat cum frigore et gelicidiis. Quarto calendas Novembris Arcturus vespere occidit; ventosus dies. Tertio calendas et pridie Novem. bris Cassiope incipit occidere; tempestatem significat. Per 
de novembre, Cassiope commenee à se coucher; clle annonee le manvais temps. On met très-bien en terre pendant ces jours-ei toutes les plantes qui sont dans le cas d'être transférées, ainsi que les arbrisseaux de toutes les espèces. On marie aussi très-bien les ormes avee la vigne, et on'propage également bien les ceps eux-mêmes, tant dans les plants d'arbres mariés à des vignes que dans les vignobles. C'est le temps d'arracher les mauvaises herbes des péplnières et de les bêcher, de déchausser les arbres et les vignes et de les tailler; enfin de tailler les ceps mariés à des arbres. Il fautaussi tailler les arbres des pépinières qui n'auront pas été effeuillés dans le temps convenable, ainsi que les petits figuiers qui sont en pépinières, et les réduire à un seul jet, quoiqu'il eût mieux valu les effeuiller pendant leur jeunesse, dans le temps de la pousse. Mais s`il est nécessaire en agrieulture que toutes les opérations soient faites avec célérité, cela est encore plus nécessaire à l'égard des semailles. Aussi les agricultcurs ont-ils un vieux proverbe qui dit que les semailles faites à temps trompent souvent leur attente, mais que celles qui sont faites trop tard ne la trompent point, paree qu'elles ne réussissent jamais. Nous preserirons done en général de commencer par ensemencer les lieux naturellement froids, et de finir par les plus ehauds. On dit que la vesce et les fèves fument les terres : pour le lupin, il ne les fume point, à moins qu'on ne le reverse en terre pendant qu'il est en fleurs ; mais, d'un autre eóté, il n'y a pas de graine que les ouvriers puissent semer ou serrer avec plus de facilité que celle-là dans les moments où ils n'ont rien à faire, puisqu'on peut la semer dès les premiers temps des semailles avant toutes les autres, et qu'on la peut récolter dans les derniers temps, après que tous les fruits de la terre sont

hos dies quæcunque semina differri debent, arbusculæque omnis generis recte ponuntur. Ulmi quoque vitibus recte maritantur, ipseque vites in arbustis el vineis com. inode propagantur. Seminaria runcare et fodere tempus 'st, tum etiam arloores ablaqueare, nec ninus vineas, "asdenuque putare, itemque in arbustis vitem deputare. Seminaria, qua suo tempore pampinata nou sunt, arbus. c:ulreque ficorum in seminariis putari, et ad singnlos sti- los redigi delsent : qua tamen melius dum tenera sunt, - ver germinationem pampinantur. Sed cum omnia in agricultura strenue facienda sint, tum maxime sementis. Ve. tus est agricolarum proverbinin, Maturam sationem saepe decipere solere, seram nuuquam, quin mala sit. Itaque in totum pracipimus : ut quisque natura locus frigidus erit, is primus conseratur : ut quisque calidus, novissi. mus. Vicia et faba stercorare agrum dicuntur. Lupinum . isi in flore verteris, nihil agrum stercoraveris. Sed nec ulla res magis vacuis operariis aut seritur, aut conditur. Nam et primis temporibus ante aliam sementim potest id obrui, et novissinis post coactos fructus tolli. Sementi facta inoccare oportet, quod sparseris. Duo jugera tres recueillis. Les semailles faites, il faut herser le grain que l'on aura jeté en terie. Trois journées suffiront tant pour herser deux jugera de terre, que pour déchausser les arbres qui s'y trouveront. Quoique les anciens aient voulu que l'on ne mit qu'une journée d̀ sareler et à herser un jugerum de terre, je n'oserais pas assurer qu'on pût en venir aisément à bout. Il faut dans le même temps nettoyer les fosses et les ruisseaux, et faire des rigoles et des tranchées pour favoriser l'écoulement des eaux. On fera bien de donner aux bœufs, dans ces temps-ei, des feuilles de frêne si l'on en a; sinon, des feuilles de figuier sauvage; et au défaut des unes et des autres, des feuilles d'yeuse. Il n'est pas non plus inutile de leur donner un modius de gland par paire de bœufs, pourvu qu'on leur en donne pendant trente jours de suite, ni plus ni moins, de peur qu'ils ne tombent malades; d'autant que si on leur en donnait pendant un moindre espace de temps, ils deviendraient galeux au printemps, comme l'assure Hyginus. Mais, avant de leur donner le gland, il faut le mêler avec de la paille. C'est encore dans ce temps-ci que si l'on veut former une forêt barbarica, c'est-à-dire une forêt qui soit composée d'arbres de différentes espèces, on peut très-bien semer les glands, ainsi que les autres semences dont elle doit éclore. Il faut aussi cueillir à présent les olives dont on veut faire de l'huile verte. La meilleure se fait avec celles qui sont tournées, et qui commencent à noircir; car on ne doit faire de l'huile acerbe qu'avec des olives blanches. Le jour des ealendes de novembre et le lendemain, la tête du Taureau se couche, ce qui annonce la pluie; le trois des nones, la Lyre se lève le matin; froid et pluie. Le huit des ides, clle se lève en entier; vent Favonius, froid. Le sept, la claire étoile du Seorpion se lève; elle

operæ commode occabunt, arboresque quæ intererunt, ablaqueabunt; quamvis antiqui singulis operis singula jugera sarriri et occari velint : quod an recte fieri possit, alfirmare non ausim. Eodem tempore fossas rivosque purgare, et elices sulcosque aquarios facere convenit. Iis. dem temporibus si sit, fraxineam; si minus, orneam; si nec haec sit, iligneam frondem bulous recte probebimus. Glandis quoque non inutile est singulis jugis modios sin. gulos dare : nec tamen ainplius, ne laborent, nec ininus diebus xxx probueris. Nam si paucioribus diebus detur, ut ait Hyginus, per ver scabiosi boves fiunt. Glans autem paleis inmiscenda est, atque ita bubus apponenda. Tum etiam silvam si quis barbaricam, id est consemineam re. lit facere, recte conseret glandibus et cxteris seminibus. Tum et olea destringenda est, ex qua relis viride oleum efficere; quod fit optimum ex varia oliva, cum incipit uigrescere. Nam acerbum nisi ex alba olea fieri non delel. Calen. Novembribus et postridie caput Tauri occidit; plu. viam significat. III noul. Novembris Fidicula mane exoritur; liemat, et pluit. vıı idus Novembris iden sidıs totum exoritur; Auster vel Favonius; hiemat. „wi iclis 
annonce le mauvais temps; froid ou vent d'est, quelquetois rosée. Le six, les Pléiades se couchent le matin; elles annoncent le mauvais temps; froid. Le cinq, e'est le commencement de l'hiver; vent de midi ou d'est, quelquefois rosée. On peut encore, absolument parlant, finir, pendant les jours qui s'écouleront jusqu'aux ides, ee que l'on n'aura pas pu achever le mois précédent : mais voiei des opérations partieulières qu'il y aura à faire. Il faudra jeter sur terre en un seul jour, lequel jour sera celui même de la pleine lune ou le précédent, la quantité de fèves que l'on voudra semer, quoiqu'on pourrait remettre à une autre époque le soin de les recouvrir de terre, pourvu néanmoins qu'on les garantisse eontre l'avidité des oiseaux et des bestiaux. On fera aussi en sorte, pourvu que le eours de la lune ne s'y oppose pas, qu'elles soient hersées a vant les ides de novembre, après avoir été semées dans un terrain qui soit neuf et très-gras, ou du moins très-fumé. Il suffira de se pourvoir de dixhuit vehes de fumier par jugerum. Or le vehis de fumier contenant quatre-vingts modii, on en peut conclure qu'il faut répandre einq modii de fumier sur un espace de dix pieds de terrain en tous sens. On voit par ee calcul qu'il n'en faudra que mille quatre cent quarante modii pour un jugerum entier. Il faut aussi déchausser à présent les oliviers; et s'ils sont peu fertiles, ou que les feuillages de leurs eimes soient desséchés, on répandra, au pied de ceux de ces arbres qui seront pilus forts, quatre modii de erottin de chèvre; it de même au pied des autres, à proportion de leur grandeur. Il faut dans le même temps déchausser les vignes, et verser au pied de ehaque

Novembris tempestatem significat et liemat. Sexto idus Norembris Vergiliæ mane occidunt, signilicat tempestatem; hiemat. Quinto idus Novembris stella clara Scorpionis exoritur; tempestatem significat; vel Vulturnus; interdum rorat. Iv idus Novembris hiemis initium, Auster, aut Eurus, interdum rorat. His diebus usque in idus, quæ superiore mense facere non polueris, adluuc tolerabiliter efficies. Sed et proprie loc observabis, ut pridie, quam plenilunium sit; si minus, certe ipso plenilunio omnem, quam saturus es, fabam uno die spargas : sed postea licebit ab aribus et pecore defensam obruas : eamque, si ita competierit lunæ cursus, ante idus Novembris occalain habeas quam pinguissimo et noro loco : si minus, quam stercoratissimo. Satis erit in singula jugera velhes stercoris comparare numero decem et octo. Vellis autem stercoris una habet modios ocloginta. Ex quo colli. gitur, oportere in denos quoquoversus pedes modios quinos stercoris spargere. Quae ratio docet unirerso jugero satisfacere modios mccccxL. Tum etiam convenit oleas ablaqueare, et si sunt parum frucluose, rel cacuminibus retorridæ frondis, magnis arboribus quaternos modios stercoris caprini circumspergere, in cateris autem pro magnitudine portionem servare : eodem tempre rineis ablaqueatis columbinum stercus ad singulas vites, quorl cep la valeur d'un sextarius de fiente de pigeon, ou un congius d'urine d'homme, ou enfin quatre sexlarii de telle autre espeee de fumier que ce soit. Deux journées suffiront pour déchausser un jugerum de vignes, dont les ceps seront plantés à six pieds de distance l'un de l'autre. Le jour des ides de novembre, temps incertain, quoique le plus souvent beau. Le dix-sept des calendes de déeembre, vent d'aquilon, quelquefois de midi avec de la pluie. Le seize, la Lyre se lève le matin; vent de midi, quelquefois d'aquilon très-violent. Le quinze, vent d'aquilon ; quelquefois de midi avec de la pluie. Le quatorze, le soleil entre dans le Sagittaire, et les Hyades se lèvent le matin; ce qui annonce le mauvais temps. Le douze, les cornes du Taureau se couchent le soir; vent d'aquilon, froid et pluie. Le onze, l'Hyade se couche le matin; froid. Le dix, le Lièvre se eouche le matin; il annonce le mauvais temps. Le sept, la Canieule se eouche au lever du soleil; froid. La veille des calendes, les Hyades se couchent en entier; vent Favonius ou vent du midi; quelquefois pluie. Il faut eontinuer pendant ces jours-ei les opérations que l'on n'aura pas faites les jours précédents. Et si l'on n'a pas beaucoup de semailles à faire, il sera très-bon de les avoir achevées avant les calendes de décembre. Mais il faut aussi prendre quelque portion sur les nuits, qui sont longues alors, pour l'ajouter aux jours; d'autant qu'il y a beaucoup d'opérations qui peuvent très-bien se faire pendant les veillées. En effet, si l'on a des vignobles, on pourra tailler et aiguiser les pieux et les échalas : si la contrée est fertile en fẻrules et en écorces, on fera des ruehes pour les abeilles; si

sit instar unius sextarii, vel urina hominis congios, vd alterius generis quaternos sextarios stercoris infundere. Jugerum vinearum in senos pedes positarum dua opera ablaqueant. Idibus Novembris dies incertus, sæpius ta. men placidus. (Septimo decimo cal. Decembris Aquilo, interdum Auster cum pluvia.) Sextodecimo calendas Decembris Fidis exoritur mane; Auster, interdum Aquilo magnus. Quintodecimo calendas Decembris Aquilo, interdum Auster cum pluvia. Quartodecimo calcudas Decembris sol in Sagittarium trausitum facit; Suculæ mane oriuntur, tempestatem significat. Duodecimo calendas Deceubris Tauri cornua vesperi occidunt; Aquilo frigidus, et pluvia. Undecino calendas Decembris Sucula mane occidit, liemat. Decimo calend. Decembris Lepus occidit mane, tempestatem significat. Septimo calend. Decembris Canicula occidit solis' ortu, hiemat. Pridie calendas Decembres totx Sucula occidunt; Favonius aut Auster, interdum pluvia. Ilis diebus, quxe præterita erunt superioribus, opera consequi oportebit. Ët, si non plurimum serimus, optimum est intra calendas Decembris sementem confecisse. Sed etiam (de) longis noctibus arl diurnun tempus aliquid adjiciendum est. Nam multa sunt, qux in lucubratione recte aguntur. Sive enim viueas possidemus, pali et ridicx possunt dolari exacuique : sive 
elle l'est en palmiers et en genêts d'Espagne, on fera des eabas et des paniers; et si elle l'est en arbustes qui ne portent que des verges, on fera des eorbeilles d'osier. Enfin, pour ne pas entrer ici dans le détail de tous les ouvrages qui peuvent se faire pendaut les veillées, nous nous contenterons de dire qu'il n'y a point de pays qui ne produise de quoi s'oceuper. En effet, il n'y a qu'un agriculteur négligent qui puisse régler son travail sur la brièveté des jours, surtout dans les contrées où les jours ne sont que de neuf heures, tandis que les nuits sont de quinze. On peut encore émonder, pendant les veillées, le saule qui aura été coupé un jour d'avance, et en préparerdes liens pour les vlgnes : s’il est peu pliant de sa nature, il faudra le couper quinze jours d'avanee, et, après l'avoir émondé, l'enfouir dans du fumier afin qu'il s'y ramollisse; mais s'il est desséché, pour avoir été coupé depuis rrop longtemps, il faut le tremper dans la marre. On aiguisera aussi pendant les veillées les instruments de fer, et on y adaptera des manches. Les meilleurs sont ceux de bois d'yeuse; viennent ensuite ceux de cliarme, et en troisième lieu ceux de frêne. Le jour des caleudes de décembre, temps incertain, quoiqu'il soit le plus souvent beau. Le huit des ides, le Sagittaire se couche à moitié; il annonce le mauvais temps. Le sept, l'Aigle se lève le matin; vent d'Afrique, quelquefois de midi; rosée. Le trois, vent d'aval ou de septentrion, et quelquefois de midi avee de la pluie. Il faudra achever pendant ces jours-ei les ouvrages qui n'auront pas été faits dans le mois précédent; ce qui s'applique néanmoins aux lieux tempérés ou chauds, car il serait trop tard pour les faire à pré- sent dans les licux froids. Le jour des ides de décembre, le Scorplon se lève entier le matill; froid. Le seize des calendes de janvier, le soleil entre dans le Capricorne; c'est le solstice d'hiver selon Hipparchus, aussi annonce-t-il souvent le mauvais temps. Le quinze, changement de vents an. noncé. Le dix, la Chèvre se couche le matin: elle annonce le mauvais temps. Le neuf, c'est ( selon l'observation des Chaldéens) le solstice d'hiver et ses annonees. Le six, le Dauphin commence à se lever le matin; il annonce lo mauvais temps. Le quatre, l'Aigle se couche le soir; froid. Le trois, la Canicule se couche le soir; elle annonce le mauvais temps. La veille des calendes, temps mauvais et venteux. Ceux qui poussent plus loin leurs scrupules en matière d'économie rurale prétendent qu'on ne doit point toucher à la terre avec le fer pendant ces jours-ci, si ce n'est pour la façonner au pastinum, à l'effet d'y planter des vignes. Aussi ne se permettent-ils alors que des genres de travaux différents de celui-là, tels que ceux qui consistent à cueillir les olives, à faire de l'huile, à échalasser la vigne et à l'arrêter en la liant par le tronc, à poser les jougs dans les vignobles et à les affermir en les attachant ensemble. Au reste, il ne faut point, pendant ce temps-ci, faire ce que l'on appelle palmare, e'est-à-dire lier les branches de la vigne, parce qu'elles se rompraient pour la plus grande partie, vu la roideur que le froid leur aura fait contracter. On peut aussi greffer commodément, pendant le cours de ces jours-ci, les cerisiers, les jujubiers, les abricotiers, les amandiers, et les autres arbres qui fleurissent les premiers. Quclques personnes même sèment des légumes. Le jour des calendes de janvier, temps incertain. regio ferula vel cortieis ferax est, apibus alvearia fieri debent : sive palma sparlive foccunda est, fiscinæ sportraue : seu virgultorum, corbes ex vimine. Ae ne catera nuic persequar, nulla regio non aliquid affert, quod ad lu. eubrationem confiei possit. Nam inertis est agrieola expectare diei brevitatem, præcipue in is regionibus, in quibus brumales dies horarum novem sunt, noetesque lorarum quindecim. Possit etiam salix deeisa pridie ad lueubrationem expurgari, et ad vitium ligamina præparari. Qux si natura miıus lenta est, ante dies quindecim pracidenda, et purgata in stereore obruenda est, ut len. tescat. Sin autem jampridem casa exaruit, in piscina maceranda est. Tum etiam per lueubrationem ferramenta acuere, et ad ea facere, vel faeta manubria aptare, quorum optima sunt ilignea, deinde carpinea, post lıxe fra. xinea. Calendis Decembribus dies ineertus, sæepius tamen placidus. Octavo idus Decembris Sagittarius medius oecitit; tempestatem significat. Septimo idus Deeembris Aquila mane oritur; Africus, interdum Auster, irrorat. Tertio idus Deembris Corus, vel Septentrio, interdum Auster cum pluvia. His diebus qua praterita erunt superiore mense opera peragi debebunt, utique in loeis tempe. ratis ant ealidis : nam locis frigidis recte fieri jam non possunt. Idibus Deeembris Scorpio totus mane exoritur ; lienat. Sextodecino calendas Januarii sol in Caprieornum transitunı facit, brumale solstititu, ut Ilipparcho placet : itaque tempestatem sæe significat. $\mathrm{xr}$ ealend. Januarias [ventorum commutationem signifieat. $\mathrm{x}$ calen. das Januarias ] Capra oecidit mane, teinpestatem significat. Nono calendas Januarias biumale solstitium ( sieut Chaldaei observant). significat. Sexto calend. Januarias Delphinus incipit oriri mane; tempestatem significat. Quarto calendas Januarias Aquila vespere oeeidit; hicmat. Tertio calendas Januarias Canicula vespere oecidit; tempestatem signifieat. Pridie calendas Januarias, tempestas ventosa. II is diebus qui religiosius rem rustican eolunt, nisi si vinearum causa pastines, negant debere terram ferro commoveri. Itaque quidquid citra id genus effiei potest, il ab his comprehendilur, ut olea legatur, et [oleuni] confieiatur, ut vitis paletur, et eapite tenus al. ligetur, ut juga vineis imponantur, et capistrentur. Cxterum palmare, id est materias alligare, hoc tempore non expedit, quia plurimax propter rigorem qui fit ex fiigore, franguntur. Possunt etiam his diebus eerasi el tuberes et Armeniacac atque amygdalac exteræque arbores qux pimx florent, inseri commode. Nonnulli eliam legumina se- 
Le trois des nones, l'Écrevisse se couche; temps variable. La veille des nones, c'est le milieu de l'hiver; grand vent de midi, quelquefois pluie. Le jour des nones, la Lyre se lève le matin; temps variable. Le six des ides, vent de midi et quelquefois vent Favonius. Le cinq, vent de midi; quelquefois pluie. La veille des ides, temps incertain. Les agriculteurs scrupuleux s'abstiennent encore pendant ces jours-ci de travailler à la terre, de façon néanmoins qu'ils mettent la main à chaque espèce de travaux le jour même des calendes de janvier, pour se rendre les augures favorables en remettant au surplus le labourage aux ides suivantes. Mais comme un métayer ne doit pas non plus ignorer ce qu'il faut donner par jour à chaque paire de bøufs, de mois en mois, nous allons aussi donner le détail de cette administration. Au mois de janvier, il leur donnera de la paillc avec six sextarii d'ers détrempé; ou un semodius de gesse moulue; ou il remplira de feuillages un panier dont on se sert pour mettre leur nourriture, qui soit de la contenance de vingt modii; ou il leur donnera autant de paille qu'ils en voudront, avec vingt livres de foin; ou bien encore des feuillages verts, soit d'ycuse soit de laurier, très-copieusement; ou enfin des herbages d'orge séchés, qui leur valent mieux quc tout le reste. Au mois de février, de même. Au mois de mars, de même; ou cinquante livres de foin s'ils doivent travailler. Au mois d'avril, des feuilles de chêne et de peuplier; mais depuis les calcndes jusqu'aux ides, de la paillc ou quarante livres de foin. Au' mois de mai, du fourrage en abondanee. Depuis les calendes de juin, des feuillages en abondanee. Au mois de juillet, de même. Au mois d'août, de même; ou cinquante livres de paille d'ers. Au mois de septembre, des

runt. Calendis Januariis dies incertus. Tertio nonas Januarii Cancer occidit; tempestas varia. Pridie nonas Jaunarii media hiems; Auster multus, interlum pluvia. Non. Januariis Fidis exoritur mane; tempestas varia. Sexto idus Januarias Auster, interdum Favonius. Quinto idus Jan. Anster, interdum imber. Pridie idus Jan. incertus status caeli. Per lios quoque dies abstinent terrenis operiLus religiosiores agricol $x$, ita tamen ut jpsis calen. Januariis auspicandi causa omne genus operis instaurent, caterum differant terrenam molitionem usque in proxinıas idus. Sed nec ignorare debebit villicus, quid uni jugo boum quoquo mense per singulos dies prosturi satis sit. Quare hinjus quoque curæ rationem suljiciemus. Mense Januario paleas cum ervi macerati sextariis sex, vel paleas cum cicercula fresx semodio, vel frondis corbem pabulatorium modiorum viginti, vel paleas quantum velint, et fueni pondo viginti, vel affatim viridem frondem ex ilice vel - lauro, vel quod his omnibus praestat, farraginem ordeaceam dabit siccam. Februario mense idem, Martio idem, vel, si opus facturi sunt, fueni pondo quin(pnaginta. A prili frondem querneam, et populueam. Lx cal. ad idus vel yaleas vel firni pondo quadraginta. Majo pabulum affitin: feuillages en abondance. Au mois d'octobre, des feuillages et des feuilles de figuier. Au mois de novembre, la valeur d'un panier de feuillages ou de feuilles de figuier jusqu'aux ides; et depuis les ides un modius de gland mêlé avec de la paille, et un modius de lupins détrempés et mêlés avec de la paille; ou des mélanges d'herbages coupés à temps. Au mois de décembre, des feuilles sèches; ou de la paille avec un semodius d'ers détrempé; ou un semodius de lupins détrempés avant d'être mesuré; ou un modius de gland, comme nous avons dit ci-dessus; ou des mélanges d'herbages.

III. Comme nous avons parcouru les travaux que le métayer doit exécuter dans les temps de l'année qui sont fixés pour chacun d'eux, nous allons à présent, en nous rappelant la promessc par laquelle nous nous y sommes engagés, joindre à la suite de ce détail la culture des jardins, dont il doit également s'occuper, tant pour diminuer la dépense de sa nourriture journalière, que pour avoir des mets de campagne non achetés, comme dit le poëte, à présenter à son maitre lorsqu'il y viendra. Démocrite, dans le livre auquel il a donné le titre de Géorgiques, est d'avis que ceux qui construisent les murailles pour clore des jardins agissent peu prudemment, parce que, d'un côté, si une muraille n'est construite qu'en briques, elle ne peut pas durer longtemps, attendu que les pluies et le mauvais temps l'endommagent communément, et que, d'un autre coté, si on la construit en pierres, ce sera une dépense trop élevée pour ce genre d'économic rustique, outre que pour enclore de cettc manière un jardin d'une grande étendue, il faudrait être trop opulent. Je donnerai done une facon de meltre un jardin à l'abri des incursions des hom-

Junio ex calend. frondem affatim : Julio idem, Augusto iuem, vel paleas ex ervo pondo quinquaginta. Septembri frondem affatim, Octobri frondem, et ficulnea folia. Novemb. ad julus frondem vel folıa ticuhea, qua sint corbis unius. Ex idibus glandis modium unum paleis immistum, et lupini macerati modium unum paleis innmistum, vel inaturain farraginem. Decemb. frondem aridam, vel paleas cum ervi semodio macerato, vel lupini, quod ex semodio macerato exierit vel glandis modium unum, ut supra scriptum est, vel farraginem.

III. Et quoniam percensuimus opera, qua suis quibus. que temporibus anni villicum exequi oporteret, memores polliciti nostri subjungemus cultus hortorum, quorum xupe curam suscipere debebit, ut et quotidiani victus sui levet sumptum, et advenienti domino probeat, quod ait poëta, inemptas ruris dapes. Democritus in eo libro, quem Georgicon appellavit, parum prudenter censet ens facere, qui liortis extruaut inunimenta, quod neque latere fabricata maceries perenuare possit, pluviis ac tempestatibus plerumque infestala, neque lapides supra rei dignitatem poscat impensa. Si vero amplum modum sepire quis velit, patimonio esse op̣s. Ipse igitur osteudam rationem, 
mes et de celle des bestiaux sans grands frais. Les auteurs les plus anciens ont préférć une haie vive à un treillis composé de pièces de bois, non-seulement parce qu'elle entrainait moins de dépense après elle, mais encore parce qu'elle durait plus longtemps que des ouvrages plus considérables. En consécquenee, ils ont donné la méthode que voici pour former des buissons en semant des épines. Il faut après l'équinoxe d'automne, et dès que les pluies auront humecté la terre, creuser deux tranchées, à la distance de trols pieds l'une de l'autre, autour du lieu gue l'on voudra clore de haies. Il suffira que ces tranchées aicnt deux pieds tant en largeur qu'en profondeur: du reste, on les laissera passer l'hiver à l'air sans y rien mettre, et l'on se contentera de préparer alors les graines que l'on se proposera d'y semer par la suite. Ces graines seront celles des plus grandes épines, et principalement de la ronce, du paliure, et de cette plante que les Grees appellent xuvóobarov, et que nous nommons sentis canis. On choisira les graines de ces ronces les plus mûres, et on les mélera a vec de la farine d'ers moulu; après quoi on roulera dans cette farine, préalablement mouillée, de vieux cordages de navires, ou telle autre espèce de corde que ce soit; lorsqu'ensuite ces cordes seront bien séchées, on les serrera sur un plancher, pour y rester jusqu'à quarante jours par delà le solstice d'hiver; puis, vers l'arrivée des. hirondelles, et lorsque le vent Favonius commencera à s'élever après les ides de février, on tarira l'eau qui pourra s'être amassée dans les tranchées pendant l'hiver, et on les remplira, jusqu'a la moitié de leur profondeur, de la terre ameublie qui était restée entassée sur leurs bords depuis l'automne. Enfin on tirera les cor-

qua non magna opera hortum ab incursu hominum pecudumque munimus. Vetustissini auctores vivam sepem structili præetulerunt, quia non solun minorem impensam desideraret, verumetiam diuturnior immensis temporibus perınaneret : itaque vepris efficiendi consitis spinis rationem talem reddiderunt. Locus, quem sepire destinaveris , ab æequinoctio autumnali simulatque terra maduerit imbribus, cireumvallandus est duobus sulcis tripedaneo spatio inter se distantibus. Modum altitudinis (et latitudinis) eorum abunde est esse bipedaneum : sed eos va. cuos perliemare patiemur præparatis seminibus, quibus obserantur. Ea sint vastissimarum spinarum, maximeque rubi, et paliuri, el ejns quau Graci rocant xuvóobatov, nos sentem canis appellamus. Horum autem ruborum semina quam maturissima legi oportet, et ervi moliti farinæ immiscere : quæ cum est aqua conspersa, illinitur vel nanticis veteribus funibus, vel quibuslibet aliis restibus. Siccati deinde funiculi reponuntur in tabulato : mox ubi hruma confecta est, internissis quadraginta diebus, circa hirundinis adrentum, cum jam Faronius exoritur, post idus Februarias si qua in sulcis per hiemem constitit aqua, exlıauritur, resolntaque liumus, quæ erat antumno des dont nous venons de parler des planchers sur lesquels elles étaient serrées, et après les avoir développées, on les étendra le long des deux tranchées, en les recouvrant de terre, de façon néanmoins que les graines d'épines adhérentes aux tourons de ces cordes ne soient pas chargées de terre au point de ne pouvoir plus germer. Elles germeront en effet vers le trentième jour; et lorsqu'elles auront commencé à prendre quelque accroissement, on les habituera à se pencher du côtéde l'intervalle qui sépare les tranchées. II faudra ficher en terre au milieu de cet intervalle une haie d'osier, sur laquelle monteront les buissons de l'une et l'autre tranchée, et qui leur tiendra lieu, pour ainsi dire, d'une espèce de soutien contre lequel ils s'appuieront, jusqu'à ce qu'ils soient fortifiés. Il est visible qu'on ne pourra jamais venir à bout de détruire ce buisson, à moins qu'on ne veuille le déterrer jusqu'aux racines : d'ailleurs personne ne doute qu'il ne soit dans le cas de reprendre encore mieux, lorsqu'il aura été endommagé par le feu. Voilà done la façon d'enclore un jardin qui a été le plus ap. prouvée par les anciens. Au surplus, il faudra, si la situation de la terre ne s'y oppose point, choisir pour son emplacement un lieu qui soit dans le voisinage de la métairie : l'important est que ce lieu soit gras, et qu'il puisse être arrosé par un ruisseau dont les eaux couleront à travers, ou, s'il ne s'y trouve pas d'eau courante, par un puits à bonne source. Mais afin d'être assuré que ce puits ne manquera jamais d'eau, il ne faudra le creuser que lorsque le soleil sera dans les derniers degrés de la Vierge, c'est-àdire au mois de septembre avant l'équinoxe d'automne, parce que le meilleur temps pour reconnaître la bonté d'une source d'eau, c'est

regesta, usque ad mediam sulcorum allitudinem reponitır. Pradicti deinde funes de tabulato prompti explicantur, et in longitudinem per utrnmque sulcum porrecti obruuntur, sed ita, ut non nimium supergesta terra semina spinarum, quæ inliærent toris funiculorum, enasci possint. Ea fere circa trigesimum diem prorepunt : atque ubi cœperunt aliquos iucrementum labere, sic insuesci debent, ut in id spatium, qnod sulcis interjacet, inclinentur. Oportebit autem virgeam sepem interponere, quam superscendant sentes utriusque sulci, et sit quo interdum quasi adminiculo priusquam corro. borentur, acquiescant. Hunc reprem manifestum est interimi non posse, nisi radicituseffodere velis. Cæeterum etiam post ignis injuriam melius renasci, nulli dubium est. Et lıec quidem claudendi horti ratio maxime est antiquis probata. Locum autem eligi conveniet, si permittit agri situs, juxta villam, præcipue pinguem, quique adreniente rivo, vel si non sit fluens aqua, fonte puteali possit irrigari. Sed ut certam perennitatis puteus habeat fidem, tum demum effodiendus est, cum sol ultimas partes Virginis obtinebit, id est mense Septemb. ante xquizoclinm autumnale : siquidem tunc maxime explorantur vires fontium, cum ex louga siccitate nestatis terra caret liu- 
Jorsque les longues séeheresses de l'été ont absoIument dénué la terre de toute eau de pluie. II faut eneore prendre garde que l'emplacement du jardin ne soit au-dessous de l'aire, de peur que korsqu'on viendra à battre le blé, le vent ne fasse voler sur la superfieie des pailles ou de la poussière, toutes choses funestes aux plantes potagères. On distingue deux saisons dans lesquelles on peut disposer le terrain et le façonner au pastinum, parce qu'il y a de même deux saisons dans lesquelles les plantes potagères peuvent être semées, la plus grande partle d'entre elles pouvant l'ètre en automne ainsi qu'au printemps. Il vaudra mleux néanmoins préparer le terrain au printemps dans les lieux arrosés, tant parce que la doueeur du temps qui se fait sentir au eommencement de l'année accueillera favorablement les semences au moment qu'elles germerout, que parce qu'on pourra remćdier à la séeheresse de l'été, qui suecédera à cette saison, par des eaux de source; au lieu que lorsque la nature du lieu ne permet point de fournir aux semenees de l'eau naturelle ou artifieielle, on n'a pas d'autre ressouree que celle des pluies d'hiver. Ce n'est pas qu'on ne puisse faire de bonue besogne dans les lieux même les plus secs, pourvu qu'on y laboure le sol au pastinum plus profondément que dans les lieux arrosés : il faudra à cet effet le fouiller à trois pieds de profondeur, de faeon que la terre qui se trouvera gonflée par le labour monte à la hauteur de quatre; lorsqu'on aura au contraire la faculté d'arroser, il suffira de retourner la terre erue avec une houe de petite dimension, e'est-à-dire, dont le fer n'ait pas tout à fait deux pieds de hauteur. Quoi qu'il en soit, on aura soin de faconner au pastinum pendant l'automne, vers les calendes de novembre, le terrain que l'on destinera à être ensemeneé au printemps, et de retourner au con- traire au mois de mai celui que l'on voudra eouvrir en automine, afin que les mottes de terre aient le temps de se dissoudre aux froids de l'hiver et aux ehaleurs de l'été, et que toutes les raeines des herbes périssent. Il ne faudra pas le fumer longtemps d'avanee; mais lorsque le temps de l'ensemeneer approchera, on en arrachera les herbes elnq jours avant et on le fumera, après quoi on le binera avec l'attention nécessaire pour incorporer ee fumier à la terre. Au reste, Ic meilleur fumier pour cet usage est le erottin d'âne, pareeque e'est eelui qui engendre le moins d'herbes : vient ensuite eelui des bêtes de somme ou des brebis, pourvu qu'il soit resté en tas pendant une année. Quant aux exeréments humains, quoiqu'ils passent pour être excellents, il n'est pas néanmoins néeessaire de les employer, à moins que le terrain ne soit d'un gravier pur, ou d'un sable très-délié et sans aueune vertu; auquel cas il lui faudrait des aliments de la plus grandc substance. Ainsi, après avoir bêehé le terrain que l'on destinera à être ensemeneé au printemps, on le laissera se consumer après l'automne par les froids du solstice d'hiver et par les bruines, parce que la violenee du froid n'affine pas moins la terre et ne la dissout pas moins en la laissant fermenter, que ne le font les chaleurs de l'été par une raison contraire. On ne répandra donc le fumier sur ce terrain que lorsquo le solstice d'hiver sera passé; ensuite on le distribuera par planehe, après l'avoir biné vers les ides de janvier. Il faut eependant avoir l'attention de ne donner à ees planches que la largeur nécessaire, pour que les ouvriers qui en arracheront les mauvaises herbes puissent aisément atteindre avec la main jusqu'au milieu, afin qu'en eherchant les herbes ils ne soient pas foreés de fouler aux pieds les semences ; mais qu'au eontraire ils puissent arracher ees herbes des deux

lierbarum necentur : nee multo ante stercorare debebimus; et cun sationis appropinquabit tempus, ante quintum diem exherbandus erit locus, stercorandusque, et ita diligenter fossione iterandus, ut fino terra commisceatur. Optimum vero stercus est ad lunc usum asini, quia minimum lierbarum creat : proximum vel armenti vel oviun, si sit anno maceratum : nam quod hounines faciunt, quamvis labeatur exeellentissimum, non tanen necesse est adlibere, nisi aut nudx glarex, aut sine ullo robore solutissima arenæ, cun niajor scilicet vis alimenti desjderatur. Igitur solum, quod vere conserere destinaverimus, post autumnum patientur effossum jacere brunta frigoribus et pruinis inurendum : quippe e contrario sicut calor astatis, ita vis frigoris excoquit terram, fermentatanque solvit. Quare peracta bruna tum demum stercus injicietur, et eirca idus Januarias lıumus refossa in areas dividitur; qua tamen sic informandx sunt, ut faeile runcantium manus ad dimidiau partem latitudinis earun perreıiant, ne qui prosequuntur herbas, seniua proculcare cogantur : sed potius per semitas ingrediantur, el alterna 
cotés des planches alternativement, en passant par les sentiers qui les borderont. Ce que nous venons de dlre par rapport à ce qui coneerne les opérations néeessaires avant l'cnsemencement doit suffire. Nous allons à présent prescrire les genres de culture qu'il faut donner au terrain suivant les différentes saisons, et entrer dans le détail des scmences qu'il y faut mettre, en commencant par traiter des graines que l'on peut semer dans les deux saisons, e'est-à-dire, en automne et au printemps. Ces graines sont celles du chou ct de la laitue, de l'artichaut, de la roquette, du cresson alénois, de la coriandre, du cerfeuil, de l'anct, du panais, du cliervi, du pavot. En effet, on peut les semer ou vers les calendes de septembre, ou encore mieux en févrler avant celles de mars, quoiqu'on puisse aussi Ies confier à la terre vers les ides de janvier dans les lieux secs ou tempérés, tels que sont les contrées maritimes de la Calabrie et de l'Apulie. Les plantes au contraire que l'on ne doit semer (ju'en automue (pourvu même que l'on ait à cultiver un terrain maritime ou exposé au soleil) sont à peu près celles-ci : l'ail, les oignons, l'oignon de Cypre, la moutarde. Au surplus, nous allons aussi parcourir mois par mois les différents temps où chaque plante doit commu. nément être confiée à la terre. On pourra done semer très-bien le passerage aussitôt après les calendes de janvier. Au mois de février on mettra cn terre, soit en plante, soit en graine, la rue et l'asperge, ainsi que la graine d'oignon et celle de poireau : on y mettra aussi la graine des racines de Syrie et celle des raves et des navets, si l'on veut en recueillir au printemps et en été. Quant à l'ail et à l'oignon de Cypre, ce temps est le dernier de ceux où l'on puisse les semer. On pourra néanmoins, dans les lieux exposés au

vicc dimidias areas ernneent. Hxe, qux ante sationem facienda sunt, dixisse abunde est. Nunc quid quoque tenpore vel colendum vet serendum sit, praccipiamus : et printum de his generibus loquerdum est, quax possunt ituobus seri temporibus, id est autumno et vere. Sunt autem semina brassicx et lactucæ, cinaræ, erucæe, nastureii, coriandri, chierepliylli, anethi, pastinacx, siseris, papaveris : hec enim vel circa calend. Septembres, vel melius ante calendas Martias Februario seruntur. Locis vero siecis, aut tepiclis, qualia sunt Calabriæe et Appulia maritina, possunt circa idus Januarias terra committi. Rursus qua tantum autumno conseri debeut (si tamen vel maritimum, vel apricum agrum incolimus) hæc fere sunt, allium, cepre capitula, ulpieum, sinapi. Sed jam potius quo quid. que tempore terra mandari plerumque conveniat, per nenses digeramus. Ergo post calendas Januarias confes. tim recte ponetur lepidium. Mense autem Februario vel flanta vel semine ruta, atque asparagus, et iterum cepae senten et porri : nec minus si vernum et aestivum frnctum voles habere, Syriaca radicis et rapa napique semina obrues. Xan allii, et ulpici ultima est hujus temporis soleil, transférer vers les calendies de múrs le poircau (s'il est déjà un peu fort), de même que l'on pourra transplanter le panax à la fin du mêmc mois, et vers les calendes d'avril le poireau, l'auxée et la plante de la rue qui aura èté semée tard. Il faut aussi semer alors le concombre, la courge et le caprier, afin qu'ils viennent de bonne heure; car pour ce qui est de la graine de poirée, on ne la sème avantageusement que lorsque le grenadier est en fleur. On peut aussi trausférer sans inconvénicnt les têtes de poircau vers les ides de mai. Passé ce temps, il ne faut plus rien mettre en terre à l'approche de l'été, si cc n'est la graine de céleri qu'on puisse l'arroser, parce qu'avec le secours de l'eau elle viendra très-bien pendant l'été. $\Lambda u$ reste, le troisième des temps auxquels on pourra semer est le mois d'août, vers les fêtes de Vulcain : c'est même le meilleur temps pour semer les racines et les raves, ainsi que les navets, Ic chervi, et même le maceron. Voild ce qui concerne les temps propres aux ensemencements. Je vais maintenant entrer dans le détail des plantes qui exigent des soins particuliers : celles dont je n'uurai point parlé seront censées n'avoir besoin d'aucun autre soin particulier, si ce n'est de celui qui consiste à arraclier les mauvaises. herbes ; et je dirai une fois pour toutes à ce sujet, qu'il faut travailler en tout temps à exterminer les mauvaises herbes. L'oignon de Cypre, que quelques personnes appellent ail punique, et que les Grecs appeilent ¿xppoxópodov, croît beaucoup plus que l'ail : il faut, avant de lc mettrc en terre, en partager la tête eu plusieurs partics vers les calendes d'octobre, parce qu'il est composé comme l'ail de plusieurs gousses adhérentes : Iorsqu'on aura désuni ces gousses, on les plantera par sillons, en les inettant sur les raics qui seront

positio. At circa calendas Martias locis apricis licet porrun (si jam ingranduit) transferre. Item pauacem ultima parte Martii mensis. Deinde circa calendas Apriles aque porrum atque inulam, et serotinam plantam ruta. Item ut maturus nascatur, eueumis, cucurbita, capparis serenda est. Nam semen belæ, cum Punicum malum florebit, tum demum op. time seritur. Porri autem caput circa idus Maias tolerabili. ter adluuc transfertur. Post hoc, niliil ingruente astate ubrui debet, nisi semen apii, si tamen rigaturus es. Sic enin optime per astatenı provenit. Caterum Augusto circa Vulcanalia tertia satio est : eaque optima radicis et rapæ, itemque napi et siseris, nee minus oleris atri. Atque lıxc sunt sationum tempora. Nune de is, quæ aliquan curam desiderant, singulis loquar, quæque præteriero intelligioportebit nullam postulare operain nisi runcatoris : de qua semel hoc dicendum est, omni tempore consulendım esse, ut herbx exterminentur. Ulpicum quod quidan allimin Punicum vocant, Graeci autem áp̧ooxópóion ap. pellant, longe majoris est increnenti quam allimm : idque circa calend. Octobris, antequam deponatur, ex uno capite in plura dividetur. Habet enin velut alliun plures 
rutre les sillons, afin qu'elles soient moins endommagées par les eaux de l'hiver. Ces raies ressemblent aux élévations de terre que les paysans ont soin de pratiquer dans les ehamps labourés, pour y placer le grain à l'abri de l'humidité; avec cette différence qu'il faut les faire moins larges dans les jardins que dans les champs. On arrangera donc sur le haut, c'est-à-dire sur le dos de ces raies, à un palmus de distance les unes des autres, les gousses d'oignon de Cypre ou celles d'ail (ear on sème aussi ces dernières de la même façon). Les sillons qui sépareront ees raies seront à un demi-pied de distance les uns des autres. Lorsque ces gousses auront jeté par la suite trois fanes, on les sarclera : car plus cette opération sera répétée souvent, plus ces semences prendront d'accroissement. II faudra ensuite, avant qu'elles forment une tige, tordre et recourber en terre tout leur fanage, afin que leurs têtes deviennent plus grosses. Mais, dans les pays sujets aux bruines, il ne faut semer ni l'une ni l'autre de ces plantes pendant l'automne, parce qu'elles périraient au solstice d'hiver : comme néanmoins la rigueur de cette saison s'adoucit communément au mois de janvier, le meilleur temps pour semer l'ail et l'oignon de Cypre dans les lieux froids, c'est vers les ides de ce mois. Au surplus, en tel temps qu'on sème ces plantes, ou qu'on les serre sur des planchers quand on les aura cueillies, on aura l'attention dans ces pays de ne les semer et de ne les déterrer que lorsque la lune sera sous terre, parce qu'on prétend qu'en s'y prenant de cette façon, elles n'ont pas le goût trop fort, et qu'elles n'empestent pas l'haleine de ceux qui les mangent. Il y a cependant bien des personnes qui les sèment au mois de décembre avant les calendes de jan- vier, au milieu du jour, lorsque la températuro douce de l'air et la nature du terrain le permettent. Il faut transférer le chou lorsqu'il aura six feuilles, en observant néanmoins de ne le mettre en terre qu'après en avoir enduit la racine avec du fumier liquide, et l'avoir enveloppé de trois pctites bandes d'algue, parce qu'avec cette préeaution il s'amollira plus tót à la cuisson, et qu'on n'aura pas besoin de recourir au nitre pour lui faire conserver sa couleur verte. Au surplus, le meilleur temps pour le mettre en terre, c'est après les ides d'avril, pour les contrées froides et pluvieuses. Si, lorsque son pied aura pris racine en terre, le jardinier le sarcle et le fumo aussi souvent qu'il lui sera possible, il s'en portera d'autant mieux, et donnera des tiges et des cimes plus grosses. Il y a des personnes qui lo mettent en terre dans des lieux plus exposés au soleil, depuis les calendes de mars; mais pour lors il montc presque entièrement en cime, et quand on l'a une fois coupé, il ne donne plus par la suite de grandes feuilles en hiver. On peut aussi le transférer jusqu'à deux fois, lors même que sa tige est forte; et l'on prétend que de cette facon il donne plus de graines, et que cette graine est plus grosse. Il faut que la laitue ait autant de feuilles que le ehoux pour être transférée. On la met très-bien en terre dans les lieux exposés au soleil et maritimes, pendant l'automne; mais on aurait tort de le faire au milieu des terres et dans les pays froids : il n'est pas non plus avantageux de l'y mettre pendant l'hiver. D'ailleurs il faut aussi enduire sa racine de fumier, ct elle demande plus d'eau que le chou, pour que ses feuilles deviennent tendres. Au reste, il y a plusieurs espèces de laitues, qu'il faut semer chacune en son temps. On sème à propos au mois de janvier cohærentes spicas, exeque cum sint divisæ, liratim seri debent, ut in pulvinis positæ minus infestentur hiemis aquis. Est autem lira similis ei porca, quam in sationibus campestribus rustici faciunt, ut uliginem vitent : sed lıæc in hortis ninor est facienda, et per summam partcm ejus, id est in dorso inter palmaria spatia spica ulpici vel allii, nam id quoque similiter conseritur, disponendx sunt. Sulci lirarnm inter se distent senipedali spatio. Deinde cum ternas fibras emiserunt spicie, sarriantur. Nam qno sxpius id factum est, majus semina capiunt incrementum. Deincle ante quam caulcm faciant, onnem viıidem super. ficiem intorquere, et in terram prosternere conveniet, quo vastiora capita fiant. Regionibus autenı pruinosis neutrum horum per antumnum seri debet : nam brumali tempore corrumpuntur : quod fere mense Januario mitescit : et idcirco frigidis locis tempus optimum est allium vel ulpicun pouendi circa idus praedicti mensis. Sed quaudopue vel conseremus, vel jan matıra in tabulatum reponemus, seryabimus in is locis, quibus aut obruentur, aut eruentur, ut luna infra terram sit. Nau sic sata, et rursus sic recon. dita, existimantur neque acerrimi saporis existere, nequic mandentium laalitus inodorare. Multi tanen hacc ante ca. lend. Januarias mediis dichus serunt mense Decembri, si coli tepor et situs terræ permittit. Brassica, cum vi folio. rum erit, transferri dcbet, ita ut radix ejus liquido fimo prius illita, et involuta tribus alga treniolis pangatur. IIac enim res efficit, ut in coctura celerius madescat et viridem colorem sine nitro conserret. Est antem frigidis et pluviis regionibus positio cjus optima post idus Aprilis; cujus depressae plantæ cum tenuerint, quantum olitoris ratio patitur, sxpius sarrita el stercorata melius convalescit, pleniorisque incremesti et coliculum facit et cymam. Nonnulli lanc eandem locis apricioribus a calend. Martiis deponunt : scd major pars ejus in cyman prosilit, nec postea libernum caulem amplum facit, cum est semel desecta. Possls autem vel maximos caules bis trans. ferre. Idque si facias, plıs seminis, et majoris increnenti prabere dicuntur. Lactuca totidem foliorum quot bras. sica trausferri debet. Locis quilem apricis, et inaritimis optime autumno ponitur, mediterraneis et frigidis contra : lieme non aeque commode dispergitur. Sed luujus quoque radix timo liniri debet, majoremque copiam desi. derat aqua, sicque tit tenerioris folii. Suntauten complur te lictucie genera, quæ šuo qujdque tempore seri oportet: 
celle dont la coulcur est brunc ct comme pourprée, ou mẻme la verte dont les feuilles sont frisées, de même que celle de Cécilius. Pour cellc de Cappadoce, dont les feuilles sont páles, peignées et épaisses, on la sème aussi au mois de février : vient ensuite la blanche et dont les feuilles sont très-frisées, qu'on voit dans la province de Bétique ct sur les confins de Gadès; on la sème très-bien au mois de mars. On recommande encore la laitue de Cypre, qui est d'un blanc tirant sur le rouge, et dont les feuilles sont lisses ct très-tendres : on la sème commodément jusqu'aux ides d'avril. On peut néanmoins semer la laitue presque pendant toute l'année, dans les climats exposés au soleil, ainsi que dans les lieux où l'on a de l'eau en abondance. Pour l'empêclier de monter trop tôt en tige, on mettra au milieu de cette plante, lorsqu'elle aura déjà pris quelque accroissement, une petite brique, dont le poids venant, pour ainsi dire, à la resserrer, la contraindra de s'étendre en largeur. On suit aussi la même méthode par rapport à la chicorće, avcc cettc différence qu'elle supporte mieux l'hiver. C'est pour cette raison qu'on peut la semer au commencement de l'automne même, dans les pays froids. On fera bien de transplanter les ceilletons d'artichaut peudant l'équinoxe d'automne, au lieu qu'il sera mieux d'en semer la graine vers les calendes de mars : mais quand on mettra les pieds d'artichaut en terre vers les calendes de novembre, on les fumera avec une grande quantité de cendre, parce que c'est l'espèce de fumier qui parait la plus convenable à cette plante potagère. On laissc la moutarde ct la coriandre, ainsi que la roquette et le basilic, à l'endroit mème où on les a semés, sans les transplanter; et la seule culture que ces plantes demandent consiste à êtrc fumées et débar-

earum qux fusci, et veluti purpurei, aut etiam viridis coloris, et crispi folii, "nti Cæciliau, mense Januario recte disseritur. At Cappadocia, qux pallido et pexo densoque folio viret, mense Februario : quxe deinde candida est, el crispissimi folii, ut in provincia Bretica et finibus Gaditani municipii, mense Mart. recte pangitur. Est et Cyprii generis ex albo rubicunda, levi et tenerrimo folio, quae usque in idus April. conmode disponitur. Fere tainen aprico creli statu, quibus locis aquarum copia est, pene toto anno lactuca seri putest : qua quo tardius caulem faciat, cum aliquod incrementum babuerit, exiguam testam miedia parte accipiat, eo quasi onere coercita in latitudinem se diffundit. Eadem est ratio etiam intybi, nisi quorl hiemem magis sustinet : ideoque vel frigidis regionibus primo autumno seri potest. Cinarx sobolem melius per autumni xequinoctiun dispronemus; semen commodius circa calendas Martias seremus; ejusque plantam circa calend. Novemb. deprimemus, et multo cinere stercorabimus. Id enim genus stercoris huic oleri videtur aptissimum. Sinapi afque coriandrum, nec minus eruca et ocimum, ita nti sata sunt, sua sede immota permaneut : ne. rassées des mauvaises herbes : du restc, on peut les semer non-seulement en automne, mais encorc pendant le printemps. Néanmoins, si l'on transfère la moutarde en pied au commencement de l'hiver, clle donnera plus de cime au printemps. On sème le panax pendant les deux saisons dans une terre bien légère et bien labourée, et l'on a soin de lc semer le moins dru que faire se peut, afin qu'il prenne plus d'accroissement. II est cependant mieux de le semer pendant le printemps. Pour avoir des poireaux que l'on puisse couper souvent, ceux qui nous ont devancés ont prescrit de les semer drus, et de les laisser dans l'endroit où ils auront été semés, pour les couper ensuite lorsqu'ils seront devenus grands. Mais l'usage nous a appris qu'il était mieux dc les transférer, pour les planter, comme les poireaux à tête, dans des intervalles modiques, c'est-à-dire de quatre doigts, et les couper lorsqu'ils seront devenus forts. Quant aux poireaux auxquels on veut procurer une grosse tête, il faut avoir soin, quand on les transplante, d'en couper toutes les petites racines, et de tondre l'extrémité supérieure de leur fane avant de les mettre en terre : après quoi on enterre de petites briques ou des coquilles sous leurs pieds, pour leur servir comme de siége, afin que leur têtc prenne plus de largeur à mesure qu'ils croittront. La culture du poireau à large tête consiste à êtrc sarclé et fumé assidûment. Il n'y a cependant pas de culture différente pour celui que l'on veut couper souvent, si cc n'est qu'ol. doit l'arroser, le fumer et le sarcler toutes les fois qu'on le coupera. On en sème la graine dans les lieux chauds au mois de janvier, et dans les lieux froids au mois de fẻvrier; et pour lui faire prendre plus d'accroissement, on a soin d'en envelopper plusieurs graines dans de petits linges clairs, a vant

que est eorum cultus alius, quam ut stercorata runcentur. Possunt antem uon solum autumno, sod et vere conseri. Plantæe quoque sinapis prima hieme translatæ plus cymæ vere afferunt. Panax utroque tempore levi et subacta terra rarissime disseritur, quo majus incrementum capiat : melior tamen ejus verna satio est. P'orruin si sectivum facere velis, densius satum praceperunt priores relinqui : et ita cum increverit, secari. Sed nos docuit usus longe melius fieri, si difleras, et eodem more, quo capitatum modicis spatiis, id est, inter quaternus digitos depangas, et cum convaluerit, deseces. In eo antem quod magni capitis eff. cere voles, servandum est, ut ante quam translalum deponas, omnes radiculas amputes, et fibrarum summas partes intondeas. Tum testulæ, vel conchæ, quasi sedes singulis subjecto seminibus adobruuntur, ut fiant capita latioris incrementi.

Cultus autem porri capitati assidua sarritio el stercoratio est. Nec alius tamen sectivi, nisi quod toties rigari, et stercorari, sarririque debet, quoties demetilur. Senıen ejus locis calidis mense Januario, frigidis Iebruario seri. tur : cujus incrementum quo majus fiat, raris linteolis. 
de les couvrir de terre. Au reste, quand sa graine est levée, il faut, dans les lieux où l'on ne peut pas lui fournir d'eau, le transplanter vers l'équinoxe d'automne; au lieu qu'on peut le transplanter au mois de mai dans ceux où on pourra lui donner de l'eau. On peut aussi planter l'ache en pied comme en graine, mais c'est l'eau qui lui fait le plus de bien; aussi fait-on très-bien de la mettre auprès des fontaines. Si l'on veut qu'elle ait des feuilles larges, on enveloppera dans un petit linge clair ce que l'on pourra pincer de sa graine avec trois doigts; et en la semant ainsi sur des planches, elle se hérissera. Mais si l'on aime mieux qu'elle ait des feuilles frisées, on en mettra la graine dans un mortier; et après l'avoir écrasée a vec un pilon de bois de saule et en avoir détaché les eoques, on l'enveloppera de même dans de petits linges avant de la couvrir de terre. On peut aussi, sans prendre tant de précautions; la faire friser, de quelque façon qu'elle ait été semée, en réprimant les accroissements, lorsqu'elle scra levée, avec un cylindre que l'on roulera dessus. Le meilleur temps pour la semer, c'est depuis les ides de mai jusqu'au solstice, parce qu'elle aime la ehaleur. C'est aussi à peu près dans le même espace de temps que l'on sème le basilic : lorsque sa graine est semée, on foule soigneusement la terre avec une hie ou avec un cylindre, parce que, si on la laissait dans son état de gonflement, il arriverait communément que cette graine se pourrirait. Le panais, le chervi et l'aunée prennent de la force dans un terrain labouré profondément au pastinum et bien fumé : mais il faut semer ces plantes trèsclair, si l'on -veut qu'elles prenuent encore plus d'accroissement. Quant à l'aunée, il faut l'espacer de trois pieds en la semant, parec qu'elle

complura grana illigantur, atque ita obruuntur. Enatum autem in is locis, quibus aqua subministrari non potest, differri debet circa æequinoctium autumni : at quibus possis lumorem prabere, mense Maio recte transfertur. Apium quoque possis plantis serere, nec minus semine. [Sed] præcipue aqua læetatur, et ideo secundum fontem commodissime ponitur. Quod si quis id velit lati folii fa. cere, quantum seminis possint tres digiti compreliendere, raro linteolo illiget, et ita in areolas dispositum releget. Vel si crispæe frondis id fieri maluerit, semen ejus inditum pila, et saligneo pilo pinsitum, expolitumque, similiter [in] linteolis ligatum obruet. Potest etiam citra hanc operam fieri crispum qualitercunque satum, si, cum est natum, incrementum ejus supervoluto cylindro coïrceas. Satio ejus est optima post idus Maias usque in solstitium : nam teporem desiderat. Fere etian his diebus ocima seruntur : quorum cum semen obrutum est, diligenter in. culcatur pavicula vel cylindro. Nam si terram suspensam relinquas, plerumque corrumpitur. Pastinaca et siser atque inula convalescunt alte pastinato et stercorato loco : sed quam rarissime ponenda sunt, ut majora capiant increnıenta. Inularn vero intervallo trium pedum seri convenit, donue de grandes tiges, et que ses racines s'étendent sous terre comme les yeux du roseau. Au reste, la culture de toutes ces plantes ne consiste qu'd les débarrasser des herbes en les sarclant : et on peut très-bien les mettre en terre au com. menccment de septembre ou à la fin d'août. Le maceron, que quelques Grees appellent $\{\pi \pi 0 \sigma \varepsilon \hat{\lambda} i$ vov et d'autres $\sigma$ uúpviov, veut être semé en graine dans un terrain faconné au pastinum, et surtout auprès des murailles, parce qu'il se plait à l'ombre, et qu'il profite dans quelque lieu que ce soit. D'ailleurs, quand il est une fois semé, il dure éternellement, pourvu qu'on ne l'arrache pas absolument par les racines, mais que l'on en laisse successivement monter les tiges en graine; et il ne demande qu'une culture légère, qui consiste à le sarcler. On le sème non-seulement depuis les fêtes de Vulcain jusqu'aux calendes de septembre, mais encore au mois de janvier. $\mathrm{La}$ menthe veut trouver une moiteur douce dans la terre; c'est pourquoi ịl est bon de la mettre auprès des fontaines au mois de mars. S’il arrive qu'on manque de graine de menthe, on pourra prendre dans des jachères de la menthastre, et la planter en renversant sa cime par en bas : cette méthode lui ôte son goût sauvage, et en fait de la menthe cultivée. Il faut transférer au mois de mars, dans un lieu exposé au soleil, la rue dont on aura semé la graine en automne; on ehargera son pied de cendre, et on arrachera les mauvaises herbes qui l'environneront, jusqu'à ce qu'elle soit fortifiée, de peur que ces herbes ne la suffoquent. Mais il faut avoir la main gantéc pour faire cette opération, parcc qu'autrement il y viendrait des ulcères dangereux. Si cependant, faute d'être instruit de ce danger, on a arraché ces mauvaises herbes avec la main

quoniam rastos facit frutices, et radicibus, ut oculıs lıa. rundinis, serpit. Nec est alius cultus loorum omuium, nisi ut sarritionibus herbx tollantur. Commodissime autem deponentur prima parte Septembris, vel ultima $\mathrm{Au}$ gusti parte. Atrum olus, quod Gacorum quidam vocant

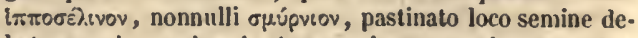
bet conseri, maxime juxta naceriam : quoniam et umbra gaudet, et qualicunque convalescit loco: idque cum semel severis, si non totum radicitus tollas, sed alternos frutices in semen submittas, xro manet, parvamque sarritionis exigit culturam. Seritur a Vulcanalibus usque in calendas Seplembris, sed etiam mense Januario. Menta dulcem desiderat uliginem; quam ob causam juxta fontem mense Martio recte fponitur. Cujus si forte semina defecerunt, licet de novalibus silvestre mentastrum colligere, atque ita inversis cacuminibus disponere : quxe res feritatem detrahit, atque edomitam reddit : rutam autumno semine satam mense Martio differre oportet in apricum, et cinerem aggerare, runcareque donec convalescat, ne her. bis enecetur. Sed velata manu debebit runcari : quam nisi contexeris, perniciosa nascuntur ulcera. Si tamen per ignorantiam nuda manu runcaveris et pru rigo atque tumor 
nue, et qu'il y solt survenu une déntangealson avec de l'enflure, on se la frottera de temps en tẹmps avec de l'huile. La tige de cette plante se conserve intacte plusieurs années, à molns qu'une femme ne vienne à la toucher dans le temps de ses règles, auquel cas elle se dessèche. Ce sont plutôt ceux qui prennent soln des ruches, que les jardinlers, qui s'adonnent, comme je l'ai déjà dit dans un des livres précédents, à semer du thym, de l'origan d'outremer et du serpolet; mais nous pensons cependant qu'il n'est pas hors de propos d'en faire aussi venir dans les jardins pour s'en servir dans la cuisine, parce que ces plantes sont excellentes pour assaisonner quelques mets. Elles ne veulent point d'un terrain gras ni fumé, mais elles demandent qu'il soit exposé au soleil; d'autant qu'elles viennent d'elles-mèmes dans des lieux très-malgres, et communément dans les contrées maritimes. On les sème tant en graine qu'en pied vers l'équinoxe du printemps : il vaut cependant micux planter de jeunes pieds de thym dans un terrain bien labouré; et pour qu'ils ne tardent pas à prendre, on fera infuser dans de l'cau un jour d'avance des tiges de thym broyćes; et lorsque cette eau sera bien imprégnée de leur suc, on en arrosera les pieds qui seront en terre, jusqu'à ce qu'ils soient bien fortifiés. Quant à la sarriette, c'est une plante trop vivace, pour que l'on se donne beaucoup de peine à la soigner. Lorsque vous aurez transplanté le passerage a vant les calendes de mars, vous pourrez le couper de temps en temps comme le poireau, quoique plus rarement; car il ne faudra pas le couper passé les calendes de novembre, parce qu'il mourrait pour peu qu'il fût maltraité pendant le froid; il rendra cependant assez bien pendant

incesserit, oleo subinde perungito. Ejusdem frutex pluribus annis permanet innoxius, nisi si mulier, quæ in menstruis est, contigerit eum, et ob hoc exaruerit. Thymum, et transmarina cunila, et serpyllum, sicut priore libro jan retuli, magis alvearia curantibus, quam olitoribus studiose conseruntur. Sed nos ea condimentorum causa (nam sunt quibusdam esculentis aptissima) non alienum putamus etiam in hortis habere. Locum neque pinguem neque stercoratum, sed apricum desiderant, ut quæ macerrimo solo per se maritimis plerumque regionibus nas cantur. Hæ res et semine et plantis circa aquinoctium vernum scruntur. Melius tamen est tliymi novellas plantas disponere; qux cum subacto solo depressæ fuerint, ne tarde comprebendant, aridi tbymi fruticem contundi oportet, atģue ita pinsito pridie quam rolueris uti , aquam medicare; quæ cum succum ejus perceperit, depositis frutscibus infunditur, donec eos recte confirmet. Ceterum cunila vivacior est, quam ut impensius curanda sit. Lepidium cum ante cal. Martias habueris dispositnm, velut porrum sectivum demetere poteris : rarius tamen. Nam post cal. Novemb. secandum non erit, quoniam frigoribus violatum emoritur : biennio tamen sufliciet, si diligenter sarritum et stercoratum fuerit. Multis etiam locis viva- deux ans, si on le sarcle et qu'on le fume avec soin. Il y a même plusieurs pays où sa vlgueur se prolonge jusqu'à dix ans. On sèrne la graine do poirée dans le temps que le grenadier est en fleur, et dès qu'elle a cinq feuilles, comme is chou; on la transplante en été, si l'on a un jardin arrosé; mais sl le terrain est sec, il ne faudra la transplanter qu'en automne, quand les plules auront commencé à tomber. On sème le cerfeuil et l'arroche potagère, que les Grees appellent

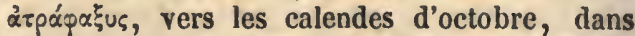
un climat qul ne soit pas très-froid; car si le pays est sujet à des hivers rigoureux, il faut transférer ces plantes de l'endrolt où elles auront été mises en masse après les ides de févrler, en les divisant. On suit la même méthode à l'égard du pavot et de l'aneth. On prépare, environ deux ans avant de les mettre en place, les pattes de l'asperge cultivée, ainsi que celles de l'asperge que les paysans appellent corruda : on en sème la graine après les ides de février, dans de petites fosses creusées sur un sol gras et fumé, de façon que chaque fosse en contienne autant que l'on pourra en pincer avec trois doigts. A peu près quarante jours après, les racines que ces graines auront jetées s'entrelacent ensemble, et font comme une seule masse : les jardiniers donnent à ces petites racines, ainsi entortillées et entrelacées, le nom de spongia. Au surplus, il faut les transférer au bout de deux ans dans un lieu exposé au soleil, et quil soit bien humecté et fumé. On les arrange dans des sillons séparés les uns des autres de la largeur d'un pied, et qui n'ont pas plus d'un dodrans de profondeur, de faecon qu'elles puissent aisément germer lorsqu'elles seront couvertes de terre. Mais on a citatem suam usque in annos decem prorogat. Beta florente Punico malo semine obruitur, et simul atque quirque foliorum est, ut brassica, differtur æestate, si riguus est hortus : ac si siccaneus, autumno, cum jam pluvine incesserint, disponi debebit. Charephyllum, itemque olus atriplicis, quod Græci vocant ג̇tpx́px $\xi_{u v}$, circa cal. Octob. obrui oportet non frigidissimo loco. Nam si regio saevas hiemes habet, post idus Februarias semina disserenda sunt, suaque de serie partienda. Papaver et anethum eandem hahent couditionem sationis, quam chærephyllum et árpápał̌vร. Sativi asparagi, et quam corrudam rustici vocant, semina fere biennio præparantur. Fa cum pingui et -stercoroso solo post idus Februarias sic obrueris, ut quantum tres digiti seminis comprehendere queunt, singulis fossulis deponas, fere post quadragesimum diem inter se implicantur, et quasi unitatem faciunt; quas ra. diculas sic illigatas atque connexas olitores spongias ap. pellant. Easque post quatuor et viginti menses in locum apricum et bene madidum, stercoratumque transferri convenit. Sulci autem inter se pedali mensura distantes fiunt non amplius dodrantalis altitudinis, in quam ita spongioJæ deprimuntur, ut facile superposita terra germınent. Sed in locis siccis partibus sulcorum imis disponenda sunt 
l'attention dans les lieux secs de les mettre au fond des sillons, afin qu'elles y restent immol)iles comme dans de petites auges; au licu que dans les lieux humides on les met au contraire sur le dos de la rale qui est entre les sillons, pour éviter que la trop grande humidité ne les endommage. Un an après qu'elles auront été plantées de cette manièrę, il faudra rompre les asperges qu'elles donneront; parce que si on voulait les arracher de terre, toute la masse de ces petites racines encore jeunes et faibles viendrait en même temps que les asperges. Les autres années, on ne les rompra plus, mais on les arrachera par les racines : autrement si l'on rompait les tiges, elles suffoqueraient les yeux des racines, et les aveugleraient, pour alnsi dire, au point de les empêcher de donner des asperges par la suite. $\mathrm{Au}$ reste, il ne faut pas arracher toutes les tiges qui seront venues les dernières pendant l'autonıne; mais il en faut laisser monter une partie en graine. Iorsqu'ensuite celles-ci auront formé des épines, on en cueillera la graine, et on brûlera les rafles telles qu'elles se comporteront, et sur le lieu même; après quoi on sarclera tous les sillons, et on en arrachera les herbes; ensuite on y jettera du fumier ou de la cendre, dont le suc, étant délayé par les pluies pendant tout l'hiver, pénétrera jusqu'aux racines de l'asperge. Enfin on bêchera la terre au printemps, avant qu'elles commencent à germer, avec des capreoli, qui sont des espèces d'instruments de fer à deux cornes, afin que les tiges lèvent plus facilement, et que, trouvant de l'aisance dans la terre, elles deviennent plus grosses. On sème très-bien deux fois l'an la graine de raifort, savoir au mois de février, lorsqu'on veut avoir de ces sortes de racines pendant le printemps; et au mois d'avril vers les fêtes de Vulcain, lorsqu'on veut en avoir dans

semina, ut tanquam in alveolis maneant. At uliginosis e contrario in summo porca dorso collocanda, ne liumore nimio lædantur. Primo deinde anno, cum ita consita sunt, asparagum quem emiserint, infringi oportet. Nam si ab imo vellere volueris, adhuc teneris invalidisque radiculis, tota spongiola sequetur. Reliquis annis non erit decerpendus, sed radicitus vellendus. Nam nisi ita fiat, stirpes præefractæangunt oculos spongiaruın, et quasi excxcant, nec patiuntur asparagum emittere. Cæterum stilus, qui novissime autumnali tempore nascitur, non omnis [est] tollendus, sed aliqua pars ejus in semen submittenda est. Deinde cum spinam fecerit, electis seminibus ipsis, $s c a$ piones ita uti sunt, in suo loco perurendi sunt, et deinde sulci omnes consarriendi, herbxque eximendx; mox vel stercus, vel cinis injiciendus, ut tota hieme succus ejus cum pluviis manans ad radicem perveniat. Vere deinde prius quam coeperit germinare, capreolis, quod genus bicornis ferramenti est, terra commoveatur, ut et facilius stilus emicet, et relaxata lrumo plenioris crassitadinis fiat. Raphani radix bis anno recte seritur, Februario mense, cum vernum fructum expectamus, et Augusto mense circa le temps qui leur est propre : mais le dernier do. ces ensemencements passe sans difficulté pour le meilleur. Tout le soin que cette racine exige consiste à être mise dans une terre fumée et labourée, et ensuite à être clıargéc de terre do temps en temps à mesure qu'elle prend de l'accroissement, parce que, Iorsqu'elle surmonte la superficie de la terre, elle devient dure et spongieuse. Lorsque l'on a de l'eau à souhait, les concombres et les courges demandent peu de soin, parce que c'est l'eau qui les aide le plus à venir. Mais si l'on est forcé d'en semer dans des lieux secs, où l'on n'ait point la commodité de faire venir de l'eau pour les arroser, il faut faire au mois de février des sillons d'un pied et demi de profondeur, dans lesquels on étendra, après les ides de mars, jusqu'au tiers à peu près de leur profondeur, de la paille sur laquelle on entassera de la terre fumée jusqu'à la moitié du sillon; et après avoir déposé les graines dans cette terre, on les arrosera jusqu'à ce qu'elles lèvent. Quand elles auront commencé à se fortifier, il faudra les suivre dans leur accroissement, et continuer de remettre de la terre dans le sillon à mesure qu'elles croîtront, jusqu'à ce qu'il soit comblé. Avec une telle culture ces plantes se porteront assez bien pendant tout l'été, sans avoir besoin d'être arrosées, et elles donneront même un fruit de meilleur goût qu'il ne le serait si elles l'avaient été. Il faut mettre en terre la graine de ces plantes le plus tot qu'on le pourra dans les lieux aqueux, pourvu que ce ne soit pas avant les calendes de mars, de façon qu'on puisse les transplanter après l'équinoxe. On ramassera la graine que l'on voudra semer dans le milieu méme de la courge, et on mettra en terre la cime renversée, si l'on veut que les fruits qu'elle produira soient d'une grosseur énorme.

Vulcanalia, cum maturum. Sed hace ratio slne dubio melior habetur. Cura est ejus, ut terra stercorata et subacta obruatur : post ubi ceperit aliquod incrementum, subinde. aggeretur. Nam si super terram emerserit, dura et fungosa tiet. Cucunis et cucurbita, cum copia est aqux, minoreu curam desiderant : nam plurimum jurantur lıumore. Siı autem loco sicco seri debuerinf, quo rigationem ministrare non expediat, mense Februario sesquipedali altitudine fossa facienda est. Post idus deinde Martias quasi tertia pars altitudinis sulci stramentis inditis tegenda, mox ster. corata terra usque in dimidium sulcum aggeranda, positisque seminibus tam diu est aqua prabenda, donec enas. cantur : atque ubi convalescere coperint, adjecta liumo incrementa eorum prosequenda sunt, donec suleus coxe. quetur. Sic exculta semina sine rigatione tola zestato satis valebunt, fructumque jucundioris saporis quam rigua probebunt. Aquosis autem locis primo quoque tempore, non tamen ante calend. Mart. semen pronendum est, ut differri possit acquinoctio confecto. Idque de media parto cucurbita semen inyerso cacumine ponite, ut fiat incre. menti vastioris. Nam sunt ad usum vasorum satis idonea, 
lin effet, il y־a des courges, telles que celles d'Alexandric, qui sont assez grosses pour servir de vases lorsqu'clles sont desséchées. Si on les destine au contrairc à être vendues comme provision de bouche, il faudra en prendre la graine dans la tête du fruit et la scmer la cime droite, parce qu'il en viendra un fruit plus long et plus mince que le premier, ct qui se vendra communément plus cher. Mais il faut éviter, le plus que l'on pourra, que des femmes n'approchent d'un endroit scmé en concombres et courges, parce qu'il suffirait presque qu'clles touchassent à ces fruits quand ils sont le plus verts, pour les faire languir; et que même, si elles se trouvaient dans le temps de leurs règles, elles les feraient mourir par leur seul regard. Le concombre est tendre et très-agréable, lorsqu'on a trempé la graine dans du lait avant de la semer : quelques personnes même, pour le rendre encore plus doux, trempent la graine dans de l'hydromel. Au reste, quand on veut avoir des concombres hâtifs, on remplit des paniers, après le solstice d'hiver, de terre fumée que l'on arrosc légèrement; et lorsquc leur graine est levée dans ces paniers, on les met de jour en plein air dans un lieu où il fassc doux et où le soleil donne, et qui soit voisin du bâtiment, afin qu'ils soientà l'abri de tout vent; et onles reporte ensuite à la maison pendant le froid et dans le mauvais temps. On suit cette méthode jusqu'après l'équinoxe du printemps, et l'on enfonce alors entièrement en terre ces paniers : c'est le moyen d'avoir du fruit hátif. On peut même, si la chose en vaut la peinc, ajuster des roulettes sous de très-grands vases, pour avoir moins de peine à les mettre à l'air et à les porter ensuite à la maison. Au surplus, indépendamment de ces précautions, il faudra encore cou-

sicut Alexandrinæ cucurbitæ, cum exaruerint. At si esculenta merci preparabis, recto cacumine de collo cucurbitie sumptum semen serendum erit, quo prolixior et tenuior fructus ejus nascatur, qui scilicet majus cxteris invenit pretium. Sed custodiendum est, ut quam minime ad eum locum, in quo vel cucumeres aut cucurbitac con. sitx sunt, mulier admittatır. Nam fere contactu ejus languescunt incrementa virentium. Si vero etiam in mens: Iruis fuerit, visu quoque suo novellos foetus necabit. $\mathrm{Cu}$ cumis tener et jucundissimus sit, si ante quam seras, semen, ejus lacte maceres. Nonnulli etiam quo dulcior existat, aqua mulsa idem faciunt. Sed qui pramaturum fructum cucumeris habere volet, confecta bruma sterco. ratam terram inditam cophinis obserat, modicumque prae. beat humorem. Deinde cum enata semiua fuerint, tepidis diebus et insolatis juxta adificium sub divo ponat, ita ut ab omni afflatu protegantur. Celerum frigoribus ac tempestatibus sub tectum referat : idque tamdiu faciat, dum xquinoctium vernum confiat. Postea totos coplinos demittat in terram. Sic enim præcoquem fructum habebit. Possunt etiam, si sit operæ pretium, vasis majoribus rotulae subjici, quo minore labore producantur, et rursus vrir ces vases do pierres transparentes, afin de pouvoir les mettre sans danger au soleil, même pendant les temps froids, quand lc jour sera sercin. C'est par ce moyen quc l'on servait à Tibère César des concombres presque pendant toute l'année. Mais nous avons lu dans Bolus deMendesium, auteur égyptien, une manière moins pénible de parvenir au même but. En effet, cet auteur ordonne d'avoir, dans un lieu du jardin qui soit exposé au soleil et fumé, des férules et des ronces plantées alternativement par rangées : il prescrit ensuite de couper après l'équinoxe ces ronces ou ces férules un peu au-dessous de la superficie de la terre, et d'en ouvrir la moelle avec un stylet de bois; et enfin, après avoirmis du fumier dans le trou qu'on y aura ainsi pratiqué, d'y insérer de la graine de concombre, afin qu'à mesure que les concombres croitront, ils s'incorporent aux férules et aux ronces, et qu'ils ne tirent point leur nourriture de leurs propres raeines, mais qu'ils la tirent pour ainsi dire de la raeine de leur mère. Il prétend que ces plantes, ainsi entées, donnent des concombres même pendant les froids. Le second ensemencement de cette plantc se fait communément aux Quinquatria. Le eâprier vient de lui-même dans nombre de provinces au milieu des jaehères; mais si l'on veut le semer dans des pays où il ne s'en trouve point, il faut lui choisir un terrain sec. On commencera par environner ce terrain d'un petit fossé, que l'on comblera de pierres et de chaux ou de mortier à la carthaginoisc, pour former une espèce de parapet impénétrable aux tiges de cet arbrisseau, qui s'étendrait presque par tout le terrain, s'il n'était pas arrêté par quelque digue; et ce n'est pas même le plus grand inconvénient qu'il $\mathbf{y}$, aurait à craindre (puisqu'on pourrait arracher ces tiges de temps

intra tecta recipiantur. Sed nililo minus specularibus integi debebunt, ut etiam frigoribus serenis diebus tuto producantur ad solem. Hac ratione fere toto anno Tiberio Cassari cucumis prabebatur. Nos autem leviore opera istud fieri apud Egyptiæe gentis Bolum Mendesium legimus, qui præcipit aprico et stercoroso loco alternis ordinibus ferulas, alternis rubos in hortis consitas habere : deinde eas confecto aequinoctio paululum infra terram secare, et ligneo stilo laxatis vel rubi vel ferula medullis stercens immittere, atque ita semina cucumeris inserere, qua scilicet incremento suo coeant rubis et ferulis. Nam ita non sıa, sed quasi materna radice aluntır : sicque insitan stirpem frigoribus quoque cucumeris præbere fructum. Satio secunda ejus seminis fere Quinquatribus observatur. Capparis plurinis provinciis sua sponte novalibus nascitur. Sed quibus locis ejus inopia est, si serenda fuerit, siccum locum desiderabit. Isque debebit ante circumdari fossula, quæe repleatur lapldibus et calce, vel Pınico luto, ut sit quasi quadanl lorica, ne possint eam perrumpere præedicti seminis frutices, qui fere per totum agrum vagantur, nisi munimento aliquo prohihiti sint. Quod tamen non tantum incommodum est (subinde enim possunt extirpari) quan. 
en temps); mais il y aurait eneore lieu de craindre que eet arbrisseau, qui renferme un poison pernicieux, ne rendit la terre stérile en lul communiquant ses sues. Au reste, ou il ne demande aueune eulture, ou il se contente de la plus légère; d'autant qu'il vient très-bien, même dans des terres abandonnées, sans aueun soin de la purt du paysan. On le sème aux deux équinoxes. l.es oignonneries demandent une terre qui soit plutòt labourée fréquemment que profondément. C"est pourquoi on lui donnera un premier labour après les ealendes de novembre, afin qu'elle se dissolve aux froids et aux gelées de l'hiver; un second au bout de quarante jours, et un troisième vingt et un jours après; puis on la fumera sur-lechamp; ensuite on la distribuera par planehes, après l'avoir fovillée uniformément à la houe, et en avoir extirpé toutes les racines. On ehoisira ensuite vers les ealendes de février un jour serein, pour jeter la graine d'oignon sur ees planelies, en l'entremêlant d'un peu de graine de sarriette, pour pouvoir se procurer cette dernière plante avee les oignons, tant paree qu'elle est agréable à manger verte, que paree qu'elle n'est point sans utilité pour l'assaisonnement des mets lorsqu'elle est sèche. $A$ u reste, il faut sareler les oignonneries au moins quatre fois, ou même plus souvent. Si l'on veut en avoir de la graine, on mettra en terre au mois de février de plus grandes têtes de l'oignon d'Ascalon, qui est celui de la meillenre espèec, en les éloignant de quatre doigts ou même de cinq; et quand elles auront commeneé à germer, on les sarelera au moins trois fois. Ensuite, lorsqu'elles auront donné une tige, on inettra, dans les intervalles qui les sépareront, des espèces de petits canterii peu élevés, pour les tenir fermes, paree qu'à moins qu'elles ne

tum, quod noxium virus labent, succoque suo sterile solum reddunt. Cultu aut nullo ant levissimo contenta est. Quippe qua res etiam in desertis agris eitra rustici operam conralescit. Seritur utroque aquinortio., Cepiua magis frequenter subactam postulat terrain, quam altius conversam. Itayue ex calendis Novembribus prosciudi suhum debet, ut hiemis frigoribus et gelicidiis pntrescat, intermissisque quadraginta dichus tum deınum iterari, et interpositis uno ac viginti diebus tertiari, ac protinus stercorari : mox bidentibus sequaliter perfossum in areas dispoui, deletis radicibus onınibus. Deinde ad calendas Februarias sereno die conveniat semina spargi : quibus aliqund satureice semen interniscendum erit, ut eam quo. que habeamus. Nam et virilis esui est juennda, nec arida inntilis ad julmentaria condienda. Sed cepina vel sxpius, rerte non ninus delsel quam qৃuater sarriri. Cujus si semen exripere voles, capita maxina generis Ascalonii, quod est nptimum, ınense Februario disponito, quaternorum, vel etianı quiuun digitorım spatiis listantia : et eum corpe. rint virere, ne minus ter consarrito : deinde cum fecerint caulem, humiliorihus quasi canteriolis interpositis rigorem stiforum conservatn. Xam nisi aruntines transversas in cor.t *LL.L.E. trouvent beaucoup de roseaux en traverse qui les soutiennent, tels à peu près que ceux qui soutiennent les vignes attachées au joug, les tigts d'oignons seront abattues, et toute leur graine sera dispersée par le vent; d'autant qu'il ne faut pas attendre pour la cueillir qu'elle ait commencé à noircir en mûrissant. II ne faut pas, dis-je, la laisser trop sécher sur pied ni tomber tout à fait; mais il faut au contraire cueillir les tiges bien entières, et les faire sécher au soleil. On sème les navets et les raves dans deux temps différents, et leur eulture est la même que eelle des raiforts. Cependant le meilleur temps pour les semer est au mois d'août : il faut quatre sexlarii de graines pour en ensemeneer un jugerum, pourvu qu'on y joigne une hemina de graines de racine de Syrie. Quand on sèmera ees racines en été, il faudra prendre garde que les moucherons qui seront engendrés par la séeheresse n'en mangent pas les feuilles toutes jeunes à mesure qu'elles pousseront : pour l'éviter, on prendra de la poussiere ramassée sur les planches, ou même de la suie qui s'attache aux foyers dans les maisons; et on en mêlera avec la graine un jour avant de la semer, en versant de l'eau dessus, pour la laisser s'imbiber du sue de ees matières toute la nuit. En effet, la graine ainsi trempée est bonne à être semée le lendemain. Quelques anciens auteurs, et Démoerite entre autres, preserivent de médicamenter toutes les graines avec lejus de l'herbe que l'on appelle sechum, et d'employer ce remède contre les inseetes; mais quoique l'expérienec nous ait confirmé la vérité de leur opinion, eomme uous n'a vons pas une assez grande quantité de eette herbe à notre disposition, nous prenons plus souvent de la suie et de la poussière dont nous venons de parler, et ncus nous en servons assez

modum jugata vinca crebras disposueris, thalli ceparum rentis prosternentur, totumqque seinen excutietur : quorl scilicet non ante legendum est, quam cum maturescere ceperit, coloremque nigrum habere. Sed nec patiendun est, it perarescat, aut totum decidat, verum integri thalli vellendi sunt, et sole siccandi. Napus et rapa duas sationes habent, et eandem culturam, quam raphanus. Melior est lamen satio mensis Augusti. Jugerum agri quatuor sextarios seminis eorum poseit, sed ita ut radicis Syriaca super hane mensuram paulo plus, quam heminam seminis recipiat. Qni astate ista seret, caveat, ne propter siccitates pulex adlue tenera folin prorepentia consumat. Idque ut vitelur, pulvis [etiam,] qui supra cameram invenitur, vel etiam fuligo, quæ supra focos tectis iuharet, colligi debet : deinde pridie quam satio fiat, connisceri cum semiuibus, et aqua conspergi, ul tota nocte snecum trahant. Nam sic macerata postero die reete seruntur. Veteres quidam auctores, ut Democritus, pracipiunt, semina omnia succo herba, quae sedun appellatur, medicare, codemque remelio adversus hestiolas uti : quorl verum esse nos experimutia docuit. Sed frequentius tamen, quoniaın hujus therbe ninus larga est facultas, fuligine et 
heureusement pour conserver les plantes en bon état. Hyginus pense quil faut, quand le grain est battu, jeter de la graine de raves sur la paille mềnc qui est restce étenduc dans l'aire, paree qu'il prétend quic ees racines deviendront plus grosses, vu que la dureté du sol s'opposera à ce qu'elles y pénètrent profondẻment. Mais comme nous avons fait eet cssal inutilement, nous eroyons qu'il vaut mieux semer les raves, les raiforts et les navets dans un terre bien ameublie. Au surplus, les agrieulteurs religieux tiennent eneore aujourd'hui à l'usage des aneiens, qui consistait à prier les dieux, en semant ees racines, de les faire croitre pour eux et pour leurs voisins. Dans les lieux froids, où l'on peut craindre que l'ensemeneement qu'on en fera en automne ne soit brûlé par les gelécs de l'hiver, on fait avec des roseaux des canterii peu élevés, et traversés par des baguettes posées dessus, sur lesquelles on étend de la paillc, pour mettre les semenees à l'abri de la bruine. Dans les pays, au contraire, exposés au soleil, lorsqu'il survient après les pluies de ees animanx pernicieux que uous appelons eruca, et que l'on nomme en gree $x \alpha ́ \mu \pi \alpha$, il faut ou les ôter avec la main ou secouer les tiges des plantes potagères, parce qu'une fuis que ces animaux, ainsi secoués pendant qu'ils étaient encore engourdis par le froid de la nuit, seront tombés à terre, ils ne pourront plus gagner en rampant la partie supérieure de ces tiges. Il est eependant inutile de prendre ces préeautions lorsqu'on a trempé les graines, comme je l'ai dit ei-dessus, dans du jus de joubarbe avant de les semer, paree qu'une fois qu'elles ont été corrigées de cette manière, elles n'ont plus rien à craindre des chenilles. Mais Démıcrite assure,

pradicto pulvere utimur, satisque commode tuemur lis incolumitatem plantarurn. Rapæ semina Hyginus putat post trituram jacentibus adluuc in area paleis inspergi debere, quoniam finnt lactiora capita, cum subjacens soli duritia non patitur in altum descendere. Nos istud sape f'ustra tentavinus : ilaque rapum, et raplıanum, et uapum melius existimanus subacta terra obrui. Servantque ad. luc antiquorum consuetndinem religiosiores agricolæ, qui cum ea serunt, precantur, it et sibi et vicinis nascantur. Locis frigidis, ubi timor est, ne autumnalis satio liemis gelicidiis peruratur, arundinibus lumiles canterii fiunt, iisque virga transversx imponuntur, et virgis stramenta supra jaciuntur, et sic \& pruinis semina defenduntur. Ubi vero apricis regionibus post pluvias' noxia incesserunt ani. malia, qua a nobis appellantur eruce, Grace autem $x \alpha \dot{\mu} \pi \alpha$ เ nominantur, vel manu colligi debent, vel matuti. nis temporibus frutices olerum concuti. Sic enim dum adhuc torpent nocturno frigore, si deciderint, non amplius in superiorem partem prorepunt. Id tamen supervacium est facere, si ante sationem semina, uti jam pradixi, succo lierbæ sedi macerata sunt. Niliil enim sic medicatis nocent erucx. Sed Democritus in eo libro, qui Guxce inscribitur

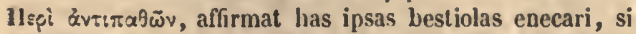
mulier, quæ in menstruis est, solutis crinibus et nudo

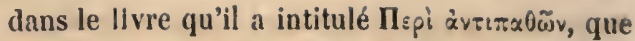
cesinsectes périssent tous, lorsqu' une femme a fait trois fois le tour d'une planche ensemeneée, les eheveux épars et les picds nus, dans le temps de ses règles, parce qu'après cette opération toutes les espèces de vel'nisseaux tombent à bas et perdent la vie. Jusqu'ici j'ai eru devoir donner des préeeptes sur la culture des jardins et sur les devoirs du métayer. Mais quoique j’aie prétendu, au eommencement de ce traité-ei, qu'un métayer devait connaitre à fond tous les travaux rustiques; comme il arrive néanmoins assez com. munément que la mémoire nous éehappe par rapport aux choses mêmes que nous avons apprises, ct qu'en conséquence nous avons souvent besoin de journaux pour nous les rappeler, j'ai joint ci-dessous les sommaires de tous mes livres, afin que l'on puisse trouver aisement, quand le eas l'exigera, toutes les opérations indiquées dans chacun de ces livres, avec la manière de les faire.

\section{IIVRE DOUZIEME.}

\section{LA METAYERE.}

\section{PRÉFACE.}

Xérophon l'Athénien, P. Silvinus, dit, dans son livre intitulé l'Économique, que le mariage a étć institué par la nature pour former la société de la vie non-seulement la plus agréable, mais encore la plus utile. Cicéron aussi remarque à ce sujet que le but de l'union de l'homme avec la femme ne se borne pas à empêcher que le genre humain ne périsse à la longue, mais qu'il tend eneore à procurer aux mortels des secours

pede unamquamque aream ter circumeat : post lıoc eniın decidere omnes verniculos, et ita emori. Hactenus praccipiendum existinıavi de cultu hortorum et officiis villici; quem quamvis instructım, alque eruditum omni opere rustico esse oportere prima parte lıjus exordii censuerim; quoniam tamen plerunque evenit, ut eorum quæ didicerimus, memoria nos deficiat, eaque sxpius ex conmenta. riis renovanda siut, omniuın librorum meorunı argumenta suljeci, ut cum res exegisset, facile reperiri possit, quid in quoque qnærendım, et qualiter quidque faciendum sit.

\section{LIBER DUODECIMUS. \\ Villica.}

\section{PREFATIO.}

Xenoplıon Atheniensis eo libro, P. Silvine, qui OEconomicus inscribitur, prodidit maritale conjugium sic comparatum esse natura, ut non solın jucundissima, verum etiam utilissina vita societas iniretur : nam primum, quod etian Cicero ait, ne genus lıumanum temporis longinquitate occideret, propter hoc inarem cum foemina esse conjunctum : deinde ut ex hac eadem societate mortalibus adjutoria senectutis, nec minus propugnacula, 
pour les aider dans leur vieillesse et pour les défendre. De plus, comme les provisions nécessaires à la nourriture et à l'entretien des hommes ne devaient point être préparées, comme eelles des bêtes féroces, aux yeux de tout le monde et dans des licux sauvages, mais dans des maisons et à l'abri, il a été nécessaire que l'ún des deux sexes sortít au dehors et s'exposát aux injures de l'air, pour se proeurer ees provislons par son travail et par son industrie, et que l'autre restât dans l'intérieur de la maison pour les y serrer et les garder. En effet, si d'un côté il êtait néeessaire de cultiver les champs, de voyager sur mer ou mème de se livrer à tout autre genre de commeree pour pouvoir acquérir des biens; de l'autre eôté il n'était pas moins essentiel, lorsqu'une fois on avait entassé à la maison les biens que l'on avait aeçuis, qu'il y eût une seconde personne destinée à les y garder, et à faire les autres ouvrages qui ne pouvaient être faits que dans l'intérieur. Les productions de la terre et les autres substances alimentaires avaient besoin d'un toit sous lequel on pût les mettre à couvert; et il fallait nécessairement garder dans un lieu clos non-seulement les petits et les fruits provenus des brebis et de tous les autres bestiaux, mais encore toutes les autres choses qui servent habituellement à nourrir comme à entretenir le genre humain. Or, eomme les objets que nous venons d'énoncer exigeaient des soins et de l'attention, puisqu'on ne pouvait pas acquérir au dehors, sans beaucoup de peine, les choses quil fallait ensuite garder à la maison: c'est avee raison, comme je l'ai dit, que les travaux de la maison sont réservés à la femme, tandis que ceux du dehors ap. partiennent exclusivement à l'homme. Aussi la nature a-t-elle constitué le mari de façon à pouvoir supporter le chaud et le froid, ainsi que les

preparentur.. Tum etiam, cum victus et cultus liumauns non uti feris in propatulo ac silvestribus locis, sed domi sub tecto accurandus erat, necessarium fuit alterutrım foris et sub dio esse, qui labore et industria compararet, quxe tectis reconderentur. Siquidem vel rusticari, vel navigare, rel etiam genere alio negotiari necesse erat, ut aliquas facultates acquireremus. Cum rero paratæe res sul tectum essent congesta, alium esse oportuit, qui et ilialas custodiret, et ea conficeret opera, quæ domi deberent administrari. Nam el fruges cæeteraque alimenta terrestria indigebant tecto, et ovium caclerarumque pecudum fortus, atque Iructus clauso custodiendi erant, nec minus reliygua utensilia, quibus aut alitur lominum genıs, aut etiam excolitur. Quare cum [et] operam et diligentiam ca qux proposuimus, desiderarent, nec exigua cura foris aç̧uirerentır, q̨ux domi custodiri oporteret : jure, ut dixi, natura comparata est mulieris ad donesticam diligentiam, riri autęn ad exercitationem forensen et extraneam. Itaque viro calores el frigora perpetienda, tum etiam itinera et labores ṕacis ac belli, id est rusticationis el militarium stipendiorum deus tribuit : unulieri deinceps, quod onni- voyages et les travaux tant de la paix que de la guerre, je veux dire ecux de l'agriculture et dn service militaire; comme elle a départi à la femme le soin des affaires domestiques, en la rendant inhabile à d'autres fonetions. Et comme elle avait donné à ee sexe la vigilance en partage, elle l'a rendu plus timide que le sexe viril, parce que la timidité est ee qui contribue le plus à assurer la garde de quelque chose; au lieu qu'elle a rendu le mari plus hardi que la femme, paree qu'il devait souvent ètre dans le cas de repousser les injures, en cherchant sa nourriture au dehors et en plein air. Mais comme, d'un autre côté, la mémoire et l'attention étaient également nécessaires à l'homme et à la femme après l'acquisition des biens, elle n'a pas moins avantagé l'un que l'autre du côté de ces faeultés. Bien plus, la simple nature n'ayant pas jugé à propos de donner à aucun être toute la perfection dont il était susceptible, - elle a voulu que chacun des deux sexes eût besoin de l'autre, parce que communément ee qui manque à l'un des deux se trouve ehez l'autre. Telles sont les réflexions utiles que Xénophon avait faites dans son $\ddot{E}$ conomique, et que Cicéron a répétées après lui, lorsqu'il a traduit eet auteur en latin, en le rapprochant des mœurs romaines. Aussi presque tous les travaux domestiques avaient-ils été départis aux femmes jusqu'à l'âge de nos pères, tant ehez les Grees que ehez les Romains, qui s'étaient modelés sur ces peuples; et les chefs de famille ne s'en mêlaient en aucune façon lorsqu'ils revenaient auprès de leurs Pénates, comme pour se remettre de la fatigue qu'ils avaient essuyée au dehors. En effet, on voyait régner dans leur ménage le plus grand respect joint à la concorde ct à l'exactitude; et les femmes, encouragées à la vigilance par l'effet d'une émulation admi-

bus lis rebus eam fecerat inlabilem, domestica negolia curanda tradidit. Et quonianı luunc sexum custodia et diligentiæe assignaverat : idcirco timidiorem reddidit, quam virilem. Nam melus plurimum confert ad diligentiam custodiendi. Quod autem necesse erat foris et in aperto viclum quarentibus nonnunquam injuriain propulsare : idcirco virum quam mulierem fecit audaciorem. Quia vero partis opibus aque fuit opus memoria et diligeutia, non minorem foemina quam viro earum rerum tribuit possessionem. Tum etiam quod simplex natura non onneis res commodas amplecti valebat, idcirco alterum alterius indigere voluit : quoniam quod alteri deest, pracsto plerunque est alteri. IIxc in QEconomico Xenophon: (et) deinde Cicero, qui eum Latinæ consuetudini tradidit. non inutiliter disseruerunt. Nam et apud Groens, et mox apud Romanos usque in patrum nostrorum memorian fere domesticus labor matronalis fuit, tanquam ad requiem forensium exercitationum omni cura deposita patribusfamilias intra domesticos penates se recipientibus. Erat enim summa reverentia cun concordia et diligentia nuista, fagrabatque nulier pulcherrima $[\mathrm{di}$, 
rable, ne eherchaient qu'à augmenter par leurs soins les possessions de leur mari. On ne voyait rien de partagé dans la maison, rien que le mari ou la femme prétendissent avoir en propre, et tous deux au contraire coopéraient unanimement a la chose eommune; de sorte que l'exactitude de la femme dans les affaires du dedans allait de pair avec l'industric du mari dans celles du dehors. Eill eonséquence, les métayers ni les métayères n'avaient pas de grandes occupations dans ces temps heureux où les maítres veillaient journellement à leurs biens, en les gouvernant par eux-mêmes. Aujourd'hui, au contraire, que la plupart des femmes s'abandonnent au luxe et il l'oisivete, au point que, loin de daigner prendre le soin d'apprêtel la laine, elles sont dégoûtées des vêtements qui sont faits à la maison, el qu'entraiıées par leurs désirs déréglés, elles en extorquent de leurs naris, à force de caresses, d'alltres qui sont plus précieux, puisqu'ils coùtent un argent énorme, et qu'ils absorbent des revenus presque entiers; il n'est point étonnant que le soin de la campagne ou des instruments rustiques leur pèse, et qu'elles regardent eomme la ehose la plus ignoble une résidence de queląues jours dans leurs métairies. L'ancien usage des mères de funille, tant Sabines que Romaines, étant done uon-seulement passé de mode, mais mẻme alssolument anéanti, il est devenu nécessaire que les soins de la métayère s'étendissent aux fonetions de la maitresse qu'elle a remplacée, d'autint que les métayers ont aussi succédé aux propriétaires, qui ne se contentaient pas autrefois de cultiver les eampagnes par eux-mêmes, puisqu'ils y faisaient encore leur résidence ordinaire conformément aux anciens usages. Au reste, comme je ne veux pas affecter de censurer hors

ligenlix] xumulatione, studens negotia viri cura sua maijora atqne netiora reddere. Niliil conspiciebatur in domo dividnum, nilil quorl aut maritus, aut formina proprinm esse juris sın diceret : sed in conımune conspirabatur ab utroque, ut cum forensibus negotiis, matronalis industria rationem parem faceret. Itaque nec villici quideII aut villica magna erat opera, cım ipsi domini quo. tidlie negotia sua reviserent atque administrarent. Nunc vero cum pleraque sic luxu et inertia difluant, ut ne la. niticii quidem curam suscipere diǵnentır, sed domi confecta vestes fastidio sint, perversaque cupidine maxime placeant, quæ grandi pecunia et totis pene censibus rediinuntur : nihil mirum est, easdem ruris et instrumentorum agrestium cura gravari, sordidissimuınque negotium Jucere paucorum dierum in villa moram. Quam ob causam cum in tolum non solum exolererit, sed etiam occiderit vetus ille matrumfamiliarum mos Sabinarnm atque Romanarum, necessaria irrepsit villies cura, qua tueretur officia matronæ : quoniam et villici quoque successerunt in locum dominorum, qui quondam prisca consuetudine non solum culuerant, sed habitaverant rura. Verum, ne videar intempestive censorium opus objurgandis morihus de propos les mœurs de notre sièele, je vais a présent détailler les devoirs de la métayère.

I. Ainsi (pour ne pas nous écarter de l'ordre des matières que nous avons suivi dans le volume précédent) une métayère doit être jeune, e'est-àdire qu'elle ne doit pas être trop petite fille, pour les raisons que nous avons déduites en parlant de l'age du métayer. II faut aussi que sa santé nc soit point altérée, et qu’elle ne soit ni diflorme, ni d'une très-belle figure, parce qu'étant d'un eóté dans une vigueur pleine et entière, elle suffira aux veilles et aux autres travaux, et que d'un autre côté sa laideur ne dégoûtera point le métayer qui doit vivre avec elle, comme sa trop grande beauté ne le rendra pas paresseux. Car si un métayer ne doit pas être volage et fuir le lit de sa compagne, il ne faut pas non plus que, retenu par elle à la maison, il soit toujours daris ses bras. Mais ce ne sont pas là les seules choses à observer dans une métayère. En effet, il faudra examiner entre autres si clle n'est point portće au vin, à la gourmandise, à la superstition, au sommeil; si elle n'a point de goût pour les hommes, et si elle sait s'occuper du soin des objets qu'elle doit se rappeler à la mémoire, on de ceux qu'elle doit prévoir pour la suite, afin d'être en état de suivre à peu près les règles que nous arons preserites pour le métayer; d'autant que presque tout doit être égal entre l'homme et la femme, et que si tous les deux doivent éviter de mal faire, ils ne doivent pas moins s'attendre à des récompenses quand ils se eomporteront bien. Elle donnera de plus tous ses soins à ee que le métayer n'ait à travailler dans l'intérieur de la maison que le moins que faire se pourra; article d'autant plus important, que eelui-ci doit sortir dés le matin avec les gens, et quil ne peut

nostrorum temporum suscejisse, jam nunc officia villicx persequar.

1. Ea porro (ut institutum ordinem teneamus, quem priore volumine inclıoavimus) juvenis ?sse debet, id est non nimium puella, propter easdem causas, quas de æetate villici retulinus : integræe quoque valitudinis, nec fo'li lıabitus, nec rursus pulcherrima. Nam illibatum robur et vigiliis et aliis sufficiet laboribus : foeditas fastidiosım, nimia species desidiosum faciet ejus contuberualem. Itaque curandum est, int nec vagum villicum et aversim a contubernio suo habeamus, nec rursus intra tecta desi. dem, et complexibus adjacentem fominx. Sed nec hre tantum, quæ diximus, in villica custodienda sinnt. Nam in primis considerandum erit, an a vino, ab escis, a superstitionibus, a somı, a viris remotissima sit, et ut cura eam subeat, quid meminisse, quid in posterun pros. picere debeat, ut fere eum morem servet, quem villico praccepimus : quoniam pleraque similia esse debent in viro atque formina, et tam malım vitare, quan præmiım recte factorum sperare. Tum elaborare, ut quam miniman opcram rillicus intra tectum impendal, cui et primo mane cun familia prodeundum est, et crepusculo peractis 
manquer d'ùtre fatiguć lorsqu'il rentre le soir à la fin de ses travaux. Cependant, en fixant les devoirs de la mćtayère, nous ne prétendons point exempter lc métayer du soin de l'intérieur de la maisoll, mais simplement le soulager dans ce genre de travail, en lui donnant quelqu'un pour l'aider. En effet, il ne faut pas s'en rapporter uniquement à la femme pour les fonctions de l'intéricur, et on ne doit les lui confier qu'autant que le métayer y aura l'œil de temps en temps. C'est le moyen qu'elle soit plus exacte, lorsqu'elle se rappellera à l'esprit qu'il y a quelqu'un auprès d'elle à qui elle doit rendre un compte fréquent. Elle demeurera aussi convaincue qu'elle doit toujours rester à la maison, ou du moins le plus que faire se pourra; et qu'elle doit en faire sortir les esclaves que le travail appellera aux champs, et y retenir ceux qu'elle jugera néeessaires à quelque ouvrage dans la métairie. Elle prendra garde que ceux-ei ne fassent manquer la besogne par une trop longue inaction, et elle examinera attentivement si les choses qu'on apportera à la maison ne sont pas gâtées, pour ne s'en charger qu'après s'être bien assurée qu'elles sont en bon état, et pour laisser cnsuite sous sa main celles qui seront destinées à la consommation, et mettre en réserve celles qui seront dans le cas d'être gardées, afin de ne pas consommer en un mois ce qui doit servir à la provision de l'année entière. Il faut encore, si quelqu'un des gens vient à tomber malade, qu'elle veille à ce qu'il soit soigné le mieux que faire se pourra, parce que ces sortes d'attentions ne contribuent pas moins à gagner leur bienveillance qu'à assurer leur obéissance ; outre que, dès qu'ils sont rétablis, ils s'appliquent à leur service avec encore plus de fidélité qu'au-

operibus fatigato redeundım. Nec tamen instituendo vil. lican domesticarum rerum villico remittimus curam, sed tantummodo laborem ejus adjutrice data levamns. Caterum munia, qux domi capessuntur, non in tolum muliebı $i$ officio relinquenda sunt, sed ita deleganda ei, ut identidem oculis villici custodiantur. Sic enim diligentior erit villica, si meminerit ibi esse, cui ratio frequenter red. deuda sit. Ea porro persuasissinum habere debebit, aut in totum, ant certe plurimum domi se morari oportere : tum quibus aliquid in agro faciendum erit servis, eos foras emittere; quibus autem in villa quid agendum videbitur, cos intra parietes continere, atque animadvertere, ne diurna cessando frustrentur opera : qua domum autem inferuntur, diligenter inspicere, ne delibata sint, et ita explorata atque inviolata recipere : tum separare, qux consumenda sunt, et qua supertieri possunt, custodire, ne sumptus annurus menstruus fiat. Tum siquis ex familia coperit adversa valitudine affici, videndum erit ut is quan commodissime ministretur. Nam ex lujusmodi cura nascitur benerolentia, nec miuus obsequium. Quinetiam fidelius quam prius servire student, qui convaluerint, cum est agris adlibita diligentia.

11. P'ost hace meminisse debebit, qua inferantur, ut paravant, lorsqu'on a bien pris soin d'eux pendant leur maladie.

II. A près cela, elle doit avoir présent à la mémoire que les choses qui auront été apportées à la maison doivent y être serrces dans les lieux convenables et salubres, pour y rester sans étre exposées à sc gáter. En effet, il n'y a pas de soin plus important à prendre que celui de préparer les endroits où l'on doit serrer chaque chose, pour l'en tirer dans le besoin. Nous avons déjà parlé des conditions requises pour ces sortes d'endroits, tant dans le premier volume de cet ouvrage, lorsque nous nous occupions de la construetion de la métairie, que dans le onzième, lorsque nous traitions des devoirs du métayer; mais nous ue scrons pas fâchés de les retracer iei en peu de mots. Les chambres les plus hautes seront donc destinées à la garde des ustensiles les plus précieux et à celle des habits; les greniers, pourvu qu'ils soient sees et aérés, semblent être convenables à la garde des blés; les celliers frais sont excellents pour celle du vin; les endroits blen éclairés sont réservés aux meubles fragiles, et aux opérations qui demandent beaueoup de jour. Ainsi, lorsque les lieux destinés à recevoir ehaque chose seront préparés, on les enfermera toutes en commun dans l'endiooit qui leur sera propre, et on en mettra même quelques-unes à part, afin de reprendre celles dont on pourra avoir besoin pour son usage habituel. Car, selon un vieux proverbe, il n'y a pas de pauvreté plus certaine que celle de ne pouvoir pas se servir des ehoses dont ou a besoin, faute de savoir, quand on vient à les chercher, l'endroit où on les a jetées au hasard. Aussi la négligence est-elle plus laborieuse dans l'économie domestique que l'exactitude même.

idoneis et salubribus locis recondita sine noxa permaneant. Nilil enim magis curandum est, quam præparare, ubi quidque reponatur, ut cum opus sit, pronnatur. Ea loca qualia esse debeant, et in primo rolumine, cum villam const;lueremus, et in undecimo, cum de officio villici disputaremus, jam dicta sunt. Sed ne nunc quidem demonstrare breviter pigebit. Nam quod excelsissimum est conclave, pretiosissima vasa el restem desiderat : quod denique horreum siccum atque aridum, frumentis habetur ido. neum : quod frigidum, commodissime vinum custodit : quod bene illustre , fragilem supellectilem atque ea postılat opera, quæ multi hminis indigent. Præparatis igitur receptaculis, oportebit suo quidque loco generatim, atque etian specialiter nonnulla disponere : quo facilius, cum quid expostulabit usıs, reperiri possit. Nam velus est proverbiun, paupertatem certissimam esse, cum alicujus indigeas, uti eo non posse, quia ignoretur, ubi projectum jaceat quod desideratur. Itaque in re familiari laboriosior est negligentia, quam diligentia. Quis enim dubitet niliil esse pulclurius in omni ratione vita dispositione atque ordine? quod etiam ludicris spectaculis licet sxpe cognllescere. Nam ubi clorus caneutimm nou ad certos modos neque numeris praeuntis magistri consensit, dissonum 
En effet, y a-t-il un homme qui ne soit pas convaincu qu'il u'y a rien ile plus beau dans toute la conduite de la vie que l'ordre et l'arrangement; et n'est-ce pas même une remarque que l'on est à portée de faire souvent dans les spectacles des jeux publics? En effet, lorsqu'un chœur de chanteurs ne s'accorde pas sur des modes certains, et qu'il ne suit pas la mesure du maitre qui le dirige, il semble aux auditeurs que le chant a quelque chose de discordant et de tumultuenx; au lieu que lorsque les chanteurs sont d'accord, et qu'ils forment, pour ainsi dire, tous ensemble une unité de chant, dont la mesure et la prosodie sont bien marquées, non-seulement cet accord de voix fait entendre quelque chose de mélodieux et de flatteur aux chanteurs eux-mêmes, mals il charme encorc les spectateurs et les auditcurs par l'effet d'une volupté délicieuse. C'est ainsi que dans une armée le soldat ni le général ne pourraient rien démêler faute d'ordre et d'arrangement, parce que, si tout y était pêle-mêle, les gens armés seralent confondus avec ceux qui seraient sans armes, les cavaliers avec les fantassins, et la cavalerie avec les chariots. On tire aussi un très-grand avantage de l'ordre et des préparatifs dans un vaisseau, parce que s'il est équipé convenablement, et qu'il survienne une tempête, les subalternes tirent, sans causer aucune alarme, les agrès de l'endroit où ils sont rangés en ordre, au moment que celui qui gouverne le vaisseau les leur demandc. Par consé quent si l'ordre et l'arrangement font un si grand effet sur les théAtres, ou dans les armées, ou même sur les vaisseaux, il n'y a pnint de doute qu'ils ne soient également nécessaires dans les fonctions de la métayère, par rapport aux choses qu'elle doit serrer; parce que, lorsqu'elles sont à leur place marquće, elles frappent plus aisément la vue, ct que si l'une se trouve égarée, le lieu

quiddam ac tumultuosum andientibus canere videtur : at ubi certis numeris ac pedibus velut facta conspiratione consensit atque concinuit, ex ejusmodi vocum concordia non solum ipsis canentibus amicum quiddan et dulce re. sonat, verum etiam spectantes audientesque lotissima voluptate permulcentur. Jam vero in exercitu neque miles neque inperator sine ordine ac dispositione quidquam va. let explicare, cum armatus inermem, eques peditem, plau. strum equitem, si sint permisti, confundant. Hæc eadem ratio proparationis atque ordinisetiam in na vigiis plurimum valet. Nam ubi tempestas incessit, et est rite disposita navis, suo quidque ordine locatum armamentum sine tre. pidatione ninister pronit, cum est a gubernatore postulatum. Quod si tantum lixe possunt vel in theatris vel in exercitibus rel etiam in navigiis : nilil dubium est, quin cura villica ordinem dispositionemque rerum, quas reponit, desideret. Nam et unumquodque facilius consideratur, cum est assignatum suo loco, et siquid forte ahest, ipse vacuus locus admonet, ut quod deest requiratur. Siquid vero curari aut concinnari oportet, facilius intelli. qu'elle devait oceuper se trouvant vide avertit lui-même dès lors qu'il faut la chercher. Outre cela, on remarque plus faeilement ce qui peut avoir besoin d'être soignć ou rajusté, quand on fait la revue générale des choses qui sont en lcur place. C'est pour cela que M. Cicéron, en se conformant à l'autorité de Xénophon dans son Économique, met ce qui suit dans la bouche d'lscomachus, en réponse à des questions que Socratc lui faisait sur tous ces objets.

III. Nous arons commencé par distribuer les ustensiles et les meubles dans les lieux convenable. ment préparés à cet effet ; et nous avons mis à part d'abord les ehoses que nous avons coutume d'employer aux sacrifices, ensuite les ajustements qui servent aux femmes les jours de fête, puis ce qui sert également à parer les hommes les jours solennels, et enfin les chaussures de l'un et de l'autre sexe; après quoi on mettait d'un côté l's armes et les traits, et d'un autre côté les outils qui sont d'usage dans les ouvrages de laine. On mettait ensuite à sa place (suivant la coutume) la batterie de euisine, puis les vases des bains ainsi que ceux de la toilette, et la vaisselle de table, tant celle à l'usage des jours ordinaires que celle à l'usage des grands repas. Quant aux choses d'une consommation journalière, nous en avons fait deux parts, l'une qui comprend la provision du mois, l'autre qui renferme celle de l'année : moyennant quoi on est à l'abri de toute erreur par rapport au temps où ces provisions doivent finir. A près avoir ainsi séparć toutes ces choses l'une d'avec l'autre, nous les avons encore arrangées ehacune à leur place; après quoi nous avons donné les ehoses d'un usage habituel à chacun des esclaves subalternes qu'elles coneernent, telles que celles qui servent aux ouvrages de laine, ou à la cuisson et à la préparation de la nourriture; et nous lui avons enseigné l'endroit où il devait les remet-

gitur, cum ordine suo recensetur. De quibus omnibus M. Cicero auctoritatem Xenophontis secutus in Economico sic inducit Isclıomacluum sciscitanti Socrati uarrantem.

III. Præparatis idoneis locis instrumentum et supellectilem distribuere cœpimus : ac prinum ea secrevimus, quibus ad res divinas uti solemus, postea mundum muliebrem, qui ad dies festos comparatur, inde ad (bella) virilem, item dierum solennium ornatum, nec minus calciamenta utrique sexui convenientia : tum jam seorsum arma ac tela seponebantur, et in altera parte instrumenta, quibus ad lanificia utuutır. Post quibus ad cibun comparandum vasis uti assolent constituebantur : deinde quæ ad lavationem, quxe ad exornationem, qux ad mensam quotidianam, atque epulationem pertinent, exponebantur. Postea ex iis quibus quotidie utimur, quod menstruum esset seposuimus, annuum quoque in duas partes divisimus : nam sic minus fallit, qui exitus futurus sit. Ilacc postquam omnia secrevimus, tum suo quæque loco disposuimus : deinde quibus quotidie serruli utuntur, quæ ad lanificia, quæ ad cibaria coquenda et conficienda per. 
tre, en lui preserivant de veiller à leur sûreté. Mais pour celles dont nous ne nous servons que les jours de fêtes ou à larrivée des hôtes et dans quelques cas rares, nous les avons mises entre les mains de l'éeonome, en leur assignant à toutes leur place. Nous comptions chaque pièce, et nous en tenions nous-même registre. Nous avons aussi prévenu l'éeonome de l'endroit où il trouverait tout ee dont on pourrait avoir besoin, en l'avertissant d'avoir des notes particulières pour se rappeler les effets qu'il aurait donnés, le temps où il les aurait donnés, et la personne qui les aurait reçus, afin de les remettre chacun à sa place, lorsqu'on les aurait rendus. Ainsi les anciens nous ont donné, dans la personne d'Ischomachus, les mêmes préceptes d'attention et de vigilance que nous donnons aujourd'hui à la métayère. Cependant elle ne doit pas borner ses soins à garder sous la elef ee qu'on lui aura apporté à la maison; mais elle doit encore en faire la revue de temps en temps, et prendre garde que les meubles ou les habits ne dépérissent pour être ensevelis dans l'ordure, ou que les produetions de la terre ainsi que les autres ehoses d'usage ne se perdent par sa négligence et par sa paresse. Il faut aussi qu'elle ait de la laine toute prête et eardée, tant afin de pouvoir tourner ses soins du côté des ouvrages de laine les jours de pluie, ou lorsque le froid ou la bruine empécheront les femmes de vaquer en plein air aux travaux rustiques, qu'afin que ces ouvrages puissent être faits plus aisément quand elle y mettra la main, ou qu'elle doniera ses ordres. En effet, il ne sera pas mal que ses lıabits, ainsi que ceux des intendants et des autres esclaves distingués, soient faits à la maison, afin que les comptes que l'on rendra au ehef de famille soient moins enflés. Voici eneore une chose

tinent, lıec ipsis, qui lis uti solent, tradidimus, et ubi exponerent, demonstravimus, et ut salva essent, pracepimus. Quibus autem ad dies festos et ad hospitum adrelltum utimur et ad yuadam rara negotia, haec proino tra. didimus, et loca omuium demonstravimus, et omnia aunumeravimus, atque annumerata ipsi exscripsimus, cumque admonuimus, ut quodcnnque opus esset, sciret uıde daret, et meıninisset atyue annotaret, quid et quando et cui dedisset, et cum recepisset, ut quidque suo loco reponeret. Igitur hac nolsis antiqui per Ischomachl perso. sam præcepta industrix ac diligentiae tradiderunt, qux nunc nos villicæ demonstramns. Nec tamen una ejus cura esse debebit, ut clausa custodiat, qua tectis illata receperit, sed subinde recognoscat atque consideret, ne aut supellex vestisve condita situ dilabatur, ant fruges, aliave ufensilia negligentia desidiaque sua corrumpantur. Pluviis vero diebus, vel cum frigoribus aut pruinis mulier sub dio rusticum opus obire non poterit, ut ad lanificium re. ducatur, præparatæ sint et pectitæ lanæ, quo facilius justa lanificio persequi atque exigere possit. Nihil enim nocehit, si sibi atque actoribus et aliis in loonore servulis restis domi confecta fuerit, quo minus patrisfunilias ra. qu'elle ne manquera jamais d'observer : c'est de faire la visite dans la métairie dès que les gens en seront sortis, pour voir s'il n'en est pas resté de ceux qui devraient être dehors à travailler à la campagne, et si quelqu'un d'eux n'a pas trompé (eomme il arrive quelquefois) la vigilanee de son mari en tergiversant dans la maison. En ee cas elle lui demandera la raison de sa négligenee; elle examinera si c'est sa mauvaise santé qui l'a forcé de rester, ou si e'est par paresse qu'il s'est caché; et elle le conduira sans retard à l'infirmeric, quand même elle s'apercevrait qu'il s'excuserait sur une maladie feinte; parce qu'il vant mieux laisser reposer un ou deux jours, en le gardant à vue, un eselave fatigué par l'ouvrage, que de l'exposer à une maladie reéalle, en l'aeeablant par un travail excessif. Enfin elle restera le moins que faire se pourra dans la même place; car son office n'est point sédentaire, et elle doit au contraire tantôt prendre un métier, pour montrer aux autres à faire de la toile si elle est la plus habile, sinon pour apprendre elle-même a en faire de eeux qui sont plus habiles qu'elle; tantôt visiter ceux qui préparent le manger des gens, et avoir soin de faire nettoyer la euisine, les étables à bœuf́s et les crêehes. Elle doit aussí ouvrir de temps en temps les infirmeries, quaud même il ne s'y trouverait point de malades, et en balayer les ordures, afin que, quand le cas l'exigera, les malades les trouvent bien arrangées, en bon état et saines. Il faut encore qu'elle soit présente toutes les fois que les pourvoyeurs et les dépensiers pèseront et mesureront quelque ehose, ou que les pâtres tireront le lait dans les étables, ou qu'ils feront tetter les agneaux et les petits des autres bestiaux; comme il faut qu'elle assiste à la tonte, qu'elle prenne soigneusement

tiones onerentur. Illud vero etiam in perpetuum custodien. duın habebit, ut eos, qui foris rusticari debcbunt, cum jam e villa familia processerit, requirat, ac siquis, ut evenit, curan contuberualis ejus intra tectum tergiversans fefellorit, causam desidix sciscitetur, exploretque utrum adversa valetudine inlibitus restiterit, an pigritia delituerit. Et si compererit, vel simulantem languoren sine cunctatione in valetudinarium dedıcat : prastiat enim opere fatigatum suh custodia requiescere unum aut alterum diem, quam pressum nimio labore veranı noxan concipere. Denique uno loco quam minime oportebit eam consistere, ueque enim sedentaria ejus opera est, sed modo ad telam debebit accedere, ac siquid melius sciat, docere : si ninus, addiscere ab eo qui plus intelligat, modo eos qui cibum familia conficiunt, iuvisere : tum etiam culiuam et bubilia, nec ninus prasepia mundanda curare : valetudiuaria quoque vel si racent ab inlbecillis, identiden aperire, et immunditiis liberare, ut cum res exegerit, bene ordinata [et ornata] et salubria languentibus praheantur : promis quoque et cellariis aliquid appendentibus ant metientilus intervenire : nec minus interesse pastoribus in stabulis fructum cogentibus, aut foetus ovium, aliarumve 
la laine qui en reviendra, et quelle compare le nombre des tolsons à celıi des bestiaux; cnfin ıu’elle force les esclaves chargés du soin des meubles de les tenir propres, de nettoyer et de polir les Instruments de fer, et de domner aux artisans ceux qui auront besoin de réparation, afin qu’ils les mettent en état. Quoique tout soit ainsi réglé, je erois néanmoins que cette distribution ne sera eneore d'aucunc utilité, à moins que, comme je l'ai déjà dit, le métayer n'y ait souvent l'œil; sans parler du maitre et de la maîtresse, qui doivent aussi y regarder de temps cn temps, et à moins qu'il ne veille au maintien de cet arrangement quand il sera une fois ćtabli. C'est aussi ce que l'on a toujours pratiqué dans les villes policées : en effet, il n'a pas paru suffisant aux ehefs et aux notables de ees villes de les pourvoir de bonnes lois, s'ils n'cusseut en même tenps com. mis la garde de ces lois à des citoyens très-exaets, que les Grees appellent vopopúd $\alpha \times \alpha \varsigma$, et dont la fonction consistait a combler d'éloges et même d'honneurs ceux qui obéissaient aux lois, comme à punir ceux qui s'en écartaient. C'est précisément ce que font encore aujourd'hui les mayistrats, qui maintiennent les lois en vigueur par l'exercice assidu de leur juridietion. Mais il suffit de ees préeeptes pour ce qui concerne l'administration générale.

IV. Nous allons à présent donner des préceptes sur d'autres objets particuliers, dont nous n'avons point parlé dans les livres précédents, parce que nous nous réservions de le faire en traitant des fonctions de la métayèe. Pour suivre un certain ordre, nous commencerons par le printemps, paree que les semailles, tant celles qui sont faites a temps que eelles des trémois, se trouvant presque toutes finies dans cette saison, il reste des

pecudum subrumantihus : tonsuris vero earum utique interesse, et lanas [etiam] diligenter percipere, et vellera ad numerum pecoris recensere : tum insistere atriensilous, ut supelleetilem exponant, et ferramenta detersa nitiden. tur, atque rubigine liberentur, cæeteraque quæ refectionem desillerant, fabris concinnanda tradantur. Postreıno his rebus onuibus eoustitutis, nilil hanc arbitror distributionem profuturam, nisi, $ı t$ jan dixi, villiens siłpius, et aliquando tamen dominus ant matrona consideraverit, animadverteritque, ut ordinatio instituta conservetur. Quod etian in bene moratis civitatibus semper est observatun; quarum primoribus atque optimatibus non satis visum est bonas leges labere, nisi custodes earum diligentissimos cives ereassent, quos Graeci vopoqúl $\alpha \times \alpha$ s appel. Jant. Horum erat officium, eos qui legibus parerent, laudibus prosequi, nee minus lonoribus : eos autem qui non parerent, pona multare. Quod nunc seilicet faciunt magistratus, assidua jurisidictione vim legum custodientes. Sed hrec in universum adninistranda tradidisse abuide sit.

IV. Nunc de cateris rebus, qua onissa erant prioribus Jibris, quoniam villica reservabantur officiis, pracipiemus, et ut aliqguis ordo custodiatur, incipiemus a verno inoments où l'on n'a rien à fairc, et où l'on peut par conséquent s'oecuper des pratiques que nous allons enscigner. La tradition nous appiend que les auteurs, tant carthaginois ct grees que romains, n’ont pas négligé le soin des petites ehoses : en effet, Magon le Carthaginois et Hamilear, dont l'exemple parait avoir été suivi par Mnaséas ct Paxamus, auteurs grees assez célèbres, n’out pas dédaigné, quand les guerres leur en ont laissé le loisir, de payer une espèce de tribut à la subsistance des hommes. C'est ce qu'ont fait également plusieurs de nos compatriotes : témoin M. Ambivius, Mænas Licinius et $\mathrm{C}$. Matius, qui se sont attaches à former, par les préceptes qu'ils leur ont domnés, des boulangers, des cuisiniers et des officiers chargés du soin des provisions de bouche. $\mathrm{Or}_{\mathrm{r}}$ tous ces auteurs ont voulu que celui qui se méler'ait de ces emplois fủt chaste ct continent, parce qu'il est important que ce qui sert à la boisson ou à la nourriture ne soit touché que par des ìnpubères, ou au moins par des personnes qui s'abs. tiennent tout à fait de l'aete vémérien; de sorte que si un homme ou unc femme mariés sont dans le cas de mettre la main aux provisions de bouche, ils prétendent qu'ils doivent préalablement se baigner dans un fleuve ou dans une cau courante; et que par conséquent il faut nécessairement avoir recours au ministère d'un enfant ou à celui d'une pctite fille, pour tirer les choses dont on aura besoin de l'endroit où clles seront serrées. A la suite de ce précepte, ils ordonnent de préparer un lieu et des vases convenables pour confire quelque chose que ce soit au sel et au vinaigrc : ils veulent que ce lieu ne soit pas exposé au soleil, et qu'il soit très-frais et très-sec, afin que les provisions de bouche ne contractent ni moisissure ni odeur de relent; que les vases dont

tempore, quoniam fere maturis atqne trimestribus consumnatis sationibus, vacua tempora jan eontingunt ad ea exequenda, qua deinceps docebimus. Parvarum rermm euram non defuisse Ponis Graeisque auctoribus atıue etiam Romanis, memoria tradidit. Nam et Mago Cartla. giniensis, et Hamilear, quos secuti videntur Grace gentis non obscuri seriptores Mnaseas atque Paxamus, tum de. num nostri generis, postquam a bellis otium fuit, quasi quoddam tributum vietui humano eouferre dedignati nou sunt, ut M. Ambivius, et Manas Licinius, tum etian C. Matius; quibus studium fuit pistoris et coei, nee minus cellarii diligentiam suis praeeptis instituere. His antem omnibus plaeuit, eum, qui rerum larum officium susceperit, castum esse continentenıque oportere, quoniam totum in eo sit, ne contractentur pocula vel eibi, nisi ant ab impubi, aut eerte abstinentissimo rebus venereis. Quibus si fuerit operatus vel vir vel foemina, debere eos flumine aut perenni aqua, priısquam penora contiıgant, ablui. Propter quod lis necessariun esse pueri vel virginis ninisterium, per quos promantur, qua usıs postulaverit. Post hoe praceptum locum et vasa idonea salgamis praparari jubent : loeum esse debere aversum a sole, quam frigidissi. 
on se servira soient de terre cuite ou de verre; que l'on en ait une grande quantité de petits, plutôt que d'en aroir de grands en moindre quantité; et que de ees vases les uns soient enduits de poix eomme il faut, et les autres propies, mais sans apprêt particulier, selon que la nature des ehoses que l'on doit confire l'exigera. Il faut faire exprès ees vases, de facon qu'ils aient une grande ouverture et qu'ils soient d'une même largeur du haut en bas, et que par conséquent leur, forme ne ressemble point à eelle des futailles, afin que, lorsqu'on en aura tiré des viandes eonfites pour son usage, tout ee qu'on y aura laissé soit également précipité au fond du vase, à l'aide d'un poids dont on chargera la superficie de ces viandes. Car pour conserver les provisions de bouelıe sans qu'elles se gatent, il faut faire en sorte qu'elles ne surnagent point, mais qu'elles soient toujours recouvertes du liquide dans lequel on les conserve; ce à quoi il serait difficile de parvenir, si elles étaient dans une futaille qui n'a point une forme régulière. Les mêmes auteurs ajoutent que le vinaigre et la saumure la plus forte sont d'un usage très-liécessaire pour ces opérations. Voici eomme on fait l'une et l'autre.

V. Pour faire du vinaigre, mettez sur quarantehuit sextarii de vin évaporé ou gâté une livre de levain, trois uncia de figues sèehes et un sextarius de sel broyés ensemble, de facon néanmoins qu'a vant de jeter ces ingrédients dans la mesure de vin que nous disons, ils aient été délayés dans un quartarius de miel. Quelques personnes jettent dans une pareille mesure de vin quatre sextarii d'orge grillée, quarante noix allumées, et une demi-livre de menthe verte. D'autres font chauffer des barres de fer jusqu'à ce qu'elles soient rouges comme du feu, et les plongent dans une pareille mesure de vin ; après quoi ils allument cinq ou six pignons sans amandes, et les y jettent tout enflammés. Il y en a qui font la même opération avee des pommes de sapin enflammées.

VI. Manière de faire de la saumure forte. On met dans la partie de la métairie la plus exposće au soleil une futaille dont l'ouverture soit trèsgrande, et on la remplit d'eau de pluie, qui est la meilleure pour eette opération, ou du moins, si l'on n'a pas d'eau de pluie, on la remplit d'eau de fontaine qui soit très-douce; après quoi on suspend dans eette futaille un panier de jone ou de genêt d'Espagne rempli de sel blanc, afin que la saumure soit plus blanche. Tant que l'on voit le sel se fondre pendant quelques jours, c'est une preuve que la saumure n'est pas eneore assez faite. C'est pourquoi l'on contiluera pendant quelque temps d'en mettre d'autre dans ee panier, jusqu'à ee qu'il y reste tel qu'on l'y aura mis, et sans souffrir aueune diminution. Lorsqu'on s'apercevra qu'il ne fond plus, on jugera dès lors que la saumure est à son point de per:feetion; et si l'on veut en faire d'autre dans le même vase, on versera la première dans des vaisseaux bien enduits de poix, et on la tiendra eouverte au soleil, paree que l'action du soleil en attirera toute la moisissure et lui fera contracter une bonne odeur. Il y a une autre manière de reconnaitre si la saumure est à son point de perfection, qui conslste à y plonger du fromage mou.: en effet, s'il tombe au fond, e'est une preuve qu'elle n'est pas encore faite; au lieu que lorsqu'il surnage, on est sûr qu'elle est à son point de perfection.

VII. Quand on aura préparé du vinaigre et dé la saumure, il faudra eueillir pour son usage vers l'équinoxe du printemps, et mettre à part mum et siccissimum, ne situ penora mucorem contralıant. Vasa antem ticlilia vel vitrea plura potius quam ampla, et eorum alia recte picata, nonnulla tamen pura, prout conditio condituræe exegerit. IIxec vasa dedita opera fieri oportet patenti ore, el usque ad imum aequalia, nec in modum doliorum formata, nt exemptis ad usum salganis quidquid superest aquali pondere usque ad fundum deprima. tur, cum ea res iunoxia penora couservet, ubi non inna. tent, sed semper sint jure submersa. Quod in utero dolii vix tieri posse propter insequalitatem figura. Maxime autem ad hoc necessarium esse aceti et durie muria usum, quae utraque sic contieri.

V. Quemadmodum ex vino rapido acetum tiat. In sextarios duodequinquaginta fermenti libraun, fici aridac pondo quadrantem, salis sextarium subterito, et subtrita cum quartario mellis aceto diluito, atque ita in proclictam mensuram adjicito. Quidam ordei tosti sextarios quatuor, et nuces ardentes juglandes quadraginta, et mentxe viri. dis pondo selibram in eandem mensuram adjiciunt. Quidam ferri massas exurunt, ita ut ignis speciem lıabeant, easque in eandem mensuram demittunt. Tum etian exem. ptis nucleis ipsas nuces pincas vacuas numero quinque vel sex incendunt, et ardentes eodem demittunt. Alii nucibus sapineis ardentibus irlem faciunt.

V1. Muriam duraın sic facito: dolium quam patentissiui oris locato in ea parte villa, quæ plurimun solis accipit. Id dolium aqua cielesti repleto; ea est enim luuic rei aptis. sima; vel si non fuerit pluvialis, certe fontana dulcissiui saporis. Tum indito sportain junceam, vel sparteanı, quae repleuda est sale candido, quo candidior muria fiat. Cum salem per aliquot dies videbis liquescere, ex eo itltelliges nondum nuriam esse maturam. Itaque subinde alium salem tamdiu ingeres, donec in sporta permaneat integer, nec ninuatur. Quod cum animadverteris, scias habere murianı maturitatem suam. Et si facere alian volueris, hanc in vasa bene picata diffundes, et opertam in sole labebis. Omnem enim mucorem vis solis aufert, et odorem bonum prabet. Est et aliud murix matura: experimentum. Nam ubi dulcem caseum demiseris in eam, si pessum ibit, scies esse adluuc crudam : si innatabit, maturam.

VII. Ilis prxparatis circa rernum aquinoctiun herbas in usum colligi et reponi oportebit, cymam, caulem, capparim, apii coliculos, rutam, oleris atri cun suo cole 
les herbes suivantes: savolr; des eimes et des tiges de chou, des eápres, des tiges d'ache, de la rue, des tiges de maceron cueillies avant que cette plante sorte de sa capsule, ainsl que des tigres de férules cueillies avant leur développement total, de la fleur nouvelle et des tiges de panais sauvage ou cultivé, de la fleur de couleuvrée cueillie avant son parfait développement, de la fleur tant d'asperge que de petit houx, de racine vierge, de digitale, de pouliot, de cataire, de lapsana, de la fleur et des tiges de cette battille que l'on appelle pied de Milan, et même de jeunes tiges de fenouil. On confit aisément toutes ces herbes ensemble dans la même sauce, c'est-à-dire, dans deux tiers de vinaigre et un tiers de saumure forte. Mais on peut aussi mettre a part, chacune dans leur bassin, la couleuvrée, le petit houx, la racine vierge, l'asperge, la lapsana, le panis, la cataire, la battille. Après avoir saupoudré ces herbes de sel, on les met deux jours à l'ombre, jusqu'à ce qu'elles rendent leur eau; ensuite, si elles ont jeté assez d'eau pour pouvoir être lavées dans leur propre jus, on les y lave, sinon on les lave avec de la saumure forte que l'on verse dessus, puis on les comprime en les chargeant d'un poids; après quoi on les met chacune dans un vase à part, puis on verse dessus une saumure, qui, comme je l'ai dit cidessus, sera composée de deux tiers de vinaigre et d'un tiers de saumure proprement dite; et on les recouvre d'une bonne poignée de fenouil sec cueilli l’année précédente pendant la vendange, pour les comprimer au point que le liquide puisse remonter aux bords du flacon. Quand on aura cueilli le maceron, la férule et le fenouil, on étendra ces herbes à la maison, jusqu'à ce qu'elles soient fanées; après quoi on en dépouillera

Gorem antequam de folliculo exeat : item ferulæ cum coliculo silentem quam tenerrimum forem : pastinacœ agres. tis vel satirae cum coliculis silentem florem : vitis albae et asparagi et rusci et tamni et digitelli et puleii et nepetæ et lapsanxe et battis et ejus coliculum, qui unilvinus pes appellatur; quin etiam tenerum coliculum foeniculi. Hacc omuia una conditura conımode servantur, id est aceti duas partes, et tertiam duræ muriæ si miscueris. Sed vitis alba, ruscus, et tarnnum et asparagus, lapsana et pastillaca et nepeta et battis generatim in alveos componuntur, et sale conspersa biduo sub umbra, dum consudent, reponuntur : deinde si tantum remiserint lumoris, ut suo sibi jure ablui possint : si minus, superfusa dura muria larantır, et pondere imposito exprimuntur : tum suo quidque vase conditur, et jus, ut sıpra dixi, quod est mistım duabus partibus aceti et una muriæ, infunditur, fivniculique aridi, quod est per vindemiam proximo anuo lectum, spissamentum imponitur, ita ut herbas deprimat, et jus usque in summum labrum fideliæ perveniat. Olusatrum et ferulam et foniculum cum legeris, sub tecto exponito, dum flaccescat : deinde folia et corticeu ounnem coliculorum detralito. Caules si fuerint pollice les tiges de leurs feuilles et de toute leur écorce. Si ces tiges sont plus grosses que le pouce, on aura soin de les partager en deux morceaux, en se servant d'un roseau pour les couper. Il faudra aussi éparpiller les fleurs elles-mêmes et les fendre en deux avant de les mettre dans les vases, pouréviter qu'elles ne soient trop grosses. Ensulte on versera dessus la saumure que nous venons de prescrire, en y ajoutant quelques petites racines de ce laser que les Grees appellent oídociov, et en recouvrant le tout d'une.poignée de fenouil sec, de façon que la saumure remonte par-dessus. Il faut laisser sécher à la maison pendant plusieurs jours, jusqu'à ce qu'elles soient fanées, les cimes et les tiges de chou, de câprier, de pied de Milan, de pouliot, de digitale, et les confire ensuite de la manière dont on confit la férule, la rue, la sarriette et l'origan. Il y a des personnes qui se contentent de faire confire la rue dans de la saumure forte, sans y ajouter de vinaigre, et qui ensuite, pour s'en servir, la trempent dans de l'eau ou même dans du vill, et l'arrosent d'huile. On pourrait aisément conserver de la même manière la sarriette verte, ainsi que l'origan vert.

VIII. Manière de faire de l'oxygala (de la jonchée). On prend un pot de terre propre, que l'on perce vers le fond avec une tarrière; ensuite on bouche avec un fosset le trou que l'on a fait, et l'on remplit ce vase de lait de brebis très-frais; puis on y ajoute de petites bottes d'assaisonnements verts, consistant en origan, menthe, oignoll et coriandre. On enfonce ces herbes dans le lait, de façon néanmoins que la ligature qui les retient y surnage. Cinq jours après, on retire le fosset qul servait à boucher le trou, et l'on vide le petit-lait. Ensuite, lorsque le lait même commence à cou.

crassiores, arundine secato, et in duas partes dividito. Ipsos quoque flores, ne sint imınodici, diduci et partiri oportebit, atque ita in vasa condi. Deinde jus, quod supra scriptum est, infundi, et paucas radiculas laseris, quod Graci oiliprov vocant, adjici, tum spissamento foeniculi aridi contegi, ut jus superveniat. Cymam, caulem, capparim, pedem milvi, puleium, digitellum, compluribus diebus sub tecto siccari, dum llaccescat, et tun eodem modo condiri convenit, quo ferulam, rutam, satureiam, cunilam. Sunt qui rutam muria tantum dura sine aceto condiant, deinde, cuin usus exigit, aqua vel etiam vino abluant, et superfuso oleo utantur. Haec conditura possit commode satureia viridis, et æeque viridis cunila servari.

VIII. Oxygalam sic facito. Ollam novam sumito, eamque juxta fundum terebrato : deinde cavum, quem feceris, surculo obturato, et lacte ovillo quam recenlissimo vas repleto, eoque adjicito viridium condimentorum fas. ciculos, origani, mentæ, cepæ, coriandri. Hlas lierbas ita in lacte demittito, ut ligamina earum extent. Post dien? quintum surculum, quo cavum obturaveras, eximito, et serum emittito. Cum deinde lac coxperit nıanare, eodem surculo cavum obturato, intermissoque triduo, ita ut su. 
ler, on rebouehe le trou avec le même fosset, ct au bout de trois jours on vide eneore le petitlait de la même manière que la première fois, et l'on jette à l'ćeart les bottes d'assaisonnements. Après quoi on ratisse sur le lait un peu de thym et d'origan secs, puis on y jette telle quantité que l'on juge à propos de poireaux qui se eoupent à différentes reprises, après les avoir hachés par moreeaux, en mêlant bien le tout ensemblje; et au bout de deux jours on vide encore le petit-lait et on bouche le trou. Enfin on y ajoute autant de sel égrugé qu'il est néeessaire, en mêlant encore bien le tout; puis on met un couverele sur le vase et on le bouche, pour ne l'ouvrir que lorsqu'on en aura besoin par la suite. II y a des personnes qui, après avoir cueilli l'herbe du passerage soit cultivé soit même sauvage, la font d'abord sécher à l'ombre; après quoi, lorsqu'elles ont fait tremper un jour et une nuit dans la saumure les fcuilles séparées des eôtcs et qu'elles les ont exprimées, elles les jettent dans le lait sans autre assaisonnement, en y ajoutant la quantité de sel qu'elles croient suffisante, et en observant pour le surplus ee que nous avons prescrit ci-dessus. D'autres mêlent dans un pot de terre des feuilles nouvelles de passerage avee du lait doux, et vident le petit-lait trois jours après, comme nous l'avons preserit; après quoi ils y ajoutent de la sarriette verte hachée par moreeaux, et même de la graino sèche de coriandre, d'aneth, de thym ct d'ache, le tout bien broyé ensemble, et mêlé avec du sel bien cuit et bien eriblé; après quoi ils observent pour le-surplus ce que nous avons dit ei-dessus.

IX. Il faut saler dans un bassin des tiges de laitue épluchée depuis le pied jusqu'à l'endroit où l'on s'aperçoit que les feuilles commencent a être tendres, et les y laisser un jour et une nuit, jusqu'à ee qu'clles dégorgent la saumure ; cnsuitc on les lavera dans eette saumure, et on les exposera sur des claies, après en avoil ex primé l'eau jusqu'à ee qu'elles solent séchées : eela fait, on mêlera ensemble de l'aneth see et du fenouil, avec un peu de rue et de poireau haclıé par morceaux, et l'on en fera un lit sur lequel on étendra ees tiges lorsqu'elles seront séehes, en les arrangeant de façon qu'elles soient séparées par des harieots verts entiers, que l'on aura fait préalablement tremper un jour et une nuit dans de la saumure forte. Lors done qque ces harieots sont séchés de mème, on les confit avec des bottes de laitue, en versant dessus une saumure eomposée de deux tiers de vinaigre et d'un tiers de saumure proprement dite, et en les ehargeant ensuite d'une poignée de fenouil see qui les retienne, de façon que la saumure remontc par-dessus. Pour la foreer de remonter et empêcher les herbes confites de se desséeher, la personne qui sera à la tête de cette besngne aura soin d'en verser souvent de nouvelle par-dessus la première. Elle essuiera aussi l'extérieur des vases avee une éponge propre, et les rafraichira avec de l'eau de fontaine nouvellement puisée. Il faut assaisonner la chicorée et les cimes de ronces, aussi bien que les tiges de thym, de sarriette, d'origan, et même eelles de grands raiforts, de la même manière que la laitue. Au reste, c'est au printemps que l'on fait ces sortes d'općrations.

$X$. Nous allons au contraire donner à présent des préceptes qui concernent les choses qu'il faut cueillir vers la moisson ou même après, pour les garder pendant l'été. Choisissez de l'oignon de Pompéi ou d'Asealon, ou même de l'oignon simple du pays des Marses, que les paysans appel-

remittant : deinde muria eluere, et expressos in cratibus pandere, dum assiccescant : tum substernere anethum aridum et focniculum rutæeque aliquid et porri concidere, atque ita miscere : tum siccatos coliculos ita componere, ut faseoli virides integri interponantur, quos ipsos ante dura muria die et nocte macerari oportebit, siniliterque assiccatos cum fasciculis lactucarum condi, et superfundi jus guod sit aceti duarum partium atque unius inuria : deinde arido spissamento foeniculi sic comprimi, ut jus supernatet. Qnod ut fiat, is qui luvic ofticio præerit, saepo suffundere jus debebit, nec pati sitire salgama, sed extriu. seeus munda spongia vasa pertergere, et aqua fontans quam recentissima refrigerare. Simili ratione intubun et cacumina rubi, qua lactucain condire oportet, nec miuns: tlıymi et satureia et origani tum etian armoraciorum ey. inam. Hæc autem, qua supra scripta sunt, verno tempore componuntur.

$X$. Nunc qua per æstatem circa messem vel efiau exactis jam messibus colligi et reponi debeant, praccipiemus. Pompeianam, vel Ascalonian cepam, vel etian Marsieam simplicen, quam rocant unionem ruslici, eligito : ea est antem, qua non finticavit, nec labuit soboles
IX. Conditura lactuca. Caules lactuca ab imo depurgatos eatenus, qua tenera folia videbuntur, in alveo salire oprortet, dienque nnum et noetem sinere, dum murian 
leut unio, c'est-à-dire, de eelui qui n'a pas monté en tiges et qui est sans eaieu. Faites-le d'abord séeher au soleil; ensuite, après qu'il aura été rafraichi à l’ombre, arrangez-le dans un llacon sur un lit de lliym ou d'origan; ct après avoir versé dessus une saumure composée de trois quarts de vinaigre et d'un quart de saumure proprement dite, couvrez-le d'une botte d'origan, de faẹon que l'oignon soit bien enfoncé : lorsque l'oignon se sera bien imbibé de cette saumure, vous remplirez le vase du même liquide. C'est dans le même temps que l'on eonfit les cormes, les prunes de couleur d'onyx et les prunelles, ainsi que les poires et les pommes de toute espèee. II faut eueillir les eormes dont on se sert pour confire les olives, ainsi que les prunelles et les prunes d'onyx, pendant qu'elles sont eneore dures et avant leur maturité parfaite, pourvu néanmoins qu'elles ne soient pas trop vertes. Ensuite on les fait sécher un jour à l'ombre, puis on mêle ensemble par parties égales du vinaigre et du vin cuit jusqu: à diminution des deux tiers ou de moitié, et on verse ce mélange dessus. Il faudra aussi y ajouter un peu de sel, pour qu'il ne s'y engendre point de vermisseaux ni d'autres animaux. On les eonservera eependant plus eommodément en mélant deux tiers de vin cuit jusqu'à diminution des deux tiers, avee un tiers de vinaigre. Lorsqu'on aura eueilli a vant leur maturité, sans cependant qu'elles soient absolument vertes, des poires de Dolabella et de Crustumium, des poires royales, des poires de Vénus, des poires volema, des poires de Nævius et de lateritius, de Déeimius, des poires laurea (qui sentent le laurier), des poires myrapia (des poires parfums) et des prunes pourprées, on examinera avee attention si elles sont saines, sans défaut et sans vers; ensuite on les arrangera dans un flacon de terre euite en-

adlıærentes. Hanc prius in sole siccato, deinde sub umbra refrigeratam substrato t!lymo vel cunila componito in fidelia, et infuso jure, quod sit aceti trium partium et unius muriæ, faseiculum cunilæ superponito, ita ut cepa deprimatur : qux cum jus combiberit, sinili mistura vas suppleatur. Eodem tempore corna, et pruna onyelina, et pruna silvestria, nee minus genera pirorum et malorum condiuntur. Corna, quibus pro olivis utamur; item pruna silvestria, et pruna onyelinaadhue solida nee maturissima legenda surt, nee tanen nimiım eruda. Deinde uno die umbra siceanda : tum æequis partibus acetum et sapa vel defrutum nisceatur et iufundatur. Oportebit autem aliquid salis adjicere, ne verıniculus aliudve animal innasci possit. Verum commodius servautur, si duæ partes sapæ eum aceti una parte misceantur. Pira Dolabelliana, Crustumina, regia, veneria, volema, Naviana, lateritiana, Decimiana, laurea, myrapia, [pruna] purpurea, eum immatura, uon tamen pereruda legeris, diligenter inspieito, ut sint integra sine vitio aut rermiculo : tum in fietili picata fidelia componito, et aut passo aut defruto duit de poix, que l'on remplira soit de vin fail avec des raisins séchés au soleil, soit de vin cuit jusqu'à diminution de moitié, de faccon que tout le fruit soit enfoneé dans la liqueur; après quoi on mettra dessus un couvercle que l'on cnduira de plâtre. Je crois devoir donner comme une maxime générale, qu'il n'y a point de fruit que l'on ne puisse eonserver dans du miel. C'est pourquoi eomme les fruits qui sont eonfits dans le miel sont quelquefois salutaires aux malades, je pense qu'il en faut conserver au moins quelques-uns de eette manière, pourvu cependant qu'on en mette à part les différentes espèces, parce que si elles étaient mêlées toutes ensemble, l'une gâterait l'autre. Et puisque eeci nous a donné l'occasion de faire mention du miel, nous ajouterons que e'est dans le même temps qu'il faut châtrer les ruches et faire le miel et la cire : mais, comme nous avons déjà parlè de cette matière dans le neuvième livre, nous ne demanderons à présent rien autre chose au métayer, si ee n'est qu'il ait soin d'assister à la eonfection du miel et de la eire, et de veiller à la conservation de ses fruits.

XI. Au reste, comme e'est dans le même temps que l'on doit serrer le miel ainsi que l'hy. dromel, dans la vue de les laisser vieillir, on se rappellera qu'il faut casser la eire en petits morceaux dès que le seeond miel aura été extrait des rayons, et la faire tremper dans de l'eau de fontaine ou de pluie; ensuite, après en avoir exprimé l'eau, il faudra la passer, la faire bouillir dans un vase de plomb, et la purger de toutes ses immondiees en l'écumant. Lorsqu'elle aura acquis par la cuisson l'épaisseur du vin cuit jusqu'à diminution de moitié, on la laissera refroidir, et on l'enfermera dans des flacons bien enduits de poix. On se sert de l'eau dans laquelle les rayons ont été trempés, en guise d'hydromel :

completo, ita ut omne pomum submersum sit, opereulum deinde impositum gypsato. Illud in totum pracipiendum existimavi, nullum esse genus pomi, guod nou possit melle servari. Itaque eum sit lixe res interdum agrotantibus salutaris, censeo vel pauea poma in melle eustodiri, sed separata generatim. Nam si eoinmisceas, alterum ab altero genere corrumpitur. Et quonianı opportune mellis fecimus mentionem, lioc eodem tempore alvi castranda, ae mel conficiendum, eera facienda est : de quibus nono libro janı diximus : nec nune aliam curam exigimus a villica, quam ut administrantibus intersit, fruetumque eustodiat.

XI. Cxterum cum eodem tempore mella nec minus aqua mulsa in vetustatem reponi debeat , meminisse oportehit, ut cum secundarium mel de favis fuerit exemptum, eeræ statim minute resolvantur, et aqua fontana rel cxlesti macerentur. Expressa deinde aqua coletur, et in vas plun. beum defusa decoquatur, omuisque spureitia eum spunis eximatur : quæ decoeta, eum tam erassa fuerit quam defrutum, refrigeretur, et bene picatis lagnenis eondalur. Hac quidanı mıclla pro aqua mulsa uluutır, nomnulli 
quelques personnes l'emploient aussi au lieu de vin cuit jusqu'à diminution de moitlé pour con. fire les olives; et je crois même qu'elle est plus propre que ce vin à cette destination, parce qu'clle a un goût plus nourrissant. D'ailleurs on ne peut pas la donner en remède aux malades au lieu d'hydromel, parce qu'elle engendre des vents dans l'estomac et dans les intestins de ceux qui en boivent.

XII. C'est pourquoi on mettra cette cau à part, et on la réservera pour s'en servír à eonfire les fruits; après quoi il faudra faire un hydromel particulier avec d'exeellent miel. Mais il y a plusieurs façons de le faire. En effet, quelques personnes renferment dans des vases, plusieurs années d'avanee, de l'eau de plule, qu'elles tiennent à l'air exposée au soleil : ensuite, après l'avoir souvent survidée dans d'autres vases pour l'éclaircir (paree que toutes les fois qu'on la transvase, le fitt-on même à différentes reprises pendant un très-long temps, on trouve toujours au fond $d u$ vase une matière épaisse semblable à de la lie), elles en mêlent un sextarius avec une livre de miel. Il y a eependant des personnes qui, pour donner à l'hydromel un goût plus âpre, ne délayent dans un sextarius d'eau que neuf uncice de miel : ces mêmes personnes, après a voir rempli un flacon de eet hydromel ainsi composé et l'avoir enduit de plâtre, le laissent quarante jours au soleil pendant le lever de la Canicule, et ne le mettent qu'au bout de ce temps sul' un plancher où la fumée puisse parvenir. D'autres, qui n'ont pas pris la préeaution de faire vieillir de l'eau de pluie, en prennent de nouvelle qu'ils font bouillir jusqu’à diminution des trois quarts; ensuitc, lorsqu'elle est refroidie, ils y mettent un sextarius de miel sur deux

etiam pro defruto in condituras olivarum; quibus quidem ulagis jdonean censeo, quod cibarium saporem labet, uec potest languentilus pro aqua mulsa remedio esse : ynoniam si bibatur, inflationeın stomachi et precordiorum ficit. Itaque seposita ea et ad condituras destinata, per se facienda erit optimo melle aqua mulsa.

XII. Haec autem non unomodo componitur. Nam quidam multos ante annos caclestenn aquam vasis includunt, et sub dio in sole habent : deinde cum sxpius eam in alia vasa transfudcrunt et eliquaverunt (uam quoties ayua unst longun tempus diffunditur, aliquod crassamentum in imo simile feci reperitur) veteris aqua sextarium cum libra mellis miscent. Nonnulli tamen qui austeriorcın volunt efficere gustum, sextarium aqux cum dodrante pondo mellis diluunt, et ea portionc repletain lagrenain gypsatamque patiuntur per Caniculæ ortmn in solc qua. Iraginta dielus esse; tum demum in tabulatum, quod fumum accipit, reponunt. Nonnulli, quibus non fuit cura calestem invelerare aquam, recentem sumunt, eamque usque in quartam partem decoquunt : deinde cum refrixe. rit, sive dulciorem mulsam facere volunt, duolııs a(quxe sextariis sextarium mellis permiscent : sive austeriorcm, sextarii d'eau, s'ils veulent faire de l'hydromel bien doux ; ou neuf uncia de miel sur un sextarius d'eau, s'ils veulent le faire plus âpre au goût. L'hydromel fait avec ees ingrédients est versé dans un flacon et exposé au soleil pendant quarantc jours, eomme je viens de dire, puis placé sur un plancher à la portée de la fumée.

XIII. Le temps le plus propre à faire du fromage pour la consommatlon de la maison, est celui où le fromage rend le moins de petit-lait, ainsi que le temps de l'arrière-saison où il n'y a plus guèrc de lait, et où par eonséquent on ne trouverait pas son profit à perdre inutilement des journées pour porter ee genre de fruit au marehé, puisque cffeetivement il arrive souvent qu'en y portant des fromages pendant la chaleur, ils s'aigrissent et se gâtent. Aussi est-ee le temps où il vaut mieux en faire pour son usage. Au reste, le soin de bien faire le fromage concerne le berger, auquel nous avons donné dans le sep. tième livre les préeeptes qu'il doit suivre à eet effet. Il y a aussi des herbes que l'on peut eonfirc à l'approche de la vendange, telles que le pourpier, et la plante potagère de l'arrière-saison, à laquelle quelques personnes donnent le nom de bassille (battis). On épluehe donc avee soin ees herbes, et on les étend à l'ombre; ensuite au bout de quatre jours on les arrange ehaeune séparément sur un lit de sel posé au fond des flacons; et après les avoir arrosées de vinaigre, on remet une couche de sel par-dessus, attendu que la saumure n'est pas bonne pour les herbes de eette espèce.

XIV. C'est dans le même temps, ou même au eommencement du mols d'août, que l'on cueille les pommes et les poires les plus agrćables au goût, dans le temps qu'elles ne sont en- sextario aqua dodrantem mellis adjiciunt, et lis portionibus factam in lagonam diffundunt : eamque, sicut supra dixi, quadragin ta diebus insolatam postea in tabulatım, quod suffumigatur, reponunt.

XIII. Caseo usibus domesticis prapparando lıoc maxime idoneum tempus est, quod et caseus seti minimun remittit : et ultimo tempore, cum jam exiguun lactis est, non tam expedit opcras morari ad forum fructibus deferendis : et sane sxepe deportati per astum acore vitiantur. Itaque praestat eos loc ipso tcmpore in usum conficcre. Id antem ut quan optime fiat opilionis officinm est, cui scptimo libro pracepta dcdiınus, quæ scqui dcleat. Sunt etiam quædam lıcrbæ, quas appropinenante vindemia condire possis, ut portulaca, et olus cordum, quod quidam [sativam] battim vocant. Hx herbx diligenter purgantur, et sub umbra expanduntur : deinde (1uarto die sal in fundis fideliarum substernitur, et separatim unaqureque earum componitur, acetogue infuso itcrum sal superponi. lur : nam lis herbis muria non convenit.

XIV. Hoc eodem tempore, vel etiam primo mense Augusto, mala et pira dulcissinj saporis mediocriter matura eliguntur, et in duas vel tres partes arundine vel 
core que médiocrement nûres, et qu'après les avoir coupées en deux ou trois morceaux avec un roseau ou avec un petit couteau d'os, on les met au soleil jusqu'à ce qu’elles soient séchées. Si l'on en a unc forte quantité, elles feront en grande partic la nourriture des paysans pendant l'hiver, cn lcur tenant lieu de bonne chère : il en est de même des figues, qui, étant serrées lorsqu'elles sont sèches, aident à les nour'rir dans le même temps.

XV. Il faut pour cela choisil la figue dans le temps où elle n'est ni trop mûre ni trop verte, et l'ćtendre dans un lieu où le soleil donne toute la journée. On enfonce à cet effet des pieux en terre à la distance de quatre pieds les uns des autres, et on les assemble cn forme de jougs avec des perches. On couvre ensuite ces jougs de roseaux travaillés exprès, que l'on éloigne de dcux pieds de terre, afin que les figues nc puissent pas attirer l'humidité que la terre rend communément pebdant la nuit; après quoi on arrange les figues sur ces roseaux, et l'on étend à terre, de droite et de gauche, des claies de berger tissues de chaume, de lèche ou de fougère, que l'on puisse relever quand le soleil se couchera, afin qu'ćtant rabattucs l'une sur l'autre ell forme de voûte comme les chaumières, elles préservent les figues, pendant qu'elles sèchent, de la roséc et quelquefois même de la pluie, qui gâtent l'une et l'autre cette espèce de fruit. Lorsqu'ensuite ces figues seront sèches, il faudra les renfermer, pendant qu'elles seront encore chaudes, dans des vaisseaux bien enduits de poix, et les y fouler avec soin pendant les chaleurs du midi, en prenant néanmoins la précaution détendre sous elles un lit de fenouil sec, et de les recouvrir d'un pareil lit lorsque les vases seront pleins. On couvrira sur-le-charnp ces vases ct on les bouchera; puis on les mettra dans

osseo cliltello divisa in sole ponuntur, donec arescant. Eorum si est multitudo, non minimam partem cibariorum per liemem rusticis vindicant. Nam pro pulmentario cedit, sicuti ficus, quæ cum arida seposita est, liemis temporibus rusticorum cibaria adjuvat.

$X V$. Ea porru neque nimium vieta neque immatura legi debet, et in eo loco expandi, qui toto die solem accipiat. Pali autem quatuor pedibus inter se distantes figuntur, et perticis jugantur. Facto deinde in lıuc usum cannæ jugis superponuntur, ita ut duobus pedibns absint a terra, ne lumorem, quem fere noctibus remittit humus, traliere possint : tunc ficus injicitur, et crates pastorales culmo vel carice vel filice textac $\mathrm{cx}$ utroyue latere super terram planæe disponuntur, ut cum sol in occasu fuerit, erigantur, et inter se acclines testudineato tecto nore tuguriorum virescentem ficum a rore, et interdum a pluvia defendant. Nam utraque res predictum fructum corrumpit. Cum deinde aruerit, in orcas bene picatas meridiano tepore calentem ficum conlere et calcare diligenter oportebit, subjecto tamen arido funiculo, et iterum vasis repletis superposito: un grenier très-sec, afiu que les figues se con. servent mieux et plus longtemps. Il y a des per. sonnes qui arrachent la queue des figues après les a voir cueillies, et qui les étendent au soleil; ensuite, lorsqu'elles sont tant soit peu séchées, elles les entassent dans des bassins de terre cuitc ou de pierre, avant qu'clles soient durcies; puis après s'être lavé les pieds, elles les foulent comme on foule la farine, en y mêlant du sesame grillé avec de l'anis d'Égypte, et de la graine tant de fenouil que de cumin. Quand elles ont bien foulé ces ingrédients aux pieds, et qu'elles n'en ont fait qu'une masse avec les figues déjà pulvérisées, elles en font des pâtes de moyenne grosscur qu'elles enveloppent dans des feuilles de figuier; et après les avoir liées avec du jonc ou avec toute autre herbe, elles les mettent sur des claies pour les faire sćcher. Enfin, lorsque ces figues sont bieu sèehes, elles les enferment dans des vases enduits de poix. D'autres renferment la pâte méme de ces tigues dans des vais. seaux sans poix, et, après les avoir bouchés, ils la font sécher sous une tourtière ou dans un four, afin que toute son humiditć se ressuie plus promptement; et lorsqu'elle est sèche, ils la mettent sur un plancher. Mais quand ils veulent s'en servir, ils sont obligés de casser le vase de terre cuitc, attendu que lorsque la pâte des figues est une fois durcie, ils ne pourraient pas l'en retirer autrement. D'autres choisissent les figues les plus grasses dans le temps qu'elles sont vertes, et les étendent au soleil pour les faire sćcher, après les avoir ouvertès avec un roseau ou avec les doigts. Lorsqu'elles sont bien sèches, ils les ramassent pendant la chaleur du midi, parce que c'est le temps où l'ardeur du soleil les ramollit; et après leś avoir arrangées les unes auprès des autres, ils les pressent conformément à l'usage des Africains et des Espagnols, pour

quxe vasa confestim operculare, et oblinire convenit, et in horreum siccissimum reponi, quo melius ficus perennet. Quidam lectis ficis pediculos adimunt, et in sole eas expandunt : cum deinde paulum siccata sunt, antequam indurescaut, in labra fictilia vel lapidea congerunt eas : tumn pedibus lotis in modum farine proculcant, et admis. cent torrefacta sesama cum aniso Ægyptio et semine fo. niculi et cymini. Ilæc cum bene proculcaverint, et totam massam comminutæe fici perıniscuerint, modicas offas foliis ficulneis involvunt, ac religatas junco vel qualibet lierba offas reponunt in crates, et patiuntur siccari : deinde cun peraruerunt, picatis vasis eas condunt. Nonuulli tıane ipsam farinam fici orcis sine pice includunt, et oblita vasa clibano vel furno torrefaciunt, quo celerius onnis humor excoquatur : siccatam in tabulatum reponunt, et cuu exegerit usus, testam couminuunt : nam duratam massam fici aliter exiınere non possunt. Alii pinguissimaın quamque virideın ficorum eligunt, et arvindine vel digitis divisam dilalant, atque ita in sole viescere patiuntur, quas deinde bene siccatas meridianis teporibus, cum calore solis 
leur fairc prendre la forme d'une étoile ou celle d'une petite fleur, ou la figure d'un pain; après quoi ils les font de nouveau sécher au soleil, ct les serrent ensuite dans des vases.

XVI. Le raisin demande les mêmes soins. II en faut cueillir de bianc, qui ait le goût très. agréabio et dont les grains soient très-gros et peu serrés, quand la lune sera dans son déclin, et par un temps serein et sec, après la cinquième heure du jour ; ensuite on l'étendra pendant quelque temps sur des tablettes, de façon que les grappes ne sc froissent point les unes contre les autres en se comprimant par leur propre poids; après quoi il faudra faire chauffer dans une chaudière, ou daus unc grande marmite neuve de terre cuite, une lessive préparée arec de la cendre do sarment. Lorsqu'elic sera bouiliante, on y versera un peu d'huile, de la meilieure qualité que fairc se pourra, et on mêlera le tout ensemble; après cela on jettcra dans la chaudière bouiliante des grappes de raisin liées ensemble au nombre de deux ou trois, seion qu'elies seront plus ou moins grosses; et on les y iaissera quelque temps jusqu'à ce qu'elles aient changé de couleur, sans leur donner cependant le temps de cuire, mais en usant de quelque modération et en prenant un certain milieu. Quand on les aura retirées, on ies arrangera sur une claie, en les éloignant assez l'une de l'autre pour qu'elles ne se touchent point mutuellement. Trois heures après, on les retournera lune après l'autre, en évitant de ies remettre à la place qu'elles occupaient d'abord, le peur qu'eiles ne se gâtent en séjournant dans l'cau qu'elles auront rendue. Il faut même les couvrir pendant la nuit comme les figues, afin qu'eiles soient à l'abri de la rosée et de la pluie. Lorsqu'elles seront tant soit peu séchées, on les

emollitæ sunt, colligunt, et, ut est mos Afris atque Hispanis, inter se compositas comprimunt in figuram stellarum flosculorumque, vel in formam panis redigentes: tum rursus in sole assiccant, et ita in vasis recondunt.

XVI. Similem curan uvæ desiderant, quas dulcissimi saporis albas, maximis acinis, nec spissis, luna decrescente, sereno et sicco exlo post lioram quintam legi opor. tet, et in tabulis paulisper porrigi, ne inter se pondere suo pressæe collidautur : deinde alieno rel in olla nora fictili ampla præparatam lixiviam cineris sarmenti calefieri convenit; quie cum fervebit, exiguum olei quam optimi adjici, et ita permisceri : deinde uvas pro inagnitudine binas, vel ternas inter se colligatas in alıeuum fervens de. nitti, et exiguum pati, dum decolorentur; nec rursus committere ut excoquantur : nam quadam moderatione temperamentoque opus est. Cum deinde exemeris, in crate disponito rarius quam ut alteraalteram contingat. Post tres deinde horas unamquamque uvam convertito, nec in eodem vestigio reponito, ne in lumore, qui defluxerit, corrumpatur : noetibus autem contegi debent quemadmodum fiei, Itt a rore vel pluvia tutie siut. Cum deinde modice aruerint, In vașa nova sine pice operculata et mettra dans un licı sec, renfermées dans des vaisseaux ncufs et sans poix, avec un couvercle enduit de plátre. Il y a des personnes qui enveloppent le raisin dans des feuilles de figuier pour le faire sécher ; d'autres couvrent les grappes, lorsqu'elies sont à demi-flétries, de feuilies de vigne, et d'autres encore de feuilies de piatane, avant de les serrer dans des amphores. Ii y en a qui brû. lent de la paille de fèves, et qui font une lessive avec la cendre qui en résuite; après quoi is mettent sur dix sextarii de cettelessive trois cyathi de sel et un d'huile, puis ils ia font bouillir, et achèvent l'opération de la manière que nous avons indiquée. Si l'on s'aperçoit qu'il y ait trop peu d'huile daus la chaudière, on en ajoutc de temps en temps ce qu'il en faut pour rendre le raisin plus gras et plus luisant. Mettez dans le même temps des cormes cueillies à la main et bien choisies dans de petites cruches enduites de poix avec des couvercles enduits de même, et bouchez-les avec du plâtre; ensuite enfonccz-les dans des fosses de deux pieds creusées à la maison dans un lieu sec, de façon que l'ouverture de ces eruches, qui seront par conséquent bien bouchées, soit renversée; enfin chargez-les de terre que vous fouierez légèrement aux pieds. Au reste, il vaudra mieux multiplier le nombre des fosses, que d'enterrer piusieurs vases à la fois dans ia même; ce qu'on ne fera pas sans les éloigner ies uns des autres, parce que s'il arrivait que, pour en oter un, on en remuât d'autres, les cormes ne tarderaient pas à se gâter. Quelques personnes conservent aussi très-bien ce fruit daus du vin cuit jusqu’à diminution de moitié, en y ajoutant une bonne poignée de fenouil sec pour l'enfoncer dans les vases, de façon que le liquide ne cesse pas de le couvrir; ce qui n'empêche pas

gypsata sicco loco reponito. Quídam uvam passam foliis ficulneis involvunt et assiccant : alii foliis ritigineis, nollnulli plataninis semivietas uras contegunt, et ita in amphoras recondunt. Sunt qui eulmos fabæ exurant, et ex eo, quod cremaverint, cinercam lixiviam faciant, deinde in lixivia sextarios decem salis tres eyathos et olei cyatlum adjiciant, tum adlibito igne calefaciant, et coetera eodem modo adrninistrent. Quod si videbitur in aleno parum inesse olei, subinde quantum satis erit adjicialur, quo sit pinguior et nitidior uva passa. Eodem tempore sorba manu leeta curiose in urceolos picatos adjieito, et opercula picata imponito, et gypso linito, tum scrobibus bipedaneis sicco loco intra tectum ractis, urceolos ita collocato, ut oblita ora eorum deorsum spectent : deinde terram congerito, et modice desuper calcalo. Melius est autem pluribus scrobibus pauciora vasa distantia inter se disponere. Nam in exemptione corum dum unum tollis, si reliqua comnoveris, celeriter sorba vitiantur. Quidam hoc idem ponuu in passo, quidam etiam in defruto commode servant, ad. jeclo spissamento aridi focnieuli, quo deprimantur ita sorba, ut semper jus supernatet, ac nililominus pirata opercula diligenter gypso linunt, ne possit spiritus introire. 
qu'on n'en bouehe soigneusement avee du plâtre les eouvereles qui seront enduits de poix, afin que l'air ne puisse pas y pénétrer.

XVII. Il y a tel pays où le vin manque, et où par eonséquent on ne peut pas faire de vinaigre. Il faut done eueillir au même temps dans ees pays-là des figues vertes très-mûres, ou même ramasser eelles que les pluies auront fait tomber, au eas que les pluies soient déjà venues; et après les avoir ramassées, on les serrera dans des futailles ou dans des amphores, où on les linissera fermenter; lorsqu'elles seront aigries et (p'elles auront rendu leur eau, on passera avee soin tout ee qui s'y trouvera de vinaigre, et on le versera dans des vases qui sentent bien la poix dont ils auront été enduits. Cette liqueur tient lieu d'un bon vinaigre de première qualité, qui ne contracte jamais de relent ni de molsissure, pourvu qu'on ne le scrre pas dans un lieu humide. Quelques personnes, qui visent plus à la quantité qu'à la qualité du vinaigre, versent de l'eau sur les figues, et en remettent de temps en temps de nouvelles très-mûres, qu'ils laissent se consumer avee les autres dans le même jus, jusqu'à ee que ee jus ait aequis le goût d'un vinaigre assez mordant; après quoi ils le passent dans de petiis paniers de jone ou dans des saes de genêt d'Espagne, et le font botillir ensuite, jusqu'à ce qu'il ne jette plus d'éeume et qu'il ne s'y trouve plus d'immondices; puis ils y ajoutent un peu de sel grrillé, pour l'empêeher d'engendrer des vers ou d'autres animaux.

XVIII. Quoique nous ayons déjà dit dans le livre préeédent, intitulé le Mélayer, ce qu'il faut préparer pour la vendange, il n'est pas eependant hors de propos de donner aussi à la métayère des préeeptes sur la même matière, afin qu'elle n’ignore point que toutes les choses rela-

XVII. Sunt quaedam regiones, in quibus vini ideoque eliam aceti penuria est. Itaque lioc eodem tempore ficus virldis quam maturissina legenda est, utique si jam pluviæ incesserunt, et propter imbres in terran decidit : quæ cum sublecta est, in dolium vel in amploras conditur, et ibi sinitur fermentari : deinde cum exacuit, et remisit liquorem, quicquid est aceti diligenter colatur, et in vasa picata bene olida diffunditur. Hoc prima nota acerrimi aceti usum prælset, uec unquau situm aut mucorem contrahit, si non hunido loco positun est. Sunt qui multifudiui studeutes aquan ficis permisceant; et subinde uaturissimas ficus recentes aljiciant, et patiantur in eo jure talescere, donec satis acris aceti sapor fat : postea in junceis fiscellis vel sparteis saccis percolant, liquatumque acetum iufervefaciunt, dum spunam et omnem spurcitiam eximant : tum torridi salis aliquicl adjiciunt, quae res prohibet vermiculos aliave innasci auimalia.

XVIII. Quanvis priore libro, qui inscribitur Villicus, jam diximus quae ad vindemiam praparanda sıut, non tamen alienum est etiam villica de iistem rebus pracirere, ut intelligat sux curæ esse debere, quxecunque sub tives à la vendange, qui doivent se faire à la malson, sont de son ressort. Si l'on possède une ter're d'une grande étendue, et que l'on ait des vigno. bles ou des plants d'arbies mariés à des vignes considérables, il faut fabriquer continuellement, pendant tout le eourant de l'année, des vaisseaux dont les uns eontiennent dix modii, et les autres trois, faire de petits paniers et les poisser : il faut aussi préparer un très-grand nombre de faueilles et de serpettes, et les aiguiser, afin que les vendangeurs n'arrachent point les grappes avee la main, ee qui ferait tomber à terre une grande partie du fruit, attendu que les grains se détacheraient alors de la grappe : il faut eneore attacher des eordes aux paniers, et des courroies aux vaisseaux qui eontiennent trois modii. Ensuite on lavera les euves dans lesquelles on foule le vin, les fosses où il doit couler à la sortic du pressoir, les aires des pressoirs et tous les vases, avee de l'eau de mer, si la mer n'est pas éloignée; sinon, avee de l'eau douee : puis on les essuiera et on les fera bien sécher, jusqu'à ee qu'il n'y reste plus d'humidité. Il faut eneore bien balayer toutes les ordures dans la eave au vin, et la parfumer de bonnes odeurs, afin d'en éearter toutes les mauvaises, et de l'empêeher de sentir l'aigre. On fera aussi très-pieusement et très-chastement des saerifiees en l'honneur de Liber, de Libera, et des instruments du pressoir. On ne s'éeartera pas, dans le temps de la vendange, du pressoir ni de la cave au vin, tant afin que eeux qui font le moût le fassent purement et proprement, qu'afin que les voleurs ne trouvent pas l'oceasion de dérober le fruit dans l'un ou l'autre de ces endroits. Il faut aussi poisser les futailles, ainsi que les vaisseaux et tous les autres vases, quarante jours avant la vendange. Au reste, ceux qui sont enfoncés en terre se poissent

tecto adninistrantur circa vindemiam. Si ager amplus, ant vineta aut arbusta grandia sunt, perenne fabricandxe decemmodix et trimodix et fiscelle texendæ et picand $x$ : nec minus falculæ, et ungues ferrei quamplurimi parandi et exacuendi sunt, ue vindemiator mann destringat nvas, et non minima fructus portio dispersis acinis in terram dilabatur. Funiculi quoque fiscellis aptandi sunt, et lora trinıdiis : tum lacus vinarii et torcularii el fora omnia. que vasa, si vicinum est mare, aqua marina, si minus, dulci eluenda sunt, et comnundanda, et diligenter assiccanda, he lıumorem habeant. Cella quoque vinaria omui stercore liberanda, et bonis odoribus suffienda, ne quem redoleat fotorem acoremve. Tım sacrificia Libero Liberæque et vasis pressoriis quam sanctissime castissimeque ficieuda : nec per vindemiam ab torculari ant vinaria cella recelendum est, ut omnia, qui mustum conficiunt, purc mundeque faciaut; nec furi locus detur partem fructuum intercipiendi. Dolia quoque et seria cateraque rasa ante quadragesimum vindemiæe diem picanda sunt, atque aliter ea qux demersa sunt humi, aliter qux stant supra terram. Nan ea quae demersa sunt, ferreis lampadibus ar- 
autrement que ceux qui sont à rez terre. En cifet, on ćeliauffe les vases qui sont enfoncés en terre avee des lampes de fer allumées; et quand on a fait eouler, à l'aide d'une de ces lampes, de la poix au fond du vase, on retirc la lampe; après quoi on promène dans toute la eapacité du vase la poix quon y a fait distiller, en détachant eelle qui tient à ses parois avec un lable de bois et une ratissoire de fer eourbée; ensuite on nettoic le vase avec un torehon, et on y verse de nouveau de la poix bien bouillante, pour l'en enduire a vee un autre rable et un balai. Quant aux vases qui sont à rez terre, on les expose au soleil plusieurs jours avant de les poisser; ct quand ils ont été suffisamment essorés, on les retourne pour les placer sur leur ouverture, de façon néanmoins qu'ils soieut suspendus en l'air à l'aide de trois petites pierres sur lesquelles is seront posés ; ensuite on allume du feu par-dessous, et on le laisse brûler le temps nécessaire pour que la chalcur pénètre au fond du vase, au point de ne pouvoir pas être supportée si l'on y mettait la main. Enfin, ou renverse la futaille à terre en la couchant sur le eôté, puis on y verse de la poix très-bouillante, $c t$ on finit par la roulcr, afin qu'elle en soit enduite dans toutes ses parties. Mais il faut faire cette opération un jour où il ne fasse pas de vent, de peur que les vases ne viennent à se casser, au cas que le vent donne dessus lorsque le feu sera altumé. Au reste, il suffit de vingt-eing livres de poix dure pour enduire des futailles de la contenance d'un culleus et demi; et il est constant qu'en ajoutant au total de la poix qu'on fera cuire un cinquième de poix tirce du pays des Brutii, il en résultera un très-grand avantage pour tuute la vendange quon mettra par la suite clans ces futailles.

X1X. II faut aussi se domner des soins pour que le moût qu'aura rendu le raisin soit de longue

dentilus calefunt, et cum pix imum in fundum destillavit, sublata lampade, rutabulo ligneo el ferrea curvata radula ducitur, quod destillavit, aut quorl in lateribus lıesit : deinde peuicillo detergitur, et ferventissima pice infusa novo alio rutabulo et scopula picatur. At qua supra terram consistunt, couplures dies antequam cureutur in solem producuntur. Deinde cmm satis insolata sunt, in labra convertuntur, et subjectis parvis tribus lapidibus suspeuduntur, atque ita ignis subjicitur, et tamdiu incenditur, donec ad fundum calor tam velıemens perveniat, ut apposita manus jatiens rjus non sit : tum dolio in terram demisso, et in latus deposito, pix ferventissima infunditur, volıtaturque, ut omnes dolii partes linantur. Sed laa c die quicto a veutis fieri debent, ne adınoto igrne cum allia verit ventus vasa rumpantur. Sunt auten satis sesfuuicullearibus doliis picis durac pondo vicenaquina. Nec dubium, quin si quinta pars picis brutiae iu universam cocturam adjiciatur, utilissimum sit omni vindemix.

XIX. Cura quoque adlibenda est, nt expressum mustuin percune sit, aut certe usque ad venditionem durabile. coluxen. garde, ou du moins pour (qu'il se conserve jusqu’à la vente. Nous allons exposer tout de suite la manière dont il faut s'y prendıc pour y parvenir, et nous montrerons les assaisonuements auxquels il faut avoir rceours à eet effet. Quelques persounes réduisent le moût, en le faisant cuire daus des vases de plomb, les uns aux trois quarts, les autres aux deux tiers; mais il est constant qu'en le réduisant à moitié on aura de meilleur vin euit, et que ce vin sela par conséquent plus utile pour les usages auxquels il est destiné : cela est même si constant, que, pour fi'clater le moût, on peut se servir de ee vin cuit jusqu'à diminution de moitié, au lieu de vin euit jusqu'à diminution des deux tiers, pourvu qu'il provienne de vignes aneiennes. Nous regardons comme le vin de la première qualité celui qui n'a pas besoin d'être frelaté pour durer longtemps; et nous croyons qu'il ne faut absolument y mettre aucune mixtion qui puisse en altérer le goût naturel, paree que ee qui peut plaire sans le seeours de l'art est supérieur à tont. Mais quand le moût aura quelque mauvaise qualité, soitque eette qualité provienne du vice du terroir, soit qu'elle provienne de la jeunesse des vignes, il faudra choisir, pour en faire du viu euit, un canton de vignes Aminées, si l'on est a portée d'en avoir; sinon, de vignes extrêmement vieilles qui donnent un vin agréable, et qui ne soient point plantées dans un terroir humide. Ensuite on observera' le temps du déclin où la lune sera sous terre, et on cueillera alors par un jour sec et serein les grappes les plus múres de ecs vignes, et après les avoir foulées, on puisera dans la cuve le vin de mère-goutte, pour en remplir les vases qui servent à faire le vin euit; ensuite on allumera le feu au fourneau, mais en observant de ne le faire d'abord et de ne l'entretenir qu'avec ces meuus bois que les paysans appellent cremia, afin que le moût bouille à lolsir. Celui qui

Quod quemadmodım fieri debeat, et quibus condituris adjuvari, deiuceps subjiciemus. Quidam partem y juartam cjus musti, quod in vasa plumbea coujecerunt, uonnulli tertiam decoquınt. Nec dubium, quin ad dimidiun si quis excoxerit, melioren sapam facturus sit, coque usibus utiliorem, adeo quidem, ut etian vice defruti, sapa, mustum, quod est ex veteribus vineis, condire possit. Quæcinque vini nota sine condimento valet perennari, optimaın esse eam censeluus, nec omnino quidquam permiscendum, quo uaturalis sapor cjus iufuscetur. Id enim prostantissimum est, quod suapte natura placere poterit. Creterum cum ant regionis vitio, ant novellarum vinearum mustum laborabit, eligetula erit pars vinex, si est facultas, Aminea, si minus, quam bellissiul vini, quaeque erit tet vetustissima et ninime uliginosa. Tum observabimus decresceutem lunam, cum est sub terra, et sereno siccorguedic uras quam maturissimas legemus, quibus proculcatis mustum quod defluxerit, ante quam prelo pes eximatur, satis de lacu in vasa defrutaria deferemus, lenique primun: inne of teutibus admolum lignis, quxe cremia rustici ap- 
prósidera à cette cuisson aura sous sa main des couloires de jone ou de genêt d'Espagne eru, c'sst-à-dire qui n'ait pas été battu, ainsi que des battons garnis par le bout de poignées de fenouil, avec lesquels il puisse parvenir jusqu'au fond des vases, ì l'effet de remuer toute la lie qui s'y déposera, de la faire remonter à la superfieie des vases, ct d'oter ensuite avec les couloires toutes les immondiecs qui s'y présenteront sur leurs bords; opération qu'il ne eessera pas de faire jusqu'à ce qu'il s'aperçoive que le moût, à foree de s'éelaireir, est absolument sans lie. Alors il y mettra des coings, qu'il en relirera lorsqu'ils seront bien cuits, ou des odeurs convenables qu'il choisira à son gré, sans cesser de remuer le vin de temps en temps avec des bâtons garnis de fenouil, de peur que quelque ehose ne s'attache au fond du vase de plomb, ee qui pourrait le faire crever. 1.orsqu'ensuite le vase pourra supporter un feu plus ardent, c'est-à-dire, lorsque le moût sera léjà cuit en partie et qu'il bouillira intérieurement, il mettra par-dessous des bủehes et de plus gros bois qu'auparavant, de façon nćanmoins que ce bois ne touche point le cul du vase, paree qu'autrement il arriverait que le vase lui-même erèvelait, ce qui n'est pas sans ex emple, ou qu'au moins le moût brûlerait indubitablement, et contracterait dès lors une amertume qui l'empêcherait d'ĉtre d'aucune utilité pour les choses auxquelles il doit servir. Au surplus, a vant de verser le moût dans les vases de plomb dont on se sert pour faire cuire le vin, il faudra les imbiber eux-mêmes intéricurement de bonne huile, et les en bien frotter. Cette préeaution empêchera le vin cuit de brûler.

XX. Néanmoins, telle précaution que l'on ait prlse en faisant le vin cuit, il arrive souvent (qu'il s'aigrit comme le vin. Souvenons-nous en pareil cas de le frelater avee du vin cuit depuis un an, et dont la bonté ait déjà été éprouvée, paree qu'un mauvais correctif ne pouriait que gáter le fruit de la récolte. Quant aux vases dans lesquels on fait cuire le vin jusqu'à diminution des deux tiers ou de moitié, ils doivent plutôt être de plomb que de cuivre, paree que le vertde-gris se détache de ces derniers dans la cuisson, et qu'ils corrompent eux-mêmes le goût des drogues qui entrent dans cette composition. Au surplus, les parfums que l'on fait cuire le plus communément avec le vin sont l'iris, le fenugrec, rt la racine de jonc. II faut jeter une livre de chaeune de ecs plantes dans un vase dans lequel on aura fait cuire quatre-vingt-dix amphores de moût, après que ce moût aura cessé de bouillir et qu'il sera purifié. Ensuite, si le moût est d'une nature légère, il faudra, lorsqu'il sera cuit jusqu'à diminution des deux tiers, retirer le feu du fourueau, et le rafraichir aussitôt en jetant de l'eau dessus. Il est vrai qu'en suivant cettc pratique, lorsque le vin cuit sera reposé, il se trollvera au-dessous du tiers même du vase; mais malgré ee déchet on y gagnera, en ce que plus il sera euit (pourvu toutefois qu'il ne soit pas brûlé), plusil sera exeellent et épais. En effet, il suffira, pour frelater du vin, de mettre sur eliaque anphore un sextarius d'un vin cuit de la sorte. Au reste, si l'on fait cuire dans un vase la valeur de quatre-vingt-dix amphores de moût, on n'y mettra les drogues qu'au moment où il sera presque cuit jusqu'à diminution des deux tiers. Or ces drogues seront ou liquides ou résineuses, e'est-àdire qu'elles consisteront en dix sextarii de poix pellant, fornacem inccudemus, ut ex commodo mustım ferveat. Isque qui praeerit huic decoquendo, cola juncea vel spartea sed crudo, id est non nalleato sparto proparata lrabeat : itemque fasciculos furniculi fustibus illigatos, quos jossit usque ad fundum vasorum demittere, ut quid. ynid fecis subsererit, exagitet et in summun redncat : tum colis omnem spurcitian, qua redundarit, expurget. Nec absistat id facere, doncc videbitur eliquatum omni fece mustım carere. Tum sive mala cydonia, quæ percocta sublaturus sit, seu q̨noscunque voluerit convenientes olores adjiciat, et nihilo minus subinde fueniculo peragitet, nẹuid subsederit, quod possit plumbeum perforare. Cum deinde jam acriorem potuerit ignem vas sustiuere, id est, cum aliqua jam parte mustun excoctum in se fervebit, tum codices et vastiora ligna subjiciantur, sed ita ne fundum contingant. Quod nisi vitatum fnerit, sape vas ipsum, [quod aliquanilo contingit,] pertundetur; vel si is factun uon erit, utique aduretur mustum, et amaritudine concepta condituris fiet inutile. Oportebit autem autequam mustum in vasa defrutaria conjiciatur, oleo bono plumbea intriusecus imbui, et bene fricari, atque ita nurstun arljici. Ea res non patitur defrutum aduri.

XX. Quinetian diligenter factum defrutum, sicut ri. num, solet acescere : quod cum ita sit, meminerimus anuiculo defruto, cujus jam bonitas explorata est, vinum condire. Nam vitioso medicamine fructıs, qui perceptus est, vitiatur. Ijsa autem vasa, quibus sapa ant defrutum coquitur, plumbea potius quan anea esse debent. Nam in coctura aruginen remittunt æenea, et medicaminis sa. jorem vitiant. Odores auten vino fere apti sunt, qui cum defruto coquuntur, iris, foenum Gracum, schœnum : harum reruin singulæe libræ in defrutarium, quod ceperit musti amplooras nonaginta, cum jam deferbuerit, et ex. purgatum erit, tnm adjici debent. Deinde si natura tenne mustum eit, cum ad terliam partem fuerit decoctum, ignis subtrahendus est, et fornax protinus aqua refrigeranda. Quod etiam si fecerimus, n iliilo ninus defrutum infra tertiam partem vasis considit. Sed id quamvis aliquid detrimenti luabeat, prodest tamen : nam quanto plus deco quitur (si modo non est adustum) melius et spissius fit. Ex loc autem defruto, quod sic erit coctum, satis est singulos sextarios singulis amphoris immiscere. Cum amplioras musti nonaginta in defrutario decoxeris, ita ut jam exiguum supersit de coctura [quod significat decoctum ad tertias ] : tum demum medicamina adjicito, qua sint aut liquida, ant resinosa, id est, picis liquida Nemeturica, 
liquide tirée du pays des Nemeturici, que l'on anua délaycie auparavant avee soin dans de l'eau de mer euite, ou en une livre et demie de téríhenthine. En mettant ees drogues on agitera beaueoup le vase de plomb, de peur qu'elles ne lrûlent. Lorsqu'ensuite le vin sera réduit au tiers par la euisson, on retirera le feu de dessous, et on remuera de temps en temps le vase de plomb, afin que les drogues se mélangent avee le vin cuit; après quoi, lorsque le vin paraitra un peu tiédi, on le saupoudrera peu à peu avee d'autres aromates broyés et eriblés, et on le fera remuer avee un ràble de bois, jusqu'à ee qu'il soit refroidi. Si l'on ne brouillait pas les aromates de la manière que nous venons de preserire, ils resteraient au fond du vase et brûleraient. Voiei quels seront les parfums qu'il faudra employer pour la quantité de moût que nous avons indiquée : une feuilledenard ; une demi-livre tant d'iris d'Illyrie que de nard des Gaules, de costus, de palmier, de souchet et de racine de jone, ou einq uncia de inyrrhe; une livie de eanne; une demi-livre de eannelle; trois uncia d'amome ; einq de safran ; une livre de eette cripa qui ressemble aux pampres de la vigne. Il faut, comne je l'ai dit, prendre ees drognes sèehes, les broyer et les piler avant de les employer, puis y ajouter du rasis, c'est-ì-dire, d'une espèee de poix erue qui passe pour être d'antant meilleure qu'elle est plus vieille, paree que le temps l'ayant endureie, il est plus ficeile de la réduire en poudre en la broyant, de sorte qu'elle s'amalgame mieux avee les autres diogues. Au reste, il suffira d'en mettre six livres sur la quantité de drogues que nous venons d'indiquer. On ne peut pas déterminer quelle sera la quantité de vin euit eomposé de eette manière qu'il faudra mettre dans quarante-huit

('um cam diligenter ante aqua marina decocta perlueris, lecem sextarios : item resine terebintlinx sesquilibram. Hirc cum adjicies, plumbeum peragitabis, ne adurantur. Cum deinde ad tertias sulısederit coctura, subtralıe ignem, et plumbenm subinde agitabis, ut defrutum et medicamenta coeant : deiude cum videbitur mediocriter calere defrutım, reliqua aromata contusa et cribrata paulatim insperges, et jubebis rutabulo ligneo agitari quod decoxe. ris, cousque dum defrigescat. Quod si nou ita, ut præcepimus, permiscneris, subsident aromata, et adurentur. Al prodictum autem modum musti adjici delient ii odores, nardi folium, iris illytica, ıardum gallicum , cos. tum, palma, cyperum, schinnum, quorum siuguloruın selibra satisfacient : item my rrlae quiucunx, calami pondo libram, casiae selibram, amoni ponde quadrans, croci quincunx , cripxe pampinacex libran. II xe, int dixi, arida contusa et cribrata debent adjici, et lis commisceri rasis, quod est genus cruda picis : eaque quanto est vetustior, Into melior laabetur. Nam longo tempore: dorior facla, cum est coutusa, ju pulverem redigitur, et lis medicuminibus admiscetur. Satis est auten prandictis ponileribus sex libras pjus misceri. Ex lıac compositione, quantum in scxtarii de moût pour le frelater, parce que c'e'st une chose qu'on ne peut estimer que d'après la qualité du vin, et qu'il faut prendre garde que le goût du vin u'annonee qu'il est frelaté, ineonvénient qui éloignerait les acheteurs. Je suis eependant dans l'habituded'eń mettresur deux amphores de mon̂t (e'est-à-dire sur quatre urnes, l'urne étant de vingt-(quatre sextarii) un tricns lorsque la vendange a été liumide, et un quadrans lorsqu'elle a été sèche. Je n'ignore pas que quelques agrieulteurs en on mis jusqu'à un quadrans par amphore: mais je sais aussi qu'ils ne l'ont fait que lorsqu'ils y ont été eontraints par la trop grande faiblesse de leur vin, qui se serait à peine eonservé pendant trente jours sans se gâter. Au reste, si l'on ne manque pas de bois, il sera eneore mieux de faire bouillir le vin que l'on aura ainsi frelaté, et de le purger de sa lie en l'éeumant, parce que quoiqu'il se trouve, en suivant eette méthode, un dixième de déehet su. le total, au moins ee qui en reste se conserve ensuite éternellement. Mais si l'on n'a pas du bois en abondanee, on se eontentera de mettre sur ehaque amphore de vin une uncia de eette matière connue sous le nom de fleur de marbre ou de platre, ou deux sexlarii de vin euit jusqu'à diminution des deux tiers; et quoique eette dernière méthode ne donne pas au vin la propriété de se garder éternellement, elle lui fait au moins conserver son goût jusqu'à la vendange suivante.

XXI. On fait enire jusqu'à diminution des devix tiers un moût dont le goût soit très-agréable, et on lui donne le nom de defrulum lorsqu'il a passé par ectte euisson de la manière que j’ai détaillée ei-dessus : lorsqu'il est refroidi, on le transvase et on le serre pour s'en servir au bout d'un an. On peut néanmoins en mêler dans

sextarios musti quadragenos octonos adjicieıdım sil, iu. certum est, quoniam pro nátura vini astimari oportet, quod satis sit : caveudunıque est, ne conditus sapor intelligatui: Nam ea res emptorem fugat. Fyo tanen, si lummila fuerit vindemia, trientem; si sicca, quadrantem medicaminis in binas anphoras uniscere solitus sum [ita, ut quatuor urnarun esset nusti modus : urna antem qua. tuor et viginti sextariorum ]. Noınullos agricolas singulis amploris quadiantem medicaminis indidisse scio, sed lıo conctos fecisse propter nimian infirmilatem viui ejusmodi, quod vix triginta diebus integrum permanchat. IInc tamen mustum, si sit lignorım copia, satius est iuferve. facere, et omuem suuuan cum fecibus expurgare : quo facto decima pars decedet, sed reliqua perennis erit. At si lignolum penuria est, marmoris rel gypsi, quod flos appellatur, uncias singulas, item arl tertias decocti defruti sextarios linos singulis amplıoris miscere oportebit. Ea res etiamsi nou in totum perennem, at certe usque in alteram vindeniam plerımque vini saporem serval.

XXI. Muslum quam dulcissimi saporis decoquatur ad tertias, el decoctuın, sicut supra dixi, tefrutumn vocatur; yuod cum defrixit . transfertur in vasa, et reponitur, 
to vin, pour le frelater, dès le neuvième jour qui suivra sa cuisson; mais il vaut mieux le laisser reposer un an. On en met un sexlarius sur deux urnes de moût provenu de vignes plantées sur des coteaux; au lieu qu'on en met trois hemince, si le moût provient de vignes plantées en plat pays. Lorsque le moût est retiré de la cuve, on le laisse bouillir et se purger pendant deux jours, et l'on n'y met le vin cuit que le troisième. Ensuite, au bout de deux autres jours, lorsqu'il a cessé de bouillir avec ce vin cuit et qu'il s'est purgé, on y ajoute encore sur deux urnes de vin la quantité de sel grillé et broyé que peut contenir une ligula, ou une mesure de demi-uncia bien pleine. On jette à cet effet du sel très-blanc dans un pot de terre cuite non poissé, que l'on mastique ensuite soigneusement dans toute sa surface avec du mortier dans lequel il entre de la paille, et on le met en cet état auprès du feu prour l'y laisser griller tant qu'il petillera ; et dès qu'il commence à ne plus faire de bruit, il est censé cuit. Outre cela, on fait tremper du fenugrec dans du vin vieux pendant trois jours; quand on l'a retiré, on le fait sécher au soleil; lorsqu'il est sec, on le broie, et on en met une cuillerée, c'est-à-dire le contenu du quart d'un cyathus, sur deux urnes de moût salé. Ensuite, lorsque le moût a cessé absolument de bouillir et qu'il est tranquille, on y met autant de fleur de platre qu'on y avait mis de sel; après quoi on nettoie la futaille le lendemain, puis on couvre le vin après l'avoir ainsi nourri, et on le bouche. Telle était la méthode que suivait ordinairement Columelle, mon oncle paternel, qui était un célèbre agriculteur, pour frelater son vin dans les fonds de terre où

ut post aunum sit in usı. Potest tamen etiam post dies novem, quam refrixerit, adjici in rinum: sed melius est, si anno requicrerit. Ejus nnus sextarius in duas urnas musti adjicitur, si mustım ex vineis collinis est : sed si ex campestribus, tres heminxe adjicinntur. Patimur autem, cum de lacu mustum sublalum est, biduo deferves. cere, et purgari. Tertio die defrutum adjicimus. Deinde interposito bidno, cum in nustum pariter cum defruto deferbuerit, purgatur, et ita eo adjicitur in binas urnas lizula cumulata, vel mensura semuncix bene plenxe salis cocti et triti. Sal anten quam candidissimus conjicitur in urceo fictili sine pice, qui urceus, cum recepit salem, di. ligenter totus oblinitur luto paleato, et ita igni admove. tur, ac tamdiu torretur, quaindiu strepitum edit. Cum silere copit, finem habet cocturae. Praterea fonum Graccum unaceratur in vino vetere per triduum: deinde eximitur, et in furno siccatur vel ín sole : idque cum est arilum factum, molitur, et ex eo molito post salituram musti cochlear cumulatum, vel sinile genus puculi ejus, quæ est quarta pars cyallii, adjicitur in binas urnas. Deinde rum jam perfecte unstnm deferbuit et constitit, tantun. dem gypsi foris miscemus, quantun salis adjeceranus : alçue ita postero dic purgamus dolium, et nutritum vinum cperimus atque oblinimus. Ilac conditura Columella pa- il n'avait que des vignes marécageuses; mais lorsqu'il frelatait du vin de coteaux, il y mettait au lieu de sel de l'cau salée, cuite jusqu'à diminu. tion des deux tiers. Il est certain que cette eau fait foisonner le vin, et qu'ellc lui fait acquérir une meilleure odeur; mais d'un autre cóté il y a du danger qu'elle ne le gâte, si elle est mal cuite. D'ailleurs, on la prend, commeje l'ai déjà dit, le plus loin du rivage qu'il est possible, parce que, plus elle est puisée en haute mer, plus elle est claire et pure. Si on la garde très-longtemps (comme faisait Columelle) en la transvasant d'abord au bout de trois ans après l'avoir éclaircie, et en ne la faisant cuire jusqu'à diminution des deux tiers que trols autres années après, elle sera bien meilleure pour frelater le vin, et il n'y aura plus de risque qu'elle le gâte. Au surplus, il suffit de mettre un sextarius d'eau salée sur deux urnes de moût, quolque bien des gens y en mettent deux, et d'autres jusqu'à trois; et je ne serais pas éloigné moi-même de m'en tenir à cette quantité, si le vin se trouvait d'assez bonne qualité pour ne pas dévoiler par son goût cette mixtion d'eau salée. C'est pourquoi un chef de famille prudent, qui aura fait une nouvelle acquisition en fonds de terre, essayera, aussitôt après sa première vendange, trois ou quatre méthodes de frelater le vin sur trois ou quatre amphores de moût, afin de s'assurer combien le vin de son cru pourra supporter d'eau salée au plus, sans offenser le goût.

XXII. Pour apprêter et conserver le moût, on peut également se servir de poix liquide. Mettez une metreta de poix liquide, tirée du pays des Nemeturici, dans un bassin ou dans un vaisseau

truns meus, illustris agricola, uti solitus est in iis fundis, in quibus palustres vineas liabebat. Sed idem, cum collina vina condiebat, aquam salsam decoctam ad tertias pro sale adjiciebat. Fa porro facit sine dubio majorem inensuram et odoris melioris : sed periculum habet, ne vilitetur vinum, si male cocta sit aqua. Sumitur auten laæc, ut jam dixeram, quam longissime a littore. Nam liquidior et purior est, quantum altiori mari hausta est. Eam si quis (ut Columella faciebat) reponat, et post triennium in alia vasa eliquatam transfundat : deinde post alternm triennium decoquat usque ad partem tertian: longe meliorem habebit condituram vini, nec ulluu periculum erit, ne vina vitientur. Satis est auten sextarios siugnlos adjicere salsæ aqua in.binas musti urnas : qrımvis multi efian binos immisceant, nonnulli etiam ternos sextarios : idque [ ego] facere non recusem, si genus viıi tantum valeat, ut aquæ salsæ non intelligatur sapor. Itaque diligens paterlamilias cum paraverit fundnm, statim prima vindemıa tres aut quatuor notas condituræ totidem amplıoris musti experietur, ut exploratum liabeat , quantum plurimum salsæ vinum, quod fecerit, sine offensa gustus pati possit.

XXII. Picis liquida alterum medicamen, quo mustum conlias. Picis liquida Nemeturica metretam adde iu la. 
quelconque, et versez dessus deux congii de les sive de cendre; ensuite remuez le tout avec une spatule de bois. Lorsque cette mixtion sera reposée, videz l'eau de lessive, ensuite remettez-en autant que la première fois, puis remuez de même le tout et passez-le; enfin répétez la même opération une troislème fois. La cendre fait passer l'odeur de la poix, et la purge de ses immondices. Ensuite prenez einq livres de poix tiréc du pays des Brulii, sinon, de telle autre poix que ce soit, pourvu qu'elle soit très-nette. Pilez-la bien menue et mélez-la avec la poix tirée du pays des Nemeturici, puls versez dessus deux congii d'enu de mer qui soit ou très-vieille, si vous en avez de telle, ou nouvelle, mais cuite jusqu'à diminution des deux tiers. Laissezle bassin déeouvert au soleil pendant le lever de la Canicule, et remuez très-souvent ce qu'il contient avec une spatule do bois, jusqu'à ce que la poix que vous aurez ajoutée la seconde fois soit fondue dans la première, et qu'elles soient amalgamées ensemble. Il faudra cependant couvrir le bassin pendant la nuit, de peur qu'il n'y tombe de la rosée. Ensuite, lorsque l'eau de la mer que vous y aurez mise paraîtra évaporée au soleil, vous ferez porter le vase à la maison sans le vider. Il y a quelques personnes qui sont dans l'usage de mettre sur quarante-huit sextarii de vin le poids de trois uncia de cette composition, et qui se contentent de cette quantité pour lc frelater. D'autres en mettent trois cyathi sur la quantité de sextarii que nous venons de dire.

XXIII. On donne le nom de corticata à la poix dont les Allobroges se servent pour frelater le vin. On la fait très-dure, et plus elle est anciennement faite, meilleure elle est pour cet usage,

brum, aut in alreun, et in eodem infundito cineris lixivia congios duos, deinde permisceto spatlıa lignea. Cum requieverit, eliquato lixiviam : deinde iterum tantunden lixivia addito, eodem pacto permisceto, et eliquato. Tertio quoque idem facito. Cinis autem odorem picis aufert, el eluil spurcitiam. Post eodem addito picis Brutix, si minus, alterius nota quam purissima quinque libras. Iræc minute concidito, et admisceto pici Nemetuicx. Tum aqua marinæ quam vetustissimæ, sierit ; si minus, ad tertiam parten recentis aquæ mariuß decoct $x$ congios dus injicito. Apertın labrum sinito in sole per Canicula ortum, et spatlıa lignea permisceto quam sxpissime, usque eo, dum ea qua addideris, in pice colliquescant, et unitas fiat. Noctibus auten labrum operire conreniet, ne irroretur. Deinde cum aquua marina, quaın addideris, sole consunpta videbitur, sub tectum vas totım ferre curabis. Hijus autem medicaminis quidam pondo quadrantem in sextarios XLrut miscere soliti sunt, et l,ac conditura contenti esse. Alii cyatlıos tres ejus medicamenti adjiciunt in totidem sextarios, quot supra diximus.

XXIII. Pix corticata appellatur, qua utuntur ad condituras Allobroges. Ea sic conticitur, ut dura sil, et quanto facla est vetustior, eo melior in usu est. Nam onni lẻnture parce qu'elle perd tout son gluant, et qu'il est dès lors plus aisé de la réduire en poudre et de la cribler. Il faut donc la broyer et la cribler avant tout ; ensuitc, lorsque le moût aura bouilli par deux fois, ce qui se fait communément en quatre jours à compter du moment où on l'a tiré de la cuve, on la nettoie arec soin entre ses mains, et on en met un sextans et une semuncia sur quarante-huit sextarii de vin, puls on l'y mẻle avec un ráble de bois, après quoi on ne touche plus au vin tant qu'il bout; il ne faut cependant pas le laisser bouillir plus de quatorze jours à par. tir du moment auquel il a été frelaté. Il faut au contraire le purifier au bout de quatorze jours, ct s'il est resté de la lie aux bords ou aux parois des vases, les ratisser et les frotter, pour les couvrir et les boucher aussitôt après. Mais sil l'on veut se servir de cette poix pour frelater le vin de toute une vendange, de facon qu'on ne puisse pas reconnaître à son goût siil est poissé, il suffira d'en mettre six scripula sur quarante-huit sextarii de vin, ce qu'on ne fera qu'après que le moût aura cessé de bouillir et qu'il aura jeté sa lie. Il faudra nćanmoins mettre en outre une semuncia de sel cuit et broyé sur la même quantitć de mcût. Au reste, ce n'est pas seulement dans le vin poissé qu'il faudıa mettre du sel, mais on en mettra la même quantité, si faire se peut, sur telle espèce de vendange et en tel pays que ce soit, parce que cette précaution empêchera le vin de conserver aucune moisissure.

XXIV. La poix du pays des Nemeturici se fait dans la Ligurie. Pour la rendre propre à frelater le vin après qu'elle est faite, il faut prendre en pleine mer et très-loin du rivage de l'eau, que l'on réduira à moitié par la cuisson : lorsque cette

misso, facilius in pulverem resolvitur atque cribratur. Hanc ergo conteri et cribrari oportet : deinde cum bis mustum deferbuerit, quod plerumyque est intra quartum dieın, quam de lacı sublatım est, diligenter manibus expurgatur, et tunc demum predicta picis sextans et semuncia in sextarios quinque el quinquaginta adjicitur, et rutabulo ligneo permiscelur, nec postea tangitur, dumı confervescat : quod tamen uon amplius diebus quatuor. decim a conditura patiendum est. Nam oportebit post lıunc numerun dierum confestim vinum emundare, el si quid fecis ant lalıris rasorum aut lateribus inlıasit, eradi, ac sufricari, et protinus operculis impositis oblini. At si ex eadem pice tolam viudeniam condire volueris, ita ne gustus picati vini possit intelligi, sat erit ejusdem picis sex scripula in sextarios quinque et quadraginta tum demum miscere, cum mustum deferbuerit, el feces expurgatx fuerint. Oportebit autem salis decocti contritique semunciam in eunilen modun musti adjicere. Nec solım lusic nolxe viui sal adlibendus est; verum, si fieri possit, in omnibus regionibus omne genus vindemix lıoc ipso poitlere saliendum est : nam ea res mucorem vino inesse non patıtur.

XXIV. Pix Nemeturica in Liguria conficitur. Ea deinle It tiat condituris idonea, aqqua marina quam lougissine a 
eau sera refroidie au polnt de ne plus brûler la ninin lorsqu'on l'y plongera, on en versera ec (ju'on jugern suffisant sur cette poix, et on la remuera soigneusement avec une spatule de bois ou avee la main, afin de la délivrer de toutes les impuretís qui pourraient y être restées. Ènsuite on laissera la poix tomber au fond, et on videra l'eau; après quoi on la lavera deux au trois fois avee ce qui était resté d'eau cuite, et on la pétrira jusqu'à ee qu'elle devienne brillante : enfin, après l'avoir passée, on la laissera quatorze jours au soleil, afin que toute l'humidité qu'elle aura pu contraeter dans l'eau se tarisse. Mais il faudia eouvrir pendant la nuit le vase dans lequel on l'aura mise, de peur qu'il n'y tombe de la rosée. Lorsquion l'aura préparće de cettc manière, et qu'on voudra frelater son vin, on mettra deux cyathi de cette poix sur quarante-huit sexturii de moût, après qu'il aura bouilli deux fois. Il faudra séparer à cet effet deux sextarii de moût sur le total de ee que l'on voudra frelater, pour les verser peu à peu sur uII sextans de poix, ct la pétrir ensuite à la main, eomme on lc pratique à l'égard du vin nêlé de miel, afin qu'elle s’amalgame plus aisément avee le moût. Mais quand ees deux sexturii serout entièrement amalgamés a vee la poix, et qu'ils ne feront plus, pour ainsi dire, qu'une seule substanee avee ellc, il faudra pour lors les reverser dans le vasc dont on les avait tirés d'abord, et en remuer le moût avec un rable de bois, afin qu'élle se mêle bien avec cette composition.

XXV. Comme quelques Grees, pour ne pas dire tous, frelatent le moût avee de l'eau salée ou avee de la saumure, je n'ai pas eru devoir passer sous

littore de pelago sumenda est, atque in dinidiam partem decoquenda : qux cum ju tantum refrixerit, quautum ne contacta corpus urat, partem aliquan ejus, qua satis vi. debitur, prodicta pici immiscebimus, et diligenter lignea spatlıa vel etiam manu peragitabimus, ut si quid inest vitii eluatur. Deinde patiemur picem considere, et cum siderit, aquam eliquabimus : postea bis aut ter ex reliqua parte açux decoctx tamdin lavabimus et subigemus eam, donec rutila fiat : tum eliquatam in sole quatuordecim diebus patiemur esse, ut quisquis ex aquı lumor remansit, assiccetur. Noctibus antem vas tegendum erit, ne irroretur. Cum hoc modo pirem praparaverimus, et vina, cum jam bis deferlmerint, condire voluerimus, in musti sextarios octo et quadraginta cyathos duos picis pradicto sic arljiciemus. Ex ea mensura, quam condituri sumus, sextarios dnos musti sumere oportebit, deinde ex lis sextariis in picis sextantem paulatim mustum infundere, et maıı tanquam mulsum suhigere, quo facilius coëat. Sed nbi toti dno sextarii cum pice coierint, et quasi unitatem fecerint, tum eosdem in id vas, unde sumpseramıs, pertundere, et ut pernisceatur medicaınen, rutabulo lignéo peragitare converriet.

XXY. Quoniam quidlam , immo etianı ferco onnes Gravi, silcnee ec geure d'éenomie. Voiei eomme il faudra $s^{*} y$ prendre dins les pays qui sont situés au milieu des terres, et où l'on ne peut pas se proeurer aisément de l'eau de mer, pour faire une saumure propre à ces sortes de mixtions. C'est l'eau de pluie qui est la plus eonvenable pour cette opération, et à son défaut eelle qui eoule d'unc sourec très-limpide. On aura done soin de mettre au soleil cinq ans d'avance une très-grande quantité de l'une ou l'autre de ces caux, en la renfermant dans d'excellents vases : ensuite, lorsqu'ellc sera pourrie, on la lalssera reprendre d'elle-même son premicr état. Quand elle l'aura repris, on aura d'autres vases dans lesquels on la passera doueement jusqu'à ce qu'on soit arrivé à la lie : car on trouve toujour's un sédiment épais au fond d'une eau qui a été en repos. A près ees premiers soins, il faudra la faire bouillir jusqu'à diminution des deux tiers, comme du vin euit : ensuite on mettra sur einquante sextarii de eette eau douee un sextarius de sel avee autant d'excellent micl. Il faudra euire tout ce mélange ensemble, et le purger de toutes ses immondiees. Ensuitc, lorsqu'il sera refroidi, on mettra ee qui en res. tera dans une amphore de moût. Si l'on a sa terre près de la mer, il faudra, pendant qu'il ne fera point de vent et que la mer sera bien calme, puiser de l'eau en pleine mer, et la faire bouillir jusqu'à diminution des deux tiers, en y ajoutant, si on le juge à propos, quelques aromates pris dans le nombre de eeux que j’ai détaillés ei-dessus, afin que, lorsqu'on l'emploiera dans le vin, elle lui donne plus d'odeur. Mais avant de tirer le moût de la cuve, on parfumcra les vases dans lesquels on doit le mettre, soit avee du romarin, soit avee du laurier ou du myrte, et on les

aq̨ua salsa vel marina mustum condiunt, cam quoque parten cura non omittendan putavi. In mediterraneo, quo non est facilis aqua marinx invectio, sic erit ad condituras conficienda muria. Huic rei maxime est idonea calestis aqua; si nıinus, ex fonte liquidissimo profluens. Harum ergo alterutram curabis quam pluriman et quam optimis vasis conditan ante quinquennim m in sole ponere : deinde cum computrnerit, tamdiu pati, donec ad pristinum modum perreniat. Quod cum factum fuerit, alia vasa labeto, et in ea sensin aquam eliquato, donec ad fecem perveuias. Semper enim in requieta aqua crassanen aliquod in imo reperitur. Sic curata cum fuerit, in modum defruti ad tertias decoquenda est. Adjiciuntur antem in aquæ dulcis sextarios quinquaginta, salis candidi sextarius, et mellis optimi unus sextarius. Hac pariter decoqui, et omuem spurcitiam expurgari oportet. Deinde cum refrixerit, tum quaıtımcunque lımoris est, tantum in anplıo. ram musti portionem adjici. Quod si ager maritimus est, silentibus ventis de alto quam quietissimo mari sumenda est aqua, et in tertiam partem decoquenda, adjectis, si videbitur, aliquibus aromatis ex iis quæ supra retuli, ut sit odoralior vini curatio. Mustum autem anteguam de lacu tollas, vasa rore marino vel lanto vel myrtu sulfu. 
remplira jusqu'aux bords, afin que le vin se purge bien en bouillant; ensuite on frottera le bord des vases avee des pommes de pin. Il faudra frelater le vin le lendemain du jour qu'on l'aura tiré de la euve, si on veut le rendre plus doux, et einq jours après, si on veut l'avoir plus dur ; on bouchera aussi les vases après les avoir remplis à mesure qu'ils auront souffert du déehet. II se trouve des personnes qui, après avoir parfumé les cruches, commeneent par y mettre les compositions dont ils se serveut pour frelater le moût, avant de l'y verser lui-mème.

XXVI. Dans les terroirs où le vin a coutume de s'aigrir, il faut, dès qu'on aura cueilli et foulé le raisin, et avant d'en porter le mare au pressoir, avoir soin de verser le moût dans un panier, et d'y ajouter un dixième d'eau douce tiréc d'un puits ereusé dans le terroir même; enfin de le cuirc jusqu'à ee qu'il soit diminué d'une quantité pareillc à celle de l'eau qu'on y aura ajoutée. Ensuitc, lorsqu'il sera refroidi, on le versera dans des vases que l'on couvrira et que l'on bouchera; moyennant quoi il se conservera plus longtemps sans s'altérer en aticune façon. II sera mieux d'y mettre de vieille eau que l'on aura gardéc pendant plusieurs années, quoique le meilleur encore sera de n'en point mettre du tout, mais de le euire jusqu'à diminution d'un dixième, et de le transvaser lorsqu'il sera froid, comme aussi d'y ajouter une hemina de gyp sur sept sextarii de moût, lorsqu'il sera refroidi après la euisson. Quant au reste du moût qu'aura rendu le mare pressuré, il faudra le consommer au premier moment, ou le vendre.

XXVII. Manière de faire du vin très-doux. Etendez au soleil pendant trois jours les grappes de raisin que vous aurez eueillies; le quatrieme

migato, el large repleto, int in effervescendo vinum se bene purget. Postea vasa nucilms pineis suffricato. Quorl vinum volueris dulcius esse, postero die; quod ansterius, quiuto die quan sustuleris, coudire oportebit, et ita sup)plere, et oblinire vasa. Nonunlli ętiam suffumigatis seriis prius condituram addunt, et ita mustum infundunt.

XXVI. In quo agro vinum acescere solet, curandum est, ut cum uvam legeris et calcaveris, prius (juam vinacea torculis exprimautur, mustum in cortinam definudas, et ayua dulcis puteaune ex codem agro parten decimam arljicias, et conuas, donec ea ayıa, quam adjeceris, decocta sil. l'ostea cum refrixerit, in vasa defundas, et operias, et oblinas : ita diutius durabit, et detrimenti nilit fiet. Melius est, si reterem servalam complurilus annis aquam arddideris; longejuc melius si aqua uiluil ad. dideris, et decimam unusti tecoxeris, frigidumique in vasa transtuleris, et si in sextarios vı ntusti teminain gypsi uniscucris, posteaquam decoctum refrixerit. Reliq̨uum unustum, quod e viuaceis fucrit espressum, primo (puopuc Iempore alssumito, aut aere commutato.

XXVIt. Vium dulce sic faceie oportet. Uvas leyito, in sole per triduum expangilo, juarto die meridiaso fempors c jour foulez-les à midi pendant qu'elles scront elsaudes, et prenez-en le vin de mère-goutte, e'est-à-dire, eelui qui aura coulé dans la euve avant que le raisin ait été pressuré : lorsqu'il aura cessé de bouillir, mettez-y une uncia d'iris bien broyće, mais pas davantage, sur einquante sextarii de vin, et versez-le dans des vases apres l'avoir purgé de sa tie en le passant. Ce vin ne sera pas moins agréable que durable et salutaire au corps.

XXVIII. Manière de eomposer d'autres sortes de mixtions exeellentes pour frelater le vin, et le rendre durable. Broyez de l'iris très-blanche, faites infuser du fenugrec dans de vieux vin, puis exposez-le au soleil ou mettez-le au four, afin qu'il se sèche; après quoi vous le moudrez trèsfii. Ensuite mêlez ensemble des parfums broyés, consistant en un quincunx et un triens à peu près d'iris eriblée, autant de fenugree, et un quincunx de racine de jone; puis vous mettrez dans le vin une uncia et huit scripula de eette mixtion par cruches de la contenance de sept amphores, avec trois hemina de gyp, si le moût provient de terroirs marécageux; un sextarius, s'il est fait avee du raisin de jeunes vignes, et une hemina, s'il est fait avee du raisin d'anciennes vignes plantées dans des terroirs sees. II faut mettre ees ingrédients trois jours après que le raisiu aura été foulé ; mais avant de faire eette opération on survidera un peu de moût d'une cruehe dans une autre, de peur qu'en bouillant avec la mixtion lorsqu'il sera frelaté, il ne s'enfuie. On mêlera dans un petit bassin ec qu'il faudra de gyp et d'autres espèees d'ingrédients pour ehaque eruelic, et après les y a voir délayés avec du moût, on les versera dans les cruehes, où on les mêlera bien : dès que le vin aura cessé de bouil.

calidas uvas proculcato, mustum lixivium, hoc est, antequam preto pressum sit, quod in lacum musti lluxerit tollito : cum deferlucrit, in scxtarios quinquaginta irim. bene pinsitam nec plus uneine pondere addito, vinum a fecibus cliquatum diffundito. Hoc vismun cril suave, fir. mum, corpori salubre.

XXVII. Alia medicaninum genera vini condituris et firmilati aptissima sic facito. Irin guam caudidissimam piusito, frenum Gracum vetere viso macerato : deinde in sole exponito ant in lurno, ut siccescat : tum commolito minutissine. Iteu odoramenta trita, ill est, irim cribra. tam, qua sit instar pondo quincuncem et tricnlem, foui Groci pondo quincuncen et trientem, selweni pondo quincuncem in unum permisceto : lum in serias singulas qua sint amphorarum septemun, addito mtedicantinis pondo unciaun et scripula octo : gypsi, cum ex locis palustrilus mustun crit, in serias singulas ternas Jemninas; cum de noveltis vineis erit, sextarium; cum de velcribus et locis siccis, heminas singulas adjicito. Tcrtio die quanı cilcave. ris, condituram infundilo, sed antequam conlias, inusti aliquantum iu seriaun de seria transferto, ne in coudiendo cum medicanento efferrescat et fluat. Sic autem curatum 
lir, on remplira les eruehes et on les bouehera. Toutes les fois que rous aurez frelaté du vin, gardez-vous de le verser aussitôt dans des vases, mais laissez-le reposer dans les futailles; et lorsque vous voudrez le transvaser des futailles ou des eruches dans d'autres vases, ayez soin que eeux-ei soient bien poissés et bien propres, et ne faites eette opération qu'au printemps, quand les roses seront en fleur, et que le vin sera purifié et parfaitement clair. Si vous voulez le garder longtemps, mettez sur un baril de la contenance de deux urnes un sextarius d'exeellent vin, ou trois sextarii de lie de bon vin qui soit nouvelle; ou si vous avez des vases dont vous ayez tiré récemment le vin, survidez-le dans ces vases. En suivant l'une ou l'autre de ces méthodes, le vin sera bien meilleur et bien plus durable : et pour peu que vous y ajoutiez en outre de bonnes odeurs, vous en écarterez toutes les mauvaises, ainsi que toutes les sortes de mauvais goût, parce qu'il n'y a rien qui attire plus les odeurs étrangères que le vin.

XXIX. Manière dont il faut s'y prendre pour faire que le moût soit toujours aussi doux que dans sa nouveauté. Avant de porter le marc au pressoir, mettez dans une amphore neuve du moût très-nouveau au moment que vous l'aurez tiré de la eure, bovehez cette amphore, et enduisez-la bien exactement de poix, afin que l'eau ne puisse pas y pénétrer ; eusuite plongez-la, de façon qu'elle soit entièrement submergée, dans un réservoir dont l'eau soit fraiche et douce, et retirez-l'en quarante jours après; vous aurez par ce moyen du vin qui se conservera doux pendant une année entière.

XXX. Du moment où l'on aura couvert les

gypsum et medicamentum in labello pernisceto, quantum seriis singulis fuerit necessarium, idque medicanentum musto diluito, et ipsa ad serias addito et permisceto : cum deferhuerit, statim repleto et oblinito. Omne vinum com condieris, nolito statim diffundere, sed sinito in doliis li- quescerc : postea cum de doliis aut de seriis diffumdere voles, per ver florente rosa, defecatum quam liunpidissiuum in vasa bene picata ef pura transferto. $\mathrm{Si}$ in velusta. tem servare voles, in cado duarum urnarum quam optimi vini sextarium, ant fecis generosa recentis sextarios tres addifo : aut si vasa recentia, ex quilus vinum exemuptum sit, labebis, in ea confundito. Si lorum quid feceris, unulto melius et firmins erit viuum. Etiam si bonos odores addideris, omuem malum odorem et saporen prohiluseris : nam nulla res alienum odorem celerius ad se ducit, quam viıum.

XXIX. Mustum ut semper dulce tanquam recens permancat, sic facito. Antequam prelo vinacea subjiciantur, de lacu quam recentissimum addito mustum in amphoram novam, eamque oblinito, et impicato diligenter, ne quidquam aqua introire possit: tunc in piscinam frigidae et dulcis aqua totam amploram mergito, ita nequa pars exstet; deinde post dies $\mathrm{xh}$ eximito : sic usque in annım dulce permanebit. futailles jusqu'à l'équinoxo du priutemp̧, il suffira de soigner le vin une fois tous les trente-six jours; au lieu que, passé l'équinoxe, il faudra le faire deux fois ou plus souvent, si les fleurs commeneent à s'y mettre, de peur qu'elles ne tombent au fond des futailles, et qu'elles n'altèrent le goût du vin. Plus la chaleur sera grande, plus il faudra soigner le vin souvent, le rafraichir et lui donner de l'air, parce qu'il se conservera toujours en bon état tant qu'on le tiendra bien frais. Toutes les fois que l'on soignera le vin, on frottera les bords ou les ouvertures des futailles avec des pommes de pin. Si vous avez des vills trop durs ou qui ne soient pas bons, soit par le vice du terroir, soit à cause des mauvais temps qui seront survenus, prenez de la lie de bon vin, et faites-en des pâtes que vous sécherez d'abord au soleil et que vous cuirez ensuite au feu; après quoi vous les broierez et vous en mettrez un quadrans dans chaque amphore que vous boucherez, et le vin se bonifiera.

XXXI. Si quelque animal, tel qu'un serpent, un rat ou une souris, vient à tomber dans le moût et qu'il y perde la vie; pour éviter qu'il ne fasse eontracter au vin une mauvaise odeur, brûlez son eorps tel que vous l'aurez trouvé, et jetez-en la cendre, quand elle sera refroidie, dans le vase où il sera tombé, puis mêlez-la avec un râble de bois : ee sera le viai remède.

XXXIl. Bien des personnes eroient que le vin de marrube est bou pour toutes les maladies internes, et surtout pour la toux. Lorsque vous ferez la vendange, cueillez de jeunes tiges de marrube, prineipalement dans les terrains ineultes et maigr'es, et faites-les sécher au soleil; après quoi vous les lierez en petites bottes avec une

XXX. Al) co tempore quo primum dolia operculaveris, usıue ad sequiruvetium vernum semel in diebus xxxvi vinum curare satis est, post aquinoctinm vernum bis, ant si vinum florere incipiet, sxpins curare oportebit : ne flos ejus pessum eat, et saporem vitiet. Quanto major æstus erit, eo sapius convent vinum nutriri refrigerariqne, et ventilari : nam quamdiu bene frigilum erit, tamdiu recte manebit. Labra vel fauces doliorum semper suffricari ıucibus pineis oportebit, quoties vinum curabitır. Siq̨ua vina ernnt duriora ant minus bona, quod agri vitio aut tempestate sit factum, sumito fecem vini boni, et paines facito, et in sole arefacito, et coquito in igne : postea terito, et pondo quadrantem amphoris singulis infricato, et oblinito, bonum fiet.

XXXI. Si quod animal in mustum ceciderit, et interiorit, uti serpens aut mus sorex ve, ne mali odoris vinum faciat, ita ut repertum corpus fuerit, id igne adoleatur, cinisque ejus in vas, quo deciderat, frigiclus infundatur, atque rutabulo ligneo permisceatur : ea res erit remedio.

XXXII. Vinum marrubii multi utile putant ad omnia intestina vitia, et maxime ad tussim. Cum vinclenian facies, marrubii caules teneros maxime de locis incullis et macris legito, eosque in sole siccato : deiude fasciculos fucito, et tonice palmea aut juncea ligato, et in seriam 
ficelle de palmier ou de jone, et vous les mettrez dans une cruehe de rin, de facon que la ligature ue soit pas plongée dans le vin. On met sur deux cents sextarii de vin doux, huit livres de marrube, qu'on laisse bouillir avee le moût; après quoi on les retire, et l'on bouehe exactement ce vin ainsi médieamenté.

XXXIll Manière de préparer le vin de scille, qui est bon pour aider la digestion, pour refaire le corps, ainsi que pour les toux anciennes et pour l'estomae. On cueille la seille quarante jours avant la vendange, et on la coupe comme des racines de raifort en très-petits morceaux, que l'on suspend à l'ombre afin qu'ils se sèchent : lorsqu'ils sont séchés, on en met une livre sur quarante-huit sextarii de moût Aminé, et on l'y laisse trente jours; après quoi on l'en retire, et on verse ce vin, après l'avoir éclairei, dans de bonnes amphores. D'autres auteurs veulent qu'on mette sur quarante-huit sextarii de mout une livre et un quadrans de seille sèche, ce que je ne désapprouve pas moi-même.

XXXIV. Ceux qui veulent faire du vinaigre de scille mettent la mème quantité de seille que nous venons d'indiquer, sur deux urnes de vinaigre, et l'y laissent pendant quarante jours. Pour faire un embamma (vinaigrette), on met sur trois amphores de moût un congius de vinaigre mordant, ou deux fois autant sil n'est pas mordant; et on fait cuire ce mélange dans une marmite jusqu'à ce qu'il soit diminué d'un palmus, (c'est-à-dire d'un quart, en supposant cette marmite de la contenance de trois ampholes) ou d'un tiers, si c'est du moût qui ne soit pas doux. On a aussi soin de l'écumer; mais il faut que ce soit du moût de premic̀re serre, et qui soit elair.

XXXV. Manière de faire des vins d'absynthe, d'hysope, d'aurone, de thym, de fenouil et de pouliot. Faites cuire une livre d'absynthe du Pont dans quatre sextarii de moût, jusqu'à ce que ce moût soit diminué d'un quart, et mettezen le reste, quand il sera refroidi, dans une urne de moût Aminé. Observez les mémes procédés pour les autres plantes que nous venons de nommer. On peut aussi faire cuire trois livres de pouliot sec dans un congius de moût, jusqu'à ce qu'il soit diminué d'un tiers ; et lorsque cette déeoction est refroidie, on en retire le pouliot, et on la verse dans une urne de moût. Rien n'empêehe d'en donner aussitôt à ceux qui sont enrhumés pendant l'hiver : eette espèce de vin s'appelle glechonites (pouliot).

XXXVI. Le vin de taille est celui que l'on exprime après la premlère serre, quand. on a coupé alentour le tas du mare. On verse cette espèee de moût dans une amphore neuve, en la remplissant jusqu'aux bords; ensuite on y met de petites branehes de romarin see liées en bottes avec du lin, et on les laisse bouillir avec le vin pendant sept jours ; après quoi on les en retire, et on enduit de platre les vases dans lesquels on enferme ee vin après l'avoir bien purifié. Au reste, il suffit de mettre une livre et demie de romarin sur deux urnes de moût. On pourra employer ce vin comme remède au bout de deux mois.

XXXVII. Manière de faire du vin semblable au vin gree. Cueillez des grappes de raisin hátif qui soient très-mûres, et faites-les sécher au so- nittito, ita ut vinculum exstet : in musti dulcis sext. cc., marruljii libras vilı adicito, ut simul cun musto defervescat : postea eximito marrubium, et purgatum vinum diligenter oblinito.

XXXIII. Vinum scilliten ad concoquendum, et ad corpus reficiendum, item ad veterem tussim et ad-stomaclum hoc modo condire oportet. Primum ante dies quadraginta quaın vinum voles vindemiare, scillam legito, eanque secato quan tenuissime, sicut raplani radicem, taleolasque sectas suspende in nmbra, ut adsiccentur: deinde cum aridxe erunt, in musti Aminei sextarios xLvu, scilla arida adde pondo libram, eanque inesse patere diebus xxx, postea eximito, el defecatum vinum in anphoras lonas aljicito. Alii scribunt in nusti sextarios xtvı, scilla arida pondo libram et quadrautem adjici oportere : quod et ipsun non improlo.

XXXIV. Scilla poudus, quod supra clivi, in aceti duas uruas adjiciunt, et per xL dies inesse patiuntur, qui scilliticim acetuni facere volunt. Ad embaminata. In tres amplioras musti mittis aceti acris congium aut dupluu, si nou est acre, et in ollain, qua fert amphoras tres, deconuis ad palmum, id est, ad quartas : aut si non est dulce mustum, ad terlias : despumetur. Sed mustum desub massa et limpithum sit.
XXXV. Vinum absinthiten, et lıyssopiten, et abrotoniten, et thymiten, et marathriteu, et gleclıoniten sic condire oportet. Pontici absinthii pondo liloram cum musti sextar. iv decoque usque ad quartas : reliquum quod erit, id frigidum adde in musti Aninei urnam. Idem ex reliquis [ rebus ] quxe suprascripta sunt, facito. Possunt etiam pu. leii aridi tres libra cum congio musti ad tertias decoqui, et cum refrixerit liquor, exempto puleio in urnam nıusti adjici : idque mox tussientibus per hiemem recte datur : vocaturque vini nota glechonites.

XXXVI. Mustum tortivur est, quod post primam pressuram vinaceorum circumcisu pede exprinitur. Id mustum conjicies in amplıoram novam, et implebis ad sumınum. Tum adjicies ranulos rorismarini aridi lino colligatos, et patieris nna defervescere per dies septem : deinde eximes ramulorum fasciculum, et purgatum diligenter vinuu gypsabis. Sat erit antem rorismarini sesquilibram in duas urnas musti adjicere. Iloc vino post duos menses possis pro remedio nti.

XXXVII. Vinum simile Graeco facere. Uvas praccoquas quam maturissimas legito, easque per triduum in sole siccato. Quarto die calcato, et inustum quod niliil habeat ex tortivo, conjicito in seriam, diligenterque curato, ut cum deferbuerit, feces expurgentur : deinde quinto die 
lell pendant trois jours : foulez-les le quatrième jour, puls versez dans une eruehe le moút qu'elles auront rendu, sans qu'il s'y trouve une seulc goutte de vin de taille mêlée, et ayez bien soin de le purger de sa lie. Lorsqu'il aura cessé de bouillir, mettez-y, cinq jours après qu'il sera purifié, deux sextarii ou au moins un de sel grillé et eriblé, sur quarante-neuf sextarii. de moût. II y a des personnes qui y mettent aussi un sextarius de vin euit, et d'autres qui en mettent jusqu’à denx, quand ils croient que le vin est d'une qualité peu durable.

XXXVIIl. Manière de faire du vin de myrte qui sera bon pour la dyssenterie, pour le flux de ventre et pour la faiblesse de l'estomae. Il y a de deux sortes de myrte, le noir et le blane. On cueille les baies du myrte noir lorsqu'elles sont mûres; après en avoir ôté la graine, on les fait séeher an soleil, et on les serre en un lieu sec dans un tlaeon de terre euite. Ensuite on eueille au temps de la vendange, pendant que le soleil est ardent, soit dans un vieux plant de vignes marices à des arbies, soit dans de très-anciens vignobles, du raisin Aminé bien mûr, dont on met le moût dans une eruehe. Le même jour et avant que le moût fermente, on broie les baies de inyrte que l'on avait serrées; après quoi on en pèse une quantité de livres égale à la quantité d'amphores que l'on veut remplir de vin de myrte; ensuite on tire un peu de moút de la cruehe, et on le saupoudre avee toute la poudre que ees baies ont donnée, comme avee de la farine. Apres quoi on fait de eette pâteplusieurs petites boulettes que l'on jette diıns la eruche, en les laissant tomber doueement le long des parois du vase, de faeon qu'elles ne puissent pas s'em-

cum purgaveris mustum, salis cocti et cribrati duos sextarios, vel, quod est minimum, adjicilo mum sextarium in sextarios musti xux. Quidaun etiam defruti sextarium miscent : uonnulli etiam duos adjiciunt, si existimant vini notam parum esse firmam.

XXXVIII. Vinum niyrtiten ad tormina, et ad alvi proluviem, et ad imbecillum stomachum sic facilo. Duo sunt genera myrti, quorum alterum est nigrum, alterum allum. Nigri generis bacca, cum sunt matura leguntur, et semiua carun eximutur, atque ipse sine seniubus in sole siccantur, et in fictiti fidelia sicco loco reponuntur. Deinde per vindemiam ex vetere arbusto, vel si id non est, ex retustissimis vineis Aminea bene matura uva sole calido leguntur, et $\mathrm{cx}$ his mustum adjicitur iu seriam, et statim primo die antequam id ferveat, bacca myrtl, qux fuerant reposita, diligenter conteruntur, et totidem tarum libra contusarum appenduntur, quot ampliorae condiri debent : tum exignum musti sumitur ex ea seria, quam medicaturi sumus, et tamquan farina conspergitur, quidquid contusum et appensum est. Post hace complures ex ea massulie fiunt, et ita per latera seria in mustum de. miltuntur, ne altera offa super atteram perveniat. Cum deinde bis mustum defeslouest, et bis curatmmest, rursus piler les unes sur les autres. Lorsqu'ensuite le moût a bouilli deux fois, ct qu'il a ćté clarifié autant de fois, on broie eneore de la mème manière qu'auparavant une quantité de baies pareille à eelle que nous venons de marquer; mais on n'en fait plus de même des boulettes, et l'on se eontente de verser dans un petit bassin dn mouit tirć de la même eruche, et de le mêler avee la mème quantité de poudre de myrte, de faęonqu’il en résulte une espèce de bouillon épais, que l'on reverse dans la eruehe après l'avoil bien mêlé, et que l'on y remue eneore avee un rable de bois. Neuf jours après eette opération, on purifie le vin et on frotte la eruehe avee des balais de myrte see, puis on la eouvre afin qu'il ne tombe rien dans le vase; après quoi on purifie eneore le vin au bout de sept jours, et on le verse dans des amphores bien poissées et de bonne odeur, en prenant la plus grande précaution pour le verser elair et sans lie. Autre faeon de faire du vin de myrte. On fait bouillir trois fois du miel attique, et on l'éeume autant de fois, ou, si l'on n'en a point, on choisit le meilleur miel possible, que l'on ćeume quatre ou cinq fois, paree, que moins le miel est de bonne qualité, plus il est elıargé d’impuretés. Lorsqu'ensuite le miel est refroidi, on eueille des baies de myrte blane qui soient très-muires, et on les éerase, en ménageant eependant la graine qu'elles eontiennent; après quoi on les met dans un petit panier de bois pour en extraire le jus, dont on mêle six sextarii avee un sextarius de niel bouilli; et après a voir versé ce jus daus une petite bouteille, on la bouche. Mais il faut faire eette opération au mois de déeembre, temps où la graine de nyırte est communément mûre. On prendra

eodem modo, et tantundem ponderis bacca, sicut suj)ra divi, contunditur : nec jam st prins massule fimnt, sed in tabelfo mustum de eadem seria sumitur, pradicto pouderi perniscetur, sic ut sit instar juris crassi : quorl cum est permistum, in eandem seriam confunditur, et rutabulo ligneo peragitatur. Deinde post nomum dien quam id fac:tuu est, vinum pmrgatur, et scopulis arida myrti seria suffricatur, operculumque superintponitur, ne quil co ite. cidat. Hoc facto post septinum dien rursus vinum jurgatur, et in amphoras bene picatas et bene olidas diffulditur : sed curandum est, ut cum diffundis, liquidun et sime fere diffundas. Vinum aliod myrtiten sic temperato. Mel Atticum ter infervere facito, et toties despunato : vel si Atticum non habueris', quam optimum mel eligito, et quater vel quinquies despumito. Nam quau to est deterius, tanto plus habet spurcitixe : cum deinde unel refrixeril, baccas albi generis myrti quam maturissimas legito, et perfriato, ita ne interiora semina conteras. Mox fistello lineo inclısas exprimito, succumque earum qui sit sextariorum sex, cum mellis decocti sextario inunisceto, et in lagunculam diffusum obtinito. Sel hoc mense Decenbri fieridelselvit, (quo fere tempore matura suut myiti se. mina : custodicndumque erit, ut ante quam, baccie legan. 
garde aussi qu'il ait fait beau temps pendant les sept ou au moins pendant les trois derniers jours qui aurnnt précédé la cueilletle des baies de myrte; en tous eas, on évitera de les eueillir lorsqu'il aura plu quelques jours avant, ou qu'elles scront couvertes de rosée. Bien des personnes cueillent des baies de myrte, soit noir, soit blanc, dis qu'elles sont mùres; et quand elles les ont un peu fait sécher en les laissant à l'ombre pendant l'espace de deux heures, elles les broient, en ménageant, autant que faire se peut, la graine qu'elles renferment; ensuite elles $\mathrm{ex}$ priment la quantité qu'elles en ont broyée à travers un tamis de lin, et enferment le jus qui en déeoule dans de petites bouteilles bien poissées, après l'a voir passé à travers une couloire de jone, sans y mêler ni miel ni rien autre chose. Cette liqueur ne dure pas à la vérité aussi longtemps que l'autre eomposition de myrte; mais d'un autre eóté tantqu'elle se conserve sans s'altérer, elle est meilleure pour la santé. D'autres font cuire jusqu'à diminution des deux tiers le jus mème qu'ils en ont exprimé, lorsqu'ils en ont une grande quantité; et après l'avoir laissé refroidir, ils l'enferment dans de petites bouteilles poissées. Ce lernier se eonserve plus longtemps que celui qui n'a pas été euit, quoique celui-ci même puisse aller jusqu'à deux ans sans se gâter, pourvu qu'il ait été fait proprement et avee soin.

XXXIX. Voici la méthode que Magon preserit pour faire d'excellent vin avec du raisin séché au soleil; procédé que jai suivi moi-même. Il faut cueillir des grappes de raisin håtif très-mûres, et en séparer les grains desséehés ou endommagés, puis enfoncer en terre, à lá distance de quatre pieds en tous sens, des fourches ou des pieux, et les assembler a vec des perehes, afin qu'ils puissent soutenir des roseaux. Ces roseaux posés

tur, si fieri potest, septem diebus, sin autem, ne minus triduum serenum fuerit, aut certe non pluerit ; et ne rorulentae legantur cavendum. Multi nigram vel albaun myrti baccam, cum jam maturuit, destringunt, et dualous loris cam cun paululum in umbra expositan siccaverunt, perterunt ita, ut quantum fieri potest, interiora seniua integra pernianeant. Tum per lineum fiscum, quod pertriverant, exprimunt, et per colum junceum liquatum succum lagunculis bene picatis condunt, neque melle neque alia re ulla immista. Hic liquor non tam est durabilis, sed quamdiu siue noxa manet, utilior est ad valetudinem quam alterius myrtitis notxe compositio. Sunt qui lunc ipsum expressum succum, si sit ejus copiosior facultas, in tertiam partem decoquant, ef refrigeratum picatis la. gunculis comdant. Sic confectum diutius permanet : scl et quod non decoxeris, poterit innoxium durare bieunio, si modo munde et diligenter id feceris.

XXX1X. Passum optimum sic fieri Mago pracipit, ut et ipse feci. Uvam pracoquan liene maturam legere, aciua mncirla aut vitiosa rejicere : furcas vel palos, qui caunas sustineant, inter yuateruos pedes figere, et perticis jugare : dessus, on y étendra les grappes de raisin au soleil, et on les eouvrira pendant la nuit, de peur que la rosée ne tombe sur les grappes. Lorsqu'elles serơnt séchées, on les égrappera, et on en jettera les grains dans une futaille ou dans une eruche, dans laquelle on versera d'excellent moût, de facon que les grains de raisin en soient entièrement recouverts. Au sixième jour, lorsque ces grains seront bien imbibés de ee moût jusqu`à en ètre gonflés, on les mettra dans un petit cabas, et on les fera pressurer sous l'arbre du pressoir. Quand on aura pris le vin qu'ils auront rendu, on versera sur le mare qui restera du moût très-nouvellement fait avec d'autre raisin qui aura été exposé au soleil pendant trois jours, et on foulera ce mare. Lorsqu'il aura été bien mêlé dans ce moût, on le remettra sous l'arbre du pressoir, et on renfermera aussitôt le second vin qui résultera de ces raisins secs dans des vases bien bouchés, de peur qu'il ne devienne trop dur. Enfin au bout de vingt ou trente jours, lorsqu'il aura eessé de bouillir, on le survidera dans d'autres vases, dont on enduira aussitot les couvercles de plátre, et que l'on reeouvrira d'une peau. Si l'on veut faire du vin avee du raisin muscat séché au soleil, on cueillera des grappes de ce raisin qui ne soient point endommagrées, et on les nettoiera en jetant de eôté les grains qui seront pourris; après quoi on les suspendra à l'air sur des perehes. Il faudra avoir soin que ees perehes soient toujours au soleil. Quand ces grappes seront suffisamment flétries, on les égrappera, et on jettera dans une futaille les grains sculs et séparés de la rafle, puis on les foulera bien aux pieds. Lorsqu'on en aura fait un lit en les foulant, on arrosera ce lit de vieux vin; après quoi on les foulera de nouveau, et on les arrosera eneore de vin. On les foulera de mène

tum insuper cannas ponere, et in sole pandere uvas, et noctibus tegere, ne irrorentur : cum deinde exarueriut, acina decerpere, et in dolium aut in serian conjicere, colem mustum quam optimum, sic ut grana subnersa sint, adjicere : ubi combiberint uvæ, seque impleveriut, sexto die in fiscellam conferre, et prelo premere, passmulque tollere : postea vinaceos calcare adjecto receutissinu musto, quod ex aliis uvis factum fuerit, quas per tricluuu insolaveris : tun permiscere, et subactam brisan prelo subjicere, passunique secundarium statim vasis oblitis includere, ne fiat austerius : deinde post viginti vel triginh dies, cum deferbuerit, in alia vasa deliquare, et confestiu opercula gypsare, et pelliculare. - Passum si ex uva Apiana facure volueris, 11 vam Apianam integram leyilo, acina corrupta purgato et secernito, postea in perticis suspendito. Perticxe uti semper in sole siut facito, uli satis corrugata erunt acina, deunito et sine scopionibus in dolium conjicito, nedibusque bene calcato. Ubi unum tabu, latum feceris, vinum vetus spergito, postea alterum sujercalcato, item vinum conspergito. Eodem modo terl:un calcato, et infuso vino ita superuatare sinito dies quiduple; 
une troisieme fois, et on versera du vin par-dessus jusqu'à ce qu'ils surnagent; après quoi on les laissera dans ce vin pendant cing jours, ensuite on les foulera aux pieds ct on les pressurera dans un cabas ncuf. Quclques personnes préparent, pour faire ce vin, de vieille eau de pluie cn la faisant bouillir jusqu'à diminution des deux tiers. Ensuite, lorsqu'elles ont fait sécher le raisin au soleil de la manière que nous venons de dire, elles l'arrosent avec cette eau au lieu de l'arroser avec du vin, et procèdent quant au reste de la manière que nous avons indiquée. Cette méthode est peu dispendieuse lorsqu'un a du bois cn abondance, et même le vin obtenu par le second procédé est plus doux à boireque cclui qui serait fait avee du raisin séché au soleil, suivant les méthodes précédentes.

XL. Manière de faire de très-bon vin de dépeise. Comptez le nombie de metretoe que pourra remplir la dixième partie du vin que vous aurez fait cn une journée, et mettez le même nombre de metreto d'cau douce sur le mare dont vous aurez exprimé le vin pendant la journée : ajoutez-y de l'écume de vin cuit jusqu'à diminution de moitié ou des deux tiers avec de la lie prise au fond de la cuve, et mêlez le tout cnsemblc : vous laisserez tremper cette bouillie pendant la nuit, et le lendemain vous la foulerez aux pieds. Quaud elle sera bien mélée par cette opération, vous la mettrez sous l'arbre du pressoir; après quoi vous verserez dans des futailles ou dans des amphores le vin qu'elle aura rendu, et vous boucherez ces vases quand il aura bouilli : il est néanmoins plus commode de le garder dans des amphores. M. Columelle faisait ce vin de dć. pense avce de vieille eau, et il parvenait à le conserver quelquefois pendant plus de deux ans sans qu'il se gâtât.

XLI. Manière de faire d'excellent viu mêlé de

postea pedibus proculcato, et in fiscina nova u vas premito. Quidam aquam calestem veterem ad luunc usum praparaut et ad tertias decoquunt. Deinde cum sic uvas, ut supra scriptum est, passas fecerunt, decoctam aquam pro viuo adjiciunt, et catera similiter administrant. Hoc ubi ligno. rum copia est, vilissime conslat, et est in usu vel dulcius, quam superiores notæ passi.

XL. Lora optima sic fit. Quantum vini uno die feceris, rjus partem decimam, quot metretas efficiat, considerato, et totidem metretas aqua dulcis in vinacea, sed quibus unius diei vinum expressum erit, addito : eodem et spumas defruti, sive sapx, et fecem ex lacu confundito et permisceto, eamque intritam macerari una nocte sinito, postero die pedibus proculcato, et sic permistam prelo subjicito: quod deinde fluxerit, aut doliis aut amploris condito, et cum deferbuerit, olsturato. Consmmodius antem servatur in amphoris. Hanc ipsan loram M. Columella ex ayua vetere faciebat, et nonnunquam plus biennio innoxian servabat.

XLI. Mulsum optimun sic facito. Mustum lixivium de micl. Prenez dans la cuve, aussitot qu'il sera fait, le vin de mère-goutte qui aura coulé sans que le raisin ait cncore étć trop foulé; mais ayez soin que ce vin soit fait avec du raisin de vignes marićes à des arbres, qui ait étć cueilli par un temps sec. Vous jetterez dix livres d'excellent miel dans une urne de ce moût, et, après l'avoir mêlé avec soin, vous le verscrez dans un flacon que vous enduirez aussitôt de plâtre, et vous le ferez serrer sur le plancher. Si vous en voulez faire une plus grande quantité, vous proportionnercz la quantité de miel qu'il y faudra mettre à celle que nous venons de fixer. Il faudra ouvrir le flacon au bout de trente ct un jours, ct survider le moût, après l'avoir passé dans uı autre vase qu'on bouchera, ct qu'ou mettra sur le four.

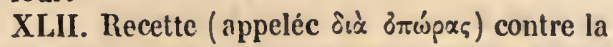
dyssenterie. On fait cuire dans une marmite neuve de terre, ou dans une marmite d'étain, une urne de moût de raisin Aminé cueilli sur des vignes mariées à des arbres, arce vingt gros coings ćpluchés, et la valcur de trois sextarii tant de ces grenades douces, connues sous le nom de grenades carthaginoises, que de cormes qui nc soient pas très-mûres : on laissera les grenades entières, mais on coupera les cormes en deux, et on en ôtera les semences. On cuit ces fruits jusqu'à ce qu'ils soient cntièrement fondus dans le moût; il faut que pendant la cuisson un jeune esclave les remue avec une spatule de bois ou avec un roseau, pour les empêcher de brûler. Lorsqu'ils sont cuits au point que le sirop est presque entièrement tari, on les laisse refroidir et on les passe; ensuite on broie avec soin jusqu'à le réduire en poudre ce qui cst resté dans la passoire, et on le fait cuire de nouveau dans son propre jus sur de la braise et à petit feu, de peur qu'il ne brûle, jusqu'à ce qu'il s'épaississc

lacu statim tollito : loc autem erit, quod destillaverit antequam nimium calcetur uva. Sed de arbustivo genere, quod sicco die legeris, id facito. Conjicies in urnam musti mellis optimi pondo $\mathrm{x}$, et diligenter permistum recondes in lagœua, eamque protinus gypsabis, jubebisque in talulato reponi, si plus volueris facere, pro portione qua supra mel adjicies. Post trigesimum et alterum diem lagœnam aperire oportebit, et in aliud ras mustum eliquatum obliuire, atque in fumum reponere.

XLII. Compositio inedicamenti ad tormina, quod roca-

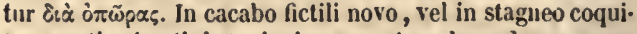
tur musti arbustivi Aminei urna, et nuala cydonea graudia expurgata viginti, et integra mala dulcia granata, quæe Punica rocantur, et sorba non permitia divisa exemptis seminibus, quae sint instar sextariorum triun. Hac ita coquuntur, it omnia poma deliquescant cum musto, et sit puer, qui spatha lignea vel arundine permisceat poina, ne possint aduri. Deinde cum fuerint decocta, ut non multum juris supersit, refrigerantur et percolantur : eaque, qua in colo sulsederunt, diligenter contrita levigaulur, et 
en forme de lic. Mais avant de retirer cette marmelade du feu, il faut ajouter à tous les ingrédients dont elle est composée trois hemince de sumac de Syrie broyè et tamisé, que l'on mêlera avec une spatule, afin que lc tout s'amalgame bien. Ensuite, lorsque cette marmclade est refroidie, on la met dans un vase de terre neuf poissé, que l’on enduit de plátre; après quoi on le suspend fort haut, de peur qu'elle ne inoisisse.

XLIII. Manière de confire le fromage. Coupez en gros morceaux du fromage de brebis sec, et fait de l'année précédente : arrangez ces morceaux dans un vase propre, que vous remplirez ensuite d'un moût d'une très-bonne qualité, de façon qu'ils en soient recouverts, et qu'il y ait un peu plus de jus que de fromage. Car le fromage, en absorbant le jus, finirait par se corrompre s'il n'en était pas continuellement recouvert. Au reste, dès que vous aurez rempli le vase, vous l'enduirez de plâtre, et vous pourrez l'ouvrir au bout de vingt jours, pour vous servir du fromage dans tel ragoût que vous voudrez. Il ne sera pas même désagréable lorsqu'on le mangera seul.

XLIV. Aussitôt que l'on aura coupé sur le cep des grappes soit de raisin à gros grain, soit de maroquin ou de raisin pourpré, on enduira leur queue de poix dure; ensuite on remplira un bassin de terre cuite neuf de paille très-sèche, et scionée de facon qu'il n'y reste point de poussière. On étendra ces grappes sur cette paille, après quoi on couvrira ce bassin d'un second bassin, en enduisant les faux joints d'un mortier dans lequel il entrera de la paille. Enfu, lorsque ces bassins seront ainsi arrangés, on les enveloppera de paille sèche, et on les serrera sur un plancher très-sec. Au reste, il n'y a pas de rai-

iterum in suo sibi jure lento igni, ne adurantur, carbonibus decoquuntur, donec crassamen in modum fecis existat. Prius tamen quam de igne medicamentum tollatur, tres hemina roris Syriaci contriti et cribrati super omnia adji. ciuntur, et spatla permiscentur, ut coeant cum cateris. Tum refrigeratum medicamentum adjicitur in vas fictile novum picatum, idque gypsatum alte suspenditur ne palIorem tralıat.

XIIII. Caseum sic condiemus. Casei aridi ovilli proximi anni frusta ampla facito, et in picato vase componito : tum oplimi generis musto adimpleto, ita, ut supervertiat, et sit jus aliqutanto copiosius quam caseus. Nam casens combibit, et fit ritiosus, nisi mustum semper supernatet. Vas autem cum impleveris, statim gypsabis : deinde post dies viginti licet aperias, et utaris qua voles adlibita con. ditura. Est [ autem] etiam per se non injucundus.

XLIV. Uras, ut sint virides usque ad annum, sic custodiemus : uvas bumastos rel duracinas vel purpureas cum desecueris a vite, continuo pediculos earum impicato dura pice : deinde labellum fictile novum impleto paleis quıan siccissimis cribratis, ut sine pulvere sint, et ita u vas superponito : tum labello altero adoperito, et circuunlinito sin qu'on ne puisse conserver sans craindre qu'il se gâte, pourvu qu'on le cueille quand la lune sera dans son déclin, par un temps serein, et après la quatrième heure du jour, lorsqu'il sera déjà essorć et qu'il ne sera plus couvert de rosée. Mais il faudra faire du feu dans le sentier le plus voisin de la vigne, pour faire bouillir la poix dans laquelle on trempera la queue des grappes aussitót qu'elles seront cueillies. Jetez une amphore de vin cuit jusqu'à diminution de moitić dans une futaille bien poissée; ensuite arrangez en travers dans cette futaille des bátons serrés les uns auprès des autres, sans qu'ils touchent au vin cuit; après quoi vous mettrez sur ces bâtons des plats de terre neufs, et vous arrangerez le raisin sur ces plats, de façon que les grappes ne se touchent point mutuellement; enfin vous les couvrirez et les enduirez. Sur ce premier lit vous en formerez un second pareil, puis un troisième et ainsi de suite, tant que la capacité de la futaille en comportera, et vous y arrangerez le raisin de la même manière. Ensuito vous imbiberez bien de vin cuit jusqu'à diminution de moitié le couvercle de la futaille, et quand elle sera couverte, vous la boucherez avec de la cendre. Quelques personnes se contentent, après avoir mis le vin cuit dans la futaille, de ser. rer les perches transversales les unes auprès des autres, d'y suspendre les grappes de façon qu'elles n'atteignent pas le vin cuit, et d'enduire ensuite le couvercle posé sur la futaille. D’autres, après avoir cueilli les grappes comme je viens de le dire, font sécher au soleil de petites futailles neuves non poissées, et, après les avoir fait refroidir à l'ombre, ils y mettent du son d'orge, sur lequel ils posent les grappos de manière qu'elles ne se compriment pas mutuellement ; en-

luto paleato, atque ita in tabulato siccissimo composita labra paleis siccis obruito. Omnis autem ura sine noxa servari potest, si luna decrescente et sereno calo post horam quartam, cum jam insolata est, nec roris quicquam habet, viti detraltatur. Sed ignis in proximo decumano fiat, ut pix ferveat, in qua pediculi uvarum statim demittantur. Aliter. In dolium bene picatum defruti amphoram conjicito, deinde transversos fustes arctato, ita ut defrutum non contingant : tum superponito fictiles noras patinas, et in lis sic uvam disponito, ut altera alteram non contingat : tum opercula patinis imponito et linito. Deinde alterum tabulatum, et tertium, et quamdiu maguitudo patitur dolii, similiter superinstruito, et eadem ratione uvas componito. Deinde picatum operculun dolii defruto large linito, et ita conpositum cinere obfurato. Nonnulli adjecto defruto contenti sunt transversas perticas arctare, et ex lis uvas ita suspendere, ne defrutum contingant : deinde operculum impositum oblinire. Quidam uras cum ita, ut supra dixi, legerunt, doliola nova sine pice in sole siccant. Deinde cum ea in unibra refrigera verunt, furfures ordeaceos adjiciunt, et uvas ita superpontunt, ut altera altrram non comprlmat : tum generis ejusilem furfures iufuudunt, 
suite ils les recouvrent de ce même son, et forment de la même façon un second lit de grappes, en répétant la même opération jusqu'à ce qu“ils aieut rempli les futailles alternativement de son et de raisin; après quoi ils enduisent leurs couvereles, et serrent ce raisin sur un plancher qui soit très-sec et très-frais. D'autres conservent de la même façon du raisin vert dans la sciure de bois de peuplier ou de sapin. Quelques-uns ensevelissent dans la fleur de gyp sèche des grappes qu'ils ont eu soin de cueillir avant qu'elles fussent trop mûres. D'autres, après avoir cueilli le raisin, coupent avec des ciseaux les grains gâtés qui peuvent s'y reneontrer, et le suspendent ainsi dans le grenier au-dessus du blé : mais cette méthode fait rider les grains, et rend le raisin presque aussi doux que s'il était sćché au soleil. Marcus Colu:nelle, mon oncle paternel, faisait faire, avec l'espece d'argile dont on fait les amphores, de larges vases en forme de plats, qu'il revêtissait d'une bonne couche de poix tant en dedans ıu'en dehors, et lorsqu'ils étaient ainsi préparês, il faisait cueillir le raisin pourpré, le raisín à gros grain, celui de Numidie et le maroquin, et faisait plonger aussitôt la qucue des grappes dans la poix bouillante; ensuite il faisait mettre chacune de ces espèces de raisin dans des plats à part, de facon que les grappes ne se touchassent pas entre elles; après quoi il faisait couvrir ces plats, et les faisait enduire d'unc bonne couehe de gyp, et poisser avec de la poix dure fonduc au feu, de manière que l'humidité n'y pût pénétrer : enfin il submergeait ees vases dans de l'eau de fontaine ou de eiterne, en les chargeant d'un poids qui les empechait de sortir de l'eau par aueun côté. II est vrai que cette méthode est excellentc pour conserver le raisin; mais quand

et alterum tabulatum uvarum eorem modo collocant : idque faciunt usque dum dolium alternis furfuribus $\mathrm{ct}$ uvis compleant. Mox opercula imposita liumn, et u vas siccis. simo frigidissimoque tabulato reponunt. Quidam cadem ratione arida populnea vel abiegna scobe virides uvas custodiunt. Nonnulli sicco flore gypsi obruunt uvas, quas non niminm maturas vitibus detraxerunt. Alii cum legerunt uvam, siqua sunt in ca vitiosa grana forficibus amputant, atque ita in horreo suspendunt, in quo triticum suppositum est. Sed lıec ratio rugosa facit acina, et pene tam dulcia, quam est uva passa. Marcus Columella patruus meus ex ca creta qua fiunt ampliora, lata vasa in modum patinarum fieri jubebat : eaque intrinsecus et exterius crasse picari : qua cum præparaveral, lum demum purpurcas et bumastos et Numisianas et duracinas uvas lcgi praccipiebat, pediculosque carum sine mora in ferventem picem demitti, et in pradict is patinis separatim sui cujus. que generis ita conıoni, ne uva inter se contingerent : post loc opercula superponi, et oblini crasso gypso : tum demum pice dura, quæ igni liquata esset, sic picari, ncquis lumor transire possct : tota deinde vása in aqua fontaua vel cisternina ponderibus impositis mergi, nec ullam on vient à le retirer de l'eau, il est sujet à s'aigrir, à moins quion ne le eonsomme le jour même qu'on l'en aura retiré. II n'y a eependant pas de méthode plus sûre pour conserver le raisin que celle qui consiste à fabriquer des vases de terre cuite, dont ehacun puisse eontenir une grappe à l'aise. Ces vases doivent avoir quatre anses, par lesquelles on pulsse les attaeher, à l'effet de les suspendre aux ecps de vignes : lcurs eouvereles doivent aussi être tels qu'ils puissent se séparer par le milieu, afin que lorsqu'on aura suspendu ces vases, et qu'on aura introduit dans ehaeun d'eux unc grappe de raisin, les deux moitiés de lcur couvercle puissent se rejoindre de l'un et de l'autre cóté des grappes pour les couvrir. Il faut poisser avec soin ees vases ainsi que leurs couvereles, tant à l'intérieur qu'à l'éxtérieur; et lorsque les grappes y seront renfermées, on les recouvrira d'une grande quantité de mortier dans lequel il entrera de la paille. Au reste, en y renfermant les grappes adhérentes aux eeps, il faudra prendre garde qu'elles ne touehent aux parois des vases par aucun còté. Au surplus, pour renfermer les grappes de raisin dans ees vases, il faut communément choisir le temps où leurs grains sont gros, et où ils eommeneent à tourner : il faut aussi que le temps soit sec et le ciel serein. Nous preserivons surtout comme une règle générale celle de ne point serrer de fruits pêle. mêle avee du raisin dans un même endroit, ni même dans deux endroits volsins l'un de l'autre, de erainteque l'odeur des fruits, en se communiquant au raisin, ne le gâte par la suite. Les différentes façons de eonserver ee fruit, que nous avons donucees, ne eonvienuent pas néan.. moins ćgalement toutes à tous les pays quels qqu'ils soient; mais les unes conviennent à un pays, lę

partem carum pati exstare. Sic optime servatur uva. Sed cum cst exempta, nisi eo die consumitur, acescit. Nilil est tamen certius, quam vasa fictilia facere, quae singulas uvas lase recipiant. Ea debent qualuor ansas liabere, quibus illigata viti dependeant : itemque opercula corum sic formari, ut media divisa sint, ut cum suspensa vasa sillgulas uvas recepcrint, cx utroquc latere appositi operculı duæe partes roëant, et contegant uras. Et lıxc vasa ct opercula extrinsccus et intra diligenter picata csse debcbunt : dcinde cum contexerunt uvas, luto paleato multo adoperiti : scd uva dependentes a matre sic in pultarios condi debcbunt, ne qua parte vasa contiugant. Tempus autem quo iucludi debent, id fere est, quo adluc siccitatibus et sereno calo crassa variaque sint acina. Illud in tolum maxime procipimus, ne in colcin loco mala et uve componantur, neve in vicino, unde odor malorum possit ad eas pervenire. Nam lujusmodi lıalitus celeriter acina corrumpunt. Eæ tanen custodiendorum pomorum rationes, quas retulimus, non omnes omnibus regionibus aptie sunt, sed pro conditione locorum et natura urarum alia aliis conveniunt.

XLV. De ollaribus uvis. Antiqui plerumque sircitu 
autres à un autre, suivant la nature des lieux et la qualité du raisiı.

XLV. Moyen de conserver les raisins dans des pots de terre. Les anciens conservaient communément dans des vases le raisin fircilula, le venu. cula, le grand Aminé, celui des Gaules, et celui dont le grain est gros, dur et clair-semé : mais aujourd'hui c'est celui de Numidic qui passe pour le plus propre à être conservé de cette facon, surtout dans le voisinage de la ville. On le cueille avec le plus grand choix lorsqu'il est médiocrement mûr, par un temps serein, et quand il n'y a plus de rosée sur terre, à la quatrième ou à la cinquième heure du jour (pourvu que la lune soit dans son déclin et sous l'hémisphère); ensuite on le met sur des claies, de façon que les grappes ne se froissent pas mutuellement. Ce n'est qu'après ces premiers soins qu'on le porte à la maison, et qu'on en coupe avec des ciseaux les grains gâtés; après quoi, horsque les grappes ont été un peu rafraichies à l'ombre, on les met dans des pots de terre au nombre de trois ou de quatre, suivant la capacité de ces vases, dont on a soin de boucher bien exactement. les couvercles avec de la poix, pour empêcher que l'humidité n'y pénètre. Ensuite on renverse un tas de mare de raisin qui ait ćté bien desséché sous l'arbre du pressoir ; et après avoir un peu éparpillé les raffles et dégagé les peaux de ce raisin, on l'étend au fond d'une futaille, dans laquelle on arrange ces pots en les renversant par en bas, et en les éloignant les uns des autres de facon que l'on puisse entasser du mare dans les intervalles qui les séparent. Lorsqu'on a formé un premier lit de ce mare en le foulant bien, on arrange d'autres pots sur ce lit de la même façon que sur le premier, et on parvient par là à compléter une sceonde couche de pots. Ensuite on remplit la fu- taille de la même manière de plusieurs couches de pots, en foulant bien le mare dans les intervalles; après quoi on entasse du mare jusqu'à ses bords, puis on la couvre aussitot et on l'enduit de cendre préparée comme du plâtre. Il faut cependant prévenir celui qui sera chargé de faire l'emplette des vases, qu'il doit prendre garde à ne pas en acheter qui boivent l'eau ou qui soient mal cuits, parce que l'un et l'autre de ces défauts contribue également à gáter le raisin, en livrant un passage à l'humidité. Bien plus, il faudra, lorsqu'on retirera les pots pour son usage, en enlever une couche entière, parce que, dès qu'on vient à ébranler le marc qui est foulé entre eux, il s'aigrit promptement et gate le raisin.

XLVI. Après la vendange, viennent les confitures des fruits d'automne, qui doivent aussi partager l'attention de la métayère. Je n'ignore pas que j'ai passé sous silence dans cet ouvrage bien des choses que $\mathrm{C}$. Matius a traitées avec un très-grand soin. En effet, cet autcur, qui se proposait pour objet de son travail le service des tables de la ville, et les apprêts des festins les plus splendides, a donné trois livres, qu'il a intitulés le Cuisinier, l'appréleur de poissons et le Confiseur: au lieu qu'il nous suffit de parler des choses que la simplicité rustique peut se procurer aisément et sans grands frais, telles que sont entre autres les fruits de toutes les espèces. Pour commencer par les grenades, il y a des personnes qui tordent la queue de ces fruits sur l'arbre même sans les déplacer, pour empécher que la pluie ne les fasse crever, et qu'étant une fois entrouverts, ils ne viennent à se perdre. Elles les attachent ensuite à des branches plus fortes que celles qui les portent, afin qu'ils ne puissent s'ent re-choquer; après quoi elles enveloppent l'arbre entier de filets de genêts d'Espagne, de peur que les corbeaux, les las et renuculas et majoręs Amineas, et gallicas, quæque majoris et duri et rari acini erant, vasis coudebant : nunc aulen circa urbem maxime ad lunnc usum Numisianxe probantur. IIæ sereno ę̧lo, cum jam sol rorem sustulit, quarta vel quinta loora, si modo luna decrescit, et sul) terris est, modice matura rectissime legnntur : statim pediculi earura picantur : deinde in cratibus ita ponuntır, ne altera alteram collidat. Tum demum sub tectum refe. runtur, et nuncida vel vitiosa grana forficibus ampntantur : et cum paululum sub umbra refrixerint, ternx ant etiam quaternxe pro capacitate vasorum in ollas demittuntur et opercula diligenter pice obturantur, ne liumorem transmittant. Tum vinaceornm pes bene prelo expressus proruitur, et modice separatis scopionibus, resoluta intrita folliculorum in dolio substeruitur, et deorsum versus spectantes ollx componuntur, ita distantes, ut intercalcari possint vinacea : quxe cum diligenter conspissata primum tabulatum fererunt, alia ollæ eodem modo componuntur explentque secundum tabulatun. Deinde similiter doliis exstrumutur ollæ et spisse incalcantur. Mox usque ad sumusum labrum vinacea condensantur, et statim oper- culo superposito cinere in ınodum gypsi temperato dolinm linitur. Monendus autem erit, qui vasa enpturns est, ne bibulas aut male coctas ollas emat. Nam utraque res transnisso Innore vitiat uvam. Qninetian oportebit, cum ad usum promuntur olla, tota singula tabulata de. tralii. Nan conspissala rinacea, si semel mota sunt, celeriter acescunt, et uvas corrumpunt.

XLVI. Sequuntır vindeniam rerum antumnalium compositiones, qua et ipsæe curam villicac distendunt. Nec ignoro plurima in liunc librum non esse collata, qux $\mathbf{C}$. Matins diligentissime persecutus est. Illi enin propositum fuit urbanas mensas et lauta convivia instruere. Libros tres edidit, quos inscripsit nominibns Coci, et Cetarii, et Salgamarii. Nobis tamen abunde sınt ea, quxe ex facili rusticae sinplicitati non unagna impeusa possunt contiugere, uti sunt in primis omnium generum mala. Quidam, ut a granatis incipiam, pediculos punicorum, sicuti sunt in arbore, intorquent, ne pluviis mala rumpantur, $\varepsilon_{i}$ liantia dispereant, eaque ad majores ramos religant, ut inımota permaneant : deinde sparteis retibus arborem cludunt, ne ant corvis aut cornicibus aliisve avibus pomum 
corneilles ou d'autres oiseaux ne becquètent ses fruits. Quelques-uns ajustent aux fruits qui pendent à l'arbre de petits vases de terre cuite, qu'ils laissent sur l'arbre après les avoir enduits d'un mortier dans lequel il entre de la paille : d'autres enveloppent chaque fruit à part de foin ou de chaume, qu'ils recouvrent d'une bonne eouche de mortier dans lequel il entre de la paille, et les attachent ainsi à de plus grosses branches quc celles qui les portent, afin, comme je l'ai dit, que le vent ne les ballotte point. Mais il faut faire cette opération, ainsi que je l'ai dit, lorsque le temps est serein et qu'il n'y a pas de rosée; quoiqu'il vaille encore mieux s'abstenir de la faire, parce que les arbrisseaux en souffent; ou du moins ne pas la faire habituellement plusieurs années de suite, d'autant que l'on peut conserver ces fruits sans qu'ils se gâtent, même après les avoir cueillis. En effet, on peut encore faire à la maison, dans un endroit très-sec, de petites fosses de trois pieds, et, après y avoir mis tant soit peu de terre menue, on enfoncera dans cette terre de petites branches de sureau; ensuite on cueillera par un temps serein les grenades a vec leurs queves, et on les fichera dans le sureau (car la moelle du sureau est si abondante et si molle qu'on peut aisément $\mathrm{y}$ iutroduire la queue de ces fruits). Mais il faudra avoir l'attention qu'clles ne soient pas à une distance de la terre moindre de quatre doigts, et qu'elles ne se touchent point entre elles. On couvrira ensuite la fosse, et on enduira les faux-joints de la couverture qu'on y aura mise avec un mortier dans lequel il entrera de la paille; puis on entassera par-dessus la terre qui en avait été tirée en la fouillant. On peut faire la même opération dans unc futaille, en la remplissant jusqu'à la moitié de sa capacité ou de terre pulvérisée à son choix, ou de sable de rivière que quelques

laceretur. Nonnulli vascula fictilia dependentibus malis aptant, et illita luto paleato arboribus harere patiuntır : alii foeno rel culmo singula involvunt, et insuper lito paleato crasse linunt, atque ita majoribus ramis illigant, ne, ut dixi, vento commoveantur. Sed laxe omnia, ut dixi, sereno calo administrari sine rore debent: qux tamen aut facienda non sunt, quia laduntur arbuscula : aut certe non continuis annis usurpanda, prassertim cum licedt etiam detracta arboribus eadem innoxia custodire. Nam et sub tecto fossulæ tripedanex siccissimo lnco fiunt eoque cum aliquantum terra minutx repositum est, infiguitır sambuci ramuli : deinde sereno calo granata leguntur cum suis pediculis, et sambuco inseruntur [quoniam sambucus tam apertam et laxam medultam habet, ut facile malorum pediculos recipiat]. Sed cavere oportebit, ne miuns quatuor digitis a terra absint, et ne inter se poma coutingant. Tum facta scrobi operculum imponitur, $\mathrm{e}^{\mathrm{t}}$ paleato .luto circumlinitur, eaque lumo, quæ fuerat egesta, superaggeratur. Hoc idem etiam in dolio fieri potest, sive quis volet resolutam terram usque ad dimidiuın vas adjicere, seu, quod quidam malunt, fluvialem are. personnes préferent en cette occasion, et en continuant de la même manière le reste de l'opération. Magon le Cartlıaginois prescrit de faire bien chauffer de l'eau de mer, et d'y plonger un instant les grenades en les attachant avec du lin ou du genèt d'Espagne, jusq̨u'à ce qu'elles aient perdu leur couleur, et, après les avoir retirées, de les faire sécher au soleil pendant trois jours; ensuite de les suspendre dans un lieu frais : et enfin, lorsqu'on en aura besoin, de les faire tremper dans de leau douce froide pendant une nuit, et jusqu'au moment du lendemain où l'on voudra s'en servir. Mais le même auteur conseille aussi d'enduile les fruits nouveaux d'une bonne couche de terre à potier bien pétrie, et quand cette terre est séchée, de les suspendre dans un lieu frais; ensuite de les tremper dans l'eau lorsqu'on en aura besoin, et de casser l'argile dont ils sont couverts. Par ce procédé les fruits conservent en quelque. sorte leur fraicheur primitive. Le même Magon ordonne d'étendre au fond d'un pot de terre neuf de la sciure de bois de peuplier ou d'yeuse, et d'arranger les fruits de façolı que l'on puisse fouler la sciure dans les intervalles qui les séparent; ensuite, après avoir fait une première couche de fruits, d'étendre de nouveau de la sciure pardessus, et de les arranger de méme jusqu'à ce que le pot soit rempli ; enfin, lorsqu'il sera plein, d'y mettre un couvercle, et de l'enduire exactement de mortier à une bonne épaisseur. Au reste, il faut toujours cueillir avec leurs queues les fruits que l'on veut conserver longtemps; il faut même, quand on le peut faire sans nuire à l'arbre, les cueillir avec de petites branches, ce qui contribue beaucoupà leur durée. Il y a bien des personnes qui arrachent les fruits de l'arbre avec leurs petites branches, et qui les font sécher au sıleil, après les avoir exactement couverts de

nam, caxteraque eadem ratione peragere. Ponus quidem Mago pracipit aquam marinam velementer calefieri, et in ea mala granata lino sparfove illigata panlum denitti, dıun decolorentur, et exempta per triduum in sole siccari : postea loco frigilo suspendi, et cum res exegerit, una nocte et postero die usque in eam horam, qua fuerit utendum, aqua frigida dulci macerari. Sed et idem auctor est crela figulari bene subacta recentia mala crasse illinire, et cun argilla exaruit, frigido loco suspendere. Mox cum exegeril usus, in aquam denittere, et cretanı resolvere. Hacc ratio tamquan recentissimum pomum custodit. Idem jubet Mago in urceo novo fictili substernere scobem populneam vel iligneam, et ita disponere, ut scobis inter se calcari possit : deinde facto primo tabulato rursus scobem substemere, et similiter mala disponere, donec urceus impleatur : qui cum fuerit repletus, operculum imponere, et crasso luto diligenter oblinire. Omne autem pomum quod in vetustaten reponitur, cum pediculis suis legendum est : sed, si sine arboris noxa fici possit, etiam cum ramulis. Nam ea res plurinum ad pereunitatem confert. Multi cum ramulis suis arbori detralimnt, et creta 
terre à potier ; ct si cette terre vient à se crevasser par la suitc cn quelque endroit, elles les enduisent de mortier, et les suspendent dans un lieu frais quand ce mortier est séché.

XLVII. Bien des personnes conservent les coings dans des fosses ou dans des futailles de la même manière que les grenades. D'autres enveloppent ces fruits de feuilles de figuicr, apres quoi ils pétrissent de la terre à potier avec de la lie d'huile pour les en enduire; et, lorsque cet enduit est sec, ils les serrent sur un plancher en lieu frais et sec. D'autres les mettent sur des plats neufs qu'ils ensevelissent dans du gyp sec, de facon qu'ils ne se touchent pas mutuellement. Mais nous n'avons pas trouvé, toute expérience faite, de mètlıde plus sûre ni plus avantageuse pour conserver ces fruits, que cclle qui consiste à les cueillir en bon état ct non tachés, quand le clel est serein et que la lune est dans son déclin, et à les arranger légèrement et de facon qu'ils soient à l'aise, afin qu'ils ne puissent pas se mcur: trir, dans un flacon neuf dont l'ouverture soit très-large, après avoir essuyé le duvet dont ils sont couverts; ensuite, lorsqu'ils sont arrangés jusqu'au col du vase, à les y contenir avec des baguettes d'osier mises en travers, de façon qu'ils soient légèrement comprimés, et qưils n’aient pas lá liberté de se soulever lorsqu'on y aura versé la liqueur; enfin à remplir le vase jusqu'aux bords d'excellent miel qui soit très-liquide, de facon que tout le fruit en soit recouvert. Nonseulement cette méthode est bonne pour conserver les fruits, mais elle procure en même temps une liqueur appelée melomeli (miel de fruit), qui a le goût du miel, et que l'on peut faire prendre de temps en temps sans danger aux personnes qui ont la fièvl'c. Mlais il faut se garder de prendre

figulari cum diligenter mala obruerunt, in sole siccant : deinde si qua rimam creta fecit, luto linunt, et assiccala frigido loco suspendunt.

XLVII. Multi eadem ratione, qua granata, in scrobibus vel doliis servant cydonea. Nounulli foliis ficulneis illigant, deinde cretam figularem cum anurca subigunt, et ea linınt ınala, quae cum siccata sunt, in tabulato frigido loco et sicco reponunt. Nonuulli hac eadem in patinas novas sicco gypso ita obruunt, ut altera altera non contingant. Nilil tamen certius aut melius experti sumus, quam ut cydonea maturissima, iutegra, sine macula, et sereno cxlo, decrescente luna, legantur, ct iu lagnena nova, quae sit patentissimi oris, detersa languine quxe malis inest, componantur leviter et laxe, ne collidi possint : deinde cum ad fauces usque fuerint composita, vimincis surculis sic transversis arctentur, ut modice mala comprimant, nec patiantur ea, cum acceperint lifuoreın, sublevari. Tum quam optimo et liquidissimo melle vas usque ad summum ita repleatur, ut pomum submersum sit. Hxc ratio non solnm ipsa mala custodit, sed etiam liquorem mulsei saporis prabet, qui sine noxa possit inter cibnm dari febricitantibus, isque vocatur mclomeli. Sed caren- des fruits qui ne soient pas mûrs pour les conser. ver dans du miel, parce que, lorsqu'ils out été cueillis verts, ils s'y dureissent au point de n'êtıe plus mangeables. Au reste, il est inutile de les ouvrir avec un couteau d'os pour en ôter les pe. pins, comme font bien des gens qui s'imaginent que ces pepins gâtent le fruit; d'ailleurs la méthode que je viens de donner est si sûre, que quand même il se trouverait un ver dans ces fruits, ils seralent à l'abri de se gâter, dès qu'on les aurait mis dans la liqueur que nous avons prescrite. En effet, telle est la nature du miel qu'il arrête les progrès de la corruption; ct c'est par cette raison qu'il rend même un cadavre incorrup. tible pendant plusieurs années. On peut donc conserver dans cette liqueur toutes les autres espèces de pommes, telles que la pomme ronde, celle de Sestius, la pomme de paradis et celle de Matius. Mais comme les fruits que l'on conserve ainsi dans le micl, semblent acquérir un nouveau degré de douceur et perdre le goût qui leur est propre, il vaut mieux, pour les conserver, préparer de petites caisses de bois de hêtre ou de tilleul, semblables à celles dans lesquelles on enferme les habits dont on se pare pour sortir, et même un peu plus grandes, et mettre ces caisses sur un plancher très-frais et en un lieu très-sec, où il ne puisse parvenir ni fumée ni mauvaise odeur, de quelque nature qu'elle soit : après quoi on étendra ces fruits au fond de ces caisses, en les ariangeant de façon que leur nombril soit tourné par en haut et leur queue par en bas, conformément à la position dans laquelle ils étaient sur l'arbre, et en les éloignant assez les uns des autres pour qu'ils ne se touchent pas mutuellement. Il faudra avoir soin, en suivant cette méthode, de mettre chaque espècc de fruit séparément dans de petites

dum est, ne, qua in melle custodire volueris, imnıalura mala condantur : quoniam cruda si lecta sunt, ita indn. rescnnt, ut usui non sint. Illud vero quod multi faciunt, ut ca dividant osseo cultro, et semina eximant, quod putent ex eis pomnm vitiari, supervacuum est. Sed ratio quain nunc docui, adco quidem certa est, ut etian si vermiculus inest, non amplius tamen corrumpantur mala, cum praedietum liquorem acceperint : nam ea mellis est natura, ut coẻrceat vitia, nec serpere ca palialur : qua ex causa cliam exaumum corpus hominis per annos plurimos innoximm conservat. Itaque possunt etiam alia genera malorum sicut orbiculata, Sestiana, melimela, Matiana, lıo liquore custodiri. Sed quia videntur in melle dulciora fieri sic condita, nec proprium saporem conservare, ar. culæ fagina vel cliarn tiliagineæ, quales sunt in quibus restimenta forensia conduntur, luvic rei paulo ampliores pricparari debent, exque in tabulato frigidissimo et siccissimo, quo neque fumus neque teter perveniat odor, collocantur : deinde carta substrata pradicta poina sic componi ut flosculi sursnm pediculi deorsum spectent, queinarlmodum etiam in arbore nata sunt, et ne inter alterum ab altero contingan tur. Item observandum est, ut 
eaisses partieulières, paree que, s'il s'en trouvait de différentes espèees renfermées ensemble dans la même eaisse, ils ne s'aceommoderaient pas de ecttc union, et ne tarderaient pas à se gâter. C'est préeisément la ralson pour laquelle le vin fait avee du raisin de différents plants n'est pas si durable que le vin Aminć pur conservé à part, ou le vin museat, ou le vin des vignes fecinice. Au surplus, lorsque ces fruits auront été arrangés avee attention de la manière que je viens de preserire, on fermera ces petites eaisses, et on les enduira d'un mortier dans lequel il entrera de la paille, afin que l'air ne puisse pas y pénétrer. Quelques personnes, pour eonserver ees fruits, pratiquent aussi la méthode que nous a vons dejjá donnée par rapport à d'autres espèces de frults, c'est-à-dire qu'elles mettent entre chaque fruit de la seiure de bois de peuplier; d'autres y mettent aussi de la seiure de bois de sapin. Il ne faut cependant pas cueillir ces fruits dans leur maturité, mais lorsqu'ils sont encore très-verts.

XLVIII. Manière de confire l'aunéc. Lorsqu'on aura arraché de terre des racines d'aunce au mois d'octobre (temps auquel elles sont très-nıûres), on óterä, eu les essuyant avec un morceau de grosse toile ou même avec un tissu de poil, tout le gravier dont elles seront eouvertes; ensuite on les ratissera grossièrement avee un couteau trèsiranchant, et l'on coupera les plus fortes en dcux ou trois tronçons de la longueur du doigt, selon qu'elles scront plus ou moins grosses; après quoi on les fera cuire légèrement avec du vinaigre dans un ehaudron de cuivre, en prenant garde qu'elles ne brûlent. Cette première opération faite, on les fera sécher pendant trois jours à l'ombie, et on les mettra ensuite dans un flacon poissé, dans lequel on versera la quantité nécessaire de vin fait avee du raisin séché au soleil, ou de vin

unumquodque genus separatim propriis arculis reponatır. Nam cum una clansa sunt diversa genera, inter se discordant, et celerlus vitianțir. Propter quod etiarn consemiualium vinearum non tam est firmun vinum, quam si per se sinccrum Amineum, vel Apianım, aut etiam fecinum condideris. Verım sicut sıpra dixi, cun diligenter mala fuerint composita, opereulis arcularum contegantur, et Into paleato linantur opercula, ne introire spiritus possit. Atıue ea ipsa ronnulli, sieut in aliis generibus supra jam diximus, populnea, quidam etiam abiegna scobe interposita, mala constodinnt. Hace tamen poma non matura, sed acerbissima legi debent.

XIVIII. Inula conditura sic fiet. Cum ejus radicem mense Octobri, quo maxime matura est, e terra erueris, aspero liuteolo vel etiam cilicin detergilo quidquid arenæ inharebit : deinde acutissimo cultello summatim eradito, et quæ plenior radicula fuerit, pro modocrassitudinis in duas vel plıres partes digiti longitudine diffindito: deinde pr aceto modice in cacabo aneo coquito, ita ne taleola Rimuicruila sint. Post lıxc in umbra triduo siecentur, et ila in fidelian picatam recondantur, adjecto passo vel euit jusqu'à diminution de moitié, pour qu'elles en soient entièrement reeouvertes : enfin, après les avoir couvertes d'une bonne poignée d'origan, on bouchera le vase et on l'enveloppera d'une peau. Autre façon de confire l'aunée. Après a voir ratissé les raeines de cette plante, on les partagera comme ci-dessus en petits troncons, que l'on fera sécher à l'ombre pendant trojs ou même quatre jours; ensuite, lorsqu'ils seront sees, on les mettra dans des vases non poissés, avec de l'origan entre chaque tronȩon. Quand l'origan y sera, on mêlera ensemble six parties de vinaigre sur une partie de vin euit jusqu'à diminution des deux tiers, avee une hemina de sel grillé, pour en faire un jus dans lequel on fera tremper les tron. çons de ces racines, jusqu'à ce qu'elles se soient entièrement défaites de leur amertume : ensuitc on les retirera pour les faire sécher de nouveau à l'ombre pendant einq jours; puis on mêlera ensemble dans une marmite trois parties de lie tant de vin épais que de vin miellé, avec une partie de bon vin cuit jusqu'à diminution de moitié; et lorsque la marmite bouillira, on y jettera les tronçons d'aunće; puis on retirera aussitôt la marmite du feu, et on remuera le tout avee une spatule de bois, jusqu'à ce qu'il soit absolument refroidi. Ce n'est qu'alors qu'on le mettra dans un flacon poissé que l'on couvrira, et que l'on enveloppera d'une peau. Troisiène façon. Quand on aura ratissć avec soin les racines de l'aunce, on les fera tremper, après les a voir coupées en petits tronęons dans de la saumure fortc, jusqu'à ce qu'elles se soient défaites de toute leur amertume. Ensuite on jettera la saumure, puis on pilera des cormes qui soient très-bonnes et très-múres, dont on aura préalablement retirć les pepins, et on les mêlera avee l'aunće; après quoi on y ajoutera du vin fait avec du raisin sé-

defruto, quod supernatet, spissamentoque cunilie imposito contectum vas pelliculetur. Alia inula conditura. Cum radices ejus eraseris, taleolas it supra facito, et in umbra tridno vel etian quatriduo siceato : deinde siccatas in vasis sine pice; interjecta cunila eonjicito. Jus infundito, quod eam compositionem labeat, ut sex partibus aceti una pars sapæ misceatur enm lıemina salis cocti. Lo jure macerentır taleolae, donee quam minimun amaritudinis resipiant. Postea exemptie itermm siecentur per dies quinque in umbra : tum erassamentum vini feculenti, nec minus, si sit, mulsi, et utriusque corum quartam partem boni defruti confundito in ollam : quæ cum inferluerit, taleolas inula adjicito, et statim al igne remoreto, ac rudicula lignea peragitato, donee perfecte refrigescant. Postea transfmulito in fideliam picatam, opereulo tegito, tumque pelliculato. Tertia ejusiem inula conditura. Cum raliculas diligenter eraseris, minute eoncisas in muria dura macerato, donec amaritudinem dimittant. Deinde effusa muria, sorba quam optima et maturissima semine defracto conttere, et cum iunla misce. Tum sive passum seu fuam ojtimum defiutum adjicito, et vas obturato. Quitlam cum 
ché au soleil, ou d'excellent vin cuit jusqu'à diminution de moitié; et on bouchera le vase daus lequel on l'aura mise. Quelquespersonnes, après avoir fait confire l'aunée dans la saumure, la font sécher, et mẻlent avec elle des coings pilcès, prealablement bouillis dans du vin cuit jusqu'à diminution de moitié, ou dans du miel; cnsuite elles versent par-dessus du vin fait avec du raisin séché au solell, on du vin cuit jusqu’à diminution de moitie; et après avoir couvert le vase qui la renferme, clles l'enveloppent d'unc peau.

XLIX. Manière de confire les olives. Battez l'olive prusia au mois de septembre ou d'octobre, quand elle est encore acerbe ct a vant que la vendange soit finie; puis, après l'avoir fait un peu tremper dans de l'eau chaude, pressezla et mettez-la dans un flacon, en y ajoutant de la graine de fenouil et de lentisque avec un reu de sel grille; aprés qunoi vous verserez. dans ce flacon du moût très-nouveau, et vous $\mathbf{y}$ enfoneercz une petite botte de fenouil vert, qui comprimera les olives de façon que-le jus les recouvre. On peut dès le troisième jour faire usagre des olives confites de cette manière. Quand vous auiez battu l'olive pausea blanehe, l'orchis, la petite olive longuc ou la regia, vous commencerez par les plonger les unes ou les autres dans de la saumure froide, afin qu'elles nc perdent pas leur couleur; et après que vous aurez donnè ce prem:er apprèt à la quantité d'olives qui sera nécessaire pour remplir une amphore, vous étendrez au fond de cette amphore une petite botte de fenouil sec. Vous aurez soin d'a voir dans une petite cruche de la graine de fenouil et de lentisque mondée, afin d'en jeter dans le vase où vous mettrez l'olive, après l'avoir tirée de la saumure et l'a voir pressée. Lorsque vous iur'ez mis des olives jusqu'au col du vase, vous

condiveruut iuulaun, muriaque maceraverunt, exsiccant, et nalis cydoneis tritis, qua in defruto rel melle decoserant, miscent : atque ita superfundunt passum rel defrutuin, et vas operculatum pelliculant.

XLIX. Olivarum allarum conditura. Acerbain pauseam meuse Septembri, vel Octobri, dum adluc vindemia est, contunde, et aqua calida paululum maceratam exprime, furviculiøue seminlbus et leutisci cum cocto sale modice permistau reconde in fideliam, et mustum quam recen. tissimum infunde. Tun fasciculum viridis faniculi superpositum merge, ut oliva prenantur, et jus superemineat. Sic curata oliva tertio die possis uti. - Alban panseam, vel orchitem, rel radiolum, vel regiam dum contundes, priman quamque, ne decolorelur, iu frigidam muriaun demerge, cujus cuun tantum paratie lıabuerıs, quantum satis fuerit impleudx amplıorx, firniculi aridi fasciculum sub. sterne in imo : deiude riridis fouiculi sennina et leutisci destricta et purgata in urceolo habeto : tum exemptam de muria olivam exprimito, et permistam pratictis semiuibus in sas adjicito : deinde cum ad fances pervenerit ejus, firni- les couvrirez de petites bottes de fenouil sec; apris quoi vous verserez dans le vase deux parties de moût nouvcau ct unc partic de saumure forte, mêlées ensemble. Vous pourrez aisėment fairc usage pendant toute l'année des olives confites de cette manière. Il y a des personnes qui ne batteut point l'olive, mals qui la coupent par tronçons avec un ruseau tranchant : ce procédé, quolque moins simple, mérite cependart la pré. férence sur le premier, en ce que l'olive est alors plus blanche que lorsqu'elle a souffert des meurtrissures qui l'ont couverte de taches livides. D'autres mêlent avec les olives, soit qu'ils les aient battues, soit qu'ils les aicnt coupées par tronçons, un peu de sel grillé mélé arec les graines que nous venons de nommer; après quoi ils versent dessus du vin cuit jusçu'à diminution des deux tiers, ou du vin fait avec du raisin séché au soleil; ou même s'ils sont à portèe de le faire, ils y versent de l'eau dans laqueltc on a trempédes rayons de miel. Nousa vons déjá donné dans ce livre memc la facou de composer eelte cau. Pour le restes on procède de la manière indiquée. Choisissez les olives posice ou les regice les plusblanches et les moins tachées que vous cueillerez à la main, et que vous jetterez cnsuite dans une amphore, apres y avoir étendu au fond du fenouil, mêlé par-ei par-lả de quelques graines tant de lestisque que de fenouil. Lorsque le vasc sera rempli jusqu'au col, vous y verserez de la saumure furte, et vous comprimerez les olives avec une bonne poignée de feuilles de roseaux, de façon qu'elles soicnt absolument plongées dans le jus; puis vous verserez encore dessus ee qu'il faudra de saumure forte, pour qu'il y en ait jusqu'aux bords de l'amphore. II est vari que lolive ainsi préparée est peu agréable, si on la mange seule; mais aussi clle est très.propre à entrer dans les ragoûts des tables les

culi aridi fasciculos superponito, et ila recentis nusti duas partes el unam duræ muria permistas adjicito. llac conditura compositis olivis toto anno commode uteris. Quislam olivan non contundunt, sed acuta arundine iusecant : ilque operosius quideın, sed melius est, quia hac caudidior est oliva, quain ea qua ex contusioue livorem contrahit. Alii sire contuderint, sive iusecuerint olivas, modico sale cucto et pradictis seminibus imuiscent: deiude sapan rel passum rel, si est facultas, mellam in. fundınt. Mella autem quomodo tiat, paulo ante lıoc ipso libro pracepinus. Cxtera omuia similiter administrantur. Oliva alla ex muria. ['osias olivas vel regias sine macula quam candidissimas manu destrictas eligito : deinde sub. strato foniculo arido in amphoram conjicito : intermistis seminibus lentisci nec uninus foruiculi : et cum ad fauces vas repleveris, adjicito inuriam duram : tum spissamento facto de arundium foliis olivam premito, ut iufra jus unersa sit : et iterum infundito muriam durain, dum ad summum amplıora labrum perveniat. At liac oliva per se parum jucında eșt; sed ad eas condituras, qua lautioribus. 
plus magnifiques, pulsque, lorsqu'on en veut faire usage, on peut la tirer de l'amphore, et l'employer, après l'avoir battue, à telle sauee que l'on juger'a ì propos. Néanınoins le plus grand nombre aime mieux hacher en petits morceaux des poireaux que l'on coupe à différentes reprises, et de la rue avec de l'ache tendre et de la menthe, et mêler ces substances avec les olives après les avoir battues; puis verser dessus un jeu de vinaigre épicé, et tant soit peu de miel ou đe vin mêlé de miel; enfln les arroser d'huile verte, et les couvrir d'une petite botte d'ache verte. Quclques-uns, après avoir cueilli de même l'olive, mettent trois hemina de sel sur un modius de.ce fruit, et, après avoir jeté au fond d'une amphore de la graine de leutisque et du fenouil, ils la remplissent d'olives jusqu'au col; après quol ils y versent du vinaigre qui ne soit pas trop mordant; et lorsque l'amphore est presque remplie, ils y enfoncent l'olive à l'aide d'une bonne poignée de fenouil, et remettent du vinaigre jusqu'aux bords du vase : enfin, au bout de quarante jours, ils vident tout ce jus, et mêlent ensemble trois parties de vin cuit jusqu'à diminution des deux tlers ou de moitié, et une partie de vinaigre, pour faire un jus dont ils remplissent l'amphore. Il y a eneore un autre procédé de confire les olives; ce procédé, qu'on approuve beaucoup, consiste à vider toute la saumure forte, dans laquelle on a fait macérer de l'olive pausea blanche, et à remplir l'amphore d'un mélange de deux parties de vin euit jusqu'à diminution de moitié, et d'une parlie de vinaigre. On pourrait aussi confire de meme l'olive regia ou l'orchis. Quelques personires mêlent ensemble une partie de saumure et deux parties de vinaigre, et font nager dans ce jus des olives posece. Si l'on veut alors

mensis adlihentur, idonea maxime est : nam cum res exigit, dc amplıora promitur, et contusa recipit quamcunque volucris condituram. Plerique tamen sectivum porrum et rutam cum apio tenero ct mentam minute concidunt, et contusis olivis miscent : deinde exiguum aceti piperati, et plusculum mellis aut mulsi adjiciunt, oleoque viridi irrorant, atque ita fasciculo apii viridis contegitur. Quidan sic lectre oliva in modios siugulos ternas heminas salis permisuent, et adjectis seminibus lentisci freniculo(juc substrato amplioram usque ad fauces replent olivis : deindc aceto non acerrimo infundunt, et cum jam pene a mplioram impleverunt, fueniculi spissamento deprimunt baccam, ct rursus acetum usque ad sumnum labrum adjiciunt. Postea quadragesimo die omne jus dcfundunt, et sapæ vel defruti tres partes cum aceti una permiscent, et amplioram replent. Est et illa probata composilio, ut cum muria dura pausea al ba ubi commaturuerit, omne jus dcfundatur, et immistis duabus partibus defruti cum aceti una, repleatır amphora. Eadem conditura possit etiam regia componi vcl orchita. Quidam unam partem muriæ et duas aceti miscent, eoque jure olivas poseas colymbadas faciunt : quibus les consommer telles (qu'elles sont, sans aucun autre assaisonnement, on les trouvera assez agréables, quoiqu'elles puissent aussi, en sortant de la saumure, reecvoir tel assaisonnement que l'oll voudra. On cueille avec leurs queues les olives posece lorsqu'elles commencent à changer de couleur et avant qu'elles soicnt mûres, pour les conserver dans d'excellente huile. C'est méme la meilleurc mèthode pour faire conserver aux olives lcur goût de verdcur jusqu'd la fin de l'annèe. Aussi se trouve-t-il des personnes qui les servent comme fraiehes an sortir de l'huile, après les avoir saupoudrées de sel égrugé. Voici encore une façon de les confire, appelée epityrum, qui est communément en usage dans les villes grecques : on cueilie à la main par un temps serein l'olive pausea ou lorchis, lorsqu'clles commencent à perdre leur blaneheur et à jaunir, et on les étend à l'ombre sur des vans pendant une jouruće; après quoi on en arrache les queues, ainsi que les feuilles ou les petites branches qui peuvent y être adhérentes. Lc lendemain on les crible, et après les avoir cnfermées dans un cabas neuf, on les met sous l'arbre du pressoir, où on les presse fortement, pour leur faire rendre si peu qu'elles peuvent contenir d'huile. Quelquefois on les laisse, pour ainsi dire, suppurer sous le poids de l'arbie pendant toute une nuit et le lendemain; après quoi on relève l'arbre du pressoir, et l'ou répand dessus un sextarius de sel grillé ct égrugré par modius de fruit. On y ajoute aussi de la graine de lentisque, avee des feuilles de rue et de fenouil séchées à l'ombre, et coupées aussi menues que lion juge à propos; puis on les laisse dans le sel pendant trois heures, jusqu'a ce qu'elles s'en soient imprégnées à un certain point. Alors on verse dessus autant de bonne huile

si per se quis uti velit, satis jucundas experietur, quamris et lax, cum exeunt de muria, condituram qualemcunque recipere possint. De olivis fuscis. Oliva poseæ, cum jam decolorantur, antequam mitescant, cum pctiolo leguntur, ct in oleo quam optimo servantur. Haec maximc nola etianı post annum repraesentat viridem saporem olivarum. Nonnulli etiam cum de olco excmerunt, trito salc aspersas pro novis apponunt. Est et illud conditura genus, qund in civitatibus Gracis plcrumque usurpatur, idque vocant epityrum. Oliva pansea vel orclita cum primum ex allon decoloratur, fitquc luteola, sereno calo manu destringitur, et in camnis uno die sub umbra expanditur : et siqui adliarent pediculi foliaque aut surculi, leguntur. Postero die cribratur, et novo fisco inclusa prelo supponitur, vclicmentcrque prcmitur, it exsudet quantulumcunque habet amurca. Patimur autem nonnunquam tota nocte et postero die pondere pressan baccam velut exaniari, tum resolutis corticulis eximimus eam, et in singulos modios oliva triti salis cocti singulos sextarios infundimus : itemque lentisci scmen rutaque et foeniculi folia sub umbra siccata, quanta satis videutur concisa minute admisccmus, 
qu'il est néeessaire pour qu'clles soient noyées dedans, et on eufonce dans lc vase unc petitc botte de fenouil sec, afin que le jus les recouvre. On prépare pour les confirc ainsi des vases de terre cuite neufs, et qui ne soicnt pas poissés; et, pour les empêcher de boire l'huile, on les imbibc d'une liqueur semblable à celle dont on imbibe les metretæe qui servent à mesurer l'huile; après quoi on les fait sécher.

L. Viennent ensuitc les froids de l'hlver, pendant lesquels la cueillette des olives n'exige pas moins de soins de la part de la métayère que la vendange. Nous commencerons donc par donner des préceptes sur la façon de confire les olives (puisque nous avons entamé cet objet), après quoi nous passerons à la manière de fairc l'huile. Ce sont les olives pausece ou les orchites, et dans quelques pays mème celles de Navius, que l'on apprête pour être servies dans les repas. II faut donc cueillir à cet effet ces sortes d'olives à la main, par un temps sercin, lorsqu'elles commencent à noircir ct qu'clles ne sont pas encorc tout à fait. mûres, et les eribler ensuite; puis mettre de cóté celles qui paraltront ou tachées, ou gâtées, ou trop petites. Ensuite on mettra sur un modius de fruit trois hemince de sel qui n'ait recu aucun apprêt, ct, après avoir brouillé les olives avce ce sel dans des paniers d'osier, on répandra par-dessus une assez grande quantité de sel pour qu'elles en soient recouvertes, et on les laissera ainsi suer pendant trente jours, ct jeter toute la lie d'huilc qu'elles contiendront. Au bout de ce temps on les versera dans un bassin, et on essuiera le sel avec unc éponge propre, de facon qu'il n'y en reste plus. Lnfin on les serrera dans une amphore que l'on remplira de vin cuit jusqu'à diminu-

patimurque loris tribus, dum aliquatenus bacca salem combibat. Tum superfundimus boui saporis oleum, ita ut obruat olivam, et founiculi aridi fasciculum deprimimus, ita ut jus supernatet. Huic autem conditurae vasa nova fictilia sine pice præparantur : quæ ne possint oleum sorbere, tamquam olivariæe metreta imbuuntır liquida gummi et assiccantur.

L. Sequitur autem frigus liemis, per quod olivitas, sicul vindemia, curam villiex repetit. Prius itarque (quoniam inclıavimus) de condituris olivarum pracipiemus, ac statim conficiendi olei rationem subjiciemus. Pausen baccx vel orchitae, nonnullis regionibus etiam Nacvixe, conviviorum epulis praparautur. Llas igitur cum jam nigruerint, nec adlusc tamen permaturae fueriut, sereno carlo destriugere maun conveuit, lectasque cribrare, et secernere, quxcum(que maculosæ sen vitiosa minorisve incrementi videbuntnr : leinde in singulos modios oliva salis integri ternas leminas adjicere, et in vimineos qualos coufundere superposito copioso sale, ita uti olivam contegat, sicque triginta dies pati consudascere, atque omnem anurcinı exstillare : postea iı alveum diffundere, muıdarpue spongia salem, ne perveniat, detergere : tum in vas tlon des deux ticrs ou de moitić, et l'on y enfoncera par-dessus une poignéc de fenoull see pour les comprimer. Cependant il se trouve des personnes qui ajoutent unc partie de vinaigre quelquefois sur dcux partles, mais plus commu'nément sur trois parties soit de vin cuit jusqu'd diminution de moitié, soit de miel, et qui les font ainsi confire dans ce jus. Quelques-uns, après a voir cuellli l'olive noirc et y avoir mis du sel dans la proportion que nous venons de prescrirc, la mettent dans des paniers en y entreinelant de la graine de lentisque, et en formant alternativement des couches d'olives et de sel jusqu'au haut des paniers. Quarantc jours après, lorsque l'olive a jeté tout ce qu'elle pouvait contenir de lie d'huile, ils la versent dans un bassin, cn la criblant pour en séparer la graino de lentisque, et l'essuient avec une éponge, afin qu'il n'y reste point de sel; après quoi ils la jettent dans une amplore qu'ils remplissent ou de vin cuit jusqu'à diminution soit de moitié, soit des deux tiers, ou même de miel s'ils en sont fournis aboudamment, et font pour lc surplus ce que nous avons prescrit ci-dessus. Il faut mettre sur un modius d'olives un sextarius de graine d'anis et de lentisque mûre, avec trois cyathi de graine de fenouil, ou bien, à défaut de graine, la quantité de fenouil haché qu'on estimera suffisante; ensuite ajouter par chaquc modius trois hemincs de sel grillé et non égruge; après quoi on serrera ces olires dans des ampliores que l'on bouchera avec de petites poignécs de fenouil, et que l'on roulera tous les jours par terrc ; enfin on jettera tous les trois ou quatre jours toute la lie d'huile qui pourra s'y trouver. Quarante jours après on versera les olives dans un bassin, en se contentant de les séparer du sel,

adjicere, et sapa vel defruto amplioram replere superposito spissamento aridi foeniculi, quod olivan deprimat. Plerique tanien ties partes defruti aut mellis et unam miscent aceti, aliqui duas partes et unam aceti, et eo, quo condiunt, jure. Quidam, cum olivam nigram legerınt, eandem portione, qua supia, saliunt, et sic. collocaut in qualis, ut immistis seminibus lentisei alterna tabulata olivarum et salis usque in sumınum componant: deinde post quadragiuta dies, cum oliva quidquid labuit amurcse exsudavit, in alveum defindunt, et cribratam separant: ab seminibus lentisci, spongiaque detergent, nequid. adlıæreat salis : tım in amplıoram confundunt adjecto defruto vel sapa vel etiam melle, si est copia, cxteraque sinil: liter faciunt. - In singnlos modios oliva singulos sextarios maturi seminis anisi, lentiscique, et ternos cyatlıos semi: nis forniculi; si id non est, ipsum foeniculum concisum, quautum satis videbitur, adjici. oporlet : deinde in singulis modiis olivarum salis cocti, sed non moliti ternas lieminas admisceri, et ita in amploris cuudi, easque fasciculis foeniculi obturari, et quotidie per terram volutari : deiule tertio quoque aut quarto die quidquid amurcse inest, emitti. Post xu dies.in alveum diffundi, et a sale tantum. 
sans les essuyer avec une éponge; puis on les scrrera dans une amphore telles qu'on les aura retirées du bassin, et sans les purger des parties de sel dont elles seront enveloppées; et après les avoir eouvertes de bonnes poignées d'herbes qui les eontiendront, on les mettra à la eave pour' s'en servir au besoin. Retirez de la saumure des olives que vous y aurez fait nager après les avoir cueillit's mûres, et essuyez-les avee une éponge; ensuite coupez-les avec un roseau vert en deux ou trois morecanx, et faites-les tremper pendant trois jours dans du vinaigre; le quatrième jour, essuyez-les avee une éponge, et jeter-les dans une cruche ou dans un pot neuf, au fond desy!nels vous aurez mis auparavant de l'ache avec un pell de rue.' Lorsque le vase sera plein d'olives ainsi coupées par morceaux, vous y verserez ensuite jusquaux bords du vin euit jusqu'à diminution de moitié : enfin vous couvrirez les olives de tendrons de laurier, à l'effet de les enfoneer dans le vase, et vous en ferez usage au bout de vingt jours.

L. On eueille les olives noires lorsqu'elles sont très-mûres, par un temps serein, et on les étend à l'ombre pendant une journée sur des roseaux, puis on met de eôté toutes celles qui sont gâtés. On arrache aussi toutes les queues adhérentes au fruit, ainsi que les feuilles et les petites branehes qui peuvent s'y trouver entremêlées. Le lendemain on les crible avee soin, afin d'en séparer toutes les ordures; après quoi on les enfurme dans un eabas neuf, et on les place sous larbre du pressoir, pour être pressurées pendant toute la nuit. Le lendemain on les met sous de's meules très-propres, et qui sont suspendues afin qu'elles ne brisent pas le noyau; et lorsqu'elles sont réduites en mare, on mêle ensemble entre les mains dusel grillé et égrugé avec d'autres

moilos separari, sie ne spongia detergeantur oliva, sed ita IIt erunt exemptx, massulis salis mistis in aunplioram coulantur, el spissamentis impositis ad usus in cellam reponantur. - Maturam olivam in stratura factom colym. baslem de muria tollito, spongia tergito : deinde canna vitidi seindito duobus vel tribus locis, et triduo in aceto luabeto: quarto die spongia extergilo, in urceun aut cacabum norum unitito substrato apio et modica ruta. Conclis deinde pleno vase olivis immilte defrutum usque al os. Lauri turiones in loe usu inittito, ut olivas deprimant. Post dies viginti utere.

L.I. Oliva nigra maturissima sereno calo legitur, eaque sub umbra uno die in caunis porrigitur, et quxeumuge est vitiosa bacca, separatur. Item siyui adlıaserant pediculi, adimuntur, foliaque et sureuli, quicumque sunt intermisti, eliguntur. Postero die diligenter cribratur, ut siquid inest stereoris separetur : deinde intrita oliva novo fisco includitur, et prelo sıbjicitur, ut tota noete exprimatur. Postero die injicitur quam mundissimis molis fuspensis, ne nueleus fraugatur. Et eum est in sampsam retacta, tune sal coctus tritusque manu permisectur cum assaisonnements sees, tels que du fenugree, du cumin, de la graine de fenouil et de l'anis d'F́. gypte. Au reste, il su?fira de mett:e une heminu de sel par modius d'olives; ensuite on versera de I'huile dessus, de peur qu'elles ne se dessechent, attention qu'il faudra mème avoir toutes les fois qu'elles paraitiont commencer à se sécher. Il n'y a point de doute que ce ne soient les olives po. sice qui auront le meilleur gout lorsqu'elles seront confites de eette façon, quoique leur goût ne se conservera pas plus de deux mois sans s'altérer. Il y a néanmoins d'autres espèces d'olives qui paraissent plus propres à être confites ainsi, telles que eelle de Lieinius et la culminea, quoiqu'en général celle qui passe pour y être la plus propre de toutes soit celle que donne l'arbre de Calabre, que quelques personnes appellent petit olivier sauvage, à cause de sa ressemblance avee ce dernier arbre.

L.11. C'est au commencenent du mois de décembre que l'on fait communément la eueilletle des olives, et e'est le temps où elle n'est ni prématurée ni tardive. En effet, c'est dans ce temps que l'on fait l'huile verte; au lieu que l'huile acerbe, appelée huile d'été, se fait plus tôt, comme l'huile mûre se fait plustard. Mais l'huile acerbe rendant peu, il n'est pas de l'intérêt d'un chef de famille d'en faire, à moins que les olives n’aient cté abattues par les mauvais temps, et qu’on ne soit dans la nécessité de les ramasser, pour empèeher qu'elles ne soient mangíes par les bêtes soit donestiques soit fauves. II est au contraire très-important d'en faire de verte, tant parce que celle-ci rend abondamment, que parce qu'elle double presque le revenu du propriéfaire, à eause du prix élevé dont elle se vend. Mais si l'on est en possession de plants d'oliviers qui soient d'une étendue imınense, on est foreé d'en

cateris aridis condimentis. Irace autem sunt, carenu, eyninum, semeu foniculi, anisum Egyptimn. Sat crit antem totidem heminas salis adjieere, quot sunt unorii olivarum, et oleun superfundere, ne exareseat : idliue fieri debebit, quotieseumque videbitur assiecarí. Nee du. bium est, quin optimi saporis sit, quae ex oliva posiat facta est. Cocterum supra duos menses sapor ejus no॥ permanet integer. Videntur auten alia genera huic rei magis esse idonea, sient Licinix et culminece. Verumtamen lıabefur praceipun in lıos usus olea Calabrica, quam quidam propter similitudinem oleastellum voennt.

LII. Media est olivitus plerumque initium mensis De. cembris. Nam et ante hoc tempus acerbum olenm conficitur, inod vocatur aestivum, et eirca hume mensem viride premitur, deinde postea maturum. Sed acerbun oleum facere patrisfamilias rationibus non conducit : quoniam exiguum fluit, nisi baeca tempestatibus in terram decidit, et neeesse est eam sublegere, ne a domesticis peeudibus ferisve consumatır. Viridis antem note conficere vel maxime expedit, quoniam et satis fluit, et pretio pene duplicat domini reditum. Sed si vasta sunt oliveta, 
réserver (quelque partie pour faire del'huile mưre. Quoique nous ayous déjà décrit dans le premier volume le lieu dans lequel on doit faire l'huile, nous allons cependant rappeler quelques articles que nous avions d'abord omis, afin de compléter eelte matièrc. Il faut a voir un plancher destiné à re. cevoir les oli ves. Il est viai que nous avons un préeepte qui ordonne de les mettre jour par jour sous tes meules et sous l'arbre du pressoir, à mesurc qu'elles sont réeoltées. Mais néanmoins, comme il arrive quelquefois que le travail des pressureurs ne peut pas suffire à la quantité prodigieuse d'olive's que l'on aura récoltées, il faut avoir un grenier plafonné dans lequel on les mettra, et dont le plancher sera semblable à ceux sur lesquels on pose les grains. Ce grenier doit aussi être distribué en tel numbre de cases que l'exigera la quantité d'olives que l'on aura, afin de mettre à part dans des cases particulières la cueillette de chaque jour. Il faut que le sol de ces eases soit pavé de terre ou de tuile, et qu'il aille cn pente, afin que toute l'humiditć s'en écoule promptement, à tra vers des canaux et des conduits qui y seront pratiqués, paree que la lie d'huile est très-contraire à cctte liqueur, et que pour peu que l'olive y séjourne, elle gâte le goût de l'huile. C'est pourquoi, lorsqu'on aura construit ees eases de la manière que nous venons de prescrire, on posera sur leur superficie de petits soliveaux éloi. gnés d'un demi-pieả l'un de l'autre, sur lesquels on étendra des elisses de roseaux qui seront d'un tissu serré et travaillées avec soiı; afin que les olives ne puissent pas passer à travers ces elisses, et quc celles-ei puissent en soutenir le poids. II faudra aussi qu'il y ait vis-à-vis ces cases, du côté par lequel s'écoulera la lie d'huile, ct sous les conduits mémes á travers lesquels elle passera , un pavé coneave ou unc pierre creusée en forme de petite fosse, dans laquelle s'arrêtera toute la liqueur qui s'écoulera, de facon qu'on puisse l'y puiser. Il faudra outre cela avoir des cuves et des fulailles toutes prêtes à la maison, pour y déposer la lie d'huile de chaque espèce d'olive, soit que cette lie ait coulé naturellcment et sans mélange, soit qu'elle n'ait eoulé qu'après que l'olive aura été salće. En efiet, l'une et l'autre de ces espèces de lic sont bonnes à différents usages. Au surplus, les meules valent mieux pour faire l'huile que le trclpète, comme le trapète vaut mieux que le canal is et la solea. En effet, il est très-aisé de gouverner les meules, paree qu'on peut les baisser ou les remonter, suivant la quautité d'olives qu'on aura à mettre dessous, pour éviter d'en briser les noyaux, qui altéreraient le goût de l'huile. D'un autre cóté, le trapète fait plus d'ouvrage, et le fait avec plus de faeilité que la solca et le canalis. II y a encore une machine, nommée túdicula (battoir), semblable à un traîneau relevé sur lc côté, qui fait assez bien la besogne; si ee n'est qu'elle est sujette à se dér’anger souvent, et que, si l'on y met un peu plus d'olives quil n'en faudrait, son mouvement s'arrête. II n'y a cependant aucune de ces machines dont on ne puisse se servir suivant la nature et l'usage des pays, quoique la meilleure de toutes soit la meule ou même le trapète. Il nous a fallu donner ce détail prèliminaire, avant de parler de la façon de faire l'huile. Maintenant nous y allons passer, quoique nous ayons omis de faire menlion de bien des choses qu'il faut préparer avant la récolte des olives, comme on le pratique avant la vendange, telles que le bois qu'il faut tenir prêt necesse est ut aliqua pars corum maturo [fructui] reservetur. Locus antem in quo confici oleun debet, etiam descriptus est priore volumine; panca tamen ad rem per. tineutia conımemoranda sunt, quße prius omiseram. 'Talulatum, quo inferatur olea, necessarium est, quamvis praceptum labeamus, ut uniuscujusque diei fructus molis et prelo statim subjiciatur. Veruntamen quia interdum immodica nultitudo baccse torculariornm vincit faburem, (si labor est) esse oportet pensile horreum, quo importentur fructus : idque tabulatum simile esse debet kranario, et liabere lacusculos tam multos, quam postuLabit modus olive, ut separetur et seorsum reponatur uniuscujusque diei coactura. Horunı lacusculorum solum lapirle vel tegulis oportet consterni, et ita eclive fieri, ut celeriter omnis humor per canales aut fistnlas defluat. Nam est ininicissima oleo amurca, qua si remansit in bacca, saporem olei corrumpit. Itaque cum lacus, quem. adnoxlmii dixinus, exstruxeris, asserculos inter se dis. tantes semipedalibus spatiis sapra solum pouito, et cannas diligenter spisse textas injicito, ita ut ne baccam trans. mittere queant, et oliva pondus possint sustinere. Juxta omues autem lacusculos, ea parle qua defluet amurca, sub ipsis fistulis in modum fossularum concarmun pari. mentuın, rel canalem lapideum esse opportebit, in quo consistat, et unde exlıauriri possit quidquid deflıxerit. Præterea lacus vel dolia præparata sub tecto habere oportebit, qua seorsum recipiant sui cujusque generis amurcan, sire qux sincera defluxerit, sive etiam qua salem receperit. Nam utrąue usihus plurimis idonea est. Oleo autem conficiendo molie utiliores sunt, quam tra. petunı; trapetum, quam canalis et solea. Mola quam facillimam patiuntur alministrationen; quoniam pro magnitudiue baccarum vel submitti rel ectiann elevari pessunt, ne nucleus, qui saporem olei vitiat, confringatur. Rursus trapetum plus operis faciliusqune quam solea et canalis efficit. Est et organun erecta tribula: sinile, quod tudicula rocatur : idque non incommode opus efficit, nisi quod frequenter vitiatur, et si baccx pluscnlum ingesseris, inpeditur. Pro conditione tamen et regionum consuetudine pradicta maclina exercentur. Sed et optima molarum opus est, tum etiam trapeti. Haec ante quuain de oleo conficiendo dissererem, præfari necesse iabui. Nunc ad ipsam rem reniendum es!, quamquam nulta omissa sunt, quæe sicut ante riudemiam, sic, et aute olivitatem praparanda sunt, tamqquam lignorum copia, quae multo ante apportanda est, ne cum res desi- 
longtemps d'avance, pour que les ouvriers ne soieıt pas détournés lorsqu'ils en auront besoin ; telles que les échelles, les paniers, les mesures de dix modii et celles de trois, dans lesquelles on reçoit l'olive à mesure qu'elle est cueillie, les cabas, les cordes de clianvre et de genêt d'Espagne, les coquilles de fer avec lesquelles on puise l'luile, les couvercles des vases dans lesquels on la net, les grandes et les petites éponges, les cruches dans lesquelles on porte l'huile au dehors, les clisses de canne sur lesquelles on met l'olive, et tous les autres ustensiles qui ne me reviennent pas à la mémoire dans ce moment. II faut done être muni de tous ces ustensiles, et mème en avoir beaucoup au delà du nécessaire, parce qu'il s'en use toujours une certaine quantité, et que le nombre en diminue à mesure qu'on s'en sert; d'autant que, si un seul vient à manquer au moment ou l'on en aura besoin, l'ouvrage se trouvera interrompu. Mais je vais poursuivre l'objet que j'ai promis de traiter. Dés que les olives auront commencé à tourner, et qu'il s'en trou vera déjà quelques-unes de noires parmi le plus grand nombre de blanches, il faudra les cueillir à la main par un temps serein, après avoir étendu sous les arbres des clisses ou des roseaux; puis les cribler et les nettoyer. Quand elles auront été nettoyées avec soin, on les portera aussitôt au pressoir, et on les enfermera, avant qu'elles rendent leur huile, dans des cabas nenfs que l'on mettra sous l'arbre du pressoir, de façon qu'elles n'y soient pressurées que le moins que faire se pourra. Ensuite, quand on aura relevé l'arbre du pressoir, il faudra les ramollir en répandant dessus deux sextarii de sel qui n'ait reçu aucun apprêt par modius de fruit, ct en exprimer le marc à l'aide de réglets, si c'est la coutume du pays, ou du moins à l'aide de cabas neufs dans lesquels on les renfermera.

leraverit, opera avocentur; tum scala, corbula, decemunodia, trimodie satorix, quibus destricha lacca suscipitur, fisci, funes cannabini, spartei, concha ferrea, quibus depletur oleum, percula, quibus vasa olearia conteguntur, spongiax nuajores et minores, urcei, quibus oleum progeritur, canne, tegetes, quibus oliva excipitur, el siqua sunt alia, quæ nunc menoriam mean refugiunt. Hac ounnia multo plura esse debent: quoniam in usu depereunt, et pauciora fiunt ; quorum siguid suo tempore defuerit, opus intermittitur. Sed jaı q̨uod pollicitıs sum exequar. Cum primum baccae rariare coperint, et jam quaxdam nigra fnc. rint, plures tamen alba, sereno calo maribus destringi olivan oportebit, et substratis tegetibus ant cannis cribrari et purgari. Tum diligenter emundatam protinus in torcular deferri, et integram in fiscis novis includi, prelisque subjici, ut quantum possit paulisper exprimatur. Poslea reso. Intis corticulis et emollitis debelunt, adjectis binis sextariis integri salis in singulos modios, (et) aut regulis, si consuetudo erit regionis, aut certe novis liscis sampsacexpıimi. Quod deiude primum defluxerit in rotundum labrum
Ensuite celui qui est chargé de survider l'huile puisera aussitôt celle qui aura coulé la première dans le bassin (lequel bassin doit être rond, parce qu'étant de cette forme il est préférable à un vase de plomb carré ou à un bassin de briques à plusieurs fonds), et il la versera dans des bassins de terre cuite préparés pour la recevoir. Au reste, il faudra avoir dans le cellier à huile trois ordres de bassins, dont le premier servira à recevoir l'huile de la première qualité, c'est-à-dire celle du premier pressurage; l'autre servira à recevoir celle du second pressurage, et le dernier celle du troisième, parce qu'il est très-intéressant de ne pas confondre le second pressurage et encore moins le troisième avec le premier, attendu que l'huile qui coule comme une lessive, et sans un grand travail, de l'arbre du pressoir, est d'un bien meilleur goût que toutes les autres. Lorsqu'ensuite l'huile se sera reposée quelque temps dans les premiers bassins, il faudra quo celui qui est chargé de la survider l'éclaircisse en la survidant d'abord dans les seconds bassins, et ensuite dans les suivants jusqu'aux derniers. Car plus on lui donnera d'air en la transvasant à différentes fois, et pour ainsi dire en la tourmentant, plus elle deviendra liquide, et moins elle sera chargée de lie. Il suffira néanmoins que chacun des trois ordres soit composé de trente bassins, à moins que les plants d'oliviers que l'on aura soient si considérables, qu'ils en demandent une plus grande quantité. Si le froid vient à congeler l'huile avec sa lie, il faudra sans contredit employer un peu plus de sel grillé que nous n'en avons exigé, parce que c'est le moyen de dissoudre l'huile et d'en séparer tout ce qui l'altère; d'autant qu'il n'y a pas lieu de craindre qu'elle devienne salée, puisque, telle quantité de sel qu'on y mette, elle n'en contracte jamais le goût. Il arrive quelquefois,

(naın id melius est, quam plumbeum quadratum, vel structile gemellar) protiuus capulator depleat, et in fictilia labra huic usui praparata defundat. Sint autem in cella olearia tres labrorum ordines, nt unus prima nota, id est prima pressurac oleum recipiat, alter secundx, tertius tertix. Nam plurimum refert non miscere iteratio. nem, multoque minus tertiationen cum prima pressura : quoniam longe melioris saporis est, quod minore vi preli, quasi lixivum defluxerit. Cum deinde panlılum in labris primis constiterit oleum, eliquare id capulator in secunda labra debebit, et deinde in sequentia usque ad ultima. Nam quauto sxpius translatione ipsa ventilatur, et quasi exercetır, tanto fit liquidius, et amurca liberatur. Sat erit autem in singuliș ordinibus tricena componi labra, uisi si vasta fueriut oliveta, et majorem uumerum desideraverint. Quod si frigoribus olenm cum amurca congelabitur, plusculo sale cocto ulique utendım erit. Là res resolvit oleum, et separat ab onmi vitio. Neque verendum est, ne salsum fat. Nam quantumcunque adjeceris salis, uililo. minus saporem non recipit olcum. Solet autem ue sic 
lorsquu'il survient de très-grands froids, que cette pratique même nc suffit pas pour la dissoudre. On grille alors du nitre, et, après l'avoir broyé, on en saupoudre les olives et on les en nourrit bien, atìn qu'il parvienne à liquéfier la lic. Beaucoup de personnes, qui cependant passent pour faire l'huile arec soin, ne mettent jamais l'olive sous l'arbre du pressoir avant qu'elle ait rendu un peu d'huile d'elle-même, parce qu'elles s'imaginent qu'il s'els perd toujours alors quelque peu, attendu que, lorsque l'arbre du pressoir vient à peser dessus, la lie d'huile n'est pas la seule liqueur qui s'en écoule, puisqu'elle entratne infailliblement avec elle un peu de liqueur grasse. Mais voici un précepte général qque j’ai d̀ donner : c'est de ne point laisser pénétrer de fumée dans le pressoir tant que l'on y fera de l'huile verte, comme de n'y point souffrir de suie, non plus que dans le cellier à huile, parce que ce sont deux choses très-contraires à ce genre de travail : aussi les plus habiles huiliers ne permettent-ils qu'avec peine de faire l'huile à la lumière d'une lampe. C'est pourquoi il faut que le pressoir et le cellier à huile soient placés du côté du ciel qui sera le moins exposẻ aux vents, parce que la vapeur du feu qu'on serait alors obligé d'y faire serait très-nuisible. Il ne faut pas se contenter de s'occuper du soin des futailles et des cruches dans lesquclles on doit mettre l'huile au temps seulcment où l'on y est forcé par la récolte; mais la métayc̀re doit, dès que les vases out été vidés par le marchand, s'appliquer à enlever aussitôt les immondices ou la lie d'huile qui peuvent y étre restées au fond. Elle ne doit pas cependart employer à cet effet une lessive très-chaude, de peur que la cire ne se détache des vases; mais clle doit les essuyer à différentes reprises, puis les frotter légèrement avec la main à l'eau tiède,

quidem resol ri, cum majora frigora incesserunt : itaq̨ue uitrum torretur, et contritum inspergitur et commiscetur; ea res eliquat amurcam. Quidam quamvis diligentes olearii baccam integram prelo non subjiciunt, quod existimant aliquid olei deperire. Nam cum preli pondus accepit, non sola exprimitur amurca, sed et aliquid secum pinguitu. dinis attralit. Illud autem in totım procipiendum habeo, ut neque fumus neque fuligo, quamdiu viride oleum conficitur, in torcular admittatur, ant in cellam oleariam. Nam est utraque res inimica huic rei ; peritissimique olearii vix patiuntur ad unam lucernam opus fieri. Quapropter ad euın statum cali et torcular et cella olearia constituenda est, qui maxiıne a frigidis ventis arersus est, ut quam minime rapor ignis desideretur. Dolia auten et serix, in quihus oleum reponilur, non tantum eo tempore curauda sunt, cum fructus necessitas cogit, sed ubi fuerint a niercatore vacuata, confestim villica debet adlibere curam, ut si qua: feces aut amurca in fundis vasorum subsede. riut, statim emundentur, et non calidissima lixivia, ne vasa ceram remittant, semel atque iterum eluantur : deinde aqua tcpida leviter manibus defricentur, el stepius et les essuyer souvent avec une éponge pour en sćcher toute l'humidité. Quelques personnes délayent dans de l'eau de la terre à potier, pour en faire une espèce de lie liquide; et après a voir lavé les vases, elles les enduisent ă l'intérieur de cette espèce de liqueur et les laissent sécher; puis elles les lavent arec de l'eau pure lorsqu'elles en ont besoin. D'autres les lavent d'abord avec de la lie d'huile et ensuite avec de l'eau, et les font sécher; après quoi elles examinent si ces vases n'ont pas besoin d'être endults de cire nouvellc. Car les anciens prétendaient qu'il fallait enduire les vases de cire au bout de six récoltes d'olives à peu près, quoique je ne concoive pas comment cela pourrait se faire. En effet, si des vases neufs reçoivent aisément la cire liquide lorsqu'on les a fait chauffer, je pense que d'anciens vases n'admettent pas une seconde fois la cirure (l'enduit de cire), à cause du suc huileux dont ils sont imprégnés. Au reste, les agriculteurs de nos jours out même rejeté le premier enduit de cire, et ils ont pensć qu'il était plus à propos de laver les vases neufs a vec de la gomme liquide, et de les parfumer de cire blanche lorsqu'ils seraient secs, pour les empècher de contracter de la moisissure. Ils estiment aussi qu'il ne faut pas molns répéter cettc fumigation à l'égard des vieux vases qu'à l'égard des neufs, toutes les fois qu'on les soigne dans la vue d'y mettre de l'huile nouvelle. Il se trouve bien des personnes qui, après avoil enduit une première fois d'une gomme épaisse les futailles ou les cruches neures, se contentent pour toujours de cet unique enduit, parce qu'effectivement un vase de terre cuite qui a étć unc fois imbibé d'huile n'admet pas un second enduit de gomıne, attendu que la graisse de l'huilo ne s'accommode pas d'unc matière d'une nature telle que celle de la gomme. Après le mois de dé-

eluantur, atque ita spongia omnis luumor assiccetur. Sunt qui cretam figularem in modum liquida fecis aqua resulvant, et cun vasa laverint, lıoc quasi jure intrinsecus oblinant, et patiantur arescere : postea cum res exigit, pura eluunt aqua. Nonnulli prius amurca, deinde aqua vasa perluunt, et assiccant. Tum considerant, numquid ceram novam dolia desiderent. Nam fere sexta quaque olivitate cerari oportere antiqui dixerunt. Quod fieri posse non intelligo. Nam quemadmodu un nova vasa si calefiant, liquidam ceram facile recipiunt, sic vetera non credideriu propter olei succum ceraturam pati. Quam tanıen et ipsam ceraturam nostrorum temporum agricola repudiaverunt, existimaveruntque satius esse nova dolia liquida gummi perluere, siccataque suffumigare alba cera, ne pallorem aut malum odorem capiant. Eamque suffitionem semper faciendam judicant quotiescunque vel nova vel vetera vasa curantur, et oleo novo præeparantur. Multi cum semel nova dolia vel serias crassa gummi lirerunt, una in perpetuum gumnitione contenti sunt. Et sane qux seinel oleum testa combibit, alteram gummitionem uon recipit. lespuit enim olei piuguitudo talcm materiam, qualis est 
cembre il faudra cucillir l'olive vers les ealendes de janvier de la manière que nous avons détailléc ci-dessus, et cn extraire aussitôt l'luuile, parce que, si on la laissait sur le plancher, elle ne tarderait pas à s'échauffer; d'autant que pendant les pluies d'hiver elle engendre plus de lie qu'en aucun autre temps, et que cette lie est très-contraire à ce genre d'opération. Il faut done prendre garde de se réduire à la nécessité d'en faire de l'huile à manger qui ne serait bonne que pour les gens. Il n'y a qu'un seul moyen d'éviter cet inconvénient; ce moyen consiste à faire écacher l'olive et à la pressurer des qu'elle est arrivée des champs, après l'avoir traitée de la manière que nous avons prescrite ci-dessus. La plus grande partie des agriculteurs s'était imaginć qu'en déposant l'olive à la maison, l'huile aúgmentait sur le plancher; mais ce système est aussi faux yu'il est faux que le blé croisse dans l'aire; et voici comme Porcius Caton l'Alıcien réfute cette erreur. Il assure que l'olive se flétrit sur un plancher, et qu'elle s'y rappetisse; mais que lorsqu'un paysan a porté à la maison la mesure d'une pressurce, et ([u'i! veut la mettre sous les meules plusieurs jours après, comme il a oublié la quantité qu'il en avait apportée d'abord, il supplée ce qui manque à la pressurée en puisant dans les autres tas particuliers qu'il avait faits de mème; d'où il arrive que 'l'olive qu'il a vait laissée sur le plancher lui semble rendre plus d'huile que l'olive nouvelle, quoique dans la réalité il en ait employé beaucoup plus de modii qu'il ne se l'était imaginé. Au reste, quand ce systeme serait très-fondé, il y atırait toujours plus de profit à faire sur le prix de l'huile verte, qui se vend toujours très-cher, que sur l'augmentation du fruit. Aussi Caton a-t-il dit que, tel surcroit de poids ou de mesure que l'on suppose du côté de

guumis. - Post mensem Decembrem circa calendas Ja. nuarias ealen ratione, qua superius, destriıgenda erii olea, et statim exprimenda. Nam si reposita in tabulatum fuerit, celeriter concalescet : quoniam hieualibus pluviis anurcx plus concipit, quạ est contraria huic rei. Carendum est utique, ne fiat olenm cibarium. Quod nuo modo vitari poterit, si protinus illata de agro bacca commolita et expressa erit, qua sic adninistrata fuerit, ut supra diximus. Pleriogue agricolarum crediderunt, si sub tecto bacca deponatur, oleum in tabulato grandescere : quod tam falsum est, quam in area frumenta crescere; idque mendacium vetus ille Porcius Cato sic refellit. Ait enim in tabulato corrugari oliram, minorempue fieri. Propter quod cum facti unius mensuram rusticus sub tecto reposnerit, et post multos dies eam molere voluerit, oblitus prioris mensura quam intulerat, ex alio acervo similiter seposito quantumcunque mensure defuit supplet, eoque facto videtur plus olei requiela, quam recens bacca reddere, cum louge plures modios acceperit. Attamen ut maxime id verum esset, uiliiloninus ex pretio viridis olci plus quam nultitudine nali nummorum conlıalitur. l'huile, on trouvera toujours une perte réelle plutôt qu'un profit véritable, si l'on veut supputer la quantité d'olives qu'on a été obligé d'ajouter pour compléter la pressurée. Ainsi nous ne devons pas balancer à éeacher l'olive et à la mettre sous l'arbre du pressoir, au premier moment qu'clle aura été cueillic. Je convieus néan. moins qu'il faut aussi faire de l'luuile à mangrer pour les gens; mais les olives qui sont tombétes parce qu'elles étaient maugles des vers, ou celles que les mauvais temps ou les pluies ont jetées dans la boue, servent de ressource en cette occasion. A cet effet on fait chauffer de l'eau dans un chaudron pour laver ces olives, qui sont malpropres : il ne faut pas cependant cmployer dans ce eas de l'eau très-bouillante; il suffit qu'elle soit modérément chaude, si l'on veut que l'huile ait un goût plus supportable; parce que si on laissait cuire l'olive, l'huile contracterait dès lors le goût des ver's, et des autres impuretés qu'elle renfermerait en elle-même. An reste, lorsque les olives auront été lavées, il faudia, pour le surplus, se comporter de la manière que nous avons prescrite ci-dessus. Mais il ne faudra pas se servir des mêmes cabas pour lc pressurage de la bonne huile et de celle que doivent manger les gens : l'on se servira de vieux cabas pour l'olive qui sera tombée d'clle-même, au lieu qu'oin réservera les neufs pour l'huile ordinaile. Il faut aussi, dès qu'une pressurée est achevée, ne pas manquer de laver sur-le-cliamp les cabas deux ou trois fois dans de l'cau trèbouillante, et de les plonger ensuite daus de l'eau courante, si l'on en a, en les courrant de pielres cui les retiennent au fond de l'enu par leur poids. Si l'on n'a pas de rivière à sa poltée, on les fera tremper daus une marre ou dans un réservoir d'eau très-pure; cnsuite on les battra

Sed et Cato dixit : Et sic quidem quicquam ponderis aut mensura oleo accedit, si portiones velis in factum adjectrc bacex computare. [Non proventım, sed detrimentum senties.] Quajropter dubitare non debemus lectam olivam primo quoque tempore commolere, preloqne subjicere. Nec ignoro etiam cibarium oleum esse faciendum. Nam ubi vel exesa vermiculis oliva decidit, vel tempestatibus et plıviis in lutım defluxit, ad prasidium aquix calidis: decurritur, ahenumyue calefieri debet, ut immunda bacexe eluantur. Sed id non ferventissima tieri oportet, veruu modice calida, quo commodior gustıs olei fiat : nam sj excoctus est, etiam vermiculorum cxterarumque immunditiarum saporem tralit. Sed cım fnerit oliva elota, reliqua, sicut supra precepimus, fieri debebunt. Fiscis autea. non iisdem probum et cibarium oleum premi oportebit. Nam veteres al cadıcam olivam, novi autem ordinario aptari oleo, semperque eum expresserint facta, statin ferventissima debent aqua bis aut ter elni : deinde si sit profluens, impositis lapidibus, ut pondere pressi detineantur, immergi : vel si nec flumen est, in lacu, aut in piscina quam purissima açua macerari, et postea virgis 
de verges, afin d'cn expulser les immondices et la lie; après quoi on les lavera encore une seconde - fois, puis on les fera sécher.

LIII. Quoique ce ne soit pas dans ce temps-ci que l'on fait l'huile gleucina (huile vierge), j'ai cependant remis à en parler dans cette partie-ci de ce volume, pour ne pas interrompre mal à propos l'exposition des récettes pour frelater les vins, en y insérant la façon de faire cette huile. La voici donc. Il faut préparer un grand vase à mettre l'huile, qui n'ait pas encore servi, ou du moins qui soit très-solide, dans lequel on versera ensuite, pendant la vendange, soixante sextarii de moût excellent et très-nouveau, avec quatrevingts livres d'huile; après quoi on enfermera, dans un petit filet de jonc ou de lin, des aromates qui ne soient ni criblés ni même broyés bien menus, mais simplement concassés légèrement: et on les enfoncera à l'aide d'un caillou peu pesant dans ce mélange d'huile et de moût. Voici quels seront les aromates qu'on emplolera en cette occasion, et les proportions qu'on suivra en les employant. On prendra du calamus, du jonc odorant, du cardamome, du baume de Judée, de l'écorce de palmier, du fenugrec qui aura été ma. céré dans de vieux vin, puis séché et même grillé, de la racine de jone, ainsi que de l'iris grec, de l'anis d'ḱgypte ; le tout par parties égales consistant en une livre et un quadrans de chacun; et on plongera ces aromates dans une metreta, après les avoir renfermés, comme nous l'avons dit, dans un petit filet; puis on la bouchera. Au bout de sept ou de neuf jours, on ótera avec la main la lie ou les impuretés qui pourront s'être attaclićes d'elles-mêmes au col de la metrela, et on l'essuiera. Ensuite on passera l'huile, et on la survidera dans de nouveaụx vases; après quoi

verberari, ut sordes fecesque decidant, et iterum elui, siccarique.

LIII. Quamvis non erat linjus temporis olci glcucini compositio, tamen luic parti voluminis reservata est : ne parum opportune vini conditionibus interponeretur. Hac antem ratione confici debel. Vas olearium ģuam maximnm, ct aut novum ant certe bene solidum præparari oportet: deinde per vindemiam inusti quam optimi generis et quam recentissimi sextarios sexaginta cum olei pondo octoginta in id confundi : tum aromata non cribrata, sed ne minnte quidem contusa, vcrum leviter confracta in reticulum jun. ccum aut lincum adjici, et ita [cum saxi ponduscnlo] in olci atque musti partem demitti. Sint antem iis portionibus pensata, quas iufra subjicimus, całani, sclueni, carda. momi, xylobalsami, corticis de palına, focui Groci vetere vino macerati ct postea siccati alque etian torrefacti, junci radicis, tun etiam irilis Grece, ncc minus anisi Aigyptii pari pondere, id est, uniuscujusque libram et quadrautem, ut supra diximus, reticulo inclusa demiltito, ct metrctam linito. Post septimum diem ant nonum apertie metretxe siquid fecis aut spurcitix fnucibus inlax. rebit, manu exinito, et detergito : deinde olcum eliquato, on retirera le petit filet, et on broiera très-proprement les aromates dans un mortier. Lorsqu'ils seront broyés, on les remettra dans la même metreta, et on y versera autant d'huile que la première fois; puis on la bouchera et on l'exposera au soleil. Sept jours après on videra l'huile, et on transvasera le moût dans un baril poissé. Ce qui en restera pourra servir de remède aux bocufs qui seront malades, ainsi qu'aux autres bestiaux, si on le leur fait boire. Pour l'huile yu'on aura mise en second lieu dans la metreta, et qui sera d'une odeur agréable, ceux qui seront tourmentés par des maladies de nerfs pourront s'en frotter tous les jours.

LIV: Manière de faire l'huile dont on se sert pour les parfums. Avant que l'olive noircisse, et dès qu'elle aura commencé à perdre sa couleur, sans cependant qu'elle soit encore tournée tout à fait, cueillez-la à la main, en choislssant de préférence celle de Licinius, si vous en avez, ou, à son défaut, la regia; et dans le cas où vous n'au riez pas mème de cette dernière, la Culminia, et après l'avoir nettoyée, mettez-la sur-le-champ telle qu'elle est sous l'arbre du pressoir, et exprimez-en la lie. Ensuite broyez-la avec une meule suspendue, et renfermez-la soit entre des r'églets, soit dans un cabas neuf, pour la remettre sous l'arbre du pressoir, où vous la pressurerez tant soit peu, sans cependant faire agir les leviers, mais en vous en tenant pour cela au seul poids de l'arbre. Lorsqu'il aura coulé de l'huile de cette manière, celui dont la fonction est de la survi. der la séparera aussitôt de la lie, et la transvasera avec attention dans différents bassins, jusqu'à ce qu'elle soit éclaircie. Le surplus de l'huile que l'on exprimera ensuite des olives pourra ser. vir de nourriture, soit qu'on veuille la manger

novisque vasis recondito. Mox reticnlum exinito, et aro. mata in pila quam mundissime contundito, tritaque in ean dem metretam repouito, et tantunden olei quantum prius infundito, ct obturato, in sole ponito. Post septimum diem olcum deplcto, ct qुnod reliqum est musti picato cado recondito. Nam id si non cxacuerit medicameutum, dabitur potandum imbecillis bubus et catero pecori. Olcum anten sccundarium non insnavis odoris puotidia. nan uuctionem prabere poterit dolore nervorum laboran. tibus.

LIV. Oleum ad unguenta sic facito. Ante quam oliva nigrescat, cum primum decolorari ceppcrit, nec tamen adhuc varia fuerit, maxime Licinian, si erit; si minus, regiam; si nec haec fuerit, tunc Culniniam baccan manu stringito, et statim purgatam prelo integram subjicito, et aunrcam exprimito : deinde suspensa mola olivan frangito, eamque vel in regulas, vel in novo fisco acljicito, subjectamque prelo sic premito, ne vasa intorqueas, scd tantum ipsius preti pondere quantulumcunque cxpriusi patiaris. Deiude cum sic fluxcril, protinus capulator amurca separet, et diligcnter seorsm in nova labra transferat, quonsque cliquet. Reliqguum olei, quod postea fuerit ev- 
scule, solt qu'on veullle la mêler avec des liuiles d'une autre qualité.

LV. Nous avons assez parlé jusqu'ici de l'huile: passons à des objets moins importants. Tel animal qu'on veut tuer, il faut l'empècher de boire la veille, et surtout le porc, afin que sa chair soit plus sèche; parce que, si on lc laissait boire, le salé qu'on en ferait serait plus humidc. On lc tuera donc dans un moment où il soit altéré; après quoi on le désossera bien, parce que e'est le moyen que le salé soit mieux fait et de plus longue garde. Lorsqu'il sera désossé, on le salera soigneusement avec du sel grillé, qui ne soit pas cependant trop melıu; il suffira même qu'il soit broyé avec une meule suspendue : on en saupoudrera surtout copicusement les parties du corps qu'on n'aura point désossées ; et après avoir arrangé sur un plancher les quartiers ou les petites pièces de chair, on les chargera de poids considérables, pour leur faire jeter leur humidité superllue. Le troisième jour on retirera les poids, et on frottera cxactement le salé entre les mains; et lorsqu'on voudra le remettre sur le plancher, on le saupoudrera auparavant de sel égrugé bien menu : on ne laịsera pas passer un seul jour sans lc frotter entre les mains, jusqu'à ce qu'il soit à son point. Si le temps a été beau pendant les jours qu'on l'aura frotté, on ne le laissera dans le sel que l'espace de neuf jours; au lieu que si le temps a été nébuleux, ou qu'il ait plu, il ne faudra le porter que le onzième ou le douzième jour au réservoir, où on le lavera soigneusement avec de l'eau douce, après avoir seeoué le sel de facon qu'il n'en reste aucune trace; et on fera sécher pour le suspendre ensuite au garde-manger, dans un elldroit où il parviennc un peu de fu-

pressum, poterit ad escam vel cum alia nota mistum vel per se approbari.

LV. Haetenus de oleo dixisse abunde est; nune ad minora redeamus. De sucidia et salsura faeienda. Omne pecus et proceipue suem pridie quam oceidatur, potione prohiberi oportet, quo sit caro siccior. Nam si biberit, plus lummoris salsura liabetit. Ergo sitientem eum occi. deris, bene exossato : nam ea res minus vitiosam, et magis dnrabilem salsuram faeit. Deinde eum exossaveris, cocto sale nee uiminm minuto, sed suspensa mola infracto diligenter salito, et maxime in eas partes, quibus ossa relicta sunt, largum salem infarcito, conıpositisque supra tabnlatum tergoribus ant frustis vasta pondera inponito, ut exsanietur. Tertio die pondera removeto, et manibus diligenter salsuram fricato; eamque eum voles reponere, minuto et trito sale aspergito, atrque ita reponito : nec desieris ejus quotidie salsuram fricare, donce matura sit. Quod si serenitas fuerit iis diebus, quibus perfricatur earo, patieris eam sale eonspersam esse novẹm diebus : at si nubilum aut pluvix, undeeima rel duodecima die ad lacum salsuram deferri oportelit, et salem prius ex. euti, deinde aq̨ua dulci diligenter elui, necubi sal iulıæreat, et paululum assiccatam in carnario suspendi, quo mée, afin que le peu d'humidité qui pourra s'y trouver encore achève de se sécher. Le temps le plus commode pour faire le salé, c'est pendant le solstice d'hiver ou même au mois de février, avant les ides, quand la lune sera dans son déclin. Voici une autre facon de saler la viande, que l'on peut mettre en usage, même dans les lieux chauds, en quelque temps de l'année que ce soit. A près qu'on aura empêché les pores de boire pendant une journée, on les tuera le lendemain, et on les pèlera, soit avec de l'eau bouillante, soit à une flamme de menu bois (ear on peut le faire de l'unc ou l'autre manière), et l'on coupera leur chair en plusieurs morcenux d'une livre chacun; après quoi on mettra dans une cruche unc couche de sel grillé, mais qui ne soit que légèrement égrugé (comme nous l'avons dit ci-dessus ) : ensuite on y arrangera tous les morceaux en les serrant les uns auprès des autres, et on fera alternativement plusieurs couches de sel et de morceaux de viande. Lorsqu'on sera parvenu au col de la cruchc, on achèvera de la remplir de sel, et on y enfoncera la viando avec des poids dunt on la chargera : cette viando se conservera toujours tant qu'on ia laissera dans sa saumure, comme du poisson salé.

LVI. Choisissez les raves qui seront les plus rondes; essuyez-les si elles sont bourbeuses, et pelez-les avec un couteau; ensuite fendez-les en sautoir (suivant l'usage des confiseurs) avec un instrument de fer fait en forme de eroissant, cu évitant néanmoins de conduire ces fentes jusqu'en bas. Répandez ensuite entre ces fentes du sel qui ne soit pas trop menu, et arrangez les raves dans un bassin ou dans un cruche; puis, après les avoir saupoudrées d'une qualité de sel un peu

modiens fumıs perveniat qui, siquid lımmoris adluc, eontinetur, siccare enm possit. Hæc salsura luna decrescente maxime per brumam, sed etidm mense Februario ante idns commode fiet. Est et alia salsura, quæ etiam Iocis calidis omni tempore anni potest usnrpari [ quae talis est ]. Cum ab aqua pridie sues prohibitæe sunt, postern die mactantur, et rel aqua candente, vel ex tenuibus lignis flammula facta glabrantır, (nam utroque modo pili detrahuntur ) caro in libraria frusta conciditur : deinde in seria substernitur sal coetus, sed modice ( ut supra diximus ) infractus : deinde offulæ carnis spisse componuntur, eti alternis sal ingeritur. Sed cum ad fauces serix perven. fum est, sale reliqua pars repletur, et impositis ponderibus in vas eomprimitur : eaque caro semper eonservatur, et tanquam salsamentum in muria sua permanet.

LVI. Rapa et napos quomodo condias. Rapa quam rotundissima sumito, eaque, si sunt lntosa, detergito, et summam eutem novaeula decerpito : deinde ( sieut consucverunt salgamarii) decussatim ferramento lunato in. eidito. Sed cavte, ne usque ad imum præcidas rapa. Tum salem inter incisuras raporum non nimium minntum aspergito, et rapa in alveo aut seria componito, et sale pluseulo aspersa triduo sinito, dum exudent. Post 
plus fortc, laissez-les rendre leur eau pendant trois jours. Au bout du troisième jour, goûtez le milieu de leur filament, pour voir si elles ont bien pris le sel. Lorsque, vous jugerę qu'elles l'auront suffisamment pris, vous les retirerez toutes de la eruehe et vous les laverez dans leur propre eau; ou si elles n'en ont pas rendu beaueoup, vous y ajoutcrez de la saumure forte, dans laquelle vous les laverez. Ensuite vous les arrangerez dans un mannequin d'osier carré dont le tissu ne soit pas trop serré, mais qui soit eependant fai solidement, et avec de gros brins d'osier; après quoi vous mettrez par-dessus une planche qui y sera adaptée de faẹon que les raves puissent étre enfoneées à l'aide de cette planche jusqu'au fond du mannequin, si le eas l'exige. Lorsque eette planche sera ainsi adaptée au mannequin, vous la ehargerez de poids eonsidérables, et vous laisserez séeher les raves pendant un jour et une nuit. Après quoi vous les arrangerez dans une futaille soit de terre euite poissée, soit de verre, et vous verserez dessus de la moutarde et du vinaigre, de façon qu'elles en soient recouvertes. On pourra aussi confire des navets comme des raves, et dans le même jus; avee cette différence qu'on ne les coupera qu'au eas qu'ils soient trop gros. Au reste, il faut avoir soin de confire ces deux sortes de raeines avant qu'elles montent en tiges ou en graine, et dans le temps où elles seront eneore tendres. Jetez dans un vase de petits navets entiers, ou de grands eoupés en trois ou quatre tronçons, et versez du vinaigre pardessus, en y ajoutant un sextarius de sel grillé par congius de vinaigre, et vous pourrez en faire usage au bout de trente jours.

LVII. Nettoyez avee soin de la graine de moutarde, et criblez-la : ensuite lavez-la dans de l'eau froide, et, après qu'elle aura été bien lavée,

terliam diem mediam fibram rapi gustato, si receperit silem. Deinde cum videbitur salis recepisse, exemptis onmilsas, singula swo sibi jure elıito : vel si non multum liquoris fuerit, muriam duram adjicito, et ita eluito : et postea in quadratam cistan vimineam, qux neque spisse, solide tamen et crassis viminibus contexta sit, rapa com. ponito : deinde sic aptatan tabulam superponito, ut usque ad fundum, si res exigat, intra cistam deprimi possit. Cum autem eam tabulam sic aptaveris : gravia poudera superponito, et sinito nocte tota, et uno die siccari. Tum in dolio picato fictili, vel in vitreo componito, et sic infundito sinapi et aceto, it a jure contegantur. Napi quo. que, sed integri, si minuti sunt, maiores auten insecti, codem jure, quo rapa comliri possunt : sed curandum est, ut lıac utraque autequain caulem agant et cymam faciant, dum sunt tenera, componantur. - Napos minutos intengros, ant rursus amplos in tres aut quatuor partes divisos in vas conjicito, et aceto unfundito, salis quoque cocti unum sextarium in congium aceti adjicito. Post trigesimum diem uti poteris.

LVII. Semen sinapis diligenter purgato, et cribrato: laissez-la dans l'eau pendant deux heures. Ensuite videz l'eau; et après avoir exprimé eette graine entre vos mains, jetez-la dans un mortier neuf ou qui soit bien nettoyé, et broyez-la avec des pilons. I.orsqu'elle sera broyée, ramassez toute la bouillie qui en résultera au milieu du mortier, et aplatissez-la avee la paume de la main. Quand clle sera aplatie, faites-y plusieurs trous, et mettez dessus quelques charbons ardents sur lesquels vous verserez de l'eau nitrée, afin que cette bouillie jette toute son amertume et sa moisissurc ; après quoi vous soulèverez aussitôt le mortier, afin que toute l'humidité s'en éeoule. Quand cela sera fait, vous. verserez sur cette moutarde du vinaigre bien mordant, et vous la remuerez avec le pilon, puis vous la passerez. Cette moutarde sera très-bonne pour confire les raves. Au reste, si vous la voulez préparer à l'usage de la table, lorsque vous lui aur'cz fait jeter son amertume, vous y mettrez des pignons très-nouveaux et des amandes que vous broierez avee soin, en y versant du vinaigre par-dessus. Pour le surplus, vous suivrez la méthode que je vieus de preserire. Non-seulement cette moutarde sera d'un bon usage pour les sauces, mais elle sera eneore belle à l'œil, puisqu'elle sera d'une blaneheur singulière quand elle aura été faite a vee attention.

LVIII. Avant que lc maceron monte en tige, arrachez-en la raeine au mois de janvier, ou même au mois de février, et frottez-la bien afin qu'il u'y reste point de terre, puis faites-la confire dans du vinaigre ct du sel; ensuite vous la retirerez de ce jus au bout de trente jours; vous la pèlerez, et vous en jetterez l'écoree. Quant à la moelle qui restera, vous la couperez par tronçons, que vous mettrez dans un flaeon de verre ou dans un flacon neuf de terre euite, en y ajoutant

deinde aqua frigida eluito, et cum fuerit bene lotum, duabus lıoris in aqua siuito. Postea tollito, et manibus expressum in mortarium novum aut bene emundatum conjicito, et pistillis conterito. Cum contritum fuerit, totan intritan ad medium mortarium contrahito, et com. primito manu plana. Deiude cum compresseris, scariflcato, et impositis pancis carbonibus vivis aquam nitratum suffundito, ut omuem anaritıdinem ejus et pallorem exsaniet. Deinde statin mortarium erigito, ut onnis lumor eliquetur. l'ost hoc album acre acetum adjicilo, et pistillo permisceto, colatoque. Iloc jus ad rapa condienda optime facit. Cxterum si velis ad usum conviviorum præparare, cum exsaniareris sinapi, nucleos pineos quam recentissimos et amygdalan adjicito, diligenterque conterito in. fuso aceto. Cartera, ut supra dixi, facito. Hoc sinapi ad embammata non solum idoneo, sed etiam specioso uteris : nan est candoris eximii, si sit curiose factum.

LVIII. Priusquau olusatrum coliculum agat, radiceın ejus eruito mense Januario vel etiam Februario, et dili. genter defricato, nequid terreni habeat, et in aceto et sále componịto : deinde post diem trigesimum eximito, et 
un jus composé de la manière suivante : Prenez de la menthe, du raisin séché au soleil, et un peu d'oignon see; broyez le tout avec du blé grillé et un peu de miel ; après quoi vous y mèlerez deux parties de vin euit jusqu'à diminution des deux tiers ou de moitié, et une partie de vinaigre; et vous verserez eette composition dans Ie même flacon, que vous buucherez et que vous envelopperez d'une peau. Lorsqu'ensuite vous voudrez en faire usage, vous tirerez des troncons de ces petites racines a vec leur jus, et vous $y$ ajouterez de l'huile. Vous pourrez confire dans le même temps la racine de ehervi de la manière que nous venons de preserire : mais, lorsque vous en voudrez faire usage, vous la retirerez $\mathrm{du}$ flacon, et vous verserez dessus de l'oxymel avec un peu d'huile.

LIX. Mettez dans un mortier de la sarriette, de la menthe, de la rue, de la coriandre, de l'ache, du poirenu qu'on coupe à différentes reprises, ou, à son défaut, de l'oignon vert, des feuilles de laitue et de roquette, du thym vert ou de la eataire, avee du pouliot vert, du fromage nouvellement fait et du fromage salé : broyez tous ces ingrédients ensemble en y mêlant un peu de vinaigre épicé, et mettez-les daus un petit plat, puis vous y verserez de l'huile par-dessus. Quand vous aurez broyé les plantes vertes que nous venons d'indiquér, vous éeraserez ee que vous jugerez suffisant de noix épluchées, en y mêlant un peu de vinaigre épicé, et vous verserez de l'huile par-dessus. Vous broierez du sésame légèrement grillé avee les mêmes plantes vertes. Vous y mettrez aussi un peu de vinaigre épicé, sur lequel vous verserez de l'huile. Vous pilerez du fromage

corticem ejus delibratum aljicito. Cxterum medullam ejus concisam in fideliam vitream vel novam fictilem conjicito, et adjicito jus, quorl sicut infra scriptum est fieri debebit : sumito mentam, et nvam passan, et exiguam cepam aridam, eamque cuin torrido farre et exiguo uelle subterito : qua cum fuerit bene trita, sapa vel de. fruti duas partes et aceti unan permiscelo : atque ita in eanlem fideliam confundito, eamque operculo contectam pelliculato. Cum deinde uti voles, cum suo jure concisas radiculas promito, et oleun arjicito. Hoc ipso tempore siseris radicem poteris eadem ratione, qua supra condire : sed cum exegierit usus, eximes de fidelia, et oxymeli cun exisno oleu superfunde.

LIX. Addito in mortarium satureiam, mentam, rutam, coriandrum, apium, porrum sectivum, aut si id uon erit, viridem cepam, folia lactuca, folia cruca, thymun viride, [vel] uepetan, tum etiam viride puleium, et ca. seum recentem et salsum : en omria pariter conterito, acetique piperati exiguun permlsceto. Hanc misturam cum in catillo composueris, olemm superfundito. Aliter. Cum viridia, quae supra dicta sunt, contriceris, nuces juglandes purgatas, quantum satis videbitur, interito, acetique piperati exigumm permisceto, et oleum infundito. Aliter. Sesamun leviter torrefactum cum is viridibus, qua snpra dicta sunt, conterito. Item areti piperati exi- de Gaule ou de telle autre espee de fromage que vous voudrez, après l'avoir coupé en petits morceaux, et vous mêlerez avee ces ingrédients des pignons, si vous en avez abondamment; sinon des avelines grillées qui auront été préalablement pelées, ou des amandes, et vous ajouterez un peu de vinaigre épicé; puis vous brouillerez tout ce mélange, et vous verserez de l'huile dessus. Si vous n'avez pas d'assaisonnements verts, vons broierez avec le fromage, soit du pouliot see, soit du thym, de l'origan ou de la sarriette sèche, et vous y ajouterez du vinaigre épieé et de l'huile. On peut cependant se contenter de mêler avee le fromage une seule de ces plantes sèches, au cas que l'on n'en ait point d'autres. On mêlera avee du miel trois uncice de poivre blane, si l'on en a, sinon de noir, deux uncice de graine d'ache, un sescuncia de cette racine de laser que les Grees appellent $\sigma(\lambda \ni i o v$, et un sextans de fromage; puis, après avoir broyé et eassé ces ingrédients avee du miel, on les conservera dans un pot de terre neuf; et Iorsqu'on voudia en faire usagre, on délayera le peu qu'on en voudra pren. dre dans du vinaigle et du garum. Vous pou. vez prendre une uncia de sermontaine, un sextans de raisin sćehé au soleil, sans pepins, et un quadrans de poivre blane ou noir, et mêler lc tout avee du miel pour le eonserver, si vous voulez ménager la dépense. Mais si votre intenfion est de faire un oxyporum à plus grands frais, vous mêlerez ees mêmes ingrédients avee la composition dont nous avons parlé plus haut, et vous serrercz ensuite ce mélange pour rotre usage. Si vous n'avez point de laser, vous pourrez aussi y substituer une semuncia de miel.

guum permisreto, tum supra oleum superfundito. Aliter. Caseum gallicum vel cujuscunque notxe volueris minutalim concidito et conterito, mucleosque pineos, si eorum copia fuerit ; si nimus, nuces a vellanas torrefactas adempta cnte, rel amygdalas anne supra condimenta pariler nisceto, acetique piperati exiguum adjicito, et permisceto, compositunque oleo superfundito. Si condimenta viridia non erunt, puleium aridnu vel tlymum vel origanum aut aridam satureiam cum caseo conterito, acetumque piperatum el oleum adjicito. Possunt tamen lıec arida, si reliquorum non sit potestas, etiam singula caseo mis. ceri. Oxypori compositio. Piperis albi, si sil; si minus, nigri uncix tres, apii seminis uncix dux, laseris radicis, quod oìçıov Graci rocant, sescunciam, casei sextantem : lıxc coutusa et cribrata melli permisceto, et in olla nova servato : deinde cun exegerit usus, quantulumcunque ex eo videbitur, aceto et garo diluito. Aliter. Ligustici unciam, passa u væ detractis vinaceis sextantem, mentæ arida sextantem, piperis albi vel nigri quadrantem : hæc, si majorem impensam ritabis, poszuut melli adnis. ceri, et jta servari. At si pretiosius oxyporum facere vo les, lıæc eadem cum superiore compositione miscebis, et ita in usum repones: quod si etiam Syriacum lasar habueris pro silplio, melius adjicies pondo semunciam.

Clansulam peracti operis mei $P$. Silviue non alienum 
Pour eonclusion de mon ouvrage, P. Silvinus, je crois qu'il n'est pas hors de propos de déelarer à ceux qui le liront (si toutefols il se tronve quelques personnes qui daigneut prendre connaissance des maticres qu'il renferme) que jc ne doute point qu'il n'y ait presque une infinité de choses qui auraient pu entrer dans mon plan, mais que j'al cru ne devoir laisser a la postérité que celles qui mont paru les plus nécessaires. D'ailleurs la nature n'a concédé à qui que ce soit, pas ınême aux personnes qui ont vleilli dans l'étude, la connaissance de toutes choses, puisqu'on dit même que si ceux qui ont passé pour être les plus sages entre les mortels en savaient beaucoup, ils ne les savaient cependant pas toutes.

\section{DES ARBRES.}

I. Comme nous croyons avoir suffisamment traité de la culture des champs dans la première partie de cet ouvrage, il ne sern pas hors de propos de nous occuper maintenant des arbreset des arbrisseaux. Le soin qu'on en doit prendre passe pour être l'une des parties les plus essentielles de l'économie rurale. Nous comptons done avec Virgile deux espèces de rejetons : ceux qui viennent d'eux-mêmes, et ceux qui sont le fiuit du travail de l'homme. Les premiers, qui viennent sans le secours de l'homme, sont plus propres à jeter du bois, tandis que ceux qui ont été cultivés sont plus propres à donner des fruits. Cette dernière especee est la principale; on la divise en trois; car tout rejeton produit ou un arbre tel que l'olivier, le figuier, le poirier; ou un arbrisscau tel que le rosier, le violier, et Ie roseau;

puto indicem lecturis, si modo fuerint qui dignentur ista cogroscere, nilil dubitasse me pene infinita esse, qux potuerint luic inseri materix : verum ea qux maxime videbautur necessaria, memoria tradenda censuisse. Nec tamen canis natura dedit cunctarum rerum prudentiam. Nam etiam quicunque sunt habiti mortaliun sapientis. simi, multa scisse dicuntur, non omnia.

\section{DE ABBORIBUS.}

1. Qunniam de cultu agrorum abunde primo rolumine nraccepisse videnur, non intempestiva erit arborum vil: gultorunque cura, quae vel maxima pars labetur rei rusticar. Placet igitur, sicuti Virrilio, nobis quoque duo esse. genera surculorum : quorum alterum sua sponte gignitur, allerum cura mortalium procedit. Illud, quod bou ope luunana provenit, materia: est magis aptum : lıc cui lalor adhilielur, juloneum fructibus. Unum lioc itaque pracipuum est, atque id ipsum genus tripartito dividitur : nam ex surculo rel arbor procedit, ut olea, licus, pirus; vel frulex, vt viola, rosie, arundines; vel tertium quiddam, quod neque arborem neque fruticem proprie dixe. oul bien encore un troisième genre mixte, que je no voudrais appeler proprement ni arbre ni arbrisseau, tel qu'est la vigne. Nous parlerons d'abord des vignes, puis nous traiterons de la culture des arbres ct des arbrisseaux. Celui qui veut former des vignobles, ou des vignes mariées à des arbres, doit commencer par faire des pépinic̀res ; e'est le meilleur moyen de connaftre la qualité et l'espèce des ceps dont il voudra garnlr sa terre. Celui qui achètc des plants n'a point de garantie certalne de leur bonté ; car il aura toujours des doutes si celui qui les lui a vendus a mis les soins nécessaires pour les bien choisir. D'ailleurs toute production ćtrangère transplantée dans notre sol se trouve en quelque sorte dépaysée, et s'acelimate difficilement. Le mieux sera doncde former une pépinière sur le terrain même que vous voulez garnir de ceps, ou dans lc voisinage. La nature du sol y est d'une grande importance; car si ce sont des collines que vous voulez planter en vignes, soit ćchalassées, soit mariées à des arbres, ii faudia avoir soin de choisir pour pépinière l'cndroit le plus sec, afin d'habituer la vigne, pour ainsi dire dès son enfance, au manque d'humidité. Au contraire, si d'un endroit humide vous la transférez dans un sol sec, elle maigrira bientôt, privée qu'elle sera de sa nourriture habituelle. Si votre terre est en plaine, et si le sol cn est humide, il sera bon de former votre pépinière dans un sol de même naturc, afin d'habituer la vigne à l'abondance de l'humidité; car si vous la transplantez d'un sol aride dans un terrain aqueux, elle ne tardera pas à pourrir. Quand le terrain destiné à la pépinière est plat et passablement humide, il suffira de le retouruer avec la houe, ce que les paysans appellent sestertium. On fouille à cet effet la terre

rimus, sicuti est vitis: Arborum et fiuticun docebimus cultum, si prius de vitibus præceperimus. Qui vineam vel arlusstum constituere volet, seminaria prius facere debebit : sic enim sciet cujus generis vitem positurus sit. Nam qux pretio parata disponitur, certam generositatis fidem non habet : quoniam dubium est, an is qui rendidit, legendis semiubus adhiluerit diligentiam : tum ctiam quod ex longinquo petitur, parum familiariter nostro solo venit, propter quod difficilius convalescit alicnum extera regionis. Optimum est itaque eodem agro, quo vitem dispositurus es, vel certe vicino facere seminarium : idque multum refert loci natura. Nam si colles vineis vel arbustis occupaturus es, providendum est, ut siccissimo loco fiat seminarium, et jam quasi ab incunabulis vitis exigno assuescat lumori : aliter cum transtuleris de lumido in aridum locum, viduata pristino alimento deficiet. At si campestres et uliginosos agros possidebis, proderit quorque seminarium simili loco facere, et viterr. largo consuescere lumori. Namque exilis cum in aquo. sum agrum transfertır, utique putrescit. Ipsum autem agrum, quem seminario destinaveris planum et succosum, sat erit bipalio vertere : quod vocant rustici sestertimm. 
à une profondeur d'un pied et demi, mais de moins de deux pieds. Cette opération exige pour un jugerum cinquante journées de travail. Quand Ic terrain est en pente, il faut le labourcr au pastinum à deux pieds de profondeur au moins, et employer pour un jugerum soixante journées. Si l'on veut former la pépinière à l'endroit même où l'on disposera plus tard le vignoble, il fauära fairc des labours de trois picds de profondeur. Cette opération demande pour un jugerum soixante journées, si toutefois il n'y a surle ter. rain ni pierre ni tuf, ni d'autre corps plus dur; car alors il est difficile de déterminer d'avance le nombre de journées qu'il faudra employer àce travail. Pour nous, nous n'entendons parler que des terroirs en plaine.

II. Les fouilles faites, on procède au choix du plant vers le mois de février et dans la première moitié du mois de mars. Les meilleurs plants sont ceux qui proviennent de vignes chcisies avec soin. A eet effet, celui qui tient à cour de former de bonnes pépinières, marquera vers le temps des vendanges celles dont les grappes parvenues à lcur maturité sont grosses et sans taches. Cette marque doit être faito avec de la sanguine mêlée de vinaigre, afin quc les pluies ne puissent l'effacer. Il faut examiner les vignes non-seulement pendant une année, mais trois ou quatre ans de suite, afin de s'assurer si elles eontinuent d'être fécondes. C'est le meilleur moyen de connaitre s! cette fécondité pruvient de la qualité du plant, et non pas de l'abondanee aceidentelle de l'année. Lorsqu'un cep aura pendant plusieurs vendanges produit la même quantité de raisin, les plants que vous en aurez tirés donneront un vin abondant ct genéreux. En général, les grap-

Ea repastinatio altitudinis liabet plıs sesquipede, minus tamen quaun duos pedes. Ejusmodi bipalio jugerum agri vertitur operis quinquaginta. Collem autem et clivosum modum jugeri, sed ne minus duobus pedibus alte, repastinabis operis sexaginta : vel si eodem loco, quo vineam ordinaturus es, facere voles seminarium, tribus pedibus alte repastinabis jugerum operis octoginta : ita tameu si neque lapis, neque toplus aut alia materia difficilior intervenerit : quæ res, quot operas ahsumat, parum ccrtum est. Nos autem de terreno loquimur.

II. Peracta repastinatione, mense Februario vel prina parte Martii senina legito. Sunt autem optima, quxe de vitibus notatis leguntur. Nam cui cordi est bona seminaria facere, circa viudemiam vites, qux et magnum et incornuptum fructum arl maturitatem perduxerint, rubrica cum aceto, ne pluviis abluatur, permista denotat, nec loc uno tantumnodo anno facit, sed continuis tribụs vel pliribus vindemiis easdem rites inspicit, an perseverent esse foecundac. Sic eniul manifestum est generositate vitium, non anni ubertate fructum provenire. Si compluribus vinclemiis eundem tenorem servarint, ex ejusmodi vitibus lecta semina multum bonumque vinum prabe. bunt. Nanque qualiscunque generis uva, quæ integra et pes, sans aucune distinction d'espèce, qui sont arrivées au point de maturité entière et sans taches, donnent un meilleur vin que les grappes qui auront cu à souffrir de l'ardeur du soleil ou de toute autre cause.

III. Choisissez du plant qui donne de gros raisins d'une saveur douce, avec une enveloppe tendre et des pepins rares ct pelits. Le meilleur plant est tiré des reins de la vigne; le seeond, des. épaules; au troisième rang vient le plant tiré des parties supérieures de la vigne, lequel prend facilement racine, et produit plus que les autres, mais pour vieillir plus promptement. II ne faut point planter les brins de sarment dits pampres, parce qu'ils sont stériles. Mettez dans des plaines grasses et humides les vignes précoces, ainsi que celles qui ont peu de grappes, ct des nœuds rapprochés, et des ceps peu robustes ; car c'est le terrain qui convient le mieux à ces espèees de vignes. Dans les lieux arides, maigres et sees, au contraire, plantez la vigne naturellement vigoureusc et féconde, et qui a beaucoup de grappes. Si vous mettez une vigne de cette sorte dans un sol gras, elle s'épuisera en bois, et le peu de grappes qu'elle aura données ne parviendront pas à leur maturitć; de même que les eeps naturellement faibles, plantés dans une tcrre maigre, ne profiteront guère, et donneront peu de fruit. Plantez les différentes espèces de vignes dans des carrés séparés; de cette manière vous pourrez faire en temps opportun la taille ct la vendange pour chaque espèce en particulier. Le nouveau plant mis en terre avec le vieux sarment prend promptement racine, croít de même; mais il vieillit aussi en peu de temps. Si au contraire vous le plantez isolément, il a plus de peine d̀ se

incorruptxe ad maturitatem perveniunt, longe melioris sa. poris vinum faciunt, quam qua pracipientur æstu, aut alia de causa.

III. Semina autem eligito grandi acino, tenui folliculo, paucis minutisque vinaceis, dulci sapore. Optima lıabentur a lumbis; secunda ab lıumeris; tertia a summa vite lecta, qua celerrime comprehendunt, et sunt feraciora, sed ea quoque celeriter senescunt. Pampinaria sarmenta doponi non placet, quia sterilia sunt. Locis pinguibus et planis et lumidis pracoques vites serito, raris acinis, brevibus nodis, imbecillas : nam tali generi vitium ejusmorli ager aptus est. Locis aridis et macris et siccis vitem sere natura feracem et validam, crebrisque acinis. Quod si pingui agro validas vites deposueris, pampinis magis eluxuriabuntùr, et qualemcunque fructun tulerint, ad maturitatem non perducent : rursus inbecillac exili agro celeriter deficient, exiguumque fractum da. bunt. Unumquodque genus vitium separatim serito : ita suo quodque tempore putabis, et vindemiabis. Semina novella cum vetere sarmento deposita cito conprehendunt, et valenter crescunt; sed celeriter senescunt: at quas sine vetere sarmento panzuntur, tardius con valescunt; sed tardius deficiunt. Semina quam recentissima terra 
fortifier, mais il dure plus longtemps. Mettez en terre les plants immédiatement après les avoir coupés. S'il y a eu quelque retard, couvrez-les bien, pour qu'ils soient à l'abri des vents et des pluies. Faites vos plantations depuis la nouvelle lune jusqu'au dixième jour, et depuis le vingtième jusqu'au trentième. C'est là le meilleur temps pour planter la vigne. Évitez surtout les vents fioids. Voici la manière de planter la crocette. La branche dont vous voulez faire la crocet te ne doit pas avoir plus de six bourgeons ; cela suppose que l'espace entre deux nœuds est très-eourt. Prenez ensuite une serpette bien aiguisée, et coupez la branche près du nœud, par le bout que vous mettrez en terre, sans cependant léser les bourgeons, et de sorte que la section (la plaie) qui en résulte présente une surface ronde; puis vous l'enduirez immédialement de fumier de bouf. Enfoncez le sarment dans une terre bien labourée et bien fumée, de sorte qu'il n'y ait pas moins de quatre bourgeons caehés en terrc. II suffira de laisser entre les plants l'espace d'un pied en tout sens. Quand ils auront pris racine, ébourgeonnez-les, afin qu'ils n'aient pas à nourrir plus de branches qu'il ne faut. Bêchez-les le plus que vous pourrez, mais ne les touchez point avee le fer. $\mathrm{Au}$ bout de vingt-quatre mois coupez-les de noureau, et les transplantez au bout de trente-six. - Mettez la vigne dans une terre reposée. Si vous la mettez dans un ancietı vignoble, il faut attendre au moins dix ans; car plantée avant cette époque elle ne prend guère, et ue se fortifie jamais. Avant de garnir de ceps notre terrain, examinez d'abord le goût de la terre; ear votre vin aura un goût analogue. Pour examiner le goût de la terre, vous n'avez (ainsi que nous l'avons mottré dans les livres précédents) qu'à délayer une motte de terre àans de l'eau, que vous passcrez par un tamis; après quoi vous la goûterez. Le sol le plus propre à la vigne est le sol sablonneux qui contient une humidité douce au goût; vient ensuite une terre où sc trouve du tuf; une terre de déblai et passablement meuble est égalcment bonne pour les vignes, de même qu'un sable sous lequel se trouve de l'argile douce. Toute terre gereée par la chaleur ne convient pas plus aux vignes qu'aux arbres. La couche inférieure de la terre entretient la vigne et l'arbre, de même que la couche supérieure les maintient. Les pierres répandues sur la superficie de la terre blessent les arbres aussi bien que les vignes; à une certaine profondeur, elles les rafraîchissent. Une terre d'une densité moyenne est la meilleure. Celle qui laisse passer les eaux de la pluic, ou qui les retient trop longtemps stagnantes à sa surface, doit être évitée. La plus fertile est celle qui est suffisamment légère en haut, et assez compacte autour des racines. Les vignes sc fortifient difficilement sur les montagnes et sur les terrains en pente; mais le vin qu'elles donnent est d'un goût solide et franc. Elles sont plus vigoureuses dans les plaines humides; mais le vin en est sans force et ne se garde point. Nous avons traité jusqu'à présent du plant et de la nature du sol ; passons maintenant aux différentes espèces de vignes.

IV. Les vignes se plaisent surtout à être soutenues par des arbres, parce que leur nature les porte à monter ; elles donnent alors plus de bois, et leurs fruits mủrissent plus également. Cette espèce de vigne est appelée arbuslivum (mariće aux arbres) : nous en parlerons en son lieu avec mandare convenit. Si tamen mora intervenerit, quo minus statim serantur, quam diligentissime obrui tota oportet eo loco, unde neque pluvias neque ventos sentire possiut. I'lantaria facito ah exoriente ad deciinam Junain, et a vigesima ad tricesimam. Hac melior est vitibus satio. Sed cum seris, frigidos ventos vitato. Malleolum sic deponito. Virgam malleolarem non amplius quam sex gemmarum esse convenit, ita tauen sunt, si brevia internodia labent. Ejus imam parteın, quam in terram denissurus es, aeutissima falce juxta nodum, sic ne gemmam ladas, rotunda plaga amputato, et statim fimo bubulo linito : tum in terram hene pastinatam et stercoratam rectum sarmentum defigito, ita ut ne minus quatuor gemma abscondantur. Pedale quoquoversus spatium sat erit inter semina relinqui : cun comprehende. rint, identidem pampinentur, ne plura sarmenta quam debent, euutriaut. Item quan sapissime fodiantur : ferro ne tangantur. Vigesimo et quarto mense resecentur : post trigesimum et sextum mensem transferantur. - In agro requicto vineam ponito. Nam ubi vinea fuerit, yulod ej. tius decimo anno severis, ægrius comprehendet, nee unquam roborabitur. Agrum antequam vineis ohseras, ex. plorato qualis saporis sit: talem enim ctiain gustum vini COLUYELLE. probebit. Sapor autem ( sicuti primo docuimus volumine) compreliendetur, si terram aqua diluas, et eum colaveris, tum demum aquam degustes. Aptissima vitibns terra est arenosa, sub qua consistit dulcis humor : probus consimilis ager, cui subest topluus : aeque utilis congesta et mota terra. Sabulum quoque, cni subest dulcis argilla, vilibus convenit. Omuis autem qui per astatem finditur ager, vitibus arboribusque inutilis. Terra inferior alit vitenı et arlorem; superior eustodit. Saxa summa parte terræ et vites et arbores ladunt, ima parte refrigerant. Et mediocri raritudine optima est vitibus terra : sed ea quæ transmittit imbres, aut rursus in sumıno diu reli. net, vitanita est. Utilissima est autem superior modice rara, cirea radices densa. Moutibus clivisque difficulter vinea convalescunt, sed firmum probumque saporem vini prabent. Humidis el jlanis locis robustissimu, sed infirmi saporis vinun, nec perenne faciunt. Et quonian de seminibus atque habitu soli pracepinnus, nunc de genere vinearum disputabimus.

IV. Vites maxime gaudent arhoribus, quia naturaliter in sublime procedunt, tum et materias anipliores creant, et fruetum æequaliter percoquunt. Ifoe genus vitium arbustivum vocamus, de quo jluribus suo loco dicemus. 
plus de détail. On eompte ordinairement trois espèees de vignes : les vignes appelées treilles, la vigne rampante, et enfin eelle qui, s’élevant au dessus de la terre, se tient droite par elle-même, comme les arbres. Cette dernière espèce, eomparée aux treilles, leur est inféricure sous quelques rapports, ct les surpasse sous d'autres. Les treilles sont plus exposées à l'air ; le fruit en est plus élevé, et mûrit plus uniformément ; mais la culture en est plus diffieile. L'autre espéce est disposée de telle sorte qu'on la puisse labourer à la charrue; ct elle devient d'autant plus féconde qu'ello est cultivée plus assidûment et à moindres frais. La vigne rampante donne beaueoup de vin, mais co vin n'est pas d'une bonne qualité. Une terre labource au pastinum convient le mieux à la plantation de la vigne; eependant, en certains endroits il y a des avantages à la disposer par sillons; quelquefois aussi on la plante dans des fossés. Un jugerum de terre est, ainsi que je l'ai dit, labouré au pastinum à la profondeur de trois pieds dans quatre-vingt-dix journées; on creuse dans une journée, si le terrain est léger, un sillon de deux pieds de profondeur et soixantedix pieds de longueur. On fait dans une journée dix-huit fossés cubiques, e'est-à-dire qui ont trois pieds en tout sens. Si l'on veut planter les vignes plus profondèment en terre, on n'aura qu'à ereuser des fossés de quatre pieds en tout sens : on en fait douze dans une journée. Quant aux fossés de deux pieds en tout sens, on en fait vingt dans une journee. On remarquera encore que dans des terrains arides, et dans des terrains en pente, il faut planter la vigne plus profondément que dans des terres humides et dans des plaines. Qu'on plante la vigne dans des fossés ou des sil-

Vinearum autem fere genera in usu tria sunt, jugata, lumi projecta, et deinde tertia, quæ est a terra subrecta, more arborun in se consistens. Id geuus comparatum jugata quadam parte deficitur, quadam superat : jugata plus aèris recipit, et altius fructum fert, et aequalius concoquit, sel difficilior est ejus cultus : adlıac ita constituta est, ut etiam arari possit; eoque uhertaten majorem conse. quitur, quod sæepius et minore impensa éxcolitur. At quæ protinus in terram projecta est, multum sed non bonx note vinum facit. Vinea optime repastinato agro ponitur, nonnımquam taınen vel melius quibusdam locis sulcis committitur : interdum etian scrobibus deponitur. Sed ut dixi, repastinatur jugerum in altitudinem pedum trium operis octoginta; sulcum autem terrenum pedum duorum altum, et longum septuaginta una opera effodit; scrobes ternarios, id est quoquoversus pedum trium, una opera facit xvı. Vel si cui cordi est laxius vites ponere, scrohes quaternarios, id est quoquoversus pedum quaternum, una opera xul facit; vel bipedaneos quoquoversus una opera Xx effodit. Curandum autem est, ut locis aridis et clirosis altius vites deponantur, quam si humidis et planis. Item si scrobibus aut sulcis vinean posituri erimus, optimum erit ante annum scrobes vel sulcos facere. Vinea, lons, le meilleur sera toujours de faire les uns et les autres une annéc avant. L'espace le plus étroit laissé entre les vignes est de einq pieds en tout sens; on les plante aussi à sept et même à huit pieds d'intervalle les unes des autres; la distanec de douze pieds, qui rend le labour si facile, est extrèmement rarc. Cette disposition sans doute prend plus de terrain; mais elle est la meilleure sous le rapport de la fécondité et de la force des eeps. En metiant en terre le plant, promenez le hoyau au fond-des fossés ou des sillons, afii d'ameublir davantage la terre. En attachant la vigne à son appui, faites en sorte qu'elle soit tournée vert l'orient. Mettez au fond des fossés des pierres de cinq livres environ, de sorte cependant qu'elles ne gênent en aueune faẹon les eeps, mais qu'elles se trouvent entre les raeines de deux vignes. Mettez-y ensuite une hemina de mare de raisin blane pour le raisin noir, et une hemina de mare de raisin noir pour le blane; et remplissez le fossé ou le sillon jusqu'à la moitić avee de la terre fumée. Dans les trois années suivantes vous eomblerez peu à peu le fossé au le sillon : de eette façon la vigne s'habitue insensiblement a jeter des raeines du dehors au dedans. Les pierres, posées au fond, traeent en quelque sorte aux racines la route où elles doivent ramper; dans l'hiver elles les mettent à l'abri des eaux, dans l'été elles y eutretiennent la fraicheur, et en favorisent beaueoup la eroissance. Après avoir traité de la plantation des vignes, nous allons donner des préceptes sur la manière de les cultiver.

V. Laissez d la vigne nouvelle tous ses bourgeons; mais dès que le pampre aura quatre

qux angust issime conseritur, quoquoversus quinque pedım spatio interposito ponitur; laxius vero inter pedes vu vel vul; sed qua rarissime (ut etiam facile arari possit) inter denos pedes constituitur. Hacc positio rinearum modun sine dubio agri majorem occupat, sed valentissima et fru ctuosissima est. Curn semina depones, imum scrobem vel sulcum bidentibus fodito, mollemque reddito. Vitem quam ponis, fac ut ad Orientem spectet adminiculo retigata. In imo scrohe lapieles circa pondo quinque ita ponito, we vitem premant, sed tamen juxta radices sint. Preterea post lıæc vinace heminam uva albxe in nigra, uvæ nigra in alla ponito, atque ita scrobem vel sulcum cum stercorata terra ad medium completo. Triennio deinde proximo paulatim scrobem vel sulcum usque in summum completo : sic vites consuescent radices deorsum agere. Spatiun autem radicibus, qua repant, lapides prebent, et hieme aquam repellunt, restate humorem probent, vinacex [que] et radicrs agere cogunt. Quoniam præcepiinus quemadmodum vites ponendse sint, nunc culturam earum docebimus.

V. Vineam novellam omneis gemmas agere siltito: mul atque pampinus instar quatuor digitorum erit, tıu deuum pampinato, et duas inaterias relinquito: alteruu 
doigts, alors ébourgeonnez-la, en n'y laissant que deux sarments : l'un que vous taillerez de facon à coustituer la vigne, et l'autre qui vous servira de ressouree, si le premier périt par une eause queleonque : aussi les paysans appellentils ce dernier gardien. L'année suivante, lorsque vous taillerez la vigne, vous y laisserez la branche qui vous paraitra ta meilleure, et vous óterez toutes les autres dans la troisième année. Lorsque la vigne est eneore tendre, vous la facomnerez, en lui donnant la forme que bon vous semblera. Si vous voulez en faire des treilles, vous laisserez un seul sarment, dont vols ratisserez. avee une serpette bien aiguisée les deux bourgeons qui sont le plus près de la terre; vous y laisserez les trois autres bourgeons, et vous couperez tout le reste de la branche. Si vous voulez que la vigne se soutienne par elle-méme, vous laisserez les branches de manière qu'elles forment en quelque sorte les bras de l'arbie, et vous lui donnerez autant que possible une forme eireulaire ; car tout eorps qui présente eette forme est dans une position moins fatigante, et trouve en lui-même son centre de gravité, puisqu'il est maintenu de tous cótés dans un équilibre parfait. Lorsque vous taillerez la vigne pour la première fois, il suffira de laisser un bourgeon à chaque sarment, afin qu'elle ne soit pas trop chargée du poids de ses branches : eette taille faite, fouillez vos vignes à la houe, profondément et uniformément; ou bien, labourez-les à la eharrue, s'il y a assez d'interralle entre les ceps. Dès les ides d'octobre, commeneez à déchausser la vigne; táchez surtout qu'elle soit déchaussée avant le solstice d'hiver. Ne travaillez pas à vos vignes pendant le solstice d'hiver, à moins que ce ne soit pour couper les racines mises à jour par le déelıaussement. C'est, eu effet, le inoment favorable pour les eouper; mais daus eette opiration prenez garde de blesser la souche, et que le fer ne s'en approche que jusqu'd un pouec. Toute raeine coupée plus près eause une plaie qui nuit beancoup à la vigne, outreque eet te plaie, en se eieatrisant, donnerait naissanee à de nou velles raeines. Le mieux sera done de n'en laisser que la plus petite partic, et de eouper toutes les petites raeines qui se montrent à la surfaee, et que les paysans appellent ostivus, paree qu'elles poussent pendant l'été. Vous pouvez aussi eouper les rejetons pendant le solstice d'hiver, d'autant que ees rejetons extirpés par les froids ne peuvent plus prendre de vigueur. Après le déchaussement, il faudra tous les trois ans, avant les froids de l'hiver, répandre sur les raeines de la vigne au moins deux sextarii de fumier détrempé, ainsi que de la eolombine ( fiente de pigeon ). Quant à cette dernière espèce de fumier, si vous en mettez plus d'une hemina, la vigne en souffrira. Après le solstice d'hiver, quand vous aurez déelhaussé la vigne, fouillez alentour. Avant l'équinoxe du printemps, qui tombe au huit des ealendes d'avril, nivelez le terrain, rendu inégal par le déchaussement. A près les ides d'aviril, répandez de la terre de déblai autour des vigues. Dans l'été suivant, pulvérisez autant que possible les grosses mottes de terre qui s'y trouveront. Un jugerum de terre, planté de vignes, est déehaussé en einq journées, fouillé également en einq, et pulvérisé en trois. Un jugerum de vignes robustes et déjà toutes formées est taillé en quatre journées, et échalassé en six. Quant aux vignes marićes aux arbres, il est difficile de déterminer le nombre des journées qu'exigent les différentes opérations, à cause de l'inégalité même des (yıam vitis constituendæ causa submittas, alteram sulssidio luabeas, si forte illa ordinaria interierit : luanc rustici custolem rocant. Proxino deinde anno, cum putabis viten, meliorem unam virgan relinquito, alteras tollito, tertio auno vitem, in quam forman voles, dum tenes a est, com. punito. Si jugatam eris facturus, unam materiam submit. tito, ita ut duas gemınas, qua sunt proxina a terra, falce acuta radas, ne possint germinare: deinde tres sequeules relinquas, reliquam partem virga amputes. Sin autem vitem in se consistere voles, sicuti arbori brachia subuitti patieris, et dabis operam, ut in orbem quam rotundissine formetur. Nam preterquam quorl speciem labet sic composita, lum etiam uninus laborat, cum undique velut xequililorio stabilita in se requiescit. Sat erit autem cum primo braclia submitteutur, singulas gemmas singulis sarmentis relinqui, ne protinus onere graretur. P'ost lane putationem lectis sarmentis, bidentibus alte el aequaliler vineam fodito : rel, si ita late disposila erit, arato. $\mathbf{A b}$ idus Octobris ablaqueare incipito, ante brumam ablaquea. tan liabeto. Per brumam vitem ne colito, nisi si voles eas radices, qua in ablaqueatione apparebunt, trersequi. Tum demum optime amputabis, sed ita ne codicent licelas, sed potĩus instar digiti unius a matre relinquas, et ila radicem reseces. Nam qua propius abraditur, præterquan quod vuluus viti prabet, eoque sucet, tum etian de jissa cicatrice plures radices prorepuut. Itaque optimum est exiguam partem relinqui, atque ita summas partes, quas ástiras rustici appellant, resecare : qua sic resecta? inolescunt, nec ultra vititus obsunt. Possunt etiam soboles per brumam coedi, co magis quod frigoribus extirpata minus recreantur. Peracta ablayueatione ante brumam tertio quoque almo macerati storcoris, ne miuus sextarios binos ad radices vitiun posuisse conveniet, praterquan columbinum ; quol si quo amplius quam lıeminan posueris, riti nocebit. Post bruman deinde ablaqueationem circumfodito. Ante anguinoctium rernum, quod est octavo cal. A pril. ablaqueationem adsequato. Post idus A prilis terram ad vitem aggerato. Aistate deinde quam potes fappisime occato. Jugerum vinex quinque operis ablaquealur, quinque foditur, trilus occatur. Jugerum valenlis et jam cous. tituta vinea quatuor operis putatur, sex alligatur. Arbusto nilsil ejusmodi polest aple finiri, quoniun ina:qualitas arborum non patitur operis justa comprelıcudi. Quibusdan placet vitem prosimo anno translatam non pulare, 
arbres. Il y a des personnes quil ne taillent pas la vigne l'année qui suit sa transplantation; ee n'est que l'annce d'après qu'ils l'émondent, et qu'ils façonnent l'un de ses sarments en le taillant jusqu'au troisicme bourgeon; la troisième année, lorsque la vigne s'est bien fortifièe, ils coupent encore un bourgeon; la quatrième année, ils en coupent deux. Ce n'est que la einquième année qu'ils attachent la vigne aux échalas. Ce procédé de culture, que nous avons essayé, nous a paru excellent.

VI. Ne coupez pas une aneienne vigne dont les racines se trouvent à la superficie du sol; car la vigne nouvelle qui renaittrait à sa place n'au rait point de vigueur, les racines flottant en quelque sorte à la surface de la terre. Aussi le fruit qu'clle donnera ne sera point abondant, et elle-même vieillira de bonne heure. Le meilleur moyen de renouveler une vigne de cette espèce est de la eoucher enticrement par terre dans des sillons faits exprès, à moins que le trone ne soit tellement desséché qu'il ne puisse plus être courbé. Si la sécheresse du trone rend impraticable ee procédé de eulture, alors déchaussez la vigne la première année, sans cependant arracher ou blesser ses racines; puis taillez-la, et ne lui laissez que peu de sarment d'une réussite eertaine; fouillez-la souvent, ébourgeonnez-la plus fréquemment encore, et ayez soin surtout qu'elle ne nourrisse pas de branehes inutiles. Cultivée ainsi, elle donnera des sarments longs et fermes, qu'on provignera l'année suivante au moyen de fosses faites entre les rangées de eeps. Les trois anıées suivantes, pendant lesquelles la vigne se fortifiera, il faudra la fouiller souvent, et épuiser autant que possible la

sequenti deinde anno purgare, et unam virgam, quam submittamus, ad tertiam gemmam resecare : tertio deinde si vitis recte convaluerit, una plus gemma subınittere : (juarto duas gemmas proxim $x$ putationi adjicere, atque if a quinto demum anno vitem jugare. Hunc eundem ordinem culturæe nos quoque experti comprobavimus.

VI. Veterem vineam, si in summo radices habebit, resecare nolito : alioquin etiam novella vinea, quae ex resectione enata fuerit, vim inutilem labebit, summa parte terræ natantibus radicibus. Quamobrem neque fructum uberem percipies, et nililominus celeriter consenescet. Ejusmodi itaque vinea, si non peraridos liabet truncos, et flecti potest, factis sulcis optime sternitur, atque ita renovellatur. Sin autem usque co exaruit, ut curvari non possit, primo anno summatim, ita ne radices ernas aut ladas, ablaqueato, et stercus ad radices addito, atque ita putato, ut paucas et certas materias relinquas, et fodias diligenter, et sacpius pampines, ne omnino supervacua sarmenta nutriat. Sic exculta longas et firmas materias creahit, quas sequenli anno scrobilsus inter ordines factis propagabis : ac deinde per triennium post, dum convalescet, sepius fodies, matremque ipsam onerabis, nilil in postêrum prospiciens ei quam sublaturts es. In postremum mère soliclie, sans vous soucier d'un plant quo vous voulez faire disparaftre. L'année d'après, vous arracherez la sotiche avee la racine, et vous disposerez la vigne nouvelle. Si une vigne aneienne, d'une bonne espèce d'ailleurs, a des raeines tellement profondes qu'elles n'apparaissent pas mème après avoir été déehaussées, vous pouvez la décliausser vers les calendes de mars, a vant de la tailler. Lorsque vous l'aurez déchaus. sée à une profondeur suffisante, voici comment vous la taillerez. On laissera le trone à la hauteur de quatre doigts à partir des racines; on le scicra auprès d'un nœud, ct on nettoiera la plaie avec un instrument bien aiguisé. Répandezy ensuite de la terre menue et passablement fumée, en sorte qu'après avoir rechaussé la vigne, la plaie se trouve couverte au moins de trois doigts de terre. De cette manière le plant ne risquera pas d'être desséché par le soleil, et l'lıumidité de la terre lui fera jeter du bois. Quant à la vigne qui est d'une mauvaise espèce et peu fertile, et dont les partiessupérieures sont moisies et rongées, il faudra la greffer, si toutefois elle a des racines profondes. Après l'avoir déchaussée, et mis à jour les parties intérieures, on la coupera tout près de la terre, de sorte qu'en la recouvrant ensuite de terre de ramas, on n'en laisse rien paraître au-dessus du sol.

VII. Il y a en général trois manières de provigner la vigne : la première consiste à eoueher dans un sillon une branche sortie de la souche; la seconde, à coucher en terre la souche elle-même, et à distribuer ses branehes sur plusieurs éehalas. La troisième manière consiste à fendre la vigne en deux ou trois parties, d'après le nombre des rangćes où l'on veut la conduire : ee dernier

anmum matrem radicitus tolles, atque ita novellam vincam ordinabis. Sin autem vetus vinea, dumlaxat generis houl radices alte positas liabebit, ita ut ahlaqueate non cunspicianlur, eam vineam circa calend. Martias antequam reseces ablaqueato, et protinus cum alte ablaqueaveris, sic resecato. Quatıor digitos ab radicibus truncum relinquito, et si fieri poterit, juxta aliquem nodum serrula desecato, et plagam acutissino ferro delevato. Deinde minutam terram mediocriter stercoratam ita superponito, ut adobruto trunco ne ininus tres digiti terræ super plaga sint. Hoc idcirco, ne sole inarescat, et ut melius materias citet percepto humore, quem terra prabet. At qua mali generis et infructuosa vinea est, summasque partes et mucidas et exesas habet, si radices ejus satis alte positæe sunt, optime inseretur ita ut ablaqueata et nudata pars ima secundum terram sic amputelur, ne cum aggerata fuerit, supra ter: ram exstet.

VII. Propagationum genera tria sunt in nsu maxime: unum quo virga edita a matre snlco commitlitur : alterum, quo ipsa mater prosternitur, atque in plureis palos per suas virgas dividitur : tertium, quo vitis finditur in duas vel tres partes, si diversis ordinibus diducenda est. Hoc genus tardissime convalescit, quia vitis divisa medullam 
procédé est le moins propre à fortifier la vigne, paree qu'étant fendue elle perd sa moclle. Mais puisque nous avons proposé différentes manières de provigner, nous allons montrer comment on doit pratiquer chacune d'elles en particulicr. Lorsque vous voulez coucher en terre une branche sortie de souehe, faites un fossé de quatre pieds en tout sens, afin que le provin ne pulsse être incommodé par les racines d'une autre vigne. Conduisez-le vers le milieu de la fosse, en y laissant quatro bourgeons qui lui fassent pousser des raeines. Ratissez le reste de la branche qui est adhérente à la mère, afin qu'elle ne jette point de sarments inutiles; ne laissez à l'autre bout de la branehe qui doit sortir de terre que deux ou tout au plus trois bourgenns. Ratissez tous les autres bourgeons qui sont cachés en terre, à l'exception des quatre d'en bas, pour que la vigne ne pousse pas de racines en haut. Cultivé ainsi, le provin se fortifie promptement; et à la troisième année il peut être séparé de la souche-mère. Si vous voulez coucher en terre la souche même, fouillez avec soin autour de la racine, sans blesser la vigne, et provlgnez-la ensuite de telle sorte que vous n'en cassiez point les racines. Lorsque vous l'aurez étendue à terre, et que vous aurez marqué jusqu'où elle doit atteindre, vous creuserez un sillon, et vous y coucherez la vigne tout entière. De ce sillon, vous conduirez des fossés, comme autant de bras, dans lesquels vous provignerez les branches de la vigne suivant leur position; puis vous les couvrirez de terre. Si vous voulez former plusieurs rangs avee une vigne qui n'a que peu de bois, de telle sorte qu'il faille la fendre pour la faire parvenir aux divers échalas, vous em-

amittit. Et quoniam genera proposuimus, unumquodque qualiter faciendum sit, demonstrabimus. Virgam cum a matre in terram deprimere roles, scrobem quoquoversus quatuor pedum facito ita, ut propago non loedatur alterius radicibus. Deinde quatuor gemmas, qux in imum scrobem perveniant, relinquito, ut ex is radices citentur. Reliquam partem, qua continens matri est, adıadito, ue supervacua sarmenta procreet. Diversie autem, quxe supra terram exstare delset, ne passus fueris plus quam duas aut ut maxime tres gemmas liabere. Reliquas, qux in terram absconduntur, exceptis quatuor imis, fac adradas, ne in summo radices vitis citet. IIoc modo propagata celeriter convalescet : et tertio anno a natre separabitur. Sin autem ipsam vitem sternere voles, justa radicem ita, ne ipsam ladas, curiose fodito, et vitem ita supplantato, ne radicem abrumpas. Cum eam straveris, et videris quous que possit pertingere, sulcum facies unum, in quem vitem integram demittas : deinde ex eo sulco quasi ramos fossa. rum facies, per quos, uti quseque virga postulaverft, propagetur, atque ila terra adoperies. Sin autem ritis exiguam unateriam liabebit, et iu diversos ordines diducenda erit, ne(pue aliter potnerit palos, ad quos perducitur, pertiugere, ¡uan. ut dilluat : curabis ut quam acutissina falce ab ea ploierez pour eette opération une serpette bien aiguisée, qui divisera le rameau à l'endroit où il présente une fourche; puis a vee le même fer vous unirez la plaie, s'il s'y présente quelque inćgalité. Divisée ainsi, elle pourra former plusieurs rangées. Nous avons aussi trouvé unc manière de provigner la vigric qui n'est pas sans avantage. Lorsqu'il n'y a pas de souche pour former une rangée, et que la branche à provigner n'est pas assez longue pour qu'on puisse la conduire au foud du fossé, la recourber et la dresser ensuite, ne vous effrayez pas du peu de longueur : prenezune branche queleonque, dont lc bout attcigne au fond du fossé ; courbez-la, et la couvrez de terre. Laissez les bourgeons qui se trouvent le plus près de la souche. mère, pour qu'ils jettent du bois de la partie supérieure. Ce n'est qu'au bout de trois ans que vous la séparerez de la souche mère; vous conduirez ensuite à son échalas cette partie séparée, et vous en formerez la tête de la vigne. Ne comblez le fossé où se trouve le proviu que suceessivement, et pas avant trois ans. Coupez les racines qui sortent de la terre; fouillez souvent.

VIII. Lorsque vous voulez greffer la vigne, coupez de la souche mère, par un vent du midi, des. branches à fruit, quand elles commeneeront à pousser des bourgeons. Qtie le sarment qui doit servir de greffe soit coupć dans les parlies supérieures de la vigne, qu'il soit rond, et qu'il ait plusicurs bons nœuds. Laissez-y les trois nœuds les plus intacts. Coupez-le ensuite en biseau audessous du troisième bourgeon, avec un fer trèsaffilé et très-mince, en ayant soin de ne pas blesser la moelle. Coupez ensuite la vigne que vous voulez greffer, unissez-en la plaie, et fendez-la;

parte, qua bifurca est, findas eam, et eodem ferro acuto plagan emendes, sicubi inæqualiter findi videbitur. Sic diducta poterit in plures ordines dividi. Non irutilis est otiam illa propagatio, quam nos reperimus, si quanclo in ordinem vitis deest, neque est tam procera virga qux cum in imun scrobem demissa fuerit, retorqueri et erigi supra terram possit : brevitatem ne refornidaveris, sed qualemcunque virgam, cujus caeumen in imum serobem pervenit, deprimito et obruito: deinde gemmas, qua secundum jpsam matrem sunt, subnittito, ut materias a superiore parte eitent. Tum denum post triennium a matreain putato, et ad suum palum eain partem, quam a matre procideris, reducito, et caput vitis facito. Propaginis scrobem ne minus triennio paulatim eompleto : summas radices pracidito : erebro fodito.

VIII. Cum viten inserere voles, optimi generis saruenta fructuaria tum, eum gemmas agere incipient, veuto Austro a matre pracidito. Sarmentum, quod inseris, de summa vite sit rotundum, bonis crebrisque nodis. Tres leinde nodos integerrinıs relinquito : infra tertian gemmam ex utraque parte duormm digitorum spatiun in nı. dun cunei tenurissimo scalpello acuito, ila ne medullam laxdas. Viten deinde, quan insiturus es, resecato, et pla- 
iutroduisez dass la fente la petite branche après l'avoir racléc préalablemeut, de manière que l’écorce de la greffe s'adapte parfaitcment à eelle de Ia souche. Liez ensuite les greffes ainsi insérćes aree du jone et aree de l'ćcoree d'orme; bouchez la fente avec un enduit mèlé de paille ct fortement attaché, afin que ni le vent ni la pluie IIy puisse pénétrer. Vous couvrirez ensuite l'euduit avee de la mousse, que vous lierez également. Ce moyen entretient la greffe dans une lıumidité coutinuelle, et l'empêche de se clessécher. Piquez de part en part la branche aulessous de la greffe et près de la ligature, avee un instrument très-affilé, afin que la séve coule plutêt de cette picqûre que de l'incision première; ear la séve s'écoulant de l'iucision nuit à la vigne, et empêche les branches greffées de prendre. Quelques anciens ont mieux aimé perforer la vigne avee une vrille, et y introduire ensuite les petites branches ratissées auparavant. Nous avons employé un meilleur procédé pour atteindre au mème but; car l'ancienne vrille pro. duit de la sciure, et brûle la partie qu'elle peree, brûlure qui empêche la plupart du temps les greffes de prendre. Nous nous servons, quant à nous, de la vrille que nous appelons gauloise. Elle peree le trone sans le brûler, paree qu'elle ne produit pas de sciure, mais des copeaux. A près a voir débarrassé le trou de ces copeaux, nous y introduisons les branches ratissées de tous eótés, et nous enduisons bien le tout (en termes d'agriculture, nous y mettons uu lut). Celte greffe prend trèsfacilement. Ayez fini de greffer vos vignes vers l'équinoxe. Prenez les boutures de raisin blane dans des terralns humides, et les boutures de raisin noir dans des terrains sces. Voicl la manière

gam levato, atquc ita findito, et paratos surculos in fissuran demiltito, eatcnus qua adrasi sunt, ita ut cortcx surculi corticem vitis sacqualiter contingat. Qnidquid inserueris, vimine rel ulmi libro diligenter ligato, atque luto subacto paleato oblinito plagam, et alligato, ne aqua rentusve peuctrare possit : deinde supra lutım nuscum imponito, et ita religato : ea res probet humoren, nec inaresccre siuit. Infra insitioncm et alligaturam falce acuta leviter vitem vulnerato ex utraque parte, ut ex lis potius plagis lıumor defluat, quan $c x$ iusitione ipsa abundct; rocet enim nimius lumor, nec patitur surculos insertos comprelıendere. Quibusdam antiquorum tcrebrari vitcm placet, atque ita leviler adrasos surculos demilti : sed nos meliore rátione looc idem fecionus. Nam antiqua terebra scobem facit, et propter lıoc urit eam partem quam perforat : perusta autem perraro unquam compreliendit insertos surculos. Nos rursus terebram, quam gallicam dicimus, lunic insitioni aptavinus : ea excaval, ncc urit, quod non scobem, sed ramenta facit. Itaquc cavalum foramen cum purgavimus, undique adrasos surculos inscrimus, atque ita circumlinimus. Talis insitio facilline convalescit. Igitur secundum aequinoctium perfectam vitium iusitioncm labeto : lumida loca de uva alba : sicca dc de reudre fertiles des vigues nalurellement peu produetives. Arrosez les vignes qui donnent peu de raisins avec du vinaigre bien sûr, mêlẻ de ecndres; et enduisez la souche avee le même mélange. Il y a des vignes dont les raisins se dessèchent avant de s'amollir et de parvenir à maturité : voici le moyen de remédier à cet inconvénient. Lorsque les grains seront parvenus a la grosseur de l'er's, coupez le tronc près de la raeine, enduisez la plaie avee une composition de terre, mêlée à doses égales de vieille urine et de fort vinaigre; arrosez les racines avce la même préparation, et retouruez souvent le sol. Ce travail fera pousser un bois qui portera des fruits.

IX. Il y a une sorte de greffe par laquelle nous obtenons sur la mème vigne des raisins d'espèee de couleur et de gront différents. Voici comment on la pratique : prenez quatre ou cinq ou même plusieurs branches de différentes espèces; adaptez-les bien ensemble, et attachez-les avee une ficelle. Mettez-les ensuite daus un tuyau de terre cuite ou dans une corne qui les tienne.bien serrées, de faȩon touicfois qu'elles ressortent par les deux bouts. Après quoi détachez un peu les bouts qui dépassent, mettez-les dans un fossé, couvrez-les de terre bien fumée, et arrosez-les jusqu'à ce qu'elles donnent des bourgeons. Lorsque les branches, au bout de deux ou trois ans, se seront jointes au point de ne présenter qu'un tout, brisez le tuyau, et seiez ces branches réunies en une seule par le milieu, à l'endroit où la cohésion est la plus forte. Unissez la plaic qul résultera de ecttc section, et mettez-y de la terre de ramas bien pulvérisée, de sorte que ectte plaie se trouve couverte d'une couche de trois doigts d'épaisseur. Lorsque le trone aura poussé

nigra inserito. Infructuosas viles foecundas sic facito: vites quax exiguum dant fructum, aceto acri cum cinere irrigato, ipsumque codicem colcm cinere linito. At si fructun qua ostendunt, ad matucitatem non perducunt, sed priusquan nitescant, uva inarescunt, lioc modo emcndabuntur. Cusn instar ad ervi amplitudinem acini lıabuerint, radice teuts vitem pracidito, plagam acri aceto pariter ac lotio vetcri permista terra linito, eodenque radices rigato, sappe fodito. Ilacc materias citant, exque fructum perferunt.

IX. Est etiam genus insitionis, quod uvas talcs crcal, in quiluus varii generis ac saporis colorisque reperiuntur aciul. Hoc autcm ratione tali eflicitur : Quatuor vel quinque sive eliam plures voles virgas diversi generis sunito, easque diligenter ct aequaliter compositas colligato, deirsle in tubulum fictilem vel cornu arcte inserito, ita ut alj. quantum exstent ab utraque parte, easque partes, qux exstabunt, icsolvito, iu scrobem dcinde imponito, cl terra stercorata obruito, ac rigato, donec gemmas agaut. Cum inter se virgne cohæeserint, post biennium aut triennium facta jam unitate, dissolves tubulum, et circa mediun fire crus, ubi maxime videbuntur coisse, vitem serra praci. dito, et plagan levato, terramque minutam aggerato, ita 
des rejetons, ehoisissez les deux meilleurs, taillez-les, et coupez les autres. De ectte manière vous obtiendrez des raisins tels que j'ai dit. Si vous voulez avoir des raisins sans grains, fendez une erocette sans blesser les bourgeons, ôtcz-cn la moelle; rapproehez ensuite les deux parties, et attachez-les avec une ficelic, sans cependant toucher aux bourgcons; vous mettrez ensuite eette erocette dans une terre bien fumée, que vous arroserez souvent. Lorsqu'elle eommeneera à pousser des rejetons, fuuillez profondément et souvent. Quand eette vigne sera parvenue à sa eroissance, elle donnera des raisins sans grains.

$X$. Les vendanges faites, eommeneez la taille; ne-vous servez à cet effet que de très-bons instruments, et aussi tranchants que faire se pourra. Les plaies n'en seront que plus légères, et l'eau n'y sera point stagnantc. Lorsque l'eau ne s'écoule pas promptement, elle gâte la vigne, et engendre des vers et d'autres animaux qui rongent le bois. Taillez toujours le bois en rond : dc ectte manière les plaies sc eicatriscront plus vite. Coupez tous les sarments trop plats ou trop vieux, ainsi que eeux qui sont contournés ou rabougris. Taillez les sarments nouveaux, les branches à fruit, et quelquefois même les rejetons les plus beaux; si la tête de la vigne n'est pas bonne, eonservez-en les bras. Faites la taille le plus vite possible. Prenez une doloirc bien tranchante pour les branches desséehées et vieilles, qui ne peuvent pas ĉtre coupées avec la serpette. Dans un terrain maigre et sec, commencez à tailler dès le solstice d'hiver, lorsque la vigne est eneore faible. Répétez eette opération vers les calendes de février, pour la partie qui n'aura point été encore émondée. Depuis les ides de déeembre jusqu'aux ides de jan-

ut tribus dlgitis alte plagam operiat : ex co codice cum egerit coles, duos optimos submittito, reliquos dejicito : sic u væ nascentur, quales proposuimus. Ut autem uvæ sine vinaceis nascantur, malleolum scindito $\mathrm{ita}$, ne gemmx liedantur, medullamque omnem eradito, tum demum in se compositum colligato, sic ne gemmas allidas, atque ita terra stercorata deponito, et rigato. Cum coles agere coeperit, sacpe et alte refodito. Adulta vitis tales uvas sine vinaceis crealoit.

x. Viudemia facta, statim putare incipito ferramentis quam optimis et acutissimis : ita plagae leves fient, neque in vite aqua consistere poterit : qua simulatque immorata est, corrumpit vitem, vermesque et alia creat animalia, quae materiam exeduut. Plagas autem rotundas facito: nau celerius cicatricem ducunt. Sarmenta lata, vetera, usale nata, contorta, omnia lıæc pracidito : novella et fructuaria, et interdum sololem idoneam, si jam. superficies parum valebit, submittito bracliaque conservato. Qnam celerrime poteris putationem perficito. Arida et vetera, falce quac amputari 11on possunt, acuta dolabra abradito. In agro nacro et sicco vineain imbecillam a bruma amuputato : (puam partem nou deputareris, circa calend. Febr. repetito : ab vier, n'approchez pơnt le fer de la vigne ui d'un arbre quelconque. En taillant la vigne, faites toujours la scetion entre deux bourgeons. Si vous eoupez trop près diun bourgeon, la vigne souffrira, et ne jettera point de bois. La section doit toujours être obliçue; de cettc manière la plaie ne souffrira ni des eaux de la pluie ni du soleil, et elle trouvera l'humidité qu'il lai faut. Plus le terrain sera gras et la vigne robuste, plus vous y laisserez de bourgeons et de branehes. A l'endroit où vous voulez former ce que nous avons appelé les bras de la vigne, vous n'avez qu'à donner un ou deux coups de la pointe d'une serpette bien effilée, à la profondeur d'un duigrt. Ne eoupez jamais tout entier un bras de la vigne, a moins qu'il ne soit desséché. Une vigne nouvelle doit être déehaussée avant le solstice d'hiver, afin qu'elle puisse reeevoir les pluics du priutemps et le limon de la terre. Les vignes et les arbres en général seront d'autant plus robustes que vous les aurez déehaussés de bonne heure. Lorsque les vignes sont situées sur des hautcurs, il faudra en les déchaussant former dans la partie superricure de petits lacs tout près de la souche, et dans la partie inférieure des tranelićes plus profondes, qui puissent eontenir plus d'eau et de limon. Quant aux vieilles vignes, il ne faut ni les déehausser, de erainte de faire desséeher les racines qui sortent de terre, ni les labourer à la cliarrue, de erainte de briscr ees racines. Passez-les souvent à la houe, à une profondeur suffisante et égale, et répandez-y avant le solstice d'hiver du fumier ou de la paille. Si vous n'avez que légèrement déchaussé la vigne, vous pouvez. la fumer tout à fait.

XI. Quand vous aurez bien taillé la vigne, il importe de l'ébourgeonner avee soin; ear les

idibus Decemb. ad idus Januarias ferro tangi vitem et arbo. rem non convenit. Cum vitem putabis, inter duas gemmas secato : uam si juxta ipsam gemmam secueris, laborabit, nec materiam citabit. Cicatrix autem semper deorsun spectet, ita neque aqua neque sole laborabit, humoremque recte capiet. In agro crasso validaque vinea plures gemmas et pralnıas relinquito, in exili paueiores. Sicubi in vite hraehium desiderabis, falee acnta semel aut bis co loco alte instar digiti mucrone ferito. Brachium quamvis longum cave totum tollas, nisi si totum aruerit. Vineam novellam ante brumam ablaquealam habeto, ut omnes imbres limumque concipiat. Vites arboresque quo citius ablaquea. veris, erunt valentiores. Sed quaccunque in clivis eruut positx, ita ablaqueandes sunt, ut a superiore parte secundum codicem lacusculi fiant, ab inferiore autem pulvinuli altiores exeitentur, quo plus aquxe limique contineant. Vinea vetus neque ablaqueanda est, ne radices, quas in summo habet, inarescait, neque aranda, ne radices abrum. pantur. Bidentibus sxpe et alte fodito rqualiter, et stercore vel palea conspergito solum ante brumain, vel cum circum ipsan vitem summatim ablaqueaveris, stercorato.

XI. Vineam quam bene putare, tam diligenter pawpi. 
branches à fruit se fortificront davantage, outre (qu'on préparc et faeilite ainsi la taille de l'année suivante. En général, l'ébourgeonnement ne laisse point de cieatriees à la vigne; car lorsqu'on ne coupe dans un cep que du vert et du tendre, il se guérit promptement. Outre ccla, les raisins mûrissent mieux. L'ébourgeonnement doit être terminé dix jours avant que la vigne commence à être en fleur. Enlevez tous les pampres superflus. Tous ceux qui seront sortis de la tête ou des bras de la vigne doivent être retranehés, bien entendu s'ils ne portent pas de raisin. Cassez les bouts des branehes, pour empéclier l'excès de la végétation. Couvrez de leurs pampres les raisins tournés vers le midi ou le couchant, afin qu'ils ne soient pas brûlés par l'ardeur du soleil.

XII. Dès que le raisin commence à tourner, fouillez pour la troisième fois. Quand il commence à mûrir, fouillez avant les grandes chaleurs du midi; quand il aura cessé de mûrir, fouillez après midi, et faites beaucoup de poussière : par là vous meltez le raisin à l'abri du soleil et du brouillard. Ne labourez ni ne fouillez une terre bourbeuse, parce qu'elle s'endurcit et se geree facilement. II vaut mieux retourner la terrc avec des hoyaux qu'à la charrue. Le hoyau remue partout la terre également; la charrue au contrairc soulève de grosses mottes de terre, outre que les bœufs qui la tirent brisent souvent des branches, et quelquefois meme des ceps tout entiers. Le nombre des fouilles n'est point déterminé; car plus vous fouillerez une vigne, plus vous la rendrez féconde.

XIII. Faites en sortc que vers le commencement du printemps des tas de paille se trouvent placés entre les rangées de ceps. Si vous crai-

nare utile est : nam et materix quæ. fructum liabent, melins convalescunt, el putatio sequentis anni expeditior, tum etiam vitis minus cicatricosa fit : quoniam quod viride et tenerum decerpitur, protinus convalescit. Super lıec quoque nielius uvæ maturescunt. Ante dies decem quam viuea florere incipit, pampinatam lıbeto. Quidquid supervacui enatum fuerit, tollito. Quod in cacumine aut in bra. cliis natum erit, decerpito, duntaxat quæ uvam non lıabebunt. Cacumina virgarum, ne luxurientur, demutilato. Uvas, quae meridiem aut occidentem spectabuut, ne perurantur, suo sibi pampino tegilo.

XII. Simulatque uva variari coeperit, fodito tertiam fos. suram : et cun jam maturescet, ante meridiem, priusquam calere incipiet; cum desierit, post meridiem fodito, pulveremque excitato : ea res et a sole et a nebula maxime uvam defendit. Lutuleutam terram neque arare neque fodere oportet, quia valde durescit et finditur. Bidentibus terram vertere utilius est, quam aratro. Bidens aqualiter totam terram vertit: aratrum praterquam quod scamna facit, tum etiam boves, qui arant, aliquantum virgarum et interdum totas vites frangunt. Finis anten fodiendi vineam nullus est : nam quanto sapius foderis, tanto uberio. rem fructum reperies. gnez que le froid n'arrive plus tôt que de coutume, metrez le feu aux tas de paille; la fumée qui en résultera écartera des vignes le brouillard et la rouille.

XIV. Broyez du lupin, que vous mêlercz avec du mare d'olives; répandez de ce mélangre sur le pied de la vigne; ou bien faites cuire du bitume avec de l'huile, et frottez-en également le pied de la vigne : c'est le moyen de la préserver des fourmis.

$\mathrm{XV}$. Les vlgnes qui se trouvent près des bâtiments ont souvent à souffrir des rats et des souris : pour prévenir cet ineonvénient, nous attendrons la pleine lune, lorsqu'elle sera dans le signe du Lion ou du Seorpion, ou du Sagittaire, ou bien encore du Taureau; nous taillerons alors la vigne pendant la nuit, à la clarté de la lune. II y a une espèce d'insectes appelées lisettes; ces animaux rongent en géuéral les jeunes pampres et les grappes : pour empêcher leurs ravages, frottez avec du sang d'ours, immédiatement apres la taillc, les serpettes dont vous vous êtes servi. Si vous possédez la peau d'un castor, essuyez-y les serpettes pendant la taille même, après les avoir aiguisées. Ce n'est qu'alors que vous commencerez à tailler les vignes. Comme nous avons suffisamment traité des vignes, nous allons passer aux plants d'arbres que l'on marie aux vignes.

XVI. L'arbre qui nourrit le plus la vigne est le peuplier; vient ensuite l'orme, et enfin le frêne. L'anbier est repoussé par la plupart des agriculteurs, parce que son feuillage ne vaut rien à la vigne. L'espeee d'orme que les paysans appellent altinia est la meilleure et la plus riche; elle donne en outre beaueoup de feuillage. Aussi faut-il la planter de préférence dans des terrains

XIII. Palearum acervos inter ordines verno tempore positos labeto in vinea. Cum frigus contra temporis consuefudinem intellexeris, omneis acervos incendito, ita fumus nebulam et rubiginem removebit.

XIV. Lupinum terito, el cum fracibus misceto, eoque imam vineam circunlinito : vel bitumen cum oleo coquito, eo quorue iruas vites tangito, formice non exedent.

XV. Vites, quß secundum aedificia sunt, a soricitus aut muribus infestantur. Id ue fiat plenam lunan ohser. vabimus, cum erit iu signo Leouis vel Scorpionis vel Sagittarii vel Tauri, et noctu ad lunan pulalsimus. Genus est animalis, volucra appellatur; id fere prorodit teneros adluc pampinos et uvas: quod ne fiat, falces, quibus vi. neam putaveris, peracta putatione, sanguine ursino linito: vel si pellem fibri luabueris, in ipsa putatione, quoties falcem acueris, ea pelle aciem detergito, atque ita putare incipito. Quonian de vineis abunde diximus, de arbustis pracipiamus.

$X V I$. Vitem maxime populus alit, deinde ulmus, deinde fraxinus. Opulus, quoniam frondem non idoneanı labet, a plerisque improbatur. Ulmus autem quam Aliniam vo. cant rustici, genernsissima est et latissima, multamque frondem habet : eaque maxime serenda est locis pinguibus 
gras, ou même médiocres. S'il s'agit de garnir d'arbres des lieux âpres et arides, le peuplier et l'orme y conviennent mieux que les frênes. On prendra des frênes sauvages qui ont les feuilles un peu plus larges que les autres espèces de frênes; ce feuiliage est pour le moins aussi bon que celui des ormes : les chèvres et les brebis le préfèrent à tout autre. Celui qui veut former une plantation pour la vigne, doit fnire des fossés de quatrc pieds en tout sens, une année avant de planter. Vers les calendes de mars, mettez dans la mème fosse l'orme et le peuplier, ou bien le frêne, en sorte que si l'orme vient à manquer, l'aubier ou le frêne puissent le remplacer. Si tous les deux réussissent, ôtez l'un pour le transplanter dans un autre endroit. Les arbres à vigne doivent être plantés à quarante pieds les uns des autres : cette disposition les fortifie, et la vigne qu'on $\mathrm{y}$ attache donne de meilleurs fruits. Les grains semés dans les intervalles y seront moins incommodés par l'ombrage. Plus vous remuerez la terre autour de l'arbre, plus vite il s'accroitra. $\mathbf{N}^{\prime}=\mathbf{n}$ approehez point le fer pendant les trois premières années : ce temps écoulé, façonnez-le pour recevoir la vigne; c'est-à-dire, coupez-en les branches superflues, et échelonnez les autres en en laissant une sur deux, et les coupant alternativement d'année en année. La sixième an. néc, lorsque l'arbre aura assez de force, vous le marierez à la vignc de la façon qui suit : Vous tiendrez la vigne éloignée du tronc de l'arbre à la distanze d'un pied, et vous ferez un fossć de quatre pieds de long sur trois de profondeur, et deux et demi de largeur. Après avoir laissé pendant deux mois ce fossé exposé aux injures du

vel etiam mediocribus : sed si aspera et siticulosa loca arboribus obserenda erunt, neque opulus neque ulmus tam idonea sunt quam orni : ex silrestres fraxiui sunt, paulo latioribus tamen foliis quam cieterx fraxini, nec deteriorem frondem, quain ulmi prastant. Caprac quiden et oves vel libeutius etiam lanc frondem appelunt. Igitur qui arbustum constituere volent, ante annum quam deponant arbores, scrobes faeiant quatuor peclum quoquoversus. Deinde circa calen. Mart. in eandem scrobem ulmum et populum, vel fraxinum deponant, ut si ulmus defecerit, opulus vel fraxinus locum obtineant. Si autem utraque vixerint, altera eximatur, et alio loco deponatur. Arbustun inter quadragenos pedes dispositum esse convenit : sic enin et ipsac arbores, et apposita vites melius convales. cent, fructumque mieliorem labunt. Segetes etiam, quae in eo erunt, minus umbra laborabunt. Arborem, quam deposueris, sæepius circumfodito, quo celeriıs adolescat : et citra triennium ferto ne tetigeris. Completis sex et triginta mensibus, ad recipiendam vitem formabis, super. vacuos ramos amputabis, alterua braclia in unodum sca. larum relinques, alteruisque aruis putabis. Sexto anno, si jam firma videbitur, maritabis loc modo. Ab ipso ar. boris crure pedale spatium intermittito, deinde sulcum in quatıor pedes longum, in tres altum, in dupondiua el temps, vous y coucherez la vigne que vous aurez tirée de la pépinière, et qui ne devra pas avoir moins de dix pieds. Etayez-la bien, et attachez-la à l'arbre. Ne la taillez point l'année suivante; à la troisième année réduisez-la à un seul sarment, et ne lui laisšez que peu de bourgeons, afin qu'elle ne puisse pas monter avant de s'être fortifiée. Lorsqu'elle aura pris assez d'accroissement, distribuez ses sarments sur tous les étages do l'arbre ; mais ayez soin de ne pas trop charger la vigne, et de tailler les brins qui vous paraitront les plus vigoureux, et les plus propres à donner du fruit. Pour une vigne mariée à des arbres, il importe de faire les ligatures avec le même soin que la taille; car c'est de ce soin que depend principalement le rapport de cette sorte de vigne. Une vigne qui aura èté fortement attachée à l'endroit convenable se conserve plus longtemps. II faut done que toutes les années la taille soit faite de telle sorte cque les liens soient renouvelés, et que la vigne soit distribuée sur les rameaux les plus propres à la reeevoir.

XVII. Lolivier se plait principalement sur les collines, et dans des terrains secs et argileux. Dans des terres humides et grasses, il donne beaucoup de feuillage sans fruit. Pour former une plantation d'oliviers, il vaut mieux prendre des trones que des boutures. Magron veut qu'on plante l'olive dans des terrains sees, après l'équinoxe d'automne et avant le solstice d'hiver. Les agriculteurs de nos jours plantent l'olivier au printemps, vers les calendes de mai. Le fossé destiné à recevoir l'olivier doit avoir quatre pieds en tout sens: on met d'abord au fond du fossé de petites pierres et du gravier; puis on y jette de

semissem latum cum feceris, patiere minime duobus men. sibus eum tempestatibus rerberari. 'Tum demum cirea cal. Martias ritem de seminario ue minorem quidem de. cem pedum sternito, et adminieulato, arborique jungilo : eam proximo anno ne putaveris : tertio vero ad unum vir. gam redigito, paucasque gemmas relinquito, ue anfequıım iuvaluerit, in altitudinem repat : deincle nbi amplum incrementum lıabuenit, per omnia arboris tabulata disponito ejus materias, ita tamen ne vitem oncres, sed eerta et robustissima flagella submittas. Arbustivan vilen quanı putare, tam alligare diligenter oportet. Nam in eo fructus maxime vis consistit, lintiusque perennat, qua firmis toris et idoneis loeis relignta est. Itaque omnibus aunis convenit subsequi putationem, ita ut tori renoventur, et vitis per idoneos ramos disponatur.

XVII. Olea maxime collibus, siecis et argillosis gaudet : at hunidis campis et pinguibus lietas frondes sine fructu affert. Melius autem truncis quam plantis olivetum constituitur. Magoni placet siccis locis olivan autumno post aquínoctium seri ante brunam. Nostra atatis agricola fere vernum tempus circa calend. Maias servant. Oportet autem scrobem olex quoquoversus pedes quatemos pa. tere, in imum serobem lapidem glareamque ahjicere, deinde super terram quatuor digitorum injicere, tum ar- 
La terre à guatre doigts d'épaisseur, et enfin on y plante l'arbrisseau droit et à la moitié de sa hauteur, de sorte qu'il y en ait autant hors du fossé que dedans. Préservez l'arbuste des vents et des orages en l'étayant avec soin, et mêlez du fumier à la terre que vous remettez dans le fossć. Lintervalle entre les rangées doit être de soixante pieds, afin que les oliviers aient assez d'espace pour eroittc en largeur; car s'ils s'élançaient en hauteur, ils deviendraient grêles, et ne porteraient que peu de fruits. La ineilleure olive est la Licinienne, puis la pausia pour l'abondance del'huile, et l'orchis pour l'huile à manger. L'olive dite royale, ainsi que celle que l'on appelle rayonnante, ne sont pas sans apparence; mais ni l'une ni l'autre ne valent les premières, ni pour la quantité, ni pour la table. Si vous plantez un olivier à la plaee d'un ehêne que vous aurez arraehé, il ne tardera pas à mourir, paree que la ra. eine du chene engendre et alimente des rers, qui rongeraient eelle de l'olivier. Si, dans un olivier, un rameau prend plus d'accroissement que les autres, il est à craindre qu'il ne le dessèehe, si l'on n'a soin de eouper ce ramenu. Il est bon de marquer les jeunes arbies avec de la sanguine avant de les transplanter, afin de les placer du même eoté vers lequel ils étaient tournés dans la pépinière; placés dans une position autre que eelle à lacquelle ils étaient habitués, ils souffriront du froid ou de la ehaleur.

XVIII. Avant de faire un verger, il est bon d'entourer le terrain que vous y destinez de murailles ou d'un fossé, afin que ni les troupeaux ni meme les homınes ne puissent y pénétrer, si ee n'est par la porte d'entrée, avant que les

busculam deponere ita rectam, ut quod a serobe exstiterit, in medio sit. Arlusculam autem a tempestatibus tueri diligenter oportet aduiniculando, et terra, qua in scrobe reponitur, stercora imuiscere. Olean docet inter sexage. nos pedes dispoui, ut epatium in latitudinem cresceudl labeat : nam quae in proceritatem extenduntur, evanidac fiunt, parumque fructus ferunt. Optima est olea Liciniaua, pausia secunda oleo, escac orchis. Sunt et regrix, et radii uon sine specie, neque oleo nec esui tam grats, quuam quas supra diximus. Si olean posueris co loco, unde quercus effossa cst, emorietur, ideo quod rerntes quidam sumt, qui in radice quercus nascuutur et educantur, iique ınaxine semiua olea consumunt. Si in olea unus ramus aliyuauto caeteris lactior est, nisi eum recileris, arbor tola fiet retorrida. Omnes arbusculas prius yuam transferan. tur, rubrica notare convenit, ut cum serentur, easdem cxli partes aspiciant, quas etiam in seminario conspexeraut: alioquin frigore vel calore laborabuut ab iis partibus, quas prater consuetudinem sub alio tractu expositas laabuerint.

XVIII. Priusq̧uam pomarium constituas, quam ma. guum laabere voles circunmunito maceria, aut fossa, ita ut nou solum pecori, sell ne homini quidem transitus sit, nisi per ostium, dum adolescant seminá. Nam si sæc- plants aient acquis une certaine foree; car si les têtes en étaient souvent brisées par les hommes ou rongées par les bestiaux, elles seraient gatées pour toujours. En disposant les arbres, il est bon de prendre garde que les faibles ne soient point opprimés par les forts; car les arbres n'étant pas tous de la meme force ni de la même grandeur, ne premnent point un aceroissement égal. La terre qui convient aux vignes convient également aux arbres.

XIX. Faites des fossés un an avant de dispo ser les arbres fruitiers; de cette facon lc terrain se ramollira au soleil et à la pluie, et les plants y viendront plus vite. Mais si vous voulez planter: vos arbires la même année que vous aurez fait vos fossés, il faudra ercuser eeux-ci au moins. deux mois d'avanee, puis les remplir de paille, et y mettre ensuite lc feu. Plus vous les ferez larges et ouverts, plus les fruits que vous recuellerez seront beaux et abondants. Ces fossés auront la forme des fours, dont lc fond est plus large que l'ouverture, afin que les racines puissent s'étendre davantage, et que l'ouverture étant ètroite, le froid de l'hiver ou la ehaleur de l'étéy pénètrent plus difficilement. On n'aura pas non plus à craindre, dans les terrains en pente, que la terre dont on aura comblé les fosses soit entralnéc par les pluies. Plantez les arbres à de grands intervalles, afin qu'en grandissant ils trouvent un espace suffisant pour étendre leurs rameaux. En effet, si vous les plantez trop près les uns des. autres, vous ne pourrez rien semer au-dessous, et les arbres eux-mèmes ne seront guère produetifs, à inoins que vous ne les éclaircissiez. Il est bon par conséquent de laisser entre les rangées un

pius cacumina manu prafracta, aut a pecore proerosa fue. rint, [quan adolescant,] in perpetuum corrumpuntur. Generatiı antem arbores disponere utilius, maximo no imbecilla a valentioribus premantur, qua nec viribus nec magnitudine sunt pares, neque pariler crescunt. Terra quse vitibus apta est, eaden qquoque utilis est arboribus.

XIX. Ante annum quam pomaria disponere voles, scrobes fodito : ita sole pluviaque macerabuntur, et quod posueris cito comprehendet. Sed si quo anno scrobes feceris, etiam semiula ponere voles, mininum ante duos menses fodito scrobes, postea strameutis cos conipleto, et incendito. Quo latiores patentioresque scrobes foceris, eo Letiores erunt uberioresque fructus. Scrobis clibano similis esse debet, inıus quam summus patentior, ut laxius radices eragentur, ac minus frigoris lieme, minusquo astate vaporis per angustum os terrn admittant : tum etiam clivosis locis terra, quae in cum congesta est, plu. viis non abluitur. Arbores raris intervallis serito, ut cun creverint, spatium labeant, quo ramos extendaut. Nam si spisse posueris, neque infra quicquam serere poleris, nec sic ipse fructuosa erunt, nisi cas interraseris. Itaque placet inter ordines quadragenos pedes, minimumque tricenos, relinqui.

XX. Semiua lege, ne minus crassa, quam manubrium 
intervalle de quarante pieds ou de trente au moins. XX. Choisissez du plant qui ait au moins la grosseur d'un manche de hoyau; qu'il soit droit, lisse, haut, sans ulcère, ct qu'il ait l'ćcorce intacte. Le plant choisi ainsi prendra bien, et promptement. Si vous le tirez d'arbres déjả formés, choisissez ceux qui rapportent toutes les années de bons fruits et en grande quantité. Ne manquez pas de reconnaitre parmi ces branches celles qui sont exposées au levant. Le plant mis en terre avec do la racine prendra plus vite son accroissement que la bouture. L'arbre greffé domne plus de fruits que celui qui n'a point été greffè, c'est-à-dire qui a étẻ planté par bouture. Avant de transplanter de jeunes arbres, failes-y une marque avec de la sanguine ou toute autre chose, afin de les présenter aux mêmes vents auxquels ils ont été exposés d'abord. Ayez soin surtout de les transfèrer toujours d'un terrain èlevé, sec et maigre, daus un terrain plat, humide et gras. Que les jeunes plants aieut une triple tige, et soient ćlevés de trois pieds au-dessus du sol. Si vous voulez mettre deux ou trois petits arbres dans la mème fosse, prenez garde qu'ils ne se toueheut, car ils seraient rongés par les vers. Lorsque vous mettrez vos plants en terie, enfoncez de dioite et de gauche jusqu'au fond de la fusse des poignées de sarments de ln grosseur du bras, de façon qu'ils en débordent un peu le niveau. Au moyen de ces sarments il vous sera facile de faire parvenir l'eau en été jusqu'aux racines des jeunes plants. Plantez vers les ides d'octobre les arbres ou les plants garnis de racines; pour les boutures ou les branches, mettezles en terre au printemps, avant que la pousse n'ait commencé. Pour empècher que les teignes

est bidentis, recta, levia, procera, sine ulceribus, integro libro. Ea bene et celeriter comprelıcndunt. Semina si ex arboribus sumes, de iis potissimum sumito, quæ omnibus annis bonos et uberes ferunt fructus. Observabis autem ab lumeris, qui sunt contra solem orientem, ut eadem decerpas. Sed si cum radice plantam posueris, incrementum citius fuerit, quam creteris, quas severis. Arbos insita fructuosior est, quam quae insita nou est, id est, quan qua ramis aut plantis ponitur. Priusquan arbusculas transferas, rubrica vel alia qualibet re signato, ut iisdem veutis, quilus aute stcterunt, constituas eas : curamque allibelo, ut ab superiore et sicciore et exiliore in planio. rem, lıunidiorem, pinguiorem agrum transferas. Semiua trifurca maxime ponito : ea exstent supra terram trihus pedibus. In codem scrobe si duas aut tres arbusculas ponere voles, curato ue inter se contingant. Nam ita vermibus interimuntur. Cum semina depones, dextra ac sinistra siugulis usfue in imum scrobeu fasciculos sarmentorum braclii lumnaui crassitudine depponito; ita ut supra terrain paululum exstent, per quos xstate parvo lalıre aquam radicibus sulıministres. Arbores aut radicata semina autumno serito circa iu. Octolores. Taleas et ramos vere, ante чұuan germinare arbores incipiant, dęrouito.
In'incommodent les plants de figulers, mettez au fond des fossés une bouture de lentisque, la cime renverséc.

XXI. Ne plantez pas le figuler pendant les grands froids. Cet arbre aime naturellement les lieux exposés au soleil, pleins de cailloux ou de gravier, et parsemés quelqquefois do rochers. II se fortifie promptement dans un terrain de cette na. ture, pourvu qu'on le mette dans des fosses grandes et larges. Les figuiers de toutes les espèces, quoique diffërents entre cux par leur forme et le goût de leurs fruits, sc plantent d'une seule et même façon, mais dans des terrains différents. Plạntez les figuiers hatifs dans les lieux froids où l'automne est humide, de sorte que vous puissiez en recueillir les fruits avant les pluies; mettez au contraire les figuiers d'hiver dans un sol naturellement chaud. Si vous voulez rendre un figuier tardif, arrachez-en les figues quand elles sont encore petites; celles qu'il donnera après ne mûriront que bien avant dans l'hiver. Il est souvent utile de couper avec un instrument très-aiguisẻ le bout des cimes, lorsque l'arbre commence à donner des feuilles; c'est le moyen de le rendre plus fort et plus productif. Mais ce qui sera toujours d'une grande utilité, c'est de répandre sur les racines, sitôt que la feuille commence à sortir, de la terre rouge détrempéo dans de l'amourque, ainsi que du fumier provenant de l'homme : ce traitement rend le fruit plus abondant; la figue elle-même devient plus pleine, et d'une plus belle apparence.

XXII. Plantez l'amandier au lever de l'Our'se, ou vers les calendes de février; cet arbre bourgeonue avant tous les autres. Il demande surtout une terre dure, chaude et sèche. Planté dans un

Sed ne tinea molesta sit scminibus ficulneis, in imum scrobem taleam lentisci, ita ut cacunen ejus deorsum spectet, obruito.

XXI. Ficum frigoribus ne serito : loca aprica, calculosa, glareosa, interdum et saxosa amat. Ejısmodi agro cito convalescit, si scrobes amplos et idoneos feccris. Ficorum genera etiam si sajore et liabitu differunt, tamen uno modo, sed dispari differentia agri, seruntur. Locis frigidis et autumni temporibus aquosis praccoques serito, ut ante plu vian fructum deligas: locis calidis libernas serito. At si voles ficum, quamvis non natura, seram facere, cum grossuli mlnuti crunt, fructum decutito : ita alterum edet fructun, et in liemem seram differet maturitaten. Nonnunquam etiam cum frondere cieperint arbores, cacumiua fici acutissino ferramento sumına amputare prodest. Sic firmiores arbores et feraciores fiunt. Scinper proderit sinulac folia agere comperit ficus, rubricam amurca diluere, et cum stercore lummano ad radicem infundere : ea res efficit uberiorem fructum, et farctum fici speciosius et plenius.

XXII. Nucem Graccam serito Arcturi sigıo, vel circs calend. Febr. quae prima gemmascil. Anrum calidum durum el siccun desiderat. Nam in locis diversis natura 
terrain d'une autre nature, il pourrit en peu de temps. Avant do semer l'amande, trempez-la dans de l'hydromel qui ne soit pas trop doux; par ce moyen, l'arbicc, lorsqu'il sera grand, donnera du fruit de meilleur goût, et en attendant vous aiderez et accélérerez même son accroissement. Mettez trois amandes en triangle, de façon que leur pointe, d'où sortent les raeines, soit renversée, ct qu'elles soient éloignées d'une palıne au moins l'une de l'autre. Celle qui forme le sommet du triangle doit être tournée vers le point du ciel d'où souffle le vent Favonius. Chacune des trois ne donnera qu'une seule raeine et une seule tige : chacune de ces racines, arrivée au fond de la fosse, se recourbe à cause de la dureté de la terre qui soppose à son passage; dès lors clle jettera d'autres racines plus nombreuses, qui sembleront former autant de branches. Voici la façon de faire des amandes et des avelines de 'Tarente. Mettez, dans la fosse destince à reecvoir cet arbie, de la terre bien pulvérisée, à la hauteur d'un demi-pied, et répandez-y de la graine de férule. Lorsque la férule aura levé, fendez-la en deux pour mettre à nu sa moelle, et cachezy une amande ou une aveline dépouillée de son écorce; puis couvrez le tout de terre. Faites cette opération avant les calendes de mars, ou mieux entre les nones et les ides de ce mois. C'est à la même époque qu'on plante les noix, la pomme de pin et les châtaignes.

XXIII. La meilleure époque pour planter le grenadier est depuis le commencement du printemps jusqu'aux calendes d'avril. Si son fruit est aigre ou peu doux, on lc corrigera en répandant sur ses racines de la fiente de pore, des excréments humains, et de la vieille urine. Ce moyen,

ejusmodi si posucris nucem, protinus putrescet. Antequam nucem deponas, in aqua mulsa, nec uimis dulei macerato : ita jucundioris saporis fructum, cum acholeve. rit, prablebit, et interim melius atque celerins nascetur. Teruas nuces in trigonum statuito, parsque aculior inferior sit, quia inde radices mitlit, muxque a nuce minime palmo absit, et anceps ad Favonium spectet. Oınnis nux unam radicem ıniltit, et simplici stilo prorepit. Cum ad scrolvis solum radix pervenit, duritia lıumi coërcita recurvatur, et extensa in nodum ramorum alias radices emittit. Nucem Gracam et Avellanam Tarentinan lıoc modo facere poteris. In quo sçrobe destinaveris nucem serere, terram minutan in modum semipedis ponito, ibique semen ferulx repangito. Cum ferula fuerit enata, eam findito, et in medullam ejus sine putanine nucem Graceam vel Avellanam abscondito, et ila adobruito. Hoc ante cal. Mart. facito, vel etiain inter nonas et idus Martias. Ifoc eodem tempore juglandem et pineam et castaniain serere oportet.

XXIII. Malum Punieum vere usque in cal. Apriles recte seritur. Quod si acidum ant minus duleem fructum feret, loc modo emendabitur. Stereore suillo et humano et lotio humano veteri radices rigato. Ea res et fertileın arborem reddet, et primitivos annos fructum vinosum, postea tout en augmentant la fertilité de l'arlure, reudra son fruit d'abord vineux, et par la suite le rend'a doux, outre que les grains n'en seront point durs. Pour nous, nous prenons un peu de laser délayé dans du vin, et nous frottons de eette préparation les cimes du grenadier; par ce moyen nous sommes parvenus à corriger l'aigreur de leur fruit. On empêehe les grenades de se fendre sur l'arlore, en enterrant trois pierres auprès de sa raeine, lorsqu'on le plante. Mais si l'arbre est déjà tout planté quand on s'apcrẹoit de ce défaut, on sème de la scille auprès de sa racine. Lorsque les grenades sont déjà mûres, on $\mathrm{cm}$ ploic une autre méthode pour les empẻeher de se crever. Cette méthode consiste à tordie la queue par laquelle elles pendent à l'arbre. On se sert du même moyen pour les garder toute l'année.

XXIV. Plantez les poiriers en automne, vingtcinq jours avant le solstice d'hiver. Pour les rendre plus productifs, déchaussez-les profondément; quand ils auront grandi, fendez-en le trone près de la racinc, et introduisez dans cette fente un coin fait de bois gommeux de pin, que vous y laisserez toujours; le déehaussement fait, répandez de la cendre sur la terre près des racines.

XXV. Plantez les pommiers d'été, les cydoniens, les cormicrs et les pruniers, depuis la seconde moitié de l'hiver jusqu'aux ides de février. La meilleure époque pour planter le mûrier est depuis les ides de février jusqu'à l'équinoxe du printemps. Plantez le carrougier, que quelques personnes appellent xepátıov, ainsi que le pêeher, pendant l'automne, avant le solstice d'hiver. Si l'amandier produit peu, pereez-en le trone, et enfonecz-y une pierre que vous laisserez se re-

vero etiam dulcem et apyrenum facit. Nos exiguum admodum laser cyrenaicum vino diluiınus, ef ita cacumina arboris sumına oblevimus : ea res emendavit acorem maIorum. Mala Punica ne rumpantur in arbore, remedio sunt lapides tres, si, cum seres arborem, ad radicem ipsam collocaveris. At si jam arborem satam lıabueris, scillain secundum radices arboris serito. Alio modo, eum janı matura mala fueriut, antequam rumpantur, petiolos, quibus pendent, intorqueto. Eo modo servabuntur etiam anno toto.

XXIV. Piros autumno ante brumam serito, ita ut minime dies quinque et viginti ad brumam supersint. Qua ut sint feraces, cum jam adoleverint, alte ablaquueato, et juxta ipsam radicem truncum findito, et in fissuram cuneum pinenm tedac adigito, et ibi relinquito : deinde obruta ablaqueatione cineren supra terram spargito.

XXV. Mala xestiva, cydonea, sorba, pruna, post mediam liemem usque in idus Febr. serito. Morum ab idibus Febr. usque in æequinoctium vernum recte seres. Siliquam Grocau, quan quidam xepx́tıov vocant, item Persieum ante brumam per autumnum serito. Anyggala si parun feracia erunt, perforata arbure lapidem adigito: ita libram arboris inolescere sinito. Omuium autem generum ranıs 
couvril de l'écorec de l'arbre. A près avoir labouré et fumé la terre daus les jardins, arrangez vers les calendes de mars des boutures de toutes espèces d'arbı'es sur des couches faites en planches. Lorsque les plants commencent à prenare de l'accroissement et à pousser de jcunes branches, il faut les épamprer pour ainsi dire, et les réduire à unc seule tige la première année. A l'approche de l'automne, et avant que le froid brûle leurs cimes, arrachez-en toutes les feuilles, ct ainsi dépouillés, couvrez-les avec des roseaux épais, auxquels vous aurcz laissé d'un côté leurs nœuds, afin qu'ils servent comme de clapeaux à ces jeunes tiges, et qu'ils les défendent di: froid et de la gelée. Deux années après, vous pourrez en toute sûreté les transplanter et les déposer en rangées, ou bien les greffer.

XXVI. On peut greffer tel rejeton que l'on veut sur quelque arbre que ce soit, pourvu que l'écorce du rejeton ne soit pas différente de celle de l'arbre; on le peut faire sans scrupule, si l'espèce à laquelle appartient le rejeton produit des fruits dans le même temps que l'arbre greffé. Les anciens nous ont enseigné trois espèces de greffe : l'une, par laquelle l'arbiee, étant coupé et fendu, reçoit dans l'intérieur de son bois des scions coupés sur un autre arbre; la seconde, par laquelle l'arbre recoit la greffe entre son écorce et son bois : ces deux sortes de greffes se font dans le printemps. La troisième est celle par laquelle l'arbre à greffer reçoit entre l'écorce et le bois des bourgeons avec une petite partie de leur écorce. Cette façon de greffer, que les cultivateurs appellent enter en écusson (emplastration), se fiit en été. Après avoir traitć de ces trois différentes greffes, nous indiquerons un autre procédé qui

circa calend. Martias in hortis, ubi et subacta et stercorata terra est, per pulvinos arearun disponere convenit: leinde cum creverint, danda est opera, ut dum teneros ramulos habent, veluti pampinentur, et ad unum stilum primo anno semina redigantur : et cum autumnus incesserit, ante quam frigus cacunina adurat, omuia folia decerpere expediet, et ita crassis arundinibus, qua ab una parte nodos integros lıabent, quasi pileolos induere, atque ita a frigore el gelicidiis teneras adluc virgas tueri. Post quartum et vigesimum deinde mensem sive transferre et disponere in ordinem voles, seu inserere, satis tuto utrumque facies.

XXVI. Omnis surculus omni arbori inseri potest, si non est ei, cui inseritur, dissimilis cortice : si vero fructum etiam eodem tempore fert, sine ullo scrupulo optime inseritur. Tria autem genera insitionum antiqui tradiderunt : unum, cum resecta et fissa arbor recipit insertos surculos : alterum, quo resecta inter librum et inateriam admittit semina : qux utraque genera rerni ternporis sunt : tertium, cum ipsas gerrmas cum exiguo cortice in partem sui delibratam recipit, quam vocant agricola $\mathrm{em}$. plastrationem. Hoc genus astatis est. Quarum insitionum rationem cun tradiderimus, a nolis quoque repertam est notre découverte personnelle. Il faut greffer tous les arbres dis que les boutons commenceront à paraitre, et dans le temps que la lune sera dans son croissant. Pour l'olivier, greffez-le depuis l'équinoxe du printemps jusqu'aux ides d'avril. L'arbre sur lequel vous voudrez prendre des greffes doit être jeune et de bon rapport, et avoir beaucoup de nœuds. Lorsque ses boutons commenceront à grossir, prenez vos greffesde l'épaisseur d'un petit doigtet à deux pointes, sur de petites branches d'un an qui soient bien intactes, et tournées vers le levant. Sciez avee précaution l'arbre que vous voudrez greffer, à l'endroit où il est le plus lisse et sans cicatrice, et prenez garde de blesser son écorce. Lorsqu'il sera coupé, unissez la plaie avec un instrument de fer bien tranchant; enfoucez ensuite un coin de fer ou d'os bien aiguisé entre l'écorce et le bois, au moins jusqu'à trois doigts, mais avec beaucoup de précaution, pour ne pas endommager ou rompre l'écorce. Ensuite ratissez par en bas avec une serpette bien tranchante les greffes que vous vous lez enter, sur une longueur égale à celle de l'ouverture formée par le coin fiché dans l'arbre, de façon que vous n'endommagiez pas la moelle de ces greffes ni leur écorce, du cóté que vous ne les aurez pas ratissées. Quand vos greffes seront prêtes, retirez le coin, et enfoncez-les aussitôt dans l'ouverture que vous aurez pratiquée pas l'introduction du coin entre l'écorce et le bois. Insérez-les par le bout que vous aurez ratissé, de fiçon qu'elles ressortent de six doigts. Vous ferez bien de pratiquer dans le même arbre deux ou trois greffes à la fois, en laissant un intervalle de quatre doigts entre chacune. Il faudra régler lc nombre des greffes sur la grandeur de l'arbre

aliam docebimus. Omnes arbores simulatque gemmas agere coperint, luna crescente inserito, olivam autem circa aequinoctiun vernum usque in idus Apriles. Ex qua arbore inserere voles, et surculos ad insitionem sumpturus es, videto ut sit tenera et ferax, nodisque crebris : et cum primum germina tumebunt, de ramulis anniculis qui solis ortum spectabunt, et integri erunt, eos legito : crassitudiue minimi digiti : surculi sint bisulci. Arborem, quam inserere voles, serra diligenter exsecato ea parte, quæ maxime nitida et sine cicatrice est, dabisque operam, ne librun loedas. Cum deinde truncum recideris, acuto ferramento plagam levato : deinde quasi cuneum ferreum vel ossenm inter corticem et materiem, ne minus digitos tres, sed leniter demittito, ne laedas aut rumpas corticem. Postea surculos, quos inserere voles, falce acuta ab ima parte eradito tam alte quam cuneum demisisti, sed ita ne medullam neve alterius partis corticem ledas : ubi surculos paratos habueris, cuneum vellito, statimque surculos demittito in ea foranina, qua cuneo adaclo inter corticem et materiem facta sunt. Ea auten fine, qua adraseris, surculos demittito ita, ut sex digitis de arbore exstent. In una auten arhore duos aut tres ramulos figito, dum ne miuus quateruum digitorum iuter eos sit spatium. Pro 
sur la qualité do son écorce. Lorsque vous aurez introduit dans un arbre toutes les greffes qu'il pourra recevoir, vous les lierez soit avec de l'ćcoree d'ormes, soit avec du jone ou de l'osier; après quoi vous enduirez avec un lut mêlé de paille toute la plaie ainsi que l'espace qui se trouve entre les greffes, de façon néanmoins qu'il en reste découvert deux doigts ; mettez ensuite pardessus de la mousse que vous attacherez fortement, afin que la pluie ne puisse y pénétrer. Si l'arbre que vous voulez greffer est petit, coupezle par en bas, de sorte qu'il n'en restc qu'un pied et demi hors de terre après l'avoir coupé ; unissez la plaie avec soin, et fendez très-légèrement le tronc par le milieu avec un instrument bien tranchant, de faęon que la fente n'ait que trois doigts de longueur. Insérez ensuite dans cette fentc un coin, et enfoncez-y des greffes ratissées des deux côtés, de façon que l'écorce des greffes s'adapte complétement à celle de l'arbre. Lorsque vous les aurez ajustées avec soin, retirez le coin, liez l'arbre, et enduisez-le comme je l'ai indiqué plus laaut. Entassez ensuite de la terre autour de l'arbre jusqu'à la greffe : c'est le meilleur moyen de le préserver des vents et de la chalcur. La troisième espèce de greffe, ćtant naturellement trèsdélicate, n'est point applicable à tous les arbres. Pour l'employer avec suceès, il faut que l'arbre ait l'écorce humide, pleine de séve, et forte, comme le figuier. En effet, cet arbre rendant beaucoup de lait, et ayant l'écorce forte, on peut trèsbien le greffer de la manière suivante. On choisit, sur l'arbre dont on veut tirer la greffe, de jeunes branches bien lisses. On trace autour du bourgeon qui a le plus d'apparence, et qui pro-

arboris magnitudine et cortieis bonitate hæe facito. Cum omnes surculos ; quos arbor patietur, demiseris, libro ulmi vel vimine arborem astringito : postea paleato luto bene subarto oblinito totam plagam, et spatium, quod est inter surculos, usque eo, et dnobus digitis insita exstent : supra lutum muscum umponito, et ita alligato, ne pluria dilaloatur. Si pusillam arborem inserere voles, juxta terram abscindito, ita ut sesquipedem a terra exstet. Cum deinde abscideris, plagam diligenter levato, et medium truncum acuto scalpro modice findito, ita ut fissura trium digitorum sit. In eam deinde cuneum, quoad patietur, inserito, el surculos ex utragne parte adrasos demittito, ita ut liIrum scminis libro arboris æqualem facias. Cum surculos diligeuter aptaveris, cuneum vellito: deinde arborem, $11 t$ supra dixi, alligato, et oblinito : dein terram circa arborem aggerato usque ad ipsum insitum. Ea res a veuto et calore maxime tuebitur. Tertium genus insitionis, cum sit subtilissimum, non omni generi arborum idoneum est : et fere ex recipiunt talem insitionem, quæ lumidum suc. cosumque et validum librum habent, sicuti ficus. Nam et lactis plurimum remittit, et corticen robustum labet. Optime itaque ea inseritur tali ratione. Ex qua arbore inserere voles, in ea quacrito novellos et nitidos ramos. In lis deiude observato gemnam. quæ bene apparebit, cer- met le plus sûrement de germer, une marque de deux doigts en earré, de facon que le bouton étant au centre de ce carré, on coupe l'éeorce tout autour avec une lame bien affilée, et on l'enlève avec soin de dessus l'arbre, en prenant garde de l'endommager lui-même. On chnisit également une branche très-lisse de l'autre arbre que l'on doit enter en écusson, on enlève de cette branehe la même partie de l'écorce que pour la première branche; après quoi on applique sur cette partic dépouillée l'écusson qu'on avait préparé, de faeon qu'il s'y adapte parfaitement. Cela fait, liez bien le tout autour du bourgeon, en prenant bien garde de le blesser. Enduisez ensuite d'un lut les joints et les ligatures, en vous arrêtant un peu avant le bourgeon, pour lui laisser la liberté de germer. Rognez les rejetons de l'arbre greffé, ainsi que ses branches supérieures, afin qu'il n'y reste rien qui puisse en détourner la séve au détriment de la greffe. Au bout de vingt et un jours, déliez avec l'écusson. On greffe de cette méme facon l'olivier avec succès. Nous avons déjà montré la quatrième faẹon de greffer, lorsque nous avons traité des vignes; il est donc inutile de répéter le procédé que nous avons indiqué alors, et qui eonsiste dans l'emploi de la vrille gauloise.

XXVIl. Les anciens ont prétendu qu'on ne pouvait pas enter toute sorte de scions sur toute sorte d'arbres; ils ont même regardé comme une loi invariable ce que nous avons dit nous-même de limpossibilité de faire réussir d'autres greffes que celles qui sont prises d'un arbie semblable par l'ćcorce et le fruit, à l'arbre à greffer. $\mathrm{Or}$, comme nous avons cru devoir détruire cette opinion erronée, nous allons donner à la postérité un

tamque spem germinis liabebit : eam duobus digitis qua. dratis circumsignato, ut medio gemma sit, et ita acuto scalpello circuncidito, delibratoque diligenter, ne gemman laedas. Deinde in qua arbore inserere voles, in ea uitidissimum ramum eligito, et ejusdem spatii corticem circumeidito, et materiam delibrato, et in ean partem, quan nudaveras, gemman lanc, quam ex altera arbore sumpseras, aptato ita, ut enplastrum circumcisæ parti conveniat. Ubi lıee feceris, circa gemmam bene vincito, ita ne ladas : deinde commissuras et viricula luto oblinito, spatio relicto, qua gemma libere germinet. Materin, quain inseveris, si sobolen vel supra ramum labelit, omuia praecidito, ne quid sit quo possit succus avocari, aut cui nuagis quam insito serviat. Post unum et vigesi. mum diem solvito emplastrum. Hoc genere optime efian olea inseritur. Quartum illud genus insitionis jam docuimus, cum de vitibus disputavinus : ifaque superracuum est lioc loco repetere jam traclitam rationem terebra. tionis.

XXVII. Sed cum antiqui negaverint posse omne genus surculorum in omnem arborem inserl, et illam quasi finitionem, qua nos paulo ante usi sumus, veluti quandam legem sanxerint, cos tantum surculos posse coalescere, qui siut cortice ac libro et fructu consimiles is arboribus, 
moyen d'enter telle espèce de greffe que lon voudra sur quelque arbre que ce soit. iit pour ne point fatiguer le lecteur par un long exorde, nous donneronsun exempleunique, àl'imitation duquel on pourra essayer de toutes sortes de greffes. Creusez d'abord une fosse de quatre pieds en tout sens autour d'un olivier, de telle sorte que les branches les plus allongées de cet arbre $\mathrm{y}$ puissent atteindre. Plantez dans cette fosse un petit figuier vigoureux et lisse. Trois ou einq ans après, lorsque ce figuier aura pris assez d'aceroissement, abaissez la branche d'olivier qui paraitra la plus lisse, et attachez-la au pied du figuier. Coupezen toutes les petites branches, et ne lalssez que les cimes que vous voudrez employer comme greffes. Coupez ensuite le figuier, et après avoir uni la plaie, fendez le trone par le milieu avec un coin. Ratissez des deux côtés les elmes de l'olivier, sans les détacher de la mère; insérez-les dans la fente du fignier, retirez le coln, et liez res eimes avee soin, de sorte que le plus grand effort ne les puisse arracher. Au moyen de ee procédé, le figuier se fortifiera avec l'olivier en trois ans, et ee ne sera que la quatrième annéc, lorsqu'ils seront bien mariés ensemble, que l'on séparera les branches de l'olivler de la mere, de la même manière que les provins. On peut enter de cette facon telle greffe que l'on voudra sur quelque arbre que ce soit.

XXVIII. Multipllez autant que possible le cytise, que les Grees appellent tantôt $\zeta^{\prime} x$, tantôt

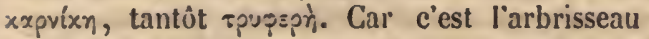
qui convient le plus aux poules, aux abeilles et aux chères, ainsi qu'aux bœufs et à toutes sortes de bestiaux, parce qu'il les engraisse en peu de temps, et (qu"il donne beaucoup de lait aux brebis. Ontre cela, on peut l'employer huit mois en fourrage vert, et les quatre autres mois en fourrage sec. Il prend très-promptement dans toutes sortes deterrains, quelque maigres qu'ils soient, et supporte sans inconvẻnient toutes les injures du temps. Si les femmes méme manquent delait, on feratremper dans de l'eau du ey tise sec; lorsqu'il y aura passé toute la nuit, on en exprimera le suc le lendemain, et on leuren donnera trois hẻmines à boire, en le coupant avec un peu de vin. Les femmes nc s'en trouveront que mieux, et leurs enfants se fortifieront par l'abondance du lait qu'elles seront en ètat de leur fournir. On plante le eytise en automne, vers les ides d'octobre, ou bien au printemps. Quand vous aurez bien labouré la terre, faites de petites planehes, sur lesquelles vous sèmerez en automne la graine du eytise, comme on sème la dragée; ensuite arrangez les jeunes plantes au printemps, de faeon qu'il y ait entre chacune quatre pieds dintervalle en tout sens. Si vous n'avez pas de graine, mettez en terre au printemps des cimes de eytise, auprès desquelles vous entasserez de la terie que vous aurez fumće. Si la pluie se fait trop attendre, arrosez-les les quinze premiers jours. Sarelez-les des qu'elles commeneeront à montrer les premières feuilles, et trois ans après coupez-les pour les donner aux bestiaux. II suffit de quinze livres de cytise pour le eheval, et de vingt livres pour le bouf. (nn endome aux autres bestiaux en proportion de leur force. On pent aussi le planter en bouture sur les lisières d'un champ. Si vous le donnez sec aux animaux, il faut faire les rations plus petites, parce qu'il a alors plus de force. II quibus inseruntur, existimavimus errorem lujus opinlonis discutiendum, tradendanque posteris rationem, qua pos. sit omne genus surculi omni generi arboris inseri. Quod ne longiori exordio legentes faligemus, unım quasi exemplum subjiciemus, qua similitudine quod quisquc genus volet omni arbori poterit inscrerc. Scrobem quoquoversus pedum quatnor ab arbore oliva tam longe fodito, ut ex. tremi rami olex possint ean contingere. In scrolsem deinde tici arbusculain deponito, diligentiaınque adlikseto, ut rolısta et nitida fiat. Post triennium aut quinquennium, cum jam satis amplun incrementum ceperit, ramum oliva qui videbitur nitidissimus, dellectc, ct ad crus arboris ficulıea religa : atque ita anputatis cxteris ranulis ea lantum cacumiua, qux insererc voles, relinquito : tım arborem fici detruncato, plagamquc levato, et mediam cuneo findito. Cacunina deinde oliva, sicnti matri inlınrent, itraque parte adradito, et ita fissura fici aptalo, cuneumque eximito, et diligenter colligato, uc qua vi revellantur. Sic interposito triennio coalescet ficus oliva : el tum demuın quarto anno, cum beue coierint, velut propagines, ramulos oliva a matre resecabis. Itoc modo omue genus in omnem arborem inseritur.

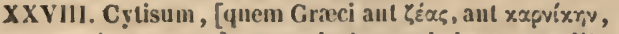

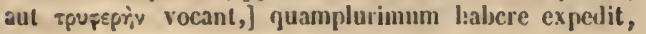

quod gallinis, apibus, ovibus, capris, bubus quoque, et omni gcueri pccudum utilissimus est, quod ex eo cito pinguescit, et lactis plurimum prachet ovibus : tum etiam quod octo mensibus viridi co pabulo uti, ct postea arido possis. Practerea in quolibct agro, quamvis macerrimo ccleriter comprcliendit, omıenquc injuriam sine noxa patiłur. Mulieres quidem, si lactis Inopia premuntur, cytisum aridum in aqua maccrari oportet : cum tota nocte permadıerit, postero die cxpressi succi ternas heminas permisceri modico rino, atque ita potandum dari : sic et ipsie valebunt, et pueri alındautia lactis confirmabuntur. Satio antem cytisi vel aulumno circa idus Octob. vel vere fieri potest. Cum terram bene subegcris, in modum horti areas facito, ibique velut ocimum semeu cytisi autumno serito : plantas deiuulc vere disponito, ut inter se quoquoversus quatuor pedun spatio distent. Si scmen non habueris, cacumina cytisorum vere disponito, stercoratam terraın circa aggerato. Si pluvia nou incesserit, rigato $X \mathrm{Y}$ proximis diebus. Simulac novam frondem agere cuperit, sarrito. Post trienuium deinde cadito, et pecori prabeto. Ejuo abunde est viridis ponto $\mathbf{x v}$, bovi pondo $\mathrm{xx}$. catte risque pecudibus pro portione viriun. Potest auten etian circa sepcm agri ramis seri. Aridum si dabis, exiguins dato, quoniam majores vircs lıabet, priusque aqua mace- 
faut même le fairc tremper d'abord dans de l'eau et le mêler a vee de la paille, après i'avoir retiré de l'eau. Quand vous voulez faire sécher du cytise, coupez-le vers le mois de septembre, lorsque sa graine commencera à grandir, et mettezlo au soleil pendant quelques heures, jusqu'à ce qu'il se fane; faites-le ensuite secher à l'ombre, et serrez-le.

XXIX. Plantez le saule et le genêt vers les calendes de mars, lorsque la lune est dans sa eroissance. Le saule demande un terrain humide; le genêt, au contraire, veut un sol see. L'un et l'autre se plantent utilement auprès de la vigne, paree qu'ils donnent des liens pour en attacher les branches. La meilleure faẹon de planter le roseau est par les raeines, que les uns appellent $o i$ gnons, et les autres yeux. Après avoil bêché le terrain, eoupez une partie de la racine avee une serpette fort aiguisée, et plantez-la par un temps de pluie. Il y a des personnes qui couchent le roseau tout entier en terre; il en pousse alors d'autres de tous ses nœuds. Mais le roseau planté

rato, et exemptum paleis permiscelo. Cytisum aridum cum facere voles, circa mensem Septembrem cum semen ejus grandescere incipiet, cadito; paucis deinde lıoris, dum flaccescat, in sole liabeto. Deinde in umbra adsiccato, et ita coudito.

XXIX. Salicem et genistam crescente luna vere circa ca. Iendas Martias serito. Salix lıumida loca desiderat, genista etiam sicca : utraque tamen circa vineam opportune sernn. tur, guoniam palmilibus idonea prabent viucula. Al'undo optinie seritur radicibus, quas alii bulbos, alii oculos vocant. Simulatque terram bipalio repastinaveris, radicen arundinis acuta falce prosectan inpendenti pluvia disponito. Sunt qui arundines integras steruant, quonian ex omni. bus nodis strata arundines emittat. Sed fere hoc genns evauidam exilemque et fıumilem arundinem affert. Melior ainsl est grêle, maigre et peu élevé. II vaut mieux suivre la méthode que nous avons exposée plus haut. Tous les ans, après avoir coupé les roseaux, remuez profondément et uniformément le terrain, et faites ensuite des irrigations.

XXX. Celui qui veut élever des violiers doit bien fumer la terre, puis la labourer au moins à un pied de profondeur, et distribuer ensuite le terrain par planches. Les jeunes plants de l'année devront être mis avant les calendes de mars dans de petites fosses d'un pied de profondeur. La graine du violier se sème comme eelle des choux sur des planches, à deux éporjues de l'année, au printemps et en automne. On la cultive de la même manière que les autres espèees de légumes; c'est-à-dire, on la bceche, on la sarcle, et quelquefois on l'arrose. Le rosier se met en graine et par bouture dans des fosses d'un pied, à la même époque que le violier. Il faut le labourer et le tailler avant les calendes de mars. Cultivé ainsi, il dure plusieurs années.

itaque satio est ea, quam prius demonstravimus. Placet autem omnibus annis, simulac arundinem cecideris, locum alte et xqualiter fodere, atque ita rigare.

XXX. Violam qui facturus est, terram stercoratam et repastinatam ne minus alte pedem in pulvinos redigat. Atque ita plantas lornotinas scrobiculis pedalibus factis ante calendas Martias dispositas habeat. Semen antem viola sicut olerum in areis dnobus temporibus seritur, vere vel autumno. Colitur autem eo modo, quo et catera olera, ut runcetır, ut sarriatır, ut interdum etiam rigetur. Rosam fructiluus ac surculis disponi per sulcos pedales convenit per idem tempus, quo et viola. Sed omnibus annis fodiri ante calend. Martias et interputari oportet. Hoc morlo culta inultis aunis perennat. 


\section{NOTES SUR COLUMELLE.}

\section{LIVRE I.}

1II , 1. Porcius quidem Cato censebat in emendo.... Toul ce que Columelle attribue ici à Caton ne se trouve pas daus cet auteur, mais dans Varron; quelques interprètes ent ont conclu que Columelle s'était trompé lorsqu'il a cité l'un de ces auteurs pour l'autre. Mais il est plus naturel de regarder ce passage comme une paraplirase de ce que dit Caton au commencement du premier cliapitre de son Économis rurale.

2. Nisi si Aütolycus ille cuiquam.... Cet homme que Columelle, d'accord arec Homère, peint conme un vo. leur insigive, était fils de Mercure ou de Dencalion, et grand-pere naternel d'Ulysse.

3. Aut Aventini montis incola Palatinis ullum gaudium finilimis sitis Cacus attulit. Cacus était fils de Vulcain; il vomissait du feu, et fiit tué par Hercule, dont il avait volé les bocufs. Servius, en expliquant le passage de l'Énéide oü il est pảrlé d Cacus, dit que c'ctait un esclave d'Évandre, très-méchant et trèsGripon; on l'avait même appelé Cacus à cause de cela, ;u mot grec $x$ axòv qui signifie mal.

4. Suaque lege C. Licinius. Columelle vent parler de C. Licinius Stolo, qui fut tribun en mème tenins que L. Sextius, et qui le premier fit décréter la loi agraire, d'après laquelle jersonne ne devait posséder plus de 500 jugera de terrain. Plus tard il fut lui-meeme condamné pour en avoir possédé mille, au mépris de sa loi.

VII, 1. Veterem consularem virumque opulentissimum L. Volusium.... C'est L. Volusius Saturninus, qui mourut à l'age de 90 ans (Pline, I, 38 ) passés, après a voir survécu à tous les sénateurs dont il avait pris les voix pen. dant son consulat.

IX , 1. Mediastinus qualiscunque status.... A la ville, on donnait le nom de mediastini aux esclaves qui étaient soumis à d'autres.

\section{LIVRE II.}

II, 1. Alternisque versibus obliqu um tencre aratrum. Pour comprendre ce passage, que tous les commentateurs ont mal expliqué, il est nécessaire de bien se reudro comple du mécanisme de la cliarrue ancienne. La charrue employée par les Roınains n’était nas faite de manière à retourner toujours la terre à droite, comine les uolres, aı tnoven du versoir; elle ne faisait que la remuer, lorsqu'on la tenait droile sans la pencher ni d'un cóté ni de l'autre. pour former un sillon bien ouvert, il fallait tenir la charrue olsliquement; le costé du soc contre le clıamp étai élevé, et, par l'effet de cette position oblique du soc et du buris, la terre était retournée d'un cóté. Avec cette char. rue ( hous dit Dickson, Traite de l'agriculture des anciens, 1, 402) de quelque manière qu'on la tiut, au lieu de faire le tour de la pièce en labourant, comme le fout nos laboureurs, le Romain revenait dans le meme sens, et, eń inclinant sa cliarrue alternativement à droite et à gauche, il tournait toujours la terre dı méue cóté. Mais pour rom. pre une terre nouvelle, ou pour donner le premier labour à une jaclière, Columelle conseille de tenir la charrue dans une position tantot oblique, tantot droite.

IV, 1. Quam terram rustici dariam cariosamque appellant. L'explication que nous donne Pline (XVII, 5) de ces deux mots, est plutot uine critique savantè di mot cariosus, qu'une explication claire et simple de la jensíe de Caton et de Columelle. Il est évident que notre auteur n'entend pas par cariosus une terre naturellement stérile, mais un sol qui n'est improductif que par l'effet d'une mauvaise culture.

2. In liram satum redigitur, quadrante opera. La graine était, comme on le dit vulgairement, semée sous le sillon, c'est-à-dire semée d'abord, et ensuite enterrée avec la charrue. Mais dans l'agriculture romaine, elle était non-seulement enterrée par un labour, mais recouverte de manière à levèr en rangs ou sillons, afin de faciliter l'opération du houage.

IX. 1. Proximus est his frument is usus ordei, quod rustici hexastichum, quidam etian caitherinum ap. pellant. Cantherinum est dérivè de canterinis, qui veut dire cheval hongre. Bien qu'il nous soit impossible de faire connaitre d'une manière cértaine le nom des productions qui servaient à la vle commune chez les Romains, il y a lieu de croire que le lordeum hexastichimi indique plutot du seigle que de l'orge. En effet, toutes les qualités que Colu. melle attribue à ce grain sont les qualités propres à notre seigle. C'est le seigle qui tient le premier rang après le blé par sa bonté; sa tige est faible, et son grain n'est couvert que par l'extrémité d'en bas; il mưrit plus tôt que le blé, et on le moissonne plus tot, de peur que le grain ne vienne à tomber; on n'a point de peine à le battre dans l'aire", et il maigrit les terres daus lesquellès il est semé. Or, nous le répétons, nous n'avons point dé grains à qui toutes ces qualités conviennent mieux qu'丸 notre seigle.

$\mathrm{X}, 1$. Paulatim ex eo ventilabris per longius spa. tium jactetur..... La manière d'operer avec lo ven. tilabrum montre que c'était une pelle; le vallus, qui est l'autre instrument nommé par Varron, śtait probablement d'une forme différente, mais destiné au même usage, c'est-d̀.dire à jeter des grains, ou telle autre chose du meme genre, d'un lieu dans un autre.

2. Quae septimontialis satio dicitur... Septimon. tialis, de septimontium, qui était une fête que l'on célébrait a Rome au mois de décembre, un peu avant les Saturnales, c'est-d̀-dire, avant la ini-décembre, en mémoire du jour où l'on a vait renfermé dans la ville la septième des collines dont elle était composée.

XIV, 1. Ac si repastines, totum, etc. Repastinare signifie littéralement retourner la terre au pastinum. Le pastinum était un instrument de culture à deux dents fort rapprochíes l'une de l'autre, qui servait non-seule. ment à retourner la terre, mais à saisir les crocettes pour les y enfoncer.

XXI, 1. Sed cum tam otii quam negotil rationem red. dere majores nostri censuerint. Cicéron, dans l'oraison pour Plancius (clıpitre 21), citéavec éloge cette maxime, 
en l'attribuant a Caton, qui l'avait inscrite au commencement de son livre des Origines.

2. Feris tantum dcnicalibus mulos jungere non licere, cateris liccre. Ces fetes 66 célébraient dans l'in. térieur des familles, lorsqu'on avait à regretter la nort d'uu parent. On croit qu’elles avaient été appelées ainsi par. ce qu'elles duraient dix jours. Ne pourrait-on pas attribuer a in reste de superstition à cet égard la défense que fait Justinien d'inquiéter les:' héritiers pendant les neuf premicrs jours de leur deuil?

\section{LIVRE III.}

II, 1... Quarum vocabulo propter hanc populationem cognominanlur. Ces raisius étaient appeléc apiance ab apibus, des abeilles, conme nous disons muscat, a mus. cts, des mouches.

$\mathrm{X}, 1$ Itaque custodiemus, ut ex prediclis locls, quos humeros rustici vocant... d'humerus, épanle. Ressemblance tirée du corps de l'homnte, auquel notre au. teur compare souvent la vigne.

XI, 1. Quam diximus pullam vocitari. Ce mot pullus, employé par Caton, clıap. cu de son Économie rurale, et par d'autt $\cong$ auteurs, peut à la vẻrité s'appliquer à une terre noiralre; mais il pourrait tres-blen s'entendre d'une terre douce et molle, quelle que soit d'ailleurs la couleur. En effet, Plinc, xvi, 5, oppose la terre qu'il appelle vieille, anus, ciı égard à sa stérilité, à la terre tendre, qu'il appelle pulla : par conséquent il y a lien de croire que le nom de pulla ne lui vient pas tant à cause de sa conleur que de sa mollesse, et/de cet autre avantage que Varron appelle teneritudo (clap. xxxvı de $l ' \hat{E}$. conomie ruvale, liv. I), qualités qui lui donnent l'apparence de la jeunesse, et quil la distinguent decelle que Pline appelle anus.

XIII, 1. Nisi si stalim uligo palustris obvia, sicut in agro Ravcnnate. Ce sont ces caux marécageuses qui produisaient les brouillards fréquents, d'après Pliue, $x: v, 2$, et empeclıaient la plupart des vignes de croitre daus le territoire de Ravenne. C'est ce que Martial exprime assez lıeu. reusement dans une de ses épigrammes, en disant : qu'il aimerait mieux avoir à Ravenne une citerne qu'nue vigne, parce que l'eau s'en vendrait bien plus cher que le vin. Quoi qu'il en soit, on prétend que le vin n'y est pas mauvais anjourd'hui, soit qu'on ait dessécleé ces marais, soit que les habitants se soient appliqués avec plus de soin à la culture de leurs vignes.

2. Ad destinatam pastinationis altitudincm : scd protinus, elc. On voit par la que le pastinum était un instrument qn'on jetail devant soi pour fouiller la terre; car ceux qui fouillent avec une becle sur laynelle ils appuient le pied, poussent devant eux la terre à inesure qu’ils la remuent, et ne la jetteut poiut derriere eux, puisquu'ils vont enx-memes à reculons.

$\mathrm{XXI}$, 1. Haic pares iis helvola respondeant. Les grappes hetrole sont celles dont la couleur est entre rouge et blanc.

\section{LIVRE IV.}

II. Quia cratem factura sit. C'est-â-dire qu'avaut de mouter perpendiculairement, comme fait le suc nutritif, dans les plantes, il commencerait par décrire une ligne transversale et parallele a l'horizon, de sorte que ces deux directions formeraient une espèce de claie, ce qui arrive aussi dans les vignes coucliées par terre.
VII, 1. Et velut reseces rclinquendi sunt, qui caleris, ctc... En effet', cette espèce de courson que Columelle appelle unguis, (un ergot), nesaurait etre coujé sans dominage pour la vigne. Plus tard, on le retranclie conme les autres sarments, Jorsqu'il est devenu sec et inutile.

\section{LIVRE V.}

I. At Galli candetum appellant in areis urbanis spatium centum pedum, in agrestibus aulem pedum cL. (quod aratorcs candetum nominant) semijugeruin quoque arepenkem vocant. Scleneider regarde les mols reulermés cntre parcuthèses comme ayant étê In. tercallés; c'est aussi notre senliment. En effet le sujet de la plurase scmijugerum quoque arepennem vocant ne pent point être ara tores en général, mais Galli (Gaulois) de la phrase précédenle, puisque arepennis cst évidemment un mot d'origine gauloise, qui s'est conservé jusqu'à nos jours (arpent, arepennis). Lancienne traduction française (Les 12 livrès de Columella, des clioses rustiqnes, traduits de latin en français par feu maistre Claude Co. tereau, chanoine de Paris (1553) est plus explicitea a cet égard. Voici comment le traducteur a rendu ce passage : Les Gaulois appellent candetum un espace de 120 pieds ès villcs, et es champs de 150 davantage; $i$ ls appellent un demi jugcrum arpent (arepenis), comme si $\mathrm{Lar}$. pent romain en tcriait deux des Gaules. Il en résulte clairement que l'arepcnnis ou arpent était dans l'ori. gine un seni-jugerum, et que ce sont les Gaulois at non les cultivateurs romaius qui se servaient de cette expression. Quant au mot candetum, c'est probablement le memo que cantroed, usité encore anjourd'luui en Bretagne ponr signifier une étendue qui embrasse cent métairies.

V,1. Quoniam plcrumquc dicti sideris tcmpore qure. dam partes ejus regionis sic infestantur Euro, quem incole Vulturnum appellant. Les Apuliens appelaient Volturnus le vent qui soufllait du fleuve Volturnus, ainsi que le dit Florus, liv. 11, 6. Dunker, dans ses Commen. taires de Florus pense que les cultivateurs de la pro. vince Bétique avaient voulu désigner ce même vent par Vulturnus.

2. Quod nostri agricolce mergos, Galli candosocco: vocant. Il est assez curieux de rechercher l'origine du mot gaulois candosocci. Il est évident qu'il se compose de deux racines fort distinctes. La première, cand, qni rappelle à notre esprit celle de candetus dont nous avons parlé plus lıaut, signifie, d'après Astruc (Mémoires de l'Histoire naturelle dc Languedoc), un provin, tandıs qu'on se sert dans ce pays du mot soccus pour désigner la tête ou le trone de la vigne. En effet, ce dernier mot s'est conservé jusqu'à nos jours, puisque nons le retronvons dans te mot sonclie. Gessner cite à l'appui de colte étyıno. logie Cangii Glossarium.

VI, I. Ulmorum duo esse genera convenit, gallicum et vcrnaculum : illud Altinia, hoc nostras dicitır. Pline parle également de ces deux espèces d'ormes, mais il ne donne point de nom particulier à l'orme de la Gaule, et il attribue à l'I talie l'espèce qui, d'aprés Columelle, est d'origine gauloise.

2. Populus quia raram neque idoneam frondem pecori probet.... Gessner, et avec lui Saboureux, lisent omulus (l'aubier) an lieu de populus. Mais la description que Columelle nous donne de cet arbre s'applique bien plus à populus qu'à opulus; et.Schneider, s'appuyant sur le passage de Pline, xvu, 32, dénontre clairement quı la véritable leçon est populus.

X, 1. Serende sunt precipue Liviance...., sulce, ... 
callistrulhia. Les figuiers de Livie étaient ainsí appelés ( d'après Pline, $\mathbf{x v}, 18$ ) du nom de la femune d'Auguste, qui les aimait beaucoup : Dion, livre Lvı, prêtend qu'elle avait empoisonué son mari avec cette espèce de figue. Quant aux mots siclca, etc., on ne les trouve dans aucun auteur, et beaucoup de commentaires les regar. dent counme altérés. Ce qu'il y a de constant, c'est qu'il y a des figures très.célèbres, telles que celles de chio et les figues folles, dont Columelle ne parle point ici, quoiqu'ıl juge d propos d'en faire mention ailleurs. Ne seraient-ce point ces dernieres qu'il fandrait substituer aux autres, dont il n'est point question dans le livre $x$ ? Quant aux

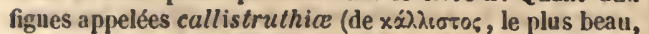
et otpouos moineau )', c'étaient probablement celles yue les moineaux mangeaient de préférence aux autres.

2. Ternas nuces in trigonum statuilo, etc.... Pour comprendre quelle sera dans un triangle rectangle celle de ces trois amandes qui formera le sommet du triangle, il faut supposer que l'une de ces amandes est posée sur une ligne perpendiculaire, et que la tête des deux autres est un peu inclinée vers sa pointe.

3. Ea sunt crustumina, regia, signina, tarentiua, elc..... Pline $(x v, 15)$ dit que quelques personnes les appe. laient testacea à cause de leur couleur de terre cuite; en ce cas, le nom de signina ne leur viendrait point de ce qu'elles croissaient sur le territoire de cetle ville, mais de ce qu'elles ressembleraient aux ourrages qui s'y faisaient. Les poires superbo (orgueilleuses) sont, d'après Pline (15, 15), celles qui viennent les premiẻres. Suivant lui, on appelait or deacece (d'orge) les poires qu'on cueillait au temps ou l'on récoltait l'orge. Il est probable que les poires de Turannius doivent leur nom a Niger Turannius, que Var. ron cite dans la préface du livre 1 de son Économie vurale comme un homme qui se livrait avec succes aux travaux agricoles.

4. Siliquam gracam, quam quidam xะpátıov vo-

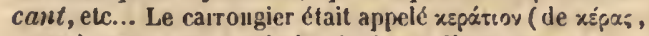
corne ), parce que son fruit a la ligure d'une corme.

\section{LIVRE VI.}

JX. Ex oleo et garo salivati more demilli. Le garum étail une sauce très-vantée clıez les anciens, qui se servaient pour la composer des intestins d'un poisson appele garus. On unettait ces intestins dans un vase, et onl les salait ; puís on les exposait pendant lougtemps au soleil, en ayant soin de les remuer souvent. Lorsque la clıaleur du soleil les avait bien macérés, on couvrait le vase avec une passoire à travers laquuelle s’écoulait le garım, de sorte qu'il ne resłait plus au fond que la matière appelée alex. On fit ensuite legarum avec les maquereaıx; et Pline dit, xxxı, 8, qu'il n'y avait pas de liqueur d'un plus lıaut prix que cellelà, à l'exception des parfums liquides.

XIV. Qua vocatur avia... Ise mot d'avia varie beancoup dans toutes les éditions, et nul autre auteur que Colu. umelle ne l'a employé; aussi personne n'a-t.il encore pu déterniner ce que c'était que cette berbe. Certains commentateurs ont cru que c'était de la fougère, et qu'elle était ainsi appelée $a b$ avibus, parce que les fenilles res. semblaient à l'aile des oiseaux. lin effet, c'est par cette raison que les Grecs donnaient à la fongère le nom de

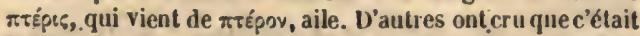
le seneçon, appelé par les Latins senecio (de senesco, vieillir); de sorte que la racine dn mot avia serait avus (grand-père), parce que les aigreltes de la semence de cette plante représenteraient la tête d'un vieillard.

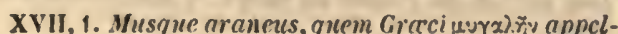

lant. Muү $x \lambda \dot{n}$, de $\mu \tilde{s}_{5}$, rat, et de $\gamma \alpha \lambda \bar{n}$, belette ou fouine, conne étant engendrée par ces animaux.

2. Sal hispanus vel ammoniacus. Le sel ammoniac

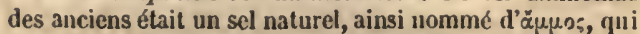
vent dire sable, parce qu'on le trouvait sur le sable. On le tirait principalement d'Arménis, ce qui lui avait fait donner le nom d'armeniacum.

3. Facil idem trita sepia tesla. Sepia est un poisson de mer, dont le dos est garni d'une espèce d'écaille con. nue dáns la médecine sous le nom d'os de séclie.

XXVII. Unde etiam veneno inditum est nomen

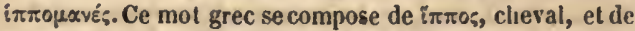
rxivopxi, etre enragé, fou. Les anciens auteurs, qui pré. tendaient que l'hippomane excitait \& l'amour, parlent tous d'une manière différente. Pline (xxvi1, 11) dit que c'est une liyueur rendue par la carale, dont la vertu est si grande que si elle se tıonve avoir été mêlée dans de l'airain mis en fision pour faire une statue cie cavale, les mâles qui s'approclieront de cette statue auront la rage du coit. Le mème auteur (vill, 42) dit que c'est une caroncule noire qui se troure sur le front du poulain au moment de sa naissance, et que la cavalle dévore aussitót qu'il est né; sans quuoi elle ne se laisserait pas téter par lui.

\section{LIVRE VII.}

I. Sape enim, ut celeberrimus poeta memorat etc. Columelle veut parier de Virgile; le passage qu'il cite se trouve dans le premier livre des Géorgiques.

II. Ex quo Nomadum Getarumque plurimi $\chi \alpha \lambda_{\alpha \times \tau o-}$

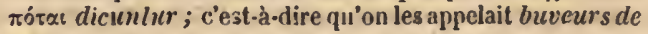
lait.

Sed etiam in tola ruris disciplina Virgilius procipit. Le passage cité par Columelle se trouve au second lirre des Gérgiques.

X. Cui succuritur, si fabricentur canales ex tamaricis e trunco. Pline, xsiv, 9 , va plus loin encore; it prétend qu'on faisait manger et boire les animaux, et même les loonmes, qui avaient mal à la rate, dans des vases faits de tamaris. Le remede recommandé par Columelle et Pline ressemlile assez au pain trempé dans du vin, ordonné par lé médecin de Molière pour faire parler les muets.

\section{LIVRE VIII.}

V. Glocientibus : sic enim appellant rustici... Le mot de glocientes, employé, comme dit Columelle, par les paysans romains, a sans doute donné lien au mot glos. ser ou glousser, que nous employons dans le même sens.

XIV. Fruticibus aut solidioribus herbis obluctatur ita pertinaciter, ut collum abrumpat. Tout surprenant que nous paraisse ce fait, il semble qu'on u'en puisse douter, dı moins en ce qui concerne l'Jtalie, puisqu'il est confirmé par Varron, livre un, clıap. $x$, et par Pline, $\mathrm{x}, 59$.

XVI. Et Ciminius lıpos auratasque procreaverunt.

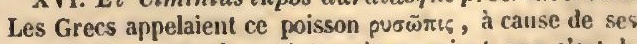
sourcils dorés. Quelques interprètes croient que c'est le poisson connu sous le nom de dorade; mais d'autres pré. tendent qu'il n'a rien de commun avec ta dorade, et qu'il est inconnu sur les cótes de France.

2. Saxatiles dicti sunt. Toutes les espices d'hultres sout comprises sous ce nom. 
3. Ralani; ce nom leur vient sans doute de leur ressrmblance arec le gland de clıcne, qu'on nommait en giec $\beta \dot{\lambda} \lambda \alpha$ vos.

6. Ul mernla turdiquc. Les turdi s'appellent aujourdhui encore torlo en Italie; nous connaissons ce polsson sous le nom de violle.

5. Nec minus melanuri. Ce mot provieut évidemment de $\mu^{\prime} x_{x}$, noir, et de oǔpo, queue, parce que le poisson conuin sisus ce nom a la queue noire : quelques interpretes veulent que ce soit la perchc de $m c r$.

6. Eumque prisca consueludine zeum appellamus. Pline, $1 x, 18$, et $x x x u, 11$, Jui donne les deux noms; on prétend que c'est le poisson que nous appelons la dorée, a cause de la couleur dorée de sa queue; et que les Marseillais appellent truic, parce qu'il grogue comme un pourceau quand on le prend.

XVI1. Vel quidquid intestini pclamis. Pline, 1x , 15, nous apprend que le pelamis est le thon lui-meme, qui, naissant en été, s'appelle cordyla jusqu'au printemps qui suit sa naissance; après quoi il s'appelle pelamis jusqu'à la fin de l'annce, du mot $\pi \eta \lambda \dot{b}$, qui veut dire bourbe, parce qu'il se caclie dans la bourbe; de sorte qu'il ne prend le uoin de thon que l'annce suivante.

\section{LIVRE IX.}

V. Siculi cancri nidon, cum cst ignibus adıslus. On était dans l'usage de faire cuire des écrevisses nollseulement pour la table (inconvénient auquel Columelle ne parait pas faire allusion dans ce passage), mais pour plusieurs remèdes usités en mélecine (Pline 32), et notanment pour préserver les arbres de la brualure et de la bruine (Pline, xvur, 29).

VII. Ncc obscanum scarabci vel papllionis gcnus. Cette espece particulière de papillons nuit anx ruclıes de plusieurs manières, comme nous l'apprend Pline, II, 19, soit elı mangeant la cire, soit en laissant dans les ruclies des excréments qui engendreut des teignes, soit en couviant dı duvet de ses ailes les toiles d'araignées qu'elle rencontre sur son passage.

vill. Atque, ut ille vatcs ait. Colnmelle parle de Virgile; le passage qu'il cite se tronve au livre 11 des Géorgiques.

1X. Nam ut idem ait. Le passage cité par Columelle est encore tiré du livre iv des Géorgiques.

XIII. IIyginus quidcm in co libro quem de apibus scripsil Aristomachus, inquil. Cetauteur, natif deStolas, avait une si grande passion pour les abeilles, qu'il passa la plus grande partie de sa vie a' s'occuper de ces insectes. I'liue, Iv, 9.

XV. Talis olla, cum esl alvcari objecta, spirits aclmolo fumus ad apcs promovetur. Puisque les abeilles en sentant la fumée se relireront sur le devant de la ruclie, et que suurent meme elles en sortiront tout à fait, il faut sinposer qu'on aura soulevé la ruclie pour faire la fumcie. par-lessous, afin que les abeilles en fuyant remontent au Lıaut de la ruche; autrement elles se jetteraient dans la fumée, et tomberaient dans le péril qu'elles veulent Éviter.

\section{LIVRE X.}

Vers 4. Et te magna Pales. C'était la déesse des patres et des paturages, que d'autres appellent Vcsta, et l'autres la Mère des dieux. On prélend que le nom de Pales lui renait du mot parere, qui vout dire engen- drer, comme si de parerc on ent fait l'alcs. Ce qu'il y a de certiin, c’est quie la fête qui se rélébrait le jour de tit foudation de Rome sappelait indifféremment Parilia et Pulilia.

v. 4. Nec non calestia mclla. Culumelle dit que le miel est émané dı ciel, soit pour se coniormer à l'opinion des ancieus, qui croyaient qu'il était formé jar la rosée soit à cause de l'origine qu'ils attribuaient aux abeilles.

v. 20. Mcestamquc ciculam. La ciguè est appeléo mosta, parce qu'à Atlıèues on condamnait les criminels à boire du jus de cette plante vénénense. Ce fut le geıre de mort auquel fut condamné Socrate.

v. 32. Nimen venerare Ithyphalli terribilis nem. bri. Columelle n'imite guère ici la chastetè de Virgile, qu'il s'est proposé pour inodèle. Il désigne sous ce nom le Priape que les ancieus mettaient à la garde de leurs jardins.

v. 54. Et adversos meluant Allantides ortus. Columelle, par cette crainte qu'il prête aux Pléiades (filles d'Atlas, et appelées de lá Atlantides), veut désigner le temps où elles se couclient.

v. 57. Tergoque Croti feslinat equino. C'est le Stgittaire; car on supposait que Crotus, fils d'Éuplième, nourrice des Muses, avait été, a leur sollicitation, mis par Jupiter au-nombre des astres après sa mort. On le peignait avec des fieclies et avec une cronpe de clieval, à cause de son amour pour la cliasse.

v. 120. Vimque stum idcirco profitelur nomine Graio. Pline prétend $(\mathrm{xx}, 17)$ que cette plante avait la vertu d'effacer les cicatrices et les autres taches de la pean, comme elle l'annonce par son nom de lcpidium, de $\lambda . \pi \zeta_{\zeta}$, écaille, ou de $\lambda \hat{\varepsilon} \pi \omega$, écorcer.

v. 173. El lacrymas initata tuas. Columelle entend, par cette myrrhe, la plante counue sous le nom de maceron, que les Latins appelaient smyrnitm (de ouvpva, (nyrrice, parce que l'odeur et le gont de la racine de cetto pliute approclient de ceux de la myrrie, (Pline, xix, 12 ), ou même parce que sa racine répand, lorsqu'on y fait une incision, une larme semblable aux larmes de la myrrlıe, suivant Columelle.

v. 175. Aeacii flores. Ce sont les jacintlıes. On prétend que lorsqute Ajax se fut tué, son sang fitt cliangé en cette flew. Ajax , le plus brave des Grecs aprìs Aclille, se donna la mort à cause de linjustice que comınirent à son çgard les juges, en adjugeant a Ulysse les armes d'Achille.

v, 19t. Premit ferali mensc Lupercus, c'est-à-dire au mois de février, temps auquel on célébrait les fêtes Lupercalia, instituées eu l'lonneur de Pan. Les prétres qui les célébraient s'appelaient Luperci : ils couraient uus par tonte la ville pendant la solennité de la fete, ct donnaient des coups de lanière de bouc dans la inain des fenunes grosses qu'ils rencontraient, pour leur procurer III Leureux accouchement. On faisait aussi des sacrifices eu l'ıonnenr des morts : ces cérémouies s'appelaient ie. valia, comme les fetes dont nous venons de parler, et le mois de février fcralis.

v. 25t. Nomine tum Graio ceu littcra proxima prime Pangitur. C'est une allusion d'ailleurs assez pen jiịuante an nom latin de la poirée, qui est bela, et à celui de la seconde lettre de l'alpliabet grec, qui est également $\beta \ddot{\gamma} \tau \alpha$.

v. 316. Et celebres Fortis Fortunce dicilc laudes. La Fors Forluna était une déesse différente dọ la Fortuna, dont la rête était célébrée par les gens de la basse classe qui n'avaient point de métier pour gij:rurr leur vie, et qui avaient un temple a Rome all dela du Tilore. 
v. 342. Hinc mala rubigo, etc. Les Romains avalent fait une d́cesse de la rouille (rubigo), afin de pré server les blés de cctle maladic, par le culte qu'ils lui rendaient.

v. 345. Tyrrhenus fixisse Tages in linile ruris. Cicéron raconte, livre 11 , de Divinal., qu'un paysan qui labourait son clıamp dans l'Étrurie vit sortir subitement, du milieu d'un sillon, un enfant qu'on nomma Tages, et qui l'instruisit dans l'art des aruspices.

v. 414. Et Caunis amula Chis. Cicéron, livre II de Divinat., dit à l'occasion de cette figue, que lorsque M. Crassus entbarquait son arméc à Brundusium ( lors de sa nallieureuse expedition contre les Parthes, Pliu., xv, 19), un urarcliand criail sur le port des figues de Caunus à ven. die. Comnne ce cri latin était Cauneas, il prétend ( aiısi que l'lin. ibid.) qque Crassus aurait du le regarder comme un mauvais présage qui lui défendait de partir, cave ne cas ! Le calcmbonrg était déjà conuu du temps de Cicéron.

\section{LIVRE XI.}

I. Nain illud verum est M. Calonis oraculum. Cet oracle attribué à Caton ne so trouve point dans son Éconoinie rưate. Il paratı néammoins qun'il s'y tronvait du temps de Columelle, ce qui prouve qu'elle ne nous est point parvenue en entier, comme nous l’avons déjà observé.

Quod ipsum expressius velustissimus auclor Hesiodus hoc versu significal. Le passage cilé par Colmmelle se trouve: "Epүwv, 11, 31.

Serere ne dubites, encore tiré de Caton, clıp. 11.

II. Num frigidis vel a quinquatribus prata recle submilluntur. C'étaient des fètes que l'on célélırait au unois de unars en l'lonneur de Pallas, à laquelle on avait délié un temple sur le mont Acentin à pareille éproxue. Ces fetes duraient cinq jours : le prentier jour on faisait des sacrifices; mendant les trois suivants ou donnait des combats de gladiateurs; et le cinquiène on purifiait les temples. Toutefois, ce n'est pas à cause du nombre des jours que ces fêtes étaient appelées quinquatria, nais parce qu'on les célébrail cinq jours après les ides, et que le lendemain des ides était un jour ater, c'est-à-dire un jour que les anciens regardaient conme mallıenreux. Quinqualria signifie douc littéralenıent quinque ab alro die.

Ita tamen ut ipsis calend. Januariis auspicandt causa omne genus operis instaurent. C'était l'usage chez les Romains de faire quelque close de sa profession ce jour-là, dans la vue de commencer lieureusement l'anuce

\section{LIVRE XII.}

VIII. Oxygalam sic facilo. I.e mot Oxygala-signifie proprement lait aigre (de ¿̇šs, aigre, et $\gamma \alpha \dot{\alpha}) \alpha$, lait). Cette espece de boisson est fort à la mode, à ce qu'on jrétend, dans la Turquie ; les Tures s'en servent peirlant hes grall. dés clıaleurs, en la délayaut avec de l'ean fruide, et en la prenaut avec dı paiı qu'ils émlettent.

XXIII. Pix corticala appellatur, qua ut untur etc. On donnail apparemment le nom de corlicala à cette espèce de poix, parce que, tout en étant glutineuse de sa nature, elle ne laissait pas d'être friable, et comme revêtue d'une écaille en forme d'écorce. Au reste, on ne trouve point ce mot appliqué à la poire par d'autres autenrs que par Columelle.

\section{DE ARBORIBUS}

III , 1. Senina novella cum vctere surmento deposita cilo comprchendun . Columelle fait sans doute allusion à ce passage du ch. I11, 17, ainsi conçu : "Les anciens laissaient au nouveau sarment uue partie du vieux lorsqu'il le plantaient en terre; mais l'ex jućrience a conda mué celte métıole, parce que tout ce qui restait de l'ancien Iwis pourrissait bientôt par l'effet de l'lumidité. »

Remarquons cependant qu'il était impossible de séparer entièrenreut le nouveau sarment du vieux bois, et qu'il en restait toujours une petile partie qui donnait au plant l'apparence d'un maillet; de là le nom de malleolus en latiu el de crosselle (de crosse) eu français.

2. Sapor aulem (siculi primo docuimus volumine.) Ce passage se trouve en effel au liv. II, 2. Colunelle dit primo volumine, parce que ces deux premiers livres n'en formaient qu'un dans le principe, lequel était suivi dı traité de Arboribus. Il parait que Colnmelle a cru devoir adopter plus tard une nouvelle division.

V. Sumnas parles quas aslivas etc. Il résulte du livre IV, 8, que ces summas parles ne sont que les $r a$ diculce, que Colunielle appelle également cestivo dans lo passage que nous renous de citer.

VI. Radicibus natantibus. Colımelle compare le terrain à une surface d'eau sur laquelle les racines ne feraient que natare. Il est à croire yu'il a voulu expriner la mêne idće dans ce passage du livre VI, 22, où il dit que les racines sont in summa labantcs.

X. Falce acula scmel aul bis eo loco alle instar digiti mucroferilo. Le mucroétait une des parties de la serjette ancienne, qui se contposait (d'après Columelle, IV, 25) dn culter (couteau), du scalprum (bistouri), du rostrum (bec), de la securis (haclie) et enfin du mucro (pointe). Le mucro, conme son nom l'indique, formait l'extréunitć de la serpe, et était penclıé sur le devant en fornu: de pointe (ejusque velut apex promus imminens mucro (Ippellatur).

XV. Quod ne fiat, falces quibus vineam putaveris, sanguine ursino linilo. Palladins nous recommanle pour le mêne usage le sevum ursinum. Pline, 17, 47 nous vante égalenent la vertı du sang de l'ours en nous disant qu'on u'aurait yu'à en frotter la serpette avaut la taillo pour empêcher les raisius d'etre mangés par les oiseaux. 


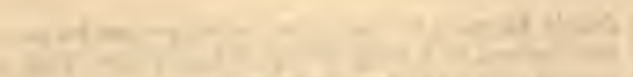
(n) $+$

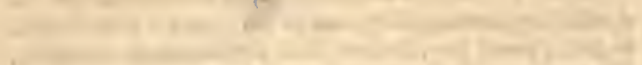

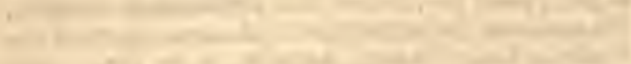

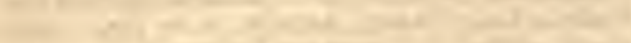

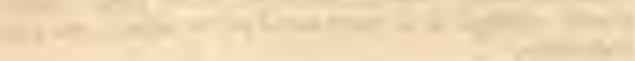

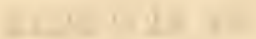

,

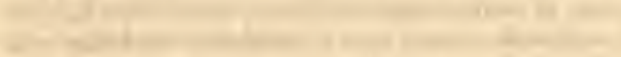

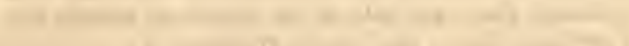

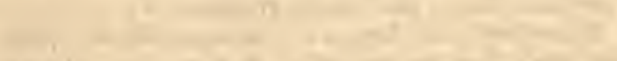

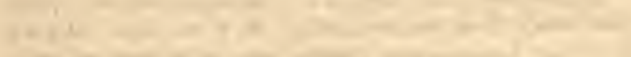

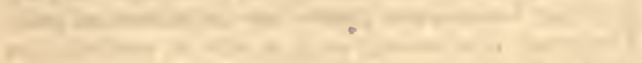

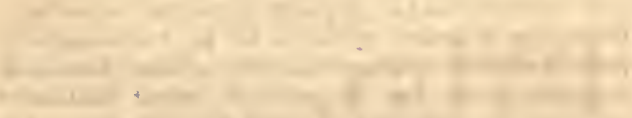

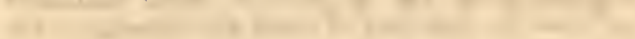

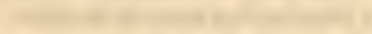

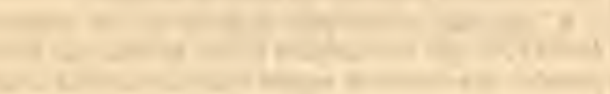

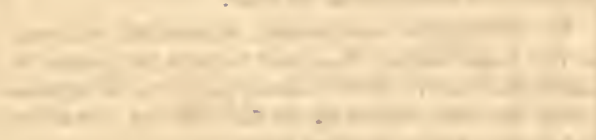

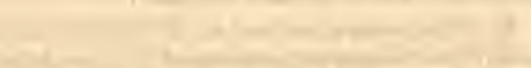

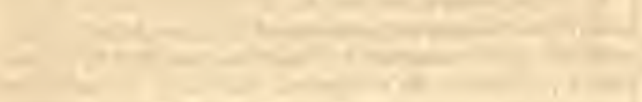

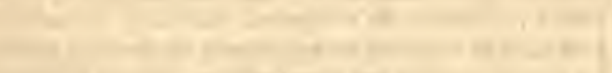
1

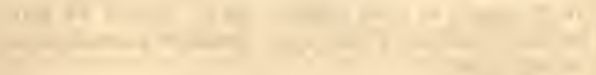

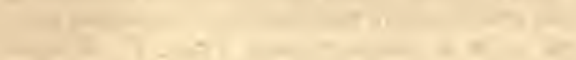

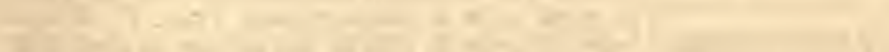

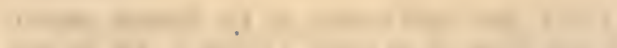
$\cdot$

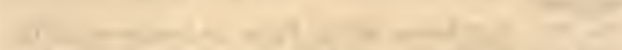

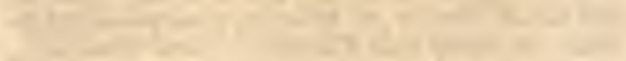

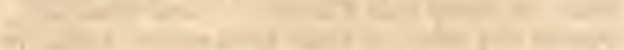

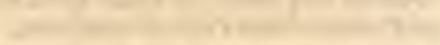
- I +

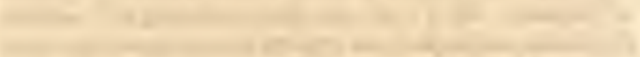
(20)

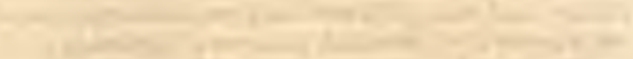
(20)

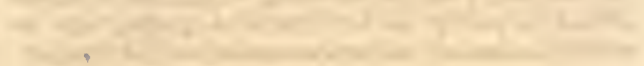
:-

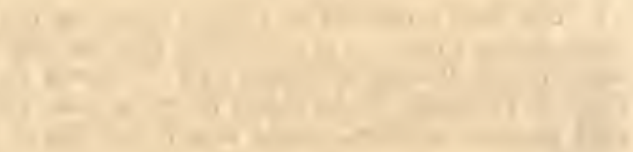

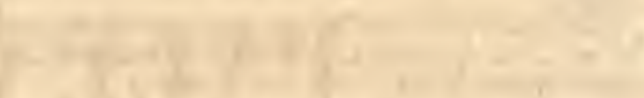

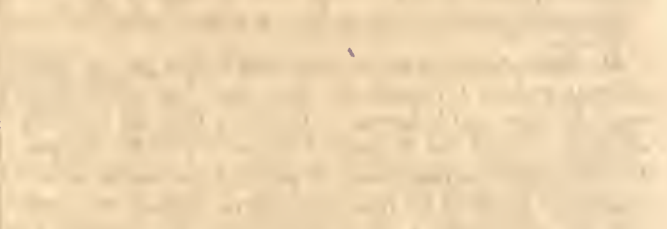

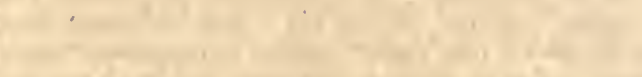

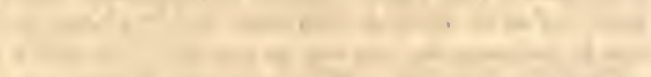

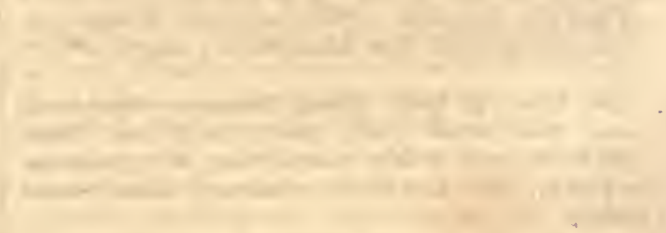

\section{$+416$}




\section{PALladiUs.}




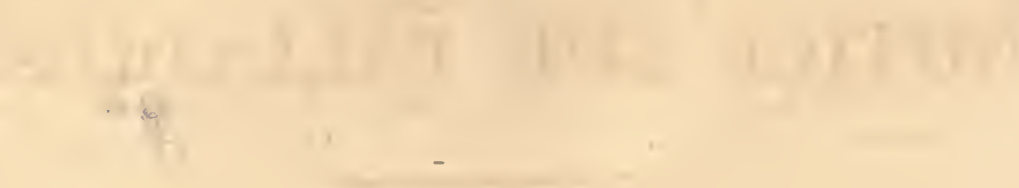

$1-$

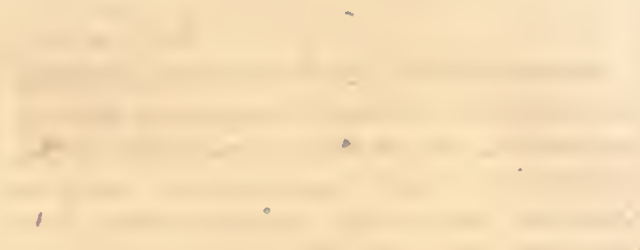

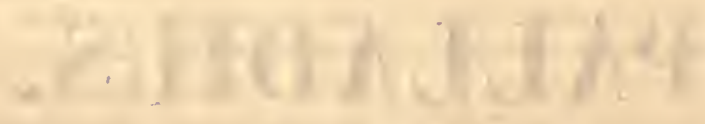

.

. 


\section{NOTICE SUR PALLADIUS.}

Palladius Rutilius Taurus Emilianus est le dernier parmi les écrivains latins qui ont traité de l'agrieulture. Son ouvrage, intitulé De re rustica, renferme des extraits d'anciens livres, surtout de Columelle, qui souvent ; est littéralenient copic. Cependant, Palladius traite d'une manière plus exacte que Columelle la partie des arbres fruitiers (à l'exception de l'olivier) et des jardins potagers, qu'il a extraite des ourrages de Gargilius Martialis. Ce qu'il dit sur la manière de conserver les fruits et le vin est tiré des Géoponiques grees, dont Palladius avait un exemplaire beaucoup plus conpiet que l'abrégé que nous en possédons

L'ourrage de Palladius est divisé en quatorze livres. Le premier renferme une introduetion géućrale; cliacur des douze suivants porte le nonı d'un des mois de l'année, et enseigue les travaux propres à clıaque saison: le quatorzic̀me livre est un poëme didactique en vers ćlégiaques sur la greffe des arbres. Le style de cet écrivain est incorrect et plein de néologismes. Les savants n'ont pu s'accorder sur le temps où Palladius a vécu; les uns le placent au comnencement du second siècle, les autres à la fin du quatrième. Quelques-uns croient le reconnaître dans ce parent dont lc poëte Rutilius parle dans son Itinéraire; d'autres ont observé que ce dernier était un jeune Gaulois envoyé par son père dans la capitale de l'empire, pour y étudier le droit, tandis que l'agronome avait des possessions en Italie et en Sardaigne; ils ont ajouté qu'on ne trouve pas le nom de ce Palladius parmi ceux des préfets et autres magistrats suprêmes de la prenière moitié du cinquième siècle, tandis que le titre de Vir illuster que porte notre agronone dans les manuscrits, indique qu'il a été revêtu de quelque laaute dignité.

Wernsdorf a tenté une autre voie pour trouver lc sièele de Palladius. Le quatorzic̀me livre de son ourrage étant dédié à un certain Pasiphilus, il s'agit de déeouvrir l'époque où a vécu celui-ci, qu'il appelle un lomme savant et dont il loue la fidélité. Ammien Mareellin, en parlant de la conspiration contre Valens, qui fut découverte en 371 , raeonte que le proeonsul Eutrope, qui était parmi les aecusés, fut sauvé par le courage du philosophe Pasiphilus, auquel les tortures ne purent arraelier une dénonciation. Ces circonstances répondent à l'éloge que fait Palladius de la fidélité de son ani; et si celui-ci est le même Pasiphilus qui, en 395, fut rector d'une provinee, comme on voit par une loi du code Tlıéodosien, on peut supposer que le quatorziènıe livre de Palladius, où il n'est pas fait al lusion à cette dignité, a été écrit entre les années 371 et 395. Il est vrai que parmi les magistrats do cette époque on ne trouve pas de Palladius, si ce n'est celui qui en 381 fut magister officiorum; mais celui-ci labitait Constantinople, et non l'Italie. A cette observation on peut répondre en di. sant qu'il ı'est pas bien sûr que le nom de famille de notre agronome fut Palladius; que Cassiodore et Isidore de Séville l'appellent Emilianus, et qu’il faudrait peut-être le chercher parmi les individus de ce noum, ou même parni les Taurus.

(Extrait de Scloëll, Histoire de la littérature romaine). 
*

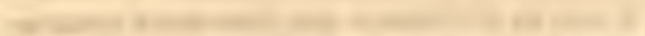

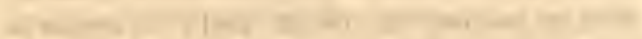

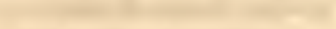
Cans n.

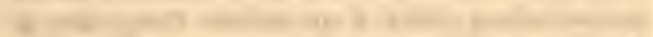

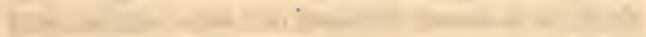

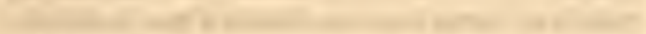

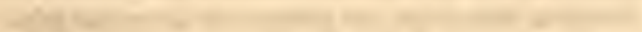

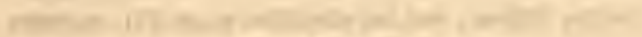

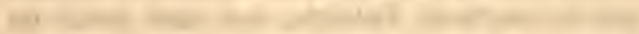

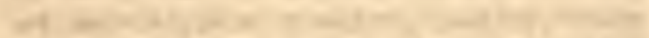
re 15.

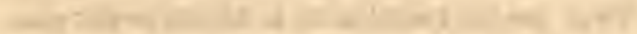

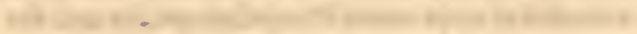

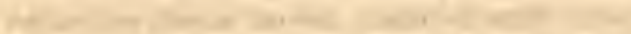

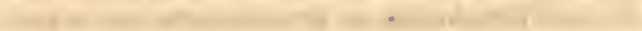
$+4=$.

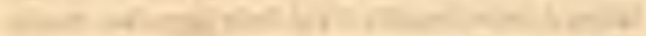

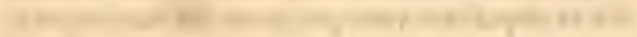

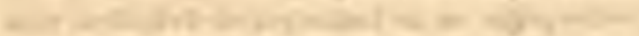

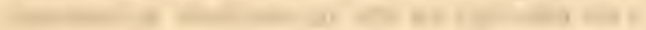

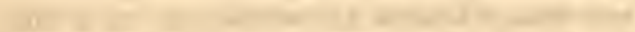

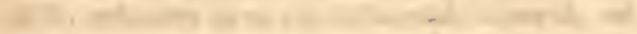

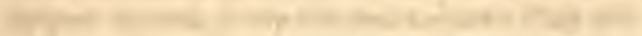

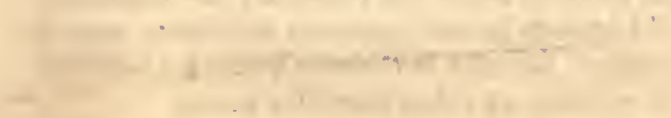

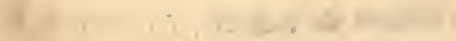

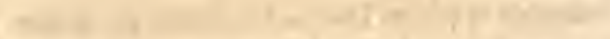

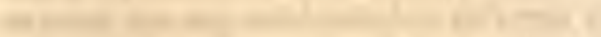

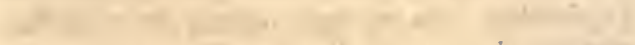

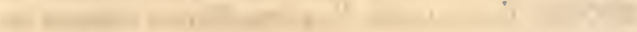

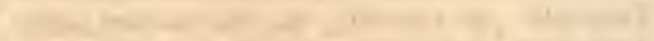

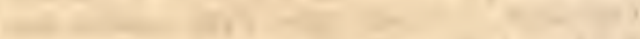
(2) 1

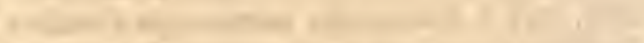
2. (x) (1) -

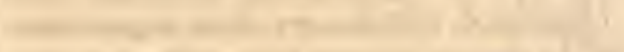

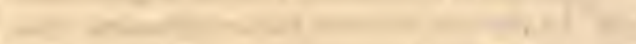

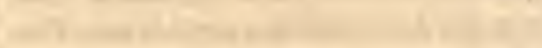

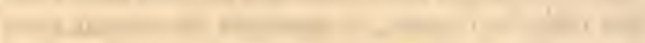
,

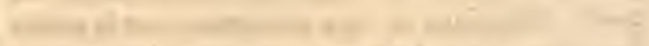

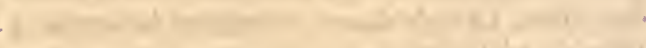

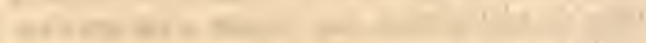

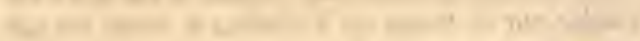

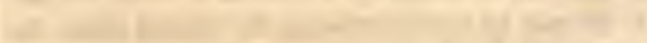

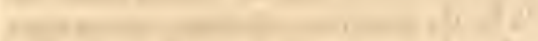

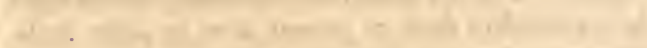

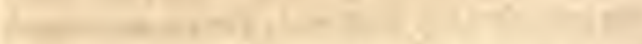

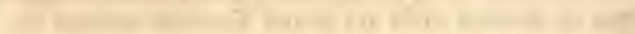

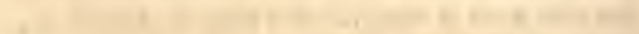

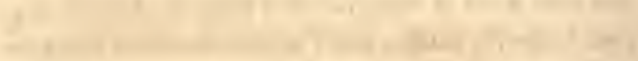

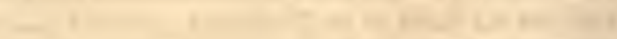

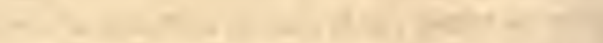

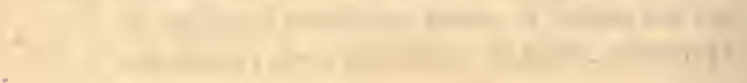

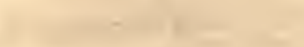




\section{R. T. EMILIANUS PALLADIUS.}

\section{DE L'AGRICULTURE.}

\section{LIVRE PREMIER.}

I. La première condition de tout enseignement est de bien songer à qui l'on s'adresse. Pour formel un cultivateur, par exemple, l'instituteur u'ira pas lutter, avec les rhéteurs de profession, d'artifice et de beau langage, ainsi que l'ont fait certains auteurs qui, à foree d'être diserts avec les paysans, ont réussi à se rendre inintelligibles même aux gens instruits. Mais coupons court à cette préface; il ne faut pas imiter ceux que nous critiquons. Nous avons done à traiter (avec l'aide d'en haut) des diverses espèces de culture, des bergeries, des constructions rurales, d'après les notions des hommes de l'art, de la découverte des sourees d'eau, et en général de tout ce qui, closes ou individus, entre dans le matériel d'une exploitation agricole, en vue de l'agrément ou du profit ; Ic tout avee méthode, et dans son lieu et place. Et pour première eondition, je veux m'astreindre à suivre l'ordre des mois, et y traiter suecessivement de chaque plante et de son éducation.

II. D'abord les conditions d'un bon ehoix du terrain et d'une bonne culture se rapportent à quatre ordres différents d'idées, qui sont : l'air, l'eau, le sol ; et le savoir-faire de l'exploitant ; trois

\section{R. TAURI ÆMILIANI PALLADII}

\section{DE RE RUSTICA.}

\section{LIBER PRIMUS.}

1. Pars est prima prudentiæ, ipsam, cui pracepturus sis, aestimare personan. Neque enim formator agricolx debet artibus et eloquentia rhetores æmulari, quod a plerisque lactum est : qui dum diserte loquuntur rusticis, hoc asse"f uuntur, ut eorum doctrina nec a peritissimis possit intelligi. Sed nos recidamus prafationis moram, ne, quos reprehendimus, fmitemur. Dicendum autem nobis est ( $\mathrm{si}$ divina faverint) de omni agricultura et pascuis et sedificiis rusticis, secunlum fabricandi magistros, et aqua inventionibus, et omni genere corum, qux vel facere vel nutrire oportet agricolam ratione voluptatis et fructus, suis tamen temporibus per universa distinctis. Sane in desquelles dépondent de la nature; la dernière est en nous. II s'agit de pouvoir et de vouloir. Il faut s'assurer d'abord de ee qui dépend de la nature, à savoir si, dans les lieux que l'on se propose de cultiver, l'air est sain et tempéré; si l'eau y est salubre et obtenue commodément, soit qu'clle prenne sa source sur les licux, vienne du dehors ou soit de formation pluviale; enfin si le sol est fertile et le site convenable.

III. On juge que l'air d'une contrée est sain, lorsqu'elle n'a point de vallées basses ni de nuits brumeuses, et que les caractères physiques de la population sont un teint de santé, la tête bien attachée sans roideur, la vue intacte, l'ouie nette, et un gosier qui prête un passage libre aux sons d'une voix claire. C'est à ces signes que l'on reconnait la bonté de l'air. Les signes opposés dénotent dans le elimat une influence pernicieuse.

IV. Voici comment on reconnait que l'eau est salubre. Il faut d'abord qu'elle ne provienne pas d'étangs ni de marais, et qu'elle ne prenne pas. sa source dans des mines, mais qu'elle soit transparente, et ne soit imprégnée d'aucun goût ni d'aucune odcur; qu'elle ne dépose point de limon, et qu'elle puisse tempérer le froid par sa tiédcur, et calmer le feu de l'été par sa fralcheur. Mais comme il arrive souvent que la nature, dont les

primis loc servare constitui, ut eo mense quo ponenda sunt singula cum sua omni exequar disciplina.

I1. Primo igitur eligendi et bene colendi agri ratio, qua. tuor rebus constat, aëre, aqua, terra, industria. Ex lis tria naturalia; unum facultatis et voluntatis. Natura est quod in primis spectare oportet, ut eis locis qua colere destinabis, aër sit salutaris et clemens, aqua salubris et facilis, vel ibi nascens, vel adducta, vel imbre collecta : terra vero foccunda et situ commoda.

111. Aēris igitur salubritatem declarant, loca ab infimis vallibus libera, et nebularum noctibus absoluta, et habitatorum considerata corpuscula, si eis color sanus, capitis firma sinceritas, inoffensum lumen oculorum, purus auditus, et si fauces commeatum liquida vocis exercent. Iloc genere benignitas aẻris approbatur. His autem contraria noxium cali illius spiritum confitentur.

IV. Aqua vero salubritas sic agnoscitur. Primum ne a lacunis aut a palude ducatur : ne de metallis originem $6 \mathbf{6 u}$ mat; sed sit perspicui coloris, neque ullo aut sapore aut odore vitietur, nullus illi limus insidat, frigus tepore sua. mulccat, xstatis incendia frigore moteretur. Sed quia solet: 
opératlons sont toujours secrètes, cache dans les éléments des qualités pernieieuses sous les plus belles apparenees, nous jugerons eneore de la qualité de l'eau par la santé des habitants, en examinant si ceux qui en boivent ont la gorge libre, s'ils ont la tête saine, et si chez cux les' affections pulmonaires ou gastriques sont rares ou fréquentes. Or, comme les maux du eorps se communiquent ordinairement du haut en bas, s'il arrive que, dans un cas où la tête est malade, le principe morbide gagne les poumons ou l'estomae, c'est moins à l'eau qu'à l'air qu'il faut alors rapporter cet effet. Il faut encore examiner si le ventre, les entrailles, les flanes ou les reins n'éprouvent point de douleurs ou de gonflements, et si la vessio n'est point sujette à quelque aceident. L'absenee de ees symptômes et d'autres analogues une fois eonstatée, ni i’air ni les eaux ne doivent plus inspirer aucune défianec.

V. Ce quion demande à la terre, e'est la féeondité. Il faut que les mottes n'en soient ni blanelies ni nues, et que ec ne soit ni un sable maigre et sans aucun; mélange de terre, ni de l'argile pure, ni du eaillou grossier, ni du gravier see, nl une poussière jaune aussi maigre que la pierre même, ni une terre salée, amère ou bourbeuse, ni un tuf sablonneux et sec, ni une masse compacte et trop ferme, comme au fond des vallées. La substance de la glèbe doit être friable, tirant sur le noir, et spontanément productive d'une couehe de verdure. 11 en est aussi de coulcur mélangée, qui rachètent par une propriété visqueuse ce qui leur manque en densité. La végétation naturelle du sol doit être fournie, vivace, pleine de séve, et consister principalement en yèble, jone, roseau, gramen, trèfle touffu, ronees aux baies

lis omnibus ad speciem eustoditis occultiorem noxam tectior servare natura, ipsam quoque ex ineolarum saluIritate noscamus. Si fauces 1ribentium purae sunt, si salvo capite, in pulmonibus ae thorace aut nulla est aut rara causatio. Nam plerumque lias noxas corporis ad inferiorem partem, qua supra sunt corrupta demittunt : sed si vitiato capite ad pulmones vel stomachun morbi causa deeurrat, tunc eulpandus aër potius invenitur. Deinde si venter aut viscera vel latera vel renes nullo dolore aut inflatione vexantur; si vitia nulla vesica sunt. Haee atque his similia si apud incolas pro majori parte constare videris, ncc de aëre ahiquid nec de fontibus suspiceris.

V. In terris vero quacrenda foceunditas : ne alba et nuda sit gleba, ne macer sabulo sine admistione terreni, ne creta sola, ne arenx squalentes, ne jejuna glarea, ne anrosi pulveris lapidosa macies, ne falsa vel amara, ne uliginosa terra, ne tofus arenosus atque jejunus, ne vallis nimis opaca et solida : sed gleba putris et fere nigra, et ad tegendam se graminis sui erate sufficiens; aut misti coloris, qua etsi rara sit, famen pinguis soli adjunctione glntinetur. Qua protulerit uce scabra sint nee retorrida, nee succi naturalis egentia. lerat, quod frumeutis dandis succulentes, et prunlers sauvages; tous indices d'une terre propre au blé. La couleur est, du reste, assez indifférente; ee qui importe, e'est que la terre soit grasse et douce. Voici d quels signes on reconnaitra si une terre est grasse. $\mathrm{Si}$, après avoir versé sur une petite motte de ectte terre de l'eau douce et l'avoir pétric entre les mains, on remarque qu'elle est gluante et que ses parties sont adhérentes entre elles, e'est une preuve sûre qu'clle renferme en elle de la graisse. De même si, après avoir fait un trou en terre, on vient à le remplir de la terre qu'on en avait ti rée, et qu'il s'en trouve de reste, e'est une preuve que cette terre est grasse; comme, s'il n'y en a pas assez pour le remplir, e'est une preuve qu'clle est maigre; et s'il n'y en a préeisément que ec qu'il en fant pour gagner lo niveau du terrain, e'est une preuve qu'elle est de qualité mixte. On reconnaitra qu'une terre est douce, au goût qu'elle aura lorsqu'on en aura pris une motte dans la partie du champ la plus suspecte, et qu'on l'aura fait détremper dans un vase de terre enite, rempli d'eau douce. On reconnait aussi que la terre est propre à la vigne, aux signes suivants : si clle n'est pas de couleur foneée, si elle a peu de consistance et s'égraine facilement; si les arbustes qu'clle produit, tels que les poiriers sauvages, les pruniers, les ronees et autres semblables, sont lisses, luisants, hauts de tige et portent frnit, et s'il ne s'en rencontre pas de tortus, de stériles, et de chétifs et rachitiques. Quant au plan du sol, il faut qu'il n'ait ni trop de niveau, l'eau y séjourne; ni trop d'inclinaison, clle ne fait qu'y glisser; ni de renfoneements abruptes où la terre vigétale se précipite et s'amasse, ni d'exhaussement prononcé qui donne trop de prise à l'intempérie ct aux ardeurs du

utile signum est, ebulum, juneum, calamum, gramen, trifolium non macrum, rubos pingues, pruna silvestria. Color tamen uon magnopere quacrendus est, sed pinguedo atyue duleedo. Pinguem sie agnoseis : Glebam parvulanı dulei aqua eum spargis et subigis, si glutinosa est ct adlaaret, eonstat illi inesse pinguedinem. Item scrolse effossa et repleta, si superaverit terra, pingnis est : si defuerit, exilis : si convenerit aequata, mediucris. Dulcelo autem eognoseitur, si ex ca parte agri qua magis displi. cet, glebam fietili vase dulei aqua madefactam judicio saporis explores. Vineis quoque utilem per laxe signa cognosces : si coloris et eorporis rari aliquatenus atque resolıti est; si virgulta, quax protulit, levia, nitida, pro. cera, foecunda sunt, ut piros silvestres, prunos, rubos, cxeleraque luujusmodi, neque intorta, neque sterilia, neque macra exilitate languentia. Situs vero terrarum neque planus, ut stagnet; neque pracuptus, ut defluat; neque obrutns, ut in imum dejeeta valle subsidat; neque arduus, ut tempestates immodice sentiat et calores : sed ex his omuibus utilis semper est mejuata mediocritas, et vel campus apertior, et lumorem pluvium elivo fallente sub. dueens; vel collis molliter per latera inclinata deductus; 
soleil. Il faut qu'une terre participe de toutes ees conditions dans une juste mesurc, de ficçon que ce suit ou une campagne ouverte dont la pente insensible laisse ćcouler les eaux de pluic; ou un coteau dont l'élévation soit douce; ou une valléc peu profonde, et où le courant de l'air ne se trouve point resscréć; ou un plateau protégć contre les mauvais vents par l'interposition d'une cime plus élevéc, ou par tel autre accident de terrain, ou qui soit couvert de forèts et d'herbes, au cas où il scrait trop rude et trop élevé. Mais comme, en fiit de tcrres, les cspèces sont nombreuses; qu'il en est de grasses ct de maigres, de compactes et de légères, de sèches et d'humides; que presquc chaque propriété a son inconvénient, bien qu'elle réponde au besoin de quelque variétć de semence; il faut choisir comme je viens de le dirc, de préfćrence un terrain qui, étant tout à la fois gras et meuble, soit dans le cas de rendre beaucoup de fruits sans exiger un grand travail, et mettre en secunde lignecclui qui, étant compacte, ne laissera point de répondre à nos espérances, tout en exigeant beaucoup de travail. Mais le pire de tous les terrains est celui qui scra tout à la fois sec et dense, maigre et froid; ct il ne faudra pas moins l'éviter qu'un terrain pestilentiel.

VI. Mais quand on aura observé avec la plus grande attention ces trois conditions, qui dépendent si exclusivement de la uature quc la main de l'homme n'y peut rien, reste au savoir-faire à jouer son rôle. Sur toutes choses, on ne perdra jamais de vue les préceptes généraux ci-après, que j’ai extraits de tous les ouvrages écrits sur l'agriculture. Quand le maitre cst présent, la terre cn vautmicux. Qu'on ne s'attache pasà la couleur du sol, indice trop peu sûr de sa qualité. En fait de plants ou de semences, n'cmployez que ce qu'il y

vel vallis cum quadam moderalione el aïris lasilate subr.issa ; vel mons alterius culminis defensus oljjectu, at a molestioribus ventis lilier anxilio alicuo, vel sublimis, asper, sed nemorosus et lierbilus. Sell cum sint genera terrarum plurima, ut pinguis aut macra, spissa vel rara, sicca vel lıumida, et ex his pleraque vitiosa, tamen propter seıninum differentiam sape necessaria, maxinı, sicut supra dixi, eligendus est pinguis ac resolıtus ager, qui unimum lalorem poscit, et fructum maximum reddit. Secundi meriti est spissus, qui labrore quidem maximo, tanıen ad vola respondet. Illud vero delerrimum genıs est, quod erit siccum simul et spissum, et macrụı vel frigidum : qui ager pestiferi more fugiendns est.

VI. Sed ubi lıæe, qux naturalia suut, neque linmana ope curari possunt, diligentius aestimaveris, exsequi te convenit partem, qua restat industrix : cujus lıxc erit cura rel naxima, ut has, quas subjeci, ex omui opere rustico in primis delseas tenere sententias. I'racsentia lomini provectus est agri. Color terra non magnoplere de. sideretır, quia Jonitatis incertus est auctor. Genera omnium surculorum vel frugum proclara sed terris tuis experta committe. In wovo enim genere seminum ante a de micux, et toujours après essai. Expérimentez toujours avant d'opérer en grand. Le grain dégé. nère plus vite dans les licux humides que dans les licux sees; c'est pourquoi il faut de temps en temps remédiè à ect inconvénient par le choix de la semenec. Ayez toujours sur les licux des ouvriers spéclaux en bois ou en fer, pour travailler aux futailles et aux cuves, afin que nul de vos gens ne soit distrait de la besogne des champs par la nécessité de courir à la ville. On plantera les vignobles du côté du midi dans les pays froids, et du côté du levant, ou même, s'il est nécessaire, du côté du couchant dans les pays tempćrés. On ne peut pas, vu la prodigieuse diversité des terres, dommer de règles certaines sur lc nombre de journées qu'clles exigeront; c'est pourquoi l'usage du canton et celui de la province rous décideront aisément sur ce nombre en tout genre de culture, plant ou semence. Plante en fleurs ne doit pas être touchée. Le choix de la semence est mal fait, quand celui qui cn est chargé en délèguc le soin. En matière d'agriculture, l'exécution aux jeuncs, la direction aux vicux. II y a trois choses auxquelles il faut avoir égard dans la taille des vignes : l'espérance du fruit, le bois qui doit remplacer par la suite celni que l'on retranche, et l'endroit du cep où l'on voudra qu'il repousse. Si on taille la vigne de bonne hcurc, on aura plus de sarments; au lieu que si on la taille plus tard, on aura plus de fruit. II faut transplanterla vigne ainsi que les arbres d'un plus mauvais terrain dans un meilleur. On taillera la vigne de plus près quand la vendange aura étć bonne, et de moins près quand clle aura été modique. Pour greffer, tailler, couper, n'cmployez que de bons outils, et donnez-leur bicn le fil. Achevez tout ec qu'il y a à faire aux vignes

experimentum non est spes tota ponenda. Locis humidis semina citins quam fsiccis degenerant : quare subinde succurrat electio. Ferrarii, lignarii, doliorum cuparunique factores necessario labendi sunt, ne a labore solenui rusticos causa desiderandx urbis avertat. Locis frigidis a meridie vineta ponantur; calidis, a septentrione; temperatis, ab oriente, vel, si necesse sit, ab occidente. Operartum ratio unum modum tenere non potest in tanta di. versitate terrarum : et ideo soli et provincixe consuctudo facile ostendet, qui numerus unamqquamquıe rem faciat sire in surculis sive iri onni genere salorum. Qux florent, couslat non esse tangenda. Bene eligi serenda non possunt, nisi hoc ofliciun prius electus assunnat. In rebus agrèstibus maxime ofticia juvenum congruunt, imperia seuiorum. In vitibus putandis tria consideranda sunt, fructunm spes, successura materies, locus qui servet ac revocet. Vitem si malurius putes, plura sarmenta : si serius, fructus plurimos consequeris. De locis reterrimis sicut arbores ila vites convenit ad meliora transferre. Post bonan viulenian strictius, post exiguam latius puta. In omni opere inserendi, putandi ac recilendi duris et achlis utere ferranreutis. In vite vel arbore qua facienda sunt, perage 
ou aux arbres avant que leurs fleurs s'ourrent ou que leurs boutons se développent. Dans un vignoble, il faut que la beche repasse sur les partles du terrain que le soc n'a pas touchées. Dans les lieux chauds, 'secs ou exposés au soleil, n'épamprez pas la vigne; clle y demande plutôt à étre couverte. Quant à ceux où la vigne est brûléc par le Vulturnus, ou par quelque autre mauvais vent qui règne dans la contrée, on y couvrira la vigne avec de la paille, ou avec toutc autre défense qu'on se procurcra d'ailleurs. S’il se trouve au milieu d'un olivier une branche qui rapportc trop de fruits, ou qui soit trop verte ou stérile, il faut la retrancher, parce qu'ellc est préjudiciable à l'arbre entier. Il ne faut pas moins éviter un canton stérilc qu'un canton pestilentiel, encore que ces deux qualités ne s'y trouvent pas rćunics ensemble. Il ne faut absolument rien mettre entre de jeunes plants de vigne dans un tcrrain façonné au pastinum : les Grecs ordonnent nćanmoins d'y mettre la troisième année tout ce qu'on juge à propos, les choux exceptés. Tous les légumes doivent être semés, suivant les auteurs grees, dans une terre sèche; la fève seule doit l'être dans une terre humide. Quiconque loue sa terre ou son champ à un propriétaire ou à un colon qui en possède déjà dans le voisinage, court à sa ruine et cherche des procès. $\mathrm{Si}$ l'on ne cultive pas les extrémités d'un clıamp, son intéricur court des risques. Tous les froments, après avoir étć semés trois fois dans un sol, se convertissent en une espèce de siligo. Trois choses nuisent au même degré : la stérilité, les maladies, et les voisins. Quiconque plante en vignes une terre stérile, n'a guc̀rc de souci de ses peines ni de son argent. Les pays plats donnent du vin plus abondamment, mais les coteaux le donnent plus fin. L'aquilon fertilise les vignes

ante apertionem floris et gemmx. In vineis aratro proter. missa fossor emendet. Locis calidis, siccis, apricis paunpinandum non est, cum magis vitis optet operiri. Et ubi vineas Vulturnus exurit aut flatus aliquis regloni inimicus, vitem tegamus straminibus vel aliunde quaxsitis. Ramıs lactus, viridis et sterilis in media olea abscindendus est, velut totius arboris inimicus. Sterilitas et pestilentia aquo modo fugienda sunt, vel si secum utræque non fuerint. In jastinato solo inter novellas vites omnino niliil est conserendun. Grxci jubent, exceptis caulibus, tertio anno quax libebit, injungere. Omnia legumina Græcis auctoribus seri jubentur in sicca terra : faba tantummodo in liumida dehet spargi. Domino rel colono coufinia possidentl qui fundum vel agrum suum locat, damnis suis ac litibus studet. In agro periclitantur interiora, nisi colantur extrema. Omne triticun in solo uliginoso post tertian sationem in genus siliginis commutatır. Tria mala xeque pocent, sterilitas, morbus, vicinus. Qui terram sterilem vineis occupat, et laboribus suis et sumtibus est inimicus. Campi largius vinum, colles nolsilius ferunt. Aquilo vites sibi objectas foccundat, Auster nolilitat. Ita in arbitrio par son souffle, et le vent du midi leur donne de la qualité. Ainsi nous avons le choix de récolter ou beaucoup, ou du bon. L'urgence ne connait point de fêtes. Quoiqu'il faille semer quand la terre est humectée, cependant les semailles jetées en terre après une longue sécheresse s'y conservent, quand elles ont étć hersées, plus sùrement même que dans des greniers. Les mauvais chemins sont aussi contraires à l'agrément qu'au pro. fit. L'homme qui cultive traitc avee un créancier à qui sans cesse il faut des intérêts, et dont il n'est jamais certain d'obtenir quittance. Quiconque, en traçant ses sillons, laisse intacts les interstices, nuit au revenu comme au renom dc sa terre. Petit terrain bien cultivé est plus fertile que grand espace négligé. N'employez jamais de raisin noir, si ce n'est dans les provinces où l'on est dans l'usage de faire du vin acinaticium. Plus le support est haut, plus haut grimpe la vigne. Tant que la vignc est jeune et verte, n'en approchez pas le fer. Lorsquc l'on taille un sarment, il faut que l'incision soit faite du côté opposé au bourgeon, de peur que la larme qui en découle ordinairement ne le fasse périr. Quand on taille la vigne, il faut lui laisser une quantité de sarments à nourrir proportionnée à sa malgreur ou à sa vigueur. En terre profonde (à cc qu'assurent les auteurs grees) l'olivier pousse en bois, mais donne des fruits moindres, qui sont aqueux, tardifs, et font plus de marc que d'huilc. Un air tempéré, rafraíchi par des vents légers, dont lc souffle n'est ni violent ni froid, est fa vorable aux oliviers. Une vigne qu'on veut assujettir par le haut doit être élevée par degrés jusqu’à quatre pieds dans les climats contraircs, et jusqu'à sept dans de plus doux. Jardin situé en bon climat, et traversć par un cours d'eau, n'exige presque aucune règle, aucune science de culture.

nostro est, [utrum] plus habeamus, an melius. Necessitas feriis caret. Quamvis temperatis agris serendum sit, tamen si siccitas longa est, semina occata tutius in agris, quam in horreis servabuntur. Viæ malitia xque et voluptati et utilitati adversa est. Qui agrum colit, graven tributis ereditorem patitur, cui sine spe absolutionis astrictus est. Qui arando crudum solum inter sulcos relinquit, suis fructibus derogat, terræ ubertatem infamat. Foecundior est culta exiguitas, quan inagnitudo neglecha. Nigras vites omnino repudies, nisi in provinciis, el ejus generis quo acinaticium fieri consuevit. Longius adminiculun vitis incrementa producit. Teneram et viridem vitem ferri acic ne recidas. Onnis incisura sarmenti avertatur a gemına, ne eam stilla, qua fluere consuevit, extinguat. Pro macie vel soliditate vitiun nutrienda sarmenta putator injungat: Terra profunda (quod Græci asserunt) olexe graudes arbores efficit, fructus minores et aquatos ac seros, magisque amurca proximos. Aēr oleas tepidus juvat, et ventis mediocribus sine vi et liorrore perflabilis. Vitis quie ad jugum colitur, per atates ad hoe perducenda est, ut loeis molestioribus quatuor pedibus a terra, placidiøribus 
Il faut lier par-dessous les grappes de raisin quand clles sont vertes, tant qu'il n'y a point de risque d'en faire tomber les grains ou de les éeraser. Changez les liens de plaec, de peur que l'adhérence continue ne fasse plaic. Si les yeux de la vigne voient la bêche du vigneron lorsqu'ils sont ouverts, l'espérance de la vendange, quelque belle qu'elle soit, sera bientôt aveuglée. Ne labourez done que lorsqu'ils sont fermés. Pour la eulture des céréales, assurez-vous d'un fond de deux pieds, c'est assez pour produire. Pour les vignes et les arbres, il en faut quatre. De mème qu'une jeune vigne croít aisément quaud on lui prodigue ses soins avec affection, de même elle meurt promptement quand on la néglige. Lorsque vous entreprendrez une culture, prenez la mesure juste de vos facultés; car si elles se trouvent au-dessous des exigences, vous serez forcé de reeuler avec déshonneur, après vous etre avancé avec présomption. II ne faut pas que des semences aient plus d'un an de date. Conservées plus longtems, il est à craindre qu'elles ne s'altèrent et ne viennent point. Le blé des coteaux donne à la vérité du grain plus robuste, mais il en rend en moindre quantité. Il faut jeter en terre toutes les semailles dans le temps que la lune croit et dans des jours tempérés, parce qu'une chaleur modérée fait lever les semences, et que le froid les resserre. Avez-vous une terre couverte de bois inutile? defriehez, et changez en guérets les meilleures parties; laissez le bois sur le reste. Les premières produiront par leur fertilité naturelle; vous féconderez les autres en y mettant le feu. Laissez après cela reposer cinq ans le sol incendié, et cette partie improductive pourra rivaliser

vero septen summitas ejus insurgat. Hortus qui calo clementi subjacet, et fontano humore percurritur, prope est ut liber sit, et nullam serendi disciplinam requirat. Subli. gatio acerbis uvis facienda est, quando excutiendi aut rumpendi acini nulla formido est. Ligatura in vitibus locum debet mutare, ne unum semper assiduitas conterat vinculorum. Fossorem si apertus vitis oculus viderit, cæecabitur spes magna rindemire : et ideo, dum est clausus fodietur. Terræ altitudinem cum foccunditate, si ad frumenta, duobus pedibus explora : quatuor vero, si ad arbusta vel vites. Vitis novella ut facile incrementum dilecta consequitur; ita interitum celerem, si negligatur, incurrit. Modum tene astimatis facultatibus tuis in assum. tione culturie, ne superatis viribus, excedente mensura, turpiter deseras, quod arroganter assumis. Semina plus. quam aunicula esse non debent, ne retustate corrupta non prodeant. Frumeutun collis [quiden] grano robustius sed mensurx miuus refundet. Omnia quas seruntur, crescente luna et diebus tẹpidis sunt serenda. Nam tepor evocat, frigus includit. Si tibi ager est silvis inutilibus tectus, ita eum divile, ut loca pinguia puras reddas novales; loca sterilia silvis tecta esse patiaris; quia illa naturali ubertate respondent, liac beneficio laetantur incendii. Sed avec les plus fertiles. Pour planter l'olivier et en cueillir le fruit, les Grees recommandent den'employer que de jeunes garęons intacts et des filles vierges; par respect, j'imagine, pour la cliaste déesse qui préside à cet arbre. Il est inutile de rien preserire sur les noms des blés, puisque de temps à autre ils cliangent de nature, suivant les lieux où ils sont semés, ou suivant leur áge. Ainsi il suffira de choisir ceux qui tiennent le premier rang dans le pays que nous eultiverons, ou d'éprouver ceux que nous aurons tirés d'ailleurs. Si l'on coupe le lupin et la vesce comme fourrage dans le temps qu'ils sont verts, et qu'aussitôt après on laboure sur leurs racines, ils féconderont les campagnes à l'instar du fumier. Mais si on les laisse sécher sur pied, ils absorberont le suc de la terre. Il faut beaucoup de fumier aux terrains humides; les terrains secs en exigent moins. Tous les travaux de la vigne se commencent plus tôt dans les climats chauds et secs, dans les localités fortement exposées au soleil, situées près de la mer ou en rase eampagne; plus tard, dans les régions froides, humides, enfoncées dans les terres, boisées ou montueuses; précepte que je n'entends pas seulement des mois ou des jours, mais encore des heures. Toute prescription de temps en fait de travaux agricoles doit s'entendre ainsi : Quinze jours a vant n'est pas trop tôt; quinze jours après n'est pas trop tard. Tous les blés se plaisent mieux dans une campagne ouverte et dégagée, ou dont la pente est tournée au soleil, que partout ailleurs. Une terre compacte, argileusc et humide fournit très-bien à la nourriturc du blé et du froment. L'orge se plait dans un sol meuble et see; l'humidité la fait mourir. Les semailles des tre.

sic urenda distingues, ut ad incensum agrum post quinquennium revertaris : ita efficies, ut xqualiter vel sterilis gleba cum foecunditate contendat. Graci julent olivam, cum plantatur et legitur, a mundis pueris atque rirginilus operandum : credo recordati arbori luic esse prasulem castitatem. Nomina frumentorum superfluum est proci. pere, qux aut loco subinde aut atate mutantur. Hoc satis est, ut eligamus pracipua in ca regione quam coliuus, vel exploremus advecta. Lupinus et vicia pabularis, si virides succidantur, et statim sıpra sectas eorum radices aretur, stercoris similitıdine agros foccundant : qua si exaruerint ante quam proscindas, in his terra succus au. fertur. Ager aquosus plus stercoris quxrit; siccus minus, Calidis, maritimis, siccis, apricis, campestribus locis omne opus vinearum maturius incloetur; frigidis, mediterraneis humilis, opacis, montanis locis tardius : quod non solum de mensibus aut diebus dixerim, sed etiam de loris operandi. Omne opus rusticum, cum fieri praccipitur, neque cito est, si ante quindecim dies; neque tarde, si post quindecin fiat. Frumenta omuia maxime lactantur patenti campo et soluto, et ad solem reclivi. Spissa et cretosa et lumida terra bene far et triticum nutrit; ordeum agro soluto delectatur et sicco : nain si in lutoso spargatur, 
mois convlennent aux lieux fioids, ò̀ il neige souvent et où l'ćté est humide; ailleurs ils réussissent rarement. On a meilleure cliance toutefois si le climat n'est que tempéré, et si l'on ne sème qu'en automne. Vous faut-il opérer sur une terre salée? attendez, pour planter ou semer, la fin de cette saison. Délayé par les pluies d'hiver, le sol perdra de sa mauvaise qualité. Il faut encore le mélanger d'un peu de terre douce ou de sable de rivière, lorsqu'on veuty faire une plantation. On ne doit former de pépinières que dans uno terre moyenne, afin que le plant gagne au change lors . qu'il sera transporté. Les pierres laissées à la superfieie du sol sont glaciales en hiver, incandeseentes en été, et nuisent aux arbustes et aux vignes. Leur présence au contraire est utile aux terres chaudes et sèches, quand elles sont enfouies et recouvertes. Quand on remue la terre auprès des arbres, il faut la changer alternativement de place, de façon que celle qui était d'abord dessous succède à celle qui se trouvait auparavant dessus. Pour fumer les arbres, on formera des couches alternatives de terre et de fumier, en eommenȩant par appliquer de la terre à leur trone et ensuite du fumier, et ainsi de suite jusqu'à la fin de l'opération. Pour régisseur, ne prenez jamais d'esclave favori, et ehoyé par vous dans sa jeunesse; car il regarderait vos privautés d'autrefois comme une assurance d'impunité pour le présent.

VII. Dans le elioix ou l'acquisition d'une terre, examinez si une culture négligente n'en a pas altéré la fécondité naturelle; si l'on n'a pas laissé lo sol dépenser ses forces pour une végétation dégénérée. Car, bien qu'on puisse raviver le plant par la greffe, toujours vaut-il mieux jouir ac-

unorilur. Trimestris satio locis frigidis [et] nivosis con. venit, nlsi qualitas aestatis humecta est; creteris raro respondet eventu. Semen trimestre loeis tepidis melius respondebit, si seratır autumno: si necessitas coget in salsa terra aliquiud operari, extrenı autımno plantanda est vel conserenda, ut malitia ejus libernis imbribus eluatur. Aliquid etiam terra duleis vel arena fluvialis subjiciendum est, si illi virgulta commitlimus. Seminarium medioeri terra instituere debemus, ut ad meliorem, qua sata fuerint, transferantur. Lapides qui supersınt, lieme rigent, xestate fervescunt : ilcirco satis arbustis et vitibus nocent; quae tamen latentia prosunt in terris calidis el siccis dummodo eis terra supersit. Terra, qua circa arbores movetur, ita est vicibus permutanila, ut ei quxe in summo fuerat, ima succedat. In lactandis arboribus crates faciemus, terram prius trunco admoventes, et mox latamen; ut sic opus natura beneficii alternante cumuletur. Agli prosulem nou ex dileetis, [et] tenere [educatis] servulis ponas; quia fiducia prateriti amoris impunitatenı culpae praesentis expectat.

VII. In eligendo agro vel emendo considerare debebis, ne boumm naturalis focunditatis eolentium depravaverit inertia, et in degeneres surculos uber soli feracis expen- tuellement, qu'attendre l'effet tardif d'une amelioration toujours incertaine. Pour le bléle remède est bientôt trouvé; c'est d'en semer d'autre. Pour ee qui est des vignes, il faudra surtout examiner si les cultivateurs ne sont point tombés dans la faute qu'ont commise bien des personnes qui, n'étant curieuses que de s'acquérir la réputation de posséder de vastes terrains façonnés au pastinum, ne les ont remplis que de plants do vignes stériles, ou de détestable produit. Si votre acquisition présente un tel ineonvénient, vous aurez fort à faire pour y remédier. En fait d'exposition, choisissez dans les eonditions que voiei. Dans les pays froids, recherchez l'exposition du levant ou du midi ; car si le champ est dominé de ces deux côtés, les hauteurs interposées lui interceptent toute chaleur; attendu que le soleil ne parait jamais du cóté du septentrion, et qu'il tarde jusqu'au soir à paraitre du cóté du eouchant. Il faut au contraire ehoisir de préférence le côté du septentrion dans les climats chauds. Giest en effet le meilleur, tant pour le profit que pour l'agrément et pour la salubrité. S’il y a une rivière dans le voisinage de l'endroit où l'on se propose de placer les bátiments, il en faut examiner la nature, parce qu'il arrive souvent qu'il en sort des exhalaisons funestes; auquel cas il faudrait s'en écarter pour bâtir. Pour les marais, il faut absolument les éviter, à cause de l'air pestilentiel qu'on respire dans leur voisinage, et des animaux pernicieux qu'ils engendrent, surtout quand ils sont au midi ou au eouchant, et que d'habitude ils restent à sec pendant l'été.

VIII. Il faut que le bâtiment soit proportionné à la valeur du fonds et à la fortune du propriétaire,

derit : quod quamvis emendari possit insitione meliorum, tamen lıarum rerum sine culpa melior usus est, quam eum spe corrigendi serus eventus. In seminibus ergo frumentorum prasens emendatio poterit esse. In viueis maxime considerandum atque vitandum est, quod plerique fecerunt studendo famæe tantum et latitudini pastinorum, semina vitium statuentes vel sterilia vel saporis indigni : quod grandi tibi labote constabit ut corrigas, si agrum compares vitiis talibus occupatum. Positio ipsius agri, qui eligendus est, ea sit. In frigidis proviniciis Orienti, ant meridiano lateri ager esse debet oppositus, ne alicujus magni montis objectu his duabus partibus exclusus algore rigescat; ant per partem septentrionis remoto, aut per occidentis in vesperam sole dilato. In ealidis vero provinciis, pars potius septentrionis optanda est, quæ et utilitati et roluptati ef saluti aequa bonitate respondeat. Si vieinus est fluvius, ubi statuinus fabrica sedem parare, ejus debemus explorare naturam, quia plerumque quod exhalat, inimicum est, a quo, si talis sit, eonveniet refugere conditorem. Palus tanen onni modo vitanda est, præcipue qua ab Austro est vel occidente, et siccari consuevit destate, propter pestilentiam vel animalia inimica, quæe generat. 
parce qu'il arrive communément, lorsque cette proportion a éte dépassée, que les constructions sont plus difficiles à entretenir qu'à élever. On réglera done sa grandeur de telle façon que, s'il survient quelque accident, le revenu d'une année de la terre, ou celui de deux tout au plus, suffise pour le réparer. Lc corps de logis du proj)riétairc sera placé dans un lieu un peu plus élevé et plus see que les autres parties du bâtiment, tant afin que les fondements n'en puissent être endommagés, que pour procurer une belle vue au propriétaire. 0 n en fera les fondements de manière qu'ils débordent d'un demi-pied, tant d'un côté que de l'autre, le corps de la muraille qu'ils auront à porter. Si le hasard veut qu'en fouillant les fondations on rencontre de la pierre ou du tuf, il n'y aura pas de difficulté à les asseoir, puisqu'il suffira de creuser leur lit à la profondeur d'un ou deux pieds. Si l'on rencontre de l'argile qui soit ferme ou compacte, on leur donnera en profondeur la cinquième ou la sixième partie de la hauteur totale que le bâtiment doit avoir; au lieu que si l'on ne trouve qu'une terre peu compacte, il faudra quelquefois les enterrer plus profondément, c'est-à-dire, jusqu'à ce que l'on rencontre l'argile pure, ne présentant aucun vestige de décombres; quoique, si l'on ne trouve point absolument d'argile, il suffira toujours de leur donuer en profondeur la quatrième partie de la hauteur du bâtiment. Il faut en outre faire en sorte de pouvoir environner le bâtiment de jardins, de vergers ou de prairies. Au surplus, la façade en sern exposée dans tout son développement au midi, de façn néanmoins que l'un de ses angles voie le levant d'hiver, et qu'elle se déţourne taut soit peu du

VIII. Erlificium pro agri merito et pro fortuna dominl oportet institui : quod plerumque immodice sumtum, difficilius est sustiuere quam condere. Ita igitur xestimanda est ejus magnitudo, ut si aliquis casus incurrerit, ex agro, in quo est, unius anni aut ut multum, biennii pensione reparetur. Ipsius autem prætorii situs sit loco aliquatenus erectiore et sicciore quam cattera, propter injurianı fundamentolum, et ut lælo fruatur aspectu. Fundamenta autem hoc inodo ponenda sunt, ut latiora sint ex utraque parte semipedis spatio, quan parietis [insuper struendi] corpus increscet. Si lapis vel tofus occurtat, facilis causa est collocandi, in quo sculpi tantum fundamenti forma debebit unius pedis altitudine vel duorum. [ $\mathrm{Et}$ ] si solida vel constricta invenietur argilla, quinta vel sexta pars altitudinis ejus, qua supra terram futura est, fundamentis deputetır. Quod si terra laxior fuerit, modo majoris altitudinis obruantur, donec munda sine ruderum suspicione occurrat argilla; qua si omnino desit, quartain mersisse sufficiet. Studendum praterea ut hortis et pomariis cingi possit aut pratis. Sed totus fabrica tractus unius lateris longitudine, in quo frons erit, meridiauam partam respiciat, in prino augulo excipiens ortum solis liberni, et paululum ab occidente avertatur $h$ iemali. Ita couchant de la mème saișon; moyennant quoi elle se trouvera ćclairéc par le soleil pendant l'hiver, sans en sentir la chaleur pendant l'éte.

IX. La distribution de bâtiment sera combinée de manière à ménager, sans prendre trop d’espace, des logements d'hiver et des logements d'été. Geux d'hiver seront placés de façon à pouvoir être égayés par le soleil d'biver presque durant toute sa course. Les planchers y seront établis en conséquence. II faut avcir soin, par rapport à la construction de ces planchers, premièrement que la charpente en soit de niveau et solide, afin qu'elle ne tremble pas, faute d'ètre bien assurée, sous les pieds des allants et des venants; en second lieu, qu'elle ne présente point de solives de chêne parmi les solives d'resculus dont elle sera composée; parce que le chêne qui a une fois pris de l'humiditć se tourmente quand il commence à se séclıer, et occasionne des crevasses dans les plafonds, au lieu que l'oesculus dure longtemps sans s'altérer. Si cependant l'on n'a point d'cesculus à sa disposition, et que l'on n'ait que du chêne, on le taillera en planches trc̀s-minces, que l'on superposera transversalement, en les attachant l'une à l'autre avec une grande quantité de clous. Les planchers de cerrus; de hêtrc ou de frêne dureront trés-longtemps, pourvu qu'on les courre de paille ou de fougère, pour empêcher l'humidité de la chaux de pénétres jusqu'au corps même du plancher. La carcasse du plancher faite, vous y établirez une couche de blocaille, composée de deux parties de pierres brisées, contre une partie de chaux. Quand cette couche sera parvenue à l'épaisseur de six doigts, et que vous aurez nivelé le terrain, il faudra, si ce sont des appartements d'hiver, là couvrir d'un

proveniet, ut per hiemen sole illustretur, et calores ejus astate non sentiat.

IX. Forma tamen debet esse ejusmodi, ut ad habitatio. nem breviter collectas ot æstati et hiemi præbeat ınan siones. Qua hiemi parantur ita sint constituta, ut possit eas hiberni solis totıs propemodum cursus hilarare. Iı his pavimenta opportuna esse debebunt. Prinum in fabricis planis earum observandum est, ut aqualis et solida contignatio fiat, ne gradus ambulantium tremorem fabrica titubantis excutiat. Deiude ut axes quernæ cum æsculeis non misceantar. Nam quercus humore concepto cum coeperit siccari, torquebitur, et rimas in pavimento faciet : æsculus autem sine vitio durat. Sed si quercn sıp. petente æsculus desit, sul,tiliter quercus secetur, et transversus atque directus duplex ponatur ordo tabnlarum, clavis frequentibus fixus. De cerro aut sago aut farno dill. tissime tabulata durabunt, si stratis sujer paleis vel filicr: hunnor calcis nusquam ad tabulati corpus accedat. Tunc super statuminabis rudus, id est saxa contusa duabus partibus ef una calcis temperante constitues. Hoc cunı ad sex digitorum crassitudinen feceris, et regula explorave. ris æquale, si loca hiemalia sunt, tale pavimentum debebis imponere, in quo vel nudis pedibus stantes ministri 
pavé composé de telle maniêrc que les valets puissent s'y tenir pieds nus, sans être transis de froid. Ce sera un composé de menus moellons ou de briques, eimenté avee du eharbon pilé, du sable, de la cendre et de la chaux, à l'épaisseur de six pouces. Le tout bien régalé formera un planchei noiratre, qui boira tout liquide épanché dessus par mégarde. S'agit-il d'appartements d'été? on les exposera au levant solsticial et au septentrion, et on les pavera, soit de briques (comme ei -ùessus), soit a vee des dalles ou carreaux de marbre, dont les angles se rapportent et forment une marqueterie régulière. $\mathbf{A}$ défaut de ces matières, on étendra sur le plancher une eouehe de stue ou de sable menu, lié avec de la ehaux.

$X$. Il faut en outre que celui qui veut bátir saelie quelle est la ehaux et le sable qu'il pourra employer. Il y a de trois sortes de sables fossiles, le noir, le blanc et le rouge : ee dernier est bieı supérieur aux deux autres, le blanc tient le second rang, et le noir est le pire. Tout sable qui eraque lorsqu'il est pressé entre les mains est bon pour íes ouvrages de maçonnerie. II sera encore excellent lorsquil ne taehera point un moreeau d'étoffe ou un linge blane dans lequel on l'aura enveloppé pour le seeouer, et qu'il n'y laisscra point de erasse. Cependant, si l'on n'a point de sable fossile, on pourra se servir de sable de rivière ou de mer. Comme celui de mer est longtemps à se sécher, on ne l'emploiera pas immédiatement; mais on laissera éeouler un certain temps avant de s'en servir, de peur que son poids ne sureharge la maçonnerie et ne l'endommage. Son humidité salée dissout aussi les enduits des voûtes. Quant au sable fossile, la promptitude avec laquelle il se sèche fait qu'il

lieme non rigescant. Inducto itaque rudere vel testaceo pavimeuto, congestos et calcatos spisse carbones cum sabulone et favilla et calce perniscebis, et lujus impensæ crassitudinem sex unciis jubebis imponi : quod exaequalum nigra pavimenta formabit, et siqua fundentur ex poculis, velociter rapta desuget. Sed si astiva mansiones suut, vrientem solstitialem et partem septentrionis aspiciant, et vel testaceum, sicut supra diximus, accipiant pavimen. tum, vel marmora vel tesseras aut scutulas, quibusaequale reddatır angulis lateribusquue conjunctis. Si laac leerunt, sujpra marnor tusum cernatur, aut arena cum calce in. ducta levigetur.

$X$. Proterea scire est necessarium construenti, qua calcis et arenxe naturá sit utilis. Arenx ergo fossicia geuera suni tria, nigra, cana, rufa : omnium praccipue rufa melior : meriti sequentis est caua : tertium locum uigra pos. sidet. lix is quæ compressa manu edit stridores, erit utilis fabricanti. Item si panno vel linter candidac vestis inspersa et excussa nihil macula reliqueril ant sordis, egregia est. Sed si fossilis arena non fuerit, de fluminibus [aut] glarea, aut littore colligetur. Mariua arena tardius siccatur, et ideo non continue sed intermissis tenyoribus construenda est, ne ojus onerata corrunı)at : camerarum est très-bon pour le ciment des murailles, comme pour les voûtes : mêlé a vec la chaux au moment même de son extraction, il n'en vaut que mieux. S'il reste longtemps exposé au soleil, ou à la geléc, ou à la pluie, il perd de sa qualité. Celui de rivière convient mieux pour enduit. Si l'on est eependant forcé d'employer du sable de mer, il sera bon de le plonger auparavant dans de l'eau douce, où, étant bien lavé, il déposera le viee que le sel lui avait fait contracter. Pour faire de la chaux, on cuira des picrres bianehes dures, ou de la pierre de Tibur, ou du caillou de rivière de couleur de pigeon, ou de la pierre rouge, ou de la picrre ponce, ou enfin du marbre. Celle qui aura éte faite avec une pierre compaete et dure sera bonne pour la bâtisse, au lieu que celle qui proviendra d'une pierre spongieuse ou molle eonviendra davantage aux enduits. Il faut toujours mettre une partie de chaux sur deux parties de sable. Si e'est du sable de rivière, l'on aura des ouvrages d'une solidité merveilleuse, en y ajoutant un tiers d'argile sèche criblée.

XI. Si l'on veut que les murnilles du corps de logis qui sert à l'habitation du propriétairè soient en briques, on aura soin, lorsque la construction en sera achevée, de faire, sur l'extrémité de ces murailles qui joindra la couverture du bâtiment, une maconnerie en briques de la hauteur d'un pied et demi avec des eorniehes saillantes, afin que si les tuiles ou les gouttières deviennent défeetueuses, les gouttes d'eau de pluie qui filtreront à travers ne puissent pas pénétrer jusqu'au mur. Après quoi il faudra erépir ees murailles quand elles seront sèches et raboteuses, paree que l'enduit n'y tiendrait pas, si on l'y mettait pendant qu'elles sont humides et lis-

quoque tectoria salso lumore dissolvit. Nam fossiles are. na tectoriis et cameris celeri siccitate utiles sunt, melioresque, si statim, cum effossae sunt, calci misceantur. Nam diutino sole aut pruina ant imbre vanescunt. Flıviales tectoriis magis poterunt convenire. Sed si uti necesse sit maris areu, erit commodum prius eam lacuua lummoris dulcis immergi, ut vitium salis aquis suavibus elota deponat. Calcem quoque [ex] albo saxo duro ve] Tiburtino aut columbino fluvialive coquemus, aut rubro aut spongia ant marmore postreno. Quac erit ex spisso et duro saxo, strucluris convenit : ex fistuloso vero ant molliori lapide tectoriis adhibetur utilius. In dnabus are. na partibus calcis una miscenda est. In fluviali vero arena si tertiam partein testa cretac addideris, operum soliditas mira pirestabitur.

XI. Quod si latericios parietes in pretorio facere volue. ris, illud servare debebis, ut perfectis parietibus, in sun. mitate, qux trabibus subjacebit, structura testacea cum corouis prominentibus fiat sesquipedali altitudine, lit si corruple tegula ant imbrices fuerint, parietem nou possint stillicidia penetrare per pluviam. Deindéprovidendum est, Itt siccis et asperatis parietibus lateriliis inducatur teclorium, fuod lumidis ac levibus adlocrere non poterit; et 
ses. On commeneera par conséquent par les revêtir de platre jusqu'à trois fois, afin que le dernier enduit qu'clles recevront ne souffre aucune altération.

XII. La chose à laquelle il faut le plus s'attacher dans les bátiments rustiques, est à ce qu'ils soient bien éclairés, et que leurs distributions, réglées, comme je l'ai dit ci-dessus, sur les différentes saisous, soient exposées au côté du ciel qui leur conviendra, c'est-à-dire que les appartements d'été soient au septentrion, ceux d'hiver au midi, ceux de printemps et d'automne au levant. Pour déterminer la hauteur des salles à manger et des chambres à coucher, on prendra la moyenne de leurs deux autres dimensions.

XIII. Pour les voûtes et plafonds, on fera bien d'employer les matériaux les plus à portée. On les fera done de planches ou de cannes, de la façon qui suit. On posera horizontalement des ais de bois des Gaules ou de cyprès, d'une grosseur uniforme, dans le tieu même où l'on doit faire la voûte, de façon qu'il se trouve un pied et demi d'intervalle entre chacun; après quoi on les assujettira à la charpente de la couverture à l'aide de chevilles de bois de genévrier, d'olivier, de buis ou de cyprès ; puis on y attachera deux perehes en traverse avec des cordes de jonc. Ensuite on étendra par-dessous une claie à mailles serrées, tissueavec des cannes de marais, ou de cette espèec moins menue dont on se sert communément, et que l'on aura préalablement battue. Quand cette claie sera attachéc dans toute son étendue tant aux ais qu'aux perehes, on eommencera par la levêtir d'un enduit de pierre ponce que l'on unira arec la truelle, afin que les brins de canne. soicnt bien resserrés entre eux; puis on la régalcra avec du sable et de la chaux, et on finira par y étendre de la poudıe de marbre broyé, mélée avec de la chaux; et l'on polira ect enduit jusqu'à ce qu'on lui ait donnć le plus beau luisant.

XIV. On se plait aussi souvent à faire ces sortes douvrages en stuc, dans la composition duquel on fait entrer de la chaux éteinte depuis longtemps. Or, pour que la chaux soit propre à ces sortes d'ouvrages, il faut qu'ellc soit de consistanee à être taillée, comme le bois, avec une hache. Si le tranchant de la hache ne rencontre aucun obstacle dans la chaux, ct que les parties de chaux qui adhéreront à la hache soient molles et visqueuses, on est assuré qu'elle est bonnc à être employée à ces sortes d'ouvrages.

$\mathrm{XV}$. Voici comme on parviendra à rendre le crépi des murailles solide et luisant. On repassera souvent avec la truelle la première couche quon y aura mise. Lorsqu'elle commencera à se sćcher, on y en mettra une seconde, puis une troisième; après quoi on lcs recrépira, la truelle à la main, arec de la poudre de marbre grossière, qui aura dû être gâchée jusqu'à ce qu'elle ne ticnne pas au râteau dont on se sert pour remuer la chaux, et qu'on puisse au contraire l'en retirer propie et net. Lorsque cette couche de poudıe dc marbrc glossière eommencera à se sécher, il faudra cncore la recouvrir d'une autre couche de poudrc plus fine, qui assurera la solidité et lc poli de cet enduit.

XVI. Il faut éviter une faute dans laquelle sont tombés bien des gens pour se procurcr de l'eau, laquelle consiste à enfoncer ses métairies dans le bas des vallćes, en préférant un bienêtre de quelques jours à la santé des habitants. L'inconvénient qui en résulte est eneore plus à craindre quand on soupconne que la province ideo tertio eos prius debebis obducere, ut tectorium sine corruptione suscipiant.

XII. In primis studendum est in agresti fabrica, ut multa luce clarescat : deinde ut partes temporibus divisas, sicut supra dixi, congruis partibus offeramus, id est æstivas septentrioni, libernas meridiano, vernas ot autumnales orienti. Mensura rero hicc servanda est in tricliniis atque cubiculis, ut quanta latitudo et longitudo fuerit, in unum computetur, et cjus nedietas in altitudinem conferatur.

XIII. Cameras in agrestibus adificis ex ea materia utilius erit formare quæ facile invenietur. In villa itaque aut tabulis faciemus aut canuis loc genere : Asseres ligni Gallici vel cupressi directos et aequales constituemus in eo loco, ubi camera facienda est, ita ordinatos, ut inter se sesquipedalis mensura sit vacua. Tunc eos catenis ligneis ex junipero aut oliva aut buxo aut cupresso factis ad confignationem suspendemus, et biuas inter eos perticas dirigemus tomicibus alligatas. Postea pajustrem cannam vel lıanc crassiorem, quæ in usu est, contusam, facta et strictim juncta crate subnectemus, et per omne spatium cum ipsis asseribus et perticis alligabimus. Dehinc primo imperisa pumicea induemus, et trulla aequabimus, ut inter se cannarum menubra constringat. Post arena et calce coxquabimus. Tertio tusi marmoris pulverem nistum cum calce ducemus, et poliemus ad summun nitorem.

XIV. Opus qunque albarium sæpe delectat, cui calcem debebimus adlibere, cum multo tempore fuerit macerata. Ergo ut utilem prohes, ascia calcem quasi lignum dolabis. Si nusquam acies ejus offenderit, et si quor ascix adliæret, fuerit molle atque viscosum, constat albariis operibus convenire.

XV. Parietum vero tectura sic fiet forlis et nitida. Primo trullis frequentetur inductio. Cum siccari caperit, iterum inducatur ac tertio. Post hæc tria coria ex marmoren grano cooperiatur ad trullam; quae inductio ante tam diu subigenda est, ut rutrum, quo calx subigitur, mundum levenus. Hac quoque marnoris grani inductio cum sic. cari inceperit, aliud corium subtilius oportet inponi : sic et soliditatem custodiet et nilorem.

XVI. Vitandum est autem, quod plerique fecerunt aquæ causa, villas [in] infimis vallibus mergere, et pancorum dierum voluptatem præferre habitatorum saluti : quod eliam magis metuenus, si provincia quam colimus, 
que l'on liabite est sujette à des maladies pendant l'été. S'il ne se trouve donc dans le lieu ni fontaines ni puits, il faudra y construire des eiternes, qui forment récipient de l'cau des toits. Or, voicl la facon de faire ces citernes.

XVII. On leur donnera telle dimension que l'on jugera à propos, suivant ses facultés, pourvu qu'elles soient plus longues que larges, et on les clorra de murs construits en ouvrage de Signia. l.e sol, sauf l'orifice du conduit d'éeoulement, sera eonsolidé par une bonne épaisseur de blo('aille, sur laquelle on étendra, pour la régaler, un ciment de brique qui tiendra lieu de pavé. On polira ensuite ee pavé, avec tout le soin possible, jusqu'à ce qu'il soit devenu luisant, en le frottant eqntinuellement avec du lard gras que l'on aura fait bouillir. Lorsqu'il sera bien sec, et qu'on n'aura plus à craindre que l'humidité n'y cause de erevasse, on couvrira également les parois d'un même enduit; et lorsque le tout sera absolument sec depuis longtemps, on y fera entrer l'eau à demeure. On aura soin d'y jeter des anguilles et des poissons de rivière, que l'on y nourrira, afin que l'eau, quoique dans un etat de stagnation, imite le mouvement de celle qui coule, lorsque ces animaux viendront à $y$ nager. S'il arrive que l'encluit du pavé ou de la muraille périelite en quelque endroit, on le réparera avec un ciment propre à eontenir l'eau qui eherchera à s'enfuir. Voici comme on réparera les erevasses et les cavités des eiternes, des viviers ou des puits, ainsi que toute espèee d’infiltration de leur maȩonnerie. On prendra telle quantitć que l'on jugera à propos de poix liquide, à laquelle on ajoutera une quantité pareille de la graisse connue sous le nom de vicux oing, ou de suif. On jettera le tout ensemble dans une marmite, où on le fera

de morbis rstate suspecta est. Cui si fons desit aut puteus, cisternas construere conveniet, quilous omnium conluci possit aqua tectorum. Fiunt autem hoc modo.

XV11. Signinis magnitudo en, qua delectaris et cui suflicis, construatur lougior magis quam latior. Hujus soIum alto rudere solidatum relicto fusoriis loco testacei pavimenti superfusione levigetur. Hoc pavimentum omni cura terendum est ad nitorem, et lardo pingui decocto assidue perfricandum. Quod ubi deducto humore siccatum est, ne rimis in aliqua parte findatur, etiam parietes simili corio velentur obducti, et ita post diuturnam et solidam siccitatem, aquxe prebeatur lospitium. Anguillas sane piscesque fluviales mitti in his pascique conveniet, ut lıorum natatı aqua stans agilitatem currentis imitetur. Sed si aliquando in quocunque loco pavimenti vel parietis tectura succumbat, loc genus maltlıe adlibebimus, ut lummor in exitum nitens possit includi. Rimas et lacunas cislernarum, et piscinas, rel puteos sarciemus lıoc genere, et si humor per saxa nanabit. Picis liquida quantum volueris, et tantundem sumes ungninis, quod vocamus axungiam, vel sevum. Tunc in olla utrumque miscebis et coques donec spumet; deinde ab igne removebis. euire jusqu'à ce que l'écume monte; après quoi on le retirera du feu. Quand ce mélange sera refroidi, on le saupoudrera de chaux très-menue, et on le remuera fortement pour que la mixtion soit eomplète ct arrive à l'état de pate, qu'on roule avèc les doigts ; ct l'oll garnira de ce mastic les fissures et pertes d'eau, en l'y pressant et foulant bien. L'eau sera plus salubre si elle passe par des tuyaux de terre cuite pour se rendre dans ces citernes, et si ces dernières sont eouvertes. Au reste, l'eau du ciel est si préférable à tou. tes les autres pour servir de boisson, que quand on pourrait s'en procurer de courante, on ne devrait l'cmployer qu'aux lavoirs et à la culture des jardins, pour peu qu'elle ne fủt point saine.

XVIII.II faut que le cellier au vin soit exposé au nord, frais, presque obscur, éloigné des bains, des étables, du four, des amas de fumier, des citernes et des eaux, et généralement de tout foyer d'exhalaisons méphiliques, et assez bien outillé pour suffire à toute exigence de réeolte; qu'ainsi que l'estrade d'une basilique, le fouloir soit élevé de trois ou quatre degrés environ, et soit flanqué de deux eôtés de réservoirs destinés à recevoir le vin. Des rigoles de maçonneric ou des tuyaux de terre cuite partiront de ces fosses pour aboutir à l'extrémité des murs, et conduire le vin, à travers des passages pratiqués au bas de ces murs, dans des futailles qui y seront adossées. Si l'on a une grande quantité de vin, on destinera le centre du cellier aux cuves; et, de erainte qu'elles n'empêchent les passants d'aller et de venir, on pourra les monter sur de petites bases suffisamment hautes, ou sur des futailles enfouies en terre, en laissant entre chaeune une distance assez grande pour que celui qui en prendra soin puisse, quand le cas l'exigera, en

Cum fuerit eadem refrigerata permistio, calcem minutim superadjicies, et ad unum corpus omnia mista revocabis. Cumque velut strigmentum feceris, inseres locis corruptis ac manantibus, et pressum summa densitate calcabis. Salutare erit aquas illuc per tubos fictiles duci, et opertis immeare cisternis. Nam calestis aqua ad bibendum omnibus antefertur, ut et si fluens adliiberi possit, quac salubris non est, lavacris debeat et liortorum vacare cul. tura.

XVIII. Cellam vinariam septentrioni debemus habere oppositain frigidam, obscuram, vel obscuræ jroximan, longe a balneis, stabulis, furno, sterquiliniis, cisternis, aquis, et cxteris odoris liorrendi : ita instructam neces. sariis, ut non vincatur a fructu; sic autem dispositam, ut basilica ipsius forma calcatorium loco habeat altiore constructum; ad quod inter duos lacus, qui ad excipienda vina linc inde depressi sint, gradibus tribus fere aut qua. tuor ascendatur. Ex his lacubus canales structi, vel tubi - fictiles circa extremos parietes currant, et subjectis lateri suo doliis per vicinos meatus manantia vina defundant. Si copia major est, medium spatium cupis deputabitur, quas, ne ambulacra prolibeant, basellis altioribus impositas, 
approcher librement. Si l'on destinc an eontrairc un emplacement séparé aux euves, cet emplacement sera, comme le fouloir, élevé sur de petites estrades, et consolidé par un pavé de terre cuite, afin que, si une cuve vient à fuir saus qu'on s'en apereoive, le vin épanché ne soit point perdu, mais qu'il soit recu dans la fosse qui sera au bas de ces estrades.

XIX. Non-seulement les greniers veulent absolument ètre du eóté du septentrion, mais leur position doit encore êtrc élevée, éloignée de toute lıumidité, ainsi que du fumier et des étables, fraielie, exposée au vent, et sèche. Il faut aussi les eonstruire avec toute l'attention nćcessaire, pour qu'ils ne puissent point se crevasser. On eouvrira donc à cet effet le sol entier de dalles de terre euite de deux pieds, ou plus petites, que l'on enfoneera dans un mortier de brique, en guise de pavé. Après quoi on établira des compartiments pour les différentes espèces de grains, si l'on est dans le eas d'espérer des récoltes abondantes. Si au contraire la stérilité de la terre ne promet pas de grandes récoltes, il faudra, ou diviser la totalité des greniers par des cloisons formées de claies, ou renfermer la récolte, si elle est absolument minee, dạns de petits paniers d'osier. Lorsque les greniers seront construits, on enduira leurs murailles de marc d'huile mêlé avee un torchis de boue, dans lequel, au lieu de paille, on fera entrer des feuilles d'olivier sauvage sèehes, ou des feuilles d'olivier franc; et lorsque cet enduit sera sec, on le recouvrira encore de lie d'huile, et on attendra qu'elle soit séchée pour y serrer le blé. Cette préparation est utile contre les eharanęons, et contre les autres animaux pernieicux aux grains. Quelquès personnes entremêlent

vel supra obruta dolia possumus collocare spatio inter se largiore distantes, ut, si res exigat, curantis transitus possit armitli. Quod si cupis locum suum deputabimus, is locus ad calcatorii similitudinem podis brevibus et te. staceo pavimento solidetur, ut etiam si ignorata se cupa diffuderit, lacu subdito excipiantur nou peritura vina quæ fluverint.

XIX. Situs horreorum quamvis ipsam septentrionis desideret partem, et superior et longe ab omni lumore et lotamine et stabulis ponendus est, frigidus, ventosus et siccus : cui providendum structura diligentia, ne rimis possit abrumpi. Solum igitur omne bipedis sternatur vel minoribus laterculis, quos suffuso testaceo pavimento debemus imprimere. Tunc divisas cellas (si magnus sperabitur seminum modus) grano cuique tribuemus. Et si terra pauperies minora promittit, vel craticiis podiis erunt discernenda granaria, vel viınineis vasculis reditus tenues colligemus. Sed factis granariis, amurca luto mista parietes limuntur; cui arida oleastri vel oliva folia pro paleis adjiciuntır : quo tectorio siccato, rursus amurca respergitur : qua ubi siccata fuerit, frumeuta coudentur. Hæc res gurgulionibus et cateris noxiis auimalibus inimica est. sliqui coriandri folia frumentis miscent ad servandum avee le blé, afin qu'il se garde, des feuilles de coriandre; mais il n'y a rien de plus favorable à sa eonservation que de le rafraîchir pendant quelques jours, en le transportant de l'airc dans un autre endroit voisin, pour ne le porter que par la suitc au grenier. Columelle prétend qu'il ne faut pas éventer lc blć, parec qüil arrive de là que les animaux pénétrent plus facilement dans le tas entier; au lieu que si on ne l'agrite pas, ils s'arrêtent à la superficie, et n'y pénètrent pas à plus d'ine palme de profondeur; de sorte qu'ils u'en gâtent que cette espèce de eroûte, et que le reste se conserve intact. Le même auteur assure eneore qu'il ne peut pas s'y engendrer d'animaux pernieieux au delà de cette épaisseur. De I'herbe aux moucherons, seehe, étendue sous le blé, lui procure une longue durée, à ee qu'assurent les Grees. Au reste, le vent du Midi ue doit jamais douner sur les greniers.

$\mathrm{XX}$. Le eellier à l'huile sera exposé au midi et protégé eontrc le froid, de façon que le jour n'y pénètre qu'à travers les transparents des fenêtres. Moyennant eette préeaution, lc grand froid II'y retardera pas le travail d'hiver, et le pressurage des olives s'y trouvera facilité par une elıaleur modérce, sans que l'huile fige jamais. C'est à l'usage que l'on a l'obligation de la forme des trapétes, des roulettes, et de l'arbre du pressoir. Les réeipients de l'huile seront toujours propres, de peur que la nouvelle n'y eontraete un goût de rance par le séjour de l'aneienne. Pour' plus de sûreté, on pratiquera sous le planeher des conduits de chaleur, dont le eontact purifiera le eellier sans fumée; ce qui n'est pas moins à redouter pour la eouleur et la saveur du fruit.

XXI. Quoique les étables des chevaux ou des

profutura. Nihil tamen diu custodiendis frumentis com. modius erit, quam si ex areis in alterum locum vicinun. transfusa refrigerentur aliquantis diebus, atque ita lıor. reis inferantur. Negat Columella ventilanda esse frumenta, quia magis miscentur animalia totis acervis. Qure si non moveantur, in summitate intra mensuram palmi subsistent, et loc velut corrupto corio cxtera illaesa dura. bunt. Asserit idem, noxia auimalia ultra prodictum mensuram non posse generari. Herba conyza sicca (ut Gracei asserunt) substrata frunentis, addit atati. Ab horreis. tamen auster debet csse aversus.

XX. Olearis cella merillianis sit objecta partibus, et contra frigus munita, ut illi per specularia debeat Innen. admitti. Ita et operas, qua lieme fıtıræe sunt, unllus algor inpediet : et oleun cum premetur, adjutun teporibus, frigo'e non ralelvit astringi. Trapetis, et rotulis et prolo nata est forna, quam consuetudo dictavit. Rece. ptacula olei semper munda sint, ne uovos sapores infecla veteri rancore corrumpant. At si quis majori diligentix studet, subjectis linc, inde cuniculis paviinenta suspeldat, et ignem suggerat fornace succensa. Ita purus caler olei cellam sine fumi nidore vaporabit, quo sape infectuin, colore corrumpitur et sapore. 
boeufs doivent être exposées au midi, elles doivent eependant avoir aussi du côté du nord des fenêtres que l'on tiendra fermées pendant l'hiver, atin qu'elles n'incommodent point les animaux, et (que l'on ouvrira pendant l'été pour les rafraî. eliir. Ces étables seront élevées au-dessus du sol, pour préserver les cornés de leurs pieds de l'humidité. Les bœufs se porteront mieux quand ils seront dans le voisinage de l'âtre, et qu'ils verront la lumière du feu. Huit pieds d'espace suffisent à une paire de bœufs lor'squ'ils se tiennent debout, et quinze, lorsqu'ils sont couehés. Les écuries seront planchéiées en chêne, sur quoi on étendra de la litière, afin que les chevaux aient à la fois une couche molle sous leurs flanes et un sol ferme sous leurs pieds.

XXII. La cour s'étendra vers le midi, et sera exposée au soleil, afin que la chaleur s'y fasse sentir plus aisément pendant l'hiver aux animaux qui la fréquenteront. II faudra aussi, pour modérer la grande chaleur de l'été, préparer à ces animaux des espèees d'auvents fabriqués de fourehes, d'ais et de feuillages, et couverts de bardeaux ou de tuiles, si l'on en a; sinon, de glaieul ou de genet, ce qui simplifie la peine et la dépense.

XXIII. II faut ménager des retraites à la volaille vers l'extrémité des murs de la cour, parce que la fiente est très-nécessaire en agrieulture, à l'exception de celle des oies, qui est contrairc à toute végétation. Quant aux autres oiseaux, il leur faut néeessairement des asiles pour chaque espèce en particulier.

XXIV. Le colombier peut être placé au haut d'une tourelle, dans le corps de logis du proprićtaire. Les murailles en seront lisses et blanchies,

XXI. Stabula equorum vel houm, meridianas quidem plagas respiciant, non tamen egeant a septentrione lumiuibus, qua per hiemem clausa niliil noceant, per xstatem patefacta refrigerent: Insa stabula propter ungulas animalium, al) omni liumore suspensa sint. Boves nitiliores fient, si focum proxime labeant, et ignis lumen intendant. Octo peles ad spatium standi siugulis boum paribus abundant, et in porrectione xv. Plaucre roboreæ supponantur stationibus equorum cum stramine ut jacen. tibus molle sit, stantibus durum.

XXII. Cors ad meridiem pateat, et objecta sit soli, quo facilius hieme aliquem teporem concipiat, propter ea qua iusunt animalia, quibus etiam ad astatis temperandum calorem porticus furcis, asseribus, et froude formari debent, quar vel scandulis, vel ( $\mathrm{si}$ copia suppetit) tegulis, vel (si facilius et sine impensa placuerit) tegentur caricibus aut genistis.

XXIII. Circa parietes cortis extremos aviaria facienda sunt, quia stercus avium maxime necessariım est agricultura, excepto anserun latamine, quod satis omnibus inimicum est. Sed labilacula cxeterarum avium maxime necessario suut.

XXIV. Columbarium vero potest accipere sublimis una turricula in pretorio constitula, levigatis ac dealbatis pa- et on y pratiquera, suivant l'usage, sur les quatre côtés de très-petites fenêtres, par où les pigeons ne puissent entrer et sortir qu'un à un. Les nids serout faconnés sur les murs mémes dans l'intérieur du colombier. Les pigeons seront en sûreté eontre les fouines, pour peu que l'on jette parmi eux des branehes d'arbrisseau raboteuses et dégarnies de feuilles, ou une vieille bottine de genet qui aura servi à chausser des animaux, et pourvu que celui qui l'apporte soit seul, et n'ait été vu par personne. II n'en mourra ni ne s'en perdra, pour peu qu'on ait soin d'attacher à chaque fenêtro un paquet quelconque de la corde ou des liens d'un pendu. Ils y amèneront d'autres pigeons lorsqu'on les nourrira assidûment de cumin, ou qu'on leur humeetera le gousset de l'aile avee du baume. Ils pondront fréquemment, lorsqu'on leur donvera souvent à manger de l'orge grillée, ou des fèves, ou de l'ers. Au reste, il suffira, pour trente pigeons jouissant de leur liberté, de trois sextarii, soit de blé, soit de criblures, par jour, pourvu qu'on leur donne de l'ers pendant l'hiver pour favoriser leur ponte. Il faut suspendre en plusieurs endroits du colombier de petites branehes de rue, pour écarter les animaux qui leur sont nuisibles.

XXV. Au-dessous du colombier seront pratiquées deux cellules, dont l'une, étroite et obseure, servira à loger des tourterelles. Ces oiseaux sont très-aisés à nourrir, puisqu'il leur suffit d'avoir toujours pendant l'été, seulesaison où ils engrais sent comme il faut, du blé ou du millet détrempé dans de l'hydromel. Un semodius de cette mangeaille suffit par jour pour cent vingt tourterelles; mais leur eau doit être fréquemment renouvelée.

rietibus, in quibus a quatuor partibus, sicut mos est, fenestella brevissima fient, ut colımbas solas ad introitum exilumque permittant. Nidi figurentur interius. A mustelis tuta fient, si inter eas frutex virgosus sine foliis asper, vel vetus spartea projiciatur, qua animalia calceanfur, ut eam secreto non videntibus aliis, unus attulerit. Non pereunt, neque locum deserunt, si per omnes fenestras aliquid de strangulati hominis loro, aut vinculo, aut fune suspendas. Inducunt alias, si cumino pascantur assidue, vel setosi lirci alarum lualsami liquore tangantur. Foctus frequentant, si hordeum torrefactum, vel fabsm, vel ervum sape consumant. Triginta autem columbis volantibus diurni tres sextarii tritici sufficient, aut cretura, ita ut ervum foetus gratia mensibus probeamus liberuis. Rutx ramulos pluribus locis oportet contra animalia inimica suspendere.

XXV. Sed columbarii cella duo subjecta cubicula fant. Unum breve, et prope obscurum, quo turtures clandi possint, quos nutrire facillimum est. Nam nilil expetunt, nisi ut restate, qua sola maxime pinguescunt, triticum vel milium mulsa mareralum semper accipiant. Scmodius unus diurnus centum viginti turturibus sufficit. Aqua sine eis frequenter mundior debet offerri.

XXVI. Aliud vero cubiculum Iurdos nutriat. Qui si 
XXYI. L'autre cellule servira à nourrir des grives. En eugraissant ces oiseaux pour le temps où ils sont maigres en état de nature, on en fait un excellent manger, et l'on en tire un très-bon produit, car le luxe met du prix aux raretés. II faut que cette cellule soit propre, claire, et blen polie partout; on y fichera des perches en travers, sur lesquelles ces oiseaux pourront se reposer, et qui les empêehcront de voler. On y mettra aussi des branehages verts que l'on chanycra souvent. On donnera avec profusion à ces oiseaux des figues sèches pilées avec de la fleur de farine; et pour prévenir le dégoût, on leur donnera de temps en temps, si on est à portée de le faire, de la graine de myrte, de lentisque, d'olivier sauvage, de lierre, d'arbousier, et surtout de l'eau propre. On les renfermera au moment qu'ils auront été pris, pourvu qu'ils ne soient point blessés, et l'on mettra parmi eux d’autres grives que l'on aura élevées précédemment, et dont la compagnic consolera leur captivité, et les encouragera à prendre de la nourriture.

XXVII. Il n'y a point de femme, pour peu qu'elle soit intelligente, quì ne sache élever des poules. Il suffira d'observer, touchant ees animaux, qu'il leur faut du fumier, de la poussière et de la cendre. Les poules doivent être préférablement noires ou dorées, mais on se gardera d'en avoir de blanches. Le raisin les rend stériles. L'orge à demi euite les fait au contraire pondre souvent, et leur fait donner de plus gros œufs. Deux cyathi d'orge sont suffisants pour nourrir une poule qui a la liberté de eourir. Quand on donne des œufs à couver aux poules, il faut toujours les leur donner"en nombre impair, et dans le temps que la lune cro!̂t, c'est-à-dire, depuis son dixième jour jusqu'à son quinzième. Il arrive assez souvent qu'elles sont incommo-

alieno tempore saginentur, et voluptatem cibi, et reditum unasimum præstant, parcitati beneficium ministraute Iuxuria. Sit autem locus mundus et lucidus, et undique levigatus. Transversæ in hoc pertica figuntur, quibus possint post inclusum volatum sedere. Rami etiam virides sxpe mutentur. Caricæ tunsæ mistis pollinibus largissime prabeantur. Myrti etiam, si facultas est, lentisci, oleastri, edera, arluti semina interdum ad excludenda fastidia, et maxine aqua munda, præbeatur. Claudantur illæsi et recenter capti, mistis aliquibus ante nutritis, quorum societate ad capiendos cibos pavidam nora capti. vitatis moestitudinem consolentur.

XXVII. Gallinas educare nulla mulier nescit, quæ modo videatur industria. Hoc de his pracepisse sufliciat, ut fimo, pulrere utantur, et cinere. Sint pracipue nigrae aut Ilavi coloris, [sed] albse vitentur. Vinacex cibo steriles. cunt : ordeo semicocto et parere sæpe coguntur, et reddunt ova majora; duobus cyathis ordei bene pascitur una gallina, qux sit vaga. Supponenda sunt his semper ora nunıero impari, luna crescente, a deciula usque in quin- dées de la pépie, qui couvre l'extrémité de leur languc d'une pellicule blanche; auquel cas on arrache légèrement cette pellicule avee les ongles, et l'on met de la cendre sur la plaie; après quoi, lorsqu'clle est nettoyée, on y exprime du jus d'ail broyé. On peut aussi leur fourrer dans le gosier une gousse d'ail broyèe dans de l'huile. Il est encore bon de mêler continuellement de l'herbe aux poux dans leur nourriture. S'il leur arrive de manger des lupins amers, on en voit aussitôt la graine paraitre sous leurs yeux; et ce serait assez pour les faire mourir, si on ne l'en retirait pas, en leur perçant légèrement la peau avec une aiguille. Après eette opération, on leur bassine extérieurement les yeux, soit avec du jus de pourpier et du lait de femme, soit a vec du sel ammoniac mêlé en parties égales avec du miel et du cumin. Pour leur ôter la vermine, on prend de l'herbe aux poux et du cumin grillé en parties égales, que l'on broie ensemble dans du vin trempé avec de l'eal dans laquelle on aura fait bouillir des lupins amers; et on les fomente a vee le tout de façon à ce que la friction pénètre jusçu'à la raeine de leurs plumes.

XXVIII. Il est très-aisé de nourrir des paons, à moins que l'on n'ait à craindre les voleurs, ou les espèces ennemies de ces volatiles. Ils trouvent communément eux-mêmes leur nourriture et eelle de leurs petits en errant dans les champs, et se perehent le soir sur les plus hauts arbres. Il n'y a qu'une attention à avoir à leur égard, qui consiste à sauver du renard les femelles qui couvent, ee qu'elles font ordinairement dans les champs. Aussi a-t-on meilleure chance à les élever dans de petites iles. Cinq femelles suffisent à un mâle. Les mâles cassent leur's œufs et persécutent leurs petits, comme s'ils rien ètaient point les pères, jusqu'à ce que la crête qui les distingue des autres oiseaux leur soit venue. Ils

tamdecimam. Pituita his nasci solet, quæ alba pellicula lingıam restit extreman. Hace leviter unguibus vellitur, et locus cinere tangitur, et allio trito plaga mundata conspergitur. Item allii mica trita cum oleo faucibus inseritur : staphis agria etiam prodest, si cibis misceatur assidue. Si amarum lupinum comedant, sub oculis illis grana ipsa procedunt. Quæe nisi acu leviter apertis pelliculis auferantur, extinguunt. Oculos portulacæ succo forinse. cus, et mulieris lacte curemus, rel Amuroniaco sale, cui mel et cyminum æquale miscentur. Pediculos earum perimit staphis agria, et torrelactum cyminum pari pondere et pariter tunsa cunı vino, et amari lupini aqua si penetret secreta pennarum.

XXVIII. Pavones nutrire facillimum est, nisi fures aut animalia inimica formides; qui plerumque per agros vagantes sponte se pascunt, pullosque elucant, et altissimas vespere arbores petunt. Una [vero] his cura debetur, ut incubantes per agrum foeminas, que hoc passim faciunt, a vulpe custodias. Ideo in insulis brevibus meliori sorte nutriuntur. Uni masculo facmina quinque sufticiuut. 
commencent à être en chaleur aux ides de février. Des fèves légèrement grillées les excitent à l'amour, pourvu qu'on les leur donne tièdes tous les cinq jours. Il suffira d'en donner six cyathi à chaque paon. Toutes les fois que le mâlc recourbe autour de son corps la queue brillante donț il est revêtu, et qu'il étale l'extrémité de ses plumes garnies d'yeux, en courant et en jetant un cri aigu, c'est une preuve qu'il désire la femelle. Si l'on fait couver des œufs de paonnes à des poules, les mères que l'on exemptera par là de couver pourront pondre trois fois par an. Leur première ponte est communément de cinq œufs, la seconde de quatre, et la troisième de trois ou de deux. Mais quand on suit, la méthode de faire couver des œufs de paonnes par des poules, il faut des poules de choix. On leur donnera neuf œufs à couver pendant neuf jour's, à dater de celui ou la lune commencera à croitre, savoir, cing de paonnes, et les autres de poules. Le dixième jour on retirera tous les oufs de poules, et on cil remettra autant de nouveaux, afin que ces derniers œufs de poules puissent éclore avec ceux de paonnes au trentième jour de la lune, c'est-à-dire, trente jours pleins après le dépôt des premiers. On aura soin de retourner souvent avec la main les oufs de paonnes qui seront sous les poules, parce que celles-ci auraient de la peine à s'acquitter elles-mêmes de ce soin. On les marquera aussi d'un côté, pour se rappeler qu'on les aura retournés successivement. Il faut cependant choisir pour cette opération de très-grandes poulcs, parce que, si elles étaient petites, il faudrait leur donner moins d'œufs à couver. Si l'on veut transporter les paonneaux éclossous plusieurs poules auprès d'une seule qui leur servira de nour.

Masculi ova et pullos suos persequuntur velut alienige. nas, priusquam illis cristarum nascatur insigne. A b idib, Februariis calere incipiunt. Faba leviter torrefacta in libidinem provocantur, si eis quinto quoque die tepida proheatur. Sex cyathi uni sufficiunt. Cupidinem coeundi masculus conlitetur, quoties circa se amictum caulạe genımantis incurvat, et singularum capita oculata peına. rum locis suis exeril cum stridore procurrens. Si ova pavolum gallinis supponantur, excusatæ matres ab incuhatione tribus vicihus per annum foctus edunt. Prinns partus quinqque ovorum, secundus quatuor, tertius trium vel duorum esse consuevit. Sed electa, si hoc placuerit, nu. trices gallinx sint, qua a primo incremento lunx novem diebus lıabeant novem ova supposita, quinque pavonina, et cxtera sui generis. Decima die [ova] omnia gallinacea subtrahantur, et alia ilem gallinacea totidem recentia supponantur, [quot ablata sunt,] ut trigesima luna, lioc est expletis triginta diehus, possint cum pavoninis oris aperiri. Ova auteu pavonum, qua galliux subjecta sunt, sape manu convertantur, quia hoc ipsa facere vix valelit. Unam partem ovi notalis, ut te subinde convertisse cognoscas. Majores tamen gallinas oportet eligere; nam minorihus pauciora suppones. Natos [antem pullos] si ad rice, Columelle prétend qu'il suffit, dans ce cas, de lui en donner vingt-cinq : pour moi, il me semble que, si l'on veut qu'ils soient bien ćlevés, il suffit de lui en donner quinze. On donnera les premicrs jours aux paonneaux de la farine d'orge arroscé de vin, ou unc bouillie de quelque subs. tance végétale que ce soit. On y ajoutera par la suite des poireaux hachés, ou du fromage nouveau qui soit bien égouté, parce que le petit lait leur est contraire. On peut aussi leur donner des sauterelles auxquelles on aura arraché les pattes. C'est ainsi qu'il faut les nourrir jusqu'à l'âge de six mois : passé ce temps, on pourra leur donner habituellement de l'orge. Cependant on peut les envoyer en toute sûreté aux champs dès le trentccinquième jour après leur naissance, pour y chercher leur páture dans la compagnie de leur nourrice, qui les rappellera à la métairie par ses gloussements. On les traite pour la pépie et les excès de nourriture de la même manière que les poules. C'est un temps de çrise pour eux lorsque leur crête commence à pousser, car ils sont alors en langueur, ni plus ni moins que les enfants dans le temps que leurs petites dents travaillent à percer leurs gencives gonflées.

XXIX. II faut avoir soin, quand on veut élever des faisans, d'en avoir de jeunes qui puissent être féconds, c'est-à-dire de ceux qui seront nés l'année précédente, parce que les vieux ne peuvent jamais l'être. Les faisans recherchent la femelle au mois de mars ou d'avril. Deux femelles suffisent à un mâle, cet oiseau étant moins lascif que les autres. Les femelles pondent une fois par an. Leur poute se réduit ordinairement à vingt œufs. Les poules couveront ces œufs mieux que les faisanes elles-mêmes, pourvu qu'entre les

unam transferre a pluribus velis, dicit Columella uni nu. trici viginti quinque sufficere. Mili vero, ut bene educi possint, videntur qulndeciun satis esse. Primis diebus far ordei conspersum vino pullis dabitur, vel undecunque cocta pulticula et refrigerata. Postea adjicictur porrum concisum, vel caseus recens, sed expressus : nam scrum pulls nocet. Locustac etian pedibus ablatis prabentur. Ita pascendi sunt usque ad sertum mensem. Deinde or. deum poteris prabere solenniter. Trigesimoquinto tamen die poslquam nati sunt, etiam in agrum tuto ejici possunt comitante nutrice pascendi, cujus singultu revocantur ad villam. Pituitas vero et cruditates is renediis submovebis, quibus gallina curatır. Maximum illis periculum est, cum incipil crista produci : nam patiuntur languores intantum similitudine, cum illis tumentes gingivas denticuli aperire nituntur.

XXIX. In phasianis nutriendis hoc servandum est, it novelli ad creandos foxtus parentur, id est qui auno superiore sunt editi : veteres enim furcundi esse non possunt. Ineunt forminas mense Marlio vel Aprili. Duabus unus masculus sufficit, quia conferas aves salacitate non æequant. Semel in anno fotus creant. Viginti fere ovis pariendi ordo concluditur. Gallina his melius incubabunt, ita it 
œufs que l'on donnera à couver à une poule il n'y en ait que quinze de faisanes, et que les autres soient de poules. On observera, quant à la lune et aux jours, ce que nous avons prescrit par rapport aux autres volailles. Les petits écloront le trentième jour de l'incubation. On les nourrira pendant quinze jours de farine d'orge bouillie et tiède, arrosée de quelques gouttes de vin. Par la suite on leur donnera du froment concassé; des sauterelles et des œufs de fourmis. Il est constant qu'il faut les empẻcher d'approcher de l'eau, si l'on ne veut point que la pépie les fasse périr. Sils viennent à l'avoir, on leur frottera habituellement le bec avec de l'ail broyé dans de la poix liquide, ou bien on extirpera le mal par le même procédé que pour le's poules. La méthode pour les engraisser consiste à les renfermer pendant trente jours, et à leur donner, pendant tout le temps de leur réclusion, un modius de farine de froment pétrie en très-petites boulettes; ou, si l'on veut leur donner de la farine d'orge, il en faudra un modius et demi pour les engraisser complétement pendant le temps que nous venons de prescrire. Néanmoins, il faut avoir soin que les boulettes qu'on leur introduira dans le gosier soient graissées d'huile ${ }_{\xi}$ de crainte qu'elles ve s'arrêtent à la racine de leur langue, ce qui les ferait périr sur-le-champ. On aura aussi la plus grande attention à ne leur point donner de mangeaille nouvelle avant qu'ils aient digéré l'ancienne, parce qu'ils succombent très-facilement aux indigestions.

XXX. Sans herbe et sans eau, les oies ne profitent guère. Cet oiseau est pernicieux aux terrains ensemencés, parce qu'il nuit autant aux semences par sa morsure que par sa fiente. On tire un revenu de ses petits et de ses plumes, que l'on

quindecim plasianina ova nutrix una cooperiat, [et] ca. tera sui generis supponantur. In supponendo de luna et diebus qua suut in aliis dicta serventur. Trigesimus dies maturos pullos in lumen enittet. Sed per quindecim dies discocto ac refrigerato leviter ordei farre pascentur, cui vini imber aspergitur. P'ost triticum fractum prabebis et locustas et ova formica. Sane ab aquae prohibeantur accessu, ne eos pituta concludat. Quod si pituitau patientur phasiani, allio cum pice liquida trito rostra corum debebis assiduus perfricare, vel vitium, sicut gallinis lieri consuevit, auferre. Saginandi lıaec ratio est, ut unius modii trilicea farina in brevissimas offulas redacta clanso plıasiano per $x x x$ dies minisirata sulficiat : vel, si ordea. cean farinam prabere volueris, unius et semissis modii farina per praslictos dies saginam replebit. Observandum sane est, ut ofrulie ipsie oleo levigentur asperso, et ita inserantur faucilus, ne sub infina lingux parte mergantur : quorl si evenerit, statim pereunt. Illud quoque magnopere curemus, uc prabeantur nova alimenta, nisi digestis aliis; quia eos facillime onus cibi lıarentis extinguit.

XXX. Anser sane nec sime herba, nec sime aqua facile arrache dans l'automne et au printemps. Trois femelles suffisent à un mâle. S'il n'y a pas de rivière dans l'endroit où on les élève, on leur fera une mare d'eau; et si l'on manque d'herbes, on sèmera pour leur nourriture du trèfle, du fenugrec, de la chicorée sauvage et de petites laitues. Les oies blanches sont les plus fécondes; les mélangées ou les brunes le sont moins, parce qu'elles ont passé du genre sauvage à l'état de domesticité. Elles couvent depuis les calendes de mars jusqu'au solstice d'été. Elles pondront davantage si l'on prend des poules pour couver. Nous permettons cependant aux mères désormais hors d'âge d'élever les petits de leur dernière ponte. Lòrsqu'elles sont prêtes à pondre, on les conduit à leur logette; et pour peu qu'on l'ait fait une seule fois, elles conserveront l'habitude d'y aller d'elles-mêmes. On fait couver aux poules des œufs d'oies de mème que des œufs de paonnes ; mais on met des orties sous ceux d'oies, de peur qu'ils ne soient endommagés. II faut nourrir les oisons dans leur logette les dix premiers jours après leur naissance. Passé ce temps, on pourra les en faire sortir par un temps serein, pour les mener dans des endroits où il n'y ait point d'orties, parce qu'ils en redoutent les piquants. On les engraisse très-bien à l'âge de quatre mois, parce qu'ils engraissent mieux quand ils sont dans un âge tendre. On leur donnera à cet effet de la bouillie trois fois par jour. On les empêchera de circuler, en les renfermant dans un lieu obscur et chaud. En suivant cette méthode, les plus vieilles mème ellgraisseront en deux mois, car les jeunes souvent sont grasses dès le trentième jour. On les engraissera encore mieux en leur donnant du millet trempé dans de l'eau, tant qu'elles en voudront. On peut

sustinetur : locis consitis inimicus est, quia sata et morsu ladit et stercore polluit : pullos præstat et plumas, quas et antumno vellamus et vere. Uni masculo tres forminæ sufficiant. Si desit fluvius, lacuna formetur. Si herba non suppetit, trifolium, fienum Græcum, agrestia intuba, lactuculas sereıus alimento. Alibi forcundiores sunt; varii vel fusci, minus : quia de agresti genere ad domesticum transierunt. Incubant a calendis Martii usque ad astivum solstitium. Plus parient, si gallinis ova supponas. Extremum partum matribus jam vacaluris educare permittimus. l'aritura ad haram perducantur. Cun semel lıoc feceris, consuetudinem sponte retinebunt. Gallinis sicut paronina etiau auseris ova suppouas. Sed anserina ova ne noceantur, suppositis subjiciatur urtica. Parvi semine papaveris primis decem dieluus intus pascendi sunt, postea sereno eos poterimus edncese, ubi urtica non fuerit, cujus aculeos formidant. Quafuor meusium bene saginantur: nam melius pinguescunt iu tenera ætate. Polenta dabitur in die ter. Large vagandi licentia prolnibetur. Loco obscuro claudentur et calido : sic majores etiam secuudo meuse pinguescunt. Naun parvuli sape die trigesimo. Saginantur melius, si ad satietaten milium priebeanus infusum. 
méler toutes sortes de légumes dans lcur nourriture, à l'exception de l'ers. II faut aussi prendre garde que leurs petits n'avalcut des poils d'animaux. Les Grees, pour engraisser les oies, font détremper dans de l'eau chaude deux parties de gruau et quatre parties de son, et leur donncnt de cette nourriture à discrétion. Ils facilitent aussi leur engrais en les faisant boire trois fois par jour. Ils leur donnent méme de l'eau au milieu de la nuit. Mais si l'on veut que lcur foie s'attendrisse, on roulera en petites boulcttes des figues sèches broyées et trempées dans de l'eau, et on leur en donnera au bout de trente jours d'engrais, et cela pendant vingt jours consécutifs.

XXXI. Ces arrangements faits, on pourvoira au reste. En effet, il faudra encore avoir auprès de la métairie deux réservoirs d'eau creusés dans le sol ou taillés dans la pierre, qu'il soit facilc de remplir d'eau de fontaine ou de pluie. L'un servira aux bestiaux ou aux oiscaux aquatiques, et l'on mettra tremper dans l'autre les baguettes, les cuirs, Ics lupins, ct toutes les autres choses que les paysans sont dans l'usage de plonger dans l'eau.

XXXII. II n'importe en quelendroit on serrera le foin, la paille, le bois et les cannes, pourvu que cet endroit soit sec, ouvert à tout vent, éloigné de la métairie, dans la crainte du feu.

XXXIII. Lc tas à fumier doit avoir sa place dans un lieu très-humide, et qui soit hors dc la portée du corps de logis du propriétaire, à eause de la mauvaise odeur qu'il exhale. L'abondance de l'eau procurera au fumier l'avantage de faire mourir les graines d'épines qui pourront s'y trouver entremêlées. Le crottin d'âne est le prcmicr de tous les fumiers, surtout pour les jai-

Inter anserum cibaria legumen omne porrigi potest, cxcepto ervo. Cavendum est etiam, ne pulti eorum setas glutiant. Fracei saginandis anseribus polentac duas partes et furfuris quatuor aqua calida temperant, et ingerunt pro appetentis volunfate sumenda. Tribus per diem vieibus potu adjuvant. Media quoque noete aquam ministraht. P'eraetis vero $\mathrm{xxx}$ diebus, si ut jecur his tenerescat, optaluis, tunsas caricas et aq̨ua maceratas in offas volutabis exiguas, et per dies viginti continuos ministrabis anse. ribus.

XXXI. Ilis ordinatis, cæetera exequenda sunt. Nam piseinx dux rel solo impressa, vel caso lapide circa villam esse debehunt; quas facile est aut fonte ant imbre suppleri, ut una ex lis usui sit pecoribus vel avibus aquatieis : alia madefaeiat virgas et coria el lupiuos, et si qua rusticitas eonsuevit infundere.

XXXII. Foeni, palearum, ligni, cannarum repositiones uil refert in gua parte [fiant,] dummodo sicce sint atque perllabiles, et longe removeautur a villa propter casum surripientis incendii.

XXXIII. Stercorum cougestio locim summ tenere debebit, qui abundet lumore, et propter odoris loorenda a pretorii avertatur aspectu. Humor abundans hoc pras- dins. Vient ensuite celui des brebis, des chèvres et des bêtes de somme; mais la fiente de porc est le pire de tous. La cendre est un excellent fumier. Quoique la fiente de pigeon soit le fumier le plus chaud, celle des autres oiseaux ne laisse pas d'avoir son mérite, si l'on en excepte les oiseaux de marais. Un fumier qui aura pourri pendant une année sera bon pour les terres ensemencées, et n'engendrera point d'herbes; plus vieux, il serait moins bon. Un fumier nouveau sera excellent pour faire foisonner les herbes dans les prés. Les immondices de la mer lavées dans de l'eau douce et mêlées avee d'autres ordures tiendront aussi lieu de fumier. Il cu est de même du limon qu'auront déposé les eaux de source ou les rivières en débordant.

XXXIV. Les jardins et les vergers doivent être très-près de la maison. Il faut que le jardin soit précisément au-dessous du tas à fumier, dont le suc seul le fertilisera, et très-éloigné de l'aire, parce que la poussière de la paille lui serait pernicieuse. Un terrain plat, légèrement incliné et arrosé par une eau courante, qui se partage cn differents bras, est une heureuse position pour un jardin. Si l'on n'a pas d'eau de source, il faut ou creuser un puits en terre, ou, si l'on ne peut pas y parvenir, construire à la superficie un réservoir que la pluie fournira d'eau, afin que le jardin puisse être arrosé pendant les grandes chaleurs de l'été. A défaut de toutes ces ressources, labourez à trois ou quatre pieds au moins de profondeur, commedans une terre qu'on façonnerait au pastinum. Le jardin qui aura reç cette façon est a l'épreuve de toutes les sécheresses. Quoique toutes les espèces de terre conviennent à un jardin, pourvu qu'elles soient aidées de fumier à propor-

tabit stercori, ut siqna insunt spinarum semina, putrefiant. Stercus asinorum primum est, maxime lortis; dein ovillum et caprinum et jumentorum; porcinum vero pessimum : cineres optimi; sed columbinum fervidissimum, exterarumque avium satis utile [est] excepto palustrium. Stercus, quod anno requieverit, segetibus utile est, nec herbas creat : si vetustius sit, minus proderit. Pratis vero recentia stercora proficient ad uber herbarum. Et maris purgamenta, si aquis duleibus eluantur, mista reliquis vicem stercoris exhibebunt, et limus, quem scaturiens aqua vel fluvii incrementa respuerint.

XXXIV. Horti et pomaria donıi proxima esse debebunt. Hortus sit sterquilinio maxime subjectus, cujus eum succus sponte focundet. Ab area longe situs [sit.] Nam pulverem palearum patitur inimicum. Felix positio est, cui leniter inclinata-planities enrsus aqua fluentis per spatia discreta derivat. Si fons desit, aut imprimendus est puteus : aut, si uequeas hoe, piseina superius construenda est, ut illiuc aquas pluvia conferente, hortus per astivos rigetur ardores. Si liac omui facultate carueris, semper altius tribus vel quatuor perlibus ad pastini sintilitudinem fodies hortulum, qui sie enitus negligit siecitat's. Sed luic quamvis contra necessitatem nista stercore 
tion de leur besoin, il en est cependant telles espèces qu'il faut èiter dans le clioix, telles que la craie que nous nommons argile, et la terre rouge. On aura aussi l'attention de distribuer en deux portions les jardinsqui n'auront point la ressource d'une humidité naturelle, et d'exposer au midi celle que l'on voudra cultiver en hiver, au nord celle que l'on voudra cultiver en été. Les jardins doivent de plus être fermés; mais il y a plusieurs facons de les enclore. Les uns renferment de la vascentre deux planches qui lui servent de moule, et font ainsi des murs qui ressemblent à ceux de briques. Ceux qui en ont le moyen construisent des murailles de mortier et de pierres. Le plus grand nombre emploie des pierres régulièrement superposées, en se passant de mortier. Quelquesuns entourent de fossés le terrain qu'ils veulent cultiver. Mais c'est une méthode qu'il faut éviter, à moins que le terrain ne soit marécageux, parce que ces sortes de fossés attirentà eux toute l'humidité du jardin. D'autres font des haies avec de l'épine de plant ou de semence sur les borảs du jardin, pour lui scrvir de rempart. Mais le meilleur procédé est de se procurer de la graine de ronce ou d'églantier quand elle est mûre. On la mêle arec de la farine d'ers détrempée. On couvre ensuite de cette préparation de vieux cordages de genêt d'Espagne, de façon que eette graine pénètre l'intérieur de ces cordages et s'y conserve jusqu'au commencement du printemps. Alors on creuse, dans l'endroit où l'on veut former une haie, deux tranchées d'un pied et demi de profondeur, éloignées l'une de l'autre de trois pieds, puis on étend au fond de chacunc de ces tranchées les cordages saturés de leur graine, et on les recouvre légèrement de terre. Par ce moyen les pousses paraitront le trentième jour, ct, tant

qualibet terra conveniat, tamen hrec genera sunt in elec. tione vitanda, creta, quam argillam dicimus, atque ru. brica. Illud quoque custodies in liortis, quos humoris natura non adjuval, ut dividas per partes, et lieme ad meridiem, astate ad septentrionem spatia colenda convertas. Debent etiam liorti esse clansi : sed ununitionis ınulta sunt genera. Alii luto inter formas clanso parietes figuralos ex lateribus imilanlur. Quibus copia suppelit, macerias luto et lapide excitaut. Plerique sine lutocon. gesta in ordiuen saxa componunt. Nonnulli fossis spatia colenda pracingant : quod vilandum est, quia lıorto sulpducit lunores, nisi forte locus palustris colatur. Alii spinarum plantas et sentina in munitione disponumt. Sel melius erit rubi semina et spiua:, qux rubus cauinus vocatur, matura colligere, et cum farina ervi ex aqua macerata miscere. Funes deluinc sparteos veteres hoc genere Inistionis sic inducere, ut intra funes semina recepta serventur usque ad verni temporis initia. Tunc ubi sejes futura est, duos sulcos trubus a se pedibus separatos, sesquipedis altitudine facienus, et per utrosque, funes cun seminibus obruemus levi terra. Ita trigesina die proce. dunt sentes, quos teneros adıniniculis opus est adjuvare, qu'ellesseront jeunes, il faudra faciliter leur croissance avec des appuis, qui serviront à les réunir dans Ics intervalles qu'elles n'auront point remplis. Tout jardin doit être divisé en deux parties: l'une qu'on ensemence en automne et dont la terre doit être remuéc dès le printemps; l'autrc qui doit être ensemencée au printemps et labourće en automne. Par là les deux labours seront mûris, l'un par le froid, l'autre par le soleil. Il faut faire les planches longues et étroites, e'est-à-dire, qui n'aient que six pieds de large sur douze de long, afin qu'on puisse les partager en deux, pour les purger des inauvaises herbes tant d'un cóté que de l'autre. Au reste, les bords en seront redressés à la hauteur de deux pieds dans les climats humides ou arrosés, au lieu qu'il suftira qu'ils soient élevés d'un pied dans les climats sees. Il faudra (si l'on est dans l'usage de faire couler l'eau sur les planches pour les arroser) que les espaces qui les sépareront soient plus élevés que la planche ellemème, afin que l'eau se rende plus aisément sur la planche lorsqu'elle viendra d'un lieu qui la dominera, et qu'après l'avoir bien abreurée, elle puisse être détournée sur d'autres planches. Quoique nous assignions par la suite les temps de chaque ensemencement mois par mois, chacun se réglera cependant surla nature du pays et du climat qu'il habite. L'ensemencement d'automne se fera de meilleure heure dans les pays froids que dans les pays chauds, et celui du printemps s'y fera plus tard; au lieu que l'ensemencement d'automne peut être fait plus tard dans les contrées chaudes, comme celui du printemps peut y être fait plus tôt. Il faut toujours semer pendant que la lune croît, et couper ou cueillir quand elle décroit.

XXXV. Remède contre les brouillards et contre

quibus inter se [sentes] per spatia vacua relicta jungentur. Partes sane horti sic dividendæ sunt, ut ex in quibus autumno seminabitur, verno tempore pastinentur : quas seminibus vere complebinus, autumni tempore debebinus effodere. Ita utraque pastinatio decoquetur beneficio algo* ris aut solis. Arex faciendx sunt angustiores et longa, id est duodecim pedum longitudine, et sex latitudine ut sint propter spatia utrinque purganda divisie. Margines vero earum locis hunidis vel irriguis duobus pedibus erigantur, siccis uno extulisse sufficiet. Inter areas, si luumor consuevit eflnere, spatia altiora ipsis areis esse debebunt, ut facilius ingrediatur aream de superiore parte lumor admissus, et ubi sitientem saturaverit, in alias possit exclusus averti. Serendi tempora licet per nienses certa signemus, tamen secundum loci et caeli naturam unusquise que custodiat. Frigidis locis autumnalis satio celerior fiat, verna vero tardior : calidis autem regionibus et autumualis. serior fieri potest et verna maturior. Qußcunque serenda sunt, cum luna crescit, seminentur : qua secanda sunt vel legenda, cum minuitur.

XXXV. Coutra nebulas et rubiginem. Paleas et purga. menta pluribus locis per lıortım disposita sinul omnia, 
la rouille : quand la brume paraít menacer, faites différents tas de toutes les pailles et immondices dispersées dans le jardiı, et mettez-y le feu. II y a de nombreux préservatifs contre la grêle, tels que d'envelopper une meule dans un inoreeau d'étoffe de couleur de rose; de lever contre le eiel, d'une faẹn menaçante, des haehes ensanglantées; d'entourer tout le jardin de couleuvrée; d'attacher un hibou les ailes ćtendues; de frotter de suif d'ours les instruments de fer avee lesquels on doit travailler. Il y a des personnes qui eonservent de la graisse d'ours battue dans de l'huile, et qui en frottent leurs serpettes avant de faire la taille. Mais cette pratique a besoin d'être tenue scerète, pour celui qui taille tout le premier. Au reste, l'on prétend que sa vertu est si grande, qu'en l'employant, on n'a rien à craindre des brouillards ni des inseetes. Le tout est d'y mettre du mystère; autrement le ebar'me est détruit. On répand du mare d'huile nouvelle ou de la suie prise aux voûtes, pour se débarrasser des moucherons et des limaçons. Préservatif contre les fourmis : si la fourmilière est dans le jardin même, on place auprès le cour d'un hibou; mais si les fourmis viennent du dehors, on trace une ligne autour du jardin avee de la cendre ou avec de la eraie. Préservatif contre les chenilles. On trempe dans du jus de joubarbe ou dans du sang de ehenilles les graines que l'on doit semer. Les poids chiches semés parmi les légumes leur servent de préservatif contre un grand nombre d'inconvénients. Il y a des personnes qui jettent sur les chenilles de la cendre de figuier, et qui sèment aussi ou du moins suspendent dans leur jardin de la scille. Quelques-uns, pour cearter les chenilles et autres insectes nuisibles, font faire le tour du jardin à une femme sans ceinture, les chevcux épars et les pieds nus, dans le temps de ses règles

cum nebulas videris instare, combures. Contra grandinem (multa dicuntur.) Panno roseo mola cooperitur. Item cruentxe secures contra cxelum minaciter levantur. Iten omne liorti spatium alha vite pracingitur : vel noctua pennis patentibus extensa suffigitur : vel ferramenta, quibus operandum est, sevo unguntur ursino. Aliqui ursi adipem cum oleo tusum reservant, et falces lıoc, cum putaturi sunt, ungunt. Sed lioc in occulto debet esse remediun, ut mullus putator intelligat : cujus vis tanta esse perlibetur, ut neque nebula neque aliquo animali possit noceri. (Interest etiam ut res profanata non valeat.) Contra culices et linaces vel amurcam recentem vel ex cameris fuliginem spargimus. Contra formicas, si in lıorto lıabent foramen, cor noctux admoveamus ; si foris veniunt, omne lıorti spatium cinere aut creta candore signemus. Contra erucas semina, quæ spargenda sunt, sempervivæ succo madefiant vel erucarum sanguine. Cicer inter olera propter multa portenta serendum est. Aliqui cinerem de fico super erucas spargunt. Item squillam vel in lıorto scrunt, vel certe suspendunt.|Ali|pui unulierem ınenstruantem, nusquan cinctau, solutis capillis, uulis pedibus
D'autres attachent avec des clous, en différents endroits du jardin des éerevisses de rivière. Préservatif eontrc les insectes qui nuisent aux vignes. On plonge dans de l'huile les eantharides qui se trouveut communément sur les roses, ct on les y laisse macérer. Ensuite, lorsque l'on veut tailler la vigne, on frotte de ectte huile les serpettes dont on doit se servir. On fait mourir les punaises, soit avec de la lie d'huile et du fiel de bœuf, dont on frotte les lits ou les autres endroits qui ensont infeetés; soit avee des feuilles de lierre broyées dans de l'huile, soit par l'odeur des sangsues brûlées. Pour empêcher que les légumes n'engendrent des animaux pernieieux, faites sécher dans l'éeaille d'une tortue toutes les graines que vous aurez à semer, ou bien semez de la menthe en plusieurs endroits de votre jardin, et partieulièrement entre les choux. On prétend qu'un peu d'ers semé, surtout dans les endroits oùil doit venir des radis ou des raves, produit le même effet. On dit eneore qu'en répandant sur les légumes de fort vinaigre mêlé avee du sue de jusquiame, on fait mourir les pucerons dont ees légumés sont infeetés. On dit aussi quon ehasse les chenilles en brûlant par tout le jardin des tiges d'ail sans têtes, et en en promenant çà et là les fumigations. Si l'on veut garantir les vignes de ees animaux, on prétend qu'il faut frotter les serpettes avec de l'ail broyé. 0 n les empêehe aussi de pulluler en aliumant du bitume et du soufre autour des trones d'arbres ou des pieds de vigne, ou en faisant bouillir dans de l'eau des ehenilles prises dans le jardin voisin, et en arrosant ensuite le sien avee eette eau. Pour empêcher les eantharides de faire tort aux vignes, il faut en écraser sur la pierre qui sert à aigulser les serpettes. Démocrite assure qu'aucune bête ne pourıa nuire aux arbres ni à telle semence que ee soit, si

contra erucas et cetera hortum faciunt circumire. Aliqui fluviales cancros pluribus locis intra lıortum clavis figunt. Contra animalia qua vitibus nocent, cantharides, quas in rosis invenire consuevimus, oleo mersas resolvi patie. ris in tabem : et cum putandæ sunt vites, hoc oleo falces [putatorias] perunges. Extinguuntur cimices amurca et felle bubulo lectis aut locis perunctis, vel foliis ederæ tritis ex oleo, vel incensis sangnisugis. Ut olera animalia infesta uon generent, in corio testudinis omuia semina, qua? sparsurus es, sicca : vel mentam locis pluribus, maxime inter caules, sere : hoc prastare fertur ervum aliquantulum satun, procipue ubi radices et rapa nascuntur. Vel acre acet un succo hyoscyami mistum fertur olerum pulices necare, si spargas. Campas fertur evincere, qui fusticulos alii sine capitibus per horti omne spatium comburens nidorem locis pluribus excitarit. Si contra easdem vitibus voluerimus consulere, allio tito falces putatorix feruntur unguendx. Nasci quoque prohibentur, si circa arlorum vel vitium crura bitumen et sulfur incendas : vel si allatas do horto vicino campas excoquas aqua, el per horti tui spatia universa diffundas. Ne cautlıarides vitibus noceant, in 
l'on met dans un vase de terre cuite, plein d'eau et couvert, une grande quantité d'éerevisses de rivière, ou au moins dix de celles de mer, que les

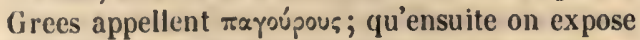
le vase en plein air; pendant l'espaee de dix jours, soumis à l'action du soleil, et qu'on arrose de cette eau tout ce que l'on voudra conserver intact; en répétant la même opération tous les jours, jusqu'ì ce que les plantes que l'on veut avoir soient venues, et qu'elles aient acquis une eertaine force. On chasse les fourmis en versant de l'origan et du soufre broyés sur l'ouverture de la fourmilière. Cette préparation nuit également aux abeilles. On obtient le même résultat en brùlant des coquilles de limacons vides, et en bouchant les trous avec leurs eendres. On met en fuite les moueherons en jetant sur eux du galbanum ou du soufre, ainsi que les pueerons en répandant sou vent sur le pavé du mare d'huile ou du eumin sauvage broyé dans de l'eau, ou de la graine de coneombresauvageseulement infusée, ou de l'eau dans laquelle on aura fait tremper des lupins mélés avec de la couleuviée blanehe amère. Mettez dans un plat du marc d'huile bien épais : la nuit, les rats s'y prendront comme at piége. Saturez d'ellébore noir un moreeau de fromage ou de pain, une certaine quantité de graisse ou de pâte; ce sera pour eux un poison. A pulée prétend qu'on préserve les graines des mulots en les faisant macérer dans du fiel de bœuf avant de les jeter en terre. Quelques personnes bouchent les trous de ces animaux avec des fleurs de laurier-rose, afin qu'après les avoir rongées, ils meurent des efforts qu'ils font pour sortir. Voiei eomment les Grees font la chasse aux taupes. Ils font pereer une noix ou toute autre espèce de fruit également solide, qu'ils remplissent de paille et de eire mêlées avec du soufre; après quoi ils font boucher bien exaetement tous les petits passages des taupes et tous les conduits d'air extérieur, à l'exception d'un seul qui soit large, et à l'entrée duquel ils font mettre cette noix, laquelle est allumée en dedans, de façon qu'elle puisse recevoir d'un cóté le vent qu'elle transmettra de l'autre eòté; moyeunant quoi les trous se trouvant remplis de fumée, les taupes s'enfuient aussitôt, ou meurent. Si l'on remplit de eendre de chêne les ouvertures des trous des rats sauvages, ils gagneront la gale à force de toucher souvent à cette eendre, et finiront par périr. On met les serpents en fuite a vec presque toute sorte de matières amères; et toute fumée de mauvaise odeur est bienfaisante, en ce qu'elle préserve de leur souffle pernicieux. Brûlons done du galbanum, ou du bois de cerf, ou des raeines de lis, ou la corne du pied de chèvre : ce sont toutes matières qui écartent ces monstres venimeux. Les Grees imaginent que lorsque des nuées de sauterelles s'élèvent tout à coup, il pourra arriver qu'elles passeront sans eauser de dommage, si tout le monde se tient caché dans la maison, et que quand même les gens seraient en plein air lorsqu'ils les observeront, elles ne nuiront néanmoins à aucun fruit, pourvu qu'on se retire aussitôt tous à la maison. On dit aussi qu'un moyen sûr pour les ehasser est de verser de l'eau dans laquelle on aura fait bouillir des lupins amers ou des concombres sauvages, en la mêlant avec de la saumure. Quelques personnes pensent qu'on peut mettre en fuite les sauterelles ou les seorpions, en brûlant quelquesuns de ces animaux au milieu de leurs semblables. D'autres combattent les chenilles avec de la cendre de figuier. Si ce moyen ne réussit pas, on en fait.bouillir quelques-unes dans de l'urine de cote, qua falces acuuntur, ipsæx sunt conterendic. Demncritus asserit neque arboribus neque satis quibuslibet noceri posse a quibuscunque bestiis, si fluviales cancros plurimos vel marinos, quos Græeci rayoúpous nominant, non minus quam decem fictili vasculo in aqua missos tegas, et sub dióstaluas, ut decem diebus sole vaporentur. Post. ea quxcunque illæesa volueris esse, [ea aqua] perfundas, et octonis diebus peractis lioc repetas, donec solide, qure optareris, adolescant. Formicas abiges, si origano et sulfure tritis foramen asperges. hoc et apibus nocet. Iteun coclitearum vacuas testas si usseris, et co cinere foramen inculces. Culices galbano infuso fugantur aut sulfure. $\mathrm{Pu}$ lices amurca per pavimentum frequenter aspersa, vol cymino agresti cunı aqua trito, vel si cucumeris agrestis semen aqua resolutum sxpe infundes, vel aquam lupinorum psilotri austeritatibus junctam. Mures, si amurcam spissam patinx iufuderis, et in domo nocte posucris, ad. laerebunt. Item necabuntur, si lielleboro nigro caseum vel panem vel adipes vel polentam permisceas et offeras. Et agrestis cucumeris et colocynthidis suffusio sic nocebil. Alversus muses agrestes Apuleius asserit semina bubulo felle macerauda ante (quam spargas. Nonnulli rhododaplınes foliis aditus eorum claudunt, qui rosis his, dum in exilu nituntur, intereunt. 'Talpas Græci looc genere persequuntur : Nucem perforari jubent, vel aliquod pomi genus so. liditatis ejusdem. Ibi paleas et cedrian cum sulfure sufficienter includi. Tunc omnes parvulos aditus et reliqua spiramenta talparuin diligenter obstrui, unum foramen, quod amplius sil, reservari, in cujus aditu nucem intus incensam sic poni, ut ab una parte flatus possitaccipere, quos ab alia parte diffundat: sic impletis fumo cuniculis talpas vel fugere prolinus, vel necari. Mures rusticos, si querneo cinere aditus eorum satures, atlaclu frequenti scabies occupabil ac perimet. Serpentes prope omni austeritate fugantur, et nocentes spiritus innocentia fumi graveolentis exagitat. Uramus galbanum vel cervi cornua, radices lilii, capro ungulas. IIoc genere monstra noxia prohilbentur. Opinio Grecorum est, si nubes: locustarum repente surrexerint, latentibus intra tecta cunctis hominibus, eam posse transire : quod si inobservantes lıomines sub aere deprehıendant, nulli fructıum noceri, si continuo om. nes ad tecta confugiant. Pelli eliam dicuntur amari lupini vel agrestis cucumeris aqua decocta, si murix mista funila. tur. Existimant aliqui locustas vel scorpios fugari posse, 
bœuf et du mare d'huile mêl's ensemble par parties égales ; et lorsque eette liqueur est refioidie, on en arrose tous les légumes. Les Grees

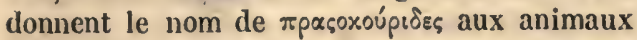
qui eausent ordinairement du dommage dans les jardins. Il faudra couvrir légèrement de terre, dans l'endroit où ces animaux se seront le plus multipliés, le ventricule d'un mouton à l'instant qu'il aura été tué, et sans le vider. Deux jours après, on y trouvera ces animaux rassemblés par tis; et, pour peu que l'on répète cette opération deux ou trois fois, on détruira toutes ces espèces malfaisantes. On croit qu'on peut se garantir de la grêle en portant autour de ses domaines une peau de crocodile, ou d'hyène, ou de veau marin, et en la suspendant à l'entrée de la métairie ou de la cour, lorsque le fléau paraitra imminent. On prétend aussi que sl l'on se promène dans les vignes en portant dans la main droite une tortue de marais renversée sur le dos, qu'à son retour on la pose à terre dans la même situation, en remplissant la concavité de sa carapace de mottes de terre, pour l'empêcher de se retourner et la foreer de rester couchée sur le dos, les nuées les plus dangereuses ne feront que passer sur l'endroit muni de ce préservatif. Il y a des personnes qui, aussitôt qu'elles se voient menacées de ce péril, reçoivent l'image de la nuée dans un niroir qu'elles lui présentent en face, et viennent à bout de la détourner par ce moyen (soit que le nuage se déplaise à voir se réfléehir sa figure, soit qu'il pousse plus loin, croyant la place occupée par son double). On croit aussi qu'une peau de veau marin, jetée sur un petit cep au milieu d'un vignoble, a quelquefois préservé le vignoble entier des accidents qui le menaçaient. On prétend que toutes les semences d'un jardin ou d'un champ sont d̀ l'abri de tout accident ei de toute bête malfaisante, lorsqu'on les a fait macérer, avant de les jeter en terre, avec des rilcines de concombre sauvage broyées. II faut aussi mettre dans son jardin le crâne d'une cavale quí ait souffert les approches de l'étalon, ou mêne celui d'une ânesse, parce que l'un et l'autre pas. sent pour féconder par leur présence tout es qui les environne.

XXXVI. L'aire doit être voisine de la métalrie, tant pour faciliter le transport du blé, qu'afin de le mettre plus à l'abri de la fraude; parce qu'on supposera que le maître ou l'agent ne sont pas loin. Il faut que le sol en soit pavé de cailloux, ou qu'elle soit taillée dans le roe, ou que ce soit un terrain qui ait été affermi, vers le temps où le blé doit être battu, tant par les pieds des bestiaux que par l'eau dont on l'aura imbibé. Elle doit de plus être close et munie de forts barreaux, à cause des bêtes de somme qu'on y fera entrer dans le temps où l'on battra le blé. Il faut avoir dans son voisinage un autre terrain plat et bien découvert, daus lequel on puisse transporter les blés pour y prendre l'air avant d'être serrés daus les greniers; précaution utilepour qu'ils se gardent longtemps. On pratiquera aussi auprès de l'aire, n'importe de quel côté, surtout dans les contrées humides, un couvert sous lequel on mettra les blés à la hâte, dans le cas de pluies imprévues ( $s i$ la nécessité y contraint), battus ou à moitié battus. Quant à l'aire elle-même, elle sera placée dans un lieu élevé, et où le vent donne de tous les côtés; pourvu néanmoins qu'cllesoit éloignée des jardins, des vignes et des vergers, paree que, si le fumier et la paillesont utiles aux racines des arbrisseaux, d'un autre côté, lorsque ces matières s'attachent á leurs feuilles, elles les percent ct les dessèchent. si aliqui ex eis urantur in medio. Campas nonnulli ficulneo cinere persequuutur. Si permanserint, urina bubula et a. murca: equaliter mista conferveant, et ubi refrixerint, olera

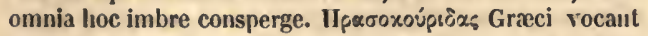
animalia, quæ solent hortis nocere. Ergo ventriculum vervecis statim occisi plenum sordibus suis spatio, quo abundant, leviter debebis operire. Post biduum reperies ibi animalia ipsa congesta. Iloc cum bis vel tertio feceris, genus omne, quod nocehit, extingues. Grandini creditur obviare, si quis crocodili pellem vel lıyænæ vel marini vituli per spatia possessionis circnmferat, et in villa aut cortis suspendat ingressu, cum malum viderit imminere. Item si palustrem testudinem dextra manu supinam ferens vineas perambulet, et reversus eodem modo sic illam ponat in terra, et glebas dorsi ejus objiciat curvaturæ, ne possit inverti, sed supina permaneat. Hoc facto fertur spatium sic defensum nubes inimica transcurrere. [Nonnulli ubi instare malum viderint, oblato speculo imaginem nubis accipiunt, et hoc remedio nubem (seu ut sibi objecta displiceat, seu tanquam geminata alteri cedat) avertunt. Item vituli marini pellis in medio vinearunı loco uni superjecta viticulæ creditur contra imıniuens malum totius vinea membra vestisse. Omnia semina lorti rel agri feruntur ab omnibus malis ac monstris tuta servari, si agrestis cucumeris tritis radicibus ante macerentur. Item equa calvaria sed non virginis intra hortum ponenda est, vel etiam asinæ. Creduntur enim sua prosentia focundare, qux spectant.

XXXVI. Area longe a villa esse non debet, et propter exportandi facilitatem, et ut fraus minor timeatur, domini vel procuratoris vicinitate suspecta. Sit antem vel strata silice, vel saxo montis excisa, vel sub ipso trituræ tempore ungulis pecorum et aquæ admistione solidata; clansa deinde et robustis inunita cancellis propter armenta, quæ, cum terilur, ind ucimus. Sit circa lane locus alter planus el purus, in quen frumenta transfusa refrigerentur, et loorreis inferantur : quæe res in eorum durabilitate proficiet. Fiat deinde [undecunque] proximun tectum, maxime in humilis regionibus : sub quo propter inbres subitos frumenta (si necessitas coëgerit) raptim vel munda vel semitrita ponantur. Sit autem [area] loco sublimi et undecunque perflabili, longe lamen ab hortis, vineis, atque pometis. Nam sicut radicibus vir. gultorum prosunt latamen et palce, ita insidentes 
XXXVII. On placera le domicile des abeilles près du corps de logis du propriétaire, dans un coin du jardin retiré, exposé au soleil, à l'abri des vents, et très-chaud. La forme en sera quadrangulaire, comme moins favorable aux voleurs et moins aceessibleaux passants et aux bestiaux. Il faut que les fleurs y abondent: c'est pourquoi on s'attaehera à les multiplier, soit en herbes, soit en arbustes, soiten arbres. Il y aura, en fait d'herbes, de l'origan, du thym, du serpolet, de la sarriette, de la mélisse, des violettes sauvages, de l'asphodèle, de la citronelle, de la marjolaine, de cette jacinthe que l'on appelle iris ou gladiolus à cause de sa ressemblance avec un petit glaive, du narcisse, du safran, ct d'autres herbes d'odeur et de saveur douces. En fait de plantes à haute tige, des roses, des lis, des fèves, du ro. marin, du lierre. En arbres franes, des jujubiers, des amandiers, des pêchers, des poiriers et d'autres arbres fruitiers, dont la fleur ne rende aucune amertume lorsqu'on la suce. En arbres sauvages, des chênes qui produisent le gland, des térébinthes, des lentisques, des cèdres, des tilleuls, des petites yeuses et des pins. Mais on en ècartera les ifs, qui sont nuisibles à ces insectes. Le suc du thym donne la première qualité de miel; la thymbre, le serpolet ou l'origan, la seconde; le romarin et la sarriette, la troisième. Les a utres plantes, telles que l'arbousier et les légumes, donnent un miel d'un goût sauvage. Les arbres seront plantés du côté du nord. On arrangera les arbrisseaux et les arbustes par ordre sous les murailles, et l'on sèmera les herbes dans le surplus du terrain au delà des arbustes. Il faut y amener une fontaine ou un ruisseau, dont le cours soit lent, et fréquemment interrompu par des bas-

frondibus [eas] perforaut, atque arere compellunt.

XXXVII. Apibus stationem non longe a domini aelibus in liorti parte secreta et aprica et a ventis remota et calidiore locare debemus, quae in quadratam constituta mensuram fures et accessus liominum pecudumque submoveat. Sit abundans floribus, quos in herbis vel infruticibus, vel in arboribus procuret industria. Ilerbas nutriat origanum, tlıymum, serpyllum, satıreiam, nelisplıyllum, violas agrestes, asplıodilum, citraginem, amaracum, lyyacinthum, qui iris vel gladiolus dicitur similitu dine foliorum, narcissum, crocum, caterasque lierbas suavissimi odoris et floris. In fruticibus vero sint rosæ, lilia, fabæ, rosmarinus, ederx : in arboribus zizipluus, amygdalus, persicus, pirus pomiferæque arbores, quibus nulla amaritudo respondet flore desucto. Silvestria vero, glandifera robora, terelbintlus, lentiscus, cedrus, tilia, ilex miror, et pinus. Sed taxi removeantur inimica. Primi sapor is unella tlıymi succus effundit. Secundi meriti tlıym. bra, serpyllum vel origanum tertii meriti rosmarinus et salureia. Catera, ut arbulus et olera saporesn rustici mellis efficiunt. Sint auten arbores a septentrionali parte disposila. Frutices atque virgulta ordines suos sub maceriis exequantur. Herbas deinde in plano post fonds, sur lesquels s'étendront des branches clairscmées, oủ les abeilles puissent se poser en sûreté lorsqu'elles viendront y boire. Mais il faut que les ruches soient éloignées de tout ce qui exhalc une mauvaise odeur, comme bains, étables, éviers. Il faut les garantir en outre de leurs ennemis naturels, tels que lézards, cloportes, et autres semblables. On effrayera aussi les oiseaux avec des épouvantails et des sonnettes. Le gardien des abeilles s'en approehera souvent en observant d'ètre propre et chaste dans le temps qu'il les visitera, et d'avoir de nouvelles ruches prêtes à recevoir les jeunes essaims encore sans expérience. Éloignez-les de l'odeur de la fange ou de l'écrevisse brûlée, aussi bien que du voisinago d'un écho. On se gardera d'avoir des herbes de tithymalle, d'ellébore, de tapsie, d'absynthe. de concombre sauvage, ou aucune plante amère; tous éléments antipathiques à la préparation du miel.

XXXVIII. Les meilleures ruches sont celles qui sont faites d'ćcorce de liége, parce qu'elles sont impénétrables au chaud comme au froid. On peut néanmoins en faire de férules, ou, à défaut de férules, on emploiera des baguettes d'osier, ou l'excavation d'un trone d'arbre, ou on les fabriquera avec des douves, comme l'on fait des cuves. Les ruches de terrc cuite sont les pires de toutes, parce qu'elles sont glaçantes en hiver, et brûlantes en été. Au reste, il faudra construire, dans l'enclos même dont nous avons parlé, des murs à hauteur d'appui, c'est-à-dire, de trois pieds d'élévation, que l'on revêtira d'un mortier de brique, et que l'on crépira avec du stuc bien poli, pour parer aux dommages que causent ordinairement les lézards ct les autres reptiles. $\mathrm{On}$

frutices conserenuus. Fons rel rivus liuc conveniat otiosus, qui lıumiles transeundo formet lacunas, quas operiant rara et transversa virgulta, sedes tutas apibus prabitura cum sitient. Sed ab lis apiun castris longo sint onnnia odoris loorrendi, balneæ, stabula, coquina fusoria. Fugemus præterea animalia quæ sunt apibus ini. mica, lacertos, blattas et lis similia. Ares etianl pannis et crepitaculis terreamus. Purus custos frequeus et castıs accedat, habens nova alvearia proparata, quibus excipia. tur examinum rudis juventus. Vitetur odor cooni, et caulcer adustus, et locus qui ad lıumanam vocem falsa imitatione respondet. Absint et lierba titlıyınalıs, helleborum, thapsia, absinthium, cucumis agrestis, et omnis amaritudo conficienda adversa dulcedini.

XXXVIII. Alvearia meliora sunt, quæ cortex formabit raptus ex subere, quia non transmiltunt vim frigoris aut caloris. Possunt tamen et ex ferulis fieri. Si lıac de. sint, salignis viminibus fabricentur, vel ligno cavata arboris, aut tabulis, more cuparum. Fictilia deterrima sunt, qua et lieme gelantur, et rstate fervescunt. Sed inter ea loca, qua muniri debere pracepimus, podia teruis alta pedibus fabricentur inducta testaceo et allbario opere levigata, propter lacertorum cxterorumque anina. 
mettra ensuite les ruehes sur ees murs, de facon. que la pluie ne puisse pénétrer jusqu'à clles, avec l'attention de laisser entre clles de petits intervalles. Il faut eependant que l'ouverture des ruelıes soit étroite, pour que les essaims ne souffrent ni du froid ni du chaud. II leur faut encore la protection d'un mur plus élevé, qui réfléchira le soleil sur le domieile des abeilles, en lc protégeant contre les vents froids. Toutes les ouvertures des ruches seront en face du soleil d'hiver, et il en faudra deux ou trois dans chaque panier, dont la largeur n'excède pas la grosseur du corps d'une abeille; parce que la petitesse du passage empêchera les animaux malfaisants de le foreer; et s'ils attendent les abeilles pour les attaquer à leur sortie, eelles-ci pourront sortir par un cotć différent de celui où ils seront à l'affût.

XXXIX. Lorsque l'on fera emplette d'abeilles, on aura soin de n'acheter que des ruches qui soient bien remplies. Or, on sera assuré qu'elles le sont, soit à l'inspection même de la ruche, soit au murmure considérable qui s'y fera entendre, soit aux rentrées ou aux sorties fréquentes de l'essaim. Il faudra aussi les acheter dans le voisinage plutôt que dans un eanton éloigné, de peur que le changement d'air ne les incommode. Si ecpendant l'on est dans le eas d'en faire venir de loin, on apportera les ruches pendant la nuit, en se gardant de les mettre en place ou de les ouvrir avant la chute du jour. On examinera cnsuite, pendant trois jours de suite, si l'essain ne sort point tout à la fois, paree que ce serait un signe de désertion. Nous donnerons par détail ce qu'il y aura à faire chaque mois, pour obvier à cet accident et à d'autres. Ou croit cependant que les abeilles ne prennent jamais la fuite, lors-

lium noxam, quiluss est moris irrepere : et supra lıxe podia alvearia collocentur, ita ut non pussint imbre penetrari, spratiolis inter se patentibus segregata. Angustus tamen aditus admittat examina propter frigoris et caloris injurian. Saue ventis frigidioribus altus paries resistat, qui locum possit defensis sedibus apricare. Adilus omnes soli opponantur liberno, qui in uno cortice duo vel tres esse lebehunt ea unagnitudine, que apis formam non possit excedere. Sic enim noxiis animatibus ingressı resistetur angusto : vel si apes obsidere volıerint exeuntes, alio, (ubi non fuerint, ) utentur egressu.

XXXIX. Apes si emendæe sınt, provideamus ut plena alvearia comparentur : quam rem vel inspectio vel murmuris magnitudo vel frequentia monstrat commeantis ac remeantis exanuinis : [et] ex vicina potius quam [ex] longinqua regione, ne aèris novilate tententur. Si vero lon. gius advelsendæ sust, nocte collo portentır : nec collocare nec aperire alvearia nisi vespere instante, debemus. Speculenur deinde per triduum, ne onıne januas suas egrediatur examen. Hoc enin signo fugam meditantur assumere. Contra lıxc et catera, sno unumqquodque mense reddemus. Tamen creduntur non fugere, si stercus primogeniti vituli adlinamus oribus vasculorum. qu'on a frotté les ouvertures des paniers avec la fiente d'un veau premier-nć.

$X \mathrm{~L}$. Le chef de famille fera bien, s'il a de l'eau cn suffisanee, de songer à construire une salle de bains, paree que e'cst une chose qui contribue beaucoup à l'agrément et à la santé. Cette salle sera placée à portće de la chaleur du fourneau, mais à l'abri del'humide vapcur qui s'en exhale. On lui donnera des jours du côté du midi et de celui du couchant d'hiver, afin que les rayons du soleil y arrivent tout le jour, etl'égayent. Voiei comme on fera le souterrain au-dessus duquel les bains seront placés. On commencera par en couvrir l'aire de dalles de deux pieds, convergentes vers le centre dans un degré d'inclinaison tel, qu'une balle jetée dessus doive nćcessairement rouler jusqu'au foyer. C'est le moyen que la flamme, dont la direction est uaturellement verticale, échauffe davantage les bains. On construira sur ce pavé des piliers de petites briques liées entre elles avee un morticr d'argile et de erin, espacés entre eux d'un pied et demi, ct élevés de deux pieds et demi. On établira sur ces piliers deux tuiles de deux pieds l'une sur l'autre, que l'on couvrira d'un mortier de terre cuite qui servira dé pavé ; après quoi on y mettra du marbre si l'on en a suffisamment. Quant au miliarium de plomb, qui sera assis sur un plateau de cuivre, on le mettra directement au-dessus du fourneau, et on le fera passer entre les bains. Il y aura un tuyau dirigé vers ce miliarium, pour y conduire l'eau froide; tt il en partira un autre de même calibre que le premier qui sera dirigé vers le bain, pour y porter autant d'eau chaude que le premier tuyau aura porté d'eau froide dans le $m i$ liarium. Les salles de bains seront disposées de

XL. Non alienum est, si aquæ copia patiatur, patremfamilias de structura balnei cogitare; quæe res et voluptati plurimum confert et salıti. Itaque balneım constituemus in ea parte, qua calor fulurus est, loco ab humore suspenso, ne uligo en $n$ fornacibus vicina refrigeret. Lumina ei dabimus a parte meridiana et occidentis hiberni, ut tota die solis juvetur et illıstretur aspectu. Suspensuras vero cellarun sic facies : aream primo bipedis sternis, inclinata sit tameı stratura arl fornacem, ut si pilam miseris, introstare non possit, sed ad fornacem recurrat. Sic eveniet ut llamma altum pelendo, cellas faciat plus calere. Supra lianc straturam pilae laterculis argilla subacta et capillo constructa fiant distantes a se spatio pedis unius et semissis, altæ pedibus binis semis. Super las pilas bipedx constituantur binæ in altum, atque his superfundautur testacea pariınenta, et tunc, si copia est, marmora collocentur. Miliarium vero plumbeum, cui ærea patina subest, inter soliorum spatia forinsecus statuamus fornace subiecta, ad quod miliarlum fistula frigidaria dirigatur, et ab hoc ad solium similis magıjitudinis fistula procedat, quæ tantum calidæ ducat interius, quantum fistula illi frigidi liquoris intulerit. Cellæe autem sic disponantur, ut quadra nou sint, sed, (verbi gratia) si $\mathbf{x v}$ pedibus longæ fuerint, $\mathbf{x}$ 
façon qu elles ne forment pas le carré, mais que si elles ont, par exemple, quinze pieds de long, elles n'en aicnt que dix de large, parce que la chaleur sera plus intense dans un lieu étroit. La forme du siége qui sera dans le bain sera à la volonté de chacun. Les salles de bains d'été recevront le jour du côté du septentrion, et celles d'hiver le recevront du cóté du midi. II faut, si faire se peut, qu'elles soicnt situées de façon que leur décharge s'écoule tout entière à travers les jardins. Les voûtes de ces salles, qui seront faites en ouvrage de Signia, seront les plus solides; mais si on les fait de planches, ces planches seront soutenues avec des arcs de fer traversés par des verges de fer. Si on ne veut point que ces voûtes soient faites en planches, on mettra sur ces ares et sur ces verges des tuiles de deux pieds, rassemblées par des crampons de fer, et liées entre elles avec un mortier de crin et d'argile; après quoi on les revêtira par-dessous d'un enduit de terie cuite, qu'on embellira cnsuite avec du stue bien poli. On peut aussi, si l'on consulte ses intérêts, faire ses appartements d'hiver audessus des bains, c'est le moyen d'entretenir la ehaleur sous son habitation, et d'épargner des fondations.

XLI. Puisque nous en sommes sur le chapitre des bains, il est bon de connaitre le ciment dont on se sert pour réparer les ouvrages destinés à contenir l'eau, tant chaude que froide; parce que si les bains viennent à se crevasser, on pourra y remédier sur-le-champ. Voici la composition du ciment qu'on emploie pour réparer les ouviages destinés à contenir de l'eau ehaude. On prend de la poix dure, de la cire blanche, de l'étoupe, de la poix liquide, de la terre cuite réduite en poudre et de la fleur de chaux, de faęon que le poids de la cire blanche soit égal à celui de la

late sint : fortius enim vapor inter angusta luctabitur. Soliorum forma pro uniuscujusque voluntate fundetur. Piscinales cella in xstivis balneis a septentrione lumen accipiant, in liemalibus a meridie. Si fieri potest, ita constituantur balıex, ut omnis earum per hortos decurrat eluvies. Cameræ in balneis [si] signinæ [fiant, ] fortiores sunt. Quæ vero de tabulis fiunt, virgis ferreis transversis, et ferreis arculous sustinentur. Sed si tabulas nolis impo. nere, super arcus ac virgas bipedas constitues ferreis ancoris colligatas, capillo inter se atque argilla subacta colırentes, et ita impensam testaceam subter inducis : deinde albarii operis nitore decorabis. Possumus etiam, si compendio studemus, liberna ædificia bảlueis impone. re : hinc et lıabitationi teprom submittimus, et fundamenta lucramur.

XLI. Scire convenit, quoniam de balneis loquimur, qux sunt maltlıæ calidariæ vel frigidariæ, ut siquando in soliis scissa sunt opera, possit repente succurri. Calidarix com. positio talis est : Picem duram, ceram albam ponderibus æquis, stupam, picis liquidæ totius ponderis dimidiam partem, testam minutam, florem calcis, omnia simul rat.LAdICS. poix dure, et que celui dé la poix liquide soit moitié du poids total de ce mélange. On mêle toutes ces matiẻres ensemble; et après les avoir broyées dans un mortier, on fait remplir les crevasses de cctte compositlon. Autre recette: On broie avec un pilon du sel ammoniac réduit en poudre, des figues, de l'étoupe et de la poix liquide, et on cnduit les crevasses de cette composition. Autre recette : 0 n enduit les crevasses de sel ammouiac et de soufre réduits l'un et l'autre en poudre, ou bien on les en remplit. On les en. duit aussi de poix dure et de cire blanche mêlées ensemble et saupoudrées de sel ammoniae, et I'on fait passer le cautère par-dessus cet enduit. On les enduit eneore de fleur de ehaux et d'huile mêlées eusemble, et l'on se garde bien d'y mettre de l'eau aussitôt après. Autre recette: On mêle de la fleur de chaux avec du sang de taureau et de l'huile, et l'on enduit les fentes avee eette composition. $\mathrm{On}$ broie eneore ensemble des figues, de la poix dure et des écailles d'huítres sèches, et on enduit avee attention les fentes avee ce milange. Voici aussi le ciment qu'on emploie pour réparer les ouvrages destinés à eontenir de l'eau froide. On broie ensemble avec un pilon du sang de bœuf, de la fleur de chaux et du mâchefcr, et on en fait une espèee de cérat, dont on enduit ees ourrages. On empêehe également l'eau froide de filtrer entre des fentes, en les enduisant de suif fondu, mêlé avce de la cendre passée au crible.

XLII.Si l'on fait une grande consommation d'eau dans les bains, il faut en diriger l'écoulement vers les boulangeries, où l'on établira des moulins à eau; ce qui sera une grande éeonomie de travail pour les hommes et les bêtes.

XLIII. On se pourvoira de tout l'attirail nécessaire à la campagne. Voici en quoi il consiste: des

mista in pila contundes, et juncturis curabis inserere. Aliter : Ammoniacum reınissum, ficum, stupan, picen liquidam tundis pilo, et juncturas oblinis. Aliter: Ammo. niacum et 'sulfur utrumque resolutum line, rel infunde juncturis. Item picem duram, ceran albam et ammonia. cum super remissum simul juncturis adline, et cautere cunta percurre. Item florem calcis cum oleo mistum junct:1. ris illine, et cave ne inox aqua mittafur. Aliter: Sanguini tauriuo et oleo florem $\mathrm{c}$ alcis armisce, et rimas conjunc. tionis olducito. Iten ficum et picem duram, et ostrei testas siccas simul tundes His omnibus juncturas diligen. ter adlines. Item malthæe frigidarix, sanguinem bubulum, florem calcis, scoriam ferri, pilo universa contundes, et ceroti instar efficies, et curabis adlinire. Item sevum liquefactum cribellato cineri admistum frigidæ aquæ inter rimas labenti, si adlinatur, obsistet.

XLII. Si aqux copia est, fusuras balnearum debent pistrina suscipere; ut ibi fol unatis aquariis molis, sine anjmalium vel lıominum labore fiumenta frangantur.

XLIII. Instrumenta vero hæc, quæe ruri necessaria sunt, paremus. Aratra simplicia, rel si plana regio permitlit, 
charrues simples, ou, si l'on cultive un pays plat qui en permette l'usage, des charrues à oreilles, par le moyen desquelles on fasse les raies du labour plus élevées, afin que les semences pendant l'hiver souffrent moins du séjour des eaux; des loyaux, des béches, des serpettes pour tailler les arbres et la vigne. Item, des faux, tant pour la moisson que pour la fenaison; des houes, des lupi, c'est-à-dire, des scies emmanchées tant grandes que petites, dont les plus grandes n'aient pas cependant plus d'un cubitus, afin de pouvoir être introduites facilement dans les trones d'arbres ou dans les ceps de vigne, à l'effet de les couper, ce qui serait impraticable avec une scie commune; des alênes pour enfoncer les sarments dans les terres façonnées au pastinum; des serpettes tranchantes par le dos, et faites en forme de croissant. Item, de petits couteaux recourbès, avec lesquels on puisse couper aisément les rejetons secs des jeunes arbres, ou ceux qui empiètent sur le trone. Item, de très-petites faticilles à dents, a vec lesquelles on est dans l'usage de couper la fougère; de plus petites scies que celles dont nous avons parlé, des houes, des outils pour extirper les épines, des haches simples ou faites en forme de doloires, des sarcloirs simples ou à deux fourchons, ou des haches dont le dos ressemble à des râteaux. Item, des cautères, des instruments de fer, tant pour la castration que pour la tonte, ou pour letraitement des animaux malades; des turiques de peau avec des capuchons, des guêtres et des gants de peau qui puissent servir non-seulement dans les forêts, mais encore dans les buissons, tant aux travaux rustiques qu'à la chasse. Après avoir acheyé tout ce qui concerne les préceptes généraux, nous allons à présent détailler les travaux de chaque

aurita, quibus possint contra stationes lumoris liberni sala celsiore sulco attolli. Bidentes, dolabras, falces putatorias, quibus in arbore utamur et vite. Item messorias vel fonarias, ligones, lupos, id est serrulas manubriatas minores majoresque ad inensuram cubiti, quibus facile est, quod per serram fieri non potest, resecarido trunco arboris, aut vitis interseri : acus, per quas in pastinis sarmenta mergưntur : falces a tergo acitas atque lunatas : cultellos item curvos minores, per quos novellis arboribus surculi aridi aut extantes facilius amputentur. Item falciculas brevissimas tribulatas, quibus filicem solemus abscindere; serrulas minores, vangas, runcones, quibus vepreta persequimur; secures sinplices vel dolabratas; sarculos vel simplices vel bicornes, et ascias in aversa parte referentes rastros. Item cauteres, castratoria ferramenta atque tonsoria, vel qux ad animalium solent pertinere medicinam. Tunicas vero pellicias, cum cucullis, et ocreas unanicasque de pellibus, quæ vel in silvis, vel in repribus, rustico operi et renatorio possint esse com. munes. Expletis lis qua ad generale pertinent præcep. tnm, nunc operas suas singulis mensibus explicabimus, et a meuse Januario faciemus initium. mois de l'annces, en commençant par celui de janvier.

\section{LIVRE SECOND.}

\section{JANVIER.}

I. Il faut déchausser les vignes ce mois-ci dans les climats tempérés; c'est ce que les Italiens appellent excodicare (essarter). Cette opération consiste à ouvrir, avec précautiolı, la terre à l'aide de la doloire autour du tronc de la vigne, et à y laisser des espèces de rigoles circulaires après en avoir bien nettoyé toutes les racines, afin que la chaleur du soleil et la pluie l'excitent à pousser.

II. C'est le moment de nettoyer les prés et de les mettre à l'abri des insultes des bestiaux, dans les lieux exposés au soleil, ou maigres, ou sees.

III. On peut déjà donner le premier labour et les premiers apprêts aux terrains gras ou secs; mais il vaut mieux attacher les boufs au joug par le cou que par la tête. Lorsque les boufs se. ront arrivés au bord du sillon, le laboureur, avant de les faire retourner, les retiendra, et poussera le joug en avant, afin que leurs cous se rafraichissent. Un sillon de labour ne doit pas avoir plus de cent vingt pieds de long; et il faut prendre garde de laisser de la terre entre les sillons sans la retourner. On brisera toutes les mottes de terre avec la doloire. Pour reconnaitre si la terre a été remuée également partout, on sonde les sillons transversalement avec une perche; et cette précaution réitérée souvent empêche les bouviers de tomber dans la négligence sur ce point. Il faut observer de ne pas labourer un champ lorsqu'il est bourbeux, ou lor'squ'il est humecté d'une pluie légère après de longues sécheresses (comme

\section{LIBER SECCUNDUS.}

I. Januario mense locis temperatis ablaqueandae sunt vites, qua Itali excodicare appellant, id est circa vitis codicem dolabra terram diligenter aperire, et purgatis omnibus velut lacus efficere, ut solis teporibus et imbribus provocentur.

II. Apricis, aut macris, aut aridis locis prata jam pur. ganda sunt, el a pecore vindicanda.

III. Pingues et sicci agri proscindi et apparari jam possunt. Sed boves melius collo quam capite junguntur; quos ubi ad versuram venerint, arator retineat, et jugum propellat, ut eorum colla refrigerentur. Sulcus autem in arationibus longior, quam centum viginti pedum esse non debet. Servandun vero est, ne inter sulcos non mota terra relinquatur. Glebæ omnes dolabris dissipandse sunt. Sed aqualiter terram motam esse cognoscis, si transversam per sulcos perticam mittas: quæ res sæpius facta, bubulcos ad hæc negligentia submovebit. Observandum est, ne lutosus ager aretur, aut, quod sæe sit, post lon. gas siccitates levi imbre perfusus. Nam terra quæe lutosa tractatur in primordio, fertur toto anno non posse trac. 
II arrive fréquemment); car on prétend qu'une terre à laquelle on a touchć pour la première fois, dans le temps qu'elle était bourbeuse, ne peut plus être maniée de toute l'année; ct l'on assure que lorsqu'on en laboure une pendant que sa superficie est légèrement humectée et que l'intérieur en est sec, clle devient stérile pour trois ans. C'est pourquoi il ne faut donner le premier labour qu'à des terres qui solent médiocrement humectées, sans être ni bourbeuses ni sèches. Si ce sont des collines, on y fera les sillons en travers sur les pentes, et on observera la même marche lorsqu'on les ensemencera.

IV. Lorsque l'hiver n'aura point été rude, on sèmera dans les climats tempérés, vers les ides de janvier, de l'orge de Galatie, qui est un grain pesant et blanc. Il en faudra huit modii pour ensemencer un jugerum.

V. On sème la gesse ce mois-ci dans un terrain gras, sous un climathumide. Il en faut trois mo. dii pour ensemencer un jugerum. Mais cette espèce de semence réussit rarement, parce que les vents du midi ou ia sécheresse, qui sont des accidents presque inévitables au temps qu'elle fleurit, en font tomber la fleur.

VI. On sème à la fin de ce mois-ci la vesce que l'on a intention de ne pas couper en fourrage, et de récolter en graine. Il en faut six modii pour ensemencer un jugerum. Il faut la semer après la seconde ou la troisième heure du jour, lorsque la rosée, qu'elle ne peut pas supporter, aura disparu, ct dans une terre qui ait recu le uremier labour. Mais on aura l'attention de la co'uvrir aussitôt de terre, parce que, si elle restáit à découvert pendant la nuit, l'humidité la corromprait. On observera de ne pas la semer avant le vingt-cinquième jour de la lune; autrement les limacons la dévoreraient.

tari : quæ autem supra leviter infusa est, et subter sicca, si tunc aretur, asseritur per triennium sterilis fieri. $\mathbf{E t}$ ideo mediocriter infusus ager, ut nec lutosus nec aridus sit, proscindi debet. Si collis est, transversus per latera sulcetur. Quæ forma tunc servanda est, cum semen accipiet.

IV. Si clemens fuerit hiems, ordeum Galaticum, quod grave el candidum est, circa idus Januarias seramus locis temperatis. Octo modiis jugerum complebitur.

V. Cicercula mense hoc seritur loco lato, cxlo humido. Tres modii jugerum complent. Sed hoc genus seminis raro respondet, quia decipitur austro, vel siccitate dum flo. ret; quod tunc prope necesse est evenire.

VI. Hoc mense ultimo colligendi seminis causa, non pabuli secaudi, vicia seritur. Jugerum sex modii occupant. Serenda est in terra proscissa post looram secundam vel tertiam, cum ros esse desierit, quem ferre non potest. Sed statim cooperienda est ante noclem. Nam si nuda inanserit, noctis liumore corrumpitur. Observandum est ne ante vigesimamquintam lunam seratur; quia sic satam limaces persequuntur.
VII. Nous semons en Italie le fenugrec que nous devons récolter en graine à la fin du mois de janvier, vers les calendes de février. Six modii suffisent pour ensemencer un jugerum. II faut que les sillons de la terre dans laquelle on le sème soient serrés, mais non profonds, parce qu'il vient difficilement quand il est enfoncé de plus de quatre doigts en terre. C'est pourquoi il y a des personnes qui ne se servent que de charrues très-petites pour donner le premier labour à la terre dans laquelle elles le sèment, ct qui le recouvrent aussitót de terre avec dessarcloirs.

VIII. On peut aussi semer l'ers à la fin de ce mois-ci dans un terrain sec et maigre. On en sìme cing modii par jugerum.

IX. Il faut profiter des jours secs et sereins de ce mois-ci pour sarcler les blés, quand il ne gèle point. La plupart des auteurs prétendent que c'est une opération qu'il ne faut jamais faire, parec qu'elle découvre ou qu'elle coupe les racines des blés, de facon qu'ils périssent aux froids qui viennent ensuite; mais il me semble qu'on peut la faire, pourvu que ce ne soit que dans des terrains pleins d'herbes. Au surplus, on sarcle le froment et le blé ador quand ils ont quatre feuilles; l'orge, quand elle en a cinq; les fèves et les légumes, lorsqu'ils sont élevés de quatre doigts au-dessus de terrc. Pour le lupin, qui n'a qu'une seulc racine, il périrait si on le sarclait. D'ailleurs il n'exige pas qu'on lui donne ce soin, parce qu'il fait mourir les herbes lui-même, et sans le secours du cultivateur. Quant à la fève, si on la sarcle deux fois, elle profitera d'autant mieux, et produira des fruits aussi recommandables par leur grosseur que remarquables par leur quantité, puisqu'il n'en faudra presque pas plus pour combler la mesure d'un modius lorsqu'ils seront moulus,

VII. Fonum græcum in Italia colligendi seminis causa mense Januario ultimo circa Februarias calend. serimus. Sex modii jugero sufficiunt. Arandunı est spisse, sed non alte. Nam si plus quam quatuor digitis obruatur, difficile nascitur. Idcirco quidam minimis aratris proscissa prius terra seminant, et sarculis statim sata cooperiunt.

VIII. Ervum seri et hoc inense norissimo potest loco sicco et macro. In jugero quinque morlii seruntur.

IX. Hoc mense serenis et siccis liebus, dum gelicidium non est, sunt sarculanda frumenta. Quod opus pleı ique negant fieri debere, quia radices eorum detegantur aut incidantur, et necentur frigore subsecuto. Mili autem videtur herbosis locis tantuın esse faciendum. Sed tinticum et far sarritur quatuor foliorum, ordeum quinque; faba et legumina, cum supra terram quatuor digitis fuerint. Lupinus rero, quia unam radicem lıabet, si sarculetur, exfinguitur; quod nec desiderat, quia herbas præter auxilium cultoris afligil. Falıa autem si bis sarculetur, proficiet, et multum fructum et inaximum afferet; ut ad nensuram modii complendi fresa propemodum sicut integra rcspondeat. Si siccas segetes sarculareris, aliquid con35. 
qu'il n'en faudrait s'ịls étaicnt en cosses. En sarclant les plantes dans le temps qu'elles sont sèches, c'est un petit sccours qu'on leur procure contre la rouille. L'or'ge surtout doit être sarclée quand clle est sèche.

X. C'cst à présent le temps de façonner la terre au pastinum; ce qui se fait de trois façons, ou en remuant toute la superficie du terrain, ou en y faisant des tranchées, ou en y creusant des fosses. Il faut fouiller un terrain dans toute son étendue quand il est en friche, afin de le débar. rasser des souches et des racines de fougère, ou d'autres mauvaises herbes. Mais quand ee sont des jachères qui ne sont point cmbarrassées, il faut les façonner au pastinum en $\mathrm{y}$ creusant des fosses, ou mieux des tranchées, parce que ces dernières livreront passage à l'eau, de facon qu'elle abreuvera tout le terrain. On fera donc ces tranehées de la longueur que l'on voudra donner aux planches, et de deux pieds et demi ou de trois pieds de largeur, de facon que deux travailleurs la creusent ensemble au loyau, en se réglant sur une ligne qui sera marquée au cordeau, et cela à la profondeur de trois pieds ou de deux pieds et demi. Après quoi, s'il s'agit d'un vignoble qui doive être eultivé à mains d'homme, ils laisseront sans le remuer un intervalle de terrain égal à celui qu'ils auront labouré, et ereu. seront une autre tranchée de la même façon que la première; au lieu que s'il s'agit de vignobles qui doivent être labourés à la eharrue, ils laisseront entre chaque tranchée un intervalle de cinq ou six pieds sans le fouiller. Si l'on veut faire des fosses, on leur donnera trois pieds de profondeur, deux pieds et demi de largeur, et trois pieds de longueur. Soit que l'on eultive les vignobles à mains d'homme, soit qu'on les eultive avec des boufs, on laisscra entre ces fosses,

tra mbiginem praestitisti. Maxime ordeum siccum sarrictur.

X. Pastinum fieri nunc tempus est : quod fit tribus generibus, aut terra in tolum fossa, aut sulcis, ant scro. bibus. Terra tota debet effodi, ubi ager imnundus est, ut silvestribus truncis et radicibus filicis, vel herbarum noxiarum spatia liberentur. Ubi autem mundæ sunt no. vales, scrobibus pastinemus aut sulcis : sed sulcis melius et it, quia humorem velut in totum spatia pastinata transmittunt. Fiunt ergo sulci tanta longitudine, quantan destinaveris tabulæ; latitudine pedum duorum et semis, rel trium, ita ut juncti duo fossores designatum linea spatium bidentibus perscquantur altitudine trium vel duorum et senis pedum. Deinde si ligonibus per lomines vinea colenda est, tantum crudi soli relinquimus, et sic alter sulcus imprimitur. Si vero arandx sunt vinex, quinqule rcl sex pedum spatia, qua non sunt fodienda, in medio relinquemus. Quod si scrobes fieri placeat; faciemus tribus pedibus altas, duobus semis latas, tribus longas. Sive fossoribus colantur vineta, seu bubus, eadem spatia, quæ inter sulcos sunt dicta, servemus. Ultra tres vero -dans l'un ou l'autre cas, les mêmes interval. les que ceux que nous avons prescrits à l'égard des tranchées. Mais il ne faut pas donner aux fosses plus de trois pieds de profondeur, de peur que les sarments qu'on y plantera ne soieut incommodés par le froid. Il faut que les eótćs des fosses soient coupés à pic, de peur que si le eep s'y trouvait posé obliquement, il ne vînt à être blessé par suite des efforts que ferait le fossoyeur pour pénétrer au fond de la terre avec ses outils. Quant aux terrains faeonnés au pastinum, dont on voudra remuer la terre dans toute leur étendue, on les fouillera à la profondeur de trois pieds ou de deux pieds et demi, et l'on prendra garde que l'ouvrier ne dissimule par fraude des parties de terre non labourées. C'est à quoi veillera le gardien, en sondant de temps en temps le terrain à mesure qu'il sera fouillé, avec une verge sur laquelle sera marquée la mesure de la profondeur que nous venons de prescrire. On fera aussi rejeter sur la superficie du terrain toutes les racines et toutes les immondices, et principalement celles qui proviennent de ronces ou de fougère. Il faut prendre ees soins dans tous les terrains, quelle que soit leur position, et par tout pays.

XI. Pour ce qui est de la distribution du terrain en planehes, le propriétaire suivra son goût, ou se réglera sur l'exigence du lieu, pour la faire, soit en formant des planches d'un jugerum entier, soit en les faisant d'un scmijugerum, soit enfin en ne faisant que des planehes quarta. narice, c'est-à-dire, des planches earrées qui ne contiendront que le quart du jugerum.

XII. Voiei la mesure de terre façonnée au pastinum que eontiendra la planche earrée d'un jugerum entier. Chacun de ses eôtés aura cent quatre-vingts pieds de longueur, lesquels, mul-

pedes altius fodiendæ scrobes non sunt, ne laborent frigore sarmenta qua panginus. Latera scrobibus aqualiter incisa sint, ne obliqua vitis saucietur alte nitentibus fer. ramentis cum fossor incumbet. Pastini vero, quod onne versabitur, trium vel duorum semis pedum altitudine terra universa fodietur. In quo est adhibenda diligentia, ne crudum solum fraude occulta fossor includat. Quam rem subinde custos virga, in qua prodicta altitudinis modus designatus est, per spatia qua fodiuntur, exploret. Radi. ces omnes et purgamenta, maxime rubi et filicis, in sunımum regeri faciat. Qux cura in omni positionis genere et ubique servanda est.

XI. Tabulas autem pro domini voluntate vel loci ratione faciemus sive integrum jugerum continentes, set medium; seu quartanariam tabulam, qua quartam jugeri partem quadrata conficiet.

XII. Mensura vero pastini liæc est, [ut] in tabula quadrata jugerali centeni octogeni pedes per singula latera dirigantur, qui [iı se] multiplicati trecentas vigintiquatuor decempedas quadratas per spatium omnc cornplebunt. Sccundun hunc nuncrum omnia qua volueris pastinare, 
tipliès l'un par l'autre, donneront, pour toute sa superficie, trois cent vingt-quatre perches carrées de dix pieds chacune. Or, on estimera, d'après ce calcul, tous les terrains que l'on voudra faconner au pastinum, puisque dix-huit perches de dix pieds chacune, multipliées par dix. huit, en donneront trois cent vingt-quatre. Ainsi cet exemple apprendra à mesurer tous les terrains, selon qu'ils seront plus ou moins grands.

XIII. Le terrain qu'on destine à la vigne doit n'être ni trop compacte ni trop meuble, mais tenir plutôt de la dernièrc condition. Il ne le faut ni maigre 'ni gras tout à fait, mais quelque chose d'approchant; ni platni abrupte, mais légèrement exhaussé; point sec, encore moins marécageux, mais arrosé modérément; enfin, qu'il ne soit ni salé ni amer, parce que tous ces défauts corrompent le vin et le rendent désagréable au goût. II faut aussi une température moyenne, mais plutôt tiède que froide, plutôt sèche qu'humide. Mais ceque la vigne redoute le plus, ce sont les tempétes et les vents. Quand on voudra façonner un terrain au pastinum, on en choisira un de préférence qui soit inculte, ou entièrement couvert de broussailles. La pire de toutes les qualités qu'il pourrait avoir serait d'avoir été anciennement planté en vignes. Si cependant l'on est forcé par la nécessité de tourner son choix sur un terrain pareil, il faudra commencer par le tourmenter par de fréquents labours, afin d'extirper les racines des anciens ceps, et de détruile tout ce qu'ils laissent après eux de détritus et de̊ pourriture, avant de lui coafier le jeune plant. Le tuf ou tel autre terrain d'une espèce mème plus dure, quand ils sont ramollis par l'action successive de la gelée et du soleil, portent de très-belles vignes, parce qu'ils maintiennent leurs racines fraiches en été, et qu'ils conservent bien l'humidité. Pour le roc qui cst couvert de

discuties. Decem et octo enim decempedæ, decies et octies supputatæ, trecentas vigintiquatuor explebunt. Quo exemplo doceberis in majore agro rel minore mensuram.

XIII. Sed solum vineis ponendis nec spissum sit nimis nec resolutum; propius tamen resoluto : nec exile, nec letissimum; tamen lxto proximum : nec campestre, nec præceps; sed potius edito campo : nec siccum nec uligiuosum; modice tamen rosciduın : nec salsum nec amarum, quud vitium sapore corrupto vina contristat. Caelum mediocris qualitatis, tepidum tamen magis quam frigidum, siccum potius quam nimis imbridum. Sed ante omıia vitis procellas ventosque formidat. Ad pastinandum rudes agros potius eligamus, vel maxime silvestres. Ultima conditio est ejus loci, in quo fuerunt retusta vineta. Qund si necessitas coegerit, prius niultis arationibus everceatur, ut abolitis radicibus prioris vinex, et omni ejus carie et squalore depulso, novella ritis tutius possit induci. Tofus et alia duriora, ubi gelı relaxantur et solibus, pulcherri. mas rineas ferunt, refrigeratis xstate radicibus, et humore detento. Sed et soluta glarea et cakulosus ager et mobiles terre, il n'expose jamais les racines de la vigne à souffrir la soif pendant l'été, parce qu'il est frais et qu'il conserve bien l'humidité. Il en est de même d'un gravier résolu en poussière, d'un terrain plein de cailloux et de pierres mouvantes (pourvu néanmoins que toutes ces natures de terrains soient mélangées de quelques mottes de terre qui soient grasses), ainsi que des terrains sur lesquels la terre s'éboule dés hauteurs voisines, ou des vallćes engraissées par les dépôts de limon que les eaux y ont formés; quoique tout ceci ne doive s'entendre que des lieux qui n'ont à craindre ni la gelée ni les brouillards. La terre mêlée d'argile est encore bonne pour la vigne; mais l'argile pure lui est très-contraire, ainsi que les autres choses que j'ai détaillées dans les préceptes généraux. Pour les terrains qui n'auront jamais produit que de misérables broussailles, ou qui seront marécageux, ou salés, ou amers, ou altérés et secs, il faut $y$-renoncer. Le sable noir ainsi que le rouge sont bons, pourvu qu'ils soient mêlés de terre forte. Le charbon maigrit les vignes, à moins qu'il ne soit fumé. Elles prennent difficilement darus la terre rougc. II est vrai que par la suite elles y trouvent suffisamment de nourriturc. Mais cette espèce de terrc est rebelle à la culture, parce que, pour peu que l'humidité ou le soleil s'y fassent sentir, elle se détrempe ou se dessèclie trop. Au surplus, le meilleur sol est celui qui ticut le milieu entre tous les cxtrêmes, et qui approche plutôt d'un terrain léger que d'un terrain compacte. Il faut que la vigne soit exposée, dans les pays froids, au midi; dars les pays chauds, au nord; dans les pays tem. pérés, au levant : pourvu cependant que la contrée ne soit point sujette à des vents de midi ou d'est qui soicnt malfaisants; auquel cas on fera mieux d'exposer ses vignobles au vent d'aquilon ou au Favonius. Il faut commencer par débar-

lapides, si tamen hæc omnia glebis se pinguibus miscuere, et silex, cui terra superposita est, quia frigidus est et lımoris tenax, radices astate sitire non patitur. Item loca, ad quae de cacuminibus terra decurrit, rel ralles, quas fluninum saturabit aggestio : sed lıc in is locis, qux gelu et nebulis infesta esse non possunt. Argillosa terra commoda est, argilla autem sola graviter inimica, et catera quæ in generalibus dixi. Nam locus, qui misera virgulta produxerit, rel uliginosus rel salsus rel amarus vel siticulosus et aridus improbatur. Niger sabulo et rubeus utilis est, sed eui fortis terra permista est. Carbunculus, uisi stercoretur, macras rineas reddit. In rubrica difficilius comprehendunt, quamvis postea nutriantur. Sed hoc genus terra operibus inimicum est, quia parro vel humore vel sole aut nimis madescit aut siccatur. At maxime utile so. lum est, quod inter omnes nimictates temperameutum tenebit, et raro proximuın, quam denso fuerit. Plagam calli vinéa spectare debet locis frigidis meridianan, calidis septentrionalem, tepidis orientem; si tamen Austms vel Euros regio non habeat inimicos. Quoul si lioc est vitiun, 
rasser le terrain que l'on voudra façonner au pastinum, de tous les obstacles qu'on y pourra rencontrer, et de tous les arbres qui s'y trouveron i brisés, de pcur que, lorsque la terre aura été iouillée, elle ne se raffermisse par la suite à foree a'être foulée aux pieds. Si le terrain cst plat, on le labourera au pastinum à la profondeur de deux pleds ct demi; si c'est une petite éminence de terre, on la labourera à la profondeur de trois pieds; si c'est une colline escarpée, on la labourera à la profondeur de quatre pieds, de peur que la terre n'en soit trop tôt entrainée; enfin si c'est une vallée, on la labourera à la profondeur de deux pieds. Mais il ne faut pas donner plus d'un pied et demi au labour dans un tersain maréeageux, d'où l'on verrait jaillir l'cau s’il était fouillé plus profondément, tel que le territoirc de Ravenne. Des expériences suivies mont appris que les vignes viennent mieux lorsqu'elles sont plantées, soit au moment que la terre vient d'être fouillée, soit peu de temps après, c'est-à-dire, avant que le gonflement de la terre, occasionné par le labour au pastinum, soit affaissé, et qqu'elle ait repris sa furmeté. J'ai fáit la même remarque à l'égard des tranchées ou des fosses, surtout quand la terre était de moyenne qualité.

XIV. Il faut semer la laitue au mois de janvier ou de cécembre, pour la transplanter au mois de février. On la sème aussi au mois de février, pour pouvoir la transplanter au mois d'avril. Mais il est eertain qu'on peut très-bien la semer dans tout le eourant de l'année, pourvu que ce soit dans un terrain gras, fumé et arrosé. On en coupera les raeines également, et on les enduira de fumier liquide avant de la planter; ou si elle est déjà plantée, on les mettra à jour pour leur donner du fumier. Cette plante veut un terrain qui soit bien remué, gras, humide et

melius in Aquilonem vel Favonium vineta dirigimus. Sed locus qui pastiuandus est, prius inperlimentis et omnibus (elisis) liberetur arboribus, ne post calcatu assiduo terra effossa solidetur. Si camprus est, duobus semis pedibus pastinetur; si clivus, tribus; collis praeruptus quatuor, ne citius terra decurrat; vallis vero duolus pedibus. Sed ager uliginosus, qui lunores altius fossus eructat, sicut Ra. vennatis soli, non amplius quam in pedem senis effodia. tur. Illud experimentis assiduis comprelıendi, vites melius provenire, si vel statim fossie terræ, vel non longe ante, pangantur, cum tumor pastiui nondun repetita soliditate subsedit. Hæc quoque in faciendis sulcis et scrobibus ap. probavi, maxime ubi mediocris est terra.

XIV. Mense Ianuario lactuca serenda est, vel Decembri, ut planta ejus Februario transferalur. Itemqie Februario seritur, ut possil A prili mense transferri. Sed certum est eam toto anno bene seri, si locus sit lactus, stercoratus, irriguus. Antequam pangatur, radices eius resecemus xqualiter, et liquido fimo linamus : (vel) qux jam pactæ sunt, nudata latamen accipiant. Amant solum subactum, fumé. Il faut airacher les herbes qui croftront entre les laitues avec la main, et non pas avec le sarcloir. La laitue deviendra plus épaisse si on la sème clair, ou si, après avoir coupé légèrement sa tige lorsqu'clle commencera à pousser, on la eomprime avec une motte de terre ou avec une tuile. On croit qu'on fait blanchir les laitues en jetant fréquemment sur la planche du sable de rivière ou de mer, et en rassemblant leurs feuilles pour les lier. Si la laitue vient à durcir par le vice du terrain, ou par l'effet de la température ou de la mauvaise qualité de la graine, on la déterrera et on la replantera de nouveau, pour la rendre plus tendre. Elle aura aussi plusieurs goûts différents, si, après avoir creusé délicatement, avec une alêne, une crotte de chèvre, et avoir insérć dedans de la graine de laitue, de cresson alénois, de basilic, de roquelte et de raifort, on enveloppe cette crotte dans du fumier, et qu'on l'enfonee dans une petite fosse creusée sur un terrain soigneusement eultivé. En effet, le raifort se portera vers la raeine de laitue, et les autres plantes s'élanceront par en haut ainsi que la laitue elle-même, qui les absorbera en conservant le goût de ehacuue d'elles. D'autres obtiennent le même résultat par le procédé que voici : ils déterrent une laitue, enlèvent les feuilles qui tiemnent à ses racines, et, après les avoir piquées à l'endroit par où elles y tiennent avec un scion d'arbre, ils y insèrent les graines que nous venons de nommer, à l'exception de celle du raifort, et les recollent avee du fumier; après quoi ils remettent en terre cette laitue ainsi greffée, et qui croit entourée de toutes ces diverses semenees. On a donné à la laitue le nom de lactuca, parce qu'elle contient uue grande quantité de lait. 11 est constant qu'il faut semer dans ce mois-ei, comme cn tout autre temps, le cresson alénois, n'importe en quel lieu ni sous

pingue, lıumidum, stercoratum. Inter lias lierba manu evellenda est, non sarculo. Latior fil, si rara ponatur, vel cum producere incipiet caulem, co leviter inciso gleba prematur aut testa. Candida fieri putantur, si fluminis arena vel litoris frequenter spargatur in medias, et collectis ips $x$ foliis alligentur. Si vitio loci vel lemporis vel seminis cito lactuca durescit, planta ejus avulsa et denno posita teneritudinem consequetur. Item multis seminibus condita nascetır, si caprini stercoris baccam subula sub. tiliter excavaveris, et in ea semen lactuc $x$, nasturlii, ocimi, erucæ, radicis immiseris, et tunc involutan timo baccam terra oplime culta, brevi scrobe demersens. Ra. plıanus nititur in radicem. Cxetera semina in summo, lactuca pariter emergente, prosiliunt, singulorum sapore servato. Alii hoc ita assequuntır : Aruls $x$ lactucx folia carpunt, quæ radicibus juncla sunt, et in eisdem gradibus surculo punctis, præter raplıanum, semina supradicta deponunt, ac fimo adlimnt. Sic obruta iterum lactuca prædictorum seminum caulibus ambietur. Lactuca dicta est, quod abundantia laclis exuberet. Hoc mense nastur- 
quel climat. Il ne veut point de fumier; et quoiqu'il aime l'eau, il s'en passe aisément. On dit qu'en le semant avec la laitue, il vient à merveille. Ne tardez pas a semer la roquette à présent, ainsi que dans tel mois et en tel lieu qu'il vous plaira. On peut aussi semer les choux dans ce mois-ci, comme pendant toute l'annéc, quoiqu'il sera mieux de les semer dans les autres mois que nous leur avons assignés dans le courant de cet ouvrage. On sème aussi très-bien l'ail et l'oignon de Cypre ce mois ci; mais l'ail profite mieux dans une terre blanche que partout ailleurs.

$\mathrm{XV}$. On sème très-bien les cormes au mois de janvier, de février et de mars dans les pays froids, et dans les pays chauds, aux mois d'octobre et de novembre, en les mettant en terre dans une pépinière quand elles sont mûres. J'ai personnellement éprouvé que des arbres venus naturellement de leur's propres fruits a vaient souvent trèsbien réussi, et que non-seulement ils croissent heureusement, mais qu'ils rapportent beaucoup. Cependant on peut à son gré en obtenir du plant, pourvu qu'on le mette en terre dans les pays chauds au mois de novembre, dans les pays tempérés aux mois de janvier ou de février, et dans les pays froids vers la fin du mois du mars. Ces sortes de fruits aiment les lieux humides, montagneax, et qui tieunent plus du froid que du chaud. Ils veulent aussi un terrain qui soit trèsyras, qualité dont on aura un indice certain, lorsquil en viendra une grande quantité par tout le terrain. II faut transférer les corniers en pied quand ils sont devenus forts. Ils veulent ètre plantés dans une fosse profonde, et séparés l"un de l'autre par de larges intervalles, afin que l'agitation continuelle du vent (qui leur est trìsutile) les aide à croître. S'ils sont tourmentés par

tiun constat et omni tempore esse nonemlım, loco quali placebit, et calo : fimun non desulerat : liunorem quanıis diligat, tameu deesse uon curat. Si cum lacurca seratur, nasci foltur egreguc. f.t unuc et uteusilus quiluns volneris et locis, erncan serese mil molesis. Iloc elım mense caules et toto anuo seri possunt, sed melius aliis quibus adscriptunı est. Hoc elianı unense allium et ulpicum bene seritur : sed allio allıs trria proficiet.

$\mathrm{XV}$. Mense lanuario, Februario et Martio locis frigidis, calidis vero Octobri et Novemhri sorha seruntur egregic, ita ut matura in semiuario ipsa poma pangantur. Ego es. pertus sum multas arbores ex pomis spoute progenitas $\mathrm{et}$ in crescendo et in ferendo extitisse felices. Plantas etian si quis ponere voluerit, labebit arbitrum, dunmodo calidis locis ntense Novembri, temperatis lanuario vel Februario, frigiclis Martio inclinante disponat. Amat loca lıumida, montana et frigidis proxima, et solım piuguissi. mum : cujus indicium certissimum facit, si frequens ubj. cumque nascatur. Plaula est transferenda robustior; scro. bem lesiderat altiorem, et spatia largiora, 1 t, quod illi unaxime prodest, a ventis frequentibus agitata grandescat. certains vermisseaux malfaisants, ordinairement roux et poilus, qui s'insinuent dans l'intérieur de leur moelle, on arrache de l'arbre quelques-uns de ces animaux, sans l'endommager ; et on les brûle dans son voisinage. C'est, dit-on, le moyen de les chasser ou de les faire périr. Lorsque cet arbre commence à rapporter moins de fruit, on insère dans ses racines un coin de bois de pin, ou bien l'on pratique au pied une fosse, que l'on remplit ensuited'un amas de cendre. On greffe les cormiers au mois d'avril sur eux-mêmes, sur coignassier et sur épine blanche sauvage, et on les greffe tant sur le tronc qu'entre l'écorce. Voici la manière de conserver les cormes. On les cueille dans le temps qu'elles sont encore dures, et on les serre; lorsqu'ensuite elles commencent à mûrir, on en rem. plit jusqu'aux bords de petites cruches de terre que l'on recouvre de gypse, et que l'on enterre, la gueule renverscé par en bas, dans une fosse de deux pieds, creusée dans un endroit sec et exposé au soleil; après quoi on les recouvre avec de la terre quel'on foule aux pieds. On les coupe aussi par quartiers, et on les fait sécher au soleil, à l'cffet de les conserver dans de petits vaisseaux, pour l'hiver. Lorsqu'on veut ensuiteen faire usage, on les met tremper dans de l'eau bouillante, et elles reprennent toute leur saveur agréable. Quelques personnes les cueillent vertes avec leurs queues, et les suspendent dans des lieux ombragés et sees. On dit aussi que l'on fait du vin ainsi que du vinaigrc avec des cormes mûres, de même qu'a vec despoires. D'autres disent que l'on peut conserver longtemps des cormes dans du vin cuit jusqu'à diminution de moitié. L'amande se sème aux mois de janvier et de février, et dans les pays cliauds, aux mois d'bctobre et de novembre, tant cn nature qu'en rejetons que l'on arrache de la rarine d'un grand amandier. Mais la meilleure

Si rermes palietur infestos, qui in ea rufi ac pilosi solent melulla interna sectari, aliquos ex his sine arboris injuria letrartos, vicino crememus incendio. Creluntur loc genere vel fingere vel perive. Si minus ferre cocperit, tedae cuneus ejus radicibus inseratur, rel circa partem ultimam fossia facta cumulo ingesti cineris adbequetur. Mense Aprili sorba inseruntur in se, in cydoneo, in spina alha, vel in trunco, vel cortice. Sorba servantur hoc genere : Lecta luriora, ac josita, nbi nitescere cœperint, fictilibus usque ad plenum clauduntur urceolis, gypso desuper tectis, et bipedanea scrobe loco sicco sub sole merguntur ore perverso, et lesuper spissius terra calcatur. Item secta per partes siccantur in sole, et servantur in vasculis in hiberuum. Cum voluerimus uti, aqua ferventi macerata revirescunt sapore jucundo. Aliqui cum pediculis suis viridia lecta suspendunt locis opacis et siccis. Item ex sorbis maturis sicut ex piris viunm fieri traditur et acetum. Alii sorba in sapa asserunt diu posse servari. Amygdalus se. ritur Ianuario et Februario, item locis calidis Octobri et Novembri, semine et plantis, guae de majoris radice tol. luntur. Sed in luc genere arboris uiliil utilins est quan 
méthode, à l'ćgard de cette espèce d'arbre, est d'en faire des pépinières. On fouillera donc une superficic quelconque de terrain à la profondeur d'un pied et demi, et on y enterrera des amandes, en ne les couvrant pas de plus de quatre doigts de terre; de façon qu'elles soient fichées en terre par la pointe, et séparées de deux pieds l'une de l'autre. Les amandiers aiment un terrain dur, sec et plein de gravicr, ainsi qu'un climat très-chaud, parce qu'ils ont coutume de fleurir de bonne heure. Il faut les disposer de facon qu'ils soient exposés au midi. Lorsqu'ils auront pris quelque croissance dans la pépinière, on $y$ laisscra le nombre de pieds suffisants pour la remplir, et on transplantera les autres au mois de février. Mais on choisira, pour les mettre en terre, des amandes nouvelles et qui soient grosses; et avant de les y mettre, on les fera tremper la veille dans de l'hydromel qui ne soit pas trop miellé, de peur que l'acidité du miel ne fasse mourir le germe. D'autres commencent par les faire maeérer dans da fumier liquide pendant trois jours; après quoi ils les laissent pendant un jour et une nuit dans de l'hydromel, qui n'ait cependant qu'un soupcon de douceur. Lorsque l'on aura arrangé des amandes dans une pépinière, s'il survient de la sécheresse, on les arrosera trois fois par mois, et on les débarrassera souvent des herbes qui croitront autour d'elles, en les bèchant. La terre de la pépinière doit être mêlée de fumier. Il suffira de laisser vingt ou vingt-cinq pieds d'intervalie entre ces arbres. Il faut les tailler au mois de novembre, et en retrancher les branches superflues, sèches et trop drues. Il faut les mettre à l'abri des insultes des bestiaux, paree que, en les rongeant, ils rendent leurs fruits amers. Il ne faut jamais les bêcher quand ils sont en fleur, autrement la fleur tomberait.

scminarium facere. Fodiemus ergo altam pede uno semis aream, in qua obruemus amygdala, non amplius quatuor digitis, ita ut cacumina figamus in terra spatio inter se binorum pedum separata. Amant agrum durum, siccum, calculosum, calum calidissimum, quia mature florere consueverunt. Ita statuendæ sunt arbores, ut ad meridiem spcctent. Cum in seminario adoleverint, relictis ibi quac spatio sufficiant plantis, alias transferenus mense Februa. rio. Sed ipsa amygdala ad ponendum et nova lcgamus et grandia, quæ aıtequam ponamus, pridie mulsa aqua, ita ut ne ninis, maceremus, ne germen extinguat ex multo melle mordacitas. Alii prius fimo liquido per triduum nuces eas macerant : deinde die et nocte esse patiunlur in mulsa, sed quæ sıspicionem tantum possit liabere dılcedinis. Cum in semiuario amygdala disponimns, si siccitas intercesserit, ter in mense rigemus, et lıerbis nascentibus circumfodiendo sæe purgemus. Terra seminarii latameu labere debet admistum. Spatı inter arbores vigiıti ant vigintiguinque pedum dedisse sufficiat. Puiandae sunt Novembri mense, ut superflua et arida et densa tollanus. Servandæ sunt a pecore; quia, si rodautur, amarescunt.
Ils rapportent davantage quand ils sont vieux. S'ils ne sont pas fertiles, on fichera dans leur racinc, après l'avoir percée avee une tarière, un coin de bois gommeux de pin, ou biell on y insérera un caillou, de iaçon que l'écorce le recouvre par la suite. Martialis dit que voici la manière de les préserver dans les pays froids des ge. lées blanches qui y sont à craindre. On décourre leurs raeines avant qu'ils soient en fleur, et on aceumule autour de ces racines de très-petites plerres blanches mêlées de sable, que l'on couvre d'abord de terre, et que l'on retire par la suite, lorsque le temps où ils doivent germer parait approcher. Il prétend aussi que l'amandier donnera des amandes tendres, si on déchausse ses racines avant qu'il soit en fleur, et qu'on les arrose d'eau chaude pendant quelques jours. D'amères que sont les amandes, on les rend douees, soit en bêchant le pied de l'amandier à trois doigts de distanee de sa racine, et en pratiquant sur le tronc une ouverture à travers laquellc filtrera l'humeur qui lui fait tort; soit en le perçant par le milieu avec une tarière, en fichant dans ce trou un coin de bois enduit de miel; soit en répandant autour de ses racines de la fiente de porc. Les amandes aver. tissent du moment où elles sont mûres et bonnes à être cueillies; c'est celui où elles quit!ent leur écorce. Elles se conservent longtemps, sans aucun soin de la part de l'homme. Si leur peau s'enlève difficilement, elle se relâehera bientôt, pour peu qu'on les ensevelisse dans de la paille. De même si, aprèsles a voir dépouillées de leur peau, on les lave daus de l'eau de mer ou dans de l'eau salée, elles blanchissent etse conservent plus longtemps. On greffe les amandiers au mois de décembre ou au mois de janvier, vers les ides, et même au mois de février dans les pays froids, pourvu cependant que l'on ait eu soin de serrer d'avance.

Circumfodi non debent quoties florent, quia inde flos ejus excutitur. In vetustate plus affert : Si fcrax non est, ted $x$ cuncum terebrata radice mergamus, vel silicem sic inse. ramus, ut libro tegente claudatur. Locis frigidis, ubi me. tus est de pruina, Martialis dicit hoc remedio subveniri : Autequam floreant, radices nudantur, et albi lapides minutissimi misti arenis congeruntur, et ubi jam tutum videbitur ut debeant germinare, effossi iterum lapides sub. moventur. Teneras nuces amygdalus creabit (ut dicit) si ante florem radicibus ablaqueatis per dies aliquot calida aq̧ıa ingeratur. Ex anaris dulces fiunt, si circumfosso stipite tribus digitis a radice fiat caverna, per quam noxium desudet liumorem, vel medius truncus terebretur, el cuneus ligni melle oblitus imprimatur; vel [si] circa radices suillum stercus affundas. Anygdala ad legendum maturjtutem fatentır, cum fuerint spoliata corticibus. Hæec sine cura lıominis servantur in longum. Si difficulter corium dimitlent, paleis obruta continuo relaxabunt. Itcm decoriata si aqua marina lavemus aut salsa, et caudida fiunt, et plurimun durant. Mense Decembri et Ianuario cirea Idus amygdalus inseritur : locis vero frigidis et Februa- 
les scions quel'on emploiera avant qu'ils germent. Les meilleurs scions sont ceux que i'on prend sur le sommet de l'arbre. On les greffe non-seulement sous l'écorce, mais encore dans le trone, tant sur cux-mêmes que sur pêcher. Les Grecs assurent qu'il viendra des amandes sur lesquelles il y aura des caractères gravés, si l'on prend une amande saine, et qu'après l'avoir dépouillée de sa peau pour écrire dessus ce que l'on voudra, on la mette en terre enveloppée de bouc et de fiente de porc. On sèmera les noix à la fin de janvier ou de février. Le noyer airne les lieux montagneux, humides et froids, et communément ceux où les pierres abondent. On peut cependant en élever aussi dans les pays tempérés, avec le secours de l'eau. Il faut semer la noix en nature de la même manière que l'on sème les amandes, et dans les mêmes mois. Nais quand on la sème au mois de novembre, on la fait sécher quelque temps au soleil, afin d'en faire exhaler l'humidité, qui est un vrai poison. Pour celles que l'on sèmera au mois de janvier ou de février, il suffira de les avoir fait tremper la veille dans l'eau. On les mettra en terre transversalement, de facon que leur flanc, c'est-à-dire, la carène formée par leur coquille; soit couchée en terre, et l'on dirigera leur pointe du côté du nord. Il faut aussi mettre dessous une pierre ou une tuile, afin qu'elles ne s'en tiennent pas à produire une seule racine, mais que celle qui germera la première, étant repoussée par la résistance qu'elle trou vera, se divise en plusieurs autres. Le noyer devient plus beau quand on le transplante souvent. II faut le transplanter dans les pays froids à l'âge de deux ans, et dans les pays chauds à l'âge de trois. Quand on plante cet arbre en pied, il ne faut pas en couper les racines (comme on a coutume de le pratiquer à l'égard des autres arbres), mais il faut les tremper dans de la fiente de boeuf. On fera cucore mieux de répandre de la cendre dans les fosses où on le déposera, de peur que la chaleur du fumicr ne le brûle; d'autant que la cendre attendrit son écorce, et qu'clle lui fait rapporter une plus grande quantité de fruits. Cet arbi'e sc plaît dans de grandes fosses, eu ćgard à sa grandeur; et il demande à être séparé de tout autrc arbre par de larges intervalles, parce que l'eau qui dégoutte de ses feuilles nuit aux arbres qui l'avoisinent, fussent-ils de son espèce. Il faut quelquefois bêcher la terre autour de son trone, dc peur qu'il ne se cave en vieillissant; ct s'il vient à se pourrir, il faut creuser une longue rigole depuis le haut du trone jusqu'en bas, moyennant quoi le soleil et le vent feront durcir les partiesqui tendaient à la pourriture. Quand'un noyer est dur ou plein de nœuds, il faut couper son écorce autour du tronc, pour détourner l'humeur vicicuse qui cause cet accident. D'autres coupent l'extrémité de ses racines; d'autres percent sa racine avec une tarière, et enfoncent dans le trou qu'ils y ont fait un morceau de buis, ou un clou, soit de cuivre, soit de fer. Si l'on veut avoir des noyers de Tarente, il ne faut mettre en terro dans la pépinière que la pulpc seule de la noix, après l'a voir enveloppcé de laine à cause des fourmis. Si l'on veut qu'un arbre qui porte déjà des noix se change en cette espèce de noyer, on l'arrose trois fois par mois pendant une année entière avec de l'eau de lessive. Quand la noix quitte son brou, c'est une preuve qu'elle est mûre, et bonne à être semée. On conserve les noix, soit en les ensevelissant dans de la paille, ou dans du sable, ou dans des feuilles de noyer sèches; soit en les renfermant dans une caisse de bois de noycr; soit enfin en les mêlant avec des oignons, auxquels en revanche elles font perdre leur âcreté. Martialis rio : si tamen surculos colligas et condas antequam germinent. Utiles sunt, qui de summitate sumuntur. Inseruntur et sub cortice et in trunco. Iuseruntur in se et in persico. Græci asserunt nasci amygdala scripta, si aperta testa nucleum sanum tollas, et in eo quodlibet scribas, et iterum clausum luto et porcino stercore involutum reponas. [ Tit. XVI. ] Nucem [juglandem] seremus extremo lanuario vel Februario. Amat loca montana, humida et fri. gida, plerumque lapidosa. Potest tamen et locis tempera. tis juvante lumore nutriri. Serenda est nucibus suis eo nore, quo (et) amygdala seruntur, et iisdem mensibus. Sed quas Norembri mense disponis, aliquatenus in sole siccabis, ut exsiccetur noxium virus luumoris. Quas vero mense Ianuario vel Februario positurus es, aqua simplici pridie macerabis. Ponemus autem transversas, ut latus id est carina ipsa figatur in terra. Cacumen ipsum, cum ponimus uucem, in aquilonis partem dirigemus. Lapis subter vel testa ponenda est, ut radicem non simplicel, sed repercussa respergat. Lxetior fiet, si sxpius transferatur. In frigidis locis bima in calidis trima transferri debet. Ra. dices plantarum, sicut in aliis arboribus solemus, in hoc genere resecare non debes. Fimo bubulo ima planta tin. genda est. Sed melius cinis spargetur in scrobibus, ne calore stercoris aduratur : nam cinis creditur vel corticis teneritudinem procurare, ve] fructuum densitatem [afferre]. Altis scrobibus delectatur pro arboris magnifu. dine, et desiderat intervalla majora, quia stillicidiis foliorum suorum proximis rel sui generis nocebit arboribus. Debet aliquando circımfodi, ne cara fat vitio senectutis : [quæ si vitietur, ] canalis longus a summo trunco ad imum debet excudi : sic beneficio solis et venti durescunt, quæ in putredinem transibant. Si durs nux erit vel nodosa, cortex circumcideudus erit, ut vitium mali deducat lıumoris. Alii radicum summa præcidunt : alii tere. brata radici palum de buxo imprimunt, vel cuprinum clarum rel ferreum. Si Tarentiıam facere rolueris, solam nucis carnem lana propter formicas obrolıtam in seıniıırio debebis obruere. Si ferentem jan iu hoc genus velis mutare, lixivo per annum continuum ter rigabis in mense. Cortex in nuce dimissus maturitatis indicium est, qualis debet et poni. Nuces servantur vel paleis obruta vel arena vel fuliis suis aridis, rel arca ex ligno suo facta incluse, 
assure, et prétend l'avolr éprouvé par lui-même, que sil'ou plonge dans du miel des noix vertes, sans autre apprêt que celui de les débarrasser de leurs coquilles, elles sont encore vertes au bout d'un an, et que ce miel devient lui-même si médicinal, que, pris en potion, il peut servir de remède eontre les maladies qui attaquent les artères et la gorge. On greffe le noyer (suivant presque tous les autcurs) au mois de février sur l'arbousier; mais, suivant d'autres, il est mieux de le greffer sur le prunier ou sur lul-même, et d'insérer la greffe dans le trone. C'est dans ce mois qu'on greffe le jujubjer sur le coignassier ; e'est aussi le moment de mettre en terre les noyaux de pêches dans les pays tempérés. Quant à l'arbre qui produit ce fruit, on le greffe sur lui-même, sur l'amandier et sur le prunier; au lieu qu'on ne greffe l'abricotier, ainsi que le pêcher, qui donne la péche précoce, que sur le prunler seul. C'est encore le temps de greffer le prunier avant qu'il jette sa gomme. On le greffe sur lui-même, ou sur le pêeher. C'est aussi l'époque de greffer le cerisier sauvage.

XVI. C'est dans cemois, commele dit Columelle, que l'on marque d'une empreinte les agneaux venus à terme, et en général les produits taut du grand que du petit bétail. C'est aussi le temps de faire le lard, de saler le hérisson, de confire les raves, et de faire les jambons.

XVIJ. On fait dans ee mois de l'huile avec des baies de myrte, de la manière sui vante : on met une uncia de feuilles de myrte sur une livre d'huile, avec une hemina de vieux vin astringent sur dix uncice des mêmes feuilles, et on les fait bouillir avee l'huilc. Si on les asperge de vin, e'est pour éviter qu'elles ne soient frites avant d'avoir bouilli.

vel cxpis mista, quibus lıanc vicissitudinem reddunt, ut eis acredinem tollant. Martialis [asserit, et ] expertum se ait, virides nuces tantım liberas putaminibus suis melle deinergi, et post annum virides esse, et ipsum mel ita medicabile fieri, ut ex eo facta potio arterias curet et fauces. Inseritur, ut plerique [asserunt, ] mense Februario in arbuto: sed melius in trunco, ut aliqui, et in pruno rel in se. IIoc mense tuberes inseruntur cydoneo. Nune locis temperatis Persicorum ossa ponuntur. Et inseritur eadem Persicus in se, in amygdalo, in pruno : sed pruno Aruenia inseremus et pracoqua. Nunc etiam prunus inserenda est antequam gumminet, in se et [in] persico. Et cerasus opportune insetetur agrestis.

XVI. Hoc mense (sicut Columella dicit) maturi agni ef animalia omnia minora atque majora cliaractere signentur. Iloc tempore lardi, echini salsi, raporum condiendorum et pernarum justa confectio est.

XVII. Hoc mense ex haccis myrti oleum conficies lıc modo: Unciam foliorum per olei libran unam mittes, et per uncias $x$ vini veteris styptici heminam, et cum oleo bullire facies. Idcirco auteu vino respargentur folia, ne frigantur antequam decoquantur.
XVIII. On fait encore du vin de myrte avec les mêmes baies de la manière suivante. On met sur dix sextarii de vin vieux, mesure de ville, trois sextarii de graine de myrte concassée, même mesure, et on laisse le tout infuser pendant dix-neuf jours. Ensuite on passe cette graine en l'exprimant, et l'on met dans le vin un demiserupule de safran, avec un scrupule de feuille indienne; enfin on tempère cette mixtion avec dix livres du meilleur miel.

XIX. On fait aussi de l'huile des baies de laurier. En voici la recette. On fait bouillir dans de l'eau ehaude une grande quantité de baies de laurier, parvenues au dernier degré de grosseur et de maturité; et quand elles ont bouilli longtemps, on recueille légèrement avee une plume l'huile qui s'en exprime et qui surnage, et on la transvase ensuite.

XX. C'est aussi le temps de faire de l'huile de lentisque. Or, voici comme on s'y prend. On ramasse le plus qu'on peut de graine de lentisque mûre, et on la laisse en tas pendant un jour et une nuit. Ensuite on pose sur plusieurs petits vases des corbeilles remplies de eette graine, et, après l'avoir arrosée avec de l'eau chaude, on la foule pour l'exprimer; après quoi on ramasse l'huile de lentisque qui surnage sur l'eau qui coule de ces corbeilles, alnsi que l'on fait pour l'huile de laurier. Mais on se souviendra d'arroser cette graine avec de l'eau chaude, pour empêcher l'huilo de se figer.

XXI. Les poules reprennent leur fécondité ee mois, après s'être reposées pendant le solstice; ct l'on commence à leur faire couver des œufs pour avoir des poussins à élever.

XXII. C'est aussi dans ce mois qu'il faut couper le bois de construction pendant que la lune

XVIII. Item eisdem baccis viuum myrtite sic facies : In vini veteris sextariis urbicis $\mathrm{x}$ mittis grana myrti conf acta sextarios urbicos 11 , qua sint decem et novem diebus infusa. Postea expressis myrti granis colabis, et in eo vino medium croci scrupulum et folii unum scrupulum nittis, et ex mellis optini decem libris onnia temperabis.

XIX. Item [ex] lauri baccis oleum conficietur lıoc modo : Lauri baccas quam plurimas et maturitate turgentes in aqua calida bullire facies : et ubi diu ferbuerint, olei, quod ex se dimiserint, supernatantis undam pennis leviter cogentilus in vasa transfundes.

XX. Lentiscini etiam olei matura confectio est, quæ fit taliter : Grana matura lentisci quamplurima colliges, et una die ac nocte supra se acervata esse patieris. Deinde sportam granis eisdem plenam cuicunque vasculo super. pones et calida adjecta calcabis, et exprimes. Tunc ex eo hummore, qui defluxerit, supernatans oleum lentiscinum sicut laurinum colligetur. Memento antem (ne rigore possit astringi) aquam calidam sæpe suffundere.

XXI.Gallinarum partus foecunditatem repetit hoc mense post brumalem quietem; et incipiunt ad educandos pullos ova supponi. 
est đans son déclin, et qu'il faut faire des échalas et des pieux.

XXIII. Ce mois-ci s'accorde avec celui de décembre par rapport à la durée des heurcs. En voici les mesures rassemblées :

A la première et à la onzième heure, le gnoinon donne vingt-neuf pieds d'ombre.

A la seconde et à la dixième, il en donne dixneuf.

A la troisième et à la neuvième, il en donne quinze.

A la quatrième et à la huitième, il en donne douze.

A la cinquième et à la septième, il en donne dix.

A la sixième, il en donne neuf.

\section{LIVRE TROISIÈME.}

\section{FÉVRIER.}

I. On commencera pendant ce mois à garder les prés dans les pays tempérés, après les avoir engraissés, s'ils sont maigres, avec du fumier qu'on y étendra pendant le croissant de la lune. Il faut le répandre sur la partie la plus élevée du terrain, afin que le suc se distribue aux parties inférieures. Plus le fumier est nouveau, plusl'herbe sera fournie.

II. On donnera ce mois le premier labour aux coteaux gras dans les pay's chauds, ou dans tout autre pays, lorsque le temps aura été doux et sec.

III. Il faut semer ce mois-ci toutes les espèces de grains trémois.

XXII. Hoc etiam mense cæedenda materies est ad fabricam, cum luna decrescit, et ridica rel pali faciendi.

XXIII. Hic mensis in horarum spatio cum Decembri mense convenit, quarum sic mensura colligitur.

\begin{tabular}{|c|c|c|c|c|c|}
\hline Hora & 1 & et & $\mathbf{x} 1$ & pades & XXIX. \\
\hline Hora & 11 & et & $\mathrm{x}$ & pedes & xix. \\
\hline Hora & III & et & IX & pedes & $\mathbf{X v}$. \\
\hline Hora & IV & et & Vill & pedes & xil. \\
\hline Hora & $v$ & et & VIII & pedes & x. \\
\hline Hora & VI & & & pedes & Ix. \\
\hline
\end{tabular}

\section{LIBER TERTIUS.}

1. Februario mense locis temperatis prata incipient custodiri, quæ prius, si macra sunt, sparso lælamine saturentur, quod ejiciendum est luna crescente. Quanto recentius fuerit, tanto plus nutriendis herbis valebit, quod a superiori parte fundatur, ut succus ejus per totum possit elabi.

11. Locis tepidis, aut si clemens tempus et siccum fuerit, colles pingues rel hoc mense prosinde.

1II. Hoc mense serendum omne trimestrium genus.
IV. On sèmera encore ce mois la petite lentille en terrain léger et friable, ou même en terrain gras, pourvu qu'il soit très-sec, parce qu'en terre forte ou humide cette graine s'altère. On la sème très-bien jusqu'au douzième jour de la lune ; et si l'on veut qu'elle lève de bonne heure et qu'elle profite ensuite, il faut la mêler avec du fumier sec, et la laisser quatre ou cing jours dans cet état avant de la semer. Un modius de graine suffira pour ensemencer un jugerum. C'est aussi le temps de semer la gesse dans les terrains que je viens de dire, et de la façon que j’ai prescrite.

V. On sèmera le chanvre à la fin de ce mois dans une terre grasse, fumée et arrosée, ou dans une campagne plate, humide, et:labourée profondément. On met six grains sur un pied carré de terrain.

VI. Il faut donner à présent le second labour aux champs que l'on doit ensemencer en luzerne (herbe dont nous examinerons la nature lorsqu'il sera questiou de la semer), et les herser avec soin, après les avoir épierrés. Et quand ils seront labourés à la manière des jardins, on y fera, vers les calendes de mars, des planches auxquelles on donnera dix pieds de largeur et cinquante de longueur, afin qu'il soit facile de les arroser et d'en arracher les mauvaises herbes en se tenant sur les deux côtés. Ensuite on répandra de vieux fumier sur ces planches, et, après cette préparation, on les laissera reposer jusqu'au mois d'avril.

VII. On peut encore semer l'ers dans tout le courant de ce mois. Il ne faut pas le semer au mois de mars, de peur qu'il n'incommode les bestiaux et ne rende les bœufs fous.

IV. Hoc etiam mense lenticulam seres solo tenui et resoluto, vel etiam pingui; sed sicco maxime : quiá luxuria et humore corrumpitur. Usque ad dnodecimam lunan bene seminatur, qua ut cito exeat atque grandescat, prius $\mathrm{cum}$ fimi ariditate miscenda est : atque uhi ita requieverit quatuor diebus aut quinque, tunc spargitur. Jugerum modii unius semen implebit. Hoc etiam mense cicercula seritur, loco et modo quo ante descripsi.

V. Hoc mense ultimn cannabum seres terra pingui, stercorata, rigua, vel plana atque humida et altius subacta. In uno pede quadrato sex ejusdem seminis grana ponuntur.

V1. Nunc ager qui accepturus est medicam (de cujıs natura, cum erit serenda, dicemus) iterandus est, et purgatus lapidibus, diligenter occandus. Et circa Martias cal. subacto sicut in hortis solo, formandxe sunt arexe latx pedibus $\mathrm{x}$, longa pedibus quinquaginta, ita ut eis aqua ministretur, et facile possint [ex utraque parte] runcari. Tunc injecto antiquo stercore in Aprilem mensem reserventur parato.

VII. Hoc mense toto ervum adluc seri potest; quia Martio serendum non est, ne pastu suo pecoribus noceat, et boves reddat insanos. 
VIII. Si l'on jettc à présent de l'urine gardée au pied des arbres fruitiers et des ceps de vigne, ils rapporteront des fruits remarquables par leur quantité et par leur beauté. Si ce sont des oliviers notamment, il sera bon d'y mêler du marc d'huile sans sel. Mais il faut faire cette opération quand les jours seront encore froids, ct avant que la chaleur commence à se faire sentir. On sèmera aussi dans les pays froids, vers les calendes de mars, l'orge de Galatie, qui est un grain blanc et pesant.

IX. C'est dans ce mois que l'on garnit devignes toutes les sortes de terrains faconnés au pastinum, soit qu'on y ait préparé des tranchées, soit qu'on y ait préparé des fosses. Au reste, la vigne est une plante de nature à supporter les climats et les sols de toutes les espèces, pourvu que les différents genres de raisin leur soient adaptés convenablement. On plantera donc dans une campagne plate l'espèce de vignes qui souticnt les brouillards ct les gelées; sur les coteaux, celle qui supporte la sécheresse et les vents; dans un terrain gras, les vignes grêles et peu fécondes; dans un terraiı maigre, les vignes productives et robustes; dans un teriain compacte, les vignes fortes et chargées de feuilles; dans un terrain froid et sujet aux brouillards, celles qui devancent l'hiver par la prompte maturité de leur raisin; ou celles qui, ayant le grain dur, fleurissent sans danger au milieu des brouillards; dans un terrain exposé aux vents, les vignes stables ct tenaces; dans un terrain chaud, celles dont le grain sera tendie et humide; dans un terrain sce, celles qui ne peuvent pas supporter la pluie. Fit, pour ne pas nous étendre davantage sur cette matière, nous nous contenterons de dire en général qu'il faut toujours choisir les vignes dont les défauts annoncent clairement qu'elles sc plairont dąns les lieux opposés à ceux dans lesquels

VIII. Nunc pomis et vitibus vetus urina si affundatur, et numero fructuum prastat et forma : cui proderit ut amurcam misceamus insulsam, maxime in ole is : sed hoc frigidioribus diebus antequam fervor incipiat. Etiam nuns ordeum galaticum, quod grave et candiduın est, seretur locis frigidis circa Nartias calendas.

IX. Hoc mense omnia genera pastinati soli, seu sulci selı scrohes vitibus compleautur. Natura autem vitis cælum omne solumque sustentat, si genera convenienter ap: teritur. Plano igitur loco statues vitem, cujus genus nebulas sustiuet et pruinas; collibus, quod siccitatem durat et veutos; pingui agro graciles atyue infoecundas; macro fe. races et solidas; ilenso validas atque frondosas; frigido et nebuloso, qua hiemem celeri maturitate praceniunt, aut qux duris acinis inter caligines securius florent; ventoso stabiles et tenaces; caliclo grani tenerioris et humidi ; sicco eis, qua jluvias ferre non possunt : et ne multa dicanus, eligenda sunt genera, qua professione vitionum sıorum contraria loca diligunt iis, in quibus durare non poterunt. Ilaciua sane regio et serena tulo genus omne suscipiet. elles ne pourraient pas subsister. Il n'est pas douteux qu'un climat où l'air est toujours calme et le ciel serein recevra sans danger quelque espèce de vigne que ce puisse être. Il est inutile de les détailler toutes. Mais personne n'ignore qu'il faut réserver pour la table le raisin dont les grappes sont les plus grosses et les plus belles à l'œil, et dont les grains sont durs et secs; comme il faut garder pour faire du vin les vignes les plus fertiles, celles dont les raisins ont la peau tendre et le goût distingué, ct principalcment celles qui quittent leur fleur de bonne heure. Lc changement de terrain influe sur la nature de la plupart des vignes. Il n'y a que les aminées qui donnent toujours de très-bon vin, en quelque lieu qu'elles soient plantées; quoiqu'elles supportent cependant plutôt un climat chaud qu'un climat froid, et qu'clles ne puissent passer d'un terrain gras dans un terrain maigrc, à moins qu'on ne les aide de fumier. Il y en a de deux espèces, savoir, la grande et la petite. Mais la petite quitte mieux sa fleur que l'autre, et de meilleure heure; ses entre-nœuds sont aussi moins longs, et le grain de son raisin est plus petit. Si on la marie à l'arbre, elle demande une terre grasse; au lieu que si on la cultive plantée par rangíes, elle en veut un médiocre. Elle s'inquiète peu des pluies ou des vents, qui font souvent périr la grande pendant qu'elle est en fleur. Le raisin muscat est encore un raisin distingué. Il suffit d'avoir cité ces espèces : un homme intelligent choisira celles qu'il aura ćprouvées, et ne les confiera qu'à des terres qui aient quelque analogie avec celles d'où ellcs auront été tirées; moyennant quoi chacune conservera sa qualité particulière. Mais il vaut mieux transférer ainsi la vigne que les arbres d'un terrain maigre dans un gras, parce qu'on n'en pourrait pas attendre de fruits, si on les transférait d'une terre grasse dans une maigre. Il faut

Vitium genera numerare non attinet. Sed notım est, majores uvas pulclira speciei, grani callosi et siccioris, ad mensam; feracissimas vero et cutis tenerioris, et sapore nobiles, et maxime qua citius deflorescunt, vindeniis esse servandas. Loca naturam plerisque vitibus mutant. Sola Aminea ubicunque sint, vinum pulcherrimum reddunt. Calidum statum potius quam frigidum sustinebunt. De pingui ad macrum trausire non possunt, nisi stercus adjuverit. Harum duo genera sunt, major et minor. Sed minor melius deflorescit et citins, internodiis minoribus et grano breviore. Si arbori applicelur, pinguen terram; si colatur in ordines, mediocrem desiderat. Imbres contemuit et ventos : nam major sæpe vitiatur in flore. Sunt et Apianx procipuxe. Satis est genera ista dixisse : indus. trius vir probata deligat, et terris talibus mandet, qux imitari eas possint unde sumuntur : sic merita sua quaeque servabit. Sed vitem vel arborem melius erit de exili ad pinguem transferre. Nam si a pingui terra ad solun exile transierint, utiles esse non possunt. Eligenda sunt sarmenta, qux pangimus, de vite media, neque de sum. 
choisir Ies sarments que l'on doit planter dans Ic milieu d'un cep, ct ne les prendre ni sur l'unc ni sur l'autre de ses extrémités, parce qu'ils ne dégénc̀rent pas aisément quand ils ont été pris dans cette place pour être transplantés. Ces sarments doivent sortir du bois vieux à une longueur de cinq à six boutons; mais il faut les prendre sur une vigne féconde. Et qu'on ne s'imagine pas que des bras de vigne soient féconds pour avoir porté une ou deux grappes chacun, puisqu'il est nécessaire, pour qu'ils soient réputés l'être, qu'ils soient courbés sous le poids des grappes. En effet, il peut arriver qu'un cep de vigne fécond ait des bras qui soient plus féconds les uns que les autres. Ce sera encore une marque de fécondité lorsque la vigne portera du fruit sur quelque partie de son bois dur, de mê!ne que lorsque les branches qui seront venues sur son extrémitè inférieure en donneront beaucoup. C'est de quoi il faudra prendre note pendant la vendange, en mettant des marques aux ceps qui seront dans cc cas, pour ne pas les confondre. Il faut choisir, pour la planter, une jeune branche sur laquelle il ne reste point de bois dur ni de vieux sarment; autrement il lui arriverait souvent de se gâter quand ce bois viendrait à pourrir. On négligera les extrémités des fouets, ainsi que les rejetons qui n'auront point donné de preuves de fertilité, quoique nés dans un bon endroit du cep. Quand même un pampre, né sur bois dur, aurait porté quelques fruits, il ne faudra pas en conclure qu'il en rapportera beaucoup; parce que, s'il a pu être fécondé par sa mère dans la place qu'il occupait sur elle, il se trouvera affecté, dès qu'il sera transféré, du vice de stérîitéqu'il tient du sort de sa naissance. Il ne faut pas tordre ni tourmenter d'aucune manière la têtc du sarment que l'on met en terre, dans la crainte que si sa partie la plus féconde se trouve absolument enterrée,

ma neque de infima, quinque vel sex gemmarum spatio a veteri procedentia, quia non faeile degenerant, quæ de loeis talibus transferuntur. Sumantur autem de vite foecunda. Neque putemus braelia esse fertilia, qux uras singulas aut binas produeunt, sed quæ multa ubertate eurvantur. Nam potest ferax vitis feraeiores in se lıabere materias. Erit et hoe signum fertilitatis, si de duro aliquo loco fruetum eitabit, si fuctu impleverit ramulos ex ima parte surgentes. Sed hoc signis positis per vindemias est notandum. Ad pangendum novellus palmes debet eligi, duri il se nilil habens et veteris sarmenti, quia hoc putrescente sape corrumpitur. Summa flagella repudiemus ac surculos, qui licet bono loco nati sint, tamen feraeitatis benefieio caruerunt. Pampinarius qui de duro naseitur, etiam si attılerit fruetus, pro frugifero non est ponendus : in suo enim loco foecundatur a matre, translatus vero tonet sterilitatis vitium, quod nascendi conditione suscepit. Caput sarmenti eum deponitur, torquendum non est, nec afiquo modo vexandum, ne demersa penitus fuecundiore parte, quod sterili proximum est, supra terram relinqua. il n'y ait plus hors de terre que ce qui se trouvera le plus voisin de sa partie stérile; ajoutez qu'il ne serait pas possible de le tordre sans le tourmenter ; tandis que la partie dont on attend des racincs ne doit souffrir aucun genie de dommage contre lequel elle soit obligée de lutter avant de pouvoir pendre en terre. On plantera la vigne par un temps cliaud et dans un jour calme. Il faut prendre garde que les sarments ne soient brûlés par le soleil ou par le vent quand on les plantera, et par conséquent les planter aussitôt qu'on les aura tirćs du cep ; ou les conserver jusqu'à ce qu'on les plante, en les enfouissant sous terre. C'est à conmencer de ce mois-ci, jusqu'à la fin du printemps, qu'il faudra planter la vigne dans les contrées froides et sujettes aux brouillards, ainsi que dans les campagnes grasses et dans les provinces humides. On donnera un $c u$ bitus de longueur au sarment que l'on mettra en terre. Quand la terre sera grasse par sa nature, on laissera de plus grands intervalles entre les ceps. Quand elle sera maigre, on en laissera de moindres. C'est pour cela qu'en distribuant des ceps sur toute la superficie d'un terrain faconné au pastinum, il y a des personnes qui laissent trois pieds d'intervalle en tout sens entre chacun de ces ceps. Or, en se réglant sur cette distribution, il y aura trois mille six cent sarments de plantés dans une planche d'un jugerum; au lieu que si l'on ne veut laisser que deux pieds et demi d'intervalle entre chaque cep, il y en aura cinq mille cent quatre-vingt-quatre. Mais voici la manière dont on s'y prendra pour les planter en ordre. On fera sur une ficelle des marques blanches, ou de quelque autre couleur que ce soit, en se réglant sur les intervalles que l'on voudra garder; ensuite, après avoir étendu cette ficelle à travers la planche, on fichera en terre des jalons dc bois ou des roseaux à toutes les places où il faudra

tur : deinde quoniam ipsa tortura rexatio est : et pars ea de qua radix futura præesumitur, injuriæ nulli subjicienda est, eum qua eontendere eogatur ante quam leneat. Ponendae sunt vites plaeidis diebus ae tepidis, curandumque ne sarmenta sole urantur aut rento, sed vel statim ponan. tur, vel obruta reserventur. Hoe mense ac deinceps toto rere vinea ponenda est regionibus trigidis, pluriosis, pinguibus campis, et humidis provinciis. Sit autem mensura sarmenti cubitus unus. Ubi pinguis est natura terrarum, majora inter vites spatia relinquemus; ubi exilis, angusta. Nonnulli itaque in iis vitibus, quas toto solo pastinato disponunt, ternos pedes inter singnlas vites quoquoversus dimittunt. Sed lıoc genere divisionis in jugerali tabula pallgentur tria millia vicena sarmenta. Quod si duos semis pedes inter vites relinqui placuerit, in eadem tabula ponentur vites quatuor millia quingentæe septuaginta octo. Sed ad ponendum utemur hoc ordine : Linean, servatis iis spatiis, qua plaeuerit custodire, candidis siguis vel quiluuseunque notabimus : tune tensa per tabulan linea iı eis - locis surculos rel calamos figemus, ubi vitis unaugıxque 
planter un cep, de façon que la superficie de la planche soit entic̀rement couverte d'un nombre de jalons correspondant au nombre de ceps qui derront y être plantés, et que cclui qui doit les planter ne puisse pas se tromper, lorsqu'il n'aura qu'à mettre cn terre les sarments déposés auprès de ces jalons. Observez de plus qu'il ne faut pas que tout un tcriain façonné au pastinum soit rempli d'unc seule espèce de vigne, de peur que, s'il survenait une année qui fût contraire à l'espèce que l'on aurait choisie, toute l'espérance de la vendange ne se trouvât détruite. C'est pourquoi on plantera des sarments de quatre ou cinq sortes de vignes de bonne qualité, et il sera trèsutile d'en réunir les espèces différentes dans des planches particulières, qui scront séparées les unes des autres par des sentiers; à moins que l'on ne soit rebuté par la difficulté de cettc distribution. Si l'on a d'ancicns vignobles cependant, il est aisé de planter dans des planclèes séparées des rcjetons pris sur toutes les espèces qu'ils contiennent, et de parvenir par conséquent à la forme de culture que nous prescrivons; forme qui estbelle et avantageuse, puisqu'ellc procure à toutes les espèces de vignes, qui ont chacune lcurs époques particulières de floraison et de maturité, l'avantage de fleurir et de mûrir dans le temps qui leur est propre. En effet, on s'exposerait à un dommage réel, si l'on était obligé de cueillir le fruit mûr en mêmetemps que le vert, parce qu'ils se trouveraient réunis sur une même planche; puisqu'on ne pourrait pas se régler sur la vendange de telle ou telle espèce de vigne çu'il serait temps de faire, sans courir le danger de donner un goût de verdeur à son vin; comme on ne pourrait pas, d'un autre côté, atteudre la maturité tardive de tellc autre espèce de vignne, sans perdre la vendange de cellcs qui seraient mûries les premières. Ajoutez à ces avantages que

ventura est. Ita spatium totius tabula șurculis complebitur ad numerum vitium futurarum : atque is qui panclurus est projecta circa surculos sarmenta sine ullo errore depouet. Praclerea non est uno genere vitium omne pastinum conserendum, ne annus iniquus generi spem vindemix totins extinguat. Et ideo quatuor aut quinque eximii generis sarmenta pangemus. Sed maxime expediet genera tabulatim disponi, et decumanis dividi, nisi deterreat operis difficultas. Quod si est vetus vinea, singnlorum generum surculis tabulatim poterimus inserere : et facile hoc genus colendi, quod est pulchrum atque utile, consequemur. Ita et maturitatis et floris tempora, quæ in vite diversa sunt, suis temporibus opportunius obtinere poterimus. Nec parvo constahit, si legalur maturitas cum acerbitate, dispendiosum unius tempestivam vindemiam sequi, permista cruditate vitiosam, et alterius seras maturitates expectare dannificum. Huic commodo adjicitur, quod pro generum diversitate per gradus accedente vindemia, minor operarum numerus eam poterit expedire, et generatim condere, ac melius puro sapore, sine luctamine alterius generis les vendanges de chaque espèce de vigne se succédant par degrés les unes aux autres, suivant leur différente nature, il faudra moins d'ou. vriers, en suivant notre méthode, pour les expédicr toutes, et pour les serrer par classes. D'ailleurs chaque sorte de vin conservera mieux le goùt qui lui est propre, quand ce goût ne sera pas combattu par le mélange d'un vin différent. Si cette pratique parait difficile, il faut au moins ne pas planter cnsemble d'autres vignes que celles dont le goût, la fleur et la maturité ont quelque analogie cnsemble. Mais la méthode que nous venons de donner par rapport à la plantation des vignes est cellc que l'on suivra dans les terrains faconnés au pastinum, ou dans les tranchées. Quant aux sarments que l'on mettra dans des fosses, il faudra les y mettre aux quatre coins, et, comme le prescrit Columelle, jeter dans la fosse, au moment qu'on les y mettra, du marc de raisin mêlé avcc du fumicr; et, si le terrain est maigre, de la terre grasse ou de la terre rapportée. Au surplus, lorsqu'on arrangera un pied de vigne ou un maillcton dans unc fosse, on les y mettra en travers. II faut aussi quele terrain soit mćdiocrement humide, et plutôt sec que bourbeux, et que lc plant ait deux boutons hors de terre, afin qu'il prenne plus aisément.

X. Si c'est votre goût d'avoir des vignes mariées aux arbres, il faudra commencer par élever dans une pépinic̀re du plant de bonne qualité, que vous transporterez, lorsqu'il aura pris racine, dans des fosses creusées au pied de chaque arbre. J'appelle pépinière une planche labourće uniformément à la profondeur de deux picds et demi. On dépose des sarments en terre, à très-peu de distance les uns des autres, dans cette planche, que l'on fait plus on moins grande, suivant le nombre des ceps ou boutures d'autre plant que l'on veut y mettre; et si cette planche est située

unaquacque vina servare. Hoc si difficile videbitur, non alias simul conseras, quam quae et sapore et flore et ma. luritate conveniunt. Sed hæc in pastinis vel sulcis ratio erit : in scrobibus vero per angulos iv sarmenta deponis. Sed (ut asserit Columella) vinaceam stercori mistam simul sparges, et si exile solum fuerit, pinguem terram scrobi inferes vel aliunde portatam. Cuin vero plantam vel malleolum disponimus, modice lummido solo, sed potius arido quam lutoso, duabus gemmis supra terram relictis, sarmenta ponemus obliqua; sic facilius compreliendent.

$X$. Quod si arbustım te habere delectat, plantam generosæe vitis prius in seminario nutrire debebis, $u t$ inde radicata transferatur ad scrobem, cui arbor injuncta est. Seminarium vero dicimus xque fossam tabulam pedum duorum semis altitudine. In liac, quam pro numero ponendarum vitium vel qualiumcunque plantarum protendis aut contrahis, brevissimo spatio distantia inter se sarmenta depones: si vallis aut lumectus est campus, trium gemmarum exceptis minutis, quas habebit inferius. Et ubi convaluerint, linc post biennium radicatas vites vel ar- 
dans une vallée ou dans une campagne plate qui soit humide, on laisse trois gros boutons à ces sarments, indépendamment des petits dont leur extrémité inférieure sera garnic. Ensuite, quand ils auront pris la forme de petits ceps ou de petits arbres garnis de racines, on les transférera au bout de deux ans, temps auquel ils auront pris une certaine consistance; et lorsqu'on les mettra dans la fosse qui leur sera destinée, on les réduira à un seul jet, en coupant toutes leurs parties galeuses, et en émondant leurs racines, au cas où il s'en trouve d'endommagées. Au surplus, quand on veut marier des vignes aux arbres, on met deux de ces ceps pourvus de racines dans la même fosse; mais, pour empêcher qu'ils ne se touchent par le pied, on les sépare avec des pierres d'environ einq livres pesaut, et on les applique aux côtés opposés de la fosse. Magon assure qu'il ne faut pas remplir la fosse de terre la première aunée, mais qu'il ne faut la combler que successivement et par intervalle, afin que les racines de la vigne y pénètrent plus profondément. Cependant cette méthode ne peut convenir que dans les contrées sèches; car daus un sol humide le plant pourrirait si la fosse n'était pas aussitôt comblée, et qu'on laissât le temps a l'eau de la noyer. Celui qui veut former un plant d'arbres mariés à des vignes doit choisir parmi les espèces suivantes, si elles abondent dans le canton, savoir, le peuplier, l'orme, et le frêne dans les terrains montagneux et escarpés, où l'orme ne viendrait pas bien. Columelle prétend qu'il faut aussi élever ces arbres dans des pépinières. Mais comme il n'y a point de province qui n'en produise d'une ou d'autre de ces especes, sans culture, il me semble qu'il raut mieux mettre en ce temps-ci, auprès des ceps qui seront déposés dans les fosses, des pieds d'arbres d'une certaine grandeur, que l'on

busculas transferas : quas cum depones in scrobe, ad singulas materias rediges, putatis omnibus quæ scabra sunt, curtatis etiam radicibus, si quas potueris invenire vexatas. In scrobe autem ad arbustum faciendum duas radicatas rites deponis, loc servans, ne se in radice contingant : sed lapides quinum prope librarum medios inter utramque constitues, et ipsas rites ad scrobis latera discreta conjunges. Mago asserit, scrohen non primo anno esse complendam, sed subiude coxquandam : qux res vitem faciet altius fundare radices. Sed luoc aridis provinciis forte conveniet : lumidis autem sala putrefient recepto liumore, nisi statim terra cumuletur. Sed arbusta qui faciet, plantas arborum de his generibus ponat, si agro suppetit abundantia, populo, ulmo : fraxino in montanis et asperis, in quibus ulmus minus lata est. Has etiam Columella dicit seminario debere nutriri. Mili videtur, quod nulla provincia est, quar non ex his quamcunque sponte producat, plantas etiam majores de locis quibus. cunque translatas, rel eorum generum truncos railicatos, hoc fempore circa scrobem vitis oportere constitui. Sed si transférera à cet effet de quelque endroit que ce puisse être, ou même des trones d’arbres avec leurs racines, que l'on choisira dans le nombre des espèces que nous venons de nommer. Si le sol sur lequel on opère est une terre à blé, on laissera quarante pieds d'intervalle entre chaque arbre, afin de pouvoir ensemencer ce terrain, et vingt pieds seulement si le terrain est maigre. Quant au cep qui sera planté dans la fosse, il doit être éloigné de son arbre à la distance d'un pied et demi, parce que, s'il en était trop proche, l'arbre en croissant absorberait sa substance. II faut aussi encager le cep pour le protéger contre les insultes des bestiaux qui chercheront à le ronger, et l'attacher dès le premier moment à son arbre. Voici encore une autre méthode expéditive pour transférer un cep d'un plant d'arbres mariés à des vignes : on fait un petit panier d'osier d'environ un pied de diametre ou un peu moins, que l'on porte auprès de l'arbre auquel la vigne est mariée, ct l'on en perce le fond par le milieu, à l'effet de faire passer un sarment par cette ouverture Après avoir done introduit dans ce panier un sarment du cep dont on veut transporter du plant, on suspend le panier même à quelque coin de l'arbre, et on le remplit de terre végétale, de facon que ce sarment, que l'on a soin de tordre auparavant, puisse y ètre entièrement caché. Avec ces précautions, le sarment renfermé dans ce petit panier y jette des racines au bout d'un an; et quand il $\mathbf{y}$ a pris racine, on le coupe dessous le panier, pour le porter avec lé panier même à l'endroit que l'on veut remplir de ceps mariables à des arbres, et on l'y enterre auprès des racines de l'arbre auquel on a intention de le marier. On transférera par cette méthode tel nombre de ceps que l'on voudra, sans avoir à craindre qu'ils ne prennent point.

XI. En fait de vignob!es, chaque localité a son

ager frumentarius fuerit, ubi arbusta disponis, quadragenos pedes inter arbores relinque, ut seri possit; in exili autem ricenos, In scrobe vero vitis ab arbore sua sesquipedis spatio distare debebit. Nam vitis multum subjecta arbori, incremento arboris opprimetur. Caveis etiam mu. nienda est adversum pecoris appetentis injurias, et arbori suæ protinus alliganda. Est et aliud de transferenda ex arbusto vite compendium : Fit ex vimine parva corbicula?, quux mensuram pedis, rel aliquanto mivus circiıi spatio possit amplecti. IJac ad arborem, cui vitis inluecet, fer. tur, et in fundi media parte pertunditur, quo sarmenti virgam possit admittere. Inducto itaque sarmento vitis ejus, de qua Lransferre disponis, corbicula ipsa ex aliq̨ua arboris parte suspenditur, et viva terra repletur, ut sarmentum terra possil includi; quod sarmentum prius intorquetur. Ita exacto annui temporis spatio, sarmentum, quorl clausum est, radices creabit intra pracdictam corbiculam. Tunc sub fundo corbis incisnm radieafum sarmen. tum cum ipsa corbe portabitur ad locum quem vitibus arbustiris destinabis implere, ibique obruetur circa arbo. 
mode de culture; mais la meilleure consistc à avoir des ceps qui se tiennent sur une tige très-courte, comme de petits arbres. On commence par les faire tenir à l'aidc d'un roseau, jusqu'à ce qu'ils soient bien affermis; mais il ne faut pas que ces ceps aient plus d'un pied et demi de hauteur. Quand ils seront devenus forts, ils se tiendront tout seuls. Il y a une autre méthode, qui consiste à distribuer plusieurs roseaux autour d'un cep, dont on lic les sarments à ces roseaux, pour les arrondir en forme de cercles. La pire de toutes les positions pour la vigne, est d'être renversée ct couchée à terre. Toutes ces différentes espèces de vignes se plantent dans des fosses et dans des tranchées.

XII. C'est en ce mois qu'il est temps de tailler la vigne dans les pays froids jusqu'à un certain dégré, ainsi que dans les pays tempérés. Mais quand on a beaucoup de vignes, on les partage en deux portions, dont on taille au printemps celle qui est exposée au nord, et en automne celle qui l'est aux autres cótés du ciel qui sont plus doux. Attachons-nous toujours, dans la taille, à donner de la force au pied de la vigne, et à ne jamais laisser deux bois durs à une jeune vigne tant qu'elle est taible. Il faut retrancher les sarments qui rapportent beaucoup, ainsi que ceux qui sont tors, faibles, ct nés dans un mauvais endroit du cep. Il faut aussi couper le sarment qui sera né sur un cep entre deux de ses bras. Mais s'il esț déjà fortifié au point d'affaiblir l'un de ces bras, c'est ce dernier qu'il faut couper, cn laissant subsister l'autre. Il faudra néanmoins qu'un homme intelligent dans l'art de la taille ménage toujours Ics sarments inférieurs qui seront nés dans un bon endroit, pour les employer à renouveler la vigne ; et qu'il les laisse sur le cep en les rognant

ris maritanda radices. Hoc genere quantum volueris numerum vitium transferes, sine ambiguitate prelıendendi.

$\mathrm{XI}$. Vineæ in provinciis multis generibus funt : sed optimum genus est, ubi vitis velut arhuscula stat brevi erure fundata. Hac primo calamo juvatur, donec solide tur : sed altior sesquipede esse non debet : ubi robusta fuerit, sola consistet. Aliud genus est, in quo cannis plu. ribus circa dispositis ipsa vitis per cannas sarmentis ligatis in orbiculos flectitur se sequentes. Ultimæ positionis vitis est, quæ per terram projecta discumbit. Hæa omnes et scrobibus ponuntur, et sulcis.

XII. Hoc mense locis frigidis aliquatenus et temperatis vitium justa putatio est. Sed, ubi multæ sunt vineæ, dividantur, et pars earum qaæ septentrionem respiciet, verno putetur; alia pars adversa clementioribus plagis, recidatur autumno. Sed in putatione semper nitamur, ut vitis fiat in crure robustior, ne [ve] debili viticulæ duo duramenta servemus. Auferenda sunt lata, intorta, debilia, malis locis nata sarmenta. Focaneus etiam, qui inter duo bra. clia medius, nascitur, debet abradi : qui si pinguitudine sua brachium quodcunque proximum debilitaverit, illi jusqu'au premier ou au second bouton. On pourra laisser à la vigne la liberté de s'étendre par en haut dans les climats doux; au lieu qu'il faudra la ravaler dans les terrains maigres ou dans les climats plus chauds, ainsi que dans les terrains en pente ou sujets aux tempêtes. On laissera dans les terres grasses deux fouets à chaque bras d'un cep; mais il est d'un homme prudent d'apprécier les forces de la vigne. En effet, celle que l'on cultive dans l'intention de la faire monter en haut, et qui est féconde, ne doit pas avoir plus de huit branches à fruit, sans compter le courson, que l'on conservera toujours dans sa partie inférieure. Il faut couper tout ce qui sera venu autour du pied de la vigne, à moins qu'elle n'ait besoin d'être renouvelée. Si le tronc d'une vigne est creusé, soit par la violence du solcil ou des pluies, soit par des animaux malfaisants, on retranche tout le bois mort, et on enduit la plaie, qui résulte de cette opération, de marc d'huile et de terre, précaution excellente pour obvier aux accidents qui pourraient s'ensuivre. On ôte aussi l'écorce qui s'est détnchée du cep, et qui pend à terre; et cette attention diminue la quantité de lie qu'aurait autrement le vin. On ratisse la mousse partout où il s'en trouve. Au surplus, les plaies que l'on fera à la vigne sur son bois dur seront obliques et rondes. En retranchant, ainsi que je l'ai prescrit ci-dessus, tous les salments qui seront nés dans un mauvais endroit du cep, ou ceux qui scront vieux, on conservera les jeunes, ainsi que ceux qui porteront du fruit. On coupera aussi les ergots des coursons quand ils seront desséchés, et qu'ils auront un an, de même que tout ce qui se trouvera de vieux ou de galeux sur un cep. On laissera quatre bras aux vignes que l'on cultive, dans l'intention de

deciso ipse succedat. Erit tamen opptimi putatoris, inferius sarmentum, quod bono loco natum fuerit, reparandx vitis causa semper tueri, et ad unam vel duas gemmas relinquere. In locis letis et clementioribus altins vitem licebil expandere : in exilibus aut astuosis aut declivibus aut procellosis, lumilior est habenda. Locis pinguibus singulis brachiis vitium bina flagella dinitte. Sed erit sapientis xstimare vim vitis. Nam qux altius colitur, et foecunda est, plus quam octo palmites labere non debet, ita ut conservemus semper in inferiore parte custodem. Circa crus quidquid nascitur, amputandum est, si non desideret vinea revocari. Qnod si truncus vitis sole aut pluviis aut noxiis animalibus est cavatus, purgamus quidquid est mortuum, plagasque eas amurca linimus ef terra : quod produrit adversun prædicta. Cortex etiam recisus et pendens a vite tollatur : quæ res minorem fecem reddit in vino. Muscus radatur?ubicunque repertus. Sed plagæ, quas in duro vitis accipiet, obliquxe et rotundæe esse de. bebunt. Decisis, sicut supra dixi, male natis omnibus et veteribus novellos et fructuarios serva. Ungues etiaul $c u$. stodum siccos el annotinos recide, et omnia qua vetera vel scabra reperies. Illæ quæ altius coluntur, ut in jugo 
les laisser monter, ainsi qu'à celles qui sont au joug ou en treilles, dès qu'elles seront élevées de quatrc pieds sur terre. On laissera un fouet par bras à une vigne maigre, et deux à une vigne grasse. Mais il faut avoir l'attention que les sarments qu'on laissera sur un bras ne soient pas tous sur le même cỏtć, auquel cas la vigne se dessécherait comme si elle eût été frappée de la foudre. Il ne faut pas laisser de sarments sur le bois dur de la vigne, non plus qu’à son extrémité supérieure, parce que les premiers, semblables à des pampres inutiles, ne rapportent point de fruits, et que les seconds sont à charge au cep par la trop grande quantité des leurs, outre qu'ils le font inonter trop haut. C'est donc dans le milieu du corps de la vigne qu'il faudra choisir les sarments qu'on lui laissera. La plaie de la taille ne doit jamais être faite auprès d'un bouton, mais il faut la faire un peu au-dessus, et du côté opposé au bouton, à cause des pleurs qu'elle répandra.

XIII. Culture de la vigne mariée aux arbres. On coupera le premier bois que cette vigne aura jeté, jusqu'au second ou au troisième houton; ensuite on laissera croitre insensiblement tous les ans un peu de bois qui montera à travers les rameaux de l'arbre, en dirigeant toujours un fouet vers sun sommet. Ceux qui veulent avoir une très-grande quantité de fruits laissent un grand nombre de fouets s'étendre à travers les rameaux de l'arbre, au lieu que ceux qui visent à avoir de meilleur vin attirent les sarments vers son sommet. Il faut mettre plus de sarments sur les rameaux de l'arbre qui seront les plus forts, et en mettre moins sur les plus faibles. Voici la facon de tailler cette espèce de vig̀ne : on coupera tous les sarments qui auront porté du fruit la première année, et on laissera subsister les nouveaux, en

vel pergula, ubi quatuor pedibus supra terram lerata steterint, quaterna brachia habeant. Si macra vitis erit, (in) singulis brachiis singula flagella dimittimus : si pinguis, bina. Sed providendum, ne in una parte sint sarnenta, qux servas : quod cum fit, vitis, tamquan si fulgure tangatur, arescis. Relinquenda sunt sarmenta neque eirca durum neque in summo: quia haec relut pampinaria minus afferunt, illa vitem nimietate f(etus onerant, et longius ducunt. Quare in medio loco servanda sunt, (quae tuenur). Plaga non juxta gemmam, sed ali. quanto superius fiat, el a vertatur a gemına propter lacry. mam defluentem.

XI11. Vitis qua in arbore collocatur. Prima ejus materia ad secundam rel tertiam gemmam pracidatur; deinde omnibus annis aliquid per ramos crescere subincle patia. nur, unam materiam semper ad cacumen arboris dirigentes. Sed qui fructum rolunt maximum, materias plures per ramos submittunt; qui vinum melius, sarmenta in cacumen extendunt. Fortioribus ramis arborum plures naleriæ, debilioribus imponenda sunt pauciores. Putandi autem ratio talis est, ut et vetera sarmenta, quibus primi

PALudics. coupant les tendons et les petites branches inutiles dont ils seront environnés. Mais il faut avoir l'attention de délier et de relier chaque année cette espèce de vigne, pour la rafraichir. Il faut ajuster les rameaux des arbres qui soutiennent une vigne, dc façon qu'ils ne soient pas étagés en ligne perpendiculaire. Si le terrain est gras, il faut que l'orme soit sans rameau jusqu'à huit pieds de terre, et jusqu'à sept pieds dans un terrain maigre. Dans les pays sujets à la rosée et aux brouillards, on dirigera par la taille les rameaux de l'arbre qui soutient la vigne vers les côtés du levant et du couchant, afin que ses flanes étant découverts, la vigne puisse être exposée aux rayons du soleil dans toutes ses parties. Il faut aussi faire en sorte que la vigne ne soit pas trop fournie sur l'arbre. Dès qu'il commeneera à manquer quelques arbres, il faudra leur en substituer d'autres. Dans les pays montueux, il faudra tenir les rameaux des arbres plus bas, alı lieu qu'on les tiendra plus hauts dans les pays plats et humides. II ne faut pas attacher à l'arbre les branches à fruit de la vigne avec un osier trop dur, de peur qu'une pareille ligature ne les coupe ou ne les froisse. C'est une attention d'autant plus importante à avoir, que la branche à fruit couvre toujours de grappes la portion d'elle-même qui pend par delà la ligature; au lieu qu'elle réserve celle qui est au-dessous de la ligature pour donner du bois l'année suivante.

XIV.Si l'on veut former, à la mode des provinces, de ces espèces de vignes dont j'ai parlé, qui se tiennent sur leurs pieds comme de petits arbres, on leur laissera des bras de quatre cótés, et on conservera sur ces bras le plus grand nombre de sarments que la vigne puisse supporter. Pour celles que l'on arrondit à l'aide de roseaux, on les taillera de la méme manière que celles qui

anni fructus pependit, omnia recidantur, et nova circum. cisis capreolis et ramulis inutilibus dimittantur. Sed providendum est, omnibus annis vitem resolvi ac religari, quia refrigeratur. Ita forınandi sunt rami arborum vitiferarum, ne alter sub alterius linea dirigatur : sed loco pingui ulnus a terra octo pedibus, gracili vero septem sine ramo relinquenda est. In solo roscido et nebuloso, rani arboris vitiferm in orienlem et occidentem putatione dirigantur, ut latera vacua solis radiis menbra totius vitis ostendant. Agendum est auten, ut vitis spissa non sit in arbore, et deficientibus primis arboribus substituenda sunt alia. In loco clivoso humilius rami arborum servandi sunt ; in plano et uliginoso altius. Palmites ad arboren non duro vimine ligentur, ne eos vinculum præcidat ant atterat. Hoc autem noveris, quia palmes, quod extra ligaturam pendens habuerit; fructu induet : quod infra ligaturaın, materix sequentis anni deputabit.

XIV. Vites, quas provinciali more velut arbusculas stare dixi, si instituere velis, ramos a quatuor partibus his relinques, et in eis brachiis sarmenta pro vilis possibilitate servabis. Viles autem, qua cannis in orbem coguntur, 
sont appuyées sur des ćehalas ou sur des pieux. Quant à celles qui sont couchées à terre sans aucun soutien, procédé auquel il ne faut avoir recours qu'à défaut de mieux, ou pour obéir à quelque nécessité locale, on ne leur laissera la première année que deux boutons; au lieu qu'on leur en laissera un plus grand nombre les années suivantes. $\mathrm{Au}$ reste, Ics vignes de cette dernière espèce doivent être taillées de trèseourt.

XV. Columelle dit qu'il faut commencer dès la première annce à façonner une jeunc vigne sur son seul et unique jet, ct qu'il ne faut pas la couper tout entière au bout de la seconde année, comme ccla se pratique d'ordinaire en Italic, parce que les vignes meurent quand elles sont ainsi coupées tout entieres, ou ne produisent que des sarments peu féconds; attendu que, lorsque leur tronc est coupé, elles ne peuvent plus s'élancer que d'unc partie de bois dur, à la manière des pampres inutiles. Nous pensons donc qu'il faut laisser un ou deux boutons auprès de la commissure même du vieux sarment : et c'est hotamment la méthode qu'il faut observer à l'égard d'une jeune vigne dès qu'elle est un peu forte, "en l'aidant d'aillcurs pendant son enfance avec des roseaux ou avec de petits pieux jusqu'à la troisième année, où elle en peut reccvoir de plus forts; d'autant que si elle est dans un terrain gras, on fera bien de la contraindre à élever trois jets dès l'âge de quatre ans. Aussitôt àprès la taille, on retirera des vignobles les sar. ments qui auruntété abattus, ainsi que les ronces et tout ce qui pourrait gêner le labour.

XVI. C'est aussi le mois où se propage la vigne; mais il sera mieux de renouveler en sautelle les vignes vieilles et ruinées, dont le bois dur aura pris trop d'accroissement, comme dit

sic putentur, quemadmodum eæ quxe nituutur ridicis aut palis. Jlla vero qux sine adminiculis jacent, quod pro sola indigentia faciendum est vel neeessitate provincia, prino anno duas gemmas, deinde plures habebunt. Sed luijus generis vinea strietius est putanda.

XV. Novellam vitem Colnmella dieit a primo anno ad unam materiam esse formandam, nee recidendam totanı, sient Italix consuetudo est, anno secundo expleto, quia vel iutereant vites in totum recise, vel infoccunda sar. meuta producant, quse ampulato capite velut pampisaria de duro cognutur exire : quare juxta ipsam commissuram veteris sarmenti, unam vel duas gemmas [censemus] relinquendas : quod est merito in viticula fortiore servandım, el sane excipiendaun calamis novellam vel exiguis palis, ut tertio auno robustiores possit accipere. Nam quadrima novella, ubi lxtun solum est, tres materias merito nutrire cogetur. Statim post putationem sarmenta decisa [a] rineis et rubi et impedimentum fossoris omne tollatur.

XVI. Hoc eliam mense propagandre sunt vites : sed relus ef exesa vinea cujus duramenta longe processerunt,
Columelle, que de les cnfouir tout entic̀res; ce qui ne manquerait pas d'attircr le blâme de tout agriculteur. Nous appelons sautelle la partie d'un cepfiché en terre par les deux bouts, qui s'élève en arceau au-dessus du sol. Lorsqu'on enterre toute la vigne, elle s'épuise, comme l'observe Columelle, par la multitude de racines qui sortent de toutes les parties de leur corps. On coupera au bout de deux ans les sautelles sur l'are qui est hors de terre, sans déranger les ceps dont on les a vait abaissées, quoique, si l'on en croit les agrieulteurs, lorsqu'on les coupe au bout de deux ans, elles n'ont encore pour l'ordinaire que de faibles racines, et ne tardent pas à pérír.

$\mathrm{XVII}$, Ce mois est très-propice à la greffe dans les licux chauds ct exposés au soleil : cette opération se fait de trois manières, dont deux seulement sont praticables à cette époque de l'anuéc. La troisièmc se pratique seulcment en étć. 0 n peut greffer ou sous l'écorce, ou sur lc tronc, ou en écussorr. Voici comme on s'y prend pour greffer sous l'écorce : on scie le tronc d'un arbre ou l'une de ses branches, en ménageant l'écorce, à un endroit qui paraisse très-lisse ct qui soit sans eieatrices; après quoi on ragrée la plaie avee des instruments de fer bien tranchants. Ensuite on enfonce, à la profondeur d'environ trois doigts, entre l'écorce et le bois (mais avec beaueoup de cireonspection, de peur que la bande de l'écoree n'éclate) une espèce de coin mince, soit de fer, soit d'os, et partieulièrement d'os de lion; et après avoir retiré ce coin de l'endroit où on l'avait enfoncé, on insère aussitôt dans la fente qu'il aura faite un scion que l'on prend la précaution de tailler d'un côté, en ménageant nonseulement sa moelle, mais encore l'éeorce dont il est couvert du côtć opposé à celui qui est taillé; cóté qui doit rester en saillie sur l'árbre à la

ut Columella dieit, mergis melius reparabitur, quam si infossione totius eorporis obrualur. Quod agricolis eertum est displicere. Mergum dicinus, quoties velut arcus supra terram relinquitur, alia parte vitis infossa. Nam (ut ait Columella) cum totas strat $x$ sunt, plurimis radieibus totius corporis fatigantur. Mergi vero post biennium reciduntur in ea parte, quæ supra est, et in loco justas vites relinquunt. Sed (ut agricolse asserunt) post biennium si recidas, plerumque infirmas habent radices et repeute simul pereunt.

XVII. Hoe mense calidis et apricis locis optime celebratur insitio, qux fit tribus generibus. Sed ex lis duo nunc fieri possunt; tertinm reservatur astati. Sunt autem genera inserendi læac aut sub cortice, aut in trunco, aut emplastro. Inseremus ergo sie : Arborem vel raınum in loco, qui nitidus est et sine cicatrice, serra recidemus non laeso cortice. Post ferraturam, plagam ferramentis acutis inci. damus. Inde quasi cuneum tenuem ferreum vel osseum, maxime leoninum, inter corticem et lignum tribus prope digitis consideranter deponimus, ne corticis fascia dissi. petur; et in eum locum subduclo cuneo, statim șurculum 
hauteur de six ou huit doigts. On met deux ou trois greffes sur le mêmc arbre, ou même un plus grand nombre, suivant la qualité de l'arbre, en les séparant l'une de l'autre par un intervalle de quatre doigts ou plus; après quoi on les resserre avec du jone, de l'orme ou de l'osier, et on les enveloppe d'un enduit de limon recouvert de mousse, que lon y applique de façon que la greffe puisse sortir de quatre doigts au-dessus. Il y a des personnes qui aiment mieux fendre par le milieu le trone de l'arbre, qu'ils ont eoupé après l'avoir serré bien fort avec des liens, et enfoncer dans eette fente des seions ratissés des deux côtés en forme de coins, sans que la moelle en soit altérée, après y avoir introduit préalable. ment un petit coin, afin que, lorsque ce coin sera retiré de l'arbre, la greffe que l'on y aura enfoncée puisse être resserrée par le bois même qui se rapprothera à l'endroit de la plaie. On emploie ces deux façons de greffer au printemps, lorsque la lune croît, et que les boutons des arbres com. meneent à grossir. Il faut que les branches d'arbres que l'on doit employer en greffes soient jeunes, fécondes et pleines de nœuds, qu'elles soient nées sur un rameau qui ne soit point vieux, et coupées sur le eôté de l'arbre qui sera exposé au levant. II faut aussi qu'clles aient un petit doigt d'épaisseur, et qu'elles soient garnies de deux ou trois cornes et d'un grand nombre de boutons. Si l'on veut enter sur un petit arbrc (et c'est incontestablement la greffe qui prend le mieux), on le coupera près de terre, on insérera la greffe entre son bois et son écorec, et on la liera. Il y a des personnes, qui enfoncent au mi'ieu de l'arbre qu'elles veulent greffer, une petite branche ratissée des deux eôtés, et d'une grosseur proportionnéc à celle de l'arbre, de faẹon quc l'écorce de cette petite branche adhère exac-

mergimus ab una parte decisum salva medulla, et cortice partis alterius, qui supra arborem sex vel octo digitis emineat. Duos vel tres vel plures surculos pro trunci qua. litale constituimus : quaternis digitis rel amplius inter cos spatium relinquemus : tunc junco aut ulmo aut vimine stringemus, et super lutum nusco tectum ponemus, ac ligabinus, ut quatuor digilis supra lutum possit surculus eminere. Plerosque delectat strictım primo sectxe arboris truncum vinculis arctioribus in medio findere, et ibi surculos ex utraque parte rasos in modum cunei, ut integra sit medılla; demergere, pramisso ante cuneolo, quo subducto, depositus surculus redeunte in plagam materia, possit adstringr. Sed hoc utrumque genus vernum est, et fit crescente luna, ubi incipit gemma arborum turgescere. Surculi autem, qui inserendi sunt, sint novelli, fertiles, nodosi, de novo nati, ab orientali arhoris parte decisi, crassitudine digiti minoris, bifurci vel trifurci, gemmis pluribus uberati. Si arboren minorem desiderabis inserere, in fjua sine dubio nueliora incrementa juroveniunt, circa terram secato : et quod melius est, snrculos inter lignum rorticemque 'depone, tune stringe. Quidam rasum ex utra. tement à celle de l'arbre dans toute sa eirconfé. rence. Au surplus, quand on greffe un jeune arbre, il faut labourer la terre à son pied, et la ramasser pour l'entasser jusqu'à la greffe même, afin de protéger celle-ci contre le vent et la chaleur. Un agricultcur très-attentif m'a assurć que toutes les espèces de greffes prenaient sans difficulté, lorsqu'en les insérant dans l'arbre on enfonçait en même temps dans la plaie de la glu non détrempée, afin que cette glu fit, pour ainsi dire, l'effet d'une espèce de colle, et qu'elle amalgamát les sues de l'un et de l'autre bois. Nous parlerons de la greffe en écusson dans lo mois où on la pratique. Columelle a donné une. quatrième faẹon de greffer, que voici : il prescrit de percer un arbre jusqu'à sa moelle avcc une tarière gauloise, dans une direction légèrement oblique; on nettoie le trou, et on y insère de vive force un eep de vigne ou une branche d'arbre, dont on aura proportionné lc volume à la largeur du trou en la ratissant; mais il faut que cette branche soit pleine de séve et humide, et qu'elle. déborde l'arbre d'un ou de deux boutons : on reeouvre ensuite exactement d'argile et de mousse l'endroit où est la greffe. On peut se servir de eette méthode pour greffer la vigne sur un orme. Un Espagnol m'a enseigné le nouveau genre de greffe que voiei, en m'assurant qu'il en avait fait l'essai sur un pêeher. Il veut que l'on perce avec une tarière le milieu d'une branchc de saule, qui soit de l'épaisseur du' bras, forte, et longue de deux cubiti ou plus, et que l'on fasse passer par le trou que l'on y aura pratiqué un picd de pêeher, sans l'arracher de la terre à laquelle il tient par ses raeines, aprc̀s l'avoir dépouillé de toutes ses branehes pour ne lui laisser que sa tigc; que l'on courbe alors en forme d'arc cette branche de saule pour l'enfoncer en terre

que parte surculum convenientem soliditati arboris inserendac sic in medio deponunt, ut cortex surculi undique cortici arboris reddatur aequalis. Sed in novella arbore terra mota usque ad ipsun insitum colligatur; qua cam res a vento et calore defendet. Mili asservit diligens agricola onne insitum siue dubio comprehendere, si depositis surculis viscum non temperatum in ipsa plaga pariter mergamus, quasi glutino quodam snccos materix utrius. que misturun. De emplastratione sıo mense dicemus. Quartım genus Colımella sic retulit. Gallica terebra usque ad medullam arborem perforandam, plaga interius levifer inclinata. Ibi educto omni scolse, vitem vel ramum ad modum foraminis impressi delibratum, succidum tamen et lumenten, stricte imprimi, una aut duabus gemmis foris relictis. Tunc argilla el nusco locum diligenter ope. riri; ita et vites iı uluı inseri posse [commissas.] llispanus quidam milhi loc genus nova iusitionis ostendit, quod ex persico se asserebat expertım. Salicis ramum brachiı crassitudine, solidum, longum cubitis duobus aut amplius, terelurari jussit in' medio, el plantam persici iu corlem loco in quo consistit, spoliatanı ramis ounnibus, solo 
par ses deux extrémilés, et que l'on bouche le trou par lequel passe le pécher avec du limon et de la mousse, le tout blen lié; qu'ensuite on coupe au bout d'un an le pêcher au-dessous de la branche dc saule, dès que sa tige sera suffisamment rejointe en cet endroit avec le saule, pour que ces deux plantes n'cn fassent plus qu'une seule; enfin qu'on transporte le pêeher, ct qu'on entasse assez de terre auprès de lui pour pouvoir ell recouvrir non-seulement l'arc formé par le saule, mais encore la pointe du pêcher qui sort de cet arc par en haut; et il prétend qu'en conséquence de cette opération le pécher donnera des fruits sans noyaux. Mais il ajoute que cettc sorte de greffe ne convient qu'aux terrains humides ou arrosés, et qu'il faut mêmc aider le saule par des arrosements, afin que ce bois, qui aime naturellement l'humidité, puissc prendre assez de force pour suffire à la nutrition d'un arbre qui est-d'une nature différente de la siennc, en partageant avec lui le surperflu de son suc vital.

XVIII. C'est dans ce mois que l'on formera des plants d'oliviers dans les pays tempérés, auquel cas il faudra ou planter ces arbres dans des terrains labourés au pastinum, de façon qu'ils bordent l'cxtrémité des planehes, ou leur affecter un terrain particulicr. Si on les plante dans un terrain labouré au pastinum, on profitera du moment ou la terre sera gonflée par le labour, pour y faire un trou avec un pieu, dans lequel on les déposera sur des grains d'orge, cn pieds garnis de leurs racines, après leur avoir coupé la tête ainsi que les bras, et avoir réduit leur tronc à la hauteur d'un cubitus et un palmus. On commencera donc par délivrer ces arbres de tout ce qui pourra s'y trouver de pourri ou de séehé, après quoi on leur coupera la tête, qu'on recou-

capite relicto per ipsum saligni manubrii foramen induci : tunc cundem salicis ramum terrac capite utreque demerso, in arcus similitudinen debere curvari, foramen Into, musco, vinculis stringi : anno deiude exemto, ubi intra medullam salicis caput plantxe sic colıxserit, ut unitas sit ex duobus nista corporibus, plantam subter incidi atque transferri, et aggerari terrain, quæ arcum salicis cum persici cacumine possit operire : hinc persici poma siuc ossibus nasci : sed lıoc locis humidis convenire vel riguis, et salices aquationibus adjuvandas, ut et natura ligni vigeat, qux delectatur lıumore, et superfluentem copiam succi germinibus ministret alienis.

XVIII. Hoc mense locis temperatis instituemus oliveta, quæ vel pastinis conserenda sunt, ut extremas circa decimanum tabulas cingant, vel suum locun tenebunt. Si ponuntur in pastino, radicata planta decisis capitibus et brachiis, et in truncum redactae usque ad mensuram cubit unius et palmi in fermento terra fossa defigantur, lucum palo antea deprimente : ordei grana subterjaciantur, et amputetur iis quiidquid putridi inventum fuerit aut aren- vrira de limon et de mousse; et on finira par les resserrer avec des liens d'orme, ou avee tclle autre espèce de ligature suffisante pour les affermir. Mais une des choses qui peuvent le plus contribuer à les faire profiter et grandir, c'est de marquer avec de la sanguine les côtés du ciel auxquels ils étaient exposés dans le temps qu'ils étaient en terre, afin de les mettre sous la même exposition. On les disposera à quinze ou vingt pieds de distance les uns des autres. On arrachera de temps à autre toutes les herbes qui croitront alentour; et chaque fois qu'il aura plu, on les excitera à pousser par de très-petites fouilles, très-souvent réitérées. On prendra aussi de temps en temps de la terre à leurs pieds, et après l'avoir remuée et brouillée, on l'entassera auprès de leur tronc jusqu'à une certaine hauteur. Si l'on veut destiner un terrain particulier à des plants d'oliviers, on choisira à zet cffet les genres de terre que voiei : une terre mêlée de gravier, et composée d'une solution d'argile mêlée de sable; ou bien un sol qui soit d'une nature compacte et humide. Il faut rejeter absolument l'argile que les potiers emploient, ainsi que Ics terres marécageuses dans lesquelles l'eau séjourne, le sable maigre et le gravier pur, parce que, bien que l'olivier y prenne, il n'y acquiert jamais de force. 0 n peut aussi les planter dans des terrains qui aurunt porté préeédemment des arbousiers ou des ycuses; car pour ce qui est du cerrus et de l'cesculus, lors même qu'ils sont abattus, ils laissent dans la terre des racines perfides, qui sont un poison pour les oliviers. Cet arbre se plait, dans les climats brûlants, sur les coteaux exposés au nord; dans les climats froids, sur ceux qui sont exposés au midi ; et il aime, dans les elimats tempérés, les teriains élevés. Il ne s'accommode ni des fonds ni des

tis : et tunc (amputata) capita luto velentur et musco, ulmeis vinculis vel tenacibus quibuscunque constricta. Sed maximum beneficium est, ut proficiat incremento, si rubrica partes notentur, quibus obversæ steterunt, et contra eas simili ratione ponantur. Sint a se discreta pedibus quindecim vel viginti. Omnis subinde circa eas herba vellatur : et quoties se imber infuderit, brevissimis ac frequentissimis fossionibus solicitentur, et subinde ducta a trunco terra atque permista in aliquanto altiores cumulos congeratur. Quod si olivetum suo loco facere volueris, lıæc genera terrarum sequeris : terram cui misla sit glarea, aut cretam sabulonis conjunctione resolutam, aut pingúem sabulonem, aut terram naturæ densioris et liumidæ. Creta figuli omnino repudianda est et uliginosa et in qua semper humor assistit, et sabulo macer et nuda glarea : quamvis enim comprehendat tamen non convalescit. Potest seri et ubi arbutus aut ilex steterat. Nam cerrus et asculus excisa radices noxias relinquit, quarum virus oleam neeat. Locis æstuosis Septentrionali colle, frigidis, meridiano gaudet, mediis, clivis delectalur. Neque imum locum neque 
escarpements, et préfère les petites éminences, telles que celles du pays Sabin et de la Bétique. On compte bien des especes d'olives, qui ont cha. eune leur nom propre, telles que la pausia, l'orchis, l'olive longue, la sergienne, la Licinienne, la Cominienne, et d'autres c[u'il est inutile de nommer. L'huile que rend la pausia est excellente tant qu'elle est verte, mais ne turde pas à se gâter, pour peu qu'elle soit gardéc. L'olive Licinienne donne d'excellente huile, la Sergienne en donne une grande quantité. Mais il suffira de dire en général, de toutes ces espèces d'olives, que les plus grosses sont bonnes à manger, et que les plus petites sont propres à faire de l'huile. Si l'on destine le terrain que l'on plante en oliviers à rapporter du blé, on mettra ces arbres à quarante pieds les uns des autres; au lieu que si c'est un terrain maigre, la distance ne sera que de vingt-cinq pieds. Il vaut mieux que les rangées d'oliviers soient tournées du côté d'où souffle le vent Favonius. Lorsqu'on les plantera, il faudra les mettre dans des fosses sèches, creusées à quatre pieds de profondeur, et avec la terre desquelles on mêlera du fumier, ainsi que du gravier lorsqu'on manquera de pierres. Si le lieu est elos, on les enterrera de faecon qu'il n'en sorte qu'une petite portion hor's de terre; mais si l'on a les insultes du bétail à eraindre, il faut donner aux trones plus de hauteur. On les arrosera aussi dans les provinces sèches quand il ne tombera pas de pluie. Si la eontrée manque d'oliviers, et que l'on ne sache d'où cn faire venir en pieds pour les planter, on en fera une pépinière, c'est-à-dire qu'on fouillera une planche de terre de la manière que j'ai donnée plus haut, pour y déposer, comme le prescrit Columelle, des branehes d'olivicrs de la longueur d'un pied et demi, coupées avec une scie; après quoi on pourra en transférer des

arduum patitur ; magis modicos clivos diligit, sicut est regio Sabina vel Bxtica. Baccarum genus numerosum est et plurium-vocabulorum, sicut Pausia, Orchis, Radius, Sergia, Licinia, Cominia, et cæteræ quas nominare non attinet. Pausia tamen olenm quod reddit, dum viride est, optimum est, sed cito vetuslate corrumpitur. Optimum Licinia dal, plurimum Sergia. Sed de his haec generaliter præccepisse sufficiet, majores bacras cibo, minores oleo profuturas. Si frumentarius ager est, quem conserimus oliveto, quadra. genis inter se pedibus distent : si inacer, vicenis quinis. Melius faciemus, si ordines in Favonium dirigamus. Cum deponentur, in scrobes siccas constituantur qualernis pedibus fossas, Glarea etiam, ubi lapides defuerint, miscea. tur el stercus. Si clansus locus est, inodice supra terram, yuie ponuntur, emineant. Si pecora formidantur, altiores trunci esse debebunt. In siccis vero provinciis cum pluvia desunt, rigare conveniet. Si provincia indiget olivetis, et non est unde planta sumatur, seninarium faciendum cst, iil est tabula effossa, sicut superius dixi, ut ibi (sicut Columella dicil) ranu serra incisi in nodum sesquipeda. pieds d'arbies qui seront devenus forts au bout de einq ans, et les planter dans le courant de ce mois dans les pays froids. Je sais que bien des personnes, vu la facilité et l'utilité de cette pratique, sont dans l'usage de distribuer, soit dans une pépinière, soit dans un plant d'oliviers, suivant leur goût, des racines de ces sortes d'oliviers qui se trouvent eommunément dans les forêts ou dans les lieux déserts, après les avoir eoupés de facon à ne leur laisser qu'un cubitus de longueur. En effet, si on aide leur développement en mêlant du fumier avec la terre, il arrivera que ees raeines, prises sur un seul pied d'arbre, domneront par la suite un très-grand nombre d'ar'bres.

XIX. On peut aussi, dans les terrains façonnés au pastinum, exposer au nord les cspèces d'arbres à fruit dont nous traiterons spécialement plus tard, les espèces d'arbres à fruit sur lesquels nous donnerons par la suite des préceptes particuliers. La terre qui convient aux vignes convieut également aux fruits. Mais on fera pour les arbres à fruit des fosses plus grandes que pour la vigne, précaution essentielle au bois eomme au fruit. Si l'on veut avoir un verger, on laissera trente pieds d'intervalle entre les rangées d'arbres à fruit, et on n'y mettra que des pieds d'arbres qui soient garnis de leurs racines; c'est en effet la meilleure méthode. Mais on prendra garde qu'ils ne soient étêtés par la main des passants ou la dent des bestiaux, ce qui les empêcherait de croitrc. On destinera à chaque espèce d'arbre sa rangée partieulic̀re, de peur que les plus faibles ne soient opprimés par les plus forts. On fera aussi une marque aux pieds d'arbres que l'on transportera, afin de les tourner du côté du ciel auquel ils étaient exposés avant d'être transplantés. On les transférera toujours d'un coteau sec et maigre dans un terrain plat, gras et liumide.

lem deponantur. Inde post quinquennium poterit valuda planta transferri, et locis frigidis lioc mense plantari. Scio jlerosque, quod facilius a tque utilius est, radices olearum quae in silvis plerumque sunt aut in locis deserlis, in cu. bilalem nensuram recisas, aut in semiuario, si placuerit, aut in oliveto solere disponere, et admistione stercoris adjuvare. Qua re proreniet, ut ex unius arboris radicibus numerosa planta nascatur.

XIX. Etiam pomiferas arbores possumus in pastinis a Septentrionali regione disponere, de quibus sigillatim dice. nus, quax specialiter sunt tenenda. Nam ponis eadem convenit terra, qua vitibus. Scrobes autem inajores facies, ut materix prosis et fructui. Si pomarium facies, inter ordines tricenos pedes relinques. Plantas statues radicatas, quod est melius. Sed servabis, ue cacumina ant manu fiacla aut erosa non crescant. Unumquenqüe ordinem sno generi deputabls, ne infirmæ a valentioribus opprimantur. Plantas similiter notabinus, ut ipsis quibus steterant cardinibus opponamus. De clivo sicco et exili, in planum, pinguem et liumidum transfercmus. Si truncos ponere 
Si on veut mettre en terre des trones d'arbres tout formés, on aura soin qu'ils soient élevés d'environ trois pieds au dessus du sol. Quand on mettra deux plantes dans une même fosse, on prendra garde qu'elles nesc touehent; autrement les vers les feraient mourir. Mais les arbres sont, ainsi que l'observe Columelle, de meilleur profit quand ils viennent d'cssence, c'est-à-dil'e de noyau ou de pepin, que lorsqu'on les a plantés en pieds ou en boutures. Quand le pays est trop sec, on les aide à croitre eu les arrosant.

XX. Il faut bêcher la vigne en ce temps dans les pays chauds et dans les régions maritimes, ou y mettre la charrue (si c'est l'usage de la province). Il faut aussi l'échalasser et la lier dans les mêmes contrées avant que ses bourgeons paraissent; ear il suffit d'un frottement ou d'une secousse pour causer un grand dommage. On donue à présent du fumier aux oliviers ainsi qu'aux auîres arbres, dans le temps que la lune est dans son déclin. Un vehis de fumier suffira pour un grand arbre, et un demi-vchis pour un petit. Pour metlre ce fumier, on ćcartera la terre du pied de l'arbre, et après l'avoir mêléc de fumier, on la rappiochera de ses racines. Il faut fouiller le pied des arbres qui sont daus les pépinières, et en couper les branches superflues, ou les petites racines qui seront poussées hors de terre autour de leur's trones.

XXI. C'est le temps dc cultiver les roses qu'on fait venir de plant ou de graines, au moyen de petites fosses ou tranchées. Mais qu'on n'aille pas croire que la graine soit cette espèce de pollen couleur d'or que l'on voit au ccur de la rose. La rose donne des baies qui ressemblent à une tréspetite poire, et qui sont remplies de graine. Ces baies sont communément mùres après. la vendange, et l'on reconnaît leur maturité à la cou-

volueris, supra terram prope tribus pedibus erigantur. Ubi duas in una scrobe plantas deponis, cavendun est, ne se contingant. Nam vermibus iuterihunt. Sed (ut Columella dicit) feraciores sunt, quæ seninibus, loc est nucibus suis, quim qua plantis ponmntur aut ramis. Ubi regio siccior est, aquationibus adjuventur.

$\mathrm{XX}$. Nunc locis maritimis et calidis fodiendac sunt vites : vel si hæc provinciæe consuetudo est, exarandx, et in eisdem locis paland $x$ aut ligand $x$ sunt vinex prius quam gemma procedat; cujus concussione vel attritı incurritur grande dispendium. Nunc olex cateracque arbores lsetamen accipiunt decrescente luna. Sufliciet autem majori arbori velıes una, minori, media; ita ut subducta a radicibus terra et fimo permista revocetur. Tempore hoc si qua sunt in seminariis planta, circunfodiend $x$ sunt, et amputandi eis rami superflui vel radiculæ, quas circa in superiore parte miserunt.

XXI. Hoc mense rosaria conseremus, quæ sulco brevissimo aut scrobibus ponenda sunt, vel virgult is, vel etian semine. Semina autem rosarum non putemus medios flosct:os esse aurei coloris, qux rosa fuerunt, sed haccas leur et à la mollesse de leur enveloppe. Si l'on a des rosiers anciennement plantés, ou les fouillera aussi par le pied avec des sarcloirs ou avec des doloires, et l'on coupera tout ce qui pourra s'y rencontrer de sec. On peut aussi renouveler à présent celles de ces anciennes plantations qui seront trop clair-semées, cn attirant des branches de rosiers pour les propager. Si l'on veut avoir des roses de très-bonne heure, on fera unc fouille cn forme de cercle autour des rosiers, à deux palmi de distance de leurs pieds, et on les arrosera deux fois par jour avec de l'eau chaude. C'est encore le moment de mettre en terre les oignons de lis, et de sarcler ceux qui y sont déjà; ce qu'il faut faire avec beaucoup de précaution, afin de ne pas endommager les yeux qui seront venus autour de leurs racines, ni leurs petits caieux, lesquels serviront à former de nouveaux plants de lis, lorsquon les aura séparés de leur mèle pour les mettre dans de nouvelles rangées. Il faut aussi planter les pieds de violettes et les bulbes de safran, et remuer délicatement la terre autour des plantations déjà existantes.

XXII. Il y a des personnes qui sèment dans ce mois-ci dix modii de glaine de lin par jugerum de terre dans un sol gras, et qui en réeoltent du lin très-fin.

XXIII. On fera dans ce temps-ci des plants de cannes en creusaut de très-petites fosses, et en enterrant dans chacune de ces fosses des yeux de cannes, que l'on éloignera d'un demi.pied les uns des autres. Si l'on cultive la terre dans une province chaude et sèche, on destinera à ces plants des vallćes qui soient humides ou arrosées. Mais si la contrée est froide, on les placera à mieóte, et dans des lieux où puissent se rendre les eaux qui s'écouleront des métairies. On peu! aussi jeter de la graine d'asperge entre les can-

mutriunt, quas in brevissimi piri similitudiuem plenas seminilous post vindemiam reddunt nıaturas, quarum tamen maturitas ex colore fusco et mollitie poterit sestimari. Siqua etiam sunt antiqua rosaria, lno tempore circumfodiuntur sarculis vel dolabris, et ariditas universa reciditur. Nunc et qux rara sunt possunt ducta virgarum pro. pagine reparari. Si rosam temperius liabere volueris, duobus palmis ab ea gyrum fodies, et aqua calida bis riga. bis in die. Nunc et liliorum bulbos ponemus, rel lilia anfe labita sarriemus summa diligentia, ne oculos circa radicem uascentes et ninores bulbulos sauciennus, qui a matre subtracti, atque in alios digesti ordines nova lilieta formabunt. Item violarum plantæe et croci bulbi serendi sunt, vel subtiliter, si fuerant ante, fodiendi.

XXII. Hoc mense aliqui lini semen laeto solo in jugerum $\mathrm{x}$ modios spargunt, et lina consequuntur exilia.

XXIII. Tempore hoc canneta ponenda sunt factis brevissimis scrobibus, et oculis cannarum per singulas scrobes ol)rutis, qui semipedis spatio inter se distare dehebunt. Si calidx et sicca provincix studemus, valles humidas vel irriguas opus est deputare caunetis; si frigila regio 
nes, afin que ces deux plantes viennent ensemble, parce que l'une se cultive commc l'autre, et qu'on met également le feu à toutes deux. Mais si l'on a d'anciennes cannaies, on les sarclera dans ce temps-ci, après avoir coupé tout ce qui pourra gêner leurs racines, c'est-à-dire, les parties qui seront pourries, celles qui s'étendront mal, et celles qui n'auront point d'yeux capables de reproduire. On piquera à présent des pieds de saules, et, à leur défaut, de genêt, ou de telle autre plante qui fournisse des liens pour les vignes. On fera aussi des pépinières pour les baies de myrte et pour celles de lauricr, ou bien on cultivera celles qui auront été faites précćdemment.

XXIV. Il faut faire, vers les ides de février, des liaies de jardins au moyen de cordes saturées de graine d'épine, de la manière que nous avons indiquée en parlant des différentes façons de clore les jardins. Les Grees prescrivent aussi de couper de grosses branches de ronces en petits morceaux, que l'on enterre dans des fosses d'une palme, que l'on entretient en les fouillant, et en les arrosant tous les jours jusqu'à ce qu'elles poussent des feuilles. On sème la laitue dans ce mois-ci, afin de pouvoir la transplanter au mois d'avril. On y sème aussi, de même que dans le mois de novembre, le cardon, le cresson des jardins, la coriandre et lc pavot, ainsi que l'ail et l'oignon de Cypre. On sème à présent la sarriette, en l'entremêlant de ciboule, dans un champ gras, et qui ne soit pas fumé, mais qui soit exposé au soleil ou, ce qui est cucore mieux, voisin de la mer. On sème aussi la ciboule dans ce mois-ci ; mais il est constant qu'il en faut semer en automne comne au printemps. Si ôn la sème en graine, elle donnera une grosse bulbe, mais elle rendra moins de graine; au lieu que si on en plante la

est, locis mediis instituantur, sed succo villarum subditis. Inter laæc asparagorum etiam semina spargere possumus, ut mista uascantur, quia et asparagi coluntur et incenduntur eo more quo canna. Sed si qua smut antiquạ canneta, hoe tempore sareientur, recisis qua in radice purganda sunt, id est putribus, male porrectis, et si qua gignendi oculos non habent. Nume salicis plantas et omnium generum, qux arbusto applicandx sunt, vel gene. sta, ubi deerit, obruemus. Ex baccis etiam inyrti et lauri seminaria faciemus vel, si fuerant, excolenus.

XXIV. Circa idus Februarias sepes hortorum ex con. gesto in funibus spinarum semine faeienda sunt, sicul dictum est, eum de munimine loqueremur hortorum. Iten Graci dicunt de crassa rubi virga fieri debere particulas, et palmaribus scrobibus obrui, et quotidic, donec frondeant, fossione et rigatione nutriri. Hoe mense laetuca seritur, ut possit Aprili mense transferri. Item carduus seritur et nasturtiun et coriaudrum et papaver, sieut mense Xovembri, et allium et ulpieum. Nune satureia seritur pingui agro nou stercorato sed aprico, vel melius unari proximo, et eun cepullis unista seminatur. Hoe etiam mense cepullas seres : sed cunstat et vere et au- bulbe, elle n'aura, à la vérité, qu'une bulbe maigre, mais elle donnera beaucoup de graive. Les oignous demandent une terre grasse, qui soit bien remuée, arrosée ct fuméc. On leur fera des planches que l'on débarrassera de toutes les herbes et de toutes les racines. On les sèmera dans un jour calme et serein, et surtout lorsque le vent du midi ou de l'est souffleront. Ceux qui sont semés dans le déclin de la lune viennent plus petits et plus âcres que ceux qui le sont quand elle croit ; Ceux-ci au contraire sont plus forts et ont un goût plus adouci. Il faut les semer clair, arricher souvent les mauvaises herbes qui croissent avec eux, et les sarcler de même souvent. Si l'on veut qu'ils aient de grosses bulbes, il faudia arracher toutes leurs feuilles, afin que toutle suc nourricicr se porte par en bas. On étayera les tiges dont on veut recueillir la graine lorsqu'elles commence. rontà monter. Lorsque la graine en sera noire, ce sera un signe de sa maturité. Il faut cn arracher les tiges garnies de leur graine avant qu'elles soient tout à fait sèches, et les faire sécher en cet état au soleil. C'est dans ce mois-ci qu'on sèmera l'aneth dans les pays froids. Il se fait à toutes sortes de climats, mais il préfère les plus tempérés. On l'arrosera, s'il ue pleut pas. On le sèmera clair. Il y a des personnes qui n'en couvrent pas la grainc de terre, parce qu'elles imaginent qu'aucun oiseau n'y touclic. On peut aussi semer à présent la moutarde. On sèmera encore dans ce mois-ci les clioux, ce qu'on peut faire au surplus dans tout le cours de l'année. Ils aiment un sol gras et qui soit suffisamment labouré, ct rcdoutent l'argile et le gravier. Ils ne se plaisent ni dans le sablon, ni dans le sable, à moins qu'ils n'y trouvent la ressource d'une eau toujours courante. Ils s'accornmodent de toute espèce de climats, mais

turuno esse seminandas. Si semen ejus severis, in caput crescit, et minus reddit in senine : si capituluin ponas, ipsinm inacescit, et multum semen educit. Terram cepa desiderant jiuguen, vehementer subactam, irriguaın, stercoratam. Ibi areas faciemus omnibus lierbis et rardice purgatas. Seremus placido et sereno die, maxine Austro vel Euro flantibus. Si ininnente luna serantur, tenues ef acriores proveniunt : si crescente, robusla et saporis Inumecti; rarius sunt ponendx; runcanda ac sarculanda sunt sxpins. Si capita voluerimus his esse majora, folia onutia debenns auferre, [et] sie suceus ad inferiora cogetur: de quibus vero semina colligenda sunt, juventuk adıniniculis, ubi caulem coperint excitare. Cun niger color seminis fuerit, praferunt naturitatus indicia. Vellendi sunt thalli adhuc semisieci eun senine, et sic in sole siccaudi. lloe mense anethum seres locis frigidis. Onnem cali statum patitur, sed tepidiore latatur. Rigetur, si se imber abstiueat. Seratur rarius. Aliqui semen ejus non obruunt, opinantes quod a nulla ave taıgatır. Nunc et sinapi serere possunnus. Hoc etiam mense caules seremus; qui et toto anno seri possunt. Solum pingue et satis subactum diligunt : argillam et glarean timeut : sabulone 
ils préfèrent les climats froids. Exposés au midi, ils rapportent plus tot; au nord, ils rapportent plus tard; mais ceux qui viennent à cette exposition l'emporteut sur les premiers par leur goût et par la force de leur tige. Ils aiment les plants inclinés; c'est pourquoi il faut, quand on les transplante, les mettre sur l'ados des planehes. Ils se plaisent à être fumés et sarelés. Quand ils sont clair-semés, ils aequièrent plus de foree. Ils cuisent plus tôt, et sans rien perdre de leur verdeur, si, au moment où ils n'ont eneore que trois ou quatre feuilles, on les saupoudre de nitre broyé et passé au tamis, ce qui les fait paraître couverts de frimas. Columelle dit qu'il faut envelopper les raeines de cette plante d'algue marine pour lui faire conserver sa verideur, en les couvrant en même temps de fumier. Il faut que les pieds de choux qu'on met en terre soient d'une certaine grosseur, paree que, quoiqu'ils prennent alors plus tard, ils deviennent plus forts. On les plantera, si l'on est en hiver, lorsque le jour commeneera à être tempéré; si l'on est en été, lorsque le soleil sera prêt à se coucher. Ils deviendront plus gros si on les couvre assidûment de terre. La graine de chou se. change en raves, quand elle est vieille. On commeneera, après les ides de ce mois, à former de nouvelles pattes d'asperges avee la graine de ce légume, ou à en planter d'aneiciınes. Il me parait également utile et plus expéditif de jeter dans un terrain inculte, ou du moins pierreux, une grande quantité de raeines d'asperges sauvages qui rapporteront immédiatement, altendu que ce terrain n'aura eu préeédemment aueune production à nourrir. On en brûlera les rafles toutes les années, afin que le fruit monte en plus grande quantité, et qu'il soit plus fort. Cette espèee d'asperges est celle qui a le goût le plus agréable.

et arenis non delectantur, nisi perennis tundo succurrat. Onnem caeli slatum caulis ratitur, frigidum magis. Contra anstrum positi citius ferunt; coutra septentrionem, serius. Sed hic et sapore caulis vincit et robore. Clivis delectatur, el ideo ponendie sunt plantxe per pulvinos arearum. Gaudel stercore et sarculatione. Rarius positus convalescit. Celerius cociuitur virore servato, si, dum est trium vel quatıor foliorını nitrum tritum cribello desuper spargas, ut speciem pruinæe canentis imitetur. Columella dicit plantarum radices alga marina involvendas servandæe viriditatis causa, fimo simul adlıarente. Ponendæ sunt plantac majoris "incrementi, quia licet seriıs comprelıendant, tamen fortiores fient. Si liems est, tepido jam die; si astas, cum sol in vesperam declinatur, planta pangenda est. Vastior fiet, si terra operiatur assiduo. Semen brassica vetustum mutatur in rapa. Hoc mense post idus spongias asparagorum vel novas formare incipiemus ex semine, vel antiquas ponemus. Mili etiam illud utile videtur ac diligens, ut asparagi agrestis radices plurimas in uuum locum congeramus incultum, vel certe saxosum, qux statim fructum dent ex loco, qui aliud nil alebat, et has annis omnibus incendamus iu scopis, ut fructus fre-
On peut aussi semer à présent la mauve. On plantera aussi la menthe en pied ou en raeines dans un terrain qui soit humide, ou autour des eaux. Cette plante veut être dans un teriain exposé au soleil, qui ne soit ni gras ni fumé. On sèmera ce mois le fenouil dans un terrain exposé au soleil et légèrement pierreux. On sème au commencement du printemps le panais en graine, ou on le plante en pied, dans un terrain gras, résolu en poussière, et faeconné profondément au pastinum. Il faut qu'il soit clair-semé, pour prendre des forces. On sème aussi à présent l'origan, et on le cultive de la mème manière que l'ail ou la eiboule. On sèmera à présent le cerfeuil dans les pays froids, après les ides. Cette plante demande un champ qui soit gias, humide et fumé. On sème la poirée dans ee mois, quoiqu'on puisse aussi la semer pendant tout le courant de l'été. Elle aime un champ qui soit ameubli, humide et gras. Il faut la transplanter quand elle aura quatre ou cinq feuilles, en enduisant ses raeines de fumier nouveau. Elle aime à être fréquemment bêehée, et saturée de fumier. Il faut scmer le poireau dans ee mois. Si l'on reut qu'il soit bon à êlre eoupé à différentes reprises, on pourra le couper deux mois après qưil aura étésumé, en le laissant sur sa planehe; quvique Columelle assure que celui même qu'on voudia couper à différentes reprises durera plus longlemps et sera meilleur, lorsqu'on le transplantera et qu'on l'aidera à croître avec de l'eau et du fumier, toutts les fois qu'on le eoupera. Si l'on veut au contraire qu'il se forme en bulbe, il faudra le transplanter en oetobre, quand il aura été semé au printemps. Il faut le semer dans un terrain gras, et surtout en plaine, sur une planche plate, façonnée profondément au pastinum, et qui ait été

quentior surgat et fortior. Hoc antem genus est sapore jucundius. Nunc etiam malra seri polest. Mentam quoque sere plantis rel radicibus loco lmmido vel circa aquas. Apricum solum nec pingue nec stercoratum desiderat. Hoc mense foniculum seres loco aprico et modice saxoso. (Seritır primo vere) pastinaca et semine pontur et plantis loco pingui, soluto, altius pastinato : raram sfatues, ut robur accipiat. Cunela etiam nunc seritur, et colitur eo more quo allium vel cepulla. Nunc crerefolium locis frigidis post idus seratur: desiderat agrum loctum, humidım, stercoratum. Hoc mense betam seremus, quanvis possit et tota sestate seminari. Amat agrum putren, lumidum, lxtum. Transferenda est (fuatıor aut quinque soliorum, radicibus fimo recenti oblitis. Amat frequenter effodi, et multo stercore salurari. Hoc meise porrus serendus: quem si sectilem velis, post duos menses, quanı satus est, poteris desecare manenlem in areis suis : quamvis asserat Columella ctiam sectivum diutiús duraturum, melioremque, si trarsferatur; et quoties secabitur, aqua juvetur et stercore. Si capilatum facere velis, quod vere severis, Octobri mense transferre debebis. Serendus est loco laeto et naxime campestri, area plana, pastinata alte, et diu 
bêchée et fumće depuis longtemps. Si l'on veut qu'il soit bon à être coupé à différentes reprises, on le sèmera dru; au lieu que si l'on veut qu'il se forme en bulbe, on le sèmera plus clair. Il faut Iui faire sentir souvent le sarcloir, et le purger des mauvaises herbes. Lorsqu'il aura un doigt d'épaisseur, on le transplantera, en coupant préalablement ses feuilles par le milieu, ct en tronquant ses racines; après quoi on l'enduira de fumier licquide, et on le mettra en terre, en l'espacant de quatre ou cinq doigts. Lorsqu'il aura pris racine, il faudra le saisir légèrement avec le sarcloir pour le soulever de terre, afin qu'étant comme suspendu, il se trouve contraint de remplir, par la grosseur de sa bulbe, le vide qui sera sous lui. Si l'on met en terre plusieurs graines de poireaux jointes ensemble, il en naittra un seul poireau, qui sera très-gros. On dit aussi que si, avant de le planter, on insère dans sa buibe de la graine de raves sans se servir d'un instrument de fer pour l'y faire entrer, il grossira beaucoup. Il sera encore mieux de répéter souvent cette opération. On sème.l'aunée dans ce mois-ci, qui est celui dans lequel on forme des plants de cannes. On en met les yeux en terre, comme on $y$ met ceux des roseaux; et il faut couper ces yeux, et les couvrir légèrement de terre, en les arrangreant sur des planches dressées au cordeau dans un terrain bêché et bien l'emué, où on les espacera ce trois pieds. On mettra, ce mois, en terre les bulbes des fèves d'Égypte. Elles aiment un lieu qui soit humide, graș et très-arrosé. Hilles se plaisent aux environs deș fontaines et des ruisseaux, et la qualité du sol leur importe très-peu, pourvu qu'on les entretienine d'eau, sans les en laisser jamais manquer. Eiles sont presque toujours en état de donner des feuilles quand on les abrite contre le froid, en les couvrant comme on cou-

subacta et stercorata. Si sectivum velis, spissius. Si capitatum, rarius seres. Sarculo fiequentandus est, el lierbis liberandıs. Cum digiti erassitıdinem habuerit, a media parte pracisis foliis et truncalis radicibus transferatur : oblitus limo liquido quaternis vel quinis digitis separetur. Cum radices agit, modice comprelıeıdendus et allevandus est sareulo, ut suspensus a terra, quod spatii vacuum subter invenerit, eapitis vastitate cogatur implere. Item plura semina in unum ligata si deposueris, grandis porrus nascelur ex omnibus. Item si capiti ejus rapo semen imnittas sine ferro et pangas, mullum fertur inerescere : melius si frequenter lioc facias. Hoc mense inula seritur, quo camneta pountur. Seritur oculis sieut calami, quos alsscindere et terra leviter debemus obruere, terra fossa et subaeta, exeitatis ad liıeam pulvinis, quibus ejıs oculos oportet infodere. Trium pedum inter se spatio separantır. Hoc mense colocasixe bulbos poremus. Amant lumidun loeım, pinguenı, maxime irriguum. Cirea fontes lixtantur et litros, nec de soli qualitate curant, si perpetıo foveantır liumore. Frondere prope senp̧er possunt, si tanquam citreta tegumentis defendantur a frlgore. Hoc vre les plants de eitronniers. On sème dans ee mois-ci le cumin et l'anis dans une terre bien labourée, dans laquelle on aura mêlé du fumier. Il faut délivrer assidûment ces plantes des mauvaises herbes, quand elles sont semées.

XXV. On mettra les pieds de poiriers en terre au mois de février dans les pays froids, et au mois de novembre dans les pays chauds : mais il faut semer les pepins au mois de novembre dans les pays tempérés, afin qu'ils y trouvent la ressourec d'un sol arrosé. C'est le moyen que ces ar. bres donnent beaucoup de fleurs, et que leur fruit devienne très-gros. Quoique les poiriers se plaisent dans un terrain pareil à celui que nous avons dit convenir aux vignobles, un teriain gras aura cependant cet avantage, qu'il donnera des arbres forts, et qui rapporteront beaucoup de fruits. On croit que les poires pierrenses perdent ce défaut quand elles sont semées dans des terres molles. Il est vrai que lorsqu'on plante le poirier en pied, il tarde communément à venir. Mais néanmoins ceux qui préféreront cette méthode à d'autres, par la raison qu'un plant dont la qualité,sera excellente ne se trouvera par là mélangé d'aucune âpreté sauvage, auront soin de déposer dans de grandes fosses, comme on le pratique a l'égard des oliviers, du plant de deux ou trois ans, garni de ses racines, en lui laissant trois ou quatre doigts d'élévation sur terre, après l'avoir étêté, et avoir recouvert la plaie de mousse mêlée d'argile. Si on sème des pepins de poires, ils viendront sans doute. Le germe en éprouve tôt ou tard l'action fécondante de la nature, patiente parce đu'elle est éternelle. Mais longueur de temps s'accommode mal avec la brièveté de la vie humaine, et dans ce cas la production dégénère, outre qu'elle est retardée. Il vaut done mieux planter au mois de novembre des pieds de poiriers

meuse cyminum et anisum seritır loco bene subacto, el cui lactanen admisceas. Quod satum est, herbis purgetur assidne.

XXV. Plautas pirorum mense Februario locis frigidis ponemus; calidis vero Novembri : sed mense Novenbri pira locis tepidis conserenda sunt, ut solo juventur irrigno. Ita et florem plurimum proferent, ef magniludinem pomi turgentis aequirent. Nasei tamen tali solo maxime diligunt, quale vinelis diximus convenire : sed lacto solo et validas arbores et fruetus plurinos eonsequemur. Lapidosi generis pira vitium mutare ereduntur, si lerris mollibus conserantır. Sed pirım plantis serere prope tardus eventıs est : tamen quibus lıoc plaeuit, "L semina generosa nilil sibi do agresti asperitate permiseeant, plantas bimas aut trimas eo more quo olex ponuntur, radicatas magnis serobibus ponant, supra terrain tribus altas vel quatuor pedibus, quatum decisa cacunina argilla mista muscus debet operire. Nam si quis pirorum semen aspergat, nasci quidem necesse est, originem suam refovente natura, eujus aternitali unlla tarditas potest afferre fastidium : sen humini loc expeetare longinquum est, cun et sero reniant, et 
sauvages garnis de leurs raeines daus des fosses bien labourées, et les greffer ensuite quand ils y auront pris. Ceux qui seront venus de plants différeront de ceux qui auront été greffés sur d'au. tres arbres, en ee que le fruit des premiers conservera ì la vérité sa doueeur et sa mollesse, mais ne sera pas de garde, au lieu que celui des autres se gardera très-longtemps. On laissera trente pieds d'intervalle entre ces arbres. Si l'on veut qu'ils profitent, il faut les cultiver en les arrosant souvent, et en beschant eontiuuellement la terre à leur pied. Ces fouilles leur sont en effet si avantageuses, que si on les en aide dans le temps même où ils ont eoutume d'être en fleur, on croit qu'ils ne perdront pas une seule des fleurs qu'ils auront montrées. Il y a aussi beaucoup de profit à leur donner, au bout d'un an, de quelque espèee de fumier que ee puisse être. On prétend néanmoins que la fiente de bœuf leur fera produire des fruits abondants, et qui seront très-gros. Il y a des personnes qui y mèlent de la cendre, dans l'idée où elles sont qu'elle donnera au fruit un goût plus fin. Je erois qu'il est inutile de détailler toutes les différentes sortes de poires, puisqu'il n'y a aueune différence entre elles toutes quant à leur plantation et à leur culture. Lorsqu'un poirier est languissant, il faut ou percer sa raeine avee une tarière après l'avoir déchaussée, et y enfoneer un pieu de bois, ou introduire dans son trone, après l'avoir également pereé avec une tarière, un coin de bois gommeux de pin, ou un coin de chêne à défaut de pin. On tue les vers qui s'attachent à eet arbre, et on empêehe qu'il n'en revienne de nouveaux, ('n versant souvent sur ses racines du fiel de taureau. On l'empêche de même de languir quand il est en fleurs, en répandant pendant trois jours sur ses raeines de la lie de vieux vin. Quand les

de generis nobilitate decedant. Melius ergo loe mense Novembri fiet, ut pirorum plantas radicatas seramus ugrestium subactis beue scrobibus, ut, eum prelienderint, inserantur. Hoe autem interest, quod quæ plaritis suis scruntur, dulcedinem ac teneritatem servant, diu tanen servata non durant: iusita vero moram temporis sustinebunt. spatia inter piros trigrinta pedum mensura diseernat. Geuns $\mathrm{l}, \mathrm{C}$ arboris ut profieiat frequenti lıumore et assiduis fossionibus est coleudum, usque adeo, ut tempore, quo tlorere eonsuevit, nilil perditura eredatur de flore pro. lato, si eam tunc fossor adjuverit. Multum prosicis, si interjecto anno quale libet lotamen adjungas : sed bubılum spissa et gravia poma generare fertur. Aliqui einerem miseent, eredeutes line coutralıi pomis argutos sapores. Generum varietates exsequi supervaeuum puto, cum in fonendis rel excolendis nnlla sit distantia. Si languida abor est piri, vel ablaqueate talicem terebras, et ibi ligneum palum deprimis, vel in trunco siniliter terebrato ex teda cuneun tigis, vel, si laxe desil, ex quercu. Verun's rjus arboris et nati uecautur et nasei probibentur, radicibus felle tanriuo frequenter infusis. Item fieces vini poires sont pierreuses, on retire de dessous l'arbre qui les donno la terre sur laquelle est couchée l'extrémité de ses raeines, ainsi que toutes les petites pierres qui peuvent s'y trouver, et l'on y substitue d'autre terre passée au erible. Mais ce remède ne produit son effet qu'au cas où l'on ne cesse pas d'arroser l'arbre. On greffe le poirier aux mois de février et de mars, sous son éeoree et sur son trone, conformément à la méthode que nous arons donnée en parlant de la greffe. On le greffe sur le poirier sauvage et sur le pommier. Il y a des personnes qui le greffent sur amandier et sur prunier sauvage. Virgile veut qu'on le greffe sur le figuier sauvage, sur le frêne et sur le coignassier. D'autres veulent qu'on le greffe sur le grenadier, mais il faut alors le greffer en fente. Lorsqu'on le greffera avant le solstice, on emploiera une greffe qui ait un an, et avant de l'insérer dans l'arbre, on la dépouillera de ses feuilles et de tout le bois tendre qui en fera partie; au licu que si on le greffe après le solstice, on insérera dans l'arbre la partie de la greffe sur laquelle sera venu le dernier de ses boutons. Le poirier se greffe de toute manière. Il faut confire les poires dans un jour ealme etquand la lune est dans son đéelin, depuis son vingt-deuxième jour jusqu'à son vingt-huitième. On renferme eneore ces fruits dans un vase enduit intérieurement de poix, après les avoir eueillis à la main dans un temps où ils étaient sees, depuis la seconde heure du jour jusqu'à la einquième, ou depuis la septième jusqu'à la dixième, en sćparant avec soin ceux qui seront sains, presque durs et un peu verts, de ceux qui seront tombès d'eux-mêmes. Ensuite on met un couverele sur ee vase, et on l'enterre, lo yueule renversée par en bas, dans une petite fosse creusée dans un lieu arrosé par quelque eau de souree. De même, après avoil entassé des poi-

veteris recentes, si radicibns affundantur per tridıum, diutius [arbores ] in floribus laborare uon faciunt. Si lapjdosa pirus est, ab extrenis radieibus tel'ram priorem leva. bis, et sceernes omnes lapillos; quibus diligenter remotis alteram terram cribro eretam in loeo ejus infundes. Sed lioc proderit, si rigare uon cesses. Mense Februario et Martio pirus inseritur ntore, quo dietım est, cum de insitione loqueremur, sub cortice et in truneo. Inseritur auten piro agresti, malo, ut nounulli amygdalo et spino; ut Vir. gilius, orno et fraxino et cydonio; ut aliqui, et I'unico, sed fisso ligno. Surculus piri, qui inseritur ante solstitimu, anuiculus esse debet, et prius quam figatur, foliis et omı j tenera parte privari: post solstitium vero eum firis, qui summum germen iuclusit. Pirus omni genere inseritur. Condienda sunt pira [ ita] die placido deereseeute lıua a rigesina sceunda usque in octavan. Eadem poma sicca et unauı leeta ab hora secunda in quintau rel a septima in decimam, a cadueis diligenter electa integra et prope dura, et aliquanto viridia in picato vase clanduntur, quod opereulo tegitur, ef deorsum os ejus intlinatur, atıue[ brevi serobe ] obruitur in co loco, circa quem premenis aqua de. 
res à chair et à peau dures, on les enferme, lorsqu'elles eommencent à s'amollir, dans un vase de terre bien euit, et bien enduit de poix au dedans et de gypse au dehors, sur lequel on met un couverele; aprrès quoi on lenfonce dans une petite fosse ereusee dans un lieu où le soleil donnc tous les jours. Bien des personnes ont conservé des poires ensevelies dans de la paille ou dans du blé. D'autres les ayant renfermécs, aussitôt après les avoir cueillies avee leurs queues, dans des cruehes enduites de poix, bouchées avec la même matière ou avee du gypse, les ont exposées au plein air, en les couvrant de sable. D'autres ont eonservé des poires dans du miel, en évitant tout contact entre elles. On fait aussi sécher au soleil des poires coupées par moreeaux, et purgées de leurs pepins. Il y a des personnes qui écument de l'eau salée lorsqu'elle commence à bouillonner au feu, et qui plongent ensuite dans cette eau, quand elle est refroidie, les poires qu'elles ont intention de conserver; après quoi elles les retirent de l'eau au bout de quelque temps, et les renferment dans une cruehe dont elles bouchent l'orifice. Ou bien elles les laissent pendant un jour et une nuit dans de l'eau salée ; après quoi elles les mettent tremper pendant dcux jours dans de l'eau pure, et les gardent ensuite plongées dans du vin cuit jusqu'à diminution des deux tiers, ou dans du vin fait de raisin séehé au soleil, ou dans du viu doux. On fait du poiré en pilant le fruit renfermé dans un sae à mailles très-larges, et en le pressurant à l'aided'un poids dont on le eharge, ou sous l'arbre du pressoir. Cette boisson se conservedurant tout l'hiver, mais elle s'aigrit au commencement de l'été. Manière de faire du vinaigle de poiles. On laisse en un tas pendant trois jour's des poires sauvages, ou d'un acabit âcre, qui soient mûres;

currit. Item qua dura sunt in carne el cutc prius in acervo posita, ubi se mollire coeperiut, in vas fictile bene coctum picatumque poumutur, el operculo superreniente gypsan. tur. Vas brevi scrobe demergitur in eo loco, qui quotidic sole tangatur. Plurimi pira obruta inter paleas aut frumenta servarunt. Alii statim Iccta cun tcnacibus suis picatis urceis condiderunt, el oribus vasculorum gypso vel pice clausis ipsa sub divo obruta sabulone texeruut. Alii pira, qux se non contiugerent, in melle servarunt. Item mcoin et purgata granis in solc siccantur. Aliquini aqjuam salsam, cum coperit undare calefacta, despumant, et ei post jaun frigidac pira scrvanda demergunt. Tunc exenta post tcmpus exiguum condunt urceo, et ejus ore lito conservant : rel nocte et die in frigida salsa mancre patiuntur : post in aqua pura biduo macerant, deinde in sapa vel passo vel dulci vino mersa custodiunt. Vinum de piris fit, si contusa et sacco rarissimo condita ponderibus comprimantur aut prclo. Hieme durat, sed prima acescit xstate. Acetum sic fit de piris : Pira silvestria vel asperi generis matura in cumulo reservantur per triduum. Deinde mittuntur in vasculo, cui fontana aut pluvialis aqua mi- après quoi on les renferme dans un petit vase rempli d'eau de fontaine ou d'eau de pluie, qu'on laisse couvert pendant trente jours. On y remettra au fur et à mesure autant d'eau que l'on en tirera de vinaigre par la suite pour son usage, afin de suppléer au déehet de eette liqueur. Manière de faire le poiré rafrafchissant. On foule des poires saines ct très-mûres avec du sel; et lorsque la chair en est réduite en bouillie, on la renferme dans de petites barriques ou dans de petits vases de terre enduits de poix. Au bout de trois mois on suspend cette préparation, pour lui faire rendre une liqueur qui est, à la vérité, d'un goût agréable, mais dont la couleur est blanehâtre. C'est pourquoi il sera bon, pour parer à eet ineonvénient, de mêler avec les poires un peu de vin foneé en eouleur, dans le temps qu’on les salera. On plantera des pommiers aux mois de février et de mars, et si le pays est chaud et sec, aux mois d'octobre et de novembre. Ces arb res sont de plusieurs espèees qu'il est inutile de détailler. Ils aiment un sol gras et fertile, et qui soit fourni d'eau, plutôt néanmoins par la nature elle-mème que par le seeours des arrosements; quoique, s'ils sont plantés dans du sable ou dans de l'argile, il faudra avoir reeours à l'irrigation artificielle. Il faut les exposel au midi dans les pays montueux. Ils viemnent fort bien dans les pays froids, pourvu qu'il n'y ait pas d'àpreté dans l'air. Ils lie refusent non plus les lieux incultes et liumides. Dans un terrailı maigre et sec, leurs fruits sont sujets à être attaqués de vers et à tomber. On les plante de toutes faecons, eomme les poiriers. Ils ne demandent ni à être labourés, ni à être bèehès; e'est pourquoi les prés leur conviennent plus que tout autre terrain. Le erottin de brebis, ou seul ou mélé avec de la cendre, est lc seul engrais dont ils s'accommodent, quoiqu'ils puissent

scelur, et opertum vas per triginta dies relinquitur, ac subinde quantum sublatum fucrit aceti ad usum, tantum redditur aquxe ad reparationem. Liquamen de piris castiinoniale sic fict : Pira unaturissima cum sale calcantur integra. Ubi carnes eorum fueriut resoluta, vel in cupellis $\mathrm{vcl}$ in vasculis fictilibus picatis condiuntur. Post mensem tertium, suspensx ex carnes liquorem dimittunt saporis ju. cundi, sed coloris albiduli. Contra lıoc illud prodcrit, ut tempore, quo saliuntur, pro aliq̧ua parte viua nigella per. misceas. Mense Februario et Martio locis frigidis mita seramus : si calida et sicca regio est, Octohri et Noreinhri. Eorum plura sunt genera, (juæ ıuıеrare superfluum est. Amant pingue ac lactum solum, et cui lumorem non tan rigatio quam uatura suppeditet. Et si [in ] arena vel argilla sit, rigationibus adjuvetur. Montanis locis debent ad meridien versa constitui. Et frigido solo proveniunt, si cali tepor adjuverit : nec in asperis et humect is sedem rc. cusant. Macrum et a ridum solum pona vermiculosa cfícil el caduca. Seruntur omni genere, sicut piri : ncque exarari neque effodi desiderant. Illcirco eis nlagis prila conveniunt. Stercus (ovillum tantum) non exigunt qui- 
s'en passer. Ils aiment à être arrosés modérément. La taille leur est bonne, ct prineipalement à l'effet d'en retraneher les branehes sèches, ou celles qui sont nées dans une mauvaise plaee sur l'arbrc. Ils vieillissent de bonne heure, et dégénèrent dans leur vieillcsse. Quand leur fruit estsujet à tomber, on introduit une pierre dans la raeine que l'on fend à eet effet, et cette préeaution le relient sur l'arbre. On les préserve de la pourriture en enduisant leur eime de fiel de lézard vert. On fait mourir les vers qui s'y attaehent, avec de la fiente de porc mclée d'urine humaine, on avee du fiel de bouf. Quand il y en aurait une multitude immense autour de l'arbre, on est sủr qu'il n'en reviendra point de nouveaux une fois qu'on les aura ratissés avec un bistouri de cuivre, pourvu qu'on enduise de fiente de bœuf l'endroit d'où on les aura fait tomber. Si les branehes sont elhargées d'une trop grande quantité de fruits, il faut en arracher les plus mauvais par-ci par-là, afin que la séve de l'arbre suffise à la nutrition des autres, et eesse de s'ćpuiser pour un luxe stérile. Le pommier peut être greffé sur toutes les mêmes espèces d'arbres que le poirier. On le greffe aux mois de février et de mars, ainsi qu'aux autres mo is auxquels on greffe le poiriel, tant sur le pommier que sur le poiricr, sur le prunier sauvage, sur le prunier, sur le eormier, sur le pêcher, sur le platane, sur le peuplier et sur le saule. Il faudra choisir avee attention les pommes que l'on voudra garder, et les disposer par tas séparés, dans des lieux obseurs et où l'air ne pénètre point, avee de la paille étendue sur une elaie. On cn múltipliera les tas de faẹon que chaeun d'eux ne soit pas trop fort. II y a des personnes qui ont donné des méthodes differentes pour les garder. Ces méthodes eonsistent ou à les cnfermer dans de petits vases de terre pois-

dem, sed libenter assumunt, vel si cineris pulveres misceautur. Anant modestas rigat iones. P'utatio illis apta est, sel maxime ut arida ant male mata tollantur. Citins sene. scit lawc arbor, et in senectute degenerat. Si caduca sunt pona, fissa radici lapis injectus poma retinebit. Lacerta viridis felle sl tangantur eacumina, non putrescit. Vermes ejus suillo stercore mistu lıumano urina aut felle bubulo extinguuntur : qui si plures circa arborem sunt, areo scalpro semel rasi non ultra nascentur, si ca loca, unde rasi sunt, lubulum stercus obducat. Si spissa pona ramos onerabunt, interlegenda sunt quæque vitiosa, ut alimentun ('xteris succus aquiparet, et generosis abundantian ministret, quam numerosa vilitate perclebat. Malus omui generi inseri potest, quo pirus. Merse lebruario, Nartio et aliis, quilus pirus, inseritur in malo, in piro, i) spino, pruno, sorbo, persico, platano, populo, salice. Diligenter legenda sunt mala, quar volumus custodire. Ea in lucis ohscuris, ubi ventus nou sit, stımentis prius in crate subjectis, in cumulus secreta disponmus : qui cumuli fiequenli divisione separentur. slicjui diversa dixernnt, [ vel sugnla ] in vasculis fictililus picatis atque oblitis claudi , sés et bouehés, ou à les envelopper d'argile, ou à en enduire simplement leurs queues, ou à les arranger sur des planehes, en les y étendant sur de la paille, et jetant d'autre paille par-dessus. On peut, sans se donner aucun soin, eonserver pendant toute l'année les pommes rondes que l'on appelle orbiculata. Il y a des personnes qui ren. ferment des pommes dans des vases de terre cnduits de poix et fermés hermétiquement, qu'ils plongent ensuite dans un puits ou dans une citerne. D'autres, après avoir eueilli des pommes saines, et en avoir plongé la queue dans de la poix bouillante, les rangent sur des planehers, où ils les étendent sur des feuilles de noyer. La plupart jettent entre les pommes de la sciure de peuplier ou de sapin. II est constant qu'il faut les poser de façon que leur queue soit renversée, et n'y pas toucher avant le temps où elles nous paraîtront nécessaires pour notre usage. On fait du cidre ainsi que du vinaigre avee les pommes, de la manière que j'ai donnée ci-dessus en parlant des poires. Les auteurs varient pour la plupart par rapport au temps auqucl ils prétendent qu'on doit planter les eognassiers; quant à moi, j'ai remarqué, d'après l'expérienee que j'en ai faite, que des cognassiers, plantés avec leurs racines cn Italie, dans les environs de Rome, au mois de février ou au commeneement de mars, dans un terrain faconné au pastinum, avaient si heureusement pris, que souvent ils avaient rapporté des fruits dès la seeonde annce. Quand ils avaient été plantés déjà grands. On les plantera dans les pays sees ct chauds à la fin d'oetobre ou au eommeneement de novembre. Les cognassiers aiment les terrains froids et humides. S'ils sont plantés dans un terrain elaud, il faut les aider à venir par des arrosements. Ils supportent néanmoins la température intermédiaire, et ne vien-

rel argilla involvi, vel solos pediculos creta adlini, vel in taluulis subst:ata palea disponi, et stramentis de superiore parte cooperiri. Mala rotunda, qux orbicnlata dicuntur, sine cura toto auno servari possunt. Alii in puteo vel in cisterna mersunt rasa fictilia, quibus diligenter picatis et clausis mala comnittuntur. Alii ex arbore mala illasa sumsel:unt, et pediculis eorum pice ferventi mersis supra tabulatum per ordinem disponunt, nucmm foliis subter expositis. Plerique scrobem populi vel abietis inter mala diffundunt. Coustat inala sic ponenda, ut pediculorum partes deorsum facias, neque ante quam usui necessaria videantur esse, contingas. Viuum et acetum fit ex nualis, sicut ex piris ante proccepi. Cydoniis serendis plerique tem. pora diversa dixerunt : tamen milii usu compertum est, in Italia circa Urbem mense Febrnario vel inclioante Martio plantas cydoniorum radicatas in pastinato solo tenusse aden feliciter, ut sxpe sequentis anui fruge gauderent, si posita majoris status fuissent. Locis siccis et calidis extremo Octobri rel Novembri inchoante ponantur. Amant cydorii locum frigidum, lumecium. Si in tepido statuuntur, opus est illis jigationc succuri. Ferunt tamen statum medio. 
nent pas moins dans les terrains plats que dans ceux qui sont inclinćs, quoiqu'ils préfèrent ces derniers. Il y a des personnes qui les plantent en cimes et en boutures, mais ils tardent à venir par l'un ou. l'autre de ces procédés. Il faut les espa. cer de telle manière que, si le vent vicut à les secouer, l'eau no dégouttc pas des uns sur les autres. Quand on les plante, et même tant qu'ils sont petits, il faut lesaider de fumier. Mais quand ils sont devenus plus grands, il suffit de répandre une fois par an sur leurs racines de la cendre ou de l'argile assez sèche pour pouvoir être réduite eu poussière. L'humidité continuelle fera mûrir promptement leurs fruits, et les rendra plus gros. II faut les arroser toutes les fois que le ciel refuse de la pluie, et bêcher leur pied dans les pays chauds aux mois d'octobre et de norembre, et, dans les pays froids, aux mois de février et de mars; parce quà moins de prendre assidûment ce soin, ou ils deviennent stériles, ou leurs fruits dégénèrent. Il faut les tailler, d'après ce que j’ai éprouvé moi-même, et les débarrasser de tout ce qu'ils peuvent avoir de vicieux. Quand ils sont malades, il faut verser sur leurs racines du marc d'huile coupć d'eau par moitié, ou enduire leur tronc, soit de chaux vive détrempée avec de l'argile, snit de résine de mélèse mêlée avec de la poix liquide : $\mathrm{Ou}$ bien, après les avoir déchaussés, on mettra aulour de, leurs racines un nombre impair de coings proportionné ằ la grandeur de l'arbre, que l'on assujettira à l'endroit où on les aura mis en les couvrant de terre. Cette pratique observée toutes les années préservera à la vérité l'arbre de toute maiadie, mais d'un autre côté elle l'empếchera de vieillir : on greffe les cognassiers au mois de février. Il est mieux de les greffer sur le trone que sous l'écorce. Il n'y a presque point de greffe qu'ils ne reçoivent,

cris situs inter naturam frigoris et caloris, et in planis et in declivibus proveniunt, magis tamen incliuata et devexa desiderant. Serunt aliqui cacuminibus et talea, sed tardus est in utroque proventus. Ita ponendæ sunt largæ arbores cydonii, ne alteram quatiente vento stillicidium tangat alterius. Dum minor est, vel quando ponitur, juretar stercore : major vero, cinere. vel cretae pulvere semel tolo anno radicibus misso. Ponıa iu his et cito matura et majoris incrementi assiduus liumor efficiet. Riganda sunt, quoties caelestis negatur infusio, et circumfodiendæ locis calidis Oclobri mense et Novembri ; frigidis vero Februario vel Martio. Nisi [ enim ] circumfodiantur assidue, aut steriles efficiuntur, aut earum poma degeneraitt. Putandæ sunt, sicut probari, et a vitiosis omnibus liberandæe. Si arbor ægra est, amurca aqua aqualiter mista radicibus debet affundi, aut calx vivas temperata cum creta, vel resina locularis pici liquidæ mista trunco arboris adlini, vel ablaqueata arbori circa radices imparis numeri poma cydo. nia pro magnitudine ejus ponenda et obruenda firmantur : quod annis singulis factum custodiet a vitiis, sed arboris longac derogabit ætati. Mense Februario cydonia inseruntur tant celle du grenadicr que cellc du cormier, ainsi que celle de tous les pommiers qui donnent lc meilleur fruit. S'ils sont jeunes et qu'ils aient de la séve, on les greffe sous l'écorce; mais s'ils sont plus grands, il sera mieux de les greffer près de la racine, lieu où lcur écorce et leur bois sont humides, grâce à la terre qui y est adhérente. Il faut-cueillir les coins quand ils sont mûrs, pour les conserver, soit en les mettant entre deux tuiles, dont on rejoint les bords avec un lut, soit en les faisant bouillir dans du vin cuit jusqu'à diminution de moitié, ou dans du vin fait avec du raisin séché au soleil. D'autres les conservent en les enveloppant dans des feuilles de figuier, lorsqu'ils sont gros. D'autres se contentent de les serrer dans des endroits secs, où l'air ne pénètre point. D'autres, après les avoir coupés par quartiers avec un roseau ou avec un couteau d'ivoire, et en avoir ôté le cœur, les couvrent de miel dans un vase de terre. D'autres les mettent également dans du miel tout entiers ; mais quand on veut les confire de cette manièrc, il faut les choisir suffisamment mûrs. D'autres les couvrent de millet, ou les ensevelissent séparément dans de la paille. D'autres les mettent dans de petits vases remplis d'excellent vin, ou les conservent dans un mélange égal de vin cuit jusqu'à diminution de moitié, et de vin sans apprêt. D'autres les plongent dans des futailles de moût, qu'ils bouchent ensuite, ce qui donne en mème temps du bouquet au vin. D'autres enfin les mettent chacun à part dans un plat neuf qu'ils couvrent de gypse sec. On met la semence ou le plant du carrouge en terre aux mois de février et de novembre. Quoiqu'il aime les contrées voisines de la mer, chaudes, sèches et plates, il produit da. vantage dans les pays chauds quand on lui donne de l'eau, ainsi que je m'en suis convaincu par

melius in trunco quam cortice in se ipsa. Recipiunt in se surculos prope omnis generis, Punici, sorbi, onınium malorum, qua meliora producunt: Inseruntur autem norellæ arbores, quibus succus est, in cortice : si major est, circa radicem melius inseretur, ubi cortex et liguum bene ficio soli adhæerentis humescit. Legenda sunt malura cydo. nia, qua lıo more servantur, vel inter binas tegulas posita, si luto ex omni parle claudantur, vel si defruto incoquantur, ant passo. Alii qua majora sunt, fici foliis involuta custodiunt. Alii tantum locis siccis repouun!, a quibus ventus excluditur. Alii canna vel ebore in quatuor partes divisa sublatis omuibus, qua in medio sunt, iu vase fictili melle obruunt. Alii in melle sic integra demit. tınt, in quo genere condiendi satis matura deliguntur. Alii milio ohruunt, rel paleis separata demergunt. Alii ple nis vino optimo vasculis immittunt : vel vini et defruti ad servanda cydonia, xequm corpus efficiunt. Alii doliis musti immergunt, atque ita claudunt, quod odoratım reddit et vinum. Alii in patina nora sicco gypso obruunt separata cydonia. Siliqua Februario mense seritur et Norembri et semine et plantis : amat loca maritima, calida, 
ma propre expérienee. On peut aussi le planter en boutures. Il lui faut une fosse large. Il y a des personnes qui eroient qu'on peut le greffer au mois de février sur le prunier ou sur l'amandier. On eonserve très-longtemps les gousses qu'il produit, en les exposant sur des elaies. Le mûrier est ami de la vigne. On peut faire venir ect arbre de graine, mais en ee cas son fruit dégénère ainsi que son bois. Il faut done le planter en boutures ou en cimes. Mais il vaut eneore mieux le planter en boutures d'un pied et demi de longrueur, qui soient bien ragréées des deux eôtés, et enduites de fumier. Ainsi, après avoir fait d'abord un trou en terre avee un pieu, on les enfoneera dans ce trou, et on les recouvrira de eendre mêlée de terre, qu'on n'entassera cependant pas à plus de quatre doigts d'épaisseur. On plante le mûrier depuis le milieı de février jusqu'à la fin de mars. Mais quand le pays est ehaud, on le plante à la fin d'oetobre ou au commencement de novembre; quoiqu'il vaille eneore mieux le planter au printemps, le neuf des ealendes d'avril. Cet arbre aime les terrains ehauds et sablonneux, et plus communément les eontrées voisines de la mer. il prend diffieilement dans le tuf ou dans l'argile. On croit que l'humidité eontinuelle ne lui est pas bonne. Il aime à ètre bêché et fumé. Il faut en tailler au bout de tiois ans les branehes pourries et sèehes. On en transfère le plant, lorsqu'il est fort, aux mois d'oetobre ou de novemble ; et, lorsqu'il est jeune, aux mois de février et de mars. Ces arbres veulent être plantés dans des fosses profondes, et séparés les uns des autres par de grands intervalles, afin qu'ils ne se nuisent pas réeiproquement par leur ombre. Cet arbre vient plus haut, dit-on, et donne plus de fruit, si l'on en peree le trone d'outre en outre en y insérant

sicca, campestria : tamen, ut ego expertus sum, in locis calidis foceundior fiet, si adjuvetur humore : potest et taleis poni. Scrobem desiderat largiorem. Inseri etiam posse mense Februario credunt aliqui in pruno vel amygdalo. Siliqua servantur diutissime, si expandantur in cratibus. Amica est morus et vitis. Mori nascuntur ex semine; sed et poina et virgulta degenerant. Serenda est taleis vel cacuminibus, melius autem taleis sesquipedalibus ex utraque parte levigatis ac fino oblitis. Cum locum jalo ante fecerimus, immergimus ac tegimus cinere terra adınisto. Non amplius quam quatuor digitis operimus. Seremus lo. cis temperatis a medio Februario et Loto Martio; locis vero calidioribus Octobri postremo vel Novembris initio; sed verno maxime die nono calendas Apriles. Amant loca calida, sabulosa, et plerumque maritima. In tofo vel argilla vix comprehendunt. Humor assiduus [moris ] prodesse nun creditur : fossionibus latatur et stercore. Putria in lis et arida post triennium sunt putanda. Plantam, si robusta [ est, ] transferes mense Octobri vel Novembri : si tenera, Februario et Martio. Scrobes desiderant altiores, intervalla majora, ne altera umbris prematur alıerius. Fe. racem lxtiorem que arborem mori fieri aliqui tradiderunt, deux eoins, un de térébinthe d'un eôté, un de lentisque de l'autre. II faut déchausser le mûrier ver's les calendes d'oetobre, et verser sur ses raeines de la lie de vin vieux très-nouvelle. On le greffe sur le figuier et sur lui-même, mais on ne le greffe que sous l'éeoree. Si on le greffe sur un orme, la greffe prend à la vérité, mais il en résulte de grands aeeidents. Il faut semer les avelines en nature, et ne pas les recouvrir de terre à plus de deux doigts d'épaisseur. J'ai eependant éprouvé que les aveliniers viennent eneore mieux de plant et de rejetous. On en met le plant ou les amandes en terre au mois de février. Ils se plaisent dans un terrain maigre, humide, froid et sablonneux. Les avelines sont mûres vers les nones du mois de juillet, pourvu eependant que le pays soit eliaud. C'est à présent que l'on sème lesnoyaux de sébestes sous un climat tempéré, et dans une terre réduite en poussière et médioerement humide, en les mettant dans un vase, où on les laisse jusqu'à ee que leur pousse ait aequis la eonsistance de plante. On greffe les arbres qui portent ee fruit au mois de mars, sur des eormiers ou sur des pruniers sauvages. C'est aussi à présent que l'on greffe les jujubes, que l'on met en terre les presses en nzyaux ou en plant, qu'on les transfère et qu'on peut les greffer; enfin que l'on greffe le néfliel, et que l'on sème les noyaux de prunes. On peut aussi planter à présent le figuier dans les pays tempérés, semer la eorme, couvrir de terre l'amande sur des planehes, et greffer l'amandier au eommeneement de ee moisei dans les pays tempérés, et à la fin du même mois dans les pays froids; pourvu eepelldant qu'on prenne la greffe avant qu'elle ne germe. On peut aussi mettre à présent en terre du plant de pistachier, ou greffer eet arbre, de même qu'on

si perforato linc inde trunco singulos cuneos inseramus terebinthi (line inde lentisci. ) Circa Octobres calendas norus ablaqueanda est, el radicibus cjus vini veleris recentissima faeces infundendac. Inseritur antem in lico et in se tantum sub cortice. Ulmo insita conjprehendit : sed parturit magnæ infelicitatis argumenta. Avellana. ponendac sunt nucibus suis non amplius supra terra ducenda est, quam crassitudine digitorum duolum. Plantis tamen et sobole expertus sun melius provenire. Mense Februario seu planta seu semen exponitur. Gaudent loco macro, hu. mido, frigirlo, el sabuloso. Mense Julio circa nonas avel. lana malura est : [ locis tamen calidis.] Nunc seruntur myxa ex mucleis in aliquo vase positis, donec plante induant firmitalem, cælo tepido, terra soluta, humore moderalo. Inseruntur mense Martio sorbis vel spinis. Etiam nunc tuberes seruntur et inseruntur, et ossa duracinorum, vel planta ejusdem generis ponuntur, el transferunlur, et inseri possunt : el mespilus inserelur, et ossa po. nentur prunorun. Ficus etiann locis temperatis nunc poni polest, et sorbus hoc etiam mense seri, et amygdali semina in areis obrui, et locis temperatis nunc inseri mense inclionnte, filgidis vero oxeunte, conditis tamen surculis 
peut semer des ehâtaignes, mettre des noix dans des pépinières, et greffer le noyer. Enfin on peut encore faire à présent des plants de piu dans les contrées froides et humides.

XXVI. C'est surtout à présent qu'il, faudra faire couvrir les truies. On choisira à eet cffet des verrats grands et forts, dont le eorps soit plus arrondi qu'allongé, qui aient le ventre et les fesses amples, le grouin court, et le chignon bien fourni de petites glandes, qui soient laseifs et qui n'aient qu'un an. Ils pourront être employés à ee serviec jusqu'à l'åge de quatre ans. On choisira des truies qui aient les flanes allongés, et un ventre d'une grande capacité, et qui se prête à sontenir le poids de leur portée : quant au reste, il faudra qu'clles ressemblent aux verrats. Ces animaux doivent avoir le poil épais et noir dans les pays froids : dans les pays ehauds, leur couleur est indifférente. Les femelles sont fécondes jusqu'à l'âge de sept ans, et commencent à l'être à un an. Les truies mettent bas au bout de quatre mois, e'est-à-dire, au commencement du cinquième. Or, comme elles conçoivent, ainsi que je viens de le dire, au mois de février, leurs petits pourront se nourrir des herbes qui seront déjà fortes au moment de leur naissance, et de la paille qui viendra après ces herbes. Quand on a la faculté de se défaire des cochons de lait, on les vend à mesure qu'ils sont nés, afin de mettre plus promptement les mères en état de donner d'autres portées. On peut avoir de ce bétail dans toutes sortes de lieux, quoiqu'il réussisse mieux dans des campagnes marẻcageuses, dans celles notamment où abondent les arbres fruitiers, qui, múrissant suceessivement les uns après les autres, fourniront à ces animaux leur pâture pendant toute l'année. Ils se nourrissent au mieux dans

antequam germinent. Et pistacix planta vel nunc statui aut inseri potest, el castanearum semina spargi. Nuces quoque juglandes etiam nunc scminariis recondi, et ipsum genns inseri; et frigidis et lumectis locis nunc poterunt pineta seminari.

XXVI. Nunc verres maxime fiminas inire debebunt. Ite. gendi sunt vasti et ampli corporis, sed rotundi potius quam longi, ventre et clunibus magnis, rostro brevi, cervice glandulis spissa, Jibidinosi, anniculi, qui usıue ad quadrimos iuire feminas possunt. Serofas vero longi lateris dehemus eligere, et quibus ad sustinendum freturac onus maguus se venter effundat, cxtera verribus similes. Sed in regionibus frigidis, densi et nigri pili, in tepidis qualescunque provenerint. Femina (ad creandum), usque in an. nos septem partus onera gestare sufficiet : ad concipien. flum annicula debet iucipere. Quarto exemto mense pariunt, ubi quintus incipict. Incipiunt autem, sicut dixi, mense Februario, ut solidioribus herbis nati et stipula succedente pascantur. Ubi facultas est transigendi, venditis qui subinde nali sunt, celerior matribus foctura reparatur. Genus hoc omnibus locis lıberi potest; melius tamen agris palustribus, quam siccis, pracipue ubi arborum des terrains fertiles en herbes, et mangent trèsbien les racines de la canne ou du jone. Mais lorsque la pâture vient à leur manquer pendant l'hiver, il faut leur donner de temps à autre du gland, de la châtaigne, ou de vieilles criblures de quelques grains que ce soit; prineipalement au printemps, ear alors la verdure nouvelle, qui est pleine de lait, les incommode ordinairement. On ne renferme pas les truies par troupeau comme les autres bestiaux; mais on fait des toits sous des appentis où l'on renferme ehaque mère à part, afin qu'étant elles-mémes en sûreté, elles puissent garantir du froid le troupeau qu'elles auront à nourrir. Ces toits auront une ouverture dans leur partie supérieure, afin que le gardien puisse faire aisément la revue dés petits, et leur porter souvent du secours, en les retirant de dessous leurs mères quand ils seront en danger d'en être écrasés. Mais il aura l'attention de renfermer chaque portée séparément avee sa mère. Une truie ne doit pas nourrir plus de huit pores, suivant ce que dit Columelle. Pour moi, il me parait plus à propos, d'après ma propre expérience, de ne lui en donner que six à nourrir au plus quand la páture ne lui manquera pas, parce que, quoiqu'à la rigucur elle puisse en élever davantage, elle s'épuiserait si elle donnait à teter à un plus grand nombre. Il y a un autre profit à retirer des pores, qui eonsiste à les en royer dans les vignes avant qu'elles soient en boutons, ou après la vendange, paree qu’ils font la guerre aux herbes aussi exactement que le meilleur ouvrier.

XXVII. On fera au commencement de ce mois du vin de myrte d'une façon différente de eelle que nous avons donnée. On mettra dans un flacon dix sextarii de vin vieux, dans lequel on jettera

fructuosarum silva suppetit, qua subinde maturis fruetibus alterna per annum mutatione succurrat. Maxime locis graminosis, et cannarum vel junei radice nutriuntır. Sel deficientibus aliment is per liemem nonnumquam prabeuda suut pabula glandis, castanexe, vel frugun vilia cxcreu:enta caterarum : verno magis, cum lactent novella virenia, qua porcis solent nocere. Neque gregatim claudenda suut porcac more aliarum pecudum, sed laras sub porticibus lacienus, qquibus mater unaquąque claudatur, et alumuum gregem lutio ipsa defendat a frigore. Qux laræ a superiori parte detecta sint, ut libere numerum pastor exptoret, et oppressis a matre foctibus sxpe subveniat subtraliendo. Curabit autem ut fotıs proprios cum unaquaque procludat. Plus vero quam octo, sicut Colımella dicit, nutrire non debet. Milii vero utilius probatur experto, porcam, cui pabula suppetunt, ut purimum sex nutrire debere, quia licet plures possil edıcare, tamen frequentiore numero sucta deficiet. In porcis etiam illud est conmodım, quod immissi vineis necdum turgentibus, vel exacta vindemia gramine persecuto, diligentiam fossoris imitantur.

- XXVII. In lıjus mensis initio aliter mygrtitem sic fa. 
cinq llvres de baies de myrte. Quand on les aura laissées pendant l'espaee de vingt-deux jours dans ce vase, que l'on aura soin d'agiter tous les jours, on passera ce mélange à traver's une corbeille de palmier, et on ajoutera sur ces dix sextarii cinq livres d'exeellent miel, cxtrêmement broyé.

XXVIII. Manière de faire une vigne antidote, dont le vin, le vinaigre, le raisin, et, jusqu'à la cendre provenant de ses sarments, soient un spécifique eontre tout poison animal. On fait au bas du sarment que l'on veut planter une fente de trois doigts de longueur, et on en retire la moelle, à laquelle on substitue une dose de thériaque; puis on le met en terre, en l'assujettissant bjen avee un lien. Il y a des personnes qui, après avoir saturé le sarment de la substance médicale, le cachent dans un oignon de seille, et le mettent en terre de la manière que nous venons de dire. D'autres versent la thériaque sur les raeines de la vigne. II n'cst pas douteux que si l'on prend un sarment d'une vigne apprêtée de la sorte pour le transférer, il n'aura pas la vertu médicinale qu'avait la souehe. Il est également vrai que cette vertu s'affaiblit à la longue, et qu'il faut la renouveler de temps à autre en réitérant l'infusion.

XXIX. Il y a une belle espèce de raisin qui ne renferme point de pepins : aussi peut-on en avaler avec grand plaisir une grappe entière, comme si elle ne formait qu'un corps, et sans trouver d'obstaele qui arrête. Or on obtient ce raisin, suivant les auteurs grees, en appelant comme suit l'art au seeours de la nature. Il faut faire au sarment que l'on veut planter une fente d'une longueur égale à celle du bois quí sera en terre, et, après en avoir ôté toute la moelle et l'avoir creusé exactement, on en rapprochera les bords, et on le

cies. Mittes vini veteris decem sextarios in lagæenam, et baccarum myrti libras $\mathbf{v}$ miscebis. Cum $\mathbf{x x}$ et duorum dierum spatium confusa transegerint, pe: quos ras quotidie convenit agitari, tunc palmea sporta colabis, et pradictis decem sextariis mellis optimi fortiter triti pondo $\mathbf{v}$ miscebis.

XXVII. Theriacam vitem sic facies, cujus iste profectus est, ut vinum ejus vel acetum vel uva vel sarmentorum cinis proficiat contra morsus omnium bestiarım. Fit autem sic: Sarmentum, quod pangendum est, trium digitorun spatio in ima parte findatur, et sublata medulla ad ejus vicen theriacre inedicamen addatur. Tunc terræe mandetur vinculo diligenter astrictum. Aliqui eadem sarmenta jam medicamine satiata intra squillo bulbum recondunt, et lerris pradicta ratione committunt. Aliqui antidoti ejus affusione radices vitis infundunt. Sane sarmentum si de hac vite sumatur ad transferendum, potentiam materni medicaminis non lenebit. Oportebit autem theriace infusione assidua vim succi senescentis iterare.

XXIX. Est pulchra species uvæ, quæ granis interioribus caret. Hinc efficitur, ut summa jucunditate sine impedimento sorberi possit, velut unum omnium corpus uva- mettra en terre en les assujettissant avec un lien. Ces auteurs assurent néanmoins qu'il faut que ce lien soit de papyrus, et que le sarment soit mis, après ees préparatifs, dans une terre humide. Il y a des personnes qui, après avoir lié cxactement ce sarment sur toute la longueur qui en aura été fendue, l'enfoneent dans un oignon de seille, parce qu'ils assurent que cet oignon aide toutes les plantes à prendre plus aisément. D'autres creusent le plus profondément qu'ils peuvent; dans le temps même de la taille, une branehe à fruit d'un cep qu'ils viennent de tailler, pour en retirer la moelle; après quoi ils l'attachent à un roseau fixé auprès de eette branche, afin qu'elle ne puisse pas se renverser. Ensuite ils versent dans le trou qu'ils y ont fait de la li-

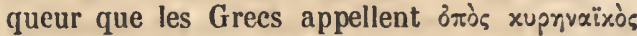
(sue de Cyrène), après l'avoir détrempée avee de l'eau jusqu'à ce qu'elle ait aequis la consistanee du vin cuit à l'évaporation des trois quarts; et ils recommeneent l'opération tous les huit jours, jusqu'à ce que les bourgeons de la vigne paraissent. Les Grees assurent qu'on peut faire la méme chose sur les grenadiers et sur les eerisiers. C'est une expérienee à faire.

XXX. Quand les vignes se dessèchent par la trop grande abondance de la séve qui monte, $\mathrm{ct}$ qu'à force de pleurer elles privent le fruit de la vertu que renferme leur bois, les Grees ordonnent de déchiler leur trone pour y faire une poche; et si ce remède est sans effet, de couper le bois le plus épais de leurs racines, afin que cette blessure guérisse leur maladie. Mais on aura soin de frotter la partie blessée avec du marc d'huile sans sel, réduit par la cuisson de moitié, en attendant qu'il soit refroidi, et de répandre de fort vinaigre sur la plaie.

rum. Fit autem Grxecis auctoribus hac ratione per artem succedente natura : Sarmentum, quod obruendum est, quantum latebit in terra, tantum findere debebimus, et medulla omni sublata ac diligentel exsculpta, membra ite run divisæ partis adunare, et vinculo coustricta deponere. Vinculum tamen papyro asserunt esse faciendum, et sic in humida terra esse poneudum. Diligentius quidam sarmentum revinctum quantum excisum est, intra scillac hulbum demergunt, cujus beneficio asserunt sata omnia comprehendere posse facilius. Alii tempore quo vites putant, sarmentum fructiferum putatæ vitis in ipsa vite, quam possunt de alto sublata medulla excavant non divisum, et calamo affixo alligant, ne possit inverti. Tunc ठ̇òv xupryaixòv, quod Graeci sic appellant, in excavata parte suffundunt, ex aqua prius ad sapæ pinguedinem resolutum, et hoc transactis octonis diebus semper renovant, donec vitis germina novella procedant. Et in granatis malis fieri loc posse tirmatur a Gracis, et in cerasis. Opus est experiri.

XXX. Vites quæ lacrymarum uimietate tabescunt, et deplorando vim roboris sui avertunt fructu, trunco earum lacerato Græci sinum fieri jubent. Si lıoc minus proderit, 
XXXI. I.es Grees preserivent encore de composer du vin de myrte de la manière suivante : (On mettra dans un linge huit uncice de baies de myyrte mùres, que l'on aura broyées après les avoir fait séclıer à l'ombre, et on suspendra ce. paquet dans le vin; après quoi on couvrira le vase, et on le bouchera. Quand ces baics seront restées plusicurs jours dans le vin, on les en retirera pour en faire usage. Il y a des personnes qui foulent anx picds ou qui exprimęnt entre leurs mains des baies de myrte, qu'elles ont cueillies dans leur maturité par un temps sans pluie et dans des terrains très-secs, et qui en mettent la valeur de huit cotulce sur une amphore de vin. Ce vin s'emploie aussi en médecine, quand on cst dans le cas d'avoir recours aux astringents : son effet ordinaire est de fortifier les estomacs (!ẻlabrés, de couper court aux crachements de sang, d'arrêter le flux de ventre, et de durcir efficacement les matières qui occasionnent les - coulcurs de la dyssenterie.

XXXII. On prétend quc les vignes donneront d'elles-mêmes du vin, soit d'absinthe, soit de rose ou de violette (de façon que l'on recevra dc la nature ce que l'on doit ordinairement à l'industrie), pour peu que l'on plonge des sarments dans un vase rempli jusqu'à moitié de l'une de ces essences, en y faisant dissoudre en même temps de la terre végétale en manière de lessive, et qu'on les y laissc jusqu'à ce que leurs yeux commencent à paraitre; après quoi on mettra ces sarnients où on voudra quand ils bourgeonneront, ainsi qu'on le pratique à l'égard de toute autre vigue.

XXXIII. Voici la mithode que les Grees ont prescritc pour faire produire au même cep des

radicum robur pingne rescindi, ut afferat mediciuam vulnus impressum. Tunc insulsa amurca ad medietatem de. cocta et refrigerata plagx excisio perlinetur, et sub lıac acetum acre fundatur.

XXXI. Graeci item myrtitem sic præcipiunt temperari : Myrti baccas maturas in umbra siccatas, et postea tusas', uncias octo miltis in linteo, et suspendis in vino, el vas cooperies ac linilsis : et cum plurinis diebus sic fuerit, auferes et uteris. Aliqui myrti baccas sine pluvia collectas maturas et locis siccioribus calcant, vel exprimunt, et viuo miscent vu cotularum mensuram per amphoram vini. Quod vinum medicinæe quoque proderit, ubi stypticis est utendum. Stomachum solidare titubantem solet, rejectiones sanguinis inhibere, fluorem veutris adstringere, linum dysenterica passionis medicabiliter asperare.

XXXI. Conditum vel absinthiatum, vel rosatum, vel violatnm procedere spoute fertur ex vitibus (ut natura suscipiat, quod procurare suevit industria) si sarmenta in vas alifuod semipleuum supradictis potionibus mersa serventur, et vivam terram simul resolvas ad lixivii modum, donec oculi sarmentorum uitantur exire : tunc eadem sar. grappes de raisin blane et des grappes de raisin noir : si l'on a un cep de raisin blane et un de raisin noir qui soient voisins l'un de l'autre, on joint enscmble, au temps de la taille, des sarments pris sur chacun de ces ceps, ct fendus en deux, de façon qlie, lorsqu'ils scront joints, les boutons qui sont au milieu de ces sarments semblent être sur un seul ct même sarment; après quoi on les lic ensemble avec du papyrus amolli, pour les resserrer; et on a soin de les enduire de terre humide, et de les arroser de trois jours l'un, jusqu'à ce que le germe de la feuille nouvelle paraisse. A dater de la fio de ce mois, on pratiquera, si l'on veut, celte méthode sur plusicurs sarments.

XXXIV. Ce mois-ci s'accorde avec celui de novembre pour la durée des heures : les roici ras. semblées sous cette proportion de nombres.

A la premic̀re et à la onzièmc heure, le gnomon donne vingt-sept pieds d'ombre.

A la seconde et à la dixième, il en donne dixsept.

A la troisième et à la neuvième, il en donne treize. dix.

A la quatrième et à la huitième, il en donne

A la cinquième et à la septième, il en donne huit.

A lá sixième, il en donne sept.

\section{LIVRE, QUATRIEME.}

\section{MisRs.}

I. La taille de la vigne, dont nous arons amplement parlé au mois de février, se fait au mois

menta gemmantia in quo volueris loco, vitium caterarum more deponas.

XXXIII. Ut vitis botryones et albos afferre possit et ni. gros, Graci sic fieri dehere jusserunt: Si vicinx sunt vites nigra et alba, cum pulantur, sarmenta utriusque iuter se divisa sic junges, ut melios utriusque generis oculos xçuando vedlere possis unitati : tuuc papyro ligabis stricto et molli, atque humida terra curabis adlinire et interjeclis ternis diebus adajuare, donec germen nova frondis ermmpat. Ilinc exemto tempre, si libuerit, genus efficies per plura sarnienta.

XXXIV. Hlic mensis in horal um mensura cum Xovem. bri mense concordat, quas lac numeri ratione culligimus :

\begin{tabular}{|c|c|c|c|c|c|}
\hline Hora & 1 & et & $\mathbf{x I}$ & pedes & XXvil. \\
\hline Hora & 11 & et & $\mathrm{x}$ & pedes & xvil. \\
\hline Hora & 111 & et & IX & pedes & xill. \\
\hline IIora & IV & et & TiII & pedes & x. \\
\hline Hora & $r$ & et & V'u & pedes & vill. \\
\hline Hora & vi & & & pedes & vil. \\
\hline
\end{tabular}


de mars dans les pays froids, tant qu'il n'y a point de ris(jue d'endommager les bourgeons par cctte opérätion. II faut greffer à présent les ceps, au moment où les larmes qu'ils répandront, au lieu d'être elaires eomme de l'eau, seront ipaisses. On aura deux ehoses à observer en ee eas : premièrement, que le eep que l'on voudra greffer soit solide et plein de sues nourriciers, sans c̀tre desséehé, soit par la vétusté, soit par les mauvais traitements qu'il aura pu éprouver; secondement, que les rejetons que l'on y insérera lorsqu'on l'aura coupé soient fermes, l'onds, et bien fournis de boutons multipliés les uns auprès des autres; quoiqu'il suffira d'y en laisser trois, quand on les emploiera en greffes. Il faudra done les ratisser sur une longueur de deux doigts, en conservant leur écoree sur un de leurs cótés. Il y a des personnes qui n'en laissent pas mettre la moelle à jour, mais qui se contentent de les ratisser légèrement, de facon que la partie ratissée soit terminée insensiblement en pointe, et que eelle qui reste garnie de son éeoree puisse ĉtre adaptée à l'éeoree de sa mère future. Le dernier bouton doit être enfoneé dans le eep de manière à y être incorporé: ce bouton sera tourné en dehors du eep, et assujetti avec une ligature de saule, et on étendra dessus, pour le leeouvrir, un lut dans lequel il entrera de la paille; puis on le protégera, à l'aide de quelque eorps étranger dont on le couvrira, eontre le vent et contre le soleil, de peur qu'il ne soit agité par l'un ou brûlé par l'autre. Si la chaleur eonmence à se faire sentir de bonne heure, il faudra verser vers le soir et à différentes reprises, à l'aide d'un pinceau, un peu d'eau sur ia ligature mème de la greffe. Cette irrigation y entretiend ra la vie, malgré l'action brûlante de la tempé-

\section{LIBER QUARTUS.}

1. Martio mense locis frigidis putatio vinearum celelsralır; de qua ahunde Februario mense locuti sumus, usique quo incipil gemma esse suspecta. Nunc oportet vineas inserere, cum vites non aquato sed spisso lumore lacrymabunt. Servabinus ergo ut truucus, 'qui iuseritur, solidus sit, et alimento lummoris exuberet, neque ulla vetustate aut injuria laceratus arescat. Tunc decisac viti surculi qui inserendi sunt, sint solidi, rotundi, gemmis spissis et pluribus nculali. Tres tamen oculi in insitione sufficicut. Raden. dum est ergo sarmentun ad niensuraun digitorum duorım, ut ab) una parte sit cortex. Aliqui non patiuntur nudare unedullam, sed leviter radunt, ut Incisura sensim possil in acumen exire, et corticata pars cortici nora matris aptetur. Iulimus oculus ita infigendus est, ut trunco junctus adlırreat, qui oculıs exteriorem partefn debet aspicere, vinculo salicis infuso ef paleato luto desıper, alligari : tegumento quoque aliquo a rentis et a sole defendi, ne li quatiant, hic adurat. Ubi calor Iemporis coeperit, ligaturn ipsi penicillo circa vesperain tenuis debet frequenter liu. wor affundi, ut looc alimento contra vim cali torrentis rature. Lorsque le bouton sera parti, et que le fouet aura pris quelque aeeroissement, on l'attaelıera à un roseau pour l'aider à se tenir, de peur que quelque mouvement ne vienne à l'ébranler tant qu'il sera dans un âge fragile; au lieu que, lorsqu'il aura aequis une eertaine eonsistanee, on coupera tous ses liens, de peur que son adolescence ne soit gênée par la dureté d'un nœud trop serré pour un germe aussi tendre. Il y a des personnes qui, après avoir déehaussé un eep à un demi-pied de profondeur, ct y avoir inséré des rejetons, reeouvrent eeux-ei d'un amas de terre, afin que cette terre fournisse de son eôté des alimeuts aux sarmeuts nouvellement entés sur le cep nourrieier, indépendamment de eeux qu'ils tireront de lui. D'autres assurent qu'il est mieux de greffer un cep vers la superfieie de la terre, paree que quand les greffes sont trop enfonećes en terre, elles premneut difficilement. On plantera des vignes dans les pays froids jusqu'aux ides de ee mois-ei, ou jusqu'à l'équinoxe, soit dans un terrain façonné au pastinum, soit dans une tranchéc ou dans des fosses, conformément à la méthode que nous avons donnée.

II. Il faut nettoyer à présent les prés et lesgarder dans les pays froids. On y défrichera aussi les eoteaux gras ainsi que les campagnes maréeageuses, et on leur donmera le premier labour. Il faudra eneore repasser les guérets qui auront été mis en état au mois de janvier.

III. On sèmera le panis et le millet dans les eontrées chaudes et sèehes. Ces plantes demandent une terre légère et ameublie, et viennent nonseulement dans le sablon, mais dans le sable même, pourvu que le elimat soit humide et le sol arrosé : elles redoutent eependant un terrain

animetur. Cum ergo germen eruperit, et aliquod ceperit iucrenentım, calami arjutorio debet annecti, ne motus aliquis fiagilen procedentis sarmenti quasset ælatem. Ubi solidiıs quantımcunque processerit, viıcula oportet abscindi, ne adolescentia mollissimi germinis nodo durx constrictionis angatır. Aliqui infra terraın semipedis spatio effossac viti surculos inserunt, et beneficio congestionis accumulant, ut loc quoque novis sarmentis præter nutricis alimenta subveniat. Nonnulli circa terras melins asse. runt inserendum, quia in altiori difficilius comprelsendunt. Usque ad idus vel requinoctium vites locis frigidis pangendx sunt seu pastino seu sulco seu scrobibus more quo dictım est.

I1. Nunc locis frigidis prata purganda atque servanda sunt. Locis gelidis colles pingues et agros uliginosos proscindere atque exarare conveniet. Vervacta etiam, quie Januario mense sunt facta repetere.

III. Calidis et siccis regionibus panicum seremus et milium. Levem et solutam terram desiderant : nec in sabul. lone solum, sed in arena quoque proveniunt, duminodo calo lıumido et solo serantur irrigno : quia siccum et 
sec et argilcux. On aura soin de les délivrer assidûment des mauvaises lıerbes : einq sextarii suffisent pour la sensence d'un jugerum.

IV. Il faut semer à présent les deux espéces de pois chiches dans un terrain qui soit très-gras, et sous un climat humide, après les avoir fait tremper la veille dans l'eau, afin qu'ils lèvent plus tôt. Trois modii sont la mesure d'un jugerum. Les Grees disent que les pois viendrout plus gros, lorsqu'on les aura arrosés d'eau chaude la veille du jour où on les sèmera. Ils ajoutent qu"ils aiment les terrains voisins de la mer, et quils viennent de meilleure heure quand ils sont semés en automne.

V. On sèmera aussi le chanvre ce mois, jusqu'à l'équinoxe du printemps, de la manière que nous a vons détaillée en février.

VI. On sème à présent la cicerole, qui ne diffère de la gesse que par sa couleur obscure ct noire, dans un terrain gras qui aura reçu le premier ou le second labour. Un jugemem en aura assez de quatre modii; mais on peut 'se contenter d'y en semer trois, ou même deux.

VII. On commenceà présent à écraser les mottes de terre dans les vignobles; ce qu'il faut faire tant aux calendes de ce mois qu'à celles de tous les autres mois qui le suivront, jusqu'à celui d'octobre, nou-seulement pour extirper les mauvaises herbes, mais cncore pour empêcher que la terre, étant trop endurcie, n'étrangle lc plant (qui est encore tendre. On cxtirpera jusqu'aux racines du gramen, qui causent un grand dommage aux vignes. Il faut bêcher à présent les vignobles dans les pays froids, et y échalasser les ceps et les lier, en observant d'employer pour les jeunes vignes des liensqui soient flexibles, parec que, s'ils ćtaient durs, ils les couperaient indubitablement, d'autantqu'elles sont très tendres.

argillosum agrum reformidant. Herbis liberentır assidue; quinque sextariis spatium jugeri complebitur.

IV. Nunc cicer ntrumque serere debemıs loco latissimo, calo liunido. Maccrandum est pridie, ut possit cilius nasci. Jugerım tribus modiis conseretur. Cicer grande nasci Grarci dicunt, si infundatur aqua tepida pridie : anare etiam loca maritima : temperius provenire, si se ratır allununo.

V. Hoc etiam mense cannabum serimus usque in cquiuoctiunı veruım, lıac ratione, qua in Februario disputa. tım est.

VI. Nunc cicera seritur, qure distat a cicercula solo coIore, quo sordet, et nigı ior est, primo sulco vel secundo, solo lato. Jugenum quatuor vel tribus vel etiam duobus morliis implcbimus.

VII. IIoc mense novella rinea incipiat pulverari ; quod nunc ac deinceps per omnes calendas usque ad octobres faciendum est, nou solım propter lierbas, seil ne tenera adluc semina solidata terra constringat. Graminum radices, qua plurimum vitibus nocent, extirpanda sunt. Nuac locis frigidis vincarum fussio celebranda est : et
On appuiera les grands ceps sur un pieu fort, et les petits sur un plus mince. Ce pieu sera posć cu face de l'aquilon, et du côté du ciel d'où vient le froid, attendu l'incommodité que son ombre occasionncrait au cep, s'il était posé autrement. Il scra d'ailleurs éloigné du cep, à la distance de quatre doigts ou d'un demi-pied, afin qu'on puisse bêcher librement autour du cep. Il y a des personnes qui tronquent à présent les vieux ceps à une certaine élévation de terre, dans la vue de les renouveler. Mais cettc méthode est vicieuse; car il arrive presque toujours qu'une plaic de cette nature pourrit au soleil et à la pluie, parce qu'elle est trop considérable. C'est pourquoi il vaudra mieux les rewouveler de cette facon-ci : On commencera par les déchausser profondément, jusqu'à ce que leurs racines soient à découvert; ensuite on les coupera en terre au-dessus de ces racines, afin qu'étant recouverts de terre par la suite, ils n'aient rien à craindre du froid ni du soleil : encore n'en viendra-t-on à cette extrémitć que lorsqu'il s'agira de ceps d'une excellente espèce, et dont les racines seront très profondes; autrement il vaudra mieux les greffer avec des sarments d'une bonne qualité. Tout ec que nous venons de dire doit être fait au commencement du mois dans les pays chauds, et après les ides dans les pays froids. On bêchera le pied des ceps qui seront malades, ou dont le fruit sèchera, et on les arrosera d'urine gardee. On mettra aussi sous la terre qui les porte de la cendre de sarment ou de chêne, mêlée de vinaigre; ou bien, après les a voir coupés près de terre, on les réchauffera avec du fumier, et on en laissera croitre les pousses qui paraîtront les plus fortes. Lorsqu'un cep aura été blessé par la houe ou par un instrument de fer quelconque, si la plaie est près de terre, enduisez-la de crottin de

palanda: alque ligandæe sunt vites : sed novellam mollibus vinculis alligenus; quia eam teneram vincula duriora præ. cidunt. Palus majoribus vitibus solitus, minoribus ponatur exilis. Propter umbrac molestiam statuatur alı Aquilone et plaga frigida, spatio qualuor digitorum rel semipellis remotus a vite, ut possit $\mathrm{cx}$ omni parte circumfoli. Vineas veteres nunc aliqui a terra altius truncaut, sludentes reparationi : sed vitiosın est; nam plerumque rastior plaga sole putrescit el roribus. Quare lıoc genere reparetur : Prius âulaqueabitur altius, dones, cjus nodıs appareat : deinde iufra terrain supra nodun recidatur, ut operta de frigore et sole nilil timeat. Hoc faciendum, si optimi gemeris vitis sit et alte posita; alioquin generosis melius erit inserenda sarmentis. Omuia sípra dicta locis calidis primo meuse; frigidis vero post idus ipsins exe. quemur. Egras vites, vel quibıs fructus arescit, circumfodies, et urinam veterem suffundes, item cineren sarmeuti aut querneum aceto mixtum subjice, aut incisas circa terram lactamine refoveto, et qux germinant fortio. ra dimittc. Cum vitis bidente lxditur aut ferro, plagam, si terrxe juncta est, adline stercore ovillo vel caprino : 
brebis ou de ehèvre, que vous y assujełtìrez avee des ligatures, et que vous reeouvrirez de terre prise à son pied. Si e'est la racine d'un eep qui a été blessée, ajoutez à eet enduit du fumier liquide, lorsque vous recouvirirez la plaie.

VIII. On versera du mare d'huile sans sel autour des racines des oliviers malades. Il n'en faudra que six congii, suivant Columelle, pour les plus grands arbres, quatre pour les arbres de moyenne taille, et plus ou moins pour les autres, à proportion de leur grandeur. D’autres jettent sur leurs racines de la paille de féves jusquà la eoneurrence de deux quali pour un grand arbre. D'autres, après avoir' préalablement couvert le trone de l'arbre, répandent dessus la quantité de vicille urine d'homme qu'ils jugent suffisante, en faisant en mème temps à son pied une excavation propre à la contenir, surtout dans les licux sees. On percera avee une tarière gauloise un olivier stérile, après quoi on prendra du eôté du midi, sur un autre arbre qui produise beaucoup, leux branehes également longues, que l'on enfoncera dans ee trou par ehaeun de ses côtés, de faȩon qu'elles s'y trouvent resserrées; et, après a voir coupé les portions de ees branehes qui déborderont de l'un et de l'autre eôté du trou, on aura soin de les reeouvrir avee un lut dans lequel il entrera de la paille. Si, au contraire, les arbres sont de belle venue, mais qu'ils ne rapportent point de fruits, on enfoneera dans leurs racines, soit un pieu d'olivier sauvage, soit des pieux de pin ou de elıêne. C'est aussi à présent que eeux ugui sont dans l'usage de sarcler les blés doivent le faire pour la seconde fois. On formera à présent, dans les pays froids, les pépinières de baies et d'autres semences dont nous avons prarlé au mois de février, et on donnera les derniers soins aux plants de rosiers au commeneement du mois.

tunc terra mista circumfossa ligare curato. Si in radice li:'sa est, operiens liquidum laetamen admisce.

VIII. Nunc oleis laborantibus circum radices insulsa amurca fundetur. Maximis arboribus ( $(1 n$ od Colnmella (licit) sex congii, mediocribus (juatuor, cateris pro astimatione sufliciunt. Alii paleas fabx, binos per majo. rem arborem qualos; alii veteris urina lumana trunco fliaulum satis videtur affundunt, et árbori mortarium slatim faciunt, maxme locis siccis, trunco ante cooperto. Olean sterilem terebra Gallica perforabis. Tunc duos lingifer $x$ arboris ab australi parte ramos ejusclem magnitudinis tollis, et stricte in foranen utrinque conjicies vel lapidem, vel pini vel querci palos, et abscisso eo quod superabit, luto paleato curabis occulere. [Sed] si sine fruge luxuriant, oleastri palum vel lapidem vel pini vel querci palos radicibus ejus infige. Nunc etiam quibus moris est, frumenta iterum sarrire conveniet. Nunc locis frigidis seminaria, quæ Februario mense dicta sunt, baccaruus et seminum fiant, et rosaria in mensis initio percolantur.
IX. Il est bon de eommeneer à présent à s'oceuper de la eulture des jardins. On sème l'artichaut au mois de mars. Ce légume aime une terre fumée et meuble, quoiqu'il lui soit plus aisé de venir dans une terre grasse. Il sera à propos, si on veut le mettre à l'abri des taupes, de le semer dans une terre qui soit eompacte, afin que ees animaux pernicieux ne viennent pas aisément à bout de la fouiller. Il faut semer les artiehauts dans le temps que la lune croit, et sur une planehe préparée d'avanee à cet effet, en laissant un demi-pied d'intervalle entre ehaque graine. II faut prendre garde que leur graine ne soit pas en terre dans une position renversée, pareequ'elle ne donnerait que des artichauts qui seraient petits, courbés et durs. Il ne faut pas non plus l'enterrer profondément, mais on la tiendra entre trois de ses doigts, que l'on enfoncera dans la terre jusqu'au niveau de la première articulation; après quoi on la recouvrira légèrement de terre, et on ne manquera pas de la délivrer assidutment par la suite des mauvaises herbes, jusqu'à ee que les tiges qu'elle produira soient fortifiées, et de l'arroser s'il survient de la ehaleur. Si l'on brise la pointe de la graine, il en viendra des artiehauts sans épines; de même que si on la met tremper pendant trois jours dans de l'huile de laurier ou de nard, ou dans du baume blane, ou dans de l'eau-rose, ou dans du mastic, et qu'on ne la mette en terre qu'après l'avoir fait séeher, il en viendia des artichauts qui auront le goût de eelui de ees parîums dont elle aura été abreuvée. Il faut ehaque année enlever quelques branehes à la tige principale, tant pour la soulager que pour multiplier le plant. On les arraehera néanmoins avee une portion de leurs raeines. Quant aux artiehauts que l'on réservera pour en tirer de la graine, il faudra, après les a voir débarrassés de tous leurs rejetons, les couvrir d'un vase

IX. Nunc horti optime sumunt cultionis initia. Mense Martio carduus seritur. Terram stercoratam et solutam diligit, quam vis in pingui possit melius provenire, et loc illi contra talpas prodest, si pangatur in solido, ne terra ab inimicis animalibus facilius perforetur. Serendi sunit cardui luna crescente, in area jam parata, semina spatio semipedis sint discreta. Cavendum est ne semina inversa ponantur. Nam ilebiles, incurvos et duros creabunt. Non alte impriınenda sunt, sed tribus digitis comprelıensa niergantur, donec ad primos articulos terra perveniat. Tunc leviter operiantur, et lierbis liberentur assidue, donec plantaria solidentur, et rigentur si æestus intervenit. Si acumina seminum confringas, spinis carebunt : Item si semina eorum inadefeceris per tridnum laurino oleo, vel nardino, vel opolalsamo, vel succo rosa, vel mastichino, et post. en siccata depresseris, ejusdem saporis orientur, cujns ungueutum semina combiberunt. Singulis sane annis a codice anferendxe sunt plantx, ut nec matres fatigentur, et soboles per alia spatia digeratur : cum aliqua tamen radicis parle vellenda sunt. Quas reservabis ad semina 
de terre ou d'une éeorce, parce que le soleil ou la plule en font communément mourir la graine. II est bon d'avoir souvent des chats au milieu des plants d'artichauts, pour les garantir des taupes. II y a des personnes qui ont à cet effet des belettes apprivoisées. Quelques-unes remplissent les trous de taupes de terre rouge at de jus de concombre sauvage. D'autres pratiquent auprès plusieurs cxcavations pour y faire pénétrer lc jour, ce qui met les taupes en fulte. La plupart mettent à l'ouverture de leurs trous des piéges suspendus avec des fils de soie. On sème aussi très-bien ce mois-ci, dans les pays froids, l'oignon de Cypre, l'ail, la ciboule et l'origan, ainsi que l'aneth. On peut aussi très-bien semer ou transplanter à présent la moutarde et les choux. On sème eneore la mauve et le grand raifort, et l'on transplante l'origan : on peut semer la laitue, la poiréc, le poireau et les câpres, ainsi que la fève d'Égypte, la sarriettc et le cresson alénois. II y a des persounes qui sèment aussi à présent la chieorée et les raiforts, quand elles veulent en avoir pour l'été. Il faut semer à présent les melons. Comme - il ne faut pasqu'ils soient trop pressés, on en mettra les graines à deux pieds de distance l'une de l'autre dans des terrains labourés ou façonnés au pastinuin, ct prineipalement dans du sable. On aura soin de faire tremper auparavant ces graines pendant trois jours dans du vin mêlé de miel et dans du lait, pourneles mettre en terre que lorsqu'elles seront séehées. Cette précaution eontribuera à donner aux melons une saveur agréable. Mais si l'on veut qu'ils aient aussî de l'odeur, on laissera la grainc, quand elle sera séehée, pendant plusieurs jours entre des feuilles de roses. On sème encore à présent les concombres dans des sillons écartés les uns des autres, auxquels on

colligenda, liberatas omnibus pullis testa supertegere debe. bis aut cortice. Nam solent semina sole vel imbribus interire. Contra talpas prodest catos frequenter liabere in mediis carduetis. Mustelas labent plerique mansuetas. Aliqui foramina earum rul)rica et succo agrestis cucumeris impleverunt. Sonnulli juxta cubilia talparum plures cavernas aperiunt, ut illa teıritæ fugiant solis admissu. Plerique laqueos in aditu earum setis pendentibus ponunt. Hoc etiam mense ulpicum bene et allium seremis, et cepullas, et cunilam locis frigidis, et anetlum. Nunc et sinapis, et caules optime seruntur vel plantantur : et malva seritur et armoracea, et origani planta transfertur. Lactuca et beta et porrus, et capparis seri possunt, et colocasia et satureia et nasturtinm. Intyba etian el raplianos nunc aliqui sernnt, quibus utantur astate. Nunc melones serendi rarius. Distent inter se semina pedibus duobus, locis subactis vel pastinatis, maxime arenls. Semina corum mulso et lacte per trlduum maceranda sunt, et tunc jam siccata ponenda : liiıc suaves efficientur. Odorati autem ituut, si corum semina multis diebus inter rosa foila sicea mergantur. Nunc et cucumeres seminantur rare, sulcis factis altitudine sesınipedilli, la titudine pedun triułn. donne un pled et demi de profondeur et trois pieds de largeur. On laissera, sans le labotier, un intervalle de huit pieds cntre ces sillons, sur lequel les eoncombres pourront s'étendre. Comme l'herbe leur fait du bien, il n'est pas nécessaire de l'arraelıer ni de les sareler. Si l'on en fait tremper la graine dans du lait de brebis et dans de l'hydromel, ils seront doux et blanes; de même que si l'on met à deux palmi de distance sous eux un large vase rempli d'eau, ils devien. dront tendres, et s'allongeront en clierchant à ga. gner cette eau. Ils n'auront point de graine, lorsqu'avant d'en semer la graine on l'a enduite d'huile du pays des Sabins, ou frottée avec de l'herbe connue sous le nom de culex, broyée. II y a des personnes qui mettent dans un roseau, après en avoir pereé tousles nœuds pour le ereuser, une fleur de concombre avec le bout de son tenon, de: sorte que le coneombre qui vient dans ce roseau s'étend jusqu'à une longueur immense. Ce légume redoute si fort l'huile, que si l'on en mettait auprès de lui , il se reeourberait en forme de erochet. II se retourne aussi toutes les fois qu'il tonne, comme par un effet de la peur. Si l'on renfernie sa fleur, sans la séparer de son tenon, dans un moule de terre cuite bien attaché, le coneombre qui en naitra prendra la forme de l'homme ou de l'animal que représentera ce moule. Tous ces faits sont attestés par Gargilius Martialis. Columelle prétend que sl l'on a des ronees ou des férules dans un lieu qui soit exposé au soleil ct fumé, et qu'après les avoir coupées près de terre, passé l'équinoxe d'automme, on les ereuse avce un stylet de bois pour y enfoneer du fumier dans la moelle, et y mettre ensuite une graine de eoneombre, le lígume qui en naftra pourra résister même aux plus grands froids. On sèmera les

Inter sulcos vin pednm spatium crudum relinques, ubi possint ragari. Herhis juvantur, ideo sarculo et runcatione non indigent. Semina si ovillo lacte et mulsa maceres, dulces nascentur et candidi. Longi et teneri fiunt, si aquam. in patenti vasculo sub eis ponas, duobus palunis inferiu. rem, ad quam festinando tales eflicientur. Sine si semine. nascentur, si prius eorum semina oleo Sabino. perungan: tur, et herba ea qux culex dicitur, trita confricentur. Aliqui florem cucumeris cum viticula sux capite caluna: inserunt, cui prius omnes nodos perforaverlnt : ili cucumis nascetur in nimiam longiturlinem tensus. Oleum sic metuit, ut si juxta posueris, velnt lamus plicetur. Quo. ties tonat, velut timore perterritus convertitur. Si ejus florem sicut in sua vite est, in forma fictili clauseris ac ligaveris, qualem vultum forma vel hominis vel aninalis labuerit, talem cucumis figuram prastabit. IIsec omuia Gargilius Martialis asseruit. Columella dicit, loco apricu et stercoroso si rubos liabeamus aut ferulas, post antumui aepuinoctium his juxta terram recisis et excavatis ligneo stilo, luter medullas latamen immittamus, et cucumeris senıen addaınus: hinc nasci fructıs, đuni possiut et inter frigora nuu necari. Hoc neuse asparagos serenus circa A priles 
asperges ce mois, vers les calendes d'avril, dans un terrain gras, huınide et labouré. Il faudra à cet effet mettre, dans de petites fosses alignées au cordeau, deux ou trois graines d'asperge, en Ies espaçant d'un demi-pied; après quoi on couvrira le sol de fumier, et on en arrachera de temps en temps les herbes, ou bien on étendra dessus pendant l'hiver de la paille que l'on otera ou commencement du printemps ; moyennant quoi il en viendra des asperges au bout de trois ans. Mais il sera plus court de mettre en terre des pattes d'asperges, qui rapporteront immédiatement. Voici comme on se procurera ces pattes. On crcusera des fosses sur un terrain gras et fumé, dans chacune desquelles on mettra, après les ides de févricr, ce qu'on pourra pincer de graine d'asperge avec trois de ses doigts, en la recouvrant lćgèrement de terre; et toutes ces graines, venant à se rćunir, formeront une racinc complexe à laquelle on donne le nom de spongia. Cependant cette racine souffre ellemême des retards, puisqu'il faut l'entretenir pendant deux ans dans sa pépinière avec du fumier, et en arracher souvent les mauvaises herbes; et qu'on ne la transfère qu'après l'équinoxe d'automne, pour recucillir des asperges au printemps. C'est pourquoi on trouvera mieux soll coinpte à acheter ces racines toutes venues, qu'à les attendic longtemps en les élevant soinuême. Au reste, de quelque façon qu'on se les soit procurées, on les arrangera sur le milieu de l'ados des planches, si le terrain est sec, et sur la pointe de leur élévation, s'il est humide. Il faut que l'eau ne fasse que passer sur les pattes d'asperges, pour les arroser sans s'y arrêter. On n'arrachera pas les asperges que ces pattes auront produites la première année, mais on les rompra, depeur d'ébranler les pattes elles-mêmes qui sont encore faibles; au lieu qu'il faudra les arracher

cal. Pingui loco, lumido, subacto, ita ut miuorilus, fossulis ad lineam directis bina aut terna grana semipedis spatio discreta ponantur. Delinc stercore solum tegatur, et lierbar subinde vellantur, vel per lienieu supra stramina jaciantır primo vere tollenda. Hisc post triennium nascentır asparagi. Sed expeditior ratio est, si asparagorum spongias ponas, quas cito fructum ministrent. Hæe sic fient : Semina asparagi guanta tribus digitis compreliendere possis, post idus Felır. Pingui et stercorato solo in singulis fossis pones, et leviter obrues. His coeuntibus radix connexa nascetur, quæ appellatur spongia. Sed et hæc moras lıabet. Nam per biennium in seminario suo est ster. core et assidua runcatione nutrienda. Deinde post aequinoctium autumni transferetur, et vere asparagun dabit. Has erit utilius comparare, quam longa expectatione nutrire. Eas tamen in sulcis disponemus. Si loca sicca sunt, inter medios sulcos; si humida, in summitate sulcorum. Humor spongias asparagorum transitu suo debet tantum rignare, non sistere. Asjaragum, quem primo protulerint, les années suivantes, afin que les yeux qui doivent en produire de nouvelles soient découverts. En effet, si on continuait de les rompre, il arriverait que des terrains ordinaircment fertiles sc trouveraicnt frappés de stérilité, par les racines d'asperges qu'on y aurait laissécs. Au surplus, c'est au printemps qu'ou pourra les coll. sommer, et on réservera pour l'automne celles dont on voudra cueillir la graine. Quand cette graine sera cueillie, on mettra le feu aux fannes; après quoi on couvrira les pattes de fumicr et de cendre vers l'hiver. On sème ce mois-ci la rue dans des lieux exposés au soleil. Cette plante se contente d'avoir de la cendrc répandue sur ellc. Elle demande des terrains élevés, hors desquels l'eau puisse s'écoulcr aisément. Si l'on en met les grinines en terre sans les tirer de leurs capsules, il faudra les y mettre avec la main les unes après les autres; au lieu que si elles sont dépouillées de leurs capsules lorsqu'on les sèmera, il faudra les jeter par-ci par-là, et lesrecouvrir avec un ráteau que l'on fera passer dessus. Les tiges qui viendront de la graine qui aura été semée avec sa capsule seront plus fortes que les autres, mais d'un autrc côté elles seront plus tardives. Les petites tiges que l'on arracliera de cette plante au printemps avec une partie de son écorce tiendront licu de plant; au lieu qu'elle périrait si on la transférait entière. Il y a des personnes qui insèrent ces petites tiges dans une fève percée ou dans une bulbe quelconque, a vant de les mettre en tcrre, afin qu'elles s'y conservent à l'aide de la vigueur que leur procurcront ces corps étrangers. On profère aussi des injures contre cette plante, et on aime micux la mettro dans une terre de brique dissoute, ce qui lui est cffectivement avantageux. Mais elle viendra encore mieux (suivant ce qu'on assure) quand elle aura été volée. Elle aime à se reposer sous

confringere debemus non avellere, ne adluc invalidam moveamus spongiam : cxteris annis avellendus est, 11 oculos suæ germinationis aperiat : quia si deinceps refringas, loca quæ focunda esse consueverunt, remanente asparagi radice claudentur. Ministrabunt autem vere: et autunıno reservabis eum, de q110 sumturus es semina. Postea scopas ejus incendes, tunc circa liemem spongiis adjicies ster. cus et cinerem. Hoc mense ruta seritur locis apricis, solius cineris inspersione contenta. Loca desiderat altiora, unde humor elabitur. Si ponas semina ejus adlıuc clausa folliculis, singulatim manu debebis affigere. Si jam minuta sunt, sparsa jactabis, et rastro obducta cooperies. Caules ejus, qui-inclusis seminibus nati fuerint, fortiores erunt, sed sero nascentur. Ramuli ejıs cım aliqua corticis parte convulsi verno tempore pro plantis teuebunt: tota vero translata morietur. Nonnulli ramulos ejus pertusa faba inserunt vel bulbo, atque ita obruunt alieno vigore serrandos. Prosequuntur etiam maledictis, et nuaxime in terra soluti lateris poumnt, quod prodesse 
l'ombre du figuier. Elle ne souffre pas qu'on ; déracine l'herbe auprès d'elle, mais elle veut qu'on l'arracho. Elle eraint d'être touchée par une femme dans le temps de ses règles. On sème la coriandre depuis ee mois-ei jusqu'à la lin d'octobre. Cette plante se plait dans une terre grasse, quoiqu'elle vienne également dans un terrain maigre. On eroit que plus sa graine est vieille, meilleure elle est. Elle aime l'eau. Une fois semée, clle vient avee toutes sortes de plantes potagères. II faut semer les eourges ee mois. Ces plantes aiment un terrain gras, humide, fumé et meuble. Elles ont eeei de remarquable, que les graines que l'on tire de leur eol donnent des eourges longues et frêles; au lieu que eelles que l'on tire de leur ventre en donnent de plus grosses, comme eelles que l'on tire de leur extrémité inférieure en donnent de larges, pourvu qu'on les mette en terre la eime renversée. Quand les courges ont commeneé à prendre une eertaine consistanee, on leur donne des appuis pour les aider à eroître. On laisse peridre à leurs tenons jusqu'en hiver eeiles que l'on eonserve dans la vue d'en avoir de la graine; après quoi on les enlève, et on les met au soleil ou à la fumée; sans quoi leur graine se pourrirait et périrait. On sème ee mois-ei la blette dans quelque terrain que ce puisse être, pourvu qu'il soit eultivé. Il ne faut ni délivrer des mauvaises lierbes ni sareler eette plante potagère. Quand une fois elle sera venue, elle se renouvellera d'elle-même pendant une suite de siècles, en répandant à terre sa semenee; de façon qu'il ue sera pas faeiie, quand même on le voudrait, de la détruire. On sème aussi à présent le serpolet, tant en plant qu'en graine. Celle-ci est toujours meilleure lorsqu'elle est vicille. Cette plante sera plus garnie de feuilles quand elle sera semée auprès d'une mare d'eau

curtissimum est. Sed (ut asserunt) melius furtiva proveuiet. Sub tici arborls unbra libentius acquiescit. Non effodi herbas, sed optat avelli. Imumudie mulieris formidat attactum. Ab hoc mense usque iu Octohrem totum coriandruı seritur. Anat terram pinguem, sed ex macro solo nascitur. Semen melius putatur, quod vefustius fue-

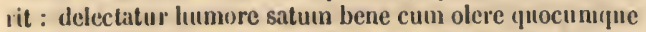
Ilascetur. Hoc mense cucurbita serenda est. Amat solıun piugue, humidum, stecoratum, solutum. Hoc in cucur. hitis iusigne est, quod lougas pariunt et exiles semina, qua in earum cervice uascuntur : qua in ventre fuerant, cucurbitas fitciunt crassiores : qune iu fundo, latas, si iuversis cacuninibus ob'uantır. Ubi arlulescere corperiut, aduiniculis adjuventur. Quie servantur ad semina, usque ad liemen in sua vite dependeaut, deinde sublalat iu sole ponazutur, aut fumo : aliter semina putrefacta depereuut. Hoc meuse blitus seritur solo qualicunique, sed culto. Olus hoc ueque runcandum est neque sarculaudum. Cıu scmel natum fuerit, i psum se per multa secula seminis sui dejectione reparabit, ıt, ctian si velis, vix possit aholeti. Nune eliam serpyllum seritu plantis et semine, stul re- ou d'un étang, ou sur le bord d"un puits. On sème aussi très-bien à présent l'anis et le eumin. Ces deux plantes réussissent mieux dans des terrains fertiles, quoiqu'elles viennent également dans d'autres, pourvu qu'on les aide avec de l'eau et du fumier.

$X$. On sèmera la grenade au mois de mars ou d'avril dans les elimats tempérés, et au mois de novembre dans eeux qui seront ehauds et sees. Le grenadier aime un terrain argileux et maigre, quoiqu'il ne réussisse pas moins dans un terraiı gras. Les pays ehauds lui sont favorables. On le sème en boutures détaehées de la racine d'un grand arbre. Il y a plusieurs façous de le semer, mais la meilleure eonsiste à eoueher oblicuement dans une fosse une branehe de eet arbre de la longueur d'un cubitus et de la grosseur d'un manehe d'instrument, qui aura été amincie par les deux bouts avee une serpette bien tranchante, et que l'on aura eu soin d'enduire auparavant de fiente de pore, tant par en haut que par en bas. On peut encore l'enfoncer profondément à l'aide d'un' maillet dans un terrain non labouré. Quand la branehe qu'on mettra en terre aura été prise sur l'arbre dans le temps qu'il était déjà garni de boutons, elle prendra beaucoup mieux. Si on a soin, en la mettant dans la fosse, de eharger sa raeine de trois petites pierres, on pourvoira par là à ee que son fruit ne se fende pas. Il faut prendre garde de ne pas la mettre en terre la tète renversée. On eroit que les fruits de eet arbre deviennent aigres quand on l'arrose trop assidûment, d'autant que la séeheresse les rend doux et les fait multiplier en abondance. Pour empetelıer néanmoins qu'il n'en vienne une trop grande quantité, il faudra opposer un peu d'eau à leur abondanee exeessive. Il faut bêcher le pied de eet arbre tant en automne qu'au printemps. S'il

tustate melioti. Lxtius fiondebit, si juxta piscinam vel la cum vel putei margiues conseratur. Anisum quoque et cyminum muc bene seritur. Locis lationibus melius provenit, item(jue cateris, si humore juvetur et stercore.

X. Locis temperatis uense Martio vel Aprili unala Pı. nica seremus; calidis vero et siccis, Novembi : amat lıec arbor solum cretosum, macileutum, sed in pingui etiau provenit. Regio illi est ap)ta, quaxe calida est. Serilut plantis cle mairum radice devulsis. Sed quamvis multis generibus seratur, melius tameu ramus ejus cubitalis iucisus manubrii crassitudine, et capite utroque acula falee levigatus, serobi velut obliçut immergifur : prius tameu porcino stercore et iu capite ef iu parte, qua ima est, oblinatur, vel iu crudo solo malleo cogatur ad inferiora defigi. Melius provenict, si ponendus ramus gemmante jan matre suinatur. Sed qui in scrobe depouit, si tres lapillos in ipsa radice constituat, providebil, ue poma fiudautır. Curandum ne virgulta iuversa deponas. Crechutur acida fieri, si rigentur assidue : nau siccitas in his el suvitateu prastat et coplaus. Cujus taucu nimietati aliouid deluet Itumotis opproni. Circumfod autumno debet et verto. Si 
donne uaturellement des fruits aigres, on répandra sur sá eime un pell de laser broyé dans du vin; ou bien l'on enfoneera un elou de bois gommeux de pin dans ses raeines, après les avoir déchaussées. D'autres enterrent de l'algue marine auprès de ses raeines, et quelques-uns y ajoutent de la fiente d'âne et de pore. S'il ne garde pas bien sa fleur, on mêlera de vieille urine avec de l'eau par parties égales, pour ell verser trois fois par an sur ses racines. II suffira d'en verser une amphora sur ehaque arbre. On pourra encore employer du mare d'huile sans sel, ou mettre de l'algue auprès deses racines, et l'arroser deux fois par mois; ou bieu il faudra entourer d'un petit eercle de plomb le trone de l'arbre quand il sera en fleur, ou l'envelopper d'une peau de serpent. Si ses fruits se fendent, on mettra une pierre au nilieu de sa raeine, ou on sèmera de la seille dans son voisinage. Lorsque ses fruits auront été tordus sur l'arbre même dans le temps qu'ils y étaient attachés par la queue, ils se conserveront toute l'année sans se gater. S'ils sont attaqués par les vers, on frotte les raciues de l'arbre avee du fiel de bœuf, et ees vers mcurent aussitôt. Il est rare aussi qu'il en revienne quand on lés a ratissés avec un clou de cuivre. De l'urine d'âne mêlée avee de la fiente de pore les empèche égalẹment de s'y mettre. De la eendre répandue fréquemment autour d'un trone de grenadier, a vee de l'eau de lessive, rend cet arbre beau et fertile. Martialis assure que les grains de son fruit seront blanes, pour peu que l'on mette sur ses raeines, pendant trois ans de suite, un mélange composé d'un quart de gypse contre trois quarts d'argile et de craic. Il dit anssi qu'il donnera des crrenades énormément grosses, sil'on enterre, dans son voisinage, une marmite de terre dans laquelle on aura enfermé une de ses bran-

acida nascantur, modicum laseris cum vino tritum per sumna arbnis cacumina oportet infundi, vel ablaqueatis rarlicibus tedae clavus infigi. Alii algam marinam obruunt ad radices, cui noumuli stercus miscent asiniumm atque jarcinun. Si florem non continet, urinam veterem cum pari mensura aqua temperabis, et ter per anumm (in) radicibus iufnudes. Uni arlori amplıora ingesta sufficiet. Vel amurcan miltes iusulsam, v(l algan radicibus junges, et bis rigabis in mense; vel arboris florentis truncum plumbeo circulo debebis includere, vel corin anguis involvere. Si crepant poma, lapidem in media arboris radice supponis, vel squillam circa arhorem seris. Li si, dum pendent poma, teuacilons, sicnt in arhore labentur, intorseris, in lotum annum sine corruptione servabis. Si vermibus laborant, langis radices felle bubulo, et continno moriuntur : ant clavo aneo si rermes cosdem purges, diflicile mascentur : vel asini un ina stercori admista porcino verunibus obviabit. Cinis cum lixirin circa Punici truncum frequenter infusus, laeta et frnctuosa redlit arbusta. Asserit Martialis caudida in his grana fieri, si argilla et cretx quartam partem gy jsi misceas, et tuto tricmuio loc ehes a vec sa fleur. En effet, lorsqu'on aura attaché eette branche à un pieu pour l'empêcher de se rapproelier de l'arbre, et que l'on aura couvert la marmite pour la préserver de l'eau qui pourrait y entrer, les fruits que l'on y trouvera en automie seront de la grandeur de la marmite même. Il prétend eneore qu'un grenadier donnera beaucoup de fruits, Iorsqu'on aura enduit son trone de jus de tithymale et de pourpier mêlés ensemble par parties ćgales, a vant que les boutons paraissent. II assure qu'on peut le greffer en joignant des branehes de deux ar. bres voisins les unes avee les autres, de façon que les branches tant d'un arbre que de l'autre étant fendues, elles se réunissent du côté de la moelle. On ne peut le greffer que sur lui-même à la fin du mois de mars, vers les calendes d'avril. Mais aussitôt qu'on aura coupé son trone pour eette opération, il faudra y insérer un rejeton très-récent, de peur que si on tardait à le faire, le peu d'humidité que ce rejeton eontiendrait ne s'évaporát. On eonserve les grenades en les mettant par rangées suspendues par la queue, que l'on aura préalablement enduite de poix. Autre manière : Quand on les a cueillies saines, on les plonge cans de l'eau de mer ou dans di: la saumure bouillante, afin qu'elles s'en imbibent. Trois jours après on les fait sécher au soleil, sans les lạisser en plein air pendant la nuit, après quoi on les suspend dans un lieu frais; et lorsqu'on veut en faire usage par la suite, on les fait tremper la veille dans de l'eau douce. On prétend qu'elles ne le cèdent pas alors en bonté aux grenades fraiehes. Il en est de même lorsqu'elles ont été ensevelies dans de la paille, séparées les unes des autres, de façon à ne pouvoir se toueher. On fait encore un long fossé ; et après avoir préparé une ćeorce de la grandeur de ce fossé, on

genus terra radicihus cjus adjungas. Idem dicit miræ magnitıdinis poma fieri, si olla fictilis obruatur circa arborem Punici, et in ea ramus cun flore claudatur, ne resiliat ligatus ad palum : tunc conperta olla contra aqua muniatur incursus. Antumno patefacta suæ magnitudius poma redlibelit. Multa in Punico ipse asserit poma procedere, si titlymali et portulacæe succus aqualiter mixtus ante quam germinet, trunco arboris adlinatur. Inseri posse aftirmat de ramorum connexione, it medulla utrinque divisa se jungat. In se tautum inseri polest circa Apriles calend. mense Martio ultimo. Sed secto trunco surculus recentissimus statim debet inseri, ne mora exignum, qni inest, siccet hımnrem. Punica mala servantur, si picatis pediculis ordinata suspendas. Aliter : Lecta integra in aqua marina vel muria fervente mergantur, ut combibant. Post tridumm sole siccentur, ut sub dio nocte non maneant: post in loco frigido suspendantur. Cum volueris uti, aq̨ua dulci pridie macerabis. Feruntur lıæe ponis recentibus anulari : item, si a tactu invicem separata paleis olsuantur. Item fossa fit longa, et cortex ejusdem unagnitulius paratur, cui mala acutis surculis suis affiguntur. Tunc 
fiehe les grenades sur cette écoree par la pointe du rejeton auquel clles sont attachées; après quoi on renverse l'écoree sur le fossé, afin qu'elle garantisse de l'humidité les grenades, qui se trouvent dés lors suspendues sous la terre sans la toueher. On les eonserve eneore en les couvrant d'argile, ct cn les suspendant dans un lieu frais quand cette argile est séchéc; ou en les cnfoncant dans un petit vaisseau de terre rempli de sable jusqu'à moitié, qu'on laissera en plein air, après avoir fiché la queue de chaque grenade dans un roseau ou dans des bagueltes de sureau, et les avoir ainsi enfoncées dans le sable, sćparées les unes des autres, de façon qu'elles soient élevées de quatre doigts au-dessus du sable. On peut aussi mettre ce vaisseau dans une fosse de deux pieds de profondeur faite à la maison. Pour les garder dans l'un et l'autre cas, il sera mieux de les cueillir avec une longue branche. Autre manière de les conserver : On les suspend dans un petit vaisseau de terre rempli d'eau jusqu'à moitić, de façon qu'elles ne rouchent pas l'eau ; et l'on ferme ce vaisseau, de peur que l'air ne s'y introduise. On les arrange encore dans une futaille pleine d'orge, de façon qu'elles ne se touchent pas, et l'on couvrc la futaille. Manière de faire du vin de grenade : on met des grains mûrs nettoyés avec soin dans un cabas de palmier, pour les pressurer dans un pressoir à vis; après quoi on fait cuire à petit feu le jus qu'ils ont rendu, jusqu'à ec qu'il soit réduit à moitié; et quand il est refroidi, on le renferme dans de petits vaisseaux enduits de poix en dedans et de gypse par dehors. Il y' a des personnes qui, au lieu de lc faire cuire, mettent une livre de miel sur un sextarius de jus, avant de le renfermer dans les vaisseaux que nous venons de dire, pour le garder. On sème le citronnier au mois de mars, de quatre façons; savoir, en pepins, en branches,

inversus cortex supra fossam ponitur, ut mala sine terræ tactu sulterpendentia ab humore defendat. Item si in. duantur argilla, et ea siccala loco frigido pendeant. Item si seriola sub dio obruatur, qua liabeat arenas usque ad medium, et mala cum tenacibus leeta imprimantur eannis singnlis, vel samluei virgulis, et ita separata in arenis figantur, ut ipsa quatuor digitis emineant ab aresa. Hoe et sub teeto in serobe bipedanea fieri potest, et utilins est ad servandum, si enm ramo longiơre tollantur. Aliter: In seriola cui ad medium aqua mittatur, suspenduniur mala, ne lumorem tangant, et seria elauditur, ne ventus irrumpat. Item in dolio intra ordeun sie ordinantur, ne se invicem tangant : et dolium desuper operitur. Vinum de malis granatis conficies hoe modo: Grana matura purgata diligenter in palmea fiscella mittis, el in coelılea exprimis, et lente coques usque ad melietatem : eum refrixerit, picatis et gypsatis vasculis claudes. Aliqui suceum non exeoquunt, sed singulis sextariis libras mellis singulas miscent, et in priedietis vasculis ponunt et eustodiunt. Mense Martio citri arbor quatuor modis seritur, semine, ramo, talea, en boutures et en billes. Cet arbre aime à se trouver dans une terre peu compacte, sous un climat humide, et à ne jamais manquer d'eau. Si on veut le semer en pepins, voiei comme il faudra s'y prendre : On bêchera la terre à deux pieds de profondeur, et après y avoir mélé de la cendre on formera de petites planches séparécs par des rigoles, à travers lesquelles l'eau s'écoulera de part et d'antre. Ensuite on creusera a vec les mains sur ces planches une fosse d'un palmus, dans laquelle on mettra trois pepins joints ensemble, la pointe renversée; puis on les recouvrira de terre, et on les arrosera tous les jours. IIs seront moins lents à venir si on les arrose avec de l'eau tiède, qui leur fera beaueoup de bien. Dès qu'ils seront une fois levés, on ne eessera pas d'arracher l'herbe autour d'eux. On peut les transplanter quand ils auront trois ans. Si on veut mettre en terre une branche de citronnier; il ne faudra pas l'y enfoneer à plus d'un pied et demi de profondeur, de peur qu'elle n'y pourrisse. Mais il est plus à propos d'en planter uric bille de la grosseur d'un manche d'instrument et de la longueur d'un cubitus, que l'on amineira par les deux bouts, et dont on otera les nœuds et les piquants, en laissant néanmoins sur le dos de la bille les boutons qui promettent un germe futur. Les personnes qui portent l'attention plus loin enduisent de fiente de bouf le dos de la bille dans tout son contour, ou en couvrent les deux bouts d'algue marine ou d'argile pétrie, avant de la déposer dans un terrain façonné au past:num. La bouture peut être moins grosse et plus courte que la bille, mais on l'enterre de la mêmo manière ; avec eette différence qu'elle doit sortir de terre å la hauteur de deux palmes, au lieu que l'on enterre la bille entièrc. Il n'est pas nćcessaire de laisser de grands intervalles entre les citronniers. Il ne faut pas les associer avec d'au-

clava. Amat terram rarioris natura, colum calidum humoremque continunn. Si granis velis serere, ita facies : Terram in duos pedes fodies, cinerem miscebis, breves areas facies, ut utrinque per canales aqua diseurrat. In his areis palmarem scrobem manibus aperies, et tria grana deorsum verso acumine juncta constitues, et obruta quotidie rigabis. Citins procedent, si beneficio aqua te. pentis ${ }^{\circ}$ taris. Natis germinibus semper proxima lerba runcefur. Potest linc trima planta transferri. Si ranumn velis ponere, non amplins sesquipede dehebis inmergere, ne putreseat. Clava seri commodius potest, qua sit manubrii erassitudine, longitudine enbitali, ex utraque parte levigata, nodis et aenleis reeisis, sed iniegra summitate gemmarum, per quas spes futuri germinis intumescat. Diligentiores et fimo bubulo adlinunt utrinque, quod summum est, vel marina alga vestiunt, vel argilla subacta partis utriusque extrema cooperiunt, atque ita in pastinato soló deponunt. Talea et gracilior et brevior esse potest; qua similiter ut clava mergetur. Sed talea palunis duobus supersit : clava ornuis obruitur. In spratio non desiderat 
tres arbres. Ils se plaisent dans les lieux cliauds, pourvu qu'ils soient arrosés, et prineipalement yuand ils sont voisins de la mer et que l'eau n'y manque pas. Si l'on veut eependant foreer eet arbre à venir dans une eontrée froide, il faudra le placer dans un lieu muni de murailles ou exposé au midi; eneore le couvrira-t-on pendant l'hiver de grosse paille, de façon qu'il soit entièrement eaché; et, dès que l'été sera venu, on le découvrira sans risque, pour le remettre à l'air. On en plante les boutures ou les billes, dans les elimats très-ehauds, en automne. J'en ai planté dans des elimats très-froids aux mois de juillet et d'août; et en les animant par des arrosements répétés tous les jours, je suis parvenu à les voir eroitre très-bien, et rapporter du fruit. On eroit que le eitronnier vient mieux quand on sìme des eourges auprès de lui, et que la cendre de leurs fannes est bonne pour ect arbre. Il aịme à être bêelié assidûment, et eette eulture lui fait donner de plus gros fruits. On ne le taille que très-rarement, et on n'en retranehe alors que les branches desséchées. On legreffe au moisd'avril dans les pays claauds, et au mois de mai dans les pays froids. On nele greffe pas sous l'écoree, mais on en fend le trone dans le voisinage de ses raeines. On le greffe sur le poirier, suivant la pratique de quelques personnes, et sur le mûrier; mais il ne faut pas manquer d'en eouvrir les greffes d'un panier ou d'un petit vaisseau de terre euite. Martialis assure que eet arbre n'est jamais sans f'uit ehez les Assyriens; et j'ai remarqué la même ehose dans des terres que je possède au territoire de Naples et en Sardaigue, où le sol et le elimat sont ehauds, ct où l'eau abonde. En effet, les fruits de cet arbre se suecedent toujours les uns aux autres comme par degrés; de sorte que les fruits mûrs sont remplaeés par des fruits verts, et que le

intervalla majora. Aliis arboribus non debet annecti. Calidis locis, sed irrignis et maritimis maxime gaudet, quibus lnmor exundat. Sed si quis lıoc genus, ut in regione fıgida nutriatur, extorquet, loco vel parietibus munito vel in meridianam partem verso disponat laanc arborem. Sed libernis mensibus tectam, stramine velet agresti : ubi acstas refulserit, aeri arbor nuda et secura reddatır. Talea sive clava ejus calidissimis regionibus et per autum. ıutII ponitur : frigidissimis Julio et Augusto positas et quo. tidianis rigationibns animatas ipse usque ad poma et magna incrementa perduxi. Citreum juvari crelitur, si cucurbita vicinis locis serantur : quarum vites etiam combusta utilem citri arboribus cinerem prabent. Gaudent assilua fossione. Hinc proveniunt pona majora. Nisi quae arida sunt, rarissime debemus abscindere. Inseritur mense Aprili locis calidis, Maïo frigidis, non sub cortice, sed fisso trunco circa ipsas radices. Inseritur et piro, ut quiclam voluıt, et moro, sed insiti surculi qualo desuper omıiıo unuiendi sunt, vel fictili vasculo. Asserit Martialis apud AsEfrios fomis lıanc arborem non carere : quod ego iu Sardinia et in territurio Neapolitano in fundis meis comperi ('puibus temps de eeux-el étant passé, il leur en sueeede d'autres qui sont en fleur, la nature ayant, pour ainsi dire, avantagé eet arbre d'une suecession continue de féeondité. On prétend que la pulpe de ees fruits, d'aigre qu'elle est, devient douee lorsque l'on a fait tremper pendant trois jours dans de l'liydromel, ou eneore mieux dans du lait de brebis, les pepins que l'on devait mettre en terre. Il y a des personnes qui pereent au mois de février le trone de eet arbre avee une tarière de bas en haut, de faecon que ee trou soit oblique, et n’ait pas d'orifice supérieur; et elles assurent qu'en laissant eouler la séve par ee trou jusqu'à ee que les fruits soient formés, et en le bouchant ensuite avee un lut, la pulpe de ces fruits devient douee. On peut eonscrver les eitrons sur l'arbre même qui les porte, presque pendant toute l'année. II sera cependant mieux de les renfermer dans de petits vases queleonques. Si on veut les eueillir pour les eonserver, il faudra le faire de nuit, et quand la lune sera cachée, sans les séparer des petites branches d'où ils pendront, auxquelles on laissera leurs feuilles; après quoi on les arrangera ehacun à part. Les unsles renferment ehaeun dans un vase partieulier, oı les eouvrent de gypse, et les gardent après les avoir arrangés ainsi dans un lieu ombragé. La plupart les eonservent en les ensevelissant dans de la seiure de eèdre, ou dans de la litière menue, ou dans de la paille. Les néfliers se plaisent partieulierement dans les pays chauds, pourvu qu'ils soient arrosés; quoiqu'ils viennent également dans les pays froids, surtout s'ils sont plantés dans un sable gras, dans une terre pleine de gravier et mêlće de sable, ou dans de l'argile mêlée de eailloux. Il faut les planter en boutures au mois de mars ou de novembre, dans un terrain qui soit fumé et labouré, et de faẹon que

solum et cxlum tepidum est, et humor exundans) per gradus quosdam sibi senıer proma succedere, cum matıris se acerba substituant, acerborum veru atatem florentia consequantır, orbem quendan continuae furcundifatis sili ministrante natura. Ferıntur acres medullas mutare dulcibus, si per triduum aqua mulsa semina ponenda macerentur, vel ovillo lacte, quod prastat. Aliqui mense Februario truncum obliquo foranine ah imo terebrant, ita ut altera parte non exeat : ex lıoc liumorem fluere permittunt, dostec poina formentur : tunc foramen luto repleut : sic, quod est medium, fieri dulce confirmant. Citreum et in arbore potest per totum annum propemodum custodiri : melius si vasculis quiluscunque claudatur. Si velis legere atque servare, nocte luna latente debebis cum ramis foliatis carpere, et secreta disponere. Alii singula vasis singulis claudunt, vel gypso adlinunt, et opaco loco ordinata custodiunt. Plerique in cedri scobe vel in strani. nilbus minutis vel in paleis lecta servant. Mespili locis calidis maxime gaudent, sed irriguis; tamen frigidis quoque proreniunt : magis sabulone pingui, atque glareosa terra, cui areua permista est vel argilla cum saxis. Sereuda est' 
les deux extrémités de la bouture soient recouvertes de fumier. Les aceroissements de cet arbre sont très-tardifs. Il aime à être taillé ct bêché autour de sun pied, ainsi çu'à être ranimé souvent avee un peu d'eau pendant les sécheresses. On en sème aussi les osselets, mais alors il faut culattendre longtemps la venue. Les vers attaquent cet arbre : il faut l'en débar'asser avec un stylet de cuivic, et les asperger de lie d huile, ou de vieille urine d'homme, ou de chaux vive, mais cependant arec ménagement, de peur de porter préjudice à l'arbre lui-même; ou enfin verser sur cux de l'eau dans laquelle on au'a fait bouillir des lupins. Si l'on craint que ess remèdes n'aient rendu l'arbre stérile, on lui rendra sa fertilité en répandant sur ses racines du fumier et de la cendre de vigne. Si les fourmis le molestent, on les fera périr avec de la terre rouge, mêléc de vinaigre et de cendre. Si ses fruits tombent, on fichera au milieu deson tronc un morecau de sa racine; que l'on coupera à cet effet. On le greffe au mois de févriel', sur lui-même, stir le poirier et sur le pommier. Il faut cependant prendre la greffe que l'on emprunte de cet arbre au milieu de son trone, parce qu'elle ne vaudrait rien si elle était prise sur ses extrémités. Il faut le greffer en fente dans le trone même, parce que la maigreur de son écorce, qui n'a aucune séve, ne pourrait pas fournir à la nourriture de la greffe. Quand on veut garder des nèfles, on les cueille avant qu'elles soient mûres, quoiqu'elles ne laisseront pas de se conscrver assez longtempe sur l'arbre même; et on les renferme dans de petites cruches enduites de poix; ou on les suspend par rangées, ou enfin on les fait confire, suivant la méthode de quelques personnes, dans de l'oxycrat ou dans du vin cuit, jusqu'à diminution des deux tiers. Il faut les cueillir au milieu d'un jour serein, et les enfouir dans de la paille, en les séparant les

taleis mense Martio rel Yovembri, sed solo stercorato et subacto, ita ut utrumque caput talex stercus obducat. Sunt ejus incrementa tardissima. Amat putari atçue circumfodi, et parco lumore inter siccitates sxpe refoveri. Seritur et semine, sel in longiorem speratur xtatem. Si vermilmus occupatur, stilo areo purgandi sunt, et amurca vel lumaua vetere urina vel viva calce perfuniendi, sed parcius propter arboris noxam, vel aģua decocti lupini. Sed putatur line arhor sterilis fieri. Finus et cinis vitium simul si radicibus infundantur, fertilem reddunt. Si forunica molesta sunt, rubrica cum aceto et cinere temperata necabuntur. Si poma labuntur, frustun de cjus radice pracisum in media trunci parte figatur. Juserilur mense Februario in se et in piro et in malo. Surculus tanen cjus ex arbore media debet assumi : nam de sımmitatibus vitiosus est. In trunco fisso iuferenda est : nam corticis macies jejuna nil nutriet. Mespila ad serrandum leguntur necdum mitia, qux et in arbore diu durabunt, rel in urceolis picatis, rel in ordinem suspensa, vel, ut quidam, posea [vel sapa] coudita. Die serena legantur ac nedia, unes des autres, de peur qu'elles ne se gatent en se touchant; ou bicn on les cueillera à demi múres avec leurs queues, et, après les avoir fait tremper pendant cinq jours daus de l'eau salée, on continuera de les en arroser souvent, afin qu'elles nagent toujours dans cette eau. On les conserve aussi dans du miel, pourvu qu'on les ait cueillies avant qu'elles fussent mûres. Le figuier se reproduit de plant pourvu de racines qu'on met en terre au mois de novembre, dans les pays chauds; en février, dans les pays tempérés; cn mars, ou mieux encore en avril, dans les pays froids. Si c'est une bouture ou une cime de figuier que l'on veut mettre en terre, il faut l'y mettre à la fin d'avril, lorsqu'clle est abreuvée par la nouvelle sévc. Lorsqu'on met du plant enraciné dans une fosse, il faut remplir de pierres le fond de cette fosse, et mêler du fumier avec la terre dont on recouvrira ses racines. Si le pays est froid, ou en mettra la cime à l'abri du froid, en la convrant de morceaux de roseaux qui seront coupés à cet cffet entrc deux mouds. Si l'on veut mettre en terre une cime de figuier, il faudra couper sur le côté de l'arbre exposé au midi une branche de deux ou trois ans, garnie de trois cornes, et la couvrir de terre de façon que ces cornes se trouvant partagées par la terre qui sera entassée entre elles, elles semblent autant de rejetons distinets. Si c'est une bouture que l'on veut mettre en terre, on s'y prendra de la même manière que pour les autres plantes, si ce n'est qu'on ell fendra légèrement l'extrémité inférieure, pour y insérer une pierıe. J'ai mis en Italie dans un terrain façonnć au pastinum, à la fin du mois de février ou de mars, des pieds de figuiers déjà forts, qui ont rapporté du fruit dans l'année même, comme pour payer leur bienvenue. Il faut choisir du plant de figuier qui soit chargé de beaucoup de

et paleis obruantur discreta, ne ea vicissim tactus afficiat. Vel cum pediculis lecta semimatura, et salsa aqua per dies quinque macerata postea sape infundantur, ut innatent. Servantur et molle, sed si minus matura collegeris. Calidis locis fici planta radicata Novernbıi mense, temperatis Februario, frigid is melius Martio vel Aprili ponenda est : si taleam vel cacumen ponas, ultimo Aprili, cum ei so viridior succus infuderit. Planta in scrobe deposita lapides substituendi suut ad radicen; fimo terra miscenda est. Si loca frigida sunt, plantarum cacumina divisis canna internodiis defendantur a frigore. Si cacumen velis ponere, trisulcum ranum bimunı vel trimesm ab australi parte decides, et sic obrues, ut divisa cacumina terra interjacente velut tres surculos reddant. Taleam sic ponomus, ut catera, cui leviter ab infima parte divisa lapidem mergemus in fisso. Ego mense Februario ultimo vel Martio in Jtalia plantas graudes ficorum per pastinatum solum? disposui, et en auno poma peperere supra couprehentindi felicitatem velut tributa reddentes. Legendac sunt plautas, in quibus frequeus nodus exuberat : sterilcs creduntur, 
nœuds. On regarde comme stérile celul qui est lisse, et dont les yeux sont séparés les uns des autres par de longs entre-nœuds. Si l'on eommenee par élever le plant de figuier dans une pépinlère, et qu'on ne le transfère dans une fosse que lorsqu'il sera avaneé, il produira de meilleurs fruits. Il y a des personnes qui assurent qu'il est fort utile d'insérer le plant de figuier dans une bulbe de seille coupée en deux, et de l'y garrotter avec des ligatures. Cet arbre demande des fosses profondes, des espacements eonsidérables, et une nature de terre dure, maigre et sèche, afin que ses fruits aequièrent un bon goût. Il vient aussi dans des terrains pierreux et raboteux, et mêne il n'y a presque point d'endroits où l'on ne puisse le planter. Comme les figues qui viennent dans les pays montagneux et froids ont moins de lait que d'autres, elles ne peuvent pas se eonserver longtemps sèches; aussi les consomme-t-on quand elles sont vertes, temps où elles sont plus grosst-s et d'un goût plus fin, au lieu que celles qui viennent dans des eampagnes et dans des pays chauds sont plus grasses, et se eonservent très-longtemps sèehes. Si l'on voulait compter toutes les espèces de figues, le nombre en serait immense. II nous suffira done de dire que la cuiture est la même pour toutes les espèces, mais que eependant quand on veut les faire séeher, ee sont les bianehes qu'il faut choisir de préférence, paree qu'elles se conservent mieux que les autres. Plantons dans les pays froids des figues préeoces, afin qu'en venant de bonne heure elles puissent prévenir la saison des pluies; plantons au eontraire dans les pays chauds et brûlants des figues tardives. Le figuier aime à être bêché assidûment. Il sera bon de le fumer en automne, et surtout avee du fumier de volière. Il faut en retraneher les branehes pourries, ou celles qui seront mal venues, et le talller de telle façon qu'étant ra. valé, il puissẻ s’étendre sur les eôtés. La figue a un goût émoussé dans les terrains humides. II faut, pour obvier à eet ineonvenlent, répandre un peu de eendre sur les racines de l'arbre, après les avoir rognées. Il y a des personnes qui plan. tent un figuier sauvage dans leurs figueries, pour se dispenser de la néeessité d'en suspendre les fruits à chaque figuier, par manière de préservatif. C'est au mois de juln vers le solstice que l'on fait la eaprification, c'est-à-dire que l'on suspend aux figuiers des figues sauvages vertes, enfilées en forme de gulrlandes. Si l'on n'a pas de figues sauvages, on y suspendra une branche d'aurone, ou bien on enterrera autour des racines du figuier de ees vessies qui se trouvent sur les feuilles des ormes, ou des cornes de bélier; ou enfin on scarifiera le trone du figuier dans l'endroit où il sera gonflé, afin que l'humeur puisse s'en écouler. Pour empêeher les vers de se mettre à un figuier, on mettra en terre, a vee le plant de cet arbre, une branche de térébinthe ou une bouture de lentisque, la eime renversée. On ratissera ecux qui s'y seront établis avec des erochets de cuivre. D'autres versent sur ses racines, après les avolr déehaussées, du mare d'huile. D’au. tres y répandent de vieille urine. D'autres enfin enduisent les retraites de ces animaux de bitume et d'huile, ou simplement de chaux vive. S'il est molesté par les fourmis, il faut enduire son trone d'un mélange de terre rouge, de beurre et de poix liquide. D'autres assurent que, pour le préserver des fourmis, il faut suspendre à ses bran. ehes un de ees poissons connus sous le nom de coracini. Lorsqu'un figuier laisse tomber ses fruits, eomme s'il était attaqué de quelque maladie, les uns le frottent de terre rouge ou de mare d'huile sans sel, mêlé avec de l'eau; les au-

tanda est, ut inclinata per latera possit expandi. In locis lumectis ficus saporis obtusi est, cui circumcisis contra loc radicibus aliquantus cius debet affundi. Alipui inter ficarias caprifici arborem serunt, ut non sit necesse per singulas arbores pro remedio eadem poina suspendi. Mense Junio circa solstitium caprificandx sunt arbores fici, id est, suspendendi grossi ex caprifico lino velut serta pertusi. Si hoc desit, abrotoni virga suspenditur, aut callum, quod in ulmeis foliis invenitur, aut arietina cornua circa radices arboris obruuntur; rel truncus arboris, quo loco turget, scarificandus est, ut possit lummor efluere. Ne vermes patiatur, ramum terebinthi vel lentisci taleam cum plantis fici cacumine ponemus inverso. Uncinis æreis tollendi sunt vermes ex fico. Alli amurcam alii veteren urinam ablaqueatis radicibus miscent. Alii bitumen et olemm aut solaun calcem vivaın latebris vermium allinunt. Si formic molesta sunt, rubrica butyro et pice liquida mista circa truncuın debet induci. Alii coracinmm piscem contra formicas in arbore suspentior dum esse confirnaut. Si fructus suos velut agra prifket, alii rubrica aut amurca iusulsa mista aqua artresem linunt; vel cancruı 
tr es suspendent à ses branches, soit unc écrevisse avec une branche de rue, soit de l'alguc marine, soit une botte de lupins : d'autres cnfin fichent un coin dans sa racinc, après l'avoir percée avec une tarière, ou font plusieurs incisions à son écorce avec une hache. Si l'on veut que les'figuiers donnent du fruit cn abondance, et que ce fruit soit gras, lorsqu'ils commenceront à proJuire des feuilles, on abattra, dès que les nouveaux germes paraîtront, l'extréınité de leurs cimes, ou simplement la cime du milieu. Si l'on veut qu'un figuier qui n'est pas tardif le devienne, on arrachera les figues qui y seront venues les premières, quand elles seront de la grosseur d'une fève. Pour faire mûrir promptement les figues, on les frottera, dans le temps qu'elles seront vertes et qu'elles commenceront un peu à rougir, avec du jus d'oignon long, mêlé d'huile et de poivre. Il faut greffer les figuiers au mois d'avril cntrc leur écorce, ou cn fente si ce sont de jeunes arbres, en prenant néanmoins. la précaution de couvrir sur-le-champ la greffe et de la lier, de peur que l'air n'y pénc̀tre. Les greffes prendront mieux sur ces jeunes arbres, lorsque avant de les grefle'r on les aura coupés près de terre. Il y a des personnes qui les greffent aussi au mois de juin. II faut choisir pour l'employer en greffe un rejeton d'un an: plus ou moins vieux, il serait regardé comme inutile. On pourra enter les figuiers en écusson au mois d'avril dans les terrains sces; mais il sera mieux de les enter de cette facon au mois de juin daus les terrains humides, et au mois d'octobre dans les pays chauds. On peut aussi propager le figuier avec ses branches. Au surplus, on le greffe sur le figuier sauvage, sur le mûrier et sur le platane, tant en employant des yeux qu'en employant des rejetons. On peut conserver des figues vertes, soit en les arrangeant dans du miel de façon qu'elles

lluvialem cum ramo ruto suspendunt; Vel algam marinam, vel fascem lupinorum; vel radici terebrata cuneum figunt, vel securi arboris corium sæe proscindunt. Cum fulia prorlucere incipiunt fici, ut fructum nultum et pinguem feraut, in principio germinis cacumina summa decutimus, vel illud tantum cacumen, quod ex arboris medietate procedit. Si maturam ficun vis serotinam facere, inci. pientes grossos decute, cum illis faba fuerit magnitudo. Ut ficus cito maturet, succo cepæe longioris cum oleo et pipere mixto unge poma, quando grossi incipiunt subru. liere. A prili mense ficum debenus inserere inter corticem : vel si novella arbores sunt, fisso ligno, quod statim ope. rieıdum est et ligandum, ne ventus introeat. Melius com. prehendunt, si circa terram recisa inserantur arbusta. Aliqui et Junio mense inserunt. Surculus legendus est anniculus : inutilis cnim creditur majoris rel minoris atalis. Inocralari ficıs locis siccis Aprili, lumidis melius Junio mediante poterit, Octobri mense locis tepidis. P'ropagati ficus ramis potest. Inserifur antem in caprificn, in moro, in platano, el oculis et surculis. Ficus virides servari pos- ne se touchent pas, soit en les renfermant chacune séparément dans une courge verte que l'on aura creusće à cet effet, et que l'on refermera ensuite avec le morceau même que l'on aura coupé pour la creuser; après quoi on-suspendra cette courge dans un endroit où il ne pénètre ni feu ni fumée. D'autres cueillent avec leurs queues des figues nouvelles avant qu'clles soient mûres, et les renferment dans un vase de terre neuf, en les séparant les unes des autres; après quoi ils suspendent ce vase dans une futaille pleine de vin, et l'y laissent nager. Martialis prétend que l'on peut faire sécher les figues de plusieurs facons, pour les conserver; mais comme une seule suffit, on préférera celle-ci, qui est usitée par toute la Campanie : On les étendra donc sur des claies jusqu'à midi, et, tandis qu'elles seront encore molles, on les mettra dansun panier; après quoi, lorsque le four aura le degrć de chaleur qu'on lui donne pour faire cuire le pain, on y renfermera ce panier posé sur trois pierres, afin que le feu n'y prenne pas, et on le fermera. Lorsque les figues seront cuites, on les renfermera toutes chaudes dans un vase de terre bien enduit de poix, en les comprimant fortement, et en les entremêlant de feuilles de figuier; puis on bouchera exactement le vase avec un couvercle. S'il pleut trop souvent pour que les claies soient exposées à l'air, on les étendra à la maison en les élevant au-dessus du sol d'un demi-pied, afin qu'elles puissent êtrc échauffées arec de la cendre chaude qu'on mettra dessous, et qui fera le mème effet que le soleil. Mais on aura l'attention de les retourner de temps en temps, pour Ies mettre alternativement sur leurs deux côtés, dont la séparation cst marquée par la nature, afin que leur peau se sèche, et que, lorsqu'on aura ensuite rapproché leur pulpe, elles puissent so conserver dans de petites boittes ou dans des cais-

sunt vel in melle ordinatx, ne se invicem tangant, rel singulie intra viridem cucurbitam clausæ, locis unicuique caratis, et item tessera, qua secatur, inclusis, suspensa ea cucurbita, ubi non sit fumus vel ignis. Alii missas ficus recentes minus maturas in novo vase fictili lectas cum pediculis et a se separatas recludunt, et in dolio vini pleno vas natare permittunt. Martialis dicit Caricas per genera multa servari, cum ratio una sufficiat. Ergo hoc genere, quo Campania tota custodit, servare debemus. In cratibus ficus expanditur usque ad meridiem, et adlıuc mollis in qualum refunditur. Tunc calefacto furno ad panis coquendi modum, suppositis tribus lapidibus, ne ardeat qualus includitur, et clauso furno ubi discocta ficus fuerit, sicut est calida , interpositis foliis suis in vaś fictile conditur bene picatum, densius pressa, et operculodiligenter obducitur. Si plıviis abur.danlibus crates non possis expandere, sub lecto eas ita ponis, ut scmipede erigantur a terra, et eas ad vicenc solis, cinis calidus subjectus vaporet, et subinde ficns, sicut est divisa, vertatur, ut ficorum coria sicceutur et pulpare tunc duplicata in cistellis serrentır aut luculis. 
ses distribuées en cases. D'autres étendent sur des elaies des figues médiocrement mûres, après les avoir partagées en deux pour les faire séeher pendant une journée entière, en prenant le soin de les rentrer la nuit à la maison. On met utilement en terre dans ec temps-ci des eimes de figuiers, lorsque ees arbres commencent à germer, pour se procurer du plant de figuier, au cas que l'on en manque. Quand on veut qu'un seul et mème figuier donne des fruits de différentes espèces, on lie ensemble en les tordant les branehes de deux figuiers, l'un rouge, l'autre blane, afin de contraindre leurs germes à se réunir ; après quoi on les met en terre arrangées ainsi : on les fume et on leur donne de l'eau pour favoriser leur développement; et, dès qu'elles commencent à pousser, on eolle entre eux, avee quelque matière visqueuse, les yeux qui paraissent les premiers. Ces germes ainsi eollés montrent par la suite deux couleurs divisées dans un seul fruit, et réunies par la séparation que la nature a marquée sur ee fruit. On peut aussi greffer et planter à présent les poiricr's ou les pommiers, ainsi que les eognassiers. On greffe eneore le prunier. On met aussi en terre les eormes et les mûres le neuvième jour des ealendes d'avril, et l'on gréffe les pistaehiers. On sème aussi la graine de pin dans les pays froids.

XI. Il faut se pourvoir d'attelages dans le mois où nous sommes : soit que l'on tire les brufs de ses propres troupeaux, soit qu'on les achète au dehors, ce moment est de tous le plus favorable. Les boufs, en effet, n'ont pas eneore pris l'enbonpoint de la saison qui aide à dérruiser leurs défauts et les fraudes du vendeur; ils ne sentent pas encore leur force, et en sont moins enelins à résister au joug. Voici ecpendant les qualités yu'il y aura à rechercher dans ees animaux, soit

Alii maturas mediocriter ficus et divisas in cratibus expan dunt toto sole siccandas, et recipiunt eas nocte sub tecta. Nunc ficulnea cacumina obruuntur utiliter, cum tumcscunt, ut plantas faciant, si carum copia non abundat. Ut etian varios fructus una ficus exhibeat, ramos duos uigra et albx arborum inter se ita vinculo stringis ac torques, ut germina miscere cogantur. Sic obruti et ster. corati et humoribus juti, ubi prodire coperint, germiuantes oculos aliqua sibi arnexione conglutina. 'Tune germen adıuatum parturiet duos colores, quos unitate dividat, divisione coujungat. Nunc ct pirns vel malus inseri ac seri potest, et cydonia et prunus inseritur, el sorba ponuntur et morus, liono calendas Apriles dic, et inseruntur pistacia, $\mathrm{et} \mathrm{locis} \mathrm{frigidis} \mathrm{pini} \mathrm{semen} \mathrm{aspergitur.}$

XI. Hoc inensc con parandi sunt boves, qui, tamen, sive de nostris capiautur armentis, sive enantur, ideirco unnc comparabuntur ulilins, quia necdun sagina tempois pleni aut celare possunt fallaciam venditoris et vitia sua, ant repuguando donituræ contumacen pleni roloris exercere fiducian. Hac tamen signa spectanda sunt in bobus, seu de nostro seu de alicno grese fucrint comparandi qu'on les choisisse dans ses propres troupeaux, soit qu'on les tire d'ailleurs : Il faudra qu'ils soient jeunes, qu'ils aient les membres earrés et gros, le eorps plein, lcs muscles et les nerfs saillants par tout le corps, les oreilles grandes, le front large et crépu, les babines et les yeux noirs, les eornes fortes et arquées, sans eependant que la courbure en-soit exagérée; les narines ouvertes et eamuses, le chignon plein de muscles et épais, le fanon large et tombant jusqu'aux environs du genou, la poitrine ample, les épaules vastes, le ventre assez grand, les flancs allongés, les reins larges, le dos droit et plat, les jambes solides, nerveuses et courtes, les ongles grands, la queve longue et bien garnic de poils, le poil dru et eourt par tout le corps, et dont la couleur soit surtout rousse ou brune. Au reste, il vaut mieux acheter des bœufs dans son voisinage, parce qu'alors le ehangement de sol et de climat ne les incommodera point; et s'il ne s'en trouve pas dans le voisinagre, on en fera venir de contrées dont les earactères physiques soient analogues. II faut surtout avoir soin qu'ils soient bien appariés du côté de la for'ee nécessaire pour tirer, de peur que la vigueur du plus fort n'entraine la ruine du plus faible. Quant à leurs dispositions, voici ce qu'il y aura à examiner : il faudra qu'ils soient fius et doux, qu'ils aient peur de la voix et de la main, et soient de bon appeiti?. II n'y a point de nourriture qui leur soit meilleure que le fourrage vert, quand la nature du pays permettra de leur en donner; mais lorsqu'on en manquera, on ne lemr en donnera qu'autant que l'abondance de ee genre de pâture le permettra, ou que le sureroît du travail l'exigrera. On se pourvoira aussi à présent de taureaux, quand on aura ì cour de faire multiplier les troupeaux; ou bien on laissera croftre

ut sint boves novelli, quadratis et grandiluns membris, ct solidi corporis, musculis (ac toris) ulique surgentibus, magnis auribus, latae frontis et crispax, labris oculisque nigrantilus, comiluss rolustis ac sinc curvatura pravitate lnnatis, patulis uarilus, ct resimis, cervice torosa atque compacta, paleariluss largis et circa genua fluentihus, pectore grandi, armis vastis, ventre non parvo, porrectis lateribus, latis lumbis, dor'so recto et plano, cruribus solidis, nervosis et brevibus, ungulis magn's, caudis longis ac sctosis, pilo totius corporis denso ac brevi, rubei maxime coloris aut fusci. Melius antem boves de vicinis locis comparabimus, qui nulla suli aut aeris varietate tenentur; aut si hoc deest, fle locis similibus ad sinilia transferamus. Illud anto universa curaudum est, ut viribus ad tralıcndum comparentur xequales, ne valentioris robur alteri procurr t exitium. In moribus lıec consideranda sunt. Sint arguti, mansueti, timentes liortamen clamoris ac verberis, cibi appetentes. Sed si regionis ratio patitur, mul. lns melior cibus est; quaun viride pabulum. Ubi vero dcest, co ordine ministretur, quo palunli copia et lahorum coget accessio. Nunc tauros quoque (quiluus cordi est armeuta 
dans ses propres troupeaux, dès leur jeunesse, ceux qui seront dans les conditions suivantes, $c^{\prime}$ està-dire, de haute taille et fortement membrés, de moyen åge et plutôt au-dessus qu'au-dessous, l'aspeet terrible, les cornes petites, le chignon vaste et plein de museles, ct le ventre serré. C'est aussi principalement à présent que l'on se pourvoira de vaches; mais on en choisira qui aient la taille très-haute, le corps allongé, le ventre d'une grande capacité, le front haut, les yeux noirs et grands, les cornes belles et partieulièrement noires, l'oreille velue, le fanon très-long ainsi que la queue, les ongles courts, les jambes noires et petites. Leur meilleur âge sera celui de trois ans, tant parce qu'elles pourront donner de lonnes portécs jusqu'à l'âge de dix ans, que parce qu'il ne faut pas les laisser couvrir avant trois ans. Mais un homme attentif re négligera pas de se défaire de ses vicilles vaches, et d'en acheter de temps en temps de nouvelles, ainsi que de reléguer celles qui seront stériles à la charrue et au travail. Les : Grees assurent que, pour leur faire coneevoir des mâles, il faut lier le testieule gauehe du taureau dans l'aete du coït, et que pour leur faire concevoir des femelles, il faut lui lier le teslicule droit; pourvu cependant que le taureau se soit abstenu de cet acte longtemps d'avance, afin que, lorsqu'il en sera temps, il s'y livie arec d'autant plus d'ardeur que sa jouissance aura èlé plus différée. Au reste, il faut avoir, pour ce genre de bétail, des terrains voisins de la mer et exposés au soleil, où on le mettra pendant l'hiver; et des terrains ombragés et frais et surtout montagneux, où on le mettra pendant l'ćté ; parce que les lieux où il trouve le mieux sa pâture sont ceux qui sont plantés en arbrissenux, et où l'herbe croit entre ces arbrisscaux, bien qu'ils paissent aussi volontiers sur les

construere) comparabit, aut his signis a tenera atate submittet; ut sint alti atque ingentibus membris, atatis medix, et magis qux juventute ninor est, quam qux declinat in seniun : torva facie, parvis cornibus, torosa vastaque cervice, ventre substricto. Vaccas etiam nunc maxime parabinus. Sed eligenus forma allissima, corporis longi, uteri capacis et magni, lata fronte, oculis nigris el grandilus, pulcluris conibus et pracipue nigris, aure selosa, jalearibus et caudis naximis, ungulis brevibus, et cruribus nigris el parvis, atatis maxime trimn, quia usque ad decennium foctura ex lis procedet utilior. Nec ante xctalem trimam tauros his oportet adnitti. Sederit studium diligentis amotis senioribus, novellas subinde conducere, et steriles aratro ac laboribus deputare. Graeci asserunt, si mares creare velis, sinistrum tauri in coitu ligandum esse testiculum ; si fuminas, dextrum : tamen tauros diu ante abstinendos, ut, cum tempus est, acrius in causas dilali fervoris incumbant. Sed lis armentis lieme maritima el aprica loca, xestate opaca paremus ac frigida, montana maxime: quia melius frutetis, et lis lierba internasceufe saturantur. Quanvis circa fluvios recte propter bords riants des rivières. Plus les caux sont chaudes, plus elles sont favorables aux vaehesqui portent; c'est pourquoi il est fort utile de les tenir dans des endroits où l'eau de pluie forme des mares chaudes, quoique ce genre de bétail supporte bien le froid, et qu'il puisse aisćment passer l'hiver en plein air. Il est à propos de proeurer aux vaches des enclos d'une grande étendue, parce qu'autrement celles qui seraient pleines eourraient le risque d'ètre blessées. Quant à leurs étables, il faudra qu'elles soient pavées en pierres ou eouvertes de gravier ou de sable, et d'un plan légèrement incliné, afin que l'humidité n'y séjourne pas. On les exposera aussi au midi, afin de les garantir des vents froids, au passage desquels on opposera même quelque barrière.

XII. Il faut dompter à la fin de ce mois des bœufs de trois ans; passé cinq ans, ils ont acquis trop de dureté, et ne sont plus traitables. On les domptera done aussitôt qu'on les aura pris, pourvu qu'on ait commencé à les apprivoiser d'avance en les maniant fréquemment dans leur jeunesse. II faudra que l'étable dans laquelle on mettra les nouveaux bœufs soit bien spacieuse, et que l'emplacement qui la précédera ne soit point resserré, afin que, lorsqu'on viendra à les en faire sortir, ils ne trouvent rien sur leur chemin qui puisse les blesser. Cette étable sera traversée par des soliveaux fixés aux murs à sept pieds d'élévation de terre, auxquels on attaehera les bœufs qui ne seront pas encore domptés. On choisira ensuite un jour où il fasse beau temps, et qui soit libre de tout empêchement, pour eonduire à cette étable les boufs que l'on aura pris. S'ils sont trop méchants, on les apaisera en les tenant atlachés pendant un jour et une nuit, sans leur donner à manger. Eusuile le bouvier s'approchant d'cux, non pas de côté ni par derrière,

amcena loca pascantur : fotura tamen aquis tepidioribus adjuvatur, unde (magis) utilius lıabentor, ubi pluvialis aqua tepentes format lacunas. Tolerat tamen frigns hoo armenti genus, et potest facile hibernare sub dio : quibus tamen septa fieri propter injuriam gravidarum convenit laxiora. Stabula vero utilia sunt strata saxo aut glareis aut arenis, devexa aliquatenus, ut humor possit elabi, parti meridiance obversa propter flatus glaciales, quiluus aliquis resistere debef objectus.

XII. Hoc mense ultimo domandi sunt trimi bores, quia post quinquennium hene donari non possunt attatis repuguante duritia. Capti ergo statim domentur, qui qui. dem prius, cnm teneri sunt, frequenti manus altrectationo mansuescant. Sed stabulum novi boves largioribus spatiis liabere debebunt, ut et ante slabulum loca unllis concludantur angnstiis, et producti non aliqua vitientur offensa. In ipso vero stabulo asseres transversi a terra septem pe. dibus alti configantur, ad quos boves ligenturindomiti. Tunc eligis absolutan tempestalibus et impedinentis onuibus diem, qua capti perducantur ad stabulum. Quorun si nimia fuerit asperitas, uno die ac nocte inter viucula miti- 
mais en face, les caressera tant par la doucenr de sa voix que par l'appat de la nourrlture qu'il leur présentera, et leur maniera les narines et lo dos, en y versant de temps en temps du vin pur. On prendra néanmoins garde qu'ils ne frappent quelqu'un du pied ou de la corne, paree qu'ils conserveraient eette habitude vieieuse, s’ils s'apereevaient qu'elle leur cût réussi dans les eommeneements. Lorsqu'ils seront adoueis, on leur frottera la gueule et le palais avee du sel, puis on leur jettera dans la gueule des noreeaux de graisse très-saléc du poids d'une livre, et on lcur versera à la eorne dans le gosier un sextarius de vin par tête. Cette méthode, observée pendant trois jours de suite, fera tomber toute leur fureur et leur méchanceté. Il y a des personnes qui les attellent ensemble, et qui leur apprennent à porter des fardeaux légers. En effet, il est très-utile, lorsqu'on les destine au labour, de eommencer à les exereer dans un sol déjà labouré, afin que ee nou veau genre de travail n'ébranle pas lcurs eous, qui sont encore délicats. Mais le moyen le plus facile pour dompter ees animaux, est d'en atteler un l'ebelle avec un appriroisé et fort, qui montrera au premier ee qu'il aura à faire, et qui viendra à bout de le foreer à remplir sa tâche. Si, après avoir été dompté, un bœuf vient à se eoucher au milieu d'un sillon, il ne faut point le réveiller par le feu ou par les eoups; mais il vaut mieux lui attacher les pieds avee des liens pendant qu'il est à terre, de faȩon qu'il ne puisse ni marcher, ni se tenir sur ses jambes, ni paitre. A force de souffrir ainsi de la faim et de la soif, il se défera de cette vicieuse habitude.

XIII. C'est dans ee mois qu'il faut faire saillir les cavales de ehoix par de bons étalons bien en-

gentur atque jejunia : tunc appellationibus blaudis, et illecelbris oblatorum cilorum, non a latere, neque a tergo, sed a fronte accedens bubulcus admulceat nares, et terga pertractet, mero subinde conspergens : liac tamen cautione, ne aliquem calce contingat aut cornu : quod vitium, si in primordiis effectui sibi cessisse senserit, obtinebit. Tunc mitigatis os et palatum salibus frica, et in gulam demitle prosulsae adipis librales offas, et vini sextarios singulos cornu iufundente per fauces : quæ res intra triduum totius saevitiae iram resolvet. Aliqui cos inter se jungunt, ac docent onera tentare leviora, et quod utile est, si arationi parantur, subacto prius solo exercendi sunt, ut novus labor tenera adhuc colla uon quasset. Expeditior autem ratio est domandi, ut asperum bovem mausueto et valido bovi conjungas, quo ostendente facile al omnia cogetur officia. Si post domituram decumbit in sulco, non afficiatur igne, vel verbere : sed potius, cum decumbit, pedes ejus ita ligentur vinculis, ut non possit progredi aut stare vel pasci. Quo facto siti ac fame lassatins carebit lıoc vitio.

XIII. Hoc mense saginati ac pasti ante admissarii generosis equabus admiltendi sunt, et repletis foeminis iterum ad stabula colligendi. Neque tamen aequalem numerum omnibus debemus adlibere, sed restimatis viribus unius- graissés et bien repus, qu'on reeonduira k̀ leurs étables lorsque les femelles seront plelnes. On ne doit pas eependant faire saillir le même nombre de cavales à tous les étalons, mais on estimera les forees de chacun d'eux, et on leur en fera saillir plus ou moins à proportion, afin qu’ils durent longtemps. Mais quelque jeune que soit un étalon, et quelque confiance que l'on ait dans sa vigueur et dans sa figure, on ne lui fera jamais saillir plus de douze ou quinze eavales. Du reste, on se règlera pour les autres suivant leurs forces. Il y a quatre ehoses à examiner dans un étalon, savoir, la forme, la eouleur, les moyens, la beauté. Les eonditions en ee qui touehela forme sont cellesei : taille élevée, membres robustes et bien proportionnés, flanes allongés, eroupe eharnue et arrondie, poitrine large et ouverte, les museles partout en saillie, le pied see, ferme, chaussé très-haut, et la corne coneave. Les traits de beauté dans un eheval sont la tête petite et sèche, la peau presque adhérente aux os, les oreilles eourtes et pointues, les yeux grands, les narines ouvertes, la crinière et la queue bien fournies, le sabot rond, ferme et bien attaehé. Un elieval de moyens a l'allure hardie, le pied léger, des membres qui tressaillent, ee qui dénote le eourage. Il faut eneore qu'il soit aussi aisé de l'exeiter à la suite du plus grand repos, que de le retenir après une course préeipitée. La vitesse se reeonnait à la forme de ses oreilles; son eourage, au tremblement de ses membres. Voici les eouleurs préférables : le bai, le doré, le gris-blane, le couleur de feu, le eouleur de myrthe, le poil de eerf, le cendré, le pommelé, le blane, le moucheté, le très-blanc et le noir foncé. Viennent ensuite les poils mélangés de eoulcurs agréables : le mêlé de noir, de blanchâ-

cujusque admissarii, submittenda sunt pauca vel numerosa conjugia, ¡uß res efficiet admissarios non parva xetate durare. Juveni tamen equo et viribus formaque constanti non amplius quam duodecim vel quindecim debemus admittere, cateris pro qualitate virium suarum. Sed in admissario quatuor spectanda,sunt, forma, color, meritum, pulcliritudo. In forma hoc sequemur, vastum corpas et solidum, robori conveniens altitudo, latus longissimum, maximi et rotundi clunes, pectus late patens, et corpus omne muscalorum densitate nodosum, pes siccus et solidus, et cornu concavo altius calciatus. Pulchritudinis partes lıæ sunt : It sit exiguum caput et siccum, pelle propemodum solis ossibus adliarente, aures breves et argutx, oculi magni, nares patulx, et erecta cervix , coma densa, et cauda profusior, ungularum solida et fixa rotunditas. Meritum, ut sit audax animo, pedibus alacris, trementiluus inembris, quod est indicium fortitu. dinis, quique ex summa quiete facile concitetur, vel ex citata festinatione non difficile teneatur. (Motus autem equi in auribus intelligitur, virtus in membris trementibus.) Colores lii procipui, badius, aureus, albincus, russeus, murteus, cervinus, gilbus, scutulatus, albus, guttatus, candidissimus, niger, pressus. Sequentis meriti, varius cum pulcluritudine, nigro vel albineo vel badio mistus, canus 
tre ou de bai, le blane mèlé de quelque couleur que ce soit, le couleur d’écume, le taché, le poil de souris, le poil elair. Mais en fait d'étalons ehoisissons de préférence les couleurs elaires et sans aucun mélange, et rejetons toutes les autres, à moins qu'un mérite distingué ne couvre les défauts de la couleur. L'examen que nous venons de prescrire tombe également sur les cavales; mais il faut surtout qu'elles aient du corps et du ventre. Au surplus, toutes ces prescriptions s'ap. pliquent seulement aux bêtes de choix. Pour les autres, on les fera saillir indifféremment pendant tout le courant de l'année, et au milieu même des pâturages, par les mâles qui seront dans leur compagnie. Il est de la nature des cavales de porter l'espace de douze mois. On aura soin d'éloigner les étalons à quelque distance les uns des autres, à cause des insultes qu'ils pourraient se faire mutuellement dans leur fureur. D'ailleurs on ehoisira pour ce bétail les pâturages les plus gras; encore faudra-t-il que ces pâturages soient exposés au soleil pendant l'hiver, frais et ombragés pendant lété, et que le terrain qui les produira ne soit pas assez mou pour que la fermeté du sabot de ces animaux y sente rien d'inégal. Si une cavale ne reut pas souffrir les approches du mâle, on exeitera son tempérament en lui frottant les parties génitales arec de la scille broyèe. Dès que les cavales seront pleines, on ne les pressera point de travail, on ne les ex. posera point aux risques de souffrir la faim ni le froid, et on prendra garde de-les resserrer dans des lieux étroits, où elles pourraient a voir le ventre comprimé. Il ne faut faire saillir que de deux années l'une les cavales préeieuses à qui on laisse nourrir leurs poulains, afin qu'elles puissent leur transmettre la vigueur qu'un lait pur et abon- dant doit nécessairement leur procarer : pour les autres, on les fera saillir indifféremment en tout temps. L'áge de la monte pour un étalon commence a rec sa cinquième annće. La femelle pourra coneevoir à deux ans, paree que, passé dix, elle ne donnera plus que des produits énervés et sans ressort. II ne faut pas imposer les mains aux poulains; un attouchement eontinu les blesse. On les garantit du froid autant que faire se peut. Les observations que jai preserit de faire par rapport aux pères ou aux mères seront aussi des preuves d'un bon naturel dans les poulains, et il faudra s'occuper d'un examen pareil par rapport à eux, en tenant compte de leur âge. La gaieté, la vi vacité et l'agilité sont encore des indiees. Il faut dompter en ce temps-ci les poulains qui auront deux ans passés. On examinera s'ils ont le corpsgrand, élaneé, bien fourni de muscles et fin, les testicules petits et bien appareillés, ainsi que les autres qualités que nous a vons exigées pour les pères. Voici les signes auxquels on connait leur âge : à deux ans et demi, les dents supérieures du milieu de la bouche tombent; à quatre ans, les canines changent; arant la sixième année, les molaires supérieures tombent; dans le cours de la sixième année, celles qui ont changé les premières se remplissent, et à la septième année elles sont toutes pleines. Passé ce temps, on n'a plus d'indices certains de leur âge, si ce n'est que lorsqu'ils sont avancés en âgre leurs tempes commencent à se eaver, leurs soureils se blanchisseut, et leurs dents deviennent communément saillantes. Il faudra châtrer dans ee mois tous les quadrupèdes, et prineipalement les chevaux.

XIV.Si l'on tient à former une race de mulets, on choisira une cavale qui ait le corps grand, les os solides et la figure belle, sans s'embarrasser cum quovis colore, spumeus, maculosus, murinus, ob. scurior. Sed in admissariis pracipue legamus clari et unius coloris : cateri vero despicieudi, uisi magnitudo neritorum culpam coloris excuset. Eadem in equabus consideranda sunt, maxime ut sint longæ et magui ventris et corporis : sed loc in generosis servetur armentis. Cateræ passim toto anno inter pascua dimissis secum naribus impleantur. Equarum natura est partum spatio duortecimi mensis absolvere. Illud in admissariis servandum est, ut mediis aliquibus spatiis separentur, propter noxam furo. ris altcrni : sed lis armentis pascua legamus pingu:ssima, hieme aprica, frigida et opaca (provideamus) astate, nec adeo mollibus locis nata, ut ungularum firmitas de aspe. vitate nil sentiat. Si equa marcm pati noluerit, trita squilla naturalia ejus infecta libidinem contraluunt. Deinde gravidæ non urgeantur, ${ }^{\circ}{ }^{\circ} \mathrm{c}$ famem vel frigus tolerent, nec inter se loci comprimantur angustiis. Generosas equas et quæ masculos nutriunt alternis annis submittere debebinus, ut pullis puri ct copiosi lactis robur infundant; cxtera passim replendx. Etas incipientis admissarii quinti anni initio esse debebit. Formina recte bima coucipiet, quia post decennium iners ex ca soboles ct tarda PALLAD:CS. nascetur. Pulli equarum nati manu tangendi non sunt, quia eos tactus ladit assiduus : quantum ratio patitur, defendantur a frigore. In pullis pro xtatis merito ea sunt consideranda, quæ signum bonæ indolis monstraut, qua in patribus vel matribus spectanda praeccpi. Dabit et hilaritas, alacritas agilitasque documentum. Nunc domandi sunt pulli, ubi tenopus bimæ xtatis excesserint. Consideranda sunt magna, longa, musculosa ct arguta corpora, testiculi pares et exigui : et catera qua in patribus dicta suut. Mores, ut vel ex summa quietc facile concitcntur, vel ex incitata festinatione non difficilc teneantur. Atatis considcratio talis est : Bimn et sex mensium dentes medii superiores cadunt. Quadrimo canini mulantur. Infra sextum anuum molares superiores cadunt. Serto anno quos primo rnutavit, exæquat. Scptimo anno omnes dentes ejus explentur. Latent ab hinc atatis note: scd provectioribus tempora cavari incipiunt, supercilia canescerc, dentes plerumque prominere. Hoc inense omnia quadrupedia maxime equos castrare debemus.

XIV. Si qucm mulorum genus crcare delectat, equam magni córporis, solilis ossibus, et forma egregia delet eligere : in qua imn welocilatem sed robur exquirat. A.tas 
si elle est vite, pourvu qu'clle soit forte. C'est précisément l'âge de quatre ans qui conviendra à cette fonetion jusqu'à dix ans. Si l'âne qu'on approehe de la cavale en parait dégoutté, on commence par lui montrer unc ânesse, qu'on lui laisse jusqu'à ee que le désir soit excité chez lui; après quol on la lui retire. Dans eet état, il ne dédaignera plus la cavalc, et, provoqué par les carcsscs que lui aura faites une bête de son espèec, il consentira à s'aecoupler avee celle d'une espeec étrangèrc. S'il mord les cavales qu'un lui présentera, on ralentira sa fureur en le faisant travailler. Les mulets viennent d'une cavale et d'un anc, soit eommun, soit sauvage; mais les meillcurs sont ceux qui sont produits par un âne eominun. Il viendra cependant de bons ćtalons l'un âne sauvage et d'une Anesse, et l'agilité ainsique la force de leurs père et mère se transmettront à leur postérité. Pour qu'un âne soit bon étalon, il faut qu'il ait le corps ample, solide et plein de muscles, les membres serrćs et forts, le poil noir, ou cneore mieux de coulcur de solliris ou de feu : si néanmoins il avait des poils de différentes couleurs aux paupic̀res ou dans les oreilles, il arriverait souvent que sa postérité serait de poil mélangé. Il ue faut pas le fairc saillir avant l'âge de trois ans, ni passć eelui dè dix. Il faut sevrer les mules à un an, et les mener paitre sur des montagnes rudes, afin qu'ćtant endureies à la peine des l'âge le plus tendre, elles se montrent indifférentes par la suite aux difficultés des routes. Pour les ànons, ils sont trèsnécessaires dans les eampagnes, parce clu'ils supportent très-bien le travail, et qu'ils se passent facilement de soins.

$\mathrm{XV}$. Les abeilles sont communément malades ce mois plutit qu'en tout autre; parce qu'après la diète dont elles ont eu à souffrir pendant l'hi-

quadíma usque in decennem luuic admissuræ justi convenict. Si asiuus visan equam fastidit admissus, osten. sam prins asinan (donec coeundi voluptas solicitetur) postea subducimns; et tunc equam libido incitati non speruet, et raptus illecebris geueris sui in peruistionem consentiet alieni. Si morsı furens laedit objectas, aliquatenus labore mitescat. Creantur ex equa et asino, vel onagro et equa muli. Sed generosius unlluın est luujus. modi animal, quam quod asino creante nascetur. Utiles tamen arlmissarii nasceutur ex onagro et asina : qui post in sobole secutıra agilitaten fortitudinemque restituant. Admissarius tamen asinus sit tujusmodi, corpore amplo, solido, muscuioso, strietis et fortibus nembris, nigri vel murini maxime coloris aut rubei : qui tamen si discolores pilos in palpebris aut auribus geret, colorem sobolis plerumque variabit. Minor trimo, major decenni non debet admitti. Aunicula mula debet a matre depelli, et per mon. tes asperos pasci, ut itineris laborem in tencra atate solidata contemnat. Ninor vero asellus maxime agro necessarins est, qui et lahorem non recusat et negligentiam tulerat. ver, elles reeherehent avee trop d'avidité les fleurs amères du tithymale et de l'orme, qui vien. nent avant les autres; et qu'elles gagnent un flux de ventre dont elles périssent, à moins qu'on ue leur administrepromptement des remèdes effiea. ees. On leur donnera done des grains de grenades broyés dans du vin Aminée, ou du raisin séché au soleil avec du sumae de Syrie et du vín dur; ou bien on pulvérisera toutes ces drogues cnsemble, et on les fera bouillir dans du vin dur; et quand elles seront refroidics, on les leur présentera dans des canaux de bois. On fait aussi bouillir du romarin dans de l'hydromel, et on $\mathrm{cl}$ met le jus dans une tuile ereuse lorsqu'il est l'cfroidi. si clles paraissent hérissées ct rapetissées, et qu'elles restent comme engourdies dans un morne silenec, ou qu'elles portent souvent hors de leúrs ruches les cadavres de leurs eompagnes qui scront mortes, il faudia verser dans des canaux de roseaux du miel euit, avec de la poussière de noix de galle ou de rose sèche. S'il se trouve dans une ruehe des portions de rayons qui soient pourries, ou des cires vides que l''ssaim, réduit par quelque aecident à un trop petit nombre, ne puisse pas remplir, on ne manquera pas surtout de les couper avec des instru. ments dè fer bien tranchants, et avec beaueoup de dextéritć, dc peur que l'ébranlement des autres parties des rayous ne contraigne les abeilles à abandonner leur domicilc. La prospérité devient souvent funeste aux abeilles. En effet, si l'année est trop abondante en fleurs, comme elles ne s'occupent alors que du soin de porter du miel à leurs ruehes, elles ne pensent point à leur postérité; ct, faute de travailler à la renouveler, il arrive que la peuplade s'épuise, ct entraine la perte de toute la génération. C'est pourquoi, lorsqu'on verra une exubérance de miel oecasionnée par une ré-

$X V$. Hloc mense maxime apibus solet morbus incum. bere. Nam post liberna jejuuia tithymali et ulmi amaris floribus, qui prius nascuntur, avidius appetitis solutionem veutris incurrurat et pereunt, nisi affueris velocitate remedii. Prabehis ergo mali granati cum vino Amineo grana contrita, vel uvæ passæ cun rore Syriaco ct austero vino, vel simul omnia levigata et incocta vino aspero. Quxe deinde in ligneis canalibus refrigerata ponantur. Item rosi marinus aqua mulsa decoctus congelatur, et in imbrice ponitur succus lıujusmodi. Quod si loorridæe videntur atque con. tractse torpere silentio, et mortitarum corpora frequenter efferre, canalibus ex canna factis mel cum galla pulvere vel siecre rosie coctum delsebis infundere. Illud ante omnia expediet, ut putres partes favorum vel vacuas ceras, quas aliquo cası examen ad paucitatem redactum non valebit implere, semper recidas acutissimis ferramentis subtiliter, ne mota alia pars favorum cogat apes domicilia concussa deserere. Nocet apibus plerumque felicitas sua. Nam si nimiis floribus aunus exuberat, dum solam curam gerendi mellis exercent, de prole nil cogitant, cujus omissa reparatione populus ileu labore confectus cxlinguitur, 
colte de fleurs abondante ct continuelle, on les empêchera de sortir, en bouchant l'ouverture de leurs ruches de trois jours l'un, ce qui les forcera de s'occuper de la propagation. Il faut soignerles ruches en ce temps-ei vers les ealendes d'avril, en retirant toutes les immondices et les ordures qui s'y seront amassćes pendant l'hiver; ainsi que les vermisseaux, les teignes et les araignées, qui corrompent les rayons, et les papillons, dont les excréments produisent des vermisseaux. On fera brůler alors de la fiente de bœuf sèche, parce que cette fumée est excellente pour procurer la santé aux abeilles; et on aura soin d'y a voir fréquem. ment recours jusqu'en automne. Fn suivant toutes ees praticues et d'autres pareilles, on aura l'attention d'être chaste et sobre, et on prendra garde de n'exhaler aucune odeur, soit de parfums à l'usage des bains, soit de nourritures âcres et d'une odeur immonde, soit de salaisons, de quelque espèce qu'elles puissent être.

XVI. Ce mois ei s'accorde avec celui d'octobre pour l'indication des heures.

A la première et à la onzième heure, le gnomon donne vingt-cinq pieds d'ombre.

A la seconde et à la dixième, il en domne quinze.

A la troisic̀mc et à la neuvième, il en doune onze.

A la quatrième et à la huitième, il en donne huit.

A la cinquième et à la septième, il en donne six. A la sixième, il en donne cinq.

\section{LIVRE GINQUIÈME.}

AVRIL.

I. Il faut semer la luzerne au mois d'avril, sur

totius generis exitio, itaque cum nellis nimietaten vide. ris ex florum grandi et continua messe defluere, interje. ctis ternis diebus, clauso foramine non eas patiaris exire. Ita al generandam sobolem se conferent. Nunc circa calend. Apriles curandi sunt alvei, ut omnia purgamenta tollaulur et sordes, quas tempus contraxit hiberumu, et veruniculi et tinex et aranex, quibus corrunpitur usus fa. vorum, et papiliones, qui vermiculos stercore suo faciunt nasci. Tunc fumus incensi [et sicci] bubuli stercoris allibeatur, qui aptus estapium saluti. Quac purgatio frequenter usque in autumui tempora celebretur. Hacc onnia creteraque efliciet custos castus et sobrius, et alienus ab alliis ct cibis acribus, et odoris immundi, atque omnibus salsa. mentis.

XVI. Hic mensis ad deprehendendas horas consentit Octobri.

$\begin{array}{llllll}\text { Hora } & \text { I } & \text { et } & \text { II } & \text { pedes } & \text { xxv. } \\ \text { Hora } & \text { II } & \text { et } & \text { X } & \text { pedes } & \text { xv. } \\ \text { Hora } & \text { III } & \text { et } & \text { Ix } & \text { pedes } & \text { xi. } \\ \text { Hora } & \text { iv } & \text { et } & \text { vil } & \text { pedes } & \text { vilı. } \\ \text { Hora } & \text { v } & \text { et } & \text { vil } & \text { pedes } & \text { vI. } \\ \text { Hora } & \text { vi } & & & \text { pedes } & \text { v. }\end{array}$

des planehes qu'on aura préparées d'avanee de la manière que nous avons indiquée. Cette herbe une fois semée dure dix ans, et on peut la faucher jusqu'à quatre et six fois paran. Elle fume les terres, donne de l'embonpoiutaux animaux, et les guérit quand ils sont malades. Un jugerum de luzerne est plus que suffisant pour fournir à la nourriture de trois chevaux pendant toute une année. II faut un cyathus de cette graine pour ensemencer une planche de cinq pieds de largeur sur dix de longueur. Mais dès qu'elle sera jetée sur terre, il faudra la recouvrir de terre avec des ráteaux de bois, sans quoi le soleil ne tarderait pas a la brûler. Quand elle est semée, on ne peut plus ell approcher le fer; mais on sc sert de râteaux de bois pour la débarrasser souvent des. mauvaises herbes, afin que celles-ci ne l'étouffent point dans le temps qu'elle est encore jeune. On la récolte tard la premiere fois, afin que sa graine se disperse un peu sur terie; au lieu qu'on pourra Ia moissonner les autres fois aussi promptement que l'on voudra, pour la donner aux bestiaux. II faut néanmoins, quand ce fourrage est daus sa nouveauté, ne leur en donner d'abord qu'avec ménagement, parce qu'il les gonfle et qu'il leur fait faire beaucoup de sang. Quand cette herbe aura été fauchée, il faudra l'arroser souvent, et arracher toutes les autres herbes quelques jours après qu'elle aura commencé à repousser. Avec de pareils soins on pourra la récolter six fois par an, et elle se conservera pendant dix années de suite.

II. C'est à présent que l'on greffe les oliviers daus les elimats tempérés. On les greffe entre l'écorce et le bois comme les arbres à fruit, et de la façon que nous avons donnée ci-dessus. Mais si loon veut enspêcher quil ne reviennc des oli.

\section{LIBER QUINTUS.}

I. A prili mense in areis, quas ante (sicut diximus) proparasti, medica serenda est. Qua semel seritur, decem annis permanet, ita ut quater vel sexies possit per annum recidi. Agrum stercorat, macra animalia reficit, curat xgrota. Jugerum ejus toto anno tribus equis abunde sufficit. Singuli cyatlui seninis occupant locum latum pedibus quinque, longum pedibus decen. Sed mox ligneis rastellis obruantur jacta seniua, quia sole citius comburmutur. Post sationeın ferru locum taugi non licet, sed rastris ligneis frequenter lıerba inundelur, - ne teneran medican premat. Prina unessis ejus tardius fiet, ut aliquantum semen excutiat. Cacteræ vero inesses quaın volueris cito peragautur, et jumentis probeautur. Sed primo parcius prabenda est novitas pabuli : inflat enim, et multum sanguinem creat. Ubi secueris, sæpius riga. Post paucos dies, cum fruticare corperit, omnes alias lierbas runcato : ita et sexies per anuum metis, et annis decem poterit manere continuis.

1I. Nunc locis temperatis oliva inseratur; qux inserilur inter corticem more pomorum, sicut supra dictum est. Sel ut oleastro iuseras, contra illud, quod ex oliveto insito et 
viers sauvages infructueux dans un plant d'oliviers franes qui aura été brûlé par aecident, voici la manière dont on s'y prendra pour les greffer. On commeneera par mettre des branches d'oliviers sauvages dans les fosses oú l'on se proposera de les greffer, et on remplira ces fosses de terre jusqu'à moitié. Lorsquc ces branches auront pris, on les greffera au fond des fosses, à moins qu'on ne les ait mises en terre toutes gref'rées, et l'on entretiendra la greffe un peu audessous de la superficie du sol; après quoi on entassera de la terre auprès d'elles à mesure qu'elles croitront. Moyennant cela 'la commissure de la greffe sc trouvant caehée au fond de la terre, s'il arrive qu'on vienne par la suite à brûler ces arbres ou à les eouper, rien ne les empêchera de se rejproduire fruetueusement, parce qu'ils joindront à l'heureuse faeulté de repousser, qu'ils emprunteront de l'olivier frane qui sera hors de terre, la fertilité de l'olivier sauvage caché en terre, auquel ils seront unis. Il y a des personnes qui greffent les oliviers dans leurs racines mêmes, et qui les déterrent ensuite, quand ils ont pris, avec unc partie de ces racines, pour les transférer comme des pieds d'arbres. Les Grees prescrivent de greffer ces arbres depuis le huitième jour des ealendes d'avril jusqu'au troisième des nones de juillet, en observant de les greffer plus tard dans les pays froids, et plus tôt dans les pays chauds. II faudra achever de bêcher les vignes avant les ides de ce mois-ci dans les pays quii seront trèsfroids, et terminer les opérations du mois de mars qui auront pu demeurer imparfaites. On greffera aussi tes vignes. On déliviera des mauvaises herbes les pépinières qui auront été forınées précédemment, et on y bêchera légrèrement le pied des arbres. On sème à présent le millet ainsi que le panis dans les lieux médioerement sees. Passé. les ides de ce mois-ci, on donne le

casu incenso renascitur oleaster infelix, sic provideudum est. Positis prius oleastri bracluis in scrolse, in qua disponemus iuserere, scrohes ita replebinus, itt inedixe vacure sint. Cum comprehenderit olcaster, inseremus in infimo, vel insitum ponemus : et insitionem prope infira terram nutriemus. Deinde sicut adolescit, terram subiude colliginus. Ita commissura in profundo latente, quispuis urit aut credit, oliva locum non aufert pullulandi : yna et apertam redeundi felicitatem de olea, ef occultam va. lendi feracitatem de oleastri conmevione retinelit. Aliqui oleas in radicibus inserunt, et ubi comprelıenderint, cuun aliqua parte radicis avellunt, et transferunt more planta. Iım. Graeci oleas ab octavo calendas Apriles die usque in tertium nonas Julias inseri debere praceipiunt : ita ut loris frigidis serius, calidis maturius inserantur. Locis frigidissimis nunc viucarum fossio ante idus peragenda est, ot siqua de Nartio meuse restabunt, vites quoque inserimus. Seminaria qua sunt ante facta, lierbis liberentur, cl leniter circumfodiantur. Nunc locis mediocriter siccis milium serimus et panicum. Hoc nemse pingues campi et agii, premicr labour aux terrains plats et gras, ainsi qu'aux terres qui retiennent longtemps l'eau, paree qu'elles sont alors dans le eas d'avoir produit tout ce qu'elles ont à produire d'herbes, et que la graine de ces herbes n'est pas encore consolidée por la maturité.

III. C'est aussi à la fin de ce mois, et presque vers la fin du printemps, que l'on peut semer les choux que l'on voudra laisser monter, attendu que le temps de les faire pommer est passé. II est bon de semer à présent l'ache, soit dans les pays chauds, soit dans les pays froids, et même en telle terre que l'on voudra, pourvu qu'elle ne manque jamais d'eau ; quoique cette plante ne se refuse pas, en cas de besoin, à venir même dans un terrain sec, et qu'il n'y ait presque pas de mois, à dater du commencement du printemps jusqu'à la fin de l'automne, où elle ne puisse être semée. On range dans la classe de l'ache le maceron, qui est cependant une plante plus dure et plus amère qu'elle, ainsi que l'ache de marais, qui a la feuille molle et la tige tendre, et qui vient dans les mares d'eau, et le persil, qui croit principalement dans les lieux incultes. Les personnes soigneuses peuvent se procurer tontes ces espèces d'aches. On aura de l'ache plus grande, si l'on renferme dans un linge clair autant de graine qu'on en pourra pineer avec trois doigts, et qu'on l'enterre dans une petite fosse, parce qu'alors les germes de toutes ces différentes graines se noueront ensemble pour ne former qu'unc unique tête, qui sera très-solide. On en aura aussi de crêpue, si l'on bat ces graines avant de les semer; de même que si on roule quelque poids sur les planches où elles seront, ou qu'on les foule aux pieds quand elles seront levées. $\mathrm{La}$ graine d'ache vient plus tôt quand elle est vieille, plus tard quand elle est nouvelle. Pourvu qu'on puisse arroser l'arroche, on pourra la semer ce

qui din aquam tenent, proscindantur post idus, cum et oumes lierbas protulerunt, et earum semina nondum ma. turitate firmata sunt.

IIf. Iloc etian mense ultimo el prone vere transacto brassicam serere possumus, quæ cauli servict, quia cynıc tempus amisit. Nunc apium bene seritur locis caliclis et frigidlis, terra quali volueris, dumnıodo ili sit lıumor as. siduns; quamvis unsci, si necesse fnerit, et in siccitale non deneget, et prope omnibus mensi!us a primo vere [usque] ad antummum seratur exfremum. Ex ipsius genere est hipposelinon, durius tamen et austerius, et helioselinon molli folio et caule tenero; quod nascitur in lacunis : et petruselinon maxime locis asperis. Haec omnia genera possunt hahere diligentes. Apios majores facies, si scuen quantum tribus digitis comprehendi polest, linteolo clanseris rariore, et brevi fossa obrueris. Ita omuium seminum germen capilis unius soliditate nectetur. Crispi iinnt, si senuina ante tundautur, vel si super areas nascen. tes aliqua poudera volitentur, aut pedibus próculcentır enata. Apii semina vetustiora citius nascuutur; qua no- 
mois-ci åinsi qu'au mois de juillet, et dans tous les autres mols qui le suivront jusqu'en automne. Cette plante demande de l'eau à satiété. Il faudra en eouvrir la graine de terre aussitôt qu'elle aura été semée, et arraeher de tempsen temps les herbes qui eroítront avee elle. II ne sera pas nécessaire de la transplanter quand elle aura été bien semée, quoiqu'elle croitra beaueoup mieux lorsqu'elle aura été seméo elair, et qu'on aura eu soin de lui donner du fumier et de l'eau pour l'aider à venir. Il faut eependant avoir la préeaution de la eouper toujours avee le fer, si l'on veut qu'elle ne eesse pas de repousser. On sème à présent le basilie. On dit que eette plante vient promptement, quand elle a été arrosée avee de l'eau ehaủde aussitót après avoir été semée. Voiei un fait relatif au basilic, qui, tout surprenant qu'il est, est attesté par Martialis : e'est qu'il donne des fleurs tantôt pourprées, tantót blanches, tantôt couleur de rose; et que, lorsque la graine en a été semée plusieurs fois, elle finit par se ehanger tantôt en serpolet, tantôt en sisymbrium. On sème eneore ee mois-ei les melons et les eoneombres, ainsi que les poireaux : on met eneore en terre au eommencement du mois les câpriers, le serpolet et les pieds de fève d'Égypte. On sème aussi la laitue, la poirée, la eiboule et la eoriandre, ainsi que la chicorée, que l'on sème alors pour la seeonde fuis, à l'effet de la eonsommer en été. Enfin on plante les eourges et la menthe, soit en raeines, soit en pieds.

IV. On met en terre le jujubier au mois d'avril dans les pays ehauds, et aux mois de mai ou de juin dans les pays froids. Cet arbre aime les lieux ehauds exposés au soleil. On peut en semer le noyau, ou le planter en bouture ainsi qu'en pied. Il eroit très-lentement. Mais, lorsqu'on le plante en pied, il yaut mieux le faire au

vella sunt, serius. IIoc mense atriplicem seremus, si rigare poterimus, et Julio, et cxteris usque ad antuınnum mensibus. Amat assiduo humore satiari. Semen statim cum spargitur obruendum est; herbæ ei subinde vellantur. Transferri necessarium non est, cum hene seritur; tamen polest melius adulescere, si spatio rariore pangatur, et ju vetur succo lataminis et humoris. Ferro tamen reciden. dum semper est, quia ita pullulare non cessat. Nunc ocimum seritur : cito nasci dicitur, si statim cum severis, aqua calida perfundas. Rem miram de ocimo Martialis aflirınat, quod modo purpureos modo albos flores modo roseos pariat, et si ex eo semine frequenter seratur, modo in serpyllum modo in sisymbrium mutetur. Hoc etiam mense melones et cucumeres seruntur et porrus, et in primordio capparis et serpyllum et colocasix plantaria poneinus, et lactucas, et betas et cepullas et coriandrum seremus, et intyba secunda satione, quibus utamur astate, et cucurbitas, et mentam radice vel planta.

IV. Locis calidis Aprili mense ziziplsum conseremus, frigidis vero Maio vel Junio. Amat loca calida, aprica. Seritur ossibns et stipite et planta. Crescit tardissime. Sel si mois de mars dans une terre molle; au lieu que, lorsqu'on en sème le noyau, le plus sûr est d'en mettre trois ensemble dans une fosse d'un palmus, de faecon que leur cime soit renversée. On répandra dans ee eas-là du fumier et de la eendre, tant au fond de la fosse que sur sa superfieie; et, dès que la plante sera levée, on la débarrassera des herbes qui croitront avec elle, en les arraehant à la main. Lorsqu'elle sera de la grosseur du pouce, on la transférera dans un terlain faeouné au pastinum, ou dans une fosse. Cet arbre se plait dans les terres qui ne sont pas trop fertiles, et il aime eelles qui sont légères et presque maigres. On lui fera du bien si l'on entasse des pierres pendant l'hiver auprès de son trone, pourvu qu'on ait soin de les retirer en été. S'il estmalade, il faudra, pour l'égayer, le ratisser avec une étrille de fer, ou verser fríquemment, mais néanmoins avee ménagement, de la fiente de bœuf sur ses raeines. On eneille les jujubes lor'squ'el!es sont mûres, et on les garde dans un long vase de terre euite que l'on bouehe, et que l'on met dans un lieu see; ou bien on les arrose de quelques gouttes de vin vieux aussitôt qu'elles sont cueillies, et on parvient par là à empéeher qu'elles ne deviennent difformes en eontraetant des rides. On les eonserve aussi avec leurs branches, que l'on eoupe sur l'arbre, ou en les enveloppant dans leurs propres feuilles et en les tenant suspendues.

V. On plantc encore et greffe ce mois-ei dans les pays tempérés les grenadiers, de la faẹon que nous avons indiquée. On peut enter le pêelier en ćeusson vers les ealendes de mai, eomme le figuier, et de la manière que nous avons preserite en parlant de la greffe de ee dernier arbre. On greffe ee mois-ei le eitronnier dans les pays ehauds, ainsi que je l'ai expliqué ei-dessus. On

plantam ponas, Martio magis [in] terra molli, si ossibus seras, in scrolse palunari, ita ut tèrna grana per scro. bem cacuminilıns ponantur inversis. Quibus in imo et in summo affundatur lactamen et cinis, et herlois adnascentibus manu planta liberetur erumpens. Cum pollicis soliditati similis fuerit, trausferatur in locum pastinatum ref in scrolvem. Terram diligit non nimis latam, sed proxinam tenui atque jejunx. Per hiemem prodest illi, nt circa codicem lapidım cumulus aggeretur, qui astate debet anferri. Si arhor lare tristis est, ferrea strigili subrasa liilarior fiet, vel si fimum bubulum radicibus modice ct frequenter affundas. Ziziplıa collecta matura in longo vase fictili servantur oblito, et loco sicciore composito : vel recenter lecta poina, si guttis vini veteris perfundas, efficitur, ne ea rugarum deformet attractio. Servantur etiam decisa cum ramis suis, aut fronde sua involuta atque suspensa.

$\checkmark$. Hoc etiam mense locis temperatis mala granata pounntur, ea ralione qua dictum est, et inseruntur. Nam circa calendas Maias persicus inoculari potest, quo more emp̧lasıratır ficus, sicut divimıs, cum de insitione lo. 
formera à présent dans les pays froids des plants de figuiers, cn se conformant à la méthode que nous avons donnée cl-dessus. Il faut aussi greffer à préscnt le figuier en fente, ou entre l'ćcorce et le bois, comme je l'ai prescrit précédemment, et l'enter en ćcusson dans les climats sces. II faut planter à présent, dans les climats qui sont exposés au solcil ct chauds, les pieds de palmiers que nous appelons cephalones. On pourra greffer le cormier ce mois-ci, tant sur lui-même que sur lc cognassier et sur l'épine blanehe.

VI. Mêlez cnsemble autant d'uncioe dẹ violettes que de livres d'huile, et laissez ce mélange pendant quarante jours en plein air. Il faudra ensuite, sur cinq livres de violettes essuyées au point qu'il n'y reste plus d'humidité, verser dix sextarii de vin vieux, ct y ajouter au bout de trente jours dix livres de miel.

VII. Les veaux naissent communément ce mois-ci. Il faudra venir à l'aide des mères en leur donnant du fourrage abondamment, afin qu'elles soient en état de fournir le tribut qu'on exige alors d'elles, tant du côté du travail que du côté de la nourriture de leurs petits. Quant aux veaux, on leur donnera, en forme de salivatum, du millet grillé, moulu avec du lait. On tondra à présent les brebis dans les pays chauds, et on marıquera ce mois-ci les agneaux qui seront nés tard. C'est aussi à présent que l'on fait saillir les béliers pour la première fois. Ce premier accouplement est le meilleur, parce que les agneaux qui en résultent sont déjà fortifiés quand l'hiver arrive.

VIII. On cherchera ce mois-ci des abeilles dans des lieux exposés au soleil. Au surplus, elles indiquent elles-mêmes les cantons qui sont propres au miel. En effet, comme elles trouvent très-souvent leur pâturc auprès des fontaines, si l'on n'en voit qu'un petit nombre dans leur

quercınır. Hoc mensc calidis locis citri arhor inseritur, sicut supra memoravi. Nunc locis frigidis fici plantaria disponemus, servantes eam, qua supra dicta est, disciplinan. Nunc etiam ficum debemus inserere in ligno vel sul cortice, sicut antc pracepi, ct eam locis siccis inoculare. Nunc planta palınarum, quam cephalonem rocamus, locis apricis et calidis est ponenda. Ifoc mense sorbum poterimus inserere in se, in cydonio, in spina alba.

VI. Tot viola uncias [infundas,] quot olei libras miscris, et diebus xu sub dio labere debebis. Violie purgata , it de rore niliil habeant, libras quinque vini veteris $\mathrm{x}$ sextariis dehehis infunderc, est post $\mathrm{xxx}$ dies $\mathrm{x}$ mellis ponderibus teınperare.

VII. Iloc mense vituli nasci solent, quorum matres abundantia pabuli juventur, ut sufficere possiultributo la. boris ct lactis. Ipsis autem vitulis tostum molitumque milium cun lacte misceatur salivari more prabendum. Nunc locis calidis tondcantur oves, et serotini fuetus loc mensc signentur. Nunc etiam prima est admissura, qux excellit, arietun, ut agnos jam maturos libernum tempus inveniat.

vIII. Hoc mense locis apricis apes ujuxrenus. Sed loca voisinage, c'est unc preuve que l'cndroit est peu propre au miel; au lieu que si clles y viennent boire en foule, voici la manière dont on pourra parvenir à trouver l'endroit où seront les essaims. On commencera par s'assurer de la distance vù ils pourront être : à cet effet, on portera avec soi un petit vase rempli de terre rouge liquide, ct, après avoir observé les fontaines et les eaux voisines, on marquera le dos des abeilles qui viendront y boire avec une petite paille trempéc dans cette liqueur, et l'on se tiendra tranquillc dans l'endroit où l'on aura fait cette opération. Si celles que l'on aura teintes de cette manière ne tardent pas à revenir, on sera assuré dès lors que leur domicile est dans le voisinage; au lieu que si elles tardent, ce sera une preuve qu'il sera plus éloigné, ct l'on pourra juger de son éloignement par le temps qu'elles auront mis à revenir. Il sera aisé de parvenir aux domiciles des abeilles qui se trouveront dans le voisinage; mais voici la manière dont on s'y prendra pour arriver à ceux qui seront plus éloignés. On coupera un morceau de roseau garni d'un nœud à chacune de ses cxtrćmités, et on y pratiquera une ouverture sur lc côté, par laquelle on y introduira un peu de miel ou du vin cuit jusqu'à diminution de moitié, ct on le la'ssera auprès de la fontaine. Lorsque les abeilles se seront rassemblées dans cet endroit, et que, guidées par l'odeur, elles seront entrées dans le roseau, on en bouchera l'ouverture avec le pouce, pour n'en laisser sortir qu'une seulc abeille à la fois, ct l'on suivra la route qu'elle prendra dans sa fuite. Cettc abeille vous mettra sur la voie du lieu où doit être son domicile. Dès qu'on cessera de la voir, on en lâchera une aulre que l'on suivra de même, et en les lâchant aiıssi successivement on arrivera sous leur conduite jusqu'au iieu de résidence de l'essaim. Il y a des

mellifica indicant apes, si circa fontes frequentissima pascantur : nam si rariores videbuntur, in his locis mellificari utiliter non potest. Quod si frequentes aquantur, ubi sint examina earum, hoc genere possumus iuvenirc. Ac primo quam longe aut prope sint, exploremus. Rubricam liquidam brevi vasculo infusam geramıs, et observemus fontes aut aquas vicinas: tunc dorsa apum bibentium tangamus illo liquore tincta festucula, atque ibidem moremur. Si cito revcrsie fuerint, quas tinximus, hospitia earun. proxima esse nosccnus : si tardc, spatio longiore sub. mota, quod pro mora temporis restimamus. Ad proxima facile renies; ad longinqua hoc genere perduceris. Cammaz unum internodium cum suis recides articulis, et in latero aperies. Ibi niel exiguunı vel defritum nittes, cl juxta fontem poures. Cum ad cum convenerint apes, alque in. gressæ fuerint post odorem, foramen pollice claudes ap. posito, et unam tantum patieris exire, cujus fugam persequere. Ea tibi partem demonstrabit lospitii. Cum ipsam coperis non videre, alteram continuo dimiltes, et sequeris. Ita singulæe subinde dimissa te facient usque ad locum examinis pervenire. Aliqui mollis brcvissimum circa aq̣uan 
personnes qui mettent un très-petit vase de miel aux cnvirons de l'eau, parce que, lorsqu'une abeille a goûté de cemiel en venant boire, et qu'elle a regagné les pâturages où sont ses compagnes, elle en amène d'autres par la suite, dont la foule augmente en peu de temps; de sorte qu'on peut les suivre jusqu'à l'endroit où sont les essaims, en remarquant le côté par lequel elles s'eu retourveront. Si l'essaim est caché dans un trou, on l'en chassera par le moyen de la fumće que l'on fera; et lorsqu'il sera sorti on l'effrayera en faisant retentir du cuivre, jusqu'à ce qu'il se soit accroché à quelque arbrisseau ou à quelque branche d'arbre, d'où on puisse le recevoir dans une ruche qu'on en approchera à cet effet. Mais s'il cst sur la branche d'un arbre creux, on pourra, après avoir coupé cette branche, tant par en haut que par en bas, avec une scie très-tranchante, l'envelopper dans un morceau d'étoffe propre, et l'emporter pour la placer au rang des ruches que l'on aura déjà. Au surplus, c'est le matin qu'il faut chercher des abeilles, afin d'avoir toute la journée pour les suivre, párce qu'une fois qu'elles ont fini leur tâche, elles ne reviennent plus d'ordinaire à l'eau. Mais il faut avoir soin de frotter les ruches dans lesquelles on vent les recevoir, avec de la citronelle ou des herbes agréables, et de les arroser d'un peu de miel. En faisant cette opération au printemps, et en mettant des ruches parfumées de cette manière aux environs des fontaines et dans les endroits où il y aura beau. coup d'abeilles, il s'en amasşera une multitude qui viendront d'elles-mêmes dans ces ruches, pourvu néanmoins qu'on puisse les préserver des voleurs. Il laut aussi nettoyer les ruches ce moisci ainsi que le mois précédent, et tuer les papillons, qui se multiplient principalement dans le temps que la mauve est en fleur. Voici la manière de les

vasculum ponunt, de quo cum apis aquando gustaverit, ad commune aabulum pergens alias exhibebit : quarum frequentiam subinde crescentem, notata revolantium parte, usque ad examina persequeris. Quod si est examen in spelunca recondilum fumo ejicielur, et cum exierit, aris so. ı:itu territum in frutice vel in aliqua silvæe se parte suspen. del, et ila admoto visculo recipietur. Si vero in cavæe arboris ramo fuerit, aculissina serra idem ramus supra infraque decisus et munda veste coopertus poterit afferri et inter alvearia collocari. Vestigantur autem mane, ut tota dies sufficiat ad sequendum. Nam vespere peracto opere ad aquam plerumque non redeunt. Vasa autem, quilus recipiuntur, perfricanda sunt citragine, vel lierbis suavibus, et conspergenda imbre mellis exigui : quod si verno fiat, et circa fontes alvearia sic tincta ponantur, locis quibus apum frequentia est, multitudinem sibi sponte conducent, si tameu servari a furibus possunt. Hoc etiam meuse, sicut supra, purganda sunt alvearia sordibus, et necandi papiliones, qui maxime abundant florentibus malvis, quos lıc genere intercipiemus. Vas acneum miliario sinile, id est altum et angustum, vespere iuter al reara prendre : On pose le soir entre les ruches un vase de cuivre semblable à un vase milliaire e c'est-àdire qui soit profond et étroit, et on met au fond de ce vase une lumière; de sorte que les papillons venant à se rassembler dans ce vase et à voltiger autour de la lumière, le peu de largeur du vase les met dans la nécessité de se brûler au feu, dont ils sont trop près.

IX. Les heures de ce mois-ci sont égales à celles du mois de septembre, suivant la proportion de ce calcul.

A la première et à la onzième heure, le gnomon donne vingt quatre pieds d'ombre.

A la seconde et à la dixième, il en donne quatorze.

A la troisième et à la neuvième; il en donne dix.

A la quatrième et à la huitième, il en donne sept.

A la cinquième et à la septième, il en donne cinq.

A la sixième, il en donne quatre.

\section{I.IVRE SIXIÈME.}

\section{MAI.}

I. On sèmera le panis et le millet au mois de mai dans les climats froids et humides, de la facon que j'ai indiquée. Presque toutes les semences sont en fleur dans ce temps-ci, et le cultivateur ne doit point y toucher. Or voici la manière dont elles fleurissent : les blés et l'orge, ainsi que les semences qui ne sont point partagées en deux lobes, sont en fleur pendant huit jours, et lorsuue la fleur de ces semences est passée, elles grossissent pendant quarante jours jusqu'à ce qu'elles soient parvenues à leur maturité; au lieu que les

collocemus, et in fundo ejus ponamus lumen accensum. Illuc papiliones convenient, et circa lumen volitabunt, et angustia vasculi ab igne proximo interire cogeutur.

IX. Hujus mensis hora, horis mensis Septembris $a-$ quantur lioc genere.

$\begin{array}{llllll}\text { Hora } & \text { et } & \text { XI } & \text { pedes } & \text { xxiv. } \\ \text { Hora } & \text { II } & \text { et } & \mathbf{x} & \text { pedes } & \text { xiv. } \\ \text { Hora } & \text { III } & \text { et } & \text { Ix } & \text { pedes } & \text { x. } \\ \text { Hora } & \text { iv } & \text { et } & \text { vin } & \text { pedes } & \text { vilı. } \\ \text { Hora } & \text { v } & \text { et } & \text { vil } & \text { pedes } & \text { v. } \\ \text { Hora } & \text { vi } & & & \text { pedes } & \text { Iv. }\end{array}$

\section{LIBER SEXTUS.}

I. Maio mense locis frigidis et lumeclis panicum serenus et nílium, more quo dixi. Nunc omuia prope, qua sata sunt, florent, neque tangi a cultore debebunt. (Florent aatem sic:) frumenta et ordeum et qua sunt seminis siltgularis, octo diebus florebunt, et deinde per dies $\mathrm{xl}$ grandescent flore deprosito usque ad maturitatis eventum. 
scmenees qui sont partagées en deux lobes, telles que les fèves, les pois et las autres légumes, sont en fleur pendant quarante jours, et mettent lc untme temps à grossir. On fauchera ce mois-ci les foins dans les climats sees, chauds, ou voisins de la mer, sans cependant attendre qu'ils soient desséclıés. Si lorsque le foin est fauché il vient à être pénétré par la pluie, il ne faudra pas lc retourner avant que la superficic en soit séchée.

II. Il faut examiner à présent les sarments qu'auront donnés les jeunes vignes, afin de n'en laisser qu'un petit nombre de ceux qui scront forts. Il faut aussi soutenir ces vignes avec des appuis, jusqu'à ce que les bras qu'elles auront produits soient consolidés. Quand on aura coupé une jeune vigne, et qu'elle viendra à repousser, on ne lui laissera pas plus de deux ou trois jets, que l'on liera au corps de la vigne, pour les mettre à l'abri des accidents du vent. J'ai dit qu'il fallait y laisser trois jets, parce que, si on en laissait moins dans ces commeneements, et que les vents vinssent à les briser, il n'en resterait aucun. Il faudra épamprer ce mois-cl ; mais cette opération ne sera avantageuse qu'autant qu'elle aura été faite daus le temps où les jeunes branches se détachent sans difficulté sous le doigt qui les presse. Au reste, elle cst utile pour faire grossir les grappes, et préparer leur maturité en livrant uII passage au soleil.

III. C'est aussi à présent qu'on donne le premier labour aux terrains graset où l'herbe abonde. Mais lorsqu'on veut donner ce labour à des terres ineultes, il faut examiner auparavant si elles sont sèches ou humides, couvertes de bois ou de gramen, d'arbrissenux ou de fougère. Si elles sont humides, on les desséchera en y creusant partout des fosses. Il n'y a personne qui ne connaisse les

Qua vcro duplicis seminis sunt, sicut faba, pisunn cxteraque legumina, $\mathrm{xL}$ diebus florent simulque grandescunt. Hoe mense in locis siccis, calidis sive maritimis fona recidantur, prins tamen quam cxarescant. Quod si pluviis infusa fuerint, converti ante non debent quam pars eorum sumına siceata sit.

II. Nune consideremus novella vitis quæ protulit sáinenta, et ei pauca ct solida relinquamus, et adminiculis firmemus, donee brachia prolata durescant. Non antem amplius sesecta et pullulanti viticula, quam dux rel tres utaterix relingquantur, et alligentur propter injuriam venti. Ideo autcm tres materias dixi debcre dimitti, ne dissipantibus ventis nulla remaneat, si in primordio reliqueris paneiores. Iloc mense pampinari conveniet. Sed tunc est opportuna pampinatio, cum teueri rami digitis stringentibus erepahunt sine difficultate carpentis. Hæc res ivvas cfficit pingutiores, $\mathrm{ct}$ maturitati consulit solis admissu.

III. Nunc quoque pingues agri et herbosi proscindantur. Sed si agros ineultos volueris aperire, considerabis, siceus an humidus sit ager, silvis ant granine, frutelis ves. vitus ant filice. Si humidus erit, fussarum ductibus ex onmi fosses apparentes; mais voiei la maniere de s'y prendre pour faire des fosses cachées. On creuse à travers lc champ des fossés de trois pieds de profondeur, que l'on remplit ensuite jusqu'à moitié de petites pierres ou de gravier; après quoi on les régale par-dessus a vec la terre que l'on avait enlevée par la fouille. Mais l'extrémité de ces fossés doit aboutir en pente à une bosse apparente, dans laquelle toute leur humidité se rendra, sans entrainer avec elle la terre du champ. Si l'on n'a point de pierres, on étendra au fond de ces fossés des sarments ou de la paille, ou des broussailles de quelque nature qu'elles soient. Si au contraire le terrain est couvert de bois, il faudra, pour le cultiver, extirper les arbrisseaux, ou n'en laisser qu'un petit nombre. S'il est pierreux, on pourra le nettoyer en faisant ramasser à la main les pierres dont il sera couvert, pour en construire des murailles qui lui serviront de défense. On parviendra à le débarrasser du jonc, du gramen et de la fougère, en multipliant les labours. On fera notamment disparaitre la fougère en peu de temps, pour peu qu'on sème souvent dans le champ qui la porte des fèves ou des lupins, ou qu'on la fauche de temps en temps à mesure qu'elle repoussera.

IV. Ce mois-ci est le temps convenable pour remblay'or, c'est-à-dire, recouvrir de terre les arbres et les ceps qui auront été déchaussés. On coupera à présent le bois propre à faire des verges d'office, quand il sera garni de toutes ses feuilles. Or, voici la mesure de ce qu'un hornme pourra en couper. Si c'est un excellent ouvrier, il doit expédier la valeur d'un modius de bois de haute futaie; un ouvrier médiocre en expédiera un tiers de moins. On bêche aussi assidûment les pépinières dans ce temps-ci. On taille les oliviers, et on ratisse la mousse qui s'y atta-

parte siccetur. Sed apertæ foss notx sunt, cæcæ vero lıoc genere fiunt. Imprimuntur sulci per agrum transversi altitudine pedum ternum : postea usque ad medielatem lapidibus minutis replentur aut glarea, et super terra, quam egesseramus, æequatur. Sed fossarum capita unam patentein fossam petant, ad quam declives decurrant : ita et humor deducetur, et agri spatia non peribunt. Si defuerint lapides, sarmentis vel stramine subjecto cooperiantur vel quibuscunque virgultis. Sed si nemorosus est, extirpatis aut raro relictis arboribus excolatur. Si lapidosus, per macerias saxorum turba collecta et purgari pote. rit, ct inde muniri. Juncus et gramen et filices frequenti aratione vincentur. Sed filicem, si sæpe fabam conseras vel lupinos, et si subinde nascentem mucrone faleis incidas, intra exiguum tempus absumes.

IV. Hoe mense arbores el vites quæ ablaqueatæe fuerant, occare, loc cst, operire jam convenit. Nunc ad rudem faciendam silva cxdatur, quando omni fronde vestita est. Cacdendi autem hic modus est, ut optimus operarins in alta silva modii spatium, mediocris vero tertia min!ıs possit abscimlere. Nunc et seminaria fodiuntur assidue, et locis pragelidis et pluviosis olex putantur, et eis mus. 
che, dans les climats très-froids et pluvieux. Si l'on a semé des lupins dans la vue de fumer ses terres, i! faudra les reverser à présent en terre à laide de la charrue.

V. Il faut façonner à présent au pastinum le terrain des jardins que l'on destine à être couverts, en automne, de semences ou de pieds d'arbres. Il est bon de semer l'ache de marais ce mois-ci, comme nous l'arons déjà dit ci-dessus. On pourra encore mettre en terre la coriandre, les melons, les courges, l'artichaut, les raiforts et la rue. On transférera aussi le poireau en pied, et on l'excitera ensuite à croìtre en l'arrosant.

VI. Les grenadiers commentent à fleurir à présent dans les pays chauds. Ainsi, si l'on enferme, comme le dit Martialis, une branche de grenadier avec sa fleur dans un vase de terre cuite enfoncé cn terre auprès de l'arbre, en attachant cette branche à un pieu, afin qu'elle ne s'élance pas hors du vase, elle donnera en automne un fruit dont la grosseur sera moulée sur la capacité dece vase. On peut aussi enter en écus. son le pêcher ce mois-ci dans les pays chauds. On greffe à présent dans les pays fioids le citronnier, conformément à la méthode que nous avons donnée. On plantera à présent le jujubier dans les pays froids, et l'on y greffera le figuier. C'est aussi dans ce mois-ci que l'on plante les pieds de palmiers.

VII. Il faut châtrer à présent les veaux, ainsi que Magon le prescrit, dans le temps qu'ils sont jeunes, en comprimant leurs testicules avec une férule feudue, et en les froissant peu à peu pour les détacher. Mais il ordonne de ne faire cette opération qu'au printemps ou en automne, et dans le déclin de la lune. D'autres, après avoir attaché le veau au travail, saisissent avec deux règles d'étain ćtroites, comme avec des tenailles,

eus abraditur. At si quis lupinum stercorandi agri causa seminavit, aratro illum nune debebit evertere.

V. Hortorum spatia, quæ per antumnum seminibus implenda destinantur, aut plantis, nune eonveniet pastiuare. Hoc mense apium bene seritur, sicut jam ante dictum est, vel coriandrum, et melones, et eueurbita, carduus, et radices, et ruta pangentur. Porri quoque planta transfertur, ut rigationibus animetır.

VI. Loeis calidis nunc mala Punica florere incipiunt. Ramus ergo cum flore (sieut Martialis dicit) si obruto circa arborem fietili vase claudatur, et ne resiliat, ligetur al palum, pro vaseali magnitudine pomum reddit antumno. Hoc efiam mense locis calidis emplastrari Persicus potest. Locis frigidis nune citri arbor inseritur, et ea, quæ dirta est, disciplina servetur. Nune frigidis loeis ziziphum conseremus, et ficum inserimus. Hoc etiam mense palma planta disponitur.

VII. Nunc castrandi sunt vituli, sicut Mago dicit, tenera atate, ut fissa ferula testiculi comprimantur, et paulatim coufracti resolvantır. Sed loc luna decrescente verno vel autunıno fieri debere pıxcipit. Alii ligato ad ma-

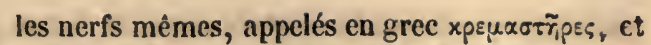
coupent avec un instrument de fer les testicules après les avoir tirés à eux, en laissant intacte une portion de l'extrémité de leurs nerfs ; précaution qui arrête la perte du sang, et qui empéche les jeunes bœufs d'ètre absolument énervés, puisqu'ils ne perdent pas dans ce cas là toute leur masculinité. Il n'est pas tolérable de contraindre les veaux à saillir après la castration, comme on le voit pratiqué par bien des personnes; parce qu'il est constant que, quoiqu'ils demeurent prolifiques, l'effort leur cause un flux de sang qui les fait périr. On frottera les plaies occasionnées par la castration avec de la cendie de sarment et de l'écume d'argent. On empêchera l'animal nouvellement châtré de boire, et on ne lui permettra la nourriture qu'en petite quantité, en lui donnant, dans les trois jours qui suivront l'opération, des cimes d'arbres tendres, des arbustes mollets, et des feuilles d'herbes vertes légèrement humectées de rosée ou d'eau de rivière. II faut panser ces plaies soigneusement au bout de ces trois jours, avec de la poix liquide mêlée de cendre et d'une petite quantité d'huile. Mais l'expérience a fait trouver récemment une manière de châtrer, qui est meilleure que les anciennes. Après avoir garrotté le jeune bœuf et l'avoir renversé par terre, on renferme ses testicules dans la peau qui leur sert d'enveloppe, et que l'on tend à cet effet; puis, en les comprimant avec une règle de bois, on les coupe soit arec des haches brûlantes, soit a vec des doloires, ou, ce qui vaut encore mieux, avec un instrument de fer fait exprès pour cette opération, et qui a la furme d'un glaive. En effet, en suivant cette méthode, le tranchant du fer qui e st brùlant pénètre auprès de la règle même; de sorte que l'opération, devenue plus rapide, en est moins

chinam vitulo, duabus angustis regulis stanneis sicut for-

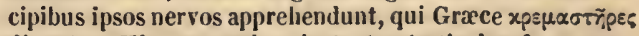
dicuntur. His comprehensis tentos testiculos ferro resecant, et ita recidunt, ut aliquid de his eapitibus nervorum suorum dimittatur hærere. Qux res et sanguinis nimietatem prohibet, et non omnino juvencos subdueto robore virilitatis effouninat. Nec admittendum est, quod plerique faeiunt, ut statim castratos enire compellant. Nam eertum est ab eis generari, sed ipsos fluxu sanguinis interire. Vulnera vero castratura einere sarmentorum et spuma linentur argenti. Castratus abstineatur a polu, et eibis pascatur exignis, et sequenti tridıo prebeantur ei teneræe arborum summitales, et frutecta mollia, et lierha viridis eoma dulciore sagina roris ant fuminis. Pice etiam liquida misto cinere et modieo oleo post triduum vuluera diligenter unguenda sunt. Sed melius genus castrationis sequens usus invenit. Alligato enim jurenco atque dejecto, testiculi stricta pelle clanduntur, atque ibi lignea regula premente deciduntur ignitis securibus vel dolabris, vel, quod est melius, formato ad hoe ferramento, ut gladii similitudinem teneat. Ita enim circa ipsàm regulam ferri 
douloureuse, et que la cicatrice, qui se forme aussi promptement que la plaie, empêehe l'effu. sion du sang.

VIII. Il faut faire à présent la tonte des brebis dans les pays tempérés. Mais, lorsqu'elles auront été tondues, on les pansera avec l'onguent dont voici la composition : On mêlera ensemble par portions égales de la décoction de lupins, de la lie de vin vieux et du mare d'huile, et on les frottera de eet onguent quand ces diogues seront bien amalgamées ensemble. Trois jours après, si l'on est à proximité de la mer, on les y plongera sur le bord du rivage; au lieu que si c'est dans l'intérieur des terres qu'on nourrit ees bestiaux , il faudra, dès qu'ils auront été tondus et frottés d'onguent, leur jeter sur le corps, en plein air, de l'eau de pluie tant soit peu bouillie avee du sel. On prétend que le bétail qui aura été soigné de la sorte sera préservé de la gale pour toute l'année, et que sa laine acquerra de la longueur et du moelleux.

IX. On fera cailler ce mois-ci du lait pur, pour en faire du fromage, soit avee de la présure d'agneau ou de bouc, soit avec cette membrane intérieure qui est adhérente aux ventres des poulets, soit avec des fleurs de chardon sauvage, soit avec du lait de figuier. Il faudra extraire du fromage tout le petit-lait, et même le comprimer en le cliargeant de poids. Quand il commencera à être ferme, on le mettra dans un lieu ombragé ou frais; et, après l'avoir comprimé en y ajoutant de temps en temps de nouveaux poids pour le raffermir de plus en plus, il faudra le saupoudrer de sel égrugé et torréfié, et le comprimer plus qu'il ne l'aura encore été, quand il sera devenu plus ferme. Quelques jours après, les pains de fromage ćtant bien dureis, on les arrangera sur des claies, de faecon qu'ils ne se touehent pas. Il faut mettre le fromage dans un lieu elos ct où l'air ne pénètre pas, si l'on veut qu'il se conserve tendre et gras. Il sera défeetueux toutes les fois qu'il scra see ou spongieux; ce qui arrivera lorsqu'il n'aura pas été assez comprimé, ou qu'il aura été trop salé, ou brûlé par l'ardcur du soleil. Il y a des personnes qui broient sur le fromage, Iorsqu'elles eommencent à le faire, des pignons verts, et qui en jettent dans le lait avant de le faire prendre. D'autres y ajoutent, au moment qu'il prend, du thym broyé et tamisé à diverses reprises. On pourıa même donner au fiomage tel goût que l'on jugrera à propos, en y ajoutant des assaisonnements, tels que du poivre ou quelque autre épice que ce soit.

$\mathbf{X}$. Les essaims eommencent à se peupler ce mois-ci, et il se forme des abeilles plus grandes que les autres dans les extrémités des rayons. Quelques personnes premnent ces abeilles pour les rois de's ruches. Mais les Grees leur donnent le nom d'oĺtrpous, et ils ordonnent de les tuer, paree qu'elles troublent le repos des essaims. Les papillons sont à présent très-multipliés, et il faudra les tuel de la manière que j'ai prescrite.

XI. C'est vers la fin de ce mois qu'il faut établir le planeher des terrasses; constructions que la gelée et les frimas sont sujets à miner et à détruire dans les pays froids, ainsi que dans ceux où il règne des brouillards. Néanmoins, si on veut en faire, on commencera par poser deux rangées de planehes transversales, sur lesquelles on étendra de la paille ou de la fougère, que l'on régalera bien avec une pierre dont la grosseur puisse remplir la main. Ensuite on couvrira ee lit de acies arientis imprimitur, unoque ictu et moram doloris beneficio celeritatis absumit, et ustis venis ac pellibus fluxu sauguinis (strictis, plaganı) cicatrix quodaunmodo cum ipso vulnere nata defendit.

VIII. Locis temperatis nuic ovium celebranda tonsura est. Serl tonsas oves lıoc unguine medicemur. Succum decocti lupiui, feces vini veteris, el amurcam pari mensura miscebis, et in unum corpus omnia redacta curabis adlinire. Post triduum deinde, si mare vicinum est, litori mergantur extremo : si in mediis terris pascimus, aquá crlestis cun sale paululun decocta sub dio debebit pecorun lousa et uncta membra dil:ıre. Hoc enim modo curatum pecus toto anno nec scabrum fieri dicitur, et prolixas lauas creare fertur, ac molles.

1X. Hoc mense caseun coagulabimus sincero lacte coagulis vel agni vel lıædi, vel pellicula, quæ solet pullorum ventribus adliarere, vel agrestis cardui floribus, vel lacte ficulneo, cui serum debet omne deduci, ut et ponderibus urgeatur. Ubi solidari coperit, loco opaco ponatur aut frigido, et pressus subinde adjectis pro acquisita soliditate ponderibus, trito ac torrefacto sale debel aspergi, el jam durior velıementius premi. P'ost aliquot dies solidala jan formula per crates ita statuantur, ne iuvi- cem se unaquæque contingat. Sit autem loco clanso et a ventis remoto, ut teneritudinem servet atque pinguedinem. Vitia casei sunt, si aut siccus sit aut fistulosus : quod eveniet, aut si parum prematur, aut siles nimios accipiat, aut calore solis uratur. In recenti caseo conficiendo aliqui nucleos virides piueos terunt, atque ita misto lacte gelaut. Aliqui flyynum tritum et frequenter colatum congelant. Qualemcunque etiam saporem relis efficere poteris, adjec. to, quod elegeris, condimento seu piperis selı cujuscunque pigmenti.

$X$. Hoc mense incipiunt augeri examina, et in extremis favorum partibus majores creantur apiculæ, quas aliuıi reges putant; sed Graeci cos otøtpous appellant, et Hecari jubent, quia requiem concutiunt quiescentis examinis. Nunc papiliones abundant, quos necemus, more quo dixi.

XI. Nunc circa extremum mensem pavimenta in solariis funt : quæ in frigidis regionibus et ubi pruinæ sunt, glacie suspenduntur et pereunt. Sed si loc placuerit, steruemus duplices ordines tabularum transversos atque directos, et paleam vel filicem substernemus, et (acqualiter) aquabimus saxo, quod manum possit implere. Pedaueum super rudus inducimus, et assiduo vecte densanus : tunc, 
mortier à un pled d'épaisseur, ct l'on chargera ce mortier d'une quantıté de barres de bois ; apres (quoi, sans attendre que le mortier so it sec, on appliquera dessus des tuiles de deux pieds, creusées sur tous leur's côtés de la profondeur d'un doigt, et l'on remplira de chaux vive détrempée avec de l'luuile les interstices; puis l'on couvrira tout le mortier de cet assemblage de tuiles, afin que, lursque tout eet apprêt sera sec, il ne forme qu'une seule masse à travers laquelle l'humidité ne pourra point pénétrer. Ensuite on ćtendra sur ce pavé six doigts d'épaisseur de mortier de brique, que l'on battra fréquemment avec des vergres, afin qu'il ne s'y forme point de crevasses; après quoi on enfoncera dans ce mortier de larges carreaux de briques, ou des tablettes de marbre quelconques, ou enfin des pierres carrées; et l'on aura une construction que rien n'est capable d'endommager.

XII. Il faut fairc ce mois-ci des briques, soit avec de la terre blanche, soit avec de l'argile ou de la terre rouge. En effet, celles que l'on fait en été se sèchent à la superticie, parce que cette partie se trouve trop subitement affectée de la clıaleur, tandis que l'humidité se tient renfermée in dedans, ce qui occasionne des crevasses. Or voici la manière de les faire : On passcra l'argile avec soin, ct on la purgera de tout grumeau; ensuite, après l'avoir mêlće avec de la paille, on la laissera fermenter longtemps, et on en remplira des moules de la forme d'une brique. Enfin un la laissera sécher au sole:I, en la retournant de temps en temps. Au surplus, les briques doivent être de deux pieds de longucur sur un pied de largeur, et d'une épaisseur de quatre uncice.

XIII. Composition du vin rosat. On jette cinq livres de roses, épluchées dès la veille, dans dix

antequam rudus siccetur, bipedas, quæ per omnia latera canaliculos lıabeant digitales, jungemus, ita ut calce viva ex oleo temperala, bipedarum canales, qui inter se connecteruli sunt, impleanlur, et earum conjunctione rudus onne copperiatur. Nam siccata omnis materia unum cor[uis efficiet, et nullum transmittet lumorem. Postea sex digitoruın testaceum superfundemus, ef frequenter virgis verberabiums, ne rimis possit aperiri. Tuuc tessellas latiores rel tabellas qualescunque marmoreas aut paginas inprinemus, et lianc constructionem res nulla vitiabit.

XII. Hoc mense lateres faciendi sunt ex terra alba vel creta vel rubrica. Nam qui æeslate fiunt, celeritate firvoris in suniua cutc siccantur, interius lummore servato: qua res scissuris eos faciet aperiri. Fiunt autem sic. Terra creta diligenter et omui asperitate purgata, mista cum paleis din macerabitur, et intra formam lateri similem dipri. metur. Tunc ad siccandum relicta subinde versabitur ad solis aspectum. Sint vern [ lateres] lougitudine pedum dusrum, latitudiue unius, altitudine qualuor unciarum.

XIII. [ De rosalo.] Quinque libras rosa pridie purgatic in vini veteris $\mathrm{x}$ sextarios merges, et post $\mathrm{x} x \mathrm{x}$ dies $\mathrm{x}$ de. spumati mellis libras adjicies, et uteris. sextarii de vin vicux; et après avoir ajoutć au bout de trente jours dix livres de miel écumé sur cette composition, on pourra s'en servir.

XIV. Composition de l'huile de lis. On fait infuser dix lis daus une livre d'huile, et on met le vase de verre qui renferme cette composition pendant quarante jours en plein air.

$X V$. Composition de l'huile de roses. On met sur unc livre d'huile uue uncia de roses ćpluchées, et on suspend cette composition pendant sept jours, tant au soleil qu'au clair de la lune.

XVI. Composition du micl rosat. On mêle une livre de miel avec un sextarius de suc de roses, et on suspend cette composition pendant quarante jours au soleil.

XVII. On viendra à bout de conserver des roses en boutons en fendant un roscau vert sur son pied, et en les renfermant dans sa cavilć, de façon que la fente puisse s'en joindre; ensuite on coupera le roseau quand on voudra avoir des roses fraíches. Il y a des personnes qui les euterrent à l'air après les avoir renfermées dans un pot qui soit propre, et qui les conservent en les garantissant par là de tout aceident.

XVIII. Le mois de mai répond à celui d'août, en ce qui concerne la durée des heures.

A la première et à la onzlème, le gnomon donne vingt-trois picds d'ombre.

A la seconde et à la dixième, il en donne treize.

A la troisième et à la neuvième, il cn donne neuf.

A la quatrième et à la huitième, il en donne six.

A la cinquième et à la septième, il cn donne quatre.

A la sixième, il en donne trois.

XIV. [ De oleo liliaceo.] Per olei libras singulas dena lilia curabis infundere, et vas vitreum $\mathrm{xL}$ dichus locare sub dio.

XV. [ De oleo roseo.] In olei libras siugulas, rosie purgatæ singulas uncias mittes, et vu diebus in sole suspen. des et lıua.

XVI. [ De rhodomeli.] In succi rosæ sextariis singulis libras singulas mellis adnisces, et diebus XL sub sole suspendis.

XVII. Rosas nondum pafefactas servabis, si in canua viridi stante fissa recludas, ita ut fissuram coire patiaris : et eo tempore cannam recidas, quo rosas virides habere volueris. Aliqui olla rudi conditas ac bene munitas sub dio obrunut, ac reservaut.

XVIII. In horarum mensuris Maius respondet Augusto,

Hora $I$ et $\mathrm{xI}$ pedes $\mathrm{x} x \mathrm{II}$.

Hora $\|$ et $x$ peles $x ı$.

Jora III et $1 \mathrm{x}$ peiles $\mathrm{Ix}$.

IIora iv et vil pedes vi.

Hora $v$ et vi pedes iv.

Hora pedes $11 \%$. 


\section{LIVRE SEPTIEME.}

JUIN.

1. Il faut apprêter au mois de juin l'aire à battre le blé. On commencera à cet effet par bicn nettoyer un terrain, en arrachant toutes les herbes qui s'y trouveront; ensuite on le bêchera lé. gèrement, et on l'aplanira après $\mathrm{y}$ avoir mêlé avec la terre de la paille et du mare d'huile sans sel, ce qui garantira les blés des rats et des fourmis. Cela fait, on comprimera le sol avec une pierre eylindrique ou un fût de colonne, qu'on roulera dessus pour le consolider; puis on le laissera sécher au soleil. Il y a des personnes qui arrosent les aires d'eau après les avoir nettoyées, et qui y menent promener le menu bétail pendant un temps considérable, afin qu'il les foule bien aux pieds; et quand la terre en a été bien comprimée par ce moyen, on attend qu'elle soit absolument sèche pour se servir de l'aire.

II. On ne commence qu'à présent. la récolte de l'orge, mais il faut l'achever avant que le grain tombe à terre; ce à quoi il est sujet quand l'épi est sec, parce que ce grain n'est point enfermé dans une capsule comme cclui du froment. Un habile moissonneur peut expédier en une journée cinq modii de terrain bien rempli; un médiocre en expédiera trois; il n'y a que le pire des ouvriers qui en fasse moins. Mais on aura soin de laisser quelque temps sur terre le chaume de l'orge, parce qu'on prétend que c'est le moyen de la faire renfler. On fait aussi à présent la récolte du froment vers la fin du mois dans les pays voisins de la mer, cbauds et secs. On connait que cette moisson est prête à faire, lorsque tous les épis sont uniformément teints d'une couleur jaune qui annonce

\section{LIBER SEPTIMUS.}

1. Junio mense area paranda est ad trituram, cujus jurimo terra radatur : deinde effossa leviter mistis paleis $\mathrm{et}$ amurca æcquatur insulsa. Quæ res a muribus et formicis frumcnta defendit. Tunc premenda est rotundo lapide, vel columna quocunque fragmento, cujus volutatio possit ejus spatia solidare, dehinc sole siccetur. Aliqui mundatis areis aq̣uam spargunt, et minuta ibi pecora din spatiari as: proculcare compcllunt. Et cum terra ungulis stricta fuerit, spectant solidam siccitatem.

II. Nunc, primo ordei messis incipitur, quæ consummanda est antequam grana arefactis spicis lapsa decurrant, quia nullis, sicut triticum, folliculis vestiuntur. Quinque modios recidere potest pleni agri opera una messoris experti, mediocris vero tres, ultimi etian minus. Sed ordei culmos jacerc in agris aliquantulum sinamus, quia fertur loo more grandcscere. Nunc ctiam mense postremo locis maritimis et calidioribus ac sîcris tritici messis abscinditur. Quam paratam esse cognosces, si æqualitcr spicarum populus maturato rubore flavescat. Pars Galliarum planior loc compendio utitur ad metendum, ct leur maturité. Les habitants des pays plats de la Gaule ont une méthode de moissonner qui épargne la main-d'œuvre, puisqu'elle n'exige que la journée d'un bouf pour expédier tout un canton. Ils ont un chariot montć sur dcux petites roues. La surface de ce chariot, qui est carrée, est garnie de planches renversées en dehors, de sorte que sa partie supérieure est plus large que l'inférieure. Ces planches sont moins hautes sur le devant du chariot que par derrière. Sur ces planches sont distribuées parordre de petites dents clair-semées, dont le nombre est proportionné à la quantité des épis. Ces dents sont recourbées par en haut. On adapte au derrière de ce chariot deux brancards très-courts, scmblables à ceux des litières dans lesquelles les femmes se font porter; et l'on attelle à ces flèches, à l'aide d'un joùr et avec des courroies, un boeuf qui a la tête tournée ver's le chariot. Il faut sans contredit que ce bœuf soit doux, et qu'il n'aille pas plus vite qu'on ne le pousse. Le bœuf promenant ce chariot à travers la moisson, tous les épis se trouvent saisis par les petites dents dont il est garni, et s'accumulent par conséquent dans le chariot, en se séparant de la paille qui reste en dehors. Le bouvier, qui suit par derrière, dirige la marche du chariot en l'élevant ou en le baissant, suivant l'exigence du cas; et il ne faut que quelques heures d’allées et venues pour expédier toute une moisson. Cette méthode est bonne pour les pays plats et dont lc terrain est égal, ainsi que pour ceux où l'on ne considère pas la paille comme objet de nécessité.

III. On fera à présent dans les climats trèsfroids les opérations qui auraient dû être faites au mois de mai. On donnera également les premiers labours aux terres dans les cantons pleins d'herbes et qui auront été gelés. On hersera les

proter hominum labores, unius bovis opera spatium to. tius messis absumit. Fit itaque vehicnlum, quod duabus rotis breviluus fertur. Hujus quadrala superficies tabulis nunitur, qux forinsecus reclines in summo rcddant spa. tia largiora. Ab ejus fronte carpenti brevior est altitudo tabularum. Ibi denticuli plurimi ac rari ad spicarum mensuram constituuntur in ordinem, ad superiorem partem recurvi. A tergo vcro ejnsdem veliculi duo brevissimi tcmones figurantur, velıt amites basternarum. Ibi bos capite in vehiculum verso jugo aptatur et vinculis, mansuetıs sane, qui non modum compulsoris cxcedat. Hic ubi veliculum per messcs corpit impellere, omnis spica in carpentum denticulis conjprehensa cumulatur, abruptis ac relictis paleis; altitudinem vel lumilitatem plerumque bubulco moderante, qui sequitur. Et ita per paucos itus ac reditus brevi horarum spatio tota messis impletur. Hoc campestribus locis rel æqualibus utile cst, et is, quibus necessaria palea non liabctur.

III. Nunc frigidissimis locis, qua Maio sunt pretermissa faciemus. Agros æeque proscinlemus. Herbosis et gelidis partibus vineta occabimus. Colligemus viciam. Fœnum Græcum resecabimus ad pabulum. Hoc meuse 
vignobles; on récoltera la vesec; on fauchera le fenugrec qui doit servir de fourrage. Il faut achever dans le courant de ce mois-ci la récolte des-légumes dans les pays froids. Il sera bou de conserver les lentilles que l'on récoltera alors, soit en les mêlant avec de la cendre, soit cn les serrant dans les vases à huile, ou dans des caques destinées aux salaisons, que l'on enduira aussitôt de gypse. On cueillera aussi les fèves au déclin de la lune, pourvu que ce soit avant le jour; et on les serrera avant que cette planète soit dans son croissant, après les avoir battues et les aroir fait rafraichir, afin que le charançon ne les endommage point. On récolte les lupins dans ce mois, et rien n'empèche de les semer aussitôt qu'on les aura tirés de l'aire, si on le juge convenable. Si on veut cependant les garder, il faudra les serrer dans des greniers éloignés de toute humidité. C'est le moyen de les conserver trèslongtcmps, surtout quand la fumée donnera continuellement sur ces greniers.

IV. On sèmera les chou: ce mois-ci vers le solstice, afin de pouvoir les transplanter au commencement du mois d'août, soit dans un lieu arrosé, soit dans un lieu détreınpé par les pluies qui commenceront alors à tomber. On pourra semer également bien l'ache, les poirées, les raiforts, les laitues et la coriandre, pourvu qu'on ne leur épargne pas l'eau.

V. On pourra aussi, comme nous l'avons dit ci-dessus, renfermer dans ce mois-ci une branche de grenadier dans un petit vase de terre cuite, afin de lui faire donner des fruits dont la grosseur soit moulée sur la capacité de ce vase. Il faut décharger à présent les branches des poiriers ou des pommiers qui seront trop chargés de fruits, en arrachant par-ci par-là toutcs les poires ou les pommes défectueuses, afin que la séve de ces ar-

locis frigidis peragenda est leguminum messis : itaque lenticulan collectam, cineri mistam, bene serrabimus, vel vasis oleariis aut salsamentariis replelis stalimque g) psatis. Nunc et faba luna minuente velletur, anle lucem sane; ef antequam luna procedat, excussa el refrigerata reponatur. Ita gurguliones non patietur infestos. Hoc mense lupinus colligitur, et si placuerit, statim seritur ex area : sed longe ab humore est ponendus in liorreis. Sic enim diulissime custoditur, maxime si granaria ejus aflaverit fumus assiduus.

IV. Hoc inense circa solstilinm brassicam seremus, quam inclıoante transferemus Augusto, vel irriguo loco, vel pluvia iniliante madefacto. A pium quoque bene serere poterimus, betas et radices et lactucas et coriandrum, si rigemus.

V. Hoc etiam ınense ramus Punici (sicul supra diximus) poterit intra fictile vasculum clandi, ut ad ejus unagriludinem poma restituat. Nunc pira rel mala, ubi ramos multa poma densabunt, interlegenda sunt quxcun. que vitiosa, ut succus qui ingrate his posset impendi, ad meliora rertatur. Hoc ctiam inense locis frigill is ziziplum bres, qui pourrait se consumer cn vaia à nourrir ces mauvais fruits, se reporte à de meilleurs. On pourra aussi semer ce mois-ci le jujubier dans les pays froids. Il faudra faire à présent la caprification des figuiers, de la manière que nous a vons exposée en dounant la méthode de culture de cet arbre. Il y a des personnes qui les greffent aussi ce mois-ci. On ente en boutons lc pêcher dans les pays froids. On béche le pied des palmiers. On ente dans ce mois-ci ou dans celui de juillet les arbres fruitiers, suivant la méthode que l'on appelle emplastratio. Cette méthode ne convient qu'aux arbres dont l'écorce contient unc séve grasse: tels sont les oliviers et d'autres semblables, comme dit Martialis; tel est aussi le pêcher. Or, voici comme se fait cette opération : On choisit sur de jeunes branches, nettes et fécondes, un houton qui promette de venir à bien, et on le cerne à la distance de deux doigts en carré, de façon qu'il se trouve au centre de quadrature; après quoi, au moyen d'un bistouri bien tranchant, on enlève l'écorce avec dextérité, et sans endommager le bouton. On enlève de la même manière un écusson garni de son bouton sur une partie de l'arbre à greffer, qui soit nette et féconde. Alors on attache le premier écusson sur ce dernier arbre d'une façon convenable, en le liant autour du bouton, pour le bien assujettir sans que le bouton soit endommagć, et de façon que le bouton de l'écusson substitué remplace celui qu'on aura enlevé; après quoi on enduit le tout par-dessus d'un lut qui doit laisser le bouton en liberté. On coupera les branches supérieures de l'arbre ainsi que ses souches, et, en ôtant au bout de vingt et un jours les ligatures qui retenaient l'écusson, on s'apercevra que le bouton d'une semence étrangère s'est incorporé merveilleusement dans un autre arbre.

serere poterimus. Nunc caprificandxe sunt arbores fici, sicut in ejus narravimus disciplina. Aliqui eas et lioc mense inserunt. Locis frigidis Persicus inoculatur : palmx planta circumfoditur. Hoc mense vel Julio celebratur insitio in pomis, quæ emplastratio dicitur. Solis arboribus conve. nit, quibus pinguis succus in cortice est, ut ficis et oleis ac similibns, ut Martialis dicit, et Persico. Fit antem sic : ex novellis ramis et nitidis ac feracibus gemman, qux bene apparebit sine dubio processura, duobus digitis quadratis circumsignabis ut ipsa statuatur in medio, et ita subtiliter cort:cem lerabis acutissimo scal pro, ne gemna ladatur. Item ex ea arbore, cui gestimus inserere, similiter cum gemma tolletur emplastrum, nitido tamen atque uberi loco. Tunc ibi convenieuter astringitur, et pressum circa gemmam vinculis conitur sine germinis laesione $c 0$ harere, it ea qua appositx redditur, locum gemma prioris includat. Tunc luto superlinis, et liberam gemman relinques. Ramos superiores ejus arboris secabis ac stir. pes: et ab uno et viginti diebus exactis resoluto vimine vinculorum, reperies externi seminis gemmam mire in as boris alienae menibra transisse. 
VI. Il est cneore bon de châtrer les veaux ce mois-ci, comme il a été dit ci-dessus. On a aussi raison de prendre ce temps pour la confection des fromages, et de tondre les brebis quand Ic pays est froid.

VII. C'est en ce mois qu'il faut châtrer' les ruches. Il y a un très-grand nombre de signes pour reconnaítre quand il est temps de récolter le miel. D'abord, aussitôt que les ruches sont bien pleines, les abcilles ne font plus entendre qu'un très léger bourdonnement. Dans les ruches en effet, comme dans l'intérieur d'un édifice, lc vide augmente l'intensité des sons; et par conséquent si le bourdonnement des abeilles semble rauque et considérable, c'est une preuve que les gáteaux de cire ne sont pas cn état d'ètre récoltés. De même, lorsqu'on voit les abeilles se donner beaucoup de mouvement pour expulser les bourdons, qui sont des mouches plus grosses qu'elles, elles annoncent par là qu'il est temps de récolter le miel. Au surplus, on châtrera les ruclıes dans la matinée, temps où les abeilles sont angourdies, et où elles 1ue sont pas encore irritécs par la chaleur. On fera parvenir dans les ruches de la fumce de galbanum et de bousc de vache sèche, qu'on entretiendra avec du charbon placé dans un fourneau de telle forme qu'il puisse renvoyer la fumée par une ouverfure étroite, et semblable à celle d'un entonnoir renversé, parce que cette fumée chassera les abeilles, et que l'on pourra dès lors couper les rayons de miel sans difficulté. Lorsqu'on récoltc les rayons dans ce temps-ci, il en faut laisser la cinquième partic pour servil' de nourriture à l'essaim, en ayant soin d'enlever surtout cequi est moisi ou défectueux. On fera le miel à présent en enveloppant plusieurs rayons dans un lingc très-propre, et en les y cxprimant avec soin. Mais, avant de les exprimer, on en retranchera

V. Hoc etiam mense vituli recte (ut diclum cst ante) castrantur. Nunc etiam cascum jure conficimus, et oves in frigida regione tondemus.

VII. Hoc mense alvearia castrabuntur, qua: matura esse ad mellis reditum siguis (quam) pluribus insfruemur. Primum si plena suut, apun subtile nurmur audimus. Nam vacuxe sedes favorum velut concava xdificia voces, quas acceperint, in majus extollunt. Quare cum murmuris souns magnus et raucus est, agnoscimus uon esse idoneas ad metenlum crates favorum. Item cim fucos, qui sunt apes majores, a sedibus suis, grandi intentione deturbant, matura mella testautur. Castrabuntur autem alvearia matutiuis horis, cum torpent apes, nec caloribus asperantır. Fumus admovetur ex galbano et arido finıo bubulo, quem in pultario factis carbonibus convenit excitare : quod vas ita figuratum sit, $n t$ velut inversi infuudi. buli angusto ore fumum possit emittere. Atque ita cedentibus apibus uıclla recidentur. Ad examinis pabulum lıoc tempore pars favorum debet quinta dimitli : sane putres ac vitiosi favi de alreariis auferantur. Nune mella confi. cimus congestis in mudissimum sabaum favis ac dili- les parties gâtées ou celles qui contiendront des petits, parce qu'elles corrompraicnt le miel ct lui donneraient un mauvais goût. Il faut laisser pendant quelques jours le miel nouvellement fait dans de petits vases ouverts, et l'écumer jusqu'à ce que sa chaleurse calme et qu'il cesse de bouillir, ainsi que cela se pratiquc pour le moût. Le miel qui coulera comme de lui-même, avant d'avoir été exprimć à différentes reprises, sera le meilleur. On fera aussi la circ dans ce mois. On commencera par l'amollir, en jetant dans un vase de cuivre plein d'eau bouillante lc reste des rayons qu'on aura cassés en petits morceaux; après quoi on la fera fondre dans d'autres petits vases dans lesquels on ne mettra point d'eau, et oll lui donnera telle forme que l'on voudra. S'il arrive que les nouveaux essaims sortent dans cc temps-ci á la fin du mois, il faudra que le gardien y ait attentivement l'œil, parce que les jeunes abeilles, que leur âge rend vagabondes, s'enfuiraient si on ne les gardait pas à vue. Comme elles restent à l'entrée de leurs ruches pendant un ou deux jours lorsqu'elles en veulent sortir, il-faudra se hâter de les recevoir dans de nouvelles ruches. Ainsi un gardien vigilant les obscrvera jusqu'à la huitième ou à la neuvième heure du jour, parce qu'il cst assez rare qu'elles s'ellfuicnt ou qu'elles fassent des émigrations plus tard, quoiqu'il s'en trouve quclques-unes qui prernent le parti de s'en aller aussitôt qu'elles sont sorties de leur ruche. Voici à quels signes on reconnaft que la désertion est imminente. Elles feront entendre deux ou trois jours auparavant un tumultc et un bourdonnement plus considérable qu'à l'ordinaire. Ainsi, dès que l'observateur en aura fait la remarque en approchant sou. vent son oreille de la ruche, il faudra qu'il redouble de précaution pour éviter tout accident.

geuter expressis. Sed antequam premamus, partes favorum corruptas, vel pullos labeutes recidemus : nam malo sapore inella cortumpunt. Mel recens paucis diebus apertis vasculis lrabendum est, atque in sunımitate purgandum, donec refrigerato calore musti (more) deferveat. Nobilin!s mel erit, quod ante expressionem secundam velut sponte profluxerit. Hoc etian mense ceram conficimus, quie iu vase anco ferveuti aqua pleno minute concisis favorum relinuiis mollietur, et deinde in alis rasculis sine ayua resolnta digeretur in formas. Nuuc si mense ultimo nova egrediuntur examina, custos esse debebit attentus, quii novellæ apes vagantibus animis juveutute nisi serventur, effugiunt. Exeuntia in aditu suo morantur uno aut duobus diebus, quæ statim novis alveariis excipienda sunt. Obserrabit antem custos assiduus usque in octavan vel nonau loram, quia post haec tempora non facile fugere aut cnisgrare consueverunt, quanris aliquae statim et procedere et abire non dubitent. Signa futura fuga liace sunt. Ante biduum vel triduum acrius tumultuantur et murmurant. Quod ubi apposita frequenter aure explorator agnoverit, solicitior adversum hice esse debelit. Solent hace 
Ce sont également les signes précurseurs d'une bataille. Mais on met fin à la mêlée par quelques grains de poussière, ou quelques gouttes d'hydromel, que l'on jette sur' les combattants; la douceur de cette liqueur étant très-efficace pour ramener la concorde parmi le peuple qui l'a produite. Puis, lorsque les bataillons scront pacifiés par ce moyen, et que les abeilles seront suspendues à une branche d'arbre, ou quelque part ailleurs que ce soit, on examinera si elles forment alors un seul groupe; auquel cas ce sera une preuve qu'il n'y a qu'un roi parmi elles, ou qu'elles sont réconciliées, et que la concorde règne entre elles. Si au contraire le peuple est suspendu sous la forme de deux ou de plusieurs mamelons, c'est une preuve qu'elles sont divisées entre elles, et qu'elles ont autant de rois parmi elles qu'il y aura de ees espèces de mamelons. On cherchera par conséquent ces rois dans les groupes d'abcilles qui paraîtront les plus nombreux, après a voir frotté à cet effet sa main de mélisse ou d'aclic de marais. Au reste, ces :ois sont un peu plus gros et plus longs, et ont les pattes plus droites que les autres abeilles. Leurs ailes sont aussi plus petites; leur couleur est bellc et luisante, et ils sont lisses et sans aucun poil, à l'exception d'une espèce de gros cheveu qui leur sort du ventre, et dont ils ne se servent néanınoins jamais pour offenser. Il y en a d'autres qui sont noirs et hérissés. Il faut les tuer tous, à l'exception du plus beau d'entre eux, que l'on conservera. Et si celui-ci vagabonde souvent avee ses essaims, on lui arrachera les ailes, afin qu'il se fixe dans la ruche, parce qu'alors aucune abeille ne s'écartera de lui. Si les essains d'une ruche ne multiplient point, on pourra $y$ joindre les abeilles de deux ou trois autres ruches; auquel cas il faudra avoir la précaution de les y tenir renfermées pendant trois jours, de les asperger de quelque liqueur

signa et cum pugnaturæe sunt, facere : quarum pugnam compescit pulvis aut mulsæ aquæ imber aspersus. Inest illi ad originis suxe reparandam concordiam dulcis auctoritas. Sed cum se agmina sic pacata in ramo aut loco quocunque suspenderint, si unius uberis eductione peudebunt, noris aut unnm regen esse universis, aut reconciliatis omnibus manere concordiam. Si vero duo vel plura ubera suspendens se populus imitatur, et discordes sunt, et tot reges esse, quot velıt ubera videris, confitentur. Ubi glo. bos apinm frequentiores videris, uncta manu succo melissoplyylli vel apii reges requiras. Sunt autem paulo majores, et oblongi magis quam cxtera apes, rectioribus cruribus, neque grandibus pennis, pulcliri coloris et nitidi, leves sine pilo, nisi forte pleniores quasi capillum gerunl in ventre, quo tamen non utuntur ad rulnus. Sunt alii fusci atque lirsuti , quos oportet extingui, et pulclurioreın relinqui. Qni si frequenter vagatur cum exaninibus, exectis alis reservetur : loc enim manente nulla discedet. Sed si mulla nascantur exanina, duorum vel trium multitudinem vasculorum ill unum conferre possumus : douce, de leur donner du miel pour nourriture, et de ne laisser à la ruche que de petites onvertures pour que l'air y puisse entrer. Lorsqu'on voudra repeupler une ruche dévastée par quelque maladie contagieuse, en y faisant passer d'autres abeilles, on examinera attentivement dans d'autres ruches bien peuplées si les cires des rayons, et surtout leurs extrémités, qui renferment les petits, ont la marque distinctive à laquelle on reconnait qu'il doit en naitre un roi ; et lorsqu'on y trouvera cettc marque, on eoupera le rayon où elle se rencontrera avec la postérité qu'il renferme, pour le porter dans la ruche qu'on veut repeupler. La marque à laquelle on reconnaít qu'il doit naître un roi d'un rayon, e'est lorsque dans le nombre des alvéoles qui contiennent des petits, il s'en trouve une plus grande et plus longue que les autres, qui a la forme d'un mamelon. Au surplus, il ne faut transporter les rayons que dans le temps où les petits, déjà prêts à naitre, s'efforcent, après avoir rongé leurs enveloppes, d'en dégager leurs têtes; parce que si on les transférait avant qu'il en fủt temps, ils périraient. S'il arrive qu'un essaim s'élève subitement en l'air, on l'effrayera par le bruit qu'on aura soin de faire avec du cuivre ou avec un petit vase de terre, et il retournera aussitôt à sa ruche, à moins qu'il ne se suspende aux feuillages voisins; auquel cas on l'en tirera avec la main ou avec une cuiller, pour le mettre dans une nouvelle ruche frottée avec les herbes accoutu. mées et aspergée de miel, laquelle ruche on laissera sur place; et l'on attendra le soir pour la ranger parmi les autres.

VIII. On fera encore en ce mois des pavés de plates-formes ainsi que de la brique, de la manière que j'ai indiquée.

IX. Les Grees assurent que les Egyptiens font les essais suivants pour s'assur'er du succès des dif-

dulci tamen liquore conspersas apes atque inclusas per triduum tenelimus, apposito cibo mellis, et exigua tantum spiracula relinquemus in cella. Quod si velis alvea. rium, cui per aliquam pestem multitudo subducta est, populi adjectione reparare, considerabis in aliis abundan! tibus ceras favorum et extremitates, quxe pullos lıbent, et ubi signum nascituri regis inveneris, cum sobole sua recides, et in id alvearium pones. Est antem lıc futıri regis signum : inter cactera foramina, quæ pullos continent, unum majus ac longius velut uber apparet. Sed tunc transferendi sunt, quando erosis cooperculis ad nascendun maturi capita nituntur exerere : naın si immaturos transtuleris, interibunt. Si autem se subitum levibit exa. men, stiepilu æris terreatur, aut testulæ : tunc ad alvearium redibit, aut in proxima fronde pendebit, et inde in novum vas herbis consuetis et melle conspersum manu attrahatur, aut trulla, et cum in eo loco requieverit, vespere inter alia collocefur.

VIII. lloc etiam mense pavimenta faciemus sul diro ef lateres, more quo dixi. 
férentes semences. Ils cultivent dans ce temps-ei un petit espace de terrain pris sur un ehamp labouré et humide, et $y$ sèment des graines de toutes les espèces de blés et de légumes, sur des plan. ches séparées les unes des autres. Ensuite ils examinent au lever de la Canicule, que les Romains plaeent au quatorzième jour des calendes d'août, quelles sont celles de ees semences que eette constellation brûlera, et celles auxquelles elle ne portera point de préjudice, pour se garder par la suite de semer les premières, et pour s'en tenir aux autres, parce que cette constellation brûlante pronostique, soit en eonsumant ees plantes, soit en les épargnant, le succès bon ou mauvais qui les attend l'année suivante.

$X$. On prend le eœur de la camomille dans le temps que cette herbe est en fleur, avec la précaution d'arracher les feuilles blanches qui en couronnent la fleur, pour ne conserver que la partie dorée de eelle-ci; et on en fait infuser la valeur d'une uncia sur une livre d'huile, puis on laisse cette infusion expǫsée pendant quarante jours au soleil.

XI. Confeetion de fleur de lambrusque. On cueille du raisin sauvage dans le temps qu'il est en ileur, et qu'il n'y a point de rosée sur terre. On l'étend au soleil, afin que toute son humidité s'évapore, et que sa fleur, étant séchée, se détache plus aisément. Alors on la passe par un petit erible serré, afin que les grains n'en glissent pas à travers, et que la fleur tombe seule en bas. On conserve cette fleur infusée dans du miel; et lorsqu'elle y a été confite pendant trente jours, on l'assaisonne par le même procédé que le vin rosat et avec les mêmes ingrédients.

XII. Composition de l'alica. On liera en bottes de l'orge à demi mûre, puis on la fera griller

IX. (Fraci asserunt Egyptios lioc more proventum futuri cuj:ısque seminis experiri : aream brevem loco sub. acto et luumido nunc excolunt, et in ea divisis spatiis omnia frumenti vel leguminum semina spargunt. Deinde in ortu Canicula, qui apud Romanos quartodecimo calendas Augusti die teletur, explorant quac semina ortım sidus exurat, qua illasa custodiat; his abstinent, illa procuraut; quia indicium nox ant beneficii per annum futurum generi unicnique sidus aridum prosenti exitio vel salute pranisit.

X. Per olei libras singulas cliannmeli herba floreıtis auream medietatem, projectis albis foliis, quibus flos am. bitur, unciarum singularum pondus infundis, et quadra. ginta diebus in sole constitues.

XI. [De onanthe.] Silvestres uras, cum florent, sine rore colligimus, et expandimus in sole, ne quid restet li1moris, et flos ad excutiendum siccior apparetur. Tunc cribello spisso cernimus, ut grana non transeant, scd flos solus decidat. Hunc in melle servamus infuso : et cum dielous triginta fuerit conditum, temperamus eo genere ef more, quo rosatum moris est temperare.

XII. Alica [Alfila.] Ordeum semimaturum, cui adliuc dans un four, afin qu'elle puisse aisément étre moulue. Ensuitc on aura soin de mêler une certaine quantité de sel par modius d'orge, en la faisant moudre, et on la conservera après l'avoir préparée ainsi.

XIII. Les mois de juin et de juillet se ressemblent sous le rapport de la durée des heures.

A la première et à la onzième heure, le gnomon donne vingt-deux pieds d'ombre.

A la seconde et à la dixieme, il en donne douze. A la troisième et à la neuvième, il en donne huit.

A la quatrième et à la huitième, il en donne cinๆ.

A la cinquième et à la septième, il en donne trois.

A la sixième, il en donne deux.

\section{LIVRE HUITIEME.}

JUILLET.

I. On bine vers les calendes de juillet les terres qui ont reçu le premier labour au mois d'avril. On achève à présent la moisson du froment dans les pays tempérés, en suivant la méthode que r.ous avons donnée. Il sera très-bon de débarrasser les terrains incultes des arbres et des broussailles dont ils seront couverts, quand la lune sera dans son déclin, en les coupant par les racines et en les brûlant. On charge de terre ce mois-ci, après la moisson, le pied des arbres qui sont plantés au milieu des ehamps moissonnés, dans la vue de les garantir de la trop grande ardeur du soleil. La journée d'un homme suffit pour en charger vingt des plus grands. Il faut aussi bêeher à présent les jeunes vignes, tant le

superest aliquid de virore, per manipulos ligabis, et torrebis in furno, ut facile mola possit infringi, et in modin uno salis aliquantum, dın molitur, miscere curabis ac servabis.

XIII. Junius ac Julius horarum sibi ąqua spatia contılerunt.

\begin{tabular}{|c|c|c|c|c|}
\hline Hora & 1 & et & XI & pedes \\
\hline Hora & 11 & et & $\mathbf{x}$ & pedes \\
\hline Hora & III & et & IX & pedes \\
\hline Hora & IV & et & VIII & pedes \\
\hline Hora & $\mathbf{v}$ & et & vil & pedes \\
\hline Hora & vI & & & pedes \\
\hline
\end{tabular}

\section{LIBER OCTAVUS.}

I. Julio mense agri qui Aprili proscissi fuerant, circa ralen. das iterantur. Nunc tocis temperatis tritici messis expletur, more quo dictum est. Silvestres agri utilissime extirpa. buntur arboribus atque virgultis', cum luna decrescit, desectis radicibus atque combustis. Hoc meuse arbores, qum in niesse steterant, sectis messibus obruantur aggestione terrarum propter nimios solis ardores. Opera una $x$; 
matln que le soir quand la chaleur est tombée, pulvériser la terre à leurs pieds, et en cearter le gramen. II sera bon d'extirper la fougère et la lèche ee mois-ei ou avant les jours eanieulaires.

II. On sème aussi ce mois-ci, la eiboule dans les pays qui sont arrosés et froids, ainsi que le raifort et l'arroelic quand on peut les arroser. On sème eneore le basilie, la mauve, la poirée, la laitue et les poireaux, qu'il faudra aussi arroser. On sèmera ce mois-ci les navets et les raves dans un lieu arrosé, dont la terre soit grasse et ameublie, sans êlre eompaete. Ces sortes de raeines se plaisent dans les lieux humides et. en pleine campagne. Mais les navets sont meilleurs quand ils viennent dans un terrain see, presque maigre, ineliné ct sablonneux. La qualité du sol change l'une de ces graines en l'autre. En effet, si ·'on sème des raves dans un terrain pendant deux ans, ellcs s'y ehangent en navets; comme eeuxci se changent en raves dans un autı. Ces raeines veulent que le terrain oì on les sème soit labouré, fumé et remué, ee grui sera également profitable aux grains que l'on y sèmera la même aınée. Quatre sextarii de raves et cinq de navets suffisent pour cnsemencer un jugerum. Si ces raeines sont trop pressées, on en arrachera quelques-unes, afin que les autres se fortifient. Pour faire grossir les raves, on les déterrera, et, après avoir arraché toutes leurs feuilles, on en eoupera la tigc à l'épaisseur d'un demi-doigt; après quoi on les remettra dans des sillons bien labourés, en les cspacant de huit doigts ; puis on les reeouvrila de terre, et on les foulera aux pieds, ce qui les fera grossir.

III. On peut aussi enter en écusson ce mois-ci de la manière que j’ai cnseignée ci-dessus. J'ai même observé, d'après l'expérience que j'en ai

maximas obruet. Nunc et novella vites mane ef vespere jan calore deposito effodi debent, et averso gramine pulverari. Hoc mense utiliter vel ante caniculares dies filices extippahis el caricem.

11. Hoc etiam mense cepullas serimus, irrignis ac frigidis locis, et radices et atriplicem, si rigare possumus, et ocinum, malvas, helas, lactucas, et porros rigandos. Iloc mense loco irrigno napos seremus et rapa, solo pntri et soluto nec spisso. (Rapa) locis lumidis lactantur et campis. Sed napus in sicco et prope tenui atque devexo et sahuloso melior uascitır. Loci proprictas utrumque semen in allerum nutat. Nan rapa in alio solo per bieunium sata mufantır in nap̧os; alio vero uapus transit in rapum. Subactum solum stercoratum versatumique conquirunt, quod et ipsis et segetibus proderit, quxe ilsi anno coden seruntur. Jugreo raporum quatuor sextarii, napi autem quinque sufticiunt. Si spissa sunt, intervelles aliq̨ua, ut coctera roborentur. Ut rero semina majora redigantur, eruta rapa foliis omnibus purgahis, et ad dimidii digiti crassitudinem in caule succilles. Tunc in sulcis diligenter subactls octonis digitis separata ohrues, et injicies ter. ram, et calcabis. Ita magna nascenur.

palladius. faite, que des poiriers ou des pommiers qui av́aicnt été entés à présent dans des pays lıumides avaient très-bien profité. Il faut aussi cueillir ee mois-ei les mauvais fruits, dont la quantité exeessive charge les branches des arbres fruitiers tardifs; comme jc l'ai dit ci-dessus, afin que la séve de ces arbres tourne à la nourriture de fruits meilleurs. II m'est arrivé de planter à présent dans des pays froids et dans un terrain arrosé une bouture de eitronnier; et je me rappelle qu'après l'avoir animée en l'arrosant tous les jours, j’ai cu le bonheur de la voir répondre à mes vœux, tant par sa belle venue que par son rapport. On peut enter à présent le figuier en bouton, et greffer le citronnier dans les terrains humides. On peut bêeher au milieu du mois les pieds de palmiers. Les amandes sont à présent bonnes à être cueillies dans les pays tempérés.

IV. C'est prineipalement à présent qu'il faut faire couvrir les vaehes par les taureaux. En effet, eomme elles portent pendant dix mois, elles se trouveront dèslors en état de vêler au printemps. Et d'ailleurs il est certain qu'elles deman. dent ardemment le mâle, quand les engrais du printemps ont excité le tempérament ehez elles. Columelle assure que quinze vaches peuvent suffire à un taureau, et qu'il faut avoir soin qu'elles ne soient pas, par excès d'émbonpoint, hors d'état de eoneevoir. Lorsque le pays où l'on élève ces bestiaux est abondant en fourragc, on peut faire colivrir les 'vaches tous les ans. Mais, lorsque le fourrage y est rare, il ne faut les faire remplir que de deux annéesl'une, surtout si l'on est dans l'liabitude de les employer à quelque travail. On choisira des béliers très-blanes ct qui aient la laine douce, pour les faire saillir ce mois-ci. Et la blancheur de la robe n'est pas la seule qualité

III. IIoc etiain mense emplastratio celebrari potest, sicut ante demonstravi, et pirus vel nualus locis lumidis nunc insita me explorante processit. Hoc etiam mense' in pomis serotinis, qua ubertate nimia ramos oneraverunt (sicut pradiri) interlegenda sunt, si (qua vitiosa repereris, ut arboris succum vertamus ad meliorum nutrimenta pomorum. Nunc citri taleam loco irrigun frigidis regionihus me plantasse memini, et quotidianis animasse liquoribus, quae el nasceulo et afferendo votum folicitatis iequavit. IJoc tempore locis liumidis inoculari ficus et inseri citrius potest : mense jam medio palına planta circunforli. Nunc loris temperatis anygglala mitura sınt ad legendum.

IV. Iloc tempore maxime tanris submittendx sunt vaccir, quia decen mensium partus sic poterit maturo vere conclurli; et certum est eas post vernam pinguedinen ge. stientes veneris amare lasciviam. Uni tanro quindecim vaccas Columella asserit posse sufficere, curandunque ne concipere nequeaut nimictate pinguediuis. Si abındantia palupli est in regione, qua pascimus, potest annis omnilsus in forturam vacca subınitti : si vero indigetur loc genere, alteruis temporibus oneraudx sunt, maximeque, si exden vaccs, alicui operi servire consueverunt. IIoc mense arie- 
qu'il faille rechercher en eux ; celle de leur langrue n'est pas moins importante. lin effet, pour peu que cette partie de leur corps soit obsetrcie parquelques taches, le mélange decouleurs qu'on y apercevra se transmettra à leurs produits. Un bélier blane donne assez souvent un produit d'une autre couleur; au lieu que, comme le dit Columelle, il ne peut jamais venir un agneau blane d'un bélier noir. On choisira les béliers hauts et de grande taille, avec ventre bas et couvert de laine blanehe, la queue très-longue, la toison épaisse, le front large, les testicules gros, et qui soient dans la troisième année de leur age; quoiqu'ils puissent saillir fruetueusement jusqu'à l'âge de huit ans. Il faut faire couvrir les brebis à l'âge de deux ans. Elles peuvent porter jusqu'à celui de cinq, mais elles dépérissent la septième année. On ehoisira des brebis qui soient d'une grande, taille, qui aient la toison longue et très-donce, et le ventre bien laineux et d'une grande capaeité. Mais il faut avoir l'attention de ne point laisser manquer ce bétail de fourrage, et de le mener paitre loin des buissons, qui détruiraient sa laine et lui déehireraient la peau. Il faut faire couvrir les brebis au mois de juillet, afin que leurs petits soient fortifiés avant l'hiver. Aristote assure que si on vent leur faire conce voir une plus grande quantité de mâles que de femelles, il faut choisir un temps sec et un jour où le vent du septentrion souffle, pour les faire eouvrir pendant qu'elles paitront vis-à-vis ce vent. Au 'lieu que si l'on veut avoir plus de femelles que de mâles, il faut chercher les vents du midi, pour les faire couvrir pendant qu'elles paitront du cóté de ce vent. Il faut substituer de nouveaux agneaux aux brebis mortes ou défectheuses. On vendra en automne toutes celles qui

tes candidissimi eligendi et admittendi sunt mollibus la. uis, in quibus non solum corporis candor considerandus $\mathrm{est}$, sed etian lingua : qux si maculis fuscabitur, varietiltem reddit in sobole. De albo plerumque nascitur colois alterius : de fuscis nunquam (sicut Columella dicit) potest albus creari. Eligemus arietem altum, procerum, ventre promisso, et lanis candidis tecto, cauda longissima, velleris densi, fronte lata, magnis testibus, atatis trima, qui tameu usque in octo annos potest utiliter iuire. Foumina dehet bima submitti, quxe usque in quinquennium forturæ necessaria est, anno septimo deficit. Eligenda est rasti corporis et prolixi velleris ac mollissimi, lanosi et inagni 1t teri. Sed providendum est in loc genere, ut pabuli ubertate saturetur, et longe pascatur a sentibus, qui et lanan minuuut, et corpus incidunt. Admiltendi sunt mense Julio, ut nati ante hiemem convalescant. Aristoteles asserit, si masculos plures creari velis, admissura tempro siccos dies', et lualitum Septentrionis eligendum, et contra eum ventum greges esse pascendos : si foeminas generari velis, Austri captandos flatus, et in cum pascua dirigenda, ac sir. ineundas matres, [ut] mortuarum vel vitiosarum numerus novella sobole reparetur. Antumno debiles quaqque pretio mutentur, ne eas iubecillits hibernum frigus se tronveront affaiblies, de peur que le froid de l'hiver ne les emporte, vu leur faiblesse. Il y a des personnes quí empêehent les. béliers de saillir pendant les deux mois qui préeèdent le temps de leur accouplement, afin que le délai da plaisir allume de plus en plus en eux le feu de la passion. D'autres les laissent saillir sans ménagement, afin d'en avoir des produits pendant tout le cours de l'année.

V. Les Grees assurent que sl l'on arrache le gramen ce mois-ci, quand le soleil sera dans le signe de l'Écrevisse, et que la sixième lune sera dans celui du Capricorne, ses raeines ne reprendront point, et qu'il mourra. Ia même chose arrivera si on l'extirpe avec des houes de cuivre préalablement chauffées au four, et refroidies non pas avec l'eau, mais avec du sang de bouc, dans lequel on les aura fait tremper.

VI. On fait ce mois-ci du vin de scille de la manière que voici : on fait sécher loin du soleil, vers le lever des Canicules, de la seille cueillie dans des pays montagneux ou voisins de la mer. On en jette une livre dans une amphore de vin, après en avoir retranché les parties superflues, et avoir jeté do cóté les feuilles dont l'extrémité de cette plante est couverte. D'autres font infuser ces feuilles mêmes dans du vin, en les y plongeant après les avoir suspendues au bout d'un fil, afin de pouvoir les en retirer quarante jours après, sans qu'elles aient trempé dans la lie. Cette espèce de vin combattra la toux, purgera le ventre, divisera la pituite, soulagera de mal la rate, rendra les yeux perçants, et aidera ì la digestion.

VII. Compositlon de l'hydromel. On prendra au commencement des jours caniculaires de l'eau de fontaine propre. Le lendemain, on mettra dans

absumat. Aliqui duobus ante mensibus arietes a coitu revocant, ut facem libidinis augeat dilatio voluptatis. Quidam coire sine discretione permittunt, ut hoc eis gevere per annum totum foctura non desit.

V. Hoc mense', cum sol Cancri tenebit hospitiun, luna sexta in Capricorni siguo posita, gramen ablatım Graci asserunt nilil de radicibus redditurum. Item si bidentes cyprei fiant, et sanguine tingantur lircino, et post formacis ardores non aqua sed eodem sanguine temperentur, per cos erutum gramen extingni.

V1. Hoc nense vinum scillite sic facimus : scillam de montanis aut maritimislocis sub ortu Canicularum lectam procul a sole siccamus Ex lac in vini amphoran unius libræ mensuraun mittimus, recisis ante tamen superflus et abjectis foliis, quibus pars extrema velatur. Quidam relamina ipsa filo inserta suspendant, ut vino infusa mer. gantur, ef non admista fecibus post $\mathbf{x 1}$, dierum spatiun serta qua appensa sunt auferantur. Hoc vini genus tussi resistet, ventrem purgabit, flegma dissolvet, spleneticis proderit, acumen præstabit oculorum, concitabit digestionis anxilia.

VII. [De hydromelli.] Inclıoantibus Canicularibus diebus aquam puram pridie sumis ex fonte. In tribus aquae 
trois sextarii de cette ear un sextarius de miel non éeumé; et après avoir partagé ce mélange avec soin dans des vases propres à faire lc vin cult jusqu'à diminution d'un tiers, on le fera agiter continuellement pendant einq heures par des enfants impubères, qui remueront les vases à cet effet; après quoi on le laissera cxposé à l'air pendant quarante jours et quarante nuits.

VIfI. Composition du vinaigre de scillc. A près avoir jeté de côté toutes les parties dures d'une seille blanehe et cruc, on en coupera en petits morceaux le plus tendre du cœur, dont' on plongera la valeur d'une livre et six uncic dans douze sextarii de vinaigre très-mordant. On bouehera le vase, pour le laisser exposé pendant quarante jours au soleil. Ensuite, après avoir jeté la scille, on passera soigneusement ce vinaigre, et on le survidera dans un vase bien enduit de poix. Autre vinaigre bon pour la digestion et pour la santé : On met dans un petit vase huit draehmes de seille et trente sextarii de vinaigre, avec une uncia de poirrc et une légère dose de menthe et de cannelle, pour s'en servir quelque temps après.

IX. On fait réduire en poudre un sextarius et demi de graine de moutarde; on mêle avec cette poudre cinq livres de miel, une d'huile d'Espagne, et un sextarius de vinaigre mordant; et quand le tout a étć bien broyé, on l'emploie à son usage.

$\mathrm{X}$. Les heures de juillet et $\mathrm{d} \Omega$ juin sont d'une égale durée.

A la première et à la onzième heurc, lc gnomon donne viugt-deux pieds d'ombre.

A la seconde et à la dixièmc, il en donne douze.

sextariis unum sextarium non despumati mellis admisces, ac diligenter per carenarias divisum quinque horarum spatio continuo per investes pueros curahis agitare vasa ipsa concutiens. Tuuc Xt diebus ac noctibus patieris esse sub exio.

VIII. [De aceto scillitico.] Syuilla albre cruda projectis duris atque extrinsecus positis omnilus, teueran medietaten ad libram el sex uncias per nimutas partes reciles, et in aceti acerrimi duolecin sextariis merges. Vas signatum quadraginta diehus patieris esse sub sole : post aljjecta słuilla acetum diligentius excolabis, et in bene picata vasa transfundes. Alind acetım digestioni et salıti accummodım : Squillae dragmas vu, accti sextarios $x \times x$ mittis in vasculo, et piperis unciam unam, inentx et casia aliquantun, et post [aliquod] tempus uteris.

IX. Sinapis semen ad modum sextarii unius et semis, redigere curabis in pulverem, cui mellis pondo $\mathbf{v}$, olei lispani unam libram, acetiacris unum sextarium misces, el tritis omnibus diligenter uteris.

X. Julii et Junii horas par mensurarun libra composuit.

Hora I et $x I$ peiles $x x i 1$.

Ilora it et $x$ pechs xil.

llora in et ix pedes vin.
A la troisieme et à la neuvième, il cn dome huit.

A la quatrième et à la huitic̀me, il en donne cing.

A la cinquième et à la septième, il en donne trois.

A la sixic̀me, il en donne deux.

\section{LIVRE NEUVIEME.}

\section{AOUT.}

I. On commence à la fin du mois d'août, vers les ealendes de septembre, à labourer les terrains plats, humides et maigres. On presse en ce moment les préparatifs de la vendange dans les pays voisins de la mer. On herse aussi les vignes dans les pays très-froids.

II. Si l'on a des terrains plantés en vignes qui solent maigres, et que la condition des eeps ne soit pas meilleure, on y sèmera dans ce nois trois ou quatrc modii de lupins par jugerum; après quoi on les hersera. Quand ees lupins seront venus, on en couchera la tige sur la terre; c'est un excellent engrais pour la vigne. Tout autie lui est contraire, et vieie la qualité du vin.

1II. On épampre à présent dans les pays froirls; au lieu qu'il vaut mieux laisser de l'ombie aux grappes dans les pays brúlants et sees, afin que l'ardeur du so!eil ne les dessèehe point; ce qu'on ne pourra néanmoins pratiquer que lorsque le peu d'étendue des vignobles; ou.la facilité de trouver des ouvricrs, le permettra. On peut aussi arracher la fougère ct la lèche ce mois-ci.

IV. Il faut mettre à présent le feu aux prairies, afin que les tiges des herbes qui montent trop vite soicnt lapprochées de leurs racines, et

$$
\begin{array}{lrrrrr}
\text { Hora } & \text { iv } & \text { et } & \text { vul pedes } & \text { v. } \\
\text { Ilora v } & \text { el vul piles } 111 . \\
\text { Hora vi } & & & \text { pedes } & \text { 1I. }
\end{array}
$$

\section{LIBER NONLS.}

J. Augusto mense ultimo circa calendas Septembres ager planus, hunidus, exilis incipiat exarari.' Nunc maritimis locis vindemia apparalus urgetur. Iloc etiam mense locis frigidissinis occatio vinearum fit.

11. Hoc lempore, si term exilis in vinea est, et vinea ipsa niserior, tres vel quiltuor lupini modios in jugero spargis, atque ita occabis. Quod ubi fiuticarerit, evertitur, et optimum stercus prabet in vineis, quia letanen propter vini vitium non convenit inferre vinetis.

III. Ninc locis frigiclis pampinatur, locis vero ferventibus ac siccis ohımbratur polius uva, ne vi solis arescat, si aut vinex brevitas aut facultas operarum permittit. Iloc etiain mense extirpare possumus carecta atque filecta.

IV. Nunc urenda sunt pascua, it et altorum fruticum festinatio reprimatır ad stirpes, ct incensis aridis nova laxtins lierba succedat. 
que les herbes sèches étant brûlécs, il leur cn succède de nouvelles avec plus d'abondance.

V. II faut encorc semer à la fin de ce mols des raves et des navets dans les pays sees, en s'y prenant comine je l'ai indiqur plus haut. On sème à la fin de ce mois-ci dans les pays secs les raiforts destinés à la consommation de l'hiver. Ces racines ainsi que les raves aiment une terre grasse, ameublie et labourée longtemps. Elles craignent le tuf et le gravier, et se plaisent sous un ciel nébuleux. Il faut les semer sur de grandes planches qui soient bêchées profondément. Les meilleures sont celles qui viennent dans les sables. On les sèmera peu de temps après la pluie, à moins qu'on ne soit à portée de les arroser. Dès qu'elles seront semées, on les recouvrira de terre à l'aide d'un sarcloir léger. Il en faut deux sextarii ou quatre, suivant la pratique de quelques personnes, pour ensemencer um jugerum. On ne leur donnera pas de fumier, parce qu'il les rendrait sponglenses; et il vaudra mieux les couvrir de paille. Elles deviendront plus agréables, quand elles scront arrosées souvent avec de l'eau salée. On regarde comme les femelles celles de ces racines qui sont les moins âcres, qui ont les feuilles les plus larges et les plus lisses, et dont la verdurc cst d'un aspect plus agréable. Ce sera donc la graine de cellesci quc l'on ramassera. On croit qu'elles grossiront davantage, lorsqu'on aura arraché toutes leurs feuilles, en ne leur laissant qu'une simple tigc, ct qu'on les aura souvent couvertes de terre. Si lorsqu'elles sont trop âcres on veut les rendre plus douces, on en fera infuser la graine pendant un jour et unenuit dans du miel, ou dans du vin fait avec du raisin séché au soleil. Au surplus, il est constant que le raifort cst ennemi

V. Hoc etiam mense ultimo siccis locis rapa et napus serenda sunt hac ratione qua ante dictun est. Hoc mense ultimo locis siccioribus radices sernntur, qua lieme sui usum ministrent. Amant terram pinguem, solutam, et diu subactam, qualem rapa. Tofum et glaream reformidant. Gaudent cali statu nebuloso. Serendae sunt spatiis gran. dibus et alte fossis. Meliores proveniunt in areıs. Serantur post novam pluviam, nisi possint forte rigari. Qnod satum est, statim debet operiri levi sarculo. Jugerum duo sextarii, vel, ut quidam, quatuor, cum seruntur, implent. Latamen non est ingerendum, sed potius palex: quia inde fungosæe sunt. Suaviores fiunt, si eas aqua salsa frequenter aspergas. Radices fominini generis putantur, quæ minus acres sunt et habent folia latiora [et] levia, et cum jucunditate virentia. Ex his ergo semina colligemus. Majores fieri creduntur, si sublatis omnibus foliis, el solo tenui caule dimisso sape terris operiantur. Si ex uimis acra dulcem fieri velis, semina die et nocte melle macerabis aut passo. Raphanum tamen sicut brassicam constat esse vitibus inimicam. Nam si circa se serantur, natura discordante refugiunt. Hoc eliam mense pastinacas se. remus. de la vigne, ainsi que le clou, puisque, dès qu'il est semé auprès d'clle, cellc-ci se recule par l'effet d'une antipathie naturellc. On sèmera aussi ce mois-ci des panais.

VI. On ente aussi à présent les arbustes en écusson. Presque tout le monde greffe à présent le poirier ct le citronnicr dans les terrains arrosés.

VII. Les frelons sont à charge ce mois-ci aux ruches; aussi faut-il leur faire la guerre ct les détruire. On fera aussi à présent tout ce qu'on aura négligé de fairc en juillet.

VIII. Si l'on manque d'eau, il faudra en chercher à présent. Or voici par quelle méthode on parvient à en trouver : Quand on voudra chercher de l'eau dans un endroit, on tournera la vuc, avant le lever du soleil, du côtć du levant, en se tenant couché sur le sol tout de son long, le menton appuyé contre terre. Si l'on voit alors s'élcver une vapeur légèrement nébuleuse, et qui se résout, on remarquera bicn l'endroit où paraltra ce phénomène, en guidant son observation a l'aide de quelque souche ou de quelque arbre du voisinagie; car cette observation cst 1 indice cons. tant d'unc source cachée. Mais on observera aussi la nature du terrain, afin de pouvoir juger de la quantité d'eau plus ou moins grande qui pourra s'y trouver. La craic ne donnera que des veines maigres, et d'une eau peu agréable. Dans le sable on ne troure que des filets d'une cau également peu potable, fortement chargée, et enfoncée sous le sol à des profondeurs considérables. La terre noire ne donnera qu'une très-petite quantité d'eau, qui filtrera goutte à goutte, et qui ne sera que le résultat des pluies et de l'humidité de l'hiver; mais cette eau sera d'un gon̂t excellent. Le gravier donnera des veines médiocres et ineertaines, mais leurs eaux l'emporteront sur toutes

VI. Etiam nunc emplastrantur arbusta. Pirum nunc pierique inserunt, et locis irriguis arborem citri.

VII. Hoc mense crabrones molesti sunt alveariis apun, quos persequi ac necare debemus. Nunc etiam quæ Julio non occurrimus facere, exequamur.

VIII. Nunc si deerit aqua, eam quarere ac vestigare debebis, quam taliter poteris invenire. Ante ortum solis iis locis quibus aqua quarenda est, æqualiter pronus mento ad solum depresso jacens in terra spectabis orientem, et in quo loco crispum subtili nebula aerem surgere videbis, et relut rorem spargere, signo aliquo vicinæ stirpis aut arhoris prænotabis. Nam constat siccis locis, ubi lıc fiet, aquam latere. Sed terrarum genus considerabis , ut possis vel de tenuitate vel de abundantia judicare. Creta tenues nec optimi saporis venas creabit; sabulo solutus exiles, insuaves, limosas, et spatio altiore submersas; nigra terra luumores et stillicidia non magna ex hibernis imbribus et liquore collecta, sed saporis egregii; glarea mediocres et incertas venas, sed suavilate præcipuas; sabulo masculus et arena et carbunculus certas et ubertate copiosas : in saxo rubro bonæ et abundantes sunt. Sed providendum est, ne inventæe inter rimas refu. 
les autres par leur goût agréable. Le sable ferme, ainsi que le gravier et les couches de charbon, donneront des veines eertaines et qui seront inépuisables. Il s'en trouvera de bonnes, et qui seront abondantes dans les roches rouges. Mais il faut prendre garde que les eaux que l'on aura trouvées ne s'échappent par les pores de la terre. Les eaux sont abondantes, fralehes et salubres au pied des montagnes, ainsi que dans les eailloutages; au lieu qu'elles sont saumâtres, lourdes, tièdes et désagréables au goût dans les pays plats. Ft quand elles s'y trouvent d'un goût exeellent, e'est une preuve quelles proviennent originairement d'une montagne. Au surplus, elles peuvent aequérir, même en pleine eampagne, la doueeur des eaux qui prennent leur souree dans les inontagnes, pour peu qu'elles soient eachées sous des arbrisseaux qui les eouvrent de leur ombre. Voiei d'autres indieations propres à guider dans la reeherehe des sourees eachées, auxquelles on pourra avoir eonfianee toutes les fois qu'il n'y aura point de mares d'eau dans l'endroit, qu'il n'y aura pas d'eau stagnante ou d'éeoulement habituel : e'est la présenee du jone ordinaire, du saule des forêts, de l'aune, du poivrier sauvage, du roseau, du lierre, et des autres plantes qui se plaisent dans l'eau. On ereusera done l'endroit où se trouveront les indieations que nous venons de donner, jusqu'à einq pieds de profondeur, sur une largeur de trois pieds; et quand le soleil sera prêt à se eoueher, on mettra'dans cette fosse un vase de euivre ou de plomb propre et graissé par dedans, dont l'ouverture sera tournée vers le fond de la fosse. Iinsuite on étendra, en l'appuyant sur les bords de la fosse, une elaie tissue de baguettes et de branehages, et l'on reeouvrira le tout de terre. $\mathrm{Si}$, lorsqu'on viendra à ouvrir la fosse le lende-

glant, et per iutervenia dilabantur. Sub radicibus montiun, et in saxis silicibus uberes, frigidis, salubres : locis campestribus sals $x$, graves, tepidæ, insuaves : quarum sapor si optimus fuerit, noveris eas sub terris exordiun de moute sumsisse. Sed in mediis campis montanorum fontium suavitatem consequentur, si unbrantibus tegantur arbustis. Sunt et hac signa vestiganda aqua, quibus tunc credimus, si neque lacuna est, neque aliquis ibi ex consuetudine humor insidet aut praterit. Juncus tenuis, salix silvatica, alnus, vitex, arundo, edera ceteraque, si qua huınore gignuntur. Locus ergo, ubi supradicta signa repereris, fodiatur latitudine pedibus tribus, altitudine pedibus quinque, et proxime solis occasum, mundum vas ibi æreum vel plumbenu interius unctum 'inversum ponatur in solo ipsius fossionis. Tunc supra foss $x$ labra crate facta de virgis ac frondibus, additaque terra, spatium omne cooperiatur. Sequenti die aperto loco, si in eodem vase sudores [intrinsecus] invenientur aut stilla, aquas ibi esse non dubites. Item si vas figuli siccum, neque coctum, eadem ratione ponatur, ac similiter operiatur; altero vero die, si aquarum vena est maln, on trouve que le vase sue pardedans, ou que l'eau en dégoutte, il u'y a point de doute que eet endroit ne renferme de l'eau. De même si l'on met dans eette fosse un vase de terre see et non passé au feu, et qu'on le reeouvre de la même manière, on le trouvera le lendemain dissous par l'humidité dont il aura été imprégné, lorsqu'il y aura une veine d'eau dans le voisinage. Ull flocon de laine mis également dans une fosse, et reeouvert de même indique aussi la présenee de l'eau en abondanee, s'il en exprime quand on vient le presser le lendemain. Un endroit renfermera eneore de l'eau toutes les fois qu'on aula mis dans une fosse, en la reeouvrant, une lampe allumée et pleine d'huile, et qu'on la trouvera éteinte le lendemain, quoiqu'il y resté encore de l'huile. De mème, si l'on fait du feu quelque part, et si, lorsque la terre sera échauffee, elle répand une fumée humide et nébuleuse, autre preuve de l'évidenee de l'eau. Une fois ees indiees reeonnus, et leur certitude bien eonstatée, on ereusera un puits pour ehereher la souree de l'eau; ou, s'il y a plusieurs sourees, on les réu. nira en une seule. Il faut ehereher les eaux partieulièrement au pied des montagnes et du eôté du nord, paree qu'elles y sont plus abondantes et meilleures que partout ailleurs.

IX. Mais il faut examiner s'il n'y a pointde danger pour les ouvriers qui travaillent à ereuser les puits, paree que le sol dégage souvent des miasmes de soufre, d'alun et de bitume, dont le mélange empeste l'air, remplit les narines des ouvriers, qui n'échappent au danger de suffoquer que par une prompte fuite. En conséquenee, avant d'atteindre le foud de l'excavation, on $y$ déposera une lampe allumee. Si. cette lampe ne s'éteint pas, e'est une preuve qu'il n'y aura aucun danger à craindre. Mais si elle s'éteint, il

in prasenti, vas concepto humore solvetur. Item vellus lanæ a:que positum et coopertum, si tantum. colligit lit. noris, ut alia die fundat expressum, copias inesse testa. bilur. Item lucerna oleo plena et accensa, si ibi similiter tecta ponatur, et secuto die inveniatur extincta superan. tibus alimentis, aquas idem locus labebit. Iteus si in eo loco focum feceris, et terra vaporata liumidum fumun nebulosumque ructaverit, aquas inesse cognosces. Ilis itaque repertis, certa signorum firınaute notitia, puteum fodies, et aquæ caput requires : vel si plura sunt, in unum colliges. Tamen maxime sub radicibus montium in Septentrionali parte quærenda sunt aqua, quia in his locis magis abundant, utilioresque nascuntur.

IX. Sed in fodiendis puteis cavendum est fossorum periculum, quoniam plerunıque terra sulfur, alumen, bitumen educit, quorum spiritns misti anliclitum pestis exlıalant, et occupatis statim naribus extorquent aninas, nisi quis fuga sibi velocitate succurrat. Prius ergo quam descendatur ad intima, in eis locis lucernam ponis accensam, quæe si extincla non fucrit, periculum non timebis; si vero extinguetur, carendus est locus, quem spiritus 
fant s'abstenir de pousser plus loin la fouille, car là réside un méphitisme mortel: Si néaumoins on ne peut pas trouver d'eau ailleurs, on crcusera des puits auprès de cet endroit, tant de droite que de gauche, jusqu'à ce qu'on soit parvenu au niveau de l'eau; et l'on pratiquera dans l'intérieur de ees puits des soupiraux ouverts de côté et d'autre en forme de narines, et par lesquels l'exhalaison funeste s'évaporera; après quoi on soutiendìa les parois des puits à l'aide d'une maconnerie. An reste, il faut que la largeur d'un puits soit de huit pieds en tout sens, sur lesquels la maȩonnerie en prendia deux. Cettc maẹonnerie sera soutenue d'espace en espace avec des barres le bois, et construitce en tuf ou en moellon. Quand l'eau est limoneuse, on la corrige en $y$ jetant du sel. Si, lorsqu'on creuse un puits, la terre, trop neuble de sa nature, vient à s'ébouler, ou que l'eau vienne à la délayer, on la contiendra de tous cótés à l'aide de planehes appuyéc's rertiealement contre elle, et soutenues avec des barres mises en travers, pour empécher quel'éboulement n'ensevelisse les tı'avalilleur's.

X. Voiei la nianière de faire l'essái d'une eau qu’on aura nouvellement trouvée : On en versera dans un vase de enivre bien poli, et, si elle n'y laisse point de taelıe, e'est une preuve (ju'elle est bonne. Elle est également bonne, lorsque, après avoir été bouillie dans un petit vase de euivre, elle n'y dépose ni sable ni limon, lorsque les légumes y cuisent promptement, lorsque ni mousse ni impureté d'aucune sorte n'en altère la limpidité. Au surplus, quand les puits sont creusés sur une lauteur, on pourra en fairc jaillir l'eau par en bas eomme celle d'une fontaine, en percant lesterres jusqu'à son lit, si la configuration du terrain inférieur n'y apporte aucun empêchement.

XI. Quand il s'agit de conduire l'eau d'un lieu à un autre, on a recours à un eaual coustruit en maçonneric, ou à des tuyaux de plomb, ou à des ('anaux de bois, ou enfin à des tuyaux de terre cuite. Si on la conduit dans un canal eonstruit en maẹonnerie, il faut que ce eanal soit bien solide, afin qu'elle ne s'éelıappe point à travers les joinls des pierres qui entrent dans sa construction. La largeur de ce eaual sera.proportionnée à la quantité d'eau que l'on y fera couler. Si co canal doit traverser dans sa route un terrain plat, on lui donnera, en le construisant, une pente insensible d'un pied et demi sur soixante ou eent pieds de longueur, afin de procurer à l'eau un ceoulement suffisant. S'il doit rencontrer une montagne sur sa route, il faudra diriger l'eau et la détourner vers les côtés de cette montagrne, ou Iui nuvrir à travers le mont un passage ì son niveau au moyen d'un aquedue. Mais s'il se trouve une vallée sur son chèmin, on élèvera des piliers ou des ares jusqu'à la hauteur de la pente que doit suivre l'eau, ou bien on la laissera tomber au fond de la vallée en la renfermant daus des tuyaux de plomb, pour la faire remonter ensuite quand elle l'aura tiaversée. Lorsqu'on conduira l'ean dans des tuyaux de terre euite, méthode qui est la plus salutaire et la plus avantageuse de toutes, on donnera à ees tuyaux une épaisseur de deux doigts, en les rètréeissant par un de leurs eôtés, afin qu'ils puissent s'emboiter l'un dans l'autre de la longueur d'un palmus, et on en garnira les joints avec do la chaux vive pétrie à l'huile. Mais avant d'introduire dans ces tuyaux l'eau qu'on veut y faire couler, on y fera passer de la cendre ehande mêlée d'un peu d'eau, pour souder les défectuosités qui peuvent se reneontrer dans ces tuyaux. La pire de toutes les méthodes consiste à conduire l'eau dans des tuyaux de plomb. Elle rend en effet l'eau dangereuse à mortifer oecupabit. Quod si alio loco aqua non polest inveniri, dextera lavaque puteos fodiemus, usque ad aqua: ipsius libramentum, $\mathrm{ct}$ ab his foramina liiic inde patefacta velut nares intus agemus, qua nocens spiritus evaporet : quo facto latera puteorum structura suscijiat. Forliendus est autern puteus, latitudine oeto perlun quoquoversın, ut binos pedes sIructura conchidat : i) lua? structura vectibus ligneis subinile densetur, et structa sit lapide tofacio, vel silice. Si aqua limosa fuerit, salis ad. nistione corrigatur. Sed dum foditur pulens, si terra nou stabit vitio generis dissolnti, ant lumore laxabitur, tabulas objicies directas undique, et eas transversis vectibus sustinebis, ue fodientes ruina concludat.

$\mathrm{X}$. Açuam vero novam sic probabis : in vase aneo nitido spargis, ef si maculan non fecerit, probabilis judicetır. Item deeouta aneo vasculo, si arenau vel limum non relinquit in fundo, utilis erit. Item si legumina cito valebit excoquere, vel si colve perlucido careus unısco, et umui labe pollutionis aliena. Sed qui in alto sunt putei, perforatis usque ad infinım patteın terris ad loca inferiora, possunt vice fontis exire, si vallis subjectio natura permiltal.

XI. Cuı vero ducenda est aqua, dueitur aut forma structili, aut plumbeis fistulis, aut canalibus ligneis, ant fictilibus tubis. Si per formam ducetur, solidandus est canalis, ne per rimas aqua possit elabi : cujus magnitudo pro aquac mensura facienda est. Si per planum veniet; inter eutenos rel sexagenos pedes sensim reclinetur structura in sesquipedem, ut vim possit labere currendi. Si quis mous interjectus occurrerit, ant per latera rjus aquam ducemus obliquan aut ad aquac caput speluncas librabimus, per quarum structuran perveniat. Sed si se vallis interserat, erectas pilas rel arcus usque ad aquax justa fastigia constrnemus, aut plumbeis fistulis clausan dejici patiemur, et explicata valle eousurgere. Sed, quorl est salubrius et utilius, fietilibus tubis cum dncilur, dıobus digitis erassi, et ex una parte reddantur angusti, ut palmi spatio unus iu alterum possit intrare : quas juncturas viva calce olco subacta dehemus illinire. Sed antequam in is aquac eursus admittatur, favilla per cos mixta exi- 
boirc, parce que lc plomb, à force d'ctre fiotté, décharge de la céruse, qui est une matière nuisible au corps humain. C'est à l'art à construire les reservoirs de facon à ec que le plus petit filet d'eau procure une abondante réserve.

XII. Voici la quantité de plomb qui doit entrer dans la fabrication des tuyaux. II en faut douze cents livies pour unc feuille de cent doigts de largeur sur unc longueur de dix pieds; neuf cent soixante pour une feuille de quatre-vingts doigts ; six cents pour une feuille de cinquante doigts ; quatre cent quatre-vingts pour une feuille de quarante doigts; trois cent soixante pour une feuille de trente doigts ; deux cent quarante pour une feuille de vingt doigts, et quatre-vingt-seize pour une feuille de huit doigts.

XIII. Manière de confle le verjus dans du miel. Versez deux sextarii de miel bien broyé sur six de jus de raisin à demi vert, et laissez ce mélange se cuire au soleil pendant quarante jours.

XIV. Il n'y a point de différences, quant à la marche du soleil, entre le mois d'août et celui de mai.

A la premic̀re et à la onzième heure, le gnomon donne vingt-trois pieds d'ombre.

A la seconde et à la dixième, il en donne treize.

A la troisième et à la neuvième, il en donne neuf.

A la quatrième et à la huitième, il en donne six.

A la cinquième et à la septième, il en donne quatre.

A la sixième, il en donne trois.

\section{LIVRE DIXIËME.}

SEPTEMBRE.

I. On labourera pour la troisième fois au mois

guo liquore decurrat, ut glutinare possit, si qua sunt vitia tuborum. Ultima ratio est, plumbeis tistulis ducere : quæ aquas noxias reddunt. Nam cerusa plumbo creatur attrito, quæ corporibus nocet lımanis. Diligentis erit aquarum receptacula fabricari, ut copiam inops vena procuret.

XII. Mensura vero fistularum plumbo servetur lujusmodi. Centenaria $x$ pedum mille ducentas libras habeat. Octogenaria noningentas Lx. Quinquagenaria similiter $\mathrm{x}$ pedum pondo sexcenta. Quadragenaria poudo quadrin. genta Lxxx. Tricenaria pondo trecentasexaginta. Vicenaria pondo XL. Octonaria pondo nonaginta sex.

XIII. [De omphacomeli.] In uva semiacerba succi sextariis sex mellis triti fortiter duos sextarios debebis infundere, et sub sotis radiis dicbus $\mathrm{x} \mathrm{t}$, decoquere.

XIV. Augustum Maio par solis cursus oequavit.

\begin{tabular}{|c|c|c|c|c|c|}
\hline ora & 1 & et & XI & pedes & AXIII. \\
\hline Hor & 11 & et & $\mathbf{x}$ & des & XIII. \\
\hline t & 111 & e & IX & & I. \\
\hline & IV & & Vill & & $v_{1}$. \\
\hline Hor & $\mathbf{v}$ & & ril & & IV. \\
\hline Hora & u & & & pedes & 1!j. \\
\hline
\end{tabular}

de septembre les terrains gras, ainsi que ceux qui sont dans l'habitude deconserver longtemps l'humidité; et l'on s'y prendra même plus tôt quand l'annee aura étć humide. On bine et l'on ensemence à présent les terrains humides, plats et maigres, auxquels nous avons dit qu'il fallait donner le premier labour au mols d'août. II faut labourer à présent pour la première fois les coteaux maigres, et les ensemencer aussitôt après, vers l'équinoxe. On fumera à présent les terres, mais on aura soin de resserrer les tas de fumier les uns auprès des autres sur les collines; au lieu qu'on les espacera davantage dans les plaines. Si l'on fait cette opération au déclin de la lune, ce scra lc moyen d'empêcher les herbes d'y eroitre. Columelle assure que vingt-quatre carpenla de fumier suffisent pour fumer un jugerum de terre, et qu'il n'en faut que dix-huit en terrain plat. Au surplus, il faudra avoil soin de n'éparpiller en un jour que la quantité de fumier qu'on pourra recouvrir de terre le même jour par le labour, de peur que ce fumier, vcuant à se dessécher, ne perde sa vertu. On peut encore fumer en quelque temps de l'hiver que ce soit ; mais lorsque quelque raisoll aura empêché de le faire dans un temps convenable, on y remédiera soit en répandant sur les terres, avant de les ensemencer, du fumier pulvérisé de la manière dont on y répand la graine, soit en y jetant à la main du crottin de chèvres, qu'on incorporera ensuite avec la terre à l'aide des sarcloirs. Il n'est pas à propos de fumer beaucoup à la fois, et il vaut mieux le faire modérément et plus souvent. Une terre aqueuse demande plus de fumier qu'une terre sèche. Si ecpendant l'on n'est pas riche en grais, ce sera une excellente méthode de répandie, en guise de fumier, sur les terres sablonneuses, de la craic ou de l'argile, comme de semer

\section{LIBLR DECIMUS.}

1. Septembri mense ager pinguis, et qui din tenere consuevit humorem, tertia vice arabitur, yuamvis luumido anno possit et antea tertiari. Nunc ager lıumidus, planus, exilis, quem primo Augusto arari diximus, iteratus et seritur. Graciles clivi nunc primum arandi el serendi sunt statim circa aquinoctium. Agri nune stercorandi sunt, sed in colle spissius, in campo rarius latamina disponentur, cum luna minuitur - quæe res si servetur, herbis officiet. Uni jugero asserit Colunella xxıv stercoris carpenta sufficere; hi plano vero $x$ vin. Sed iiden cunuli tot dissipandi sunt, quot eadem die poterunt inarari, ne stercora exsiccala niliil prosint. Ejiciuntur quidem lotamina, et qua. libot hiemis parte. Sed si tempore suo ejici aliqua ratione non poterunt, ante quam seras, more seminis per agros pulverem stercoris sparge, vel cajrinum unanu projice, et terram sarculis misce. Nec prodest nimium stercorare uno tempore, sed frequenter et modice. Ager aquosus plus stercoris, siccus vero ininus requirit. Sed si lataminis copia non abundat, hoc pro stercore optime cedit, ut sa- 
du sable sur les terres argileuses ou trop eompactes. Outre que eette methode est favorable aux moissons, elle rend eneore les vigues très-belles, d'autant qu'en donnant du fumier à eelles-ci, on altère souvent la qualité du vin.

11. On sèmera ee mois-ei vers l'équinoxe, quand le temps sera au beau fixe, le froment ainsi que le blè adoreum dans les terrains maréeageux, ou maigres, ou froids, ou ombragés, afin que les raeines de ees blés puissent prendre quelque eonsistance a vant l'hiver.

III. La terre rend souvent une humidité amère qui fait périr les blés. Il faut répandie sur les endroits où eela arrivera, de la fiente de pigeon ou des feuilles de eyprès, et les labourer en même temps, afin que ee genre de fumier s'amalgame avec la terre. Mais le meilleur remède est de détourner eette humidité pernieieuse au moven d'une saignée qui la portera ailleurs. On ensemencera un jugerum d'une terre médioere avee einq modii de froment, et la même quantité de blé adoreum. Il n'en fant que quatre pour une terre grasse. On assure que ees semenees viendront à bien, lorsqu'on aura recouvert d'une peau d'hyène le modius dont se servent les semeurs, et qu'on aura laissé le grain pendant quelque temps dans ce semoir. Comme il arrive assez souvent que certains animaux qui vivent sous terre font périr les blés en les coupant par la lacine, il sera également bon, pour prévenir cet aecident, de faire tremper les grains une nuit, avant de les semer dans du jus de l'herbe appelée sedum (joubarbe), mêlé avee de l'eau, comme d'expriner du jus de eoneombre sauvage, ou de faire infuser dans de l'eau la racine broyée de eette plante, pour y tremper ensuite les gr'ains que l'on aura à semer. Il y a des personnes qui, dèsqu'elles

\section{(4)}

bulosis locis cretam id est argillam spargas, cretosis ac nimium spissis salıulonem. Hoc etiam segetibus proficit, et vineas pulelerrimas reddit. Nam latamen in vineis sapo. ren vini vitiare consuevit.

11. Hoc mense uliginosis locis ant exilibus aut frigidis aut opacis eirca requinoetium triticnm et adoreum seretur, flum serenitas constat, ut radices frumenti ante lieme!n couralescant.

III. Solet terra lıımorem salsum vomere, qui segetes neeat. Ubi hoc fit, eolumbinum stercus aut eupressi folia oportet inspargere, et ita, ut eadem nisecantur, illarare. Melius tamen omnibus remediis erit, si aquarius suleus noxium deducat lumorem. In medioeris agri jugero $v$ tritiei modios et adorei totidem eonseremus. Nan quatuor [ager] pinguis accipiet. Si modiım, quo seretır, lıyacna pelle restieris, et ibi aliquamdiu quod serendun est, esse patiaris, sata bene provenire firmantur. Item quoniam quadam animalia subterranea seetis radicibus necant plerumque frumenta, contra hace proderit, si lierba, qux sedunt dicitur, succus aqua mistus uns nocte madefaciat quae spargenda sunt semina : vel agrestis cucumeris humor expressus el ejas radix trita si aqna diluatur, et codem voient leurs moissons attaquées de ect aceident, versent sur les sillons et sur les charrues, sans attendre que le mal ait fait de plus grands progrès, du mare d'huile sans sel, ou de l'eau dont nuus velions de faire mention.

IV. On sème à présent dans les terrains maigres l'orge cantherinum. Il en faut eing moclii par jugerum. On laissera reposer les terres qui auront porté eette espèce de grain, à moins qu'on n'aime mieux les fumer.

V. On sème à présent ou un peu plus tôt les lupins en quelque terre que ee soit, ne fût-elle pas même labourée. Il sera à propos qu'ils soieut semés avant que les froids eommenceut. Ils ne réussissent point dans les terres limoneuses, et eraignent l'argile; ils se plaisent au contraire dans les terres maigres, ainsi que dans les terres rouges. Il en faut dix modii pour ensemeneer un jugerum.

VI. On sèmera les pois à la fin de ee mois. Ils aiment une terre légère et qui ne soit point compacte, un pays ehaud et liumide. Il suffira d'en semer trois ou quatre modii par jugerum.

V11. On sème à présent le sésame dans un terrain friable, ou dans des sables gras, ou dans des terres rapportées. Il en faudra semer quatre sextarii ou six par jugerum. On labourera pour la première fois à la fin de ce mois les terres où l'on voudra semer de la luzerne.

VIII. C'est à présent que l'on fait le premier ensemeneement de la vesee et du fenugree, quand on les destine à servir de fourrage. Sept modii de graine tant de vesee que de fenugree seront suffisants pour un jugerum. On sème aussi les herbages que l'on doit couper avant leur maturité, dans un terrain auquel on aura fait produire toutes les années sans se reposer,

qua serenda sunt inacerentur lıumore. Aliqui ubi hæc segetes suas perferre senserint, inter initia vitiorum insulsa aumca vel praclieta aqua sulcos et arata perfundunt.

IV. Nunc gracili solo ordeum seritur cantheriunm modiis v per jugerum. Post linc genus agros cessare patieris, nisi forte latamen aspergas.

V. Nune vel malurius aliquanto lupinus seritur in qua. lieunque terra vel crudo solo : eni lıoc proderit, ut seratur ante quam frigus ineipiat. Limoso agro non naseitur : cretam reformidat : amat exilem terram atque rubricam : $x$ modiis jugeri mensura completur.

VI. Iloc mense postremo pisum seremus, terra facili et solufa, loco tepido, calo delectauır lıumecto. Jugero quatuor modios vel tres sparsisse sufficiet.

VII. Nunc sisamum seritur putri solo vel pinguibus arenis vel terra eongestieia. Jugero quatuor vel sex sexlarios sevisse conveniet. Hoc mense postremo prima vice agros proscindemus, qui habiluri sunt medican.

VIII. Nunc vicia prima satio est et foeni Gracei, eum pabuli caısa seruntur. Vicix vn modii jugerum aque et funi Græeci semen implebit. Farrago etiam loeo restibili stercorato seritur : ordei cantherini in jugero $x$ inodios 
et que l'on aura fumé: auquel cas il faudra y semer dix modii d'orge cantherinum par jugerum, et le faire vers l'équinoxe, afin que ce grain se trouve fortifié avant l'hiver. Si on veut le faire paitre souvent par les bestiaux, il pourra suffire a leur pâture jusqu'au mois de mai; au lieu que si l'on veut en retirer du grain, il ne faudra le leur laisser paítre que jusqu'aux calendes de mars, et, passé ce temps, leur en interdire la pâture.

IX. On sème vers les ides de ce mois ei des lupins, pour fertiliser les terres maigres; et, dès qu'ils sont venus, on les verse en terre, afin qu'ils y soient eoupés par le soc de la charrue, et qu'ils y pourrissent.

$X$. On peut faire à présent de nouvelles prairies, si on le juge à propos. Lorsqu'on aura le choix du terrain, on préférera pour cette destination, soit un terrain gras où la rosée séjourne, uni ou légèrement incliné, soit une vallée dont la position soit telle, que l'eau ne soit pas dans le cas d'y tomber par une eliute préeipitée, ni d'y rester stagnante. On peut eneore mettre en prairies un terrain meuble et maigre, pourvu qu'on ait soin de l'arroser. On arrachera done, pour dégrager ce terrain, tout ce qui pourra l'embarrasser, tant les herbes hautes et dures que les arbrisseaux dont il sern couvert. Ensuite, lorsqu'il aura étésouvent remué et ameubli par des labours multipliés, on en ramassera les pierres, et on en pulvérisera toutes les mottes; après quoi on le fumera avec du fumier récent, dans le temps que la lune croitra. On aura le plus grand soin d'en ćcarter les bêtes de somme, surtout quand il fera liumide, de peur qu'en imprimant leurs pas sur le sol, elles ne le rendent inégal en différents endroits. Mais lorsque de vieux prés seront eouverts de mousse, il faudra les gratter, et répan-

spargimus circa squinoctium, ut ante hiemem convale. scat. Si depasci snepius velis, usque in Maium mensem ejus pastura sufticiet. Quod si ex ea semen etiam redigere, usique ad Martias calendas, et deline pecora prolibebis.

IX. Hoc mense, ut loca fuecundentur exilia, lupinus circa idus seritur, et ubi creverit, vertitur vomere, ut putrefiat excisus.

X. Nunc prata, si libuerit, possumus novella formare. Si eligendi facultas est, locum pinguem, roscidum, plaıum, leniter inclinatum, vel luıjusmodi vallem deputahinus, ubi luunor nec statim pracipitari cogitur, nec diu debet iuhaerere. Potest quidem et soluto et gracili solo prati forma, si rigetur, imponi. Extirpandus est itaque locus looc tempore, et lilseranlus impedimentis omnilus, vel herbis latioribus et solidis atque virgultis. Deinde cım frequenter exercitatus fuerit, ac multa aratione resolutus, subuntis lapidibus, et glebis ubique confractis, stercoretur Inna crescente recenti latamine. $\mathbf{A b}$ ungulis jumentorum summa intentione servetur iutactus, pracipue quoties luumescit, ne inacuale solum reddant nultis locis impressa vestigia. Sed si prata vetera muscus obduxeril, abradendus est, et scalptis cisdem locis focui spargenda sunt dre de la graine de foin dans les parties qui en auront été grattées. On y répandra eneore souvent de la cendre, qui est un excellent préservatif de la mousse. Si une portion de prairies est devenue stérile par moisissure, négligence ou vétusté, on la labourera et on l'aplanira de nouveau. En général, il faudra labourer souvent les prés stériles. On pourra aussi semer des raves dans les prairies nouvelles; et quand on les aura recueillies, on achèvera les opérations que nous venons de détailler, pour y semer ensuite de la graine de foin, en la mêlant toutefois avec de la vesee. Il ne faudra point arroser ees semences avant qu'elles aient eonsolidé le sol en croissant, de peur que l'eau venant à eouler sur une terre peu solide, n'en enlève la superficie.

XI. Il faut faire la vendange ee mois-ei dans les pays chauds et voisins de la mer, et se préparer à la faire dans les pays froids. On reconuaft que lc temps est venu de faire la vendange, lorsqu'en exprimant les pepins renfermés dans les grains de raisin, il s'en trouve de gris ou tout à fait noirs, ce qui est le signe de la maturité du fruit. Voici la quantité de poix qu'on emploiera pour l'apprêt des futailles : il en faudra douze livres pour enduire les futailles de deux eents congii de contenance, et moins à proportion pour celles d'une plus petite contenance. Ceux qui veu. lent raftiner mêlent une livre d'excellente circ sur dix livres de poix ; ce mélange est bon pour procurer de l'odeur et de la saveur au vin, paree que la douceur de la cire tempère la poix, et l'empêehe de s'écailler penảant les froids. Il faut eependant goûter la poix pour s'assurer de sa doueeur, parce qu'il arrive souvent que son amertume gâte le vin.

XII. On récolte à présent dans quelques can-

semina, et qnod ad necandum muscum prodest, cinis sæpius ingerendıs. Quod si sterilis factus est locus carie, incuria, vetustate, exaretur, ac de novo rursus aquetur. Nanı prata sterilia plerumque arare conveniet. Sed in novo prato rapa conserere possumus, quorum messe finita, cectera qux dicta sunt, exequemur. Viciam tamen forni seminilus mixtam post lıac spargemus. Rigari vero antequam durum solum fecerit, non debebit, ne ejus cratem minus solidam vis interflui corrumpat liumoris.

XI. Hoc mense locis tepidis maritinisque celebranda viudemia est, frigidis apparanda. Sed natu ilatem vindemixe cognoscimus loc genere : si expressa uva vinacia, quae in acinis celantur (lioc est grana), sint fusca, et nonuulla propemodım nigra : quam rem naturalis maturitas facit. In doliis picandis hic modus erit, ut dolium ducentorum congiorum xul libris picetur, deinde pro minoris astimatione subducas. Diligentiores optimæ cera in decem picis libras unam libran miscent, qua et odori proficit et sapori, et picem lenitate permulcens, frigoribus eam non patilur dissilire. Picis tamen gustu exploranda dulcedo est, quia sxepe vina ejus amaritudine vitiantur.

XII. Nunc quibusdam locis panicum metetur et ıi- 
tons le panis et ic millet. On sèmera dans ce temps-ci les haricots que l'on destine pour la tablc. On apprête à présent les perches nécessaires pour la chassc aux hibous, ainsi que les autres parties de l'appareil. Le temps de cette chassc est vers les calendes d'octobre.

XIII. On sème à présent le pavot dans les pays sees et chauds. On peut aussi le semer avec d'autres herbes potagères. On prétend qu'il vient mleux dans les terrains sur lesquels on a brùlé des baguettes et des sarments. C'est dans ce tcinps qu'il y a le plus d'avantage à semer les choux, afin de les transférer en pieds au commencement de novembre, et de pouvoir les récolter en feuilles pendant l'hiver, et en cimes au printemps. Il faudra labourer au pastinum cc mois-ci, à trois pieds de profondeur, les planches des jardins, que l'on doit ensemencer pendant lc printemps, et les fumer au déclin de la lune. On sìmera le thym à la fin de ce mois. II viendra mieux quand il sera plauté en pied que lorsqu'il aura été semé en graine; quoiqu'il puisse aussi venir de cette dernièrc facon. Il aime les terrains exposés au soleil, maigres ct voisins de la mer. On sèmera l'origan dans ce temps, vers l'équinoxc. Il demande à être fumé et arrosé jusqu'à ce qu'il ait pris une certaine consistance. II se plait dans les lieux sauvages et au milieu des rochers. On sème à la même époque le câpries. Cette plante serpente au loin, et son suc nuit aux terres. C'est pourquoi, pour l'empêcher de s'étendre trop, on la sèmera dans un terrain sec et maigre, que l'on cnvironnera d'un fossć, ou d'une muraille construite avec de la boue. Le câprier fait de lui-même la guerre aux herbes. Il fleurit en été, et se dessiche vers le coucher des Pléiades. Il est à propos de semer la nielle à la fin de ce mois-ci.

linun. Tempore loc faselus ad escam seratur. Nunc in amitibus apparetur aucnpium noctuæ, cæleraque instrumenta captura, ut circa calendas exerceatur Octobres.

XIII. Nunc papaver seritur locis siccis et calidis : potest et cum aliis oleribus seminari. Fertur utilius provenire, uli virgae et sarmenta combusta : sunt. Tempore hoc brassicam seres utilins, nt plantas ejus Novembri inchoante transponas : de quibus et hieme olus et vere possit cyma produci. Iloc mense spatia lortorum, qux per vernum seminibus impleturus es, alte tribus pediluus pastinare debebis, et luna decrescente (his) stercus inferre. Hoc mense ultimo thymun seremus; sed melius plantis nascitur, quamvis possit et seminc. Agrum diligit apricum, macrum, maritimum. Nunc circa sequinoctium seres origanum : stercorari ac rigari, donec convalescat, appetit. Amat loca aspera atque saxosa. lisclem diebus seritur capparis : late serpit : succo suo terris nocet. Serendum est ergo, ne procedal ulterius, circumreniente fossato, vel luto structis parietibus, solo siccu el gracili : herbas sponte persequilur \& floret astate. Sed occasu Vergiliarum capparis arescit. Cith lıoc mense ultimo bene
On sèmera ce mois-ci le cresson alenois et l'aueth dans les pays tempérés ainsi que les pays chauds; les raiforts, dans les pays sees; les panais et le cerfeuil, vers les calendes d'octobre; les laitues, la poirée, la coriandie, les raves et les navets, dans les premiers jours du mois.

XIV. On sèmera au mois de septembre vers les calendes d'vetobre, ou au mois de février, les pêches-noix, soit en rejetons, soit en noyaur. L'enfance de cet arbre exige des soins minu. tieux. On arrachera un rejeton de l'arbre avec ses raclnes, ct on l'enduira de fiente de bouc; puis on l'enterrera en grande partie dans un sol gras et labouré, en le posant sur des coquilles et de l'algue marine. D'autres metteut en automne, dans une terre grasse et soigncusement passée au crible, les noyaux de ce fruit séchés au soleil, en les joignant trois par trois; et l'on prétend que les germes de ces noyaux se réunisscnt entre eux pour ne former qu'un seul arbustc, dont il faut aider la croissance en l'arrosant souvent; et en grattant légèrement avec la bêche le sol qui le porte, pour lul donner de la vigueur dans le temps de sa jeunesse. On trans. fère ensuite au bout d'un an, ou un peu plus tard, la plante qui est résultéc de ces semences; moyennant quoi clle donne des fruits plus doux qu'ils n'auraient été sans cette attention. Les rejetons de cet arbre profitent à merveille, lorsqu'ils sont greffés sur le cognassier à la fin du mois de janvier ou au mois de février. On les greffe aussi sur toutes les espèces de pommlers, sur les poiliers, sur les pruniers, et sur l'épine sauvage. II est mieux de les greffer en fente sur le trone que sous l'écorce. On couvre l'arbre, quand il est ainsi greffé, d'un panier ou d'un vase de terre cuite, que l'on remplit de terre labourée et mêlée de

seritur. Hoc mense nasturtium seremus et anethum locis temperatis et calidis, et radices locis siccis, et pastinacas et carefolinm circa Octobres calendas, et lactucas et betas et coriandrum, et primis diebus rapa et napos.

XIV. Mense Septembri circa calendas Octobres vel. Februario tuberes seremus subole vel nucleis, cujus tevera diligenter nutriri debet infantia. Sumatur cun radicibus planta divulsa : bubulo fimo linatur ac luto : statuatur pingui terra et subacta, subuitis conclis et marina alga : terris magna sui parte condatur. Alii pomis statim grana decissa et sole siccata pingui et probe cribrata terra autumno tria simul ponunt, qua feruntur in unum coire virgultum : quod assidua rigatione juvandum est atque fossura, qua solum leviter scalpens teneritudini robur inducat. Post annum deinde vel aliquanto tardins, qua fuerit de semine planta transfertur : et hoc genere fructus efficit dulciores. Mense Januario ultimo vel Fehruario tuberum surculus 'mirabiliter proficit cydonio insitus. Inseritur antem malis omuibus (et piris), et prunis et Calabrici : melius trunco fisso quam cortice. Desuper qualo vel fictili vase munitur, repletis usque prope sum. mitatem surculi terra subacta curn stercore. Prosunt 
fumier, presque jusqu'à l'extrémité supéricure de la greffe. Les soins que j’ai dit être profitables aux pommiers, le sont aussi aux pêehes-noix. On conservera ces fruits en les ensevelissant dans du millet, ou en les renfermant dans de petites cruches cnduites de poix et bouchées.

XV. On fera aussi ce mois-ci des pavés pour les plates-formes, ainsi que de la brique, de la manière que j'ai décrite au mois de mai.

XVI. Composition du sirop de mûres. On fera bouillir tant soit peu du jus de mûres sauvag̨es; après quoi on mêlera deux tiers de ce jus avec un tiers de miel, et l'on fera bouillir ce mélange jusqu'à ce qu'il ait aequis l'épaisseur du miel.

XVII. Quand on voudra garder du raisin, on cueillera des grappes bien saines, dont les grains ne soient ni fermes jusqu'à la verdeur, ni amollis jusqu'à l'excès de maturité. Il les faut tıansparents à la lumière et élastiques au toucher. S'il se trouve dans ees grappes des grains eoriompus ou défectueux, on les coupera. On rejettera aussi ceux dont la verdeur insurmontable aura résisté sans s'adoueir aux earesses du soleil d'été. Ensuite on coupera la queue de ces grappes, et, après les a voir trempées daus de la poix bouillante, on les suspendra dans un endroit sec, frais, obscur, et impénétrable à la lumière.

XVIII. Il faut épamprer sur les eôtés, trente jours avant la vendange, les ceps dont le fruit pourrira par trop d'humidité, et ne leur laisser que les feuilles dont ils seront gar nis par cn haut. lilles serviront à.garantir leuı eime de la trop grande ardeur du soleil.

XIX. Les jours de septembre et d'avril se ressemblent entre eux par rapport à l'égalité des heures.

tuberibus, qux malis prodesse memoravi. Tuberes servabuntur, si obruantur in milio vel urceolis picatis et oblitis.

$\mathrm{XV}$. Hoc etiam mense pavimenta in solariis et lateres faciemus eo more quo Maio mense deseripsi.

XVI. [De diamoro]. Succum mori agrestis paululum facies defervere. Tunc succi [ipsius] duas partes et unam nellis adnisces, et mista curabis ad pinguedinem mellis cx coquere.

XVII. Uvas quas servare volumus, legamus illasas, neque acerbitate rigidas, ne.que naturitate deflıentes, sed quibus est et granuun luce penetrabile et splendidum, et tactus cum molli jucunditate eallosus. Si qua sunt (corrupta vel) vitiosa, resecemus : nee patiamur interesse, quilous inexpugnabilis acerbitas contra blandimenta astivi caloris induruit. Tunc incisos botryonum tenaces calidla pice oportet anıbiri, atque ita iu loco sicco, frigido, et olscuro sine luminis irruptione suspendi.

XVIII. Vitis cujus fruetus luunore putreseit, per latera pampinanda est ante trigesimum vindeuia diem, et sola frous illa servanda est, qua in summitate posita solem I jmium defendit a vertice.

XIX. Septembris et $\Lambda$ prilis dies loris similibus conferuntur.
A la première et à la ouzième heure, lo gno. mon donne vingt-quatre pieds d'ombre.

A la seconde et à la dixième, il en donue quatorze.

A la troisième et à la neuvième, il en donne dix.

A la quatrième et à la huitième, il en donne sept.

A la cincquième et à la septième, il en donne cinq.

A la sixième, il en donne quatre.

\section{LIVRE ONZIEME.}

\section{OCTOBRE.}

1. On sèmera le blé adoreum, ainsi que le froment, au mois d'octobre. Le temps préfix pour semer ces grains est depuis le dix des calendes de novembre jusqu'au six des ides de décembre, pour les contrées tempérées. C'est aussi le temps de eharrier et d'étendre le fumier dáns les ehamps. On sèmera cncore ce mois l'orge appelée cantherinum. Ce grain se sème en terrain maigre et sec, ou dans une terre très-grasse. En effet, il a la propriété de faire maigrir les guérets. Or cette vertu malfaisante sera surmontée par une terre grasse, ou bien elle ne pourra faire grand mal à une terre que sa maigreur met déjà hors d'état de rapporter autre chose. Il faut done fumer le champ quand on le sème à eette époque. On sèmera aussi à présent l'ers, les lupius, les pois et le sésame, comme je l'ai dit. Le sésame se sème, ainsi que le haricot, jusqu'aux ides d'octobre, pourvu que ee soit dans une terre grasse, et qui rapporte tous les ans sans se reposer. Un jugerum en demande quatre modii.

$\begin{array}{rrrrrr}\text { Hora } & \text { I } & \text { et } & \text { xI } & \text { pedes } & \text { xxiv. } \\ \text { Iora } & \text { II } & \text { et } & \text { x } & \text { pedes } & \text { xiv. } \\ \text { Hora } & \text { III } & \text { et } & \text { Iñ } & \text { perles } & \text { x. } \\ \text { Hora } & \text { IV } & \text { et } & \text { viII } & \text { pedes } & \text { vir. } \\ \text { Hora } & \text { v } & \text { et } & \text { vII } & \text { pedes } & \text { v. } \\ \text { Ifora } & \text { vi } & & & \text { pedes } & \text { Iv. }\end{array}$

\section{LIBER UNDECIMUS.}

I. Octobri mense adoreum sereuns ac triticum. Justa satio est a decimo calendas Novembres, usque al sextum idus Decembres regionibus teniperatis. Nune etiam lata. men effertur ac spargitur. Hoc etiam mense seremus or. deum, quod dicitur eantlıerinum. Seritur macra et sicea terra, vel multun pingui. Nam qula loe semine macescunt arva, pingui vineitur agro : alteri non labet quorl amplius nocere possit, cum propter macritatem semen aliud ferre non valeat. Loto agro suue est serendun. Elian uune ervum, lipiumm et pisum et sisamum sere. uns (ut dixi) : sisammm usque ad idus Oetobres, et fa selım, tanen terra pingui aut restibili agro : quatuo: modiis jugcrun complebimus. 
II. On sèmera la graine de lin ce mols, si on le juge à propos; quoiqu'il vaille mieux renoneer à cette plante, qui épuise les forces de la terre.: $\mathrm{Si}$ on veut néanmoins en avoir, on en sèmera huit modii par jugerum, dans un terrain très.gras et médiocrement humide. Il y a des personnes qui en sèment une plus grande quantitédans un terrain maigre, et qui obtiennent un lin plus fin par eette méthode.

III. C'est à présent le temps favorable pour faire la vendange; e'est aussi celui d'observer quels sont les eeps les plus féeonds, et de les marquer de faecon à les reeonnaitre, afin de pouvoir ehoisir sur ees eeps des sarments propres à ètre mis en terre. Columelle soutient qu'on ne peut pas s'assurer de la léeondité d'un eep en une année, mais qu'il en faut quatre pour y parvenir; ct que ce n'est qu'après ce nombre d'années écoulées que l'on connait, à ne s'y point méprendre, la bonté d'un rejeton.

IV. II est très à propos de planter des vignes à la fin de ee mois-ei dans loss eontrées à température chaude et sèche, ¿̇ terres légères et meubles, à coteaux abrupts et dégarnis. J'ai traité eette matière tout au long dans le mois de févirier. C'est à présent le meilleur temps pour faire, dans les terrains sees, ehauds, maigres, peu fertiles, sablonneux et exposés au soleil, toutes les opérations que nous avons détaillées préeédemment, par rapport aux faeons des terres au pastinum, à la plantation les vignes, à leur taille, à la manière de les previgner et de les réparer, et à la formation des plants d'arbres mariés aux vignes, afin qque les pluies d'hiver rendent eeś opérations profitables, en dépit de la maigreur de ces sortes de terres; ee qui ne pourra manquer d'arriver, parce que les plantes y trouveront de l'humidité quand elles seront altérées, et qu'elles y seront

II. Hoc mense lini semen seremus, "si placet, quod ta. men pro malitia sni serendinin non est, nam terro uber exlıanit. Sed si velis loco pinguissimo et nodice lıumido, seretur in jugero vill modiis. Aliqui maero solo spissum serunt : ita assequuntur ut linım subtile nascatır.

III. Nunc opportuna vindemia est, eujus tempore no. tanda est focunditas vitimm et notis quibuscunque signau. da, Itt ex lis ad ponendum sarmenta possimus eligere. Asserit autem Coluniclla explorari foccunditatem uno anno non posse, sed qualuor : quo numero cognoseitur vera generositas surculorum.

IV. Hoc mense postremo, ubi calidi ae sicci aeris qualitas est, ubi exilis el aridus [est] cainpus, ubi eollis praruptus aut macer, vites utilissime ponuntur, de quilus satis mense Februario disputavi. Nune locis siccis, calidis, exilibus, maeris, arenosis, aridis, quæcunque de pastinis, de vitibus ponendis, putandis, propagandis, reparandis, vel arbusto faeiendo ante dieta sunt, reetius liunt, it contra exilitatem gleba liibernis imbribus adjuventır. Sic et hmmoreın sitientibus conferunt, et recisa vol mersa gla. à l'abri d'être brûlées, ne pouvant être $\mathrm{nl}$ seiées par les glaçons, ni ensevelies sous eux, attendu que les frimas sont chose ineonnue en ees régions.

V. Il faut déchausser après les ides d'oetobre toute la jeune vigne dans les vignobles plantés, suit au pastinum, soit par voie de fosses et tranehées, à l'effet de couper les racines superflues qu'elles auront jetées pendant l'été. En effet, si ces dernières venaient à se fortifier, elles finiraient par faire périr les raeines les plus profon des; de sorte que la vigne resterait eomme suspendue sur la superficie du sol, et se trouverait exposée par là au froid eomme à la chaleur. Il ne faut pas eependant couper ces petites racines jusqu'auprès du trone, de peur qu'il n'en sorte une plus grande quantité de la plaie, ou que eette plaie, qui s'attaque au corps même de la vigne, ne la rende dans les premiers temps trop sensible à l'impression $\mathrm{du}$ froid qui suivra ectte opération. On leur eonservera done en les coupant une longueur de doigt, après quoi on laissera les vignes à déeouvert, si I'hiver est doux dans le pays; au lieu que, s'il est rude, on aura soin de les reeouvrir avant les ides de décembre; et même, s'il est excessivement froid, on répandra à l'approche de l'hiver un peu de fiente de pigeon au pied des jeunes vignes; ee que Columelle veut que l'on pratique pendant einq années entières, pour obvier aux trop grands froids.

VI. C'est à présent le meilleur temps pour provigner dans les elimats dont j'aijparlé, paree que toute la séve se porte aux raeines, se trouvant débarrassée du soin de donner des branches à fruit.

VII. Il y a des personnes qui sont dans l'usage de greffer ee mois-ei les vignes ainsi que les arbres dans les pays très-chauds.

cie ron adurunt, quia talibns locis pruinarum vis et natura nescitur.

V. Post idus Oetobris ablaqueanda est omnis novella vinea sell in pastino, sell in scrobibus aut suleis, ut anputentur radices supervaeux, quas produxit astate : quae si eonvaluerint, iuferiores radices faciunt iuterire, et ita remanebit vitis in summitate suspensa : quxe res eam frigori obnoxiam faeiet et calori. Sed liæ radicula non ad siceum debent reeidi, ne aut plures inde nascantur, aut nova plaga eorpori vitis impressa vi secuti algoris utatur. Reeidemus autem relicto digiti spatio : et si plaeida ibi hiems est, apertas relinquemus vites : si violenta, ante Deccmbres idus operiemus : si prafiigida, aliquantum columbini stercoris sub ipsa hieme circa vitieularum restigia largiemur, quod eontra frigus nimium Columella dieit tolo faciendum esse quinquennio.

VI. Hor tempore ideirco loeis quibus dixi propagatio melior est, quia furmandis radicibus vitis incumbit, cuu proferendi palmitis ean eura non permovet.

VII. Hoc mense aliqui vites et arbores locis calidissimis inserere consueverunt 
VIII. On formera aussi à présent, dans les pays chauds et les localités exposées au soleil, des plants d'oliviers de la manière que nous avons donnée dans lc mois de février, et en observant l'arrangement que nous avons preserit. On plantera également dans le même temps et dans les mêmes pays des pépinières d'oliviers, et l'on procédera aux soins de toute nature qu'cxige la culture de cet arbre. On confira aussi les olives blanches de la manière que nous donnerons par la suite. Il faut déehausser à présent les oliviers dans les provinces sèches et chaudes, afin que leurs pieds puissent être humectés par l'eau qui tombera de leur tête. Columelle ordonne d'arracher tous les rejetons de ces arbres. Pour moi, il me semble qu'il faut toujours laisser quelques jets robustes, dont on puisse faire choix pour remplacer la mère quand elle sera vieillie, ou que l'on puisse transférer de bouture, lorsque après avoir été bien élevés, à l'aide de ln terre qu'on aura cntassée auprès d'eux, ils auront aequis des raeines en propre, et qu'on pourra se proeurer par leur secours des plants d'oliviers, sans avoir pris la peine d'en former des pépinières. Il faut, si le cas èchoit, fumer à présent dans les pays trèsfroids les oli viers, qui ne doivent cependant l'être que de trois en trois ans. Six livres de crottin de chèvre ou un modius de cendre suffiront pour chaque arbre. On ne cessera cependant pas de ratisser la mousse de ces arbres. On les taillera aussi quand ils auront passé l'âge de huit ans, suivant Columelle. Pour moi, je pense qu'il faut en eouper chaque année les branches sèehes, ainsi que celles qui ne produisent rien pour avoir été trop faibles dans leur prineipe. Si un olivier ne rapportc point de fruit, quviqu'il se porte bien, on le percera avec une tarièrc gauloise, de facon que le trou que l'on y fera pénètre jusqu'à la

VII. Nunc etiam locis calidis et apricis olireta instituemus more vel ordine, quem Februarius mensis ostendit. Scminaria quoque olearum locis talibus facienuus hoc tempore, et omnia qua ad oleam pertinebunt. Olivas quorque albas condiemus, sicut postea referetur. Hoc tempore ablaqueandæ sunt arbores ole $x$ provinciis siccioribus ac tepidis, ita ut eis a superiori parte lumor possit induci. Omnem sobolem convelli Columella pracepit. Mili autem videtur paucas dinitti semper ac solidas, ex quibus vel in vetustate matris loco delecta succedat, vil melius nu. trita, et aggest $x$ terra beneficio etiam suas labens radices ad olirefum faciendum sine cura seminarii transferatur arbuscula. Nunc si suppetit, intermisso triennio stercoranda suut oliveta locis maxime frigidis. Caprini stercoris sex libra uni arbori rel cineris modii singuli sufficient. Muscus tamen semper radatur arboribus: et putentur ( sicut Columella dicit) octo annorum atate transacta. Vi. detur mili unorpuoque anno sicca et infructuosa cum aliqua debilitate nascentia debere recidi. Quod si fructus ar. bor lacta non afferet, terebretur Gallica terebra usque ad medullam foramine impresso, cui oleastri informis talea moelle, ct on y cnfoneera arce effort une bouture informe d'olivier sauvage qui remplisse exactement lc trou; après quoi on déchaussera l'arbre, et on l'arrosera avec du marc d'huile sans sel, ou de l'urine gardée. En effet, aucune stérilité ne résiste à ce genre de fécondation; mais il ne faut pas attendre pour greffer l'arbre que le vice ait disparu. On nettoiera ce mois-ci les fossés et les ruisseaux.

IX. Les Grees ordonnent de transvaser le mout qui aura commencé à bouillir, lorsque le raisin dont il aura été exprimé aura trop souffert de la pluic. Entrainée par sa pesanteur spécifique, l'eau se précipitera au fond du vase nouveau; et le vln, dégagé de ce mélange hétérogène, se conservera mieux.

$X$. On fera à présent l'huile verte, de la manière qui suit. On cueillera les olives les plus nouvelles, lorsqu'elles seront tournées; et si on a mis quelques jours à les cueillir, on les étendra, de peur qu'elles ne s'échauffent. On séparera du tas celles qui pourront se trouver pourries ou desséchées; et lorsqu'on en aura amassé la quantité que le pressoir en pcut contenir, on les saupoudrera de sel ćgrugé ou en grains, ce qui vaut encore mieux, à raison de trois modii de sel sur dix d'olives; puis on les moudra d'abord; après quoi on les mettra avec leur sel dans des paniers, et on les y laissera pendant toute la nuit, afin qu'elles en contractent le goût; on les livrera ensuitc au pressoir le lendemain matin, et l'on en obtiendra une huile salée du meilleur goût. II faudra sans contredit laver avant tout à l'eau chaude les canaux à travers lesquels l'huile coulera, ainsi que tous les réservoirs dans lesquels elle se rendra, afin qu'ils ne conservent point l'odeur de relent que leur aura laisséel'huile de l'année préeédente. On n'approchera pas non plus le feu de l'huile,

( rehementer) arctetur, et ablaqueatæ arbori amurca insulsa, vel vetus urina infundatur. Hoc enim velıt coitu steriles arbores uberantur, quas tamen durante malitia oportebis inserere. Hoc mense fossas rirosque purgabimus.

IX. Graeci jubent, si uram nimius imber infuderit, postcaquıam mustum ejus primo ardore fervebit, ut ad alia vascula transferatur. Jta propler naturæe gravitatem rema. nens aqua sulısidet, et translatum vinum pure servabitur, relicto quicquill se illi $\mathrm{ex}$ imbre miscuerit.

$X$. Nunc oleum viride faciemus hoc genere. Oliranı quam recentissimam, cun varia est, colligis, et si diebus aliquol collegeris, expandis, ne calefiat. Si qua ibi putris aut sicca est, remores. Ubi vero compleveris modum factorii, sales tritos vel non tritos, quod est melius, in olivam eandem miltis per decem modios tres salis, et molis primo, et sic salitam in noris canistris esse patieris, ut pernoctel cum salibus, et ducat in se eosdem sapores : ac mane premi incipiat olei meliorem fuxum redditura, salis sa. pore concepto. Canales sane et omuia receptacula olei calida aqua prius lavabis, ut nihil de anni præeteriti rancore custodiant. Focos etiam non propius admovebis, be olei 
Vle peur que la fuméc n'en corrompe le goùt. Dans les pays sees et chauds, c'est à la fin de ce mois que l'on cueille les baies de laurier pour en faire de l'huile.

XI. Il faut semer au mois d'octobre la chicorée que l'oll voudra consommer en hiver. Cettc plante aime l'humidité ct les terres meubles. Elle monte très-haut dans les terrains sablonneux, salés et voisins de la mer. On lui préparera des planches aplaties, de peur que ses racines ne viennent à se découvrir, au cas que la terre s'éboule. Quand clle aura quatre feuilles, on la transplantera dans un terrain fumé. On plante à présent les artichauts cn pied. On coupe avec le fer l'extrémité de leurs racines en les mettant en terre, et on trempe ces racines dans du fumier. On en met.deux ou trois pieds ensemble dans des fosses profondes d'un pied, qu'on éloigne de trois pieds l'une de l'autre, pour que le plant eroisse mieux. On répand souvent sur ces plantes de la cendre et du fumier, à l'approche de l'hiver, dans les temps sees. On sèmera la moutarde ce mois-ci. Cette plante se plait dans une terre qui a été !abourée, et, si faire se peut, rapportéc, quoiqu'elle vienne également bien partout. Il faut la sarcler assidûment, afin qu'elle soit toujours couverte de poussière; ce qui contribuera à l'ćehauffer, quoiqu'clle n'en aime pas moins l'humidité. On laissera dans l'endroit même où on l'aura semće la moutarde dont on se proposera de 'cueillir la graine; au lieu qu'on fcra renfler, en la transférant, celle qu'on destinera à être mangée. La vieille graine de moutarde n'est borne ni pour l'ensemencement ni pour la table. On est sûr qu'elle est nouvelle, lorsque étant cassée cn tre les dents elle paraít verte à l'intéricur; au lieu que si elle parait blanche, c'est une preuve qu'elle est vieille. Il faut semer la mauve cc

saporem fumus inficiat. Nunc mense postremo locis siecis et calidis ad oleun faciendum lauri baccas legemus.

XI. Mense Octobri serenda sunt intyba, qux lieni serviant. Amant lumores et terram solutam. Arenosis et salsis locis atque marilimis summa proveniunt. Area his planior apparetur, ne radices eormu terra fugiente nudeutur. Quatuor foliorum transferantur ad locum stercoratum. Nunc plantae cardui ponuntur quas cun ponenus, radices earum summas ferro resecamus, ac fimo tingimus : ternum pedum spatio scparamus incrementi causa, pedali scrobe depositas binas aut tcrnas. Cinerem sacpe sub hieme diebus siccis fimumque miscebimus. Hoc-mense sinapim sercmus. 'Terram diligit aratam, et si fieri potest, congcstician, quanvis ubicunque nascatur. Sarculari dcbet assidue ut respergatur pulvere, quo fovctur. Non minus gandet humorc. De quo semen legere disponis, suo loco esse patieris; quod ad escam parabis, robustius facies transferendo. In sinapi vetus semen inutile est vel sationi vel usui : quod dentibus fractum si intus viride videbitur, novum cst: si album fuerit, vetustatem fatetur. Hoc mense malva serenda est, quae occursu lienis ab incrementi longitudine reprimetur. Loco pingui delectatur et lıumido : mois-cl, parce que la venue de l'hiver l'empêcherait de prendre accroissement. Cette plante sc plait dans les terrains gras et luumides; elle aime lo fumier. On la transfère en pied quand elle commence à avoir quatre ou cinq feuilles. Le plant en prend mieux quand il cst jeune. En effet, si on la transférait quand elle est déjà grande, clle languirait. Elle a meilleur goût quand elle n'a pas été transplantée. Au reste, pour l'empêcher de monter trop promptement en tige, on cache au milicu de cette plante des mottes de terre légères ou de petits cailloux. Il faut la semer clair. Ellc aime être sarclée assidument. Il faut la débarrasser des herbes qui l'environnent, sans ébranler ses racines. Elle pommera, si on noue ses racines Iorsqu'oul la transplantera. On sèmera aussi à présent l'aneth dans les climats tempérés et chauds. On seme eneorc ce mois-ci les ciboules, la menthe, le panais, le thym et l'origan, de mêne que la câpre au commencement du mois. On sèmera également la poirée dans les terrains sees, ainsi que le grand raifort; ou bien on transplantera ce dernicr d'une terre inculte (car c'est un véritable raifort sauvage) dans un terrain cultivé, afin qu'il s'y améliore. Il faudra transférer à preésent le poireau qui aura été semé au printemps, afin que sa tête grossisse. Il n'est pas douteux qu'il ne faille sarcler assidument les poireaux, et les soulever, en les saisissant comme avec des liens, afin qu'à mesure que leur tête prendra de l'accroissement, elle remplisse le vide que cette opération aura laissé sous leurs racines. On sèmera aussi à présent le basilic. On prétend qu'il viendra plus tôt dans ce temps-ci, quand il aura ćté trempé légèrement dans du vinaigre, avant d'être semé.

XII. Celui qui veut travailler pour les siècles

gaudel lætamine. Transferuutur plantæe ejus, cum cœperint folia quatıor labere vel quinque. Melius comprehendit cjus planta quæ tencra est : major cuim translata lan. gnebit. Sapor illis est melior, si non transferantur. Sed ne cito erigantur in caulem, in medio carum glebulas constitues aut lapillos. Rara ponenda est, sarculo dclcctatur assiduo. Si liberandx sunt herbis, ne motum sentiant in radice. Si transferendis plantis nodum facias in radice sessiles fient. Nunc etiam locis temperatis et calidis anethum seremus. Cepulla seruntur etiam hoc mense, vel menta ct pastinaca, thymum et origanum, et capparis mensis initio. Item betam locis siecioribus, necnon armoraceam serenus, vel transferemus ad culta, ut mclior fiat : nam lıec agrestis est raplianus. Nunc porrum verno satum transferre debemus, ut creseat in caput. Sanc sarculis circumfodiatur assidue, et comprehensa porri planta velut tenacibıs allevetur, ut inanitas spatii, qux radicibus suberit, ineremento capitis suppleatur. Ocimun quoque cliam nunc seremus, quod citius nasci fertur hoc tempore, si aceti imbre leviter spargatır infusum.

XII. Cui placet curas agere sxeculorum, de palmis cogitet conserendis. Hoc igitur mense dactylorum non vetc. 
à venir peut s'oceuper de la plantation des palmicrs; auquel eas il lui faudra mettre en terre ce -mois-ci des noyaux fraichement extraits de dattes qui ne soient pas trop anciennes, mais fraiches et pleines, et mêler de la cendre avec la terre dans laquelle il les déposera. Si l'on en veut faire venir de plant, il faut s'y prendre dès avril et mai. Cet arbre se plait dans les terrains exposés au soleil ct à la chaleur. Il faut l'entretenir d'eau pour le faire eroitre. Il demande une terre meuble ou du sable, quoiqu'il veuille aussi avoir, soit autour de lui, soit sous lui, de la terre grasse au moment qu'on le plante en pied. On le traus. plante au bout d'un an ou deux, au mois de juin ou au commencement de juillet. On le bêchera assidument au pied, pour faciliter les fréquents arrosements qu'il faudra lui donner, et qui lui feront braver les chaleurs de l'été. L'eau salée à un certain degré lui est salutaire ; c'est pourquoi il faudra en imprégner de sel à cet effet, quand on n'en aura pas qui soient naturellement salées. Si ect arbre vient à se mal porter, on lc déchaussera, et on l'arrosera avec de la lic de vin vieux, ou bien on coupera l'excédant du chevelu de ses racines; ou enfin on y enfoncera un coin de bois de saulc, en les mettant à jour à cet effet. Au surplus, il est constant que tout endroit où il croít ṇaturellement des palmiers n'est bon pour presque aucuuc sorte de fruits. On plante les pistaches en automne au mois d'octobre, soit en rejetons, soit en amandes, quoiqu'il soit encore micux de mettre en terre les pistaches elles-mêmes, tant le mâle que la femelle, en les accouplant. On appelle pistache mâle celle dont l'écorce renferme des noyaux qui ressemblent à des testicules allongés. Veuton rafiner sur la culture de cette plante? on se procurera de petits verres percés, qu'on remplira

rum sed novorum ac pinguium recentia ossa debebit obruere, terræ cinerem miscere. Si plantam velit, ponenda est A prili mense vel Maio. Locis delectatur apricis et calidis. Fovenda est, ut crescat, humore. Terram solutam vel sabulouem requuirit, ita lamen, ut quando planta deponitur, circa eam vel sub ea pinguis terra fuudatur. Anuicula transferatur aut bima Junio mense vel Julio iucipiente. Circumfodiatur assidue et rigatione contiuuns astatis vincat ardores. Aquis palmæe aliquatenus salsis jurantur, qua infici debent salibus, etiam si tales eas natura non praebuit. Si agra est arbor, feces vini veteris ahlaqueatxe oportet infundi, vel radicum supervacna ca. pillamenta decidi, vel cuneum salicis interfossis radicihus imprini. Constat auten locum prope rullis utilen fru. ctibus, in quo palma sponte nascuutur. Pistacia seruntur autumuo mense Octobri, (et) sobole et uucibus suis : sed melius ipsa pistacia juncta ponuntur mas ac foemina. Marem dicunt, cui sub corio velut ossei longi videntur litere lesticuli. Qui diligeutius facere voluerit, pertusos caliculos, et stercorata terra repletos parabit, et iu lis pistacia terua constituet, ut ex omulbus germen quodcunyue pro. de terre fuméc, ct dans lesquels on mettra trois pistaclies ensemble, afin que toutes les trois donuent à la fois un germe; après quoi, lorsque la plante qui résultera de ces germes aura pris des forces, il sera plus facile de la transplanter, ce qu'il faudra faire au mois de février. Le pistachier aime les terrains chauds, pourvu qu'ils soient humectés; aussi faut-il l'arroser et le mettre au soleil. On le greffe sur térébinthe au mois de février ou de mars, quoique d'autres assurent qu'on peut le greffer sur amandier. Le cerisier aime les climats froids, ainsi que ceux que leur position rend humides. II profite pei dans les contrées tempérées, et ne peut venir cll climat chaud. Il se plait dans les contrées montagneuses ou sur les collines. Il faudra trausplanter au mois d'octobre ou de novembre des pieds de cerisiers sauvages, que l'on greffera au commencement de janvier, quand ils auront pris en terre. On peut aussi former des pépinières de cerisiers, en mettant en terre, dans les mêmes mois, des cerises qui y prendront avee la plus grande facilité. L'expérience m'a montré combien il est aisé de faire venir cet arbre, puisque je puis certifier que j'ai vu monter en arbres des baguettes de cerisiers que j'avais enfoncées en terre dans des vignobles, pour y servir de soutiens aux ceps. On peut encore semer les cerises au mois de janvier. Il sera mieux de greffer le cerisier au mois de novembre, ou, s'il est nécessaire, à la fin de janvier. Il y a même des auteurs qui ont dit qu'il fallait le greffer en octobre. Martialis preserit de greffer les cerisiers en feute dans le trone de l'arbre; mais je me suis toujours bien trouvé de les avoir greffés entre l'écoree et le bois. Ceux qui les grefferont en fente dans le trone de l'arbre, comme le veut Martialis, auront soin d'ôter tout le duvet dont il sera

cerlat : quod ubi convaluerit planta, hinc facilius transferatur mense Februario. Anat locum calidum, sed lıume. ctum, et rigatione gaudet et sole. Inseritur terebintho mense Februario vel Martio : at alii amygdalo inseri posse firma. runt. Cerasus anat cæli statum frigidum, solum vero positionis humectx. In tepidis regionibus parva provenit. Citlidum non potest sustinere. Montana vel in collibus constituta regione lætatur. Cerasi plantam silrestram transferre debemus meuse Octobri vel Noveınbri, et eam primo Ja. uuario, cum comprelıendit, iuserere. Plantaria vero creari possunt, si praedistis mensibus spargantur poma, quae summa facilitate uasceutur. Ego sic luujus arboris facilitatem prohavi, ut virguta ex ceraso pro adminiculis per vineam posita in arboren prosiluisse confirmem. Et Januat io uense seri potest. Inseritur inense Novembri melius, rel, si necesse sit, extremo Januario. Alii et Octobri inserenda esse dixerunt. Martialis in trunco inseri jubet. Mili inter corticem et lignum feliciter semper evenit. Qui in trunco inserunt, sicut Martialis dicit, omnem Ianuginem, qua circa est, auferre debebunt ; quam si remanserit, insitis uocere manifestat. In cerasis looc servand :mu eșt, et in 
environné, parce que cet auteur prouve que ce duvet nuirait aux greffes, si on le laissait. Il faut observer, a l'égard des eerisiers et de tous les autres arbies qui portent de la gomme, de ne les greffer que dans le temps où ils n'ont point eneore de gomme, ou quand elle a eessé de eouler. On greffe le eerisier sur lui-même, sur le prunier, sur le platane, et, selon quelques auteurs, sur le peuplier. Il aime des fosses profondes, des espacements larges, des fouilles fiéquentes. Il faudra en retraneher les branches pourries et sèches, ou eelles qui seront trop serrées les unes auprès des autres, afin de les éclair. cir. Il n'aime pas le fumier, qui le fait effectivement dégénérer. Voici la manière dont Martialis dit qu'il faut s'y prendre pour faire venir des cerises sans noyaux. On coupera un jeune arbre à deux pieds de terre, et on le fendra jusqu'à la raeine; ensuite on aura soin de ratisser avee un fer la moelle des deux parties, et aussitôt après on les resserrera l'une auprès de l'autre avee des liens; enfin on enduira de rumie t tant la partie supéricure de l'arbre que les joints qui seront sur les côtés. Au bout d'un an, alors que la eicatrice sera consolidée, on greffera cet arbre avec des rejetons qui n'aient pas encore rapporté de fruits, et il en viendra, si l'on en eroit cet auteur, des cerises qui n'auront point de noyaux. Si un cerisier vient à pourrir par suite de l'hnmidité qu'il renfermera dans son trone, on y fera un trou par lequel elle puisse s'éeouler. S'il est tourmenté par les fourmis, il faudra verser dessus du jus de pourpier coupé par moitié avec du vinaigre, ou en frotter le trone avec de la lie de vin pendant la floraison de l'arbre. S'il se trouve aceablé par la chaleur de la eanieule, on fera verser sur ses racines, après le coucher du soleil, trois sextarii d'eau, dont chacun sera puisé dans une fontaine différente, cn évltant de lui administrer ee remèle quand la lune paraitra; ou bien on entortillera son trone avec de la jusquiame tordue en forme de couronue, ou enfin on étendira à son pied un lit de la même herbe. Il n'y a pas d'autre faecon de conserver les eerises, que de les faire sécher au soleil jusqu'à ee qu'elles soient ridées. Il y a des personnes qui plantent au mois d'oetobre les pommiers dans les contrées ehaudes et sèches, qui mettent en terre dans des pépinières, vers les ealendes de novembre, les coins, ainsi que les eormes ou les amandes, et qui y sèment de la graine de pin. Il faut eonfire les fruits ce mois-ci, et les conserver à mesure qu'ils mûriront, de la manière que l'on trouvera expliquée sous les titres qui eoneernent ehaeun d'eux.

XIII. On châtrera aussi les ruches ce mois-ci, de la faẹon que nous avons donnée. Il faut eependant faire attention à la quantité de miel qui s'y trouvera, afin de n'en "pas laisser; daus le eas où il y en aura abondamment; d'en laisser la moitić pour subvenir à la disette de l'hiver dans le cas où il n'y en aura qu'une quantité médioere; et de n'en point ôter du,tout dans le cas où les alvéoles paraitront en manquer. Nous avons déjà donné plus haut la façon de faire le miel, ainsi que eelle de faire la eire.

XIV. Pour ne rien omettre de ce que j'ai trouvé dans les livres que jai lus, je vais faire connaître les pratiques imaginées par les Grees par rapport à la façon de frelater le vin. Voici les distinetions qu'ils établissent entre les différentes espèees de vins, et les divers efiets qu'ils prétendent en résulter. Ils soutiennent qu'un vin doux est lourd; qu'un vin blanc et tant soit peu salé est bon pour la vessie; qu'un vin qui flatte par sa couleur de safran est digestif; qu'un vin blane omnibus gummatis, ut tunc inserantur, quando lis vel non est vel desinit gumma effuere. Cerasus inseritur in se, in pruno, in platano; ut alii, in populo. Anat scrobes altas, spatia largiora, assiduas fossiones. Putari in ea putria et sicca debebunt, vel quae densius arctata protulerit, ut rarescat. Fimum non amat, atque inde degenerat. Cerasa ut sine osse nascantur, ita fieri Martialis hoc dicit. Arboren tene. ram ad dnos pedes recides, et eam usque ad radicem findes, medullam partis utriusque ferro curabis abradere, et statim utrasque patres (in se) vinculo stringis, et oblinis fimo (et) summam partem et laterum divisuras. Post annum cicatrix dncta solidatur. Hanc arborem surculis, qui adhuc fructum non attulerunt, inseres, et, ut asserit, ex lis sine ossibus poma nascentur. Si cerasus concepto humore putrescit, in trunco foramen accipiat, quo possit educi. Si formicas patitur, succum portulacx debebis infundere cum aceti nuedia parte permistum, vel vini fecilus truncum arboris florentis adlinire. Si restu Canicularium fatigatur, trium fontium singulos sextarios sumtos post solis occasum radicibus arboris jubeamus inflnere sic, ne remedium luna deprehendat vel heıbam synphoniacam circa arboris truncum torquebimus in coronam, vel ex ea juxta imum codicem cubile faciemus. Cerasa non aliter quam in sole usque ad rugas siccata servantur. Mense Octobri aliqui mali arborem calidis et siccis regionibus nonunt, et cydonia circa Novembres calendas, et sorbum vel anygdala in seminariis obruunt, et pini semen aspergunt. Hoc mense poma condienda sunt, atque servanda eo more, quo in singulorum titulis continetur, vel ut qua:que inatura processerint.

XIII. Hoc etiam inense alvearia castrabuntur, more quo dictum est. Quac tamen oportet inspicere, et si abundantia est, demere : si mediocritas, partem mediam relinquere pro hicmis inopia : si vero sterilitas apparet in cellis, nil prorsus auferre. Mellis vero et ceræe superius est demonstrata confectio.

XIV. Ne lecta præeteream, quæ Graci sua fide media de condiendi vini genere disputarunt, demonstrare curavi : qui vini naturam tali ratione discernunt, et hanc in eo volunt esse distantiam, ut quod dulce est, gravius dicant; quod albnm, et aliquatenus salsnm, convenire vesicæ; quod croceo colore blanditur, digestioni accommodum; 
et astrlngent est propre nux estomaes reláchés; que le vin d'outre-mer rend pâle, et diminue la masse du sang; que le raisin uoir donne du vin fort; que le raisin rouge en donne d'agréable au goût; et que le raisin blane en donne eommunément de médiocre. 11 y a des peuples grees qui, pour frelater le vin, y ajoutent du moût euit jusqu'à diminution de moitié ou des deux tiers. D'autres ordonnent de puiser un an d'avanee, dans un endroit où la mer soit pure et ealme, de l'eau propre, pour la mettıe en réserve; et ils prétendent que la nature de eette eau est telle, que ee temps suffit pour lui faire perdre son goût salé ou son amertume et son odeur, de façon qu'elle s'adoueit en veillissant. En conséquence ils en mèlent une quatre-vingtième partie avee le moût, en y joignant une einquantième partic de gypse; ils remuent fortement ce mélange au bout de trois jours, et garantissent que eette opération fait gagner au vin non-seulement de l'áge, mais eneore une couleur brillante. Ausurplus, il faut remuer le vin et le soigner tous les neuf jours, ou au moins rous les onze jours, paree qu'en y l'egardant solvent on sera en état de jugrer s'il faut le vendre ou le grarder. Il en est qui jettent dans une futaille trois uncice de résine sèche broyée, qu'ils remuent ensuite avee soin, et veulent persuader qu'on peut donner aux vins uno vertu diurétique par eette méthode. Voiei la manière dont ils ont preserit de soigner le moût, quand les pluies fréquentes l'ont trop délayé, défaut dont on pourra s'assurer en le goûtant. Ils urdonnent de le faire euire en entier, jusqu'à évaporalion du vingtième. Ils prétendeut même qu'il sera eneore mieux d'y ajouter une eentième partie de gypse. Mais les Laeédémoviens le font euire jusqu'à diminution d'un ein- quième, et ne le bolvent que Iorsqu'il cat a sa quatrième feuille. Pour adoueir un viu dur, ils preserivent de mettre dans un petit vase de viı deux cyathi de fleur de fariné d'orge, pétrie avee du vin, et de l'y laisser l'espace d'une heure. II y a des personnes qui y mêlent de la lie de vin doux ; d'autres y ajoutent un peu de réglisse séehe, et ne boivent le vin qu'après l'y avoil fait ineorporer en remuant longtemps les vases. Ils disent aussi que lorsqu'on jette dans un tonneau des baies sèches de myrte sauvage, eueillies sur des montagnes, après les a voir pilées, le vin eontracte une exeellente odeur en peu de jours, pour peu qu'on le laisse reposer pendant dix jou's, et qu'on le passe avant de le boire. On amassera aussi des fleurs de vignes marices à des arbres, que l'on fera séeher à l'ombre, et, après les avoir bien pilées et eriblées, on les conservera daus un vase propre, pour en mettre, quand on le jugera à propos, la valeur de la mesure appelée par les Syriens chcenica, sur trois tonneaux de vin. On bouchera ensuite ees tonneaux, et on ne les ouvrira que le sixième ou le septième jour suivant pour son usage. On prétend que l'on peut rendre du vin agréable à boire, en $y$ plongeant une quantité suffisante de fenouil ou de sarriette, et en l'emuant le tout; ou en mettant dans un vasc deux amandes de pignons grillées et enveloppées dans un linge, pourvu que l'on bouche ensuite le vase, et que l'on ne boive ee vin qu'au bout de cinq jours. On prétend encore que l'on peut donner à du vin nouveau la qualité des vins vieux, en eoneassant et en broyant ensemble telle quantité que l'on jugera suffisante d'amandes amères, d'absinthe, de gomme de prunelier portant fruit, et de fenugrec, pour en mettre dans ce vin la valeur d'un cyathus par amphore, quod album et stypticum, prodesse stomaclıo laxiori; transmarinum, pallorem facere, et tantum sauguinein non creare : uvis nigris fieri forte, rubeis suave, albis vero plerumque mediocre. In condiendo ergo vino aliqui Gracorum mustum decocfum ad medietatem vel tertiam par. teın viıo adjiciunt. Alii Graeci ita jubent, aqguam marinam mundam de puro et quieto mari, quan anıo ante compleverint, reservari : cujus talem esse naturam, ut et salsedine vel amaritudine per hoc tempus careat et odore; et dulcis fiat actate. Ergo ejus octogesinam partem musto admiscent, et gypsi quinquagesimam. Post tertiam deinde diem fortiter commovent, ac pollicentur non actatem solum vino, sed splendorem quorjue coloris afterre. Oportet autem nona quaqne die vinum moveri atıue curari : vel si tardius, undecima. Frequens enim respectus faciet judicare, utrum vendenda sit species an tenemla. Quidan resiux sicca: trite uncias tres dolio immergunt et permovent, et vina diuretica sic fieri posse persuadent. Mustum vero, quod per pluvias frequentes leve est, sic curari [debere ] jusserunt, quod probari gustu ipsius poterit. Onue mu. stum decoqui jubent, donec pars ejus vigeslına possit absumi : melius quoque fieri, si ceutesimam partem हypsi i'ALLADIT. adjicias. Lacedæmonios vero eousque decoquere, donec vini quinta pars pereat, et quarto anno usibus minis!rare. Suave vinum de duro fieri docent, si orleacei pollinis cyalloos duos simul cum vino subaclos mittas in viui vasculo, et lıora una ibi esse patiaris. Aliqui feces vini dulcis admiscent. Aliqui addunt glycyrlizx siccx aliquantulum, et utuntur, cum diu vasoruin conmotione uniccuerint. Vinum quoque intra pancos dies optini odoris effici, si baccas myrti agrestis monlanas siccas et tunsas mittas in cabum, et decem diebus requinscere patiaris : tunc coles et utaris. Vitis etiam flores arbustirac collectos in umbra siccare curabis. Tunc diligenter tunsos et cretos laalsebis in vasculo novo, el cum volıeris, tribus cadis unam floris mensuram, quam Syri (cabum, Greci) clıœnicam rocant, adjicies, et superlines dolium, et sexta vel septima die aperies et uteris. Vinum fieri ad potandam suave ita dicunt : Faniculi vel satureiæ singulorum congruum modum vino immergi atcue turbari, vel fructum quem duæ nuces :inex produxerint, torrefactum et linteo ligatum milti in vasculo, ac superliniri, et usui esse quinque diebus cxactis. Vinum autem velıt vetus effici de novello, si anygdala amara, absinthium, pini frugiferi comam, fo: 
et que e'est le moyen d'en faire du vin do première qualité. Si l'on eraint que ee vin n'ait quelque viee, on mêlera du miel dans cette eompo. sition avec de l'aloès, de la myrrhe et du mare d'huile de safran; le tout broyé par parties égaIes et réduit en poudie, pour en mettre la valeur d'un cyathus par amphore de vin que l'on vouIra frelater. Veut-on que le vin de l'année paraisse vieux? on broie et l'on crible une uncia de mélilot, trois de réglisse et de nard eeltique, et deux d'aloès hépatique; et l'on met six cuillerées de cette composition sur einquante sextarii de vin reufermé dans un vase que l'on expose à la fumée. On assure qu'on peut faire changer du vin rouge de couleur de la manière suivante: On jette dans ee vin de la farine de fèves, ou l'on introduit, dans une bouteille qui en est pleine, trois blanes d'œuf qu'on remue longtemps, et le vin se trouve blane le lendemain. Si on y jetait de la farine de pois d'Afrique, il pourrait changer de couleur dans le jour même. On dit aussi que la vigne a eette propriété, que si l'on rédait en cendre des ceps qui produisent du: raisin blane ou de ceux (jui en produisent de rouge, et qu'on mette cette eendre dans le vin, il prendra la couleur du raisin dont la vigne aura donné cette eendre; de façon qu'il deviendra rouge avee la eendre le la vigne qui porte du raisin rouge, et blane avee eelle de la vigne qui en porte de blane; pourvu qu'on ait l'attention de mettre sur une futaille de dix amphores la valeur d'un modius le eendre de sarment brûlé, et qu'après avoir laissé eette eendre pendant trois jours dans le vin, on le tienne eouvert et bouché; et, en effet, on le trouvera au bout de quarante jours blane ou rouge, selon la couleur qu'on aura jugé à propos de lui donner. On assure eneore que l'on peut

num Graecum simul frigas quantum sufficere astimaris, et pariter tundas, et ex lyis unum cyathum per amplıoram mittas, ct ınagna vina conficies. Si vero senseris peceatıra, lutic confectioni aloën, myrrham, erocomagna, singnla modis aqualibus tuisa et in pulvercm reilacta cum inelle iniscebis, et uno cyatho unam amphoram condire curabis. Anuiculum quoque vinum ut longan simulare videatur matem, meliloti unciam unam, glyeyrhiza uncias tres, nitrdi celtici tantuntem, aloës epatices uncias duas tundis et minis, et in sextariis quimuaginta coclulearia sex reconde, el vas ponis in fumo. In alhun colorem vina fusca mutari asserunt, si ex falo lomentum factum vino quis adjiciat, vel ovorum trium laganae infundat alborcu, diuque conmoveat, sequenti die candidun reperiri : quod si ex Afra pisa lomentım adjiciator, eadem die posse mu. tari. Vitibus quoque hane esse naturam, ut alba vel nigra si redigantur in cinerenı, vinoque adjiciantur, ei unam. quiuncue formam sui coloris imponere, ut ex nigra fuscum, canulidum vero reddatur ex allı; ea ratione seilicet, ut combusti sarmenti eineris modii unius mensura mit. tatur in dolio, yuod labebil amphoras $x$, et triduo $s$ :relictum post operiatur ac lutetur : allonm vel (si ita visun. donner de la forec à du vin faible en suivant la mithole que voicl: On y mettra soit des feuilles, solt des racines ou de jeunes tiges d'althoe e'est-à-dire, de guimauve ordinaire, après les a voir fait bouillir. On y pourra eneore mettre du gypse, ou deux cotula de pois ehiches, ou trois nolx de eyprès, ou une poignée de feuilles de buis, ou de la graine d'ache de marais, ou de la cendic de sarments que l'aetion du feu aura dćpouillée de toute partie ligneuse, et réduite à l'etat de poudre impalpable. On assure aussi qu'un vin âpre deviendra elair et excellent en un jour, lor'squ'on aura broyé ensemble, dans une pelite quantité devin, dix grains de poivre et vingt pistaches, pour les mettre dans six sextarii de ce vin. En effet, si après avoir remué longtemps ee mélange on lc laisse reposer, et qu'on passe en. suite le vin, on pourra le boire sur-le-champ. On dit également que du vin trouble ne tardera pas à s'élaircir, si l'on y met sept pignons sur un sextarius de liquide, et qu'on le remue longtemps. En effet, dès quoon l'aura laissé reposer quelque temps, il deviendra elair, et sera potable après avoil' été passé. On dit eneore fet l'on prétend même que c'est un seeret qui a été montré aux habitants de la Crète par l'oraele d'Apollon Pythien), que le vin deviendra blane, et qu'il contractera un goût de vin vieux, si l'on y jette les drogues suivantes, après les avoir broyées eusemble et les avoir réduites en poudre très-fine, en les seeouant à l'aide d'un erible : ees drogues sont quatie uncice de jone odorant et autant d'aloès hépatique, une uncia d'excellent mastic, et autant de casse et de poivre, une semi-uncia de spiea-nard, et une uncia tant d'excellente myrrhe que d'ericens mâle qui ne soit pas rance. Ces drogues mises dans le moût, on le fera bouillir; et

fuerit) nigrum reperiri quadraginta diebns exactis. Vinun quoque asserunt ex molli forte sic fieri : Althex, hoe est, ibisci, folia vel radices, ant ejus caulem tenerum decoctum mitti, aut gypsum, aut ciceris cotulas duas, ant cupressi pilulas tres, aut buxi folia, quantum manus ceperit, aut apii semen, aut cinerem sarmentorum, cui vis flammax corpus reliquit exile omni soliditate detraeta. Vinum vero eadem dic ex austero lympidum atque optimum fieri, si grana piperis decem, pistacia viginti adjecto modico vino simul conteras, et in sex vini sextarios mittas, diu omnibus ante eommotis, tunc requiescere patiaris, et coles usui mox futurum. Item feenlentım statin lympidum reddi, si vil pini nueleos in (unumı) vini sextarium mittas, diuque commoveas, et paululum cessare patiaris : mox sumere puritatem, colarique debere, et in $11 \mathrm{sum}$ referri. Item (quod Cretensibus oraculum Pythii Apollinis monstrasse menoratur) fieri sic candidum, et sumere vetustatis sapo$\mathrm{rem}$, si spuinuanthos uncias quatuor, aloës cpatica uncias quatuor, mastici optimi unciam unan, cassixe fistula unciam unam, piperis uneiam ınam, spica. Inlice semuncian, myrrlae opttma unciam unam, thuris masculi non rancidi unciam unam : tundis universa, et in tenuis- 
après qu'il aura bouilli on l'écumera, ct l'on jettera de côté tous les pepins de raisin qui auront surıagé en bouillonnant. Ensuite on niettra, sur dix amphores de vin, trois sextarii italiques de gypse broyé et eriblé, après avoir cependant transvasé la quatrième partie du vin que l'on voudra frelater, de facon que l'on n'ajoutera ce gypse que dans le vin qui restera ; après quoi on agitera fortement la futaille, pendant deux jours, avec un roseau vert et garni de ses raeines. Le troisième jour, on fera couler bien doucement dans dix amphores de vin la valeur de quatre cuillerées de la poudre dont nous venons de parler, et l'on remettra par-dessus ld quatrième partie de ce vin qui avait été transvasée, comme nous l'avons dit ci-dessus, pour remplir la futaille, que l'on aura soin de remuer encore longtemps, afin que toute la masse du moût soit imprégnée de la vertu de ces drogues. Ensuite on couvrira la futaille, et on la bouchera, en y laissant néanmoins une petite ouverture qui servira à donner de l'air au viı pendant qu'il houillira. Enfin, au bout de quarante jours on bouchera cettc ouverture; après quoi on pourra boire de ce vin quand on le jugera à propos. Une chose qu'il ne faut pas perdre de vue, c'est d'avoir l'attention, toutes les fois que le vin aura besoin d'ctre remué, qu'il le soit par la main d'un enfant impubère, ou d'une personne chaste. Il ue faudra pas non plus couvrir l'enduit avèc lequel on aura bouché une futaille avec du gypse, mais avec de la cendre de sarments. On donne cneore une méthode pour faire du yin qui préservera des maladies contagieuses, et qui sera bon pour l'estomac. Cette méthode consiste à mettre dans une metreta d'excellent moût, avant qu'il bouille, huit uncia d'absinthe broyée, que l'on enve-

simum pulverem cribro excutiente deducis. Cum vero mustum ferbuerit, despumabis, et omuria uvarum grana, qua fervor in sumumu rejecit, expellcs. Tunc gypsi triti atque cribrati tres Italicos sextarios Iuittis in vini amploras decent, prius tanen partem quartam vini conliendi in alia vasa transfundes, et ita gypsun adjicies, ct dolium viridi ac radicata canna per bidunm fortiter agitahis. Tertia vero die, ex suprascriptis pulveribus quaterua cochlearia com. pleta modestius in denas vini amplıoras miltes, ct vini, sicut supradictum est, quartan parteu, quam alibi diflinderas, superadjicies, et dolium replebis, et iten diu agitare curabis, ut specierum vis onue musti corpus inticiat. Tunc operies atque oblinies, relicto brevi foramine, quo astuantia vina suspircut. Sed exemtis quadraginta diclous, $\mathrm{ct}$ lone spiraculum claudis, et dcinde ut libuerit, gustas. Illud mcmento servare pro cateris, ut quoties vium movetur, investis pucr hoc, aut alipuis satis purns efficiat. Liutimentum quoque dolii uon gypso sed sarmentorum cinere debehis inducere. Itcm vinum, quod salutare contra pestilentian sit, ct stomacho prosit, fieri hoc genere fertur : in optimi musti metreta una ante quam ferveat, funsi absinthii octo uncias linteo involutas demittes, et loppe dans un linge; on fait ensuite retirer ectte absintlec du vin au bout de quarante jours, et on transvase le vin dans de petites bouteilles pour te boire. Ceux qui sont dans l'usage de frelater le vin avse du gypse le font à présent, lorsque lo moût écume et qu'il a jeté son premier bouilIon. Au reste, quand le vin eșt naturellement trop doux et d'un goût aqueux, il suffit d'y mettre deux sextarii de gypse sur cent conyii de viu. Quand il est ferme de sa nature, on peut se contenter de la moitié de cette dose pour pareille mesure de vin.

$X V$. On fera à présent du vin rosat sans roses, de la manière suivante: 0 n descend dans un vase de moût, avant qu'il commence à bouillir, des feuilles de citronnier vertes, enfermées dans un panier de palmier; puis on bouche le vase, et, après y a voir ajouté du micl, au bout de quarante jours on s'en sert en guise de vin rosat, quand on le juge à propos.

X VI. On fait ce mois-ci des vins avee tous fes fruits dont nous ayons parlé en leur lieu.

XVII. Composition du vin miellé. On prend la quantité que l'on jugre à propos de moût provenant de belles vignes et de bon eru, vingt jours après sa sortie de la cuve, et l'on y méle un cinquième de miel excellent et non écumé, après l'avoir fortement broyé jusqu'à ce qu'il soit blan. clsi; puis on l'agite fortement avec un roseau garni de ses racines, durant quarante ou mieux cinquante jours de suite; et celạ, après l'avoir couvert d'un linge propre, à travers lequel il puisse prendre l'air quand il viendra a bouillir. Au bout des cinquante jours on enlèvera avec la main, après l'a voir lavée, tout ce que l'ébullition aura rejeté à la surface; puis on le mettra dans un vase que l'on bouchera bien avec du gypse, et il

exactis $\mathrm{xL}$ diebus curabis anferre. Id vinum refundis lagonis minoribus, et uteris. Nuuc condiunt, primo amne musti spumaintis egesto, quibus moris cst gypso vina medicari. Scd si natura lenius vinum cst, et saporis humecti, in congiis centum dnos gypsi sextarios misisse sufficiet. Quod si vinum nascilur virtnte solidius, medietas abunde proedictis poterit satis esse mensuris.

$X V$. Nunc rosatum sine rosa facies sic. Folia citri viridia sporta palmea missa in musti nondum ferventis vase depones, et claudes, et cxemtis quadraginta diebus melle addito ad modum rosati, cum placebil, uteris.

XVI. Hoc mcnse, omuia quax locis suis leguntur, ex pounis vina conficies.

XVII. [De aenomelle]. Mustum de inajoribus et egregiis vitibus post $\mathrm{xx}$ dies, quam levatum fuerit ex lacu, quant:am volucris sumis, et ci mellis non despumati optiui upuintaun partcm (prius) tritam fortiter, donec albescat, admisces, et agitabis ex canna radicata velseurenter. Muvebis autem sic per dies xL continuos, rel quod est melins, quinquaginta, ita ut cum moveris, mundo linten tcgas, per quod facile confectio astuabunda suspiret. P'ost dies autem quinquaginta munda manu purgas quorlcunque 
se eonservera très-vícux. Il sera ecpendant mieu $x$ de le survider au printemps suivant dans de plus petits vases enduits de poix, que l'on couvrira après les a voir bien bouehés avee du gypse, afin de les mettre au frais soit dans un caveau souterrain, soitdans du sable de rivière, ou de les enfoneer en partie sous le sable au fond d'une rivière. Ce vin ue segâtera jamais, à quelque vieillesse qu'il parvienne, pourvu qu'il ait été fait avee soin.

XV'III. On fera à présent le defrutum, le carcenum et la sapa. Tous ces vins se font également avee du moût, mais la façon n'est pas la même; de là différenee de noms et de propriétés : ainsi le defrutum, qui tire son nom du mot defervere, est censé fait, lorsque le moût a été fortement écumé jusqu’à ce qu'il soit épaissi; le carœnum, forsqu'il est réduit aux deux tiers; ct la sapa, lorsqu'il est réduit à un tiers. Ce dernier sera cependant meilleur quand on l'aura fait euire a vee des coings, sur un feu de bois de figuier.

XIX. On fera à présent, a vant la vendange, le passum (vin de raisin séché au soleil), qu’on a partout en Afrique, le seeret de rendresi moelleux et si agréable, et qui, employé en guise de miel pour confire, devient un préservatif eontre les vents. On eueillera done une très-grande quantité de grappes de raisin, que l'on fera séeher au soleil; et, après les avoir renfermées dans de petits paniers de jone à elaires voies, on eommencera par les fouctter vigoureusement avee des verges. Ensuite, lorsque tous les grains seront amollis par les coups, on soumettra le panier à l'action du pressoir. Le jus qui s'en exprimera sera le passum, qu'on renfermera dans un petit vase pour le conserver comme du miel.

XX. Manière de faire le cotignac. Après avoir

supernatabit, et in vasculo gypso diligenter includis, et ad vetustatem reservas. Melius tamen si in minora et picata vascula proximo vere transfundas, et gypsata diligenter operias, et in terrena et frigida cella recondas, vel arenis furialibus vel codem solo vascula ex aliqua parte subwergas. Hoc "nulla vitiatur xtate, si tamen diligenter effeceris.

XVIII. Nunc defrutun, carouum, sapam conficies. Cum omnia uno genere conficiantur ex musto, modus his et virtutem mutabit et nomina. Nam defrutum a deferrendo dictum, ubi ad spissitudinem fortiter despumaverit, effectumn est. Caronum, cum tertia perdita duß partes remauserint. Sapa, ubi ad tertias redacta descenderit; quam tamen meliorem facient cydonia simul cocta, et igni supposita ligna ficulnea.

XIX. Passum nunc fiet ante vindemiam, quod Africa suevit universa conficere pingue atque jucundum, et quo ad conditum si utaris mellis vice, ab inflatione te vindices. Leguntur ergo uvæ passa quamplurimx, et in fiscellis clausa junco factis aliquatenus rariore contextu, virgis primo fortiter verberanfur. Deinde ubi uvaruın corpus vis contusionis exsolverit, coclılea supposita sporta compriuitur. IInc passum est quicquid eflluxerit, et conditum vasculo mellis more servatur. pelé des coings mûrs, on lés coupe en petits morceaux très-minees, en jetant de eôté les parties dures qui se trou vent dans l'intérieur de ee fruit. Ensuite on les fait bouillir dans du miel, jusqu'à ce que cette composition soit réduite à moitié, en les Saupoudrant de poivre fin pendant qu'ils euisent. Autre manière : On mèle ensemble deux sextarii de jus de coings, un et demi de vinaigre et deux de miel ; puis on fait bouillir tout ee mélange jusqu'à ce qu'il devienne' aussi dense que du miel pur ; après quoi on y fait mêler deux uncice de poivre broyé et de gingembre.

XXI. Manière de conserver du levain pour faire des gâteaux au vin doux. On fait une pâte avee du froment nouveau bien épluché, que l'on arrose avee du moût de première pression, en mettant une lagena de moût sur un modius de farine: Ensuite on fait séeher cette pâte au soleil, après quoi on l'arrose encore de la même faęon, et on la fait sécher de même. Quand on a répété cette opération jusqu'à trois fois, on fait avec eette pâte de très-petits pains de même forme que les gâteau $x$, et, après les avoir fait sécher au soleil, on les serre dans des vases de terre euite bien nets, que l'on enduit de plâtre. On s'en sert au lieu de levain, dans la saison où l'on veut faire des gâteaux au vin doux.

XXII. Manière de faire du raisin see à la façon des Grecs. On tordra sur le eep même les grappes du raisin qui paraitra le meilleur, le plus doux et le plus transparent, et on les y laissera séeher d'elles-mêmes; ensuite, lorsqu'on les aura cueillies, on les suspendra à l'ombre; puis on les attachera plusicurs ensemble pour les mettre dans des vases, où on les posera sur des pampres frais sans aucune humidité, et où on les foulera avec

XX. [De cydonite]. Abjecto corio mala cydonia matura in brevissimas ac tenuissimas particulas recides, et pro. jicies durum, quod habetur interius. Dehinc in melle decoques, donec ad mensuram mediam revertatur, et coquendo piper subtile consperges. Aliter : Succi cydoniorum sextarios duos, aceti sextarium unum semis, et mellis duos sextarios miscebis, et decoques donec tota permistio pinguedinem puri mellis imitetur. Tunc triti piperis alque zinziberis binas uncias miscere curabis.

XXI. [De fermento musteorum servando.] Ex novo tritico purgato farriculım facies, et ex musto de sub pedibus rapto curabis infundere, ita ut modio farris lagonan musti adjicias : deinde sole siccabis, et item similiter infundis ac siccas. Hoc cum tertio feceris, panes ex eo brevissimos admodum facies musteorum, et in sole siccatos vasculis novis fictilibus recondis et gypsas. Pro fermento, quo tempore auni musteos facere volueris, hoc uteris.

XXII. Uram passam Græcam sic facies. Melioris acini et dulcis et lucidi botryones in ipsa vite torquebis, et patieris sponte inarescere, deinde sublatos in umbra suspendis, et uvam constrictam componis in vasculis, substernis pampinos sicco algore frigentes, et manu comprimis, et ubi vas impleveris, item desuper pampinos addis (ni- 
la main : quand les vases seront pleins, on recouvrira eneore le raisin de pampres qui ue soient pas moins frais que les premiers; puis on couvrira ees vases, et on les mettra dans un lieu sec, mais frais, où la fumée ne puisse pénétrer.

XXIII. La projection de l'ombre en octobre est égale à eelle de mars.

A la première et à la onzième heure, le gnomon donne vingt-einq pieds d'ombre.

A la seconde et à la dixième, il en donne quilıze.

A la troisième et à la neuvième, il en donne douze.

A la quatrième et à la huitieme, il en domne huit.

A la cinquième et à la septième, il en donne six.

A la sixic̀me, il en donne cinq.

\section{LIVRE DOUZIEME.}

\section{NOVEMBRE.}

1. On sème au mois de novembre le froment et le blé : e'est même le véritable temps des semailles et de l'ensemeneement annuel. Il faut einq modii, tant de l'un que de l'autre grain, pour ensemeneer un jugerum. II sera également temps à présent de semer l'orge. On sème les fèves au commencent de ce mois. Elles demandent un terrain qui soit très-gras ou fumé, ou une vallée fertilisée par les eaux des hauteurs voisines. On commence par jeter les fèves sur terre, ensuite on doune un premier labour; après quoi on les pare en sillons. II faut les herser sans ménagement, afin qu'clles puissent être couvertes de terre le plus possible. Il y a des personnes qui prétendent que lorsqu'on sème des fèves dans les terrains

hilo minus non calentes, ) et operculabis, ac statues in loco frigido sicco, quein unllus fumus infestet.

XXIII. October Martiun similibus umbris sibi fecit xinari.

\begin{tabular}{|c|c|c|c|c|c|}
\hline Ifora & I & & XI & pedes & $\mathrm{xxv}$ \\
\hline Ilora & \| & el & $\mathrm{x}$ & pedes & xv. \\
\hline Hlora & iII & et & IX & pedes & . XI. \\
\hline Ilor & IV & et & viII & jerles & vili. \\
\hline Ilor & $v$ & et & VII & perles & vi. \\
\hline Iora & vi & & & pedes & v. \\
\hline
\end{tabular}

\section{LIBER DUODECIMUS.}

I. Tovembrimense triticum seremus et far satione legitima, (ac semente solenni.) Jugermm utriusque seminis modiis qquinqque tenebitur. Ninnc et ordeu m maturum adiuc sereınıs. In lujus principio fabam spargimus, qua pin. guissimum vel stercoratum desiderat locum, vel vallem, quam succus reniens a summitate fuecundel. Primo ser $j$ - frolds, il ne faut pas en briser les mottes, afn que les germes de ees semences puissent ètre protégés contre lo froid, en se tenant à l'abri sous ces mottes pendaut les gelées. Si les semailles de cette nature de grains font peu de tort à la terre, au moins ne la fertilisent-elles point, comme le veut l'opinion eommune. Aussi Colu. melle prétend-il qu'une terre qui sera restée en jachère l'année préeédente sera plus convenal)le au blé que eelle dont on aura réeolté une moisson de fèves. Il faut six modii de fèves par jugerum quand la terre est grasse, et ulle plus grande quantité quand elle est médioere. Elles réussissent très-bien dans un terrain compacte, et no peuvent s'aceommoder d'un sol maigre ni d'un eiel nébuleux. II faut surtout avoir soin de l's semer au quinzième jour de la lune, pourvu que eette planète nesoit pas eneore frappée des rayous du soleil. C'est pour cela que quelques personnes prétendent qu'il vaut micux ehoisir à cet efiet le quatorzième jour de la lune. Les Grees assurent qu'il ne croitra point d'herbes nuisibles aux fèves, lorsque celles-ci auront été trempées dans du sang de ehapon avant d'être semées; qu'elles pousseront plus tôt quand on les aura fait macérer dans l'eau un jour avant de les semer; et qu'enfin, si on les arrose d'une solution de nitre, elles euiront aisément. On fait à présent les premiers ensemeneements de lentilles de la manière qui a été donnée au mois de février. On pourra aussi semer de la graine de lin dans tout le courant ds celui-ci.

II. C'est surtout au commencement de ce mois que l'on peut former de nouveaux prés, de la façon qui a déjà été expliquée. Il faudra aussi planter des vignes, pendant toute sa durée, dans les terrains ehauds et sees; ou exposés au soleil. II sera encore à propos de les provigner, comme de

tur, deinde proscinditur, et func sulcatur. Occanda est large, ut tegi plurimuu possit. Aliqui locis frigidis dicunt in faba satione glebas non esse fraugendas, ut per eas gelicidiorum tempore possint germina obumbrata defendi. Satione ejus generis, sicut opinio habet, non fuectmmlatur terra, sed minns lxditur. Nam Columella dicit agrum frumentis utiliorem probari, qui anuo superiore vacuus fuerit, quau qui calanos fabacex messis eduxit. Pingue jugerıu ser modii occupant ; mediocre, amplius. Spisso bene provenit: macrum solum nebulosumplue non patitur. Curaudun est praccipue, ut luna $\mathrm{xv}$ seratur, si adlusc ictum solis ropercussa non sensit. Aliqui dicunt quartamdeciuam potius eligeudam. Sanguine caponis Greci asserunt fabie semina macerata lierlsis adversautibus non noceri. Aqua priclie infusa citius nasci, nitrata aqua respersa cocturam non habere difficilem. Nunc seritur prima lenticula, sicut Fe. bruario mense narratum est. Hoc etiam toto mense poterit liui semen aspergi.

11. In lujus maxime [mensis \} principio, possumus lus. tituere nova prata, more quo dictun est lloc etiam toto mense locis calidis et siccis vel' apricis erit vitiuen cele- 
becher la terre aur pied des jemes ceps, et de les reeouvrir de terre, ainsi que les plants d'arbres daus les pays froids, tant à present (ju'avant les lides. On sévrera à présent les marcottes des ceps, cest-à dire, les arceaux que forment les provins; ce qu'on ne doit faire que trois ans après qu'ils auront été couchés ell terre.

III. C'est à présent et dans les temps postérieurs à celui-ci qu'on déchaussera, pour les saturer de fumier, les vieilles vignes attachées à des jougs, ou-soutenues sur des treilles, quand leur trone sera robuste et sain ; qu'on les taillera de près, en les rognant avec le tranchant d'un fer aigu, à la distance de trois ou quatre pieds de terre, dans la partic où leur écorce sera la plus verte, en les exeilant à venir par des fouilles fréquentes; parce qu'il sortira d'ordinaire un germe de cette plale, ainsi que l'assure Columclle, et qu'à l'approehe du printemps elles jetteront du bois, qui pourra servì à réparer les vieux ceps.

IV. On fait à présent la taille :"automne tant des vignes que des arbres, surteut dans les provinces où la douceur de la ternpérature y invite. (in taille aussi lesplants d'oliviers, et on récolte les olives dont on doit faire la première huile, lors'ju'elles commeneent à tourner. En cffet, quand elles sont absolument noires, clles perdent ell qualité, mais en revanche le rendement augmente. La taillc des oliviers ainsi que celle des autres arbres sera fructueuse, pourvu que la méthode du pays n'y soit pas contraire, lorsqu'on en coupera les cimes, et qu'on leur fera jeter des láneaux qui s'étendiont sur les côtés de l'arbre, lesquels còtés seront eux-mèmes Inclinés vers la terre. Si l'on hablte au contraire un pays qui ne soit ni fréquenté ii cultivé, il faudra d'alsord faire en sorte que le trone de l'arbre soit entière-

branda positio. Nunc et propago jure ducetur, et locis fri. gidis novellas vites et arborum plautas circumfodere atyue operire conveniet; et ante Ilus nunc mergns, loc est propaginis curvatura, post triemuium, quam pressa fuerat, recidetur a vite.

III. Nunc ac deinceps vinea vetus, qux in jugo est vel pergula, si robusto et integro trunco sit, abliqueata limo satietur, ct angustius putata inter quartun et tertimun peden a terra virilissima parte corticis acuto ferranenti mucrone feriatır, ac fossa frepueutius incitetur. Nam ( sicut asserit Columella) ex eo toco germen plerunque pro. ducit, et reniente vere fundit materiam, qua vitis reparetur antipua.

IV. Nunc putatio autumnalis celebratur in vitibus et arloribus, maxime ubi invitamur tepore provincis: : et pu. tantur oliveta : et oliva, cum varia coeperit esse, colligitur, ex qua primum fiet oleum. Nam cum tota nigrescet, quod speciei merito posteravit, fundendi ubertate con? pensat. Est utilis olearum putatio, cacterarumque arbormm, si loci patitur discipliua, ut decisis cacumiuibus, rami Anentes per latera prona fundantur. Quod si regio insolens et incustodita contigerit, agendum prius toto arboris cor. ment dépouillé de ses branches à la portéc des animaux, de facon que ceux.ci ne puissent point lui nuire, et qu'on u'ait à soigner que des arbres qui solent déjà à l'abri de toute injure par leur seule élévation.

V. On forme aussi à présent des plants d'oliviers dans les terrains chauds et dans les contrées sèches, de la manière qul a été détaillée au mois de février. Ces arbres aiment à être plantés daus les lleux élevés, pour être à l'abri de l'humidité; de même qu'ils se plaisent à être ratissés assidument, à être engraissés avec un fumier abondant, et à être doucement agités par des vents qui les fertilisent. On appliquera aussi ce mois-ci aux oliviers stériles les remèdes que nous arons prescrits ci-dessus. Rien n'empêche de fairc à présent des paniers, des pieux et des éelhalas. C'est aussi le temps propice pour faire l'huile de laurier dans les climats tempérés.

VI. Il est à propos de semer l'ail ce mois ci, ainsl que l'oignon de Cypre, prin I Ipalement dans des terres blanches, bêchées ct labourées, pourvu qu'elles ne soieut pas fumées. On tracera dne sur des planches des sillons, dans la partie la plus élevée desquels on mettra ces semences, en les séparant de quatre doigts l'une de l'autre, et sans les enfoncer trop en terre. On les sáreleri souvent, afin qu'elles croissent davantage. Si on veut que l'ail donne une forle tête, on le foulera aux pieds quand sa tige comınencera à monter, et dès lors la séve refluera vers les gousses de celte plante. On prétend que l'ail sera sans mauvaise odeur quand on l'aura semé dans le temps où la lune est cachée sous la terre, pourvu qu'on le cueille dans le même temps. On le conservera, soit en l'ensevelissant dans de la paille, soit en le suspendant à la fumće. On peut aussi semer à

pore ab inferiore parte purgato, ut altitudine animalium supergressa modus transccudatur injurix, et arbor janı spatio suo tuta curetur.

V. Nunc etiam locis calidis ac siccis regioniluns oliveta ponuntur, sicut Februario disputatum est. Amat lisec at bor ardno locorum sitn mediocriter ab lıumore suspendi, sealpi assidne, laetaminis ubertate pingnescere, feracibus ventis clementer agitari. Hoc etian mense oleis sterilibus qux supradicta sunt remedia facienus. Nunc et corbes et pali et ridica bene fieri passunt, Etiau nunc locis temperatis est laurini olei justa confectio.

VI. Hoc mense allium hene seritur et ulpicnm in terra maxime alla fossa et subacti sine stercore. Sulcos in areis facies, et semina in locis altioribus pones iv digitis sepa. rata, neque altius pressa. Sareulabis frequenter, inde plus crescent. Si capitatun facere volueris, ubi creperil caulıs prodire, proculca; ita succus revertetur ad spicas. Fertur, si luna sub terris posita seratur, et item sub terris luna latente vellatur, odoris foeditate cariturum. Vel paleis condila allia, vel fumo suspensa durahumt. Nunc et cepulla seri potest, et carduorum planta disponi, et armoracea seritur et cunela. 
présent la eiboule; de même qu'on peut planter des pieds d'artichauts, et semer le grand raifort et l'origan.

VII. On eloisira ce mois-ci dans les pays ehauds, et le mois de janvier dans les autres, pour mettre en terre des noyaux de pèche dans des planches façonnées au pastinum, en les éloignant de deux pieds l'un de l'autre, afin que lorsque les plantes qu'ils donneront auront pris quelque eroissance, elles puissent être transférées. Mais on aura soin d'en tourner la pointe par en bas lorsqu'on les mettra en terre, et de ne pas les enfoncer à plus de deux ou trois doigts de profondeur. Il y a des perzonnes qui eommencent par falre sèeher les noyaux quelques jours avant de les mettre en terre, et qui les gardent ensuite dans des paniers qu'elles remplissent d'une terre bien pulvérisée, mêlée de cendre. Pour moi, jen ại souvent gardé, sans aucune préeaution, jusqu'au temps où je les ai mis en terre. Les pêchers réussissent, à la vérité, dans quel. que endroit qu'ils soient plantés; maisils rapportent davantage et durent plus longtemps quand ils rencontrent un climat chaud et un sol sablonneux et humide; au lieu qu'ils périssent dans les pays froids, surtout lorsque ees pays sont sujets aux vents, à moins qu'on ne mette quelque corps étranger devant eux pour les abriter. Tant que les germes de ees arbres seront tendres, on les béchera souvent, pour les débarrasser des herbes qui croissent autour. On pourra très-bien les transférer en pieds dans une petite fosse, quand ils auront deux ans. Il ne faut pas alors les ćloigner beaucoup les uns des autres, afin qu'ils se protégent mutuellement contre l'ardeur du soleil. On les déchausscra pendant l'auțomne, et on les fumera avee leurs propres feuilles. Il faut tailler lc pêcher en automne, mais on n'en retranchera que les bagucttes qui seront sèches et pourries; paree que si on lui coupait quelque partie verte,

VII. Hoe mense locis calidis, exteris vero Januario Persici ossa in pastinatis areis sunt ponenda, binis a se imelibus separata, ut cum ibi planta excreverint, trans. ferautur. Sed ossa ponantur acumine deorsum verso, et Inon amplius quan duobus aut tribus palmis obruantur. Ossa vero quæ ponenda sunt, aliqui siccala prius paucis diebus cineris mistione terra soluta in qualis reservant. Eou) vero usque ad serendi tempus sine ulla cura sape servavi. Locis quidem qualibuscumı̨ue proveniunt. Sed et pomis et frondibus et durahilitate praccipua sunt, si corlum calidum, solum arenosum et liumidum fortiautur : frigidis vero et maxime ventosis uisi objectu aliquo defen. dantur, intereunt. Dum tenera sunt germina, saepe lierbis circumfossa liberentur. Bimam plantam recte transferemus scrobe brevi. Nec a se longe statuendx sunt, ut invicem se a calore solis excusent. Ablaqueanda sunt per autumnum, et suis stercorandac foliis. Putanda persicus in autumno est, ut arida et jutrida tantum virgulta tollantur : nam siquid viride resecemus, arescit. Languenti arbori veteris vini il se dessécherait. Quand eet arbre sera malade, on l'arrosera avec de la lie de vieux vin coupéc avee de l'eau. Les Grees assurent qu'il viendra des pêches sur lesquelles on remarquera des earactères gravés, lorsqu'on aura couvert de terre des noyaux, et que sept jours après, quand ils auront commencé à s'entr'ouvrir, on les aura ouverts pour en óter l'amande, et éerire telle chose qu'on aura jugé à propos avee du cinabre; pourvu qu'avant de remettre ees amandes en terre, on les ait recouvertes de leur enveloppe, en l'assujettissant de faẹon qu'elle ne puisse se séparer. Les différentes espèces de pêches sont les pêches fermes, les pêches précoces de Perse, et celles d'Arménie. Si l'ardeur du soleil vient à desséeher un pêcher, on entassera souvent de la terre auprès de son trone, on l'arrosera le soir poir le soulager, ct l'on interposera quelque obstacle à l'intensité des rayons. Il est eneore bon de suspen. dre à ses branches une peau de serpent. Pour pré. server un pécher de la brulne, il faut lui donner à présent du fumier, ou de la lie de vin coupéc avec de l'eau, ou du bouillon de fèses, qui vaut encorc mieux. S'il est tourmenté par les vers, on les fera mourir, soit avee de la eendre détrempée de lie d'huile, soit avee de l'urine de bouf eoupée avec un tiers de vinaigre. Si le fruit de eet arbre est sujet à tomber, on enfoneera un eoin de lentisque ou de térébinthe, soit daus sa racinc qu'on découvrira à cet effet, soit dans son tronc; à moins qu'on n'aime mieux percer l'arbre par lo milieu, pour y enfoncer ensuite un pieu de saule. Si l'arbre donne des frui:s qui soient ridés ou pourris, on en coupera l'écorce vers le bas du trone, et, après qu'il en sera sorti une certaine quantité d'humidité, on recouvrira la plaie avec de l'argile, ou avee un lut dans lequel il entrera de la paille. Un pêcher donnera de gros fruits sI on l'arrose, dans le temps qu'il sera en fleur, pendant trois jours, avee trois sextarii de lait de

feces aqua mistas oportet infundi. Affirmantibus Græcis Persicus scripta nascetur, si ossa ejus obruas, et post dies vu, ubi patefieri coperint, apertis lis nucleos tcllas, et lis cinnabari, quod libelit inscribas. Mox ligatos simul cuin suis ossibus obruas diligentius adharentes. [Genera eorum sunt lıæc, duracina, praecoqua Persica, Armenia.] Si hac arbor ardore solis inarescit, frequenti aggestione cumuletur, vespertino juvetur liumore, et objectis defelldatur umbraculis. Juvat in ea et spolium serpentis appencli. Nunc jam contra pruinas stercus ingeratur Persico, vel feces vini cum aqua permistic, vel quod magis prodest, aqua in qua falja decocta est. Si vermes Persicus patitur, cinis eos amurcx mistus extinguit, rel bovis uriua cun aceti tertia parte confusa. Si poma caduca sunt, uudata radici ejus vel trunco lentisci ant terebinthi cuneus aftigitur, vel terebrata in medio palus salicis impuiuetur. Sf poma rugosa crealit aut putrida, circa imunı truncum cortex recidatur, et cum inde norlicus lumnor eflluxerit, argilla vel paleato luto plaga retegatur. Magna ponua l'er- 
chevre. Quand un péeher a des défauts, il cst tron d'y attacher du genet d'lspagne, ou d'en suspeiidre à ses branches. On greffera le pècher au mois de janvier ou de février dans les pays froids, et au mois de novembre dans les pays hauds. On le greffera particulièrement auprès de terrc, et l'on cmploiera en greffes les scions les plus forts qui seront poussés au pied de l'arbre, parce que ses cimes ne prendraient point, ou que si elles prenaient, elles ne pourraient pas durer longtemps. On le greffera sur lui-même, sur l'amandier et sur le prunier. Mais les pêchers d'Arménie ainsi que les précoces prentent mieux sur les pruniers; de même que ceux qui donnent des pêches fermes prennent micux sur les amandiers, et y parviennent à un âge avancé. On peut greffer en éeusson le pécher au mois d'avril ou de mai dans les pays ehauds. On le greffe de cette manière en Italie à la fin de l'un et de l'autrc de ces mois, ou au mois de juin; c'est ee qu'or appelle emplastrare. Cette greffe se fait sur le trone même, que l'on a soin de couper auparavant par en haut, et auquel on applique plusieurs houtons, suivant la méthode que nous avons donnéc. Cet arbre donne des fruits rouges quand il a cité greffé cn fente sur le platane. On conserve les pêehes fermes en les faisant eonfire dans de la saumure et de l'oxymel, ou en les suspendant pour les faire sécher au soleil eonme des figues, après en avoir óté les noyaux. J'ai eneore vu confire dans du miel des pêches fermes dont on avait ôté les noyaùx, et elles avaient un goût agréable. On les conserve eneore fort bien en leur bouchant l'ombilic avec une goutte de poix chaude, et en les faisant ensuite nager dans du vin cuit jusqu'à diminution des deux tiers, dont on remplit un vase que l'on ferme hermétiquement. On croit que le pin est favorable à toutes les plantes qui croissent sous son ombre. $O$ n sème

slcus affert, s: florenti per triduum ternos sextarios caprini lactis ingesseris. Contra vitia Persici proficit spartum liga. tum vel spartea sıspensa de ramis. Mense Januario vel Februario locis figidis, Novemlni calidis Persicus inseratur, maxime circa terram surculis plenioribus et prope arborem natis. Nam cacumina vel non tenebunt, vel diu duzare nou poterunt. Inseritur in se, iu amygdalo, in pruno: sed Armenia vel procoqua prunis, duracina amygdalis melius adhorescunt, et tempus xtatis acqujirunt. Mense Aprili vel Maio locis calidis, in Italia vero utroque exennte vel Junlo Persicus inoculari potest, quod emplastrari dicitur praciso supèr trunco, et emplastratis pluribus gemmis, more quo dictum est. Persicus rubescit, si platanu inserta figatur. Duracina servantır, condita ınıria et oxymelle, vel detractis ossibus ficorum more in sole siccinlur ac pentent. Item sepe villi detractis ossilmus du. racina melle comliri, et saporis esse jucundi. Item bene servantur, si unbilicum pomj gulta picis calentis oppleveris, ut sic sapa innatıre cogantur vase concluso. Piuns creditur prodesse omnibus quxe sub ea seruntur. Pinum les pignons au mols d'octolire ou de norembre dans les contrées chaudes et sèehes, et au mois de février ou de mars dans eelles qui sont froides et humides. Cet arbre aime les terrains maigres, et ordinairement ceux qui sont voisins de la mer. C'est sur les montagnes et au milieu des rochers qu'il atteint son plus grand développement. Le vent et l'humiditélui sont favorables; mais en quelque endroit qu'on veuille le planter, soit sur des montagnes, soit partout ailleurs, on lui destinera des terres qui ne puissent pas convenir à d'autres arbres. Ainsi, après a voir labouré ees terrains aree attention, on les nettoiera, et l'on y sèmera les pignons commc on sème le blé, en prenant soin de les recouvrir de terre avec un léger sareloir, parce qu'ils ne doivent pas être cnfoncés en terre de plus d'un palmus. Dans son enfanec il faut le garantir des bestiaux, de peur qu'ils ne le foulent aux pieds dans le temps qu'il est encore faible. Il profitera très-bien quand on aura trempé les pignons dans de l'eau trois jours avant de les semer. Quelques personnes prétendent que le fruit de cet arbre s'adoueit quand il a été transplanté, mais voici les soins qu'elles emploient. Elles commencent par enfoncer, dans de petits verres remplis de terre et de fumier, une grande quantité de pignons; ct lorsque ces pignons sont venus, elles ne conservent que le plus fort, et retirent tous les autres. Quand celui-ci a pris un accroissement convenable, elles le transferent en pied à l'âge de trois ans, sans le retirer du verre, qu'elles brisent ensuite, pour donner aux racines la libert de s'étendre dans la fosse où l'arbrisseau est planté. Elles mêlent d'ailleurs avec la terre de cette fosse du crottin de eavale, en faisant des couches tant de terre que de crottin qui s'ćlèvent alternativement les unes sur les autres. Il faut cependant avoir soin que la raeine de cet arbre, qui est unique, et dont la direction est

seremus nucteis suis calidis et siccis regionibus' mense Octobri vel Novembri; frigidis et humectis Februario vel Martio. Anat locum gracilen, siepe maritimun : inter montes et saxa vastior et procerior invenitur : ventosis et lumidis, arbormm finut incrementa lotiora. Sed sive moutes velis conserere, seu spatia quacunque, lıxc lunic generi deputabis, qua alteri utilia esse non possunt. Exara. bis ergo ea loca diligenter, atque purgabis, et frumenti more semen asperges, ac levi sarculo curabis operire : nec enim plusquam palmo debet abscondi. Defendenda est tenera arhor a pecore, ne calcetur invalida. Proficiet, si nıcleos arjua ante triduum ınacerabis. Aliqui dicunt fructum pineum translatione mitescere : sed plantas hoc modo procurant, nt prius multa semina in caliculis terra et fimo repletis obruant, quæ ubi processerint, relicto eo quod solidius est, auferunt alia : ubj justum ceperit incrementum, trimam plantam cun ipsis caliculis transferunt, quibus fractis in scrobe indulgent radicibus largitatem. Terra tamen equa stercıs adıiscent, facientes straturam alterno ordine subinde crescestem. Servandum est tamen, ut ra- 
droltc, puisse êtrc trausféréc saine et entière d'une extrćmité à l'autre. La taille avance les Jeunes pins (ainsi que je l'ai éprouvé moi-même) au point que la rapidité de leur croissance en est double. On peut aussi laisser les pignons sur l'arbre jusqu'à préscut pour les cueillir plus mûrs, quoiqu'il faille néanmoins les eueillir avant qu'ils ne 's'ouvrent. Les amandes ne s'en peuvent pas conserver à moins qu'clles nc soient pelées. Cependant il y a des personnes qui assurent qu'on peut les garder, en les mettant avec leurs coques dans des vases neufs de terre cuite, remplis de terre. Si l'on plante en automne des noyaux de prunes, il faudra les enfouir à la profondeur de deux palmi, au mois de novembre, dans un terrain bien meuble et bien retourné. On les met aussi en terre au mois de février. Mais il faut alors les faire tremper pendant trois jours dans de l'eau de lessive, pour les contraindre de germer promptement. On plante encore les pruniers cn rejetous tirés du trone de l'arbre à la lin du mois de janvier ou vers les ides de février, en enduisant de fumier leurs racines. Ils se plaisent dans un terrain fertile et humide, et réussissent mieux sous un climat chaud, quoiqu'ils puissent supporter les climats froids. Si on les aide avec du fumier dans les terrains pierreüx et pleins de gravier; où ils n'auraient, sans ce secours, que des fruits sujets à tomber et à être piqués des vers, ils se corrigeront dc ce vice. Il faudra arraeher les rejetonsqui sortent de leurs racines, à l'exeeption des plus droits, que l'on conservera pour les planter. Lorsqu'un prunier est languissant, il faut, répandre sur ses racines du marc d'huile avec de l'eau ou de l'urine de bœuf pure, ou de vieille urine humaine eoupéc avec deux tiers d'eau, ou enfin des cendres prises au four, et sur-

dix ejus, qux una et directa est, usque ad summilatem suam possit integra et illasa transferri. Putatio novellas piui arbores tantum promovet (quod expertus sum) ut qua speraveras incrementa, duplicentur. Nuces pinexe et usque in loc tempus in arbore esse possunt, et maturiores legentur. l'rius tamen legendae sunt quain palescaut. Nuclei nisi purgati durare non possunt. Tamen aliquit in vasis fictilibus novis et terra repletis cum testis suis missos asserunt custodiri. Pruna si ossihus serantur autumno, mense Novembri solo putri et subacto duobns palmis oloruantur ossa. Eadem ponantur et mense Februario. Sed tuuc prius lixivio sunt maceranda per triduum, ut cito gerıninare cogantur. Ponuntır et plantis, quas sumenus ex cudice mense Januario exeunte, vel Februario circa idus, radicibus fimo oblitis. Gaudent loco lacto et humido : calo tepillo melius proferuntur, tamen queunt et frigidum sustinere. Locis lapidosis et glareosis si jurantur latamiue, excusant ne poma caduca et rermiculosa nascautur. lixtirpanda sunt soboles a radice, exceptis rectioribus, quae servabuutur ad plantas. Si languida pruni arbor est, auuurca cum aqua aqualiter temperata radicibus debet in. fundi, vel bubulum lotium solum, vel liumanum vetus tout des cendres de sarment. Si ses fruits sont sujets à tomber, on enfoneera dans sa racine, que l'on percera à cet effet avec une tarièrc, une cheville de bols d'olivier sauvagc. En le frottant avec de la terre rouge et de la poix liquide, on fera mourir les vers et les fourmis qui le tourmentent; mais la frietion doit ètre ménagée de facon à ne pas entamer l'arbre, autrement le remède serait pire que le mal. Des arrosements fréquents et des fouilles assiducs l'aideront à croltre. On greffe le prunier à la fin de mars ou au mois de janvier, avant qu'il commence à jeter sa gomme. Il est mieux de lc greffer en fente sur le trone que sous l'écorce. On l'ente sur lui-mème, et il recoit la greffe du pêcher, ou de l'amandier, ou du pommier, quoique ce dernier le fasse dégénérer et le rende petit. On sèche les prunes au soleil, en les disposant sur des claies dans un endroit see : ee sont là les prunes que l'on appelle Damascena. D’autres plongent des prunes nou. rellement cueillies dans de l'eau de mer ou dans de la saumure bouillante, et après les en a voir retirées, ils les font sécher dans un four éehauffé, ou au soleil. Les châtaigniers se sèment tant en plant qui vient de lui-même, qu'en graine. Mais quand on les a semés en plant, ils sont si maladifs, que l'on est souvent dans le eas de douter pendant deux ans s'ils vivrout ou non. Il faut donc semer les ehâlaigues elles-mêmes, c'est-âdire la graine du ehâtaignier, aux mois denovembre et de décembre, ainsi qu'au mois de février. Pour semence, il faut ehoisir les plus nouvelles, les plus grosses et les plus múres. Rien de plus facile en novembre; e'est l'époque où ce fruit donne. Mais si l'on veut semer les chataignes en février, voiei ce qu'il faudra faire pour les conserver jusque-là : on les fera sécher en les éten-

cum duabus aquæ partibus mixtum, vel cineres ex furno, maxime sarmentorum. Si poma decurrant, oleastri epiu. rum terebratx inlige radici. Vermes ejus atque furmicas rubrica cum pice liquuida si adlinatur extinguet : sed moles. tius propter arboris noxan, ne idem faciat remedium quod venenum. Juvatur frequenti lumore et assidua fossione. Mense Martio extremo prunus inseritur melius trunco fisso quam cortice, vel mense Januario, antequam incipiat gumen lacrymare. Inseritur in se, et Persicum recipit, vel amygdalum vel malum, sed eam degenerem reddit et parvam. Pruna siccantur in sole per crates loco sicciore disposita. Hac sunt qua Damascena dicuntur. Alii in aqua mariı vel in muria fervente recens lecta pruna deunergutt, ct inde sub!ata aut in furno tepido faciunt aut in sole siccari. Castanca seritur et plantis, qux sponte nascuntur et senine. Sed qux plantis seritur, ita xgra est, ut biennio de ejus vita sape lubitetur. Serenda est ergo ipsis castaneis, hoc est seminibus suis, mense Novembri et Decembri, item Februario. Eligendx sunt castanex ad pouendum recentes, grandes, natura : quas si Novembri mense seramus, facilem se prósentia fructus ipsius prostat. Si vero Februario ponamus, ut usque tunc durent, ita fa- 
dant à l'ombre; après quol on les transportera dans un lieu étroit et see, où on les mettra par tas, en les couvrant toutes exactement de sable de rivière. Au bout de trente jours, on les retlrera du sable pour les faire tremper dans de l'eau fraiche. Alors celles qui seront saines iront au fond, et toutes celles qui seront défectueuses surnageront. On enfoneera de mème dans le sable celles qu'on aura déjà éprouvées, et on les éprouvera encore de la même façon au bout de trente autres jours. Quand on aura répété cette opération par trois fois jusqu'au commencement du printemps, il faudia semer celles qui se seront maintenues en bon état. II y a des personnes qui les conservent dans de petits vases qu'elles remplissent également de sable. Les châtaigniers ainent un sol meuble et friable, mais non pas aréneux. Ils viennent dans le sable, pourvu qu'il soit humide. La terre noire leur convient, de même que le eharbon et le tuf, quand il est pulvérisé avec soin. Ils viennent diffieilement dans une terre compaete, ainsi que dans la térre louge, et point dans l'argile $n i$ lans le gravier. Ils aiment les pays froids, mais ils ne refusent pas les elimats tempérés quandils sont humides. Ils se plaisent sur les coteaux, de même que dans les eantons ombragés, et prineipalement dans ccux qui sont exposés au nord. Il faudra faconner au pas. tinum, à la profondeur d'un pied et demi ou de deux pieds, le terrain que l'on destinera à eet arbuste, soit en donnant cette façon à toute l'étendue du terrain, soit du moins en y traçant avec la charrue des sillons qui seront dirigés parallèlement entre eux, ou qui se croiseront en différents sens. Lorsque ce terrain sera saturé de fumier et bien dissous, on y mettra les chàtaignes, - sans les enfoneer au delà d'un dodrans de pied, en observant de planter un piquet auprès de cha-

ciendum est : in umbra castanex siccentur expausx : tunc in angustum et siccum locum translata cumrulum faciunt : et eas oinnes fluvialis arena diligenter operiat. Post dies $\mathbf{x \times}$ cas remota arena in aquam frigidam millis. Quae sanæe sunt, merguntur : supernatat quacunque vexata est. Item quas probasti, similiter obrues, et post $\mathbf{x x x}$ dies aeque probas. Hoc cum tertio feceris, usque ad veris inilium, serere debebis qua manseriut illibata. Aliqui in vasculis servant, aıcua pariter immissa. Amant soluin molle et solutum, non tanien arenosum. In sabulone proveniunt, sed lumecto : nigra terra illis apta est et carbunculus et lofus diligenter infractus : in spisso agro et rubrica vix provenit : in argilla et glarea non polest nasei : diligit cali sta. tum frigidum, sed et tepidum non recusat, si humor assenserit : delectatur elivis et opacis regionibus ae maxime in Septentrionem rersis. l'astiuari ergo locus debebit, qui luic destinatur arbusto, altitudine pedis unius semis vel duorum vel tolus, vel sulcis in ordinem destinatis, ant cerle aratris resolvi liue inde findeutibus : qui fimo satiatus ac redactus in pulvereu castatcearum semen accipiat pon amplius pedis dodrante deusersum. Unicuique senini eune, afin de reeonnaitre l'endroit oủ elles seront. Il faudra en mettre trois ou eing à la fois dans le même trou, en éloignant tous ees petits tas l'un de l'autre de quatre pied. Ceux qui voudront transplanter les ehataigniers en pieds attendrontuécessairement qu'ils aient deux ans. Au reste, la châtaigneraie sera garnie de rigoles qui serviront à l'écoulement des eaux, de peur que, si elles venaient à y séjourner, le limon qu'elles y déposeraient ne fit périr le germe des eladtaignes. On pourra, si on le veut, propager les chátaigniers à l'aide des rejetons inférieurs qui sortent de leurs racines. Il faut bêcher assidument les nouveaux plants de ehâtaigniers. Ces arbres profitent davantage quand ils sont aidés par la taille aux mois de mars et de septembre. On greffe le châtaignier (ainsi que je l'ai éprouvé moi-mème) sous son écoree, nu mois de mars ou au mois d'avril ; quoiqu'il réponde également à nos soins quand il est greffé sur le trone. On peut aussi le greffer en éeusson. On le greffe sur lui-mème et sur le saule. Mais quand il est greffé sur le saule, son fruit est plus tardif et d'un goût plus âpre. On conserve les châtaignes soit en les disposant sur des claies, ou en les enfoneant dans du sable, de façon qu'elles ne se touchent point mutuellement, soit en les enfermant dans de petits vases neufs de terre euite, et en les ensevelissant sous terre dans un lieu see, soit en les serrant dans des coffres faits avee des baguettes de hêtre et enduits de lut, de façon qu'ils n'aient aueune ouverture, soit enfin en les couvrant de paille d'orge très-menue, ou en les enfermant dans des mannequins faits avee des herbes de marais, et dont le tissu soit très-serré. On płante ee mois-ci, dans des terrains chauds et sous un elimat sec, des pieds de poiriers sauvages que l'on greffe par la suite, ainsi que des

propter notam surculus debet affigi. Jpsa semina singulis locis simul terna vel quiua ponantur, et inter se quatuor pedum spatio separentur. Quibus transferre placuerit, bimas plantas transferre debebunt. Locus tamen deduclo. ria liquuoris accipiat, ne lıumor insidens limo germen extinguat. Cui placet, potest castaneie in propaginem ducere iuna virgulta, qua iu radice nascuntur. Novim castanetum circumfodi debet assiduc. Mense Martio et Septembri in. erementum majus aequirit, si putationibus adjuretur. Cas. tanea inseritur (sicut probavi ipse) sub cortice mense Martio vel Aprili, tamen genere utmque respondet. Potest et inoculari. Jnseritur in se et in salice, sed ex salice tardius maturat, et fit asperior in sapore. Castanex servantur vel in cratibus dispositx, vel intra sabulonem ne iuvicen tangantur immersa; vel in vasculis tictilibus novis condita, el loco sicciore defossa; vel inclusa virgeis ex fago receptaculss et lutatæ, ut spiracula non relinquas; vel ordei paleis minutissimis obrule, vel palustri ulva figuratis densioribus, sportis reclusæe. Hoc mense locis calidis ac siccis regionibus ayrestium pirorun plautas ponimus, quas postea possimus inserere, et malorum, vel mali I'unici, 
pieds de pommiers ou de grenadiers, de coignassiers, de eitronniers, de néfliers, de figuiers, de cormiers et de earoubiers. On plante aussi des pieds de eerisiers sauvages que l'on greffe ensuite, et des boutures de múriers. Enfin on sème des amandes et des noix dans des pépinières, suivant la méthode que nous arons donuée.

VIII. Les abeilles font du miel au eommencement de ee mois-ci avee des fleurs de tamarin et d'autres plantes sauvages; mais il ne faut pas leur enlever ee mlel, qui est leur provision d'hiver. Il faut purgerles ruches des immondices dans le courant du mème mois, parce qu'il n'est pas à propos de les remuer ni de les ouvrir de tout I'hiver. Mais on ehoisira, pour faire ees opérations, un jour où il fasse soleil et qui soit chaud, et on nettoiera toutes les parties intérieures de la ruche où la main ne pourra pas atteindre, en employant de préférence à cette opération des plumes de grands viseaux, qui aient de la roideur, ou quelque autre iustrument analogue. On bouchera ensuite, avee de la boue et de la fiente de bouf mẻlćes ensemble, toutes les fentes qui paraitront à l'extérieur des ruehes; et on pratiquera au-dessus des espèces de portiques avee du genèt ou d'autres matières propres à les eourrir, afin qu'elles puissent ètre à l'abri du froid et des mauvais temps.

IX. Il faudra tailler à présent de près, dans les terrains chauds et exposés au soleil, les vignes qui, dépourvues de fruits, mais exubérantes en feuilles, eompensent la disette des uns par le luxe des autres. Cette taille se fera dans les terrains froids au mois de février. Si ee viee ne se eorrige pas, il faudra, après les avoir bêehćes, entasser à leur pied du sable de rivière ou de la cendre. Quelques personnes insèrent

et cydorii, et citri, et mespili, fici, sorbi, siliyua, et plantas agrestis cerasi, post inserendas, et mori taleas, et amygdali senina, et nuces juglandes, si in seminariis (quo dictum tst more) pangantur.

VIII. Hujus mensis initio apes ex tamarisci noribus reliquisque silvestribus mella couficiunt : quæ anferenda non sunt, quia servautur hilserno. Eodem mense sordibus liberandi sunt alvei, quia tota hieme cos movere aut ajerire uon decet. Sed lsac die aprico tepidoque facienda sunt, et penuis maxine avium majorum, qua lıabent rigoren, vel aliquo simili onnia interiora mundentur, quo manus non valebit attingere. Tum rimas omnes, quae suut extrinsecus, luto et timo bubulo mistis linanus : et insu• per genestis vel aliis tegumentis similitudinem porticus imitemur, ut possint a frigore et tempestate defendi.

IX. Locis calidis et apricis vites, qua fructu carent, fronde luxuriant, et pauperiem foetuum coupensant ubertate foliorum, ıulı putare pressius convenict : frigidis vero mense Februario. Si perunanebit hoc vitiun, circum. fossas arena fluviali vel cinere delschimus aggerare. Quidam lapides inserunt inter flexuosa radicun.

$\mathrm{X}$. Hisdem temporibus et lucis vitem qux sterilis fuerit, des picres entre les sinuosités de leurs racines.

X. Quand la vigne aura été stérile, les Grees preserivent de la soigner aux mêmes temps, de la manière qui suit. On introduit une pierre dans solt trone, après l'avoir fendu, et l'on répand autour d'elle quatre cotula d'urine humaine gardée, de facon que eet arrosement pénètre jusqu'à ses racines. Ensuite on y ajoute du fumier mélé de terre, et l'on retourne en entier le sol autour de ses racines.

- XI. Quoique février soit le mois des rosiers, on peut cependant en planter en novembre dans les terrains chauds, exposés au soleil et voisins de la mer. Si l'on manque de plant, et qu'on veuille se procurer beaucoup de rosiers avec le peu qu'on en aura, il faudra eouper des rejetons de quatre doigts garnis de leurs boutons avee leurs nœuds, les coucher en terre eomme des provins, et les aider à venir avee du fumier et des arrosements. Quand ils auront plus d'un an, on les transférera dans un autre endroit, où ils seront espacés d'un pied. C'est ainsi qu'on remplira de rosiers le terrain que l'on destinera à ce genre de eulture.

XII. Les Grees assurent que pour eonserver du raisin sur le cep méme jusqu'au commeneenient du printemps, il faudrait faire auprès de ee eep, quand il est ehargé de fruits, une fosse de trois pieds de profondeuret de deux pieds de largeur, dans un lieu ombragé, et y étendre du sable dans lequel on fichera des roseaux ; après quoi on entortillera avee soin ees roseau $x$ avee des sarments chargés de fruits qu'on y attachera, sans endonmager les grappes, et de façon qu'elles ne touchent pas au fond de la fosse; puis on recouvrira le tout, afin que la pluie n'y puisse pas pénétrer. Ils preserivent eneore, lorsque l'on veut conserver longtemps des grappes sur un cep ou des fruits sur un

Graci ita precipiunt esse curaudam. Trunco ejus fisso la. pidem asserunt includendum, et ibi urina veteris huna. uxe quatuor cotulas circa truncum debere suffundi, ut ad radices instillatio ipsa descendat. Tunc adjiciendum terra lixtamen adunista, et circa radices solum ounne vertendum.

XI. Quauris mense Februario sint conserenda rosaria, tamen locis calidis, apricis atque maritimis hoc etian mense poterimus instituere roseta. Quxe si indigus plantarum volueris ex paucis virgnlis labere copiosa, quaternorum digitorun surculos gemuantes cum geniculis suis debebis excidere, [et] iu uodum propaginis sternere [et] stercore ac rigationibus adjuvare : ubi anui atatem conpleverint, pedis spatio inter se transferre disjunctos, atque ita solum quod luic generi deputabis inplere.

XII. Gracis asserentibus, ut uram serves in vite usque ad veris initia, circa ipsam vitenn quae fructu plena est, loco unbroso scrobem fodies, altitudine trium pedım, latitudine duorum, et mittis sabulonem, et ibi calanюs tigis, in quibus retorquetis assidue sarmenta fruclibus plena, et illarsis hotryonibus alligabis, ut solum nou coutin. gant, et cooperies, ut imber eo penctrare nun pussit. Item Gracis ducuntibus uvas in vite, aut poma in arbore si diu 
arbre, de les lalsser suspendus à leurs branches en Ics renfermant dans de petits vases de terre cuite percés par le bas et bien fermés par en haut, quoique cette méthode soit assez inutile par rapport aux fruits, puisqu'on les conserve aussi trèslongtemps en les couvrant de gypse.

X111. C'cst dans ce mois-ei que naissent les prcmiers agneaux. Dès qu'un agneau sera né, on l'approchera du pis de sa mère, en observant nćanmoins de tirer auparavant à celle-ci avec la main un pcu de lait, parce que les premières gouttes, qui sont d'une nature trop épaisse, et que les bergers appellent colostrum, incommoderaient l'agneau, si l'on n'en débarrassait pas la mère. On commencera par enfermer les nouveau-nés avee leurs mères pendant deux jours; après quoi on se contentera de les retenir dans des clos obscurs et chauds, de façon qu'ils soient séparés des brcbis, quand on enverra celles-ci aux pâturages. Il suffira de permettre aux agneaux de teter leur mère le matin avant la sortie, et le soir au retour de la pâture. On les nourrira dans l'étable, jusqu'à ce qu'ils aicnt pris de la force, avee du son ou de la luzerne, qu'on mettra devant eux, ou avec de la farine d'orge, si l'on en a une grande provision; et on leur continuera ce genre de nourriture jusqu'à l'âge où ỉls sont capables de suivre la mère au pâturage. Les pâturages qui convienment aux brebis sont ceux qui croissent dans les jachères ou dans les prairies sèches. Ceux des marais leur sont funestes, et ceux des furêts sont pernicieux pour leur laine. Au reste, il faut provoquer leur appétit en saupoudrant souvent de sel leur pâture, eten en mêlant à leur breuvage. Pournourriture d'hiver, si l'on manque de foin, on leur donnera de la paille ou de la vesce, ou, ce qu'on se procure plus aisément, des feuilles d'orme ou de frêne.

servare volueris, vasculis clausa fictilibus ab ima parte pertusis diligenter a summo tecta suspende, quamris poma et gypso cooperta in longain serventur xetatem.

XIII. Ioc meuse agnorum prima generatio est. Sed agnus statim natıs uberibus maternis admovendus est manu. prius tamen exiguum lactis, in quo spissior est natura, mulgendum est, quod pastores colostram vocant : namque lıo agnis, nisi auferatur, nocelit. Ac primo per biduum natus cum matre claudatur. Tune septis obscuris servetur et calidis : ita secluso parrulorum grege matrices mittantur in pascua. Sufficiet autem, priusquam procedant matrices mane, et cum satura revertuntur ad vesperam, agnis ubera laurienda permittere. Qui donec firmentur, intra stabulum furfuribus vel medica lierba, vel (si est copia) farina ordei pascantur ingesta, donec concepto paulisper robore xtatis, pascuum matribus possint liabere commune. Pascua ovillo generi utilia sunt, qua vel in novalibus vel in pratis siccioribus excitantur : palustria vero uoxiasunt, silvestria damnosa lanatis. Salis tamen crebra conspersio vel pascuis mista vel canalibus frequenter oblata debet pecoris levare fastidium. Nam per liemem, si penuria est, fuenum, vel palea, vel vicia, vel ficcilior vic- que l'on aura gardées à cet effet. Pendant l'élé. les brebis paitront au commencement de la journée, moment où l'herbe attendrie par la rosće est le plus savoureuse. A la quatrième heure du jour, temps où il fera chaud, on lcur fera boire de l'cau puisée dans une rivière purc, ou tirée d'un puits ou d'une fontaine. Une vallée ou un arbre touffu les garantiront de l'ardeur du soleil au milieu du jour. Lorsque ensuite la chaleur commence à s'adoueir, et que les premières gouttes de la rosée du soir auront mouillé la terre, on conduira de nouvcau le troupeau aux pâturages. Mais lorsqu'on mènera paître les brebis pendant les jours canieulaires, ct même dans tout le courant de l'été, il faudra avoir soin que lcur tête soit toujours tournée du côté opposé au soleil. Elles ne doivent point aller paître en hiver, ni au printemps avant que le givre soit fondu, parce que l'herbe couverte de frimas oceasionne des maladies à ce bétail. Il suffira aussi de les mener boire une seule fois par jour dans ces deux saisons. Les Grecs, commeles Asiatiques ou les Tarentins, sont dans l'usage de nourrir leurs brebis plutôt à l'étable qu'aux champs, et de former le sol do l'étable de planches percées à jour, afin que l'humidité ait un écoulement. L'habitation du bétail en devient plus salubre, et leur toison, supérieure à celle des autres brebis, reste intacte. Il faudra frotter les brebis à trois reprises différentes dans le courant de l'année arec de l'huile et du vill, par un jour de soleil, et après qu'elles auront été lavées. Pour chasser les serpents qui se glissent parfois sous la crèche, on y brûlera souvent du cèdre, ou du galbanum, ou des cheveux de femmes, ou de la corne de cerf. Il faut faire saillir à présent les boucs, afin que leurs petits puissent être élevés au com mencement du printemps. Mais

tus ulmi servatis frondibus probeatur aut fraxini. Estivis mensibus pascantur sub lucis initio, cum graminis teneri suavitaten roris mistura commendat. Quarta Lora calescente potus puri fluminis aut putei præbeatur aut fontis. Medios solis calores villis aut arbor unhrosa declinet. Deinde ubi flexo jam die ardor infringitur, et solum primo imbre respertini roris liumescit, gregem revocemus ad pascua. Sed Canicularibus et xestivis diebus ita pascendac sunt oves, ut capita gregis semper avertantur a solis objectu. Ilieme autem vel vere nisi resolutis gelicidiis ad pascua prodire non debent : nam pruinosa lierba lıuic generi morbos creabit. Ac tunc semel adaquare sufficiet. Grac cas oves sicut Asianas vel Tarentinas moris est potius stabulo nutrire quam canıpo, et pertusis tabulis solum, in quo claudentur, insternere : ut sic tuta cubilia propter injuriant pretiosi velleris lumor reddat elabens. Sed tribus per annum (totum) diebus aprico die lotas oves ungere oleo oportebit et vino. Propter serpentes, qui plerumque sub prosepibus latent, cedrum rel galbanum vel mulieris ca. pillos aut cerviua cornua frequenter uranus. Nunc lirci admittendi sunt, ut fotum primi veris fovere possit exorfus. Sed caper eligendus est, cui sub maxillis dux viden. 
il faut choisir, pour ectte opération, dles boues qui aient deux petites verrues qui leur pendent sous les máchoires, le corps grand, les jambes épaisses, le chignon court et plein, les oreilles cour. bées et lourdes, la tête petite, le poil lisse, épais et long. Ces animaux sont propres à la propagation même avant d'avoir atteint l'âge d'un an; mais ils ne vont pas au delà de six ans. Il faut choisir des chèvres dont le corps soit semblable à celui des boues, et qui aient le pis développé. On ne renfermera pas cependant, dans le même enelos, unc aussi grande quantité de chèvres que de brebis, et on aura soin qu'il n'y ait ni boue ni fumier dans cet enclos. Outre le lait, dont on ne laissera pas manquer les chevreaux, il faudra encore leurdonner souvent du lierre et des cimes d'arbousier et de lentisque. Les chèvres peuvent très-bien nourrir leurs petits à trois ans. On vendra ceux dont les mères seront plus jeunes, et on ne gardera pas celles-ci au delà de huit ans, parce que ce bétail devient stérile en avançant en âge.

XIV. Il faut s'occuper dans ee temps-ei du soin de ramasser et serrer le gland. Ce soin peut facilement être confié aux femmes et aux enfants, ainsi que celui de ramasser les fruits tombés.

XV. Il faut couper à présent le bois de construction, quand la lune sera dans son déclin. Mais, avant de mettre bas un arbre, il faudra le laisser quelque temps sur pied, après avoir entaillé le trone jusqu'à la moelle, afin que s'il reste de la séve dans ses vaisseaux, elle s'écoule par cette plaic. Voici les arbres qui sont les plus utiles: le sapin, que l'on appelle gallica, est léger et ferme, ct il durc éternellement lorsqu'il est travaillé et employé à sec. L'utilité du larix est inappréciable. Si l'on soutient les tuiles d'un batiment avec des lattes faites de ce bois, tant sur la face qu'aux extrémités des toits, on n'aura pas à craindre les incendies, parce que ce bois ne s'enflamme ni ne se carbonise. Le chêne est de durée quand il soutient des ouvrages de terre; on en fait encore des pieux qui sont aussi de résistance. L'cesculus est un bois propre à la construction, et bon pour fáire des échalas. Le chátaignier dure très-longtemps, et sa soliditć est admirable, soit qu'on l'emploie dans les champs, soit qu'on l'emploie pour les toits et pour les autres ouvrages de l'intérieur. Il n'a d'autre défaut que son poids. Le hêtre est bon à être employé à sec; l'humidité le pourrit. Les deux espèces de pcupliers, le saule et le tilleul sont des bois de sculpture. L'aune ne saurait entrer dans la construction, mais on ne peut s'en passer pour les pilotis. Lorme et le frêne se roidissent en séchant; verts, on peut les courber pour elı faire des chevrons. Le charme est de bon usage. Le cyprès est excellent. Le pin ne dure pas, s'il n'est cmployé à sec. J'ai vu employer le procédé que voici, en Sardaigne, contre son altération trop rapide. On submergeait entièrement, dans une mare, des poutres faites avec ce bois, pendant une année entière, avant de les mettre en œuvre, ou bien on les enfonçait dans le sable sur le bord de la mer, ùe facon que le flux pùt baigner le sable dont elles étaient couvertes, dans son retour alternatif après le reflux. Le cèdre est durable, à moins que l'humidité ne l'atteigne. Tous les arbres coupés du côté du midi sont les meilleurs. Ceux qui sont coupés du côté du nord sont, à la véritẹ, les plus hauts, mais ils sc gâtent aisément.

XVI. On transplantera ce mois-ci les arbres à haute tige plantés dans les terrains sees, chauds et exposés au soleil, après avoir rogné. lcurs branehes, sans endommager leurs racines; et on tur pendere verrucula, magni corporis , crässis cruribus, brevi plenaque cervice, auribis nexis et gravibus, parvo capite, nitido spisso ef longo capillo. Ad jneuudas farminas et ante anniculum congruus. Noul autem durat ultra sexenniun. Capella similis corporis, sed maguis uberibus est eligenda. Fon tamen ita multac capra, ut oves una statione claudaıtur, quam In to et stercore carere conveniet. Ilxedis supra lactis abundantiam edera et arbuti et leutisci cacuunina sunt sape priebenda. Trinix educare optime possunt; quod teneriores matres generant, transigendum est. Sed ultra octo aunos servandae non sunt matrices, quia genus hoc longiore sterilescit atate.

XIV. Hoc tempore glandis legendac ac servandac cura nos excilet; qurod opus focmineis ac puevilibus operis celebrabitur facile more bacrarum.

XV. Nunc materies ad fabricam caelenda est, cun lına decrescit. Sed arlores qux cxolentur usque ad medıllau securibus. recisas aliquaudiu stare patieris, ut per eas partes lumor, siguis in veuis contiuclur, excurrat. Utiles autem sunt liø maxime : abies quam Gallican rocaut, nisi perluatur, levis, rigisls, et in operiluss siccis pereune durabilis. Larix utilissima, ex qua si tabulas suffigas to. gulis in fronte atque extremilate tectorum, prosillium contra incendia coutulisti. Neque enim flammam recipient, aut carlones creare possunt. Quercus durabilis si terreıis operibus obruatur, et aliquatenus palis. Asculıs arlificiis et rillicis apta materies. Castanea unira soliditate perdurat in agris et tectis et operilus cateris intestinis, cujus so. lun poudus in vilio est. Fagus in sicco utilis, lumnore cormumpitur. Populus utraque et salix et tilia in scalpturis necessarix. Anus fabrica inutilis, sed uecessaria, si lumidus locus ad accipieudi fuudauenta palaudus est. Ulmus et fraxinus si siccentur, rigescunt, ante curvahiles, catenis ntiles habeutur. Carpinus utilissina. Cupressus egregia. Pinus nisi in siccitate uon durans, cui contra celerem putredinens comperi in Sardiuia hoc genere provideri, ut excisa trabes ejus aut in piscina qualibet anno toto mersa laterent, post operi future, aut arenis obruetentur in littore, ut aggestionem, qua tectx esseut, alternis aestibus reciprocaus fluctus allueret. Cedrus durabilis, nisi humore taıgatur. Quacunque autem ex paste meridiana caeduntur, utiliores sunt : qur vero ex Septentrionali, proceriores, sed facile vitiantur.

XVI. Hoc mense locis siccis, calirlis et apricis majores 
lesaidera par la suite à venir, en les fumant beau. coup et en les arrosant.

XVII. Voici les préceptes qu'ont donnés les Grees pour la confection de l'huile : Il faut cueillir en un jour autant d'olives qu'on en pourra pressurer la nuit suivante. La meule doit être légèrement suspendue pour extraire la première huile, parce que si elle brisait les noyaux, ceux-ci corrompraient l'huile. Aussi la première huile doit être faite avec la seule pulpe du fruit. Il faut aussi que les paniers soient confectionnés avee des baguettes de saule, parce qu'on prétend que le bois de cet arbre est favorable à l'huile. La meilleure huile sera celle qui coulera d'ellemême. Ils ordonnent ensuite de mêler du sel et du nitre avec l'huile nouvelle, afin que ce mélange la dispose à s'épaissir; après quoi, lorsqu'elle aura déposé sa lie, on la transvidera pure, au bout de trente jours, dans des vases de verro. La seconde huile se fait de la même manière que la première, mais il faut briser les olives avec une meule plus forte.

XVIII. Les Grees assuient qu'on fait une première huile qui ressemble à eelle de Liburnie, en mêlant dans d'excellente huile verte de l'aunée sèche, des feuilles de laurier, et du souchet; le tout broyé ensemble, et passé par un crible fin avee du sel grillé et égrugé, et en remuant longtemps ce mélange, pour se servir de cette huile lorsqu'elle sera reposée, au bout de trois jours ou un peu plus tard.

XIX. Si l'huile est trouble, ils prescrivent d'y jeter du sel grillé pendant qu'il est encore chaud, et de la couvrir avec soin; moyennant quoi elle s'épure en peu de temps.

XX. Si l'huile a quelque mauvaise odeur, ils

arbores transferenus truncatis ramis, illaesis radicibus, multo stercore et rigationibus adjuvandas.

XVII. Gracci in conficiendi olei praceptis ista jusserunt. Tantuin legendum esse oliva, quantum rocte veniente possimus expricsere. Molam primo oleo debere leviter esse suspensam. Ossa enjm confracta sordescunt : quare de solis carnibus sit prima confectio. [Et de] salignis canistros fieri debere virgultis, quia genus loc oleum dicitur adjuvare. Nohilius erit quod sponte defluxerit. Sales deinde ac uitrum jubent novo oleo misceri, ut lıac res spissitudinem cjus absolvat : deinde cum amurca subsederit, oleum purum $\times x \times$ diebus exactis, in vitrea vasa transferri. Secundım, simili disciplina fieri, sed mola fortiore quassari.

$\mathbf{X V I I I}$. Oleum primum Liburuico simile fieri asserunt Groci, si in optimo viridi [oleo] inulam siccam et lauri folia et cyperum, omnia simul tusa, et subtiliter creta permisceas cum salibus torrefactis ac tritis, et diu oleo injecta perturbes, deinde tribus aut aliquanto amplius [decursis] diebus, cunı quieverit, utaris.

$X I X$. Si surdet oleum, frictos et adhuc calentes sales injici jubent, et diligenter operiri. Ita mundum reddi post tempus exigunm.

ג.. Si fuerit odoris horrendi, virides olivas sine ossi- ordonnent de battre des olives vertes sans noyaux, et d'en mettre deux chanicé dans une metreia d'huile. Si l'on n'a pas d'olives, il faut battre de la même manière dés tiges d'olivier très-tendres. Quelques personnes mêlent des olives avec ces tiges, en y ajoutant même du sel. Elles enveloppent ees malières dans un linge, et les suspendent ainsi dans le vase d'huile. Ensuite elles les retirent au bout de trois jours, et transvasent l'huile. D'autres y mettent de vieille brique torréfiée. La plupart y plongent de petits pains d'orge enveloppés dans un linge clair, en les changeant de temps en temps pour leur en substituer de nouveaux; et, après avoir répété cette operation deux ou trois fois, ils y mettent du sel; puis ils transvasent l'huile, et la laissent reposer pendant quelques jours. S'il arrive par hasard que quelque animal soit tombé dans l'huile, et qu'il l'ait corrompue en pourrissant, les Grees ordounent de suspendre une poignée de coriandre dans la metreta d'huile, et de l'y laisser quelques jours. Si l'infeetion ne diminue pas, il faut changer la coriandre, jusqu'à ce qu'on soit venu à bout de corriger ce vice. Mais il sera très à propos de survider l'huile au bout de six jours dans des vases propres, qui n'en vaudront que mieux s'ils ont contenu du vinaigre. Il y a des personnes qui mêlent de la graine de fenugrec, sèche, et broyée dans l'huile, ou qui y font éteindre souvent des charbons de bois d'olivier enflammés. Si l'huile sent l'aigre, ils ordonnent d'y plonger la partie acide des grappes de raisin, que les Grees appellent yiyaprov, après l'avoir pilée et réduite en páte.

XXI. Les Grees assurent qu'on peut corriger l'huile ranee de la maniere suivante. On jette

bus tundi, et in olei metreta clınicas duas mitti. Si bacca defuerint, caules tenerrimos olea similiter esse tundendos. Nonnulli utraque permiscent, adjecto etianı sale. Sed omnia intra linteum clausa suspendunt, atque ita in vas olei demitlunt. Postea tribus diebus exemtis aufernnt, et oleum in alia vasa transfundunt. Quidam mittunt vetustum laterem torrefactum. Plerique ordeaceos panes breviter figuratos et raro linteo involutos mergunt, et novos subinde permutant : ubi lıoc bis aut tertio fecerint, sales mittunt, et in alia vasa translalum per paucos dies subsidere patiuntur. Q11od si aliquod animal forte deciderit, et oleum putredine ac nidlore vitiaverit, jubent Graci coriandri manipulum in olei metreta snspendi, atque ita paucis diebus manere. Si niliil de nidore discusserit, nuutandum est coriandruın, donec superetur lıoc vitium. Sed maxime proderit, post senos dies in vasa munda transferre; melius, si acetum ante vexerunt. Quidam foeni Græci semen siccum tritumque permiscent, vel incensos oleaginos carloones in ipso oleo frequenter extingnunt. Si acerbus odor fuerit, uva excrementa, qua Graci $\gamma$ i $\gamma \alpha \rho \tau \alpha$ vocant, præcipiunt tusa et in massam redacla mersari.

XX1. Oleum lancidum Græci asserunt sic posse curari. Albain ceram mundo et optimo oleo resolutam et adiuc 
daus cette huile de la eire blanehe fondue dans de l'huile propre et excellente, tandis qu'elle est encore liquide, et ensuite on $\mathbf{y}$ ajoute du sel grillé pendant qu'il est chaud; puis on la eouvre et on l'enduit de gypse; moyennant quol l'huile se purge, et ehange de goût et d'odeur. Au reste, il faut eonserver les huiles de toutes les espèees dans des eaveaux pratiqués sous terre. Telle est la nature de cette liqueur, que le soleil ou le feu l'épurent, ainsi que l'eau bouillante quand elle est mêlée avee elle dans le mème vase.

XXII. On confira aussi les olives ce mois-ci. On s'y prend de différentes façons. Voiei la manière de faire des olives qui nagent dans un jus : On étend sur des elaies des olives et du pouliot alternativement par eouches, et l'on verse, entre ehaque couche, du miel, du vinaigre, et un peu de sel. On étend eneore les olives sur des tiges de fenouil, d'aneth ou de lentisque, en mettant dessous de petites branches d'olivier; on verse par-dessus une hemina de sel avee de la saumure, et l'on multiplie ees eouehes jusqu'à ee que le vase en soit rempli. Autre manière de les confire : on fera maeérer dans de la saumure des olives de choix; quarante jours après on jettera toute la saumure; après quoi on mettra dans le vase deux tiers de vin euit jusqu'à diminution de moitié, et un tiers de vinaigre, avee de la menthe haehée par petits morceaux; puis on remplira le vase d'olives, de facon que la liqueur, que l'on y aura versée en quantité suffisante, les surmonte. Autre manière : on laisse, pendant une nuit en' ière, exposées à la vapeur d'un bain, des olives eueillies à la main, et étendues sur une planehe ou sur une elaic; ensuite, après les avoir retirées le matin, on les saupoudre de sel broyé, et on en fait usage. Mais on ne pourra pas garder les olives ainsi préparées plus de huit jours. Autre manière:

liquentem mitti in oleo jubent. Tunc sales frietos ealentes adli, operixi, atque gypsari. Sic fieri ut oleum pargetur sapore ef odore inutato. Oleum tamen onne in terrenis locis esse servandum, et cam ejus esse naturam, ut sole vel igne purgetur, vel aqna ferventi, si simul misceantur in rasculo.

XXII. Hoc efiam mense olivas condiemus. Harum genera sunt diversa. Colymbades oliva fiunt sic : alternis eratilous olivarum puleiun spargis et mel et acetum et sales modice, stratura intereedente, suffundes. Item sternes olivas supra sureulos fơniculi vel anethi sive lentisei, et ramulis oliva sublitis aeeti lieminam et muriam superfunles, et las construetiones usque ad vaseuli plenitulinem patieris insurgere. Aliter. Electas olivas murin maturabis, post $\times \mathrm{L}$, dies unuriam fundis universam : tunc duas defruti jartes, aceti unaın, mentam minute ineisam vaseulo arljieies, et olivis replélis, ut justa infusione liquor supernatet. Aliter. Olivas mam leetas una noete integra in balnei vapore esse paticris talumla vel erati superpositas : mane lalneis exemtas salibus tritis eonsperges et nteris : qua non ampllius quan vu dies poterunt custodiri. Aliter. Oli.
On commence par mettre dans de la saumure des olives saines; quarante jours après on les en retire, et on les coupe avee un roseau tranelant; puis on verse dessus deux tiers de vin euit jusqu'à diminution des deux tiers, et un tiers de vlnaigre, quand on veut qu'elles soient douces; ou deux tiers de vinaigre et un tiers de vin pareil, quand on veut qu'elles soient plus aigres. Autre manière : A près avoir mêlé ensemble un sextarius de vin fait avec du raisin séehé au soleil, plein les deux mains de cendre bien criblée, un semi-sicilicus de vin vieux, et une petite quantité de feuilles de eyprès, on verse tout ce mélange sur les olives, que l'on foule, et que l'on sature de eette composition, de manière d̀ ce qu'une espèee de eroûte se forme sur chaque eouche d'olives, dont le vase doit être rempli à eomble. Autre manière : On ramasse des olives tombées à terre, et racornies au point de se couvrir de rides; on les étend au soleil, après les avoir saupoudrées de sel, et on les y laisse jusqu'à ce qu'elles soient séehées; ensuite on dispose plusieurs eouches de laurier et d'olives alternativement, en eommençant par la couche de laurier; après quoi on fait jeter deux ou trois bouillons à du vin euit jusqu'à diminution de moitié, qu'on. a mis sur le feu à cet effet a vec une petite botte de sarriette; ; et lorsque ee vin est tiédi, on en verse sur les olives qu'on a arrangées par couehes, en y mêlant un peu de sel. Enfin, après avoir jeté dans le vase une botte d'origan, on verse dessus tout le reste de ce jus. Autre manière: On confit des olives aussitót après qu'elles ont été cueillies sur l'arbre, on les arrange par eouches, entre ehacune desquelles on étend de la rue et du persil, en remplissant les vides, qui se trouvent entre les eouches de sel égrugé, avec du cumin, dont on les saupoudre, puis on verse

vas illæsas primo mittis in muria : post dies XL levabis, atque intercides aeuto ealamo : et, si duleiores habere volueris, duas sapae partes et acuti unam; si aeriores, aceti dıas et sapac unam debebis infundere. Aliter. Passi sextarium ınım, cineris bene creti quantum manus utraque gestabit, vini veteris unum semisicilieum, et aliquantum cupressi foliorum : mistis omnibus olivas infundis, inculeas, et subinde erustam faciendo saturabis, donee ad vasenlorum summa ora pervenias. Aliter. Olivas quas jacentes repereris, rugis contralıentibus crispas eolligis, et salibus tritis respersas expandis, donec sole inareseant. Tunc substrato lauro alteruas erates baecarum sxpins ordinabis : tune defrutum emm satureiæ fiseiculo duahus aut tribus undis fervere patieris : et postquan tepuerit, supra com. positas baceas refundes admisto sale paululo, et origani fasee eoujecto, supri jus omne perfundes. Aliter. Leetas liaecas ex arbore statim condies, rutam et petroselinum sternes inter spatia structionis, et subinde cyminati salis aspersione cumulabis. Postremum mel et acetun super. fundes. Novissine optimi olei quantumeunque miscelis. Aliter. Legis olivas ex årbore nigras, et compositas unuria 
par-dessus du miel et du vinaigre; après quool on y ajoute tant soit peu d'huile exeellente. Autre manière : On euellle des olives noires sur l'arbre; après les avoir arrangées, on les arrose de saumure; ensuite on met dans une marmite deux sixièmes de miel, un sixième de vin, et une moitié de vin euit jusqu'à diminution de moitié, et l'on fait bouillir le tout ensemble; après quoi on retire la marmite $d u$ feu, on la secoue, et on y ajoute du vinaigre; et ilorsque ee jus est refroidi, on étend sur les olives des rejetons d'0rigan, et on le verse tout entier dessus. Autre manière : On verse de l'eau pendant trois jours sur des olives cueillies à la main avec leurs queues, ensuite on les fait tremper dans de la saumure, et, après les en avoir retirées au bout de sept jours, on les met dans un vase avec une dose égale de vin doux et de vinaigre; et lorsque le vase est rempli, on le eouvre, en y laissant quelque ouverture pour lui donner de l'air.

XXIII. Ies heures du jour sont d'une égale durcé dans les mois de novembre et de février.

A la première et à la onzième, le gnomon donne vingt-sept pieds d'ombre.

A la seeonde et à la dixième, ll en donne dix-sept.

A la troisième et à la neuvième, il en donne treize.

A la quatrième et à la huitième, il en donne dix.

A la einquième et à la septième, il en dome huit.

A la sixième, il en donne sept.

\section{LIVRE TREIZIEME. DÉCEMBRE.}

I. On sème au mois de déeembre les blés, le froment, l'adoreum et l'orge, quoiqu'il soit

diluis : tunc olla adjicis mellis partes duas, vini-unam, defruti dinidiam, et ubi simul deferbuerint, deponis, ac pernuves, et acetum misees : eum refixerint super olivas origani surculos steruis, et supra jus onme diffundes. Aliter. Olivas manu leetas cum pediculis arua spargis tribus diebus : deinde mittis in muria, et post vı dius exemtas in vase adjicis cum musti et aceti requis pourleribus. Et inpletum vas ita operies, ut aliqua spiramenta dinittas.

$\mathbf{X X I 1 1 . ~ N o y e m b r e m ~ e t ~ F e b r u a r i u m ~ r a t i o ~ t e m p o r i s ~ p e r ~}$ horas dierun fecit aequales.

$\begin{array}{rrrrrr}\text { Hora } & \text { I } & \text { et } & \text { xi } & \text { pedes } & \text { xxriI. } \\ \text { Hora } & \text { II } & \text { et } & \mathbf{x} & \text { pedes } & \text { xvil. } \\ \text { Hora } & \text { III } & \text { et } & \text { Ix } & \text { pedes } & \text { xilı. } \\ \text { Hora } & \text { Iv } & \text { et } & \text { vilı } & \text { pedes } & \text { x. } \\ \text { Hora } & \text { v } & \text { et } & \text { vil } & \text { pedes } & \text { vilı. } \\ \text { Hora } & \text { vi } & & & \text { pedes } & \text { vil. }\end{array}$

\section{LIBER DECIMUS TERTIUS.}

Decembri mense seruutur frumenta, triticum, far , ordeum : quamvis ordei satio jam sera sit. Et faba eirca sep- déjà tard pour ee dernier grain. On peut eneore semer les fèves vers la septimontium (fête des septmonts); ear on aurait tort de le faire après le solstice d'hiver. On pourra aussi semer la graine de lin ee mois-ei jusqu'au sept des ides de décembre.

II. On eommeneera à présent, pourvı que ce ne soit pas avant les ides, à faconner la terre au pastinum pour y planter des vignes de la manière que nous avons exposée ei-dessus. II sern eneore à propos de eouper le bois ce mois-ci. On fabriquera aussi des pieux, des paniers et des éehalas. On fera encore, dans les pays froids, de l'huile de laurier. On brisera les baies de myrte et de lentisque, pour en extraire l'huile; et l'on fera infuser de nouveau du myrte dans le vin, de la faȩon que nous avons donnée précédemment.

III. Il faut semer la laitue dans ee temps-ci, afin de la transplanter au mois de févirer. On pourıa aussi semer dès à présent l'ail, l'oignnon de Cypre, la eiboule, la moutarde et l'origan, suivant la méthode et de la manière que nous avons données précédemment.

IV. Les hypomélides sont (ainsi que Martialis l'assure) des fruits semblables à la corme, qui viennent sur un arbre de moyenne hauteur, dont la fleur est blanchâtre. Ces fruits ont quelque doueeur, et un arrière-goût piquant. On les sème au mois de déeembre, en mettant leurs noyaux dans de petits vases. Maison les transplante au mois de février, temps où ils ont acquis une certaine foree, et où ils sont de la grosseur du pouce, pour les planter dans une très-petite fosse, ereusée sur un terrain rendu bien meuble, dans laquelle on met beaueoup de fumicr. II faut protéger eet arbre contre les vents, dont le souffle dessécherait bientôt ses raeines. Il s'aecommode de quelque sol

timontium seri potest. Nam post exaetam brumam male seminatur. Hoc etiam mense atluc lini semen spargi po. terit, usque ad vu idus Deeembres.

II. Nunc ad instituendas vites, sed post idus pastina inclioemus effodere, sicut ante traetatum est. Et ntateriem bene hoc mense cademus : palos quoque et eorbes faciemus et ridicas. Et locis frigidis olemn faeiemus ex lauro, et myrti baccas at $q u$ lentisci in olei sui confeetione quas. sabimus, et virum myrtitem, sicut dictum est ante, tingemus.

III. IIoc tempore serenda est lactuca, ut planta ejus Februario transferatur. Et jam nune allium et ulpieum et cepulla et sinapi et eunela seri poterunt disciplina et more, quo ante narratum est.

IV. Iypomelides poma sunt (ut Martialis asserit) sorbo sinilia. Medioeri arhore naseuntur, et flore candidulo. Dulcedo luie fruetui eum acuto sapore comnista est. Seritur mense Decembri nucleis in vasculis positis. Mense autem Februario hypomelidis planta sed pollieis maguitudine robusta transfertur brevissimo scrobe, soluta terra, plurimo stereore. Sed munienda est, quia eito areseit, sI 
que ce soit. Il aime les climats chauds, exposés au soleil et voisins de la mer; souvent même il se plait au milieu des rochers. Il craint les climats froids. On ne peut pas le greffer, et il vit peu de temps. On conserve ses fruits dans de petites cruches enduites de poix, ou dans de la sciure de peuplier, ou dans des pots de terre pleins de marc, et placés parmi des grappes de raisin.

V. On s'occupe en ce temps de plonger, pour les confire, dans de la moutarde détrempée avec du vinaigre (suivant l'usage), des raves coupées en petits morceaux et légèrement cuites, après les avoir bien fait sécher pendant toute une journée, pour qu'il n'y reste aucune humidité. Quand on en aura rempli des vases, on les bouchera, et on n'en tirera pour son usage qu'après y avoir goûté au bout de quelques jours. On pourra aussi faire la même chose aux mois de janvier et de novembre.

VI. Ceux qui auront l'avantage de la proximité de la mer feront aussi confire à présent, dans du sel, de la chair de hérisson de mer, quand l'accroissement dela lune favorisera cette opération; parce que c'est le temps où cette planète fait grossir les membres de tous les êtres vivants que la mer renferme dans son sein, poissons et co. quillages. Au reste, cette opération se fait de la manière accoutumée. Elle se pratique également bien pendant tout l'hiver. On fait aussi des jambons, et on sale du lard non-seulement ce moisci, mais dans le courant de tous les mois d'hiver danslesquels le froid est rigoureux. Il faudra tendre dans ce temps-ci des piéges au milieu ảes bois taillis et des plants d'arbustes féconds en baies, pour y prendre des grives et d'autres oiseaux. Cette chasse dure jusqu'au mois de mars.

VII. Le mois de décembre ressemble, pour la

radices ejus ventus aflaverit. Terram qualemcunque non respuit. Amat loca tepida, aprica, maritima, et sæepe saxosa. Statum rigidum reformidat. Inseri non potest, exigua durat ætate. Ponıa ejus ant in picatis et minutis urceolis, aut scobe populi, aut in ollis inter uvas vinaceis obruta servabuntur.

V. Nunc rapa in partes minutas recisa et leviter cocta et tota die diligentius exsiccata, nequid reservent humoris, sinapi ex aceto ( condire curabimus, et repleta vasa claudemus, ac post aliquantos dies gustibus explorata proferemus usuri. Quam rem Januario quoque et Novembri mense poterinus efficere.

VI. Nunc etiam quibus litus in fructu est, ubi luna jurabit angmentum, quæ omnium clausorum maris animalium atque concliarum jubet incremento suo meinbra turgere, echini carnes salibus condis curabunt. Quod solito more conficitur. Hanc quoque rem per omnes menses beve faciemus hibernos. Pernas elıain et lardum conficimus non solum mense hoc, sed omnibus, quos hiemalis algor astringit. Tempore hoc per humiles silvas et baccis foe. cunda virgulta ad turdos et cacteras a ves capiendas laqueos PALS.A DIES. durée des heures, à celui de janvier par des raisons contraires, puisque les jours de l'un de ces mois croissent dans la même proportion que ceux de l'autre décroissent.

A la première et à la onzième heure, le gnomon donne vingt-neuf pieds d'ombre.

A la seconde et à la dixième, il en donne dixneuf.

A la troisième et à la neuvième, il en donne quinze.

A la quatrième et à la huitième, il en donne douze. dix.

A la sixième, il en donne neuf.

\section{LIVRE QUATORZIEME.}

\section{AU TRÈS-DOCTE PASIPHILUS.}

Recevez, comme un nouveau gage de l'affection que je vous ai vouée, ce poëme relatif à l'art de la greffe. Cette addition à mon premier envoi est une façon de payer l'intérêt de mon retard. Si vous avez attendu plus longtemps que vous ne le désiriezces volumes relatifs aux travaux agricoles, n'en accusez que la leuteur du copiste; c'est un défaut pour lequel je me montre toujoursassez indulgent. Connaissant par expérienceles manœuvres de ceux qui nous servent, j'aime mieux attendre, afin de pouvoir compter sur de meilleure besogne. Je ne sais si j'ai cela de commun avec les autres maitres, mais je remarque que le caractère des esclaves est de donner toujours dans les extrêmes. Tant il est vrai que dans cette condition les meilleurs penchants se dénaturent, et

expedire conveniet. Hoc usque in Martium mensem tendeLur aucupium.

VII. Decembrem Januario in horis causa dispar adjunxit, cum linea simili ille augeatur, iste decrescat.

\begin{tabular}{|c|c|c|c|c|c|}
\hline Hora & 1 & et & $x_{1}$ & pedes & $x x i x$ \\
\hline Hora & II & et & $x$ & pedes & XIx \\
\hline Hora & 111 & et & $1 \mathrm{x}$ & pedes & $\mathrm{XV}$ \\
\hline Hora & IV & et & Vill & pedes & XII \\
\hline Hora & $\mathbf{v}$ & et & vil & pedes & $x$ \\
\hline Hora & v1 & & & pedes & $1 X$ \\
\hline
\end{tabular}

\section{LIBER DECIMUS QUARTUS.}

\section{AD PASIPHILUM VIRUM DOCTISSIMUM.}

Habes aliud indulta fidei testimonium. Pro usura tem. poris hoc opus de arte insitionis adjeci. Sed quod volumina hæc ruris colendi serius quan jusseras, scripta sunt, librarii manus segnior fecit, cujus ego tarditatem nunquam maligne æstimo. Scio enim, quo frequenter inclinet argutia famulorum. Malo operam ejus expectare potius quam timere. Nescio utrum commune sit dominis : mihı difficsle 
(qu'll n'est pas de qualité qui ne puisse y devenir défaut. Une nature promptechez eux est toujours près du mal. Ia paresse du moins a l'allure de la bonhomie. Plus on ineline à l'indolenee, et moins on est propre au crime. Du reste, mon hésitation d vous offrir cet ouvrage est celle d'un bon serviteur. J'ignore à la vérité si votre esprit se sent porté vers ces minuties, mais votre attention va les grandir et les élever au niveau de votre attente. Aussi, pour peu que vous pensiez avantageusement de ces bagatelles, je n'hésiterai pas à y mettre moi-même le plus grand prix. Le eurieux, en contemplant une médaille, ne tient pas compte de la poussière qui la couvre; il ne voit que l'effigie, portrait en raccourci de quelque grand personnage d'autrefois.

\section{DES GREFFES.}

Pasiphilus, type de l'amitié, dépositaire, à sl juste titre, de tous les scerets de mon ame, vous louez, vous prisez et vous chérissez ces quatorze petits livres sur l'agrieulture; ceuvre vulgaire, anti-poétique s'il en fut, affranehie de tout rhythme, qui n'emprunte rien de la souree d'Hippoerène, ft n'a pour tout mérite que sa simplieité rustique. Mais la rustieité même vous plaira chez un ami. Ma présomption est aecrue de cette eonfianee, et j'ose offrir aujourd'hui ce petit poëme à votre approbation. Au reste, le but de ma muse n'a rien que de louable, puisqu'elle se propose de traiter d'une opération rustique, que l'on peut regarder comme urbaine, qui consiste à joindre

contigit, in servilibus ingeniis invenire temperiem. Ita sxpissime natura lıxc vitiat cominodum si quod est, et miscet optanda contrariis. Velocitas procurrit in facinus; segnities figuram benignitatis imitatur, et tantum recedit ab agilitate, quantum recessit a scelere. Diu tamen apul te pudorem menm distuli, sed lıoc quasi bonus famulus feci. Verum nescio, si tuum ad lias modo minutias inclineturingenium. Grande erit, et par desiderio suo, quod studii tui quaret affectio. Et licet de lis nugis favorabiliter sentias, ego meas opes astimare non differo. Non est magni loci assibus intuendis oculos duxisse per pulverem, quia nescio quomodo notæ sunt quædam maximarum pelsonarum minuta compendia.

\section{DE INSITIONIBUS.}

Pasiphile ornatus fidei, cui jure fatemur, Siquid in arcano pectoris numbra tegit,

Bis septem parvos, opus agricolare, libellos, Quos manus hæc scripsit, parte silente pedum,

Nec strictos numeris, nec Apollinis amne fluentes, 5 Sed pura tantum rusticitate rudes,

Commendas, dignaris, amas, et rustica dicta Affectu socii sollicitante colis.

Nunc ideo modicum crescens fiducia carmen Obtulit, arbitrio lactiticanda tuo.

Est nostra studium non condemnabile musx, ensemble des arbres heureux, par un mariage devant douer leur progéniture des avantages de tous deux; à revêtir un arbre ineorporé à un autre d'un ombrage qui lui soit analogue; à ennoblir le résultat de eette union par un double feulllage; enfin à réunir des sues agréables par l'effet d'une allanee charmante, et à eonfondre deux saveurs dans un même fruit. J'enseignerai done quels sont les arbres qui donnent l'hospitalité à d'autres ; à quels arbres ils la donnent, et comment cenx-cl vont parer leur front d'une chevelure adoptive. Le modérateur du ciel, qui fait errer les étoiles brillantes, qui a affermi la terre sur ses fondements, et qui donne l'éeoulement aux eaux de la mer, aurait pu revêtir lui-même les branehes des arbres de différentes espèees de fleurs, et orner une forêt chargće de fruits d'un feuillage varié. Mais, daignant donner à nos travaux l'oeension de se signaler en cette partie, il a voulu que l'art format une seeonde nature. Je ne crois pas que l'entreprise de ma muse soit sans fruit, ni que ce petit ouvrage manque absolument de grâce et d'utilité. On voit bien la euriosité humaine allier l'ardente cavale à l'âne paresseux, bien qu'il ne sorte de cette allianee qu'une progéniture rétive et stérile, un rejeton inhabile à transmettre à d'autres la vie qu'il a reçue. Pourquoi un arbre infruetueux ne serait-il pas féeondé par le moyen d'un autre germe, en retour de l'hospitalité qu'il lui a donnée? Pourquoi ne deviendrait-il pas plus brillant en partageant les honneurs d'une fleur étrangère? J'entre en matière, en me conformant dans mon travail à tous les éerits des

Urbanum fari rusticitatis opus :

Sub thalami specie felices jungere silvas, Ut soboli mistus crescat utrinque decor :

Connexumque nemus vestire affinibus umbris,

Et gemina partum nobilitare coma :

Focderibus blandis dulces confundere succos, Et fetum duplici fruge saporis ali :

Quæ quibus hospitium prastent virgulta docebo

Qux sit adoptivis arbor onusta comis.

Ipse poli rector, quo lucida sidera currunt,

Quo fixa est tellus, quo fluit unda maris,

Cum posset mistos ramis inducere flores,

Et varia gravidum pingere fronde nemus,

Dignatus nostros hoc insignire labores,

Naturam fieri sanxit ab arte novam.

Non segne officium nostræ reor esse camœeric,

Si velocis equac pigro miscetur asello

Ardor, ut in sterilem res cadat acta gradum,

Focundumque genus productus deleat liares

Cur non arbor inops pinguescat ab hospite gemma,

Incipiam, quidquid veteres scripsere coloni,
Aut operis parvi gratia fiet inops.

Et sibi defectum copia prolis agat: Et decus externi floris adepta micet?

Sarraque priscorum verba labore sequar. 
agricultcurs qui m'ont prócédé, et aux paroles consacrées par les ancicns.

Dans l'origine, l'active industrle a Inventé bien des sortes de greffes, ct a voulu qu'unc main habile les mit en ouvre. En effet, les méthodes suivantes apprennent d̀ tout arbre paré de fcuilles étrangères à porter les fruits qu'on lui confic : ou l'on enfonce de nouveaux germes entre son écorce, que l'on en sépare à cet effet; ou on le fend a l'extrémité supérieure de son trone, pour recevoir ces germes; ou enfin on adapte les yeux verdissants d'un bouton étranger et humide à l'un de ses bourgeons, qui resserre le premier dans son sein humide de séve.

La branehe à fruit de l'arbuste de Bacchus l'Échionien est la première à qui l'on ait appris à se marier, afin que la grappe de raisin fût gonfléc par un vin étranger. Les membres féconds de la vigne sont entrelacés de bourgeons eutortillés autour d'elle; et, dès qu'eilc est adulte, eile nourrit ceux de l'espèec qu'elle a reçue cntre ses bras : de sorte qu'un pampre doux couvre de son ombre un pied de vigne dont le feuillage est d'une autre nature que le sien, et que celte plante se courbe sous le poids du dieu replet.

Les rameaux de l'arbre de Palias embellissent les chênes des forèts, et la superbe olive ennoblit des fruits sauvageons. L'olivier sauvage, tout stérile qu'il tst, féconde celui dont nous recueillons les olives grasses, et lui apprend à donner des fruits qu'il ne saurait produire lui-même.

Le poirier au germe bianc prête sans jalousie ses fleurs de couleur de neige, et s'u nit amoureusement à un bois different du sicn. Tantôt il arrache les armes cruelles de ses sœurs ćpineu-

Principio multas species industria solers

Protulit, et doctam jussit ínire manum.

Nam quxecunque virens alienis frondibus arbos

Comitur, his discit credita ferre modis.

Aut nova discreto figuntur germina libro, Aut aliud summo robore fissa capit,

Aut virideis oculos externi gemma tumoris Accipit, et lento stringitur uda sinu.

Primus Echionii palmes se jungere Baccli

Novit, et externo tenditur uva mero.

Nexilibus gemmis focundos implicat artus

Vitis, et amplexum pascit adulta genus

Degenerisque comæ vestigia mitis inumbrat

lampinus; et pingui curvat onusta deo.

Robiora Palladii decorant silvestria rami,

Nobilitat partus bacca superba feros;

Fucundat sterilis pingues oleaster olivas,

Et quae non novit munera ferre docet.

Gernine cana pirus, niveos lıaud invida flores

Connmodat, et varium nectit amore nemus.

Nunc rapit lirsutis horrenda sororibus arma,

Et docet indomitas poncere tela piros. ses, et apprend aux poiriers indomptés à déposer leurs traits; tantót il produit des pommes dont ia rondeur se termine en une pointe.insensible, et fait fléchir les rameaux du frêne en le revêtant de nouveaux honneurs. Il apprend en outre à Phyílis à porter des fruits plus doux et d'un plus gros volume, et prête ses membres à la peau dure dont elle est couverte. Il dote les pruncliers stériles, ainsi que l'orme sauvage qui ne produit aucuns fruits, et les force à chérir un honneur qui leur était inconnu. Ses branches, entées sur le cognassier, changent la nature de celui-ci, et, son odeur se confondant avec celle de ce dernier, il lui fait procréer des fruits charmants. Il dépouille ies fruits du châtaignier de l'éeorcepiquantequi les enveloppe, et change le poids dont ils sont chargés en un fardeau plus doux. Il dépouille le néflier menaeant de son apparefl de guerre, étouffant ses mauvais desseins sous une écorcc paisible. Ses germes, diton s'unissent aux branches de l'arbre de Libye, et, fécondés par lui, peuvent jouir d'un éelat empourpré.

Le grenadier, qui dédaigne pour son fruit l'importation d'un goût nouveau, ct pour ses rameaux une parure empruntée, augmente de lui-même le nombre de boutons en changeant de semence, et se plait à être peint d'une rougeur qui a de l'affinité avec ses teintes propres.

Le pommier, enté sur de plus hautes branelıes que les siennes, continue de croître, et change à l'amiable le poirier qu'on lui a assoeié. Il s'exhorte lui-même à laisser dans les forêts ses mours sauvages, et se plait à porter un fruit pius distingué. II rend lisses les prunclicrs garnls d'épi-

Nunc teretem pingui producit acumine malım,

Fraxineasque novo flectit honore manus.

Phyllida quin etiam grandi mitescere fructu

Instituens, duræe dat sua membra cuti.

Et steriles spinos, et inertem foetibus ornum

Dotat, et ignotum cogit amare decus.

llujus et immissi vertere cydonia rami,

Pomaque confusus blanda creavit odor.
45

Lixuit, et placido pondere mutat ouus.

Mespilaque exarmat pugnaciluss lıorrida menbris,

Et mala tranquillo cortice vota premit.

Creditur et Libycis sua germina nectere ranis,

Laetaque puniceo posse decore frui.

Punica non alios unquam dignata sapores

Mala, nec externis associata comis,

Ipsa suas augent mutato semine gemmas,

Et sibj coguato picta rubore placent.

55
Castanex septos aspro velamine foetus

Et sociam mutat malus amica pirum.

Seque feros silvis hortatur linquere nıoies, Et partu gaudet nobiliore frui. 
nes, ainsi que les chènes armés de piquants, et les revêt en croissant d'une belle chevelure. Il sait gonfler d'un suc agréable la petite corme, et faire descendre le fruit de l'arbre qui la donne a la portée des mains qui le désirent. Il se plait à changer de nom sur les souches du saule, et à répandre ses fleurs sur des forêts agréables aux Nymplies. Il apprend au platane, cet arbre sympathique de Bacchus, à rougir, chargé d'un fruit nouveau. Le pêcher admire son feuillage, auquel il n'était point accoutumé; et la chevelure du peuplier porte ses dons éblouissants par leur blancheur. La nèfle lui obéit, et, changeant ses entrailles pierreuses, elle grossit et rougit en se remplissant d'une liqueur blanche. Au lieu des pieux lourds et des armes grossières qu'ils fournissaient auparavant, les châtaigniers donnent de nouveaux fruits, qui leur font honneur par leur couleur jaune.

Le pècher charge lui-méme ses branches d'un meilleur germe, et associc sa nature au prunier. Il couvre d'ombres légères le tronc de Phyllis, et apprend à devenir lui-même plus fort par cette transmigration.

Quoique l'arbre qui produit des coings jaunes se prête à donner l'hospitalitć à toutes sorles de fruits, il ne se confie à aucun autre arbre pour la recevoir. Il est fier, et méprise l'écorce d'un bois étranger, convaincu qu'il n'y a point d'arbre qui puisse ajouter quelque chose à ses avantages particuliers. Mais, offrant d̀ ses propres branches des lits qu'elles connaissent, il se contente d'ennoblir un bien qui lui appartient.

Le. dur néflier, rival du poirier sauvage, se

Spiniferas prunos, armataçue robora sentes

Levigat, et pulchris vestit adulta comis.

Exiguam sorbum dulci distendere succo Nuvit, et ad cupidas flectere poma manus.

Stipitibus gaudet nomen mutare salignis,

Et gratum Nymphis spargere flore nemus.

Robora thyrsigero platani concordia Bacclio Fœtibus instituit plena rubere novis.

Illius insolitas miratur persicus umbras,

Populeæque ferunt candida dona comæ.

Mespilus huic paret, lapidosaque viscera mutans

Tenditur, et niveo plena liquore rubet.

Pro sudibus foetis, et pro pragnantibus armis Castaneæ fulvum dant nova mala decus.

Ipsa suos onerat meliori germine ramos

Persicus, et pruno scit sociare genus.

Imponitque leves in stipite Phyllidis umbras, Et tali discit fortior esse gradu.

Oum prastet cunctis se fulva Cydonia pomis, Alterius nullo creditur hospitio.

Iioboris externi librum aspernata superbit, Scit tantum nullo crescere posse decus.

sed propriis pandens cognata cubilia ramis, stat, contenta suum nobilitare bonum. greffe sur des pommiers dont on rebute le fruit, et se trouve en sûreté quand son germe y est reçu, parce que de doubles armes le rendent alors plus redoutable qu'auparavant; de sortc que son bois cruel épouvante les mains avides.

Les branches du citronnier souffrent aussi qu'on leur prête les enfants élevés par le mûrier sous son écorce pleine, et changent les piquants dont les poiriers sont ordinairement armés, pour nourrir les fruits odoriférants de ceux-ci d'un suc flatteur.

Les pruniers ajoutent à leurs propres membres d'heureux germes, et portent des présents fertiles dans un corps analogue au leur. Lorsqu'on les force d'habiter dans le châtaignier, ils désarment à la vérité son fruit, mais ils arment ses bras.

Les caroubiers accoutument leurs fruits à s'amollir avec le secours d'un suc vert, et nourrissent tous les autres fruits dans leur sein.

Le figuier détermine les mủres à quitter leur couleur noire, et fait la loi aux branches dont if s'est emparć. Il s'admire aussi lui-même lorsqu'un suc mieux nourri le fait grossir, et se réjouit de voir ses fruits excéder leur grosseur ordinaire. Le noble platane, cher aux amis de la table, dont la chevelure se prête avec amour aux entrelacements de la vigne, le platane ouvre aussi les bras au figuier, qui trouve un abri désirć sous son écorce nourrissante,, et remplit en crolssant le sein qui l'a adopté.

Le figuier entretient en outre un commerce réciproque avec la mûre, et prodigue sa substance au germe qu'elle lui offre à nourrir. Le frèno

Emula dura piri despecti mala saporis

Mespilus admisso germine tuta subit.

Et geminis sese violeuthor inserit armis, Atque avidas terrent robora sæva manus.

Nec non et citrei patiuntur mutua rami

Pignora, quæ gravido cortice morus alit.

Pomaque pasturi blando redolentia succo Armatis mutant spicula nota piris.

Pruna suis addunt felicia germina membris, Donaque cognato corpore lata ferunt.

Exarmat foetus, sed brachia roboris armat Castanex prunus jussa tenere larem.

Assuescunt siliquæ viridi mollescere succo, Et gremio pascunt cælera poma suo.

Persuadet moris tetrum mutare colorem Ficus, et invasis dat sua jura comis.

Se quoque miratur pingui grandescere succo, Et solitum gaudet vịncere poma modum.

Insignes foliis platanos, felicia mensis Braclia, gaudentes vitis honore comas, Ingrediens pingui se cortice maxima ficus Servat, et optatos implet adepta sinus.

Mutua quin etiam moris commercia ficus Præstat, et oblatum robore gernen alit.
105 
prète aussi ses membres à cette sœur avide; et, se voyant alors baigné de sang, il redoute ses nouveaux enfants. Le hétre géant recoit aussi la teinture du mûrier. La chátaigne hérissée, ce fruit à l'enveloppe dure et piquante, apprend de lui à devenir noire comme de la poix, et, nourrie de ce suc nouveau, voit s'augmenter son volume. Le térébinthe, dont l'odeur est si agréable, obéit au mûrier, et produit alors des fruits dont le mérite est double.

Le cormier a l'avantage d'augmenter, en se renouvelant de lui-mème, la beauté de son fruit, et l'arbre se courbe alors sous le noble effort de ce surcroit de production. Cet arbre dépouille de leurs piquants les membres durs de l'épine, et cache les armes de cette plante sous de douces écorces. Il se plait à unir le coing doré a vec son propre fruit, et chérit des présents d'une couleur étrangère.

Les cerisiers se greffent sur le laurier, et le fruit qu'ils le contraignent de donner teint d'une pudeur adoptive les joues de cette vierge. Il force les platanes ombragés, ainsi que le prunier hérissé, à revêtir sa luisante écorce. Et le peuplier s'ennoblit d'une adoption qui nuance d'un rouge flatteur la blancheur de ses rameaux.

Phyllis, cachée cntre l'écorce d'un prunier fendu, en couvre les membres parfumés de fleurs précoces, et chango les fruits du pècher en y ajoutant une enveloppe, et en leur apprenant à prendre une couverture dure qui leur sert de peau. Elle arrondit sous une moindre forme le fruit du caroubier lorsqu'il se gonfle, et enrichit d'une belle odeur les feuilles sauvages de cet arbre : Elle dépouille la châtaigne de son enveloppe cruelle, et force l'arbre à admirer la peau lisse de son fruit.

Les pistaches se glissent entre les branches de l'amandier, et le moindre fruit devient alors le plus recherché. Le térébinthe aussi leur offre son ombre paternelle, et les ennoblit par son adoption.

Les membres élevés du châtaignier fécondent le saule des rivières, et prennent dela forcelors. qu'ils sont abreuvés d'une grande quantité d'eau.

Le vaste noyer s'empare sous son ombre des feuilles de l'arbousier, et rapporte des fruits qui sont en sûreté sous leur double écorce.

On a essayé d'antres procédés, qu'une expérience habile pourra perfectioner avec le temps. Mais pour un poête qui n'est habitué qu'à retourner la terre, c'est déjà beaucoup d'avoir énoncé ceux-ci en vers même médiocres Lisez-les ces vers, fabriqués parmi les instruments du labourage. Ils sont rudes, mais d'une rudesse que tempère l'utilité de leur objet.

Discissi pruni cortice fixa tegit.

Fravinus huic avide confert sna membra sorori, Et metuit foetus sparsa cruore noros.

Proceras fagos, et poma hirsuta virentis Castanex, duris aspera mala comis

Inficiens, monstrat piceo nigrescere partu, Et succo pascit turgida poma novo.

Obsequitur moris blando terebintlus odore, Et geminis veniunt munera mista bonis.

Sorba suos partus merito majoris honestant Seminis, et pulchro curva labore nitent.

Hæc arbos spinæ duros mucronibus artus

Exuit, ac libris mitibus arma tegit.

sureaque annexo miscere cydonia fœtu

Gaudet, et externi dona coloris amat.

Inseritur lauro cerasus, partuque coacto

Tinguit adoptivus virginis ora pudor.

Umbrantes platanos, et iniquam robore prunum

Compelnt gemmis pingere membra suis.

Populeasque noro distinguit munere frondes,

Sic blandus spargit braclia cana rubor.

Plyllis odorates primæris foribus artus
Pomaque permutat velamine persica misto, Duritiemque docet tegminis esse loco.

In modicam tornat siliqua tendente figuram, Et frondes pulchro ditat odore feras.

Gastaneamque trncem depulsis cogit echinis Mirari frnctus levia poma sui.

Quin et amygdaleos subeunt pistacia ramos Et meritum majus cie brevilate petunt. Nutrit adoptivis nobilitanda comis.

Flumineam salicem focundant ardua membra Castanex, et multo pasta liquore vigent.

Arbuteas frondes vastæ nucis occupat umbra, Pomaque sub duplici cortice tnta refert.

Cætera, quæ solers processu temporis usus Exprimet, exemplis instituere novis.

Hac sat erit tenui versu memorasse poetam, Quem juvat effossi terga movere soli.

Carmina tu duros inter formata bidentes Aspera, sed miti rusticitate, leges.
Hæc et cognato cingens terebinthus amictu 


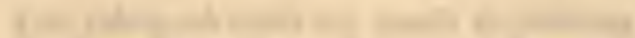

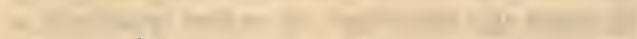

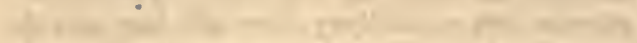

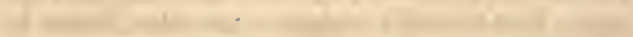
r. and 0

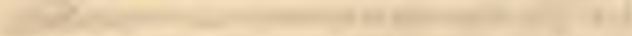

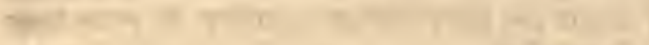

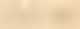
(5)

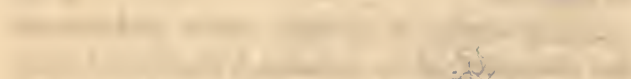

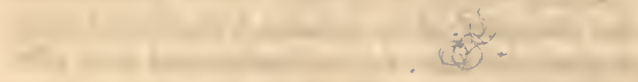

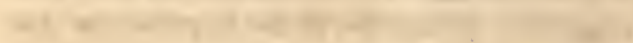

(5)

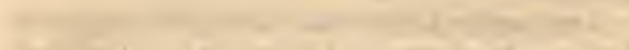

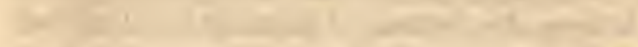

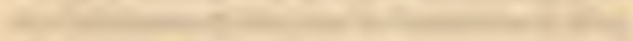

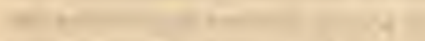

.

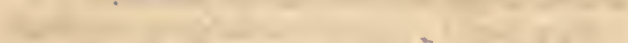

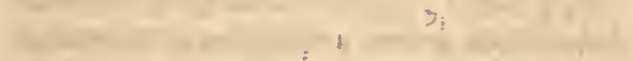

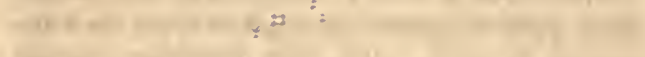

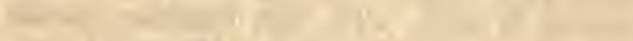

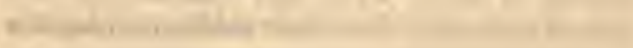

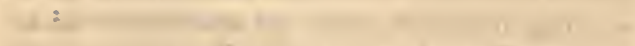
win

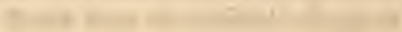

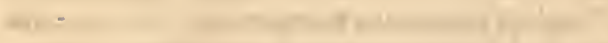

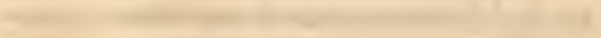

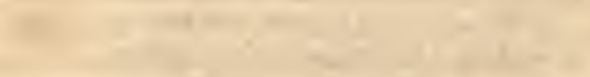
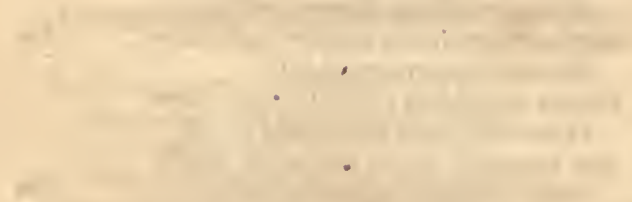

: + - +

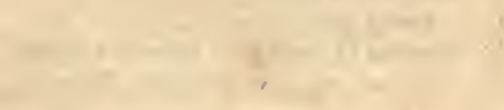

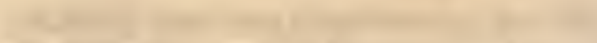

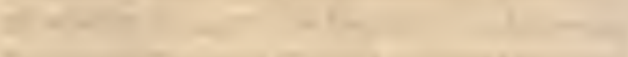

and

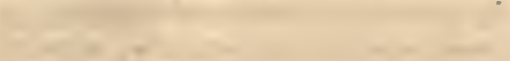

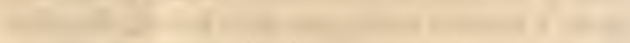

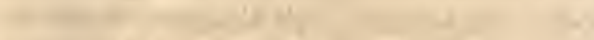

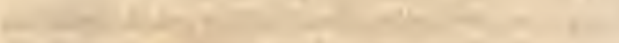

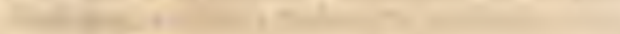

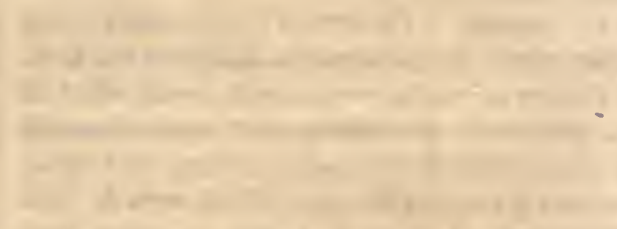

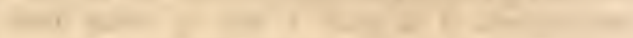

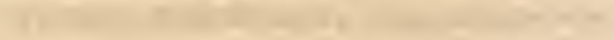

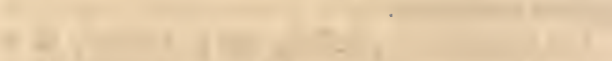

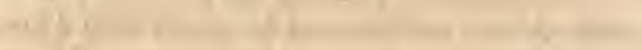

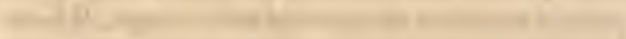

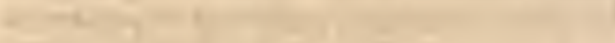

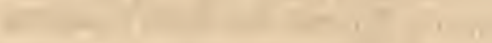

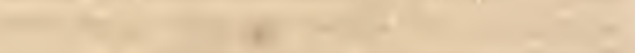

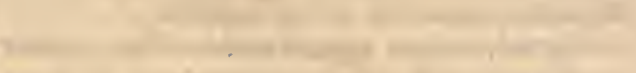
1.

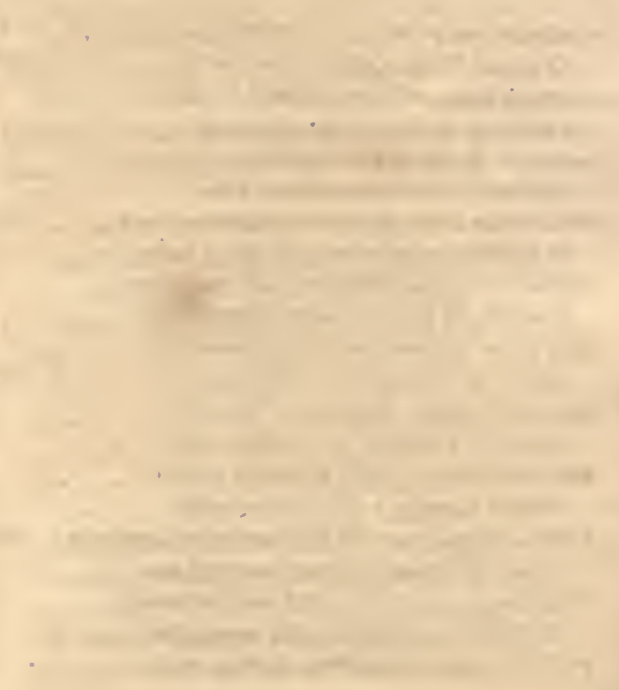




\section{NOTES SUR PALLADIUS.}

\section{LIVRE I.}

I. Quod a plerisque factum est. Le trait paratt dirigé contre le style de Columelle. Mais Palladius est assez. souvent, et très-ridiculement, tombé dans le meme défaut.

IV. De metallis originem. L'observation peut ctre vraic si le mot metallis est pris dans le sens général de produit fossile. Dans le sens restreint de mines, elle a contre elle l'expérience.

V. Vulturnus. Nom donué par les habitants de la Bétique au vent du sud-est.

Impastinato solo. Voir l'Économie rurale de Columelle, liv. XIII, clıap. 3 , touclıant la manière de façouner un terrain au pastinum.

Acinaticium. Vin fin qui ne se fabriquait qu'arec les grains de raisin séparés de la rafle. Le mot est dérivé d' $a$ cinum, grain de raisin.

Caecabitur spes magna vindemice. C'est-d̀-dire qu'il ne faut pas becher la vigne pendant qu'elle bourgeonne, parce qu'on risque d'en faire tomber les boutons et le ruiner l'espérance de la vendange. Jeu de mots sur les yeux de la vigne, où l'auteur exagère le défaut de siînplicité qu'il a lui-même critiqué.

IX. Quernce cum Esculeis non misceantur. L'Esculus était l'espèce de chêne consacrée à Jupiter. C'est celle dont Virgile a dit : tantum radice ad auras othereas, tantum radice in tartara tendil.

De Cerro. Le père Hardouin dit, dans ses notes sur Pline, que cette espèce de clıêne ne vient point en France, et, conséquemment, n'a pas de nom dans notre langue.

$\mathrm{X}$ VII. Signinis. Voir le mot signia à la table des villes, etc., de Columelle.

XVIII. Ut basilica ipsius forma. Le nom de basilique fut donné primitivement aux ódifices où se rendait la jus. tice. Les tribunanx y tenaient leurs séances dans des salles voutées, où les juges étaient placés sur une estrade. Double conformité qui aura donné à Palladius l'idée de ce rapprochement avec les celliers où se déposait le vin.

XX. Per specularia. Ces transparents se formaient de pierres taillées en feuilles minces et diaplianes, et qui teuaient lieu de nos vitres. Les meilleurs venaient de la Cappadoce et de l'Espagne Citérieure. On lit dans Pline que l'usage de ces pierres ne remontait qu'au temps d'Auguste. Il paralt que e'était une espèce de tôle. Mais on n'a conservé aucune notion précise de leur description, ni du nom qu'on leur donnait.

Trapetis et rotulis. Trap̀̀te. Voir la description de celte macline, Économie rurale de Caton, chap. $x x$, XXI et XXII.

XXIV. Spartea, qua animalia calceantur. Voir rem. ploi de ces bottines, Économie rurale de Columelle, liv. VI, cliap. $x u$ et $x v$.

De strangulati hominis loro. Cette superstition de l'antiquité qui s'étendait à tout ce qui avait servi comme instrument de supplice, et lui pretait une vertu efficace, a traversé les siècles pour arriver jusqu'à nous. Aujourd'hui même encore une locution proverbiale en consacre l'existence ou le souvenir.

XXVI. Alieno tempore saginentur. C'est-à-dire à la fin de l'automne.
XXVIII. Capita oculata. Notre langue a conservé aux monclielures des plumes de la queue du paon, le nom d'yeux, qui est à la fois piltoresque et traditionnel.

XXXIV. Quce rubus caninus vocatur. Littéralement rose à chien. C'est le rosier dans l'état de nature. La lleur et le fruit ont cliez nous, dans la langue du bas peuple, des dénominations encore plus mallıonnetes.

Propter spatia utrinque purganda. Le jardinier pent ainsi, de clıaque côté de la planche, étendre la main à trois pieds pour arracher les mauvaises herbes, sans cou. rir le risque d'endommager ce qui se trouve planté sur ses bords.

XXXV. Vel incensis sanguisugis. L'odeur de la punaise brülée produit, suivant Columelle (liv. VI, cliap. xviu) l'effet réciproque sur les sangsues.

IIpxбoxoupioxs Grceci vocant. Espece de pucerons qui

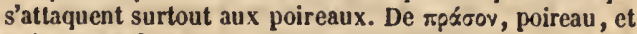
xeipetv, tondre.

XXXVII. Qui iris vel gladiolus. Littéralement petiŁ glaive. C'est vraisemblablement l'iris bulbeux de l'É. mery.

XL. Miliarium. C'est le nom du vaso où l'on faisait chauffer l'eau des bains.

Cui area patina subest. Ce plateau de cuivre servait probablement à défendre le miliarium, qui était de plomb, de l'action immédiate du feu.

XiLII. Palladius est le seul des écrivains agronomiques qui ait fait mention de moulins mus par l'eau. Comment ce procédé, une fois connn, n'a.t-il pas été mis généralement en usage? Il l'étail du temps de Pline, qui nous ap. prend que la plus grande partie du blé de l'Italie se broyait encore à force de bras. Cette singularité ne peut guère s'expliquer que par la nécessité d'occuper la multitude des esclares.

\section{LIVRE II.}

X. Ne laborent frigore sarmenta. Parce que la clialeur du soleil pénètre difficilement la terre à plus de trois pieds de profondeur.

XI. Tabulas átem. Le unot tabula que nous traduisons par planclıe, et auquel les jardiniers de l'antiquits n'attachaient, non plus que les notres, aucun sens do mesure, s'entendait dans la langue technique de l'arpentage d'une superficie de soixante douze perches carrées.

XII. Tabula quadrata jugerali. La planche du juge. rum entier ne devrait contenir que deux cent quatre-vingthuit perches ou vingt-luuit mille lunit cents pieds carrés, la perche étant supposée de dix pieds. Mais Palladius procède ici tout autrement dans ses calculs. Il prend la moyenne proportionnelle entre la longueur du jugerum, qui est de deux cent quarante pieds, et sa largeur qui est de cent vingt pieds; cette moyenne est cent quatre-vingts, dont le carré trente-deux mille quatre cents pieds, ou trois cent vingt.quatre perches, d'où il résulte une mesure plıs considérable que la véritable.

XIII. Ne citius terra decurrat. II fant nn labour plus profond sur un sol en plan incline, afin d'offrir à l'entral 
nement de la terre régétale par les eaux une résistance plus considérable.

XV. Tadœ cuncus radicibus ejus inseratur.. Cette insertion d'un morceau de bois, ou d'une matière également dure, est souvent recommandée par les ouvrages agronomiques comme remède à la stérilité des arbres. On serait tenté de n'y voir qu'une lpratique absurde; une parodie de l'acte de la génération, parodie à laquelle la superstition antique aurait attribué la même vertu de fécondation qu'à l'acte lui-nếme. Toutefois en y rếléchis. sant, il n'est pas impossible d'en trouver une explication rationnelle. En effet, la présence d'un corps étranger, qui resserre les fibres de l'arbre a l'endroit de son intromission, opposant une résistance au cours de la séve, doit lui imprimer un mouvement accéléré lorsqu'elle a trouvé un libre passage, et la porter plus rapidement aux extré. mités de la plante.

Martialis dicit hoc remedio subveniri. Gargilius Martialis, auteur supposé du livre de Arboribus qui appartient à Colımelle. Nous n'avons aucune notion sur sa personne, ni sur le lieu de sa naissance. Mais Lampride nous apprend qu'il vivait sous l'empereur Alexandre Sévère, et l'on voit par d'autres auteurs qu'il avait écrit sur l'histoire, et aussi sur le jardinage et sur l'art vétérinaire. Gesner a meme donné dan sa collection un fragment de lui, qui est relatif au traitement des boufs. $C$ est tout ce qui reste de cet écrivain, encore le fragment est-il si mutilé qu'il ne mérite aucune attention.

XVIII. Sexlariis urbicis. On voit par ce passage que la mesure du sextarius n'était pas la même à Rome que dans le reste de l'Italie.

XXIII. Hic mensis in horarum spatio. Palladius ne dit pas à quel cadran il a rapporté les mesures absolues qqu'il indique pour ce mois et pour les mois suivants. Comme la longueur de l'ombre est subordonnée à l'élévation du corps qui la projette, il faut croire que ses observations ont étê faites sur un gnonion d'une mesure déterminée et connue, et qui servait en quelque sorte de régulateur.

\section{LIVRE III.}

IX. Ne quod sterili proximum est supra terram relinquatur. En effet, lorsqu'on recourbe le sarment pour l'enterrer, il ne reste au dessus du sol que l'extrémitế su. périeure, à laquelle on donnait le nom de sagitta en agriculture, et qu'on regardait comme absolument stérile. ('Voir l'Économie rurale de Columelle, liv. 111 , clı. xul.)

Minor operarum numerus cam poterit expedire. On conçoit que dans un vignoble, partagé en planches d'espèces différentes, qui mürissent successivement, il faille relativement un moins grand nombre de mains pour la vendange, que dans ceux où la maturité de toutes les vignes est simultanée.

Ut asscrit Columella. Ce passage tiré du chap. Iv de Arboribus, et cité par Palladius comme appartenant à Columelle, est une preuve que cet économiste est l'auteur du livre.

X. Mago asserit scrobem. Virgile dit la même chose dans le livre II des Géorgiques. C'est pourquoi quelques commentateurs ont voulu lire ici Maro au lieu de Virgile. Mais Virgile a pu le dire d'après Magon, et il est probable que Palladius aura cité l'auteur didactique de préférence au poëte.

XV. Novellam vitem Columella. Ce passage n'est pas textuellement dans Columelle. Tout au plus trouve-t-on des principes qui aient pu servir de fondement à l'observation de Palladius.
XVII. Quartum genus Columella sic relulit, Voir le livre de Arboribus, cliap. vuı.

XIX. Sed (ut Columella dicit) feraciores. On ne troure rien de semblable dans Columelle. Aurons-nous perdu quelque cliose de cet auteur?

XIV. Semen brassicce vetustum mutatur in rapa. Cette observation est bien suspocte. Elle ge foude proba. blement sur l'erreur de quelque jardinier qui, en semant, aura pris l'une pour l'autre entre deux graines dont la différence est peu sensible.

XXIX. 'Oто̀: Kuprquixòs, suc de Cyrène, autrement dit laser.

\section{LIVRE IV.}

VIII. Stricte in foramen utrinque conjicies. Il fant supposer, l'arbre étant foré diamétralement d'outre en outre, que ces branches introduites en sens inverse par les deux ouvertures, sont ensuite tirées fortement de cha. que côté, à peu près conme les cordonniers tirent leurs fils, en sorte que le lout le plus mince de l'une s'adapte réciproquement avec le gros bout de l'autre.

IX. Herba ea qua culex dicitur. Le père Hardonin croit que c'est l'herbe aux puces. (Notes sur Pline, liv. XIX, chap. v.)

Prosequuntur etiam maledictis. 11 subsiste encore de nos jours des pratiques de superstition non moins extravagantes que celle-là.

X. In Sardinia et in territorio neapolitano. Il ne faut pas confondre cetle ville, située en Sardaigne, avec la capitale du royaume actuel de ce nom. Le nom de Naples

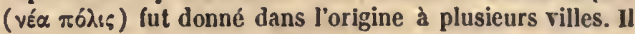
en existe encore aujourd'lui une troisieme, sous le nom moderne de Nauplie, ou Napoli de Romanie.

Alii Coracinum piscem. Ce nom paraft être donné à ce poisson, à cause de sa couleur noire, analogue à celle du corbeau. On l'appelle meme encore aujourd'lsui cor. beau dans quelques-unes de nos provinces, ainsi que l'observe le père Ilardouin dans ses notes sur Pline.

XII. Absolutam impedimentis omnibus diem. Palladius, qui a tiré tout ceci de Columelle, veut apparemment désigner ici un jour non férié, comme l'exige cet auteur. (liv. VI, cl. 2.)

\section{LIVRE V.}

V. Quam cephalonem vocamus. De $x \in \varphi ̧ x \lambda \hat{\gamma}$, tete. Ce qui veut dire que le principe de vie, pour cet arbre, réside dans sa cime, et non dans seś racines. C'est en ce sens que Pline appelle Cerebrum, cerveau, la partie supérieure du palmier.

\section{LIVRE VI.}

IV. Modii spatium. Le modius était le tiers de juge rum. C'était par conséquent un espace de 80 pieds de long, sur 40 de large.

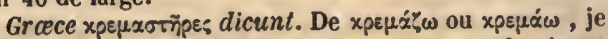
suspends; parce que les testicules sont suspendus à ces nerfs.

XII. Altitudine quatuor unciarum. Palladius donne aux divisions du pied les noms de celles de la lirre. Ainsi quatre uncia sontle tiers d'un pied. 
LIVRE VII.

V. Quare emplastratio dicitur. C'est ce que nous appellons la greffe en écusson.

XII Alica. Espèce de bière. Le mot alc des Anglais en est peut-être dérivé.

\section{LIVRE IX.}

IX. Si aqua limosa fuerit, salis admistione corrigatur. Oı lit, dans le deuxième livre des Rois, chap. II, que le prophète Élisée corrigea les eaux de Jéricho en y jetant du sel. On pourrait mettre en question, d'apres notre auteır, s’il opéra un miracle en qualité de prophète, ou s'il ne fit que se servir d'un secret de la plıysique.

XII. Mensura fistularum plumbo. etc. Les anciens auteurs ont prétendu que ces noms de nombre désignaient le diamètre des tuyaux. Mais nous avons suivi l'interprétation de Vitruve qui dit qu'un tuyau de plomb quelcon. que emprunte toujours son noin de la largeur de la feuille qu'on roule pour le fabriquer. De sorte que si une feuille a cinquante doigts de largeur, le tuyau qui en sera formé s'appellera Quinquagenaria fistula; et ainsi des atitres. Quant au rapport du poids au diametre, on ne saturait reconnaitre la justesse de la progression établie par Palladius, bien qu'elle soit appuyée de l'autorité de Pline et de Vitruve. Cette progression suppose en effet une épaisseur identique pour toutes les dimensions de tuyaux, ce qui est évidemment inadmissible.

\section{LIVRE $X$.}

Carpenta. Littéralement charreles. Mais ce mot ne présente à l'esprit aucune idée précise de contenance. Aussi avons-nous transporté dans notre traduction le mot latin qui exprime une mesure déterminée.

\section{LIVRE XI.}

III. Asserit autem Columella. Ce passage ne se trouve pas dans l'Économic ruratc, mais il est tiré du livre $d c$ Arboribus. Nouvelle preuve que ce livre est bien de Columelle.

XIV. Choevica, Palladius fait venir ce mot du syrien, i) est purement grec. Xoivı $\xi$ était en effet, chez les Grecs, une inesure, tant pour les solides que pour lee liquides, lápuelle équivalait, suivant la plıpart des auteırs, à la Iuitième partie du modius, et au double du sextarius; c'est ce qui fait qu'on donnait le nom de chonica a la ration de nourriture que cliaque esclave recevait par jour chez les Romains, parce que cette ration était de quatre modii par ınois, ce qui revesait à peu prìs à un huitième de modius. Il paraft cependant qu'il y avait des chonica de diflérentes contenances, puisqu'il se trouve d'anciens anteurs qui prétemlent que cette mesure contenait trois colylce, équivalentes a un sextarius et demi ; et d'autres qui veulent qu'elle contint jusqu’a quatre sextarii.

XVIII. Defrutum, carcenum et sapa. Ce sont tous vins cuits, de diverses compositions, et par divers procédés.

\section{LIVRE XII.}

1. Si adhuc ictum solis repercussa non sentit, c'est-itdire avant la pleine lune. Iarce que! quand la lune est dans son plein, on la voit cucore sur l'horizon au monent ob le soleil se lève, et que, conséquemmeut, elle est alor's frappée de ses rayous.

IV. Per latera prona fundanlur. Notre auteur vent que les arbres doment plutot sur la lasgeur que sur lo liant de leurs branches, alin que leur's fruits présentent un coup d'neil plus agréable, et soient plus aisés à cueillir. Avantage réalisé plus efficacement chez nous par l'lıtro. duction des arbres nains.

VII. Damascena. C'est la prune de Damas. Nom de la ville d'où provient originairement ce fruit.

Pcdis dodrunte demcrsum. Le dodrans équivant t neuf uncice, ou aux trois quarts dn pied ; suivant l'usage d'appliquer a toute division de mesure les noms de fractions de la livre.

XIII. Quod pastores colostram vocant. Nous Ilounons aussi le nom de colostram à ces premières gouttes de lait, ainsi qu'à la inaladie que ce lait, qui est toujours raillé, occasionne tant aux enfants qu'aux petits des animaux.

XV. Gallica. Sapin des Gaules.

Larix. Cet arbie n'est pas celui auquel les botanistes donnent aujourd'lui le même nom, et qu'ils iłentifient au mélèse. Ėı effet le mélèse est un arbre résineux. Or, la propriété attribuće ici au larix par Pulladius ainsi que plar Pline, et qui consiste à résister au feu, parait directement opposée à la nature d'un arbre résineux : outre que cette propriété ne se rencontre pas effectivenent daus le Inélèse. Quel arlore est-ce donc que le larix?

XXII. Unum semi sicilicum. Le sicilicus ćtait le quart de l'uncia, et par conséquent la quarante-lutitième partic de la livre. En appliquant cette division à l'amplıore qui était l'unité de nesure pour les liquides, le sicilicus sera la quarante-huitieme partie de cette contenance, ou le scxlarius, et, par conséquent, le dcmi-sicilicus doit valoir la moitié du sextarius, ou, ce qui revient au mème, une hemina.

\section{LIVRE XIII.}

I. Scptimontium. Voir ce que c'était que cette f'to dans la note 4 du chap. $x$. de Columelle.

IV. Uypomclides. On ne tronve le nom de ce fruit dans ancun autre ancien auteur. Serait.ce l'espèce de néfle dont parle Dioscoride, et qu'il appelle érıนทxí.

\section{LIVRE XIV.}

IIabes aliud indulta fidei testimonium. Pour comprendre le sens de l'expression nouveau gage, il faut supposer que Palladius a donné deux éditions de son traité, et que l'une de ces éditions, comprenant quatorze livres, tous en prose, avait été envoyée à Pasiphilus, comme un premier gage d'amitić. Il est mème vraisemblable que ce premier envoi élait précédé d’ıne épltre que le tempis ne nons a pas conservée. Le second gage dont il parle ici, consisterait donc, dans celte hypothèse, à adresser à son ami, en vers, le quatorziène livre que celui-ci n'avait d'abord reçu qu'en prose avec les treize autres. Colımelle aussi a traité des jardius en vers dans le dixième livre de son Économie rurale, et en prose dans le onzième. L'idée de ce double mode de composition est done commune aux deux économistes, et seulenent chez Columelle la prose a suivi les ver, et c'est le contraire chez I'allarlins.

Pro usura tcmporis. Palladius considere ce quatorzième livre en vers comme l'intérêt da à s'asiphilus pont le temps qu'il lui avait fait attendre les puatorze livros eu prose. 
Quasi bonus famulus feci. C'est-à-dire eomme un serviteur qui craint de n'a voir pas assez bien fait.

Quos manus scripsit parte silente pedum. La main est ici mise en opposition avec les pieds des vers. Jeu de mots intraduisible, et dont la perte n'est pas à regretter.

Urbanum fari rusticitatis opus." Palladius donne à l'opération de la greffe l'épithète d'urbaine, dans le même sens que les Romains donnaient le nom d'urbana aux arbres francs, pour les distinguer des sauvageons.

Sub thalami spceie. En effet de meme que, dans le maviage, un père et une mère, nés de familles différentes, coopèrent à la génération du même enfant, deux arbres entés l'un sur l'autre concourent a la production d'un seul et même fruit.

Primus Echionii. Échion était un des compagnons de Cadmus, premier roi de Thèbes et père de Sémélé, qui donna naissance à Bacclıus.

Pingui eurvat onustce deo. Bacclus, dieu du vin, est représenté dans les ancienıes statues avec un gros ventre.

Germinc cana pymus. Les rejetons et les germes du poirier ont une teinte de blancheur à leur extrémité.
Indomitas ponere tela pyros. Les épines du poirier sauvage disparaissent quand il a reçu une greffe prise du poirier franc.

Phyllida quin etiam. Phyllis était une reine des Thraces, éprise de Démoplion, fils de Thésée; se croyant méprisée de son amant, elle se pendit de désespoir, et fut clıangéc en amandier.

Libycis sua germina credere ramis. L'arbre de Libye, nom poétique du grenadier.

Nec externis associata comis. Palladius a dit plus laut que le poirier se greffait sur le grenadier. Mais il suffit, pour qu'il n'y ait pas contradiction, que le grenadier ne puisse pas se greffer réciproquement sur le poirier.

Seque feros silvis hortatur linquere mores. C'est-àdire qu'on greffe le pomnier franc sur le pommier sauvage. Ad cupidas flcetere poma manus. C'est-à-dire que le poids, plus lourd des pommes, fait fléchir les branches du cormier.

Robora platani coneordia Bacehus. Allusion à l'usage oì étaient les anciens de chercher pour boire l'ombre d'un platane, ou à celui d'arroser cet arbre de vin. 


\title{
TABLE DES MATIERES
}

\author{
CONTENUES DANS CE VOLUME.
}

A vertissement des éditeurs.

\section{P. CATON}

Traduction de feu Antoine, professeur a la ferme modele de Roville.

Notice sur M. Porcius Caton.

III

Économite RURALE................ 1

Notes sur l'Economie ru RaLE de Caton"...

\section{VARRON.}

Traduction de $M$. Wolf.

Notice sur Varron..................

De L'A griculturb. Livre I. ...........

Livre II. ..................... 100

Livre III...................... 129

Notes sur le Traité d'agriculture de Varron. 156

\section{J. MODERATUS COLUMELLE.}

Traduction de Saboureux de la Bonnetterie, revue.

Notice sur Columelle............... 167

Dr l'Agriculture. Livre I............ 169

Livre II....................... 192

Livre III. .................... 222

Livre IV.................... 254

Livre V...................... 282

Livre VI..................... 309
I Livre VII....................... 337

Livre VIII...................... 360

Livre IX..................... 380

Livre $X \ldots \ldots \ldots \ldots \ldots \ldots \ldots \ldots \ldots . \ldots, 408$

Livre XI...................... 418

Livre XII..................... 450

Traité des Arbres................ 495

Notes sur le Traité d'Agriculture de Columelle, et sur le Traité des Arbres...... 51:

\section{R. T. EMILIANUS PALLADIUS.}

Traduction de Saboureux de la Bonnetteric, revue.

Notice sur Palladius................ 52

De l'Agricultunb. Livre I............ 52:

Livre II. ..................... 54

Livre III. ................... 55

Livre IV. .................... 57

Livre $\mathrm{V} . . . \ldots \ldots \ldots \ldots \ldots \ldots \ldots \ldots \ldots$

Livre VI...................... 59

Livre VII..................... 60

Livre VIII. ..................... 60

Livre IX..................... 61

Livre $X \ldots \ldots \ldots \ldots \ldots \ldots \ldots \ldots \ldots 61$

Livre $X 1 . . \ldots \ldots \ldots \ldots \ldots \ldots \ldots \ldots \ldots 61$

Iivre XII................... 62

Livre XIII.................... 64

Livre XIV..................... 64

Notes sur Palladius................ 64 


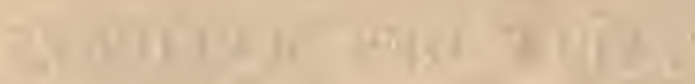

$$
\begin{aligned}
& y^{-1}+24 x+2 \\
& \text { ल5 }
\end{aligned}
$$

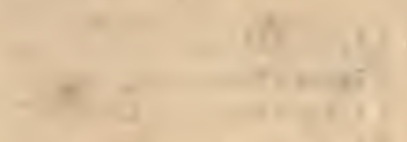

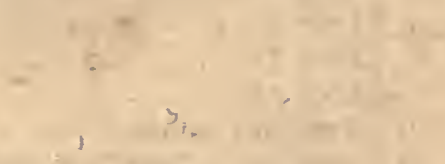

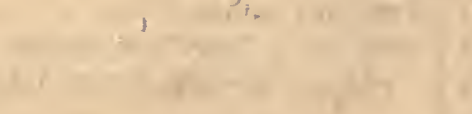

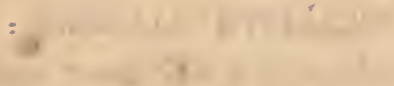

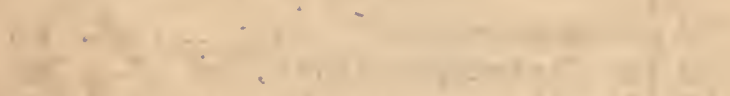

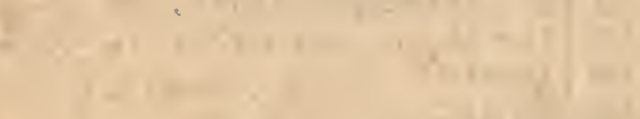

$$
\begin{aligned}
& =1+ \\
& +2 .
\end{aligned}
$$

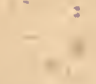

an.

(1)

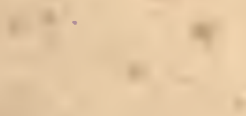

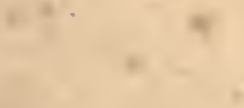

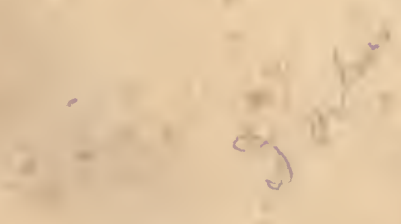

F

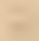

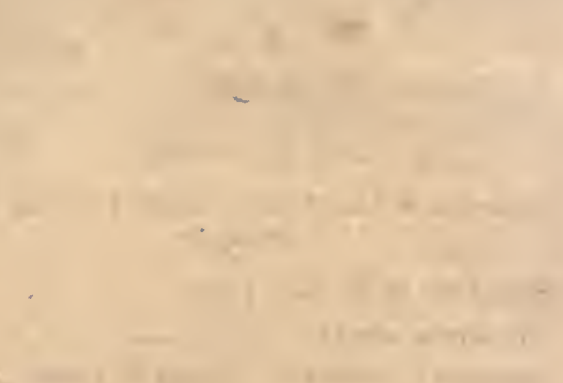



$\therefore$

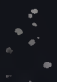


. 


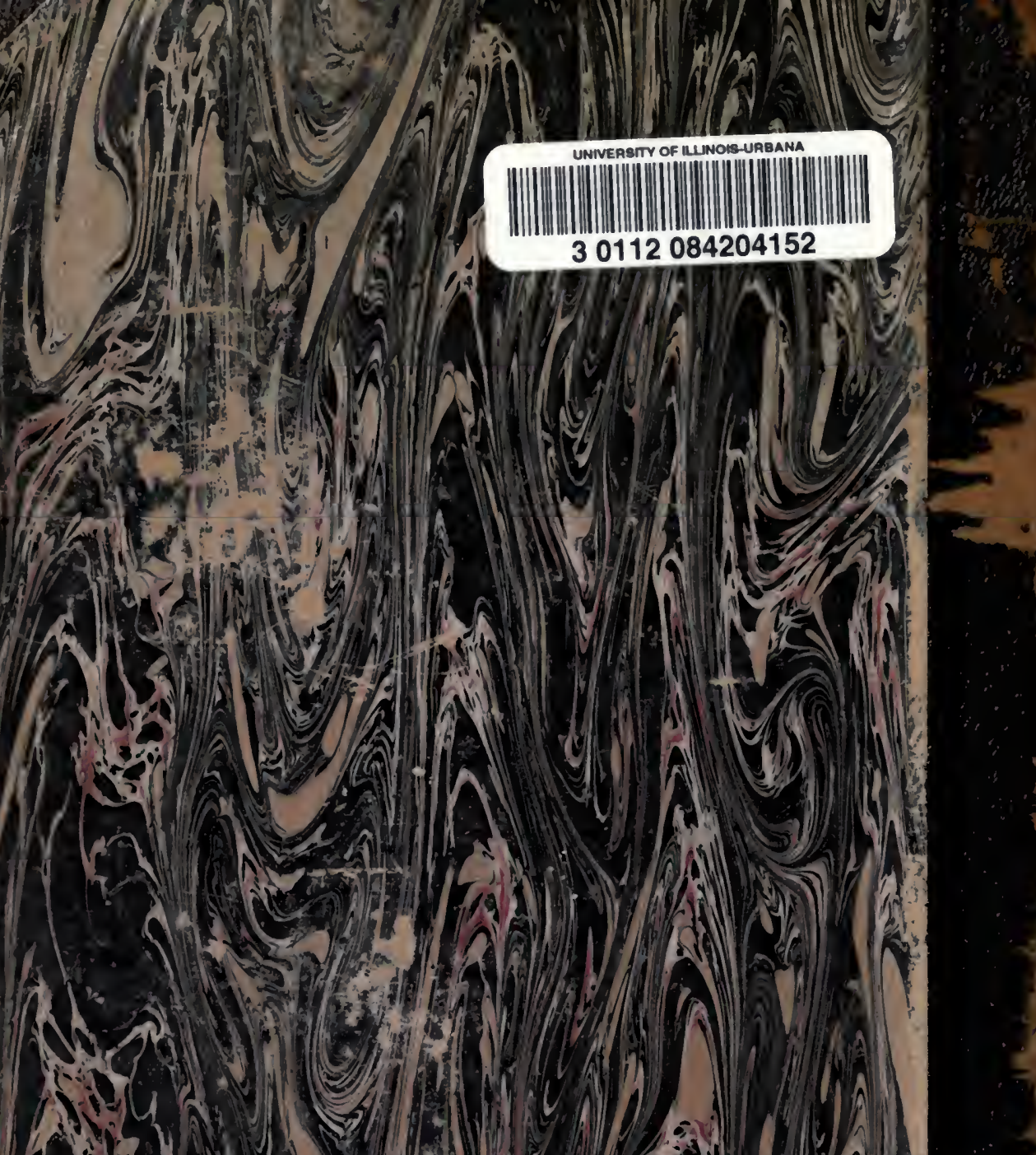

